

$$
\begin{gathered}
+.07 \\
.05 \\
\text { sect }^{+} .1
\end{gathered}
$$

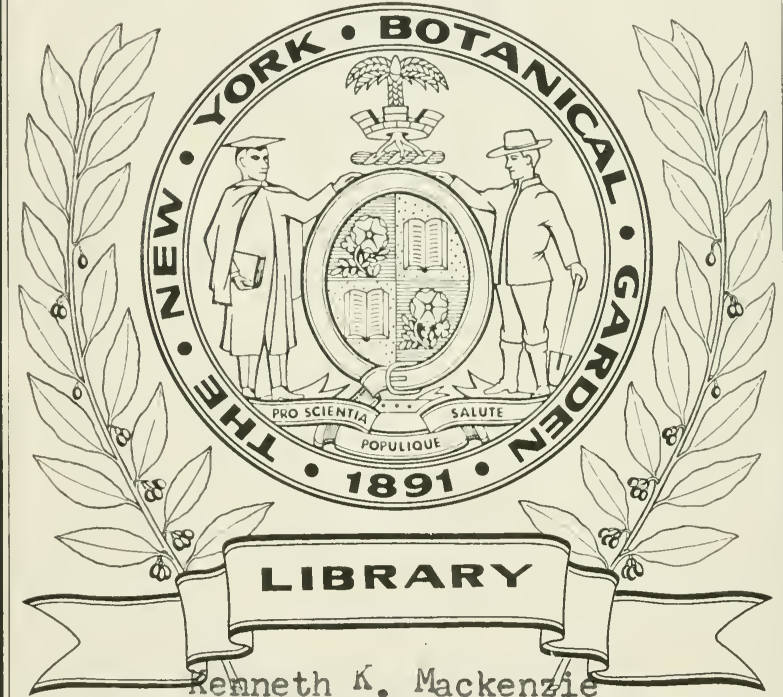

Collection 
Released fiom Library

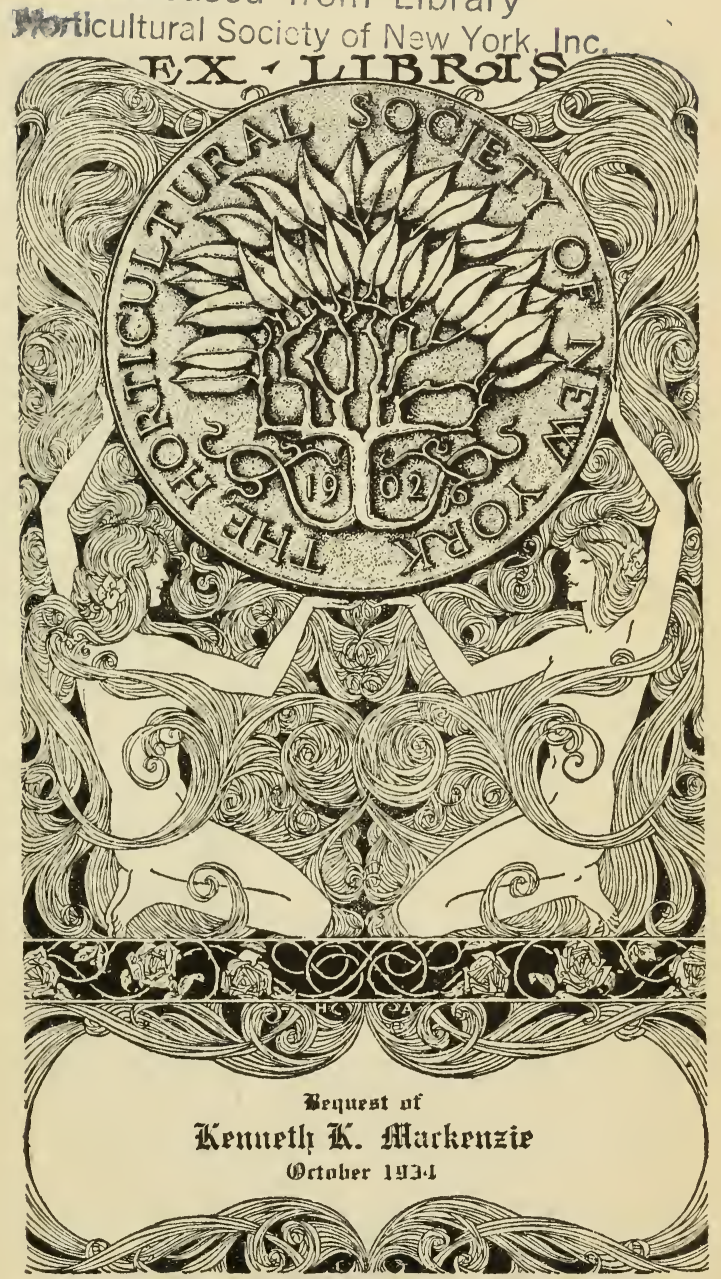





\title{
SINDPSTS
}

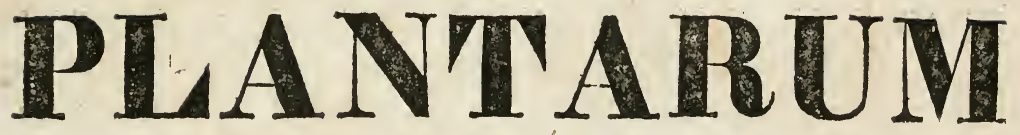

SEU

\section{ENUMERA'TIO SYSTEMATICA}

PLANTARUM PLERUMQUE ADHUC COGNITARUM CUM DIFFERENTIIS SPECIFICIS ET SYNONYMIS SELECIIS

\section{AD MODUM PERSOONII ELABORATA}

\author{
AUCTORE
}

\section{DR. DA VIT IIETICH,}

SOCC. PLUR. LITT. SODALI.

\section{TOMUS PRIMUS.}

SECTIO PRIMA. - CLASSIS I-V:

\section{VIMA I I I E, 1839.}

SUMTIBUS ET TYPIS BERNH. FRIEDER. VOIGTII. 


$$
\begin{aligned}
& \text { Q QK97 } \\
& \text { D7 } \\
& \text { aroti. }
\end{aligned}
$$




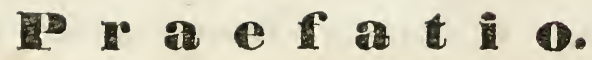

Nullum ad hoc usque tempus de plantis omnibus adhuc cognitis et descriptis recentius opus editum est, si Linnaei systematis editionem decimam sextam a Sprengelio curatam atque Candollii prodromum omittimus, quod praesentem plantarum copiam, quae ut scimus maximopere aucta iest, paucis tantum voluminibus complectatur. Qua re commotus id mihi propositum est plantas omnes, quaecunque praesenti tempore imnotuerunt, Personium aemulans pro facultate mea et viribus perscrutari et describere. Quamquam difficillimum hoc negotiun est, maximo tamen studio et amore ad rem accessi. Usus sum in scribendo hoc libro scriptis botanicorum maxime excellentium, ut Candolli, Sprengelii, Reichenbachii, Kochii, Kunthii, Alb. Dietrichii, Blumii aliorumque, quae et bibliotheca mea botonica, et amicorum humanitas atque benevolentia, et Vimariensis atque Goettingensis ingens librorum thesaurus mihi praebuit.

Descripsi plantas secundum systema Limnaeanum, adjecto semper famfitite ritaturatis nomine in enumerandis singulis generibus, hanc ob causam, ut non solum viri eruditi, sed etiam tirones investigare plantas non satis cognitas facile possint. 
Citantur scmper auctores, icones fere omnes et synonyma plurima, addito colore, patria et magnitudine.

Diagnoses cum ex optimis scriptis botanicis integrae sumtae, tum descriptiones copiosiores et fusiores, ne libri volumen et pretium nimis augeatur, brevioribus verbis et concisioribus illaeso diagnoseos sensu redditae sunt.

In describenda graminum familia Kunthii ordinem et dividendi rationem secutus sum. Plura igitur gram minum genera, ut Oryzam, Bambusam etc. ad classem sextam pertinentia ad usum inprimis tironum in ordine secundo classis tertiae collocavi.

Index scriptorum botanicorum et abbreviationum exploratio et illustratio huic volumini addetur. Necesse etiam est, cum retardata aliquamdiu editio hujus voluminis primi sit, supplementa, imprimis ex Kunthii Cyperographia nuper prolata, Hilarii, Hookeri, Blumii, Wallichii aliorumque scriptis nostro libro addere, quae librarius tanquam mantissam propriam paucis post diebus missurus est.

Indulgeant mihi, qui difficillimum hoc a me susceptum opus esse intelligant et cognoverint atque in futurum auxiliis suis me adjuvent lectores.

\section{Jenae mens. Jul. MDCCCXXXIX.}




\section{Corrige nd a ${ }^{*}$ ).}

Pag. 37 no. 4. Ioco reruculosis lege ver- -62 no. 121 pro v. hispida 1. horuculosis.

- no. 2 Chionanth. astigiatus lege fastigiatus.

- 38 no. 2 Syring. vulg. ante Persiam adde $\mathbf{E}$.

- 40 no. 31 pro violaceol. violacea.

- 41 Col. 1 no. 5 dichotomis l. dichotomiis.

- Col. 2 no. 7 post Brasilia adde ;

- 43 no. 22 involucelli. 1. involucellaque.

- - no. 4 filamenta 1. filamentis.

- 45 no. 9 post pedunculis deleatur ;.

- no. 10 pro puberilis l. puberulis.

- no. 25 pro Corymbosa l. C. corymbosa.

- 50 no. 23 pro subsessiliter 1. subsessili.

- 53 no. 70 pro radicalis 1. radicales.

- no. 2 post $P$. grandiflora All. 1. Lam. ibid. adde Syn. P. leptoceras Rchb. ic. 82. et $\mathbf{P}$. angustifolia DC.

- 56 no. 23 pro pioso lege pilaso.

- no. 28 post Hab. adde in rup.

Hercyniae.
-57 no. 30 pro spithamẹs 1. spithaspita M. et $K$.

- 61 Sanchetia ovata pro semiterelibus 1. semiteretibus.

- Lysionotus pro spesiosae 1. speciosae.

- Baea pro Calcolariae 1. Calceolariae.

Columella no. 1 pro entrorstum 1. extrorsum.

65 E. ramosa pro inter laciniis $I$. inter lacinias.

- - N. tomentosa pro strbulifera 1. strobilifera.

- 66 P. guttatus pro abbriviato lege abbreviato et pro fruticulis I. fruticulus.

68 Rostell. no. 9 pro margine 1. margineve, pro media l. medio.

- 70 Leptostach. no. 1 pro deltid. I. deltoideis.

- yt no. 17 E. hypocrateniforme 1.

hypocrateriforme.
- no. 22 pro lacinii 1 . laciniae et pro babii 1. Iabii.

- 74 no. 27 del., post bracteis.

- 79 no. 12 pro angustis l. angustatis. mea. pleuroides.

*) Erratorum, qui irrepserant aliorum correctorum negligentio, veniam a lectoribus maximopere peto. 
Pag.81 Peristrophe no. 8 prosuperioris I. superiore.

Hypoëstes pro Hyprestes.

- 83 no. 19 pro Hymelto l. Hymetto. pag. 85. 110. 48 pro s. argenta I. s. allgentea

no. 53 pres. integrifolia Hardw. In Himalaya 4 quae pertinent ad s. lanatam lege:

53. S. emaryinata Me!. et Dre!. fol. ovalibus ohtusis sinuato-dentatis Iyratisque ciliatis; Iabio calycis stlperiore late truncato, In Afr. anstr. - 89. no. 147 pro s. scorodonia lege scorodonia.

- 90 no. 161 pro Cor. caerulascens 1. caerulescens.

- 92 no. 107 propetiolutis l. petiolatis. - no. 212 pr.oblongatis l.oblongis. - 93 no. 123. pro octusiusculis 1. obtusiusculis.

- no. 230 pro ramis 1. ramisque. - 94 110. 243 pro viridissimo l. splendidissime.

- 95 no. 289. pro vertiellis 1. verticillis.

- 96 no. 1 pro S. off. 1. IR. officinalis.

97 Cunila no. 10. pro patentissimi stecti 1. patentissimis tectis.

- 99 no. 3 del., post utringue.

- no. 6 post usque adde ad.

100 Boerliavia Vaill. pr. 1818 l.1\%18.

102 Circaea no. 1 pro petalis calyce longioribus 1 . brevioribus.

103 Millingt. no. 3 pro ferrugineotomentosa 1. ferruginco-tomentosis.

104 Margyriocarpus no. 1. pro linari 1. lincari-.

- 105 no. 11. pro lauceolatis 1. lanceolatis.

- 106 no. 39 pro oblougis l. ohlongis.

- 107 Fraxinus no. 1 sulisellibus 1. subsessilibus.

- Fraxiuus no. 3 umbellatis lege unıluellatis.

- 110 no. 70 pro Pevuviae 1. Peruviae.

- 113 no. 136 pro Garolina 1. Caroliua.

- 114 no. 153 pro similis 1. simile.

- 118 no. 247 pro P. Carpupiga lege Carpupija.

- - no. 256 pro P. Redemeyeri 1. Bedemeyeri.

- 121 no. 321 pro P. muricutum lege p. muricalum.

- 123 Cladium no. 1. adde syn. Cladium Mariscus $\mathbf{l}$. Br.
Pag. 124 no. 10 pro orelanatis 1. ore lantatis.

- Lenna no. 3 pro praecidenti lege praecedente.

- 125 Diarhena p. Tenese J. Tenessee.

- 126 Nematostigma pro 6-partito 1. 6-partita.

- 128 no. z07 pro Hlelebreae I. Illecehreac.

- no. 225 pro prismctica 1. prismatica.

- - no. 226 pro spicae 1. spica.

- 129 no. 238 p. speculae l.spiculae.

- - no. 2-13 pro terminale 1. terminales.

- _ no. 268 pro fermine 1. feminea.

- 131 no. 273 p.3-nervas I.3-nervia.

- no. 27. pro Monoicae 1. Spiculae monoicac.

- - no. 275 pro terne lege temae.

- no. 279 pro stigmta l.stigmata.

- 132 no. 292 pro 1-gluma I.1-paleaceo et p. bigluma 1.2-paleaceo.

- 133 pro Gymmostrix 1. Gymmotrix.

- - 110. 311 pro exima lege extima et pro caudem 1. caudam.

- no. 313 deleatur sterilis post 1-paleaceus.

- - no. 316 pro varia 1. paria. chidata.

- - no. 320 pro neutra 1. neutro.

- 131 no. 323 pro superantibus lege superautes.

no. 331 deleatur Coleanthus cum descriptione quia sub Sclmidia subtilis p.125. desciptus est.

- 136 no. 357 pro aristatis 1. aristis.

- 137 no. 388 pro tortilis 1. tortili.

- 138 110. 398 pro Trioidia 1. Triodia.

- 139 no. 418 pro LANARKLA I. CHRYsumes et ib. pro bifidam 1 . bifidum.

- 142 no. 478 p.epipetalis 1. epipetala.

- no. 481 p., Capsula 1. Capsulae.

- - Iris no. 9 pro I. xipioides lege xiphioites.

- 143 Iris no. 14 pro fol, I. fol..

- - Iris. no. 17 pro lineribus i.li-

- nearibus et p. subfulcatis 1. subfalcatis.

- no. 28 pro dodecagonis lege dodecagynis.

- 114 no. 39 pro I. spurea 1. I. spuria. 110. 40 pro germine 6-gono 1 . germen 6-gonum. 
Pag. 144 no. 46 pro scacinosis 1. scariosis.

- - no. 48 pro subcariosis 1. 6ubscatiosis.

- 145 no. 67 ante deflexis adde,

_- - no. 713 -pedales quod vuit Alh. Dietr. lege 3-6-poll.

- 146 no. 10 pro lata flava 1. laete flava.

- 147 no. 28 adde In Prom. b. spei.24.

- 148 Marica no. 6 pro Ottto I. Otto.

- 149 no. 19 pro Maraca 1. Moraea.

- 152 no. 8 pro tubo l. tubi.

- 15:3 no. 20 didyma 1. didymo.

- 15.1110 .14 pro aequante 1. aequata.

- 156 no. 24 pro inferiotibus 1. inferioribus.

- no. 25 pro tristi lege tristis.

- - no. 22 pro Africa meridionali 1. Afticae meridionalis.

- 157 no. 39 pro laciuiis lege laciniis et dele post inferioribus,

- no. 41 adde syn. G. Boucheauts schl.

- 158 no. 44 pro aequante 1. aequali.

- - no. 46 pro lancolatis 1. lanceolatis.

- no.6 pro 6-dentato 1.6-dentata.

- 159 no. 6 pro folio lege folia.

- no. 9 pro stigmate 1. stigmata.

- 160 no. 7 pro oxcicis lege excisis.

- 168 no. 7 pro collibns lege collibus.

- - 110. 9 post Hispaniae, adde Germaniae.

- 110.10 adde et Germaniac.

- 169 no. 23 pro F. comminata lege carinata.

- 176 syena. pro Nutalliana 1. Nuttallianla.

- 197 Macrolob. no. 1 pro Cajenna 1. Cayenna.

- 180 Polycn. no. 2. pro bracleas 1. bracteis.

- 187 Rhynchosp. no. 4 pro R. armenioidos 1. armerioides.

- no. 7 pro nuce 1. nuci.

- 188 no. 26 pro scrahro 1. scabro.

- 189 no. 57 pro brevoribus 1. brevioribus.

- 3 adde et Germania.

- 190 no. 25 pro equisetoidus 1. equisetoides.

- 191 no. 5 pro Hystria 1. Hystrix.

- 192 E. verruculosa: pro versucoso 1. verucoso.

- 107 Fimbristylis adde Scirpus L.

- 198 no. 10 pro extrorsim 1. extrorsum.
Pag. 200 no. 66 post phyllis dele ; .

- 206 no. 7 pro tereciuso l. teretiusculu.

- Morelotia. pro Fructu deciduo

1. Fructus deciduus.

- 207 pro Anthrostylis 1. Arthrostylis.

- no. 8 anle Host. adde Hoppe.e

-212 no. 110 seberianus 1. Sieberianus.

- 213 no. 128 pro capitulaeformi 1. capituliformi.

- 214 no.137 pro9-nervis 1.9-nerviis.

- 222 no.317 pro tubifera l.tuberifera.

- - 110. 321 pro strictis 1. striatis.

- 223 no. 325 pro 9-nervis 1. 9-nerviis.

- 224 no. 4 posí 5̌-6 dele -

- - no. 14, 25 et 30 pro Killingia I. Kyllingia.

- 230 no. 12 pro Trachynstia 1. Trachynotia.

- 231 Hydrop. post feminea adde ; pro elevalis 1. clavatis.

- 234 adde adde ad Alop. fulvum syu. A. paludosus Beauv.

- 235 no. 11 pro aristata glumis 1. arista glumis.

- 236 no. 7 pro Chilochlon 1. Chilochloa.

- - มо. 12 pro quaedruplo 1. quadruplo.

- 240 no. 24 pro orispilosis 1. oris pilosis, pro puberules 1. puberulis.

- 241 no. 45 pro Synterisma 1. Syn therisma.

- 442 no. 60,74 et 93 pro solitarium 1. solitariarum.

- 218 no. 145 lege rachi lineari duplo- vel $3-p l o$ spiculis 4 - $\mathrm{fa}-$ riis imbricatis ellipticis ptr berulo - hispidis angustiore glabra etc.

- no. 149 pro speciosissimus $l$. speciosissimum.

- - no. 151 pro pilosts 1. pilosis.

- 249 no. 162 pro 4 -serialibis 1. 4serialibus.

250 no. $16 \%$ pro bifioriis 1. bifloris.

- Olyra no. 1. pro Lithachue 1. Lithachne.

253 no. 8 pro Mortivideo 1. Montevideo.

- - no. 12 deleatur Nees.

- Urochloa no. 4 pro dentibus rachi flaxuosa 3 -5-flora lege dentibus racheos flexuosac 3-5-floris. 
Pag.255 no. 19 pro spica 1. spicam. - 257 110. 39 pro dimido 1. dimidio.

- no. 43 pro Pers. 1. Koehl.

- 259 nо. 71 pro imfinis 1. infimis.

- 260 110. 81 pro paniculaformibus 1. paniculacformibus.

- 264 no. 120 pro continibus lege confinibus.

- 265 nо. 138 post patentibus; lege pro ramis ramulis.

- - no. 142 pro biseriabilis 1. biserialibus.

- 266 no. 148 pro unilaturalibus 1 unilateralibus.

- 267 no. 160 pro sericis 1. scriceis.

- - no. 167 pro congylodes I.gongylodes.

- 269 no. 188 pro oblongo l. oblonga.

- 285 no. 251 pro filamentorum l. fiIamentosum.

- 276 no. 293 pro parbiformi 1. barbiformi.

- 279 no.330 pro coarctata lege coarctato.

- 280 no. 341 pro paleacea lege paleaceo.

- - 110.351 pro orientali lege orientalis.

- no. 353 post oryzetorum adde Ind. or.

- 282 no. 371 pro filiformi l. filiformi.

- no. 37t pro umbrosae lege umbrosis.

- 283 no. 399 pro suliata 1. sulcata.

- 284 no. 409 pro masculo l. mascula.

- 285 lchnanth. no. 2 pro noununquam 1. nonunquam.

- 286 no. 5 pro aristis 1. aristatis.

- 287 no. 7 pro ciliato 1. ciliata.

- no. 9 pro subtenis 1. subdenis.

- no. 13 pro bipaleasei lege bipaleacei.

- 288 no. 21 pro dimido 1. dimidio.

- no. 29 pro aristadis 1. aristatis.

- 289 no. 32 pro dimido 1. dimidio.

- 110. 35 post ligula dele; et adde. ante ligula;.

- 110. 38 pro Anericia 1. America.

- 290 no. 43 pro aristato 1. aristata.

- 292 110. 16 pro involncelli 1. invoIucelli.

- 110.22 pro flosculis I.fosculos.

- 295 no. 10 pro bevissimis I. brevissimis.

- 301 no. 17 pro sublente l. sub lente.

- 305 no. 20 pro flliformi l. filiformi.

- 307 no. 39 pro perianthis lege perianthio.

- 309.10. 8 pro paleas I. paleis.
Pag.316 no. 10 pro aequabibus l. aequalibus

- 319 no. 74 pro panicula 1. paniculae.

- 321 no. 11. pro lacinis setacea I. laciniis setace 0 -

- 322 no. 1 deleatur sub.

- 324 no. 25 pro longioribus 1. brevioribus.

- 10.34 pro peranthii 1. perianthii.

- 327 Gynerium no. 2. pro Wild, 1. Willd.

- 329 no. 6 palea 1. paleae.

- 332 no. 2 pro digitaria 1.Digitaria.

- no.4 pro Rabdochloa 1. Hhabdochloa.

- 333 no. 21 post Eleussine adde Roxb.

- 336 110. 8 pro neutrus 1. neutrius.

- 337 no. 5 pro Americis 1. America.

- 339 no. 30 pro flosculo l. flosculos.

- Airopsis pro species geminae 1. gemina et pro sp. anomalae $\mathrm{I}$. anomala.

- 343 no.12 pro sedensis 1. sidenensis.

- 346 110. 15 pro valvula 1. valvulae.

- 350 110.15 pro vaginorum 1. vaginarum.

- 110.18 pro pinata 1. pinnata.

352 no. 55 pro Beauv, 1. Link.

353110.84 pro pellicidis l. pellucidis.

354110.91 pro fasculata 1.fasciculato.

- - 110. 9-t pro clareosa 1.glareoso.

- 356 no. 125 pro Limna a 1. Linuaea.

- 357 no. 156 pro capitulaeformi $I$. capituliformi.

- 361 no. 220 pro indigue 1. undique.

- 363 no. 248 pro culmes I. culmeis.

- 370 12. 11 pro Agialitis 1. Aegialitis èt pro Mauritiana 1. Mauritania.

- 37. lin. 1 post et adde in.

- 375 no. 59 pro culmis 1. culmeis.

- 377 no. 82 pro spadica I. spadicea.

- 378 no. 92 pro Colopaxi l. Cotopaxi.

- 380 no. 15 pro stipulis 1. spiculis.

- 386 Guadua. no.2 pro linearibus oblongis 1 . lineari-oblongis.

- 388 110. 15 pro Idriae 1. Adriae.

- 390 no. 47 post Bracliypodium pro L. I. R. et $\mathbf{s}$.

- 391 Secale. no. 1 pro Caspium 1. Caspico.

- 392 ио. post superiore deleatur; .

395 Psilurus c. descript. del. quia in cl. I jam descriptus est.

396 no.9 pro pedunculatis 1. pedunculatis.

398 Saccharum no. 1 deleatur altum.

400 Sacch. uo. 3, deleatur gigantea.

402 Androp. no.8. pro cilia 1. cilias. 
Pag. 404 no. 91. deleatur australi.

- 406 no. 81 post Poir. pro ; scribe.

- 408 no. 114 pro decoloraus 1. decolorans.

- 411 no. 169 post solitariae adde rachi.

- 413 no. 25 pro cristatis lege aristatis.

- 414 Apluda no. 4 post calyce adde, .

- 415 Xerochloa pro spoi 1. spei.

- 419 Opercularia post abortientibus adde .

- - Mitchella pro germine lege germini.

_ - pro Hydnophythum 1.Hydnophytuil..

- 420 Galium post geminac adde laeves.

- 421 Hedyotis. pro bifida 1. bifido.

- 426 Potamogeton. pro Alismaeae 1. Alismeae.

- 427 pro Globaluria 1. Globularia.

- 428 Allion. no. 1 pro Cnmana 1. Cumana.

- - pro Tenasse lege Tenessee.

- 432 no. 29 pro Hortel. I. Hortul.

- 433 Plantago pro a. Fol. integris. * Latiusculis lege a. Fol. integris, * latiusculis. ibid. post pedales deleatur punctum et adde 1-pollicaresve

- 435 no. 33 pro Missou; ri lege Missou - ri.

- 436 no. 48 pro W. et $K$. lege M. et $\mathbf{K}$.

- 440 no. 11 pro glauduloso 1. glanduloso.

- Pladera. no. 2. pro Boxb. lege Roxb.

- 243 pro Frassera 1. Frasera.

- 444 pro Galdneria 1. Gardneria.

- 445 Patrinia. no. 4 pro longissimo lege longissima.

- 446. Dipsacus sylvestris, lacinatus et Fullonum sunt non $\odot$ sed $\odot$.

- 447 no. 7 pro ambrosioidis 1. ambrosioides.

- 448 no. 46 pro dendiculata 1. denticulata.

- 452 Declieux no. 1 pro frnticosa 1. fruticosa.

- 453 no. 3 pro partita 1. partito.

- 455 no. 25 pro crisseo 1. griseo.

- 456 no. 9 pro T. axiliflorum 1. T. axilliflorum et ibid. pro $\mathrm{Fe}-$ ramea lege Faramea.
Pag. 461 no. 15 pro angulis lege angulos.

- no. 21 deleatur viride.

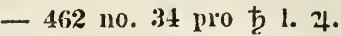

- 464 no. 14 pro G. pumilium M. et

K. 1. G. supiuum M. et K.

- 467 no. 96 pro decimis lege denis.

- 468 no. 96 ante angulos adde ad.

- 470 no. 117 pro infinis 1. infimis.

- 472 no. 11 pro compan. 1. campanulatum.

- no. 17 pro infinis 1. infumis.

- 476 no. 36 pro verticellatis 1 . verticillatis.

- 478 no. 23 pro flavicanto 1. Alavicanti.

- 479 no. 36 pro pedalis 1. pedales.

- 483 no. 29 pro radula 1. Radula.

- 484 Knoxia no 10 adde post pilosis semicolon et ibid. post rotundatis apud Lasianth.

- pro a. Calycis limbo brevisso lege brevissimo.

fascianth. no. 12 post confertis deleatur ;

- 489 no. 17 pro fimbricata 1. fimbriata.

- 490 no. 16 pro crataegoum 1. Crataegonum.

- 492 no. 52 pro trichotonis 1. trichotomis.

- 49t no. 26 pro adscendento 1. adscendente

- 495 Kadua no. 3 pro Mensiesianae 1. Menziesiana.

- ibid. no. 4 pro coralligna 1. coralligera.

- 497 pro Ptelia lege Ptelea.

- - Majepea. pro Clioranthus lege Chionanthus.

- 498 in lin. uItima pro versu 1. versus.

- 499 Lepta. pro ramosissimus 1. ramosissima.

- - no. 4 pro suprne 1. superne.

- no. 5 pro subfulcatis 1. subfalcatis.

- 501 no. 45 pro obovoto 1. obovato.

- no. post mission adde punctum.

- 502 1. 80 pro naupalensis 1. nepalensis et pro Nepaulia Nepalia.

504 no. 5 adde . In Europa. ち.

505 Amannia no. 2 pro romoso 1. ramosa.

- 527 no. 11 pro ovario lege ovarium.

529 no. 43 pro Anadernia lege Anadenia idem in no. 45.

530 no. 63 pro oblongi lege oblongo-. 
Pag.530 no. 70. pro obavatis lege obovatis.

- 536 Lomatia. no. 2 pro foliolia Iege foliola.

- 541 Camplorosma. no. 2 post affinis dele punctum.

- 542 Majanth. no. 2 pro birarius 1. hi-rarius.

- Alchemilla. no. 8 pro Qnito 1. Quito.

- 544 no. 24 pro acuminutis 1. acuminatis.

- 549 Hypecoum littorale pro Carinthiae lege Littoralis.

- 551 no. 4 pro inaequalites lege inaequaliter.

- 5.56 no. 32 pro Naugasaki 1. Nangitsaki.

- 557 no. 10 pro Imatis lege lanatis.

- 560 Echium. pro angulate 1. anguIatae.

- 563 Metternichia. aute 5-fido adde limbo.

- Calibrachoa. pro angulato lege angulata.

- 564 pro Sabattia lege Sabbatia et ib. stigmateque lege stigmataque.

- Cryptolepis. pro alternantes 1. altermantibus.

- Prestonia. pro Cor. lege Corona.

- Cinchona pro linearis lege lineares.

- 570 Schoepfia. post inter adde punctum.

- 571 Solena. pro stygma 1. stigma.

- 572 Hirtella. pro spirales lege spiralia.

- - Hhamnus. pro cartilagnieo 1. cartilagineo.

- 573 Diosma. pro bivalvis lege bivalves.

- 575 Impaticus, pro CaI. 1. Caps. et post tortis adde Balsaminear.

- 577 Desmochaeta. pro uncinilis I. uncinatis.

- Hebanthe. pro staminiferio lege staminiferae.

- no. 1136 post inter pro, pinge.

- 1149 pro applicato lege ampliato.

- 579 no. 1173. pro aucta lege acuta.

- 1180 pro exteruum lege exsertum.
Pag.582 no. 1262 pro tetraptarus lege tetrapterus.

- 1265 pro biscutatus lege bisulcatus.

- 5831267 ante involucra adde;.

- 1295 pro subapitatis lege subcapitatis.

- 585 nо. 5 seselineae. pro mirocarpiis lege merocarpiis.

- 588 no. 1386 pro Xantoxylom lege Xanthoxylon.

- 586 no. 1347 pro contractus lege erostratus.

- no. 1350 pro cristatis 1. aristatis.

- 589 no. 1408 pro tubolosus 1. tubulosus.

- 590 no. 1439 pro Cel. lege Cal.

- 594 no. 2 ebracteatis lege braclealis.

- 595 no. 72 rostratum lege prostratum.

- 596 no. 23 cuneifolium lege cupeifolium.

- no. 11 pro longis lege oblongis.

- 598 Pulmonaria no. 2 pro b. lege 4.

- Purshia Carolinia lege Carolina.

- 599 no. 19 pro lineari lege linearilus.

- 600 no. 15 pro Altissima lege Altissimum.

no. 21 pro strigilosis strigulosis.

602 no. 60 pro rosacei lege rosei.

604 no. 6 pro ruguilosus lege rugulosis.

- 606 no. 18 pro dephyllis lege diphyllis.

- 607 no. 2 post australi adde et media.

- Stematechium lege Stomotechium.

608 no. 3 pro post. lege portug.

614 no. 69 pro serico lege sericeo.

617 n0. 52 pro coriaceis I. cordatis.

- - no. 61 pro obtusiusculi sundulatis lege obtusiusculis undulatis.

- 621 Bladhia. no. 3. spithamaeus 1. spithamea.

- 622 Thela. 110. 1. coccineus lege coccinei.

- 629 no. 56 pro tol. lege fol.

- 632 no. 20 pro campanulutum I. campanulatum. 
Pag.633 styphelia. no.4. plabris lege glabris.

- Astrolob. no. 5 pro attauuatis 1. attenuatis.

- 634 Cyathodes no. 6 pro ; fol. 1. . Hol.

- 636 no. 53 pro solitaris lege solitariis.

- 639 Leea no. 7 pro adreniis lege aveniis.

- 641 no. 21 pro fioribus lege pedunculis.

- - no. 20 pro Asterolion lege Asterolinon.

- 612 Cyclam. no. 1 lobos lege Iobis.

- 643 no. 7 pro Linne 1. Lehm.

- 614 no. 18 pro Baun 1. Bugg.

- - 10. 26 pro Enudi 1. Emodi.

- 645 no. 43 pro aequante lege aequato.

- - no. 58 pro saxifragiaef. lege saxifragif.

- 651 no. 55 pro Cartagena 1. Carthagena.

- 6ŏ 1 Vallaris. no. 2. pro Pelthanthera 1. Peltanthera.

- 6.58 Verhascum. no. 9 dele V. crassifolium sichl.

- 659 no. 26 adde et Germania.

- 660 no. 47 pro bugullaef. lege bugulaef.

- 662 Petuna nyctaginifi. adde Cor. albida.

- 664 no. 19 pro liniari lege lineari-.

- 666 no. 65 pro argulosis lege angulosis.

- 671 no. 15j pro nymphaefolius 1. nymphaeaefolius.

- 6 б̆ 6 no. 302 pro meditterrannei lege niediterranei.

- S8y no. $18 \hat{~ p r o ~ g l a n d u l i f e r a ~ l e g e ~}$ rlandulifero.

- 678 no. 337 dele prostrato.

- 691 Cestrum. no. 9 post schl. adde Linnaea.

- 693 Dartus. pro tomentotis lege tomentosis.

- 696 Solanum. no. 1 pro tubifera 1. tuberifera.

- 700 no. 84 pro laciinis lege laciniis.

- - no. 97 pro calycepl. lege calygnaphalum.

- 702 no. 126 post minore adde ,.

- 704 no. 167 pro iynota lege ignota.

- no. 176 pro pinnatif. lege pinnatifido.
Pag.706 no.216 pro Gugana lege Gujana.

no. 218 pro $R$. et $P$. lege $\mathbf{R}$. Br.

- 707 no. 230 pro psendo-sappaceum lege pseudo-saponaceum.

- 808 no. 252 pro oporium lege oporinum.

no. 263 pro fruticosa lege fruticoso.

- 10 Witheringia no. 5. tomototis lege tomentosis.

- 721 no. 29 pro $\mathrm{R}$ - - lege Rio.

729 no. 50 pro lanceolato- 1. lanceolatis.

735 no. 168 Humboldiaua 1. Hunboldtiana.

- no. 174 pro secunde lege secundo.

- 736 no. 191 pro lacus lege lacubus.

- 711 no. 8. dele Alp. et pro 4-6lege $1-1 \frac{\mathrm{I}}{2}-$ ped.

- 42 no. 18 adde et Germania.

- no. 21 pro romoso lege ramoso.

- 743 no. 10 pro et Bytlyno 1. Bithynico.

- 745 no. 40 pro crenulalis I. crenulatis.

- 16 no. 55 pro -serrulatis lege -serratis.

- 78 no. 87 pro Poucela lege Roncela.

- 749 no. 96 pro D. lege C.

- 850 no. 124 dele australi.

- 757 no. 180 pro banksiana lege Banksiana.

- 760 no. 12 post subdentatis dele cumeatis.

- 72 no. 42 pro oblato lege lato-

- $76 \tilde{~ n o . ~} 108$ pro myrthiphyllum 1. Mythipyllum.

- 766 no. 118 pro balbisiana 1. Balbisiana.

132 pro lampophylla lege lamprophylla.

- 768 no. 158 pro gandarussae folia lege gendarussaefolia.

- 774 no. 5 pro villoso lege villosa.

775 no. 24 pro Pernia lege Peruvia.

- 782 no. 46 post Gallia adde Germania.

- 789 no 12 pro Retinophyllum Iege Retiniphyllum.

- 795 Linea no. 1 pro obtutis lege obtusis. 
Pag.80 (no. 32 pro pilioli lege petiolis.

- 802 no. 8 post cor. adde punctum.

- no. 8 pro velutino lege velutina.

- 805 Harpullia pro integrrima lege integerrima.

- 806 no. 19 dele austr.

- no. 23 pro Atlantae Jege Atlantis.

- no. 26 pro polygymis lege polygamis.

- 808 no. 49 pro polyfolius lego polifolius.

- 809 no. 28 pro subcorrdato lege subcordato.

- no. 28 pro inaequalite lege inaequaliter.

- 810 no. 30 pro Jujeba 1. Jujuba.

- 811 no. 10 pro canove-Iutinis lege cano-velutinis.
Pag. 812 no. 16 post petiolis dele ;

- 813 no. 13 pro mal. lege malay.

- 816 no. 16 pro fasciculatis 1. fasciculatum.

- 818 no. 14 pro trivalibus lege trivalvibus.

- 820 Stavia no. 3 pro incurvo lege incurvo.

- 822 no. 1 pro Comimersonia lege Commersoniana.

- 827 no. 77 pro dilatis lege dilatatis.

- 828 no. 93 post revoluto dele -.

- 840 no. 1 adde syn. K. alba Bess.

- 841 no. 20 adde syn. umbrosa Hoppe.

- 8.13 no. 70 post $V$. pratensis dele Mart. et adde M. et $K$.

- - no. 77 post floribus adde sessilibus.

- 845 no. 102 post Cor. flava adde et violacea. 


\section{I e $\mathrm{x}$.}

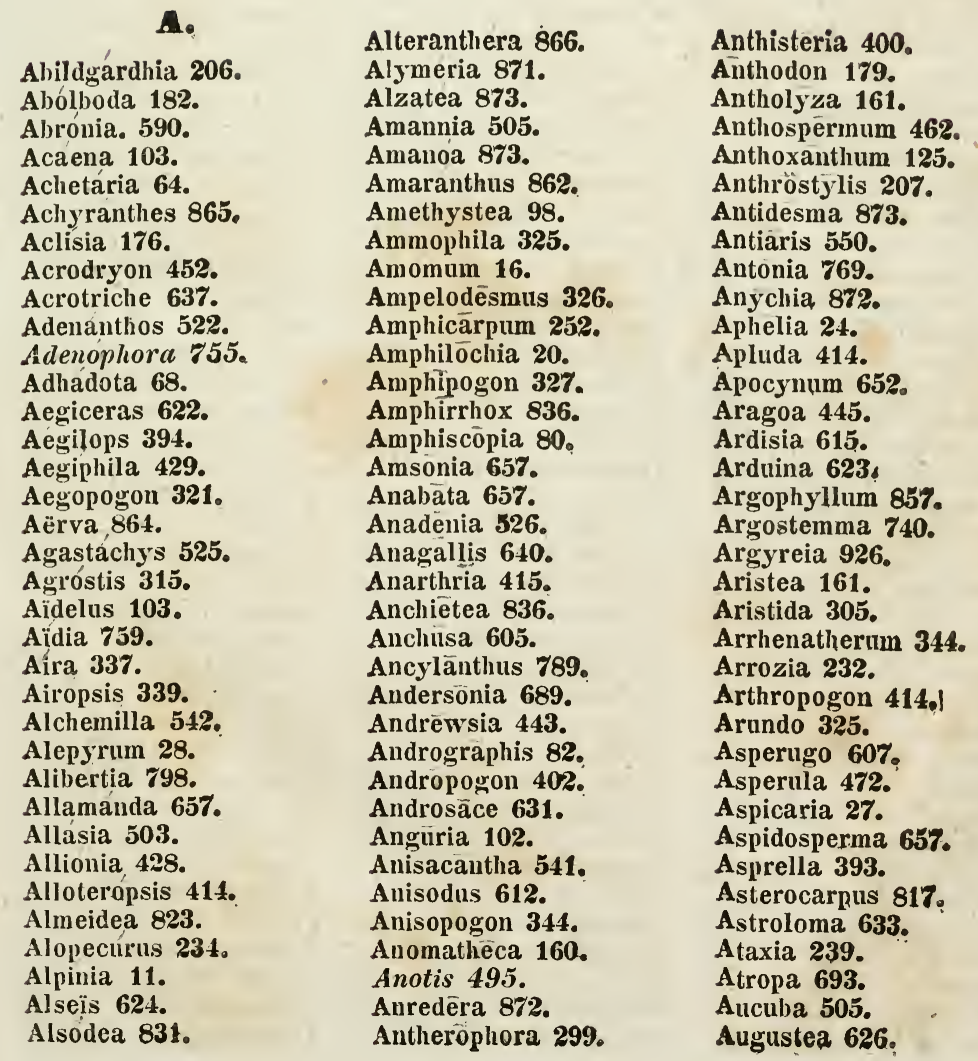


Aulax 509.

Avena 341 .

Axanthus 797.

Axia 170.

Ayenia 821 .

Azalea $68 \%$.

IB.

Babiana 15 .

Baconia 455.

Bacopa 616.

Baea 64 .

Bacohotrys 802.

Baeothryon 191.

Balfourea 65t.

Bambusa 385.

Banksia 537.

Barreria 61 .

Baumea 228.

Beaumontia 652.

Beckmannia 236.

Beeshea 387.

Bellendena 525.

Belonia 615.

Beloperone 68.

Bertiera 801.

Berzelia 861.

Beureria 629.

Billardiera 835.

Bladhia 621 .

Blairia 443.

Blitum 26.

Blysmus 187.

Boerhaavia 101.

Bolivaria 38.

Bonneya 40.

Bomplandia 625.

Borrago 605.

Borrera $47 \%$.

Boscia $5 \mathbf{5} 2$.

Botryceras 499.

Boussingaullia 871 .

Bouvardia 489.

Brabejum $\tilde{\mathbf{z}}$.

Brandtia 345.

Breweria 626.

Brexia 836.

Briza 365.

Brodiaea 171.

Bromus 380.

Brucea 553.

Brunia 848.

Brunonia 591.

Euchia 430.

Buddlea 431.

Bufforia 5ั\$9.

Bulliatda 505.3.

Bumelia fiz?.

Burnıamia 162.

nurchellia 794.
Bursaria 8:35.

Büttneria 821.

Byblis $8 \mathbf{4} 8$.

\section{C.}

Calamagrostis 322.

Calceolatia 44.

Calihrachoa 646.

Calisperumum 835.

Callicarpa 428.

Callisia 176.

Callistliene 19.

Callitriche 27.

Calodendion 834.

Calotheca 366 .

Camax 614.

Cameraria 657.

Campanula $\mathbf{7}+3$.

Camphorosma $3+1$.

Campylanthus 101.

Cantuylus 690.

Canala 595.

Canephora 617.

Camma 3.

Cansiera jّo.

Canthitm 878.

Cantua 685 .

Capsicum .694.

Carissa 61 s.

Caroxylon 872.

Carpha $18 \%$.

Carphalea 488.

Carpodetus 856.

Catabrosa 365.

Catalpa 8?.

Cateshaea $48 \%$.

Cathestecum 329.

Calonia 519.

Caustis 207.

Ceanothus 808.

Ceurela 826.

Celastrus 813.

Celosia 861.

Cenarilienes 525.

Cenchrus 23:\%.

Centotheca 364.

Centranthus 24.

Centrolepis 28.

C'entunculus 433.

Cephaëlis 782.

Cephalanthus 452.

Ceritonia 875.

Cerhera 623.

Certia 24.

Cerintlie 591 .

Cerium 614.

Cervaniesia 873.

Cestrum 69:.

Cevallia 859.

Chactospora 183.
Chaetotropis $3: 0$.

C'haeturus 321.

Chamaeraphis 4\%).

Cliamagrostis 235.

Chamissoa 863.

Chapeliera 797.

Chascolytrum 366.

Chilianthus 430 .

Chimarthis 619.

Chiococca 784.

Chionanthus 38.

Chironia $6 \pm 5$.

Chloris 330.

Chomelia 459.

Chondrosium 333 .

Choretrum 878.

Chrysophyllum 637.

Chusquer i85.

Cicca 5.56.

Cinchona 620.

Cinna :31:.

Circaea 102.

Cissus 499.

Cladium 128.

Cladostachys 861.

Claytenia 8\%1.

Cobaea 686.

Coccocypselum 486.

Codarium 102.

Collonopsis 7.57.

Coelache 365.

Coelospermum $49 \%$.

Collea $78 \%$.

Coix 234.

Coldenia 592.

Coleanthus 311.

Colladonia 780.

Colletia 808.

Collinsonia 86.

Collomia 686.

Colpodium 311.

Colsmannia 603.

Columella 64.

Cometes 543.

Commelina 171.

Condalea 873.

Conocarpus 879.

Conoeephalus $5+0$.

Conohoria 831.

Conospermum 52J.

Convolvulus 663.

Cordia 611.

Coris 631 .

Corispermum 27.

Coruucopiae 234.

Cornulaca 865 .

Cornus 50:3.

Cortesia 623.

Cortusa 640. 
Ci rymbium 591.

Cuynephorus 337.

Corynocarpus 804.

Corynostylis 837 .

Cosmelia 659.

Costus 15.

Cottea 328.

Coumia 631.

Coussarea $\mathbf{4 5 9}$.

Coutoubea $\mathbf{4} \mathbf{H}$.

Craniospermum 603.

Crocus 151.

Crucianella $4 \mathbf{7} 4$.

Crucita 551.

Crusea $\$ 81$.

Crypsis 234.

Crypta 124.

Cryptandra 625.

Cryptocarpus $5 \mathbf{5 1 .}$

Cryptolepis 653.

Cryptophragmium 66.

Cryptostoma 625.

Cryptotheca 101.

Ctenium 334.

Cuncea 454 .

Cunila 97.

Cunniughamia 459.

Curcuma 17.

Curtisia 499.

Cuviera 789.

Cyathodes 634.

Cyclamen 6+2.

Cyliudria 444.

Cynodon 329.

Cynoglossum 607.

Conosurus 371.

Cyphia 859.

Суреrus 207-223.

Cypselea 104.

Cyrilla 805.

Cyrtandra 44.

Cystauthe 689.

\section{D.}

Dactylis 370.

Dactyloctenium 330.

Dampiera 760.

Danthonia $3 \mathbf{4 5}$.

Danais 624.

Daphnitis $5 \mathbf{1 3}$.

Daitus 693.

Dasus 759.

Datura 686.

Decaspora 637.

Declieuxia 452.

Deeringia 864.

Dentella 625.

Desfontainea 614 .

Desmochaeta 865 .
Despretzia 239.

Deyeuxia 324.

Dialium 104.

Diarrhena 125.

Diapensia 684.

Diasia 162.

Diaspasis 763.

Dicaryum 224.

Dichromena 202.

Dicliptera 79.

Dicoryphe 5อง0.

Dictyoloma 834.

Diectomis $\mathbf{4 1 2}$.

Dilatris 162.

Dimeria 398.

Dierbachia 712.

Diervilla 759.

Digera s05.

Diodlia 481.

Dioclea 603.

Diosma 824.

Diplarrhena 102.

Diplocalymma 615.

Diplophyllum 63.

Diplopogon 327.

Dipsacus $\mathbf{4 4 6}$.

Dodecatlieon $6 \mathbf{4 2 .}$

Donatia 416.

Doraena 691.

Douglasia 633.

Dracophyllum 689.

Drapetes $\mathbf{5} \mathbf{4 0}$.

Dryandra 539.

Drymaria 849.

Dulichium 223.

Dunalia 485.

Dupontia 337.

\section{E.}

Echiochilon 602.

Echinospermum 616.

Echites 649.

Echium 599.

Eriochloa 252.

Erisma 20.

Echinaria 329.

Echinolaena 298.

Ehretia 629.

Ehrharta 232.

Ektrosia 372.

Elaeagnus 5 47.

Elaeodendron 819.

Elegia 415.

Eleocharis 199.

Eleogiton 192.

Eleusine 334.

Elionurus 400.

Ellisia 631.

Elymus 392.
Elytraria 64.

Elytrophorus 372.

Embelia 620.

Embothrium 536.

Empleurum $5 \mathbf{5}$.

Eudopogon 66.

Epacris 685.

Epicampes 312.

Epimedium 497.

Eranthemum 70.

Eriachme 344.

Erianthera 81.

Eriantlus 399.

Eriophorum 20\%.

Eriochloa 253.

Erisma 21.

Ernodea $\mathbf{4 5 3}$.

Erycihe 615.

Erythraea $\mathbf{6} \mathbf{6}$.

Escallonia 836.

Esenbeckia 831.

Euparea 850.

Eustachys 330.

Euthemis 830.

Eutoca 639.

Eutriania 336.

Evodia 498.

Evouymus 820.

Evosmia 486.

Exacum 440.

Exarrhena 605.

Exocarpus 873.

Exostemma 622.

Fabiana 663.

Fedia 168.

Ferraria 151.

Festuca 372.

Fimbristylis 197.

Fissilia 180.

Flindersia 836.

Fluegrea 873.

Fontanesia 36.

Forgesia 740.

Forsythia 36.

Franklandia 525.

Frasera 443.

Fraxinus 107.

Froelilichia 456 .

Fusanus $\mathbf{5} \mathbf{4 9}$.

Fuirena 227.

Gaertnera 623.

Galax 818.

Galaxia 150.

Galium 463.

Galurus 415.

Gardenia 795.

Gardneria 414. 
Gastridium 320.

Gaudichaudia 805.

Geissorrhiza 160.

Gendarussa 69.

Genipa 794.

Gilia 685.

Gilliesia 162.

Gladiolus 155.

Glaux 875.

Globba 19.

Globularia 427.

Glossarrhen 837.

Glossoma 505 .

Glyceria 364.

Gomphrena 868.

Gonotheca 495.

Gonyanthes 163.

Gonzalea 486.

Goodenia 637.

Gounania 856.

Graphephorum 327.

Graptophyllum 68.

Gratiola 39.

Grevillea 526.

Gronovia 857.

Grumenaria $855 \%$

Guadua 386.

Guichenotia 830.

Guilleminea 872.

Guettarda 787.

Guevina 522.

Gunnera 124.

Gussonia 223.

Gymnandra 43.

Gymnocarpus 872.

Gymnostachys 549.

Gymnopogon 336.

Gymnosiphon 163.

Gymnostachyum 70 .

Gymnotrix 295.

Gynerium 327.

Gynochtodes 497.

Gyrocarpus 548.

\section{II.}

Haemodorum 162.

Hagenbachia 170.

Hakea 531.

Halocnemum 25.

Hamamelis 580 .

Hamelia 792.

Iamiltonia 878.

Hancornia 691.

Haplachne 399.

Ilaplanthus 82.

Harpechloa 334.

Parpullia 505.

Hebanthe 870.
Hedera 853.

Hedycarpus $\check{\jmath} \mathbf{4 3}$.

Hedychium 9.

Iledyotis 490.

Helicanthera 760.

Hellenia 13.

Heliotropium 592.

Helospora 487.

Hemiadelphis 66.

Hemianthus 100.

Hemichlaena 227.

Henkelia 41.

IIesperantha 160.

Heteranthera 176.

Hexarrhena 237.

Hexasepalum 481.

Hilaria 236.

Hierochloa 238.

Hippion 618.

Hippocratea 177.

Hippotis 798.

Hippuris 25.

Hirtella 803.

Hoffmannia 487.

Hoitzia 685.

Holarrhena 652.

Holboellia 298.

Holcus 238.

Holoschoenus 202.

Holosteum 415.

Hordeum 393.

Hortia 834.

Hoslundia 98.

Hosta 100.

Hoplotheca 870.

Hottonia 646.

Houstonia 442.

Houttuynia 416.

Hovenia 818.

Huerta 804.

Humbertia 633.

Humboldtia 849 .

Hunteria 623.

Hybanthụs 838.

Hydnocarpus 896.

Hydranthelium 177.

Hydrophylax 459.

Hydrophylium 625.

Hydrophytum 459.

Hydropyrum 231.

Hymenella 552.

Hymenanthera 805 .

Hymenopogon 624.

Hyoscyamus 661.

Hypecoum 549.

Hypelytrum 227.

Hypoèstes 81 .

Hypobathrum 496.
Jahorosa 612.

Jacquinia 638.

Jasione 857.

Jasminum 34.

Icacina 804 .

Ichnanthus 285.

lchnocarpus 652.

Illecebrum 871 .

llex 554.

Impatiens 845.

Imperata 399.

Intsia $17 \%$.

Johnia 179.

Johnsonia 171.

Iresine $\mathbf{8 7 0 .}$

Is achue 302 .

Iris 142.

Ischaeunum 41\%.

Isolepis 193.

Isopogon 513.

Itea 848.

Justicia 72.

Ixia 152.

Ixora 457.

\section{I.}

Kaempferia 14.

Knightia 536.

Knoxia 483.

Koeleria 369.

Koenigia 416.

Kohautia 495.

Kyllingia 226.

\section{I.}

Labatia 431.

Labichea 104.

Lachnanthes 162 .

Lacistema 12\%.

Lagoecia 860 .

Lagenula 543.

Lagurus 339.

Lamarckia 663.

Lambertia 534.

Landolfia 625.

Lappago 298.

Lasiagrostis 300 .

Lasianthus 484.

Lasiochloa 371.

Lasiopetalum 829.

Latipes 298.

Lavradia 847.

Lecananthus 624.

Lechea 415.

Lechonaultia 637. 
Lecontea 617.

Leea 638.

Lecrsia 230.

Lehmannia 662.

Lemua 124.

Leonia 691.

Lepideilema 298.

Lepidosperma 185.

Lepta 499.

Leptaspis 234.

Leptochloa 332.

Leptomeria 878.

Leptopterium 398.

Leptostachya 70 .

Lepturus 395.

Lepyrodia $\mathbf{4 1 6}$.

Letisbudesia 861 .

Leucadendron 509 .

Lencocoryne 171.

Leuconotis 439.

Leucopogon 634.

Leucospermum 516 .

Leycesteria 802.

Licania 874.

Lichteusteinia 789 .

Lightfootia 838.

Lieustrum 36.

Lisianthus 682.

Lita $6+8$.

Lithophila 104.

Lithosanthes 496.

Lithospermum $\mathbf{5 8 5}$.

Lohelia 626-636.

Lohostemon 607.

Loefnlingia 177.

Lorania 680.

Lolium 387.

Lomatia 536.

Lonicera 780.

Lopezia 23.

Lophatherum 372。

Loxanthus 66.

Luhinia 642.

Lucya 496.

Ludwigia 507.

lucaea 399.

Luziola 231.

Iycium 612.

lycopersicum 711.

Lycopus 98.

Lycopsis 602.

Lycurus 311.

Lygeum 234.

Lyonsia 657.

Lysimachia 640.

Lysinema 689.

Lysionotus 64.

Lysipoma 616.

Lyssantle 634.
II.

Machaerina 206.

Machaonia 617.

Macrochloa 300.

Macrolobium 177.

Macrocuemum 620.

Majanthemum 542.

Maltebrunia 241.

Manisurus 397.

Manettia 488.

Mandragora 693.

Mangifera 23.

Mapania 227.

Maranta $\boldsymbol{\gamma}$.

Margyriocarpus 10\%

Marica 147.

Maripa 626.

Mariscus 223.

Mattuschkea 427.

Mayepea 497.

Maytenus 817.

Melancranis 228.

Melasanthus 100 .

Melica 367.

Melichrus 633.

Melinus 486.

Menaïs 631.

Menestoria 626.

Menyanthes 649.

Merciera 759.

Meristostigma 161.

Merostachys 385.

Metternichia 646.

Micranthemum 100 .

Microcarpea 61.

Microchloa 329.

Microdon 757.

Microlaena 233.

Milium 251.

Millingtonia 103.

Mimetes 517.

Mina 615.

Minuarta 416.

Mirabilis 590.

Mitrasacme 441.

Mitreola 657.

Mitschella 452.

Mniarum 27.

Moenchia 553.

Mogiphanes 867 .

Molinia 363.

Moldenhauera 548.

Mollia 849.

Moltkia 599.

Monarda 97.

Monetia 498.

Montia 416.

Montinia 505 .
Monotcca 610.

Moraea 146.

Morelotia $\mathbf{2 0 6 .}$

Morinda 783.

Morus 550.

Mühlenbergia 309.

Murucoa 623.

Mussaenda 623.

Musschia 758 .

Myginda 553.

Myonima 485.

Myoschilos 879 .

Myosotis 604 .

Myrica 551.

Myrmetia 648.

Myrmecodia 485.

Myrsine 618.

Mystroxylon 817.

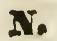

Nardus 229.

Nastus 385.

Nauclea 789.

Navaretia 626.

Nectouxia 615.

Nelsonia 65.

Nematostigma 150.

Nemophila 626.

Nerium 654.

Nertera 550.

Neuracline 399.

Nicandra 614.

Nicotiana 661 .

Nieremberyia 663.

Nivenia $\mathbf{5 2 0 .}$

Nolana 637.

Noisettia 837.

Nonatelia 788.

Notelaea 38.

Nowodworskia 320.

Nuxia 431.

Nyctanthes 36 .

Nyssa 878.

Nyssanthes 541.

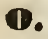

Obolaria 542.

Octarillum $\mathbf{5} \mathbf{4 9}$.

Olax 180.

Oldenlandia 492.

Olea 37.

Oligarrhena 102.

Olinia 830.

Olyra 251.

Onosma 599.

Opercularia 445.

Ophiorrhiza 625. 
Ophiurus 396.

Opilia 804.

Opitzia 335.

Oplismenus 486.

Oreoholus 228.

Oreocallis 536.

Orites 535.

Orixa 499.

Oropetium 396.

Ortegia 177.

Orthoclada 384.

Oryza ₹31.

Oryzopsis 299.

ottonia 558.

Outea $17 \%$.

Oxera 82.

Oxyanthus 801. 표.

Pacliysandra 552.

Paederia 778.

Paederôta 63.

Pagamea 5.50.

Palicourea 769.

Panicum 254-285.

Pappophorum 328.

Papyrus 223.

Pariana 395.

Paronychia 871.

Paspalum 240-250.

Patersonia 180.

Patrinia 445.

Pavetia $45 \%$.

Penaea 444.

Penicillaria 298.

Pennantia $8 \mathbf{7 3 .}$

Pennisetum 296.

Pentameris 346.

Pentapogon 323.

Pentarrhaphis 336.

Peplidium 54.

Perchtoldia 290.

Pereilema 321.

Peristrophe 80.

Perobachue 401.

Perotis $39 \%$.

Perrotetia 805.

Persónia 522.

Petesia 460.

Petitia 430.

Petrophila 511.

Petunia 662.

Pfaffia 867.

Pliacelia 625.

Phalaris 237.

Pliarus 2:33.

Phelline 432.

Philagonia 497.

Philydrum 24.

Phillyrea 36.
Philoxerus 870.

Phippsia 311.

Phleum 236.

Phlogacanthus 66.

Phlox 62.4.

Phragmites 328.

Phyla 510.

Phylica 875.

Physalis 694.

Phytemma 740.

pimélea 104.

Pinguicula 53.

Pinkneya 621.

Piper 107-123.

Piptatherum 300.

Pittosporum \$34.

Plantago 433.

Pladera 440.

Planera 551.

Platonia 385.

Plectronia 856.

Pleuraphis 337.

Pleuroplitis 398.

Pleuropogon 365.

Plocama 780.

Plumbàyo 590.

Poa 349.

Podostemnm 124.

Pogonopsis 414.

Polemonium 684.

Pollichia 24.

Polycardia 819.

Polycarpon 416.

Polycnemum 180

Polyozus 430.

Polymeria 622.

Polyodon 336.

Polypogon 320.

Polypremum 448.

Polyschistis 336.

Pomaterrls 818.

Pommereullia 230.

Ponāmia 622.

Poncelletia 689.

Porana 626.

Portlandia 625.

Potamogeton 5.56.

Potamophila 231.

Pouchetia 621.

Pouteria 431.

Preslea 629.

Prestonia 654.

Prieurea 170.

Primula 643.

Prionotes 690.

Prismatocarpus 756.

Proserpinaca 416.

Protea 514.

Psilobium 740.
Psilūrus 26.

Psychotria 760 .

Ptelea 497.

Pterāntlıs 5-1.

P'terolepis 186.

Ptiletus 86.4.

Pulmonaria 598.

Pupallia 866.

P'üshia 599.

Pyrostria 485.

Quālea 21.

Quinchamala 591.

\section{푤.}

Rachicàllis 496 .

Haddisia 179.

Radiola 5š̉.

Lamondia $6+6$.

Raphidospora 81.

lieboulea 365.

lieichenlachia 107.

Meimaria 128.

lienirea 228.

rieneàlıia 13.

Metzia 683.

Reyuautia 239.

Iohabdia 631.

Ihagodia 872.

Hhamnus 805 .

lhinacänthus 78.

Rhynchospora 188.

hìhes 850 .

lichea 690.

Richeria 805.

liqueria 556.

Rivina 541.

$110 \ddot{l l a} 616$.

liomanzorvia 658.

Roudeletia 617.

Ropala 535.

Horidula 821.

lioscoea 11.

Hosmarinus 96 .

Rostellaria 67.

Lottboëllia 396.

Houssea 44.

Jotula 631.

Iubia 460.

liudgea 784.

Küngia 78.

Rüppia 558.

lintidea 759.

1 uys schia 835.

\section{s.}

Sabhātia 647.

sābia 804.

sācclıarum 398. 
หagina รัว์.

sialicia 189.

salicōnia 24.

valvadora 4.13 .

salvertia 23.

salvia 82-96.

Samara 497.

sianolus 615 .

sanchēzia 6-1.

sangnisorba 439 .

+antalum 548.

saprosma 459.

Sarunicuta 64 .

sauvagesia 8\%7.

ceahiosa $44 \%$.

sicaerola 785.

vcliaefiera 550.

Achismus 370.

schizantluus 5⿺.

schizostachým $38 \%$.

schmidtia 125.

sichoenefeldia $\mathbf{3 2 9}$.

schoenus 184.

schoepfia $\% 60$.

schrebera 100.

sichwenkfeldia $\mathbf{8 9 2}$.

schwenkia 46.

sicilpus 203.

Scintus 100.

Scolosanthus 459 .

Scoparia 433.

sicyphiphora 483.

sebaea 441.

Necale 391.

selliera 802 .

Seringia 497.

Nerissa 788.

Serrúria 518.

sessea 616 .

Seslēria 348.

setaria 291.

Sherardia 474.

sibthorpia 658.

sickinugia 626.

Siderodèudron 459.

sideroxylon 622.

Simsia 525.

sipanea 619.

Siphanthera 503.

Siphocampylos 636.

sisyrinchium 148.

Sikimmia 498.

solandıa 61t.

solanum 69t.

Soldanella 642 .

Solea 838.

Solena 798.

Sonerila 180.

Sorocephalus 521.
Sparaxis 159.

Niputina 229.

spatalla 521.

Specularia \%.j\%.

ipermacoce 474.

spermadictyon 615.

spermaxyrum 180.

siphaerocarya 856.

- visenoclea 683.

spigelia 681.

spinifex 299.

spinanthera 82.

iporobolus 312.

Aprengelia 689.

sitátia 821.

stachytarpheta 99.

stáelia 481.

silenantiera 633.

stenocāıpus 536.

stenotāphrum 486.

stephanophystum 430.

witilbe 427.

-ípa 300.

stipagrostis 309.

sitipulicida $18 \%$.

Stomatēchium 607.

streblidia 182.

virelitzia 850.

strephium 252.

Streptāchne 304.

streptogyne 385.

stiva 101.

sitroemia 802.

siophānthus 65 เ.

strumpfia $85 \%$.

strutliola 540.

sitrychmos 690.

stylocoryue 794 .

styphelia 633.

sufirenia 104.

sjena 176.

Symiphyandra $1 \% 58$.

sympliyonema 525.

sympliytum 607.

Symapliea 526.

syndesmus 804.

Syphōia 783.

syringa 38.

\section{I.}

Tahernaemontāna 655.

Tectönia 6:\%.

Tertrea 4 šร.

Tessiera 483.

Tetrarrhena $\mathbf{2 3 3}$.

Tetramêrium 456 .

Thela 622.

Thelepogon 414.

Thenardia 653.
Theophrasta 690.

Thesium $8 \% 6$.

Thoniasia 830 .

Thouarea 299.

Tiaridium 610.

Tigridia 151.

Tillaea 416.

Toddalia 830.

Torreya 615.

Toumefortia 627.

Traganum 865.

Trattinickia 615.

Trachēlium 742.

Trapa 505.

Trasia 252.

Trelkeldia 181.

Triaena 336.

Triathera 336.

Trichelostylis 201.

Trichinimm 864.

Trichocārpa 637.

Trichodesma 607.

Trichonema 159.

Trichophorum 207.

Tricycla 590.

Triguera 637.

Triodia 347.

Triodon 481.

Triosetum 780.

Triplasis 337.

Tripsacum 397.

Triraphis $32 \%$.

Trisetaria 339.

Tristachya 344.

Tristicha $2 \%$.

Trisetum 339.

Triticum 387.

Tritonia 154.

Trujanoa 804.

Turpinia 832.

Ucriana 798.

Ulloa 694.

Ullucus 591.

Uniola 384.

Uralepis $34 \%$.

Urochloa 253.

Ustēria 23.

Utricularia 49.

\section{V.}

Valāntia 473.

Valēriana 163.

Vallaris 652.

Vallèsia 611.

Vanguëria 789.

Velleỉa 683.

Ventilago 804. 
Verbāscum 658.

Verōnica 55.

Vieusscuxia 148.

Villarezia 804.

Villarsia 649.

Vinca 655.

Vincentia 207.

Viola 838.

Viscum 543.

Vitis 832.

Vochysia 21.

Vogelia 591 .

W.

Wachendōrfia 170.

Wahlenbergia 751.
Walkēria 830.

Wallenia 430.

Wangenheimia 370.

Watsonia 158.

Webera 792.

Weigelia 591.

Wendlandia 739.

Whitea 64.

- Wibelia 850.

UVillichia $17 \%$.

Willughbeya 614.

Winterlia 821.

Witheringia 711.

Witsenia 161.

Vrightia 65\%。

Wulfenia 63.

\section{X.}

Xerōchloa 414.

Xiphidium 171.

Xylomelum 535.

Xyris 181.

Zea 234.

Zièria 498.

Jingiber 13.

Zizania 231.

Ziziphora, 96.

Yiziphus 808.

Zoysia 398.

Zuccarinia 759 .

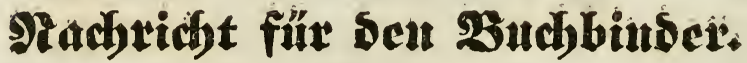

Die mit Seite 443, 645-648 und 835 bezeidjneten Blátter werben auz ben $\mathfrak{B o g e n} 28,41$ uno 53 berauzgejdynitten und bie bort eingelegten Eartonz bafur eingeheftet.

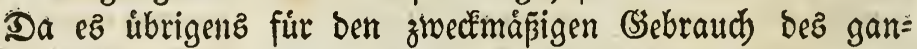

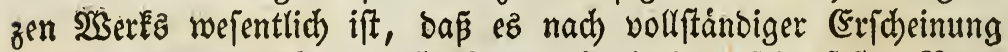
in einen, wenn âth febr ftarken, Dod einzigen febr feften Band gebunden wirb, fo ift ez ratbjam, gegenwartigen erften Theil

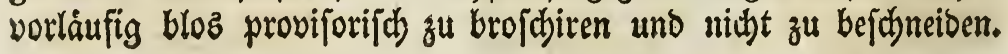




\section{I A S S I S I.}

\section{MONANDRIA.}

\section{MOYOGINIA.}

1. Camina. Anthera simplex marginalis in filamento petaloideo. stylus terminalis. Capsula 3-locularis polysperma. Scitamineae.

2. Dramanta. Anthera simplex marginalis in filamento petaloideo. stylus teretiusculus saepe curvatus. Stigma impressum aut foveolatum. Scitamineate.

3. Phrymivama. Cor. Marantae. Anthera 1-locularis filamento laterali superne adnata. Stigma infundibuliforne. Scitamineae.

4. Hedychirenn. Corollae limbus interior 3-partitus, lacinia media labiiformi. Anthera duplex terminalis in filamento articulato. Scitamineae.

5. Eoscoea. Cal, integer. Cor. limbus exterior tripartitus; interior 2-labiatus, labiis simplicibus. Anthera terminalis incurva basi bicalcarata. Scitaminecie.

6. Apinia. Cal. tridentatus. Cor. limbus interior 1-lahiatus, Iacinulis duabus ad basin. Filamentum uon appendiculatum. Anthera duplex terminalis. Scitamineae.

\%. Hellenia. Cal. 2-3-fidus. Cor. limbus exterior 3-partitus ; interior 1-labiatus, lacinulis duabus ad basin. Anthera filamento lineari coronata. Scitamineae.

8. Renealnnia. Cal. duplex. Cor. limbus exterior 3-partitus, lacinia media antherifera, interior 1-labiatus, anthera opposita. Anthera didyma. Stigma peltatum perforatum triangulare. Scitumineae.

๑. ring Cor. limbus exterior 3-fidus, interior unilabiatus. Filamentum supra antheram rostratum. Anthera duplex. Stylus sulco antherae receptus. stigma infundibuliforme ciliatum. Semina arillata. Scitaminecue.

10. Kaempremia. Cal. tubulosus. Cor. limbus exterior 3-parti- tus ; interior 3-partitus, lacinia media labiiformi. Filamentum petaloideum supra antheram bifidum. Stigma capitatum. Scitaminecue.

11. Costus. Cal. 3-fidus. Cor. limbus exterior 3-partitus, interior 1-labiatus cucullatus fissus. Anthera centro filamenti petaloidei affixa. Stigma 2-lahiatum. Scitamineae.

12. Ang (d) Cor. limbus exterior 3-partitus, interior 1-labiatus. Filamentum 3-fidum, petaloideum, lacinia media antherifera. Anthera duplex. Stigma infundibuliforme. Scitamineae.

13. Curecumar. Cal. 3-dentatus. Cor. limbus exterior 3-partitus, interior 1 - labiatus. Filamentum petaloideum 3-lohatum, lobo medio antherifero. Anthera hasi bicalcarata. stigma capitatum. Scitamineae.

1.4. CHoblon. Cal. 3-fidus. Cor. limbus exterior 3-partitus; interior 3-partitus, lacinia infima labiiformi. Filamentum appendiculatum. Anthera duplex appendiculata aut nuda. Stigma incrassatum. Ścitumineae.

15. Callisthene. Cal.5-phyllus, phyllum supremum calcaratum. Petalum unicum. Capsula corticata 3-locularis 3-valvis, valvulis absque dissepimento, loculis $1-2$-spermis. Semina spermacophoro centrali Iongitudinaliter affixa. Vochysieae.

16. Ann hilloelnia.Cal.5-phyllus, phyllum supremum maximum breve calcaratum. Cor. petalum unicun obcordatum. Anthera 4-locularis. Capsula lignosa 3-locularis 3-valvis, loculis 1-2-spermis. Iochysieae.

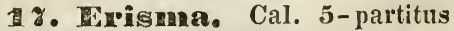
irregularis, lacinia suprema maxima basi calcarata. Cor. petalum unicum obcordatum. Anthera 4-locularis. Filamenta sterilia 3-4 minima. Fructus desideratur. Mart. Vochysiecte.

18. Guarea. Cal. 5-plyllus 5-partitus; phyllum st?prenum hasi 
calcaratum. Cor. petalum unicum (raro duo) obcordatum. Stamen fertile unicum. Filamenta sterilia duo. Capsula 3-locularis 3 -valvis, valvulis medio dorso septigeris. semina numerosa. Vochysieat.

19. Voelnysia. Cal. 5-partitus coloratus, lacinia suprema maxima cucullata basi calcarata. Petala 3. Stamina 3. Filamentum intermedium fertile. Capsula 3-locularis 3-valvis, valvulis loculicidis. Semina apice alata. Vochysieae.

zo. Sulventia. Cal. 5-partitus, lacinia suprema calcarata. Cor. 5-petala subirregularis. Stamen fertile unicum et sterilium rudimenta plerumque duo. Ovarium 3-loculare. Vochysiecte.

21. IInngifera. Cal. 5-partitus. Cor. 5-petala. Stamen unicum fertile, filamentis $2-4$ sterilibus. Drupa 1-sperma, putamine fibrillis lignosis. Terelinthaceae.

2\%. Usteria. Cal. 4-dentatus, dente quarto maximo. Cor. hypocrateriformis 4-partita. Caps. oblonga 2-locularis. Semina numerosa imbricata, margine alato.

23. Lopezia. 4-phyllus caducus. Cor. 5-petala irregularis. Petala 2 lateralia spathulata, inferiore cucullato complicato genitalia impuhia occultante, duo superiora basi glandulosa. Caps. 4-10cularis polysperma. Onagreae.

24. Centurantous. Cal. superus limbo integerrimo involuto. Cor. 5-loba calcarata. Achenium inferum pappo plumoso coronatum. Valerianeae.

25. Phily elrume. Spatha monoplyylla. Perianthium 4-petalum coloratum, petalis duobus angustioribus. Filamenta 3 inferne commata, basi petali exterioris inserta, lateralia petaloidea sterilia. Caps. 3-locularis 3valvis. Semina numerosa. Jancineae.

26. Aploelia. squamac spicae distichae 1-florae. Gluma 1-valvis interior. Utriculus hinc longitudinaliter dehiscens.

\%ร. Folliclain. Cal. 5-dentatus inferus. Cor. 0. Anthera didyma. Stigma bifidum. Semen unicum, fuudo calycis iucrassati inclusum, squama receptaculi carnosa suffultum. Paronychieae.

28. Cextia. Cal. 5-partitus in- tus corollinus, laciniis apice setigeris. Cor. 0. Caps. 1-locularis polysperma. Paromychieae.

29. Salicomia. Cal. integer squamatus tumidus, spicae ita inuidulaus, ut post anthesin foveolae supersint. Senen calyci immersum. Chenopodeae.

30. Haldenemum. Cal, communis amenti squama truncata, proprius e squamis ternis adpressis, post anthesin nuda superest rachis filiformis. Anthera 2-Ioba. Semen calyce persistente tectum. Chenoporlecie.

31. II ippuris. Perianthium subnullum. Stamen germini insidens. Achenium albumine carnoso. Najades.

\section{DIGYNIA.}

32. Psilurus. Spiculae solitariae 2 -florae sessiles. Gluma unica minuta untica. Paleae 2 membranaceae, inferior apice aristata, superiorem involvens. Stam. 1. Caryopsis 3-gona. Gramineae.

33. Fitumn. Cal. 1-phyllus 3-fidus demum coloratus et baccatus. Cor. 0. Semen crustaceum in calyce baccato occultum. Chenopodeae.

3 4. Callituiclne. Cal. 0. Cor. dipetala, petalis incurvis canaliculatis. styli capillares. Capsulae quaternae hinc alatae 1-spermae. Hulorageae.

35. Con'ispenunum. Cal, diphyllus. Cor. o. Anthera ovalis. Styli capillares, stigmatibus acutis. $\mathrm{Ca}-$ ryopsis compressa. Chenopodede.

36. DIniarum. Cal. 4-fidus urceolatus persistens. Cor. 0. Anthera didyma. Utriculus 2-spermus calyce cinctus. Chenopodeae.

3\%. Aspicaria. Perianthium 5-partitum $\ddot{3}$-bracteatum. Stamen brevissimum anthera obcordata. Stigma truncatum 2-lobum. Nucula 1sperma. Malpiglieae.

\section{TRIGYNIA.}

38. Tristichn. Cal. 3-phyllus inferus. Cor. 2 -petala. Anthera filamento laterali adnata. Styli reflexi. Capsula 1-locularis 3-valvis. Semina minuta. Najades.

\section{POLYGYNIA.}

39. Centrolepis. Spatha 2valvis multiflora. Receptaculum pi- 
leaceum vel nudum. Cal. 2-valvis. Styli 3-10, distincti vel basi commati. Utriculi 1-spermi longitudinaliter dehiscentes. Restiaceae.

40. Mepyran. Spatha 2-valvis 1-pauciflora. Cal. o. Styli plures basi connati. Germina plura, axi communi adnata lateralia. Restiaceae.

\section{HONOCYNA.}

\section{CANNA C. Gesn. (1561).}

A. Cor. limbo interiore tubo longiore.

1. C. coccinea Ait. fol. oblongolanceolatis acuminatis filiformi-apiculatis ; laciniis limbi cor. interioris erectis, lateralibus latioribus emarginatis, media minore. C. rubra W. C. indica B. M. 454. In Jamaica et Amer. austr. 4.

2. C. occidentalis Rosc. fol. oblongo-ovatis acuminatis; sepalis ovato-oblongis; Iaciniis labii superioris subspathulatis strictis, interdun una alterave tripartita; lab. infer. revoluto. B. H. 922. In Ind. occ. 4.

3. C. chinensis W. fol. oblongoovatis acuminatis; laciniis lah. superioris lanceolatis patulis sub-2-partitis; lab. inferiore lineari-spathulato revoluto. C. indica hosc. mon. pl. t. 41. In China, Brasilia et Cochinchina. 24.

4. B. Roscoeana Hort. Berol. fol. oblongo-lanceolatis acuninatis ; laciniis lab. superoris ohlongo-spathulatis patentibus subbipartitis; lab. inferiore lineari-spathulato 2-partito revoluto. In Ind. 4 .

5. C. lutea Ait. fol. oblongo-ovatis acuminatis; sepalis ovatis obtusis; laciniis lab. sup. lineari-spathulatis, rarissime una alterave bipartita, lab. inf. lineari revoluto. Rosc. t.58. In $\mathrm{Am}$. austr. 4.

6. C. commutata Bouché; fol. ovatooblongis acuminatis; Iaciniis lab. superioris sublinearibus, rarissime una alterave 2 -partita; lab. inf. sublineari nutante. C. lutea Hortul. In Amer. austr. 4.

\%. C. maculata $L k$. fol. ovatis acuminatis; laciniis lab. superioris oblongo-spathulatis patentiusculis, rarissime una alterave bipartita. pallidae var. Rosc. t. 18. In Ind. occ. 4 .

s. C. pallitla Rosc. $t$. 17. fol. lanceolatis acuminatis; Iaciniis lab. superioris patentibus, rarissime una alterave bipartita; lab. infer. lineari revoluto. In Amer. austr. 4.

9. C. flavescens LK. fol. ovatolanceolatis acuminatis; laciniis lab. superioris lanceolatis erecto-patentibus, interdum una alterave 2-partita; labio inferiore lineari spathulato subrevoluto. C. orientalis Rosc. t. 50. In Ind. or. 4.

10. C. layunensis Iindl. B.R. 1311. fol. ovato-oblongis longe acuminatis; laciniis lab. superioris angustato-lanceolatis patentibus, rarissime una alterave bipartita; lab. inferiore sublineari revoluto. In Mexico. 4. Cor. lutea.

11. C. tenuiflora Bouché; fol. ovatis acuminatis; laciniis lab. superioris lineari-spathulatis substrictis rarissime una alterave bipartita; lab. inferiore lineari nutante. In Ind. occ. 4. Cor. purpureo-miniata.

12. C. Ehrenbergii Bouche'; fol. subovatis acuminatis; sepalis obtusis coloratis; laciniis lah. sup. oblongospathulatis cum labio inferiore lineari patentibus. $\quad$ In ins. St. Thomae. 4. Cor. purpureo-Iutea.

13. C. polymorpha Hort. Berol. fol. oblongo-ovatis acuminatis; sepalis acutiusculis; laciniis lab. sup. lanceolatis erectis; lab. inferiore oblongo lineari oblique deflexo apice revoluto. Patria ignota. 4. Cal. sanguineus.

1t. C. leptochila Bouche; fol. oblongo-ovatis subacuminatis; sepalis acutis coloratis; laciniis lab. sup. strictis lanceolatis; Iab. inferiore lineari oblique deflexo. Patria ignota. 2.

15. C. orientalis Rosc. $t$. 49. fol. oblongo-ovatis acuminatis; laciniis lab. sup. lanceolatis patentiusculis; lab. inferiore lineari-spathulato revoInto. C. indica Roxb. In Ind. or. 4.

16. C. humilis Bonché; fol. subovatis acuminatis; laciniis lab. super. spathulatis erectis subbipartitis; lab. infer. oblongo-spathulato oblique deflexo. In China. 24. Cor. coccinea.

1\%. C. aurantiaca Rosc. $t$. 7t. fol. ovato-lanceolatis acuminatis; Iaciniis lab. superioris patentibus; lab. 
inferiore sublineari deflexo. In Brasilia. 4.

15. C. speciosa B. M. 231\%. fol. oblongis acuminatis; laciniis lab. superioris oblongo-spathulatis erectopatentibus rarissime 2-partitis; lab. infer. recurvato. C. bifida Herb. In Nepalia. 4.

19. C. compacta Rosc. t. 9. fol. oblongo-ovatis acuminatis; laciniis labii stiperioris oblongo-spathulatis erecto-patentilus rarissime 2 -partitis; lab. inferiore lineari nutante. Patria iynota. 4.

20. C. lanuginosa Rosc. $t .89$. fol. oblongo-ovatis hreve acuminatis; laciniis lab. sup. oblongo-spathulatis erecto-patentibus; lab. inferiore spathulato subrevoluto. In Ind. or. 4.

21. G. Achiras Gill. B. R. 1358. fol. ovato-oblongis abrupte acuminatis: laciniis lah. super. lanceolatis substrictis; lab. infer. oblongo-spathulato recurvato. In Mendosa. 4.

22. C. indica $L$. fol, ovatis acutis; laciniis lab. superioris strictis oblovero-spathulatis rarissine 2-partitis; lah. inf. oblongo revoluto. B. $R$. 156. C. varialibis IV. In Ind. or. b. Cor. purpurea.

23. C. carnea Posc. $t$. 66. fol. late lanceolatis acuminatis; laciniis lab. sup. oblongo-lanceolatis strictis; Iabio inferiore lineari revoluto. In brasilia. 4.

21. C. Lamberti Lindl. B. R. 17. fol. oblong 0 -lanceolatis acuminatis; lacinis lab. sup. oblongis patentibus; inferiore lineari-spathulato revoluto. Rosc. t. 97. C. maxima Lodd. In Amer. austr. et ins. T'rinit. 4.

25. C. edulis Ker B. R. 7\%5. fol. ovalibus hrevissime acuminatis supra nedium concavis; laciniis lah. sup. oblongo-spathulatis patulis apice reflexis; lab. inf. oblongo revoluto. B. M. 2498. C. indica $R$. et $S$. In Peruvia. 4.

26. C. discolor Lindl. B. R. 1231. fol. oblongo-ovatis acutis rubro-marginatis; laciniis lab. superioris oblongo-spathulatis patentibus; lab. inf. spathulato revoluto. In ins. Trinidad. 4.

2\%. C. mexicana H. Berol. fol. lanceolatis acutis glaucescentibus; laciniis lab. superioris oblongis reflexis; lab. inf. oblongo revoluto. C. glauca ß. rufa B. M. 2302. C. liturata Lk.

In Mexico. 4.

28. C. nepalensis I. Par. fol. oblongo-lanceolatis acuminatis glancescentibus clavato-apiculatis ; Iaciniis lab. sup. oblongo-spathulatis deflexis; lab. inferiore sublineari revoluto. In Nepalia. 24. Cor. viridi-purpurea.

29. C. glanca $L$. fol. lanceolatis acutis glancis; laciniis lah. superioris oblongo-spathulatis patentibus apice deflexis; lah. inf. lineari revoluto. Red. Lil. t. 354. Hosc. t. 105. In Ind. occ. 4.

20. C. stolonifera H. Berol. fol. anguste lanceolatis acutis glaucis; laciniis lab. superioris oblongis deflexis; lab. inferiore oblongo revoluto. In Montevideo. 2.

31. C. flaccilla Salisb. fol. oblongo-lanceolatis acuminatis glaucescentibus; laciniis lab. superioris cuneatospathulatis flaccidis; lab. inferiore orhiculato bilabiato. C. glauca $\beta$. flaccida W. Red. t. 106. In Carolina. 4.

32. C. pedunculatis Sims. B. M. 2323. fol. oblongo-lanceolatis acutis clavato-apiculatis; laciniis lab. superioris oblongo-cuneatis recurvis; lab. inf. oblongo revoluto. C. Buckif Weinm. C. reflexa Nees. In Brasilia. $2 \%$.

33. C. patens Rosc. fol. lanceolatis acutis longe capillace 0 -apiculatis; laciniis lah. sup. ohlongo-spathulatis apice deflexis; lab. infer. lineari-spathulato deflexo. B. M. 444. C. thyrsiflora Hegetsw. Comm. t. 1. f.8. C. crocea R. et S. In ins. Helenae.

31. C. limbata Rosc. fol. lanceolatis acutis subapiculatis; laciniis labii superioris oblongo-spathulatis patentibus apice deflexis; lab. inferiore lineari-spathulato nutante. B. R. 771. C. aureo - vittata Lodd. C. patens Hook. exot. fl. to 222. In Brasilicl. 4.

35. C. Sellowii H. Berol. fol. oblongo-lanceolatis acuminatis; laciniis lah. superioris deflexis; lab. inferiore sublineari revoluto. In Brasilia. 4. 4-6-ped. Cor. ext. Iutea inter. coccinea. B. Cor. limbo interioro tubo
breviore.

36. C. sylvestris Rosc. t. 81. sepalis lanceolatis acutis; laciniis labii 
superioris linearibus convergentibus; lab. inf. sublineari declinato. Patria ignota. 2.

37. C. gigantea Desf. vaginis crispis; fol. oblongo-lanceolatis acuminatis junioribus fusco-marginatis ; laciniis lab. superioris oblongo-spathulatis divaricato-patentibus; lab. inf. spathulato divaricato-patente. Red. t. 331. C. latifolia Rost. t. 34. C. gemella Nees. In Brasilia. 4.

38. C. xalapensis II. Berol. vag. crispis ; fol. lineari-lanceolatis acuminatis; laciniis lab. sup. oblongo-spathulatis patentissimis; lab. infer. lineari-spathulato. In Jalapa. 4. 45-ped. Cor. miniata.

39. C. heliconiaefolia $\boldsymbol{H}$. Berol. vag. superne crispis; fol. oblongolanceolatis acuminatis; laciniis Iah. sup. lineari-spathulatis patentibus apice incurvis; lah. inf. lineari-spathulato patente apice recurvo. In Mexico. 24. 4-8-ped. Cor. ext. rubro-ochracea.

40. C. iridiflora $R$. et $P$. vag. superne crispis; fol. ohlongo-lanceolatis acuminatis brevissime setace 0 -apiculatis subtus deciduo-lanatis; laciniis lab. sup. oblongis deflexis; lah. inf. ovato bifido apice deflexo. B. M. 1968. B. H. 609. Kosc. to 33. In Peruvia. 4.

41. C. Renudata Rosc. t. 25. vag. rubro-narginatis; fol. lanceolatis acuminatis; cor. lab. sup. deficiente, Infer. sublineari recto. Patria ignota. 2 .

42. C. brasiliensis Spr. fol. late lanceolatis acutis; lah. sup. deficiente; lab. infer. spathulato recto. C. denudata Rosc. t. 20. In Brasilia. 4.

43. C. miniata Bonclé,; vag. rubro-marginatis; fol. oblongo-lanceolatis acuminatis; lab. supericre deficiente, inferiore sublineari recto. In Brasilia. 4.

44. C. Linkii Bouche'; vag. ruhromarginatis; fol. ovato-oblongis acuminatis ; sepal. basi coloratis; lah. sıperiore deficiente; lab. inf. oblongolineari erecto. In Brasilia. 4.

\section{Species dubiac.}

15. C. paniculata $R$. et P. peruv. Ł. 1. f. a. fol. ovatis subtus lanatis argenteis ; petalis interioribus breviortbus. In f'erucia. 4.

46. C. pentaphylla Nees et Mart. in Nov. Act. XI. fol. ovatis glabris; pedunc. geminis; cor. limbo interiore 3-partito genitalihusque rectis aequalibus. In Brasilia. 4.

17. C. angustifolia $L$. fol. lanceolatis petiolatis costatis. W. sp. pl. In Amer. austr. 24.

48. C. juncea Retz; fol. linearibus nervosis Retz. In China. 4.

49. C. montani Blume; fol. ovato-lanceolatis marginatis; flor. geminatis subsessilibus; cor. lab. inter. 3-partito, laciniis obtusis, labello reflexo. In Java. 24. Cor, coccinea.

\section{MARANTA Plum.}

\section{Caulescentes.}

1. M. dichotoma Roxb. fruticosa dichotoma; fol. cordatis acuminatis glabris. Roxh. ind. 1. p. 17. Arundinastrum Tonchat. Rumph 4. t. 17. In benqulia. 24. 3-ped. Cor. alba.

2. Mr. Tonchat Aubl. caul. articulato fruticoso erecto compresso; ramis dichotomis hirsutis ; fol. ovato-lanceolatis breviter nodoso-petiolatis glabris ohliquis; caps. ovata. Rosc. m. pl. t. 51. M. angustifolia Sims. Bot. Mag. 2393. In Gujana et Cayenna. ち. Rad. repens. Cor. pallide caerulea.

3. M. indic r Rosc. caul. ramoso fruticoso; ram. dichotomis glabris; fol. longe petiolatis lanceolatis basi cordatis glabris, carina subtus villosa; panicula panciflora; ped. bifloris. Alb. Dietr. sp. pl. 1. p. 18. M. sylvatica smitl. M. arundinacea Aubl. In Barbados. 4. Rad. tuberosa. Cor. alba.

4. M. Jacquini Schult. caule ramoso glahro; fol. breviter petiolatis ovatis glabris; panicula spicaeformi; spicis alternis distichis; bracteis involutis. Alb. Dietr. 1. c. M. lutea Jacq. ic. t. 70. In Brasilia et Caracas.24. Rad. tuberosa. Cor. albida.

5. M. cuspidala Rosc. m. pl. t.99. caul. erecto articulato; fol. ovatis acutis basi cordatis apice apiculatis ohliquis, costa pubescente; petiolis Iongis erectis intermediis hirsutis; for. geminis. Rosc. In Sierra Leona. 4. Cor. lutea purpureo-irrorata. 
6. M. cristata N. et M. culmo ramoso herbaceo; foliis ellipticis apiculatis subtus pubescentibus; pedunc. cristato-paniculatis secundis; peclicellis 2-floris. Nees et Mart. 1. c. p. 25. In Brasilia. 24. Cor. alba.

\%. I. furcatu $\mathrm{N}$. et Mr. culmo stricto dichotomo; fol. ohlongo-lanceolatis sessilibus glaherrimis; pedunc. geminatis $\boldsymbol{z}$-floris; germ. pubescente. Nees et Mart. 1. c. p. 24. In Brasilia. 24. Cor. alba.

8. MI. arundinacea L. culmo ramoso berbacco; fol. ovato-lanceolatis subtus pilosiusculis; pedunc. 2-floris. Willd. sp. pl. 1. p. 13. Ihed. Lil. 1.57. Hosc. n. pl. t. 27. In Ind. occidentali. 4. Cor. alba.

9. N. gibba Sm. rad. filırosa; caul. fruticoso dichotomo: fol. alternis cordato-lanceolatis aequilateralibus angustis breviter petiolatis; petiolis pilosis; semine gibhoso. Hosc. MI. pl. 1. 11. In Barbados. t. Cor. alba.

10. M. divaricata Rosc. caul. herbaceo erecto dichotome ramoso; fol. alteruis late lanceolatis acutis obliquis subtus glaucescentibus. Kosc. m. pl. t. 64. In Brasilia. 24. Cor. alba.

11. M. geniculata L. caul. ramoso; fol. lanceolatis acutis, costa superne curvata; floribus paniculatis; ramis pedunculisque geniculatis; bracteis florum geminatis inaequalibus 2-floris. All). Dietr. 1. c. In America meridionali. 24. 4-6-ped. Cor. alba violaceo-maculata.

12. H. mirpurascens Link. caul. lierbaceo; vaginis imhricatis; ramis dichotomis; fol. ovato-acutis subtus costaque pallide purpureis. M. divaricata var. Rosc. 111 . pl. t. 68. In Brasilia. 4. Cor. alba. Siemen succosum.

13. M. virgata Alb. Dieir. caule simplici; fol. distichis lanceolatis; spica termiuali filiformi composita. Phrynium Roxb. 1. c. p. 4. In Malabaria.21. 6-8-ped. Cor. alha inodora.

14. M. racemosa $A l b$. Dietr. caule simplici; fol. subpetiolatis oblongolanceolatis acutis, costa puhescente; racemo terminali; pedunc. pubescentibus. Willd. sp. pl. p. 21. Thalia Humb. In America meridionali. 4.

15. M. Myrosma Alb. Dietr. caule ramoso; fol. petiolatis lanceolatis acutis subtus glaucescentibus; spica petiolari imbricata pedunculata; hracteis generalibus rhomboideis. Alb. Dietr. 1. c. p. 22. Phrynium Hosc. m. pl. t. 90. In regno Surinamo. 4. 13-ped. Cor. alba.

16. H. commessa Hort. Berol. caule ramoso compresso; fol. petiolatis lanceolatis; spica petiolari breve pedunculata imbricata; bracteis generalibus ovatis acuminatis carinatis. Alb. Diett. sp. p. I. p. 22. Hab.... 4 . 3-4-ped. Cor. Iutea.

1\%. U. setosa Rosc. fol. lanceolatis obliquis; spica petiolari imbricata hasi concava apice convexa lirsuta; bracteis exterioribus cordatis acuminatis extus hirsutis purpureo-marginatis, interioribus alatis s. carinatis albis. Rosc. 111. p. t. 107. In Brasiliu. 21. z-ped. Cor. alba. s. pallide caerulea.

18. M. niveifior Alh. Dietr. caule glabro; fol. longe petiolatis anguste lanceolatis glahris subtus glaucescentibus; spica petiolari subpedunculata; bracteis gencralibus orbiculatis. Alb. Dietr. sp. pl. 1. p. 23. In insula Trinidad. 4. 2-ped. Cor. nivea.

19. M. gracilis Rudge Guj. t. 3. fol. ovatis cumeatis mucronatis; spicis gracilibus terminalibus. Rudge. In Gujana.

20. M. humilis Aubl. culmo ramoso folio breviore; radicibus tuherosis. Aubl. I. c. In Cayenna. 24. Fl. albi.

21. M. polyphylla; caule adscendente geniculato; ramis fasciculatis; fol. ovato-oblongis acutis glaberrimis; spicis terminalihus solitariis teretibus; hracteis pubescentihus; vaginis ciliatis. Calathea Poepp. et Endl. t. 121. In Irrasilia. †.

22. M. rotundifolia; caule scandente geniculato; fol. ovato-oblongis acutis glaherriuis; spicis solitariis teretibus deflexis curvatis; cor. tubo sericeo. Calathea Poepp. et Endl. In Peruvia. 4.

23. M. hexantha; paniculis lateralibus geminis pedunculatis compressis: pedicellis secundis ternis bifidis bifloris; bracteis lineari-lanceolatis secundis; fol. glahris. Thalia Poepp. et Endl. t. 122. In Pernvia.24. 2-ped.

24. M. unilateralis; racemis lateralibus geminis inaequalibus compositis cristato-compressis; bracteis secundis rhombeo-ovalibus; fol. glabris; 
caule pubescente. Thalia Poepp. et Endl. t. 123. In Peruvia. 24.

25. M. lencocephala; caule humili simplici abido; fol. ovato-oblongis acuminatis longe petiolatis subtus glaucis; spicis strictis ramosis; limbi ext. laciniis linearibus. Calathea Poepp. et Endl. t. 129. In Peruvia. 4. 1 $\frac{1}{2}-$ ped. Cor. alba.

26. M. Laxa; caule glaberrimo laevigato apice $1-p h y l l o$; folio lineari oblongo; paniculae ramis longissimis; spicis distichis compressis. Calathea Poepp. et Endl. t. 130. In Peruvia.4.

2\%. M. bambusncea; caule scandente geniculato; ramis ad nodos fasciculatis; fol. oblongo-lanceolatis acuminatis glaberrimis; spicis simplicibus teretibus. In Peruvia. 24. 2030-ped. Cor. albida.

M. pumila Arab. Fl. flum. I. $t$. s. In Brasilia.

M. clarata Arab. Fl. flum. t. 9. In Brasilia.

M. prolifera Arab. Fl. flum. t. 10.

In Brasilia.

M. monophylla Arab. Fl. flum. $t$. 11. In Brasilia.

M. mischantha Arab. Fl. flum. t. 12. In Brasilia.

M. tuberosa Arab. Fl. flum. t. 13. In Brasilia.

\section{A caules.}

28. M. dealbata Fras. fol. latis lanceolatis acutis longe petiolatis; scapo simplici; spica composita; bracteis imbricatis ovatis incanis 2-floris. Alb. Nietr. sp. pl. 1. p. 22. Thalia Rosc. m. p. t. 75. Peronia stricta. Red. Lil. t. 342. In humidis Carolinae. 4. 4-6-ped. Cor. rubro-caerulea.

29. M. bicolor Ker. Bot. Rey. 786 . opica laxa usque ad medium vaginis petiolorum involucrata; floribus alterne fasciculatis; fol. late-ovatis cuspidatis subtus rubro-ferrugineis; geniculis pilosis. Rosc. m. pl. t. 59. In Brasilia. 24. Cor. alba rubro-maculata.

30. M. obliqua Rudge; fol. ellipticis apice oblique truncato-acuminatis; spicis fasciculatis elongatis. Rudge Guj. p. 8. t. XI. In Gujana et Surinamo. 24. Cor. rubra.

31. M. Parkeri Rosc. fol. radicalihus longe petiolatis late ovato-ellipticis; scapo articulato erecto radicali lanato; spica fasciculata imbri- cata; bracteis generalibus ovatis strictis mucronatis. Phrynium Rosc. nl. pl. t. 69. In Granata. 4. Cor. Iutea. 32. M. zebrina Sims. Bot, Mag. 1926. fol. radicalibus oblique ovatooblongis supra zonatis subtus purpurascentibus; spica compacta. Plirynium Rosc. t. 52. In Brasilia. 4.

33. M. flavescens Lindl. Bot. Reg. 932. fol. radicalibus oblongis acuminatis glaberrimis subtus glaucescentibus; capitulo sessili ovato; bracteis generalibus lanceolatis acutis flore hrevioribus. Alb. Dietr. 1. c. In Brasilia. 4. Cor. lutea.

34. M. violacea Alb. Dietr. fol. radicalibus longe petiolatis late ovatis; scapo petiolari erecto; spica cylindrica conglomerata; bracteis generalibus orbiculatis strictis. Calathea Lindl. Bot. Reg. 962. Phrynium Rosc. t. 106. In Brasilia. 24. Cor. violacea.

35. M. longebracteata Lindl. Bot. Reg. 1020. fol. radicalibus longe petiolatis ovato-oblongis lucidis subtus pubescentibus ; spica petiolari subconglomerato-squarrosa breve pedunculata; hracteis lanceolatis flore duplo longioribus. Alb. Dietr. 1. c. In Brasilia. 24. Cor. violacea.

36. M. grandifolia Lindl. petiolis longis cylindricis hasi vaginatis aplculatis subundulatis lucidis glabris concoloribus; capitulis oblongis; bracteis undulatis olutusis flore brevioribus; Iabio cuneato apiculato. Calathea Lindl. Bot. Reg. 1210. In Brasilia. 2. Cor. Iutea.

37. M.truncata Link. fol. radicalibus petiolatis ovalibus acutiusculis subtus pubescentibus; scapo laevi; spica oblonga imbricata; hracteis gen. latis truncatis integris. Alb. Dietr. 1. c. In Brasilia. 24. Cor. lutea.

38. M. cylindrica Rosc. fol. latis ovatis inaequilateralibus, acutiusculis; spica cylindrica erecta; bracteis exterioribus cordatis apice recurvis 2-floris. Phryuium Rosc. m. p. t. 101. In Amer. meridionali. 4 . Cor. Iutea. 39. M. macilenta Lindl. in Bot. Reg. 1210. fol. oblongo-lanceolatis glabris; petiolis marginatis vaginatis; spicis ovatis subnutantibus compressis; bracteis gen. subrotundis planis. Alb. Dietr. 1. c. In Brasilia. 24. Cor. alba.

40. M. Casupo Jacq. fol. radicalibus petiolatis lanceolato-ovatis acu- 
tis subtus pruinosis; scapo petiolari superne folioso; spicis oblongis imbricatis; bracteis generalibus ovatis concavis coriaceis. Alb. Dietr. 1. c. Calathea lutea Meyer. Phrynium hosc. t. 84. In America meridionali. 4. 12-14-ped. Fol. 2-3-ped. Cor. lutea.

41. M. Arouma Aubl. caule virgato inferne nudo; fol. caulinis petiolatis; pedunc. communibus squanosocoriaceis; corollis 5-partitis. Jacq. Fragm. t. 72. Mr. petiolata Rudge Guj. t. 37. Calathea juncea spr. In Gujana et Surinumu. 24. Lad et Cor. rubra.

42. $M$. capitat $\boldsymbol{R}$. et $P$. caule simplici apice florifero; capitulo depresso. Huiz. et Pav. peruv. 1. t. 5. In Peruvia. 24. Cor. lulea. 21.

43. II. lateralis; scapo simplici ad medium florifero; capitulo globoso. Ruiz. et Pav. I. c. In Peruria. 4.

41. M. comosa L. acaulis; scapo nudo spicaeformi comoso; comae foliolis reflexis. Linn. suppl. p. 80. Mr. Myrosma spr. Phryuium Rosc. t. 91. In Surinamo et Ind. occidentali. 4. 3-ped. Fol. 2-ped. Ionga. Cor. Intea.

45. M. Allouy A Abl. caulescens; fol. ovato-lanceolatis petiolatis nervosis; spica ovata pedumculata terminali. Jacq. fragm. t. 71. In Martinica et Domingo. 24. 2-3-ped. Cor. alba.

46. M. ovata $N$. et $M$. scapo 1folio ; fol. radicalibus oblongo-ovatis acuminatis subtus pubescentihus; spica ovala. Nees et Mart. N. Act. XI. p. 27. In Brasilia. Cor. Intea.

1\%. M. spicata Aubl. acaulis; scapo radicali spicaeformi imbricato fol. breviore; fol. oblongis acuminatis. Nees et Mart. 1. c. Phrynimn ellipticum. Hosc. t. 81. In Hrasilia. 7. Cor. straminea.

48. IM. grandiflora Alh. Dietr. fol. radicalibus longe petiolatis late lanceolatis; flor. centralibus radicalibus; bracteis generalibus 1-floris lanceolatis acutis floribus hrevioribus. Alh. Dietr. sp. pl. 1. p. 30. Phrynium llosc. t. 43. In Brasilia. 24. Cor. magna pallide flava.

4.9. M. parviflora Roxb. acaulis; fol. radicalihus longe petiolatis late lanceolatis acutis; spica petiolari sessili subglobosa imbricata. Phrynium Rosc. t. 2. In Bengalia. 2. Cor. albu-aurantiaca.
50. M. Placentaria Alb. Dietr. acaulis; fol. radicalibus longe petiolatis oblongis; capitulis pedunculatis terminalibus glomeratis; bracteis truncatis incurvis. Koxb. ind. Naru Killa Hort. Malah. XI. t. 34. In India orientali. 2. Cor. purpureo-rosacea.

51. M. imbricata Alb. Dietr. fol. radicalibus longe petiolatis oblongolanceolatis utrinque attenuatis; spica hreviter pedumculata; bracteis generalihus trumcatis ovatis multidentatis. Alb. Dietr. I. c. Phrynium Roxh. In Bengalia. 4. Cor. pallida rubro-fuscescens.

52. M. caespitosa Alb. Dietr. acaulis; fol. radicalibus distichis oblongis; spicis radicalibus petiolis brevioribus subcylindricis distichis imbricatis. Joxb. ind. 1. p. 5. In Pegu. 4. Cor. alba.

\section{PHRYNIUMI W. (1797).}

1.P. exscapum Poepp. et Endl. t.126. acaule; spicis sessilibus ovoideis; bracteis imbricalis ovatis acuminatis puberulis; stylo villoso; petiolis hasi sericeis; fol. oblongis actminatis glabris. In Peruvia. 24. Cor. alba.

2. P. propinquum Poepp. et Endl. acaule; spicis scssilibus ovoideis; bracteis imbricatis ovalibus puberulis; cor. tubo villoso; stylo petiolisque glabris; fol. late ovalibus obliquis. In Peruvia. 24. Cor. albida.

3. P. chrysoleucum Poepp. et Endl. acaule; spicis pedunculatis cylindricis; bracteis oblongis acutis petiolisque glaberrimis; cor. extus pilosa; fol. latissime ovalibus. In Peruvia. 4. Cor. flavida.

4. P. velutinum Poepp. et Endl. t. 126. acaule; spicis pedunculatis turbinatis; bracteis imbricatis subrotundis molliter ferrugineo-villosis; cor. glaberrima; fol. subrotundis subtus pubescentibus supra zomatis. In $\mathrm{Pe}$ ruvia. 4. Cor. lactea.

5. P. pachystachyum Poepp. et Endl. $t$. 12\%. acaule; spicis pedunculatis cylindricis elongatis compositis; bracteis foliaceis puberulis; cor. tubo villoso; fol. oblongis acuminatis glaberrimis, In Peruvia. 24. Petioli 83-ped. 
6. P. microcephalum Poepp. et Endl. $t$. 128. $a-b$. spicis longe pedunculatis ovalibus; bracteis subrotundis apice reflexis acuminatis glaberrimis; fol. oblongis utrinque rotundatis. In Peruvic. 2. Cor. alba purpureo-punctata.

\%. P. altissimum Poepp. et Endl. spicis longissime pedunculatis ovoideis; bracteis lineari-lanceolatis adpressis; cor. villosa; fol. oblongis acutis glaberrimis. In peruvia. 4. Cor. albida.

8. P. dicephalum Poepp. et Endl. t. 128. spicis suhcylindricis; bracteis imbricatis rotundis apiculatis floribusque glaberrimis; fol. ovato-acuminatis subtus argenteis. In Peruvia. 4. 2-ped. Cor. albida.

9. P. maximum Blume; fol. radic. maximis bifariis oblongis acuminatis; spica centrali composila; spiculis bifariam imbricatis. In Java. 4.

10. P. latifolium Blume; fol. radic. bifariis lato-oblongis acuminatis; spica radicali pedunculata bracteis bifariam imbricata. In Java. 4.

11. P. pubigerum Blume; fol. radic. late oblongis utrinque acutiusculis glabris; spicis solitariis sessilibus; bracteis imbricatis sericeis. In $\mathbf{J} a$ e'a. 4.

12. P. pubinerve Blume; fol. radic. oblongis utrinque acutis subtus pubescentibus; spicis glomeratis sessilihus; bracteis floralibus partim cristatis. In Java. 4.

\section{HEDYCHIUM Koenig (1783).}

1. H. coronarium Koen. fol. lanceolatis; spica compacta imbricata; laciniis corollae lab. semilunatis. Roxb. find. 1. p. 1. Rosc. t. 7\%. In Bengalia. 24. Cor. alba.

2. H. maximum Rosc. fol. sessilibus late lanceolatis, subtus pubescentibus; spica capitata imbricata; filamentis lab. brevioribus; lab. latissimo 2-lobo ; bracteis superioribus imbricati.s. Rosc. t. 29. Hab..... 24. 1012-ped. Cor. alba lacinia media lutea.

3. H. fluvescens Carey; spica terminali capitata imbricata; bracteis exterioribus cylindricis $\mathbf{2}-\mathbf{3}$-floris; filamento crasso longitudine labii lati bilobi. Irosc. t. 20. In India. 4. 6-8-ped. Cor. pallide flava.
4. H. flavum Wall. fol. Iatis lanceolatis; spicis termiualibus imbricatis; bracteis sub-4-floris; laciniis interioribus corollae linearibus; lab. obcordato apice retuso. $130 \times \mathrm{xb}$. ind. 1. p. 12. Rosc. t. 19. In Bengalia. 4. Cor. lutea.

5. H. spicatum Smith; spica terminali simplici laxa imbricata; bracteis exterioribus latis ovatis apicibus pilosis; filanento lab. breviole; lab. profunde 2-fido; cor. Iacinia exteriore erecta; fol. anguste lanceolatis. Rosc. t. 58. Bot. Mag. 2300. In Nepalia. 4. 3-ped. Cor. sordide alba.

6. H. gracile Roxb. fol. Ianceolatis; spicis terminalibus laxis; flor. solitariis sparsis; laciniis labii bifidi sessilis lanceolatis. Roxb. ind. 1. p.12. In Bengalia. 24. Cor. alba.

\%. H. ellipticum Smith; fol. late lanceolatis glabris; spica capitata imbricata; bracteis exterioribus ovatis acutis 1-floris; labio ovato acuminato apice subbifido filamento breviore. Alb. Dietr. 1. c. hosc. m. pl. t. 45. In Nepalia. 4. 4-5-ped. Cor. flava.

8. H. thyrsiforme Smith; fol. ellipticis undulatis filiformi-acuminatis subtus pubescentibus; spica ovata densa; bracteis exterioribus convolutis subreflexis 2-3-floris; labio profunde 2-partito filamento breviore; laciniis lanceolatis. Alb. Dietr. 1. c. Rosc. t. 6. H. heteromallum. Bot. Reg. 767. In Ind. orient. et Nepalia. 24. Cor. alba.

9. H. acuminatum Rosc. $t$. 12. fol. lanceolatis subtus villosis; spica laxa; bracteis cylindricis mucronatis 1-floris; labio oblongo profunde 2-partito filamentum recurvum superante; laciniis acutis. Alb. Dietr. Cor. flava.

10. H. glaucum Rosc. $t$. 3. fol. lanceolatis acutis subtus glaucis; spica gracili; bracteis exterior. cylindricis 1 -floris; lab. ovato profunde 2 -fido filamento breviore; laciniis acutis. Alb. Dietr. In Ind. orient. 24. Cor. alba.

11. H. villosum Wrall. fol. lato ovatis acuminatis nervo medio margineque pubescentibus; flor. itregularibus; bracteis exterior. involutis tubulosis villosis; lab. oblongo profundo 2-fido filamento breviore. Alb. Dietr. 1. c. Rosc. t. 85. In Bengalia. 24. Cor. alba fragrans.

12. H. Gardnerianum Rosc. . 13. 
spica laxa regulari; nor. 6-stichis; bracteis 2 -floris; lab. lato 2 -fido ovato filamentis duplo longiore; caps. 3-loculari. Hosc. 1. c. In Nepalia. 4. Cor. lutea. Caps, ribra.

13. H. speciosum Wall. fol. obIongo-lanceolatis margine subundulatis; spica elongata; fasc. aproximatis bifloris; hracteis exteriorihus magnis obtusis; lab. ovato integro acuto. Hoxh. ind. 1. p. 13. In Bengulia. 24. Cor. extus virens.

14. H. elatum Bot. Reg. 526. fol. late lanceolatis acmminatis subtus rlaucis villosis; spica 6-sticha; bracteis exteriorihus cylindricis 3-4floris; lab. bilobo filamento hreviore, lobis ellipticis obtusis. Alb. Dietr. l. c. Bot. Cal. 856. Hosc. t.36. In Nepalia. 4. Caul. 12-ped. Cor. flavescenti-alba. Lab. hasi incarnatum.

15. H. carneum Lodd. fol. lanceolatis cuspidatis subtus vaginisque vilJosis; spica 6-sticha; rachi hirsuta; hracteis exterioriluus lanceolato-tubulosis 2-floris; lah. biloho filamento hreviore; lobis ellipticis. Alb. Dietr. 1. c. Bot. Cah. 693. Bot. Mag. 2637. Mosc. t. 92. In India orient. 4. Caul. ¿-6-ped. Cor. incarnata.

16. H. longifolium Rosc. t. 4. fol. linearibus glaucis, costa media subtus hirsuta; spica 6-sticha; bracteis biforis; lah. ovato apice hiloho filamento hreviore. All. Dietr. 1. c. In India orient. 4. Caul. 6-8-ped. Cor. rubra.

17. I. angustifolium Roxb. fol. lineari-lanceolatis glabris fitiformiacuminatis; spica 6-sticha; bracteis 2-floris; lahio biloho filamento breviore, lohis semi-ovalibus. Alb. Dietr. 1. c. Hosc. 1. 35. H. coccineum Wall. in Bot. Reg. 1209. In Bengalia. 4. Caul. 5-6-ped. Cor. lateritia.

18. H. coccineum Smith; fol. Ianceolatis acutis, carina subtus pubescente; spica 6-sticha; bracteis 2-floris; labio bilobo filamento breviore, lobis ovatis. Alb. Dietr. 1. c. Hosc. t. 28. H. angustifolium Bot. Reg. 157. Roxb. cor. t. 251. In Nepalia. 4. Caul. 5-6-ped. Cor. coccinea.

19. H. aurantiacum Rosc. $t .44$. fol. lanceolatis nervo medio apiceque hirsutis; spica 6-sticha; bracteis apice villosis 2-3-floris; lab. profunde bilobo filamento breviore, lohis ovatis. Alh. Dietr. I. c. H. angustifolium Bot.
Mag. 2078. In Nepalia. 24. Caul. junior purpurascens. Cor. rubra; lab. aurantiacum.

20. H. trilobum Wall. spica elongata pauciflora; bracteis convolutis remotiusculis 1-floris; lab. obcordato tritobo filaucntum discolor his superante, lobo intermedio cuspidato. Alb. Dietr. 1. c. In Nepralia. 4.

21. H. Roscoi Wall. fol. Ianceolatis patentibus subtus glahris; spica ohlonga elongata; fasciculis 3 -floris; limbi Iaciniis interioribus cultriformibus; labio rhomboideo subrotundo obtuso plicato hilobo, lobis obtusis, ungue brevi, stamine concolore, labium bis superante. Alb. Dietr. 1. c. In Nepalia. 24.

22. H. Hasselti Blume; fol. lanccolatis acuminatis glabris; spica elongata laxe imbricata; spathis obtusis sericeis; lahelti 2-partiti segmentis falcato-lanceolatis obtusiusculis. In Java. 4.

23. H. simile Blume; fol. lanceolatis acuminatis glahris; spica hrevi erecta; spathis acutis margine sericeis; labelli 2-partiti segmentis falcato-lanceolatis acuminatissimis. In Java. ち.

24. H. intermedium Blume; fol. lineari-lanceolatis ad costam subtus pubescentibus; spica elongata laxa; lahelli 2-partiti segmentis falcato-lanceolatis obtusiusculis. In Java. 24.

\section{ROSCOEA SM. (1801).}

1. R. purpurea Smith exot. b. $t$. 108. spica foliorun vaginis obvoluta; calyce ohliquo integro. Hosc. t. 86. In Nepalia. 24. Caul. 12-15-ped. Flor. pallide purpurascentes ant lilacini.

2. $\boldsymbol{R}$. gracilis $\mathbf{S} m$. spica exserta pauciflora laxa; calyce retuso. Smith in Linn. Trans. XIII. p. 460. In Nepalia. 4.

3. R. elatior Sm. spica exserta multiflora subcolorata; calyce retuso. Snı. I. c. In Nepalia. 4.

4. R. spicate Sm. spica exseria multiflora coarctata; cal. emarginato uudo ; fol. lanceolatis. Sm. 1. c. In Nepalia. 4.

5. R. capitata $\mathrm{S} m$. spica exserta capitata nultiflora; calyce 2-cuspidato ciliato; fol. linearibus. Sm. 1. c. In Nepalia. 4. 


\section{ALPINIA Plum. (1703).}

1. A. Cardamomum Roxb. fol. lanceolatis superne pubescentihus subtus sericeis; pauicula hasi caulis composita flexuosa; lah. 3-lobo basi calcarato. hoxb. ind. 1. p. 70. Roxls. corom. t. 326. Amomum repens somnerat. Elettaria White. et Matt. Elettari Hheede. 11. t. 4. 5. In Malubaria. 4. Caul. 6-9-ped. Cor. pallide vireus.

2. A. meelia $s p m$. fol. lineari-lanceolatis utrinque attenuatis subtus villosis; racemis radicalibus laxis; lab. cordato; caps. pedicellata conica 9alata. Koxb. 1. c. sub A. Cardamomum medium. A. costata. Roxb. corom. t. 252. In silhet. 4. Fol. 2-3ped. Cor. rubra fragrans.

3. A. occidentalis $S u$. fol. Ianceolato-ovatis glaberrimis; racemo radicali composito erecto; lab.inferiore limbi interioris apice emarginato. sw. ind. p. 11. A. jamaicensis Gaertn. t. 12. In Jamaica, Hisjaniola etc. 4. Cor. pallide flava.

4. A. linguiformis Roxb. fol. lanceolatis glahris; spica radicali lineari laxa; lah. linguiformi 2-fido, lateribus incurvis, basi lato ecalcarato. Roxb. ind. 1. p. 75. corom. t. 27. Elettaria R. et s. In Bengalia inferiore. 24. Caul. 4-6-ped. Cal. rufus. Cor. rubra; lab. Iuteum medio rubrum.

5. A. punicea Roxb. fol. lanceolatis; spica radicali conglomerata imbricata; lab. integro subparabolico basi calcarato. Roxb. ind. p. 73. In regno Sumutrano. 4. Caul. numerosi 6-8-ped. Cor. kermesina.

6. A. magnifica Rosc. fol, linearilanceolatis ; spica laterali; florib. aggregatis racemosis, in receptaculo communi; lab. lineari apice ovato coccineo albo-marginato; filamentis styloque pubescentibus. Roxh. t. 103. In ins. St. Mauritii. 2. Flor. numerosi 8-10 in racemo conico.

\%. A. racemosa L. fol. lanceolatis; racemo terminali spicaeformi; floribus subgeminis; lal. 3 -fido, lacinia media emarginata.Willd. Alp. caribaea Gaertn. t. 12. Amom. pyramidale Lam. In Indice occid. 24. Caul. 4-5-ped. Fol. ped. Cor. alba. Caps. purpurea.

8. A. Galanga $S w$. fol. sessilibus late-lanceolatis; panicula terminali; lab. oblongo unguiculato apice 2-fido; caps. ovata angusta glabra. Roxb. ind. p. 59. In China. 4.

9. A. Allughus Roso. fol. lanceolatis glabris; panicula terminali; lab. 2-partito; laciniis bifidis. Alb. Dietr. 1. c. Rosc. t. 102. Hellenia Willd. Heritiera Retz obs. t. 1. In Bengalia et Ceylonia. 24. Caul. subcompressus 2-3-ped. Cor. alba.

10. A. malaccensis Rosc. fol. lanceolatis petiolatis subtus villosis; racemo terminali simplici; lab. sub-3Ioho basi $\boldsymbol{z}$ - calcarato, lateribus incurvis; capsula oblique - globosa. Hoxl. ind. p. 64. Bot. Keg. 328. Marauta L. Galanga Rumph. V. t. 71. f. 1. In Malacca et Java. 2. Caul. 6-10-ped. Fol.2-3-ped. Lab. aurantiacum et kermesine variegatum.

11. A. mituns Rosc. fol. lanceolatis glabris margine ciliatis; racemo untante; pedicellis infimis 2-3-floris; lab. late ovato 3 -lobo crenato, lobo medio apice subbifido; capsulis sphaericis. Alb. Dietr. 1. c. Sm. exot. b. t. 166. Rosc. t. 61. Globba Red. t. 60. Zerumbet speciosum Jacq. fragm. $t$. 68. Costus Zerumbet Pers. Renealmia Andr. rep. t. 360. In Ind. orient. 4. Caul. 8-10-ped. Cor. alba; lab. ex aurantiaco et coccineo varium.

12. A. auriculata Rosc. fol. Ianceolatis subtus costa media ferrugineopilosa; racemo terminali nutante; lab. late ovato, apice crenato, basi utrinque processu auriculato. Alb. Dietr. 1. c. Rosc. t. 21. In India. 2. Caul. 10-14-ped. Cor. alba et rosea; lab. flavum rubro-striatum.

13. A. penicillata Rosc. t.93. fol. lanceolatis; racemo terminali nutante; lab. subrotundo tubulari-involuto, margine undulato; filamento crasso ovato. Alb. Dietr. 1. c. In China. 4. Cor. alba apice rubens; lab. extus alboroseum, intus flavum rubro-striatum.

14. A. mutica Roxb. fol. breve petiolatis linearibus glabris; racemo terminali parum declinato; lab. ohscure trilobo medio apice bifido. Alb. Dietr. 1. c. Rosc. t. 6. In ins. Prince of Wales. 4. Caul. 5-6-ped. Cor. alba; lab. latum flavum purpureo-venosum.

15. A. calcarata Rosc. $t$. 5. fol. lineari-lanceolatis glabris; racemo terminali parum declinato; lab. ovato simplici crenato apice 2 -fido. Alb. Dietr. Bot. Reg. 141. Globba erecta 
Red. Lil. t. 174. Renealmia Andr. rep. 421. In Chinc. 24. Caul. 3-5ped. Cor alba; lab. flavum purpureovenosum.

16. A. diffissa Roxb. t. 54. fol. lanceolatis; spica terminali reclinata; lab. panduraeformi inteuro obtuso; filamento profunde 2-partito. Hosc. In China. 24. Cor. albo-rubescens; lab. flavum lituris coccineis.

17. A. spicat 1 Roxb. fol. sessilibus late-lanceolatis acutis. Roxb. ind. 1. p. 68. In Sumatra. 24. Caul. 2-ped.

18. A. cernua not. Reg. 1900 ? fol. Janceolatis margine denticulato scabris acumine elongato-lineari; racemo composito cernuo; bracteis albescentibus ; lab. apice emarginato undulato. Lindl. In Inıl. orient. 4 . Cor. alba; lab. hasi et media parte lituris aurantiacis rubrisque, apice rubro.

19. A. alcta Alb. Dietr. fol. Ianceolatis acutis; petiolis vaginarum superiorun alaeformibus ; lab. panduraeformi 3-partito crenato; filamento subulato; anthera ovata. Alb. Dietr. 1. c. A. bracteata Rosc. t. 87. In China. 24. Caul. spiraliter tortus. Cor. candida; lab. flavum radiis purpureis.

20. A. bracteata Roxb. fol. lanceolatis utrinque attenuatis subtus villosis; racemo terminali simplici; pedicellis $\mathbf{1}$-floris; bracteis ${ }^{\circ}$ viridibus; 1ab. sub-3-lobo; laciniis lateralibus in tubum curvatis. Roxh. In Ind.or. 2 . Cor. alba; lab. kermesino-flavoque mixtum.

21. A. brevilabris prest. fol. lineari-lanceolatis utrinque attenuatis glabris; racemo terminali; pedicellis fasciculatis; lab. corolla breviore 4lobo, lobis linearibus. Heliq. Haenk. 2. t. 17. In ins, Luzon. 24. Caul. ped. Cor. parva rubra?

22. A. aromatica Jacq. fragm. t. 74. et 75. fol. ovato-lanceolatis; racemo composito; racemulis patentibus. Alb. Dietr. 1. c. A. multicaulis Aubl. In st. Domingo. 4 . Fol. 5ped. Cor. lutea parva.

23. A. Paco-Secora Jacq. fraym. t. 6\%. fol. ovatis; racemo simplici. Jacq. Costus secundus Aubl. In ins. st. Iincent. Cor. purpurascens lab. luteo. Fruct. sanguineus.

21. A. pallida; fol. lanceolatis; epicis hemisphaericis; bracteis adpres- sis sericeis; labello ovato obtusissimo. Elettaria Blnme. In Java. 4.

25. A. solaris; fol. petiolatis oblongis glabris; spicis lemisphaericis; bracteis adpressis sericeis; labello bifido. Elettaria Blume. In Java. 4.

26. A. mollis; fol petiolatis ovalioblongis acntis; spicis oblongis in scapo ferrugineo tomentoso elevatis; labello obtuso integerrimo. Elettaria Blume. In Java. 4.

2\%. A. foetens; fol. petiolatis lanceolatis acuminatis subtus serice $0-p u-$ besceutibus; spicis oblongis obtusis dense imbricatis; labello spathulato elongato. Elettaria Blume. In Jara. 4.

28. A. minuta; fol. subsessilibus lanceolatis utrinque acuminatis subciliolatis; spicis radic. minutis paucifloris; lahello anguste semibifido, laciniis inflexis. Elettaria Blume. In Java. 4.

29. A. coccinea; fol. subsessilibus lanceolatis utrinque acuminatis superue ciliatis; spicis oblongis obtusis; lahello elongato semibifido: laciniis involutis. Elettaria Blume. In Java. 4.

30. A. minor; fol. subsessilibus lanceolatis acuminatis glabris ad marginem tomentosis; spicis radic. oblongis ; bracteis ovatis obtusis ; labello obtuso concavo. Elettaria Blume. In Java. $\hbar$.

31. A. alba; fol. petiolatis lanceolatis acuminatis; spicis semisubterraneis ovatis; bracteis acuminatis; lahello rotundato margine revoluto crispato. Elettaria Blume. In Java. 4. Flores albi.

32. A. Pininga; fol. oblongo-lanceolatis acuminatis glabris margine ciliolatis ; spicis dense imbricatis; bracteis obtnsis mucronulatis ciliolatis. Donacodes Blume. In .Java. 4.

33. A.rubra; fol. lanceolatis utrinque acuminatis glahris; spicis laxe imbricatis ohovatis ohtusis; bracteis apice rotundatis mucronulatis glabris. Donacodes Blume. Ad hanc fortasse Cenolophon rubrum Blume. In Java. 4.

34. A. paludosa; fol. oblongo-lanceolatis basi subobliquis subtus villosis; spicis ovato-oblongis acutis dense imbricatis; bracteis mucronatis glabris. Donacodes Blume. In Juva. 4.

3.5. A. tomentosa; fol. oblongolanccolatis glabris; spicis ovato-ob- 
longis acutis dense imbricatis; bracteis mucronatis araclinoideo-tomentosis margine sericeo-villosis. Donacodes Blume. In Java. 4.

36. A.? Walang; fol. elongatolinearibus utrinque acuminatis glabris. Donacodes Blume. In Java. 4.

3\%. A. javanica; inflorescentia terminali dense spicata, bracteis lineari-lanceolatis cincta. Diracodes Blume. In Java. 4.

35. A. pyramilata Blume; fol. lanceolatis utrinque acutis subtus sericeo-villosis; panicula terminali pyramidata densa; labello obovato bifido undulato. In Java.

39. A. Blumei; fol. petiolatis maximis utrinque attenuatis glabriusculis; pedicellis nutantibus 5-7-floris; bracteis ventricosis; la!jello ovato integro crispato; caps. globosis sericeis. A. javanica Blume. In Juva. 24.

40. A. gigantea Blume; fol. petiolatis maximis subtus villosis; racemo nutante longissimo; bracteis tubulosis truncatis; labello obsolete 3 -dentato. Rumplı 6. t. 62. In Jara. t.

41. A.speciosa; fol. petiolatis oblongis obliquis glabris; spicis elevatis ovatis; bracteis reflexis obtusis; Iabello ovato obtuso. Elettaria Blume. In Java.

42. A. hemisphaerica; fol. petiolatis lanceolatis acuminatis tenuiter ciliatis ; spicis hemisphaericis ; bracteis obtusiusculis, inter. linearibus adpressis; labello ohtusiusculo. Elettaria Blume. In Jar $\alpha$.

\section{\%. HELLENIA Willd. (1797).}

1. H. caerulea $\boldsymbol{R}, \boldsymbol{B r}$. labello emarginato ; fol. integerrimis capsulaque colorata glabris; stylo hirsuto. R. Br. prodr. 1. p. 30\%. Hosc. t. 30. In Nora Hollandia. 4. Caul. 6-8ped. Cor. alba; lab. flavescens.

2. H. alba Willd. fol. integerrimis; lab. 2-lobo; capsulis obsolete angulosis strictis coloratis. Willd. sp. pl. 1. p. 5. Aipinia Rosc. Heritiera Retz. In Ind. occid. 24. Cor. viridi-alba; 1ab. album venulis roseis.

3. H. chinensis Willd. fol. oblongis subciliatis; lab. margine denticulato diphyllo. Willd. 1. c. Alpinia Rosc. Heritiera Retz. In Chinc. 4. Caul. 2-3-ped. Cor. sublutea; lab. venis quatuor sanguineis.
4. H. rufa Presl. fol. Ianceolatis acuminatis calycibus capsulisque hirsutis; lahio emarginato mucronulato; stylo glabro. Heliq. Haenk. t. 21. In ins. Luzon. 4. Cor. flavescens rubropunctata.

5. H. aquatica Willd. fol. oblongis margine deuticulatis; panicula oblonga subnutante; lab. obcordato 4dentato. Willd. sp. pl. 1. p. 5. Heritiera Retz. Alpinia Rosc. In Ind. orient. 4. Caul. 4-ped. Cor, alba, lab. roseo-fuscum.

6. H. abnormis lindl. fol. ovatoIanceolatis acuminatis glabris versus apicem ciliatis; labio subrotundo emarginato; germine 1-loculari 1-spermo; stylo glabro. Lindl. in Trans. of the Hort. Soc. V. p. 1. p. 60. In Chinc. 4. Cor. alba, lab. purpureum margine crispum.

\%. H. scabra Blume; fol. subsessilibus Ianceolatis acuminatissimis supra scabris; panicula divaricata terminali; labello 3-partito. In Java. 4.

8. H. bracteata Blume; fol. sessilibus lanceolatis utrinque acuminatis glabris; spica terminali bracteata; Iabelli trilobi lobo medio 3-partito. In Java. 2.

\section{RENEALMIA Linn.suppl.(1\%17).}

1. R. exaltata Linn. fol. lanceolatis glabris; scapo radicali villoso; racemo elongato; bracteis alternis; calyce inferiore 2-fido. Alb. Dietr. sp. pl. 1. p. 49 . Rosc. t. 108. Alpinia Meyer Esseq. A. tubulata Bot. Keg. 787. Bot. Mag. 2492. In Ind. occ. 4. 8-10-ped. Cor. tubulosa rubra.

2. R. fasciculata Rosc. mon. pl. 14. t. 109. fol. ovato-lanceolatis; spicis radicalibus; bracteis sessilibus fasciculatis. In India. 24. Rad. composita e tuberibus pluribus annulatis. Cor. alba.

3. R. macrantha Poepp. et Endl. Nov. Gen. $t$. 13t. racemo radicali simplicissimo; bracteis campanulatis 3-fidis dense pubescentibus; fol. lanceolatis sessilibus. In Peruvia. 4. Cor. lutescens.

4. R. breviscapa Poepp. et Endl. t. 135. racemo radicali capitato paniculato ramulisque bi-vel trifloris pubescentibus; bracteis ovatis flore brevioribus; caps. puberulis; fol. lanceo- 
Iato-oblongis petiolatis. In Peruvia. 4. 2-ped. Cor. lutea.

5. R. strobilifera Poepp. et Endl. t. 136. spica caulina laterali recta ovali bracteis rigidis acuminatis imbricata; lahello oblongo apice emarginato; anthera sessili; fol. oblongolanceolatis acuminatis sessilibus. In Peruvia. 4. 9-ped. Cor. citrina.

R. geniculata Fl. flum. $t$. 1 .

$\boldsymbol{R}$. marantaefolia Fl. flum. $t .15$.

R. concolor Fl. flum. $t$. 16.

R. erecti $F l$. flum. $t$. 18.

R. tuberosa Fl. flum. $t .18$.

\section{ZINGIBER Gaertn. (1\%SS).}

\section{A. Spicis radicalibus.}

1. Z. officinale Rosc. l. c. t. $\%$. bracteis ovato-lanceolatis; laciniis corollae revolutis; nectario 3 -lobato. Rosc. in Limn. Trans. VIII. p. 348. Amomum Zingiber Willd. Jacq. Vind. t. 75. Tratt. Arch. t. 202. In India orientali. 4. 2-3-ped. Cor. flavicans, nect. purpureo, fusco- et flavovariegato.

2. Z. Mioga Roxb. laciniis corollae acutis concavis aequalibus; nectario ovato concavo. Hosc. in Lim. Trans. VIII. p. 318. Amomum Thunh. jap. In Japonia. 4. Pedalis. Cor. alba, labium flavum.

3. Z. Zerumbet Rosc. bracteis ovatis obtusis; laciniis corollac erectis acutis; nectario 2-lohato. Hosc. I. c. Sm. exot. bot. t. 112. Amomum Lim. Jacq. Vind. t. 54. Tratt. Arcli. 203. In Ind. or. 24. 3-4-ped. Cor. pallide straminea.

Æ. Z. Cassumunar Roxb. caulihus erectis; fol. sessililus lineari-lanceolatis; spicis compactis strohuliformibus elevatis lanceolatis acutis; bracteis obovatis acuminatis; labio 3-lobo. Roxb. asiat. Kesearch. XI. p. 347. t. 5. Bot. Nag. 1426. Z. purpureum Rosc. In Ind. or. 4. Rad. flava. Cor. alha aut pallide staminea.

5. 'z. montamum Link. fol. petiolatis ovatis glabris; scapis radicalibus lateralibus; hracteis rotuudatis; labio 3-loho, lobo medio acuto. Link. Ms. Alb. Dietr. sp. pl. 1. p. 52. In Malacca. 24. Rad. nodosa. Caul. 4ped. Cor. alba.

6. Z. squarrosum Roxb. fol. lanceolatis utrinque attenuatis; spicis squarrosis terrae ad medium usque immersis; bracteis linearibus apice longa undulata subulata recurvatis; lahio tritoho apice bifido. Hoxb. 1. c. Hosc. mon. pl. t. 94. In regno Burmano. 4. Caul. 4-5-ped. Cor. alba.

\%. '/. pauluratum Roxb. fol. ad vaginas petiolatis late lanceolatis utrinque attenuatis glabris, ligula magna scariosa; spicis radicalibus ad medium terrae immersis laxis; bracteis lanceolatis; labio panduraeformi; lamina ovata emarginata. Roxb. Fl. ind. 1. 53. In Bengalia. 24. Cor. pallide rubra, lab. pallidissime flavum.

8. Z. ligulatum Roxb. fol. approximatis sessilibus lanceolatis; spicis laxis obovatis apice horizontalibus hracteis cuneiformilus; labio subhastato. Roxb. asiat. Hesearch. XI. p. 348. Corom. t. 253. In Ind. or. 4. Caul. 2-3-ped. Cor. rubescens labium pallide flavum.

9. Z. roseum Rosc. fol. breve petiolatis lanceolatis; spicis laxis admedium usque immersis terrae; bracteis lanceolatis coloratis; labio integro. Roxl. asiat. Research. XI. p. 347. Amomum Corom. t. 26. Kosc. t. 71. In Ind. or. 4. 3-4-ped. Cor. rubra, lab. crenatum flavum auriculis aurantiacis.

10. Z. rubens Roxb. fol. lanceolatis utrinque attenuatis; spicis laxis terrae ad medium usque immersis; bracteis lineari-lanceolatis strictis; labio anguste ovato integro. Roxb. I.c. Rosc. mon. pl. t. 37. In Bengalia. 24. Caul. 6-8-ped. Cor. tubus villosus, limbi lacinia rubra, labium rubro- et luteo-variegatum.

11. ' $Z$. dubium Afz. bracteis subrotundis; vaginis scapi truncatis; fol. late lanceolatis acuminatis. Af z . remed. Guinens. p. 9. In montibus sterilibus Sierrae Leonae. 4. 8-10-ped. Flor. in capitulum congesti.

12. Z. flavescens Alb. Dietr. fol. petiolatis lanceolatis subtus tenue pilosis; spicis radicalibus emersis sessilibus bracteis oblongis; labio integro. Alh. Dietr. sp. pl. 1. p. 54. In Ind. orient. 24. 2-3-ped. Cor. rubescens; labium flavum.

13. Z. chrysanthum Rosc. fol. sessilibus lanceolatis subtus pubescentibus apice acuto reflexo torto villoso; lahio 3-lobo. Rosc. moll. pl. t. 22. In Nepalia. 24. Caules numerosi 7-8ped. Cor. coccmea, labium aureum. 
B. spicis terminalibus.

14. Z. elatum Roxb. fol. bifariis linearibus recurvis; spicis terminalibus lanceolatis utrinque attenuatis arcte imbricatis; hracteis lanceolatis unifloris. Roxb. ind. 1. p. 56. In Bengalia. 24. Caul. 4-5-ped. Cor. flava.

15. Z. capitatum Roxb. fol. linearilanceolatis amplexicaulibus; bracteis exterioribus lanceolatis interioribus ovatis. Roxb. asiat. XI. p. 318. Rosc. moll. pl. t. 46. In Ind. orient. 4. Caul. 3-ped. Cor. flava.

16. $\mathscr{Z}$. marginatum Roxb. fol. sessilibus lanceolatis; bracteis exterioribus ohovatis margine lato transparente membranaceo. Hoxb. l. c. Patria ignota.

17. Z. ovoideum Blume; fol. Iaiceolatis acuminatis subtus villosis; spicis ovoideis obtusis; bracteis cumeatis; labello 3-lobo flavo. In Java. 4.

18. $Z$. amaricans Blume; fol. lanceolatis utrinque acuminatis subtus arachnoideo-pubescentihus ; spica compacta ovoidea; labelli lobo medio rotundato flavo. Rumph. 5. t. 64. f. 1. In Java. 4.

19. Z. inflexum Blume; fol. lanceolatis acuminatis subtus puberulis; spicis squarroso-elevatis marginibus inflexis; labelli lobo medio rotuindato atro-purpureo. In Java. 4.

20. Z. сииоsum Blume; fol. Ianceolatis acuminatis glabris; spica elevata oblonga acuminata imbricata; bracteis lanceolatis demum rubentibus. In Java. 4.

21. Z. odoriferum Blume; fol. oblongo-lanceolatis acuminatis subtus puberulis; vaginarum ligula retusorotundata; spicis compactis; labello ovato concavo atro-violaceo.In Jar a.24.

22. Z. gramineum Blume; fol. lineari-lanceolatis subtus puberulis ; vaginarum ligula brevissima depressorotundata; bracteis lanceolatis villosis. Rumph. 5. t. 66. f. 2. In Java. 4.

\section{KAEMPFERIA Linn. (1737).}

1. $\boldsymbol{K}$. rotunda Linn. fol. oblongis subtus coloratis; spica radicali ante folia emergente; laciniis superioribus limbi interioris corollae lanceolatis acutis. Roxb. asiat. Research. XI. p. 327. Jacq. H. Schoenbr. t. 317. Bot. Mag. 850. K. longa Redouté Lil. t. 49 . In Ind. orient. $\odot$. Caulis nullus. Cor. alba marginibus laciniarum purpureis.
2. K. Galanga Linn. fol. sessilibus subrotundis; spica centrali; laciniis superioribus limbi interioris corollae ovatis. Roxb. 1. c. p. 327. Bot. Mag. 850. Red. Lil. t. 144. Rosc. t. 70. In Ind. $\odot$. Caulis abbreviatus s.nullus. Fol. 4-6-poll. longa. Calyx albus. Cor. alba ; lab. purpureo-maculatum.

3. K. Lutifolia Don; fol. orbiculatis ovatis undulatis subtus pubescentilanatis alhidis. Hornem. H. Hafn. p. 6. In Ind. orient. 24. Caul. nullus. Cor. alba fusco-punctata.

1. I. panciurata Roxb. fol. petiolatis late-lanceolatis utrinque attenuatis; spicis centralibus; laciniis duabus superioribus limbi interioris corollae obovatis obtusis, inferiore panduraeformi. Roxb. asiat. Research. XI. p. 328. t.2. Rosc. t. 38. Zerumbet claviculatum Rumph 5. t. 69. f. 1. In Sumatra. 4. Cal. pallide roseus. Cor. pallide rosea, lab. obscure rubrum.

5. K. diversifolia Link. Ms. fol. inferioribus ovatis superioribus lanceolatis; spica centrali; labio bilobo lobis mucronatis; filamento apice trilobo, lobo medio emarginato. Alb. Dietr. sp. 1. p. 57. K. ovalifolia. Rosc. t. 31. In Ind. orient. 4. Vagina foliorum purpurascens. Cal. et Cor. alba; lab. purpureum profunde 2-pariitum.

6. K. angustifolia Rosc. $t$. 62. fol. radicalibus lanceolatis; spica centrali; laciniis duahus superioribus limbi interioris corollae lineari-oblongis obtusis. Roxb, asiat. Research. XI, p, 328. Redouté 1. t.389. K. undulata Link. K. Roxhurghiana R. et $\$$. In Rengalia. $\odot$. Cor. alla, lals. purpureum uugue albo.

7. K. ovalifolia Roxb. ind. 1.p. 18. fol. ovatis; spicis centralibus; crista antherarum ciliata. Roxb. 1. c. Corom. t. 278. In Malacca. Caul. brevissimi. Cor. alba, lab. purpureo-variegatun.

s. K. marginatu Carey; fol. lateovatis margine coloratis subtus glaucis et villosis; spica centrali; labio late-ovato 2 -lobo, Iobis emarginatobifidis. Alb Dietr. 1. c. Hosc. t. 8. In Ind. orient. Cor. alba, laciniae interiores purpurescentes, Iab. purpureum.

9. Ir. Roscoeana Wall. fol. subrolundis acuminatis supra variegatis subtus pallidis; spica centrali; Iabio profunde bilobo, lobis rotundatis. Wall. Bot. Reg. 1212. In Nepalia. 4. Caul. nullus. Cor. candida, lab. flavicans. 


\section{COSTUS Linn. (1737).}

1. C. speciosus $\mathrm{Sm}$. fol. sessilihus spiraliter circumstantibus oblongis subtus villosis. Roxl. asiat. Rescarch. XI. p.349. C. arabicus L. Amomum hirsutum. Lam. ill. t. 3. Hellenia Retz. In Asia meridionali. 4. Caul. 4-6-ped. Cor. pallide rosea subferrugineo-inspersa.

2. C. pictus Don iIs. fol. lanceolatis pilosis; spica ovata terminali; bracteis apiculatis; labello 3-lobo ; lacinia intermedia brevissime inciso-dentata revoluta. Bot. Reg. 1549. In Mexico. 4. Flor flavi, labellum purpureoaureoque variegatum.

3. C. nepalensis Rosc. mon.pl.t.55. fol. hrevissime petiolatis lanceolatis filiformi-acuminatis subtus villosis; ochreis coloratis fimbriatis; spica capitata; labio integro crenato; filamento dorso hirsuto. Alb. Dietr. C. speciosus v. $\beta$. angustifolins Bot. Reg. 665. In Nepalia. 24. Caul. 4-5-ped. Cor. rubens, lab. album, faux pilis flavis clausa.

4. C. afer Ker; fol. breve petiolatis lanceolatis longe acutatis; ochreis viridibus; spica turbinata coarctata; labio integro eroso denticulato; filamentis dorso glabris. Alb. Dietr. 1. c. Bot. Reg. 683. In Sierra Leona. 4. Pelalis. Cor. alba.

5. C. maculatus Rosc. mon. pl. $\boldsymbol{t}$. \%. fol. subsessilibus lanceolatis subtus villosis; ochreis hirsutis; spica radicali capitata; lab. ovato crenato. Alb. Dietr. l. c. Hab.... 4. 1-1 $\frac{\mathrm{I}}{2}$-ped. Cor. allua, lab. fance pilis navis et lituris 2 flavis.

6. C. discolor Rosc. $t$. 10t. fol. breve petiolatis late-ovatis obtusis glabris subtus purpurascentibus; ochreis ciliatis; spica terminali ovata; lab. 3-Iobo undulato. Alb. Dietr. 1. c. In Maranha. 24. Caul. 4-ped. Cor. lab. litura flava et fauce pilis flavis.

\%. C. glabratus Sw. fol. utrinque glabris; nectario ovato integerrimo. hosc. in Lim. Trans. VIII. p. 349. In Ind. occident. 4 . Caul. sesquiped. Cor. alba, lal). medio flavum.

8. C. spicatus $\mathbf{S m}$. fol. acuminatis integerrimis nitidis basi acuminatis; nectario undulato subtrifido. Rosc.l.c. mon. pl. t. 32. Alpinia Jacq. am. t. 1. In Ind.occ. 4. Caul. spiraiis. Cor. flava.

9. C. niveus Meyer; fol. sessilibus ovalibus glahris; squamis ellipticooblongis; limbo corollac interiori un- dulato subtrifido. Meyer Esseq. p. 1. In Essequebo. 4. Cal. purpureus. Cor. nivea.

10. C. comosis Rosc. fol. utrinque subvillosis; labio oblongo erecto apice 5-dentato. Hosc. in Linn. Trans. VIII. p. 350. Alpinia Jacq. ic. t. 102. In Caracas. 4. Cal. villosulus ruber. Cor. flava.

11. C. cylindricus Rosc. mon. $p l$. t. 110. fol. brevissime petiolatis latolanceolatis obtusis subtus glaucis; ochreis fimbriatis; spica cylindrica; labio rhomboideo. Alb. Dietr. sp. 1. p. 63. In ins. Trinislad. 6-ped. spica 5-8-poll. Cor. flava.

12. C. secundus Spreng. caulescens; fol. petiolatis ovatis subfalcatis; spica terminali parum incurva unilaterali; crista filamenti integerrima. Kaempferia Roxls. Fl. ind. p. 19. In Bengalia.

13. C. spiralis Rosc. nectario concavo integerrimo; fol. elongato-ellipticis coriaceis nitidis. Rosc. 1. c. Alpinia Jacq. H. Schoenbr. t. 1. C. Pisonis Bot. Reg. 899. In Amer. merid. 4. Cal. purpurasceus. Cor. rosea.

11. C. linearis Spr. caulescens; fol. sessilibus lineari-lanceolatis stipulatis; floribus terminalibus raris; crista integra. Kaempferia Wall. in Fl. ind. 1. p. 20. In Bengalia.

1.5. C. scaber Ruiz et Pav. thyrso conico; hracteis ovatis adpressis; corollis semiclausis. Fl. peruv. 1. t. 3. In Peruvia. Caul. plures biulnares. Fol. subpedalia. Bracteac puniceae. Cal. ruber. Cor. Iutea.

16. C. laevis Ruiz et Pav. tlyyrso conico; bracteis lanceolatis apice incurvis; corollis patentibus. Fl. peruv. 1. p. 15. In Peruvia. Caul. 2-orgyalis. Folia pedalia. Cal. ruber. Cor. luteo-carnea.

1\%. C. argenteus Ruiz et Pav. thyrso oblongo; bracteis reflexis; corollis patentibus. Fl. peruv. t. 4. In Peruvia. - Caul. 2-oryyalis. Cal. Inteo-viridis. Cor. lutescens.

18. C. sericeus Blume; fol. subsessilibus oblongis subtus argenteosericeis ; spica densa ohlonga; labello undulato crispato. In Java. 4.

19. C. globosus Blume; fol. subsessilibus oblongis acuminatis glabris; vaginis ore subciliatis; spicis globosis radicalibus. In Jara. 


\section{AMOMUM Linn. (1787).}

1. A. Cardamomum Linn. fol. breve petiolatis; spicis ternis semiimmersis laxe imbricatis; bracteis villosis lanceolatis acutis unifloris; labio 3-lobo; filamento apice 3-lobato. Alh. Dietr. 1. c. p. 65. A. racemosum Lam. ill. t. 2. f. 2. Cardanımum minus Rumph 5. t. 5. f. 1. In Sumatia. 4. Caul. biemis 2-4-ped. Lobo medio labii cor. flavo, lineis 2 roseis.

2. A. dealbatum Rorb. fol. late lanceolatis utrinque atienuatis subtus villosis; spicis radicalibus; bracteis (ovatis et) lanceolatis, obtusis valde caducis; limbo exteriore fornicato; lahio rotundato ovato; crista ex lobo lato truncato; capsulis ovato - oblongis 9-alatis. Roxb. ind. 1. p. 43. In Bengalia. 4. 3-5-ped. Cor. alba; 1ab. crispum Iuteo-maculatum.

3. A. subulatum Roxb. fol. Ianceolatis planis; spicis ovatis; acuminibus laciniarum supremae limbi corollae exterioris echinatis; Iabio oblongo. Roxb. ind. 1. p. 44. In Bengalia. 4. 4-ped. Cor. Iutea.

4. A. aromaticum Roxb. fol. lanceolatis utrinque acuminatis glabris; spica radicali imbricata clavato-rotundata; lahio subrotundo indiviso basi omnino nudo. Roxb. ind. 1. p. 44. In Bengalia. 4. 2-3-ped. Cor. flava, lab. rubrum.

5. A. sericeum Roxb. fol. lanceolatis utrinque attenuatis subtus sericeis; racemis radicalibus subglobosis ramosis; labio ovato basi calcarato. Roxb. 1. c. p. 46. In Bengalia. 24. Fol. 2-ped. Flores longe setosi. Cor. magna alba; Jab. cum macula lutea ferrugine0-venosum.

6. A. angusifiolium Somnerat it. t. 137. fol. late-lanceolatis; spicis elongatis oblongo-linearihus compactis; bracteis cuneato-oblongis acuminatis; labio obovato - cuneato inlegerrimo; filamento 3-lobo. Roxb. ind. p. 39. A. madagascariense Lam. ill. t. 2. f. 1. In Madagascar. 24. Caul, numerosi 6-10-ped. Cor. rubra, lab. flavum.

\%. A. Grana Paradisi Linn. scapo ramoso laxo; fol. ovatis. Liun. sp. pl. 1. p. 2. In Guinea, Madayascar et Ceylonia.24. Caul.3-ped. Flor. magni albi.

8. A. Melegueta Rosc. mon. $p l$. t. 112. fol. subsessilibus angustatolanceolatis; scapo radicali; bracteis imbricatis cuspidatis; floribus solita ris labio late-ovato crenato; filamento apice 3-dentato. Alb. Dietr. 1. c. In Demerary. 4. Caul. 6-ped. Cor. alba; lab. flavum maryine roseum.

9. A. Afzel $i$ Rosc. scapo brevissimo (subnullo); floribus aggregatis ; fol. distantibus ovato-acuminatis integerrimis glabris. Rosc. in Linn. Traus. VIII. p. 354. A. exscapum Sims. Ann. of Bot. 1. p.548. c. icone. In Sierra Leona. 24. 3-ped. Cor. diInte carnea; lab. maximum medio virescens, margine niveo.

10. A. villosum Lour. scapo vaginato brevissinı; spica subrotunda; bracteis lanceolatis fore longioribus. Willd. sp. 1. p. 8. Rumph VI. t. 61. f. 2. In Cochinchina. 4 . Caul. 6-ped. Cor: pallide rubra. Caps. villosa rufa.

11. A. uliginosum Koenig; flor. pedunculatis; caulibus remotis; fol. acutis; capsulis glohosis echinatis. Kosc. l. c. p. E53. In umbrosis Indiue orientalis. 4. Caul. 3-ped. Cor. rosea, lah. margine albo.

12. A. aculeatum Roxb. fol. subsessilibus cordato-lanceolatis; spica ohovata laxa cum liumo parallela; labio ovato ventricoso; crista ampla 3-loba; capsulis echinatis. Roxb. ind. 1. p. 40. ejusd. asiat. res. XI. t. 4. In Archipelago malaccensi. 4 . Caul. 5-10-ped. Flor. intense aurantiaci.

13. A. maximum Roxb. fol. petiolatis lanceolatis ntrinque attenuatis subtus villosis; spicis ovatis horizontalibus; bracteis lanceolatis; crista integra semilunari; capsulis globosis, alis septem. Roxh. asiat. res. XI. p. 344. Bot. Reg. 929. In Archipelago malaccensi. 4. Caul. 6-8-ped. Cor. alba, lah. medio stria flava.

14. A. latifolium Af zel; scapo subterraneo; floribus aggregatis ; fructu ovali arciforni; caule sterili simplici; fol. lato - lanceolatis. Afz. remed. guin. coll. p. 5. In Sierra Leona. 4. Caul. 3-ped. Flor. magni nivei.

15. A. sylrestre Swartz; scapo nudo ; spica elongata; bracteis oblongis ventricosis; fol. lato-lanceolatis. Willd. sp. 1. p. \%. In Jamaica. 4. Caul. 4-8-ped. Cor. flava. Caps. 3-gona carnea.

16. A. grandiflorum $\mathrm{Sm}$. fol. breve petiolatis oblongo-lanceolatis acuminatis undulatis; scapo abbreviato; foribus confertis numerosis; lab. in- 
diviso; filamento apice 3-lobo, lobo medio minimo. Alh. Dieir. 1. c. p. 69. Smith. exot. bot. 2. t. 11. In Sierra Leona. 2. Caul. 3-ped. Cal. ruber pubescens. Cor. rubescens, lab, album basi flavum.

1\%. A. thyrsoideum Ruiz et Pa:. scapo spathis oblongo-ovatis vestito; spica conico-thyrsoidea. Fl. peruv. t. 2. In Peruvia. 4. Caul. 3-uJuaris. Cor. Iutea. Caps. magna rubra.

18. A. racemosum Ruiz et Pav. scapo spathis oblongis tecto; racemo composito. Fl. perav. t. 1. f. b. In Peruvia. 24. Caul. 2-uluaris. Fol.1-3ped. Cal. ruber. Cor. flava. Caps. nigra.

19. A. parviflorum Presl. fol. breviter petiolatis lanceolatis utrinque attenuatis; spica laterali; bracteis ovatis acuminatis tomentosis flore paulo hrevioribus; labio oblongo verrucoso cristato apice 2 -lobo. Presl. Reliq. Haenk. 2. p.112. In ins. Luron. 4. Caul. 2-ped. Cal. duplex albidts.

20. A. scypliferum Koenig; fol. sessilihus subtus tomentosis; spicis radicalibus subsessilibus superne dilatatis; squamis imbricatis; lab. lanceolato ohtuso basi auriculato; filamento apice rotundo. Alb. Dietr. Hornstadtia Scyphus Retz. obs. IR. et S. In Malacca. 24. Caul. E-ped. Cor. intense coccinea.

21. A. Leonurus Koenig; fol. glabris ciliatis; filamento apice bifido. Koenig in Retz. olss. 3. p. 65. Hornstadtia Retz. In Malacca. 4. Caul. 5-6-ped. apice nutans. Cor. atro-sanguiuea; lab. sanguineum auriculis albicantibus.

22. A. echinatum Willd. spica radicali sessili sulgglohosa; capsulis sulcatis echinatis glohosis. Willd. sp. 1. p. 8. Rumph V. t.;61. f. 1. In Ind. orient. 4.

23. A. gracile Blume; fol. lanceolatis acuminatissimis glabris; spicis radic. subclavatis; Ialello ovato-obtuso indiviso; capsulis asperis. In Java. 4.

24. A. ciliatym Blume; fol. oblongo-lanceolatis acuminatissimis glabris; spicis radic. densis; bracieis ciliatis; labello fornicato rotundato; crista ampla triloba. In Java. 4.

25. A. heterantlum Blume; fol. lanceolatis longiter acuminatis glabris; spicis radic. subglobosis; labello sub- trilobo utrinque hasi bidentato; crista ampla triloha. In Java. 4.

13. CURCUMA Val. Cord. (1561).

a. Spica laterali.

1. C. Zedoaria Curt. Bot. May. 1516 ; bullris palmatis intus pallide stranineis; fol. Iate-lanceolatis breve petiolatis, litura media purpurascente; comae bracteis apice purpureis ; dahio emarginato. Hosc. mon. pl. t. 24. C. 'serumbet loxh. ind. 1. p. 23. corom. t. 201. In Ind. orient. et in Chittagong. 4. 4-ped. Cor. pallide stramixea; Iab. flavum.

2. C. aromatica Salisb. tuberibus palmatis intus flavis; fol. sessilibus late-lanceolatis subtus sericeis; comae bracteis roseis; labio integro. Hosc. mon. pl. t. 24. C. Zedoaria Roxb. ind. In India orientali et in China. 4. 4-ped. Cor. rulsens; Iab. luteum.

3. C. caesia Roxb. bulbis ovatis tulseribusque palmatis intus caesiis; fol. lanceolatis utrinque attenuatis petiolatis, nubecula purpureo-ferruginea per mediun decurrente ad paginam inferiorem usque penetrante, caeterum tota viridis. Hoxb. asiat. res. XI. P. 325. In Bengalia. 4. 4-ped. Cor. lutea marginibus purpureis.

4. C. aerugizosa Roxb. hulhis ovatis numerosisque tuheribus palmatis incurvatis, intus aeruginosis ; fol. petiolatis late-lanceolatis utrinque attenuatis supra medium macula obscure purpurascente nec ad paginam inferiorum penetrante; caeterum tota viridis. Roxb. asiat. res. XI. p. 335 . In Pegu. 24. Fol. 2-3-ped. Ċor. pallide rosea, intus flava.

5. C. ferruginea Roxb. bulbis tuberibusque palmatis copiosis intus pallide flavescentibus; vaginis scapi foliisque rubro-ferrugineis macula dilute rubella in medio paginae superioris. Roxb. asiat. res. XI. p. 336. Rosc. mon. pl. t. 56. In Bengalia. 4. Caul. ferrugineo-ruber. Cor. magna rubra; lab. flavum.

6. C. rubescens Roxb. bulbis ovato-lanceolatis tuberibusque palmatis intus margaritaceis; fol. late-lanceolatis utrinque attenuatis petiolatisque et costis saturate rubris; floribus bractea longioribus. Roxb. asiat. res. XI. 
p. 336. Rosc. mon. pl. t. 48. In Benyalia. 24. 4-5-ped. Cor. purpurea, lab. flavum lituris 2-obscurioribus.

\%. C. comosa Roxb. bulbis latis ovatis intus pallide ochraceis; spica clavata; bracteis fertilibus pallide rubro-fuscis; coma copiosa rosea; fol. petiolatis lanceolatis utrinque attenuatis; tota viridis. Roxb. asiat. res. XI. p. 337. In Pègu circa Rangoon. 24. Magna, elegantissíma. Fol. 4-6-ped. Cor. limbus exterior fuscus, interior flavus.

8. C. leucorrliza Roxb. bulbis ovatis tuberibusque palmatis longis late expansis intus pallide stramineis; fol. petiolatis late-lanceolatis glabris pure viridibus; spicis paucifloris; coma longitudine spicae fertilis. Roxb. asiat. res. XI. p. 337. Hosc. mon. pl. t. 8. In Ind. oient. 4. 3-4-ped. Cor. alba margine rubro; lab. album rubro-tinctum apice flavum.

9. C. xanthorrhiza Roxb. bulbis ovatis; tuberibus palmatis pendulisque intus profunde flavis; fol. in vaginis viridibus sessilihus late lanceolatis, sub medio nubecula purpturea persistente. Roxb. ind. 1. p. 25. In Amboina. 24. Caul. 4-ped. Cor. rubra.

10. C. latifolia Rosc. mon. $p l$. $t$. 39. bulbis magnis uti tuberibus palmatis intus flavis; fol. petiolatis late lanceolatis subtus pubescentibus supra litura purpurascente; comae bracteis purpurascentibus; labio lato-ovato subulato. Alb. Dietr. l. c. p. 74. In Ind. orient. 24. Planta 6-12-ped. Cor. fiava; lab. lineis 5 brunneis.

11. C. angustifolia Roxb. bullis tuberibusque pendulis ohlongis, palmatis nullis; fol. petiolatis anguste lanceolatis utrinque attenuatis; floribus bractea longioribus. Hoxb. asiat. res. XI. p. 338. In Ind. orient. 24. Fol. 1-2-ped. Cor. pallide flava, lacinia superior fornicata.

12. C. elata Roxb. bulbis oblongis obovatis tuberibus copiosis magnis incurvis palmatis intus pallide flavis; fol. in vaginis sessilibus oblongis, subtus villosis ex toto viridibus. Roxlo. ind. 1. p. 25. Rosc. mon. pl. t. 63. In regno Burmano. 4 . Planta 6-8ped. Cor. albo-rubens; lab. flavum.

13. C. amarissima Rosc. mon. $p l$. $t$. 80. bulbis Iongis uti tuberilhus palmatis intus flavis et aeruginosis; fol. sessilibus late-ovatis glabris viridi- bus; comae bracteis albis; labio obtuse 3-lobo, loho medio crenato. $A^{1}$ b. Dietr. 1. c. In India orientali. 4. Caul. rufescens. Cor. rubra; lab. flavissimun.

\section{b. Spica centrali.}

11. C. longa Linn. bulbis parvis numerosisque, tuberibus palmatis longis intus saturaie aurantiacis; fol. longe peliolatis late-lanceolatis utrinque attenuatis totis viridibus. Roxb. asiat. res. XI. p. 340. Bot. Reg. Es6. Amomum Curcuma. Jacq. H. Vind. t. 4. In tota India culta. 24. Cor. alba, fauce pilis favescentibus clausa.

15. C. Amada Roxh. bulbis conicis (uberibusque palmatis jitus pallide flavis; spica tenui rarifora; fol. longe peliolatis late-lanccolatis ntrinque attenuatis; tota viridis. Roxb. asiat. res. XI. p، 341. Rosc. t. 15. In S $\mathbf{c}^{\prime-}$ matra. 24. PJauta 5-6-ped. Cor. alba aut pallide flava; lab. flavum litura media obscuriore.

16. C. viridiflora Roxb. bulbis oblongis tuberibusque palmatis intus saturate favis; fol. oblongis longe petiolatis; tota viridis. Roxh. asiat.res. XI. p. 341. In Sumatia. 4. 1-3-ped. Spica viridis, Flor. parvi pallide flavi.

17. C. montona liosc. bullbis conicis; tuberibus palmatis pallide flavis; fol. oblongis breviter petiolatis; comá rosea; caeterum tota viridis. Roxb. asiat. res. XI. p. 342. Corom. t. 151. In montibus Circars Indiae orientalis. 4. Cor, pallide rubro-fusca.

18. C. reclinata Roxb. bulbis fusiformibus, tuberibus palmatis fere nullis, pendulis numerosis oblongis ovatis stramineis; fol. petiolatis oblongis recurvatis. Roxb. 1. c. In Ind. orient. 24. Minima hujus generis. Cor. parva obscure rubra, lab. in medio macula flavida.

19. C. petiolata Roxb. bulbis tuberibusque palmatis paucis parvis intus pallide flavis, tuberibus pendulis numerosis e fibris brevibus filiformibus; fol. longe petiolatis oblongis ovatis, basi rotundatis; tota concolor viridis coma lilacina excepta. Roxb. Fl. ind. 1. p. 37. Fosc. t. 96. In Pegu. 24. Flor. flavi.

20. C. purpurascens Blume; tutuheribus suhpalmatis intus pallide stramineis; fol. late lanceolatis supra 
maculatis; spica oblonga viridi. In Jur 1.24.

20. C. Roscoeana Wall. $p l$. asiat. rai. $t$. $5 \%$. C. parviflora Wall. pl. asiat. vid. in add.

\section{GLOBBA Linn. (176\%).}

1. G. maiantian Iinn. fol. lanceolatis utrinque attematis; spicis terminalibus sthessilibus strobiliformibus bulbiferis; antheris quadricornibus. Hoxh. asiat. res. XI. p. 358 . Hosc. mon. yl. t. 64. Smith exot. bot. t. 103. Colebrockia bulbifera lioxb. Ceranthera amomoides Horm. In Moluccis. 4. Caul. 1-2-ped. Bracteae violaceae. Cal. et Cor. flava.

2. G. rece.nosa Smith exot. bot. t. 11\%. racemo elongato cylindrico; appendice filamenti sagittaeformi. Smith 1. c. In Nepalia. 24. Caul. 3-ped. Cal. rubro-punctatus. Cor. flava.

3. G. orixensis Roxb. fol. oblongis; panicula terminali; antheris nudis; capstia verrucosa. Roxb. asiat. res. p. 338. t. 6. Corom. t. 229. In vallibus humidis montium Ciscars. Ind. orient. 4. Caul. 2-3-ped. Cor. flava.

4. G. Hura Roxb. fol. ovato-oblongis; racemo terminali erecto; pedicellis ternis 3-floris; anthera coronula membranacea. Alb. Dietr. G. versicolor smith exot. bot. t. 117. f. ac. G. Koenigiana Spr. In ins. Yung, Ceylonia et is Malacea.4. Rad. nodosa. Cor. aurea.

5. G. pendula Roxb. fol. lanceolatis; racemis terminalibus compositis fol. multo lonerioribus pendulis; antheris bicalcaratis. Roxb. asiat. res. XI. p. 359. In ins. Pulo-Pinang. Rad. fibrosa. Cor. Mava.

6. G. Careyana Roxb. fol. ovatoJanceolatis, subtus villosis; racemis terminalibus compositis bulbiferis; corollae segmentis 2 limbi interioris longitudine labii; anthera nuda suborliculari. Koxb. ind. 1. p. 77. Lodd. Bot. Cab. 691. In Peyu. Rad. tuherosa. Cor. subvillosa saturate fiava.

\%. G. saltatoria liosc. mon. $p l$. t. 16. panicula radicali; filamento basi ala utrinque subulata; antheris senilunaribus alatis. Mantisia Roxb. G. purpurca Andr. Rep. t. 117. G. radicalis Roxb. Corom. t. 230.
8. G. spathulata Roxb. panicula radicali; filanıento utrinque ala spathulata; anthera utrinque ala semiltlarí. Hoxb. ind. 1. p. 80. Mantisia $R$. et s. In sillet. 4. Cor. Ilava.

9. G. sessiliflnia Sims. Bot. Mag. 1425. caulihus bubiferis; fol. oblongis; racemis terminalilrus erectis folio hrevioribus hulhiferis. G. halbifera. Roxh. asiat. res. XI. p. 358. Tratt. 679. In Pegu et Circars. 4. Cor. lava.

10. G. japonica Thunb. racemo terminali cemuo; foliis ensiformibus integerrimis. Thunl. jap. p. 23. In Japonia. 24. Caul. 2-ped. Caps. rubra.

11. G. cuspielata N. et M. fol. obIongis acuminatis hasi cuneatis glabris; vaginis ciliatis; spica sessili vagina foliorum involuta. Nees et Mart. Act. Leop. 11. p. 28. In Brasilia. 2 . Caul. 1 $\frac{1}{2}$-ped. Flores intense crocei.

12. G. parviflora Presl; fol. sessilibus lanceolatis acuminatis; panicula terminali multifora; pedicellis simplicibus 1-floris; antherae appendicibus duahus ovatis acutis hyalinis. Reliq. Haenk. Fasc. 2. p. 115. In ins. Luzon. 24. Scap. 1-1 $\frac{1}{2}-p e d$. Cor. flavescens.

13. G. subsessilis $N$. et $M$. subacaulis; fol. ovatis hasi cumeatis breviter acuminatis pubescentibus; vaginis laciniatis; spica sessili vaginis foliorum involuta. Nees et Mart. Act. Leop. 11. p. 29. In Brasilia. Caul. 2-uncialis. Cor. pallide flava.

14. G. maculata Blume; fol. oblongo-lanceolatis acuminatissimis subtus pilosiusculis; vaginis maculatis; pedicellis patentibus 3 -floris; anthera coronula terminata basi bicalcarata. In Java. $\odot$.

\section{CALLISTHENE Mart. (1824).}

1. C. major Mart. glabra; fol. ellipticis vel ovato-oblongis obtusis vel acutis. Mart. nov. gen. et sp. 1. p. 126. t. 75. Qualea disticha spr. In Brasilia. ち. Arbor 15-20-ped. Petalum flavum coccitieo-lineatum.

2. C. minor Mart. pubescens; fol. lineari-oblongis obtusis glandulosomucronatis. Mart. 1. c. t. 76. Qualea Spr. In Brasilia. 4. Arbor 15-20ped. ramis villoso-pubescentibus. Petalum sulphreetum. 
3. C. fasciculata Mart. fol. ovatooblongis obtusis subenarginatis supra glabris subtus villosis; floribus axillaribus fasciculatis. Mart. 1. c. Qualea Spr. In Brasilia, ち. Petalum pallidun.

\section{AMPHILOCHIA Mart. (1S2t).}

1. A. dichotoma Mart. fol. e hasi rotundato-subcordata anguste oblongis obtusiusculis subtus pubescentibus. Mart. 1. c. t. 77. In Brasilia. ţ. Arbor ramis dichotomo-decompositis.

2. A. cordata Mart. fol. e basi profunde cordata subovato-lanceolatis acutiusculis utrinque glahris glaucescentihus. Mart. 1. c. Qualea spr. In Brasilia. ち. Petalum sericeum sulphureum uacula fusca.

\section{ERISMA Rudge (1S06).}

1. E. floribundum Rudge; fol. oppositis ovalibus acuminatis glabris; ramulis stellato-pubescentibus; panicula terminali bracteata; pedicellis hrevissimis incrassatis. Alb. Dietr. Tratt. obs. t. 105. Debraẹ $R$. et $\mathbf{s}$. Ditmaria Spr. In Gujana. 古.

2. E. violaceum Mart. fol. oblongis vel oblougo-lanceolatis cuspidatis utrinque glabris remote costatis; bracteis deciduis; floribus uudis speciosis violaceis. Mart. 1. c. t. 82. Qualea calcarata Link. In Brasilia. $\hbar$. Arbor spectabilis 30-ped. Cor. violacea.

3. E. maliforme Link. fol. ovalibus subtus tomentosis; racemis axillaribus brevibus; calcare calyce breviore; petalo spathulato truncato. Link. Mss. In Brasilia. t. Arbor ramis subtomentosis. Petalum videtur album.

4. E. niveum Link. fol. ovalibus vel oblongis obtusis apiculatis supra glabris nervis pubescentibus subtus tomentosis albis; racemis axillaribus; calcare longitudme calycis tomentosi. Link. Mss. Alb. Dietr. sp. pl. 1. p. 102. In Brasilia. 5 . Arbor ramis tomento tenui. Petalum bilobum.

\section{QUALEA Aubl. (17\%5).}

1. Q. roser Aubl. guj. t. 1. petalo integro; nectario calyce breviore.
Vahl en. i. p. 6. Cand. prodr. III. p. 28. In Gujana. ち. Arbor 60-ped. ramis 4-angulis subvillosis. Cor. rosea.

2. Q. caerulea Aubl. guj. t. z. petalis emarginatis; nectario longitudine calycis. Vahl. en. 1. p. 6. In Gujana. Ђ. Arbor excelsa. Flor. parvi caerulei.

3. Q. Gestasima St. Hil. fol. Ianceolatis acumninatis glabris; petiolis pedunculisque pubescentibus; calyce fiubriato; lạb. superiori emargiuato; petalo cordato. Cand. I. c. In Brasilia. . Arhor 100-ped. alta. Petalum magnum luteum purpureo - punctatun.

t. Q.ecalcarcita Mart. fol. linearioblongis acuminatis supra glabris subtus costatis reticulatis subfulvopubescentibus; racemis lateralibus subcorymbosis paucilloris ; calyce ecalcarato. Mart. 1. c. t. 78. In Brasilia. ђ. Arbor 20-ped. Flores ochroleuci.

5. Q. grandiflora Mart. fol. lineari-oblongis vel oblougis acuminatis supra glabris repticulatis pubescentitomentosis; nervis venisque glabrescentibus; florihus axillaribus terminalibusque solitariis aut racemosis; calycis calcare elongato - acutiusculo. Mart. 1. c. t. 79. In Brasilia. ち. Arbuscula $10-20$-ped. Pẹtalum luteoalbum.

6. Q. multiflora Mart. fol. oppositis ternisve ovalis late lanceolatis vel oblongis acuninatis supra glabris subtus costatis reticulatis glahris vel pubescentilus; pedunculis pilosis; racemis axillaribus terminalihusque; florun verticillis distantibus calycis foliolo summo truncato-emarginato; calcare ovarionue birstitissimis. Mart. l. c. t. 80. var. $\alpha$. glerbra; fol. angustioribuș utrinque glaintis et $\beta$. pubescens, fol. latioribus utringue, praesertim subtus pubescentilus. Mart. In $B r^{*} a-$ siliu. †. 10-12-ped. Petalum ochroleucum.

7. Q. parviflora Mart. subpulverulento-lomentoso-incana; fol. oppositis vel alteruis ohlongis vel utrinque vel subtus tantum canescenti-tomentosis vel subglabris costatis reticulatis; racemis lateralibus vel terminalibus nounuuquam subpaniculatis; calycis canescentis calcare patente obluso. Mart. l. c. t. 81. $\alpha$. tomentosa, fol. utrinque molliter incano-tomentosis. adultioribus tanden supra canescentibus. f. glabrata, fol. utrinque gla- 


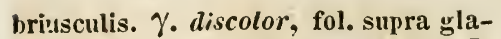
bris subtus canescentibus. Mart. In Brasilia. ち. Petalum violaceum basi albidum.

8. Q. lutea Desf. Herb. fol. ovalibus acutis supra nitidis costis lateralibus 7-9; ramulis paniculae striatis glabriusculis. Erisnıa nitidum. De Cand. 1. c. In Cayenna. 4.

9. Q. macroptera Alb. Jietr. fol. oblongo-lanceolatis acutis supra pubescentibus opacis subtus nervis tomentosis racenis terminalibus in ramis lateralibus; calcare longitudine calycis subtomentosi. Alb. Dietr. sp. pl. p. 1Co. In Brasilia. ち. Petalum bilobum flavum.

10. Q. subvillosa Link. Mss. fol. oblongo-lanceolatis acutis supra pubescentibus subtus nervis interdum tomentosis ; racemis terminalibus; calcare longitudine calycis villoso-tomentosi. Alb. Dietr. 1. c. B. glabraefolia, fol. ylabris nervis flavicantibus. In Brasilia. ち. Petalum praeced. simile flavum, maculis fuscescentibus.

\section{VOCHYSIA Juss, gen. (1798).}

1. V. Gujanensis Iam. ill. t. 11 . fol. oppositis obovato-oblongis apiculatis utrinque glabris; racemis simplicibus terminalibus densis; calcare patente. De Cand. prodi. 3. p. 26. Vochys. Aubl. t. 6. In Gujana et Brasilia. ち. Arbor excelsa. Flores Intei.

2. I. excelsa Willd. racemis terminalibus erectis densifloris; fol. oppositis oblongis obovatis glabris apiculatis. Cacullaria Meyer Esseq. p. 13. In Gujuna. b. Arbor excelsa. Flores lutei.

3. I. tomentosa Neyer; racemis terminalibus laxis subcerunis; fol. oppositis oblongo-ovalibus acuminatis subtus ferrugineo-tomentosis. Cucullaria Meyer Esseq. p. 13. C. excelsa Vahl. In Gujana. b. Arbor excelsa. Flores lutei.

4. V.tetraphglla de Cand. racemis axillaribus simplicissimis; fol. quaternis coriaceis utrinque glabris. Meyer 1. c. In Essequebo. $\hbar$. Flores flavi.

5. $V$, verticillata Alb. Dieir. fol. Oppositis et verticillatis lauceolatis attenuatis emarginatis glaberripis sul'ra lacvibus subtus reticulatis; race- mis terminalilus brevilus laxis; calycibus glabris. Alb. Dietr. Qualea spreng. In lirasilia. ђ.

6. V. emaryinata Poir. fol. oppositis oblongis ohtusissinis emarginatis ntrinque glabris subcoriaceis ; racemis terminilibus erectis. De Cand. I. c. Cucullaria Vahl. Vochy Vand. in lioem. script. 69, t. 6. f. 1, In Brasilia. $\hbar$.

7. V. citrifolia Poir. fol. oppositis ovatis obtuse aouminatis glabris; racemis terminalibus paniculatis. De Cand. 1. c. Cucullaria $\mathrm{R}$, et S. In Brasilia, ち, Racemi longitudine foliorunt.

8. V. pruinosa Poll; fol, verticillatis quatemis aguregatis sessilibus ovali-ellipticis basi subcordatis apice emarginatis pruinosis; racemo elongato tomentoso; pedunculis subtrifloris tomentosis, Polıl bras. 2. p. 22. t. 114. In Brasilia. $\hbar$. Arborescens, Flores lutei.

9. V. cuneata Polıl; fol, verticillatis aggregatis subquinatis breve petiolatis subcuneatis ovato-oblongis apice cordato-emarginatis; racemis pyramidatis; pedunculis 4-floris. Pohl bras. 2. p. 26. t. 117. In Brasilia. ち. Arborescens. Flores lutei.

10. V. elongata Poll; fol, verticillatis tri-quateruisve breve petiolatis oblongis seu oblongo-ellipticis apice emarginatis subrotundis basi attenuatis reticulatis; racemis elongatis strictis; pedunculis 2-3-5-floris. Pohl bras. 2. p. 25. t. 116. In Brasilia. ち. Arboresceus. Flores lutei,

11. I. thyrsoidea Pohl; fol. verticillatis oblongo - ellipticis retusis, hasi non attenuatis; racemis pyramidalibus; pedunculis sub 8-floris. Pohl

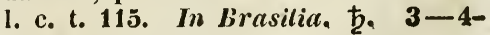
orgyalis. Flores lutei.

12. 1. diveryens pohl; fol. verticillatis ternatis divaricatis longe petiolatis oblongo-ellipticis apice subenarginatis; racemis longissimis ; pedunculis sub-3-floris pubescentibus. Pohl. 1. c. t. 121. In Brasilia. ఫ. 2-orgyalis; ramis luteo-rufis nitidis. Flores lutei.

13. V. sericea Pohl; fol. confertis verticillatis petiolatis obovato-oblongis basi attenuatis apice cordato-emarginatis; racemo sericeo-subtomentoso; pedunculis subtrifloris. Pohl 1. c. In biasilia. ђ. Orgralis. Mami juniores 
luteo-nigrescentes. Racemi 1-ped. Flores lutei.

14. V. cinnamomea Pohl; fol. verticillatis 6-9-ternis aggregatis subsessilibus oblongis obtusis emarginatis, supra subtomentosis subtus nitido-fusco-tomentosis ; racemo. Iongissimo verticillato; pedunculis tomentosis. Pohl 1. c. t. 120. In Brasilia. †. Orgyalis. Cal. ferrugineo-tomentosus. Cor. lutea.

15. I. micrantha Pol, ; fol. verticillatis ternatis petiolatis oblongis apice obtusiusculis subemarginatis basi attenuatis; racemis elongatis; pedicellis solitaris. Pohl 1. c. t. 112. In Brasilia.t. Bioryyalis. Flores lutei.

16. V. rotundifolia Mart. tota glaberrima; fol. ternis quaternisve subsessilibus e hasi obcordata orbicularibus emarginatis glaucescentibus coriaceis firmis; racemis terminalibus solitariis; ovariis glahris. Mart. Nov. Gen. et Sp. 1. p. 140. t. 83. In Brasilia. b. Arbuscula ramis virgatis. Flores lutei.

17. I. elliptica Mart. fol. oppositis ternis quaternisve subsessilibus e basi cordata vel rotundata ellipticis obtusis glabris coriaceis tenuiter venosis glancescentibus; racemis terminalibus solitariis; pedunculis calycibusque pubescentibus; ovariis villosis. Mart. 1. c. t. 84. In Erasilia. †. Arbor 10-12-ped. Flores lutei.

18. I. Tucanorum Mart. fol. verticillatis (ternis ad octonis) lanceolatis oblongis vel ovato-oblongis basi attenuatis obtusis. vel subrotundis emarginatis utrinque glabris, venis longe intra marginem combinatis remotisculis; racemis terminalibus solitariis elongatis vel abbreviatis; calcare patente vel calyci adpresso; ovariis glabris. Mart. 1. c. t. 85̃. In Brasilia. $\hbar$. Arbor 40-ped. cortice cinereolutescente. Flores lutei.

19. V. rufa Mart. ramulis. incrassatis tomentosis; fol. verticillatis quaternis ad octonis petiolatis oblongis obtusis subtus praesertim junioribus ferrugineo-tomentosis venosis reticulatis coriaceis; racemis terminalibus colitariis longissimis sparsiftoris; pedunculis calycibusque tomentosis; ovariis hirsutissimis. Mart. 1. c. t. 86. In Brasilia. 5 . Arbor 15-ped. Ramuli cortice suberoso ferrugineo-fusco. Flores lutei.
20. Y. alpestris Mart. fol. oppositis breviter petiolatis ellipticis vel oblongo-ellipticis rotundatis emarginatis utrinque glahris tenuiter venosis; racemis terminalibus solitariis longis cylindricis; ovariis glabris. Mart. 1. c. t. 87. In Brasilia. ち. Arbor. 1525-ped. cortice laeviga'o albo cinerascente. Flores lutei.

21. V. grondis. Mart. fol. quaternis petiolatis obovato-oblongis rolundatis vel subtruncatis parum emarginatis utrinque glabris membranaceis tenuiter venosis; racemis termiualibus longis cylindricis aggregatis; ovariis glabris. Mart. 1. c. t. 88. In Brasilia. ち. Arbor ligno molli spongioso, ad centum pedes altu, basi 2-3-pedum diametro: Flores lutei.

22. V. Haenkeana Mart. fol. quaternis longe petiolatis oblongo-lanceolatis. subcuspidatis apice obtusiusculis emarginatis utrinque glabris, tenuiter venosis; racemis terminalibus compositis paniculatim aggregatis.; ovariis tomentosis. Mart. l. c. t. 89. In Brasilia. ђ. Arbor. Flores lutei.

23. $\Gamma$. pyramidalis Mart. fol. op-s positis quaternisve e basi cordata vel rotuuda oblongo-lanceolatis. acuminatis subtus costato-venosis aeque ac ramis petiolis pedunculisque tenuiter cinerascenti-tomentosis; racemis terminalihus solitariis pyramidatis ; ovariis glabris. Mart. 1. c. t. 90. In Lrasilia. ち. Arbor elegans. 20-ped. et major. Flores lutei.

21. V. floribunda Mart. fol. oppositis temis quaternisve oblongis cuspidatis subtus costato-vcnosis et ad venas strigulosis scabriusculis; racemis terminalihus agruegatis; calycis calcare brevi recto conico; ovario glabro.

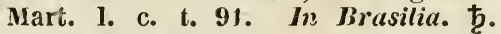
Arbor 30-ped. Flores lutei.

25. I. ferruyinea Nurt. fol. oppositis, ovato-oblongis. vel oblongis acuminatis supra glabris subtus costatovenosis, nervo medio venis venulisque interjectis reticulatis ramisque fuscotomentosis; racemis terminalibus erectis strictis; calycis calcare adunco; ovariis glabris. Mart. 1. c. t. 92. In Brasilia. ち. Arbor 20-ped. Flores igneo-flavi.

26. V. pumila Pohl; fol. ternis quaternisve breve petiolatis oblongis hasi attenuatis apice obtusis cuspidatis subtus glaucis; racemis longis- 
simis; pedunculis 2-floris pubesoentihus. PohI I. c. t. 113. In Brasilia. t. Frutex uhnaris, Flores lutei.

27. V. herbacea Pohl; fol. verticillatis ternis quaternisve breve petiolatis obovatis mucronatis pilosis; racemis elongatis; pedunculis 5 -floris fulvo-tomentosulis. Pohl 1. c. t. 118. In Brasilia. ち. Caul. sublignosus 2ped. Flores Iutei.

28. V. racemosa Poir. Dict. fol. oppositis ovato - lanceolatis acutis glabris membranaceis; racemis axillaribus. De Cand, 1. c, In Cayennu. $\frac{\hbar}{}$.

\section{SALVERTIA St. Hil. (1820).}

1. S. convallariodora St, Hil. fol. verticillatis obovatis obtusis glahris coriaceis; racemo terminali solitario maximo. Mart. 1. c. t. 93. In Brasiliu. ち. Arbor pulcherrima ad triginta ped. cortice cinereo nigricante. Flores albi.

2. S. thyrsiflora Pohl; fol. verticillatis obverse oblongo-ovatis ant oblongis obtusis mucronatis; thyrso paniculato. Pohl bras. t. 110. In Brosilia. b. Arhor 20-ped. cortice crasso suberoso, Flores canescenti-albi.

\section{MANGIFERA Linn. (1718).}

1. M. indica Linn. fol. lanceolatis; racemis terminalibus; petalis demum apice reflexis; drupa subreniformi glabra. - Jacq. ic. t. 337. M. domestica Gaertn. t. 100. In India orientuti, t. Arbor 40-ped. sempervirens, Flores parvi albo-flavescentes.

2. M. oppositifolia Roxb. fol. oppositis lanceolatis aouminatis; paniculis terminalibus; staminibus $\mathbf{4 - 5}$ fertilibus Roxb.ind. 1. p. 640. In Ind.or. t. Flores numerosi parvi lutescentes.

3. M. sylvatica Roxb. fol. alternis lanceolatis nitidis; paniculis terminalibus; floribus monandris; drupa oblique conica, mucrone obliquo. Roxb. ind. 1. p. 614. In India. $\hbar$. Flores parvi numerosi albi.

4. M. foetisla Lour. fol. Ianceolatis petiolatis; paniculis erectis; petalis integris recurvis; drupa cordata pubesoente. De Cand.prodr. 2. p, 63, Rumph amb. 1. t. 28. In Cochinchina et in ins. Ifoluccanis. $\hbar$. Flores parvi rubri.
5. II. Iaxiflora Desrous; fol. late lanceolatis sessilihus; paniculis laxis pendulis; floribus pentandris; drupa subrotunda. De Cand. 1. c. In ins. Mauritii. ち. Iami nodoso-cicatrisati. Fol. $\frac{J}{2}-$ ped. Ionga.

\section{USTERIA Willd. (1792).}

1. I. guineensis Willd. Monodynamis Iserti Gmel. Frutex ramosus. Folia opposita ovalia breve petiolata glabra. Panicula divaricata. Rami pubescentes. Flores pallide-violacei. In Gujana et Sierra Leona. ち.

\section{LOPEZIA Cav. (1791).}

1. L. mexicana Jacy. herbacea glabra; fol. alternis ovato-lanceolati.s serratis basi attenuatis; racemis ad ramos terninalibus; bracteis pedicellis hreviori!us. De Cand. prodr. 3. p. 62. L. racemosa Bot. Mag. 257. Bonpl. navarr. t. 25. In Mexico. $\odot$. 2-3-ped. Corolla purpurea.

2. L. cordata Hornem. herbacea glabra; ramis sulcato-angulatis; fol. alternis suhrotundo-ovatis basi cordatis subciliatis. De Cand. 1. c. $\odot$. Flores purpurei.

3. I. coronat Andr. herbacea glabra; ramis angulatis; fol. alternis ovatis serratis hasi attemunatis; racemis terminalibus; bracteis inferiorihus pedicellis longioribus. De Cand. I. c. Jacq. eclog. t. 110. L. axillaris Schweigg. L. minuta Lag. In Mexico. ○. 2-4-ped. Corolla ruhescens.

4. L. minima Lay. herbacea glabra; caule 4-angulo subsimplici; fol. ovatis acutis argnte dentatis subacuminatis, plurimis oppositis, supremis alternis. De Cand. 1. c. In Mexico. $\odot$. Flores rubescentes.

5. L. oppositifolia Iag. herbacea glabra; fol. ovatis dentato-serratis, plerisque oppositis, supremis alternis; racemis terminalibus; floribus supremis aphyllis. De Cand. 1. c. In Hispaniola. ().

6. L. integrifolia $\mathrm{DC}$. herhacea glabra; fol. alternis ovato-lanceolatis utrinque acuminatis integerrimis; racemis foliosis terminalibus. De Cand. 1. c. In Mexico. $\odot$. 
7. L. miniata DC. frutescens, glabra teres; fol. alternis ovato-lanceolatis; racemis terminalibus. De Cand.l.c. Jacq. eclog. t. 109. L. frutescens IR. et \$. L. fruticosa schrank. In Hispariola. $\odot$. 1-4-ped. Cor. miniata.

8. L. pumila Borpl. Naicrr. caule simplici hirsuto tereti; fol. breve petiolatis ovatis acutis dentatis, superioribus lanceolatis utrinque puhescentilus; racemis terminalibus; floribus longe pedunculatis. De Cand. I. c. In Mexico. $\odot$. Flores pubescentes.

9. L. lirsuta Jac\%. Coll. 5. p. 5. t. 1.5. f. 1. caule suffuticoso hirsuto, tereti; fol. ovato-lanceolatis pubescenti-hirsutis subserratis ; racemis terminalibus. De Cand. 1. c. In Mexico. $\odot$. Cor. rubescens.

10. L. pubescens $H$. et $K$. caule ramoso; fol. ovali-oblongis acutis pubescentibus. De Cand. 1. c. In Mexico. $\odot$.

\section{CENTRANTHUS DeCani.(1805).}

1. C. ruber De Cand. fol. ovalilanceolatis, superioribus ovatis acuminatis. Rchb. excurs. p. 197. Valeriana rubra Linn. Engl. Bot. 1531. In Europa meridionali. 4. 1-2-ped. Cor. coccinea persicina et alba.

2. C. angustifolius De Cand. fol. linearilsus Rchb. 1. c. Valeriana Cav. ic. t. 253. In Helvetia.24. 2-ped. glaucescens. Cor. coccinea.

3. C. Calcitrapa De Cand. fol.pinnatifidis Rchb. l. c. Valeriana Lim. In Hispunia, Gallia et Italia. $\odot$. Spithamaeus et pedalis. Cor. rubescens.

4. C. nervosus Moris; fol. oblongo-lanceolatis undulatis; caule stricto tereti. Valeriana trinervis Viv. floc. cors. p. 3. In Sardinia et Corsica. Cor. rubescens.

\section{PHILYDRUM Banks (1788).}

1. P. lanuginosum $\boldsymbol{R}$. Br. spica cum perianthiis capsulisque lanatis; antherae lohis spiralibus. R. Br. prodr. 1. p. 205. Gaertn. t. 16. f. 10. Garciana cochinchinensis Lour. In Cochinclina et Nova Hollandia. 4.

2. P. pymaeum R. Br. spica cum perianthiis capsulisque glabris: antherae lobis reniformibus. In Nova Hollandia. 4.

\section{APHELIA R. Br. (1810).}

1. A. cyperoides $\mathrm{R}$. Br. In Nova Hollandia.

\section{POLLICHIA Ait. (1789).}

1. P. campestris Sm. Enyl. bot. 1. $t$. 1. Neckeria Gmel. Meerburgia Moench. - Caul. ped. ramosus diffusus subtomentosus. Folia verticillato-quaterna senaque linearia sessilia. Flores axillares glomerali. In Prom. b. spei. 4.

\section{CERDIA De Cand. (1823).}

1. C. virescens $F l$. mex. ic. ined. fol. oppositis. De Cand. prodr. 3. p.377. In Mexico. 24. Cor. albo-viridis.

2. C. purpurascens $\mathrm{Fl}$. mexic. ined. fol. quaternis s. verticillatis. De Cand. 1. c. In Mexico. $\odot$. Flores rubentes.

\section{SALICORNIA Linn. (1737).}

1. S. lerbacea Limn. patula; articulis apice compressis emarginatis; spicis axillaribus oppositis pedunculatis; squanis obtusis. Willd. sp. pl. 1. p.23. Fl. Dan. t. 303. S. acetaria Pall. haloph. t. 1. S. annua Engl. bot. 415. In Europa et America ad ora maris et in locis salsis. $\odot$.

2. S. procumbens $\mathbf{S} m$. herbacea prostrata; articnlis obconicis ; ramis simplicibus; spicis fastigiatis; staminibus duobus. Engl. bot. 2475. In sabsis Holsutiae. $\odot$.

3. S. rallicans $\mathrm{S} m$. canle lignoso radicante; articulis subcylindricis; geniculis compressis emarginatis retusis; spicis incrassatis. Rchb. excurs. 676. Engl. bot. t. 1691. In uliginosis salsis Angliae et Germuniae. 4.

4. S. braclicita Roxb, perennis erecta; ramis nunierosis decussatis; articulis cmeatis; spica cylindrica. Roxb. ind. 1. p. 84. In Ind. orient. 4.

5. S. fruticosa Linn. geniculis teretibus integris; articulis aequalibus; spicis cylindraceis obtusis. Rchb. 1. c. Lam. ill. t. 11. f. 2. Engl, bot. 2467. Zanoni ist. t. 32. Ad ripas maris mediterranei. 4. 1-2-ped.

6. S. macrostachya Moric. caule fruticoso; ramis adscendentibus ; arti- 
culis superioribus vix crassitie longioribus; spicis crassis subclavato-cylindricis sessilibus. Rchb. 1. c. Halocnemum fruticosum Alb. Dietr. In V'enetia versus portam de Malamacco. $\hbar$.

7. S. indica Willı. Berl. Mag. 2. t. 4. f. 2. floribus 5-7 diandris; spicis terminalihus cylindraceis : articulis clavatis compressiusculis retusis; caule suffruticoso; ramis adscendentibus. $\mathbf{H}$. Br. prodr. p. 267. In littoribus maris circa Tranyuebar. .

8. S. Arbuscula R. Br. floribus ternis monandris; articulis clavato-oblongis, emarginatis; caule fruticoso erecto. R. Br. I. c. In Nov. Holl. $\hbar$.

9. S. peruviana $H$. et $K$. caule fruticoso pubescente ramoso; articulis cylindraceis apice incrassatis truncatis glahris; spicis teretibus oppositis. Kunth. syn. 1. p. 478. In Peruvia. ち.

10. S. cruciata Vahl; fruticosa; articulis inferioribus subglohosis, superiorihus cylindraceis decussatis. Vahl en. 1. p. 11. In Aegypto. ђ.

11. S. ambigua Mchx. fruticosa adscendens inaequali-ramosa. Michx. am. 1. p. 2. In Carolina.

12. S. perfoliata Vall; fol. alternis perfoliatis; ramis diclıotomis. Vahl en. 1. p. 13. In Mare rubro. $\hbar$. Caulis 1-ped. diffusus non articulatus.

13. S. arabica Linn. caule herbaceo; ramis alternis; fol. alternis cylindraceis decurrentibus. Alb. Dietr. I. c. Pall. it. app. t. D. f. 3. ill. t. 5. 6. A. foliosa Vahl. Pall. it. t. C.

14. S. amplexicaulis Iahl; fol. cordatis amplexicaulihus. Vahl en. 1. p. 13. In agro Tunetano et in IIisp. austr. $\mathfrak{\hbar}$.

\section{HALOCNEMUM Marsch. Bieb. (1819).}

1. H. strobilaceum M. B. suffruticosum diffusum aphyllum; articulis caulinis brevissinis. M. Bieh. suppl. adfl. caucas 1. p.3. S. strohilacea Linn. Pall. it. app. t.B. f. 1. 2. ill. 1. t. 4. Ad lacus salsos Tauriae et ad nare caspicum.

2. H. caspicum M. B. caule fruticoso; ramis oppositis vagis, fimbriis arcte adnatis superne et utrinque prominentibus; spicis longiusculis filiformihts. Alb. Dietr. 1. c. Salicornia Limm. Pall. it. app. t. D. A. fo 2. Ad mare

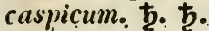

\section{HIPPURIS Linn. (1737).}

1. H. vulgaris Linn. fol. verticillatis 6-12 linearibus Rchb. excurs. p. 632. Fl. Dan. t. 78. Dict. calı. 20. Caulis emersus strictus. Folia patentia. B. fluitans; caule fluitante, fol. suhmersis reflexis, emersis saepe in spicam tortis H. vulgaris $\beta$. Web. Hols. In Europa in fossis et piscinis profund is et ad fluvios. 4.

2. H. maritima Hellen. fol. senis ovali-lanceolatis obtusis. Rchb. 1. c. Fl. Dan. 1261. Rchb. ic. 182. H. vulg. j. Koch. Ad oram sinus botnici. $\hbar$.

3. H. montana Ledeb. flaccida, subramosa; fol. senis linearibus acutis. Ledel., in Rchl. ic. 181. In Unalasckae montibus turfosis. 4.

\section{DIGINIA.}

\section{PSILURUS Trin. (1820).}

1. P.nardoides Trin. Nardus stricta Linn. Rotthoellia monandra Cav. Asprella nardiformis Host. In Europa meridionali. $\odot$.

\section{BLITUM Linn. (178\%).}

1. B. capitatum Linn. glomerulis terminalibus aphyllis; seminís margine acute carinato. Hchb. excurs. p. 582. Schkulır t. 1. f. 4. In Europa merillionali. $\odot$. Caul. 2-ped. Cal. maturus ruber.

2. B. virgatum Linn. glomerulis onnilus axillaribus; semine laevi margine canaliculato. Rchb. 1. c. B. capitatum. Sturm 2. In tota Europa australi. $\odot$. Caul. 2-3-ped. Cal. maturus ruber.

3. B. petialore Link. fol. hastatis subdenticulatis; glomerulis florum summis bracteatis. Link en. 1. p. 8. Hab..... ๑.

4. B. chenopodioides Lam. fol. liastatis sinuato-dentatis; calycibus fructus exsuccis. Lam. enc. meth. 2. p. 11. In Europa australi et orientali. $\odot$.

5. B. maritimum Nutt. fol. Ianceolatis utrinque attenuatis inciso-dentatis; glomerulis axillaribus spicatis; calycilus membranaceis. Alb. Dietr. In Nova Caesarea. 


\section{CALLITRICHE Fab. Column. (1616).}

1. C. verna Linn. fol. variis; hracteolis aequalibus persistentibus filamentoque elongato slylisque erectis; fructu subsessili (minuto) oblongo; carpidiis angustissime marginatis per paria adflexis. Rchb. excurs. p. 753. ic. $1179-1183$. In aquis stagnantibus per totam Europam. $\odot$.

2. C. stagnalis Scop. fol. obovatospathulatis subretusis quintupli-sextupli-nervibus; bracteolis lanceolatofalcatis couniventibus; filamento elongato; stylis demum reflexis; fructu breve pedunculato sub-obcordato; carpidiis alatis cruciatis Rchb. 1. c. Ejusd. ic. 1184-1186. Cum praecedente. $\odot$.

3. C. platycarpa Kützing; fol.variis excisis; bracteolis lineari-falcatis aequalibus persistentibus conniventibus; filanento subelongato; carpidiis alatis per paria parallelis. Kchb. 1. c. Ejusd. ic. 1187-1199. Cum precedente. $\odot$.

4. C.autumnalis Linn. foliis variis; bracteolis falcato-aduncis (minutis) caducis filamento pluries longioribus; stylis sub anthesi divaricatis demum reflex0-adpressis; fructu breve pedunculato obcordato; carpidiis subulatis cruciatis. Rchb. 1. c. Ejusd. ic. 1200 -1220. In aguis stagnantibus.

\section{CORISPERMUM Marsch. Bieb. (1819).}

1. C. microspsermum Host; caule ramisque sparsim stellato-pilosis; spicis sparsifloris tenuilus; utriculo brevi ovali utrinque rotundato subulato. Rchl). excurs. p. 584. C. tenue. Link. In Hungaria. $\odot$.

2. C. nitidum Kit. nitidum purpurascens; spicis laxiusculis; utriculo ovali exserte apiculato aptero. Rchb. 1. c. C. purpurascens Host. In Hungaria et Germania. $\odot$.

3. C. hyssopifolium Linn. glabriusculum opacum; spicis breviusculis condensatis cano-pilosis; utriculo elliptico acutato vix alato. Kchb. 1. c. Pall. ross. t. 98. f. 1. Fl. graec. t. 1. In Europa orientali et Sibiria. $\odot$.

4. C. intermedium Schweigg. fol. hracteisque lineari-lanceolatis mucronatis spicisque demum crassis com- pactis pentandris canescentibus. Rchb. I. c. C. canescens Kit. C. patens $\mathbf{R}$. et S. C. suhpentandrum. Pall. ill. t. 59. Ad ripas maris baltici. $\odot$.

5. C. bracteatum Viv. caule tomentoso; fol. bracteisque lineari-lanceolatis margine cartilagineis; floribus demum longissime laxeque spicatis; utriculi subrotundi margine late-alato superue denticulato apice exciso. Rchb. 1. c. C. elatum Host. C. Marschallii Stev. Sturm. 1. 67. In Italia, Hungaria et Germania. $\odot$.

6. C. latifolium Link. fol. lanceolatis; floribus spicatis; bracteis ovatolanceolatis ; fructu integro. Alb. Dietr. 1. c. hyssopifolium. Pall. ross. t. 98. f. B. et C. C. squarrosum Link. In Sibiria. $\odot$.

\section{MNIARUM Forst. (17\%5).}

1. M. biflorum Forst. gen. $t .1$. caulibus caespitosis; ramis glaberrimis ; fol. basi denticulatis superne integerrimis; pedunculis fructiferis folio longiorilus. R. Br. prodr. p. 412. M. pedunculatum Labili. t. 1. Ditoca muscosa Gaertn. t. 126. f. 1. In Nova Hollandia et ins. Van Diemen. 4.

2. M. fasciculatum $\boldsymbol{R}, \boldsymbol{B r}$. caule multiplici procumbente ramoso; ramis tenuissime pubescentibus; fol. Iongitudinaliter denticulatis; pedunculis fructiferis folia vix aequantibus. R. Br. 1. c. In Nova Hollandia. 4.

\section{3\%. ASPICARIA Lag. (1814).}

1. A. urens Lag. A. hirtella Rich. mem. du Mus. 2. $t$. 13. Caul. volıbilis pilis urentibus hispidus. Folia opposita cordato-ovata. Pedunculi axillares.

\section{TRIGINIA.}

\section{TRISTICHA Thouars. (1809).}

1. T. trifaria Spreng. fol. linearioblongis obtusis: ternatis. Bory de st. Vinc. in Willd. sp. pl.5. 5. p5. In aquis stagnantibus ins. Madagascar. et in Mascarenhas. 4. Caul. Iongus nataus nigricans. 
2. T. alternifolia Aub. Pet. Thouars; fol. lineari-lanceolatis acutiusculis alternis. Dufourea Koem. et Schult. In stagnantibus ins. Madagascar. 4.

3. T. Mypmoides Spreng. caule brevissimo ramoso; fol. sparsis minimis ovato-triangularihus; pedunculis terminalibus 2-spathaceis. spreng. syst. 1. p. 28. Dufourea st. Hil. In brasilia.

\section{POLEGTA.}

\section{CENTROLEPIS Labill.}

a. Receptaculum paleaceum.

1. C. Mulvinata $R$. et $s$. receptaculo paleaceo; stylis $6-7$ distinctis; spathis muticis; valvula inferiore hispidiuscula, superiore glahra; fol. scapos subaequantibus. Desvauxia. R. Br. jrodr. p. 252. In Australia.

2. C. Patersonii $R$. et S. receptaculo paleaceo; stylis 8-9 distinctis; spathis mucronatis multifloris; valvula superiore glabriuscula, inferiore hispida; scapo adulto foliisque hoc triplo hrevioribus pilosis. Desvauxia $\mathbf{R}$. Br. 1. c. C. aemula Rudge in Linn. Trans, t. 13. f. 2. In Australia.

3. C. striyosa $R$. et S. receptaculo paleaceo; stylis 5-7 distinctis; spathis mucronatis; valvulis ambabus hispidis; scapo adulto glahro fol. hispidulis triplo longiore. Desvauxia $\mathbf{H}$. Br. 1. c. In Australia.

b. Receptaculum epaleaceum. Spatlae hispidae.

4. C. fascicularis Labill. Nov. Holl.t. 1. receptaculo epaleaceo; stylis 2-3 hasi comatis; spathis hispidis; aristis valvulas subaequantibus; fol. pilosiusculis; scapo glabro. Desvauxia Billardieri $\mathrm{H}$. Br. 1. c. C. $\mathrm{Cu}_{-}$ spidigera Rudge 1. c. t. 12. f. 1. In ins. I'an Diemen.

5. C. temior $\boldsymbol{R}$. et $\mathrm{S}$. receptaculo epaleaceo; stylis $\mathbf{4 - 5}$ basi connatis; spathis submuticis foliisque hispidis; scapo pilosiusculo. Desvauxia $\mathrm{H}$. Br. 1. c. In ins. Ian Diemen.

6. C. exserta $\boldsymbol{R}$. et $\mathrm{S}$. receptaculo epaleaceo; stylis 7-10 distinctis; spathis muticis hispidis; flosculis apice exsertis; scapis foliisque pubescentibus. Desvauxia R. Br. 1. c. In Nocu Hollandia.

c. Receptaculum epal eaceum. spatlae glabrae.

7. C. Banksii R. et S. receptaculo epaleaceo; stylis 8-10; spathis muticis glaberrimis multifloris margine membranaceis; scapo foliis 3-4-plo longiore. Desvauxia R. Br, 1. c.

8. C. pusilla $R$. et $\mathbf{S}$. receptaculo epaleace ; stylis 6-7; spathis muticis glaberrimis paucifloris margine membranaceis; scapis folia subaequantibus utrinque glabris. Desvauxia $\mathbf{R}$. Br. 1. c. In Nova Hollandia.

9. C. aristata $R$. et S. receplaculo epaleaceo; stylis $6-7$ basi connatis; spathis elongato-aristatis glahris; scapo ancipiti. Desvauxia R. Br. 1. c. In Nova Hollandia.

\section{ALEPYRUM R. Br. (1810).}

1. A. polygamum $\boldsymbol{R}$. Br. spathis 1-floris; valvula exteriore foliąceo-aristata; ovariis 15-18; scapo foliis 2-3-plove longiore $\mathbf{R}$. Br. prodr. p. 203. In Nova Hollandia.

2. A. pumilum R. Br. spathis 1-floris; valvula exteriori foliaceo-aristata; ovariis 6-9; scapo folia aequante. R. Br. 1. c. In Nova Hollandia.

3. A. muticum R. Br. spathis paucifloris; valvula exteriore mucronata. R. Br. 1. c. In Nova Hollandia. 


\section{CLA S S I S II.}

\section{I A N D R I A.}

\section{MONOGYNIA.}

1. Flores perfecti.

A. Corolla 1-petala. a. Fructus superi.

41. Wasmintun. Cal. tubulosus 5-8-dentatus. Cor. hypocrateriformis 5-8-fida. Bacca dicocca aut 2-locularis, carne seminibus arcte adnata.. Semiua 2 fundo baccae affixa. Jasmineue.

42. Hyctantics. Flores aggregati involucrati. Cal. tubulosus integer. Cor. 5-fida. Capsulae duo conjunctae compressae 1-spermae. Jasmineae.

43. Fontamesia. Cal. 5-partitus. Cor. ad basin 4-partita. Stigmata 2 reflexa. Capsula compressa 2locularis evalvis. Semina apici pericarpii affixa. Jasmineae.

13. Forsyt thia. Cal. 4-pariitus. Cor. campanulata 4-partita. stigma bilobun. Capsula? Jasmineue.

15. Tigustrum. Cal. tubulosus abbreviatus 4-dentatus. Cor. infundibuliformis 4-fida. Antherae 2-I0culares. Stigma 2-fidum. Bacca globosa 2-locularis, loculis 1-2-spermis. Jasminecte.

16. Hhillyrea. Cal. 4-dentatus. Cor. breviter campanulata 4-fida. Ntigma crassiusculum. Lacca globosa 2-lucularis; loculo altero saepe abortiente. Jasmineae.

\%. M1ea. Cal. 4-dentalus. Cor. breviter campanulata 4-fida. Stigma bifidum, laciniis emarginatis. Drupa 2-locularis, Ioculo altero abortiente. Nux oblonga. Jasmineae.

8. Chionant lnus. Cal.4-partitus persistens. Cor. tubo brevissimo, limbi laciniis longissimis linearibus. Antinerae cordatae erectae. Stigina 3-fidum. Drupa 1-sperma, putamine chartaceo striato bivalvaceo 1-loculari. Jasmineae.

49. Notelaea. Cal. 4-fidus inferus. Cor. 4-partita; laciniis ovalibus. Drupa 1-sperma, putamine chertaceo striato bivalvaceo 1-loculari. Jasmineae.
50. Syringa. Cal. 4-dentatus persistens. Cor. infundibuliformis 4fida. Stigma crassiusculum 2-fidum. Capsula ohlonga 2-locularis 3-valvis; valvis dissepimento contrariis. Semina solitaria oblonga compressa, margine membranaceo. Jasmineae.

51. Bollvaria. Cal. 5-partitus. Cor. campanulata 5-partita, laciniis acutis. Antherae biloculares. Stigna capitatum. Capsula cartilaginea didyma circumscissa 2-locularis, loculis 2-spermis. Semina angulata reticulata. Jasmineae.

52. Gratiola. Cal. 5-partitus bracteatus vel nudus. Cor. resupinata, limbo-4-partitn, lobo superiore emarginato latiore. Filamenta 4, duo sterilia. Stigma 2-lamellatum. Capsula 2 -locularis. Personatae.

53. IBonreya. Cal. 5-partilus subbracteatus. Cor. ringens, lah. superius integram inflexum, inferius 3lobun. Stamina 2. Capsula linearis subtetragona. Personatae.

54. Sehwenkia. Cal. tubulosus 5-fidus. Cor. limbus plicatus 5-dendatus aut undulatus, g! andulae clavatae in limho. Stam. 5, tria sterilia. Capsula 3-locularis 2-valvis polysperma. Personatae.

55. Denkeliz. Cal. 5-fidus. Cor. tubuloso-ventricosa, 5-loba. Stam. 4 quorum 2 sierilia. Capsula siliquosa 2-locularis 2-valvis, valvis demum tortis. Pessonatae.

5f. Fymmandira. Cal. ovat.Is longitudinaliter fissus 3-dentatus. Cor. ringens, lab. superius integrum, inferius 2-3-fidum. Antherae cordatae. Capsula oblonga 2-locularis, apice 4-dentata, loculis 1-spermis. Personotae.

5y. Cyrtandra. Cal. 5-parlitus. Cor. infundibuliformis, fance ampliata, limbo irregulari 5-lobo. Stam. 4, quorum 2 sterilia. Eacca 2-locularis polysperma. Dissepjmenta bifida revoluta. Personatue.

58. Calceolaria. Cal. 4-fidus, lacinis ovatis. Cor. 2-labiata, lab. sup. minimum acutum, inf. calceiforme 
marginibus involutis. Capsula 2-10cularis, dissepimento medio utrinque in placentas incrassato. Personutue.

55. Ctricularia. Cal, 2-partitus coloratus deciduus. Cor. personata calcarata, lab. inf. declinatum. Stigma bilabiatum. Capsula 1-locularis polysperna circumscissa operculata. Persomatae.

60. Pinguieuna. Cal. bilabiatus, lal). sup. 3-, inf. 2-fidum. Cor. ringens calcarata. Capsula 1-locularis, polysperma. Semina cylindrica. Personatae.

61. Selnimanthus. Cal. 5-partitus. Cor. 2-labiata resupinata: lab. sup. 5-partitum, laciuia media emaryinata concava. Stam. 4, quorum 2 sterilia. Capsula 2-locularis 2-valvis. Semina rugosa. Personatae.

62. Peplidium. Cal. tubulosus 5-dentatus. Cor. 5-fida. Stam. incurva. Capsula 2-locularis non dehiscens. Persomatae.

63. Veromien. Cal. 4-5-partitus. Cor. subrotata 4-loba, lobo quarto angustiore. Capsula 2-locularis obcordata polysperma. Personatae.

64. Paederota. Cal. 5-partitus aequalis. Cor. tubulosa bilabiata, lab. sup. 3-dentatum, inf. integrum aut 2 -dentatum. Stam. adscendentia. Capsula compressa 2-locularis 2-valvis. 8em. numerosa ninuta. Personatae.

65. Wulfemia Cal. 5-partitus. Cor. tubulosa basi subgibba, limbo ad faucem barbato bilabiato, lah. sup. integro stamina involvente, inf. 3-lobo. Capsula compressa 2-10cularis 4-valvis. Personatae.

66. Diploplnyllum. Cal. diphyllus compresso-clausus, phyllis cordatis serratis. Cor. rotata 4 -loba. Capsula subrotunda compressa 2-1ocularis 2-valvis 4-sperma. Personatae.

6\%. Sanchezia. Cal. 5-partitus. Cor. 5-fida inaequalis, laciniis revolutis. Stam. 4, quorum 2 sterilia. Antherae aristatae. Capsula 2-10cularis 2-valvis. Personatae.

88. Sarmienta. Cal. 5-partitus inaequalis. Cor. obovata-ventricosa, limbo 5-fido. Stam. 5, quorum 3 sterilia. Capsula circumscissa. Personatae.

69. Whitea. Cal. 5-fidus. Cor. infundibuliformis, tubo ampliato, limbo 5-fido irregulari, laciuiis 2 superioribus reflexis. Ntam. 5 , quorum 3 sterilia. Capsula baccata elongata siliquae formis. Semina pulpa tenui cincta. Personatae.

ร 0. NHicrocarpaen. Cal.tubulosus 5-fidus. Cor. bilabiata. Capsula 2-valvis, dissepimento e medio valvulae, demum libero. Personatae.

1. A elner arin. Cal.2-bracteatus 5-phyllus, phyllum supremum maxiınum. Cor. riugens. Capsula calyce persistente cincta 2-locularis. Senina irregulariter angulata scrobiculata. Personatae.

ร. Mysionotlnus. Cal. 5-pars titus. Cor. tubuloso-campanulata, limbo 5-loho, 2-labiato. Stam. 4, quorum 2 superiora sterilia. Stigma infundibuliforme. Semina utrinque villis comosa. Personatue.

ร 3. Faca. Cal. 5-partitus. Cor. 2-lahiata, lab. sup. 3-, inf. 2-lobum. Capsula longa corniculata contorta 2-locularis 2-valvis. Personatae.

74. Columella. Cal. 5-partitus aequalis. Cor. tubo brevissimo, limbo 5-partito subaequali. Antherae plicato-undulatae. Capsula 2-locularis 2-valvis polysperma, valvis apice 2fidis. Personatae.

\%5. WAlythmenta. Cal. 5-partitus. Cor. 2-labiata. Stant. 4, quorum 2 sterilia. Antherarum locelli paralleli. Capsulae loculi a basi octospermi. Acanthaceat.

76. Melsonia. Cal. 4-partitus, lacinia infera 2 -fida. Stam. sterilia nulla. Antherarunt locelli oblique divergentes. Capsulae loculi a basi 8spermi. Acanthaceae.

ว ซ. wemiadelphis. Cor. ringens. Filamenta dilatata. Antherae post pollen emissum contortae. Capsula angusta a basi polysperna Acanthaceae.

\% 8. Fmdopogon. Cor. 2-labiata inflata, lab. sup. 2-fido latiore intus pilis cincto stylum recondente. Capsula a basi 4-sperma. Acanthaceae.

y. Hoxanthus. Cor. limbus obliquus 5-fidus subregularis, tulus incurvus. Stam. sterilia duo. Capsula a basi polysperma. Acanthaceae.

80. Plilogacanthus. Cal. 5-fidus. Cor. 2-labiata, lab. sup. 2-fido latiore; tubus incurvus. Stamina sterilia nulla. Capsula a basi 
asperma superue 8-sperma. Acanthaceae.

81. Cry ptopleragnium. Cal. 5-fidus. Cor. bilabiata, lab. sup. bifido breviore; tubus elongato-obcovicus strictus. Stam. sterilia nulla. Antherae uniocellatae. Capsula a basi polysperma. Acanthaceae.

82. Kostellaria. Cal. 4-fidus, lacinia suprema minima. Cor. 2-labiata, lah. sup. plano 2-dentato. Capsula 4-sperma. Acanthaceae.

83. Groptophyllum. Cal. 5-fidus aequalis. Cor. 2-labiata, Iab. sup. rectum. Antherae muticae locellis parallelis. Capsula 4-sperma. Acanthaceae.

84. Reloperone. Cal. 5-fidus aequalis. Cor. ringens, lab. sup. rectum. Antherae muticae s. basi calcaratae. Capsula 4-sperma. Acanthaceae.

85. Adlnadota. Cal. 5-fidus aequalis. Cor. bilabiata, lab. sup. fornicatum. Antherarum locelli oblique alter super altero positi, inferior calcaratus. Capsula 4-sperma. Acanthaceae.

86. Gendarusga. Cal. 5-fidus aequalis. Cor. 2-labiata, lab. sup. fornicatum. Capsula 4-sperma. Acanthaceae.

8\%. Teptostachya. Cal. 5fidus aequalis. Cor. ringens. Antherarun locelli oblique alter super altero positi mutici. Capsula 4-sperma. Acanthaceae.

85. Cymmostaclnyum. Cal. 5-fidus inaequalis, lacinia superior minor. Cor. bilabiata, lab. sup. 2fido minore. Spica laxa secunda. Acanthaceae.

89. Eranthemum. Cal. 5fidus. Cor. hypocrateriformis vel elongato-infundibuliformis, limbo subaequali. Staminum sterilium rudinenta. Capsula 4-sperma. Acanthaceae.

90. Justicia. Cal. 5-fidus. Cor. bilabiato-hypocrateriformis, lab. sup. angusto. Stamina 2. Capsula 4-sperma. Flores spicati. Acanthaceae.

31. TE hinneantlnus. Cal. 5-fidus. Cor. bilabiato-hypocrateriformis, lab. sup. angusto. Stamina duo. Capsula 4-sperma. Spiculae sub-paniculatim solutae. Acanthaceae.

92. Rungia. Cal. 5-fidus aequalis. Cor. orthotropa labiata. Capsula 4-gona 4-8-sperma. Acanthaceae.

93. Dielyptera. Cal. 5-fidus aequalis. Cor. resupinata bilabiata, lab. sup. 3-dentato resupinato integro vel 2-dentato. Capsula 4-yona 4-8-sperma. Flores in capitulum aygregati. Acanthaceae.

94. Amn niscopia. Cal.5-fidus aequalis. Cor. orthotropa ringens. Capsula al inferiore parte compressounguiculata asperma. Acanthaceae.

95. Peristroplne. Cal. 5-fidus subaequalis. Cor, resupinata 2-Iabiata, lab. sup. 3-dentato resupinato integro vel 2-dentato. Antherae muticae. Capsula basi longe unguiculatim compressa; dissepimentum adnatum. Acanthaceae.

D6. Hypö̌stes. Cal. 5-fidus subaequalis. Cor. orthotropa 2-labiata, lab. inf. profunde 3-partito. Capsula basi breviter unguiculatim compressa; dissepimentum adnatum. Acanthaceae.

๑). Rlnaplnidospora. Cal. 5-fidus subaequalis. Cor. resupinata subringens, lab. 3-fido resupinato concavo. Capsula hasi breviter unguiculatim compressa; dissepimentum aduatum. Acanthacene.

b8. Erianthera. Cal. 5-fidus. Cor. 2-lahiata, lalo. sup. integro. Antherarum locellus inferior in lanam solutus. Capsula a basi depressa ovata pleiosperma. Semina subangulata. Flores axillares pedicellati ebracteati. Acanthaceae.

D9. Ifaplantiaus. Cal.5-fidus. Cor. subbilahiata 5-fida, tubo incurvo. Antherarum locelli tomentosi. Racemi axillares et terminales subspicati. Acanthaceae.

100. Andrographis. Cal. 5-fidus. Cor. bilabiata, lah. inf. 3-fido. Antherarum locelli subbarbati. Flores racemosi vel spicaeformes subsecundi. Acanthaceae.

101. Catalpa. Cal. 2-partitus. Cor. campanulata limbo 4-lobo aequali. Stamina 5, quorum 3 sterilia. Stigma bilamellatum. Capsula siliquaeformis 2-valvis. Sem. plura. Bignoniaceae.

102. Dxera. Cal. 4-partitus scariosus. Cor. tubulosa fauce dilatata limbo 4-fido. Stamina 4, duo sterilia. Stigma bifidum. Germen 4-10bum. Bignoniaceae. 
103. Salvia. Cor.2-labiata, lab. sup. integro. Filamenta trausverse pedicello affixa. Labiatae.

10 4. Rosmantixass. Cal.2-labiatus, lah.sup. integro, inf. bifido. Cor. 2-lahiata, lab. superiore 2-partito. Filamenta superne dente instructa. Labiatue.

105. Collinsonia. Cal. 2-labiatus, lab. sup. 3-dentatunı, inf. 2fidum. Cor. sublabiata, lacinia inferiore longiore fimbriata. semina 4, quorum 3 ahortientia. Labiatae.

106. Riziplaora. Cal. striatus 5-dentatus fauce barbatus. Cor. ringens, lab. sup. integrum reflexum, inf. 3-fidum. Semina 4. Iabiatae.

$10 \%$. Cumilla. Cal. cylindricus striatus, ore 5-dentato villoso. Cor. ringens, lab. sup. planum emarginatum, inf. 3-lobum, lobo medio emarginato. stamina 4, quorum 2 sterilia. Labiatae.

108. IN ornaned r. Cal. 5-dentatus. Cor. ringens, lal. sup. angusto stamina involvente, inferiore 3-Iobo. stigma bifidum acutum. Labiatae.

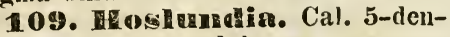
tatus. Cor. ringens, lab. sup. concavo, inf. 3-fido. Stamina 4, quorum 2 sterilia. Semina 4 infra calycem baccatum. Labiatae.

110. Ameringtea. Cal. subcampanulatus $\mathbf{5}$-ficlus. Cor. subbilabiata 5-fida lacinia infima magis producta concava. Sem. quatuor. Lubiatce.

111. Tycopus. Cal. tubulosus 5-fidus. Cor. suhaequalis 4-fida, lacinia superiore latiore emarginata. Stamina distantia. Sem. 4. Iubiatae.

112. Stachy tarplieta. Cal. tubulosus 4-dentatus. Cor. hypocrateriformis, tubo incurvo, limbo 5-fido. Stamina 4, quorum 2sterilia. Caryopsis. Verbenaceae.

113. Hosta. Cal. brevis 5-dentatus. Cor. 4-partita inaequalis patens. Stamina 4 , quorum 2 sterilia. Stigma 3-fidum. Drupa monopyrena. Viticeae.

114. Seiurus. Cal.5-fidus. Cor. tubulosa incurva, limbo 5-partito subbilabiato. Stamina 4-5, quorum 2 antherifera. Germen pentagonum. Caps. 4-5 coalitae. Viticene.

115. Melasanthus. Cal, subplicatus breviter $\mathbf{5}$-dentatus. Cor. tubulosa subinfundibuliformis, limbo 5lobo. Stamina 4, quorum 2 sterilia. Capsula elliptica 2-locularis 2-sperima. Verbenaceae.
116. Selnower.r. Cal. 2-lahiatus. Cor. 5-7-fida. Capsula pyriformis 2 -locularis 2 -valvis. Siemina 4-5 singulo loculo, membranaceo-alata. Eiynoniciceae.

11. Hemianthus. Cal. fissus, 4-dentatus. Cor. 2-labiata, lab. sup. obsoleto, inferiore 3-partito; lacinia media incurva truncata. Capsula 1 -locularis 2 -valvis polysperma. Primulaceate.

18. Thi cromtlnemunes. Cal. 4-partitus inaequalis. Cor. campanulata, lobo hrevissimo, limbo inaequaliter 4-partito. Capsula subglobosa 1 - Iocularis 3 -valvis polysperma. Primulaceae.

119. Campylanthus. Cal. 5-dentatus inaequalis. Cor. infundibuliformis 5-fida aequalis. Antherae peltatae. Capsula 3-locularis polysperma. Semina numerosa compressa.

1:0. Strigag. Cal. 4-fidus' persistens, laciniis subulatis. Corolla hypocrateriformis, tubo longo superne incurvo. Capsula 1-locularis polysperma.

121. Cryptotleca. Cal. infundibuliformis 4-fidus. Petala 4, miuima vel uulla. Capsula 1-locularis apice irregulariter circumscissa. Semina numerosa. Salicaitae.

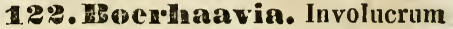
squanulatunı panciflorum. Cor. infundibuliformis, limho plicato sublobato. Nectarium urceolatum staminiferum. Nucula monosperma. Nyctagineae.

123. Codanoinme. Cal. 5-partitus aequalis. Cor. petalum unicum lanceolatum nectario annulari insertum. Legumen pedicellatum 2-valve 1-spermum. Leyuminosae.

12 1. Oliganrirena. Cal.4-partitus bracteatus. Cor. 4-fida persisteus. Nectaria 4 squamulosa. Germen 2-loculare. Epacrideae.

\section{b. Fructus inferi.}

125. Fugura. Flores monoici. Cal. 5-dentatus. Cor. 5-fida cum calyce coalita. Pepo subtetragonus 4locularis polyspermus. Sem. compressa. Cucurbitaceae.

126. Biglanorherna. Cal. corollinus 6-partitus inaequalis. Stamina 3, quorum 2 fertilia. S'tigma hilabiatum. Capsula oblonga 3-gona. sem. plano-depressa. Iridene. 
B. Corolla pleiopetala.

12\%. Cireaca. Cal. 2-partitus superus coloratus. Cor. dipetala, petalis bifidis. Capsula obovata, setis uncinatis hispida, 2 -locularis, disperma. Onauprae.

129. Prilling gonoia. Cal.3-phyllus, calyculatus. Cor. 3-petala, squamis isectariferis ternis. Filamenta apice 2-fida. Drupa sub2-locularis 2-valvis, 1-sperina.

129. Aiclelus. Cal. 4-partitus. Cor. 4-petala. stamiua brevissima. stigma sessile. Capsula compressa, 1-locularis 2-valvis. Caryophyllae?

130. A erenen. Cal. basi squamis duabus sullultus, tubulosus glochidihus armatus. Cor. 4-5-petala. stamina 2, 3, 4. Stigmata penicilliformia. Sem. 1, 2, calycis tubo inclusa. Rosacere.

131. Habicenen. Cal. 3-partitus sub 5-phyllus. Cor. 5-petala, petala ovato-orbicularia. Germen stipitatum 1-locularo. Leguminosae.

\section{Flores incompleti.}

132. Maregriocarmus. Cal. 4-0̄-partitus, superus, laciniis extus ad basin spinula dentiformi instructis. Stigma multifido-plumosum. Drupa nucleo monospermo. Rosaceae.

133. IBialiuna. Cal. 5-partitus ant 5-phyllus. Stamina receptaculo inserta. Legumen intus pulposum, 1-2spermun. Leguminosae.

134. Git Ins 3-bracteatus inferus, phylla 2-navicularia. Cro. 0. Capsula 2-locularis. Chenopodeae.

135. Cymserea. Cal. campanulatus persisteus, coloratus 5-partitus, inaequalis. Cor. o. Capsula 1-locularis circumscissa, polysperma. Sedeae.

136. Sigurremia. Cal. tubulosocampanulatus, 4-fidus, ad sinus dentibus quatuor minimis. Cor. O. Capsula 2-valvis, demum 1-locularis. Sem. numerosa. Salicariae.

13\%. Pinmeder. Perianthium infundibuliforme, 4-fidum. Cor. 0. Stam. fauci inserta. Nucula corticata, 1-sperma. Thymeleae.

1.3. Theichembrezaia. Cal. corollinus, tubulosus, 5-dentatus, inferus. Stigma pedicellatum. Utriculus 1-spermus, calycis basi inclusus. $N y c t a-$ ginea.
138. Fraximus. Flores polygami. Cal. 4-partitus aut nullus. Cor. t-petala, 4-partita aut nulla. Stigma bifidum. Fructus 2-locularis, compressus apice alatus, submonospermus. Jasmineac?

119. Proer. Amenta subandro„yna. Cal. 0 . Squamae appressac laterales vel bracteae peltatae aut lineares. Stamina 2 , vel incerti numeri. Stylus unicus vel nullus. Stigma 1, peitato-fimbriatun, vel 2,3 . Bacca 1-sperma. Semen albuminosum. $\mathrm{Pi}$ pereae.

14. Cladiumer. Spiculae undique imbricatae, 1-2-florae, squamis infimis vacuis. Stigmata 2 , hirta. Nncula putamine duplici.

142. Heman. Perianthium spathaceum, membranaceum. Filamenta suhcurvata. Antherae didymae subglobosae. Utriculus 1-spermus. $\mathbf{N a}$ jades.

\section{DIGYNIA.}

143. Cry fota. Cal. inferus 2-sepalus. Cor. clausa, $2-3$-petala. stigmata minima 2-3. Capsula 2-3valvis, 2-3-Iocularis. Sem. subcylindrica, striata. Salicariae.

144. Gunhern. Amentum verticillatum ; squamis persistentibus. Cal. 2-dentatus. Drupa cum calyce tumido coalita. Urticeae.

145. Podostemon. Cal. disepalus subquamatus. Filamenta pedicellata. Stigmata duo sessilia. Capsula ovata striata 2-locularis, 2-valvis, polysperma. Podostemeae.

146. Facistenan. Flores amentacei. Calycis loco squamae 3. Cor. infera 4-partita. Stamina 2 basi coalita. Stigmata 2-3, subulata. Capsula 1-10cularis 3-valvis 1-2-sperma. Semiua pendula arillata. Amentaceae.

148. Antlooxantlinnil. Panicula spicaeformis interrupta. Spiculate 3-florae; flores 2 inferiores, unipaleacei neutri, dorso aristati, summus minor, bipaleaceus, hermaphroditus muticus. Caryopsis ovato-ohIonga. Gramineae.

18. Heimaria. Spiculae 2-florae; flore inferiore 2-paleaceo, neutro, membranaceo, acutato-subulato, 3-nervio. Glumae nullae. Caryopsis oblo:iga. Gramineue.

1.8.5 clnmidira. Spiculae 1-10rae. Glumae unllae. Paleae 2, mem- 
branaceae, inferior ovata 1-nervia, acuminato-aristata, arista brevi, superior dimidio brevior, z-ncrvia, 2-carinata, apice 2-fida. Gramineae.

150. Diarmenem. Spioulae 8-9-forae. Glumae 2, muticae; inferior lorevior. Pateac $\mathbf{2}$, inferior ovata, dorso convexa, superne 3-nervia acuminato-mucronata; superior brevior, 2-carinata. Fructus stipitatus coriaceo induatus. Gramineae.

\section{JASMINUM Dodon. (1558).}

\section{Folia simplicia.}

1. J. Sumbac I. fol. oppositis ovatis subcordatisve glabris; ramis petiolisque pubescentibus. B. M. 1775. In Indiu orient. †. 10-12-ped. Cor. alla.

2. J. pubescens $L$. fol. oppositis ovatis cordatisve ramisque hirsutis. sm. exot. b. t. 118. J. hirsutum Willd. In Malabaria, China et Calcutta. $\grave{b}$. Cor. alla.

3. J. arborescens Roxb. fol. oppositis ternatisque oblongis pubescentibus; 1lor. mumerosis; limb. 10-12-fido. In Bengalia. ந. 10-12-ped. Cor. alba.

4. J. elongatum Willd. fol. oppositis ovato-lanceolatis attenuatis; pedunc. Irichotomis. Berg. Act. t. 11. In India orient. $\hbar$. Cor. alba.

5. J. aemulum $\boldsymbol{R}$. $\mathrm{Br}$. fol. ovatoacuminatis pubescentihus; sem. integumento cribroso. In Nova Hollandia. 5 .

6. J. undulatum Willd. fol. cordato-ohlongis, nitidis, ramis pedunculisque hirtis. Hurm. ind. t. 3. f. 1. Cor. alha. In Clina. b.

7. J. sessiliflorum Vaht. fol. oblongo-ovatis acutis lucidis; floribus terminalibus sessilibus. J. cuspidatum Willd. In India. t).

8. J. tubiflorum Roxb. fol. sessilibus ovato-oblongis glabris; tubo corollae gracili longissimo. Hoxb. In India orient. $\mathbf{b}$.

9.J. angustifolinm Willd. fol. ovatis mucronatis suh 3-nerviis ; pedunc. terminalis sub 3-floris. J. triflorum. Pers. Lam. ill. t. 6. In India orient. $\downarrow$. Cor. alha.

10. J. laurifolium Roxb. fol. ovatolanceolatis lucidis 3-nervibus; laciniis calyc. 6-7-filiformibus. In Bengalia. $\hbar$.

11. J. glabrum Horsf. fol. oblon- gis acuminatis ramisque pubescentilus; paniculis axillaribus calyc. pubescente. In Jư a. ђ.

12. J. scamlens Vahl. fol. oppositis ovato-uhlongis, attenuatis; panic. bracteata; laciniis calyc. refexis. In Benguliu. Ђุ. Cor. allia.

13. J. trinerve Vull. fol. ovatis attemuatis 3-nervihus; calyo. laciniis subulatis. B. H. 918. J. acuminatum Pers. In Jura. ち. Cor. alha.

14.J. stenopetalum Lindl. fol ovatolanceolatis acuminatis 3-nervihus glabris; calyc. laciniis subulatis. J.trinerve Hoxl., in sillet. 5 . Cor. alla.

15. J. bracteritum Roxh. ind. fol. oppositis ovato-oblongis acutis villosis, cor. 5-8-fida. In Sumutra. \$. Cor. alba. Bacca nigra.

16. J. coarctatum loxh. ind. fol. oblongis acutis lucidis; florib. coarctatis 3-natis, bracteatis subsessilibus. In Chittagong. ‡. Non scandit; valde ramosis.

17. J. latifolium Roxh. ind. fol. oppositis cordatis petiolatis; calyc. 5-7-fido, pubescente ; cor. 10-12-fida. J. trichotomum $\beta$. Hoth. In Circars. t. Cor. alla.

18. J. trichotomum Roth. nov. gen. fol. oppositis ovato-lanceolatis, sultus ferrugineo-tomentosis supra glabris. In India occidentali. †.

19. R. montanum fioth. nov. gen. fol. obcordatis oblusis glabris, ramulis, petiolis pedunc. calycibusque hirsutis. In India occidentali. $\hbar$. Cor. alba. Bacca nigra.

20. J. simplicifolium Forst. fol. oppositis ovato-lanceolatis acuminatis; calyc. campanulatis. B. M. 980. J. australe. Pers. In ins. Amicorum. 卢.

21. J. oblongum Burm. ind. $t$. 3. f. 2. fol. oppositis oblongis mucronatis; pedunc. axillaribus 1-floris. In Java. ち. Cor. lutea odoratissima.

22. J. glaucum Ait. fol. oppositis lanceolatis mucronatis coriaceis; pedunc. terminalibus sub 3-floris. Vent. Cels. t. 55. J. rivulare Salisb. t. 8. In Prom. b. spec. $\hbar$. Cor. alla.

23. J. dichotomum Iahl. fol. ovatis glaberrimis; panic. terminalibus dichotomis; laciniis calyc. subulatis. In Guinea. ち. Frut. orgyalis. Cor. alba. 24. J. nepalense Spr. fol. oppositis ellipticis acuminatis glabris lucidis; cor. octofida obtusa. J. dichotomum. Don. nep. In Nepalia. $\$$. 
2.5. J. aracile Andr. rep. t. $1 \geq 7$. fol. oppositis ovato-ellipticis; calyc. laevihus campanulatis hrevissime dentatis. Jacq. H. Schwenhr. t. 321. J. geniculatum Vent. In Prom. b. spec. ち̋. Cor. alba.

26. J. Lanceolatum $\boldsymbol{R}$. et $\boldsymbol{P}$. per. t. 7. f. $\alpha$. fol. lanceolato-ellipticis, oppositis; pedunc. axillaribus terminalibusque. In sylvis Pozuzo. ђ. Cor. albo-purpurascells.

z\%. J. molle $R$. Br. fol. ovatis acuminatis, pubescentihus subtus mollissimis ; calyc. dentibus brevissimis; pedunc. 3-chotomis. In Nova Hollundiu. 古.

2s. J. rigidum Zenk. fol. oppositis ovatis, submucronatis, glalerrimis; calyc. laciniis 4-fi-subulatis. Zenk. ind. t. 5. In India (Ctacamund). ち. Cor. alla.

29. .J. myrtophyllum Zenli. ind. t. 7. fol. oppositis lanceolatis ohtusis, nucronatis glaberrimis; caule ramosissimo. In India (Cotagiri). \$. Cor. alba.

\section{Folia ternata.} * opposita.

30. J، nocturnum Afz. fol. termatis simplicibusque, ovato-oblongis, acuminatis utrinque glabris, In Sierru Leone. t. Cor. alba.

31. J. aurivulutum Vahl. fol. ramulorum floriferorum simplicilus ; calyc. angulatis ramisque teretibus, pubescentibus, J. trifoliatum Pers. B. M. 264. In Malabaria. †. Cor, alba.

32. J. flexile Vah. glabrum; foliolis ovato-oblongis, acuminatis ; racemis axillaribus luachiatis ; caule scandente. In India orient. $\hbar$.

33. J. azoricnm L. foliolis ovatis subcordatisque; calyc. campanulatis glabris. B. M. 1889. B. R. 89. In ins، Azoricis. ђ. Cor. alba.

34. J. tortuosum Willd. foliolis lanceolatis mucronatis; caule volubili; ramis puhescentibus. J. flexile Jacq. Schœenlır. t. 190. J. campanulatum Lk. In Prom. b. spec, b. Cor, alba.

3.5. J. capense Thunb. foliolis ovatis; ramulis angulatis petiolisque villosis; calyc. tubulosis. J. angulare Willd. In Prom. b. spec $\downarrow$. Cor. alba.

36. J. didymum Forst. glabrum; foliolis ovato-lanceolatis ; racemis axil- larihus. In ins. anicorum. †. Cor. alba.

37. J. divaricatum R. Br. glabrum; foliol. subovatis, dentilus calyc. obsoletis; seur. integumento perforato. In Nora llollandia. †.

38. J. lineure R. Isr. foliol. linearibus acutis pubescentibus; ramis tere(ibus; piniculis axillaribus 3-chotomis. In Nora Hollandia. $\hbar$.

3.9. J. dispermm Wall. foliolis ovato-ohlongis, acmunatis, 5-nerviis ; haccis didymis. In Nepalia. ఫ. Cor. alba.

-Ho. J. paniculatum Roxb. ind. p. 97. foliolis ovalibus oblongisve acuminatis obtusis lucidis; panicula terminali. In China. ந. Cor. flavescens.

41. J. Lanceolaria Roxb. ind. 1. p. 9\%. foliolis lanceolatis; racemis terminalibus. In silhet. $\quad$.

42. J. heterophyllum Wall. in Roxb. ind. 1. p. 9\%. fol. alteruis simplicibus ternatisve, ovato-lanceolatis undulatis nitidis, In Nepalia. Ђ. Cor. lutea.

\section{** alterna.}

43. J. fruticans $L$. fol. simplicibus terratisque; foliolis subcureatis; calyc. laciniis subulatis. B. M. 461, In Europya et Africa. ђ. Cor. lutea.

14. J. humile L. foliolo terminali ohlongo acutato; calyc. Iaciniis brevissimis. Bot. Hep. 352. Hab.? t. Cor. llava inodora.

45. J. odoratissimum $\boldsymbol{L}$. foliolo terminali ovali obtusissimo subapiculato; calyc. laciniis brevissimis. $B$. M. 285. In Madeira. $\hbar$.

\section{Folia pinuata.}

46. $J$. officinale $\mathrm{L}$. foliolis ovalibus acuminatis; calycibus corollae tubo duplo brevioribus. B، M. 31. Prope Canton Sinarum. †. Cor. alba.

1\%. J. Wallichiamum Lindl, foliolis ovatis, acutis glabris, impari acuminato; ramis angulatis; pedunc. 3-floris. B. R. 1409. In Nepalia. t. Cor. lutea.

48. J. grandiflorum $L$. foliolis obtusiusculis gemuis horizontalibus Linn. suppl. B. H. 91 . In India et ins. St. Thomas. †. Cor. alba extus rosea.

49. J. nervosum Lour. foliolis ovatis 3-nerviis; pedunc. multifloris, caule scandente Lour. Coch. 1. p. 20. In Cochinchina. 
50. J. aureum Don. glahrum ramis 5-angulatis; foliolis ovatis acutis 3-nerviis; paniculis lateralibus terminalihasque Doll. Nep. p. 106. In Nepalia. t).

51. J. revolutum Sims. B. M. 1731. fol. alternis, foliolis ohtusis sessilibus; dentihus calyc. brevissimis. In India orient. t. Cor. flava.

52. J. pubigerum Don. ramis angulatis hirtis; foliolis \%, ovatis oblongisve acntis utriuque pubescentibus Don. nep. 106. In Népalia. 支.

\section{NYCTANTHES Linn. (1737).}

1. N. Arbor tristis Linn. Bot. R. 399. Rheede I.t.21. Frutex 15-20ped. ramis junioribus 4-angulatis pubescentibus. Folia cordato-ovata. In Indin orientali. $\hbar$.

\section{FONTANESIA Labill. (1791).}

1. F. phillyveoides Labill. syr. $t$. 1 . Frutex 8-12-ped. Fol. opposita lanceolata acuta. Flores racemosi alborubentes. Capsula viridis. In Syria. $\mathbf{b}$.

\section{FOISSYTHIA Vahl (1801).}

1. F. suspensa Yalil. Syringa Thunl). jap. t. 13. Caul. pendulus 4-angulatus. Fol. ovato-acuta serrata. Flores lutei. In Japonia. ђ.

\section{LIGISTRUM Virg.}

1. I. vulgare $L$. fol. elliptico-lanceolatis glabris mucronatis; racemis compositis coarctatis. Engl. b. 764. In Europa. ち. Cor. alba. Bacca atropurpurea.

2. I. japonicum Thunb. fol. ovatis acuninatis; panicula divaricata. Thunb. jap. t. 1. In Japonia. t. Cor. alba. Bacca nigra.

3. L. lucidum Ait. fol. ovato-oblongis acuminatis supra lucidis; panicula divaricatissima. Ait. Kew. 1. p. 19. In China. t.

4. K. nepalense Wall. fol. ovatooblongis acuminatis subtus villosis; panicula terminali villosa. Roxb. ind. 1 . p. 49. L. spicatum Don. In Nep. ち.
5. L. sinense Lour. fol. lanceolatis tomentosis; racemis coarctatis Lour. coch. 19. In Cunton. Ђ. 8-ped. Cor. alba.

6. L. bracteolatum Don. fol. oppositis ovato-lanceolatis aculis ramisque pubescentibus; pedunculis valde pilosis Don. nep. 107. In Nepalia. ђ.

\section{PHILLYREA Diosc.}

1. P. ilicifolia Willd. ful. sessilibus ovatis; cordatis grosse serratis. P. spinosa R. et S. P.latifolia Fl. portug. In Hispania et Lusitania. †.

2. P. latifolia $L$. fol. breve petiolatis, ovatis cerdatisque oblusis serrulatis. P. microphylla Lk. Sibth. gr. t. 2. In Europa meridionali. $\hbar$.

3. R. obliyua Ait. fol. lanceolatooblongis serratis, utrinque acutis, venosis oblique flexis. P. coriacea et buxifol. Lk. In Europa merid. t.

4. P. ligustrifolia $R$. et $S$. ramis strictis; fol. lanceolatis undique serrulatis, P. virgata IVilld. In Italia et Africa. b. 5-6-ped.

5. P. pendula Willd. en. ramis deflexis; fol. lanccolatis versus apicem serrulatis. Hab.... b.

6. P. media Willd. en. $p$. 11. fol. lanceolatis hinc inde serrulatis triplinerviis. In Europa australi. ђ.

\%. P. olenefolia Willd. fol. Ianceolatis lincinde scrulatis subundulatis subtriplinerviis. In Europa australi. ந.

8.P. angustifolia $L$. fol. Ianceolatis et linearibus integerrimis; var. $\alpha$. lanceolate ramis arrectis, fol. lanceolatis $\beta$. rosmarinifolia ramis erectis, foliis linearihus $\gamma$. brachiata, ramix divaricatis, fol. oblongo-lanceolatis brevioribus. In Europa australi. t.

9. P.laevis Willd. en. p. 12. ramis strictis, fol. ovalibus linceolatisque hinc inde serratis. In Gallia australi. 直. Frut. 8-12-ped.

10. T. paniculata Roxb. ind. fol. ovato-oblongis supra nitidis glabris subtus glaucis. In China. 5 . 15-20ped. Cor. parva alba.

11. P. robusta Roxb. ind. rol. ovato-oblongis acuminatis; panicula terminali; ramis villosis. In Sillet. Arbor magna. Drupa olivaceo-purpurea.

12. P. pedunculata Bory voy. 
fol. oblongo-lanceolatis, integris, mucronatis; pedunculis fructo duplo longioribus. In Morea. t.

\section{OLEA Var. Cat.}

1. O. sativa LK. ramis inermibus argenteis; fol. lanceolatis mucronatis supra subsquamulosis subtus argenteis. o. europaea L. In Oriente. t. var. fol. latioribus. Cor. flavescens.

2. O. Oleaster $L k$. ramis spinescentibus argenteis; fol. oblongis mucronatis supra glabris subtus argenteis. o. europaea $\alpha$. L. Sibth. gr. t. 3. In Europa australi. b. 15-ped.

3. O. chrysophylla Lam. fol. lineari-lanceolatis acutis attenuatis subtus aureo-nitidis. O. europ. ferruginea Ait. $H a b . .$. t.

4. O. verrucosa I.k. en. ramulis squamato-argenteis, veruteułosis; fol. lanceolatis subtus squamato-albicantilus. In Prom. b. spec. ち. Arbor excelsa.

5. O. lancea Lam. ramis verrucosis; fol. longe lanceolatis, acutis integerrimis; panicnlis terminalibus. 0 . exasperata WVilld. In ins. Munritii. $\hbar$.

6. O. undulata Jac\%. H. Schœnbr. t. 2. rumis subverruculatis; fol. oblongis acuminatis undulatis subdenticulatis. O. laurifolia Lam. In Prom. b. spec. t. Arbor sat magna. Cor. parva alba.

7. O. paniculata R. Br. prodr. p. 523. fol. lanceolato-ellipticis, acuminatis integerrimis; pedicellis ultimis 3-floris. In Nova Hollandia. t.

8. O. capensis $L$. ramis subveruculatis; fol. ovati-subrotundis, brevissime mucronnlatis subemarginatis. $B$. R. 613. In Prom. b. spec. 古. Arb. excelsa. Cor. alba.

9. 0. cermuc Vahl. en. 1. p. 43 . ramulis suliverruculatis; fol. ovalibus obtusis integerrimis; floribus cernuis o. obtusifolia Lam. In ins. Mauritii. $\quad$ b.

10. O. americana L. ramis junioribus pulverulento-hirtis; fol. lanceolatis attenuatis integerrimis Michx. arb. am. 3. t. 6. In C'arolina. ち.

11. excelsa Ait. Kew. 1. p. 22. ramis glabris fol. oblongis subacuminatis attenuatis integerrimis. 0. exasperata Jacq. Schœenhr, t. 251. In $\boldsymbol{H} \alpha-$ deira. b. Arò. magua Cor. alba.
12. O. emarginata Lam. ill. 1. t. 8. f. 2. fol. obovatis emarginatis, racenis paniculatis terminalibus pauciforis. Vahl en. 1. p. 42. In IIradagascar. t. Arhor 20-ped. Drupa maguitudine fere nucis Juglandis.

13. 0 . fragrans Tleunb. jap. t. 2. fol. elliptico-lanceulatis subserratis, pedunculis lateralibus aggregatis. Valil en. 1. 1. 43. In Cochinchina, China et Japonia. ち. Cor. fragrantissima.

11. O. Roxburghii $l t$. et 5 . fol. oppositis, petiolatis, oblongis, integerrimis, glabris; paniculis axillaribus; bracteis deciduis; lohis stigmatis divaricatis. 0 . paniculata. Roxb. ind. 1. p. 104. In Indic orient. t. Arbor parva.

15. O. Aioica Roxb. arborea, dioica; fol. oppositis breviter petiolatis, oblongis, serratis; paniculis axillaribus Roxb. ind. 1. p. . I In Silket et Chittagong. Ђ. Arbor magna.

16. o. microcerpa I'ahl fol. ellipticis acuminatis serratis; racemis terminalibus. Vahl en. 1. p. 43. Phillyrea indica Lour. In Cochinchina. t.

\section{CHIONANTHUS Linn. (1737).}

1. C. virginica L. panicula terminali 3-fida; pedunculis 3-floris, fol. acutis. Willd. sp. 1. p. 46. Lam. ill. t. 9. In America sept. t. Variat. Cor. 4, 5, 6-fida et staminibus quatuor.

2. C. incrassata $S w$. paniculis decussatis fastigiatisque; cor. laciniis incrassatis; fol. oblongis Sw. prodr. p. 13. In Jamuica. t. Arbor excelsa. Flor. diandri, alloi.

3. C. pubescens H. et B. fol. elliptico chlongis, subabtusis coreaceis, subtus molliter pubescentibuș; paniculis terminalibus abbreviatis, 3-fidis, ramulis 3-floris; corollis rubris; laciniis linearibus Kunth. syn. II. p. 301. In Nova Granata. t. Arbor 3-1orgyalis. Cor. rubra.

4. C. ramiflora Roxb. arborea; fol. oppositis, late lanceolatis utrinque attenuatis, integerrimis; panicula sub) foliis. Roxb. ind. 1. p. 106. In IIoluccis. †. Truncus erectus cortice cinereo. Flor. parvi, flavi.

5. C. dichotoma Roxb. fruticosa dichotoma; fol. cunciformi-lanceolatis, utrinque attenuatis, recurvis integerrunis; racemis axillaribus; pedicellia 
3-floris. Hoxb. Ind. 1. p. 107. In $\mathrm{Co}-$ romandel. \$. Cor. parva, alloa.

6. C. smilacifolia Wrull. fiuticosa ccandens ramis 4-quetris; fol. ovalibus, acuminatis, 3-nervihus glatucis, panicula terminali et axillari, ramis brachiatis Koxly. ind. 1. p. 102. In silvis Chittayong. t. Frutex sempervirens. Cor. carnosa flavo-virens.

7. C. compacta Su. paniculis Irichotomis, ultimis floribus subcapitatis; calycihns villosis; fol. lanceolato-ohlongis, antheris acuminatis sw. prodr. p. 13. Jacq. Coll. II. t. 6. f. 1. In ins. Caribaeis. 5 . Arbor 20-ped. Drupa nigra.

8. C. tetrandra Vahl; paniculis trichotomis axillaribus; floribus pedicellatis tetrandris, petalis ovatis altenuato-subulatis Vahl en. 1. p. 45. C. gujanensis Pers. Mayapea Aubl. guj. t. 31. Linociera R. Br. In Gujanu. f́. Frutex humilis. Flor. corymbosi albi odorati.

9. C. ligustrina Alb. Dietr. fol. lanceolatis, paniculis terminalibus; flor. erectis Thouinia Sw. prodr. 15. Linociera sw. ind. In Jamaica et I/ispaniola. $5.8-10$-ped. Flor. thyrsoidei.

10. C. purpurea Lam. fol. ellipticis glaberrimis; floribus purpureis u11tantibus. Lam. ill. 1. p.30. 'Thoninia I. C. zeylanica Roxb. In Ceylonu. b.

11. C. cotinifolia Willd. panicula terminali trichotoma; pedmeulis 3-1loris; fol. ohtusis. Willd. sp. pl. 1. p. 47. C. zeylanica Lam. ill. t. 9. f. 1. Arbuscula etc. Pluk. t. 241. f. 4.

\section{NOTELAEA I'enten (1803).}

1. $N$, bongifolia Ait. fol. lanceolatis acuminatis subreclinatis racemis longitudine petiolorun Ait. Kew, edl. 2.p.22. Vent. Choir. t. 25. Olea apetala Andr. rep. t. 316. In Nova Zeelandia. ђ. Rami pubescentes. Cor. parva.

2. N. qunctuta $R$. Br. fol. lanceolatis basi attenuatis, supra venosis; subtus glaberrimis creberrime punctatis venis olssoletis $\mathbf{R}$. Br. prodr. $\mathbf{I}$. p. 524. In Nova Hollundia. t).

3. $N$. ovata $R$. $B r$. fol. ovatis glabris impunctatis; calyc. laciniis aequalibus; stigmate sessili indiviso. R. Br. proar. 1. p. 524. In Novu Hollandic. †.

4. N. ligustrina Vent. Choir. fol. anguste lanceolatis elongatis, petiola- (is glaherrimis margine simplicibus subtus punctatis venis utrinque obsoletis. H. Br. 1. c. In ins. van Diemen. $\quad$.

5. N. microcarpa R. Br. fol. lineari-lanceolatis elongatis hasi attenuatis subsessilibus glaberrimis; subtus obsolete punctatis, supra venis manifestis. 1R. Br. I. c. In Nova Hollandia. b.

6. N. rigidu Desf: fol. oppositis rigidis, lato-lanceolatis integerrimis; racemis axillaribus Desf. arbr. 1. p. 120. In ins. I an Diemen. †.

7. N. /laricans I'ahl; fol. obovatis retusis; paniculis axillaribus; petalis ovatis. Vahl ell. 1. p. 47. Thouinia IVillem. Herb. Hab....

8. N. Posur Hon; fol. oppositis elliptico-oblongis acuminatis, pedunculis axillaribus cernuis glomeratis unifloris; calyc. dentibus aequalibus; stigmate capitalo. Don. Nep. 107. In Nejalia. $\hbar$.

\section{SYRINGA Dodon. (1557).}

1. S. vulyaris L. fol. cordatis ovatisque. L. schmidt Baumz. t. 77. Lam. ill. t. 7. Persia in Europum delata, ubi ubique sponte. $ち$. FI. racemosi lilacini, purpurei alhive.

z. S. chinensis Hilld. fol. oblongis WVilld. Baumz. s. dubia Pers. in Chinu. †. Cor, violacea et alloa. 3. S. persica L. fol. lanceolatis interdum partitis pinnatifidisque. 1.. sichmidt Baumz. t. 78. Bot. Mag. 486. in Persia. b. Filor. albi et coerulei.

4. S. villosa l'ull,; fol. oblongis utrinque acutis subtus villosis Vahl el. 1. p. 38. In montibus circa Pekin. t).

5. s. Josileceed fac\%. fil. tol. ovatioacuninatis, discoloribus. Hehls. crit. ic. 1049. Arborescens. Cor. lilacina. Ad rupes in Humyuria. †.

\section{BOLIVARIA Schlecht. (1826).}

1. B. integrifoliu Schlecht. fol. lineari-lanceolatis, integerrimis. Calyptrospermum All. Dietr. 1. c. Schlecht. limnaea 1. t. 4. f. 1. In lirasilia. 古. 1-2-ped. ran. 4-anguli.

2. B. Irifida schlecht. fol. linearibus 3-fidis, pimmatifidis integrisque. Calyptrospermum All. Dietr. in Brasilia. t. Minor. Rami acutanguli. 


\section{GRATIOLA Dodon. (1557).}

\section{Caulescentes.}

1. Filamenta sterilia integra.

A. Calyces bracteati.

1. G. officinalis $L$. fol. lanceolatis serratis subtrinerviis; flor. pedunculatis. Vahl en. 1. p. 88. Hayne III. 13. schkuhr t. 2. a. In paluilosis Europue. 4. Had. repens articulata. Caul. ped. suh 4-gonus. Flor. axillares albescentes purpureo striati.

2. G. linifolia Vall; fol. linearibus integerrimis ; pedunculis axillaribus longitudine foliorum Vahl en. 1. p. 89. Hotfmsege. Flor. port. t. 31. G. officinalis Brot. In Lusitainia. 24. Semiped. Cor. purpurascenti-alba.

3. G. crussifolia Lag. fol. Ianceolatis integerrimis crassis; pednnculis 1-floris caule erecto. Lag. nov. Gen. p. 1. n. 6. In locis udis circa Sulmanticam. 24.

t. G. curolinensis Pers. caule basi procumbente; foliis oblongo lanceolatis oltusiusculis dentatis 3-nerviis ; pedunculis pubescentibus, capsulis globosis. Alh. Dietr. 1. p. 547. G. virginica Walt. G. officinalis Michx. G. ackminata Porsh. In Carolina et Florida. 4. Cor. alba intus pubescens.

5. G. virginica L. fol. lanceolatis obtusis crenatis Gronov. virg. 6. G. acuminata Vahl. In Canada ad Hissisippi usyue. 24. Cor. alba intus pubescens, tuhus flavus.

6. G. viscosa Schueinitz caule adscendente viscoso-pubescente, fol. ovato-lanceolatis acutis dentatis 3-nerviis, capsulis ovatis calycem aequantihus. Le Conte an. nat. Hist. of NewYork 1. p. 106. G. virginica. Elliot. In Virqinia et in Carolina boreali, 4. Cor. alba purpureo-striata.

7. G. Hurea Muehtenh. fol. Iatolinearibus sessilibus integerrinis 3-nerviis supra punctatis; pedunc. oppositis vix longitudine foliorum ; filamentis castratis nullis Pursh. Fl. Am. Sept. 1. p. 102. In New-York "sipue ad Floridam. 4. Cor. lutea intus pubescens.

8. G. euadridentatı Mich.x. fol. lineari-lanceolatis extrorsum pauci dentatis; pedumculis longitudine foliorum; capsula calyce subulato triplo breviore. Michx. am. 1. p. 6. Lam. ill. t. 16. f. 2. In Carolinae areis arenosis. \%. Cor. griseo-alba.
9. G. pilosa Micler. fol. cordatoovatis; flor. axillarihus suhsessililus cauleque erecto pilosis. Michx. am. p. 95. (6. pernviana Walt. In siccis pinetis Carolinae ad Floridam ustrue. $\odot$. Cor. alba intus glahra.

10. G. peruciene Linn. fol. ovatoohlongis suh-5-herviis serratis; flor. axillaribus seswilihus Vaht en. 1. p. 89. Feuill. peruv. 1II. t. 17. In Peru et Chili. 24. Caul. 4-6-poll.

11. G. amara Roxb. annua, repens; fol. petiolatis cordatis serratis; pedunc. axillaribus 4-6-foris; calyc. 4-loho; phyllis 2 exterioribus cordatis interioribus, wubulatis; capsula ovata calyce ahscondita. Koxb. ind. 1. p. 135. Serratula Kumph. t. 170. In ins. Moluccis. $\odot$. Mami tetragoni colorati.

12. G.ocymifolia Vahl: fol. oblongis integerrimis infimis petiolatis; flor. racemosi.s. Vahl en. p. 96. In Indiu orient. $\odot$. Palmaris. Caps. globosa.

13. (Y. hispiclula Vahl; fol. ovatis crenatis cauleque pilosis; peduuc. axillaribus oppositis. Vahl. en. 1. p. 94. In Java. Caul. filiformis.

14. G. punctata Vahl fol. lanceolatis serratis enerviis subtus punctatis; flor. sessilibus. Vahl. en. 1. p. 130. In Java. Caul. basi repens.

15. G. latifolia B. Br. glahra; fol. ovatis olutusis obsolete crenatis integerrimisve; flor. sessilibus $\mathbf{H}$. Br. prodr. 1. p. 435. In Nova Hollandia.

16. G. pubescens R. Br. glanduloso-pubescens; foliis lanceolatis dentatis; forihus sessilibus $\mathbf{R}$. Br. 1. c. In Nora Ilollandia.

1\%. G. pelunculata R. Br. pulvevulento-puhescens; fol.lanceolatis extra medium dentatis; pedunculo vix longioribus. H. Br. 1. c. In Nova Holiandia.

18. G. involucrata Rorh. fol. inaequariter petiolatis, rotundato-cordatis; lobis rotundatis magnis, multinervibus serrulatis villosis; capitulis longo pedunculatis bracteatis; filamentis sterilibus liberis; capsula in calyce villoso gibho quinquedentato abscondita. lioxb, ind. 1. p. 137. In ins. Holuceis.

19. G. Musilla Willd. caule simplicissimo; fol. ovatis acutis crenatis; pedunc. axillarihus 1-floris folio longioribus Willd. sp. pl. 1. p. 105. In India. $\odot$. Minutirsima hujus generis.

20. G. minimul Roth. caule tiliformi erecto, simplicissimo; fol. ses- 
silibus oblongis remote serrulatis, laciniisque calycis fimbriatis florulibus solitariis secundis; pedunculis oppositifoliis; capsulis oblongis pedunculo sublongioribus. Ruth nov. plant. sp. p. 8, In India orient. Caul. 3-pollicaris.

21. G. stricta Lour. fol. ovatis spica longa terminali Lour. coch, 1, p. 28. In Coclinchina. †. Caul. sesuluipedalis. Cor. alba.

22. G. ruyosa Lour. fol. lanceolatis rugosis spica ramosa Lour. coch. p. 28. In Cochinchina. ち. Caul, 3-ped. Cor. purpurascens.

\section{B. Calyc:s ebracteati.}

23. G, integrifolia Roxb. caule tetragono juniore erecto, denum divaricato; fol. sessilibus ovatis 3-nerviis integerrimis; pedunculis solitariis axillaribus 1-floris; capsulis longitudine calycis. Hoxb. ind, p. 137. Psaugapupum Rheede mal. IX. t,57. In Bengalia.

21. G. chamaedrys Roth. caule dichotomo suhpiloso; fol. ovatis obtusis petiolo attenuatis, 3-nerviis, acute vel obtuse serratis; pedunc. fol. longioribus; calycibus sub 5-angulis 5 -fidis hoth. 1. c. In India orient.

\section{Filamenta sterilia bifida.}

25. G.parviflor Roxb, caule erecto ramoso; fol. sessilibus ovato-ohlongis 3-nervibus serratis; floribus longe pedunculatis solitariis; filamentis sterilibus bifidis; capsulis ohlongis. Roxh. ind. 1. p. 141. In Bengalia. ๑. Caul, tetragonus 6-pollicaris, Flor. nunc albi nunc caerulei.

26. G. dilatata Muhlenb. caule procumbente 4-gono, fol. oblongis aut ovatis amplexicaulibus 3-4-nerviis sub-dentatis; peduculis axillaribus solitariis, folia excedentibus Alb. Dietr. 1. c, G. anagalloidea Michx. Lindernia pyxidaria Pers. In America boreali. $\odot$. Caul. squarrosus. Cor. pallide purpurea.

27. G. attenuata Spr, caule procumbente 4-gono; fol. spathulato-lauceolatis serrulatis, pedunculis folio 3-plo brevioribus Alb. Dietr. Lindernia Muehlenb. In Carolina et Georgia. ๑. Filamenta villosa.

28. G, tetragona Ilool. glabra; catile 4-gono angulis obtuse alatis; fol. lanceolatis acute serratis inferne attenuatis subatriculatis; foribus subsessitibus subspicatis Hook Bot. Mag. 3134. In Buenos-Ayres. 24. Caul. ped. Flor. coerulei.

\section{Apliyllae.}

29. G. lobelioides Retz. caule inferne folioso, superne squamuloso fol. oblongo-lanceolatis integerrimis; flor. racemosis lhet: obs. IV. p. 7. In Ind. orient. $\odot$. Facies Loiscliae Dortmannae. Caul. 1-1 - -ped.

30. G. cuneifolia Roxb. erecta simplex subnuda, pari foliorum cuneiformium obtusorum ad basin, superne pari uno alterove minutorum; solitariis longe pedunculatis; capsulis rotundis. lioxi). ind, 1. p. 143. In humidis littoris Coromandel. $\odot$.

31. G. nudicaulis Willd. caule filiformi supra hasin nudo superne dichotomo; fol. ovatis subcarnosis, venosis integerrimis; capsula ovali-oblouga, calyce dimidio longiore. G. aphylla foth 1. c. p. \%. In India orient. Caul. strictus purpurasceus. Cor, caeruleoviolaceo.

\section{HONNEYL Link (1321).}

\section{Foliis serratis ant crenatis.}

1. B. brachiata $L$. et $O$. caule erecto diffuso; fol. opposilis sessilibus, oblongis acutis basi attenuatis mucronulato-serratis, glabris. Link et Utto Abbild. In Manila. $\odot$. Caul. I-ped. Cor. a!ha lab. inferius incaruato-picturn.

2. B. serrata Alb. Dietr. anuna, erecta, 4-quetra glabra; fol. oppositis amplexicanlibus, oblongis glab: is, acutissime serratis, racemis in divisionibus ramorum terminalibusque longe pedunculatis; capsulis linearibus divergentibus. Roxb. und. 1. p. 139. Pee tsjanga Rhcede mal. 9. t. 59. In Bengalia. $\odot$. Caul, 2-8-poll. Cor. rufo-fiusca.

3. B. veronicuefolia spr. fol. oblongis acute serratis, caule repente; flor. racemosis. Gratiola Retz. ohs. IV. p. 8. Rnellia antipoda Linn. Zeyl. Roxb. Coron. t. 15. Genthenella Pluk. t, 186. f. 2. In Indiu orient. $\odot$.

1. B. Rotliii Alb. Dietr. caule adscendente simplici; fol, omuibus oppo= sitis unfimis obovatis crenatis reliquis oblongis obtuse serratis, basi in petiolum decurrentibus integerrimis, racemo terminali nudo, foribus opposi- 
tis. Gratiola racemosa Roth I. c. p. 9. In Ind. orient. Caul. ped.

5. B. ruellioides Spr. fol. oblongis petiolatis argute serratis, caule decumbente; racemis terminalibus inque dichotomis. Gratiola Colsm. Grat. p.12. In Jana. $\odot$.

6. B. ciliate $\mathrm{Spr}$. fol. lanceolatoollongis serratis, serraturis aristatis; floribus racemosis. Colsm. Grat. p. 11. In Java.

7. B. marginata Spr. fol. Ianceolatis oblongisve marerine incrassatis argute serratis, caulibus repentibus; floribus racemosis. Gratiola Colsm. Grat. p. 11. In India orient. Caul. digitalis.

8. B. puleyifolia Spr. fol. oblongis serratis; pedunculis axillaribus oppositis. Gratiola Vahl en. 1. p. 98. In India orientali. $\odot$.

9. B. origanifolia Spr. fol. subrotundo-ovatis petiolatis crenatis; floribus axillaribus subsessilibus Gratiola Vahl en. 1. p. 99. In Guinea. ๑. Caul. procumbens palmaris.

10. B. cordifolia Spr. fol. obcordato-ovatis petiolatis crenatis, pedunculis axillaribus; caulibus prostratis Gratiola Vahl en, 1. p. 97. In Ind. orientali. Caul. simplicissimus sesquipetalis. Cor. nivea fauce lutea.

II. Folits integerrimis.

11. B. tenuifolia spr. fol. linearibus extro:sum 2-dentatis integerrimisque pedunculis axillaribus alternis Culsm Grat. p. 8. In Ceylon. ๑. Caul. digitalis.

12. B. verbenaefolia Spr. (caule erecto) subdichotomo; foliis lanceolatis integerrimis; floribus racemosis. Colsm Grat. p. 9. In India orientali, ๑. Caul. ped.

13. B. Roxburghiana Alb. Dietr. caule erecto, fol. sessilibus linearilauccolatis integerrimis, racemis terminalibus brachiatis; flor. longe pedicellatis; capsulis linearibus calyce 3-plo, 4-plo longiorihus Alb. Dietr. 1. c. p. 5.59. Gratiola racemosa Roxb. G. Roxburghiana $\mathbf{R}$. et $\mathbf{S}$. In India orient. $\odot$.

\section{SCHWENKIA Royen (1767).}

I. Glandulis clavatis duabus. 1. S. glabrata H. et B. n. y. et sp. t. 178. caule simplici foliisque glabriusculis, lanceolatis; floribus paniculatis Kuntl. syn. 2. p. 130. In Nova Granata. ๑.

2. S. pallens H. et B. t.179. caule ramoso puhescente; fol. lanceolatis hirtis; floribus paniculatis Kunth. syn. 2. p. 130. In Venezuela. ๑. 2-ped. Cor. purpurascens.

\section{Glandulis clavatis quinis.}

3. S. adscendens Willd. caule ramoso subpubescentc; fol. lanceolatis hirtis; floribus paniculatis $\mathbf{S}$. americana Kuntl. syn. 2. p. 130. H. et B. n. g. et sp. t. 180. In America meridionali. Caul. ped.

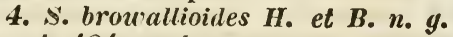
et s. $t$. 181. caule ramoso, cano pubescente; fol. ovatis acuminatis subcordatis glabriusculis ; pedunculis axillaribus 1-3-floris. Kunth. syn.2.p.131. In Caracas. 24. Canl. 2-ped.

5. S. brasiliensis Poir. fol. ovatis integerrimis glabris; pedunc. axillaribus 1-floris. Poir. Enc. Meth. suppl. V. p. 88. Chaetochilus lateriflorus Vahl. In Brasilia. ち. Caul. fruticosus.

6. S. pubescens $N$. et $M$. caule ramoso, foliisque ovatis acuminatis pubescentibus ; floribus filiformi-pedunculatis; limbo 5-seto. Nees et Mart. Nov. Act. 11. p. 48. In Brasilia.

7. S. mollissima $\mathrm{N}$. et M. caule ramoso foliisque cordato-ovatis mollissime pubescente villosis; floribus terminalibus composito-racemosis in ramulis subsessilibus; limbo 5 -set 0 . Nees et Mart. 1. c. In Brasilia tota planta albo-pubescens. Cor. virescens.

8. S. Hillariana DC. caule ramoso gracillimo glabriusculo; fol. lanceolatis acuminatis glabris; floribus glandulas clavatas gerentibus laxissime paniculatis. De Cand. Plant. rar. Genev. p. 35. t. 10. In Brasilia. Caul. 1-1 $\frac{1}{2}-$ ped. Cor. viride purpurea.

\section{HENKELIA Spreng. (1817).}

\section{Caulescentes.}

1. H. barbata spr. fruticosa; fol. oppositis ovatis, subinaequalilateralibus hirsutis, pedunculis gracilibus axillaribus fasciculatis 2-6-floris; staminibus apice barbatis. Didymocarpus 
Jack. in Linn. Trans. 14. p. 38. In Sumutra. ந.

2. II. frutescens Spr. caule suffruticoso, erecto; fol. oppositis longe petiolatis, ovato-lanceolatis, utrinque attenuatis, supra glabris, subtus puhescentibus; flor. axillaribus, fasciculatis didynamis. Didymocarpus Jack. 1. c. In ins. Pulo-Pinang in freto Malaccae, ち.

3. H. corniculato Spr. erecta; fol. alternis, obovatis, acuminatis, serratis; noribus adscendentibus, secundis; pedunculo axillari elongato. Didymocarpus Jack. 1. c. In Sumatra. Caul. 1-2-ped. Cor. alba.

4. H. aromatica Spr. caule folioso; fol. oppositis, subrotundo-ovalibus, crenatis superne sericeis; supremis sessilibus, subcordatis; pedunc. 3-4ternis, paucifloris, calycibusque glanduloso-pilosis, laciniis calyc. ovatis acutis. Didymocarpus Jack. 1. c. In Negalia. 24. Caul. palmaris. Cor. purpurea.

5. H. crinita Spr. erecta; fol. alternis; longe spathulatis acutis, serratis, pilosis, subtus rubris; pedunc. 2-5, axillarihus, unifloris basi cum petiolis coemtihus. Didymocarpus Jack. 1. c. In insula Pulo-Pinang in freto Malaccae. Cor. albida extus purpureo-variegata.

6. H. racemosa Spr. fol. oppositis lanceolatis, utrinque attenuatis, duplicato-serratis; supra glahris; pedunoulis axillaribus 2-fidis; flor. racemosis; pedic. geminatis. Didymocarpus Jack. t. 11. f. 2. a-i. In Sumatra. Cal. ruber. Cor. alha.

7. H. elongata Spr. herbacea, erectiuscula, didynama; fol. oppositis, ovatis utrinque acutis, serratis; spicis axillaribus, secundis; ped. geminatis remotis. Didymocarpus Jack. I. c. In Sumatra. Caul. I-ped.

8. H. Roxburghiana Alb. Dictr. annua, repeus; foi. oppositis oblongis subrotundis; serratis; racenis terminalibus; staminibus sterilibus liheris; capsula lineari. Gratiola reptans lhoxb. ind. 1. p. 140. Bouneya spr In ins. Moluccis. $\odot$. Caul, ped. Cor. pallida.

9. H. reptans spr. prostra, repens; fol. petiolatis, ellipticis, crenulatis; pedunculis 1-3, axillaribus, 1-floris; stamina 2 , pollinifera. Didymocarpus Jack. 1. c. Fol. subtus rubra. Coroll. alha. In ins. Pulo-Pinang in freto Malaccae.
10. H. villosa Spr. caule 4-phyllo, utrinque villosissimo; fol. petiolatis ovalibus, duplicato crenatis, utrinque sericeo-villosissimis ; pedunculis solitariis geminisve, multifloris glabris, fol. longioribus; calyc. laevibus. Didymocarpus Wall. in Don. Nep. p. 123. In Nepalia. Caul. 2-6-unc. Cor. purpurea.

11. H. oblonga Spr. caule 4-phyllo, lanuginoso; fol. breve petiolatis, elliptico-ohlongis, acutis duplicato-serratis, rugosis, villosiusculis; pedunc. geminis solitariisque pancifloris; fol. brevioribus, puhescentibus; involncris calycibusque glabris. Didymocarpus Wall. in Don. nep. p. 123. In Nepalia. 24. Flor. purpurei.

12. H. primulifolia Spreng. canle 4-phyllo pubescente; fol. cordato-ovalibus, petiolatis 2-crenatis, utrinque rugosis sericeisque; pedunc. geminis; multifloris calyceque pilosis; involucris subrotundo-ovalibus, cuspidatis basi comnatis. Didymocarpus Wall. in Don. nep. p. 123. In Nepalia.

13. H. oppositifolia Alb. Dietr. fol. lineari-lanccolatis, serratis ; florihus inferiorihus axillaribus, alternis, superioribus racemosis oppositis. Gratiola Vahl en. 1. p. 93. Bonneya spr. In India orientali. $\odot$. Caul. filiformis 4-angulus, 2-5-uncialis. Cor. coerulea.

14. H. grandiflora Alb. Dietr. fol. inferioribus suhcuneatis, superiorihus lanceolatis serratis; pedunculis axillaribus. Gratiola Vahı en. 1. p. 98. Bonneya Spr. In India orient. $\odot$. Caul. 4-angulus. Cor. coerulea.

1.5. H. alata Alb. Dietr. anma; fol. petiolatis, ovatis, serrato-dentatis; racemis terminalihus; calyce 5 -dentato, 5-alato; filamenta sterilia libera; capsula lineari calyce alsscondita. Gratiola Roxb. ind. 1. p. 137. Bonneya Spr. In ins. Moluccis. $\odot$.

16. H. urticae/olir All. Dictr. caule adscendente basi radicante; fol. ellipticis acutis subaequalibus serratis, pedunculis fol. breviorihus, laciniis calycis lineari-lanceolatis ohtusis. Chirita Hamilt. Don. nep. p. 90. Didymocarpus speciosa Wallich. In Nepalia. Flor. ruhro-purpurei.

17. H. pumila Don; fol. inaequalibus ellipticis obtusiusculis serratis subtus rubris, pedunculis hefforis folium subaequantibus. Chirita Don. nep. 
p. 90. Bonneya pumila spr. In Nepalia. Caul. vix 2-pollicaris.

15. H. bifolia Hon. caule erecto diphyllo pubescente; fol. valde disparibus pubescentibus crenatis, altero minimo petiolato, altero maximo cordato sessili, pedunculo terminali 1-floro. Chirita Don. нep. p. 90. Didymocarpus IVall. Bomeya spr. In Nepalia. Caul. filifornis 2-1-uncialis. Flor. rosei.

19. H. Wallichiana Alb. Dietr. caule adscendente; fol. ovatis acuminatis pilosis, pedunculis axillaribus nunc paucifloris nunc 1-floris. Chirita Wall. pl. rar. asiat. p. 43. In Nepalia. Cor. flava rubro-reticulata.

\section{Acaules, scaposubumbellifero.}

30. H. incana Spr. fol. radicalibus longe petiolatis ovatis obtusis incisocrenatis deuse tomentosis, scapo piloso, involucris calycilusque villosis Alh. Dietr. Hottlera Vahl. Gratiola montana liottl. In India orient. Cor. lutea.

21. H. plicata Alb. Dietr. fol. binis subsessilibus orbiculato-cordatis carnosis, supra rugoso-plicatis sericeocandidis subtus lacunoso-venosis margine revolutis; scapo pubescente multifloro Alb. Dietr. 1. c. Didymocarpus Don. In Nepratia. 24. had, ramosissima. scapus 5-uncialis.

22. H. macrophylla spreng. fol. cordato-0valibus, dentato-serratis, crenatisve supra villosis subtus nudiusculis, scapis glahris fol. plurimum brevioribus, involucris involucellisque rotundatis integerrimis, basi connatis, laciniis calycinis rotundatis. Didymocarpus Wall. in Don. nep. p. 122. In Nepralia. 4. Fol. ampla. Flor. involucellique purpurei.

2:3. H. cinerea Spr. fol. cordatoovalihus inaequaliter crenatis supra petiolisque cinereo-tomentosis, scapis farinosis pancifloris folio brevioribus involucris subdentatis involucellisque cinereo-tomentosis; laciniis calycinis ovatis acutis. Didymocarpus Don. In Nepaliu.

2t. U. grandifolia Alb. Dietr. radice repente; fol. longissime petiolatis, ovato-cordatis, scapo elongato, patuciforo, corolla cylindrica medio ventricosa. Chirita macrophylla WVall. pl. asiat. rar. p. 56. In Nepalia. Caul. 1-2-ped. Cor. flava.

\section{GYMNANDRA Pall. (1776).}

1. G. integrifolia Willd. fol. radicalibus caulinisque ovatis, integerrimis; spica cylindrica; laciniis labii inferioris 2-fidis; antheris subsessilibus. Willd. Mag. d. Gesells. Nat. Fr. 5. p. 392. t. 9. f. 1. G. borealis Pall. it. Tab. A. f. 1. Bartsia Gymnandra L. Lagotis glanca Gærtn. t. 18. In alpibus Dauriae. 4.

2. G. altaica Willd. fol. radicalihus ovato-oblongis caulinisque ovatis remote obtuse serratis; spica cylindrica; bracteis flore longioribus; corollae labio inferiore 3-partito; antheris subsessilibus. Willd. 1. c. t. 9. f. 2. In alpibus altaicis. 24.

3. G. minor Willd. fol. radicalihus oblong0-lanceolatis, remote obtuse serratis; caulinis lanceolatis subintegerrimis; spica cylindrica; lab. inferiore 3-fido; filamentis longitudine lahii superius repandi. Willd. I. c. t. 9. f. 3. In Sibiria orientali. 4. spica pollicaris.

4. G. dentata Willd. fol. radicalibus oblongis grosse dentatis; caulinis oblongis remote olutuse serratis; spica cylindrica, laxa; lab. inferius 3-fidum; filamenta labium superius aequantilus. Willd. 1. c. In Sibiriı orientali. 24. spica pollicaris.

5. G. gracilis Willd. fol. radicalihus oblongis acutis inaequaliter serratis basi attenuatis; caulinis ovatooblongis subserratis; spica cylindrica laxa; corollae labio inferiore bifido; filamentis lah. superius repandum aequantibus Willd. 1. c. t. 9. f. 5. In ins. inter Asiam et Americam sitis. 4. Caul. $\frac{1}{2}-$ ped.

6. G. elongata Willd. fol. radicalibus oblongis remote serratis, caulinis ovatis subserratis, spica cylindrica elongata; corollae labio inferiore 2-fido, filamentis labio obtuso superiore duplo hrevioribus. Willd. I. c. t. 10, f. 7. In summis alpibus Sibiriae orientalis. 4. Caul. 6-8-poll.

\%. G. ovata Willd. fol. rarlicalibus oblongis profunde subduplicato-dentatis, caulinis ovatis remote serratis; spica ovata elliptica; cor. labio inferiore 2-fido; filamentis lab. superiore obtuso dimidio hrevioribus. Willd. 1. c. t. 10. f. 8. In sibiria orientali et in Kantschatka. 4. Caul. 4-5poll. 
8. G. reniformis Willd. fol. radica'ibus reniformibus repando-crenatis caulinis subrotundo-ovatis serratis; spica densa cylindrica; labio inferiore 3-partito; filamentis labio superiore emarginato duplo breviorihus. Willd. 1. c. t. 10. f. 9. In Unalasckya. 24. Caul. 4-poll.

\section{CYRTANDRIA Forst. (1775).}

I. Fruticosae; corolla ringens.

1. C. biflora Forst. fol. ellipticis subintegerrimis glabris ; pedunculis subramosis. Besleria Forst. prodr. n. 236. In ins. Tahiti. ‡. Rami apice pulverulenio-ferrugineo-tomentosi.

2. C. cymosa Forst. fol. ovatis crenatis basi obliquis subtus pubescentibus, pedunculis subcymosis Besleria Forst. In ins. Tanna. ‡.

3. C. staminea Vahl; pedunc. aggregatis ; fol. ellipticis denticulatis basi aequalibus, genitalibus exsertis; caule radicante. Vahl en. 1. p. 105. Justicia parasitica Lam. In Java. †.

4. C. frutescens Jack. erecta; fol. oppositis, lanceolatis serratis, glabris; pedunc. axillaribus 3-floris. Jack. in Linn. Trans. 14. p. 31. Hab.... ち. Cor. purpurea.

5. C. rubiginosa Jack. erecta; fol. obovato-lanceolatis, serratis; pedunc. axillaribus, fasciculatis, 1-floris, calycibusque viscoso-pilosis Jack. 1. c. Hab.... ち. Cor. obscure purpurea.

\section{Herbaceae; corolla subirre- gularis.}

6. C. macrophylla Jack. fol. subrotundo-ovatis, serratis, glabris; involucro 1-phyllo; pedunc. folio brevioribus. Jack. 1. c. In Sumatra. 4. Flor. numerosi, albi.

\%. C. maculata Jack. fol. subrotundis, cordatis, acutis, serratis, supra glabris; corollae lobis tribus inflexioribus macula purpurea. Jack. I. c. In Sumatra. Cor. alba.

8. C. bicolor Jack. fol. ellipticolanceolatis, basi cordatis, supra glabra subtus rubescentibus, villosis; pedunc. petiolo brevioribns. In Sumatra. Cor. magna alba.

9. C. hirsuta Jack. fol. ellipticoovatis, basi cordatis, crenatis, gla- berrimis; capitulis paucifloris hirsutis; involucro 2-fido. Jack. 1. o. In $\mathrm{S}^{\prime} \iota$ matra.

10. C. glabra Jack. fol. late ovatis scrratis, glabris; capitulis breve pedunculatis; involucro 1-phyllo. Jack. i. c. In sumatra. Cor. alla.

11. C. incompta Jack. hirsuta; fol. ellipticis, ovatis serratis; flor. capitatis hirsutis; involucro diphyllo. Jack. 1. c. In sumatra. Erecta, pilis fuscis lirta.

12. C. aurea Jack. fol. oppositis subrotundo-ovatis, acuminatis, serratis, sericeo-pilosis; capitulis densis, subsessilibus. Jack. 1. c. In Sumatra. Caul. 4-angulus adpresse pilosus. Cor. Iutea.

13. C. peltata Jack. fol. peltatoovatis. acuminatis. Jack. I. c. In Sumatra. Caul. adscendens. Cor. alba.

11. C. carnosa Jack. fol. lanceolato-oblongis basi obliquis carnosis oppositis, altero minimo subrotundo. Jack. 1. c. Hab.... Repens scandensve. Flores albi, brevissime pedicellati.

58. CALCEOLARIA Feuil. (1725),

I. Foliis simplicibus integerrimis.

\section{A. Foliis alternis.}

1. C. alternifolia Cav. fol. linearibus, alternis; pedunc. axillaribus 3-floris. Cav. ic. 5. p. 28. t. 445. f. 2. In Peru. Caul. 2-ped.

\section{B. Folitis oppositis.}

2. C. pinifolia Cav. subacaulis; fol. linearibus margine revolutis; pedunc. scapiformibus, 2-fidis; pedicellis umbellatis. Vahl. en. 1. p. 174. Cav. ic. t. 442. f. 2. In Cordilleras Chili. 4. Cor. lutea.

3. C. rosmarinifolia $L a m$. fol. lineari-lanccolatis, integris, maryine rcvolutis, subtus tomentosis; flor. umhellatis. Vahl en. 1. p. 189 . C. felruginea Cav. ic, t. 445 . f. 1. Ad montem Chimborazo et in Chili. Rami violacei. Cor. lutea.

4. C. graminifolia $\boldsymbol{H}$. et $\boldsymbol{B}$. suffruticosa, erecta; ramis glabriusculis; fol. sessilibus linearibus, angustatoacuminatis, margine revolutis, supra glabris et subglutinusis subtus cano 
tomentosis; corymbis terminalibus, 3-fidis, dichotomis; pedicellis hirsutiusculis Kunth. syn. 2. p. 137. In Quito. 5. 4-6-ped. Cor. Iutea.

5. C. lavandulaefolia $\boldsymbol{H}$. et $B$. suffrutex; ramulis hirtellis; fol. sessilibus linearibus obtusiusculis, margine revolutis; supra glabris subtus canotomentosis ; flor. terminalibus, corymbosis; pedicellis viscosis Kunth. syı. 2. p. 137. In Quito. ち. Cor. Iutea.

6. C. hyssopifolia $H$. et $B$. fruticosa; ramulis pedicellisque hirtelloglutinosis; fol. subsessilibus, auguste linearibus, obtusiusculis margine intercrimis et revolutis, utrinque glabrîs, supra glutinosis; flor. terminalibus corymbosis. Kunth. syn. 1. p. 158. Ad montem Chimborazo. $\hbar$. Frut. orgyalis ramosissimus.

7. C. linearis $R$. et $P$. fol. linearibus integris subtus alhidis; pedunc. axillaribus 1-floris. Fl. peruv. 1. p. 19. In Peru. t. Caul. 2-ped. Cor. lutea.

8. C. ericoides Juss. fruticosa ramosissima ; microphylla ; ramis confertis foliisque utriuque hirtellis sessilibus, linearibus margine integerrimis et revolutis; pedunc. terminalibus et axillaribus 1-3-floris hirtis. Kunth. syn. 2. 138. In Quito. ち. 2-3-ped. Cor. luta.

9. C. lanceolata Cav. fol. linearilanceolatis subvillosis, pedunculis ; terminalibus solitariis 1-floris. Cav. ic. 5. p. 27. t. 444. f. 2. In ins. Maclovianis. Caul. semipollicaris. Cor. lutea.

10. C. helianthemoides $\boldsymbol{H}$. et $\boldsymbol{B}$. fruticulosa, ramis pedicellisque canescenti-puberilis; fol. subsessilibus, suboblongis utrinque acutis, integerrimis, glabris; floribus terminalibus subcorymbosis. Kunth. syn. 2. p. 138. In Peru prope urbem Loxa. t. Pedulis. Cor. flava.

11. $C$. argentea $H$. et $B$. fruticosa; albo-lanata; fol. petiolatis suboblongis, utrinque acutis integerrimis; floribus terminalibus et axillaribus, subsolitariis. Kunth. syn. 2. p. 138. In Peru. ち. Frut. ped. ramosissimus. Cor. lava.

12. C. Fotheryillii Ait. herbacea; fol. petiolatis spathulatis; pedunc. scapiformibus 1-floris. Ait. Kew. 1. p. 30. t. 1. In ins. Falklandiae. §. Caul. uncialis. Cor. lutea.
13. C. cance Cav. fol. oppositis, confertis, crassis, Ianatis, ovatis basi attenuatis. Cav. ic. p. 27. t. 443. f. 2. In Peru. 4. Caulis 2-pollicaris. Cor. parva lutea.

14. C. nana Smith; scapo 1-floro; fol. ovatis integerrimis. Smith ic. ined. 1. p. 1. t. 1. C. uniflora Lam. ill. t. 15. f. 3. Ad fretum Magellanicum. 2. Vix pollicaris, decumbens. Flores magni flavi.

II. Foliis simplicibus non integerrimis.

\section{A. Folic oppositis.}

15. C. Neeana Spr. herbacea; fol. spalhulatis, crenatis, villosis; pedunculis scapiformibus 1-floris. Alh. Dietr. sp. pl. 1. p. 584. C. Fothergilli Cav. ic. t. 442. f. 1. In Peru. Caulis uncialis. Cor. lutea, limbo rubro; lah. inferius flavum, supra ad latera saturate rubrum, circa medium luteum fascia rubra variegatum.

16. C. tomentosa $R$. et $P$. fol. cordato-triangularibus, duplicato-serratis subtus tomentosis; petiolis connatis; pedunculis 6-8-floris. Fl. peruv. 1 . p. 15. t. 22. f. 6. In umbrosis Tarmae, Cuchero. Caul. 4-ped. Cor. lutea magna.

17. C. perfoliata Linn. fol. perfoliatis spathulatis, sagittatis (dentato-incisis). Linn. suppl. 86. Fl. peruv. t. 21. f. 2. In Peru et Nova Granata. 4. Viscoso-villosa. Caul. sesquipedalis. Cor. Iutea.

18. C. petiolaris Cav. fol. oppositis, ovato-acutis in petiolum alatum attenuatis inaequaliter dentatis; foribus paniculatis. Cav. ic. 5. p. 30. t. 445. Prope Guayaquil. Caul. sesquipedalis. Cor. lutea.

19. C. plantaginea Smith; scapis paucifloris; fol. rhombeis serratis. Smith ic. ined. 1. p. 2. t. 2. Jovellana Fl. peruv. t. 18. f. 6. Ad fretum Magellanicum et in alpibus Peruviae. 2. Cor. lutea.

20. C. pol:yrrhyza Cav. fol. ovatis in petiolum attenuatis: floribus umbellatis Cav. ic. 3. p. 25. t. 441. In America meridionali et in insulis Falklandicis. Caulis vix pollicaris. Cor. lutea punctis rubris variegata. 21. C. montana Cav. fol. radicalibus spathulatis, tomentosis inaequaliter dentatis. Cav. ic. 5. p. 27. t. 413 . 
f. 3. In Cordilleras Chili. Scapus sesquipedalis.

22. C. racemosa Cav. fol. ovatis dentatis rugosis tomentosis; floribus terminalibus racemosis. Cav. ic. 5 . p. 29. t. 448. Prope st. Caroli et in insulis Maclovianis. Caulis 6-10-poll. tomentosis. Cor. lutea.

23. C. crenutiflora Cav. fol, ovatis parce tomentosis; floribus corymbosis; corolla 3-crenata. Cav. ic. 5. p. 28. t. 446 . C. anomala Pers. In humidis St. Caroli Chili. Caulis $\frac{1}{2}$-ped. Cor. lutea lab. inferius rubro-punctatuin.

24. C. paralia Cav. fol. ohlongoovatis, tomentosis, dentatis, superioribus connatis, radicalibus petiolatis; capsulis tomentosis. Cav. ic. 5. p. 29. t. 447. In Chili. Caulis 2-pedalis. Cor. Iutea.

25. Corymbosa $\boldsymbol{R}$. et $\boldsymbol{P}$. fol. radicalibus ovatis cordatisque petiolatis bicrenatis, caulinis cordatis seniamplexicaulibus. FI. peruv. 1. p. 14. t. 20. f. b. Bot. Mag. 2418. Bot. Reg. 723. In Chili. $\odot$. Caulis quadrangularis. Cor. saturate lutea lal). superius minutissimum.

26. C. oblonga $R$. et $P$. oblongis serratis; pedunculis 3-fidis; corollis punctatis. Fl. peruv. 1. p. 15. t. 22. f. b. In Panathuas nemoribus. $\odot$. Hirsuta. Caul. sesquiped. simplicissimus. Cor. lutea intus punctis coccineis maculata.

27. C. punicea $\boldsymbol{R}$. et $\boldsymbol{P}$. fol. ovalibus serratis; caule repente. Fl. peruv. 1. p. 15. t. 24. f. a. In Panathuas nemoribus. Hirsuta. Cor. punicea, slabra.

28. C. purpurea Grah. herbacea, glanduloso-pubescens; fol. serratis rugosis hispidis: radicalihus cuneatospathulatis acutis; caulinis amplexicaulihus cordato-ovatis, acuminatis; floralibus integerrimis; pedunculis terminalibus corymbosis. Grah. in Bot. Mag. 2775. In Chili. 24. Cor. purpure0-violacea.

29. C. arachnoidea Grah. herhacea lanata; fol. ligulato-oblongis, subdentatis; pedunculis terminalibus geminatis elongatis dichotomis; pedicellis calycilusque arachnoideis. Bot. Mag. 2874. In Chili. Cor. subglobosa purpurea.

30. C. ovata Smith; fol. ovatis serratis crenatisque; pedunculis gemi- nis filiformibus. Smith ic. ined. 1. p. 3. t. 3. C. integrifolia Linn. C. dichotoma Lam. C. hiflora. Fl. peruv. t. 20. f. a. In Peru. Caul. semiped. dense pilosus. Cor. parva lutea.

31. C. Lamiifolia $H$. et $B$. caule herbaceo suberecto ramisque pilosis; fol. petiolatis, ovatis acutis, basi truncato-rotumdatis, subcordatis, yrosse serrato-crenatis, utrinque adpressopilosis, sublus alhidis; pedunculis terminalibus subgeminis, pilosis. Kunth. syı. 2. p. 135. Prope urbem Quito. 4. Fl. Junio. Caul. 1-2-ped. Cor. flava glabra.

32. C. bicrenata $R$. et P. fol. ovatis biserratis subtus tomentosis. Fl. peruv. 1. p. 15. t. 23. f. b. In Cuchero nemoribns. Caul. 2-ped. Cor. lutea calyce duplo major.

3.3. C. heterophylia $R$. et $P$. fol. ovatis ellipticis, subcordatisque; pedunculis longissimis dichotonis. Fl. peruv. 1. p. 16. t. 21. f. b. In Peru. llirsutissima. Cor. lutea semiaperta glahra.

34. C. saxatilis $H$. et $B$. caule herbaceo erecto; ramis villoso-pilosis; fol. breviter petiolatis, ovatis obtusiusculis, hasi rotundatis, subcordatis, iuciso-crenatis, supra hirtis, sulitus incano tomentosis; corymbis terminalibus ; pedicelliș pilosis. Kunth. syn. 2. p. 135. In locis saxosis muntis Chimborazo. 4. Fl. Junio. Subped. Cor. crocea.

3.5. C. sibthorpioides $\boldsymbol{H}$. et B.caulibus herbaceis procumbentibus; ramis hispido-pilosis; fol. petiolatis, ovatosubrotundis, acutiusculis, cordatis crenato-incisis, utrinque piloso-luirtis ; flor. terminalibus corymbosis; pedunculis glanduloso-pilosis. Kunth syn.2. p. 135. In locis gelidis montis Gualyayoc. 4. Caul. 4-pollicaris. Cor. flava.

36. C. rotundifolia $H$. et $B$. caule herbaceo simplici, 1-3-floro foliisque tenuissime pubescentihus, petiolatis subrotundis, ohtusis grosse crenatis convexis crassis. Kuntl.. syu. 2. p. 133. In Peru. 4. Caul. 6-8-pollicaris. Cor. flava, fauce hirsuta.

37. C. divaricata $H$. et $\boldsymbol{B}$. herbacea volubilis; ramis divaricalis, glabris; fol. petiolatis ovatis, acutis cordatis, grosse crenato-serratis, ciliatis, glabris, subtus in veuis puberalis; paniculis terminalibus, foliatis; floribus corymbosis; pedicellis piloso- 
glandulosis. Kunth syu. 2. p. 135. In Peru. 24. Cor. Alava.

38. C. serrata $H$. et $B$. herbacea erecta, ramis tomentoso-pubescentibus; fol. petiolatis ovatis acutis basi acutiusculis argute serratis, tenuissime puberulis, subtus canescentibus; corymbis terminalibus, subdichotomis; pedicellis pubescentibus. Kunth syn. 2. p. 134. C. inflexa. Fl. peruv. t. 25. f. a? In Quito. 4. 2-3-ped. rubescens. Cor. Iutea glabra.

39. C. inflexa $R$. et $P$. fol. ovatis acutis crenulatis; pedunculis inflexis 3-4-floris. Flor. peruv. 1. p. 16. t. 25. f. a. C. serrata $\mathbf{H}$. et $\mathbf{S}$. In Cantae proreruptis. Caul. ramosissinus ferrugineo-purpurascens. Cor. luteo-aurea.

to. C. scabra $R$. et $P$. fol. oblongis venoso-lineatis dentatis, caule aspero. Fl. peruv. 1. p. 19. t. 20. f. a. In Peru. Caul. 3-ped. Cor. parva lutea.

41. C. Punctata Vahl; fol. obIongo-ovatis, 2-serratis; pedunculis axillaribus terminalibusque; corollae labiis subaequalibus. Vahl en. 1. p.177. Jovellana Fl. peruv. t. 18. f. a. Baea viscosa Pers. Gesnera Feuille peruv. III. t. 16. In Chili. ち. Caul. 3-ped. Cor. albo-violacea.

42. C. pulverulenta $R$. et $P$. fol. oblongo-lanceolatis, dentato-serratis, ramis pulverulentis. Fl. peruv. 1. p. 19. In Cantce praeruptis. ち. Caul. orgyalis ramosissimus. Cor. Iutea.

43. C. salicifolia $R$. et $P$. fol. lanceolatis serratis, pedunculis geminis terminalibus umbellatis dichotonisque. Fl. peruv. 1. p. 18. t. 19. f. b. In praeruptis et utiginosis Peruviae. ち. Glaberrima. Cor. maxima sulphurea pubescens.

4. C. deflexa R. et P. fol. ovatolanceolatis serrulatis; floribus terminalibus corymbosis; pedicellis 4-5floris nutantibus. Fl. peruv. 1. p. 18. t. 30. f. b. In provincia Caxatompo. ち. Caul. 2-ulnaris, purpureus. Cor. luteo-crocea.

45. C. viscosa $R$. et $P$. fol. ovatis acutis serratis subtus canescentibus viscosissimis; calycibus tomentosis. Fl. peruv. 1. p. 18. t. 30. f. a. In alpibus Peruviae. †. Tota viscosoresinosa. Cor. Inteo-pallida, extus leviter pubescens.

46. C. cuneiformis $R$. et $P$. fol. cuneiformi-ovatis, inciso-serratis. Fl. peruv. 1. p. 19. t.27. f. b. In Tarmue et Cantae alpibus. ち. 2-ped. ramosissimus. Cor. lutea.

47. C. violacea Cav. caule fruticoso; fol. oppositis ovatis dentatis; flor. terminalibus corymbosis. Cav. ic. 5 . p. 31. t. 452. Baea Pers. Ad tittore maris Tulculuunia Americae. $\hbar$. 6-8-ped. Rami violaceo-rubri. Cor. dilute violacea.

48. C. involuta $R$. et $P$. fol. ovatis acutis serratis glahris; corollis involutis calycem semitegentibus. Fl. peruv. 1. p. 15. t. 23. f. a. In Pllnathuas nemoribus. ち. 3-ped. Calyx reflexus.

49. C. Herbertiana Lindl. caule suffruticoso ramoso; fol. oblongis, rugosis, crenatis, pubescentibus, utrinque concoloribus; pedunculis terminalibus corymbosis pilosis; corollae labello cuneato obtuso. Bot. Reg. 1313. $\beta$. parviflora corollis duplo minoribus; labello sulcato Liudl. Bot. Reg. 1576. In Chili. 2-ped. Cor. lutea.

50. C. polifolia Hook. caule suffruticoso erecto ramoso, fol. ovatis oblongisve crenatis, in petiolum attenuatis; pedunculis dichotomis Bot. Mag. 2897. In Cordilleras. †. Pedalis. Cor. subglobosa, llava.

51. C. crenata Lam. fol. sessilihus oblongis acutis crenatis, floribus cymosis caulem et ramos terminantibus Lam. Dict. 1. p. 556. Bot. Reg. 790. In Peruvia. †.

52. C. trifida R. et P. fol. cordatis ovatisque crenato-serratis; pedunculis 3-fidis multifloris umbellatis. Fl. peruv. 1. p. 17. t. 26. f. b. In locis umbrosis Cheuxin. ち. 2-3-ped. Cor. litea.

53. C. flexuosa R. et $\boldsymbol{P}$. fol. cordatis crenatis, pedunculis multifloris umbellatis. Fl. peruv. 1. p. 17. t. 26. f. a. In praeruptis Cantae. ち. Caul. viscoso-villosus. Cor. lutea.

51. C. sessilis $\boldsymbol{R}$. et $P$. fol. lanceolatis serratis semiamplexicaulibus rugosis canescentibus. Nl. peruv. 1. p. 18. In locis aridis Chili. ţ. 2-ped. Cor. flava.

5.5. C. viscosissima Lindl. suffruticosa, viscido-ylandulosa; fol. caulinis oblongis rugosis sessilibus cordatis vel amplexicaulihus v. connatis crenatis v. irregulariter denticulatis; paniculis confertis corymbosis; cor. lab. subaequalibus Lindl. Bot. Reg. 1611. 
56. C. rugosa Alb. Dietr. suffruticosa; fol. ovato-lanceolatis, lanceolatisve subsessilibus suhregulariter serratis rugosis opacis subtus ferrugineis, caule calycibusque puhescentibus, paniculis terminalibus pedunculatis. Alb. Dietr. sp. pl. 1. p. 597.

a. latifolia, fol. ovato-lanceolatis argute serratis. C. integrifolia. Bot. leg. 744.

$\beta$. angustifolia, fol. utrinque attenuatis grosse dentatis, paniculis longe pedunculatis. C. rugosa Fl. peruv. t. 28. f. b. C. integrifolia Linn. c. $\beta$. Bot. Reg. 1083. ct 1588. C. salviaefol. Pers. In Chili. ち. 2-ped. Cor. sulphurea.

5\%. C. albu R. et P. fol. linearibus denticulatis; racemis longis; floribus umbellatis; . umbellis compositis. Fl. peruv. 1. p. 19. t. 27. f. b. In collibus aridis Chili. $\hbar$. Viscosoresinosa Hosmarini odore. Cor, alba.

58. C. thyrsiftora Grah. fruticosa ramosa; fol. sessilibus linearibus basi attenuatis, lineatis serrato-dentatis glabris viscosis; thyrsis ternunalibus confertis, pedicellis decompositis umbellatis. Bot. Mag. 2915. In Chili. $\hbar$. Cor. subglobosa flava.

5.9. C. stricta $H$. et $B$. fruticosa (?) ; ramis strictis, junioribus glutinosis; fol.petiolatis lanceolato-oblongis, valde. acuminatis, basi angustatis, denticulatis glabris; corymbis terminalibus subdichotomis; pedicellis glutinosis. Kunth. syn. 1. p. 133. In Regno Novo Granatensi. ち.? Rami rubescentes. Cor. lutea glabra.

60. C. padifolia $H$. et $B$. fruticosa ; ramulis subglutinosis; fol. petiolatis oblongis aut ovato-oblongis acuminatis, basi acutis dentatis, glabris; floribus terminalibus corymbosis; pedicellis subglutinosis. Kunth syn. [2. p. 134. In Peruvia. t. Fol. supra nigro-viridia. Cor. flava glabra.

61. C. nivalis $\boldsymbol{H}$. et $B$. fruticosa; ramis foliisque glabris, petiolatis, ovatis acutis, basi acutiusculis, crenato-serratis, subcoriaceis subtts flavescentibus; corymbis terminalibus; floribus umbellato-fuscieulatis; pedicellis hirtellis. Kunth syn. 2. p. 134. C. fasciculata Willd. Herb. In Quito. t. 3-ped. Cor. llava.

62. C. lanata $H$. et $B$. suffruticosa; densissime albo-lanata; fol. pe- tiolatis deltoideo-ovatis acutis leviter cordatis, duplicato-crenatis; corymbis terminalibus fastigiatis. Kunth. syn. 1. p. 136. In Quito. b. Caul. $1 \frac{1}{2}$-ped. Cor. magna flava teiragono-compressiuscula.

63. C. adscendens Iindl. caule suffruticoso adscendente piloso ; fol. petiolatis ovatis denticulatis rugosis pubescentibus .inferioribus basi acutis, umbellis pancifloris suluramosis longe pedunculatis. Bot. Heg. 1215. In Cordilleras. ђ. 1-1 -ped. Flores aurantiaci.

6.t. C. amplexicaulis H. et B. suffruticosa; ramis pilosis; fol. amplexicaulibus ovato-oblongis, acuminatis, cordatis crenato-serratis pedicellisque piloso hirtis; corymbis terminalibus; floribus umbellato-fasciculatis. Kunth syn. 2. p. 136. Humb. et Boupl. Gen. et spec. II. t. 171. In C/ili. ち. 3-4-ped. Cor. flava.

6.5. C. floribunda $\boldsymbol{H}$. et B. sufiruticosa ramis pedicellisque hirtelloglandulosis; fol. amplexicaulibus lanceolatis, acuminatis cordatis, denticulatis, subtus hirtellis; racemis bifidis; paniculatis aut corymbosis; floribus subgeminis. Kunth syn.2. p. 136. In Quito. ち. Cor. aurantiaca glabra.

66. C. connata Hook. herbacea subpubescens; fol. ovatis grosse dentatis basi cordatis inter lobos attenuatis connatis, superioribus sessilibus, floralibus integerrimis; panicula trichotoma patentissima. Bot.Mag. 2876. C. floribunda Lindl. B ot. Keg. 1214. In Chili. $\odot$. 2-ped. Cor. flava.

B. Foliis ternis aut verticillatis.

67.C. gemelliflora Cav. fol. verticillatis ovatis, serratis; pedınc. ternis 3-floris. Cav. ic. 5. p. 30. t. 450. f. 2. In saxosis Peruviae. 2-3-ped. Cor. lutea.

68. C. terniflora Cav. fol. verticillatis ternis ovato-oblongis, serratis; pedunc. ternis 3-floris. Cav. ic. 5. p. 30. t. 450. f. 2. In Peruvia. Caul. 3-ped. Cor. sulphurea.

69. C. angustiflora $R$. et $P$. fol. ovato-Ianceolatis aclite serralis; pedunc. 4-floris; corollis basi angustissimis. FI. peruv. 1. p. 1\%. ז. 16. f. a. In Cuntae circuilu circa vicum Obrajillo. t. Caul.2-ped. ramosissimus. Cor. lutea basi punctis purpureis maculata. 
73. C. multiflora Cav. fol. verticillatis teruis subsessilihus ovato-acutis, serratis; flor. paniculatis. Cav. ic. 5. 1. 29. t. 449. In Peruria. Caulis. orgyalis. Panicula pedalis. Cor. lutea.

Ft. C. dentata R. et P. fol. (opposilis teruisque) ovatis argute bidentatis; (pedicellis secundis). Fl. peruv. 1. 1) 18. t. 29. f. b. In Chiti. Viscosa rautosissima. Cor. lutea. Sem. fulva.

75. C. uniflore R. et $P$. fol. ovatis serratis; pedunc. longis filiformilus 1-floris. Fl. peruv. 1. p. 16. t. 20. f. c. C. monanthos Poir. In umbrosis Turmue ad Cures. Ђ̆. 4-ped. ramosissima. Cor. lutea.

Ft. C. bicolor Is. et P. fol. ovatocordatis acutis venosissimis biserratis; pedunculis multifloris dichotomoumbellatis. F'l. peruv. 1. p. 16. t. 25. f. 1). In Cantue morruptis. Ђ. Caulis 2-ulnaris, ramosissimus. Cor. alba superne aureo-sulphurea.

77. C. verticillata $R$. et $P$. fol. ternis cordatis acutis serratis; pedunc. 4-floris. Fl. peruv. 1. p. 17. In Cantale mopruptis ad Quive. †. Caul. orgyalis. Cor. Intea.

\section{Foliis pinnatifidis pinna- tis que.}

78. C. triendra Vahl; fol. incisopinnatifidis, ramis pedunculis marginilusque calycis glanduloso-pilosis; flor. triandris. Vahl en. 1. p. 181. Jovellana Cav. ic. t. 453. In Peru. ち. 3-ped. cortice atro-sanguineo. Cor: lutea.

79. C. lobata Cav. caule erecto dichotomo; fol. cordatis lobatis tomentosis. Cav. ic. 5. p. 26. t. 443. f. 1. In Peru. ち. 2-ped. rubescens. Cor. Intea.

80. C. tripartita $R$. et $P$. fol. 3-partitis, lobis ovatis serratis. Fl. peruv. 1. p. 14. t. 22. f. a. In nemoribus Panatluuas. $\odot$. Cor. Intea.

81. C. pinnata Linn. fol. pinnatis Linn. Mant. 171. Act. Holnt. t. 8. Bot. Mag. 41. Flagelia flavicans Gmel. In humidis Peruriae. ๑. Caul. 2-ped. basi radicans. Cor. flava.

82. C: scabiosaefolia Sims. fol. inferioribus pinnatis, superiorilus pinnatifidis; foliolis petiolatis duplicatoserratis, pubescentibus subtus albicantibus. Bot. Mag. 2405. C. pinnata
1. et P. t. 19. f. 1. In humidis pemuiae. Hat. repens. Caul. 2-ped. Cor. luteo-sulphurea.

83. C. chelidunioides $\boldsymbol{H}$. ct $\boldsymbol{B}$. herbacea; fol. pionatis superne pinnatipartitis supra hispidulis, sub(us glabris; foliolis pinmatitido-incisis argute serratis, ciliato-ulandulosis; floribus alaribus geminis; terminalibus subumbellatis. Kunth. syll. 2. p. 133. In Quito. ๑. 2-3-ped. Cor. lintea.

84. C. yracilis H. et B. herhacea fol. inferiorihus pinnatis et ternatis superiorihus subsimplicibus, serratis supra hispidulis, subtus albido-pilosis; floril. alarihus et axillaribus geminis, terminalihus subcorymbosis. Kunth syu. \%. p. 133. In Quito. $\odot$. Pedalis, dichotomo-ramosissima. Cor. pallide flava.

\section{UTRICULARIA L. (1737).}

$$
\text { 1. Aphyllae. }
$$

1.U. reticulatu Smith. exot. Bot. t. 11.9. scapo volubili tereli, squamis alteruis acutis, calyce acuminato corollae longitudine, palato reticulato 2-lobo. simith 1. c. Rheede mal. 9. t. 70. In inumalatis oryzaceis Indide orientalis. Rad. verlicillata. Caulis 9-12-unc. Cor. alba.

2. U. caerulea Linn. nectario subulato longitudine labii inferioris, scapo tortuoso. Limu. Fl. zeyl. p. 23. In paludosis Zeyloniae et Indiae oricntalis. Flor. caerulei.

3. U. capillaris Don. scapo capillari paucifloro, squamis minimis acu tis instructo, labiis indivisis, superiore subrotundo, inferiore ovato-acuto longiore, calcari conico. Don. Nep. p.86. In Nepalia. Caulis 3-4-unc. Flores caerulei.

4. U. recurva Lour. nectario conico recurvo; floribus spicatis Lour. Coch. 1. p. 26. In rivulis Cockinchinae. sicapus 4-poll. Flores Iutei.

5. $U$. aurea Lour. nectario compresso conico, floribus racemosis Lour. I. c. In fluviis lentioribus Coclinchinae. Scap. 3-poll. Flores aurei.

6. U. bifida Osbek it. t. III. f: 2. nectario acuto conico longitudine labil superioris; scapo bifido vel simplici. Vahl en. 1. p. 204. In China et Zeylona. scap. palmaris 2-3-florus. Cor, lutea. 
7. U, nivea Yahl; nectario conico obtuso; scapo sul 4-floro; squamis adnatis basi solutis; capsulis cernuis glohosis. Vahl ell. 1. p. 203. In roridis Zeylonae. Scap. 3-tlorus. Cor. alba.

8. U. humilis Vaht; nectario conico acuto, labio superiore breviore, calycibus subrotundis, capsulis carinatis. Vahl en. 1. p. 203. In Ind. orient. scap. sesquipollicaris 3-4-florus.

9. U. ramosal'ali; nectario conico brevi, scapo simplici vel ramoso paucifloro; pedicellis fiuctiferis cernuis. Vahl en. 1. p. 204. In Ind. orient. Scap. digitalis. Flores parvi.

10. U. capillacea Willd. nectario tereti obtusiusculo, scapo setaceo nudo subtrifloro; floribus nutantibus; capsulis subulatis. Willds sp. pl. I. p. 113. In Indic orient. Scap. vix semipollicaris.

11. U. mimutissima $\mathrm{rahl}$; nectario conico; scapo capillari simplici subbinoro; squanis adnatis basi solutis; bracteis subulatis. Vahl en. 1. p. 204. Circa Malaccam. Flor. caerulei.

12. $L$. juncen Ricli, nectario subuIato longitudine labii superioris; scapo squamoso racemoso; squamis remotis. Vahl ell. 1. p. 202. In Cajenna et Portorico. had. brevissima. scap. ped. simplicissimus. Bractea arida minuta.

13. U. angulosu P'oir. nectario subulato longitudine labii superioris, scapo fliformi angulato; squamis minimis remotis; flor. suhracemosis subsessilibus. Poir. Enc. meth. 8. p. 273. In humidis Cajemare. sirapus purpureus 10-12-poll. Flores lutei.

11. U. strictu Meyer; nectario subulato; scapo filiormi suly \&-floro; bracteis ad pedicellorm hasin pluribus. Meyer Essequebo p. 14. In. Ns sequebo. scaptis $1_{2}^{\mathrm{I}}$-ped. Flores lutei.

15. U. pusilla Tahl; scapo capillari subdiviso superue flexuoso; floribus racemosis remotis. Vahl en. 1. p. 202. U. nicrocarpa Dielr. Gartenl. 10. p. 305 In Cajenna. Rad. brevissima.

16. U. tenuis Cav. nectario subnlato lahio inferiore longiore; scapo 1-floro. Vahl en. 1. p. 203. Cav. ic. t. 440. f. 2. In Chili. ๑. Scapus 1 $\frac{1}{2}$-poll. Cor. Iutea.

17. U. aphylla R. et $P$. scapo 2-3-floro squainis totidem apice fureatis. Fl. peruv. 1. p. 20. t. 31. f. d.
In imundatis et humidis Limae. $\odot$. Scapus sesquipalmaris. Cor. lutea.

18. U. filiformis $R$. et $\mathbf{S}$. nectario tereti acuninato, scapo setaceo apice dichotomo subflexuoso, floribus nutantibus R. et s. sy'st. 1. p. 199. U. capillaris Herb. Hoftingg. In Brasilia. $\odot$. Scapus 4-poll.

19. U. fimbriata $\boldsymbol{H}$. et $\boldsymbol{B}$. scapo capillaceo trifloro; bracteis calycihusque dentato-fimbriatis; calcare brevissimo obtuso. Kunth. syn. 2. p. 21. In ripe flum. Orinoci. $\odot$. Cal. et Cor. flava.

20. U. gibba Iinn. nectario gibboso ; scapo sub 1-floro. Gronov. virg. ed. 1. p. 129. Le Conte Ann. of the Lyc. of Nat. Hist. of New-York 1. p. 76. t. 6. f. 5. In America boveali. 4. Rad. repens. Flores parvi lutei.

21. $U$. personatı Le Conte; floribus parvis; racemo longo setaceo, 4-10-floro squamis bracteato; labio superiore emarginato; inferiore obtuso, truncato acuminato; calcare recto, subincurvo subulato acuto, longitudine fere corollae. Nutt. 1. c. p. 15. La Conte 1. c. t. 6. f. 10. In Nova Anglia ad Floridam. $\odot$. Cor. lutea.

22. U. setacea Hichx. nectario obtuso labio infernore breviore scapo subhifloro. Michx. am. hor. 1. p. 12. Le Conte 1. c. t. 6. f. 11. A New-York ad Floridam. $\odot$. Cor. parva lutea.

23. U. cornuta Michx. nectario subulato porrecto; corollae lahium inferius amplissimum; scapo subsessiliter, 2-fioro. Michx. am. bor. 1. p. 12. In Canara. Subarrhiza. Cor. magna laete lutea.

\$.k. I. hirta Klein. aphylla scapo hirto subtrifloro; foribus sessilibus. Link Jahrb. 1. 3. p. 5t. In India orientuli. Digitalis.

\section{Foliis radicalibus simplicibus saepe deciduis.}

25. U. alpina Limn. nectario sululato; scapo sub1-floro; fol. ellipticolanceolatis. Vahl ell. 1. p. 194. Jacq. an. t. 6. U. unifolia. Fl. peruv. t. 31. f. b. U. grandifiora Pers. In alpibus ins. Martinicae et l'eruvianis. 24. Cor. alba aut parum caerulescens.

26. U. hispida Lam. scapo filiformi paucifloro inferne lispido; fol. lineari-subulatis. Lam. ill. 1. p. 30. 
In Cajenna. Scapus semipedalis. Flores parvi.

27. C. cupensis Spr. fol. caespitosis linearihus ohtusis, scapo simplici stricto paucifloro; calycihus acutis; calcari subulato corolla breviori. spr. syst. 1. p. 50. A. aphyllum Lim!. Linaria aphylla Spr. syst. 2. 1. 797.

In Prom. bon. speri.

28. I. volubilis $R$. Br. scapo voIubili tereti subbifloro, lahiis indivisis ; superiore cumeato; inferiore maximo securiformi; calcari descendente obtuso depresso; calycis foliolis obtusis. H. Br. prodr. p. 430 . In Nova Hollandia.

2.9. $\boldsymbol{I}$. speciosa $\boldsymbol{R}$. Br. scapo stricto cemidencrso; fol. radicalihus spathulatis nervosis elougato-petiolatis, pedunculis oppositis; Iabio superiore retuso; inferiore maximo securiformi integro; calcari ohtuso. H. Br. prodr. p. 430. U. dichotoma Labill. Hov. Holl. t. 8. Ad Portum Jackison.

30. U. oppositiflora $\boldsymbol{R}$. Br. scapo stricto tereti enerso; fol. radicalihus ovatis obtusis petiolatis; pedunculis oppositis, lahiis integris; inferiore maximo securiformi; palato lohato; calcari obtuso. R. Br. 1. c. Ad Portum Jackison.

31. C. uniflora R. Br. scapo stricto tereti emerso 1-floro; fol. radicalibus pancis subrotundis deciduis; labio superiore cuneiformi retuso; inferiore maximo securiformi integiro; palato lobato; calcari obtuso. R. Br. 1. c. Ad Portum Jackson.

32. $\boldsymbol{U}$. simplex R. $\boldsymbol{B r}$. scapo capillari simplicissimo 1-floro; labiis integris rotundatis; inferiore latiore quam longo; calcari porrecto depresso emarginato. H. Br. 1. c. In Nova Hollandia.

33. U. Menziesii R. Br. scapo filiformi 1-floro; fol. radicalibus numerosis spathulatis; labio superiore-_inferiore indiviso; calcari descendente cylindraceo obtuso, labiis duplo longiore $\mathrm{H}$. Br. In Nova Hollandia.

3H. $\boldsymbol{U}$. violacea $\boldsymbol{R}$. Br. scapo capillari simplicissimo 1-floro; labiis subintegris; inferiore deflexo longitudine calcaris descendentis sulhcyliudracei integri ; folio radicali subsolitario ovato. R. Br. 1. c. In Nova Hollandia.

35. U. albiflora R. Br. scapo filiformi 1-floro; labio superiore emarginato; inferiore cuneiformi 3-dentato; calcari conico descendente. R. Br. In Noü Hollundiu.

36. $\boldsymbol{C}$. compressa R. Br. labio superiore emarginato: inferiore stih trilobo loho intermedio emarginato; calcari conico-complanato, porrectoadscendente. R. Br. 1. c. In Nova Hollcindiu.

3\%. I. cyanea R. Br. scapo simplici stricto paucifloro; florubus lateralibus remotis; pedunculis 3-bracteatis, calycihus acutis corollam subaequantibus; labiis integris, calcariconico-subulato acuto descendente; capsula compressa; fol. linearibus decumbentibus. R. Br. 1. c. Ad Portum Jackson.

38. C. graminifolia Vaht; scapo simplici; fol. linearibus; calycis phyllis oblongis acutis; calcari conico. Vahl en.1. p. 195. U. uliginosa Vahl. U. coerulea Liinn. Herh. In Indlu orientali et in Nova Hollandia. Cor. caeruleoviolacea.

39. I. biloba $\boldsymbol{R}$. Br. scapo simplici tereti; squanulis distantibus adnatis, racemo paucifloro; pedunculis 1-bracteatis, lahio superiore emargiuato; inferiore bifido lobis obtusis, calcari descendente-porrecto obtuso plano-convexo. R. Br. 1. c. Ad Portum Jackson.

10. U. limosa $\boldsymbol{R}$. $\boldsymbol{B r}$. scapo simplici tereti; racemo multifloro; labio superiore integro; inferiore bilobo, lobis acutiusculis divaricatis; calcari conico complanato porrecto. R. Br. 1. c. In Nova Hollumlia.

41. U. pyymaea $R$. Br. scapo simplici subhiforo; labio superiore integro; inferiore 3-partito laciniis indivisis lateralibus linearibus divaricatis; calcari conico porrecto $\mathrm{R}$. Br. 1. c. In Nova Hollandia.

42. $C$. tenella $\boldsymbol{R}$. $B r$. scapo subsimplici pancifloro; labio superiore 2-partito: inferiore trifido lobis indivisis intermedio majore; fol. ellipticis R. Br. I. c. In Nora Hollandia.

43. U. barbata R. Br. scapo subsimplici paucifiolo, labio superiore emalginato: inferiore 3-fido lacinia intermedia 2-loha; palato intus harbato; calcari subulalo descendente. R. Br. I. c. In Nova IIollandia.

41. U. "flava R. Br. scapo filiformi; racemo multifloro raro; labio superiore bifido: inferiore 3-fido lobis 4 * 
indivisis; calcari subulato descendente. R. Br. I. c. In Nor Hollundia.

4.5. C. chrysuntice R. Br. scapo subramoso; spicis racemosis muttifloris; labio superiore bifido: inferiore 4-lobo; calcari subulato conico descendente; pedicellis 3-bracteatis; bracteis calycihusque coloratis. $\mathrm{R}$. $\mathrm{Br}$. 1. c. In None Eollundia.

46. It. multifida $R$. Br. scapo simplici filiformi pancifloro; labio superiore 2-fido; laciniis e latiore hasi subulatis, inferiore 3-fido: lohis subaequalibus semibifidis; laciniis emarginatis; calcari obtuso compresso. $\mathrm{H}$. Br. In Nore Illollandia.

\section{Foliis radicalibus compo- sitis.}

Scapis aphyllis.

47. I. exlyaris timn. nectario conico; labio superiori integro, palato aequali; fol. pim!ato-inultipartitis. Rchb. f. excurs. 387. Schrad. Journ. 1800. t. 6. Schk. t. 3. In puludesis Germanife. 4. Cor. maxima flava.

48. I. intermedir Hayne; nectario conico labio superiori integro palato duplo longiori; fo!. :-partito-dichotomis. Rchb. I. c. sichrad. Journ. 1800. t. 5. Fl. Dan. 1262. In puludosis et fossis Germaniae. 24. Cor. flava rubrostriata.

49. $\boldsymbol{U}$. minor $\boldsymbol{L}$. nectario carinato, labio superiore emarginato palato aequali; fol.3-partito-dichotomis. Rchl. 1. c. Schrad. Jouru. 1800. t. 6. Fl. Dan. 128. In paludosis et fossis Germaniae. 2. Cor. flava.

50. U. macrorrhisa tec Conte; fol. pinnato-multifidis, vesiculiferis, laciniis linearibus scapo squamato multifloro, labio superiore subtrilobo, inferiore integro, calcari ohtuso emarginato. Le Conte l. c. 73. t. 6. f. 2. A Canada ad Carolinam. 24. Cor. Iava.

51. I. austratis $R$. Br. scapo pancifloro; labiis integris; inferiore duplo latiore quam longo; calcari adscendente antice plano subtus cariuato. R. Brown. p. 430. In ins. Fun Diemen.

52. U. neglecta Viehm. fol. subbinatis bipinnatis cauleque vesiculiferis; labio superiore palato subtriplo longiore, inferiore deflexo lateribus inflexis; calcare conico subcompresso.
Lehmann in Linn. 5. 3. p. 336. In locis palulosis Humburgensibus. 4. Cor. aurantiaca rubro-striata.

53. I . confervacfolia Jackson; fol. capillaceo-multifidis; scapo recto paucifloro, labio inferiore 2-lobo, superiose longiore indiviso, calcari hrevissimo conico, acuto subtus carinato. Jackson in Herh. Iamh. Don. nep. p. 84. In Nepalia.

5t. $\boldsymbol{L}$. foliosa 1 . nectario conicoacuto; scapo multifloro; fructibus cermis radice repente. Vahl el. 1. 1.198. Plum. ic. t. 165. f. 2. In America australi. Cor. Iutea.

5.5. U. exoletu R. Br. scapo 1-2floro; lahio inferiore indiviso; superiore integro et semitrilolo; calcari adscendente emarginato. H. Br. p. 430. Ad Iortum Juckson.

56. U. Fornicata Le Conte; scapo 2-floro, labio superiore 3-lobo, inferiore integro; calcari incurvo conico obtuso integerrimo Le Conte 1. c. t. 6. f. 6. U. gibba Elliot. A New-York ud Georgiam. $\odot$. Fluitans. Cor. lutea.

57. I. flexuosu I ahl; scapo flexuoso; pedicellis fructiferis reflexis. Vahl en. 1. p. 198. In India orientuli.

58. U. striatu Le Conte; scapo squamato 5-6-floro, labio superiore expanso 3-Ioho, labio inferiore subtrilobo lateribus refexis, calcari porrecto ohtuso emarginato. Le Conte I. c. t. 6. f. 4. U. fibrosa Elliot. A NeuFork ad Floridam. 4. Caul. 2-3-ped. Cor. magna lutea.

5.9. I. Longirostris Le Conte; scapo squamoso 1-2-floro; labio superiore subtrilobo; lobis lateralibus adpressis; labio inferiore subintegro, calcari lineari subulato adscendente subincurvato emarginato longitudine labii inferioris. Ie Conte 1. c. t. 6. f. 7. In Georgia. $\odot$. Natans. Cor. lutea.

6o. $U$. integra Le Conte; scapo squamoso 1-2-floro; labio superiore subtrilobo; lobis lateralibus subinvolutis; lahio inferiorc integro; calcari conico-complanato obtuso integerrimo, lahium inferius subaequante Le Conte 1. r. 1. 6. f. 8. U. bipartita Elliot. In Georyia. ๑. Fluitaus. Cor. lutea.

61. $C$. fibrosa Wult. scapo sub1-floro foliisque setaceis, calcari obtuso. Walt. carol. 64. In Carolina. Scapus tenuissimus. Flores aurantiaci.

62. U. hydrocarpa Rich. fol. seta- 
ceis scapo fliformi, pediceltis alternis remotis fructiferis reflexis. Vahl en. 1. p. 200. In Cajenna. Cor. purpurascens.

63. I. murpurea Walt. scapo subtrifloro; flor. parvis purpureis; fol. fihrosis Walt. Fl. car. p.6t. le Conte 1. c. t. 6. f. 9. In Carolina. 21. 1-2-ped. Cor. purpurea.

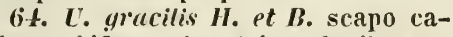
pillaceo bifloro; bracteis calycibusque integerrimis; calcare conico longitudine labii inferioris. Kunth syu. 2. p. 24. In inundatis mope Havanam. 4. Cor. flava.

6.5. $U$. olstusa $S w$. nectario inflexo ohtuso subemarginato. Sw. prodr. 14. In rirulis paludosis Jamaicue. Cor. parva lutea.

66. C. alba Hoffmgg. fol. radicalibus compositis scapo florihus 2-3longe pedicellatis, calcari brevi conico adscendente. Link Jahrb. 1. 3. p. 54. In Brusilia.

\section{B. Scapis involucro utriculato.}

6\%. U. inflata I'alt. scapi fol. vesiculosis cylindricis divisis apice ramentaceis. Vahl ell. 1. p. 197. suh U. ceratophylla. Le Conte I. c. t. 6. f. 1. I Veu-Iorli ad Mexico. ơ. Cor. flava.

65. C. in/lex Forsk. fol. dichotomis pedumculo racemoso, hasi ntriculis vertitillatis; nectariis inflexis truncatis. Forsk. descript. p. 9. In Arabia, Aegypto, in Guinea aruis stagnantibus. Cor. albida venis purpureis.

69. I. stellaris $L$. involucri phrllis subgloboso-oblongis indivisis undique barhatis; calcari nullo. IVilli. sp. 1. p. 114. In India orientali agris oryzuceis. Flor. flavi.

70. U. fisciculate. Roxb. natans aphylla; scapis nudis: racemis 4-8floris; utriculis 2-cornibus; subuyatis, per fibras rudicalis sparsis; nectario corniculato adscendente, ad marginem lahii inferioris; capsulis rostratis pendulis. Roxh. Fl. ind. 1. p. 143. In staynis circa Calcnttam. Caul. articulatus. Cor. mayna flava.

7l. U. dianthe R. et $s$. nalans aphylla; scapo nudo bifloro; utriculis ovatis apice filamentosis; neclario corniculato ad labium inferits adscendente; capsulis globosis erectis. U. biflora Koxb. ind. 1. p. 14t. U. Hox- burghii spr. In staynis circa Catcuttam. Cor. parva flava.

\section{0, PFYGLICUIAA C, Gesn. (15.5.5).}

\section{I. ścano glabo.}

1. P. vulguris Linn. nectario aculn; corollae labio superiori 2 -lobo, infericris labis obtusis ; fol. ovalibtis. Hchl. excurs. p. 387. cjusd. ic. 175. schkuh\% t. 3. Fl. Dan. 93. P. alpina Web. In Europae uliginosis. 4. scap. 6-poll. Cor. Iilaciila in palato pallida.

2. P. grandiflora All. ill. $t$. 14. f. 2. nectario lineari recto corollam compressam subaequante; labiis valdo inaequailhus; fol. lineari oblungis basi vix attenuatis. P. Iongifolia. Hehh. excurs. p. 387. Hook. Lond. t. 128. In alpibus Europae austialioris et in Britumnia. 4.

3. P. atpina Linn. nectario conico petali laciniis hreviore recurvo. Wahleub. Fl. lapp. p. 9. Gunn. Noveg. t. 4. f. 4. $\beta$. corolla najore albida, fauce mascula duplici flava, lahii inferioris lobo medio emarginato. P. alpestris. Pers. In alpibus Europae. 24.

t. P. acutifolia Michx. minima; fol. erecto-rosulaceis, confertis, ovalibus, acutissimis. Michx. am. 1. p.11. In America boreali. 4.

5. P. antaretica Vahl; nectario conico obtuso, petalo breviori; scapo nudo. Vahl en. 1. p. 192. In freto magellanico. 24. scap. digitalis. Cor. paria.

6. P. caliptiata H. et B. fol. ovatis, obtusis, convexis, sessilihus, scapisque vlahris; calcare conico obtuso, corolla breviore. Kunth syn. 2. p. 25. P. antarctica spr. In Nova Grunata. 2). Cor. violacea fauce hirsuta.

\%. P. moranensis $H$. et $B$. fol. spatholatis obtusis, convexis, glabris, apice ciliatis, sessilibus ; scapo wlabro; calcare filiformi recto corolla longiore. Kunth syu. 2. p. 25. Prope Morun in Mexico. 24. Cor. ringens violacea. 8. P. dourick Pall. scapo foliisque glabris; nectario subulato, corollae laciniis breviore; lab. inferius 1-lobum. Link. Jahrb. 1. p. 54, In Dauria. sicap. 3-pollicaris.

9. P. macroceras Pall. scapo foliisque glabris; calcare turbinato, corollae laciniis longiore. Link. 1. c. Kchb. 
tc. 82. In Tnalaschlia. Scap. 4-6-poll. longus. Cor. violacea.

\section{Scapo pubescento s. villoso.}

10. P. brachyloba Iredeb. nectario adscendentc; calycis labio superiore trilentato: dentibus obtusis subaequalihus. Ledel). in litt. In Livonia. Cor. caerulescens.

11. I. villosa dimn. nectario aciculari recto, petalo Ionuriore; scupo villoso apice nutante. Linn. Lapp. t. 12. f. 2. Fl. Dan. 1021. Iichb. ic. 83 . In Lapponia et G'roentandia. Planta pusilla vix 3-poll. longa. Cor. dilute violacea, fauce striis flavescentibus.

12. In. lasitanica Linn. nectario conico apice incrassato ohtuso petalo breviore; scapo villoso; capsula yiobosa. Limn. sp. pl. p. 25. Engl. Dot. 145. Brot. Phytogi. Lus. 1. t. 1. P. villosa Huds. In Lusitinies, finclia et scotia. 24. Folia hirsuta. Cor. rubescens.

13. P. crystallina Siblit. "raec. t. $\&$. coroila inaeyuali, nectario obtuso petalo breviore; laciniis calycinis oblongis; scapo basi glabro. Sibth. In rivulis ins. Cypri. 24. Fol. involutoconcava, glaniuloso-cristallina. Flor. ex albido-caerulei.

1.t. Platior Michx. scapo dewse pubescente, stperne subscabro, erecto; calyce glanduloso-pubescente; corolla majore; tulio valde inflato. Michx. am. 1 . p. 11. P. caerulea Walt. In Carolina

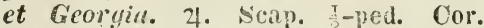
quadruplo major quan in $P$. vulgari, amethysteo-rubens.

15. P. spathulutu tedeb. nectario conico recto obtuso breviore; corolla fauce barbata; fol. spathulatis ciliatis; scapo villoso-viscoso. Ledeh. obs. bot. in Fl. ross. In regione I'ransbaicalense. Afruis P. luteae.

16. I. luteu Wult. nectario suhulato recurvo corolla campanulata breviore; fance harbata; labiis dentatis; scapo subvilloso. Walt. car. p. 63. P. campanulata Lam. Joum. 9. t. 18. f. 1. In Curolina. 24. Hol. poll. Scap. palm. Cor. lutea.

1\%. P. edentula Irool. exot. Fl. t. 16. scapo pubescente; corolla campanulata 5-loba, lobis emarginatis integerrimis; palato prominente ; calcari subulato recurvo corolla breviore. Alb. Dietr. sp. pl. 1. p. 460 . In America boreali. Differt. a P. Iutea corollae lobis emarginatis nec 4-dentatis.

18. P. mumila Michx. scapo brevl subglabro; cor. parvula, clilute violacea; tubo oblongo, calcari breviore. Míchx. an. 1. p. 11. In humidis apricis Georgiae. 2.

19. P. involuta $R$. et $P$. peruv. t. 31. : c. nectario conico curvato, lonvitudine petali; laciuiis lahiorum emaluinatis; scapo villoso. Vahl en. 1. p. 193. In Peruria. $\odot$. Folia depressa, subtus castanei coloris. Cor. violacea.

20. H. macrop!ylla H. et B. fol. subrotundo-ovatis, obtusis, planis, glahris, petiolis scapisque tenuissime glanduloso-pilosis. Kmith. syn. 2. p. 25. in Nora Nispania. 24. Fol. 3-poll. Ionga. Scapi $\frac{\mathrm{I}}{2}$-ped.

\& 1. lilacint Sclilecht. fol. rotundo-ovatis; ohtusis utrinque nigropunctatis supra pilosiusculis; lohis corollae integerrimis; calcari cylindrico, corolla quacirupio breviore. sichlecht. Limaca 5. 1. p. 9\%. In Mexico. Fol. rosulata. Scap. 1-2-poll. longus. Cor. lilacina, extus subglanduloso-pilosa.

\section{SCHIZAVTHUS R. et P. (1794).}

1. S. porrigens Hools. caule fructifero patulo, diútiso. Hook exot. Fl. t. 86. \&. pinnatis Hofrmge. In Chili. $\odot$.

2. S. pinnatus R. et p. prevus. b. t. 17 ; canle fnctifero in uno latere usque ad basin lieclinato $\mathbf{H}$. et P. In Chili. $\odot$. $\approx-$-i-ped. Hol. decrescentipinnata. Cor. purpurea ant purpureoviolacea.

3. S. retusus Ino?. Cor. tubo hrevi, lobis lateralibus labii inferioris intermedio biloho, hreviorihus, loho medio lahii superioris subriomloideo, acuminato, obtuso; calycis foliolis retusis. Lindl. Bot. Peg. 15.4. Bot. Mag. 3015. In undibus provinciae Mendoza. ๑. Cor. rosea; lah. sub. luteum, basi albidum apice roseum.

\section{PEPLIDIUM Delile (1813).}

1. P. Iumifusum Delile Fl. Aegypt. t. 4. $f$. 2. caule prostrato ramoso; fol. oppositis obovatis glabris; flor. sessilibus oppositis axillaribus. Alb. Dietr. sp. pl. 1. p. 561. Prope Da- 
miette. $\odot$. Planta humilis; ramis oppositis. Fol. carnosula. Cor. tubulosa. Sem. angulata numerosa.

2. P. capense spreng. acaulis; fol. lineari-spathulatis; scapo $\mathbf{1 - f l o r o . ~}$ Alb. Dietr. 1. c. Limosella diandra Limi,. Mart. 252. Ad Prom. b. spei. Planta minima, stolonihus repentibus. scapi capillares longitudine foliorum.

\section{VERONICA Fuchs (1512).}

\section{Corolla tubulosa.}

1. I. sibirice spicata altissima; fol. (5-7) verticillatim dispositis (sessilibus). Amm.ruth. 20. t. 4. In Dauria. 4. 4-5-ped. Cor. caerulea fauce pubescente.

2. V. virginica $L$. fol. subquinis Ianceolato-0vatis petiolatis. Vahl en. 1. p. 56. Plukn. t. 70. f. 2. In Virginia et Japonia. ち. 4-5̄-ped. Cor. alba.

\section{Corolla rotata.}

A. Racemi terminales.

3. I. sjuria I. fol. ternis oppositisque lanceolatis aequaliter serratis utriurue attenuatis. Vahl en. 1. p. 57. Schrad. Ver. t. 2. f. 4. V. paniculata Ledeb. V. amethystina Willd. In Sibiria. 4. 4-ped. Cor. cacrulea.

4. I. foliosa Waldst. fol. ternis ovatis duplicato-serratis. Valıl en. 1. p. 56. Waldst. et Kit. t. 10?. V. brevifolia Marsh, a Bieb. V. spuria spr. hal. t. 1. f. 1. In Ilungaria, Gialia, circa IIalam et in regione Caucasica. 4. Cor. coerulea.

5. I. linariaefolia Pall. fol. oppositis linearihus sensim attenuatis longe acutatis remote serratis; bracteis pedicello longioribus. Liuk. Jahrb. 1. 3. 1. 35. V. angustifolia Fisch. H. (:0renk. In Sibiria. 4. 1-2-ped. Cor. marna caerulea.

6. V. maritima L. fol. ternis quaternis, oppositisque oyato-lanceolatis inaequaliter serratis. Vahl en. 1. p. 57. Fl. Dall. 37t. Siclirad. Ver. t. 1. f. 1. In Europa boreali. 4.

7. medice scilrad. fol. oppositis ternisve lanceolatis acutis serratis cauleque pubescenti-tomentosis; serraturis approximatis ina equalibus. Schrad. suppl. ad Ver. t. 1. f. 2. V. longifolia Roth. In humidis Europae me- diae. 4. 4-5-ped. pubescens. Cor. caerulea.

8. V. arguta Schrad. fol. Ianceolatis acutis simpliciter serratis apice integerrimis; serraturis remotis inaequalibus. Schrad. Ver. suppl. n. 7. t. 2. f. 1. In Itcilia. 4. 4-ped. Cor. caerulea.

9. Ir. mesot!pu Link; fol. oppositis ternisque oblongis ex ovali hasi attennatis acutis nargine serratis apice integerrimis, bracteis pelicellis calyce longioribus Link. Handb. 1. p. 522. V. falcata Mart. Erlang. In Germania? 4. Caul. 4-ped.

10. I. nitens $\boldsymbol{R}$. iet $\mathbf{S}$. fol. oppositis ternisve, ovatis acutis, basi attenuatis, medio serratis, apice subserratis glahris. Link en. 1. p. 20. sulnitida. V. aruta Willd. en. Hab..... ち. 4-pel. Cor. sat magna caerulea.

11. I: persicifolia Schott; fol. oppositis teruisque lanceolatis ex oblonga basi altenuatis longissime acumiuatis, ad apicem usque serratis; bracteis pedicello longiorihus. Link en. alt. p. 21. Hub.... 2. 2-ped. Car. caerulea.

1\%. V.australis Schrad. fol. ovatolanceolatis simpliciter serratis, apice integerrimis cauleque pubescentibus; serraturis approximatis inaequalibus. schrad. Ver. 11. 9. t. 2. f. 3. In Europa austruli. 4. 4-5-ped. Cor. caerulea.

13. V. longibracteata Link; caule glahrinsculo; fol. ternis oppositisque, oblongis lanceolatisve, acutis, ex oblolla hasi sensim attenuatis, apice integerrimis; bracteis inferioribus foliaceis integerrimis. Link en. alt. 1. p. 20. V. brevitolia L. en. 1. p. 21. V. brachyphyla $R$. et $\mathbf{S}$. lícb.... 4. 4-5-ped. Cor. magrna caerulea.

14. I. canescens Schrad. incanotomentosa; fol. lanceolatis serratis acutis, basi cunealis integerrimis; caule ereotw. V. neglecta Vahl en. 1. p. 59. V. incana Waldst. et Kit. t. 214. In collibus Hungariac et Sibiriae. 4. 3-4-ped. Cor. magna caerulea.

1.5. I. incana $L_{\text {. }}$ incano-tomentosa; fol. lanceolatis crenatis, subintegarrimisque obtusis, caule erecto. vahl en. 1. p. 59. Hoffm. Comm. Goett. XV. t. VI. In Russia et I'au- 
ria. 24. 2-ped. adscendens. Cur. catrulea.

16. V. glabra Ehrle, fol. oppositis ternis subcordalo-lanceolatis simpliciter serratis cauleque crlahris; serraturis remotis suhaequalibns. sichrit. Ver. p. 25. 1. 1. f. 4. In Europu austruli. 24. 3-1-ped. Cor. mayna caerulea.

17. I. elegans IDC. fol. oppositis oblongo-lanceolatis ex ovata hasi attenuatis serratis apice integerrimis glahris; petiolis ciliatis; bracteis pedieello longioribus breviorilsusque; pedicellis calyce longiorihus. Alb. Dietr. sp. 1. p. 489 . In paludosis Belgii. 4 . Adscendens 3-4-ped. Cor. incarnata.

18. I. rubicunda hed. villosopubescens; fol, opposilis in petiolum attenuatis oblongis lanceolatisve serratis; bracteis ommibus pedicello longioribus calyceque glanduloso-pilosis. Ledeb. in Fi. ross. t. ż08. In Duvuriu. 4. Cor. speciosa rosea,

19. I. serrulatu Pall. caule tenui tomentoso; fol, oppositis ternisfue, petiolatis inferioribus oblongis, supevioribus lanceolatis omnibus e lanceolata longaque basi attenuatis, serrulatis; hracteis inferioribus pedicello longiorilus, calyce pubescente. link Jahrbüich 1. 3. In Sibiritu Cor. lilacina?

20, I. Steplanianu $R$. et $\mathbf{s}$. caule tenui-tomentoso; fol. oppositis ternisque lanceolatis basi attemuatis acutis serratis tenui-tomentosis, candicantihus, bracteis pedicello hreviorihus lis. et si. Mant. 1. p. 96. V. mollis Lk. In Persia. 4.

21. V. ramosa Poìl. caule pubescente; fol. caulinis ternis, oblongolanceolatis, remote serrulatis ramis oppositis, confertis linearihus, summis Integerrimis. Link Jahrb. 1. 3. p. 38. In sibiria. 4. Pedalis. Cor, caerulea.

22. V. cartilayinea hed. caule pubescente, fol. glabris, inferioribus oppositis spathulatis, versus apicem serratis, superioribus alternis linearibus serrulatis, bracteis inferioribus calycen superantibus; laciniis calycis glabris ciliatis nervosis, Ledeb, ic. Fl. ross. t. 210. In I)aruria. 24. 1'-2-ped. Cor. caerulea.

23. 1 . luxurians Inedeb. caule pioso; fol. glabritusculis oppositis peliolatis oblongis actuninatis basi ro- lundatis ex toto acute simpliciter serratis, serraturis subaequalibus; bracteis pedicellis subaequantibus, calycibus patentibus. Ledeb. ic. Fl. ross. t. 211. Prope urbem Ircutium. 24. Caul, debilis fistulosus. Cor. caerulea.

2-t. I. longifolie $I$. fol. oppositis temisque lanceolatis e cordata et subcordata basi attenuatis ad apicen usque serratis. Alh. Dietr. sp. 1. p. 492. schrad. Ver. t. 2. f. 1. V. grossa, acuta, ambigua et ringens Mart. H. Erlang. V. complicata Hofm. phytogr. t. F. f. 1. In Europa mediu. 4. 2-3-ped. Cor. caerulea alba ant lilacina.

2.5. V. asurea link; fol. lanceolatolinearibus, longissimis sensim attenuatis, ad apicen usque argute serratis, serraturis haseos profundioribus; bracteis pedicello longioribus. Link en. alt. 1. p. 22, Haí.... 4. 3-ped. Cor. intense caerulea.

26. I. elatior Elerh. fol. oppositis ternisque elongatis nitidis e cordata hasi attentis ad apicem usque profumde serratis, serraturis baseos profundioribus. Alb. Dietr. sp. 1. p. 493. In Europa australi et Russia meridionali. 24. 7-9-ped. Cor. caerulea.

27. I. gronelis Fisch. fol. oppositis cordato-0blongis, inciso-dentatis, hasi sulpinnatifidis, nudis; racemo terminali elongato; capsulis subglobosis. Spr. N. Entd. II. p. 122. In Sibiria. 4. Cor. albilla fauce harhata.

28. I. cremulutu Ho/fm. fol. ternis epposiliseque oblongo-Ianceolatis serratis; calycihus acutis; laciniis corollae crenulatis. Vahl en. 1. p. 57. Hoffin. Plıvtogr. t. 5. f. 3. Y. villosa schrad. t. i.f. J. Hali.... 4. 1-1 -ped. Cor. caerulea et alba.

29. I. Jonae Gourn. fol. cordatoovatis sessililus oltusissimis cauleque simplicissimo pilosis, racemis pancifloris calycilus glahris. Vahl, en. 1. p. 78. Gotlan ill. t. 1. f. 1. V. sempervirens Lam. V. pmuila All. ped. t. 22. f. 5. In summis alpibus peslemontanis et in Pyrenceis. 4. Palmaris. Cor. caerulea.

30. I. stelleri lall. caule simplici hirsuto ; fol. sessilibus cordatis, serrato-crenatis, ohtusis; racemo hrevi; bracteis crenatis, pedicello hreviorihus; calyce hirsuto, Link Jahrl). 1. 3. p. 50. In Camitschatka et Uncilaschka. 
4. Digitalis et spithaneus. Cor. caerulea.

31. 1. laciniata Ait. Kew. fol. subfasciculatis hreviter petiolatis linearibus pimmatifidis laciniis integerrimis racemo subsolitario laciniis calycinis ohlongo-ovatis. schrad. Ver. p. 22. V. spuria Junghans ic, rar. Cent. 1. f. 2. In Sibiric. 4. 1-2-ped. Cor. caerulea aut alhida.

32. I. incisc tit. tol. subfasciculatis, petiolatis lanceolatis pinnatifidis, laciniis suhintegerrimis, racemis pluribus; laciniis calycinis lanceolatis. schrad. Ver. p. 33. In Sibiria. 4. 1-1 I-ped. Cor. caerulea.

3.3. I. pinnut $L$. caule adscendente; fol. subfasciculatis, inferiorihus pimnatis, superioribus pinnatifidis simplicilusque; foliolis laciniisque filiformihus divaricatis. Hort. Kew. 1. p. 28. Hoffu. Comm. Goett. XV, t. x. V. hispanica Meerb. t. 11. In Sibivia et in Attui. 21. I-2-ped. Cor. pallide caerulea; alba aut rosea.

34. I. sessiliflora Bunge; fol. ohlongis basi cuneatis in petiolum attenuatis, pectinato-pinnatifidis; laciniis integerrimis ohtusiusculis supremis linearihus integerrimis cauleque erecto puhcscentihus; florihus in spica terminali subsolitaria densa exacte sessilihus. Ledlel, ic. Fl. ross. t. 126. In locis stcritibus al fluvios Kurai ct Tschuja. 4. 5-poll. Cor. caerulea.

3.5. I. spicata $L$. fol. oppositis obtusis inferioribus ohovatis aut ohlongis in petiolum decurrentibus crenatis superioribus lanceolatis sessilibus serrulatis, calycis laciniis suhacqualibus oblongis; corollae laciniis ohlongo-ovatis; capstila obcortata. Alb. Dietr. sp. 1. p. 497 . V. hybrida Vahl. Will, V. Vaill. paris. t. 33. f. 4. Engl. bot. t. 2. Swensk bot. t.2. In Europa. 24. 4-poll. Cor. caerulea. 36. I. orclidea Crants; tenuiter pubescens; fol. crenulatis, radicalilus oblongo-ovatis in petiolum decurrentibus, caulinis lanceolatis acutiusculis subsessilihus; florihus dense spicatis; laciniis corollae lineari-lanceolatis, antheras superantihus. schult, syst. 1. p. 94. Hochel Bonat. t. 21. f. 42. V. cristata Bernh. V. nitens Host. In Austria, Gulticia, Pannonia, Callcaso. 24. Caul. ped. Cor. pallide caerulea.

3\%. V. gentianoides Vahl; corymbo terninali ; fol. lancenlatis margine cartilagineis; inferiorihus connatis vaginantibus; caule adscendente. Vahl symh. 1. p. 1. Vent. Malm. t. 86. Bot. Mas. 1002. In Turria, Cappudocia, Armenia. 24. Culta 2-3-pet. Cor. caerulea.

38. I'. olympica Pall. fol. radicalibus lineari-lanceolatis, versus apicent crenulatis hasi vaginantihus, catulinis linearihus integerrimis; racemo laxo. Pall. in WVilld. Hb. Link Jahrb. 1. 3. p. to. In Ol!mmpo. 4-poll.

39. I. bellidioides $\mathrm{L}$. fol. ohovatis crenatis cauleyue adsceudente piloso, racemo suliquinquefloro. Vahl en. 1. p. 61. Hall. list. t. 15. f. 1. In ilpibus Pyrenaeis, Ifelretiae, Nilesiae, Bohemiae, Austriae. 24. -ped.

to. V. Fruticulosa Linn. fol.ellipticolanceolatis subserratis; caulihus erectis fruticulosis; racemo multifloro. Vahl ell. 1. p. 62. Jacq. Coll. 4. t. 5. In alpibus Ilelretiae, Austriae et Scotime. 24. Spithamea. Cor. ruhella purpureo-striata.

+1. I. arbustulosa Hoffgg. filiformifruticosa; fol. oblongo-lanceolatis, sub)integris, revolutis; racemo paucilloro; capsula ovata calycis longitudine. Bchb. ic. 1226. In llort. Hiesdensi culta. 24. Cor. alha roseo-striata.

4. I. macrostemma linnce; caulihus fruticulosis ramosis; fol. inferiorihus suhrotundo-ovatis integerrimis; superioribus oblongis serrulatis pubescenti-villosis, racemis terminalibus villosis, multiforis demum e!ongatis, capsula pubescente calycem duplo superante. Ledeh. ic. FI. ross. t. 12\%. In lapidosis summarum alpium Altuicurum. t. Cor. magna violacea.

43. I. saxatilis $\mathrm{L}$. fruticulosa, ramosa ; fol. superioribus oblongo-ovatis subserratis; racemo pattifloro corymboso; capsulis ovato-attenuatis calyce majorihus. Hchh. f. exc. p. 369. Fl. Dan. 342. V. subfruticosa. Bot. Cab. 704. In rupibus Germaniare. 4. Cor. laete caerulea anuulo purpureo, aut alhido.

14. I. cretica Pall. caule procumbente; fol. lineari-spathulatis, scaberrimis; racemo hrevi denso. link Jahrb. 1. 3, p. 41. In Creta. 4. Herb. Willd.

15. I. nummularia Gouan. racemo hrevi conferto; fol. suhrotundo-ovatis, confertis; calycius laciniis obtusis, 
ciliatis; caulibus prostratis fruticosis Gouan ill. 1. t. 1. f. 2. V. irregularis Lapeyr. V. saxatilis $\beta$. Willd. In Pyrenaeis. t. Caul. Jignosis, Cor. laete caerulea.

46. $V$. densiflora Ledeb. caule fruticuloso bifariam piloso; fol. sessilibus ellipticis dense serratis obtusis glabriusculis hasi ciliatis; racemo terminali conferto subcapitato; bracteis calycibusque articulato-pilosis. Ledeb. ic. Fl. ross. t. 125. V. alpina sievers. In summis alpibus Altuicis. ந: 2-3-poll. Cor. magna late caerulea.

47. 1. alpina $L$. caespitosa; fol. elliptico-ovatis integerrimis serratisve, raceno paucifloro condensato; cor. campanulata ; capsula obcordato-subrotunda. Kchls. exc: p.369. var. a.lapponica fol. grossius serratis, capsulis glaberimis. Limn. lapp. t. 9. f. 4. B. anstralis : foliis subintegerrimis capsulis pilosis. Engl. Iot. 494. Kroker siles. t. 3. V. integrifolia Schrank. V. Wormskjoldi 1R. et s. In alpibus Europae a. in Scandinaria $\beta$. in Europa australiori. 4. Cor. caerulescens.

48. I. serpyllifolia I. adscendens racemo folioso laxe elongato; fol. ovato-oblongis stibrenatis; capsula ohverse reniformi fichb. excurs. p. 369. Enel. bot. 1075. Fl. Dain. 492. V. tenelia All. t. 22. f. 1. In Europa et Americu. 24. Cor. pallide caerulea, alla ant rubella.

49. V. foutuna Pall. caule repente pubescente; fol. sessilibus ovatis obtusis crentitis glabris; hracteis foliaceis; pedunculis bractea multo brevioribus. Link. Jabrh. 1. 3. p. 41. In Cnalaschlia et Kamtschatla. 24. Caul. radicins 4-poll.

50. I. thymifolia Sibth. corymbo terminali; fol. linearibus revolutis incanis; caulibus fouticulosis diffusis; capsularum lolis divaricatis. Nibth. Fl. Graec. t. 6. In ins. Cretu. 4. Cor. cyanea, tubo albo.

51. V. telephieifolia Valil; caule repente, fol.obovatis integermmis. Vahl en. 1. p. 65. In Avmenia.

\section{Racemilaterales.}

52. I. aphylla I. fol. radicalihus subrotundis oblongisve; caule nudo brevissimo; pedunculo scapiformi subtrifloro. Vahl en.1.p.68. Seguier. Ver.t.3. f. 2. V. subacaulis Lam. V. depau- perata Waldst. et Kit. In alpibus Enropae et Asiae. 2. Cor. magna caerulea.

5.3. V. euphrasiaefolia Link; caule repente superne puhescente; fol. oblongis, acutis crenato-serratis, glahris; racemis paucifloris; pelicellis elongatis; laciniis calycinis ovatis glabris. Link Jahrl. 1. 3. p. 41. V. thymifolia Iferl. Willd. In monte Ghilan. 4-pollicaris. Cor. cacrulea.

5t. V. panciflora Kit. caule procumbente superue pubescente; fol. subsessilibus oblomgis, serrato-crenatis acutis ulahris; racentis panciforis ; pedicellis elongatis; laciniis calycinis ovatis glabris. Link 1. c. In Curpathis.

5.). V. livsutu Hook. Scot. glanduloso-hirta; caule adscendente; fol. oblongis acutis subcrenatis; racemo elongitto. Link en. aIt. 1. p. 24. In Scolia. 4. I. setigera Don.

56. V. officiualis $h$. repens fol. ohovatis elliplicisve serratis pubescentilus; racenis elongatis hchh. excurs. p. 36\%. Hayne Arzn. IV. t. 3. Fl. Dall. 218. var. $\beta$. V. Toumefortii et V. Allionii sm. lumilis fol. obovatosubrotundis racemo shosolitario) flor. majoribus laete caeruleis Mchb. ic. 1053. 10.5t. In sylri.s et alyibus Europue. 4.

$.5 \%$ V. Beccobunge L. radicans adscendens; fol. ellipicis obtusis serrulatis; ctipsula oncoldato-subrotunda. Rehb. excurs. p. 368. HI. Dan. 511. Engl. bot. 6.55. In rirulis, fiossis et ad scaturifines Europue siviviue et Americae borealis. 24. Caul. suecosus. Cor. caerulea.

5.8. r. carolinimu Poir. elahra racemis subteminulibus; fol. ovatoohlongis, ohturis suhintegris ; inferiorihus petiolatis; caule erecto, apice dichotomo. Poir. enc. VIII. p. 520. In Carolina.

5.9. I. punctata Ifamilt. glahra caule repente; fol. superiorihus amplexicaulinus lanceolatis acutis crenulatis, racemis tennifforis; hracteis lanceolatis acutis pedicellis Iongioribus; laciniis calycis ovatis acuis. Doul. nep. p. 93. In Vepalia. Tota planta nitida.

60. I. Anafullis $I$. erecta fol. lancenlatis acutis serratis; capsula obcordata Fl. Dan. 303. Eugl. hot. 781. In fossis Europap, Orientis I irginiae 
et Japoniae. $\odot$. $\frac{1}{2}-2$-ped. Cor. albida lineis purpurascentibus.

61. V. scutellatu L. adscendens; fol. lineari-lanceolatis denticulatis ; pedicellis filiformibus fructiferis reflexis; capsula olverse reniformi maxime compressa. Rchb. excurs.'p.367. Fl. Dan. 209. Engl. bot. 782. $\beta_{\text {. pilosa caule }}$ foliisque pubescentibus. V. Parmularia Poit et Turp. paris. t.14. Tratt. austr. t. 20. In Europae inundatis. 24. Digitalis et sesquiped. Cor. albida subincarnata aut caerulescens.

62. Ir. tenuis Ledeb. caule erecto stricto; fol. wlalsris oblongo lanceolatis acutiusculis serrulatis ; racemis axillarihus, intermediis oppositis; calycihus 4-partitis ; capsulis elliptico-ovatis obtusis integris. Ledeh. ic. FI. ross. t. 217. In Persia boreali. $\odot$.

6:3. V. Lutifolia Limn. capsula orbiculari-emarginata, masis minusque lirta; ful. sessilibus ovalibus et oblongis grosse crenatis calycilous 5-partitis hirtis et glabriusculis. Alb. Dietr. sp. 1. p. 511. Q.fol.ovalibus V. Pseudo-chamaedrys Jacq. austriaca. t. 60. $\beta$. fol. oblongis. V. Tencrium Vahl. V. minor latifolia Moris. 3. 23. f. 13. montana. Riv. t.95. In Europa media. 4. $\frac{1}{2}-2$-ped. Cor. caerulea.

64. I. 'Teucrium Linn. caule adscendente; fol. sessilihus oblongis serrutis, superiorihus suhintegerrimis; calycilus 5-partitis, laciuiis ciliatis; capsulis accisis pilis minutis. Alb. Nietr. I. c. V. dentata scluad. V. paniculata Willd. V. Schmillii R. et $\mathbf{s}$. In Europa media et australiori. 4. 6-9-lin. altus adscendens.

6.5. V. prostiata $I$. caule prostrato; fol. sessilihus ohlongis et lauceolatis serratis; superiorihus linearibus suhserratis; calycilus 5-partitis glahriusculis ; capsulis emarginatis glabris. Alb. Dietr. 1. c. V. Iatifolia $\mathbf{~}$ Koch. V. angustifolia minor Riv. t. 95. In Europa media.

66. I. himalensis Don. caule erecto piloso; fol. sessilibus ovali-oblongis obtusis inciso-crenatis, utrinque hirsutis; racemis longe pedunculatis; bracteis lanceolatis pedicello longioribus; laciniis calycis linearibus obtusis ciliatis. Don. nep. p. 93. In Nepalia.

$6 \%$. . pectinata I Iinn. fol. oblon-
gis pectinato-serratis; caulibus pro- stratis; pedunculis inferne foliatis. Vahl en. 1. p. 71. Buxh. Cent. t. 39. f. 1. Ad Constantinopolin. 24. Palmaris et ultra.

68. I. tuurica Willd. caule decumbente; fol. sessilibus linearibus crenato-pinnatifidis, summis integerrimis, ommibus pilosiusculis; racemis elongatis; calycibus 4-partitis. All). Dietr. I. c. V. orientalis Var. taurica auctorum. In '́'curia. 24. Cor. rosea aut lilacina.

69. I. orientalis Ait. Kew. fol. lineari-lanceolatis integerrimis serratis pinnalifidisque ; pedicellis capillaribus bractea longioribus. Vahl en. 1. p. 71. V. heterophylla salish. t. 4. In yraminosis Armeniae et Iberiae. 4. 70. V. parrifolia Vuhl; fol, pinnatifidis; caulihus herhaceis; bracteis pedicellos aequantibus. Vahl en. 1. p. 72. Buxl, cent. 1. t. 41. f. 2. In Cappadociae et Armeniae yraminosis. 21.

\%1. 1. rosea Desfont. fol. pinnatifidis; caule fruticoso adscendente; hracteis pedicellos aequautibus. Vahl ell. 1. p. 73. V. allantica Pers. In Atlunte. ち. Cor. rosea.

72. 1. arestiviace $L$. caule erecto; fol. sessilihus inferioribus multifidis, superiorilus lanceolatis sintato-pinnatifidis, calycilns 4-partitis glahris; capsulis emarginalis glabris. Alb. Dietr. 1. c. Jacq. austr. t. 329 f. 5. V. multifida schnidt. V. polymorpha Willd. V. laciniata Mœench. B. pilocerpa. V. pilocarpa Linn. V. trichocarua R. et s. V. orientalis Willd. In Envopu meriut et australi. 24. Pedalis. Cor. caerulea.

83. 15. Jacquini Schott. caule erecto; fol. sessilibus onnibus multifidis ; laciniis linearibus ; calyce 5-partito hirto; capsula emarginata puherula. Alb. Dietr. 1. c. V. austriaca Jacq. aust. t. 329. f. 1-4. V. multifida Mert. et Koch. In Europa et 'Iauria. 24. Pedalis Cor. caerulea.

74. I. tentifolia steven. fol. pinnatifidis laciniis lineari-filiformilsus; calycinis segmentis subulatis, superioribus brevissimis; caulibus adscendentihus. Marsch. a Bieb. cauc. 1. p. 13. In Iberia. 4.

75. I. multifila Linn. fol. bipinnatifidis; laciniis lanceolatis linearibusque; calycinis segmentis inaequalibus subulatis; caulibus procumben- 
(ibus hasi liguescentibus Marsch, a. Bieb. 1. c. Bot. Mag. 1679. In Siltiric, 'Tauria et in regione Caucasi. 4.

z6. V. Cuncasica Marsch. ¿ Bieb. fol. bipinnatifidis; laciniis lanceolatis linearibusque; pedicellis capillaribus, calycinis segmentis subaequalibus lanceolatis; caule erectiusculo Marsch. a Biel. Fl. Taur. Cauc. 1. p. 13. 1. 32. V. ossetica stev. In Iberia. Cor. coerulea.

7\%. V. micrantha Hoffinsegg. caule erecto undique hirto; fol. subsessilibus ovalihus grosse acuteque crenatis hirtis; calyce 4-partito corolla majore; capsula compressa, profunde emarginata. Flor. Portug. p. 286. t. 57. V. Tencrium Brot. V. mollis Zea; R. et S. In Lusitunia. 24. Caul. pilis crispis tectus. Cor. allo anmulo purpurascente.

78. V. plebeja R. Br. racemis lateralihus laxis; fol. ovatis inaequaliter inciso-serratis glalıris; caule tenuissime-puhescente; petiolis inferiorihus dinuidio folio longioriluss. lh, Br. prodr. p. 435. Ad portum Jackson.

79. I. Brounii $R$, et $S$. racemis lateralibus laxis; fol. ovato-lanceolatis glahris inaequaliter serratis, caule bifariam puhescente, petiolis inferioribus folio ter hreviorihus. V. arguta. H. Br. 1. e. Sd portum Jackson.

80. I: distans $\boldsymbol{R}$. Br. corymhis lateralibus pedunculatis paucifloris ; fol. ovatis late serratis glabris, peliolis ciliatis; caule decumbente bilarian pilosa. 1R. Br. I. c. In Nova Hollandia.

Si. V. Chamaedrys $L$. adscendens; fol. subsessilibus inciso-serratis ; summis cordato-ovatis; calycihus irregularilus; caule bifariam piloso; caps. obcordata longitudine latiore. Hchb. f. excurs, p. 367. Fl. Dall. 448. Engl. hot. 623. Ii Europa. 24. 1-1 Cor. caerulea.

82. I. chumuerlyoides Bory; caule basi repente, pilis sparsis suliglutinosis (nec hifarium piloso); fol. ovatocordatis inciso suhpinnatifilis crenatisque; laciniis calyc. Ianceolatis oltusis Bory Voy. en Niorée t. 1. In Morea. 4.

8:3. I. pilosa Schmiat ; caule prostrato undique piloso; fol. ovatis ohtusis plicatis profunde dentatis. IVilld. sp. pl. 1. p. 66, V. plicata Pohl, V. Chamaedrys Fl. port. In Bohemia,
Hispania et Lusitania. 24. Cor. caerulea.

84. V. peduncularis Marsch. a Bieb. racenis (laxis) fol. ovatis inciso-serratis; caule hirto hifarian pilosiore; pedicellis fructus capillarihus (hractea duplo longiorihus) Marsch. a Bieb. casp. p. 126. V. pedunculata Vahl. Buxl. Cent. 1. t.41. f. 1. In nemoribus umbrosis Cancasi. 4. Cor. caerulea minor quam in V. Chamaedryoide. 8.5. V. nemorum Pall. caule prostrato pubescente; fol. hreve petiolatis ovato-ohlongis serratis hasi integerrimis; pedicellis elongatis bracteis dentatis. Liuk Jahrol. 1. 3. p. 42. In '́anria. 24. Cor. pallide caerulea magna.

86. V. syriaca R. et S. fol. ovatis serratis inferioribus petiolatis oppositis; pedicellis patentihus hractea triplo longioribus; capsulis ciliatis. $V$. pedunculaila Labill. syr. dec. V. t. 8. f. 2. Juxta Damascum. ○. Caul. spithameus.

8\%. V. Novae Hollandiae Poir. fol. petiolatis ovatis inciso-crenatis ; racemis lateralihus; florihus longe pedicellatis; caule puhescente Poir. Euc, V111. p. 526. "n Yora llallan!iu. 24. 88. Y amblosa Marsch. "lieh. racemis lateralihus; fol. scahris inferiorihus ovatis grosse serratis superioribus ohlongis subserratis; caulihus repentihus; calyce aeruali corollam subaequante M. a Biel. tanro-cauc. 1. p. 11. pl. ross. t. 7. In T'auria. 4. 8.9. Ir petiate Siev, racemis subcorymbosis; fol. ovatis serratis, caule hirto; pedicellis filiformihus bractea vix loneiorihus. 13. et sichult. syst. Veg. 1. 1. 115. In Cuncuso. 2.

90. V. Baumgurtenii R. et $\mathrm{s}$. caule digitali erecto simplici glabro, apice corymo dichotomo terminante; fol. inferioribus opposilis, sessilibus ovali: hus, s. ovato-lanceolatis serratis summis alternis; semiamplexicanlibus, lineari-lanceolatis; pedunculis filiformihus; erecto-patulis, 1-floris ; calycinis laciniis aequalibus; corollis calyce duplo majorihus pallide caeruleis. 11. et s. syst. Veg. 1. p. 100. V. petraea Baumg. ţanș. Hoch. Banat. t. 21. f. 44. In alpibus Banati. 7. Cor. pallide caerulea.

91. I. stolonifera Talim. stalonibus reptantihus hirsutis, pilis demum distichis; fol. petiolatis cordato-ovatis 
grosse serrato-dentatis; calycihus foliosis capsula longiorihus Lehnı. ind. sem. in Hort. Hamb. 1824. p. 20. In America septentrionali. 4.

92. I. unduluti Wull. glabra erecta; fol. lineari-lanceolatis, undulatis, inaequaliter serratis racemis terminalibus axillarilusque elongatis; pedumcnlis tectis pilis glandulosis hrevibus. Roxh. ind. 1. 147. In India orientali. 24. Caul. fistulosus. Cor. alla.

93. V. parviflora Vahl; fol. Inearilanceolatis integerrimis glahris mucronatis caule fiuticoso. Symb. bot.3. p. 4. In Nova Zectandia. †.

9. I. macrocarya Iuhl; fol. lanceolatis integerrimis, glahris planis; caule fruticoso; racemis erectis. Vahl symb. bot. 3. p. 4. In Nora Zeelundia. †. Fol. 4-poll. longa.

9.5. 1. salicifolia Forst. fol. lanceolatis utrinque attenuatis integerrimis; caule fruticoso; racemis nutantihus. Vahl. en. 1. p. 67. In Nova Zeelanilia. t. Tota glabra. Rami cortice fusco.

96. 1 . clliptica Forst. fol. ellipticis integerrimis. Vahl en. 1. p. 67. In Nova Zeelandia. $\hbar$.

97. V. decussata Ait. racemis paucifloris; fol. ellipticis perennantihus, integerimis; caule fruticoso. Hort. Kew. 1. p. 31. Bot. Mag. 2+2. Hehe magelianica Juss. In ins. Fulklandiae et in freto magellanico. $\hbar$. Frutex sempervireus 1-2-ped. Cor. alba caeruleo-striata.

98. V. formosa R. Br. fruticosa; fol. perennantihus decussatis lanceolatis integerrimis glaherrimis basi acutis; ramis bifariam pilosiusculis; corymbis axillarilus pauciforis $\mathbf{R}$. Br. prodi: p. 434. In ins. Van Diemen. $ђ$.

9.9. V. catarractue Forst. caule suffruticoso; fol. lanceolatis serratis; racemis laxis. Forst. prodr. n. 9. In Nova zeelandia. Ђ.

100. V. labiata $R$. Br. racemis axillarihus longissimis; fol. elongatolanceolatis acuminatis inaequaliter serratis. Ii. Br. prodr. 1. p. 434. Bot. Mag. 1660. V. Derventia Andr. Kep. 531. In Nova Hollandia et in ins. Van Diemen. $\hbar$. Folia decussata. Cor. pallide violacea.

101. V. perfoliata R. Br. racemis lateralibus pedunculatis multifloris fol. integerrimis glaberrimis ovatis acu- minatis hasi conuatis. R. Brown prodr. 1. p. 43t. Hot. Mag. 1956. Ad portum Jackson. 2-ped. Cor, violaceopurpurea ant raerulea.

IO2. V. gracilis $R$. Br. corymhis lateralibus paucifloris; fol. linearilanceolatis integris cauleque subsimplici glaherrimis. H. Br. 1. c. $A d$ portum Jackson.

103. V. calycina $R$. Br. racemis lateralihus paucifloris; fol. ovatis rugosis inaequaliter crenatis, petiolatis cauleque repente hirsutis; calycibus pilosis ciliatis capsula longiorihus. $\mathbf{R}$. Br. prodr. p. 435. In Nowa Hollanlia et in ins. Van Diemen.

104. V. Ieltoidea Spr. erecta glaherrima; fol. deltoideo-ovatis acutis hasi cumeatis inaequaliter dentatis ; racemis laxis; hracteis foliaceis obtusiusculis. Spr. syst. veg. cur. post. p. 17. Sieb. 11. 483. In Nova Hollandia.

10.5. I. Rillardieri Iahl; fol. Ianceolato-oblongis integerrimis caulibusque prostratis incanis. Vahl en. 1. p. 70. In Syria.

106. V. macrostachya Vahl; fol. lineari-oblongis extrorsum profunde serratis caulihusque prostratis incanis; racemis longissimis. Vahl en.1. p. 71. In Syric. Tota villoso-incana.

10\%. V. Frolichiana Rchb. adscenlens ; fol. ovatis serratis racemis oppositis erectis elongatis laxifloris $\mathbf{R c h b}$. excurs. p. 367. In alpinis Germaniale. 4 .

108. V. maxima Stev. racemis lateralibus; fol. ovatis subsessilibus, grosse serratis pilosis; calycibus capsulisque ciliatis. M. Biel, suppl. ad Fl. tauro-cauc. ined. Buxb. t. 34. In Iberia. $\odot$. Cor. parva pallide caerulea.

109. V. urticaefolia Jac\%. stricta; fol. sessilibus cordalo-ovatis acuminatis serratis ; capsula orbiculariemarginata. Rchb. excurs. p. 367. Jacq. austr. t.59. In Helvetiu, Austrin, Bithynia et Bavaria. 24. Pedalis. Cor. albide-rosea striis saturatioribus.

110. V. montanı L. decumbens; fol. petiolatis cordato-ovatis serratis; capsulis obverse reniformihus maxime compressis. Rclib. excurs. p. 367. Jacq. austr. t. 108. Fl. Dan. 1201. Hoffm. FI. 1791. t. 1. In nmbrosis Europae mediae. 4. Cor. dilute caerulea.

111. V. Michauxii Lam. floribus 
sulnglomeratis; fol. ovatis dentatis sessilibus. Lam. ill. pl. p.44. In Oriente. Caul. fistulosus 4-6-poll.

112. V.reniformis Rafinesque; caule procumbente lispido; fol. sessilibus reniformihus integris villosis; florihus axillaribus solitariis subsessilibus Schmaly Jour de Bot. 1808. T. 1. p. 228. In America boreali. 24. Flores magni pallide caerulei.

\section{c. Pedunculis axillaribus ani-} floris.

113. $\Gamma$. acinifolia Linn. floribus pedunculatis; fol. inferioribus petiolatis ovatis serratis; floralibus subsessilibus pedunculos aequantibus; capsula obcordata compressa; canle erectiusculo. lichl, excurs. p. 366. Poit. et Turp. Fl. par. t.23. Vaill. Par. t. 33. f. 3. V. romana All. ped. t. 85. f. 2. In Gallia, Italia et in Germania. $\odot$. Viscoso-hirsuta. Cor. pallide caerulea.

114. V. pracox Allione auct. $t$. 1. f. 1. erecta; fol. inferiorihus petiolatis cordato-ovatis serratis ; foralibus subsessilibus pedunculo brevioribus; capsula obovata emarginata turgida. Rchb. excurs. p. 365. Hagenb. Bas. t. 1. In arvis Europae. $\odot$. Tota planta pilis viscidis obsita. Cor. cyanea.

11.5. V. arvensis linn. fol. inferioribus petiolatis cordato-ovatis serratis; floralibus sessilibus flore subsessili longioribus; capsula olicordata compressa. Rchb. l. c. Engl. hot. 734. FI. Dan. 515. In arris cultis Europae. $\odot$. 6-10-poll. Cor. pallide caerulea, striis obscurioribus.

116. V. biloba Linn. flor. pedunculatis; fol. ovatis serratis acutis glabris; laciniis calycinis aequalibus ovatis 3-nerviis. Vahl cn. 1. p. 79. Rchb. ic. 668. Buxb, Cent. t. 36. In regione Cancasica et Altaicu. $\odot$. Caul. 3 T-poll. altus. Cor. minuta pallide caerulea.

117. V. glauca Sibth. fol. cordatis inciso-serratis, caulibus procumbentibus; laciniis calycinis utrinque dentatis. Sibth. graec. 1. p. 5. t. 7. Prope Athenas. $\odot$. Caul. ramosissimus. Cor. caerulea ore albo.

118. $\mathrm{V}$. didyma Tenor; flor. pedunculatis solitariis; fol. profunde crenatis, pubescentilus; capsulis didymis rotundatis; pedunculis fructiferis re- volutis. Tenore neap. p. 6. In regno Neapolitano.

119. V. agrestis Iinn. fol. cordatooblongis serratis; laciniis calycinis oblongis obtusis; capsulae turgidae loculis 4-5-spermis. Rchb. ic. 440 . hiv. t. 99. V. versicolor Fries. In agris et arvis Europae. $\odot$. Flavo virescens. Cor. caerulea ant rosea.

120. V. filiformis Smith. fol. cordatis crenatis pedunculo brevioribus laciniis calycis lanceolatis. Smith. in Linn. Traus. 1. p. 195. Kchb. ic. 867. In Oriente. $\odot$. Caul. procumbens. Cor. caerulea.

121. V. Buxbaumii Tenore neap. t. 1. fol. cordatis grosse serratis; calyce acuto, capsula acuata. Hchb. ic. 430. 431. V. persica Poir. V. agrestis var. hyzantiaca Fl. graec. t. 8. V. Tournefortii Gmel. Bad. V. hispida M. et K. In Europa media et orientali, in Asia minore, Tauria et in Persia. $\odot$. Maxima in hac serie. Cor. coerulescens, Jilacina aut alljida.

12:. V. cymbalariaefolia Vahl; fol. subcordatis 5-7-lohis, pedunculo hrevioribus; laciniis calycis ohlongis obtusis. Vahl en. 1. p. 81. Buxb. Cent. t. 39. f. 1. Silhth. fl. graec. t. 9. V. pumila Clarke. V. Clarkeana $\mathbf{H}$. et 5. In Germania, Italia, Tauria el Thracia. ๑. 1-1, -ped. Cor. alba aut parum cacrulescens.

123. I. amoena Stev. flor. solitariis subracemosis; fol. ovatis crenatis, floralibus oblongis integerrimis pedunculis brevioribus; segmentis calycinis linearibus caule patulo. Marsch. a Bieb. taur. cauc. 1. p. 12. Cent. pl. ross. t. 18. In campis Iberiue. $\odot$. Flos magnus cyaneus fundo albido.

12. I. xalapensis 1 . et I. caule erecto pubescente; fol. oblongis crenulatis; floribus axillaribus, solitariis, hreviter pedunculatis, folio hrevioribus ; laciniis calycinis oblongis, erectis. Kunth syu. 2. p. 108. In Mexico prope Xulapa. $\odot$. Caul. simplicissinutus.

12.5. $\mathrm{I}$. chillensis $\boldsymbol{H}$. et $\boldsymbol{B}$. caule repente pubescente; fol. oblongo-spathulatis serratis; floribus subsessilibus folio brevioribus; laciniis calycinis lanceolatis, in fructu reflexis. Kunth syll. 2. p. 108. V. peruviana Willd. Herb. In Quito prope Chillo. $\odot$. Caul. spathameus simplicissimus. Cor. alba. 
126. V. rotundifolia Ruiz. fol. orhiculato-reniformibus crenatis; caule filiformi repente. FI. peruv. 1. p. 6. In uliginosis Peruviae. Hirsuta. Corolla roseo-purpurea.

127. $\mathrm{V}$. hederaefolia himn. fol. 5-lobis summis 3-lobis laciniis calycinis cordatis corollam excedentibus, fructui adpressis. Rchb. Fl. excurs. p. 365. Engl. bot. 784. Fl. Dan. 428. In ayris Germaniae. $\odot$. Procumbens. Cor. pallide caerulea saturatius striata.

1:3. V. opaca Fries; fol. cordatosubrotundis rugosis; laciniis calycinis spathulatis obtusis; capsulae turgidae loculis 2-spermis. Hchl). Fl. excurs. p. 365. ic. 441. In agris cultis Europae. $\odot$. Cor. laete caerulea.

129. V. polita Fries; fol. suhcordatis inciso-serratis laevibus glabriusculis; sepalis corollam aequantibus ovato-acutis; capsulae turgidae immarginatae loculis decaspermis. Rchb. ic. 404. 405. In agris Germaniae et Sueciae. $\odot$. Fol. crassiuscula nitida. Cor. Iaete caelestina.

130. V. digitata Vahl. floribus sessilibus; fol. omnibus digitato-partitis Valil symb. 1. p. 2. Pchb. ic. 36 . V. cliamaepithyoides Lan. In Monspelii inque ilispunia. $\odot$.

131. V.triphyllos Linn. erectiuscula; fol. digitatis summis 3-partitis; pedunculis calyce longiorihus; capsula acuata. Rchb. excurs. p. 366. Engl. bot. 26. FI. Dan. 627. In ugris cultis Europae. $\odot$. Glutinoso-hirta. Cor. Iaete caelestina.

132. T. rerna Linn. stricta; fol. digitato-partitis, sunmis indivisis; pedunculis calyce brevioribus. Mchb. excurs. p. 366. Fl. Dan. 232. Enel. bot. 25. V. Bellardi Willd. V. polygonoides Lam. In agris Europae. $\odot$. Herba glandulosa $3-8$-poll. Cor. caerulea striis saturatioribus.

133. I. peregrina Linn. flor. axillaribus subsessilibus; capsula obcordata, compressa, glabrit; fol. linearioblongis obtusis iutegerrimis subserratisve; seminibus granulatis, $\mathbf{R}$ chb. ic. 8t-76. V. romana Pohl tent. in f. 2. V. romama Linn. V. calnosula Lain. In Europa et America boreali. $\odot$ Glabra. Cor. caerulescens aut alba.

\section{HAEDERO'TA Linn. (1761).}

1. P. Ageria Linn. fol. ovatis acuminatis; calyce corollae longitudine; galea bifida Rchl). excurs. p. 372. P. Bonarota Jacq. H. Vind. t. 121. Wulfenia smith. In alpibus Europae medice. 24. 4-8-poll. Cor. sulphurea fauce hirsuta.

2. P. Zanichellii Brign. caule folioso; fol. subsessilibus subcordatis, serratis, inferioribus subrotundis obtusis, superioribus ovatis acuminatis; calycibus glabris corolla dimidio brevioribus; capsulis ovatis obtusis. $R$. et syst. veg. 1. p. 178. In alpestribus Carniae ad nivem deliquescentem. 4. 1-3-poll. alta. Cor. lutea fauce glaberrina.

3. P. Bonarota Linn. fol. ovatis subrotundis; corolla calyce longiore; galea integra. Kchb. excurs. p. 372. Jacq. austr. t. 39. Sturm 24. Wulfenia sm. In alpibus Austriae, Corinthiae Ituliaeque. 24. 4-8-poll. alta adscendens, villosa basi rubescens. Cor. violacea fauce glabra.

t. P. humilis Willd. Herb, canle simplici bifarian villoso; fol. sessilibus, obovatis apice dentatis ; corymbis terminalibus capitatis. Alb. Dietr. In montibus altaicis. Pollicaris, dense foliosa.

5. P.obliqua Alb. Dietr.; pubescens; fol. caulinis ovatis, acutis, integris, petiolatis basi obliquis, semicordatis; floribus remotis; calycibus 5-partitis; corollae lab. sup. duplo breviore; fauce nuda. Wulfenia Wall. in Don Fl. nep. p. 92. In Nepalia. Caul. palmaris. Cor: caerulea.

\section{WULFENIA Jac\%. (1781).}

1. W. carintliace Linn. Jacq. Misc. Il. t. 8. f. 1. ic. rar. t. 2. Bot. Mag. 2.500. Paederota nudicaulis Lam. ill. t. 13. f. 2. In alpibus Corinthiacis. 4. Fol. radicalia oblonga, spathulata serrata; cor. lilacina, fauce albida.

\section{DIPLOPHYLLUM Lehm. (1811).}

1. D. veronicaeforme Lehm. V. crista galli Stev, in Linn. Trans. 11. t. 31. Caul. subdichotomo-ramosus; decum- 
bens hifariam pilosus. Fol. rad. nervosa ohtuse serrata. Cor. calyce sub)ciliato hreviore, caerulea. In nemoribus umbrosis Caucusi. ๑.

\section{SANCHEZIA R. et P. (17.91).}

1. S. oblongra R. et P.peruv. t.8. f:b.; fol. oblongo-lanceolatis, acuminatis; petiolis alatis Fl. peruv. In inundatis Peruciule. Cal. luteus. Cor. hirsuta.

2. S. ovata $\boldsymbol{R}$. et $\boldsymbol{P}$. fol. ovatis acuminatis; petiolis semiterelibus. Fl. peruv. t. 8. f. c. In Peruvia c. praecerlente. Caul. oryyalis, herbaceus, 4-gonus. Cal. purpurens. Cor. lutea.

\section{SARHIENTA R. et P. (1791).}

1. S. repens R. et P. peruv. t. $\%$. f. c. Urecoltria etc. Feuill. ohs. t. 43. Planta parasitica, scandens. Caul. ramosissimus, sarmentosus. Hami dependentes. Cor. punicea extus pubescens. In Chili.

\subsection{WHITEA BlumE (1923).}

1. W. oblongifolia Blume cat. Buitensory. Frutex scandens, ramis 4angulis. Fol. carnosa, avenia, acuminata basi obliqua, margiue subciliata. Flores fasciculati brevissime pedumculati. Bracteae coloratae hirsutae. In Juva. $\hbar$.

70. MICROCARPEA R. Br. (1810).

1. M. muscosa R. Br. caulihus filiformibus repeutibus; fol. oppositis petiolatis ovalihus integerrimis floribus axillaribus subsessilibus Alb. Dietr. sp. pl. 1. p. 5.50. Paedarota Koenig. In India et Nova Hollandia. 24. Facies Peplidis Portulae.

2. M. americana Spreng. caulibus repentilus; fol. oppositis petiolatis ovato-subrotundis subserratis, pedunculis axillarihus 1-floris. Alb. Dietr. 1. c. Lindernia Sw. Herpestes chamaedryoides Kunth. In Hispaniola 4. 3-4-poll. Flores parvi.

\section{ACHETARIA Schlecht. (1824).}

1. Sprengelii Schlecht. Linn. 8. p. 567. Herpestes erecta Spreng. In brasilia. Tota planta praeter capsulam pilis longis articulatis alhis crispatis, tecta o versadpe glandulis mimutissimis glohosis aureis. Caul. obsolete 4-gonus. Fol. ovata, obsolete denticulata.

\section{LISIONOTIS Don. (1823).}

1. I. sevratus Don nep. p. $12 t$. In Nepalia. 4. Rad. repens, ligmosa, fusca. Caul. erectus palmaris subcarnosus. Fol. terua ovata-lanceolata, acuminata, glabra. Umbellae 5-10 florae. Cor. magnae spesiosae roseae. Capsula palmaris et pedalis,

\section{BAEA Lam.}

1. B. magellanica Lam. ill. 1. p. 5.3. $t$. 15. In rupibus humilis freti Magellanici. 24. Facies Calcolatiae plantagineac. Fol. rad. elliptico-ovata, serrata, villosa scapus digitalis incanus. Cor. 2-labiata $\frac{3}{2}$.

\section{COLEREIIAA Ruiz. et Pav. (1798).}

1. C. oblonga $R$. et P. peruv. s. t. $\boldsymbol{S}$. $f$. a fol. ohtongis entrersum serratis petiolatis; florilus corymhosis Vahl en 1. p. 300. C. arhorescens Pers. In sylvis Peruviae. ђ. Arhor 4-orgyalis, ramosissinus. Flor. corymbiosi lutei.

2. C. sericea $H$. et $B$. fol. oblongis integerrimis sulitus sericeis; pedunculis terminalibus, $\mathbf{2}-\mathbf{3}$-floris. Kunth syn. 2. p. 139. In Quito. ち. Arbor 18 ped. ramis fragilihus 4-gonis sericeo-pubescentibus. Cor. lutea.

3. C. obovata R. et P. peruv. $t$. 12. $f$. $b$. fol. obovatis serratis integerrimisque sessililums, pedmuculis sub 1-floris. Vahl I. c. C. frutescens Pers. In collibus aridis Peruriae. $\hbar$. Frutex 8-ped. Cor. lutea.

\section{ELYTHRARIA Michx. (1803).}

1. E. crenata Vahl.; squamis floriferis ovatis integerrimis scapi lanceolatis margine nudis; fol. oblongis crenatis. Valıl en 1. p. 106. Plantaginis facie etc. Plukn. t. 438. f. 1. 
E. indica Pers. In India orientali. 4. Scapi simplicissimi. śpica terminalis cylindrica.

2. E. lyrata Vahl; squamis floriferis ovatis, scapi lanceolatis; fol. lyrato-pinnatifidis, laciniis terminalibus integerrimis. Vahl 1. c. In India orientali. 24. Scapus 3-poll. Fol. poll.

3. E. virgata Michx. fol. superne integris, nervis subtus glabellis; scapis longissimis; capsula obtusiuscula. Michx. am. 1. p. 9. t. 1. E. caroliniensis Pers. In Carolina. 4 . Scapus pedalis. Cor. alba.

1. E. tridentata Vahl; squamis floriferis lanceolatis 3-dentatis, scapi subulatis; fol. lanceolatis integerrimis. Valı 1. c. E. imbricata Pers. In Brasilia. 24. Scapus spithameus.

5. E. fasciculata $H$. et $\boldsymbol{B}$. subacaulis; fol. supr'a hispidis; pedunculis fasciculatis simplicibus, polystachiis ; spicis fasciculatis; bracteis apice tridentatis. Kunth syn. 2. p. 32. In Caracas. 24. Caul. brevissimus. Spicae 6-11 in fasciculum congestae. Cor. caerulea,

6. E. frondosa $\boldsymbol{H}$. et $B$. caule nudo; pedunculis subumbellatis, simplicibus $1-3$ stachyis; bracteis 2 fidis inter lacinias mucronato-aristatis. Kunth syn. 2. p. 32. In Nova Granata. (․ Cor. caeruleae, maculis albis.

7. E. ramosa $H$. et $B$. acaulis; fol. subtus hispidis, pedunculis trichotomo-ramosis; spicis solitariis; bracteis bifidis, inter laciniis anistato-mucronatis. Kunth syn. 1. c. In Mexico. 4. Had. ramosa lignosa. Cor. caerulea.

8. E. caulescens Ledeb. caule superne dense folioso, ramoso; ramis floriferis aphyllis, ramulosis, squamosis; squamis omnibus ovatis, acuminatis integris ciliatis, Ledeb. in. sem. H. Dorpat. 1820. In Manilla. 4. Caul. lignosus, inferne aphyllus, simplicissimus.

9. $\boldsymbol{E}$. scorpioides $\boldsymbol{R}$. et $\boldsymbol{S}$, caule superne dense folioso; pedunculis squamosis, bi-tristachyis, squamis linearilanceolatis acuminatis, ciliatis. R. et S. syst. veg. mant. 1. p. 128. In Insula St. Martha. Rad. infracta. Caul. simplicissimus. Cal. laciniis albidis diaphanis.

10. E. marginata Vahl; squamis scapi foriferisque ovatis integerrimis margine membranaceo-ciliatis; fol. ckneatis integerrimis. Vahl en. 1. p. 108. In Guinea. 4. Fol. 2-poll. S'cap. digitalls.

\section{NELSONIA R. Br. (1810).}

1. N. campestris IR. Br. fol. ellipticis lanatis; bracteis spicae acutis; calycis foliolo antico semibifido; dorsali acuto corollaeque laciniis integris. R. Br. prodr. 1. p. 481. In Nova Hollandia.

2. N. rotunäifolia $\boldsymbol{R}$. Br. fol. subrotundis; adultis pilosiusculis; bracteis spicae acutis; calycis foliolis 2 latioribus corollaeque laciniis emarginatis. R. Br. 1. c. In Nova Hollandia.

3. N. nummulariaefolia $R$. et $\mathbf{S}$.; villosa; spicis axillaribus imbricatis; bracteis rhombeo-ovatis; fol. subcordatis lineatis; caule procumbente $\mathbf{H}$. et s. syst. veg. 1. p. 173. Justicia Vahl. In Puertorico. Pedalis Caps. loculis 2-spermis.

4. N. albicans $H$. et B. fol. ovatooblongis, cano-pubescentibus; bracteis acuminatis; calycis lacinia antica semibifida. Kuntli syn. 2. p. 32 . In Nova Granata. ๑. Caul. ped. Cor. alba minuta.

5. N. canescens Kunth ; spicis terminalihus imbricatis lanuginosis; bracteis subrotundis; fol. ovalibns laevibus; caule repente. Justicia Vahl en. 1. p. 122. In Africa. Caul. spithameus.

6. N. tomentosa Alb. Dietr. tomentosa; fol. lanceolatis utrinque attenuatis tomentosis; spicis terminalibus strobuliformibus; capsulis conicis, loculis tetraspermis. Alb. Dietr, sp. pl. 1. p. $419 . \quad \beta$. caule quasi sarmentoso Nees in Wall. pl. asiat. J. lamiifolia Roxb. Nelsonia lamiifol. Spr. $\gamma$. ajugoides: caule flagellari; fol. radicalibus maximis. J. ajugoides Hamilt. Herb. In India orientali. 4. Caul. 1-2-ped. Cor. purpureo-caerulea.

7. N. origanoides $\boldsymbol{R}$. et $\mathbf{S}$. spicis axillaribus terminalibusque imbricatis cauleque lanuginosis; bracteis foliisque ovalibus integerrimis nervosis. Justicia Vahl en. 1. p. 122. Habitat.... Cor. parva.

8. $\boldsymbol{N}$, hirsuta $\boldsymbol{R}$. et S. spicis axillaribus terminalibusque tetragonis; bracteis ovatis hirsutis imbricatis; fol. 
dentatis. Justicia Vahl symb. 2. p. 3. J. brunelloides Lam. In Java.

9. N. lamiifolia Spr. tota tomentosa, procumbens, amuna fol. ovatis; spicis terminalibus imhricatis; calyce 4-phyllo. Justicia Roxh. ind. 1. p. 135. In India orientali. $\odot$. Caul. numerosi 1-2-ped. subglutinosi. Cor. purpurea.

\section{7\%. HEMIADELPHIS Nees (1833).}

1. H. polysperma Nees in Wall. pl. asiat. Justicia Roxh. Ruellia Roth. Adenosma Spr. In Bengalia. $\odot$. Caul. 6-12-poll. articulatus ramosissimus. Cor. pallide caerulea.

\section{ENDOPOGON Nees (1833).}

1. E. Amomum Nees; bracteis oblongo-lanceolatis, setaceo-cuspidatis, imhricatis, glanduloso-pubescentilus; fol. late ovatis utrinque acutissimis glabris dentatis. Nees 1. c. Huellia sesamoides Wall. cat. Justicia venosa Hb. Wight. In India orientali. Caul. 2-3-ped. Cor. speciosa fulva.

2. E. hypoleucus Nees; bracteis setace 0 -cuspidatis, pubescenti-glandulosis; fol. late ovatis, crenatis subtus cano-tomentosis. Nees l. c. var. $\alpha$. fol. euprà glabris. Ruellia sesamoides Wall. Cat. $\beta$. fol. supra hirsutis, tomentulo subtus magis fugace. Justicia sesamoides Hb. Madr. Ruellia Wall. Cat. In India orientali. Forte varietas E. Amomi.

3. E. consanguineus Nees; bracteis ovato-ellipticis, acutis hirsutoglandulosis; fol. ovato-ellipticis utriuque attenuatis glabris. Nees l. c. Ruellia secunda Wight. In montibus Dindygul, Con?tallum. Flor. parvi. Col. non notatus.

\section{LOXANTHUS Nees (1833).}

1. L. Gomezii Nees Wall. Cat. n. 170. In montibus prov. Silhet. Frutex speciosis ramis 4-gonis; fol. oblongo-cuneiformibus, integerrimis glabris, 10-poll. et viltra longis 3-poll. latis; petiolis pollicaribus; thyrso terminali dense tomentoso 3-4-pollicari. Cor. tomentosa lutea.?
80. PHLOGACANTHUS Nees (1833).

1. P. curviflorus Nees; caule erecto 4-angulari, strigoso-tomentoso; fol. amplis ellipticis utrinque acutis repando-dentatis glabris; corolla elongata. Nees 1. c. Justicia Wall. pl. asiat. t. 112. In mont. Silhet. Planta speciosissima, thyrsi 4-12-poll. lougi. Cor. 2-poll. tomentosa e luteo-rubicunda.

2. P. tubiflorus Nees. caule erecto t-gono superne pubescenti-scabro; fol. amplis ellipticis utrinque acutis subrepaudis subtus pubescentibus; racemo thyrsoideo; corolla brevi. Nees I. c. Justicia Hamilt. In mont. Camrupae ad Goalparam Indiae orientalis.

3. P. thyrsiflorus Nees; caule erecto, novello 4-quetro; fol. oblongocuneiformibus, integerrimis glabris; racemo elongato. Nees 1. c. Justicia loxb. ind. In Bengalia. ち. Caul. 4-8-ped. ramis purpurascentibus. Cor. magna aurantiaca.

4. P. guttatus Nees; caule basi inclinato, dein erecto 4-angulari; fol. oblongis repando-crenatis glabris; racemo abbriviato. Nees. 1. c. Justicia Wall. pl. as. rar. t. 28. In montibus Bengaliae orientalis. Fruticulis 12-ped. Cor. alba purpure0-maculata.

5. P. asperulus Nees; caul. novello 4-quetro, angulis denticulato - exasperatis; fol. elliptico-oblongis, longe acuminatis, glahris. Nees 1. c. Justicia asperula Wall. Mss. J. hedyotidifolia Wall. ex parte. In Silhet. Cor. lutea s. aurantiaca.

\section{CRYPTOPHRAGMIUM Nees (1833).}

1. C. venustum Nees; spica terminali composita, brachiata; fol. ellipticis in petiolum alate decurrentihus, denticulatis scabris; corolla calyce multo longiore. Nees 1. c. Bot. Mag. t. 3208. Justicia Wall. pl. asiat. rar. t. 66. In Silhet. ‡. Cor. purpureo-violacea.

2. C. canescens Nees; spicis axillaribus in terminalem transeuntibus; bifidis secundifloris, glanduloso-hirsutis;. fol. ovatis acutiusculis basi ctneiformibus repandis pubescentibus; capsula calyce setaceo duplo longiore. Nees 1.c. In India orientali. 
3. C. cordifolium Nees; racemis axillaribus secumblis, in terminalem compositum abeutibus ; floribus distantihus ; fol, ovatis acutis supra punctulato-scabris, inferioribus subcordatis. Nees 1. c, Justicia Hb. Heym. J. clandestina Hb. Russell. In Courtallum Indiae orientalis. Cor. purpurascens.

t. C. serrulatum Nees; spicis axilJarihus trichotomis, ramis secundifloris, foliisque ovatis acutis in petiolum contractis crenato-dentatis, pubescentiscabris; capsula calyce triplo longiore. Nees 1. c. Justicia Hb. Heyn. In India orientali. Cor. pallide purpurea?.

\section{ROSTELLARIA Nees (1833).}

1. R. rotundifolic Nees; caule repente foliisque orbiculatis hirsutissimis; calycis laciniis, bracteisque calyce paullo hrevioribus ex ovato cuspiclatis, margine late membranaceis hirto-ciliatis. Nees 1. c. Justicia WVall. ex parte J. mollissima Wall. J. procumbens Hb. Madr. $\beta$. fol. superioribus ovatis rel ellipticis angustioribus, labio subtus scabro. J. Vahlii $\beta$. imberhis Roth. J. procumbens Vahl en. In Nepalia et Travancore. var. $\beta$. in Pagonea.

2. R. hedyotidifolia Nees; caule erecto a basi divaricato-ramoso, foliisque ovatis subcrenatis acutis scabriusculis; spicis terminalibus infra apiculique axillaribus brevibus basi interruptis; calycis 4-partiti laciniis lanceolatis margine meinbranaceis glabris, bracteis calycem aequantibus, bracteolis calyce hrevioribus utrisque setaceis. Nees 1. c. Justicia Wall. In India orientali. Spithamea annua. Cor. purpurea.

3. R. diffusa Nees; caule procumhente diffuso, foliisque lanceolatis ellipticis subrotundisve lineolatis glabris parceque pilosulis; spicis compressis gracilihus; calycis laciniis lanceolatis margine memhranaceis, subtilissime ciliatis; bracteis consimilibus calyce brevioribus. Nees 1. c. $\alpha$. fol. Ellipticis vel subrotumdis. Justicia Willd. J. prốcumbens $\delta$. thyrsiflora $R$. et $\mathbf{s}$. $\beta$. fol. linearibus vel lineari-lanceolatis, J. procumbens Wall. Cat. In pascuis kumidis in Mongluis, Travancore var. $\beta$. in Prome Ind. orient.
Cor. carliea.

A. R. procumbens Vees; caule procumbente alscendenteve, foliisque ex ovato-lanceolatis, ciliatis hirtis; spicis subtetragonis; calycibus 4-j-partitis bracteisque lanceolato-linearibus aequalibus hilsito-ciliatís. Nees 1. c. $\alpha$. caule procumbente, spicis saeps hrevioribus; fol. ohlongo-lanceolatis ohlongisve. Justicia procumbens $\mathbf{L}$. J. hirtella IVall. $\beta$. caule erecto reliquis ut in $a$. Justicia quinquangularis Wall. $\gamma$. caule procumbente fol. ovatis vel subrotundis. J. procumbens Wall. ex parte. $\delta$. cingustifolic fol. lineari-lanceolatis. J. procumbens Blume. ¿. caule simplici erecto. J. simplex Dou Nep. In pascuis costa Coromandelinae var. $\gamma \cdot$ in orysetis $\delta$. in Promae montibus. $\odot$ Cor. rosea.

5. $\boldsymbol{R}$. crinita Nees: caule procumbente adscendente, trichotomo pubescenti-cano, fol. ellipticis ovatisve hirtis; spicis terminalibus sessilibus brevibus; calycihus t-partitis apice hracteisque aequalibus patenti-hirsutissimis. Nees. var. $\alpha$. fol. ellipticis utrinque acutis longe petiolatis $\beta$. fol. ovatis hasi obtusis brevi petiolatis. J. micrantha Wall. In Indic orientali. Caul. $\frac{1}{2}-1$-ped. 6-angularis. Cor. pallide purpurea.

6. R. molissima Nees; caule procumbente repente, foliisque ex ovatolanceolatis, hirsutis; spicis 4-gonis; calycibus, bracteolis lanceolatis, bracteisque rhombeo-ovatis acuninatis aoqualibus, membranaceo-marginatis ciliatis flavicantibus. Nees. Justicia Wall. J. micrantha et hispida Heyne Hb. $\beta$. caule elongato flaccido subsimplici. In Nepalia. Cor. alba.

\%. R. adenostachya Nees; caulo procumbente diffuso; fol. oblongo-lanceolatis, lineolatis, glabris; spicis pedunculo brevioribus, calycis laciniis, bracteis bracteolisque linearibus obtusis glanduloso-pilosis, margine angusto membranaceo. Nees. Justicia procumbens Wall. Cat. J. diffusa Hb. Madr. In Travancore. Cor. alba, lab. inferius purpureum.

8. R. peploides Nees; caule erecto ramis divaricatis diffusis repentibus foliisque subovatis obtusis punctulatio glabris, spicis densis basi foliosis caIycis laciniis, bracteis bracteolisgute 
conformilus aequalihus ex oblongo-linearibus obtusis, membranaceo-marginatis, apice exasperatis, serrulatoque ciliatis. Nees. Justicia procumbens Wall. In Indic orientali. Cor. pallida, labium inferius purpureo naculatum.

9. IR. quinquangularis Nees: caule erecto procumbenteve foliisque linearilanceolatis acutis lanceolatisque elongatis ad tactum scabris; calyce bracteolis bracteisque sub anthesi aequalihus, lanceolatis obtusis margine anguste memliranaceis laevibus marginene scabris; antheris glabris; labio subtus in media scabro. Nees. In ripa Gangetis et in Nepalia inferiore.

10. R. Vullii Nees; caule procumbente folisque lineari-lanceolatis elongatis ad tactum scabris; calyce bracteolisque aequalibus oblongo-lanceolatis, bracteisque paullo longioribus ovato-oblongis cuspidatis margine late membranaceis, apice scabriusculis ciliolatisque; antheris apice subtus barbatis. Nees. Justicia Roth J. Vahliana I. et S. J. diffusa Vahl. In India orientali. Cor. lab. purpureum.

\section{S3. GRAPTOPHYLLUM Nees. (1833).}

1. G. hortense Nees. J. picta Linn. Rumpl. amb. t. 30. Bot. Reg. 1227. In India orientali. 21. Fol. subpetiolata, 2-3-poll. longa, patentissima, glabra, disco macula longitudinali irregulari lucida. Racemi 3-4-poll. longi. Cor. pollicaris pallide lilacina.

\section{BELOPERONE Nees (1833).}

1. $\boldsymbol{B}$. Amherstiae Nees; spicis axillaribus, bracteis linearibus; calycis laciniis oblongis; antheris muticis; fol. ovato-oblongis acnminatis repandis glabris. Nees. Ex horto Amherstiae. Fruticulus 4-5-ped. Cor. coccinea.

2. B. oblonga Nees; spicis axillaribus bracteis bracteolisque cum foliis lanceolatis; antheris basi calcaratis. Nees. Justicia oblongata Link ot Otto. In Brasilia.

3. B. plumbaginifolia Nees; spicis terminalibus trifidis; bracteis linearibus; antheris basi calcaratis ; fol. ovato-oblongis flaccidis. Nees. Justicia Jacg. Ecl. t. 12. In Erasilix. ţ.

\section{ADHADOTA Herm.}

1. A. argyrostachya Nees; spicis axillaribus oppositis tetragonis villosis; bracteis generalibus ovatis obtusiusculis basi albidis apice reticulatis propriis oblongo-lanceolatis acuminatis membranacis calyce vix longioribus; antherarum locello inferiore calcarato; fol. late ovato-ellipticis, utrinque acuminatis supra pilis inspersis non lineolatis. Nees. Justicia Wall. In montibus Promae Ind. orient. Herba speciosa erecta. Cor. vix 6 lin. longa ochroleuca, lab. inf. purpureo lineolato.

2. A. Betonica Nees; spica terminali secunda; bracteis generalibus partialibusque ovato-ellipticis, ciliatis venoso-reticulatis, antherarum locello inferiore calcarato; fol. ovatis utrinque acutis supra lineolatis subpubescentibus repandis dentatisve. Nees Justicia Linn. J. pseudo-Betonica Roth. J. ochroleuca Blume. In India orientali. $\mathbf{t}$.

3. A. ramosissima Nees; spicis axillaribus terminalibusque secundis; bracteis bracteolisque ovato-lanceolatis acuminatis glabris albis venoso3-nerviis, reticulatisque; lacello inferiore antherarum calcarato; fol.late ovatis acumine obtuso glabris supra obsolete lineolatis. Nees. Justicia Roxb. In Coromandel. Ђ. Acaulis. Cor. alba lab. inf. centro roseo-venosum.

4. A. nilgerrhensis Nees; spica terminali 4-gona; bracteis generalibus terminalibusque ovato-acuminatis venoso-trinerviis glabris antherarum locello inferiore calcarato; fol. lanceolatis sessilibus glabris, laevibus. Nees. Justicia Wall. Cat. J. pectinata Wight. Hb. In inundatis ad Travancore provinciae Tanjore in montibus Nilgherry Ind. orient. $\hbar$. Caul. romosus fruticosus. Cor. albida purpureo-striata.

5. A. trinervia Nees; suffruticosa; caule procumbente; spicis terminalibus secundis; bracteis bracteolisque aequalibus oblongo-lanceolatis acuminatis, venoso-reticulatis; antherarum locelio inferiore calcarato; fol. lanceolatis ovalibusque obtusis sessilibus glabris. Nees. Justicia Vahl. Dicliptera ivilld. 
6. A. arenaria Nees; suffruticosa; caule procumbente, diffuso; spicis terminalibus secundis; bracteis bracteolisque oblongis herbaceis, locello antherarum inferiore calcarato ; fol. lineavilus obtusis emarginatis glabris sessilihus. Nees. Justicia Wall. Cat. Crescit in arenosis humidis Vellingan!y Negopatam Tangore Ind. orient. \$. Caul. palmaris. Cor. 4 lin. Ionga albida nacula purpurea.

7. A. Vasica Nees; spicis axillaribus oppositis ovatis longe pedunculatis; bracteis herbaceis glabris ovatis, bracteolis ellipticis minoribus, locellis oblique parallelis, inferiore basi mucronato; fol. elliptico-oblongis utrinque attenuatis glabris supra minute papillatis. Nees. Justicia Adhadota Linn. Bot. Mag. 861. Herm. Agdb. t. 643. Plukn. t. 173. f. 3. In India orientali et in ins. Ceylon. $\hbar$. Cor. magna viride-albicans.

\section{GENDARUSSA Rumph.}

a. Spicatae thyrsoideae,hracteis bracteolisque conformibus.

1. G. vulgaris Nees; fruticosa spicis terminalibus subverticillifloris basi foliosis, hracteis parvis, fol. lanceolatis glahris. Nees. Justicia Gendarussa Linu. Rumph. amb. 4. t. 28. $\beta$. Dohona, fol. apicem versus repando exaratis. J. Dohona Hb. Hanil. In India orientali. purpureo-venosa. Cor. purpurascens.

2. G. vasculosa Nees; fruticulosa caule inferne tereti repente apice adscendente; spicis terminalibus compositis ramis secuudis; floribus oppositis; bracteis bracteolisque calyce paullo brevioribus ovato-lanceolatis; antheris calcaratis ; fol. olllongo-ellipticis utrinque attenuatis supra lineolatis. Nees. J. vasculosa WVall. cat. Ruellia rivinaefolia Wall. Cat. In montibus provinciae Silhet. Caul. 1-2-ped. Cor. alba maculis sanguineis, venulis labii superioris purpureis.

3. G. bifaria Nees; fruticosa; caule inferne tereti superne bifariam hirstito; racemulis axillaribus spiciformibus scallris; floribus solitariis oppositis; bracteis generalibus partialibusque lineari-subulatis calyce brevioribus; fol. ellipticis utrinque acuminatis glahris lineolatis, repando-den- ticulatis. Nees. In rupibus prope Ringa ad ripam Trawaddi.

4. G. Wineadensis Nees; fruticosa; caule tereti laevissimo lineato; spicis axillaribus patentibus nutantibus, basi diphyllis glanduloso-pubescentibus ; florilus solitariis oppositis; bracteis ovatis deciduis, bracteolisque lineari-subulatis calyce breviorihus; antheris hasi calcaratis; fol. oblongis utrinque attenuatis supra substrigosis, inferioribus crenato-dentatis. Nees. Justicia Hb. Heyn. J. lineata Wall. Cat. In India orientali. Cor. 4 lin. longa pubescens venoso-purpurea.

5. G. decussata Nees; fruticosa caule tetragono pubescente-hirtu decussatim rainoso; spicis terminalibus elongatis interruptis dense pubescentibus; floribus glomerulato-verticillatis; hracteis parvis spathulatis; bracteolis lineari-lanceolatis corollae ringentis labio inferiore convexo, antherarum locello utroque calcarato; fol. ovatis in petiolum attenuatis glabriusculis supra lineolatis. Nees. Justicia decussata Roxb. In Peyu. 古. Cor. pallide rosea.

b. spicatae, bracteis foliaceis majoribus demum deciduis.

6. G. ventricosa Nees; fruticosa articulata, spicis in caule ramisque terminalihus subverticillatifloris; bracteis universalibus decussatis ovalibus orbiculatisve acutis ciliatis; propriis subulatis parvis, labio superiore plano, antherarum locello inferiore calcarato; fol. oblongis glabris. Nees. Justicia fragilis Wall. Cat. J. ventricosa Wall. pl. asiat. rar. t. 93. In India orientali. $\hbar$.

\%. G. orixensis Nees; herbacea, spicis terminalibus axillaribusque subsecundis, lracteis orbiculato-spathulatis, ciliatis, superioribus sterilibus, bracteolis oppositis lineari-subulatis; antherarum locello inferiore calcarato; fol. ovatis dense lineolatis glalıriusculis, caule pubescenti-scabro. Nees. Justicia Kœnig. J. Tranquebariensis Roxb. nec L. Vulgaris inter virgulta orae Coromandelinae.

8. G. Tranquebariensis Nees; fruticosa, canescenti-pubescens; floribua axillaribus solitariis, in spicam terminalem adscendentibus; bracteis orbicralatis retusis, bracteolis calycem ae- 
quantihns linearihus; locellis antherarum inferiorum calcaratis; fol. subrotundis parvis. Nees Justicia L. J. parvifolia Lam. Frequens in aridis provinciue Muderas.

c. Axilliflorae verticillatae vel floribus solitaris.

9. G. Neesiana Nees; fruticosa; Roribus axillaribus geninis subverticillatis; bractea utrinque parva spathulata; labio superiore angusto concavo; staminibus reflexis, locello antherarum inferiore calcarato; fol. lineari-lanceolatis glabris. Nees. Justicia Neesiana Wall. Cat. In montibus morincice silhet. ち. Fruticulus elegans $1-1-p e d$. altus. Cor. lutea?

10. G. qundrifuria Nees; herhacea ; florilus verticillatis, hracteis obcordato-spathulatis; antherarum 10cello inferiore calcarato; fol. oblongoIanceolatis utrinque puberulis. Nices. Justicia Wall. Citt. In montibus provincice Silhet. 24. Caul, pedalis et ultra; corolla calyce paullo longior, pallida.

11. G. furcata Nees; fruticosa; floribus solitariis aggregatisve, terminalihus subternis; bracteola utrinque parva lineari-lanceolata; labio superiore bifido, inferiore lato convexo trilobo, locelli inferioris calcare hifido cristatorue ; fol. ohlongis utrinque attenuatis pubescentibus Nees. Justicia Jacq. H. schonhr. t. 3. J. peruviana Cav. ic. t. 28. In Peru et in Norct Hispania. 24. Cor. pollicaris, violacea.

\section{8\%. LEPTOSTACHYA Nees (1833).}

1. L. viryata Nees; fol. deltideis supra lineolatis; spicis tomentoso-scabris Nees. Justicia IVall. Cat. In Taong Dong. Cor. 3-4 lin. Ionga, pallide pupmea?.

2. L. Wallichii Nees; fol. oblongis supra punctulato-asperis; spicis glandulosis Nees. Ruellia Wall. Cat. In India orientali?. Cor. purpurascens.

3. I. polita Nees; fol. oblongis utrinque attenuatis, glahris; spicis axillaribus terminalibusque umbellatis dissitifloris; florihus alternis secundis, caule tetragono laevi. Nees. Adrivulos in Serra de Estrella legit Beyrich.
88. GYMNOSTACHYUM Nees (1833).

1. G. leptostachyum Nees. In Tanoy legit Gomes. Herhacea caul. $\frac{1}{2}-p e d$. hasi radicans sub 4 gonus, hirsutus. Fol. oblonga supra pilosa. Spicae terminale: filiformes. Cal. glanduloso-pubescens, Cor. pubescentiviscida purpurea.

\section{ERANTHEMUM R. Br.}

\section{Armata.}

1. E. verticillatum spreng. erectum, pilosum ; spinis verticillatis, apicibus 2-3-fidis; fol. petiolatis ovatis; flor. inter verticillos spinarun subsessilibus Spreng. syst. veg. 1. p. 88. Justicia verticillaris Roxb. In India orientali.

2. E. acanthophorum R. et $\mathbf{S}$. fol. ovatis oppositis; hracteis spinosis; flor. axillaribus solitariis. E. spinosum Lour. coclt. 1. p. 19. In Mozambic. 24. Caul. suffruticosus, pedalis. Flor. dilute violacei.

3. E. aciculare R. Br. spinosum; pedmeulis axillaribus solitariis; fol. ohlongis apiculatis. $\boldsymbol{H}$. et $\$$. syst. veg. 1. p. 174. Justicia sw. In calcareis fruticetis Jamaicae. $\hbar$. Fruticulus pedalis. Cor. albida.

4. E. crmatum R. Br. aculeatum; pedunculis axillaribus 1-floris; fol. cuneiformi-ohlongis, emarginatis $\mathbf{R}$. et $\mathbf{s}$. 1. c. Justicia sw. In rupibus montium Jumaicae. ち. Caul. 3-4-ped. Cor. coccinea.

5. E. microphyllum R. Br.; pedunculis axillaribus 1-floris; fol. lineariohlongis cuneiformibusque aggregatis; spinis axillaribus hrevissimis rigidis. R. et s. 1. c. Justicia Lam. In st. Crux et Hominyo. ち. Caul. fruticosus, ranis decussatis cortice cinereo.

6. E. spinosum R. IBr.; pedunculis submifloris; fol. oblongis; spinis axillarihus. 1R. et. s. 1. c. Justicia Jacq. am. 2. t. 2. f. 1. In America meridionali. ち. Rami glaherrimi cortice nigro punctati. spinae decussatae.

\%. E. acanthoides Spreng. ranis pubescentibus; fol. oblongis coriaceis, utrinque attenuatis; spinis alternis remotis sub 3 -fidis erecto-patentibus; pedunculis axillaribus sulngeminis 1floris. Spreng. 1. c. In Hispaniola. 
8. E. lycioides Desf.; fol. minimis cuneiformibus, integerrimis, glabris; spinis geminis, firmis, rectis; pechunculis axillaribus solitariis. Link Jahrb. 1. 3. p. 47. In Antillis. t. Mami ferruginei. Cor. alba?

9. E. emarginatum Desf.; fol. suhrotundo-ovatis, emarginatis integerrimis glaberrimis; spinis geminis tencribus rectis; spicis terminalibus. Liuk. 1. c. In st. Thomas. $\hbar$. Mami fuscocinerei. Cor. in Hb. IVilld. deest.

\section{In ermia.}

10. E. vincoilles $\boldsymbol{R}$. Br.; pedunculis axillaribus 3 -foris; fol. ollongis glahris, caule inermi; limbo corollarum plano 5-partito. Justicia Lam. In Madagascar. $\hbar$.

11. E. bicolor Schrank; pedunculis axillaribus 3-floris, petiolo hrevioribus; fol. ovalibus acuminatis glahris; limbo corollae plano; tubo longissimo. sims. Bot. Mag. 1423. Schrank H. Monac. t. 8. In insula Luçon. ち. Rami atropurpurei, incano-pubescentes; Cor. alha lacinia infima latior, basi gibha macula magna sanguinea ct punctis sanguineis dense adspersa.

12. E. parvillorum R. Br. in Spreng. syst. 1. p. 88. fol. lanceolatis; floribus axillaribus subternis sessilibus; corollis minimis regularibus. Alb. Dietr. sp. pl. 1. p. 443 . Justicia Ortega. In Mexico. Caul. herbaceus $\frac{1}{2}$ ped.

13. E. repandum $\boldsymbol{R} . \boldsymbol{B r}$. pedunculis axillarilus trifidis; fol. ellipticis repandis. R. et S. 1. c. Justicia Forst. In ins. Tanna. Caul. fruticosus.

11. E. sinuatum $R$. $B r$. pedunculis axillaribus 3-fidis; fol. lanceolatis sinuato-pinuatifidis. R. et $\mathbf{S}$. I. c. Justicia Forst. In ins. Tamna. Hami angulati cortice cinereo. Fol. 3-poll. longa.

15. E. variabile $R, B r$. suffruticosum tenuissime pubescens inerme; spicis terminalihus laxiusculis floribus subternis; pedunculisve axillaribus paucifloris, calyciluus bracteisque subulatis; fol. ovatis oblongisve integerrimis v. subdentatis. H. Br. prodr. p. 477. In Nova Hollandia. 方.

16. E. eleyans $R$. Br. spicis terminalibus; bracteis margine pilosis, tertia maxima; laciniis limbi profundis obtusis; fol. ovato-acuminatis, basi attenuatis petiolatis. Justicia elegans Pal. Beauv. Fl. d'Owar. et Benin t. 50. Circa Agathon in Benin. $t$.

17. E. hypocrateniforme $\boldsymbol{R}$. Br. spicis terminalibus; bracteis subulatis; fol. ovatis. Justicia Valıl len. 1. p. 165. In Guinea. ち.

18. E. rosenm R. Br. spicis axillaribus imbricatis elongatis; bracteis subcuneiformibus venoso-reticulatis ciliatis; fol. ellipticis. Justicia rosea Vahl. In India orientali. $\hbar$.

19. E. nervosum R. Br. spicis axillaribus terminalibusque imbricatis; bracteis oblongis venosis foliisque ovatis acuminatis. Justicia VahI en. 1. p. 16\%. J. pulchella lioxh. corll. 2. t. 177. E. pulchellum Andr. Rep.t. 88. Inuellia variaus Vent. Cels. t. 177. In India orientuli. $\downarrow$. Frut. 3-ped. Fol. patentissima.

20. E. montanum Roxb. fruticosuin diffusum; fol. oblongis acutis; spicis terminalibus; bracteis linearibus pilosis. Roxh. ind. 1. p. 110 . Justicia liozb. coron. In montibus Circar. $\downarrow$. Caul. articulati, procumbentes repentesque. Flores pallide caerulei.

21. E. suffiruticosum Roxb. fruticosum, erectum; fol. ovato-oblongis glabris; spicis terminalibus, bracteis cuneiformibus nudis; staminibus duohus inclusis. Roxly. ind. 1. p. 112.

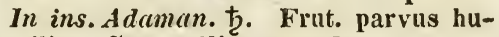
milis. Cor. pallide caerulea.

22. E. diuntherum Roxb. suffruticosum erectum; fol. late lanceolatis utrinque attenuatis vlabris, racemis terminalibus ex umbellulis axillaribus pedunculatis ; corolla subbilabiata; antheris didymis. Hoxh. ind. 1. p. 112. In Moluccis. $\downarrow$. Caul. simplex incurvus. Flor. parvi albi erubescentes punctis minutis ad hasin lacinii mediae bahii inferioris.

23. E. racemosum Roxb. suffiruticosum; fol. ohlongis ventricosis racemis terminalibus; corolla subbilabiata, labio utrogue partito. Roxl). ind. 1. p. 113. In Moluccis. t. Caul. 2-ped. Cor. pallide rufo-fusca allave.

21. E. barlerioides Roxb. fruticosum, erectum ; fol. ovato-oblongis glalrris; spicis terninalibus ; bracteis cuneiformibus nudis; staminilus in tubo longo gracili, fllamentis $\mathbf{2}$ abortivi. iisdem adnatis. Roxb. ind. 1. p. 114. In ins. Adaman. $\hbar$. 
25. E. strictum Colebr. suffinticosum erectum pubescens, ramis adscendentibus decussatis simplicilus; fol. lanceolatis utrinque attenuatis olisolete crenulatis; spicis terminalibus gracilibus multum elongatis; bracteis oppositis quaternis remotis 1 -floris. Wall. in Roxh. ind. 1. p. 114. In montibus prope Silhet. t. 3-5-ped. Cor. pallidissima.

26. E. cinnabarium Wall. $j l$. asiat. rar. p. 20. fol. oblongo-ellipticis attenuatis longissime acuminatis glabriusculis; racemis terminalihus recurvato-patentibus paniculatis; bracteis filiformilus; floribus suhsessilibus secundis; corollae laciniis ovatis. Wall. In Nepalia. ち. 4-ped. Flor. magni speciosi rubicundi.

37. E. modestum Nees; ramis axillaribus terminalibusque; florihus verticillatis; bracteis setaceis; fol. ovato-oblongis, sessilibus, superne hirsutis. Nees et Mart. N. Act. Ac. N. cur. XI. p. 68. In Brasilia. 24. -1-ped. Cor. pallide caerulea.

28. E. detruncatum Noes; spicis terminalibus trichotomis; bracteis subulatis, serrulato-ciliatis ; fol. ovatooblongis in petiolum attenuatis pubescentibus; pulvillis detruncatis. Nees 1. c. In Brasilia. 4. Caul. 5-ped. Elor. albi.

29. E. verbenaceum Nees; spica terminali simplici; floribus oppositis; bracteis ovato-subulatis; fol. oblongis, in petiolum decurrentibus, utrinque lineolatis, glabris. Nees 1. c. In Brasilia. 4. Caul. 1-2-ped. Flor. albi.

30. E. cristatum Humb. spicis terminalibus brevibus; bracteis lanceolatis acutis margine serrato-spinulosis; fol. breviter petiolatis oblongolanceolatis, acuminatis attenuatis integerrimis, hirtis. Link. Jahrb. 1. 3. p. 46. Prape Turbaxo. Caul. $\frac{\mathrm{I}}{2}$-ped. Fol. flavo-hirta. Cor. caerulea.

31. E. macrophyllum Wall. fol. elliptico-cuneiformibus acutis infra apicem dentatis margine scabris; spicis axillaribus basi infracta hibracteatis; bracteis ellipticis mucrounlatis reticulatis. Nees in Wall. pl. as. rar. In India orientali. Cor. coccinea.

32. E. tetragonum Wall. caule fruticoso glabro, spicisque axillarihus 4-gonis; fol. ovato-oblongis acuminatis lineolatis glabris bracteis inbrica- tis elliptico-oblongis hirtis, corollae laciniis subrotundo-ovatis. Nees. In India orientuli. Cor. coccinea.

33. E. purpurascens Nees.; caule 4-quetro foliisque late ovatis acuminatis repando-crenatis glabris, superioribus obcordatis brevissime petiolatis; spicis axillaribus oppositis longe pedunculatis imhricatis, bracteis ovatorhombeis longissime attenuatis ciliatis. Nees. 1. c. E. montanum Wall. Cat. Justicia purpurascens Hb. Hamilt. B. spicis ahbreviatis squarrosis, inferiorihus longissime pedunculatis. In Ind. orient. Cor. purpurea.

31. E. Wightianum Wall. fruticosuin; caule tetragono pubescentitomentoso, fol. ovatis utrinque acutis glabris; floralibus subrotundis ; spicis terminalibus corymbosis; bracteis lineari-lanceolatis acutis strictis pubescenti-scabris. Nees 1. c. In India orient, in montibus Dindygul et Courtullum.

3.5. E. graciliflorum Nees; herbaceum? erectum; caule punctis exasperato, fol. ovalihus cuspidatis in petiolum longun desinentibus repando-subcrenatis subtus ad costas scalıris ; racemo terminali simplici ternisve spiciformibus; rhachi multisulcata ; floribus spicatim subverticillatis confertis; bracteis bracteolisque subulatis brevihus calycibusque scabris; corolla subhilabiata, laciniis ovatis obtusis. Justicia Wall. In India orientali.

36. E. palatiflorum Nees; fruticosum erectum; fol. oblongis acumiuatis subintegerrimis brevi-petiolatis glabris; racemis terminalibus suhternis spiciformibus recurvis; floribus erectosecundis; bracteis bracteolisque subulatis brevibus; cor. bilabiata; stam. binis? Justicia palatifera Wall. pl. as. rar. 1. t. 92. In montibus sillet.

\section{JUSTICIA Houst. L. (1737).}

\section{Antherae loculis parallelis.}

A. Spicis racemisve terminalibus; fruticosae.

1. J. Ecbolium L. spicis terminalibus tetragonis imbricatis; bracteis ovalibus foliisque ohlongo-ovatis acuminatis; galea lineari Vahl symb. 2. p. 14. Rheed. nal. 2. t. 10. Bot. Mag. 1847. Caul. fruticosus 2-4-ped. Cor. 
purpureo-caerulescens. In Ind. orient. et Arabia. ち.

2. J. dentata Klein; fol. ohlongis acuminatis subrepandis pubescentibus; epicis tetragonis longissimis; bracteis ovalibus eroso-dentatis. Klein in Willd. ub. In India orientali. $\hbar$.

3. J. carnea Lindl. fol. ovato-lanceolatis, acuminatis, subcrenatis longissime petiolatis; bracteis maximis. Bot. Reg. 139\%. Cor. carnea. In Rio Janeiro. 24.

4. J. laetevirens Vahl; fol. ohlongis utrinque attenuatis, glahris venosis; hracteis lanceolatis striatis pubescentibus. Vahl ell. 1. p. 118. Pallide virens. Cor. extus pilosa. In Madayascar. $\hbar$.

5. J. ligustrina Vahl; fol. lanceolatis pubescentibus bracteisque ciliatis; lah. corollae superiore lineari reflexo. Vahl en. 1. p. 118. In India orientali. $\hbar$. Cor. alhido-puhescens.

6. J. sericea $R$. et $P$. fol. lanceolatis sericeis mar.gine revolutis; lah. cor. superiore recto emarginato. Fl. peruv. 1. t. 9. f. b. In Quito. ђ. 4-ped. Cor. magna coccinea.

7. J. coccinea Aubl. fol. ohlongoacuminatis utrinque glabris; lab. cor. superiori lanceolato reflexo. Aubl. Guj. 1. p. 10. t.'3. In Cajenna ad ripas rivulorum. t. Cor. coccinea.

8. J. interrupta Kunth; fol. ol)longo-acuminatis glahris nitidis; for. oppositis remotis; lab. cor. superiori bipartito. Kunth syn. 2. p. 30. In Nora Granata. ‡.

9. J. gonystachya Nees; fol. oblongo-lanceolatis, in petiolum ciliatum altenuatis, crenatis lineolis inspersis; bracteis minutis Nees et Mart. Nov. Act. 11. p. 52. In Brasilia. t. Cor. alla.

10. J. humiliflora Nees; fol. ovatis utrinque attenuatis ciliatis; spicis villosis; bracteis ovato-orhiculatis aristatis. Nees 1. c. In Brasilia. ち. Cor. alba pubescens.

11. J. vitellina Roxb. fol. Iate lanceolatis utrinque attenuatis reflexis glabris; lab. cor. superiore recto bifido, fauce ampliato. Roxb. ind. 1. p. 117. In collibus Chittagong. $\mathbf{b}$. Cor. flavo-rufescens.

12. J. latifolia Vahl; fol. ovatis acuminatis, spicis subramosis; flor. inferioribus verticillatis. Vahl en. 1. p. 124. In India orientali.
13. J. nigricans Lour. fol. lanceolato-linearibus; spicis distichis; bracteis setaceis. Lour. Coch. 1. p. 24. In Cochinchina. ち. 6-ped. Cor. alba rubro-variegata.

14. J. lineolata $R$. et P. fol. ovatis subdentatis; spicis racemosis pubescentibus; for. oppositis; cór. lab. superiore indiviso. Fl. peruv. 1. t. 13. f. 2. In Peruvia. ち. 2-ped. Cor. purpureo-caerulea.

15. J. variegata Aubl. fol. subsessilibus ellipticis; calyc. hirtis subverticillatis; cor. lab. superiore bifido. Aubl. Guj. 1. t. 4. In sylvis Gujanae. ち. 5-ped. Cor. alba.

16. J. rubra Vahl; fol. lanceolatis; racemis simplicibus solitariis; bracteis setaceis. Vahl Eclog. 2. p. 1. In America meridionali. ち. Cor. pollicaris glabra.

17. J. calycotricha Iink et Otto; fol. oblongis undulatis crenatis; calyc. laciniis tenuissimis corollae longitudine; lab. cor. superiori reflexo bifido Link. et Otto. Abh. t. 53. B. M. 2816. J. flavicoma Lindl. In Brasilia. †.

18. J. hispida Willd. ramis hispidopubescentibus; fol. oblongo-lanceolatis ; calycis laciniis et bracteis ciliatis. Willd. sp. pl. 1. p. 84. In sierra Leone. $\hbar$. Cor. alba.

19. J. lapathifolia Vahl; fol. elliptico-lanceolatis; racemis compositis; lab. superiori bifido. Vahl en. 1. p. 126. In India orientali. $\hbar$.

20. J. nitida Jacq. fol. petiolatis lanceolato-ellipticis; bracteis minutis subulatis; cor. lals. superiore bifido, laciniis lanceolatis. Jacq. am. p. 5. J. brachiata Rich. In America meridionali. t. Fol. spithamea.

21. J. bracteolata Jacq. ramis scabris 4-gonis; fol. oblongis utrinque acuminatis; cor. lab. superius bifidum semireflexum. Jacq. Coll. 3. p. 253. ic. rar.t. 205. In Caracas. ち. 6-ped. Fol. semipedalia. Cor. purpurea.

22. J. salicina Juss. fol. Ianceolatis; foribus terminalibus sessilibus solitariis. Vahl en. 1. p. 132. In Peru. ђ. Cor. eleganter rubens.

23. J. rotundifolia Nees; fol. eIliptico-ovatis obtusis, hracteisque subrotundis denticulatis, glabris; lab. superiore lineari reflexo. Nees in Wall. pl. asiat, In Tangore. 
B. Spicis racemisve terminalibus: herbaceae.

24. J. polysterma Roxb. fol. sessitihus lanceolatis pubescentihus; bracteis ternis 1-floris, lanatis ; capsulis 20-30-spermis. Hoxl). ind. 1. p. 120. In Bengalia. $\odot$. Caul. repens 6-12pollicaris.

25. J. simplex Don.; caule simplici foliisque ovatis obtusis venosis pilosis; calyce 4-partito. Don. nep. p. 118. In Nepalia. $\odot$. Caul. simplicissimus, pedalis. Cor. caerulea.

26. J. mutans Burm. fol. ovatolanceolatis dentatis; racemis nutantibus; flor. resupinatis. Burm. ind. 10. t. 5. f. 1. In Java. Fol. patentissima.

2\%. J. macrophylla Spreng. caule erecto; fol. lanceolatis utrinque attenuatis elongatis glairis; bracteis, olovatis reflexis coloratis. spr. syst. veg. 1. p. 79. In Brasilia.

29. J. tenuiflora $R$. et $\boldsymbol{P}$. fol. lanceolatis attenuatis; spicis pubescentibus; labio superiore integro. Fl. peruv. 1. t. 12. f. a. J. tenuifolia spr. In Peruvia. 24. 2-ped. Cor. punicea.

29. J. longistaminea $\boldsymbol{R}$. et $\boldsymbol{P}$. fol. subovatis utrinque acutis subrerandis; pedunculis dichotomis; staminibus longissinis. F1. peruv. 1. t. 10. f. a. In Peruvia. 4. Fol. tripalmaria. Cor. purpurea.

30. J. spicata $R$. et $\boldsymbol{P}$. bracteis foliisque ellipticis; lab. cor. superiore lanceolato recto; stigmate capitato. Fl. peruv. t. 9. f. a. In Peruvia. 4. 6-ped. Cor. punicea.

31. J. quadrungularis Hook; fol. petiolatis ovato-lanceolatis acutis subserratis; bracteis minutis; corolla incurvata. Hook. B. M. 2845. In ins. st. Mauritii. Caul. ped. Cor. purpurea.

\section{Spicis racemisve axillaribus.}

32.J. eustachyana Jacq. fol. ovatoJanceolatis; bracteis linearibus apice latiusculis acuminatis. Jac\%. am. p. 4. t. 4. B. M. 2076. In ins. St. Eustachii. t. 3-ped.

33. J. alba Roxb. fol. ovato-lanceolatis; flor. remotis; cor. tubo filiformi; limbo 2-labiato. Roxb. ind. 1. p. 132. In ins. Adaman. $t$. Cor. candida.

31. J. tunicata Afzel; fol. lanceolatis acuminatis glabris bracteis foliolisque calycis eubulatis. Afzel rem.
Guin. 3. p. 17. In Sierra Leona. $\odot$. Caul. ped. Cor. alba.

35. J.strobifera Lam. fol. ellipticolanceolatis ; bracteis conduplieatis nervosis glaberrimis. Lam. ill. 1. p. 36. In Madagascar. Ђ. Rami stricti. Fol. 5-pollicaria. Cor. J. Echolii.

36. J. sphaerosperma Vahl; fol. ovatis subsessilibus glabris; spicis oppositis; bracteis elongatis; staminibus globosis nitidis. Vahi symb. 2. p. 3. In Caribaeis. Capsula pubescens.

3\%. J. longifolic I rehl; fol. Ianceolatis elongatis; spicis axillaribus geminis oppositis secundis. Vahl symb. 2. p. 4. In ins. Mahé. Cor. parva.

38. J. pubescens Lam. fol. Iancelato-ellipticis acuminatis; flor. secundis; bracteis subulatis calyce brevioribus; pedicellis hirtis. Lam. itl. 1. p. 40. J. stricta Vahl. In Malaboria. Caul. utrinque sulcatus.

39. J. spathulata Nees; fol. ohlongis utringue attentiatis pubescentibus; spicis hifidis secundis; lracteis spathulatis. Nees 1. c. In Brasilia. †. Caul. 15-ped. Cor. coccinea.

40. J. elonyata Vahl; fol. ovatis; racemis elongatis; flor. remolissinis subternis. Vahl cn. 1. p. 130. In Ind. orientuli. Cor. parva extus pubescens.

11. J. gangetica Limn. fol. subpetiolatis integerrimis, margine subciliatis; calycibus alternis hispidis; bracteis obsotetis. Linn. an. acad. 4. p. 250. Burm. ind. t. 4. f. 2. In Ind. orientali. Caul. ad genicula pilosus.

42. J. opaca l'ahl; fol. ohlongoacutis, margine nervisque subtus villosis; unbellis axillarihus; hacteis lanceolatis muticis hirsutis. Vahl ell. 1. p. 138. In Guinea.

43. J.nusuta I. fol. Ianceolato-ovalibus, utriuque attenuatis ohtusis; pedunc. hifidis; Iah. cor. superiori linearisubulato reflexo. Vahl symh. 2. p. 15. Bot. M. 325. In India orientali. $t$. Cor. carmea.

4. J. scandens Iahl; ramis vilIosis; fol. ovatis acuminatis repandis; pedunculis 3-chotomis divaricatis. Vahl symb. 2. 1. \%. In Malabaria. †.

45. J. tinctoria Lour. caule procumbente; fol. lanceolatis oblongis, subcrenatis, pabescentibus; pedunc. congestis 1-floris. Lour. coch. 1. p. 25. In Cochinchina. Cor. rosea.

46. J. pumila $F$. G. Dietr. fol. petiolatis lanceolatis acuminatis acutis 
Integerrimis, glabris, basi subobliquis ; flor. tubuloso - -fidis. F. G. Dietr. Gart. Lex. suppl. 4. p. 197. Hab.... ந. Cor. coccinea.

47. J. racemulosa Wickstr. fol. subcordato-ovatis obtusis pubescentibus; racemulis axillaribus bracteatis; cal. et corolla 4-fida WVickstr. Fl. st. Barthol. Fruticulus ramosus. In ins. st. Bartholomai et Jumaica. \$.

48. J. infracta Burm. fol. ovatoattenuatis, petiolatis subrepandis ; spicis secundis subtomentosis; bracteis bifariis villosissimis, ovatis. Valıl en. 1. p. 155. In Indiu orientali. t. Semipedalis basi repens.

49. J. sanginolenta Tahl; caule repente; fol. oblongis, subcrenatis; pedunculis axillaribus 1 -floris alteruis. Valıl sym. 2. p. 10. In ambrosis Zeyloniae. †.

\section{Antherarum loculis distan- tibus.}

\section{Corolla recta.}

A. Spicis racemisve terminalibus : fruticosae.

50. J. lucilla Andr. fol. oblongis venosis bnllatis lucidis; lab. corollae superiore lanceolato. Andr. Rep. 313. Bot. Mag. 1014. In liarbados. Caul. 3-ped. Cor. saturate coccinea.

51. J. yeniculatu Sims.; fol. ovatolanceolatis, glabris subtus pallidis distantibus; paniculis cernuis; bracteis subulatis. Bot. Mag. 2487. In ins. st. Jincentii. ந. Cor. coccinea.

52. J. caracasana Jacy. fol. ovatoohlongis acuninatis glahris, florib. spicatis, oppositis; lab. cor. superiore integro Jacq. Coll. 4. p. 116. ic, rar. 2. t. 206. In Caracas. ち. 5-6-ped. Cor. purpureo-violacea.

5i3. J. formosa Willd. fol. ovatis acuminatis, spicis terminalibus, hracteis lanceolatis pubescentibus. Willd. en.1.

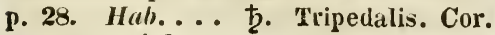
purpureo-violacea.

54. J. viclacea Tahl; fol. lanceolatis, basi rotundatis "integerrimis; bracteis exterioribus lanceolatis ciliatis, interioribus setaceis. Vahl symb. 2. p. 15. In Arabia felici. t. Rami pulverulento-villosi.

5.5. J. mucronata $R$. et $P$. fol. obiongis remote dentato-spinosis; florihus spicatis, oppositis, remotis; bracteis dentatis. Fl. peruv. 1. p. 8. t. 10. f. b. In Peruvia. ‡. 12-ped.
B. Spicis racemisve terniualibus : herbaceae.

56. J. sulcatc Vahl; caule sulcato; fol. ovato-cordatis, calyce duplici; antherarum loculo inferiori aristato. Vahl symb. 2. p. 13. In Arabia felici. Caul. 6-sulcatus. Cor. alba striis purpureis.

5\%. J. vulguris Bertero; fol. longe lanceolatis acuminatis ; bracteis linearilanceolatis acuminatis margine membranaceis. spr. syst. veg. 1. p. 81. In Portorico. 2-ped. Cor. sicca laete ferruginea.

58. J. caripensis Kunth; fol. ovatooblongis utrinque angustatis crenatis glabriusculis; flor. secundis remotis; cor. lab. superiori integro. Kunth. syn. 2. p. 31. In Nova Andcilusia. 4. Cor. purpurea.

59. J. Rohrii Iahl; fol. ellipticis integerrimis; spicis compositis, pubescentibus; bracteis ovatis. Vahl symb. 3. p. 6. In Cajenna. Caul. 4-gonus.

60. J. carthagenensis Jac\%. fol. ellipticis oblongisve basi attenuatis; bracteis oblongis, ciliatis obtusis. Jacq. am. 2. p. 5. t. 5. In Carthagena et Martinica. Herbacea. Hami oppositi 4-goni.

61. J. nemorosa Su. fol. ovatolanceolatis, bracteis imbricatis ovatis acutis villosis. Sw. prodr. 11. In America calidiori. Cor. sanguineopurpurea.

62. J. puinctata Iahl; fol. lanceolato-ovatis; florihus remotis verticillatis; bracteis lanceolatis acuminatis. Vahl symb. 2. p. 15. In Arabia felici. Cor. alba violaceo-punctata.

63. J. genuflexa Nees; fol. ovatis cauleque repente hirsutis; calycis la ciniis linearibus ciliatis ma minore. Nees N. Act. II. p. 57. In Brasilia. Caul. ped. Cor. parva pallide violacea.

61. J. reptans $S w$. caul. repente; fol. ovatis obtusis; spicis filiformibus; flor. secundis. Swartz. prodr. 13. In Hispaniola. ๑. Caul. filiformis. Flor. minuti.

65. J. pectoralis Jacq. fol. subsessilibus lanceolatis integerrinis glabris; flor. alternis oppositisve remotis; lab. superiori cor. integro. Jacq. am. 3. t. 3. pict. t. 4. In ins. Antillorum. 4. Caul. 2-3-pedalis.

66. J. undulata Vahl; fol. Ianceolatis undulatis; umbellis terminalibus simplicibus 3-fidisque; bracteis seta- 
ceis. Vahl symb. 2. p. 8. Burm. ind. 2. t. 5. f. 1. In Java et Malabaria. Rami pedales.

67. J. Vellozii R. et S. fol. ovatooblongis cauleque subramoso utrinque pilosis. R. et S. syst. veg. 1. p. 166. In Brasilia.

68. J. trifoliata R. et S. fol. ternis lanceolatis utrinque villosis renexis; spicis propriis ternis comosis. H. et $\mathrm{S}$. syst. veg. 1. p. 166. In Brasilia.

69. J. racemosa $R$. et $P$. fol. lanceolatis acuminatis integerrimis; racemis terminalibus; pedunc. inferioribus dichotomis. Fl. peruv. 1. p. 9. t.9. f. b. In Peruvia. 24. Caul. 3-ped. Cor. punicea.

70. J. humifusa $S w$. caule decumbente; fol. ovatis cordatisve; spicis umbellatis filiformilbus. Sw. prodr. 14. In Jamaica. ๑. Caul. dichotomus, tetragonus.

71. J. plicata Vahl; caule repente; fol. lanceolato-ellipticis; spicis tetragonis; bracteis lineari-lanceolatis ciliatis. Vahl en. 1. p. 157. In Guinea. Caul. ped. Spica 2-3-pollicaris.

72. J. comosa Vahl; fol. ellipticis; thyrsis terminalibus subimbricatịs subcomosis. Vahl. en. 1. p. 155. In America meridionali. Cor. villosa.

73. J. juncea $\boldsymbol{R} . \mathrm{Br}$. caule erecto; fol. linearibus margine scabris; spica terminali densa. $\mathrm{R}$. Br. prodr. p. 276. In Nova Hollandia.

74. J. media R. Br. fol. lanceolatis hasi attenuatis subpetiolatis cauleque erecto undique pilosis; spica terminali densa. R. Br. I. c. In Nova Hollandia.

75. J. adscendens $R$. Br. fol. angusto-oblongis obtusis basi attenuatis, cauleque ramosissimo diffuso hirsutis; spica terminali densa. A. Br. 1. c. In Nova Hollandia.

76. J. brachioides Roth; caule erecto brachiato; fol. ovalibus subpilosis, basi subattenuatis; spicis distichis; bracteis ovalibus. Roth. Nov. pl. sp. p. 16. In India orientali. Caul. ped. Cor. ringens.

7\%. J. orixensis Roxb. ramis divaricatis tetraquetris; fol. cordatis repandis; bracteis orbicularibus ciliatis; seminibus echinatis. Roxb.ind. 1.p. 133. In India orientali.
C. Pedunculis axillaribus fruticosae.

78. J. salviacfolia Kunth; fol. ovato-lanceolatis, acuminatis pubescentibus; flor. colitariis sessilibus. Kunth syn. 2. p. 31. In Hort. bot. Mexicuno. $\hbar$. Ramulis viscoso-puhescentibus.

79. J. biflora Vahl; pedunculis axillaribus bifloris fol. ovatis aequantibus; bracteis subulatis. Vahl symb.2. p. 9. In India orientali. $\hbar$.

80. J. cuspidata Vahl; pedunculis axillaribus subtrifloris; bracteis cuneatis aristatis exterioribus ciliatis. Valıl symb. 2. p. 9. In Arabia felici. $\hbar$.

81. J. Ryani Vahl; fol. ovatolanceolatis attenuatis; bracteis linearibus. Vahl Eclog. am. 1. p. 1. In ins. Caribaeis. Ђ. Caul. lignosus.

82. J. sylvatica Lour. fol. lanceolatis tomentosis; paniculis axillaribus. Lour. cochinch. 1. p. 26. In Cochinclina. †. 5-ped. Cor. alba.

83. J. debilis Vahl; spicis axillaribus terminalibusque; bracteis ovatis imbricatis ciliatis. Vahl symb. 2. p.15. In Arabia felici. bescens.

81. J. polygonoides Kunth; fol. lanceolatis acuminatis integerrimis glabriusculis subsessilibus; cor. lab. superiore emarginato. Kunth syu.2. p. 30.

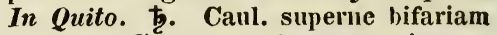
pilosus. Cor. alba violaceo-striata.

8.5. J. periplocacfolia Jacq. fol. ovato-Ianceolatis; flor. axillaribus solitariis sessilibus, terminalibus subspicatis. Jacq. Coll. suppl. p. 5. t. 7. f. 2. In Caracas. ち. $1_{2}^{\mathrm{I}}$-ped. Cor. purpurea.

86. J.reflexiflora Rich. fol. linearilanceolatis ovatisve; spicis axillaribus terminalibusque subsessilibus; bracteis linearibus. Vahl en. 1. p. 157. In ins. St. Thomas. ‡. Cor. dilute violacea.

87. J. tomentosa Tahl; caule repente; fol. tomentosis; pedunculis apice umbelliferis; bracteis ohovalis. Vaht en. 1. p. 160. J. repens Pers. R. et P. Fl. peruv. t. 15. f. 6. In Lima.

88. J. trisulca Vahl; fol. oblongis obtusis; pedunc. axillaribus subtrifioris; floribus sessilibus. Vahl symb. 2. p. 10. J. biftora. Lam. In Arabia felici. t. Flores sessiles. 
89. J. hyssopifolia $L$. fol. lanceolatis integerrimis obtusis; pedunc. ancipitibus; bracteis calyce brevioribus. L. Mill. ic. t. 13. In Canariis' ђ. Cor. pallide flava puhescens.

90. J. capensis Thunb. fol. Inearilanceolatis submucronatis, junioribus villosis ; flor. axillaribus sessilibus oppositis. Thunb. cap. p. 104. J. divaricata Licht. In Prom. b. spec.

91. J. orchioides $\mathbf{L}$. glabra ; ramis flexuosis ; fol. lanceolatis utrinque acutis sessilibus; bracteis calyce breviorihus. L. Vent. Malm. t. 51. In Prom. b. spei. $\hbar$.

92. J. cuneata Vahl; fol. obovatis emarginatis; flor. solitariis sessilibus. Vahl symb. 2. p. 10. In Prom. b. spei. b. Frutex rigidus.

93. J. patula licht. fol. oblongis glabriusculis obtusis vel recurvatosubmucronatis; caule glabro divaricato. R. et S. syst. veg. 1. p. 164. In Prom. b. spei. $\hbar$. Frut. rigidus. Cor. alba.

94. J. glauca $L$. caule suffruticoso; fol. ovatis integerrimis acuminatis obtusisque ; flor.axillaribus solitariis sessilibus terminalibus spicatis. Rottler. In India orientali. $\hbar$.

9.5. J.odora Valli; fol. subrotundis coriaceis; floribus axillaribus sessilibus oppositis. Vahl symb. 2. p. 11. In Arabia felici. $\hbar$.

\section{Peduncnlis: axillaribus herbaceae.}

96. J. lithospermifolia Jacq. caule subvilloso; fol.lineari-lanceolatis utrinque acutis pubescentibus; antherarum Ioculo inferiori aristato. Jacq. Hort. Schanbr. t. 4. In Peru. ђ. Caul. 6-angularis. Cor. violacea.

97. J. sessilis Jacq. fol. ovatis subcrenatis integerrimisve; floribus axillaribus sessilibus solitariis. Jacq. am.3. t. 2. f. 2. J. pauciflora Vahl. In $\mathrm{C} a-$ ribaeis. 4. 1-2-ped. Cor. extus villosa.

98. J. ciliaris $\boldsymbol{L}$. fol. lanceolatis obtusis basi ciliatis; calycilus hispido ciliatis L. suppl. 84. J. ciliata. Jacq.

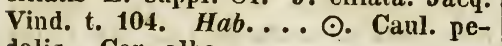
dalis. Cor. alba.

9.9. J. humilis Michx. fol. oblongolanceolatis subsessilibus serrulatis; spicis axillaribus alternis elongatis; hracteis lanceolatis. Michx. 1. p. 8 . In Carolina australi. 4. Caul. 8-12poll. Cor. violacea.
100. J. pedunculosa Michx. fol. lanceolato-ensiformibus elongatis ; spicis longissime pedunculatis; bracteis lineari-lanceolatis. Michx. 1. c. J. americana Vahl. J. ensiformis Elliot. In America boreali. 4.

101. J. comata $\$ w$. fol. lanceolatis; spicis axillaribus terminalibusque; filiformibus; spiculis verticillatis Sw. obs. 14. In Jamaica. 24. Flor, alterni parvi.

102. J. alcta Vahl; canle subalato; fol. lineari-lanceolatis; racemis axillaribus. Vahl eu. 1. p. 139. In India orientali. Caul. quadrangulo-angulato.

103. J. polystachya Lam. fol. lanceolato-ovatis integerrimis; spicis secundis; bracteis ovatis hirsutis. Vahl symb. 2. p. 7. t. 26. In Cajenna. Caul. strictus 4-angulus.

101. J. cuneifolia Nees; fol. ovatoellipticis basi cuneiformibus crenatis; bracteis orbiculatis mucronatis ciliatis. Nees N. Act. 11. p. 58. In Brasilia. 4. Caul. 2-ped. Cor. parva glabra.

105. J. radicans Vahl; fol. lanceolatis; bracteis ovato-lanceolatis; aristatis calycibusque ciliatis. Vahl en. 1. p. 137. J. ciliata Pers. $R$. et P. Fl. peruv. t. 14. f. a. In Peru. Caul. 2-ped. Cor. purpureo-violacea.

106. J. lancea Thunb. fol. lanceolatis integris; floribus verticillato-aggregatis. Thunb. Linn. trans. 2. p. 338. In Japonia. $\odot$. Subpedalis. Bractea apice piliferae.

107. J. crinita Thunb. umbellis axillaribus solitariis; bracteis oblongis ciliatis. Thunb. 1. c. J. japonica Thunb. jap. t. 4. In Japonia. $\odot$. Pedalis. Cor. purpurea.

103. J. glabra Konig; fol. petiolatis ovatis acutis; pedunculis 3-chotomis; antheris inferioribus canaliculatis. Roxb. Fl. ind. 1. p. 132. In Coromandel. $\odot$. Caul. articulatus. Cor. albo-virens.

109.J. reticulata Lam. fol. oblongis obtusis; spicis filiformibus; flor. distantibus; bracteis setaceis. Vahl en.1. p. 157. Hab. ... Caul. repens spithameus. Flor. parvi.

110. J. antirrhina Nees; fol. ellipticis acuminatis integerrimis glabris ; floribus secundis hasi gibbis. Nees N. Act. II. p. 59. In Brasilia. Caul. 3-4-ped. Cor. albida.

111. J. secundiflora Vahl; fol. ovalibus obsolete crenatis acutis glabris; 
spicis axillaribus; floribus secundis. VahI en. 1. p. 158. R. et P. FI. peruv. t. 15. f. a. In Peru. Caul. 3-ped. Cor. purpurea.

112. J. appendiculata Vall; fol. lanceolatis undulatis hasi appendiculatis; spicis axillaribus umbellatis. Vahl en. 1. p. 159. 1R. et P. Fl. peruv. t. 11. f. a. In Peru. Caul. orgyalis. Cor. purpurea.

113. J. jalappaefolia Tahl; caule dichotomo; fol. ovatis subcrenatis; umbellis dichotomiae triradiatis; bracteis lanceolatis. Vahl en. 1. p. 160. In Juva. Cor. purpurea.

114. J. inficiens Vahl; hirsutissima; fol. ovatis acutis integerrimis; pedunculis geminis 2-floris; hracteis oblongis. Vahl en. 1. p. 161. Fl. peruv. t. 13. f. b. In Peru. Caul. 2-ped.

11.5. J. Moretiana Burm. fol. lanceolatis glabris; lahio corollae inferiori 3-fillo. Burm. Zeyl. t. 3. f. 1. In arenosis Indiae.

116. J. serpyllifolia Rottler; caule procumbente villoso; fol. subrotundis; loribus axillaribus subsessilibus solitariis. Vahl en. 1. p. 169. In India orientali. Cor. parva.

2. Corollae tubotorto, limboresupinato.

117. J. retorta Vahl; fol. ovatis; pedunculis axillaribus suls-floris; bracteis subulatis. Vahl en. 1. p. 150. In India orientali. Caul. herb. sulcatus.

118. J. speciosa Roxb. fol. ovatis cordatis; pedunc. proliferis paucifloris ; bracteis oppositis foliaceis; lab. superiore cor. 3-fido. Roxl. ind.1. p. 122. B. M. 1722. In Bengalia. 24. Cor. pulcherrima kermesina.

119. J. latebrosa Kanig; fol. petiolatis cordato-oblongis acutis ; cor. lab. superiore 3-fido. Roxb. ind. 1. p. 126. In India orientali. 4. Caul. vix ullus. Cor. magna splendide rubra.

120.J. brasiliana Roth. fol. petiolatis ovatis acuminatis obsolete crenatis; bracteis ternis.lineari-setaceis calyce longioribus. Roth. nov. pl. sp. p. 18. In Brasilia. ち. Cor. speciosa purpurea.

3. Corolla calcarata. Loculi inanes aperti, a laefermes.

121. J. heterophylla Schlecht. caule pubescente; fol. inferioribus petiola- ti.s hasi acutis, superiorihus subsessilibus subcordatis bracteis minutis. schlecht. Liun. 1. 1. p. 95. In Serro Colorado.

\section{RHINACANTHUS Nees (1833).}

1. R. communis Nees; pauiculis trichotomis; lab. superiore lineari-recto; fol. ovato-oblongis. Nees in Wall. pl. pl. as. rar. J. nasuta ef scandens Willd. In India orientali.

2. R. Rotllerianus Nees; caulo scaberrimo; fol. oblongo-cuneiformubus ohtusis; panicula corymbosa 3-fida. Nees 1. c. In India orientali.

3. R. calcarutus Nees; fol. ovatooblongis; panicula 3-chotoma; lab. superiore lineari-attenuato incurvo angustissimo bifido. Nees I. c. In Silhet. Cor. alba.

\section{RUNGIA Nees (1S33).}

1. R. linifolic Nees; caule foliisque lanceolatis obtusis scabris; bracteis ovalibus, cuspidato-mucronatis, subtilissime ciliatis. Nees 1. c. In India orientuli. Caul. palmaris. Cor. pallide purpurea.

2. R. parviflora Nees; caule diffuso repenteve; fol. lanceolatis obtusis; hracteis suborbiculatis cuspidatis ciliatis; nervoso-venosis. Nees 1. c. In India orientali et in Nepalia.

3. $R$. polygonoides Nees; fol. inaequalibus obtusis; inferioribus ovalibus minoribus, superioribus lanceolatis; bracteis suborbiculatis ciliatis. Nees 1. c. In Inllia orientali.

4. $R$. origanoides Nees $l$. $c$. fol. lanceolatis oltusis glabriusculis; bracteis orbiculatis muticis villosis. Nees 1. c. J. pectinata Blume. 'In India orientali. Cor. laete caerulea.

5. $R$. repens Nees; caule repente; fol. oblongo-lanceolatis acutis; bracteis ovatis cuspidatis margine lato argenteo. Nees 1. c. Justicia L. In India orientali.

6. R. Wightiana Nees; caule herbaceo; fol. ovato-oblongis apice valde attenuatis; bracteis fertilibus rhombeocuneiformibus versus apicen hyalinis. Nees 1. c. In India orientali. Cor. rosea. 
7. R. Punduana Nees; fol. oblongis utrinque attenuatis; bracteis rhombeo-spathulatis acutis veuosis. Nees 1. c. In Pundua. நृ.

S. R. ciliata Nees; fol. ohlongoIanceolatis utrinque acuminatis ; bracteis fertilibus orbiculatis in petiolum attenuatis, ciliatis. Nees I. c. In India orientali. \$. Cor. purpurea.

\section{DICLIPTERA Juss. 180\%.}

\section{Floribus spicatis.}

1. D. assurgens Juss, ramis angulatis foliisque ovatis glahris; bracteis linearibus acuminatis; calycibus aristatis. Juss. Anu. Mus. 9. p. 269. In Jamaica. Cor. coccinea.

2. D. scorpioides Juss, ramis teretibus; fol. ovato-ohlongis hirsutis; spicis recurvatis; bracteis linearibus mucronatis. Juss. 1. c. Justicia Banks. Forst. t. 1. In Vera Cruce. t. Flor. secundi.

3. D. portoricensis $\boldsymbol{R}$. et $\mathbf{S}$. ramis angulatis; fol. petiolatis ovatis sul)hirsutis; spicis rectis; floribus subsecundis solitariis confertisque. $\mathbf{R}$. et $\mathbf{S}$. mant. 1. p. 149. In Portorico. Caul. $1 \frac{1}{2}$-ped. Cor. rubra?

4. D. xipotensis $R$. et $S$. fol. breviter petiolatis ovatis hirsutis spiois dichotomis recurvatis; bracteis subulatis calycibusque villosis. $\mathbf{R}$. et $\mathbf{S}$. 1. c. D. brasiliensis Nees. D. recurvata. Spr. In Brasilia. 4. Cor. coccinea.

5. D. retusa Juss. fol. ovatis acuminatis canleque glabris; floribus oppositis; bracteis obovatis retusis imbricatis glabris. Juss. 1. c. In ins. $\mathbf{S t}$. Crucis. Cor. magna purpurascens.

6. D. repens Alb. Dietr. diffusa; fol. subsessilibus lanceolatis; spicis compressis; bracteis ovatis albis, membranaceo-marginatis. D. retusa. Juss. I. c. Burm. Zeyl. t. 3. f. 2. In India orientali. 4. Cor. pallide rosea.

7. D. pectinata Juss. fol. oblongis ohtusis ; spicis secundis villosis ; bracteis dorsalibus lanceolatis bifariis basi margine membranaceis. Juss. 1. ๔. Roxb. corom. t. 153. In India orientali. 4. Caul. spithameus.

8. D. trinervia Juss. fol. linearilanceolatis sessilibus cauleque glabris; bracteis lanceolatis coloratis trinerviis. Juss. 1. c. In India orientali. Cor. extus villosa.

9. D. brasiliensis spr. fol. oblongis integerrimis; bracteis obovatis coloratis, calycem subulatum superantibus spr. N. Entd. 3. p. 123. In Brasilia.

\section{Floribus axillaribus verticil-} latis vel pedunculatis.

10. D. resupinata Juss. caule herbaceo 6-angulari; fol. ovatis glabris; bracteis bivalvibus subcordatis. Juss. 1. c. J. sexangulata Cav. t. 203.

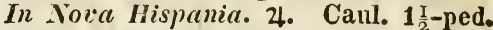
Cor. purpureo-violacea.

11. 1). brachiata Spr. caule 6-angulari ramosissimo; fol. ovatis acutis longissime petiolatis; bracteis obovatis 3-floris. spr. syst. veg. 1. p. 86. In Carolina. 4. Cor. rubella extus pilosa.

12. D. multiflora Juss. caule sulcato-angulato foliisque pubescentibus ovatis acutis basi in petiolum angustis; hracteis obovato-cuneatis. Juss. l. c. R. et P. peruv. t. 14. f. 6. In Peru. 24. Cor. violacea.

13. D. pilosa Kunth; caule sulcato-angulato foliisque strigoso-liirtis ovatis breviter petiolatis; bracteis obovatis longissime mucronatis villosis. Kunth syn. 2. p. 34. In Nova Granata. 24.

14. D. peruviana $J$. caule tereti striato foliisque hirsutis ovatis acuminatis mucronatis breviter petiolatis: flor. verticillatis. Juss. 1. c. D. mucronata. Fl. peruv. t. 16. f. a. In Peru. 2-ped. Cor. purpurea.

15. D. congesta Kunth; caule hexagono glabriusculo, fol. oblongis acuminatis basi angustatis subtus pubescentibus. Kunth syn. 2. p. 34. In Hort. Mexicano. 24. Caul. 2-ped. Cor. purpurea.

16. D. pubescens'Juss. fol. ovatis pubescentibus, umbellis axillaribus oppositis ; bracteis ovato -subrotundis mucronatis. Juss. 1. c. 'J. coerulea Poir. In Nova Caledonia. $\hbar$.

17. D. clavata Juss. fol. ellipticis; paniculis axillaribus subumbellatis bracteis lineari-cblongis. Juss. 1. c. In ins. societatis. Kami 4-goni. Flor. parvi.

18. D. frondosa Juss. fol. ovatis; 
umbellis axillaribus compositis; bracteis obovatis rhombeis obtusis glabris. Juss. 1. c. In Otaheiti.

19. D. acuminata Juss. caule hexagono piloso; fol. oblongo-lanceolatis acuminatis; bracteis lanceolatis ciliatis. Juss. 1. c. Fl. peruv. t. 16. f. 6. In Quito. 24. 2-ped. Cor. purpurea.

20. D. ocymoides Juss. fol. ovatis; umbellis axillarihus sub-5-floris; bracteis lanceolatis cuspidatis. Juss. 1. c. In America. Caul. ped. herbaceus. Pedunculi brevissimi.

21. D. umbellata Juss. fol. oblongis; umbellis axillaribus subgeminatis -fidis; bracteis subcuneatis aristatis 2-floris ciliatis. Juss. 1. c. Ad Senegal. ち.

22. D. laevigata Juss. fol. ovatis; pedunculis axillaribus oppositis sub3-floris; hracteis oblongis mucronatis pubescentibus. Juss. I. c. J. falcata Lam. In Isle de France. ђ. Cor. pubescens.

23. D, martinicensis Juss. fol. ellipticis acuminatis integerrimis; pedunculis 3-fidis; bracteis elliptico-ovatis acutis 3-nerviis. Juss. 1. c. Jacq. am. t. 2. f. 1. Ad sepes Martinicae. Cor. rubens.

21. D. bivalvis Juss. fol. ovatooblongis subcrenatis; pedumc. 3-fidis; bracteis ovato-subrotundis nervosis cristatis. Juss. I. c. J. foetida. Forsk. Rheede 9. t. 43. In India orientali et in Arabia.

25. D. chinensis Juss. fol. ovatis cordatis integerrimis; umbellis pedicellisque distichis; bracteis ohovatis inaequalibus. Juss. 1. c. Burm. ind. 8. t. 4. f. 1. In China et in Arabia. felici. ђ. Cor. rosea.

26. D. ciliata Juss. fol. ovatooblongis glabris; pedunculis cymosis 3-fidis; bracteis ovato-subrotundis ciliatis 1-floris. Juss. 1. c. In Gujana.

27. D. sexangularis Juss. canle sexangulari; fol. ovatis; umbellis axillaribus 3-floris; bracteis cuneiformibus. Juss. 1. c. J. annua Amm. In Vera-Cruce et Jamaica. $\odot$.

28. D. speciosa Nees; fol. ovatooblongis subcrenatis lineolis exasperatis; bracteis exterioribus ovato-venosis. Nees N. Act. 11. p. 61. In Brasilia. ち. 6-7-ped. Cor, coccinea.

29. D. parvibracteata Nees; fol. ovatis acuminatis basi acutis, supra lineolatis setulis adspersis; involucro dipliyllo lanceolato. Nees in Wall. pl. as. rar. In India orientali.

30. D. cuneata Nees; fol. ovatis hasi acutis cauleque minute lineolatis glabris; bracteis cuneiformilus mucronatis. Nees 1. c. J. umbellata Wall. J. latebrosa Wight. Hb. In Travancore et Courtallum.

31. D. publeuroides Nees; fol. ovatis acuminatis basi acutis supra lineolatis glahris; bracteolis acuminatocrinitis. Nees 1. c. J. canescens et rotundifolia Wall. cat. In silhet et Nepalia.

32. D. cardiocarpa Nees; fol. ovatis basi acutis supra lineolatis glabris; involucris ciliatis; capsula obcordata hirsuta. Nees I. c. In Nihinaghur.

33. D. Roxburghiana Nees; fol. ovatis subcordatis utrinque acutis supra substrigosis; capsula ovali-subrotunda, compressa hirsuta. Nees 1. c. J. chinensis Roxb. In Calcutta.

3t. D. Burmanni Nees; fol. ovalibus utrinque acutis supra substrigosis; involucris 2-phyllis spathulatis; capsula orbiculari compressa tomentosa. Nees 1. c. In China. Cor. ro* sea?

35. D. riparia Nees; fol. ovatis basi acutis cauleque minute lineolatis glabris; capsula unguiculata ovall pubescenti scabra mucronata. Nees 1. c. In montibus Promae. Cor. purpurea.

36. D. micranthes Nees; fol. ovatis acuminatis; umbellis axillaribus sessilibus; capsula sessili oblongotetragona. Nees l. c. J, chinensis.Vahl. In China.

\section{AMPHISCOPIA Nees (1833).}

1. A. Beyrichii Nees. In rupibus umbrosis sylvarum Serra d'Estrella Americae meridionalis. 24. Fruticulus 2-3-ped. basi repens. Folia oblonga. Corolla purpurea.

\section{PERISTROPHE Nees (1833).}

a. Flores capitati.

1. P. montana Nees; fol. ohlongis attenuatis lineolatis cauleque glahris; capitulis 3-5-floris; involucri diphylli foliolis mucronulatis. Nees 1. c. Justicia purpurea Wight. var. $\beta$, sylvestris : fol. oblongis longissime acuminatis 
basi acutis. J. sylvestris Hb. malrasp. J. rubra Hb. Wight, In umbrosis montinm Courtallum $\beta$. in Tracancore. Cor. purpurea.

2. P. firagilis Nees; caule scabro; fol, oblongis apice longa attennatis; pedunc, ancipitibus. Nees 1. c. In T'aroy.

3. P. tinctoria Nees; fol. ovatis obtusis lineolatis suhtus cauleque ptibescenti-scahris; involucri foliol. cordato-ovatis, subciliatis. Nees I. c. J. Hoxhurghiana Willu. In T'uroy. 24.

1. P. speciosa Vees; fol. ovatis basi acutis supra lineolatis cauleque obtuso hexagono glabris; bracteis exterioribus cuneiforni-linearibus. Nees 1. c. Justicia Willd. In Bengalia et Nepaliu. ந.

5. P. acuminata Nees; fol.oblongolanceolatis longissime acuminatis lineolis exasperatis ad nervos scabris; calycihus enerviis. Nees 1. c. In Taroy et silhet. 24. Caul. trichotomus. Cor. $\frac{3}{4}$-poll. longa puhescens.

6. P. bicalyculata Nees; caule hexagono hirto; fol. ovatis acuminatis lineolatis glizhris; involucello 5 -phyllo, hasi connato. rees 1. c. Justicia Vahl. In Indiu orientuli. 44.

\%. P. Lanceolaria Nees; fol. oblongo-lanceolatis utrinque acuminatis, lineolatis, sabriusculis; panicula 3-fida viscido-lirita. Nees 1. c. Justicia Willd. In India orientali. 4.

\section{b. Flores dichotomo-paniculati.}

8. P. mubigera Nees; fruticosa pubescens; fol. rhombeo-oblongis, repandis; cor. |lab. superioris fornicato. Nees I. c. In India orientali. $\downarrow$. Cor. atropupurea.

\section{HYPOESTES R. Br. (1810),}

1. II. Wallichii Nees; fol. ovatis, repando-crenatis supra strigoso-hirtis; involucro 4-phyllo. Nees. In Nepalia. Caul. 1-2ped. Cor. pallida.

2. H. purpurea $\boldsymbol{R}$. $B r$. fol. ovalihus utrinque acuminatis, integerrimis, subtus ramisque pubescenti-scabris; involncro tubuloso. Nees 1. c. Rumpl. 6. t. 22. f. 2. In China et India orientali. Cor. purpurea.

3. H. fistuosa R. Br. fol, ovalihus utrinque attenuatis; for. secundis; involucris 2-floris, R. Br. Justicia Vahl symb. 1, t. 1. In India orientali. $\hbar$.

t. H. Forloelei R. Br. fol. ovatis acuminatis; fol. floralibus ovatis acutis; involucris 1-floris. Justicia Vahl. In Arabia felici. t.

5.H. floribunda R. Br. fol. ellipticolanceolatis acuminatis glahris; involucri laciniis semilanceolatis muticis, interioribus minoribus, R. Br, prodr. 1 . p. 47\%. In Nora Hollandia.

6. H. aristata $R, B r$. fol, ovatis ramisque villosis axillaribus verticillatis subsessilihus; hracteis ovalibus; involucri laciniis aristatis. H, Br. $\boldsymbol{A} \boldsymbol{d}$ Prom. b. spec. 24. Cor. villosą.

7. H. verticillaris $\boldsymbol{R}$. $\mathrm{Br}$, herbacea villosa; fol. ovatis; floralibus verticillatis; iuvolucri laciniis muticis. $\mathbf{R}$. Br. Aid Prom. b. spec. 24. Caul, ped. Cor. incaruata.

S. H. serpens $\boldsymbol{R}$. Br. canle repente; fol. ohlongis; involucri laciniis linearilanceolatis, suprema longiori. R. Br. In ins. Nt. Matritii.

9. H. triftorct R. et S. fol. ovatis; pedunc. axillaribus sub3-floris; involucri laciniis linearilus inaequalihus. R. et S. Syst. veg. 1. p. 141. In Arabia felici. 21.

10. H. involucrate Spr. fol. lanceolatis denticulatis cauleque pilosis; involucri laciniis lanceolatis acktis margine membranaceis. Spr. syst, veg. 1. p. 88, Circa Calcuttam. Cor. albida.

11. H. Cephalotis Link; fol. petiolatis oblongis acutis suhintegerrimis, margine nervisque scabris; bracteis calycihusque ciliatis. Link Jahrb. 1. 3. p. 48. In Ind. orientali. Rami obscure ferruginei.

\section{RAPHIDOSPORA Nees (1833).}

1. R. glabra Nees; vide Justicia glabra IVi!ld. sub .hả 90.

\section{ERIANTHERA Nees (1333).}

1. E.lobelioides Nees; canle suffruticoso diffuso; fol. orbiculatis petiolatis; floribus terminalibus racemosis. Nees. Justicia Wall. In Indiu orientali. $b$. Truncus semipedalis. Cor. purpurea. 
99. HAPLANTHLS Nees (1833).

1. II. tener Nees; variat $\alpha$. humilis: racemo terminali trifilo. B.elongatus: racemis axillarilus terminalibusque quaternis. Justicia tenuiflora Wall. In India orientali. Cor. purpurea.

\section{ANDHOGRAPHIS IVaIL.}

1. A. proniculata W'all. herbacea; caule foliisrue lanceolatis in petiolum attenuatis glahris; rapsulis polyspernis. Necs 1. c. Justicia Burm. Hhced. mal. 9. t. 56. In India orientali. $\odot$. Cor. rosea.

2. A.linerita Nees; herhacea; caule foliisque ovato-oblongis sesvilibus glahris; raccmis glanduloso-pubescentibus. In Indiu orientuli. Cor. alba.

3. A. affinis Nees; herhacea; caule glahro; fol. pubescentibus; racemis axillaribus dimidiato-cymosis, glanduIos0-puhescentibus. Nees I. c. In Intdic orientali.

4. A. viscosula Nees; fruticosa; caule foliisque oblongo-lanceolatis in petiolum attenuatis glabris; floribus secundis; capsula ovali octosperma. Nees 1. c. In India orientali. Cor. albida nervis purpureis.

5. A. glandulosa fies; fruticosa caule foliis ovalious petiolatis racemisque axillaribus hifidis subcymosis, gianduloso-villosis ; caps. 4-spermis. Nees 1. c. Justicia Willd. In India orientali. $\hbar$.

6. A. echioirles Nees; lierhacea; hirsuta; fol. oblungis obtusis sessilibus, subcrenatis; racemis reflexis; caps. 4-spermis. Nees 1. c. Hileed. 9. t. 46. In Coromandel. Cor. alba lab. inferius apice purpureo-striatum.

\section{CATALPA Juss. (1789).}

1. C. syringaefolia Sims. fol. cordatis repandis ternis; paniculis terminalibus. Lour. B. M. 1094. Bignonia catalpa L. Dul. arb. t. 41. In America boreali. $\hbar$. Arbor 40-50-ped. Cor. alba.

2. C. longissima Sims. fol. ovatis undulatis subternis; racemis terminalibus paniculatis Sims. Bignonia. Jacq. am. to 176. f. 78. In India orien- tali. t. Arbor 40-50-ped. Cor. albicans.

3. C. cassinoides Spr. fol. ellipticis coriaceis multinerviis; racemis terminalibus paucifloris. Spr. syst. veg.1. p. 70. Bignonia Lan. In Brasilia. t. Cor. magna glahra.

4. C. microphylla ram. fol. obovatis ohtusis; pedunculo sulh-3-floro terminali. Smr. 1. c. Bignonia Lam. In Hispaniola. ち. Frutex magnitudine Prumi spinosac. Cor. alba.

5. C. lirsuta Spr. fol. oblongis utrinque attenuatis venosis hirsulis; lobis corollae integerrimis. spr. 1. c. In Brasilia. 市.

\section{OXERA Labill. (1821).}

1. O. pulchella Iabill. Sertum austro-caled. p. 23. t. 28. Ocoma sipr. In Nova Caledonia. ち. Frut. orgyalis, ramis verrucosis, pallide sulphureis. Holia ovali-oblonga.

\section{SALVIA Plin.}

1. S. lavandulaefolia Vahl; fol. lineari-oblongis crenulatis subtus incauis; pedunculis clongatis, caule fruticoso. Vahl en. 1. p. 222. s. Hispanorum Lag. S. tenuior Desf. In Hispania. †.

2. S. cretica L. fol. lineari-lanceolatis; floribus digynis; calycilus diplyylis Willd. sp. pl. 1. p. 128. In Creta. S. tenuifolia. Riv. t. 128. Caul. 1 $\frac{1}{2}-$ ped.

3. S. officinalis $I$. fol. lanceolatoovatis crenulatis; verticillis pancifioris; calycihus mucronatis hracteis lougioribus. Vahl l. c. In Europa. ђ. 1-ped. Cor: caerulco-violacea.

1. S. crassifolia Desf. fol. petiolatis, ovatis, obtusis, subcordatis, croso-crenatis, pubescentihus, utrinque tomentosis. Benth. l. c. In Europe. $\hbar$.

5. s. grandifora Ettling. fol. oblongis cordatis crenatis rugulosis tomentosis; hracteis ovatis calyce acuto parum hrevioribus. Eltl. Nalv. n. 2. Jacq. Eclog. 4. t. 36. In Tuuria. t. Cor. caerulea.

6. S. confusa Benth. fol. petiolatis plurimis interrupte semipinnatifidis, rugosis subtus albo-lanugiuosis; lacinia 
suprema naxima. Bentl. Lab. non. p. 190. s. aurita schult. In Europa. ђ.

7.S.triloba 1. ramis tomentosis; fol. petiolatis rurosissimis trilobis; loho internedio producto ohlongo, lateralihus ovatis obtusis. Limu. S. Clusii Jacy. Schoenhr. t, 195, s. baccifera Ell1. In Syria et Archipelago. †. Cor. rubelis.

8. S. interrupta Schousb. fol. interrupte-pimnatis ; foliolis crenatis rugosis sultomentosis; minoribus sessilibus subrotundis. Schoush. Bem. p. 6. t. 1. In Mauritania. t. 3-4-ped. Cor. albido-cuerulescens.

9. s. vingens sioth. fol. interruplepimatis crenatis subrevolntis rugosis, subtus lanatis; corolla declinata recurva. sibth. gr. t. 18. In Graecia. 4. 1-ped. Cor. caerulea.

10. S. pinnatu L. villoso-viscosa; fol. interrupte pinnatis; foliolis petiolatis alternis ohlongis erosis inaequilateralibus. Limn. Boerh. Lugd. I. t. 167. In Oriente et Creta. ๑. Cor. purpuiea.

11. S. incarnata Tahl; fol. pinnatis inferioribus 5-jugis superioribus ternatis; foliolis ohlongis serratis lugosis. Etll. 11. 15. In Oriente. 24. Caul. retrorsum villosus. Cor. magna carnea.

12. s. rosuefolia $\mathrm{Sm}$. fol. pimatis 2-jugis; foliolis petiolatis obovatis villosis serratis, subtus incanis; bracteis ovato-lanceolatis. Sm. ic. ined. 1. t. 8. In Armenia. 方.

13. S. bracteata Russ. fol. pinnatis hirtis; calycis laciniis subulatis; bracteis foliaceis calyce longioribus. Russ. hist. 2. p. 145. Circa Aleppo.

14. S. scabiosaefolia Linn. fol. pinnatis sub 4-jugis; foliolis aequalibus lanceolato-linearihus acuminatis integerrimis villosis. Lam. Jour. h. nat. t. 27. S. Hahitziana Pall. S. Scahiosae Pers. In Tannia. 4. 1-2-ped. Cor. caerulescens.

15. S. Linkiana; fol. pinnatis $2-$ 3 jugis; foliolis sessilibus lanceolatis ohtusinsculis crenulatis rugosis subtus incanis; bracteis cordatis. Ih. et s. Maut. 1. p. 183. s. psilantha Link. Hub.... b. Caul. 2-3-ped. Cor. caerulea.

16. S. acetabulosa Vahl. Fol. inferioribus ternalo-pimnatis, superioribus simplicibus; foliolis obovatis crenatis rugosis villosis. Vahl. S.peregriua ctc. Schmied. ic.t. 12. f. 103. In Oriente. t. Cor. allida?

17. S. hydrangea Herb. fol. semipinnatis; $3-4$ jugis, laciniis oblongis, obtusis, integerrimis utrinque pubescentibus calycibus coloratis. In Persia. Oliv.

18. S. pomiferce $I$. fol. ovato-lanceolatis ohtusis crenulato-umdulatis, rugosis albido-tomentosis, bracteis ovatis deciduis. Linn. Sibtl. gr. t. 15. s. fragifera Ettl. In Creta, Graecia, Syric. ந. 2-ped. Cor. caerulescens, lab. albo-maculato.

19. S. calycina sibth. fol. ovatis crenatis reticulato-venosis tomentosoincanis; lobis ealycinis rotundatis retusis mucronulatis. Sibtlı. gr. t. 16. In monte fiymelto. $\hbar$. Cor. pupurascens.

20. S. multicaulis V'ahl. tomentosa ; fol. subcordato-oblongis, obtusissimis, crenatis; calycibus hirtis. Vahl en. 1. p. 225. In Oriente. 4. Caul. I-ped.

21. S. Moluccellae Benth. fol. longe petiolatis, obtusis ovatis, crenatis, cordatis, rugosis utrinque pubescentiluss. Benth. 1. c. In Syria prope Aleppo. 24.

22. S. aurec I. fol. inferiorihus subrotundis basi truncatis crenulatis, superioribus oblongis integerrimis ; calycibus coloratis. L. B. M. 182. All. Mus. 15. t. 15. f. 7. In Pr. b. spec. †. 2-ped. Cor. aurea.

23. S. africanc L. ramis villosis; fol. inferioribus spathuatis serratis basi truncatis dentatis: superioribus oblongis subintegerrimis subtus tomentosis. L. Comm. Hort. t. 91. In Prom. b. spec. ち. Caul. 4-ped. Cor. caerulea.

\#4. S. panicalata $L$. ramis villosis; fol. obovato-cuneiformibus denticulatis; floribus paniculatis Limu. s. minor etc. Breyn. Cent. 1. t. 5. In prom. b. spei. ち. 4-ped. Cor. albovariegata.

25. S. dentata Ait. fol. linearioblongis dentato-pinnatifidis; verticillis 2-floris; laciniis calyeinis obtusis. Ait. Kew. I. p. 37. S. rigida Thumb. In Prom. b. spei. t. Cor. purpureoviolacea.

26. S. nivea Thumb, fol. lancelatis integerrimis, albo-tomentosis; ranis dilatatis. Thumb. cap. S. lanceolata Lam. In Prom. b. spei. b. 23-ped. Cor. purpurea. 
27. S. cancisiesusis 1. fol. hastatotriangularibus oblongis crenatis obtusis. Ait. Kew. 1. 1. 44. In ins. $\mathrm{Ca}$ nariis. t. Orgyalis. Cor. purpurea.

25. s. cumpremulata Wull. caule adscendente, hirto; fol. longe petiolatis ample ovalis, acutis, profunde crenatis; rortatis, utringtie subhispidis. Benth. 1. c. In Ind. orientali. 4. 1-2-ped. Cor. caerulea?

29. S. Giditinosa I. fol. cordatosagittatis serratis acutis. Ait. Kew. 1. p. 44. Amn. Mus. 15. t. 15. f. 11. In Europa. 4. Caul. 2-3-ped. Cor. sordide flava.

30. S. mibicola Wall. fol. petiolatis, ovato-lanceolatis, crenatis, ntrinque pubescentibus, inferioribus lıastato-cordatis superioribus rotundato-attenuatis. Wall. Swet. Fl. Gard. t. 140. In Ind. orientali.

31. S. hians Royle fol. longe petiolatis, late ovatis, basi cordato-sagittatis; calyce colorato striato viscoso. Benth. 1. c. In Ind. orientali. 4. Cor. magna caerulea.

32. S. viridis $L$. caule lanato; fol. oblongis ohtusis aequaliter crenatis petiolatis, floralibus amplexicaulibus calycibus fructiferis reflexis; Linn. Jacq. ic. rar. t. 4. In Graecia et Africa boreali. ठో. Cor. incarnata.

33. S. Horminum L. caule piloso; fol. oblongis obtusis cordatis crenatis; bracteis cordatis summis sterilibus majoribus coloratis. Limu. Sibth. 'gr. t. 20. In Italia, Gallia et Graecia. ○. Caul. 1-2-ped. Cor. caerulea aut rubra.

34. S. Forskolei $L_{\text {. }}$ Caule herbaceo subaphyllo; fol. lyrato-auriculatis; corollae galea hifida. Linn. IVilld. H. ber. t. 20. S. bifida Forsk. In Oriente. 24. Caul. 1 I-ped. Cor. caernlea.

35. S. miltiorrhisa Bunge; fol. petiolulis semipinnatis; laciniis $3-7$ petiolatis, ovatis, crenatis, suprema maxiuıa 2-fida. Benth. 1. c. In C'inina. 3-4-ped. Cor. caernlca.

36. S. indica L. fol. oblongis cordatis duplicato-crenatis, lateralibus sublobatis summis sessilibus; verticillis remotissimis. Linn. Jacq. Vind. t. 78. In India. 24. 3-ped. Cor. caernlea.
37. S. commutata Benth. fol. petiolatis, ovatis, obtusis, eroso-crenatis, cordatis, crassis, tuberculato-rugosis, utrinque concoloribus hirtis. isenth. s. dominica. L. In Ituliu et Syria. 4.

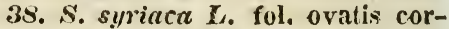
datis repando-dentatis crenatis rngosis subtomentosis; stylo corollam duplo superante. L. In Syria. \$. Cor. alba.

39. S. odorata Willd. fol. utrinque tomentosis repando-erosis inaequaliter dentatis, inferiorihus cordati superioribus ovatis Jacq. Eclog. t. 26. prope Baydad. †. Cor. alba.

40. N. canditissima Vall; incana; fol. cordato-ovatis sub eroso-dentatis rugosis utrinque lanatis; caule aphyllo. Vahl en. 1. p. 268. S. crassifolia Silhtlı. gr. t. 26. In Armenia et in ins. Cypro. 24. Habilus s. Sclareac.

11. S. Sclarea $L$. caule villoso subviscido; fol. cordatis acutis crenatis; bracteis cordatis coloratis; calycibus spinulosis. L. Sibth. gr. to 25. In Europa, Graecia et Syria. o. 24-ped. Cor. caerulescenti-albida.

42. S. spinosa L. fol. oblongis repandis rugosis cauleque utrinque hirsutis; calycibus spinosis; bracteis cordatis mucronatis concavis. L. Jacq. ic. rar. t. 7. S. praecox Valil. In Aegypto. 24. Caul. ped. Cor. alba.

43. S. palastina Benth. fol. petiolatis oblongis subsemipinnatis, rugosis, lobis eroso-dentatis, obtusissimis cauleque glanduloso-hirtis. Benth. S. syriaca Delile. In Palaestina.

14. S. tingitana Ettl. fol. cordatis oblongis eroso-dentatis rugosissimis; bracteis cordatis mucronatis ciliatis; calycibus spinosis. Ettl. Salv. n. 30. S. foetida Lam. Riv. t. 62. In Africa boreali. b. Cor. sordide alba.

4.5. S. praecox Vahl; fol. oblongoovatis subrepandis laevilus subpiIosis; bracteis cordatis venosis, acuminatis calycis longitudine. Vahl en. I. p. 2\%6. In Africa boreali.

16. S. Aethiopis 1 . fol. inferioribus pinnatifidis reliquis sinuatis erosis cordatis oblongis lanatis; bracteis spinulosis recurvatis L. Jacq. austr. t. 211. In Europa. o. Canl. 2-3-ped. Cor. alba pilis rubentibus.

17. S. compressa lahl; sublanata; fol. dentatis radicalibus cordato-oblon- 
gis; bracteis subrotundo-cordatis muticis, summis sterilibus. Vahl en. 1. p. 27.5. Vent. cels. t.59. In Oriente. 24. Cor. alba.

4S. S. uryenta $L$. caule glutinoso; fol. oblongis cordatis angulato-dentatis; panicula brachiata. L. Jacq. schuenlur. t. 6. In Creta. ठో. Caul. subtomentosus. Cor. alba.

49. S. verbascifolix Bieb. fol. cordato-ovatis, duplicato-serratis rugosis lanatis; bracteis cordatis mucronatis calyce brevioribus. Bicb. cauc. suppl. p. 22. S. candidissima Bieb. Laur. cauc. In Cancaso. 24. Cor. alba.

50. S. Broussoneti Benth. fol. petiolatis ample ovatis obtusis, sinuato-crcnatis, hasi cordatis, crassis, rugosissimis subtus albo-tomentosis. Benth. 1. c. In Africa boreali et 'Teneriffa.

51. S. Moorcroftiana Wall. caule basi lanato; fol. inferioribus longe petiolatis, late ovatis, eroso-crenatis, basi attenuatis, rugosis, subtus hirtis. Bentl. In Asia.

52. S. lumata Roxb. caule caespitoso; fol. oblongo-lanceolatis, obtusis integris, subcrenatis basi longe attenuatis, rugosis subtus niveo-lanatis. Wall. as. rar. II. t. 116. s. Stenarrhena Doll.

53. S. integrifolia IIardw. In Himalayo.

51. S. phlomoides Asso; fol. Ianceolatis subintegris cauleque lanatoviscosis. Asso introd. in Oryctogr. arrag. t. 4. In Arragonia. 万.

55. S. canescens Meyer; fol. oblongo-lanceolatis, integris s. sinuatolobatis, hasi longe attenuatis, rugosis, subtus dense albo-lanatis. Benth. 1. c. In Caucuso.

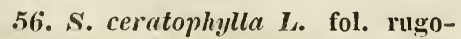
sissimis lanatis radicalibus hipinnatifidis; caulinis pimmatifidis; 'verticillis summis sterilibus Lim. S. exasperata Cav. Aun. 3. t. 17. ic. t. 556. In Maritunia, Syria ei Persia. ðૅ. Cor. purpureo-violacea.

5\%. S. yrareolens Vahl; fol. cordatis rugosis, crenatis, inferioribus subsinuatis; hracteis cordatis; spicis hirsutissiuis. Vahl en. 1. 1. In Aegypto. ち. Ramis villosissimis.

58. S. varia Vaht; fol. cordatis inaequaliter crenatis rugosis, subtus cauleque glaucescenti-tomentosis. Vahl en. 1. p. 273. In Armenia. 4.

5.9. S. Vicolor Ilesf. atl. t. 2. fol. infimis petiolatis, late-ovatis, incisodentatis semipinnatis s. palmato-lobatis, intermentiis ovato-lanceolatis actminatis profunde dentatis, ommihus basi cordatis. Benth. I. c. B. M. 177 t. In Algiria. 2-i-ped. Cor. lutescens.

60. S. algeriensiss llesf: fol. inferioribus ovatis, crenatis hasi atteuuatis; calycibus spinoso-dentatis; bracteia reflexis. Desf. atl. 1. 3. In Altiria.

61. S. latifolia lahl; fol. remote dentatis glabris, inferioribus oblongis basi attennatis, supcrioribus cordatio pedunc. elongatis. Vabl cu. 1. p. 271. In Numidiu. Caul. purpurascens.

62. S. incmone Vahl; canescens: fol. cordato-triangularibus inaequaliter dentatis; bracteis cordatis reflexis. Vahl en. 1. p. 269. In Hispania.

63. S. uustriaca $L$. fol. cordatoovatis eroso-sinuatis; caule aphyllo; verticillis villosissimis; staninibus longissimis. Vahl ell. 1. p. 272. Jacq. austr. t. 112. B. IR. 1019. S. distans et sclarea Crantz. In Austria. 4. Cor. ochrolenca.

61. S. limbatu Meyer; fol. ratícalibus petiolatis late ovatis, integris, eroso-lentatis, basi cordatis, rugosissimis hispidilis. Bentli. I. c. In Cosucaso. 4.

6.5. S. ceratophylloides $\boldsymbol{L}$. fol, pinnatifidis rugosis petiolatis verticilliz ommilus fertilibus hirsutissimis. Vahl. en. 1. p. 279. Ard. sp. 2. t. 2. In Aegypto et Sicilia.

66. S. matensis $I$. fol. cordatooblongis crenatis summis amplexicanlibus; verticillis subuudis, corollis galea glutinosis. Vahl en. 1. p. 262. E. B. t. 158, s. Barrelieri Ten. neap. t. $\mathbb{Z}$. S. Tenorii Sweet. Fl. Garl. t. 26. In Europa et Caucaso. 24. Cor. caert?leo-violacea.

67. S. dumetorum Andr. fol. cordato-oblangis acutis, sinuato-ilentatis crenatis rugosis; cor. galea rectiuscula bifida. Andrzeiowski apud Bess. Fl. Volh. p. 3. et 40. In mratis Volhiniae, Podoliae et Altaicis. 4. Cor. parva cacrulea.

68. S. Lusitanica Jacq. F. fol. radicalibus petiolatis; caulinis anplexicaulibus, omnibus 3-angulari-ova- 
tis basi truncatis, subcordatis, acutis, laciniato-dentatis, rugosissimis, subtus hirsutis. Benth. Jacq. Eclog. t. 38. In Hispania.

69. S. virgata Ait. fol. ohlongis cordatis rugosis crenatis; pilis caulis calycisque apice glandulosis. Ait. Kew. 1. p. 39. Jacq. Vind, t. 37, In Armenia. 4. 4-ped. Cor, pallide rosea.

70. S. viscosa Jac\%. villoso-viscosa; fol. ohlongis cordatis acutiusculis rugosis suberoso-crenulatis ; bracteis cordatis acuminatis, Jacq. ic. rar. t. 5. In Italia. 24. $1 \frac{1}{2}$ ped. Cor. purpurea.

71. S. rugosa Thunb. fol. cordatis oblongo-lanceolatis eroso-crenatis rugosis pilososiusculis; staminibus corolla brevioribus. Thmb. prodr. 97. In Prom. b. spei. 4. Canl. 1 1 -ped.

72. S. disermas $L$. caule gilandtloso-piloso glutinoso; fol. oblongis sinuato-erosis crenulatis rugosis acutis inferioribus cordatis. Linn. Ard. sp. 1. t. 1. In Syria. 24. Cor. alba.

73. S. Sibthorpii Sm. fol. cordatis crenatis lobatis rugosis scabris, caulc subaphyllo ramoso; staminum apendiculis dilatatis. Smith pr. Fl. gr. p. 15. Sibth. gr. t. 22. In Pelopormeso et Zacyntho. 24.

\%. S. sylvestris $\boldsymbol{L}$. caule herbaceo incano; fol. lanceolatis ohlongisve cordatis crenatis et crenato-serratis; bracteis coloratis calycen aequantibus. S. nemorosa $L$. Iichb. ic. t. 527. S. deserta Rchb. ic. t. 528. S. elata Host. S. Valentina Vahl. In Europa et Asia. 24. 1-3-ped. Cor. purpureoviolacea.

7.5. S. pendula Valil; caule tetraquetro, folioso; fol. lanceolatocordatis aequaliter crenatis; racemo ante anthesin nutante bracteis coloratis ciliatis. Vahl en. 1. p. 281. S. cremenensis Bess. S. betonicaefolia Ettl.

In Podolia. 4. Cor. caerulea.

76. S. nutans $L$. caule simplicissimo subaphyllo; fol, oblongo-cordatis ; recemis florentibus pendulis Waldst. et Kit. Hmg. t. 62. s. liastata Ettl. S. pendula Bess. In Europa boreali et in Caucaso. 2. Caul. 2-3-ped. Cor. violacea.

7\%. S. bullata Schonsb, fol, ohlongis cordatis crenato-dentatis erosis bullatis submaculatis. Vahl en. 1. p. 265. S. Insitanica Poir. s. elongata Spr. In IIispunia. 2. Cor, rubra.
78. S. nulicanlis Vahl; fol. radicalihus Ianceolatis rugosis ctenatoerosis, caule subaphyllo. Vahl. ell. 1. 1. 266. S. abyssinica L. In Arubiu. Caul, $\frac{1}{2}$ ped. Cor. parva.

89. S. verbenaca $L$. fol. serratis sinuatis laeviusculis; corollis calyce angustioribus. Limn. syst. veg. 70. s. polymorpha Hofimss. port. t. 19. Rchl). ic. 719 . S. oblongata lichb. ic. 522. s. multifida sibth. Rchb. ic. 720. In Africa boreali et Hispania. 4.

80. S. clundestina L. fol. oblongoovatis, laciniato-dentatis s. semi-pinnatis, rugosis, glabris, inferioribus petiolatis cordatis. L. In Europa et Aficice. 24.

81. N. controversa Ten. fol. oblongis, laciniato - semipinnatis; laciniis oblongo-linearibus, obtustssimis, laciniato-crenatis, bullatis, rugosissimis, margine revolutis, utrinque pilosis. benth. S. lanigera Poir. 's. clandestina sibth. gr. t. 24. In Hispania, Calabria et Graecia. 24.

8. S. deserti Ducaisne; ramis patentilus pilosis; fol. parvis, oblongis, petiolatis, crenatis, bullato-rugosis, maryine revolutis, glancescentipubescentibus. Benth. In descrtis Sinui.

83. S. Mubia Ait. fol. oblongis subcordatis inaequilateralibus rugosis crenatis hasi subauritis. Ait. Kew. 1. p. 42. In Africa.

8t. S. sclareoides Brot. fol. radicalibus subcortatis s. oblongo-ovatis, acutiusculis, rugosis duplicato-crenatis tomentosulis. Brot. lus. p. 17. In Lusituniu. 1-3-ped. Cor. intense violacea.

8.5. S. Barvelieri Ettl. fol. hastatolanceolatis, inaequaliter serratis ; canle folioso erecto. Ettl. Salv, 46. In Hispania.

86, S. pyrenaica $I /$, villoso-viscosa; fol. dentatis, sinuatis, obtusis; staminibus calyce duplo longioribus. Liun. sp. pl. 36. In Pyrenaeis. Cor. caerulea.

87. S. parviflora Vahl; fol. coldato-ovatis, crenatis, rugosis; racemis terminalihus compositis; bracteis cordatis calyce brevioribus. Labill. syr. dec. 4. t. 7. In Oriente. Cor, lutescens.

83. S. canescens Meyer; fol. ol-longis sinuato-lyratis lanatis, subtus glaucescentibus; bracteis orbiculatis, 
apiculatis, Neycr pl, cauc. p. 86. In Caucuso.

89. s'. limbata Heyer; fol. hispidis; ralicalibus petiolatis ovato-cordatis, ohtusinsculis, eroso-crenatis; caulinis sessilibus acutis. Meyer 1. c. In Cuucuso. Cor. alba luteo-marginata.

90. s. occidentalis $\mathbf{S u}$. caule herbaceo hirto; fol. ovatis acutis subcuneatis, crenato-serratis supra hirtis subtus pubescentibus. swartz. prodr. 11. 14. \$. procumbens Lam. In India occidentali. 4 . Cor. alhida.

91. S. Misella H. et $\boldsymbol{K}$. caule herhaceo, piloso; fol. roluulato-rhombeis, acutis, hasi cuncatis, crenatis, glahris. línth syn. In Hispaniola. $1_{2}^{\mathrm{I}}$-ped. Cor. violizcea.

92. S. obscura Benth. fol. petiolatis ovalis, acutis, serratis, baxi attenualo-cuneatis, supra hispidis. Benth. In Jamaicr.

93. S. tenella Su. caule filiformi repente; fol. cordatis; spicis adscendentibus. Sw. prodr.1. p. 1\%. In montibus altissimis Jamaicae $\odot$. Caul. 4-5-ped. Cor. caerulea.

91. S. micrantira Vrahl; fol. cordati:3 crenatis hullatis margine undulatis obtusis glabris. Vahl. en. 1. p. 235. S. bullata Orieg. In America boreali et is ins. Cuba. 24. Caul. ped. Cor. albilia.

9.7. S. serotina $\boldsymbol{L}$. fol. corlatis scrratis mollibus; floribus racemosospicatis; corollis vix calycem excedentibus. I.in!. Jacq. ic. ral. t. 3. s. dominica Vahl. In Chio. ち. Caul. $1 \frac{1}{2}$ ped. Cor. minuta.

96. S. humilis Benth. caule patentipiloso ; fol. petiolatis, late ovatis, acutiusculis, crenalis, hasi subcordatis, suhtilissimc pubescentibus. Benth. In Merico.

9\%. S. inconspicua Benth. fol. hrevissime petiolatis; ovato-lanceolatis, oblusis crentitis, hasi cordalis, rugosis, suhtus rufo-tomentosis. Benth, 1. c. In Merico.

9S. S. riparia $H$. et $K$. fol. oh10ngo-ovalis aculis corlatis, serratis utrimune piloso-pulescentihus. Kunth. In Peru. Cor. cacrulea.

99. S. tilinefolia lahl: fol. lateovatis, crenatis, hasi truncatis s. cordatis, igosis, utringue pilosiusculis. Kunth. 11. et B. Nov. Gen. et Sis. t. 149. Iи Peru. 方.
100. S. flexuosa presl. fol. petioIatis, ovatis, acntis serratis, hasi rotumblato-cumeiformilus, glabris. Presl. iss. In Mexico.

101. S. tanceolutu Willd. fol. lanceolatis obtusis remote serratis subtus puhescentibus, petiolatis; spioia alari, verticillis 2 -floris. Jilcq. fil. Eclog. 2. t. 12 . \$. reflexa Hornem. In Noru Fïspaniu. 24. Caul. 1-2-ped. Cor. caerulea.

102. S. leptophylla Benth. caule adscendente; fol. subsessilibus, anguste linearibus, acutis, integcrimis, crlabris; verticillis remotis subz-floris. Benth. I. c. In Mexico.

10.3. S. anymslifolia Cav: caule hirto; fol. linearibus elabris integerrimis; inferiorihns suliserratis; calycis laho inferiore latissimo. Cav. ic. 4. t. 31\% S. reptans Jacq. Schoenbr. t. 319. S. virmata Orteg. In Nover Hispania. 4. Hami $\frac{3}{4}$-ped. longi. Cot. caerulea.

104. S. paltill Benth. caule prostrato; fol. petiolatis ovato-lanceolatis, acuninatis, hasi attenuatis, junioribus glauco-tomentosis; verticillis remotis 6-floris. Benth. 1. c. In Brasilia (Ścllo).

10.5. . a. anrea Tam. fol. linearilanceolatis, inferioribus extrorstun serratis cauleque grabris; laciniis calycinis rotundatis. Lam. S. acuminatissima Vent. Cels. t. 50. s. mexicana Valt. \$. acuminata Pers. In America boreali. 24. Cor. caerulea.

106. S. Dilcheri Torrey Mss. caulc erecto tomentoso-pubescente; fol. pctiolatis oblongo-lanceolatis, acutis, subserratis, basi attenuatis, utrinque tomentosulis. Benth. 1. c. In America boreuli.

10\%. S. Laeris Bcuth. caule erecto glalro; fol. petiolatis oblongo-lauccofatis, utringue altenuatis, remote serratis, glabris; calycihus ciliatis. Ienlit. In Mexico. Cor. palide coerulea.

108. S. uliginose Benth. caulc erecto glatiusculo; fol. petiolatis ohJongo-lanceolatis, aculis, serratis, hasi attenuatis, erla!riusculis; calycis lab. sulp. integro. Benth. 1. c. In Brasilia. 2-G-ped. Cor. alba.

10\%. S. lavandubides $\boldsymbol{H}$. et $\boldsymbol{B}$. caule foliisnge cano-pubescentihus subtus alhidis lanceulatis acutis crenatis; verticillis multigoris. Kunth. S. ILum- 
boIdtiana $\mathrm{R}$. et $\mathrm{S}$. In Nora Hispariola. 2. Cor, pallide caerulea.

110. S. Stachyoides 11 . et 13 . caule suthsimplici; fol. pubescentibus concoIoribus Ianceolatis actitis crenato-serratis; calycibus cano-villosis. Kunth. H. et B. 1. G. et Sp. pl. 2. t. 138. In Mexico. 4. 3-ped. Coi. caerulea.

111. S. elonguta H. et B. caule simplici cano-pubescente; fol. oblongis acutiusculis basi angustatis crenatoserratis concolorihus superne scahriusculis. Kuntlı. H. et B. 1. c. t. 139. s. betonica $\mathrm{R}$. et $\mathbf{S}$. In Nova IIispania. 24. Cor. violacea.

112. S. corrugata Vahl; fol. subovato-lanceolatis crenatis; supra rogosissimis glabris, subtus lanatis; calycihus subhirtis. Vahl en. 1. p. 251. In Peru. $\hbar$.

113. $S$. collinc $H$. et $B$. ramis foliisque subtus albo-tomentosis, supra pubescentibus, lanceolato-oblongis obtusinsculis hasi acutis crenatis. Kunth. In Peru. 古. Cor. caerulea.

114. S. ussurgens $H$. et $B$. caule ramoso adscendente; fol. ovato-ellipticis, utrinque acutis, crenato-serratis, glabriusculis; calyce sericeo-hispido. Kunth. In Mexico. Cor.pallide violacea.

115. S. spicata R. et $\mathbf{s}$. ramis junioribus glauco-pubescentilus; fol. oblongo-lanceolatis, subcrenatis, superne pubescentibus subtus albo-tonentosis. S. saligna Willd. In Hispania. t. 3-ped. Cor. caerulea.

116. s. helianthemifolia Renth. ramis virgatis puberulis; fol. subsessilibus, oblongis, acutis, subpuhescentibus, rugulosis; stylo barhato. Benth. In Mexico. $1_{2}^{\mathrm{I}}$-ped. Cor. caerulea.

11\%. S. sideritidis prest. Mss. ramis erectis albo-tomentosis; fol. subpetiolatis, ovatis, obtusiusculis, serrato-crenatis, luasi cuneatis rugosis sulitus albo-tomentosis. Benth. I. c. In Peru.

118. S. chamaedryoides Cav. caule prostrato; fol. petiolatis, oblongoovatis, obtusis, obtuse crenatis, ramisque subtus wlanco-tomentosis. Andr. Rep. t. 416. Willd. H. ber. t. 29. In Mexico. †. Cor. cacrulea.

119. S. thymoides Benth. caule ramosissimo; fol. minimis, subsessilibus, ovatis, integerrinis, albicantibus margine revolutis. Benth. In Nova Hispania. b. Cor. caerulescens.

120. S. glechomaefolia $H$. et caule subsimplici; fol. ovatis obtusis 3-angulis, hasi subcuneatis, crenatis, clabriusculis. H. et B. 1. c. f. 141. In Nova Hispania. 24. 1-2-ped. Cor. caerulea.

121. S. nana, $H$. et $B$. acaulis; fol. ovatis obtusis basi attenuatis, supra lispidulis, subtus tomentoso-hispidis. Kunth. In Nova Hispania. 4 . Cor. caerulea.

122. Munelloides $H$. et B. fol. ovato-oblongis obtusis hasi acutis crenatis supra glabris subtus pilis raris obsitis; verticillis 4-floris. Kunth. In hî́xico. 24. Caul. 2-poll. Cor. caerulea.

123. S. arenaria st. Hit. ramis pilosis; fol. petiolatis oblongo-lanceolatis, acuminatis, serrato-crenatis, hasi cuneato-attenuatis, utrinque glabris concoloribus. Benth. In Brasilia. ந. t-pel. rawosissima.

124. S. serrutı Benth. caule subsimplici; fol, petiolatis ovatis, s. oblongo-lanceolatis, acutis, argute lnaequalibus serratis, glabris calycis lab. sup. integro. Benth. 1. c. In Brasilia. Cor. caerulea.

125. S. Irugayensis St. Hil. fol. ovato-lanceolatis, acutis, serrato-cienatis, hasi rotundato-cuneiformibus piIosiusculis, subtus pallidis; calycibus glanco-lirtis. Benth. 1. c. In Brasilia. 4.

126. S. urticaefolia $L$. canle villoso-viscoso; fol. rhoubeo-ovatis dentatis subtus punctatis, per petioium decurrentihus; corollis calyces subaequantilus L. Horuinum. Mor. 3. 11. t. 13. f. 31. In Virginia è Curolina. 4. Cor. caerulea.

12\%. S. gracilis Benth. canle suhglabro; fol. sessilihus, ovatis, acuminatis, basi subrotundis, serratis, utrinque piloso-puhescentibus. Benth. 1. c. In Nora Hisjrania. Caul. purpurasceils. Cor. carnea.

12S. S. leptostachys Benth. caule ramoso alho-tomentoso; fol. Ionge petiolis, ovato-rotundis, acutis, hasi truncatis, subtilissime pubescentibus. Benth. 1. c, In Nova Hispania. Cor. caerulea.

12.9. S. membranacea Benth. caule erecto-glabro; fol. longe petiolatis, Iate-ovatis, acutis, crenatis, hasi rotundatis, glabris; calycibus peudulis glabris. Benth.1. c. In Mexico. 2-3-ped. Cor. caerulea. 
130. S. rhombifolia $R$. et $P$. hirsuta; fol. serratis inferioribus "homheo-ovatis petiolatis: superioribus cordatis subsessilibus; racemis terminalibus ternis. Fl. peruv. 1. t. 26. f. b. In Peru. 1-ped. Cor. violacea.

131. S. herbacen Benth. caule ramoso hirto; fol. longe petiolatis, late ovatis rhombeisque, subcordatis pubescentibus; calycihus ovatis pubescentibus. Benth. 1. c. In Mexico.

132. S.Tafallae Bentl. caule erecto ramoso hirto; fol. petiolatis ovatis, basi subcuneiformibus, puberulis; calycibus ovatis hirtis; Benth. 1. c. In Peru. 1-ped.

133. S. violacea $R$. et $B$. fol. ovatis crenatis; floribus spicatis; verticillis 6-floris; labio corollae pendulo. Fl. peruv. 1. t. \$3. f. b. In Peru. 2-ped. Cor. violacea.

134. S. glandulifera Cav. fol. ovatis serratis villosis; ramis, bracteis calycilusque piloso-glandulosis. Cav. Anu. H. par. 2. 8. ln Chimborazo. 1-3-ped. Cor. violaceo-purpurea.

13.5. S. liirtı H. et 13. caule bifarian piloso; fol. oblongyo-ovatis, serrato-crenatis, suhtus alho-puhescentibus; bracteis acuminatis hispidis. Íunth. In rupibus Peruviae.

136. S. Cruixshanlisii Bienth. fol. subsessilibus, ovalis ohtusis hasi rotundat is subcordatis, crenatis, subtus puhescentibus; caule glabriusculo. Benth. l. c. s. rhombifolia $\beta$. Hook Misc. In leru. ち. Cor. caerulea.

137. S. yuleata $R$. et $P$. fol. ovatis serratis; calycis lah. sup. galeato; lah. corollae sup. involuto. $\mathbf{R}$. et $\mathbf{P}$. peruv. 1. f. 42. In Peru.

139. .s. mitis $R$. et $P$. fol. ovalis acutis serratis, tomentosis, spicis terminalibus, aphyllis; verticillis multifloris. H. peruv. In Peru. Caul. 4-ped. Cor. albo-cacrulea.

139. S. incurvate $R$. et $P$. fol. cordatis aculis serratis; labiis calycinis incurvis; corollae galea bifida. Fl. periv. 1. 1. 42. f. 1). In Peru. 2-ped. Cor. purpureo-caerulea.

110. S. hispanica $L$. caule retrorso pubescente; fol. ovatis serratis utrinque inucronatis. Limn. Alduin sp. 1. t. 2. In Europa meridionali. $\odot$. $1 \frac{\mathrm{I}}{2}$-ped. Cor. caerulea.

111. S. angulata Bentl. caule erecto subpubescente; fol. petiolatis late ovatis, acuminatis, serratis, basi rotundatis, pubescentibus subtus glaucescentilius. Benth. I. c. In Curacus.

112. S. polystachya Orteg. caule erecto pubescente; fol. oblongo-ovatis acuminatis serratis subtus cano-pubescentibus; spicis secundis. $\mathbf{S}$. caustis Willd. S. linariaefolia Lag. In Mexico. Caul. 1-2-ped. Cor. caerulea.

143. S. densiflora Benth. caule erecto subpubescente; fol. petiolatis ovatis obtusis, crenatis, basi rotundatotruncatis, rugosis, utrinque puhescentibus; calycibus glabriusculis. Benth. In Dominyo.

141. S. Keerlii Benth. fol. peliolatis ovatis obtusis crenatis, hasi rotundis, truncatis, rugosissimis, subtus glancotomentosis. Benth. I. c. In Mexico.

145. S. semiatrate Zuccar. ramis serice-tomentosis ; fol. petiolatis, ovatis, obtusis crenatis, cordatis rugosissimis subtus albo-tomentosis. Bentl. 1. c. In Mexico. ђ.

116. S. fruticosa Benth. caule humili ramosissimo ; fol. petiolatis ovatis, obtusis crenatis, corlatis, rugosissimis, subtus ramisque alho-tomentosis. Bentli. 1. c. In Mexico. ђ.

14\%. S. scorodomia Poir. fol. petiolatis, ovatis oblongisve, ohtusis, crenulatis, basi subcordatis, rugosissimis, subtus ramisque albo-tomentosis Benth. s. melissiodora Lag. s. hirta Schwk. In Mexico. ち. Cor. cacrulea hasi albida.

118. S. amarissima Orteg. caule ramoso patenti-piloso-setoso; fol. pctiolatis, ovatis cordalis crenatis rugosis subtus glancescentibus pubescentihus. s. circinata. Cav. ic. t. 318. s. amara Jacq. Schoulhr. t. 255 . \$. nepetoides H. et B. t. 150. In Nora Hispunia. 2-ped. Cor. caerulescens.

119. S. cuspiatate R. ei fol. petiolatis, ovalis ohtusis crenatis basi corcuatis, rugosis siatus pallidioribus ramiscae pubescentibus. Fl. peruv. t. 40. In Feru. 3-ped. Cor. caerulea.

150. S. cardioplyplla Bentle. ful. petiolatis ovatis crenatis, cordatis, rugosis ramisque utrinque villoso-pubescentibus. Benth. In America meridionali. ち.?

151. S. Gilliesii Denth. fol. petiolatis ovato-lanceolatis, obtusiusculis, crenato-dentatis, hasi truncatis cordatis rugosis ramisque subtus albo-to- 
mentosis. Benth. In Chile. t. Cor. caerulea?

152. S. racemosa $\boldsymbol{R}$. et $\boldsymbol{P}$. fol. cordatis acutis sublanceolatis, serratis; racemis terminalihus compositis; bracteis ovatis acuminatis 13 . et $P$. peruv. In Peru. Cor. caterulea.

153. S. carnea $H$. et $\boldsymbol{B}$. caule crecto glabro; fol. rotundato-ovatis, acutis, cordatis, crenato-serratis, calycibusque hirtis. H. et B. 1. g. et sp. pl. t. 151. In Nova Granata. ђ.

154. S. paleaefolia $H$. et B. caule ramisque pilosis; fol. cordato-sagitlatis, apice rotundatis, crenatis, utrinque hirtis subtus albicantibus. H. et B. 1. c. t. 15\%. In andibus novue Granatae. Cor. caerulea.

155. S. Mocurrens Benth. caule hasi repente, radicante, ramis adscendentibus; fol. petiolatis late ovatis; glabris hirtisve. Benth. I. c. In Americu meridionali.

156. S. propinqua Benth. caule basi repente demum adscendente fol. petiolatis ohovato-obtusis, crenatis ramisque hirtis. Bentlı. 1. c. In Brasilia.

15\%. S. ovalifolia St. Hil. caule repente; fol. brevissime petiolatis, ovatis, obtusis crenatis coriaceis ramisque adscendentibus, glabris. Benth. In Brasilia. Caul. nigricans.

158. S. lechnostachys Benth. caule repente; ramis adscendentibus hirsutis ; fol. sessilibus, ovato-oblongis, ohtusis crenatis rugosis subtus rufoluteis, tomentosis. Benth. 1. c. In Brasilia. 1-2-ped. Cor. cacrulea.

159. S, viscida St. Hil. ramis glauduloso-sctosis; fol. subsessilibus, ovato-lanceolatis, acutiusculis, serrato-crenatis cordatis, sub) hispidis. Benth, In Brasilia. †. 3-4-ped. Cor. caerulea.

160. S, covilata Ienth. caule crecto hirsuto; fol. sulppetiolatis ohlongoovatis acutis, crenatis, cordatis, mgosis, supra pubescentibus subtus albo-tomentosis, In Brasilia. 3-1-ped. Cor. cacrulea.

161. S. nerrosa Benth. caule subsimplici rufo-tomentoso; fol. subsessilibus subcordatis, acutis crenato-serratis, coriaceis, fllpra rigosis subtus rufo-tomentosis. Benth. I. c. In Brasilia. 2-3-ped. Cor. caerulascens.

162. S. rigjida Benth. fol. sessilibus lanccolatis linearibusque, basi cor- datis, crenatis, glabris, subcoriaceis rigidis. Benth. 1. c. In Brasilia. $1 \frac{1}{2}-$ ped. Cor. caerulea.

163. S. rosmarinoilles $\mathrm{st}$. Hil. ramis virgatis tomentoso-villosis; fol. sessilibus linearibus, acuminatis, crenatis, cordatis, rigidis subtus allotomentosis. Benth. 1. c. In Brasilia. 2-ped. spicae 1-ped. longae. Cor. cacrulea. albo-striaia.

16\%. S. axillaris Moc. et Sess. Msc. liunilis; fol. oblongo-linearihus, acutis, integerrimis, hasi attenuatis, setoso-scabris. Benth. 1. c. In Nov'a

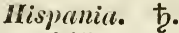

165. S. cuneifolia Benth. Iumilis ramis decumbentibus villosis; fol. sessilibus ovato-cuneiformibus, suhdentatis hasi attenuatis, utrinque viridibus. Benth. 1. c. In Nifexico. 1 1 -ped.

166. S. calaminticapolie Vaht; fol. ovatis crenatis incanis; pedunculis axillaribus verticillatis Valıl el. 1. p. 233. In st. Domingo. ђ. Cor. caerulea.

16\%. S. ballotaeflora Benth. Inmilis ; fol. petiolatis ovato-rotundatis, oltusis, crenatis, basi truncatis cordatisve subtus albo-tonentosis. Benth. I. c. In Mexico. ђ. Hruticulus ramosissimus.

163. S. buppleuroides Pressl. fol. petiolatis, ovatis, acutis, crenatoserratis, basi attentatis, utrincule viriclibus; ramis abbreviatis. Benth. In Mexico. Flor. minimi.

169. S. Mocinni Beuth. ramis adscendentibus; fol. petiolatis, ovatis acuminatis, serrato-crenatis, hasi cuneatis, glahriusculis. Benth. I. c. In Nova Hispania. Cor. cacrulea.

170. S. hirsuta Jac\%. Schocubr. $t$. 25. fol. lanceolatis ovatis remole serratis hirtis petiolatis; bracteis ciliato-pilosis. S. phlomoides Cav, ic. t. 320. \$. hractcata Poir. In Mexico. $\odot$ 1-ped. Cor. caerulca.

171. S. clinopodioirles $I I$. et $B$. caule superie albo-litnalo; fol. ovatis abtusiusculis basi rotumdatis crenatis subtus pubescentibus. Kunth. In Nora Hispania. 4. Cor. pallide cacrulca.

172. S. speciosa Presl, ramis superne allo-hirtis; fol. petiolatis, ovatis, acutis, serratix, hasi rotuldatis, rugosis supra pubescentihus suhtus albo-tomentosis. Benth. 1. c. In leru. 173. 5. Pastguernensis Iloc. et 
Sess. Msc. caule supcrne albo-tomentoso; fol. longe petiolatis, late ovatis, acutis, basi rotundatis, in petiolum alatum decurrentibus, utrinque pubescentibus. Benth. 1. c. In Nova Hispania. Cor. caerulea.

17t. S. macrostachya II. et B. hirla; fol. petiolatis, ovato-rotundis acutis basi profunde cordatis auriculatis, imbricatis, utriucue, subvillosis. Benth. In Peru. 3-ped.

17.5. S. Hathewsii Benth. ramis superne valde tomentosis; fol. petiolatis, late ovatis basi profunde cordatis, Jaxis, glabris utrinque viridibus. Benth. 1. c. In Peru.

1\%6. s. leucocephala $\boldsymbol{H}$. et $\boldsymbol{B}$. $l$. c. $t .1 .56$. caule fruticoso ; ramis glaucotomentosis fol. ovatis, obtusis, cordatis, crento-serratis, subtus glaucotomentosis. Kunth. In Peru. Cor. violacea.

17\%. S. breviflor Moris et Sess. IIsc. ramis 4-angulis glauco-tomensis; fol. petiolulatis, ovatis acutis, creuulatis, subcordatis subtus allotomentosis. Benth. In Nova Hispania et Mexico. †.

178. S. farinacea Benth. fol. petiolatis oblongo-ovatis inaequaliter serrato-crenatis, hasi attenuatis glabritsculis. Benth. 1. c. In Mexico.

179. S. revoluta $\boldsymbol{R}$. et $\boldsymbol{P}$. caule fruticoso; fol. lineari-lanceolatis crenatis margine revolutis; floribus secundis, calycibus corollisque tomentosis Fl. peruv. t. 41. f. b. In Peru. †. 3-ped. Cor. albo-violacea.

180. S. leucautha Car. fol. lanceolatis serratis rugosis subtus incanis; calycibus delsissime tomentosis subviolaceis. Cav. ic. t. 2t. In Mexico. 4. 5-ped. Cor. alba.

181. S, velutina Benth. ramis dense foliosis; fol. subpetiolatis oblongo-lanceolatis, obtusis crenatis, basi attenuatis, rugosis ramisque lanato-velutinis. Benth. In Brasilia. ち. Cor. alba.

182. S. eriocalyx Bertero; ramis patulis glanco-pubescentilus; fol. ohlongo-lanceolatis, acuninatis, serratis hasi cuneatis, subtus dense tomentosis. Benth. 1. c. In Jrmaica. †.

15.3. S. confertillover Pohl; fol. petiolatis oblongo-ovatis, acutis crenatis basi cuncatis petiolo decurrentibus, supra rugosis subtus ramisque fulvo-tomentosis. Pohl. In Brasilia. ち. Cor. rubescens.

131. S. Lasiantha Benth. ramis dense lanatis; fol. subsessilibus, oblongo-ovatis. ohtusis, crenatis, hasi cordatis supra rugoso-hispidis sublus albo-lanatis Benth. In Mexico.

18.5. S. tomentella Pohl; ramis fulvo-tomentosis; fol. sessilibus ohlongo-ovatis, obtusis, crenatis, hasi attenuatis, rugosis, sublus tomentosulis. Pohl. In Brasilia. ち. 2-3-ped. Cor. albo-lanata.

186. S. lutea H. et D. l. c. t. 113. ramis pilosis; fol. obloneris subacutis, cordatis crenatis supra glabris subtus albo-tomentosis; calyce glandulosopiloso. Kunth. In Quito. †. Cor. litea.

18\%. S. punctata R. et P. villosoviscosa; fol. oblongis extrorsum serratis, calycihus glauduloso-punctalis; lah. sup. tricuspidato. Wl. peruv. t. 39. f. b. In Pevi. t. 3-ped. roetida. Cor. alba.

135. S. Pavonii Benth. caule bifariam piloso; ramis superno villosoglandulosis; fol. petiolatis ovatis oltusis integerrimis glabris. Benth. 1. c. In Peru. Ђ. Cor. Intea.

189. S. integrifolia $\boldsymbol{R}$. et $P$. frulicosa; fol. integerrimis viscoso-resinosis aveniis; bracteis lanceolatis. Fl. peruv. t. 35. f. b. In Peru. ђ. 2-ped. Cor. crocea.

190. S. oppositiflora $R$. et $P$. fol. ovatis serratis rugosis obtusis; racemis terminalibus; floribus oppositis, Fl. peruv. t. 43. f. s. In Quito. ち. 2-ped. Cor. coccinea grate odora.

191. S. glumaced H. et B. ramis pubescentibus ; fol. ovatis obtusis cordatis subintegerrimis coriaceis glabriusculis. Kunth, In Nova Hispania. 方.

1.9\%: S. strictiflora Hook. ramis brevibus tomentoso-puhescentibus; fol. petiolatis ovatis acutis, crenato-serratis carnosis, glahriusculis. Benth. In Peru, t. \&-ped. Cor. croceo-purpurea.

19.3. S. tubiflora Sm. fol, cordatis crenatis subpilosis; floribus racemosis secundis suhgeminatis; calycilus pedicellisque lanatis. sim. ic. ined. 2. t. 26. In Lima. ち. Cor. coccinea.

19.1. S. leonuroilles Glox. ramis grlabris; fol. ovatis obtusis inacqualiter cordatis, serrato-crenatis, subtus 
incano-pubescentibus. Glox. in obs. hot. p. 15. t. 2. S. formosa L'Herit. stirp. t. 21. S. nodosa $\mathrm{H}$. et $P$. peruv. t. 41. f. a. In Peru. ち. Cor. coccinea.

1.95. S. plumosa $R$. et $P$. fol. sulucordato-ovatis crenatis acutis; caule fruticoso ferrugineo-subtomentoso; stylo plumoso. Fi. peruv. t. 37. f. a. In Peru. ち. 6-ped. Cor. purpurca.

196. S. balanstina Pohl; ic. bras. t. 189. fol. petiolatis oblongis acutis scrratis basi attenuatis, utrinque viridibus pilosis. Pohl. In Brasilia. †. Cor. coccinea.

19\%. S. asperifolia Benth. caule breve-pubescente; fol. sessilibus, ohlongis crenatis basi attennatis supra tuberculatis, rugosissimis, subtus glabriusculis. In Brasilia. ち. Cor. coccinea.

198. S. scabrida Poll. ic. bras. t. 19.5. fol. subsessilibus oblongo-lanceolatis, obtusis, crenatis hasi attenualis, supra scabro-tuberculatis subtus glabriusculis. In Brusilia. ち. Cor. purpurea.

199. s. persiciflor $\mathbf{S t}$. Hil. ramis superne hirsulis; fol. subsessilibus oblongo-lanceolatis, acuminatis, serratis, hasi attenuatis supra scabris subtus glabris. In Brasilia. ち. 5-7-ped. Cor. coccinea.

200. S. Mariana Mart. ramis villoso-tomentosis; fol. subsessilibus, oblongo-lanceolatis, utrinque attenuatis, supra hreve pilosis subtus pubescentibus. Cor. calyce duplo Iongiore. In Brasilia. †.

201. S. Ifilarii Benth. ramis glahis; fol. petiolatis oblongis s. ovatolanceolatis, acuminatis subserratis, hasi atlenuatis utrinque viridilus, glahris; cor. Ianata calyce duplo lougiore. Benth. In Brasilia. t).

202. Ss salicifolia loul l. c."t. 196. ramis puliescentilous s. fulvo-villosis; fol. subpetiolatis, oblongo-lanceolatis, orenato-serratis, utrinque attenuatis, glabris s. subtus fulvo-tomentosis.

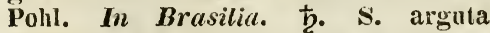
Benth.

203. S. Honkei Beuth. ramis glancotomentosis superne viscos $0 \sim$ villosis; fol. suhsessilihus ovato-lancelatis acutis serratis rugosis subtus allo-tomentosis. Benth. I. c. In Peru. Cor. coccinea. 201. S. tortuosa H. et It. rol. ovalo-lanceolatis acutis serratis hasi attenuatis, suhtus fusco-tomentosis; spicis secundis. In rupibus Americae. $\hbar$.

205. S. curviflora Bentle. ramis tomentoso-pubescentibus; fol. petiolatis oblongo-lanceolatis, acntis, crenatoserratis basi attenuatis, supra pubescentibus subtus tenerrime glaucotomentosis. Benth. 1. c. In Nexico. Cor. roseo-purpurea.

206. S. Neovidensis Renth. ramis pubescentibus; fol. petiolatis, ovalis acuminatis, serrato-crenatis, hasi subrotundis, suhtus pallide tomentosis; cor. calyce 4-plo longiore. Benth. In Brasilia. Cor. coccinea.

2017. S. fructicetorum Benth. fol. petiolutis, ovatis acuminatis serratis basi cuncatis utrinque viridibus glahriusculis. Bentl. In Brasilia. 4-ped. Cor. coccinea.

208. s. altissima Polı . c. t. 192. fol. petiolatis oblongo-ovatis, acutis, serratis, supra glabriusculis subtus pubcscentibus. In Brasilia. †. 6-ped. Cor. purpurea.

209. s. moschate H. et B. l. c. t. 14.5. fol. ovatis acutis hasi cuneatis serratis cauleque glabris ; corolla clongata galea augusta recta. Kunth. In Nova Granatu. b. 3-ped. Cor. purpurea.

210. S. hirtella Vaht; fol. ohlongis crenatis glabris; caule calycihusque hirto-viscosis; staminious longissimis. Vall en. 1. p. 249. In Peru. 4. 1-ped. Cor. coccinca.

211. S. secundu Benth. ramis pubescentibus; fol. petiolatis oblongis, utrinque attemuatis, acutis, serratis, supra hispidis subtus glabris. In Brasilia. Cor. coccinea.

212. S. ciliata Benth. ramis olongatis glabriusculis ; fol. petiolatis, ovatis acutis, crenalo-serratis hasi rotundis subcordatisque, glabriusculis. Benth. In Merico. Cor. coccinea.

213. S. eleyuns Valil; fol. ovatis acutis hasi acutiusculis serrato-crenatis, glahriusculis; corollis longissimis. s. incariata. H. et B. 1. c. t. 144. s. microcaulis Poir. In Mexico. ち. Cor. sanguinea.

214. S. mentiens Poll l. c. t. 1.93. fol. petiolatis ovatis, acuminatis scrratis hasi rotunciatis, utrinque viridibus, glabris. In Brasilia. $\frac{1}{2}-p e d$. Cor. amoene coecinea.

915. S. splenders Sello fol. ovatis 
utrinque glahris serratis; bracteis nullis; calycilus coloratis corollas excedentibus. B. H. 68\%. S. brasiliensis Spr. S. colorans Hortul. In Brasilia. 4. Cor. sordide rubra.

216. S. involucrata Cav. glahra; fol. cordato-ovatis acuminatis serratis; hracteis magnis coloratis deciduis ; corolla ventricosa Cav. ic. t. 105, In Mexico. †. 4-ped. Cor. rosea.

21\%. S. Sessei Benth. fol. petiolatis oblongo-ovatis, acuminatis basi rotundatis, utrinque glabris s. subtus pubescentihus; corolla calyce triplo longiore. S. calyciflora Moc. et Sess. In Nova IIispania. Ђ. Cor. coccinea.

218. S. pubescens Benth. ramis tomeutoso-pubescentibus; fol. petiolatis ovatis obtusiusculis basi rotundatis rugosis supra pubescentibus subtus glauco-villosis. Andr. In Mexico.

21.9. S. agglutinans Lag. fol. cordatis, ovato-ianceolatis, acutis serratis suhtus glaucis; corolla pubescente calyce 4-plo longiore; caule setosoviscoso. S. fruticosa Moc. et Sessé. In Nova Hispania. Cor. coccinea.

220. S. Regla Cav. ic. $t$. 495. fol. petiolatis, rotundatis, obtusis, sinuatocrenatis, liasi late cordatis, coriaceis, rugosis, supra hispidis subtus pubescentibus. S. deltoidea Pers. In Mexico. 24. 3-ped. Cor. coccinea.

221. S. Grahami Benth. ramis tenuissime 2-fariam pilosis; fol. petiolatis, ovatis, obtusis, hasi rotumdatis, medio crenulatis glabriusculis. Grah. B. R. 1370. In Mexico.

222. S. microphylla $\boldsymbol{H}$. et $\boldsymbol{B}$. ramis foliisque subtus tenuissime puhescentilus, ovatis obtusis basi rotundato-trumcatis crenatis. Kunth. In Nova Hispania. ち. 1-ped. Cor. purpurascens.

223. S. subrotunda St. Hil. ramosa glabra; fol. petiolatis lato-ovatis, suhrotundis octusiusculis, crenato-serratis, glabris. Benth. 1. c. In Brasilia.

22t. S. coccinea $L$. fol. cordatis tomentosis serratis; corollis calyce duplo longioribus Linn. suppl. S. rosea Vahl. glaucescens Pohl ic. t. 192. In brasilia. 24. 1-2-ped. Cor, coccinea.

22.5. S. pseudoccinea Jacq. ramis pilosis; fol. oblongo-ovatis acutis subcordatis crenatis subtus cano-pubescentibus. Jacq. ic. t. 209. In Nova Andalusia. \$.
226. S. lineate Benth. ramis hifariam pilosis; fol. petiolatis ovatis ohtusis crenatis hasi truncatis utrinque viridibus, pubescentibus; stylo plumoso. In Merico.

22\%. S. phoenicea H. et B. $l$. c. t. 155. ramis muricato-hispidis; fol. ovatis acutis subcordatis serratis glabris; calycilus hispido-glandulosis. Kunth. In Quito. ‡. 4-ped. Cor. sanguinea.

228. S. milchella DC. fol. cordatis acutis glahriusculis crenatis sumnis sessilibus; corollarum galea hirta integra. DC. Hort. Monsp. t. 34. In America meridionali. $\hbar$. Cor. coccinea.

229. S. fulgens Cav. caule herbaceo; fol. cordato-ovatis crenatis subtus incanis; corollarum galea villosa. Cav. ic. t. 23. S. cardinalis $H$. et $B$. 1. c. t. 151. In Mexico. 4. 3-ped. Cor. coccinea.

330. S. rubescens $H$. et B. I. c. $t$. 1.5t. caule ramis muricato-hispidis; fol. ovatis acutis subcordatis serratis glabris. Kunth. In Quito. ち. Cor. amoene purpurea.

231. S. stqualens $\boldsymbol{H}$. et $\boldsymbol{B}$. caule ramisque piloso-glutinosis; fol. ovatooblongis obtusis cordatis crenatis coriaceis supra rugosis subtus incanotomentosis. Kunth. In Peru. Ђ. Rami et Cer. purpurea.

232. S. Ayavacensis $H$. et $\boldsymbol{B}$. caule ramisque flavo-hirsutis; fol.ovatis acutis cordatis crenatis subtus pilosis. Kunth. In Peru. ђ. 6-ped. Cor. purpurea ex Boupl.

233. S. acuminata $\boldsymbol{R}$. et $\boldsymbol{P}$. hirsuta viscosa; fol. cordatis acute serratis altenuatis rugosis; bracteis coloratis longitudine calycis. Fl. peruv. t. 37. f. b. In Peru. 24. Caul. 6-ped. Cor. incarnata.

231. S. longiflora $\boldsymbol{R}$. et $\boldsymbol{P}$. pubescenti-viscosa; fol. cordatis acutis bicrenatis; racemis nutantibus; bracteis calycilousque coloratis; corollis longissimis. Fl. peruv. t. 40. f. a. In Peru. ந. 18-ped. Cor. alba.

235. S. rumicifolia $H$. et $B$, caule ramisque pubescenti-hirtis; fol. oblongis hastatis obtusiusculis crenatis subtus incanis et tomentoso-lanatis. Kunth. In Quito, ち. 4-5-ped,

236. S. vitifolia Benth. caule villoso; fol. petiolatis late-deltoideis, angulato-lobatis, hasi truncato-hastatis, 
crassis ntrinque villoso-hirtis sulotus fulvis. Benth. 1. c. In Mexico. Cor. cacrulea.

2337. S. petiolaris $\boldsymbol{I r}$. et $\boldsymbol{H}$. canle ramoso tenuissime puhescente; fol. longissime petiolatis deltoideis, cordato-lastatis obfusinsculis irregulariter crenato-serratis hirtis. Kuuth. In I'eru. 2. $1 \frac{1}{2}$-ped. Cor. caerulea.

23s. A. sayittata $\boldsymbol{W}$. et $\boldsymbol{P}$. villosoviscosa; fol. hastatis inaequaliter crenatis subtus incanis; racemis compositis secuudis. Fl. peruv. t. 35. f. a. In Peru. 24. Cor. caerulea.

239. S. macrophylla Benth. caule erecto piloso-hispido; fol. longe petiolatis late ovatis cordatis superioribus hastatis, rugulosis, utrinque viridibus, hispidis. Benth. In Peru. Cor., caerulea.

2t0. S. scutellarioides $\boldsymbol{I}$. et $\boldsymbol{B}$. caule adscentiente; ramis piloso-pubescentibus; fol. petiolatis ovato-deltoideis, acutiusculis crenato-serratis; ntrinque hispidis. Kunth. In Quito. 24. Cor. caerulea.

211. S. patens Cav. ic. t. 4.54. caule piloso; fol. subhastatis crenatoserratis subtus incanis; flor. axillaribus terminalibusque oppositis. Cav. In Nova Hisqunia. 2-ped. Cor. caerulea.

212. S. longistyla Benth. caule tomentoso-villoso; fol. petiolatis late ovatis acuminatis, crenatis hasi late cordatis, rugosis, utrinque villosiusculis. Bentl.. 1. c. In Mexico. Cor. caerulea.

243. S. amethystina Sm. ic. ined. t. 2\%. fol. cordatis acutis serratis subtus lanatis; verticillis nudis; calycibus 3-fidis; corollis pubescentibus sim. In Nova Granata. 24. Cor. viridissime violacea.

241. S. Karuinski Benth. fol. petiolatis ovatis acuminatis crenatis, basi rotundatis supra rugosis subtus ramisque fulvo-lanatis. Benth. In Mexico.

245. S. cyanea Benth, ramis 4-angularibus glauco-pubescentibus; fol. petiolatis ovatis acuminatis, crenato-serratis basi cordatis, utrinque pubescentibus. Benth. In Nora Hispania. 4.

216. S. mexicana $L$. caule crecto ramoso pubescente; fol. ovatis acuminatis dentato-serratis supra pubescentibus subtus tenuissime cano-tomentosis. Cav. 1. c. t. 26. S. melissaefolia
Desf. S. papilionacea Cav. ic. t, 319. In Mexico. t. Cor. violacea.

247. N. ulabrata If. et b. caule fruticoso ereoto foliisque glahris subrotundis aculis argute serratis, cordatis. Kumth. In Aora Audulusia, t. 3-ped. Cor. ex Bonpl. violacea.

248. .'. concolor Herb, C'amb. ranis glahris; fol. petiolatis, ovatis, acumilatis serratis, basi truncatis, glabris. In Mexico. ち. Cor. caerulea. 219. N. caernleu Benth. ramis glabris s. patenti-pilosis; fol. ovatis actminatis, basi truncatis rotundato-cordatis, petiolatis glabris. Benth. 1. c. In Brusilia. Cor. caerulea.

2.50. s. Cav. ic. t. 2.5. caule glahriusculo; fol. petiolatis, late ovatis crenato-serratis, basi rotundato-truncatis, subtus subglaucescenti-pilosis. Benth. 1. c. S. longiflora Willd. In Mexico. Cor. violacea.

251. S. guaruntica $\mathbf{s t}$. Hit. ramis patenti-pilosis fol. petiolatis, ovatis, acutis serratis basi trumcato-cordatis, rugosissimis, subtus albo-tomentosis. Benth. 1. c. In Brasilia. Cor. caerulea.

252. S. Iamiifolia Jacq. Schonbr. t. 318. caule fruticoso fol. petiolatis ovatis crenato-serratis, basi rotundatis s. cuneatis glabris. Bentl. l. c. s. Boosiana Jacq. 's. hyemalis Boose. s. cyanea Fisch. S. amoena sims. S. azurea et caerulea Hortul. In ins. St. l'incenti, Andersonii et Trinitatis. Cor. caerulea.

2.53. S. affinis Chamiss. caule frutticoso, ramis glabris; fol. petiolatis ovatis acuminatis serrato-crenatis, basi rotundis glabris s. pubescentihus. Benth. 1. c. In Mexico. Cor. pallide violacea.

251. S. purpurea Cav. ic. t. 166. fol. ovatis serratis attenuatis glahris; petiolis hasi 2-glandulosis; calycibus tomentosis coloratis. Cav. In Mexico. 4. Caul. 6-ped. Cor. violacea.

25.5. S. cupheaefolin $\boldsymbol{H}$. et $\boldsymbol{B}$. caule bifariam piloso; fol. elliptico-ovatis, ohtusiusculis, hasi acutis, crenatis, glabris, margine setosis. Kunth. In sylvis Peruviue.

2.56. S. v'ufula H. et $\boldsymbol{B}$. caule subfruticoso erecto, foliisque ovatis acuminatis basi attenuatis serratis sulitus tomentoso-rufis. In Nova Granata. ち.

25\%. S. Tolimensis B. et B. caule futicoso, erecto rufo-pubescenti; fol. 
ovato-lanceolatis, acutis, crenato-serratis subtus dense pubescentibus. Kunth. In America. $ᄒ$.

25S. S. discolor H. et $\boldsymbol{B}$. caule erecto glauco-tomentoso ramis junioribus viscidlis; fol. ovato-lanceolatis, tomentosulis hasi rotundatis, integerrinis, subtus albo-tomentosis. Kunth. In alpibus peruvianis. $\hbar$. Cor. splendide violacea.

2.5.9. s. acutifolia $R$. et $\boldsymbol{P}$. fol. cordatis acutis, olutuse serratis; spicis verticillatis. HI. peruv. 1. t. 38. In Peru. Caul. 3-ped. Cor. purpurea. 260. S. paucifiora H. et B. caule suffruticoso, erecto; ramis setosis; fol. ovatis, ohtusis, cordatis crenatis subtus glaucescenti-tomentosulis. Kunth. In Nora Ilispania. ち.

261. S. carducicea Bentli. caule sinullici albo-lanato; fol. petiolatis, obIongis pinnatifidis, suhtus albo-lanatis. Benth. 1. c. In California.

262. S. Columbariae Benth. caule herbaceo erecto pauciramoso ; fol. piofunte pimatifidis, rugosis pilosiusculis, lohis ohlongo-linearihus, obtusis, eroso-dentatis. Benth. In California.

263. S. nilotica Vaht; fol. cordato-ovatis crenatis rugosis villosis; fioribus verticillatis; calycibus mucronatis. Jaeq. Vind. t. 92. s. abyssinica L. In Aegypto. 24. Caul. 2-ped. Cor. purpureo-caerulea.

264. S. sylvicola Burch. canle adscendente villoso, fol. hreve petiolatis late ovatis, acutis dentatis, hasi cordatis, sublobatis utrinque hirtis. Bentl. 1. c. In Prom. b. spei. Caul. 2-ped. Cor. hirsuta.

265. S. tenuifolia Burch. caule ramoso, tomentoso; fol. longe petiolatis, ovato-rotundatis, obtusis, dentatis s. laciniatis, basi subcordatis subhastatis. utrinque villosis. Bentl. In Prom. b. spei. $\frac{1}{2}-1-p e d$. Cor. caerulea.

266. S. aurita Thunb. cap. 69. caule erecto villoso; fol. petiofatis lyrato-pinnatifidis, s. semipinuatis; laciniis eroso-dentatis, subtus venosis glatuco-pilosis. Benth. In Prom. $b$. sipei.

267. S. scabra Thunb. caule paniculatim ramoso; fol. Iyrato-pinnatifillis, rugoso-scahris, margine crosocrispis subtus venosis glaucescentibus. Benth. In Prom. b. spei. Caul.
268. S. runcinata $L$. herhacea scabra; fol. rumcinato-pinnatifidis rugosis dentatis; ramis flexuosis. Thunb. cap. p. 97. Jacq. schenbr. t. 8. In Prom. b. spei. Caul. ped.

269. S. stenoplyylla Burch, herbacea erecta, glabriuscula; fol. petiolatis ohlongo-lanceolatis, runcinatis subpimatifidis, rugosis. Benth. In Prom. b. spei.

270. S. repens Burch. caule basi repente, folioso; fol. subradicalibus petiolatis elongatis; runcinato-pinuatifidis subrugosis. Benth. In prom. $b$. spei.

271. S. lypata $I$. fol. radicalihus lyratis dentatis; corollarum galea brevissima; caule subaphyllo retrorsum piloso. Limn. Melissa atrorubens etc. Dill. f. 216. In rirginia et Carolina. 4. Spithanca. Cor purpureo-violacea.

272. S. obovata Elliot. caule subpiloso; fol. late ohovatis, integris, simuatis, glabriusculis, basi attenuatis. Benth. l. c. In America boreali.

2\%3. S. acaulis Vahl; fol. radicalibus obovato-oblongis petiolatis; scapo piloso. Vahl en. 1. p. 257. In Indic orientali. Caul. $\frac{1}{2}-$ ped.

27. S. japonica Thunb. jap. t. 5. fol. inferioribus bipinnatis, superioribus pimatis foliolis obovatis sinuatodentatis, supremis indivisis lanceolatis. Thunb. In Japonia. ๑. 1-2-ped. Cor. rubra.

275. S. chinensis Benth. caule erecto pubescente; fol. petiolatis, integris, s. inferioribus 3-fidis, late ovatis, obtusis crenatis, basi cordatis. Benth. In China.

2\%6. S. triangularis Thunb. villosa, hispida; fol. triangularibus dentatis; ramis patentibus. Thunb. In Prom. b. spei.

277. S. obtusata Thunb. villosa; fol. ovatis profunde crenatis; ramis tortis. Thunb. cap. 97. In Prom. $b$. spei. Caul. ped.

278. S. Claytoni Elliot. fol. cordato-ovatis, sinuatis dentatis rugosis; calycis dentihus lah. superioris controversis. In Carolina.

279. S. plebija R. Br. fol. Ianceolatis crenatis tenuissime pubescentibus omnihus petiolatis; vertieillis distinctis; bracteis parvis. R. Br. prodr. 1. p. 501. In Nora Hollandia. s. brachiata Roxb. Lumnitzera fastigiata 
Spr. In China et Australia. Caul. 2-3-ped.

280. S. pumila Benth. caule cacspitoso; pilis longis harbato; fol. sessilibns, lancoolato-linearibus, acutis dentatis, basi in petiolum atfenuatis. Benth. S. aegyptiaca. Jacq. Vind. t. 108. Thymus hirtus Viv. f. Lib. t. 14. f. 1. In Africe. Caul. 6-9-pollicaris.

231. S. saxicolı Wall. caule caespitoso basi ramoso; fol. radicalilus rotundato-cordatis, crenatis, glabris : caulinis ovato-lanceolatis, profunde dentatis. In India orientali et $\mathrm{Ne}$ qualia. Caul. $\frac{\mathrm{I}}{2}-1 \frac{\mathrm{I}}{2}-$ ped. Cor. caerulescens.

282. S. verticillata I. fol, cordatohastatis duplicato-crenatis obtusis basi subauriculatis; verticillis multifloris subsecundis, stylo deflexo. Alb. Dietr. Nirhel Ann. d. Mus. 15. t. 15. f. 10. In Europa orientali et australi. 4. Caul. 1 $\frac{1}{2}$-ped. Cor. caerulea.

283. S. napifolia Jac\%. Vind. t. 152. caule erecto piloso-hispido; fol. inferiorihus lyratis lobis maximis, superioribus ovato-oblongis, sinuatocrenatis, basi cordatis, utrinque subvillosis. Benth. I. c. In Criente.

284. S. Russelli Benth. caule pubescente; fol. petiolatis oblongis acutis, sinualo-dentatis, crassis, rugosis utrinque albo-lanatis. Benth. In Syria.

\section{0t. ROSMARINUS Columell.}

1. S. officinalis $L$. Sibth. graec. t. 14. Fruticosus $2-4-p e d$. dense ramosus et foliosus. Folia sessilia, linearia, integerrima margine revoluta, subtus incano-lomentosa. Cor. albidocaerulea. In Europa australi, Africa boreali et Oriente. $\hbar$.

2. R. chilensis Mollin. fol. petiolatis. In Chili, †.

\section{COLLINSONIA Linn. (1739).}

1. C. canadensis L. Hort. Cliff. t. 5. caule glabro; fol. corlato-ovatis pilosiusculis serratis superioribus integerrimis; panicula terminali composita. Alb. Dietr. In America boreali. 4. Caul. 2-3-ped. Cor. nava.

2. C. ovalis Pursh; fol. ovatis utrinque subulatis cauleque glabris; petiolis longissimis; dentibus calycis brevissimis. Purslı. Fl. am. hor. 1. p. 21. In Carolina austrati. 24. Cor. flava.

3. C. verticillata Baldu". fol. verivillatis oblongis acuminatis; racemo verlicillato-terminali. Baldw. in Elliot. bot. p. 187. In Georyia. Caul. ped. Cor. purpurea.

4. C. punctata Elliot; fol. ovatolanceolatis acuminatis dentatis subtus pubescentihus paniculaque romposita resinoso-punctatis. Elliot. Bot. p. 187. In Carolina australi. 4. Caul. 2-6ped. Cor. flava.

5. C. scabrinscula Ait. fol. subcordato-ovatis acutiusculis supra scahris subtus cauleque pilosiusculis. Ait. Kew. C. scabra Pers. C. praecox Walt. In Floricia. 24. Caul. 2-3-ped. Cor. flava.

6. C. tuberosa Michx. radice tuberosa; caule ramoso sulvvilloso; fol. subrhombeo-oblongis utrinque attenuatis glabris. Michx. am. 1. p. 17. C. serotina Walt. In Carolina. Caul. 3-1-ped. Cor. flava.

\%. C. anisata Pursh; fol. cordatoovatis rugosis supra glabriusculis subtus cauleque ranoso pubescentihus; forihns tetrandris. Pursi am. p. 21, In Carolina merillionali. 4. Caul. 2-ped. Cor. pallide flavicans.

\section{ZIZIPHORA L. (1836).}

1. Z. clinopodioiles ram. fol. ovato-lanceolatis acutis integerrimis puherulis; foralibus nudis; calycihus pube adpressa canescentibus Lam. ill. 1. p. 63. Z. capitata Falk. Cunila 1. In Altaicis et Armenia iberica. t. Caul. ped. Cor. caerulescens.

2. 'Z. mediu Link; fol. ovalis acutis integerrimis $s$. denticulatis glabriusculis; calycibus pilis patentibus hispidis Link en. 1. p. 17. '/. clinopodioides $\beta$. Rudolph. Mem. Petersb. 1810. t. 11. In Sibiria et Altaica. b.

3. Z. serpyllacea M. a Bipb. fol. lineari-lanceolatis integerrimis s. subdenticulatis nudis; calycibus pilis brevissimis reflexis M. a. Bieb. taur. cauc. 1. p. 18. Z. Mussini Adam. Z. odoratissima Lodd. In Cancuso et lleria. †. Caul. suffiruticosus, Cor. roseo-lilacina.

4. Z.. dasyantha IM. a Bieb. fol. subrotundo-ovatis acuninatis cronatis 
basi subciliatis; floribus capitato-spicatis; calycihus undique hirsutissimis. M. a Bieb. Z. Puschlini Adam. In Caucaso.

5. $Z$. capitata $L$. fol. Ianceolatis intecrerrimis glahriusculis, floralihus ovatis cuspidato-acuminatis ciliatis; floribus capitatis; calycilous hispidis Linn. sp. pl. 1. p. 31. Buxb. Cent. t. 51. f. 1. In Sibiria, Tauria, Armenia et syria. $\odot$.

6. 2 . tenuis $L$. fol. integerrimis ciliatis; inferioribus ovato-oblongis; floralihus lanceolatis; calycibus hispidis. Limm. 1. c. Acinos Moris. sect. II. t. 19. f. 3, 4. In Syria et Altaica. $\odot$. Caul. $\frac{1}{2}$-ped. Cor. lilacina.

\%. "z. taurica Bieb. fol. Ianceolatis integerrimis ciliatis; floribus lateralihus; calycilus hirtis; corollis fauce inflatis. Biei. pl. ross. t. 82. In saxosis calcariis Tauriae. $\odot$.

8. $Z$. acinoiles Limn. fol. ciliatis inferioribus ovato-orluiculatis acuminatis subdenticulatis, superioribus ovatis integerrimis. Lam. In Sibiria. $\odot$. Caul. 9-12-poll. Cor. rosea.

9. \%. hispanica Linn. fol. ovatis; floralilus ohovatis nervosis acutis; floribus racemoso-spicatis. Lim. Caul. palmaris. In Hispania. $\odot$.

10. Z. pungens Runge; fol. petiolatis oblongis profunde dentatis superiorihus bracteisque integerrimis cuspidatis pubescentibus. Ledeb. pl. ross. t. 124. In monte Arkaul. ๑. 4-7-pollicaris. Cor. albida v. rubella.

11. 'Z. javanica Blume; fol. petiolatis repando grosse-serratis, utrinque cauleque prostrato pubescentibus. Blume Bydr. 822. In Jav'a.

\section{0\%. CUNILA L. (1761).}

1. C. mariana $L$. fol. subsessilibus ovatis serratis glabris; calyce 10-striato, fauce barbato. Ziziphora $R$. et S. Calamintha Plukn. t. 344. f. 1. In Virginia et Carolina. 24. Caul. 1-2-ped. Cor. allsa.

2. C. incisa Benth. fol. petiolatis ovato-rhombeis, profunde partitis, dentatis, hasi integerrimis, cumeatis ; cor. intus pubescente. Benth. 1. c. In $B r a-$ silia. t.

3. C. angustifolia Benth. fol. breve petiolatis elliptico-linearibus integris dentatisve glabris. Bentl. In Brasi- lic. ち. Fruticulus dense foliosus ramis 4-angulis.

4. C. incana Benth. fol. petiolatis, ovato-oblongis et obovatis, obtusis utrinque albo-tomentosis. In Brasilia. t.

5. C. lencantha Benth. herbacea glabra; fol. breve petiolatis, ovatom oblongis integerrimis basi rotundatis: caule 4-angulo. Benth. I. c. In IIexico. ち. Cor. alha intus pilosa.

6. c. potycintha Benth. caule erecto pubescente; fol. breve petiolatis, ovatis subserratis, basi rotundatis. Benth. in Mexico. 4. Caul. ped. Verticilli 40-50-flori. Cor. alba.

\%. C. lythrifolic Benth. caule erecto puhescente; fol. oblongo-lanceolatis, serratis; calyci hus villosissimis. Benth. In Mexico. Caul. ped. Folia 2-poll. spicae 1-2-poll. longae.

8. C. spicata Benth. decumbens; ramis villosis; fol. breve petiolatis obovato-ohlongis, obtusis remote serratis, hasi attenuatis. Benth. I. c. In Brosilia. Caul. 4-angulus pilis fasciculatis tectus.

9. C. strictu Benth. herhacea; caule stricto; fol. linearibus obtusis, integerrimis strictis. Benth. In Brasilia. Caul. 1-2-ped. Cal. 13-15-costatus. Cor. alba.

10. C. menthoides Benth. herbacea decumbens; ramis villosis; fol. petiolatis late ovatis obtusis subcrenatis hasi rotundatis. Benth. In Brasilia. hami elongati, pilis patentissimi stecti.

11. $C$, galioides Bentl. fruticulo decumbente; fol. parvis, fasciculatis lanceolatis, ohtusiusculis integerrimis. In Brasilia. †. Corolla pallide caerulea.

12. C. fasciculata Benth. fruticulo decumbente; ramis piloso-setosis; fol. sessilibus fasciculatis, oblongis ohtusis integerrimis margine revolutis utrinque setosis. In Brasilia. $\hbar$.

13. C. microcephala Benth. herbacea decumbens; ramis subpubescentibus; fol. petiolatis oblongis s. oblongoovatis obtusis sub sinuatis. Benth. 1. c. 4. Cor. alba.

\section{MONARDA L. (1738).}

1. $\boldsymbol{M}$. didyma $\boldsymbol{L}$. fol. petiolatis ovato-lanceolatis, acuminatis, basi lo- 
tnndatis, subcordatis, utrinque setosis. var.

B. purpurea Pursh. fol. glabriusculis; capitulis magnis foliosis; bracteis exteriorihus magnis latis ovatis, scuminatis, coloratis, scrratis; calycibus coloratis fauce barbatis.

r. Liulmiuna Pur'sh. fol. sparse setonis; capitulis maximis ovatis; bracteis exteriorihus coloratis, lanceolatis, attenuatis; calycecorollaque pubescente. Benth.

In America boreali. 4. Caul, fistulosus 2-ped. argute 4-gonus. Cor. cocciuea.

2. M. fistulosa $I_{\text {. }}$ fol. petiolatis ovato-lanceolatis basi rotundatis, subcordatis, glahris s. setoso-pubescentibus. Bentli. M. clinopodia L. M. altissima Kchl. M. affinis Link. M. involucrata. WVend. M. menthaefolia B. M. 2958. In Africa boreali. 24. Caul. 2-5-ped. Cor. pallide purpurea.

3. M. Bradburniana Beck; fol. subsessilibus ovato-lanceolatis, hasi rotundatis, subtus glauco-tomentosis. Bcnth. 1. c. In America boreali. 4. Caul. 3-ped. Cor. pallide rubro-puncrata.

f. M. Russeliana Nutt. glabriuscula; fol. subsessilibus lauceolatis, basi rotundatis sucordatis. Benth. 1. c. In America boreali. 24. Cor. gracilis inferne punctata.

5. M. punctata L. pubescens; fol. petiolatis lanceolatis, basi attenuatis; floralibus bracteisque exterioribus sessilibus, basi longe attenuatis coloratis. Benth 1. c. M. lutea B. R. 87. B. Fep. t. 546. In America boreali. 4.

6. M. aristata Nutt. albicans; fol. oblongo-lanceolatis basi attenuatis, sessilibus bracteisque exter. sessilibus coloratis, subulato-aristatis. Beuth. M. eitriodora Cerv. In America boreali.

\section{Species non satis notae.}

\%. M. scabra Beck. perennis, subpilosa; fol. ovato-lanceolatis, sulccordatis, serratis, margine revolutis, asperis, crassis punctatis subvillosis. Beck. in Sillim Am. jour. 10. 260. In America boreali. 24 . 3-ped.

8. M. gracilis l'ursh. glaberrima; fol. hineari-lanceolatis, acummatis, serratis; bracteis exter. linearibus ciliatis. Pursh. am. p. 17. In America boreali. 4.
9. M. ciliate Raf: fol. sessilihus ovato-oblongis, basi attenuatis, subtus glaucis, floralihus bracteisque exteriorilus ovatis acutis coloratis. Blephilia Benth. In America boreali. 4.

10. M. liirsuta Pursh. fol. petiolatis ovatis hasi corlato-subrotundis, utriuque hirsutis; bracteis superiorilous lineari-subulatis; calycibus recurvis. Blephilia Benth. M. ciliata Pursh. In America boreali. 4.

\section{HOSLUNDIA Vahl (1801).}

1. H. opposita Vall; fol. ovatooblongis, oppositis. Vahl en. 1. p. 212. Fl. d'oware t. 33. In Guinea. 4. 3-ped, ramosissima. Flor. alhi.

2. H. verticillata Vahl; fol. ternatis verticillatis. Vahl 1. c. All flumen Senegal. . . Flor. parvi villosoalbicantes.

\section{AMETHYSTEA L. (1718).}

1. A. caeruled I. A. corymbosa Pers. A. montana Hall. Act. Ups. 1742. f. 4. Lycopus amethystiuus stev. Mem. Mosc. t. 5. 1-2-ped. caerulescens. Folia 3-fida laciniis lanceolatis serratopartitis; pedunculis 3 -fidis. In Sibiria. $\odot$.

\section{LYCOPUS L. (1737).}

1. L. europaeus $L$. fol. ovato-lanceolatis, villosis, sinuato-serratis. Vahl el. 1. p. 210. L. palustris Lam. ill. t. 18. L. vulgaris Pers. In Europa et America boreali. 4. 2-3-ped. Cor. albida rubro-variegata.

2. L. exaltatus $L$. fol. basi pinnatifido-serratis; laciniis integris serratisque. Vahl en.1. p. 210. Sibth. graec. t. 13. In Europa et America boreali. 4. 5-ped.

3. L. australis R. Br. fol. lanceolatis acuminatis serratis pubescentibus, supra glabris subtus glandulosis; basi attenuatis. R. Br. prodr. 1. p. 500. In Nova Hollandia.

1. L. angustifolius Elliot. fol. lanceolatis serratis; calyx 5 -fidus; laciniis spinoso-acuminatis. Elliot. L. sinuatus Elliot. In Carolina et Georgia. 4. 
5. L. virginicus $L$. fol. lanceolatis inferiorilus hasi pinnatifidis superioribus remote serratis cauleque glabris. Vahl 1. c. L. ruhellus Wenderoth. In Virginia et Carolina. 24. 1-2-ped. Cor. rubro-allida.

6. L. uniflor'us Michx. fol. Ianceolatis subserratis, ylahris; stolonibus decumbentibus. Vahl 1. c. sub. L. pumilo. In Canada.

\%. L. obtusifolius Michx. fol. lanceolatis, remote obtuseque serratis. Vahl 1. c. Ad firetum Hudsonis. Caul. palmaris,

\section{STACHYTARPHETA Vahl (180t).}

1. S. angustifolia Vahl; fol. Ianceolatis, utrinque attenuatis, remote serratis, glabris. Vahl en. 1. p. 205. Verbena indica Jacq. ohs. t. 86. In America merilionali. $\odot$.

2. S. indica l'ahl; fol. oblongolanceolatis basi attemnatis, remote dentatis canleque glaberrimis. Vahl en. 1. p. 206. Verhena $\mathrm{L}$, In Keylonia et Guinea. $\odot$. spicae pedales.

3. s. elatior schrad. caule herbaceo; fol. lineari-lanceolatis, utrinque, remote serratis scabris carina margineque ciliatis; spicis longissimis. Schrad. In Brusiliu. $\odot$. Caul. 4-5-ped. spica $1 \frac{1}{2}$-ped. Cor. violacea.

t. S. aristata Vahl; fol. lanceolatooblongis serratis, acutis subtus glancescentibus; hracteis ovatis acuminatis. Vahl ell. 1. p. 206. Verhena Vahl Ecl. 2. f. 11. In America meridionali. †. Rami purpureo-cinerei.

5. s. jamaicensis Vahl; caule herhaceo; fol. ovali-oblongis serratis ciliatis supra scabris. Vahl en. 1. p. 206. Verbena L. Sloane Hist. t. 107. f. 1. In Americu. $\odot$. Cor. caerulea.

6.S.urticaefolia Sims. glabriuscula; fol. ovatis acutis usque basin serratis; bracteis subulatis calyce adpresso brevioribus B. M. 1814. Zapania Poir. Hab.? 4. Cor. violacea.

7. S. dichotoma Vahl; fol. ovatis apice angustatis crenulatis supra scabris subtus cano-hirtis. Vahl 1. c. Verbena $R$. et $P$. peruv. t. 34. In Peru et Mexico. †. Cor. violacea.

8. S. lirta $H$. et $B$. fol. ovatis apice angustatis crenato-serratis supra scabriusculis subtus cano-hirtis. Kuntl.
In Nora Grancita. ち. Caul. 4-gonus. Cor. pallide violacea.

10. S. marginata rahl; fol. ovatosubrotundis dentato-serratis glabris, dentibus margine cartilagineis. Vahl ell. 1. p. 207. In India occidentuli. t. spica $\frac{I}{2}-$ ped.

11. S. strigosa Vahl; caule suffruticoso ramis foliisque ovato-oblongis crenato-serratis pilosis. Vahl l. c. In India occidentali. ‡. Spica palmaris.

12. S. cajanensis Vahl; fol. ovatis crenato-serratis obtusissimis glabris; bracteis subulato-aristatis. Vahl. 1. c. Verbena Rich. In Cajenna et Novi Andalusia. Ђ. Cor. caerulea.

13. S. mubrosa $I$. et $B$, fol. oblongo-ovatis utrinque acutis grosse et argute serratis utrinque glahris. Kunth. In Cumana. ち. Cor. caerulea.

11. S. cunescens $H$. et $B$. fol. ovato-ellipticis acutis serratis villosocanescentibus; hracteis lanceolatis suhulato-aristatis. Kunth. In Peruvia. $ђ$. Caul. densissime villosus. Cor. violacea.

13. S. orubica V'ahl; fol. rhombeoovatis acutis serratis utrinque pubescenti-scahriusculis; bracteis subrotundis cuspidato-subulatis Verbena $\mathbf{L}$. Ehret pict. t. 5. f. 1. In ins. Oruba et in Nova Grunata. ち. 6-ped. Cor. violacea.

14. S. mutabilis Trhl; fol. ovatis serratis rugosis, superne scabris subtus incano-pubescentibus. Vahl. 1. c. Vent. malm. t. 36. s. Zuccagni R. et S. In America meridionali. †. Corolla coccinea tum rosea,

17. S. prismatica Vahl; fol. ovatis acutis serratis glabriusculis; bracteis subulatis calyce brevioribus. Vahl. Verbena L. Jacq. ic. t. 108. In America meridionali. Cor. caerulea.

18. S. crassifolia Schrad. fol. oblongo-ovatis obtusis serrato-crenatis supra glabris subtus venoso-reticulatis pubescentibus. Schrad. In Brasilia. $\hbar$. Cor. violacea.

19. S. quadrangula Nees; caule 4-angulo; fol. ovatis aculis crenatoserratis subtus scabris. Nees. In Brasilia. ち. Cor. saturate caerulea.

20. s. hispida Nees; tota hispidissima; fol. ovatis basi cuneiformibus apicem versus obtuse serratis. Nees N. Act. 11. p. 69. In Brasilia. ち. Caul. 3-4-ped. Cor. pulchre caerulea. 
21. S. Trispicata Nees; ramis compressis; fol. oblongis utrinque attennatis crenato-serratis glahris subtus venoso-reticulatis scabris. In Brusilia. t. 6-ped. Cor. caerulea.

22. S. siuamosa V'ahl; fol. ellipticolanceolatis serrulatis alternis; peduneulis axillarihus longissimis. Vahl. Verbena Jacq. Schœubr. t. 5. Hab.? 4. Cor. caerulea.

\section{IIOSTA Jacq. (1797).}

1. H. caeruler Jacq. Schonbr. t. 114. racennis axillaribus 3 -chotomis. Cornutia punctata Willd. C. pyramidata Ait. In America boreali. 2-4-ped. Cor. caerulea.

2. H. grandiflor a schlecht. ramis obtuse 4-angulis; fol. late ovatis, sinuato-dentatis, integrisque, in petioIum attenuatis, supta villosis subtus tomentosis Linnaea 5. 1. p. 97. Apud Jalappam. Cor. caerulea.

3. $\boldsymbol{H}$. longifolia $\boldsymbol{H}$. et $\boldsymbol{B}$. ramis obtuse 4-angulis; fol. ovato-oblongis supra hirsutiusculis subtus albo-tomentosis. Kunth. Cornutia Spr. In Mexico? ち. Cor. cacrulea?

4. H. latifolia $H$. et $B$. ramis 4-angulis ; fol. ovato-rotundatis, integerrinis, pubescentibus bicoloribus. Kunth. Cornutia spr. In Mexico. b.

5. H. pyramidata Alb. Dietr. panicula terninali, nuda elongata Alb. Dietr. Cornutia Willd. Plum. ic. t. 106. f. 1. In Caribaeis et Cambeclia. b.

\section{SCIURUS Willd.}

S. aromatica Willd. fol. oppositis ternatisque; foliolis lanceolato-acutis, glabris integerrimis, pallide punctatis. Alb. Dietr. Rapintia Aubl. Guj. 272. Galipea Spr. In Gujana. \$. 2-ped.

2. S. trifoliata Nees; fol. ternatis; foliolis lanceolato-acumınatis, glabris; staminibus 4. Alb. Dietr. s. corymbosa Spr. Galipea Aubl. t. 269. In Gujana. Ђ. Cor. virescit.

3. S. odoratissima $D$. fol. obovatis, ntrinque obtusis breve petiolatis; staminibus 5 frnctiferis. Galipea LindI. R. Br. 1420. In Rio Janeiro. ち. Cor. alba. Cal. atro-purpureus.

\section{MELASANTHUS Pohl (1827).}

1. M. villosus Pohl; fol. subrotundis crenatis, ciliatis basi cuneatis attenuatis villosissimis. Pohl ic. t. 60. In lirasilia. ち. Caul. spithamens fragulis. Cor. atro-purpurea.

2. M. longespicatus Poll ic. bras. t. 61. fol. crassis, rhombeis, crenatis, ciliatis apice rotumdatis basi subcuneatis pilosiusculis. Pohl. In Brosilic. ち. 2-ped. Cor. atro-purpurea.

3. M. rhomboildalis Pohl ic. $t$. 62. fol. subrhombeis, apice serratis dente magno terminali, glabris. Pohl. In Brasilia. ち. 2-ped. Cor. atra intus incalla.

4. M. triphyllus pohl ic. t. 63. fol. ovali-ellipticis, apice crenatis deute magno terminali, glabris. Pohl. In Brasilia. ち. 2-ped. Cor. rubro-atra.

5. M. integrifolius Pohl ic. $t$. 6.t. fol. crassis, ovalibus acutis glabris, integerrimis, pruinosis. Pohl. In $\mathrm{Br}^{\mathrm{a}}$ silia. †. Caul. fragilis 3-ped. Cor. atra tubo fulvo.

6. H. glancus Pohl; fol. crassis ellipticis, glabris, apice dentatis, glaucis pruinosis. Pohl ic. t. 65. In Brasiliu. ち. Caul. fragilis strictus 3-ped. Cor. atra tubo fulvo-atro.

\section{SCHREBERA Roxb. (1798).}

1. S. suitenioides Roxb. Cor.t. 101. Arbor alta. Fol. pedalia opposita impari-piunata 3-4-juga, foliola ovata acuta integerrima. Cor. fragrans albofusca.

\section{HEMIANTHUS Nutt (1818).}

1. H. micranthemoides Nutt. Herpestes Pers. Gratiola repens Sw. ic. t. 3. Herba repens 2-pollicaris dichotoma. Fol. sessilia opyosita ovato-elliptica. Cor. alba. In America boreali. $\odot$.

\section{MICRANTHEMUM Michx. (1807).}

1. M. orbiculatum Michx. fol. subrotundis; floribus pedunculatis. Michx. am. t. 2. Glohifera nmbrosa Pers. In Carolina et Georgia. 24. Caul. repens filiformis. Cor. parva virescens. 
2. M. emarginatum Elliot. fol. ovatis s. ohovatis emarginatis; floribus sessilihus Elliot. bot. In Carolina et Georyia. 4.

\section{CAMPYLANTHUS Roth (1821).}

1. C. salsoilles Roth. Eranthemum L. Fruticulus. Fol. sparsa, pollicaria, sessilia, carnosa, filiformia glabra. In Teneriffa.

\section{STRIGA Lour. (1790).}

1. S. lutea Lour. coch. p. 22. Caulis herbaceus simplicissimus, 4-sulcatus, pollicaris. Folia lanceolato-linearia, intererrima, sessilia. Cor.lutea. Prope Cantone Sinarum.

\section{CRYPTOTHECA Blume (1827).}

1. C. dichotoma Blume; fol. linearilanceolatis hasi latioribus semiamplexicaulibus; corolla 4-petala. Blume. In puludosis Javae. $\hbar$.

2. C. apetalu Blume; fol. breve petiolatis, lanceolatis; pedunculis multifluris; floribus apetalis. Blume. In Jacu. நे.

\section{BOERHAAVIA Vaill. (1813).}

\section{Herbaceae.}

1. $B$. erectc $I_{\text {. }}$ caule 4-angulo, glabro; internodiis viscosis; fol. suhangulatis sulıtus nigro-punctatis Vahl ell. 1. p. 28t. Jacq. Sichœubr. t. 5. 6. B. paniculata Lam. In Americe meridionali. 24. 1-2-ped. Cor. albocanescens.

9. B. discolor $\boldsymbol{H}$. et $\boldsymbol{B}$. caule tereti glabro; ramis juniorilus pilosis; fol. ovatis acnitis subrepandis glabris sub.tus punctatis. Kunth. In Quito. 4. Cor. alba.

3. H. virgatu $I$. et B. caule erecto 1-angulo ; internodiis viscosis ; fol. ovatis, repandis, glabris, subtus punctatis. Kunth. In Fova Granata. ち. 2-ped. Cor. alba.

4. B. procumbens Roxb. radice fusiformi; fol. varie cordatis subtus pellicula argentea; staminihus tribus lloxh. ind. 1. p. 118. C. erecta. Gartn. t. 12\%. B. diandra et erecta Burm. ind. t. 1. In India orientali. 24. Caul. nullus. Cor. plicata alha aut rubra.

5. B. repanda Willal. fol, cordatis repando-sinuatis, racemis terminalibus verticillatis; floribus triandris. Willd. sp.pl. 1. p. 22. Valeriana Burun. ind.15. t. 6. f. 1. B. Lelenae R. et $\$$. In China, Coromandel et St. He!ena. 4.

6. B. glutinosa Vahl; villosoviscosa ; floribus suhcapitatis; fol.ovatis acutis integris. Vahl elı. 1. p. 287. In Java. 4.

7. B. afivicana Lour. caule diffuso hirto; fol. cordato-rotundis; racemis dichotomis terminalibus. Lour. Coch.1. p. 16. In Mozambic. Caul. 2-ped. Cor. plicata.

8. B. pulverulenta Vahl; caule erecto fol. lanceolatis basi obtusis undulatis ; floribus undulatis pubescentivillosis. Vall 1. c. Ad flumen Senegal.

9. B. viscosi Layasc. caule procumbente tereti foliisque pubescentiviscosis ovatis repandis ; fructibus viscosis. Vahl en. 1. p. 288. In Per'u et Quito. 24. Caul. 2-3-ped. Cor. coccinea.

10. B. hirsuta $\mathrm{L}$. caule tereti diffiffuso, puhescenti; fol. ovatis subcordatis repandis ciliatis subtus rugosis albidis. Jacq. Vind. t. 7. In India occidentali. 24. 1-2-ped. Cor. coccinea.

11. B. adscendens Willd. fol. oblongo-ovatis subcarnosis; floribus paniculatis ; pedunculis 2-floris; caule adscendente. Willd. sp. pl. 1. p. 19. In Guinea. 24.

12. B. decumbens Vahl; caule basi decumbente pilosiusculo; fol. subrotundo-ovatis subrepandis glaberrimis; fructilus viscoso-pubescentibus. Vahl en. 1. p. 284. B. paniculata Rich. B. laxa Pers. In Gujana, Cumana et in ins. St. Crucis.

11. B. tetrandra Forst. caule repente; flor. umbellatis tetrandris; fol. subrotundis emarginatis basi acutis. Forst. prodr. n. 5. In insulis Societatis.

14. B. matabilis $R$. Br. procumbens; caule tereti; fol. repandis subovatis obtusis paginis discoloribus; di-triandris. R. Br. prodr. 1. 1. 422 . In Nova Hollandia.

15. B. pubescens $\boldsymbol{R}$. Br. procumbens pubesceus; fol. repandis subova- 
tis ohtusis utrinque pilis articulatis pubescentibus. R. Br. prodr. 1. p. 422. In Nova Hollandia.

16. B. littoralis $\boldsymbol{H}$. ct $\boldsymbol{B}$. caule decumbente tereti, foliisque glabris ovatis cordatis integerrimis ciliatis; flor. 3-t-andris. Kunth. In Peru. 4. 1-3-ped. Cal, violaceus.

17. B. plumbaginea Cav. caule erecto glabro; fol. subrotundis acutis cordatis repandis subtus pubescentibus. Cav. ic. t. 112. B. repens Nieh. Hl). In Aegypto et Hispamiu. 24. Cor. alha.

15. B. repens Delile Aeg. $t$. 3. $f .1$. caule diffuso puhescente; fol. petiolatis ovatis ohtusis repandis glaberrimis; fructibus asperis. Delile. In Aegypto. 4.

\section{Fruticosae.}

19. B. patula Dombz; villosa, caule diffuso; pedunculis hifidis; fol. oblongo-cordatis obtusissinis. Vahl en. 1. p. 287. In Peru. ђ.

20. B. scundens $L$. caule scandente glabro; fol. ovatis cordatis subrepandis; pedunc. umbelliferis ; invoIucri villis setaceis. Jacq. Vind. t. 4. In India occidentali. ち. Caul. 6-ped. Cor. virens glahra.

21. D. excelsa Wìlld. caule erecto floribus umbellatis 3-andris; fol. inferiorilus cordato-ovatis summis ovatis. Willd. phyt. 1. n. 5. Hab.? ち. Cor. glabra rubra.

22. B. tuberosa Lam. radice tuberosa; fol. cordato-ovatis acutis integris; floribus umhellatis Lam. In Peru. ђ.

23. B. arborea Iag. et Rodr. fol. ovatis integerrimis villosis; floribus umbellatis subdecandris. Vahl en. 1. p. 189. B. arborescens Pers. In Nova Iispaniu. ち. Arbuscula 5-6-ped.

21. B. periplocaefolia I ahl; scandens; fol. ovato-oblongis integris; floribus umhellatis 3-andris. Vahl en. 1. p. 290. In Madayascar. ち. Cor. villosa

25. B. dichotoma Vahl; caule scandente; fol. ovatis obtusis integris; foribus umbellatis 3-andris. Vahl en. 1. p. 290. Valeriana Forsk. In Arabia felici. $\downarrow$.

26. B. angustifolia Linn. fol. linearibus acutis. Linn. syst. veg. 52. Hab? Duhia a nemine visa post Linnaeım.

\section{CODARIUH Sol.}

1. C. acutifolium $A f z$. foliolis inaequalibus, sub ohtuse acuminatis, concoloribus, glahriusculis. DC. prodr.4. p. 520. C. nitidunı Vahl Dialium Guineense. Willd. in Røm. Arch. 1. t. 6. In Guinea. †.

2. C. obtusifolium Afz. foliolis aequalihus apice rotmudatis utrinque concolorilus glabriusculis. Vahl en. 1. p. 401. In Guinea. \$.

2. C. discolor DC. foliolis ellipticooblongis utrinque acuminatis, superne glabris suhtus pube minutissima rufa velutinis, In Guinea. ち.

\section{OLIGARRHENAR.Br. (1810)}

1. O. micrantha R. Br. Fruticulus erectus ramosissimus. Fol. imbriciata, minima. Flores spicati parvi albi. In Nova Hollandia. 支.

\subsection{ANGURIA Jacq. (1763).}

1. A. triloba $L$. fol. trilohis $L$. sp. pl. u. 1376. Jacq. am. t. 156. In Cartagena. b.

2. A. pedata $L$. fol. pedatis serratis Limu. sp. pI. u. 1377. Jacq. am. t. 155. In Domingo. 4.

\section{DIPLARRHENA Labill. (1798).}

1. D. Moraea Labill. voy. $t .15$. Moraea diandra. Valı. Caul. foliosus. Fol. ensiformia. Spatha 2-valvis. Flores pedunculati alhi; laciniis interioribus variegatis. In Nova Ilollandia.

\section{2\%. CIRCAEA Lobel (15.9I).}

1. C. alpina r. glaberrima; petiolis planis membranaceo-alatis; fol. sinuato-dentatis; petalis calyce longioribus. lichb. excurs. p. 638. sturm. 1. 23. In Germania. 4. Spithamea. Cor. alba.

2. C. intermedia Ehrh. glabra; petiolis teretibus canaliculatis; fol. sinuato-dentatis; petalis calyce longituline. lichb. 1. c. In umbrosis Germaniae. 4. Spithamea. Cor. alba.

3. C. Lutetiana L. superne pu- 
hescens; petiolis teretihus-canaliculatis ; fol. ovatis remote repando-dentatis. Rchb. l. c. Fl. Dan. 210. sturm. 1. 23. In umbrosis Germuniae. 4. sub pedalis. Cor. albida.

\section{MILLINGTONIA Roxb. (1521).}

1. M. simplicifolia Roxb. fol. alternis, simplicibus, late-lanceolatis. Roxb. ind. 1. p. 102. In Silhet. ち. Arbor alta. Cor. parva alla.

2. M. pinnata Roxb. fol. alternis interrupte pinnatis, foliolis 6-12-jugis, lanceolatis. lioxb. 1. c. In silhet. $ђ$. Arbor mediocris. Cor. parva alba.

3. H. ferruginea Nees; fol. imparipinnatis ; foliolis elliptico-oblongis, paniculisque ferrugineo-tomentosa. Nees in Bol. Zeit, 1825. Meliosma. Blume. In Java. ち.

t. M. lunceolata Nees; fol. imparipinnatis; foliolis lanceolatis; subtus ferrugineo-tomentosis. Nees. 1. c. Meliosma. Blume. In Java. 4.

5. M. Nitida Nees; fol. imparipinnatis; foliolis lanceolafis hasi attenuatis, supra nitidis suhtus glabriusculıs. Nees 1. c. Meliosma. Blume. In Javu. 4 .

\section{AIDELLS Spreng. 1827).}

1. A. micranthus Spr. Herba decumbcus raunosa glabra. Fol. opposita oblonga, dentata. Flores axillares albi. In Nepulia.

\section{ACAENA Mutis (1781).}

\section{a. Petala libera.}

1. adscendens Vahl; fol. oblongis.s obovatisque, glalıriusculis; spicis glohosis; caule decumbente. Vahl en. 1. p. 297. Ancistrum humile. Pers. $A d$ fretum magellanicum. 24. Spithamea.

2. A. laerigata Ait. foliolis ovalibus crenatis incisis, supra glabris subtus wancescentibus; spica terminali cylindracea; caule decumbente. Ait. Kew. 1. p. 69. Ancistrum. Lan. Ad fretum Magellanicum. $\hbar$.

3. A. trifila $R$. et $\boldsymbol{l}^{\prime}$. slanca; foliolis cuncatis 3-5-fidis; spicis globosis; caule erecto. Fl. peruv. t. 104. f. c. Vahl en. 1. p. 296. In Chili. 4. Villosissima; caulis pedalis. Drupa 3-5-gona.

t. A. magellanica Vahl; foliolis ohovatis, serrato-laciniatis, 3-fidis subtus glaucis; spicis globosis. Ancistrum. Lam. ill. t. 22. All fretum magellanicum. 24. Fruticulus spithameus.

5. A. lucidu laul; caule decumbente; fol. pinuatis 8-9-jugis; foliolis 3-5-fidis; laciniis linearibus subtus villosis; spicis ovato-oblongis. Ancistrum. Lam. ill. 1. t. 22. f. 3. In Falklandia. 4. Pedunculus palmaris.

6. A. pumila I'uhl; foliolis ovalibus, serratis, glaberrimis; pedunculis scapiformiins; spicis teretibus; caule demerso. Vahl 1. c. Ad fretum magel-lanicum. 2. Pollicaris. Fructus armatus.

7. A. Sanguisorbae Vahl; cauls adsccudente, piloso; fol. renote pinnatis 7-jugis; foliolis cuneiformibus serratis subtus sericeis. Forst. Geu. t. 2. A. decumbens Gæertn. t. 32. In Nova Seelandia. 4. Caul. spithameus. purpureus,

8. A. ovalifolia $R$. et $P$. foliolis oblongis subcuneatis, subtus villosiz; spicis glohosis; caule repente. Fl. peruv. t. 103. f. c. Ancistrum. Vent. cels. f. 6. In Peruvia. 4. Lamosissima.

9. A. sarmentosa Carmich. spicis globosis; caule repente; foliolis -6jugis ; profunde serrato-laciniatis, supra elabris subtus sericeis. DC. In Tristan da Cunha.

10. A. argentea $R$. et $P$. spicis glohosis; caule repente; foliolis $3-5$ jugis, ovato-oblongis, serratis subtus sericcis. FI. t. 104. f. 2. DC. I. c. In Peruria. 24.

11. A. cylindristach!na $R$. et $P$. spicis cylindricis; pedunculis scapiformibus; caule demerso; foliolis oblongris serratis subtus sericeis. Fl. peruv. t. 104. f. 2. In Tarmu. 21. Frtictus t-angularis, aristis $\downarrow$ uncinatis cornnatus.

\section{b. Petala connata.}

12. A. sericea Jucr. Eclog. t. 5.5. caule dccumbente; foliolis ohovatis, dentato-laciniatis, pubescentibus, subtus sericeis. DC. Ancistrum Acaena Lag. In Nora Ilispania. 4.

13. A. pinnatifida $\boldsymbol{R}$. et $\boldsymbol{P}$. spicis cylindricis; caule erecto; foliolis liucari-lanceolatis, serrato-partitis, suh- 
tus hirtis. DC. In Cllili. 24. 2-ped. Cor. intus purpurascens.

14. A. multifida Alb. Dietr. caule adscendente; foliolis $4-5$-jugis $3-5-$ fidis, sericeis, laciniis linearibus; spicis subglobosis. Lindl. Bot. Heg. 1271. In Chili. 24.

15. A. incisa Lindl. erecta seriсеa; foliolis 6-9-jugis, oblongo-cuneatis, serrato-partitis ; capitulis spicaeformibus. Lindl. I. c. In Chili.

16. A. myriophylla Lindl. erecta pubescens; foliolis 7-9-jugis, linearibus profunde pimnatifidis, subtus sericeis. LindI. I. c. In Chili.

17. A. ovina Cunningh. glaucohirta; caule reclinato, subemerso; foliolis profunde-laciniatis, pinnatifidis; laciniis oblongo-obtusis. Cumingh. in Fields geogr. Mem. Iis New South Wales.

18. A. Zatebrosa Ait. caule dedecumbente; fol. pimmatis, foliolis oblongis villosis incisis; spicis elongatis. Ait. Ancistrum. Willd. In Prom. 6. spei. 24. Pedalis.

19. A. elonyat $I_{\text {. }}$. caule erectiusculo; Roribus in racemo elongato; foliolis oblongis serratis. DC. In Prom. b. spec. 24. Ramosissima 2-pedalis. 20. A. Eupatorii schlecht. Linn.2. p. 30. caule erecto patenti-sericeovilloso; fol. pinnatis ; foliolis oblongis basi obliquis, inciso-serratis subtus canescenti-sericeis. Alb. Dietr. In Brasilia. 24. 2-pedalis.

21. A. agrimonioirles $I I$. et $I B$. foliolis oblongits, grosse serratis, grabris, junioribus pubescentibus; floribus spicatis alternis. DC. In Mexico. 4. Rami fisco-purpurei.

22. A. lapplacer $R$. et $P$. canle erecto; foliolis oblongis serratis; floribus racemosis, patentibus 4-5-andris. DC. Fl. peruv. 3. f. a. In Peravia. 支. Fuctus 4-goni lappacei.

\section{LABICHEA Gaudich. (1825)).}

1. L. cassioides Gandich. in Freyc. Voy. $t$. 25? Frutex dumosus glaher. Folia impari pimata: foliolis spinosomucronatis cartilagineis. Flores Intei. In Nova Hollandia.
132. MARGYRIQCARPUS R. et P. (179.1).

1. M. setosus $R$. et $P$. Frutex ramosissimus ; foliis impari pimatis $3-1$ jugis; foliolis sessilibus, linari-subulatis; petiolis margine villosis. In $\mathrm{Bra}$ silia, Peruvia et Chili. $\hbar$.

\section{DIALIUM L. (1793).}

1. L. indicum $L$. fol. pinnatis; foliolis elliptico-oblongis, acutis ; panicula nutante; antheris filantento triplo longioribus. Alb. Dietr. 1. c. In Java. ち. Arboreum.

2. I). divaricatum Vahl; fol. pinnatis; foliolis ovato-acuminatis ; panicula decomposita: antheris filamento hreviorihus. Alb. Dietr. Aruna gujauensis. Aubl. In Gujana. ち. Arboreun. Cor. flava.

\section{IITOPHILA Sw. (1768).}

1. L. muscoides Sw. ic. $t$. 1. Planta 2-pollicaris. Caulis divisus squamis albidis tectus; folia parva amplexicaulia. Flores aggregati albi Sw. In India occidentali. 4.

\subsection{CYP,SELEA Turp. (1906).}

1. C. humifusa Turp. Ann. mus. \%. t. 12. f. 5. Radiana petiolata Raf. Herba pusilla, subsucculenta, ramis prostratis. Flores axillares minimi virescentes. In St. Domingo. $\odot$.

\section{SUFFRENIA Beilard. (1796).}

1. S. filiformis Bell. tuur. 7. t. 1 . f. 1. In Uxyzetis Lombarliae. $\odot$. Caul. 3-6-pollicaris filiformis basi repens. Folia opposita sessilia cbtusa integerrina. Flores parvi flavicantes.

\section{PIMELEA Banks et Sol. (1789).}

a. Folia opposita; capitula terminalia; involucrum 4-phyllum, phylla foliis ramies dissimilia.

1. P. linifolia Sm: Nov. Holl. $t$. 11 . fol. subsessilibus olverse lanceolatis 
mucronatis 1-nerviis; involucri phyllis ovalibus capitulo brevioribus; corollis extus pilosis. Sim. I. c. P. filamientosa. liudge. In Nova Hollandia. t. 3-t-ped. Cor. alba.

2. P. linoides Cunningh. fol. oblongo-lanceolatis, apicilus callosis intermedio plus duplo longioribus; iuvolucri phyllis ovatis; corollae tubo villosissimo. Cunningh. 1. c. Ad Portum Juclison. ђ.

3. P. collina $R, B r$. fol. decussatis subsessilibus obverse lanceolatis 3-nerviis; corollis extus pilosis. H. Br. prodr. 1. p. 359. In Nova Hollandia. 5 .

t. P. cernua R. Br. fol. obverse lanceolatis utrinque glabris; receptaculo capituli pilis densis; corollis supra articulationem pilosiusculis. R. Br. 1. c. P. spathulata. Labill. nov. Holl. t. 4. In ins. Van Diemen. $\frac{7}{\text {. }}$

5. P. brevifalia R. $B r$. fol. linearibus internodiis vix longioribus, involucri phyllis ovatis capitulo quadruplo brevioribus. I. Br. 1. c. In Nova Hollandia. 古.

6. P. paludosa R. Br. fol. linearibus interuodiis longioribus; involucri phyllis ovatis intus subsericeis capitulo dimidio brevioribus; corollae tubo sericeo. R. Br. 1. c. In Nova Hollandia. ち.

\%. P. angustifolia R. Br. fol. linearibus internodiis longroribus ; involucri phyllis orhiculato-ovatis intus subsericeis; corollae basi persistente hirsutissima. R. Br. In Nova Hollandia. b.

8. P. glauca R. Br. fol. linearilanceolatis glaucis; involucri phyllis ovatis acutis intus sericeis; receptaculo capituli laxo penicillato. $\mathbf{R}$. Br. I. c. Lodd. 1611. Rudge Linn. Trans. X. t. 13. f. 2. In Nova Hollandia. †.

9. P. ligustrince Labill. $l . c . \quad t .9$. fol. ovali-lanceolatis venosis; involucri phyllis extus venosis intus pubescentibus; receptaculis fructiferis ovatis pube hrevissima; corollis cernuis. Labill. Ad Fortum Jackson et in ins. Yan Diemen. ち. 5-ped. Cor. sericea.

10. P. decussuta $R$. Br. fol. decussatis oblongis coriaceis brevissime acuminatis; corollae tulo hispido. $\mathbf{R}$. Br. P. ferruginea Labill. 1. c, t. 5. In Nova Hollandia. b. Cor. rosea.

11. P. rosea R. Br. fol. lauce $0-$ lato-linearibus; involucri phyllis ova- tis acutis utrinque glabris; corollae tubo basi hirto. R. Br. I. c. B. M. 1458. Lodd. 88. In Nova Hollandia. 5 .

12. P. hispida R. Rr. fol. lanceolatis linearibusve; involucri phyllis ovatis intus sul)sericeis; corollae tubo inferne hispido. H. Br. 1. c. In Nova Hollandia. †.

13. P. diosmaefolia Lodd. fol. decussatis, oblongis, attenuatis glabris; involucri phyllis ovatis acuminatis. Lodd. B. C. 1708. In Nova Hollandia. ち. Cor. rosea.

1.. P. arenaria Cunningh. fol. decussatis, ellipticis, obtusiusculis, patulis, subtus glaucescenti-hirtis; corollis urceolatis lanuginosis. B. M. 3270. In ins. Van Diemen. ち. Cor. alba.

15. P. hispida R. Br. fol. lanceolato-linearibus; involucri phyllis ovatis intus subsericeis; curollae tubo basi hispido. IR. Br. Lodd. 1966. B. K. 1578. In Nova Hollandia. ち.

16. P. Lanata $R$. Br. fol. lanceolatis; involucri phyllis ovatis nıargine membranaceis intus sericeis; corollis villosis. R. Br. I. c. In Nova Hollandia.

II. Folia opposita; capitula teruinalia. Folia floralia rameis subsimilia.

17. P. pauciflora B. Br. fol. liuearibus; floralibus capitulum pauciflorum longe superantibus; receptaculo corollisque glabris. Lodd. 179. In Nova Hollandia. 方.

15. $P$. serpyltifolic $R$. $B r$. fol. utriuque glabris ovatis ovalibusque: floralibus quaternis capitulo paucifloro longioribus; receptaculis villosis; corolla giabra. R. Br. 1. c. In Nova Hollurdia. †.

19. P. prostrata Willd. caule decumbente; fol. decussatis imbricatis, ovalibus obtusis carnosis. Alb. Dietr. Passerina laevigata. Gærtn. t. 39. Cookia Gmel. In Nova Hollandia. Hami pilis densis alhissimis strigosi.

20. P. sylvestris $\boldsymbol{R}$. $\boldsymbol{B r}$. fol. glaberrimis lanceolato-acutis; floralibus 4-5, capitulo multifloro brevioribus. $\mathbf{K}$. Br. prodr. 1. p. 36. In Nova Hollandia. \$.

21. $\boldsymbol{P}$. humilis $R$. Br. fol. utrinque glabris oblongis obtusis; floralibus ovalibus intus villosiusculis; perian- 
thiis sericeis; ramis pubescentibus. $\mathbf{R}$. Br. prodr. 1. p. 361. In Nova HoL landia. 古.

22. P. flava $\boldsymbol{R} . \mathrm{Br}$. fol. utrinque glabris obovatis orbiculatisque; floralibus conformibus quaternis capitulo longiorilsus; perianthiis sericeis; caule ramisque glahris. R. Br. In Nova llollandia. $\hbar$.

23. P. microcephala $R$. Br. fol. wtrinque glabris lineari-lanceolatis acntis; floralibus lanceolatis capitulo paucifloro longiorilsus. R. Br. 1. c. In Nova Hollandia. $\hbar$.

21. P. Gnidia Willd. fol. oblongis lanceolatisque acutis coriaceis; floralibus ovatis; perianthiis villosis. Alb. Dietr. 1. c. Passerina L. Banksia Forst. Cookia Gmel. In Nova Seelandia. 卢.

25. P. clavata $R$. Br. fol. subtus pubescentibus lanceolatis; floribus dioicis; capitulis masculis pedunculatis nudis. 12. Br. 1. c. In Nova Hollandic. t.

26. P. imbricata R. Br. fol. oblongo-linearibus, imbricatis, subtus pubescentibus; floralibus sericeis; perianthiis hirsutisissimis. $\mathrm{l}$. $\mathrm{Br}$. In Nova Hollandia. $\hbar$.

27. P. longiflora $R$. Br. fol. linearibus villosiusculis passim alternis, periant!hiis sericeis; stylo incluso. R. Br. I. c. In Nova Hollandia. $ђ$.

28. P. octophylla R. Br. fol, ohlongo-linearihus passim alternis ramisque villosis; perianthiis hirsutis. $\mathbf{R}$. Br. In Nora llollandia. $\hbar$.

29. P. sericere $R$. Br. fol. ovatis ohtusis imbricatis subtus argenteoscriceis, supra glabris. H. Br. 1. c. In Nova Hollandia. Ђ.

30. $P$. cinerea $R$. $B r$. fol. Ianceolato-oblongis pianis subtus incanis supra glahris; perianthii tuho ovato persistente. H. Br. I. c. In Nova Hollandia. ち.

31. P. pilosa Uilld. ramulis pilosotomentosis incanis ; fol. lanceolatis oblongisve obtusis subtus pilosiusculis; corollis hirsutis. Willd. sp. pl. 1. p.50. Passerrina L. Banksia Forst. In Nove Zeelandia. $\hbar$.

32. P. graciliflora Hook. glabra; fol. oppositis, patentibus Ianceolatoaentis, supra-punctatis; perianllio glabro. Hook. B. Mig. 2388. In Nova Hollandia. 卉.

33. P. intermedia Lindl. fol. glabris, lanceolato-acutis; perianthiis se- riceis, tubo cylindrico incurvo. Lindl. B. Reg. 1436. In Nova Hollandia. $\hbar$. 31. P. viryata Vahl; fol. Ianceolatis acutis, subtus pilosis; ramulis tomentosis; floribus terminalibus aggregatis. Vahl en. 1. p. 306. In Nova zeelandia. ち. Folia subtus pilis longissimis albis tecta.

35. P. longifolia Wickstr. caule glabro ; fol. Iongissime lanceolatis achminatisque utrinque glabris venosis. Wickstr. Act. Holm. p. 283. Passerina Thunb. In Nova Zeelandia. ţ. Omuitim speciosissima.

36. P. drupace Labill. $l$. c. $t .7$. fol. ovali-oblongis planis subtus pubescentibus; floralibus capitulo longioribus; drupa baccata. H. Br. In Nova Hollandia. $ち$.

37. P. incana $\boldsymbol{R}$. Br. fol. ovatis distinctis margine recurvatis subtus incano-tomentosis supra glabris ramulis cinereis. 1. Br. In Nova Hollandia. 古.

38, P. nivea Labill. Nov. Holl. t. 6. fol. orbiculatis imbricatis margine incurvis sultus incano-tomentosis, ramulis albis, B. Br. In ins. I'an Diemen et in Nova Hollandia. †. 3-ped.

39. P. Hypericinu Hook. caule ramoso; fol. oppositis, ressibus, ovalioblougis, acutis glabris; perianthio subcurvato, hirsuto. Hook. B. Mar. 3330. In Nova Hollandia. †. Cor. rosea.

III. Folia opposita. Flores demum spicati.

40. P. spicata, R. Br. fol. ovalibus glabris; spicis umdis; floribus polygamis; corollis glahris. R. Br. Rudye in Lillu. Trans. X, t, 14. f. 2. In $A u-$ stralia.

IV. Folia opposita. Flores axillares.

41. P. argentea $R$. Br. fol. lanceolatis utrinque argenteis; floribus 2-1-axillaribus. 12. Br. In Nova Hollındiu. $\hbar$.

\section{Folia alterna.}

42. P. curviflora R. Hr. fol. lineari-oblongis, supra glabris, subtus ramisque pilis adpressis subsericeis; corollis sericeis. R. Br. In Nove Cambria. t. Frutex ramosissimus. 
t3. P. gracilis R. Br. fol. oblongolinearibus basi attenuatis subtus pilosiusculis; perianthiis sericeis tuho rectiusculo. 12. Br. In Nova Hollandia. 5 .

14. P. lutifolia R. Br. fol. oblongis basi acutis pulescentibus subtus subsericeis; perianthiis villosis. $\mathbf{R}$. Br. 1. c. In Nova Hollandia. ち.

\section{Species dubiae.}

45. $\boldsymbol{P}$. Cornucopiue $\mathrm{B}$. $\mathrm{Br}$. involucro monoplyyllo 4-fido infundibuliformi, laciniis semilanceolatis acutis; caule herbaceo. H. Br. 1. c. In Nova Hollandia.

16. P. muicea R. Br. involucro monophyllo infundibuliformi 4-fido; laciniis semiorbiculatis obtusis; caule herbaceo.

138. REICHENBACHIA Spr. (182t).

1. R. hirsuta Spr. syst. veg. 1. p. 24. In Brusilia. b. Frutex. Folia alterua oblonga stellato-pubescentia apice incrassato. Flores cymosi, hirsuti.

\section{FRAXINUS Iirg.}

1. H. excelsior I. fol. suh 6-jugis cum impari, lanceolatis acuminatis, subsessilihns, serratis, basi cuneatis; gemmis nigris. lichb. excurs. p. 431. Fl. Dall. 969. In Germanic. ђ. Arb. 130. ped. Antherae purpureae.

2. F. Ormus $h$. fol. sub 3-4-jugis foliolis petiolatis, ovato-oblongis, serratis, acutis, subtus pubescentibus; genumis cinereo-pulverulentis; ramis flavo-punctatis. Rchl. l. c. Ker. t. 610. Duham. 101. Oruus europaea Pers. In Europa. †. 20-30-ped. Cor. alha.

3. F. rotundifolia $\mathrm{L}$. fol. 3-1-jugis ; foliolis subsessilibus, subrotundis, subacutis, duplicato-serratis, glabris. Oruns Alb. Dietr. O. mammifera Host. F. aleppensis. Plukn. t. 182. f, 21. In Calaboic et Oriente. ち. Arbor humilis. Flores purpurei.

t. F. strigkitu Bosc. fol. 7-jugis, subtus petiolisque villosis; foliolis ohlongis petiolatis acutis dentatis; gemnis griseis; ramis striatis. Bosc. Hem. de l'ist. 9. p. 217. F. striata Spr. In griente. 支.
5. F. floribunda Wall. fol. 3-jugis subtus glabris reticulatis; foliolis oblongis acuminatis acute inaequaliter serratis. Wall. in Roxb. Fl. ind. 1. p. 150. In Nepalia. ち. Arbor magna. Cor. alba inodora.

6. F. cappadocica Juss. fol. 2-jugis; foliolis ovato-oblongis, grosse inaeqnaliter dentatis, glahris, imparí subrotundo. Alb. Dietr. In Oriente? ‡.

\section{PIPER Horat.}

I. Peperomia R. et P. Alb. Dietr. sp. pl. 1. p. 142-186. Bracteae squamiformes minutae. Stylus simplex minutissimus. stigma punctiforme aut peltatum.

A. Caulis lignosus.

1. P. sidaefolium Link et Otto; $A b b$. $t$. 6. ranis apice pubescentibus; fol. cordato-subrotumlis membranaceis multinerviis rugosissimis, pellucidopunctatis; petiolis undique pilosis. Alb. Dietr. Peperomia Kunth. In America meridionali. \$. 4-5-ped.

2. P.peltatum L. fol. peltatis orbiculato-cordatis multinerviis obtusis subrepandis; spicis umbellatis. Linn. In India occidentali. $ち$. Fol. maxima.

3. P. scutatum Willd. Herb. fol. peltatis subrotundis breve acuminatis cordatis denticulatis nervosis; spicis umbellatis. Peperomia. All. Dietr. In Brasilia. ち. Fol. maxima.

t. P. speciosuin H. et B. fol. subrotundo-o vatis acutis basi rotundo-truncatis centro peltatis subcoriaceis glabris pellucido-pumctatis. Peperomia Kunth. In Venesuela. ち. 4-6-ped.

5. $P$. pruinosum $H$. et $B$. ramis foliisque subtus pruinoso-farinosis subrotundo-ovatis acutis basi peltatis. Peperomia. Kunth syn. 1. p. 124. In Nova Grancita. ち. 3-6-ped. Umbella 8-10-stachya.

6. P. sulpeltatum Willd. fol. subrotundo-cordatis, acuminatis multinerviis; spicis umbellatis. Willd. sp. pl. 1. p. 167. Lomba Rumph. 6. t. 39. f. 1. In Amboina. 支.

B. Caulis carnosus.

1. Canlescentes.

* Foliis alternis.

7. P. salignum $R \cdot{ }^{*}$ et $S$. caule erecto ramoso; fol. lanceolatis utrinque 
angustis obtusis venosis glabris subsessilibus Peperomia H. et B. In Nova Granata. b.

8.P. Roxburghianum R. et S. caule scandente et repente; fol. sessilibus oblique lanceolatis glaberrimis. P. angustifolium. Roxb. In Archipelago malayensi.

9. P. amplexicuule $S w$. fol. amplexicaulibus late lanceolatis deorsum attemuatis obtusiusculis multinerviis. In Jamaica. 24. Canl. pedalis.

10. P. amplexifolinm Link; fol. ohlongis lanceolatisve basi attemuatis sessilibus nervoso-venosis, glaberrimis carnosis; spicis longissimis. Peperomia talinifolia. Link. In Jumaica. 4.

11. P. perforatum $D$. caule, petioloque piloso; fol. lanceolatis 3-nerviis pilosis pellucido-punctatis, spicis filiformibus. Opiz in Reliq. Hænk. 3. p. 162. A. f. 2. var. fol, glabris. In IIexico. 4.

12. P. pepuloides Roxb. fol. ovatis lanceolatisque breviter petiolatis acuminatis 3-5-nerviis glabris. Roxb. ind. 1. p. 59. In Silhet. 24. Caules ranique alterni repentes.

13. P. lanatum Roxb. repens lanatum ; fol.petiolatis ovato-lanceolatis ohsolete 3-nerviis; haccis peclicellatis clavatis. Roxh. ind. 1. p. 161. In Archipeluyo Mralayense.

1. I'prilosum I'ahl; caule flexuoso erecto; fol. oblongo-lanceolatis basi inaequalibus supra pilosis; spicis filiformibus. Vahl. R. et P. peruv. t. 50. In Pozu:o Peruriae.

15. $P$. emarjinatum Vuhl; caule nexuoso repente; fol. cumeiformibus emarginatis; spicis conjugatis. Vahl. Peperomia. Fl. peruv. t. 49. f. a. In sylvis Pozuso.

16. P. cuneifolium .jncy, ic. $t$. 211 . caule erectiusculo radicante; fol. cuneiformibus 8-nerviis; spicis terminalibus conjugatis. Jacq. In Caracas. Caul. 3-ped.

17. P. conjugatum $R$. et $S$. caule sulcato; fol. oblougis utrinque acutis 3-nerviis carnosis slabris subtus albidis longe petiolatis. P'eperomia. Kunth in H. et B. nov. Gell. et sp. pl. 1. t.9. In Peruvia. 4. Caul. 1-ped,

18. P. cristallisum Iuhl; canle tetragono dichotomo; fol. oblongis subtus excavato punctatis. Vahl. Peperomia. R. et P. In collibus Limae.

19. P. nyrtifolium Vahl; caule erecto; fol. rhombeo-oblongis 3-nerviis glabris obtusis; spicis subgeminis. Vahl. In insula st. Crucis. Caul. pedalis simplicissimus.

20. P. dolabriforme Vahl; fol. dolabriformibus carnosis confertis; pedunculo terminali polystachyo. R. et s. Humb. 1. c. t. 4. var. fol. pulverulento-glancis. In Peru. 24.

21. P. talinifolium $R$. et s. caule ramoso; fol. oblongis obtusis hasi subcumeatis obsolete venosis carnoso-subcoriaceis glabris. Peperomia. H. et B. 1. c. t. 8. In Nova Granata. 4.

22. P. acuminatum Pers. caule erecto; fol. oblongis acuminatis ; spica terminali filiformi acuta. Peperomia. $\mathbf{R}$. et $P$. peruv. t. 51. f. a. P. nemorosum. Vahl. In Peruvia.

23. P. obliquum Pers. caule erecto; fol. oblongo-ovalibus, apice obliquis acuminatis; spicis terminalibus filiformilus. Peperomia. R. et $\mathbf{P}$, peruv. 1. t. 51. f. c. P. acuminatum L.P. herhaceum. B. M. 1822. In America meridionali. 4.

21. P. macrostachyon Vahl; caule erecto; fol. ovato-oblongis acuminatis ohscure multinerviis spicis longissimis pendulis. Vahl. In Cajennu.

25. P. alalum l'ahi; caule dichotomo alato; fol. oblongis utrinque attenuatis 5-nerviis; spicis subulatis. Vahl. Peperomia. lil. peruv. t. 18. f. b. In Peruvia et St. Domingo. 2.

26. P. trinerve Vahl; caule inferme radicante; fol. ovalibus utrinque acntis 3-nerviis; spicis geminis. Vahl. Peperomia. Fl. peruv. t. 50. f. b. In Peruvia.

2\%. P. dendrophilnm D. caule diffuso radicante ; fol. rhomboideo-ellipticis, in petiolum attenuatis, lente pubescenti-ciliatis, immerse 3-nerviis. Peperomia schlecht. Linn. t. 1. p. 7.t. Prope Julapam. Caul. stoloniferus.

\&3. P. Blattarum Spr. caule dichotomo ; ramis pubescentibus ; fol. ollongis obtusiusculis utrinque glabris 3-nerviis. Spr. N. Entd. 2. p. 100. In Portorico.

29. P. coloratum R. et S. caule simplici foliisque giabris oblongo-elIlpticis utrinque acutiusculis triplinerviis camosis subtus coloratis, Kunth iil H. et B. 1. c. t. 11. In saxosis lemperatis Popayae. 4.

30. P. striatum Iahl; caule simplicissimo striato; fol. oblongo-ovalibus 
ntrinque attenuatis puhescentihus. Peperomia. 11. et P. Fl. peruv. t. 52. f. b. In nemoribus Peruviae.

31. P. purpureum Vahl; caule flexuoso; fol. ovalibus acuminatis venosis; spicis pendulis. Peperomia $\mathbf{L}$. et P. peruv. t. 49 . f. b. In umbrosis montibus Peruviae.

32. p. rupestre $R$. et $s$. caule nodoso, foliisque glabris, ovato-oblongis acuminatis basi acutis carnosis; spicis elongatis pendulis. Kunth in $\mathbf{H}$. et B. In Nova Andalusia. 4. 3-ped.

33. $P$. elongatum $D$. caule erecto simplici ; fol. ovato-ellipticis, acuminatis basi rotundatis quintuplinerviis carnosis glabris; spica terminali solitaria. Peperomia. Kunth. P. extensum R. et S. In Cumana. 4. 2-ped,

34. P. tithymaloides Vahl; caule erecto ; fol. subovatis acutiusculis; spicis fructiferis refractis. Vahl. In st. Domingo. 4. Caul. inferne radicans.

35. $\boldsymbol{P}$. murinum $\boldsymbol{R}$. et $\boldsymbol{S}$. caule erecto ramoso; fol. ellipticis utrinque acutis carnosis venosis glabris. Peperonia elongata Kunth in H. et B. In Noru Andalusia. 2. Caul. 2-ped.

36. $\boldsymbol{P}$. simplex $\boldsymbol{D}$. caule erecto simplici foliis caducis inferne cicatricato; fol. ovato-oblongis 3-nerviis. Peperomia Hanilt. Pl. ind. occ. p. 2. In Jamaica.

3\%. P. monostachyon Vahl; caule simplicissimo raclicante; fol. obovatis ovatisque; spicis terminalihus. solitariis. Vahl. In Peruvia. Caul. 2-palmaris.

38. P. pallidum Forst. fol. oblong0ellipticis glabris trinerviis; spicis filiformibus; baccis distinctis. Vahl. In insulis Societatis.

39. $\boldsymbol{P}$. tenellum $\mathbf{S} w$. caule simplici decumbente; fol. distichis ovatis aveniis ciliatis; spica adscendente. Sw. ind. occ. 1. p. 75. In Jamaica. $\odot$. Caul. 3-4-uncialis.

40. P. rostratum Roxb. repens, partibus tenerioribus pilosis; fol. obovatis cuneatis obtuse acuminatis vilIosis 5-7-nerviis tomentosis supra basin contiguis. Roxb. ind. 1. p. 162. In Molccuis.

41. P. spathulatum $D$. glabrum filiforme repens; fol. obovatis subemarginatis longe petiolatis in petiolum attenuatis. Peperomia Hamilt. 1. c. In Jamaica.

48. P. magnoliaefolium Jacq. ic t. 213. caule ramisque radicantilus; fol. obovatis obtusissimis emarginatis. Jacq. In Americu meridionali.

Caul. 3-ped.

43. P. obtusifolium $\boldsymbol{L}$. caule documbente radicante; fol. obovatis retusis rubro-marginatis; spica terminali solitaria. VahI. P. magnoliaefolimm Haw. P. clusiaefolium. Jacq. ic. t. 212. In America boreali. 4.

44. P. subrotundum Tahl; caule diffuso ; fol. petiolatis obovatis rotundis crasso-coriaceis concoloribus Ham. succ. Hab.... 4. 1-2-ped.

45. P. cordifolium Sw. caule repente; fol. obcordatis planis convexis carnosis; spicis lateralibus filiformibus Sw. prodr.16. In Jamaica. Caul. scandens.

46. P. retusum $L$, caule repente ancipiti; fol. ovato-subrotundis retusis, spicis terminalibus. Liun. In Prom. b. spei. Caul. tenues ramosi.

47. P. ruscifolium $R$. et $\boldsymbol{S}$. caule erecto ramoso; fol. ovatis apice angustato-acuminatis basi acutiusculis obsolete 5-nerviis glabris. Peperomia. Kunth in H. et B. In Cumana. 24.

13. P. foliosum $\boldsymbol{R}$. et $\mathrm{S}$. caule erecto ramoso; fol.ovatis acutis 5-nerviis carnosis glahris confertis. Peperomia. Kuntli in $\mathbf{H}$. et $\mathbf{P}$. In Nova Granata. 24. Caul. spithameus.

49. $P$. molle $R$. et $S$. caule filiformi repente ramoso foliisque molliter piloso-pubescentibus ovatis acutiusculis enerviis subcarnosis. Peperomia Kuntlı in $\mathbf{H}$. et B. In Nova Granata. 4.

50. P. nemostachyum R. et S. fol. ovatis acuminatis margine undulatis aveniis crassis supra pilis stellatis adspersis subtus subvillosis. Peperomia Link. Jahrb. 1. 3. p. 63 . In Brasilia.

51. P. distachyum $\boldsymbol{L}$. caule ramoso radicante, fol. ovatis acuminatis 5-nerviis, spicis conjugatis erectis. In America meridionali. 4.

52. P. glabellum $\boldsymbol{S w}$. caule declinato radicante ramosissimo; fol. ovatis acuminatis 5-nerviis; spicis filiformibus subaduncis Sw. P. scandens Sw. prodr. 16. In Jamaica. Caules longissimi.

53. P. myosuroides Rudge Guj. $t$. 5. fol. ovatis acuminatis supra pruinosis ; spicis longissimis laxis ; bracteis peltatis. In Gujand. Caulis gracilis. 
54. P. brachyophyllum Hilld. caulibus flexuosis suhnodosis; fol. ovatis acutis obsolete 3-nerviis basi sulcomplicatis; petiolis ciliatis. Willd. ell. p. 3. Hab... 4. Caul. 6-9-poll. longus.

55. P. hernandiaefolium Iahl; caule repente; fol. peltatis ovatis acuminatis enerviis; spicis axillarihus solitariis. Vahl en. 1. p. 344. In India occidentali.

56. P. alpinum Sw. caule erecto simpliciusculo; fol. ovato-subrotundis acutis subtus aveniis; spicis axillarihus. Sw. prodr. 15. In summis alpibus Jamaicae, 24.

57. $\boldsymbol{P}$. furcatum $\boldsymbol{D}$, caule repente ramoso glabro; fol, ovatis vel rotundato-ohtusis glabris 5-7-nerviis margine pubescenti-ciliatis. Peperomia Opiz. 1. c. In Peruviae montanis. 4.

58. $P$. diversifolium $\boldsymbol{R}$. et $\boldsymbol{S}$. caule erecto sulcalo, foliisque tenuissime pubesceutihus ovatis acutiusculis aut subrotundis obtusis quintuplinerviis membranaceis. Kunth in H. et B. In alpibus Peruviae, 4.

59. $P$. pumilum $D$, caule piloso inferne radicante; fol. petiolatis ovatis obtusiusculis 3-nerviis pilosis; spicis filiformibns. Peperomia Opiz. 1. c. In Peruviae montanis. 4? Caul. brevissimus.

60. $R$. biunciale $R$. et $S$. caule erecto dichotomo foliis glabris subrotundo-ovatis obtusis quintuplinerviis meubranaceis. Peperomia. Kunth in H. ef B. In Nova Granata. 4. Canl. 2-pollicaris.

61. P. tristachyum $\boldsymbol{k}$. et $\mathrm{s}$. fol. subrotundo-ovatis acuminatis basi peltatis multinerviis glabris. Peperomia. Kunth in H. et B. t. 6. In Nova Granata. 24. Caul. pedalis.

62. P. peltoideum $R$. et $S$. caule repente; fol. subrotundo-ovatis acutis sulpeltatis 5-7-nerviis. Peperomia: Kunth in H. et B. t. 7. In Cumana. 4.

63. P. repens $R$. et $s$. caule repente ramoso; fol. pubescentibus subrotundis obtusis quintuplinerviis subcarnosis ciliatis. Peperomia. Kunth in H. et B. In Nova Andalusia. 4.

64. P. Myosurus Herb. Willd. canle repente ramoso; fol, orbiculato-sulovatis glabris aveniis; spicis terminalibus subgeminis. Alb. Dietr. In st. Domingo. Canl. vix semipedalis.

65. $\mathcal{P}$. rotundifolium $L$. caule re- pente filiformi; fol. subrotundis obtusis planis enerviis carnosis glabris margine pubescentibus. Peperomia. Kunth. In montosis Americue calidioris. 5 .

66. P. pulicare $D$. caule repente filiformi; fol. petiolo pilosiusculo orhiculatis enerviis margine pilosiusculis. Peperomia Opiz. Rel. Hank. 3. t. 30. f. 1. In Mexico. 4.

67. P. nummulariaefolium $\mathbf{S w}$. caule repente filiformi; ramis glabris; fol. orbiculatis convexo-concavis encrviis varnosis pubescentibus. Peperomia Kunth. In Nova Granata et Jumaica. 4. 2-3-ped.

68. P. sarmentosum Roxb. caule basi sarmentoso; fol. late cordatis ohlongisve glabris sub 5-nerviis superioribus subsessilibus. Roxb, ind.1. p.162. P. Iatifolium Kunth. In ins. malayensibus. Caul. 6-18-pollicaris.

69. $P$. plantuginifolium $D$. fol. petiolatis glabris planis 9-nerviis; petiolis vaginantihus alatis. Peperomia. Opiz in Rel. Hank. 3. p. 164. In Chili. 24. Caul. articulatus.

\%0. P. longepedunculatum D. fol. longe petiolatis glabris cordatis subundulatis; spicis filiformilus pedunculo hreviorihus. Peperomia Opiz 1. c. In Pevuviae montanis. 24.

F1. P. depenlens Vuhl; caule radicante; fol. ovatis cordatis acutis 13-nerviis utrinque glabris dependentibus. Peperomia. Fl. peruv. t. 48. f. a. In umbrosis Pozuzo. Planta pedalis inodora.

72. P. Opizianum D. fol. longe petiolatis glabris cordatis subundulatis 13-nerviis; pedunculis petiolo multo brevioribus; spicis filiformibus. Peperomia. Opiz. In Peruviae montanis.

\%3. P. Guildingiunum Spr. fol. ovato-cordatis glabris aculis basi reniformibus appendiculatis 5-nerviis. Peperomia reniformis. Hook. exot. Fl. t. 164, In ins. St. Vincent.

7. $P$. reniforme Poir. fol, ovatocordatis glahris acntis reniformihus appendiculatis, 5-nerviis.Poir. Enc.Meth.5. p. 465. In Indiis.

7.5. P. maculosum L. caule repente; fol, peltatis ovatis cordatis acutis; pedunculis serratis distachyis. Peperomia. Hook exot. Fl. t. 22. P. variegatum. Pers. In $\mathbf{s t}$. Domingo.

76. P. laxiflora $R$. et $\mathrm{s}$. caule adscendente subramoso tereti, fol. ova- 
tis obeolete cordatis apice angustatis 5-nerviis carnosis glabris. Peperomia. Kuntl. In Nova Granata. 4. Caul. 10-12-poll.

77. I'. secundum Poir. caule erecto villoso; fol. cordato-subrotundis 5-nerviis subtus albidis; spicis racemosis secundis. Peperonia. FI. peruv. t. 45. f. a. P. racemosum. Valı. In montibus Pillao. Caul. pedalis.

78. P. pellucilum 1 . caule procumbente ramoso debili foliisque glabris subrotundu-ovatis acutis subcordatis 5-7-nerviis membranaceis. Linn. Iort. Cliff. t. 6. Peperomia. Kunth. In America meridionali. $\odot$. Canl. semipedalis pallidus, pellucidus.

79. $P$. concinnum Ham. nudum laeve; fol. alternis patulo-pendulis coldatis obtusis 5-nervilus lucidis; petiolis decurrentibus; ramulis flexuosis. Haw. succ. rev. p. 198. In Jamaica. $\hbar$.

80. P. scandens Vahl; caule scandenti repente; fol. subrotundis breve acuminatis subcordatis carnosis ; spicis subulatis. Peperomia. Fl. peruv. t. 51. f. b. P. serpeus Sw, In Peru et Jamaica.

81. P. tenuiflorum D. caule dichotomo glabro; fol. petiolatis subrotundocordatis basi latioribus obtusiusculis glaherrimis pellucidis $\mathbf{5}-\mathbf{7 n e r v i i s . ~ P e - ~}$ peromia Opiz l. c. In Mexico. $\odot$.

82. $P$. hispidulum $S w$. caule erectiusculo glabro; fol. subrotundis petiolatis tenuissimis supra hirtis; spicis solitariis. Sw. prodr. 15. ic. t. 4. In Jamaica et Martinica. ๑. Caul. 3-4-uncialis.

83. P. polybotryum $R$. et S. fol. subrotundo-ovatis acuminatis subcordatis basi peltatis reticulato-multinerviis, glabris pellucido-punctatis. Peperomia. Kunth. In Peruvia. 4.

81. P. asarifolium $D$. glabrum caule erecto obligophyllo; fol. longe petiolatis ; cordato-suborhiculatis obtusis, tenuiter multinerviis. Peperomia. Schlecht. Linn. 5. 1. p. 75. In Mexico, Caul. subpollicaris.

85. P. yrandifolium Eckeland. in Afz. Rem. caule suberecto flexuoso laevi glabro; fol. orbiculato-cordatis acuminatis venosis, spicis umbellatis. P. afzelianum. R. et S. In montibus Sierrae Leone. 24. Caul. 2-ped.

86. P. incanum Haw. caule erecto; fol. subcordatis acutis integerrimis crassis enerviis mollissime tomentosis; spicis Iongissimis. I Iink et Otto Abild. t. 7. In Brasilia. 5. Caul. 1-2-ped. 8\%. P. lunare $D$. glabrum repens filiforme; fol. longissime petiolatis latoreniformibus subemarginatis floribus spicatis remotis. Peperomia. Hanilt. p. 1. ind. occ. ${ }^{\circ}$. 2. In St. Domingo.

B. Foli is oppositis verticillatisve.

88. P. basellaefolium $\boldsymbol{R}$. et $\boldsymbol{S}$. caule erecto ramoso; fol. alternis oppositisque ovatis acuminatis basi acutis obscure venosis camosis, glabris ciliatis. Peperomia. Kunth. In Peru. Caul. 8-10-poll. longus.

89. P. ellipticum Lram. fol. oppositis, obovato-subrotundis glabris ; spicis terminalibus solitariis. Lam. ill. 1. p. 83. In ins. Borboniae.

90. $\boldsymbol{P}$. cassinoides $\boldsymbol{L}$. caule filiformi repente; fol. oppositis lanceolato-ohlongis subtus 5-nerviis; spicis globosis. Lam. ill. 1. p. 82. In Carolina.

91. P. humile Vahl; caulibus erectis foliisque villosis oppositis oblongis acutis enerviis, Vahl en. 1. p. 349. In ins. St. Crucis.

92. P, tetragonum Vahl; caule radicante tetragono; fol, oppositis ovalibus acutis coriaceis 5-nerviis; spicis pendulis. Peperomia. Fl. peruv. t. 47. f, a. In Peruvia. Caul. ped.

93. P. angulatum $\boldsymbol{R}$. et $\mathbf{S}$. caule repente acute 4-angulo; fol. oppositis ovato-ellipticis obtusis 3 -nerviis carnosis coriaceis glabris. Peperomia. Kunth. In Cumana. $\hbar$.

94. P. quadrangulare Thomps in Linn. Trans. 9. t. 21. f. 1. caule radicante 4-angulari; fol. oppositis rhombeis; spicis binatis. In ins. Trinitatis.

95. P. Vahlii $D$. caule erecto pubescente; fol. oppositis oblongis enerviis; spicis axillaribus solitariis. P.pubescens. Vahl 1. c. Hab.... Caul. pedalis.

96. P. maypurense $R$, et $S$. caule ereoto tereti; fol. oppositis ellipticis retusis, basi acutis 5-nerviis carnosocoriaceis margine revolutis glabris. Peperomia. Kunth. In sylvis Orinocensibus. 4. Caul. 1-6-ped.

97. P. heterostachyum $D$, caule ramoso glabro; fol. oppositis ternis quaternisve ovato-lanceolatis 3 -nerviis glabris; spica intermedia longissima. Peperomia tristachya Opiz in Hænk. Rel. t. 30. f. 4. In Peru. 4. 
98. P. pubescens $R$. et $\boldsymbol{P}$. caule orecto pubescente; fol. oppositis ohovatis 3-nerviis subtus puhescentibus. P. saxicolım. Vahl. In Peruvia. Caul. 2-ped.

99. P. dissimile $\boldsymbol{R}$. et $\boldsymbol{S}$. caule erecto ramoso hirsuto; fol, oppositis Inferioribus elliptico-rotundatis 5-nerviis puhescentihus. Peperomia. Kunth in H. et P. 1. c. t. 13. In Nova Granata. 24. Canl. ped.

100. $\boldsymbol{P}$. rotundatum $\boldsymbol{R}$. et $\mathrm{S}$. caule procumbente ramoso villoso; fol. oppositis suborbiculato-reniformibus, reticulato 5-nerviis, subtus pilosis nigropunctatis. Peperomia. Kunth. In Regno Nova Granatensi. 24.

101. P. muscosum R. et $\mathrm{S}$, caule repeute fol. oppositis subsessilibus ellipticis obtusis integerrimis 3-nerviis glaberrimis. Peperomia, Link. In Brasilia.

102. P. circinnatum $R$, et $\mathbf{S}$. caule repente; fol. oppositis sessilibus orbiculatis 3-nervibus pubescentibus. Peperomia. Link. In Brasilia.

103. $P$. manritianum $R$. et $s$. caule procumbente; fol. oppositis petiolatis orbiculatis venosis glabris. Peperomia. Link. In ins. Munritii. Caul. 4-poll. altus.

104. P. Haworthianum $R$. et $S$. caule erecto; fol. oppositis rarissime ternis rhombeis coriaceo - carnosis 3-nerviis, minutissime pubescentibus ciliatisque. P. pubescens. Haw. In India? 4.

105. P. septemnerve Vahl; caule erecto radicante tereti; fol. oppositis ternisque oblongis utrinque attenuatis coriaceis 7-nerviis. Peperomia. Fl. peruv. t. 47. f. c. In Peruvia.

106. $P$, portulacoides Lam. caule repente; fol. oppositis ultimis ternis oblongis obovatisque. Lam. ill. 1. p. 82. In sylvis ins. Mauritii.

107. $P$. ciliatum $R$. et $S$. caule subramoso pubescente; fol. oppositis summis ternis oblongis utrinque acutis trinerviis subramosis ciliatis. Peperomia. Kunth. In Nova Andalusia. 4. Caul. ped,

108. P. tomentosum Vahl; hirsutum; caule repente; fol. oppositis ternisque sessilibus ovatis. Vahl en. 1. p. 351. In Java.

109. P. pallens $R$. et $S$. caule repente ramoso; foliisque tenuissime pilosiusculis ternis ellipticis obtusis aveniis sulicarnosis subtus coloratis. Peperomia. Kunth. In Papayana. 4. Caul. spithameus.

110. $P$. ovalifolium $D$. caule repente tereti pubescente; fol. breviter petiolatis oppositis ternisque ovalibus retusis, punctatis vix pubescentibus, Peperomiat. Hook. In ins. St. Vincente. Canl. (;-8-pollic. longus.

111. P. obversum V'uhl; caule repente; fol. ternis petiolatis obovatis emarginatis glabris. Valıl. In Montferrat.

112. $P$, trifolium $L$. caulescens; fol. ternis petiolatis subratundis, undulatis glabris. Willd. In Gujana. Caul. 2-ped.

113. P. Deppeanum $D$. caule dichotomo radicante apice pubescente; fol. ternis petiolatis subrotundis basi subcumeatis obtusissimis maruine tenuissime ciliolatis. Peperomia. Schlecht. Liun. 5. 1. p. 75. In Mexico.

114, P, serpyllifolium V'ahl; caulibus filiformilus repentihus; fol. oppositis terminalibus ternis quaternisque subrotundis glabris. Vahl l. c. P. nummularium. Lan. In ins. Mauritiuna.

115. $P$. plicatum $D$. caule triangulo, fol, ternis late lanceotatis brevissime peliolatis margine reflexis coriaceis glahris. Peperomia. Opiz in Rel. Huuk. t. 29. f. 2. In Acapulco, 4.

116. P. longiflorum Willd. Hb. caule repente; fol. oppositis ternisque subsessilibus oblongis utrinque attenuatis obtusis glabris 3-nerviis. Alb. Dietr. Hab....

11\%. P. pereskiaefolium Jacq. ic. t. 212. fol. teruis quaternisque ovatoellipticis utrinque acutis trinerviis; carnoso-coriaceis glabris. Peperomia. Kunth. In Caracas. 24. Caul. 1-2-ped.

118. P. polystachyum Hook. caule repente; ramis erectis; fol. ternis rlombeo-subrotundis, petiolatis 3-nerviis pubescentibus. Hook. exot. Fl, t. 3. P. obtusifolium. Jacq. ic. t. 9. In Jamaica. 4.

119. P. stellatum $\mathrm{S} w$. caule erecto; fol. ternis quaternisque oblongis acuminatis 3-nerviis glabris. Swartz. prodr. 16. In Jamaica. 4.

120. $\boldsymbol{P}$. rubioides $\boldsymbol{R}$. et $\boldsymbol{S}$. caule repente dichotomo; ramis 4-sulcatis; fol. ovato-oblongis oltusis aveniis glabris. Peperomia. Kuntlı. In Nova Andalusia. 4.

121. $\boldsymbol{P}$. concavum Vahl; caule 
erecto; fol. oppositis quaternisque sessilihus ellipticis t-nerviis subtus convexis. Peperomia Fl. peruv. t. 46. f. c. In nemoribus Peruviae. Caul. 2-palmaris.

122. P. blandum Jacq. ic. $t$. 218. caule erecto subramoso pulescente; fol. petiolatis ohlongis 3 -nerviis villosis subtus sanguineis. Peperonia Kunth. In Caracas. 24. Caul. ped. ruber.

123. $P$. fontinale $\boldsymbol{R}$. et $\boldsymbol{S}$. caule glabro; fol. inferioribus quaternis summis opositis sessilibus reflexis lanceolalis acuminatis carnosis glabris. Peperomia Kunth in $\mathrm{H}$. et B. t. 16. Ad ripam fluvii Amasonum. 4. Caul. ped.

121. P. filiforme $S u$. ic. $t$. 8 . caule filiforme repente; fol. lincari-oblongis obtusis inferioribus oppositis summis quaternis. In Jamuica.

125. $P$. angustatum $R$. et $S$. caule repente glahro; fol. quaternis oblongis longe acuminatis, reticulato 3 -nerviis; membranaceis glabris. Peperomia Kunth 1. c. In Cumana. 4.

126. P. pulchellum Ait. caule erecto; fol. quaternis subsessilibus oblongis enerviis. Ait, Kew. 1. p. 72. In Jtmaica. 4. Semipedalis.

12\%. P. rubellum Haw. pubescens; fol. subquaternis petiolatis ellipticis rugosis subtus rubris 3-nerviis. Peperomia Hook. exot. FI, t. 58. In America meridionali. 4.

128. P. Roliinyo $R$. et $S$. caule pubescente; fol. quaternis lanceolatis obtusis, apiculatis, nervoso-venosis, clliatis Peperonia Link Jahrb. 1. 3. p. 65. Hab....

12.9, P. portulacaefolium $\boldsymbol{R}$. et $\mathbf{S}$. caule decumbente radicante; fol. quaternis ovato-oblongis emarginatis aveniis carnosis ylabris brevissime petiolatis. Peperomia Kuntl. In Peruvia. 4. Caul. ped.

130. $P$. saxatile Wall. caule sulcato repente; articulis villosis; ramis fasciculatis; fol. obovato-cuneatis carnoxis subtus villosis. Wall. in Roxb. ind. 1. p. 163. In Nepalia.

131. P. quadrifolium $L$. caule adscendente basi radicante dichotomo; fol. quaternis obovatis carnoso-coriaceis, brevissime petiolis. Peperomia kiunth. Hook. exot. Fl. t, 22. In America meridionali. 4.

132. P. loxense $R$. et $S$. caule erecto basi radicante ramoso; fol. qua- ternis ohovato-ellipticis obtusis aveniis nervosis glabris brevissime petiolatis. Peperomia Kunth. Prope Loxam. 4. Caul. $\frac{1}{2}$-ped.

133. P. verticillatum $L$. caule erecto; fol. quaternis ellipticis obtusis trinerviis; spicis verticillatis. Vahl en. 1. p. 353. In Jamaica. Caul. ped. 134. P. rhombeum Vahl; caule radicante furcato; fol. quaternis breviter petiolatis rhombeo-oblongis enerviis. Fl. peruv. t. 46. f. c. In Peruvia. Caul. 2-palmaris.

13.5. P. reflexum $L$. caule repente; fol. quaternis breviter petiolatis rhombeo-subrotundis reflexis. P. tetraphyllun Forst. In India occidentali et in Prom. b. spei.

136. P. ovbiculatum Poir. caule radicante hispido; fol. subsessilibus quaternis minimis orbiculatis hirsutis. Poir. Enc. Meth. 5. p. 476. In Garolina.

13\%. $\boldsymbol{P}$. peploides $\boldsymbol{R}$. et $\boldsymbol{S}$. caule procumbente ramoso tetragono; fol. quaternis ohovato-subrotundis, obtusis junioribus pubescentilus. Peperomia Kunth. Ad montem Cotopaxi. 4. Caul. spithameus.

138. P. microphyllum $\boldsymbol{R}$. et $\mathbf{S}$. caule adscendente dichotomo; ranis 4-gonis foliisque pilosiusculis quaternis aut quinis lanceolato-oblongis. Peperomia Kuntlı. in H. et B. t. 15. f. $\mathbf{z}$. In Nova Granatu. 5 .

139. P. brachystachyum Vaht; canle repente; fol. ternis ad quinis ohovato-subrotundis subtus convexis. Fl. peruv. t. 47. f. 4. In Peruvia. Caul. filiformis purpureus.

110. P. tricarinatum Haw. fol. subquinatis elliptico-ovatis, concavocanaliculatis acumine obtusato sultus praecipue inferme nervoso-tricarinatis. Haw. Suppl. p. 102. Hab.... Caul. subpedalis.

111. P. rubricaule Nees Hor. phys. $t, 8$, caule erecto gtahro; fol. quaternis quinisve subsessilibus lanceolatis concavis trinervibus. In Brasilia. 4. Caul. ped.

112. $P$. galioides $R$. et $S$. caule subramoso; fol. subsenis lanceolatooblongis obtusis trinerviis carnosis scabriusculis apice ciliatis reflexo-patentibus. Peperomia Kunth in $\mathbf{H}$. et $\mathbf{B}$. t. 17. In Reyno Novo Granatensi. 4. Caul. ped. debilis.

143. $P$, suaveolens Desf. ranis 
simplicibus ; fol. subscnis ovato-oblongis glaberrimis. Desf. Cat. IIort. Par. ed. 2. In Cuba. 24. Caul. carnosus 3-ped.

141. P. indequalifolium $\mathrm{Vahl}$; caule adscendente basi radicante dichotomo; fol. subsenis obovatis retusis carnosis, subsessilibus reflexis. Fl. peruv. t. 46. f. a. P. aromaticum Willd. In Lima et Peru. 4. Caul. pluripedalis.

145. P. congestum $R$. et S. fol. quinis ad septenis sessilibus ovatis acutis aveniis carnosis, subtus convexis utrinqueglabris. Peperomia Kunth. In Peru. 4.

116. P. Phyllanthus Willd. fol. oppositis summis ternatis cordatis inaequaliter repandis pilis solitariis ciliatis basi floriferis. Peperomia Opiz 1. c. In Pernvia. 4.

147. P. foliiflorum Iahl; caule erecto; fol. umbellatis oblongis cordatis basi floriferis; spicis aggregatis fexuosis, Fl. peruv. t. 45. fo c. In Peruvia. Caul. $\frac{1}{2}$-pedalis.

148. P. Honkeanum $D$. radice dentato-tuberosa; fol. terminalibus numerosis cordatis inaequaliter repandis subtus pubescentibus. Peperomia Opiz. In Peruviae montanis. 4.

\section{Acanles.}

159. P. umbilicatum R. et S. glabrum; fol. orbiculatis centro peltatis Enerviis; spica radicali. Fl. peruv. t. 45. f. b. P. globosum Poir. In Mexico et Lima. 24.

150. P. macrorrhizon $B$. et $S$. glabrum; fol. orbiculatis centro peltatis subcucullatis aveniis spica radicali. Peperomia Kunth. In alpibus Peruviae. 24. Rad. bulbosa placentiformis.

151. P. scutellaefolium Vahl; radice tuberosa; scapo erecto; fol. ovatis peltatis concavis nervosis. Fl. peruv. t. 44. f. b. P. scutellatum Pers. In collibus Peruviae.

152. $P$. tuberosum $D$. radice tuberosa obtuse dentata; fol. cordatis 7-nerviis margine tenuissime pubescentibus. Peperomia Opiz in Rel. Hænk.3. p. 164 In Mexico. 4.

153.. P. stoloniferum $R$. et $S$. hirsuto-puiescens; fol. subrotundo-reniformibus, 7 -nerviis longe petiolatis. Peperomia Kunth. In Regno Novo Granatensi. 24. Similis Asaro europaeo.

154. P. hemionitidifolium D. gla- brum; caudice subterraneo; fol. ovatooblongis subspathulatis obscure venosis; capitulo subramoso. Peperomia Hamilt. In St. Domingo. 4.

II. PIPrer. Linn. Bractea squamiformis sub singulo flore. Styli 3 et plures. Stigmata patentia. Bacca monosperma.

A. Foliis venosis non cordatis.

15.5. P. angustifolium Lam. fol. subpetiolatis lineari-lanceolatis utrinque acutis glaberrimis enerviis; spicis subglobosis. In Gujana. $\hbar$.

156. $P$. salicifolium lahl; ramis superne villosis; fol. petiolatis lanceolatis attenuatis acutis hasi obtusis supra scabris subtus villosis. Vahl en. 1. p. 312. In Surinamo. ђ.

157. P. viminale Cpiz; ramis hispidulis; fol. breviter petiolatis lancelatis basi acutis glabris venoso-nervosis; petiolis ciliatis. Opiz in Pressl. Rel. Hænk. 3. p. 150. In ins. Luzon. 古.

15s. P. saliuncum Opiz; ramis glabris fol. breviter petiolatis, lanceolatis glabris venoso-nervosis. 0 piz 1 . c. In Mexico et Panama. $\hbar$.

159. P. impunctatum Link; fol. petiolatis lanceolatis acuminatis venosis glabris subtus ferrugineo-nitentibus. Link Jahrb. 1. 3. p. 62. In Brasilia. $\hbar$.

160. P. Hoffmanseggianum $\boldsymbol{R}$. et S. fol. petiolatis lanceolatis acuminatis venosis glaberrimis concoloribus. P. citrifolium. Link. In Brasilia. $\mathbf{b}$. 161. P. linguefolium Hamilt. caule flexuoso incano-rugoso; fol. alternis oblique lanceolatis subreticulatis subtus rugosis. Hamilt. Prod. ind. occ. p. 3. In montibus Hispaniolae. $\hbar$.

162. P. lanceatum Hamilt. fol. alternis lanccolatis acutis, basi oblique rotundatis utrinque rugosis. Hamilt. 1. c. In Jamaica. $\hbar$.

163. P. lanceolatum $R$. et $\boldsymbol{P}$. fol. late lanceolatis utrinque acutis punctatis glabris. Fl. peruv. t. 61. f. b. In nemoribus Peruviae. $\hbar$.

161. P. nigricans Willd. Hb. fol. suhsessilibus, late lanceolatis brevi acuminatis margine reflexis basi inaequilibus, lacvibus glabris. Alb. Dietr. In ins. $\mathbf{S t}$. Mauritii. $\hbar$.

165. P. retrofractum Vahl; fol. elliptico-lanceolatis attenuatis multi- 
nerviis rugosis basi inaequalibus; pedunculis retrofractis. Vahl en, 1. p.314. In India orientali. $\hbar$.

166. $P$. rugosum Vahl; ramis villosis scabris; fol. ovato-lanceolatis attenuatis rugosis supra nitidis subtus villosis. Lam. ill. 1. p. 81. P. bullatum. Vahl. In St. Domingo et $\mathrm{Ca}$ jenna. 市.

167. P. nitidum $\mathrm{S} w$. glaberrimum; fol. lanceolato-ovatis obliquis venosis nitidis. Sw. Prodr. p. 15. P. praemorsum Rottb. In Jamaica et Surinamo. $\hbar$.

16s. P. aequale Vahl; fol. ellipticolanceolatis attenuatis glabris basia equalibus subtus impunctatis. Vahl Ecl. 1. p. 4. In ins, Caribaeis et in Peru. t.

169. P. phytolaccaefolium Opiz; ramis angulatis glabris; fol. ovatooblongis utrinque attenuatis glabris basi inaequalibus; spicis brevissimis. Opiz. In Guayaquil. †.

170. P. curvatum R. et $P$. ramis glabris; fol. petiolatis oblongis acuminatis basi vix inaequalibus laevibus subtus punctatis nitidis; spicis curvatis. Fl. peruv. t. 54. f. a. In Peruvia. †. Frut. 8-ped.

171. P. brevespicatum Opiz; ramis teretibus glabris; fol. ovato-oblongis utrinque attenuatis pilis minutis obsitis, inaequalibus; spicis brevissimis, Opiz. 1. c. Hab.... 卢.

172. P. divaricatum Meyer; fol. oblongis acutis glabris utrinque cum ramis pedunculisque elevato-punctatis; epicis curvatis. Meyer Esseq. p. 15. In Essequebo. Ђ.

173. P. falcatum Opiz; ramis angulatis scaberrimis; fol. ovato-oblongis utrinque attenuatis pilis sparsis obsitis margine ciliatis; spicis arcuatis mucronatis, mucrone piloso. Opiz 1. c. In Peruvia. ђ.

17t. P. microstachyon Vahl; fol. oblongis acuminatis laevissimis basi aequalibus; spicis brevissimis coronatis, Vahl Eclog. 2. p. 3. In $\mathrm{Ca}$ jenna. $\hbar$.

175. $\dot{\boldsymbol{P}}$. lineatum $\boldsymbol{R}$. et $\boldsymbol{P}$. fol. ovato-oblongis acutis lineatis basi inaequalibus subtus pilosis; spicis recurvatis. Fl. peruv. t. 60. f. a. In Peruvia ad fluvios. $\hbar$.

176. $P$. celtidifolium $H$. et $B$. ramis junioribus hirtis; fol. oblongo-lanceolatis acuminatis basi angustatis utrinque glabris lineatis, venis petio- lisque hirtis. Kunth. syn. 1. p. 106. In Regno Novo Granatensi. b. Arbor 30-ped.

177. P. gracile $\boldsymbol{R}$. et $\boldsymbol{P}$. fol. ovatooblongis acuminatis acutis basi inaequalibus subtus rugosis pubescentibus. Fl. peruv. t. 50. f. b. In nemoribus Peruviae, †. Frutex biulnaris.

178. P. dichotomum $R$, et P. fol. ovato-oblongis acuminatis acutis basi subaequalibus, spicis cylindricis, fructiferis pendulis. Fl. peruv. t. 60. f. b. In sylvis Peruviae. ち. Frutex 3-ulnaris.

179. P. callosum $\boldsymbol{R}$, et $\boldsymbol{P}$. fol. oblongo-ovatis acuminatis basi biglandulosis; spicis brevibus subechinatis. Fl. peruv. t. 53. f. a. In Peruviae nemoribus. ち. Frutex ulnaris.

150. P. juliflorum Nees; fol. venosis oblongis obtusis basi inaequalibus eglandulosis glabris; spicis breviter subechinatis. Nees et Mart. in Nov. Act. 11. p. 9. In Brasilia. 2-ped.

181. P. punctatum $R$. et $P$. fol. ohlongis acuminatis basi aequalibus utrinque punctatis, nervis supra prominentibus. Fl. peruv. t. 62. f. a. In Peruvia. 古. Frutex 4-ped.

182. $\boldsymbol{P}$. caribense $H$. et $B$. ramis teretibus laeyibus foliisque glabris oblongis longe acuminatis basi aequalibus rotundatis. Kunth. In Cumana. Frut. 15-ped.

183. $P$. crassinervium $H$. et $\boldsymbol{B}$. ramis subangulatis foliisque glabris ovato-oblongis acuminatis basi angustatis subcoriaceis. Kunth syn. 1. p. 104. In Regno Novo Granatensi. ち. Frut. 10-ped.

181. $\boldsymbol{P}$. secundum $\boldsymbol{R}$. et $\boldsymbol{P}$. ramis scabris; fol. oblongis acuminatis glabris laevibus pendulis basi subaequalibus. Fl. peruv. t. 62. f. a. P. heteromallum Pers. In Peruvia. t. Frut. 8-ped.

185. $P$. excavatum $R$. et $P$. fol. ovalibus acuminatis basi subinaequa. libus leviter repandis glabris lineatis. FI. peruv. t. 54, f. b, In nemoribus Peruviae. †. Frut. biorgyalis.

186. $P$. longifolium $R$. et $P$. fol. oblongo-ovalibus, acutis basi inaequalibus utrinque nitidis venosissimis. Fl. peruv. t. 61. f. a. In Peruvia. \$. Frut. biorgyalis.

187. P. citrifolium Lam. fol. ovatooblongis acutis glabris subtus reticu- 
lato-rugosis hasi subaequalihus. Lam. ill. 1. p. 80. In Cajenna et Brasilict. b.

15s. $\boldsymbol{P}$. heterophyllum $\boldsymbol{R}$. et $\boldsymbol{P}$. fo'. oblongo-ovatis acuminatis basi suhaequatibus nitidissinis utrinque punctatis. Fl. peruv. t. 56. f. a. In Peruvia. ђ. Frut. 12-ped.

189. 1'. colubrinum Link; caule variegato glahro; fol. petiolatis sul)acuminatis apiculatis basi subaequalibus glabris nitidis subtus pustulatis. Link Jalirh. 1. 3. p. 61. In Brasilia. †.

190. P. crocatum R.et S. fol.ovatooblongis acuminatis acutis, basi inaequalibus utrinque rugosis supra asperis subtus pubescentibus. Fl. peruv. t. 35. f. a. In Peru. ち. Frut. subulnaris.

1.91. P. stipposum Alb. Dietr. ramis angulatis tomentosis, petiolis hispido-tomentosis; fol. rugosissimis lacunosis acuminatis subtus hispidotomentosis. P. rugosum Opiz 1, c. In Peruvia. $\hbar$.

192. $P$. aduncum $I$. ramis scabriusculis; fol. ovalibus acuminatis basi inacqualihus utrinque scabris subpubescentibus; spicis uncinatis. Jacq. ic. t. 210. In India occidentali. $\hbar$.

193. P. asperifolium $R$. et $\boldsymbol{P}$. ramis hispidulis ; fol. ovali-oblongis acuminatis basi inaequalibus asperis subtus hispidulis. Fl. peruv. t. 56. f. b. In Peruvia. ђ.

191. $\boldsymbol{P}$. asperiusculum $\boldsymbol{H}$. et $\boldsymbol{B}$. fol. ovato-lanceolatis acuminatis, basi inaequalibus subrotundis superne scabris subtus glabriusculis. Kunth 1. c. In Regno Novo Granatensi. ђ.

19.5. P. umbrosum $\boldsymbol{H}$. et $\boldsymbol{B}$. ramis striatis piloso-hirtis ; fol. ovato-ellipticis acuminatis hasi subaequaliter rotundis piloso-hirtis. Kunth 1. c. In Regno Novo Granatensi. $\hbar$.

196. $\boldsymbol{P}$. dilatatum Rich. fol. oblongo-ovatis basi inacqualiter venosis laevibus medio dilatatis. Vahl en. 1. p. 320. In America meridionali. $\hbar$.

197. P. obovatum $\boldsymbol{R}$. et $\boldsymbol{P}$. fol. ollongis antrorsum latioribus acuminatis basi attenuatis aequalibus utrinque laevibns punctatis. FI. peruv. t. 53. f. b. In Peruvia. †. Frut. 3-ulnaris. 198. P. botrytis Vahl; fol. ovatooblongis elliptico-lanceolatisque attenuatis basi inaequalibus nervis subtus villosis. Vahl 1. c. In America. ち.

199. P. scabrum Sw. fol. lato- ovatis acuminatis obliquis rugosis $8 \mathrm{ca-}$ bris; spicis rectis. sw. ind. occ. 1. p. 59. In Jamuica. t. Frut. 5-6-ped.

300. P. scabrinsculum Opiz; fol. ovatis acuminatis basi inaequalibus utrinque scabriusculis venoso-reticulatis subtus avenits adpresse pilosis. Opiz 1. c. In Peruvia. $ђ$.

201. P. obesum Vahl; fol. ovatis acutis rugosissinis subtus pubescentibus supra asperis; spicis rectis. Vahl l. c. P. scahrum Fl. peruv. t. 55. f. b. P. asperum Pers. In Peruvia. $\downarrow$. 4-origyalis.

202. P. cuspidatum Hamilt. fol. alternis lato-ovatis acuminatis infra attenuatis obliquis subtus nervosoreticulatis nervis vagis hirtis. Hamilt. prodr. ind. occ. p. 3. In Irispaniola. $\mathbf{b}$.

203. P. tumidum H. et B. fol. obIongo-ellipticis basi inaequaliter rotundatis coriaceis reticulato-rugosis subtus ad venas hirtis. Kunth 1. c. In

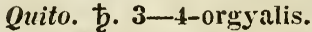

20t. $\boldsymbol{P}$. velutinum $\boldsymbol{H}$. et $\boldsymbol{B}$. ramis tomentoso-hirtis ; fol. ovato-oblongis acuminatis utrinque lanato-pubescentibus. Kunth. 1. c. In Peruvia. t. Arbor 3-ped.

205. P. reticulosum Opiz; ramis petiolisque villosis; fol. ovatis acuminatis nervoso-venosis margine fimbriato-ciliatis subtus lacunosis. Opiz I. c. In Mexico et Guayaquil. \$.

206. P. pilosiusculum Opiz; ramis angulatis petiolisque villosis; fol. ovatis nervoso-venosis utrinque pilosis. Opiz 1. c. t. 29. f. 1. In Panama. ち. 20\%. P. patens Opiz; ramis pilosis exasperatis; fol. ovatis acuminatis coriaceis venoso-nervosis supra rugosis scabris pilis adpressis. Opiz 1. c. In Peruvia. ち.

208. P. nitidulum Opiz; fol.ovatooblongis basi aequaliter rotundatis acuminatis supra glabris nitidulis subtus reticulato-venoso-nervosis in nervis venisque pubescentibus. Opiz 1. C. t. 27. f. 1. In Mexico.

209. $\boldsymbol{P}$. oblongum $\boldsymbol{H}$. et $\boldsymbol{B}$. fol. ovato-oblongis acuminatis basi inaequaliter rotundatis glabris subtus in venis pubescentibus. Kunth 1. c. In Cumana. ち. 15-ped.

210. P. flexuosum Rudge Guj. t. 13. fol. ovali-lanceolatis cauleque flexuoso pubescentibus; spicis erectoincurvis. In Gujana. $\$$.

211. P. dumosum Rudge Guj. t. 11. 
fol. oblongo-lanceolatis laevibus utrinque hirsutis; caule flexuoso-scaliro. In Gujana. \$.

212. $P$. granatense $D$. ramis verrucosis foliisque glahris ovatis acuminatis basi oblique rolundatis coriaceis. P. grandifolium Kunth 1. c. In Regno Novo Granatensi. ‡. Arbor sulitriorgyalis.

213. $P$. angustum Rudge $t$. $\%$. fol. ovato-oblongis acuminatis minute punctatis; bracteis peltatis ciliatis. In Gujana. Ђ.

214. P. geniculatum. Sw. fol. oblongis acuminatis multinerviis, glabris basi inaequalihus; geniculis nodosis. Swartz plodr. 15. In Jamaica et insula Trinitatis. $ђ$.

215. $P$. nodulosum Link; caule rodis tumidis approximatis; fol. petiolatis ohlongo-lanceolatis acuminatis nervoso-venosis subtus punctatis nervis pubescentibus. Link cn. 1. p. 36. Hab.... †.

216. 1. eucalyptifolium Rurlge Guj. t. 6. fol. late lanccolatis attenuatis apice oblique curvis nervosis; bracteis peltatis integris. In Gujana. 直.

21\%. P. hirsutum Sw. fol, oblongis acuminatis rugosis basi obliquis geniculisque hirsutis. Sw. ind. occ. 1. p. 60. P. hispidum Sw. prodr. In Jamaica. ち.

218. P. hispidum H. et $\boldsymbol{l}$. ramis hirtis; fol. ovato-oblongis actuninatis basi inaequaliter rotundatis lineatis supra punctalo-scahris suhtus in venis petiolisve hirtis. Kunth 1. c. In Regno Novo Granatensi. ђ.

219. P. psilostachyum $\boldsymbol{H}$. et $B$. ramis pubescentibus; fol.oblongis acuminatis hasi subaequaliter rotundatis utrinque scahris; petiolis puhescentibus. Kunth 1. c. In Regno Noro Granatensi. †. Frut. 9-ped.

220. P. macrourum H. et I3. ramis glabris albo-punctatis verrucosis; fol. oblongis acutis supra nitidis subtus in nervo medio petiolisque pubescentihus. Kunth 1. c. In Regno Novo Granatensi. ち. Arbor 3-orgyalis.

221. P. tubercniatum. Jacq. ic. t. 201. ramis verrucosis; fol. subsezsilibus ovato-oblongis, aculis supra nitidis scabris, subtus in venis ptibescentihus. In Camana et Caracas. t. 6-8-ped.

822. P. Linkii Alb. Dietr. $\iota_{\text {. }}$ c. ramis sublaevibus; fol. oblongo-ovatis venoso-rugosis glahris repandis. In America meridionali. $\hbar$.

223. P. verrucosum sw. fol. ovatooblongis acuminatis coriaceis hasi inaequalibus, ramis petiolisque verrucosis. Sw. prodr. p. 15. In Jumaicu. t. Arhor 15-20-ped.

224. P. Curumaya R. et P. fol. ovatis acuminatis acutis hasi inaequalihus glabris. Fl. peruv, t. 58. f. b. In Perveria. †.

225. P. ovatum Vahl; Eclog. t. 1. fol. ovatis acuminatis acutis hasi aequalibus; spicis pedurculatis distantibus. In ins. Trinitutis.

226. 1. oblongutum opiz; ramis petiolisfue glabris; fol coriaceis ovatolanceolatis longe acuminatis venosonervosis. Opiz 1. c. In Pernviu. ち.

227. P. rule $H$. et $\boldsymbol{B}$. ramis $\mathrm{pu}-$ hescenti-hirtis; fol. oblongo-lanceolatis acuminatis hasi inaequaliter rotundatis supra hullato-rugosis subtus lacunosis. Kunth 1. c. In Regno Novo Granctensi. 古.

228. P. albc-maculatum D. ramis albo-maculatis foliisque glahris ohlongis longe acuminatis hasi inaequaliter rolundatis. P. variegatum Kumth 1. c. In Regno Novo Granatensi. †. 8-10ped.

229. $P$. cumanense $H$. et $B$. ramulis suhtrigouis; fol. oblongis longe acuminatis basi inaequalibus rotundatis. Kunth. In Cumana. ち.

330. $\boldsymbol{P}$. celtidiforme Upiz; ramis juniorilus triquetris; fol. ovato-ohlonvis, hasi inaequaliter rotundatis acuminatis glabris. Opiz 1. c. In ins. Luะon. †.

231. P. cassinoilles Opiz; petiolis stipulacois; stipulis latissimis obtusis; fol.rotundato-ovatis acuminat is venosoncrvosis subtus in vetis et nervis villosis. Opiz 1. c. In Peruria. ђ.

232. P. crossispicatum Opis; petiolis membranaceo-alatis vaginantibus; fol. ovato-oblongis acuminatis glahris reticulato-venosis. Opiz 1.c. In Panama. ち. Frutex ramosus.

233. $P$. riparium $H$. et $B$. ramis subtetragonis glabris; fol. ovatis apice andustatis acutis basi rotundatis supra glahris subtus in venis petiolisque puhescentibus. Kunth 1. c. In Regno Novo Granatensi. †. Folia pedalia.

231. P. laurinum $\boldsymbol{R}$. et S. ramis teretibus laevibus foliisque glabris 
ovato-oblonuris acuminatis basi aequaliter rotundatis coriaceis. P. laurifolium Kurth In Peruvia. ち. 6-8-ped. 235. P. racemosum Mili. fol. ovatolanceolatis, rugosis, nervis alternis. P. staphyle $\mathrm{R}$. et S. In Vera Cruz. ђ. 10-12-ped.

236. P. chelseanum $\boldsymbol{R}$. et $\boldsymbol{S}$. fol. ovato-lanceolatis tomentosis ; caule arborescente. P. tomentosum Mill. In Vera Cruz. †. 12-14-ped.

23\%. P. coriaceum Vahl; fol. latelanceolatis coriaceis attenuatis; baccis pedicellatis. Vahl 1. c. In India orientali. 5 .

238. P. exasperatum Vahl; ramis inferne scabris superne angulatis; fol. ovato-oblongis acutis multinerviis basi inaequalibus. Vahl en. 1. p. 322. In India orientali. $\hbar$.

239. P. celebicum Blume Act. Bat. 11. $f$. 1. caule scandente; fol. breviter petiolatis elliptico-oblongis acuminatis penninerviis subtus petiolisque hirsutis. Blume. In ins. Celebes. $\hbar$.

240. P. sulcatum Blume l. c. f. 2. caule divaricato ; fol.petiolatis ellipticooblongis acuminatis quintuplinerviis reticulato - venosis glabris. Blume. In Java. ち.

B. Foliis venosis cordatis.

211. P. grande Vahl; fol. inferioribus cordatis, superioribus oblongis laevibus; spicis folio brevioribus. Vahl Eclog. 2. t. 11. In ins. Luzon. ち.

212. P. arboreum Aubl. Guj. t. 23. ramis strialis foliisque glabris ellipticis acuminatis basi inaequaliter subcordatis; petiolis marginatis. P. ma-

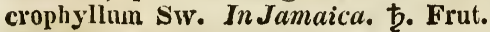
12-ped.

243. P. Ruizianum D. fol, ovatis oblique cordatis obtusis; spicis longissimis pendulis. $\mathbf{R}$. et $\mathbf{P}$. Fl. peruv. t. 63. f. 1. In Peruvia. ఫ. Frut. 2-orgyalis.

214. P. aristolochioides Lam. fol. cordato-sagittatis attenuatis ovatisque; caule repente petiolisque villosis. Lam. ill. 1. p. 80. In ins. Port Praslin. $\hbar$.

245. P. acutifolium $R$. et $P$. fol. ovatis acuminatis acutis oblique cordatis rugosis supra scabris subtus pubescentibus. Fl. peruv. t. 6t. fo a. In Peruvia. \$.

216. $\boldsymbol{P}$. mite $\boldsymbol{R}$. et $\boldsymbol{P}$. fol. ovatis acuminatis acutis basi aequaliter cordatis reticulatis supra glabris subtus pubescentibus. Fl. peruv. t. 58. f. a In Peruvia. ち.

217. P. Carpunga $R$. et $P$. fol. ovatis acuminatis acutis basi aequaliter cordatis coriaceis nitidis. Fl. peruv. t. 63. f. b. P. Carpupiga Pers. In Peruvia. ち. Arbor 3-orgyalis.

248. P. javitense $\mathrm{H}$. et $\mathrm{B}$. caulibus scandentibus tomentosis; fol. ovatis acutis hasi inaequaliter cordatis subtus canis tomentoso-hirtis. Kunth. In regione Orinoci. \$.

249. P. flagellare $H$. et $B$. fol. late ovatis basi profunde inaequaliter cordatis subtus tenuissime pubescentibus; ramis striatis. Kuntl. In Caracas. $\hbar$.

250. P. auritum $\boldsymbol{H}$. et $\boldsymbol{B}$. fol. late ovatis acuminatis basi profunde inaequaliter cordatis utrinque petiolisque tenuissime pubescentibus. Kunth 1. c. In Nova Hispania. ђ. Frut. 12-ped.

251. P. potamogetonifolium Opiz; petiolis vaginantibus; fol. cordatoovatis acuminatis coriaceis glabris nitidis margine revolutis. Opiz l. c. In ins. Marianis. $\hbar$.

252. $P$. coruscans $H$. et $B$. ramis striatis glabris; fol. ovato-oblengis acuminatis cordatis subtus in venis petiolisque puhescentibus. Kunth. In ripa fluminis Magdalenae. ち. Frutex 6-8-ped.

253. P. piluliferum $\boldsymbol{H}$. et $\boldsymbol{B}$. ramis angulato-striatis pilosiusculis ; fol.sessilibus oblongo-lanceolatis longissime acuminatis basi auriculato-cordatis subtus in venis hirtis. Kunth. In Quitov $\hbar$.

251.P. cornifolium $\boldsymbol{H}$. et $\boldsymbol{B}$. ramis tenuissime puhescentibus; fol. sessilibus ovato-ellipticis acumiuatis basi inaequaliter cordatis subtus in venis pilosiusculis. Kuntl. In ripa fiuntinis Magdalenae. $\hbar$. Frut. 3-t-ped.

255. P. lacunosum $\boldsymbol{H}$. et $B$. fol. subrotundo-ovatis acutiusculis basi inaequaliter subcordatis supra rugosobullatis, subtus in venis et venulis hispidis. Kunth 1. c. In Jaen de Bracamoros. ち. Frut. 9-ped.

256. Rredemeyeri Jacq. Eclog. t. 8t. fol. oblongo-cordatis basi inaequalihus acuminatis rugosissimis supranitidis et scabris. P. rugosum. Bred. Hab.... t. Caul, 4-ped.

25\%. P. lanceaefolium $\boldsymbol{H}$. et $\boldsymbol{B}$. ramis junioribus albo-pilosis; fol. oblongo-lanceolatis longissime acuminatis inaequaliter cordatis supra bullatis 
subtus lacunosis piloso-pubescentibus. Kunth 1. c. In ripa fluminis Amazonum. ᄒ.

258. $P$. Radula $H$. et $B$. ramis tomentoso-hirtis; fol. ovato-lanceolatis, acuminatis, inaequaliter cordatis supra bullato-rugosis scaherrimis, subtus molliter fuscescenti-pubescentibus. Kunth. In Caracas, ち. 12-ped.

259. P. cuneifolium Jacq. caule ramisque viridihus emaculatis; fol. cordato-ovalibus acuminatis rugosis glabris mollibus. Jacq. Eclg. 1. 94. In Caracas. $\bar{~}$.

260. P. Jacquinianum $R$. et $S$. caule ramisque lineato-maculatis; fol. oblongo-cordatis, acuminatis rugosis glahris mollibus. P. flexuosum Jacq. Eclog. t. 95. Hab.... ち. 2-ped.

201. P. caracasanum opiz; ramis angulatis; petiolis supra medium memhranaceo-alatis vaginantibus barbatis; fol. oblongo-cordatis supra glabris. Opiz 1. c. In Mexico. $\hbar$.

268. P. alveolatum 0piz; ramis angulatis superne verrucosis, petiolis basi membranaceo-alatis vaginantibus; fol. membranaceis cordatis, supra rugosobullatis margine pubescentibus; spicis crassis. Opiz 1. c. In Peruvia. $\downarrow$.

263. P. nutans Opiz; ramis tuberculatis junioribus nutautihus; petiolis membranaceo-alatis pulverulentis; fol. cordato-oblongis nitidis. Opiz 1. c. In Mexico. ђ.

261. P. granulosum $\boldsymbol{R}$. et $\boldsymbol{P}$. fol. Janceolatis acuminatis basi inaequaliter cordatis rugosissimis scabris; spicis uncinatis. Fl. peruv. 6t. f. b. In Peruvia. ђ.

265. P. purpurascens $D$. fol. elongato-lanceolatis acuminatis hasi inaequaliter cordatis rugosis scahris subtus pubescentibus spicis uncinatis. Vahl en. 1. p. 312. P. angustifolium FI. peruv. t. 5\%. f. a. In Peruvia. Frutex biorgyalis.

266. P. maculatum Blume $\boldsymbol{l}$. $c$. f. 20. caule scandente; fol. petiolatis oblongis acuminatis basi subobliquecordatis interdum suhpeltatis coriaceis glahris. Blıme. In Java. ‡. Rami juniores purpureo-maculati.

\section{Foliis nervosis non cordatis.}

26\%. P. Amalago I. fol, ovatoohlongis acutis hasi aequalibus 5-nerviis rugosis utrinque glabris. Alb.
Dietr. P. frutex Pluclin. t. 215. f. 2. In Jamaica. $\hbar$.

268. $\boldsymbol{P}$. albidum $\boldsymbol{H}$. et $\boldsymbol{P}$. ramis tomentoso-pubescentihus; fol. ovatis acuminatis basi inaequaliter rotundatis reticulatis septuplinerviis tenuissime subtus tomentoso-pubescentilus canecentibusque Kunth. In Carthagena. ち. Frut. 4-5-ped.

269. P. brirbatum $H$. et $B$. fol. ovatis acuminatis basi inaequaliter rotundatis reticulatis septuplinerviis utrinque glabris. Kunth. In Quito. ђ. Frutex 5-ped.

270. P.denudatum Opiz; ramis petiolis foliisque villosis ovato-oblongis elongatis septuplinerviis, supra glaberrimis. Opiz 1. c. In ins. Luzon. ち.

271. P. saururoides Hamilt. fol. lato-ovatis a cuminatis subobliquis 7-nerviis subtus glaberrimis; spicis fructiferis dense dispositis sulmmucronatis. Hamilt. prodr. Fl. ind. occ. p. 3. In Portorico et St. Thomas. ち.

272. $\boldsymbol{P}$. ceanothifolium $\boldsymbol{H}$. et $\boldsymbol{B}$. ramis striatis tenuissime pubescentibus; fol. ovato-oblongis acuminatis basi inaequaliter rotundatis reticulato5-nerviis utrinque glabris subus nervis pubescentibus. Kunth. In $\mathrm{Cu}$ mana. 5 .

273. P. interruptum Opiz; caule radicante; fol. late ovatis 5 -nerviis reticulato-venosis glabris; spicis laxis interruptis. Opiz I. c. In ins. Luzon. $\hbar$.

274. P. abbreviatum Opiz; ramis junioribus angulatis; fol. ovatis utrinque altenuatis 5-nerviis reticulatovenosis glabris; spicis ovato-oblongis. Opiz 1. c. In ins. Lnzon. ち.

275. P. glandulosum Opiz; petiolis canaliculatis glabris; fol. ovato-lanceolatis hasi subinaequaliter rotundatis hasi inferiore uniglandulosis, 5 -nerviis. Opiz 1. c. In ins. Luzon. Ђ.

276.P. tenue H. et B. ramis striatis, ramulis pilosiusculis; fol. Ianceolato-oblongis longe acuminatis, subcoriaceis reticulato-5-nerviis, supra nitidis. Kuntl. In ripis fluminis Magdalenae. †. 6-ped.

28\%. P. laevigatum $\boldsymbol{H}$. et $B$. ramis striatis ; fol. ovato-oblongis longe acuminatis basi rotundatis subcoriaceis reticulato-5-nerviis utrinque glabris nitidis. Kunth. In ripis fluminis Magdalenae. †. 6-ped.

278. $\boldsymbol{D}$. smilacifolium $\boldsymbol{H}$. et $\boldsymbol{B}$. fol. 
ovato-ellipticis longe acuminatis basi rotundatis subcoriaceis, reticulato 7 -nerviis. Kunth. In Cumuna. b. Arhor 2-ped.

279. P. latum II. et B. fol. sul)rotundo-truncatis subcoriaceis reticulato-9-nerviis utrinque glahris nitidis. Kuntl. In ripa fluminis Magdalenae. 5. Frutex 12-ped.

280. P. Laurifolium Mill. fol. lanceolato-ovatis nervosis; spicis brevibus. Mill. Dict. 11. 6. In Vera Cruz. †. 9-10-ped.

281. P. glabrum Mill. fol. ovatolanceolatis acminatis glaluris trinerviis. Mill. 1. c. In Campechia. \$. Caul. 10-ped., ramis curvis.

382. P. capense $\boldsymbol{L}$. fol. ovatis acuminatis 5-nerviis, nervis subtus villosis; caule scandente. L. In Prom. $b$. spei. 古.

283. P. Lonchites R. et $\boldsymbol{S}$. caule repente; fol. breviter petiolatis latelanceolatis 5 -nerviis glabris; spicis filiformibus. P. lanceolatum hoxh. P. moluccanum Spr. In ins. Iloluccanis. $\hbar$.

281. P. Chaba Hunter; caule candente radicante; fol. ovato-oblongis, quintuplinerviis reticulato-venosis membranaceis glabris ; spicis foemineis cylindrico-conicis erectis denum pendulis. Hunt. in Asiat. Res. 9. p. 391. P. Iongum Rumpl. 5. t. 116. f. 1. In Bengalia et Java. t.

2S5. P. trioicum Roxb. caule scandente radicante; fol. oblique ovatis acuminatis glancis $5-7$-nerviis; spicis cylindricis pendulis. Hoxl). ind. 1. p. 153. In India orientali. ђ.

286. P. sylvestre Lam. fol. ovatis attenuatis 5-nerviis venosis basi inaequalibus petiolis pubescentibus. Lam. ill. 1. p. 79. In Cochinchina. †.

287. P. Suipigu Humilt. fol, ovatis 5-nerviis glabris basi rotundatis; picis filiformibus; caule volubili. Hamilt. in Don prodr. p. 20. In Nepalia. $\hbar$.

288. P. Mullesua Hamilt. fol. ellipticis acuminatis 3-nerviis glabris basi aculis; capitulis globosis, petiolo longioribus. Hamilt. 1. c. In Nepalia.

239. P. Guigual Iramilt. fol. ovatis actminatis 5 -nerviis glabris basi rotundatis; capitulis globosis. Hamilt. 1. c. In Nepalia.

290. P. laxum Vahl; fol. ovatp- oblongis acuminatis 5 -nerviis venosis hasi aequalibus, petiolis glabris. Vahl. In ins. Mascarenis et Philippinis. Ђ.

291. P. Muscurense D. fol. ovatoohlongis attenuatis 5-nerviis hasi subinaequalihus; baccis distinctis sessilibus. P. pyrifolium Vahl. In ins. Mascurenis. $\hbar$.

2.92. P. Loncany Blume l. c. f. 5. caule scandente; fol. petiolatis 5 -nerviis, inferiorihus ovato-oblongis, stlperioribus ohlongo-lanceolatis, suhtus petiolis ramulisque dense pubescentihus. In Java. ђ.

293. P. anriculatum Blume $t$. $c$. f. 8. caule scandente; fol. petiolatis ovato-oblongis acuminatis hasi rotundatis cum auricula, glahris. In Java. ђ.

294. P. buccatum Blume l. $c$. $f$. \%. caule scandente; fol. petiolatis oblique ovatis acuminatis, coriaceis glabris subtus alhidis; spicis filiformibus pendulis; fructibus tuberculis suffultis. In Jara. Ђ.

29.5. P. recurvum Blume l. c. caulc scandente; fol. petiolatis subrotundoovatis acuminatis, subtus albidis glabris; spicis incrassatis recurvis. In Java.

296. P. arcuatum Blume l.c. f. 11 . canle scandente; fol. petiolatis ovatooblongis quintuplinerviis glabris; spicis cylindricis arcuatis. In Java.

29\%. P. acre Blume $1 . c$. $t: 13$. canle scandente; fol. petiolatis elliptico-oblongis acuminatis septuplinerviis memhranaceis glabris subtus albicantibus. In Java. †. Baceae aurantiacae.

2.98. P. sundaicum Blume; caule scandente; fol. breviter petiolatis ovatoaut ovali-oblongis, acuminatis 7-9-nerviis glahris. In Juva. ち. Geniculis incrassatis annulo late albo circumdatis.

399. P. crassum Blıme l. c. f. 15. caule striato repente; fol. longe petiolatis ovatis acuninatis 7-nerviis venosis coriaceis glahris. In Java. ち. Rami olivacei profunde striati.

300. P. syringaefolium Vahl; fol. rhombeo-ovatis 5-nerviis hasi aequalibus attenuatis glabris. Vahl. In India orientali. ち. Kami dichotomi compressi.

301. P. terminale Konig; fol. ovato-oblongis attenuatis, sulicoriaceis 5-nerviis hasi sul,aequalibus, geniculis aequalibus. Vahl en. 1. 
p. 329. In Malaburia. ち. Caul. scandens.

302. P. laeve V'all; fol. inferioribus ovatis, superioribus oblongis acuminatis 5-uerviis hasi aequalibus; baccis distinctis. Vahl 1. c. In Indiu orientali. $\hbar$.

\section{Folits nervosig cordatis.}

303. P. nigrescens Blume $\boldsymbol{l}$. $c$. f. 3. caule subscandente, fol. petiolatis ovato-oblongis acuminatis hasi Inaeruali-subcordatis 5-nerviis membranaceis wlabris. In Java.

304. P. Buntumense Btume $\boldsymbol{l}$. c. $f$. 5. caule scandente tereti; fol. petiolatis ovato-oblongis acuminatis, quintuplinerviis coriaceis ylabris margine inferne recurvis. In $\boldsymbol{J}_{\boldsymbol{1}} u$. ち. Rami dichotomi.

305. P. miniatum I3lume l. c. f. 6. caule scandente; fol. membranaceis breviter petiolatis elliptico-oblongis, subcordatisve 5 -nerviis glabris; spicis longis pendulis. In Java. t. Baccae rubrae carnosae, magnitudine seminis silnapeos.

306. P. arborescens Roxb. caule scandente; fol. petiolatis ovato-ellipticis acuminatis cordatisque membranaceis supra glabris infia glaucis et puberulis; spicis longissimis pendulis. Roxb. ind. 1. p. 161. Blume 1. c. f. 12. Rumpl. 5. t. 28. f. 1. In Moluccis et in Jara. 5 .

30\%. P. Malamiri $L$. caule scandente; fol. petiolatis ovato-oblongis, oblique cordatis, reticulato-quintuplinerviis coriaceeis infia ramulisque pubescentibus. Blume 1. c. f. 22 . In India orientali. $\hbar$. Caulis basi crassitie infantis.

:30s. $\boldsymbol{P}$. Hetle $\boldsymbol{L}$. caule scandente; ramis petiolisque striatis; fol. ovatocordatis acuminatis quiutupli usque ad septuplinerviis basi obliquis coriaceis glabris. Hheede mal. 7. t. 15. In India orientali. $\hbar$.

309. P. sylvaticum Roxb. fol. petiolatis late cordatis 5-7-nerviis obtusis ; spicis erectis pedunculatis ; florihus masculis tetrandris. Roxb. ind. 1. p. 158. In montibus Iiengaliae.

310. P. caninum Blume l. c. f. 26. caule radicante scandente; fol. petiolatis ovatis vel ovato-oblougis subquintuplinerviis membranaccis subtus pubescentibus. P. Cubeba Roxb. Rumpl.
5. t. 28. f. 2. In Java et ins. Prince of Hales. $\hbar$.

311. P. Cubeba L. caule scandente; fol. petiolatis oblongis vel ovato-oblongis acuminatis, basi oblique cordatis nervosis coriaceis glabris; baccis longe pedicellatis. Blume 1. c. f. 21 . In Juva. ఫ.

312. P. Siriboa $L$. caule scandente; fol. petiolatis ovato-oblongis acuminatis basi vix inaequali-subcordatis quintupli ad septupli nerviis reticulatis membranaceis glabris; spicis pendulis. Blume 1. c. f. 24. Rumph. 5. t. 117. f. 2. In India orientali. tॄ.

313. P. falla:x Vahl; fol. cordatis acuminatis sub 7-nerviis; petiolis inferne marginatis. Vahl 1. c. In India orientali. $\hbar$. Rami dichotomi.

3l1. P. spurium Link; caule scandente glabro; fol. petiolatis cordatis acuminatis basi subaequalibus septuplinerviis glaberrimis; spicis gracili-

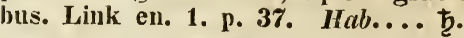

315. $P$. longum $L_{\text {. }}$ caule scandente; fol. subsessilibus basi oblique cordatis obsolete 4-6-nerviis coriaceis criseo-pubescentibus; spicis cylindricis. Blume 1. c. f. 19. Humplı. 5. t. 116. f. 2. In India orientali. b.

316. P. densum Blume l. c. f. 18. caule scandente; fol. petiolatis ovatis acuminatis hasi subobliquis reticulatosub 3-5-nerviis; spicis cylindraceis carnosis pendulis, In Java. ち.

317. P. al!nm Vulu; fol. cordatis attenuatis 7-nerviis duobus superioribus glabris; petiolis aequalibus. Vahl en. 1. p. 334. In Jar

315. P. albilo-punctatum. Blume l. $c . f .16$. caule scaulente radicante; fol. petiolatis 5-nerviis hasi subcordatis coriaceis glabris subtus albido-punctatis. In Nusa Kimbanyan. 市.

319. P. nigrum L. caule scandente radicante; fol. ovatis subcordatis 5-7nerviis coriaceis glabris margine rocurvis subtus glaucesceutibus fructibus distinctis. Blume 1. c. f. 17. Hheede 7. t. 12. In India orientali. $\hbar$.

320. P. mucronulatum Blume $t$. $c$. f. 27. canle repente; ramis fasciculatis petiolisque striatis; fol. cordatis c. mucronulo, coriaccis glabris. Blume. In ins. Nusa Kambangan. $\hbar$.

321. P. muricutum Blume $t$. c. 
f.28. fol. petiolatis, inferioribus cordatis obtusiusculis, superioribus basi inaequalibus sub quintupli ad septuplinerviis supra hirtis subtus subrogosis petiolisque dense pubescentibus. Blume. In Java. t. Caul. 3-4-ped.

322. P. diffusum Vahl; caule striato inferne repente! fol. petiolatis; inferioribus subcordato-ovatis, superioribus oblongis basi obliquis infra rugosis membranaceis glabris. Blume 1. c. f. 29. In Zeyloniu et Java. †.

323. P. mollissimum Blume; caule scandente radicante; fol. longe petiolatis subrotundo-cordatis acuminatis, 5-7-nerviis supra glabris subtus petiolisque mollissimis. Blume. In $\mathbf{J} a$ va. 5 .

321. P. majusculum Blume; caule scandente; fol. petioaltis elliptico-oblongis, oblique cordatis reticulato-multinerviis glabris; spicis elongatis pendulis. Blume. Rumph. 5. t. 27. In Java

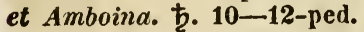

325. P. excelsum Forst. fol. orbiculato-cordatis 7 -nervilis; pedunculis terminalibus solitariis 2-fidis. Forst. prodr. n. 20. In Nova Zeelandia. Ђ.

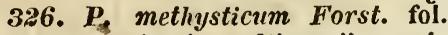
cordatis acuminatis multinerviis; spicis axillaribus brevissimis; pedunculis patentissimis. Forst. In ins. Societatis, Amicorum et Sandwigiae. $\mathbf{b}$.

32\%. P. latifolium Forst. fol. subrotundo-cordatis multinervilis; petiolis glabris; spicis axillaribus aggregatis pedunculatis. Forst. prodr. n. 22. In ins. Societatis, Amicorum et novarum Hebridium. $\hbar$.

328, $\boldsymbol{P}$. gemellum Willd. fol. late cordatis acuminatis glabris punctatis; spicis binatis. P. latifolium Lam. $\boldsymbol{H} a b \ldots$....

329. P. radicans Vahl; fol. inferioribus cordato-ovatis, superioribus oblongis acuminatis, nervis subtus petiolis cauleque villosis. Alb. Dietr. In ins. Franciae. †.

330. P. hirsutissimum D. ramis hirsutis, nudis radicantibus; fol. cordatis 5-nerviis petiolisque utrinque hirsutis. P. Hænkeanum Opiz. In ins. Luzon. .

331. P. marianum Opiz; ramis glabris nudis radicantibus; fol. exacte cordatis, sinu acuto acuminatis 5-9nerviis glabris. Opiz 1. c. In ins. Guahane Marianarum maxima. $\$$.

332. P. rufinerve Opiz; ramis nu- dis radicantibus petiolisque glabris; fol. rotundato-ovatis subcordatisve acuminatis glabris 5-nerviis, nervis rubris. Opiz. In ins. Luzon. $\hbar$.

333. $P$. Andicola $H$. et $B$. ramis pubescentibus; fol. ovatis acuminatis 7-nervis inaequaliter cordatis subtus canis. Kunth syn. 1. p. 110 . In Peruvia. t.

334. P. discolor $\mathbf{S} w$. fol. late cordatis 5-nerviis basi inaequalibus glaberrimis subtus discoloribus; spicis laxis flosculis remotis. Sw. prodr. n. 15. Gmel. in Nov. Comm. Petrop. t. 80. In montibus altis Jamaicae. $t$.

335. P. plantagineum Lam. fol. ovatis cordatisque acuminatis 5-nerviis basi subaequalibus; petiolis junioribus pubescentibus; spicis gracilibus nutantibus; baccis distinctis. Lam. ill. 1. p. 80 . P. medium. Jacq. ic. t. 8. In Caribaeis. $\hbar$.

336. P. californicum Opiz; ramis petiolisque glabris; fol. cordato-sub)rotundo-ovatis 5-9-nerviis glabris; baccis ovatis patentissimis. Opiz 1. c. In California. 市.

337. P. triquetrum Opiz; ramis 3-quetris junioribus petiolisque pubescentibus; fol. ovatis subrotundo-cordatis, acuminatis glabris 5 -nerviis. Opiz. In Mexico. $\hbar$.

338. P. stipulaceum Opiz; ramis junioribus dense tomentosis; petiolis villosis; fol. rotundato-cordatis 7-9nerviis supra pulverulentis subtus pulverulento-tomentosis rugosis. Opiy 1. c. In Mexico. $\hbar$.

33.9. P. reticulatum Linn. fol. cordatis acuminatis 5-9-nerviis glaberrimis reticulatis; petiolis aequalibus. Linn. In Caribaeis. ‡. Caul. orgyalis.

310. P. incurvum Sieb. fol. cordatis acuminatis 7 -nerviis glabris; nervis venisque pustulosis; petiolis submarginatis; spicis incurvis. Alb. Dietr. Sieb, in Fl. Mart. n. 254. In Martinica. 5 .

3H . P. decumanum $L$. ramis junioribus sulcatis; fol. ovatis angustatoacuminatis cordatis coriaccis 9-11nerviis, suhtus in nervis leviter pubescentibus; petiolis dilatato-alatis. Kunth. 1. p. 112. In India occidentali. 5 .

312. P. marginatum Jac\%. fol. cordatis 8-10-nerviis reticulatis subvillosís; petiolis inferne alatis. Jacq. ic. 
t. 215. P. decumanum. Valiı. In India occidentali. $\hbar$.

343. P. alare Hamilt. fol. alternis sub 9-nerviis profunde cordatis late ovatis acuminatis acutis leviter asperis; petiolis membranaceo-alatis; spicis longissimis funicularibus. Hamilt. Prodr. ind. occ. p. 3. In Cayenna. $\hbar$. 34. P. populifolium Opiz; petiolis longis supra medium membranaceoalatis; fol. cordatis sinu obtusissimo acuminatis reticulato-venosis pellucide punctalis glaberrimis ciliatis. Opiz 1. c. In Mexico.

34.5. P. anisatum H. et B. ramis striatis glabris; fol. subrotundo-ovatis acuminatis profunde-cordatis reticulato 9-nerviis, tentuissime membranaceis pellucido-punctatis supra adpresso-pilosiusculis, margine fimbriato-ciliatis. Kunth syn. 1. p. 113. Ad Orinocum. ち. 346. $P$. catalpaefolium $H$. et $B$. fol. subrotundo-ovatis acuminatis profunde cordatis reticulato-9-12-nerviis membranaceis pellucido-punctatis supra adpresso-pilosiusculis, margine fimbriato-ciliatis. Kunth 1. c. In Cumana. ఫ. 15-ped.

347. P. unguiculatum $R$. et $P$. fol. subcordatis acuminatis mucronatis $\mathbf{b}$-nerviis basi inaequalibus. Fl. peruv. t. 57. f. b. P. glaucescens. Jacq. Eclog. t. 761 .

348. $P$. terminale $H$. et $B$. fol. junioribus pubescentibus; fol. lanceolatoovatis apice angustatis mucronatis, cordatis reticulato-5-nerviis subcoriaceis. Kunth. In Nova Hispania. †. Frut. 4-5-ped.

319. P. dubium Alb. Dietr. fol. 3-5-nervilis alternis oblique oordatis lanceolatis acutis margine tenuissime cartilagineis glaberrimis. R. celtidifolium. Hamilt. prodr. ind. occ. p. 3. In Antillis. 专

350. P. caudatum Vahl; fol. subrotundo-ovatis acuminatis profunde aequaliter cordatis reticulato-9-nerviis pellucido-punctatis; spicis secundis. Vahl 1. c. P. Nhaudi Rich. In Brasilia et Cajenna. $\hbar$.

351. P. tiliaefolium Hamilt. ramis incano-pulverulentis; fol. oppositis latocordato-ovatis acuminatis 3 -nerviis oupra nitidis subtus pubescentibus; spicis subgeminis difformibus. Hamilt. $1 . c$. In Cajenna. $\hbar$.

352. P. scutiphyllum Hamilt. fol. peltatis cordato-ovatis acuminatis basi obliquis reticulato-multinerviis, nervis radiantibus. Hamilt. prodr. occ. p. 3. In Hayti. 卢.

\section{E. Foliie pinnatie.}

353. P. pinnatum Lour. fol. ovatis pinnatis; caule erecto aculeato. Lour. In China. ち. Caul. ramosissimus aculeatus.

\section{CLADIUM P. Br. (1756).}

1. C. germanicum Schrad. culmo tereti folioso; fol. Ianceolato-linearibus margine et carina serrulato-aculeatis ; panicula subcorymbosa. Schrad. germ. 1. t. 5. f. 7. In paludosis Europae, Americae et Novae Hollandiae. 24.

2. C. articulatum $R$. Br. panicula decomposita bracteata; culmo folioso tereti foliisque articulatis. $\mathbf{R}$. Br. prodr. 1. p. 237. In Nova Hollandia.

3. C. teretifolium $\boldsymbol{R}$. Br. panicula coarctata composita squamis ciliatis; culmo teretiusculo; fol. radicalibus elongatis angulato-teretibus: caulino abbreviato. H. Br. 1. c. Ad Portum Jackson.

4. C. glomeratum $\boldsymbol{R}$. $\boldsymbol{B r}$. panicula coarctata spathacea spiculis capitatoconjestis bifloris, nucibus ovalibus, culmo tereti compresso laevi. R. Br. 1. c. Ad Portum Jackson.

5. C. junceum R. Br. spica indivisa; spiculis subgeminatis sessilibus 1-floris ; culmis teretibus exsulcis; vaginis strictis; fol. brevissimis verticalibus. R. Br. 1. c. Ad Portum Jackson et in ins. Van Diemen.

6. C. pauciflorum R. Br. spica panciffora rara; spiculis 1-floris; squamis mucronatis; culmis striatis vaginarum foliolis brevissimis setaceis. $\mathbf{R}$. Br. 1. c. Ad portum Jackson.

\%. C. decompositum R. Br. panicula decomposita; bracteis aristatis spiculis geminatis duplo longioribus; culmo tereti folioso; fol. convolutis asperrimis. R. Br. 1. c. In prom. van Leeuxin.

8. C. Radula R. Br. panicula composita effusa; spiculis alternis approximatis; squamis acuminatis; culmo tereti folioso; fol. convolutis asperrimis. R. Br. 1. C. In prom. van Leeuwin. 9. C. deustum $R$. Br. culmo tereti folioso; fol. convoltis asperis imfi- 
morum vaginis harbatis; squamis acumiuatis bracteisque margine lanatis. R. Br. 1. c. In prom. van Leeutin. 10. C. medium R. Br. culmo tereti folioso; fol. canalicnlatis setaceis laevibus, vaginis orelanatis; panicula subspicata. H. Br. 1. c. In prom. van Lecuuin.

11. C. lanigerum R. Br. culmo tereti folioso; foliis filiformibus laevibus breviore, vaginis ore lanatis: nucibus 3-quetris. $\mathbf{R}$. Br. I. c. In prom. I'an Leeuxin.

12. C. dubium Nees; culmo tereti 1-nodo basi folioso; fol. conıpressis angustissimis; panicula racemosa ; bracteis hasi ciliatis. Nees in Sieb. Agrost. n. 5. In Nova Hollandia.

13. C. Filum R. Br. paniculac glomerulis alteruis compositis; spiculis subulatis; squamis aristatis 4-audris; fol. involutis elongatis asperis. R. Br. 1. c. Schoenus Labill. Nov. Holl. t. 19. In ins. Van Diemen. Culmus 2-3-ped.

14. C. schanoides $\boldsymbol{R}$. $B r$. spica subcomposita; spiculis lanceolatis 1-floris; squamis nudis; culmo aphyllo foliisque radicalibus longioribus conıressis vaginis imberbibus. $\mathrm{h}$. Br. Scloenus acutus. Lahill. 1. c. t. 18. In ins. Van Diemen. Culm. 6-8-ped.

\section{LEMNA Daleghamp (1.5S7).}

1. L. minor $I$. phyllodiis obovatis utrinque planiusculis; radicibus solitariis. lichh. excurs. p. 10. Nichn. t. 281. Hook. Lond. 120. In aquis stagnantibus Europae. $\odot$.

2. I. gibba L. phyllodiis obovatis convexiusculis subtus hemisphaericis; radicibus solitariis. Rchh. 1. c. Schk. t. 281. Sturm. 1. 44. Ibidem. $\odot$.

3. I. polyrrhiza $\mathrm{L}$. phyllodiis rotundato-obovatis radicibus confertis. Iichb. 1. c. Schk. t. 181. Sturnu. 1. 44. Cum praecidenti. $\odot$.

4. I. trisulca $L$. phyllodiis petiolatis elliptico-lanceolatis proliferis. Rchb. 1. c. Hook. Lond. 119. Sturm 1. 4. Cum praecedenti. $\odot$.

\section{DYGLNA Etyli duo.}

\section{CRYPTA Nutt (1817).}

1. minima Nutt. Jour. Acad. Philad. 1. p. 117. t. 6. f. $t$. Peplis ame- ricana Pursl. Herba minima carnosa dichotoma. Fol. opposita integerrima supra pilosa. In paludosis Pensylvaniae.

\section{GUNNERA L. (1767).}

1. G. scabra R. et P. fol. Iobatis; venis venulisque subtus hispidis; scapo breviori petiolisque muricatis. Peruv. t. 43. f. a. G. chilensis Lan. ill. t. 801. f. 1. In humidis Chili. 24. Acaulis.

2. G. pilosa $H$. et $B$. fol. lobatis venis venulisque subtus petiolisque dense piloso-hispidis. H. et B. In Quito. 24.

3. G. perpensa $L$. fol. reniformihus dentatis scapo frutifero brevioribus; scapo petiolisque laeviluus. Liun. Mart. 121. In prom. b. spei. 24.

4. G. plicata Vahl; fol. reniformibus crenatis; scapis fructiferis attioribus; scapo petiolisque laevihus. Vahl en. 1. p. 309. G. magellanica. Lam. ill. t. 801. f. 2. Ad fretum magellanicum. 4.

\section{PODOSTEMUM Michx. (1803).}

1. P. ceratophyllum Michx. am. t. 14. Caulis fitiformis natans. Folia pinnata. Flores axillares. In rupibus ad ripas Ohio.

\section{LACISTEMA Su: (1288).}

1. L. myricoides su. ic. f. 1. fol. ohlongis acuminatis integerrimis vel obsolete serratis utrinque glabris; petalis ovatis. Sw. In America meridionali. ђ. Arb. 2-3-orgyalis.

2. I. oblongum $\mathbf{s p r}$. fol. oblongis integerrimis venosis nitidis amentis subsolitariis; stylo simplici; stigmatibus 1-3. spr. syst. veg. 1. p. $12 \%$ In Brasilia. $\hbar$.

3. I. pubescens Mart. n. g. et sp. I. t. 9t. fol. oblongo-lanceolatis acuminatis subintegerrimis supra glabris subtus molliter pubescentibus; petalis linearibus. Mart. 1. c. In Brasilia. b. Arh. 6-8-ped.

3. L. Berterianum $\boldsymbol{R}$. et $\mathrm{S}$. fol. lanceolato-ellipticis acuminatis olssolete serratio utrinque glabris; stigma- 
tibus 3, iterum divisis. Mart. 1. c. L. alterum Spr. Jn Domingo. ఫ.

5. L. servulatum Mart. fol. lanceolatis acuminatis, serratis, utrinque acutis; petalis linearihus; stylo simplici; stigmatibus 3. Mart. 1. c. t. 95. In Brasilia. b. Arbor 10-ped.

\section{ANTHOXANTHUM L. (1845).}

1. A. odoratum $L$. panicula spicata ; flosculis patulis; corollae glumis exteriorihus ciliatis. Willd. Schreh. Gram. 1. t. 5. Trin. ic. 2. t. 14. In Europa, Sibiria et Pensylvania. $\hbar$.

2. A. ovatum Lag. spica ovata densa; vaginis glabris; fol. ciliatis. Lag. Trin. ic. 2. t. 16. Circa Gades. $\odot$.

3. A. gracile Bivona; spica brevi pauciflora; flosculis arista duplo brevioribus; culmo filiformi. Bivon. Stirp. sic. Manip. 1. t. 1. f. 1. Trin. ic. 2. t. 13. In Sicilia. $\odot$.

4. A. amarum Brot. panicula spicata; flosculis arcte adpressis; corollae glumis exterioribus pilosis. Willd. en. suppl. 3. Triu. ic. 2. t. 15, In Lusitania. 4.

5. A. pulchellum Lour. fol. Ianceolatis undulatis; panicula spicata. Lour. coch. p. 36. In Cochinchina.

6. A. avenaceum Retz; spica secunda; calycibus pilosis ; flosculi arista torta geniculata. Retz, obs. 3. 8. In India orientali.

\section{REIMARIA Flügge (1810).}

1. R. acuta Flügge; canle repente; rachibus partialibus basi nudis ; spiculis basi pilosis. H. et K. $\mathbf{~}$. g. et sp. pl. I. t. 21. In Brasilia. ち.

2. $R$. conferta Nees; caule adscendente; rachibus partialibus a basi spiculiferis; spiculis basi minute ciliatis Nees; in Mart. bras. 2. 15. In $\mathrm{Bra}$ silia.

\section{SCHMIDTIA Tratt. (1819).}

1. S. subtilis Tratt. austr. t. 1. Coleanthus Seid. CuImus 3-4-pollicaris, filiformis. Folia lineari-canaliculata, reflexa. Flores umbellati. In Germania. $\odot$.

\section{DIARRHENA Pal. de Beauv. (1928).}

1. D. americana Pal. de Beauv. Festuca diandra Michx. am. t. 10. Reimaria Zea R. et S. Corycarpus arundinacea Zea. Culmus pluripedalis Folium 1-2-ped. Panicula divaricata. In Kentuky et Tenesse. 24. 


\section{I A S S S I I S III.}

T R I A N D R I A.

\section{MONOGYNIA. \\ 1. Fructus inferi.}

151. Iris. Cor. 6-partita; laciniis 3 reflexis, 3 erectis. Stylus superne 3-partitus: laciniis petaloideis. Irideae.

158. IIoraca. Cor. 6-partita, laciniis 3 interioribus minoribus patentibus. Stylus 3-fidus: laciniis petaloideis bifidis, staminibus oppositis. Irideae,

153. IIariea. Cor, 6-partita, laciniis 3 interioribus minoribus; stylus 3-fidus, laciniis petaloideis integris, staminibus alternis, Irideae.

154. Vieusseuxia. Cor, 6 -partita, laciniis alternis minimis. Filamenta comnata. Stylus 3-fidus, laciniis petaloideis. Irideae.

155. Sisyrimchium. Cor, 6-partita subaequalis. Stamina libera, Stylus 3-partitus laciniis filiformibus: Irideae.

156. Talaxia. Cor. tnbo longissimo, limbo 6-partito regulari. Filamenta connata. Stylus multifidus. Irideae

15\%. Patersonia. Cor. tubo gracili; limbo 6-partito laciniis interioribus minutis. Filamenta connata, Stylus 3-fidus, laciniis laminaeformibus indivisis. Irideae.

15s. Nematostigma. Cor. 6-partito, laciniis interioribus majoribus. Filamenta distincta aut infra connata. Stigmata 3, involuto-filiformia, Irideae.

159. Tigmidlia. Cor. 6-partita laciniis interioribhs minoribus. Filamenta in cylindrum longum coalita. Stylus 3-partitus laciniis bifidis. Irideae.

160. Ferraria. Cor. 6-partita, laciniis undulatis interioribus angustioribus. Filamenta connata. Stylus tripartitus laciniis penicillatis. Irideae.

161. Crocus. Cor. tubo longissimo, limbo 6-partito regulari.
Stigma profunde 3-partitum. Irideae.

162. Ixia. Cor. basi tubulosa, limbo 6-partito regulari. Stigmata 3, angusta recurva. Irideae.

163. IB albiana." Cor. tubulosa limbo 6-partito irregulari, Stigmata 3, dilatata patentia indivisa. Irideae.

164. Tritonia. Cor. basi tubulosa, 6-partita regularis. Filamenta inclinata. stigmata 3 , recurvato-patentia indivisa. Irideae.

165. Cladiolus. Cor, basi tubulosa, limbo 6-fido, inaequali subringente. Stigmata 3 filiformia indivisa. Irideae.

166. Votsonia. Cor, basi tubulosa, limbo 6-fido regulari. Filamenta erecta glabra. Stigmata 3, gracilia 2-partita. Irideae,

19\%. Sparaxis. Cor. basi tubuloso-infundibuliformis limbo 6-partito regulari. Stigmata 3 , recurvata patentia. Irideae.

168. Trichonema. Cor. tubo brevi limbo 6-partito regulari, Filamenta pilosa erecta. Stigmata 2-3fida. Irideae.

169. Coissorrhiza. Cor. tubulosa limbo 6-fido regulari, Stylus incurvatus. Stigmata latiuscula fimbriata. Iridecae.

110. Kesperantha. Cor. tubulosa, limbo 6-partito regulari. Stigmata 3 , ad tubum usque distincta. Irideae.

1.7. Anomatheea. Cor. hypocrateriformis, limbo 6-fido subaequali. Stigmata 3, 2-fida. Irideae.

1\%: Meristostigma. Cor. hypocrateriformis, tubo gracilitimo sensim ampliato limbo 6-partito regulari. Stigmata 3, gracilia 2-partita patentia. Irideae.

1.z3. Vitgenia. Cor, tubulosa limbo 6-partito regulari. Stigma leviter 3-fidum. Irideae.

184. Aristea. Cor. 6partita regulari. Stigma unfundibuliforme. Irideae. 
175. Antholyza. Cor. tubo gracili limbo 6-fido ringente. Stigmata 3 , indivisa. Irideae.

1. 6. Diasia. Cor. campanulata 6-fida, subregularis. Stigmata 3, gracilia recurvo-patentia. Irideae.

1 ร. Gilliesia. Perianthium duplex: exteruum e bracteis 5 petalodeis compositum, internum carnosum labelliforme. Stamina 3 perfecta, 3 sterilia dentiformia.

18. Wnemodorum. Cor. glabra 6-partita; stamina 3, hasi laciniarum interiarum inserta, Haemodoreae.

1.9. Dilntris. Cor. extus hirsuta 6-partita; petala basi staminifera. Stamina 6, quorum 3 antherifera, anthera unica maxima. Haemodoreae.

180. Tachmanthes. Cor. extus lanata 6-partita. Stamina 3, basi laciniarum interiarum inserta. Antherae aequales. Haemodoreae.

181. Hurmannia. Cor. tubo trialato vel tricarinato limbus 6-partitus irregularis. Stamina 3. Stylus sulcatus. Stigmata 3, dilatata subbiloba. Burmanniaceae.

18\%. Gonianthes. Cor. tubo 3-quetro; limbus 3-partitus. Stamina 3. Stylus 3-sulcus. Stigmata 3, dilatata staminibus cohaerentia. Burmanniaceae.

183. Gymmosypinom. Cor. tubo cylindraceo, limbus 3-partitus. Stamina 3. Stylus 3-gonus. Stigmata 3 dilatata. Burmanniaceae.

184. Valeriama. Calycismargo involutus germen coronans, demum in pappum transiens. Cor. infundibuliformis, 5-fida. Valerianeae.

185. Fealia. Calycis margo dentatus persistens. Cor. infundibuliformis 5-fida. Valerianeae.

156. Axia. Lour. Cor. campanulata10-fida. Antheraebicoccae. Fructus 1-spermus hirsutus.

18\%. Somerila. Calyx 3-dentatus. Cor. 3-petala. Capsula 3-10cularis polysperma. Ericeae.

188. Prieurea. Calyx tubulosus, 3-fidus; cor. 3-petala. Capsula 3-locularis. Onagrariae.

\section{I1. Fructus superi.}

158. Waehendorfia. Cor. 6-partita, laciniis 3 exterioribus ma- joriłus; stamina $3-6,2-3-s t e r i l i a$. Stigma indivisum. Xiphideae.

190. Hachenbachia. Cor. 6-partita, laciniis alternis angustioribus. Stamina 3. Stigma sub capitatum. Xiphideae.

191. Xiphidium. Cor. 6-partita, laciniis 3 exterioribus majoribus calycinis. Stigma 3-lobum. Xiphidiaae.

192. Hrodiaea. Cor. tubulosa limbo 6-partito. Stigma 3-fidum. Asphodeleae,

193. Wencocoryme, Cor, hypocrateriformis limbo 6-partito. Stamina 6, 3 sterilia. Germen sessile. Stigma simplex. Asphodelecie.

194. Jolnmsonia. Cor. 6-partita. Stamina 3. Filamenta inferno dilatata et comnata. Stigma simplex. Asphodeleae.

155. Commelina. Calyx 3-phyllus. Cor. 3-petala. Stamiua 2-3. Parastamina 3-4, superne cruciformia. Stylus simplex. Capsula 3-Iocularis 3-valvis. Commelineae.

196. Syena. Calyx 3-phyllus. Cor. 3-petala. Stamina 3, receptaculo inserta. Stigma 3-fidum. Commelineae.

198. Callisia. Calyx 3-phyllus. Cor. 3-petala. Filamenta 3, sub apice dilatata, diantherifera. Stigmata 3 , penicillata. Commelineae.

10s. Aclisia. Calyx 3-phyllus. Cor. 3-petala, Stamina 3. Parastamina 3, glandulifera. Stylùs simplex. Bacca exsucca. Commelineae.

199. Heteranthera. Cor. tubo longissimo, limbo 6-partito aequali. Stamina 3. Stigma concavum fimbriatum vel capitatum. Pontedereue.

200. Williehia. Calyx 4-fidus. Cor. rotata, limbo 4-fido. Caps. 2-10cularis, 2-valvis. Personatae.

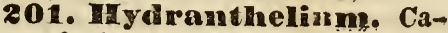
lyx profunde 4-partitus. Cor. infundibuliformis 3-fida. Personatae.

202. DInerolobium. Cal.4-fidus basi 2-bracteatus. Petalum unicum. Stamina 3. Legumen 1-sperm!im. Leguminosae.

203. Dutea. Cal. 5-fidus basi bracteatus. Petala 5, 4 minima, quintum maximum. Stamina $3-4$ quartum sterile. Legumeñ monospermum. Leguminosae.

201. Intgia. Cal. 5-fidus. Petalum unicum. Stamina 9, 3-anthifera., 
Legumen pelicellatum compressum, sub) hexaspermum. Semina in pulpa nidulantia sub quadrata. Leguminosae.

205. Drtegra. Cal. 5-fidus. Cor. nulla. Capsula 1-locularis apice trifariam dehiscens, semina funiculis umbilicaribus capillaribus ad fundum capsulae haercutia. Paronychieae.

206. Stipulicida. Cal. 5-partitus laciniis integris. Cor. 5-petala; petala receptaculo inserta. Caps. 1-10cularis 3-valvis oligosperma. Illecebrue.

20\%. Moeffingia. Cal. 5-partitus, laciniis basi $\mathbf{2}$-dentatis. Cor. 5-petala; petala calyci inserta. Capsula 1-locularis polysperna semina spermacophoro centrali affixa. Ilelebreae.

208. Hippoeratea. Cal.5-fidus. Cor. 5-petala cucullata; caps. tres, 2-valves, 1-loculares.' Semina deorsum alata. Hippocruteae.

209. Anthodoln. Cal. 5-partitus. Cor. 5-petala. Bacca 2-3-10cularis; loculis abortu 1-spermis. Scmina ovata mucilagine obvoluta. Hippocrateae.

210. Faddisia. Cal. 5-plıyllus. Cor. rotata 5-fida. Capsula 2-10cularis, loculis polyspermis. Semina subglohosa axi centrali affixa. Hippocrateae.

211. Salacia. Cal. 5-partitus. Cor. 5-petala. Bacca 1-locularis polysperma. Hippocrateae.

212. Xolnmia. Cal. 5-partitus. Cor. 5-petala. Bacca 1-aut oligosperma. Semina $1-2$ peltata in 10culo singulo. Hippocrateae.

213. 1 Iax. Cal. parvus integer tanden ampliatus baccatus. Cor. 6-petala. Parapetala 6, filiformia 2-fida. Olacineae.

214. Fissilia, Cal. integer post anthesin ampliatus. Cor. 5-petala; petalis 4 per paria connexa. Drupa exsucca 1-sperma. Olacineae.

215. Spermaxymum. Cal. parvus integer, demum ampliatus. Cor. 5 -petala; petalis 4 , medio conmatis. Drupa exsucca 1-sperma. Olacineae.

216. Poly enenunur. Cal. corollinus 5-phyllus, bracteis duabus suffultus. Cor. 0. Stigma 2-fidum. Utriculus 1-spermus, apice marginatus. Chenopodeae.

31\%. 'ThreIkeldia. Cal. urceolatus, intra marginem squamis tri- bus membranaceis. Utriculus calyce Irupaceo baccato inclusus. Semeu ovatum alluminosum.

218. Xyris. Cor. 3-fida. Stamina 6, 3 sterilia. Stylus 3-fidus. Capsula 1-locularis 3-valvis, polysperma.

819. Abolboda. Cor. tuhus gracilis limbo hypocrateriformi 3-loho stigmatibus 2-3-fidis. Capsula 1-10cularis 3-valvis polysperma.

\section{$G \boldsymbol{l} u \boldsymbol{m}$ a $\boldsymbol{c} \boldsymbol{e} \boldsymbol{a} \boldsymbol{e}$ 。}

a. Cyperaceae.

* Cal. gluma 1-valvis; cor. nulla.

220. Strellibia. Spicae terminales. Rachis flexuosa. Stylus hasi urceolato-dilatatus; setae hypogynae. Nux 3-gona truncata mucrone brevissimo.

221. Clnatospora. Spicao terminales et laterales iuvolucro dipolyphyllo. Rachis rectiuscula. Glumae 1-valves imbricatae. Nux 3-gona mucrone brevi ant vix ullo.

22\%. Selnoenus. spicae terminales et laterales, Rachis rectiuscula. Glumae inferiores ninores steriles. Nux 3-gona mucrone brevi aut vix ullo. Setae nullae.

223. Hepidosperma. Spicae terminales. Kachis subflexuosa. Nux obovata 3-quetra. Setae hypogynae 6, basi connatae.

224. Pterolepis. Umbella lateralis. Spiculae multiflorie, hermaphroditae, sterilibus intermixtae. Squamae hypogynae 5 membranaceae ciliatae basi connatae. Nux apiculata, squamis tecta.

285. Carplan. Spica 1-flora terminalis. Stylus subulatus. Stigmata 2-3. Nux prismctica, stylo persistente cuspidata. Setae liypogynae 6-12-plumosae vel capillares.

226. HIysmus. Spicae composita. Rachis rectiuscula. Nux sulcompressa attenuata stylo filiformi secedente. Setae hypogynae plures aut nullae.

32\%. Rhymelnosporn. Spicae terminales et axillares, involucro polyphyllo. Rachis rectiuscula aut sulfflexuosa. Setae hypogynae 3-10. Nux compressa subtrigona.

228. Wleochnris. Spica terminalis, iuvoluero uullo, hachis rectius- 
cula. Stylus basi dilatatus persistens. Nux anceps rarius triquetra. Setac hypogynae 6-10.

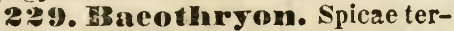
minales, basi bracteis duabus vestitae. Rachis rectiuscula. Stylus filiformis hasi non dilatatus. Nux anceps aut 3-gona. Setae lypogynae 1-10.

230. Fle aritom. Spica aut spicae terminales. Rachis rectiuscula. stylus fitiformis nuce secedens. Nux anceps aut 3-gona mucrone b!evi. Setae hypogynae nullae.

?3. Hsolopis. Spicae terminales aut laterales. Machis rectiuscula. Gluma 1-valvis valvae sensim decrescentes. Stylus 2-3-partitus filifornis a nuce secedens. Nux anceps rarius 3-gona mucrone brevi. Setae nullae.

23 . Fimmorstylis. Spicae terminales. Hachis rectiuscula; stylus fimbriatus, basi dilatatus, a nuce secedens. Nux anceps aut 3-gona. setae nullac.

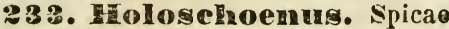
terminales e spiculis conglonieratae. Rachis rectiuscula. Stylus filiformis a nuce secedeus. Nux 3-gona mucrone brevi. Setae nullae.

231. Hiclommena. Spicae terminales aggregatae. Rachis rectiuscula. stylus 2-3-partitus basi dilatatus cum nuce connatus. Nux anceps aut trigona. Setae nullae.

235. Sciñus. Spicae laterales aut terminales. Rachis rectiuscnla. Stylus 2-3-partitus filiformis basi secedens. Nux anceps aut 3-gona mucronata plerumque linc plana hiuc convexa.

236. Albirdorardia. Spica aut spicae terminates, bracteis valvaceis ad basin; valvis glumae distichis. Nux anceps aut 3-gona. Stylus basi incrassatus a nuce secedens. setae nullac.

\$3\%. VI alıaenima. Panicula terminalis, spicae aggregatae. Stylus 3-fidus. Nux pedicellata, setae bypoyyuae parvae.

23\%. HoreRotia. Panicula terminalis; spiculae multivalves apice 1-florae. stylus filiformis. Stigmata 3, plumosa. Nux elliptica, ossea nitens.

\$35. Vicentia. Speculae subsexflorae. Antherae bivalves 4-sulcae. stylus inferne dilatatus. Setae nullae.

240. Anthrostylis. Spica 1-flora. Valvao imbricatae, inferiores vacuae. Stylus subulatus 3-gonus ovarlo articulatus deciduus. Setae nullac.

211. Catstis. Spicae sub-2florae. stamina 3-5. stylus basi dilatatus. stigmata $3-1$. Nux ventricosa basi bulbosa stylo coronata.

21:. 'Troichophorum. Spiculae terminales. Slylus 2-partitus filiformis basi secedens. Nux 3-gona mucronata. Setae hypogynae, cum valvis caducae.

213. Nuin 1 Porum. Spica ant spiculae terminale. Rachis rectiuscula. Stylus filiformis a basi secedens. Setae hypogynae.

\section{* Gluma bivalvis. Cor. nulla.}

24. Cyperus. Spica terninalis; cal. gluma subbivalvis, valvae interiores totae rachi adnatae. Nix anceps aut 3-gona. Setae nullae.

24. Pry nales. Glumae hivalves aut distichae. Nux anceps aut 3-gona. Stylus filiformis a nuce secedens. Setae nullae.

246. Gussomen. Spiculae terminales 2-florae. Glumae distichae imbricatae 1-florae, stylus filiformis supra medium 3-fidus basi pyramidatoincrassatus, apicem nucis amplectens. Nux 3-gona.

24. Dulichium. Spicae axillares. Cal. gluma subbivalvis, valva interior rachi adnata. Stylus basi die latatus, persistens; setae hypogynae.

248. Fariscus. Spiculae terminales in capitula congestae. Cal. gluma sub bivalvis, valvae inferiores persistentes, interior rachi adnata. stylus tripartitus. Nux trigona. Setae hypogynae nullae.

249. Hillingia. Spiculae terminales, in capitula aggregatae. Gluma calycina terminalis 2-valvis. Stylus 2-partitus. Nux anceps. Setae nullae.

B. Gluma 6-valvis. Cor. nella.

250. II apania. Spicae terminales, capitatae. Nux calyce involuta.

C. Calys et Perigọnium.

253. Hemichlaena. Spicae terminales. Gluma 2-valvis, valvae distiche imbricatae, "compresso-cavi- 
natae; 1-florae, Infima vacua. Nux obovata triquetra versus basin perigynio tenuissimo aureo arcte velata.

358. Fuirenn. Spicae terminales multiflorae. Perigynimm trivalve germen amplectens. Stylus nliformis basi secedens. Nux anceps aut 3-gona.

\section{Calyx et Corolla.}

253. Hypelythrum. Spicae terminales. Hachis recta pedicellorum intiis. Stylus 3-partitus. Nux trigona ntrinque attenuata. setae nullae.

254. Melaneranis. Spicae terminales capitatae. Spiculae 4-7forae bracteatae. Glumae calycis 2-valves. Gluma corollina 1-valvis. Setue nnllae.

255. Taumea. Spicae terminales 1-florae. Calycis gluma 2-valvis. Gluma corollina 2-valvis. Germen ellipticum. Stylus basi conicoincrassata hirsuta. Nux trigona basi conica hirsuta stylo coronata.

256. Remirea. Spiculae terminales, capitatae. Gluma calycina 2-valvis. Gluma corollina 2-valvis. Nux oblonga corolla inclusa. Setae bypogynae nullae.

25 . Dreobnins. Spicae terminales. Gluma calycina 2 -valvis, valvae spathaceae decidnae 1-florae. Gluma corollina 6-valvis, valvae cartilagineae. Nux cristacea.

\section{Gramina.}

258. Nardus. Spicnlae 1-florae; ealycis gluma nulla. Gluma corollina 2-valvis. Stigma villosum. Semen liherum.

258. Cenelnerus. Involucrum 1-phyllnm induratum; extus spinis aceretis. Spiculae 2-florae, flosculus alter hermaphroditus alter masculus. Glumae calycis et cor. 2-valves. Semen tectuu.

260. Spartina. Spiculae 1-00rae. Gluma calycina 2-valvis. Gluma corollina 2 -valvis valva utraque carinata. Stigmata plumosa. Semen tectum. spica composita.

261. Pommereullia. Gluma ealycina 2-valvis 3-6-flora; valvae cuneiformes 4-fidae setigerae dorso aristatae. Stigmata aspergilliformia.

\section{DIGYNIA.}

$$
\boldsymbol{G} \boldsymbol{a} \boldsymbol{m} \boldsymbol{i} \boldsymbol{n} \boldsymbol{a} .
$$

1. onyzear. Spicnlae nune 1-florae, glumis saepe alortientibus, nuno 2-3-florae; floribus 1-2 inferioribus 1-paleaceis nentris, terminali fertili. Paleae chartaceo-rigidae. Flores saepe diclines, plerumque hexandri. Phalaroideis proxime affines. Kunth. Agrost. 1. p. 5.

268. Keersia. Spiculae 1-florae compressae. Glumae nullae. Paleae 2, clartaceae, compresso-carinatae muticae. stigmata plumosa ramosa. Caryopsis compressa, lihera glahra.

263. Dryza. Spiculite 1-florae. Glumae 2, parvae membranaceae muticae. Paleae 2, chartaceo-coriaceae compresso-carinatae, inferior latior apice aristata. Stamina 6. Caryopsis glalira ohlonga.

264. Mraltebrumia. Spiculae 1-florae. Glumae 2, parvae canaliculato-carinatae muticae. Paleae 2, memhranaceo-chartaceae, inferior latior mutica. Squamulae 2 subcarnosae. Stam. 6.

265. Potamoplnila. Spiculae polygamae saepius nonoicae, superiores hermaphroditae 8 . masculae inferiores femineae. Glumae 2, minimae. Paleae 2, membranaceae inferior 5-nervia superior 3-nervia. Stam. 6. Stigmata plumosa pilis 2-fidis aut dichotomis.

366. Hydropyrum. Spicnlae 1-florae masculae et femineae in eadem panicula. Glumae masculae nullae. Paleae 2, inferior suhmucronata 5-nervia, superiorem 3-nerviam involvens. Stam. 6. Squamulae 2 subcarnosae. Palea feminea inferior 3-nervia in aristam longissimam desinens. Caryopsis gracilis elongata sulco longitudinali notata.

26y. Tizania. Spiculae 1-florae, masculae et femineae in eadem panicula. Glumae masculae 2 , minimae; Paleae 2 , inferior 5-nervia mucronata; femine inferior aristata 7-nervia. Caryopsis stipitata laterihus lenticnlari-compressa.

259. Iuziola. Spiculae 1-florae, masculae et femineae in distinctis paniculis. Glumae nullae. Paleae 2, memhranaceae muticae. Stamina 6-11. 
Squamulae 2, in flor. masculis 3 , hyalinae. Stigmata villoso-plumosa. Caryopsis elliptica laevis.

269. Arrozia. Spiculae 1-fiorae, masculae et femineae in eaden panicula. Glumae 2, muticae. Paleae nullae. Stam. 6. Caryopsis globosa libera.

2 8. Ehrlharta. Spiculae compressae 3-florae, flores approximati, 2 inferiores neutri subulato-aristati, terminalis hermaphroditus 2-paleaceus. Stam. 6. Stigmata plumosa, pilis Iongissinis. squamulae 2 , bilobae subaristatae.

281. Tetrarrlnema. Spiculae 3-florie, flor. 2 inferiores neutri. Glumae 2. Paleae ovato-oblongae 7-nerviae. Staminz 4.

2 ระ. Microlaena. Spiculae 3-florae; flosculis 2 inferioribus 1-paleaceis. Paleae flosc. neutri subulatoaristatae, 5-sulcatae. stän. 4. stigmata plumosa pilis longissimis lyyalinis. Caryopsis linearis.

2 z 3. Pfaarius. Śpiculae 1-florae, geminatae, altera parva pedicellata mascula, altera sessilis feminea. Masc. Gluma inferior 3-nervas superior2-nervia. Stam.6. Palea inferiorsubteres involuta. Stiunnata papilloso-pilosa. Caryopsis linearis cylindrica.

2 ร. Heptapsis. Monoicae 1-florae. Masc. Glumae 2. Paleae 2, interior angustior lin earis plana. squamulae nullae. Stam. 6. Foem. Palea exterior ventricosa suhglobosa, interior minuta linearis. Caryopsis inflata.

II. PHalabotirak. Spiculae hermaphroditae polygamae, rarius monoicae, nunc 1-florae cum vel absque rudimento stipitiformi floris alterius superioris, nunc hiflorae flore terminali fertili, reliquis incompletis. Glumae plerumque aequales. Paleae saepe nitidae inque fructus induratae. Agrostoideis et Avenaceis affines. Kunth.

2\%5. Fygeum. Spiculae 1-florae, glumis destitutae, geminae vel terne inferne in tubum carnosum extus dense sericeo-hirsutum $\mathbf{2}-\mathbf{3}$-locularem connatae. Paleae rigido-membranaceae. Caryopsis oblonga hinc convexa.

3\%6. Zea. Flores monoici terminales masculi racemosi axillares, feminel arcto spicatí, vaginis pluribus aphyllis arcte involuti; stigmatibus longissimis exsertis.

ะg. Coix. Inflorescentia spicata. Spiculae basilares involucratae, media sessilis feminea. Involucrum clausum ovatum lapideum, nitidum, apice perforatum pro emissione rachis liberae et stigmatum.

2 \%. Contheopine. Spiculae complures físciculatae involucratae 1-florae; involucro campanulato crenato. Glumae carinatae inferne connatae. Palea unica carinata, inferue 6-nervia apice hiloba. stigmata longissima puhescentia. Caryopsis oblique ovata.

2 ร. Cryosis. Spiculae 1-florae; flore sessili imberhe. Glumae compresso-carinatae, muticae. Paleae membranaceae muticae, superior 2-nervia. sityli longissimi. Sitigmta plunosa pilis denticulatis.

260. Alopecunous. Inflorescentia spicata; spiculae 1-florae. Glumae naviculari-carinatae muticae inferne connatae. Palea inferior membranacea, compresso-carinata, dorso plerumque infra medium aristata. Sticymata longi:isima, pulsescenti-plumosa. Caryopsis ohlique elliptica.

281. Chamagnostis. Spiculae 1-florae. Hlores sessiles glumis ovato-ohlongis 1-nerviis breviores. $\mathrm{Pa}$ leae tenuissime membranaceae, extus villosae, inferior 5-nervia. Caryopsis obovato-elliptica.

28z. Beckmannia. Spiculae lenticulares 2-florae. Flores sessiles. Glumae obovatae, compresso-llaviculares. Palea inferior ovata concava 3-nervia, superior apice bifida. Squamulae bifidae. Caryopsis oblonga plana.

283. SPI I Um. Spiculae 1-fiorae. Glumae naviculari-carinatae muticae vel apice aristatae. Paleae tenuiter membranaceae, superior2-carinata.stylus brevissimus incurvus. Caryopsis oblique ovata $s$. elliptica.

284. Hilaria. Spiculae tres inferne connatae, 2 inferiores $2-3$ florae masculae, superior 1-flora feminea. Fem. Glumae 2, suboppositae inter lobos aristatae. Caryopsis glabra.

885. Hexarrhema. Spiculae ternae, 2 superiores 3 -florae masculae, inferior 1-flora, feminea. Gluma inferior flosculi femineí lenticularis pellucida, 3-nervia, superior 1-neivia 
286. Phulneis. Spiculae 3-norae; flores inferiores 2 , minimi, squamosi. Glumae membranaceae muticae, inferior major superiorem involvens. Pili stigmatum bullato-papillosi.

387. Hol cus. Npiculac 2-florae; flores inter se et a glumis remotae, superior aristatus. Glumae menuranaceae naviculari-carinatae, flores superantes. Styli brevissimi. Caryopsis glabra libera.

289. Hierocinon. Spiculae 3-florae; flores 2 inferiores maseuli, saepius aristati ; terminalis hermaphroditus, 2-andrus, submuticus. Caryopsis oblique oblongo-elliptica.

259. Ataxin. Spiculae 3-florae; flore inferiore masculo, 2-paleaceo, intermedio neutro 1-paleaceo; terminali hermaphrodito. Glumae 2 inaequales Habitus Anthoxanthi.

290. Reymaudin. Spiculae 1-florae; flore sessili imberbi. Palea inferior apice 2 -fida aut breviter aristata sub 5-nervia, superior 1-nervia aculeato-mucronata. Stigmata penicilliformin.

291. Depretzia. Spiculac 3-1forae; flores 2-paleacei, mutici, inferior feminens. Glumae apice 3-lobae inferior 7, superior 3-nervia. Palea inferior floris feminei 9-nervia apice 4-loba.

III. Paxcear. Spiculae 2-florae; flore inferiore incompleto. Glumae paleis tenuiores, saepe inferior rarissime ambae abortientes. Paleae magis minusve coriaceae nec chartaceae plernmque muticae, inferior concava. caryopsis embryoni parallele compressa.

292. Prspalumh. Spiculae 2-florae cum pedicello articulatae tardius deciduae; flore inferiore nettro 1-gluma superiore hermaphrodito 2-gluma.

298. Milium. Spiculae 2-florae, pedicelli non articulati. Gluma 1 , mutica membranacea concava. Paleae muticae, inferior concava superiorem 2-nerviam amplectens. Caryopsis oblonga.

284. Amphicarpum. Spiculae 2-fiorae, flore inferiore 1-paleaeeo nentro, masculas et femineae in eadem planta, Masc. Glumae paleae- que concavae muticac. Squanulae 2, carnosae truncato-subtriloliae.

255. Iу го. Śpiculao masculas et fenineae in eadem planta, biflorae. Mase. Gluma inferior acuminatoaristata. Paleae nullae. Squamulae 3. Stigmata pilosa, pilis ramosis.

2\$6. Streptuitna. Spiculae 1-florae, muticae masculae et femineae in distinctis racemis ejusdem plantae. Glumae lineari-lanceolatae. Paleae nullae. Carypsis paleis corticata.

29 ร. Traสya. Spiculae2-florae; flores utrique 2-paleacei, inferior masculus superior hermaphroditus minor. Masc. Palea inf. profunde 2-partita laciniis in carinis setoso-ciliatis, sub apice subaristatis.

25. Eridelolom. Spiculae 2-florae, basi articulatae. Gluma inferior minutissima. Paleae coriaceae; inferior apice mucronata. Squamulae 2, carnosae truncato-emarginatae. stigmata penicilliformia denticulata.

259. Unochelloa. Npiculae 2-florae nudae. Glumac membranaceae concavae muticae. Palea inferior floris hermaphroditi apice aristato-mucronata. Squamulae sub-3-lobae, lobo medio longiore.

300. Fami cumn. Spiculae 2-florae nudae. Glumae inaequales concavae muticae. Paleae floris hermaphroditi coriaceae, muticae inferior superiorem 2-nerviam amplectens. Stigmata penicilliformia, pilis denticulatis. squamulae dolabriformes.

301. Helnhantinus. Spiculae 2-florae. Glumae ovatae acutae concavac muticae. Paleae floris hermaphroditi ovato-oblongae, acutatac involuto-concavac, superior 2 -nervia. stigmata aspergilliformia.

302. Isnelne. Spiculae 2-florae, flore utroque 2-paleaceo, coriaceo. Glumae concavac apice rotundatas muticae. Paleae coriaceae concavae. Stigmata plumosa. Caryopsis paleis induratis inclusa.

303. Stenotaphrum. Spica compressa ad unum latus sinubus alternis pro receptione spicularum excavata. Spiculae 2-florac. Gluma inferior minuta. Palcae coriaceae, inferior siperiorem bicarinatam amplectens.

304. Mrelinus. Spicula 2-flora, basi cum pedicello articnlata. Paleas 
Aoris neutri bifidae et aristatae. Stigmata penicilliformia, pilis denticulatis. Squamula unica flabellato-truncata.

B05. Dplismenus. Spiculae Q-florae nudae. Glumae membranaceae concavae, plerumque aristatae. Palea foris hermaphroditi inferior acuminata mucronata concava superiorem amplectens. Squamulac 2, caruosae truncatae.

306. Chamacraphis. Spiculae 2-florae, ad hasin arista Iongissima persistente instructae. Squamulae 2 , membranaceae. Caryopsis paleis cartilagineis inclusa.

30\%. Berchtoldia. Spiculac solitariae, lanceolatae, 2-florae. Glumae lanceolatae, arista longa recta terminatae, inferior hasi convoluta in formam stipitis barbati. Stignata aspergilliformia. Caryopsis oblonga apice 2-cornuta, scutello magno instructa.

305. Setaria. Spiculae 2-florac, Involucratae. Involucrum persistens 1-laterale setosum. Glumae membranaceae concavae muticae. Squamulae 2, carnosae truncato-obtusatae,

309. Gymmostrix. Spiculae 2-fforae solitariae involucratae. Involucrum una cum spicula deciduum multisetum. Squamulae 2 , caruoso-membranaceae irregulariter bilobae.

30. Fenmisetum. Spiculae biflorac solitariae geminae vel plures involucratae. Involucrum setosum; setis inferioribus inferne plumosis. Glunae 2, membranaceae concavae. Squamuląe minutissimao v. plerumque nullae. Caryopsis compressiuscula paleis coriaceis inclusa.

311. Tepithilenn. Axis caduciformis. Spiculae solitariae, linearilanceolatae. Involucellum coriaceum duplex; exterius: squamae (4-6) ab)breviatae, apice inaequaliter dentatae, 5-7-nerviae ; interius : squamae 2-3elongatae forma spiculic; exima in caudem praelongam eapillaceam attenuata.

312. Penicillaria. Spiculae solitariae vel geminae involucratae 2-florae ; flosculo superiore hermaphrodito inferiore masculo; involucrum dimidiatum multisetosum setis inaequalibus hispido-scabris.

313. Anthephora. Spiculae 2-florae 4-ternae, basi connatae. Flos sperior hermaphroditus; inferior ste- rilis 1-paleaceus stcrilis fertilem amplectens. Caryopsis elliptica.

314. Tampago. Spiculae in pedicello communi hrevl geminao vel quinae 1-florae. Gluma superior cartilaginea externe echinata. Stigmata plumosa; pilis hyalinis denticulatis.

215. Honboedia. Flores monaici vel p.olygami racemosi; racemo lineari-cylindraceo. Glumae nullae. Palcae 2, minute elevato-punctatae. Fructus paleis induratis nigrescentibrs tectus.

316. Tatiposa Spiculae 1-florae 4-ternae, ramo hrevi coniplanato apice hifido per varia insidentes. Squamulae 2, membranace-hyalinae, truncato-2-lobae, glabbrae. Caryopsis oblonga.

31\%. Felninolnena. Spiculae 2-ftorae; inferior masculus, sruerior hermaphroditus ninor, fructifer basi articulatus. Glumae 2, externe papilloso-piliferae, superiof echinato-glochidata. Squamulae 2, truncato-2-3lobae.

31. Thounren. Spiculae 2-florac; flores sessiles masculi et hermaphṛoditi, Msc. Gluma superior ovatooblonga concava, inferior nulla. squamulae 2, truncato-emarginatae. Caryopsis elliptica.

319. Spinifex. Polygamụ, dioicus; spiculae masculae et androgynae in distinctis plantis; lae solitariae ad hasin rachis longissimae subulato-aristaeformis. Filamenta longissima.

$3: 0$. Neurachme. Spiculae 2-florac; flor.exteriore neutra, interiore hermaphrodito. Glumae hispidae, fruotiferae induratae. Caryopsis libera e paleis rembranaceis decidens.

IV. STIPACrak. Spiculae 1-fíorae. Palea inferior involuta, apice aristatainque fructu plerumque indurata arista simpliciv. trifida saepissime torta et basi articulata. Ovarium stipitatum. Squamulae plerumque 3. Kunth.

321. Pryzopsis. SpicuIa 1-flora; flos breviter stipitatus. Glumae $\mathbf{2}$, subaequales muticae. Palea inferior marginibus involuta apice aristata, arista basi articulata. Squamulae apice ciliatae.

322. Pipaptinerum. Spicula 
1-flora; hasi haud articulata. Paleae 2, tnferior convexa, superiorem involveus, apice aristata; arista hasi articulata, decidua; palea superior 2-nervia.

3:3. Insiagrostis. Spicula 1-flora; flore breviter stipitato. Glumae 2, membranacene, muticae, florem superantibus. Palea inferior subcarinata externe hirsuta apice hifida, inter lobos aristata. Antherae lobis barbatis.

324. Mrerochion. Spicula 1-flora, flore stipitato. Glumae exterue sericeo-hirsutae; inferior 5-nervia, involuta apice 2-fidit inter lobos aristata, superior apice bicuspidata; arista longissima.

325. tipa. Spicula 1-flora; flore stipitato. Glumae muticae canaliculatae, florem superantes. Paleae 2, cylindraceo-involutae, inferior apice aristata; arista torta, hasi articulata.

326. Streptreline. Spicula 1-flora, flore stipitato. Glumae laxae muticae. Palea exterior cylindrico-involuta; arista terminali simplici inarticulata, infra tortili.

32\%. Aristida. Spiculae 1-florae; flore stipitato. Glumae inaequales saepissime muticae, inferior plerumque brevior. Palea inferior teretiinvoluta apice aristata; arista trifida.

328. Stipagrostis. Spicula 1-flora; flore callo stipitato. Glumae fore Iongiores. Palea chartaceomemluranacea convoluta apice emarginato-biloba inter lohos aristata, arista articulata 3-fida decidua. Caryopsis 1-sulcata.

V. Agrostombak. Sploula e 1-florae, rarissime cum rudimento subulato floris alterius superioris. Glumae paleaeque 2 , membranaceo - herbaceae; ex his inferior saepe aristata. stigmata plerumque sessilia. Kunth.

225. Nuellewbergia. Sp:culae 1-florae; flore sessili, hasi barbato. Palea inferior apice aristata superior 2-nervia.

330. Hy gurus. Spiculae geminae 1-florae; altera hermaphrodita pedicellata; altera mascula vel neutra subsessilis. Gluma superior 1-aristata. Palea inferior apico aristata superior 2-nervia.
3:1. Coleanthins. Spiculae 1-florac. Glumae nullae. Palea inferior ovata 1-nervia, carinata, acuminato-aristata, superior $\mathbf{2}$-nervia, 2-cariuata apice 2-fida lohis acutis.

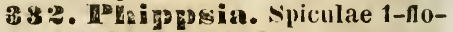
rae, hasi haud articulatae. Glumae vacuae muticae, inferior minor enervia, superior obsolete 1-nervia. Palea inferior ohsolete 3-nervia, superior 2-nervia, 3-t-dentata.

33. Colpordium. Spicula 1-flora; flore subsessili. Glumae subcarinato-concavae. Paleae apice hyalinae, inferior carinato-concava, 2-nervia apice rotundato-enarginata, interdum dorso subaristata.

334. Cirma. Spicula 1-flora. Glumae carinatae flore breviores. Paleae hasi pilis cinctae; inferior acutata interdum apice vel sub apice mucronatosubaristata, superior 2-nervia.

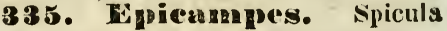
1-flora; flore glumas paullo superante. Glumae 2 ovatae, enerviae muticae obtusae integerrimae. Palea inferior superiorem basi complectens, nervo medio aristata, superior 2-nervia, obtusissima genitalia involvens.

336. Sporolbolus. Spicula 1-flora. Glumae carinatae, inferior minor. Paleae imberbes, inferior mutica superior 2-carinata. Caryopsis decidua pericarpio membranaceo hyalino Iaxo solubili.

33 . A Arostis. Spiculae 1-florae. Glumae florem plerumique multo superantes carinatae muticae. Palea inferior dorso aristata, superior 2-carinata interdum minuta. Stam. 1-3. Squamulae 2, subintegrae.

338. Crastridium. Spiculae 1-fiorae. Glumae 2 lanceolatae, florem multo superantes, clausae v. ventricosae. Palea inferior apice truncato-dentata, superiorem binerviam bicarinatau amplectens. Caryopsis obovato-elliptica, intus sulco longitudinali notata.

335. Chnetotropsis. Spica 1-flora; flore sessili inberbi, glumis dimidio breviore. Glumae oblongo-lanceolatae, acutato-mucronatae, carina pectinato-spinulosa, clausae superne patulae; inferior longior. Palea truncato-3-dentata.

340. Nowodworskya. Spiculae 1-florae, flore basi imberbi. Glumae oblong-lanceolatae, apice 
subulato-aristatae, dorso subrotundae 1 -nerviae nervo spinuloso-hispidae, basi constrictae patulae. Palea inferior ovata 3-nervia, apice trifido-nucronata.

341. Polypogon. Spiculae 1-florae, flore sessili basi imberbi. Glumae carinatae membranaceae aristatae forem multo superantes. Paleac tenuiter membranaceae; inferior apice truncato-denticulata, sub apice aristata. Squamulae falcatae.

34:. Chaeturus. Spicula 1-flora; flore sessili imberbi. Glumae florem superantes; inferior apice aristata. Paleae nuticae, inferior superiorem triplo breviorem involvens. Pilis stigmatum argute denticulatis.

343. Pereilemna. Spiculae2-4, involucro e foliolis 8-19 setiformihus composito-obvallatae, 1-florae; flore pilis cincto. Glumae apice 2-fidae. Palea inferior 3-nervia, apice longissime aristala.

314. Aegopogon. Spiculae geminae vel ternae 1 -florae; laterales saepius tabescentes masculae; flore breviter pedicellato imberbi. Glumae apice 2-fidae aristatae. Palea inferior 3-nervia, superior binervia, apice biaristata.

VI. ARUNDINACear. Spiculae modo 1-florae cum vel absque pedicello floris alterius superioris, modo multiflorae. Flores plerumque pilis longis mollibus obsiti vel basi cincti. Glumae et paleae duae, membranaceherbacae, illae saepe flores aequantes vel superantes; ex his inferior aristata vel mutica.

Gramina pleraque elata.

34. Calamagrostis. Spiculae 1-florae; flore sessili ad hasin pilis longis cincto. Glunae canaliculatae, acutatae vel subulatae, florem multo superantes. Palea inferior apice vel dorso aristata, rarissime mutica, superior 2-nervia.

346. Pentapogon. Spiculae paniculatae, 1-florae; flore pedicellato. Glumae 2, aequales, muticae. Palea exterior apice 5-aristata, arista intermedia dissimili tortili. Stigmata villosa.

34. Deyeuxia. Spiculae 2-florae; flore inferiore sessili hermaphrodito basi barbato; superiore ad pedi- cellum plumosum redacto. Palea inferior dorso aristata; arista tortili; superior 2-carinata.

348. Ammophila. Spiculae 2-florae; flore inferiore breviter pedicellato, basi harbato; superiore ad pedicellum superne plumosum redacto. Glumae lanceolatae carinatae, inferior 1, superior 3-nervia. Palea' inferior ovato-lanceolata 5 -nervia sub apice bifida mucronulata vel breve aristata. Stigmata pilis hyalinis, papilloso-denticulatis plumosa.

349. Arumdo. Spiculae 2-5florae; flores distichi distantes, hermaphroditi, sumutus tahescens. Glumae canaliculato-carinatae inter se remotae. Palea inferior apice bifida, inter lobos subulatos brevissime aristata, pilis longissimis sericeis obsita.

350. Ampelodesmos. Spiculae 2-4-florae; rachis articulata, pilis longiusculis obsita. Glumae 2 ovato-lanceolatae, subulatae canaliculatae. Palea inferior acutata, inferue pilis ohsita, superiorem involvens. Pilis stigmatum ramosis denticulatis hyalinis,

351. Fraphophorums. Spiculae 3-5-florae, compressae; flores distichi distantes imberbes, nomisi ad basin pilis rhachis involucrati, summus minutissimus. Palea superior breviter 2-carinata, carinis ciliato-scabris. Stigmatum pilis argute dentatis.

352. Phragmites. Spiculae 3-6-florae; flores distichi distantes, imberbes; imfimus masculus, reliqui hermaphroditi; rachis pilis longis sericeis olssita. Pilis stigmatum bifidis papilloso-dentatis, hyalinis.

353. Gynerium. Spiculae 2-florae, masculae et femineae in distinctis plantis; flore altero sessili altero pedicellato. Palea inferior feminea externe pilis longissimis olssita, 2-carinata, carinis pectinato-ciliatis.

VIII. PAPPOPHORKAE. Spiculae 2 multiflorae; flores superiores tabescentes. Glumae paleaeque 2, membranace-herbaceae. Palea inferior 3-multifida, Iaciniis subulato-aristatis. Inflorescentia capitato-spicata vel paniculata. Kuntl.

354. Amphipogon. Spiculae 1-florae; flore sessili vel pedicillato 
glumis longiore. Palea inferior 3 , superior 2-fida, laciniis subulato-aristatis, aristis rectis scahris.

355. Difplopogens. Spiculae 1-florae. Glumae 2, laxao membranaceae aristatae. Palea exterior apice 3-aristata, arista intermedia dissinili torta, interior 2-aristata.

35f.'Triraphis. Spiculae 2-3forae; floribus distichis; inferioribus hermaphroditis reliquis masculis vel neutris. Palea inferior apice 3-fida, laciniis subulato-aristatis longissimis, intermedia longiore.

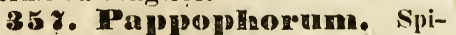
culae 2-1-forae; flore infimo hermaphrodito; superioribus tabescentibus sterilibus. Palea inferior subelliptica, concava, 9-13 aristata, aristatis sub)ulatis rectis. Stignata pilis denticulatis.

35 3. Cotten. Spiculae 6-9-florae; flores distantes distichi, summus tabescens. Glunae multinerviae apice trilobae. Palea inferior 5-fida, 11-aristata, superior apice bifida; lobis acute mucronatis.

359. Felnimaria. Spiculae 2-florae; flos superior pedicellatus, saepe tabescens vel ad pedicelímu redactus. Gluma inferior apice 2-aristata. Palea inferior 5-nervia apice 5-fida; superior 2-fida.

360. Catasetum. Spiculae 3, laterales inferiores sessiles, 2-florae intermedia 4-flora. Glumae linearilanceolatae, setoso-hispidae subcoloratae. Palea inferiore apico 2-fida, aristata, aristis plumosis.

VIIl. ChLoridrae, Spicula in s p icls 1 -laterales 1-multiflorae; floribus superioribus tabescentibus, Giumae palea eque 2 membrauceo - herbaceae ; hae muticae velaristatae; illae in rachi persistentes; superior externe spectans. Spicae digitatso vel paniculatae, rarisnime solitariae, rachis had articulata. Kuntl.

861. Microchloa, Spica solitaria. Spiculae 1-laterales, 1-florae; flore sessili. Paleae glunis breviores tenuissime membranaceae hyalinae, externe deuse pilesae, inferior 3-nervia mucrone membranaceo.

362. Sch oenefeldia.
1-3. Spiculae 1-laterales, sessiles 1-florae; flore sessili basi batbata. Patea inferior sub apice longissime aristata, superior dorso ciliata. Squamulae minutae.

363. Cymoden. Spicae digitatae geminatae vel racemosae. Spiculae 1-laterales sub 2-florae. Palea superior dorso 2-aristata. Squamulae carnosae connatae.

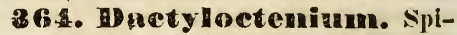
cae digitato - fasciculatae, rarissime solitariae, secundae, 2 -4-florae; flosculis distichis, superiorihus obsoletis.

365. Fastaclays. Spicae digitato-fasciculatae; spiculae 1-laterales, sessiles, 2-llorae; flore superiori sterili.

366. ChIoris. Spicae digitatofasciculatae, rarissime solitariae v. geminae. Sipiculae 1-laterales, sessiles, 2-8-florae; flores distichi. Caryopsis elongata 4-gona.

36\%. Heptocilloa. Spicae racemosim dispositae. Spiculae 1-laterales sessiles, 2-multiflorae distichac. Caryopsis oblonga glabra.

369. Elevsinze. Spicae digitato-fasciculatae; spiculae sessiles. 1-laterales, 2-multiflorae. Gluma inferior 1-carinata, superior 2-carinata,

365. STrupediloa. Spiculae 1-laterales, imbricato-distichae, 4-florae, inferioribus hermaphroditis superioribus tabescentibus glabris. Palea inferior dorso et marginilsus dense ciliata.

3 ช0. Ctenimm. Spiculae 1-laterales, imbricato-distichae $\mathbf{4 - 5}$-florae; flores 2-inferiores steriles, 1-2-paleaceae sub apice aristatac, 1-2-terminales talescentes muticae neutrae. Palea inferior trigono-carinata sub apice mucronata vel aristata, margine dense ciliata.

3 81. Clnometrosiun. Spicae subfalcatae, solitariae rarius $2-5$, distantes; spiculae 1-laterales sessiles, imbricatae, distichae 2-florae; flore inferiore sessili, hermaphrodito, superiore obsolete 3-aristato.

\$ช (1). Dpizia. Rachis spicaeformis; spiculae distichae, 3-florae; flore inferiore hermaphrodito, 2-superiores nentri. Palea inferior apice 2-fida. Caryopsis subrotunda.

3ร3. Futriamia. Spicae abbreviatae, racemosim dispositae; spiculae 1-laterales, sossiles, alteruae 
2-3-forae; flore terminali tabescente, \&-aristato, vel ad pedicellum subulatium redacto.

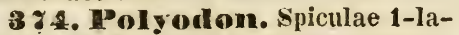
terales, 2-florae; flore altero hermaphrodito sessili; altero sterilı, pedicellato. Palea inferior $\bar{j}$-dentata, dentibns lateralibus et intermedio aristatis.

3 z. Pentan'haphis. spiculae 3-florae; flore infimo hermaphrodito sessili; medio masculo, pedicellato, summo sterili aristaeformi. Palea inferior floris masculi 7-dentata.

3 86. Holysehistig. Spiculae 2-florae; flore inferiore hermaphrodito; superiore neutro pedicellato; pedicello piloso. Palca inferior floris hermaphroditi apice $\mathbf{3}$-fila, lacinia media 2-fida inter lobos aristata.

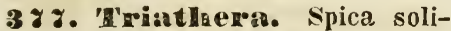
taria, simplex; rachis haud articulata. Sipiculae sessiles alternae distichae, distantes, 2-florie, cum rhachi articulatae, flore inferiore sessili hermaphrodito, superiore hreviter pedicellato, tabescente ad aristas 3, longissimas scabras rectas redacto.

388. 'R'idiena. Spiculae 2-florae; fore altero hermaphrodito, altero neutro 3-aristato. Gluma inferior basi aristata; arista glumae usque ad medium adhaerente.

389. Gymanoposom. Spiculae 2 -florae rachí paraliela; flore inferiore hermaphrodito, sessili basi barbato; superiore pedicellato taliescente minuto, aristato. Palea inferior cylindraceo-iuvoluta, sub apico 2-lobo aristata.

380. "Triplasis. Spicula 4-flora, floribus distantibus, summo abortivo. Palea inferior profunde hifida, inter laciuias longissine aristata, superior reflexa.

384. Pleuropinus. Flores spicati, flosculi terni hasi involucro villoso suftulti, laterales masculi. Cal. centralis 1-florus 2-valvis ö-setus.

IX. AVknackar. Spicula e 2-multiflorae; flore terminali plerumque tabescente. Glumae paleaeque duae, membranaceherbaceae; palea inferior in pluribusaristata; aristasaepe dorsali et tortili.

352. Corynowhorus. Spiculae 2-florae; flore utroque hermaphro- dito. Palea inferior medio aristata, arista recta, medio articulata, apice clavulata.

383. Dupontin. Spiculae 2-3florae; floribus distantibus; terminali saepe clavato, setuliformi. Squamumulae lyalinae apice eroso-dentatae.

394. Aira. Spiculae 2-florae; flores subaequales. Glumae carinatae magnae. Palea inferior apice 2-fida, dorso aristata, arista inferne torta.

355. A inoplsis. Spiculae 2-florae, flore utroque fertili. Glumae muticae naviculares. Paleae hyalinomembranaceae, inferior lata ohsolete 3-loba externe pilosa. squsmulae falcato-lanceolatae.

386.' Trisetaria. Spiculae 2-1lorae; flore inferiore hermaplirodito, breve pedicellato, basi barbato; superiore longe pedicellato, breve aristato.

35\%. Hagrurus. Spiculae 1-florae; flore breve pedicellato, basibarhato. Gluma inferior apice 2-aristata, superior carinata. Palea inferior concava, apice 2-aristata, infra apicem arista longiore sub geniculata instructa.

389. Trisetum. Spiculae 2-1florae. Palea inferior apice 2-cuspidata dorso aristata; superior 2-aristata tortili.

389. Arena. Spiculae 3-multiflorae; flores remati; stummo tabescente. Palea inferior dorso supra lasin aristata, apice plerunique 2-cuspidata, Ovarium apice hirsutum. Squamulae magnae bifidae.

350. Ariphaterum. Spiculae 2-florae cum rudimento filiformi tertii floris, flos inferior masculus. superior hermaphroditus. Palea inferior concava aristata, superior 2-carinata. Arista in flore masculo longissima.

391. Thistaclnya. Spiculae 2-florae, per ternas in apice ramorum congestae, media saepe macrior vel effeta; flore inferiore sessili masculo vel neutro; superiore pedicellato, basi barliato.

342. Misopogon. Spiculae 1-florae, flore cum rudimento alterus superioris. Glumae 9-nerviae. Palea inferior cylindraceo-involuta, apice aristata, arista niedia longissima, suporior apice bifida.

393. Erinclne. Spiculae2-fiorae; floribus sessilibus v. pedicellatis 
hermapliroditis. Palcae barbatae, superior 2-carinata.

394. IBrandtia. Spiculae 2-norae; flores sessiles valde inaequales, 2-paleacei ; inferior hermaphroditus, muticus superior femineus aristatus. Palea inferior apice rotundata mutica.

395. Danthonia. Spiculae 2-multiflorae; flores distichi, summus plerumque tabescens. Palea inferior multi-9-nervia, apice 2-fida, arista dente inferne spiraliter torta.

396. Pentaneris. Spiculae 2-florae cum rudimento stipitiformi floris tertii terminalis ; flos inferior sessilis, superior pedicellatus. Glunae acutato-subulatae. Palea inferior apice 2-fida et triaristata, arista media longrissima.

39\%. Uralepis. Spiculae multiflorae; flores distichi, summus tabescens. Palea inferior 3-nervia, concava apice 2 -fida. Squamulae truncato-rotundatae.

398. Trioidia. Spiculae multiflorae. Palea inferior 3-dentata, deute intermedio stricto.

X. Festucacear. Spiculae multiflorae (rarius pauciflorae). Glumae et paleae 2 , membranaceherbaceae, rarius coriaceae; harum inferior plerumque aristata, arista haud torta. Inflorescentia paniculata, paucis exceptis.

399. Seslerin. Spiculae 2-6-florae, distichae. Palea inferior aristatomucronata 3-5-dentata, superior 2-cariuata apice 2 -fida.

400. Pon. Spiculae 2-multiflorae; spiculis distichis. Stigmatum pilis aryute serrato-denticulatis. Squamulae 2-fidae $v$. integrae.

401. Centotheca. Spiculae 3-florae compressite. Flores remoti; summus rudimentarius. Palea inferior ovato-oblonga, versus marginem tuberculata, tuherculis retrorsum setigeris.

402. Alycerin. Spiculae multiflorae; flores imbricato-distichi; rachis articulata. Paleae rigidulae; inferior ovato-elliptica, rotundato-obtusa vel obsolete subtriloba 7 -nervia.

403. Pleuropogon. Spiculae multiflorae, cylindraceae; fiores distantes. Palea inferior obovato-oblonga, 5-7-nervia apice scariosa; superior apice profunde emarginata, 2-nervia, 2-carinata nervo utroque biaristato, aristis duahus brevissinis.

101. Heboulea. Spiculae sub 1-florae, flore superiore ad pedicellum clavatum redacto. Palea inferior ovatooblonga apice rotundata, compressocarinata 1-nervia superior apice emarginato-2-loba.

405. Catabrosa. spiculae 2-florae; flore inferiore sessili, superiore pedicellato, utroque hermaphrodito, aequali. Glumae coloratae; superior apice grosse crenata vel erosodentata. Palea inferior trigono-carinata.

406. Coelachme. Spiculae 2-florae; flore hermaphrodito seasili pedicellato, minore femineo. Palea inferior ovato-subrotunda ventricosoconcava. squamulae hyalinae, truncato-subbilobae.

40\%. BBriza. Śpiculae multiflorae; floribus imbricato-distichis, rachi tardius articulata. Palea inferior subrolunda, concavo-compressa, pilis ramosis dentalo-serratis.

405. Cinaseolytinume. Spiculue 8-12-florae; flores disticho-inhricati; rachis articulata. Palea inferior cymlaliformis, hasi cordala, apice mucronato-aristata. siquamulae emarginato-2-lobae.

409. Calotleen. Spiculae multiflorae; flores imbricato-distichi; summus tabescens; rachis articulata. Glumae membranaceo-hyalinae; inferior 3-nervia, superior 5 -nervia. Palea inferior utroque latere in alam falciformem producta.

410. Neliea. Spiculae $3-5-$ florae; flores $2-3$ superiores tabescentes.

411. Molimin. Spiculae 2-5florae; flore summo saepe tabescente, rachi tardius articulata. Palea inferior semitereti-convexa. Squamao dolabriformex.

412. Koeleria. Spiculae 2-7florae, distichae. Palea infra apicem breve aristata, superior apice 2-fida. Squamulae apice plerumque $2-3$-fidae.

418. Seluismnus. Spiculae 5-7florae; floribus distichis, distantibus. Gluma inferior 7-nervia superior 3-5nervia. Palea inferior apice 2-fida 9-nervia dorsoque ciliato-pilosa.

41. Wangontheimia. Spi- 
culae 2-florae. Palea inferior subcarinato-concava, 1-uervia; superior 2-carinata. Squamulae 2-lohae.

415. Dactylis. Spiculae 2-7forae. Glumae mucronato-aristatae. Palea inferior 5-mervia mucronatoaristata cariua ciliata.

416. Lasioelnoa. Spiculae 3-1-florae; flores distichi, basi callosi, concavi externe papilloso-hispidi. Palea interior 9-nervia herbaceo-membranacea, nucronata.

11. Cymosurus. Spiculae 2-5-florae, distichae, spiculis sterilihus pectiniformibus. Glumae 1-nerviae, hreviter aristatae. Palea superior apice bifida.

418. Tamnarekia. Spiculae 2-florae; spiculis crebrioribus sterilihus intermixtis ; floribus remotis; altero hermaphrodito, altero rudimentario arista suffulta, Palea inferior cylindraceo-convoluta, infra apicem bifidam aristata.

11. Eetrogia. Spicula multiflora; florihus distichis distantibus, infimo hermaphrodito, reliquis tabescentibus masculis vel neutris longius aristatis. Palea inferior 3-nervia apice 2-loba.

420. Toplantherum. Spiculae multiflorae; flore inferiore fertili, 2-paieaceo; superiorihus neutris. Palea exterior ovato-ohlonga convoluta 7-nervia, apice in aristam brevem rectam rigidam desinens.

421. Wlytianophorus. Spiculae 3-7-florae; flures distichi imberbes. Palea inferior 3-nervia apice subulato - aristata, superior carinis memhranaceo-alatis apice 3-loba.

422. Festuca Spiculae 2-multiflorae; rachis fuctifera articulata; fores distichi. Palea inferior in aristam desinens. Squamulae apice biflorae acutae.

423. Bromius. Spiculae3-multiflorae; rachis fructifera articulata, flores distichi. Palea inferior sub apice uristata, apice saepe fisso, superior carinis pectinato-ciliatis.

124. Orthoelada. Spiculae compressae, 3-florae; flores remoti, terminalis tabescens. Palea acutatomucronata, dorso naviculari-compressa.

4\$. Uniola. Spicula multi- flora compressa; fores 1 vel plures, inferiores steriles, 1-paleacei. Palea inferior carinato-compressa, superior 2-carinata, carinis alatis. Squamulae 2-filae v. obsolete lobatae.

426. Streptogyna. Spiculae 3-florae, terminali tabescente. Glumae involutae, infericr brevior. Palea inferior 7-nervia, apice aristata. Stigmata longissima torta. Squamulae 3, lanceolatae acutae.

4: \%. Chusquen. Spiculae 2-fiorae; flores disticlo-imbricati; duo inferiores 1-paleacei, neutri; terminalis 2-paleaceus, hermaphroditus. Squamulae 3, integrae, glabrae vel apice ciliatae, tertia minor.

428. Platonia. Spica ovata compressiuscula 3-flora, floribus imbricato-distichis; terminali 2-paleaceo, hermaplurodito, inferioribus minoribus 1-paleaceis, neutris. Squamulae 3, membranaceo-ciliatae, multinerviae.

429. Merostachys. Spiculae 1-laterales, 2-florae; flos inferior breviter pedicellatus, hermaphroditus ; superior longe pedicellatus, tabescens minutissimus, in sulco dorsali floris inferioris receptus.

430. Nastus. Spiculae oblongae compressae distichae, multiflorae, flores inferiores 1-paleacei, neutri, gradatim minores, terminalis 2-paleaceus hermaphroditus, ad hasin flore pedicellato tabescente auctus.

431. Hambusa. Spiculae multiflorae; flores imbricato-distichi; nonnulli inferiores 1-paleacei, neutri glımis similes, reliqui 2-paleacei, nunc omnes hermaphroditi, nunc unus hermaphroditus, caeteri masculi.

432. Gundua. Spiculae cylindraceae, multiflorae; floribus distichis, nomullis inferioribus masculis vel unipaleaceis neutris. Palea inferior concava, superior bicarinata. Squanulae 3.

433. Beslna. Spiculae 3-4-pluriflorae; flores distichı, inferiores masculi vel ueutri, 1-paleacei; stamina 6 , stigmata 3 villosa.

434 . Selnizostachyum. Spiculae teretiusculae, glomerato-spicatae, inferne compositae, interjectis inter glumas pedicellis sterilibus, uniflorae. Paleae nullae. Stamina 6; stigmata 6 tabescentia. 
XI. нондкаскак. Spiculae trimultiflorae, nonnunquam uniflorae saepe aristatae; flos terminalis tabescens. Glumae paleaeque 2 berbaceae; illae rarissime deficientes. stigmata sessilia. Ovarium in plerisque villosum. Inflorescentia spicata; spica simplexsolitaria; rachis rarius articulata.

435. Ioliumn. Spiculae multiforae distichae rachi contrariae sessiles. Flores basi imberbes. Palea inferior sub apice aristata. Styli brevissimi. Squamulae integrae vel bilobae.

436. Triticum. Spiculae3-multiflorae; rachi fructifera plerumque articulata; florilus distichis. Palea inferior mutica superior in carinis et marginibus aculeato-ciliata.

43\%. Secare. Spiculae biflorae; flores sessiles distichi cum rudimento lineari tertii terminalis. Palea inferior apice aristata superior bicarinata. Ovarium pyriforme villosum.

438. Flymus. Spiculae geminac quaternae 2-7-florae; hore summo tahescente. Glumae rigidae subsecundae. Parea inferior in aristam desinens.

43\%. AspreIla. Spiculae 3-florae; floribus distantibus; summo tabescente. Palea inferior aristata, superiorem bicarinatam involvens. Squamulae membranaceae subciliolatae.

40. Hordeum. Spiculae ternae laterales, plerumque tabescentes, biflorac; flore superiore ad rudimentum suhulatum redacto. Palea inferior concava aristata. Ovarium apice villostum.

441. Aegilopos. Spiculae 3-5norae, rachi parallelae; flore terminali tabescente. Glamae indurato-coriaceae, apice truncato 2 -4-dentatae; dentibus subulato-aristatis.

442. Pariama. Spiculae verticillatae, quiuae vel senae 1-fiorae, muticae, 4 vel 5 exteriores pedicellatao masculae; centralis sessilis foeminea. Stamina 30. Squamulae 4, apice ciliatae.
XII. nOTTBOELIACKAE. In ftor e s C elltia spicata; rachis in pluriII is articulata. Spiculae 1-2flarae, rarissime 3-florae, In excavatione rachis locatac. nu uc solitariae, nunc geminae, altera pedicellata saepo talesens. Flos alter cujuslibet spiculac biflorae, saepissime incompletus. Paloa membranaceae rarius aristatae. Styli $1-2$, interdum brevissimi vel Hulli.

413. Psillurus. Spica teretiuscula, articulata, arliculis alternatim excavatis. Spiculae biflorae sessiles. Flos inferior sessilis hermaphroditus, superior pedicellatus tabescens. Stamen unicum. Caryopsis trigrona.

44. Fepaturus. Spica teres articulata. Glumae acutato-subulatae, in spicula terminali semper oppositace. Paleae muticae, inferior superiorem binervian involens.

45. Dropetium. Spica compressa inarticulata bifaria. Rachis compressa flexuosa. Gluma inferior minuta, superior flore longior.

46. 19. Do articulata. spicula una in quolibet articulo, ejus excavationi immersa, biflora; flore exteriore masculo vel neutro, interiore hermaphrodito utroque incluso, mem̧loranaceo, mutico.

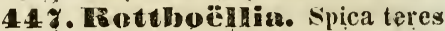
articulata. spiculae 2 in quolibet articulo; altera sessilis biflora rachi immersa, altera pedicellata tạbescens. Flores inclusi. sqquamulaẹ oblique truncatae.

44. Tripipara eum. Spicae solitariae vel teruac superne masculae inferne foemineae articulatae. Spiculae sessiles rachi immersae. Palea inferior concava, superior bicarinata. Stigma bipartitum longissimum. Squamulae apice truncato-bilohae.

49. Mranisuneis. Spiculac geminae uniflorac, inferior hermaphrodita, superior nęutra. Gluma inferior suborbiculata, saccato-concava.

XIII. ANDROPOgONKAR. Spicula e biflorae; flore inferiore semper incompleto. Palcae glumis teneriores plerumque hyalinae.

450. Perotis. Spiculac 1-florae. Glumac longe aristatac. Palcae minutae. 
451. Heptotheriam. Spiculae 1-florae; flore sessili minuto. Gluma superior involuta. stigmata penicilliformia, pilis ramosis.

452. Zoysia. Spiculae 1-florae fore sessili. Gluma unica carinatocomplicata. Paleae 2, inferior uninervia carinato-complicata. Squanulae nullae.

453. Dimeria. Spiculac omnes fertiles sessiles spicatae biflorae. Glumae basi harbatae. Arista torta.

45. Eucaen. spica articulata. Spiculae solitariae remotae biflorae. Glumae muticae. Palea inferior basi aristata. Squamulae 2 subdolabriformes. Caryopsis subfusiformis.

45.5. Haplachne. Spiculae fasciculato-approximatae. Glumae cartilarineae, carina piloso-ciliatae. Palea inferior diaphana, apice laciniatobifida, superior nulla. Stamina 2.

456. Pleuroplitis. spicae breves fasciculato-confertae. Spiculae alternae rachi articulatae adpressae, biflorae; flore altero hermaphrodito, altero neutro. Stamina 2. Squamula unica lata.

45\%. Sacelnarimk. Spiculae omnes fertiles geminae, altera sessilis, altera pedicellata, basi articulatae biflorae; flore inferiore neutro unipaleaceo, superiore hermaphrodito bipaleaceo.

453. Impernta. Spiculae geminae, altera sessilis, altera pedicellata, omnes fertiles, basi articulatae biflorae. Flos interior unipaleaceus hyalinus. Stamina 2. Squamulae nullae.

459. Eviantinus. Spiculae omnes fertiles pilis longissimis obsitae geminae, altera sessilis, altera pedicellata, basi articulatae, biflorae. Paleae hyalinae, inferior aristata.

460. Dlionumus. Spiculae geminae, altera sessilis fertilis biflora, altera pedicellata tabescens sterilis. Gluma inferior apice bifida.

461. Anthistria. Spiculae septenac, 3 in centro, 4 in circumferentia, hae neutri plerumque sessiles reliquas involucrantes. Palea inferior, in aristam longissimam desinens. Squamulae truncato-erosae.

463. Perobachne. Panicula secunda rachi non articulata. Vaginae snpremae coloratae. Spiculae fa- sciculatae, subverticillatae. Gluma inferior extus e tuberculis setosa.

463. Ancliopogon. Spiculae geminae, terminales ternae, una completa aristata, 1 vel 2 tabescescentes, muticae. Palea inferior longissime aristata.

161. Dicctomis. Spiculae geminae, terminales ternae, una completa sessilis, 1-2-pedicellatae, difformes, steriles. Gluma superior longissime aristata. Caryopsis breviter pedicellata, tereti-trigona. Culmi ramosi.

465. Ischnemum. Spiculae geminae, altera pedicellata, saepissime magis minusve tabescens. Glumae muticae. Squamulae oblique truncatae, sublobatae.

466. Holuda. Spiculae ternae, spatha bracteiformi suffultae, intermedia sessilis, laterales pedicellatae tahescentes. Gluma inferior apice bifida, superior carinato-navicularis.

46r. Alloteronsis. spicae valde abbreviatae, 2 neutrae, pedicellatae; bracteae disticho-imbricatac, infima trinervia mucronato-aristata. Glumae apice hifido-dentatae.

\$f8. Pogonousis. Spicae solitariae rachı articulata. Spiculae binatae 1-florae, altera sessilis foeminea, altera pedicellata mascula, pilis longis obvallata. Arista paleae superioris fracta.

469. Xerochloa. Spicula biflora; flore utroque bipaleaceo, exteriori masculo triandro, interiori foemineo. Styli basi connati. Squamulac nullae.

4 80. TeIopogon. Involucrum monophyllum cartilagineum adpressum. Spicula triflora; floribus sessilibus, intermedio hermaphrodito, lateralibus masculis. Pistillun nullum. Gluma exterior elegantissime undulatopapillosa.

4.1. Arthropogon. Spiculae pedicellatae, onınes conformes, biflorae cum pedicello articulatae, basi pilis mollibus cinctae. Caryopsis immatura lateribus compressa.

\section{TRIGYNIA.}

4\%. Elegia. Flores dioici amentacei. Perianthium 6-phyllum. Capsula trilocularis. Restiaceae.

4. 3 . Wepyrotya. Flores dioici 
vel hermaphroditi. Perianthium hracteatum 6 valve. Antherae peltatae. Capsula trilocularis trisperma. Restiacecte.

47. Annrthria. Flores dioici in spica composita, bracteati. Perianthium 6 valve; antherae didymae utrinque bifidae. Capsula trilocularis, trisperma. Restiaceae.

475. Falurus. Flores dioici spicati. Perianthium 3-partitum; styli 3 laciniato-multifidi. Capsula tricocca. Tricoccae.

4.6. Holosteum. Cal. 5-sepalus. Cor. 5-petala; petalis denticulatis. Capsula 1-locularis polysperma, apice in 6 dentes dehiscens. Caryophylleae.

4\%. Lechea. Cal. 3-sepalus, bracteis binis suffultus. Petala 3 lanceolata. Capsula 3-valvis, valvis medio septiferis. Cisteae.

8 8. Il ontia. Cal. 2-sepalus. Cor.5-petala. stamina epipetalis. Capsula 2-valvis, 3-sperma. Portulaceac.

4.9. Polycarpon. Cal. 5-sepalus; sepalis mucronatis. Petala 5 emarginata. Styli brevissini. Capsula 1-locularis, 3-valvis polysperma. Paronychine.

480. Minuarta. Cal. 5-sepalus. Petala 5 calyce multo minora. styli 3, filiformes. Capsula 1-locularis, 3-valvis, polysperma. Caryophyllecte?

481. Tillaea. Cal. 3-partitus. Petala 3. Filamenta 3, sterilia hypogyna, Capsula 3, dispermae, intus dehiscentes. Sedeae.

482. Koenigia. Cal. 3-partitus corollinus. Stamina filamentis capillaribus. Stigmata sessilia. Caryopsis nula in fundo calycis.

453. Donntin. Cal. 3-sepalus; sepalis acuminatis, Petala octona aut dena, calyce duplo longiora. Antherae didymae. Capsula infera 3-locularis. Saxifrageue?

484. Proserpinaca. Cal. superus tubulosus, limbo tripartito. Corolla 0 . Nux triquetra, 3-locularis, 3-sperma. Halorageae.

485. Houteuynia. 4-phylla corollam referens. oblongus, genitalihus nudis tectus. Antherae biloculares. Capsula 1-10cularis polysperma.

\section{IRIS Theophr.}

I. Imberhes.

A. Radix b u l bo a

I. persica I. fol. linearihus, planis; scapo 1-floro; petalis interioribus hrevissimis, patentissimis. L. Lam. ill. t. 33. f. 3. B. M. 1. In Persia. 4. Cor. alba linea lutea violaceo-punctata.

2. I. alata Poir. acaulis; fol. canaliculatis; laciniis cor. 3 erectis, minimis, tubo longissimo. I. scorpioides Dest. atl. t. 6. I. microptera Vahl. In Sicilia et Barburia. 4. Cor. caerulea.

3. I. caucasica Bieb. fol. Ianceolato-falcatis caule 2-floro; petalis 3 alternis minimis, reflexis. Hotfm. In collihus circa Tiflin. 4. Cor. flava crista lutea.

4. I. mauritiana Clus. bulho membranaceo; caule sub 2-floro; fol. subulatis canaliculatis; spatha diphylla, acuta; tubo elongato. I. juncea Desf. atl. t. 4. In collibus Algeriue. 4. Cor. Intea.

5. I. juncea poir. imherhis; fol. filiformibus; scapo 1-floro; spathis aristatis Poir it. 2. t. 1. In Alyeria. 4. 1-ped. Cor. Iutea.

6. I. syrtica Viv. fol. filiformijunceis, subcanaliculatis; spathis 1-valvis, elliptico-lanceolatis; laciniis cor. exterioribus maryine fimbriatis. Viv. Fl. Lib. In Africa. 2 .

\%. I. lusitanica Ker. fol. canaliculatis ; scapo 2-floro; laciniis cor. interioribus emarginatis; germine sub incluso. B. M. 679. In Lusitania. 4 . Cor. lutea, unguibus luteis.

8. I. Xiphium L. fol. suhulatis canaliculatis ; caule 2-floro; laciniis corollae stigmate angustioribus; germine ohtuso trigono. B. M. 686. Hed. Lil. 337. I. variabilis Jacq. In Hispanic et Lusitania. 4. Cor. caerulea.

9. I. xhipioides Elth. fol. canallculatis; caule 2 -floro; laciniis corollae stigmate multo latioribus; germine acuto angulato. Hed. 212. B. M. 687. I. Xiphinm Jacq. In Gallia et Hispania. 4. Cor. alba, violaceo-caerulea et pallide caerulea.

10. I. reticulata Alam; scapo 1-floro, foliis 4-gonis breviore; cor. tubo fliformi. Bieb. cauc. p. 34. In 
Iheria. 24. Cor. caerulea, cum plaga media lutea caeruleo-punctata.

\section{B. Radice bubsos.}

a. Foliis angulatio.

11. I. tuberosa Vahl; fol. 4-gonis scapo suh 1-floro longioribus; cor. tuho fliformi, laciniis interioribus acutis. Red. t. 48. B. M. 531. in Europa meridionali et Oriente. 24. Cor. virescens.

\section{b. Foliis linearibus 8. angulatis}

12. I. tenuifolia Pall. acaulis; fol. filiformibus longissimis; corollae tubo longissimo. Pall. it. 3. t. C. f. 2. In Davuria ad Wolgam. 4.

13. I. ventricosa Pall. $l$. c. $t$. B. f. 1. sub caulescens; fol. lineari-filiformilus elongatis; scapo sub 2-floro; spathis ventricosis; germine 3-yono. Willd. In montosis Davuriae. 24. Cor. pallide caerulea.

14. I. gruminea $L$. fol, linearibus caule sub 2-floro ancipiti longiorilous; germinilus 6-angularibus. VVilld. B. I. 681. Jacq. austr. t. 2. In Germanice. 4. Corolla pallide violacea.

15. I. ensata. 'Thunb. caule sub 2-floro, tereti; germine sub 6-angulari. Vahl I. graminea Thunb. In Japonia. 4.

16. I.verna Pursh; acaulis, 1-fiora ; fol. Jongissimis gramineis glaucis; tubo longissimo; capsulis subrotundis ad terram sessilibus. Purslı. In Virginia. 24. Cor. pallide caerulea.

17. 1. uniflora Pall. fol. lineribus longe acutis sub falcatis; spathis suhscariosis, tubo corollae longioribus Willd. In Sibiria.

18. I. tenax Dougl. B. R. $121 \mathrm{~s}$. fol. lineari-ensiformibus tenacissimis; corollae tubo brevissimo, laciniis exterioribus ohovatis acuminatis venosis. In California. 4.

19. I. humilis Bieb. fol. lineariensiformibus; scapo longioribus; tubo elongato; capsula obtuse 6-angulata Bieh. ross. t. 31. In alpinis Caucasi. 4. Cor. pallide caerulea.

20. 1. rutienica Ait. fol. linearilanceolatis scapo 1-fioro longioribus; germine ohsolete 6-angulo; laciniis eoroliae apice bifidis. B. M. 1393. I. caespitosa Pall. In Sibiria et Davuria. 24. Cor. violacea.

91. I. triflora Bab. fol. lineari- lanceolatis, acutis, scapo 3-floro longioribus; stigmatibus inciso-serratis. Red. 481. In Italia. 24. Cor. caerulea.

22. I. unguicularis Brot. subacaulis; fol. lineari-lanceolatis scapo 1-floro longioribus; tubo longissimo. I. stylosa Desf. atl. t. 5. In Barbaria. 4. Cor. caerulea.

23. I. prismatica Pursh; fol. angustissimis scapum teretem subaequantibus; germinibus prismaticis. Pursh. B. M. 1504. I. Boltoniana $\mathrm{R}$. et $\mathrm{S}$. In America boreali. 4. Cor. pallide purpurea.

24. I. haematophylla Fisch. fol. linearibus scapo 2-floro longioribus; tubo brevissimo; germine 3-gono, 1. biglumis Willd. In Sibiria et in Altai. 4. Cor. violacea.

25. I. sibirica I. fol. linearihus caule fistuloso 3-floro brevioribus; tuho germine 3-gono breviore. B. M, 50. I. pratensis Lam. In Sibiria et Germania. 24. Cor. plerumque pallide caerulea violacea aut albido-venosa.

26. I. acuta Willd. fol. linearibus acutis erectis strictis scapo sub 3-floro brevioribus; cor. tubo germinibus broviore. Willd. H.... 4. 3-ped. Cor. caerulea.

27. I. moraeoides Ker; fol. lineariensiformibus scapo vaginato 1-floro longioribus; laciniis corollae patentibus alternis duplo latioribus. I. compressa Thunh. Moraea iridioides L. Nill. ic. t. 239. f. 1. In Prom. b. spei. 24. Cor. albida.

28. I. longispatha Fisch. fol. lineari-lanceolatis falcatis, scapo subtortuoso 1-floro; germinibus dodecaginis; spatha exteriori longissime attenuata B. M. 2528. In Russia. 4. Cor. violacea.

29. I. bicolor Iindl. scapo tereti apice ramoso; spathis longis convolutis; laciniis corollae exterioribus subrotundo-ovatis. Lindl. B. R. 1404 . Hab.... 4. Cor. nagna lutea, laciniis exteriorihus macula nigra.

30. I. caricifolia Pall. fol. linearibus scapo 2-floro sub longioribus; spathis longe acuminatis. Pall. In Sibiria. 4.

31. I. setosa Pall. fol. linearibns longe acutatis; corollae laciniis interioribus truncatis seta terminali. Pall. In Sibiria. Fol. pedalia.

32. I. clandestina Lekm. scapo 
sub 2-floro, brevissimo; fol. ensifurmihns glaucis distich is; germine 3-gono. Lehm. H. Hamb. In Brasilia. 4.

c. Fol. cnsiformibus.

33. I. Pseudacorus $L$. caule erecto multifloro; styli laciniis hifidis serrulatis L. FI. Dan. 494. Engl. Bot. 578. In paludosis et ad ripas Europae, Sibiriae et Carolinac. 4. Cor. Iutea.

3-1. I. Monnierii DC. caule ramoso multifloro; fol. ensiformibus; laciniis corollae interioribus emarginatis ; germine 6-angulari. IRed. t. 236. In Creta. 24. Cor. lutea.

35. I. foetilissima $L$. caule compresso multifloro; fol. ensiformibus; corollae tubo germine oblongo vix longiori. lied. t. 35\%. I. foetida Pers. In Europa et Basbaria. 24. Cor. plumbeo-coerulea.

36. I. viryinica Gronov. canle sub ancipiti multifloro, corollae tubo germinibus 3-gonis falcatis breviore. Jacq. ic. t. 223. B. M. 703. 1. hexagona Wall. In America boreali. 4 . Cor. magna caerulea.

3\%. I. versicolor $I$. caule tereti flexuoso; corollae tubo germinibus subtrigonis breviore; stylis laciniis basi 2-dentatis. IRed. t. 339. B. M. 21. In America boreali. 24. Cor. pallide caerulea.

38. I. cuprea Pursh; caule tereti flexuoso; cor. tubo germinibus 6-gonis longioribus; laciniis interioribus lanceolato-linearilous. Pursh. 1. fulva $B$. H. 1496. In Georgia. 4. Cor. splendide cuprea.

39. I. spurea $\boldsymbol{L}$. caule multifloro fol. linearibus altiori; corollae tubo germini 3-gono aequali; styli laciniis acutis bifidis. Jacq. austr. t. 4. Hed. t. 349, B. M. 58. I. spathulata Lam. In Germania et Gallia. 24. 1-2-ped. Cor. caerulea.

40. I. Güldenstaedtiana Bieb. caule multifloro; spathis acutis pruinoso-scabris; corollae tubo germine 6-gono aequante; styli laciniis obtusis. I. desertorum Güld. I. spathulata Willd. var. $\beta$. ochrolenca, cor. ochraceis. I. spuria. B. M. 1131. $\gamma_{\text {. diluta, cor. }}$ sulphureis I. diluta. Bieb. Rosc. t. 8. j. stenogyna, cor. ocirroleucis \&. aurea eor. pallide lutea, laciniis in media anreis. I. ochroleuca B. M. 61. I. aurea Link. In Tauria et Sibiria. 4.

1. I. halophila Pall. fol. formibus scapo 3 -foro longioribus s germine alato 3-gono. Pall. it. t. 13 . f. 2. I. salsa Pall. ibid. In Sibiria et in Altui. 4 .

42. I. notha Bieb. spathis acuminatiśsimis ; laciniis corollae exterioribus deflexis; germine 6-gono. Bieh. ross. t. 77. I. halophila B. M. 875. In collibus Cucasi. 24. Cor. amoene caerulea.

43. I. biglumis Vahl; spatha diphylla grlunacea; capsnlis 3-quetro6-angulatis Vahl. 1. spuria Pall. it. t. 6. f. 1. In vibiria. 24. Cor. cyanea.

t4. I. tripetala Vuhl; caule teretI fol. longiore; corollae laciniis interioribus minutis 3-dentatis; styli Iaciniis 2-lobis, lobis dentatis. B. M. 2886. I. tridentata Pursh. In Carolina. 2. Petala et stigmata caerulea.

4.J. I. lacustris Nutt. fol. brevibus; corollae laciniis basi attenuatis capsula turbinata, 3-quetra marginata. Nutt. gen. In America ad insulas lacus Ifuronum. 24. Cor. pallide caerulea.

\section{Barbatae, foliis ensifor-} mils us.

-46. I. germanicu L. spathis scarinosis; floribus inferioribus pedunculatis, tubo corollae germine longiore; laciniis exterioribus subemarginatis harhatis. B. M. 670. In Europa. 4. Cor. magna odorata violacea s. caerulea.

\$\%. I. florentina I. fol. glaucescentibus caule multifloro brevioribus: spathis subcariosis; floribus sessilibus; laciniis exterioribus integris barbatis. B. M. 671. Recl. 23. In Einvopa et in ins. Cypro. 4.

18. I. pallidı Lam. fol. ensiformibus scapo multifloro brevioribus; spathis scariosis; laciniis exterioribus brevissimis. Jacq. Schœubr. t. 9. 1. germanica Sibth. graec. t.40. Hab.... 4. 2-4-ped. Cor. pallide caerulea.

千9. I. neglecta Hornem. fol. ensiformilus scapo multo brevioribus; spathis medio viridibus; laciniis erectis integerrimis, deflexis subemarginatis B. M. 2435. Hab. ... 24. Cor. pallide caerulea.

50. I. squalens $L$. corollae tubo germine fere longiore; laciniis deflexis replicatis erectis emarginatis. Red.Lil. 365. B. M. 787. In Eiropa anstrali et in Bohemia. 24. Cor, extus virescens intus violaceo-purpurascens. 
51. I. sambucina $L$. spathis obtusis viridibus; corollae tuho incurvo germine duplo longiore; laciniis emarginatis deflexis planis. B. M. 187. Red.t. 338. I. lurida Ait. B. M. 669. et 986. Red. t. 318. In Europa australi. 4. Cor. purpure0-violacea.

52. I. sordirla Willd. spathis viridibus; floribus sessilibus; corollae tuho germine plus quam duplo longioribus; Iaciniis erectis emarginatis. Hab.... 24. Cor. ochroleuca.

53. I. dichotoma Pall. fol. ensiformihus sulcatis, caule gracili ramoso multo hrevioribus; cor. tubo fere nullo, laciniis interioribus minorihus Pall. it. t. A. f. 2. I. pomeridiana Fisch. In Davuria. 4. Cor. violaceopurpurea.

54. I. flavissima Pall. scapo subbifloro folia lanceolata ensiformia sub)aequante; laciniis interioribus apice vix hifidis, subdenticulatis; stigmata profunde bifida. Jacq. ic. rar. t. 200. In Sibiria et in Altai. 24. Cor. flava.

5.5. I. Susiana L. scapo 1-floro; corollae laciniis interioribus erectis latioribus, exterioribus reflexis; caps. subtrigona. B. M. 91. Ked. t. 18. I. livida Tratt. In Oriente 24. Caulis pedalis. Cor. maxima, sordide alba, atropurpurea nigroque variegata.

56. 1. paradoxa Ster. caule 1-floro, foliis conduplicatis linearibus recurvatofalcatis altiore. Steven Miemoir. Mosquit. 5. 1. 355. In Iberia. 4. Cor. saturate violacea.

5\%. I. glaucescens Bunge; scapo bifloro folia glauca falcata subaequante; laciniis exterioribus integris, interioribus apice emarginatis. Ledeh. fl. Ross. t. 101. In Altai. 4. Cor. caerule 0 -violacea.

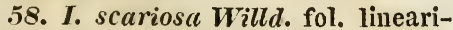
ensiformibus scapo longiorihus; spathis diphyllis bifloris scariosis maximis. Link Jahrb. 1. 3. p. 71. In Sibiria. 4.

59. I. iberica Stev. seapo 1-floro fol. circinnato-falcatis conduplicatis paulo longiore. Bieb. Tauro-Cauc. 1. p. 30. Circa Tiflin. 24. Cor. sordide rubella.

60. I. chinensis $L$. scapo compresso ; spathis herbaceis; styli laciniis laciniato-fimbriatis. B. M. 373. I. fimbriata Vent. cels. t. 9. Red. t. 152. In Chinc et Indiu orientali. 4 , Cor, caerulescens flavo-maculata.
61. I. murlicaulis Lam. scapo submultifloro nudo; spatha ventricosa viridi.I. aphylla VahI. I. bohemica Schmidt. In Bohemia, Silesia et ad Caucasum. 4. Cor. magna violacea.

62 . I. biflorc $L$. spathis vegetis; floribus longe pedunculatis; laciniis repando-mudulatis. Bieb. Koss. t. 51. In Lasitania, Sibiria et ad Cancasum. 4. Cor. violacea.

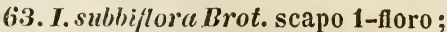
spathis vegetis; laciniis corollae ol)ovatis rotundatis. B. M. 1130. In Lusitania. 24. Cor. violacea.

64. I. Suertii Lam. scapo multifloro; spathis scariosis; corollae tubo germen subaequante; laciniis deflexis undulatis. Red. t. 360. I. aphylla $\gamma$. B. I. 870. Hab.... 24. Cor. albida.

6.5. I. plicata Lam. caule tereti multifloro foliis ensiformibus falcatis altiore; spathis scariosis; laciniis undulatis. I. amoena Red. t. 336. $\beta$. floribus majoribus. I. plicata Red. t.356. 4. Cor. violacea albostriata.

66. I. juponica Thunb. fol. ensiformibus falcatis glabris; scapo conpresso multifloro hrevioribus. I. squalens Thunb. fl. jap. p. 33. In Japonia. 24. Cor. alba.

67. I. variegata $L$. spathis viridibus, corollae tubo germine vix longiore; laciniis erectis oblongis undulatis deflexis emarginatis. Jacq. austr. t. 5. Red. t. 292. In Germania. 4. Cor. flava.

68. I. virescens Red. $t$. 295. fol. lineari-ensiformibus scapo unifloro sublongioribus; laciniis oblongis obtusis undulatis. 2\%. Cor. pallide-flava.

69. I. hungarica Waldst. et Kit. Hung. $t$. 226. spathis coloratis inflatis, suprema biflora; laciniis interioribus erectis oblongis unguiculatis. In Hungaria. 24. Cor. saturate violacea.

70. I. nepalensis Wall. stapo tereti subbifloro foliis multo breviore; corollae tubo filiformi germine obtuse trigono triplo longiore. B. R. 818. In Nepalia. 24. Fol. bipedalia. Cor. magna violacea.

71. I. mumila $L$. fol. ensiformibus scapo 1-floro longioribus; tubo corollae spatham excedente. B. M. 9. et 1209. Sturm. 1. 40. Red. t. 262. In Europa, Tauria et ad Cancasum. 4. 3-ped. Cor. viride flavesceus, superne caerule 0 -violacea.

77. I. lutescens Lam. fol, ensifor1) 
nibus scapo 1-floro brevioribus; spatha erecta (ubum corollae arcte involvente. 13ed. t. 263. In Europa. 4. Cor. Ravescens.

73. I. aequiloba Led. scapo 1-floro; spatha corollae tubo hreviore; laciniis corollae omnibus latitudine aequalibus j. Iongiflora Jed. hort. Dorpat. 1822. (in deserto Tanviae. 24. Cor. intense violacea.

\%. I. arenaria Waldst. et Kit. t. 5\%. scapo subbifloro; flore superiove abortiente; spathis herhaceis trivalvibus; laciniis interioribus lanceolatis undulatis. In Hunguriu. 24. Cor. tava.

\%5. I. cristata Ait. scapo compresso sub 1-floro, longituline foliotum; barba cristata; tuho longissimo; yermine trigono. B. M. 412. Hed. i. 3\%6. 1. verna Walt. In Virginia. 2. Cor. caerulea.

\%6. I. Tigridia Bunge; germine trigono; tubo elongato spatlas membranaceas acuminatas excedente; laciniis corollae obtusis bifidis interjecto dente. Bunge in Led. fl. alt. 1. p. 61. In Altai. 24. Cor. violacea, roseo et albo-maculata.

\%. I. decora W'all. fol. acuminathsimis plicato-nervosis longissimis; spat?is remotis acmminatis; laciniis coroliae laciniato-serratis. Wall. pl. asiat, rar. 1. p. 77. t. 86. In Nepalic. 4. Cor, dilutissime caerulea.

\subsection{MORAEA Mill. (1731).}

\section{T. Laciniae styli amplae.}

\section{A. Barbatae.}

1. M. minuta lier; caule 1-floro; fol. ensiformilous glabris; corollae lacintiis exterioribus barbatis. Iris minuta Tluunb. In Prom. b. spei. 4. Cor. Iutea.

2. M. ciliatn Ker; canle 1-floro vaginato; fol. linearibus ciliatis; styli laciniis harbatis. Iris Thunb. B. M. 1061. In Prom. b. spei. 24. Cor. lutea.

3. M. plumaria Ker; caule subramoso multifloro; styli laciniis multifidis. Iris Thunb. M. iriopetala Willd. In Prom. b. spei. 4 . Cor. extus virens, intus dilute caerulea.
4. I. lurida Ker; caule gracili 1-floro vaginato; fol. linearibus flaccidis: laciniis corollac exterioribus papillosostbharlatis; filamentis subcomnatis. B. R. 312. In Prom. b. spei. 24. Cor. rubro-fusca.

B. Im berbes.

5. M. Sisyrinchium Fier; fol. canaliculatis recurvis; tubo corollae brevissimo; styli laciniis acute 2 -fidis. Iris led. t. 458. I. fugax 'Tenore neap. t. 4. In Europa anstrali. 4. Cor. caerulea.

6. M. papilionacea Ker; B. M. 9.50 fol. linearibus pubescentibus; laciniis corollae exterioribus nectariferis; Iris Thunb. Jace. ic. t. 3. l. 2. In Prom. b. spei. 4. Cor. viridi-variegata s. flava.

\%. M. setacea Fer; folio filiformi lineari erecto scapum superante; spathis acutis membranaceis. 1ris Thumb. diss. 29. t. 1. f. 1. In Prom. b. spei. 21. Cor. caerulea.

8. H. unyustu her; B. M. 1276. folio radicali fistuloso lineari-convoluto; laciniis corollae interiorihus linearibus. Iris Thunh). In Prom. b. spei. 4. Cor. flava.

9. M. erlulis Ker; B. M. 613. folio lineari scapo subramoso triplo longiore; laciniis cor. revolutis. M. vegeta Jacq. ic. t. 224. M. fugax Jacq. Vind. 1. 20. Iris Thumb. In Prom. b. spei. 24. Cor. fragrans lilacino-caerulca.

10. M.Candolleana Spr. fol. distichis ensiformilus; spathis foliaceis; Iaciniis cor. internis obtusis. Iris curtopetala DC. Viesseuxia iridioides Red. t. 310. 4. Cor. late flava venis violaccis.

11. M. sprthacea her; fol. linearibus nervosis rigidis, scapo tereti 2-floro; spathis longissinis. Ker. Iris Thumb. In Prom. b.spei. 4. Cor. Intea.

12. H. gracilis Alb. Dietr. fol. lineari-nervoso; scapo sub-1-floro; laciniis cor. lanceolatis utrinque dentatis apice setaceis. Licht. in $\mathbf{h}$. et s. syst. veg. 1. p. 478. In Prom. b. spei. 4. Cor. viridis.

13. M. longiflora Ker; canle brevissimo simplicissimo; fol. fasciculatis; tubo filiformi; unguibus cyathiformi - conniventibus. Ker, in $\mathbf{B}$. M. 712. In Prom. b. spei. 4. Cor. flava.

14. M. ramosaker; fol. serrulatociliatis; scapo ramosissimo; laciniis 
corollae deflexis oblongis. Iris L. In Prom. b. spei. 4. Cor. lutea.

15. M. polystachya Ker; fol. linearihus setaceis; scapo ramoso multifloro; spathis apice laceris. Iris $\mathbf{L}$. I. lacera Lam. In Prom. b. spei. 4. Cor. magna caerulea.

16. HI. tristis Ker; fol. linearilanceolatis undulato-glabris; scapo villoso; laciniis cor. patentissimis. M. sordescens Jacq. ic. t. 225. M. vegeta L. M. tricolor Andr. 83. Iris B. M. 577. In Prom. b. spei. 24. Cor. rufescens.

1\%. M. viscaria Ker; scapo ramoso glutinoso; spathis convolutis; laciniis cor. reflexis; styli laciniis serratis. Ker. Iris B. M. 587 In Prom. b. spei. 4. Cor. Iucido-purpurea basi ocello caeruleo.

18. M. bituminosa Ker; fol. infimo spiraliter torto; scapo glabro; pedunculis viscosis. Ker; B. M. 1045. Iris Thunb. In Prom. b.spei.24. Cor. flava.

19. M. Gawleri Spr. fol. reflexis crispis; scapo sulcato; Iaciniis omnibus patentissimis, alternis minorihus. M. crispa Ker. B. M. 759. In Prom. b. spei. 4. Cor. lıtea caerulea aut incarnata.

20. M. Herberti Lindl. B. R. 94.9. fol. acuminatis plicatis; ramis fasciculatis; spathis inflatis; laciniis cor. interioribus ahrupte incurvo-revolutis. Tigridia B. M. 2599. Iris Thunb. In Prom. b. spei. 4. Cor. luteo-aurantiaca.

21. M. linearis Funth; caule apice trifido; fol. lineari-ensiformibus glabris caulem aequantibus. Kunth syn. 1. p. 321. In Gujana. 4. Cor. violacea, macula flava.

22. M. foliosa Funth; caule compressiusculo 5-floro, foliis 5-7-nerviis plicatis, longiore. Kunth syn. 1. p. 314. In Quito. 4. Cor. violacea.

23. M. catenulata Iindl. B. R. 10\%s. fol. distichis, tortis perennantilus; flore terminali solitario; laciniis cor. interuribus versus basin utrinque verrucosis. In ins. St. Mauritii. 4. Cor. alba pallide caerulescens.

\section{Styli Iaciniae angustae.}

21. M. virgatı Jacq. caule tereti ramisque virgatis; fol. lineari-setaceis longissimis. Jacף. ic. t. 228.
Iris Willd. In Prom. b. spei. 4. Cos. lutea.

2.5. MI. spicata Ker.; B. M. 1283. fol. radicali longissimo, floribus remote spicatis; corollis hypocrateriformibus; styli laciniis angustissimis. Nisyrinchium R. et S. In Prom. b. spei. 2. Cor. lutea.

26. M. collina Thunb. fol. linearilus convoluto-concavis; spathis herbaceis acuminatis; cor. turbinato-rotata, Iaciniis striatis. Jacq. ic. t. 226. B. M. 1033. M. lineata Andr. t. 404. Sisyrinchium Red. t. 250. In Prom. b. spei. 4. Cor. ochrolenca.

27. M. curantiaca Alb. Dietr. caule rortuoso; fol. radicali canaliculato longissimo; ramis 2-floris. Hab.... 4. Cor. rosea basi luteo-viridis.

28. M. polyanthos Thunb. caule ramosissimo; fol. subulatis glabris flexuoso-erectis; laciniis cor. alternis minoribus. Thunb.

\section{Dubiae.}

2.9. M. crispa Thunb. scapo tereti articulato; folio convoluto crispo reflexo. Thunb. diss. n. 13. In Prom. b. spei. 4. Cor. caerulea.

30. M. ovata Thunb. scapo tereti simplici; fol. ovatis. Thunb. cap. 1. p. 280. In Prom. b. spei. 4.

31. M. pilosa Hendl. scapo erecto piloso; fol. quaternis gramineis pilosis; pedicellis glabris. Wendl. olss. bot. 42 . In Prom. b. spei. 24. Cor. rubra.

32. M. chimboracensis Kunth; caule ramoso, ramis solitariis 4-floris; fol. strictis striatis glabris. Kuntl syn. 1. c. In Quito. 4.

33. M. gladioloides Kunth; ramis solitariis sub 3-floris; fol. distichis striatis glabris, caule brevioribus. Kuntl syll. 1. p. 315. In Peru. 4. Cor. caerulea.

34. M. acorifolia Kunth; caule apice ramoso compresso; ramis geminis sub 3-floris; fol. striatis glabris caule brevioribus. Kunth syn. 1. p. 315. In Caracas. 24.

\section{3, MARICA Schreb. (1789).}

1. M. paludosa IVilld. fol. linearibus striatis; flor. fasciculatis; laciniis cor. interioribus brevissimis cochleariformibus. B. M. 646. M. Cipura $10 *$ 
Gmel. In Guyana et Cajenua. 24. Cor. caerulescens.

2. H. grominea Wilhl. fol. lineariensiformibus caule 2-floro lengioribus; laciniis cor. exterioribus oblongis. Cipura Kuntl. Ad Orinocum. 24. Cor. alba.

3. II. humilis R. et S. fol. lineariensiformilus caule subtrifloro longioribus; laciniis cor. ohovatis nucronatis. Cipura Kunth. In Nova Granata. 2. Cor. alla.

4. M. Northiumu Schreh. fol. latoensiformibus, flabellato-tistichis ; scapo alato-ensiformi; laciniis cor. exterioribus deflexis. Andr. Kep. t. 255. M. vaginata DC. In Brusiliu. 21. Cor. alba basi flava rubro-maculata.

5. M. martinicensis Ker; fol. ensiformibus distichis; laciniis corollae interioribus cuculiatis basi nectariferis. Iris L. Jacq. Am. t. \%. pict. t. 10. Red. t. 172. Cipura Kunth. In India orientali. 24. Cor. flava.

6. M. longifolia Link et Ottto. ic. select. $t$. 58 . caule alato ex folio lecurrente; laciniis cor. interioribus apice elongato recurvo. In Brasilia. 4. Cor. purpurea.

\%. M. cuevulen Ker; B. R. \%13. florihus corymbosis; spathis luerbaceis ; laciniis cor. exterioribus rotundis. In Brasilia. 24. Cor. caerulea basi flavo-nigroque variegata.

8. M. coelestis Lehm. fol. plicatis ensiformibus; cor. Iaciniis minoribus cucullatis basi nectariferis. Lehm. Patriı ignota. 4. Cor. caerulea basi maculata.

9. M. Tigridia Lehm. fol. lineariensiformibus 2-plicatis; laciniis cor. majoribus panduraeformibus; antheris sub laminas pistilli aduatis. Lehm. Patrice ignota. 24. Cor. flava.

\section{VIEUSISEUXIA De la Roche (1266).}

I. Barbatae.

1. V. tripetaloides DC. fol. radicali unico lineari; laciniis cor. exterioribus barbatis, interioribus subulato-linearibus. Iris Jacq. ic. t. 224. Moraea B. M. 702. In Prom. b. spei. 4. Cor. caerulea.

2. V. aristata Houtt. scapo cum folio lineari pubescenti; laciniis cor. interioribus 3-cuspidatis. Hontt. Lin. fl. syst. 11. t. 80. f. 1. Iris tricuspis Thumb. In Prom. b. spei. 4. Cor. intus flava nigro-punctata.

3. V. gluucopis DC. scapo cum folio lineari glabro; laciniis cor. interioribus 3-dentatis, exterioribus balloatis. Hed. t. 42. Iris tricuspis Jacq. Coll. 4. t. 9. f. 1. 1. Pavonia B. M. 168, 696 et 782. In Prom. b. spei. 4. Cor. intus virilli-flavesceus, fusco-maculata, hirsuta.

t. V. temis R. et S. scapo cum folio fistuloso glabro; laciniis interioribus 3-dentatis, dente intermedio longiore involuto. Moraea B. M. 10-17. Iris tricuspis var. minor Jacq. ic. t. 222. In Prom. b. syei. 4. Cor. viride flava.

5. T. rillosa, S $m$. scapo cum folio lineari villoso; laciniis interioribus 3-fidis, lacinia intermedia elongata. Iris Ker. B. M. 571. In Prom. b. spei. 4. Cor. purpurea.

\section{I $m$ berbes.}

6. T. Pavonia DC. folio unico scapoque bifforo villosis; laciniis cor. exterioribus maculato-punctatis. Iris Thunl). diss. и. 35. t. 1. f. 3. Andr. 1. 364. In Prom. b. spei. 4 . Cor. pulcherrime aurautiaci.

\%. I'. fugax La Roche; fol. radicali unico lineari scapo 3-plo longiore; laciniis exterioribus submaculatis, interioribus linearibus. Moraea edulis var. $\gamma$. B. M. 1238. In Prom. b. spei. 4. Cor. flavescens.

8. 1: spiralis La Roche; diss. n. 1. f. 5. fol. linearibus nervosis; spathis convolutis actuminatis ; laciniis cor. interioribus 3-dentatis contortis. V. unguicularis R. et $\mathbf{s}$. Moraea Ker. B. M. 598. In Prom. b. spei. 24. Cor. alba.

9. I. mutila Licht. fol. filiformi erecto scapoque sub-1-floro glabris; cor. 3-partita. R. et S. syst. 1. p. 477. In Prom. b. spei. 4. Cor. caerulescens odorata.

\section{SISYRINCHIUM Theophr. Breyn. (1678).}

\section{Caulis anceps.}

1. S. aphyllum Spr. scapo foliisque compresso-ancipitibus; fasciculis florum lateralibus involucro longe hre- 
viorihus. Moraea Thunb. 9. t. 2. f. 1. In Prom. b. spei. 24. Cor. Iutea.

2. S. vaginatum $\mathbf{S})$. caule dichotomo aphyllo; vaginis acutis scariosis ; spatha 1-flora. spr. syst.1. p.166. In Monte Vidleo.

3. S. restioides $S p r$. caule subdichotomo filiformi; vaginis linearilus subfoliiferis; superioribus spathaque 1-flora laceris. Sinr. I. c. In Monte rideo.

7. S. filiforme spr. scapo foliisque filiformibus compressis; flore solitario terninali. spr. l. c. Moraea Thunb. diss. 10. t. 1. f. 2. In Prom. b. sprei. 4. Cor. lutea.

5. s. Bermudiumn L. caule ancipiti folioso ramoso; spatla sub 4-flora; laciniis cor. mucronatis. Cav. diss. t. 192. Red. t. 149. In Bermudis. 4. Cor. basi flava apice cacrulea.

6. s. ancepss Lam. fol. lineariensiformibus; spatha sub 4-flora, floribus longiore; laciniis cor. emarginatis mucronatis. Cav. diss. t. 190. f. 2. S. gramineum B. M. 461. Ked. t. 282. In Virginia et Canada. 4. Cor. caerulea.

\%. S. chilense Hook. caule ramoso ancipiti-alato ; laciniis cor. retusis mucronatis; capsula pyriformi mucronata. B. M. 2786. In Chili. Cor. pallide purpurea.

8. S. Cervantesii E. Meyer; caule simplici ancipiti; spatha multiflora; pedunculis elongatis; capsula subturhinata. Meyer in Presl. Hel. Hænk.2. p. 117. In Mexico. 4.

9. S. gladiatum Spr. scapo ancipiti folia linearia aequanie; spatha sub-t-flora floribus breviore; pedunculis villosis. Ixia L. Moraea Thumb. Marica B. R. 229. In Prom. b. spei. 4. Cor. Iutea.

10. S. culifornicum Spr. scapo ancipiti foliaceo; fol. linearibus; laciniis cor. ovato-ablongis. spr. Marica Ker. B. M. 983. In California. 4. Cor. lutea.

11. S. convolutum Nocce H, ticin. f. 1. caule ancipiti ramoso; fol. lineari-ensiformilus scapo brevioribus. Red. t. 47. Willd. H. ber. t. 91. In Prom. b. spei. 4 . Cor. lutea.

12. S. tinctorium Kuntlı; caule simplici aphyllo ancipiti; fol. radicalibus ensiformibus striatis. Kunth. In Guyanc. 4. Cor. sicca flavescens.

13. S. palmifolium L. scapo an- cipiti foliaceo; fol. ensiformilus verrucoso-plicatis; florihus spicato-fasciculatis. Limn. S. racemosum Pers. Moraea alata Vahl. In Brasilic et Peruria. 24.

11. S. boyotense Kunth; scapo ancipiti aphyllo sub-4-floro; fol. 4-nerviis; cor. laciniis emarginatis. Kunth. In humidis Boyotae. 24. Cor. flava.

15. s. micranthum Car. caule ancipiti folioso; fol. linearihus candiculatis ; laciniis cor. linearibus acuminatis. Cav. diss. t. 191. f. 2. In pern. 4. 2-pollicaris.

16. S. tennifolium Willd. caule adscendente ancipiti foliato 3-floro; fol. lineari-filifornibus; capsula hirta. Willd. H. ber. t. 92. B. M. 2117 et 2313. In Merico. 4. Cor. Iutea.

1\%. S. iridifolium Funth; caule ramoso ancipiti folioso multifloro; fol. linearibus multinerviis margine ciliatoscabris; corollis extus pubescentibus. Kuntl. S. laxum B. M. 2312. Marica B. H. 646. In America meridiunali.24. Cor. ochroleuca.

18. S. pusillum Kunth; caule 1-phyllo, 1-floro; fol. radicalibus lineari-filiformibus 2-nerviis; capsula glabra. Kunth. In Quito. 2. Cor. sicca flava.

19. S. striatum Sm. ic. t. 9. caule compresso folioso; floribus spicatis; laciniis cor. Ineatis obovato - cuneatis mucronatis. s. spicatum Cav. t. 104. Maraea sertata Jacq. schœubr. t. 11. Marica. B. M. 701. In Mexico. 4. Cor. flavescens fauce purpureopunctata.

\section{Caulis teretiusculus.}

20. S. latifolium Sw. radice bulbosa; scapo tereti; pedunculis subternis; pedicellis subumbellatis ; laciniis corollae obovatis. S. palmifolium Cav. diss. t. 191. f. 1. Moraea Jacq. ic. t. 227. M. plicata B. M. 665. In ins. Caribaeis. 4. Fol. 2-t-pedalia. Cor. alba.

21. S. grandiflorum Cav. caule tereti simplici; fol. lanceolatis plicatis; spatha sub 3-flora; laciniis cor. lae obovatis obtusis. Cav. diss. t.192. f. 2. Moraea Pers. In Peru. 24. Cor. lutea.

22. S. elegans Willd. scapo tereti 1-floro, folio radicali lineari acuminato breviore; laciniis cor. oblon- 
sis acutis. Moraea Jacq. Schoubr. t. 12. In Prom. b. spei. 24. Cor. externe flava.

23. S. mucronatum Michx. foliis scipisque simplicibus subsetaceis; spathate coloratae valva altera longe cuspidata. Michx. am. 2. p. 33. In America boreali. 24. Cor. pulchre caerulea.

24. S. Donglasii Alb. Dietr. caule stricto glauco striato; corolla pedicello sulaequali.s. grandiflorum Dougl. 13. 13. 1364.. In America boreali. 4 . Cor. atro-purpurea; styli sanguinei.

25. s. flexuosum spreng. caule articulato multifloro; folits reflexis linearibus suhundulatis; spica flexuosa; antheris incurvis. Moraea L. B. M. 695.) Ixia longifolia Jacq. Vind. 1. 90. In Prom. b. spei. 24. Cor. flava.

26. S. orloratissimum B.R. 1283. foliis angustissimis glaucis; floribus longe pedunculatis nutantibus infundihulifornibus. In America meridionali. 4. Cor. sordide alla fusco-purpurea striata.

27. S. junceum E. Meyer; spathae valvula exteriore elongata recta; floribus pseudo-lateralibus. Reliq. Haenk.2. 1. 118. In Cordilleris chilensibus. 4.

28. S. Gandichandii All. Dietr. caule striato multifloro; foliis radicalihus filiformibus; capsulae glahrae loculis 3-6-spernis. s. filiforme Gaud. in Freyc. voyag. p. 421. In ins. Haclorianis. 4 .

2.9. s. maculatum Hook. caule folioso subcompresso; perianthii laciniis obovatis acutis, tribus macula magna atro-sanguinea. B. M. 3197. In Chili. 24.

30. s. speciosum Hook. caule sul)flexuoso; foliis linearibus striatis; florilus speciosis; perianthii laciniis patentissimis; stigmatibus emarginatis velutinis. B. M. 3544. In Chili. 24. Cor. purpurea caerulea basi intense nava.

\section{GALAXIA Thunb. (1782),}

1. G. ovata T/hunb. subacaulis; foliis ovato-oblongis ciliatis villosiusculis, Jacq, ic. t, 291. Red. t. 246. B. M. 1208 et 1516, G, multiflora Spreng. In Prom. b. sjuei. 4. Cor. flava.

\%. G. graminea Thumb. caulescens; fuliis fasciculatis linearibus canalicu- latis. B. M. 1292. Jacq. Coll. 2. i. 18. f. 2. In Prom. 1) spei. 24. Cor. flava.

3. G. narcissoides Willl. caule erecto ; foliis lineari-eusiformibus ; florihus cermuis. Sisyrinchimm. Cav. diss. t. 191. f. 3. In freto Magellanico. 4. Cor. alba.

\section{5\%. PATERSONIA R. Br. (1810).}

1. $\boldsymbol{P}$. sericea $\boldsymbol{R}$. $\boldsymbol{B r}$. fol. ensiformibus strictis striatis, marginibus tenuissime pubescentibus; carina baseos lanata; stigmatihus deflexis. 13 . M. 1041. In Noéa llollandia. Cor. violacea.

2. P. lanata R. Br. fol. ensiformibus plano-convexiusculis tenuissime striatis, marginibus carinaque haseos lanatis. 13. Br. prodr. 1. p. 303. In Nove Hollandia. 24.

3. P. longifolia R. Br. fol. anguste linearihus; scapo 4-6ies longiorihus infra medium pilis patentibus vel inflexis ciliatis; stigmatihus deflexis; spathis sericeis. R. Br. 1. c. In Nova Hollumalu. 21.

t. P. media R. Br. scapo glahro caule longiori ; foliorum carina baseos lanata; spatha communi sericea. $\mathbf{R}$. Br. 1. c. In Nora Hollandia. 4 .

5. D. glabrata R. Br. scapo caule longiori spathisque glaberrimis nitidis; carina baseos lanata; stigmatihus deflexis. R. Br. I. c. B. R. 51. In Nora Hollandia. 24.

6. P. glanca $\boldsymbol{R}$. $\boldsymbol{B r}$. fol. linearihus convexinsculis marginibus carinaque glahris; spathis subtrifloris striatis; stylus apice incrassatus; stigmatihus erectis. H. Br. 1. c. Genosiris fragilis Labill. nov. Holl. t. 9. In Nora Hollanelia. 24. Cor. caerulea frawilissima.

\%. P. occilentalis $\boldsymbol{R}$. Br. spathis 4-5-floris laevibus scapoque folia eltsiformia aequante glaberrimis ; stignatibus erectis. H. Br. 1. c. In Nora Hollandia.

\section{NEMATOSTIGMA Alb. Dietr. (1833).}

1. N. ixioides Alb. Dietr. scapo compresso; fol. lineari-ensiformibus strictis glaberrimis; filamentis distinctis. 
sisyrinchium Forst. Ferraria Willd. In Noru Leelandia. 4. Cor. alba.

2. N. paniculutum Alb. Dietr. caule paniculato; fot. nervosis margine scabris ; filamentis ad medium connais. Sis yrinchium R. Br. Libertia spreng. In Nora Hollarilia.

3. 1. pulchellum All. Dietr. caule subsimplici; fol. margiue laevihus; filamentis distinctis. sisyrinchinm $\mathbf{R}$. Br. Libertia spreng. In Nova Hollandia.

\subsection{TIGRIDIA Juss. (1761).}

1. T. Paronin .Juss. Real. $t$. 6. Ferraria L. F. Timridia sims. B. M. 532. In Mexico, Peru et Quito. Cor. magna ruhra purpurea basi lava maculis purpureis variegata.

\section{FERRARIA Burm. (1761).}

1. F. undulutu $L$. caule ramoso; fol. ensiformibus; corollae laciniis undulato-crispis omuibus maculatis. Cav. diss. t. 199. Ined. t. 28. F. punctata Pers. In Prom. b. spei. 4. Cor. flava intus purpureo-fusca.

2. F. Ferraviolu Hilld. canle simplici; fol. eusiformibus; corollae laciniis interiorihus hand maculatis Red. t. 484. F. minor Pers. F. antherosa 13. M. 751. F. viridiflora Audr. Rep. t. 285. In Prom. b. spei. 24. Cor. intus striis violaceis, extus sordide flava.

3. F. Musilla Link et Otto pl. sel. t. 59. fol. linearibus scapum aequantibus; laciniis corollae exterioribus basi maculatis. Link et Otto. In Brasilia. 4. Cor. flava basi maculis purpureis.

\section{CROCUS Cels.}

1. C. sativus $L$. corollae fauce barbata; laciniis obtusis integris; filamentis hirsutis; stigmatihus tubulosoclavatis antheras superantibus. Red. t. 173. Hayne, Arzneigew. t. 25. In Oriente. 24. Cor. pallide violacea, striis purpureis.

2. C. Pallasii Goldb. bulbi tunica filamentosa; corollae tubo limbo longiore; staminibus stigmata truncata subaequantibus. C. autumnalis Pall. In collitus apricis Tauriae. 4.
2. C. serotinus Salib. parad. t. 30 . stigmatibus multifidis erectis antheras superantibus. Rchb. ic. 1271. B. M. 1267. In Europa australi. 24. Cor. paltide violacea; fauce obsoletissime pubescente.

3. C. muliflorus $\mathrm{Sm}$. cor. tubn longissimo; stigmatibus inclusis multifido-laciniatis penicilliformibus. Engl. bot. 491. C. medius Balb. Rchb. ic. 1270. In Auglia et Pyrenaeis. 2]. Cor. purpureo-violacea, tubus fere pedalis.

5. C. speciosus Bieb. stigmatibus multifido-radiantibus; perianthii laciniis valde inaequalibus acuminatis. Rchb. ic. 1276-1278. Biel). ross. 1. 71. In Tauria et Caucaso. 2.

6. C. oulorus Bix. bulbo reticulatofibroso ; cor. tubo longissimo; staninibus stigmata multifida superautibus corolla breviorihus. C. longiflorus leaf́. Rchb. ic. 1\%72-1273. In siciliu. 4 .

8. 'Thomasii 'T'en. stigmatibus subcylindricis, truncatis; fol. ciliatis; cor. fauce hyalina villoso-nlandulosa. R(hb. ic. 1281. In Calabria. 4. Cor. flava.

8. C. autumnalis Mill. fol. angustissimis; corollae tubo brevissimo; stigmatibus tuhuloso-clavatis corollam aequantibus. In Gulliı. 4. Cor. magna purpureo-caerulea.

9. C. vernus All. staminibus stigmate brevioribus basi harbatis; perianthio sulcampanulato connivente; folii costa utrinque 1-canaliculata, lamina enervi. Rchb. ic. 1250-125t, 1247, 1255. C. ß. albiflorus, grandiflorus, pictus Sab. ramoso - lineatus, strictus et tubo-striatus Ihchh. 1. c. In Europa. 4. Cor. lutea caerulea, albida caeruleo-striata, caeruleo-purpurascens, violaceo-striata.

10. C. minimus DC. fol. tennissimis filiformibus; stigmate trifido corolla breviore erecto. Hed. t. 81. In lictoribus Corsicae. 4 . Cor. profunde violacea alboque variegata.

11. C. Imperati Ten. stigmate incluso 3-fido staminibus longiore; 10his cumeiformibus incisis crentatis. Rchb. ic. 1260. Ten. Croc. t. III. In Culabria. 24. Cor. violacea fundo lutea.

12. C. candidus Clarlie; corollae laciniis ellipticis; stigmatibus antheras subaequantilus profundissime multipartitis. In Asia minore. 24.

13. C. bi/lorus Mill. tunica bulbi 
Aupra hasin circumscissa. Rchb. ic. 125̋. C. versicolor B. M. 1110. C. reticulatus Br. C. var. pusillus Richb. B. C. 145 t. In Italia, T'unia et Iberia. 4.

14. C. reticulatus $\beta$. Ster. stigmatihus truncatis antheras subexcedentihus; perianthii laciniis oblongo-lanceolatis, triaristatis. Rchb. ic. 1262 -1265. C. variegatus Hoppe. Sturu 52. In Tauria et Caucaso. 4. Cor. aurea et pallide violacea.

15. C. Susiums Ker; spatha radicali nulla; filamentis pubescentilus; stigmatibus recurvato-patentibus, tuhuloso-clavatis, antheras superantibus. Ker. B. M. 652. Hed. t. 35̃3. In Turcia. 24. Cor. sulphurea.

16. C. stellatus Alb. Dietr. spatha radicali nulla; corollae laciniis acutiusculis; filamentis glahris; stimmatibus recurvato-patentibus tubuloso-clavatis antheras aequantibus. All. Dietr. Patria ignota. 4.

17. C. Iutens Lam. biflorus; staminibus pilosellis stigmata vix superantibus; perianthii hasi campanulati laciniis rectis concavis obtusis. Rchb. ic. 1247. C. vernus B. M. 45. C. maesiacus Gawl. C. veruus $\beta$. Hoppe. In Tauria. 4. Cor. Iutea.

18. C. sulphureus Ker; stigmatihus inaequalibus antheras superantibus; filamentis pubescentibus, B. M. 938 . lichb. ic. 1248. C. Susianus Hayue. Patria ignota. 24. Cor. sulphurea.

19. C. aureus sibth. hillorus; staminibus stigmata superantibus; filamentis postice pubescentibus ; perianthii hasi infundibuliformis laciniis ovalibus comniventi-patentibus. Rchb. ic. 1246. B. M. 2986. In Graecia prope Sestum. 4. Cor. aurea.

20. C. Reinuardti Rchb. folii costa utrinque 2-canaliculata. Hohb. ic. 1261. Patria ignota.

21. C. nervifolius Rchb. stigmatibus hreve infundibularihus ciliatis; perianthii laciniis obovatis basi 2-nervibus; filamentis basi harbatis, folii Iamina utroque 1-nervi. Rchb. ic. 1268 et 1269. Patria ignota.

22. C. multifiaus $\mathbf{S m}$. stigmatilsus patentibus multifidis; perianthii laciniis lancoolatis acutis suhaequalibus. lichb, io, 1274-75, In Cancaso. 24.

23. C. nivalis Bory et Chaub. Exp. Hor. t. 23. stimmatibus profunde partitin, valde intequalihus, apice dilata- tis subciliatis. In Morea. 24. Cor. pallide violacea.

21. C. laevigatus Bory et Chaub. l. $c$. $t$. 21. stigmatihus profunde partitis, valde inaequalibus; laciniis filiformibus partitis; tunica coriacea nitida. In Morea. 4. Cor. violacea.

2.5. C. Boryi Gay. t. c. t. 2.5. stigmatihus usque faucem partitis; laciniis filiformibus divisis ; tunica fibrosa membranacea. In Morea. 4. Cor. candida.

\section{IXIA Mill. (1731).}

1. 1. minuta $L$. fol. lineari-setaceis subfastigiatis; scapo 1 -floro. Tlıunb. diss. 1. t. 1. In Prom. b. spei. 4. Cor. alla purpureo-striata.

2. I. coelestina Batr. fol. linearisubulatis, scapo 1-floro longioribus. Willd. sp. pl. 1. p. 200. Bart. it. t. 3. In Carolina. 4. Cor. caerulea.

3. I. linearis $L$. fol. angustissimis ; florihus secundis ; spathis lance $0-$ latis acutis. L. I. capillaris B. M. 370. In prom. b. spei. 24. Cor. alha.

1. I. incarnata Jac\%. ic. $t$. 381. fol. ensiformibus margine reflexis ; floriluts sessilibus secundis; spathae valva exteriore 3-dentata. I. capillaris B. M. 61\%. f. 2. In Prom. b. spei, 24. Cor. pallide rosea.

5. I. aulica Ait. fol. ensiformibus nervosis scapo multifloro ramoso hreviorihus ; flor. distichis ; spathis denticulatis. I. capillaris $\gamma$. B. M, $1013 \mathrm{~J}$. phlogiflora lied. t, 432. In Prom. b. spei. 4. Cor. violacea,

6. I. capillaris $L$. fol. linearibus cartilagine -marginatis; spathis scariosis dentatis; striatis cor. reticulatovenosis. B. N. 61\%. I. Iancea Jacq. ic. t. 281. I. rapunculoides Red. t. 431. In Prom. b. spei. 24. Cor. albida.

\%. I. renosa Link en. 1. p. 5l. fol. lineari-ensiformibus; spathis scariosis dentatis; laciniis cor. obtusis 3-nerviis. Gladiolus Willd, In Prom. b. spei. 24. Cor. albida v. ochroleuca.

8. I. acuta licht. fol, linearibus; floribus secundis; spathis medium tubo excedentibus; laciniis corollae acutis. R, et s. syst. 1. p. 388, In Prom. b. spei. 4.

9. I. striata Vahl; fol. lineari-ensiformihus marginatis; spathae valva exteriore 3-dentata longitudine tuhi. 
Valil ell. 2. p. 65. In Prom. b. spei. 4. Cor. alba veuis fuscescentibus picta. 10. I. flexuosa $L$. spathis scariosis cuspidatis ; cor. campanulato-erecta, laciniis oblongis patentibus; scapo subflexuoso. B. M.624. I. polystachya Red. t. 126. I. patens Willd. In Prom. b. spei. 24. Cor. rubra, alba rubro-striata.

11. I. coccinea $T / h u n b$. fol. lineariensiformibus multinerviis scapum poJystachyum subaequantibns; floribus immaculatis. Thumb. cap. 1. p. 241. In Prom. b. spei. 24. Cor. purpurea.

12. I. scaviosa Thunb. l. c. fol. ensiformibus obtusis falcatis multinerviis scapo polystachyo brevioribus; epathis scariosis aculis. In From. b. spei. 24. Cor. caerulea.

13. I. aristata Thunb. I. c. fol. ensiformilus nervosis marginatis; spathis aristat $0-$ dentatis ; laciniis corollae patentissimis. B. M. 589. In Prom. b. spei. 2. Cor. albo-incarnata.

14. I. reticulatı Thunb. monostachya; fol. equitantibus ensiformibus scapo brevioribus; floribus spicais alternis. In Prom. b. spei. 4. Cor. alba.

15.). I. monarlelpha De la Roche; fol. lineari-ensiformilous ; filamentis hasi comnatis stigmata excedentibus. B. M. 607. Galaxia ixiaeflora Red. t. 41. I. curta Andr. Rep. t. 554. In Prom. b. spei. 21. Cor. purpurea, vel caerulescens.

16. I. columnaris Ker; fol. lineariensiformihus scapo brevioribus, laciniis corollae ligulato-ohlongis ; filamentis basi commatis; antheris comiventibus. B. M. 630. Galaxia ramosa DC. Red. t. 41. In Prom. b. spei. 24. Cor. extus purpureo-albida, intus saturate carnea fascia circulari coccinea.

17. I. maculata $L$. fol. lineariensiformibus marginatis scapo brevioribus; corollae tubo capillari, limbo explanato basi maculato; stigmatibus infra antherarum bases replicatis. hed, t. 137. B. M. 549. 789. 1285. I. viridiflora Lam. Red. t. 476. Jacq. H. schœubr. t. 19-23. In prom. b. spei. 24. Cor. albida, flava, purpurea, caerulea, violacea, viridis etc.

18. I. cruteroides Ker; tubo corollae brevissimo; limbo heuisphaericocampanulato, lacinits ovalibus; stigmatilus antheras superantibus. B. M. 594. I. speciosa Andr. Kep. t. 186. In prom. b. spei. 4. Cor. kernesina.
19. I. scillaris L. floribus spicatis; stigmatibus infundibuliformi-liantibus, antheris subjectis. B. M. 442. Ked. t. 127. I. polystachya Jacq. Coll. suppl. t. 2. f. 1. In Prom. b. spei. 4. Cor. extus purpurea et alba.

20. I. retusa S'alisb. floribus spicatis; laciniis corollae ligulato-ohlongis ; antheris didyma-rotundis ; stigmatibus hifidis patentissimis. I. polystaclyya Jacq. ic. t. 275. B. M. 629. I. scillaris $\beta$. B. M. 542. In Prom. $b$. spei. 24. Cor. rosea.

21. I. erecta Bery. fol. ensiformibus: corollae linbo immaculato; stigmatibus ad tubum usque distinctis. B. M.623. 1173. I. erecta Jacq. H. schœubr. t. 18. In Prom. b. spei. 4. Cor. rosea, violacea, lutea vel aurantiaca.

22. I. conica Sulish. racemis confertis, limbo corollae patente basi maculato; stigmatilus apice distinctis. B. M. 539. I. dubia Vent. choix. t. 16. Red. t. 64. In Prom. spei. 4. Cor. aurantiaca vel straminea.

23. I. patens Ait. florihus racemosis ; corollae tulo filiformi ; limbo campanulato-patente; filamentis coarctatis erectis. B. M. 522. Red. t. 129. I. filiformis Vent. I. c. t. 48. Ked. t. 30. I. lencantha Jacq. ic. t. 278. I. candida. Red. In Prom. b. spei. 4. Cor. punicea interdum flava.

24. I. crispa Thumb. fol. linearibus undulato-crispis; florihus remotis; antheris brevissimis subdidynamis extrorsum deflexis. Thunh. diss. 8. t. 2. f. 3. B. M. 599. Red. t. 433. In Prom. b. spei. 4. Cor. caerulea vel hermesina.

\section{Species dubiae.}

25. I. elliptica Thunb. fol. ellipticis glabris; scapo ramoso; floribus secundis. In Prom. b. sluei. 24. Cor. caerulea.

26. I. squalida Thunb. fol. lineariIanceolatis glahris; scapo ramoso; laciniis limbi excisis. I. Thunbergii $\mathbf{R}$. et s. In prom. b. spei. 4. Cor. lutea venis fuscis.

27. I. bicolor Thunb. fol. ensiformilous multinerviis reflexis; scapo ramoso; corollis luteis basi caeruleis. In Prom. b. spei. 4. 


\section{BABIANA Gmel. (1805).}

1. B. ringens $\mathrm{Ker}$; fol. ensiformibus plicatis; scapo dichotomo villoso; corollae lacinia suprema longissima, reliquis divaricatis undulatis acuminatis; fance inflata elongata. Antholyza L. In Prom. b. spei. 4. Cor. incarnata.

2. B. Thunberyii Ker; fol. plicatis villosis; scapo hirsuto; spathis ovatis villosis; corollae lacinia suprema erecta, inferioribus patulis. Antholyza Thunh. In Prom. b. spei. 24. Cor. purpurea.

3. B. tubiflor Ker; fol. oblongis plicatis lirisutis scapo polystachyo hirsuto longioribus; corollac tuho longissimo; lacinia suprema divaricata. Ker. B. M. $84 \%$. Red. t. 361. var. fioribus ochroleucis B. M. 680. Gladiolus tubatus Jacq. ic. 204. $\gamma$. /loribus lilacinis Jacq. ic. t. 265. In Prom. b. spei. 4. Cor. carnea.

4. B. spathacea Ker; fol. rigidissimis plicatis pungentibus junioribus villosissimis; spathis aristatis. B. M. 638. Gladiolus L. In Prom. b. spei. 4. Cor. pallide violacea.

5. B. sambucina Ker; scapo ramoso subcompresso; spathis plicatis acuminatis villosis; corollae laciniis alternis undulatis, linea longitudinali saturatiore notatis. Ker B. M. 1019. Gladiolus Jacq. H. Schœuhr. t. 15. In Prom. b. spei. Cor. caerulea hasi macula lutea.

6. B. disticha ker; fol. rigidiusculis subvillosis, plicis alte liratis; laciniis corollae lineari-oblongis crispatulis. B. M. 626. Gladiolus Jacq. ic. t. 337. In Prom. b. spei. 4. Cor. albido-caerulescens.

\%. B. plicata Ker; fol. ohlongolanceolatis mollissimis laxe plicatis villosis; limbo 2 -labiato patente; lacinia suprema convoluta. B. M. 576. Gladiolus fragrans Jacq. Schœulor. t. 14, In Prom. b. spei. 4. Cor. pallide vioIacea.

8. B. mucronata Ker; fol. ensiformibus plicatis hirsutis; vaginis scapoque angulato-glahris; corollis subringentibus. Gladiolus Jacq. ic. t. 253. In Prom. b. spei. 4. Cor. pallida.

9. B. reflexa Alb. Dietr. fol. reflexo-patentibus subincurvis plicatis hirtis; corollis subringentibus campanulatis. Gladiolus Riclit. In Prom. b. spei. 2. Scapus brevissimus. Odor suavissimus.
10. B. sulphuren Ker. B. N.10.53. fol. ensiformibus nervoso-plicatis villosis; scapo declinato ; corolla campanulata. Gladiolus Jacq. ic. t. 239. In Prom. b. spei. 4. Cor. violacea.

11. 13. strictu Ker; caule subassurgente stricto; fol. ensiformilous; corollis infundibuliforni-campanulatis. B. M. 621 et 637. In Prom. b. spei. 4. Cor. saturate caerulea.

12. B. purpurea ker; fol. lanceolato-ensiformibus villosulis plicatis distichis; corollae limbo patentissimo; laciniis acutis. Ixia Jacq. ic. t. 286. In From. b. spei. 2. Cor. violacea.

23. B. obtusifolia $\mathrm{Ker}$; fol. ohlongolanceolatis, totis villosis subplicatis distichis. Ixia villosa Jacq. ic. t. 284. In P'rom. b.spei. 4. Cor. dilute violacea.

14. 13. villosa lier; fol. oblongis plicatis; spathae tubo filiformi aequante; corolla campanulata regulari. B. M. 583. Ixia punicea Jacq. ic. t. 287. Gladiolus mucronatus lied. t. 142. In Riom. b. spei. 24. Cor. violacea.

15. B. vubro-cymen ker; fol. oblongo-lanceolatis plicatis distichis ; corollae limbo patentissimo; Iaciniis rhomboideo-oblongis basi maculatis. Ixia Jacq. ic. t. 285. I. cyanea Pers. In Prom. b. spei. 24. Cor. tubus pallide ruhens, laciniae cyaneae.

16. B. nana spm. fol. lanceolatis plicatis pilosis scapum multiflorum aequantihus; spatha crassa 2 -valvi. Gladiolus Andr. Rep. t. 13\%. In Prom. b. spei. 4. Cor. caerulea.

\section{TRITONIA Garl. (180.5).}

1. T. rividis Ker; fol. distichis lato-nervosis scapo subtriquetro brevioribus; limbo patente reflexo. B. M. 1275. Gladiolus auct. In l'rom. spei. 4. Cor. viridis.

2. T. crispu her; fol. lanceolatoensiformibus undulato-crispis; florilus secundis; limbo 2-Iabiato. B. M. 678. Gladiolus auct. In Prom. b. spei. 4. Cor. albo-incarnata.

3. 'T. rosen $\boldsymbol{R}$. $\boldsymbol{B r}$. fol. gramineoensiformibus nervosis; spica composita; corollae tubo longissimo, lacinia suprema majori. T. capeusis Ker. $\mathbf{B}$. M. 618. Gladiolns Jacq. ic. t. 61. In Prom. b. spei. 24. Cor. rosea.

4. T. longiflora Ker; caule ramoso; fol. lineari-cnsiformibus; spatha exteriore 3-dentata; tubo longissimo; la- 
ciniis patentissimis. Ixia B. M. 256. Red. t. 34. Gladiolus Jacq. ic. t. 263. B. MI. 1502. In Prom. b. spei. 4.

5. 'T'. Rochensis Ker; spica multiflora laxa; spatha cuspidata; tubo corollae longissimo cernuo. B. M. 1503. Ixia paniculata De la Roche diss. t. 5. in prom. b. spei. 4.

6. 'T. pectinata Ker; fol. revolutosubulatis; floribus secundis; spathis membranaceis obtusissimis. Ixia Vahl. In Prom. b. spei. 4. Cor. albido-incarnata.

\%. 'T. striata Ker ; fol. lanceolatoensiformihus crispis ciliatis; corolla divaricata ringente; laciniis 3 alternis crispis. Gladiolus Jaç. ic. t. 260. In Prom. b. spei. 24. Cor. flavesceus.

8. T. lineatı lier; fol. linearilanceolatis; spathis serrato-mucronatis; corollae laciniis 2 superioribus lateralibus enaroinatis. Gladiolus Red. t. 5.5. B. M. 48\%. In Prom. b. spei. 4. Cor. straminea aurantiaco-tincia.

9. T. securiger her ; fol. lineariensiformibus; laciniis 3 limbi inferioribus callosis; callo unguiformi perpenticulari. Gladiolus B. M. 383. Jacq. Fragm. t. 48. f. 2. Monthretia lied. t. 53. In Prom. b. spei. 4. Cor. pallide flava.

10. T. flar:a Ait. fol. lanceolatoensiformilus; laciniis limbi $\mathbf{3}$ inferioribus hasi callosis; spatha cuspidata. Gladiolus Ait. In Prom. b. spei. 21. Cor. intense flava.

11. $T$. refiacte $\mathrm{Ker}$; spicis refractis secundis; spathis hrevissimis; corolla resupinata; stigmatihus bifidis. Gladiolus Jack. ic. t. 241. Red. t. 419. In Prom. b. spei. 24. Cor. crocea.

12. T. squalida Ker; fol. ensiformilus striatis; spathis dentatis; limbi campanulati laciniis inferne margine hyalinis. B. M. 581. Ixia hyalina Red. I. t. 27. In Prom. b. spei. Cor. pallide rufescens s. sordide carnea.

13. T. crocatı her; fol. cinsiformibus; linhi campanulati laciniis ovatis basi hyalino-fenestratis. Ixia Red. t. 335. B. M. 184. In From. b. spei. 24.

14. B. fenestrata Ker; B. MI. 704. fol. ensiformibus; flor. secundis ; laciniis corollae distantihus ohovatis inferne margine hyalinis. B. M. 704. Ixia Jacq. ic. t. 289. In Prom. b. spei. 4. Cor. flava.

1.). T. murpuren ker; fol. ensiformibus subsulcatis nervosis; corollae laciniis margine concoloribus. Ixia Lam. In prom. b. spei. 4.

16. 'T. densta Ker; fol. lanceolatis nervosis; limhi laciniis exteriorihus basi gibhis, intus maculatis carinatis. B. M. 622. Ixia Ait. I. miniata ked. t. 39. In Prom. b. spei. 21. Cor. fulva.

1\%. T. miniata Ker; caule patenter polystachyo; fol. ensiformibus longo acuminatis; laciniis cor. superioribus hasi maculatis. B. M. 606. Ixia Jacq. schœubr. t. 14. I. deusta Vahl. In Prom. b. spei. 2. Cor. miniata.

18. 'T. xunthospila Ker; caule simplici flexuoso; corolla subringenticampanulata; laciniis obtusis flavopunctatis. Gladiolus DC. in Red. t.124, In Prom. b. spei. 24. Cor. alba maculis punctisque sulphureis.

\section{GLADIOLLS Ptin.}

\section{Foliis angustissimis.}

1. G. quatrangularis Ker; fol. sulcato-quadrangulatis; corolla geniculato-recurva, fuuce cylindrica; lacinia suprema maxima, infima subulata minima. B. M. 567. (r. ahbrevialus Audr. Rep. t. 166. In Prom. b. syei. 24. Cor. flava.

2. G. edulis Bruch. fol. linearihus 2-sulcis; spica subcomposita; laciniis corollae ovato-acuminatis undulatis. B. 1. 169. In Africa australi. 21.

3. G. tristis $L$. fol. linearihus 1-0nis 4-sulcatis; laciniis corollae acuminatis tortis. Red. t. 3.5. B. M. 1098. In Prom. b. spei. 4. Cor. ochrolenca.

4. G. gracilis Juc\%. fol. linearibus marginibus utrinque laminato-costatis; corollae subringentis fauce inflata; laciniis infimis maculatis. Jacq. ic. t. 246. B. H. 562. Red. t. 425 . In Prom. b. spei. 4. Cor. pallide violacea.

5. G. scaber Link; fol. linearibus convolutis margine scanris; caule pancifloro; labio corollae inferiore proninente. Link Jahrb. 1. 3. p. 70. In Prom. b. sprei. 24.

6. G. laevis Thunb. fol. linearibus 2-sulcis ; corollis secundis cernuis; spathis tubo longioribus. Thumb. prodr. p. 184. In Prom. b. spei. \%. Cor. Intescenti-alhida.

\%. G. setifolius I. canle ramoso 
polystachyo; fol. lineari-setaceis; corollis ringentibus. Linn. suppl. p. 96. In Prom. b. spei. 4. Cor. alba.

S. G. recurvus I. caule erecto simplici; vaginis radicalibus maculatis; laciniis corollae omnibus recurvis, infimis subcuncatis striatis. B. M. 578. G. ringens. Red. t. 242. G. punctatus Jacq. ic. t. 247. In Prom. b. spei. 4. Cor. flava caeruleo et purpureopunctata.

9. G. angustatus $L$. scapo ancipiti; corollis sulringentibus secundis; laciniis lanceolatis inferne macula pedunculata rhombea sanguinea. B. M. 602. Hed. t. 344. In Prom. b. spei. 4. Cor. flavescens.

10. G. vermeabilis De la Roche diss. $t$. 2. fol. angnstissinis marginato-costatis ; spicis secundis ; cor. ringentis laciniis spathulatis longe unguiculatis. In Prom. b. spei. 24. 2-3ped.

11. G. trichonemifolius Ker; fol. quadrangulis sulcatis; spica 3-flora secunda; fauce corollae ventricosa; laciniis apice convolutis. B. M. 1483. In Prom. b. spei. 4. Cor. flava striis purpureis.

12. G. tenellus Jacq. folio radicali unico angustissimo; scapo flexuoso subhifloro; laciniis corollae lanceolatis obtusis. Jacq. ic. t. 248. $\beta$. luteus cor. Intea. Jacq. Coll. 4. t. 3. f. 1. In Prom. b. spei. 4. Cor. ochroleuca.

13. G. involutus De la Roche diss. $\boldsymbol{t}$. 3. fol. angustissimis; corollis ringentibus; tubo spathis breviore; laciniis lanceolatis lateralibus margine involutis. In Prom. b. spei. 4. Cor. rosea.

14. G. papilionaceus Licht. fol. lineari-falcatis; scapo 1-floro bulbifero; corolla ringente; laciniis tribus inferioribus multo angustioribus spathulatis. In Prom. b. spei. 4. Cor. carmea.

15. G. flexuosus $\boldsymbol{L}$. fol. linearibus canaliculatis; scapo flexuoso; corolla filiformi spatham coloratam superante; laciniis lanceolatis acutis. Thunb. diss. 1. 2. t. 2. In Prom. b. spei. 4. Cor. albido-incarnata.

16. G. biflorus Thunb. fol. linearibus; scapo $2-$ floro vaginis tecto ; corollis erectis campanulatis. Thunb. In Prom.b. spei. 24. Color corollae tristis.

17. G. dichotomus Thunb. fol. radicali unico lineari-filiformi, scapum dichotomum 4-florum superante; spathis lineari-setaceis. Thubb. In Prom. b. spei. 4.

18. G. paleaceus Vahl; fol. linearibus scapo inferne pilosiusculo brevioribns; spicis imbricatis; tuho corollae filiformi. Vahl. In Prom. b. spei. 4.

II. Fol. Iatioribus, ensiformibus.

19. G. Cunonia Gartn. fol. lineari-ensiformilns ; spica disticha; corollae lacinia suprema longissima, lateralibus adscendentibus, infima minima. Autholyza Limn. B. M. 343. In l'rom. b. spei. 24. Cor. coccinea.

20. G. Watsonius Thunb. fol. Iinearilus utrinque 3-costatis; spathis acuminatis; cor. subcampanulatis cernuis, laciniis recurvis. B. M. 450. Red. t. 369. In Prom. b. spei. 24. Cor. purpurea.

21. G. psittacinus Hook. fol. ensifornibus medio costatis; cor. campanulatis, laciniis 3 inferiorihus late ovatis mucromulatis, suprema obovata convexa. B. M. 3032. B. H. 1442. In Prom. b.spei. 4. Cor. Iutea coccineopunctata.

22. G. Milleri Ker; B. M. 632. fol. ensiformibus 3-nerviis; spathis herbaceis tubum superantibus; corollae campanulatae laciniis umdulatis. In Prom. b. spei. 4. Cor. flavicans.

23. G. viperatus Ker B. M. 688. fol. lineari-ensiformibus; scapo polystachyo; lacinia suprema spathulata incurva, inferioribus acutis pendulis. G. alatus Jacq. ic. t. 259. G. orchidiforus Andr. Hep, t. 241. In Prom. b. spei. 24. Cor. fragrans criseo-viridis.

24. G, alatus $I$. fol. rigidis striatis; lacinia corollae suprema obovata recurva, inferiotibus spathulatis acuminatis pendulis. B. M. 586. Andr. Rep. t. 8 .

25. G. virescens Thunb. fol. linearibus 2-sulcis scapo longioribus; corollae laciniis lateralibus latissinis. Thunb. In Prom. b. spei. 4. Cor. color tristi.

26. G. namaquensis Ker; B. M. 592. fol. ohlongis coriaceis olutusis marginatis; lacinia corollae suprema fornicata, inferioribus spathulatis mucronatis pendulis. G. galeatıs Andr. Rep. t. 122. In Namaqua Africa meridionali. 2. Cor, viridi-flava. 
27. G. equitans Thunb. fol. ensiformilus multinerviis marginatis; scapo compresso ; corollae campanulatae tubo brevissimo; laciniis ovatis. Thunb. In Prom. b. spei. 4. Cor. purpurea.

23. G. Irevifolius Jacy. ic. t. 219. bulbi sterilis folio unico lineari puhescenti, bulbo florifero aphyllo; laciniis corollae lanceolatis. G. carneus Andr. Rep. t. 240. G. hirsutus $\alpha \cdot \beta$. B. M. 727 et 992. In Prom. b. spei. 24. Cor. incarnata.

29. G. hirsutus Jac\%. ic. $t$. 250. fol. lineari-ensiformibus villosulis; vaginis pilosis; corollis subregularibus campanulatis; laciniis subundulatis. G. hirsutus roseus. B. M. 574. G. Merianellus Thunb. In Prom. b. spei. 4. Cor. purpureo-rosea.

30. G. versicolor Andr. fol. lineari-ensiformibus utrinque 3-costatis; laciniis extimis ellipticis, lateralibus inferioribus angustioribus unguiculatis. $\alpha$. major: cor. fuscescente $B$. M. 1042. G. grandis Thunb. $\beta$. inaequalis Breyn. ic. t. 7. f. 1. $\gamma \cdot t e-$ nuior: laciniis corollae apice convolutis. B. M. 556. \&. lonyifolins: c0rollis subviolaceis punctatis. G. tristis Jacq. ic. t. 245. In Prom. b. spei. 24.

31. G. carneus Jacq. fol. ensiformibus marginatis; corollis subringentibus distichis cernuis apice convolutis, suprema recurva inferiore pendula. Jacq. ic. t. 255. B. M. 591. G. cuspidatus Andr. Rep. t. 147. Red. t. 36. In Prom. b. spei. 4. Cor. carnea.

32. G. cuspidatus Jacq. ic. t. 252. floribus secundis cernuis; corolla subringente, tubo duplo longiori; laciniis lanceolatis cuspidatis undulatis, 3 inferioribus macula ocellata. B. M. 582. Red. t. 136. In Prom. b. spei. 24. Cor. pallide carnea.

33. G. trimaculatus Lam. floribus cernuis ; cor. subringente; tubo curvo limbo longiore; laciniis 3 inferioribus macula cordata purpurea. Lam. ill. t. 32. f. 3. In Prom. b. spei. 24. Cor. albido-incarnata.

34. G. blandus Willd. fol. linearilanceolatis; limbo campanulato subringente; lacinia suprema concava, 3 inferioribus maculatis. B. M. 625, 645, 648. G. albidus Jacq. ic. t. 211. In Prom. b. spei. 24. Cor. pallide rubens.
35. G. undulatus Jac\%. spica composita; cor. erectis infundibuliformihus; laciniis undulatis superiorilous ovatooblongis, summa majori, inferioribus subrecurvis. Jacq. ic. t. 251. B. Mr. 538. 647. Red. t. 122. In prom. 6. spei. 4. Cor. pallide carnea.

36. G. floribundus Jac\%. fol. ensiformilos marginatis; spica composita elongata; corollis erectis; limbo turbinato-campanulato. Jacq. ic. t. 254. B. M. 610. G. grandiflorus Andr. Rep. t. 118. In Prom. b. spei. 21. Cor. pallide ochroleuca media linea purpurea.

3\%. G. cardinalis Curt. B. M. 13.5. spicis pluribus secundis; spathis herbaceis albo-marginatis ; corollae campanulatae laciniis lanceolatis allomaculatis. Red. t. 112. In Prom. $b$. spei. 24. Cor. purpureo-coccinea.

38. G. byzantinus Hill. spica disticho-secunda multiflora; laciniis corollae obtusis; antheris filamento longiorilus ; stigmatibus cuneiformibus. B. M. 874. In Prom. b. spei. 24. 2-ped. Cor. dilute kermesina.

39. G. segetum Ker; spica secumda remotiuscula; laciuiis corollae inferioribus, dependentibus; antleris filamento longioribus; stigmatibus obovatis. B. M. 719. Rchb. ic. 819. In Europa media et custrali. 24. Cor. rubra.

40. G. communis $L$. floribus secundis; laciniis superioribus conniventibus, inferioribns spathulatis; antheris filamentis perigynis brevioribus. B. M. 86. Hed. t. 267. Rchb. ic. 817. In Europa australi. 4. Cor. splendide kermesina.

41. G. pratensis Alb. Dietr. Fl. boruss. $t$. 13. fol. acutissimis; spica pauciflora secunda; antheris filamento hrevioribus; stigmatibus linearibus. Alb. Dietr. I. c. In pratis Europae borealis. 24. Cor. splendide kermesina.

42. G. imbricatus $L$. fol. lineariensiformibus, obtusissimis; spica secunda imbricata; stigmatibus cuneiformilus retusis. Bieb. ross. t. 60. Alb. Dietr. 1. c. t. 44. Rchb. ic. 818. G. neglectus schult. In pratis Europae et ad Caucasum. 24. Caul. 1-2-ped. Cor. kermesina.

43. G. hyalinus ic. $t$. 212. fol. ensiformi-linearibus glabris caule erecto multo brevioribus; corolla subringente, laciniis lanceolatis. G. strictus Jacq. Coll. In Prom. b. spei. 4. Cor. caerulescens. 
44. G. montanus $L$. fol. ensiformilus nervosis; floribus spicatis; corolla ringente; tubo spathae ohtusae aequante. Thumb. diss. t. 1. G. parviflorus Jacq. ohs. t. 78. In Prom. $b$. spei. 4. Cor. prirpurea.

4.5. G. luastatus Thunb. fol. linearibus hisulcatis; corollae campanulatae tuho spathis hrevioribus; laciniis ovatis obtusis, 3 inferioribus macula hastata. B. H. 1564. In Prom. b. spei. 4. Cor. albo-incarnata.

46. G. campanulatus Andr. fol. lanccolatis glabris; scapo sub-2-floro foliis longiore ; corolla subcampanulata. Andr. hep. t. 187. In Prom. b. spei. 4. Cor. purpurascens.

47. G. luteus Lam. fol. lineariensiformibus angustis longissimis ; floribus spicatis subsecundis; cor. tubo curvo spathis breviore; limbo campanulato. Lam. ill. 1. p. 117. In Ml dagascar. 24.

4S. G. rudis Iicht. fol. lanceolatis nervosis; scapo 2-floro; corollis ringentibus; spathis tubo longioribus. Licht. in R. et S. syst. 1. p. 408. Cor. pallide purpurea.

49. G. exscapus Thunb. fol. ensiformibus 3-nervibus; scapo flexuoso; spathae laciniis lanceolatis obtusis; corollae ringentis tubo filiformi. $G$. flexuosus L. G. Thumergii G. Dietr. G. L.ex. In Prom. b. spei. 24. Cor. alha.

50. G. latifolins Lam. hirsutus; fol. late-lanceolatis plicatis nervosis racemo longioribus; corollae tubo spathis hreviore. Lam. ill. 1. p. 119. In ins. Franciae. 4.

\section{WATSONIA Gaul, (1S05).}

1. W. spicata Ker; fol. teretihus fistulosis, uno breviore verticali molliter mucronato; spica disticba subamentiformi. B. M. 553. G. fistulosus Jacq. Schœubr. t. 16. Ixia cepacea Red. t. 96. In Prom. b. spei. 4. Cor. albida apicibus violaceis.

2. W. triticen Spr. fol. linearibus; spica disticha imbricata; spathis truncatis; corolla erecta. Gladiolus Tluub. In Prom. b. spei. 4.

3. W. Lamarkii Alb. Dietr. scapo simplici villoso; floribus imbricatospicatis. Gladiolus spicatus Lam. G. parviflorus Valıl. In Prom. b. spei. 4.

t. W. plantaginea Ker; caule alato ancipiti; folio infimo falcato compresso fistuloso, caeteris plano-solidis; limbo campanulato-patente. B. M. 553. G. alopecuroides I. Ixia hed. t. 198. In Prom. b. spei. 4. Flores copiosi 50 -100 in spica imbricata, minimi cacrulei.

5. W. punctula Ker; fol. subulatis teretiusculis; cor. tubo spathis obtusis nervosis longiore; laciniis oblongis subaequalihus. Gladiolus 1R. et S. Ixia Andr. Kep. t. 177. In Prom. b. spei. 4. Cor. violacea.

6. W. marginata Ker; B. M. 608. et var. 1530. fol. late ensiformibus margine incrassatis; spiculis pluribus adpressis ; corolla cernua infundihuliformi; fauce 6-dentato. In Prom. b. spei. 24. Cor. pallide rosea.

\%. W. rosen Ker; fol. Iate ensiformihus margine incrassatis; spica paniculata; corollae limbo campanulato; fauce nuda. B. M. 1072. G. pyramidatus Andr. Rep. t. 335. In Prom. b. spei. 24. Cor. purpurascenti-violacea.

8. W. brevifolia Ker; B. M. 601 . fol. subfalcatis brevissimis; corollis pedicellatis campanulatis; tubo filiformı longitudine spathae. Antholyza Andr. Rep. t. 56. G. lestaceus $\mathrm{R}$. et S. In Prom. b. spei. 2. Cor. fulva.

9. W. iridifolia Ker; B. M. 600. fol. late ensiformibus superioribus conduplicatis; florihus secundis recurvis; limbi laciniis acutis. Gladiolus R. et s. Jacq. ic. t. 23 4. Antholyza fulgens Andr. liep. t. 192. In Prom. b. spei. 4. Cor. pallide carnea.

10. W. Meriama Mill. ic. t. 286. corollis infundibuliformibus recurvis cernuis fauce compressiusculis. B. M. 1194. G. Jacq. ic. t. 230. Red. t. 11. In Prom. b. spei. 4.

11. W. humilis Mill. fol. angustioribus verticalitcr ensiformihus strictis. tortiusculis. Mill. ic. t. 297. f. 2. B. M. 631. G. laccatus Jacq. ic. t. 232. Hed. t. 343. In Prom. b. spei. 4. Cor. albida.

12. W. aletroides lier; fol. ensiformibus marginatis; floribus tubulosis cermuis; fauce lacinias ovatas acutas comiventes quadruplo superante. Jacq. ic. t. 229. In Prom. b. spei. 4. Cor. saturate coccinea.

13. W. roseo-alba Ker; corollae laciniis ellipticis aequalibus ; fol. lineariensiformilus. Gladiolus Jacq. Schœuhr. t. 13. In Prom. b. spei. 4. Cor. rosea. 
1+. W. strictiflora Ker; B.M. 1-106. fol. lanceolatis rigidis; corollae limbo rotato, laciniis oblongis obtusis. Gladiolus ked. t. 399. In Prom. b. spei. 4. Cor. saturate purpurea.

15. W: rubens Ker; B. M. 1072. fol. linearibus nervosis; corollae laciniis oblongis subaequalibus. Gladiolus Vahl. In Prom. b. spei. 4.

\section{6\%. SPARAXIS Gawl. (1S05).}

\section{Limbo corollae regulari.}

1. S. tricolor fier; fol. ensiformibus erectis; spathis fusco-maculatis tenuissime sulcato-plicatis; laciniis limbi maculatis. Ixia Curt. B. M. 381. lied. t. 129. var. corolla sanguineopurpurea, violaceo-purpurea et subroseo-albida. In Prom. b. spei. 4.

2. s. yrandiflora Ker; scapo subcompresso flexuoso; spathis aristatolaceris; limbi laciniis ovato-ohlongis marginatis. B. M. 789. Ixia Red. t. 139. et 362. Var. corolla purpurea, flavescens et albida.

:3. S. bulbiferct Ait. fol. lineariensiforuibus; scapo subcompresso, flexuoso; spathis setaceo-laceris. Ixia Red. t. 128. B. M. 548. Moraea Jacq. Hort. schœubr. t. 197. In Prom. b. spei. 4.

t. S. fragrans ker; fol. linearibus reclinatis; scapo compressiusculo; spathis rubro lineatis, laciniis cor. elongato-lanceolatis. Jacq. ic. t. 2774. In Prom. b. spei. 24. Cor. lutea.

5. S. anemonaeflora Ker; fol. lineari-ensiformibus scapum 1-florum aequantibus; spathis dentatis; laciniis corollae patentissimis. Ixia Jacq. ic. t. 273. Hed. t. 84. In Prom. b. spei. 4. Cor. alba.

6. S. pendula Ker; fol. linearibus strictis; scapo polystachyo; spicis pendulis. B. M. 1428. R. Br. 1360. In Prom. b. spei. 4. Cor. lilacina.

II. Limbo corollae subirregulari.

7. S. bicolor Ker; fol. ensiformibus; spathis coloratis maculatis laceroso-aristatis; corollae limho 2-labiato, laciniis infimis convolutis. Ixia. B. M. 548. Gladiolus. Jacq. ic. t. 240. In Prom. b.spei. 4. Cor. apice caerulea.

8. S. galeata Ker; fol. eusiformi- bus ohtusis; spathis dentatis; corollae laciniis divaricatis ringentibus, summa erecta. Gladiolus Jacq. ic. t. 258. In Prom. b. spei. 24. Cor. ex violaceo sordide pallens.

\section{TRICHO NEMA Gaxl. (1805).}

1. 'T. Bulbocodium Ker; scapis suhgeminatis; fol. filiformi-compressis sulcatis flexuosis; stigmatibus 2-partitis. Ixia jacq. ic. t. 271. B. M. 265. Red. t. 88. In Italia. Istria et Dalmatia. 2. Cor. fundo crocea, apicibus roseo-violacea.

2. 'T. Columnae Rchb. scapo 1-floro subsolitario subnutante; fol. filiformicompressis sulcatis flexnosis; stigmatibus apice 2-fidis. Ixia Bulb. A. Red. t. 88. f. a. In collibus Italiae. 4. Cor. albo-lutescens.

3. 'T. roseum Ker; B. M. 1225. fol. filiformibus laxis elongatis; scapo brevissimo; cor. campanulatis scapo longioribus. Ixia L. In Prom. b. spei. 4. Cor violacea striis purpureis.

t. $\boldsymbol{T}$. recurvifolium Poir. fol. gladiatis; scapo ramoso acute 3 -quetro, et in angulis duobus ala fusca marginata multo longioribus. Ixia lied. t. 251. f. 1. In Prom. b. spei. 24. Cor. viridi-flavescens.

5. 'I. tortuosum Licht fol. filiformibus flexuoso-tortuosis; flore solitario subsessili; spathis tubo longiorihus. R. et s. syst. 1. p. 375. In Prom. b. spei. 4. Cor. flava.

6. 'T'. ornithogaloides Licht. fol. lineari-subulatis; scapo 1 -floro folio subaequante; spathis tubo longioribus. R. et s. syst. 1. p. 375. In Prom. b. spei. 24. Cor. flava.

7. T. chloroleucum Pers. fol. linearibus subulatis, unico lougissimo falcato reflexo; corollis snhcampanulatis. B. M. 1225. Ixia Jacq. ic. t. 272.

In Prom. b. spei. 4. Cor. crocea.

8. 'T. cruciatum Ker; fol. linearibus 4-carinatis utrinque 3-costatis; laciniis corollae recurvato-patentibus. B. M. 575. Ixia Jacq. ic. t. 290. In Prom. b. spei. 4. Cor. intus rubra.

9. T. speciosum Ker; fol. teretiattenuatis 4-sulcatis unico longissimo; pedunculis divaricatis ; staminibus stigmate excedentibus. B. M. 1476. Ixia neglecta R. et S. In Prom. b. spei. 4. Cor. flava lineis obscurioribus. 
10. T. pudicum Ker; fol. Ianceolato-linearibus, utrinque tricostatobisulcis, summis duobus oppositis, altero pedunculis dichotomo-geminis longiore, altero brevissimo bracteaeformi. B. M. 1244. Cor. dilute ribra fundo alba stella fusca.

\section{GEISSORRHIZA GaUl. (1805).}

1. G. Rochensis Ker; caule foliisque uudis; spatha subventricosa ovali; laciniis corollae foveola melliflua basi insculptis. Ixia. B. M. 598. In Prom. b. spei. 4. Cor. rubro-violacea, vel purpurea fascia albida.

2. G. secunda Ker; fol. nudis; scapo lanugine perminuta densissima vestito; rhachide perarcuatim flexuosa. Ixia Jacq. ic. t. 27\%. B. M. 597. Red. t. 406. In Prom. b. spei. 4. Cor. caeruleo-violacea.

3. G. juncea Link; fol. filiformibus; spathis longissimis scariosis; laciniis corollae oblongis. In Prom. $b$. spei. 4. Cor. alba extus rubescens.

4. G. scillaris Thunb. fol. linearihus scapo ramoso multifloro brevioribus; floribus secundis; tubo corollae brevissimo. Ixia phalangoides $\mathbf{k}$. et $\mathbf{s}$. In Prom. b. spei. 24. Cor. flava.

5. G. sublutea Ker; fol. radicalibus convoluto-setaceis; scapo 1-floro longioribus, spatha tubum aequante. In Prom. b. spei. 4.

6. G. obtusata Ker; B. M. 672. fol. ensiformibus rigidiusculis dense nervoso-liratis ohtusis ; laciniis corollae turbinato-campanulatis, imis latioribus. Ixia geminata Vahl. In Prom. b. spei. 24. Cor. lutescenti-alba.

\%. G. excisa Ker; fol. ovato-ol)longis margine interiore inferne excicisis; rhachi dichotomoideo-flexuosa; fforibus erectissimis; stigmatibus revolutis fimbriato-pilosis. Ixia. B. M. 584. In Prom. b. spei. 4. Cor. rufescens, intus alba.

8. G. hirta Ker; fol. radicalibus ensiformibus villosis; scapo glabro simplici; floribus secundis. Ker. Ixia Thunb. In Prom. b. spei. 4.

9. G. imbricata Ker; fol. radicalibus linearibus; scapo polystachyo; floribus secundis; spathis longitudine tubi ovatis acutis. Ker. Ixia $\mathbf{R}$. et $\mathbf{s}$. In Prom. b. spei. 4. Cor. extus rubra intus luteo-alba.
10. G. setacea Ker; B. M. 125.5. fol. radicalibus lineari-ensiformibus nervosis; scapo filiformi ; spathis subinflatis ovatis. In Prom. b. spei. 4. Cor. intus alha extus purpureo-striata.

11. G. humilis Ker; fol. radicalibus linearihus sulcatis, scapo filiformi subramoso Iongiorilsus; spathis truncatis; floribus secundis. Ixia Thunb. In Prom. b. spei. 4. Cor. lutea, vel albido-rufescens sive incarnata.

\section{HESPERANTHA Gavl. 1805).}

1. H. radiata Ker; fol. fistulosis deorsum vaginanter teretibus exinde compresso-planis; floribus secundis ceruuis; stigmatibus flexuoso-tortis, dependentihus. Ixia Jacq. ic. t. 280. Red, t. 441. J. fistulosa Andr. Rep. t. 59. In Prom. b. spei. 24. Cor. sordide rubens.

2. H. angusta Ker'; fol. linearibus glabris; scapo simplici flexuoso; floribus secundis. Ixia Jacq. ic. t. 279. In Prom. b. spei. 4.

3. H. pilosa Ker; fol. 3 angustatogramineis divergentibus pilosis; corollae limbo erecto. Ixia L. B. M. 1254. In Prom. b. spei. 24. Cor. intus alba extus punctis purpureo-cimmamomeis dense adspersa.

4. H. cinnamomea Ker; fol. subfalcato-reflexis undulato-crispis; spathis tubo brevioribus; floribns erectis. B. M. 1054. Ixia Thumh. In Prom. b. spei. 24. Cor. alba extus purpureostriata.

5. H. falcata Ker; fol. ensiformibus falcatis; spathis tubum aequantibus; laciniis patulis. Ixia Thunh, Jacq. ic. t. 276. B. M. 566. In Prom b. spei. 4. Cor. tubus purpurascens, limbus extus ruber intus albus.

\section{ANOMATHECA Gaul. (1805).}

1. A. juncea Ker; corollae limbo subregulari; laciniis 3 inferioribus basi maculatis; macula intermedia discolore. Gladiolus Red. t. 41. Lapeyrousia B. M. 606. In Prom. b. spei. 4. Cor. intense rosea.

2. A. cruenta Lindl. corollae limbo sub 2-labiato; laciniis tribus inferioribus basi maculatis, maculis concolo- 
ribus. B. R. 1369. In Prom. b. spei. 4. Cor. coccinea.

172. MERISTOSTIGMA Alb. Dicir. (1533).

\section{(LAPETROESIA lier. Orierla Spr.}

1. Mr. corymbosum L. scapo ancipiti ramuloso; folio radicali ensiformi crispo striato; floribus paniculato-corymbosis. Ixia Jacq. •ic. t. 288. I. crispifolia Audr. Rep. t. 35. In Prom. b. spei. 24. Cor. caerulea.

2. M. falcatum Thunb. scapo compresso flexuoso; folio radicali lanceolato falcato; spathis viridilus; florihus subracemosis. Gladiolus Thumb. diss. n. 4. t. 1. f. 3. In Prom. b. spei. 4. Cor. caerulea.

3. M. heterophyllum Willd. caule folioso; fol. lineari-ensiformibus subplicatis, superioribus undulatis. Galaxia plicata Jacq. ic. t. 291. In From. b. spei. 4. Cor. alba.

1. M. fissifolium Alb. Dietr. caule sulalato; fol. ovatis undulatis, hinc fissis subtus hirsutiusculis; spica foliosa. Jacq. ic. t. 268. In Prom. b. spei. 4. Cor. purpurea allove.

5. H. anceps Alb. Dietr. caule folioso ancipiti, angulis dentatis; spathis dentato-crispatis. Gladiolus Jacq. ic. t. 269. In Prom. b. spei. 4. Cor. pallide caerulescens.

6. $\boldsymbol{M}$. silenoides Alb. Dietr. caule teretiusculo; fol. lineari-ensiformibus; floribus subracemosis; spathis 3-valvibus. Gladiolus Jacq. ic. c. 270. In Prom. b. spei. 24. Cor. eleganter purpurea.

7. M. bracteatum Alb. Dietr. caule eompresso ramoso; fol. ensiformi-falcatis; laciniis limbi ovatis. Gladiolus Thunh. Act. havn. VI. c. f. In Prom. b. spei. 4. Cor. alba.

8. M. Fabricii Alb. Dietr. caule conıpresso ramoso, ramis virgatis; laciniis limbi lineari-filiformibus. Gladiolus Thunb. In Prom. b. spei. 4. Cor. alba.

9. M. laxum Alb. Dietr. caule filiformi divaricato-ramoso; laciniis limbi linearibus. Gladiolus Thunb. In Prom. b. spei. 2 .

\section{WITSENIA Thunb. (1781).}

1. W. maura Thunb, caule subsimplici; floribus spicatis extus tomentosis. Vahl en. II. p. 47. B. R.5. Red. t. 245. In Prom. b. spei. 4. Cor. lutea.

2. II. corymbosa $\mathbf{S m}$. fol. lineariensiformibus glaucescentibus hasi alternatim amplexantibus; corollis extus glahris. Sim. ex. hot. t. 68. B. M. 895. In prom. b. spei. 4. Cor. azurea.

3. II. partita ker; fol. linearibus nervosis recurvis, hasi dilatatis spathisque membranaceis. Sophronia caespitosa Licht. in $\mathbf{R}$. et $\mathbf{s}$. syst. 1. p. 482. In Prom. b. spei. 4. Cor: lutea.

4. W. ramosa Tahl; caule ramoso fruticoso; fol. linearibus distiche imbricatis. Ixia fruticosa Lam. ill. t. 31. f. 4. In Prom. b. spei. 4. Cor. caerulescens.

5. W. pumila Forst. Comm. goett. 9. $t$. 20. caule simplici 1-floro. Ixia Lam. Moraea Willd. Galaxia Cav. diss. t. 189. 4. Ad fretum magellanicum. 4.

\section{ARISTEA Ait. (1789).}

1. A. cyanea Ait. capitulo terminali; spathis laceris; scapo ancipiti. Vahl 1. c. p. 123. lied. t. 462 . Andr. Rep. t. 10. A. eriophora Pers. In Prom. b. spei. 4. Cor. caerulea.

2. A. caerulea Ait. floribus capitatis racemosis; spathis integerrimis; scapo tereti. Valıl 1. c. p.124. A. major Andr. Rep. t. 160. A. capitata B. M. 605. In Prom. b. spei. 4. Cor. caerulea.

3. A. spiralis Ker; floribus alternis subsecundis; scapo ancipiti. Vahl 1. c. p. 124. B. M. 520. In Prom. b. spei. 4. Cor. alba, deflorata spiraliter torta.

4. A. melaleuca Ker; caule subbifloro; fol. subfalcatis. Moraea Vahl 1. c. p. 153. B. M. 127\%. In Prom. b. spei. 4. Cor. albo-caerulea.

\section{ANTHOLYZA Linn. (1711).}

1. A. aethiopica Linn. fol. ensiformibus utrinque attenuatis; spathis oblongis mucronatis; spica disticha. 
Fel. 1. 110. 13. M. 561. Gladiolus ringens Audi. Rep. 1. 32. In Prom. 6 . spei. 4. Cor. fulvo-aurantiaca.

2. A. praealta DC. in Red. t. 33\%. fol. lineari-lanceolatis acuminatis ; floribus distichis; bulbo depressissimo reticulato; hracteis exteriorihus acnminatis integris. IRed. t. 38\%. In Prom. b. spei. 2. Cor. aurantiaca.

3. A. nervosa 'thunb. fol. ensiformibus 4-nerviis; spica oblonga diGlicha. Thumb. diss. n.3. Gladiolus Antholyza Lam. In lrom. b. spei. 4. Cor. carnea.

4. A. uninquenervis Schrank; hirsuta; caule flexuoso; spica disticha; spathis duplicatis, interiore diphylla. In Prom. b. spei. 24.

5. A. Lucidor Thunb. fol. radicalibus basi filiformibus, apice linearibus nervosis; caule simplici folioso. Watsonia lucens Pers. In Prom. b. spei. 4. Cor. purpurea.

\section{DIASIA DC. (1SOZ).}

1. D. graminifolia DC. corollae tubo brevissimo, laciniis subaequalihus aristatis; scapo paniculato; fol. linearibus scapo fere hrevioribus. DC. hed. t. 163. Gladiolus Jacף. ic. 236. In Prom. b. spei. 24. Cor. albido-virescens, intus linea purpurea.

2. D. iridifolia DC. polystarhya; scapo laxo; spicis capillaribus fexuosis; fol. distichis scapo brevioribus. DC. in Red. t.54. Melasphaerula graminea Ker. B. R. 615. In Prom. b. spei. 24. Cor. violacea.

\section{9\%. GILLTESIA Lindt. (1826).}

1. G. graminea Findl. Fol. radicalia humifusa. Umbella pauciflora. Spatha 2-valvis, viridis, persistens. Flores virides, cernui. B. K. 992. B. M. 2716. In Chili. 4.

\section{HAEMODORUM ST. (1\%98).}

1. H. coccineum R. Br. corymbis compositis; fol. planis; foliolis exterioribus perianthii obtusis fere dimidio brevioribus. R.Br.prodr. 1. p. 300. In Nova Hollandia.

2. H. planifolinm R. Br. corymbis compositis; ramis patentibus; fol. planis; foliolis exterioribus perianthii paululo brevioribus, interioribus basi staminiferis. 13. Br. 1. c. B. M. 1610. In Nora Hollandia.

3. H. teretifolinm R. Br. corymbis compositis; ramis erectis; bracteis Ianceolatis acmuinatis; fol. teretiusculis; perianthii foliolis interioribus paulo longioribus medio staminiferis. i. Br. 1. c. In Nova IIollandia.

A. H. laxum R. Br. coryubis compositis; ramis patulis; bracteis oblongis obtusis scariosis; fol. teretiusculis. IR. 13r. 1. c. In Nova IIollandia.

5. H. spicatum R. Br. spicis elongatis; peticellis geminis. Ii. Br. I. c. In Nova Hollandia.

\section{DILATRIS Berg. (176\%).}

1. D. umbellata I. petalis ovatooblongis; corymbo fastigiato hirsuto. Vahl en. 2. p. 161. D. ixioides Lan. ill. 1. 34. In Prom. b. spei. 24. Cor. purpurea.

‡. D. viscosa Thunh. pelalis linearibus; coryino fastigiato villoso viscido. Linn. Suppl. p. 101. In Prom. b. spei. 4. Cor. viscida. Canlis hirsutissimus.

3. D. paniculata Thunb. Panicnla oblonga villoso-viscosa; petalis lanceolatis. Vahl en. 2. p. 161. In Prom. b. spei. 21. Cor. purpureo-flavesceus.

\section{IACHNANTHES Elliot. (181\%).}

1. T. tinctoria Ell. Dilatris carolina Iam. Heritiera hosc. In America boreali. 4 . 2 ped. Cor. extus piIosa, intus lutea.

\section{BURMANVIA L. (1737).}

\section{Caulis multiflorus.}

1. B. Risticha $L$. fol. radicalibus ensiformibus; spica gemina; florihus secuulis; tubo corollae 3-alato. hoxl. cor. t. 242. B. distachya 11. Br. In paludosis heyloniae, Coromandelinae, Nepalensis et Novae Hollandiae. 4. Cor. caerulescens.

2. B. dasyantha Mart. scapo multifloro; floribus plurimis iu spica 2 - fida 2-3-seriatis, secundis, dense coar- 
ctatis; alis periantlii linearibus tubo angustioribus. Mart. n. g. et s. t. 5 . f. 3. In Brasilia. 24. Cor. pallide caerulea.

3. B. alba Mart. scapo multiforo; spica 2-fida disticha; perianthii alis subnullis. Mart. l. c. In Brasilia. $\odot$.

4. B. capitata Mart. scapo multifloro; fol. subulatis; floribus capitatis : capitulis globosis sub-2-fidis; (cor. apteris. Mart. 1. c. Tripterella Michx. am. 1. t. 3. In Carolina, C'ayenna et Brasilia. $\odot$. Cor. Ilava.

5. B. paniculata Hilld. Hb. caule setaceo paucifolio; fol. squamacformibus; floribus terminalibus paniculatis. Alb. Dietr. 1. c. In Madagascar.

\section{Caulis pauciflorus.}

6. B. quadriflora Willd. $\mathrm{Hb}$. caule filiformi subramoso; fol. radicalibus oblongis acutis brevibus; flor. terminalibus subquaternis. AIb. Dietr. 1. c. In Gujana.

7. B. javanica Blume; caule simpliciusculo filiformi $2-3$-floro; fol. linearibus; cor. 3-alata, alis semiohovatis, apice truncatis tubo latioribus. Blume en. pl. jav. 1. p. 28. In Java. $\odot$.

8. B. bicolor Mart. caule 2-4-rarius multifloro; alis perianthii semiobovatis; tubi diametro duplo latioribus. Miart. 1. c. t. 5. f. 1. In Brasilia. 4. Cor. violacea.

9. B. flava Mart. caule 2-3 floro; alis perianthii dimidiato-lanceolatis, tubi diametrum vix aequantibus. Mart. 1. c. t. 5. f. 2. In Brasilia. 4. Flos Iuteus.

10. B. brachyphylla Uilld. Hb. caule filiformi sub-2-floro; fol. radicalibus ovato-lanceolatis abbreviatis. Alb. Dietr. 1. c. In humidis ad Orinocum.

11. B. biftora $\boldsymbol{L}$. caule filiformi sub-2-floro; fol. suhulatis; corolla 3-carinata; capsula 3-alata; alis truncatis. Linn. sp. pl. 401. In Virginia et Brasilia. Flores caerulei.

12. B. juncea Soland. Aoribns 2-3; alis semiovatis apice rotundatis. $\mathbf{h} . \mathbf{B r}$. In Nova Hollandiu.

13. B. capensis Mart. caule filiformi 3-floro subaphyllo; alis semicircularibus. Mart. 1. c. In Prom. b. spei.

11.

B. marlagascariensis Mart. caule aphyllo 2-3-floro. Mart. 1. c. In Madagascar.

1.5. I. coelestis Don; caule filiformi sub 3-floro; fol. radicalibus lanceolatis cuspidatis brevissimis; alis capsulae oblongis apice rotundatis. Don nep. p. 41. In Nepalia.

16. F. uniflorc Rottl. caule filiformi 1-floro; fol. lanceolato-linearihus acutis ; coro!la 3-carinata; capsula 3-alata, alis ohlongis. Spr. syst. veg. cur, post. p. 23. In India orientali.

\section{GONYANTIIES nlume (1829)。}

1. G. candida Blume en. $n t . j a v .1$. p. 28. In Java. ๑. Herba pusilla subramosa tota albida. Caulis aphyllus, superne corymboso-2-5-florus.

\section{GYMNOSTPHON Blume (1527)。}

1. G. aphyllum Blume, en. pl. jav. 1. p. 38. In Java. ๑. Herba tenera annua facie fere Burmanniae. Caul. subramosus aphyllus. Flores spicati secundi caerulescentes.

\section{TALERIANA Brunf. (1532).}

\section{Acaules.}

1. $V$. rigida $R$. et $P$. acanlis; fol. lanceolatis aggregatis imbricatis expansis sensim decrescentibus. Vahl ell. 2. p. 18. Flor. peruv. t. 65. f. c. In Quito et Peruvia. 4. Cor. alla.

2. $\boldsymbol{I}$. Iennifolic $\boldsymbol{R}$. et $\boldsymbol{P}$. acaulis; fol. lineari-subulatis aggregatis sessilibus imbricatis expansis, extimis longissimis. Vahl 1. c. Flor. peruv, t. 65. f. a. In Peruvia. 4. Cor. alba.

3. V.obovata Schult. acatilis, caespitosa; fol. stellatim dispositis linearispathulatis obtusis hirsuto-pilosis. DC. prodr. 4. p. 633. Ad ripas fluminis Missouri. 4.

\section{Caulescentes; fraticosae.}

4. $\boldsymbol{T}$. spathutate R. et $P$. fol. spathulato-oblongis pubescentibus; floribus terminalibus sessilibus involncratis; corollis 3-fidis. Vall 1. c. Fl. peruv. t. 68. f. b. In Peruvia. 4 。

5. V. alypifolia Kunth; catilibus procumbentibus; fol. spathulatis car- 
nosis glaberrimis approximalis; cor. 5-fidis; stylo exserto; staminibus inclusis. In Quito.

6. V. aretioides Kunth; caulihus caespitosis subprocumbentibus; fol. imbricatis lineari-teretibus carnosis glabris basi dilatatis et ciliatis; staminilus exsertis. Kunth syn. 3. p. 3. In Quito. Ђ. Cor. flava.

\%. V. sedifolia d'Urvill. caule patulo; ramulis hrevibus alscendentibus; fol. imbricatis crassig coriaceis apice retusis basi angustatis minutissime ciliatis. DC. 1. c. In ins. Maclovianis. †. Flores Iutei.

8. V. microphylla Kunth; caule erecto: ramis teretibus pubescentibus; fol. ovato-oblongis integerrimis 3-nerviis subcoriaceis supra pubescentibus. Kunth 1. c. Humb. et B. Nov. Gen. t.273. In Peruvia. ந. Caul. 1-ped. Cor. rubra.

9. V. connata $\boldsymbol{R}$. et $\boldsymbol{P}$. fol. lanceolatis connatis integerrimis; corymbis racemosis conpactis; caulibus suffruticosis procumbentibus. Vahl 1. c. Wl. peruv. t. 67. f. a. In Peruvia. t. Cor. alba.

10. V. quadrangularis Kunth ; caule ramisque 4-angularibus glahris, nodis pilosis; fol. ovato-oblongis basi denticulatis triplinerviis; corymhis dichotomis. Kunth 1. c. In Andibus Peruviae. t. Cor. rubra.

11. I. triphylla Kunth; ramis lignosis teretibus; ramulis sulcato-angulatis; fol. ternis sessilibus lanceolato-oblongis coriaceis glabris. Kunth 1. c. In Nova Granata. 卢.

12. I. hirtella Kunth; caule tereti hirto, ramulis hirsutis; fol. linearilanceolatis integerrimis, supra pilosiusculis, subtus glabris; paniculis ramosissimis; floribus 3-andris. Kunth

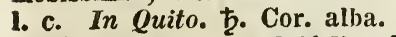

13. V. chamaedrifolia Schlecht. caule erecto; summitatibus pubescentibus dense foliosis; fol. ovato-lanceolatis grosse obtuse serratis; paniculis strictis pyramidalibus. Schlecht. Linn.3. p. 129. In Brasilia. t. Flores minimi.

14. V.tomentosa Kunth; scandens; ramis teretilus cano-tomentosis; fol. ovatis cordatís basi denticulatis supra pabescentibus subtus albo-tomentosis. Kunth 1. c. In Quito. ᄒ. Cor. alba.

15. V. Clematitis Kunth; scandens; ramis teretibus glabris; fol. ovatis triplinerviis uhintegerrimis; paniculis ramosissimis. Kunth 1. c. In Quito et Nova Granata. ந.

16. V. crassifolia Kunth; scandens; ramis teretibus glabris; fol. ovato-ellipticis obtusis integerrimis; corymbis 3-chotonis. Kunth 1. c. H. et B. nov. Gen. t. 274. In Nova Granata. ђ. Cor. alba.

17. V. laurifolia Kunth; ramis teretibus glabris junioribus 4-gonis; fol. ovato-oblongis acuminatis integerrimis glaberrimis nitidis. Kunth 1. c. In Nova Granata. ‡.

\section{Caulescentes; herbaceae.}

a. Foliis omnibns indirisis.

18. V. pilosa $R$. et $P$. pilosa; fol. lanceolatis integerrimis malgine revolutis; corymhis racemosis. Vahl l. c. Fl. peruv. t. 66. f. a. In locis frigidis Peruviae. 4.

1.9. V. longifolia Kunth; caule tereti pilosiusculo; fol. integerrimis coriaceis glahris, radicalibus linearilanceolatis petiolatis, caulinis linearilus sessilibus, var. $\alpha$ caule pedali et $\beta$ caule 3 -pedali, fol. radicalibus pedalibus. Kunth 1. c. In Nova Granuta. 4.

20. V. Salicariaefolia $\mathrm{Vahl}$; fol. lanceolatis integerrimis sessilibus; corymbis terninalibus decompositis. Kunth 1. c. In Bonaria.

21. I. plantaginea Kunth; caule erecto tetragono sulcato glabro; nodis pilosis; fol. integerrimis coriaceis glahris, radicalihus ohlongo-spathulatis petiolatis, caulinis lanceolatis sessilibus basi connatis. Kunth 1 . c. In Quito. 24. Cor. alha.

22. I. lapatíifolia Vahl; fol. cordato-ovatis suhintegerrimis indivisis, superioribus sessilibus. Vahl 1. c. Ad firetum magellanicum. 24. Caul. ped.

23. I. urticaefolia Kunth; caulo tereti hirto; fol. subrotundo-ovatis subcordatis acute dentatis ant sinuato-dentatis, supra pilosiusculis ; panicula ramosa. Kunth 1. c. Humb. et B. 1. c. t. 275. In Nova Granata. 4. Cor. alba.

24. $\boldsymbol{V}$. scorpioides $D C$. caule tereti erecto pubescente; fol. ovatis subrotundisve dentato-crenatis, supra et
margine pilosiusculis; fructu ovato 
parvo. DC. prodr. 4. p. 635 . In Mexico. 4.

2.5. Ir. procera Kunth; caule sulcato ylabro; fol. caulinis sessilibus ovatis glabris valde acuminatis argute dentatis; paniculis ramosissimis; acheniis villoso-pilosis. Kunth 1. c. In Mexico. 4.

26. I. macrorrhiza Popp. pl. exs. glabra; fol. radicalihus spathulatis ohtusis in petiolum limbo duplo longiorem attenuatis; panicula racemosospicata. I)C. prodr. 4. p. 635. In Chili. 2. Flores albi.

2\%. I. coarctutu $R$. et $P$. fol. cuneato-lanceolatis denticulatis ciliatis; loribus verticillato-spicatis. Vahl en. 2. p. 17. Fl. peruv. t. 68. f. a. In Peruciu. \%. Folia extus purpurascentia.

28. I. serrata R. et P. fol. cuneatolanceolatis, extrorsum serratis; floribus verticillato-spicatis. Vahl 1. c. Fl. peruv. t. 68. f. c. In frigidis Peruviae. 4 .

29. V. carnosa Smith. fol. ovalibus dentatis carnosis glaucis. Sm. ic. ined. t. 52. V. magellanica Lam. $A d$ fretum magellanicum. 4.

30. I. obtusifolia DC. erecta; glabra; radice tuberosa; fol. obtusis inferioribus obovatis ovalibusque petioJatis, superiorihus hasi dentatis; corymbo coarctato. DC. prodr. 4. p. 635 . Ad fretum magellanicum. 4 .

31. V. alliariafolia Vahl; glabra; fol. cordatis attenuatis inaequaliter dentatis, omnibus simplicibus, superioribus sessilibus. Vahl 1. c. V. macrophylla Bieb. Buxb. Cent. 2. t. 11. In Cappadocic et Iberia. 24. Cor. alba.

32. I. montana $L$. floribus dioicis; fol. ovatis, inferioribus obtusis superiorilus acutis. Rchb. exc. p. 200. Jacq. austr. t. 269. var. $\alpha$. Fol. omnibus integerrimis. $\beta$. Fol. undique pubescentibus. $\gamma$. Fol caulinis profunde et inaequaliter dentatis. In alpibus Europae. 2. Cor. albida.

33. $V$. saxatilis $\boldsymbol{L}$. floribus dioicis; fol. radicalibus ovalibus in petiolum longum decurrentibus, caulinis duobus oppositis sessilihus lineari-lanceolatis. Rchb. 1. c. Jacq. austr. t. 267. In alpibus Europae. 24. Cor: alba.

31. $\boldsymbol{F}$. supina $\boldsymbol{L}$. floribus triandris tetrandrisque; fol. radicalibus cuneifornibus, caulinis oblongo-obovatis lanceolatisque. Rchb. I. c. Jacq. Misc.
2. t. 17. Sturm. 1. 24. In alpibus Europae. 21.

35. V. Salinnca All. ped. t. 70. f. 1. glabra; fol. radicalibus lincaricuneatis, caulinis linearibus basi subdentatis; floribus hermaphroditis. Rchb. 1. c. V. supina DC. In alpribus Europae. 4.

36. V. celtica $L$. floribus thyrsoideis; fol. ollongo-obovatis integerrimis, radicalibus in petiolum attenuatis. Rchb. 1. c. Jacq. Coll. 1. t. 1. Hayne Arzn. 10. t.28. In Europa. 4. Cor. lu= teola.

b. Fol. aperioribus divisis aut pinnatis.

37. V. tuberosa $L$. fol. obtusis radicalibus ovato-oblongis integris, calllinis lineari-pinnatifidis; floribus hermaphroditis. Rchb. I. c. Lob. ic. 717. Sturm 1. 51. In Europa. 4. Cor. ru= bella.

38. I'. globulariaefolia Ramond. glåbra ; glaucescens; fol. radicalibus petiolatis ohlongis obtusis integerrimis, caulinis lyrato-pinnatifidis. DC. prodr. 4. p. 636. V. heterophylla Lois. gall. t. 2. In Galliae et Hispaniae alpibus. 4 . Cor. rubella.

39. Ir. intermedia Vahl; fol. simplicibus subintegerrimis, radicalibus et inferioribus cordato-oblongis, supremis lanceolatis, caulinis ternis. Vahl en. 1. p. 9. In Pyrenaeis. 4.

10. V. tripteris Linn. floribus dioicis; fol. radicaliluus cordatis, caulinis ternatis. Rchb. 1. c. Jacq. austr. t. 268. Sturm 1. 44. V. intermedia Hoppe. In alpibus Europae. 24. Cor. alba aut rubella.

11. V. alpestris Stev. fol. radicalibus subintegerrimis obtusis, caulinis 3-partitis teruatisve acutis, summis linearibus integris. V. montana Bieb. In Sibivia et alpibus Altaicis. 24. Cor. candida.

42. V. pyrenaica Linn. fol. cordatis inaequaliter dentatis, inferioribus simplicibus superioribus pinnatis ternatisque, omnibus petiolatis. Vahl 1.c. Engl. bot. 1591. In Pyrenueis et Scotia. 2. Cor. alba aut pallide rubra.

43. V. italice Lam. fol. dentatis radicalibus oblongis simplicibus pinnatisque, caulinis pinnatis; foliolis lanceolatis; floribus tetrandris. Barr. ic. 825. In montibus Liguriae et in Creta. 4. 
44. V.elongatra Jaco. glabra erecta; caule striato; fol. radicalibus petiolatis ovatis obtusis, caulinis inciso-sublastatis acutis; floribus hermaphroditis thyrsoideis. Rchb. 1. c. Jacq. austr. t. 219. Sturm 1. 4. In summis alpibus Austrice. 24. Cor. ochrolenca.

45. I. ascrifolia Dufr. glabra erecta; fol, radicalibus petiolatis cordato-reniformibus subdentatis, caulinis paucis pinnatis, summis linearibus. DC. 1. c. Alp. exot. p. 132. ic. In anontibus Cretae. 4.

46. V. Phu L. floribus hermaphroditis; fol. radicalibus oblong0-spathulatis integerrimis, caulinis pimmatis. Rchb. 1. c. Plenk t. 28. Hayne 3. ধ. 33. In Europa media. 4. Caul. 1-3-ped. Cor. alba.

4\%, $V$. dioica $L$. floribus triandris dioicis; fol. radicalibus ovatospathulatis, caulinis pimatis. Rchb. f. c. Hayne 3. t. 32. Sturm 1. 9. var. $\beta$. simplicifolia, fol. omnibus integris. In Europae paludosis $\beta$. in Silesia et Borussia. 4 . Cor. incarnata.

4S. T. Irechenaultii DC. caule erecto simplici, geniculis pilosis; fol. radicalibus petiolatis obtusis crenatis ntrinque hirsutis; fructibus villosis. DC. Tn India orientali. 4.

49. V. repens Ir all. tota pube minima asperiuscula; caule striato, geniculis basi radicante; fol. infimis insivisis subdentatis longe petiolatis cordatis; floribus corymbosis. DC. proảr. 4. p. 640, In Nepalia. 4.

50. V. Wallichii DC. caulibus erect is striatis simplicihus glabriusculis, fol. radicalibus petiolatis cordatis subdentatis margine petioloque villosis ; fructibus villosis. DC. 1. c. V. villosa Wall. Herb, In Nepalia. 24. 8-10-pollicaris.

51. W. Hartuickii Wall. villosa; caule crecto striato; fol. radicalibus numerosis longe petiolatis ovato-cordatis acutis inaequaliter sinuatis carmosis, Wall. in Roxb. ind. 1. p. 166. In India orientali. 2. Cor. pallida, intus villosa.

52. $\boldsymbol{V}$. tenera $\boldsymbol{W}$ all. slabriuscula; erecta; caule striato ad genicula villoso; fol. radicalibus parvis reniformihus longe petiolatis, canlinis piunatis; Dorymbo subovato. DC. 1. c. In Insis orientali, 24. 5-6-poll, Ionga.

53. V. cupitata Dull, Glabra; erecta; fol. sessilibus basi pimatilidis; laci- niis $\mathbf{1}-\mathbf{2}$ intermediis oblongis acutis nervosis; fructibus glabris. DC. 1 c. In Americi. 4.

54. V. oblongifolia R. et P. pilosa; fol. radicalibus oblongis dentatis obtusis, canlinis linearibus serratoincisis. Vahl 1. c. Fl. peruv. t. 65. f. a. In alpibus Peruviae. 4.

5.5. $\boldsymbol{V}$. laxiflora IDC. glabra, adsceudens, basi suffruticosa ; fol. petiolatis ovatis ovalibusque dentibus paucis grossis irregulariter dentato-incisis. DC. 1. c. In Chili. 4.

56. V. hyalinorrhiza $R$. et $P$. fol. radicalibus spathulato-subrotundis crenatis integris auriculatisque, caulinis pinnatifidis. Valı 1. c. Fl. peruv. t. 67. f. b. In Pernvia et Chili. 24. Caul. 14 -15-pollicaris.

5\%. V. vaginata Kunth; caulibus caespitosis 4 -gonis foliisque glabris; radicalibus ohlongo-ellipticis subdentatis, caulinis sinuato-pinuatifidis. Kuntl 1. c. In humidis Novae Hispaniae. 2. Cor. alba.

58. $\boldsymbol{I}$. pimnatifida $\boldsymbol{R}$. et $\boldsymbol{P}$. fol. infimis lanceolatis integerrimis, reliquis piunatifidis, Iaciniis serrato-incisis; corymbi ramis dichotomis. Vahl l. c. Fl. peruv. t. 69. f. b. V. brachiata Pers. In collibus Limae. 4. Caul. simplicissimus. Flores albi.

59. V.leucocarpa DC. erecta, glabra; fol. infimis longe petiolatis obovalioblongis obtusis hasi attenuatis membranaceis, caulinis paucissimis parvis hasi pimatifidis; fructibus compressis. DC. 1. c. In Chili; ex Рepp. 4.

60. $V$. paniculata $R$. et $P$. fol. radicalibris indivisis cordatis, caulinis pimnatis; foliolis ovatis denticulatis; paniculae ranis dichotomis. Vahl 1. c. 11. peruv. t. \%0. f, a. In Peruvia. 4. 61. V. pauciflora Michx. fol. radicalibus pinnatis, canlinis teruatis; foliolis ovalibus acutis serratis; paniculis laxis paucifloris. Vahl 1. c. In America boreali. 4. 3-ped. Cor. carnea.

62. V. lyjata Vahl; fol. radicalibus lyratis; laciniis oblongis dentatoscrratis; terminalibus subpinmatifidis, caulinis lineari-lanceolatis. Vahl 1. $\therefore$ In Peruvia. 24. Caul. spithameus diphyllus.

63. V. hebecarpaDC. erecta; glahra: fol.inferioribus obovato-oblongis grossc dentatis, superioribus pinnati-partitis: louis tentatis. DC, I, c. Inz Chilit. 4. 
61. I. Papilla Bert. caule erecto glahro; fol. glahris lyrato-pinnatifidis; lobis lateralibus linearibus integerrimis; panicula trichotoma; fructibus hispidissimis. DC. 1. c. In Chili. 4.

c. Fol. omnibus pinutis.

6.5. V. pyrumidalis Kunth; glahra; caule tereti sulcato; fol. pinnatis; foliolis sessilibus ovatis cordatis integerrimis glahris; panicula ramosissima; fructihus glabris. Kunth 1. c. All muros urbis Qnito. 24. Cor. alba.

66. I. polemonioides liunth; pubescens; caule erecto tereti; foliolis oblongis integerrimis subsessilibus subcarnosis; panicula ramosissima. Kunth 1. c. In Quito. 2. Cor. alba.

6\%. V. Ilecussatu R. et P. puiescenti-lirsuta; foliolis lanceolatis subtus incanis; panicula lichotoma. Fl. peruv. t. 70. f. b. In Peruvia. 4. Cor. minima, alba.

68. 1. polystachya Sm. ic. t. 51. glahra, erecta; caule substriato ; foliolis linearibus integerrimis acutis; racemo composito; spicis oppositis. Sm. In aynosis Bonariae.

69. I. sorbifolia Kunth; caule erecto tereti pilosiusculo; foliolis sessilibus ovato-oblongis hasi cuncatis grosse serratis; panicula ramosissima. kunth. In Iexico. 24. Cor. alha.

ro. $\mathrm{T}$. sangnisorbaefolia Cav. ic. $\boldsymbol{t}$. 4.56. caule adscendente; foliolis sessilibus ovatis dentatis aequalibus; panicula racemosa. Cav. In Cordilleris. 4.

1. V. ylanca Popp. pl. exs. caule tereti apice nudo; foliolis glancis ohovato-oblongis dentatis ad hasin petioli parvis; bracteis linearibus. DC. prodr. 4. p. 639. In Chili. 4.

82. V. virgata $R$. et $P$. fol. pinnatis pinnis $2-3$-fidis; corymbi ramis dicliotomis. Vahl en. 1. p. 9. Fl. peruv. t. 66. f. b. In Peruviu. 4.

73. I. gtobifera $\boldsymbol{R}$. et $\boldsymbol{l}$. pilosa; fol. pinnatis; foliolis sinuato-dentatis; capitulis globosis. Vahl ell. 2. p. 5 . Flor. peruv. t. 65. f. b. In Peruvia. 21.

74. I. interrupta R. et P. fol. radicalibus interrupte pinnatifidis; laciniis longioribus subpinnatifidis; caule suhaphyllo. Vahl 1. c. Fl. peruv. t.67. f. a. In alpibus Peruviae. 4. Cor. alba.

5.5. V. ceratopkylla Kunth; caule erecto tereti striato glahro; foliolis trifido-liastatis sessilibus glabris; fitictibus piloso-pubescentibus. Humb. et B. 11. g. t. 276. In Inexico. 24. Cor. alba.

76. V. Toluccana DC. caule erecto teretiusculo; foliolis 3-1-jugris cum impari membranaceis repando-dentatis, summorum angustioribus; fructibus puberulis. DC. 1. c. In valle Toluccana Hexici. 24.

78. V. mexicana $D C$. caule subangulato; foliolis oblongis 2-jugis, cum impari majore ovato saepe hasi auriculato, omnibus repando-dentatis; fructibus scabridis. DC. 1. c. In $\mathrm{Me}$ xico. 4.

78. V. scandens Lafl. it. caule scandente; ramis teretibus glaberrimis ; fol. ternatis, foliolis ovato-lanlanceolatis stabintegerrimis; 'fructibus pilosiusculis. Kunth. In Nova Audalusia. 4.

\%9. T. elata Don; caule ramoso Iaevi tereti; foliolis Ianceolatis integerrimis pubescentibus; fructibus suIcis villosis exaratis. Don Nep. p. 159. In Nepalia. 2 !.

80. I. sisymbriifolia Vahl; fol. omuibus pinnatis; foliolis ovato-subrotundis integerrimis; corymbo densifloro. Vahl en. 1. p. \%. Ann. du Mus. XI. t. 28. In Criente. 4 .

81. I. Cardamines Bieb. fol. omnibus pinnatis; foliolis distinctis integris subquinis, imis ovatis, summis linearibus; corymbo conferto dichotomo. Biel. cauc. 1. p. 24. In Caucaso. 4.

82. I. Dioscoridis Sibth. radice tuberosa; fol. omuibus pinnatis; radicalium foliolis ovatis repando-dentatis, caulinorum linearibus. Sibth. graec. t. 32. In Asia minore. 4.

83. V. sambucifolia Mikan; caule erecto striato glabro ad genicula piloso; fol. omulbus pinnatis; foliolis caulinorum decurrentibus lanceolatis dentatis. In paludiosis Germaniae. 4. Cor. alla aut rubescens.

84. V. officinalis $\mathbf{L}$. glabriuscula; caule erecto sulcato; fol. omuibus pinnatis; foliolis lanceolatis dentatis; fructibus glabris. Fl. Dan.5\%. Hayne 3 . t. 32. var. $\beta$. exaltata; pinnis latioribus inciso-dentatis. $\gamma$. anyustifolia: pinnis linearibus integerrimis. In humidis Europae. 4.

8.5. V. dubia Bunge; fol. radicalibus primariis integerrimis auricula- 
lisve, cacteris lyrato-pinnatifidis citllliniscue pinuatis, summis decurrentibus. Ledeb. alt. 1. p.52. V. officinalis ralk. In alpibus altaicis. 24. Cor.alba.

86. I. petrophila Bunge; caule simplici; fol. ommibus lyrato-pinnatifidis; lacinia extina maxima oblonga, omuibus integerrimis obtusis. Ledeb. alt. 1. p. 54. Ic. Moss. t. 19. In summis alpibus altaicis. 24.

87. I. altermifolia Ledeb. fol. canlinis alternis pinuatis, pinnis lanceolato-villosituscnlis. Ledel). alt. 1. p. 52. adı. In sibivia. 4.

88. I. capensis Thunb. fol. pinnatis; foliolis ovatis dentatis. 'Thumb. prode. p. \%. In Prom. b. spei. 4.

\section{FEDIA Adans. (1863).}

l. Locustae, fructu maturo 2-3loculari, loculo uno fertiliad dorsum celluloso-gibbos o, duobus sterilibus fertili a equalibus aut latioribus distinctis nunc septo evanido coadunatis.

\section{* Fructu maturo 2-loculari.}

1. F. Olitoria Monch; fructu globoso-compresso glabro obliquo; loculis sterilibus 2 in unicum septo incompleto concretis; fol. lineari-chlonyis subintegris. Valerianella DC. prodr. 4. p. 625. Rchb. ic. t. 60. Valeriana Willd. In Europae seffetibus. $\odot$.

2. F. raliata Ibufir. fructu oblongo glabro laevi; calycis limbo oblique truncato subnullo; loculis sterilibus septo incompleto in unicum fertili aequalem concretis. Valeriauella DC. 1. c. In arris Pensylvaniae. $\odot$.

3, F. exscapa Stev. fructibus 2-10cularibus, loculo altero sterili, obovatis costatis glabris ad collum sessilibus apice protrusis 5-6-dentatis; caule nullo. DC. I. c. Ad Caucasum. $\odot$.

\section{** Fructu maturo 3-loculari.}

4. $F$. turgida $D C$. fructu subgloboso hinc compresso concavo-convexo submutico glabro; loculo fertili dorso turgido convexo celluloso, loculis sterilibus 2 fertili subaequalibus. DC. I. c. In arris Tauriae. $\odot$.

5. F. gibbosa DC. fructu globoso compresso-glahro ecoronato hinc coarctato plano illinc gibho utrinque bistriato; loculo fertili dorso turgido celluloso unisulcato. DC. In apricis montosis Siciliae. $\odot$.

6. F. costuta DC. fructu subrotundo compressiusculo glalıro ecoronato; loculo fertili dorso turgido-celluloso convexo, 2 sterilibus dorso profunde sulcatis; fol. linearibus integerrimis. DC. 1. c. In Caucaso. $\odot$.

2. psilocaklae, fructu triloculari antice planiusculo, loculo fertili dorso non celluloso turgido, sterilibus 2 filiformibus fertili multo-angustioribus, saepe dissitis nerviformibus.

* Cal. limbo in dentes recurvos rigidulos partito.

7. F. uncinata Dufr. fructu pyramidato-oblongo, juniore subpubescente, adulto glabro; loculis sterilibus 2 angustissimis; calycis limbo tubuloso 7-9-dentato, dentibus recurvis. DC. 1. c. Rchb. ic. 69. In collibns apricis Tauriae. $\odot$.

8. F. echinata $D C$. fructu oblongo subtrigono trisulco glabro, loculis sterilibus 2 angustissimis; dentibus 3 conico-subulatis rigide recurvis. DC. 1. c. Hchb. ic. 68. In arvis reg. MIediterraneae. $\odot$.

\section{** Cal. limbo erecto dentato aut in- tegro, nunquam recurvo.}

9. F. eriocarpa Desv. fructu ovato obsolele costato hispido; Ioculis 2 sterilibus angustissimis; cal. limbo oblique truncato campanulato bidentato; dentibus erectis. DC. 1. c. F. muricata schult. F. campanulata Presl. Rchb. ic. 65. In aris Hispaniae et Tauriue. $\odot$.

10. F. mixta Dufr. fructu ovato villoso; loculis 2 sterilibus angustissimis ; cal. limbo oblique breviter 3 -dentato; fol. oblongis integerrimis. DC. 1. c. In arvis Galliae, Italiae, Tauriae, $\odot$.

11. F. Morisoni DC. fructu ovato subconico pubescente; cal. limbo obliquo hinc 3-dentato, dentibus 1-2 illinc subobsoletis; loculis 2 sterilibus filiformibus fertili multo angustioribus. DC. 1. c. F. dentata dasycarpa Rchb. 
ic. F. leiocarpa Rchb., ic. 62. 63. In arvis Europae et Tauriae. $\odot$.

12. F. mubrula $D C$. fructu ovato puberulo duriusculo subangulato non umbilicato; cal. limbo brevissimo obliquo sul) 8-5̃-dentato; loculis 2 sterilibus filiformibus angustissimis; bracteis ciliato-denticulatis. DC. 1. c. F. microcarpa Rchb. ic. 114. Inter segetes Siciliae et Calabriae. $\odot$.

13. F. truncata DC. fructu ovoideo pubcrulo, dorso convexo antice 2 -costato, loculis sterilibus 2 filiformibus fertili nulto angustioribus; cal. limbo auriculaeformi oblique truncato integerrimo fructus longitutudine aequali; bracteis ciliato-serratis. DC. 1. c. Rchb. ic. 115. In Creta. $\odot$.

3. PLATYCOELAE, f r uctu tril o cul ari antice sulcato, $10 \mathrm{cul} 0$ fertili, dorso non celluloso gibboso, sterilibus 2 fertili diametro latioribus aut aequalibus contiguis, sect. transv. suborbicul a tis.

* Cal. limbo integro ant dentato erecto, dentibus apice non uncinatis.

11. F. Auricula DC. fructu ovato glabro; cal. limbo oblique truncato subintegerrimo acute auriculaeformi; loculis 2 sterilibus fertili latioribus; hracteis patulis linearibus glahris. DC. 1. c. Rehls. ic. 63. F. Olitoria Gærtu. t. 86. In agris Europae. $\odot$.

1.5. $F$. dentata DC. fructu ovato glabro laeviusculo antice rimoso; calycis limbo oblique truucato auriculaeformi 3-dentato; loculis 2 sterilihus fertili latioribus. DC. 1. c. In agris Europae. $\odot$.

16. F. mumila $D C$. fructu inflato subglohoso glabro antice exaralo apice retuso; cal. limbo 3-dentato. DC. 1. c. Rchb. ic. 113. In Europa et Tauria. $\odot$.

1\%. $F$ : sphaerocarpa $D C$. fructu globoso hinc umbilicato illinc convexo 2-costato; cal. limbo 3-dentato, dente unico longiore; bracteis patulis lanceolatis acutis margine scariosis serrato-ciliatis DC. 1. c. Cuss. pl. rar. t. 4. f. I. In pascuis Siciliae. $\odot$.

18. F. trichocarpa DC. fructu 3gono glabro antice late excavato apice subecoronato, angulis callosis; loculis 2 sterilibus fertili majoribus. DC. 1. c. Circa Constantinopolin. ๑.
** Limbi calycini dentibus apice uncinulatis.

19. F. hamate Bast. fructu ovoideo extus villoso subtetraquono antice exarato; loculis steriiilus 2 fertili subaequalibus; cal. limho fructu latiore patente intus glaberrino ultra medium 6-lobo. DC. Mem. t. 3. f. 7. F. coronata integrifolia kchb. ic. 66. f. 1. In regione Meditern'uneu. $\odot$.

20. F. coronata Relib. fiuctu oroideo villoso sub 1 -gono antice exarato; loculis 2 sterilibus fertili subaequalibus; cal. linbo fructu latiore cyathiformi intus lirsuto ultra medium 6-10bo. DC. 1. c. Valeriana Dufr. val. 60. t. 3. f. 2. Rchb. ic. 66. f. $\beta$. et $\gamma$. var. $\beta$. discoidea, cal. limbo irregulariter 7-12 lobo. Rchl). ic. 116. In regione Mediterranea. $\odot$.

*** Calycis limbo inflato vesicario dentibus calycinis inflexis clauso.

21. F. vesicaria Moench; fructu villoso coronato; calycis limbo vesicario inflato 6-dentato, dentibus conniventibus acutis; loculis $\mathbf{2}$ sterilibus fertili paulo minoribus. DC. I. c. Richb. ic. 70. In regione Mediterranea. $\odot$.

4. Selexocoelae, fructu triloculari antice late sulcato, loculo fertili dorso non cellulosogibboso, sterilibus 2 fertili latioribus curvis sect. transv. lunulatis.

* Calycis lobis uncinulatis.

22. F. platyloba DC. fiuctu ovoideo extus villoso sub 4-gono antice late exarato cymbaeformi; calycis limho fructu latiore patente intus sublirsuto 6-lobo. DC. 1. c. F. discoidea Rchb. ic. 67. In regione IIediterranea. $\odot$.

\section{** Calycis limbo recto.}

23. F. coninnata Lois. fructu oblongo hinc longitudinaliter cynbaeformi seu rimoso carinato glahro; 10culis sterilibus 2 compressis curvis fertili subaequalibus. DC. 1. c. Rchb. ic. 61. In arvis Germaniae Galliae et Tauriae. $\odot$.

\section{* Non satis notae.}

21. F. chenopodifolia $D C$. dichotoma; fol. ovatis acutis inferne den- 
tatis; cymis nudis divaricatis, filamentis longis. Pursh. In Virginia. $\odot$.

25. F. Cormucopiae DC. fol. sessilibus ovato-oblongis subintegris; floribus fasciculatis; pedunculis incrassatis. Valeriana L. Sibth. graec. t. 23. In arvis Europae anstralis, Orientis et Africal borealis. $\odot$.

26. F. scorpioides DC. fol. ovatis petiolatis imis integerrimis mediis irregulariter dentatis summis ovatolanceolatis vix pimmatifidis. DC. Circa Tanger Africae borealis. $\odot$.

2\%. F. paniculata Colla; fol. inferioribus spathulatis subintegris, mediis lanceolatis obsolete dentatis, summis lineari-lanceolatis integerrimis; paniculis dichotomis. DC. 1. c. Patria ignota. $\odot$.

\section{AXIA Lour. (1790).}

1. A. cochinchinensis Lour. coch. ๆ. 36. In Cochinchina. ち. Fruticosa, 2-ped. ramosissima, decumbens, rubescens. Fol. opposita, ovato-lanceolata, tomentosa. Cor. albo-rubella.

\section{8\%. SONERILA Roxb. (1821).}

1. S. maculata Roxb. fol. opposilis inaequalibus cordatis, hispido-maculatis, serrulatis, ciliatis. Roxb. 1. c. 1. p. 180. In Benyalia et Nepalia. 21. Cor. rubella hispida.

2. S. emaculate Roxb. fol. oppositis inaequalibus attenuatis acutis hispidis concoloribus serrulatis ciliatis. IRoxb. I. c. In Bengalia.

3. S. angustifolia Roxb. fol. oppositis inaecfualibus oblongo-lanceolatis utrinque attenuatis serrulatis, pilosis. 130xb. 1. c. In Bengalia.

4. S. squarrosa Wall. caule brevi spinis herbaceis vestito; fol. glahris subsessilibus confertis subverticilatis cumeato-lanccolatis serrulatis. Wall. in Hoxb. Fl. ind. 1. p. 182. In Nepalia. 4. Cor. rosea.

5. S. speciosa Zenk. caule basi sub-dichotomo suh 4-angulo; fol. suboppositis, petiolatis ovatis serrulatoaculeatis glabris; norihus corymbosis. Zenk. pl. ind. t. 18. In Indiı orientali. 24. Caul. ped. rubellus. Cor. violacea.

\section{S. PRIEUREA DC. (1S2S).}

1. I. senegalensis DC. mem. 3. $t$. 12. In uliyjinosis S'enegaliae. Herba demissa glabra obscure viridis ramosa. Fol. alterna oblongo-linearia. H'lores axillares.

\section{WACRENDORFIA J. Burm. (17.58).}

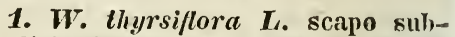
simplici villoso; fol. ensiformibus 5nerviis plicatis perennantilus; panicula coarctata L. Med. t. 93. B. M. 1060. In Prom. b. spei. 4 . Cor. extus aurantiaca intus flava.

2. W' paniculata L. scapo polystachyo; fol. ensiformilus trinerviis plicatis glabris annuis. Red. t. 92. B. M. 616. In Prom. b. spei. 4. Cor. flava extus pubescens rubicunda.

3. W. hirsuta Thumb. scapo polystachyo; fol. ensiformilus plicatis villosis annuis. B. M. 614. W. villosa Andr. Iiep. t. 398. In Prom. l. spei. 4. Cor. intus flava, extus stria pilosa rufescente.

4. W.brevifolia Ker; fol. ellipticoensiformibus hirsutis; corollis glabris. B. M. 1116. In From. 6. spei. 4. Cor. sordide cuprea.

5. W. Breyniana Ker; fol. lanceolato-ensiformibus corollisque hirsutis. Ker. Breyn Cent. f. 37. In Prom. b. spei. 4 . Caul. ped. Cor. purpureo-phoenicea.

6. W. tenella Thunb. scapo polystachyo; fol. linearibus trinerviis glahris; panicula patente. Vahl 1. c. In Prom. b. spei. 21. Cor. purpurea.

\%. W. graminea Thumb. scapo polystachyo; fol. ensiformilus canaliculatis glabris; panicula patente. Thunb. prodr. p. 12. In Prom. b. spei. 4. Cor. lutea.

8. W. orinocensis Kunth; caule simplici hirto; fol. ensiformibus striatis glabris. Kunth syu. 1. p. 312. In ripa fluminis Orinoci. 21. Cor. flavo-rubra.

\section{HAGENBACIIIA Nees (1823).}

1. H. brasiliensis Nees; Hacmodorum Spr. In Brasilia. 2\%. llad. fibrosa fasciculata. Fol. pelalia; sca- 
pus triqueter quadruplo brevior. Cor. alba.

\section{XIPHIDIEM Loefl. (17.5s).}

1. $X$. floribundum su: ind. 1. $t$. 2. var. $\alpha$. albidum, fol. glabris subintegerrimis; floribus albidis, laciniis angustioribus. $X$. albidum Lam. X. album Willd. B. caeruleum, fol. pilosis serrulatis; floribus caerulescentibus, lac. latioribus. X. caeruleum Aubl. t. 11. In America boreali. 4.

\section{BRODIAEA. Sm. (1811).}

1. B. grandiftora $\mathrm{S} m$. pedunculis umbellatis, bracteis multo longioribus; filamentis sterililut lanceolatis obtusissimis. B. M. 2877. Hookeria coronaria Salisb. Lond. t. 98. In insula Salomonis. 4. Cor. caerulea.

2. B. congesta $\mathbf{S m}$. umbella subcapitata; filamentis sterilibus subbifidis. Sinith in Lim. Trans. X. t. 1. In insula Salomonis. 24. Cor. cyanea.

\section{LEUCOCORYNE Lindl. (1835).}

1. L. odorata Lindl. fol. linearibus glaucis; limbi laciniis lanceolatis sullaciniatis B. Reg. 1293. In Chili. 24. Cor. alba, tubus atro-viridis.

2. L. ixioides Lindl. fol. linearilus glancescentibus; limbi laciniis oblongis laciniatis subaequalibus. Brodiaea B. M. 2382. In Chili. 24. Cor. viridi-violacea.

3. L. alliacea Lindl. fol. linearibus; limbi lacinis erectis acuminatis subaequalibus; staminibus sterilibus clavatis. B. R. 1293. In Chili. 4.

\section{JOHNSONIA R. Br. (1S10),}

1. J. lupulina R. Br. prodr. 1. p. 25\%. Rad. fibrosa Fol. disticha. Scapus simplicissimus. Flores parvi. In Nora Hollandia. 4.

\section{COMMELINA Dill. (1732).}

\section{Flores involucrati.}

A. Petalis aequalibus caeruleis.

1. C. subulata Roth; caule repente; fol. subulatis; involucris cordatis conduplicatis mucronatis ciliatis. Hoth nov. pl. sp. p. 23. In India orientali. Cor. minuta caerulea.

2. C. attenuata Koeniy; caule repente; fol. lineari-lanceolatis glahris; involucris cordato-lanceolatis intus villosis. Vahl ell. 2. p. 168. In India orientali. Cor. caerulea.

3. C. angustifolia Mich.x. caule erectiusculo; fol. lineari-lanceolatis glabris; vaginis subciliatis; involucris cordatis basi truncatis cilialis. Vahl 1. c. C. truncata Schult. In Carolina. 24. Cor. pallide cacrulea.

4. C. graminifolia Kunth; canle erecto ; fol. subtus glabris supra vaginisque scabris margine ciliatis. Kunth syn. 1. p. 267. In Nork Hispania. 2. Caul. ped. Cor. caerulea. 5. C. longifolia Lam. fol. linearilanceolatis sessilibus glabris; involucris cucullatis turbinatis. Lam. ill. 1. p. 29. In Jara.

6. C. sulicifolia Roxb. caule ramoso repente; fol, sessilibus linearilanceolatis supra scahris; involucris petiolatis oppositifoliis cordatis conduplicatis; floribus polygamis. Roxb. ind. 1. p. 176. In Coromandelia et Butavia. $\odot$.

\%. C. lanceolata $R, B r$, fol. lanceolato-linearibus elongatis supra margineque scahriusculis; involucris apice attenuatis. R. Br, prodr. 1. p. 269. In Nova Hollandia. 4.

8. C. dianthifolia DC. radice tuberosa; fol. lineari-lanceolatis elongatis 5-nerviis vaginisque ciliatis; involucris cordato-lanceolatis. Red. t, 390 . Patria ignota. 4. Cor. caerulea.

9. C. longicaulis Jacq, caule repente; involucris ovatis conduplicatis; pedicellis geminis filiformibus geniculatis. Jacq, ic. t. 294. In Caracas. 4. Cor. caerulea.

10. C. decumbens E. Meyer; caule decumbente ramoso; fol. lanceolatis acutis utrinque pulescentibus; involucris disco et basi hispidis. E. Meyer. In Mexico et Chili. 4.

11. C. acuminata Kunth; caule erecto; fol. lanceolatis utrinque pubescentibus; vaginis glabris ciliatis; 
involucris cordatis pilosiusculis. Kunth. In Nova Hispunia. 2. Cor. caerulea.

12. C. livtella Vahl. tota pubescens; fol. petiolatis longissime lanceolatis conduplicatis ; vaginis ciliatis ; involucris sessilibus aguregatis. Vahi 1. c. In Virginice et Carolina. 4. 2-ped. Cor. caerulea.

13. C. nerrosa $\boldsymbol{R}$. et $\boldsymbol{P}$. caule erecto; fol. suhpetiolatis lanceolatis sedecinmervilus glabris hasi vaginisque hirsutis. Fl, peruv. 1. p. 44. In Peruvia. Cor. purpureo-violacea.

14. C. virginica. L. caule erecto simplici; fol. lanceolatis supra scabris; vaginis ciliatis; involucris reniformibus. L. sp. pl. G. In America boreali. Cor. caemulea.

1.5. C. parviflora Link.; calle vaginis foliisque pubescentilus; fol. sessilibus lanceolatis longe acutatis; involucris glabrioribus. Link en. 2. p. 61. I'atria ignota. 4. Cor. caerulea.

16. C. cyanea $\boldsymbol{R}$. Br. caule decumbente geniculato; fol. lanceolatis ; vagina pilosiuscula ciliata; iuvolucris conduplicatis. R. Br. prodr. 1. p. 269. In Nova Hollandia.

17. C. pacifica Vahl; caule erccto; fol. sessilibus ovato-lanceolatis; involucris cordatis attenuatis conduplicatis. Vahl en 2. p. 168. In ins. Tongatabu.

18. C. glabra Neyer; fol. lanceolatis petiolatis cauleque erecto glahris; involucris pedunculatis cordato-ovatis. Meyer Esseq. p. 22. In Essequebo. Cor. parva caerulea.

19. C. coyennensis Rich. caule procumbente; fol. petiolatis ovato-lanceolatis acuminatis acutissimis glaberrimis; parastaminibus bilohis. Rich. Act. par. hist. nat. 1. p. 106. In Cayenna.

20. C. prostrata Kunth; caule procumbente repente; fol. ovato-ohlongis vaginisque glabris ciliatis, involucris cordatis complicatis glabris. Kunth syn. 1. p. 26\%. In Peruvia. 4. Cor, caerulea.

21. C. elliptica Kunth; caule adscendente; fol. ovato-ellipticis complicatis glabris, margine vaginisque ciliatis; involucris cordatis basi pubescentibus margine ciliatis. Kunth 1. c. In Cumana. 4.

22. C. pilosula Rich. pumila; diffusa; fol. lanceolatis . vaginis et in- volncris ciliatis. Rich. 1. c. In $\mathrm{Ca}$ yenna.

23. C. barbata Lam. caule repente; fol. sessilibus ovatis; vaginis barbatis; petalis subaequalibus. Lam. ill. 1. p. 129. In ins. Mauritiana. Cor. cacrulea.

24. C. turbinata Tahl; pubescens; caule repente; fol. petiolatis ovatooblongis, involucris cncullatis turbinatis. Vahl en. 2. p. 171. In ins. St. Crucis. 4. Cor. caerulea.

25. C. mollis Jacy. ic. $t$.293. villosa; caule repente; fol. petiolatis ovatis; involucris semiorbicularibus margine conduplicatis. Jacq. Coll. 3. p. 235. Ad Caracas 4.

26. C. canescens Iuhl; caule repente; fol. petiolatis ovatis acutis piloso-canescentibus; involucris cucullatis turbinatis. Vahl. en. 2. p. 175. In Arabia. Cor. caerulea.

2\%. C. oblitua I alel; fol. ovatolanceolatis petiolatis basi ohliquis cauleque glabro; involucris reniformibus conduplicatis. Vahl en. 2. p. 172. Patria i!nota.

28. C. suffruticosa Blume; caule ramoso inferue prostrato glahro; fol. oblique lanceolatis; staminibus styloque spiraliter convolutis. Blume eu. 1. p. 3. In Jura. 24.

29. C. persicarinefolia DC. caule simplici; fol. oblongis utrinque acuminatis nervosis glabris; vaginis strictis ciliatis; involucris cordatis. DC. Patria iennota.

30. C. Forstioolii Valel; fol. sessilibus ovato-oblongis glabris; involıcris lateralibus terminalibusque pedunculatis cordatis conduplicatis. Vahl ell. 2. p. 172. In Avabia. Cor. caerulea.

31. C. tuberosa L. caule erecto; fol. sessilibus ovato-lanceolatis ciliatis; involucris cordatis conduplicatis. Limn. syst. veg. 96. Fed. t. 108. B. M. 1685. B. C. 193. In Mexico. 4. Cor. caerulea.

32. C. dubia DC. erecta; ramosa; fol. ovato-lanceolatis glabris tenuiter ciliatis; vaginis tomentosis. Red. t. 359. Patria ignota. 2. Cor. pallide caerulea.

33. C. fasciculata $\boldsymbol{R}$. et $\boldsymbol{P}$. radice fasciculata; caule assurgente; fol. lanceolatis acutis; vaginis ciliatis; involucris cordatis. Fl. perur. t.72. f. 6. In Linza. 4 . Cor. caerulea. 
34. C. coelestis Willd. caule erecto; fol. oblongo-lanceolatis sersilibus glahris; vaginis ciliatis; pedunculis pubescentihus. Link en. 1. p. 61. Patria ignota. 24. Cor. caerulea.

3.). C. pallida Humb. caule erecto; fol. oblongo-lanceolatis supra scaloris suhtus pubescentibus; vaginis pubescenti - hirtis; involucris complicatis pubescentilus. Kunth syn. 1. p. 268. C. rubeus Iied. t. 367. In Mexico. 4 .

36. C. hispida $\boldsymbol{R}$. et $\boldsymbol{P}$. caule erecto; fol. ovato-lanceolatis obtusis lispidulis margine scabris; involucris cordatis conduplicatis. Willd; Fl. peruv. t. 73. f. a. In Peruvia.

\section{B. Petalis inaequalibus caeruleis.}

3\%. C. communis Linn. caule repente, ramoso; fol. sessilibus ovatolanceolatis acutis glabris; involucris cordatis conduplicatis. C. vulgaris Red. t. 206. In America meridionali. $\odot$.

38. C. polygama Roth ; ramis prostratis ralicantibus; fol. ovato-lanceolatis attenuatis glabris; involucris cordatis conduplicatis; floribus polygamis. C. communis Thunb. In $\mathbf{J a}$ ponia. $\odot$.

39. C. cuespitosa Roxb. polygama; repens; fol. lanceolatis ; involucris cordatis pedunculatis pauciforis; capsulis 3 -locularibus $1-2$ spermis. Koxb. ind. 1. p. 173. In India orientali. Cor. eleganter caerulea.

40. C. Donii Hamilt. caule erecto; fol. lanceolatis acuminatis inaequilateris; vaginis ore ciliatis; involucris cucullatis. Don prodr. p. 115. In Nepalia. 4.

41. C. caroliniana Walt. caule decumbente radicante; fol. sessilibus lanceolatis pubescentilus; vaginis ciJiatis; involucris cordatis complicatis ciliatis basi subtruncatis. Walt. car. p. 68. C. communis Pursh. In Carolina. 4.

12. C. sulcata Link.; canle repente sulcato glabro; vaginis ventricosis ciliatis; fol. lanceolatis acutıs. Link Jahrl). 1, 3. p. 74. In Brasilia. 2-ped.

43. C. elegans Kunth; caule procumbente; fol. lanceolato-oblongis supra strigoso-pilosiusculis subtus pubescenti-lirtis margine subundulatis; involucris cucullato-complicatis. Kunth syn. 1. p. 268. In Nova Granata. 4.

41. C. brticensis Milld. Ml. fol. lanceolatis pubescentibus; varinis ciliatis; involucris cordatis conduplicatis extus pilosis. Link Jahrb. 1. 3. p. 73. In Rrasilia.

4.5. C. gracilis $R$. et $P$. canle adscendente ramoso repente colorato piloso, pilis reflexis; involucris cordatis compressis. Fl. peruv. t. 72. f. a. B. H. 30:7. C. formosa Gralı. In Lima. 4.

46. C. Lebilis Ledeb. caule erecto debili; fol. petiolatis oblongo-lanceolatis subglabris; vaginis hinc pubescentibus ; involucris suborbiculatocordatis. Ledeb. in $\mathbf{H}$. et \$. mant. 1. p. 342. Patria ignota. 4.

17. C. caripensis Kunth; fo!. oblongo-lanceolatis supra scabriusculis subtus pubescentibus; vaginis glahris margine ciliatis; involucris cucullatocomplicatis. Kunth syn. 1. p. 269. In Vora Andalusia. 24.

48. C. deficiens Herb. fol. oblongo-lanceolatis acutis basi ciliatis; vaginis striatis; involucro cordato-cucullato; cor. dipetala; anthera tertia maxima. B. M. 2614. In Brasilia. 24.

19. C. erecta L. caule execto puhescente; fol. ovato-lanceolatis scahris; vaginis pilosis; involucris cucullatis turbinatis. Linn. Walt. In irginia. 4.

50. C. bengalensis Murrey; caule repente piloso; fol. ovato-cordatis, obtusis undulatis pubescentibus; vaginis rufo-ciliatis ; involucris cordatocucullatis. Murr. Com. Goett. 1779. p. 18. t. 5. C. cucullata L. In Indice orientali. 4.

51. C. Blumii Alb. Dietr. canlo ramoso repente lineis alternis pubero; fol. petiolatis ovato-lanceolatis hasi obliquis nervis infra pubescentibus. C. auriculata Blume en. fasc. 1. p. 2. In Java. $\odot$.

52. C.paludosa Blume; caule subramoso adscendente inferne radicante glabro; vaginis rufo-ciliatis; involucris cucullato-complicatis. Blume en. f. 1. p. 2. In Java. 4.

53. C. diffusa Burm. caule repente diffuso; fol. ovato-lanceolatis supra scahriusculis; vaginis ciliolatis cum linea scalıra. Burm. ind. t. 7. f. 2. in humidis Javae. $\odot$. 
54. C. pedunculosa Link; caule prostrato repente striato glabro; vaginis ciliatis; pedunculo intra involucrum elongato pubescente. Link Jahrb. 1. 3. p. 74. In India orientali.

5.5. C. obtusifolia Vull; caule procumbente; fol. semiamplexicaulibus ohlongis ohtusiusculis; vaginis hrevissimis. Vahl en. 2. p. 168. In Moluccis et ins. Bonra.

56. C. divaricata Tahl; ramis divaricatis; fol. sessilibus ovato-lanceolatis; involucris cordato-ovatis conduplicatis ciliatis. Valıl en. 2. p. 169. In Arabia.

5\%. C. ensifolia $\boldsymbol{R}$. $\boldsymbol{B r}$. caule procumbente; fol. lanceolato-linearibus utrinque laevibus; involucris cucullatis. 12. Br. prodr. 1. p.269. In Nova Hollandia.

58. C. unitulate R. Br. fol. lanccolatis umdulatis utrinque laevibus; involucris cucullatis; antherarum fertilium tertia majori. R. Br. prodr. 1. p. 270. In Nova Hollandia.

59. C. auriculata E. Heyer; canle adscendente ramoso; fol. ovato-lanceolatis margine scabris; involucris cordatis complicatis apiculatis ; capsula muricata 3-cocca. In Mexico. 4.

\section{Petalis flavis.}

60. C. africana $L$. caule decumbente ramoso, foliisque lanceolatis sessilibus nervosis glabris. Linn. syst. veg. 95. B. M. 1431. In Africa. 4 .

\section{Flores nudi.}

61. C. nudicaulis Burm. ind. $t$. 8 . f. 1. radice fibrosa; -fol. radicalibus lanceolatis; scapo bifloro medio bracteato. Vahl en. 2. p. 175. In Java. Cor. caerulea.

62. C. scapiflora Roxb. radice tuberosa; fol. serotinis caespitosis; racemis radicalibus erectis; spathis alteruis multifloris. Hoxb. ind. 1. p. 178. In India orientali. 4.

63. C. medica Lour. radice tuberosa; fol. radicalibus subulatis glabris; scapo subspicato multifloro. Vahl en. 2. p. 175. In China et Cochinchina. 24. Cor. caerulea.

6t. C. mudiflora $L$. ramis repentibus; fol. linearibus sessilibus ; floribus terminalibus racenosis diandris.
Roxb. ind. 1. p. 177. Plukn. t. 27. f. 4. In Intia orientali. $\odot$.

6.5. C. Hookerii Alb. Dietr. caule erecto; fol. linearibus acuminatis basi ciliatis; filamentis barbatis. C. longifolia. spr. syst. cur. post. p. 25. Aneilema Hook. exot. fl. t. 204. In Africa. Cor. pallide purpurea.

66. C. Hamiltonii s'pr. caule assurgente laevi basi radicante; fol. lanceolatis acuminatis hasi asperis; vaginis ore ciliatis. Spr. syst. veg. 5. p. 186. C. hispida Hamilt. Aneilema Doul. In Nepalia. 4.

6\%. C. radicans Spr. caule procumbente radicante; fol. linearibus acutis; vaginis villosis; pedunculis 5-floris. Spr. 1. c. Aneilema Dou. In Nepalia. Caps. nitidissima.

68. C. vaginuta L. caule adscendente; fol. linearibus; pedunculis lateralibus terminalibusque vagina involucratis 1-floris. Limm. 17\%. In India orientali. $\odot$.

69. C. gigantea Vahl; caule erecto simplicissimo; fol. linearibus; vaginis ore nudis ; racemis terminalibus 2-partitis; floribus secundis. Vahl 1. c. Aneilema R. Br. In India orient. et Nova Hollandia.

70. C. sinica $R$. et $S$. caule ramoso diffuso; fol. ligulatis acuminatis; staminibus tribus barbatis, uno castrato. R. et S. mant. 2. 1. p. 376. Aneilema B. H. 659. In China. 4. Cor. caerulea.

91. C. graminea Poir. erecta; pilosiuscula; caule semitereti glabro laevi; fol. gramineis subciliatis; filamentis omnibus barbatis. Poir. Enc. suppl. 2. p. 344. In Nova Hollandia.

2. C. affinis Poir. erecta; glabra; caule angulis scabris; fol. linearibus; filamentis omnilus barbatis. Poir. 1. c. Aneilema 1R. Br. In Nova Hollandia.

\%3. C. anthericoides Poir. erecta; pubescens; caule teretiusculo; fol. linearibus; panicula terminali; filamentis omnibus barbatis. Aneilema R. Br. In Nova Hollandia.

71. C. moluccrina Roxb. caule repente; fol. sessilibus oblongo-lanceolatis sub 5-nerviis ; floribus subsessilibus. Hoxb. ind. 1. p. 176. In Moluccis. $\odot$.

75. C. herbacen Roxb. ramis articulatis adscendentibus; fol. lanceo- 
latis ; capsulis 3-locularihus polyspermis. Loxb. ind. 1. p. 179. In Sumatri. 24. Cor. pellucide e caerulescente alba.

86. C. $\operatorname{rar} a$ Roxb. caule repente; fol. anplexicaulibus cordato-lanceolatis; capsulis 3-locularibus polyspermis. I3oxb. ind. 1. p. 176. In humidis Indiae orientalis. $\odot$.

\%. C. temuis Roth; caule filiformi ramoso; fol. subpetiolatis mucronatis nervoso-punctatis apice serratis hasi vaginisque ciliatis. Hoth nov. pl. sp. 3. p. 23. InIndia orientali. Cor. cacrulea.

78. C. spivata $L$. caule repente; fol.amplexicaulibus cordato-lanceolatis undulatis glabris; bracteolis semivaginantibus. Alb. Dietr. I. c. In Inclia orientali. $\odot$.

89. C. simplex Vall, caule erecto simplicissimo; fol. lineari-lanceolatis basi ciliatis; racemo terminali subcomposito. Vahl en. 2. p. 177. In Guincu. ち. Flores nutantes.

80. C. ambigua beane. Fl. d'Ovare et Ben. $t$. 1.5. caule solido snblignoso nodis foliaceis remotis; fol. longis fasciculatis villosis. Circa Benin. Ђ. Cor. caeruleo-violacea.

81. C. aequinoctialis Beauv. $l$. c. $t$. 3s. caule hasi subrepente hirsuto ; fol. ovato-lanceolatis acuminatis ; vaginis villosis inflatis. Circa urbem Benin. 4.

82. C. serrulata Valli caule erecto; fol. subpetiolatis ovato-lanceolatis margine scaberrimis. Vahl Eclog. 2. p. 4. In Cayenna.

83. C. mexicana Presl; caule repente; ramis adscendentibus; fol. sessilibus lanceolatis acutis serrulatis; umbellis sulggeminis. Reliq. Haenk. 2. p. 137. In Mexico. 4. Cor. parva caerulea.

81. C. floribunda Kuntl,; caule repente; ramis adscendentibus; fol. oblongis acutis sessilibus vaginisque ciliatis. Kunth 1. c. In Cumana. 4.

8.5. C. japonice 'Tlumb.; caule erecto angulato piloso; fol. ovatolanceolatis undulatis glabris; floribus paniculatis. Alb. Dietr. 1. c. In Japonia.

86. C. elata Tahl; caule erecto; fol. ovato-lanceolatis ciliatis; floribus paniculatis. Vahl en 2. p. 178, In India orientali, Petala venosa.
8\%. C. lineolata Blume; caule simplicissimo adscendente inferne radicante; fol. amplexicaulihus lanceolatis undulatis, infra albido-lineolatis. Blume el. 1. p. 3. In Java. ๑.

sS. C. secundifiora Blume; caule subramoso adscendente inferne radicante; fol. lato-lanceolatis subtus vaginisque scabriusculis; floribus seculdis. Blume en. 1. p. 3. In Jara. 4. 89. C. cymosa Blume; caule simplici adscendente glabro; fol. sessilibus lanceolatis supra scabris; vaginis linca tomentosa ore longiter ciliatis. Blume 1. c. In Java. $\odot$.

90. C. densiflora Blume; caule simplici adscendente radicante glabro; vaginis pubescentibus, ore longius ciliatis ; thyrso glanduloso - piloso. Blume 1. c. In Java. $\odot$.

91. C. scabervima blume; canle adscendente pubero; fol. Ianceolatis acuminatis sessilibus utrinque scaberrimis; vaginis subtomentosis. Blumo 1. c. In Java. $\odot$.

92. C. micrantha Vrahl; caule procumbente; fol. petiolatis ovatolanceolatis glabris; floribus racemosis. Vahl en. 2. p. 178. In India orientali.

93. C. monadelpha Blume; caulo subramoso repente; fol. petiolatis ovato-Ianceolatis acuminatis scabris; vaginis ciliatis; staminibus fertilibus basi monadelphis. Blume 1. c. In Java. 4.

94. C. conspicua Blume; caule subramoso adscendente; fol. lanceolatis acuminatis breviter petiolatis glabris; racemis compositis; parastaminibus uullis. Blume 1. c. In Java. 4.

9.5. C. paniculata Tahl; fol. ovatis sulpetiolatis acutis basi ciliatis; florihus paniculatis. Vahl en. 2. p.179. C. tuberosa Forsk. In Arabia.

96. C. beniniensis Pal. de Beauv. t. $c_{\text {. } t . ~} \boldsymbol{s} \%$. fol. ovato-oblongis, marginibus scabriusculis serrulatis; floribus parvis paniculatis. In motis prope Benin. 4.

97. C. umbrosa Iahl; raule erecto; fol. ovatis nervosis petiolatis; petiolis ciliatis; racemis compositis. Vahl en. 2. p. 179. In Guinea.

98. 3. Palisotii Alb. Dietr.; caule subsimplici glabro; fol. ovato-oblongis laevibus glabris; panicula terminali effusa; stipnlis mimutissimis, C. 
ovato-oblonga Pal. de Beauv. 1. c. t. 104. f. 1. In matis mrope Benin.

9.9. C. chaitransia $R$. et $\mathbf{S}$. caule adscendente; panicula pauciflora; fol. ovato-lanceolatis apice attenuatis acu1issimis. Aneilema africana Pal. de Beauv. 1. c. t. 93. In Ouvre et Benin.

100. C. biflora Poir. glabra; caule repente; fol. lanceolatis; pedunculis 2-floris. Aneilema R. Br. In Nova Hollandia.

101. C. silicnlosa Poir. caule adscendente; fol. ensiformihus sessilibus supra scabris, superioribus nanis distantibus. Aneilema R. Br. In Nova Hollandia.

102. C. Brounii Alb. Dietr.; fol. lanceolatis breviter acuminatis subpetiolatis, supra laevibus margine scahris. Aneilema R. Br. In Nova Hollandia.

103. C. laxa Poir. caule adscendente; fol. ellipticis acutis subacuminatisve petiolatis supra scabris; summis minoribus distinctis. Aneilema $\mathbf{R}$. Br. In Nova Hollandia.

101. C. macrophylla R. Br. glabra; caule erecto; fol. oblongo-lanceolatis acuminatis laevibus petiolatis; bracteis superioribus coloratis. Aneilema H. Br. In Nova Hollandia.

105. C. crispata Poir. glabra; caule erecto; fol. elongato-lanceolatis acuminatis; vaginis superioribus collo-crispato; bracteis ommibus foliaceis Aneilema $\mathbf{R}$. Br. In Nova Hollundia.

\section{SYENA Schreb. (1789).}

1. S. fluriatilis Willd.; S. nutalliana 1. et \$. Mayaca fluviatilis Aubl. Guj. t. 15. Planta natans minima facies musci frondosi. Radix repens. Flores axillares albi. In rivulis Gujanae, Brasiliae, Carolinae et Georgiae. 4.

\section{CALLISIA Loefl. (1758).}

1. $C$. repens $I_{\text {. }}$ caule repente; fol. ovato-lanceolatis sessilihus; floribus axillaribus sessilibus. Haplanthus Jacq. am. t. 11. pict. 14. In America boreali. 4.

2. C. umbellulata Lam.; caule superne pedunculisque pilosis; unbellis lateralibus et terminalibus pedunculatis. Lam. ill. t. 35. f. 2. In America merislionali. 4.

2. C. ciliatu Kunth.; caule repente; fol. lanceolatis sessilibus; vaginis inflatis margine ciliatis. Kunth syn. 1. p. 269. In Nova Granutu. 24. Cor. violacea.

\section{ACLISIA E. Meyer (1832).}

1. A. sorzogonensis E. Meyer in Presl Reliq. Huenk. 2. p. 138. In insula Luzon. 4. Caul. spithameus sulcatus superne puhescens. Folia ovato-oblonga petiolata integerrima. Paniculae erectae subverticillatae.

\section{HETERANTHERA R. et. P.} (1795).

1. H. graminea Vahl; fol. ommibus linearibus. Vahl en. 2. p. 45. Leptanthus Michx. am. t.5. f. 2. Schollera graminifolia Willd. In Pensylvania et Virginia. 24. Cor. Iutea.

2. H. zosteraefolia Mart. caule herbaceo natante ramoso; fol. sessilibus distichis linearibus; spathis 2-floris. Mart. nov. gen. et sp. 1. t. 3. In Itrasilia. 4. Cor. albida.

3. H. limosa lahl; fol. ovato-ohlongis; spathis lanceolatis 1-floris. Vahl en. 2. p. 44. Pontederia sw. Lepthanthus ovalis Michx. t. 5. r. 1. In America boreali et in India orientali. 21. Cor. caerulea.

4. H. alismoirles Willd. Hb. fol. subcordato-oblongis acutis repandis; spathis oblongis acuminatis. Link Jahrb. 3. p. 73. In Caracas,

5. H. diversifolia Vahl.; fol. cordato-ovatis petiolatis linearibus sessilibus. VahI en. 2. p. 44. In Gujana.

6. H. cordata Vahl.; fol. cordatoovalibus ohtusissimis; spathis subtrifloris oblongis obtusissimis. Vahl en. 2. p. 44. In America meridionali.

\%. H. pubescens Vahl; fol. cordatis acutis; spathis linearibus multifloris. Vahl en. 2. p. 43. Pontederia Loefl. In paludosis Americae meridionalis.

8. H. reniformis $\boldsymbol{R}$. et $\boldsymbol{P}$. peruv: t. \%1. f. a.; fol. subrotundis reniformibus; spathis oblongis acuminatis; 
stamine tertio multo majore. H. acuta Willd. In peruvia pensylvania et rirginia. 24. Cor. allso-viridis.

\section{IITLLCHIA Mutis (17\%1).}

1. W. repens Linn. mant. 55s. In Mexico. ๑. Rad. fibrosa. Caulis repens, filiformis, ramosus, lierbaceus, lirsutus, sub2-pedalis. Folia suborbiculata. Flores parvi rosei.

\section{IYDRANTIELIUM Eunth. (1825).}

1. M. calitrichoides Iiunth in Irumb. et Bonpl. Nov. gen. et Sp. pl. t.646. In cataractis Orinoci. $\odot$. Caulis natans. Folia opposita, integerrima 7-nervia. Flores axillares, alterni, petiolati, minimi, albi.

\section{MACROLOBIUM Schreb. (1789).}

1. M. hymenceoides Willd.; fol. conjugatis; foliolis sessilibus ovatis ncuminatis obliquis; elevato 1-nerviis; leguminibus linc alato-marginatis. M. bifoliun Pers. Vouapa Aubl. Guj. t. 7. In Cajenna et Gujana. t. Cor. violacea.

2. M. sphatecarpum Willd. fol. conjugatis ; foliolis petiolatis subovato-lanceolatis hasi aequalibus; leguminibus ovalibus margine undique laevibus. Willd. sp. pl. 1. p. 186. Vouapa Aubl. Guj. t. 8. In silvis Gujanae. $\hbar$.

3. M. stamineum Meyer; fol. conjugatis; foliolis sessilibus lanceolatooblongis, obtusiusculis; calycis laciniis reflexis. Meyer Esseq. p. 18. In Essequebo. ち. Petala alha.

\section{OUTEA Aubl. (17\%5).}

1. O. gujanensis Aubl. guj. t. 9.; fol. pimatis; foliolis bijugis ellipticooblongis obtusis. Macrolobium pimnatum Willd. In Gnjana. ち. Arbor alta. Cor. violacea.

2. O. multijuga DC. fol. pinnatis ; foliolis 3-5-jugis ohovato-cuneatis oblongis obtusissimis retuse emar- ginatis. DC. prodr. 2. p. 510. In Gujana. $\hbar$.

3. O. bijuga $D C$. fol. pimnatis 2jugis; floribus triandris; filamentis sex sterilibus. DC. 1. c. Macrolobium Colebr. In Indic orientali.

\section{INTSIA Aubl. (1775).}

1. I. madayascariensis DC. prodr. 2. p. 509. In Marlagascar. $\hbar$. Arbor alta. Folia impari-pinuata. Flores racemosi.

\section{ORTEGIA Loefl. (1758).}

1. O. hispanica $L$. canle erecto suhsimplici; fol. linearibus; stigma capitatum. Cav. ic. t. 47. In Castilia et salamanca. 2.

2. O. dichotoma All. stirp. ped. t. 4. f. 1. caule ramoso, diffuso; fol. linearibus; pedunculis dichotomis; stigma 3-fidum. Alb. Dietr. In Italia. 4. Cor. viridis.

\section{STIPULICIDA Michx. (1S11).}

1. S. setacea Michx. am. t. 6. Polycarpon stipulicidum Pers. In Carolina inferiore. $\odot$. Radix fibrosa. Caul. 6-10 pollicaris, setaceus 2-3 chotomus. Folia radicalia, spathulata. Cor. parva alba.

\section{LOEFLINGIA L. (1758).}

1. $L$. hispanica $L$. erecta; viscoso-pubescens; fol. lineari-subulatis lateribus utrinque 2-dentatis; floribus 3-andris. Loefl. it. t. 1. fo 2. In IIispania et Gallia. $\odot$.

2. L. pentandra Cav. ic. t. 148. f. 2. procumbens; villosa; fol. subulatis; floribus pentandris, trigynis. Cav. ic. t. 148. f. 2. In arenosis Meaiterranei. $\odot$. Cor. alba.

\section{S. MIPPOCRATEA L. (1737).}

1. I. obcordata Lam.; fol. ovatoIanceolatis serratis; racemis corymbosis folio brevioribus; capsulis obcordatis. Lam. ill. 1. p. 400. t. 28. f. 1. H. scandens Jacq. am. t. 9. In America meridionali. t. Cor. ferrugineotomentosa. 
2. H. uniflorc Moc. et Sessé fol. oblongis basi cordatis integris; pedunculis 1-floris; capsulis obcordatis. DC. prodr. 1. p. 567. In Mexico. $\hbar$.

2. H. ovatı Lam. ill. $t$. 2s. f. 2. carpellis ovatis; paniculis axillaribus subdichotomis; fol. oblongo-ovatis ellipticisve serratis. DC. I. c. In Domingo. $\hbar$.

4. H. Ineviyata Rich. carpellis ....; paniculis axillaribus subdichotomis; pedicellis 2,1 -floris in divistiris; fol. ovato-ohlongis, obsolete crenatis. DC. 1. c. In Cayenna. ఫ.

5. H. discolor Meyer Ess. carpellis ovatis; paniculis axillaribus, subdichotomis rufo-velutinis; ramis minoribus multifloris; fol. ovalibus breviter acuminatis obsolete crenato-serratis. DC. 1. c. In Gujana. t.

6. H. viridis R. et P. Hl. peruv. t. Ft. f. a. carpellis ovalibus emarginatis; corymbis dichotomis folio brevioribus; fol. ovatis obtuse acuminatis integris serratisque. DC. 1. c. In Andium nemoribus. b.

\%. H. acutiflore H. mex. carpellis obovatis; corymbis dichotomis folio hrevioribus; petalis acutis; fol. oblong $0-0$ valibus dentatis. DC. 1. c. In Mexico. †. Cor. viridis.

8. II. celastroides Funth; carpellis subrotuudo-obovatis ; corymbis dichotomis gylahris, folio dimidio brevioribus; fol. Ianceolato-oblongis, acutocuspidatis. DC. I. c. In Mexico. ț. Cor. viridis.

9. H. Acropulcensis Funth; carpellis obovatis; pelunculis dichotomis multifloris glabris folio subaequalibus; fol. obovato-ohlongis brevissine cuspidatis; ramis verrucosis. DC. Prope Acapulco. b. Cor. viridis.

10. II. malpighiaefolia Rudge guj. t. 8. panicnlis axillarihus terminalibusque; fol. anguste ovalibus integerrimis acuminatis, subtus ramisque asperis. DC. 1. c. In Gujana. ఫ.

11. H. vervucosa Funth; carpellis obovatis ; pedunculis ramosissimodichotomis, multifloris glabris folio subaequalibus; fol. elliptico-oblongis remote serrulatis; ramis verrucosis. In Nova Granata. b.

12. I. comosa \$w. carpellis oblongis obovatisque; paniculae pedunculis multifidis capillaribus; fol. ovatis acuminatis integerrimis basi ob- tusis aut subcordatis. DC. 1. c. In Hispaniola. $\hbar$. Cor. alha.

13. H. emarginata Rudge guj. $p$. 11. $t$. 9. paniculis axillaribus brevihus dichotomis; fol. olovatis integerrimis emarginatis; caulc pustulis minutis aspero. DC. I. c. In Gujana. ђ.

1.1. I. paniculata Iahl; paniculis axillaribus dichotomis folio hrevioribus; fol. oblongis utrinque acutis obtuse serratis. DC. I. c. In Nierra Leona. ђ.

15. II. macrophylla Vahl; paniculis axil!arihus dichotomis folio brevioribus; fol. ovatis integerrimis nitidis basi obtusis apice acuminatis. DC: I. c. In Sierra Leona. $\hbar$.

16. H. velutina A/:- racemis axillarilus; fol. oblongis acuminatis integerrimis, subtus venosis rufo-villosiusculis. DC. 1. c. In Guinea. ち.

1\%. H. indicu Willd. carpellis oblongis 2-spermis; paniculis corymbosis dichotomis folii fere longitudine; fol. ovalibus acutis serratis nitidis. DC. 1. c. H. disperma Vahl. In sylris montosis Indiae. t.

18. H. obtusifolia Roxb; carpellis obovatis 4-spermis, corymbis terminalibus axillaribusque; fol. ellip(ico-oblongis integris obtusis; ranulis cirrhosis. DC. I. c. In Coromandelia. ち.

19. II. arborea Roxb. carpellis linear-ohlongis subcumeatis 2-spermis; corymbis axillarihus dichotomis; fol. cllipticis serrulatis mucrone cuspidatis; ramis subadscendentibus. DC. l. c. In India orientuli. $b$.

20. II. Cassinoiles DĆ. corymbis axillarihus dichotomis folio triplo brevioribus; fol. ellipticis basi et apice acumiuatis sulsserrulatis sulmembranaceis; ramulis apice compressis. DC. 1. c. In insula Timor. $\hbar$.

21. H. panciflora DC. corymbis axillaribus dichotomis 5-7-foris, vix petiolo longioribus; fol. elliptico-oblongis obtusissime subcrenulatis. DC. 1. c. In insula Timor.

22. II. ellipticı Kunth; peduncnlis tenuissime tomentosis dichotomoquadrifidis folio brevioribus; fol. ellipticis acutis, remote crenato-serrulatis, ramulis quadrangularibus. DC.l.c. In Nexico. ち. Cor. alba.

23. I. excelsı Kunth; pedunculis bifidis multifloris pulverulento-hirtellis, folio triplo quadruplove brevioribus ; 
fol. elliptico-oblongis undulato-crenalis. DC. 1. c. In Mexico, t. Cor. albo-viridis.

\section{ANTHODON R. et P. (1799).}

1. A. decussritum R. et P. R.peruv. t. $711 \mathrm{f}$. 2. fol. oblongo-ovatis subacuminatis obtuse serratis nitidis; paniculis axillaribus dichotomis; petalis ovato-oblongis argute serratis. DC. 1. c. In Andibus. $\hbar$.

2. A. paniculatum Mart. fol. ovatis obtusiusculis obsolete et subundulato-serratis; petiolis inaequaliter dentatis. Mart. in schult. mant. 1. p. 253. Ad Rio Janeiro. ђ.

3. A. undulatum Mart $t$. c. fol. ovatis acutis utrinque attenuatis obtuse subundulato-scrratis; petalis fimbriato-dentatis. DC. Ad Rio Janeiro.

1. A. ellipticum Miart l. c. fol. crassis ellipticis, utrinque rotundatis margine incrassato integerrimis; pctalis suborbiculatis serrulatis. DC. $A d$ Rio Janeiro. t.

.). A. grandiflomem Mart. I. c. fol. crassis oblongis obtusis integerrimis; floribus ageregatis brevissime pedunculatis ; petalis ovato-suborbiculatis denticulatis. DC. 1. c. Ad Rio Janeiro. $ち$.

6. A. oblongifolinm Mart. I. c. fol. crassis oblongis obtusiusculis antice remote et subundulato-crenatis, petalis obovato-oblongis denticulatis. DC. 1. b. In Bahia. $\hbar$.

7. A. glomercitum Mart. $t$. c. fol. crassis oblongo-lanceolatis obtusiusculis; floribus glomeratis axillaribus lateralibusque; petalis orbiculatis vix denticulatis. In Bahia. ち.

9. A. crassifolium Mart. fol. crassis subemarginatis lineari-ellipticis, petalis obovato-orhiculatis integerrimis, In Goyazana. ち.

\section{RADDISIA Leand.}

1. $\boldsymbol{R}$. arborea Leand. de Sacramento $t$. 1.5. Arbor 12 ped. ramosissima. Folia opposita, serrata, elliptica. Flores axillares purpurci. In insulis ad Rio Janeiro. t.
211. SALACIA L. (1781).

1. S. scabra DC. fol. ovato-oblongis subintegerrimis subtus venosis et asperis; paniculis dichotomis. DC. prodr. 2. p. 570. Tontelea scandens Aubl. t. 10. In Cayenna et insula Trinitatis, ち.

2. S. laerigata DC. fol. petiolatis oblongis acutis subundulatis integerrimis glabris subtus subasperis; petalis ciliatis. DC. 1. c. Tonsella Hoffm. l'atria ignota. $\hbar$.

3. S. multifiora DC. fol. ohovatis integerrinis nitidis; pelunculis congestis suhtrifioris. DC. 1. c. Hippocratea obovata Hich. In Cayenna. b.

4. S. africana DC. fol. ovalibus nitidis extrorsum denticulatis, dentibus sulglandulosis; pedunculis congestis 1-floris. DC. 1. c. Tonsella Willd. In Guinea. நृ.

5. S. Senegalensis DC. fol. ohlongis acuminatis laevilus nitidis extrorsum serratis; ramis scahris; pedunculis congestis e tubero axillari ortis. DC. 1. c. Hippocratea Lam. Tonsella Vah1. In Senegalis. ђ.

6. S. Madagascariensis DC. fol. lanceolato - oblongis subintegerrimis acuminatis laeviluus nitidis; petalis linearibus. DC. I. c. Ji Madagascrir. 支.

\%. S.? Culypso DC. fol. ovato-oblongis obtuse suhdenticulatis venosis; petalis ovatis; pedunculis subternis e tuhero axillari. Calypso Pet. Thuar afr. t. 6. In Madagascar. ち.

s. minoides DC. fol. ellipticis obtusis apice olssolete serratis; pedunculis axillarihus confertis elongatis 1-floris. DC. 1. c. Tonsella Willd. In Indiu orientali. $ђ$.

9. S. cochinchinensis Lour. fol. ovatis subacuminatis, suhserratis; pedunculis axillaribus congestis $\mathbf{1}$-floris; petalis subrotundis. DC. I. c. In Cochinchina. ఫॄ.

10. S. Chinensis Linn. fol. alternis? ovalibus integerrimis laevibus; ramis angulatis. DC. I. c. In China. Ђ.

\section{JOHNIA Roxb. (1823).}

1. J. salacioides Roxb. fol. integris; calyce 5-partito; petalis sessi12 * 
libus. Roxb. ind. 1. p. 172. In Bengalia. $\downarrow$. Nlores parvi aurantii.

2. J. Coromandeliana Roxb. fol. scriulatis; calyce 5-dentato; petalis unguiculatis. lioxb. 1. c. In sylvis montosis Coromandeliae. $\hbar$.

\section{OLAX L. (197).}

1. O. Zeylanica $L$. fol: glabris; ramis angulatis flaccidis; caule inermi. DC. prodr. 1. p. 532. In Reglonia.ち.

z. O. scandens Roxb. corom. $t$. 102. fol. subtus pubescentibus; ramis scandentibus; caule aculeis validis armato. DC. 1. c. In Coromandelia. t.

3. O. imbricata Roxb. scandens fol. ovato-lanceolatis oblongis bifariis integris nitilis; racemis ante anthesin bifariam imbricatis; drupis ovatis. DC. 1. c. In India or. ad Chitilagony. ち.

4. O. obtusa Blume; fol. bifariis ovatis 8. ovato-oblongis, obtusissimis, subtus pubescentibus; spicis axillaribus ante anthesin bifariam inbricatis; Irupis glohosis. Blumo Bydr. 3. p. 139. In Java. ђ.

\section{FISSILIA Juss.}

1. F. Psittacorum Iam. ill. 1.t. 28. Glax Vahl. In insula Mauritii. ち. Rami rigidi. Folia ovato-oblonga aut lanceolata persistentia cnervia.

\section{SPERMAXYRUM Labill.(1805). Olax R. Br. prodr.}

1. S. Phyllantha Labill. t. c. $t$. 233; fol. ovalibus retusis. DC. 1. c. In Nova Hollandia. 方.

2. S. strictum $D C$ : fol. oblongolinearibus nucronatis. DC. 1. c. In Nova Hollandia ad Port-Jackson. ち.

3. S. aphyllam $\boldsymbol{R}$. Br. fol. sulbnullis; florihus sessilibus subspicatis. DC. 1. c. In Nova Hollandia.

\section{POLYCNEMUM L. (173\%).}

1. arvense $L$. caule ramoso divaricato; fol. subnlatis subtriquetris $\mathrm{mu}-$ cronatis erecto-patulis interuodiis multo longioribus. Alb. Dictr. Sp. pl. 2. p. 697. Jaq. austr. t. 365. var. $\beta$. recurvum, fol. subsetaccis linearibns subsparsis calycibus bracteas subaequalihus. P. inundatunı schrank. P. arvense sclikulir t. 5. f. a. In arvis Europae. $\odot$.

2. P. verrucosum Lang. caule ramosissimo angulato verrucoso scabriusculo flexuoso; fol. subulatis internodiis brevioribus adpressis. Alb. Dictr 1. c. In arvis Hungariae, $\odot$.

3. P. americanum Nuttal; perenne; caulibus caespitosis; fol. oppositis connatis coufertis subulato-triquetris subpungentibus; floribus terminalibus. Alb. Dietr. 1. c. In collibus aridis Missouri. 4.

1. P. bonariense Willd. IIb. fol. alternis linearibus nucronatis; floribus aggregatis axillaribus. Link Jalurb. I. 3. 1). 68. In Brasilia.

5. P. erinacenm Pall. ill. $p l$. $t$. 18. pereune caespitosum sempervirens; fol. tematis carinatis sul-spinosis; floribus terminalibus. Alb. Dietr. 1. c. In Sibiria. 4.

6. $\boldsymbol{l}^{2}$. monandrum Pall. ic. app. $t$. G. f. 1. ill. $p l$. t. 19. annum, incanum; ramis alternis; fol. filiformibus muticis. Alh. Dietr. 1. c. Nalsola. Gmel. sib. 3. 1. 1\%. f. 2. In Sibiria. $\odot$.

ซ. P. salsum Willd. triandrum, erecto-divaricatum; ramis oppositis alterne ramulosis; fol. elongatis filiformibus muticis. Willd. sp. pl. 1. p. 192. P. Volvox Pall. ill. pl. t. 50. Arabasis Bich. In Iinssia. $\odot$.

8. P. sibivicum P'all. ill. pl. t. 51. annuum pentandium erectum tomentosum glaucum; fol. amplexicaulibus ramisque oppositis. Camphorata Gmel. sib. t. 23. f. 1. In Sibiria. $\odot$.

9. P. crassifolium Pall. ill. pl. $t$. 5.5. pentandrum; amuum ; ramosissimum; assurgens; glabrum; floribus carnosis cylindricis. $\Lambda$ lb. Dietr. 1. c. In Russia. $\odot$.

10. P. brachicitum Pall. ill. pl. $t$. 52. annuum; pentandrum; opposite ramosum ; glaucam; fol. semicylindricis carnosis; florilus confertis. Alb. Dietr. 1. c. P. oppositıfolium R. eb S. In IRossia. $\odot$.

11. P. glaucum Pall. ill. pl. t. 53. 54. pentandrum; prostratum; ramosissimum; glaucum; fol. creberrimis tereticompressis. Alb. Dietr. 1. c. In Asia media. $\odot$. 
12. P. sclerospermum pull. it. 3. (tpp. t. M. F. 3. ill. $)$ l. t. .56 ; triandrum anıum ramosissinum patulum; fol. canosis crassis cylindricis subulato-mucronatis; infimis oppositis. Alb. Dietr. In Asia media. $\odot$.

13. P. malacophyllum Bieb. nentanlrum; pilosum; fol. semiteretibus obtusis; florum capitellis clavatis pedunculatis. Salsola pilosa Pall. ill. pl. t. 20. Ad flumen Cyrum. $\odot$.

1. P. juniperinum Bieb. pentandrum; caule suffuticoso ramosissimo diffuso ; fol. subulatis pungentibus imbricatis. Alb. Dietr 1. c. In Sibiria. b.

15. P. Heuffelii Lang; Syll. pl. p. 219. caule erecto ramoso puberuloviscido; fol. filiformibus sulsspinosis confertis reclinatis. Alb. Dicti I, c. In IIungaria.

\section{THREITELDIA R. Br. (1810).}

1. T. diflusa R. Br. prodr. 1.p. 410. In Nova IIollandia. Suffrutex litoretis, diffusus. Folia alterua semiteretia. Flores axillares solitarii, sessiles.

\section{XYRIS R. et P. (1799).}

\section{Foliis angustissimis.}

1. $\boldsymbol{X}$. subulata $\boldsymbol{R}$. et $\boldsymbol{P}$. fl. peruv. t. 71. fol. lincari-subulatis; vaginis margine piloso-lanatis. Alb. Dietr. sp. 1). 2. p. 37. In Peruvia. Cor. lutea.

2. X.operculata Iabill. Nov.Holl. t. 10. scapo tereti; fol. sctaccis, capitulo obovato; hracteis 5 -fariis, incrmibus. Alls. Dietr. 1. c. In Nova Lollandia. Cor. flava.

3. X. lanata R. Br. scapo tereti Iaevi; fol. angustato-linearibus ; capitulo subglohoso; bracteis 5 -fariis apice lanatis. Alb. Dietr 1. c. In Nova Hollantia.

t. X. filiformis Lam. scapo filiformi ancipiti; capilulo ovato minimo; bracteis oblongis. Lam. ill. 1. p. 133. Ad Sierram Leonam.

5. X. elongata Lamb. in Limn. Truns. $X . t$. 15. f. 1. scapo ancipiti lougissimo; fol. subulatis; capitulo oblongo; bractcis inferioribus acute carinatis. Ad lortum Jackson. Cor. flava.

6. X. pranciflore rilld. phyt. 1. t. 1. f. 1. scapo 1 -gono; fol. linearisubulatis margine scainis; capilulo ovato; bracteis obtusis. IVilld. 1. c. In Malabaria et Nova Hollandia. 4.

7. $\boldsymbol{X}$. capensis Thunb. scapo filiformi stricto; fol. lincaribus abbreviatis; capitulo ovato; bracteis ovatis obtusis. 'i'humb. prodr. p.12. In Prom. b. spei. Cor. Intea.

8. X. compressa Uilld. IIb. scapo compresso ; fol. linearibus abbreviatis; capitulo globoso; hracteis ovatis obtusis. Alb. Dietr 1. c. In Mada yascar.

9. nitida Willd. Hb. scapo ancipili vaginato; fol. linearibus glabris bracteisque nilidis; capitulo globoso. Alb. Dietr 1. c. In insula Mantitii.

10. $\boldsymbol{X}$. anceps Lam. fol. linearibus rigidiusculis; scapo ancipiti laevi; capilulo subgloboso; bracteis subcmarginatis. Lam. ill. 1. p. 132. X. indica Vahl. In Malabaria. Cor. Iutea.

11. $X$. surinamensis Ant. Spr. Tent.p.2. fol. linearibus rigidis; scapo compresso superne ancipiti glabcrimo scabro. Ant. Spro. In Śurinam.

12. X. ciliata IIolm.; scapo striato laevi; fol. linearibus obtusis brevilus; vaginis ciliatis; capitulo oblongo. Holin pl. Bras. dec. 3. In Brasilia.

13. X. Grevifolia MIichx. am. p.23. scapo superne compresso; fol. subulato-ensiformibus laevibus; capitulo subgloboso; bracteis inciso-dentatis. Alb. Dicir. In America boreali. 4.

14. X. Balduiniana R. et S. scapo tereti basi vaginato; fol. teretibus fistulosis acutis; capitulo ovali; bracteis subrotundis. X. juncea Elliot. In Carolina astrali. 24.

15. X. ruludosu R. Br. scapo teretiusculo laevi superne angulato; fol. subfistulosis; bracteis undique imbricat is orhiculatis nitidis. R. Br. prodr. 1. p. 256. In Nova Hollandia.

16. $\boldsymbol{X}$. junceu $\boldsymbol{R}$. $\boldsymbol{B r}$. scapo tereti compresso subflexuoso foliisque laevibus subulatis; stigmatibus multifidis. I. Bi. 1. c. In Nora Hollandia.

1\%. X. gracilis $\boldsymbol{R}$. Br. scapo filiformi laevi parum tortili; fol. anguste linearibus, strictis margine scabris; stigmatibus indivisis. I3. Br. I. c. In Nova liollandia. 
18. $X$. bracteata $R, B r$. scapo trigono, angulo acntiori scabriusculo; fol. linearibus marginibus carinaque baseos scabris. R. Br. 1. c. Ad Portum Jackșon.

19. $\boldsymbol{X}$. Alexifolia $\boldsymbol{R}$. Br. scapo filiformi tortili foliisque laevibus flexuosis compresso-filiformilus; capitulo ovali. H. Br. 1. c. In Nova Hollandia,

20. $\boldsymbol{X}$. teretifolia $\boldsymbol{R}$. $\boldsymbol{B r}$. scapo foliisque teretibus strictis scabriusculis; capitulo ovato multifloro; ibractels lacero-multifidis. 12. B. 1. c. In Nova Hollandia.

21. X. lacera $\boldsymbol{R}$. Br. scapo tereti laevi; capitulo subglohoso multifloro; bracteis undique imbricatis lacero-multifidis. IR. Br. 1. c. In Nova Hollandia.

22. X. laevis R. Br. scapo ancipiti foliisque laevibus angusto-linearibus; capitulo subovato; calycibus carina ciliata. R. Br. 1. c. In Nova HoL landia:

\section{Foliis latioribus.}

23. $\boldsymbol{X}$. denticulata $\boldsymbol{R}$. Br. scapo teretiusculo laevi; fol. abbreviatis, linearibus margine denticulato-scabris; bracteis nitentibus. 1R. Br. 1. c. In Nova Hollandia.

21. $\boldsymbol{X}$, pusilla $\boldsymbol{R}$. Br. scapo ancipiti foliisque láevibus ensiformibus abhreviatis; capitulo subgloboso ancipiti. R. Br. 1. c. In Nova Hollandiı. 25. $X$. scabra R. Br. scapo ancipiti tortili, angulis acutioribus scabris; capitulo ovato vel oblongo. $\mathrm{H}$. $\mathrm{Br}$. 1 . c. In Nova Hollandia.

26. $\boldsymbol{X}$. complanata $\boldsymbol{R}$. $\mathrm{Br}$. culmo plano - compresso, marginibus cartilagineis scabris; spica ohlonga; squamis orbiculatis veutricosis. $\mathbf{R}$. Br. 1. c. In Nova Hollandia.

2\%. $X$. platycaulis Poir. scapo. lato compresso striato; capilulis globosis apice retusis. Poir Enc. suppl. p. 820. In Madagascar.

28. X. torta Smith; fol. linearihus nervosis margine scabris spiraliter tortis; scapo folia superante subancipiti; bracteis orbicularibus. Smith in Spr. syt. 1. p. 183. In America borcali.

29. X. fimbriata Elliot. scapo scairiusculo; fol. ensiformilus longis; capitulo oblougo laxe imbricato; ca- lyce fimbriato. $\mathrm{n}$. et s. mant. 1. p. 331. In Georgia.

30. $X$. caroliniana Walt. scapo ancipiti glabro; fol. ensiformibus tortuosis; capitulo ovato arcle imbricato 3 calyce pilosiusculo. X. jupicai Miclıx. X. anceps Pers. In America boreali. 4.

31. X. americana Aubl. Guj. t. 11. fol. lineari-lanceolatis; scapo superue ancipiti ; capitulo ovato oblongo; bracteis apice emarginatis. Alb. Dietr. 1. c. X. caerulea Lam. In Cayenna. 4.

32. vivipara Funth; fol. lineari-ensiformibus; vaginis margine ciliatis pedunculo conpresso apicem versus scabritsculo; capitulo demum comoso. Kunth syn. 1. p. 265. Ad Orinocum. 4. 33. $X$. vaginata Spr. fol. lineariensiformibus rigidis subulatis; scapo compresso torto glabro; capitulo ovato; bracteis denticulatis mucronatis. Spr. syst. veg. 1. p. 183. In Brasilia.

31. X. macrocephala Vaht; fol. lineari-lanceolatis; scapo 1-angulato; capitulo ovato; bracteis ovatis obtusis dorso cinereis. Valıl en. 2. p. 204. In Cayenna.

35. $\boldsymbol{X}$. indica $\boldsymbol{L}$. fol. lineari-ensiformibus; scapo tereti striato; capitulo globoso; hracteis rotundis. $\mathbf{L}$. Zevl. p. 14. Plukn. t. 416. Hheedo mal. 9. t. 7. In India orientali. $\odot$. Cor. flava.

36. X.pubescens Poir. scapo striato subcylindrico, vagina pubescente involuto. P'oir Euc. Meth. 8. p. 819. In Antilis.

\section{ABOLBODA Kunth, (1812).}

1. A. julchella Kunth in H. et $B$. $p l$. aeq. 2. $p$. 110. t. 111. harbata; stigmate tripartilo, laciniis bifidis. Kunth 1. c. Ad Urinocum. 24. Cor. caerulea.

2. A. imberbis Kunth; imberbis; stigmate multifido. Kunth syu. 1. p. 266. In Gujana. 24. Cor. albo-violacea.

\section{STIREBLIDIA Link (1828).}

1. S. ferruginca Link en. 1. $\%$. 286. Schwrus llost grum. 4. t. 81 . 
S. nigricuns Hoppe. In turfosis Europae. 4. Culmi 4-poll. ad ultra pedem alti. Fol. poll. convoluta tenuissima. Capitulum terminale e spicis $3-1$ pedicellatis.

\section{CHAETOSPORA R. Br. (1810). Schoenus Auct.}

1. Cul mo nudo.

1. C. Capitellum Alb. Nietr. culmo filiformi; fol. setaceis; capitulo ovato, involucro subdiphyllo breviore. Schouns Thunb. Schoenus indicus Lam. In India orientali et Prom. b. spei. 4.

2. C. striata Alb. Dietr. culmo foliisque filiformibus; capitulo ovato involucro triphyllo breviore. Schoenus Thuul). prodr. p. 16. In Prom. b. spei. Culmi 2-3-ped. bulhosi.

3. C. munctoria Alb. Dietr. culno tereti apice subulato rigido punerente; fol. nullis; spicis paniculatis. Schuenus Vahl en 2. p. 21\%. In Prom. b. spei.

t. C. lanuta R. Br. culmo tereti laevi basi foliato; vaginis ore barbatis; valvis enervibus margine lanatis; setis plumosis. R. Br. prodr. 1. p. 232. Labill. Nov. Holl. t. 20. In Nor'a llollandic.

5. C. curvifolia $R$. Br. culmo nudo teretiusculo subangulato; fol. subsetaceis; capitulo glohoso; valvis enervibus imberbibus; setis plumosis. 12. Br. 1. c. In Nova Hollandia.

6. C. turbinate R. Br. fol. radicaỉibus involucrisque setaceis; capitulo turhinato; valvis enervilus margine villosis; setis villosis. $\mathbf{R}$. Br. 1 . c. In Nova Hollandia.

\%. C. brevisetis $\boldsymbol{R}$. Br. culmo tereti striato; vaginis ore barbatis; valvis enervilus margine pubescentibus; intimis hasi hispidis. 11. Br. 1. c. In Nora Hollandia.

8. C. deformis R. Br. culmo tereti scabro; vaginis ore barbatis; spiculis sulssolitariis; involucro 1-phyllo; valvis margine lanatis. R. Br. I. c. In Nova Hollandia.

9. C. pedicellata $\boldsymbol{R}$. $\boldsymbol{B r}$. culmo tereti laevi; vaginis ore barbatis; spiculis distichis subfalcatis; valvis marrine villosis, intimis hasi hispidis. $\mathrm{H}$. Br. 1. c. In Nova Hollandia.

10. C. sphaerocephala R. Br. culno teretiusculo hasi foliato; vaginis ore lanatis, capitulo globoso; valvis hasi nervosis. H. Br. 1. c. Ad Portum Jackson.

11. C. nitens $\boldsymbol{R}$. Br. capitulo laterali; valvis nitidis enervibus; setis hypogynis plumosis; nucibus 3-uronis lacvibus: 1R. Br. I. c. In Nova llollandia.

12. C. anceps $\boldsymbol{R}$. Br. culmo anclpiti; capitulo globoso involucro breviore; valvis basi nervosis. $\mathbf{1}$. $\mathbf{B r}$. 1. c. In Nova Hollandia.

13. C. ? tetrayona $\boldsymbol{R}$. Br. culmo angulato 1-folio; fasciculo elongato involucrato paleacco. R. Br. I. c. In Nova Hollandia.

11. C.? stygia R. Br. culmo tereti nudo; capitulo involucrato; valvis recurvato-aristatis. 11.Br. 1.c. In Nova Hollandia,

\section{Culmo folioso.}

15. C. culostachyce R. IBr. culmo semitereti ; fol. cariualis maruine asperis; vaginis densis inberbibus, setis capillaribus nucem rugosiam subaeruantibus. R. Br. In Nova Hollandia.

16. C. paludosa R. Br: culmo semilereti filiformi; fol. planis laevihus; valvulis enervibus nudis; setis nuce hrevioribus. 11. Br. 1. c. Ad Portum Jackson.

17. C. imberbis R. Br. culmo folisque lacvibus; vaginis imberbibus; valvis enervibus; pauicula foliata. It. Br. I. c. In Nove flollandia.

15. C. axillaris R. Br. culmo filiformi foliisque laevihus; pelunculis distichis; vilvis enervilus cariua denticulatis. 1R. Br. 1. c. S. maschalinus R. et S. In Nova Hollandia.

19. C. arundinacea Alb. Dietr. fol. longissimis; paniculis diffusis axillaribus terminalihusque; spicis sulssolitariis. Vahl en. 2. p. 220. In Nove Caledonia. 4.

20. C. dactyloiles Alh. Dielv. culmo superme trigono; capitulis paniculatis; spicis lanceolatis; valvis infmis ciliatis. Schœun Vahl 1. c. In Prom. b. spei.

21. C. tenera Spr. culmo teret1 foliisque capillaribus strictis; spiculis subternis spadiceis; valvis lanceolatis striatis. Spr. N. Eutd. 3. p. 9. In Prom. b. spei.

22. C. dispar $\mathbf{S p r}$. fol. subtriquetris culmum stperautibus; vikginis 
laxis; involucris scariosis. Spr. N. Entd. 3. 1. 8. In From. b. spei.

23. C. circinulis Schrad. fol. lineari-setaccis circinatis; panicula coarctata foliosa secunda; setis hypogyuis subpilosis. Sichrad. Goett. Anz. 1821. и. 208. p. 2070. In Prom. b. spei.

\section{SCHOENCS L. (1737).}

\section{Culmo nudo.}

1. S. nigricans L. spicis terminalibus capitato-fasciculatis; involucro diphyllo; valvis lanceolatis acutis fuscis. Host. Gram. 2. t. 54. Engl. bot. 1021. In paludosis Europae.24.

2. S. atraitus Schrad. culmo tereti foliisquc setaceis involucro triphyllo; valvis lanceolatis mucrouatis carina hispidulis. Schrad Ann. In Prom. b. spei. 24. Spithameus.

3. S. hypomelas .spr. fol. filiformibus erectis; involucro diphyHo; valvis navicularibus carina laevi. Spr. N. Entd. 3. p. 8. S. nigricans Thunb. In Prom. b. spei. $2 \%$.

4. S. pilosus Willd. phyt. 1. p. 3. f. 1. $f$. 3. fol. vaginisque pilosis; involucro diphyllo villoso; valvis lanceolatis mucronatis. Schrad. In Guinea et Senegal. 24. Culm. $\frac{1}{2}$ ped.

5. S. ajhyllus Vahl; culno tereti; vaginis glabris; spicis capitatis involucro diphyllo brevioribus. Vahl en. 2. p. 209. In insula Franciae. Culmus pedalis.

6. $S$. pusillus $S w$. ic. $t$, 6. culmo capillari 3-gono; fol. ciliatis; involucra monophyllo spicas terminales aequante. Sw. Hypoelytrmm Berterii spr. In Jamaica, Domingo et Guadeloupe.

7. S. lateralis V'all; culmo foliisque filiformibus; spicis lateralihus conglomeratis sessilibus; valvis ovatis obtusis. Vahl en, 2. 1. 211. In Prom. b. spei. 4.

8. S. filifomnis Thunb. culmo foliisque filiformibus involucro triphyllo; valvis ovatis acuminatis. Thunb. prodr. p. 16, In Prom. b. spei. 4. Culnus pedalis.

9. S.juncoides Valil; culmo filiformi; fol. setaceis; involucro 3-phyllo spicis longiore hasi dilatato scarioso. Vahl cu. 2. p. Âl1. In IIoxterideo.
10. S. imberbis R. Br. culmo simplici filiforni sulcato aphyllo; foliolo subulato; valvis margine nudis. 1 . Br. prodr. 1. p. 231. All Port. Jackson.

11. S. ericetorum R. Br. culmo sulcato-angulato, aphyllo; fasciculo duplici; spiculis 2-floris; valvis margine lanatis. 12. Br. prodi. 1. p. 231. Ad Port. Jackson.

12. S. brevifolius $\boldsymbol{R}$. Br. culmo tereti exsulco aphyllo; fasciculis pluribus; valvis margine parum ciliatis. R. Br. prodr. 1. p. 231. Ad Port. Jackison.

13. S. melanostachys R. Br. culmo simplici tereti exsulco aphyllo; panicula coarctata; valvis margine nudiusculis. R. Br. 1. c. Ad Port. Jackson.

11. S. Bobartiae Ret $\approx$ obs.4. p. 9; culmo compresso; fol. linearibus; capitulo terminali involucro pentaphyllo breviore. In Ceylonia.

15. S. ruber Lour. culmo tereti nudo; capitulo suhrotundo; involucro monophyllo lanuginoso. Lour. coch. p. 41. In Cochinchina. Cumus 2pedalis.

16. S. mucronatus Linn. spicis aggregatis; involucro 6-phyllo, unico longissimo; valvis lanceolatis e carina mucronatis. Host. gram. 4. t.78. In Europa australi et Africa boreali. 4.

1\%. S. tristachyos Thunb. culmo tereti articulato laevi; capitulis tribus terminalibus. Thunb. prodr. p. 16. In 2rom. b. spei. 24.

18. S. aristatus Thunb. culmo tereti aphyllo; involucro diphyllo, valvis cuspidatis. 'Thumb. prodr. p. 16. Ad Prom. b. spei. 4.

1.9. S. secunilus Valli; culmo toreti filiformi; fol. setaceis; spica secunda; spiculis ovato-subglobosis. Vahl en. 2. p. 210. s. bulbosus Tliunb. In Prom. b. spei. 4.

20. S. spicatus Thunb. culmo tereti foliisque capillarihus; capitulis spicatis involucratis. Thunb prodr. 1. p. 16. In Prom. b. spei. 4.

21. S. bulbosus Linn. culmo foliisque setaceis; spicis glomeratis; glomerulis alternis; involucris solitariis. Sicirpus capensis Rottb. t. 16. f. 3. In Prom. b. spei. 21.

22. S. compar I. culmo tereti aphyllo; spieis alternis subgeminatis 
sessilibus pedicellatisque; involucro solitario. liotb. grain. t. 18. f. 4. In Prom. b. spei. 2 . Culmus 2 pedalis...

23. S. cuspirlatus Thunb. culmo tcreti; fol. filiformibus ; spicis paniculatis, involucro solitario brevioribus. lloth. Gram. t. 18. f. 3. In Prom. b. spei. 4.

2.. S. inanis Thunb. culmo tereti nplyyllo; panicula terminali; spicis valvisque oblongis acntis. Thunb. prodr. p. 16. In Prom. b. spei. 4.

25. S. aggregatus Thunh. culno tercii striato aply-llo; spiculis terminali-aggregatis. Thunb. 1. c. In Prom. b. spei. 4 .

26. S. asper Schrad. culmo basi folioso; fol. linearibus recurvatis rigidis margine scaberrimis; valvis mucronatis. Schrad in schult. mant. 2. p. 41. In Brasilia. 4 .

\section{Culmo folioso.}

8\%. S. laevis Thunb. culmo trigono folioso; capitulis lateralibus; spicis ovatis; valvis mucronatis. Thunb. prodr. p. 17. In Prom. 6. spei. 4. Culnus 2-pedalis.

28. S. capillaceus Thunb. cnlmo tereti; fol. capillaceis; spicis suhracemosis; valvis mucronatis. Thunb. prodr. p. 16. In Prom. b. spei. 4.

29. S. fasciatus Rottb. gram. $t$. 16. f. 5. fol. setaceis; spicis subsolitariis terminalibus axillaribusq. valvis aristatis. R. ct. S. syst. 2. p. 69. In Prom. b. spei. 4.

30. S. setaceus Berg. culmo trigono foliisque setaceis; spicis subternis; floribus diandris. Berg. in Act. helv. 7. p. 130. t. 9. Rottb. t. 21. f, 2. In India occidentali. 4.

31. S. lispidulus Fahl; culmo angulato; fo! filiformibus hispidulis; pcdunculis tristachyis; spicis subglobosis. Vahl en. 2. p. 219. In Carolina. Culmus spithameus hispidulus.

32. S. microstachys Vahl; culmo roliisque filiformilsus glabris; spicis subgeminatis sessilibus oblongis. Vahl en. 2. pI 220. In Prom. b. spei.

33, S. villosus R. Br. culmo simplici tereti foliato; vaginis ore lanais ; spicis angustissimis; valvis margine villosissimis, $R$. Br. l. c. $\mathrm{Ad}$ I'ort. Jackson.
31. S. acuminatus R. Br. culmo filiformi compresso striato foliato; fol. selaceo-canaliculatis; valvis imberbibus. H. Bi. 1. c. In Nova Hollandia.

35. S. sparteus R. Br. culmo filiformi tereti paucifolio; vaginís ore lanatis; spicis falcatis; valvis margime nudis. R. Br. 1. c. In Noru Hollandia.

36́. S. punctatus $\boldsymbol{R}$. Br. culmo filiformi, compresso, foliato ; fol. setaceis; vaginis inberbibus; nucibus impress0-punctatis. H. Br. 1. c. In Nova Hollandia.

37. S. falcatus $\boldsymbol{R} . \boldsymbol{B r}$. culmo compresso foliato; fol. planis; vaginis imberbibus; spiculis falcatis; nucibus puncticulatis. R. Br. l. c. In Nova Hollandia.

38. S. lanceus Thunb. culmo trigono folioso; spicis paniculatis lateralibus valvisque lanceolatis. Thunb. prodr. p. 17. In Prom. b. spei. 4.

39. S. ustulatus Linn. culmo tereti; fol. filiformibus; spicis racemosis lanceolato-ohlongis; valvis aristatis. Hotth. gram. t. 18. f. 1. I/ Prom. b. spei.

10. S. flexuosus Thunb. culmo toreti; fol. linearibus planis; valvis ovato-lanceolatis mucronatis. Thunb. prodr. 1. 16. In Prom. 6. spei. 4.

\section{LEPIDOSPERMA Labill. (1804).}

\section{Culmo apliyllo.}

1. L. elatius Labill. Nov. Holl. $t$. 11. culmo complanato utrinque convexiusculo; fol. margine scabris. $\mathbf{K}$. Br. 1. c. In Nova Hollandia. Culmus 2-3-pedalis.

2. L. concavrm R. Br. culmo complanato hinc concaviusculo; marginibus foliisque laevilus; spicularum squamis acuminatis. H. Br. 1. c. Ito Nova Hollandia.

3. L. gladiatum Labill. $l$. c. t. 12. culmo complanato axi utrinque elevato marginibus foliisque laevibus; spicularum squamis acutiusculis, 1R. $\mathrm{Br}$. 1. c. In Nova Hollandia.

4. L. longitudinale Labill. 7. c. $\boldsymbol{t}$. 13. culmo foliisque complanatis axi utrinque convexiusculo marginibus scabris. R. Br. 1. c. In Nova IIol= landia. 
5. L. laterale $\boldsymbol{n}$. $B r$. ranis alternis subsimplicibus; involucro ensiforml breviore; culmo hinc plano inde convexiusculo; marginilus scabris. It. Br. 1. c. In Novu Hollundia.

6. L. tetralymum $\mathrm{R}$. $\mathrm{Br}$. culmo complanato utrinque convexiusculo marginibus scabris; squanulis hypogynis subulatis; stylo 4-fido. H. Br. 1. c. In Nova Hollandia.

7. I. exaltatum R. Br. culmo utrinque convexiusculo marginibus laevibus; panicula elongata; bracteis vagina brevioribus. IR. Br. 1. C. In Nova Hollandia.

8. L. viscidum R. Br. culmo plano foliisque margine scabris basibus viscidis; ramulis spicisve confertis fucatis. R. Br. I. c. In Nova Hollandia.

9. $\boldsymbol{L}$. congestum $\boldsymbol{R}$. $\mathrm{Br}$. culmo foliisque hinc convexiusculis inde concaviusculis, margine laevibus; spıcularum squamis acumiuatis. 1R. Br. 1. c. In Novil Hollandia.

10. L. laeve $R$. Br. culno utrinque convexiusculo foliisque laevilus; spica composita; spiculis ovatis. It. Br. 1. C. I $n$ Nora Hollandia.

11. L. squamatum Labill. $t . c$. $t$. 16. culno hinc plano inde convexiusculo; marginilus scabris ; foliorum basilus equitantilus, nitidis. 12. Br. 1. c. In Nova IJollandia.

12. L. angustatum R. Br. culmo lineari ; marginibus scahris; apice inde laevi sulcato; spica composita lanceolata; squamis acuminatis. $\mathbf{R}$. Br. 1. 0. In Nova Hollundia.

13. L. lineare $R$. Br. culmo complanato utrinque convexiusculo marginibus scabris; spica composita lanceolata; squamis acutis. H. Br. 1. c. In Nova Hollandia.

14. L. globosum Labill. t.? $_{\text {. }}$ t. 14. culmo complanato marginibus scabris; spica composita; spiculis subglobosis; squamis hypogynis oltusis. H. Br. 1. c. In Nova Hollandia.

15. L. aphyllum R. Br. culmo plano laevi flexuoso medio 1-vaginato, basi vaginis imbricatis; spica subsimplici. H. Br. 1. co In Nova Hollandia.

16. I. gracile $R$. Br. culmo ancipili lacvi; fol. planiusculis; spica subsimplici; valvis acuminatis. $\quad \mathrm{H} . \mathrm{Br}$. 1. c. In Nora Hollandia.
17. L. flexuosum R. Br. 'culmo tereti; fol. teretiusculis; spica simplici et divisa; spiculis distinctis subulatis. 1. Br. 1. c. In Nova Itollandia.

18. I. filiforme Iabill. $l$. c. $t$. 1.5. culmo filiformi tereti; fol. compressis; spica brevi; spiculis oblongis. $\mathbf{A}$. Br. 1. c. In Nova Hollandia.

19. I. striatum $\boldsymbol{R}$. Br. culmo tereti tenniter striato laevi; spica divisa: ramis alternis; spiculis imbricatis. 11. Br. 1. c. In Nova Hollandia.

\section{Culmo foliato.}

20. L. tetragonum Iuabill.- culmo obtuso angulato; fol. tetragonis; panicula coarctata; ramis parun divisis. R. Br. l. c. In Nova Hollandia.

2T. L. thermale Schrad. culmo 3-gono; fol. lato-linearibus; panicula nutante; valvarum setis leviler recurvis. schrad. in schult. mant. 2. p. 474. In Prom. b. spei. 4.

22. L. Rottboellii schrad. culmo subtrigono; fol. angusto-linearibus attenuato-cuspidatis; panicula nutante; valvarum setis rectis. Schrad. I. c. Schoenus thermalis Ihottb. t. 18. f. 2. In Prom. b. spei.?

23. L. involucratum R. et S. paniculis nutantibus; spicis congestis; valvis inferioribus lineari-lanceolatis aristatis. 11. et s. syst. vg. 2. p. 81. Schocmus Rottb. t. 19. f. 1. In Prom. b. spei.

24. I. Burmanni Spr. culmo tereti; fol. setaceis vaginantilus; florum panicula stricta. Spr. syst. 1. p. 194. sclıoenus Vahl. In prom. b. spei.

25. L. anceps Willd. culmo compresso ancipiti; fol. latis ensiformibus; spiculis glomeratis. Link Jahrb. 1. 3. p. 75. Scirpus Poir. In Madagascar.

25. L. iridifolium Willd. IIb. culmo compresso altissimo ; fol. cusiformibus angustis; paniculis fastigiatis; spiculis obtusiusculis. Link. l. c. Scirpus Poir. In Madagascar. -

221. PTEROLEPIS Schrad. (1817).

1. P. scirpoides Schrad. in Schult. mant. 2. p. 45. Culmus 2-3-ped.; Umbclla multiradiata, involucrata; in-• 
volucro dipliyllo; Involucellis multo minoribus. In Prom. b. spei. 4.

\section{CARPHA R. Br. (1810).}

1. C. alpina $\boldsymbol{R}$. Br. culmo foliato laevi; fol. scabris; setis hypogynis 6, fere ad apicem plumosis. H. Br. 1. c. In Nora Hollandia.

2. C. deusta R. Br: culmo aphyllo; fol. radicalibus subsetaceis; setis hypogyuis 3, basi plumosis. R. Br. l. c. In Nova Hollandia.

3. C. avenacea R. Br. culmo foliato teretiusculo; setis hypogyuis quatuor subedentulis, basi ciliatis. $\mathbf{M}$. Br. 1. c. In Nova Hollandia.

4. C. diandra R. Br. culmo folioso teritiusculo; panicula subcoarctata; setulis 5-6, capillaribus edentulis basi ciliatis; squamis aristato-acuminatis. R. Br. 1. c. In Nova Hollandia.

5. C. clandestina R. Br. spica elougata; spathis alternis ; spiculis geminatis inclusis; culmo tereti folioso. R. Br. 1. c. In Nova Hollandia.

\section{BLYSMUS Panz.}

1. $\boldsymbol{B}$. compressus Panz. culmo teretiusculo; spiculis multifloris; foliis graminosis. Hchb. exc. p. 514. Carex et Schoenus L. E. B. 791. Host. 3. t. 57. In Europae turfosis. 4.

2. B. rufus Panz. culmo tereti; ramulis pancifloris; foliis tereti-canaliculatis. S. rufus. Scluad. germ. t. 1. f. 3. Fl. Dan. 150\%. S. littoralis Fluegge. Ad mare balticum. 4.

\section{RDYNCHOSPORA Vahl. (1805).}

\section{Spiculis capitatis.}

1. R. cephalotes Vahl; culmo 3gono foliis linearibus alteriori; spicis globosis, involucro 4-phyllo brevioribus. Scirpus Rottb. gram. t. 20. In surinam. 24.

2. I. longisetis R. Br. capitulo globoso; rostello longitudine nucis; setis squamosis subaequantibus; involucro basi ciliato. R. br. 1.c. In Nova Iollundia.
3. R. capitata $\boldsymbol{R}$. et $\mathbf{S}$. culmis triquetris glabriusculis; fol. setaceotriquetris scabris; valvis acuminatis. nuce rostrata. Chaetospora $\mathbf{H}$. et $\mathbf{B}$. In ripa Orinoci. 4.

4. R. armenioides Presl. Rel. Haenc. 3. t. 32. f. 2. culmo 3-quetro fol. planis ciliatis longiore; capitulo obconico polystachyo; setis longissimis. Presl. 1. s. In isthmo Panamae. 4.

5. R. globosa R. et S. culmo triquetro glabro; fol. planis maryine scabris; involucro polyphyllo; valvis ovatis acutis infra apicem mucronulatis. Presl. 1. c. t. 36. Chaetospora Kunth. Ad ripas Orinoci et in Mexico. 24.

6. R. semiinvolucrata Presl. culmo 3-quetro scabriusculo; fol. planis margine scabris culmo breviorilus; involucro diphyllo; setis barbatis, germine ancipiti triplo longioribus. Presl. 1. c. In Pernvia. $\%$.

7. R. Haenkei Presl. fol. planis margine scabris culmo trigono brevioribus; involucro polypinyllo basi ciliato; setis nuce obovata ancipiti laevi a equilongis. Presl. 1. c. In ins. Luzon. 4 .

8. $R$. pterocarpa $R$. et $\mathbf{S}$. culmis trigouis foliisque glabris planis; vaginis pilosis; involucro suboctoplyyllo; nuce lenticulari alata subrostrata. Chaetospora Kunth. Schoenus globosus Rudge t. 15. In humidis Orinoci et Gujana. 4.

9. R. capitellata Tahl; culmo filiformi triquetro; fol. setaceis; valvis ovatis carinatis acutis; setis scalıris nuce longioribus. VahI en. 2. p. 235. Schoenus Pers. In Carolina.

\section{Spicis aggregatis aut co- rymbosis.}

10. R. capillacea Torrey; fol. setaceis; spicis $\mathbf{2}-\mathbf{5}$, subterminalibus ; bractea inifima setacea; setis 6 hispidis, nuce triquetra longioribus. Torrey Fl. of the united states 1. p. 55. In Pensylvania.

11. R. fusca $R$. et S. culmo trigono; fol. setaceis canaliculato-carinatis; valvis triandris fuscis; setis hypogynis ternis. Eingl. hot. 1575. Fl. Dan. 1562. In turfosis Europae. 2. 
12. R. albu Vall; culmo trigono; fol. lincaribus canaliculatis; spicis anrregalo-corymhosis; valvis diandris albentibus; setis lypogynis $6-10$. Schuenus Limt. Fl. Dan. 320. Fngl. hot. 985. Host. t. 72. In turfosis Europae. 4.

13. R. micrantha Vaht; culmo folisque filiformibus; corymhis diffusis; muce obovata rugosa. Vahl l. c. In America boreali. 4.

11. R.plumosa Elliot; culmo gracili triquetro; fol. linearibus; involucris aristatis; nuce rugosa; setis plumosis. Elliot. 1. c. In Carolina.

15. R. pilulifera Bertol. fol. linearibus elongatis planis; spicis axillaribus compositis; spiculis globulosis nudis. Bertol. Piant, del bras. p. 2. In Brasilia.

16. R. vilida Spr. culmo tereli glabro aphyllo; spiculis glomeratis nitidis 8-floris; involucro 1-phyllo. In Prom. b. spei. 4.

1\%. R. filiformis Valiz; calmo obcusangulo lacvi foliisque filiformibus; corymbis axillaribus simplicilus terminalibus subcompositis. Vahl 1. c. In l'ortorico.

15. R. sparse Tahl; calmo 3-quetro folioso ; corymbis diffusis ; pedunculis capillaribus; seminibus rostro longioribus. Vahl 1. c. śchœus Michx. In Carolina el Georgia.

19. R. gracilis Vall; fol. linearibus culmo filiformi latioribus; spicis corymboso-fasciculatis. Vahl ch. 2 . 1. 234. In samaica.

20. R. tenerrima Nees; culmo foliato foliisque setaceis laevibus; valvis mucronato-aristatis; nuce rugosa subtridentata. Nees in Sieb. Agrost. 116. In Jamaica.

21. R. setacea Tahl; culmo foliisque setaceis; corymhis axillaribus terminalibusque paucifloris. Vahl. 1. c. Schonus Poir. In America meridiozali.

22. IR. glauca Tahl; culmo acutangulo; fol. linearihus; spicis corymboso-fasciculatis approximatis solitariis. Vahl en. 2. p. 233. In America meridionali.

23. R. fascicularis Vall; culmo acutangulo; fol.linearibus; spicis axillarihus terminalibusque corymbosofasciculatis. Vahle In Curolina.

21. R. triflovel l'ahl; culmo acutangulo scabro; spicis subgeminis; ro- stello longiluline semius. Vahl. 1. c. In Judia orientali.

25. 12. glomerata rahl; culmo trigono folioso; fol. linearibus planis margine scahris; spicis remotissimis geminatis. VahI 1. c. In Americo boreali.

26. R. Broucnii R. et S. culno angulato gracili scrahro; rostello obtuso exsulco nuce rugosiuscula breviore. Ii. Iaxa L. Br. In Nova Hollanuia.

27. R. ciliata Tahl; culmo filiformi; fol. linearihus ciliatis; bracteis oblusiusculis ciliatis. Vahl 1. c. Schoeuus Michx. In Florida.

28. R. hirsutu Full; culmo foliisque filiformilus; corymbis axillaribus patentihus simpliculus; terminalibus composilis. Vahl en. 2. p. 231. In America.

29. R. penctata Elliot; culmo triquetro ; fol. lineari-lanceolatis nargine scabris; nuce rugosa punctata. Eiliot 1. c. In Georgia.

30. R. distans Vahl; culmo trique!ro; fol. lincaribus; nuce laevissime sulcata. Vahl 1. c. Schœnus Michx. In America boreali.

31. IR. Longirostris Elliot; culmo triquetro; fol. lineari-lanceolatis margine serrulatis; rostello longissimo. i. laxa Vahl I. c. In America boreali.

32. R. inexpansa Vahl; culmo trigono; fol. serrulatis; paniculis pendulis; 'setis scabris; nuce oblonga rugosa duplo longioribus. Vahl I. c. In Carolina.

33. R. cymosa Elliot; culmo triquetro; bracteis setaceis; valvis inferioribus ohcordatis mucronatis. Elliot 1. c. Scirpus Spr. In America 6oreali.

31. R. caluca Elliot; culno triquetro; nuce lesticulari rugosa; setis nuce duplo longioribus. Elliot 1. c. In Carolina.

35. R. conica Hamilt. culmo argute triquetro, inferne repente; spiculis laxis albescentibus; involucro 3phyllo. Hamilt. ind. occid. p. 15. In Cayenna.

36. R. pyramidata Hamilt. panicula clongata interrupta; rhachi subpilosa; spiculis albescentibus. Uamilt. 1. c. In Jamaica.

3\%. R. Ellioti Alb. Dielv. paniculis decompositis pendulis; spiculis fa- 
sciculatis; nuce ohovata rugosa. Scirpus schoenoides Elliot. In Georgia.

38. R. gigantea Hilla. Ilb. fol. latissimis margine et nervo scaherrimis; valvis acutis carinatis fuscis. Link Jahrb. 1. 3. p. 76. In Brasilia.

39. $R$. comata Link; fol. planis glancis vaginis hirtis; involucro panicula contracta longiore; valvis oblongis mucronatis. Link I. c. In IBrasilia.24.

10. R. cyperoides Mart. culmo triquetro folioso; umbella terminali; spiculis glomeratis. Mart. Denkschr. 6. p. 149. Schoenus Sw. In Jamaict.

11. R. vicosensis R. et $\boldsymbol{S}$. spiculis ovato-oblongis; squamis cuspidatis; nuce transversim undulata, rostrata. Chactospora schrad. In Brosilia prope Vicosa.

12. R. ferruginea $\boldsymbol{R}$. et $\mathrm{S}$. culmis triquetris glabris; squamis ovatis mucronato-aristatis, nuce lenticulari transversim undulato-rugosa. Chaetospora liumth syn. 1. p. 159. In America merillionali. 4 .

13. R. polyphylla Vahl; culmo triquetro folioso; corymbis contractis; pedunculis villosis; rostello longitudine nucis. Vahl 1. c. In India orientali. 24.

14. R. florida Alb. Dietr. culmo rolioso triquetro; pedunculis inferiorihus distantihus; nuce calyptrata. Schoenus Rudge Guj. t. 18. In Gujana et Essequebo. 4.

4.). R. anvere Valh; fol. planis margine carinaque serulatis; nuce sublenticulari, subrugosa longe rostrata. Vahl 1. c. Schoenns Botth. t. 21. f. 1. In India, America et Nova Hollandia. 4.

46. R. globulifera Willa. culmo triquetro folioso; capitulis globosis subternis, intermedio sessili. Schoenus triceps Vahls. polyceplaalus Presl. In America merirlionali.

47. R. rigfide s $m$. fol. riggidis; culmum triquetrum superantibus; valvis appressis. spreng. syst. veg. 1. p. 196. In Jamaica.

48. R. articulate $R$. et S. culmo triquetro articulato folioso; stylo indiviso; nuce ohovata setosa, stylo coronata. schoenus Roxb. ind. 1. p. 189. In montibus Circars. Culm. $5-6$ ped.
49. R. mollis $\boldsymbol{R}$. et $\mathrm{S}$. fol. angustis sctaceis villosis involucro subseptemphyllo umbella breviore villoso; valvis ovatis subaristatis glabris. R. et S. syst. mant. 2. p. 19. Sicirpus Roxb. In Nepalia.

50. Kyssor Roxb. culmo 3-angtlari hispido umbella supradecomposita; spicis ovatis; nuce ohlonga triangulari selis $\mathbf{5}$ villosis cincta. Roxb. ind. 1. p. 2:3. In Bengalia.

51. Li. macrostylis Alb. Ditr. culmo teretiusculo aphyllo stricto; fol. culmo brevoribus linearibus ciliatis ; involucro polyphyllo. Eleocharis Spr. In Cuba.

III. Spicis solitaris.

52. R. spicata Spr. culmo flexuoso ; fol. linearihus faccidis; valvis suhulatis patentibus. spr. syst. ver. 1. p. 194. In Brasilia.

\section{S. ELEOCHARIS R. Br. (1810). Scirpus Auct.}

\section{Culmo tereti.}

1. E. palustris $R$. et S. cnImo basi stolonifero tereti striato; nuce ancipiti ; stylo 2-partito hasi corrugato. ścirpus Linu. Fl. Dall. 273. E. B. 131. Host Gram. 3. 8. 55. In uliginosis Europae et Americue borealis. 4.

-2. E. uniglumis R. et S. culmo hasi stolonifero; spica ovali; bractea unica; stylo basi crassissimo non corrugato. Sicirpus Link. Rchb. ic. 182. In Germania, Suecia et Helvetia. 4.

3. E. multicaulis Sm. culmo non stolonifero; spica ovata; bractea spicam amplexante apice emarginata ; valvis oltusissimis; nuce 3-quetra; stylo 3-partito. E. B. 1187. In Anglia. 4.

4. E. caúuca R. rt S. culmo basi stolonifero; spica ovata; bracteis duabus valvisque oblongis obtusis caducis; nuce obcordata. Ścirpus Delile Aegypt. 8. 6. f. 2. In Aegypto. 4.

5. E. ovata R. et S. cuhro tereti subcompresso striato; spica subglohoso-elliptica; nuce ancipiti; stylo 2-partito basi corrugato fusco. Scirpus llost Gram. 3. t. 56. In galulosis turfosis Europae. $\odot$.

6. E. pellucida Prest. culmo tereti striato; spica ovata; valvis oblongis obtusis 1-ncrviis; stylo filiformi trifido 
globoso-dilatato. Presl. Reliq. Haenc. 3. p. 196. In Lazonia. 4.

\%. E. obtusa Link; culmo tereti striato; spica ovali; bractea una alterave rotundata; valvis ovalibus obtusis. Link. Hort. 1. 1. 282. In America boreali. 4.

8. E. glaucescens Link; culmo stolonifero tereti compresso striato glaucescenti; stylo 3-partito basi corrugata a unce nargine cincta. Link 1. c. In America boreali. 4.

9. E. simplex Elliot; culmo tereti; spica subovata; valvis obtusis; nuce obovata triquetra. Elliot bot. 1. p. 76. In Carolina. 4.

10. E. tuberculosa R. et S. culmo tereti; spica ovata acuta; valvis subrotundis; nuce subglobosa, tuberculo ovato lato coronata. $\mathbf{l}$. et $\mathbf{S}$. I. c. In Carolina. 4.

11. E. compacta R. Br. culmo inarticulato intus celluloso; spica cylindracea; valvis densissime inibricatis cuneato-ohovatis ecarinatis. $\mathbf{R}$. Br. 1 . c. In Nova Hollandia.

12. E. acuta. R. Br. culmo laevissimo inarticulato; vaginis truncatis mucronulo foliaceo; valvis lanceolatis acutis carinatis. R. Br. 1. c. In Nova Hollandia.

13 E. gracilis R. Br. culno setaceo striato; vaginis obliquis mucronulatis; spica ovali acuta; valvis obtusis; setis 4 hypogynis ovario parum longioribus. R. Br. S. tener spr. "Ad Portum Jaclison.

1. E. misilla R. Br. culmo setaceo striato; vaginis ore obiquo mutico; spica lanceolata; setis hypogynis 4-5. 11. Br. 1. c. S. Pumilio Spr. Ad Portum Jackson.

15. E. setacen R. Br. culmo filiformi striato; spica globoso-ovata; valvis ovalibus obtusis; nucibus fuscis. R. Br. 1. c. S. Brownii spr. Iu Nova Hollandia.

16. E. atricha R. Rr. culmo tereti; spica oblongo-cylindracea acuta; valvis obtusiusculis; setis lypogynis nullis. 1i. Br. 1. c. Ad l'ortum Juckson.

17. E. limosa 1 . et $\mathbf{S}$. radice repente; culmis teretibus; vaginis truncatis mucronatis; valvis obtusis. R. et s. 1. c. Scirpus Schrad. In Prom. b. spei. 4 .

18. E. chataria $R$. et S. culmo sefaceo recto; spica ovata sub 5-flora.
R. et S. 1. c. Cyperus setaceus Hetz. In Calcuttae graminosis.

19. E. congesta Don; culmis cacspitosis teretibus sulcalis; spica clliptica; valvis obtusissimis scariosis. Dou prodr. p. 41. In Nepalia.

20. L. montana R. et S. repens; spica cylindracea; valvis subrotundis acutis enerviis; nuce subtrigona laevi. 13. et \$. Scirpus Kunth. In Nova Granata. 4.

21. E. atropurpurea Presl. culmo tereti inarticulato; spica ovata; stylo filiformi bifido, hasi globoso dilatato. Presl. 1. c. In ins. Marianis. 4.

\section{Culmo articulato.}

22. E. interstincta $\boldsymbol{R}$. et $\mathbf{S}$. culmis teretibus superne approximate interstinctis; valvis subrotundis laevibus. $\mathbf{R}$. et $\mathrm{S}$. In Caribaeis.

23. E. sphacelata R. Br. culmo articulato inani; spica cylindracea; valvis ovalibus margine sphacelatis. R. Br. 1. c. In Nova Ilollandia.

2. E. elegans R. et S. culmis teretibus; spica cylindracea; valvis oblongo-cuneatis, 1-nerviis; nuce lenticulari punctata scabra. Scirpus Kuntl. 1. p. 155. In Peruvia. 4.

25. E. Ellioti Alb. Dietr. culmis duplicato-articulatis; spica cylindrica terminali; valvis obtusissimis. Scirpus equisetoidus Elliot bot. 1. p. 79. In Carolina boreali.

26. E. equisetina Presl. valvis elliptico-subrotundis 1-nerviis; stylo compresso bifido basi dilatato, setis 6 ; nuce ancipiti punctulata. Presl. 1. c. In Luzonia. 4.

2\%. E. plantaginea R. et S. culmis remotiuscule interstinctis; spica subcylindrica acuta, valvis oblongis obtusis. Ścirpus hottl). Gram. t. 15. f. 2. In India orientali.

28. E. tumida R. et S. culmis ventricosıs aequaliter interstinctis; valvis lente lanceolatis acutis; setis hypogynis simplicibus. $\mathbf{R}$. et $\mathbf{S}$. I. c. Scirpus Roxb. In India orientali.

29. $\mathrm{E}$. tuberosa $\mathrm{R}$. et $\mathrm{S}$. radice tuberosa; culmis aequaliter interstinctis; valvis oblongis; stylo basi cordato; nuce obcortlata; setis glochidiatis. Scirpus 12oxl). corom. t. 231. In India orientali.

30. E. geniculata R. et S. culınis teretibus approximate interstinctis; spi- 
ca ovato-oblonga; valvis ovato-subrotundis; nuce pyriformi. Scirpus Lim. In India occidentali.

31. E. constricta $R$. et s. culmis teretilus approximate interstinctis ; valvis oblong-ovatis; nucibus oblongis 3-gonis. $\mathbf{R}$ et $\mathbf{S}$. In Brusilia. 4.

32. E. nodulosa $R$. et S. culmis filiformilus approximate interstinctis; vaginis truncatis dente solitario. 13 . et s. mant. 2. p. 87. In Brasilia.

III. Culmo nngulato.

33. E. capitata R. Br. culmo filiformi, sulcato-angulato; vaginis inflatis; valvis oblongis obtusissimis. IR. Br. l. c. Scirpus carihaeus Rottb. Gram. t. 15. f. 3. In India occidentali et orientali et in Nova Hollandia. 4.

31. E. tenuis Link; culmo filiformi superne 4-gono; spica oblonga; nuce ancipiti; stylo 3-partito hasi corrugato. Link Hort. 1. p. 282. Scirpus Willd. In America boreali. 4.

3.5. E. acicularis R. et S. culmo 4-gono setaceo; nuce ancipiti; costis longitudinalibus; stylo basi corrugato. Ncirpus Link. E. B. 749. Host. Gram. 3. t. 60. In uliginosis Europae. 4 .

36. E. vivipara Link; culmo angulato setaceo; spica bracteata superne prolifera; stylo hasi corrugato. Link Hort. 1. p. 283. Patria iymota. 4.

3\%. E. intermealia schult. culmo 4-angulo sulcato; spica ovato-ohlonga acuta; nuce pyriformi tuherculo conico coronata. Schult. mant. 2. p.91. In America boreali. 4.

38. E. maculosa $\boldsymbol{R}$. Br. culmis filiformibus angulatis ferrugineo-maculatis; nuce orhiculo coronata. $\mathbf{R}$. Br. In Guadelouye.

3.9. E. spiralis IR. et S. culmo triquetro; spica cylindrica ohtusa; valvis spiraliter dispositis truncatis cuneiformilus. Ir. et s. S'cirpus Iiotth. Gram. tab. 15. f. 1. In Indla orientali.

10. E. acutungula R. et $N$. culmo tringulari angulis subulatis; spica attenuata acuta; valvis spiraliter dispositis; setis hypowynis. Sicirpus Roxb. ind. 1. p. 216. In India orientali.

41. E. media R. et S. culmo trigono; angulis rotundatis; spica subcylindrica; valvis ovatis obtusis; setis hypogynis. scirpus lioxb. I. c. In India orientall.
42. E. mutata R. et S. culmo triquetro; spica cylindrica; valvis subrotundis enervibus margine membranaceis laceris; nuce obovata ancipiti. Scirpus L. In Jamaica et Mexico. 4. 13. E. qualrangulati R. et S. culmo acuto 4 -angulato, lateribus trihus concavis uno latiore plano; valvis oltusissimis. H. et S. I. c. In Americu boreali. 4.

229.

\section{BAEOTHRYON Alb. Dietr. (1533). Scirpus auct.}

\section{Culmo tereti.}

1. B. caespitosum Alb. Dietr. vaminis laxis oblique truncatis lamina foliacea hrevissima; bracteis duabus, exteriori subfoliacea spica majori. Scirpus Host. Gram. 3. t. 59. E. B. 1029. Eleocharis Link. In turfosis Europae. 4.

2. B. panciflorum Alb. Dietr. vaginis laxis truncatis aphyllis, bracteis duabus, exteriori non foliace spica minori. S. pauciforus. E. B. 1122. Host. 5. t. 58. Eleocharis Link. In turjosis Europae. 4.

3. B. nanum Alb. Dietr. culmo aphyllo evasiuato; bracteis duabus spica brevioribus; valvis ovatis acutis. Scirpus Spr. S. parvulus $\mathbf{R}$. et $\mathbf{S}$. $\mathbf{S}$. humilis WVallr. Eleogiton Link. In inundatis lacus hoelmensis in Mansfeldia.

4. B. flavescens Allb. Dietr. culmo stricto; spica minima suln1-flora; bracteis duahus oppositis spica hreviorihus. Sicirpus Poir. 1. c. p. 756. In Puerto-Rico.

5. B. Hystria Alb. Dictr. vaginis aphyllis brevi mucronatis; spica obovata; bractea infima spica hreviori; valvis acuminatissimis squarrosis. Vahl en. 2. p. 226. In Prom. b. spei.

6. B. variegatum Alb. Diets. vaginis aphyllis truncatis; apica conica; valvis apice rotundatis variegatis. Scirpus Poir. 1. c. p. 749. In Madagascar.

\section{I. Culmo angulato.}

7. B. pygmaeum Alb. Dietr. culmis subangulatis setiformibus; spica oblonga subbiflora. Scirpus Lam. ill.1. p. 139. In India orientali. 
8. B. pusillum Alb. Dietr. culmo 4-angulo aciculari; vaginis truncatis ohtusis; spica 1-bracteata, ovata. Sicirpus capillaris Michx. In America boreali. 24.

9. B.trichodes Alb. Dietr. repens; culmis 4-gonis capillaceis glabris; spica oblonga compressa; nuce 3-gona hasi setis cincta. Scirpus Kunth syn. 1. p. 155. In Nova Granata.

10. B. teniusculum Alb. Dietr. culmis selaceis compresso-trigonis; vaginis truncatis mucronatis; spica ovato-oblonga; valvis obtusissimis. sclırad. 1. c. Schult. mant. 2. p. 74. In Brasilia.

11. B. retroflexum Alb. Dietr. culmo subtereti angulato setiformi folio vix longiore; fol. capillaceis retroflexis diffusis; spica minima. Poir. 1. c. In Portorico.

12. B. confervoides Alb. Dietr. culmo communi setaceo radicante nodoso; fol. subverticillatis capillaceis; spica minima. Poir. 1. c. In Madagascar.

13. B. festucoides $A l b$. Dietr. culmo 4-quetro filiformi; fol. caespitosis setaceis; spica ovata; valvis scariosis. Poir. 1. c. In Mallagascar.

11. 13. crinitum Alb. Dietr. culmo sctace 3 -quetro; fol. setaceis; spica sublaterali obtusa compressa. Poir. 1. c. In Maslagescar.

15. 13. fistulosum Alb. Dietr. culmo subtriquetro molli nudo; spica cylindrica; valvis ovatis obtusis apice membranaceis. Poir. Enc. 6. p. In Madagascar.

\section{ELEOGITON Link (1S22)}

1. E. fluitans Link; culmo stolonifero ramoso folioso; fol. linearibus 3-nerviis; valvis obtusis sublaceris; nuce laevi punctata. Scirpus L. FI. Dau. 1082. E. B. 216. In arpuis Europue et Novae Hollandiae. 4.

2. E. cermuc Alb. Dietr. culmis angulatis capillaribus; vacinis mucronatis; spica ovato-oblonga. Isolepis 13. et s. Sicirpus Vahl. In Lusitania. 24.

3. E. elonyantha Alb. Dietr. culmo tereti setaceo basi folioso; spica pauciflora involucrum diphyllum vix superante. Isolepis Meycr in Ledeb. all. Ad fluvium T'schujum. 4.
4. E. filiformis Vahl; spica cylindrica oblonga obtusa; valvis subrotundis; nucilus vertice nudis. Isolepis I. et S. In Carolina. 4 .

5. E. atropurpurea Alb. Dietr. aphylla; spica ovato-oblonga erecta; valvis ovatis laevibus; floribus monaudris. S'cirpus Retz ols. 3. p. 14. Isolepis I. et $\mathbf{S}$. In India orientali.

6. E. ralicuns $A$ lb. Dietr. radice repente stolonifera; culmis subcompressis striatis filiformibus nudis; spica minima. Scirpus Poir. In Portorico.

7. E. monostachya Alb. Dtr. cnlmo stricto teretiusculo adscendente basi folioso; spica ovata; valvis obtusis. Scirpus Roxb. ind. 1. p. 221. Isolepis Spreng. In India orientali. 8. E. planifolia Alb. Dietr. culmo subnudo 3-quetro; fol. planis linearibus striatis margine scabris; spica 6-flora. Scirpus Mühlenb. descr. ub. p. 32. Isolepis Spr. In America boreali. 4.

9. E. exigua Alb. Dietr. repens; culmis 4-angularibus glabris; spica ovata compressa; staminibus duabus. Scirpus Kuntl. syn. 1. p. 154. Eleocharis R. et S. In Nova Granata.

10. E. verruculosa Alb. Dietr. culmo flaccido basi vaginato; vaginis brevissime foliatis; spica ovata acutiuscula; nucibus nitidis versucososcahridis. Scirpus Steud. in Bot. Zeit. 1829 I. p. 145. In puludosis montis tabularis.

11. E. scariosa Alb. Dietr. culmo tereti nudo; fol. radicalilus canaliculatis; spica cylindrica acuta; valvis margine scariosis. Scirpus bulbosus Rotib. Gram. t. 16. f. 2. In Prom. b. spei. 4.

12. E. caricoirles Alb. Dietr. culmo basi ramoso foliaceo; fol. linearibus glabris; valvis ovatis concavis striatis submucronatis. Schocnus steud. 1. c. In fissuris rupium montis tabularis.

13. E. scabra Alb. Dietr. culmo erecto angulato; spica oblonga; valvis oblongis diandris; nuce obcordata scalira. Scirpus Roxl. ind. 1. p. 222. vimbristylis $\mathrm{I}$. et $\mathrm{S}$. In Coromandel.

11. E. spadicea Alb. Dietr. culmo setaceo; spica ovato-oblonga obtusissima; involucro 1-plydlo spica breviore. 
Scirpus Vahl, en. 2. p. 210. In Dominyo.

B31. ISOLEPIS R. Br. (1810). Scirpus auct.

I. Spiculis lateralibus.

1. I. setacea $\boldsymbol{R}$. $B$ r. culmo tereti filiformi; vaginis oblique truncatis, lamina brevi; valvis ovatis oblusissimis ; nuce subtrigona lineis elevatis. $\mathbf{R}$. Br. prod. 1. p. 222. Scirpus Host. Gram 3. t. 65. Hl. Dan. 311. E. B. 1693. In uliginosis Europae et Novae Hollandiae. $\odot$.

2. I. sariana R. et S. culmo tereti filiformi; vaginis truncatis; nuce subtriquetra, tuberculis minimis scabriuscula, Schult. mant. 2. p. 63. In Europa australi.

3. I. pumila $\boldsymbol{R}$. et $\mathbf{S}$. culmis setaceis basi 1-phyllis; involucro subdiphyllo; nuce trigona laevi. R. et $\mathbf{S}$. syst. 2. p. 106. I. leptalea Koch. In Europa australi. 2.

4. I. minima schrad. culmis foliisque capillaribus; valvis ovatis obtuse mucronatis 1-andris. Schrad. in Schult. mant. 2. p. 63. Scirpus setaceus liottb. Gram. t. 16. f. 4, 5, 6. In Prom. b. spei.

5. I. temuis Presl; culmo 3-quetro setaceo; vaginis foliiferis; nucibus compressis triquetris rugosis. Presl in Delic. Prag. 1. p. 14. In ins. Creta. $\odot$.

6. I. rubescens. Prest; culmis angulatis; vaginis aristatis; involucro diphyllo mucronato; spica ovata compressa; nucibus 3-quetris tuberculatis albidis. Presl 1. c. In humidis ad kio Janeiro. 24.

7. I. brachyphylla Presl; cuImo filiformi; vaginis folio setaceo terminatis; bracteis duabus ovatis; altera aristata; nuce ancipiti apice tuberculata. Presl in Reliq. Haenk. 3. p. 187. In Peruvia. 4.

8. I. acuminata Alb. Dietr. culmo basi vaginato foliaceo foliisque setaceis rigidusculis; spica laterali ovata; involucro 1-phyllo. Scirpus steud. 1. c. In monte tabulari.

9. I. oligantha Alb. Dietr. culmo foliisque setaceis flaccidis; vaginis radicalibus solubilibus; nuce triquetra punctata. Scirpus Steud, 1. c. In monte tabulari.
10. I. Pseudoschoemus Alb. Dieîr. culmo asperulo setaceo; fol. setaceis rigillis; spica laterali solitaria pauciflora; involucro 1-phyllo ; valvis striatis. Steud. 1. c. In monte tabulari. 11. I. riparia $\mathbb{1 2}$. Br. culmis setaceis basi vaginatis; valvis subrotundis obtusis diandris; nucibus obtuse triquetris scabriusculis. R. Br. 1. c. Ad Portum Jackson.

12. I. lenticularis R. Br. culmis capillaribus basi 1 -foliis; valvis ovatoIanceolatis diandris; stylis 2-fidis; nucibus lenticularibus. R. Br. 1 . c. $\boldsymbol{A} d \boldsymbol{b}$ portum Jackson.

13. I. numidiance $R$. et $\mathbf{S}$. culmis setaceis; vaginis aristatis; spicis subglohosis subsolitariis; valvis subrotumdis. R. et S. 1. c. In Numidia.

11. I. cyperoides $\boldsymbol{R}$. Br. culmis angulato-setaceis basi 1-foliis; spicis 1-2 oblongo-lanceolatis; valvis diandris. R.Br. l.c. In Nova Hollandia.

15. I. cartilaginea $R$. Br. culmis setaceis basi 1-foliis; spiculis $1-3$, ovatis culmi apicem aequantibus; valvis cartilagineis carinatis nervosis 3-andris. H. Br. 1. c. In Nova Ilollandia.

16. I. inundata $R$. Br. culmis setaceis basi vaginatis; spiculis $2-6$, glomeratis; nucibus sublenticularibus laevibus. R. Br. 1. c. In ins. van Diemen.

17. I. propinqua R. Br. culmis setaceis basi vaginatis 1-phyllisve; stylis 3-fidis; mucibus triqnetris laevibus. 1. Br. 1. c. In Nova Hollandia.

18. I. supina R. Br. culmo tereti nudo; vaginis laxis saepe fissis; valvis mucrone brevissimo; nuce trigona transversim rugosa. R. Br. l. c. Scirpus L. Host. Gram. 3. t. 64. In Europa, India orientali, Africa, Noves Hollandía. $\odot$.

19. I. natans Thunb. culmo compresso folioso flexuoso-erecto; spicis duahus Iateralibus. Scirpus Thunb. prodi. p. 17. In Prom b. spei.

20. I. Mühlenbergii Alb. Dietr. culmo setaceo triquetro subnudo; spicis 1-4, una sessili; stylo 3-fido; nuce transversim rugosa. Scirpus capillaris. Pursh. In America boreali.

21. I. Wallichiana R. et S. culmis hasi diphyllis foliisque setaceis striatis; vaginis apice barhatis; nucibus triquetris laevibus. I. capillaris Don. Scirpus Spr. In Nepalia. $\odot$. 
22. I. uninodis Delile; culmo triangulari uninodi; vaginis subfoliiferis; nuce globosa alata. Delile Aegypt. t. 6. f. 1. In Alegypto.

23. I. Carmichaelii Alb. Dietr. capitulo laterali glohoso polystachyo; valvis late ovatis nervosis margine scariosis apice calloso. I. sulcata Carm Fl. Trist. in Lin. Trans. XII. 2. p. 503. In insula Tristan da Cunha.

24. I. substuarrosa Schorat. culmis setaceis curvatis; fol. filiformihus; valvis 1-andris obovatis, acumine recurvo. Schrad. in schult. mant. 2. p. 6.1. Scirpus ninimus Pursh. In America boreali.

25. I. micrantha $\boldsymbol{R}$. et $\boldsymbol{S}$. culmo foliisque setaceis; spicis ovatis acutis ternis aphyllis; valvis oblongis. $\mathbf{H}$. et S. syst. veg. 2. p. 110. In America meridionali.

26. I. tristachya $R$. et $\boldsymbol{S}$. culmo setaceo; spicis ohlongis subternis; involucro diphyllo; valvis integris ovatis. R. et s. 1. c. Gram. pusillum etc. Bum. Zeyl. t. 47. f. 2. In Prom b. spei et in India orientali.

2\%. I. corymbosa R. et S. pedunculis pedicellisque compressis; spiculis ovatis fasciculatis pauciftoris; valvis ovatis acuminatis integris. Schult. mant. 2. p. 65. In India orientali.

28. I. aristata Presl; culmo foliisque 3-quetris; involucro diphyllo, foliolo exteriore longissimo; valvis ovatis mucronatis. Presl 1. c. In Hungaria. 4 .

29. I. Thuarsii Alb. Dietr. culmis angulatis ramosissimis; fol. fasciculatis; capitulis proliferis; involucro diphyllo. Pet. 'Thuar. I. prolifera Carmiclı. Fl. trist. da Cunl. t. 9. In ins. Tristan da Cunka.

\section{Spiculis terminalibus ag- gregat is.}

30. I. hemisphaerica Alb. Dietr. culmo filiformi aplyllo basi vaginato; capitulo lımisphaerico, involucro monophyllo e latissima hasi lineari-canaliculato multo breviore. Scirpus Roth. nov.pl.sp. p. 29. In India orientali.

31. I. marginate Thunb. culmo capillari; capitulo 3-stachyo; valvis integris glabris; involucro 1-phyllo. Scirpus Thunb. prodr. p. 17. In Prom. b. spei.
32. I. capillaris R. et $S$. culmo nudo capillari; spicis pedunculatis ternis, intermedia sessili. R. et S. 1. c. In Acthiopia.

33. I. bispicato R. et S. culmis suberectis filiformibus; spicis $2-3$ terminalibus sessilibus pedunculatis involucratis; nuce obcordala margine callosa. schult. mant. 2. p. 61. scirpus rariflorus schrad. \$. hispicatus Itoxb. ind. In India orientuli.

31. I. trichodes Schral. culmis foliisque capillaribus glabriusculis; involucro diphyllo; valvis ovatis ciliatis. Schrad. in schult. mant. 2. p. 64. In Irrasilia.

3.5. I. uncinata R. et S. pilosa; culmo tereti folioso; capitulis axillaribus terminalibusque pedunculatis. R. et S. 1. c. Scirpus Willd. Pluckn. t. 190. f. 7. In India orientali.

36. I. nigricans Kunth; repens; culmis foliisque glahris planis; involucro diphyllo; nuce triquelra acuminata punctato-scabriuscula. Kunth syn. 1. p. 151. In Peruria. 4.

3\%. I. squarrosa H. et S. culmo triquetro setaceo; capitulis squarrosis; involucro diphyllo; valvis ovatis aristalis; aristis recurvatis. schult. mant. 2. p. 65. Scirpus Rottb. t. 17. f. 5. In India orientali.

38. I. Humboldtii. Alb. Dictr. culmis 3-gonis glabris 1-phyllis; folio setaceo glabro; nuce oblonga obtusa compressiuscula papilloso-scabriuscula. Kunth. syn. 1. p. 151. Ad Orinocum. $\odot$.

39. I. elachista $R$. et $\mathbf{S}$. culmis setaceis curvis, folio brevioribus; involucro triphyllo; spicis glohosis squarrosis, longitudine fere involucri. Scirpus hoxb. In India orientali.

10. I. acugnana $R$. et $S$. culmis angulato-filiformilous indivisis basi foliatis; fol. angustissimis; spiculis 12-20 ovatis; involucro diphyllo deflexo. I. squarrosa. Carmich. 1. c. In insula Tristan da Cunha.

41. I. barbata R. Br. culmis foliisque capillaribus vaginis ore barhatis; capitulo globoso involucrato; valvis alte carinatis mucronatis. $R$. Br. prodr. 1. p. 222. Scirpus Rotlb. Gram. t. 17. f. 4. In Prom. b. spei, India orientali, Guinea et in Nova Hollandia. 4.

42. I. antarctica. R. et S. culmo triquetro nudo; capitulo globoso; in- 
volucro 1-phyllo. R. et S. 1. c. In Prom. b. spei.

43. I. coronaria $R$. et S. culmo fliformi triquetro; fol. setaceis ore nudis; capitulo globoso; involucro 4-phyllo elongato; valvis acutis. H. et s. syst. 2. p. 113. Prope Ischandraconam.

14. I. paradoxa Schrad. culmis hasi hulbosis; fol. setaceis culmo breviorihus; involucris vaginisque margine capillaceo-laciniatis; valvis multifidis. Schrad. Ann. in Goett. gelehrt. Anz. n. 208. p. 3068. In From. b. spei.

45. I. filamentosa $\boldsymbol{R}$. et S. culmo setaceo 4-gono; fol. setaceis; vaginis ore nudis; capitulo glohoso; valvis ovatis. R. et S. 1. c. In Guinea.

16. I. radiata $R$. et $s$. culmo teretiusculo; capitulo hemisphaerico; involucro octophyllo Iongissimo. R. et S. syst. 2. p. 113 . Scirpus Thunb. In Prom. b. spei. 4.

47. I. Beryianu $R$. et S. fol. lineari-filiformibus culmo brevioribus; spicis subquinis involucro diphyllo brevioribus; valvis acutis margine 8cariosis. R. et S. I. c. In Prom. b. spei.

43. I. diabolica Alb. Dietr. fol. convoluto-setaceis culmum aequantibus ; spiculis capitato-glomeratis; valvis oblongis apice obsolete laceris. Scirpus steud. 1. c. Ad radicem montis diaboli.

49. I. Ecklonii. Alb. Dietr. culmo tereti striato; fol. basi membranaceovaginantihus convoluto-setaceis ; involucro triphyllo; valvis apice laceris. Scirpus steud. 1. c. In monte tabulari.

50. I. acrostachya Alb. Dietr. spicis capitato-aggregatis; involucro dipbyllo; valvis ovatis mucronatis, interioribus linearibus. Scirpus Steud. 1. c. In monte Tabulari.

51. I. prolifera $\mathrm{R}$. $\mathrm{Br}$. culmo striato aphyllo hasi vaginato; capitulis polystachyis passim proliferis; stylo 3-partito; nuce ancipiti laevi. R. Br. 1. c. In Prom. b. spei et ad portum Jackson. 4.

52. I. bicolor Carmich. culmis angulato-filiformibus; fol. canaliculatis angustissimis; involucro subdiphyllo; phyllo altero deflexo; valvis margine coloratis. Carmich. 1. c. In ins. Tristan da Cunha.

\section{Spicis umbellatis.}

53. I. courctata Elliot; culmo foliisque filiformibus; umbella composita coarctata; spicis parvulis linearilanceolatis; involucro setaceo. Elliot. bot. p. 83. In Carolina.

51. 1. Martii R. et s. culmo acuto 3-quetro folioso; fol. margine dorsoque denticulato-scabris; panicula foliosa supradecomposita. $\mathbf{R}$. et $\mathbf{S}$. 1 . c. Ad Tarraconam. 24.

55. $\boldsymbol{I}$. nitens $\boldsymbol{R}$. et S. culmo tereti; corymbis subcompositis; spicis ovatis pedicellatis. I. et s. 1. c. Scirpus Vabl. In Virginia et Carolina.

56. I. pubescens $R$. et $\mathrm{S}$. culmo folioso triquetro superne puhescente; spiculis paucis secundis ovatis; valvis mucronatis. R. et S.l. c. Scirpus Desf. atl. t. 10. In Africa et in Corsica.

5\%. I. glomerata Alb. Dietr. culmo nudo teretiusculo; fol. linearibus obtusis rigidis; involucro diphyllo umbella glomerata breviore. Scirpus Retz obs. 4. n. 11. In India orientali.

58. I. obtusifolia R. et S. culmo nudo; fol. linearibus obtusis rigidis; involucro subtriphyllo umbella composita breviore; spicis glomeratis. $\mathbf{R}$. et S. 1. c. In India orientali et in Guinea. 4.

59. I. Schraderi Alb. Dietr. culmo nudo foliisque linearibus nudis; spiculis sessilibus pedunculatisve ovatis; valvis obtusissimis; stigmatibus duobus. I. glomerata Schrad. in Schult. mant. 2. p. 67. In Brasilia.

60. I. racemosa $R$. et S. culmo triquetro; foliis filiformibus; involucro universali elongato; partialibus sensim minoribus scariosis; spiculis 1floris. R. et. S. 1. c. In India orientali.

61. I. falcata $\boldsymbol{R}$. et $\mathrm{S}$. culmo basi folioso; fol. linearibus falcatis; involucro subdiphyllo umbella composita breviore. $\mathbf{R}$. et S. 1. C. In India orientali.

62. I. cuspidatu Alb. Dietr. culmo folioso inferne compresso ancipiti superne triquetro; fol. linearibus longe cuspidatis; unbella 2-radiata; valvis ovalibus mucronatis extus puhescentibus. Scirpus Hayne in Roth nov. pl. sp. p. 310 . In India orientali.

63. I. pallescens Alb. Dietr. culmo teretiusculo umbellis supradecompositis; valvis obtusis monandris; nuce 13 * 
obcordata striata rugosa. Scirpus Roxb. ind. 1. p. 233. In India orientali.

64. I. stricta Alb. Dietr. culmo erecto; umbella composita; involucris paleaceis; valvis obtusis diandris ; nuce subrotunda compressa. Scirpus Roxb. ind. 1. p. 229. In India orientali.

65. I. Hacnkei Presl; fol. angustis culmo 3-quetro brevioribus; involucro 3-phyllo umbellam decompositam aequante; nuce obovata ancipiti punctulata. Presl Reliq. Haenk. 3. p. 187. In ins. Inzon. 4 .

66. I. dipsacen $R$. et $S$. culmo setaceo; fol. capillaribus; umbellis simplicibus; spicis oblongis squarrosis. R. et S. 1. c. Scirpus Rottb. Gran. t. 12. f. 1. In India orientali.

6\%. I. glaucescens Schrad. culmis setaceis glabris; fol. filiformibus vaginisque pubescentibus; involucro 45-phyllo; valvis setaceo-acuminatis monandris. Schrad. in Schult. maut. 2. p. 68. In Brasilia.

68. I. globulosa R. et S. aphylla; culmo tereti; umbellis simplicibus eompositisque; spicis globosis ; involucro subnullo. R. et S. 1. c. In Zeylonia.

69. I. cinnamometorum R. ei S. culmo 4-gono; fol. setaceis; spicis oblongis acutis; involucro diphyllo umhella decomposita breviore. 13. et s. 1. c. In cinnamometis Zeyloniae.

\%0. I. Millilenoui $R$. et $S$. repens; culmo compresso margine scabro; nuce ovata triquetra verrucosotuberculata. R. et s. 1. c. Scirpus anceps Willd. Berl. Mag. 2. t. 8. f. 2. In ins. Luzon et in Java. 24.

1. I. complanata R. et S. culmo compresso margine scabro; fol. undulatis; nuce obovata triquetra rugosa punctatissima. R. et S.l. c. Fimbristylis Link. In India orientali.

72. I. autumnalis Alb. Dietr. culmo compresso margine serrulato-scabro; valvis ovato-lanceolatis mucronatis carinatis; nuce subtriquetra ancipiti. R. et S. 1. c. Scirpus Willd. 1. c. t. 8. f. 1. In America boreali et India occidentali. 24.

\%3. I. anceps Roxb. culmo compresso erecto pedali ; involucro diphyllo umbella supradecomposita quinquies breviore. Hoxb. ind. 1. p. 234, In Bengalia.
71. I. tetragona $R$. et S. culmo 4-gono; involucro involucellisque setosis; valvis rotundatis subdiandris; nucibus rotundis. R. et S. 1. c. Roxb. ind. 1. p. 233. In India orientali.

\%5. I. pentagona R. et S. culmo fere pentagono; involucro paleaceo; floribus monandris; nuce obovata 3angulari. Scirpus Roxl). ind. 1. p. 221. In India orientali.

16. I. pubigera schrad. culmis subcompressis basi foliatis foliisque lincaribus subtus pubescentibus; valvis monandris; nucibus cancellatis. Sclırad. in Schult. mant. 2. p. 476. In India orientali.

7\%. I. hirtella schrad. culmis setaceis basi foliosis folliisque capillaribus pubescenti-hirtis; valvis ovatis alte carinatis; nucibus laevibus. Schrader in schult. mant. 2. p. 70. In Brasilia.

98. I. congesta schrad. culmis gracilibus basi foliosis foliisque setaceis glabris; spiculis mucronatis scabris; nucibus laevibus. schrad. 1.c. In Brasilia.

99. I. asperula Kunth; culmis foliisque setaceis scabris; involucro 3 phyllo setaceo; valvis ovatis ciliatis, nuce subtriguetra undulato-lineolata, apice tuberculata. Kunth. syn. 1. p. 152. I. fusca Link. In Gujana, Nova Granata et in Quito.

80. I. scubra Prest; fol. setaceis scabris culmo triquetro brevioribus; varinis ore barbatis; valvis ovatis ciliatis; nuce obovata apice tuberculata transversim lineata. Presl 1. c. In Peruvia. 4.

81. I. bufonia Funth; fol. setaceis 3-gonis scabris; involucro 3pliyllo; valvis ovatis acutis glabris; nuce triquetra ohtusa. Kuntl. syn. 1. 1. 152. In Nova Andalusia.

82. I. ciliutu Presl; fol. setaceis margine scaloris; vaginis ore barbatis; involucro 3-phyllo setaceo; unce obovata 3 -quetra transversim striata. PresI 1. c. In Peruvia et Panama. 4.

83. I. Prestii Alb. Dietr. fol. planis margine scabriusculis, culmo 3quetro ramoso brevioribus; valvis ovatis acuminatis; nuce ohovata ancipiti transversim undulato-lineata $I$. corymbosa Presl 1. c. In Panama.

81. I. junciformis Kunth; culmis triquetris foliisque glabris setaceis; involucro 3-phyllo wubella breviore; 
valvis ovatis acuminatis; nuce 3 -quetra. Kunth syrl. 1. p. 152. \$. Humboldtii spr. In ripe Orinoci. 4.

85. I. densa Wull. culmis caespitosis foliisque brevibus setaceis; vauninis barbatis; umbella decomposita; involucris squarrosis subulatis. Wall. in Roxh. ind. 1. p. 231. 1. tenuissima Don. In Nepalia. $\odot$.

86. I. maxima Alb. Dietr. culmis strict is 3-angularibus ; umbellis decompositis; nuce obcortata triangulari uuda. Scirpus grossus lietz. In staynis profundis Indiae orientalis.

8\%. I. Elliolli Alb. Dietr. spicis ovato-lanceolatis; umbella composita involucrum subaequante; nuce longitudinaliter sulcata. Elliot, Bot. 1. p. 56. S. Balduinianus $\mathrm{R}$. et $\mathrm{S}$. In Surannah.

85. I. divaricata Alb. Dietr. culmo obluse triquetro; umbellis decompositis divaricatis; spiculis ovalibus pendulis. Scirpus Elliot, l. c. In $\mathrm{Ca}$ rolina.

89. I. tenuifolia Alb. Dietr. culmo setaceo angulato sulcato; valvis ovatis brevissime mucronatis. Scirpus Hudge guj. t. 22. In Gujana et Esseqnebo.

90. I. megapotamica Ant. Spr. culmo foliato sub 3-gono; fol. linearibus flaccidis maroine scabris; panicula interrupta; bracteis scariosis lanceolatis. Ant. Spr. tent. 4. In Brasilia.

91. I. Latifolia Alb. Dietr. fol. ensiformibus; corymbis compositis axillaribus pedunculatis; spiculis solitariis ovatis valvisque apice mucronato-setaceis. Scirpus Bertol. Bras. p. 2. In Brasilia.

92. I. Roylei Nees; squamis ovatis cuspidato-acutis scariosis; involucro elongato articulato-nodoso; nuce olovata 3-quetra undulato-rugosa atra nitida. Nees in Wight Contr. p. 107. In Nepalia.

93. I. lupulina Nees; squamis ovalis pungentibus scariosis; involucro elongato compresso canaliculato; nuce obovata 3-quetra interrupte rugosa atra nitida. Nees in Wight 1. c. In Nepalia.

9. I. incurvata Nees; capitulis ad basin culmi; involucro dense articulato; squamis ovatis obtusis; nuce obovata 3-quetra. Nees 1. c. Scirpus lioxb. Circa Calcutam.
95. I. trifida Nees; involucro subdiphyllo, foliolis e basi membranacca setaceis; nuce obovata 3-quetra transversim crenulato-rugosa atra cuspidata; culmo filiformi. Nees 1. c. In Nepalia.

96. I. gracilis Nees; squamis 3quetris ovatis alte carinatis cuspidatoacutis brumeis rugosis monandris; nuce obovata 3-quetra transversim rugulosa, lutea nitida. Nees 1. c. In India orientali.

\section{FIMBRISTYLIS Vahl (1805).}

I. Spica solitaria.

a. aphyllae.

1. F. acuminate Vahl; culmo filiformi; spica ovata attenuata acuta sotitaria. Vahl en. 2. p. 285. In India orientali.

2. F. nutans Vahl; culmo subcompresso; spica ovato-oblonga nutante; valvis ovatis striatis. Vahl en. 2. p. 285. In uliginosis Malaccae. 4.

3. F. Pygmaea Vahl; culmo filiformi subapliyllo; spica ovata obtusa; involucro sub-1-phyllo. Vahl en. 2. p. 285. In Bonaria.

4. $\boldsymbol{F}$. sulcata $R$. et $\mathbf{S}$. culmis setiformibus compressis sulcatis; vaginis oblique truncatis dentatis. Scirpus Roth. 1. c. In Brasilia.

5. F. panciflora R. Br. culmo setaceo basi vaginato; spica erecta subulata pauciflora; nucibus scabriusculis; floribus monandris. R. Br. 1. c. In Nova Hollandia.

6. F. androgyna R. Br. spica erecta conico-subulata nuda; valvis inferioribus hermaphroditis 3-andris, superioribus minoribus femineis. $\mathbf{R}$. Br. 1. c. In Nova Hollandia.

7. F. acicularis $\boldsymbol{I}$. Br. culmo capillari basi vaginato; spica lanceolata compressa; stylo basi dilatato; nucibus transversim rugosis. R. Br. 1. c. In Nova Hollandia.

S. $\boldsymbol{F}$. juncea $\boldsymbol{R}$. Br. culmo teretiusculo filiformi nudo; spica ovata terminali involucrum aequante. $\mathbf{R}$. Br. In ins. societatum.

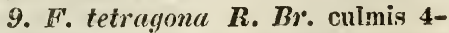
gonis basi vaginatis; valvis ovalibus obtusissimis enervibus; stylis longri- 
tudinaliter fimbriatis trifidis. $\mathrm{I} . \mathrm{Br}$. In Nova Hollandia.

\section{b. culmo foliato.}

10. F. servulate Vahl; culmo angulato filiformi aphyllo; spica ovata; involucro diphyllo foliisque linearihus extrorsim serrulatis. Vahl, Eclog. 3. p. 1. In America meridionali.

11. F. polytrichoides $\boldsymbol{R}$. $\mathrm{Br}$. culmis setaceis basi foliatis; spica ovali; involucro 1-phyllo; valvis obtusiusculis 1-andris. R. Br. 1. c. Gram. polytrichum liumph. VI. b. 7. f. 1. In źeylonia et Nova Hollandia.

12. F. punctuta R. Br. culmo angulato striato basi foliato; valvis obtuse mucronatis 3-audris; stylis bifidis supra ciliatis; nucihus impressopunctatis. IR. Br. 1. c. In Nova Hollandia.

13. F. pterygosperma R. Br. culmo angulato basi foliato; spica glohosa; valvis orbicularibus; stylis 3fidis complanatis; nucibus alatis nudisve. R. Br. 1. c. In Nova Hollandia.

14. F. xyridis R. Br. culmo 4gono; fol. planis ciliatis pilosiusculis; spica subnutante; valvis orbiculatis margine lanatis. H. Br. l. c. In $\mathrm{No}$ va Hollandia.

15. F. leucostachya R. et S. culmis 3-quetris foliisque margine scabris; involucro 1-phyllo; nuce 3-gona punctato-scabra apice tuberculata. Isolepis Kuntl syn. 1. p. 151. In Intmidis Orinoci. 4.

16. F. lanata R. et $\mathrm{S}$. culmis angulato-sulcatis scabris; fol. setaceis glaloris; valvis ovatis obtusis ciliatis. Isolepis Kunth 1. c. Ad Orinocum. 4.

\section{Spicis geminis aut teruis.}

17. F. spiralis $R$. Br. culmis setaceis; vaginis baseos mucronatis; spica altera pedunculata refiracta; nucibus 3-gonis rugosiusculis. 12. Br. 1. c. In Nova Hollandia.

18. F. schoenoides Vahl; culmo foliisque filiformibus; spicis ovatis oltusis solitariis subternisve, lateralibus pedunculaiis. Vahl en. 2. p. 286. In India orientali.

19. F. hirtella Vahl; fol. pilosis culmoque setaceis; spicis ovatis geminatis, altera pedunculata. Vahl Eclog. 3. 1. 1. In America meridionali.
20. F. tristachya R. Br. culmis angulatis scabris hasi foliatis; valvis ovatis mucronatis; stylis basi nudis; nucibus lacviluss. $\mathrm{n}$. Br. In Nova llollandia.

III. spicis conglomoratis.

21. F. Vahlii Link; culmis foliisque scabris; spiculis subternis capitatocongestis sessilibus ovatis; involucro 4-phyllo longissimo. Isolepis Kunth. In America meridionali. $\odot$.

22. F. argentea Vahl; culmis sulerectis; capitulo terminali e spiculis pluribus; involucro 2-3-phyllo; nuco subglobosa compressa. Scirpus Rottl. Gram. t. 17. f. 6. In India orientali.

23. F. monandra $\boldsymbol{R}$. et $\mathbf{S}$. culmis erectis angulosis ; iuvolucro $\mathbf{2}-\mathbf{3}$-phyl10; nuce rotundata angulata. Scirpus liottl). t. 14. f. 3. In India orientali.

21. F. cupitata R. Br. culmis angulatis basi vaginatis; involucro brevissimo; valvis obtusis; stylis trifidis nudis. H. Br. 1. c. In Nova Hollandia.

IV. Umbellis simplicibus.

25. F. nana Roth; culmis triquetris cum fol. setaceis scabriusculis; spiculis lanceolatis squarrosis; valvis ovatis acuminatis. Roth 1. c. In Brasilia.

26. F. stans Fich. culmo basi 1phyllo polystachyo; spicis subumbellatis; valvis apice subvillosis. Rich. in spr. pugill. 1. p. 6. In st. Domingo.

2\%. F. exilis $\boldsymbol{R}$. et $\mathbf{S}$. culmis foliisque triquetris et hirtis setaceis; valvis ovatis acuminatis brevissime aristatis; nuce triquetra. Isolepis Kunth syll. 1. p. 153. In Cumana.

28. 'H. arvensis Vahl; culmis compressis sulcatis; fol. tortis; involucro 1-2-phyllo; nucibus obcordatis striatis punctatis. Vahl en. 2. p. 291. In India orientali. 4.

29. $\boldsymbol{F}$. tenera $R$. et $S$. culmis foliosis subcylindricis; umbellis raris vix compositis; involucris minutis; stylo basi dilatato; nuce obovata margaritacea. Schult. mant. 2. p. 57. S. tenellus lioxb. In Coromandel.

30. F. umbellata J'ahl; culmo nudo; umbclla termiuali simplici; involu- 
cro 2-phyllo brevissimo. Vahl. P(ttria igniota.

3i. H. ferruginea Vaht; culmo 3quetro subuudo; involucro sub 2-phylIo; valvis medio subtomentoso-incanis. Vahl I. c. In Indit occidentali. 4.

32. $\boldsymbol{F}$. compressa R. et S. culmo compresso; involucro subdiphyllo umbellam simplicem superante; spicis ovatis; valvis apice subtomentosis; 1. et S. 1. c. In A/rica.

33. F. mucronata Iahl; umbella simplici; involucro sub-1-phyllo brevi rigrido; spicis oblongis. Vahl en. 2. p. 293. In ins. Mahon.

34. F. cylindrica Vahl; spica subcylindrica ohtusissima; involucro sui)1-phyllo rigido. Vahl, en. 3. p. 293. In America septentrionali.

3.5. F. castanea Vahl; culmo subtereli striato; involucro diphyllo rigido ; spicis ovato-oblongis ohtusis. Vahl cu. c. p. 92. Patria ignota.

36. F. verrucosa Presl; fol. planis cilialis; vaginis hirsutis; valvis rotundatis infimis mucronatis; nuce obovata ancipiti, Iongitudinaliter costata transversim striata, apice tuberculata. Presl 1. c. In Mlexico et in Culifornia. 4.

37. F. juncifolia Presl; fol. angustis planis flaccidis; valvis subrotundis 1-nerviis mucronatis; nuce ohovata ancipiti longitudinaliter costata et transversim striata. Presl 1. c. In Mexico. 4.

3s. F. Inumboldtii Presl; fol. setaceis canaliculatis margine scahris; radiis umbellac compressis; nuce obovata ancipiti striata punctata. PresI 1. c. Isolepis dichotoma Kunth. $A d$ Fortum Acapulco et ad Orinocam. 21.

39. F. divaricata Hamilt. culmis caespitosis hirto-pilosis basi subramosis; ramis divaricatis; nmhellis irregularilus; spiculis glohosis. Hamilt. prodr. p. 14. In Portorico.

40. F. Spartium Hamilt. scapo subcomplanato basi distiche folioso; fol. filiformibus; spiculis nigerrimis ovato-acutis; involucro diphyllo. Hamilt prodr. p. 14. In Portorico.

41. F. depauperata R. Br. culmis compresso-setaceis basi foliatis; vaginis pubescentibus; spiculis ovatis valvisque acutis; nucibus cancellatis.
17. Br. prodr. 1. p. 227. In Nova Hollandia.

12. $\boldsymbol{F}$. demulata R. Br. culmis setaceo-compressis; involucro brevissimo squamato mutico; valvis ellipticis; stylis longitudinaliter ciliatis; nucihus rugosiusculis. It. Br. 1. c. In Nova Hollandia.

43. F. rara R. Br. culmis angulatis; involucro 1-2-phyllo; spiculis subglobosis; valvis subrotundis; stylis 3-fidis. IR. Br. 1. c. In Nova Hollandia.

14. F. parvifora R. Br. culmis setaceis ; involucro polyphyllo ; spiculis subglobosis; valvis mucronatis; stylis bifidis; nucibus cancellatis. $\mathbf{R}$. Br. 1. c. In Nova Hollandia.

45. F. propinqua $R$. Br. culmis setaceo-angulatis basi foliatis; umhella semicomposita; stylis bifidis; nucihus cancellatis. H. Br. 1. c. In Nova Hollandia.

46. F. elata $R$. $B r$. culmis angu= latis lacvibus hasi vaginatis; umbella subsimplici effusa ; involucro hrevissi110 ; nucibus laevibus subglobosis. IR. Br. 1. c. In Nova Hollandia.

17. F. caespitosa $\cdot \boldsymbol{R}$. Br. culmis angulatis laevilus basi vagiuatis; spiculis ovatis; valvis 3 -andris; stylis hifidis; nucibus laevibus, $\mathbf{K} . \mathbf{B r}$. I. c. In Nova Hollandia.

48. $\boldsymbol{F}$. brevifolic $\boldsymbol{R}$. $\mathrm{Br}$. culmis angulatis laevilus umbella simplici et semicomposita; spiculis ovali-oblongis; nucibus minutissime cancellatis. $\mathbf{R}$. Br. 1. c. In Nova Hollandia.

49. F. variabilis $\boldsymbol{R}$. Br. culmis angulatis basi foliatis; pedicellis invo= lucro longioribus; valvis obtusis diandris; nucihus cancellatis. R. Br. 1. c. In Nova Hollandiu.

\section{Umbcllacomposita.}

50. F. marginata Labill. Sert. t. 16. culmo 4-quetro-compresso, foliis vaginatis longiore; spiculis subsericeis; nucibus marginatis. R. Br. In Nova Caledonia.

51. F. striata Iabill. Sert. t. 16 . f. 2. culmo compresso vix foliis duplo longiore; spiculis ovalis glahris; nucibus striato-muricatis. F. ohtusifolia Nees. In Nora Caledoniu. 
52. F. gracilis $\boldsymbol{R}$. Br. culmis angulato-setaceis basi foliatis; vaginis pubescentibus; valvis acutis; stylis extrorsum ciliatis. 1R. Br. 1. c. In Nov'a Hollandia.

53. F. veluta $R$. Br. culmis augulato-setaceis basi foliatis; vaginis glahris; valvis mucronulatis 1-andris; stylis basi lanatis. IR. Br. I. c. In Nova Hollandia.

5f. Fr. stricta R. Br. culmis compressis basi foliatis; umbella coarctata; spiculis subsessilibus ovatis; valvis obtusiusculis $\mathbf{1}$-andris. IR. $\mathrm{Br}$. 1. c. In Nova Hollandia.

5.5. F. elongata R. Br. culmis angulatis laevibus basi foliatis; spiculis ovali-oblongis; valvis carinatis acutis mucronatis monandris; nucibus cancellatis. 11. Br. 1. c. In Nova Hollandic.

56. F. sericed R.Br. culmis striatis pubescentibus; fol. subtus argenteo-tomentosis; valvis acutis; stylis 3-fidis. 12. Br. 1. c. In Nova Hollandia.

5\%. F. furva $\boldsymbol{R}$. Br. culmis angulatis basi vaginatis; involucro brevissimo; stylis 3 -fidis ciliatis basi barbatis; nucibus elevato-punctatis. R. Br. 1. c. In Nova Hollandia.

58. $\boldsymbol{F}$. cyperoides R. Br. culmis compresso - setaceis hasi foliatis; invoIucro 1-phyllo; spiculis subutatis; valvis acutis punctatis; stylis trifidis nudiusculis. R. Br. I. c. In Nova Iollandia.

5.9. F. matritiana 'Étuesch; spicis ovatis obtusis pubescentibns; involucro diphyllo, umbella subsimplici longiore. Tausch in Sieb. Herb. maur. 28. In ins. Mauritii.

60. F. speciosa Rhode; culmo teretisculo polystachyo; fol. glaberrimis canaliculatis; spicis teretibus valvisq. obtusis. spr. pug. 1. p. 5. Ścirpus domingensis Pers. In Dominyo.

61. F. bromeliciefolia A. s pr. culmo 3-gono superue nudo; fol. rigidis giganteis latissimis ; valvis obtusis appressis. Scirpus ludge Guj. t. 21. In Gujana et Surinam.

62. F. tenuis $\boldsymbol{R}$. el $\mathrm{S}$. repens; culmis 3-quetris; valvis ovatis acuminatis; nuce 3-quetra punctato-scabra. Scirpus gracilis H. et B. Ad Orinocum.

63. F. miliacea Vahl; culmo 3quetro hasi folioso; spicis globosis; involucris subdiphyllis uabella decom- posita brevioribus. Vahl en.2. p. 287. Rottb. t. 5. f. 2. In Ind. orientali.

61. F. yualrangularis A. Dietr. culmo 4-angulari; fol. gladiatis; spiculis conico-subrotundis brevibus; involucro diphyllo. Scirpus Poir. In Madagascar.

6.5. F. spathacea Roth; culmo sub3-quetro ; involucio et involucellis brevissimis; valvis ovatis margine albo-membranaceis. Roth N. Sp. p. 25. In Ind. orientali.

66. F. foliosa Link; culmo angulato hasi folioso; involucro polyphyllo umbellan superante, phyllis; basi ciliatis ; valvis oblongis mucronatis. Isolepis schrad. In Ind. orientali.

67. F. angularis Link; culmo angulato hasi folioso, fol. canaliculatis multo brevioribus; valvis oblongis e cariua brevius mucronatis. Isolepis. Schrad. In India 4.

68. F. aestivalis Vahl; culmo 3gono; spicis teretibus subquarrosis; involucro sub 6-phyllo; flosculis monandris. Vahl en. 2. p. 288. F. comata Necs. In India orientali.

69. F. glauce Vahl; spicis oblongis oltusis; involucro subdiphyllo umbella decomposita breviore. Valll $I$. c. In India orientali.

70. F. brachyphylla Spr. culmis erectis; umbella decomposita; involucellis paleaceis; valvis cuspidatis 1-andris; nuce obcordata striata. Spr. syst. 1. p. 202. F. hrevifolia $\mathrm{R}$. et s. In India orientali.

11. F. diphylla Vahl; culmis subcompressis; spicis ovato-oblongis; involucro diphyllo; flosculis monandris. Vahl I. c. In India orientali.

22. F. pubigera Link; culmo subtriquetro; fol. culmum subaequantibus parvis pubescentibus; spiculis oblongis; valvis oblongis carinatis mucronatis. Scirpus Bcrml. In America boreali. $\odot$.

173. F'. mezostachya Link; culmo sub-3-quetro; fol. culmum superantibus planis basi pubescentibus; spiculis oblongis; valvis oblongis carinatis plus minusve mucronatis. Link IIort. 1. p. 209. $\odot$.

71. F'. dichotoma Vall,; fol. culmo subbrevioribus planis pubescentibus; pilis sparsis; valvis eminenter carinatis mucrone plus minusve longis et recurvis. Vahl. Scirpus Koth. 13. f. 1. s. annuus Host. Gram. III. to 69 . In 
Europa, Africa, Ind. orientali et ins. Luzonia. $\odot$.

95. F. annua R. et S. culmo subtriquetro; fol. culmo brevioribus planis sparse pubescentibus; spiculis oblongis; valvis oblongis carinatis parum mucronatis. R. et S. Scirpus All. t. 88. f. 5. In Italia. $\odot$.

76. F. cymosa R. Br. culno angulato laevi fol. strictis carinatis duplo longiore; spiculis globoso-ovatis ; stylis 3-fidis nudiusculis; nucibus 3quetris laevibus. 1R. Br. 1. c. In Nova Hollandia.

7\%. F. pallescens Link; culmo snbtriquetro fol. planis basi sparse puhescentibus longiore; spiculis oblongis; valvis oblongis superne carinatis parum nucronatis. Link H. 1. p. 291. In Caracas. $\odot$.

18. F. squarrosa Tahl; culmo filiformi ; fol. setaceis squarrosis ; involucro 4-phyllo, umbellan decompositam aequante. Vahl 2. p. 289. In America meridionali.

79. F. puberula Vall; cnlmo compresso striato; involucro 3-phyllo umbellam compositam superante; spiculis ovatis pubescentibus. Vahl 1. c. scirpus Pers. In America boreali. 4.

80. F.tomentosa Vahl; spicis ovatis acutis; involucro subpentaphyllo basi foliisque pilosissimis. Vahl 1. c. In India orientali. 4.

81. F. pilosa Vahl; vaginis hirsutis; fol. planis ciliatis culmum subtriquetrum glabrum aequantibus; spiculis ovatis; valvis ovatis mucronulatis. Vahl. In Guinea et ins. Lazonic. 4.

82. F. Candelabrum Link; vaginis hirsulis; fol. complicatis culmo striato multo brevioribus; spiculis ovatooblongis. Link Jalirl. 1. 5. p. 80. In Brasilia.

83. F. affinis Presl; fol. planis culmo triquetro brevioribus vaginisque lirsutis; involucro 4-phyllo; valvis subrotundis striatis ; nuce obovata ancipite, punctato-striata. Presl Haenk. 3. 191. In ins. Guaham. 4.

81. F. villosa R. et S. tota villosa; culmo striato 3 -quetro inferue folioso; involucro diphyllo longissimo. 1. et S. 2. p.98. In uliginosis Portorico.

8.5. F. lirta $\boldsymbol{R}$. et S. culmis 3quetris glabris; involucro 6-plyyllo hirto; valvis oblongo-ellipticis acu- minato-aristatis; nuce lenticulari. Isolopis H. et B. In Venezuela.

86. F. laxa Vahl; culmo foliisquo filiformibus; spicis ovatis glabris; involucro subdiphyllo umbella decomposita breviore. Vahl 1. c. In America meridionali.

87. F. spadicea Tahl; calmo compresso; fol. canaliculato-filiformilus margine scabris; spiculis ovatis; valvis inferioribus mucronulatis; nuce ancipiti. Vahl eu. 2. p. 294. In America. 4.

88. F. Haenkei Presl; fol. planis margine scabris; involucro 4-phyllo brevissimo; spiculis glomeratis ovatoIanceolatis; nuce obovata 3-gona tuberculata. F. brevifolia Presi Haenk. 3. p. 192. In California. 21.

89. F. tenella Link. fol. setaceis culmo striato nudo brevioribus; spiculis subglobosis; involucro polyphyllo umbella multo breviore. Liuk Jahrb. 1. 3. p. 80. In Brasilia.

90. F. Luduigii Steud. culmo 3quetro; fol. striatis culmum aequantibus ; pedunculis compressis ; spicis lanceolatis teretibus. steud. bot. Zeit. 1828. I. p. 139. In Prom. b. spei.

91. F. Roxburyhii A. Dietr. culmo subcontpresso umbella composita involucro diphyllo Iongiore; spiculis ovalibus; nuce longa obovata glabra. Scirpus globosus Roxb. In India orientali.

92. F. scaberrima Nees; involucro diphyllo; fol. longis linearibus planis obtusis glaucis margine facieque versus apicem scabris; culmo ancipiti ad unum latus plano. Whight. In Silhet et ins. MIauritii.

93. F. decora Nees; fol. culnı siriato strigoso-pubescente hrevioribus; acutis, supra argenteo-sericeis; involucro brevissimo. Wight. contr. p. 101, In China.

\section{2b. TRICHELOSTYLIS. Lestibar (1830).}

\section{a. Spica solitaria terminall.}

1. T. filiformis Nees; culmo filiformi striato; vagina basilari aphylla obliqua truncata; nuce obovata tuberculata. Wight 1. c. Isolepis Wall. In India orientali. 
b. Spiculis umbellatis.

2. T. scabra Nees; calmo 3-quctro striato subcompresso; involucellis diphyllis foliisque lineari-falcatis scaberrimis; nuce obovata 3-quetra obsolete striata. Nees in Wight. contr. In Nepalia.

3. T.tetragona Nees; culmo basi aphyllo, profunde 4-gono, angulis acutissimis; spiculis subglobosis ; nuce suhglohósa obtusa 3-gona rigida alba. Nees. Scirpus Roxb. In Silhet et Nepalia.

4. T. quinquangularis Nees; culmo profunde 5-augulari; valvis 1-andris, rubro-ferrugineis; nuce obovata 3-quetra Inteola transverse striata, tuberculisque strigulosis. Nees. S. pentagonus et plantagineus hoxb. In Bengalia inferiore.

5. T. pentaptera Nees; culmo 5angulari hirsuto; iuvolucris involucellisque scariosis, aristatis ; staminilus 4; nuce 3 -quetra tuberculata rugosa. Nees 1. c. In Zeylonia.

6. T. Salbundia Nees; culmo 5gono aphyllo glabro; involucro subulato umbella multo breviore; caryopsi truncata obovata obtuse carinata subtiliter punctata striata. Nees. In Nepalia et Silhet.

\section{c. Spiculis capitatis.}

7. T. torta Nees; culmo sulcatostriato subcompresso foliisque linearibus rigidis tortis; valvis brunneis alho-marginatis; nuce alba tuberculata. Nees 1. c. In India orientali.

8. T. chaetorrhiza Nees; culmo compresso 3-gono striato; fol. anguste linearibus reflexis; spiculis subcapitatis; valvis obtusis cariuatis subacutis. Nees 1. c. In Nepalia et India.

9. T. latifolia Nees; culmo sulcato-angulato, superne compresso; fol. late linearibus, margine scabris subtortis; spiculis ovato-augulatis ; valvis carinatis subtilissime scabris. Nees 1. c. In India orientali.

10. T. junciformis Nees; culmo tereti-compresso sulcato; fol. linearibus recurvatis; stylo basi bulboso superue scabro. Fimbristylis Wall. In Nepalia ad ripas Irawaddi.

\section{HOLOSCHOENUS Link.}

1. H. vulyaris Lk. culmo subangulato hasi vaginis foliiferis; spicis globosis; spiculis densissimis; valvis superne subpubescentilus ; nuce 3-gona mucronata laevi. ścirpus L. Host. 3. t. 62. In Europa. 4.

2. H. Thunbergii Alb. Dietr. culmis teretiusculis; spiculis capitatoglomeratis; capitulis globosis; involucro brevissimo; valvis glabris. Isolepis Schrad. Scirpus Thunb. In Prom. b. spei.

3. H. globiferus Alb. Dietr. culmo tereti nudo; umbella composita; capitulis globosis; involucro diphyllo. Scirpus L. In Teneriffa.

4. H. atrovirens Linn. culmo 3quetro; fol. vagina stricta; spiculis subglobosis conglomeratis; involucro polyphyllo; valvis lanceolatis acutato-mucronatis. Scirpus IVilld. In America boreali. 4.

5. H. nodosus Alb. Dietr. culmo compresso basi vagiuato; capitulo glohoso polystachyo; involucro nullo; valvis oltusis integris. Isolepis $\mathbf{h}$. Br. S. gracilis liuge Limn. Trans $X$. t. 15. f. 2. In Prom. b. spei et in Nova Hollandia. 4.

6. H. incurvatus Alb. Dietr. culmis caespitosis aplyyllis interceptis; spicis in verticillo globoso nudo ad basin culmi. Scirpus Roxb. Isolepis Nees. In humidis prope Calcuttum.

\%. H. subarticulatus Alb. Dietr. culmis dissepimentis innumeris interceptis; spicis obtusis in capitulum prope basin coacervatis Scirpus hoxb. In India orientali.

\section{DICHROMENA V'ahl (I805).}

1.D. leucocephalaMichx. glahra; fol. strictis culmo longiorilus; involucro 3-phyllo; phyllis infernis capituloquo candidis. Schoenus Sw. In Caribaeis et in Carolina. 4.

2. D. nervosa Vahl ; glabra; invoIucris undique concoloribus multinerviis. Vahl en. 2. p. 241. In America meridionali.

3. D. microcephala Bertero; radice fibrosa; involucris concoloribus angustis foliisque laxis culmum subaequantibus glaherrimis. Bertero. In America meridionalt. 
4. D. repens Vahl; glabra; culmo repente; involucris undique concoloribus. Vahl en. 2. 1. 247. In America merialionali et in Gujana.

5. D. compressa $\$ \mathrm{~m}$. fol. convoluto-filiformihus culmo compresso brevioribus; involucris sulncoloratis diplyyllis angustis. Spr. N. Entd. I. P. 239. In Brasilia.

6. D. latifolia Balduin; fol. praelongis culmum laxe vaginantihus; involucro polyphyllo majusculo; phyllis albidis; capitulis compressis. Elliot Bot. 1. 1. 90. In Georgia et Florida. 24.

7. D. caespitosa Mühlenb. glabriuscula; fol. setaceis; vagina pilosa; involucris coloratis polyphyllis ciliatis. Mühlenb. descr. p. 14. In Carolina et Georgia.

8. D. longifolia Spr. culmo 3-quetro; fol. nervosis laevibus; capitulis parvis, intermedio sessili; valvis vermicularibus. Spr. syst. 1. p. 203. Schoenus Rudge guj. t. 16. In Gujana.

9. D. fragifera Alb. Dietr. culmo folioso 3-quetro; pedunculis inferiorilus distantibus superioribus in umbellam aggregatis; pericarpio calyptrato. schoenus Rudge guj. t. 17. In Gujana.

10. D. Tahlii Alb. Dietr. culmo 3-quetro folioso; pedunculis axillaribus; spicis alternis spicatis subquaternis. Vall en. 2. p. 226. In Portorico.

11. D. tenuifolia Spr. repens; culmis 3-angularibus glabris; fol. glaucescentibus margine scabris; nuce lenticulari transversim undulato-rugosa. Scirpus Kuntl. In Cumana. 4.

12. D. ciliata Vahl; culmo augulato; fol. glabriusculis ciliato-scahris; vaginis pubescentibus; nuce ancipiti transversim undulato-rugosa. Vahl en. 2. p. 240. Schoenus Meyer Esseq. In America septentrionali et in India occid.

13. D. Preslii Alb. Dietr. culmo 3-quetro glabro; fol. ciliatis; involucro 4-phyllo longissimo; nuce lenticulari-subglobosa laevissime ancipiti punctata. D. ciliata Presl in Haenk. lleliq. 3. t. 32. f. 2. In Peruvia.

14. D. nubera Vahl; fol. involuerisque undique concolorilus ciliatis; spiculis pubescentibus. Valu el. 2. p. 211. Schoenus H. et B. In America meridionali. 4.

15. D. globosa R. et S. culmis 3-quetris; fol. margine scahris cariua hispido-ciliatis culmum aequantibus; capitulo globoso; nuce obovata lenticulari transversim undulato-rugosa. schocnus $\mathrm{H}$. et $\mathrm{B}$. In monte Quindiu. 4.

\section{SCIRPUS L.}

\section{Spicis lateralibus.}

1. S. subterminalis Torrey; culno fluitante sulcato inflato basi folioso; spica solitaria subterminali lanceolata; nuce 3-quetra. Torrey Fl. of unit. stat 1. p. 4\%. In fluviis Anericae borealis.

2. S. strobilinus Roxb. culmis 3quetris; valvis cordatis cuspidatis; stylo 2-partito; nuce plana. Roxb. ind. 1. p. 222. Ad ripas Gangis.

3. S. juncoides Roxb. culmo tereti; spicis ovalibus $3-5$ in capitulo sessili congestis; nuce ancipiti. $30 x b$. ind. 1. p. 218. In uliginosis Indiae orientalis.

4. S. debilis Pursh; culmo canaliculato basi vaginato; spicis lateralibus glomeratis sessilibus; nuce apiculata rugosa. Pursh am. 1. p. 55. In America boreali. 4.

5. S. luzonensis Presl; culmo tereti vaginato; involucro 1 -phyllo longissimo; valvis rotundatis mucrounlatis; nuce obovata plano-convexa rugulosa. Presl. 1. c. In ins. Luzosia. 4.

6. S. monophyllus Presl; culmo 3-quetro inferme 1-phyllo; folio canaliculato rigido; involucro $1-p h y l l o$; valvis ovalibus mucronulatis; nuce plana convexa punctulata. Presl Reliq. Hænk. In montibus Peruviue. 4.

7. S. badius Presl; culmo 3-quetro folioso, fol. canaliculatis; involucro 1-phyllo longissimo; valvis ovalibus lacero-ciliatis. In California.4.

8. S. mucronatus $L$. culmo 3-quetro, basi vaginato; spiculis multis conglomeratis sessilibus; involucro 1-phyllo; valvis ovatis mucronulatis carinatis. S. glomeratus Host. 4. t. 68. In Europa. 4.

9. S. Preslii Alb. Dietr. culmo 3quetro vaginato; involucro 1-phyllo demum obliguo; valvis ovatis striatio 
mucronulatis. S. acutus Presl 1. c. In ins. Lazon. 4.

10. S. conglomeratus $\boldsymbol{H}$. et $\mathrm{B}$. culmis teretibus apice $\mathbf{3}$-gonis subulato-pungentibus; vaginis aphyllis; valvis ovalibus acuminato-aristatis; nuce lenticulari apiculati. H. et B. Nov. gen. 1. p. 227. In Peruria. 4.

11. S. pungens Vahl; culmo 3-quetro; spiculis pancis sessilibus conglomeratis; involucro diphyllo; valvis ovalibus marginatis mucronatis fimbriatis; nuce ancipiti laevissima. Vahl 1. c. Plukn. t. 40. f. 1. In Europa et America boreali. 4.

12. S. triqueter L. culmo 3-gono; umbella laterali; spicis sessilibus pedunculatisque; involucro subdiphyllo; valvis ovalihus fimbriatis. Fl. Dau. t. 1563. In Europa et Nova Hollandia. 21.

13. S. littoralis Schrad. germ. 1. f. 5. f. \%. culmo 3-quetro; umbella explicata; involucro diphyllo; valvis ovalibus emarginatis mucronatis denticulatis. In lacubus Europae et Africae. 4.

11. S. articulatus $\boldsymbol{L}$. culmo tereti aphyllo, septis interstincto; spicis lateralibus glomeratis ovatis. s. praelongatus Poir. Hheede mal.12. t. 71. In Indiis. 4.

15. S. muticus Don; culmo acute triquetro aphyllo obtuso supra canaliculato; valvis late rolundatis mucronulatis cymbiformibus; setis retrorsum denticulatis. Don nep. p. 41. In Nepalia.

16. S. triangulatus Roxh. culmis caespitosis nudis acute 3-angularibus; setis gracilibus; spicis 8-12. Roxb. ind. 1. p. 219. In Chittagong. Caul. 2-ped.

17. S. pectinatus Roxb. culmo tereti; valvis pugioniformibus; nucibus rotundatis; setis 4 pimnatis. IRoxb. ind. 1. p. 220. Malachochaete Nees. In India orientali.

18. S. vaginatus Thunb. culmo filiformi; capitulis alternis involucro brevioribus. Thunb. prodr. p. 17. In Trom. b. spei.

19. S. biceps Poir. calmo filiformi striato subcompresso; fol. setaceis vagina nivea; spicis sessilibus 2-spicatis; involucro 1-phyllo setacco. Poir. Enc. 6. p. 761. In Prom. b. spei.

20. S. lateralis Forsk. aphyllus; culmo angulato vaginato; vaginis ob- tusis sulhmucronatis; valvis acutis maruine diaphanis. In Aeg!yto.

21. S. carinatus Smith; culmo subtriquetro; vaginis aphyllis; umbella expansa; involucro $2-3$-phyllo majorc pungente; valvis oblongis fimbriatis. Engl. Bot. 1983. S. Duvallii Hoppe. In Europa. 4.

22. S. Tabernaemontani Gm. culmo tereti glauco; vaginis aphyllis; valvis oblongis emarginatis scabropunctatis fimbriatis. S. glaucus E. B. 2321. S. Iacustris $\beta$. Schrad. In Europa. 4. 2-ped.

23. S. lacustris L. culmo tereti; vagina suprema foliifera; umbella expansa; valvis ovalibus emarginatis mucronatis lacero-fimbriatis. E. B. 666. Host. 3. t. 61. In lacubus Europae et Americae 24. Culm. 4-12 ped.

2t. S. aculus Mühlenb. culmo tereti; vaginis aphyllis; umbellis lateralibus; valvis mucronatis pubescentibus; nuce obovata. Muhlenb. 1. c. In Pensylvania. 4. 4-ped.

2.5. S. validus Vahl; culmo aphyllo; umbella decomposita; involucro brevissimo; valvis dorso villosis. In America. 4.

26. S. plumosus $\boldsymbol{R}$. Br. culmo tereti aphyllo; umbella composita; valvis ovatis mucronatis glabris margine nudis, setis plumosis. R. Br. l. c. valde variat. In Nova Hollandia.

2\%. S. subulatus Vahl; spicis oblongis; involucri foliolum longius rigidum laeve; valvis carina pubescentibus; stylo 3-fido. Vahl eu. 2. p. 268. In ins. Nicobaricis. 4.

28. S. riparius Presl; culmo 3quetro; involucro 2-phyllo; umbella supradecomposita ; valvis ellipticosubrotundis 1-nerviis mucronatis; nuce plano-convexa punctata. Presl 1. c. In Peruvia.

29. T.tranquebariensis Roth; culmis compressis striatis subnudis; spicis ovalibus terminalibus, centrali sessili; involucro diphyllo breve serrulato. Roth Cat. p. 6. In India orientali.

\section{Spicis terminalibus.}

30. S. Iristrix Thunb. culmo capillari; capitulo subdistachyo ; involucro 1-phyllo; valvis acuminatis squarrosis. Thunb, prodr. p. 17. In Prom. b. spet. 
31. S. trispicatus $L_{\text {. }}$ culmo angulato aphyllo; spicis tribus terminalihus. Lim. sp. suppl. p. 103. s. Sparmami Lam. In Prom. b. spei.

32. S. gracilis Poir. culmo tereti subcompresso; fol. filiformibus strictis; involucro diphyllo; capitulo globoso terminali. Poir. Euc. 6. p. 763. In Prom. b. spei.

33. S. bonariensis Poir. culmo filiformi subtriquetro nudo; fol. setaceis; spiculis glomerato-capitatis sessilihus; involucro diphyllo capillari lougo. Poir. 1. o. In Buenos Iyres.

34. S. truncatus Thunb. culmo tereti; fol. linearibus; capitulo glomerato glohoso; involucro diphyllo. Thunb. prodr. p. 17. In Prom. b. spei. Culmus spithameus.

3.5. S. laciniatus Thunb. cnlmo tereti; capitulo 3-angulari; involucro 3-phyllo; valvis ovatis ciliatis. Thunb. prodr. p. 17. In Prom. b. spei. Culmus pedalis.

36. S. fastigiatus Thunb. culmo filiformi; capitulo compresso convexo; involucro nullo; valvis extimis mucronatis. Thunl). prodr. p. 18. In Prom. b. spei. Culmus digitalis.

3\%. S. pilosus Tilumb. culmo compresso; capitulo ovato; involucro 4phyllo; valvis lanceolatis ciliatis. Thunb. prodr. p. 18 . In Prom. b. spei.

35. s. membranaceus Thunb. culmo tereti; capitulo angulato; involucro diphyllo; valvis ovatis membranaceis. Thumb. prodr. p. 17. In Prom. b. spei. Culm. pedalis.

39. S. aristatus Willa. culmo tereti striato folioso; pauicula termiuali 3-phylla subfastigiata; spiculis ovatis squarroso-echinatis. IVilld. sp. pl. 1. p. 300. In Inslia orientali.

10. S. fragrans $R$. et $P$. culmo filiformi tereti striato nudo pubescente; fol. semiteretihus; involucris polyphyllis pubescentibus. In Peruvia. Rad. odoratissima.

41. S. bivalvis Lam. culmo semitereti; spicis oblongis; involucro diphyllo; valvis ovatis mucronatis. Lam. ill. 1. p. 141. In Madagascar.

42. S. elongatus Hamilt. fol. linearibus planis carinatis margine carinaque denticulato-scabris; umbella prolifera; valvis obovato-lanceolatis ; setis numerosis. Don Nep. p, 40, In Nepalia.
43. S. Donianus Spr. culmo 4-gono inferne vaginato; umbella prolifera; valvis ovatis mucronulatis. S. quadrangulus Don. In Nepalia. 4 .

4t. \$. muritimus I. culmo 3-quetro folioso; fol. elongatis; involucro polyphyllo Iongissimo; valvis apice bifidis mucronatis, lacinulis dentatis. Engl. bot. 512. Host. 3. t. 67. In Europa, Asia, Africa America et Nova Hollandia. 4.

4.5. S. robustus Pursh; culmo 3quetro folioso; involucro $\mathbf{3}$-phyllo elongato; valvis ellipticis pubescentihus lacero-serratis $\mathbf{3}$-fidis squarrosis. Pursh F1. 1. p. 56. In America boreali. 4.

46. N. affinis Roth; culmo 3-quetro folioso laevi; involucro sub 3-phyIlo; valvis ovalibus discolorihus apice 3-fidis, lacinia intermedia aristacformi. Roth nov. pl. sp. p. 30. In India orientuli.

47. S. cephalotes $\boldsymbol{L}$. culmo 3-quetro nudo; capitulo ovato squarroso; involucro 3-phyllo longo. Linn. sp. pl. 1. p. 76. In Indiu.

15. S. Lusulae $\boldsymbol{L}$. culmo 3-quetro nudo; umbella foliosa prolifera; spiculis subrotuudis. Linn. I. c. In India orientali.

49. S. tridentatus Roxb. culmo erecto triquetro; involucro 2-3-phylIo; spiculis acutis; valvis Iobatis laceris pugionifornibus. Roxb. ind. 1. p. 228. In India orientali.

50. S. asper Prest; culmi triquetri angulis scahris; iuvolucro 4-phyllo; valvis oblongis 1-nerviis mucronatis ciliatis. Presi 1. c. In Cordilleris Chilensibus. 24.

51. S. brumeus Wühlenb. culmo 3-gono folioso; fol. carinatis serulato-scabris; involucro polyphyllo; valvis mucronatis. Mühleub. l. c. s. exaltatus Pursh. In America boredli. 4 .

52. S.grossus $\boldsymbol{T a h t ; ~ c u l m o ~ 3 - q u e - ~}$ tro basi folioso; umbella supradecomposita; involucro subdiphyllo longissimo. Vahl 1. c. Hymenochaete Nees. In India orientali. 4.

53. S. microcarpus Presl; culmo 3-quetro folioso; fol. planis marciuo scahris; involucro 4-phyllo; valvis ovatis mucronatis; nuce obovata ancipiti. Presl 1. c. In Notkasund. 24. 51. S. sylvaticus L. culmo 3-quetro folioso; umbella ampla decompo- 
sita ; involucro polyphyllo; valvis lanceolatis ohtusis mucronatis. E. B.919. Host 3. t. 69. In sylvaticis Europae. 24. Had. repens. Culmus 1-3pedalis.

5.5. S. radicans Schk. culmo 3-qnetro folioso; umbella decomposita ampla; valvis lanceolatis obtusis muticis; setis curvatis nuce ancipiti longiorihus. Host. 4. to 69. In Europa. 4. Culmi floriferi pedales.

56. S. junciformis Retz; culmo nudo filiformi sub3-gono; paniculae spiculis sessilibus pedunculatisve; involucro diphyllo. Retz obs. 6. p. 19. In China.

5\%. S. polyphyllus rahl; culmo folioso ; corymbo termiuali; spicis capitulisque suhglobosis glomeratis. Vahl en. 2. p. 274. In America boreali. 4 .

58. S. hispidulus Vahl; pilosus; culmo angulato; foliis setaceis; unbella subuniradiata; spicis oblongis acutis. Vahl en. 2. p. 276. In Guinea.

59. S. quinquangularis I'ahl; culmo 5-angulato; fol. hrevissimis; involucro sub3-phyllo umbella supradeconposita breviore; spicis ovatooblongis. Vahl 1. c. In India orientali.

60. S. lineatus Michx. culmo 3quetro folioso; fol. planis maruine scahris; umbella supradecomposita, demum pendula; valvis ovatis mucronulatis. S. pendulus Mühlb. S. ambiguus R. et S. Trichoplorum Pers. In America boreali. 4. Culmus 2-3-ped.

\section{ABILDGARDIA Tahl (1S0s).}

1. A. monostachya Vahl; culmo 3-quetro; fol. supra punctulatis margine subserrulatis; valvis ovalibus carinatis submucronatis; nuce tuberculata; Cyperus L. In India occidentali et Americn meridionali. 4.

2. A. indica Pers. monandra; spica solitaria; caespite stricto; valvis plurimis aristatis. Pers. syn. 1. p. 65. Cyperus monostachyus Hottl). Gram. t. 13. f. 3. In India orientali.

3. A. schoenoides $R$. Br. spica solitaria nuda; valvis extimis sterilibus brevioribus, terminalibus angustio- ribus; mucronulis patulis. IR. Br. prodr. 1. 1. 85. In Nova Ilollandia.

4. A. compressa Presl; culmo compresso; fol. subcanaliculatis maroine scahris culmo brevioribus; valvis ovato-rotundatis inferiorihus mucrouatis; nuce obovata tuberculata. Presl. In insula Lazonia. 4.

5. A. nervosa Presl; culmo 3-quetro; fol. planis margine scahris; valvis ovatis acutis nervoso-striatis ; nuce ohovata compressa punctato-striata. Presl. In ins. Luzonia. 4.

6. A. pubescens Presl; culmo 3quetro foliisque brevibus filiformi pubescenti; valvis ovato-subrotundis acutis 1-nerviis pulsescentibus. Presl. 1. c. In Mexico et in Luzonia.

7. A. tristachya Vahl; culmo terestiusculo; fol. culmo hrevioribns; spica intermedia sessili; valvis inferioribus mucronatis. Cyperus triflorus Linu. In India orientali. Culmus 1-2-ped.

8. A. vaginata R. Br. culmo setaceo-angulato 2-phyllo basi vaginato; spicis subternis, intermedia sessili; valvis mucronatis. R. Br. 1. c. In Nova Hollandia.

9. A. barbata Pal. Beauv. Fl. d'Owar. $t$. 56. $f:$ 1. culmis angulatis gracilibus nudis; fol. radicalibus setaceis; valvis basi pilosis; bracteis mucronatis, carina viridi. Ad ripas fluvii Formose.

\section{3\%. MACHAERINA Vahl (180.5).}

1. M. restioides Fahl en. 2. p. 238. Schonus Sw. S. lavarum Poir. S. iridifolius Bory Joy. $t$. 23. In India occidentali. ち. Culmus simplicissimus. Folia facie Iridis germanicae.

\section{S. MORELOTIA Gaudich (1S.29).}

1. M. gahniaeformis Gandich in Freyc. Voy. t. 28. In ins. Sanduichianis. Culmi caespitosi erecti. Holia angustissima. Fructu deciduo. 
239. VINCENTIA Gaudich. (1828).

1. I. anyustifolia Gaulich. l. c. In ins. Sandwichianis. Folia anguste limearia culmo breviora.

\section{ANTHROSTYLIS R.Br.(1810).}

1. A. aphylla R. Br. l. c. In Nora Hollundiu. Culmo gracili enodi; Capitula turbinata, involucro 3-4phyllo longiora.

\section{CALSTIS R. Br. (1810).}

1. C. flexuosu R. Br. spiculis flexuosis; lamulis ultimis laevibus; valvis glabris. 11. Br. 1. c. In Nova Hollandia.

2. C. dioica R. Br. paniculis flexuosis subcoarctatis; ramulis ultimis margine scabris; spicularum valvis pubescentihus. H. Br. 1. c. In Nova Hollandia.

3. C. pentandra $R$. Br. ramis ramulisque strictis; florihus pentandris. R. Br. I. c. In Nova Hollandia.

\section{TRICHOPHORUM Pers. (1805).}

1. T. cyperinum Pers. culmo ohtuse trigono; umbella supraulecomposita; involucro 5-phyllo; phyllis $1-2$ Iongissimis. Eriophorum L. Scirpus Michx. In America septentrionali. 4.

2. $T$. comosum Wall. glaucum; fol. radicalibus involucroque longissimis; corymbo nutante; pilis seminum longis rectis argenteis. Wall. in lioxb). ind. 1. p. 234. In Nepalia.

\section{ERIOPHORUM L. (1737).}

1. Spica terminali unica.

1. E. alpinum L. culmo 3-quetro; fol. brevissimis; vagina summa truncata crispa; valvis lanceolatis acutiusculis; setis crispulis. I. B. 311. Krok. Sil. I. t. 17. In alpibus Europae et Americae. 4.

2. E. vaginatum L. colmo superne 3-quetro; fol. canaliculatis angustissinis; vagina summa inflata; valvis lanceolatis expansis scariosis. F. D.
236. E. B. 873. In paludosis Europae. 4.

3. E. Chamissonis C. A. Meyer, culmis solitaris teretibus, cum foliis compressis laevibus; vaginis parum inflatis. Led. Alt. 1. p. 70. In Altai $\odot$.

4. E. S'cheuchzeri Hoppe; culmis vaginatis teretibus; vagina summa inflata aphylla; valvis lanceolatis scariosis margine membranaceis; antheris corlato-ovatis. E. capilatum Host. 1. t. 38. E. B. 2387. In Europae paludosis. 4.

2. Spicis terminalibus subcorymbosis.

5. E. latifolium Hoppe; culmo subtrigono; fol.planis apice 3-quetris; spicis 5-10 pedunculatis nutantibus; ochreis 2-partitis. Host. 4. t. 73. F]. D. 1381. E. polystachyon L. In pratis paludosis Europae. 4.

6. L. angustifolium Reich. colmo sul 3-gono; fol. canaliculatis ancustis apice 3-quetris; pedunculis laevissimis; ochrea 2-partita; valvis lanceolatis acutis scariosis. FI. D. 1442. Svenk Bot. 490. f. 1. E. Iatifolimm Host. 1. t. 37. In paludosis Europae et Americae. 4.

\%. E. gracile Koch; culmo 3-quetro; fol. canaliculatis angustissimis; spicis subtomentosulis; valvis viridihus margine membranaceis. E. B. 2402. Swenk Bot. 490. f. 2. E. triquetrum Host. 4. t. 74. In pratis puludosis Europae. 4.

8. E. virginicum $I$. culno teretiusculo folioso; fol. planis longis; spicis congestis subsessilibus involucro 2-3-phyllo brevioribus. In America boreali. 4.

9. E. montevidense Link; culmo teretiusculo compresso aphyllo; vagina oblique truncata; capitula subglobosa; valvis lanceolatis e carina longe acutis. Link Hort. 1. p. 331. In Montevideo. 4.

\section{CYPERUS Linn.}

1. Culmo tereti, septis transversis distincto.

1. C. articulatus $L$. culmo stricto aphyllo; involucro brevissimo; nuce 
oblonga trigona minutissime punctata. S. nodosus Willd. In America. 4.

2. C. gymuos R. et S. culmo aphyl10; spiculis linearibus; involucro paleaceo; nuce sublineari-trigona. C. nudus lloxb. ind. 1. p. 291. In India orientali. 4.

3. C. niloticus Forsk. culmo aphyl1o; spiculis linearibus compressis brevibus; involucro sub-1-phyllo, phyllo paleaceo latissimo. Forsk descr. p. 13. In Aegypto. 4 .

2. Culmo tereti subteretique, septis transversis non distincto.

4. C. Koenigii Vahl; culmo aequali nudo; involucro 3-phyllo umbella breviore; spiculis teretiusculis brevibus. Vahl en. 2. p. 302. In India orientali. 4.

5. C. seminudus Roxb. culmo nudo; umbella decomposita; involucro dimidio altitudinis; stylo 3 -fido; nuce 3 quetra. Roxb. ind. 1. p. 191. In India orientali. 4.

6. C. marginatus Thunb. culmo aphyllo; umbella composita; involucro diphyllo brevissimo; spiculis oblongis. Thuub. prodr. p. 18. In Prom. b. spei.

भ. C. textilis Thunb. culno aphylIo; involucro dodecaphyllo laevi; spiculis oblongis. Thuub. prodr. p. 18. In Prom. b. spei.

8. C. vaginatus $R . B r$. culmo basi vaginato; involucris 6-8-phyllis planis; spiculis lineari-lanceolatis serratis multifloris. H. Br. 1. c. In Nova Hollandia.

9. C.Preslii Alb. Dietr. culmo stricto tereti; involucro diphyllo umbellis breviore; spiculis ovatis 6-floris in capitula ovata subglobosa aggregatis; valvis lanceolatis striatis. C. globuliferus Presl. In Peruvia. 4.

10. C. trigynus syr. culmo compresso aphyllo basi vaginato; involucro paucifloro rigido abbreviato; spiculis lanceolatis 10-floris. Spr. syst. p. 210. In Montevideo.

11. C. pennatus Lam. culmo semitereti; involucro 6-phyllo; spicis corymbosis; spiculis alternis confertis. Lam 1. c. 1. p. 144. In Java.

12. C. nudicaulis Poir. culmo subcylindrico gracili nudo; involucro subdiphyllo brevi; spiculis sessilibus ova- tis planis. Poir. Enc. 7. p. 241. In ins. Madagascar.

13. C. spicigerus Tahl; culmo aphyllo; involucro 6-phyllo, umbella simplici multoties breviore; spicis cylindricis imbricatis; spiculis subulatis. Vahl en. 2. p. 300. Prope Para. 4. 11. C. ellusus Rottb. $t .12$. f. 2. capitulis subternis intermedio sessili; involucris rigidis unico longiore adunco. Ad Meccam in Arabia.

15. C. prolifer Thunb. culmo aphylIo; capitulis glohosis glomeratis proliferis; spiculis ovatis; valvis margine membranaceis. Thunb. prodr. p. 18. In Prom. b. spei.

16. C. tener Vahl; culmo nndo; spiculis oblongis obtusis capitatis; valvis striatis. Vahl en. 2. p. 299. In Guzurate.

1\%. C. pectinatus Vahl; culmo aphyllo; spiculis terminalibus sessilibus oblongis laevibus involucrum aequantibus. Vahl el. 2. p, 298. In Guinea.

18. C. lateralis Forsk. culmo aphyI10 ; capitulo e spiculis 5-6 sub apico rigido culmi sessilibus; nuce ovali compressa. Forsk. In Coromandel et in Arabia. 4.

19. C. Roxburglii Alb. Dietr. cnlmo tereti aphyllo seminudo; involucro 1-phyllo; muce ovali rotundata. C. mucronatus Retz. In India orientali.

20. C. arenarins Retz; culmo teretiusculo hasi folioso; spiculis ovatis subgloboso-capitatis involucro subdiphyllo brevioribus. Plukn. t. 100. f. 7. In India orientali. 4 .

21. C. reflexus Vahl; culmo semitereti; capitulis ovatis glomeratis involucro 3-phyllo reflexo brevioribus; spiculis ovatis. Vahl en. 2. p. 299. In Montevideo.

22. C. crassipes Fahl; nmbella contracta, radiis brevissimis; spiculis aggregatis lanceolatis. Vahl en. 2. p. 299. Ad Senegal.

23. C. serrulatus Vahl; fol. lineari-lanceolatis; spiculis subcapitatis lanceolato-oblongis obtusis; involucro 3-phyllo. Vahl en. 2. p. 300. In Madagascar.

24. C. striatus $\boldsymbol{R}$. et $\boldsymbol{P}$. culmo tereti striato retrorsum scabro; fol. subulatis canaliculatis, spiculis ovatis terminalibus umbellatis. C. collinus Vahl. C. atropurpureus Pers. In Peruvia. 
25. C. pusillus Vahl; culmo tereti; umbella composita involucrata; iuvolucro 4-phyllo; spiculis lanceolatis; valvis mucronatis. Vahl en. 2. p.303. In Tranguebria.

26. C. viscosus Ait. fol. convolutoteretibus involucrisque asperis ; spiculis argregatis ovatis sulosquarrosis. Ait. Kew. 1. p. 79. Jacq. ic. t. 295. C. elegans Rottb. t. 6. f. 4. In humidis Caribaearum. 24.

2\%. C. compactus Retz; nmbella decomposita; involucro 5-phyllo; spiculis subulatis; capitatis subspiralibus. C. congestus Poir. In China.

25. C. maritimus Poir. radice repente; culmo pumilo; fol. margine asperis ; umbella composita; involucro polyphyllo undo. Poir. Enc. 7. p. 240. In Madagascar. 4.

29. C. setifolius Don; umbella 4-6-radiata; involucris sub-5-phyllis foliisque setaceis apice scabris; spiculis linearibus squarrosis; valvis in acumen recurvatum productis. Don. prodr. p. 39. In Nepalia.

30. C. tenellus $\boldsymbol{L}$. culmo teretiusculo setaceo; fol. filiformibus; spiculis subureminis sessilibus; involucro subdiphyllo; nuce triquetra transversim subtilissime rugosa. C. pygmaeus Lam. Plukn. t. 300. fo 4. In Prom. b. spei. $\odot$.

31. C. geminatus Schrad. culmis compresso-tetragonis; vaginis nuncronatis; valvis mucronatis. $R$. et .s. mant. 2. p. 9.5. In Brasilia.

32. C. pleurantlies Nees; radice repente flexuosa; culmo teretiusculo apice 3 -gono; spiculis aggregatis lateralihus; valvis ovatis obtusis valde imbricatis. Nees in Wight Contr. p. 73. C. 'Iateralis Roxb. In Coromandel.

33. C. macrorrhizos Nees; culmo semitereti compresso, uno latere valde sulcato; spiculis oblongo-convexis; valvis ovatis mucronatis carinatis albidis hasi purpureo-striatis. Nees 1, c. In Aegypto.

\section{Culmo 3-quetro.}

A. Spiculis solitariis.

31. C. depauperatus Vahl; culmo setaceo incurvato; spiculis solitariis ohlongis sub 3-floris; involucto nullo. Vahl en. 2. p. 305. In India orientali.
35. C. debilis $\boldsymbol{R}$. Br. culmis setaceis; spiculis solitariis lineari-lanceolatis; valvarum lateribus subenerviis; involucris 2-3-phyllis elongatis. $R$. Br. I. c. In Nova Hollandia.

B. Spiculis aggregatio.

36. C. yracilis $\boldsymbol{R}$. Br. culmis setaceis; spiculis 2-4, linearibus; valvarum lateribus nervosis acutis apicibus patulis; involucris 3-phyllis. $\mathbf{R}$. Br. 1. c. In Nova Hollandia.

37. C. enervis R. Br. culmis laxis; spiculis 3-4, linearihus; valvarum lateribus enerviis apicibus acutis strictis; involucris foliisque setaceis. $\mathbf{R}$. Br. 1. c. In Nora Hollandia.

38. C. luevis R. Br. culmo erecto; involucris 2-3-phyllis; spiculis 6-8 congestis lineari-lanceolatis; valvarum lateribus subenerviis. H. Br. Jn Nova Hoilandia.

39. C. Rothianus $\boldsymbol{R}$. et S. culnis triquetris foliisque setaceis pubescentibus; involucro diphyllo, altero spiculas aequante. C. minutus Roth. Plulin. t. 300. f. 5. In Prom. b. spei.

10. C. margaritaceus Iahl; fol. convoluto-setaceis culmoque rigidis; spiculis aggregatis subulato-lanceolatis involucrum 4-phyllum aequantibus. Vahl 1. c. In Guinea.

11. C. mucronatus Rottb.-gram. 19. $t$. S. f. t. culmo 3-quetro basi 1-phyllo; fol. setaceo brevi; valvis ovatis breviter acutatis. C. distachyos Willd. C. junciformis Cav. ic. t. 204. f. 1. Desf. atl. 1. t. 7. f. 1. In Europa et Africa. $\odot$.

42. C. leucostachiyus $\boldsymbol{H}$. et $\boldsymbol{K}$. repens; culmo erecto 3 -quetro; fol. subulato 3-gonis; involucro 1-phyllo ; valvis ovatis obtusis. C. mucronatus Kuntlı. In Mexico. 4.

43. C. pannonicus $L$. culmo 3 gono basi $1-p h y l l o$; fol. carlaliculatis; spiculis 3-8 oblongis brevissime pedunculatis; valvis obtusis medio striatis. Host 3. t. 70. In Europa. ๑.

14. C. oligostachyns $H$. et $K$. culmis caespitosis erectis 3 -yonis filiformihus; fol. setaceis; valvis ovatis mucronatis; nuce 3-gona. Kunth syn. 1. p. 139. In Nova Andalusia. $\odot$.

15. C. fasciculatus Elliot; spiculis ovato-oblongis multifloris fasciculato-terminalibus; involucro diphyllo 
foliisque angustissime linearibus.

Elliotianus 11. et \$. In Georyia.

46. C. nivens Retz; culmo debili filiformi; spicis aggregatis valvisque lanceolatis involucro diphyllo breviovibus. Ret\% 5. p. 12. In nemorusis Indiae orientalis. 4.

1\%. C. pectiniformis $R$. et $\mathbf{S}$. culmis 3-gonis foliosis rectis; involucro Iongitudine unbellulae; spiculis pectinatis; valvis mucronatis. C. pectinatus loxb. C. coromandelinus spr. In Coromandel.

13. C. cimicinus Presl; culmo 3quetro; fol. planis culmo brevioribus; iuvolucro 3-phyllo spiculas excedente; valvis ovatis $\mathbf{1}$-nerviis obtusis; nuce apiculata rugoso-tuberculata. In 1 ruviu et Chili? 2.

49. C. diandrus Torrey; spiculis compressis mutifloris; valvis acutiusculis; nuce ovali compressa. In Nova Caesurea. 24.

50. C. tenuis $\mathbf{S} w$. culmo filiformi; spiculis subulatis confertis horizontali-reflexis; involucro 6-phyllo lineari. Sw. In Jamaica.

5 . C. litos $\boldsymbol{R}$. et $S$. radice tuberosa; spiculis alternis lanceolatis acutis basi bracteolatis. C. tenuis Mühleub. In Pensylvania.

5. C. adustus Presl; culmo 3-quetro; fol. planis glaherrimis; valvis ovatis obtusis 1-nerviis; nuce oblonga marginata. Presl. Mel.Haenk. In Perucia et Chili. 4.

\section{Spiculae capitulatae.}

53. C. sphaerocephalu.s I'ahl; culmo obtusangulo rigido; fol. convolutosubulatis; capitulis glohosis; spiculis ovatis obtusis. Vahl. 1. c. In Prom. b. spei.

51. C. laevigatus L. culmo 3-quetro nudo; capitulo globoso involucro diphyllo breviore; spiculis valvisque obtusis. Rottb. t. 16. f. 1. In Prom. b. spei.

5.5. C. obtusiflorus Vahl; fol. carinatis culmoque rigidis; spiculis aggregatis ovatis obtusis involucro diphyllo brevioribus. Vahl 1. c. In Madagascar.

56. C. rubicundus rahl; fol. linearibus culmoque filiformi laxis; spiculis aggregatis oblongis obtusis involucro diphyllo brevioribus. Vahl 1. c. In Portorico.
57. C. rigidus Vahl; radice repente; fol. culmoque rigidis; spiculis aggregatis obtusis involucro 4-phyllo brevioribus. Vahl I. c. In Madagascar.

58. C. flavissimus Schrad. culmo hasi hulboso; spiculis capitato-congestis ovatis compressis; iuvolucro polyphyllo. schrad. in schult. maut. 2. p. 98. In From. b. spei. 4.

5.9. C. recurrus lahl: culmo foliisfue setaceis; capitulo involucro 3 phyllo breviore; valvis obtusis aristatis. Vahl 1. c. In Sierra Leona.

60. C. striatulus Vukl; culmo acutangulo; spiculis capitatis ovatis complanatis; involuero 3 -phyllo; valvis lanceolatis. C. compactus Lam. In Biralagasior.

61. C. capitellatus $R$. et S. culmo setaceo subanguloso caespitoso; spiculis agglomeratis sessilibus; valvis striatis obtusis virillihus. C. capitatus Poir. In Mallagascar.

62. C. mollis poir. culmo anguloso subcompresso; fol. sublinearibus planis; spicis numerosissimis. Poir Enc. 7. p. 247. In Malagascar.

63. C. cephalotes Iahl; culmo obtusangulo; capitulo globoso ; spiculis complanatis; valvis ovatis. Vahl l. c. In insulis Micobaricis.

6.1. C. scirpoides Vulh; capitulo glohoso; foliis involucrisque canaliculatis recurvis rigidis. Vahl l. c. In Guinea.

6.5. C. coloratus Iahl; capitulo ovato; involucro 5-phyllo foliisque culmo longioribus laxis. VahL I. c. In Guinea.

66. C. Kullingaeoiles V'ahl; culmo setaceo triquetro; capitulo globoso; spiculis sub-8-floris; involucro 4-phyllo foliisque carinatis Iaxis. C. dubius Rottb. t. 4. f. 5. In India orientuli.

6\%. C. monocephalus Roxb. culmo striato; capitulo ovato composito; involucro 3-4-phyllo; stylo indiviso; nuce trigona supra receptaculum spongiosum. Roxb. ind. In Bengalia.

68. C. pugioniformis Roxb. diffusus; capitulis glomeratis sessilibus; spiculis incurvis; valvis pugioniformibus; involucro polyphyllo. Hoxb. l.c. liumph 1. t. 5t. In india orientali.

69. C. pulchellus R. Br. culmis erectis setaceis; capitulo globoso polystachyo; involucris 3-phyllis diva- 
ricatis; valvis obtusis monandris. $R$. Br. 1. c. In Nova Hollandir.

90. C. intricatus schrod. culmis 3-quetris laxis; fol. angustissimis brevihus; valvis carina prominente serrulatis. schult. mant. 2. p. 98. In Brasilia.

71. C. seslerioides Funtl; culmo obtuso 3-gono glahro; involucro 3phyllo capitulum longe superante; nuce 3-quetra punctato-scabra. Kunth syn. 1. p. 142. Ad Orinocum.

72. C. divergens Kunth; radice tuberosa; capitulo globoso polystachyo; involucio 4-phyllo; valvis mucronatis; nuce 3-quetra. Kunth I. In Mexico. 4.

73. C. tenerrimus Prest; fol. filiformi-planis ; involucro 5-phyllo; valvis lanceolatis 5-nerviis ohtusissimis; nuce lineari-ohlonga trituetra apiculata Presl IIaenk. 3. p. 166. In Acapulco.

7. C. leucoceplialus Retz; fol. culmo filiformi brevioribus; involucro 4-phyllo setaceo; valvis obtusis. Retz obs. 5. p. 11. In India orientali.

ซ.). C. pygmaeus Rotth. Gram. $t$. 41. . . 1.5. culmis triquetris ageregatis; involucro polyphyllo; capitulis glohosis; spiculis ovatis. In India orientali.

76. C. hamulosus Bieb. culmo 3quetro nudo; valvis uncinato-aristatis; involucio sub-3-phyllo. Bieb. Cauc. p. 35. Scirpus stev, In Cherson. $\odot$.

8\%. C. Michelianus Link; culmo 3-quetro; capitulo globoso; involucro 4-5-phyllo, phyllis majoribus longissimis; valvis lanceolatis, mucrone apice reflexo. Scirpus Host Gram. 3. t. 69. Isolepis 1R. et $\$$. In Europa. $\odot$.

78. C. filiculmis Tall; spiculis linearibus globoso-capitatis patentissimis; involucris 3-phyllis culmisque setaceis. Vahl 1. c. In Carolina.

\%9. C. mariscoides Nutt. fol. linearibus canaliculatis; spiculis lineari-lanceolatis; involucro 2 - - phyllo. Mariscus umbellatus Pursh. M. glomeratus Bart. \$. lupulinus spr. In America boreali. 24.

80. C. minutulus Vahl; culmo 3quetro folioso; involucro 6-7-phyllo; phyllis tribus longissimis; spiculis squarrosis; valvis mucronatis. C.pygmaeus Cav. Ann. 3. t. 26. f. 2. In Iauritania.
81. C. capitatus Retz; culmo subangulato compresso medio folioso; involucro 3-phyllo; spiculis linearioblongis capitatis sessilibus. Retz obs. 4. p. 9. In Inclia.

2. C. uncinatus Poir. fol. filiforunilus ; involucro 3-phyllo longo ; spiculis congestis lineari-ohlongis; valvis mucrone uncinato. Poir Enc. In Madagasca:

S3. C. inflexus Mühlenb. culmo setaceo 3-quetro; involucro 3-phyllo longissino valvis apice squarrosis mucronatis, mucrone recurvo. C. uncinatus Pursh. C. Purshii R. et S. In America boreali.

B. Spiculae in umbella magis minusve composita magis minusve explicata dispositae.

a. Spiculae confertae at in capi. tula conglomeratae.

81. C. aristatus Rottb. t. 6. f. 1. fol. linearilus carinatis; involucro 4phyllo longissimo; valvis aristatis; arista recurva. s. lappaceus Lam. In India orientali et Prom. b. spei. $\odot$.

8.5. C. Rrounii $R$. et $\mathbf{S}$. involucris 3-plyyllis; capitulis subrotundis polystaclyyis; valvis nervosis acumine uncinato-recurvo, monandris. C. uncinatus 1 . Br. In Nova Hollandia.

86. C. jolystrechyns Rottb. $t$. 11. f. 1. involucro 5-phyllo longissimo; valvis linearibus brevissime mucronatis; nuce oblonga ancipiti laeviuscula. In India orientali, Africa et Nova Hollandia. 4.

8\%. C. punctatus Roxb. umbella composita ; involucro sub-4-phyllo longissimo; nuce ovata compressa punctata. Boxh. ind. 1. p. 197. In India orientali.

88. C. capillaris Kanig; culmo filiformi 3-gono; umbellula unica sessili; involucro 3-phyllo filiformi; floribus diandris. Roxb. ind. 1. p. 198. In India orientali.

89. C. brunneus $\mathbf{S w}$. fol. lato-linearibus planis; involucro 3-phyllo; spiculis lanceolatis sulisessilibus glomeratis; valvis striatis. Sw. ind. 1. p. 116. In India orientali.

90. C. brizaeus Rich. fol. retrorsum subscabris; involucro 3-phyllo nubella duplo longiore; spiculis in capitulum hemisphaericum congestis. In 
India orientali, Mexico et in Corolina. 24.

91. C. polyphyllus Vahl; fol. linearibus culmum filiformem aequantibus; involucro 3-plyyllo filiformi; spiculis complanatis confertis divergentibus. Vahl 1. c. In Guinea.

92. C. Teneriffue Poir. culmo 3quetro hasi folioso; spiculis lato-complanatis; valvis memlranaceis apice subreflexis. Poir. Enc. 7. p. 24. In Tenerifia.

93. C. globosus All. spiculis glomerato-capitatis patulis Ianceolatis; involucro 2-4-phyllo longissimo relexo; valvis dorso striatis. In Italia. $\odot$.

94. C. incarnatus Link; fol. margine scabris; umbella contracta; phyllis duobus involucri longissimis; valvis oblongis striatis aculis. Link. In Brasilia? $\odot$.

95. C. Sellowii Link; fol. sulcatis margine praesertin scabris; involucro 3-4-phyllo, phyllis 2 longis; valvis oblongis acutissimis dorso striatis. Link. In Montevideo. $\odot$.

96. C. conglomeratus Rottb. $t$. 15. f. 7. fol. canaliculatis; radiis umbellae congloneratae brevissimis; involucro 4-plyyllo longissimo; nuce 3-gona subretusa. In Arabia. $\odot$.

9\%. C. caespitosus Poir. culmo filiformi 3-quetro; fol. linearilus planis; valvis obtusis dorso purpurascentilus. Poir. Enc. 7. p. 251. In Madagascar. 9S. C. stoloniferus Retz; rhizomate nodoso; fol. rigidulis margine scabris; spicnlis lanceolatis 10-14 foris; valvis ovatis acutis multinerviis. In India orientali et insula Luzon. $2 \%$.

99. C. croceus Vahl; spiculis teretibus globoso-capitatis; involucro sub-5-phyllo umbella longiore. Vahl 1. c. In Portorico. 4.

100. C. virens Michx. culmo acutissime triquetro; umbellis decompositis; spiculis ovato-lanceolatis compactis; involucro longissimo. Michx. am. In America boreali. 4.

101. C. ochraceus Vahl; involucro 5-phyllo umbella longiore; spiculis lineari-oblongis globoso-capitatis patentibus; valvis ovatis. Vahl en. 2. p. 325. In insula St. Crucis. 4.

102. C. confertus Sw. fol. linearibus; spiculis oblongis confertis subgloboso-capitatis patentibus; valvis oblongis striatis mucronatis. Sw. I. c. In Caribaeis. 4.

103. C. fulvus $R$. Br. culmo ohtuse angulato laevi; involucro 4-5phyllo plano; umbella 5-6-radiata; spiculis pinnatifidis 5-6-floris; valvis nervosis mucronulo erecto. $\mathrm{l}$. Br. 1. c. In Nora Hollandia.

10\%. C. sporobolus R. Br. culmo obfuse angulato laevi, fol. duplo longiori; involucellis selaceis; spiculis linearibus 5-floris pimnatifidis; valvis nervosis mucrouatis. In Nora HoL landiat.

10.5. C. sexflorus $R$. Br. involucris 6-phyllis elongatis; involucellis umbellula hrevioribus; spiculis linearibus subsexforis pimnatifidis; valvis nervosis. H. Br. 1. c. In Nova Hollansia.

106. C. microcephalus R. Br. culmo scaluro; involucro 3-4-phyllo longissimo; spiculis umbellato-capitatis pinnatifidis; valvis nervosis. In Nova Hollanalia.

10\%. C. Holoschoenus R. Br. culmo ohtusangulo laevi; capitulis globosis polystachyis; spiculis 4-5-floris ovatis; valvis enervibus obtusiusculis. R. Br. 1. c. In Nova Hollandia.

108. C. carinatus $R$. Br. capitulis polystachyis ; spiculis linearibus incisis 12-14-floris; valvis nervosis acutiusculis. R. Br. 1. c. In Nova Hollandia.

109. C. alterniflorus $\boldsymbol{R}$. Br. culmo acutangulo; involucro 3-phyllo longissimo reflexo aspero; valvis distiuctis nervosis acutiusculis. $\mathbf{R}$. Br. 1. c. In Nova Hollandia.

110. C. Seberianus Spr. culmo 3quetro scaberrimo folia linearia superante; involucro 3-phyllo longissimo; spicis compressis sub)-20-floris fulvis; valvis obtusiusculis appressis. R. Bi. I. c. In Nova Hollandia.

111. C. vegetus Willd. fol. margine serrulato-scahris; involucro polyphyllo, phyllis longissimis; valvis ovatis acutis 3-nerviis; nuce triquetra apiculata minutissime punctulata. C. monander Pers. C. compressus Jacq. H. Vind. t. 12. In Carolina. 4.

112. C. formosus Vahl; involncro 6-phyllo longissimo margine scabro; spiculis ovato-lanceolatis capitatis. Vahl en. 2. p. 327. In Lutisiana et Caribaeis. 
113. C. rufus Kunth; culmo 3-quetro angulis scahro; umbella 10-radiata; iuvolucro 8-phyllo; valvis mucronatis punctatis. Kunth 1. c. C. ubertus Willu. In Bogota. 4.

111. C. surinamensis Rottb. gr. t. 6. $f$. 5. involucro longissimo; uuthclla composita; capitulis subglobosis glomeratis; spiculis ovatis. In America merialionali. 4.

115. C. Manimae Kunth ; fol. carinatis scahris culmo dimidio brevioribus ; capilulis ellipticis ; involucro 8phyllo umbellam superante; valvis mucronatis; nuce punctato-scalıra. C. anisos 1. et $\mathrm{S}$. Ad Orinocum. 4.

116. C. Jasulce Rottb. t. 13. $f$. 2.; fol. planis apice carinatis margine scahris; involucro polyphyllo; valvis ovatis acutis 3-nerviis; nuce oblongo-ohovata 3-gona laevi. C. polyceplialus Lam. In America. 4.

117. C. glomuliferus Schrad. culmo 3-gono glabro; capitulo glomerato ;-radiato; involucro polyphyllo umbella multo longiore; spiculis paucifloris. schrad. In Irrasilia. 2 .

118. C. lanceolatus Poir. culmo 3-quetro; fol. angustis culmo brevioribus; involucro 3-phyllo umbellam subsimplicissinıan superante; valvis ovatis ohtusis 3-nerviis; nuce pyriformi apiculata punctulata. Poir. Enc. 7. p. 245. In Madayascar. 4.

119. C. pumilus L. culmo 3-gono; involucro sub 3-phyllo umbella longiore; spiculis valvisque cuspidatis. Rottl. gr. t. 9. f. 4. In India orientali.

120. C. nitens Retz; culmo 3-quetro hasi folioso; involucro 3-phyllo umbella longiore; spiculis subsquarrosis mucronatis; valvis obtusis. In India orientali.

121. C. squarrosus Linn. culmo 3-quetro; fol. involucrisque linearibus; epiculis linearibus confertissimis; valvis aristatis recurvis. Rottl, gram. t. 6. 1. 3. In India orientali. $\odot$.

122. C. flaridus Retz; culmo 3gono foliis plerumque hreviore; involncro diphyllo umbella breviore; umbellulis subglohosis; nuce obcordata 3-gona. In India orientali.

123. C. Nuttallii Spr. involucro 4-phyllo, phyllis 2 longissimis; spiculis lineari-lanceolatis compressis; nuce oblonga obtusa compressa. Spr. Entd. p. 240. C. Torreyanus R. et $\mathbf{S}$. Is Noce Caesarea. 4.
124. C. flavescens $I_{\text {. }}$ umbella subcomposita 3-phylla; spiculis lanceolatis; bracteolis obtusis. Rchb. Pycreus Beauv. Host. 3. t. 72. HI. graec. t. 47. In Europa et . America. $\odot$. Palmaris.

12.5. C. fuscus $\boldsymbol{L}$. umbella triphylla subcomposita; spiculis confertis linearibus; bracteolis nigris acutiusculis; scapo 3-quetro. Host. 3. t. 73. Fl. Dan. 179. Schk. t. 7. In paludosis Europae. $\odot$. Palmaris.

126. C. Forskoilei Alb. Dietr. culno 3-quetro basi folioso; unbella polyphylla; spiculis linearihus 7-floris. C. ferrugineus Farsk. descr. 1. 11. Ad Nilum. 4.

12\%. C. melanostachyus Lunth; culmis caespitosis adscendentibus; umbella sub-8-radiata, umbellulis 4-6stachyis; valvis subrotumdis acutis; nuce compressa punctato - scabra. Kunth. syn. 1. p. 141. In Nova Granat $\odot$. $\odot$

125. C. variegatus Funth; culmo hasi repente adscendente; umbella subcapilulaeformi; valvis obtusis; nuce compressa. Kunth 1. c. In Mexico. 4.

12.9. C. cuspidatus Kunth; culmis caespitosis 3-quetris foliisque glabris setaceis; involucro 3-phyllo unbellam superante; valvis emarginatis recurvato-aristatis; nuce 3-gona punctatoscabra. Kunth 1. c. Ad Orinocum. $\odot$.

130. C. aurantiacus Kunth; culmis 3-gonis foliisque glabris setaceis culmo brevioribus; involucro 3-phyllo; valvis emarginatis mucronatis. Kunth 1. c. Ad Orinocum. $\odot$.

131. C. aureus Funth; culmo 3quetro glabro 1-phyllo; umbella sub10-radiata; valvis emarginatis mucronatis; nuce 3-quetra punctato-scabra. C. quitensis spr. In Guajaguil et in California. $\odot$.

132. C. platystylis R. Br. umbella simplici 1-6-radiata; spiculis linearilanceolatis; valvis acutis enervibus; stylis compressis ciliatis. $\mathbf{R}$. Br. 1. C. In Nova Hollandia.

133. C. poceformis Pursh; invoIucro 3-phyllo longissimo; spiculis oblongis complanatis fasciculato-corymbosis. In Carolina australi. 4.

131. C. erythrueus Schrad. culmo 3-rono glabro; spiculis lineari-oblongis; valvis lato-ovatis carina nervosis; 
nuce globoso-obovata 3-gona. C. erubescens. Link. Patria iguota. $\odot$.

13.5. C. difformis I. spiculis confertissimis glohoso-capitatis; valvulis olovatis; involucro diphyllo umbella Iongiore. Botth. t. 9. 1. 7. In India orientali et in Guinea.

136. C. chrysometinus Link; involucro 3-4-phyllo; phyllis duohus longissimis; valvis ovalihus sub apice e carina mucronulatis; nuce trigona subretusa. Link Hort. 1. p. 305. In Nepalia. 4.

13\%. C. rigens Presl; involucro 4-phyllo; spiculis 8-floris subulatis in capitula ovata dense congestis; valvis oblongis 9-nervis. Presl Haenk. In Peruria. 2.

138. C. cephalophorus Prest; involucro 6-phyllo; umbella 6-radiata; spiculis 6-floris; valvis ovatis obtusis multinerviis. Presl Haenk. I. c. In Peruria. 4.

139. C. sordidus Presl; fol. angustis glaucis margine serrulato-scabris; involucro 4-phyllo longissimo; spiculis 12-floris; valvis ovatis multinerviis. PresI Haenk. In California. 24.

140. C. scoparius Poir. culmo iriquetro angulis asperis; involucro 4phyllo maximo denticulato; involucellis brevissimis. In Madagascar. 4.

111. C. ligularis $L$. fol. glaucis margine carinaque serrulato-scahris; involucro polyphyllo; phyllis 3 longissimis; valvis acutis multinerviis. Hottb. t. 11. f. 3. In Prom. b. spei, in Gininea et America. 4.

1+2. C. Poireti R. et S. culmo 3-quetro; involucro sub 4-phyllo; phyllo longissimo scabro; spicis subramosis. C. bidentatus Poir. In India orientali. 2.

113. C. involucratus Poir; culmo inferne folioso; umbellis spicatis subcylindricis; involucro longissimo aspero; spiculis minimis. In Iiadagascar.

1.11. C. alopecuroides Rottb. $t$. 8 . f. 2. involucro 4-6-phyllo, phyllis longissimis; valvis ovatis obtusis mucronulatis margine inflexis; nuce ancipiti, C, dives Delile Aeg. t. 4. f. 3. In Aegypto, Arabia et Nova Hollandia, 4 .

145. C. verticillatus Roxb. invoJucro polyphyllo Iongissimo; involuedlis filiformibus; spicis umbellae verticillatis; valvis acumine ohtuso. Roxb. ind. 1. p. 209. Prope Calcuttam. 24.

116. C. Thunbergii Vahl; spicis oblonwis glomeratis imbricatis sessilihus ; spiculis subulatis erectis ; ligula ochreae hifida, laciniis divaricatis. C. alopecuroides Thunb. In Prom. $b$. spei. 4.

11\%. C. dilutus Vahl; spicis sul)ulatis teretiusculis confertissimis subglohoso-capitatis; involucellis umbellam aequautibus. Vahl en. 2. p. 357. In India ovientali. 4.

1.18. C. congestus Vahl; involucro 3-phyllo; ligula ochrearum 2-dentata; spicis capitato-glohosis; spiculis subulatis confertissimis reflexis rectis. Vahl en. 2. p. 358. In Prom. b. spei. 4.

14.9. C. lucidus R. Br. involucro 4-6-phyllo longissimo foliisque margine scabris; spicis ollongis densis; valvis alternis acutis nervosis nitidis. 1. Br. I. c. In Nova Hollandia.

1.50. C. biceps V'ahl; culmo obtusangulo; umbella sub-1-radiata; spicis coupactis; spiculis linearilus confertissimis; valvis oblongis acuminatis. Vahl 1. c. In Galam.

1.51. C. glaber L. culmo 3-quetro nudo laevi; umbella 3-phylla; floribus gloneratis inferioribus brachiatis. Fichb. ic. t. 203. Seg. Ver. suppl. t. 2. f. 1. In Italia et Asia minore.

152. C. anstralis schrad. involucro universali 5-6-phyllo; partiali sub-3-phyllo; capitulis sessilibus pedunculatisve. C. glomeratus Bieb. Host. 3. 1. 71. In Germania, Italia et ad Caucasum. 24.

15.3. C. glomeratus. $L$. involucris involucellisque 3 -phyllis umbella longioribus; spicis glomeratis imbricatis; valvis linearibus. Patria ignota.

1.54. C. callophorus Meyer; involucro longissimo partiali setaceo; spiculis ohlongis. Meyer Esseq. p. 32. In America. 4.

155. C. multiceps Link; culmo 3quetro basi folioso; involucro polyphyllo longissimo; spiculis linearibus densissime glomeratis; nuce trigona. C. Linkianus R. et S. Patria ignota. 2.

156. C. spimulosus Roxb. culmo rigido; umbella decomposita; spiculis rigidis 3-1-ftoris; involucro involu- 
cellisque polyphyllis. Roxb. ind. 1. p. 207. In India orientali.

1.57. C. firmus Presl; culmo 3-yono scabriusculo; involucro polyply illo longissimo; umbella 10-radiata; spiculis in capitule ovato-cylindracea conglomeratis; valvis acutis striatis. Presl 1. c. In Acupulco. 4 .

158. C. laetus Prest; culmo 3-quetro; fol. margine scahris; iuvolucro 5-phyllo; valvis lanceolatis acutis 5nerviis; nuce subelliptica 3-gona scabriuscula. Presl I. c. In Chili. 4.

159. C. Haentiei Prest; involucro 5-phyllo; umbella multiradiata; spiculis linearibus acutissimis 8 -floris; valvis ovato-oblongis acutis multinerviis. Presl 1. c. In monte Rey Californiae. 4.

b. Spiculae alternae minus confertae aut in spicas dispositae.

160. C. patulus Host, Gr. 3. t. 71. fol. margine carinaque scabris; spiculis lanceolatis; involucro longissimo 6-phyllo; valvis ovatis ohtusis mucronatis; nuce 3-gona punctulata. In Europa et Oriente. 4.

161. C. paramattensis Link; culmo 3-quetro hasi tuheroso; fol. culmo longioribus margine serrulato-scabris; spiculis lineari-lanceolatis; phyllis involucri 1-2 longissintis; valvis mucronulatis. C. Paramatta. In Nora Holiandia. 4.

162. C. olivaris Targ. scapo 3quetro hasi folioso; spicis distichis lanceolatis; radicis tuberibus subovatis odoratis. C. radicans silhth. C. rotundus DC. In Europa. 4.

16:3. C. pallesçens Desf. culmo 3-quetro; involucro 4-phyllo; phyllo unico maximo ; spiculis $6-8$ linearibus ; valvis acutiusculis; nuce trigona truncata. Desf. atl. 1. f. 9. C. esculentus R. et S. mant. In Africa et Candia. 24.

161. C. xanthocomus I,ink; culmo 3-quetro; fol.laevihus ; nvolucro 2-3 phyllo; phyllo unico maximo; valvis ovalibus obtusis striatis. C. auricomus sieb. Prope Damiette. 4.

16.5. C. damiettensis Dietr. culmo teretiusculo; fol. margine carinaque serrulato-scabris, phyllis $3-4$-involucri longissimis; valvis ovatis ohturissimis saepe emarginatis. C. Sieberianus Link. Prope Damiette. 14.
166. C. esculentus $L$. tuberibus oblongis zonatis; scapo 3-quetro hasi folioso; umbella decomposita subpentaphylla. Host, 3. t. 75. In Europa et Africa. 4.

16\%. C. Tenorii Presl; radice repente tuberculosa, culmo 3 -quetro; fol. laxis culmo brevioribus; umbella 5-radiata; valvis oblongis oblusis; nuce 3-gona subtruncata. C. aureus Ten. Rchî. ic. 212. In Italia et Sicilia. 4.

168. C. compositus R. Br. culmo laevi; involucro 3-phyllo longissimo; valvis obtusis nervosis arcte imbricatis. R. Br. I. c. In Nova Hollandia.

169. C. ornatus $\mathrm{R}$. Br. involucris 3-phyllis elongatis; spicis 6-12-floris; spiculis lanceolato - linearibus; valvis arcte imbricatis obtusis enervibus margine scarioso discolori. $\mathbf{R}$. Br. In Nuva Hollandia.

170. C. prolixus Kunth; fol. planis carina margineque scabris; spiculis fasciculatis; involucro 10-phyllo umbellam superante; valvis mucronatis; Kuntl. syn. 1. p. 141. In Nova Granata. 4.

171. C. albus Presl; culmo 3-quetro; fol. angustis; culmo longioribus versus apicem margine scabris; involucro 6-phyllo; valvis ovatis acutis 3nerviis. Presl. 1. c. In ins. Lu$\approx 0 n$. 24.

172. C. comosus $\mathrm{Sm}$. tuberibus ovatis zonis obsoletis; culmo 3-quetro nudo; umbella foliosa; spiculis linearibus longissimis. Śm. prodr. 1. p. 30. Prope Patras. 24.

183. C. densiflorus Meyer; spicis umbellatis; ovato-oblongis ; spiculis confertis subulatis; involucro umbella longiore. Meyer Esseq. p. 34. In Essetpuebo. 4.

174. C. nemorosus Meyer; radice fibrosa; spiculis corymbosis distantibus linearihus; involucro umbella longiore; partiali diphyllo setaceo. Meyer 1. c. In ins. Arovabisch. 4 .

175. C. Hydra Michx. radice tuberosa; fol. carinatis culmo brevioribus; umhella suh-6-radiata; involucro 3-phyllo; spiculis linearibus; valvis ovatis obtusis mucronatis; stylo 2-fido. Michx. am. 1. p. 27. In America boreali et in Mexico. 4.

176. C. bicolor Vahl; involucro diphyllo umbella 3-radiata longiore; spiculis linearibus convexiusculis ter- 
nis, Vahl en. 2. p. 340. In ins. Miascarenis.

17\%. C. tuberosus Rottb. Gram. p. 28. t. 7. $f$. 1. culmo 3-quetro basi folioso; involucro umbella 5-radiata longiore; spiculis lineari-lanceolatis convexiusculis. In India orientali.

178. C. phymadotes Mühlenb. radice tuberosa; fol. glabris laevibus longitudine culmi; involucro 3-9phyllo; spiculis confertis lineari-lanceolatis; valvis oblongis mucronulatis. C. repens Elliot. C. tuberosus Pursh. In America boreali. 4.

179. C. tetragonus Elliot; spicis oblongis cylindricis; spiculis sub-1gonis paucifloris; involucro longissimo; involucellis nullis. Ell. bot. 1. p. 71. In Georgia.

180. C. tetrastachyns Desf. atl. 1. \%. 41. $t$. 8. culmo 3-quetro foliisque margine serrulato-scabris; valvis ohlongis obtusis. In Algiria.. 4.

181. C, rotundus $L$. tuberibus oblongis; umbella foliosa supradecomposita; involucro 3-phyllo; spiculis altcrnis lanceolatis ovatis. C. tetrastachyus Ten. In Italia et Graecia. 2.

182. C. hexastachyus L. Rottb. Gr. $p$. 28. $t$. 13. f. 2. radice tuberosa; involucro 3-4-phyllo umbella pauciradiata longiore; valvis oblongis obtusis; nuce 3-yona attenuata laevi. C. rotundus L. In Africa, India orientali et in Nova Hollandia. 4.

133. C. littoralis $\mathbf{R}$. $\mathrm{Br}$. involucris diphyllis umbellam superantibus foliisque carinatis intus maculatis culmum laevem subaequantibus; spiculis linearihus; valvis arcte imbricatis obtusis enervibus. H. Br. 1. c. In Nova Hollandia.

181. C. nervosus Bertol. radice tubifera; iuvolucro 5-phyllo; spicis umbellatis; spiculis linearibus erectopatulis; valvis obtusis multinervibus. Bertol. Piant. Bras. p. 3, In Brasilice.

18.5. C. pertenuis Roxb. culmo superne 3-angulari basi subtereti; involucro 3-phyllo; spiculis filiformibus multifloris; uuce 3-gona. Hoxb. ind. 1. p. 202, In India orientali.

156. C. torosus Vahl; involucro sub-3-phyllo umbella longiore; spicis corymbosis patentibus; spiculis teretiusculis. C. strigosus Rottb. t. 11. f. 3. In India orientuli.

187. C. mestulatus Vaht; involucro umbella longiore; spiculis lineari- oblongis confertissimis convexis obtusis; valvis margine sphacelatis. Vahl en. 2. p. 341. In Guinea.

188. C. sphacelatus Rottb. involucro sub-4-phyllo; spiculis lineari-lanceolatis complanatis acutis; valvis margine sphacelatis. Vah! I. c. In Guinea.

159. C. rigidulus Vahl; involucro diplıyllo umbella 1 -radiata Iongiore foliisque filiformibus rigidis; spiculis linearihus confertissimis. Vahl 1. c. In India orientali.

190. C. bulbosus Tahl; radice bulbosa; involucro umbella 1-radiata longiore foliisque setaceis; spiculis lineari-lanceolatis distantibus. In India orientali et in Africa.

191. C. diphyllus Retz; involucro diphyllo hrevissimo; spicis corymbosis; spiculis teretibus. Retz obs. 5 . p. 11. In India orientali. 4.

192. C. scuriosus R. Br. culmo laevi fol. carinatis duplo lorigiore; involucro diphyllo; spiculis lineari-subulatis ; rachi alata; valvis acutiusculis subenerviis. H. Br. 1. c. In Nova Hollandia.

193. C. areolatus $\mathrm{R}$. $\mathrm{Br}$. involucris 2-3-pliyllis elongatis foliisquo planis; valvis acutis enervibus diandris; stylo bifido; nuce lenticulari. $\mathbf{~} \boldsymbol{H}_{\text {. }}$ Br. 1. c. In Nova Hollandia.

19t. C. puncticulatus Vahl; involucro 3-phyllo umbella longiore; spicis corymbosis distichis; spiculis lineari-lanceolatis subpendulis distantibus. Vahl I. c. In India orientali.

19.5. C. macrostachyus Iatm. involucro suhdiphvlio; umbellis amplissimis; spicis corymbosis; spiculis lineari-lanceolatis remotiusculis longissimis arcuatis. Lam. ill. 1. p. 147. In India orientali.

196. C. latifolius Poir. culmo excelso triangulari laevi; fol. culmum aequantibus; iuvolucro maximo sub4-phyllo; valvis distinctis. Poir Enc. 7. p. 268. In Madagascar. 4 .

197. C. lancens Thunb. involucro sub-3-phyllo; spiculis lanceolato-oblongis arcte imbricatis confertis. Tlumb. prodr. p. 18. In Prom. b. spei. 4.

198. C. niger Ruiz et Pav. culmo triquetro nudo glabio ; fol. ensiformibus; umbella foliosa; pedunculis plurinis longis; spicis laxis nigricantibus. In Peruvia. 
199. C. ferox Rich. spiculis filiformi-subulatis confertissimis flexuosis reflexis; involucro partiali subnullo. In America meridionali. 4.

200. C. flexuosus Vahl; spicis olIongis retrorsum imbricatis; spiculis subulatis flexuosis; involucellis 5-phyllis longitudine umbellulae. Vahl 1. c. In America meridionali.

201. C. monoplyllus Vahl; umhella involucrum diphyllum subaequante; spicis corymbosis; spiculis teretibus laxe imbricatis. Vahl 1. c. In America merilionali.

202. C. parriflorus Iahl; involucro 7-phyllo longissimo; spicis corymhosis linearibus teretiusculis; spiculis oblongis teretibus distantibus. Vahl I. c. In Java.

203. C. albidus Retz; culmo 3quetro uudo; involucro polyphyllo longissimo; spiculis latis; nucibus apice capitulatis. Vahl 1. c. C. Retzii Poir. In China.

201. C. radiatus Vahl; culno acutangulo; involucro 3 -phyllo; spicis sessilihus imbricatis teretibus; spiculis oblongis subsquarosis. Valll. 1. In India orientali.

20.5. C. umbellatus Burm. ind. $t$. 9. f. 1. culmo 3-quetro nudo; umbellae ratiis elongatis involucro diphyllo longioribus; spiculis linearibus. Vahl 1. c. In India orientali.

206. C. hirtus Thunb. culmo 3-gono aphyllo; umbella simplici; involucro sub-3-phyllo; fol. filiformibus hirtis. In Prom. b. spei.

207. C. hyalinus Vahl; involucro 6-phyllo longissimo; spiculis oblongis multifloris remotiusculis squarrosis; valvis ovatis attenuatis. VahI I. c.

In India orientali. $\odot$.

208. C. bidentatus Vahl; involucro 5-phyllo longissimo; spiculis confertis oblongis sub-3-floris; valvis oblongis acuminatis. Valı 1. c. $A d$ Senegal. 4.

209. C. membranaceus rahl; fol. involucrisque linearibus; spiculis oinlongis confertissinis squarrosis; valvis oblongis obtusis mucronatis laevibus. Vahl 1. c. In India orientali. $\odot$.

210. C. filicinus Vahl; involucro 3-plyyllo umbella longiore foliisque Jaxis; spiculis lineari-lanceolatis remotiusculis laxe imbricatis. Vah! 1. c. In Virginia.
211. C. intactus Vahl; involucro 3 phyllo foliisque rigidis; spiculis linearibus remotis. VahI 1. c. In Galam. 4.

212. C. olivaceus Vahl; involucro umbellam aequante; spicis corymbosis laxis; spiculis lineari-lanceolatis rectis. Vahl 1. c. In Prom. b. spei.

213. C. olidus Iahl; involucro 3phyllo umbella triradiata longiore; umbellulis corymboso - fasciculatis; spiculis lineari-lanceolatis arcuatis. Vahl 1. c. In America meridionali.

21+. C. puniculatus Rottb. involucro 6-phyllo; umbellulis corymbosofasciculatis lineari-lanceolatis. C. scopellatus Rich. In India occidentali.

215. C. patens Tahl; fol. linearisubulatis; involucro sub-3-phyllo; spiculis linearibus remotiusculis; valvis oblongis nucronatis patentibus. Vahl 1. c. In Guinea. $\odot$.

216. C. curvatus Vahl; involncro sub-3-phyllo subulato umbella longiore; spiculis lineari-lanceolatis approximatis incurvis. Vahl en 2. p. 338. In India orientali. 4.

217. C. incurvatus Roxb. culmo 3-augulari hasi folioso incurvato; spiculis acicularibus incurvis; valvis oblongis ohtusis. Roxh. ind. 1. p. 200. In India orientali. 4.

21S. C. tortuosus Koenig; culmo obtuse trigono; umbella composita longitudine involucri; spiculis linearibus incurvis; florilus diandris; nuce obovata compressa exangulata. Roxb. 1. c. In India orientali.

219. C. Caricinus Don; fol. Iate linearibus culmo 3-quetro longioribus; racemis lateralibus simplicibus; bracteis lineari-sctaceis rachique scal)ris; valvis ellipticis mucronatis. Don prodr. p. 39. In Nepalia.

220. C. cruentus Rottb. Gr. t. 5. f. 1. involucro 5-phyllo, phyllis oninibus umbella longioribus; spiculis sul)quinis oblongis convexis; valvis punctatis. C. globosus Forsk. In Arabia. 4.

221. C. sanguinolentus Tahl; involucro 3-phyllo; spiculis suhquinis oblongis approximatis; valvis maryine sanguinolentis. Valıl en. 2. p. 351. In India orientali.

222. C. Wallichianus Spr. culıno 3-quetro laevi involucris 5-phyllis foliisque margine revoluto-asperis; spiculis limearibus; valvis ovalibus ob- 
tusis striatis laevibus. Spr. syst. veg. 1. p. 28. C. pulcher Don. In Nepalia.

223. C. trisulcus Don; fol. liuearibus margine scabris culmo 3 -sulco brevioribus; spiculis ovali-oblongis obtusis adpressis margine repandocrispatulis. Don 1. c. In Nequalia.

221. C. Doniames Alb. Dietr. fol. late linearibus cuspidatis margine scabris culmo triquetro duplo Iongioribus; spiculis lineari-subulatis ; valvis ellipticis acuminatis rachique pilosis. C. paniculatus Don 1. c. In Nepalia.

225. C. strictus Roxb. culno recto rigido foliis breviore, angulis scahris; umbella decomposita recla; floribus diandris; nuce obovata compressa exangulata. hoxb. 1. c. In India orientali.

226. C. malaccensis Lam. umbella paniculata; involucro 3-phyllo Iongissimo; spicis corymbosis; spiculis linearibus teretibus curvatis; valvis fructiferis basi hiantibus. Lam. ill. 1. p. 146. In Malacca. 4 .

22\%. C. planifolius Rich. fol. praelongis planissimis; involucro sub-5phyllo longissimo; spiculis linearilanceolatis confertis convexis. Rich. Act. par. 1. p. 106. In India occidentali. 4.

228. C. pilosus Vahl; spicis sessilibus radiatis lanceolato-oblongis; spiculis patentibus distinctis remotiusculis; rachi ciliata. Vahl I. c. In India orientali. 24.

22.9. C. canescens Vahl; spicis sessilibus imbricatis spiculisque oblongis teretiusculis reflexis. VahI 1. c. Hheede 12. t. 42. In India orientali. 21.

230. C. racemosus Retz; culmo 3-quetro nudo; umbella supradecomposita; involucro polyphyllo longo; spicis corymbosis imbricatis; spiculis linearibus. Retz obs. 1. p. 20. In India orientali.

231. C. holosericeus Link; culno 3-quetro; involucro hexaphyllo: phyllis 3 longissimis; spiculis linearibus acutis; valvis ovatis acutis carinatis non striatis. Link 1. c. 1. p. 307. Patria ignota. 4.

232. C. striyosus $L$. fol. culmo Iongiorihus margine scabris; involucro 6-phyllo; spiculis densissime aggregatis saepe reflexis; nuce subtruncata lacvi. Jimn. C. Michauxianus $R$. et S. In America boreali. 4.
233. C.erythrorlizos Mühlenh. umbella decomposila; involucro 3-6phyllo longissimo; spiculis linearibus horizontalibus subduodecinfloris anguste linearibus. Mühlenb. 1. c. In America boreali.

234. C. dentatus Torrey; involucro 3-phyllo umbella longiore; spiculis 3, compressis 8-floris; valvis acutis nervosis apice pungentibus. C. parviflorus Mühleul. C. micrantlus $\mathbf{R}$. et $\$$. In America bor. 4.

23.5. C. Pangorei Rottb. gr. $t$. $\%$ f. 3. culmo 3-quetro; involuero 3phyllo; spicis corymbosis; spiculis filiformihus remotiusculis; valvis linearibus obtusis. In india. 4.

236. C. badius Desf: atl. $t$. 7. f. 2. fol. margine carinaque serrulatis; involucro 3-phyllo; spiculis lineari-lanceolatis. In Alyiria. 4.

23\%. C. longus $\boldsymbol{L}$. unbella supradecomposita 4-6-phylla; spiculis linearihus; bracteolis imbricatis; radice repente. Host 3. f. 76. In paludosis Europae. 4. Culm. 2-pedalis.

235. C. procerus Rotth. t. 5. f. 3. culmo acuto 3 -quetro, angulis scahris; involucro 3-phyllo; spiculis racemosis lineari-lanceolatis patentissimis; nuce obcordata. Ihheede 12. t. 50. In India orientali. 4.

23.9. C. corymbosus Rottb. $t$. 7 . $f$. 4. culmo vaginato involucro umbella decomposita longiore; spicis corymbosis; spiculis linearibus teretiusculis. In Arabia, India orientali et in Prom. b. spei. 4 .

2-10. C. gramineus Poir. culmo debili suhtriquetro humili basi folioso; involucro subdiphyllo; umbella supradecomposita; spiculis minimis. Poir. Enc. \%. p. 207. In India orientali.

211. C. tenniflorus Rottb. $t$. 14. $f$. 1. culmo 3-quetro folioso; involucro 3-4-phyllo, phyllis 2-3 longissimis; valvis oblongis ohtusis; nuce 3 -gona subattenuata. Jacq. ic. t. 296. In India orientali et in Europa. 24.

212. C. pulcher Thunh. fol. linearibus culmo $\mathbf{3}$-quetro longioribus; involucro sub 6-phyllo longissimo; umbella decomposita. Thunb. prodr. p. 18. In Prom. b. spei.

213. C. spectabilis Link; involucro 6-phyllo; plyyllis $2-3$ longissimis; spiculis 20 linearibus sexfloris; valvis inferioribus ovalibus obtusis- 
simis; nuce subretusa laevi. Link Ho:t. 1. p. 318. Patria i.jnota. 24. $2 t$. C. Nonti $L$. unhella deconposita 4-5-phylla; spiculis lanceolatis; hracteolis remotiusculis; radice repente. Pycreus Beauv. Host. 4. t. 6\%. In Earopa. 4.

24.5. C. bengalensis Spr. aphyllus; culmo 3-angulari; umbella supradecomposita; involucris involucellisque paleaceis; nuce ohlonga compressa exaugulata. C. nudus hoxb. C. GulaMethli $\mathrm{R}$. et s. In Bengalia. 2!.

246. C. tegetum Roxb. culmo exacte triangulari; foliis longitudine culni ; involucro $4-5$-phyllo, phyllo unico longissimo; staminihus 2 ; nuce compressa obcordata. In India orientuli. 4.

21\%. C. fustigiatus Rottb. $t . \%$ f. 2. phyllis involucri exterioribus longissinis; spicis cylindricis; valvis infimis ovalibus ohtusis, superioribus nucrounlatis. C. imbricatus Ret $\%$. C. odoratus Burm. ind. 20. t. 8. f. 2. In India orientali. 24.

218. C. venustus R. Rr. culmo striato laevi; involucro 4-phyllo; involucellis selaceis; spicis elongatis distichis; valvis obtusiusculis mucronulatis. R. Br. I. c. In Nova Hollandia.

24.9. C. ventricosus $R$. Br: invoJucro 4-5-phyllo longissimo; spiculis oblongo-lanceolatis; valvis nervosis acutis arcte imbricatis. R. Br:- Rheede 12. t. 55. In Nora Hollandia.

250. C. subulatus R. Br. involucro 4-phyllo umbellam superante; spiculis corymboso-confertis patulis subulatis; valvis alternis acutis dor'so striatis. R. Br. 1. c. In Nora Hollandil.

2.5t. C. acutus R. Br. involucro 3-phyllo umbellam superante; umbella 3-4 radiata indivisa; spiculis sub4-floris subulatis; valvis alternis obtusiusculis nervosis. R. Br. 1. c. In Nova Ilollandia.

252. C. purpurascens Tahl; involucro longissimo scaberrimo; corymbis ovatis fasciculatis ; spiculis linearisubulatis convexiusculis. Vahl 1. c. In ins. St. Crucis. 4.

2.53. C. flavicomus Michx. culmo 3-quetro basi folioso; involucro longissimo; umbella composita; spiculis lincari-lanceolatis; valvis oblongis ohtusis; fructiferis patentibus. Michx. ain. 1. p. 27. In America boreali. 4 .

2.5-1. C. Iria I. culmo triquetro seminudo; umbella foliosa decomposita; spiculis alteruis; granis distinctis. Limn. syst. p. 67. C. Santonici Rotth. t. 9. f. 1. In India orientali et in ins. Luzon. 24.

25.5. C. distans $I$. culmo 3-quetro nudo; unhella supradecomposita; spicis alternis filiformibus; flosculis distan(i)us. Fled'Oware 1. t. 20. C. elatus Rottb. t. 10. In Indiis. 21.

2.56. C. jubcteforus Rudye Guj. t. 21. culmo 3 -quetro nudo; umbella foliosa composita; spicis ohlongis dense imbricatis; spiculis subulatis. In India occillentali.

25\%. C. expansus Poir. culmo praealto nudo 3-angulari; umbella supradecomposita ranisque expansis complanatis; involucro sub4-phyllo longissimo; spiculis subulatis. Poir. Enc. 7. p. 268. In Madagascar.

2.58. C. laxus Valal; umbellulis fastigiatis laxis; spicis corymbosis; spiculis filiformibus. Vahl I. c. In India orientali. 24.

2.5.9. C. nutıns Iahl; umbella laxa; corymbis contractis nutantibus; spiculis linearibus erectis; flosculis distantibus. Vahl 1. c. In India orientali.

260. C. elatus L. culmo acutangulo; umbella subdecomposita; spicis omnibus subsessilibus linearibus; spiculis numerosis 6-18 floris; nuce oblonga 3-gona. Linn Amoen. 4. p. 300. In Coromandel.

261. C. speciosus Tall; culmo acutangulo; spicis corymbosis ; spiculis distichis; umbellulis involucellis brevioribus; ochreis $\mathbf{2}$-aristatis. Vahl 1. c. In Virginia et Carolina. 24.

262. C. Enslenii Pursh; involucro octophyllo umbellam subaequante; spiculis numerosis divaricatis confertis linearihus suhsexfloris; valvis ohlongis striatis. Pursh am. 1. p. 58. In Virginia et Carolina. 4.

263. C. exaltutus Retz; umbelIulis terminalibus 3-fidis; spicis laxis; spiculis linearihus subdistichis; ochreis 2-aristatis. Retz obs. 5. p. 11. C. canaliculatus Retz. In India orientali. 4 .

264. C. Schottii Hortul. involucro polyphyllo; umbella decomposita; spicis cylindricis; spiculis 6-foris; fio- 
sculis distichis remotis; valvis linearibus dorso striatis. Patria igmota. 2. 265. C. cupreus Presl; culmo inferne folioso; involucro 5-phyllo unbellam 8-radiatam excedente; involucellis nullis ; spiculis 14-floris imbricatis dorso spicatis; valvis lanceolatis 1-nerviis. Presl Haenk. In California. 4.

266. C. holciflorus Presl; culmo obtuse triquetro; fol. planis glaucescentibus rigidulis margine scabris longe excedentihus; spiculis 4-floris; valvis ovatis acutis multinerviis. Presl 1. c. In ins. Luzon. 24.

26\%. C. spicatus Presl; fol. margine spinuloso-scabris; involucro 5phyllo, phyllis 2 longissinis; valvis ovato-subrotundis emarginatis mucronato-aristatis 1-nerviis. In ins. Luzon et in Mexico. 4.

26s. C. philippensis Prest; invoIncro 5-phyllo umbella 5-radiata longiore; spiculis linearibus 6-floris ; valvis ovato-oblongis aculis 1 -nerviis; nuce minutissime punctulata. Presl 1. c. In ins, Luะon. 4 .

269. C. Iusonensis Presl; fol. culmum aequantibus; involucro 5-plyyllo; spiculis 8-12-floris; valvis ovatis mucronatis $\mathbf{5}$-nerviis carina scabris; nuce rugulosa. Presl 1. c. In ins. Luzon. 4.

c. Spiculacin umbellulas digitatim autasciculatim dispositae.

270. C. castaneus Willd; culmis foliisque setaceis; spicis linearibus digitatis squarrosis; involucro 5-phyllo; valvis aristatis recurvatis. Willd. In India orientali. $\odot$.

271. C. amabilis Vahl; fol. convoluto-subulatis culmo filiformi brevioribus; involucro longitudine umbellae; spiculis linearibus digitatis; valvis muticis. Vahl 1. c. In Guinea. $\odot$.

272. microstachyus Valt; umbellulae involucellis foliisque subulatis; spiculis linearibus digitatis sulıquinis; valvis muticis. Vahl 1. c. In Guinea. $\odot$.

273. C. denticulatus Selirad. culmo triquetro foliisque linearibus scabris ; spiculis congestis ; involucro 4phyllo; valvis apice denticulatis. $R$. et S. mant. 2. p. 104. In Brasilia.

271. C. trinervis $\boldsymbol{R}$. Br. involucris sub-4-phyllis umbella duplo lon- gioribus; spiculis linearibus; valvarum lateribus 1-nervibus acutis. $\mathbf{H}$. Br. 1. c. In Nova Hollandia.

275. C. imbecillis $\boldsymbol{R}$. Br. culmo foliisque laxis; involucris diphyllis: longiore umbellam subaequante; spiculis 1-4-linearibus 1-nervibus acutis. H. Br. I. c. In Nova Hollandia.

276. C. aquatilis $\mathrm{R}$. Br. involucro diphyllo: majore umhella breviore foliisque planis flaccidis; spiculis lineari-lanceolatis; valvis acutis semiscariosis diandris. H. Br. 1. c. In Nova Hollandire.

27\%. C. flaccidus $R$. $\mathrm{Br}$. involucris 1-phyllis; umbellae radiis 4-6capillaribus indivisis pancifloris; spiculis oblongo-linearilus inciso-serratis; valvis semiscariosis apice acuto recurvato-patulo. R. Br. 1. c. In Nova Hollandia.

278. C. inuudatus $\boldsymbol{R}$. Br. involucris 1-phyllis umbella brevioribus; spiculis lineari-lanceolatis pinnatifidis; valvis acutis. $\mathrm{R}$. Br. In Nova IIollandia.

279. C. tetraphyllus $\boldsymbol{R}$. Br. involucris 4-phyllis longissimis foliisque culmo longioribus; umbellae radiis strictis indivisis; valvis acutis tenuissime nervosis. H. Br. 1. c. In Nova Hollandia.

280. C. breviculmis $\boldsymbol{R}$. Br. umbella culnum erectum v. involucrum diphyllum subaequante; spiculis linearibus pinnatifidis; valvis acutis diandris. H. Br. 1. c. Iu Nova Hollandia.

281. C. angustatus $R$. Br. involucris 3-phyllis longissimis; unhella multiradiata composita; spiculis $\mathbf{3}-\mathbf{5}$ patulis angusto-linearibus teretiusculis; valvis nervosis acutis. R. Br. 1. c. In Nova Hollandia.

282. C. concinnus $\boldsymbol{R}$. $\boldsymbol{B r}$. culmo extrorsun scaloro; involucro 3-phyllo umbellulam superante; spiculis subternis ovalibus valvisque ohtusis scariosis. IR. Br. 1. c. In Nova IIollandia.

283. C. autumnalis I'ahl; umbella involucrum diphyllum subaequante; spiculis linearibus digitato-sulternis. Vahl 1. c. Scirpus lottb. t. 17. f. 3. In America boreali.

28t. C. amentaceus Rudge t. 19. culmo compresso nudo; umbella laxa gracili; spica divaricata; valvarun 
apicibus deciduis amentiformibus. In Gujanı.

285. C. Haspan L. culmo 3-gono; Involucro diphyllo; spiculis linearibus sul)-4-ternis digitatis (runcatis; nuce subulobosa scabra. Plukn. t. 192. f. 2. In India orientali.

286. C. plutyculmis R. Br. culmo conpresso fol. duplo longiore; umbella multiradiata composita effusa; involucro diphyllo; spiculis subternis linearihus; valvis acutiusculis 3-andris; uncibus laevibus. H. Br. 1. c. In Nova Hollandia.

257. C. longifolins Poir. culmo 3-quetro hasi longe folioso; umbella supradecomposita; involucro polyphyl10 longissimo. Poir. Euc. 7. p. 270. In Madagascar.

2s8. C. Mühlenbergii Spr. culmo gracili acute 3 -quetro; fol. triquetris; iuvolucro diphyllo brevi; spiculis linearibus minutis subdigitatis; valvis lanceolatis acutis. C. gracilis Mühllenh. C. leptos $\mathrm{R}$. et S. In Georgia et Carolina.

259. C. aequalis Vahl; culmo 3gono; involucro subnullo; umbella composita; radiis numerosissimis aequalibus; spiculis subgeminatis linearibus. Vahl en. 2. p. 320. C. prolifer Lam. C. papyroides Poir. In insula Franciae.

290. C. diffusus Taht; fol. culmo altiorihus; involucro unbella longiore; umbella supradecomposita diffusa; spiculis subgeminatis lanceolatis. Vahl 1. c. In India orientali. 4.

291. C. iridifolius Presl; fol. latis subeusiformibus culmo longioribus margine scabris; involucro 7-phyllo; umbella multiradiata supradecomposita longiore; spiculis lanceolatis sexfloris; valvis ovato-subrotundis 5-nerviis refexo-mucronatis. Presl 1. c. In ins. Luzon. 4.

292. C. breviflorus Alb. Dietr. culmo inferne folioso; fol. involucro 4phyllo quadruplo longioribus; spiculis 10-floris; valvis ovatis obtusis 3-nerviis. C. micranthus Presl. In ins. Luะon. 4.

293. C. alternifolius $I_{\text {. }}$ involucro polyphyllo longissimo; umbellulis sub4-stachyis; spiculis lanceolatis basi 2-bracteatis; valvis linearibus cuspidatis Limn. In Madagascar. 4.

29-1. C. canus I'resl; involucro polyphyllo; involucellis ovatis; och- reis breviter acuminatis ; spiculis dioecis lanceolatis usque vigintifloris; valvis ovatis acutis 3-nerviis. Presl 1. c. In Hexico. 4.

29.5. C. flabelliformis Rottb. $t .12$. f. 2. involucris alternis utrinque culmoque sulcato scabris; umbellis umbellulisque corymbosis; spiculis ovatolanceolatis. C. gradatus Forsk. In Arabia. 4.

2.96. C. tremulus Poir. culmo basi folioso ; involucro polyphyllo ; phyllis extremis masculis; spiculis subulatis; valvis obtusis allo-marginatis. Poir. 1. c. In Madagascar.

297. C. nudus Iiunth; culmo aphyllo vaginato; involucro diphyllo umbella dimidio breviore; valvis ovatis subemarginatis mucronatis; nuce 3gona. C. vaginatus Willd. C. tunicatus R. et S. In Nexico. 24.

298. C. ferrugineus Poir. fol. ensiformibus subcoriaceis ; involucro lougissimo polyphyllo; umbella composita brevi subagglomerata; spiculis bracteolatis acutis. Poir. 1. c. In Malagascar.

299. C. giganteus Tahl; culmo obtusangulo; umbella supradecomposita; umbellulis involucellum aequantibus; ochreis 2-fidis; spiculis subulatis. Vahl 1. c. In India occidentali. 4.

300. C. elegans $L$. fol. culmo brevioribus; spiculis digitatis subternis oblongis; valvis subrotundo-ovatis mucronatis; nuce obovata obtusissima. C. laxus Lam. In America meridionali et India occidentali.

301. C. chalaranthens Presl; involucro polyphyllo umbellam multiradiatam supradecompositam excedente; valvis ovatis 5 -nerviis nucronatis. P'resl Haenk. 3. t. 32. f. 1. In Peruvia. 4.

302. C. toluccensis Kunth; fol. planis carina margineque scabris culmo brevioribus; involucro 5-phyllo umbellam supcrante; valvis emarginatis reflexo-mucronatis; nuce 3-quetra. Kunth. C. pauciflorus Willd. In Hexico. 4.

303. C. simplex Kunth; fol. plania margine scabriusculis culmum superantibus; involucro 5-phyllo; valvis acuminatis; nuce triquetra pulverulento-pubescente. Presl Haeuk. 3. t. 31. f. 1. In Mexico. 4. 
304. C. flarus Presl; fol. anguslissimis culmo brevioribus; involucro diphyllo; spiculis lineari-lanceolatis; valvis ovatis obtusis 3 -nerviis; nuce ohovato-subglobosa. Presl 1. c. In Inexico. 24.

30.5. C. angastifolius Presl; culmo 1-pliyllo; fol. angustissinis culmo brevioribus; spiculis linearihus $16-$ floris; valvis subrotundo-ovatis obtusissimis mucronatis; nuce oblonga punctulata. C. tenellus Presl 1. c. In California. $\odot$.

306. C. denudatus $\mathrm{L}$. involucro sub1-plyyllo hrevissimo; umbella composita; spiculis linearibus digitalis subsenis; valvis lanceolatis apice patulis. In Prom. b. spei. 4.

30\%. C. diaphamus schrad. fol. carinatis glabriusculis culmo longioribus; involucro unbella multo lougiore; spiculis valvisque oblongo-ovatis obtusis; nuce ohovata leviter compressa transversim rugosa. R. et $\$$. mant. 2. p. 47\%. In Nepalia. $\odot$.

308. C. compressus L. fol. junioribus maruine serrulato-scabris; umbella 4-radiata; involucro 6-phyllo unbellam superante; valvis mucronatis; muce triquetra. Rottb. t. 9. f. 3. In America et Indiis. $\odot$.

309. C. brachiatus Poir. fol. angustis lincaribus brevibus; unbella composita; radiis lateralibus patentissimis; valvis acutis apice patentibus. Poir. 1. c. In Madagascar.

310. C. jemenicus Rotio. culmo foliisque filiformihus incurvis; involucro 4-phyllo setaceo scabro; umbella simplici; spiculis lanceolatis sub-4-ternis. Hottb. t. 8. f. 1. In Arabia.

311. C. bulbiferus Retz; culmo basi bulbifero; spiculis sessilibus alternis linearibus; valvis acutis; nuce 3-gona subrotunda. C.jemenensis Retz. In India orientali.

312. C. unioloides $\boldsymbol{R}$. $\boldsymbol{R}$. culmo acutangulo laevi; involucris 3-phyllis longissimis; spiculis $8-10$ confertis lanceolatis serratis; valvis acutis enervibus; nucibus orbiculatis lenticularibus rugosiusculis. Ii. Br. l. c. In Nova Hollandia.

313. C. ater Vakl; involucro 3phyllo lineari-lanceolato, umbella longiore; spiculis subdigitatis ovato-lanceolatis. Vahl I. c. In India orientali.
314. C. digitatus Roxb. culno 3gono; umiclla decomposita fastigiata; involucro involucelloque polyphyllo; valvis acumine longo recurvis. Roxb). ind. 1. p. 209. In sudiu orientuli.

31.5. C. Eragrostis Iall; involucro diphyllo; umbella 3-radiata; spiculis quateruis lanceolatis obtusiusculis. Vahl en. 2. p. 322. C. cruentus lietz. In Traniquebaria.

316. C. luteriflorus steud. fol. carinatis margine serrulato-scabris; spicis lineari-lanceolatis; valvis ovatis obtusis; involucro diphyllo corymbum subaequante. Steud. bot. Zeit. 1929. p. 152. In Prom. b. spei.

31\%. C. cilictus Schlecht. radice fibrosa tubifera; culmo angulis cilia10-scalris; fol. planis malgine carinaque scabris; valvis ovatis acutis; uuce 3-angulari. Schlecht. Linn. 6. 1. 25. In Mexico. 24.

315. C. thyrsiflorus Schleclit. culmo triquetro glabro; fol. planis margine serrulato-scaloris; spicis thyrsoideis; spiculis alternis linearihus acutis; valvis submucronatis. Limaea 6. p. 24. In Hexico. 4.

319. C. angulatus Nees; involucro 1-phyllo foliisque convolutis margine serrulatis; spiculis lineari-lanceolatis compressis; valvis ovatis, acuto-carinatis papyraceis; nuce punctulata striata obovata mucronata. Wight Contr. of. Ind. In Nepalia et Ava.

320. C. stramineus Nees; culmis incurvis geminis uno compresso altero 3 -quetro; valvis ovatis acuminulatis, dorso 3 -carinatis; nuce lenticulari rugosa. Wight. I. c. In Silhet. 321. C. Wightii Nees. fol. anguste linearibus plicatis; spiculis oblongolanceolatis compressis 10-30 floris; valvis imbricatis ovatis subulato-cuspidatis subtilissime strictis. Nees 1. c. C. pectiniformis Wight. In /ndia orientali.

322. C. versicolor Nees; culmo acute 3-quetro crasso; spiculis compressis subpurpureis; valvis basi late ovatis recurvato-subulatis, 7 -nerviis. Nees 1. c. In Tanjore et Negopatam. 323. C. Silletensis Nees; culmo 3-quetro versus apicem folioso; squamis pallidis oblongis obtusis rectis latere 1-nervis; nuce ovali 3-angulari acuta laevi. Niees 1. c. In silhet. 
321. C. mocerulus Nees; radice tuherosa; culno 3-quetro basi folioso; valvis lateovatis acutiusculis muticis rufo-lineatis latere pallide lıteis, marwine membranaceo. Nees 1. In India orientali.

32.5. C. Retsii Nees; culmo 3-quetro supra hasin folioso; spiculis compressis sul- $\mathbf{- 2 0}$-floris; valvis ovatis apice attenuatis acutis muticis ferrugineis; carina viridi. Nees I. c. C. Pangorei Koenig. In India orientali.

326. C. Neesii D. culmo 3-quetro foliisque linearibus angulis scahro; involucellis bracteisque setaceis ; squamis late oratis ontusis badiis albomareinatis, muticis 7-nervis. C. Wallichii Nees C. inumdatus Herb. In Benyalia inferiore.

327. C. marginellus Nees; culmo acute 3-quetro; spiculis lanceolatis 14-18-floris; valvis ovatis acutis subtus nervosis pallide rubris albomarginatis; nuce ovata subtilissime punctata. Nees 1. c. In Chince et Zeylonia.

328. C. obliquns Nees; culmo 3quetro angulis acutis; rachi spicarum villosa; valvis arcte imbricatis Iate ovatis convexis apice rotundatis subnuticis rubris 5 -nerviis. In India orientali.

329. C. fimbriatus Nees; culmo 3angulari, angulis cum foliis involucrisque fimbriatis; rachi hirsuta; spiculis valvisque obtusis rufis. In Nepalia.

330. C. ustulatus Rich. culmo 3-quetro laevi; fol. margine costaque denticulatis; valvis carinatis strictis obtusis sub apice mucronatis. Kich. in Urville voy. In Nova Zeelandia.

\section{PAPYRTS Thuars (1809). (Cyperus Auct.).}

1. P. antiquorum Willd. culmo nudo 3-quetro basi vaginato; involucellis 3-phyllis filiformibus longissimis. Mich. gen. t. 19. In Sicilia et Africa. 4.

2. P. madagascarensis Willd. culmo nudo triquetro basi vaginato; involucellis 3-phyllis linearibus brevissimis. Willd. Abh. 1812. p. 72. In Madagascar. 21.
3. P. laxiflorus Spr. culmo 3-quetro utido; umbella radiis numerosissimis longissimis; involucro polyphyllo brevi; partiali subdiphyllo. spr. syst. 1. p. 232. In Madagascar.

t. P. odoratus Willd. culmo 3gono hasi foliato; involucris 5-phyllis umbella longioribus; involucellis diphyllis umbellas partiales suhaequantihus. Cyperus Auhl. Guj. p. 20. In America meridionali et in India occidentali. 24.

5. P. lutifolius Willd. culmo 3quetro hasi folioso; involucris umbellae longissinis; involuccllis 8-phyllis umbella partiali duplo brevioribus; spiculis imbricatis. Willd. 1. c. Circa Tranquebar.

6. $\boldsymbol{P}$. comosus $\boldsymbol{W}$. culmo 3-gono; involucris subemeaphyllis umbella hrevioribus; involucellis 8-phyllis umbella partiali multo longioribus. IVilld. 1. c. In Quito. 4.

7. P. dehiscens Nees; culmo basi 1-folio superne 3 -quetro; valvis oblongis obtusis patentihus nervosis, margine badiis; involucro 3-phyllo. Nees in Wight Contr. p. \%2. In India.

\section{GUSSONEA Presl (1S33).}

1. G. cyperoides Presl Haenk. 3. p. 183. $t$. 38. Radix fibrosa. Culmus caespitosus, pedalis. In California. 4.

\section{1\%. DULICHIUM Pers. (1805).}

1. D. spathaceum Pers; culmo superne 3-quetro; spicis compositis, spiculis lanceolatis patentibus sub)-6floris. Cyperus L. Plukn. t. 311. f. 1. In Anerica boreali. 4.

2. D. canadense Pers. culmo superne teretiusculo; spicis simplicibus; spiculis lanceolatis erectis sub-10-floris. Pers. syn. 1. p. 65. In Canada. 4.

\section{MARISCUS Vahl (180.5).}

I. Spica depauperata, solitaria.

1. N. capillaris Vahl; culmo basi folioso; spica oblonga retrorsura 
Imbricata; involucro diphyllo. Vahl en. 2. p. 372. Schoenus sw. Cyperus rarus Willd. In ins. Caribaeis et Martinique.

2. IN. gracilis Tahl; aphyllus; spica subglohosa sessili; involucro 2-3-phyllo setaceo. Vahl en. 2. p. 373. In Americu meridionali.

3. H. apllyllus Vuhl; aphylus; spica globosa sessili; involucro brevissimo. Vahl 1. c. Sloane 1. t. 81 . f. 2. In Hispuniola. 4.

4. MI. havainnensis hunth; culmo 3-quetro glabro aphyllo?; spiculis 5-6-alternis confertis 3-5-floris ; involucro diphyllo; valvis emarginatis; nuce 3-quetra. Kuntl syn. 1. p. 115. In Cuba. 24.

5. M. filiformis Kunth; culmo 3quetro glabro foliato; fol. margine dorsoque scahris culmum superantibus; spiculis 10 alternis confertis 2-3-floris; valvis acuminatis. Kunth 1. c. Cyperus Sw. C. Omithopus Pers. In India occidentali. 4.

II. Spicis densis, solitariis, ternis aut pluribus, sessilibus.

6. M. agyregatus Willd. culmo triquetro; fol. margine scabris culmum superantihus; involucro polyphyllo; spiculis oblongis bracteis linearibus elongatis interstinctis; valvis cuspidatis Willd. en. 1. p. 70. Patria iynota. 4.

7. M. confertus Kunth; repens; fol. apice serrulatis culmo 3 -quetro glabro longioribus; spiculis ovatis 1-2-floris; involucro 8-phyllo longissimo; valvis acutis. Kumth. 1. c. In Nova Hispania. 24.

8. M. flaves Vahl; repens; fol. apice serrulatis culmum aequantibus; spiculis 2-floris lineari-lanceolatis; involucro sub-5-phyllo; valvis acumiuatis subulatis. Vahl 1. c. In America et California. 24.

9. M. Iaevigatus $R$. et $S$. spicis subquinis ellipticis; spiculis lanceolatis hifloris; involucro 5-phyllo longissimo; valvis obtusis infra apicem mucronatis. M. laevis Kunth. Ad Orinocum. $2 \%$.

10. M. Haenkei Presl; repens; fol. margine scabris; involucro 3phyllo longissimo; spicis ovato-ellipticis; valvis lanceolatis acutis 9-ner- viis; nuce oblonga triquetra laevi. Presl. 1. c. In California. 4.

11. M. huarmensis liunth ; fol. margine scahris; spicis 8-10 ellipticis; spiculis linearihus 3-floris; involucro 4-phyllo longissimo; valvis emarginatis brevissime mucronatis. Kunth 1. c. In Pernvia. 4.

12. M. littoralis Meyer; spicis cylindricis sessilibus pedunculatisve; spiculis ovato-subulatis; sub-2-floris; bracteis lineari-subulatis; involucro spicis breviore. Meyer Esseq. p. 57. In Essequebo. 4.

\section{Spicis umbellatis.}

A. Umbellis simplicibus.

13. $M$. rigidus $S p r$. involucro polyphyllo longissimo; spicis numerosis cylindricis; spiculis oblongis $\mathbf{1 - f l o r i s}$ erecto-patulis striatis bracteas setaceas superantibus. Carex Sieberi Nees. In Nova Hollandia.

14. M. paniceus Vahl; fol. margine scabris culnum vix superantibus; involucro 4-phyllo longissimo; spiculis erecto-patentibus; valvis striatis. M. conflexus Link. Killingia L. Gaertn. 1. t. 2. f. 8. In India orientali et Arabia. 4.

15. M. ovularis Vall; involucro 4-phyllo longiusculo; spicis snbglobosis pedunculatis; spiculis patentibus bracteatis; valvis striatis. Vahl 1. c. IN. echinatus Elliot. hot. t. 3. f. 1. Schoenus Jacq. ic. t. 10. In America boreali. 4.

16. M. cylindricus Elliot; culmo obtuse triquetro glabro; umbellis simplicibus; spicis cylindraceis; spiculis lanceolatis subcompressis paucifloris patentibus. Elliot 1. c. In Carolina.

17. M. refractus $\mathrm{Vahl}$; fol. pubescentibus carinatis ; involucro 3-phyllo; spicis obovatis retrorsum imbricatis; spiculis retrofractis; valvis subtilissime striatis. Scirpus L. Gaertn. 1. t. 2. f. 5. Plukn. t. 415. f. 4. In Virginia et Carolina. 4.

18. IV. mubscens Presl; pubescens; fol. culmo hrevioribus; involucro sub-6-phyllo; spicis cylindraceis; valvis ovato-lanceolatis acutis nervosis. Presl 1. c. In California. 4.

19. M. flabelliformis Kunth; fol. margine scabris; unbella sub-12-radiata; spiculis linearibus 1-floris; involucro 10 -phyllo; valvis infra api- 
cem laevissime mucronatis. Kunth 1. c. In Caracas. 24.

20. M.'Torari linth; repens; fol. scalıris culnum subaequantibus; umbella 6-8-radiata; spiculis linearibus 1-floris; involucro 5-phyllo; valvis intra apicem brevissime mucronatis. Kunth 1. c. In Caracas. 4.

21. M. pycnostacliyus liunth; fol. margine cartilagineo-serrulatis; involucro 8-phyllo umbella duplo longiore; valvis infra apicem brevissime mucronatis. H. et Kunth Nov. Gen. pl. t. 66. In Nora Hispania. 4.

22. M. Mutisii Kunth; fol. margine scahris; spicis lineari-cylindricis; spiculis lanceolatis $\mathbf{1}-\mathbf{2}$-floris; involucro enneaphyllo; valvis obtusis. H. et Kunth 1. c. t. 66. In Nova Hispania. 4.

23. Mr. coriaceus Meyer; spicis corymboso-umbellatis cylindricis; spiculis oblongo-subulatis 3 -floris; valvis acutis; involucro longissimo polyphyllo. Meyer Esseq. p.38. Ad radices arbonum in Essequebo. 4.

21. H. palustris Schrad. fol, versus apicem scabris; spiculis linearibus 1-floris; valvis intermediis infra apicem brevissime mucronatis. $\mathbf{R}$. et $\mathbf{S}$. mant. 2. p. 141. In Brasilia. 4.

25. M. Suartzii Alb. Dietr. umbella terminali simplici; spicis ovatis acutis; involucro 3-phyllo, partiali nullo. M. filiformis Spr. Killingia $\mathbf{S w}$. In Jamaica et Hispaniola.

26. M. rufus Iiunth; culmo foliisque papilloso-asperatis serrulatis; involucro 7 -phyllo umbella multo longiore; valvis obtusis; nuce 3-quetra. Kunth 1. c. t. 67. In Fova Hispania. 24.

27. M. polycephalus Link; fol. latis margine scabris; umbellae radiis expansis; capitulis ovalihus; spiculis compressis arrectis; involucro emmeaphyllo, phyllis 7 longissimis. In $\mathrm{Br}(-$ silia. 24.

23. $M$. riparius; fol. margine carinaque scabris culmum superantibus; spicis solitariis oblongis basi compositis; spiculis lanceolatis 2-floris. $\mathbf{f}$. et s. mant. 2. p. 142. In Prom. b. spei. 24.

29. M. laevis R. Br. culmo laevi; umbella indivisa; involucro :-phyllo unbellam superante foliisque planis; spiculis curvatis $2-3$-floris; valvis ? alternis. R. Br. 1. c. In Nova Hollandia.

30. Mr. conicus $R$. Br. umbella indivisa; involucro polyphyllo; fol. asperis; capitulis conicis sub-3-lobis; spiculis 1-floris; squamis 5 imbricatis tertia sterili, intima juxta apicem constricta. 12. Br. 1. c. In Nova Hollandia.

31. M. cyperinus Fall; umbella simplici; involucro polyphyllo longissimo; spicis cylindricis; bracteis spiculis hrevioribus. Vahl en. 2. p. 377. Kyllingia Retz. In India orientali et Guinea. 4.

32. H. umbellatus Vahl; fol. culmo longiorihus latis; capitula cylindrica; spiculis reflexis; involucro 6phyllo, phyllis 4 longissimis; valvis oblongis striatis acutiusculis. Vahl l. c. Kyllingia Kottb. t. 4. f. 2. Rlieede 12. t. 63. In India orientali. 4.

\section{B. Umbellis compositis.}

33. N1. alternifolius Iahl; spicis cylindricis retrorsum imbricatis; involucris pedunculisque alternis. Vahl 1. c. In Gujana. 4.

34. MI. elatus Vahl; spicis cylindricis; spiculis patentissimis; bracters spiculis longioribus. Vahl 1. c. Killingia incompleta Jacq. ic. t. 800 . Ad Caracas et in Cayenna.

35. M. neglectus $R$. et $\mathbf{S}$. umbella composita; involucro 8-phyllo longissimo; spiculis patulis 3 -floris; bracleis linearibus. $\mathbf{R}$. et S. 1. c. In America boreali.

36. IH. Jaquinii Kunth; involucro polyphyllo longissimo; spicis cylindricis; spiculis patentissimis subulatis acutis; valvis imbricatis inferioribus obtusis. Carex hermaphrodita Jacq. ic. t. 615. Elacocharis 1 . et $\mathbf{S}$. $A d$ Caracas.

37. M. polyphigllus Funth; radice tuberosa; fol. serrulatis; spiculis linearibus sub-4-floris; involucro 7phyllo; valvis infra apicem mucronatis. In Quito. 4.

38. M. microcephalus Presl; fol. culmo tereti scabro longioribus; involucro 4-phyllo; spicis subglobosis; spiculis linearibus sub-3-floris; valvis ohlongis acutis striatis. Presl. 1. c. In insula Luzon. 4.

39. M. cyperoides Roxb. culmo 3-quetro; umbella composita; capitulis 
globosis ; spiculis numerosis ; involucro 3-phyllo, nuce oblonga 3-quetra. Roxb. ind. 1. p. 187. In India orientali.

10. M. scahes R. Br. culmo scabro; involucro polyphyllo umbellam contpositam superante; spiculis subulatis teretibus curvatis 2 -floris; valvis alternis. I. Br. I. c. In Nova Hollandia.

11. M. decompositus $\boldsymbol{R}$. Br. umbellis compositis decompositisque; inrolucris 5-phyllis elongatis foliisque asperis; spiculis strictis ovato-lance $0-$ latis; valvis imhricalis. R. Br. I. c. In Nova Hollundia.

12. M. Iunthumus Gaud. fol. rigidis derso margineque scabris culmum aequantibus; spicis fasciculatopaniculatis; involucro 6-phyllo; valvis oblongis mucronatis glabris fuscescentibus. Gaud. in Freyc. Voy. bot. p. 415.

43. II. albescens Gaud. fol. planis rigidis margine serrulato-scaloris; panicula umbellato-fasciculata involucro 5-phyllo; phyllis longissimis: valvis ovatis acutatis cinereo-albidis. Gaud. in Freyc. Voy. bot, p.415. In insulis Moluccensibus.

\section{KILLING1A Rottb. (17\%3).}

\section{Capitulo solitario.}

1. K. monocepleala I. fol. angnstissinis margine scabris; capitulo solitario globoso; invoîncro 3-phyllo elongato; spiculis 1 -floris; valvis ovatis nervosis carina ciliatis. Scirpus cephalotes Jacq. Vind. t. 98. In Indiis. 24.

2. K. intermedia R. Br. fol. linearibus culmo Jaevi duplo breviorihus; involucro 3-phyllo; spiculis 2floris; valvis nudis nervosis, interiori majori. R. Br. 1. c. In Nova Hollandia.

3. R. obtusata Presl; repens; fol. rigidis glabris; involucro 3-phyllo elongato; capitulo globoso; valvis ovatis emarginatis mucronulatis 3-nerviis. Presl 1. c. In P'eruvia. 4.

4. I. pumila Michx. fol. subulatis; capitulo globoso; involucro 3phyllo elongato; spiculis 1-floris 2-andris; valvis compressis acutis glabris. Michx. aw. 1. p. 28. In Carolina. 24.
5. K. brevifolia Rottb. $t$. 4. f. 3. fol. linearihus lacvissinis; capitulo globoso; involucro 3-phyllo longissimo; valvis lanceolatis acuminatis; apice reflexis dorso striatis saepe ciliatis. K. uncinata Link. In America et in Indiis. 4.

6. K. sifuamulata Tahl; capitulo ovato sessili; involucro elongato; spiculis carina squamuloso-spinosa. Vahl.

\section{In Guinea.}

\%. I. pungens Link; fol. margine scahris; capitulo unico; involucro 3phyllo; phyllis 1-2 capitulo longioribus acutis pungentihus; valvis lanceolatis acutiusculis. Link Hort. $\boldsymbol{P}(t-$ tria iynotit. 4.

8. K. vayinata Lam. aphylla; capitulo globoso sessili; involucro brevi. K. peruviana Lam. K. globosa Beauv. Fl. doware t. 31. In Perucia et Guinea. 4.

\section{Capitulis aggregatis.}

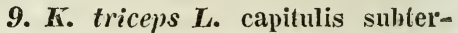
nis aggregatis; involucro 3-phyllo longissimo; spiculis confertissimis subimbricatis; valvis ovatis striatis acuminatis carina subciliatis. Rottb. t. 4. f. 6. K. nivea Pers. Plukn. t. 197. f. 7. Rheede 12. t. 52. In Africa. 4.

10. K. capensis Steud. radice tuberosa; culmo solitario 3-quetro; fol. culmo brevioribus subserratis; capitulis solitariis $2-3$. steud. bot. Zeit. 1819. p. 158. In Prom. b. spei.

11. F. bulbosa Beauv. Fl. d'Ouare t. 8. $f$. 1. radice tuberosa; culmo solitario canaliculato; capitulis glomeratis; involucro 3-phyllo. In Guinea.

12. K. odorata Vahl; fol. cuImo brevioribus; capitulis subternis glomeratis; involucro 3-phyllo; spiculis distinctis patentissimis; valvis striatis ciliatis. Vahl 1. c. In America meridionali. 4.

13. K. elongata Kunth; culmo 1phyllo; capitulis $3-4$; involucro 4 phyllo capitulis multo longiore; valvis striatis glabris. Kunth syn. 1. p. 144. In Peruvia. 4.

14. K. maculata Michx. capitulis subternis ovatis; involucro 3-phyllo patentissimo; flosculo monandro. Mariscus $\mathrm{R}$. et $\mathrm{S}$. In Carolina. 


\section{MAPANIA Aubl. (1775).}

1. M. sylvestris Aubl. Guj. 2. p. 47. t. 17. In Gujana. 4. Culmi 3quetri $\frac{1}{2}$-pedales flores in capitulum collecti.

\section{HEMICHLAENA Schrad. (1818).}

1. H. capillifolia Schrar. culmo elongato; fol. sparsis capillaribus; pedunculis terminalibus lateralibusque. 12. et. S. mant. 2. p. 94. In Prom. b. spei.

2. II. angustifolia Schrad. culmo diffuso: fol. confertis lineari-setaceis; pedunculis terminalibus. $\mathbf{R}$. et $\mathbf{S}$. $\mathbf{l}$. c. In Prom. b. spei.

\section{FUIRENA Rottb. (1973).}

1. umbellata Rottb. t. 19. f. 3. culmo 4-gono foliisque glabris; umbellis compositis decompositisve; spiculis glomerato-capitatis. F. paniculata L. In India occidentali et in Nora Hollandia. 4.

2. F. tereticulmis Presl; culmo vaginisque teretibus glabris; fol. ciliatis; spicis umbellarum glomeratocapitatis ovatis hirsutis; valvis late ovatis emarginatis recurvato-aristatis. Presl Haenk. 3. p. 186. In Acapulco. 4.

3. F. canescens Vahl; culmo foliisque villoso-incanis; spicnlis glomerato-capitatis. Vahl en. 2. p. 235. Ad Senegal.

1. F. squarrosa Michx. culmo glabro; fol. ciliatis; vaginis pilosis umbellis simplicibus; spiculis ovatis. Miclix. am. 1. p. 37. Elliot. bot. 1. t. 1. f. 3. In America boreali.

5. F. lispida Elliot; caule superne hispido; fol. praelongis vaginisque hispidissimis; laciniis perigyuii ovatis acutis. Elliot 1. c. In Carolina et Georgia.

6. F. glomerata Lam. culmo vaginisque glabris; spiculis umbellarum subternis aggregatis ovato-oblongis. Lam. ill. 1. p. 150 . F. ciliaris Roxb. Scirpus Rottb. t. 17. f. 1. Plukn. t. 417. f. 6. In India orientali et in Nova Hollandia.

\%. F. livta Vahl; culmo 3-quetro superne hirto; fol. subtus cum vaginis dense hirtis; involucro 2-3-phylIo; valvis subrotundis aristatis hirsutis; setis hypogynis tribus. Scirpus Hottentotus L. In Prom. b. spei.

8. F. caerulescens Steud. culmo 3-quetro foliisque ensiformibus glabris; spicis capitato-glomeratis; valvis lato-0vatis obtusissimis mucronatis caerulescentibus. Stend. b. Zeit.1S29. p. 154. In Prom. b. spei.

9. F. cephalotes Steud. culmo folioso foliis vaginisque hirtis; spiculis capitato-glomeratis globoso-ovatis involucro brevioribus. Steud. I. c. In Prom. b. spei. 4.

10. F. simplex Vahl; umbellis simplicibus compositisque; spiculis ovatooblongis solitariis. Vahl en. 2. p. 381. In America meridionali.

11. F. verticillata Spr. culmo stricto alternatim excavato foliisque rigidis glaherrimis; spiculis teretiusculis truncatis glabris sub-4-floris. Spr. nov. prov. p. 47. In Brasilia.

12. F. Weigelti Ant. Spr. culmo 3-quetro glabro; fol. flaccidis elongatis margine scabris; pedunculis pubescentibus; spiculis lineari-lanceolatis acuminatis 1-floris. Ant. Spr. tent. p. 4. In Surinamo.

13. F. arenosa $R$ : $\mathbf{R} r$. culmo foliisque glabro; spiculis solitariis oblongis pilosis; aristis valva dimidio brevioribus. $\mathrm{R}$. Br. 1. c. In Nova Hollandia.

11. F. scirpoidea Michx. aphylla; spiculis terminalibus subternis. Vagim naria Richardi Pers. In America boreculi. 4.

15. F. pumila Torrey; culmo superme pubescente; fol. glabris, vaginis margine ciliatis; valvis mucronatis, infima pilosa. Spr. syt. 1. p. 23\%. F. squarrosa, $\beta$. pumila Torrey. In America boreali.

\section{HYPELYTRUM Tahl (1803).}

1. H. pungens Vahl; spicis ovatooblongis; involticro pungente; valvis calycinis obtusis. Vahl. 1. c. In America meridionali.

2. H. argenteum Vahl; fol. linearibus; spiculis ovatis glomeratis; involucro diphyllo spiculis Iongiore; valvis calycinis rhombeis acuminatis: nuce 3-quetra. Scirpus senegalensis 
I,am. In America australi, India orientali et al fluvium Senegal. 4.

3. H. sphucelatum Vahl; culmo 3-quetro 1-phyllo; folio canaliculato culmo breviore; valvis calycinis oblongis; nuce oblonga triquetra acutiuscula punctata. Vahl. 1. c. In Panama et Mexico. 4.

4. H. filiforme Vahl; culmo filiformi; fol. setaceis; spicis oblongis. Vahl. 1. c. In Guinea.

5. H. microcephalum $\boldsymbol{R}$. Br. culmo setaceo 3-quetro; involucro diphyllo Iongissimo; spiculis ternis subglobosis; valvis cuneato-linearibus aristatis. R. Br. 1. c. In Nova Hollandia.

6. H. triceps Roxb. culmo subcompresso; spicis terminalibus $2-3$; involucro diphyllo. Roxb. ind. 1. p. 18\%. In Coromandel.

7. H. Laevigatum Spr. culmo 3gono; spicis terminalibus plurimis ; involucro 3-phyllo. Tumga laevigata Roxb. In India orientali.

8. H. nemorum Beav. Fl. d'Oware 2. $t$. $6 \%$. fol. longissimis planis margine carinaque serrulato-scabris; valvis calycinis ovatis acutis; nuce sul)globosa. Albikia scirpoides Presl. in Rel. Hacuk. t. 35. In Guinea, insula Luzon et India orientali. 4.

9. H. trinervium Willd. fol. Iongissimis planis 3-nerviis margine carinaque scabriusculis; valvis calycinis ovato-rotumdatis; nuce ovata. Scirpus anomalus Retz. Albikia schoenoides Presl. t. 34.. - Rheede 12. t. 58. In India ovientali et insula Luzon. 4.

10. H. gracile Rich. caule debili; fol. angustis; spiculis 3 subglobosoovatis; valvis spathulatis; stamine unico; stignatibus duobus. Pers. syn. 1. p. 70. Patria ignota.

11. H. diandrum Alb. Dietr. culmo folioso 3-quetro; corymbis terminalibus; iuvolucris alternis; foribus diandris; stylo bifido. Tunga Roxb. ind. 1. p. 188. H. latifolium Spr. In Amboina.

12. H. latifolium Rich. maximum glabrum; fol. latis 3-nerviis; corymbo decomposito; staminibus duobus. Pers. syn. 1. p. 70. In India.

13. H. macrocephalum Gaudich. spiculis arcte fasciculato-congestis; fasciculis capitatis bractea elongata suffultis. Gaudich. in Freyo Voyage p. 415. In Moluccis.

\section{MELANCRANTS Vahl (1505).}

1. M. scariosa rahl; capitulo oblongo; involucro sub-3-phyllo. Vahl en. 2. p. 239. In Prom. b. spei.

2. M. nigrescens Schrad. cnlma foliisque setaceis; capitulo oblongo; involucro sub-4-phyllo. IR. et S. mant. 2. p. 136. In Prom. b. spei.

3. M. vadictu Vahl; capitulo subgloboso; involucris polyphyllis. Vahl 1. c. In Prom. b. spei.

1. M. rubiginosa Spr. fol. teretibus; involucro 1-phyllo scarioso; bracteis glabris coloratis; stylo 3-fido. Schoenus Forst. Fuireua $\mathbf{R}$. et S. In Nova Zeelandia.

\section{BAUMEA Gaudich. (1828).}

1. B. glomerata Gaudich. spiculis capitato-congestis; capitulis subglobosis paniculatim dispositis; nuce aurantiaca laevi. Gaudich. in Freyc. Voyage bot. p. 416. t.29. In Moluccis.

2. B. mariscoides Gaudich. panicula ramosissima; spiculis subsolitariis sessilibus vel pedicellatis; nuce atro-rubra Iaevi. Gandich. 1. c. In insulis Marianis.

\section{REMIREA Aubl. (17\%5).}

1. R. maritima Aubl. capitulo terminali subsessili. Aubl. Guj. t. 16. Miega maritima Willd. In America meridionuli. 4 .

2. R. pedunculata $\boldsymbol{R}$. Br. pedunculo communi spicis longiori. $\mathbf{H}$. $\mathrm{Br}$. 1. c. Ad littor maris Novae Hollandiae.

\section{5\%. OREOBOLUS R. Br. (1810).}

1. O. Pumilio R. Br . culmis ramosis scapis axillaribus compressis; fol. linearibus strictis basi dilatatis. R. Br. 1. c. In Nover Hollandia.

2. O. obtusangulus Gandich. culmo 3-gono sexsulcato; fol. linearisubulatis. Gaudich. Fl. des iles Ma- 
louin. in Ann. sc. nat. 1825. t.2. r. 1. In ins. Muclorianis.

\section{Gramina.}

858. NARDUS. Linn. (Lobel 15\%0).

1. N. stricta $L$. spica recta secunda. Schreh. t. 7. Host. 2. t. 4. Leers t. 1. f. 7. In Enropa et ad Caucasum. 24. Fol. fasciculata.

\section{CENCHRLS (Linn. 173\%).}

1. C. myosuroides Humb. et Kunth. Nor. Gen. $t$. 3.5. culmis erectis; fol. scabris : involucro 10-fido scabro. Pennisetum spr. In insula Cuba et in Peruvia. $\odot$.

2. C. alopecuroides Presl; cnlmis erectis; fol. planis scabris superne villosis; involucro multifido scabro. Presl Haenk 1. p. 317. Patria ignota.

3. C. pilosus Humb. et Kunth $l$. c. t. 36. culmo erecto; fol. pilosis; iuvolucro sub-12-floro piloso basi setoso. In America calidiore. $\odot$.

4. C. echinatus $L$. culmis erectis vel procumbentibus; involucro 10-fido piloso, hasi setoso, spiculis subquinis duplo longiore. Cav. ic. t. 462. In America. $\odot$.

5. C. pungens Humb. et Kunth; culnis procumbentibus; involucro sub9-fido piloso basi setoso, spiculis geminis parum Iongiore. Kunth. In $\boldsymbol{B r}^{r} \alpha-$ silia? $\odot$.

6. C. tribuloides $\boldsymbol{K}$. spica spiculis alternis; involucris integris spinosis. Vahl. en. 2. p. 394. Cav. ic. t. 461. Moris. 8. t. 5. f. 4. In Mexico et Montevideo. $\odot$.

7. C. inflexus R. Br. involucris 1-floris profunde 6-7-filis, laciniis angusto-lanceolatis margine nudis, fructiferis inflexis; spica cylindrica. C. Brownei $\mathbf{R}$. et S. In Nova Hollandia.

8. C. australis $\boldsymbol{R}$. Br. involucris 1-floris 10-partitis laciniis subulatis plumoso-ciliatis apice denticulis retrorsis. 11. Br. 1. c. In Nova Hollandia.

9. C. anomoplexis Labill. Nov. Cal. t. 19. involucro sub10-partito laciniis subulatis pilosis, denticulis ad apicem retrorsis; spiculis solitariis ternis. C. australis var. Spr. In Nova Caledonia. 4.

10. C. multiflorus Presl; culmis erectis foliisque hirsutis; involucro multifido triseriali, seriei intimae inferne villoso; seta una longissima. Presl. 1. c. In Mexico.

11. C. calyculatus Cav. ic. $t .463$. culmo simplici erecto; spica glomerata; involucro polyphyllo setaceo. Pennisetum Spr. In Babao insula Amicorum.

\section{Species dubiae.}

12. C. biflorus Roxb. spicis simplicibus cylindricis; involucris 2-floris; laciniis subulatis uncinatis interne pilosis. Roxb. ind. 1. p. 238. In $\mathrm{Co}$ romandelia.

13. C. Elliotii Kunth; spica tereti stricta; involucro multipartito; Iaciniis tereti subulatis rigidis scabris, flosculos paulo superantibus. Panicum cenchroides Elliot bot. 1. p. 111. Pennisetum pungens Nutt. Setaria Schult. In America meridionali. 4.

11. C. viridis $\mathbf{S p r}$. involucris sub5partitis spinulosis basi setosis; fol. lato-lanceolatis vaginisque scabris. spr. syst. 1. p. 301. In Guadalupe.

15. C. ovatus Lam. ill. $t .838$. f. 2. fol. glabris duriusculis; spica dense ovata. Poir. Enc. 6. p. 51. In Prom. b. spei.

16. C. tomentosus Poir. fol. supra tomentoso-lanatis, subtus striatis; spicis ovato-oblongis. Poir. Enc. 6. p. 51. In Prom. b. spei.

1\%. C. ramosissimus Poir. caule frutescente, ramis dichotomis; spicis longissimis; involucellis mollibús setaceis nudis. Poir. 1. c. In Aegypto. 18. C. frutescens $I$. capitulis lateralibus sessilibus; fol. mucronatis caule fruticoso. Linn. sp. 1489. Alp. Exot. t. 104. In America. $\hbar$.

\section{SPARTINA Schreb. (1789).}

1. S. juncea Willd. fol. distichis setaceo-convolutis; spicis remotis patulis; calycis acuminati carinis asperis. Limnetis Pers. Trachynotia Michx. Cynodon Trin. In Carolina et Georgia. 4. 
2. S. stricta Roth; fol. couvolutis pungentibus, spicis paucis adpressis pubescentihus; calycis carinis innermibus. Limnetis Pers. Host. 4. t. 66. Dactylis Ait. Rottboella Tenore. In Gallia. 4.

3. S. laevigata Link; fol. apice convolutis; spiculis secundis alternis adpressis; rachi laevigata. Dactylis maritima Valt. In America boreali.

4. S. densiflora Brongn. spica cylindrica subfusiformi; ramis undique imbricatis; spiculis lanceolatis coriaceis glaberrimis lucidis; carinis dellticulatis. Brongn. in Dup. Voy. bot. p. 14. In Chili.

5. S. cymosuroides Willd. subglauca; fol. longissimis; spicis plurimis alternis secundis; calyce suharistato acuminato; carinis acutatis. Limmetis cynosuroides. 1Rich. Act. Petrop. 2. t. 6. In Virginia et Canada. 4.

6. S, polystachya Willd. fol. latis; spicis pluribus; undique versis, longis linearibus ; carinis aculeatis. Limnetis Rich. Trachynotia Michx. In America boreali.

\%. S. brasiliensis Raddi; spicis numerosis alternis disticho-imbricatis; fol, angustis praelongis demum convolutis ; gluma superiore dorso hispida; rachi recta. Nees. In Brasilia. 4.

8. S. ciliata Kunth; vaginis foliisque glabris involuto-filiformibus; spicis crebris arcte adpressis; glumis carina ciliatis; paleis spinuloso-ciliatis. Brogn. in Dup. it. bot. t. 2. In Brasilia et Montevideo.

9. S. pectinata Bosc. spicis convolutis; spiculis alternis solitariis secundis rachi glabra; valvulis dorso scaberrimis. Link Jahrb. 3. p. 150. In Anerica boreali.

10. S. mumila Roth; spicis terminalibus subbinis; spiculis secundis adpressis, densissime imbricatis ; fol. involutis, In America boreali. 4 .

11. S. arundinacea Carmich. spica communi teretiuscula, partialibus arcte imbricatis; valvula minore glumae exteriorem oblique truncatam perianthii superante. Pouceletia Thonars. In insula Tristan da Cunlea.

12. S. patens Mühlenb. culmo foliisque apice filamentosis glabris; spicis alternis secundis; calycis valvula longiore mucronata dorso hispida. Mulikenb. deso. p. 55. Dactylis Ait.
Trachynstia Poir. In America boreali. 4 .

13. S. fasciculata Beauv. spicis linearibus erectis fasciculatis subdigitatis ; florihus distichis ; rachi adpressis. Dactylis Lam. In America meridionali.

14. S. alternifiora Lois. culmo stricto; fol. planis apice involutis; spicis paniculatis, coarctatis; rachi flexuosa; spiculis alternis distinctis. Cand. In Gallia. 4.

15. S. geniculata Beauv. culmo geniculato; spicis distichis ternis; fol. linearibus, plicatis mucronatis. Dactylis Burm. t. 12. f. 3. In Java.

\section{POMMEREULLIA. Linn.}

1. P. Cornucopiae Linn. spica basi obvallata folio spathaeformi; spiculis alternis flosculis nudis. Roxb. Corom. t. 131. In India orientali.

2. P. monoeca Roth; racemo secundo, demum reclinato liorizontali; spiculis monoecis; calyce strigoso. lioth Nov. sp. 33. In India orientali.

\section{LEERSIA Soland. (Asprella R. et S.).}

1. I. oryzoides $\mathbf{S} w$. panicula effusa; spiculis 3-andris patulis; glumis carina ciliatis. Willd. Sp. Host. Gr. t. 35. In Europa, Persia et America boreali. 4.

2. L. virginice Willd. panicula effusa; ramis horizontaliter patentibus; flosculis 3-andris arcte adpressis. Willd. sp. In America boreali. 4 .

3. L. hexandra Sw. panicula effusa flosculis alternis hexandris; glumis sublaevibus. Sw. ind. In Jamaica.

4. L. mexicana $\boldsymbol{H}$. et $B$. panicula effusa; floribus hexandris; palearum carinis marginibusque ciliatis. Kunth Gr. t. 1. In Mexico et Gujana. 4.

5. L. anstralis $\boldsymbol{R}$. $\boldsymbol{B r}$. panicula effusa subsimplici; floribus hexandris; valvularum carinis ciliatis; nervis denticulatis. R. Br. In Nova Hol landia.

6. L. Ienticularis Michx. panicula diffusa; ramis infimis oppositis sca- 
hris; spiculis papyrace-membranaceis orhiculatis setoso-ciliatis; floribus diandris. Kunth Gr. t. 2. In America boreali. 4.

\%. L. monandra $\mathbf{S} u$. panicula effusa; spiculis remotis laxis; frosculis secundis 1-andris; glumis laevibus. sw. ind. In Jamaica.

S. L. Luzonensis Presl; panicula contracta; spiculis ovalibus pedicellatis imbricatis nervis pilosis; nodis hirsutis. Presl. Haeuk. In Luzonia. 4.

\section{Species dubiae.}

9. L. brasiliensis Spr. panicula cffusa; glumis acutis nervosis lonrissime ciliatis; ligula elongata. Spr. In Brosilia.

10. L. ovata Poir. panicula contracta; glumis ovatis subciliatis hirtis; culno debili; fol. sublaevibus. Poir. Enc. In America boreali.

11. L. imbricata Poir. paniculae ramis alternis; spiculis sessilibus imbricatis subglahris; culmo gracili ramoso. Poir. Enc. In Carolina.

12. I. digitata Poir. spicis linearibus quaternis, subdigitatis; glumis subcomplanatis mulicis ad latera fimhriatis. Poir. Enc. In America meridionaíi.

\section{ORYZA $L$.}

1. O. sativa $L$. fol. linearibus elongatis scabris; panicula racemosa contracta; glumis muticis caudatovearistatis. Nees. Zenk. WV. t. 6. valde variat. In Europu, Asia, Africa et America. $\odot$.

2. O. minuta Presl. spiculis seta terminatis; ligula abbreviata 2-partita; mucrone paleae superioris acuta. PresI Haenk. In Lazonia. $\odot$.

3. O. latifolia Desv. culmo elato; ligula brevissima; paniculae ramis verticillatis; paleis hispidis; inferiore acutato-aristata. 0 . latifolia et platyphylla. R. et S. In America boreali.

4. a. subutata Nees fol. in petiolum decurrentibus; panicula simplici; glumis basi dilatatis $\mathbf{1 - 2}$-dentatis ; squamula emarginata. Nees. Kunth Gr. t. 2. t. 1. In Brasilia. $\odot$ ?

\section{MALTEBRUNIA Kunth.}

1. Mr. leersioides fiunth Gr. 1 . t. 3. In Madagascaria.

\section{POTAMOPHILA R. Br. (Ziza nia Auct.}

1. P. parviflora R. Br. prods?. Nunth Gr. 1. t. 5. In Nova Iullandia.

\section{MYDROPYRUM Lin\%.}

1. H. esculentum Link; panicula pyramidata, inferne mascula superne feminea fulcris florum elavatis; aristis longis. Pursh. Am. Linn. Trans. \% t. 13. In America boreali.

2. II. fluitans Runth; pusillum; culmis ramosis fluitantibus; spicis setaceis; glumis muticis. Mrichx. In America boreali.

\section{6\%. ZIZANTA L。}

1. Z. miliacea Michx. panicula effusa; glumis breviter aristatis : semine ovato laevi. Pursh Am. Z. aquatica IVilld. Reimaria diffusa spr. In America boreali et Jamaica. 4.

2. $Z$ ?' ciliata Spr. panicula subramosa; calycilus apetalis ciliatis muticis. Retz. In India orientali.

3. $Z$ ? aristutı Kunth; panicula umbellata calycibus apetalis, arisfatis nudis. Pharus lietz. In Indica orientali.

Species dubia.

4. Z. terrestris $L$. panicula subramosa. L. Rheede 12. t. 60. In $M I a-$ labaria.

\section{LUZIOLA Juss.}

1. L. peruviana Juss. Mey. Esseq. t. 2. L. mexicana Kunth. Milium natans Spr. In Brasilia, Esserfuebo, Peruvia et Mexico. 4. 
269. ARROZIA Schrad.

1. A. micrantha schrad. Caryochloa brasiliensis Trin. In Brasilia.

\section{EHRHARTA Thunb.}

\section{Culmo basi buIboso.}

1. E. Mnematea Thunb. culmo erecto simplicissimo; fol. undulatis; valvulis transversim rugosis rotundatis; fasciculis pilorum gluma brevioribus. Schrad. E. capensis. Lam. ill. t. 263. f. 2. In prom. b. spei. 2 .

2. $\boldsymbol{E}$. aemula schrad. fol. siccitate involutis; valvulis neutris transversim rumosis, rotundatis mucronulatis; fasciculis interiorihus pilorum gluna longioribus. Sclurad. In Prom. b. spei. 4.

3. E. bulbosa $\mathbf{S}$. culmo simplicissimo; fol. planis; valvis neutris subaristatis; fasciculis pilorum gluma breviorihus. Schrad. Trochera Beauv. t. 12. f. 3. In Prom. b. spei. 4.

4. E. Ottonis Funth; culmo erecto simplici; fol. rigidis; ore vaginae ciliato; floribus hispidulo-scabris; supra basin barbatis muticis, inferiore superne tuberculato. Kunth Gr. In prom. b. spei.

5. E. Longifolia Schrarl. Anal. culmo simplicissimo; fol. longissinis, margine involutis; panicula ramosa. Schrad. In Prom. b. spei. 4.

\section{Culmo basi non bulboso.}

6. E. aphylla Schrad. culmo suffruticoso basi procumbente ramosissimo aphyllo; valvulis truncato-obtusis muticis transversim rugosis. Schrad. E. racemosa steud. In Prom. $b$. spei. 4.

7. E. ramosa Sw. culmo suffirticoso erecto ramosissimo; inferne folioso; valvulis neutris, (runcato-obtusis nulicis elevato-nervosis. Sw. Act. soc. Liun. 6. t. 3. f. 3. In Prom. b. spei. 4.

8. E. panicea Smith; culmo basi procumbente stolonifero subramoso; fol. leviter undulatis; panicula subramosa; valvulis neutris gluma duplo fere longioribus muticis; interiore transversim rugosa. Lam. ill. t. 263.

f. 1. In Prom. b. spei.
9. E. melicoidis $\mathbf{S} \boldsymbol{u}$. culmo erecto simplici glabro; nodis pubescentibus; fol.linearibus planis; panicula ramosa; spiculis oblongis; valvulis neutris muticis exteriore dimidio hreviore. Trans. Linn. 6. t. 3. f. 4. In Prom. b. spei. 4.

10. E. brevifolia schrad. culmo erecto simplici nodisque glabris; fol. lanceolato-linearibus planis ; panicula subramosa; valvulis neutris gluma paulo hrevioribus, obtusis muticis pubescentibus ; exteriore dimidio breviore. In Prom. b. spei. $\odot$ ?

11. E. calycina Sm. ic. $t$. 35 . culmo basi procumbente ramoso; fol. linearibus, siccitate involutis; valvulis neutris glumam vix superantibus pilosis, interiore oblique truncata. Trochera Beauv. Agrost. t. 12. f. 4. Aira L. In Prom. b. spei. 24.

12. E. ovata Nees; culmo adscendente ramoso nodisque glabris; fol. brevihus lanceolato-linearihus siccitate convolutis; panicula subramosa densa; valvulis neutris glumam aequantibus obtusis muticis pubescentibus aequalibus. Nees. In Prom. 6. spei.

13. E. laxiflora Schrad. culmo erecto simplici; fol. linearibus planis; panicula raınosa laxa; valvulis neutris glumam vix superantihus pilosis obtusis subaristatis. Schrad. In Prom. b. spei. 24.

11. E. geniculata Sw. in Trans. Linn. 1. $t$. $f .6$. culmo basi decumbente; fol. linearibıs leviter undulatis; panicula subramosa; valvulis neutris gluma paulo longioribus pilosis ; interiore subaristata. schurad. E. paniculata Poir. Melica Thunb. In Prom. b. spei. 4.

15. E. versicolor Schrad. culmo erecto simplici; fol. linearibus rigidis siccitate involutis; panicula elongata subramosa; spiculis oblongo-Ianceolatis; valvula interiore acuminata. schrad. In Prom. b. spei. 4.

16. E. villosa Schult. culmo erecto simplici; fol. linearibus rigidulis supra margineque scabris siccitate involutis; panicula angusta; valvulis neutris villosis subaristatis; arista valvula interiore quintuplo breviore. Schrad. E. gigantea. Steud. In Prom. b. spei. 4.

17. E. gigantea $S \mathrm{~S}$. in Trans. Jim. 6. $t$. t. f. 8. culmo erecto stolonifero; fol. rigidis lincaribus, 
apice subulato-involntis; panicula subverticillata; valvulis neutris gluma duplo fere longioribus, villosis aristatis; arista valvulis dimidio breviore. schrad. Mclica Thunb. Aira villosa L. In Prom. b. spei. 4 .

15. E. Echloniana Schrad. culmo erecto simplici; fol. lanceolatolinearibus planis scabriusculis; valvulis neutris gluma plus duplo longioribus, aristatis. E. longiflora Eckl. In prom. b.s pei. 4.

19. E. longiflora Sm. ic. $t$. 32. culmo erecto simplici; fol. lanceolatolinearilus planis glabris; panicula ramosa; valvulis neutris gluma plus duplo longiorihus leviter transversim rugosis. schrad. E. Banksii Gmel. In Prom. b. spei. 24.

20. E. Crvilleana Tunth. Gr.t.6. fol. membranaceis planis margine scabris; panicula sulssecunda; pedicellis lispidis; floribus sterilibus subulatosubaristatis hispidulo-scabris, transverse rugosis. Kuntl. In insula $\mathbf{S t}$. Helencie.

21. E. longiseta schrart. culmo erectiusculo; fol. lanceolato-linearibus planis scabris; spiculis oblongo-lanceolatis; valvulis neutris transversim rugosis aristatis. In Prom. b. spei. 4.

22. E. avenacer Willd. glumis corollae exterioris laevibus glabris aristatis hasi pilosis; panicula verticillato-coarctata. Willd. In ins. Bonrbon.

23. E. festucaced Willd. glumis corollae exterioris inaequalibus acutis muticis laevibus; panicula coarctata; fol. pubescentibus. Willd. In IIadagascaria.

\section{2\%1. TETRARRHENA R. Br. (1810).}

1. T. distichophylla $\boldsymbol{R}$. Br. floribus pubescentibus; perianthiis nervosis obtusis; valvula extima duplo breviore; fol. strictis vaginisque pilosis; culmo basi ramoso. Elirharta Labili. Nov. Holl. t. 147. In Nova Hollandia.

2. $T$. acuminata $R$. Br. floribus glabris; perianthiis nervosis; exteriore acuto: valvula altera interiore parum breviore: altera longiore acuminata; fol. vaginisque glabris; culno ramoso. R. Br. Ehrharta Spr. In Nova Hollandia.
3. $\boldsymbol{T}$. juncea $\boldsymbol{R}$. Br. floribus glabris imbricatis, glumis enervibus perianthiisque obtusis nervosis; culmo ramoso foliisque strictis glabris. $R$. Br. In Nov'c Hollandia.

4. $T$. laevis $R$. Br. floribus glabris distinctis; glumis nervosis, acutiusculis; perianthits obtusis enervibus laevibus; culmis simplicibus; fol. glabris planis laxiusculis. R. Br. In Nova Hollandia.

\section{2\%2. MICROLAENA R. Br. (1S10).}

1. stipoides R. Br. Ehrharta Labill. Nov. Holl. $t$. 115. Culmus filiformis. Folia glabra. In Nova HoL landia.

\section{PHARUS R. Br. (1S10).}

1. P. scaber H. et Kunih; foI. lanceolato-oblongis acuminatis supra scabris ; palea inferiore scabra superne pubescente acuminata glumis paulo longicre. H. et K. Nov. Gell. 1. p. 196. P. Iatifolius Lam. t. 769. f. 2. In Nova Granata, Gujana et Brasilia. 24.

2. P. glaber H. et Kunth; fol. oblongis acuminatis glabris; palea inferiore pubescente mucronata, glumis duplo longiore. Kunth 1. c. P. lappaceus Lam. In Nova Andalusia et Antillis. 24.

3. I. brasiliensis Raddi;' fol. lanceolatis acuminatis subtus pubescentiscabris; rachi hirsuta. Nees in Mart. bras. 2. p. 302. In Brasilia.

1. P. micrauthus Schrad. fol. Ianceolatis utrinque acuminatis supra glabris subtus tenuissime pubescenti-hirtis; paniculae ramis patenti-divergentibus; palea inferiore pubescente, glumis paulo Iongiore. Nees 1. c. Iic Brasilia. 4.

5. P. glochidatus Presl; fol. oblongis acuminatis subtus scabriusculis, culmo superne rachi ramisque ejus villosis; palea inferiore glumis longiore, apice dorso glochidiato-strigoso. Presl. In Pernvia. 4.

6. P. latifolius Linn. panicula ramosa; glumis muticis lavibus; fol. ovato-lanceolatis. Willd. sp. 4. p. 296. sloane Hist. 1. t. 73. f. 2. In Jimaica et Gujana. 4. 
274. LEPTAPSIS R. Br. (1810).

1. L. Banksii R. Br. Pharus Spr. In Nova Hollandia.

\section{LYGEUM Loeffling (1758).}

1. 亡. Spartum Loeffling it. $t$. 2. Rich. Act. Paris. 2s. t. 3. In Hispunica et Africa. 4.

\section{ZEA Linn. (1737).}

1. Z. Mais $\boldsymbol{L}$. fol. integerrimis. Lam. Ill. t. 749. Gaertu. 1. t. 1. f. 9. Patria ignota. $\odot$.

2. Z. Curagna Molin. fol. serratis. In Chili. $\odot$. Omuibus partibus minor.

\section{8\%. COIX Linn. (173\%).}

1. C. Lachryma $\boldsymbol{L}$. culmo superne semitereti obtuso; floribus nudis; fructibus ovatis. Willd. sp. 4. p. 202. Rumph. 5. t. 75. Hheede 12. t. 70. C. arundinacea Lam. In India orientali. $\odot .24$.

2. C. arundinacea Koenig; culmo superne semitereti acuto; floribus involucratis; fructibus ellipticis. Willd. sp. 4. p. 203. C. Konigii Spr. Prope Tranchane. 4.

3. C. agrestis Lour. culmo tereti; floribus nudis; fructibus subrotundis. Willd. sp. 1. c. Rumplı 6. t. 9. f. 1. In Amboince et Cochinchina. 4.

\section{2\%8. CORNUCOPIAE L. (1737).}

1. C. cucullatum L. Schreb. Gr. t. 41. Sm. spic. t. 14. Sibth. t. 51. In Graecia et Asia minore. $\odot$.

\section{CRYPSIS Ait. (1787).}

1. C. alopecuroides Schrad. culmis simplicibus teretiusculis; paniculis subspicatis oblongo-cylindricis nudis; floribus 3-andris. Schrad. germ. 1. p. 167. C. macrostachya. Brot. Host. 1. t. 29. In Europa et Sibiria. $\odot$.

2. C. schoenoides Lam. 1. f. 42. 1. culmis ramosis compressis; pani- culis subspicatis oblongis hasi vaginatis; floribus 3-andris. Schrad. 1. c. Heliochloa Host. 1. t. 30. Phleum L. Jacq. ic. t. 15. In Europa, Caucaso et sibiria. $\odot$.

3. C. aculeatu Ait. culmis ramosis compressis paniculis subspicatis hemisphaericis, involucro foliaceo ciuctis; floribus diandris. Host. 1. t. 31. schoenus schreb. t. 32 . Ad littora Maris medilerranei et in Sibiria. $\odot$.

4. C. phalaroides Bieb. spicis oblongis obtusis basi nudis. Bieb. cauc. 1. p. 45. In Caucaso, ad Wolgam. $\odot$.

5. C. acuminate Trin. culmo geniculato laevi; fol. lineari-lanceolatis strictis scabris vaginisque pilosis; glumis calycinis acuminatis hispidis, corollina superiore truncata denticulata. Trin. In Sibiriu.

6. C. syuarrosa Nutt. caule decumbente ramosissimo; fol. brevibus rigidis pungentibus; capitulis squarrosis; valvula corollina apice subdentata, cuspide brevi centrali subulata. Nutt. Ad Missouri. $\odot$.

\section{ALOPECURUS Linn. (1735).}

1. Species genuinae.

1. A. agrestis $L$. culmo erecto superne scabriusculo; panicula subspicata cylindracea acuta; glumis calycinis ultra medium comnatis acutis. schrad. germ. 1. p. 171. Trin. ic. 4. t. 37. Host. 3. t. 12. In Europa et ad Caucasum. $\odot$.

2. A. creticus Trin. panicula cylindrica glumis ad apicem usque connatis obtusiusculis; superne ciliatulis; corolla truncata; stylis connatis. Trin. 4. t. 41. In Creta.

3. A. geniculatus $T_{\text {. }}$ culmo adscendente; panicula subspicata cylindracea obtusa; glumis calycinis basi comnatis obtusis subvillosis corollaque apice crenulatis. Schrad. 1. c. Trin. ic. 4. t. 42. In Europa, Sibiria, Japonia et America boreali.

4. A. fulvus Sm. Engl. 13. t. 146\%. culmo adscendente geniculato; spica composita cylindrica; arista longitudine calycis; antheris subrotundis. A. geniculatus. Host. 2. t. 32. A. subaristatus Pursh. In Europa et America boreali. 4. 
5. A. bulbosus L. culmo erecto; spica simplicissima attenuata; glumis calycinis distinctis villosis ; radice bulbosa. Sm. E. B. 1249. Trin. ic. 4. t. 40. In Galtia et Anglia. 4.

6. A. pratensis $\boldsymbol{L}$. culmo erecto glabro; panicula subspicata cylindracea obtusa, deflorata concolore; glumis calycinis infra medium comatis, acutis subvillosis ciliatis. Willd. sp. 1. p. 357. Schreb. Gram. t. 19. f. 1. Host. 2. t. 31. Trin. ic. t. 44. In Europa, Cancaso, Sibivia et America boreali. 4.

\%. A. nigricans Hornem. culmo erecto glabro glaucescente; panicula deflorata nigricante, glumis villosociliatis; corolla calyce breviore. A. sihiticus Jacq. A. nigrescens Jacq. Eclog. 2. t. 13. A. ventricosus Pers. In Russia. 4.

8. A. alpinus Sm. E. B. 1126. spica ovata; arista perianthii glumam sericeam lateribus villosissimis subaequante; vagina suprema ventricosa. R. Br. A. ovatus Fl. Dan. 1565. A. antarcticus Gies. In Scotia et America boreali. 4.

9. A. colobachnoides Trin. ic. 4. t. 39. Panicula ovata; glumis basi connatis obtusis undique lirsutis; corolla obtusa; stylis comnatis. Trin. In Sibiria.

10. A. lanatus Sm. prodr. 1. $p$. 43. spica capitata; glumis calycinis acutis mucronatis villosis arista dimidio brevioribus; fol. lanatis. Sm. Trin. ic. 4. t. 43 . In Olympo. Bithynico.4.

11. A. antarcticus Vahl; culmo erecto glabro; fol. planis brevibus; spica ovata; glumis hirsutis; palea dorso aristata; aristata glumis longiore. A. magellanicus Lam. Ad fretum magellanicum.

\section{Species anomalae.}

12. A. vaginatus Pall. spica ovata; glumis retusis mucronatis villosis arista duplo wreviore; fol. radicalibus angustissimis. Sihth. graec. t. 64. Polypogon Pers. Colobachne Beauv. A. Pallasii Trin. ic. 1. t. 2. In Tauria et Caucaso. 4.

12. A.brachystachyıs Bieb. culmo erecto; spicis ovatis hirsutis; aristis spica longiorihus; vagina folii supremi inflata Bieb. cauc. In Sibiria transbaicalense.
14. A. Gerardi rill. delp. t. 2. $f$. 6. racemo spicato subrotundo; glumis lanceolatis acuminatis villosis inaequalibus. Phleum Jaç. ic. 301. In Carniola, Styria, Italia, Gallia et $\boldsymbol{P}_{y-}$ rencieis. 4.

15. A. utriculatus Pers. culmo adscendente; racemo spicato ovato; glumis calycinis carina ultra medium dilatatis. Sinth. oraec. t. 63. Trin. ic. 4. t. 46. In Europa. $\odot$.

16. A. borealis Trin. Fund. p. 58. panicula oblonga cylindrica; glumis dentiformi-acutis basi connatis, undique sericeis; corolla oblique truncata barbata. Trin. In Asia et America boreali.

1\%. A. Lasiostachyus Link; panicula oblonga cylindracea; glumis dorso pilosis; corollis basi aristatis. Willd. Act. Berol. 3. 414. In Estramadu$r a$.

18. A. macrostachyus Poir. culmo subinfracto; spica crassa oblonga; spiculis ramosis, villoso-ciliatis; radice bulhosa. A. bulbosus it. 2. p.24. In Barbaria. 4.

19. A. capensis Thunb. spica cylindrica; glumis glabris muticis. Thunb. In Prom. b. spei. 4.

20. A. caudatus Thunb. panicula spicata caudata; flosculis aristis convallatis, Thunl. Nov. Act. Ups. 3. p. 208. Iu Japonia.

21. A. latifolius Cav. fol. Iance0latis amplis; panicula verticillata; calycibus ciliatis muticis. Cav. descr. p. 37. In insula Tabago.

22. A. ovatus Forst. panicula ovata coarctata spicae aemula; petalo exteriore ante apicem aristato. Forst. Fl. austral. p. 8. In Australasia.

23. A. sericens Gaertn. Fruct. 1. p. 2. $t$. 1. f. 2. culmo erecto superue nudo; spica ovata cylindrica villosissima aristata. Lam. ill. 1. p. 168.

21. A. villosus Poir. fol. supra villosis ; spicis gracilibus; glumis aristatis, carina pilosa ; culmo tenui subinfracto. Poir. Enc, 8. p. 777. In Helvetia.

\section{CHAMAGROSTIS Borkh.}

1. C. minima Borkt. Knappia Sm. E.B. 1127. K. verna Trin. ic. 2. t.17. 
Sturmia Hoppe Mibora verna Adans. Beauv. Agr. t. 8. f. 4. In Germania, Gallia, Anglia et Lusitania. $\odot$.

\section{S2. BECEMANNIA Host. (150.5).}

1. B. eruca formis Host. Gram. 3. t. 6. Phalaris L. Joachimia plaalaroides Tenore Neap. 16. t. 5. In Europa, Sibiria, Oriente, ad fretum Hudsonis et ad Missuri. 4

\section{PIILEUM Linn. (1735).}

a. Spicula rudimento floris alterius stipitiformi subulato ad basin paleae superioris instructa.

1. P. tenue Schrad. panicula subspicata cylindracea; glumis calycinis oblongo-ellipticis mucronulatis scabriusculis. Schrad. germ. 1. p. 191. Phalaris Host. Gram. 2. t. 36. P. cylindrica DC. Achnodonton tenue et Bellardi Beauv. Phalaris sativa Pers. In Europa australi et Oriente. $\odot$.

2. P. asperum vill. panicula subspicata cylindracea; glumis calycinis cuneiformibus mucronatis scabris. Schrad. germ. 1. p. 185. Jacq. ic. t. 14. Phalaris aspera Host. Gram. 2. t. 37. In Europa. $\odot$.

3. P. annuum Biel. spica lobata cylindrica; spiculis ciliatis sub apice gibbis; radice annua. Biel). cauc. 1. p. 46. In Caucaso et Tauria. $\odot$.

4. P. Boehmeri Wib. panicula subspicata cylindracea glumis calycinis lanceolatis obtusis submucronatis scahriusculis Sclıad. germ. 1. p. 186. P. glabrum Bernh. Chilochloa Beauv. Phalaris Host 2. t. 34. FI. Dan. t. 531. In Europa et Sibiria. 4.

5. P. arenarium Limn. panicula subspicata obovata; glumis calyciuis lanceolatis acutis, carina ciliatis culmis adscendentibus. Schrad. Crypsis Desf. Chilochloa Beauv. In Europa, Graecia et Africa boreali. $\odot$.

6. P. Michelii All. panicula subspicata cylindracea glumis calycinis lanceolatis acuminatis carina ciliatis. Schrad. P. hirsutum. Sut. Phalaris alpina Host. Gram. 2. t. 35. In Europa. 4.
7. P.cuspidatum Willd. spica cylindrica; spiculis 3-gynis. R. et S. P. trigynum schrad. Phalaris trigyna Host. Gram. 4. t. 20. Chilochlon 11. et s. In Comitatu Tyrolensi. 4.

b. Spicula flore altero subulato destituta.

S. P. pratense $\boldsymbol{L}$. racemo spicato cylindraceo; calycibus truncatis mucronato-aristatis carina ciliatis; aristis calyce brevioribus. Schrad. Host. Gram. 3. t. 9. Trin. ic. 1. t. 5. var. culnis humilioribus; racemo spicato hreviore. P. nodosum L. FI. Dan. 380. Host. 4. t. 21. Trin. ic. 1. t. 5. In Europa, Sibiria, Caucaso et America boreali. 4.

9. P. echinatum Host. Gram. 3. t. 11. spica subovata; calycis valvulis aristatis, arista hrevioribus; radico annua. Host. P. Felinum Sm. In Dalmatia et insula 'Zucynthi. $\odot$.

10. P. alpinum I. racemo spicato ovato ohlougo; calycihus truncatis, mucronato-aristatis, carina ciliatis; aristis calycem aequantibus Schrad. P. pratense Schreb. - Host. Gram. 3. t. 10. Trin. ic. 1. t. 21. In Europa, Graecia, Sibiria et Caucaso. 4.

11. P. Haenkeanum Presl; panicula ovato-oblonga glumis truncatis mucronato - aristatis carina ciliatis; mucronibus gluma brevioriluss; palea inferiore emarginato-3-dentata. Presl. In Simu Notkuensi.

12. P. Bertolonii DC. racemo spicato cylindrico; flosculis inferioribus ahortivis; glumis truncatis carina ciliolatis, mucronato - aristatis ; aristis gluma quaedruplo brevioribus DC. Cat. Monsp. p. 132. Circa Sarzanam. 4.

13. P. Africanum Lour. spica cylindrica flosculis undique coarctata; pedunculis trifloris pilosis. Lour. Coch. 4. p. 61. Ad oram Africae orientalis.

\section{HILARTA Humb. et Eunth (1815).}

1. $\boldsymbol{H}$. cenchroides $\boldsymbol{H}$. et $\boldsymbol{K}$ unth Nov. Gen. et $S p$. pl. 1. t. 3\%. Gramen repens ramosum. Folia plana. Spica articulata, rachi hirsuta In Mexico. 4. 
285. HEXARRHENA Presl (1532).

1. H. cenchroides Presl; Culmi caespitosi basi ramosi. Folia plaua margine argute serrulata; rachi 3-quetra. In Mexico. 4.

\section{S6. PHALARIS Diosc.}

a. Species genuinac.

1. P. canariensis $\boldsymbol{L}$. panicula spicacformi ovali; ylumis superne marginatis, margine integerrino; floribus sterilibus fertili parum brevioribus; paleis hujus adpresso-pilosis. Link in Linnaea 1. p. 96. Schreb. Gram. 1. t. 10. f. 2. Host. Gram. 2. t. 38. In insula Fortunati. $\odot$.

2. P. brachystachya Link; spica ovali; glumis superne marginatis, margine integerrimo; floribus sterilibus minimis; paleis floris fertilis subadpresso-pilosis. Link in Schrad. Journ. 1. 3. p. 134. Trin. ic. 7. t. 75. In Lusitania.

3. cuevulescens Desf. culmo basi tuberascente; spica cylindrica; glumis superne marginatis, margine sublacero apice subaristato; floribus sterilibus obsoletis. Link in Linaea 1. p. 98. P. bulbosa Cav. ic. t. 6ł. Trin. ic. t. 56. In Europa australi et Africa boreali. 4.

1. P. minor Retz; spica oblonga cylindracea; glumis superne maryinalis, margine sublacero; flore sterili altero minimo. Link l. c. P. aquatica Host. Gram. 2. t. 39. In Europa, Aegypto, Prom. b. spei et in insula Adscensionis. $\odot$.

5. P. macrostacleya DC. panicula subspicata ovata; glumis subnavicularibus dorso integerrimis lanceolatis acuminatis; perigonio bivalvi pubescente. DC. Cat. p. 131. Trin. ic. $\%$ t. 7\%. P. intermedia Bosc. In America boreali. $\odot$.

6. P. angusta Nees; panicula mutica cylinelracea spiciformi; glumis naviculari-lanceolatis acuminatis, carina haud alatis serrulato-scabris; fol.scabris; radice annua fibrosa. Nees in Mart. Bras. 4. p. 391. In Brasiliı. $\odot$.

\%. P. nodosa L. culmo hasi tuberascente; spica cylindracea; glumis superne marginatis, maryine integerrimo; flore sterili altero minimo. Trin. ic. 7. t. 81. P. aquatica sibtl. Graec.

\section{t. 57? In Europa, Graecia et Orien- te. 4 .}

8. P. nepalensis Trin. ic. 7. t. SO. radice fibrosa; culmis erectis adpressitusculis ; fol. lanceolatis asperis; panicula ovata; glumis acutis :-nerviis; carina superne alata; ala repandocrosa denticulata. In Nepalia.

9. P. paradoxa limn. panicula subspicata cylindrica ramorum flosculo intermedio hermaphrodito, acuminato reliquis imperfectis praemorsis. Sclurad. Germ. 1. t. 12. Trill. ic. 7. t. 82. In Itulia, Galliu et Oriente. $\odot$.

10. P. appendiculata Schult. panicula subspicata; oblongo-ovata; flosculis neutris praemorsis hermaphroditorum calycibus breviter mucronatis, carinatis ; lobis carinae appendiculatis. schult. Mant. 2. p. 216. P. dentata sieb. In Aegyjto.

\section{Species anomalae.}

11. P. arundinacea Linn. panicula patente, glomerata; glumis calycinis obtuse carinatis; corolla exteriore bivalvi brevissima pilosa. Willd. enum. p. 84. Fl. Dan. t. 259. Host. Gram. 2. t. 33. Baldingera Fl. IVett. Digraphis Trin. In Europa, Caucaso, Sibiria et America septemtrionali. 4 .

12. P. americana Elliot; panicula oblonga spiciformi; glumis calycinis navicularibus, serrulatis; corolla 4valvi; valvulis exterioribus inaequalibus omnibus pilosis. Elliot bot. 1. p. 101. In America boreali $\odot$.

\section{Species dubiae.}

13. P. crypsoides Trill. caule suberecto nodoso minimo basi ramoso; fol. glabris ample vaginantibus; spica obovata subrotunda; glumis acutis cariuatis compressis glaherrimis. Urvill. enum. 1. p. \%. In Gracia. $\odot$.

14. P. pectinata Roth. paniculs spicata cylindrica; glumis calycinis navicularibus, margine membranaceis, ciliato-pectinatis; corolla exteriore bivalvi, villosa. Roth. Nov. sp. p. 3t. Patria ignota.

15. $\dot{P}$. caroliniana Walt. panicula spicata ovata; petalis aristatis; calycibus striatis. Walt. Car. p. 74. In Georgia et C'arolina. $\odot$.

16. P. dentata Thunb. spica subpaniculata cylindrica; glumis serratis; 
culmo geniculato. Thunb. Phleum dentatum Pers. Chilochloa dentata Trin. ic. 7. t. 73. In Prom. b. spei. $\odot$.

17. P. hispida Thunb. spicis digitatis; glumis scabris; fol. ovatis. Thumb. Jap. p. 44. Digitaria Spr. In Japonia.

19. P. quadrivalvis Lag. glumis acutis integris; calyce 4-valvi; valvulis exterioribus duabus ovatis brevissimis glabris. Lagasca Elench. p. 3. In Hispania.

19. P. chilensis Prest; panicula spicaeformi cylindracea utrinque acuta; glumis navicularibus scabris, carina membranaceis scabrisque; paleis pilosis. Presl. Rel. Haenk. 1. p. 245. In Chili.

\section{8\%. HOLCUS L. (173\%).}

1. H. lanatus $L$. panicula aequali; flosculo hermaphradito inferiore mutico; masculi arista recurvata calyce inclusa; radice fibrosa. Schrad. Avena lanata Koel. Host. Gram. 1. t. 2. Fl. Dail. t. 1181. In Europa et America boreali. 4.

2. H. mollis Limn. panicula aequali; flosculo hermaphliodito inferiore mutico; masculi arista geniculata caIycem excedente; radice repente. Host. Gram. 2. t. 3. Engl. Bot. 1170. In Europa et America boreali. 4.

3. II. argenteus Agardh; panicula aequali; flosculo hermaphrodito inferiore mutico; masculi arista recurvata, calycem excedente. Agardh in $\mathbf{R}$. et S. syst. 2. p. 656. In Hispania. 2?

4. H. setiger Nees; panicula aequali condeusata; ramis hirtis; gluma superiore longe setigera; arista floris masculi geniculata calycem excedente; culmo ramoso; fol. pubescenti-mollibus. Nees 1. c. In Prom. b. spei. ๑.

\section{Species dubiac.}

5. Ir. nervosus Roxb. erectus; pilosus ; panicula oblonga; glumis 3-5nerviis cuspidatis, 2-floris; floribus sessilibus; altero hermaphrodito aristato; altero masculo et mutico. Roxb. ind. 1. p. 320. In Coromandelia.

6. H. ciliatus Roxb. erectus pilosus; panicula lineari-lirsuta; glumis papillosis ciliatis 2-floris; floribus ses- silihus; altero hermaphrodito aristato; altero masculo mutico. Roxb. ind. 1. p. 321. In Coromandelia.

\%. H. striatus $\boldsymbol{L}_{\text {. }}$ glumis 2-floris striatis muticis, acuminatis; panicula conferta oblonga. Linn. sp. 1486. In Virginia.

8. H. racemosus Forsk; spica cylindrica; spiculis ternatis pedicellatis ; involucris setaceis longissimis. Forsk. Aeg. p. 175. In Arabia.

\section{S. HIEROCHLOA I. (1737).}

1. II. borealis $R$. et $S$. panicula subsecunda; pedunculis glabris; flosculo hermaplirodito mutico; masculis subaristatis; radice repente. Holcus Schrad. Germ. 1. p. 252. Fl. Dan. 963. Host. 3. t. 3. In Europa et Asia boreali. 4.

2. H. arctica Presl; panicula subsecunda; pedunculis glabris; glumis flores excedentibus; paleis inferioribus apiculatis, supra medium hirsutis ; margine paleisque superioribus nervis ciliatis. Presl 1. c. In Sinu Notkae. 4.

3. H. custralis R.etS. paniculis subsecundis ad spicularum basin pilosis; flosculo hermaphrodito mutico ; masculo inferiore infra apicem brevissime aristato. Holcus schrad. Host 4. t. 4. In Europa. 4.

4. H. alpinc $R$. et $s$. panicula coarctata; calycihus oblongis trifloris; flosculis pilosis; arista geniculata dorsali Iongiuscula. Holcus Wahlenb. Lapp. t. 2. Fl. Dan. 1508. In America et Asia. 4.

5. $\boldsymbol{H}$. fragrans $\boldsymbol{R}$. et S. panicula patula; glumis 3-floris muticis; hermaphrodito intermedio diandro glabro; valvula exteriore levissime ciliata. Holcus Willd. sp. 4. p. 936. In America boreali. 4.

6. H. antarctica $R$. Br. panicula eflusa subuutante; glumis basi 3-nerviis, carina laevibus; floribus masculis pubescentibus dorso margineque ciliatis; fol. planis. Disarrenum antarcticum Labill. Nov. Holl. 2. t. 232. Torresia redolens $\mathrm{H}$. et $\mathbf{S}$. In Nova Hollandia et insulis Macloviamis.

\%. H. redolens $\boldsymbol{R}$. et $\mathrm{s}$. differt a praecedente floribus majoribus, panicula coarctata; glumarum carinis den- 
ticulis sparsis scabriusculis. R. Br. 1 . c. Holcus Vahl. Avena Pers. In Terra del Fueyo.

8. H. vitriculata Kunth; panicula coarctata spicaeformi cylindracea; glumis carina glabris basi 3 -nerviis, fol. planis vaginisque scabriusculis. Kuntlı. Gran. 1. p. 193. t. 8. Torresia R. et P. Avena coquimbensis 1 . et $\mathbf{S}$. In Chili.

9. H. panciflora $R \cdot B r$ racemo simplici; flosculo maseulo superiore brevissime setigero; fol. culmi brevissimis, radicalibus involutis. $\mathrm{R} . \mathrm{Br}$. 1 . c. In insula Melvilleana.

10. H. glabra Trin. radice repente; culmo glabro; vaginis pubescentilus; florum masculorum palea inferiore subtruncata sub-5-nervia 2-cuspidata glaberrima. Trin. in Spr. syst. 1. 274. In Daruria.

\section{ATAXIA R. Br. (1810).}

1. A. Horsfielulii Irunth Gram. 1. p. 22. In Java.

\section{REYNAUDIA Kunth (1833).}

1. R. filiformis Kunth Gram. 1. t. 9. Pollypoyon Spr. In Domingo. 4.

\section{DEPRETZIA Funth (1833).}

1. D. mexicana Irunth Gram.2. t. 157. In Mexico.

\section{PASPALUM L. (1759).}

1. P. membranaceum Lam. ill. 1. p. 1\%1. t. 43. f. 2. rachi cymbiformi spiculis multoties latiore; glumis hirstitissimis interiore ovata; fol. glaucis glabriusculis. Fluegge Monogr. p. 37. Ceresia elegans Jacq. Fragm. t. 86. In Perviria. 21.

2. P. fluitans Innth Gram. culmo repente adscendente plerumque fluitante; glumis calycinis allis, punctatis parce pilosis. Elliot bot. 1. p. 109. In Georgia et Carolina. $\odot$.

3. $\boldsymbol{F}$. Wcilterianum schult. glabrum; culmo repente; fol. brevibus; vaginis uudis; glumis biseriatis sub- ovatis rachi latissima glumas obtegente; dentibus 1-floris. Leconte Monogr. in Jour. de Phys. 9. p. 285. P. vaginatum Elliot. In Georgia et $\mathrm{Ca}$ rolina. $\odot$.

t. P. stellatum Fluegge; fol. canaliculatis hirsutissimis ; vaginis inferioribus papilloso-hirtis; spicis geminis; glumis basi margineque pilosis Kunth syn. 1. p. 164. Trin. ic. 10. to 119. In Nova Granate et Brasilia. 4.

5. P. carinatum Fluegge; fol. convolutis papilloso-pilosis; vaginis glabris; spicis subgeminis; rachi carinata glabra spiculis biseriatis latiore; glumis albo-pilosis. Kunth in Humh. et Bonpl. Nov. Gen. 1. p. 85. In Popaya. 4.

6. P. distichophyllum Inımb. et Kunth; fol. distichis planis inferne pilosis; vaginis glahris ciliatis; spicis geminis; rachi plana; gluma inferiore lanato-ciliata. Kuuth 1. c. P. polyphyllum Nees. Trin. ic. 12. t. 141. In Nova Granata et Brasilia. 2.

\%.P. canaliculatum Nees; Spicis geminis rachi triquetra; glmmis lanceolatis, inferiore torso canaliculata margine longe ciliata; superiore hispida. Nees 1. c. In Brasilia. 24.

8. P. dissitiflorum Trin. spicis geminis rachi 3-quetra spiculis solit:ariis remotiusculis duplo angustiore; glumis lanceolatis e tuberculis hirsintis; fol. filiformibus, tuberculoso-pilosis. Nees 1. c. Triu. ic. 9. t. 103. In Brasilia. 24.

9. P. fastigiatum Nees; spicis subgeminis rachi 3-quetra; spiculis solitariis disticho-inbricatis duplo singustiore; culmo ramosissimo fastigiato; foliis vaginisque pubescenti-vililosis. Nees 1. c. In Brasilia.

10. P. Humboidtianum Fluegge; fol. planis papilloso-hirsutis summo glabro; vaginis hirsutis; rachi plana glabra spiculis medio 4-seriatis angustiore; gluma inferiore ad marginem albo-lanata; superiore ylabra. Humb. et Kunth 1. c. t. 23. In Quito et Mexico. 4.

11. $\boldsymbol{P}$. ciliatum Kunth; fol, supra glabris, subtus margineque pilosis; vaginis apicem versus margineque ciliato-pilosis; rachi plana glabra; gluma inferiore ad marginem basimque lanato-ciliata. Humb. et Kuntlı 1. c. t. 24. P. plephorophorus R. et S. Trin. 
ic. 12. t. 131. In Nova Granata et Brasilia. 4.

12. P. pectinatum Nees; spicis hinis ternisve subdigitatis; glumis planis inferiore cordato-delloidea superiore angustiore pectinato-ciliata. Nees l. c. In Brasilia.

13. P. eucomum Nees; spicis solitariis geminisve; rachi plana adpresso-subhirsuta, spiculis solitariis latiore; glumis obovatis molique lanatis; fol. hirsutis. Nees in Mart. Bras. 2. p.37. Trin. ic. 10. t. 110. In Irasilia. 4.

11. P. gnttutum Trin. ic.9. t. 10t. spicis subternis subdigitatis; rachi plano-carinata flexuosula glabra; glumis ovatis acutis, intus sanguineopunctatis undique lanatis, utraque 3nervi. Nees 1. c. In Brasilia.

15. P. erianthum Nees; rachi plana flexuosa, spiculis geminis angustiore; glumis ovato-ellipticis undique lanatis, superiore 3-nervi; culmo bulboso glabro. Nees 1. c. Triu. ic. 12. t. 145. In Brasilia.

16. P. sanguinolentum Trin. rachi plana glabra recta, spiculas subgeminatas aequante; glunis oblongis acutis undique villosulis, utraque 5nervi; culmo glabro. Nees 1. c. Triu. ic. 12. t. 142. In Brosilia.

17. $\boldsymbol{P}$. ammodes Trin. spicis approximatis erectis basi harbatis; rachi plano-carinata flexuosula laevi; glımis oblongis obtusinsculis, undique patenti-pilosis 5-nervibus. Nees 1. c. írin. ic. 13. t. 152. In Brasilia.

18. P. Bomplandiunum Flueg!e; fol. utrinque villosis; vaginis pubescentibus; rachi subcanaliculata pubescente. Humb. et Kunth Nov. Gell. 1. p. 87. In Quito. 24.

19. P. gracile Rudge; panicula longa simplici; spicis plurimis alternis binatisque; rachi acumiuata; floribus distichis. Rudge Guj. p. 20. t. 26. In Gujana.

20. P. candidum Kunth; fol. pubescentibus; vaginis glumisque glahris; spicis crebris verticillatis alternisque; racli carinata; spiculis $1-\mathrm{se}-$ riatis latiore. Humb. et Kuntl. Nov. Gel. 1. p. 17. t. 25. Reimaria Fluegge. In Quito. 4.

21. P. pallidum Humb. et Kunth l. c. fol. utrinque pubescentibus; vaginis glumisque glahris; spicis crebris verticillitis alleruisque; rachi plana spiculis 2-seriatis latiore. Kunth. In Quito. 4.

22. P. Mramilate Nees; spicis ununerosis verticillatis; glumis ovatoellipticis acutis glabris flosculo longioribus; fol. planis pubescentihus vaginisque tuberculatis his apice 1-dentatis Nees 1. c. Ad flumen Amazonum 4 .

23. P. depanperatum Presl; culmo adscendente ramoso flaccido compresso; nodis barlatis vaginisque ore pilosis; glumis glaberrimis, superiore 1-nervia longitudine paleae inferioris; gluma inferiore brevissima. Presl Haenk. 1. p. 215. In Pernvia.

2甘. p. microstachyum Prest; culmo compresso glabro; vaginis glabris; fol. e basi cordata linearibus orispilosis; rachi pariter longissime pilosa; glunis spiculam aequantibus; puberilis; inferiore 5-nervia puncticulata. Presl 1. c. Patria ignota.

25. P. repens Berg. in Act. Helv. \%. $t$. \%. culmo repente fol. vaginisque scabris; rachi canaliculatic scahra, spiculis 2-seriatis latiore; glumis glabris. Kunth. In Gujanu. 24.

26. P. stolonifervm Bosc. culmo radicante; fol. utrinque glabris margine scabris; spicis creberrinis paniculatis; rachi plana margine undulata ciliata; glumis glabris. Kunth P. racemosum Jacq. ic. 2. t. 302. Milium latifolium Cav. ic. t. 273. In Nova Caesarea, Peruvia et Quito. 24.

2\%. P. fasciculatum Willd. fol. carinatis glabris margine scabris; vaginis glabris; spicis fasciculatis; rachi glalja planiuscula; glumis glabris vel ciliatis. Kunti. In Brasilia et Quito. 24.

28. P. hirtum Humb. et Funth l.c. fol. vaginisque hirto-pilosis; spicis teruis alteruis; rachi plana glabra, spiculis 2-seriatis angustiore; glumis glabris. Kunth 1. c. In Nova Granata. 4.

29. P. scoparium Fluegge; fol. glabris margine vaginisque scabris spicis crebris paniculatis, inferioribus ramosis; rachi 3-quetra scabra; glumis subpubescentibus. Kunth. In $\mathrm{No}$ va Andalusia. 24.

30. P. eminens Nees; rachi 3-quetra; glumis oblongis glabris flosculi latitudine; culmo paucinodo; fol. linearibus, inferioribus subhirsutis. Nees 1. c. In Brasilia. 4. 
31. P. pellitum Nees; spicis crebris simplicihus; rachi 3-quetra latitudine spicularum; glumis oblongis subpubescentibus; culmo paucinodi; vaginis foliisque densissime sericeolanatis. Nees I. c. In Brasilia.

32. P. maryinatum 'Trin. spicis subquinis digitatis; rachi flexuosa glabra; glumis lineari-oblongis obtusis dorso subenervibus in ambitu strigosis. Nees Trin. ic. 9. t. 105. In Brôsilia. 4.

33. P. siccum Nees; spicis crehris alteruis coarctatis; rachi 3-quetra; glumis oblongis ohtusis glabris flosculi longitudine; culmi nodis harbatis; fol. convolutis vaginisq. scabris. Nees 1. c. In Brasilia. 4.

3-1. P. barbigerum Kunth; spicis approximatis fastigiatis; rachi plana flexuosa, glabra basi tomentosa; glumis oblongo-lanceolatis obtusis marrine ciliolatis; culmi nodis hirsutis; vaginis compressis apice Ionge barbatis. P. harbatum. Nees. Trin. ic. 9. t. 98. In Brasilia. 4.

3.5. P. suffiltum Mikan; culmo erecto glabro basi compresso; fol. glabris rigidis; spicis paniculatis confertis; rachi flosculis angustiore; corollis tenuissime punctatis. Trin. ic. 9. t. 108. In Brasilia. 4.

36. P. ischnocuulon Trin. culmo erecto gracili simplici; vaginis striatis glabris subcarinato-compressiusculis ore barbatis; rachi lineari flexuosa, margine denticulata. Trin. ic. 11. t. 126. In India orientali.

3\%.P. leptostachyum Fluegge; spicis pluribus simplicibus; rachi triquetra spiculis angustiore; glumis lanceolatis pubescentibus, valvis tertia parte Iongioribus; culmo multinodi. Fluegre Monogr. p. 123. In Veneznela. $\odot$.

33. P. debile Poir. spiculis subquinis approximatis; rachi 3 -quetra, spiculis duplo angustiore; glunis lanceolatis acuminatis valvis muticis longioribus; culmo decumbente. Fluegoe 1. c. Panicum debile Desf. Digitaria Willd. In Numidia.

39. P. lanuginosum Nees; racemis 5-7, fastigiatis ; rachi 3-quetra flexuosa, spiculis geminis remotiusculis triplo angustiore; glumis lanceolatoacuminatis glahris; exteriore 7-nervia; culmo procumbente ramoso; vaginis foliisque lanuginosis. Nees l. c. In Brasilia. $\odot$ ?
40. P. filiforme sar. rachi 3-quetra, spiculis dimidio angustiore; glumis elliptico-lanceolatis acutis, interiore valvis muticis paulo breviore; culmo stricto. Fluegre. Panicum Trin. ic. 13. t. 148. Digitaria Auct. In America boreali, Mexico, China et Luzonia. 4.

4. P. Consanguineum Lunth; culmis caespitosis substrictis indivisis; fol. planis, subtus scabris vaøinisque villosis nargine scaberrimis. Digitaria Gaudich. in Freyc. it. bot. p. 410 . D. villosa Pers? In insulis Moluccanis et Sandrichensibus.

42. D. digitatum Kunth; spicis digitatis subquaternis subsessilibus; flosculis nuticis adpressis secundis; fol. margine cartilagine 0 -serratis. Milium Sw. prodr.p. 24. Axinopus R. et S. Digitaria Jamaicensis Spr. In Jamaice anstraii.

43. P. fiscum Presl; culmo repente adscendente compresso vaginisque glabris; fol. maryine scahris ; raclii plana scahra spiculis lanceolatis paulo latiore; glumis albo-pubescentibus inferiore 3-, superiore \%-nervia; palea inferiore lanceolata demum fusca. Presl 1. c. In Luzonia? Peruvia? et Mexico? 4.

14. P. Preslii Kunth; culmo suberecto compresso ramoso glabro; nodis vaginisque dense molliter hirsutis; glumis aequilongis, acutis albo-puhescentibus, inferiore $3-$, superiore 7 nervia. P. pubescens Presl 1. c. In Peruvia. 4.

15. P. serotinum Fluegge; spicis subquinis approximatis; rachi plana spiculis paulo latiore; glumis ellipticolanceolatis acutis pubescentibus; vaginis pilosis; culmo decumbente. Fluegge l. c. Synterismia Walt. Digitaria Michx. D. pilosa Willd. In Carolina.

16. P. mollicomum Finth; culmis compressis basi repentibus uno latere alternatim canaliculatis ramosis, glaberrimis; nodis vaginis foliisque molliter pubescentibus; glumis ciliatis, inferiore lanceolata 3-nervia; superiore ovato-lanceolata 5-nervia. P. molle Presl 1. c. In Lusonia. $\odot$.

47. P. fuscescens Presl; culmis adscendentibus hasi repentibus glabris; nodis subbarbatis; fol. scabriusculis margine subhirsutis; glumis aequilongis glabris inferiore 3-, superiore 5nervia. Presl 1. c. In Peruvia. 4. 
18. P. Thouarsianum Fluegge; spicis subquinis approximatis; rachi plana spicularum latitudine; glumis ellipticis obtusiusculis, interiore valvis dimidio breviore; vaginis glabertimis. Fluegge 1. c. In Malagascreria. 4.

49. P. distans Nees; rachi 3-quetra spiculis angustiore; glumis lanceolatis villosis, inferiore flosculo dimidio breviore; fol. vaginisque inferioribus villosis. Nees I. c. In $\mathrm{Hra}-$ silia. $\odot$.

50. P. inaequivalve Raddi; racemis pluribus alternis; rachi planioscula spicularum latitudine; glumis ellipticis acutiusculis margine pubescentibus, inferiore flosculo dimidio breviore; fructu candido. Nees 1. c. In Brasilia. 4.

51. P. corymbosum Kunth; vaginis foliorum setosis; calycibus 2-valvibus; seminibus oblongis glabris. $\mathrm{Pa}-$ nicum Roxb. ind. 1. p. 295. In montibus Circar.

52. P. incequale Link; vaginis foliisque inferioribus hirtis; spicis senis approximatis, filiformibus; valvula calycina exteriore duplo minore. Link en. p. 103. Digitaria Spr. In Manilla. $\odot$.

53. P. flaccidum Nees; rachi 3quetra spiculis obovatis glabris duplo angustiore; gluma posteriore ovata acuta, fosculo dimidio breviore; culmo glabro; fol. lineari-filiformibus villosis. Nees 1. c. In Brosilia.

51. P. Neesii Kunth; rachi 3 -quetra spiculis 3-plo angustiore; glumis oblongis 5-nerviis glabriusculis; fol. hirsutis filiformibus, radicalibus culmum aequantibus. P. angustifolium. Nees 1. c. P. lineare Trin. ic. 10. t. $m$ ? In Brasilia. 4.

55. P.ligulare Nees; racemis paucioribus ( 3 - 4) alternis; rachi planiuscula, spiculis geminis obovatoellipticis glabris dimidio angustiore; glumis aequalibus 3-nerviis; fol. complicato-angustis vaginisque glahris ; ligula Jonga lacera. Nees in Mart. Bras. 2. p. 60. In Brasilia. 4.

56. H'. brevifolium Fluegge; spicis duabus conjugatis; rachi plana; spiculis paulo latiore; glumis oblongolanceolatis acutis aequalibus valvarum longitudine; vaginis glabriusculis; culmo repente. Fluegge Monogr. p.150. In India orientali.

57. P. platycaule Poir. peduncu- lis longis subfasciculatis; spicis subternis; rhachi 3-quetra spiculas aequante; glumis lanceolatis obtusiusculis margine pubescenti-ciliatis, flosculi longitudine; vaginis foliisque linearibus obtusis strictis glabris; culmo uninodi compresso. P. compressum. Nees in Mart. Bras. 2. p. 23. - Trin. ic. t. 118. Milium Sw. In Jamaica, Portorico, Hispaniola, Quito, Peruvia et Brasilia. $\odot$.

58. P.platyculmum Thouars; spicis subternis; rachi triquetra spiculis angustiore; glumis ellipticis acutis pubescentibus flosculo longioribus; vaginis lacviusculis; fol. lanceolatolinearihus, obtusis flaccidis pubescentibus; culmo 1-nodi compresso. Nees in Mart. Bras. 2. p. 24. In ins. Mauritii.

59. P. complicatum Nees; pedunculis gracilibus longis subfasciculatis; spicis subternis; rachi triquetra spiculis solitariis imbricatis angustiore; glumis ellipticis acutiusculis glabris, flosculi longitudine; vaginis foliisque ovato-lanceolatis acutis ciliatis; culmo subunimodi compresso procumbente. Nees in Mart. Bras. 2. p. 22. In Brasilia. $\odot$.

60. D. acuminatum Raddi; spicis plurihus alternis, rachi lineari plana latitudine spicularum solitarium, vel latiore margine aculeolato; glumis lanceolato-acuminatis 5-nervibus glabris flosculo longioribus; culmo ramosiusculo foliisque lanceolatis glabris; ramulis axillaribus geniculatis patentissinis. Nees in Mart. Bras. 2. p. 24. In Rirasilia.

61. P. extemuatum Nees; pedunculis longis fasciculatis filiformilus; spicis geminis; rachi triquetra, spiculis solitariis distantibus angustiore; glumis Ianceolatis obtusis pubescentibus, flosculi longitudine; culmo ramoso fasciculato compresso; vaginis foliisque planis acuminatis pilosis. Nees in Mart. Bras. 2. p. 25. In Brasilia. $\odot$.

62. P. capillare Lam. spicis $2-3$ filiformibus; pedunculis capillaribus; floribus ovato-oblongis altemis. Lam. ill. 1. p. 176. Kunth Gram. t. 11. Trin. ic. t. 100. In America calidiore. $\odot$.

63. P. molle Poir. caule debili; spicis subternatis alternis; flosculis 
bifariis pedicellatis. Poir. Enc. 5. p. 34. In ins. St. Thomae in America.

64. P. Poiretii $R$. et $S$. spicis subternis gracilibus; spiculis 2-seriatis ovatis glabris; fol. linearibus basi oreque vaginae subpilosis; culmis caespitosis filiformibus. Poir. Panicum gracile Poir. Enc. suppl. 4. p. 313. In st. Domingo.

65. P. fissifolium Rarldi; spicis ternis quaternisve alternis pedunculisque filiformilus; rachi plana flexuosa; glumis ovatis bincrvibus ciliatis; culmo repente fol. linearihus emarginato-bifidis fissisque hasi ciliatis. Nees in Mart. Bras. 2. p.36. In Brasilia.

66. P. mulchellum Kunth; fol. convolutis pilosis; vaginis pubescentibus; spicis subternis; rachi plana glabriuscula, spicularum biseriatarum latitudine; glumis glahris inaequalibus; inferiore triplo minore. Humb. et Kunth Nov. Gell. 1. p. 90. t. 26. Reimaria elegans Fluegge. In Cumana. 4 .

6\%. P. hyalinum Nees; spicis subternis alternis; rachi plana flexuosa, spieulis solitariis angustiore; glumis obovato-orbiculatis glabris, inferiore tota superioreque basi media hyalinis; caule erecto ramoso coarctato; fol. complicato-subulatis tuberculato-ciliatis. Nees in Mart. Bras. 2. p. 49. In Brusilia.

68. P. parviflorum Rohde; spicis subtribus alternis; rachi plana valde flexuosa spicularum latitudine; glumis ellipticis obtusis glabris; fol. lirsutissimis; culmo stricto ramoso. Fluegge Monogr. p. 98. Trin. ic. t. 116. In Portorico et Brasilia. $\odot$.

69. P. popillosum Spr. spicis subgeminis solitariisque; rachi dilatata herbacea; flosculis orbiculatis glabris; fol. planis papilloso-pilosis spicas superantibus. Spr. Nov. Prov. p. $4 \%$. In Brasilia. 4.

\% 0. P. multicaule Poir. spicis duabus conjugatis angustissimis; spiculis suborbiculatis minimis biserialibus; fol. Iinearibus erectis subpilosis ramis axillaribus. Poir. Euc. suppl. 4. p. 369. In Brasilia.

F1. P. granulare Trin. cnlmo dehili filiformi compressiusculo sulcato; vaginis internodiis brevioribus glabris; fol. linearibus glabris; racemis binatis divergenti-recurvis; rachi angustissi- ma margine scahra; Iocustis minimis biserialibus oblongis solitariis vel rarius binis. Trin. in spr. N. Entd. 2. p. 47. In India orientali.

8. P. Haenkeumem Presl; fol. planis lanceolatis pubescentibus, margine ligulisque pilosis; spicis ternis alternis approximatis ; rachi plana spiculam latiludine aequante glabra; spiculis hiseriatis glaberrimis; glumis 3-nerviis. Presl in Rel. Haenk. 1.p. 210. In Peruria. 4.

93. P. pusillum Venten. spicis subtribus alternis; rachi plana recta spiculis paulo angustiore; glumis obovato-orbiculatis obtusiusculis foliisque. glabris; culmo repente ramoso. Fluewge Monogr. p. 160. P. orbiculatum Poir. In ins. St. Thomae, Portorico et Mexico.

7. P. serpens Nees; spicis ternis quatemisve approximatis; rachi plana recta spicularum solitarium latitudire; glumis ovatis lacvbus glabris planiore marginata; radice culmisque basi repentibus; fol. angustis. Nees in Mart. Bras. 2. p.50. Ad /lumen Simazonum. $\odot$.

\%.5. P. conjugatum Bery. spicis duabus conjugatis; rachi plana recta spicularum latitudine; glumis orbiculato-ovatis acutiusculis, interiore ciliata; vaginis compressis; fol. olabriusculis. Fluegge Monogr. p. 102. Trin. ic. t. 102. P. tenue Gaertn. t. 80. f. t. In America calidioie et Africa aequinoctiali. $\odot$.

76. P. littorale R. Br. spicis conjugatis subaequaliter pedunculatis; flosculis ovatis acutis glabris; fol. involutis culmo compresso. R. Br: prodr. 1. p. 188. Trin. ic. t. 112. In Nova Hollandia et ins. Mauritii.

g.\%. P. notutum Fluegge; spicis duabus approximatis; rachi plana spiculis angustiore; glumis ovatis obtusiusculis laevigatis valvarum longitudine; vaginis remotis. Fluegge Monogr. p. 106. Trin. ic. t. 114. In ins. St. Thomae, Brasilia, Mexico et $\mathrm{Ca}$ rolina. 4.

78. P. mumilum Nees; spicis binis approximatis; rachi plana spiculis solitariis angustiore; glumis orbiculatoellipticis obtusis glabris flosculum aequantibus; culmo simplici adscendente paucinodi; fol. lanceolato-linearibus planis. Nees in Mart. Bras. 2. p. 52. In Bahia. 4. 
\%.9. 1). vavinatum, Sw. fol. carinatis glabrisculis; vaginis compressis glabris fauce pilosis; spicis duabus conjugatis; rachi plana spicularum biseriatarum latitudine; glumis subglabris. Ifumb. et Kunth Nov. Cen. 1. p. 91. In Americu, Jumrica, Nova Ilollendia et ifiver aequinoctiali. 4 .

50. Misticknm Bn'm. spicis duabus conjuga! is divaricato-lorizontaliดแs; spiculis hiseriatis latiudine rachis planae; fol. involutis distichis vaginisque glabris; ligula pilosa ; glumis oblongis subacmuinatis aequalibus xlabris; culno basi repente. Kunth sy. 1. p. 52. P. longiflorun Beauv. filor. 2. t. 85. In Indire orientali, ins. Marritii et IAzonia?

81. I'. Thteinianm Presl; radice repenie; culmo basi brevissime ramoso erecto; vaginis distichis oris apice piloso-harhatis; fol. hrevibus rigidis involutis; spicis binis erectis adplessis; rachi flexuosa triquetra glaherrima latiludine spicularum 2-seriatarum ovato-lanceolatarum sessilium adpressarum; glumis aequalibus trinerviis acutis glaherrimis; paleis laevissimis; inferiore fasciculo pilormm brevissimorum mucronato. Presl in Mel. Haenk. 1. p. 209. In India orientali. $\odot$.

8. 1'. Boryanum Presl; radice repente; culmo compresso ubique longe ramoso glaberimo vaginis laxis distichis ore supremo pilosis; fol. clongatis lierbaceis canaliculato-planis ylaberrimis; spicis binatis patcnibus; rachi rectiuscula 3-quetra glaberrina; spiculis biseriatis secundis imbricatis sessilihus lanceolatis latitudine rachis; glumis membranaceis aequalibus glaberrimis trinerviis; fore glumis breviore; paieis aegualibus lanceolatis acutissinis apice pilosinsculis. Presl 1. c. In Lazonia. $\odot$.

S3. I'. barbatum schult. culmo compresso glabro nodo unico barbato; vagrinis ad culmi basin confertis distichis compressis glabris; fol. oblongolanceolatis supra pilosulis margine ciliatis; spicis duabus binatis linearibus; rachi compresso-iriangula glabriuscula; locustis oblongis acutis; calycis glumis dissite pubescentihus corolla longioribus; corollae valvula inferiore apice barbala. Schult. mant. 3. p. 558. P. obtusifolium Raddi. Trin. ic. t. 115. In ins. Bcurboniae et in Brasilia. 4.
81. P. michauxianum Kunth; spicis geminis basi subvillosis; rachi latiuscula glabra; foribus solitariis bifariam imbricatis glabris; fol. patentibus; vaginis glabris collo villosis; culmo repente. Pursh. P. bracteatum Dufour Digitaria paspaloides Michx. Pursh. In America boreali, Brasilia et in ins. Mnaritii.

85. I'. foliosum Kunth; spicis geminis glabris; floribus solitariis pelicellalis; culmo repente folioso; ligulis longe riliatis. Diggilaria Lagasea Elench. p. 4. In Ilivanna.

86. P. tivistuchyum Leconte; glabrum repens; in aquis erectum in terra prostratum; fol. brevilus angustis glaberrimis; vaginis latis ad oras barbatis; spicis ut plurimum ternis subpatulis basi nudis; glumis ovatis biseriatis; rachi latiuscula dentibus unifloris. Leconte Monogr. in Journ. de Phys. 11. p. 285. Digitaria sichult. In Georgia. 24.

8\%. P. farcatum Fluegge; spicis duabus conjugatis; rachi triquetra spiculis angustiore; glumis ovato-lanceolatis acuminatis glaberrimis, valvis tertia parte longioribus; vagins laevibus; culmo nullinodi. Fluegge Monogr. p. 114. In Carolina et Mexico.

85. P. taeve Hichx. spicis tribus pluribusve alternis remotis; rachi plana flexuosa spiculis duplo fere angustiore; glumis orbieulato-ellipticis obtusiusculis nitidis; fol. glabris. Fluegre Monogr.

89. D. scrobiculutum limn. spicis paucioribus alteruis; rachi plana recta spicularum latitudine; glamis subrotundis ohtusis glabris; fol. superioribus nudis. Fluegge Monogr. p. 86. Trin. ic. t. 143. P. Kora Willd. Hort. t. 74. P. orbiculare Ir. Br. In India orientali, Nora Irollandia, Africa aeruinoctiali etc. 24.

90. P. auriculatum Presl; fol. planis ex cordata hasi linearibus margine scabris; varinis glabris; spicis 2-4 alternis; rachi plana glabra margine scabriuscula spiculas orbiculatas obtusissimas biseriales latitudine aequante; glumis rotundis obtusissimis glaberimis inferiore trinervia. Presl Hel. Haenk 1. p. 217. In Luzonia. 2.

91. P. cartilagineum Presl; fol. planis linearibus superno margine scabris vaginisque glabris; spicis 4- 
5, alternis; rachi plana glabra margine scabra, njiculas ovatas obtusiueculas biseriales imhricatas latitudine aequante; glumis ylaberrimis; inferiore membranacea 3 -nervia superiore carlilaginea convexiuscula 3-nervia sulcis duobus longitudinalibus notata. Presl in Rel. Haenk 1. p. 216. In ins. Mariue Annue et Lasomia.

92. P. flexuosum Kilein; culmo erecto hasi subramoso notisque glabris ; fol. hasi carinatis, margine nervorue medio scabris; rachi cummuni elongata senitereti, angulis oppositis marcrinatis ad ortum spicarum in bracteau excedentibus; spicis pluribus dissitis; rachi partiali dilatata margine scabra, spiculas 4 seriatas ellipticas latitudine multoties superante; gltumis pubescentibus acutiusculis; palea superiore obtusissima. Presl in Mel. Hatenk 1. p. 215. In Iuzonia.

93. P. dissectum L. spicis subternis alternis, defloratis cernuis; rachi plana spicularum solitarium latitudine; glumis obovato-orbiculatis glabris trinerviis, nervis lateralilus geminis; culmo hasi repente fasciculatim ramos0; fol. vaginisque glabris; ligula rotundata exerta. Nees in Mart. Bras.2. 1. 57. Trin. ic. t. 12t. In America meridionali. $\odot$.

91. P. commutatum Nees; spicis quaternis alternis; rachi dilatata subtus concava ciliata spiculis quadruplo latiore; spiculis solitariis obovato-orbiculatis glabris trinerviis; nervis lateralihus geminis; culmo erecto; fol. vaginisque inferioribus hirsutis, superioribus ciliatis. Nees in Mart. Bras. 2. 1. 59. P. dissectum L. In Brasilia.24.

9.5. P. polyjstachyum R. Br. spicis numerosis confertis ; flosculis glabris orbiculatis; valvula exteriore glumae 5-nervia; fol. planis laevibus margine simplici denticulato. $\mathrm{H}$. $\mathrm{Br}$. prodr. 1. p. 188. In Nova Hollandia.

96. P. pubescens R. Br. spicis alternis distinctis sessilibus; flosculis ovalis; glumis pubescentibus; valvula exteriore trinervia; fol. planis supra pilosis scalris margine incrassato denticulato. R. Br. prodr. 1. p. 188. P. puberulam IR. et S. In Nova Hollandia.

97. P. Boscianum Fluegge; spicis plurihus; rachi plana recta spiculis paulo latiore; glumis subro(undis obnas glalris 5-nervibus; fol. basi pi-
Iosis. Fluegge Monogr. p. 170. In Curolinu.

95. P'. melcinospermum Poir. spicis subquinis arcuatis; spiculis sultriserialibus orbiculatis; fol. lato-liniarihus glaberrimis; vagina terminali Icngissima ; culmo ramoso. l’oir. Fuc. suppl. 4. p. 315 . In Cajenrea.

99. 1 . coromandelianum Lam. spicis altemis sessililus; Rorihus 01biculatis bifariis glabris; rachi semiseptifer: lam. ill. 1. 1., 175. In India orientuli.

102. B. sumatrense Roth; spicis quaternis unilatcralibus remotis; rachi recta plana margine argute serrulata; spiculis compressis duplo latiore; glumis subrotundis obtusis glabris; culmo compresso ; fol. linearibus complicatis cum vaginis praelongis ancipitibus. Itoth Nov. El. p. 35. In India orientuli.

iOi. P. Iongifolium Roxb. erectum; simplex; fol. Iongitudine culmi; panicula e spicis simplicilus altemis divergentibus dispersis circa rachim triquetran; valvis calycinis 3 -nerviis; semine ovali lucido, sccobiculis minutis notato. Hoxb. ind. 1. p. 283. Trin. ic. 1. 138. P. quadrifarium Sp:. In Sumutre?

10?. P. Sivartzianum Fluegge; spica sulsolitaria; rachi convexa spiculis augustiore; glumis ovatis acttiusculis glahris; fol. setaceo-linearihus. Hlerere Monogr. p. 96. P. filiforme sw. In India occidentuli.

103. 1'. setaceum Michx. strictum; erectum ; culno setaceo ; fol. villosissimis; spica unica gracili; glumis geminis suborbiculato-ohovatis glabris; Fluegge Monogr. p. 15t. Trin. ic. t. 12.9. P. hirsutum Poir. P. supinum Bosc. Trin. ic. 1. 130 . P. ciliatifolium et debile Michx. P. infirnum $\mathbf{R}$. et $\mathbf{s}$. In Carolina et Hispaniola.

10t. P. singulare link; culmo decumbente; nodis lanatis; fol. pilosis; spica solitaria; spiculis biseriatis; valvis rotundatis trinerviis glabris. Liuk Hort. 1. 1. 48. In Brusilia.

10.5. P. \&asiogonum Link; culmo ad nodos hirto; fol. pubescentibus; vaginis superue margiue hirtis; spicis 3 patentibus flexis; spiculis biseriatis; valvulis rotundatis 3 -nerviis glabris. Link 1. c. Patria ignota. $\odot$. 106. P. spathaceum Poir. spica
subsolitaria; glumis ovatis biseriatis 
glabris; fol. lineari-lanceolatis argute ciliatis; vaginis laxis ore pilosis; folio terminali spathaceo bifido. Poir. Enc. 4. 1. 314. In America boreali.

10\%. P. dasyphyllum Elliot; culmo decumbente glahro; fol. vaginisque hirsutissimis; spicis paucis patentibus; floribus 3-seriatis. Ell. Bot. 1. p. 105. P. macrospermum spr. In America boreuli.

10S. I'. supinum Hornem. spicis alternis (2-3); rachi lineari flexuosa suhmembranacea; calycibus ovalihus 1-nerviis; fol. vaginisque pubescentipilosis; culmo adscendente. Hornem. Hort. Hafn. 1. p. 7\%. In America septentrionali.

109. P. dubinm DC. spicis $3-4$, duahus inferiorihus longe pedicellatis, duabus superioribus ad apicem rachis cummunis glabrae sessilibus conjugatis; rachi propria subrecta; glumis subrotundis subenerviis tenuissime puberulis; fol. planis utrinque pubescentibus; vaginis ad oras et apicen villosis. DC. Cat. Monsp. p. 130. Patria ignota, 4.

$110, P$. incertum $R$, et $S$, spicis 2 sessilibus, una terminali aitera paulo infra apicem; rachibus glahris; propria flexuosa gracili; glunis subrotundis 1-nerviis glabris; fol. glabris utrinque villosis; vaginis ad oras et apicem villosis. P. leptostachyum DC. Cat. Monsp. p. 130. Patrice ignota. 4.

111. P. arenarium Schrad. culmis adscendentibus; fol. ciliatis; spicis 2-3 alternis; rachi triquetra basi pilosa spiculis biserialibus angustiore; calycinis valvulis subrotundo-obovatis 1-nervibus superiore pubescente. Schrad. in schult. Mant. 2. p. 172. Trill. ic. t. 109. In Brasilia.

112. P. longepedunculatum Leconte; culmo glabro erectiusculo apice setaceo elongato; fol. glabris hrevibus vaginisque ciliatis; spicis $1-3$ erectis basi pilosis; glumis orhiculatis parvis 3-seriatis; rachi angusta flexuosa, dentilus 2-floris. Leconte Monogr. in Jouru. de Phys. 91. p. 284. In Carolina boreali.

113. P, difforme Leconte; culmo glabro obliquo; fol. hrevihus glabris hasi vaginarumque dorso ciliatis; spicis $3-4$ erectis basi pilosis; glumis 2 - seriatis orbiculatis majusculis; rachi flexuosa latiuscula, dentibus
1-2 floris. Leconte Monogr. in Jour. de Phys. p. 91. p. 28t. In America septentrionali.

11t. I'.latifolinm Leconte; glabrum; culmo erectiusculo; fol. Iongis latis ciliatis, vaginis exceptis ad oras undis; spicis $2-3$ alleruis erectiusculis basi pilosis; glumis orloiculatis basi triseriatis, serie intermedia pedicellata; rachi angusta dentibus lateralibus bifloris. Leconte 1. c. In Carolina. 4.

11.5. 1. Leconteanum Schult. glabrum; culmo erecto; fol. longis latiusculis margine undulosis vaginisque undis; spicis 4-6 alternis, erectis hasi pilosis; glumis 2 -seriatis orbiculatis; rachi angusta flexuosa, dentibus 1-floris. P. undulosum Leconte 1. c. In America septentrionali.

116. P. angustifolinm Leconte; glabrum culmo gracili erecto; fol. angustis longis; vaginis nudis; spicis 2-3 alternis divaricatis secundis basi pilosis; glumis orbiculatis biseriatis; rhachi angusta flexuosa, dentibus unifloris. Leconte 1. c. In America septentrionali.

117. P. tenue Kunth; erectum glabrum; fol. In'igis angustis basi vaginisque ad oras ciliatis; spicis $4-5$, alteruis patentibus, basi pilosis; glumis magis orbiculatis triseriatis; rachi flexuosa angusta; dentibus 2-floris. P. gracile Leconte 1. c. P. Orthus Schult. In Rensylvania, Nova Caesurea et Georgia. 4.

118. P. altissimum Leconte; glabrum erectum altum; fol. longis basi vaginisgne ad oras ciliatis; spicis 45 alternis erectis basi pilosis; glumis magnis orbiculatis hiseriatis; rachi latiuscula, dentibus unifloris. Leconte 1. c. In Carolina boreali. 4.

119. P. hir'sutum Retz; spicis alternis subhinis; rachi membranacea; calycibus multinerviis, laevibus; fol. pedicellisque hirsutis. Retz obs. 2. p. \%. In China.

120. P. pilosum Lam. spica solitaria; flosculis ellipticis alternis confertis ; rachi pilosa; fol. villosissimis. Lam. ill. 1. p. 175, In America calidiori.

121. $P$, riparium Nees; racemis subsenis alteruis; rachi plana spicularum geminatarum latitudine; glumis suborhiculatis obtusis 5-nerviis subpubescentibus; fol. Ineari-lanceolatis, planis basi pilosis vagiuisque margine 
ciliatis; ligula exserta oltusa. Nees in Mart. Bras. 2. p. 56. Ad flumen Amaะonum. $\odot$.

122. P. caespitosum Fluegye; spicis subquaternis alteruis; rachi plaua spicularum latitudine; glumis obovatis obtusiusculis 5-nervihus subpubescentibus; fol. planis glahris. Fluegge. Monogr. p. 161. Trin. ic. t. 121. P. dissectum Sw. In Hispaniola et Essequebo. 4.

123. P. plantagineum Nees; racemis pluribus alternis erectis; rachi plana, spiculis geminis inaequaliter pedicellatis angustiore, basi pilosa; glumis obovato-oblongis, 5-nerviis subpubescentibus; vaginis ore barbatis; fol. lanceolatis ciliatis supra pilosis subtus minute puberulis. Nees in Mart. Bras. 2. p. 69. P. corcovadense Raddi. Trin. ic. t. 163. In $\mathrm{Br} a-$ siliu.

12t. P. coryphaeum Nees; racemis pluribus elongatis erectompatulis; rachi convexa glabra, spiculis geminis inaequaliter pedicellatis duplo angustiore basi barbata; glumis obovatoellipticis, obtusiusculis sub 5-nervibus villosulis; vaginis glanduloso-scabriusculis; fol. linearibus glabris, basi barbulatis. Nees 1. c. In Brasilia.

12.5. P. glabrum Poir. spicis subquaternis alternis; rachi plana spicularum latitudine; glumis obovatis obtusiusculis 3-nervibus interiore pubescente, exteriore nuda; fol. glabris subcarinatis. Fluegge 1. c. In Portorico, st. Thoma et Hispaniola. 4.

126. $\boldsymbol{P}$. heterophyllum Poir. spicis alternis sessilibus remotis subquinis; spiculis ovatis subtriseriatis; fol. inferioribus Ianceolatis; vaginis ore pilosis. Poir. 1. c. p. 315. In St. Domingo.

12\%. P. arundinaceum Poir. glaberrimum spicis alternis elongatis; spiculis subtriseriatis glumis obtusis aequalibus; fol. subeusiformibus margine asperis. Poir. l. c. p. 310. In Carolina.

12s. P. milioideum Desv. spicis subseptenis alternis sessilibus longissimis; spiculis ovatis numerosis subinordinatis; fol. superne convolutosubulatis glabris; vaginis margine pilosis. Poir. 1. c. p. 315. P. miliaceum Spr. In lortorico.

129. P. Forsterianum Fluegge; spicis subquaternis alteruis; rachi plana, spiculis paulo latiore; glumis elliptico-lanceolatis acutiusculis $\tilde{5}$-nervibus glabris; fol. undulatis. Fluegge l. c. P. undulatum Spreng. In Nova Caledonia.

1:30. P. macrospermum Flueyge; spicis duahus alternis; rachi plana spiculis angustiore; glumis ellipticis ohtusiusculis glabris 5-nervibus; fol. hasi pilosis. Fluegge 1. c. P. floridanum Michx. Pers. In Carolina, Florida et Georgia.

131. P. convexum Fluegge; fol. planis utrinque papilloso-hirsutis; vaginis glabris ciliatis; spicis subternis alternis; rachi plana glabra spiculis quadriseriatis angustiore; glumis glabris. Kunth in Humb. Nov. Gen. 1. p. 91. In Mexico. 4.

132. P. macrophyllum Humb. et Kunth; fol. planis glabris ciliatis; vaginis pilosiusculis; spicis quinis alternis; rachi plana glabra spiculis quadriseriatis angustiore; glumis pilosiusculis. Kunth I. c. In Nova Grancita. 24.

133. P. lentiferum Iam. spicis subsenis; rachi plana, spiculis conpressis angustiore; glumis subrotundis obtusis glahris 3-nervibus; fol. glabertimis. Fluegge 1. c. Triu. ic. t. 137. In Carolina.

134. P. paniculatum I. spicis numerosissimis; rachi subtriquetra glabra spiculis duplo fere angustiore; glumis obovato-orbiculatis retusis pubescentibus trinervibus; fol. pilosis. Fluegge 1. c. Gaertu. t.80. f. 2. Trin. ic. t. 127. P. compressiusculum Raddi. P. hemisphaericum Poir. P. strictum Pers. In Americu culidiori. 4.

135. P. lentiginosum Presl; culmo erecto compresso; vaginis ciliatis; fol. planis hasi cordatis ima basi colloque pilosis, marghe undulatis et tuberculato-ciliatis; spicis alternis solitariis; rachi communi 3-quetra spiculis binis 4-seriatis ovato-orbiculatis, rachi dorso plana ciliato-pilosa duplo latioribus; glumis lepidotis pubescentibus 3-nerviis. Presl. Rel. Haenk. 1. p. 218. In Mexico. 4.

136. P. patulum Hornem. spiculis filiformibus paniculatis alternis; floribus subpedicellatis; fol. glabris. Hornem. Hort. Hafn. 1. p. 78. Patria ignotu. 4.

13\%. P. mucronatum Mühlenb. culmo glabro repente, in aqua natante; 
fol. latiusculis basi ciliatis; vaginis latis turyidis ciliatis; spiculis raris, breviusculis ; angustis, inferioribus verticillatis, caeteris sparsis basi nulis; glumis ovatis, minimis hifariis; rachi latissima, glumas subtegente apice acuta nuda clentibus 1-fícris. P. natans Leconte 1. c. P. paniculatum Walt. In Georgia et ad IHissisippum. 4.

138. 1. elegans Fluegge; spicis pluribus; rachi plana glahra spicularum latitudine: ylumis obovatis obtusis 3-nerviis foliisque utrinque pubescentibus. Fluegge 1. c. p. 18\%. P. tenellum Hort. Par. P. pubescens Hortul. Patria ignota. 21. 1-3-ped.

13.9. P. fimbriatum rumth; fol. planis ciliatis; vaginis pilosiusculis; spicis subteruis; rachi plana glabra ciliata latitudine spicularm 4-fariarum; giumis margine ciliatis alatis. liminth 1. c. In Pova Granata et Barasilia. 4.

1:0. P. scututum Nees; racemis 4-6 alternis; rachi convexa, triplo angustiore spiculis aristatis; glumis ohovato-rhombeis, mucronatis, inferiore plicata; fol. planis vaginisque villosis. Nees 1. c. In Brasilia. ๑.

111. P. dilatatum Poir. spicis ternis una sessili; alternis longe pedunculatis; flosculis 4-fariis secundis. Poir. 1. c. P. ovatum Nees Trin. ic. t. 139. In Buenos-Ayres. Culmi erecti compressi.

142. P. pedunculare Fresl; colmo erecto compresso glabro; vaginis mlabris; fol. ....; spicis pluribus alternis; rachi superne plana glabra, spiculis angustiore; spiculis pedicellatis 4-fariis, imbricatis, orbiculato - ovatis, acutis, 3-nerviis, villosis, margine ciIiato-lanatis; palea inferiore hrevissima, cuspidata, glaherrima 1-nervia. Presl I. c. F'ulrie iynota.

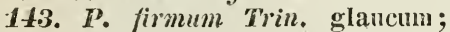
culmo erecto 3 -quetro compresso, vaginisque glabris carinato-compressis, striatis; fol. lineari-lanceolatis, planis glabris margine hispidis; racemis 4-6, patentibus; rachi lineari glahra, membranacea, spicula duplo latiore; spiculis 2-fariis imbricatis, oblong0-rotundatis, acutiusculis glabris. Trin. ic. t. 125. In ins, Nan atii.

114. P. quadrifurium Lasn. spicis pluribus erectis subpaniculatis; glumis ovatis 3-1-fariis; rachi pilosa. Lam. ill. 1. p. 176. Trin ic. t. 128. P. virgatum 11. et S. In Montevideo. 3-4 ped.

115. P. ferrugineum Trin. culmis caespitosis, erectis teretibus simplicibus, glabris pilosiusculisque; fol. erectis, firmis margine involutis, scabris; spicis crebris solitariis geminatisve erecto - patulis; rachi linearl duplo vel triplo spiculis 4-fariis, imbricatis ellipticis puberulo-hispidis, angustiore glabra margineque adpressopilosa. Trin. ic. t. 136. P. quadrifarium Hort. herol. In Montevideo.

1-16. P. variegatum Link; fol. bas! pilosis; spicis subpedicellatis arrectis, basi pilosis; spicnlis geminatis sub 4-fariis; valvis ovalibus subacutis pubescentibns. Link Hort. 1. p. 10. Patria ilyota. 24.

11\%. P. denticulatum Trin. culmo erecto compresso simplici spathisque glaluris carinatis; fol. arrecto-linearibus; spicis 10, erecto-patulis; rachi lineari margine subscabra latitudine spicularum; spiculis 3-fariis imhricatis, orhiculato-obovatis lenticulari-compressis, glabris margine denticulatis. Trin. ic. t. 123. In America boreali.

118. P. africanum Poir. spicis duabus alternis longissimis filiformibus; spiculis orbiculatis bifariis dense imbricatis; glumis margine pubescentibus; fol. lineari-lanceolatis margine subvillosis hasi vaginarum pilosis. Poir. 1. c. In Africa.

149. P. densum Poir. spiculis numerossimis; rachi plana spicularum latitudine margine pilosa; glumis subrotundis retusis undique glabris 3 -nervibus; fol. glabris margine scaberrimis. Fluegge 1. c. p. 186, In Portorico. 24. Speciosissimus. Spiculae 40-60, confertae.

150. P. compactum Roth; spicis mumerosissimis verticillato-fasciculatis, glomeratis simplicibus; rachi triquetra plana margine scaberrima spicalisque aequalibus; glumis ellipticolanceolatis obtusis, exteriori 5-nervi; vaginis foliorum hispidis, scabris superne carinatis. Hoth Nov. sp. p, 36. Panicum imperfectum Roxb. In India orientali.

151. P. lenticulare Kunth; fol. glabris margine cartilagineis et scabris interne basin versus papillosopilosus; vaginis ciliatis; spicis crebris 
paniculatis subalternis; rhachi plana glabra spicularum 4-seriatarum latitudine; glumis glabris. Kunth 1. c. In Nova Andalusia. 4.

152. P. virgatum L. fol. planis glabris margine scabris; vaginis glabris fauce harhatis; inferioribus margine pilosis; spicis plurihus; rachi plana margine pilosiuscula; spiculis 4-seriatis panlo angustiore; glumis margine hirsutis, rarius glabris. Kunth 1. c. Trin. ic. i. 131. 132. In America meridionuli. 4.

153. P. laxum Lam. spicis alternis laxis, inferioribus pedunculatis; floribus ovatis pedicellatis geminis. Lam. 1. c. p. 176. In America meridionali. 4.

15t.P. lanceolatum Link; culmo simplici apice subvaginato, glabro; vaginis compressis laxis limbo villosis; fol. lanceolatis margine villosis; panicula subracemosa, basi villis barbata; rachi florious angustiore; spiculis 4-fariis geminatis oblongis glabris. Trin. in Spr. N. Entd. 2. p. 48. In Brasilia.

15.5. P. purpurascens Elliot; culmo suberecto; fol. longiusculis purpurascentibus hasi pilosis; spiculis numerosissimis, basi pilosis; floribus 4-fariis. Elliot. 1. c. sloane hist. t. 69. f. 1. In Georgia et Carolina.

1.56. P. confertum Leconte; culmo erecto glabro; fol. longis latiusculis supra scabris; vaginis ad oras nudis; spicis confertis plurimis erectis hasi pilosis; glumis orbiculatis confertis 4-seriatis seriebus intermediis pedicellatis; rachi lata non flexnosa dentibus lateralibus unifloris. Leconte 1. c. In Georyia. 4.

15\%. P. undulatum Poir. spicis pluribus rachi plana, spiculis paulo angustiore; glumis ellipticis obtusiusculis 5-nervibus interiore pubescente extoriore sulspicata; fol. glabris hasi pilosis. Fluegge 1. c. p. 168. Trin. t. 140. P. montevidense Spr. P. plicatum Pers. In Portorico, Georgia et Carolina. 4.

1.)8, $P$. mandioccanum Trin. spicis pluribus alternis; rachi ohtuse carinata apice flexuosa hasi barbata, spiculis geminatis angustiore; glumis elliptico-acutis 5-nerviis, glahris; fol. planis lanceolatis ciliatis basi villosobarbatis. Nees in Mart. Bras. 2. p. 68. In Brasilia. 4.
159. P. pubifolium Presl; culmo erecto simplici; nodis vaginisque glahris; fol. strictis, ahbreviatis, carinatis, interne pubescentibus, externe pilosis; spicis 3 alternis; spiculis 3 -seriatis obovatis obtusis, rachi margine scalora duplo latioribus; glumis 3-nerviis glabris. Presl 1. c. p. 219. In Peruvia. 4.

160. P. exaltatum Presl; culmo compresso glabro; vaginis inferne hirsutis; fol. convolutis margine scabris, limbo pilosis; spicis pluribus alteruis maroine scabris pilosisque latitudine spicularum lanceolato-acutarum 4-seriatarum ; glunis oblongo-acutis, inferiore pubescente superiore glabra. Presl 1. c. p. 219. In Chili. 4.

161. P. fictum Presl; fol. planis linearibus margine scabris, vaginisque glaherrinis; spicis secundis alternis; rachi partiali spiculis lanceolatis bifariis angustiore; glumis aequilongis sepalis acutis longioribus. Presl 1. c. p. 220. Patria ignota.

162. P. conspersum Schrad. fol. margine scabris; vaginis papillosis; spicis plurihus alternis; rachi plana margine scabra basi barbata, spiculis 4-serialibis angustiore; calycinis valvulis elliptico-ovatis 1-nervibus: superiori pubescente. Schrad. in schult. mant. 2. p. 174. In Brasilia.

163. P. Lagascae $R$. et $\mathbf{S}$. spicis alternis secundis, basi pilis fasciculatis; floribus alternis geminis pubescentilus. P. pubescens Lagasca Nov. Gen. n. 21. In Havanna et Hontevideo. 24.

16\%.P. elegantulum Presl; culmis erectis compressis; rachi triquetra scalora; vaginis inferne hirsutis; fol. strictis glaberrimis, canaliculatis cariuatis obtusis, angulis ciliatis; spicis pluribus corymbosis culmo longioribus; spiculis bifariis, sessilibus basi fasciculo pilorum fulcratis, oblongis obtusis; glumis oblongis obtusis, 2nervibus longitudine paleae. Presl. 1. c. P. tenue IVilld. In Peruvia. 4.

16.5. P. altenuatum Presl; culmo erecto compresso nodisque glahris; vaginis foliisque hirsutis, planis rigidis obtusiusculis; spicis pluribus corymbosis; rachi partiali 3 -quetra, scabra; spiculis bifariis basi nudis, oblongis oltusis glaberrimis. Presl 1. c. P. tenue Willd. Hb. In Perueria. 
166. P.; appendiculatum P'rest; culmo erecto ramoso compresso nodisque glabris; vaginis limbo pilosis; fol. glahris margine ciliatis; spicis subquinatis alternis, curvatis; rachi communi angulata partiali $\mathbf{3}$-quetra e nodis hirsuta; spiculis oblongis, glaberrimis bifariis. sessilibus; glmmis tenuissimis. Presl. 1. c. In panatma. 2 .

16\%. P. chrysotrichum Presl; culmo erecto simplici compresso nodisque glabris; vaginis bifariis limbo pilosis; fol. rigidis, margine scabritlsculis; rachi communi conpressa hispida; spiculis 10, alteruis, dilatatis; rachibus partialibus 3 -quetris margine subangulosis, setosis; spiculis 2-floriis, oblongis glaberrimis. PresI 1. c. In insula Luionia.

16s. P. aureum Kunth; fol. planis margine scabris; vaginis glabris; spicis digitatis ; rachi plana interne margineque papilloso-setosa, spiculis biseriatis latiore; glumis glabris. In regno Noro-Granatensi. 4.

169. $\boldsymbol{~}$. pulchrum Will. spicis pluribus; approximatis fastigiatis; raclí commui pilosa; partiali plana, sub spiculis et margine papilloso-setosa; glumis ovatis, scabro-pilosis; culmo simplici; vaginis glabris; fol. angustatis, planis; supra hasin et ad marginem pilosis hasirue sipsa Ionge ciliata. Nees in Mart. Bras. 2. p. 79. Digitaria Spr. In "Brasilia.

170. P. ramosissimum. Nees; culmo ramosissimo; nodis imberbibus; fol. distichis linearibus planis interne sulcatis rigidis vaginisque glabris carinatis margine ciliato-lanatis; spicis subdigitato-quinis, interne margineque aureo-setosis; spiculis 2 -seriatis latitudine rachis; glumis subaequalibus, binerviis glabris. Kunth Gram. 2. t, 164. In brasilia.

171. D. exasperatum Nees; spicis pluribus approximatis, fastigiatis; rachi communi villosa, propria triquetra sub spiculis margineque papillososetosa, spiculis biseriatis angustiore; glumis ovatis subpubescentibus; fol. planis vaginisque apice tuberculatohispidis. Nees in Mart. Bras. 2. p.81. Cabrera chrysophlepharis Lagasc. In Brasilia. 4.

172. P. chrysostachyum Schrad. fol. carinatis villoso-hirtis subrecurvis; vaginis summis glabris; rachi triquetra interne margineque setosa, spiculis biserialibus angustiore; glumis glabris. Schrad. in Schult. Mant. 2. p. 176. Trin. ic. t. 101. In Brasilia. 4.

173. P. canescens Nees; spicis subquaternis approximatis, subdigitatis fastigiatis; rachi communi pilosa; propria triquetra sub spiculis margineque papilloso-setosa, spiculis biseriatis subangustiore; glumis obovato-ellipticis pubescentibus; fol. planis vaginisque villoso-canis. Nees in Mart. Bras. 2. p. 99. Trin. ic. t. 99. In Brusilia. 4.

\section{Species dubiae.}

171. P. tomentosum Poir. spicis duabus, altera longe pedunculata, longissimis; spiculis 2 -seriatis; rachi cauleque pilosis; pedmuculis tomentosis; fol. late linearibus utrinque hirsutis. Poir. 1. c. p. 308. Patria ignota.

195. P. cubense Spr. spicis gracilibus; pedunculis capillaribus; rachi filiformi ; flosculis subrotundis, apiculatis glabris subuniserialibus; fol. scabris; ligula exserta. Spr. N. Entd. 3. p. 12. In ins. Cuba.

1\%6. P. lanatum Spr. spicis binatis altemis; rachi angusta; flosculis 4-serialibus ovatis acutis uninervibus lanatis; fol. latiusculis undulatis glabris. Spr. Cur. post. p. 30. P. eriophorum schult. In Rio-Grande.

17\%. P.? nematodes Schult. repens, glahrum; fol. brevibus; processu stipulari ad faucem vaginae; racemis $2-3$, terminalibus erectis; floribus alteruis solitariis muticis. Milium filiforme Roxb. ind. 1. p. 317. Digitaria Roxburglii spr. In India orientali.

188. P. ? velutinum Runth; spicis 8-9, alternis filiformibus; flosculis exaristatis subpubescentibus geminatis inaequaliter pediccllatis; fol. et imprimis vaginis molliter breviterque velutinis. Milium velutinum DC. Cat. Monsp. p. 126. In Mexico. $\odot$.

179. P. ? cochinchinense Willd. spica longissima erecta glabra; glumis cuspidatis; fol. subulatis; culmo suberecto. Phleum cochinchinense Lour. In Cochinchina. 


\section{MHLILM Linn.}

1. M. e/russum L. panicula diffusa; florihus muticis. schrad. germ. 1. p. 197. Fl. Dam 1143. Host. Gram. 3. t. 22. var. florihus paniculatis confertis etc. M. confertum Mill. In Europa et Sibiria. 24. $1-4$ pedalis.

2. M. vernule Bieb. panicula composita; spiculis altemis approximatis acutis muticis; radice annua. Bieb. cauc. 1. p. 53. Agrostis vernalis

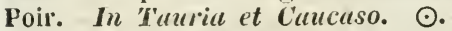

3. IJ. Lanutum R. et S. fol. convolutis; panicula ramosa contracta; gluma floreque neutro externe villosolanatis. Kunth in Fumb. et Bonpl. Nov. Gen. 1. p. 94. t. 29. Kunth Gram. t. 163. In Miexico et Brasilia. 4.

4. H. molle Finth; panicula patula; glumis villoso-lanatis; fol. convoluto-filiformibus; flaccidis villosis. Leptocarphium Nees in Mart. Bras. 2. p. 85. In Brasilia. 4 .

\section{Species dubiae.}

5. M. roseum Spr. paniculae pyramidatae ramis capillaribus glabris; calycibus coloratis glaberrimis; fol. vaginisque laevilus; culmo erecto. spr. syst. 1. p. 125. In insula Mascarenae.

6. II. tomentosum Rottb. panicula laxa capillacea; pedicellis unifloris; calycibus bivaivilous striatis membranaceis; flosculis ovalibus parvis. Willd. Act. Berol. 4. p. 440. In Indiu orientuli.

\%. M. capillare Roth; panicula capillari effusa; floribus muticis; glumis oblongis aequalibus; fol. utrinque cum vaginis pubescenti-scabriusculis. Roth. Nov. sp. p. 39. In India orientuli.

8. M. microspermum Lagasc. culmo decumbente ramosissimo; panicula patula capillari; floribus muticis. Lagasca Elench. p. 2. In Mexico. ๑.

9. II. Hühlenbergiınum Schult; culmo tereti nodoso glabro striato; fol. lanceolatis acuminatis glabris; vagina elongata superne margine pilosa; ligula brevissima harbaeformi; paniculae ramis alternis solitariis; florum pedicello sub calyce articulato. Mühlenb. descr. p. 78. In America boreali.
10. M. nigricans Ruiz et Pav. floribus paniculatis confertis; valvulis calycinis nitidis nigrescentihus fol. ensiformihus longissinis. IR. et P. peruv. 1. p. 47. In Peruria.

11. M. sparsum Mill. panicula sparsa erecta; glumis aristatis. Mill. Dict. p. 2. In Vera Cruz.

\section{AMPHICARPUM Kunth (1533).}

1. A. Purshii Kunth Grum. 1.p. 28. Milium amphycarpon. Pursh am. t. 2. In Nova Caesarea.

\section{OLYRA Linn.}

1. O. pauciflora $S w$. fol. oblongis suhdimidiatis acuminatis utrinque glabris; floribus axillaribus. schlecht. pat. in Berl. Mag. 8. 1819. p. 149. o. axillaris Lam. ill. t. 751. f. 1. Lithachue Beauv. In Jamaica et Cajenna. 4.

2. O. arundinacea $H$. et $\mathbf{K}$. fol. oblongo-lanceolatis utrinque scabris; vaginis glahris; panicula simplici coarctata; spiculis femineis terminalibus solitariis. Kunth in Humb. et Bonpl. Nov. Gell. 1. p. 197. In Nova Granata et Brasilia.

3. O. scabru Nees; fol. oblongis acuminatis, subtus vaginisque scabris glaucis; ligula ovata; paniculae racemosae compositae angustae ramis scabris; spiculis femineis in ramis terminalibus pluribus glabris. Nees in Mart. Bras. 2. p. 306. O. pubescens var. glabra. Raddi. In Brasilia.

4. O. glaberrima Raddi; fol. ohlongis acuminatis basi acutis utrinque vaginisque glahris et laevibus viridibus; ligula nulla; paniculae racemosae compositae ramis laxis scabris, inferioribus verticillatis plerisque masculis; spiculis femineis in ramorum superiorum apicibus solitariis glabris. Nees in Hart. Bras. 2. p. 307. In Erasilia. 4.

5. O. jubescens Raddi; fol. lanceolato-oblongis acuminatis basi rotundatis subtus subpubescentibus viridibus; vaginis hirtis; ligula nulla; paniculae racemosae compositac ramis strictis; rachi hirta; spiculis gla- 
bris; femineis in ramorum apicibns subsolitariis. Nees in Mart. Bras. 2. p. 307. O. paniculata s'chlecht. In Brasilia. 4.

6. O. paniculata Sit. culmo ramoso; panicnla terminali. Sw. Ois. p. 347. O. latifolia Linn. Lam. ill. t. 751. f. 1. Jamaica. 4.

7. O. latifolia IIumb. et Irunth; fol. ovatis glabris, maroine serrulatoscabris; vaginis piloso-lirtis; panicula simplici patula ; spiculis femineis terminalibus solitariis. Kunth 1. c. In Insula Cuba.

8. O. humilis Nees; fol. ovato-oblongis acuminatis subpetiolatis glaucis subtus scabris; vaginis margine ciliatis subpilosiusculis; ligula nulla; paniculae terminalis angustae rachi ramisque laevibus; spiculis femincis solitariis terminalibus; flosculo basi sericeo. Nees in Mart. Bras, 2. p. 30t. In Brasilia. 4.

9. O. longifolia Humb. et Funth; fol. lanceolato-oblongis subcordatis supra vaginisque glabris subtus scabris; panicula simplici coarctata; ramis aliis femineis aliis masculis. Kunth 1. c. In Gujana.

10. O. cordifolia Humb. et Kunth; fol. ovato-oblongis cordatis glabris margine scabris; vaginis pilosis; panicula ramosa verticillata patula; spiculis nommulis terminalibus femineis. Kunli 1. c. In Nova Granata et Brasilia. 24.

11. O. ciliatifora Raddi; fol. deltoideis vaginisque ore cilialis; rachi hirta; paleis albis pilosis. Nees in Mart. Bras. 2. p, 308. In Brasilia. 24.

12. O. floribunda Raddi; fol. oblongis subpetiolatis obtusis apiculatis basi subcordatis ciliatis vaginarum marginibus pubescentibus; spiculis masculis terminalibus paniculatis; femineis in ramis axillaribus distinctis. Nees in Nart. Bras. 2. p. 309. Raddia brasiliensis Bert. In Brasilia.

13. O. micrantha Humb. et Funth; fol. oblongis angustato-acntatis basi rotundato-suhcordatis vaginisque glahris margine scabris panicula ramosa patula; inferme mascula, superne feminea; ramis verticillatis ramulisque hirtello-pubescentihus; glumis femineis acuminato-subaristatis; hispidulo-scabris; paleis punctato-orbiculatis. Kunth 1. ci In Brasilia.
14. O. ventricosa Nees; fol. oblongo-lanceolatis acmminatis vaginisque glabris margine asperulis; paniculae compositae et decompositae ramis hirtis superioribns femineis; spiculis femineis ventricosis lirtis; glumis scrobiculatis. Nees in Mart. Bras. 2. p. 303. O. hirsuta Trin. O. scrobiculata schrad.

\section{Species dubiac.}

15. O. ovata Hamilt. culmo elato stricto; fol. petiolatis ovatis ntrinque allenuatis acuninatis glahris; vaginis supcrioribus subpubescentihus; panicula subterminali glunis acutis. Hamilt. prodr. p. \%. In Cajenna.

16. O. orientalis Lour. culmo 3quetro ; spicis compositis; seminibus 3-quetris, scahris Lour. Coch. 2. p. 674. In Cochinchina.

\section{STREPHIUMI Schrad. (1829).}

1. S. distichophyllum Schrad, ined. In Brasilia.

\section{TRASYA Iunth (1815).}

1. T. paspaloides Kunth; culmo ramoso; fol. utrinque puhescentibus; flore hermaplrodito 2 -andro. Kunth in Humb. et Bonpl. Nov. Gen. 1. p. 121. t. 39. Ad Orinocum. 24.

2. T. hirsuta Nees; culmis caespitosis simplicilus fol. utrinque pubescentibus, ciliatis; laciniis paleae inferioris masculae supra hirsutis, muticis. Kunth Gram. t. 102. Trin. ic. t. 151. In Brasilia.

3. T. cultrata Nees; laciniis valvae inferioris floris masculi muticis, apice glabris; culmo simplici; fol. hirsutis margine sulgglandulosis; rachl spiculis latiore erecta. Nees in Mart. Bras. 2. p. 95. Trin. ic. t. 145. In Brasilia. 24.

\section{S. ERIOCILLOA Kunth (1828).}

1. E. disiachya Funth; spiculis geminis; palei apice fimbriatis muti- 
cis. Humb. et Bonpl. Nov. Gen. 1. p. 95. t. 30. Ad Orinocum et in Panamat. 4.

z, E. mollis Funth; rachi glumisque valde pubescenti-pilosis; spicis solitariis alternis simplicissimis. Panicum Michx. am. 1. p. 47. P. Michauxii 12. et \$. P. georgicum spr. Nonache milateralis Beauv. Agr. t. 10. f. 9. In Floride et Georgia.

3. L. villosa bunth; culmo foliisque pubescentibus; spicis 4 , alternis; 2-fariis pubescentilus rachi villosobirsuta triplo latiorilus; paleis flosculi neutri 5 -nerviis, hermaphrodito rugoso. Kunth Gram. 1. p. 203. t. 10. Paspalum villosum Thumb. jap. t. 8. Helopus villosus Nees. In Jagonia.

4. E. polystachya Kunth; spicis crebris alternis; paleis glaherrimis, inferiore apice mucronata. Kunth syn. 1. p. 172. Humb. et Boupl. l. c. t. 31. In Quilo. 4.

5. E. punctata Hamilt. spicis plurihus; rachi subtriquetra hirsuta; glumis ovato-lanceolatis, acuminatis, pilosis; culmo superme puhescente. Fluegge. Milium L. Paspatum Trin. ic. t. 15.5. Oedibachne Link Piptatherum Beauv. Agr. t. 5̃. f. 11. In India occidentali, Americameridionali, Mexico, Nor'a Hollandia et Seneyalia. 4.

6. E. acuminulu Presl; nodis colloque vaginarum sericeis; fol. planis margine scabris; rachi puhescenti; glumis pilosis 3-nerviis. Presl. Rel. Haenk. 1. p. 221. In Mexico. 4.

7. E. hunthii Meyer; culmo puhescente; panicula pyramidali; lobis corollae glahris exteriorihus apice subulato-aristatis. Meyer Esseq. p. 47. Paspalum Meyerianium spr. In Essequebo. 24.

8. E. annulata Kunth; spicis plurihus; rachi 3-quetra, glahra, spiculis quatruplo angustiore; glunis ovatolanceolatis pilosis, valvula cuspidata longioribus. Fluegge. Milium Retz. Paspalum Trin. ic. t. 135. Helopus Nees. In India orientali, Manilla et Montivideo. 4.

9. E. succincta Kunth; puhescens; glauca; culmis caespitosis procumbentibus, ramosis, angulatis striatis; spiculis 2-1 seriatis, lanceolato-ellipticis acuminatissimis puberulis. Paspalum Trin. ic. t. 156. In Asirachan.
10. E. globosa Kunth; panicula patula; glumis muticis; pedicellis cingulo luteo. Milium Thumb. Agrostis Poir. In Japonia.

11. E. brasiliensis spr. spiculis connatis; rachi filiformi, flexuosa ; flosculis alternis suhremotis papillosopilosis; fol. convolutis, setaceis, vaginisque hirsutis. Spr. syst. 1. p.219. In Brasilia.

12. E. pulcinella Kunth; spicis compositis; spiculis 4-fariis, ovatis acutis rachibusque hirsutis; culmo repente ramosissimo nodisque pubescentibus. Nees Panicum Raddi. Trin. ic. t. 178. In Brasilia. 2.

\section{CROCHLOA Beaux. (1812).}

1. I. mubscens Kunth; spiculis pluribus, alternis oppositisque; spiculis alternis 2 -fariis glumis puhescentibus; vaginis villosis. Setaria pilifera Spr. Panicum Helopus Trin. ic. t. 183. In ins. Mascarenis et in Nova Hollandia.

2. I. panicoides Beaun. spicis 3, alternis 2-fariis; glumis puhescentibus; vaginis villosis. Kunth Gram. p. 205. f. 14. Panicum sanguinale Burm. ind. t. 10. f. 1. Oplismenus javanicus R. et $\mathbf{s}$. Helopus Nees. In India orientali et Java.

3. U. fasciculata Inunth; spicis 5-7 digitato - fasciculatis; spiculis subgeminatis, subpedicellatis; gluma superiore margine villosa; fol. fimbriatis; vaginis pubescentibus. Panicum Lam. In Jamaica.?.

1. E. semialata Kunth; spicis 2 -4, digitatis; dentibus rachi flexuosa 3-5-flora; glumis acuminatis, interiore emarginata ciliata; vaginis inferioribus sericeis; genu barbato. $\mathbf{R}$. Br. In Nova Hollandia.

5. U. cimicince Kunth; culmo adscendente simplici; fol. lanceolatis margine cartilagineo ciliato undulato; vaginis pilosis ; spicis sulsquinis, digitatis pedunculatis; gluma superiore margine dense serico-fimbriata. Kunth Gram. 1. p. 31. t. 103. Milium L. Axonopus Beauv. In India orientali.

6. U. uniseta Presl; culmo erecto ramoso, compresso; vaginis glabris; fol. margino scabris; spiculis bas? 
sela fulcrata. Presl. 1. c. p. 319. In Mexico. 4.

\%. I. paspaloides Presl; spicis teruis, alternis hasi nudis; palea superiore flosculi nentri minima. Presl 1. c. In insula Luzonia. 4 .

\section{PANTCUM Plin.}

\section{Spicae solitariae Kunth.}

1. P. rarum $\boldsymbol{R}$. Br. spica rara filiformi; floribus subsessilibus glabris distinctis; flosculo heruaphrodito rugoso; culmo ramoso. H. Br. prodr. 1. p. 189. Kunth. Gram. t. 15. Trin. ic. t. 200. In Nora Hollandia.

2. P. rottboellioides $H$. et $K$. culmo erecto nodisque glahris; fol. pubesceutibus; spica solitaria; spiculis distichis; glumis sericeo-pilosis. Humb. et Kunth nov, gen. 1. 96. t. 32. Ad ripas Orinoci. 24.

3. P. Lolium Nees; spica solifaria; spiculis distichis; gluma inferiore spathulata neutroque flosculo utrinque fulvo-bariatis, superiore gluma pallido-hirsuta; culno simplici erecto glabro; foliis vaginisque villosis. Nees in Mart. Bras. 2. p. 102. In Brasilia. 24. ?

4. P. eriochrysoides Nees; spica solitaria; spiculis distichis; glumis neutroque flosculo dense ferrugineohirsutis; culmo simplici erecto glabro; nodis, foliis, vaginisque hirsutis. Nees, in Mart Bras. 2. p. 103. P. ferrugineum. Trin. ic. t. 90. In Brasilia. 4 .

5. P. prippophorum Nees; spica solitaria; spiculis distichis; glumis pallido-villosis, inferiore lineari-spathulata infra apicem et superiore apice barbatis; flosculo neutro bivalvi margine hirsuto dorso excavato; culmo ramoso adscendente; nodis hirtis; foliis planis basin versus e tuberculis ciliatis. Nees in Mart. Bras. 2. p. 104. In Brasilia. 4.

6. P. exaratum Nees; spica solitaria; spiculis disticho-alternis; glumis subaequalibus totis neutroque flosculo apice albido-hirsutis, loc dorso canaliculato; culno erecto foliisque setaceis glabris. Nees in Mart. Bras. 2. p. 105. Trin. ic. t. 194. In Brasilia. 4.
\%. P. decumbens $\boldsymbol{R}$. S. culmis decumbentibus fasciculato - ramosis; ramis foriferis $7-9$ monostachyis; fol. lanceolato-linearibus planis rigidis ciliatis pubescentibus; vaginis nodisque pilosis; spica arcuatofalcata; spiculis unilateralibus geminis biseriatis obovatis glabris; flore hermaplirodito tuherculato, neutro bipaleaceo. Kth. Itoem, et Schult. syst. 2. 429. Nees in Mart. Bras. 2. 107. Kunth Gram. 1. 208. t. 16. Triu. ic. t. 1\$6. Paspalum decumbens Swartz ind, occ. 1.p. 138. P. nutans Lam. 1. pedunculatum Poir. P. eriostachyum hardi Agrost. 26. In Jamaica, Gujana, ad flumina Amazonum et Rio Negro. 21.

S. P. monostachyum H. et $\boldsymbol{K}$. culmo simplici vel ramoso erecto versus nodos pilosiusculo; nodis sericeo-pilosis; fol. planis apice angustato-acutatis utrinque molliter pilosis; vayinis carinato-compressis pilosis; pedunculis monostachyis solitariis-ternis ; spiculis unilateralibus geminis quadriseriato-imbricatis ellipticis plano-convexis glabris; gluma inferiore brevissima; flore masculo bipaleaceo hermaphrodito lineolis crenulatis scabrato. Humb. et Kunth nov. gen. 1. p. 96. Kunth Gram. t. 104. Orinoco. 2.

9. P. repandum Nees; spica solitaria vel geminis sessilibus unilateralibus; spiculis geminis $\mathbf{4 - f a r i i s ~ n e r - ~}$ rosis; rachi dilatata repanda; culmo erecto; geniculis, vaginis foliisque lineari-acuminatis hirsutis. Nees in Mart. Bras. 2. 98. Trin. ic. t. 150. In Brasilia australi. 4.

Species dubiac.

10. P. plileoiles $\boldsymbol{R}$. $\boldsymbol{B r}$. spica cylindraceo-oblonga; floribus imbricatis ovatis acutis pubescentibus; fol. planis culmoque basi ramoso glahris. Brown. prodr. 1. 189. Nova Hollandia.

11. P. myosurioides $R$. $B r$. spica cylindracea; floribus imbricatis ovatis ohtusiusculis foliisque glahris planis; culmo repente. R. Br. prodr. 1. 189. Nova Hollandia.

12. P. arcuatum R. Br. spica cylindracea racemosa; floribus imbricatis oblongis curvatis hispidulis; fol. planis culmoque erecto glabris. 
Brown, prodi. 1. 189. In Nova Hollandia.

\section{Spicae geminac.}

13. P. paspaliforme P'rest in Rel Haenk. 1. 296; culno adscendente ramoso compresso glaberimo; nodis compressis barbatis; fol. linearibus planis glabris margiue scabris; spicis duabus conjugatis erectis; rachi plana spiculis ovatis acutis biseriatis latiore; gluma inferiore spicula dimidio breviore ovata acuta enervia, superiore ovata acumiuata pubescente trinervia; floris neutrius palea ovata acula minutissime seriatim tuberculata. In Peruria.

1t. P. polyrhiaum Prest; culmo hasi repente adscendente; nodis, vaginis foliisque hirsutis; spicis subbinis alternis secundis; spiculis ovatis acutis biseriatis imbricatis rachi plana scabriuscula latioribus; gluma inferiore minima rotundata suhpersistente, superiore paleaque floris nentrius inferiore aequalibus ovatis trinerviis puherulis; palea floris neutrius superiore multo minore lanceolata; flore hermaphrodito ovalo acutiusculo. In califormia.

\section{Spicae plures racemosim dispositae.}

15. P. paspaloides Pers. spica composita; partialibus alteruis imbricatis muticis; spiculis hifaris ovatoventricosis; gluma inferiore hrevissima trucata; superiore obovata rotundata flosculis parum lreviore; flosculo inferiore masculo hivalvi; caryopsi ovata acuta laeviuscuia; culmo vaginato foliisque lineari-attenuatis glaliris. Pers. syn.1. 1. 81. P. affine Nees Paspalun adiressum Kich. Panicum hrizoicies Lam. Digitaria afthis H. S. In America meridionali, Dauritio, Eusonil.

16. Huiluns Rets; spica composita; pariialibus alternis appressis muficis; spiculis hifariis ellipticis, linc planiusculis ; gluma inferiore brevissima truncata, superiore obovata, rotundata flosculis parum hreviore; flosculo inferiore neutro univalvi; caryopsi elliptica acuta subtilissime rugulusa; culmo vaginis folisque lineari-attenuatis levibus. Retz. obs. 3. p. 8. et 5. B. Vahl symh. 1. 8. Willd spec. 1. 338. Koxb. fl. ind. 1. 297. Nees in Mart. Bras. 2. 115. P. geminatum Forsk. descr. 18. 11. 59. In India orientuli, Madagascaria, Arabia. 4.

17. Drisoilles Jac\%. spica composita; partialilus alternis appressis distantihus muticis; spiculis bifariis ovatis ventricosis; gluma utraque ovata; inferiore flosculis triplo, superiore paulo breviore; flosculo inferiore masculo bivalvi; caryopsi ovata obtusa levi; cuhno, vaginis foliisque lineari-attenuatis glahris. Jacq. eclog. 1. t. 2. Nees in Mart. Bras. 2. p. 115. P. brizoides Limn. Mant. 184? In India orientali. 4.

18. P. brisalorme Presl in Ret. Huenk. 1. p. 302. culmo simplici compresso nodisque vaginisque glaberrimis; ligula ciliata; fol. superne scabris; spicis pluribus alternis distantibus secundis; rachi communi glabra, partialibus margine scabris; spiculis biseriatis ovatis acutis ; yluma inferiore ovato-rotundata truncata mulio breviore superiore 5-uervia acutiuscula, panlo breviore paleis hermaphroditis transverse rugosis, inferiore acuta; flore masculo hipaleaceo. Presl. In Luzonia.

19. P. mucronatum Roth; spicis alternis scssilibus secundis remotis; rachi in mucronem subulatum spica supereminentem elongata; spiculis oblongo-ovatis; calycis valvula exteriore ovato-sulırotunda; corollis hermaphroditi fosculi transversim undilatis. Roth nov. spec. 45. Nees, in Mart. Bras. 2. 116. In India orieniali.

20. P. flaxidum Retz; spica composita; partialibus alternis appressis üistantibus muticis; spiculis bifariis ovatis ventricosis; gluma utraque ovata ohtusa, inferiore flosculis duplo, steperiore paulo breviore; flosculo inferiore niasculo bivalvi; caryopsi ovato-elliptica obtusa rugulosa; culmo vaginis foliisque linearibus glabris. Hetz, obs. 4. 15. IVilld. spec. 1. 339. Brown, prodr. 1. 190. Nees in Mart. Bras. 2. 416. Kunth Gram. 1. 211. t. 17. P. granulare Lam. Trin. ic. t. 159. B. P. brizoides Roxb. In India orientali, in insula Francia et Java. 
21. P. cruciforme Sibth. spicis alternis sessilibus secundis pilosis; valvula calycina tertia exigua acutiuscula; cuimo ranoso. Sibth. Graec. 1. t.59. Smith, prodr. 1. 40. Insula Samos. 21.

22. P. obtusiforme Delile; culmo basi repente geniculato ramoso; fol. oblusis; spicis secundis axi communi dilatato excavato immersis. Delile, Aegypt. 6. t. 5. Poir. encycl. suppl. 4. 275. Digitaria obtusifolia Hoem. et Schult. In Aegypto.

23. P. pubiflorum Trin. mss. spica composita stricta; rachi hinc canaliculata; spicis partialibus alternis approximatis pluribus appressis; spiculis bifariis ovatis hinc convexis glabris; gluma utraque ovata apiculata, exteriore flosculis duplo, superiore vix breviore; flosculo inferiore neutro 1valvi; culmo glabro. Nees, in Mart. Bras. 2. p. 117. In Nora Hollandia.

24. P. truncatum Nees; paniculae erectae ramis flexuosis; spiculis grandiusculis ovatis; glumis aequalibus obtusissimis; flosculis duplo brevioribus, masculo 2-valvi; culmo simplici; nodis hirsutis; fol. linearibus elongatis scal)ris. Nees, in Nart. Bras. 2. 215. Trin. diss. 2. 130. ejusd. ic. t. 168. In Brasilia. 4.

25. P. strictum R. Br. spicis paucifloris sulapproximatis; floribus ovalibus obtusis; glumis glabris; flosculo hermaphrodito sericeo, neutro 1valvi glabro; fol. involutis, caulinis brevissimis; culmo ramoso. R. Br. prodr. 1. 190. Trin. ic. t. 179. In Nova Hollandia.

\section{Species dubiae.}

26. $\boldsymbol{P}$. gracile $\boldsymbol{R}$. Br. prodr. 1 . 190. spicis approximatis paucifloris racemosis; rachilus apice nudo aristaeformi; floribus subimbricatis ovatis glabris; flosculo hermaphrodilo tenuiter rugoso; fol. subinvolutis glabris. In Nova liollandia.

2\%. P. argenteum R. Br. spicis alternis racemosis; rachi glabra; floribus turbinatis truncatis; valvula interiore glumae exterioreque flosculi neutrius juxta apicem sericeo-barbatis; fol. lineari-lanceolatis strictis utrinque tomentosis mollibus, marginibus denticulato - asperis undulatis. R, Br. prodr. 1. 190. Trin. ic. t. 170. In Nova Hollundia.

28. P. holosericeum R. Br. spicis distinctis; rachi villosa; floribus sericeis; glumis acuminatis; exterioro valvulaque aristata flosculi neutrius juxta apicem argenteo-harbatis; cuImo foliisque villosis undulatis margine denticulatis. H. Br. prodr. 1. 190. Kunti gram. t. 18. Trin. ic. t. 177. In Trova Hollandia.

29. P. Gayamum Kunth, gram. 1. 239. $t$. 31. culmo erecto simplici; fol. linearibus scabriusculis interne ciliatis; vaginis hispidulis; spicis geminis; spiculis pedicellatis; gluma inferioro minuta, superiore floreque neutro unipaleaceo pilis longis sericeis obsitis; flore hermaphrodito punctulato - scabrato glabro. In Senegalia.

30. P. polyphyllum R. Br. prodr. 1. 190. spicis alternis floribusque distinctis glabris muticis; culmo polyphyllo foliisque villosis planis margine denticulatis asperis. Trin. ic. t. 177.

\section{In Nova Hollandia.}

31. P. obseptum Trin. mss, racemo composito; partialibus alternis secundis subfastigiatis; spiculis subgeminis oblongo-lanceolatis glabris; pedicellis longis nudis; glumis inaequalibus acutis, inferiore quintuplo breviore obtusa; flosculo neutro 1-valvi; caryopsi laevi; culmo hasi ramoso et repente adscendente toto vaginato; vaginis foliisque linearibus. glabris, ore vaginarum nodisque pubcscentiharbulatis. Nees in Mart. Bras. 2. 113. In Nova Hollandia. 2.

32. P. subquadriparum Trin. mss. spica composita; spicis partialibus alternis patulis elongatis paucis; rachi angusta; spiculis alteruis secundis ovatis acutis glabris subsolitariis plicato-nervosis; gluma inferiore introrsum versa quadruplo breviore, superiore flosculo longiore; flosculo neutro 1-valvi; caryopsi rugulosa; culmo ramoso foliisque glabris; vaginis ore ciliatis. Nees in Mart. Bras. 2. 117. Trin. ic. t. 186. In Indice orientali. 4.

33. P. fulciferum Trin. mss. spica composita; spicis propriis 4 secundis falcatis secundifforis; rachi propria latiuscula convexa; spiculis solitariis ovatis obtusis pubescentibus; gluma inferiore ovato-truncata multinervia duplo breviore introrsum versa; flos- 
culo inferiore masculo hivalvi; valvula acula puhescente; culmo hasi folioso elougato foliisque linearihus glabris. Nees, in Mart. Bras. 2. 117. 'rrin. diss. 2. 127; ejusd. ic. t. 147. In Guinea. 4.

4. Spicae suldicitato-fasciculatae vel paniculatae; flore ueutro unipaleaceo (Digitaria e).

31. P. Aenulatum Finnth; fol. pilis sparsis; spicis alteruis quinis; valva exteriore vix ulla, interiore minima; valvula neutra ovali acuta 3-nervia, glumellac fertili aequali; valvulis acutis atropurpureis. Kth. gram. 1. 32. Digitaria denudata Link, hort. 1. 222. l'atria igmota.

35. P. schrateri limuth; fol, glahritsculis; vayinis pilosis; spicis alternis pluribus; pedicellis pilosis; valva exteriore vix ulla, interiore miuuta; valvula neutra ovali acuta 5nervia glumellae fertili aequali; valvulis acutis virentibus. Kth. ibid. Digritaria lascicularis Link. P. fasciculare schrad. Patria? $\odot$.

36. P. puberulum Kunth; fol. pilosis; spicis alteruis tribus filiformibus divaricatis; valva exteriore vix ulla, interiore parva; valvula neutra oblonga obtusa pube crispula glumellae fertili aequali; valvulis fertilihus acutiusculis pupurascentihus. K(h. ibid. Digitaria puberula Link. I'atvia?' $\odot$.

37. P. brevifotium kunth; fol. brevibus pilosis; vaginis hirsutissimis; spicis alteruis patentibus; valva exteriore minuta, interiore glumella vix duplo hreviore, superne pilis paucis; valvula neutra lanceolata trinervia acuta margine suhpilosa. Íunth. I.c. Digitaria hrevifolia Link. In Mexico.๑.

38. P. horizontale Meyer; spicis verticillato-paniculatis, pilis singulis adspersis; floribus oblongo-lanceolatis; foliis vaginisque piloso-villosis; culmis hasi radicautibus. Mey. Esseq. 54. Digitaria horizontalis. W. D. setigera hoth. In Brasilia, Essequebo, st. Domingo, st. Thomas.

3.9. F. stipatum Presl in rel. IIaenk. 1. 297. culmis adscendentibus rlaberrimis; vaginis foliisque margine undulatis tuberculatis villosis; spicis corymbosis subalternis erecto-patentibus; rachi flexuosa triquetra scabra; spiculis triseriatis lanceolato-subulatis binatis, altera subsessili, basi fasciculo pilormm stipatis; gluma inferiore minima, superiore lanceolata acuta ciliata; dimido breviore flore hermaphrodito; palea neutra ovalo-lanceolata acuta ciliata paleam interiorem hermaphroditi excedente Presl. In Mexico. $\odot$.

40. l'. rarlicosum Presl $l$. c. culmo repente adscendente semitereti nodisque glabris; vaginis infimis puhescentibus; fol. scabris margine undulatis; spicis subquateruis, alternis corymbosis ; rachi partiali plana margine scabra latitudiue spicularum triseriatarum lineari-lanceolatarum; gluma inferiore minima, superiore lineari, spicula triplo minore paleaque neutra florem hermaphroditum aequante, margine fimbriatis trinerviis. Digitaria repens Willl. herb. In Lnzonia.

11. P. fimbriatum Eunth; caule basi repente; geniculis subbarbatis; fol. basi pilis sparsis obsitis; vaginis inferioribus pilosis, superioribus saepe glabris; spicis alternis 5-7 patentibus; valva exteriore minima, interiore glumella duplo minore, superne pilosa; valvula neutra lanceolata 5-nervia acuta ciliato-fimbriata link hort. 1. 226. In Brasilia, Mexico, Californicl. $\odot$.

42. P. microbachne Prest in rel. Haenl, 1. 295. culmo erecto basi ramoso compresso nodisque glabris; fol. lincaribus margine cartilagineis undulatis vaginisque scabris; spicis verticillatis corymbosis; rachi triquetra scabra ciliata; spiculis binis inaequaliter pedicellatis ohlougo-lanceolatis; gluma inferiorc minutissima, superiore lineari trinervia, palea floris nentrius 5-nervia ciliata quadruplo minore. Patria ignota.

43. P. ciliare Retz; spicis 4-5 digitatis indivisis $;$ florihus imbricatis; glumae valvula exteriore minutissima enervia; interiore flore duplo breviore exterioreque floris neutrius cilialis; fol. lanceolatis undulatis pilosiusculis; vaginis laevibtis. H. Br. IRet $z$, obs. 4.16. Willd. spec. 1. 344. Host. gram. 4. t. 15. R. Br. prodr. 1. 192. Roxb). f. ind. 1. 293. Digitaria ciliaris Pers: D. commutata schult. P. sanguinale var. commutatum Nees. Syntherisua ciliare Schrad. Paspalum ciliare DC. In Europa australi, Oriente, 
India orientali, Jara, China, Cap. b. Sp., Noia Hollumbir. $\odot$.

H. P. Rottleri Kunth; spicis suldigitatis, erectis, filiformilus; rachi nexuosa serrulata; dentibus biforis, fore altero sessilı; altero pedicellato; valvula exteriore 3-5-nervia. P. nervosum IVillı. act. berol. 4. 194. Digitaria nervosi li. S. In promont. b. $s p$.

t5. P. umbruticula Kunth; caule diffuso, debili; fol. pilosis basi undulatis; vaginis meliis hirsutissimis; spicis alteruis pluribus pateutibus; valva exteriore minima; interiore glmmella duplo minore superne pilosa; valvula neutra lanceolata acuta b-nervia margine sublanata purpurascente; valvulis fertilibns lanceolatis aculis subpurpurascentihus. Digitaria umbrosa. Link, hort. 1. 227. Patria ignota. $\odot$.

7\%. P. samguinale L. spicis digitatis erecto-patulis suhquaternis; foliis vaginisque subpilosis; flosculis oblongis margine pubescentibus. Willd. spec. 1. p. 342 . schreh. gram. t. 16. Engl. Bot. t. 849 . Flor. Dan. t. 388. Host. Gram. 2. t. 1\%. Trin. ic. t. 93. 94. P. Linkianum Kunth. Syutherisma vulgare schrad. S. praccox W'alt. Cynodon praecox R. S. Digitaria praecox Willd. enum. 91. Paspulum sanguinale Lam. Dactylon sanguinale 'Vill. Delph. Digitaria sanguinalis Scop: D. narginata Link. Phalaris velutina Forsk. In Europa, fisia, Americu: $\odot$.

48. bicorine Funth; spicis geminis longis subfiliformilus; flosculis conjugatis, altero pedunculato; gluma exteriore hasi ciliata. Poir: Kunth gram. 1. 33. Paspalum bicorne Lant. iil. 1. 176. In Indire orientali.

49. P. aegyptincum Ret:; basi repens; spicis 4-8 corymbosis glabris; floribus geminatis inaequaliter pedicellatis; valvula accessoria calycis minula vel nulla, reliquis duabus inaequalibus nervatis nonnisi margine ciliatis. Hoxh. fl. ind. 1. 293. Hetz, olis. 3. 8. Willd spec. 1. 343. Digitaria aegyptiaca Willd. P. filiforme Jacq. Paspalum sanguinale $\beta$ Lam. In Pamioniu, Oriente, Aegypto, America, India orientali. $\odot$.

50. P. pruriens Trin. culno prostrato infeme repente ramoso; vaginis carinatis striatis strigoso-hirsutls rel pubescentibus nunc asperis; race- mis 3-9-erectis approximatis; rachi flexunsa hispidula; spiculis geminis lineari-lanceolatis acutis adpressis, alteria subsessili; gltmis minutis inaequalibus; flore sterili unipaleaceo ad marginem villosiusculo, fertili glahro. Trin. diss. 2. 87. ejustl. ic. t. 92. Insula Nucaliera.

51. P. glabrum Gaudin; spicis digilatis patulis subquateruis; foliis vaginisfue glabris; flosculis ovatis matgine nudis. Willd. Gaud. Agrost. 1. 23. Trin. ic. t. 149 . P. htenifusum Kunth. P. lineare Krock. P. Ischuemum schreb. P. arenarium Bicb. flor. 2. 53. Paspalum ambigum UC. Digitaria humifusa Pers. syu. 1. . 85. Willd. entur. 93. syutherisma grlabrum schrad. Digitaria glabra li. s. syst. 2. 471. In Luropa, liusia austruli, Uiviente. $\odot$.

52. P. timorense Kunth; culmis substrictis indivisis; : fol. pollicaribus lineari-lanceolatis' margine vaginisque scabrosis; spicis $2-3$ divaricatis; spiculis linearibus t-seriatis glabris, interioribus sessilihus. Digitaria propinqua Gavidich. in Freyc. It. bot. 410 . ile 'ímor.

.)3. P. adscendens H. et K. Nov. Gen. 1. 98; caule repente; ranis adscendentilous glahris; nodis pilosis; fol. scaberrimis; spicis subdenis verticillatis; spiculis subquadriseriatis; glumis piloso-ciliatis. Kmulh. ' In ihova Andulusia, Permin, Mexico. 4.

5. P. mollissimm Kunli Grum. 1. 33. canle difítiso; fol. pilosis; vagina pilis densis mollissimis; spicis altemis pluribus tandem divaricatis saepe compositis; valva exteriore minuta; interiore el valvula neutra ohlongis acutis 5-nerviis purpurascentibus margine lanatis; - valvulis fertilibus oblongis acutis virentibns. Link. Digitaria mollissima schrad. P'utrice iginotı. $\odot$.

j.5. H. Neesii Kunth; spicis subquaternis erectis nudis; spiculis oblongo-lanceolatis margine pubescentibus; gIuma superiore bifida; fol. glaucis glabris basi pilosis; vaginis basi subpilosis; culmis hasi radicantibus. P. glancescens Nees in Mart. Bras. P. sanguinale et longiglume Trin. mss. In Brasilia australi. $\odot$.

56. P. violascens linnth; caule basi repente; fol. scabris; vargina superne pilosa; spicis altenis pluribus 
temuissinis; rachi flexuosa; valva exteriore vix ulla; interiore et valvula neulra lanceolatis aculis 7-nerviis virenlibus margine subciliatis; valvulis fertilibus lanceolatis acutis purpurascentibus Digitaria violascens Link. In Brosilia. $\odot$.

.7. 1. bavbrutu limth; spicis geminalis erecto-palulis ; calycihus margine subpubescentibus; corollis setoso-hirsutis; foliis vaginisque glahris; culmis diffusis repentibus. Digitaria barbata Willd. In insula Burboniae.

.5. P. diductylum fiunth; spicis geminatis ternisve erectis; calycibus lanceolatis puhescentihus: foliis vaginisque glabris. Digitaria didactyla Willd. enum. p. 91. In insula Burbonicae.

5.9. P. biforme Funth; spicis digitatis subsenis; calycibus lanceolatis vlahris; corollis setoso-ciliatis; fol. ylibbris; vaginis mar.rine ciliatis. Diwitaria hiformis Willd. In insulis Manritii et Rurboniae.

60. P. domingense Zuccagni; spiris s!bdigitatis elongatis erectis secundis; spiculis alternis hifariis bifloris; flore altero sessili; fol. hirsutissimis ; culıno glahro. Zuccag. Digitaria repens Hort. Paris. In ins. st. Domingo.

61. P. Hromiltonii Kunth; caule filiformi hasi repente adscendente; vaginis foliisque pilosis; spiculis suhverticillatis linearihus longissimis; florihus suhremotis; rachi setosa, setis fore triplo longiorihus. Digitaria setosa Hamilt. prod. p. 6. In Antillis.

62. F. appressum Willd. spicis geminatis; calycihns ciliatis adpressis; corollis hirsutis; culmo remoso radicante. Willd. act. Berol. 4. p. 193. Digitaria Rottleri $\mathbf{R}$. et $\mathbf{s}$. In India orientali. 21.

63. P. Ornithopus Trin. culmo prostrato glabro; vagiuis glabris basi pilosis; racemis terminalibus ternis alternis approximatis; spiculis binis, altera longius pedicellata, ohIongis; flosculis ohlongis villosiusculis. Trin. in Spreng. N. Entd. 2. p. 83. In insula Adscensionis.

61. P. parviflorum R. Br. spicis alternis approximatis filiformilus, interioribus compositis; florihus imberhibus ; glumae valvula exteriore ovatolanceolata uninervi, interiore longitn- dine floris; fol. linearihns. K. Br. prodr. 1. p. 192. In Nora Hollanalia. 6.5. $P$. alstrule spreng. spicis plurilus approximatis indivisis filiformibus; floribus ovalibus glabriusculis; glumae valvula exteriore enervi obsoleta, interiore longtudine flotis; marginihus puhescentibus; fol. linearibus glabris P. striatum $\mathbf{R}$. Br. prod. 1. 192. P. striatum sclunlt. Manit. 2. 252. In Nova Hollandia.

66. P. ruliutum $R$. Br. spicis numerosis approximato-alternis indivisis raris divaricatis; floribus imberbibus; valvula exteriore glumae enervi ohtusa; interiore flore breviore; fol. pubescentibus. 1R. Br. prodr. In Nova Hollandia.

6\%. P. divaricatissimm $\boldsymbol{R} . \boldsymbol{B r}$. spicis 6-10 subdigitatis elongatis raris divaricalissimis; floribus lanceolatis ; glumae valvula exteriore minutissima entervi; interiore flore breviore exterioreque flosculi neutrius margine lanatis; foliis planis linearibus vaginisque glabris. 1R. Br. 1. c. In Nova Hollandia.

6s. P. Brownei R. et. S. spicis 3-8 approximato-alternis filiformibus; floribus distinctis acutis; glumae valvula exteriore minuta glabra; interiore longiludine floris flosculique neutrius exteriore lanatis, disco nudiusculo; fol. linearibus glahris. P. villosum 1. Br. prodr. In Nova Ilollandia.

69. P. papposum R. Br. spicis plurimis semiverticillatis filiformihus raris divaricatis; floribus lana copiosa tectis; gluma univalvi. R. Br. prodr. In Nova Hollandia.

70. P. tenniflorum R. Br. spicis 2-3 digitatis filiformibus modice patentibus; floribus subimbricatis ovalibus; glumae valvula exteriore obsoletissima; interiore flosculique neutrius exteriore lana brevi appressa; fol. planis glabris; vaginis pubescentibus; ligula imberbi subincisa. $\mathbf{1 R}$. Br. prodr. 1. 193. In Nova Hollandia.

r I. P. mopinquum R. Br. spicis 2-3 digitatis filiformiluus patentibus; floribus subimbricatis ovalibus; gluma univalvi flosculique neutrius valvula exteriore lana appressa brevi; fol. planiusculis; vaginis imfinis pubescentibus; ligula imberbi subincisa; culmo repente. I. Br. I. c, In Nova Hollandia, 
ซ2. P. gibbosum R. Br. culmo erecto inferne ramoso; fol. anguste linearibus planis glahriusculis; vaginis pilosiusculis ; spica solitaria crecta lineari; spiculis terno-fasciculatis unilateralibus subimbricatis acutis intus ad basim gibbis; gluma interiore nulla; superiore soribus breviore sericea; flore hermaphrodito striatulo glalro; nentro unipaleaceo trinervio ad utrumque marginen dense sericeo. Kunth gram. t. 105. In Nova HolIandia.

\%3.P.phaeotrix Trin. culmo erecto gracili simplici; vaginis foliisque glabris erectis filiformi-involutis; racemis circiter $\overline{5}$ erectis solitariis vel geminis alternis; rachi flexuosa ad angulos hispidula; spicis ellipticis acutis; gluna superiore fermgineo-hirsuta florilus dimidio breviore; inferiore nulla; flore neutro hipaleaceo dorso hirsuto; hermaplirodito glabro. Trin. ic. t. 91. In Montevideo.

\%1. P. adustum Nees; racemis pluribus fastigiatis erectis; spiculis ternis oblongis pubescentibus apicem versus ferrugineo-fimbriatis; foliis lineari-elongatis glahris coriaceis; vaginis inferioribus strigosis; culmis erectis strictis. Nees in Mart. Bras. 2. p. 101. In Brasilia meridionali. 24 .

ซ5. P. Gandichaudii Inunth; glabrum; culmis caespitosis strictis indivisis; fol. planis; spicis 12-16 fasciculatis confertis strictis ; spiculis solitariis biseriatis hispidulo-scabris. Gaudich. Kunth, gram. 2. t. 106. Digitaria stricta Gandich. in Freyc. it. In insulis Bariae Annae.

5. Paniculae rami simplices; $s$ iculae spicatim vel racemosim dispositae.

\%. P. striatum Lram. panicula oblonga; glumis majusculis glábris viridihus pulchre striatis. Lam. ill. 1. 172. P. Boscianum Spreng. P. striolatum schult." In Caroline.

\% . P. Myurus Lam. cilmo erecto ranioso nodisque glabris; fol. margine scabris; spicis creberrimis paniculatocongestis; spiculis fasciculatis; glumis acuminat 0-subulatis glabris. Kunth. Lam. ill. 1. 172. P. Myosurus Rich. Hymenaclue Myuros Beativ. H. Myuros et amplexicaulis Nees. Agrostis alopecuroides Vahl. A. monostachya Poir. Panicum amplexicaule Rudgc. Triu. ic. t. 205. In America. 4.

78. P. nephelophilum Gaurlich. culmis caespitosis; fol. glahris; vaginis villosis; panicula ramosa effusa; ramis verticillatis ramulisque capillaceis; spiculis ovalihus acutiusculis glabris. Gaudich. in Freyc. it. bot. 1. 411. In insulis Sanduricensibus.

79. P. phleiforme Presl; culmo simplici erecto glabro; fol. elongatis linearibus planis margine scabriusculis superue raro pilosis; vaginis glaberrimis; racemo spicato cylindraceo continuo; rachi angulata; peslunculis bifloris; spiculis lanceolato-ovatis brevissime pedicellatis; gluma inferiore flore hreviore ovato-lanceolata acuta; superiore ovato-lanceolata obtusa hispida flores aequante; floris neutrius palea solitaria obtusa hispida; hermaphroditi laevissima. flore nentro breviore. Presl in Rel.Haenk. 1. p.302. In Mexico.

80. P. strumosum Presl; culmo erecto tereti, nodis vaginisque glabris teretibus; fol. linearibus clongatis planis margine scabriusculis; racemo spicaeformi simplici tereti continuo; spiculis pedicellatis subtemis ovatolanceolatis hasi obliquis; gluma interiore late ovala spicula dimidio breviore 7-nervia acuta; superiore ovatolanceolata 9-nervia acuta piloso-hispida hasi strumosa; floris neutrius palea inferiore longitudine glumae superioris ovato-lanceolata 7 -nervi versus apicem piloso-hispidla acuta; flore hermaphrodito oblongo, gluma superiore breviore; palea inferiore cartilaginea nitida acuta. PresI in Hel. Haenk. 1. p. 303. In California.

81. P. polystachyum Prest; culmo erecto compresso ramoso nodisque glabris; fol. late cordato-linearihus ulargine scabris basi vaginisque ciliatis; spicis paniculaformibus creberrimis verticillatis patentibus; spiculis lanceolatis secundis; glumis inaequalibus; palea floris masculi acuminata superante floren hermaphroditum acutum glumamque superiorem. Presl in Rel. Haenk. 1. 1. 313. In Peruvia. 4.

82. P. leptostachymm Presl; culmo repente; ramis erectis teretilus; nodis harbatis; linea internodiorum longitudiuali alteruatim decurrente pi- 
Iosa; vawinis hirsutis; fol. ovato-lanceolatis hrevibus maruine basi ciliatis superne hirsutis interue glahris; spicis alternis pluribus; richibus angustissimis; spiculis minutis secundis hiseriatis ovato-lanceolatis acutis; grluma inferiore spicula hreviore, superioreque paleaque inferiore floris neutrius trinerviis hirsulis; palea inferiore floris hermaphoditi laevissima. presl in Mel. Haenk. 1. p. 311. In Mexico. 4.

8.3. P. interruptum Willa culmis supra aquam erectis; spicis simplicihus cylindricis; floribus confertis ylabris polygamis; semine laevi. lloxb. f. iucl. 1. p. 289. P. caudatum Thumb. In India orientuli.

84. P. curvatum $I$. culmis erectis; spicis curvatis; floribus confertis glabris hermaphroditis; semine laevi. Limu. syst. nat. 12. p. 730. In India orientuli.

8.5. P. coryophorum Kunth Gram. 2. $t$. 10\%. culmo erecto tereti; nodis inberbibus; fol. lineari-lanceolatis planis rigido-membranaceis striato7-nerviis glabris margine scabris; vaginis striatis glabris internodiis brevioribus; panicula erecta ramosa patula; ramis rachique glalris; spiculis sparsis secundis, cermuis, glabris; gluma superiore galeato-concava 11nervia, inferiore minuta; flore neutro bipaleaceo; hermaphrodito dimidio breviore laevi glahro nitido. Kunth l. c. In insula Mada!gscariensi.

86. P. inundatum Kunth; racemo simplici spicato limeari-attentuato; rachi pedunculis communibus adnatis decurrentibus maxime angulata; pedicellis imbricatis brevilus curvatis sparsis subbifloris; spiculis lanceolatis nervoso-angulatis glaberrimis; calycis gluma exteriore ovata obtusa; culmo foliisque glahris. P. uliginosum lioth, 1. spec. p. 50. In India orientali,

87. P. microstachyum Lam. spica lineari parva nuda; glumis striatis ventricosis alternis pedicellatis. Lam. ill. 1, p. 170. In India orientuli,

Ss. P. Trinii Kunth; culmo erecto firmo glabro; nodis pubescentibus; vaginis sulcato-striatis, radicalihus confertissimis serice-pubescentibus; fol. strictis riøidis lanceolato-linearihus siccis subinvolutis sulcato-nervosis glabris; panicula conferta cylin- dracea densa erecta; spiculis ellipticis; glumis acutis pilosiusculis; superiore longiore flores glabros subaequante; flore inferiore neutro bipaleaceo. P. rigidifolium Trin. ic. t. 211. In Brasilia.

S9. P. Elliottianum schult, racemis multifloris appressis spicau teretem reterentibus; calycis valvulis conspicue nervosis; exteriore basi gibba; floribus cadueis. P. gibbum Elliott. bot. p.116. In America sept.

90. P. vilfoirles Trin. racemo composito subcylindrico interrupto ereeto; glumis inaequalibus ovatis subulatis; majore dorso hispida; fol. linearibus elongatis planis laevibus. Hymenachne fluviatilis rees 1. c. Trin. ic. t. 204. In Brasilia. Giujuna.

91. I'. camporum Nees; racemo composilo cylindrico elongato cernuo; gluma superiore paleaque neutrius floris majore, margine villosis; fol. limearibus elongatis scabris. Nees in Mart. Bras. 2. p. 27t. In Brasilia.

92. I'. stoloniferum Poir. culmo ramosissimo repente; fol. lanceolatis supra scabriusculis subtus nodisque puberulis; vaginis ciliatis; spicis 8 10 alternis distantibus patentibus unilateralibus; glumis acutis carinatis glabris inaequalibus flore hermaphrodito laevi. Kunti graur. t. 22. P. ctenodes Trin. ic. t. 171. P. trichoclados Rchb. in WVeigelt. herb. Suriu. In Cajenna, Brasilia.

93. P. palleus swarts; panicula composita ovata; ramis confertis erectis; spiculis ovatis subulatis; culmo subdiviso geuiculato; fol. ovato-lanceolatis; vaginis collo margineque ciliatis. Swartz. prod. p. 23. Trin. ic. t. 211. Apluda Zeugites Aubl. Agrostis nutans Poir? In Brasilia, St. Domingo, Jamaica, Mexico.

94. $\boldsymbol{P}$. condensatum Bert. glahrum ; decumbens; fol. cordato-lauceolatis amplexicaulibus; panicula racemosa densiflora striclissina; spiculis unifloris; glumis lanceolatis acutis. Bert. piant. Bras. 4. n. 6. et opusc. scient. di Bol. 3. p. 408. In Brasilia.

9.5. P. grossarium $L$. racemó composito; partialibus afternis secundis imbricatis; spiculis geminis ovatis mucronatis; pedicellis brevissimis apice setigeris; glumis inaequalihus obtusis pubescentibus; caryopsi transversiu 
rugulosa; culmo ramoso hasi repente; fol. subperfoliatis lanceolato-acuminatis basi vaginisque ciliatis. Nees in Mart. Bras. 2. p. 110. In America meridionali cum insulis.

96. P. Cureyumm Nees; spica composita; propriis secundifloris alternis; spiculis solitariis ovatis glihlris subsessilibus; flosculo neutro hivalvi; caryopsi oblonwa transversin rugulosa; culmo repente; fol. ovato-lanceolatis molliter pubescentihus. Nees in Mart. Bras. 2. p. 118. adu. P. grossarium. In Inalia orientali.

9\%. P. prostratum Lame. culmis caespitosis prostratis repentihus; fol. rigidis marginatis basi sulucordatis vaginisque ciliatis; spicis 7-9 alternis erectiusculis racemosis; rhachibus imberbibus; palea inferiore hermaphrodita mucronata transversim rugulosa. ham. ill. 1. 171. Ejusd. encycl. 4. 7.0. Trin. ic. t. 184. 185. A. B. P. caespitosum Swartz. P. Sie’eri Link. In Jamaica, st. Domingo, Guadelnpu, Aegypto, India orientuli.

98. P. setigerum Retz; culmis hasi repentibus sublignosis; foliis basi cordatis margine ciliatis; insertionibus spicularum et florum setosis; corolla 3-valvi; semine ovali transverse rugoso. Roxb. ketz, obs.4. p.15. P. repens Burm. ind. t. 2. f. 1. P. prostratum $\gamma$. Lam. P. affine Poir. In China, India orientrali.

9.9. P. umbrosum Ret:; spicis subquaternis remotis; fosculis geninis inaequaliter pedicellatis; culmo repente flaccido. Ret $\%$, obs. 4. p.16. Digitaria unbrosa Pers. P. prostratum f) Lam. P. procumbens $\gamma$ umbrosum Nees, P. grossarium Koenig, Naturf, 22. p. 205. P. barbatum Lam. Setaria barbata et subcordata Kunth. P. subcordatum koth. In India orientuli, Mauritio, Lusonia. 4.

100. P. lentigerum Presl; in rel. Haenk, 1. 299, culmo tereti ramoso inferne repente, uno latere alternatim pubescente; innovationibus longissimis; nodis villosis ; vaginis pubescentibus; fol. lanceolatis basi ovatis et in petiolum brevissimmm attenuatis; spicis alternis; spiculis bisetialibus secundis aristatis lanceolatis acutis pilosis; glumis acutis ; inferiore 3-nervia spicula dimidio breviore; superiore 7-nervia; floris neutrius palea solitaria 5-nervia, dorso granulis 2 notata; floris hermaphroditi palea inferiore membranacea hinervia, nervis asperis Presl. Putria ignotu.

161. 1". adispersum Trin. mss. racemo conposito; partialibus paucis alternis secundis; spiculis geminis ovatis; pedicellis longiusculis mulis; glumis inaegualihus cuspidatis glabris; interiore quadruplo breviore; flosculo neutro bivalvi; caryopsi rugulosa; culno ranoso hasi repente; fol. lanceolatis glabris; vaginis lanmginosociliatis. Nees in Mart. Bras. 2. p. 111. Trin. ic. t. 169. P. caespitosum spreng. In ins. St. Domingo. 21.

102. 1listichophyllum 'Trin. racemo composito; partialibus alternis secumdis spiculisque geminis ovatis pubescentilus ; pedicellis longiusculis setigeris; glumis inaequalibus mucronulatis; inferiore triplo breviore; flosculo nentro bivalvi; caryopsi rugulosa ; culmo ramoso basi repente; ramis striclis; vaginis foliisque subdistichis lineari-lanceolatis margine cartilagineo - denticulatis pubescentibus. Nees 1. c. Tritl, ic. t. 182, P. cartilagineum. Nees. In Guinea? 4.

103. P. Peticerii 'T'vin. mss. racemo composito; partialihus alternis secundis; spiculis geminis ellipticis; pedicellis brevihus nudis; glumis inaequalihus acutiusculis pubescentibus; inferiore dimidio breviore; flosculo neutro hivalvi; caryopsi rugulosa; culmo ramoso basi repente; fol. lineari-lanceolatis vaginisque minute pubescentihus Nees. 'Irin. ic. t. 176. In India orientali. 4.

10-f. 1". distachyum L. spicis subternis secundis laevibus; fol. planis brevibus margine scabris. Pers. Linn. mant. 138. lietz, obs. 3. 17. Lam. ill. t. 43. f. 2. Digitaria distachya Pers, syn. In India orientali.

10.5. P. conjugatum Roxb. spicis conjugatis secundis; florihus solitariis sessilibus muticis; corolla instructa valvula accessoria neutra. Hoxb. fl. ind. 1. p.291. Digitaria conjugata sichult. In Coromandelia.

106. $\boldsymbol{P}$. puludicola Nees; racemo decomposito denso lanceolato; ramis secundifloris glabris; racemis fasciculatis brevibus; spiculis lanceolatis scabris; flosculo neutro univalvi; culmo tereti simplici; vaginis glabris; fol. cordato-lanceolatis amplexicatilibus supra sulpilosis. Nees in Mart. 
Bras. 2. p. 179. P. donacifolium hatdi. In ifrusilia.

(0\%. ". fromlescens Metjer panicula simplici coarctala: foribus confertis ohlongis auminatis; culmo ramnsissimo; fol. oblongo-lanceolatis. Mey. Esseq. p..jz. Nees in Mart. Bras, 2. 177. 'Trit. ic. t. $21 \times$. P. olyraefolium haddi. P. palustre 'Trin. In Eisseryucho, Brasilia.

108. P. excelsum Tees; racemo decomposito deuso ohlongo-lanceolato; ramis secundifloris mlabris; racemulis hrevisstmis hipartitis 5-f-floris; spienlis oblongis subincurvis ; flosculo neutro univilvi; culmo tereti simplici; fol. Lanceolato-linearihus acuminatis strictis vaginisque glabris. Nees in Hart. Bras. 2. p. 180. Agrostis Pernambucensis Spreng. In Brosilia meridionuli.

109. P. rivulare Trin. mss. raccno decomposito denso subfastiuriato; ramis secundifloris ulahris scaberrimis; racenulis simplicilous secundis; spicis geninis oblongis oblusis scabris; flosculo neutro univalvi gluma superiore paulo longiore; culmo tereti simplici; vaginis foliisque glabris lancolitto-linearibus acuminatis. Nees in Mart. Bras. 2. p. 181. In Brasilice.

110. P. virescens Poir. glaberrimum; panicula racemosa; flosculis ovatis coufertis turgidis; caule flexuoso de!)ili ramoso; fol. linearibus reflexis. Poir. encycl. suppl. t. p. 278. Patria ignola.

111. P. ayuaticum Poir. glabrum; panicula erecta parce composita; valvulis calycinis aculis, tertia corollisque ohtusis; fol. linearihus; culmo compresso subgeniculato. Poir. encycl. suppl. 4. p. 281. In Portorico.

112. P. plantayinenm Link; foliis latis; spicis remotis longinsculis; inferioribus longe perlicellatis; rachi laevi; spiculis secundis; valvis nervosis laevihus; extima ohtusa; interiorihus ohlongis acutiusculis; valvula exteriore fertili transversim subtilissiure undulata. Link hort. 1. p. 206. Culmus erectus. Putria ignota. $\odot$.

113. P. alecipiens hink; spicis remotiusculis subsessilibus brevilus divaricatis; rachi lacvi; spiculis geminis secundis nutautilus subpedicellatis: valvis ovalibus nerrosis lacvibus acutis. Link 1. c. Culmus basi decumbens. I'atria ignota. $\odot$.

11. P. heteranthum Linh; foliis brevibus latis glabris; marginibus vaginae longe pilosis; panicula ramis paucis tenubus; valva cxtima glumellae neutri subaequali herhacea; interiore ventricosa subpilosa; vallvula exteriore neutra acuta, glunella fertili longiore; interiore angustia subaequali; valvula exteriore fertili laevissina. link, hort. 1. p. 212. Culmus hasi prostratus, repens. In Birasilici.

11.5. P. molle Suartz; spicis paniculatis alternis secundis patentibus; spiculis approximatis pedicellatis secundis; culmo adscendente; fol. villosis. Swart\%, prodr. p. 22. In Jumaicu, Surinum.

116. ". velutinum Nees; puinescenti-molle; spicis alternis paniculatis erectis secundis; spiculis gennis ovatis acutis: flosculo masculo neutrove 1-valvi; hermaphrodito transversim ruguloso; culmo basi ramoso repente adscendente; fol. Ianceolatis. Nees in Nart. Bras. 2. p. 121. Trin. ic. t. 180. P. Petiverii Trill. In Brusilia. 4.

118. P. numidianum Lam. panicula rauis subsimplicibus racemosis Iaxis; giumis ovato-acutis laevibus; pistillis coloratis. Lam. ill. 1. p. 172. Desf. flor. t. 11. Trin. ic. t. 17t. P. leiogontun siel. P. muticun Link. In Numidia, Aegypto.

118. P. muticum Forsk. spicis alternis secundis; spicnlis remotis geminatis muticis; altera pedicullata; rachi trigona flexuosa. Forsk. Aeg. 20. schult. mant. 2. 225. In $\mathrm{Ae}$ gypto.

11.9. P. pyromidale Lam. foliis linearibus glahris maroine spiculososcahris; spicis creberrimis in apice culmi subverticillato-spicatis patulis; spiculis unilateralibus 4-serialis; gínmis inaequalibus in nervis spinulusoscahris; flore masculo hipaleaceo superne in nervis spinuloso-scalno: hermaphrodito leviler striatulo glabro nitido. Kunth, gram. t. 23. P. polystachyum Rich. In senegalia.

120. P. grumosum Nees; racemo decomposito stricto oblongo; racemis psendo-verticillatis ereuto-palulis ramulisque subsecundis scabris; pedicellis subsecundis fasciculatis; rachi 
glabra; spiculis oblongis truncatis; culno suhranıso foliisque lineari lanceolatis acuminatis strictis glabris. Nees in Mart. Bras. 2. 182. 'Trin. ic. t. 207. In Montevideo et in continibus terrae Paraguayensis. 4.

121. P. arvense finuth; culmo dichotomo-ramoso inferne radicante; nodis geniculatis lanatis; fol. lanceolatis planis multiuerviis margine scabris; panicula pytamidata; ramis patulis sulcato-angulatis hispidulo-scahris, superioribus simplicibus ; spiculis gemuinis ellipticis acutis moltiter pilosis; perlicellis setoso-pilosis; glumis valde inaequalilus; flore hermaphrodito trausverse undulato-rugoso glabro submucronato; neutro bipaleaceo. Kunth gram, t. 109. In arvis seneyaliue.

122. "palmifolium Poir. panicnla simplici stricta; spiculis adpıessis; fol. oblongis lineato-plicatis; vaginis pubescentibus. Willd. Poir. encycl. suppl. 4. 282. P. plicatum Villd. Jacq. Eclog. gram. t. 1. In India orientali.

123. P. sulcatum Aubl. panicula praelonga; ramis erectis lateralibus apice nudis; fot. latissimis plicatosulcatis; vaginis lispidis. Iaam. encycl. 4. p. 746. Aubl. Guian. 1. 50. Milium Iatifolium Plım. In Guinna, Antillis, Brasilia.

124. P. costatum Roxb. culmis repentibus; fol. lanceolatis plicatis vaginisque valde pilosis, his internodio hrevioribus; panicula composita; racemis spicatis brevilus patentihus secumlis; fioribus polygamis. lioxb. Al. ind. 1. 314. In insula Hauritii.

12.5. P. nepulense Spreng. erectum, 3-4-pedale; fol. lanceolatis plicatis; vaginis internodia superantibus ore barluatis; panicuta tenuissima; ramis longis simplicilus filformibus remotis; floribus plermome solitariis; corolla instructa valva nentra. Hoxb. Spreng. syst. 1. 321. P. nervosum Roxb. P, neurodes schult, In Nepalia.

126. P. plicatum Letm. spicis alternis remotis muticis hrevilus ; corolits rugosis; fol. plicato-sulcatis. Lam. ill. 1. p. 171, Trin. ic. t. 233 . In insula IMaritii. 4.

12\%. p. excurvens Trin, ic. $t$. 8.9. culno temui geniculato-erecto sulcatoangulato simplici vauinisque ylabris; fol, linoari-lanccolatis acuminatis in- ferne angustatis planis glabris plicato-striatis margine hispidulis; panicula simplici crecta angusta; ramis subsimplicibus undique floriferis erectis; inferioribus remotis; spiculis breviter pedicellatis ovato-ellipticis acutis glabris; floribus glumas inaequales superantihus; inferiore neutro bipaleaceo; superiore hermaphrodito undulato-rugutoso. Trin. 1. c. In Nepalia.

128. P. fitsciculatum Swartz; cuImo erecto ramoso ramisque glabris; nodis pilosis; vaginis hirtis; fol. glabriusculis margine scaloris; spicis crebris paniculatis spiculis subgeminis; glumis acutis glabris. Kunth. Swartz, fl. ind. occ. 1. 145. P. fusco-rubens Lam. P. fasciculatum Nees. P. fastigiatum Poir. In In Quito, hexico, st. Thoma. 4.

12.9. P. fuscum suartz; panicula simplici; ramis erectis; flosculis secundis geminis, attero hrevius pelicellato; culmo erecto subdiviso; fol. lato-lanceolatis. Swart $\%$, prod. p. 23. Trin. ic. t. 206. P. fasciculatum $\gamma$ Nees, In Jamaica.

130. P. carthaginense Swartz; spicis paniculatis foliis brevioribus; spiculis secundis ovatis acutis; culmo prostrato geniculato ramosissimo; vaginis pubescentibus. Swartz, prod. p. 22. P. fasciculatum $\delta$ Nees. Carthagenae (Am. mevidl.).

131. P. agrostidiforme Lam. racemis linearibus strictis glaherrimis; glumis minimis oblongis laevibus subsecundis. Iam. ilt. 1. p. 172. P. agrostoides Npreug. Pug. 2. 4. In America mevidionuli et boreali. 4.

132. P. tenniculmum Mey. panicula simplici nutante; ramis inferioribus remotis; floribus ovali-oblongis approximatis; fol, linearibus laxis, Mey, Esseq. p. 58. Trin. ic. t. 215. P. àrostidiforme Raddi. In Essequebo, Brasilia, jumaica. $\odot$.

133. P. fallux kunth; panicula contracta subcylindrica;- spiculis ol)longo-lanceolatis nervoso-striatis ; glumis inaequalibus; culmo basi repente ramosoque cum vaginis compresso foliisque linearibus glabris. Nees Kunth, gram. 1. p. 35. P. decipieus Nees. In Brasilia.

13t, P. pilosum Swartz; spicis paniculatis alternis secundis; spiculis geminis attera minore acuminatis lacvibus; rachi compressa pilasa; cul- 
mo divaricato geniculato. Sw. prodr. 22. 'Trill. ic. t. 213 . Netaria pilosa liunlh. P. heterophyllum Spr. P. sprengeliamum schult. In India occid., Brosilia, Mexico. 4.

13.5. P. distichum Lam. culmo ramoso compresso-trigono nodisque glahris; fol. margine scahris; vaginis piloso-ciliatis; spicis crehris alternis; juvolucro uniseto spiculis unilateralibus geminis longiore; glumis glabris; paleis floris liermaphroditi laevibus; flore neutro hipaleaceo. Kunth; setaria disticha H. et K. Nov. gen. 1. 112. P. Pemnisetum Iioth. In Cumana, Guima, Jamaica.

136. I. prilisparsum Mey. panicula simplici elongata; ramis pilis setaceis adspersis; floribus ovalibus suhpeudulis; culmo ramoso alscendente. Mey. Fsseq. p. 5\%. Setaria Meyeri Kunth. In Essecyuebo. $\odot . ?$

13\%. P. trichophorum Schrad. culmo erecto simplici; fol. margine scahris; vaginis glabris; spicis numerosis alternis; rachibus setosis; spiculis confertis unilateralibus geminis ternisve ovalibus; flore neutro bivalvi. Schral. in schult. mant. 1) 247. Setaria schraderi Kunth. P. pilosum $\delta$ Nees. In Brasilia.

13.9. P. diandrum Kunth; culmo ranıso geniculato - adscendente comjressiusculo nodisque glabris; fol. linearibus acutato-subulatis planis interme scabriusculis margine scabris; vasinis tereti-compressis ciliatis; panicula erecta diffusa; ramis spicaeformibus patentibus; ramis unilateralibus adpressis scahris; spiculis ellipticis minutis glabris; glumis inaequalihus carina scabriusculis violascentibus; flore neutro bipaleaceo; hermaphrodito acuto laeviusculo diandro. Kimth gram. 2. t. 110. In Brocilia, Guarlelupa.

139. P. leptomerum Presl; culmo repente adscendente compresso; vaginis foliisque cordato-linearibus hasi ciliatis; spicis alternis; spiculis ovatis ohtusis scabriusculis secundis binatis loreviter pedicellatis; glumis inaequalibus; inferiore 1-, superiore paleaque floris neutrius 3-nerviis; flore hermaphrodito ovato obtusiusculo laevi. Presl in rel. Haenk. 1. p. 311. Patriat imnote.

110. P. polygonalum Schrad. culmo repente ramoso; ramis adscenden- tibus glabris; nodis barbatis; foliis vaginisque villosis; panicula subramosa patente; ramis sulsetosis; spiculis confertis unilateralibus geminis ovalibus; flore neutro univalvi. sichrad. in Schult. mant.2. p. 256. Setaria poIygonata Kunth. In Brosilia, Mexico.

1+1. P. l'errottetii Kunth; culmis erectis simplicibus; fol. Ianceolatis planis margine unclulatis vaginisque gla!)ris; paniculis simplicibus; ramis verticillatis patulis inferne pilosis; spiculis pedicellatis solitariis; gluma inferiore nulla; superiore floreque neutro 1-paleaceo trinerviis, inter nervos margineque pilosis; flore hermaphrodito acutato nitido laeviusculo glabro. Kunth gram. 2. t. 111. In arvis Seneyaliae.

112. 1'. miliiforme Presl; culmo procumbente ramoso glabro; nodis, vaginis foliisque pilosis linearibus; spicis alteruis sessilibus; spiculis oblongis lanceolatis acutis secundis biseriabilis solitariis sessilibus; gluma inferiore ovata acuta flore breviore; gluma superiore paleaque floris neutrius lanceolatis acutis aequilongis; palea floris hermaphroditi inferiore tuberculata. Presl in reliq. Haenk. 1. 1. 300. In ins. Luzonia.

143. P. obtectum Presl; culmo erecto tereti; ramis adpressis; vaginis superne dorso et toto margine foliisque ex ovata hasi linearibus margine e tuberculis pilosis; spicis 3-alternis erectis; rachi plana glabra; spieulis 4 -seriatis ovato-lanceolatis acutis; glumis 3-nerviis paleaque neutrius floris solitaria 5-nervia aequilongis pilosiusculis margineque pilosociliatis; gluma floris hermaphrouliti inferiore glaherrima 5-nervia. Presl in rel. Haenk. 1. p. 301. In Mexico.

14. P. noilosum Inunth; culmo repente adscendente, uno latere alternatim pubescente; nodis glahris; vaginis tuhereulato-hirsutis ciliatis; foliis e basi rotundata linearibus tuberculato-pilosis; panicula erecta patente rara; ranis alternis spicigeris; spiculis solitariis suhsecundis lanceolatis utrinque acutis; glumis inaequalibns ovato-lanceolatis ohtusiusculis spicula breviorihus; floris neutrius palea solitaria, aequilonga paleae floris hermaphroditi inferiori lacvissimae. P. multinode Presl in reliq. Hacnk.4. 1. 303. In ins. Luzonia. 4. 
145. P. Haenlieanum Prest; culmo erecto simplici pubescenti-piloso; vaginis pilosis; foliis e basi ovati lanceolato-linearibus, maroine scabris hirsutis undulatis; panicula ramosa; ramis fasciculatis ramosis; spiculis lanceolatis solitariis sparsis; glmma inferiore ovata acuta spicula breviore; superiore ovato-lanceoiata acuta glahra spiculan aequante; flosculo neutro 1-paleaceo; hermaphroditi palea inferiore laevissina. Presl in rel. Haenk. 1. 304. In Mexico.

1+6. P. compressum Biv. panicula erecto-patente; staminibus pistillisque coloratis; culmo ramoso compresiso; fol. pubescentibus; ligula ciliata. Bivoul-Beru. Stirp. sic. n. 35. In sicilia.

14\%. P. Isachne Roth; paniculae secundae contractae ramis alternis secumdis bifariam imbricatis subsimplicibus; spiculis pedicellatis ovalibus pilosis; calycis gluma exteriore minutissima cordata; culmo repente radicante ranoso ad nodos barbato; fol. lineari-lanceolatis pubescentibus; vaginis pilosis. lloth, nov. spec. p. 51. In Indiu orientali.

6. Paniculac rami magis minusvedivisi; spiculaesolitariae, sparsae.

148. P. obtusum H. et K. Nov. Gen. 1. 98. culmis compressis nodisque glabris; fol. planis margine serrulato-scabris supra puberulis; spicis 4-7 racemosim dispositis alternis distantibus; spiculis geminis unilateralibns subquadrifarian imbricatis elliptico-ohovatis obtusis ylabris; glumis inaequalibus, inleriore $5-$, superiore -ucrvia; flore masculo bipaleaceo; hermaproclito ovato-elliptico laevi. hunth, gram. 2. t. 116. In Mexico. 4 .

i-9. P. turgidum Forsl. descr. 18. culno junceo frutescente; ramis icl nodos fasciculatis; vagina foliorim multiplici spathacea persistente; p.rniculis terminalibus; spiculis omnihus pediceliatis ovatis fumidis; calycis valvula exteriore flosculis inclusis paulo longiore. Delile, Aeg. 19. t. 9. f. 2. Trin. ic. t. 22\%. In Aeyyjto, Arabia. 4.

l.jo. P. Teneriffae R. Br. fol. subulatis planis; floribus paniculatis mu- ticis; involucro piloso nullo; calyce villosissimo. spr. syst. 1. p. 315. saccharum Teneriffae linn. Sibth. Grace. 1. 53. Agrostis plumosa Tenore. Tricholaena micrantha schrad. P. villosmm Presl. In Teneri/fie, Sicilia, Calubria. 24.

1.51. J. villosum Lam. panicula racemosa minima; ramulis alteruis brevilus ; calycihus pedunculisque villosis. Lam ill. 1. p. 173. In India orientali.

1.52. P. Ho/fmanseggii ; R. et S. ramis paniculato-racemosis; ramulis alternis elongatis ; calycibus pedunculisque villosissinis lluflinansegy. mss. Roem. et Schult. syst. 2. p. 450 . Trin. ic. t. 219. In Brasilia mevill. 4.

153. P. trachystuchyum Nees: racemo composito coarctato pedunculisque bifloris secundis spiculisque ellipticis glanduloso - punctatis husutissimis; gluma interiore minuta; culno simplici erecto, nodis vaginisque glabris; fol. filiformibus apice basique pilosis. Nees in Mart. Bras. 2. p. 125. Trin. ic. t. 16\%. In Brasilia. 24.

1.5\&. P. uubigenum Kunth; culmis caespitosis foliisque sericeo-pubescentibus planis; panicula subspicata ramosa. Neurachne montana Gandich. Generalit. 94. t. 26. P. montanum Gaudich. In insulis Sanduicensibus.

15.5. P. ignoratum Kuntle; culmo erecto glabro; fol. anguste linearibus planis ciliatis; panicula gracili stricta; spiculis solitariis pedicellatis; gluma solitaria paleaque inferiore mascula aequalibus 5-nerviis, externe sericeovillosis. Kunth Gram. 217. t. 20. Phalaris villosa Michx. Anthaenantia villosa Beauv. Aulaxanthus ciliatus Elliott. In Carolina.

156. P. rufum Runth, gram. 1. 3.5. culmo erecto; fol. glaberrimis; panicula majuscula subappressa; villis calycis rufis. Elliott. Anthaenantia sechult. Aulaxanthus Elliott. bot. 1. 103. Aulaxia. Nutt. In Americ boreali.

15\%. P. serratum R. Br. culmis inferue fasciculato-ramosis foliosis; fol. subdistichis lanceolato-linearihus rigidis, interne puberulis margine serrulato-ciliatis; spicis $6-7$-alternis pancifloris; glumis floreque masculo purpurascenti-pilosis; flore hermaphrodito punctulato glabriusculo. Kminth gram. t. 19. Holeus Thunh. Sorghum ii. et S. In Promont. b. spei. 
1.58. I'. scopuliferum Trin. culmo ab ima basi ramoso elabro; vaginis sulcato-striatis inferioribus puhescentibus, superioribus glabris; fol. lanceolato-linearibus acntis planis marrine denticulatis glahris; spicis circiter 5 alteruis patulis; spiculis biserialii.us imbricatis ohlongis vel ovalibus obtusis; glumis dense pilosis; flore inferiore masculo hipaleaceo, superiore hermaphrodito subundulatopunctulato. Trin. ic. 14. t. 165. In Fromont. b. splei.

1.5.). P. Urvilleamum Kunth; culmis, vaginis foliisque retrorsum arrenteo-sericeis; paniculis ramosis diffusis; spiculis sparsis pedicellatis subracemosis sericeo-hirsutis; flore inferiore masculo, superiore hermaphrodito laevi; glumis paleaque inferiore mascula multinerviis. Kunth gram. 1. 35 et? t. 115. In Chili.

160. P. veptans Kunth; culmo hasi repente stolonifero; foliis rigidis sulcatis involutis glabris; vaginis retrorsum strigoso-sericis; panicula-subsimplici; spiculis pedicellatis; flore masculo hipaleaceo; glumis suhaequalibus paleaque superiore mascula mulrinerviis densissime lanatis. Kunth Grauı. 1. 219. t. 21. Saccharum reptans Lam. ill. 1. 115. Monachne racemosa Beaur. Agrost. t. 10. f. 10. P. racenosum spreng. Eriolytrum junceum Desv. in herb. Juss, Thalasium montevidense spr. In Montevideo. 4.

161. P. perforatum Nees; racemo decomposito contracto; spiculis subglomeratis ovatis glanduloso-punctatis, rachi, culmo, vaginis foliisque villosis, linearibus, planis; gluma inferiore minuta lanceolata. Nees in Mart. Bras. 2. p. 126. Trin. ic. t. 175. In Brasilia merial. 4.

162. P. bulbosum H. et K. nov. gen. 1. 1.99. culmis nodisque glahris; fol. supra pilosis margine scahris; panicula ramosa; ramis scahris alteruis oppositisque; spiculis geminis subquadrifariam imbricatis ovatis acutis; glumis inaequalibus glabris; flore neutro hipaleaceo. Kumth. In Mexico. 4.

163. P. axenaceum H. et K. l. c. culmis nodisque glahris; fol. serulato-scabris supra pilosis; panicula ramosa verticillata; spiculis weminis ovatis acutis; glumis inaequalibus glabris ; flore masculo bipaleaceo. Kunth. In Quito, Guiana. 4.

16t. P. decolorans $\boldsymbol{H}$. et $\boldsymbol{K}$. $n$. yen. 1. 100. culmis nodisque glabris; fol. margine scabris; panicula ramosa; ramis alternis subfastigiatis; spiculis geminis ovatis acutis; glumis inaequalihs glabris; flore neutro bipaleaceo. Kunth. In Mexico. 2.

16.5. P. rigidulum Bosc. mss. panicula racemosa supratlecomposita; rachi hinc canaliculata; ramis compressis ; spiculis lanceolatis acmminatis scabris; flosculo masculo 2-valvi 5-nervi; culmo foliisque glahris linearibus margine serrulato-scahris. Nees in Mart. Bras. 2. p. 163. In America boreali?

166. P. rebile Poir. glahrum; erectum ; fol. angusto-longis ; panicula pyramidata; ramis paucis dissitis plerisque geminis simpliciusculis divaricatis reflexisque; floribns mulicis binis; altero pedicellato neutro. Michx. Poir. encycl. suppl. 4. 283. P. divaricatum vichx. P. patentissimum $\mathbf{R}$. et $\mathbf{s}$. P. hians Elliott. In Carolina.

16\%. P. proliferum Lam. glaberrimum; paniculis ohlongis electis ; glumis striatis majusculis; caule ramoso. Lam. encycl. 4. 747. P. dichotoniflorum Michx. P. geniculatum Mühlenb. P. attenuatum Willd. P. congylodes Jacq. Gram. 3. t. 21. P. miliaceum Walt. Car. 72. In America septentrionali.

168. P. virgatum L. panicula virgata ramosissima; glumis ovatis acuminatis muticis hifloris; fol. Iongissimis planis. Pursh. flor, 1. 67. spreng. act. Petrop. 2. 292. t. 5. Trin. ic. t. 228. In America septentrionali. 4 .

16.9. P. psilopodium Trin. mss. panicula capillari erecta; ramis inferioribus strictis; ramis subfasciculatis pedicellisque tenuissinis flexuosis; axi!lis nudis; spiculis oblongis acntis wlabris nervoso-striatis; gluma inferiore obtusa duplo breviore; culmo adscendente ramoso: vaginis foliisque glahris linearibus. Nees in Mart. Bras. 2. 199. P. virgatum hoxh. P. ramosum Koenig. In India orientali.

180. P. scubriusculum Elliott; culno erecto majusculo foliisque subtus scahriusculis; panicula majuscula pyramidata patente; floribus ovatis acntis glabris. Ell. bot. 1. p. 121. In ins. Sacannah. 
171. P. multiflorum Poir. glaberrimum: panicula deusissima multiflora; foribus oblongis subacutis parvulis; ramis asperis; fol. lato-linearibus vitginisque glabris. Poir. encycl. suppl. 4. 282. In Carolina.

172. O. subalbidum Kunth; culmo ramoso; nodis geniculatis imberbibus: fol. planis vayinisque glaberrimis; panicula ramosa diffusa; ramis angulatis scabris patentibus inferne nudis; ramulis adpressis; spiculis sparsis glabris albidis; glumis inaequalibus acutis; flore hermaphrodito laevi nitido; neutro 1-paleace glumae superiori simillimo. Kunth gram. 2. t. 112. In Seneyalia.

173. P. trinerve Trin. glaucescenti-viride; radice fihrosa; culmo erecto simplici tereti glahro; vaginis striatis glabris vel asperiusculis; fol. erectis linearibus acuminatis rigidulis planis asperiusculis ; panicula erecta ramosa apice nutante; ramis hinis pertenuihus erecto-patulis asperiusculis; spiculis ovatis; glumis inaequalibus acutis carinatis 3-nerviis superne exasperatis floribus hrevioribus; flore nentro bipaleaceo glumis simili; hermaphrodito acutinsculo apice exasperato. Triu. ic. 19. t. 226 . In Brasilia.

124. P. jumentosum Pers. sym. 1. 83. culmis glabris; nodis sericeis; fol. linearihus margine serrulato-scahris; panicula ramosissima patente; ramis verticillatis scallis; spiculis subeminis ovatis acuminatis ; glumis inaequalihus glabris; flore neutro bipaleaceo. H. et K. 11. gen. 1. p. 104. P. polygamum Sw. P. maximum Jacq. ic. 1. 1. 13. P. Iaeve Lam. In India occid. et America tropica cultum; olim ex oris Africal allatum. 4.

17.5. P. hirticaulum Prest; culmo erecto ramoso compresso; vaginis foJiisque elongatis tuberculato-hirsutis; nodis barbatis; panicula erecta patente composita; rachi scahra; spicuJis pedicellatis solitariis oblongis acutis; glunis inaequalihus acutissimis; inferiore ovata acuminata 3-5-nervia; superiore duplo longiore ovata 7-nervia acuminata; floris neutrius palea inferiore ovata 7-nervia; superiore multo minore; flore hermaphrodilo spicula hreviore ovali laevi. Presl. in Hel. Haenk. 1. 308. In Mexico.

176. P. discolor Trin. mss, racemo decomposito virgato; racemulis subsecundis appressis; pedunculis unifloris; spiculis ellipticis nervosis; glumis subaequalibus obtusis, apice puhescenti-harhatis; flosculo hermaphrodito basi inappendiculato; caule simplici, vaginis foliisque glabris lanceolatis subtus glaucis. Nees in Mart. Bras. 2. p. 14t. Trin. ic. t. 231. $l$. penicillatum Trin. In Brasilia.

17\%. I'. penicillatum Nees; racemo decomposito patulo; racemulis subsecundis hrevibus; pedumculis bifloris; spiculis ovato-ellipticis nervosis; glumis aecualibus subulalo-acumiuatis; flosculo hermaphrodito basi appendiculato; culmo subramoso vaginisque glabris; fol. cordato-lanceolatis strictis supra glabris, subtus pubescentibus. Nees in Mart. Bras. 2. 145. In Brısilia.

178. P. ruile Nees; racemo decomposilo stricto; ramis patulis villosulis; pediccllis subsecundis, inferioribus trifloris; rachi hirsuta; spiculis ovatis; culmo pubescente; fol. ovalo-lanceolatis acuminatis strictis hasi villoso-cilialis. Nees in Mart. Bras. 2. p. 158. In Brasilia. 4.

17.9. P. juncenm Nees; panicula racemosa patula supradecomposita; ramis laeviluss; pedicellis apice pilosulis; spiculis subfasciculatis ovatis cuspidatis; culmo tereti glabro laevi ramoso; ramulis cirriformibus ; foliis angustis margine cartilagineo-serrulatis. Nees in Mart. Bras. 2. 159. In Brasilia. 1 .

180. P. pungens Trin. mss. panicula racemosa decomposila patula; ramis divisis glabris; ramulis bifloris; spiculis ellipticis obtusiusculis al carinas scahriusculis; culmo simplici; fol. linearihus tenacissimis basi vaginisque radicalibus villosis. Nees in Mart. Bras. 2. 160. In Brasilia. 4.

181. '. molinioides Trin. mss. panicula racemosa verticillata ramosissima patente; ramulís capillaribus; spiculis parvis obovatis coloratis; gluma inleriore parva pallente; culmo stricto ramoso glahro; nodis gihhosis; vaginis margine ciliatis; fol. elongatis rigitlis pungentihus margine scahris. Nees in Mart. Bras. 2. 162, In $\mathrm{Br}(\ell-$ silia. 21.

182. P. Prionitis Nees; panicula terminali lateralibusque racemosis supradecompositis; rachi hinc canaliculata; ramis compressis; spiculis ova- 
tis acutis scabris; flosculo masculo bivali 5-nervi; culmı ramoso ; fol. angustis nervo crassissimo rigentibus arg̈ute serrulatis glabris. Nees 1. c. In Brasilia. t.

183. N. elephantipes Nees; panicula racemosa supradecomposita coarclata glahra; pedicellis bifloris; spiculis lanceolatis acutis; gluma exteriore hrevi 1-nervi; flosculo neutro 1-valvi 7-nervi; culmo simplici erecto crasso, nodis, vaginis foliisque ulahris, basi orisque vaginarun ciliatis. Nees in Mart. Bras. 2. p. 165. In Brasilia.

181. P. Laltissimum DC. panicuIa composila elfusa; floribus obtusis; glumis calycinis 1-floris; vaginis glabris. Hornem. Patria iynot $\iota$.

15.5. P. hirsutum Suartz; panicnla composita capillari patente; culmo vaginisque setoso-hirsulis; fol. lanceolatis acuminatis nervosis strictis. Swartz flor. ind. occ. 1. p. 173. In Jamaica, Hispuniola.

156. I'. repens I. caule stolonifero; fol. conduplicatis hasi pilosis ; inferioribus brevibus patulis; panicula tenui; ramis arrectis; valva extima rotundata; interiore et valva extima neutra superne plicato-nervosa. Linn. spec. 87. Willd. spec. 1. 347. Cav. ic. 2. t. 110. P. arenarium Brot. ejusd. pliyt. Lils. 1. 15. t. b. In Europa anstrali, Mexico. 4.

187. P. stenocladium Trin. glabrum; culmo ramosissimo inferue repente, ramis subfastigiatis; fol. linearibus acutis planis vel involuto-setaceis; panicula subramosa; ramulis subsolitariis patulis capillaribus; spiculis subrotundo-oblongis ; glumis acutiusculis; inferiore hreviore 3-nervia; superiore flores subaequante 5nervia; flore inferiore neutro bipaleaceo. Trin. diss. 2. p. 200. ejusd. ic. t. 240. In Brasilia.

185. R. obliquum Roth; panicula capillari subpatula laxa subnutante; spiculis longe pedicellatis solitariis obliquis hinc ventricosis; apice puhescentibus obtusissimis; calycis gluma exteriore semilunari oblongo; culmo repente radicante ramoso; fol. lanceolatis punctato-pellucidis basi vaginisque pilis nomullis longis ciliatis. Koth nov. spec. p. 51. P. patens spreng. In India orientali.
18.9. P. difforme Roth; panicula capillari contracta suhmutante; spiculis subfasciculatis obovatis obtusissimis pilosis, linc ventricosis; calycis gluma interiore obovata naviculari; culmo filiformi ramoso; fol. lanceolatis punctato-pellucidis utrinque pilosis, hasi vaginisque ciliatis. Hoth n. spec. p. 52. In India orientali.

190. P. coloratum $I$. panicula patente; staminihus pistilliscue coloratis; caule ramoso. Limn. mant. 30. Jacq. ic. 1. t. 12. P. virgatum Mühleub. In Aegypto, America boreali, Promont. b. spei. $\odot$.

191. P. murvirascens Radali, Agrost. Bras. p. 17. panicula racemosa decomposita elongata palente; ramis angulato-flexmosis scabris basi hirsutis; ramulis brevissimis peclicellisque pilosis; glumis nervosis glabris virili-purpurascentibus; culmo erecto suhramoso; nodis hirsutis; vaginis o tuberculis hirsutis; fol. ensiformibus basi puhescentibus. Nees 1. c. In Brasilia.

192. P. amarum Elliott; glaberrimum; fol. crassis glaucisque; panicula adpressa; glumis acuminatis. EIl. hot. 1. 121. In America septentrionali.

193. P. sabulosum Lam. panicula ramosa flexuosa mediocri; glumis ovalibus obtusis striatis; pistillis coloralis; culmo ramoso. Lam. encycl. 4. 744. In Montevideo.

19t. P. leiogonum Delile; paniculis lateralibus pauperulis elongatis paucifloris; flosculis ovatis subsolitariis; fol. angustissimis glahris hasi vaginaque suhpilosis; culmis filiformibus; ranis divaricato-flexuosis. Poir. encycl. suppl. 4. 284. In Aegypto.

19.5. P. miliacenm Linn. spec: 86 . pilosissimum; culmis erectis ramosis 2-4-pedalibus; panicula oblonga; glumis calycinis cuspidatis; corolla trivalvi; valva accessoria bidentata; semine ovali glahro 5-striato. Roxb. fl. ind. 1. p. 312. Trin. ic. t. 221. Villd. spec. 1. 348. Host gram. t. 20. P. Milium Pers. syl. In Indic orientali, in Europa cultum. ๑.

196. P. sumatrense Roth; panicula erecta laxa flaccida; spiculis ovato-acuminatis; calycis valvula exteriore cordato-subrotunda subenervia spiculam basi involvente; nodis, vaginis foliisque glaberrimis linearibus. 
Hoth nov. spec. I. 50. In Coromandelia.

19\%. 1'. miliare tam. culmis erectis ramosis 2 -3-pedalis glahris; panicula tenui; florihus in pedicello communi geminatis, suffultis pedicellis parlialibus inaequalibus; corolla trivalvi; semine ovato ulabro 5-striato. loxh. fl. ind. 1. p. 311. In Incliu orientuli.

198. P. scabervimum Latyasca: panicula erecto-patente; ranulis 3gonis strictis deorstum scaberrimis; glumis bifloris radice tuberosa. Lay. Elench. 2. P. ligulare Nees. In Merico.

199. P. asperrimum Lag. mss. vaginis pilosis; fol. glabris; panicula nutante; ramulis asperrimis; valvula calycina minore longe acuminata nervosa. Link, enum. 1. p. 7\%. P. miliaceum $\beta$ tenuius Heyne mss. Hutria ilmotı. $\odot$.

200. P. rumulosum Michx. gracile, debile, ramulosum; culmo vaginisque glabris; geniculis nudis crassiusculis; fol. lanceolato-linearibus patulis glabris, inferne pilis Iongis rurioribus subciliatis; panicula pusilla capillari laxa; floribus minutis ovatis, ommibus longiuscule pedicellatis. Michx. flor. 1. 50. P. debile Ell. P. Imbrosum Leconte in Cat. of plants of New-York. P. verrucosum Mülılenb. In Americu septentr. 4.

201. P. Pragile Kinnth, uram. 1. 36. culmo assurgente fragili; panicula diffusa; floribus parvulis solitariis longissime pedmculatis. Ell. P. divergens Mühlenl). cat. Elliott. bot. 1. 130. In America septentr. 4 .

202. P. coynutum sichult. mant. 2. 23.5. culmo erecto tenui simplici; foliis subulatis vawinisque glabris; ligula ovata; panicula divergente capillari rigida; axillis pilosis; ramis virgatis longissimis unifloris sursum -hispidis; corolla fusca. P. divergens Mühlenb. descr. 120. In Corolina.

203. 1'. muscurium. Trin. culmis caespitosis adscendentibus ramosis filiformibus; fol. angustissime linearihus planis pilosss glaucescentibus; paniculis ramosis erectis; ramis solitariis binisve, capillaribus rachique glabris, palulis; spiculis minimis; glumis carinatis acuminatis 3-nerviis flores aequantibus. Trin. ic. t. 235. In Sierr Leonu.
204. I. dichotomum Gronor. Iiry. 133. paniculis simplicissimis paucifloris; glumis obovatis; fol. lineari-lanceolatis divaricatis glabris basi et collo barhatis; caule dichotomo. Pursh. alor. 1. 6\%. spreng. in act. Petrop. 2. 290. t. 4. In Americu septents. ๑.

205. P. nodiflorum Lam. paniculis minimis Iateralibus terminalihusque; gltumis ovatis subpubescentilus; fol. angustis breviusculis. Lam. enivel. 4. 744. In Curolina.

206. P. micrunthum H. et K. nov" gen. 1. 10.5. culmis ramosis glabris; nodis foliisque interne pilosis linearibus margine scabris; panicula ramosa patula; ramis alternis glabris; flore neutro 1-paleaceo? Kunth. In Caracas. 24.

20\%. P. auricomun Nees; panicula capillari flexuosa glahra; ramis trans basin divisis; spiculis oblongis acutis costatis hirlis; gluma inferiore dimidia acuta; flosculo masculo bivalvi; culmo erecto ramoso, nodis, vaginis foliisque glahris lineari-acnminatis superne glaucis; ligula rotundata ad basin villis cincta. Nees in Mart. Bras. 2. p. 222. Ad Flumen Nigrum. 4.

20s. P. rupestre Trin. mss. paniculis capillaribus laxis patulis ; ramis mox supra basin divisis; ramulis subtriftoris; spiculis oblongo-ellipticis ohtusis pilosis; gluma inferiore ovata acutiuscula; culmo suberecto ramosiusculo; fol. iuvolutis strictis. Nees in Mart. Bras. 2. p. 222. Trin. ic. t. 239. In Brasilia.

20.9. P. consanynineum Kunth yram. I. 36. villosum; culmo erecto subramoso; panicula pauciflora; florilus ovatis; fol. erectis planis rigidis. Elliott, P. villosum Ell. bot. 1. p. 124. In America septentr. 4.

210. P. setucenm Müllenb. pedunculis solitariis unifloris, rarius panicula terminali; culmis caespitosis erectis dichotomis subpubescentihus. Mülılenb. descr. 99. In Georyia.

211. P. Mühlenbergianum Schult. mant. 2. 230. culmo e hasi ramoso vel dichotomo glabro; nodis sursur pilosis; fol. linearibus nervosis glabris; paniculae ramis solitariis a bas ramulosis; pedicellis flexuosis subpuhescentihus. Mühlenb. descr, p. 118. In Georyia. 
212. P. nitilum Lam. panicula capillacea ramosa; glumis striatis pubescentilus; seminibus nitidis; fol. remotis lanceolato-linearibus collo barhatis; caule glabro. Pursh flor. 1. p. 67. Lam. encycl. 4. 74x. Michx. flor. 1. 49. In America septentrionali. $\odot$.

213. P. lencophlephurum 'rvin. panicula capillati flexuosa pilosa patula; ramis a basi fasciculatim divisis; spiculis suborbiculatis plano convexis laevihus glabris; gluma inferiore suborhiculata triplo hreviore; culno erecto nodis foliisque glabris lanceolato-acuninatis rigidulis basi amplectentilus margineque basin versus e vranulis ciliatis; ligula nulla. Nees ill Mart. Bras. 2. 229. Trin. Clav. Agrost. 23t. p. nitidum $\delta$ pilosuni Torrey, flor. Amer. In America boreali.

21t. P. or ale Elliott; pubescens; panicula diffusa; floribus oblongis pilosis; fol. ovato-lanceolatis sulpcordatis. EII. bot. 1. p. 123. Nutt. geu. 1. 53. In Corolina, Georgia.

21.5. P. Lumginosum Elliot; puhescens; pauicula difítusa subcapillari; floribus ovalibus parvulis; fol. angustato-lanceolatis; vaginis collo villosis. Ell. l. c. P. pubescens $\beta$ spiculis minoribus Nees. In Georyia. 4.

2/6. I'. microcurpm nühlenb. panicula capillari ramosissima patente: floribus ovalibus minulis glabris; fol. lineari-lanceolatis glaberrimis. Eu. hot. 1. 127. Mühlenb. descr. 111. spieng. N. Eutd. 2. p. 102. In America septentr. 21.

21\%. P. oligosanthes Schult. panicula patente pauciflora; floribus majusculis : fol. augustato-lanceolatis hasi ciliatis; vauninis pilosis. Elliol. sichult. mant. 2. 256. P. pauciflorum Elliot, bot. 1. 120. In Georyill. 4.

2ls. P. depaliperatum Mühleub. panicula terminali erecta depauperata; glumis acutis lanceolatis nervosis glabris, lertia minore trinervi obtusa; fol. lineari-lanceolatis, inferioribus ah)reviatis, supremo elongato, pilosis glabrisve; vaginis pilosis. Mühlenb. descr. p. 112. In Pensylvania, C'arolina. 4.

219. P. viscidum Elliot; "pubentissinum ; canescens; viscidum; culmo infra nodos anuulatim glabro. Ell. bot. 1. p. 123. In America septentrionali. 4.
230. P. ciliatifolium Kunth. gram. 1. 36. culmo decumbente; foliis vayinisque glahris pulchre ciliatis; panicula pauciflora patente. P. ciliatum Ell. bot. 1. p. 126. In Georyiu. 4.

221. P. ensifulinm Bulluin; parvulum, glabrum; fol. ovato-lanceolatis acutis patentibus; panicula parvula pauciflora; floribus subovatis pubescentibus. Baldw. in Ell. bot. 1. p. 126. In Georgiu. 24.

2:2. P. bubulatum Hichx. parvulum; culmo gracili subramoso; nodis amulatim barbulatis; fol. lanceolato-lincaribus nitidule glahris, ad collum sparsim pilosis; panicula parvula capillari composite ramosa; floribus brevi-ovatis. Michx. flor. 1.p. 49. In Carolina.

22:3. P. pubescens Lam. erectum; ramosissimum; pubesceus; paniculis parvis paucifloris laxis sessilibus: "glumis glohoso-ovatis subpedicellatis puhescentibus. Pursh flor. 1. p. 68. Iı America boreali. $\odot$.

224.P. sphuerocurpum Elliot: fol. lineari-lanceolatis acutissimis basi vaginisque ciliatis; panicula patente; floribus parvulis subrotundis pubescentibus. Ell. bot. 1. p. 125. In Geolgia. 2.

22.5. P. mollicomum Kunth; culmo erecto basi ramoso tereti; nodis, vaginis foliisque piloso-pubescentilus linearibus; panicula simplici patente; rachi hirsutula; spiculis ohovatis ohtusis; glumis inaequalibus paleaque neutra inferiore pubescentilus olstusis; flore hermaphrodito ruguloso; neutro bipaleaceo. P. lanuginosum Presl in rel. Haenk 1. p. 306. In Permviu. 7. 226. P. xulupense Kunth; culmis ramosis glabris; fol. linearibus utriuque pilosis margine ciliato-scabris; panicula ramosa divaricata; ramis alternis pilosis; spiculis ovatis obtusis; glumis inaequalibus pilosis; flore nentro bipaleaceo. H. et K. n. gen. 1. p. 103. In Mexico. 4.

227. P. angnustifolium Elliot; panicula pauciflora patente; foliis sparsis lineari-lanceolatis subtus glabris parce ciliatis. Ell. hot, 1. 129. Nut. gen. 1. 53. Nees in Mart. Bras. 2. i. 226. P. nitidum $y$ gracile Torrey flor. Am. P. Iancearium Trin. In Americu septentriunali.

228. P. parvifolinm Lam. paniculis parvis pateutibus; glumis obtusis; 
culmo filiformi; fol. minimis villosis. Lam. ill. 1. 173. ejusd. encycl. 4. p. 7+2. Trin. ic. t. 236. In America meridionali.

229. P. gramuliferum Kunth; culmis simplicibus nodisque wlabris; fol. ovato-lanceolatis subcordatis, utriuque pruinoso-glaucescentibus, margine scabris; panicula ramosa diffusa; ramis alteruis glabris; spiculis globosis; glumis glabris; flore neutro bipaleaceo. H. et K. u. gen. 1. p. 19. P. parviflorum $\beta$ Nees. In Guianu.

230. D. raripilum Kunth; canlibus debilibus procumbentibus ramosis nodisque glabris; fol. Ianceolatis acutis basi rotundatis planis rigidulomembranaceis glaucescenti - viridibus, utrinque vaginisque superne molliter pilosis ; spiculis ellipticis glabris ; gluwis inaequalibus; flore nentro bipaleaceo; hermaphrodito laevinsculo. Kumth gram. 2. t. 11t. Ad ripum fluminis Gambiae, in oryzetis.

231. P. Luxuriuns Willı. mss. paniculis compositis angustis glabris; spiculis ovatis; glumis aequalibus; caule ramoso filiformi repente; foliis lanceolatis vaginisque villoso-pubescentibus; ligula in setas soluta; flosculo hermaphrodito hispido. Nees in Mart. Bras. 2. p. 233. In ins. Lusonia.

232. P. lineatum Trin. culmo ramoso prostrato superne angulato et pubescente; foliis lanceolatis acuminatis planis pubescentibus; panicula rectiuscula; ramis solitariis vel binis erectis rachique puhescentibus; spiculis elliptico-ovatis acutis glabris; pedicellis glabris pilisve raris adspersis; gluma inferiore dimidio minore sub-5-nervia; superiore flores aequante 7-9-nervia; fore liermaphrodito elliptico-ovato acutiusculo glabro; neutro bipaleaceo glumis simili. Trin. ic. t. 233. In Sierra Leona.

233. P. chnoodes '́rin. mss. panicula patula; ramis e medio divisis suhcorymbosis; spiculis ellipticis obtusis glabris coloratis; gluma inferiore dimidio breviore; flosculo nen1ro bivalvi; culmo simplici; vagínis foliisque sericeo-villosissimis linearihus; rachi pilosa. Nees in Nart. Bras. 2. p. 216. In Brasilia. 4.

234. P. loreum Trin. mss. panicula capillari flexuoso-crispata patente; ranis a basi divisis; ramulis pau- cifloris ; spiculis ellipticis ohtusiusculis glabris ; gluma inferiore ovata spicula dimidio breviore; culmo stricto simplici foliisque glabris linearibus tenacissimis suhpungentibus; ligula nulla. Nees in Mart. Bras. 2. p. 217. In Brasilia. 4.

235. P. ovuliferum Trin. mss. panicula terminali erecta; ramis basi fisciculatim divisis virgatis triquetris, (paniculis) lateralibus subsimplicibus vaginatis; spiculis oblongis obtusis glabris raris; glumis inaequalibus; flosculo neutro 1-valvi; culmo simplici; vaginis nodisque patenti-hirsutissimis; foliis lanceolatis pilosis. Nees in Mart. Bras. 2. p. 218. Trin. diss. 2. 191. ejusd. ic. t. 222. In Brasilia. 4.

236. P. stigmosnm Trin. mss. panicula obovata; ramis a basi racemosis patulis flexuosis; spiculis obovatis glabris raris; glumis inaequalibus; flosculo neutro bivalvi; culmo simplici; vaginis tuberculato-hirtis ciliatis; fol. lineari-lanceolatis glabris. Nees in Mart. Bras. 2. p. 219. Trin. diss. 2. 194. ic. t. 225. In Brasilirt. 4.

23\%. P. rugulosum Trin. mss. panicula decomposita erecta; ranulis villosulis apice racemoso-divisis; pedunculis 1-floris patulis; spiculis obovatis obtusis; glunis inaequalibus, superiore 5-nervi nentroque flore bivalvi rugosis, valvula superiore angustissima; fore hermaphrodito trausversim undulato-ruguloso; culmo procumbente; fol. cordato-lanceolatis amplexicaulibus, subtus vaginisque superne molliter pubescentibus. Nees in Mart. Bras. 2. p. 204. Trin. diss. 2. 195. ejustl. ic. t. 238. In Brasilia.

238. P. cyanescens Nees; panicula capillari subflexuosa glohosa; raunis fasciculatim divisis; spiculis globosis glabris; gluma inferiore ovatoorhiculata vix dimidio breviore; culmo erecto stricto subramoso cum nodis glabro ; fol. lanceolato-linearilins strictis scalyris; lignla truncala extrorsum ciliis cincta. Nees in Mart. Bras. 2. p. 220. Trin. ic. t. 230. P. firmifolium Trin. Inss. In Brasilia meridionali. 2.

239. P. tenellum Lam. glaherimum; panicula parva patente; glumis obtusis curvatis; culmo ramoso filiformí. Lam. ill. 1. 173. ejusd. encycl.4. 
753. P. imbelle Spr. In Sierra Leona.

210. P. glancescens Kunth; culmis simplicibus nodisque wlabris; foliis lineari-lanceolatis suhtus scabris glancescentibus; margiue cartilagineo-serrulatis; vaginis dorso pilosis; panicula ramosissima; ramis alternis pilosiusculis; spiculis subglobosis; glumis apice pilosis; flore neutro bipaleaceo. H. et K. 11. gen. 1. p. 10.. In Nova Andalusia, Nova Granata. 24.

241. 1'. rigens Surtz; culmis ramosis nodisque glabris; fol. lanceolatis subtus adpresso-pilosis tardius margineque scabris; panicula ramosa diffusa; ramis suhalternis pilosis; spiculis obovatis; glumis suhaequalibus apice puhescentibus; flore neutro bipaleaceo Kunth. Swart $z$, fior. intl. occ. 1. 154. In Jamaica, ad ripas Orinoci. 4.

212. P. rigidifolium Kunth gram. 1. 3\%. panicula simplici pauciflora; ramis brevihus; glumis ovato-concavis muticis; fol. brevibus utrinque attenuatis, apice subulatis. Agrostis riridlifolia. Poir. encycl. suppl. 1. p. 257. In St. Domingo.

2.13. P. firmum Kunth $l$. c. panicula erecta; valvis calycinis obtusis emarginatis glabris diaphanis; fol. linearibus rigidis margine scahris. Milium pungens spr. N. Entd. 2. p. 102. In America boreali.

214. P. heterophyllum Bosc. mss. panicula capillari contracta; ramis fasciculatim divisis; ramulis elongatis; spiculis ellipticis ohtusis pubescentibus ; gluma inferiore orhiculata 6-tuplo bleviore; culmo simplici flaccido glabro; nodis vaginisque inferioribus pubescentibus; fol. inferioribus lanceolatis, superioribus linearibus remotis holosericeo-pubescentibus; ligula angustissima. Nees in Mart. Bras. 2. 227. P. laxiflorum Spr. Mem. de St. Petersb. 2. 291. t. 5. P. discolor Spr. Mant. P. multiflorum Ell. P. polyanthes Schult, P. ovale spr. syst. P. nitidum $\rho$ barbatum. Torrey fl. Am. 1. p. 146. In America boreali.

215. P. laxiflorum Lam. encycl. 4. 748. panicula capillari erecta flexuosa; ramis a basi racematim divisis rachique villosulis; spiculis ellipticis obtusis nervoso-striatis pubescentibus; gluma inferiore orbiculato-ovata quadruplo breviore; culmo humili subsim- plici ; fol. lineari-lanceolatis planis, inferiorihus vaginisque lanatis; lana cinguloque al hasim vaginalum reversis; ligula brevi truncato-lacera. Nees in Mart. Bras. 2. 228. P. hirsutum $\beta$ Lam. encycl. 4. 7+1. P. nitidum $\alpha$ ciliatum Torrey fl. Am. 1.146. In America boreali.

2\$6. P. millegrana Poir. panicula patente elongata; ramis ramulisque setaceis 1 -floris sulverticillatis; fol. lineari-lanceolatis, basi vaginaque ciliatis; culmo delili. Poir. encycl. supp. 4. 278. P. hirsutum Lam. Iи America meridionali.

247. P. listum Lam. culmo ramoso basi repente adscendente; fol. ovato-oblongis subcordatis ciliatis pilosiusculis vayinis nodisque pilosis; panicula simplici patente; spiculis aculatis cermuis supra pilosis, nomnullis hirsutis intermixtis; flore hermaphrodito laeviusculo. Kunth gram.1, 225. t. 24. Lam. encycl. 4. 7+1. Nees in Mart. Bras. 2. 209. In Guicina, Brasilia. $\odot$.

218. P.trachyspermum Nees; panicula patente; rachi glabra; ramis paucifloris; spiculis ovatis gibhis scabris (junioribus glauduloso-pubescelltibus); flosculo masculo bivalvi ; hermaphrodito scabro; culmo ranioso basi repente laevi; vaginis tuberculatohirsutis; fol. oblongo-lanceolatis scabris pubescentibus. Nees in Mart. Bras. 2. 212. P. hirtum IVilld. herb. In Prove. Paraënsi.

24.9. P. incomptum Trin. mss. panicula capillari oblonga densa; rachi pilosa; ramis racemoso-decompositis ramulisque flexuoso-intricatis sulpilosis; spiculis ovoideis glahris; flosculo neutro hivalvi; culmo vaginisque pus bescentibus; fol. lanceolato-linearibus elongatis utrinque piloso-scabris. Nees in Mart. Bras. 2. 207. 'Trin. diss. Z. 200. ic. t. 232. In Manilla.

250. P. sciurotis 'J'rin. mss. panicula capillari obovata; rachi ranisque patenti-hirsutis; ramis erecto-patulis a basi dense fasciculato-ramosis; pedicellis 1-foris; spiculis oblongis, acttis, glabris; flosculo neutro hivalvi; caryopsi laevi; culmo ramoso basi repente; nodis hirsutis; vaginis ciliatis basi e tuberculis hirsutis; fol. condato-oblongis acuminatis utringue subvillosis. Nees in Mart Bras. 2. 209. In insula St. Catharinae Brasiliae. 4. 
251. I. trichoides Swartz; culmis ramosis nodisque pubescentibus; fol. ovato-lanceolatis glabris maloine scabris; panicula ramosissima patente; ramis fasciculatis, superioribus alternis scabris; spiculis obovatis acttis; glumis inaegualibus pubescentibus; flore sterili 1-paleaceo. Kunth 1. 176. H. et K. n. gen. 1. 105. Presl in rel. Haenk 1. 309 . P. capillaceum Lam. ill. P. brevifolium Lim. spec. 67. VVilld. s]. 1. 353. P. filamentorum Pers. In Jumaica, in ripis fluminis St. Magdalenue, in Brasilin, Bierico.

252. P. carinatum Presl; culmo ramoso adscendente ad nolos pubescenti-piloso: vaginis ore suhpilosis; fol. Ianceolatis pilosis margine scabris; panicula patente; ramis alternis; spiculis obovoideis obliquis compressis; paleis inaequalibus; flore hermaphrodito, compresso, carinato. Presl in rel. Haenk 1. p.309. P. carinatum $\beta$ procerius Presl. In Luzonia, Hexico?

\$.53. P. malacense Trin. mss. panicula rigidula erecta ohovata densa capillari; rachi ramisque glabris, his it hasi fasciculatim divisis; spiculis ovoiseis, glumis aequalihus; inferiore lanceolata carinata, carina scahra; superiore obtusa fosculoque neutro 1-valvi hispidalis; culmo humili repente; vaginis hasi hirsutis; foliis ovatis brévilus hasi stihciliatis. Nees in Mart. Bras. 2. p. 212. In India orientuli.

25.4. P. ovalifolium Poir. panicula capillari laxa glaberrima; floribus minutis ovatis; fol. ovato-lanceolatis subciliatis; vagina pilosa; culmo inferne flexuoso. Poir. encycl. suppl. 4. p. 279. Bealv. flor. Oware t. 110. f. 1. P. guineense Desv. mss. P. amplexicanle Poir. In Africa requinoctiali.

25.5. P. chactophorum $\boldsymbol{R}$. et $\mathbf{s}$. panicula composita; ramis capillarihus setosis; glumis hirtis; fol. lanceolatis basi nodisque setosis; culmo basi decumilente et repente, apice erecto et ramoso. H. e $\ell$ S. syst. 2. 884 . P. setigerum beauv. flor. Oware t. 49. In Africa aequinoctiali.

256. P. nervosum Lam. culmis erectis sumplicibus foliosis; fol. lanceolatis basi rotundatis utrinque pilosis; panicula ramosissima; ramis semiverticillatıs; spiculis subrotundo- ellipticis glabris; flore hermaphrodito laevi; masculo bipaleaceo. Kunlh gram. 1. 227. t. 25. Lam. encycl. 4. 747. fin Guiuna gallica.

25\%. P. melicarium Michx. dehile, glaberrimum; panicula gracili longa; ramulis raris allpressis; glumae membranaceae valvis subaequalibus lanccolatis; fol. angnstis longis. Pursh Fl. 1. p. 69. P. milioides Nees. In Carolina, Georgia et? Irrasilia. 4.

2.58. 19. diffusum Nuartz; panicula smpliciuscula capillari patente; flosculis remotiusculis acutis; culmo decumbente simplici; fol. linearibus collo villoso. Sw. prod. p. 23. In India occillentali.

2.59. P. auritum Presl. ms.s. paniculae decompositae contractae ramis alternis approximatis racemosis; racemulis confertis hrevilus; spiculis oblongo-lanceolatis sulgeminis; glumis inaequalibus glabris; flore neutro bivalvi; culmis simplicihus compressis; vaginis margine ciliatis; foliis e hasi cordata lanceolato-linearibus. Nees in Mart. Bras. 2. 176. In ins. Luzonia et? Mexico.

260. P. caespititium Lam. panicula laxa capillari; glumis raris acuminati, ; culmo filiformi; fol. Iongis angustissimis. Lam. ill. 1. 173. ej. encycl. 4. 743. In America merilionali.

261. P. ancep.s Nichx. erectum; paniculae ramis simplicibus interrupte racemulosis; flore accessorio neutro; hermaphrodito valvis primariis semibreviore obtusissimo; fol. longis; vaginis compressis pilosis. Pursh flor. 1. 69. P. rostratum Mülilenh. P. pensylvanicum spr. In Pensyllania, Carolina. 4.

262. P. capillare Gron. panicula capillari erecta patente; pedunculis strictis; calycibus acuminatis laevibus; foliorum vaginis hirsutissimis. Het $z$ obs. 3. 9. Willd. sp. 1. 349. Pursh flor. 1. 67. P. strigosum Mülllenl. in Elliot. bot. In America boreali, Montevideo, Jamuica. $\odot$.

26:3. P. commelinaefolium Rudge, Guian.t. 28. panicula capillarl erecta; spiculis solitariis longe pedunculatis; fol. ovato-lanceolatis acuminatis pubescentibus ad oram harbatis; vagini* appressis sulcatis ciliatis. Mey. act. Bonn. 12. p. 769. In Guiana.

364. P. Bobartii Lam. panicula composita capillacea; glumis acutis; 
fol. hirsutis, supremo spathaceo. Lam. encycl. 4. 748. In America septentrionali?

265. P. torridum Gaudich. culmis elongatis foliisque serice - pubescentibus flavescentibus; panicula ramosa subeffusa. Gaud. in Freyc. it. bot. 411. Neurachne Gaud. Genéral. 93. In insulis Sunduicensibus.

266. P. campestre Nees; panicula capillari erecta patente villosa; pedunculis strictis; spiculis ovatis acuminatis; gluma inferiore aculiuscula, superiore 7-9-nervi; culmo ramoso; vaginis foliisque villosis angustis; radice repente. Nees in Mart. Bras. 2. p. 197. Trin. ic. t. 229. In Brasilia. 2.

267. P. rariflorum Lam. panicula ramossima patente; pedicellis praelongis capillaceis; glumis acutis inaequivalvibus; fol. subpetiolatis. Lam. encycl. 4. p. 746. Orthoclada Nees Poa R. et s. In Brasilia.

268. P. autumnale Bosc. in Spreng. syst. 1.p. 320. paniculae effusae ramis asperis strictis capillaribus 1-floris; flosculis oblongis acutis nervosis glabris; axillis barbatis; foliis convolutis vaginisque glabris. Spr. Patria ignota.

269. P. scoparium Lam. panicula erecta composita setaceo-ramosissima; glumis ohovatis puhescentibus; fol. lanceolatis villosis. Pursh flor. 1. p. 68. Mlichx. flor. 1. p. 49 . In Carolina. $\odot$.

270. $\boldsymbol{P}$. crijennense Lam. culmis ramosis glabris; foliis subtus vaginisque hirsuto-pilosis margine scahris; panicula ramosissima; ramis alternis scabriusculis; spiculis ovatis acutis; glumis inaequalibus glahris; flore nentro bipaleaceo. H. et K. nov. gen. 1. p. 103. P. scoparium Rudge, Guian. t. 29. P. Rudgei R. et s. In Guia$n a$, in ripis Orinoci, Brasilia. 4.

281. P. laetum Kunth, gram. 2. t. 113. culmo procumbente; ranis fasciculato-ternis geniculato-adscendentibus; foliis lanceolato-linearibus planis membranaceis, externe pilosis; vaginis pilis patentissimis obsitis; panicula ramosa patente; ramis hispidulo-scabris; spiculis sparsis longillscule pedicellatis glabris; glumis inaequalibus acutis nervosis; flore hermaphrodito laevi; neutro bipaleaceo. Kunth. In Senegalia.
272. P. laterale Presl; culmo glaberrimo ramoso; ramis divaricatis; vaginis scabris; foliis e basir ovata lanceolatis ohtusiusculis margine ciliatis; paniculis terminalibus patentissimis; rachi glaberrima; sjiculis solitariis ellipsoideis; gluma inferiore brevissima; superiore ovali pubescente florem aequante ; fore neutro 1-paleaceo; palea flure hermaphrodito longiore ellipsoidea laevissima. Presl in 13el. Ifaenk. 1. p. 305. In Peruria.

273. I'. polygonoides Lam. paniculis minutis patentibus; glumis obtusis subventricosis; folits brevibus; vaginis hirtis. Lam. encycl. 4. 71? In Cajenna, Mexico. 4.

284. P. macilentum Sres?; culmo ramoso procumbente glaherrimo; nodis hissutis; vaginis pilosis; panicula patente simplici; ramis alternis; rachi glahra; spiculis subglobosis; glumis ovatis acutiusculis aequilonisis; flore neutro bipaleaceo; palea inferiore cartilaginca; flore hermaphrodito subgloboso apiculato pubescente. Presl in rel. Haenk. 1. p. 310. In ins, Luzonia.

275. P. poaemorphum Presl; culmo compresso erecto inferne glabro; vaginis foliisque planis anguste linearibus scabriusculis; panicula simplici apice nutante; spiculis ovatis compressis; glumis aequalibus 1-nerviis, carinatis, scahris; palea floris neutrius solitaria inferioreque floris hermaphroditi tuberculato-scabris aequalibus. Presl 1. c. In Peruvia.

276. P. ventricosum Lam. panicula ramosa; glumis ventricosis obtusis nervosis subhispidis; culmo basi repente. Lam. ill. 1. 173. ej. encycl. 4. 741. In india.

28\%. P. trigonum Retz; panicula erecta; pedunculis bifloris; calycibus obtusis hispidis 1-floris; seminibus trigonis. Retz obs. 3. p. 9. P. patens Burm. ind. t. 10. f. 2. In India orientali.

278. P. multinorle Lam. panicula capillari laxa; foliis pilosis; culmo repente geniculis crebris distincto. Lam. encycl. 4. p. 747. P. hirsutum Lam. in herb. Mus. Par. In insulce Franciae.

279. P. accrescens Trin. ic. 8. $t$. 88. culmis ramosis decumbentibus inferne radicantibus glabris; vaginis ore pilosis; foliis lanceolatis acutis planis 
supra subpilosiusculis subtus punctulatis, margine hispidulis; panicula ramosissima patente pauciflora; ramis capillaceis apice floriferis; spiculis ninutissimis subrotundis glahris pedicellatis; flore inferiore neutro 1-2paleaceo; superiore hermaphrodito tenuissime striato. Trin. In Nepalia.

250. P. aciculare Desr. in l'orr. cncycl. suppl. 1. 2\% \&. spicis lateraiibus minimis simplicibus; florihus ovatis suhglabeis vis pelicellatis; foliis acicularibus; caule ramosissimo. Poir. P. subunillorum Bosc. In India orientaii.

251. P. caricoides Nees; spicis pauciforis secundis simplicibus fasciculatis; spiculis ovatis obtusis solitariis racheos dentibus barbatis impositis; flosculo neutro 2-valvi; culmis erectis caespitosis ramosis filiformihus glabris i vaginis foliisque angustis canaliculatis subvillosis oris longe barbatis. Nees 1. c. In Brusilia. 4.

282. P. serpens Kunth; spicis foliis brevioribus $3-4$-noris; spiculis ovatis aculis villosis; culmo repente; ramis abbreviatis erectis; fol. lanceolato-linearibus vaginisque pubescentibus vel lanuginosis. P. serpens. Nees in Mart. Bris. 2. p. 236. var. P. pygmacum sipr. In ins. Franciue et Borbeniae.

283. 1'. juniperinum Nees; culmo ramosissino procumbente repente; ramulis adscendentibus foliosis; fol. ovato-lanceolatis utrinque vaginisque pilosis; paniculis valde depauperatis; spiculis 4-6 oblongis acutis glabris; flore hermaphrodito laevi nitido; sterili 2 -paleaceo. Kunth Gram. 1. p. 229. t. 26. In ins. Borboniae.

384. P. lycopodioides Bory; spicis folia subaequantihus; spiculis solitariis; caule procumbente; ramis erectis simplicibus vel fasciculatis; fol. ovato-Ianceolatis suimbricatis vaginisque striatis glabris. Nees l. c. In ins. Borboniae.

28.5. P. latifolium $\boldsymbol{L}$. panicula racemis lateralibus simplicibus; fol. ovato-Ianceolatis collo pilosis. Linn. sp. p. 86. Moris hist. 3. s. 8. t. 5. f. 4. In America boreali. 24.

286. P. Boscii Poir. panicula brevi pauciflora, subpubescente; glumis nervosia ; semine nudo; fol. lanceolais erectis glabris; vagina basi margi- neque barbata; caule glabro simplici. Poir. Enc. 4. p. 276. In Curolina.

28\%. D. Wulteri Poir. fol. Ianceolatis amplexicaulibus glabris; vaginis subtomentosis; basi circa nodum colloque harhatis; panicula sessili glabella subramosa; glumis pubescentibus ; valvula extima ovali. Poir. Enc. 4. p. 282. P. Iatifolium IValt. In Virginia é Carolina. 4.

288. Pl. clandestinum $L$. racemis occultatis inira folioruin vaginas. Limn. sp. p. 86. spr. Act. Petrop. 2. t. 5. In America boreali. $2 !$.

25.9. D. macrocarpum Leconte; culmo erecto vaginisque pubescentibus; nodis nudis; fol. cordato-lanceolatis utrinque nervosis glabris ciliatis; panicula subcomposita ramosa; glunis majusculis turwidis ovatis pubescentibus striatis. Torrey in Cat. of plants of N. York p. 17.

2.90. P. maculatum Aubl. scandens; caule arundinaceo arborescente altissimo; panicula racemis lateralibus compositis; fol. ovato-lanceolatis acuminatis. Sichult. Mant. 2. p. 238. P. Iatifolium $\beta$. Lam. In Portorico et St. Domingo.

291. P. Sellorii Nees; racemo decomposito contracto; ramis elongatis; pedunculis subbiforis; spiculis ohovatis pubescentibus; culmo erecto dichotomo-ramoso; fol. oblongo-acuminatis hasi rotundatis supra pilosís subtus nodis vaginisque unimute pubescentibus. Nees 1. c. In Brasilia. 4.

292. Pr. Beyrichii Kunth; arborescens; glabrum; fol. ovato-lanceolatis basi rotundatis planis rigidulis margine scabris; vaginis superiorihus ciliatis; panicula simpliciter ramosa; ranis elongatis inferne nudis patulis; spiculis glabris ellipticis pedicellatis; flore fertili undulato-rugoso. Kunth Gram. 1. p. 231. t. 28.

293. P. commutitum Scliult. culmo nodisque nigrescentibus glabris; fol. Ianceolatis acuminatis margine scabris basi ciliatis; vaginis striatis elongatis, margine pubescentibus purpurascentibus ; ligula parbiformi; panicula terminali; ramis plurimis patulis glabris subflexuosis; calycis valvula minima ovata acuta, ceteris acutis nervosis. P. nervostum Mïhlenb. In America boreali.

294. P. hydrophilum Schult. cul- 
no compresso subpubescente: fol. lineari-lanceolatis nervosis acuminatis panicula contracta; ramis erectis; peilicellis sub calyce nodosis angulatis glabris flexuosis; calycis valvulis acutis glabris nervosis. P. aquaticum Mühlenb. In ayuosis imericat borélis. $\odot$.

29.5. P. Zizanoides II. et IB. culmis notisque glabris; fo!. Ianceolatis margine serrulato-scaibris; panicula ramosi, ramis alternis; glumis subaequalibus; flore meutro 2 -palcaceo. Kuntl in H. et 13. Nov. g̈en. 1. 1. i00. In Vora Granate. 4.

2.96. D. Bulbisianum Schult. culnis ramosis glabris; fol. lanceolatis acuminatis, supra basin pilis rarissimis; margine serrulato-ciliatis ; panicula subsimplici ramis patentibus alternis scahris; spiculis ovato-lanceolatis acuminatis; glumis inaequalibus glabris. sichult. mant. 2. p. 25t. P. atuense Herb. Balb. In st. Domingo.

29\%. P. petiolatum Nees; paniculis racemosis axillaribus terminalihusque conpositis; ramis alternis strictis; glumis subaequalibus $\tilde{\mathbf{5}}-\mathbf{7}$-nervibus apice incurvis; culmo prostrato nodisrue lanuginoso - villoso; fol. ovatooblongis in petiolum attenuatis, vlabris marogine lauuginosis. Nees 1. c. In Brasilia.

2.98. P. axillare Nees; panirula racemosa axillari terninalique composila; ramis alternis strictis; ylumis subaequalions utraque 3-nervi; valvula inferiore flosculi hermaphrouiti 5-nervi; culmo repente nodisque pubescenti-scabris; fol. cordato-ohlongis, amplexicaulibus supra pilosis. Nees 1. c. In Brasilia.

2.99. P. perfolutum Nees; panicula terminali dichotona stricta; sijculis sessilibus subgeminatis obtusis; glumis aequalibus pubescentibus; culno erecto volisque glaluris; fol. ohlongo-lanceolatis cordatis amplexicaulibus ciliatis. Nees 1. c. In Brasilia. 2 .

300. P. varinatum Nees; culmo crecto simplici; foliis lanceolatis pubescenti-pilosis; vagina summa aphylla; ramis ad basin harbulatis; gluma superiore 5-nervia. Kunth Gram. 2. t. 166. In Inrasilia merialionale. 24.

301. I. olyroides Kunth; culmis ramosis? glabris; fol. linearibus subtus pilosis integerrimis; panicula ra- mosa ramis alternis oppositisque glabris subfastioriatis; spiculis ovatis acuminatis; tis glabris; flore neutro 2-paleaceo. II. et K. I. c. In Nova Andalusice. 4.

302. P. bumbusoilles Hamilt. culno divaricato - ramoso arboreo; ramis apice foliosis; fol. lanceolato-chlonris; vaginis pubescentibus; panicula iivaricato-ranosa elongata; flosculis solitarits; pedunculis elongatis scabriusculis. Hamilt. prodr. p. i0. In Portorico.

303. P. sorghoideum Hamilt. culmo arborescente ramoso; fol. latolanceolatis subtus puberulis; paniculs ramosa; ranis subfasciculatis. Ilamilt. prode. p. 10. In Portorico.

301. P. agylutinans Kunth; culmo ramoso glabro; fol. lineari-lanceolatis pilosis margine scairis panicula ranosa; ramis patentibus pubescentibus; spiculis ovatis; glumis inaequalihus ciliatis; flore masculo bipaleaceo. Kunth, P. glutinosum Lam. ill. t. 43. f. 3. In Ámerica calidiore. 24.

30.5. P. gullinosum Sw. panicula composita patente ramis fiexuosis; spiculis pedicellatis distantibus glutinosis; culmo erecto simplici; fol. latioribus. Sw. prodr. p. 2t. In America meridionali et Jamaica.

306. P. fiexuosum Retz; panicula capillari patente; pedunculis flexuosis; calycibus ovatis; geniculorum barba refiexa. Retz obs. ¿II. p. 9. In Indiu.

30\%. P. Innatum Șu. paniculs composita erecta grabra; spiculis ovatis; culmo ramoso; fol. ovato-lanceolatis pubescentibus; vaginis lanuginoso-hirsutis. siw. proùr. p. 21. In Jamaica et Peraria.

303. P. divaricatum J. paniculis brevilus muticis culmo ramosissimo divaricatissimo; pedicellis 2-floris altero hreviore. Liun. Amoen. V. p. 392. Jacq. Hort. Sichoenb: 1. t. 25. Kunth Grain. t. 29. In America moridionali. 4.

309. P. tuberculatum Presl; culmo erecto tereti simplici; vaginis tuberculato-hispidis; fol. e basi rotundata lauceolato-linearihus glahris margine scabris; ramis paniculae verticilatis simplicibus; spiculis subsecundis, geminatis ovatis; gluma inferiore ro- 
tundata spicula breviore superiore paleaque inferiore flosculi hermaphroditi ovato-acuta, laevissima. Presl. Rel. Haenk 1. p. 307. In Luzonia.

310. ․ plciophyllum Link; ramis junioribus foliisque densis basi rotundalis, pubescentibus; spiculis subremotis compositis arrectis non secundis; rachi pubescente scabraque valvulis oblongis nervosis margine lanatis, pubescentibus. Link Hort. 1. p. 208. Patria ignota. 4.

311. P. ruscifolium Kunth; culmo ramoso glabro; fol. ovato-oblongis subcordatis membrauaceis pubescentibus margine scalris; panicula simplici depauperata; ramis pubescentibus; spiculis subglobosis; glumis inaequaIilus, apice piloso-ciliatis; flore neutro 2-paleaceo. Humb. et Kuntl. Nov. Gen. 1. p. 101. In Mexico. 4.

312. P. divergens Funth; culmis ramosis foliisque giabris lineari-lanceolatis, serrulato - ciliatis; panicula ramosa subverticillata ramis divaricatis glabris; spiculis obovatis obtusis; glumis inaequalibus puberulis; flore neutro 2-paleaceo. Humb. et Kunth 1. c. In Quito. 24.

313. P. megustachynm Nees; racemo composito contracto; partialibus elongatis pubescentibus subsecundis; pedicellis bifloris; spiculis ellipticis obtusis glabris hasi harhatis altera ad basin pedicelli subsessili; fol. elongatis vaginisque glabris. Nees in Mart. Bras. p. 15t. Trin. ic. t. 234. In Brocisilia.

214. P. elatius Kunth; panicula verticillata laxa; ramis simplicibus elongatis paucifloris; florilus ovatis vaginis papillato setosis; fol. lanceolatis. Nieyer Esseq. p. 63. P. megiston Schult. In Esserjuebo et Brasilia. 24.

315. P. Preslii Kunth; culmo erecto simplici tereti glabro; vaginis deorsue hirsutis; fol. involuto-canaliculatis; panicula contracta; rachi glaberrima; spiculis ovoilleis; glumis exteriore parina hirsutissimis inaequalibus; floris masculi bipaleacei palea inferiore glaberina ovata acutiuscula. P. megastachyum Presl 1. c. In Peruvia.

316. P. luzonense Presl; culmo ramoso prostrato, vaginis foliisquo pilosis linearibus; panicula composita secunda; rachi communi partialibusque pilosis; spiculis oblongis; gluma inferiore ovata acuta spicula hreviore; superiore ovata lanceolata spiculam aequante; flore neutro bipaleaceo; floris hermaphroditi palea inferiore laevissima. Presl 1. c. In Luzonia.

317. P. streptostachys Spr. fol. lato-lanceolatis vaginisque pilosis; panicula sessili ; ramis elongatis. Streptostachys hirsuta Beauv. Agr. p. 49. t. 10. f. 11. S. aspera Desv. In America meridionali.

\section{Species hujus sectionis o Nova Hollandia.}

31s. P. marginatum R. Br. panicula lanceolata e spicis divisis; spiculis paucifloris; floribus ovatis acutis glumis glabris; valvula exteriore minuta enervi; flosculo hermaphrodito sericeo neutro 1-valvi; fol. planis glabris marginatis. H. Br. prod. 1. p. 190. In Nova Hollandia.

31.9. P. pubigerum $R$. et S. panicula patente lanceolata; ramis strictis parum divisis; pedunculis 2-floris; pedicellis inaequalibus; rachibus glumisque villosis mucronatis; culmis foliisque pubescentibus mollibus; marginibus simplicibus scabris. P. pubescens. R. Br. 1. c. In Nova Hollandia.

320. P. airoides R. Br. panicula subefusa; floribus ovatis muticis; hinc gibhosis acutis glabris; flosculo exteriori masculo hermaphroditum superante; valvula exteriore apice ciliata; culmo foliisque glabris planis; collo vaginae harlato. $\mathrm{R}$. Br. 1. c. In Nova Hollandia.

321. P. foliosum R. Br. panicula patente lanceolata; ramis strictis parum divisis simplicilusve; rachibus villosis; glumis pubescentibus acutis; fol. lanceolatis undulatis marginatis utrinque pilosis; culmo ramoso. $\mathrm{K}$. Br. 1. c. In Nova Hollandia.

322. P. panciflorum R. Br. panicula simplicissima rara; ramis patentibus paucifloris ; floribus ovalibus acuminatis glabris; fol. linearibus glabris vaginisque pilosis. I. Br. l. c. In Nova Hollandia.

323, P. pygmaeum R. Br. panicula patente rara e racemis subsimplicibus; rachibus subflexuosis; flori- 
hus ovalibus acutiusculis glabris; fol. lanceolatis ciliatis; culmo repente; ramis adscendentibus pilosis. I. Br. 1. c. In Noere Hollandia.

321. I. minutum li. Br. panicula efiusa rara; ramis parum divisis paucifloris; rachibus villosis; floribus obovatis pubescentibus; fol. late lanceolatis pilosiusculis; culmo multiplici erectiusculo villoso. 1R. Br. 1. c. In Nora Hollandia.

32.5. W. bicolor $R$. Mr. panicula lanceolata; ramis patentihus strictis parum divisis; ramulis paucifloris; floribus ovatis acutis glabris; flosculo neutro 2 -valvi hermaphrodito glaberrimo nitido; fol. villosiusculis linearilus. 12. Bi: 1. c. In Nova Hollandill.

326. P. uncinulatum R. Br. panicula lancevlata; ramis subsimplicibus; noribus ovalibus; glumis pilosis, pilis uncinulatis flosculo hermaphrodito taevi; fol. linearihus culmoque ramoso glabris. H. Br. 1. c. In Nova Hollandia.

32\%. P. effusum R. Br. panicula conıposita patente rara capillari; ramulis pedicellisque flexuosis; floribus acutis glabris; fol. vagiuisque pilosis scabris, geniculorum barba patente. 12. Br. 1. c. In Nova Hollundia.

3:s. P. decompositum R. Br. panicula decomposita patente capillari floribus acutis nudis; fol. vaginistue glabris geniculis imberbibus. H. Br. 1. c. In Nove Hollandia.

\section{Species dubiae hujus sectio- uis Kunth.}

32.9. P. aturense Funth; culmis simplicibus glabris; fol. lanceolatis interne pilosis margine ciliatis; panicula simplici coarctata; ramis alternis glabris; spiculis oblongo-lanceolatis acuminatis; glumis subaequalibus glabris; flore neutro 2 -paleaceo. If. et K. Nov. Gell. 1. p. 103. t. 33. Ad cataractas Aturenses.

330. P. viridiflorum Nees; racemo subsimplici, coarctata; ramis alternis basi divisis; spiculis lanceolatis acuminatis; glumis aequalibus $7-9$ nerviis; flosculo neutro 2 -valvi margine villoso; culmo adscendente ramoso; fol. lanceolatıs, supra pilosis maroine ciliatis. Necs 1. c. Palria ignota.
331. P. isoculycinum Heyer; panicula erecta flexuosa; ramis basi pilorum fasciculis stipatis; floribus oblongis acuninatis; calycis valvulis omnibus aequilongis 7 -9 nerviis. Meyer Esseq. 1. 59. In Essequelo. $\odot$.

33ż. I'. blepharophorum I'iesl; culmo erecto lamoso, compresso, glabro; nodis wlaberrimis; vayinis foliisque hirsutis ciliatisque; panicula coarctata simplici; ramis alternis glabris; pedicellis filiformibus; spiculis lanceolatis acutis; glumis 7-nerviis acuminatis; inferiore submajore; palea inferiore flosculi neutrius lanceolatociliata, superiore minore apice 2-fida; palea inferiore flosculi hermaphroditi ovato-lanceolata, laevissima, acutissima. Presl liel. Haenk, 1. p. 312. In Nexico. 4.

333. P. calvescens Nees; panicula decomposita capillacea; ramis basi harbatis; pedunculis 2-floris; spiculis ovatis obtusis compressis; glumis aequalibus superiore $\mathbf{5}$-nervia; flosculo hermaphrodito 2-valvi; culmo ramoso nodisque glabris; fol. lineari-lanceolatis junioribus yagrinisque subhirsutis. Nees 1. c. In Brusilia.

334. P. Phrugmites Nees; panicula lecomposita; ramis tenuibus basi callosis glabris; pedunculis 2 -floris adpressis; spiculis oblongis obtusis teretibtis; Elmnis subaequalibus superiore 5-7 nervia; flosculo neutro 1 valvi; culmo ramoso nollisque glabris; vaginis sparse tuberculato-hirsutis; fol. lineari-lanceslatis subtus glaucis. Nees 1. c. In lirasilia.

33.5. P. moluscideum Trin. racemo composito denso; ramis solitariis e medio racemosis, paucifloris; spiculis oblongis acuminatis; gluma inferiore minore $8-9$ nervia, superiore 10-nervia; flosculo neutro 2 -valvi margine nudo; flosculo hermaphrodito basi paleis harbato; culmo erecto foliisque linearibus strictis glabris. Nees 1. c. In Brasiliu.

336. P. leucophaeum Kunth; culmo erecto nodisque glabris; fol. glabris subtus glancescentibus; spicis creberrimis verticillatis subfastigiatis; spiculis geminis; gluma superiore externe villosa. H. et B. Nov. Gen. 1. p. 97. Trin. ic. t. 220. Milium villosum Sw. Andropogon insulare L. In Nova Andalusia et Nova Granata. 4. 
33\%. P. recalvum Iunth; racemo Eubfastigiato; spiculis lanceolatis dorso glabris, pedicello longioribus; fol. lineari-lanceolatis, scabris; vaginis hirsutis; ligula truncata. Nees 1. c. In Brasilia.

338. P. tenerrimum Kunth; racemis partialibus paucis $(3-6)$ adpressis; spiculis lanceolatis, pedicello Iongiore hrevioribus; glumis dense villosis; fol. linearibus supra pubescenti-scabris subtus vaginisque laevibus; ligula ovata acutiuscula; culmo ranosissimo. Trichachue tenuis. Nees in Mart. Bras. 2. p. 89. In Brusilia. 4.

339. P. vestitum Funth; racemo fastigiato; spiculis ovatis oblongis; fol. linearii)us vaginisque pilosis. Nees 1. c. In Brasilia meridionali. 4.

30. P. ferragineum funth; culmis simplicilus; nodis imberbibus; fol. convolutis rigidis vaginisque glabris interue sulcatis scabriusculis; spicis quateruis-senis fasiciculato-congestis ; spiculis teruis pelicellatis ovato-oblongis; gluma inferiore nulla superiore trinervia ferrugineo-villosa; flore bermaphrodito glabro; neutro 5 -nervio, ferrugineo-villoso, dorso glabro bipaleaceo; palea superiore minuta. Kunth Gram. 1. p. 39. t. 165. Trichachne Nees. In Ironterideo. 4.

3\$1. P. saccharoides Funth; spicis creberrimis filiformibus paniculatis fastigiatis; spiculis ovato-lanceolatis acutatis pedicellatis remotis; gluma inferiore nulla; superiore pilis longissimis mollibus ciliata; flore neutro 1paleacea enervio; fol. interne sericeopubescentibus; ligula hirsuta; culmo erecto altissimo. Kunth Gram. 1. p. 13\%. t. 30. Saccharum polystachyum \$w. Paspalum Nees. Trip. ic. t. $10 \%$. In America calidiori.

342. P. acariferum Trin. ic. $t$. 8\%. culmo duro farcto tereti glabro; vaginis cylindricis glaberrimis; fol. latissimo - lanceolatis acuminatis planis utringue glabris striatis subtus pruinoso-glancis; panicula magna patente ramis alternis compositis penrulis; spiculis pusillis; glumis acutiusculis, apice barbatulis, 5-nerviis subaequalibus; flore inferiore unipaleaceo neutro, superiore hermaphrodito ad utrumque narginem papilloso-pi10so. Kunth Agrost. p. 125. Melica liosb. In India orieníali,
343. P. ramosum $L$. ramis paniculae simplicibus; noribus subternis, inferiore subsessili; culmo ramoso. Linu. Mart. p. 27. In Indiu.

34t. 1. ischatemoides Retz; panicula erecta contracta; caly cibus bifloris, polygamis, acutis; culmo simplici; fol. distichis rigidis. Retz obs. 4. p. 17. In udis Malabariae.

34.5. 13. remotum Ret:; paniculae ramis 3-quetris; fosculis subgeminais, altero pelicellato; culmo ramoso 4-gono, compresso. Hetz 1. c. In Traninebaria.

346. P. antidotule Retz; panicnla nutante; calycibus 2 -floris polygamis acutis; culmo erecto ramosissimo. hetz 1. c. Coüitur in hortis Malabarorum.

34\%. P. notatum Retz; panicula patente; axillis notatis ; fol. lanceolatis ciliatis. Retz 1. c. In Sumatra.

318. P. rudicuns Retz; paniculatum culmo ramoso radicante; foliorum basi vaginisque longitudinaliter ciliatis. Hetz I. c. In China.

34.9. P. patens L. panicula oblonga flexuosa capillari patente; calycibus 2-floris; fol. lineari-lanceolatis; culmo radicante. Lim. sp. p. 86. In India.

350. P. Roxburghii 8pr. culmis adscendentibus; fol. longis; paniculis oblongis ramosissimis; floribus solitariis remotis; valvulis calycis secundis recurvis aculis; corolla trivalvi; semine ovato glabro 5-nervio. P, tenellum Roxb. ind. 1. p. 309. P. tryplieron 13. et $\$$. In India orientali.

351. R. servulatum Roxb. culmis erectis, 2-4-petum; fol. ensiformibus marginibus serrulatis; panicula spicata; valvulis calycis acutissimis; semine oblongo glabro. hoxb. 1. c. In vallibus humidis Indiae orientali.

3.5:. 1) paludosum Roxb. culmis erectis 2-3-ped.; panicula erecta ovata teuni ; ramis paucis 3 -quetris; angulis acutis hispidis; pedicellis 2fioris; valvis calycis cuspidatis; $\mathrm{CO}$ rolla 3-valvi; senine oblongo glabro. 13oxb, 1, c. In aunosis montium Circars.

353. P. uliginosum Roxb. culmis erectis $2-4$ pedum; panicula tenui; ramis 4-gonis glahris; floribus solitariis polygamis; semine oblongo glahro. Roxb. 1. c. P. Roxhurghiantum il. et s. Ald snargines oryzetorum. 
3.5. P. surmentosum Roxb. peremue; inaue; pilosum ; sarmentostun; sarmentis sulierectis, floriferis e geniculis; panicula patenti; floribus solitariis; calycibus glahris obtusis; flore altero hermaphrodito, altero neutro. Loxb. 1. c. In Sumutra.

3.5.5. P. tenue Roxb. culmis erectis ramosis 1-6 pel.; panicula tenui ; floribus in pedunculo communi geminatis, pedicellis partialibus fulcratis; corolla 3-valvi; semine ovato transverse undulato. IRoxb. 1. c. In montibus Circurs.

3.56. P. montanum Roxb. culmis erectis glabris $3-4$ ped.; fol. lanceolatis nervo inaequaliter divisis; panicula oblonga; ramis capillaribus rectis; corolla 2 -valvi; semine glabro ovali dorso trinervio. Roxb. 1. c. In monitibus Circars. 4.

3.57. P. asperatum Kunth; erectum herbaceum; pilis rigitlis asperatum; fol. lanceolatis plicatis; panicula lanceolata; ramis compositis; floribus geninis polygamis. P. plicatum Hoxh. 1. c. In Sumatra. 4.

3.58. P. atrovirens Trin. culmo suhramoso vaginisque glabris; fol. lanceolatis atrovirentibus asperrimis; panicula laxiuscula; spiculis orbiculatis; glumis calycis subaequalibus nosculo breviorilus punctulatis. Trin. in spr. N. Entel. 2. p. 29. In India orientali.

3.59. P. Monachne Trin. paniculae rarae ramis fiexuosis; flosculis obtusis glaberrimis; fol. linearibus firmis; culmo ramoso. Spr. syst. 1. p. $\mathbf{3 1 3}$. In ins. Mascarenis.

360. P. subuniflorum Bosc. panicula pauperrina vaginata erecta; fosculis obtusis nervosis puhescentibus; fol. convoluto-setaceis rigidis basi ciliatis; vaginis striatis glabris; culmo ranoso. spre. syst. 1. p. 312. In Curolina.

361. P. Sprengelii Funth; panicula pauciflora erecta longe peduncuIata; flosculis ovatis acutis glaherrimis striatis; fol. linearihus subconvolutis hirsuto-ciliatis; culmo basi ramoso glabro. P. Mühleuhergii spr. syst. 1. p. 314. P. acumiuatum Mülıleub. In America boreali.

362. P.elongatum Purst ; glabrum; elatum; paniculis pyramidatis Iateralibus geminis elongato-pedunculatis terminalibusque ramulis alternis divarica- tis; glumis alternis ohlongis acutis pedicellat is coloratis; fol. Iongis; collo subbarbato; caule compresso. Pursh Fl. am. bor. 1. p. 69. In stagnis et humidis reip. New Jersey ad Virginiam. 4.

363. 1. tremuium spr. paniculae ramis gracilibus divergentibus glabris flexuosis; flosculis obtusiusculis striatis; culmo compresso striato fuliiscue glabris Spreng. syst. 1. p. 319. In Nova Caesarea.

36-1. P. rectum $\boldsymbol{R}$. et $\mathbf{S}$. panicula solitaria folio teruninali breviore; ramis simplicihus flexuosis; glumis alternis pedunculatis obovatis turgidis; valvulis multiseriatis acutis; fol. linearibus strictis sensim acutissimis supra striatis subtus pilosis; vaginis longissime pilosis. P. strictum Pursh Am. sept. 1. p. 69. Ad ripas fluvii Delaware, in Pensylvania.

36.5. P. cartilagineam Mühlenb. paniculae erectiusculae ramis flexuosis; flosculis ohtusis pubescentibus; fol. lanceolatis margine cartilagineis; vaginae oris ligulaque harbatis; culmi nodis glabris." spr. syst. 1. p. 314. In Georgia.

366. P. eriophorum Schult; paniculae difusae ramis capillaribus glahris; flosculis ohovatis villosis; fol. lineari-lanceolatis vaginisque lanatis. P. lanugiuosum Spk. syst. 1. p. 315. In Carolina.

36\%. P. spretum schult; culmo glabro striato; nodis glabris; fol. lineari-lanceolatis, radicalibus abbreviatis; ligula alha harbiformi; panicula terminali contracta ramosissima densa; ramis glabris ternis ramulisque flexussis; valvulis calycinis puherulis parvulis. Muhlenb. descr. ub. p. 125. In Nova Anglia.

365. P. densum Mühtenb. culmo crasso pubescente, nodis pilosis; fol. lanceolatis nervosis pubescentibus margine pilosis; ligula pilifera; vaginis elongatis strialis pubescentihus; panicula densa multiflora, pedunculis pedicellisque subglabris. Mühlenh. descr. uh. p.122. In America boreali. 369. P. macrum Funth; culmo tenui caespitoso; nodis glabris; fol. lineari-lanceolatis glabris acuminatis; vaginis inferiorilus pilosis; ore pubescente; paniculae ramis ternis, divisis glabris calyce pubescente; valvula proxima ovata. $P$. tenue Muhlenb. I. c. p. 118. P. deustum 
Brick. et Enslin. P. liton Schult. In America boreali.

3z0. H. acuminatum Su. paniculis simplicibus; fol. brevioribus; ramis capillarilus diffusis; spiculis remotis obovatis; culmo decumbente greniculato ramoso; fol. lanceolato-subulatis erectis; vaginis villosis. Sw. prodr. p. 23. In campis arenosis Jamuicae montosae.

371. P. laxum Su. panicula simplici nutante; ramis capillaribus; spiculis approximatis alternis appressis; culmo simplici filiformi flaccido; fol. lineari-lanceolatis. Sw. 1. c. p. 23. In nemorosis aridis Jamaicae.

372. P. flavescens siw. panicula simplici erecta stricta; ramis subfastigiatis, imfinis oppositis; spiculis approximatis secundis; pedicellis bifloris. Sw. 1. c. p. 23. P. fasciculatum $\beta$ Nees. $3-4$ pedale. In aridis Jamaicae anstralioris.

373. P. oryzoides $\mathbf{S} w$, panicula subsimplici; ramis erectis spiculis remotiusculis ovatis acutis; culmo erecto indiviso; fol. lato-ranceolatis basi rotundatis; vaginis sulcato-striatis. sw. 1. c. p. 23. 3-t pedale. In Jumaica australi.

37 4. P. patentissimum Poir. glabrum; erectum ; fol. angusto-oblongis ; panicula erecta pyramidali; ramis paucis dissitis plerisque geminis simpliciusculis divaricato-patulis etiamque reflexis; floribus muticis binis; altero pedicello neutro. P.? divaricatum Michx. FI. hor. 1. p. 50. In excelsis montibus umbrosae Carolinae.

37.5. P. multinerve Poir; panicula glabra diffusa erecta; fol. lato-lanceolatis longissimis glaberrimis; glunis ovatis obtusis; valvula tertia minima. Poir. Enc. 4. p. 219. In Antillis.

376. P. vimineum Schrad. culmo erecto simplici; fol. lanceolato-linearibus planis subtus leviter pubescentihirtis; vaginis ciliatis; paniculis ramosis terminalibus axillaribusque; ramis alternis villoso-pubescentibus; spiculis ohlongis; calycinis valvulis inaequalibus pilosis; flore neutro 2valvi. Schrad. Mss. In Brasilia.

37\%. P. Maximiliani Schrad. culmo erecto simplici; fol. ovato-lanceolatis undulatis pubescentibus; panicula ramosa; ranis alternis patentibus vaginisque villoso-pubescentibus; spicu- lis oblongis; calycinis valvulis subaequalibus pilosis; flore neutro 2-valvi. sclirad. Mss. In Iirasilia.

378. 1. nemorale Schrad. culmo adscendente inferne radicante ramoso; fol. lanceolatis leviter undulatis hasi vaginisque villosis; panicula subramosa; ramis alternis patentibus scabris basi pilosis; spiculis obìongis; calycis valvulis subaequalibus, glabris; flore neutro 2-valvi. schirad. Mss. In Brasilia.

379. P. latissimum Mikan; culno vaginis foliisque latissimis ovato-lanceolatis, glabris; panicula oblongolanceolata, nutante; rachi glalira; spiculis oblongo-acutis; gluma inferiore ohlonga 3 -nervi flosculo breviore, subpilosa; superiore glabra; flosculo hermaphrodito acuto glaberrimo. Trin. ic. t. 202. In Brasilia. 4.

350. P. subulatum Spr. glaherimum paniculae aequalis ramis capillaribus; flosculis ovatis ohtusiusculis nervosis; fol. subulatis; culmo ramosissimo gracili. Spr. syst. 1. p. 319. In Brasilia.

381. P. setifolium Nees; paniculis capillaribus parvis patulis; ramis basi racematim divisis simplicihusve spiculis ovato-subglobosis pubescentibus; gluma inferiore ovata obtusa dimidio hreviore culmo adscendente dichotomo ramoso; vaginis velutino-ciliatis; fol. superiorihus convoluto-setaceis erectis ; ligula hrevissima truncata minute crenulata. Nees 1. c. In Brasilia meridionali.

352. P. Heynii Roth; paniculae oblongae ramis strictis divisis basi pilosis; infimis verticillatis cum ramulis fasciculatis flexuosis asperis; pedicellis alternis solitariis; calycis gluma exteriore cordata ohtusa spiculam involvente; fol. argute serratis; vaginis margine et ad oras pilosis. Roth. Nov. Sp. p. 49. In India orientali.

353. P. Mertensii Roth; paniculae oblongae ranis strictis simplicibus basi subpubescentibus omnibus verticillatis; pedunculis geminis valde in aequalibus; calycis gluma exteriore cordata obtusa spiculam hasi obvolvente; foliorum vaginis superue strigosis. Roth. 1. c. In Essequebo.

381. P. ornatum Hamilt. culmo alto ramoso subvilloso; fol. cordatolanceolatis pubescentibus nodis verti- 
cillatis pilosis; ramis paniculae villosis; flosculis alternis pubescentibus. Hamilt. prodr. p. 11. In Portorico. 385. P. portoricense Hamilt. culmis flexuosis subfasciculatis apice ramosis; nodis nudis; fol. lineari-lanceolatis glaberrimis basi fimbriatis; panicula subsessili divaricata; flosculis patentissimis, subovatis pilosiusculis. Hamilt. 1. c. In Portorico.

386. P. auriculatum Willd. paniculae ramis strictis; flosculis lanceolatis acuminatis glabris nervosis; fol. cordato-auriculatis lanceolatis basi ciliatis. spr. syst. 1. p. 322. In America australi.

35\%. P. bisulcatum Thunb. panicula capillari patente; calycibus 3nerviis; vaginis foliorum duplicatosulcatis margine fimbriatis. T'lumb. Nov. Act. Cps. 7. p. 141. P. grossarium Thunb. jap. In Japonia.

358. P. convolutum Reaur. culmo tereti erecto simplici glaberrimo; vaginis ore barhatis; fol. linearibus canaliculatis glaherrimis; panicula foliosa patente, rachi communi partialibusque scahris; spiculis solitariis ovato-lanceolatis; gluma inferiore rotundata obtussima; superiore et palea neutra inferiore ovato-lanceolatis acutis; gluma liermaphrodita inferiore ovato-lanceolata laevi. Presl Rel. Haenk. 1. p. 304. In Africa aequinoctiali et lausonia.

38.9. P. madagascariense Spr. paniculae diffusae ramis divaricatis glabris; flosculis oblongis acutis glaberrimis obsolete nervosis; fol. convolutis vaginisque laevilsus; culmo ramoso. P. coloratum Thouar. In Madagascar et ins. Franciae.

390. 1'. confertum Desv. panicula erecta lanceolata apice conferta; fol. elongato-lanceolatis glabris vaginis superne liheris convolutis ore harbatis. Poir. Enc. 4. p. 279. In Antillis.

3.91. P. festucoides Poir. panicula sessili subdiffusa glahra; flosculis elongatis; glumis scariosis muticis corolla brevioribus; fol. arundinaceis glahris. Poir. Enc. 4. p. 279. In India.

392. P. Pterygodium Trin, radice repente culmis erectis simplicibus glabris basi subbulbosis nodis sericeovillosis; vaginis ciliatis; fol. convoIuto-setaceis sericeo-scabris; panicula contracta lineari lasiuscula; spiculis ovatis obtusis ; glumis brevibus aequalibus; flore utroque 2-paleaceo; inferiore masculo. Nees in Mart. Bras. 2. p. 272. In Brasilia.

\section{Species dubiae.}

393. P. squarrosum Lam. spicis linearibus alternis subfasciculatis; calycihus subulatis scabris; valvula tertia obtusa. Lam. 1. c. Echinochloa R. et s. Ad Senegal.

394. P. abovtivum R. Br. panicula effusa e spicis alternis raris paucifloris; floribus lanceolatis acuminatis; glunae valvula interiore hispida; fol. supra pilosiusculis; culmo ranoso compresso vaginisque retrorsum scabris. R. Br. prodr. 1. p. 49. In Nova Hollandia.

3.9.5. P. spinescens R. Br. panicula patente lanceolata e spicis alternis indivisis ratis; floribus lanceolatis acuminatis semicoloratis fuliisque glabris planis; vaginis retrorsum laeviusculis. H. Br. l. c. In Nova HoL landia.

396. P. muricatum Retz; panicula patente; floribus solitariis muricatis; culmo radicante adscendente. Retz. obs. 5. p. 18. In India.

397. P. deustum Thumb, panicula patente; floribus solitariis; glumis glabris apice purpureis. Thunb. prodr. 1. 19. In Prom. b. spei.

398. P. inconstans Trin. racemo composito; racenulis brevibus paucifloris inferioribus subpatulis; spiculis solitariis, ovato-ohlongis, acutis glahris; gluma inferiore partem quartam breviore quam superiore; culmo ramoso elongato; fol. lineari-lanceolatis glabris pubescentibusque. Nees 1. c. In Brasilia.

399. P. abludens $R$. et S. panicula subcontracta stricta; ramis basi villosis cum ramulis fasciculatis alternis; spiculis ovalibus; calycis 1valvis gluma suliata villosa; culmo ramoso; fol. linearibus sursum scabris. P. paradoxum hotl. Nov. Sp. p. 53. In India orientali.

400. P. capense Lichtenst. panicula capillacea; ramis basi fasciculato-partitis, a basi spatio nudis ramulisque fasciculatis, flexuosis glabris; spiculis ovatis obtusis villosis; gluma inferiore oblonga, spicula triplo breviore; losculo masculo 2-valvi; 
culmo hasi ramoso adscendente foliisque lineari-acuminatis supra velutino-sericeis; ligula truncata denticu1ata. Nees in Limaea 7. 1. 275. In Prom. b. spei.

401. E. Iymnocarpon Elliot; spicis paniculatis; spiculis distichis paucifloris; calycis valvis subaequalibus patentibus corolla multo longioribus. Elliot bot. p. 117. In Savannah. 24. 102. 1'. speciosum Wult. panicula elongata erecla geniculata; ramis verticillatis simplicibus brevibus; floribus solitariis subsessilibus. Walt. corol. p. 73. In Curolina.

403. P. phalaroides $\boldsymbol{R}$. et $\boldsymbol{S}$. racemo subspicato-cylindrico; spiculis subunifloris pedicellatis undique imbricatis subrecurvis; glumis calycinis duabus majoribus longilndinaliter striatis, apice villis barbatis. R. et $\mathbf{s}$. syst. 2. p. 452. Hymenachne Nees. In Jara.

40-. $P$. neglectum $R$. et $S$. panicula brevi; racemulis brevibus uttantibus; culmo ramosissimo ramis palentilus, ad apicem fere usque vaginato; fol. patentibus reflexisque. h. et s. 1. c. In Africa. 4.

405. \%. megupotunicum spreng. paniculae ramis patentibus; flosculis brevissime pedicellatis glabris acutis nervosis; corollis lucidis; culmo angulato foliisque couvolutis glabris. Spr. Ad Rio Grande.

406. P. densiflorm Willt. paniculae contractae ramis angulosis, scabris; flosculis membranaceis ovatis, fuscis glabris; culno ramoso; fol. linearibus cuspidatis ciliatis; vaginis nodisque hirsutis. Spr. syst. 1. p. 320. Ad ripas Orinoci.

10\%. P. indicum $L$. culmis 4-8policaribus, e basi repente adscendentilus ; spicis subcylindricis nudis calyce glabro; involucris nullis. Roxb. ind. 1. p. 285. Trill. ic. t. 197. In India orientali et Manilla.

408. 1. conglomeratum L. spica secunda subovala; flosculis oblusis. limu. Mant. p. 324. In India orientali.

109. P. pellitum Trin. racemo decomposito coarctato; spiculis oblongo-lanceolatis pedicellis rachibusque villosis; glumis aequalibus flosculos excedentibus, masculo 2 -valvi; culmis caespitosis adscendentibus ramosis vaginis foliisque linearibus planis vil- losis. Nees in Mart. Bras. 2. p. 14\%. 'rin. ic. t. 237. In insula $0-W_{\text {a }}$ lu. $\odot$.

H10. P. P'seulagrostis Trin. racemo capillari-virgato erecto supradecomposito; ranulis basi nudis racemoso-divisis rachique pubescentibus; spiculis lanceolatis angustis; glunis aequalibus flosculo hermaphrodito Iongioribus; flosculo neutro bivalvi; culmo erecto foliisque lato-linearibus vaginisque pubescentibus. Nees 1. c. 1. 149. In insula $0-W a h u .24$.

411. T. acutiforum Poir. glabrum; panicula simplici patentiuscula; floribus alternis patentibus acutis oblougis; fol. oblongo-lanceolatis glabris; vagina sulgelahra. Poir. 1. c. p. 283. Patria ignota.

412. P. melicoirles Poir. glaberrimum; panicula debili elongata; floribus geminis altero sessili; glumis acutis; fol. Ianceolatis. Poir. I. c. p. 283. In Brasilia? 21.

413. 1). poneforme Poir. panicula spicata intermpta elongata; ramis brevibus subfasciculatis flosculis ovatis compressis; fol. angusto-lanceolatis; culmo debili. Poir. 1. c. p. 284. Patria ignota.

\$1ћ. P. fracilescens Desv. ramis paniculae gracilibus elongatis glaberrimis; glumis ovatis oblusis; fol. Ianceolatis asperis denticulatis; ultimo elongato longe vaginato. Poir. 1. c. 1. 279. In Curolinu.

415. P. grucilentum Poir. spica brevi subpaniculata gracili erecta; flosculis lauceolatis acutis; calycilus 2-floris; rachi flexuosa; fol. gramineis glabris. Poir. 1. c. p. 276. Patria ignota.

416. P. haematodes Poir. panicula simplici ramis altemis; rachi angulata; locustis racemosis secundis binis, allera sessili; glumis ovatis paleisque hispidis 3-nervilus; gluma inferiore mucronata; culmo compresso; fol. patentiluss maculatis. Presl. Fl. sic. 1. 1. 43. In Sicilia.

41\%. P. Rafinesquiamum Schult. fol. lanceolatis patentibus basi ciliatis; panicula pubescente; pedunculis flexuosis; glumis ciliatis. Kafinesq. Jour. bot. 4. p. 473. In Nova Caesarea.

415. P. cafrorum Retz; panicula verticillata ramosa; corollis nullis; nectariis villoso-laceris. Ketz obs. 2. p. 7. In Afirica australi. 
119. P. fugax Koeniy; culmo decumbente; paniculis celerime marcidis. Koenig. Naturf. 23. p. 209. Patria ignota.

420. I. Lamarkii Intht paniculis oblongis muticis lacvibus; calycibus brevissimis culno reclinato ramosissimo. Agrostis panicoides Lam. ill. 1. p. 162. Putria ignota.

121. P. Paractaemim Kunth; panicula simplici; spiculis mucroue suffultis; flore neutro 2-paleaceo; ligula barbata. Paractaenum Novae Hollandiae Beaus. Agr. 1. 47. t. 10. f. 6. In Nova Hollandia.

\section{ICHNANTHUS Beauv (1812).}

1. I. panicoides Beaur. ramis nodisque pubescentibus; fol. inaequilatero-oblongis acuminatis striato-multinerviis membranaceis glabris; vaginis puberulis; glumis ovatis acutis inaequalibus glabris; flore inferiore neutro bipaleaceo; flore liermaphrodito laevi. Kunth Gram 1. p. 245. t. 34. In America meridionali.

2. I. almadensis Kunth; culmo basin versus nonumquam ramoso; vaginis glabris pubescentibus vel villosissimis; fol. lanceolatis acuminatis planis striatis glabris; vel subpubescentibus margine hispidis; panicula erecta ramosa; ramis geminis vel ternis laevibus strictiusculis; paniculis glabris; gluma superiore majore, florem inferiorem masculum aequante; flore hermaphrodito laevi. Kunth Gram. 1. p. 245. t. 34. Kunth. Agrostogr. 1. p. 135. Panicum Nees. Trin. ic. t. 21\%. In Brasilia.

3. I. leiocarpus Kunth; culmo nodisque pilosis; fol. inaequilatero-lanceolatis utrinque sulcatis supra scabriusculis subtus puberulis; vaginis lanuginosis; panicula ramosa erecta; ramis geminatis subfastigiatis scabris; glumis inaequalibus apice scabriusculis; flore inferiore masculo; superiore hermaphrodito laevi nitido. Kunth Gram. 2. t. 168. Navicularia lanata Raddi Agrost. t. 1. f. 1. In Brasilia.

\section{ISACHNE R. Br. (1810).}

1. I. australis $\boldsymbol{R}$. Br. panicula lanceolata simplici; ramis pedicellisque flexuosis; culmo erecto. R. Bi. l. c. Panicum antipodum spr. In Nova Hollandia.

2. I. tricarinata Roth; panicula capillari subeffusa, intra ramos pilis longis patulis; ramis subverticillatis dichotomis flexuosis cum ramulis milfloris tricarinata aspera; fol. lato-lanceolatis striatis glabris; vaginis margine ciliatis. Roth. Nov. sp. p. 57. In India orientali.

3. I. miliacea Roth; panicula subeffusa capillari; ramis subverticillatis ramulisque asperis flexuosis; spiculis ovalibus obtusissimis; mascula corolla feminean supereminente; fol. linearilanceolatis asperis; vaginis margino ciliatis. Roth Nov. sp. p. 58. In India orientali.

t. I. mulchella Roth; panicula subeffusa capillari ramisque subverticillatis subflexuosis; spiculis ovali-subrotundis minutis; corollis aequalibus; culmo filiformi debili ad nodos balhato; fol. Iato-lanceolatis utrinque asperis basi rotundata setis remotis cum vaginis laxis margine ciliatis. Roth 1. c. Panicum Spr. In India orientali.

5. I. mauritiana Kunth; culmis ramosis nodis imberbibus; fol. utrinque scabriusculis vaginis margine ciliatis; panicula ramosa diffusa; ramis ramulisque alternis glabriusculis; spiculis ohovatis glabris; flore inferiore hermaphrodito superiore femineo utroque fructifero; glumis aequalibus 5nerviis. Kunth Gram. 1. p. 243. t. 33. Panicum biflorum Lam. In insula Franciae.

6. I. meneritana R. Br. panicula composita ramis pedicellisque capillaribus; floribus miuimis; fol. ore vaginae hirsutis; Poir. Enc. suppl. 3. p. 185̃. Neurachne R. et $\mathbf{s}$. In Keylona.

\%. I. dispar Trin. culmo ramoso inferne radicante tereti glahro; nodis strigulosis vel pubescentibus; vaginis margine striguloso-pilosis, punctatoexasperatis saepe pubigeris; fol. cordato - oblongis amplexicaulibus acutis asperulis nargine albis et hispidis dorso glancescentibus; paniculis ramosis; ramis fasciculatis vel solitariis 
patulis rachique flexuosis pertenuihus; spiculis obtusis; glumis aequalibus glabris flores aequantibus; flore inferiore masculo glabro superiore femineo pubescente. Trin. ic. t. 86. In Nepalia.

8. I. minutula Kunth; culmo ramosissimo diffuso repente; fol. lanceolatis acutis planis nultinerviis pilosiusculis; vaginis ore harbatis; paniculis ramosis ramis alternis patulis ramulisque flexuosis glabris; glumis subaequalihus; superiore margine puherula flore masculo sessili glabro; femineo stipitato hemisphaerico molliter pubescente. Kunth Gram. 2. t. 11\%. Panicum Gaudich. In ins. Mariae Annae.

9. I. albens Trin. culmo ramoso inferne radicante vaginisque glabris superne ad margines saepe piliferis; fol. lineari-lanceolatis acutis planis plicatulo - striatis glaucescentilsus, asperulis angustissime albo-marginatis, margine hispidis; paniculae ramis patentibus rachique glahris; spiculis suborbiculatis ; floribus ambohus hermaphroditis pubescen(ibus, glumas subrotundas concavas subaequales paulo superantibus. Trin. ic. t. 85 . In Nepalia.

10. I. dubia Kunth; panicula composita capillari patente; seminibus geminis; fol. arminaceis nervosis glaberrimis. Panicum dispermum Lam. ill. 1. p. 173. P. arundinaceum Sw. In America meridionali et Jamaica.

\section{STENOTAPHRUM Trin.}

1. S. complanatum Schrank; spica dimidiata compressa; sinubus raclidis 5-floris. Sw. in Act. Mag. Amic. berol. cur. 1810. p. 89. t. 5. Lam. ill. t. 48. f. 1. a. In India orientali et in Borbonia.

2. S. Koenigii Schrank; rachi complanata flexuosa; spiculis subtribus aggregatis: duahus rachi, una duabusve pedunculo communi insidentibus, una ad basin pedunculi sessili; fol. linearibus extiorsum attenuatis vaginisque solutis longissimis. Schrank in bot. Zeit. 1824. Beil. p. 26. In India orientali. 4.

3. S. americanum Schrank; rachi complanata flexuosa; spicularum pari- hus secundis alternis: altera sessili altera brevissime pedicellata; fol. lineari-lanceolatis ohtusis vaginas solutas vix excedentibus. Schrank l. c. p. 2\%. In Brasilia Antillis et in ins. Bermudianis.

\section{MELINUS Beauv. (1812).}

1. M. minutiflora Beauv. Agr. $p$. 51. t. 11. f. 4. Tristegis Nees horas berol. t. \%. Suardia Schrank Hort. Mon. l. 58. In Brasilia. 4.

\subsection{OPLISMENUS BeaUv. (1812).}

1. glumis subaequalibus, cariuatis, aristatis.

1. O. undulatifolius $R$. et S. fasciculis subdenis; rachi pilosissima; valvulis calycinis aristatis glabris subciliatis; fol. ovato-acuminatis undulatis. Panicum Gaud. Agrost. helv. 1. p. 28. P. hirtellum Host. Gr. III. t. 52. In Europa meridionali et in India. $\odot$.

2. O.pseudo-undulatifolius Kunth; fol. ohlongo - lanceolatis, undulatis, profunde striatis glabris; canle inferne ramoso repente geniculis radicante; racenis 6 , alternis. $\quad h$. et $\$$. 2. p. 484. In Cayenna.

3. O. setarius $\boldsymbol{R}$. et $\boldsymbol{S}$. culmo procumbente; fol. lanceolatis acuminatis glahris; vagina margine pilosa; spica composita interrupta, spiculis 5-floris; arista purpurea hispida. Panicum Mülılenl). descr. p. 102. In Carolina.

4. O. sylvaticus $R$. et S. spicis alternis erectis longis multifloris; glumis distantibus glabris aristatis. $\mathrm{Pa}-$ nicum Lam. Enc. 4. p. 743. In silvis ins. Franciae.

5. O. Burmanni Beauv. culmis ramosis foliisque pubescentibus ovatis; spicis suhquinis; rachi conmuni partialibus glumisque pilosis aristis; floro neutro umipaleaceo. Humb. et Kuntls Nov. Gen. 1. p. 106. Panicum hirtellum Burn. ind. t. 12. f. 1. In silvis pascuisque orinocensibus prope Carichana. $\odot$.

6. O. velutinus Schult. spicis ol)longis sessilibus spiculis 2-3-floris; 
calycihus triaristatis; arista exteriore longiore; fol. lanceolatis subtus velutino-pubescentihus. Panicum Neyer Esser. p. 51. In Essequebo prope Soplienbury. $\odot$.

7. O. Hinarum Nees; culmo subsimplici prostrato; fol. lanceolatis sulpetiolatis supra marginequne scaherrimis subtus subtilissime puhescentiluss; spicis 8-10, alternis; spiculis geminatis, inferioribus partion sterilibus; wlums aristatis, inferiore ciliato; floscuilo masculo duplo paleaceo mutico. Nees in Mart. Bras. 2. p. 208. In Brasilia. 4.

8. O. hirtellus $R$. et $\mathbf{S}$. spica composita; spiculis adpressis alternis; calycihus geminis; valvulis omnibus aristatis, extima longissima. Panicum Linn. sp. p. 83. Orthopogon K. Br. In India occ. et Nova Hollandia.

9. O. loliaceus Beaur. caule simplici linea pilosa notato; fol. oblongolanceolatis supra margineque scabris subtus adpresso-pilosis; spicis subtenis alternis; rachi communi glabra, partialibus setoso-pilosis; glumis glabris aristatis; flore neutro unipaleaceo aristato. Humb. et Kunth I. c. p. 106. Panicum pers. In insula Cuba juxta Harannam. $\odot$.

10. O. Jacyuinii Kunth; panicula simplicissima; spicis alternis remotis secundis; flosculis geminatis brevissime pedicellatis; valvis calycinis corollaeque exteriore aristatis; fol. undulatis. Willd. Andropogon undulatus Jacq. Coll. 3. p. 237. ejusd. ic. t. 361. In ins. Mauritii.

11. O. rariflorus Presl; culmo hasi repente adscendente, tereti ramoso nodis barbatis; vaginis barbatis ; fol. ovato-lanceolatis pubescentihus; panicula e spiculis 6 remotis composita; rachi communi partialibusque elongatis laxe 3 -quetris acutis; spiculis geminatis remotis; glumis flosculoque neutro apice aristato acutis, lanceolatis 5-nerviis. Presl. Rel. Haenk. 1. p. 320. In Acapulco. 4.

12. O. tenuis Presl; culmo repente adscendente ramoso; vaginis pilosis; fol. lanceolatis pilosis; ramis paniculae fasciculatis spicaeformibus; rachi communi partialihusque 3-quetris scabris; spiculis solitariis brevissime pedicellatis lanceolatis; gluma inferiore lanceolata, seta spiculam excedente terminata; superiore florem hermaphro- ditum excedente aristata; floris neutrius palea solitaria glumam superiorem aequante; flore hermaphrodito lanceolato-lineari obtuso laevissimo. Presl Kel. Haenk. 1. p. 319. In Mexico et Panama.

13. O. secundus Presl; culmo erecto ramoso tereti vaginisque hirsutis; fol. ex ovata basi lineari-lanceolatis acutissimis superue scabris inferne pilosis; spicis alternis secundis paniculatis; spiculis secundis oblongo-lanceolatis; glunis suhaequalihus; interiore setigera; floris nentrius bipaleasei palea inferiore mutica. Presl ReI. Haenk. 1. p. 322. In peruvia.

14. O. cristatus Presl; pubescens culmo basi repente adscendente ramoso; nodis barbatis; vaginis ciliatis; fol. lanceolatis; spicis pluribus secundis; rachi glumis paleaque neutrius floris solitaria bifido-dentatis aristatis pilosissimis. Presl Rel. Haenk. 1. p. 323. In Hexico. 4.

15. O. Preslii Kunth; culmo basi repente adscendente ramoso pubescente; nodis barbatis; vaginis pilosissimis; fol. lanceolatis pilosis; spicis subsenis secundis; rachi glumis paleaque neutrius floris solitaria bifidodentatis aristatis pilosis. 0 . affinis. Prest Reliq. Haenk. 1. p. 323. In Panama.

16. O. africanus Beauv. rachi spicata simplici; locustis sessilibus multifloris $(7-9)$ alternis, distantibus; flosculis et pedunculis uno latere pilosis; fol. planis lanceolatis. Beauv. Fl. 2. p. 15. t. 67. f. 1. P. compositum Trin. ic. t. 188. In Africa aequinoctiali.

17. O. affinis Schult; spicis sessilihus ovatis secundis approximatis; calycihus corollisque aristatis pilosis. schult. Mant. 2. p. 273. In St. Hurtha.

13. O. compositus R. et S. spiculis multifloris; floribus geminis hirsutis; glumis ambabus aristatis exteriore parum majore; interioris arista ahbreviata; flosculo nentro mucronulalo; fol. lanceolatis. Orthopogon R. Br: prodr. 1. p. 194. Digitaria Willd. Orthopogon remotus Trin. In Keylonia Nova Hollandia, Nepalia, ins. Hauritii et Manilla.

19. O. elatior $\boldsymbol{R}$. et $\boldsymbol{S}$. spica composita; spiculis oblongis sparsis ad- 
pressis; flosculis confertis; calycibus mucronato - aristatis. Panicum L. suppl. p. 107. In Malabaria. $\odot$.

20. O. aemulns Kunth Gram. spiculis 4-6-floris; florihus hispidis; glumis ambabus aristatis interioris arista brevissima; flosculo neutro mutico; fol. lanceolatis vaginisque pilosis; geniculis barhatis villis subreflexis. 11. Br. prodr. 1. p. 194. In Nova Hollandia.

21. O. flaccidns Funth; spiculis 4-6-floris; floribus alternis glahris ciliatis; glumis ambahus aristatis; interiori arista valvula dimido breviore; flosculo neutro mutico; fol. Ianceolatis apice attenuato-glahris; geniculis inberbibus. Orthopogon R. Br. 1. c. In Nova Hollandia.

22. O. imbecillis Funth; spiculis 3-6-floris, floribus alternis glabris ciliatis; gluma exteriore aristata; interiore mucronulata; flosculo neutro nutico; fol. lineari-lanceolatis linearibusve vaginisque glabris; geniculis imberhibus. Orthopogon R. Br. l. c. Panicum Trin. ic. t. 191. In Nova Holíandia.

2. Glumae inaequales; flos sterilis aristatus; spiculae paniculatim rarius racemosim dispositae, (Echinochloa B eauv.).

23. O. colonus liumb. et liunth; rpicis alternis secundis muticis ovatis scabris; rachi teretiuscula. Linn. sp. p. 84. Ehret. pict. t. 3. f. 3. Trin. ic. t. 160. In India orientali et America meridionali. 4.

24. O. pseudo-colonus Kunth; spicis alternis secundis breviter pedunculatis; hasi setis nonullis munitis approximatis; spiculis sessilibus ovatis ventricosis strigosis, trifariam inbricatis; fol. margine argute serrulatis vaginisque glabris. Panicum Iioth. Nov. sp. p. 47. In India orientali et Java. $\odot$.

2.5. O. repens Presl; radice repente; culmo erecto ramoso compresso; nodis vaginisque glabris; fol. pagiua utraque margineque scabriuscuis; spicis pluribus alternis distantibus secundis sessilibus; spiculis secundis 3 -serialibus oblongis; glumis inaequalibus acuto-mucronatis; palea floris hermaphroditi inferiore oblonga longi- fudinaliter striata rugulosa f flore neutro 2-paleaceo; palea inferiore mucronata. Presl. Mel. Haenk. 1. p. 321. In Mexico. $\odot$.

26. O. dubius Kunth; panicula simplici spiciformi compositaque; spicis allernis ; spiculis subsecundis; valvis (et valvula exteriore neutra) ovalibus muticis nervosis laevibus; valva interua valvulis duplo fere minore. Panicum Link Hort. 1. p. 205. l'atria ignota. $\odot$.

2\%. O. margaritacens Kunth; spicis ramosis sessilibus brevibus; spiculis secundis; valvulis ovalihus muticis nervosis laevihus, interiore reliquis duplo minore. Panicum Link Hort. 1. p. 205. Patria ignota. $\odot$.

2S. O. Zelayensis H. et B. culmis ramosis nodis foliisque glabris linearibus margine serrulatis; spicis subdenis altemis approximatis; rachi communi glabra, partialibus scabris; spiculis fasciculatis; glumis acumintto-mucronatis hispido-scabris inaequalibus; flore sterili 2 -paleaceo; palea inferiore acuminato-nucronata. Humb. et. Kunth. Nov. Gen. 1. p. 108. In Mexico. 4.

29. O. lispidulus Krunth; culmis erectis $3-4$ pedal.; spicis paniculatis erectis lanceolatis; spiculis secundis; floribus geminatis sessilibus, valvis calycis setosis, media cuspidata interiore aristata; corolla 3-valvi; semine ovato acuto nitido. Panicum Roxb. ind. 1. p. 306, Ad margines oryzoetorum.

30. O. Crus Galli Kunth; panicula secunda; spiculis approximatis aristadis hispidis; rachi 5-angulari; fol. nudis. Rchl. Fl. excurs. p. 23. var. $\beta$. spiculis submuticis. Panicuu $\mathbf{L}$. Echinochloa 1. Br. P. stagninum Host. gx. 3. t. 51. In agris arenosis Europae, Asiae, Africae, Americae et Novae Hollandiae. 4.

31. O. limosns Presl; culmo simplici erecto compresso; vaginis scabriusculis; fol. margine scabris; spicis alternis paniculatis; spiculis secundis ovatis; glumis paleaque inferiore flosculi neutri scabris nervis fuherculatociliatis; palea inferiore flosculi hermaphroditi ovati gibbi longitudinaliter striata; flosculo neutro hipaleaceo aristato. Presl. 1. c. In lu zonia. 
32. 0. stagninus Kunth; spica composita erecta; partialibus alternis; spiculis ovato-oblongis tuberculatis setoso-ciliatis; gluma inferiore ovatoelliptica acuta spicula dimiclo breviore; superiore setigera; flosculi neutrius palea longe setigera; caryopsi oblongo-acuminata; culmo e nodis inferioribus verticillato-radiculoso ramoso fluitante; vaæinis foliisque glahris laevibus; ligula ciliato-lacera. Panicum Nees in Mart. Bras. 2. p. 261. Orthopogon sipr. In India orientali. 4.

33. O. C'rus paronis $I$. et $K$. culmis simplicibus nodis foliisque glabris late linearibus margine serrulatis; spicis crebris suhpaniculatis; inferiorihus ramosis; rachi communi partiaJibusque hispido-scabris; spiculis fasciculatis; glumis hispido-scabris valde inaequalibus; superiore aristata; flore neutro 2-paleaceo; paleis aristatis. Kunth. 1. c. 1. p. 108. In Cumana. $\odot$.

3t. O. scaber Funtir; spica composita erecta; partialibus alternis secumlis ; spiculis elliptico-ovatis setoso-ciliatis; gluma inferiore ovata acuta spicula dimidio breviore; superiore setigera; flosculi masculi palea inferiore longe setigera; caryopsi elJiptica acuta; culmo erecto stricto vaginisque glabris laevibusque; fol. linearihus subulato-acuminatis glaucis, facie scaberrimis; ligula ciliato-lacera. Panicum Nees in Mart. Bras. 2. p. 261. Echinochloa R. et s. Ad Senegal.

3.5. O. spectabilis Kunth; spica decomposita erecta; partialibus alternis subsecundis; spiculis ternis ovatis seloso-ciliatis; gluma inferiore ovata acuta spicula duplo breviore, superiore acuminato-setigera; caryopsi ovatoelliptica utrinque acuta; culmo erecto stricto, nodis setoso-hirsutis; vaginis hispidis; fol. lanceolato - acuminatis planis strictis scabris ligula; ciliatolaeera. Panicum Nees 1. c. Trin. ic. t. 166. In Angole et in Brasilia cultus.

36. O. muricatus Kunth; spicis altemis erectis solitariis simplicibus; glumis ovatis muricato-hispidis aristatis; arista altera longissima; rachi trigona; vaginis hispidissimis; fol. glabris. Panicum Walteri Pursh Am. 1. p. 66. P. hirtellum Walt. In Cunada. $\odot$.
37. O. Sabulicola Kunth; spica composita decompositave erecta stric. ta; partialibus altemis oppositisve cylindricis densis; rachi inferue com. pressa superne 3-angulari; spiculis ovatis hirtis; gluma inferiore orbicu. lato - cucullata longe mucronata 3. nervi; superiore acuminato-mucronata; flosculi neutrius palea inferiore lon. gius setigera; caryopsi ovato-elliptica rostrata; culmo erecto subramoso; vaginis foliisque lineari-elongatis glabris, his margine scabermis basique e tuberculis dentiformibus ciliatis; ligula inulla. Panicum Nees in Mart. Bras. 2. p. 258. P. Crus galli var. Trin. ic. t. 163. In Monterideo. $\odot$.

38. O. echinutus Kunth; spicis alternis secundis; glumis aristatis muricato - echinatis; rachi trigona. Panicum Willd. en. 1032. Jacq. Eclog. t. 20. P. Crus galli var. longiseta Trin. ic. t. 162. In Amercia meridionali. 4.

39. O. evianthos Funth; panicula contracta elongata; calycibus hirtis subbifloris; fol. longis angustis glaberrimis. Panicum Poir. Enc. suppl. 4. p. 284. In Carolina.

40. O. holciformis $H$. et $\mathrm{L}$. culmis ramosis nodisque glabris; fol. late linearibus utrinque scabris margine serrulatis; spicis suboctonis subalternis elougatis; rachi communi scabra; partialibus pilosis; spiculis subgeminis; glumis hispidis valde inaequalibus; superiore aristata; flore neutro 1-paleaceo, Humb, et Kunth Nov. Gen. 1. P. 10\%. In Mexico. 4.

11. O. polystachyus $H$. et $K$. culmis ramosis? nodis foliisque glabris late lineabribus utrinque scabris margine serrulato-scabris; spicis crelris suhoppositis approximalis ; rachi communi partialibusque scabris; spiculis subgeminis; glunis hispidis valde inaequalíbus; superiore aristata; flore masculo 2-paleaceo; palea inferiore aristata. Kunth I. c. Ad ripas Orinoci. 4.

42. O. longisetus Kunth; culmo tereti glabro; fol. lanceolatis pollicem latis subglaucis; spica composita subpaniculata densa subnutante; spiculis alternis suboppositisve; calycibus 3-floris; valvula exteriore minima; reliquis inaequalibus ovato-acuminatis hispidis, singulis longe aristatis. $\mathrm{Pa}$ - 
nicum Torrey in Sillim. Am. Journ. 2. 1. 134. In America boreali.

43. O. lanceolutus Funth; culmis repentibus; fol. lanceolatis; vaginis ore elevatis et barluatis; floribus hermaphroditis; valvis calycinis aequalibus; exteriore aristato; semine oblongo glaliro. Panicum Roxl. ind. 1. p. 297. Echinochloa 12 . et $S$. In India orientali et China.

4. O. frumentaceus Kunth; culmis erectis 2-t-pedalibus; paniculis erectis; spicis secundis incurvis; floribus ternatis inaequaliter pedicellatis; valvulis calycinis cuspidatis vel aristatis; semine ovato glabro. Panicun foxb. ind. 1. p. 30\%. Trin. ic. t. 164. Echinochloa Link. In India orientali cultus.

45. O. festucoides Kunth; culmis simplicibus glabris; nodo infimo subhirsuto; vaginis ciliatis apicem versus pulsescentibus; fol. linearibus pilosis; racemo composito spiciformi stricto; glumis inaequalibus floreque neutro unipaleaceo longe aristatis. Chaetima restucoirles Nees in Míart. Bras. 2. p. 270. In Brasilia. 4 .

\section{Species dubiae.}

46. O. cuspidatus Kunth; basi repens; totus glaber; fol. linearibus ligula destitutis; spicis compositis secundis; spiculis adpressis secundis; floribus 1-3 aequaliter subsessilibus, ompibus hermaphroditis; valvis calycinis 3 -nerviis cuspidatis; semine cuspidato. Panicum cuspiclatum. Roxb. ind. 1. p. 301. In Bengalia. 4.

1\%. O. strictus, ,chult. culmis strictis 2-3-pedalibus; spicis compositis cylindricis strictis; spiculis crebris patentibus; glumis calycinis pilosis acutis; corolla 3 -valvi; valvula interiore aristata. panicum Roxb. ind. 1. p. 306. P. bengalense Spr. In Bengalia.

15. O. pratensis Schult. spicis secundis nultifloris; rachi applanata pilosa; flosculis remotiusculis solitariis pilosinsculis longissime aristatis; fol. linearibus glabris; vaginis pubescentilus. Orthopogon sprng. syst. 1. p. 306. In ins. Franciae.

49. U. cubensis fiunth; spicis alternis secundis multiforis; rachi hirta; flosculis subglutiuosis longissime aristatis; fol. lato-lanceolatis gla- briusculis; vaginarum oris villosis. Orthopogon cubensis spr. syst. 1. p. 307. Echinochloa schult. In Cuba.

50. O. parvifolius Kunth; fol. Ianceolatis planiusculis; spica composita; spiculis 5-8-floris; aristis viscillis. Orthopogon hirfellus (parvifolius) Nutt. Gen. 1.p. 55. In Americuspptentrionali.

j1. O. Wulteri Kunth; spicis alternis subappressis unilaterifloris ; floribus 3-seriatis muticis, gemmis 2-floris. Panicum Elliot Bot. 1. p. 115. P. carolinianum Spr. P. hemitomun schult. In America septentrionali. $\odot$ ?

52. O. intermedius Kunth; spica tereti; racemulis confertis; involucellis 2 -floris bisetis ramulo duplo longiorihus; rachi tereti villosa. Panicum Hornem. Echinochloa $\mathbf{~}$. et $\mathbf{s}$. Patria iynota. $\odot$.

53. O. jamaicensis Kunth; spicis paniculatis subverticillatis subternis; spiculis secundis; calyce hasi setis $2-3$ longis stipato; ejus gluma interiore longe aristata. Panicum aristatum Macfadyen in Hook Bot. Misc: 2. p. 115. In Jamaica.

\section{CHAMAERAPHIS R. Br。 (1510).}

1. C. hordeacea R. Br. culmo simplici basi ramulis sterilibus instructo foliisque strictis linearibus rigidis distichis; spica stricta; spiculis subsessilibus imbricatis distichis. Kunth Cram. t. 26. In Nora Hollundia.

2. C. paradoxa schnet. culmo ramosissimo repente ; fol. lineari-lanceolatis membranaceis; spica subracemosa; spiculis pedicellatis ternis vel sparsis. Kunth 1. c. t. 32. Freyc. it. t. 24. Panicum R. Br. In Nova Hollandia.

\section{0\%. BERCHTOLDIA Presl (1832).}

1. B. bromoides Presl; in ReI. Haenk. 1. \%. 324. t. 13. In Mexico. Culmus erectis simplex. Folia linearia plana hirsuta. Panicula simplex subsecuuda contracta. liachis inarticulata. 


\section{S. SETARIA Beauv. (1S12).}

1. S. gracilis H. et $\boldsymbol{K}$. culmo adscendente ramoso; fol. interne pilosis malgine scalıris; spica filiformi; involucro multiseto spiculis solitariis multo longiore; ylumis ylabris; palea inferiore floris hermaphroditi transversinn undulata; flore neutro 2-paleaceo. Kuntl. Panicum glaucum var. Trin. ic. t. 196. A. In Vora Granata. $\odot$.

2. S. glauca Beaux. thyrso cylindraceo; setis surstum seabris aurantiis; hermaphroditi glumellis transversim undulatis. Prchb. exc. p. 29. P. glaucum L. Host. 2. t. 17. Schreb. t. 25. Trin. ic. t. 195. P. penicillatum Nees. Penisetum R. Br. In Eurofa, America, India orientali, Senegalia et in Nor:a Hollandia. $\odot$

3. S. flara Lunth. racemo simplici; involucellis 1-floris pallidis spicula Iongioribus; flosculo hermaphrodito trausversim profunde rugoso; culmo crecto ramoso glabro sub racemo ancipiti; vaginis margine orisque foliisgue lineari-lanceolatis culmo brevioribus supra villosis. Panicum Nees in Mart. Bras. 2. p. 238. In Evasilia. $\odot$.

t. S. intermedia $\boldsymbol{R}$. et S. panicula contracta oblonga subspicata; ramis alternis; involucellis sursum hispidis; corollis flosculi hermaphroditi transversim undulatis. Panicum lioth. Nov. Sp. p. 47. In Indiu erientali.

5. S. imberbis R. et $\mathbf{s}$. involucellis longioribus sub-1-floris; fol. vaginisque ore pilis destitutis. Panicum Poir. Enc. suppl. 4. p. 27\%. In America septentrionali, Portorico et Brasilia.

6. S. helvola R. et S. Spica tereti; involucellis 1-floris fasciculato-setosis; seminibus nervosis. Panicum L. suppl. p. 107. Pennisetum R. Br. In India orientali. $\odot$.

\%. S. compressce Kunth; spica cylindracea simplici; rachi pubescente; involucellis 1-floris elongatis completis ; floribus lanceolato-subulatis; flosculo hermaphrodito laevi; stylis basi connatis; fol. canaliculatis vaginisque glabris; culmo compresso. Pennisetum R. Br. prodr. 1. p. 195. In Nova Hollandia.

8. S. geniculata $R$. et $\mathbf{S}$. spica elongata gracili indivisa; involucellis 1-floris fasciculato-setosis brevilus; seminihus transverse rugosis. panicum Lam. Enc. 4. p. 73\%. Pennisetum Jacq. Eclog. Gran. t. 27. Pall. dasyurum Nees. In Antillis. 4.

9. S. tejucensis Funth; racenó elongato cylindrico; involucellis 2-3floris spiculis longiorihus; flosculo hermaphrodito transversim rugoso ; nentro 2-paleaceo; culmo erecto ramoso glabro sub racemo tereti striato; vaginis glahris; fol. culmo brevioribus lanceolato-linearibus supra villosis. Panicum Nees in Mart. Bras. 2. p. 213. In Brasilia.

10. S. rariflora Presl; culmo hasi repente adscendente ramoso compresso; vaginis ore cioiolatis; fol. scabris; panicula spicata intertuptit; involucro subuniseto spicula solitaria duplo Iongiore; glumis spicnla brevioribus; iuferiore 3 -superiore 5-nervia; palea hermaphrodita inferiore evidenter transverse undulato-striata; flore netitro 1-paleaceo. Presl. I. c. In Acapulco. $\odot$.

11. S. globularis Prest; culmo ramoso adsendente compresso vayinisque glabris; fol. planis gramineis utrinque scahris internodio longioribus; panicula spicaeformi simplici crecta tereti; involucro 1-seto, spiculis ovato-globosis solitariis longiore; glumis glabris; inferiore rotundatoovata trinervia; superiore ovato-rotundata apiculata 9-nervia; palea inferiore hermaphrodita transversim undulato-striata; flore masculo bipaleaceo; palea inferiore apiculata. PresI Rel. Haenk. 1. p. 314. In ins. Plilippinis.

12. S. viridis Beauv. spica cylindracea; involucellis 2-floris fasciculato-pilosis hispidis; corollis hermaphroditis Iaeviusculis; vaginis puhescentibus. Panicum viride L.sp. p. 83. Ilost. 2. t. 14. Fl. Nall, 352. Trif. ic. t. 203. Pennisetum H. Br. In Europa, Cancaso, Sibiria, Japonia e America septentrionali. $\odot$.

13. S. purpurascens $\boldsymbol{H}$. et $\boldsymbol{F}_{3}$, culmo erecto ramoso; fol. interne margineque scabris; spica cylindracea; involucro multiseto spiculis solitariis paulo longiore; glumis glabris; palea inferiore floris hermaphroditi transversim undulata; flore nasculo 2-paleaceo. Kunth. Panicum glaucum var. 
Trin. ic. t. 196. B. In Quito, Peruvia, dlexico. $\odot$.

14. S. Trinii Kunth; culmo decunbente vel adscendente subcompresso glabro fasciculato-ramoso inferne repente; vaginis striatis superiorihus pubescentibus; fol. lanceolato-linearibus acuminatis planis striatis scabris interdum pubesccutihus; spica composita cylindracea angusta stricta; setis 2-3 spiculan giahram duplo el longius superantibus hispitis; flore hermaphrodito transversim undulato; nentro 1-paleaceo. Panicum scandens Trin. ic. t. 201. In Brasilia.

15. S. scandens Schral. culmo ramoso; fol. lineari-lanceolatis subpilosis; vaginis ciliatis; spica composita cylindrica; involucro subhiseto superne denticulis nervosis hispido, spicula solitaria duplo longiore; corolla hermaphrodita obsolete transversim undulata. Schrad. in Schult. mant. 2. p. 279. Panicum tenacissimum Nees. In Brasilia. $\odot$.

16. S. semirugosa linuth; racemo spicato cyliudrico; involncelli triflori setis spicula triplo longioribus retrorsum scabris; flosculo neutro bipaleaceo; hermaphrodito basi undulato rugoso apice laevi; culmis caespitosls erectis basi ramosis; vawinis glabriusculis margine orisque ciliatis; fol. lineari-lanceolatis scabriusculis. Panicum semirugosum Nees in Mart. Bras. 2. p. 243. In Brasilia.

1\%. S. pumila Sclault. fol. scabris; vaginis undique pilosis; spicis partialihus dense aggregatis et hrevissimis; setis nullis; valvulis fertilibus transversim subtilissime rugosis. Panicum Link en. 1. 76. Patria ignota. $\odot$.

18. S. macrochaeta spr. panicula spicata subcylindrica; rachi villosa; setis involucri sursum hispidulis flosculos multo superantibus; corollis nervosis laevibus; fol. vaginisque glabris. Spr. syst. 1. p. 305. Pennisetum Jacq. Eclog. Gram. t. 25. In India orientali. $\odot$.

19. S. tenacissima Schrad. culmo ramoso; fol. linearihus scabris; vaginis ciliztis; spica composita cylindrica; involucro 1-2-seto denticulis reversis hispido spicula solitaria multo longiore; corolla hermaphrodita obsolete transversim undulata. Schrad, in schult. mant. 2. p. 279. Panicum Nees. In Brasilia.

20. S. Antillarum Lunth; spica gracili elongata; involncellis glahris inaequalibus; fol. angusto-linearibus striatis supra vaginaque pilosis sub-tus glalıris; culmo gracili ramoso. Panicum Poir. Enc. suppl. 4. p. 275. Saccharmm Antillarum $\mathbf{R}$. et S. Fo Antillis.

21. S. verticillata Beanr. thyrso verticillatim interrupto cylindraceo; setis deorsum scabris; hermaphroditi bracteolis laeviusculis. Rchb. excurs. p. 29. Panicum L. Host. 2. t. 13. Trin. ic. t. 202. In Europa, Cancaso Oriente, Rosisia, India orientali et America septentrionali. $\odot$.

22. S. Rotlleri Spm. panicula spicata cylindrica laxiuscula; setis involucri flosculis superantibus deorsum hispidis; corollis nervosis; seminibus rugulosis; fol. latiusculis hirsutis. spr. syst. 1. p. 30\%. Panicum Rottl. In India orientali.

23. S. nubica Iink; fol. scabris; vagina superue margine pilosa; spica erecta; spiculis lougiusculis aggregatis; setis deorsum scabris spicula 6-8-plo longioribus; valvis fertilibus ohsolete transversin rugulosis. Link Hort. 1. p. 220. In Dongola Nubiae. $\odot$.

21. S. italica Beauv. thyrso nutante lohato; bracteolis fertilibus obsolete transversin rugulosis. Kchb. excurs. p. 29.- Panicum IIost. 4. t. 14. var. $\beta$. P. germanicum Roth germ. 2. p. 72. Host. 2. t. 17. P. italicum var. germanicum Trin. ic. t. 199. Setaria Beauv. In Euroya, Indiis et Nova Follandia. $\odot$.

2.5. S. caudata $R$. et S. racemo caudato gracili; spicis alternis remotiusculis sensim minoribus; rachibus setiferis; glumis laevibus. Panicum caudatum Lam. ill. 1. p. 171. In Gujana et Brasilia.

26. S. corrugata Schult. mant. spica tereti composita setosa; spiculis multifloris $(7-10)$; corollis transverse rugosis. Panicum Elliot. bot. 1. p. 123. Pemnisetum Nutt. In Savannah. 2\%. S. vulpiseta R. et $\boldsymbol{S}$. racemo praelongo dense setoso; spicis creberrimis subdivisis; rachibus setiferis; glumis muticis. Panicum Lam. 4. p. 745. In St. Domingo. 
2S. S. macrostachyce H. et K. culno erecto simplici (?) nodisque glahris; fol. scabris; vaginis glabrinsculis; panicula spicaeformi; invulucro uniseto spiculis solitariis multo longiore; glumis glabris; palea inferiore floris hermaphoditi transversim undulata; flore neutro 2-paleaceo. Kunth 1. c. S. setosa Beauv. Panicum sw. Trin. ic. t. 95. 96. P. tenax hich. P. cylindricum Link. In Jumaica, Gujuna, Mexico et Brcisiliu. $\odot$.

29. S. compositı H. et $K$. culmo erecto ramoso (?) scahro ; fol. utrinque scahris cartilavineo-serrulatis nodis vaginisque apice pubescentibus; panicula ranosa spicaeformi cylindracea subuutante; involucro 1-seto spiculis solitariis multo longiore; glumis glabris; palea inferiore floris hermaphroditi transversim undulata; flore sterili 2-paleaceo. Kunth 1. c. S. poJystachya schrad. Panicum Nees. In America calisliore. $\odot$.

30. N. scabrifolia Kunth; racemo decomposito laxiusculo; rachi hirsuta; involucellis 2 -floris, $2-\boldsymbol{t}$-setis coloratis; glumis glabris utraque flosculis hreviore; flosculo hermaphrodito transversim undulato; neutro 2-paleaceo; culmo simplici nodisque glabris; vaginis scabris margine orisque ciliatis; fol. fasciatis utrinque glabris. Panicum Nees in Mart. Bras. 2. p. 246. In Frresilia. 24.

31. S. impressa Kinnth; racemo decomposito patulo hasi vaginato; rachi hirsuta; involucellis 2 -floris hisetis; flosculi hermaphroditi ohsolete transversim undulati palea inferiore basi impressa laeviuscula; flosculo neutro bipaleaceo; culmo erecto subramoso nodisque glabris; vaginis margine oreque villosis; fol. limeari-lanceolatis scabriusculis. Panicum Nees in Mart. Bras. 2. p. 247. In Brusilia. 4.

32. S. lachnea Iiunth; racemo erecto decomposito cylindraceo-conico; rachi viliosa; involucellis bifloris bisetis; glumis glabris utraque flosculis breviore; flosculo hermaphrodito trausversiu undulato; neutro 2-paleaceo; culmo erecto ramoso nodisque glabris; vaginis villosis; fol. utrinque pubescentibus. Panicum Nees in Mart. Bras. 2. p. 218. In Brasilia. 4.

33. S. leucophylla Kunth; racemo terminali erecto decomposito coarctato acumiuato; rachi villosa; pedicellis subsecundis subhifloris; involucellis unisetis subsingula spicula ista duplo longioribus ; flosculo inferiore masculo bipaleaceo hermaphrodito transversim undulato; culmo ramoso hasi radicanle; vaginis foliisque lanceolato-acuminatis glahris, his margine scabris. Panicum. Nees in Mart. Bras. 2. p. 249. In Brasiliu. 4.

34. S. cernua $\boldsymbol{H}$. et $\boldsymbol{K}$. culmo erecto ramoso (?) pilosiusculo; nodis glabris (?) ; fol. interne pubescentibus margine scalris; vaginis ore pilosis; panicula simplici spicaeformi cylindracea cernua; involucro uniseto aut unllo spiculis solitariis longiore; glumis glabris; palea inferiore floris hermaphroditi transversim striata; floro masculo bipaleaceo. Kunth I. c. In Quito. $\odot$.

3.5. S. Crus Ardecie Kunth; racemo suhdecomposito ramisque secundis subverticillatis erectis; spiculis brevissime pedicellatis subsolitariis erectis plerisque seta longiore ad insertionem pedicelli stipatis; culmo ramoso glabro; vaginis apice annulo villoso cinctis; fol. anguste lanceolatis utrinque attenuatis scabris. Panicum. Nees in Mart. Bras. 2. p. 253. In Americu meridionali.

36. S. Poiretianc Kunth; spica paniculata longissina stricta; spiculis glabris; rachi aristata; foliolis petiolatis louge lanceolatis glaberrimis laevibus. Panicum elongatum Poir. Enc. suppl. 4. p. 278. P. Poiretianum Schult. P. speciosum Nees? In Brasilia.

37. S. elongata Spr. culmo nodisque glabris; fol. linearibus utrinque vaginisque pilosis; spicis numerosis alt ernis; involucro biseto spiculis unilateralibus solitariis geminisque longiore; glumis glahris; paleis floris hermaphroditi nervosis. Spr. in Schult. mant. 2. p. 280, In St. Domingo.

35. S. bracliata Kunth; panicula laxe pyramidata; ramis distantibus pateutissimis; ramulis subpendulis; involucellis rachibusque flexuosis glabris; fol. late linearibus subasperis. Panicum Poir. l. c. p. 282. P. chloroticum B. sylvestre. Nees. In Antillis (Brasilia).

39. S. Ventenatii Kunth; culmo erecto ramoso compressiusculo, gla- 
hro; nodis pubescentibus; fol. anguste lincaribus scaluriusculis margine scahris; spicis in ramis elongatis solitariis cylindraceis; setis longis purpurascentibus; flore hermaphrodito undula:0-rugoso. Kuntlı Gram. 1. p. 251. t. 37. Cenchrus parviflorus. Poir. Pennisetum domingense spr. In Portorico et Hispaniola.

\section{Species dubiae.}

40. S. subcordata Kunth; spicis alternis sessilihus subsecundis approximatis; pedicellis apice setigeris; fol. subcordato-lanceolatis mucronatis argite serulatis basi vaginisque ciliatis. Panicum Roth Nov. Sp. p. 46. li India orientali.

1. S. longifolia Link; culmo inferne nodis nultis approximatis; fol. suabris culmo multo longioribus; spicis partialibus brevibus dense aggregatis; setis sursum scahris; spicula $2-3$-plo Iongioribus; valvis fertilibas laevissimis. Link Hort. 1, p. 220. Paticia ignota. 4.

1. S. laevigata Schult. fol. Iineari-lanceolatis nervosis vaginaque striata gla!ris; ligula harbiformi breyi; Jracteis pedumculo puhescenti insidentibus apice purpureis, 5-7, caJyce nervoso glabro triplo longioribus. Panicum. Mülılenb. descr. p. 100. Th America boreali.

43. S. affinis Schult. fol. linearilanceolatis vaginaque striata pilosis; lịula harbiformi; bracteis pedunculo pubescenti insidentibus apice purpurascentibus fasciculatis elongatis. Panicum Mühlenh. I. c. p. 101. In Georgia et Pensylvania.

11. S. laxurians Spr. spicis subpaniculatis confertis erectis ; setis subteruis gracilihus laevibus; flosculis ovatis acutis nervosis glabris; culmo repente radicante; fol. cordato-lanceolatis subtus vaginarumque oris pilosis. Spr. syst. 1. p. 305. In India orientali.

45. S. ocreata Spr. spicis paniculatis remotis; setis gracilibus gloneratis glabris; flosculis ovatis nervosis laevibus secundis; fol. cordato-lancoolatis amplexicaulibus basi vaginarunque oris ciliatis; culmo erecto. sur. syst. 1. p. 305 . In India orientali.

46. S, mauritiana Spr. spicis pa- niculatis secundis subfasciculatis; ramis pilosis; setis flexuosis sursum hispidis; flosculis ovatis nervosis acutis scabriusculis; seminibus rugulosis; fol. Iate Ianceolatis; nodis barbatis. spreng. syst. 2. p. 305. In ins. MIauritii.

17. S. floribunda $\mathbf{S p r}$. spicis paniculatis confertis divaricatis; rachi angulata flosculisque ovatis obtusiusculis nervosis glabrus; fol. lato-lanceolatis pilosiusculis; vaginis glahris. spr. syst. 1. p. 305. In India orientali.

13. S. vayinata Spr. panicula spicata elongata vaginata; setis subsolitariis sursum asperis; flexuosis ; flosculis acutis glabris nervosis; culmo foliisque laevihns. spr. Cur. post. p. 33. In Rio Grande.

49. S. purpurea $K$. et $\mathrm{S}$. spica tereti; involucris 1-2-setis inaequalibus flosculo majoribus unifloris; culmo tereti ramoso. Panicum Huiz. et Pav. peruv. 1. p. 48. In Peruvia.

50. S. sericea $\boldsymbol{R}$. et $\mathbf{S}$. spica tereti; involucris setaceis villosis unifloris Iongitudine flosculorum; fol. planis. Panicum Ait. Kew. 1. p. 88. In India orientali. $\odot$.

51. S. hirsuta Kunth; fol. Iate lanceolatis loasi cordatis et anılexicaulibus undatis ciliatis pilosis; floribus polygamis solitariis sessilibus; semine ovato transverse rugoso. Panicum Hoxb. ind. 1. p. 393. P. Koenigii Spr. P. Helopus Trin, In India orientali.

52. S. tomentosa Kunth; culmis suherectis; fol. pilosis; spicis 10-12oblongis 6-8-floris; involucellis hispidis setosis intermixtis; semine ovato transverse rugoso. Panicum Roxb. ind. 1. p. 303. Oplismenus Schult. Iin India orientali.

53. S. livta fiunth; spicis alternis fastigiatis breviter pedunculatis secundis; spiculis subsessilibus ovatis mucronatis hirtis basi pilorum fasciculo muticis; flosculi hermaphroditi corollis transversim rugosis; culmo adscendente ramoso; fol. vaginisque pilosis. Panicum hoth nov. Sp. p. 46. Oplismențs R. et $\mathbf{S}$. P. Rothii Spr. In India orientali.

5t. S, canescens Kunth; paniculae ramis alternis laxis elongatis secundis simplicibus; pedicellis cum rachi pilosis, apice fasciculo setarum 
spiculam muniente terminatis; spiculis ovalibus mucronatis pilosis; calycis gluma exteriore cordato-ovata, spicu!am hasi involvente; culmo foliisque villoso-canescentilus. Panicum. lloth Nov. Sp. p. 5t. In India orientuli.

5.5. S. stricte Kunth; spicis subfasciculatis paniculatis longissimis setaceis strictis basi barhatis; spiculis ovalibus margine pubescentibus basi setarum fasciculo extrorsum semiinvolucratis; fol. cum vaginarmm oris pilosis. Panicum. Roth 1. c. p. 38. In India orientali.

56. S. longiseta beanv. panicula laxa glabra; ramis inaequalibus; involucro sela 1 flexuosa locustae longitudine triplici; fol. elongatis angustis marginilus paulo pilosis et tenerrime serrulatis; vagina pilosa; ligula truncata setosa; palea inferiore transverse rugulosa. Beauv. Fl. d'Oware 2. p. 81. t. 110. f. 2. In Africa aequinoctiali.

\section{GYMNOTRIX Beauv. (1812).}

\section{Styli inferne counati. Invo-} lucrum pedicellatum.

1. G. cenchrointes $R$. et $\mathbf{S}$. spica cylindrica elongata; involucellis 1-floris setosis; flosculis acutis; culmo erecto; vaginis ore harbatis. Panicum hordeiforme Willd. en. p. 1031. Cenchrus Thunb. Pennisetum spr. In Prom. b. spei, India orientali et ins. Mauritii. 4.

2. G.japonica Kunth; culmo erecto pilosiusculo; fol. involuto-compressis praelongis vaginisque glabris; racemo laxo mutante; rachi pilosa; spiculis pedicellatis $1-2$, hifloris; involueri setis scahris atropurpureis spicula longioribus; glumis calycinis flosculis brevioribus. Pennisetum Trin. ic. 2. t. 19. Cenchrus purpurascens Thunb. In Japonia.

3. Gr. Thonurii Beauv. Agr. 59. $t$. 13. $f$. 6. spica solitaria; involucro spiculam multo superante; glumis valde inaequalihus superiore majore; flore hermaphrodito dimidia breviore; stylis hasi connatis. Kunth Agr. syn. 1. p. 159. In ins. Franciue.

\section{Styli saepissime liberi. In-} volucrum sessile.

4. G. purpurascens schrail. fol. linearibus carinatis; superioribus matgine carinaque scabris; spica solitaria; iuvolucro spicula multo longiole; calyce univalvi brevissimo; floris neutrius valvula aristata; arista florem hermaphroditum superante. schrad. Anal. ad Flor. cap. sect. 2. Pennisetum alopecuroides steud. In prom. b. spei.

5. G. caudata Schrad. culmo erecto simplici; fol. rigidis interno margineque scabris; vaginis glabris; spica solitaria elongata cylindracea; involucro spiculam superante; glumis brevibus; flore inferiore unipalcacco neutro; paleis inferioribus utriusquo floris aequalibus scabriusculis valde acutatis, nentra 5-, hermaphrodita 7nervia. Kunth Gr. 1. p. 253. t. 38. In Prom. b. spei.

6. G. crinitu $\boldsymbol{H}$. et $\boldsymbol{K}$. fol. glabris margine sermulatis; spica solitaria; involucro spiculam subaequante; glumis valde inaequalibus; superiore majore florem hermaphroditum subaequante. Kunth. In Mexico. $\odot$.

\%. G. nevrosa Nees; spica solitaria; involucro spiculan superante subaequali; gluma inferiore superiore duplo breviore hac flosculum nentrum aequante 7-nervi; fol. lineari-lanceolatis vaginisque hiantibus glabris. Nees in Mart. Bras. 2. p. 27\%. In Brasilia.

8. G. nigricans Presl; fol. interne pilosis margine scabris convolutis; spica solitaria; involucro spiculam subaequante; glumis inaequalibus; superiore majore flore hermaphrodito breviore 5-nervia. Presl in Rel. Haenk. 1. p. 315. In Iazonia. $\odot .4$.

9. G. tristachya $H$. et $K$. Nov. Gen. $t$. 678 . fol. interue margineque scabris; spicis ternis longe pedunculatis; involucro spiculam multo stiperante; glumis valde inaequalibus; superiore majore flore hermaphrodito quadruplo breviore. Kunth. In Quito. 24.

10. G. latifolia Schult. spicis axillaribus in pedunculo communi solitario vel gemino fasciclilatis longe pediccllatis declinatis cylindricis amentiformibus; seta involucri una, spiculam multo superante; glumis bevissi- 
mis; fol. late lanceolatis subpetiolatis glabris. Nees in Mart. Bras. 2. p. 278. Pennisetum Spr. In Montevideo. 4.

11. G. Preslei Kunth; fol. Ianceolatis planis utrinque margineque scabris; spicis ternatis longe pedunculatis; involucro spiculau superante; glumis valde inaequalibus; superiore fiorem hermaphroditum excedente. Presl kiel. Haenk 1. p. 316. In Perucia.

\section{Species dubiae.}

12. G. domingensis $\mathbf{S} p$ r. fol. utrinque glabijs convolutis; spica solitaria; involucro spiculam triplo quadruplo superante; calyce corolla breviore; utritusque floris valvulis corollinis subaequalibus acuminatis. Sichult, Mant. 2.. 284. In st, Domingo.

13. G. hordeoides Kunth; spica elongata tereti tenui albicaute; involucellis setosis glabris unifloris; culmo polystachyo. Pauicum Lam. ill. 1. p. 170. In Sierra Leona,

\section{0, PENNISETUM Beauv. (1811).}

1. P. purpurascens $H$, et $K$. fol. interne margineque scabris; spica soItaria; spiculis solitariis involucro dimiclio brevioribus; glumis valde inaequalibus; superiore longiore florem hermaphroditum superante; flore masculo bipaleaceo. Kunth. P. setosum Rich. in Pers. syn. Trin. ic. t. 20. Cenchrus Sw, In India occidentali et Mexico. 4.

2. P. flavescens Presl; fol. inferne glabriusculis margine scabris sulperue tuberculatis villosis; spica solitałia; spiculis solitariis bifloris involucro brevioribus; glumis valde inaequalibus; superiore ovata 5 -nervia apice 3-dentata mucronata inferiorem ovato-lanceolatam duplo superante; flore masculo 2-paleaceo. Presl. 1. o. 1. 316. In Mexico. 4.

3. P. breve Nees; spica solitaria oblonga; spiculis solitariis involucro duplo brevioribus; glunis valde inaequalibus ; inferiore lanceolata; flosculo masculo 2-paleaceo; fol. linearibus facie pilosis, Nees 1. c. p. 281. In Brasilia. $\odot$.

4. P. Richardi Kunth; fol, planis glabriusculis; vaginis glabris; spica elongata cylindracea; spiculis involucro dimidio brevioribus bifloris; flore masculo bipaleaceo; palea inferiore glumaque superiore 5-7-nerviis exterue scabriusculis; stylis liberis. Kunth Gir. 1. p. 49. et 25̃. t. 39. Panicun cenchroides. Kich. Setaria $R$. et s. Pemnisetum hirsutum. Nees. In Cajenna et Brasilia.

5. P. unifiorum II. et K. Nov. Gen. 1. $t$. 3 . fol. interne margineque scabris basi ciliatis; spica solitaria; spiculis solitariis unifloris involucro brevioribus; glumis aequalibus apice tridentatis paleas superantibus. Kunth. In Nova Andalusia et Mexico. 4 .

6. P. dichotomum Delile; culmo junceo diffuso; fol. pagiua superiore scahris; ranis erectis subterno-fasciculatis ; spicis terminalihus flavidis; rachi aspera glahra. Delile Aegypt. p. 15. t. 8. f. 1. Panicum Forsk. Phalaris setacea Forsk. P. phalaroides. Schult. In Arabia et Aegypto. 4.

\%. P. violaceum Rich. culmo ramoso; fol. vaginisque pilosis; spica cylindracea; involucris sessilibus spiculam bifloram subaequantibus; flore utroque 2-paleaceo superne scabritusculo; superiore hermaphrodito 5-nervio ; inferiore masculo 3-nervio; gluma una minuta; stylis commatis. Kunth Gr. 1. p. 257. t. 48. Panicum Lam. Ad Senegal.

8. P. orientale Pers. fol. subsetaceo-subulatis; involucro sparso stipitato; setis parvis flore longioribus plumosis. Riol. Panicum WVilld. In Galatia. 4.

9. P. rufescens Spr. fol. glabris; spica elongata; involucris confertis setiformibus rufescentibus inferne villosis flore triplo longioribus; calycibus subbifloris. Cenchrus Desf. Atl. 2. p. 388. In Barburia.

10. P. asperifolium Kunth; fol. retrorsum asperis; spicis elongatis cyliudraceis; involucris breviter pedicellatis; spicula solitaria uniflora; glumis inaequalibus; superiore paleaque inferiore breviter aristatis; stylis inferne conuatis, Kunth. Cenchrus Desf. In Barbaria.

11. P. borbonicum Kunth; culmo ramoso; fol. linearibus interne margineque scabris; vaginis glabris; spica cylindracea; spiculis iuvolucro 
multo brevioribus; flore sterili bipaleaceo; palea inferiore glumaque superiore 5-nerviis apice scabriasculis; stylis liberis. Kumth Gi. 1. p. 259. t. 41. Panicum longisetum. Poir. In ins. Boiboniue.

12. P. cenchroides Rich. culmo geniculato; involucris alternis dupla florum longitudine; setarmm una subulato-paleacea longiore. Bich. in Pers. syu. 1. p. 72. Cenchrus ciliaris Giesecke ic. t. 23. In prom. b. spei, Barbaria, ins. Caribaeis et Cumanu. $\odot$.

13. P. Prieurii Kunth; culmo ramoso; fol. linearihus interne sulcatis scabris externe vaginisque striatis scabriusculis; spica cylindracea; spicula solitaria vel gemina involucro multo hreviore; gluma superiore 3-nervia inferiore nulla; flore sterili mipaleaceo 5-nervio, hermaphrodito acuminato punctato-scabriusculo; stylis hasi comnatis. Kunth Gram. 2. t. 119. Ad seneyal.

14. P. pallidum Nees; spica solitaria cylindrica densa; spiculis solitariis involucro multo breviorihus; gluma unica paleaque neutra apice 2-dentatis ex apice mucronato-setigeris; fol. linearibus vaginisque tuberculato-hirsutis. Nees in Mart. Bras. 2. 1. 285. In Brasilia. 4.

\section{Species non satis notae.}

15. P. Tahlii Kunth; spica spiculis approximatis; involucris setaceomultifidis glabris. Cenchrus setigerus. Vahl ell. 2. p. 395, In Arabia.

16. P. artivulare Trin. culmo basi procumbente ramosissimo scabriusculo; fol. angusto-linearibus vaginisque scabriusculis; spica subnutante; rachi pubescente; spiculis approximatis solitaris sessilibus; setis flexuosis scabris spicula paulo-longioribus. Trin. in Spr. N. Entd. 2. p. 77. In ins. Nucahiva.

1\%. P. Linnaei Kunth; panicula subspicata cylindracea; involucellis setaceis ciliatis; culmi geniculis glabris. Penicillaria ciliata IVilld. en. p. 1037. P. cylindroides $\mathbf{R}$. et $\mathbf{S}$. Panicum alopecuroides L. Pennis. alopecuroides spr. In India orientali et Prom. b. spei. $\odot$.

18. P. alopecuroides Hamilt. culmo ereoto; fol. linearibus subscabris vaginisque glaherrimis faucilus barbartis; spicis longissinis longe barbatis; involucris pilosis. Hamilt. prodr. p. 11. In India occidentali.

19. P. erubescens Link; fol. brevihus supra et margine scaherrimis; spica undique imbricata; setis scahris elongatis; spiculis hinis. Iink Hort. 1. p. 215. Panicum Villd. Setaria R. et s. In ins. St. Thomas.

20. P. basbatum Schult. culmis 3-5-pedalibus superue ramosissimis; fol. lanceolatis; spicis simplicihus cylindricis ; involucellis simplicibus harbatis ubique florem singulum cingentibus; semine glabro. Panicum lioxb. ind. 1. p. 28.5. In Sumatra et Amboina. $\odot$.

21. P. holcoides Schult. erectum; involucellis crebris sparsis unifloris alternatim Iongioribus et lanatis reliquis brevioribus et glabris; floribus interdum polygamis; semine oblongo glabro simili grano parvo Avenae sativae. Panicum Rox!. 1. c. p. 288. Panicum polystachyum L. Rumph 6. t. 7. f. 2. A? In India orientali.

22. P. asperum schult. fol. basi pilosis vaginis laxis glabris; laminis convolutis glabris; setis scahris elongatis; spiculis binis. Panicum Link Hort. 1. p. 214. In Prom. b. spei.

23. P. aureum Link; fol. culmum longe superantibus, basi margine longe ciliatis; spica undique imbricata; setis scabris elongatis strictissimis; spiculis solitariis. Link Hort. 1. p. 215. In India.

21. P. nepalense Spr. flosculis undique imbricatis glabris nervosis; sterilibus duobus fertili assidentibus; setis involucri scabris coloratis flosculos superantihus; spicae elongatae rachi villosa; fol. elongatis scabris; vaginis ore pilosis; culmo glabro. spreng. syst. 1. p. 303. In Nepalia.

25. P. Sieberi Kunth; culmo ramoso geniculato adscendente; fol. utrinque margineque scaherrimis linearibus planis; involucri setis basi plumosis calyce quadruplo longioribus; calyce longitudine fere corollae; valvulis corollinis subaequalibus acutis. Gymnotrix geniculata. scluult. mant. 2. p. 28t. In Martinica.

26. P. Thunbergii Kunth; racemo spicato simplici; florum involucro polyphyllo scabro; culmo geniculato. 
Cenchrus geniculatus. Thunb. prodr. p. 20. In Prom. b. spei.

\section{LEPIDEILEMA Trin. (1830).}

1. L. lancifolium Trin. in act. Petrop. 18:0. 1.p. 93. Sireptochaeta spicata schrad. In Brasilia. 2-pepale, saturale viride. Fol. ovato-lanceolata. Inflorescentia simplicissima depauperata.

\section{PENICILLARIA Sw.}

1. P. spicata Willd. panicula suhspicata cylindracea elliptica; involucellis setaceis scabris; culmi geniculis villosis. Willd. ell. p. 1037. Jacq. Eclog. Gr. t. 17. Beauv. Agr. t. 13. f. 4. Holcus L. Panicum Roxb. Pennisetum trphoideum Pers. Delile Aeg. t. 8. f. 3. P. Pluknetii Link. In India orientali. $\odot$.

2. P.? imolucrata Schult. erectum; spicis cylindricis crebris sparsis bifloris alternatim longioribus ciliatis, brevioribus glabris; calycihus bivalvibus; valva exteriore minuta; interiore corolla breviore emarginata. Panicum. Inoxb. 1. c. p. 28\%. In India orienttali.

\section{ANTHEPHORA Schreb.}

1. A. eleyans Sclireb. Gr. 2. $\boldsymbol{p}$. 105. $t$. 41. Beauv. Agr. $t .13 . f .8$. Tripsacum hermaphroditum Lam. dec. t. 9. Calladoa monostachya Pers. Cenchrus laevigatus Trin. In Jamaica, Nova Barcelona et Mexico. $\odot$. Gramen ramosum. Spiculac quaternae inferne counatae.

\section{LAPPAGO Schreb.}

1. I. racemosa Willd. Host. Gr. 4. $t$. 36. Sibth. graec. t. 101. Cenchrus schreb. Gr. t. 4. L. biflora. Hoxb. L. aliena Spr. Tragus occidentalis et orientalis Nees. $\beta$. erecta. Kunth gr. t. 120. In Europa Caucaso, Oriente, Barbaria, Jamaica, st.
Domingo, Brasilia, Mexico $\beta$. in senegumbia. $\odot$. Gramen diffusum repeus.

\section{IOLBOELLIA Wall.}

1. I. orinthocephala Hook. Bot. Misc. 2. p. 1\#1. t. $\% 6$. In Indies orientali apma montes Madurae. $\odot$. Culni caespitosi basi procumbentes. Fol. lineari-lanceolata undulata marginibus cartilaginis scabra, inferne culmum longe vaginantia.

\section{LATIPES Kunth (1832).}

1. L. senegalensis Kunth Gr. 1. p. 161. $t$. 12. Tragus Gay. In Senegalia. Fol. linearia plana externe glahra interne scabriuscula et sulcato-striata. In Senegulia.

\section{ECHINOLAENA Desv.}

a. Spica solitaria.

1. E. scabra H. et K. Nov. Gen. 1. p. 1 18. t. 38. fol. lineari-lanceolatis scabris; spica solitaria reflexa. Kunth. Panicum Echinolaena. Nees. In Gujana et Brasilia. 4.

2. E. hirta Desv. culmo apice ramoso; internodiis glabris; fol. lanceolatis suhobtusis vaginisque lispidis; ligula nulla. Desv. Jouru. de hot. 3. p. 75. Cenchrus inflexus. Poir. C. marginalis. Iudge Guj. t. 25. In Gujana.

\section{b. Spicae plures.}

3. E. polystachya H. et $\boldsymbol{K}$. Nov? Gen. 1. p. 119. t. $6 \% 9$. fol. oblongolanceolatis interne adpressso-pilosis margine scahris; spicis 5-6, alternis, distichis. Kunth. Panicum uncinatum. Trin. ic. t. 216. Ad ripas fluminis Magdalenae in Brasilia et Mexico. 2.

4. E.? nemorosa Kunth; panicula simplici ramis distantihus erectis ; flosculis remotis ovatis acmminatis ; culmo decumbente geniculato; vaginis colloque pilosis. Panicum s'w. prodr. 
p. 22. Trin. ic. t. 210. Millum spr. In Jamaicu, Hispanio!a et Biasilia.

5. L.? nuricularis Runth; raceno ramosissimo patente; spiculis glaberrimis (compressis ohlongis); glumis subaequalibus (superiore g-nervi flosculo neutro 2 -valvi); culmo nodis vaginis foliisque glabris lanceolatis longe acuminatis hasi attenuatis. Panicum Nees in Mart. Bras. 2. p. 136. Navicularia grlabra liadài. In Bratsilia.

6. E.? brachystachya Funth; racenfo composito; racemulis secundis patentibus; spiculis ventricosis; glumis masculique valvula inferiore e glandulis hirsutis; gluma inferiore flosculis duplo breviore; culno ramoso; fol. lineari-lanceolatis strictis villosis. Panicum brachystachyum. Nees 1. c. p. 129. Trin. ic. t. 15\%. In Drasilia. 4.

\%. E.? procurrens Funth; racemo composito; racenulis secundis; spicnla terminali longissime pedicellata; glumis acuminatis hirsutis; culno ramoso procumbente; vaginis foliisque villosis linearibus margine cartilagineis. Panicum Nees l. c. p. 130. Trin. ic. t. 224. In Brasilia. 24.

S. E.? loliuce Kunth; fol. Ianceolato-linearibus supra pubescentibus; culmo vaginisque hirsutis; panicula racemosa laxiflora stricta; calycihus 1-floris oblongis hirsutis muticis exquisite nervosis. Panicum Bertol. Piant. del Bres. p. 4. P. candicans Nees. P. Bertolonianum schult. In Brasilia.

\section{TIOUAREA R. Br. (1810).}

1. T. latifolia R. Br. foribus androgynis binis; culmis puhescentibus; fol. lanceolatis utrinque sericeis $\mathrm{R}$. Br. prodr. 1. p. 197. In Nova Hollandia.

2. T. sarmentosa Pers. fol. Ianceolatis externe serice-villosis interne pubescentibus; culmis glabris; spicula audrogyna solitaria. Kunth Gr. 1. p. 247. t. 35. In iflalagascaria.

3. $\boldsymbol{T}$. media $\boldsymbol{R}, \boldsymbol{B r}$. floribus androgynis solitariis; fol. lineari-lanceolatis subtus culmisque glahris. 13 . $\mathrm{Br}$. 1. c. p. 197. In Nova Hollandia.

4. $\boldsymbol{T}$. imoluta $R$. Br. spica secunda mutica 4-flora involuta; recep- taculo foliaceo concavo. Iscliaemum Forst. prodr. 11. 385. In ins. societatis.

\section{SPINIFEX Linn. (173\%).}

1. S. longifolins R. Br. glaber; fol. inermibus flaccidis semiteretibus marginihus longitudinaliter laevilus rachi fructifera longioribus; glumis masculis glahris. 12. Br. 1. c. p. 198. In Nova Hollandia.

2. S. frayilis R. Br. glaher; fol. inermihus flaceidis semiteretihus margine scabris rachi fructifera longioribus. R. Br. 1. c. p. 198 . In Nova Hollandia.

3. S. sericeus R. $\boldsymbol{R r}$. sericeus; fol. inermilus intus vaginisque glabris; acumine racheos masculae spica aliquoties breviore. R. Br. 1. c. p. 198. In Nova Hollandia.

4. S. hirsutus Labill. Nov. Holl. t. 230. 231. sericeus; fol. inermibns intus vaginisque villosis; racheos masculae acuinine spicam subaequante. R. Br. 1. c. p. 198. In Nova Hol landia.

5. S. squarrosus $\boldsymbol{L}$. capitulorum bracteis fasciculatis maximis; involucris mucronatis; flosculis muticis. Stipa spinifex. Linn. mant. p. 34. Moris. $s$. 8. t. 8. f. 11 . Rumph 6. t. 2. f. 2 . Rheede 12. t. 75. In India orientali. 4 .

\section{NEURACHNE R. Br. (1810).}

1. N. alopecuroides $\boldsymbol{R} . \boldsymbol{B r}$. prodr. 1. $\%$. 309. Panicum spreng. In Nova Hollandia. 24. Culmus multiplex erectus; geniculis serice 0 -barbatis. Spica unica ovata.

\section{ORYZOPSIS Rich.}

1. O. asperifolia Rich. in Michx. Fl. 1. p. 51. t.9. Urachne lencosperma et melanosperma Link. Piptatherum Torrey. In America boreuli. 21.

2. O. mutica Link en. 1, p. 1 . corolla pubescente albente mutica. Link. In America boreali. 2. 


\section{PIPTATHEREM Beauv. (1512).}

1. P. caerulescens Beaur. Agr. t. 5. f. 10. panicula laxa; corolla subaristata glabra; arista calyce hreviore; stipulis elongatis erosis. Smith proth. 1. p. 4.5. Aqrostis caerulescens DC. In A/rica boreali et Europa austraii. 2 .

2. P. paradoxum Beauv. panicula patente laxa pauciflora; floribus aristatis; gluma calycina utraque 3-nervia. Milium schrad. germ. 1. p. 196. Host. 3. 1. 23. schreh. t. 25. f. 2. Oryzopsis Nutt. Urachne Trin. In Europa austruli et Cancuso. 4.

3. P. multiflorum Beant. panicula patente multiflora; floribus aristatis; gluma calycina exteriore 5 -nervia. Milium. schrad. 1. c. p. 195. Urachue multiflora et frutescens Link. In Europa ustruli et vibiria.

4. P. Thomasii Kunth; culmo stricto basi geniculato glauco; fol. convolutis laevihus linearibus angustis; ligula brevi truncata; panicula elongata laxa subcoarctata; pedicellis semiverticillatis; glumae valvulis glahris acuminatis suhaequalihus ; arista terminali recta spiculam paulo superante. Milium Duby et DC. bot. Gall. 1. 1) 505. In Corsica.

5. P. holciforme R. et S. panicula nutante; ramis longissimis; corolla glabra; glumae exterioris arista teruinali spiculae longitudine. Agrostis Bieb. cauc. 1. p. 5\%. et 41\%. Trachne grandiflora. Ledeb. ic. Fl. Ross. $t$. 221. In Tauriu et Sibiria.

\section{LASIAGROSTIS Link.}

1. I. Calamagrostis Link; panicula incrassata, perigonii extus lanati valvula exteriore apice aristata; culmo saepius ramoso. DC. Agrostis L. Arundo Halleri Willd. Calamagrostis speciosa. Host Gr. 4. t. 45. In Europia anstrali. 2.

2. L. splendens Kunth; culmo glabro; fol. basi calloso-auriculatis strictis glabris; paniculae tortae secundae subcontractae ramis semiverticillatis scabriusculis; calycibus splendentibus variegalis asperis; corollae valvula inferiore villosa apice emarginata; arista đexuosa parum tortili flosculo duplo
Iongiore. Stipa Trin. in Spr. N. Entd. 2. p. 51. In Sibiria transbaicalense.

\section{MACROCHLOA Kunth (1532).}

1. M. tenacissima Kunth; aristis hasi pilosis; panicula spicata; fol. filiformibus. Stipa Limn. amoen. 4. p. 266. Desf. all. t. 30. In Hispania, Altica et Barbaria. 4.

2. M. arenaria fiunth; panicula divaricata; spiculis pendulis plerumque 1-floris; calycibus hirsutis aristatis; arista dorsali glahra glumam multolies superante. Avena Cavanillesii Lagasc. Elench. p. 4. Stipa Brot. S. gigantea Link. In Hispania et Lusitania.

\section{STIPA L. (1737).}

1. S. pennata L. glumis subulatis perianthio ultra semipollicari superne nudo plus duplo longioribus; inferiore paulo majore; arista tortili plicata superne plumosa glunis octies longiore; antheris nudis. Trin. in Act. Petrop. 1830. 1. p. 82. Host. Gr. 4. t. 33. In Europa et Sibiria. 4.

2. N. barbuta Desf. fol. rigidis hinc striatis; panicula laxa elongata; aristis longissimis a basi ad apicem harhatis. Desf. atl. 1. p. 97. t. 27. In Africa boseali. 2.

3. S. juncea L. glumis subulatis perianthio 5-lineali superne nudo tertiam partem longiorilus ; inferiore parum najore; arista tortili plicata pilosa glumis sexies longiore; antheris barhatis. Trim. in Act. Petrop. 1830. 1. p. 81. Sibth. graec. t. 85. In Gallia, IIispania, Lycia, Creta et ad ripas Missuri. $\odot$.

4. S. Sparta Trin. glumis subulatis perianthio ultra semipollicari superne nudo duplo longioribus; nunc inferiore nunc superiore parum majore; arista tortili plicata flexuosa pubescenti-hirtula glumis plus triplo longiore. Trin. I. c. p. 82. In America boreali.

5. S. Lagascae $\boldsymbol{R}$. et $\boldsymbol{S}$. fol. setaceis; aristis longissimis hrevissime pubescentibus; pedicellis glabris scabris. Lagasc. Elench. 3. \$. juncea $\beta$. Desf. Aîl. t. 28. In Hispania. 4. 
6. S. capillata $L$. nanicula basi inclusa; aristis longissimis geniculatis clabris. Mert. et Koch germ. 1. p. 532. Host. Gram. 3. t.5. In Europu, Graecia, Caucaso, I'auria et Sibiria. 24.

\%. S. gigantea Lagfasc. glumis longissime subulatis perianthio semipollicari superne nudo multo longioribus; inferiore paulo majore; arista subtortili flexuosa temuissime pubescente glumis quinquies longiore. Trin. in Act. Petrop. 1830. 1. p. 81. s. jumcea Cav. In Hispunia. 4.

8. S. canadensis poir. fol. setaceis; panicula parva; calycibus glabris obtuse ovatis semen pubeus aequantibus; aristis crassis brevibus. Pursh Fl. 1. p. 72. Oryzopsis parviAlora Nutt. In Cancila.

9. S. erecta Hort. Hadrit. glumis subulatis perianthio semipollicari ad nervos praesertim inferne hirto duplo longiorihus; inferiore parum majore; arista tortili plicata flextosa nuda glumis octies longiore; antheris nudis. Trin. 1. c. Patria ignota.

10. S. Aristella L. glumis rostrato-acuminatis perianthio trilineali pilis adsperso paulo longioribus; inferiore submajore; arista aequa hispida glumis duplo longiore; antheris nudis. Triu. 1. c. Gouan ill. 3. t. 1. f. 3. Host. Gr. 4. t. 34. Silhth. Gr. t. 87. In Europa meridionali et Asia minore. 4.

11. S. tortilis Desf. panicula spicata basi involuta; calyce interiore villoso; aristis contortis inferne villosis. Desf. Atl. 1. p. 99. t. 31. f. 1. S. humilis Brot. S. paleacea Sm. Sibth. Gr. t. 86. S. seminuda Hornem. In Europa australi, Aegypto, Barbaria et Prom. 6. spei. $\odot$.

12. S. parvifiora Desf. glumis acuminatis; superiore duplo breviore, perianthium subultra-lineali pilosiusculum vix superante; arista plicata recurva unda glunis sexies longiore; antheris barhatis. Trin. in Act. Petrop. 1830. 1. p. 77. s. elongata Roth. In Africa boreali et Creta. 4.

13. S. lumilis Cav. floribus paniculatis spicatis vagina subinclusis; aristis pennatis. Cav. ic. t. 466. In America meridionali.

11. S. ibarrensis $H$. et $K$. fol. scabris; panicula ramosa secunda laxa; rachi scabriuscula; glumis acuminatis paleis duplo longioribus; paleis aristaque albo-pilosis. Kunth. In Quito. 24 ,

15. S. eminens Car. ic. t. 16\%. f. 1. fol. scabris; pauicula ramosa secuuda verticillata; rachi glabra; glumis acuminatis paleam superantibus; paleis scahris hasi apiceque pilosis; arista pilosa. Kunth. In Hexico, Brosiliu et Quito. 4.

16. S. mucronata $H$. et $K$. fol. glabriusculis; panicula simplici sulsecunda verticillata; glumis acuminatis paleis paulo lougiorihus; paleis pilosiusculis; arista pilosa. Kunth 1. c. In Mexico. 4.

17. S. arenacea $I$. glumis acutis subaequalibus parianthio fere $k-\mathrm{li}-$ neali excepta basi nudo apice barbatulo parum longioribus; arista tortili plicata sublente pilosula glumis 5-8ies longiore; antheris nudis? Trin. in Act. Petrop. 1830. 1. p. 79. \$. bicolor. Trin. Unifl. In America boreali. 4.

18. S. virfjinicu Pers. panicula rarifora; ramulis simplicibus 1-floris geminis; glumae valvis exterioribus majusculis acuminatis; valvula seminifera stipite densa rufaque harba obsito suffulta; arista longissima crassa nuda. s. barhata Michx. FI. 1. p. 58. s. avenacea Walt. In Virginia et Carolina. 24.

19. S. bicolor Vahl; glumis subulatis subaequalibus perianthio 3 -lineali excepta basi nudo verrucoso apice coronato duplo longioribus; arista tortili flexuosula vix plicata pubescendo-villosula glumis fere triplo longiore; antheris barbatis. Trin.l. c. Cav. ic. t. 466. f. 2. In Brasilia et Chili. 4.

20. S. ovata Trin. glumis oblongis caudatis subaequalibus perianthio sesquilineali basi villoso truncaio torulo coronato tertiam partem vel subduplo longioribus; arista terminali subtortili plicata flexuosula glumis quater longiore. Trin. 1. c. In Honterideo.

21. S. panicoides Lam. culmis caespitosis ; fol. convoluto-setaceis rigidis scabriusculis vagimsque glancescenti-viridihus; racemo contracto; spiculis pedicellatis geminis solitariisque; glumis purpurascentıbus acuminato-cuspidatis superne scabriusculis; inferiore majore florem duplo superante; palea inferiore striata tubercu- 
lato-asperata; arista glahra leviter torta palca quadruplo longiore. Kunth Gram. 2. t. 122. Oryzopsis selacea. Rich. In Chili et Brasitil. 4.

22. S. setifolia Kuntle; culmo inferne ramoso erecto striato glaherrimo folioso; fol. glaucis convolutosetaceis, jumiorihus scahriusculis; vaginis teretilus striatis glaberrimis; spica paniculata cylindracea erecta; glumis ovatis acuminatis 5-nervis; palea inferiore compresso-lenticulari carinata striatula tuberculata; arista torta scahra basi articulata. Piptochaetium Presl in Rel. Haenk 1. p. 222. t. 37. f. 1. In P'eruria.

23. N. fimbriata H. et $\boldsymbol{K}$. fol. interne scabriusculis; panicula ramosa subsecunda laxa; glumis concavis glabris paleas piloso-sericeas vix superantibus; superiore submucronata; arista scabrituscula. Kunth Gram. 1. p. 263. t. 43. In Nexico. 4.

2-1. S. virescens H. et K. fol. scabris ; panicula simplici laxa; ramis oppositis ; rachi glabra; glumis fimbriato-dentatis paleis paulo longioribus hrevissime aristatis; paleis piloso-sericeis; arista scabriuscula. Kunth 1. c. In Mexico. 4.

25. S. cuerulea Presl; culmo vaginis foliisque scabris convoluto-setaceis longissimis; paniculae simplicis ranis fasciculatis; rachi ramisque scahris; glumis aequalihus mucronatis 5-nerviis aequantibus corollam pilosant ; arista scabriuscula. Presl Rel. Haenk 1. p. 227. In Mexico. 4.

26. S. lyyalina Nees; fol. linearibus planis facie scabriusculis culmoque ramoso glahris; paniculae aequalis contractae decompositae ramis fasciculatis; glumis subaequalibus lanceolatis longissine acmminatis hyalinis flosculo hasi puhescente apice calloso lacero fimbrialo dimidio longioribus; arista nuda gracili vix sesquipollicari. Nees in Mart. Bras. 2. p. 378. S. avenacea Spr. In Montevideo.

2\%. S. trichotoma Nees; culmis caespitosis; fol. convoluto-selaceis rigidis scahris; panicula ramosa erecta secunda; ramis ramulisque geminis vel teruis scabris; spiculis sparsis longe pedicellatis; glumis subaequalibus superue augustatis trinerviis purpurascenti-fuscis ad nervos hispidulis, florem duplo superantibus; palea iufe- riere tuberculato-spinulosa scahrata; arista hispido-scahra inferne leviter torla glumas sextuplo superante. Kunth Gram. 1. t. 121. In Montevileo. 4.

25. S. eriostachyı $H$. et $K$. fol. scabris; panicula ramosissima coarctata apice nuante; rachi glahriuscula; glumis muticis paleis triplo longioribus; paleis apice longissime papposo-pilosis; arista pilosa. H. et K. Nov.Gen. 1. p. 127. t. 41. In Quito et Mexico. 24.

29. S. Ichu Kunth; fol. involutis subulatis; spica paniculata. S. Jarava 13. et P. peruv. 1. p. 5. t. 6. f. 6. s. Jarava Beauv. In Peruria.

30. S. mollis $\boldsymbol{R}$. $\mathrm{Br}$. aristis a basi ultra geniculum plumosis apice nudo; perianthiis sericeis; fol. involutis; vaginis pubescentibus. R. Br. prodr. 1. p. 174. In Nore Hollandia.

31. S. semibarbatı $\mathbf{R}$. $\mathrm{Br}$. aristis a basi ad geniculum plumosis superne nudis; perianthiis sericeis; glumis coriaceis scabriusculis. $\mathrm{R}$. Br. prodr. 1. p. 17t. In Nova Hollandia.

32. S. pubesceus R. Lir. aristis infra geniculum tenuissime pubescentihus; parianthiis sericeis; glumis truncatis parum erosis; fol. involutis; ligula abbreviata; geniculis pubescentibus. R. Br. I. c. In Nova Hollandia.

3.3. S. setacea $\boldsymbol{R} . \boldsymbol{B r}$. aristis nudis geniculatis; perianthiis pubescentibus; glumis setace 0 -acuminatis lacvibus; fol. involutis vaginisque glabris; ligulis elongatis integris geniculisque nudis; panicula effusa. H. Br. 1. c. In Nora Hollandia.

31. 5. eleganlissima Labill. aristis nudis; pedicellis plumosis. Labill. Nov.Holl. 1. p. 23. t. 29. In Nova Hollandia.

3.5. S. flarescens Labill. l. c. t.30? aristis nudis; perianthiis pubescentibus; glumis setaceo-acuminatis; fol. involutis; geniculis vaginisque inferioribus pubescentibus; ligula brevissima ciliata. 11. Br. 1. c. In Nova liollandia.

36. S. compressa $\boldsymbol{R}$. Br. aristis nudis longissinis rectiusculis ; perianthiis sericeis; culmo compresso vaginisque glahris laevibus; fol. involutis; ligula eiongata nuda subincisa. $\mathbf{R}$. Br. 1. c. In Nova Hollandia.

3\%. S. crinita Gaudich. culmis caespitosis foliisque erectis convolutis 
vaginisque scahriusculis; panicula ramosa coarctata erecta; glumis acuminato-subulatis dorso scabriusculis paleas sericeo-pubescentes duplo superantibus; arista longissima hispidu1a. Gaudich. in Freyc. it. bot. p. $40 \%$. In Noen Ilollandiu.

38. S. verticilluia Nees; paniculae effusae ramis inferioribus verticillatofasciculatis; calycihus angustissimis acuminatis; arista longissima flexmosa basi puhescente; fol. planiusculis; lisula nulla. Nees in vieh. Agrost. n. 64. In Nora Hollandia.

3.9. \$. micrantha Car. ic. t. 167 ? aristis nudis; perianthiis gुlabris sulısessilibus; glumis mucronatis; panicula effusa; culmo ranoso vaginisque laevilus; fol. planiusculis scabris. $\mathbf{R}$. Br. 1. c. p. 175. In Nova Hollandia.

10. . . ramosissima Trin. glumis cuspidatis perianthio vix lineali scabro paulo longiorihus; inferioré paulo majore; arista plicata hispida ylumis quinquies sexiesve lonsriore. Crachne Trin. Unifl. p. 1 73 . \$. micrantha. Trin. In Noé Nollamilia.

11. S. carayana Trin. glumis acutis aequalibus perianthio subultralineali pilis adsperso apice villoso fere tertiam partem longioribus; arista caduca aequa recta glumis subtriplo longiore; antheris barhatis. Trin. in Act. Petrop. 1830. 1. p. 74. Ad Mare Caspium.

12. S. altaica Trin. glumis acutis ; superiore $\frac{I}{4}-\frac{I}{5}$ majore periauthium 2-lineale villosum aequante; arista aequa curvula hirta glumis fere bis longiore; antheris barhatis. Ledeb. ic. pl. Koss. ill. t. 222. ejusd. Fl. alt. 1. p. 80. In Sibiria altaica. 4 .

43. S. Redowstii Trin. glumis ohtusiusculis subaequalibus; perianthio 2-lineali villoso $\frac{I}{4}$ longioribus; arista aequa aut vix torta hispida grlumis duplo longiore; antheris barbatis. Ledeb. 1. c. t. 98. S. conferta Poir. In Sibiria altaica.

11. S. coulata Trin. glumis breviler caudatis aequalibus perianthio 2-lineali villoso apice harbato parum longioribus; arista tortili plicatula nuda glumis triplo longiore; antheris barbatis. Trin. in Act. Petrop. 1830. 1. p. 75. In Chili.

45. S. megapotamica Spr. glumis acutis aequalibus perianthio 2 -lineali ad medium usque pilosulo superne ver- rucoso-scabro truncato subcoronato tertiam partem longioribus; arista tortili flexuosa inferne pubescendo-pilosiuscula glumis sexies longiore. Trin. ill Act. Petrop. 1830. 1. p.77. In Brasilia meridionali.

46. S. filifolia Nees; fol. filiformibus scabris; culmo simplici stricto laevi; ligula chartacea bifida; paniculae decompositae subsecundae contractae deusae ramis subverticillatis; glumis subaequalibus lanceolato-subulatis hyalinis flosculo lineari-lanceolato pubescenti-scabro apice denticuIalo duplo longioribus; arista nuda flexuosa, flosculo nultoties longiore. Nees in Mart. Bras. 2. p. 379. In Montecideo.

17. S. penniglumis Trin. glumis collateralibus setiformibus plumosis perianthio subultra bilineali dorso nudo fronte villoso brevioribus; arista tortili plicata inferue spiraliter villosa glumis fere decies longiore; antheris mudis. Trin. in Act. Petrop. 1830. 1. p. 87. In Brasilia.

45. S. papposa Nees; fol. linearibus convolutis culmoque subranoso glabris; paniculae subsecundae laxae decompositae ramis semiverticillatis; rachi laevi; glumis subaequalibus lineari-subulatis hyalinis flosculo apico longe barbato lineari paulo brevioribus; arista nuda flosculo duplo triplove longiore. Nees in Mart. Bras. 2. p. 377. Calamagrostis plumosa spr. In Monterideo.

49. S. sibirica Lam. glumis acutiusculis subaequalibus perianthium trilineale villosum aequantihus; arista tortili plicatula piloso-lispida glumis bis longiore; antheris barbatis. Ledeb. ill. pl. Ross. ic. t. 99. Avena L. In sibiria. 4.

50. S. orientalis Trin. glumis subulato-acuminatis subaequalibus, perianthio 3-lineali piloso duplo Ionvioribus; arista tortili plicata tota plumosa glumis plus triplo longiore; antheris nudis. Ledeh. ic. pl. Moss, ill. t. 223. In Altai et Caucaso orientali. 4.

51. S. hulosericed Trin. glumis subulatis aequalibus perianthio semipollicari superue longe nudo plus duplo longioribus; arista su!tortili flexuosula sericeo-pubescente glumis octies longiore; antheris nudis. Trin. in Act. Petrop. 1830. 1. p. 81. In Persia.

5*. S. stricta Lam. panicula elon- 
gata aristata; pedunculis articulatis strictissimis; aristis nudis subflexuosis. Lam. ill. 1. p. 158. In Carolina.

53. S. setigera Prest; culmo ad nodos piloso; vaginis foliisque convolutis scalıris; panicula secunda; rachi ramisque scabris; flore stipite piloso suffulto; glumis palea inferiore nervo medio margineque pilosa duplo longiorihus in setam exeuntihus; arista pi10sa. Presl 1. c. Patria ignota.

51. S. melanosperma Prest; vaginis foliisque convoluto-setaceis glabris; panicula simplici; rachi ramisque glahris; glumis flore stipite piloso suffulto quinquies longioribus in setam attenuatis; palea inferiore nitida apice angulata scabra; arista hirsuta longissima. Presl l. c. Patria ignota.

5.5. S. inconspicua Presl; culmis vaginis rachique scahriusculis; fol. convolutis scabris; panicula composita secunda patula; glumis acutis floribus paulo longioribus integerrimis glabris; palea inferiore pilosa examnulata; arista scabra. Presl 1. c. In Peruciu.

56. S. capensis Thunb. aristis hasi pilosis; panicula spicata; fol. ensiformilsus. Thumb. prodr. p. 19. In Prom. b. spei. 4.

57. S. membranacea Pursh; fol. convoluto-filiformilus glahris; panicula laxa; pedicellis flexuosis; calycibus memhranaceis 3 -nervihus longe acuminatis; corollis calyce breviorilus sericeo-villosis; villis corollam superantihus ; arista nuda recta calyce panlo longiore. Pursh am. 2. p. 728. Eriocona cuspidata Nutt. Milium spr. s. hymenoides $\mathrm{R}$. et $\mathrm{S}$. Ad ripas fluminis Missuri.

58. S. striata Link; fol. planis; ligula trumcata; panicula simplici; valvis subaequalibus longe acutatis ; exteriore longiore; valvula pilis arrectis; arista brevi gyris laxis semel fracta tota scahra. Link Hort. 1. p. 98. In Australasia. 24.

5.9. S. rudis spr. panicula contracta pauciflora; calycilus elongatis linearihus acuminatis glahris nervosis; arista valida torta longissima; fol. convoluto-filiformilus. Spr. Cur. post. p. 31. In Nova Hollandia.

60. S. ucranensis Lam. aristis nudis rectis; calycibus subrufis semine longioribus. Lam.ill. 1. p. 15\%. Tirsa
Guett. Mem. 1. p. 19. f. 12. In Ucrania.

326. STREPTACHNE R. Br. (1810).

1. S. stipoides $\boldsymbol{R}$. Br. prodr. 1. 1. 17t. In Nova Hollandia.

\section{2\%. ARISTIDA Linn. (1\%3\%).}

1. A. capillacea Lam. panicula patula; glumis acuninatis perianthio lineali longioribus; inferiore quartam partem breviore; arista infra medium divisa; laciniis hilinealibus media paulo longiore. Trin. in Act. Petrop. 1830. 1. p. 87. A. elegans Rudge Guj. t. 30. A. capillaris Cav. ic. t. 468. f. 1. In America meridionali.

2. A. humilis H. et K. culmo simplici; fol. convoluto-subulatis glabriusculis; panicula simplici subverticillata coarctata; glumis subulatis; aristis aequalibus. Kunth 1. c. Clıaetaria R. et s. In Cumana. 4.

3. A. mauritiana Kunth; fol. involuto-filiformibus culmisque glahris erectis subsimplicibus; panicula simplici racemosa; glumis inaequalibus obtusiusculis glabris; inferiore carina scabra mucronulata; palea inferiore glabriuscula, gluman superiorem subaequante; aristis inaequalibus scabris. Kunth Gram. 1. p. 265. t. 44. In ins. Franciae.

t. A. squarrosa Trin. panicula contracta stricta; glumis longe caudatis; superiore duplo longiore perianthio 5-lineali dimidio breviore; aristae laciniis valvula plus duplo Iongioribus sqarrosis; media paulo majore. Trin. iu spr. N. Entd. 2. p. 62. Chaetaria li. et s. In America boreali.

5. A. dichotoma Michx. culmis erectis subdichotomo-ramosis; fol. anguste linearibus convoluto-setaceis; spiculis laxe ramosis; glumis brevissime aristatis, florem dorso adpressopuberulum hasi pedicellatum et barbatum superantihus; superiore apice 2-dentata. Kunth Gr. t. 174. Curtopogon Beauv. Agr. t. 8. f. 7. In Americu boreali. $\odot$.

6. A. crinita Presl; culmo simplicissimo compressiusculo; fol. convoluto-setaceis margine scabris; paui- 
cula spicaeformi simplici contracta; spiculis fasciculatis; glumis linearilanceolatis setiferis nervo scahris ; inferiore minore superiore paleam inferiorem carina scabram excedente; aristis longissimis, stipiti brevissimo insidentibus aequilongis scabris. Presl. 1. c. In Peruvia. 4.

\%. A. bromoides $\boldsymbol{H}$. et $\boldsymbol{K}$. culmo ramoso; fol. convolutis externe pubescentibus; panicula simplici secunda patula; glumis subaristatis; aristis subaequalibus, H. et K. Nov. Gen. 1. p. 112. Chaetaria 11. et S. In Quito. 4 .

8. A. gibbosa Kunth; culmo ramoso stricto; fol. linearibus convolutis strictis facie pilosis; vaginarum collo ciliato; paniculae ramosae subsecundae contractac ramis fasciculato-divisis; glumis suhaequalibus lanceolato-acutis setigeris flosculum acquantibus; setis rectis divergentibus inaequalibus flosculum duplo superantibus. Clıaetaria Nees in Mart. Bras. 2. p. 383. In Brasilia. 4.

9. A. Sanctae Luciae Trin. panicula subpatula; glumis bidentatis breviter setigeris; superiore tertiam partem longiore perianthium bilineale aequante; aristae laciniis valvula fere triplo longioribus; media paulo longiore. Trin. diss. 2. p. 25. In Brasilia.

10. A. divaricata Willd. culmo simplici; fol. convolutis margine scabris; panicula ramosa subverticillata divaricata; glumis brevissime aristatis; aristis subaequalibus. H. et K. Nov. Gen. 1. p. 123. Chaetaria R. et S: In Mexico et Brasilia. 4.

11. A. coarctata $H$. et $\mathrm{K}$. culmo simplici (?); fol. planis interne scabris; panicula ramosa secunda subverticillata; glumis subaristatis; aristis subaequalibus. H. et K. Nov. Gei. 1. p. 122. Cliaetaria R. et $s$. In Mexico. 4.

12. A. spadicea $H$. et $K$. culmo simplici; fol. planis margine scabriusculis; panicula ramosa secunda subnutante; glumis brevissime aristatis; aristis ineaqualibus. Kunth I.c. Chaetaria 18. et S. In Mexico, ad ripas Orinoci, in Guagaquil et Brasilia. $\odot$.

13. A. setifolice $H$. et $K$. culmo ramoso; fol. convoluto-setaceis marrine scabriusculis pilosiusculis; panicula ramosa secunda subnutaute verticilla- ta; glumis subaristatis; aristis subaequalibıs; Kunth I. c. Claetaria H. et s. in Cumuna et Brosilia. $\delta$.

1t. A. longiramea Presl; culmo simplici tereti; fol. convoluto-sctaceis margine carinaque scalıis; paniculae compositae contractae secundae nutantis ramis hinis longissimis; glumis brevissime aristatis flore brevioribus; inferiore 3-nervia superiore 1-nervia; arista media longiore. Presl. 1. c. In Mexico. 4.

15. A. oligantha Michx. culmo stricto subramoso; fol. convolutofiliformibus; floribus distantibus solitariis; aristis longis divaricatis. Pursh Fl. 1.p. 72. Chaetaria Beauv. In America boreali. 4.

16. A. virgata Trin. panicula patula elongata; glumis acuminatis perianthio bilineali non numis Iongioribus, inferiore paulo minore; aristae laciniis lateralibus valvula plus duplo, media eadem fere quadruplo longioribus. Trin. in spr. N. Entd. 2. p. 60. In America boreali.

17. A. stricta Michx. fol. pubescentibus culmisque stricte erectis; racemo Iongo spicato coarctato; aristis gluma longioribus. Chaetaria Beauv. In America boreali. 4.

15. A. gracilis Elliot; panicula contracta; glumis acuminatis perianthium subultra bilineale aequantibus; inferiore multo minore; aristae laciniis lateralibus longitudine valvulae, media eadem plus duplo longiore. Triu. in Act. Petrop. 1830. 1. p. 86. In America boreali.

19. A. affinis Kunth; culmo erecto quadrangulo; fol. linearibus striatis basi pilosis apice scabris; panicula contracta; aristis tribus terminalibus hispidis patulis. A. racemosa Mühlenb. descr. p. 172. In America boreali.

20. A. Antillarum Poir. caule repente ramoso; fol. flliformi-subulatis; paniculae ramis brevibus subsecundis; calycibus bifloris. Poir. Encycl. 1. p. 451. Atheropogon Spr. Chaetaria $\mathbf{H}$. et S. In Antillis.

21. A. nigrescens Presl; culmo ramoso tereti; fol. convoluto-setaceis intus pubescentibus margine scabriusculis; ligula truncata brevissima integerrima glaberrima; paniculae secundae subsimplicis lamis subternis; glumis brevissime aristatis; superiore paleam inferiorem scabram aequante; 
aristarum sessilium ramo medio longiore. Presl Rel. Haenk 1. p. 223. In Mexico. $\odot$.

22. A. recurvata II. et K. culno simplici; fol. convolutis margine scabris; panicula ramosa subverticillata coarctata conferta; glumis subaristatis; aristis suhaequalibus. H. et $\mathbf{k}$. Nov. Gen. 1. p. 123. Chaetaria Nees. Ad ripas Orinoci, in Brasilia. 4.

23. A. torta Kunth; culmo simplici; fol. lineari-elongatis complicatis facie scahris; vaginarum collo harbato; panicula ramosa subverticillata coarctata subcontorta; glumis acutis; superiore flosculum superante; setis lateralihus rectis flosculum scabrum aequantibus; media reflexa duplo lougiore. Chaetaria Nees in Mart. Bras. 2. p. 386. In Erasilia.

21. A. depressa Ret $\approx$; culmis 3fido-ramosis decumbentibus; aristis scabriusculis. Retz obs. 4. p. 22. Chaetaria Beauv. In Malabaria.

25. A. Adscensionis L. panicula contracta; glumis acuninatis; superiore tertiam partein longiore perianthium 3-lineale paulo superante; aristae laciniis valvula bis et ultra longioribus; media paulo majore. Triu. in Act. Petrop. 1830. i. p. 83. Chaetaria Beauv. In ins. Adscensionis.

26. A. lanata Poir. fol. longissimis scabris; vaginis lanatis; ramis paniculae elougatis subverticillatis; pedunculis basi pilosis; aristis subaequalibus. Poir. Enc. 1. p. 453. Chaetaria gossypina Beauv. In Carolina.

27. A. clatior Car. culno ramoso altissimo; panicula elongata; calycibus violaceis; aristis acqualibus. Cav. ic. t. 589. f. 1. Chaetaria Beauv. In IIspania.

28. A. Sieberiana Trin. panicula contracta; glumis 2 -dentatis breviter setigeris; interiore duplo minore perianthium 5-lineale aequante; arista infra medium divisa; laciniis aequalibus bipollicaribus. Trin. in spr. N. Entd. 2. p. 61. A. caerulescens Sieb. Chaetaria scliult. In Pataestina.

29. A. setucer Ret:; panicula contracta subsecunda; glumis acutissimis; superiore subduplo longiore perianthium 4-lineale subaequante; aristae laciniis subaequalibus valvula parum longioribus. Trin. in Act. Petrop. 1. p. 84. Clauetaria $\mathbf{R}$. et $\mathbf{S}$. In India orientali.
30. A. Irystrix Thunb. panicula patula; glumis sub-2-dentatis setigeris; superiore inferiore et perianthio 3 -lineali fere dimidio longiore; aristac laciniis valvula plus triplo longioribus; media paulo majore. Trin. in Act. Petrop. 1830. 1. p. 83. Chaetaria Beauv. Arthratherum Nees. In Malabaria.

31. A. cacrulescens Desf. atl. $t$. 21. f. 2. panicula contracta subsecunda; glumis obtusis; superiore tertiam partem duplove longiore perianthium 3-1-lineale subaequante; aristae laciniis valvula vix aut quartain partem longiorilus; media paulo majore. Trin. 1. c. Clıaetaria Beauv. A. canariensis IVilld. A. divaricata Jacq. Eclog. Gr. t. 6. In Barbaria, Hispaniu, ins. Fortunatis, Palaestina et Brasilia. $\odot$. 32. A. murina Car. panicula subspicata; ramulis alternis binis sub-5floris; calycibus violaceis. Cav. ic. $t$. 469. f. 1. In ins. Philippinis.

33. A. rigida Cav. panicula contracta; fol. rigidis acuminatis glabris culmo parallelis; aristarum media duplo, longiore. Cav. ic. t. 469 . f. 2. In ins. Philippinis.

31. A. pallens Cav. panicula plerunque contracta; glumis subulatoacuminatis; superiore inferiore duplo, perianthio fere semipollicari subduplo vel multo longiore; aristae lacinits vix inaequalibus, valvula $8-12-18-p l o$ longioribus. 'Trin. in Act. Petrop. 1830. 1. p. 85. Chaetiria Beauv. In Chili, Montevideo et Louisiana.

3.). A. laevis liunth; culmo simplici foliisque linearibus elongatis laevissimis; vagiuarum collo subciliato; paniculae erectae contractae ramis solitariis racemoso-compositis; glumis subulatis inaequalibus; superiore fosculum parum superante; setis subaequalibus divergentibus; media flosculum triplo superante. Chaetaria Nees in Mart. Bras. 2. p. 38t. In Brasilia. 4.

36. A. laxa Cav. ic. t. 4\%0. f. 1. panicula laxa; glumis acutissimis; aristae laciniis lateralibus brevissimis melia valvulae longitudinem paulo excedente. Trin. In Plilippinis et Brasilix.

37. A. sorzogonensis Presl; ligula brevissima pilosa; glumis 1-nelviis aristatis aequalibus; inferiore dorso pubescente; aristis stipatis aequilongis. Presl. 1. c. In Luzonia. 
38. A. luzonensis Cav. culmo ramoso; panicula contracta; spiculis alternatim pluribus; aristis subaequalibus. Cav. ic. t. 470. f. 1. Chaetaria Bealv. In Lusonic.

39. A. vagans Cav. ic. $t$. 471. panicula effusa rara; glumis coloratis mucronulatis aeçualibus, perianthii dimidio brevioribus aristas subaequantihus. R. Br. prodr. 1. p. 173. In Nove Hollanelia.

40. A. rumosa R. Br. culmo erecto ramoso; panicula subsimplici coarctata; glumis coloratis; aristis longitudine florum. R. Br. I. c. Cliaetaria $\mathbf{R}$. et $\mathbf{S}$. In Nov'a Hollandia.

41. A. calycina R. Br. culmo erecto simplici; panicula subranıosa; clumis coloratis mucronatis longitudine perianthii; aristis flore longioribus. R. Br. 1. c. Chaetaria R. et $\mathbf{S}$. In Nova Hollandia.

42. A. pilosa Labill. panicula elongata contracta; culmis simplicibus infra pilosis; corolla calyce longiore; arista media productiore. Labill. Nov. Caled. 12. t. 17. In Nova Hollandia.

43. A. interrupta Cav. paniculae ramis interruptis; fol. vaginantihus subulato-longissimis; aristis ciliatis. Cav. ic. t. 471. f. 2. In Mexico.

41. A. elliptica Kunth; culmis ramosis adscendentibus pubescenti-scabris ; panicula glomerato-spicaeformi; glumis mucronato-setigeris; setis flosculo longioribus. Chactaria Nees 1. c. In Brasilia.

4.5. A. longifolic Trin. panicula contractiuscula; glumis acuminatis; setis lateralibus valvula sesqui-media eadem plus duplo longiore. Trin. in Act. Petrop. 1830. 1. p. 84. In Blasilin.

46. A. complanata Trin. panicula contracta ; glumis acuminatissimis ; aristae laciniis valvula triplo longioribus. Trin. I. c. In Brosilia.

1\%. A. diffusa Trin. panicula diffusa lucidissina; glumis obtusiusculis bifido-dentatis; superiore duplo longiore. Trill. I. c. In Prom. b. spei.

\section{Arista 3-fida, cum palea non articulata.}

48. A. scabra Eunth; panicula subsimplici diffusa; ramis ternis rachique scabris. H. et K. Nov. Gen. 1. p. 124. t. 40. In MIexico. 4 .
49. A. tenuis frunth; panicula subsimplici diflusa; ranis geminis rachique scahris. H. et K. Nov. Gen. 1. p. 124. In Cumana et Mexico. 4.

50. A. jorullensis Kunth; panicula subsecunda; ramis geminis scahris pilisque raris obsitis; lachi glabriuscula. H. et K. I. c. p. 12t. In Mexico.

51. A.? domingensis Funth; spica simplicissima involuta; rachi pedicellisque pilosis. Streptachne. Schult. mant. 2. n. 188. in st. Domingo. 4.

\section{Arista 3-fida cum palca ax- ticulata.}

52. A. stipoides $\boldsymbol{R}$. $B r \%$ racemo subdiviso; aristis 3 -pollicalibus infra divisuram perianthio longioribus. If. Br. 1. c. Arthratherum $\mathbf{1 1}$. et $\mathbf{s}$. In Nova Hollandia.

53. A. arenaria Gaudich. culmo ramoso caespitoso; fol. convoluto-setaceis curvatis scabriusculis; panicula subromosa; aristis $\frac{1}{2}-2$-pollicaribus. Gaud. in Freyc. it. bot. p. 407. In Nova Hollandia.

5t. A. liygrometrica R. Br. racenis subsimplicibus; pedunculis inferioribus 1-2-foris; aristis 3-fidis 5-poll. infra divisuram perianthio longioribus. 1. Br. 1. c. In Nova Hollandia.

5.5. A. gigunted I. panicula elongata effusa secunda; calycibus 1-floris; aristis corollinis subaequalibus rectis. L. suppl. p. 113. Chaelaria 17. ct $\$$. In Teneriffa.

56. A. stipaeformis Lam. panicula composita effusa capillacea; calycibus 1-floris; arista trifida praelonga laevi. Lam. ill. 1. p. 15\%. Chaetaria Lamarkii schult. In Senegalia.

5\%. A. pungens Desf. atl. t. 35. panicula patula stricta; arista supra basin divisa; laciniis .5-linealibus plumosis, media sublongiore; fol. rigidis pungentibus. Trill. 1. c. Arthratherum 11. et S. In Aegypto et Barbaria.

58. A. pennatc Trin. panicula patula laxiuscula; arista supia basin divisa; laciniis plumosis, media sublongiore; fol. filiformibus laxis. Trin. 1, c, Ad Baku.

59. A. ciliata Desf. panicula patula; arista longe infra medium divisa; laciniis lateralibus pollice minoribus nudis; media 2-poll. superne plumosa. Trin. 1. c. Arthatherum Nees. In Barbaria et Prom. b. spei. 4. 
60. A. plumosa L. paniculata; arista intermedia longiore lanata; culmis villosis. L. sp. pl. No. 1666. Valıl Symb. t. 3. In Iberia, Persia, Aegypto et Armenia. 4.

61. A. capensis Thunb. panicula trichotoma patente; calycibus corollam aequantihus; aristis divaricatis villosis apice nudis; culmo foliisque filiformibus glabris. spr. syst. 1. p. 269. Kunth Gr. t. 171. Chaetaria R. et S. Arthratherum Nees. In Prom. b. spei, 4.

62. A. uniylumis Licht. panicula patente; glumis acutis; arista infra medium divisa ad divisuram lanata; arista media superne plumosa. Trin. Act. Petrop. p. 80 . In Prom. b. spei.

63. A. congesta $R$. et $S$. culnis caespitosis duris; fol. complicato-ensiformibus glaucis; panicula subeylindracea spicaeformi; gluma superiore apice bifida; arista 3-partita articulata. Kunth Gr. t. 172. In Prom. $b$. spei.

64. A. hordeacea Kunth; culmo ramoso; fol. angustis glaucis convolutis; spicis compositis densis; glumis scabris aristatis; superiore longiore apice 2-dentata florem scabrum basi barbatum superante. Kunth Gr. t. 173. In senegambia.

65. A. sabulosa Kunth; panicula contracta sublineari; gluma inferiore tertiam partem breviore; arista paulo supra basin divisa. A. arenaria. Trin. diss. 2. p. 25. In Brusilia.

66. A. repens Trin. panicula lineari-contraeta; glumis subbidentatis, inter dentes hrevissime cuspidatis. Tril. in Act. Petrop. 1830. 1. 1. 87. In ins. Gallopago.

\section{Species dubiae.}

67. A. tuberculosa Nutt. culmis rigidis dichotomis; tuberculis parvis axillaribus ad ramos singulos; panicula rigida; valvis calycinis carinatis; aristis glabris longissimis, spiraliter convolutis. Nutt. Gen. 1. p. 57. In Georyia.

68. A. spicaeformis Elliot; fol. glabris; panicula subspicata ; arista intermedia basi villosa. Ell. In America boreali.

69. A. purpurascens Poir. fol. angusto-subulatis striatis; panicula longe spicata; aristis subaequalibus. Poir.
Enc. 1. p. 452. Chaetaria R. et S. In Carolina.

70. A. longespicata Poir. culmo subcompresso filiformi ramoso; fol. filiformilus; spica uracili elongata ; aristis valde inaequalibus. Poir. Enc. 1. p. 452. In Carolina.

71. A. fasciculata Torr. paniculae elongatae spicaeformis ramulis fasciculatis; calycibus corollam suhaequantibus; aristis elongatis patulis; fol. lineari-filiformibus; ligula barbata. Torrey in spr. Cur. post p. 31. In Cancala.

72. A. megapotamica Spr. paniculae strictae elongatae spicaefornis ramulis fasciculatis; calycibus longissimis aristatis glahris; arista corollae longissima. Spr. Cur. post. p. 31. Chaetaria schult. Ad Rio Grunde.

73. A. ternipes Cav. panicula coarctata longissima; ramulis alternatim ternis capillarihus; aristis 2 lateralibus hrevibus. Cav. ic. 5. p. 56. In Panama.

74. A. vestita Thunb. panicula trichotoma patente; aristis aequalibus glabris; calyce inaequali. Thunb. cap. 1. p. 395. Clıaetaria Beauv. In Prom. b. spei.

75. A. piligera Burchell; culmo uninodi; geniculo verticillatim piloso; panicula simplici; arista intermedia plumosa. Burch. In Prom. b. spei.

76. A. racemosa Spr. panicula contracta eylindrica spicaeformi; aristis aequalibus calyce triplo minoribus. Spr. Chaetaria R. et S. In ins. St. Helenue.

77. A. arundinacea I. paniculata; arista intermedia longiore laevi. L. Avena Koenigii Spr. In India orientali.

\%8. A. rigescens $R$. et S. panicula subcontracta; culmo flexuoso ramoso; fol. convolutis rigidis. A. rigida Roth Nov. sp. p. 42. Arthratherum Schult. In India orientali.

79. A. festucoides Poir. fol. angusto-subulatis; panicula spicata subsecunda; aristis subaequalibus. Poir. Enc. 1. p. 453. Chaetaria $H$. et $\mathrm{S}$. In Senegalia.

80. A. lanosa Muehlenb. panicula erecta appressa; floribus racemosis; calyce corolla longiore; vaginis foliorum lanatis. Ell. bot. 1. p. 143. In America boreali. 4. 
328. STIPAGROSTIS Nees (1530).

1. S. crpensis Nees; fol. teretiusculis; culmo gracili ad genicula infracto glabro. Nees in Linuaea 7. 1. 291. In Prom. b. spei. 4.

2. S. oblusa Nees; fol. capillaribus striatis; vaginis ore tomentosis; culmo filiformi erecto undique glaberrimo 1-phyllo; corolla brevissima 2dentata. Aristida Delile Aeg. p. 31. t. 13. f. 2. In Aegypto.

\section{MUEHIEVBERGIA Schreb. (1789).}

1. M. implicata Trin. culmis ramosis foliisque pubescentlbus; panicula subramosa implicato-convoluta depauperata; glumis subdenticulatis cnerviis. Podosacmum H. et K. Trichochloa $\mathbf{R}$. et S. In Mexico. 4.

2. M. debilis Trin. culmis ramosis foliisque scabris; panicula simplici depauperata; glumis subdentatis 1-nerviis; paleis dorso scabris; superiore 2-dentata. H. et K. Nov. Gen. 1. P. 128. t. 681. Agrostis Spr. In Quito.

3. M. tenuissima Kunth, culmo ramoso 3-gono; vaginis foliisque convoluto-setaceis scabris; gluma superiore 3-dentata; palea inferiore 3-nervia 3-dentata, superiore 2 -dentata dorso pilosa. Podosaemum Presl Rel. Hacnk 1. p. 230. In Panama et Mexico.

4. M. calamagrostoidea Iunth; culmis erectis; fol. vaginisque pubescenti-scabris; panicula ramosa coarctata; glumis 1-nerviis dorso scabris; palcis pilos multo superantibus. Calamarrostis quitensis. H. et K. 1. c. p. 133. Arundo $\mathrm{R}$. et $\mathrm{S}$. In Mexico. 4 .

5. M. tenuifolia Trin. culmis crectis aut procumbentibus glabris; fol. vaginisque scalıris; panicula ramosa; glumis 1-nerviis dorso scahris: paleis pilos multo superautibus. Calamagrostis. 1. et K. 1. c. p. 134. Arundo tenella spr. In Merico. 4.

6. M. tenella 'rin. culmis ramosissimis sub-4-gonis; panicula simplici filiformi; glumis breviter aristatis; paleis dorso ciliato-scabris; superiore 3-dentata. Podosaemum H. et K. 1. c. p. 128. Trichochloa $\mathbf{R}$. et $\mathbf{S}$. Polypogon Spr. In Maxico. 4.
7. M. ciliata Trin. culnis ramosis glabris; fol. vaginisque ciliatis; panicula diffusa ramosa; glumiš aristatis dorso ciliatis; superiore bidentata. Podosacmun II. et K. I. c. p. 128. Trichochloa R. et $\mathbf{S}$. Polypogon spr. In Mexico. $\odot$.

S. M. setosa Trin. culmis ramosis subangulatis; panicula gracili depauperata; glumis $2-3$-dentitis 1nerviis palcas quadruplo breviorihus; palea sup. bidentata. Podosaemum II. et K. 1. c. p. 129. Trichochloa 1R. et S. Agrostis Spr. In Mexico. $\odot$.

9. M. rigilla Trin. culmis foliisque scabris; varinis glabris; panicula ramosa verticillata; wlumis obsolete 2-nerviis dentatis; palca sup. acuta. Podosaemum H. et K. 1. c. p. 129. Trichochloa R. et $\mathbf{S}$. Agrostis Spr. In Mexico. $\odot$.

10. M. fasciculata Trin. panicula suhthyrsode interrupta; glumis oblongis obtusinsculis perianthio 2-dentato longe setigero triplo brevioribus. Trin. Unif. p. 192. In America boreali.

11. M. Beyrichiana Inuth; fol. planis vacrinisque scabris; ligula $a b$ breviata ciliata; pauicula subsecunda glomerata; glumis longe aristatis; palea inferiore 3-nervia superiore 2cuspidata. Kunth Gr. 1. p. 63. In Brosilia.

12. M. glomerata Trin. panicula glonerata subspicata; calycibus subulatis scabris; culmo adscendente basi ramoso. Polypogon Willd. en. p. 87. Trichochloa 'Trin. Podosaemum Liuk. In America boreali.

13. M. diffusa Willd. culnis ramosis diffusis; fol. vaginisque glabris; panicula contracta. Willd. sp. 1. p. 320. Sichrch. Fr. t. 51. Dilepyrum minutiflorum Michx. In America boreali. 4.

14. M. Willdenouii Trin. pauiculac contractae simplicissimae ramis adpressis; cor. subaequalibus calyce longioribus; valvula majore apice aristata; aristis flore longioribus ; culmo ramoso erecto. Agrostis tenuiflora. Willd. sp. 1. p. 364. Cimna Link. In America boreali. 4.

15. M. erecta Presl; culmis erectis sub nodis deorsum hirsutulis ramosis ; fol. conduplicatis ; panicula ramosa patentissima; gluma inferiore minima rotundata; superiore majore 
margrine emarginata crenata; flore basi villis stipato. Presl Ii. Haenk 1. p. 231. In Hexico. $\odot$.

16. M. mucronata Trin. culmis vaginisque glabris; fol. scalris; panicula verticillatim ramosa; glumis suldentatis mucronatis; paleis glumas 4-plo superantibus, superiore acuta. Podosaenum H. et K. I. c. p. 129. Irichochloa $\mathbf{I}$. et $\mathbf{S}$. Agrostis spr. In Mexico. $\odot$.

17. M. glabrata Trin. culmis vaginis foliisquo glahris margine scabris; panicula ramosa verticillata; flumis dentatis ; inferiore bi-, superiore 1-nervia. Podosaemum H. et K. 1. c. p. 130. Trichochloa $R$. et $\mathbf{S}$. Agrostis Spr, In Merico. $\odot$.

15. M. eleyeins Trin. culmis glabris; fol. vaginisque scabris; panicula subverticillata; glumis acutis 1-nerviis; paleis glumas 3-plo superantibus scabris. Podosaemum $\mathbf{H}$. et K. l. c. p. 130. Trichochloa IR. et S. Agrootis Spr. In Quito. $\odot$.

19. M. quadridentata Trin. culmis foliisque scabris; vaginis glabris; panicula simplici coarctata filiformi; gluma inferiore 1 -nervia acuminata, superiore 4-dentata 3-nervia paleas aequante If. et K. I. c. p. 130. t. 682 . Trichochloa $\mathbf{H}$. et $\mathbf{S}$. Agrostis Spr. In Mexico. $\odot$.

20. M. alpestris Trin. culmis angulatis glabris; spica filiformi; glumis 1-nerviis mucronato-aristatis; paleis glumas 4-plo superantilus glabris, superiore 2-fida. Podosaemum H. et K. 1. c. p. 131. In Caracas. $\odot$.

21. $M$, stipoides Trin, culmis sulcato - angulatis glabris; panicula simplici subnutante patula; glumis subbidentatis 1-nerviis; paleis scahris, superiore hifida; laciniis subulato-aristatis. Podosaenum H. et K. 1. c. p. 131. Trichochloa $\mathrm{I}$. et $\mathrm{S}$. Agrostis Spr, In Quito et Mexico. $\odot$.

22. M. gracilis Trin. culmis compressis vaginisque scabriusculis; fol. interne hispido-scabris; panicula gracili subnutante; glumis inaequalibus; inf. minore 2-, sup. 3-dentata. Podosaenum H. et K. 1, c. p. 131. t. 683. In Mexico.

23. $M$, virescens Trin. culmis compressis; vaginis foliisque externe scabris; panicula ramosa coarctata secunda; glumis 3-nerviis; superiore 3-dentata; paleis pilosis. Podosaemum I. et K. l. c. p. 132. In Mexico. $\odot$. 21. M. angusta Iiunth; culmo superne tereti foliisque convoluto-setaecis margine scabris; panicula coarctata spicaeformi; glumis 1-nerviis scabris; palea inferiore aristata, superiore 2-dentata. Podosacmum Presl hel. Haenk 1. p. 229. In Peruvia. 4.

25. M. stricta Kunth ; culmo stricto vaginisque scabriusculis; fol. convoluto-setaceis scabris; panicula stricta patente; grluma superiore setacea; inferiore integerrima sela terminata, superiore bidentata. Podosaemum PresI I. c. p. 231. In Miexico. 4 .

26. M. Berteroniana Kunth; culmis subteretibus; fol. externe scabriusculis; panicula ramosa; glumis 3-nerviis; inferiore breviore acuta, superiore acuminata submucronata; corollinis calycinis brevioribus pilosiusculis. Trichochloa schult. mant. 2. p. 209. In St. Domingo.

2\%. M. capillaris Trin. fol. convolutis longissimis glaucis; flosculorum pedicellis confertis arista multo longioribus; aristis flore longioribus. Trichochloa R. et S. syst. 2. p. 384. Polosaemum Desv. In America boreali. 4.

28. M. Polypoyon Trin. fol. convolutis glaucis; flosculorum pedicelIis confertis flosculo multo langioribus; aristis flosculo longioribus. Trichochloa DC. Cat. p. 152. In Carolina. 24.

29. M. microsperma Trin. fol. linearibus planis; flosculorum pedicellis arista brevioribus; aristis flore longioriluss, Trichochloa DC. Cat. p. 151. Agrostis Spr. In Mexico. $\odot$.

30. M. Clomena Trin, panicula racemosa; valvis corollae bifido-dentatis calycem dentatum excedentibus; arista fiexuosa elongata; culmo foliisque scaberrimis. Agrostis peruviana spr. syst. p. 262. A. Clomena Beauv. Agr. t. 7. f. 10. In Peruvia et Mexico. $\odot$.

31. M. simplex Kunth; racemo stricto; calycilus rigidis scabris sub basi barbatis; corolla breviter aristata; fol. canvolutis culmoque glabris; ligula nulla, Polypogon Spr. Cur. post. p. 30. In Nova Hollandia.

32. M. spicata Kunth; paniculae ramis faccidis spicatis basi barbatis; 
calycibus alternis distichis; aristis Inaequalibus strictis scabris; culmo adscendente fiaceido basi folioso. PoJypogon sipr. syst. 1. p. 213. In Brasilia.

33. H. aristata Pers. culmo firmo simplici foliisque pubescentibus; panicula laxa ; calyce 2 -valvi ; arista longissima. Michx. Microchloa erecla sichreb. Gr. t.50, Brachyelytrum Beauv. In America boreali. 4.

\section{LYCURUS H. et K.}

1. L. phleoides H. et K. Nov. Gen. 1. \%. 5t2. t. 45. culmo erecto; ariotis longissimis. In Mexico. $\odot$.

2. L. phataroides $H$. et K. I. c. culmo adscendente; aristis longitndine glumarum palearumque. In Mexico. $\odot$.

3. L. muticus Spr. culmo erecto; fol. convolutis elongatis superioribus ciliatis; flosculis lanatis muticis. Spr. In Montevideo.

\section{COLEANTHUS Seidet (1827).}

1. C. subtilis S'cidel; Schmidtia utriculosa Sternb. in Bot. Zeit. 1819.1. c. ic. S. subtilis Tratt. aust. t. 451. In Bohemia. $\odot$.

\section{PHIPPSIA R. Br. (1810).}

1. P. algida R. Rr. Chlor. Melv. p. 27. Agrostis Wahlenb. Lapp. t. 1. a-1. F1. Dan. 1505. Trichodiun Svenk hot. 545. f. 2. Vilfa Trin. ic. t. 83. var. $\beta$. V. monandra. Trin. ic. t. 81. In Finmarchia, Groenlandia et ins. Melcilleana.

\section{COLPODILII R. Br. (1810).}

1. C. latifolium $\boldsymbol{R}$. Br. panicula coarctata lanceolata; fol. planis latolinearibus. H. Br. ChIor. Melv. p. 27. Trin. ic. t. 55. In America arcica, ins. Melvilleana et Sibiria.

2. C. Stereni Trin. Fund. t. \%. panicula mutica glabra patula; corolla obtusissima calycem acutiusculum ex- ccdentc. Agrostís versicolor Stev. Stirp. In Caucaso. $\%$.

3. C. altaicum Trine panicula contractiuscula sublineari; spiculis 1-floris; glumis florem subaequantibus; radice stolonifera. Ledeb. ic. pl. Hoss. ill. t. 226. In Altai.

\section{CINNA L. (1764).}

1. C. arundinacea $L$. panicula conferta subsecunda; flosculis monandris; calycibus inaequalibus acutis bifloris; corollis inacqualibus; valvula majore sub apice aristata. Agrostis Cimna WVilld. cn, p. 95. Schreb. Gr. t. 49. In America boreali. 4.

2. C. mexicana Link; panicula coarctata; calycibus mucronatis hispidis corollam aequantilus; corollis basi pilosis; culmo ramosissimo erecto. Agrostis Willde sp. 1. p. 374. Podosaemum Link. In Nexico. 4.

3. C. racemosa Kunth; culmis erectis ; fol. anguste lincarihus; racemo oblongo e spicis densiforis subinterrupto. Agrostis Michx. am. 1. p. 53. Vilfa Beauv. Ad ripas Misisippi eb Missuri.

1. C. lateriflora Kunth; culmis ereotis nodosis; paniculis pusillis coarctatis densifforis; glumae nuticae et scaberulac valvis acutissimis, interioribus basi barbulatis. Agrostis Michx. am. 1. p. 53. Vilfa Beauv. In America boreali. 4.

5. C. filiformis Link; panicula coarctata subspicata ; calycibus aristatis hispidis; corollae valvula majore apice aristata; culmo ramosissimo. Agrostis IVilld. en. 1. 95. Podosaemum Link. In America boreali. 4.

6. C. sobolifera Link; paniculae contractae filiformis simplicissimae ramis adpressis; corollae valvula majore apice brevissime aristata; culmo ramosissimo adscendente. Mühlenbergia Trin. Unifl. t. 5. f. 4. Podosacmum Link. In America boreali. 4.

\%. C. arachnoidea Kunth; panicula laxa patentissima; ramulis complicatis arachnoideis; fol. anguslis subinvolutis. Agrostis Poir. Enc. 1. p. 249. Vilfa Beauv. In Carolina.24.

8. C. decipiens liunth; panicula laxa subnutante; glumis acntis; valvula exteriore perianthii 5-nervia; ari- 
sta dorsali brevissima; fol. involutis. Agrostis 1R. Br. prodr. 1. p. 172. Vilfa Beauv. In Nova Hollandia.

9. C. ovata Kunth; panicula ovata vel oblonga spicaeformi ; arista glumis longiore; setula ad basin valvulae interioris. Agrostis R. Br. l. c. p. 171. Labill. Nov. Holl. t. 31. In Nora Hollandia.

10. C. phleoides Kunth; culmo erecto simplici glabro; fol. vaginisque scabriusculis laxis; spica densa cylindracea; glumis acuminato-subulatis; paleis inaequalibus. Crypsis II. et K. 1. c. p. 140. In Cumana. 4.

11. C. stricta Kuntl; culmo erecto simplici; fol. vaginisque scahriusculis laxis; spica densa cylindracea; glumis actuminato - subulatis; paleis subaequalibus. Crypsis H. et K. l. c. p. 140. In Nova Granata et Mexico. 4 .

12. C. macronra Kunth; culmo erecto simplici (?) glabro; fol. vaginisque scabris; panicula spicaeformi longissima cylindracea ; glumis longitudine fere palearum. Crypsis H. et K. 1. c. p. 140 , In Mexico. 4.

13. C. setifolia Kunth; culno erecto sinplici glabro; fol. convolutosetaceis vaginisque scabris; panicula spicaeformi cylindrica; glumis aequilongis acutis scabris longitudine paleae inferioris 3-dentatae. Crypsis Presl 1. c. In Mexico. 4.

11. C. (?) Pur'shii Kunth ; panicula laxa diffusa; calycihus uninoris; corollis calyce brevioribus membranaceis; valva exteriore apice incisa dorso hrevissime aristata, interiore minima. Arundo agrostoides Pursh am. 1. p. 89. Calamagrostis Spr. In America boreali. 4 .

\section{EPICAMPES Presl (1832).}

1. E. stricta Presl; culmis comprossis strictis, nodis glaberrimis; fol. glaucescentilus ; panicula stricta densa spicaeformi; palea inferiore trinervia. Presl 1. c. In Mexico. 4.

2. E. pubescens Presl; culmo erecto simṕlici compresso, iufra nodos pubescente; panicula ramosa; glumis punctato-scabris; paleis acutis pubescentilus. Presl 1. c. Agrostis H, et K. In Mexico, 4 .
3. E. Lanata Presl; culıno erecto simplici compresso pulescente; fol. vaginisque piloso-lanatis; panicula ramosa; glumis externe pilosis. Agrostis H. et K. I. c. p. 136. In Mexico. 4.

\section{SPOROBOLCS R. Br. (1810).}

1. S. spicatus Kunth; panicula spicata; fol. illvolutis rigidis in geniculis coacervatis ; ramis infractis. Agrostis Vahl syml. 1. p. 9 Delile Aeg. t. 10. f. 1. Vilfa Trin. ic. t. 12. In Aegypto et Nenegalia. 24.

2. S. humifusus Funth; culmis adscententibus simplicilus; fol. interue scabris; panicula simplici coarctata; gluma inferiore duplo hreviore; paleis acutis. Vilfa $H$. et K. I. c. p. 137. Agrostis R. et \$. In Cumana. 4.

3. S. tremulus Kunth; panicula simplici subspicata; calycibus subaequalibus corolla mutica brevioribus; fol. rigidis convolutis distichis. Agrostis Willd. sp. 1. p. 372. A. juncea Lam. ill. t. 41. f. 2. In India orientali et ins. Mauritii. 4.

4. S. virgineus Kunth; culmis erectis aut procumbentibus ramosis; panicula simplici coarctata; paleis glumas subaequantibus acutis. Kunth. Agrostis Labill. Nov. Holl. t. 22. Vilfa Beauv. Podosaemum Lk. In America boreali, Nova Hollandia et Prom. b. spei. 4.

5. S. asper Kunth; culmis stricte erectis ab imo ramosis; vaginis collo villoso-barluatis; fol. longissimis recurvo-pendulis asperrimis. Agrostis Michx. am. 1. p. 53. In America boreali.

6. S. pungens Kunth; panicula coarctata mutica; fol. involutis rigidis pungentibus; superioribus oblique oppositis; culmo ramoso. Agrostis Schteb. Gram. t. 27. f. 3. Cav. ic. t. 114. Vilfa Beauv. Trin. ic. t. 47. In Europa et Africa boreali.

7. S, piliferus Kunth; radice fibrosa; culmis erectis inferne appressoramosis; vaginis subcompresso-carinatis sulcatis; panicula contracta angusta. Vilfa Trin. ic. t. 58. Ejusd. diss. t. 157. In Nepalia et Brasilia.

8. $\mathbf{S}$, indicus $\mathrm{R}$. $\mathrm{Br}$. panicula contracta cylindrica e spiculis imbricatis divisis simplicibusve, H, Br. In 
India occid., America bor. et Nova Hollandia.

9. S. tenacissimus Beaur. racemo decomposito contracto elongato; ramis strictis subverticillatis; glumis obtusis; fol. lineari-elongatis siccitate convolutis. Vilfa Nees in Mart. Bras. 2. p. 393. Trin. ic. t. 60. Agrostis Jacy. ic. t. 26. In America calid. et Mexico. 4.

10. S. orientalis Kunth; racemo decomposito contracto lineari-elongato; ramis alternis; glumis lanceolatis; Inferiore paleis duplo longiore; culmo repentc apice adscendente; fol. convoluto-selaceis. Agrostis Nees in Mart. Bras. 2. p. 393. A. elongata 1hoth. A. tenacissima L. In India orientali. 4.

11. s. purpurascens Hamilt. panicula lineari angusta erecta; ramis racemosis; spiculis Ianceolato-acuminatis; fol. lineari-convolutis; vavinae ore barbato. Agrostis Nees 1. c. p. 398. Vilfa Beauv. In India occid. et Mexico.

12. S. Sprengelii Kunth; panicula pyramidali erecta; ramis subverticillalis virgatis racemoso - compositis; spiculis lanceolatis; fol. vaginarum oris ciliatis. Vilfa Nees 1. c. p. 396. Agrostis sporobolus Spr. In Brasilia. 4.

13. S. minor Kinnth; glaherrimus; vaginis striatis, inferioribus compresso-carinatis; fol. linearibus compressis glaucescentibus; panicula angustissime spicaeformi; ramis subverticillatis erecto-adpressis; gluma inferioro truncata. Vilfa Trin. ic. t. 59. In Brasilia.

1t. S. rupestris Kuuth; panicula contracta ; spiculis subracemosis ; culmis gracilibus glabris; fol. brevibus planis pilosiusculis; vaguis ciliatis. Kunth Gram. 1. p. 267. t. 45. In Brasilia. $\odot$.

15. S. capensis Kunth; glaucescens ; culmo geniculato incurvo compressotrigono vaginisque striatis glabris; pauicula angustissime cylindracea, conferta basi interrupta; spiculis oblongis acutis. Trin. ic. t. 55. In Prom. b. spei. 4.

16. S. elongatus $R . B r$. panicula coaretata elongata e spicis alleruis divisis; inferioribus distantibus. R. Bi. prodr. 1. p. 170. Vilfa Trin. In Aora Hollandia.
17. S. diander Beauv. glaber; culmis erectis 1-3-pedalibus; panicula lineari; ramulis brevibus expansis ; floribus geminatis diandris; semine obovato rugoso. Agrostis diaudra Roxb. 1. c. p. 319. Vilfa Trin. In India orient. et ins. Moluccanis.

18. S. littoralis kunth; panicula contracta subspicata; calycibus inaequalibus; vaginis foliorum barbatis. Agrostis Lam. ill. 1. p. 161. Vilfa Beauv. var. $\beta$. ramis paniculac longioribus. Agrostis barbata Pers. In America merid. $\beta$. ad senegal.

19. S. reneus Kunth; rhizomate nodoso; culmo stricto tereti; vaginis striatis margine hirsutiusculis; fol. strictis involutis striatis basi intus pilosis; panicula subpyramidata; spiculis glaherrimis; glumis lanceolatis acutis. Vilfa Trin. ic. t. 23. In Brosilia. 4.

20. S. affinis Kunth; panicula patente parva pyramidata; calycihus corolla longioribus; vaginis ore pilosis. Agrostis pyramiclata Lam. ill. 1. p. 161. In America meridionali et Antillis.

21. S. pyramilalis Beauv. panicula effusa; ramis plerumque verticillatis subsimplicibus raro solitariis; superioribus alternis brevioribus; fol. glabris. Beauv. F'. d'Oware 2. p. 36. t. 80. Agrostis owariensis schult. In Africa aequinoctiali.

22. S. robustus Kunth; culmis erectis simplicibus foliisque rigidis margine scabriusculis; vaginis superne oreque ciliatis; panicula dilfusa subpyramidali; glumis acutis; flore glabro. Kunth Gram. 2. t. 126. In Senegalia.

23. S. coromandeliumus Funtl; culmis 4-8-pollicaribus; panicula verticillata; ramis simplicibus secundis; calycis valva exteriore minuta; semine obovato rugoso. Agrostis hoxb. 1. c. p. 318. Vilfa Beauv. Trin. ic. t. 11. In India orientali et Arabia.

2-1. S. commututus Kuntlı; culmis erectis ramosis; vaginis laxis striatis foliisque glaucescentibus margine hispidis firmis; ramis paniculae verlicillatis patentissimis; spiculis minutissimis; gluma inferiore minuta. Vilfa commutata. Trin. ic. t. 10. In India orientali. 4.

25. S. domingensis Kunth; culmis ramosis; fol. glaucis glabris; panicula contractis sublineari; pcdiccllis apice 
incrassatis; gluma corollina inferiore obtusa emarginata. Vilfa Trin. ic: t. 14. Agrostis schult. In St. Domingo.

26. S. Jaquemontii Ínthth; fol. sulcato-9-nerviis externe glabris; panicula stricta subpyramidali; ramis racemiformibus; glumis flore $3-4-$ plo hreviorihus; inferiore minore. Kunth Gram. 2. t. 127. In St. Domingo.

27. S. atrovirens Kunth; culmis crectis simplicibus; fol. vaginisque glabris; panicula ramosa coarctata; palcis glumas duplo superantibus aequalibus acutis. Vilfa II. et K. Nov. Gell. 1. p. 138. t. 685. Agrostis 11. et $\mathrm{S}$. In Mexico. $\odot$.

28. S. mimutus LK. fol. angustis brevilus; paniculae ramis patentibus ramosissimis; valvula exteriore obtusa glumella 4-plo minore. Lk. Hort. 1. p. 88. Patria ignota. $\odot$.

2.9. S. minutiflorus Lk. panicula capillari elongata patente composita; fosculis adpressis minutissimis; fol. margine asperis glaberrimis, pro ligula denticulis brevissime ciliatis. Panicum tenuissimum. Schrank Regensh. Denkschr. 3. p. 13 . Vilfa Trin.Agrosticula muralis Raddi Agr. 33. t. 1. f. 2. In Brasilia. 4.

30. \$. ramosissimus Kunth; panicula ramosissima diffusa; ramulis capillaribus; spiculis minutissimis 2-3floris; fiore terminali tabescente; glumis flore paulo brevioribus. Kunth Gram. 1. p. 269. t. 46. In Cumana et Brasilia. $\odot$.

31. S. pulchellus R. Br. culmo filiformi; fol. planis vaginisque ciliatis; ramis verticillatis capillaribus rachique glabris; glumis inaequalibus superne scabriusculiș; paleis glabris. Kunth Gram. t. 123. Agrostis 1R. et s. Vilfa Trin. In Nova Hollandia et India orientali.

32. S. argutus Kunth; panicula erecta; ramis racemoso-compositis patulis; spiculis ovatis laevibus; gluma inferiore paleis 4-plo breviore; culmo adscendente simplici; fol.ciliatis margine cartilagineo-serrulatis glaucis; vaginis margine villosis. Vilfa arguta Nees 1. c. p. 395. In Brasilia. $\odot$.

33. S. tenellus Kunth; panicula patente brevi; ramis alternis; glumis obtusis integerrimis; culmo basi ramosissimo; fol. distichis obtusis striatis. Vilfa brevifolia. Nees in Linnaca
7. p. 291. Ehrharta A. Spr. In Prom. b. spei.

31. S. subtilis Inunth; panicula ramosa depauperata; ramulorum geniculis verticillo villorum longorum instructis; vaginis teretibus ore barhulatis; spiculis bifforis; flore altero setiformi. Kunth Grau. 2. t. 124. In Madagascaria.

3.5. S. ramulosus Funtl; culmo erecto ranoso 4-angulo; fol. vaginisque margine scabris; panicula ramosa coarctata; glumis paleis dimidio brevioribus. Vilfa H. et K. Nov. Gen. 1. p. 137. t. 684. Agrostis $h$. et $S$. In Mexico. $\odot$.

36. S. junceus Inunth; fol. stricto erectis convoluto-setaceis rigidulis; panicula oblongo-pyramidata; floribus muticis; valvula extima duplo minore. Agrostis Michx. am. 1. p. 52. Colpodium Trin. Vilfa Trin. ic. t. 57. In America boreali. 4.

3\%. S. repens Presl; culmis repentibus compressis ramosis; fol. convoluto-setaceis; panicula simplici spicaeformi; glumis aequalibus; palca inferiore apice tridentata. Presl in Rel. Haenk 1, p. 241, in Mexico.

38. S. fastigiatus Presl; culmis erectis dichotomis fastigiatis glaherrimis; fol. distichis convolutis obtusissimis; panicula depauperata; palea inferiore apice 3-dentata. Presl. 1. c. In Peruvia? 4.

39. S. humilis Presl; culmis repentibus ramosis ramisque erectis compressis; vaginis foliisque glabris; panicula spicaeformi; glumis inaequalibus flore paulo minoribus. Presl 1. c. In Luzonia. 4.

40. S. ciliatus Presl; culmo adscendente erecto ramoso; fol. planis pilosis vaginisque ciliatis; glumis inaequalibus; superiore paleas aequilongas aequante. Presl liel. Iaenk 1. p. 242. In Panama. 4.

11. S. eminens Presl; culmis compressis subramosis erectis strictis vaginisque glabris; fol. margine scabris interne pilosis convolutis; panicula composita patente. Presl. I. c. In Acapulco.

42. S. scoparius Presl; culmo erecto farcto; fol. late lanceolatis; panicula eymosa; gluma superiore rotundata; palea superiore piloso-ciliata. Presl 1. c. In Luzonia. 
43. S. durus Brongn. culmis erectis ramoso-lasciculatis; fol. linearisuhulatis rigidis convolutis; pauicula contracta; ramulis fasciculatis erectis; gluma interiore paleas subaequante. Brongn. in Dup. it. bot. p. 18. t. 4. In ins. Adscensionis.

14. S. caespitosus Inenth; culmis simplicibus compressis glabris; fol. lineari-subulatis convolutis glabris nargine scabris, 5 -nerviis; ramis paniculae depauperatae adpressis. Kunth Gram. 2. t. 125. In insula Adscencionis.

45. S. parviflorus Funth; panicula effusa capillari; glumis aequalibus; perianthii valvula exteriore truncala, interiore minutissina. Agrostis R. Br. prodr. 1. p. 170. In Nova Hollandia.

46. S. Carmichaeli Funth; culmis filiformibus ramosissimis; fol. setaceis; panicula simplicissima; carina glumae supra denticulata; setula apicis brevissima. Agrostis ramulosa. Carmich. in Liun. Trans. 12. p. 504. In ins. Tristan da Cunha.

4\%. S. Muehlenbergii Kunth; fol. alternis linearibus vaginaque nervosis glabris; ligula alba ovata lacera; ramis paniculae geminis hispidis. Agrostis Mfuchlenb. descr. p. 75. Agrostis affinis schult. In America boreali.

48. S. villosus Kunth; panicula spicata subcylindrica; flosculis nitidis; culmo vaginato stricto simplicissimo; fol. lanceolatis cuspidatis vaginisque villoso-hirtis. Agrostis Spr. Tent. suppl. p.5. In Surinam.

49. S. compressus Kunth; glaberrimus; culmo erecto compresso simplici ; panicula ramosa capillari; calycibus aequalibus acutis. Agrostis Torrey Cat. of plants. A. Torreyana Scluult. Vilfa Trin.

\section{AGROSTIS Linn. (1735).}

1. A. crinita $R$. Br. monandra; panicula elongata; glumis longe acuminatis; vaginis scalsriusculis. $\mathbf{R}, \mathrm{Br}$. prodr. 1. p. 170. Anthoxanthum Linn. Labill, Nov. Holl, t. 263. Apera Beauv. In Nova Hollandia et Nova Zeelandia.

2. A. sciurea $\boldsymbol{R}, \boldsymbol{B r}$. monandra; panicula elongata; glumis acuminatis; valvula exteriore perianthii emarginata minorem glumae aequante; arista dorsali valvula duplo longiore. R. Br. prodr. 1. p. 171. In Tova Hollandia.

3. A. rara R. Br. monandra; panicula sulicontracta; ramis paucifloris; perianthii valvula exteriore glunam aequante, juxta apicem arista flexuosa longissima. 13. Br. prodr. 1. p. 171. In Nova Hollandia.

4. A. quadriseta R. $B r$. triandra; panicula cylindracea; ramis ramulisquc imbricatis; glumis acuminatis; valvula exteriore perianthii glabra apice 4-dentata; dentibus setaceis. R. Br. prodr. 1. p. 171. Avena Labill. I. c. t. 32. Calamogrostis spr. Pentapogon Billardieri Beauv. Agr. t. 8. f. 11. In Nova Hollandia.

5. A. cylindrica R. Br. triandra; panicula cylindracea; ramis imbricatis; glumis subacutis; fol. planis. $\mathbf{R}$. Br. prodr. 1. p. 171. Vilta Beauv. In Nova Hollandia.

6. A. montana R. Br. triandra; panicula subcylindracea; ramis imhricatis; glumis acuminatis coloratis; valvula exteriore perianthii pubescente apice $\mathbf{2}$-dentata, infra medium aristata. Vilfa Beauv. A. monticola R. et S. In ins. van Diemen.

\%. A. lobata R. Br. triandra; panicula subspicata decomposita lobata; glumis acuminatis; valvula perianthii exteriore scabriuscula, apice 4-dentata juxta basin aristata. R. Br. prodi. 1. p. 171. In ins. Van Dimen.

8. A. dulcis R. Br. culmis simplicibus subgeniculatis; fol. scabris; panicula ramosissima; paleis subaequalibus glumis dimidio brevioribus. Vilfa H. et K. Nov. Gen. 1. p. 138. Agrostis vulgaris $\gamma$, dulcis Pers. In IIexico. $\odot$.

9. A. alba Schrad. panicula florifera diffusa oblongo-conica fructifera coarctata ; ligula oblonga; fol. linearibus. Schrad. grerm. 1. p. 209. A. stolonifera L. Fl. Dan.564. Vilfa Beauv. var.

a. A. alba Linn. A. stolonifera Host. Gram. 4. t. 56 . A. ambigua $\mathbf{R}$. et $s$,

B. Schrad. Germ. t. 2. f. 1. A. decumbens Gaud. A. coarctata Hoffm. A. capillaris Poll. Leers Herb. $t$. 4. f. 3. A. varia Host. 4, t. 57. 
. A. gigantea Gaud. A. alba Ioffm. Leers Herb. t. 4. f. 5.

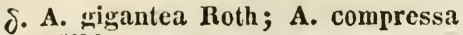
IVilld.

E. A. pauciflora schrad. Germ. t. 3. f. 2. A. patula Gaud.

In Europa, Sibiria et Nimu Notkae.24. 10. A. cupillaris 1. panicula capillari patente flexuosa; calycibus subulatis aequabibus glabris muticis. Nm. ic. t. 54. Trin. ic. t. 25. Vilfa Beauv. In Europa.

11. A. straminea Hartm. panicula oblonga; ramis glabris; corollae valvula exteriore supra medium dorsi aristata; arista calycem aequante; ligula oblonga. Hartm. Gram. Scand. p. 4. In littoribus Hollandiae.

12. A. stolonifer $\alpha$ Linn. panicula coarctata; culmo ramoso repente; floribus congestis; calycibus aequalibus lanceolatis pubescentibus. Smith Brit. 1. p. 80. A. verticillata Vill. Vilfa Beauv. In Europa.

13. A. glomerata Kunth; culmis ercetis teretibus simplicibus; vaginis foliisque planis scabris; panicula erecta spicaeformi deinde interrupta; glumis acutissinis scaloris; paleis apice hifido-dentatis. Vilfa Presl in Rel. Haenk. 1. p. 239. In Peruvia. 4.

14. A. muricata Kunth; culmis crectis teretibus vaginisque glabris; ligula ovata; panicula spicato-lobata; rachi ramisque scahris; glumis nervo hispidis; palea iuferiore 3-mucronata 3-nervia; superiore mucronata bidenticnlata. Vilfa Presl in Rel. Haenk. 1. p. 140. In Peruria. 4.

15. A. tennifolia Bieb. panicula oblonga patentiuscula scabra; calycibus aequalibus acutis; fol. linearisetaceis. Bieb. Fl. 1. p. 56, Trin. ic. t. 35. In Caucaso.

16. A. exarata Trin. culmis vaginisque sulcato-striatis et glabris; fol. linearilus retrorsum scabris; ramis paniculae subverticillatae adpresso-crectis hispidis; glumis carina denticulatis. Trin. ic, t. 27. In ins. Aleuticis.

17. A. involuta Poir. panicula angusta spicata; fol. glahris involutosubulatis; culmis ramosis geniculatis. Poir Enc. suppl. 1. p. 172. Vilfa Beauv. In ugro Maroccano.

18. A. vulgaris With. paniculae ovato-oblongac ramis laeviusculis, ramulis divergentibus; ligula brevissima truncata. IRchb. excurs. p. 25. Engl. bot. 1671.. Hoftim. Fl. t. 7. Host. 4. t. 59. schrad. germ. t. 2. f. 3. FI. Dan. 163. Schk. t. 12. A. divaricata et tenella Hoffin. a rubra L. Trin. ic. t. 34. Trichodium rubrum IR. et S. A. decumbens Host. 4. t. 31. In Europa et ins. St. Helenae. 4.

19. A. stricta Uilld. panicula elongata stricta; corollis calyce minoribus; arista e basi petali tortili flore longiore. Willd. sp. 1. p. 366. Trichodium strictum $\mathbf{R}$. et S. In America boreali et Groenlandia.

20. A. Juressi Link; fol. planis; ligula brevi obtusiuscula; panicula contracta; calycis valvulis dorso serrulatis. Lk. in schrad. Journ. 1799. 4. p. 312. Trill. ic. 1. 29. In Hispania et Lusitania.

21. A. Bergiana Trin. panicula patente pauciflora; perianthio (dorso brevi setigero) glumas aequante; valvula superiore paulo minore; fol angustissimis. Trin. Uniff. p. 203. Agrostis capensis steud. In Prom. b. spei.

22. A. geminata Trin. fol. angustissimis exlabris; panicula ramosa depauperata diffusa; pedicellis apice incrassatis; glumis acutissimis, inferiore carina denticulata; arista hispidula. Trin. ic. t. 28. In ins. Aleuticis.

23. A. magellanica Lam. calycibus hirsutis corolla duplo Iongioribus; petali exterioris arista recurva, longiuscula. Lam. ill. 1. p. 160. Ad fretum Magellanicum et in ins. Maclovianis.

21. A. caespitosa Gandich. culmo erecto simplici striato glabro; fol. planis scabris; panicula spicacformi erecta basi interrupta; ylumis dorso rachique ciliato-scabris. Gaudich. in Freyc. it. bot. p. 407. In ins. Maclovianis.

25. A. maritima Lam. panicula spicata; ramulis hrevissimis ; calycihus muticis laevibus aequalihus. Lam. ill. 1. p. 161. Vilfa Beauv. In Gulliu australi. 24.

26. A. pallida $\boldsymbol{D C}$, fol, planis angustissimis; ligula oblonga bidentata; panicula ramosissina; glumella obtusa brevissime bimucronulata. DC: Fl. gall. suppl. p. 251. Triu. ic. t. 30. In Corsica, Galloprovincia, Calabria et Lusitania. $\odot$. 
27. A. setacea Curt. corolla hasi aristata; arista geniculata; fol. radicalibus setaceis; calycilous lanceolatis. smith brit. 1. p. 79. 'Trichodium R. et s. A. canina $\beta$. With. A. rubra $\beta$. Wahlenb. Vilfa Beauv. In Anglia, Gallia et Lusitania. 4.

28. A. glaucina Bast. fol. angustissimis glaucis; glumae valvulis acuminatis; glumella apice binucronulata; arista basilari geniculata spiculam paulo superante. Trichodiun $\mathbf{k}$. et $\mathbf{S}$. In Andegavia. 4.

2.9. A. pusilla Dumort. glumis carina scabris; corollae arista geniculata alba; lignla foliorum inferiorum obtusa; superiorum multifida; radice repente. Trichodium Vall. Hall. Flor. Belg. 1. p. 56. In Belyia.

30. A. canina $L$. panicula diffusa ovata; ramis divergentibus scabriusculis; glumis ovato-lanceolatis acutis; floribus infra medium aristatis; fol. radicalibus setaceis. Mert. et Koch Germ. 1. p. 512. Hort. Gram. 4. t. 53. Trichodium schrad. A. pallida schk. A. alpina koth. A. hybrida. Gaud. Trichodium diffusum Lk. In Europa et sibiria. 4.

31. A. nutkaensis Kunth; culmo erecto tereti glaberrimo; vaginis foliisque scabris; ligula exserta ovata; panicula ramosa patentissima; paleis 4-denticulatis. Trichodium album. Presl in Rel. Haenk. 1. p. 214. In Sinu Nutkaensi. 4.

32. A. tropica Beauv. panicula coarctata; axi ramis glumisque pilis hirtis; arista supra medium inserta. Beauv. Fl. d'Oware 2. p. 37. t. 80 . In Africa aequinoctiali. 4.

33. A. alpina Scop. panicula ovali oblonga ; ramis patulis hispidulis ; glumis lanceolatis acuminatis; flosculis basi aristatis; fol. radicalibus setaceis. Mert. et Koch germ. 1. p. 515. Host Gram. 3. t. 50. Trichodium rupestre Schrad. t. 3. f.5. A. flavescens Host. 4. t. 52. In Europa.

31. A. rupestris All. panicula angusta oblonga; ramulis patentibus glabris; glumis lanceolatis acutis; floribus infra medium aristatis; fol. radicalibus setaceis. Mert. et Koch Germ. 1. p. 514. A. setacea Host. Gram. 3. t. 49. A. alpina Willd. Trichodium Schrad. germ. t. 3. f. 4. Agraulus alpinus Beauv. In Europa media.
35. A. toluccensis $\boldsymbol{H}$. et $\boldsymbol{K}$. culmo erecto simplici glahro; panicula ramosa coarctata; glumis dorso scaliris; palea inferiore 4-, superiore 2-dentata. H. et K. Nov. Gen. 1. p. 135. In Mexico. 4.

36. A. mexicana Iiunth; culmis erectis glabris; fol. planis vaginisque scabris; panicula contracta spicaeformi; glumis acutissimis; aristus supra medium dorsi ortis. Agraulus mexicallus. Presl in Rel. Haenk. 1. p. 236. In Mexico. 4.

3\%. A. pulchella Finth Gram.t. 128. culmis erectis vel adscendentibus; ligula elongata fissa glabra; panicula ramosissima; glumis carina hispidoscabris; palea superiore nulla, inferiore 5-nervia mutica. Vilfa elegans H. et K. Nov. Gen. 1. p. 139. A. elegans $\mathbf{R}$. et $\mathbf{S}$. In Quito. 4.

38. A. fiesciculata R. et S. culmis erectis vel geniculato-adscendentibus inferne radicantibus; panicula ramosissima; glumis carina hispidulis; palea superiore minutissima subrotunda; inferiore enervia mutica. Vilfa fasciculata H. et K. Nov. Gen. 1. p. 139. In Quito. 2.

39. A. dispar Michx. panicula laxa subverticillato-pyramidata multiflora; glumae muticae valvis exterioribus majoribus, interiorum altera minima. Michx. am. 1. p. 52. Trichodium elatum Pursh. Cornucopiac altissimum Wall. Vilfa dispar Beauv. In America boreali. 4.

40. A. laxillora Richards, culmis filiformibus erectis; fol. convolutosetaceis; vaginis sulcato striatis; ligula elongata; ramis paniculae capillaceis patentissimis; glumis 1-nerviis carina hispidulis. Kunth Gram. 2. t. 130. Trichodium Michx. A. scabra Villd. T. laxum et Muehlenhergianum schult. In America boreali. $\odot$.

41. A. monteridensis $\mathbf{S} / n$. culmis ramosis; fol. linearibus; panicula diffusa; ramis capillaceis trichotomis hispido-scabris; spiculis longissime pedicellatis; palea inferiore dorso arislata superne 4-nervia apice 4-dentata; superiore minuta. Kunth Gram. 2. t. 169. In Montevideo. 2.

42. A. Cormucopiae Fras. panicula ramosissima; ramulis trichotomis patentissimis; calycibus acutis; culmo decumbente ramoso. Trichodium decumbens Willd. eu. p. 98. A. ano- 
mala Willd. sp. A. Michauxii var. $\alpha$. Trill. In America boreali. 4.

43. A. elegans Thore in Lois. Not. t. 1. f. 1.; fol. involuto-subulatis; culmo erecto simplici; panicula laxa capillari; pedicellis laevibus tenuissimis; perigronio obtuso 1-valvi. DC. et Duby Bot. 1. p. 503. Trin. ic. t. 26. A. capillaris Thore Chlor. Trichodium $\mathbf{R}$. et $\mathbf{S}$. Circa Aquas T'arbellicas. $\odot$.

41. A. trichodes $R$. et $\mathbf{S}$. culmis geniculato-adscendentibus ; fol. vaginisque scabris; glumis dorso ciliatis; paleis glumas paulo superantibus, denticulatis. Vilfa H. et K. Nov. Gen. 1. p. 139. Aira triclodes Spr. In Peruvia. 4.

45. A. tenerrima Trin. fol. setaceis; perianthio mutico glumis obtusiusculis paulo breviore; valvula superiore obsoleta. Trin. Unifl. p. 205. A. pulchella Lois. In Hispania meridionali.

46. A. Spica Venti L. panicula diffusa multiflora; flosculo infra apicem arista longissima subflexuosa instructo; antheris lineari-oblongis. Mert. et Koch Germ. 1. p. 504. Engl. bot. 951. Hl. Dall. 853. Host. Gram. 3. t. 17. A. purpurea Gaud. In Europa et Sibiria. $\odot$.

47. A. interrupta $L$. culmo subuninodi; panicula attenuata contracta; antheris subrotundo-ovalibus. Rchb. excurs. p. 24. Vaill. bot. par. t. 17. f. a. Host. 3. t. 48. Apera Beauv. In Europa meridionali. $\odot$.

18. A. hygrometrica Nees; ramis paniculae contractae spicaeformis subfusciculatis scabris; palea inferiore apice biseta; superiore nulla; collo antice barbulato; seta subbasilari. In Brasilia meridionali. $\odot$.

49. A. Freslei Funth; caespitosa; fol. rigidis canaliculatis obtusis glaloris; culnis teretibus ; arista supra basin enata erecta; palea inferiore 3nervia. A. cacspitosa. Presl in Rel. llaenk. 1. p. 237. In Peruvia.

50. A. rigescens Presl; caespitosa; fol. rigidis canaliculatis culmum superantibus glaberrimis; arista e medio dorsi enata recta; palea inferiore 5nervia. Presl 1. c. In Peruvia.

51. A. mucronata P'resl; culmo vaginis foliisque scabris; glumis mucronatis, nervo scabris; palea inferiore 5 -nervia e dorso aristata; arista longitudime paleae bilaciniatae; palea superiore acutissima integra. Presl l. c. Putria ignota. $\odot$.

52. A. arundinacea Presl; culmo tereti foliisque scabris; panicula ramosa nutante; flore villis basi cincto longitudine glumarum; palea inferiore 2-dentata; superiore integra. PresI 1. c. In Pernvia. 4.

53. A. nank Iunth; culmis caespitosis; vaginis foliisque glabris convoluto-setaceis; panicula secunda spicaeformi; rachi scabra; glumis 1-nerviis palea apice denticulata 5-nervia longioribus. Trichodiun nanum. Presl Rel. Haenk. 1. p. 243. In Peruvia?

51. A. glabra liunth; culmo tereti vaginisque glabris; fol. scabris; panicula semiverticillata patentissima; rachi glaberrima; glumis 1-nerviis nervo scabris; palcis gluma brevioribus 4-dentatis 5-nerviis. Presl Rel. Haenk. 1. p. 214. In Chili.

5.5. A. plebeja R. Br. panicula capillari; glumarum carinis nudiusculis; valvula exteriore pubescenti apice biaristata basi arista duplo longiore; fol. subsetaceis. R. Br. prodr. 1. p. 172. Lachnagrostis Trin. In Nova Hollandia.

56. A. media Carmich. culmis filiformibus ramosis; fol. setaceis ; panicula simplici rara; glumis acutissimis pubescentibus; carina longitudinaliter denticulata; perianthio sessili. Carmich. in Limn. Trans. 12. p. 504. In ins. T'istan da Cunha.

5\%. A. Torreyi Kunth; paniculae contractae pedicellis superne incrassatis; calycibus cuspidatis corollam superantibus glaberrimis coloratis ; corollae scalırae arista elongata; fol. distichis rigidis convolutis. spr. A. caespitosa Torrey. Ad ripas fluminis Missuri.

58. A. airoides Torrey; panicula pyramidata glabra; calycibus corolla brevin̨ribus; valvula altera acuta obtusa; fol. linearibus glabris; vaginis ore harbatis. spr. Cur. post. p. 31. In America boreali.

59. A. Urevifolia Nutt. culmis solidis compressis basi ramosis; fol. anguste subulatis culmo multo hrevioribus; panicula composita; racemis alternis adpressis interruptis; corollac valvulis coloratis; gluma dorsali breviter mucronata. Nutt. Gen. 1. p. $4 \%$ Ad ripas fluminis Missuri. 
60. A. filifolia Lk. culmo ramosissimo; fol. involutis filiformibus tenerrinis; panicula contracta. Ik. in schrad. Journ. 1799. 4. p. 313. In Lusitania.

61. A. comosa Poir. panicula maxima nutante; floribus aristatis; fol. subasperis arundinaceis. Milium Poir. Enc. suppl. 1. p. 25\%. Uraclune Trin. In Italia.

62. A. trichopodes Elliot; panicula diffusa capillari; valva corollae breviter aristata; ligula exserta elongata. Elliot Bot. 1. p. 134. In America boreali.

63. A. arachnoides Elliot; panicula elongata gracili; calycibus corollam 1-valvem aequantibus; arista longa debili dorsali; anthera subunica. A. Elliottiana schult. mant. 2. p. 202. In America boreali.

64. A. pauciflora Pursh; racemis unifloris filiformibus; corollis aristatis calyce inaequali duplo Iongioribus lirsutis; vaginis villosis. Pursh Fl. 1. p. 63. Polypogon Spr. In Virginia et Carolina. 4.

65. A. maxima Roxb. culmis erectis 4-12-pedalibus; panicula ovata expausa; calycibus minutis; valva exteriore corollae pilis longis fimbriata; staminibus duobus. Hoxb. ind. 1. p. 319. In India orientali. 4.

66. A. procera Retz; paniculae pedunculis racemosis erectiusculis; floribus hirsutis muticis lanceolatis. Retz obs. 4. p. 19. Vilfa Beauv. In $M a-$ labaria.

67. A. noveboracensis Spr. paniculae laxae ramis alternis subfasciculatis capillaribus calycibusque acqualibus glaberrimis; ligula elongata obtusa. Spr. syst. 1. p. 260. In regione Noveboracensi.

68. A. clarata Trin. culmo erecto compressiusculo; fol. linearibus scabris; ligula oblonga exserta; panicula apice nutante; pedicellis clavatoincrassatis; calycis glumis apice hispidis; corollae valvula superiore minore dilatata truncato-emarginata. Trin. in Spr. N. Entd. 2. p. 57. Trichodium clavatum Schult. In Camtschatka.

69. A. effisc Spr. culmo basi radicante; ligula obtusa; fol. angustolinearibus; calyce acutissimo corolla duplo longiore; corollae valvula inferiore basi nervosa apice bisetosa; arista flexuosa. Trin. Trichodium Ik. In Lusitania.

\%0. A.trichantha Schrank; panicula coarctata ; arista e hasi corollae aqualis elongato-pilosae; fol. angustissimis siccitate involutis. Schrank in hegensb. Denkschr. 2. p. 5. Trichodium schult. In Labrailor.

\%1. A. neglecta Schult. panicula depauperata patente; arista e dorsi medio; culmis erectis; radice fibrosa. Schult. austr. ed. 2. 1. p. 179. In Pannonia. 4.

\%2. A. Schultesii Kunth; paniculae ramis subtrichotomis; calycis valvulis acuminatis; arista supra basin valvulae; fol. convolutis setaceis. Trichodium schult. austr. ed. 2. 1. p. 166. In Pannonia. 24.

73. A. Kitaibelii Schult. panicula ante et post anthesin contracta; arista sub dorsi medio; culmis adscendenlibus; radice stolonifera. Schult. austr. ed. 2. 1. p. 178. In Pannonia. 4.

1. A. affinis Funth; panicula ramis trichotomis hispidulis; ramis divaricatis flexuosis; calycibus acuminatis; arista fere e dorsi medio. Trichodium Kitaibelii Schult. austr. ed. 2. 1. p. 165. In Pannonia. 4.

75. A. sicula Kunth; panicula contracta; fol. brevibus rigidis glancescentibus. Vilfa Presl Cyp. et Gram. sic. A. glaucescens Spr. In Sicilia.

86. A. parvula Schult. panicula fructifera contracta subspicata; culmis adscendentibus. schult. austr. ed. 2. 1. p. 182. In Pannonia. 4.

78. A. gracilis Schult. panicula depauperata; ramis subhispidulis appressis; ligula brevissima; fol. angustissimis. Schult. austr. ed. 2. 1. 1. 186. In Pannonia. 4.

8. A. distichophylla R. et S. panicula simplicissima racemoso-spicata; calycibus aequalibas corolla brevioribus; fol. rigidiusculis ensiformicomplicatis setaceis distichis. $\mathbf{R}$. et S. syst. 2. p. 351. In Nora Hollundia.

79. A. valentina $\boldsymbol{R}$. et $\mathbf{S}$. paniculae ramis calycumque carina hispidis; ramulis subappressis; ligula elongata; radice repente stolonifera; fol. subconvolutis rigidiusculis. 12 . et $\mathrm{S}$. syst. 2. p. 318. In Hispania. 4.

so. A. Hichauxii Zucc. panicula contracta aristata; racemis lateralibus alternis appressis; culuno eburneo: 
fol. approximatis asperis. Zucc. Cent. 11. 22. In Kentuky.

81. A. Salmantica Kunth; panicula patente; glumis acuminatis subaequalibus arista calycina brevioribus. Trichodium Salmanticum Lag. Elench.

3. Circa Salmanticam. $\odot$.

82. A. brachystachys schult. panicula glomerato-spicata subsecunda; glumis lanceolatis acutis; inferiore minore; caule basi ramosissimo decumbente; fol. brevibus planis. Schult. mant. 2. p. 569. Vilfa Presl. Crypsis alopecuroides Guss. In Sicilia.

83. A. hirsuta L. panicula subspicata; culmo foliisque hirsutis ; corollinis glumis dorso aristatis apice bifidis. Limn. suppl. p. 108. In Teneriffa.

84. A. capensis Lam. panicula capillari; calycibus acuminatis; corollae arista terminali curva. Milium capense. Linn. mant. p. 154. Achnatherum Beauv. In Prom. b. spei.

85. A. composita Kunth; paniculae compositae pedunculis racemoso-spicatis erectis; glumis corollinis acutis calyce longioribus; fol. asperis longíssimis. Poir. Enc. suppl. 1. p. 254. A. polystachya Bosc. Vilfa Beauv.

In Carolina.

86. A. monandra Hornem. panicula effusa; floribus monandris; arista petali exterioris terminali. Hornem. Hort. Hafu. 1. p. 72. In America boreali? $\odot$.

8\%. A. plicata Lour. fol. plicatis; spica lineari mutica. Lour. Coch. p. 64. In China. Culmus anceps.

88. A. odorata Lour. spicis secundis congestis muticis. Lour. Coch. p. 64. All littora Cochinchinae. Culmus erectus foliosus. Folia amplexicaulia.

89. A. compressa Poir. panicula elongata; pedunoulis subverticillatis; glumis compressis; valvulis calycinis inaequalihus nuticis; exteriore acuta longiore; semine ovato fusco. Poir. Enc. suppl. 1. p. 258. Axonopus Poiretii R. et S. In Carolina.

\section{GASTRIDIUM Beauv. (1812).}

1. G. australe Beanv. Agr. $t$. 6. f. 6. panicula subspicata laxiuscula viridi-argentea; calycibus acuminato- elongatis nitidis; seta corollae elongata. Spr. syst. 1. p. 250. Milium Iendigcrum L. schrel). Gram. t. 23. f. 3. Host. Gram. 3. t. 24. Sihth. Graec. t. 65. Calomagrostis Schwahii spr. teste keichb. Aruudo scliwabii schult. mant. Ad littora maris mediterranei, in Chili et Dalmatia. $\odot$.

2. G. muticum Guenth. panicula subspicata stricta; calycihus ohlongis aculis glabris; seta obsoleta. Spr. syst. 1. p. 250. G. scabrum Pres1. G. siculum Trin. In Sicilia. $\odot$.

\section{CIIATOTROPIS Kunth (1832).}

1. C. chilensis Kunth Gram. 1. p. \%2 et 271. t. 4\%. In Clili. Culmi erecti simplices. Folia plana sulcata. Ligula longissima. Pedicelli hispidi.

\section{NOWODWORSKYA Prest (1831).}

1. N. agrostoides Presl in Rel. Haenk. 1. p. 3.51. t. HO. Raspailia Presl l. c. In Peruvia. 24. Culmus erectus simplex teres. Nodi glaberrimi, infimi radicantes. Ligula exserta. Pedicelli incrassato-clavati.

\section{POLYPOGON Desf. (1S00).}

1. $\boldsymbol{P}$. monspeliensis Desf. aristis bractea triplo longioribus; arista bracteolae subterminali; radice fibrosa. Rchb. excurs. p. 24. Agrostis panicea Host. Granl. 3. t. 46. Plileum crinitum Schreb. Gram. t. 20. f. 3. Engl. bot. 1701. var. a. panicula majori. Alopecurus monspeliensis L. Santia plumosa sav. b. panicula minori minus divisa.Alopecurus paniceus b. Wibth. In Europa australi, Afica boreali et australi, Oriente et Montevideo. $\odot$.

2. P. maritimus Uilla. culmo erecto simplici; panicula coarctata: glumis valte pubescentihus, dorso-ciliatoaculeatis bilobis; lobis aculis; palea truncata 4-dentata. Brongn. in Dup. it. bot. p. 22. P. tataricus Fisch. plileum crinitum. Roxb. P. pumilum Clarke. Ad littora maris mediterra- 
nei, in Gallia occidentali, Sibiria et India orientali. $\odot$.

3. P. subspathaceus Requien; panicula ovata laxa basi inclusa; glumis apice dilatatis bifidis nitentihus valde ciliatis longe aristatis. Requien in Ann. des Scienc. nat. 1825. Aug. In Corsica.

4. P. tenellus $\boldsymbol{R}$. $\boldsymbol{B r}$. panicula coarctata subcylindracea; glumis dense villosis; perianthii arista dorsali tortili glumarum arista duplo longiore. $\mathbf{R}$. $\mathbf{B r}$. prodr. 1. p. 173. In Nora Hollandia.

5. P. australis Brongn. culmo erecto simplici; fol. planis scabris; panicula oblonga coarctata; glumis ncutis integris pulescenti-scabris ; palea exteriore truncato-4-dentata aristata. Brongn. in Dup. it. bot. p. 21. In Chili.

6. P. affinis Brongn. culmo adscendente; fol. planis nervosis scabris; panicula subeffusa pyramidali; pedicellis pubescenti-scahris; glumis externe asperis 1-nerviis; palea exteriore 4-dentata, inter dentes aristata. Brongn. in Dup. it. bot. p. $19 . \quad$ In Chili.

7. P. interruptus $H$. et $K$. culmo erecto simplici; fol. scabris; panicula coarctata subverticillata interrupta; glumis oblongis scabris. H. et K. Nov. Gen. 1. p. 134. t. 44. Ad ripas Orinocci, in Peruvia. 4.

S. P. tenuis Brongn. culmo erecto simplici; fol. angustis convolutis rigidis; panicula panciflora spicaeformi; glumis pubescentilus; aristis longissimis; palea exteriore profunde bidentata. Brongn. in Dup. it. bot. p. 22. In ins. Adscensionis.

9. P. littoralis $\mathbf{S m}$. panicula coarctata lobata; valvis lineari-lanceolatis apice aristatis; floribus sub apice aristatis; radice repente. Mert. et Koch germ. 1. p. 499. Agrostis With. Bot. Arr. t. 23. Engl. Bot. 1251. P. Lagascae R. et S. In Anglia, Germ. et Hispania. 24.

10. P. crinitus Trin. panicula subthyrsiformi; seta glumarum subterminali ; gluma sua hirta subintegra acuta 4-plo, seta perianthii 3-plo longiore. Trin. Unifl. p. 171. In Chili.

11. P. strictus Nees; panicula spicaeformi elongata angusta; valvula inferiore apice angusta profunde bifida; lacinis setacea 2-dentatis. Nees in Linnaca 17. p. 297. In Prom. $b$. spei. $\odot$.

12. P. elongatus II. et $\boldsymbol{K}$. culmo erecto simplici; fol. scahris; panicula ramosissima nutante diffusa; glumis lanceolato-subulatis scahris. H. et $\mathbf{K}$. Nov. Gen. 1. p. 134. In Quito, Peruvia et Brasilia. $\odot$.

13. P. flavescens Presl; culmo erecto simplici; fol. planis vaginisque scahris arista brevioribus; palea inferiore 3-fida; dente medio setigero. Presl in Rel. Haenk. 1. p. 234. In Peruria. 4.

14. P. intermedius Carmicl. panicula coarctata lohata; glumis sululatis pulescentibus; seta perianthii terminali valvula 4-dentata breviore. Carmich. Fl. Trist. in Lim. Trans. 12. p. 504. Phalaris mollis Thouar. In ins. Tristan da Cunla.

\section{CHAETURUS Lk. (1792).}

1. C. fasciculatus $L k$. in Schrad. Jour. 1799. 2. p. 313. Polypogon subspicatus Willd. P. fasciculatus Pers. Agrostis articulata Brot. In Hispania et Lusitania. $\odot$.

\section{PEREILEMA Presl (1831).}

1. P. crinitum Presl in Rel. Haenk. 1. p. 233. t. 3\%. fo a. In Panama. $\odot$ Culmus ramosus. Fol. linearia scabra. Ligula brevis truncata.

\section{AEGOPOGON Willd. (1801).}

1. A. cenchroides Willd. spiculis ternis. H. et K. Nov. Gen. 1. p. 132. t. 42. In Caracas, Quito et Miexico. 4.

2. A. geminiflorus $\Pi$. et $\boldsymbol{K}$. spiculis geminis. H. et K. 1 . c. to 43 . $A d b$ ripas Orinocci. 4.

3. A. unisetus $R$. et S. glumis calycibusque truncatis emarginatis uniaristatis.Hymenothecium Làgasc.Eleuch. 4. In Mexico. $\odot$.

4. A. pusillus Beanv glumis acutis; calycis valvula exteriore uniaristata. Hymenothecium Lagasc. Elench. 4. Cynosurus tenellus Cav. H. Madr. 
1. t. 5. f. 2. A. tenellus Trin. In Lima. $\odot$.

5. A. trisetus $R$. et $S$. calycis valvula exteriore triaristata. Hymenothecium Lagasc. Elench. 4. Cynosurus gracilis Cav. Hort. Madr. t.5. f. 3. In Mexico. $\odot$.

6. A. quinquesetus $R$. et $S$. calycis valvula exteriore 5-aristata. Hymenothecium Lagasc. Elench. 4. In Mexico. $\odot$.

\section{CALAMAGROSTIS Adans. (1762).}

1. C. lanceolata Roth; panicula diffusa; glumis anguste acutatis; pilis forem superantibus; palea apice in emarginatura brevissime aristata. Mert. et Kocl. Germ. 1. p. $518 \mathrm{sub}$ Arundo. Engl. bot. 403. et 2169. Fl. Dall. 2159. C. ramosa Host. 4. t. 44. C. Gaudiniana. Rchb. excurs. In Europa, Caucaso et Sibiria. 4.

2. C. littorea DC. panicula diffusa; glumis anguste lanceolatis; apice subulato-compresso; pilis florem superantibus; arista terminali plerumque palea dimidio breviore. Arundo Mert. et Koch 1. c. A. glauca Bieb. C. glauca Rchb. c. laxa. Host. Gram. 4. t. 43. A. annulata $R$. et $S$. In Europa meridionali et America boreali. 4.

3. C. nutans Saut. panicula laxa natante; bracteis acuminatis 1-nerviis; arista dorsali recta pilisque bracteolam exteriorem trifidam aequantibus. Rchb. excurs. p. 26. In Comitatu Tyrolensi et Carinthia. 4.

4. C. Huebneriana Rchb. panicula longissima; bracteola brevissima; externa obtusato-bifida e fissura aristata; pilis bracteolam excedentibus copiosis. Rchb. excurs. p. 26. In Saxonia. 4.

5. C. canadensis Nutt. panicula ohlonga; calycibus 1-floris pubescentibus; corollis dorso aristatis; pilis corollam aequantibus; fol. culmisque glabris angustis. Arundo Pursh am. 1. p. 86. In America boreali. 4.

6. C. Epigejos Roth; panicula stricta glomerato-lobata ; glumis lanceolatis in apicem compressum subulatum desinentibus; pilis florem superantibus; arista erecta. Arundo Mert. et Koch 1. c. Host. 4. to 42. Engl.
Bot. 402. A. lithuanica et vilnensis schult. In Europa et Sibiric. 4.

7. C. muritima liunth; panicula contracta subsecunda; glumis subulatis; corolla pilis duplo longiore infra apicem aristata; arista parum excedente. Arundo maritima Agardh in Bot. Zeit. 1824. p. 561. In Scania.

8. C. Halleriana DC. panicula diffusa glumis lanceolatis acutatis; pilis fore lougioribus; arista infra medium dorsi recta. Arundo Pseudo-Pliragmites. Mert. et Koch. I. c. Schrad. Germ. t. 4. f. 3. A. Halleriana Gaud. C. varia Iost. Grant. 4. t. 47. In Germania, Helvetia et Sibiria. 4.

9. C. pulchella Saut. panicula erecta; glumis aculis; arista dorsali bracteola sua breviore recta; pilis ea paulo longiorilus. Kclıb. excurs. p. 26. In Europa. 4.

10. C. monteridensis Nees; glumis subaequalibus lineari-lanceolatis acuminatis; processu accessorio floscula 4-plo breviore, apice subpiloso; panicula subverticillata subsecunda patula; culmo simplici. Nees in Mart. Bras. 2. p. 401. In Montevideo. 4.

11. C. tenella Ll. panicula diffusa glumis lanceolatis acutis ; pilis longitudine flosculi; flosculis muticis vel dorso aristatis. Arundo Mert. et Koch 1. c. Schrad. Germ. t. 5. f. 1. A. pilosa Gaud. C. alpina Host. Gram. 4. t. 51. f. a. $\beta$. C. tenella Host. 4. t. 50. In Europa media.

12. C. conspicua Gmel. calyciluns unifloris; panicula laxa erecto-patente; petali exterioris arista reflexa longissima. Arundo Forst. prodr. n. 48. In Nova Keelandia.

13. C. cuspidata Spr. panicula laxa subverticillata; calycibus subaristatis corollam superantibus; pilis brevissimis; valva exteriore bifida dorso aristata; fol. convolutis setaceis glaberrimis. Spr. syst. 1. p. 253. Arundo Schult. mant. 3. p. 404. In Mexico.

14. C. groenlandica Kunth; panicula contractissima tereti; spiculis 1floris; gluma corollina breviuscula; fol. angustissime linearibus. Arundo Schrank. in Hegensb. Denkschr. 2. p. 8. In Groenlandia et Labrador. 
346. PENTAPOGON R.Br. (1810).

1. P. Billardieri R. Br. prodr. 1. p. 173. Agrostis quadrifida Labill. Nov. Holl. t. 22. In Nova Hollandia. Calamagrostidi affinis.

\section{DEYEUXIA Beauv. (1812).}

1. D. coarctata $\boldsymbol{I I}$. et $\boldsymbol{K}$. fol. convolutis glahris; panicula simplici coarctata; paleis inaequalibus; superiore 3-plo breviore acuta inferiore 4-dentata; flore sterili brevissimo. H. et K. Nov. Gen. 1. p. 143. In Quito et Nova Granata. 24.

2. D. toluccensis $\boldsymbol{H}$. et $\boldsymbol{K}$. fol. convoluto-setaceis scahris; panicula ramosa subverticillata secunda; palea inferiore 4-superiore 2-dentata. H. et K. Nov. Gen. 1. p. 143. In Mexico? et Peruria. 4.

3. D. junciformis $\boldsymbol{H}$. et $\boldsymbol{K}$. fol. convoluto-setaceis scabris; panicula ramosa verticillata diffusa; glumis dorso ciliato-hispidis; paleis inaequalibus, inferiore 4 -superiore $\mathbf{2}$-dentata. H. et K. I. c. In Mexico. 4.

1. D. vigida $H$. et $H$. culmo glabro; fol. convoluto-setaceis scahris; panicula ramosa verticillata stricta; paleis inaequalibus 2-dentatis; flore sterili plumoso-lanato. H. et K. l. c. In Quito et Peruvia. 4.

5. D. recta $\boldsymbol{H}$. et $\boldsymbol{K}$. culmo scabro; fol. convoluto-setaceis scabris; panicula ramosa subverticillata stricta; glumis dorso scabriusculis coloratis; paleis inaequalibus bidentatis; flore sterili pubescente. H. et K. I. c. t. 686. In Quito, Peruvia et Mexico. $24^{\circ}$.

6. D. planifolia $H$. et $K$. fol. planis scabris; panicula ramosa verticillata subsecunda nutante; ylumis dorso ciliato-scabris; paleis inaequalibus 2-dentatis. H. et K. 1. c. In Peruvia. 24.

7. D. eriantha $H$. et $K$. fol. convoluto-setaceis scabriusculis; panicula ramosa laxa subsecunda nutante; ramis geminis; glumis dorso scabris; palea inferiore bidentata superiore acuta. H. et K. I. c. In Mexico. 24. s. D. ligulatc $H$. et $K$. fol. canaliculatis glabris ; panicula ramosa verticillata coarctata subsecunda; glumis paleas duplo superantibus; palea inferiore 4-superiore 2-dentala. H. et K. 1. c. In Quito. 4.

9. D. effiusa $H$. et $K$. fol. convoluto-setaceis glabris; panicula ramosa verticillata patula; glumis dorso scabris; palea inferiore 3-superiore 2dentata. H. et K. I. c. In Quito. 4 .

10. D. stricta $H$. et $K$. fol. convoluto-setaceis scabris; panicula ramosa verticillata patula; glumis dorso scabris; paleis subaequalibus, inferiore 3-superiore 2-dentata. $\mathbf{H}$. et $\mathbf{K}$. 1. c. In Nova Granata. 4.

11. D. ovata Presl; culmo vaginisque glabris; panicula spicaeformi ovata ; glumis lanceolatis glabris; corolla glumis dimidio breviore; pilis basi stipata corollam superantibus; paleis bilaciniatis; pluma pilos aequante. Presl in Rel. Haenk. 1. p. 246. In Peruvia. 24.

12. D. spicigera Presl; culmo vaginisque glahris; fol. convoluto-setaceis; panicula spicaeformi oblonga; palea inferiore hilaciniata; laciniis bidentatis; pluma corollam aequante. Presl. 1. c. In Peruvia,

13. D. chrysantha Presl; culmo vaginisque glabris; panicula spicaeformi; glumis aequilongis; nervis scabris; paleis inaequalibus bidentatolaciniatis superiore 4-nervia inferiore 2-nervia. Presl 1. c. In Peruria. 24.

14. D. brevifolia Presl; fol. convoluto-setaceis scabris; panicula subspicata oblonga; glumis acutis dorso scabris ; paleis inaequalibus; superiore breviore bidentata inferiore 4-dentata; flore sterili plumoso. Presl 1. c. In Peruvia. 24.

15. D. densiftora Presl; culmo glabro; panicula spicaeformi coarctata; glumis nervis scabris; paleis aequalibus ad medium usque bilaciniatis; laciniis apice fimbriatis; flore sterili plumoso. In Peruria. 4.

16. D. alba Presl; culmo vaginisque glabris; fol. planis scabris; paniculae ramis alternatim fasciculatis patulis; glumis angusto-lanceolatis; corolla basi villis stipata; paleis hidentatis; arista reflexa arcuata. PresI I. c. In Peruvia.

17. P. fuscata Presl; culmo glabro; vaginis subscabris; panicula spicaeformi contracta; glumis dorso nervoque scabris; paleis aequilongis bilaciniatis denticulatis 2-nerviis; pe- 
dunculo floris neutrius brevissime plumoso. Presl 1. c. In Peruvia. 4.

1S. D. pallens Presl; fol. convoluto-setaceis vaginisque scahriusculis; panicula ramrosa subverticillata secunda laxa; paleis aequaliluus 2-dentatis; fore neutro brevissime plumoso-lanato. Presl 1. c. In Peruvic et Quayaquil.

19. D. intermedia Presl; fol. convoluto - setaceis compressis, vaginis calmoque scabris; panicula ramosa secunda; paleis aequilongis 2-dentatis; flore neutro plumoso-lanato. Presl 1. c. In Peruvia.

20. D. eminens Presl; culmo glabro; fol. vaginisque scahris; panicula ramis alternatim fasciculatis secunda; glumis inaequalibus acutis margine dentato-laciniatis; corolla pilis obvallata; paleis dentato-bilaciniatis. Presl 1. c. In Peruvia.

21. D. nutkaensis Presl; culmo scahro; vaginis glabris; fol. scabris; panicula ramis alteruatim fasciculatis patentibus; corolla basi pilis stipata; paleis bidentatis inferiore scabra. Presl. 1. c. In Sinu Nutka. 4.

22. D.? Chamissonis Kunth; panicula patula; glumis oblongis acuminatis perianthio pilosiusculo duplo longioribus; arista glumis breviore subaequa. Lachnagrostis. Trin. Unifl. p. 216. In ins. Paschatis.

23. D. splendens Brongn. culmo erecto; fol. planis apice vix convolutis acutis; panicula ramosissima splendente; glumis aculis lucidis dorso denticulatis. Brongn. in Dup. it. bot. p. 23. In ins. St. Catharinae Brasiliae.

24. D. nevlecta Iiunth; panicula angusta patente stricto-erecta; glumis acutis; pilis flore brevioribns; arista infra medium recta. Arundo Mert. et Koch. Schrad. Germ. t. 4. f. 5. Engl. Bot. 2160. Calamagrostis Trin. Unifl. t. 4. f. 12. C. stricta Spr. In Europa et America boreali. 4.

25. D. varia fiunth; panicula patente; calycibus acutis; pilis corollam aequantibus s. duplo longioribus; arista dorsali geniculata calycem vix excedente. Arundo Schrad. Germ. 1. p. 216. t. 4. f. 6. Arundo montana Gaud. Cálamagrostis Host. Gram. 4. t. 46. In Europa, Caucaso et Sibiria. 24. var. spiculis minoribus. C. sylvatica Host. 4. t. 48. A. Hostii R. et $\mathrm{s}$.

26. D. lapponica Iiunth; panicula stricta; calycilus acutisculis; arista dorsali geniculata pilisque corollam aequantibus. Arundo Wahlenb. Lapp. p. 27. t. 1. f. a-c. Calamagrostis Hartm. Gram. 5. In Lapponia. 4.

27. I). "ecutiflora Beaux. panicula patente; glumis subulatis; pilis longitudine flosculi vel dimidio brevioribus; arista geniculata glumas vix superante. Arundo Mert. et Koch 1. c. Calamagrostis DC. C. subulata Dumort. Agr. t.9. f. 36. In Germanice anstruli et Gallia. 4.

28. I). Langsdorfii Kunth; fol. planis Iaeviusculis; panicula stricta; setis corollae aequalibus patulis subreflexis emersis. Arundo Lk. en. 1. p. 74. Calamagrostis Trin. Unifl. t. . f. 10. In Sibiria et Tobolsk. 4.

2.9. D. confinis linnth; panicula patente; calycihus 1 -floris acuminalis; pilis corollam subacquautibus; arista dorsali geniculata calycem excedente. Arundo Villd. en. p. 127. Calamagrostis Nult. In America boreali. 4.

30. D. sylvaticu Kunth; pauicula patente; calycihus acutis; pilis hrevissimis; arista dorsali geniculata calycem excedente. Arundo siclirad. Germ. 1. p. 218. t. 4. f. \%. Calamagrostis arundinacea holl. C. pyramidalis Host. 4. t. 49. In Europu et Sibiria. 4.

31. I. Preslei Kunth; panicula contracta; glumis subulato-acuninatis scabris; inferiore 1 -superiore 2nervia; arista dorsali recta. Calamagrostis scahra. Presl 1. c. In Ninu Nutlia. 4.

32. H. strigosa Iiunth; panicula erecta sparsa; calycibus subllnearibus acmminatis; arista tenui dorsali corollam aequante. Arundo Wahlenl). Lapp. p. 29. t. 2. a-d. Calamagrostis Hartm. In Lapponia et Groenlandia. 4.

33. D. purpurea fiunth; panicula subsecunda patula; glumis lanceolatis acuminatis hispiclis; corollae valvula inferiore oblonga calyce breviore; fol. retrorsum scabris. Arundo purpurea Trin. in Spr. N. Entı. 2. p. 62. Ad littora lacus Baicalis.

34. D. Billarlieri Kunth; panicula capillari; glumarum carinis denticulatis; valvula exteriore perantlii 
bimucronulata; sctula villosa ad basin valvulae interioris; fol. planis. Agrostis 12. Br. prodr. 1. p. 171. Avena fliformis Labill. Nov. Holl. t. 31. In Nova Hollandia.

35. D. Forsteri Kunth; panicula crecta tenuissima; calycihus 1-floris; aristis calyce duplo longioribus. Avena Forst. prodr. n. 46. Agrostis filiformis spr. A. Forsteri R. et s. Lachuagrostis Trin. In Nova Keelandia et ins. Paschatis.

36. D. murpurascens Kunth; panicula spicata; urlumis scabris; perianthii valvula inferiore scabra, apice 4-dentata dorso aristata; rudimento plumoso villis baseos duplo longiore. Calamagrostis $\mathrm{H}$. Br. in Frankl. Jour. 1. Arundo schult. In America arctica.

3\%. D. retrofracta Iiunth; panicula patentissima; arista infracta infra medium petali exterioris; corollis liirlis; culmo adscendente basi ramo60. Agrostis Willd. en. p.94. Lachnagrostis Willdenowii Triu. In Nova Hollandia. 4.

38. D. aemula Funth; panicula capillari; glumarum carinis denticulatis; valvula exteriore perianthii longitudinaliter pubescente bimucronata; sctula villosa ad basin valvulae cxterioris. Agrostis IR. Br. prodr. 1. p. 172. In Nova Hollandia.

39. D. scabra Funth; panicula capillari; glumarum carinis lateribusque scahris; valvula exteriore perianthii glabra apice denticulata; arista dorsali inclusa; setula villosa ad basin interioris. Agrostis R. Br. prodr. 1. p. 172. Lachnagrostis rudis Trin. Unial. In Nora Hollandia.

40. D. viridi-farescens Kunth; calycibus subbifloris; panicula louga coarctata; spiculis acutis. Arunưo Poir. Enc. 6. p. 271. Donax R. et S. In Monterideo.

41. D. megapolomica Spr. paniculae cffusae ramis racemosis; calycibus corolla brevioribus Iongissine lanatis; arista elongata geniculata; rudimento articulato calycem superante; fol. planis glahris. Spr. Cur. post. 1. 30. Ad Rio Grande.

\section{AMIMOPHILA Host. (1811).}

1. A. arundinacea Host. Gram. 1. t. 41. panicula subspicata; calycibus aculis; pilis corolla triplo brevioribns; tol. involutis. Arundo schrad. Germ. 1. p. 221. t. 5. f. 2. Hook. Lond. t. 181. Calamagrostris 13oth. Psamma arenaria $\mathbf{H}$. et $\mathbf{S}$. Plialaris Ammophila Lk. P. maritima Nutt. In Europa et America boreali. 4.

2. A. baltica Lk. panicula suhspicata lobata; calycibus acuminatis; pilis corolla dimidio hrevioribus; fol. involutis. Arundo Schrad. Germ. 1. p. 223. t. 5. f. 3. Fl. Dall. $165 \%$. Psamma 11. et $\mathrm{S}$. Ad littora maris baltici. 4.

\section{ARUNDO Linn. (1732).}

1. A. Donax L. calycibus euhtrifroris ; fosculis calycem aequautibus. Schrad. Germ. 1. p. 225. Donax arundinaceus Beauv. Agr. t. 16. f. 4. et t. 19. f. 1. Scolochloa Mert. et Koch. A. sativa Lam. var. $\beta$. procerior. A. aegyptiaca Desf. Delile Aeg. In Europa australi, Caucaso, Sibiria et Aegypto. 4.

2. A. altissima Benth; spiculis 3-5-floris; glumis inaequalibus; cxteriore flosculis timichio breviore. Beuth. Cat. p. p. 62. In Gallice australi.

3. A. marritanica Desf: culmo fruticoso ; foribus paniculatis ; calycibus 1-3-floris; gluma exteriore subaristata. Desf. Atl. 1. p. 106. A. micrantha Lam. A. Plinii Turr. A. colliua Tenore. Donax mauritanicus Beauv. 1. et $s$. Calamagrostis mauritanica Spr. C. altissima Host. In Africa boreali, Ibalia et Hispania. 4 .

4. A. nitida $\boldsymbol{H}$. et $K$. panicula ramosissima effusa; glumis spica subtriflora longioribus; palea inferiore lanam duplo superante. H. et $K$. Nov. Gen. 6. p. 249. f. 688 . In Nova Granata. 4.

4. A. madagascariensis Kunth $t$. 15; panicula maxima ramosissima effusa secunda; spiculis 5 -floris glumas triplo superantibus; floribus hermaphroditis ad ventrem lanatis; aristis flexuosis recurvatisve. Kunth. Domar 
Thouarii Beauv. Agr. t. 16. f. 5. In Madagascaria.

5. A. Reynaudiana Kunth; panicula ramosissima diffusa; spiculis sub7 -floris ; flore inferiore 1-paleaceo veutro reliquis hermaphroditis ad ventrem lanatis; summo tahescente. Kunth Gram. 1. p. 275. t. 49. In Pegu.

6. A. bifaria Retz; culmo erecio folioso ; fol. bifariis; panicula coarctata; calycibus 3-floris. Retz obs. 4. p. 22. Donax Trin. In India orientali.

7. A. pilosa Vrville; panicula contracta subovata; calycibus acutissimis; glnuis villis albidis longis copiose cinctis; interioribus sub apice bifidis; fol. striatis distichis. Ampelodesmos australis Brongu. in Dup. it. Bot. p. 31. In ins. Maclovianis.

8. A. bengalensis Retz; culmis 6-10-pedalibus fistulosis; fol. hifariis ensiformihus nutantibus; valvulis calycis 2-3-floris; valvula corollae exteriore lanata cuspidata 3-nervia. Roxb. ind. 1. p. 349. Donax Beauv. Aira Gmel. In India orientali.

9. A. australis Cav. culmo erecto folioso; fol. strictis setaceo-convolutis; panicula ovata; calycibus 5-floris. R. et S. syst. 2. p. 511. In Australicl. 4.

10. A. Egmontiana R. et S. culmo erecto folioso; fol. strictis setaceo-convolutis ; panicula ovata; calycibus 5-floris. R. et S. syst. 2. p. 511. In Portu Egmont.

11. A. airoides Poir. calycibus biforis; panicula molli subcoarctata incurva; fol. planis scabris. Poir. Enc. 6. p. 270. Deyeuxia R. et $\mathbf{S}$. In America septentrionali. 4.

12. A. airaeformis Raddi; calycibus bifloris; panicula patente; floribus muticis; fol. inferioribus distichis laevibus. Kaddi in s'chult. mant. 2. p. 291. In Madeira.

13. A. Sellouna Schult. panicnlae ramosissimae ramis flexuosis; calycibus sub-6-floris; flosculis remotiusculis longissime cuspidatis diaphanis dioecis; fol. linearibus serrulatis; spr. A. dioeca Spr. Gynerium argenteum Nees. In Montevideo. 4.

1t. A. occidentalis Sieb. culmo erecto folioso ; fol. strictis; panicula ramosissima contracta; spiculis 5-10ris. Schult. mant \&. p. 259. In Martinica.
15. A. Rarka Retz; calyciluus 1floris nudis flore subulato intus lanato multo brevioribus; panicula secunda nutante. Retz obs. 4. p. 21. T'richoon Karka Roth. In India orientali. 4.

16. A. minutiflora Brongn. culmo cylindrico; fol. unilateralibus nervosis scahris; panicula fastigiata; ramulis virgatis longissimis filiformibus; spiculis minutis 2-floris. Brongu. in Dup. it. Bot. p. 29. In ins. Bourou.

17. A. flexuosa Brongn. culmo cylindrico erecto; fol. planis; panicula flexuosa; pedicellis filiformibus; palea exteriore floris neutri subulata convoluta; pilis tenuissimis paleis brevioribus. Brongn. in Dup. it. bot. p. 29. t. 4. In ins. Bourou.

15. A. Roxburghiana Knnth; erecta; glabra; foliosa ; 8-12-pedalis ; panicula laxa verticillata; calycibus 3-4-floris; gluma corollae exteriore trinervia. Arundo Karka Roxh. Flor. ind. 1. p. 348. In Bengalia et Coromandelia.

19. A. Quila Motina; calycibus trilloris; fol. subulatis pubescentilous; internodiis approximatis. Molina Chil. p. 279. In Chili.

20. A. Yaldiviana Molina; calycibus trifloris; fol. subulatis pubescentibus; internodiis approximatis. Molina Chil. p. 279. In Chili.

21. A. Rugi Molina; calycibus bifloris; fol. subulatis glabris. Molina Chil. p. 279. In Chili. Gramen 1220-pedale.

22. A. dioeca Lour. calycibus 1floris; spicis fasciculatis compositis; spiculis linearihus. Lour. Coclı. p. 70. In Cochinchina.

23. A. piscatoria Lour. calycilus 1-floris; spica terminali; culmo ramoso; spiculis minusculis. Lour. Coch. p. 70. In Cochinchina.

\section{AMPELODESMOS Link. (1822).}

1. A. tenax Link; calycibus bifloris; panicula laxa; fol. involutis subulatis, Arundo tenax Valıl symb. 2. p. 25. Donax tenax Beauv. R. et $\mathbf{S}$. Arundo festucoides Desf. Atl. t. 31. A. Ampelodesmos Cyrill. Neapol. t. 12. In Africa boreali. 4. 
2. A. bicolor Kunth; panicula coarctata elougala; calyce bifloro; flosculo altero sterili; glumis subaristatis. Arundo Poir. Desf. Atl. t. 33. Donax Beauv. H. et s. In Africa boreali. 4.

\section{GRAPHEPHORUM Beauv, (1812).}

1. G. melicoides Beau: panicula parva subracemoso - coarctata; gluma communi partialihusque lineari-lanceolatis muticis; floribus basi villosis. Aira Pursh. Flor. 1. p. 76. Triodia spr. In America boreali. 4.

2. G.? Elliottii Kunth; panicula gracili erecta; calycibus acutis; spiculis superioribus trifloris; fol. brevibus planis. Aira Elliot. Triodea Grenii spr. In Georgia. 4.

\section{PHRAGMITES Trin. (1822).}

1. P. communis Trin. panicula effusa ; spiculis 4-5-floris. R. Br. Arundo Phragmites L. Host. Gram. 4. t. 39. Schrad. Germ. t. 5. f. 4. Czernya arundinacea Presl. In Europa, Caucaso, Sibiria, Japonia, America, et Nova Hollandia.

2. P. isiacus Kunth; panicula ohlonga maxima; spiculis muticis 3-5foris calyce multo Iongioribus; fol. vaginisque glaberrimis glaucis. Arundo schult. mant. 2. p. 288. A. maxima Forsk. In Aegypto.

3. P. mauritiams Kunth; fol. scabriusculis margine denticulatis; panicula ramosissima diffusa nutante; floribus inferioribus hermaphroditis; summo tahescente. Kunth Gram. 1. p.80. et 277. t. 50. In ins. Franciae.

\section{GYNERIUM H. et B. (1812).}

1. G. saccharoides $\mathrm{H}$. et $\mathrm{B}$. $\mathrm{Pl}$. aeq. 2. $r$. 112. $t$. 215. spiculis bifloris; panicula secunda laxa; fol. planis latis. Nees. G. sagittatum Beauv. Arundo sagittata Pers. In America calidiore $\hbar$.

2. G. parviflorum Nees; spiculis masculis sub-1-floris; panicula secunda laxa virgata; fol. ensiformibus di- stichis. Nees in Mart. Bras. 2. p. 463. Maxim. Princ. Wild. it. t. 5. Mart. Reis. Atl. t. 1. V.t. 1. In Brasilia. t.

\section{AMPHIPOGON R. Br. (1810).} (Aegopogon Beauv.)

1. A. lagurvides $\boldsymbol{R}$. $\boldsymbol{B r}$. capitulo globoso; glumis lispidis; pilis basi dilatatis; valvula exteriore acumine suo duplo longiore. R. Br. prodr. 1. p. 175. In Nova Hollandia.

2. A. turbinatus $R$. Br. capitulo obovato; glumis villosis; villis basl simplicibus; valvula exteriore acumine suo vix longiore. $\mathrm{H}$. Br. 1. c. In Nova Hollandia.

3. A. strictus R. Br. glumis ciliatis integris perianthio glabro brevioribus; aristis foliisque strictis. $\mathbf{K}$. Br. Aegopogon Beauv. In Nova Hollandia.

4. A. debilis $\boldsymbol{R}, \boldsymbol{B r}$. glumis trifidis perianthio glainro brevioribus; aristis strictis; fol. laxiusculis. IR. Br. 1. c. In Nova Hollandia.

5. A. arenuceus $\boldsymbol{R}$. Br. glumis acuminatis integris; perianthio sericeo longioribus; aristis patentibus. IR. Br. 1. c. In Nova Hollandia.

\section{DIPLOPOGON R. Br. (1810).}

1. D. setaceus $R$. Br. Dipogonia setacea Beauv. In Nova Hollandia.

\section{TRIRAPHIS R. Br. (1810).}

1. T. pungens R. Br. panicula effusa; perianthii valvula exteriore coriacea tenuissime pubescente; aristis aequalibus; intermedia simplici; fol. involutis strictis patulis. $\mathbf{R}$. Br. prodr. 1. p. 185. Sesleria Spr. Pappophorum Trin. In Nova Hollandia.

2. T. mollis R. Br. panicula coarctata; parianthii valvula exteriore villis patulis barbata; arista intermedia utrinque lacinula setacea aucta. IR. Br. 1. c. Sesleria Spr. In Nova Hollandia.

3. T. pumilio $\boldsymbol{R}$. Br. panicula coarctata abbreviata; calyce 3-floro; flosculo infimo perfecto reliquis neutris 
1-valvilus 12. Br. in App, ad Denl. et Clappert. Voy, p. 245. S'esleria spr. In Africa media.

\section{PAPPOPHORUM R.Br.(1810).}

1. $\boldsymbol{P}$. cenchroides Lichtenst. thyr60 cylindraceo subelongato; glumis pilosulis 3-nerviis; subulis valva duplo longioribus ad medium usque plumosis. Trin. in Act. petrop. 1830. 1. p. 92. In Prom. b. spei.

2. P. phleoides Hort. Madrit. thyrso ovato; glumis ad carinam pilosulis 3-5-nerviis ; subulis valva subsesquilongioribus paulo supra medium usque plumosis. Trin. 1. c. Enneapogon $\mathbf{R}$, et $\mathbf{S}$. In Arabia felici.

3. I'. nigricans R. IBr. aristis 9 plumosis; spica composita subcylindracea; lobis imbricatis; glumis tenuissime pubescentibus; fol. vaginisque glabris scabriusculis. R. Br. prodr. 1. p. 185. Enmeapogon Desv. In Noea Hollandia.

4. P. pallidum $\boldsymbol{R}$. Br. aristis 9 plumosis; panicula spicaeformi cylindracea conferta; fol. molliter pubescen(ibus; glumis molliter pilosis. Kunth Gr. 1. p. 279. t. 51. Enneapogon Desv. In Nova Hollandia.

5. P. purpurascens $R$. Br. aristis 9 plumosis coloratis; spica lobata lanceolata; ramis alternis racemosis; glumis foliisque pubescentibus. $\mathbf{H}$. Br. 1. c. Enmeapogon Desv. In Tova Hollandia.

6. $\boldsymbol{P}$. gracile $\boldsymbol{R}$. $\boldsymbol{B r}$. aristis $9 \mathrm{plu-}$ mosis; spica infra divisa; apice simplici; glumis puhescentilus; fol. involutis culniscque glabris. R. Br. 1. c. Enneapogon Desv. E. Desvauxii Beauv. Agr. t. 16. f. 11 . In Nova Jlollandia.

\%. P. caernlescens Gandich. fol. vaginis culnisque pubescentibus; geniculis barbatis; spica ovato-oblonga; glumis tenuissime pubescentibus; aristis 9 plumosis basi villosis. Gaudich. In Freyc. it. bot. p. 409. In Nova Hollandice.

8. P. molle Kunth; radice fasciculata; fol. planis puhescentibus; panicula ramosa pyramidata; setis corollae pinnatis. Enneapogon Lehm. Pugill. 3. p. 40. In Prom. b. spei.

9. P. scabrum Kunth; radice fasciculata; fol, planis culmisque re- trorsum scabris; panicula patula domun contracta; setis corollae simplicibus. Enmeapogon Lehn. 1. c. In prom. b. spei. 21.

10. P. alopecuroideum Tahl; culmo ramoso; fol. attenuato-acuminatis subtus vaginisque glabris; panicula subspicata elongata cernua; spiculis 3-floris. Schrad. in sclult. mant. 2. 1. 312. In America meridionali.

11. P. laguroideum schrad. culmo simplici; fol. attenuato-cuspidatis subtus vaginisque glabris ; panicula coarctata elongata sulmutante; spiculis 2-3-floris. schrad. in schult. mant. 2. p. 342. In India occidentali et Montevideo.

12. P. mucronulatum Nees; culmo ramoso; fol. attenualo - acuminatis convolutis vaginisque glabris; panicula spicata angusta elongata cernua; spiculis sub-4-floris; glumis oblongis setace-mucronatis. Nees in Mart. Bras. 2. p. 412. In Brasilia. 4.

13. P. macrostachyum Nees; culmo simplici in apicem longissime setaceum attenuato basi vaginisque atpresso-pilosis; panicula coarctata longissima subutante; spiculis 3-floris. s'chrad. in Schult. mant, 2. p. 342. In brasilia. 24.

11. P. megapotamicum Spr. racemo spicato paucifloro; pedunculis abbreviatis villosis; aristis subduodenis longissimis patentibus; culmo simplici; fol. ciliatis. Spr. Cur. past. p. 34. Ad Rio Grande.

15. P. elongatum Spr. panicula cylindrica elongata lobata; calycibus glabris; aristis subvicenis; fol. convolutis longissimis. Spr. Cur. post. p. 34. In Montevideo.

16. P. pumilio Trin. thyrso ovatocapitato; perianthiis piloso-scabris; infimo 5-, secuudo 7-, reliquis 9-setis. Trin. in Act. Petrop. 1830. p. 92. In Persia. Culnus digitalis.

17. P. syarrosum Russ. spiculis multifloris. Russ. Alep. 2. p. 214. In Persia.

\section{COTTEA Eunth (1S32).}

1. C. pappophoroides Kunth Gram. 1. p. 81. f. 281. t. 52. In Peruvia. Culmus ramosus. Vaginae foliague 
pubescentia. Kamis paniculae pubescenti-pilosis.

\section{ECHINARIA Desf, (1800).}

1. E. capitata Desf. Atl. 2. p. 285. Sesleria Host. 3. t. 8. Cenchrus capitatus. sibth. Graec. to 100. In Europa australi, Africa boreali et Bithynia. $\odot$.

360. CatestecuM Presl. (1830).

1. C. prostratum Presl in Rel. Maenk. 1. $p$. 295. t. 42. In Mexico. Culmi prostrati radicantes glaberrimi. Folia linearia margine scabra. Ligulac margo pilosus.

\section{MICROCHLOA R. Br. (1810).}

1. M. setacen R. Br. H. etK. Nov. Gen. t. 22. Nardus indica L. Rottboella Roxb. Corm. t. 132. In Mexico, Montevideo, India orientali et Nova Lollandia. 4.

\section{SCHOENEFELDIA ISUnth (1832).}

1. S. gracilis Kunth Gram. 1. p. 253. $t$. 53. In Senegalia. Culmus simplex. Ligula brevissima pilosa. Folia angusta involuto-filiformia.

\section{CYNODON R. Br. (1810).}

1. C. Dactylon Pers. spicis $3-5$ digitatis; perianthiis glabris subciliatis gluma longioribus; setula inberbi ad hasin valvulac interioris. $\mathbf{h}$. Br. prodr. 1. p. 187. Panicum L. Host. Gram. 2. t. 18. Enyl. hot. 850. Digitaria stolonifera. schrad. Germ. t. 3. f. 9. Cynodon linearis Presl; C. maritimum $\mathbf{H}$. et $\mathbf{K}$, Chloris maritima Triu. In Europa, Cuucaso, Oriente, India orientali, China, Luzonia, Noea Hollandia, Taiti, America et Prom. b. spei. 24.

2. C. arcuatus Presl; culmo repente ramoso compresso; vaginis oris pilosis; fol. distichis planis ciliatoserrulatis; spicis 1-seriatis; glumis carina ciliolatis. Presl in Rel. Haenk. 1. 2. 290. In Luzonia.

3. C. pascuus Nees; culmis ropentibus ramosissimis compressis; fol. distichis; spicis digitatis quaternis quinisve; palea inferiore dorso subciliata mutica; rudimento setuliformi. Nees in Mart. Bras. 2. p. 425. In Brasilia.

4. C. erectus Presl; culmis erectis ramosis compressiusculis; fol. distichis planis supra scabris; glumis corolla brevioribus; paleis carina ciliatis. Presl in Rel. Haenk. 1. p. 290. In Mexico et Peruvia. 4.

5. C. radiatus Roth; spicis digitatis suboctonis patentibus; calyce adpresso; culmo erecto ramoso; fol. margine scabris cum vaginis nudis. Roth Nov. Sp. p. 38. Digitaria radiata spr. In India orientali.

6. C. tenellus R. $\mathbf{B r}$. spicis 2-3, digitatis; palea inferiore villoso-pubesceute; gilumis paulo breviore setula nulla ad basin palea superioris. R. Br. prodr. 1. p. 187. Digitaria didactyla Spr. In Nova Hollandia.

\%. C. polystachyus R. Br. spicis plurimis racemosis ; perianthiis pubescentibus gluma scabriuscula parum longioribus. 1R. Br. prodr. 1. p. 187. Digitaria Spr. In Nova Hollandia.

8. C. tener Presl; culmis repentibus adscendentibus ancipitibus; fol. superne pilosis margine scabris; spicis 3-4 erecto-patentibus; spiculis secundis; glumis lanceolatis palea brevioribus; palea inferiore rotundata margine pilosociliata. Presl in Rel. Haenk. 1. p.291. In Luzonia. 4.

9. C. incompletus Presl; culmis repentibus ramosis compressis; fol. glancis glabris; ligula dentioulata valvula inferiore dorso ciliata nutica; rudimento nullo. Nees in Limnaea 7 . p. 301. In Prom. b. spei.

10. C. notutus Nees; culmis repentibus ramosis sub-4-gonis; fol. vaginisque villosis; ligula lacero-ciliata; spicis digitatis divarícatis; valvula inferiore dorso subciliata apice rotundata; rudimento nullo. Nees in Linnaea 7. p. 302. In Prom. b. spei. 11. C. stellatus Willd. spicis digitatis quaternis basi vaginatis; calyce adpresso; fol. nudis margine scabriusculis. Agrostis Willd. sp. 1. p. 
376. C. Dactylon var. $\gamma$ - Nces, In ins. St. Helenu. 4.

12. C. elongatus Trin. culmo filiformi asperulo; vaginis superue tumescentibus glabris; fol. angustissimis retrorsum scabris; spiculis imbricatoerectis; yluma calycina superiore sctosa; corollina superiore apice bifida setosa. Trin. in spr. N. Entd. 2. p. 64. Digitaria Spr. Agrostis filiformis. Koenig. In India orientali.

13. C. pilosus R.et S. spicis digitatis linearilus; fol. margine pilosis. Agrostis Retz obs. 6. p. 22. In India orientali.

\section{DACTYLOCTENIUM Willd. (1797).}

1. D. aegyptiacum Willd. spicis digitatis quaternis quinisve; rachi spicae glahra mucronata; fol. basi ciliatis; culmo adscendente. Willd. en. 1029. Cynosurus L. Chloris nutucronata Michx. Eleusine cruciata. Lam. ill. t. 48. f. 2. Dactyloctenium mucronatum. Trin. ic. t. 69. In Asia, America, Africa et ins. Moluccis. $\odot$.

2. D. mostratum Willd. spicis digitatis geminatis; rachi spicae glahra mulica; fol. a medio ad basin ciliatis; culmo repente. Willd. ell. 1029. Chloris prostrata Poir. Eleusine Spr. In Malabaria.

3. J. vodulans Beauv. spicis quaternis patulis; glumis bifloris; valvula interiore aristata; perianthii valvula exteriore acuminata; fol. planis pilosis. Eleusine R. Br. prodr. 1. p. 186. In Nova Hollandia.

1. D. aristatum $L k$. fol. Iongis pilosis; pilis basi parum bulbosis margine scabris; spicis 5 subpatentilus; rachi apice nuda; arista valvula fere Iongiore. Lk. Hort. Berol. 1. p. 59. In Aegypto.

\section{EUSTACHYS Desv. (1812).}

1. E. petraed Desv. spicis fasciculatis $4-7$ strictis; palea inferiore ohtusa dorso infero marginibusque superue sericeo-ciliolatis; fol. subdistichis linearibus cum mucronulo scabrisque. Nees in Mart. Bras. 2. p. 419.
Jacq. Gram. t. 11. Cynosurus Vahl symb. t. 27. Andropogon capense Huttw. Pflanzensyst. 12. t. 93. f. 3. Chloris Lagasc. et Spr. syst. In Prom. b. spei, Jamaica, America boreali et Montevideo. 4.

2. E. distichopleylla Nees; culmis ramosis repentibus vaginisque compressis ; fol. distichis acute inucronulatis externe margineque scahriusculis; spicis 11 digitatis patulis. Kunth Gram. 1. p. 285. t. 54. Chloris fasciculata Schult. mant. Paspalum superbum Spr. In Chili et Brasilia. 4.

3. E.? polystacleya Kunth; spicis pluribus patentibus; calycibus flosculisque glabris muticis; culmo compresso. Chloris Lagasc. Elench. 4. In Mexico.

\section{CHLORIS Sw. (1797).}

\section{a. Species genuinae.}

1. C. submutica $H$. et $K$. fol. scabris; ligula ciliata; spicis crebris umbellato-fasciculatis; glumis acuminatis; inferiore truncata mucronata subciliata. H. et K. Nov. Gen. 1. p. 167. t. 50. Eustachys R. et $\mathbf{S}$. Chloris imberbis Desf. In Mexico et Brasilia. $\odot$.

2. C. ciliata $S w$. spicis digitalis subquinis erectiusculis; glumis corollinis margine ciliatis. Sw. FI. ind. occ. 1. p. 197. Andropogon pubescens Ait. In India occidentali, Brasilia et Mexico. $\odot$.

3. C. virgata Sw. fol. scabris; ligula ciliata; spicis crebris fasciculatoumbellatis; glumis aristatis; paleis bifido dentatis; aristis palea inferiore ciliata triplo longioribus. H. et $\mathbf{K}$. Nov. Gen. 1. p. 166. Rabdochloa Beauv. In Antigua et Mexico. $\odot$.

4. C. elegans H. et K. fol. interne margineque scabris; ligula ciliata; spicis crehris umbellato-fasciculatis; glumis acuminato-subulatis; paleis integris, inferiore apice longe barbata. H. ct K. Nov. Gen. 1. p. 66. t. 49. In Mexico. $\odot$.

5. C. polydactyla Sw. spicis plurimis fasciculatis laxis; glumis corollinis margine ciliato-villosis. Sw. ind. occid. 1. p. 199. Jacq. Eclog. Gr. 1. t. 9. Andropogon L. In Jamaica, Cumana et Brasilia. $\odot$. 
6. C. fasciculata Schrad, fol. margine scabris; spicis numerosis umbellato-fasciculatis; valvulis corollinis Integris; exteriore hermaphroditi nıargine longe ciliata; apice cum corollina sterilis et calycina interiore mucronata. schrad. in schult. Mant. 2. p. 339. In Brosilia.

\%. C. consanguinea Kunth; culmis vaginisque glabris; fol. planis nervosis margine scabris; spicis crebris (20) fasciculato-digitatis elongatis; rachibus scabris. Kunth Gram. 1. p. 89. In Rio Janeiro.

8. C. barbata $S u$. spicis digitatis secundis; corolla hermaplurodita ciliata aristata; neutra e valvis duabus aristatis. Roxh. ind. 1. p. 331. Jacq. Eclog. 1. t. 8. Andropogon barbatum L. Chloris caribaea Spr. In India orientali, ins. Plitippinis et Brasilia.

9. C. alba Presl; culmo vaginisque compressis; ligula brevissima ciliolata; spicis 14 fasciculatis; gluma superiore florem hermaphroditum aequaute bidentata; palea hermaphroditi inferiore 5-nervia medio gibba apicem versus longe dorsoque secus marginem ciliata. Presl in Rel. Haenk. 1. p. 289. In Mexico. $\odot$.

10. C. montanc Roxb. spicis digitatis secundis basi coadumatis; flore hermaphrodito ciliato aristato neutro e valvis 3 muticis. Roxb. ind. 1. p. 331 . In India orientali.

11. C. polystachya Roxb. spicis $10-12$ fasciculatis; gluma exteriore floris hermaphroditi margine ciliata; flosculis neutris duobus; valvulis solitariis glabris. Roxh. ind. 1. p. 332. C. Roxhurghiana schult. In Peninsulı Indicte.

12. C. humilis Kunth; radice fibrosa; culmis caespitosis; fol. planis margine scabris; vaginis compresso-carinatis; spicis ternis patulis; flore hermaphrodito basi harhato sterili pedicellato minuto. Kunth Gram. 1. p. 89. et 2. t. 180. In Rio Janeiro. $\odot$.

13. C. foliosa Willd. spicis suhquaternis erectis; calycinis valvulis subequalibus corollinis Jongioribus; culmo ramoso folioso stricto. IVilld. sp. 4. p. 924. Kunth Gram. t. 59. Gymnopogon Nees. In India occidentali et Brasilia. 4.

14. C. cruciata $S w$. spicis subquaternis cruciatis; flosculis acumina- tis. Sw. prodr. p. 25. Agrostis L. (Sloane hist 1. t. 69. f. 1.) In Jamaica et Cuba. $\odot$.

15. C. Beyrichiana Kunth; culmis ramosis repentihus vaginisque compressis ; spicis $6-8$ digitatis patentibus ; rachibus complanatis; glunis lanleolato-subulatis; palea inferiore longissime aristata. Kunth Gram. 1. p. 89. et 289. t. 56. In Rio Janeiro.

16. B. radiata $S w$. spicis plurimis fasciculatis erectiusculis; flosculis subulatis glabris. Sw. prodr. p. 26. Kth. Gram. t. 179. Andropogon fasciculatum L. Chloris scoparia Desf. C. pallida Willd. C. compressa DC. In India occidentali et Prom. b. spei. $\odot$.

1\%. C. pucnotrix Trin. culmo basi repente foliisque planis obtusissimis glahris; spicis digitatis subseptenis; glumis lanceolatis superiore acuminata setigera. Nees in Mart. Bras. 2. p. 423. C. radiata Raddi. In Brasilia. $\odot$.

18. C. truncata R. Br. spicis 6 8 digitatis divaricatis glumis bifloris subulatis; perianthiis truncatis compressis glabris; arista valvulam bis superante. R. Br. prodr. 1. p. 186. Kuntlı Gram. t. 178. C. dolichostachya Lag. C. megastachya schrad. C. elongata Poir. In Nova Hollandia, ins. Philippinis et Timor. 4.

19. C. divaricata R. Br. spicis 6-9 digitatis divaricatis; glumis bifloris subulatis; periauthiis subulatolanceolatis scabriusculis nudis 3 -aristatis; aristis lateralibus brevissimis; intermedia elongata. $\mathrm{K}$. Br. prodr. 1. p. 186. In Nova Hollandia.

20. C. Prieuri Kunth; culmo inferne compresso; vaginis compressocarinatis superue ciliatis; paleis flosculi hermaphroditi dorso puuctatoasperatis. Kunth Gram. 1. p. 89. et 2. t. 134. In Senegalia.

21. C. distachya Iunth; culmis basi ramosis repentibus compressis glabris; fol. angustissime linearibus complicatis; spicis subgemiuis; spiculis trifloris; flore summo tabescente mutico. Kunth. Gram. 1. p. 291. t. 57. C. monostachya Poir. Cynosurus Vahl. Eleusine monostachys Spr. In India orientali et ins. Mauritii.

22. C. Gayana Kunth; culmis ramosis vaginisque glahris ore pilosis; spicis $12-15$ fasciculato-congestis; flore infimo ad marginem piloso-ciliato. 
Kunth Gram. 1. p. 79. et 293. t. 58. In Senegalia.

23. C. villosa Pers. culmis compressis vaginis foliisque glabris complicatis; spicis reminis ; floribus hermaphroditis sericeo-pilosis tahescentibusque longe aristatis. Chloris Tctrapogon Beauv. Tetrapogon villosus Desf. Atl. t. 255. In Barbaria.

\section{b. Species minus cognitae.}

21. C. ventricosa R. Br. spicis 3-4 digitatis divaricatis; glumis bifloris coloratis; valvulis acutis ; intcriore lanceolata; perianthiis truncatorotundatis ventricosis scabris nudis; arista valvula parum longiore. H. Br: prodr. 1. p. 186. In Nova Hollandia.

25. C. incomplete Roth; spicis subquinis crectis; calycis gluma interiore corollaeque bermaphroditae basi pilosae valvula exteriore rudimentoque misculi floris aristatis; vaginarum oris pilosis. Roth Nov. sp. p. 60. In India orientali.

26. C. tenella Roxb. spicis solitariis; spicularum floribus $3-4$ hermaphroditis aristatis rudimentoque nenirius. Hoxb. ind. 1. p. 330. Ctenium indicum spr. In peninsula Indiae.

27. C. panicea Willd. spicis subquaternis cruciatis; calicinis valvulis aristatis; oris vaginarum ciliatis. Willd. sp. 4. p. 923. In India orientali. 4.

28. C. pubescens Lagasc. spicis umbellatis; perigonii valvula exteriore oblonga dorso subpilosa, apice ciliata et longe aristata; fol. tenuiter pubescentihus. DC. Cat. Monsp. p. 95. In Pernita. $\odot . ?$

29. C. inflata $L k$. vaginis glaberrimis; spicis vioenis; valvula exteriore corollae flosculi hermaphroditi apice longe ciliata; flosculis duobus nentris aristatis inflatis. Lk. en. 1. p. 105. In Catifornia. 4.

30. C. penicillata Pers. spicis digitatis; calycihus $\mathbf{4}$-floris dorso aristatis; petalis exterioribus hermapluroditi aristatis; penicillis harbatis. $\mathbf{C y}$ nosurus penicillatus. Vahl symb. 2. p. 21. Eleusine spr. In India orientali.

31. C. rufescens Lag. spicis digitatis senis; glumis muticis; calycibus imberlbilus ; culmo compresso. Lag. Elench. 5, In ins. Philippinis.
32. C. gracilis Durand; spicis plurimis subverticillatis digitatis glabritsculis; perigonii hermaproditi gluma exteriore et flosculi sierilis rudiniento infra apicem aristatis; arista longa. Durand. Chlor. p. 10. Jacq. Eclog. Gram. t. 10. C. Durandiana schult. In Panama et Mexico. $\odot$.

33. C. crinita Lag. spicis fasclculatis plnrimis; corollarum valvula exteriore apice indiviso triaristato. Lagasc. Elencli. 5. In ins. Plitippinis. $\odot . ?$

31. C. pumilio R. Br. spicis 2-1, erectiusculis glumis biloris; valvulis acuminato-aristatis; perianthiis ciliatis lanceolatis triaristatis; aristis lateralibus valvula brevioribus; intermedia elongata. R. Br. prodr, 1. p. 186. In Nova Hollandia.

\section{6\%. LEPTOCHLOA Beauv. (1812).}

1. $\boldsymbol{L}$. domingensis $L k$. paniculae ramis simplicibus; spiculis subsessilibus sub-5-floris; flosculis omnibus aristatis. Cynosurus Jacq. ic. t. 22. Eleusine Pers. Rabdochloa Beauv. I. et S. Leptastachys Meyer. In Jamaica, St. Domingo et Mexico. 24.

2. I. digitaria Nees; fol. margine scabris inferioribus interne pilosis; ligula ciliata; spicis subverticillatis filiformibus; paleis ciliatis; inferiore 2-dentata. Chloris Digitaria $\mathbf{H}$. et $\mathbf{K}$. Nov. Gell. 1. p. 168. Leptostachys Meyer. In Quito. $\odot$.

3. L. gracilis Nees; fol. interne pilosis; ligula ciliata; spiculis 4-6floris; paleis ciliatis; inferiore 2-dentata; arista paleam inferiorem subaequante. H. et K. Nov. Gen. 1. p. 168. Leptostachys Meyer. In Quito et Brasilia. 4.

4. L. virgata Beanv. fol. utrinque glabris margine scahris; ligula ciliata; spicis creberrimis; paleis ciliatis inferiore 2 -dentata superiorc acuminata; arista brevissima. Chloris poaeformis $\mathbf{H}$. et $K$. Leplostachys Meyer. Rabdochloa Beauv. In America meridionali. 4.

5. L. tetraquetra Presl; fol. scabrinsculis; ligula fimbriata ; spicis creberrimis; spiculis sub-6-floris ; palca inferiore integerrima obtusa mutica pilosiuscula. In Luzonia. $\odot$. 
6. L. procerc Nees; vaginis foliisque glabris; panicula laxiuscula; spiculis sessilibus sub-3-floris brevissime mucronatis; culmo frutescente. Nees In Mart. Bras. 2. p. 431 . Festuca filiformis Lam. In Brasilia $\beta$. minor in Peruvia.

7. L. scabra Nees; vaginis compressis ore nudis vaginisque scabris; spicis confertis; spiculis muticis pellucidis; palea inferiore acute carinata mucronato-acuta; culmo compresso ; radice amuua. Nees in Mart. Bras. 2. p. 435. In Brasilia.

8. L. tenervima R. et $\boldsymbol{S}$. spicis alternis gracillimis; spiculis distichis muticis; fol. basi subpilosis vaginis compressis glahris. Eleusine tenerrima Hosnem. Poa chineusis Burch. ind. t. 11. f. 3. Poa sessilis Lam. In India orientuli et Clina. $\odot$.

9. L. mucronata Kunth; vaginis pilosis; spicis numerosis filiformibus paniculatis; spiculis minutissimis; calyce mucronato 4-floro; floribus muticis. Pursh Fl. 1. p. 87. Eleusine Michx, Oxydenia Nutt. In America boreali. $\odot$.

10. L. filiformis $\boldsymbol{R}$. et $\mathbf{S}$. panicula ramosissima coarctata ; ramis simplicihus filiformihus; spiculis altemis $2-4-$ floris muticis vaginis subpilosis. Eleusine Pers. Jacq. Eclog. t.at. Leptostachys Meyer. Oxydenia Nutt. Poa virgata hoth. In America meridiomali, Mexico et Lusonia.

11. L. cynosuroides $R$. et S. spica solitaria disticha; calycibus subulatis 3-floris; flosculo sterili mutico. Cynosurus Vahl symb. 2. p. 20. L. filiform is Beauv. Chloris filiformis. Poir. Pollinia filiformis Spr. In India orientali.

12. L. mollis In̈tnth; culmo erecto simplici; fol. lanceolato-linearibus; vaginis molliter pilosis; ligula ovata glabra; glumis carinatis acutato-subulatis; palea inferiore sub apice bilobo hreviter aristata margineque pilosa. Kunth Gram. 2. t. 135. In Senegalia. $\odot$.

13. L. arabica Kunth; glumae valvulis aequalibus; flosculis pedicellatis muticis hermaphroditis. Dinehra aegyptica DC. Jacq. Fragm. t. 121. f. 1. Delile Aeg. t. 11. f. 3. Dactylis paspaloides Willd. In Aegypto, Senequmbia, Arabia et India orientali. $\odot$.
14. I. polystachya Kunth; panicula elongata; rauis approximatis strictis; spiculis oblongis 8-10-fluri: adpressis aristatis. Festuca Willd. en. p. 117. Diplache fasciculata. Beany. Agr. t. 16. f. 9. Bromus poacformis spr. In America boreali. 4 .

15. L. Lindleyana Fumik; culmis ramosis scabriusculis; fol. linearibus planis utrinque vaginisque molliter pilosis; ligula abbreviata plicato-crenata; glumis carina hispidulo-scahris apice subulatis; palea inferiore apice biloba. Kunth Giauı. 2. t. 215. I/6 ins. Albermarle.

16. L. fusca Kunth; culmo basi geniculato ramoso; vaginis basi dilatatis ; paniculae ramis simplicibus erectis; valvulis subacutis vel mucronulatis dorso subcarinatis. Hestuca L. Delile Aeg. t. 11. f. 1. In $\mathbb{P} a-$ laestina et Aegypto.

1\%. L. dubic Nees; fol. scalris; ligula ciliata; spiculis sub-8-floris; florihus distantibus; paleis sulnciliatis; inferiore emarginato-hifila 3-nervia; arista mucroniformi hrevissima. Chloris H. et K. Nov. Gen. 1. p. 169. t. 69\%. Leptostachys Meyer. In Mexico. $\odot$.

18. L. patens Kunth; culmo tereti glabro; vaginis scabriusculis ; fol. margine ad basin pilosis; panicula corymbosa; spiculis sub anthesi ovatis; palea inferiore aristata. schismus. Presl in Rel. Hacnk. 1. p. 169. In Chili. 4.

19. pectinata Kunth; spicis linearibus compressis pectinatis alteruis; spiculis distichis calyce mucronato brevioribus. Cynosurus Lam. Enc. 2. p. 188. Eleusine indica Spr. In In-

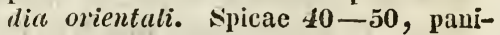
culatae.

20. L. verticillata Kunth; erecta glabra; 1-4-pedalis; fol. distichis; spiculis crebris paniculatis; calycibus 8-12-floris; glumis subulatis; seminilus oblongis rugosis. Eleusiue Roxb. ind. 1. p. 346. In India orientali.

21. I.? calycinc Funth; erecta, 2-3-pedalis; panicula lineari; spicis crehis alternis; glumis calycis aequalibus, iis corollae multo majoribus subulatis 3-floris; seminibus 3-angalaribus rugosis. Eleusine ind. 1. p. 317. In Intia orientali.

22. L. vacemosa Kunth; paniculae patulac racemis densis secundis; spi- 
culis 12-floris; corollae valvulis ovato-mucronatis; interiore persistente, ad marginem replicatam villosa; culmo compresso. Roth. Nov. sp. p. 80. sub Eleusine. In India orientali.

\section{ELEUSINE Gaertn. (1788).}

1. E. indica Gaertn. culmo compresso hasi ramoso; fol. glahris; ligula pilosa; spicis digitatis strictis; spiculis subsexfloris. H. et K. Nov. Gen. 1. p. 165. Trin. ic. t. 71. Lam. ill. t. 48. f. 3. Cynosurus L. Eleusine distans Moench. In India orientali, Aegypto, ins. Mauritii, Lusonia, Amboina, Japonia et America. $\odot$.

2. E. oligostachya link; spicis hinis ternisve strictis; spiculis 4-seriatis 5-floris; valvula exteriore ohlonga acutiuscula; seminibus globosis. Link Hort. 1. p. 60. Patria ignota. $\odot$.

3. E. distans $L k$. spicis 5 , patentibus strictis; spiculis $5-\mathbf{7}$-floris distantibus; valvula exteriore lanceolata acutiuscula; seminibus oblongis trigonis Lk. Hort. 1. p. 61. Patria ignota. $\odot$.

4. E. coracana Gaertn. spicis digitatis demum incurvis septenis; rachi spicae menibranacea; culno compresso erecto; fol. approximatis ore pilosis. Willd. ell. p. 112. Trin. ic. $t$. 70. Hheede 12. t. 78. Rumph. 5. t. 76. f. 2. In India orientali et Japonia.

5. E. tristachya Kunth; spicis ternatis crassis ohtusis erectis; spiculis secundis sessilibus adpressis sub-4floris. Cynosurus Lam. Enc. 2. p. 188. In Montevideo.

6. E. floccifolia Spr. spicis linearibus rectis; fol. conduplicatis margine altero barbatis. Cynosurus Vahl symb. 1. p. 10. Chloris Poir. In Arrabia et Aegypto.

\%. E. stricta Roxb. cnlmis erectis 2-5-pedalibus compressis; fol. distichis; spicis digitatis strictis; calycibus 3-6-floris; seminihus subrotundis. Roxb. ind. 1. p. 344. In India orientali.

S. E. rigida. Npr. spicis digitatis subquaternis stellato-patentilous; rachi glabra spiculisque 8-floris muticis culmo adscendente; oris vaginarum pilosis. Spr. Cur. post. p. 36. Cyno- surus rigidus Hort. Berol. Patria ignota.

\section{HARPOCHLOA Funth (1833).}

1. H. capensis Funth Gram. 1. p. 92. Chloris falcata Sw. in Act. Berol. 3. t. 1. f. 1. Cynosurus falcatus Thumb. Willd. Eleusine spr. In Prom. b. spei.

\section{3\%0. CTENIUM Spr. (1S25).}

1. C. americanum Spr. spica unica; spiculis 6-floris; floribus aristatis margine barhatis; gluma calycis exteriore scrobiculato-glandulosa dorso aristata. Chloris monostachya Pursh am. 1. p. 87. Campuloa gracilis Desv. Campulosus monostachyus Beanv. Agr. t. 13. f. 1. C. monostacliya $R$. et $s$. Ctenium Panz. Ideen t. 13. f. 3. a-f. Monerma Gangetis $\mathrm{R}$. et $\mathrm{S}$. In America boreali. $\odot$.

2. C. eleyans Kunth; culmis erectis; vaginis glabriusculis; fol. sul-. catis scabris; spiculis 4-floris; gluma exteriore 2-nervia versus medium tuberculato-sulbmucronata ; carina papilloso-scabra. Kunth Gram. 1. p. 93. et 295. t. 59. Campuloa elegans Gay. In Senegalia.

3. C. cirrosum Kunth; culmis fasciculato-ramosis glabris; fol. linearibus strictis hirtellis; spica subfalcata; spiculis 4-floris; gluma superiore integra binervia, dorso aristata; nervo altero papilloso - tuberbulato; arista floris neutrius secundi longissima. Kunth Gram. 4. p. 445. t. 136. Campulosus Nees. In Brasilia. $\odot$.

4. C. brachystachyum Kunth; culmis caespitosis simplicihus glabris; fol. anguste linearibus sulcato-striatis; spica falcata; gluma superiore bifida, nervis tuberculatis. Kunth Gram. 2. p. 447. t. 137. Campulosus Nees. In Brasilia. $\odot$.

5. C. planifolium Kunth; culmis vaginis foliisque scabris; spica unica subspirali; spiculis 5-4-fioris; gluma superiore 2-nervia nervo uno glanduloso-tuberculata; paleis inferioribus pilosis. Campulosus Presl in Rel. Haenk. 1. p. 287. In Mexico. $\odot$. 
371. ChONDROSIUM Desv. (1813).

1. C. humile Beauv. culmo geniculato scabriusculo; fol. glabris; spica falcata; glumis coloratis dorso ciliato-scabris; palea inferiore dorso basique pilosa. H. et K. Nov. Gell. 1. p. 175. t. 56. Actinochloa IVilld. Hb. Atheropogon Spr. In Quito et Nova Granata. 4.

2. C. tenne Beaur. culmo scabriusculo; fol. interne subpubescentibus; spica falcata; rachi glabra; glumis dorso hispido scabris; palea inferiore dor'so margineque piloso-ciliata. H. et K. Nov. Gen. 1. p. 176. t. 57. Actinochloa Willd. Hb. Atheropogon procumbens Jacq. Eclog. Gram. 2. t. 12. In Mexico et ins. Philippinis.

3. C. gracile $\boldsymbol{H}$. et $\boldsymbol{K}$. culmo glabro; fol. margine scabris; spica recta; glumis coloratis; superiore dorso glandulosa; glandulis piliferis; palea inferiore basi pilosa. H. et $\mathbf{K}$. Nov. Gen. 1. p. 176. t. 58. Actinochloa IVilld. Hb. Atheropogon Spr. In Mexico. 4.

4. C. hirtum H. et $\boldsymbol{H}_{\text {. }}$ culmo geniculato adscendente foliisque pilosis; spica falcata; glumis coloratis superiore bifariam glandulosa; glaudulis piliferis; palea inferiore pilosa. Н. et K. Nov. Gen. 1. p. 176. t. 59. Atheropogon Spr. Bouteloua Lag. Actinochloa hirsuta R. et $\mathbf{S}$. In Mexico. $\odot$.

5. C. Humboldtianum Kunth; culmo erecto; spicis racemosis; racemo subsecundo; glumis inaequalibus; palea inferiore subpubescente; aristis abortientilus; flore sterili triaristato. Dinebra chondrosioides $\mathbf{H}$. et $\mathbf{K}$. Nov. Gen. 1. p.173. t. 53. Atheropogon chondrosioides. R. et S. Spartina Link Jalırb. Bontelona ovata Lag. In Mexico. 4.

6. C. simplex Kunth; culmo erectiusculo monostachyo ; spica terminali oblonga glalerrima. Bouteloua Lag. Elench. G. Actinochloa R. et S. In Peruvia et ins. Philippinis. $\odot$.

\%. C. prostratum Iunth; culmo ramosissimo prostrato; ramis monostachyis; spicis linearibus glaberrimis. Bouteloua Lag. Elench. G. Actinochloa R. et S. In Mexico. $\odot$.

8. C. scorpioides Kunth; culmo erecto filiformi monostachyo; spica lineari-oblonga spiraliter revoluta. Bouteloua Lagasc. Eleuch. S. Athe- ropogon Spreng. Actinochloa $\mathbf{K}$. et $\mathbf{S}$. In Mexico. 4.

\section{OPIZIA Presl (1830).}

1. O. stolonifera Prest in Rel. Haenk. 1. $p$. 29.3. t. 41. f. 1. In Acapulco. $\odot$. Gramen annum repens. Folia linearia plana. Vaginae compressae. Spiculae $12-16$, socundae.

\section{EUTRIANIA Beauv. (1812). (Heterostega Desi.)}

1. E. curtipendula Trin. culmo erecto; spicis racemosis suhreflexis secundis; glumis inaequalihus; palea inferiore glabra; flore sterili 1-aristato. Chloris curtipendula. Michx. FI. 1. p. 59. Jacq. Eclog. Gram. t. 7. Bouleloua Lag. Dinebra DC. Cat. Cynosurus secundus Pursli. Dineba 13. et S. In America boreuli, Mexico, Peruvia et ins. Philippinis. 4.

2. E. aristidoides Kunth; culmo erecto; spicis racemosis; racemo disticho; glumis inaequalibus; palea inferiore glabra; flore superiore sterili triaristato. Dinebra H. et K. Nov. Geu. 1. p. 172. t. 51. Atheropogon $\mathbf{R}$. et s. In Mexico. 4.

3. E. repens Kunth; culmo repente; spicis racemosis; racemo sul)secundo; glumis inaequalibus; palea inferiore glabra; flore masculo triaristato. Dinelora H. et K. Nov. Gen. 1. p. 172. t. 52. Atheropogon $h$. el s. Bouteloua Lag. Elench. S. In Actmulco Mexicanorum. 4.

t. E. juncifolia Kunth; culmo assurgente geniculato; fol. linearibus strictis; flosculis sulisecundis alternis appressis approximatis; rachi compressa subflexuosa ; altera arista dorsali, altera terminali. Heterastya Hamilt. prodr. p. 9. H. et K. Nov. Gen. t. 54. Aristida americana. sw. obs. t. 2. f. 2. Heterostega americana Desv. Dineba Beauv. Bouteloua litigiosa Lag. Atheropogon Spr. Eutriania. Triu. In Antillis et Cuba. 4.

5. E. multiseta Nees; culmis caespitosis hasi repentibus geniculaloadscendentibus; fol. margine scalsris supra glaucis; spicis secuudis $4-5$ - 
floris; flore inferiore hermaphrodito; reliquis in fasciculum longissime 911-aristatum congestis; glumis mucronato-aristatis. Pappophorum elltrianoides. Irin. ined. In Nonterideo. 24.

6. E. Lagascae Irunth; culmo adscendente sub-3-staclyyo; spicis lanceolatis subpilosis; fol. convolutofiliformibus. Bouteloua juncifolia. Lag. Elenoh. 5. Actinochloa juncifolia $\mathbf{k}$. ct S. In Mexico. 4.

\%. E. bavbata fiunth; glumis aristatis laevibus; flosculi hermaphroditi valvula exteriore inferne ciliato-harbata. Bouteloua Lag. Elench. 5. Actinochloa $\mathbf{R}$. et $\mathrm{S}$. In Mexico et ins. Philippinis. $\odot$.

8. E. oligostachya Frunth; spicis 2-3 subterminalibus multifloris cajyce corollaque pilosis; valvula exteriore corollae distincte 3 -aristata; aristis lateralihus hrevioribus e dorso valvulae; valvula neutrus triaristata. Atheropogon oligostachys Nutt. Gen. 1. p. 78. Ad Missouri.

374. POLYODON H. et K. (1815).

1. P. distichum I. et K. Nov. Gen. 1. p. 175. $t$. 5.5. Atheropogon distichus Spr. In Quito. 24. Culmus ranısus. Folia linearia striata plana; rachi spicata apice bifida. spicae racemoso-distichae.

\section{PENTARRHAPHIS H. et $\mathrm{K}$. (1815).}

1. P. scabra H. et K. Nov. Gen. 1. p. 178. t. 60. Atheropogon Pentarraphis Spr. In Mexico. 24. Culmus erectus ramosns. Folia linearia plaua.

\section{POLYSCIISTIS Presl (1830).}

1. P. paupercula Prest in Rel. Haenk. 1. p. 291. t. 41. 12. In ins. Luzonia. ๑. Culmi caespitosi erecti teretes alternatim canaliculati teneri. Folia linearia acuta. Vaginae subinflatae. Ligula brevissima truncata. Kachis angustissima.

\section{3\%\%. TRIATHERA Desi: (1810).}

1. T. americana Desv. in Bulletin de la Soc. Phil. dec. 1810. F. juncea Beauv. Agrost. t. 9. f. 4. Atheropogon domingensis Spr. In Hispeniolu. $\odot$. Gramen ramosissimum. Folia involuto-setacea rigida; vaginarum ore barbato.

\section{TRIAENA II. et K. (1815).}

1. T. racemosa H. et K. Nov. Gen. 1. $p .179 . t$. 61. Atheropogon Triaena Spr. In Mexico. $\odot$. Culmus ramosus. Folia linearia plana. spicae terminales solitariae.

\section{GYMNOPOGON Beauv. (1812).}

1. G. racemosus Beauv. Agrost. p. 41. $t$. 9. f. 3 . Glumis acuminatis; paleae inferioris nudiusculae seta hac palea subtriplo, rudimento pseudoflosculoso duplo longiore; culmo adscendente; fol. ovato - lanceolatis subtus sulcato-striatis. G. scoparius Nees in Mart. Bras. 2. p. 429. adn. Andropogon ambiguus Miclix. Allogatherus amhiguus Elliot. Anthopogon lepturoides Nutt. In Carolina, Georgice et Nova Caesarea.

2. G. laevis Nees; culmis ramosis erectiusculis; fol. lanceolatis nervoso-striatis margine scabris; glumis acutato-subulatis; arista floris fertilis paleam dorso pilosiusculam longitudine triplo florem sterilem adjecta arista duplo superante. Kunth Gram. 2. p. 451. t. 139. In Montevideo. 24.

3. G. fastigiatus Nees; glumis subulatis; seta paleae inferioris hirtae hac palea quadruplo longiore; rudimento setiformi nudo; flosculo breviore; culmo simplici; fol. Ianceolatis scabriusculis. Nees in Mart. Bras. 2. p. 430. In Brasilia.

4. G. mollis Nees; glumis lanceolatis; flosculo fertili rudimentoque basi et apice barbatis utriusque setis inter se flosculoque subaequalibus; culmo erecto ramoso; fol. linearibus utrinque pubescentibus. Nees 1. c. I/ Brasilia. $\odot$. 
3S0. TRIPLASIS Beatv. (1812).

1. T. americana Beauv. Agrost. p. 81. t. 16. f: 10. Poir. Enc. suppl. t. 912. In America boreali. spica composita; ramis alternis apice floriferis.

\section{S1. PLEURAPIIIS Torrey. (1S21).}

1. P. Jamesii Torrey in Ann. of the Lyc; of New-York 1. p. 148. $t$. 10. Inymenothecium quinquesetum Lag.? In America boreali. Gramen gracile gralırum. Radix repens. Folia angustissima scabra.

\section{S2. CORYNERHORUS BEAUV. (1812).}

1. C. canescens Becurv. Agr.t.18. f. 2. panicula patente contracta; flosculis calyce minoribus; arista apice clavata calyce minore; fol. setaceis. Aira canescens Schrad. Germ. 1. p. 263. Fl. Dan. 1023. Engl. bot. 1190. Avena Wel). Weingaer(neria Bernh. In Europa.

2. C. articulatus Beauv. paniculata; calyce flosculo Iongiore acuto nitido; arista medio nodosa e basi glumae prodeunte. Aira Desf. Atl. 1. p. 70. t. 13. Aira canescens $\beta$. Trin. C. aetnensis Schult. In Europa australi et Barbaria. 24.

\section{DUPONTIA R. Br. (1810).}

1. D. Fischeri R. Br. in Parrys Voy. p. 191. Melica Spr. Cur. post. In Melville Island. Gramen glabrum, erectum. Folia linearia, plana.

\section{AIRA L. (1735).}

\section{a. Species genuinae.}

1. A. praecox $L$. panicula subspicata; flosculis calycem subaequantibus; arista geniculata calycem excedente; fol. setaceis. Schrad. Germ. 1. p. 262. Host. Gram. 4. p. 37. Fl. Dan. 383. Engl. bot. 1296. Avena praecox Beauv. Trisetum Dumort, In Europa et Virginia. $\odot$.
2. A. caryophyllea L. panicula divaricato-patente; flosculis calyce minoribus; arista geniculara calycem excedente; fol. setaceis. Schrad. Germ. 1. p. 261. Host. Gram. 2. t. 41. EngI. Bot. 812. Fl. Dan. 382. A. inflexa et A. Leersii Lois. Avena Web. var. a) A. divaricata Pourr. Act. Tol. 3. p. 30\% A. canescens Host. Gram. 4. t. 36. In Europa, Tauria, Chili, ins. Haclovinnis et Prom. b. spei. $\odot$.

3. A. elegans Willd. ined. fol. setaceis; flore utroque sessili, altero superiore aristato, altero inferiore mutico; gIuma exteriore 2-mucronata. A. capillaris Host. Gram. 4. p. 20. t. 35 . Avena capillaris Mert. et Koch. Aira caryophyllea $\gamma$ ) Triu. In Helvetia, Tyroli et Dalmatia. $\odot$.

4. A. mulchella Willd. ined. panicula divaricata; ramis trichotomis; flosculis subtribus calyce thajoribus; arista geniculata calycem excedente; fol. setaceis; ligula oblonga obtusa. Willd. en. 1. p. 101. Avena Beauv. Airopsis Tenore. Aira Tenorei Guss. In Hispania, Sicilia, Calabria et Taus ria.

5. A. danthonoides Trin. gInmis perianthia inaequaliter denticulata dorso aristata excedentibus; arista geniculata glumis longiore; fol. angustissimis. Trin. in Act. Petrop. 1830. 1. p. 57. In Americis.

6. A. Lagascae Kunth; panicula capillari laxa trichotomo-ramosa subfastigiata; flosculis muticis glumis carinatis brevioribus. Aira Lag. 1. c. Nilium gallecicum n, et S. In Hisprnia et Cor'sica. $\odot$.

\%. A. involucrata Cav. spiculis muticis; paniculae ramis verticillatis; verticillo infimo sterili. Airopsis involucrata. R. et S. syst. 2. p. 578. Periballia hispanica Trin. In Hispania. $\odot$.

8. A. montance $\boldsymbol{L}$. fol. setaceis; panicula angustata; flosculis basi pilosis aristatis; arista tortili longiore. Linm. Suec. 68. et 72. A. bottnica WallIenb. t. 4. Deschampsia Trin。 In Suecia et Lapponia. 4.

9. A. flexuosa $L$. panicula patente; flosculis calycem vix superantibus; arista geniculata calycem excedente; fol. setaceis. Schrad. Germ. 1. p. 152. Host. 2. t. 43. Fl. Dan. 15\%. Avena Mert. et Koch. Aira montana Koel. Leers, to 5, f, 2. A. scabroso s seta- 
cea. Knapp. t. 32. A. uliginosa. Rchb. Cent. 2. t. 150. In Europa, Caucaso, America boreali et insulis Maclovianis. 24.

10. A. alpina $I$. fol. subulatis; panicula densa erectiuscula; pedunculis laevilus; flosculis calycem aequantibus; arista subterminali hrevi subinclusa. Wahlenb. Lapp. p. 34. t. 3. Deschampsia alpina et laevigata $\mathbf{R}$. et s. A. laevigata Engl. Bot. 2102. In Lapponia, Groenlandia et Scotia. 4.

11. A. atropurpurea Wahlenb. fol. planis; panicula divaricata paupera; fosculis calyce multum brevioribus apice pilosis. Wahlenb. Lapp. p. 37. A. alpina Vahl in Fl. Dan. 961. Avena atropurpurea Link. In Lapponia.

\section{b. Species dubiac.}

12. A. tenuissima Spr. paniculae pyramidatae ramosissimae ramis flexuosis capillaribus; calycibus carina scabris, flosculis demum breviorihus rudimento tertii; fol. convolutis elongatis vaginisque glabris. Spr. syst. 1. p. 276. Panicun tenuissimum Willd. Hb. In America meridionali.

13. A. filiformis Koeniy; glabra; erecta ; pedalis ; fol. ensiformibus; paniculis ohlongis compositis e racemis simplicibus linearibus secundis. Hoxb. ind. 1. p. 328. In India orientali.

14. A. clinensis Retz; fol. setaceis; panicula erecta ; flosculis aristatis villosis. Retz obs. 3. p. 10. In China.

15. A. setacea Retz; fol. setaceis; panicula diffusa; flosculis basi pilosis, inferiore unutico, superiore arista brevi. Retz ohs. 3. p. 10. In Europa.

16. A. glabra Brot. fol. planis; panicula laxa patente; pedunculis glabris; flosculis infra apicem aristatis; arista reflexa. Brot. Fl. Lus. p. 91. Trisetum glabratum Schult. In Lasitania. $\odot$.

17. A. lendigera Lag. panicula trichotomo-ramosa divaricata; corollis infra apicem aristatis; arista longiore; fol. lineari-setaceis laevibus. Lag. Elencl. 3. In Hispania. $\odot$.

18. A. subtriflora Lag. panicula erecta confertiuscula; calycibus plerumque 3-floris; corollis basi pilosis infra medium aristatis; arista recta foribus subaequali; fol, subulatis stri- ctis. Lagasc. Elench. 3. In Hispania. 2.

19. A. oryzetorum Spr. flosculis calycem excedentihus brevissime aristatis glabris; panicula erecta ; ligula subnulla. Spr. Pug. 2. p. 18. A. palustris Pollin. Festuca Pollin. Hort. Veron. plant. nov. t. 1. f. 2. Prope V'eronam. 4.

20. A. nitida Spr. mutica; panicula contracta cylindrica ; glumis truncatis; flosculo altero pedicellato; valvulis hyalinis. Spr. Mant. 1. p. 32. In Pensylvania.

21. A. pallescens Kit. panicula laxa contracta; spiculis subtrifloris cunciforni-ohovatis; glumis ohtusis; inferiore calycem aequante foliisque glahris; culnis erectis. Kit. in R. et s. syst. 2. p. 685. In Hungaria.

22. A. tenera Kit. panicula patente; fosculis laevibus calyce longioribus; fol. planis; culmis erectis; radice aunua. Schult. austr. 1. p. 199. In Slavonia. $\odot$.

23. A. versicolor R. et $\mathbf{S}$. fol. setaceis; culmis vaginatis ; panicula subcontracta; peduncutis capitlaribus flexuoso-tortis. 12. et S. syst. 2. p. 679. In Portu Eymont.

24. A. regilopsoides Walt. mulica; spicis secundis; corollae valvula ovata acuminata; altera columnari obtusa. Walt. Car. p. 78. In Carolina.

25. A. brerifolia Pursh; panicula subverticillata; ramis simpliciusculis alteruifloris; florihus muticis calycem aequantihus; glnmis omnibus lanceolatis acutis; fol. glahris; culmo stricto glabro nudiusculo. Pursh. F'. 1. p. 76. In America septentrionali. 4. 26. A. capillacea Lam. panicula capillacea effusa; flosculis muticis calyce longioribus; altero pedicellato; glumis acutis cariua asperis; fol. angustis glabris brevilus; culmo erecto. Pursh FI. 1. p. 76. In America boreali. 4.

27. A. Aurinscula Poir. caespitosa; culmo rigido humili; fol. brevibus subulato-convolutis; panicula patente; floribus singulis aristatis. Poir. Enc. suppl. 2. p. 76. Patria ignota. 28. A. multicaulis Dumort. dense caespitosa ; culmis simplicibus; panicula contracta; flosculis gluma hrevioribus, superiore stipitato. Dumort. 
Agrost. tent. p. 121. t. 7. f. 28. Proge Trajectum al Rhenum.

29. A. festucoides Vill. fol. filiformilus teneris; panicula erecta; floribus coloratis ultra medium aristatis. Vill. Delph. 2. p. 86. In Delphinatu. 24.

30. A. argentea Lou'e; caespitosa; paniculae coarctatae apice nutantis ramis verticillatis scabris; flosculis basi pilosis; arista subdorsali, recta flosculo duplo excedente; fol. conduplicatis filiformilus compressis. Lowe Prim. Mad. et Port. Sanct. in Trans. Cambr. Plil. Soc. 4. 1. p. 9. In sylvis Maderae.

31. A. triaristataclarke; panicnla spicaeformi oblonga; glumis calycinis sulcatis villosis; valva corollae exteriore triaristata; vaginis foliorum amplissimis. schult. mant. 2. p. 3!3. In Palaestina.

32. A. sabulorum Labill. flosculis muticis acuminatis; panicula erecta; fol. convolutis. Labill. Nov. Caled. 16. t. 21. In Nova Caledonia.

\section{AIROPSIS Dest. (1813).}

a. Species genuinae.

1. A. globosa Desv. culmo erecto filiformi; fol. involutis subulatis; panicula stricta; glumis calycinis glabris, hemisphaericis, corollinis margine ciliatis. Desv. in Journ. de Bot. 1. p. 2CD. A. globosa Thore in Journ. de Bot. t. 7. f. 3. 4. Milium tenellum Cav. ic. t. 274. f. 1. Paspalum globosum Rasp. In Gallia et Hispania.

\section{b. Species anomalae.}

2. A. agrostoidea DC. spicis bifloris subtruncatis; panicula laxa; perigoniis tenuibus membranaceis glabris gluma minoribus; culmo basi geniculato aut radicante. Poa agrostoidea DC. syn. p. 132. Ejusd. ic. t. 1. Aira minuta Lois. Airopsis Candollii Desv. Catal)rosa agrostoidea Presl sic. In Gallia, Sicilia et Hispania. 4.

\section{c. Species dubiae.}

3. A. aurea Nees; panicula stricta; ramis geminis subtrichotomis basi callosis; spiculis ovatis; flosculorum valvula inferiore nervosa sericeo-strigulosa; vaginis margine foliisque supra lanatis. Nees in Limnaea 7. p. 317. Aira steud. In Prom. b. spei. 4.

4. A. Steudelii Nees; paniculae brevis ramis trichotomis paucifloris axillis barbulatis; spiculis oblongis; flosculorum valvula iuferiore integra margine fimbriata; fol. convoluto-setaceis glabris. Nees in Linnaea 7. p. 318. Eriachne capensis steud. In Prom. b. spei. 4.

\section{TRISETARIA Forsk.}

1. T. linearis Forsk. culmo stricto; fol. inferioribus subvillosis; panicula lanceolata spiciformi; spiculis 1-2-floris; pedicello flosculi abortivi incluso; setis aristisve adpressis erectis. Delile Aeg. bot. p. 29. t. 12. f. 3. Trisetum arenarium Labill. Syr. t. 7. Trisetum Trisetaria Forsk. In Syric et Aegypto. $\odot$.

\section{8\%. LAGURUS L. (1737).}

1. L. ovatus Linn. sp. p. 119. Sclureb. Gram. t. 19. f. 3. Host. 2. t. 46. Sibth. Graec. t. 90. Engl. Bot. 133-. In Europa australi et Asice occidentali. $\odot$.

\section{8s. TRISETUM Pers. (1805).}

1. T. ovatum Pers. spica terminali ovota densa; spiculis compressis 3 -5-floris; fol. villosis brevihus. Bromus ovatus Cav. ic. 6. p. 67. t. 591. f. 2. Trichaeta Beauv. Avena Gmel. In Hispania et Lusitania.

2. T. subspicatum Beauv. panicula subspicata; arista reflexa calycem excedente. Aira subspicata Schrad. Germ. 1. p. 264. Host. Gram. 2. t. 45. Wulf. in Jacq. Coll. 3. t. 19. f. 3. Fl. Dan. 228. Trisetum airoides $R$. et S. Koeleria Mart. Rchb. In Europa, Asia et America maxime arctica. 4.

3. T. phleoides Kunth; totum mollissime pubescens; panicula racemoso-spicata; spiculis bifloris nitidis; aristis geniculatis glumis longioribus; calycibus dorso ciliatis subaristatis; 
glumis laevihus apice bifidis. Avena phleoides Urville Flore des Malouin. in Dup. it. p. 29. In ins. Maclovianis. 4.

4. T. molle Iíunth; universe minutim molliterque puberulum; racemo confertiuscule appresso-spicato; glumis bifloris; floribus imberbibus aristatis; arista horum longitudine non contorta. Avena mollis Michx. am. 1. p. 72. In Canala.

5. T. toluccense Runth; culmo superne pubescente; fol. scabris; panicula coarctata cylindracea; glumis spiculam bifloram subaequantibus; paleis inaequalibus, inferiore majore bifido-dentata; dentibus subaristatis ; arista dorsali reflexa. Kuntl Gram. 1. p. 101. et 297. t. 60. Avena H. et K. In Mexico. 4.

6. 'T. elongatum Kunth; culmo glaberrimo; fol. margine scabris; panicula coarctata cylindracea; glumis spicula biffora brevioribus; paleis inaequalibus bifido-dentatis; dentibus subaristatis; arista dorsali recta. Kunth Gram. 1. p. 101. Avena H. et K. In Peruvia et Mexico. 4.

\%. T. viride Kunth; fol. interne pilosiusculis margine scabris; panicula subverticillata patula subsecunda; glumis spiculam trifloram subaequantibus ; paleis inaequalibus, inferiore majore 4-fido-dentata; dentibus subulatis. Kunth Gram. 1. p. 101. Avena H. et K. In Mexico. $\odot$.

8. T. parviflorum Pers. fol. pubescentibus; panicula patula; spiculis 2-3-floris; arista brevi setiformi infra glumae apicem emergente. Avena Desf. Atl. 1. p. 103. t. 32. Festuca segetum Savi Pis. t. 1. f. 3. Koeleria parviflora Lk. Trisetum micranthium 12. et S. In Italia et Barbaria. $\odot$.

9. $\boldsymbol{T}$. condensatum Presl; panicnla patula densiuscnla brevi; glumis bifloris, superiore paulo majore; callo nudo; rachis pilis brevissinis ; perianthiis biaciculatis supra medium aristatis; ovario nudo. Trin. in Act. Petrop. 1830. 1. p. 63. Avena Link. Trisetum neglectum Presl. Avena sicula spr. In Siciliu et Neapoli. $\odot$.

10. 'T. neglectum R.et $\mathrm{s}$. panicula conferta subsecunda; spiculis 4-floris; corollae valvula exteriore bifida mucronata; arista dorsali recurvata; radice fibrosa annua. Avena neglecta
Willd. in Ber. Mag. 1803. p. 289. Savi Pis. 1. t. 1. f. 4. var. $\beta$ ? pisanum Pers. A. panicea Lam. Hostraria lacvis Trin. Fund. In Italia, Hispania, Lasitania et Gallia meridionali. $\odot$.

11. T. Alopecurus R. et S. panicula densa post florescentiam contracla subspicata; calycihus 6-floris; flosculis apice 2-aristatis; dorso arista geniculatia longiore; receptaculis setosis. Avena Alopecurus Roth Cat. 3. p. 20. Patria igmota. $\odot$.

12. 'T. Loeflingianum Beauv. panicula contracta subthyrsiformi brevi; glumis hifloris, superiore quartam partem longiore; calli racheosque pilis subohsoletis; perianthiis pilosulis longe bisetis nudis dorso aristatis; ovario nudo. Trin. in Act. Petrop. 1830. 1. p. 63. T. hispanicum Pers. Avena Loefflingiana Lim. Willd. Berl. Mag. 2. t. 8. f. 3. In Hispania. $\odot$.

13. 'T. Cavanillesii Trin. panicula contracta subthyrsiformi; glumis bifloris, suneriore paulo longiore; pilis calli brevilus, racheos praelongis; perianthiis longe bisetis paulo supra medium aristatis; ovario nudo. Trin. in Act. Petrop. 1830. 1. p. 63. Avena Loefflingiana. Cav. ic. t. 45. f. 1. Arundo pygntaea Spr. In Helvetic et Italia.

11. T. pumilum Kunth; floribus paniculato-spicatis; spiculis sub-4-floris; ylumis dorso ciliatis; arista setiformi longitudine glumae. Avena Desf. 1. p. 103. In Barbaria. $\odot$.

15. 'T. deyeurioides liunth; fol. scabris; panicula verticillata patula; spiculis 3-floris; flore superiore sterili plumoso; glumis spicula paulo brevioribus; palea inferiore duplo longiore apice 2-dentata. Avena $H_{\text {. et }} \mathbf{K}$. Nov. Gell. 1. p. 147. t. 687. In Mexico. 4.

16. T. rigidum $R$. et $S$. panicula aequali; spiculis subbifloris; flosculis dorso aristatis calycem subaequantibus; receptaculis pilosis; fol distichis; ligula exserta amplexicauli; radice repente. Avena Bieb. Fl. 1. p. 77. A. Irevifolia spr. T. Willuelmsii Ledeb. Arundo Wilhelmsii Ledeb. in Act. Petrop. 593. c. ic. In Caucaso. 4.

1\%. T. nitidnm Pers. panicula spicata; glumis memhranaceis nitidis pubescentibus triaristatis. Avena nitida Desf. Atl. 1. p. 102. t. 31. f. 2. In Barbaria. 
18. T. argenteum $R$. et S. panicula aequali; spiculis sub-3-floris ; gluma corollina exteriore majore 1-nervia; fol. distichis glabris; ore vaginarum piloso; radice repente. Avena Willd. en. p. 125. A. distichophylla Host. Gram. 2. t. 53. A. sesquitertia Willd. sp. T. distichophyllum $\beta$. Trin. In Carniolia, Carinthia, 'Tyroli et Helvetia. 4.

19. T. distichophylum Beauv. panicula aequali; spiculis subtrifloris; flosculis calycem acquautibus; valvulis corollae aequalibus, exteriore 3-nervia; fol. distichis subpuhescentibus; radice repente. Avena Willd. Sp. 1. 452. Vill. Delph. t. 4. f. 4. A. brevifolia Host. Gram. 3. t. 40. Trisetum brevifolium 18. et $\mathbf{S}$. In Tyroli, Vallesia et Delphinatu. 4.

20. T. flarescens Beauv. panicula aequali; spiculis suhtrifloris; flosculis calycem excedentibus; gluma corollina exteriore 5-nervia; radice subrepente. Avena schrad. Germ. 1. p.387. Host. Gram. 3. t. 38. schreh. Gram. t. 9. Engl. hot. 952. Fl. Dan. 1507. T. pratense Pers. In Iberia, Cancaso, Nibiria, Camtschatca et America boreali. 4.

21. T. tenue $\boldsymbol{R}$. et $\mathbf{S}$. panicula aequali ; spiculis subtrifloris ; flosculis calyccm excedentibus; inferiore apice 1-aristato; reliquis apice aristis 2 brevihus et 1 dorsali geniculata instructis; radice fibrosa annua. Avena tenuis schrad. Germ. 1. p. 375. Host. Gram. 2. t. 55. A. dubia Leers Herb. t. 9. f. 3. A. triaristata Vill. Delph. t. 4. T. striatum Pers. In Europa et sibiria. $\odot$.

22. T. Berteroamum linnth; culmis erectis simplicibus vaginisqte glahris; fol. angustissimis; ligula elongata; floribus 1-andris, terminali ad pedicellum sericeum redacto; glumis flores basi sericeo-pilosos superantibus. Kunth Gram. 2. p. 45\%, t. 142. In Chili.

\section{S9. AVENA Linn. (1737).}

1. A. alpestris Host. Gram. 3. $t$. 39. panicula aequali; spiculis 4-5floris; flosculis calycem excedentilus; gluma corolliua exteriore 5-nervia; ra- dice fibrosa perenni. Schrad. Germ 1. p. 379. A. sesquilertia Host. syn. Trisetum alpestre Beauv. var. $\beta$. purpurascens DC. In Europa medic 4.

2. A. setacen Vill. Delph. t. 5. fol. setaceis ; vaginis lanuginosis; panicula purpurascente; spiculis majusculis; glumis 2-3-floris; aristis nigris recurvis. Danthonia setaceaBeauv. In Delphinatu.

3. A. flexuosu Schrank; pinicula coarctata; ramis canleque intemedio undulatis; fol. setaceis. Schrnk in Deukschr. d. Regeusb. Geselbch. 2. p. 7. In Labrador.

4. A. versicolor Vill. Delpls $t .4$. f. 5. racemo simplici; spiculis $\mathbf{0}$-floris; flosculis calycem excedentibus; radice fihrosa perenni. schrad. Gem. 1. p. 384. A. schenchzeri Host. Gram. 2. t. 52. A. glauca $\mathrm{h}$, et S. In Europa 4.

5. A. pubescens $\boldsymbol{L}$. panicula aequali; spiculis subtrifloris; flosculis calycem excedentibus; fol. pubescentibus; radice subrepente. Schrad. Germ. 1. p. 140. Engl. bot. 1610. A. sesquitertia Host. Gram. 2. t. 50. Fl. Dan. 1203. Trisetum R. et S. In Europa, 'I'uria et Siberia. 4.

6. A. curpathica Host; panicula patente; spiculis sub-4-floris; foliorum vaginis compressis pilosis; radice repente. Host. Gram. 4. t. 31. 'Trisctum carpathicum et fuscum $\mathbf{R}$. et $\mathbf{S}$. In montibus Carpatli. 4.

\%. A. amethystina DC! panicula erecta angusta; glumis bifloris; nosculo inferiore 1-aristato, superiore interilum 2-aristato. DC. syu. 1. 1. 126. In Gallia. $\odot$.

8. A, caryophyllea Sm. spicata; calycibus 8 -floris; receptaculis nudis; fol. planis glabris. Sm. prodr. 1. p. 67. In ins. Cimoli.

9. A. pratensis L. racemo simplici; spiculis 5-floris; fol. scabris, fasciculorum augustissimis complicatis. schrad. Germ. 1. p. 385. Fi. Dall. 1038. Host. Gram. 2. t. 51. Engl. Bot. 1204. A. pratensis $\beta$. Ledeb. aIt. In Europa et Sibivia. 24.

10. A. planiculmis Schral. panicula aequali; spiculis suh-5-floris; culmis vaginisque conpressis; radice repente. Scluad. Germ. 1. p. 381. t. 6. f. 2. A. Iatifolia Host. Gram. 4. t. 32. Inclicotrichum Bess. In Sile- 
sia, Moravia, Pannonia et Transylvania. 4.

11. A. alpina $\mathbf{S m}$. panicula erecta simplici; receptaculis apice barbatis; fol. serrulatis nudis; vaginis scabris. Sm. in Linn. Trans. 10. p. 335. Trisetum R. et S. A. planiculmis Engl. Bot. 2111. In Scotia. 4.

12. A. sempervirens Vill. Delph. t. 5. punicula aequali; spiculis sub4-floris; flosculis calycem excedentibus bisique pilosis; radice fibrosa. Schrad Germ. 1. p. 376. Host. 3. t. 41. A sedensis DC. A. fallax R. et S. In Delphinatu, Pyrenaeis, Austric et Sibiria. 4.

13. A. brevis Roth; panicula secunda: spiculis subbifloris; flosculis apice :-dentatis; arista dorsali geniculata radice fibrosa amuua. schrad. Germ. 1. p. 369. Host. Gram. 3. t. 42. In Germania, Austria et Pannonia. $\odot$.

14. A. alba Vahl; paniculata; calycibus bifloris corollis pilosis, altera aristata. Vahl Symb. 2. p. 24. In Africa boreali et Gallia meridionali. 4 .

15. A. sutiva L. panicula aequali; spiculis 2-floris; flosculis calyce minoribus basi nudis, altero aristato; radice fibrosa annua. Willd. sp. 1. p. 446. var. a. A. podolica $\beta$. A. anglica, A. cinerea, A. trisperma et A. flava. In Europa culta. $\odot$.

16. A. orientalis Schreb. panicula secunda contracta; spiculis hifloris calyce minoribus; flosculo altero mutico. Schrad. Germ. 1. p. 371. Host. Gram. 3. t. 44. In Europa culta. $\odot$.

17. A. strigosa Schreb. panicula secunda; spiculis sub-3-floris; arista dorsali longissima geniculata, reliquis 2 terminalibus brevibus rectis. Schrad. 1. c, p. 368. Host. Gram. 2. t. 56. Engl. bot. 1266. Danthonia Beauv. A. nervasa Lam, In Europa. $\odot$.

13. A. nuda $L$. panicula aequali; spiculis subtrifloris calycem excedentibus; flosculis basi nudis ; radice fibrosa aunua, schrad. 1. c. Host. Gram. 3. t. 43. In Europa culta. $\odot$.

19. A, hirtula Lag. panicula subsecunda; glumis 2-floris; calycibus hirsutis 3-aristalis; aristis 2 termiualibus setaceis, Lag. Elench, 4. In Hisprmia. ๑.

20. A. filifolia Lay. panicula attenuata; calycilous 3 -floris; flosculis aristatis hasique pilosis; fol. convolntis filiformibus pungentibus. Lag. Elench. 4. In Hispania.

21. A. fature L. panicula aequali; spiculis sub-3-floris; flosculis calyce minorihus basique pilosis. Schrad. 1. c. Host. Granl. 2. t. 58. Fl. Dan. 1639. Engl. bot. 2221. Inter segetes Europae et Caucasi. $\odot$.

22. A. lirsuta Roth; panicula patula; flosculis linearihus apice 2-aristatis, infra medium utrinque pilosissimis. Hoth Cat. 3. p. 19. A. barbata Brot. In Italia, Hispania, Lusitania, Caucaso, Tauria et Montevideo. $\odot$.

23. A. sterilis $\boldsymbol{L}$. panicula secunda; spiculis sub-5-floris; flosculis inferioribus aristatis et pilosis, superioribus muticis glabrisque. Schrad. 1. c. Host. Gram. 2. t. 57. Jacq. ic. t. 23. Inter segetes Europae australis et ins. Plitippinis. $\odot$.

21. A. pilosa Bieb. paniculata; spiculis 3-floris; rachi pilosa; flosculorum valvula exteriore nuda, dorso aristata, apice 2-aristata; fol. pubescentibus. Bieb. cauc. p. 81. Trisetum R. et S. In Iberia. $\odot$.

25. A. leonina Steud. culmo simplici; fol. planis margine scabris; panicula simplicissima; spiculis 4-floris; floribus remotis basi barbatis. Kunth Gram. 2. p. 251. t. 175. Danthonia Steud. In Prom. b. spei.

26. A. fragilis $\boldsymbol{L}$. culmo ramoso, vaginis foliisque pubescentibus; spiculis solitariis 4-7-floris glabris. Host. Gram. 2. t. 54. sibth. Graec. t. 88. Gaudinia Beauv. In Europa australi. $\odot$.

2\%. A. geminiflora Kunth; ramosissima; molliter pubesceus; spiculis geminis breviter aristatis. Kunth Gram. p. 103. t. 61. A. coarctata Desf. Cat. Bromus coarctatus Hornem. Arthrostachya Link. Putria ignota. $\odot$.

28. A. striata Michx. panicula coarctata rariflora; gluma 5-flora; floribus eadem longioribus imberbibus; valvula exteriore striata, dorso lonvius aristata; semine nudo. Miclux. In America boreali.

29. A. pensylvanica L. panicula attenuata; calycibus bifloris; seminibus villosis; aristis calyce duplo longioribus, Linn. sp. 117. Trisetun Beauv. In America boreali. $\odot$. 
30. A. palustris Michx. panicula sublineari-contracta; callo piloso; perianthio inferiore brevirostrato, superiore infra apicem sqarroso-aristato. Trisetum palustre Trin. in Act. l'etrop. 1830. 1. p. 60. Aira pallens Mühlenb. In America boreali. 4.

31. A. nutkaensis Presl; culno glabro; vaginis foliisque scabris; panicula secunda laxa; spiculis 4-floris; palea inferiore 7-nervia scahra setaceo-bilaciniata. Presl in Rel. Haenk. 1. p. 254. In Sinu Nutka. 4.

32. A. Preslei Kunth; pilosa; panicula spicaeformi coarctata; spiculis bifloris; paleis inferioribus bifido-laciniatis; laciniis seta terminatis; arista dorsali fracta. A. pilosa. Presl 1. c. In Chili. 4.

33. A. trichopodia Presl; vaginis foliisque planis hirsutis; panicula patula erecta composita; spiculis bifloris; floris alterius pedicello piloso. Presl 1. c. In Mexico. 4.

31. A. macra Bieb. racemosa; calycibus subtrifloris; flosculis glabris, infimo mutico, caeteris aristatis. Bieb. Fl. 1. p. 77. Trisetum Beauv. In Iberia et Tauria meridionali.

3.5. A. Forsteri Kunth; panicula contracta patulave; glumis 2-3-floris; pilis calli brevissimis; perianthiis 2-dentato-acutis; ovario nudo. Trisetum antarcticum. Trin. in Act. Petrop. 1810. 1. p. 60. Toresia Beauv. Aira IVilld. Danthonia spr. In Nova Zeelandia.

36. A. lutea $L$. panicula patente; calycilus bifloris subulatis; corollis nudis 3-aristis; arista intermedia flexuosa. Linn. suppl. p. 112. Trisetum Pers. In Nartinica.

37. A. nervosa Beauv. panicula simplici rara nutante; spiculis sub-5floris; perianthii valvula exteriore 7nervia, glumis longiore apice lacinulata. 1R. Br. prodr. 1. p. 179. In Nova Hollandia. 4.

35. A, villosa Bertol. fol. vaginisque glabris; culmo villoso; panicula stricta; calycilus bifloris; flosculis basi stipiteque barbatis. Bertol. Enc. 6. n. 3. Trisetum Schult. mant. In montibus Amutii. 4.

39. A. montana Brot. panicula laxa; spiculis sub-4-floris; corollis acutis integerrimis. Brot. Lus. p. 109. In Lusitania.
40. A. scabriuscula Lag. panicula contracta angusta; spiculis 3-floris; flosculis glabris; fol. margine involuto-subulatis. Lag. Elench. 4. Circa urbem Legionem. $\odot$.

11. A. sunurrosa Schrank; pubescens; panicula spicata conferta; flosculis aristatis ; aristis undulatis patentibus. Schrank Denkschr. Hegensh.2. p. 7. In Labrador.

42. A. hirta Schrad. culmo glabro; fol. vaginisque pubescenti-hirtis; panicula contracta; floribus calycem excedentibus basi harbatis; corollima valvula exteriore 3-aristata. Schrad. ad. Fl. Cap. in Schult. mant. 2. p. 374. In Prom. b. spei.

43. A. aristidloides Thunl. panicula trichotoma; calycilus bifloris; corollis hifidis aristatis. Thunb. prodr. p. 22. Trisetum Pers. In Prom. b. spei.

1. A. elephantina Thunb. panicula composita ; calycibus 4-floris; corollis pilosis bifidis aristatis. Thunb. prodr. p. 23. In Prom. b. spei.

45. A. antarctica Thumb. panicula coarctata; calycihus; 4-floris; $\mathrm{CO}_{-}$ rollis bifidis aristatis. Thunb. prodr. p. 23. Trisetum Nees. In Prom. $b$. spei.

46. A. quinqueseta Steud. fol. planis vaginisque glabris; panicula stricta contracta; spiculis 2-floris; flosculorum valvulac exterioris dentilus bifidis, lacinula interlore setigera. Trisetum steudelii in Linnaea 7. p. 308. In Prom. b. spei. $\odot$ ?

1\%. A. stipaeformis Iinn. paniculata; calycilus bifloris; aristis semine duplo Iongioribus; culno ramoso. Limn. Chatetaria Beauv. In Prom. b. spei.

18. A. cermea Finnth; panicula laxa nutante; glumis $3 \longrightarrow t$-floris; pilis calli brevibus; perianthiis bisubulatis, supra mediuu longe aristatis; ovario harbato. Trisetum cernum Trin. in Act. Petrop. 1830. 1. p. 61. In ins. Sitka,

49. A. Pourretii Willd. panicula patula; calycilus corolla supra basin aristata longioribus; arista geniculata; culmo basi ramoso. Willd. in Berl. Mag. 2. p. 290. t. 8. f. 4. Trisetum 11. et S. Agrostis Spr. In Hispania. $\odot$.

50. A. muberula Guss. panicula spicifera coarctata; spiculis 3-4-floris; yluma majorc mutica; palea exteriore bifida; arista sctiformi recta; vaginis 
foliisque pubescentibus. In Italia et Sicilia. $\odot$.

51. A. longifolia Req. fol. angustis Involutisve supra asperis; ligula oblonga acuminata; spiculis 5-8-floris ; axi parce pilosa; glumellae valvula externa 7-nervia basi breviter pilosa. DC. Bot. Gall. 1. p. 574. In Gallia meridionali. 4.

52. A. Thorei DC. et Dub. fol. angustis involutis rigidis longissimis; vaginis nodisque pubescentibus; flosculo inferiore aristato, superiore mutico; axi piloso. DC. et Dul). Bot. Gall. 1. p. 514. A. Iongifolia Thore. Circa aquas Tarbellicas. 4.

53. A. praeusta Rchb. glabra; panicula erecta; spiculis 5 -floris, bracteolis longe exsertis apice testaceoscariosis; fol. serrulatis, supra scabris, pone ligulam ciliatis. Rchb. excurs. p. $140^{\mathrm{b}}$. In Carniolia. 4.

54. A. rigida Steud. panicula simplici laxa; calycibus bifloris; corolla pilosa; gluma exteriore triseta; culmo erecto folioso. Steud. in Flora 1829. 2. 1. 482. In Prom. b. spei.

5.5. A. andropogoides Steud. panicula composita laxa erecta; ramis racemosis; calycibus 3-4-floris; flosculis pilosis; gluna exteriore 3-seta; setis minimis; fol. apice couvolatosetaceis. Steud. in Flora 1829. 2. p. 486. In Prom. b. spei.

\section{ARRHENATHERUM BeaUv. (1812).}

1. A. avenaceum Beauv, fol. planis. Holcus avenacees Scop. Avena elatior L. Host, 2. t. 49. Schreb. Gram. 1. t. 1. Fl. Dan. 165. Schkuh. t. 17. var. nodosun. Avena bulbosa Willd. Holcus Schrad. In Europa. 4.

2. A. pallens Lk. fol. convolutis. Lk. Hort. 1. t. 124. Avena Brot. In Lusitania. 2 .

\section{TRISTACHYA Nees (1829).}

1. T. leiostachyc Nees; triandra; glumis laevibus glabris; fol. convolutis externe glabris interme margineque scahris. Monopogon Presl in Rel. Haenk. 1. 325. t. 44. In Mexico. 4.
2. T. mexicana Funth; glumis laevibus glabris; fol. planis glabris margine scabris. Monopogon avenaceus Presl 1. c. In Mexico. 4.

3. T. chrysotrix Nees; diandra; gluma inferiore tuberculata fulvo-hirsuta. Kunth Gram. 2. t. 141. In Brasilia. 4.

4. T. leucothrix Trin. glumis tuberculatis albo-hirsutis. Nees in Mart. Bras. 2. p. 460. In Prom. b. spei.

\section{ANISOPOGON R. Br. (1810).}

1. A. arenaceus $\boldsymbol{R}$. Br. Kunth Gram. t. 62. Deyeuxia Spr. Danthonia Anisopogon Trin. ic. t. 61. In Nova Hollandia.

\section{ERIACHNE R. Br. (1810). (Aiv'a Spr.)}

\section{a. Aristatae.}

1. E. rara $R$. $B r$. aristis flosculo longioribus; panicula simplicissima; ramis paucifloris distinctis; glumis glabriusculis; fol. vaginisque pilosis scabris ; articulis sericeo-barbatis. $\mathbf{R}$. Br. prodr. 1. p. 193. In Nova Hollandia.

2. E. squarrosa R. Br. aristis flosculo longioribus; spica subramosa; glumis hispidis acuminatis; fol. vaginisque scabris; articulis sericeo-barhatis. 12. Br. 1. c. In Nova Hollandia.

3. E. gracilis Brongn. spica pauciflora; ramis distantilus $3-1$-floris; glumis acutis ; paleis sericeo-villosis aristatis; ligula foliisque margine ciliatis, Brougn. in Dup. it. bot. p. 25. In Moluccis.

4. E. glauca $\boldsymbol{R}, \boldsymbol{B r}$, aristis flosculo longiorihus; panicula coarctata; ramis nultifloris floribusque imbricatis; glumis hispidis; fol. vaginisque glahris laevibus; articulis imberbibus. Ii. Br. 1. c. Kunth Gram. t. 6t. In Nova Hollandia.

5. E. avenacea $\boldsymbol{R}$. Br. aristis flosculo brevioribus, floribus distinctis; glumis glaberrimis nervosis; perianthii valvula utraque basi exterioreque marginibus harbatis; fol. setaceis vaginisque glabris. H. Br. I. c. In Nova Hollandia. 
6. E. ciliata R. Br. aristis flosculum aequantibus; panicula subcoarctata simplici; floribus distinctis; glumis glabriusculis acuminatis; perianthiis longitudinaliter barbatis; fol. vaginisque hispidis. Ir. Br. l. c. In Nova Hollandia.

\%. E. pallescens R. Br. aristis flosculum subaequantibus; panicula effusa rara; ramis capillaribus; glumis glabris obtusiusculis; fol. vaginisque glabris laevibus. 1R. Br. I. c. In Noe'a Hollandia.

\section{b. Muticae.}

8. E. mucronata R. Br. panicula coarctata simplici; ramis paucifloris; glumis glabris; perianthii valvula exteriore mucronata, infia medium hispida; fol. strigoso-ciliatis. H. Br. 1. c. In Nova Hollandia.

9. $\boldsymbol{E}$, brevifolic $\boldsymbol{R}$. Br. panicula coarctata simplici; ramis paucifloris; glumis glabris; fol. setaceis strictis vaginisque laevibus glabris. R. Br. 1 . c. In Nova Hollandia.

10. E. obtusa R. Br. panicula coarctata; ramis inferioribus parum divisis; glumis glabriusculis acutissimis; fol. vaginisque glabris. $R$. Br. 1. c. In Nova Hollandia.

11. E. capillaris $\boldsymbol{R}$. Br. panicula effusa capillari rara; ramis paucifloris; rachi villosa; glunis glahris; fol. vaginisque hispidis. H. Br. I. c. In Nora Hollandia.

\section{BRANDTIA Kunth (1833).}

1. B. holcoides Kunth Gram. 2. p. 511. t. 170. In Pegu. Culmi hasi procumbentes ramosi. Folia plaua, striato-sulcata. Panicula ramosa.

\section{DANTHONIA R. Br. (1810).}

1. D. decumbens DC. panicula subsimplici contracta pauciflora; spiculis oblong 0 - ovatis $3-4$-floris; vaginis foliisque pilosis; radice subrepente. Poa schrad. Germ. 1. p. 305. Host. 2. t. 72. Engl. Bot. 792. Fl. Dall. 160. Triodia Beauv. Sieglingia Berul. In Europa et Rossia. 24 .
2. D. paradoxa R. Rr. panicula effusa; spiculis sub-4-floris gluma longioribus; valvula exteriore perianthii basi pubescente apice 3-dentata, dente medio dissimili. R. Br. 1. c. In Nova Hollandia.

3. D. Forskaelii Trin. paniculata; calycibus trifloris; corollis hirsutis aristatis; culmo ramoso; fol. involutis rigidis. Avena Willd. sp. 1. p. 447. Delile Aeg. t. 12. f. 2. A. pensylvanica Forsk. Deschampsia spr. In Aegypto. $\odot$.

4. D. movincialis DC. arista longa tortili; glunis 5-6-floris; fol. glabris ore pilosis, inferioribus convoluto-setaceis. DC. Gall. 3. p. 33. Trin. ic. t. 67. Avena calycina Vill. Delph. t. 2. f. 9. D. alpina Vest. D. calycina Rchb. In Galloprovincia, Delphinatu, Carintitia, Carniolia et Tauria. 4.

5. D. spicata R. et S. spicata; calycibus spiculis sexfloris longioribus; petalo exteriore apice aristato furcatoque. Avena L. sp. p. 119. - Kunth Grau. t. 65. Triu. ic. t. 54. In America boreali. 4

6. D. sericea Nutt. culmo erecto racemoso composito; spiculis 9-13. 8-9-floris; valvula exteriore lance 0 lata, marogine dense villosa, apice bifido-setosa. Nutt. Gen. 1. p. 71. Trin. ic. t. 53. Avella spicata Ell. In Amevica boreali.

\%. D. secundillora Presl; culmo erecto; fol. involutis setaceis acutis ; vaginis glabris; glumis lanceolatis scabris; palea inferiore basì marginibusque pilosa 3 -aristata; arista media tortili. Presl in Rel. Haenk. 1. p. 255. In Peruvia. 4.?

8. D. panciflora R. Br. spiculis 3-floris; perianthii valvula exteriore basi medioque barbata; villis seriei superioris longitudine valvulae; fol. strictis glabris culmisque setaccis. $\mathbf{R}$. Br. 1. c. In Nova Hollandia.

9. D. setacea $R$. Br. racemo subsimplici; spiculis sub-4-floris; perianthii valvula exteriore hasi medioque barbata; serie superiore villorum valvulam subaequante. $\mathrm{R}$. Br. I. c. In Nova Hollandia.

10.D. racemosa R. Br, raoemo subsimplici; spiculis 7-8-floris; perianthii valvula exteriore basi medioque barbata; seriei superioris villorum fascioulis distinctis; arista intermedia val- 
vula dimidio breviore, collo barbato. H. Br. 1. c. In Nova Hollandia.

11. D. caespitosa Gaudich. culmis simplicibus; vaginis foliisque glabris convoluto-setaceis; glumis angustatoacutis; palea inferiore 9-nervia apice bifida et 3-aristata; arista intermedia longissima spiraliter torta. Gaudich. in Freyc. it. bot. p. 408. Kunth Gram. t. 177. In Nova Hollandia.

12. D. semiannularis $R$. Br. panicula lanceolata; spiculis sub-5-floris; perianthii valvula exteriore basi medioque barbata, serie villorum superiore longitudine dimidii tortilis aristae intermediae lateralibus sesquilongioris. 18. Br. 1. c. In Nova Hollandia.

13. D. pallida $R$. Br. panicula effusa; spiculis sub-4-floris gluma laevi brevioribus; perianthii valvula ad medium villosa, supra uuda; fol. setaceis; collo barbato. R. Br. 1. c. In Nova Hollandia.

14. D. longifolia $R, B r$. panicula effusa ; spiculis sub-4-floris gluma laevi brevioribus; perianthii valvula exteriore ad medium villosa; villis supremis elongatis valvulam occultantibus; fol. subsetacei collo imberbi. R. Br. 1. c. In :. \& Hollandia.

15. D. lanata Schrad. fol. linearibns glabris; vaginis inferioribus tomentoso-lanatis; panicula coarctata ovata; spiculis $3-4$-floris; corollae valvula extcrioris dentibus cuspidatis. Avena Schrad. An. ad Fl. cap. sect. 2. in Goett. Anz. 1821. p. 2075. A. Iupulina Steud. In Prom. b. spei 4 .

16. D, coronata Trin. panicula subcapitato-ovata; spiculis sesquilinealibus 3-floris; glumis subacuminatis; arista longitudine perianthii infra puhescentis medio pilis densis coronati. Trin. in Act. Petrop. 1830, 1. p. 70. In Prom. b. spei.

17. D. micrantha Trin. panicula ohlonga patula; spiculis sesquilinealibus bifloris; glunis caudato-acuminatis; setis longitudine perianthii villis adspersi. Trin. in Act. Petrop. 1830. 1. p. 71. Polypogon capense Hormem, In Prom, b. spei.

18. D. Thunbergii Kunth Gram. t. 176. panicula trichotoma; calycibus hifloris; corollis 3-aristatis; aristis lateralibus basi villosis brevioribus. Avena triseta. Thumb. prodr. p. 22.
Pentameris villosa Necs. In Prom. b. spei.

19. D. purpurec Beruv. panicula coarctata; calycibus 4-floris; corollis villosis aristatis; culmo decumbente. Avena Thumb. prodr. p. 23. In Prom. b. spei.

20. D. lupulina Beauv. culmo simplici; vaginis radicalilus dense tomentosis; panicula ovata; spiculis 4-5floris; flosculis inferne lanatis; seta recta rigida brevi. Nees in Limaca 7. p. 315. Avena Thumb. In Prom. $b$. spei. 4.

21. D. calycina R. et $\mathrm{S}$. paniculata; calycibus bifloris flosculis duplo longioribus ; corollis aristatis ; pedunculis capillaribus. Avena Lam. ill. 1. p. 2C0. In Prom. b. spei.

22. D. Linkii kunth; fol. longissimis cum vaginis pilosissimis; glumis nervosis floribus 3-4-plo longioribus; palea inferiore ultra medium bipartita longe pilosa; arista dorsali inflexa. Avena Lk. Hort. 1. p. 113. In Australia. 4.

\section{PENTAMERIS Beauv. (1812).}

1. P. Thouarsii Beauv. Agr. p. 93. t. 18. f. 8. Kunth Gram. t.66. Pentameris tortuosa Nees. Trisetun villosum Sieb. Danthonia tortuosa Trin. ic. t. 68. Avena pallida Thunb. A. colorata steud. In Prom. b. spei. 4.

2. P. papillosa Nees; fol. vaginisque papilloso-pilosis; panicula palula; floribus calyce duplo brevioribus pilosis; corollae valvulae exterioris dentibus setigeris. Danthonia schrad. in Scluult. mant. 2. p. 385 . Trin. ic. to 66. Avena capensis steud. Holcus asper Thuub. Willd. In Prom. b. spei. 4.

3. P. glandulosa Nees; fol. involuto-setaceis glanduloso-viscidis ; panicula trichotoma; floribus basi pilosis; corollae valvulae exterioris dentibus setigeris. Danthonia sclurat. All. a. Fl. Cap. In Prom. b. spei. 4.

4. P. pallescens Nees; fol. involuto-filifornibus supra margineque scabris subpilosis; panicula licichotoma; corollae valvulac exterioris dentibus setigeris. Danthonia schrad. l. c. In From. b. spei. 4 .

5. P. macrantha Nees; fol. involuto-filiformibus supra scaloris; flori- 
bus calyce triplo brevioribus basi apiceque barbatis; arista calyce breviore. Danthonia schrad. 1. c. Trin. ic. t. 68. Avena macrocalycina steud. In Prom. b. spei. 4.

6. P. curvifolia Nees; fol. involuto-filiformilus curvatis glabris; panicula spicaeformi; floribus villosis; corollae valvulae exterioris dentibus bifidis; lacinia interiore setigera. Danthonia Schrad. An. ad Fl. cap. Avena glomerata steud. var. culmo altiore; panicula glomerato-composita; ramis basi nudis. Danthonia Trin. ic. t. 50. In Prom. b. spei. 4.

7. P. stricta Nees; culmo foliisque setaceis glabris; panicula angusta patula; spiculis 5-6-floris; corollae valvulae exterioris dentibus subbifidis; arista calyce paulo longiore. Danthonia sichrad. An. ad Fl. cap. In Prom. b. spei. 4.

8. P. involucrata Nees; culmo glabro; fol. linearibus supra margineque scabris; panicula angusta; pedicellis barhatis; corollae valvulae exterioris dentibus setigeris. Danthonia Schrad. in Schult. mant. 2. p. 383. Avena Sclurad. Au. cap. In Prom. $b$. spei. 24.

9. P. distichophylla Nees; panicula subcoarctata lanceolata; corolla hirsula; fol. approximatis filiformisubulatis distichis; vaginis striatis margine villoso-ciliatis. Danthonia Lehm. pug. In Prom. b. spei.

\section{URALEPIS Nutt. (1818).}

1. $U$. aristulata Nutt. valvulis calycis obtusis inaequalibus laceris; dentibus lateralibus valvulae corollinae externae obtusis; arista brevissima. Nutt. Gen. 1. p. 63. Aira Muehlenb. In America boreali.

2. U. purpurea Nutt. panicula sparsa purpurea; floribus aristatis; ylumarum altera bifida nervo aristata, altera integra plumosa concava; fol. subulatis; culmo crecto. Aira Pursh El. 1. p. 77. In America boreali. $\odot$.

3. U. pulchella Kunth; culmo repente; fol. planis subulatis scabris; ligula pilosa; panicula valde depauperata; paleis piloso-lanatis. Triodia H. et K, Nov. Gen. 1. p. 155. t. 47. Kocleria Spr. In Mexico. 4.
4. U. arenacea Kunth; culmo repente ; fol. planis externe pilosis; ligula ciliata; panicula simplici coarctata; spiculis subbifloris; glunuis dorso scabris; paleis hasi lanato-pilosis. Triodia H. et K. Nov. Gell. 1. p. 156. t. 48. Koeleria Spr. In Mexico. 4.

5. U. cuprea Kunth; panicula effusa secunda; ramis suldivisis spicatis ; spiculis lanceolato-oblongis 6-7floris; corollae gluma exteriore ad nervos ciliata. Poa sesslerioides Michx: P. quinquefida Jacq. Eclog. 2. t. 16. Tricuspis noveboracensis Beauv. Festuca quadridens Poir. Poa arundinaca Poir. Tricuspis Beanv. Agr. t. 15. f. 10. Eragrostis Trin. In America boreali. 24.

6. U. virens Nees; spicae compositae ramis strictis; spiculis teretibus adpressis altemis; culmo compresso adscendente vaginisque glabris; fol. planis scabris. Tridens Nees. In Brasilia. 4.

\%. U. capensis Nees; racemo composito; spicis compressis alternis; culmo ancipiti stricto; fol. convolutofiliformibus. Tridens capensis Nees in Limnaea 7. p. 324. In Prom. b. spei.

S.U. pallida Kunth; paniculae flaccidae ramis flexuosis; calycibus 5-floris pallidis abbreviatis; corollae basi nudae valva exteriore 5 -dentata; ligula exserta lanceolata. Triodia Spr. Windsoria Eddy. In America boreali.

9. $\boldsymbol{U}$. ambigude Iunth; panicula spicata patente; spicis ovatis crassis sessilibus 5-6-floris; valva exteriore corollae mucronata. Poa ambigua Elliot. Bot. 1. p. 165. Windsoria Nutt. In Carolina et Georgia. 4.

10. U. pungens Kunth; spica glomerata ovata; spiculis sexfloris lanuginosis ; fol. involutis rigidis. Festuca pumgens Valıl Eclog. 1. p. 10. t. 2. T. mucronata Forsk. Calotheca arabica Spr. In Arabia. 4.

\section{TRIODIA R. Br. (1S10).}

1. $T$. mungens $R$. $B r$. panicula coarctata erecta; spiculis lanceolatis subsexfloris; fol. involutis patentibus; vaginis inferioribus viscidis. $\mathrm{I}$. $\mathrm{Br}$. 1. c. Triodia viscida R. et S. In Nova IIollandia. 
2. T. mocera R. Br. panicula effusa; spiculis breviter pedicellatis 3-4-floris; perianthii valvula exteriore carina glaherrima; fol. involutis laxiusculis; collo sericeo-barbato. $\mathbf{l l}$.

Br. 1. c. In Nova Hollandia.

3. $T$. parviflora $R$. Br. panicula cffusa elongata; perianthii valvula exteriore carina nuda, marginilous pubescentulis; fol. involutis; ligula lacera. R. B. 1. c. In Nova Hollandia.

4. T. microstachya R. Br. panicula elongata subcoarctata; ramis spicatis; perianchii valvula exteriore obtusa brevissime 3-dentata; collo vaginae barbato. I. B. 1. c. In Nova Hollandia.

5. T. irritans $\boldsymbol{R}$. $\boldsymbol{B r}$. panicula coarctata; spiculis imbricatis lanceoIatis; perianthii valvula exteriore basi villosa; fol. involutis patulis rigidlis pungentilus. 1R. Br. 1. c. In Nova Hollandia.

6. 'í. ambigua R. $\boldsymbol{B r}$. panicula effusa; ramis semiverticillatis; spiculis 6-10-floris; perianthii valvula marginihus sericeis; interiore ciliata; ligula lacera. H. Br. 1. c. In Nova Hollandiu.

\section{SESSLERIA Arduin. (1761).}

1. S. caerulea Ard. sp. 2. $t$. 6. f. 3-5. spica ovali-ohlonga subsecunda; spiculis $2-3$-floris; palea inferiore 3-rarius $\mathbf{5}$-aristata; aristis gluma brevioribus. M. et K. germ. 1. p. 626. Host. Gram. 2. t, 98. Engl. bot. 1613, FI. Dan. 1506. Cynosurus L. In Europa. 4.

2. S. alba Sibth. graec, t. 72. spica ovato-oblonga imbricata; bracleis alternis; petalis exteriorihus lanceolatis acutis indivisis. Smith prodr. 1. p. 52. Prope pagum Belgrad. 4.

3. S. phleoides Bieb. spica ovata; fol. planis ; spiculis subbiftoris; corollae gluma exteriore subbicuspidata, interiore bicuspidata. Stev. in R. et $\mathbf{S}$. syst. 2. p. 604. In Caucaso orientali.

4. S. cylindrica DC. spica densa cylindrica elongata; fol. acutissimis DC. Gall. suppl. p. 279. Cynosurus Balb. s. caerulea $\beta$. DC. S. argentea Savi S. Koeleria caerulea Ten. In Gallia et Italia. 4.
5. S. tenuifolia schrad. spica cylindracea; spiculis subtrifloris; palea inferiore 3-5-aristata; fol. setaceis. M. et K. 1. c. S. juncifolia suffr. in Iost. Gram. 4. t. 22. Aira juncifolia Wulf. In Istria et Dalmatia. 4.

6. S. sphaterocephala Ard. sp. t. 7. spica subrotunda; spiculis sub-3floris; palea inferiore 1-aristata. M. et K. 1. c. Irost. 2. t. 99. var. $\alpha$. caerulescens. Cynosurus Jacq. ic. t. 20. Willd. sp. $\beta$. alhida. Cynosurus sphacrocephalus Koel. Hoffm. Sesleria leucocephala DC. In Carniolia, Carinthia, Comitatu Tyrolensi et Salisburyia. 4.

ฑ. S. tenella Host. Gram.2. t.100. spica ovata; spiculis bifloris; palea inferiore 5-aristata; aristis gluma longioriluus, M. et $\mathbf{K}_{\text {. }}$ l. c. Cynosurus microcephalus Hofm. Psilatera tenclla Lk. In Carintlia, Tyroli, Salisburgia. 4.

S. S. echinatı Lam. ill. t. 4\%. f. 2. culmo erecto superne nudo; spiculis terminalibus sessilibus in capitulum congestis; involucro squamoso. Dactylis pungens Desf. Atl. t. 16. Schreb. Gram. t. 2\%. f. 1. Koeleria et Calotheca pungens Spr. In Barbaria. $\odot$.

9. S. elongata Host. Gram. 2. t. 9\%. spica cylindracea elongata; spiculis subtrifforis; palea inferiore 3-5aristata; fol. linearibus; radice stoIonifera. Kunth, Aira alba Wulf.Phleum autumnale scop. In Istria et Helvetia. 4.

10. S. rigida Heuffel; thyrso ovato ; spiculis 2-3-floris; bracteola exteriore aristata 2-4-dentata; fol. linearibus ommino complicatis rigide sub)lignosis culmum excedentihus. IRchì). excurs. p. 140. In Bunatu. 2.

11. S. disticha Pers. spica ovata disticha; spiculis 3-6-floris; palea inferiore mutica submucronata; fol. filiformibus. M. et K. 1. c. Poa Jacq. ic. t. 19. Host. 2. t. 76, P. sesslerioides All. ped. t. 91. f. 1. In Germania australi. 4.

12. S. dura Kunth; panicula secunda coarctata rigida; spiculis ol-longis obtusis 3-5-floris ; floribus nervosis obtusis emarginatis; radice fibrosa. Poa M. et K. 1. c. Host. 2. t. 73. Cynosurus L. Poll. Pal. t. 1. f. 1. Sclerochloa Beauv. In Europa et Caucaso. $\odot$. 
13. S. albicans Kit. racemo spicato oblongo-ovato ebracteato; valvulis calycinis ovato-lanceolatis; arista brevissima. Schult. austr. 1. p. 216. In montibus Carpatli. 4 .

14. S. nitida Ten. spica ovata; spiculis 4-floris nitidis mucronatis; corollis caeruleis; fol. vaginantibus obtusis glabris, caulinis hrevioribus. Tenore Neap. p. 10. In Italia. 4.

15. S. mutica Badaro; panicula panciflora; perigoniorum aristis brevissimis, interni gluma exteriore glabra lucida vix apice dilatata. Padar. in Giorn. d. Fis. 1824. 7. p. 363. In Monte st. Calloceri vallis Albingaunensis.

16. S. dactyloides Nutt. culmo setaceo folioso; fol. subulatis subpilosis; ligula barbata; calycibus plerumque 2-floris corollisque acmuinatis integris. Nutt. Gen. 1. p. 65. Ad Missouri.

\section{POA Linn. ' (1737).}

\section{Species genuinae.}

a. Spiculae spicato-racemosae.

1. P. littoralis Gouan; spica composita interrtipta; fol. rigidis involutis. M. et K. germ. 1. p. 594. Festuca Sibtl. gr. t. 80. Dactylis Willd. Host. 4. t. 28. D. maritima schrad. Germ. t. 6. f. 1. D. repens Desf. Atl. t. 15. In Europa, Sibiria et Africa boreali. 2 .

2. P. Smithii Kunth; stoloniluns repentibus; fol. omnibus planis; capitulis subglobosis compositis e spicis tribus secundis; calycilbus acutis 6-12-floris; corollis pilosis acutis. Dactylis Roxb. ind. 1. p. 342. D. lagopodioides L. Burm. ind. t. 10. f. 1.? Koeleria brevifolia spr. In IHalabaria. 4.

3. P. lagopodioides Kunth; repens; fol. rigidis apice spinescentibus; capitulis globosis; calycibus 6-8-floris corollisque pilosis; antheris caeruleis. Dactylis Roxb. ind. 1. p. 342. Burm. ind. t. 12. f. 2. Sessleria Spr. In Malabaria. 4.

4. P. distichophylla $\boldsymbol{R}$. Br. spica ramosa aequali pauciflora; spiculis sub -10-floris; fol. bifariis involutis; vaginis imbricatis; culmo ramoso. $\mathrm{K}$.
Br. 1. c. Uniola Labill. Nov. Holl. t. 24. Poa paradoxa H. et S. In Nova IIollandia.

5. P. Michanxii Kunth; panicula racemoso-coarctata; spiculis approximatis adpressis 6-floris muticis; fol. convoluto-subulatis rigidis ; culmo erecto glabro. Festuca distichophylla Pursh Fl. 1. p. 8t. Uniola distichophylla 1. et s. U. spicata L. Nees. In America boreali, Chili et Montevideo. 4.

6. P. scoparia Funth; culmis fasciculato-ramosissimis; spiculis compressis 5-6-floris glabris; palea inferiore sub-11-nervia. Kunth Gram. 2. p. 535. t. 180 . Uniola Nees. In Monterideo.

\%. P. sessiliflora Iunth; spicis simplicissimis; spiculis sessilibus minimis distantibus; glumis uncinatosubacutis. Uniola Poir. Encycl. 8. p. 185. In Carolina.

8. carinate Poir. panicula brevi subdiffusa; valvulis compressis dorso coronatis; culmo repente. Poir. 1. c. In Portorico.

9. P. prostrata $\boldsymbol{H}$. et $\boldsymbol{K}$. culmis ramosis prostratis repentibus; spiculis 4-14-floris; flor. dioicis; palea inferiore 6-9-nervia; fructu oblique ovato. Megastachya $\boldsymbol{R}$. et $\mathbf{S}$. $P$. areraria spr. syst. In Nova Andalusice et Chili. 4.

10. P. thalassica $H$. et $K_{\text {. }}$ culmis ramosis prostratis repentilus; spica fasciculata; spiculis linearibus dioicis; glumis glabris, inferiore 9-nervia. Kuntl. Megastachya $\mathbf{R}$. et $\mathbf{S}$. In Peruvia et Chili. 4.

11. P. Preslei Kunth; culmo repente ramoso; spiculis lanceolatis 6-8-floris; paleis inferioribus acutis muticis nervo medio scabris. Brizopyrum pilosum Presl in Kel. Haenk. 1. p. 280. In Acapulco. 4.

12. P. borealis Iiunth; culmo erecto subramoso; pauicula secunda simplicissima; spiculis sub-10-floris; glumis paleisque 9-nerviis glaberimis. Brizopyrum boreale. Presl 1. c. Patria ignota. $\odot$.

13. P. subspicata Funth; culmo adscendente compresso; panicula erecta contracta; glumis paleisque ovatoacutis 1-nerviis; nervis pilosis; arista brevissima. Brizopyrum Presl. 1. c. In Peruvia? 4. 
11. P. calycina Funth; culmis erectis; rachi ramis pedicellisque scahris; spiculis 2-floris; glumis trinerviis acutis; palea inferiore obtusiuscula. Brizopyrum. Presi 1. c. Patria ignota. $\odot$.

b. Spiculae paniculatac 5-multiflorae.

15. P. brizoides Lim. culmo compresso; fol. vaginorum ore pilosis; panicula contracta; spiculis ovatis sub-8-floris; floribus hasi liheris. Briza capensis Thumb. Megastachya R. et S. Eragrostis capensis Trin. In Prom. b. spei. 4 .

16. P. bifaria Vahl; glabra; culmis erectis; fol. complicatis rigidis glaucescentibus; spica 1-laterali-disticba; spiculis sessilibus lanceolatolinearibus, inferioribus 3-11-floris, superioribus 15-17-floris. Kunth Gran. 1. p. 335. t. 80 . In India orientali.

1\%. P. coromandeliana Roth; spiculis distichis sessilibus in rachis foveis, lanceolatis nitidis compressis; fol. setaceis. Koth Nov. Sp. p. 70. Eragrostis Trin. In Caromandelia.

18. P. cynosuroides Retz; stricta; 1-3-pedalis; fol. longis acutis ; panicula stricta subcylindrica; spiculis dependentibus 6-12-floris. 1ioxb. ind. 1. p. 334. Uniola pinata I. Eragrostis 12. et s. In Aegypto et India orientali.

19. P. pastoënsis H. et K. culmis caespitosis hasi repentibus; panicula ramosa spicaeformi; spiculis oblongis 5-floris; palea inferiore longe trinervia. H. et K. Nov. Gell. 1. p. 160 . Megastachya R. et S. In Nova Granata. 4.

20. P. tenax H. et $\boldsymbol{K}$. culmis erectis simplicibus; vaginis glabris; panicula ramosa verticillata; ramis rachique scabris; glumis dorso scabris; palea inferiore 3-nervia. H. et K. 1 . c. Megastachya 1. et S. In Quito. 24.

21. $\boldsymbol{P}$. aturensis $\boldsymbol{H}$. et $\boldsymbol{K}$. culmis erectis ramosis; fol. interne scahris; panicula ramosa verticillata; ramis abhreviatis scabris spiculis 9-11-floris; palea inferiore majore 3-nervia. Megastachya R.et $S$. Ad Orinocco. 24.

22. P. acutiflora $\boldsymbol{H}$. et $\boldsymbol{K}$. culmis erectis ramosis; panicula ramosa patula stricta; spiculis oblongis 7-floris; palea inferiore longiore acuminata 3nervia. H. et K. I. c. Megastachya
R. et S. Eragrostis Trin. In Nova Granata, Panama et Brasilia. 4.

23. P. Wahowensis Kunth; fol. involutis subulato-attenuatis longissinis; ligula ciliari barbata; valvula superiore parum hreviore serrulata. Eragrostis Walıowensis Trin. In ins. ilahu.

24. P. squamata Lam. paniculis plurimis remotis; spiculis lineari-lanccolatis sub-15-floris; corollarum valvulis interioribus persistentibus. Lam. ill. 1. p. 185. In Sierra Leona?

25. P. psammodes Kunth; panicula nutante; spiculis angustis 12-18floris; floribus ovatis acutis; valvula superiore serrulata; ligula ciliari eherbi. Eragrostis Trin. in Act. Petrop. 1830. 1. p. 40J. In Brasilia.

26. H. patula H. et $\boldsymbol{K}$. culmis simplicibus erectis; panicula ramosa patentissima; spiculis oblongis 5-floris; palea inferiore paulo majore 3nervia. H. et K. l. c. Megastachya H. et S. In Quito. 4 .

2\%.P. nigricans H.et $\boldsymbol{K}$. culmis caespitosis; panicula ramosa stricta; ramis scabris patulis; spiculis oblongis 5-7floris violascenti-viridibus. H. et K. 1. c. Megastachya R. et S. In Quito. 4.

28. P. virescens Kunth; culmo erecto tereti basi ramoso subprocumhente; vaginis pilosis; ligula brevissima; spiculis linearibus 8-floris; paleis inferioribus ovatis pubescentibus 3-nerviis, superioribus carina ciliatis. Eragrostis Presl 1. c. In Chili. $\odot$.

29. $P$. Montufari $H$. et $K$. culmo erecto ramoso; ligula ciliata; spiculis lineari-lanceolatis sub-7-floris; palea inferiore majore 3-nervia. H. et K. 1 . c. Megastachya $\mathbf{R}$. et S. In Quito. 24.

30. P. Olmedi H. et K. culmis erectis simplicibus; spiculis oblongo-linearibus sub-6-floris; palea inferiore 1nervia. H. et K. 1. c. Megastachya R. et S. In Peruvia. 4.

31. P. pectinacea Michx. panicula laxa patula erecta; spiculis linearibus 10-floris; rachi deflorata valvulis persistentibus pectinata. Mich. Fl. 1. p. 69. In America boreali. $\odot$.

32. P. pilosa L. panicula aequali, florifera contracta, fructifera diffusa; spiculis linearibus 5-12-floris; flosculis acutis nervo laterali obsoleto; radice fibrosa. M. et K. 1. p. 595. Host. 2. t. 68. Eragrostis Beauv. P. Poi- 
retii R. et S. In Europa meridionali, Tauria et Sibiria. $\odot$.

33. P. verticillata Cav. ic. $t .93$. panicula patente capillari flexuosa; spiculis 11-floris lineari-subulatis. Willd. sp. 1. p. 393. Eragrostis R. et $\mathbf{S}$. P. chinensis Lk. In Ilispania, Lusitania et Brasilia. $\odot$.

34. P. punctata $\mathrm{L}$. glabra; 6-18pollicaris; panicula oblonga; spiculis 12-14-floris; seminibus ohlique oblongis. Roxl, ind. 1. p. 339. In $\mathrm{m}$ dia orientuli.

3.5. P. atrovirens Desf. glabra; culmo erecto; fol. rigidulis; vaginis intermediis breviorihus; panicula patente; spiculis planis linearibus. Desf. All. 1. p. 73. t. 17. In Burbaria.

36. I. pilosissima Kunth; fol. vaginisque pilosissimis; panicula effusa; spiculis 5-floris; valvis 1-nerviis membranaceis, exteriore duplo minore. Eragrostis Lk. Host. 1. p. 189. Putria ignota. $\odot$.

3\%. P. murpurascens spr. panicula lanccolata elongata; spiculis adpressis coloratis linearihus 10-floris; valvula exteriore trinervia; ligula nulla. Spr. Nov. Prov. p. 33. Eragrostis Schult. In Montevideo et ins. St. Catharinae Brasiliae. $\odot$.

38. P. ferruginea Thnnb. panicula patula capillari; spiculis 5-floris oblougis, glumis glahris. Thunb. jap. p.50. Eragrostis Beanv. In Juponia.

3.9. P. Cambessediana Kunth: culmis prostratis longissimis ramosissimis; ramis caespitoso-fasciculatis ; spiculis lineari-oblongis 7-27-floris. Kuntlı Gram. 2. p. 429. t. 148. In Senegambia.

40. P. tephrosanthus Spr. panicuIa divaricata; spiculis 4-9-floris; corollis remotis 3-nervilus ovatis obtusis; ligula pilosa. Eragrostis Schult. mant. 2. p. 316. E. poaeoides var. $\gamma$. Trin. In Martinica. $\odot$.

41. P. megapotamica Spr. paniculae ramosissimae laxae ramis capillaribus; spiculis unifloris linearihus coloratis; nosculis acutis trinervibus. Spr. 1. c. post. p. 35. Eragrostis R. et S. Ad Rio Grande.

42. P. mexicana Lag. panicula patentissima stricta; spiculis ovatis sub-8-floris; ligulis abhreviatis eros0ciliatis; culmo tereti ramoso. Lag. Elench. 3. Eragrostis Lk. Poa capillaris Lk, en. In Mexico. $\odot$.
43. P. lugens Fimth; panicula racemoso-supradecomposita; ramificationihus omnibus barbatis; pedicellis gracillimis; palea inferiore acuta ovata suh-1-nervia. Eragrostis Nees in Mart. Bras. 2. p. 505. In Hontevideo.

14. P. hirsuta Michx. panicula ramosissima capillari; spiculis longe pedicellatis; fol. culmo longioribus; vaginis hirsutissimis; culmo erecto ramoso. Pursh. Fl. 1. p. EJ. In America boreali. $\odot$.

15. P. capillaris I. panicula laxa patentissima capillari; floribus ovatis acutis pubescentibus; fol. collo pilosis; culmo ramosissimo. Pursh. Fl. 1. p. 79. Eragrostis Nees. P. caroliniana Spr. In America boreali, Chili, Jumaica et $\mathbf{s t}$. Domingo. $\odot$.

46. 1'. polytricha liunth; panicula racemoso-decomposita; ramis verticillatis ; ramificatiouibus omnibus harbatis; palea inferiore 3-nervia; fol. vaginisque hirsutissimis. Eragrostis Nees. In Brasilia.

1\%. P. aspera Jac\%. panicula ramosissima patentissima; pedunculis asperis; spiculis 10-floris; vaginis foliorum antice hirsutis. Jacq. Hort. 3. t. 56. var. $\beta$. minor; fol. angustissimis; vaginis subnudis. Patria ignota 3. in Portorico. 4.

48. P. madagascariènsis Lam. panicula ramosa laxa patentissima; spiculis sul)-10-floris; vaginis nudis; culmo simplici. Lam. ill. 1. p. 185. In Madagascaria.

49. P. abyssinica Jacq. panicula capillari laxa erecta; spiculis 4-floris laevibus lineari-lanceolatis; fol. wlabris convolutis Ait. Kew. 1. p. 100. Eragrostis Lk. In Abyssinia. $\odot$.

50. P. nutans Ret:; erecta; glabra; 3-5-pedalis; ramis paniculae adpressis; spiculis 8-12-floris; seminibus oblongis. Ihoxb. ind. 1. p. 337. In Indiu orientali.

51. P. domingensis Pers. alta; panicula ramosissima subcontracta; spiculis parvulis 4-floris; fol. Ianceolatis longissimis. Pers. syn. 1. p. 88. Eragrostis gigantea Trin. In st. Dominyo. $\odot$.

.52. P. Berteroniana Kunth; panicula contracta; ramis strictis simplicihus ; spiculis lineari-lanceolatis 10-20-floris; fol. basi vaginisque 10tis hirsutissimis; ligula barbata. Me- 
gastachya sclult. mant. 2. p. 330. Yoa polymorpha Balb. In St. Domingo. $\odot$.

53. P. tremula Lam. panicula ramosissima capillari patente; spiculis linearibus glabris sub-30-floris. Lam. ill. 1. p. 185. In Senegalia.

54. $\boldsymbol{P}$. biformis Kunth; culmis erectis ramosis foliisque rigidis; paniculis subramosis; spiculis linearibus 6-41-fioris; palea inferiore 3-nervia. Kunth Gram. 2. p. 471. t. 149. In Senegambia.

55. P. Eragrostis $I$. panicula patente aequali; ramis inferioribus pilosis; spiculis lineari-lanceolatis 820-floris; flosculis ohtusis nervo laterali prominente; vaginis pilosis. M. et K. Germ. Host. 2. t. 39. Schreb. 1. t. 73. Eragrostis poaeformis Beautv. In Europa, Caucaso, Sibiria, Barbaria, America boreali, Mexico et India orientali. $\odot$.

56. P. Brounii Kunth; panicula patente; spiculis lanceolatis 10-20floris; perianthii valvula exteriore glabra, interiore ciliata; fol. involutis; collo barbato. P. polymorpha. $\mathrm{R}$. Br. prodr. 1. p. 180. Megastachya R. et S. In Nova Hollandia. Valde variat.

5\%. P. rujescens Schral. culmis adscendentibus subramosis; fol. basi pilosis; panicula ramosa contracta; valvula corollae exteriore ovata breviter acuminata trinervia; interiore persistente. Schrad. in schult. mant. 2. p.319. Eragrostis inconstans Nees. Poa cuspidata Roth. Niegastachya Schult. Calotheca Spr. In Brasilia. $\odot$.

58. P. megastachya Koel. panicula aequali patente; ramis inferioribus pilosis; spiculis lineari-oblongis 15 25-floris; flosculis obtusis emarginatis breviter mucronatis; vaginis glabris ore pilosis. Mert. et Koch. 1. c. Poa Eragrostis Cav. ic. Briza L. Schreb. t. 39. Eragrostis major. Host. 4. t. 24. In Europa, Africa boreali et America. $\odot$.

5.9. P. obtusa Nutt. spiculis compressis oblongo-ovatis obtusis $8-15-$ floris; culmo simplici debili compresso. Nutt. gen. 1. p. 67. Briza Walt. Megastacbya schult. P. Nutallii Spr. Glyceria obtusa Trin. Prope Philadelphiam.

60. P. spinosa Thunb. culmis ramosissimis lignosis diffusis; ramis pa- niculae distichis patentissimis complanatis apice pungentibus; spiculis reflexis 7-10-floris. Kunth Gram. 2. p. 551. t. 190. Festuca L. Eragrostis Trin. In Prom. b. spei. 4.

61. 1. Bergiana Kunth; culmis basi caespiteso-ramosissimis repentibus; panicula subramosa patula; spiculis breviter pedicellatis ovato-ellipticis 10-12-floris; palea inferiore acuiiuscula superne carinaque scabriuscula. Kunth Gram. 2. p. 549. t. 189. In Prom b. spei. 4.

62. P. mucronata Poir. panicula spicata laxa; floribus numerosis, 1118; valvis glumae et calycis acuminatis; fol. latis lanceolatis. Beauv. Agr. 1. p. 5. t. 4. In Africa aequinoctiali.

63. P. elongata Willd. panicula elongata; ramis patentibus distantibus abbreviatis; spiculis linearibus 7-11floris adpressis; ligulis abbreviatis ciliatis. Willd. en. 1. p. 108. P. dependens Horn. Eragrostis elongata Jacq. Eclog. Gram. t. 3. Megastachya Beauv. Eragrostis brasiliensis $\gamma$. Nees. In India orientali. 24.

61. $\boldsymbol{P}$. amabilis $L$. panicula patente; spiculis ovatis $\mathbf{1 2}-\mathbf{2 0}$-floris, flosculis inferioribus deciduis; fol. lineari-lanceolatis; culmo ramoso. Vahl. P. rubens Lam. Megastachya amabilis Beauv. In India.

6.5. P. rubens' Lam. panicula parva patente; spiculis 18-floris obtusis; glumis laevibus confertissimis. Lam. ill. 1. p. 184. t. 45. f. 2. In India orientali et Amboina.

66. P. unioloides Retz; erecta; glabra; 1-2-pedalis; panicula ovata; ramis inferioribus fasciculatis; spiculis longe pedicellatis 10-20-floris ; semine oblongo. Hoxb. ind. 1. p. 310. Uniola indica Spr. In Indiu orientali.

6\%. P. Roxburghiana Schult. suberecta; flexuosa; natans; 18-24-pollicaris; panicula ovata conferta ; insertionibus pilosis; spiculis 20-floris; semine globoso. P. flexuosa. Roxb. ind. 1. p. 340. P. tortuosa. Spr. syst. In India orientali.

68. P. subsecunda Lam. panicula oblonga laxa; spiculis linearibus acutis multifloris; lateralibus extrorsum versis. Lam. ill. 1. p. 184. $\beta$. spiculis minoribus. Pluku. to 190, fo 3. In China. 
69. P. Vahlii R. et $\mathrm{S}$. spiculis lineari-lanceolatis compressis; racemis composilis; pedunculis basi harbatis; fol. involutis subpilosis. Vahl Eclog. 1. p. \%. Eragrostis Vahlii Nees. Megastachya swainsonii Raddi. In America meridionali. $\odot$.

r0. $\boldsymbol{P}$. Meypurensis $\boldsymbol{H}$. et $\boldsymbol{K}$. fol. anguste linearihus; pauiculac ramis hasi barbato-pilosis; spiculis 11-15floris; palea inferiore acuminato-suhulata; caryopside laterihus deltoideocompressa, reticulato-alveolata. Kunth Gram. 2. p. 537. t. 183 . Megastachya Maypurensis 1R. et $\mathbf{s}$. Eragrostis panamensis Presl. Ad Orinoccum et in zanama. $\odot$.

\%. P. Neratianc Tunth; cnlmis diffusis; vaginis pilosis; axillis panicularum harbato-pilosis; spiculis lineari-ohlongis sub-20-floris; floribus diandris; palea inferiore acuminalocuspidata, superiore carinis ciliatis. Kunth 1. c. t. 184. In Brusilia.

72.P. solida hunth; fol. linearibus convoluto-subulatis rigidis utrinque vaginisque superne villosiusculis; spiculis 13-17-foris; floribus diandris; palea inferiore acuta carina scabra, superiore carinis ciliatis. Kunth Gram. 2. p. 543. t. 186. In Madagascaria.

83. P. Chapelieri Irunth; repens?; fol. anguste linearibus; margine ligulari ciliato; spiculis fasciculalo-racemosis, compressis 11-19-floris ; floribus diandris; palea inferiore trinervia, superiore 2-carinata ciliata persistente. Kunth Gram. 2. p. 5.43. t. 186. In Madagascaria.

\%1. $\boldsymbol{P}$. aegyptiaca Willd. panicuIa aequali diffusa; spiculis linearibus 9-15-floris; ligula truncata ciliata; culmo ramosissimo adscendente. Willt. en. p. 107. Delile aegypt. t. 10. f. 2. Eragrostis Lk. In Aeg.ypto. $\odot$.

75. P. reptans Michx. culmis ramosis repentibus; fol. vaginisque glabris; panicula simplici ovata palula; spiculis linearibus compressis mulifloris; floribus dioicis. Kunth. Miclix. Fl. 1. t. 11. Eragrostis Nees. Megastachya reptans et hypnoides Beauv. In America boreali et meridionali. $\odot$.

76. P. viscosa Retz; culmo adscendente 9-19-pollicari viscoso; panicula lineari-oblonga; ramis verticillatis brevibus patentibus; glumis interioribus corollae ciliatis. Roxb. ind.
1. p. 337. Eragrostis Trin. In India orientali.

8\%. P. permviana Jac\%. panicula spicata; spiculis oblongis sub-5-floris; valvulis corollae interioribus dorso subciliatis; culmis procumbentibus. Willd. sp. 1. p. 402 . Jacq. ic. t. 18. Eragrostis Triu. In Peruric. $\odot$.

8. P. ciliceris L. panicula con. tracla; glumarum valvulis interioribus piloso-ciliatis. Linn. syst. 99. Jacq. ic. t. 304. Megastachya Beauv. Eragrostis Lk. In America calidiori. $\odot$.

79. P. Boryana Willd. panicula glomerato-subspicata; spiculis oblongis 12-floris; flosculis oblique truncatis; valvula corollae interiore maryine ciliata. Willd. en. p. 109. adn. Megastachya $\mathbf{R}$. et $\mathbf{S}$. In ins. Borbonice et Inaritii.

80. P. riparia Hilld. panicula coarctata stricta; spiculis oblongis 6-floris; valvula corollae interiore margine ciliata; fol. canaliculatis; radice fihrosa. Willd. en. p. 109. adn. Megastacliya R. et S. Eragrostis Nees E. ciliaris $\beta$. Trin. In India orientall.

81. P. interrupta Lam. fol. linearihus memhranaceis; panicula ramosa angusta inferme interrupta; spiculis 5 -8-floris viridulo-albidis; floribus diaudris; paleae superioris carinis hispidulo-scahris; caryopside elliplica laevi. Kunth Gram. 2. p. 51\%. t. 188. Eragrostis Beauv. In Coromandelia, Peg'll et ins. Timor.

S2. P. barbate Thunb. panicula patula capillari; spiculis 5-fioris oblongis; glumis glabris carinatis. Thunb. jap. 51. t. 10. In Japonia. $\odot$.

83. P. tenella L. erecta; glabra; 1-2-pedalis; panicula lineari-oblonga verticillata; spiculis pedicellatis 4-6-floris glahris. Hoxb. ind. 1. p. 338. Kunth Gram. t. 147. Burm. Zeyl. t. 47. f. 3. Eragrostis Beauv. In India orientali, ins. Mariae Annae, Luzonice et Moluccis. $\odot$.

81.P. tenellula Kunth; panicula oblonga; spiculis 5-6-floris semipellicidis glabris; culmo ramoso; fol. planis; perianthiis trinerviis. P. tenella. H. Br. 1. c. In Nova Hollandia.

85. P. plumosa Retz; glabra; panicula ovato-oblonga; ramis sparsis horizontalibus; ramulis dependentibus; spiculis pedicellatis 4-6-floris; val- 
vis interioribus corollae ciliatis. Roxb. ind. 1. p. 338. Rumpl. 6. t. 4. f. 3. Bheede 12. t. 41. P. decipiens et tenella Lk. In India orientali: 4 .

86. P. japonice 'Thunb. panicula patula capillari; spiculis 7-floris foliisque glahris; culmo ramoso. Thumb. jap. p. 31. Eragrostis tenella $\beta$. R. et S. In Japonir.

8\%. P. voriubilis Goudich, vaginis ore barbulatis; panicula simplici erecta; ramis fasciculatis patulis; spiculis multifloris; glumis dorso denticulato-scabris. Kunth Grail. 2. p. 545. t. 187. Eragrostis Gaudich. In ins. Sunduicensibus.

88. P. fulcutı Gaud. ligula abbreviata laciniato-ciliata; panicula simplici diffusa; spiculis lincaribus subfalcatis 10-16-floris; palea exteriore obtusa. Gaulich. in Freyc. it. bot. p. 408. t. 25. In Nova Hollanclia.

8.9. P. rubiginosa Kunth; paniculae simplicissimae ramis brevissimis; florihus ovatis obtusis distincte nervosis, superiore tenuissime serrulato; ligula ciliari barbata. Eragrostis Triı. 1. c. In Prom. b. spei.

90. P. chalcantha Fiunth; paniculae radiis brevissimis; spiculis brevissime pedicellatis ovato-ellipticis sub7-floris; valvula superiore aequilonga tenuissime serrulata; ligula ciliari barbulata. Eragrostis Trin. 1. c. In prom. b. spei.

91. P. fascicularis Funth; paniculae julbalis radiis confertis; spiculis pedicello multo longioribus linearibus 8-16-floris; valvula superiore inferiorem subexcedente superne scabriuscula; culno per intervalla longa fasculato-ramosissimo. Eragrostis Triu. 1. c. In Congo.

92. P. Neesii Funth; paniculae lıcidae rediis brevibus; spiculis lineariellipti is 5-15-floris; valvula superiore laevi; fol. planis pilosis; ligula ciliari. Eragrostis brasiliensis var. d. Nees. Eragrostis Nesii Trin. In brasilia.

93. P. leptantha Kunth; paniculae linear-contractae radiis verticillatis; spiculis angustissimis 7-9-floris; valvula superiore parum breviore tenui-serrulata; ligula ciliari barbata. Eragrostis Trin. 1. c. In Brasilia.

91. P. clareosa Kunth; paniculae jubalis demum patentis lucidae radiis subsolitariis; spiculis ovato-linearihus 8-10-floris; valvula obsolete denticulata; fol. distichis compresso-planis pumentibus hirsutissimis; ligula ciliari. Erigrostis 'Trin. in Act. Petrop. 6. 1. 1. 406. In Irrasilia.

9.5. P. seminulu Funth; paniculae patentissimac radiis ternis supra basin compositis; valvula superiore paulo breviore serrulata; fol. seminvolutis hirtis; ligula obsoleta. Eragrostis Triu. I. c. In Brasilia.

96. P. sclerophylla Runth; paniculae juhalis strictae patulae lucidae radiis $2-3$, mox supra hasin compositis; axillis ohsolete harbatis; valvula superiore fere $\frac{1}{3}$ breviore laevi; ligula ciliari parce barhulata. Eragrostis 'Irin. 1. c. In Brotsilia.

9\%. P. Diomedarum finth; jubae thyrsodis densissimae radiis brevissimis a hasi floriferis; axillis pubescentibus ; spiculis 10-20-floris ; valvula superiore pubescendo-serrulata; fol. strictissimis; ligula ciliari eherbi. Eragrostis Triu. In Albutros-Eiland.

88. P. esputans kunth; paniculae jubalis strictae radiis subfasciculatis; axillis villosis nudisve; spiculis suhsessiibus 3-floris; fletinus aculissimis superue valvulaque superiore breviore serrulatis; ligula ciliari barhata. Eragrostis Trin. 1. c. In ins. Walu.

99. P. Calotheca Eunth; paniculae nutantis radiis longe supra basin compositis; floribus latis mucronato-acutis suhobsolete nervosis; valvula superiore puhescendo-serulata. Eragrostis Triu. 1. c. In Brasilia.

100. P. naraioides Lunth; racemi simplicissimi spiculis sessilibus subuniseriatin alternis secundis; valvula superiore parum hreviore tenere serrulata; fol. filiformibus. Eragrostis Trin. 1. c. In Nepalia.

101. I. Cniolae Schrad. fol. convoluto-filiforuibus curvis vaginisque glabris; spica hasi composita distichosecunda; calycibus acuminatis glabris; corollina valvula exteriore basi pilosa. schrad. in Goett. Anz. 1821. n. 205. Briza imbricata steud. In Prom. b. spei. 4.

102. P. papillosa Schrad. fol. involuto-filiformibus rigidis; spica disticho-secunda; calycibus acuninatis papilloso-hirsutis; valvula corollina basi pilosa. Schrad. 1. c. In Piom. b. spet. 
103. P. bahiensis schrad. fol. lineari-setaceis strictis; vaginarum ore barhato; panicula ramosa patula; spiculis Iinearibus multifloris; valvula corollae exteriore ovata breviter acuminata 3-nervia. - schrad. in sichult. mant. 2. p. 318. P. brasiliensis Haddi. In Brasilia. 4.

104. P. brosiliensis Spr. paniculae ramosissimae striclae ramis glabris; spiculis lanceolatis compressis; flosculis pellucidis; fol. convolutis vaginisque glahris; ligula nulla. spr. syst. 1. p. 3+2. Megastaclya schuIt. E. elegans Nees. In Brasiliu. $\odot$.

105. P. expansa fimth; panicula expansa; ramis elongatis flaccidis; spiculis 12-14-floris; valvulis 1-nerviis acutis. Eragrostis Lk. Hort. 1. p. 190. In Monterideo. 4.

106. P. compte liunth; panicula tenui elongata; ramis adpressis; spiculis 10-1loris; flosculis patentibus; valvula exteriore obtuse 3-nervia, interiore nervo longe ciliata. Eragrostis Lk. Hort. 1. p. 193. In Niontepideo. 4.

10\%. P. bromoirles Tahl; panicula subspicata; spiculis lanceolatis 25-floris superioribus sessilibus; fol. bifariis involutis. Vahl Symb. 3. p. 10. In Lima. 4.

108. P. acicularis Kunth; paniculae racemulis radiis solitariis a basi subappresso-floriferis; spiculis ovato-lanceolatis $12-25$-floris; valvula superiore dimidio hreviore serrulata; fol. setaceo-involutis; pilis adspersis; ligula ciliari liarbata. Eragrostis Trin. 1. c. In America boreali. $\odot$.

109. P. Linkii Kunth; fol. demum convolutis filiformibus; vagina ore ciliata; paniculae ranis arlectis glahris; valvis 1 -nerviis submembranaceis acutis; valvula exteriore colorata. Eragrostis Lk. Host. 1. p. 191. Poa tenella Pursh. in Brotsilia.

110. P. amoence Funth; culmo ramoso compresso; panicula erecta contracta; rachi glabra; ramis brevissimis; spiculis fasciculatis 14-32-floris; palea inferiore ovata acuminata 3 nervia. Eragrostis Presl in Rel. Haenk. 1. p. 275. In Mexico. $\odot$.

111. P. secundiflora Kunth; rigida; culmis ramosis compressis; vaginis ore ligulaque foliisque planis supra pilosis; ramulis pedunculisque basi pilis stipatis; spiculis secundis 18-40-floris. Eragrostis Presl I. c. Jil Mexico. 4.

112. P. lucida Funth; culmis teretibus erectis glabris; ligula hrevissima ciliata; spiculis lincaribus 8 10-floris; paleis rotundato-ovatis mucromulatis scabris 3-nerviis. Eragrostis Presl 1. c. In Feruriu. 4 .

113. P. flavescens kunth; culmis ramosis teretilus glabris; panicula erecta simplici; ramis hasi pilorum fasciculo stipatis; spiculis linearibus 14-28-floris; palea inferiore 3-nervia nervo scahra. Eragrostis Presl 1. c. in Nexico. $\odot$.

11. P. stenocladia Kunth; radice fibrosa; culmis erectis simplicibus compressis; panicula erecta composita contracta ; spiculis lanceolatis 10-12floris; glumis 1-nerviis dorso scabris. Eragrostis Presl 1. c. In Peruvia. 4.

115. P. Haenkei Kunth; culmo erecto ramoso tereti vaginisque glaherrimis; ligula brevissima; panicula patentissima; rachi ramisque basi rudimento setiformi stipatis scabris. Eragrostis Presl 1. c. In Mexico. 4.

116. P. atbe Funth; culmo simplici compresso vaginisque glahris; ligula angustissima ciliata; spiculis paniculae contractae 4-floris; glumis 1-nerviis; palea inferiore 3-nervia acuta glabra. Eragrostis Presl 1.c. In California. 4.

11\%. P. simplicifiora Kunth; culmo erecto ramoso compresso; fol. planis interne pilosis; panicula patente; spiculis linearibus 8-fioris; palea inferiore 1-nervia carina scabra. Megastachya Presl 1. c. In Mexico. $\odot$.

113. P. panicoides $\mathbf{K u n t h}$; culmis compressis repentihus; spiculis lanceolatis 6-floris utrinque oltusis; glumis obtusis; paleis obtusissimis aristulatis pilosis. Megastachya Presl I. c. In Acapulco Inexicanorum. 4.

119. P. uninervia Funth; culmo compresso subramoso glabro; vaginis folisque convolutis scahris; panicula contracta; spiculis secundis 5-floris; glumis paleisque inferioribus obtusis 1-nerviis. Megastachya Presl 1. c. In Mexico. 4.

120. P. condensata Kunth; culmo erecto tereti glabro; vaginis pilosis; fol. convoluto-filiformilous extus margineque scabris; panicula cylindrica densa; spiculis lanceolatis 8-floris; 
glumis caducis 1 -nerviis. Megastachya Prest 1. c. In Mexico. 4.

121. P. nitens Kunth; paniculae ramis solitariis-ternis ad hasin fere foriferis; spiculis secundis sessilibus 8 -10-floris; valvula exteriore sub apice aristulata subreflexa. Eragrostis Lk. Hort. 1. p. 193. In Aegypto et Subiu. $\odot$.

122. p. rucemosa Thunb. panicula coarctata; spiculis ovatis 9-floris; pelunculis hrevissimis. Thunb. prodr. 1. 21. In prom. b. spei.

123. P. sarmentosa Thunb. panicula elongata decomposita; spiculis imbricatis 6-15-floris; valvula inferiore ovata acuta 3 -nervia margine cariuaque denticulata scabra; caule sarmentoso-decumbente ramoso polyphyl10. Eragrostis Nees in Limnaea 7. p. 330. In Prom. b. spei. 4.

121. P. glabrota Kunth; panicuIa racenoso-composita; spiculis cinereis lanceolato - linearibus $6-8$-floris; culmo fasciculatim ramosissimo. Eragrostis Necs 1. c. In Prom. b. spei.

12.5. P. striata Thunh. panicula patente; spiculis ovatis sub-10-floris; culmo repente. Thumb. prodr. p. 22. in prom. b. spei, 4.

126. P. cyperoides Thumb. panicula elongata; ramis a hasi glomerato-spicalis ; axillis ferrugineo-tomentosis; valvula inferiore trinervia superiorem aequante; culmo semiteretitrigono; fol. distichis convoluto-pungentilus. Eragrostis Nees 1. c. In Prom. b. spei. 4.

12\%. P. filiformis Thunb. panicula patente; spiculis acutis 4-floris; fol. filiformilus. Thumb. prodr. p. 21. Nees in Limnaoa 7. p. 330. In Prom. $b$. spei. 4 .

128. P. curvula schrad. culnis erectis; fol. filiformibus curvatis; vaginis ore harbatis inferioribus villosis; valvula corollae exteriore ovatoohlonga 3-nervia. Eragrostis filiformis var. $\beta$. vaginis inferioribus villosis minor. Nees 1. c. In Prom. $b$. spei. 24.

129. P. cernua Willd. panicula contracta; spiculis duodecimfloris linearibus; vaginis fauce pilosis. Willd. in Act. am. nat. cur. Berol. 4. p, 182. In India orientali.

130. P. polymorpha Willd. panicula divaricata; spiculis 12-floris; corollis distantibus 3 -nerviis ovatis; va- ginis barhatis. Willd. 1. c. Eragrostis 11. et s. In India orientali et Hanillu.

131. P. procera Roxb. glahra; erecta; $3-5$-pedalis; ligula magna; ramis paniculac simplicihus; spiculis pedicellatis linearibus multifloris. Roxh. ind. 1. p. 334. In India orientali.

1:32. 1). cylindrica Roxtb. erecta; eracilis ; 12-18-pollicaris ; fol. gracilibus; panicula cylindrica; ramis adpressis 6-12-floris; floribus diandris: valva coroilae exteriore ciliata. Hoxh. ind. 1. p. 335. Megastachya schult. In Chinu.

133. Po lobata Kunth; paniculae thyrsiformi-contractae sublohatae radiis brevissimis; spiculis suhsessilibus 7-9-floris; floribus mucronatis; valvula superiore Ionge ciliata. Eragrostis Trin. 1. c. In Guinea et ins. Mauritii.

134. P. ciliata Roxb. glabra; suberecta; 1-2-pedalis; spiculis 6-12floris; valvis ommibus calycum et corollarum margine cilialis; semine globoso. Roxb. ind. 1. p. 336. Megastachya schult. In India orientuli.

135. 1). Loenigii Kunth; erecta; glahra; 1-3-pedalis; ramis paniculac linearis hrevibus, in fasciculos remotos congestis; spiculis 6-12-floris; seminibus olcordatis. Roxb. ind. 1, p. 336. India orientali.

136. p. diarrhena Schult. erecta; glabra; fol. longis acuminatis; panicula lineari dimidiam partem totins plantae constiluente; ramis expansis; spiculis 4-8-floris; floribus diandris. P. diandra Roxh). ind. 1. p. 337. In Bengalia.

137. I. elcgantula Kunth; suberecta glabra; $1-3$-pedalis; panicula oblonga nutante; ramis solitariis ramosis alpressis; spiculis 8-12-floris; semine glohoso. P. elegans Roxb. ind. 1. 1. 349 . P. chariis schult. In India orientali.

138. P. multiflora Roxb. suberecta; glabra; 6-18-pollicaris; panicula reliquae plantae longitudinem excedente nutaute; spiculis confertis 5070-floris; semine wloboso. Eragrostis Trin. I. c. In India orientali.

139. P. paniculata lioxb. erecta; glabra; 2-1-pedalis; fol. Iongis oribus vaginarum barbatis; panicula oblonga; ramis creherrimis filiformibus; valvis calycinis ciliatis; semino glo- 
hos0. Roxb. ind. 1. 1). 341. In Rudius orientali.

110. P. gangetica Roxb. dense caespitosa; panicula rara; spiculis linearibus $30-\frac{4}{4} 0$-floris. Roxh. ind. 1 . p. 341. Al ripas Gangis.

1+1. P. mucronuta sinnth; paniculae aequalis patulae ranis basi nudis; spiculis lanceolatis 10-13-floris; flosculis apice liberis; corollae valvula exteriore ohlusa sub apice hrevissime mucronata; vaginis margine et ad oras barbatis. P. mncronata Holh Nov. Sp. p. 6t. Eragrostis 11 . et s. Calotheca spr. In India orientali.

112. P. Rothii Kunth; paniculae elongatae atteunatae interruptae ramis verticillatis numerosis ramosissimis; spiculis 4-floris minutis; flosculis omnibus breve pedicellatis. P. interInpta Both Nov. Sp. p. 6\%. In India orientuli.

143. P. rupestris Roth; paniculae subcylindricae ramis densissime compactis brevissimis hasi barbatis; vaginis foliorum margine et ad oras barhatis. Koth Nov. Sp. p. 71. Megastachya 11 . et $\mathbf{S}$. In India orientuli.

1.1. P. stricta Roth: paniculae contractae ramis fasciculatis ramosissimis densis; spiculis (compressis sul)12-floris; flosculis ohtusis omnilus sessilibus. Roth Nov. sp. p. 96. In India occidentali.

145. $P$. intercepta $S m$. panicula coarctata elongata; spiculis sessilibus imbricatis 16-21-floris; valvula exteriore glabra, interiore ciliata; collo vayinae hrevissime pubescente. P. Interiupta 1. Br. prodi. p. 150. In Nora Hollandia.

146. P. diandra R. Br. panicula coarctata; ramis indivisis approximatix; spiculis lanceolatis sul-10-floris; perianthiis diandris; valvula cxteriore glabra, interiore ciliala. K. Br. 1. c. In Nora Hollumelia.

147. P. concinne R. Br. panicula coarctata simplicissima; ramis alternis pancifforis; spiculis hreviter pedicellatis 12-20-floris; perianthii valvula interiore sursum ciliata apice rotmulato; collo vaginae harbato. R. Br. prodr. 1. p. 180. P. venusta h. et s. In Nova Hollandia.

148. P. Teptostacliya $\boldsymbol{R}$. $\mathrm{Br}$. panicula cfusa; ramulis alternis hasi divisis; spiculis lanceolato-linearibus 8-12-floris; valvula exterioro glahra interiore utula; collo brevissimo cilialo. 11. Br. prodr. 1. p. 160. In Nora Ilollamalia.

1f.9. P. purrifora $R$. Br. panicula effusa capillari nulante; ramis divisis; spiculis racemosis distantibua \& 12-fluris; valvula interiorc erosotruncata. 18. Br. 1. c. P. micrantha spr. Eragiostis Trin. In Noca Hollundia.

150. P. stenostachya R. Br. grabra; panicula simplici stricta; ramis alternis subindivisis spiculisque divaricatis subulatis 7-10-floris; fol. involutis vaginisque laevibus. h. Br. 1. c. In Nora Iiollandia.

151. I’. pellucirla R. Br. trabra; panicula simplici stricta; ramis alternis subindivisis; spiculis linearibus sub-16-floris; floribns pellncidis; perianthii valvula interiore ohsolele ciliata; seminihus exsulcis reticulatis: collo brevissime ciliato. H. Br. 1. c. In Nora Hollandia.

1.5:. P. elegans R. Br. panicula effusa; ramis alternis divisis; spiculis linearihus planis 10-22-floris; valvula exteriore glabra, interiore nana unda truncata; foliorum collo barluato. H. Br. prodr. 1. p. 181. P. speciosa Sichult. In Nora IIollandia.

15.3. '. mbescens $R$. Br. panicula effusa; ramis alteruis patentibus; rachi pubcscente; spiculis sessilibus linearibus suh-?0-floris; valvula exteriore glabra, interiore ciliata. I. Br. 1. c. In Norka Hollandiu.

1.54. $\boldsymbol{P}$. deciniens $\boldsymbol{R}$. Br. panicula mutante; spiculis 2-3-floris; valvula exteriore dorso glabro marginibus sericeis apice obtuso, interiore ciliata: fol. anguslo-linearibus; ligula incisa. h. Br. 1. c. In Sova Ibollandia.

15.5. P. imbecilia T. Br. panicula subnutaule; ramis spicatis; spiculis distinctis 3 vula exteriore obtusa, dorso wlal,ro; ligula erosa. \$. Br. P. asthenes H. ef s. In Nove Hollundia.

1.56. P. abortira R. Br. panicula coarctata capitulaeformi ; spiculis congestis multiforis; valvula exteriore glabra, dorso alato, interiore replicata ciliata. H. Br. 1. c. In Nova Hollandia. 
c. spiculae paniculatae, compressae, pauciflorae.

15\%. P. anmua L. panicula subsecunda divaricata; ramis demum deflexis; spiculis oblongo-ovatis; ligulis superiorihus ohlongis; culmo subcompresso; basi interdun radicante. Mert. et Koch. germ. 1. p. 598 . Host. 2. t. 64. Engl. bot. 1141. var. $\beta$. supina. P. anuua varia Gaud. P. supina Host. 4. t. 2\%. In Europa, Caucaso, Sibiria, Africa boreali et America. $\odot$.

158. P. secunda Presl; culmo erecto compresso vaginisque glabris; panicula simplici contracta secunda; spiculis ovatis sub-1-fioris; palea inferiore sub-5-nervia scabra. Presl 1. c. In Chili. $2 !$.

159. P. aestivalis Presl; culmo crecto compresso vaginisque glalris; fol. margine scabris; panicula simplici patente; rachi glabra; paleis inferioribus obtusissimis. PresI 1. c. In Peruia. ๑.

160. P. infirma $\boldsymbol{H}$. et $\boldsymbol{K}$. culmis ramosis erectis; fol. ohtusis vaginisque glabris; spiculis oblongis 3-4floris; floribus distantibus; palea inferiore 5 -nervia. H. et K. 1. c. Megastachya R. et S. In Nova Granata. $\odot$.

161. P. laxa Hcenke; panicula subracemosa apice nutante; ramis filiformilus geminis vel solitariis; spiculis subtrifloris; ligula oblonga; radice fihrosa. Mert. et Koch. germ. 1. p. 599. Host. Gram. 2. t. 15. P. flexuosa sim. Engl. Bot. 1123. In Euroju. 4 .

162. P. arctica $R$. Br. panicula effusa; ramis paucifloris capillaribus locustisque coloratis; perianthii valvula basi lanata; carina lineaque marginali sericeis, interstitiis pubescentihus; ligula subquadrata erosa. $\mathbf{R}$. Br. P. Iaxa $\mathbf{R}$. Br. P. flexuosa var. $\beta$. Trin. In ins. Melville, Inalaschka, ins. St. Laurentii et Camtschatka.

163. P. minor Guud. panicula coarctata subracemosa uutante; ramulis capillaceis solitariis vel geminis; spiculis ovato-ohlongis 4-6-floris; ligulis inferioribus brevibus, superioribus oblongis acutis. Mert. et Koch. germ. 1. p. 603. P. stolonifera Bellard. In Carinthia. 4.

16t. P. cenisia All. panicula ae- quali oblonga patente; ramis geminis filiformibus; spiculis ovato-lanceolatis 3-J-floris; ligulis inferioribus brevibus truncalis; radice stolonifera. Mert. et Koch I. e. P. distichophylla Gaud. P. stolonifera Bellard. In Carinthic et monte C'enisii. 4.

16.5. 1. flexuosa Wahlenb. panicula diffusa patentissima; spicis ovato-oblongis :-1-floris; flosculis lanceolatis; ligulis inferioribus hrevibus truncatis; radice stolonifera. M. et $\mathbf{K}$. 1. c. Host. Gram. 4. t. 26. P. laxa Wahlenb. In Austria, Tyroli, Helvetia, P'yrenaeis, America boreali et Camtschatka. 4.

166. P. Halleridis $R$. et $\mathbf{S}$. panicula ovata patentissina; ramis capillaceis; spiculis ovatis 5-4-floris; ligulis inferioribus ovalibus acutiusculis; radice repente. M. et $\mathbf{K}$. 1. c. P. pallens Gaud. In Germania, Salisburgia et Helvetia. 4.

16\%. P. alpina L. panicula aequali ovali vel oblonga patentissima; ramis capillaccis; spiculis late ovatis 4-10-floris; flosculis ovatis ; ligulis inferioribus brevihus; radice fibrosa. M. et K. 1. c. var. $\beta$. vivipara Host. 2. t. 67. fig. dextr. Fl. Dan. 807. $\gamma$. minor $\delta$. brevifolia $\varepsilon$. badensis Haenke P. brevifolia DC. P. collina Host. 2. t. 66. P. trivialis Poll. P. thermatis Pers. P. cenisia Lk. P. Molinieri Ball. Misc. t. 5. f. 1. P. compressa Urv. In Europa, Cancaso, America boreali et ins. Maclovianis. 4.

168. P. anyusta Presl; culmo erecto conpresso vaginisque glabris; fol. compresso - canaliculatis scabris; spiculis ovatis 3-floris. Presl 1. c. In Peruvia. 4.

169. P. sudetica Haenke; panicula erecta patente; spiculis trifloris glaberrimis mucronatis; culmo erecto compresso; vàginis ancipitihns. Host. Granl. 3. t. 13. P. sylvatica Vill. Delpl. t. 3. P. trinervata DC. In Europa et Caucaso. 4.

170. P. sulcata Lag. panicula patula; spiculis sub-8-floris; calycis valvula exteriore 5-nervia; culmo vaginisque ancipitibus. Lao. Elench 3. P. commutata $\mathbf{R}$. et $\mathbf{S}$. In Valgrande. 4.

171. P. hybrida Gaud. culmo vaginisque compressis; spiculis subpubescentibus; glumis acuminatis nervo- 
sis. Gaud. Agrost. 1. p. 215. P. sudetica $\beta$. Trin. In Jura et Sudetis. 4 .

172. P. bulbosa I. panicula aequali ovali pateute; ramulis scabriusculis geminis; spiculis ovatis 4-7floris; culmo fasciculisque foliorum bulbosis. Mert. et Koch. 1. c. Host. 2. t. 65. var. $\beta$. viripara. P. bulboка $\beta$. Hoth. In Europa, Oriente, Cancaso, Sibiria et Barbaria.

173. $P$. triviulis $L$. panicula aequali diffusa; spiculis ovatis subtrifloris; flosculis basi villo laevi connexis 5 -nervis. M. el K. l. c. P. scahra Elırl. P. dubia Leers herb. t. f. f. 8. In Europa, Caucaso, Sibiria, Japonia et America boreali. 4.

18!. P. Lungeana Reichb. panicula aequali laxa; spiculis rhombeis 5-6-floris; culmo compresso hasi repente. Rchb. exc. 140. In rupibus ad Rhenum. 4.

175. P. pratensis I. panicula aequali diffusa; spiculis ovatis $3-5-\mathrm{flo}_{0}$ ris; flosculis hasi villo commexis 5 nerviis; ligula brevi truncata; radice repente. M. et K. I. c. P. trivialis Leys. $\beta$. Iatifolia Kunth. P. subcaerulea Engl. Bot. 1004. $\gamma$. angustifolia Kunth. Leers herh. t. 6. f. 3. P. strigosa et setacea Hoffm. In Europa, Cracaso et Sibiria. 4.

186. P. pallens Poir. panicula clongata; spiculis circiter duodecimfloris ; fol. longissimis ; canle compresso. Poir. Enc. 5. p. 91. In BuenosAyres.

17\%. P. bonariensis Funth; panicula oblonga angusta subuitida; spiculis 3-floris; glumis acutis villosiusculis. Festuca Lam. ill. 1. p. 192. In Buenos-Ayres.

178. P. viridis Schrcb. panicula diffusa; glumis lanceolatis 3-nerviis; ligula hrevi truncata. Pursh Fl. 1. p. 79. In America septentrionali. 2 .

179. P. fertilis Host. Gram. 3. $t$. 14. panicula aequali diffusa; ramis scabris suhquinis; spiculis ovato-lanceolatis 2-5-floris; flosculis basi subpilosis; radice fibrosa. M. et K. P. serotina Gaud. P. effusa Kit. In Germania, Snecia, Punnonia, Caucaso, Sibivia, Camtschatka et America boreali. 2.

180. P. limbata tink; caule ramoso; fol. vargina scahriuscula; ligula elongata; spiculis 5-floris; valvula exteriore ad basin villo vix ullo; nervo dorsali subvilloso. Link Hort. 1. p. 179. In Nepalia. 4.

181. P. nemoralis $L$. panicula aequali subsecunda; ramis scabris geminis quinis; spiculis elliptico-lanceolátis 2-5-floris; floribus basi pilosis; ligula brevissima subnulla; radice ropente. M. et K. l. c. var.

$\alpha$. vulyaris Kunth. Leers. IJerl. t. 5. f. 3. Fl. Dan. 749. Engl. Bot. 1265.

B. amiflora.

$\gamma$. firmula Host. 2. t. 71.

c. rigilula Kunth. P. polymorvina Wil). P. serotina Sclirad. P. platensis Ieers. P. palustris DC.

E. cooretutu Kunth. P. gracilescens schrad. P. trivialis Leers. P. dubia et Scheuchzeri sut.

ל. montunu.

भ. ylauca Kunth. P. glauca Smith. Engl. Bot. 1720.

9. caesia Kunth. P. glauca Poir. P. glancanthos Schleich. P. glaucescens Roth.

In Europa, Caucaso, Sibiria, Camtschatka et America boreali. 4.

182. P. crocata Hichx. panicula laxa patula; spiculis ovatis $4-5-10-$ ris pedicellatis; floribus subpubescentibus; fol. glabris; vaginis collo nudo; culno erecto glabro. Pursh Fl,

1. p. 80. In America boreali.

183. 7. subuniflora Kunth; fol. planis interne margineque scabris; panicula ramosa verticiliata secunda; glumis dorso ciliato-hispidis; palea inferiore sub apice titucronulata; flore sterili brevissimo. kimth Gram. 1. p. 115. et 339. 1. 83. Deyeuxia poaeformis ${ }^{1}$. et $K$. in Mexico. 4 .

1st. P. miliacea $1 / k$. fol. brevihus angustis laevibus; panicula obtusa ; valvulis laevissimis, apice truncatodenticulatis, interiore inclusa. Lk. Hort. 1. p. 17t. Aira Vill. In Gallia et Italia. 4.

18.5. P. sterilis Bilb. panicula attenuata; ramis brevissimis; spiculis subtrifloris acutis glabris; fol. hrevibus, culmeis disticho-patentibus. Bieb. cauc. 1. p. 62. P. serotina var. Trin. In Tauria. 2.

186. P. rariflora Desf. culmis caespitosis ramosis basi repentibus; ramis geniculato-adscendentibus glabris; ligula abbreviata rotundata gla bra; panicula valde depauperata; fio. 
ribus hasi villosis. Kunth Gram. 2. p. 473. t. 150. In Gallia. 4 .

187. P. Gaudini R. et s. panicula flexuosa; flosculis obsolete nervoois subvillosis; culmis caespitosis superne scabris. P. aspera Gaud. Agrost. 1. p. 198. P. caesia Sm. In Helvetiu et Scotiu. 24.

188. P. altaica Trin. paniculae coarctatae hispidac spiculis $2-3-10-$ ris; floribus elliptico-lanceolatis actutis obsolete nervosis basi contortuplicato-lanatis. Ledeh. ic. pl. ross. ill. 1. 225. Ejusd. alt. 1. p. 97. In Altai. 4.

189. $P$. compressa $I$. panicula secunda coarctata; spiculis oblongoovatis 5-9-floris; flosculis hasi villo commexis ; cu!no compresso ancipiti basi procumbente. M. et K. 1. c. Host. 2. t. 70. Fl. Dan. 742. P. muralis IVib. In Europa, Caucaso, Sibiria, Camtschatia et America boreali. 4.

190. P. amboinensis $\boldsymbol{L}$. panicula coarclata secunda; culmo tereli. Lim. mant. p. 557. In India.

191. P. remota $H$. et $\boldsymbol{K}$. culmo erecto simplici; fol. utrinque scabris; panicula coarctata; spiculis obtongis 8-floris; palea inferiore 5-nervia. II. et K. Nov. Gen. 1. p. 163. In Quito. 24.

192. P. depauperata $\boldsymbol{I I}$. et. $\boldsymbol{K}$. culmo erecto simplici; fol. convolutis vaginisque glahris; panicula ramosa verticillata; spiculis oblongis hifloris; palea inferiore 5-nervia. H. et $K$. 1 . c. P. pauciflora R. ot $\mathrm{s}$. In Quito. 4 .

193. P. mulalensis H. et K. culmo erecto compresso; fol. externe scabris; panicula ramosa verticillata patula; spiculis ovatis 3-floris; palea inferiore 5-nervia. H. et K. 1. c. In uuito. 4.

19.4. P. Sellorii Nees; ramis paniculae semiverticillatae apice densifluris ; epiculis subsecundis ovatis sub4-floris; floribus acuminatis hasi villis connexis; culno compresso; vaginis foliisque cartilagineo-marginatis glaherrimis. Nees in Mart. Bras. 2. p. 491. P. sudetica $\mathcal{\beta}$. Trin. In Montevideo. 4.

195. P. lanigera Nees; culmo simplici; fol. distichis compresso-carinatis externe sulcatis scaloris; spiculis 2-5-floris omnilus femineis; staminibus effetis; floribus basi longissime lanatis; palea inferioro dorso maryineque densissime sericeo-ciliata. Kunth Gram. 2. p. 469. t. 153. In Brasilia et Monterideo. 4.

196. D. Lamujinosa Poir. panicula subspicata coarctata; spiculis latissimis sub-10-floris; glunis corollae extus valde lannginosis mucronatis. Poir. Enc. 5. p. 91. Festuca lanata Spr. In Nonterideo et Cirili. 4.

198. P. Álopecurus fiunth; pancula ampla; spiculis nitidis compressis 6-8-fioris; ealycibus dorso margineque minute ciliatis; glumis bas! lana candida floccosa parce einctis. Arundo Gaudich. et Urville Mal. p. 33. Festuca Brongll. In ins. Maclovianis. 4.

193. P. borbonica Poir. culmis caespitosis simplicihus erectis; fol. convolutis filiformilus; spicula subbiflora; glumis 3-nerviis carina hispidoscabris. Irunth Gram.2. p. 475. t. 151. In ins. Borboniue.

199. P. Thouarsiana Kunth; culmo simpliei inferne repente; panicula patentissima; spiculis compressis lanceolatis 4-16-floris; palea inferiore 7-nervia; fructu ovato 3-angulari. Kunth Gram. 2. p. 477. t. 152. In Madagascaria.

200. P. dactyloides $\boldsymbol{H}$. et $\boldsymbol{K}$. culmo erecto; fol. convoluto-setaceis; panicula ramosa stricta; spiculis 3floris ; glumis paleisque subulatis, inferiore 5-nervia. Kunth. In monte Antisanae. 4.

201. P. holcoides Presl; culmo tereti vaginisque scabris; fol. conduplicatis cartilayineo - acuminatis; sub6-floris; glumis ovalibus acuminatis nervo medio scahris. Presl. in Rel. Ifaenk. 1. p. 2'́2. In Chili. 24.

\&02. P. angustata R. Br. panieula simplici coarcfata lineari-lanceolata; locustis $4-5$-floris; perianthiis apice erosis; valvula inferiore basi elanata. 18. Br: in Parry's Voy. p. 187. In Melville Island et Americu arctica.

203. P. abbreviata R. Br. panicula simplicissima suhovata; locustis 4-5-floris; glumae valvulis acutissimis, perianthia hasi lanata lateribus pubescentia aequantibus. $\mathrm{K}$. Br. 1. c. In Melville Island et America arctica.

201. P. australis R. Br. panicula subeffusa; spiculis 5-6-floris lanceo- 
Iatis; glumis scabris; periantlii valrula exileriore basi lanata; ligula brevissima. 1. Br. prodr. 1. p. 179. Alundo poaeformis. Labill. Nov. Iloll. 1. p. 27. t. 35. In Nork Hollandia.

20.5. N. Sieberiana spr. paniculae nutantis ranis flexuosis; spiculis coloratis; fol. filiformis angulatis ; ligula uulla. sipr. Cur. post. p. 35.1 . australis Nees. P. inuplexa Trin. In Nova Hollandia.

206. P. taeris R. Br. panicula subcoarctata; spiculis $\downarrow$-5̆-floris ; valrula exteriore basi parce lumata, apice scariosa; fol. setaceo-involutis; ligrula hrevissima. R. Br. 1. c. In Rova Iollandiu.

20\%. P. plebeja R. Br. panicula cffusa ; spiculis 5-6-floris Ianceolatis; glumis scabris; perianthii valvuIa exteriore cariua maroginibusque basi lanatis; ligula brevissima. H. Br. I. c. In Nova Hollandia.

208. P. affinis $\boldsymbol{R}$. $\boldsymbol{B r}$. panicula subeffusa; spiculis 4-5-floris lanceolatis; perianthii valvula exteriore hasi lanata; ligula brevissima. R. Br. 1.c. In Novu Hollandia.

209. $\boldsymbol{P}$. saxicola $\boldsymbol{R}$. $\boldsymbol{B r}$. panicula coarctata; spiculis 3-1-floris; glumis margine pubescentibus; valvula exteriore hasi nuda; maroginihus pubescentibus. 11. Br. 1. c. In Nova Hollanclice.

210. P. persica Trin. paniculae ramis augulato-filiformilus; spiculis elliptico-linearibus 3-6-floris; perianthiis linearibus nudiusculis; ligula producta. Trin. in Act. Petrop. 6. p. 1. t. 373. In Persia.

211. P. leptocoma Trin. paniculae ramis capillaceo-filiformibus laevissimis; spiculis sub-3-floris; perianthiis subobsolete nervosis lineari-lanceolatis, basi contortuplicato-lanatis. In Cumischatia.

212. P. stenantha Trin. paniculae ramis filiformibus; spiculis $\mathbf{2}-\mathbf{5}$-floris; perianthiis obsolete nervosis lanceolato-linearibus, basi subbarbulatis. Triu. 1. c. In Camtschatia, Unalaschlia et ins. Fúrayin.

213. P. ochtensis Trin. paniculae ramis subqualernis subangulato-filirormibus; spiculis sub 7-floris; perianthiis distincte nervosis ciliatis; hasi parce contortuplicato - lanatis. Trin. 1. c. In provincia Ocistensí.
21. P. caucasica T'rin. paniculac radiis $2-3$ filiformibus; spiculis $3-f l 0-$ ris; perianthiis obsolete nervosis elliptico-lanceolatis ad carinam pilosulis; ligulis subproductis. 'Trin. 1. c. In Cuncuso.

21.5. 1'. rotunilata T'rin. paniculae radiis angulato-filiformibus; spiculis 3-floris hreve pedicellatis; periauthiis obsolete nervosis lineari-ellipticis, dorso basique contortuplicato-villosulis. Trin. 1. c. In Inalaschtia.

216. P. fulva 'Prin. paniculae radiis subangulato-filiformibus; perianthiis obsolete nervosis lauceolato-ellipticis, basi vix barbatulis; radice repente. Trin. 1. c. In sinu Eschscholtziano et fietu Lotzebuensi.

17. I'. glumuris Trin. paniculae radiis 2-3 angulato-filiformibus ; spiculis 2-3-floris; periantliis linearilanceolatis acutis basi barbatis; ligulis brevissim is; radice repente. Trin. 1. c. In Camtschatia, ins. Laurentii, Unalasclilia et fretu Kotzebuensi.

215. P. umbrose Trin. paniculae radiis quinis angulato - filiformibus; spiculis $6-7$-floris; perianthiis distincte nervosis lineari-lanceolatis subvillosulis; radice repente. Trin. I. c. In Brasilia.

21.9. P. albida Turcs; paniculae radiis crassiusculo-filiformibus; spiculis sub-6-floris brevi pedicellatis ; perianthiis lineari-lanceolatis dorso hispidis; ligulis obsoletis. Trin. 1. c. In Nibivia transbaicalensi.

220. J. phryganodes Trin. paniculae ramis binis; spiculis herbaceis linearibus sub-1-floris; perianthiis obsolete nervosis lineari-lanceolatis indique nudis; radice stolonifera. Irin. 1. c. Ad fretum liot:ebuense.

221. P. costata Schumacher; panicula coarctata spicaeformi ; spiculis ovatis sub-3-foris subpubescentibus; valvulis florum nervosis; culuo erecto vel aulscendente tereti. Schumach. en. 1. p. 28. In Saelandia.

22\%. P. microstuchya Lk. fol. demum convolutis; pauicula elongata nutante; ramis capillaribus; spiculis 5-floris compressis; valvis acutatis 1-nerviis; valvulis glaherrimis. Link Hort. 1. p. 185. In Hontevideo. $\odot$.

233. P. aivoides Ítnth; panicula supradecomposita patente multiflora; ramis capillaribus; spiculis subbifloris; palea inferiore obsolete trinervia; va- 
ginis margine oreque pilosis. Aira Irasiliensis Raddi Agr. bras. p. 36. Eragrostis airoides Nees. In Brasilia. 4.

221. P. nutkaensis Presl; culmo erecto tereti; vaginis foliisque glabris convolutis; panicula superne simplicissina; spiculis linearibus utrinque acutis 8-floris; glumis paleisque inferioribus acutis. Presl in liel. Haenk. 1. p. 272. In sinu Nutka et Mexico. 225. P. eminens Presl; culno tereti glabro; panicula erecta spicacformi ; spiculis ovatis 6-floris; glumis ovatis 3-nerviis; floribus basi villo stipatis; palea inferiore acuta. Presl 1. c. In sinu Nutka. 4 .

226. $P$. subfastigiata Trin. paniculae radiis crassiusculis compressis et strictis; spiculis sub-5-floris; floribus lanceolatis undique nudis; ligula suprema productiuscula; radice repente. Ledeb. ill. pl. Ross. t. 224. In Altai et Sibiria iransbaicalensi.

22\%. P. mouticola Gaudich. culmis erectis simplicibus ; vaginis foliisque glabris convolutis apice rigidis collo harbatis; panicula longissima; spiculis 5-10-floris lineari-oblongis. Gaudich. in Freyc. Voy. p. 408. In ins. Sanduicensibus.

\section{Species dubiac.}

228. P. glutinosa Sw. panicula patente stricta; spiculis sub-9-floris birsutiusculis elutinosis; culmo simplici; fol. suhpilosis. Swartz prodr. p. 26. sloane list. t. \%1. f. 2. Eragrostis Trin. In Jamaica.

22.9. P. prolifera Sw. paniculis patentibus strictis; spiculis multifloris; culmo ramosissimo nodoso ad nodos prolifero. Swartz prodr. p. 27. In ins. Caribaeis.

230. I'. virginica Zucc. panicula patente; spiculis 20-floris appressis; fol. subtus glaberrimis; culmi nodis inferioribus latere gibhosis Zucc. Cent. n. 25. In America. $\odot$.

231. P. flava Gronov. panicula aiffusa; spiculis ovato-oblongis nitidis. Linn. Sp. p. 100. In Virginia.

232. P. subverticillata Pers. panicula laxa hasi verticillata; spiculis raris sub-5-floris; corollis laevihus. P. laxa Lam. ill. 1. p. 183. In Virginia.

233. P. Nutallii Kunth; panicula erecta subverticillata; spiculis raris lincaribus acutiusculis arcte imbricatis ; glumis calycinis inaequalibus brevissinis. P. tenella Nutl. Gen. 1. p. 6\%. In America boreali.

23t. D. spectabilis Pursh; panlcula ramosissima; spiculis pendulis lincaribus 10 -floris; floribus ovatis marogine dorsoque scahris; vaginarum collo axillisque paniculae pilosis. Pursh Fl. 1. p.81. P. amabilis Walt. Car. p. 80. P. refracta Muehleub. In America boreali. $\odot$.

235. P. tenuis Ell. panicula ramosissima patentissima capillari; spiculis trifloris glabris longe pedmculatis; fol. linearibus praelongis. Elliot bot. 1. p. 156. In Brasilia. 4 .

236. P. articulata Kunth; panicula brevi ovata composita patente; pedicellis inferioribus hifloris; palea inferiore ovata acuunata trinervia superiorem nudam superante; fol. margine calloso - tubercutatis ciliatisque; costa subtus albo-punctata. Eragrostis Nees in Mart. Bras. 2. p. 502. In Brasilia. $\odot$.

23\%. P. micrantlea schult. panicula diffusa capillari semiverticillata ramosissima; spiculis parvis sub-4floris; floribus exquisite striatis; ligulis lanceolatis acuminatis. P. parviflora. Pursh Fl. 1. p. 80. In America boreali.

238. P. Lamarckii Funtle; panicula diffusa capillari; spiculis glahris sub-5-floris; corollis exquisite striatis. Lam. ill. 1. p. 183. P. sulcata R. et \$. In Virginia.

239. P. autumnalis Muehlenb. caespitosa; fol. planis; paniculis diffusis; spiculis subtrifloris obtusis; floribus pubescentihus apice compressis. Elliot hot. p. 195. P. compressa Walt. In America boreali. 4.

240. P. nitida Elliot. culmo erccto glaberrimo; panicula majuscula diffusa capillacea subverticillata ; pedunculis praclongis; spiculis lanceolatis 8-floris. Elliot bot. 1. p. 162. In America septentrionali. $\odot$.

2+1. P. conferta Elliot; paniculis terminalibus axillaribusque erectis coarctatis confertifloris, spiculis 8floris glabris. Elliot. lot. 1. p. 158. P. glomerata Walt. Eragrostis Trin. In Americu boreali.

242. P. brachypliylla scluelt. panicula laxa; ramis horizontalibus ge- 
minis ternisve glabris flexuosis; spiculis 3-1-floris; glumis acutis; culno subangulato; radice repente. P. brevifolia Muchleub. descr. p. 139. In Pennsylvania. 24.

213. P. stolonifera Inuehlenb. panicula verticillata aggregataque diffusa ; culmo subscabro geniculato; stolonibus compressis; ligula inferiore ohtusa, superiore acuminata elongata. Muehlenb. descr. p. 139. In America septentrionali. 2 .

211. P. campyle Schult. panicula erecta rachique glabra et subscabra; ramis geminis alternis elongatis flexuosis bifidisque scabris compressis 4-floris; glumis acutis. P. flexuosa Muehlenb. descr. p. 148. In America boreali.

215. P. Torreyana Spr. paniculae elongatae ramis subspicatis; spiculis secuudis 4-floris; valvis nervosis ovatis acutis; fol. elongatis glabris; ligula nulla. Spr. N. Entd. 1. p. 104. P. elongata Torrey. In America boreali.

216. P. glomerata Thunb. panicuIa spicata glomerata; spiculis 4-floris; corollis ciliatis. Thuul,. prodr. p. 22. In Prom. b. spei.

217. P. tenuiflora Lichtenst. panicula verticillata ramosa conferta; spiculis linearibus 11-floris; flosculis distantibus. Lichtenst. in $\mathbf{R}$. et $\mathbf{S}$. Dyst. 2. p. 5̈6\%. In Prom. b. spei.

245. P. suuarrosu Licht. panicula contracta; ramis adscendentibus incurvis; spiculis 6-floris; glumis acutis :-nerviis; fol. culnes linearibus convolutis, radicalibus setaceis. Lichtenst. 1. c. In Prom. b. spei.

219. P. livta Thunb. panicula patula virgata; calycibus sub-3-floris angulatis; vaginis punctato-ciliatis. Willd. sp. 1. p. 399. In Juponic.

2.50. P. contracta Retz; panicula contracta; flosculis Ianceolatis trifloris undis sessilibus; fol. filiformibus. Rety obs. 3. p. 11. In India.

251. P. biflora Retz; panicula densa; calycibus subtrifloris glabris; culmo adscendente. Het $\%$ obs. 5. p. 19. Aira Koenigii Gmel. A. ciliata Spr. Eragrostis minutiflora PresI. In India orientali.

252. P. indica contracta capillari; linearibus; vaginis basi ramoso. Willd. in Act. Berol. 4. p. 194. In Inciia orientali.

2.53. P. caespitose schrad. panicula aequali subdiffusa; spiculis ovatis 4-floris subpubescentibus; fol. convolutis linearibus culmum superantibus. Spr. Mant. 1. p. 33. In Nova Zeelandia. 4.

25t. P. anceps Forst. panicula diffusa; spiculis 5 -floris acutis basi pubescentibus; culmo ancipiti. Forst. prodr. no. 43. In Nova Źeelandia.

25.5. P. Sprengelii Kunth; panicula Iaxa diffusissima; spiculis 5-floris linearibus; flosculis remotiusculis; fol. linearibus longissimis, P. imbecilla spr. Mant. 1. p. 33. In Nova Zeelandia.

2.56. R. digitata R. Br. spicis dlgitatis numerosis; spiculis imbricatis sub-7-floris; perianthii valvula exteriore obtusa, basi subsericea. $\mathbf{R}$. Br. prodr. 1. p. 182. Eleusine Spr. In Pora Hollandia.

2.5\%. floccosa Lehm. paniculis patulis abbreviatis; spiculis ovatis truncatis sub-6-floris; valvis trinerviis nudis obtusissimis; fol. lanceolatis rigidis glaucis; vaginis inferioribus floccoso - tomentosis. Lehm. pug. 3. p. 39. In Prom. b. spei. 4.

25s. tristriata Stev. panicula contracta; calycibus bifloris acutis; corollis obtusis; gluma exteriore trinervia; ligula exserta brevi. Stev. Stirp. rar. it. Caucas. in Act. Mosquens. 3. p. 232. In Caucaso orientali. 4.

25.9. P. scariosa Lay. panicula elongata contracta subsecunda; glumae valvulis scariosis cuspidatis; spiculis sub-7-floris. Lag. Elench. 3. In Hispania. 4.

260. P. leersioides Inunth; panicula contracta; ramis glabris; locustis ovatis 2-4-floris; fol. planis panicnlam excedentibus; ligula pilosa; radice fibrosa. Megastachya Presl Cyp. et Gram. Sic. in Schult. mant. 2. p. 330. In Sicilia.

261. P. triticea Kuntle; panicula spicata simplici; rachi inferne complanata; locustis ovalibus distichis compressis, sessilibus 6-floris; ligula exserta; culmis diffusis. Megastachya Presl 1. c. In Sicilia.

262. P. papposa Dufour; panicula patente; pedicellis flexuosis; spiculis sub-6-floris; foliorum vaginis apice papposo-pilosis. R. et $\mathbf{S}$. sub Me- 
gastachya in Syst. 2. p. 585. In HIspania.

263. P. 'Zeae $R$. et $S$. panicula ramosissima subcontracta; spiculis copiosissimis 7-floris, in ramis rigidis sessilibus appressis; fol. longissimis; culmo compresso. 13. et s. Syst. 2 . p. 558. In Nova Granata. 4.

264. P. dissitiflora R. et S. panicula stricta erecta; spiculis ovatis 5-7-floris; flosculis dissitis; ligula oblonga. R. et S. syst. 2. p.540. In Groenlandia.

265. P. gelida $R$. et $S$. panicula diffusa nutante rariflora; spiculis ovatis $\mathbf{5}$-7-floris; flosculis basi villo connexis; ligula brevissima; radice repente. 12. et $\mathbf{S}$. 1. c. In Groenlandia.

266. P. Kitaibelii Funth; paniculae patentis ramis hispidiusculis paucifloris; spiculis sub-4-floris; flosculis remotis basi villosis. P. depauperata. Kit. in spr. pug. 1. p. 7. In Pannonia. 4.

26\%. P. versicolor Bess. panicula magna subuutante; spiculis lanceolatis 5-floris; flosculis hasi lanatis 5zerviis versicoloribus; ligula oblonga; radice filrosa. Bess. en. p. 41. d. rupestris Bieb. In Vollynia.

268. P. gracilis H. Par. panicula verticillata subdiffusa; spiculis subE-floris obtusis; fol. convolutis rigidis glaucis. P. glauca Poir. Enc. 5. p. 73. Patria iynota.

26.9. P. Schullesii Kunth; panicuIa patentissima; spiculis lanceolatis 2-3-floris; ligula brevi bifida; paniculae ranis capillaribus longissimis. P. miliacea hit. in sichult. austr. ed. 2. 1. p. 227. In Comitatu Abaujvar. 280. P. caroliniana Spr. panicula patentissima; ramis subverticillatis; spiculis lanceolatis acutis 5-floris glabriusculis; fol. glabris. Spr. mant. 1. p. 33. In Carolina boreali. $\odot$.

271. P. spicuta L. panicula spicata; foribus subulatis ; flosculis remotis. Limn. Mant. p. 32. P. festucoides Lam. In Lusitania, Hispania et Belgio.

272. P. virgata Poir. panicula stricta longissima; ramulis appressis; spiculis secundis brevibus subtrifloris. Poir. Enc. 5. p. 78. Sloane hist. t. 72. f. 1. In St t. Domingo.

273. P. anomala Kunth; panicula contracta spiciformi; spiculis trifloris imbricatis ovatis obtusissimis; palea inferiore sub apice mucronata; ligula elongata truncato-lacera. Eragrostis Uniolae Nees in Mart. Bras. 2. p. 491. In confinio regni P'arayuayensis. 24.

27t. P. semineutra Trin. panicula diffusa; glumis acutis; flosculis calycem excedentibus, altero hermaphrodito, altero neutro. Aira Willd. ell. 1. p. 100. Phalaris? R. et S. P. trivialis var. Trin. In Hungaria. 4.

285. P. arundinacea Link; panicula oblonga secunda mutica imbricata; fol. planis. Aira Linn. sp. p. 95. Eragrostis collina Trin. In Oriente, Cancaso et Persia. 4.

zq6. P. melicoidea Ih. fol. demum convolutis; panicula elongata; ramis brevibus subsolitariis distantibus; valvis acutis 1-nerviis; valvula exterioro 3-nervia obtusissina scabra. Lk. Hort. 1. p. 186. Patria ignota. 4 .

27\%. P. malabarica L. paniculac ramis simplicissimis; floribus sessilibus; seminibus distantibus; culmo repente. L. sp. p. 100 . Syntherisma malabaricum Sw. Digitaria 12 . et $s$. Melica diandra koxb. In India orientali.

2\%8. P. rhenana Koel. spiculis 5 -7-floris ovatis; panicula patula; ligulis abortivis; ore calloso subciliato; fol. complicato-canaliculatis. DC. Gall. 3."1. 720. Circa Mogontiacum. 4.

\section{CENTOTHECA Beauv. (1813).}

1. C. Iappacea Desv. Journ. de Bot.1813. \%. 70. Beauv. Agr. t. 14. f. $\%$. Kunth Gram. $t$. $\%$ o. Cenchrus L. Poa Forst. P. malaharica L. Burm. ind. t. 11. f. 1. Uniola lappacea Trin. In India orientali, Moluccis, Nora Guinea, Java, Lazonia, Taiti, ins. Carolinae et Mariae-Annae, et $A$ instralia.

\section{GLYCERIA R. Br. (1810).}

1. G. aquatica Sm. panicula acquali diffusa ramosissima; spicutis linearibus 5-9-floris; floribus liberis 7-nerviis; nervis prominentibus; radice repente. G. spectabilis $M$. et $K$. Post L. Host. 2. t. 60. Engl, bot. 1315. F. Dan. 920. P. altissima Mocsich. 
Hierochloa Hartm. In Europa, Caucaso, Sibiria, Nora Hollandia et America boreali. 24. Culmus 4-6-pedalis. Panicula maxima.

2. G.? arundinacea Kunth; panicula diffusa; ramis longissimis; spiculis linearihus suh-J-floris; calycinis valvulis corollinis minoribus. Poa Bieh. cauc. 1. p. 6. G. spectabilis v. ¿. Trin. In Cuucuso. 4.

3. G. fluitans $\boldsymbol{R}$. Brr. panicula secunda divaricata; spiculis lincaribus 7-11-floris, fructiferis adpressis; floribus obtusis 7-uerviis; radice repente. M. et K. I. c. Festuca L. Schreb. Gram. t. 3. Ilost. 1. t. 3. II. Dan. 237. Schmidt Fl. t. 10. Poa scop. In Europa, Cancaso, America boreaii, Chili et Nova Hollandia. 4.

4. G. rauciflora Presl; panicula crecta composita patentissima; spiculis 4-floris patentibus; glumis rotumdatis 1-nerviis; palea inferiore 5-nervia. Presl in hel. Mảenk. 1. p. 257. In sinu Nutka. 4.

5. G. Michanxii Krunth; radice subrepente; culmo suhangulato; vaginis vix apice fissis foliisque scabriusculis exterue striato-sulcatis; spiculis 5-6-floris; floribus diandris. Kunth Gram. 1. p. 118. et 343. t. 85. P. striata Michx. P. nervata Willd. P. lineata Pers. In Pennsylvania et Virginia. 4 .

403. PLEUROPOGON R. Br. (1S10).

1. P. Sabini R. Br. Cloris Melv. p. 31. t. D. Ejusd. in Pary's Voy. t. D. f. 1-10. In ins. Nelville et Ameca arctica. Gramen elegans. Hacemi cernui purpurei nitentes.

\section{REBOELEA Funth (1S33).}

1. R. gracilis Kunth Gram. t. 81. Airopsis obtusata Desv. Eatonia purpurascens Raf. Koeleria peunsylvanica DC. Aira Spr. in Act. Petrop. t. 7. A. truncata Muehlenb. Aira nitida Spr. In America boreali. 4.

\section{CATABROSA Beauv. (1813).}

1. C. aquatica Beauv. t. 19. f. 8. panicula aequali diffusa; spiculis linea- ribus plerumque bifloris; Aoribus trinerviis; radice repente, $M$. et K. I. c. Aira L. Vaill. Bot. Par. t. 17. f. 7. Host. Gram. 2. t.41. Engl. hot. 15j7. Poa airoides Koel. Molinia IVih. Glyceria smith. G. airoides Rchh. Colpodium aquaticum Tiril. In Europa, Catcaso, Sibiria et America septentrionuli. 4.

3. C. ririlula R. et $\mathbf{S}$. fol. planis; panicula coarctata; pedunculis verticillatis subsecuudis; corolla glabra vix longitudine calycis. Aira viridula Poir. Enc. suppl. 2. p. 75. Aira scabra Hortul. Putria iynoice.

3. C. pumilı R. et $\mathbf{S}$. panicula parva fastigiata; florihus muticis obtusis calyce duplo longioribus; valvulis margine membranaceis. Aira pumila Pursh Fl. 1. p. 76. In Pennsylvania. 4.

4. C. humilis Trin. panicula patente; flosculis muticis calyce duplo longiorihus; glunis truncatis apico membranaceis denticulatis. Aira humilis Bieb. Fl. 1. p. 5\%. Colpodium bulbosum Trin. In Caucaso. 4.

5. C. minuta Trin. panicula laxa subfastigiata ramosissima; flosculis muticis. Aira ninuta Loefl. it. p. 117. sclireb. Granı. t. 12. f. 2. Airopsis Desv. Poa Trin. In Hispania. $\odot$.

6. C. tenuifolia Presl; fol. angustissime linearibus canaliculatis; paniculae ramis alternatim fasciculatis scahris; spiculis ovatis 3-floris. Prest in Rel. Haenk. 1. p. 256. In Chili. 4 .

\%. C.? scabra Kunth; panicula patente verticillata; flosculis muticis margine foliorum ramulis calycihusque rërorsum scahris. Aira Zuccariu. Cent. n. 24. Patria ignota? 4.

\section{COELACHNE R. Br. (1810).}

1: C. pulchella R. Br. Kunth Gram. t. 113. In Nova Hollandia. Culmus ramosus ramis adscendentibus. Panicula angusta.

\section{BRIZA L. (1737).}

1. B. maxima $L$. panicula apice nutante; spiculis oblongo-cordatis $1: 3-$ 17-floris. Schrad. Germ. 1. p. 110. 
Host. 2. t. 30. Jacq. ols. t. 60. Silitl. Graec. t. 76. In Europa australi, Prom. b. spei et in India. 24. $\odot$.

2. B. rubra Lam. pauicula simplici; spiculis cordato-ovatis erectis 9-floris; glumis margine rubris. Lam. ill. 1. p. 187. B. maxima $\beta$. DC. In India orientali.

3. I. mulchella Kunth; panicula depauperata 2 -3-stachya; spiculis nutantibus suhrotutio-ovatis 8-12-floris; palea inferiore glaberrima 7-nervia; fol. ciliatis. B. major. L. In Teneriff $\iota . \odot$.

t. B. media L. panicula erecta patente; spiculis demum cordatis 5 -9floris; calyce flosculis minore. Schrad. Germ. 1. p. 309. Hl. Dall. 258. Host. Gram. 2. t. 29. Engl. bot. 310. B. tremula Koel. var. B.repens scheuchz. Ayr. t. 4. f. 9. In Europa, Tauria et America septentrionali. 4.

5. B. elatior Sibth. Graec. $t$. $\% 5$. spiculis cordatis 12-floris; calyce flosculis breviore; corollä giblıosa; stipula hrevissima ohtusa. simith prods. 1. p. 57. In monte Athos. 4.

6. B. virens $L$. spiculis ovatis; calyce flosculis (7) aequali. Lim. sp. p. 103. Heyne term. bot. t. 25. f. 6. B. media $\beta$. Trin. In Europa, Asia minore, ins. Mauritii, Prom. b. spei et America. $\odot$.

\%. B. minor L. panicula erecta diffusà; spiculis triangularilus, 5-7floris; calyce flosculis majore. Sclurad. germ. 1. 1. 308. Host. Gram. 2. t. 28. Engl. hot. 1316. Sibtlı, Graec. t. 74. B. aspera Kuapp. t. 61, In Europa australi, Aegypto, Persia, Prom. b. spei, Brosilia et Peruvia. $\odot$.

8. B. spicata Sibth; spiculis ovatis erectis 7-floris; calyce flosculis breviore; corolla ventricosa; panicula subspicaia erecta. Smith prodr. 1. p. 57. B. humilis lieb. In monte Parnasso, T'auria et Smyruic. $\odot$.

9. $\boldsymbol{B}$. canadensis Michx. spiculis 4-10-floris; gluma communi parvula; florum valva exteriore acuta ovata; fol. longis; culmo erecto. Pursh am. 1. p. 82. Poa Beauv. Gilyceria Trin. in Cunada et Pennsylvania.

10. B. geniculatı 'hunb. spiculis ovatis; calyce floribus breviore; culmo geniculato. Thunb. prodr.1. p.21. In jrom. b. spei.

11. B. murpurascens Muehlenb. culmo erecto; vaginis nodisque glabris; fol. setaceis abbreviatis; ligula pilifera; spiculis 5 -floris purpurascentihus, una sessili altera pedunculata. Muchlenb. descr. p. 154. Megastachya schull. Calotheca spr. In Carolina.

\section{CHASCOLYTRUM Desi. (1813).}

1. C. erectum Desv. lignla elongata; panicula subsimplici; spiculis subduodecimfloris majoribus; palea inferiore acuto-sulsmucronata dorso glabra. Kunth Gran. 1. p. 345. t. 86. Briza Lam. Festuca spr. In Montevideo. $\odot$.

2. C. subaristatum Desv. ligula brevi; panicula ramosa; spiculis 8floris minoribus; palea inferiore apice bidentata mncronato - aristata dorso hispidula. Kunth Gram. 1. p. 347. t. 87. Briza L. Calotheca brizoidea. Beauv. t. 17. f. 1. Festuca Commersonii Spr. In Montevideo.

3. C. barbatum Kunth; pedicellis inferioribus bifloris ; spiculis suborbiculatis 10-floris; superiore palea infracta barba porrecta; fol. planis vaginisque villosís. Calotheca Nees Briza Trin. In Brasilia. $\odot$.

4. C. rotundatum Runth; culmo glumis foliisque scabrís convolutis; panicula verticillata; spiculis subrotundis 6-floris; paleis glabris; arista brevissima. Bronus $\mathbf{H}$. et $\mathbf{K}$. Nov. Gell. 1. p. 15\%. Calotheca $\mathbf{R}$. et $\mathbf{s}$. In Mexico. 4.

5. C. spicigerum Presl; culmo, vaginis foliisque scabris; spiculis ohovatis compressis scabris sub-4-floris; arista brevissima. Presl 1. c. In $\mathbf{P} e-$ ruvic et Chili. 4.

6. C. rufum Presl; culno foliisque scabris planis; spiculis ovatis compressis sub-3-floris glomeratis scabris; arista brevissima. Presl l. c. In Peruvia.

\section{CALOTHECA Lunth (1833).}

1. C. elegans Beanv. Agr. t. 17. f. \%. Funth Gram. t. 88. panicula erecta; spiculis ovatis glabris aristatis; corollis superne dilatato-auriculatis membranaceis. Bromus brizoides Lanı. ill. 1. p. 103. C. poaeformis Spreng. 
Briza Lamarckiana Nees. C. dilatata Lk. In Montevideo. 4.

2. C. tribob Kunth; paniculis racermosis; spiculis sub-4-gonis ovatis 10-12-floris; palea inferiore 3-loba; lobo medio acuto 9-nervio. Briza Nees in Mart. Bras. 2. p. 482. In Monterideo. 4.

3. C. macrostachya Presl; culmis vaginisque glabris; panicula subspicata; spiculis ovoideis tetrayonis sub10-floris glaberrmis, inferiore 5-, superiore 7-ilervia. Presl I. c. In Peruciu. 4 .

1. C. reniformis Prest; culmis apice scabris; panicula coarctata subspicaeformi; spiculis rotundato-ovatis 4-gonis; paleis rotundato-reniformibus acuminatis brevissime aristatis. Presl 1. c. In Peruria. 24.

5. C. microstachiya Presl; culmis apice vaginis foliisque scahris; panicula contracta composita; spiculis ovatis; glumis inferiorihus 3 superioribus 5-nerviis. Presl loc. ${ }^{\prime}$, "ia "eruria. 4.

\section{MELICA L. (178\%).}

1. M. ciliata $\mathbf{I}$. flosculi inferioris petalo exteriore ciliato; panicula subspicuta aequali; spiculis erectis. schrad. Germ. 1. p. 266. Host. Gram. 2. $t$. 12. Beckeria Bernl. In Europa, Caucaso, Sibiria et Persia. 4.

2. M. persica Kunth; vaginis foliisque externe puhescenti-villosis, interne villoso-tomentosis albidis; ramis adpressis; spiculis sub-6-floris; flore infimo dorso pilis longissimis mollihus patentissimis obsito. Kunth Gram. 1. p. 122. et 351. t. 89 . In Persia.

3. MI. Caffrorum Sclirad. fol. vaginisque scaberrimis; panicula subsimplici secunda; spiculis trifloris; flore tertio imperfecto; valvula florum exteriore margine ciliata. Schrad. in Goett. Anz. 1821. n. 208. In Prom. b. spei. 4.

4. M. Bunlini All. paniculae ramis horizontalibus; spiculis secundis; flosculi inferioris petalo exteriore ciliato. Willd. en. p. 201. Host. Gram. 4. p. 23. M. pyramidalis Desf. M. setacea Pers. In Europa meridionali et Barbaria. 4.

5. M. aspera Desf. fol. angustis convolutis asperis; panicula patente pyramidata; glumis imberbibus. Desf. Atl. 1. p. 71. H. ramosa Vill. M. pyramidalis Lam. N. minuta All. In Enropa australi, P'eloponneso et ins. Cypri. 4.

6. M. sarmentosa Nees; ylumis subaequalibus ovatis patulis spiculam subtrifloram aequantibus; floribus exasperatis glahris; culmo sarmentoso prostrato; ligula truncato-lacera. Nees ill Mart. Briss. 2. p. 485. In Brasilill. 4 .

\%. M. minuta L. culmo filiformi subramoso ; fol. lineari-angustissimis; ligula elongata; flosculis nutantibus imberbibus." Bertol. Amoen. it. p. 111. M. saxatilis Sm. Sibth. Graec. t. 71. 17. nntans Cav. ic. t. 175. f. 2. M. raceuniosa Lois. In Italia et Graecict. 2 .

8. M. nutans $L$. petalis imberbibus; panicula subsecunda laxa; spiculis nutantibus ovatis 3-floris; flosculo tertio imperfecto. schrad. Germ. 2. p. 20\%. Host. Gram. 2. tt. 10. Schreb. Gram. 2. t. 6. f. 2. Engl. Bot. 1659. In Earopa, oriente, monte Atlios et Sibiria. 4.

9. M! macra Tees; glumis subaequalibus oblongis convolutis "acutis, spicula subtriflora lanceolata nutante brevioribus; panicula secunda; fol. strictis apice 1-2-dentatis; ligula obsoleta. Nees 1. c. In Ionterideo.

10. M. uniflor Ret $^{\text {; }}$ petalis intberbibus; panicula ramosa secunda; spiculis erectis ovatis hifloris, altero inperfecto. Schrad. Gern. 1. p. 209. Host. 2. t. 11. Fl. Dả. 114. Engl. bot. 1058. Poa Lobelii Vill. Delph. t. 3. f. 3. M. untans Lam. In Europa et Oriente. 4.

11. M. scabra I. et $K$. fol. interne puisescentibus ciliatis; panicula sinplici secuuda; spiculis bifforis; flore altero imperfecto; palea inferiore 7-nervia. H. et K. Nov. Gell. 1. p. 164. In Quito. 2.

12. MT. pallida H. et $K$. fol. vaginisque pubescentibus; panicula ramosa patente; spiculis bifloris; flore altero imperfecto; palea inferiore 7nervia glabra. H. et K. Nov. Gell. 1. p. 164. t. 693. In Quito. 4.

13. M. chilensis Presl; vaginis foliisque margine ciliatis utrinque scabris; spiculis bifloris; glumis acutis; flore altero imperfecto clavato, alterius palea inferiore 7-nervia tubercu- 
lata apice appendiculata. Presl 1. c. In Chili. 24.

14. M. speciosa Muehlenh. petalis imherbibus; panicula simplici; ramis patentibus; spiculis secuudis. IVilld. ell. p. 102. M. altissima $\beta$. Willd. Moris. hist. 3. s. 8. t. \%. f. 51. M. glabra Michx. M. rariflora śchreb. 1. 54. M. mutica Walt. In America boreali. 4.

1.5. M. altissime L. petalis imberhibus; panicula coarctata secunda interruptis; ramis adpressis. Willd. en. p. 102. Host. 2. t.9. M. Sibirica Lan. Gmel. sil. t. 20. In Sibiria, Caucaso, Galicia et Pamonia. 24.

16. 17. diffusa Pursh; panicula diffusa ramosissima; floribus acutis inberbibus; caule erecto pubescente. Pursh Fl. 1. p. 7\%. M. altissima Walt. In Virginia et Carolina. 2!.

17. M. aurantiaca Desrouss. panicula subspicata; calycis valvula exteriore maxima amantia. Cav. ic. t. 472. f 1. In Monterideo.

18. M. papilionaceu $L$. caiycis valvula inferiore maxinia, colorata; petalo exteriore subciliato. Limn. mant. p. 31. P. brasiliana Ard. sp. t. 6. f. 1. et 2. In Brasilia et Mexico. 4.

19. M. violacea Cav. pauicula subspicata secunda corollis violaceis ciliatis; calycis valvula exteriore argentea apice denticulata. Cav. ic. 5. p. 47. t. 472. f. 2. M. papilionacea 3. Desrouss. In Chili.

20. N. rigida Cav. panicula subspicata secunda; calyce corollis aequali; corollarum altera ciliata. Cav. ic. 5. p. 47. t. 472. f. 1. In Montevideo.

21. M. laxiflora Cav. panicula divaricata; calycis exteriore valvula corollis longiore, corollarum altera ciliata. Cav. ic. 5. p. 48. t. 473 . f. 2. In Chili.

22. M. Gmelini Turcz; panicula patentissima; pedicellis barbulatis ; floribus $1-3$ perfectis apice membranaceo-appendiculatis; inferioribus pilis adpressis. 'Trill. in Act. Petrop. 6. 1. p. 368. Gmel. sil). 1. t. 19. f. 1. In Sibiria transhaicalensi.

23. M. viryata Turcs; panicula subthyrsiformi-racemosa elongata; pedicellis barbulatis; glumis inaequalibus flosculis tertiam partem brevioribus; flosculis 3 perfectis membranaceo-subappendiculatis dorso pilis ad- pressis. Trin. 1. c. In Sibiria transbuicalensi.

2t. Wh. racemoca Thunb. corollis hirtis; racemis cernuis; culmo erecto. Thunh. prods. p. 21. In Prom. $b$. spei.

2.5. MT. decumbens Thanb. corollis hirsutis; floribus racemosis nutantibtis; culmo decumbente. Thunb. prodr. p. 21. In P'rom. b. spei.

26. M. festucoides Licht. corollis glabris hasi pilosis; panicula erecta; ramis simplicibus adscendentibus ahhreviatis. Lichtenst. in IR. et $\mathbf{S}$. syst. 2. p. 530. In Prom. b. spei.

2\%. M. dendroides Lellm. racemis sulocompositis; spiculis nutantibus muticis; corollis villosis calycem glahrum aequantibus; culmo ramosissimo foliisque scaberrimis. Lehm. pug. 3. p. 39. In Prom. b. spei. 4.

28. $M$. digitata Roxb. culmis 45-pedalihus; spicis plerumque quinatis; calyce 1-floro; valvis exteriorihus cciollae, rudimentoque aristatis. lioxb. ind. 1. p. 328. Clenium Spr. In India orientali.

29. M. refiacta Roxb. perennis: adscendens; fol. lanceolatis; panicula ovata; ramis refractis; petalis barbatis setosis; setis rigidis refractis. Roxb. ind. 1. p. 329. In ins. Moluccanis. 4.

30. M. major Sm. petalis imberhibus; panicula divaricata; ramis hinatis; floribus cernuis; culmo simplici; fol. involuto-pungentilus. Smith prodr. 1. p. 51. Patria ignota. 4.

31. M. Muehlenbergiana Schult. ligula pilifera subhifida; panicula sexflora; flosculis nutantihus; gluma calycina altera obtusa, altera acuta glabra. M. racemosa Muehlenb. decr. p. 88. In Carolina et Georgia. 4.

32. IH. capilluris Russ. panicula capillari patentissima; corollis imberbibus cylindraceo-suluulatis. Russel Besclir. von Aleppo 2. p. 147. In Aleppo.

33. M. exasperata R. et $\mathbf{S}$. panicula racemosa secunda; spiculis superioribus nutantihus; petalo exteriore floris infimi ciliato-barhato; fol. scaherrimis. R. et s. syst. 2. p. 530. I. asperrima Thouin. Patria ignota. 24.

34. M. hirsute Koel. panicula coarctata; fol. linearibus hirsutis ciliatis; calycibus sessilibus sub-3-floris; 
floribus muticis. Koel. Gram. p. 144. M. Gmelini Hoth. Aira Gmel. P'rope Tubingam.

\section{MOLINIA Schrank. (1789).}

1. M. caerulea Moench. panicula sulbcoarctata; spiculis erectis mulicis subtrifloris; floribus 3-nerviis; culmo subnudo. Mert. et Koch. 1. c. Aira L. Leers lierb. t. 4. f. 5. Fl. Dan. 239. Melica L. mant. Engl. bot. 750. Host. 2. t. 9. Enodium Gaud. Aira atrovirens Thouill. var. $\beta$. major; sylvatica; spiculis multifloris. M. altissima Lk. Molinia arundinacea Schrank. M. littoralis Host. Enodium littorale Rchb. In Europa. 4.

2. MI. serotina Mert. et Koch. panicula patente; spiculis $\mathbf{2}-\mathbf{5}$-floris subaristatis; florihus 5-nerviis; culmo vaginis obtecto. M. et K. 1. c. Agrostis et Festuca L. Host. Gram. 2. t. 92. Bromus Scop. Schoenodorus $R$. et S. Diplachne Lk. In Europa australi. 2.

3. M. squarrosa Trin. spiculis subtrifloris subadpressis; floribus acuminato - conoideis, 5-nerviis; culmo flexuoso-sqarroso; fol. culmeis setaceis. Ledeb. ic. pl. Ross. ill. t. 227. Hl. alt. 1. 1. 205. In Altai.

\section{KOELERIA Pers. (1805).}

\section{Muticae.}

1. $\boldsymbol{K}$. cristata Pers. panicula spicaeformi; spiculis 3-4-floris acutissimis; fol. planis inferiorilus ciliatopubescentibus; culmo glabro. Aira L. Engl. bot. 648. Poa With. Host. Gram. 2. t. 75. Dactylis Bieb. Festuca Vill. Airochloa Lk. Poa pyramidata Lam. P. gracilis Pers. P. nitida Lam. Koeleria grandiflora Bertol. In Europa, Caucaso et Sibiria. 4.

2. K. glauca DC. panicula spicaeformi; fol. planis glaucis; culmo longe exserto glabriusculo. DC. Cat.Monsp. p. 116. Aira Spr. Fl. Dan. 1566. Poa Schrad. Dactylis lobata Biel). K. 10bata R. et S. Airocliloa cristata $\beta$. glabra Lk. Festuca glaucescens Hoth Nov. Sp. In Germania, Oelandia, Tauria et Sibiria. 4.
3. I. albescens DC. panicula spicaeformi basi folio superiore subvaginata; spiculis $\mathbf{2}-\mathbf{3}$-floris muticis; fol. inferioribus angustissimis. DC. Cat. p. 117. Airochloa albescens Lk. In Gallia. 4.

4. K. Linkii Kunth; canle superne pubescente; glumis floribus parum longioribus; palea exteriore sub apice aristata, carina ciliata lateribus pilosa. Airochloa Lk. Hort. 1. p. 128. In Gallia anstrali. 4.

5. K. nitida Nutt. spica elongata lobata; lolis adpressis; pedicellis brevissimis ; fol. vaginaque subpubescentibus; ligula pilosa. Nutt. Geu. 1. p. 74. Ad Missouri. $\odot$.

6. K. paniculata Nutt. panicula oblonga glahra; spiculis 2-3-floris nitentibus; valvula calycis majore truncata obtusa. Nutt. Gen. 2. In Florida orientali.

\%. K. valesiaca Gaud. panicula dense spicata; spiculis sub-2-3-floris acuminatis ; fol. convoluto - setaceis glaberrimis; culmo longe exserto glabro. DC. Agrost. 1. p. 149. Aira All. Airochloa Lk. In V'alesia. 4.

8. I. capensis Nees; panicula spicaeformi subcontinua; spiculis subtrifloris ; valvulis oblongo-lanceolatis glumisque ad carinam scabris; culmo foliisque caulinis pubescenti-scabris, his basi ciliatis. Nees in Mart. Bras. 2. p. 321. Aira capensis Steud. In prom. b. spei. 4.

9. $K$. setacea $D C$. panicula denso spicata; spiculis 2-3-floris acuminatis; glumis clorso ciliatis ; fol. glaberrimis; culmo exserto apice velutino, DC. Cat. p. 118 . K. tuberosa $\beta$. Pers. Festuca splendens Pourr. Poa pectinata Lam. K. splendens Presl. In Europa australi. 4.

\section{Aristatae.}

10. Z. hirsuta Gaud. panicula subovata, hasi vix interrupta; spiculis bifloris hirsutis valvulis apice aristatis ; culmo apice tomentoso. DC. Cat. p. 118. Festuca DC. Gall. Aira Schleich. In Valesia. 4.

11. K. villosa Pers. panicula spicaeformi ovali-cylindrica; spiculis 2. floris, dorso villosis; fol. planis mol liter villosis. DC. Cat. p. 118. K, pubescens Beauv. Trisetum Trin. Aira Vahl. Alopecurus littoreus All. Pha- 
laris Barellieri Ten. Airochloa Lk. var. $\beta$. macilenta Agialitis temuis Trill. In Hisyania, Gallia australi, Italia tt IIuritiana. $\odot$.

12. K. phleointes Pers. panicula cylindracea; spiculis $2-5$-floris; flosculorun valvula exteriore extus piloso-exasperata suh apice aristata; arista molli. DC. Cal. p. 119. Festuca Vill. Delph. t. 2. f. 7. Desf. AtI. t. 23. Host. 3. t. 21. Trisetum Trin. Bromus alopecuroides Lag. Koeleria cristata Bertol. Isophochloa Rchlo. In Europa, Creta, Martinica et Tauria. ๑.

13. K. hispida DC. panicula spicaeformi; flosculorum valvula sub apice aristata extus pilosa; crista rigida flosculorum longituline. DC. Cat. p. 119. Nestuca Savi Pis. t. 1. f. 5. Cynosirus phleoides Desf. Atl. t. 18. In Algiria et Itulia. $\odot$.

1t. K. brachystachya DC. panicula spicaeformi ovata; perigonii valvula exteriore glabrata sub apice aristata; fol. planis pubescentibus. DC. Cat. p. 120. Trisetum phleoides var. pumila brachystachya Trin. Bromus cristatus Spr. In Pyrenaeis. $\odot$.

15. K. $\operatorname{taxa} L /$. fol. angustis glahris ciliatis; panicula spicaeformi interrupta; glumis longe acutatis; palea exteriore nervosa laevi, sub apice arista longinscula instructa. Lk. Hort. 1. p. 161. In Aey!nto. $\odot$.

16. K. mucilentu DC. panicula gracili laxa; spiculis glabris lucidis subaristatis $3-4-$ floris; radice amuna. R. et s. Trisetum macilentum Trin. Festuca sicula Presl sic. In Hispania, Gallia et Nicilia. $\odot$.

17. K. Alopecurus Nees; panicula serrato-lohata; spriculis sulutrifloris lanceolatis; valvulis hrevisetigeris, culmo foliisque linearihus elongatis glahris. Nees in Limaea 7. p. 320. Alopecurns capensis Ecklon. Herb. 9t\%. In Prom. b. spei. 4.

\section{Species dubiae Kunlh.}

18. F. macrantha Schult. panicula oblonga interrupta mutica; glumis acuminatis; flosculis calycem excedentilus; fol. brevissimis glabris; ligula elongata hifida margine lacera. Ledeb. in Act. Petrop. 1812. p. 515. sub Aira. In montibus Jablomuoichrebet.
19. K. intermedia Fries; culmo apice puhescente; fol. radicalibus subsetaceo-linearibus glabris ; ligula brevissima. Fries Nov. Wl. suec. p. 2. In Suecir.

20. K. tumicata Presl; panicula spicata elongata; rachi pilosa; locustis 4-floris glahris; palea apice triaristata; culmis basi nodosis reticulato-tunicatis. Presl Cyp. et Gram. Sic. 1). 34. In Siciliu.

21. R. Aluctyloirles Rchb. thyrso subspicato Ioloato ; hracteis bracteolisque lohatis; fol. glaucis rigidulis glabris. Aira dactyloides Hoch. Beauv. t. 1. f. 3. In Ranatu. 4.

\section{SCHISMLS Bean: (18I2).}

1. S. marginatus Beam, panicula coarctata; spiculis linearihus; calyce flosculis longiore; fol. basi harhatis. Festuca l. Cav. ic. t. 44. f. 2. Lam. ill. t. 46. f. 5. Koeleria DC. In Hispanie, Gallia et Prom. b. spei. $\odot$.

2. S. minutus R. et S. spiculis linearihus mulicis; calyce glabro acutissimo, flosculis hirsutis longiore; fol. setaceis hasi harbatis. Festuca miuuta stev. Dec. pl. Ib. S. hirsutus Trin. Prope Elisabethaepolin. $\odot$.

\section{WANGENHEIMIA Moench. $(1894)$.}

1. Wr. disticha Hoench Meth. $p$. s00. Crmosurus Iima Locfl. Cav. ic. t. 91. W. Lima Trin. Dinebra Lima Beauv. Poa Lima Trin. In Ilispania.

\section{DACTYLIS L. (1738).}

1. D. glomerata $I$. panicula secunda glomerata; ramis loasi nudis; spiculis sub-3-floris; fol. carinatis M. et Koch. I. c. Host 2. t. 94. D. scabra Manu. Festuca All. In Europa, Sibiria et America boreali. 4.

2. D. glancescens Willal. pauicula secunda glomerata; spiculis 6-8-floris; fol. carinatis glancescentilons. Willd. ell. 1. 111. In I'enetiis. 4.

3. D. hispunica Roth; panicula secumda glomerato-spirata; spiculis sub-3-floris; fol. carinalis glancescen- 
tibus. Willd. ell. p. 111. D. villosa Ten. Festuca phalaroides Lam!. In Hispania, Gallia et Italia. 4.

species dubiae.

4. D. cynosuroides Roth; racemis densis secundis corymboso-capitatis; corollae valvula dorso harhata; fol. margine argute serratis; culmo repente ramosissimo. Roth Nov. sp. p.

\section{7t. In India orientali.}

5. D. capituta Schult. spica solitaria ovata compressa; calycibus acutissimis; flosculis subcoloratis muticis; fol. ahhreviatis planis; ligula elongata vaginante. Spr. mant. 3. p. 628. Festuca Balb. In Sardinia.

6. D. altuica Bess. panicula secunda glomerata; spiculis 6-floris; calycihus ciliatis; germine clavato; nectariis commatis bilohis, lobis acntis, postice inaequaliter in dentes setaceos fissis. Bess. in schult. mant. 3. p. 626. In Altai.

\%. D. glauca Roth; panicula aequali ante et post florescentiam coarctata; spiculis sub-t-floris muticis; glumis carina serrato-scahris. Roth Cat. 3. p. 10. Aira glauca Spr. Patrice ignota. 4.

S. D. abbreviata Bernh. paniculae ramis brevissimis; valvis aristulatis dorso ciliatis; valvula exteriore acuta dorso superne ciliata lateribus scabris. Lk. Hort. 1. p. 153. Patria ignota. 2.

9. D. capitellata $L k$. panicula capitulum formante; spiculis 4-floris; valvis et valvulis sub apice mucronulatis, carina superne longe ciliatis. Lk. Hort. 1. p. 153. 'In Gallia meridionali. 4.

\section{LASIOCHLOA Kunth (1831).}

1. I. ciliaris Kunth; culmis diffusis; fol. planis interne glaucescentibus et serice 0 - pilosis externe vaginisque pilosis; spiculis trifloris. Kunth Gram. 2. p. 555. t. 192. Dactylis Thunb. Festuca capensis Spr. In Prom. b. spei. $\odot$.

2. L. longifolia Kunth; fol. convoluto-filiformibus externe glabris culmum erectum superantibus; spiculis 3-floris. Kunth 1. c. t. 193. Dactylis Schrad. In Prom. b. spei. 4.
3. L. hirta Finth; fol. convolutoselaceis rigillis externe tuberculosopilosiusculis interne scabriusculis; spiculis 4 -floris. Kunth 1. c. t. 191. Dactylis schrad. In Prom. b. spei. $\odot$.

t. L. hispida Kunth; panicula spicata ovata nuda; glumis hispidis; geniculis barbatis. Dactylis hispida Thunb. prodr. 1. p. 22. Festuca melangaea spr. In P'om. b. spei.

5. L. villosce Kunth; panicula spicata; glumis villosis. Dactylis Thunl. prodr. 1. p. 22. In Prom. 6. spei.

b. L. serrata lumth; panicula coarctata; glumis carina serrulatis Dactylis serrata Thunb. prodr. 1. p. 22. In Prom. b. spei.

\%. L. laevis Kunth; panicula coarctata; glumis laevibus. Dactylis Thunb. prodr. 1. p. 22. D. capitata L. In Prome. b. spei.

8. I. adscendens Kirnth; culmo adscendente; fol. linearibus supra piIosis subtus glabris summo vaginante; spiculis bifloris; calycibus setaceocuspidatis hispidis; valvula corollae exteriore tenuissime ciliata. Dactylis Schrad. Annal. ad Flor. Cap. sect. 3. Alopecurus echinatus Thunb. In Prom. b. spei. $\odot$.

\section{1\%. CYNOSURUS L. (173\%).}

1. C. cristatus $L$. panicula spicato-conferta lineari recta; spiculis mucronatis; fol. linearibus. In Europa. 2.

2. C. echinatus $L$. panicula spicato-coarctata ovata; spiculis longe aristatis. M. et K. 1. 632. Chrysurus Beauv. In Europa australi, Caucaso, Oriente et Montevideo. $\odot$.

3. C. eleyans Desf: panicula ovata laxa; floribus fasciculatis; calycis valvula altera aristata; bracteis setiformibus. Desf. Atl. 1. p. 82. t. 17. Chrysurus Beauv. C. effusus Lk. In Europa australi et Africa boreali. $\odot$.

4. C. multibracteatus R. et S. spica secunda subincurva; bracteis pectinatis ad spiculas. C. polybracteatus Poir. In Barbaria.

5. C. paniculatus Thunb. spica conposita ovata; calyce multifloro; gluma altera mucronata; corollis hasi pilosis. Thunb. prodr. p. 23. In Prom. b. spei. 
6. C. ternatus Forsk. spiculis ternatis quaternisque patentissimis lanceolatis muticis 4-floris. Forsk. Aeg. p. 21. In Arabia.

\section{LAMARCKIA Moench. (1794).}

1. L. aurea Moench meth. p. 201. Cynosurus L. Host. Gram. 3. 1. 4. Sibth. Graec. t. 79. Chrysurus cynosuroides Pers. Beauv. Agr. t. 22. f. 5. In Europa australi, Barbaria et oriente. $\odot$.

\section{ECTROSIA R. Br. (1810).}

1. E. leporina R. Br. panicula coarctata; arista flosculi hermaphroditi valvula exteriore parum breviore, secundi valvula longiore. R. Br. prodr. 1. p. 186. Kunth Gram. t. 69 . In Nova Hollandia.

2. E. spadicea $\boldsymbol{R}$. $\boldsymbol{B r}$. panicula coarctata; arista flosculi hermaphroditi valvula exteriore dimidio breviore secundi valvulam vix aequante. $\mathbf{R}$. $\mathrm{Br}$. prodr. 1. p. 186. In Nova Hollandia.

\section{LOPHATHERUM Brongn. (1829).}

1. L. gracile Brongn. in Dup. It. bot. p. $50 . t$. 8. In Amboina. Vagim na foliorum patens glabra. Ligula pilosa brevissima. Paniculaglaberrima.

\section{ELYTROPHORUS Beauv. (1812).}

1. E. articulatus Beauv. Agr. p. 67. t. 14. f. 2. Kunth Gram. t. 154. Dactylis Willd. Sessleria Spr. Echinalysiun strictum Trin. E. articulatum Trin. 1. c. In Malabaria, Coromandelia et Senegalia. Panicula conferta glomerato-spicata. Spiculae ut in Cynosuro cristato.

\section{FESTUCA $L$. (1737).}

1. Flores spicularum pedicellatarum obtusi, acuti, rarissime mucronati.

1. F. expansa liunth; paniculae ramis corymbosis; pedunculis clavatis; spiculis 4-floris; fol. filiformibus. Poa divaricata. Willd. sp. 1. p. 402. P. divaricata Gouau. ill. 4. t. 2. f. 1. P. expansa Gmel. Sclerochloa divaricata Beauv. R. et S. Sphenopus Gouani Trin. S. divaricatus Rchb. In Europa australi. $\odot$.

2. F.purvula Funth; panicula divaricata erecla; ramis capillaceis; flore altero pedicellato; caule foliisque brevibus. Poa minuta Poir. Poa parvula $\mathbf{R}$. et $\mathbf{S}$. In Oriente.

3. F. divaricata Desf. panicula simplici patente; spiculis compressis lanceolato-subulatis; culmo geniculato. Willd. en. p. 118. schoenodorus 13. et S. Dactylis nemphitica spr. Roth. In Europa australi et Africa boreali. $\odot$.

4. $F$. maritima $D C$. calycibus multifloris; flosculis mucronatis; spica ramosa. Triticum L. Bosc. Mus. t. 95. Schenchz. t. 6. f. 5. Brachypodium R. et S. Sclerochloa dichotoma Lk. S. maritima Rchb. In Italia, Barbaria et Arabia.

5. F. rigida Funth; panicula dichotomo-secunda, rigida; spiculis linearibus acutis 5-11-floris; floribus obtusis emarginatis. Poa rigida M. et K. 1. c. Host Gram. 2. t. 74. Engl. Bot. 1371. Megastachya pulchella $\mathbf{H}$. et S. Sclerochloa patens Presl. In Europa' australi et Africa boreali. $\odot$.

6. F. procumbens Kunth; panicula lanceolata secunda scabra; spiculis sub-5-floris; flosculis obtusiusculis nervosis. Poa procumbens Smith. brit. 1. p. 98. Curt. Lond. t. 11. P. rupestris With. Bot. Arr. p. 140. t. 20. Sclerochloa Beauv. In Anglia et Hollandia. $\odot$.

7. F. Hostii Kunth; panicula patula; spiculis 9-floris; flosculis basi villo convexis 5-llerviis; radice repente. Poa festucaeformis Host. Gram. 3. t. 17. Glyceria Rchb. Glyceria capillaris Wahleub. Molinia Hartm. Poa arenaria var. $\beta$. Trin. In Dalmatia, Gallia meridionali, Corsica. Rossia, Caucaso et Sibiria. 4. 
8. F. convoluta Iiunth; panicula subcontracta; spiculis subbifloris; flosculis basi liberis; fol. glaberrimis involuto-setaceis rigridis glancis. Poa convoluta Hornem. H. Hafu. 2. p. 953. Patria ignota. 4.

9. F. distans Funth; paniculae divaricatae ramis fructiferis deflexis; spiculis linearibus sub-5-floris; flosculis obsolete 5-nerviis. Schrad. Germ. 1. p. 282. Poa salina Poll. P. retroflexa Curt. Lond. 6. t. 1. Glyceria distans Wahlenb. Aira arenaria $\beta$. Huds. P. arenaria var, $\alpha$. Trin. In Europa, Caucaso et Sibiria. 4.

10. F. delauarica Kunth; fol. brevibus conduplicatis laevibus ligula mediocri obtusa; paniculae ramis arrectis strictis; valvula exteriore breviter acuta. Poa Lk. In America boreali. 4.

11. F.? Nuttalliana Funth; culmo erecto; paniculae ramis erectis; spiculis oblongis obtusis subsessilibus; Poa airoides. Nutt. Gen. 1. p. 68. Ad Missouri.

12. F. thalassica Kinth; panicula patente; ramis fructiferis contractis; spiculis brevibus sub-5-floris; flosculis obsolete 5 -nerviis; radice repente. Poa maritima Schrad. Germ. 1. p. 281. Engl. bot. 1140. Fl. Dan. 251. et 1626. Glyceria Mert. et Koch. In Europa et Sibiria. 4.

2. Flores spicalarum spicatarum sessilium plerumque mutici.

13. F. unioloides Fiunth; spica disticha compressa; spiculis lanceolato-oblongis sessilibus. Poa sicula Jacq. ic. 2. t. 303. Cynosurus siculus Jacq. obs. t. 43 . Briza cynosuroides scop. Del. t. 11. Triticum unioloides Ait. Vahl Willd. Brachypodium et Brizopyrum siculum Lk. In Italia, Sicilia, Sardinia et Burbaria. 4.

14. F. Poa Kunth; spiculis 4-6foris glabris ovatis obtusis muticis; culmo tenello solitario. Triticum DC. Gall. 3. p. 86. T. Halleri Viviani Fragm. t. 26. f. 1. Brachypodium Poa R. et S. T. Iolioides Pers. Agropyrum Halleri Rchb. var. $\beta$. spica inferne ramosa. Triticum Festuca DC.
T. Lachenalii Gmel. In Europa australi.

15. F. hispanica Funth; calycibus 6-floris; flosculis secundis apice aristatis. Trilicum maritimum L. mant. p. 325. Brachypodium $\mathrm{R}$. et $\mathrm{S}$. In Hispania et Liguria.

16. F. unilateralis Schrad. calycibus unilateralibus alternis muticis. Triticum L. mant. p. 35. Brachypodium unilaterale $\mathbf{R}$. et $\mathbf{S}$. In Italia et Gallia australi.

17. F. rottboelloides Kunth; spica secunda angusta rigida basi subramosa; spiculis ovatis; radice fibrosa. Poa loliacea M. et K. 1. c. Triticum loliaceum Engl. bot. 221. T. unilaterale Host. Gram. 2. t. 27. Viviani Fragm. t. 23. f. 1. Brachypodium loliaceum $\mathbf{R}$. et $\mathbf{S}$. In Anglia, Gallia et Italia. $\odot$.

18. $\mathbf{H}$. gracilis $\mathrm{Kunth}$; calycihus sub-4-floris; flosculis muticis acutis; fol. setaceis. Triticum tenellum $\mathbf{L}$. sp. p. 127. Moris hist. 3. s. 8. t. 2. f. 3. In Gallia.

19. F. tenuicula $\mathrm{L} k$. fol. involutis subulatis; spica simplici stricta; spiculis ovato-oblongis 7 -floris; corollis aristatis. Brachypodium tenuiculum R. et S. Triticum hispanicum Viviani Fragm. t. 23. f. 2. B. Nardus Lk. In Europa australi.

20. F. tenuiflora Schrad. spica secunda; spiculis ovato-oblongis $3-7$ floris, breviter pedicellatis; floribus lanceolato-subulatis aristatis. M. et K. 1. c. Triticum tenellum. Host Gram. 2. t. 26. Brachypodiun tenuifiorum et tenellum R. et $\mathbf{S}$. In Europa australi. $\odot$.

3. Spiculae pedicellatae racemosae vel paniculatae longe aristatae.

21. F. uniglumis Soland. panicula secunda; flosculis subulatis compressis aristatis; calycis valvula altera brevissima. Smith brit. Fl. 1. p. 118. Engl. bot. 1430. Host 4. t. 61. Vulpia membranacea Lk. V. uniglumis Rchb. Bromus hordeiformis Hchb. In Europa australi. $\odot$.

22. F. magellanica Lam. fol. pabescentibus setaceis rigidis; panicula secunda; paleis patentibus distantibus aristatis. Brongn. in Dup. It. bot. p- 
38. Ad fretum Magellanicum et ins. Nuclorianis.

23. F. Myurus I. panicula secunda spicaeformi subcaerulea; floribus 1-andris apice scabris arista brevioribus; culmo vaginato. M. et K. I. c. Vulpia Guel. Bromus bohemicus schmidt. V. Pseudomyurus Rchl). In Europa et America. $\odot$.

24. F. muralis Kunth; culmo vaginisque glahris; fol. anguste linearibus; panicula secunda; spiculis Ianceolatis 5-9-floris; arista Iongissima; stamine unico. F. Mijurus $\mathbf{H}$. et $\mathbf{K}$. Nov. Gell. 1. p. 155. In Quito.

25. F. ciliuta Danth. spiculis 46-floris ciliato-hirsutis; panicula nutante. DC. Gall. 3. p. 5อ. F. Myurus Gouan. In Gallice et Italir. $\odot$.

26. F. bromoides $\mathrm{L}$. panicula secunda spicaeformi; floribus 1-andris apice scal)ris, arista brevioribus; culmo superne glabro. M. et K. I. c. F. sciuroides lioth ed. 1. Mygalurus Lk. Bromus ambiguus Cyrill. Nap. t. 2. Vulpia sciuroides et bromoides Rchl. exc. In Luropa et ins. Maclovianis. $\odot$.

2\%. F. tenella Willd. panicula simplicissima secunda; spiculis oblongis aristatis; culmo superne 4 -gono basi ramoso; ligula 2 -aurita. WVilld. sp. 1. p. 419. F. bromoides Michx. am. F. 8-flora Walt. Schenodorus tenellus R. et $\mathbf{S}$. Brachypodium Lk. F. setacea Poir. In America boreali et Montevideo. 4.

28. F. cynosuroides Desf. spiculis solitariis compressis secundis sessilibus; glumis acutis subaristatis. Desf. Atl. 1. p. 88. t. 21. Triticum Spr. In Barbaria. $\odot$.

29. F. delicatula Lay. panicula secunda lanceolata; spiculis patentibus 5-floris; calycis gluma altera brevissima. Lag. Varid. 2. p. 19. et 39. Mygalurus et Vulpia Lk. In Hispanic. $\odot$.

30. $F$. geniculata Willd. panicula contracta; spiculis lanceolatis ; pedunculis cuneatis ancipitibus; culmo basi geniculato. Willd. en. p. 118. Bromus I. Schreh. Gram. t. 31. F. stipoides Desf. Mygalurus et Vulpia Lk. Vulpia ligustica lichl. In Europa australi et Africa boreali. $\odot$.

31. F. Michelii Kunth; panicula contracta secunda; spiculis 4-floris; floribus subulatis; pedunculis lineari- bus. Bromus Savi. Vulpia Rchb. In agro Florentino.

32. F. alopecurus Schousb. Descr. racemo suhspicato; spiculis distichis alternis sub 8-floris; corollae valvula exteriore ciliata. Willd. en. p. $11 \%$. Bromus borealis savi. Festuca ciliata Lk. Mygalurus et Vulpia Alopecurus Lk. In Hispania, Lusitania et Africa boreali. $\odot$.

\section{Festucae legitimae Kunth.}

33. F. ovinc $\boldsymbol{L}$. panicula contracta angusta; spiculis oblongis suh-4floris; fol. capillaceis; ligula 2-auriculata. M. et K. I. c. Leers lierb. $t$. 8. f. 3. Host. 2. t. 81. var. $\beta$. tenuifolia. F. ovina $\beta$. Leers t. 8. f. 4. $\gamma$. villosa $\delta$. vivipara. F. ovina $\beta$. L. In Europa, Sibiria et Sinu Notka. 4.

34. F'. dolichopliylla Presl; culmo compressiusculo; ligula ciliolata; panicula secunda; rachi ramisque triquetris scahris; aristis brevissimis. Presl. Haenk. 1. p. 258. In Peruvia. 4.

3.5. F. Hrachypleylla Schult. racemo subsimplici; flosculis teretibus supra scabriusculis; fol. setaceis vaginisque laevibus. F. brevifolia. R. Br. Chlor. Melv. p. 31. In Melville Island.

36. F. erecta Urville; fol. setaceis erectis glaberrimis; spiculis ovato-Ianceolatis 3-4-floris; glumis paleisque inaequalibus; palea exteriore acuminata. Brongn. in Dup. It. bot. p. 37. t. 7. In ins. Maclovianis. 4 .

37. F. alpina Gaud. panicula contracta; spiculis oblongis 4-floris; fol. capillaceis glabris; ligula 2-auriculata. M. et K. I. c. In Helvetia. 4.

38. F. Guudini Kunth; racemo spicaeformi; spiculis oblongis 4-floris, superioribus sessilibus, inferioribus pedicellatis; ligula biauriculata. M. et K. I. c. In Helvetia et Germania. 4.

39. F. Halleri All. spiculis 4-5floris oblongis aristatis; perigonii valvula exteriore pubescente; panicula stricta. DC. Gall. 3. p. 53. In Sabaudia et Gallia. 4.

40. F. aurata Gaud. panicula subpatente ramosa; spiculis demum dilatatis distichis; fol. mollibus capillaceis ; culmeis complicatis. Gaud. Agr. 1. p. 234. F. aurita et pallida MIur- 
rith. Schenodorus violaceus 13 . et $\mathbf{s}$. in Helretia. 4.

H. F. livila $S \mu r$. culmo foliisque rlabris; panicula depauperata; spiculis lanceolatis compressis; glumis paleisque scabriusculis; arista hrevissima. Bronus H. et K. Nov. Gell. 1. p. 150. t. 689 . sichenodorus $R$. et s. In Mexico. $\odot$.

12. F. toluccensis $\boldsymbol{H}$. et $\boldsymbol{K}$. culmis, vaginis foliisque scabris setaceo-1riquetris; spiculis ovato-oblongis compressis. Kunth. In Quito. 7.

43. F. violacea Guud. panicula angusta patente laxa; spiculis sub-1-1loris breviter aristatis ; fol. capillaceis ; ligulis hiamiculatis. M. et K. l. c. Schenodorus 1h. et s. In Helvetia. 21.

H. $\boldsymbol{H}$. andicola $H$. et $K$. culmis, vaginis foliisque glabris sub-3-quetris; panicula filiformi; spiculis ovaloIanceolatis compressis 6-floris; atrista brevi. Kunth 1. c. In Quiio. 4.

f.5. F. duriuscula L. panicula patente; spiculis oblongis 5-floris aristalis; fol. setaceis; ligula biauriculata. M. et K. I. c. F. ovina schrad. F. stricta Host 2. t. 86. F. intermedia 11. et s. F. $\gamma$. villosa Host. 2. t. 85 . F. caesia Eugl. bot. 1917. In Europlu.

46. 6. longifolin Viviuni; panicula erecta coutracta; fol. longissimis filiformibus ; slumis corollae ciliato-laceris. Viv. Flor. Ital. in Amn. di Bot. 1. 2. p. 145. In Ligurill. 1 .

17. F. fallax '́lemill. majuscula; glaberrima; fol. Iongiusculis; panicula viridula albida subsecumda; spiculis subroctofloris. Thuill. Par. p. 50. In Lutetia. 4.

48. F. clandestina Muehlenb. culmo uninodi; fol. longe vaginatis linearilus; ligula acuminata; panicula clandestina; spiculis 10-floris, altera sessili. Muehlenb. descr. 1. 162. In Americu boreuli.

49. F. glance Schrad. panicula patente; spiculis oblongis sulb-z-floris aristatis; fol. setaceis rigidis glabris; ligula biauriculata. M. et K. F. palIens Host Gram. 2. 1. 88. F. F. gluucu Lam. ill. t. 46. f. $3 . \%$ laeviyata $F$. pallens 1R. et s. In Europa. 4.

50. F. compressifolia Presl; radice repente; ligula ovata fimbriata; panicula simplici laxa; rachi ramisque triquetris scabris; spiculis ovalibus 8-floris; arista hrevissima mucroniformi. Presl 1. c. In Peruria. 4.

51. F. valesiaca Goud. panicula subcoarctata; spiculis oblongis sub5-floris; fol. filiformibus scaberrimis glaucescentibus. M. et K. I. c. F. stricta Bess. F. pallens Pauz. In Vulesia. 4.

52. F. yuestfulica Boenningh. glaucescens; paniculae pyramidatae ramis sul anthesi patenti-divergentibus; spiculis 5-floris ovali-rhembeis; ligula olsoleta biaurita foliisque capillaceis hispidulis. Helıh. exc. p. 1403. F. $\beta$. Weihe Grues. XI. 11. 264. In Guestfalia. 2 .

53. F. pannonica Irulf. in Host Gram. t. t. 6\%. spiculis lineari-ohlongis 7-10-floris arislatis ; fol. setaceis; ligulis biamiculatis. M. et K. l. c. In Austria et P'onnoniu. 4.

5t. F. vaginuta $W$. et Kit. spiculis patenlissimis oblongis sul-6-floris aristatis vel muticis; fol. setaceis glabris rigidis; ligula bianriculata. M. et K. 1. c. In Hunguria. 4.

5.j. H. Fenus Luy. panicula secunda; spicis oblongis 6-floris; floribus acmminatis muticis; fol. planis. Lag. Elench. p. 4. F. tenax Lk. In $\mathrm{Hi}_{-}$ spania.

56. F. amethystince Host Gram. 2. $t$. 89. panicula patente; spiculis oblongis sub-t-floris; fol. setaceis rigidis; ligula biauriculata. $\mathbf{M}$. et $\mathbf{K}$. 1. c. In Eirropul media. 4.

5\%. F. prictı Kit. panicula patente; spiculis ohlongis; valvula calycina exteriore glahra, corollina aristata; culmo gracili; ligula hiaurita non ciliata. sichult. austr. 1. p. 236. In p'annoniul.

.5. F. rubru I. panicula patente; spiculis obloneis suh-j-floris; floribus lanceolatis acutalis; fol. radicalibus setaceis, culmis planis; ligula biauriculata; radice caesputosa repente. M. et K. 1. c. Host Gram. 2. t. 82. var. B. villost. F. dumetorum L. F. barhata schrauk. $\gamma$. lanuginosa; $\mathbf{F}$. cinerea DC. F. rubra $\beta$. arenaria Fries. F. villosa Baer. F. dumetorum haf. F. Askelofiana Schult. In Europa, Sibiria et America boreali. 4.

59. $\boldsymbol{F}$. heteropliylla Haente; panicula patula; spiculis oblongis sub5-floris; flosculis lanceolato-subulatis; fol. radicalihus setaceis, culmis planis M. et K. I. c. Host 3. t. 18. Vaill. 
par. t. 18. f. 6. F. nemorum Leyss. F. duriuscula L. In Europa. 4.

60. F. nigrescens Lam. panicula patente; spiculis ovatis sub-5-floris; fol. radicalibus setaceis; ligula biauriculata; radice filbrosa. M. et $K$. $l$. c. F. rubra sut. Schenodorus 1. et $s$. F. versicolor. Presl. Hb. In Helvetia et Sibiria. 21.

61. F. pumila Vill. panicula patula ovata; spiculis lineari-ohlongis 3-4-floris, aristatis ; fol. setaceis flaccidis; ligula oblonga obtusa. M. et K. 1. c. Host Gram. t. 91. F. varia Hoppe. Schenodorus R. et S. In Europa media.

62. F. nitida Schult. panicula patente subpauciflora; spiculis ohlongolanceolatis aristatis 4-5-floris; culmo angulato torto; fol. filiformibus; ligula brevissima. Schenodorus $\mathbf{h}$. et S. syst, 2. p. 706. In Croatia. 4.

63. $F$. alpestris $R$. et $S$. panicula secunda demum nutante; spiculis lanceolato-ovatis sub-6-floris; ligula ohlonga acuminata. $\mathrm{K}$. et S, In Croatia. 24 .

61. F. rhatica Sut. panicula patente; ramis inferioribus subverticillato-quinis; spiculis ovatis sub-3floris; rachi infra flosculos pilosa; ligula oblonga lanceolata acuta. M. et K. 1. c. F. pilosa Gaud. F. poaeformis Host Gram. 2. t. 81. Poa violacea Bell. Schenodorus. R. et S. In alpibus Europae. 4.

65. F, laxa Host Gram. 2. $t, 80$. panicula patente laxa; spiculis lineari-lanceolatis 3-6-floris nucronatis; fol. setaceis; ligula truncata abbreviata. M. et K. In Carniolia et Carinthia. 4.

66. F. poaeoides Michx. glaberrima; paucifolia; culmo subbinodi geniculato; spiculis proxime alternis subsessilibus oblongis 9-10-floris. Michx. F1. 1. p. 67. All flumen St. Laurentii. 4.

6\%. $\boldsymbol{F}$. procera $\mathrm{H}$. et $\boldsymbol{K}$. culmo scabro; fol. interne lanatis; panicula secunda; spiculis compressis sub-9floris; glumis paleisque dorso scabris; arista brevissima. Kunth 1. c. In Quito. 4 .

68. F. scirpifolia Kunth; fol, scahris compresso-striatis; ligula acutissinta biauriculata glaberrima; panicula secunda; spiculis obovatis 4-floris; palea inferiore 1-nervia versus apicem scabra. Diplachne Presl 1. c. In Peruvic. 4.

69. F. rigescens Kunth; fol. compresso-setaceis acutis; ligula biauriculata; panicula secunda; spiculis obovatis trifloris; glumis apice scabris; palea inferiore 1-nervia apice scabra; arista brevissima. Diplachne PresI 1. e. In Peruria. 24.

\%0. F. Huenkei Kunth; fol. convolutis compresso-setaceis; ligula brevissima ciliolata; panicula erecta secunda; rachi ramisque triquetris; spiculis ohovatis 4 -floris; palea inferiore ovato-lanceolata 5-nervia. Diplaclıne Presl 1. c. In Peruvia.

g1. F. elıtior L. panicula diffusa cernua; spiculis ovato-lanceolatis $4-5$ floris; floribus sub apice mucronatis; fol. planis lanceolato-linearibus; ligula brevissima. F. arumdinacea M. et K. 1. c. Bromus littoreus Host Gram. 1. t. 8. B. elatior Spr. Schenodorus Beauv. IR, et S. In Europa et Sibiria. 4.

82. F, decolorans M. et K. panicula patente nutante; spiculis lanceolatis compressis sub-4-floris; bracteolis acute nervosis carinatis subintegris. Bromus Rchb. exc. p. 44. F. laxa Gaud. In Helvetia. 4.

\%3. F. borrealis M. et K. panicula flaccida nutante; spiculis plerumque 4-floris; flosculis hasi fasciculato-pilosis, apice denticulatis; ligula oblonga elongata. M. et K. Arundo festucacea Willd. Donax Beauv. Schenodorus R. et S. In Germania et Ostrogothia. 4.

\%. F. pratensis Huds. panicula secunda patente; ramis racemosis plerumque geminis; spiculis 5-10-floris; fol. planis lanceolato-linearibus; ligula brevissima. M. et K. 1. c. F. elatior L. Host. 2. t. 79. Bromus Koel. Schenodorus Beauv. R, et S. Bronus pratcusis Spr. In Europa et Sibiria. 4.

75. F. loliacea Huds, racemo disticho subcernuo; spiculis lineari-oblon is alternis distantibus, superiorihus sessilibus. M. et K. 1. c. Curt. Lond. t. 9. Engl. bot. 1821. Poa 10liacea Koel, Brachypodium Lk. Triticum patens Brot. Festuca fluitans Leers. Schenodorus Ioliaceus R. et $\mathbf{S}$. In Europa. 4.

86. interrupta Desf. culmo filiformi; spica secunda interiupta; pedicel- 
lis brevibus adpressis; spiculis sub5-floris; glumis acutis. Desf. All. 1. p. 89. Brachypodium $\mathbf{R}$. et $\mathbf{S}$. In Barbavia.

7\%. F. patula Desf. pedunculis hinis elongatis superne floriferis; calycibus sub-5-floris; glumis acuminatis. Desf. Atl. 1. p. 86. In Barbaria. 4.

75. F. triloba Desf. panicula nutante elongata; spiculis subtrifloris acutis muticis teretibus. Dest. Atl. 1. p. 87. In Barbaria.

89. F. Drymeja $\boldsymbol{R}$. et $\boldsymbol{S}$. panicula nutante ramosissima; spiculis 3 5-floris; flosculis acutis muticis 5-nerviis ; fol. lanceolato-linearibus; stolonibus longis squamatis. M. et K. $\mathbf{~ l . ~ c . ~}$ F. sylvatica Host. Gramı. 2. t. 78. F. montana sterub. Schenodorus sylvaticus R. et S. In Europa media. 4.

80. F. sylvatica rill. panicula erecta diffusa ramosissima; spiculis 3-5-floris; floribus acutis muticis; fol. lanceolato-linearibus planis; vaginis infimis aphyllis; stolonibus nudis brevibus. M. et K. l. c. Host 4. t. 60. F. calamaria Engl. bot. 1005. Poa trinervata Schrad. Fl. Dan. 1145. P. sylvatica. Poll. Schenodorus calamarius 13. et \$. In Europa. 4.

81. F. varia Haenke; panicula patula ohlonga; spiculis lineari-lanceolatis $\tilde{5}-8$-floris; fol. setaceis rigidis; ligula oblonga obtusa; radice fibrosa M. et Koch. I. c. Host. Gram. 2. t. 90. F. acuminata Gaud. F. flavescens Kit. in Host Gram. 3. t. 19. F. Eskia Ram. F. versicolor Tausch. F. Iuprica Lapeyr. In Europa et Caucaso. 4.

82. F. spadica Gouan; panicula ramosa patula; spiculis oblongis 4 8-fioris; fol. linearibus pungentibus; ligula oblonga emarginato-biloba. M. et K. 1. c. Host. 3. t. 20. Poa spadicea Koel. P. Gerardi All. Anthoxanthum paniculatum L. F. aurea Lam. Schenodorus spadiceus $\mathbf{R}$. et $\mathbf{S}$. In Europa media. 4.

83. $\boldsymbol{F}$. ferruginea Rchb. panicula angusta; pedunculis paucispiculatis ; spiculis 1-coloribus sub-6-floris; bracteis acuminatis; ligula oblonga; radice fibrosa. Rchb. exc. p. 140. 4. Sohenodorus Vest. In Carintlia, 4.

81. F. caerulescens Desf. fol. linc striatis rigidis; panicula secunda coarctata; spiculis sub-3-floris; glumis acutis muticis. Desf. All. 1. p. 87. F. elatior var. major Poir. It. Schenodorus I. et S. In Jarbaria. 24.

s.5. F. Scheuchzeri Gaud. panicula patente ramosa sulnutante; spiculis 4-5-floris; fol. linearibus planis; ligula oblonga obtusa; radice repente. M. et K. 1. c. F. pulchella schrad. Germ. t. 5. f. 5. F. spadicea Mielichh. F. nutans Host Gram. 4. t. 61. Schenodorus Scheuchzeri et nutans R. et S. F. cernua Schult. austr. In Europa media. 4.

86. F. compresse DC. panicula oblonga patente; spiculis acutis 3-4floris; culmo superne tereti; fol. plicatis margine scabris dorso laeviluus R. et $\mathbf{S}$. Schenodorus $\mathbf{R}$. et $\mathbf{S}$. Poa montana Delarb. In Avernia. 4.

8\%. F. quadridentata $H$. et $\mathbf{K}$. culmo vaginisque scabris; fol. scabris subtus glaucis; panicula ramosa secunda nutante; spiculis ovatis compressis sub-5-floris; gluma inferiore 4-dentata, inter dentes breviter aristata. H. et K. Nov. Gen. 1. p. 15 t. t. 690. Sessleria quitensis Spr. Diplachne toluccensis Spr. In Quito.4.

S8. F. mollis Funth; culmo superne pubescente; fol. interne vaginisque piloso-lanatis; panicula depanperata; ramis paleisque lanato-pilosis; spiculis compressis sub-5-floris; arista brevissima. Bromus procerus. $H$. et K. 1. c. Schenodorus R. et S. In Quito. $\odot$.

89. F. Cádasii Kunth; culmo foliisque glabris; panicula subsimplici nutante secunda; spiculis oblongis 4floris compressis; glumis paleisque dorso scabris; arista brevissima. Bromus Caldasii H. et K. 1. c. Schenodorus R. et $\mathbf{S}$. F. quitensis Willd. Hb. In Quito.

90. F. gigantea Vill. panicula patentissima laxa; ramis apice nutantibus; spiculis lanceolatis 5-8-floris; aristis palea duplo longioribus; ligulis brevissimis. M. et K. I. c. Bromus giganteus L. Host Gram. 1. t. 6. Schreb. Gram. t. 11. Fl. Dan. 1630 var. $\beta$. F. triflora Sm. Engl. bot. 1918. Bromus Fl. Dall. 440. In Europa et Sibiria. 4.

91. F. mutans Spr. panicula.e ramis secundis nutantibus scabris; spiculis ovatis compressis sub-6-floris; flosculis acutis muticis. Willd. en. p. 116. Poa nutans Lk. F. obtusa Spr. 
Schcnodorus obtusus R. et S. In America boreali. 4.

92. F. dasyantha H. et K. cuhmo vaginisque glabris; fol. convolutis inteme lanatis; panicula ramosa patula; spiculis oblongis compressis 5-9floris; glumis paleisque piloso-lanatis. H. et K. I. c. p. 15t. In monte $\mathrm{Co}-$ lopaxi. 4.

93. F. fimbriat Nees; paniculae constrictae ramis geminis scabris; spiculis muticis 3-6-floris; glumis paleisque margine minute lacero-ciliatis acutis; fol. lato-linearibus scaberrimis; ligula brevissima; radice stolonifera patente. Nees in Mart. Bras. 2. 1. 47. In Montevideo. 4.

\section{Species dubiae.}

94. F. bulbosa Bern. panicula angustata secusda; spiculis sub-t-floris compresso-carinatis; fol. lineari-suhulatis; radice bulbosa. Bern. Bivon. Stirp. Sic. Manip. 4. n. 36. In Sicilict. 4 .

95. F. arenaria Lam. glaberrima; fol. convolutis pungentibus, inferiorihus flabellatis; spiculis conıpressis sul-3-floris; palea exteriore acuta. Brongu. in Dup. It. bot. 36. In ins. Maclovianis.

96. F. caespitosa R. et S. panicula ovata coarctata undique spiculis imhricata. Dactylis forst. Comm. Goett. 9. p. 22. F. antaretica spr. In ins. Novi Ammi. 4.

97. F. flabellute Lam. fol. glaberrimis convolutis acutis, inferioribus flahellatim distichis; panicula densa oblouga; spiculis compressis sub-5-floris; palea exteriore acuminata. Brongn. in Dup. It. bot. 36. In ins. Macloriunis.

98. F. antarctica Funth; fol. Ionge vaginantibus angustis linearibus rigidis; panicula contracta basi interrupta; spiculis compressis patentibus; fasciculis pilorum raris. Brongn. in Dup. It. bot. 34. Arumdo antarctica Urville. In ins. Maclovianis. 4.

9!). F. littoralis Labill. Nov. Ioll. t. $2 \%$. panicula coarctata; spiculis imhrical is compressis muticis; glumis floscu to parum brevioribus; perianthiis hasi rubescentibus, apice obsolete tridenta tis. 1R. Br. prodr. 1. p. 178. Scliersodorus R. et S'. Triodia Billardieri Spr. In Nova Hollandia.
100. H. plebeja R. Br. panicula racenosa secuuda; spiculis 8-10-floris aristatis; culmo tereti ; fol. involutis; ligula bipartita. R. Br. prodr. 1. p. 178. In Nova Hollundia.

101. F. sculora V'ahl; panicula secunda coarctata erecta; spiculis compressis 6-floris; flosculis scahris. Vahl symh. 1. p. 21. 5. aspera Poir. It Prom. b. spuei. 4.

102. F. panciflora Thumh. panicula patula; spiculis sub-4-floris aristatis scabris; fol. villosis. Thunl). jap. p. 52. In Japonia.

103. F. blepharopliora $R$. et s. panicula erecta ramosa; spiculis trifloris; flosculis duobus superiorilus extus ad marginem strigis exstantihus adspersis; fol. lato-lanceolatis. F. Jatilolia Koth Nov. sp. 1. 75. In Indice orientali.

104. F. Teneriffae Roth; paniculae secundae ramis dichotomis rachique lriquetris; pedunculis compressodilatatis truncatis; glumis valvulisque margine serrulatis. Roth Nov. sp. p. 75. In Teneriffa.

105. F. quadriflore Halt. panicula contracta secunda; flosculis lanceolatis; aristis scahris valvulas quadruplo excedentibus; fol. setaceis. $F$. Myurus Muehleul. descr. p. 158. In Marylandia et Georgia. $\delta$.

i06. F. brevifoliu Wralt. panicula flexuosa clandestina; spiculis 4-floris; flosculis pilosis; nodis sursum pubescentibus pilosisque; radice elongata tenuissima. Muehlenb. descr. p. 158. In America boreali.

10\%. F. mbescens Willd. culmo adscendente angulato; fol. convolutis laevibus; panicula nutante arcta spiculis 9-10-foris pilosis. Lk. en. 1. p. 91. F. Kitaibeliana sichult. In Hungaria. 4.

108. F. reptatrix L. paniculae ramis simplicilus; spiculis sulısessilibus 1. sp. p. 108. In Arabia et Palaestina. 24.

109. F. balearica Gualleri; panicula erecta ramosa; spiculis t-floris; florum valvula exteriore aristata, altera menhranacea mutica. Vuccagn. Cent. 11. 26. In ins, Balearicis.

110. F. munctoria Sm. panicula secunda simpliciuscula; culmo tereti nudiusculo; fol. recurvis rigidis involuto-pungentibus. Smith. prodr. 1. p.16. In Bithynia. 4. 
111. F. rlactyloides $\mathrm{S} m$. panicula ovata coarctata; fol. planis patentibus; culmis erectis; glumis ommibus carinatis scabris. simith prodr. 1. p. 61. Sibth. Graec. t. 81. In Graecia. $\odot$.

112. F. spicata Pursh; spiculis alternis scssilibus erectis sub-5-floris; foribus suhulatis glabriusculis aristis longis scabris; fol. linearibus culmoque glabris. Pursh Fl. p. 83. Triticum missuricum spr. In America boreali. 4.

113. F. parviflora Elliot; panicuIa subaequali gracili appressa; spicu-

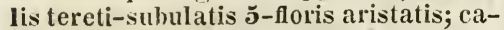
Iycibus muticis. Elliot. hot. 1. p. 170. In Americu boreali. 4.

11.1. F. exaltata Presl; panicula ramosissima nutante; locustis compressis muticis 1-4-floris ; glumis 3nerviis; radice repente. Presl. sic. 1. p. 45. Schoenodorus schult. F. sylvatica Presl Cypr. et Gram. Sic. In Sicilia.

115. F. multiflora Presl; panicula patentiuscula ramosa; locustis lanceolatis 8-10-floris aristatis. Presl Cypr. et Gram. Sic. F. pauciflora schult. in Sicilia.

116. F. misera Thunb. panicula coarctata ; glumis aristatis scabris; culmo geniculato. Thuub. jap. 52. In Japonia.

117. F. Willdenouiana schult. panicula nutante pauciflora; spicis trifloris strigoso-hispidis aristatis; fol. linearibus augustissimis. F. maxima Spr. Syst. 1. p. 356. In Mexico.

118. F. alienc spr. panicula simplicissima nutante; flosculis margine serrulatis; aristis rigidis elongatis; fol. flaccidis angustissimis. spr. syst. 1. p. 356. F. capillata Willd. Hb. Patria ignota.

119. $F$. mexicana $R$. et $\mathrm{S}$. pauicula spicaeformi; spiculis teretibus 12-floris aristatis; vaginis scabris. Lagasc. Elench. 4. In Mexico. $\odot$.

120. $\mathrm{F}$. borbonica $\mathbf{s p r}$. pedicellis incrassatis; spiculis sub-6-floris longe aristatis; fol. setaceo-capillaribus. spr. syst. 1. p. 352. In ins. Mascarenis.

121. F. Hemipoa Delile; paniculae ramis rigidis coloratis; spiculis subsessilibus 4-6-floris muticis; culmo stricto; fol. angustissimis glabris. Spr. Cur. post. p. 36. In Monspelio.
122. F. glahra Spr. paniculae patentis ranis secundis; spiculis muticis sexfloris; fol. glaberrimis. Spr. syst. 1. p. 353. In America boreali.

123. F. latifolia DC. pedicellis ramosis; spicularum 6-7-floralum axi flexuosa; pcrigonii valvula exteriore acutissima ; ligula exserta ; fol. retrorsum scabris. DC. Cat. Mousp. p. 111. Patria ignota. 24.

121. F. Smithii Kunth; fol. convolutis culmum superantihus; spiculis teretibus 3-4-floris; corollis aculatis subaristatis. F. maritima Lk, in Buch Canar. ins. p. 139. In ins. Fortunatae.

125. F. compacta Presl; panicula spicata lobata; spiculis subsexfloris; valvis corollinis ommibus glabris aristatis; aristis subdorsalibus. Russ. Besclir. von Aleppo. In Aleppo.

126. F. glomerata Russ. panicula spicata lohata; spiculis 4-floris; valvulis corollinis exterioribus omnilhus hispidiusculis aristatis. Russ. 1. c. In Aleppo.

127. F. bracteat $D C$. panicula patente; braclea pedicellorum fasciculo suljecta; spiculis 7-8-floris; calycis valvula cxteriore apice multinervia. DC. Cat. Monsp. p. 111. Putria ignotı. 4 .

128. F. capillifolic Dufour; fol. glahris capillaribus elongatis; culmo erecto gracili; panicula subsecunda nutante; spiculis 4-floris. Dufour in R. et S. syst. 2. p. 735. In Hispania.

129. F. altaica Trin. radiis subsolitariis; floribus brevissime rostratis distincte nervosis; fol. ommibus involutis; ligula hrevissima. Ledeb. ill. t. 228. In Altai.

130. F. Donax Lou:e; panicula subsecunda nutante; spiculis linearilanceolatis glomeratis ; flosculis linearibus muticis; fol. planis margine scabris ; ligula exserta ovata. Lowe in Cambr. Phil. Jouru. 4. 1. p.9. In Madera.

131. F. albida Loue; dense caespitosa; paniculae ramis rachique pubescentibus; spiculis puberulis; fol. scaberrimis serulatis; Iigula abbreviata; vaginarum oris ciliatis. Lowe 1. c. In Madera.

132. F. indica Retz; panicula contracta erecta; spiculis compressis subaristatis sub-6-floris. Retz obs. 4. p. 


\section{Diplacline Spr. In India orien- tali.}

133. F. Thunbergii Kunth; panicula mutica; gluma angulata ciliata. Agrostis ciliata Thunb. In Japonia.

\section{BROMUS L. (1737).}

1. B. inermis Poll. panicula erecta; spiculis linearibus subteretibus nudis; Ilosculis imbricatis muticis vel brevissime aristatis; fol. glabriusculis. schrad. Germ. 1. p. 359. Host Gram. 1. t. 9. Festuca Leyseri Moench. F. speciosa Schrel). Schenodortus inermis $\mathbf{R}$. et $\mathbf{S}$. F. poaeformis Pers. In Europa, Caucaso et Sibiria. 4.

2. B. secalinus $L_{\text {. }}$ panicula demum nutante; flosculis demum distinctis ; aristis flexuosis bractea brevioribus. Host Gram. 1. t. 12. B. arvensis Fl. Dan. 293. var. $\beta$. divergens. In Europa inter segetes. $\odot$.

3. B. velutimus Schrad. Germ. t. 6. $f$. 3. panicula deflorata nutante; floribus fructiferis margine contractis; aristis longitudine paleae; vaginis glabris. B. grosstis DC. B. multiflorus Knapp. t. 80. Engl. hot. 1884. B. nitidus Dumort. In Europa. $\odot$.

4. B. racemosus L. panicula nittante fructifera contracta ; floribus late ellipticis margine rotundatis, fructiferis margine imbricatis; fol. vaginisque inferioribus pilosis. B. pratensis Ehrl. Engl. bot. 1984. B. multiflorus hoth. germ. ed. 1. B. hordeaceus L. B. Gaudini R. et S. In Europa. $\odot$.

5. B. elongatus Gaud. panicula erecto-patente; spiculis oblongis glaberrimis; corollis imbricatis depressis. Gaud. Agr. 1. p. 305. $\beta$. pratensis Murrith. In Helvetia. $\odot$.

6. B. longifolius Schousb. culmo basi ramoso ; fol. involuto - subulatis; spiculis teretibus recurvatis. Schousb. Marocc. ed. Germ. 1. p. 31 . Brachypodium R. et S. Circa Tanger.

\%. B. mollis $\boldsymbol{L}$. panicula erecta; spiculis subovalis pubescentibus; bractea exteriore apice hifida; aristis rectis bracteolam aequantibus; fol. mollissime pubescentibus. Host. Gram. 1. t.19. Schkuhr t. 16. Leers t. 11. f. 1. Engl. bot. 1078. B. rarus Weig. obs. t. 1. g. B. $\beta$. leptostachys Pers. In Europa, Caucaso, Chili, Montevideo et Prom. b. spei. $\odot$.

S. B. commutatus Schrad. panicula laxa patente deflorata nutante; nnribus fructiferis margine imbricatis; aristis rectis, palea parum longioribus. Schrad. Germ. 1. 1. 353. In Germania. $\odot$.

9. B. confertus Bieb. panicula contracta erecta; spiculis erectis oblongis multifloris scabris; aristis divaricatis. Bieb. Flor. 1. p. 71. Jacq. Eclog. Gr. t. 14. B. ovatus Gaertn. in Nov. Act. Petrop. 14. t. 19. f. 1. In Iberia.

10. B. wolgensis Jacy. Eclog. t. 15. pauicula nutante; spiculis ovatooblongis hirsutis; aristis rectis gluma longioribus; fol. utrinque hirsutis. Jacq. 1. c. B. squamosus $\beta$. Bieb. B. hirsutus Schrank. In Tauria et Gallia australi. $\odot$.

11. B. asper $L$. panicula ramosa nutante; spiculis lineari-lanceolatis 7-9-floris; fol. sublinearibus villosis planis; ligula brevissima. B. montanus scop. Gmel. sib. t. 21. Festuca M. et K. B. altissinus Web. B. nemorosus Vill. B. hirsutus Curt. Lond. 2. t. 8. B. hirsutissimus Cyrill. In Europa, Cancaso et Sibiria. 4.

12. B. depauperatus Presl; radice repente; panicula secunda nutante patentissima; paleis inferioribus teretiusculis 3-nerviis scabris. Presl in Rel. Haenk. 1. p. 263. In sinu Nutka. 2 .

13. B. humilis Cav. panicula fasciculata; spiculis sessilibus glabris; fol. pagina superiore pilosis. Cav. ic. 6. p. 65̃. t. 589. In Hisyania.

1t. B. squarrosus I. panicula fructifera nutante; spiculis oblongolanceolatis; floribus margine acutangulis imbricatis; aristis rectis tardius horizontaliter pateutibus. Engl. Bot. 1885. Scheuchz. t. 5. f. 11. Barr. t. 21. f. 1. var. $\beta$. spiculis pubescentibus Host 1. t. 13. B. villosus Gmel. In Europa, Caucaso, Sibiria et Africa boreali. $\odot$.

15. B. palulus M. et K. panicula deflorata nutante; stipulis lanceolatis; aristis tardius divergentibus palea longioribus; fol. vaginisque pilosis. B. commulatus Koch. B. multiflorus DC. Host Gram. 1.'t. 11. In Germania et Caucaso. $\odot$. 
16. B. vestitus Schrad. culmo glahro; fol. vaginisque villosis; panicula secunda nutante; spiculis 9-11-floris pubescenti-hirsutis; valvula corollae angustiore apice bifido-dentata. Schrad. An. ad Flor. Cap. 2. In Prom. b. spei. $\odot$.

1\%. B. divaricatus Rhode; panicula erecta subcontracta; spiculis lineari-lanceolatis $10-15$-floris pubescentibus; gluma corollina exteriore bifida; aristis basi contortis. Lois. in Jour. de Bot. 2. p. 214. B. lanuginosus Poir. B. turgidus Pers. In Gallia.

15. B. macrostachyus Desf. culmo basi geniculato; spiculis maximis teretibus; aristis rigidis patentibus. Desf. Atl. 1. p. 96. t. 19. f. 2. In Africa boreali et Hispania. $\odot$.

19. B. alopecuroides Poir. panicula conferta erecta; spiculis oblongis pubescentibus 15-floris subsessilihus; aristis inferne spiraliter tortis. Poir. it. 2. p. 100. B. contortus Desf. AtI. 1. p. 95. t. 95. B. Alopecurus Vahl. In Barbaria et Hispunia. $\odot$.

20. B. lanceolatus Roth; panicuIa erectiuscula; spiculis lanceolatis subcompressis; flosculis arcte imbricatis; aristis maturescente semine reflex0-patentibus. Willd. sp. 1. p. 429. Ad Mare Caspium. $\odot$.

21. B. unioloides $\boldsymbol{H}$. et $\boldsymbol{K}$. culmo glabro; panicula secunda; ramis verticillatis; glumis paleisque scabris; spiculis linearibus compressis sub-10floris. H. et K. Nov. Gen. 1. p. 151. Schenodorus $\mathbf{R}$. et $\mathbf{S}$. Festuca quitensis Spr. In Quito. $\odot$.

22. B. Willdenouii Kunth; panicula nutante patula; spiculis compressis 8-floris; foliorum vaginis apice harbatis. F. unioloides Willd. Hort. 1. p. 3. t. 3. Ceratochloa Beauv. Agr. t. 15. f. 7. In Carolina et Montevideo. $\odot$.

23. B. Schraderi Kunth; víridis; fol. planis; panicula effusa pendula; spiculis subsexfloris. Ceratochloa pendula Schrad. Ind. Sem. 1830. In Carolina.

24. B. Haenkpanus Kunth; culmo glahro; vaginis scabro-pubescentilus ; fol. hirsutis; ligula ovata; panicula nutante; gluma inferiore 9-nervia; palea superiore nervis hispido-ciliata. Ceratochloa Presl in Haenk. Rel. 1. p. 28.5. In Cliti et Peruvia. $\odot$.
25. B. Preslei Kunth; culmo glabro; vaginis inferioribus pubescentihirsutis; panicula secunda nutante; spiculis 7 -9-floris; glumis 7-nerviis acutis; palea inferiore 7 -nervia scabra. Ceratochloa secuuda. Presl 1. c. In Peruvia? $\odot$.

26. B. strictus Kunth; glaberrimus; panicula erecta stricta ; spiculis lanceolatis compressis 3 -floris aristatis; fol. filiformibus. Festuca Poir. Enc. Ceraiocliloa Boryana R. et $\mathbf{S}$. In ins. Borboniae.

2\%. $\boldsymbol{B}$, arduennensis Kunth; panicula nutante; spiculis compressis glabris; fol. lanceolatis facie ef margine villosis dorso glabris. Libertia Lejeune in Nov. Act. Bonn. 12. p. 757. t. 65. Michelaria bromoides Dumort. B. polystachyus Desf. B. multifloris $\beta$. Rclıb. In prox. Leodinensi. $\odot$.

28. B. purgans $L$. panicula nutante; spiculis lanceolatis teretibus; flosculis aristatis pilosis; aristis rectis; fol. utrinque glabris; vaginis pilosis. Willd. sp. 1. p. 431. In Pennsylvania et Canada. 4.

29. B. catharticus Vahl; panicula patente erecta subsimplici; spiculis lato-lanceolatis striatis scabris; aristis brevibus rectis. Vahl symb. 2. p. 22. In Lima. 4.

30. B. pendulinus schrad. panicula nutante; spiculis lanceolatis compressis nudis; flosculis demum remotiusculis; aristis rectis gluma brevioribus; fol. nudis. Schrad. in N. Jouru. 4. p. 70. Festuca Spr. In ins. Fortunatae et? Hexico. $\odot$.

31. B. pubescens Muehlenb. panicula nutante; spiculis lanceolatis compressis nudis; flosculis aristatis; aristis rectis; fol. utrinque pilosis; vaginis glabris. Willd. en. 1. p. 120. In Pennsylvanic. 4.

32. B. quitensis $\boldsymbol{I}$. et $\boldsymbol{K}$. culmo foliisque glabris interne scaloris; panicula ramosa verticillata diffusa; spiculis lanceolatis compressis sulı-5-floris; paleis pubescentibus; arista brevissima. H. et K. Nov. Gen. 1. p. 152. In Quito. $\odot$.

33. $\boldsymbol{B}$. segetum $\boldsymbol{H}$. et $\boldsymbol{K}$. culmo glabro; fol. vaginisque pilosis; panicula secunda; ramis rachique hispidoscabris; spiculis linearibus hispido-scabris; arista longitudine paleae. H. et K. 1. c. In Quito et Mexico. 4. 
31. B. canadensis Michx. nodis minute barbatis; fol. rariter pilosis; panicula laxa capillari pendula; florum valva exteriore versus margines villosa. Michx. Hl. 1. p. 65. In Canada.

3.5. 13. altissimus Pursh; panicula nutante; spiculis ohlongis sub-6-floris; valvula exteriore 3 -nervata breviter aristata; fol. vaginisque glahris; culno glabro altissimo. Pursh FI. 2. p. 728. All Missouri.

36. B. avensis $I_{\text {. }}$. panicula frueti"fera subnutante; spiculis lineari-lanceolatis; floribus elliptico-lanceolatis margine obtusangulis; aristis rectis longitudine paleae. M. et K. I. c. Hort. Gram. 1. t. 14. Engl. Bot. 920. B. versicolor Poll. B. multiflorus Weig. ohs. t. 1. f. 1. B. spiculi-tenuata Knapp. t. 81. In Europt. $\odot$.

3\%. B. japonicus 'Thunb. panicula patente ramosa; spiculis oblongis glahris; aristis divaricatis. Thunb. jap. p. 51. t. 11. In Japonia. $\odot$.

38. B. verticillatus Cav. panicula aperta; pelunculis horizontalibus verticillatis elongatis simplicibus ramosisque. Cav. ic. 6. p. 66. t. 590. In Arragonia.

3.9. B. pallens Cav. panicula erecta subcontracta; pedunculis inaequalibus sub-5-floris; aristis capillaribus longissimis. Cav. ic. 6. p. 66. t. 591. f. 1. In Manilla.

40. B. arenarins Labill. villosus; panicula patula; spiculis 5-floris. Labill. Nov. Holl. 1. p. 23. t. 28. In Nora, Hollandia.

4. B. anstralis R. Br. villosus; panicula nutante; ranis 1 -2-floris; spiculis $6-8$-floris; aristis valvula lougioribus; culmis strictis glabriusculis. R. B:. prodr. 1. p. 178. In Nova Hollandia.

42. I. erectus IIuds. panicula aequali erecta; spiculis lineari-lanceolatis 5-10-floris; floribus sub apice aristatis; fol. radicalibus angustissimis ciliatis; ligula brevi. M. et K. 1. c. B. pseudarversis Koel. B. montanus FI. Wett. B. angustifolius Schrank. B. perennis Vill. B. agrestis Host Gr. 1. t. 10. B. glaucus Lapeyr. Pyr. t. 53. Festuca montana Savi. In Europa et Caucaso. 24.

13. B. auleticus Trin. spiculis lanceolatis 5-7-floris pubescenti-scabris; gluma superiore 7-nervia; fol. fasci- culorum angustis ciliatis; ligula hrevi obtusa. B. erectus $\beta$. hirsutior. Nees in Herb. Reg. Berol. In Montevideo. 4.

4. B. sterilis $\mathrm{I}$. paniculae ramis apice pendulis; floribus lanceolatosubulatis; aristis rectis palea longioribus; culmo glahro. M. et K. Host. Gram. 1. t. 16. Fl. Dan. 1325. Engl. bot. 1030. B. distichus Moench. In Europa et Oriente. $\odot$.

45. B. longiflorus Willd. paniculae ramis pendulis; spiculis lanceolatis compressis hirsutiusculis; fol. ciliatis scabris; ligula lacera spr. Patria ignota. 4.

46. B. tectorum $\boldsymbol{L}$. panicula nutante secunda; spiculis linearibus; floribus lanceolato-subulatis ; - aristis rectis; culmo superne puhescente. M. et K. 1. c. Sibtl. Graec. t. 82. Host. Gram. 1. t. 15. B. grandiflorus $\beta$. Weig. Obs. 9. B. scabriflorus Opilz. In Europa, Caucaso et Sicilia. $\odot$.

4\%. B. laxus Hornem. panicula florente nutante; spiculis pendulis compressis linearibus pubescentibus; fol. laxis pubescentibus ciliatis. Hornem. Hafn. 2. p. 95t. In montibus Saxoniue. 4.

45. B. ciliatus I. panicula nutante; fol. utrinque vaginisque subpilosis; glumis ciliatis. L. sp. p. 113. In America boreali. 4.

1.9. B. rigidus Roth; spiculis oblongis superne latioribus; floribus lanceolatis angustatis; aristis rectis palea longioribus; culmo superne pubescente. M. et K. B. rubens Host. Gram. 1. t. 18. B. madritensis Vahl. B. villosus Forsk. In Europa australi. $\odot$.

50. B. madritensis $I$. panicula pedicellisque erectis; spiculis linearioblongis; floribus lanceolato - subulatis; aristis longitndine paleae; culmo nudo. M. et K. Host Gram. 1. t. 17. B. diaudrus Curt. Lond. t. 70. B. gynandrus lioth. Festuca madritensis Desf. B. polystachy'us DC. B. multispicatus R. et S. In Europa australi et Africa boreali. $\odot$.

51. B. maximus Desf. fol. villosis; panicula patulo-erecta; aristis longis rectis; rachi pubescente. Desf. Atl. 1. p. 95. t. 26. B. madritensis Cav. In Barbaria, Hispania et Gallia. $\odot$. 52. B. pilosus Dietr. Lex. panicula densa nutante; spiculis longissime 
aristatis hirsutis ; seminihus planis dorso incurvis. Dietr. Lex. 1. p. 558. B. Inaximus Roth Beitr. B. diandrus Lk. In Europu. $\odot$.

53. B. vubens L. culmo palmari; spicis villosis lanceolato - linearibus 7-12-floris; dentilus valvulae floscuJorum externac ciliato-villosis. Delile Aew. p. 25. t. 11. f. 2. sihth. Gr.t. *3. F. Iubens Pers. In Ilispania, Graeciu et Ae(!!) to. $\odot$.

5t. B. scopurius I. panicula fasciculata ; spiculis sulosessililus glahris; aristis patulis L. Amoen. Acad. 4. p. 266. 13. ruhens Cav. ic. t. 45. f. 2. II Ilispamia, Gallia orientali et Afieica boreali. $\odot$.

5.5. B. Biebersteinii R. et $\mathbf{S}$. panicula contracta subracemosa; spiculis lineari-lanceolatis nudis; aristis gluma multoties brevioribus; fol. planis nudis. 13. et s. syst. 2. p. 638. B. chloriticus Bieb. In Caucaso orientali. 4.

56. B. variegatus Bieb. panicula cuntracta subracemosa; spiculis lanceolatis nervosis nudiusculis; aristis rectis gluma breviorihus; culmo vagrinisque undis. Bieb. Fl. suppt. p. 79. In Caucaso orientali. 4.

\section{Speciesignotae.}

57. B. glaucus $\mathbf{S})$ r. fol. complicatis glabris; panicula elongata; spiculis 5-6-floris; flosculis subpatentibus; palea exteriore obtusiuscula pilosí. Lk. Hort. p. 170. Putria ignota. 4.

58. B. angustifolius Hornem. panicula nutante arcta; valvulis corollinis laevissimis glaberrimis; fol. vaginisque gtahris striatis; ligula brevissinta; aristis rectis. Hornem. Hort. suppl. p. 13. Patria ignota. 4.

5.9. B. lenis Presl; vaginis foliisque pilosis; panicula simplici flaccida secuuda nutante; rachi pubescente; spiculis sexfloris; palea inferiore 7nervia; arista brevissima. Presl. 1. c. In Peruria. $\odot$.

60. 13. viryatus Presl; fol. vaginis rachique scabris; pauicula erecta patente; ramis elongatis virgatis post anthesin divaricatis; spiculis secundis; paleis inferioribus subulatis pilosis apice integris. Presl 1. c. In Peruviu et Mexico. 4.

6i. B. secundus Prest; fol. planis intus scabriusculis; ligula brevissima; panicula secuuda nutante; paleis inferiorihus hirsutis 3-nerviis arista lougiorihus. Presl 1. c. In sinu Nutka. 4.

62. B. setifolius Presl; . caespitosus; culmis, vaginis foliisque convoIuto-setaceis rigidis pubescentilus ; paleis 9-nerviis villosis grlumisque convexis. Prest 1. c. In Chili et Mexico. $\odot$.

63. B. Brongniartii Inunth; fol. planis asperis valde pilosis; ligula oblonga truncata; glumis paleisque inferioribus $7-9$-nerviis acutis; paleis apice brevissime aristatis. B. strictus Brongu. in Dup. it. bot. p. 45. In Brasilia.

64. B. tomentosus Trin. panicula erecta; spiculis lanceolatis compressis glabris; aristis gluma brevioribus; culno foliisque strictis mollissime tomentosis. Trin. in Act. Petrop. 1813 -14. t. 9. B. Triniauus schult. In Gilan. 24.

6.5. B. scaberrimus Tenore; panicula aperta; pedunculis erectis verticillatis; locustis 12-floris hispidis scaberrimis fuscis; aristis glumarum longitudine; fol. villosis. Tenore Fl. Neap. p. 10. In Italia.

66. B. temis 'Tineo; humilis; culnis rracilibus adscendentibus; fol. lineari-acuminatis; spiculis 6-8-distichis; pedicellis incrassatis; gluma corollina interiore bifida mutica. Tineo, Plant. Sicil. n. 1. In sicilia. ๑.

6\%. B. pentastachyns Tineo; humilis; culmis basi geniculatis dein erectis; spiculis sessilibus $\mathbf{4}-\mathbf{5}$, distichis, 8-10-floris; glumis calycinis mucronatis. Tineo 1. c. Festuca Presl. In Nicilia. $\odot$.

68. B. megapotamicus Spr. panicula erecta racemosa contracta ; spiculis ovatis subsexfloris hirsutis; valvula corollina exteriore obtusa scariosa; fol. pubescentibus; vaginis villosis. Spr. Ad Rio Grande.

69. B. Sardous Spr. paniculae ramis articulatis subincrassatis; spiculis sub-10-floris glaberrimis; valvula interiore corollae subaristata; fol. angustis culmoque geniculato laevibus. spr. Cur. post. p. 36. Ad Rio Grande.

70. B. chrysopogon Vivian. fol. nodisque culmi longe pilosis; panicula contracta fascicu!ata; spiculis sulsessilibus lineari-lanceolatis sub-8- 
floris. Vivian. Fl. Lybic. 4. t. 2. f. 2. In pascua Cyrenaica.

71. B. tenuiflorus Vivian. panicnIa in spicam contracta; spiculis subsessilibus linearibus divergentibus; gluma exteriore ciliata aristam superante; vaginis foliisque hirsutis. Viv. 1. c. 5. t. 1. f. 1. In pascua Cyrenaica.

72. B. canescens Vivian. culmo foliis tecto; panicula fasciculata ovata canescente; spiculis 5-floris linearilanceolatis ; valvulis, glumis, foliis vaginisque hirsutissimis. Viv. 1. c. In Italia.

73. B. festucoides LK. fol. planis glabris; panicula ranis pancis arrectis; calycis valvula altera spiculac aequali, altera triplo hreviore. Link in Schrad. Journ. p. 1799. 4. p. 315. In Lusitania.

94. B. pectinatus Thunb. panicula patente; spiculis ovatis glabris; corollae valvula interiore ciliata mutica. Thumb. prodr. 1. p. 22. In Prom. b. spei.

\%5. B. hirtus Lichtenst. pauicula simplici; spiculis lanceolato-linearibus compressis 5-floris pubescentibus; aristis patulis spicula hrevioribus; culmis foliisque hirtis. Lichtenst. in $\mathbf{R}$. et $\mathbf{S}$. syst. 2. p. 654. In Prom. b. spei.

76. B. trichodes Kunth; paniculae flaccidae ramis subbinis; spiculis sub6-floris; calycibus patentibus aristatis; flosculis deciduis scabris; fol. angustis pilosis. B. pilosus Spr. syst. 1. p. 358. Schenodorus Schult. In ins. Mascarenis.

7\%. B. avenaceus Lam. panicula coarctata subsimplici; spiculis erectis glabris, 3-4-floris aristatis. Lam. ill. 1. p. 194. Patria ignota.

78. P. rigens L. panicula spicata; spiculis subsessilisus erectis pubescentibus sub-4-floris. L. Mant. p. 33. In Lusitania.

79. B. simplex Pers. panicula simplici, spiculis sessilibus 8 -10-floris glabris; aristis subdorsalibus divaricatis; vaginis villosis. Pers. syn. 1. p. 96. Patria ignota.

80. B. polystachyus Forsk. panicula patente; ramis spicatis; spiculis alternis adpressis linearibus brevissime aristatis. Forsk. FI. p. 23. In Aeyypto.

81. B. massiliensis Forsk. spiculis compressis; glumis interioribus va- ginis pubescentibus superioribus glabris. Forsk. p. 203. In Massilia.

82. B. canariensis Zucc. panicula patula spiculis inordinatis $\mathbf{1 0}$-floris; glumis emarginatis dorso breviter aristatis; fol. nodisque pubescentibus. Zucc. Cent. n. 27. In ins. Fortunatae.

83. B. bifidus Thunb. panicula erecta ramosa; spiculis ovatis sub-3floris ; glumis bifido-setaceis; arista divaricata. Thunb. jap. p. 53. In Japonia.

81. B. spicatus Nees; spiculis disticho-spicatis linearibus; floribus basi villosis; fol. ciliatis. Nees in Mart. Bras. 2. p. 471. In Brasilia.

85. B. circinatus T'enore; panicula ramosa; spiculis subcylindricis 57-floris glabris viridibus; palea altera ciliata aristata; arista spiraliter contorta. Tenore Lez. bot. 1. p. 52. Barr. ic. 24. f. 2. In Italia. $\odot$.

86. R. parviflorus Desf. culmo erecto; fol. vaginisque villosis; panicula apice nutante; spiculis glabris 7-9-floris; aristis rectis. Desf. Cat. p. 387. Patria ignota.

\section{ORTHOCLADA Beauv. (1812).}

1. O. laxa Beauv. Agr. t.11. f.9. panicula subumbellata, in fructu patentissima; fol. oblongis glabris. Nees in Mart. Bras. 2. p. 522. Kunth Gram. 1. t. 71. Poa subumbellata. H. et $\mathbf{S}$. o. rariflora Beauv. In Gujana et Brasilia. 4.

2. O. rariflora Nees; panicula patula; spiculis sub-3-floris; valvulis apice subulatis; fol. lanceolatis supra pilosis. Nees in Mart. Bras.2. p.521. In Provincia Paraensi. 4.

\section{UNIOLA L. (1737).}

1. T. Iatifolia Michx. panicula laxa; spiculis omnibus longe pedicellatis; calyce trivalvi; floribus 1-andris subfalcatis carina pilosis; fol. latis planis. Pursh Fl. 1. p. 82. In America boreali. 4.

2. U. nitida Baldw. fol. planis angustis; panicula sparsa patula; spi-. culis subsessilibus paucis; calycibus 3-valvulis; floribus 1-andris. Baldw. in Elliot. bot. 1. p. 167. In America boreali. 
3. E. paniculata $I$. panicula longa; spiculis subsessilibus ; calyce multivalvi; florilus 3-andris carina glahris; fol. convolutis; culmo altissimo. Pursh Fl. 1. p. 82. Catesh. Carol. p. 32. U. maritima Michx. Briza caroliniana Lam. ill. t. 45. f. 3. In America boreali. 4.

t. C. mucronato $L$. spica disticha; spiculis ovatis; calycilus subaristatis. L. sp. p. 104. In India orientali.

5. $\boldsymbol{U}$. grucilis Michx. panicula Iongissinı subspicata; ramis adpressis; floribus 1-andris; calyce 3-valvi; culmo compresso. Pursh Fl. 1. p. 82. Kunth Gram. t. 72. Holcus laxus L. Chasmanthium gracile Lk. In America boreali. 4 .

\section{STREPTOGYNA Beauv. (1812).}

1. S. crinitu Beauv. Agr. p. 80. t. 16. f. s. Poir ill. suppl. t. 912. In Carolina et Gujana.

\section{2\%. CHUSQUEA Kinth. (1822).}

1. C. scandens Kunth; fol. linearilanceolatis mucronato-subaristatis subsessilibus; paniculis diffusis; paleis apice acutato-subulatis. Nastus Chusquea H. et K. Nov. Gell. 1. p. 201. Bambusa. Poir. In Nova Granata et Quito. 4.

2. C. Dombeyana Kunth; fol. Ianceolatis acuminato-subulatis subtus rachique pubescentibus; spiculis lanceolato-fusiformibus puhescenti-hirtellis; paleis acutatis. Kunth Gram. 2. p. 553. t. 191. In Peruvia.

3. G. Quila Kunth; fol. linearilanceolatis acutato-subulatio subsessilibus subtus glaucescentibus et puberulis; paniculis diffusis; spiculis ovato-oblongis; paleis apice acutato-mucronatis. Kunth Gram. 1. p. 138. et 329. t. 77. Arundo Quila Poir. Nastus Quila R. et S. In Chili.

4. C. Gaudichaudii Irunth; fol. ovato-lanceolatis subpetiolatis; paniculis ellipticis; spiculis oblongis; paleis obtusiusculis. Kunth Granı. 1.p. 138. et 331. t. 78. Rettbergia bambusacoides Raddi Agr. t. 1. f. 1. In Rio Janeiro.

\section{PI.ATONIA Kunth (1S29).}

1. P. elata Kunth Gram.1.p. 139. et 32\%. t. 76. In Loxa Quitensium. Folia longissima coriacea. Panicula ramosissima.

\section{MEROSTACHYS Spr. (1821).}

1. M. speciosu Spr. spiculis solitariis; valvula inferiore acuminata hirsuta. Nees in Mart. Bras. 2. p. 527. In Brasilia. $ђ$.

2. M. ternata Nees; spiculis ternis; valvula inferiore brevissime mucronata scalora. Nees in Mart. Bras. 2. p. 529. In Brasilia. 卢.

\section{NASTUS Juss. (1789).}

1. $N$. borbonicus Gmel. culni arborei ramis verticillatis; fol. linearilanceolatis; vaginis superne ciliatis ore setosis. Bambusa alpina Bory it. 1. p. 310. t. 12. N. paniculatus sim. Stematospermum verticillatum Beauv. Lam. ill. t. 264. f. 1. b. c. d. In ins. Borboniae. t).

2. N. capitatus Kunth; fol. linearioblongis basi rotundatis; vaginarum ore ciliato-setoso; spiculis lanceolatosubulatis, setulis nigris obsitis. Kunth Gram. 1. p. 325. t. 75. In Marlagascaria.

3. N. Tjankorreh R. et S. culmi scandentis ramis fasciculatis; spicis paniculatis subfiliformibus; spiculis 1floris; glumis ventricosis rotundatoovatis nucronulatis. R. et S. syst. 7 . 2. p. 1358. Bambusa scandens Blume. In Java. $\hbar$.

\section{BAMBUSA Schreb. (1789).}

1. B. arundinacea Willd. spinosa; panicula ramosa divaricata; spiculis verticilatis 2-6-floris; flore uno hermaphrodito, reliquis masculis; stigmate bifido. Roxb. Cor. t. 89. Arundo Bambos L. Bambos arundinacea Retz. In India orientali。 $\hbar$.

2. B. stricta Roxb. Cor. $t .80$. subinermis; spiculis arcte verticillatis subtrifloris; floribus omnibus hermaphroditis; palea exteriore villosa acu- 
te mucronata. Nastus stricta Sm. In India orientali. $ђ$.

3. B. Thouarsii Kunth; suhinermis; spiculis fasciculatis sub-8-floris; palea inferiore acutato-mucronata glabra superne ciliata; stigmate trifido; fol. margine scabris subtus glaucescentibus. Kunth Gram. 1. p. 323. t. 73. et 74. Nastus Beauv. Agr. t. 25. f. 3. Bambusa vulgaris $R$. et $\mathbf{s}$. B. arundinacea Ait. Kew. In ins. Madagascar et Borbonia. †.

4. B. spinosa Roxb. trunco erecto spinoso; spinis geminis ternisve; vaginis hispidis; paniculae ramis pendulis; valvula exteriore maxima interiore ad angulos ciliata. $\mathbf{R}$. et $\mathbf{s}$. $\%$. p. 1342. Ily Rheede Mal. 1. t. 16. In India orientali. ђ.

5. B. Blumeana $R$. et $\mathbf{S}$. culmis erectis; spinis ternis recurvis; fol. lineari-lanceolatis utrinque glabris; vaginis margine oreque ciliatis; spiculis subulatis dense verticillato-capitatis. R. et S. 7. p. 1343. B. spinosa Blume. In Java. 古.

6. B. agrestis Poir. florihus hexandris; panicula spicata; spiculis congestis; ramis culmi inferioribus spinosissimis; calycibus 1-floris. Arundo Lour. Coch. 1. p. 73. Arundarbor Rumph. Amb. 4. t. 14? In Cockin-

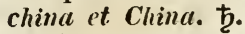

\%. I. verticillata Willd. spica terminali simplici verticillata; spiculis ovato-oblongis obtusis 5 -multifloris; flosculis inferiorihus sterilibus. $\mathbf{R}$. et s. 1. c. Arundarbor tenuis Rumpl. Amb. 4. t. 1. Nastus S'm. In India orientali. $\hbar$.

8. B. multiplex Raeusch. floribus hexandris; spicis interruptis; spiculis verticillatis; culmo diviso; calycibus 1-floris. Arundo Lour. Coch. 1. p. 73. In Cochinchina. $\hbar$.

9. B. Tabacaria Poir. culmo tenui rectissimo, omnino aequali aspero ramoso; internodiis longissimis scahris. Schult. 1. c. Arundo Lour. Coch. Arundarbor spicularum Rumph 4. t. 7 .

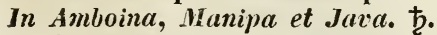

10. B. mitis Poir. florilus hexandris; panicula erecta coarctata; spicis longis imbricatis; culmo aequalissimo inermi. Arundo Lour. Coch. 1. p. 73. Arundarbor fera Rumph. 4. t. 4. In Cochinchina.

11. B. maxima Poir. stipitibus rectissimis ad verticem usque simpli- cibus; spinis densissimis. Schult. 1. c. Arundo Lour. In Amboina et Cochinchina. 方.

12. B. aspera R. et S. culmis alhide farinoso-lannginosis; fol. glabris Schult. 1. c. In Amboina et Huamahela. $\hbar$.

13. B. Apus R. et $S$. fol. amplis lanceolatis acuminatis basi subattenuatis margine scaberrimis nervoso-striatis; vaginis truncatis inferne pilosis margine ciliatis. 1R. et s. 1. c. In Java. 古.

11. B. Bitung $\boldsymbol{R}$. et $\mathbf{S}$. fol. amplis ovato-lanceolatis acuminatis basi in petiolum brevissimum hispidum subattenuatis, subtus margineque scaberrimis; vaginis truncatis inferne setosis. schult. 1. c. In Java Blume. 古.

\section{GUADUA H. et K. (1815).}

1. G. angustifolia Kunth syn. fol. anguste linearibus margine subtusque scabris; spicis depauperatis longe pedunculatis ; spiculis 7-8-floris. Bambusa H. et B. pl. aeq. 1. p. 68. t. 20. Nastus Gadua Spr. In Nova Granata et Quito. t.

2. G. latifolia Kunth syn. fol. linearibas oblongis glaberrimis; spiculis subfasciculatis cylindraceis subarcuatis 8-10-floris. Kunth syn. 1. p. 254. H. et B. pl. aeq. 1. t. 21. Spix et Mart. Reise in Bras. VegetationsForm. t. 5. f. 2. Nastus Spr. Ad ripam fluvii Cassiquaire. 古.

3. G. amplexifolia Presl; ramis dichotomis; fol. ovato-linearibus margine scabris; spicis longis; spiculis cylindraceis 9-floris subarcuatis. Presl in Rel. Haenk. 1. p. 256. Bambusa H. et $\mathbf{s}$ In Mexico. $\downarrow$.

4. G. Tagoara Kunth; culmo ramoso; spicae compositae ramis recurvatis; spiculis glomeratis subternis 6-8-floris; fol. oblongis glabris acuminatis. Bambusa Tagoara Nees in Mart. Bras. 2. p. 532. Spix et Mart. Reise Veget.-Form. t. 1. f. 9. In Brasilia. .

5. G. parviflora Presl; ramis alternis; ligula elongata culmum involvente; fol. lanceolatis margine scabris; panicula patente; spiculis 4-floris. Presl Rel. Haenk. 1. p. 257. In Peruvia. \$. 


\section{BEESHA Rheede (1691).}

1. B. Rheedii Kunth; culmo celsissimo simplici; fol. glabris; fructihus apice nudis. Melocanna bambusoides. Spr. syst. 2. p. 113. Beeslia Hheede 5. t. 60. Bambusa baccifera Roxb. Cor. t. 243. Meloc. humilis Roep. Beesha baccifera $\mathbf{R}$. et $\mathbf{S}$. In India orientali. $\hbar$.

2. B. humilis Kunth; fol. glaucis subtus lanatis; fructihus apice comosis. Melocanna humilis Spr. syst. 2. p. 113. Arundo Falx Lour. Bambusa Falx. R. et S. In Amboina. $\hbar$.

\section{SCHIZOSTACHYUM Nees (1829).}

1. S. Blumei Nees in Mart. Bras. 2. p. 535. In ins. Java. ち. Arboresceus. Folia subpedalia.

\section{LOLIUM L. (1737.)}

1. $L$. perenne $L$. spiculis lanceolatis muticis vel breviter aristatis glumam superantilus; culmo nudo; radice perenni. M. et K. I. c. schreh. Gram. t. 37. Engl. Bot. t. 315. Fl. Dall. 747. Host. Gram. 1. t. 25. var. $\beta$. tenue; L. tenue L. L. perenne $\beta$. Sm. L. Halleri Gmel. $\gamma$. compositum. L. perenne $\delta$. Smith. L. compositum Thouill. d) ramosum. L. perenne $\gamma$. Sm. L. perenne $\beta$. Leers Herb. t. 12. f. 1. In Europa, Caucaso, America boreali et ins. Maclovianis. 4.

2. L. arvense With. Aorihus Ianceolatis magis minusve aristatis ; aristis palea brevioribus; gluma longitudine fere spiculae. L. complanatum Schrad. L. maximum Willd. L. asperum Roth. L. anuuum Beruh. L. rigidum Gaud. L. temulentum Huds. In Europa, Asia occidentali et Brasilia. $\odot$.

3. L. multiflorum Lam. spiculis 13-25-floris gluma duplo triplove longioribus; floribus superioribus spicularum aristatis; radice annua. Kunth ell. Gram. p. 436. In Gallia. $\odot$.

4. L. Boucheanum Kunth; spiculis $5-\mathbf{1 0}$-floris aristatis glumam triplo superantihus; radice perenui. Kuntl Gram. 2. t. 220. In Italia. 4.
5. L. speciosum Stev. valva spiculam superante; floribus fructiferis ellipticis. Koch syu. p. 828. L. arvense Lej. L. robustum Rchb. ic. 1340. In agris Europae. $\odot$.

6. L. ten lentum $L$. valva spiculam aequante; arista recta paleam superante. Koch syn. p. 828. FI. Dan. 160. Schreb. Gr. t. 36. Engl. bot. 1124. Craepalia Schrank. L. annuum Lam. Inter segetes Europae, Japoniae, Novae Hollandiae et Americae. $\odot$.

7. L. scabrum Presl; fol. margine scalıris; glumis spicula decemflora dimidio brevioribus; paleis inferioribus 5-nerviis. Presl in Rel. Haenk. 1. p. 267. In Peruvia. 4.

8. L. brasilianum Nees; spica submutica; spiculis 5-10-floris calyce longioribus; valvulis acutis; culmo compresso superne retrorsum scaberrimo. Nees in Mart. Bras. 2. p. 443. In Montevideo. 4.

9. L. canadense Michx. spica mutica; spiculis calycem aequantibus sub12-floris; culmo subcompresso. R. et S. syst. 2. p. 893. In Hort. Monspeliensi colitur.

10. L. distachyum L. spica binata; calycinus 1-floris; corollis lanatis. Linu. mant. p. 187. In Malabaria.

\section{TRITICUM L. (1737).}

\section{A. Species genuinae.}

1. Glumae ventricoso-concavae, ovato-oblongae, obtusae vel truncatae.

1. $\boldsymbol{T}$. vulgare $\boldsymbol{L}$. spica tetragona imbricata; valvis ventricosis ovatis mucronatis sub apice compressis. Host. 3. t. 26. Metzger cer. t. 1. et 2. var. spica aristata. T. aestivum $\mathbf{L}$. et spica mutica. T. hybernum L. T. compactum Host. 4. t. 7. Colitur $\odot$. et $\odot$.

2. T. spinulosum Lag. glumis aristatis 4-5-floris; flosculis inferioribus aristatis; culmo frutescente. Lagasc. Elench. 7. In Havamna. .

3. $T$. turgidum $L$. spica tetragona; rachi tenaci; valvis ventricosis ovatis carinatis; carina subulaeforml. Host. Gr. 3. t. 28. T. compositum L. Host. Gram. 3. t. 27. T. sativum turgidum Delile Aeg. t. 14. f. 2. Colitur. $\odot$. et $\odot$. 
4. T. durum Desf. spica tetragona imbricata; valvis oblongis ventricosis latitudine sua triplo longiorilus lato-mucronatis carinatis; carina subulaeformi. T. aestivum $\beta$. Pers. T. hordeiforme Host. Gr. 4. t. 5. T. fastuosum Lag. T. villo rum Host. 4. t. 6. Colitur. $\odot$. et $\odot$.

5. 'T. polonicum L. spica irregulariter 4-zona vel compressa; valvis subventricosis oblongo-lanceolatis herbaceo-chartaceis conspicue multinerviis. Host. Gr. 3. t. 31. 'T. Cevallos Lag. Colitur. $\odot$. et $\odot$.

6. T. Spelta $L$. spica compressa imbricata; rachi fragili; valvis latoovatis truncatis hidentatis; dente carinali recto anteriore obsoleto. T.Zea Host. Gram. 3. t. 29. Colitur. $\odot$. et $\odot$.

7. T. dicoccon Schrank; spica opposite compressa arcte imbricata ; rachi fragili; valvis ohlique truncatis dentato-mucronatis; cariua compressa valde prominente superne cum apice inflexa. T. Spelta Host. 3. t. 30. T. amyleon Sering. T. atratum Host. 4. t. 8. T. tricoccon schïbl. Colitur. $\odot$. et $\odot$.

8. T. monococcon $L$. rachi fragili; valvis apice 2 -dentatis, dentibus acutis carinaque apice rectis. Koch. l.c. Host. Gr. 3. t. 32. T. puhescens Bieb. In Tauria et Caucaso. $\odot$. et $\odot$.

9. T. villosum Beauv. spica disticha; spiculis sub-4-floris; valvis cuneatis truncatis aristatis rachique fasciculato-pilosis; fol. tuberculato-pilosis. Koch 1. c. Secale Sibth. tah. 97. Host. 2. t. 47. Agropyrum Lk. Hordeum ciliatum Lam. In Europa australi et Oriente. $\odot$.

10. $\boldsymbol{T}$. venulosum Seringe; spica compressa arcte imbricata; gluma 1dentata bicrenata ad carinam venosa. Seringe Monogr. p. 133. In Aegypto.

11. 'T. bicorne Forsk. fol. planis linearibus hirsutis; culmis erectis spica gracili aspera; spiculis 3-4-floris; flosculo supremo aristato; valvulis calycis striatis apice lanato emarginatis. Delile Acg. p. 35. t. 15. f. 1. In Aegypto. $\odot$.

2. Glumae lanceolatae vel lineari-oblongae acutatae v. obtusae.

12. T. repens $\mathrm{L}$. spica disticha; valvis lancoolatis 5-nerviis acumina- tis; rachi plerumque scabra; fol. supra punctulis acutis solitariis magis minusve scalıris; radice repente. Koch. syn. p. 825. Host. Gram. 2. t. 21. schreb. t. 26. Engl. bot. 909. Fl. Dall. 748. Agropyrum Beauv. var. floribus acutis acuminatisve et obtusis iisque aristatis mucronatis muticisve; fol. viridilous glancisve. Elymus caninus Leer's Herb. t. 12. f. 4. Agropyrum caesium Presl. In Europa, Sibiria et America. 4.

13. T. geniculatum Trin. spica lineari laxa; axi continuo; spiculis sul)5-floris; glumis concavo-lanceolatis 5-nerviis; radice fibrosa. Ledeb. ill. t. 247. In Sibiria. 4.

14. T. ramosum Trin. spica lineari laxiuscula; axi continuo; spiculis sub-5-floris; glumis concavo-subulatis ; radice repente. Ledeb. ill. t. 245. In Sibixia et Astrachan. 4.

15. T. rupestre Ih. culmo erecto, fol. plauis supra striatis; spiculis 3floris; valvulis calycinis $\mathbf{5}$-nervibus corollinis aristatis glabris. I.k. en. 1. p. 98. Agropyrum rupestie Schult. Patria ignota.

16. T. littorale Host. Gram. 4. t. 9. spica disticha; spiculis sub-5-floris; glumis lanceolatis 5-nerviis acuminatis; fol. supra scabris; radice repente. Agropyrum Rchb. In littoribus Idriae. 24.

18. T. densiflorum Willd. spica disticha; spiculis linearibus; calycibus aristatis sub-10-floris; flosculis hrevissime aristatis; radice subrepente. Agropyrum 12. et s. syst. 2. p. 733. In Sibiria. 4.

18. T. acutum DC. spica disticha; spiculis 5-8-floris; valvis lineari-lanceolatis 7-nerviis; fol. supra punctulis acutis dense obsitis scabris. Koch syn. p. 825. In Gallia et Germania. 24.

19. T. sibiricum Willd. spica disticha; glumis calycinis trinerviis 6floris; flosculis muticis; radice fibrosa. Willd. en. p. 135. Agropyrum 12. et S. In Sibivia. 4.

20. T. variegatum Fisch. radice perenni repente; spiculis sub-8-floris muticis; valvula exteriore 5-nervia; ligula truncata; fol. glaucescentilus. Spr. Pug. 2. p. 21. Agropyrum R. et S. Patria ignota. 4.

21. T. dasyanthum Spr. culmis stoloniferis; fol. interne sulcatis scabrin- 
sculis; spiculis ellipticis sub-6-floris; floribus muticis lanuginoso-villosis; glumis pateutibus. Kunth Gram. 1. p. 353. t. 90. Agropyrum Ledeb. Ad Borysthenum. 4.

22. 'T. attenuatum $H$. et $K$. spicuculis 3-floris; flore superiore saepius sterili; glumis lanceolatis $\mathbf{5}$-nerviis; palea inferiore brevissime aristata. H. et K. Nov. Gell. 1, p. 180. Agropyrum 18, et s. In Quito. 4.

23. T. condensatum liunth; fol. involutis scabriusculis; spica disticha; rachi 3-ruetra; spiculis 6-floris; palea inferiore 5-nervia scahra mucronata; superiore emaryinato-2-dentata. Agropyrum Presl in Rel. Haenk. 1. 1. 266. In Chili. 4?

21. T. secumdum Krtnth; spica secunda; spiculis 3-floris; glumis lanceolatis $\boldsymbol{7}$-nerviis mucronatis; palea inferiore 5-nervia; radice repente. Agropyrum Presl 1. c. In Chili. 4.

25. T. pilosum Kunti; vaginis foliisque canaliculatis pilosis; paleis inferioribus muticis acutis nervo medio scabris; culmo repente ramoso. Agropyrum presl 1. c. In Acapulco. 4.

26. T. caninum Schreb. spica disticha; valvis lanceolatis $3-5$-nerviis acuminatis; rachi setuloso-scabra; fol. utrunge scabris; radice fibrosa. Koch. кyn. p. 826. Fl. Dall. 1447. Engl. bot. 1372. Host. Gram. 2. t. 26. Agropyrum $\mathbf{R}$, et $\mathbf{s}$. var. $\beta$. Gmelini Ledeb. ill. t. 248. In Europa et Sibiria. 4.

27. T. imbricatum Stev, spica ovato-oblonga compressa villosa; glumis paleisque subulato-aristatis; culmo erecto pubescente. Agropyrum R. et s. A. cristatum Gaertu. In Iberia, Taurict et Sibiria. 4.

2S. 'T' muricatum Lk. culmo erecto; fol. lanceolatis; valvulis calycinis aristatis 8-floris margine ciliatis; corollinis subulato-aristatis hirtis. Lk, e11. 1. p. 97. Agropyrum schult. In Sibiria. 4.

29. T. cristatum Schreb. calycibus 4-floris aristatis; spicis lanceolatis imbricatis; culmis pubescentibus. Schreb. Gram. 12. t. 23. f. 2. Host. Granı. 2. t. 24. Engl, bat. 226\%. Bromus L. Agropyrun R. et S. In Tauria, Caucaso, Pannonia, Castilia et sibiria. 4.

30. T. pectinatum Bieb. spica ovata disticha glabra; calycibus sub-7nerviis aristatis sub-8-floris; spiculis subulato-aristatis; culmis crectis gla- hris. Willd. en. p. 135. T. cristatum Pers. Agropyrum pectiniforme R. et $\mathbf{s}$. In Tauria. 4.

31. T. desertorum Fisch. spica angusto-lineari densa; spiculis 3-6-floris; glumis ovato-lanceolatis 3-nervibus; floribus breve caudato-subulatis; radice filrosa vel subrepente. Ledeb. ill. t. 146. Ejusd. Alt. 1. p. 115. Agropyrum Schult. Ad Irtysch. 4.

32. T. angustifolinm ik. culmo erecto; fol. subfiliformibus; valvulis calycinis aristatis suh-8-floris carina ciliatis; corollinis subulato-aristatis hirtis. Agropyrum Lk. Hort. 1. p. 35. In Siliria. 4.

3.3. $T$. mostratum $L$, spica ovata compressa hifaria; glumis calyciuis corollinisque glabris; aristis flosculo hrevioribus. Ait. Kew. 1. p. 121. Jace. Hort. Vind. t. 44. Agropyrum triticeun Gaertn. in Nov. Comm. Petr. 14. t. 19. A. prostratum 12. et s. secale reptans Pall. In Euroya australi, Sibirirs et Oriente. $\odot$.

31. 'T. crinitum hunth; culmo basi prostrato; spica brevi disticha; spiculis dense approximatis $3-4$-floris patentibus; glumis evidenter carinatis obtuso - aristatis. Agropyrum Lk.

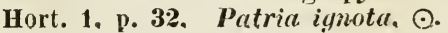

3.5. T. orientale Bieb. spica ovatooblonga compressa hirsuta; glumis ommibus subulato-apistatis; culmo basi procumbente; vagina summi folii tumida. Bieb. Fl. 1. p. 86 . Secale L. Willd. Act. Nov. Soc. nat. cur. 2. t. 4. f. 3. Agropyrum R. et S. In Tutria, Graecia, Oriente et Sibivia. $\odot$.

36. T. squrrosnn Roth; spica disticha; spiculis 4-floris muticis approximatis; flosculis binis intermediis sterilibus, fertilibus cuspidatis; calycinis valvulis maryine cartilagineo-incrassatis; culmo adscendente. T. patulum Willd. en. p. 134. Secale pungens Pers. T. Bounopartis spr. T. planum Desf. Agropyrum patulum Trin. In Aeglypto. $\odot$.

3\%. T. obtusiflorum DC. spica disticha subcontinua; glumis obtusissimis 9-nerviis; rachi scabra; fol. pla110-subconvolutis glancis. DC. Cat. Monsp. p. 153. Agropyrum li. et S. In Zeelandia. 4

38. $\boldsymbol{T}$. junceum $\boldsymbol{L}$. spica r'sticha; spiculis remotis 5 -8-floris; valvis linearihus 9-11-nerviis; fol. supra molliter deusissime brevissimeque velutinis; 
radice repente. Koch. syn. p. 824. Host. Gr. 3. t. 33. Engl. hot. 814. Fl. Dan. 916. Sibth. graec. t. 99. Bromus truncatus scop. Agropyrum Beauv. In Europa, Tauria et Caucaso. 4.

39. T. strictum Dethard; spiculis j-floris approximatis; valvis linearilanceolatis 5-nerviis; floribus a basi supra medium axeque pilosis; fol. supra densissime brevissimeque velutinis scahriusculisque; radice longe repente. Koch, 1. c. Agropyrum Rchl. Ad littora maris mope Warnemünde. 4.

40. T. punyens Per's. spiculis $5-$ 10 -floris; valvis lanceolatis 7 -nerviis acutiusculis breviterque mucronatis; fol. supra setulis solitariis scaberrimis; radice repente. Koch. 1. c. Agropyrum repens H. et s. In Germania australi et Gallia. 4.

41. T: glaucum Desf. spiculis sub5-floris approximatis; valvis oblongis 5-7-nerviis obtusissimis; fol. supra punctulis acutis solitariis scahriusculis; radice repente. Koch. I. c. T. intermedium Host. 2. t. 22. Agropyrum R. et S. In Germania, Austria et Helvetia. 4.

42. $T$. rigidum Schral. spiculis 5 -10-floris; valvis 9-llerviis latotruncatis; fol. supra setulis scaherriuis; radice fibrosa caespitosa stolonibus destituta. Koch. 1. c. T. elongatum. Host. Gram. 2. t. 23. T. junceum $\beta$. giganteum Roth. Agropyrum rigidum et giganteum $\mathrm{R}$. et $\mathrm{S}$. In $\mathrm{Eu-}$ ropa media. 4.

3. Glumae lanceolatae acutae. spiculae brevissime pedicellatae, solitariae geminae vel racemosae.

43. T. sylvuticum Moench; spica disticha multiflora nutante; aristis florum superiorum palea longioribus; fol. planis lauceolato-linearibus flaccidis. Bromus sylvaticus Poll. Host. Gram. 1.t. 21. Festuca sylvatica Huds. F. gracilis. Moench. Brachypodium gracile $\mathbf{R}$. et $\mathbf{S}$. In Europa, Caucaso et Oriente. 4.

4. T. pinnatum Moench; spica subnutante; aristis palea brevioribus; fol. planis linearibus rigidis; radice repente.' Koch. 1. c. Bromus piunatus L. Host. Gram. 1. t. 22. Engl. hot. t. 730. Festuca pinnata Moench. Brachypodium Beauv. Agr. t. 19. f.3.
T. gracile DC. Bromus rupestris Host. Gr. 4. t. 17. B. caespitosus. Host. Gram. 1. t. 18. In Europa et Sibiria.

45. T. luzonense Funth; radice fibrosa; culmo nodisque glahris; vaginis foliisque piloso-puhescentihus; ligula ovata fimbriata; spiculis hirsutis 4-floris. Bromus Presl in liel. Haenk. 2. p. 262. In Luzonia.

46. T. strigosum Iunth; spicula simplici gracili; aristis divaricatis gluma longioribus; spiculis alternis contiguis glabris. Bromus strigosus Bieb. Fl. suppl. p. 81. Brachypodium Schult. In 'Tauria. 2.

47. T. phoenicoides $\boldsymbol{D C}$. fol. convolutis pungentibus; spica simplici recta disticha; spiculis $10-20$ - foris brevissime pedicellatis; glumellae valvula interna tenuissime ciliata, externa acuminato-aristata. DC. Gall. 6. p. 284. Brachypodium L. Festuca $L$. In Gallia meridionali. 4.

48. T. caespitosum $D C$. radice repente; culmo basi ramosissimo; fol. convolutis glaucis tenuissimis; valvula glumellae interna tenuissime ciliata. DC. Bot. Gall. 1. p. 530. Festuca Desf. atl. t. 24. f. 1. Bromus ramosus Silth. t. 84. Brachypodium ramosum R. et S. B. Pluknetii Lk. Ins Europa australi, Oriente et barbaria. 4.

19. T. Barrelieri Kunth; spica simplici disticha; spiculis sulssessilibus 20-floris remotis muticis. Festuca Tenore prodr. p. 9. Brachypodium R. et S. In Lacania. $\odot$.

50. $T$. ciliatum $D C$. spiculis $1-3$, 6-12-floris; aristis palea longioribus; culmo foliisque glahris; radice fibrosa. Koch. 1. c. Host. Gram. 1. t. 20. F. distachya Koel. Bromus ciliatus et polystachyus Lam. Festuca monostachya Desf. atl. t. 24. f. 2. Brachypodium distachyon R. et S. Trachynia Lk. In Europa australi, Barbaria et Oriente. $\odot$.

51. T. brevisetum DC. spiculis 5-6, 20-30-floris; flosculis breviter aristato-mucronatis; culmo a basi ad apicem scabro. DC. Cat. Mousp. p. 153. Brachypodium R. et S. Patria ignota. $\odot$.

52. T. asperum DC. spiculis 1-3, 6-8-floris; flosculis spiculae superioris longe aristatis; radice filrosa. DC. Cat. Monsp. p. 153. Eestuca rigida 
Both. Brachypodium asperum R. et $\mathbf{S}$. Trachynia Lk. In Hisjuniu. $\odot$.

5.3. 'F'. scabrum R. Br. spica elongata; spiculis distinctis adpressis 5-6floris; glumis lanceulatis nervosis nosculo duplo brevioribus ; fol. planiusculis scabris. 1R. 13r. prodr. 1. p. 178. Festuca Labill. Nov. Holl. t. 26. In Nova Hollandia.

5t. T. Brounei Kunth; spiculis distinctis divaricatis 5-6-floris, fructiferis reflexis; glumis acuminatis; aristis perianthio brevioribus; fol. planis ciliatis. T. pectinatum. K. Br. prodr. 1. p. 178. Festuca Labill. 1. c. t. 25. In Noru Hollundia.

55. 'T. genuense $\mathrm{DC}$. spiculis $2-3$ alternis 8-10-floris; flosculis breviter aristatis; radice repente; fol. omnihus subtus margineque pilosis. DC. Gall. 6. p. 284. Brachypodium R. et s. Prope Genuam. 4 .

\section{Species dubiae.}

56. T. filiforme Poir. spica angusta lineari; spiculis distichis biforis aristatis; fol. canleque filiformibus; radice repente. Poir. Enc. 2. p. 677. In Ins. Borboniae. $\odot$.

57. $T$. peruvianum Lam. spiculis 10-floris muticis confertis subspicatis; culmo ramoso repente. Lam. ill. 1. p. 212. Agropyrum $\mathrm{H}$. et $\mathrm{S}$. In aquis stagnantibus Peruviae. 4.

58. 'T. siculum R. et $\mathbf{s}$. spicis undique imbricatis; aristis spica longioribus divaricato-patentibus; fol. glabris. 1R. et S. syst. 2. p. 765. In Sicilia colitur. $\odot$.

59. T. ichiostachyum Seidl. spica gracili teretiuscula; spiculis subimbricatis glahris aristatis; valvulis obtusis aristatis; fol. superne hirtis. Seidl. in Opitz Verz. p. 106. Patria ignota. $\odot$.

60. T. Linnaeanum Lay. glumis ventricosis glabris brevilus parvis acutiusculis, breviter mucronatis anguste carinatis. Lag. Elench. 6. In Hispania colitur. $\odot$.

61. $\boldsymbol{T}$. vaginans Pers. fol. vagina sulverticosa spicam basi includente; spiculis trifloris aristatis. Pers. syn. 1. p. 109. Agropyrum R. et $\mathrm{S}$. In America merilionali.

62. 'T. distichum Thunb. calycibus 4-floris glabris muticis; floribus distichis; fol. filiformibus. Tluunl. prodr. p. 23. Agropyrum R. et S. In Prom. b. spei.

63. T. nigricans Pers. spica tetragona; glumis margine villosis nigrescentibus; aristis longis. Pers. syn. 1. p. 110. Brachypodium 1 . et s. In Vormandia.

6f. 'T. subulatum Russel; calycibus unilateralibus subulatis subtrifluris; corollis calyce brevioribus aristastis. Hussel. Agropyrum R. et s. In Aleppo.

6.5. T. biflorum Brignoli; glumts calycinis brevissime aristatis trinervibus bifloris; flosculls aristatis; radice fibrosa aunua. Brignoli Fasc. Forojul. p. 18. Agropyrum $\mathrm{H}$. et $\mathrm{S}$. In monte inatajurae. $\odot$.

\section{SECALE L. (1737).}

1. S, cereale $I_{\text {. }}$ calycibus aristisque scabris. IVilld. sp. 1. p. 471. S. creticum Hb, Siel,. var. $\alpha$. hybermum Blackw. t. 424. et $\beta$. vernum llost. Gram. t. 48, In deserto CaucasicoCapsium. $\odot$.

2. S. fragiie Bieb. glumarum ciliis scabris; calycibus subulatis aristatis flosculis praeter aristam longioribus; spica matura articulatim dehiscente. Bieb. Fl. suppl. p. 93. S. cereale Bieb. Fl. S. sylvestre Host, 4. t. 11. S. campestre schult. In Rossia australi, Punnonia et Podolia. $\odot$.

3. S. creticum L. glumis extrorsum ciliatis. L. sp. p. 125. Triticum R. et $\mathbf{s}$. Hordeum bulbosum sieb: H. Siberianum Bess. In Creta et Corsica.

4. S. glaucum Urville; fol. striatis glaberrimis, supremo spicam vaginante; squanis calycinis setaceis; glumis glabris nitidis; exteriore in aristam longissinam 3-4-uncialem excedente. Urville en. p. 12. All littora maris nigri. 4.

5. S. montannm Gussone; differt a $\mathbf{S}$. cereali radice perenni et articulata; a fragili glumis brevissime aristatis. In Sicilia. 4.

\section{ELYMUS L. (1737).}

Species verae.

1. E. arenarius $\boldsymbol{L}$. spiculis plerumque trifloris pubescentibus in me- 
dio spicae teruis glumam dorso ciliatam aequantibus superantibusque; fol. denique convolutis rigidis. Koch. syı. p. 826. Sichreh, Gram. t. 40. Fl. Dalı, 847. Engl, bot. 1672. Host. Gram. 4. t, 12. In Europa et Sibiria. 4.

2. E. dives Presl; culmo tereti rachique villoso-pubescentibus; fol. planis superue scabris; spica erecta stricta; glumis villosis 5-11erviis; palea inferiore 9-nervia hirsuta. Presl in Hel. Haenk. 1. p. 265. In simu Nutkia. 4.

3. E, condensatus Presl; culmo tereti vagiuisque wlabris; spiculis 6floris; glumis setaceis; palea inferiore obsolete 5-nervia acuta mutica. Presl 1. c. In California. 4.

4. E. Delileanus Schult. culmo palmari suberecto; fol. summis vagina rlabris lamina hirsutis; spica articulis hirsutis; calycihus oppositis 2foris flosculo altero mutico abortivo. E. geniculatus Delile Aeg. p. 30. t. 13. f. 1. E, aegyptiaous Spr. In Aegyjto. $\odot$.

5. E. geniculatus Curt. spica laxa erecta demum infracta; spiculis subtrifloris pubescentibus iuferioribus renotis; fol. involutis rigidis. Willd. en. p. 130. Engl. bot. 1586. With. Bot. Arr. t. 2. f. 26 . In maritimis Angliae et Hollandiae. 4.

b. E. sabulosus Bieb. spica erecta arcta; spiculis 4-floris a medio ad basin pubescentibus; fol. involutis rigillis. Willd. en. p. 130. E. gigai:teus Vahl; E. racemosus Lam. E. macrostachyus Spr. In Tauria, Sibiria et Cancaso. 4.

\%. E. sibiricus $\boldsymbol{L}$. spica pendula arcta; spiculis biuatis calyce lougioribus. I. sp. p. 123. Schreb. Granı. t. 21. f. 1. E. teuer L. suppl. var. $\beta$. luxurians; spica ramosa. E. ranosus Desf. In Nibiria. 4.

S. E. canadensis $L$. spica nutante patula; spiculis 6-floris, inferiorihus ternatis superioribus binatis; fol. planis. E. philadelphicus L. In Americe bareali. 24.

9. E. glaucifolius Muehlenb. spioa nutante patula; spiculis 6-floris aristatis geminatis; fol. planis subtus glaucis, Willd, en, p. 131. In America boreali. 4.

10. E. villosus Muellenb. spica erecta; spiculis 3 -floris aristatis villopis teruatis; calycibus aristatis spicu- las superantihus; fol. planis. Willd. ell. p. 131. In America boreuli. 4.

11. E. virginicus l. spica erecta; spiculis 3-floris aristatis glabris geuninatis; calycibus lanceolatis nervosis spiculas aequantilus. Willd. ell. p. 131. In America boreali. 4.

12. E. striatus Willd. spica erecta; spiculis bifloris aristatis hispidis geminatis; calycibus linearibus nervosis spiculas fere superantibus; fol. planis vaginisque glabris. Willd. 1. p. 470. E. hordeiformis. R. et $\mathrm{S}$. In America boreali. 4.

13. E. europaeus $\boldsymbol{L}$. spica erecta; spiculis 2-floris scabris ternatis; calycibus lineari-subulatis aristatis; vaginis pilosis. Willa. ell. p. 132. Host. Gram. 1. t. 28. Fl. Dan. 1621. Engl. bot. 1317. Triticum sylvaticun salisb. Hordeun montanum schrank. H. elymoides Vest. In Europa, Caucaso et America boreali. 4.

14. E. hirsutus Presl; culmo compresso vaginisque glabris; fol. scahris subtus hirsutis; spica erecta; spiculis binis 3-floris; glumis 5-1:erviis; palea iuferiore 5-nervia. Presl in Fel. Haenk. 1. p. 264. In Sinu Nutka. 4.

15. E. cingulatus Presl; culmo adscendente semitereti basi ramoso; fol. scabris spica erecta; glumis 3-nerviis palea inferiore 5-nervia superiore; 3 nervia: nervis aculeata-scabris. Presl 1. c. In Peruvia? 4.

16. E. agropyroides Presl; culmo tereti vaginisque glabris; fol. planis superne scabris; spica erecta densa stricta; glumis trinerviis acutis paleaque inferiore 5-nervia scabris. Prest. I. c, In Chili. 2 .

1\%. E. platatherus Ll, spica erectiuscula; spiculis geminis subhifloris; valvis basi arrectis superne patentibus longe aristatis; aristis angustioribus; valvula exteriore longissime aristata. Lk. Hort. 1. p. 18. In Aegypto. $\odot$.

18. E. crinitus Schreb. Gram. $t$. 24. $f$. 1. spica erectiuscula; spiculis geminis sub-2-floris; valvis basi arrectis superne patentibus longe aristatis; valvula exteriore longissime aristata scabro-pilosa; aristis patulis. Lk. Hort. 1. p. 18. Host. 1. t. 27. sibtl. Graec. t. 96. Hordeum Desf, E. intermedius Bieb. In Pannonia, Tauria, Iberia, Oriente, Africa boreali. $\odot$. 
19. E. Caput Medusae L. spica erecta; spiculis bifloris aristatis geminatis; calycibus setaceis basi cartilagineo-connexis patentissinis. Willd. en. p. 130. schreb. Gram. t. 24. f. 2. In Lusitania, Hispania et Pannomia. $\odot$.

20. E. mollis Trin. culmo superne velutino-pubescente; vaginis sulcatis glabris; fol. involuto-compressis ; spiculis binis imbricatis 7 -floris pubescentilus. Trin. in spr. N. Entd. 2. p.72. In Camtschatca et ins. Aleuticis.

\section{Species dubiae.}

21. E. angustus Ledeb. spica lineari erecta arcta; floribus accuminatis pubescentibus involucrum glabrum lanceolato-subuliforme et obsolete nervosum aequantibus; fol. planis rigidis. Ledeb. ill. t. 229. In Sibiria.4.

22. E. dasystacleys Trin. spica lineari erecta arcta; spiculis $2-\mathbf{4}$, 4-8-floris; floribus pubescendo-hirsutis breviter subulatis; involucello glabro subuliformi. Ledeb. ill. t. 249. In Sibiria. 4.

23. E. lanuyinosus Trin. spica lineari erecta; spiculis binis bifloris; foribus brevissime subulatis una cum involucellis subuliformibus ipsosque aequantibus sericeo-hirsutis. Ledeb. ill. t. 250. In Altai. 4 .

21. E. ovatus Trin. spica erecta oblonga arcta; spioulis quaternis 46-floris; fioribus breviter subulatis superne ciliatulis hirtulisque involucello glahriusculo et suhobsolete nervoso longioribus. Ledeb. ill. t. 251. In Sibiria. 24.

2.5. E. junceus Fisch. in Act. Nosc. 1. p. 45. c. ic. spica lineari erecta arcta; spiculis teruis 2-3-floris; flosculis acuminatis vel breviter subulatis hirtis involucello subuliformi et hispido longioribus. Ledel). Fl. alt. 1. p. 119. In Sibiria. 4.

26. E. altaicus A. Spr. spica erecta elongata continua; spiculis ternis 3-floris pubescentibus involucra setacea excodentibus; fol. flaccidis nervosis apice tortis. Spr. Tent. suppl. p. 5. In monte Imaus.

27. E. panciflorns Lum. spica brevi erecta pauciflora; calycibus 1-floris; aristis longissimis. Laul, ill. 1. p. 207. Patria ignota.

25. E. pilifer Russel; spica erecta; spiculis sub-4-floris; valvulis calyci- nis rugosiusculis pilosis; involucris diphyllis setaceis. Russ. Beschr. v. Aleppo 2. p. 149. In Aleppo.

29. E. carolinianus Walt. spica erecta laevi; spiculis involucro aequalibus trifloris; flore intermedio pedicellato sterili longitudine florum fertilium. Walt. Car. p. 82. In Carvlina.

30. E. sibulatus For'sk. spica subulata; spiculis 1-floris distichis alternis adpressis. Horsk. Arab. p. 26. In Aeg!njto.

31. E. Sitanion Schult. culmo striato foliisque scabris glaucis; spica recta laxiflora; involucris 5-phyllis multifloris aristisque longissimis scaljris divaricatis. sitanion elymoides. Rafin. in Journ. de Pliss. 89. p. 103. Ad Rissouri,

\section{ASPRELLA Humb. (1S15).}

1. A. Hystrix Willd. en. p. 132. Elymus L. Jacq. ic. 2. t. 305. Hystrix patula Moench. Gymuostichun Schreb. Gram. t. 47. E. Pseudohystrix Schult. In Oriente et America boreali. 4.

\section{HORDEUM L. (1737).}

1. H. valyare $I$. spiculis omnihus hermaphroditis; fructiferis 6 -fariam dispositis seriebus binis utrinque prominentiorihus. Koch. syn. p. 827. Host. Gram. 3. t. 34. var. $\beta$. seminibus omnibus nudis. H. coeleste Viborg Cereal. t. 1. $\gamma$. H. nigrum Willd. In. Sicilia et Tartaria. $\odot$.

2. H. hexastichum $\boldsymbol{L}$. fiosculis omnibus hermaphroditis aristatis; seminibus 6-fariam positis. L. sp. p. 125. Viborg 1. c. t. 2. Host. Gram. 3. t. 35. Patria ignota. $\odot$ et $\odot$.

3. H. distichum L. spiculis lateralibus masculis muticis intermediis hermaphroditis aristatis adpressis ; aristis erectis. Koch syn. p. 827. Viborg 1. c. t. 3. Host. 3. t. 36. Zeocriton distichon Beauv. $\beta$. seminihus nudis. H. nudum Arduin. In Tartaria. $\odot$.

4. H. Zeocriton $\boldsymbol{L}$. spiculis Iateralibus masculis muticis intermediis hermaphroditis aristatis cum aristis flabelliformi-patentibus. Kocl. 1. c. Schreb. 
Gram. t. 17. Host. Gram. 1. t. 37. Zeocriton communo Beauv. In Europa cultum. $\odot$.

5. H. bulbosum L. flosculis omnibus fertilibus ternis aristatis; involucris setaceis basi ciliatis. Linn. spec. p. 125. Sibth. graec. t. 98. Moris. 3. sect. 8. t. 6. f. 7. H. ciliatum Lam. H. strictum Desf. H. nodosum Savi. In Italia, Oriente et Africa boreaii. 4 .

6. H. pratense Huds. glumis caIycinis omnibus setaceis scabris. sclirad. germ. 1. p. 405. Engl. bot. 409. H. secalinum Schreb. Host. Gram. 1. t. 33. Trin. ic. t. 3. H. nodosum L. Zeocriton secalinum Beauv. H. maritimum. Fl. Dan. 630. var. $\beta$. spiculis pubescentibus. H. pratense hoth. $\gamma$. brevisubulatum Trin. ic. t. 4. In Europa, Asia et America boreali. 4.

\%. H. adscendens $\boldsymbol{H}$. et $\boldsymbol{K}$. culmo adscendente; spiculis lateralibus sterilibus; glumis omnibus subulatis; palea inferiore 5-nervia; aristis palea duplo longioribus. H. et K. Nov. Gen. 1. p. 180. In Mexico. $\odot$.

8. H. murinum $L$. glumis calyctnis intermediis lineari-lanceolatis ciliatis scabris. Schrad. Germ. 1. p.104. Host. 1. t. 32. Fl. Dan. 629. In Europa, Oriente, Montevideo et Prom. b. spei, var. $\beta$. chilense Brongn. In Chili. $\odot$.

9. H. chilense Brongn. spicis cylindricis gracilihus; glumis subulatis subaequalibus scabris; fol. apice involutis glaberrimis. Brongn. in Dup. It. bot. 51. In Chili.

10. H. capense Thunb. spiculis lateralibus masculis pedicellatis brevius setigeris; glumis omnibus setaceis scaberrimis antice canaliculatis imnarginatis. Nees in Linnaea 7. p. 305. In Prom. b. spei. 4.

11. H. maritimum With. valvis omnium spicularum scabris interioribus spicularum lateralium semilanceolatis caeteris setaceis. Koch syn. p. 827. Host. Gram. 1. t. 34. Engl. bot. 1205. Fl. Dan. 1632. H. geniculatum All. ped. t. 91. f. 3. H. Hystrix Roth. H. chilense $\mathbf{R}$. et S. In Europa, Asia occidentali et America meridionali. $\odot$.

12. H. muticum Presl; culmis basi repentibus; fol. planis pubescentibus; spica nutante; glumis setaceis; flori- bus lateralibus neutris. Presl in Rel. Haenk. 1. p. 327. In Peruvia.

13. H. musillum Nutt. flosculis masculis neutrisque lateralibus nuticis acutis; glumis calycinis 4 internis coriaceis. Nutt. gen. 1. p. 87. Ad Missouri.

14. H. jubatum, $L$. aristis involucrisque setaceis longissimis; Linn. sp. p. 126. Critesium geniculatum Hafin. Elymus Lk. In America septentrionali. $\odot$.

15. H. comosum Presl; radice repente; fol. planis superne vaginisque pubescentibus; glunis ommibus setaceis scabris; paiea floris hermaphroditi 3-nervia apice scabra. Presl. 1.c. In Chili. 2.

16. H. bifarium Roth; flosculis omnibus aristatis dorso glabris, lateralibus fertilibus, iniermedio neutro; involucris setaceis, interioribus versus basin intus barhatis. Kotl. Nov. sp. p. 59. In Sicilia.

17. H. himalayense Rittig; flosculis omnibus hermaphroditis aristatis; seminibus nudis; aristis aspero-ciliatis. Scliult. mant. 2. p. 481. Triticum hordeiforme Wall. Cultum in Himalaya. $\odot$.

\section{AEGILOPS L. (1737).}

1. A. ovata $L$. spica ovata; calycibus omnibus 4-aristatis scahris : culmis adscendentibus. Willd. sp. 4. p. 942. Host. Gram. 2. t. 5. Sibth. graec. t. 93. Phleum Aegilops Scop. In Europa australi. $\odot$.

2. A. triaristata Willd. spica obIonga; calycibus omnibus triaristatis; culmis erectis. Willd. spec. 4. p.943. A. ovata Rotl. A. neglecta Requien? In Hispania, Gallia et Italia. $\odot$.

3. A. triuncialis L. spica cylindrica; calycihus inferioribus biaristatis reliquis 3-aristatis; aristis florum binorum terminalibus reliquorum duplo longioribus. Willd. sp, 4. p. 943. Schreb. Gram. t. 10. f. 1. Vaill. par. t. 17. f. 1. Host. Grain. 2. t. 6. In Gallia australi et Oriente. $\odot$.

4. A. squarrosa L. spica cylindrica; calycibus 2-dentatis; dentibus inaequalibus muticis; corollis 1-aristatis. Willd. spec. 4. p. 944. Triticum Aegilops Beauv. In Oriente. $\odot$.

5. A. caudata $L$. spica cylindrica; calycibus bidentatis; dentibus inaequa- 
libus; corollis muticis ; floris terminalis valvulis calycinis $\mathbf{1 - a r i s t a t i s ; ~ a r i - ~}$ stis spica longioribus. Willd. spec. 4. p. 944. A. cylindrica Host. Gram. 2. t. 7. Sibth. Graec. t. 95. In Pannonia, Graecia et Italia.

\section{PARIANA Aublet. (1775).}

1. P. campestris Aubl. Guj. t. 33\%. Involucris basi strigosis; glumis masculis paleis dimidio fere brevioribus ovato-subulatis; fol. ovato-ellipticis basi rotundatis glabris subtus pallide viridibus oris longe setosis. Nees in Mart. Bras. 2. p. 293. In Gujana et Brasilia. 4 . 古.

2. P. ylanca Nees; involucris basi strigosis; glumis masculis paleis subaequalibus ovato-lanceolatis; fol. oblongis subtus laevibus glaucisque oris longe setosis. Nees 1. c. In Brasilia. 4.

3. P. scabra Nees; involucris basi strigosis; glumis masculis paleas aequantibus lanceolato-acuminatis; fol. oblongis acuminatis basi acutis subtus pallidioribus oris setosis. Nees 1. c. In Brasilia. 4.

4. P. sylvestris Nees; involucris basi setigeris; glumis masculis paleis tertia parte brevioribus Ianceolatoacuminatis; fol. ovato-oblongis acuminatis subtus glaucescentibus oris setosis. Nees 1. c. In Brasilia. ந.

5. P. lunata Nees; involucris pubescentibus; glumis masculis paleis plus duplo brevioribus oblongis obtusis; fol. lanceolato-oblongis subtus pubescenti - scabris glabrisve; vaginis transversim substrigosis, auricula semilunari longissime barbata. Nees 1. c. In Brasilia. 4.

6. $\boldsymbol{P}$. mollis Nees; involucris pubescentihus; glumis masculis paleis dimidio brevioribus ovato-falcatis acutis; fol. oblongis subtus pubescentimollibus canescentibus; vaginis transversim strigosis ore truncato-barbatis. Nees 1. c. In Brasilia. 4.

ק. P. imberbis Nees; involucris albido-subvillosis; glumis masculis ovato-subfalcatis acutis; vaginis transversim strigosis ore nudis; ligula rotunda bifida. Nees 1. c. In Brasiha. 4 .

8. P. angustifolia $\mathbf{S} \mathrm{pr}^{\circ}$. floribus dioecis elongato-spicatis; flosculis con- fertis; calycihus ohtusis ; fol. linearihus glabris. Spr. syst. 2. p. 609. Panicum triticeum Willd. Hb. Ad ripas Orinocci.

\section{PSILURLS Trin. (1820).}

1. P. nardoides Trin. Fund. p.93. Nardus L. Rotthoellia monandra. Cav. ic. t. 39. f. 1. Asprella Host. 4. t.29. In Europa meridionali.

\section{LEPTURUS R. Br. (1510).}

1. L. incurvalus Trin. spica tereti subulata incurvata; calyce bivalvi 1-floro; flosculo mutico; fol. planis; radice annua. Willd. sp. 1. p. 463. Engl. Bot. t. 760. Sibth. Graec. t. 91. Host. 1. t. 23. Ophiurus Beauv. In Europa, Oriente et Africa boreali. $\odot$.

2. L. filiformis Trin. spica tereti subulata subcompressa erecta; calyce hivalvi 1-floro; flosculo mutico; fol. canaliculatis; radice peremni. Willd. spec. 1. p. 464. Rotthoellia Rotli. Ophiurus R. et $\mathbf{S}$. Rotthoellia incurvata $\beta$. DC. In Europa australi. 4 .

3. L. subulatus Kunth; spica tereti subulata erecta; gluma solitaria ensiformi acuminata adpressa. Rottboellia subulata Savi Pis. 4. p. 230. f. 4. 8. Monerma Beauv. Rotth. cylindrica Willd. In Italia, Gallia et Prom. b. spei. $\odot$.

4. L. pannonicus Funth; spica tereti subulata erecta; calyce 2 -valvi bifloro; flosculis muticis; fol. planis; radice annua. Rotthoellia Willd. en. p. 129. Host. Gram. 1. t. 24. R. biflora Roth. Pers. Ophiurus Beauv. Pholiurus Trin. In Pannonia, Gallia, deserto Cumani et ad Wolgam. $\odot$.

5. L. repens R. Br. Brongn. in Dup. it. bot. 5\%. t. 16. spica tereti subulata; gluma 1-valvi indivisa. lottboellia repens. Forst. prodr. n. 151. In Nova Hollandia et insulis maris pacifici.

6. L. paniculatus Nutt. rachi incurva composita acute 3-angulari ramis et apice florifera; spicis unilateralibus compressis subulatis; floribus omnibus hermaphroditis Nutt. Gen. 1. 
p. 81. Rottboellia Spr: Ad IMissouri. $\odot$.

\%. L. ramosa Iunth; culmo ramoso; spicis teretibus subulatis; gluma calycina 1-valvi integra. Rottboellia Cav. Anmal. de scienc. nat. 3. p. 11. In Tanger.

8. L.? simplex Funth; culmo erecto basi ramoso nodisque glabris; fol. margine scabriusculis; spicis solitariis filiformibus erectis. Monerma Gaudich. in Freyc. bot. p. 412. In Nova Holzandia.

\section{OROPETIUM Trin. (1820).}

1. O. thomaeum Trin. Fund. p. 98. Nardus Thomaea L. Rotthoellia Willd. Roxb. Corom. 2. t. 133. Rottbocllia pilosa Willd, In India orientali.

\section{OPHIURUS R. Br. (1810).}

1. 0. corymbosus Gaertn. spicis aggregatis; rateralibus filiformibus flosculis bifariis patentibus; fol. basi ciliatis. Kotthoellia Lim. suppl. p. 114. Roxb. Corom. t. 181. R. punctata Retz. Aegilops exaltata L. In $M a$ Zabaria et Nova Hollandia.

2. 0. monostachyus Presl; fol. conduplieatis scabris; vaginis glabris; spica pedunculata tereti; rachi striata; gluma inferiore ohsolete nervosa. Presl in Rel. Haenk. 1. p. 330. In Luzonia.

\section{ROTTBOELLIA R. Br. (1810).}

1. R. exaltata $I$. spicis teretihus undique flosculis imberbibus; glumis obtusis : exteriore hermaphrodita enervi rachibusque scaberrimis. Presl. 1. c. In Luzonia.

2. R. Coelorachis Forst. spica tereti 1-laterali; flosculis geminis altero pedicellato; calyce bivalvi. Forst. prodr. n. 49. In ins. Tanna et Nova Caledonia.

3. R. setosa Presl; culmo erecto ramoso semitereti; vaginis tuberculatis strigoso-pilosis; fol. planis margine et pagina superiore hispidis; rachi tereti glahra. Presl. in Rel. Haenk. 1. 1. 329. In Luzonia.
4. R. formosa $\boldsymbol{R}, \boldsymbol{B r}$. spica tereti undique flosculosa; articulis glumisque exterioribus hermaphroditi sericeis ncutris glabriusculis vacuis. $\mathrm{R}$. $\mathrm{Br}$. prodr. 1. p. 206. Kunth Gram. t. 91. In Nova Hollandia.

5. R. hirsuta Vall, spica subulata hirsuta; flosculis hermaphroditis patentibus ; sterilihus pedicellatis adpressis. Vahl symh. 1. p. 11. Triticum aegilopoides Forsk. In Aegypto. 4.

6. R. villosce poir. fol. margine scabris; gluma calycina bivalvi biflora; flosculis sterilibus pedicellatis, fertilibus sessilibus; rachi basi articulorum villosa. Poir. Enc, 6, p, 313, In India orientali.

ฑ. R. muricata Retz; spicis teretibus pluribus longe pedunculatis; calycibus ciliato-aculeatis neutris bifidis. Retz ohs. 3. p. 12. Spreng. in Act. Petrop. 1810. 2. t. 7. Aegilops Retz. Coelorachis Brongn. in Dup. it. bot. t. 14. In India orientali, Amboina et ins. Bonrou. $\odot$.

8. R. fasciculata brongn. fol. linearibus basi cordatis margine vaginisque rigide ciliatis; pedunculis fasciculatis vagina spathacea ciliata semiinvolutis; spicula abortiva fertili quadruplo minore. Brongll. in Dup. It. bot. 63. t. 14. In ins. Bonrou,

9. $R$. ciliata Nutt. culmo erecto gracili; spicis teretibus longe peduuculatis; pedicellis rachique margine villosis; calyce et corolla hivalvibus. Nutt. Gen. 1. p. 83. In Georgia.

10. R. flabra Roxb. versus basin repens; extremitatibus erectis glahris; calyce unifloro; corolla 3-valvi, Roxb. ind. 1. p. 353. In India orientali.

11. R. pilosa Roth; calyce hivalvi; spiculis subtrifloris submuticis; flosculis basi pilosis; fol. convolutosetaceis vaginisque pilosis; culmo setaceo. R. trichantha Roth Nov. sp. p. 43. In India orientali.

12. R. biflora Roxb. setacea; spicis simplicibus subulatis; rachi non articulata bifariain excavata pro receptione flosculorum hiflororum. Roxh. ind. 1. p. 357. R, Roxburghiana schult. In Peninsula Indiae.

13. R. Cymbachne Willd. spicis geminis dimidiatis; foliorum vaginis ciliatis. Willd. sp. 1. p. 465. Cymbachne ciliata Retz. In Bengalia.

14. R. sanguinea Retz; paniculac spicis aristatis alternis simplicibus pe- 
dunculatis; florum bractea laterali ciliata. Retz. ohs. 3. p. 25. Thelepogon sanguineus Spreng. In China.

15. R. digitata Nibth. spicis terminalibus fasciculatis; richi angulata scahra; glumis acuminatis; foliorum vaginis pilosis. smith prodr. 1. p. 71. Sibth. Graec. 1. t.92. Pholiurus graecus Spr. In Bithynia. 4.

16. R. compressı L. glumarum acuminibus strictis. Hemarthria $\mathbf{R}$. Br. prodr. 1. p. 207. - lioxb. Corom. t. 156. R. tripsacoides Lam. ill. t. 48. f. 1. 6. In Nora Hollandia, India orientali et Prom. b. spei.

1\%. R. uncinuta R. Br. acumine glumae interioris solutae hamato. Hemarthria. K. Br. l. c. Brongn. Dup. it. bot. t. 15. In Nora Hollandia.

18. R. altissimu Poir. spicis axillaribus aggregatis arcuatis; floribus 4-fariam dispositis. R. fasciculata Desf. Atl. 1. p. 110. t. 36. Lodicularia Beauv. Agx. t. 11. f. 6. Lepturus Trin. In Africa boreali et Hispanil. 4.

19. R. rugosa Nutt; culmo compresso sulcato ramoso; spicis subcompressis, valva exteriore transversim corrugata longitudinaliter rugosa. Nutt. gen. 1. p. 84. Hemarthria Kuntl. R. corrugata Baldw. In Georyia et Florida.

20. R. perforata Roxb. culnis erectis glahris $\mathbf{3}-\mathbf{5}$-pedalibus altis ; rachi perforata calyce plerumque bifloro; flore altero masculo. Roxb. Corom. t. 182. Hemarthria Kuntl. In India orientali.

21. R. Iaevis Retz; pedunculis Iongissimis; spica flosculis binatis lateralibus; calycibus ovatis impunctatis iaevibus. Retz obs. 3. p. 11. Mnesithea Kunth. In Tranyuebaria.

22. R. pulcherrimu Wall. mss. culmo decumbente stolonifero monostachyo; vaginis compresso-carinatis. Katzeburgia Kunth. Gram. t. 158. Aikinia elegans WVall. pl. as. rar. t. 273. In India orientali. 4.

23. R. Loliacea Bory et Chaub. spica terminali incurvata; valvula calycina integerrima ohtusa flosculis longiore; ligula truncata brevissima. Bory in Expedit. scient. bot. In Moraea. $\odot$. Culmi digitales et ultra.

\section{TRIPSACUM L. (1738).}

1. T. monostachyum Willd. spica solitaria superne mascula inferne feminea. Willd. Hort. Berol. 1. t. 1. In Neu-York et Carolina. 4.

2. 'T. dactyloides Limn. spicis ternis agregatis superne masculis inferne femineis. Willd. sp. 4. p. 201. Lam. ill. t. 750. Beauv. Agr. t. 22. f. 1. Ischaemum glabrum Walt. Coix angularis Mill. In America boreali, California, Mexico et St. Domingo. 4.

3. T. cylindricum Michx. spica solitaria hermaphrodita cylindrica; spiculis contiguis in articulos secedentibus. Willd. sp. 4. p. 202. In Florida.

\section{MANISURIS $L \cdot\left(1737^{\prime}\right)$.}

1. I. gramularis $\mathbf{S} w$. florum femineornm globosorum valvulis calycinis tesellato-verrucosis; culmo erecto ramoso; vaginis hirsutis. Willd. sp. 4. p. 945. Hoxb. Corom. t. 118. I. polystachya Beatv. Fl. t. 14. Cenchrus granularis. L. mant. In America meridionali et boreali, Mexico, Africa calidori et India orientali. $\odot$.

2. M. Myurus L. florum femineorum compressorm valvulis calycinis planis margine memhranaceis emarginatis; culmo adscendente; vayinis glahris. Willd. sp. 4. p. 945. Peltophorus Desv. Beauv. Agr. t. 21. f. 11. In India orientali.

\section{PEROTIS Ait. (1810).}

1. P. latifolia Ait. culmis fistulosis 9-18-pollicarihus; fol. brevibus nudatis ciliatis, racemis cylindraceis. Roxb. ind. 1. 239. Kunth Gram. t. 102. Authoxanthum indicum L. Agrostis spicaeformis Willd. sp. In India orientali, Japonia et Prom. b. spei. 4.

2. P. raru R. Br. culmo erecto suhracemoso; fol. linearihus laevibus, inferioribus planis superioribus involutis. R. Br. prodr. 1. p. 172. Xystidium maritimum. Trin. Fund. to 2. In Nova Holhandia. 
451. LEPTOTHERIUM Kunth. (1831).

1. I. rigidum Kunth Gram. 1. p. 156. Zoisia rigida Willd. Hb. In America calidiori.

\section{ZOYSIA Willd. (1797).}

1. Z. pungens Willa. in Nov. Act. nut. cur. Berol. 3. p. 140. Agrostis Matrella L. Matrella juncea Pers. In India orienlali, ins. Mauritii et Nova Hollandia.

\section{DIMERIA R. Br. (1810).}

1. D. acinaciformis $\boldsymbol{R} . \mathrm{Br}$. floribus lanceolatis; barba baseos manifesta; gluma interiore apice acinaciformi ; arista infra geniculum edentula. R. Br. prodr. 1. p. 204. Saccharum Spr. In Nova Hollandia.

2. D. ornithopoda Trin. spicis terminalibus ternis; flosculo neutro nul10 ; corolla hermaphroditi inversa ; staminibus coustanter duobus. Trin. Fund. p. 496. t. 14. In India orientali.

\section{LUZAEA Kunth (1831).}

1. L. gracilis Kunth Gram. 2. p. 489. $t$. 159. Culta in Horto Kewensi. 24. Gramen erectum ramosum facie Chloridis cruciatae.

\section{HAPLACHNE Presl (1831).}

1. H. pilosissima Presl in Rel. Haenk. 1. $\%$. 235. $t$. 28. In ins. Mariae-Annae. 4.

\section{PLEUROPLITIS Trin. Fund. (1820).}

1. P. Langsdorffiana Trin. Fund. p. 175. $t$. 16. Deyeuxia japonica spr. In Nangasaki. Culmus prostratus ramosissimus inferne radicans. Folia brevia basi cordato-amplexicaulia scaberrima.

\section{5\%. SACCHARUM L. (173\%).}

\section{Species geutinae.}

1. S. fiscum Roxb. erectum; 5 8-pedale altum; fol. sublanceolatis glabris; panicula patente verticillata; lana calycis brevi et parca; corollis trivalvibus. Roxb. ind. 1. p. 241. In Bengalia.

2. S. semidecumbens Roxb. perenne; culmis inferne procumbentibus; fol. angustis canaliculatis; panicula laxa; corolla 1-valvi. Roxb. ind. 1. p. 241. In India orientali. 4.

3. S. officinarum $L$. panicula effusa ; floribus triandris; glumis obsolete 1-nerviis dorso longissime pilosis. Kunth. Tussac. Fl. Antill. 1. t. 23. variat, caule flavo, purpureo, giganteo et pallido. Colitur in utraque India. 4.

4. S. violaceum T'uss. Antill. t.25. culmo foliisque violace 0 -coloratis; panicula effusa; floribus 3 -andris ; glumis 4-nerviis dorso longissime pilosis. H. et Kunth. Nov. Gell. 1. p. 182. In utraque India cultum. 4.

5. S. procerum Roxb. perenne; 10-20-pedale ; erectum ; fol. ensiformibus costa alba, marginibus lispidis. Roxb. ind. 1. p. 248. In Bengalia.

6. S. sinense Roxb. peremue; 610-pedale; fol. planis margine hispidis; paniculis ovatis; corolla 2-valvi 1-laterali. Roxb. ind. 1. p. 244. In China.

\%. S. aegyptiacum Willd. panicula elongata conferta; ramis inferioribus compositis; flosculis geminis altero sessili; rachi villosa; culmo pubescente. Willd. en. p. 82. In Aegypto.

8. S. spontaneum $\boldsymbol{L}$. fol. convolutis; panicula effusa; spicis capillaribus; floribus remotis involucratis geminatis altero pedunculato. L. mant. p. 183. S. biflorum Forsk Descr. Imperata spontanea Beauv. In Malabaria et Arabia. 4.

9. S. arundinaceum Retz; paniculae confertae pedunculis divisis; flosculis geminis, sessili pedicellatoque; corollis 3-valvibus polygamis. Retz obs. 4. p. 14. In Tranquebrir.

10. S. Sura Roxb. erectum, ; 812-pedale; fol. planis marginibus spinulosis; panicula densa; floribus geminatis altero sessili. Roxb. ind. 1. p. 249. Prope Calcuttam. 4. 
11. S. exaltatum Roxb. culmis 10-16-pedalibus; fol. planis marginibus spinulosis; calycibus lanatis; corolla 2-3-valvi. Roxb. ind. 1. n. 249. In India orientali.

12. S. Munja Roxb. strictnm;8-10pedale; totum glabrum; fol. hispidis alho-nervosis; florihus omnibus hermaphroditis; corolla 2-valvi. Roxb. ind. 1. p. 250. Circa Bentres.

13. S. benglualense Retz; paniculae confertae pedunculis divisis; flosculis geminis sessili pedicellatoque; corollis bivalvibus hermaphroditis. lietz olos. 5. p. 16. In Bengalia. 4.

1. S. canaliculatum Roxb. perenne; erectum (8-12-pedale); fol. subulatis profunde caualiculatis longissimis ; valvis calycinis basi crassis callosis marginibus fimbriatis. Koxb. ind. 1. p. 251. In Bengalia.

\section{Species anomalae.}

15. S. contractum $\boldsymbol{H}$. et $\boldsymbol{K}$. ligula glabra; panicula coarctata cylindracea; floribus monandris; glumis dorso longissime pilosis. $H$. et $K$. Nov. Gen. 1. 82. \$. contractum Poir. In America calidiore. 4.

16. S. dubium $H$. et $K$. ligula ciliata; panicula superue contracta inferne patula; floribus 1-andris; glumis dorso longissime pilosis. H. et K. Nov. Gen. 1. p. 183. Anatherum Berterianum Schult. A. portoricense spr. A. caudatum Sieb. In America meridionali et insulis. 4.

1\%. S. caudatum Mey. panicula contracta cylindracea; foribus geminis altero brevius pedicellato; pilis glumis triplo longioribus. Mey. Ess. p. 68. In Essequebo. 24.

18. S. spicatum Presl; culmo erecto glabro; nodis longe barbatis; vaginis hirsutis; ligula brevi ; panicula spicaeformi; spiculis hinatis ; glumis longissime pilosis; paleis duabus. Presl. in Rel. Haenk. 1. p. 346. In Luzonia. 4.

19. s. confertum Presl; radice repente; culmo erecto compresso; nodis barbatis; ligula abbreviata; spiculis binatis, altera sessili; glumis dorso longissime pilosis; paleis duabus. Presl. 1. c. In Luzonia. 4.

\section{Species dubiae.}

20. S. mexicanum Broussonet; panicula spicata; geniculis glabris; fo- liorum basi pilis longissimis ciliata. Hornem. Hort. Hafn. 1. p. 75. In Mexico. $\odot$ ?

21. S. hirsutum Forsk. spica hirsuta; spiculis geminis: altera sessili altera pedicellata. Forsk. Aeg. p. 16. In Arabia.

22. S. jaculatorium Lour. culmo fistuloso simnlici; fol. longissimis carinatis; panicula spicata oblonga. Lour. Coch. 1. p. 67. Imperata jaculatoria. 1. et S. In Cochinchina.

\section{IMPERATA R. Br. (1S10).}

1. I. arundinacea Cyrill. ic. 2. $t$. 11. Saccharum cylindricum Lam. Enc. t. 40. f. 1. Lagurus cylindricus L. Imperata cylindrica Beauv. Agr. t. 7. f. 1. Saccharum Sisca Cav. ic. 3. t. 292. In Europa australi, Africa boreali, Senegalia, India orientali e屯 Chili. 4

\section{ERIANTHUS Rich. (1805).}

1. E. saccharoides Michx. culmo altissimo; vaginis foliorum ad collum confertissima lana barbatis; valvis exterioribus juxta margines longe villosis. Michx. Fl. 1. p. 55. Anthoxanthum giganteum Walt.saccharum Pers. Erianthus Muehlenb. Andropogon Erianthus Lk. In America boreali et Brasilia. 4.

2. E. asper Nees; panicula contracta; spiculis geminis ternisve villis brevioribus ; glumis glabris ; nodis barbatis; fol. linearibus vaginisque tuberculato-scabris. Nees in Mart. Bras. 2. p. 315. In Brasilia. 4.

3. E. angustifolius Nees; panicula spicata; spiculis geminis ternisve villos aequantibus; glumis dorso villosis; nodis vaginis ligulaque glabris; fol. linearibus canaliculatis. Nees in Mart. Bras. 2. p. 316. In Montevideo. 4.

4. E. breviberbis Michx. vaginis collo subvillosis; panicula stricta glumae villis involucrantibus multo longiore; valvis acutissimis nudis. Michx. Fl. 1. p. 55. Calamagrostis rubra Bosc. In America boreali. 4.

5. E. strictus Baldu. involucro subnullo; paniculae ramis remotiusculis arcte adpressis; pedunculis bifforis ; 
aristis rectis calyce duplo longioribus. Elliot bot. 1. p. 39. Saccharum strictum Nutt. S. Baldwini Spr. In America boreali.

6. E. contortus Elliot; villis invoIucrantibus calycem acquantibus; valva interiore corollae auriculata; arista spiraliter contorta. Elliot hot. 1. p. 40. Saccharum Nutt. In America boreali.

\%. E. Ravennae Beauv. panicula ramossisima; fol. canaliculatis ; corolla 3-valvi. Saccharum havemae Schrad. germ. 1. p. 421. Host. Gram. 3. t. 1. Äudropogon Mert. et Koch. Ripidium Havenuae Trin. Ad Littora Maris Mediterranei el Caspii. 24.

8. E. floridulus Schult. florihus paniculatis; racemis spicatis linearibus summis fastigiatis; floculis geminis aristatis inaequaliter pedunculatis. Labill. Nov. Caled. 13. t. 18. In Nova Caledonia.

9. E. japonicus Reauv. racemis fasciculatis; petalis ciliatis, exterioribus aristatis. Saccharum polydactylon Thumb. Jap. p. 42. s. japonicum Thunb. in Linn. Trans. Ripidium japonicum Trin. In Japonia. 4.

10. E. irritans Kunth; spicis digitatis aristatis; rachi serice0-harbata; glumis pulsescentibus; perianthii arista elongata inferne harbata. Saccharum irritans 1R. Br. prodr. 1. p. 203. In Nova Hollandia.

11. E. fulvus Kunth; spicis digitatis; rachi sericeo-barhata; glunis villosis muticis; perianthii arista imberhi; geniculis barbatis. Saccharum R. Br. prodr. 1. p. 203. In Nova Hollandia.

12. E. repens Beauv. panicula patula; flosculis geminatis sessilibus aristatis; fol.planis; vaginis pilosis. Saccharum repens Willd. sp. 1. p. 322. In Guinea. 4.

13. E. aureus Beauv. spicis confertis hirsutis rufo-flavis numerosis. Alldropogon Bory it. 1. p. 367. t. 21. Eulalia aurea Kunth Gram. t. 93. Sacclarum Spr. In ins. Borboniae.

\section{ELIONURUS Will. (1805).}

1. E. tripsacoides H. et $\boldsymbol{K}$. glumis hermaphroditis subpubescentibus; paleis glabris; glumis masculis clausis.
H. et K. Nov. Gen. 1. p. 192. t. 62. Elyonurus Willd. sp. Anatherum spr. In Caracas, Nova Granata et Mexico. 4.

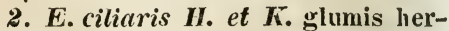
maphroditis pubescentibus inferiore apice scriceo-lanata; paleis pubescentibus; glumis masculis apertis. H. et K. 1. c. t. 63. All Orinoccum, in Nova Granata, Mexico et Montevideo. 4.

3. E. elegans Kunth; culmis simplicibus monostachyis; nodis sericeobarbatis; vaginis ore pilosis ; pedicellis villoso-pilosis. Kunth Gram 1. p. 161 et 361. t. 94. Andropogon elegans Gay ined. In Senegalia.

4. E. mostratus Nees; spiculis ovatis planis; gluma hermaphrodita inferiore in rostrum bifidum attenuata valvulisque obtusis ciliatis masculisque apertis. Nees in Mart. Bras. 2. p. 357. In Montevideo. 4.

5. E. dubius Nees; spiculis lanceolatis glabris; hermaphroditi gluma inferiore acuminata integra; neutris clausis. Nees 1. c. In Brasilia. 4.

\section{ANTHISTERIA L. (173\%).}

1. A. ciliata $I$. fol. superioribus hasi involucrisque ciliatis. Hetz ohs. 3. p. 11. Cav. ic. 5. t. 459 . Desf. Journ. de Phys. 40. t. 1. Andropogon nutans L. mant. In India orientali, Jamaica et Virginia. $\odot$.

2. A. polystachya Roxb. culmis crebris suberectis; fol. a basi subciliata angustatis; valvis exterioribus 4 sessilium papillosis apicem versus ciliatis. Roxb. ind. 1. p. 252. In Bengalia.

3. A. barbata Desf. glumis vaginisque harbato-glandulosis; Desf. in Journ. de Phys. 40. p. 294. t. 2. A. ciliata $\beta$. Gaertn. fruct. 2. t. 175. A. japonica Willd. Andropogon ciliatum Thunb. In Saponia.

4. A. Desfontainii Kunth; culmo ramoso; glmmis imberbibus. A. imberbis Desf. 1. c. p. 292. t. 1. Calamina imherbis Beauv. In Africa boreali et Syria.

5. A. imberbis Retz; fol. involucrisque undis. Retz obs. 3. p. 11. Stipa arguens Thunb. Houtt. Pflanz. syst. 12. t. 92. f. 1. A. ciliata var. $\beta$. glumis neutris glabris aut subglabris. In Prom. b. spei. 
6. A. glanca Desf. culmo ramoso compresso; panicula laxa; glumis imberbibus; arista inferne villosa geniculata. Desf. Atl. 2. p. 3s0. t. 254. Stipa paleacea Vahl. In Barbaric, Aegyjto et Guinea. 4.

7. A. arguens Willd. culmo simplici; panicula angusta; invelucris aristisque basi lanatis. Willd. sp. 4. p. 901. Stipa arguens L. (Rumph 6. t. 6. f. 1.) In India orientali. 4.

8. A. prostrata Willd. repens; fol. vix vagrina longioribus; flosculis accessoriis masculis; calyce $\mathbf{2}$-valvi piloso; corolla 1 - valvi mutica. Roxb. ind. 1. p. 25\%. Andropogon L. Cymbopogon glandulosus spr. In India orientali. 24.

9. A. custralis R. Br. culmis involucrisque imberbibus strigisve paucissimis; fol. vaginisque glabris; culmo tereti. R. Br. prodr. 1. p. 200. In Nora Hollandia.

10. A. frondosa $\boldsymbol{R}$. Br. glumis masculis barbatis; involucris foliaceis vaginisque hirsutis; pedunculis villosissimis; culmo compresso scabriuscu10. R. Br. prodr. 1. p. 200. In Nova Hollandia.

11. A. reflexu $H$. et $\boldsymbol{K}$. ramis paniculatis patentibus; fol. interne pilosis externe scabris; ligula barbata; vaginis sericeo-pilosis; gluma inferiore hermaphroditi bifida. $\mathbf{H}$. et $\mathbf{K}$. Nov. Gen. 1. p. 191. Andropogon bracteatus Willd. Cymbopogon refiexus R. et S. C. Humboldtii Spr. In Nova Andalusia et Brasilia. 4.

12. A. foliosa $H$. et $K$. ramis adpressis; fol. utrinque scabris; ligula subciliata; vaginis spathisque sericeopilosis. H. et K. 1. c. Cymbopogon R. et S. In Nora Andalusia et Mexico. 4.

13. A. arundinacea Roxb. culmo apice fasciculato ramosissimo folioso; ramulis floriferis compressis ; fol. lonyissimis; vaginis ore lanuginosis; spiculis papillosis et aureo-hirsutis. Kunth Gram. 1. p. 363. t. 95. Cymbopogon H. et S. In Bengalia. 4

11. A. cymburic Roxb. erecta; ramosa; calyce bivalvi ciliato; corolla 1-valvi mutica. Roxb. ind. 1. p. 255. Andropogon L. Spr. in Act. Petrop. 1810. t. 9. Cymbopogon elegans spr. In India orientali. 4.

15. A. villosa Poir ; fol. involucrisque nudis; floribus duobus herma- phroditis villosissimis; arista brevi. Poir. Enc. suppl. 1. p. 396. Lam. ill. t. 841. f. 3. In Java.

16. A. scandens Roxb. peremis; ramosa; scandens; geniculata; fol.floralibus basi ciliatis; paniculis crebris villosis; valva exteriore quatuor flosc. sessilium papillosa apicem versus ciliata. Roxb. ind. 1. p. 253. In Bengalia.

1\%. A. heteroclita Roxb. culnis declinatis geniculatis; fol. ciliatis ; involucris 5-floris; floribus duobus hermaphroditis aristatis; tribus masculis ciliatis. Roxb. ind. 1. p. 253. Prope Calcuttam.

18. A. tortilis Presl; culmo erecto nodis pubescente; vaginis glabris; fol. anguste linearibus mucrone longo tortili terminatis; ramis paniculatis patentibus. Presl in Rel. Haenk. 1. p. 347. In Luzonia. 4.

19. A. pilosa Presl; culmo erecto tereti nodisque glabris; fol. margine scabris subtus vaginisque serice $0-$ pilosis; ligulis barbatis; vaginis supremis spathaeformibus pilosis. Presl 1. c. In Peruria. 4.

20. A. hispida Thunb. racemosa; calycibus 3-floris pilosis. Thumb. cap. 1. p. 403. Avena Thunb. A. capensis L. Danthonia Spr. In Prom. b. spei.

21. A. Forscalii Kunth; spicis terminalibus subcapitatis; culmis superne ramosis; vaginis amplis compressis ensiformibus, suprema spathacea. Themeda polygama Forsk. Aeg. Arab. p. 178. In Arabia.

22. A. gigantea Cav. ic. t. 458. culmo laevi farcto; fol. linearihus vaginisque glabris asperis ; panicula maxima, partialibus axillaribus pedalibus; spiculis hirtis s. villoso-sericeis. Brongn. in Dup. it. bot. p. 78. var. $\alpha$. fol. angustis et $\beta$. fol. latioribus. In Luz0nia, Amboina et Java. 4.

\section{PEROBACHNE Presl (1831).}

1. P. secunda Presl in Rel. Haenk. 1. p. 348. t. 48. 'In Luzonia. 4. Culmus superne secunde ramosus. Vaginae striatae. Ligula brevis barbata. Glumae spicularum mascularum inferiores coloratae setis rufescentibus munitac. 


\section{ANDROPOGON L. (173\%).}

1. Rachis spicata.

a. Spicae in apice culmi vel ramorum solitariae.

1. A. Allionii DC. culmo ramoso; nodis compressis; fol. scabris; vaginis glabris; glumis femineis hispidis, masculis glabris; arista longissima pubescente. H. et K. Nov. Gell. 1. p. 185. A. contortum All. ped. t. 91. f. 4. Heteropogon glaber Pers. H. Allionii R. et s. In Helvetia, Gallia, Barbaria el Mexico. 4.

2. A. contortus $L$. spicis solitariis terminalibus aristatis ; involucro nullo; glumis masculis acutis tenuissime striatis apice barbatis; aristis lougissimis contortis pubescentibus. $\mathbf{R}$. $\mathrm{Br}$. prodr. 1. p. 201. Heteropogon hirsutus Pers. H. contortus R. et s. Stipa spicata Thumb. In India et Nova Hollandia. 24.

3. A. firmus Kunth; culmo erecto ranoso ad nodos compresso piloso; vaginis glabris; fol. linearibus setaceo-acuminatis scabris; spicula hermaphrodita basi pilis stipata; arista longissima hirsuta. Heteropogon Presl in Rel. Haenk. 1. p. 334. In Mexico.

4. A. polystachyus Roxb. strictus; spicis crebris axillaribus, singula pedunculo longo nodoso vaginato insidente; flore uno femineo longe aristato, altero masculo mutico. 1hoxb. ind. 1. p. 265. Heteropogon Schult. In Peninsula Indiae.

5. A. angustifolius $\boldsymbol{H}$. et $\boldsymbol{K}$. culmo simplici; nodis barbatis; vaginis inferioribus pilosis; glumis hermaphroditis albo-sericeis, masculis glabris; arista longissima serice-pilosa. H. et K. Nov. Gen. 1. p. 184. A. stenophyllus 18. et S. Trachypogon Mart. Bras. In Mexico. 4.

6. A. Montufari $H$. et $K$. culmo simplici; nodis barbatis; fol. scahris; vaginis glabris; spica solitaria; arista longissima piloso-sericea. H. et. K. 1. c. Trachypogon Nees. In Quito, Brasilia anstrali et Mexico. 4.

7. A. mollis Kunth; culmis caespitosis 1-stachyis; nodis sericeo-barbatis; spicis molliter pilosis; arista longissina molliter pilosa. Kunth Grain. 2. p. 561. t. 195. Trachypogon mollis Nees. In Brasilia. 4.

8. A. canescens Lunth; totus vil- loso-sericeus; ligula in cilia soluta; rachi pubescente; arista spiculae lıermaphroditae pedicellatae longissima villosa torta. Trachypogon Nees in Mart. Bras. 2. p. 343. In Brasilia. 4.

9. A. stipoides Kunth; culmo erecto simplici; nodis barbatis; fol. scabris; rachi hirsuta ad ortum spicularum nuda; glumis inferioribns aristaque longissima hirsutis. Heteropogon stipoides Presl in Hel. Haenk. 1. p. 335. In Mexico. 4.

10. A. secundus Tunth; culmo erecto simplici; nodis barbatis; rachi glabriuscula ad ortum spicularun fasciculo pilorum munita; glumis inferioribus albo-sericeis; aristis longissimis basi plumosis. Heteropogon Presl 1. c. In Hexico. 4.

11. A. tenuis $\boldsymbol{R}$. Br. glumis masculis exterioribus emarginatis tenuissime striatis glabris; aristis geniculatis ; geniculis imberbihus; spicis solitariis terminalibus. H. Br. prodr. 1. p. 201. In Nova Hollandia.

12. A. striatus lilein; spica simplici; floribus geminatis, hermaphrodito sessili aristato, masculo pedicellato; valvula calycis exteriore nervosa. Willd. sp. 4. p. 903. Pollinia striata spr. Schizachyrium Nees. In Malabaria. 4.

13. A. Brounei Funth; spicis solitariis terminalibus aristatis ; involucro nullo; glumis masculis exterioribus acutis glabris. Kunth Gram. 1. p. 163. In Nova Hollandia.

14. A. triticeus $R$. Br. spicis solitariis terminalibus aristatis; involucro uullo; glumis acuminatis imberbibus; aristis longissimis contortis pubescentibus; culmo ranoso. H. Br. prodr. 1. p. 201. In Nova Hollandia et Moluccis.

15. A. fragilis R. Br. spicis alternis solitariis spatha inclusis; flosculo pedicellato neutro; rachibus sericeo-harbatis ; vaginis laevibus ; collo barbato. h. Br. prodr. 1. p. 202. Pollinia Spr. In Nova Hollandia.

16. A. citreus R. Br. spicis spatha inclusis semi-exertis muticis; rachibus sericeo-barbatis; gluma exteriore hermaphroditi acumine hifido pectinatim ciliato; culmo ramoso vaginisque laevibus. R. Br. prodr. 1. p. 203. In Nova Hollandia.

17. A. brevifolius $\mathbf{S w}$. culmis decumbentibus ramosis compressis; spi- 
culae fertilis gluma apice $\mathbf{2}$-dentata dorso strigulosa; palea profunde bifida. Kuntli Gram. 2. t. 196. Pollinia Spr. Schizachyrium Nees. Andropogon Poir. Pollinia vaginata Spr. In Jamaica, Portorico, Gujana et Senegambia. $\odot$.

18. A. debilis Kunth; culmo debili adscendente compresso glahro ranoso; vaginis laxis spathaeformibus glahris; spicis minimis; hermaplrodita sessili; palea inferiore longissime aristata. A. tenellus Presl in Hel. Haenk. 1. p. 335. In Nexico. $\odot$.

19. A. velatus Liunth; culmo erecto stricto ramoso inferne compresso vaginisque glabris; pedicello externe ciliato piloso; gluma inferiore versus apicem scabra apice bifido-dentata; palea superiore bilaciniata. A. vaginatus Presl 1. c. In Mlexico. 4.

20. A. Preslii Kunih; culmo stricto superne ramoso; spicis solitariis cylindricis; pedicello ciliato-barbato; gluma hermaphrodita superiore profinde bilaciniata. A. gracilis Presl 1. c, In Peruvia. 24.

21. A. campestris Kunth; culmo hasi fasciculatim diviso foliisque filiformibus, his basi superue villosis ; racheos articulis pedicelloque spiculae alterius masculae mucronatae apice extrorsum barbatis; glumis glabris. schizachyrium filiforme Nees in Mart. Bras. 2. p. 388. In Brasilia.

22. A.tener Funth; culmis filiformibus superne ramosis; spicis gracilibus; articulis racheos basi barbatis; palea iuferiore bifida ciliata; arista inferne torta spicula triplo longiore. Kunth Gram. 2. p. 565. t. 197. Schizachyfum tenerum Nees. In Brasilia meridionali. 4.

23. A. hirtiflorus Kunth; culmis superne ramosis; articulis racheos pedicellisque spicularum sterilium molliter pilosis; palea bifida scabra. Kunth Gram. t. 198. Schizachyrium Nees. In Brasilia meridionali. 4.

2t. A. semiberbis Kunth; monander; culmo fasciculato-ramoso; fol. basi hirsutis; pedicello neutrius altero latere barbato, hujus gluma inferiore apice setigera. Schizachyrium Nees 1. c. In Brasilia australi. 4.

25. A. Myosurus Presl; culmis erectis; fol. linearibus complicato-subfalcatis rigidis; spiculae sessilis gluma inferiore dorso convexa apice trun- cato-bidentata superiore navicularicarinata; palea bifida ciliata. Kunth Gram. 2. p. 571. t. 199. Pitlecurus gracilis Willd. In Mexico.

26. A. malacostachyis Presl; fol. lanceolatis obtusis mucronatis glahris; rachi, pedicello spiculae neutrius glumaque hermaphroditi floris inferiore plumosis; palea superiore profunde bilaciniata. PresI 1. c. In Acapulco. $\odot$.

2\%. A. scoparius Michx. vaginis villosis; ramis ramosis purpurascentibus in longam paniculam strictis; involucellis brevissimis. Michx. H'. 1. p. 57. Pollinia scoparia Spr. In $\mathrm{Ca}$ rolina. 4.

28. A. divaricatus $L$. spica obIonga; floribus lanatis remotis divaricatis; arista flexuosa nuda. Lim. Sp. p. 1480. In Tirginia.

29. A. foreolatus Delile; lamina foliorum basi margine utroque barbulata; nodis breviter ciliatis; flosculis sessilibus, foveola dorsali hemisphaerica sub apice impressis. Delile Aeg. p. 16. t. 8. f. 2. A. annulatus scluult. A. monostachyus Spr, In Aegypto.

b. Spicae ill apice culmi vel ramorum conjugatae ternao vel piures subdigitatae.

30. A. serratus Retz; floribus imbricatis exterioribus sessilibus, interioribus biseriatis pedicellatis masculis muticis. Roxb. ind. 1. p. 257. A. filiformis Pers. Lepeocercis servata Trin. Fund. t. 18. In India orientali.

31. A. tenellus Roxb. filiformis; spicis geminatis; floribus geminatis, sessilibus hermaphroditis aristatis, pedicellatis neutris muticis; utrorumque valvis calycinis exterioribus ohlongis striatis pilosis tridentatis. Roxb. ind. 1. p. 259. Heteropogon S'chult. In Bengalia.

32. A. Neesii Kunth; spicis terminalibus geminatis lateralibus solitariis longe pedunculatis; glumis integris; vaginis foliisque villosis; culmo ramoso; nodis barbatis. Heteropogon villosus Nees in Mart. Bras. 2. p. 362. In Brasilia australi. 4.

33. A. binatus Retz; gracilis; versus basin repens; spicis geminatis incurvis; corolla bivalvi mutica. Roxb. ind. 1. p. 259. In India orientali.

34. A. conjugatus Roxb. strictus; ramosissinus; filiformis; spicis conju- 
gatis ; flore utroque hermaphrodito aristato; valvis calycinis exterioribus lanceolatis valde ciliatis. Roxb. ind. 1. p. 266. Saccharum Spr. In Bengalia.

35. A. filiformis Roxb. annuts; erectus; spicis geninatis; floribus omuibus sessilibus solitariis; hermaphroditis diandris; corolla 1-valvi longe aristata. Roxb. ind. 1. p. 260. A. Hoxburghianus schult. In Calcutta.

36. A. tridentatus Roxb. spicis geminatis hirsutis; tlore utroque hermaphrodito aristato; calycihus villosis; valvis exteriorihns cuneatis truncatis 3-dentatis; corollis 4-valvibus. Roxh. ind. 1. p. 261. Saccharum Spr. In Coromandelia.

3\%. A. Gayanus Kunth; culmo ramosissimo; ramis subfasciculatis distachyis; vaginis spathiformibus involutis; pedicellis ciliato-lannginosis; gluma inferiore spiculae hermaphroditae multinervia ad medium sulco Iongitudinali exarata margine ciliato-scabra. Kunth Gram. 1. p. 165. In Senegalia.

38. A. distachyus $L$. spicis geminatis terminalibus; flosculis geminis aristatis, hermaphrodito sessili, masculo aristato; culmo indiviso. Willd. sp. 4. p. 917. Jacq. ic. t. 630. Host. Gram. 3. t. 2. Sibth. Graec. 1. t. 69. Pollinia Spr. In Europa atustrali et Barbaria. 24.

39. A. serrulatus $L k$. spicis geminis ternisve; valva exteriore hermaplirodita aristata membranacea hifida, nervis scabra margine serrulato-ciliata, interiore longius acutata. Lk. Hort. 1. p. 24. Patria ignota. 24.

10. A. furcatus Muehlenb. spicis digitatis subquaternis; floribus geminatis, hermaphrodito sessili aristato, masculo mutico pedicellato; rachi pilosa. Willu. sp. 4. p. 919. In America boreali. 24.

41. A. hirtus $r$. spicis conjugatis pedunculatis paniculatis ; floribus geminis hirsutis, altero sessili hermaphrodito aristato; altero masculo mutico. Willd. sp. 4. p. 917. Host. Gram. 4. t. 1. Trachypogon Nees. In Europa australi, Barbaria, Oriente et Prom. b. spei. $4 \%$

42. A. pubescens Tisiani; spicis axillaribus terminalibusque pedunculatis vaginatis; pedunculis apice pubescentibus; flosculis hirsutis; fol. an- gustissimis glaucis sparsin pilosis. Visiani in Bot. Zeit. 1829. 1. In Dalmatia, 4.

43. A. rufus Kunth; culmo ramoso; nodis glabris; vaginis maxime ciliatis oreque barbatis; spicis subgeminis fasciculato-paniculatis; rachi spiculisque ferrugineo-hirtis; seta longa ferrugineo-hispida. Trachypogon Nees 1. c. In Brasilia. 24.

11. A. pumilus Roxb. erectus; 12pollicaris; pedunculis longis nodosis vaginatis; calyce floris hermaphroditi sessilis aristati cuspidato. Moxb. ind. 1. p. 278. In Coromandelia.

45. A. parviflorus hoxb. adscendens; fol. linearibus; panicula foliata tenui; spathis propriis uodosis foliaceis; utrinque floribus aristatis, pedicellato nomnisi rudimentario. Roxh. ind. 1. p. 27\%. In montibus Circar.

46. A. mocerus R. Hr. panicula elongata; spathis alternis; spicis conjugatis aristatis; ligula membranacea imberbi; rachi harbata villis patulis strictis; culmis elongatis ramosis; geniculis imberbibus. R. Br. prodr. 1. p. 202. In Nova Hollandia.

4\%. A. exaltatus $R$. Br. panicula elongata; ligula membranacea inberbi; aristis spicam subaequantibus; rachi barbata villis patulis; glumis glabris; culmis ramosis. R. Br. 1. c. In Nova Hollandia.

48. A. lancitus R. Br. panicula coarctata; spathis alternis margine scariosis; spicis conjugatis aristatis; ligula membranacea; rachibus densissime lanatis; geniculis pubescentibus. 13. 13r. I. c. In Nova Hollandia.

49. A. Bombycims R. Br. panicula coarctata; spathis alternis margine scariosis; ligula membranacea imberbi; geniculis tomentosis. $\mathbf{R}$. Br. 1. c. In Nova Hollandia.

50. A. refractus $\boldsymbol{R}$. Br. panicula spathis alternis; spicis conjugatis muticis refractis; ligula nembranacea imberbi; glumis acuminatis glabris. 12. Br. 1. c. In Nova Hollandia.

51. A. Schoenanthus L. panicula subsecunda lincari foliata; pedicello conimuni spatha iustructo; foribus onunibus muticis; corolla mascula bivalvi. Roxh. ind. 1. p. 278. Hamacciam Rheede Mal. 12. t. 72. Schoenanthum amboinicum liumph. 5. t. 82. f. 2. Cymbopogon schoenauthus spr. R. et S. Audropogon marginatus stevid. 
In Bengalia, Arabia et l'rom. $b$. spei, 4.

52. A. Ianiger Desf. spicis paniculatis foliaceis; floribus geminatis lana involutis, altero sessili liermaphrodito, altero pedicellato mutico; rachi villosa; fol. involutis. A. eriophorus Wille. sp. 4. p. 910. In Barbaria. 4.

53. A. Juarancusa Plialos. Trans. 80. \%. 281. $t$. 16. erectus; fol. Iongis valde teunibus; paniculis linearihus; foribus hermapluoditis aristatis, masculis 1 -valvilous muticis. Roxl. ind. 1. p. 279. Cymbopogon Jwarancusa schult. In montibus borealibus Indiae orientalis, ad rivum Rapta et circe Hurducar. 24.

5t. A. Nartini Roxb. perennis; erectus; paniculis tinearilus subsecnndis ; spiculis geminatis 3-noclosis; spathis nonnisi communihus; corollis hermaphroditis e valva et arista, masculis muticis. Roxh. ind. 1. p. 280 . In montibus Balla-ghat Indiae orientalis. 4 .

55. A. glaucescens $\boldsymbol{H}$. et $\boldsymbol{K}$. culmo ramosissimo; nodis glabris; fol. glancescentibus interne vaginisque scabris; rachi pedicelloqne foris masculi alboplumosis; arista pubescente. H. et K. Nov. Gen. 1. p. 186. In Quito, Mexico et Hontevideo.

56. A. bicornis $\boldsymbol{L}$. panicula hracteata, fastigiato-corymhosa ; floribus ternis muticis, intermedio hermaphrodito scssili, lateralibus nentris pedicellatis; rachi longissima ciliata. Willd. sp. 4. p. 916. Anatherum bicorne Beauv. Agr. t. 22. f. 11. In Brasilia, Gijana, Jumaica et Martinica. 24.

5\%. A. condensatus $\boldsymbol{H}$. et K. culmo ramosissimo; ramulis fasciculato-congestis fastigiatis; vaginis superioribus aphyllis; rachi pedicelloque floris neutrius plumosis. H. et K. Nov. Gen. 1. p. 188. Cymbopogon Spr. Schizachyrium Nees. In Nova Granata, Montevideo et Mexico. $\odot$.

58. A. consanguinens Kunth; monauder; culmo fasciculato ramoso foliisque linearibus glabris; spicis linearibus incurvis; rachi pedicelloque spiculae neutrius subulatae setigerae rectae plumosis. Schizachyrium intermedium Nees in Mart. Bras. 2. p. 334. In Nontevideo.

59. A. paniculatus Funth; culmis erectis compressis superne paniculatiun ramosis nodisque glaberrinis; vaginis compressis ; ligula brevi memhranacca; pedicello Ionge harloato; arista brevissima. A. scoparius Presl 1. c. In Mexico. 4.

.60. A. complus Presl; culmo erecto semitereti superne ramosissimo nodisque glahris; vaginis supremis aphyllis; fol. margine serratis; rachi pedicetloque foris masculi plumosis; palea superiore bilaciniata. PresI 1. c. In Peruvia.

61. A. macrurus Michx. vaginis foliorum ad margines manifeste villosis; paniculis lateralibus fasciculatopolystachyis in longam confertamque paniculan constrictis ; floribus 1-apdris. Michx. Fl. 1. p. 57. Cinna glomerata Walt. In Carolina et Florida. 4.

62. A. ilissitifloms Micllx. vaginis foliorum glabellis; culmis stricte erectis fere ah imo floridis; floribus monandris; arista longa recta. Nichx. Fl. 1. p. 57. Cinna lateralis Walt. In Carolina et Florida. 4.

63. A. lateralis Nees; culmo simplici; nodis vaginisque glabris; fol. linearibus basiu versus superne subpilosis circa ligulam longe harbatis; spicis partialibus subdichotomis; articulis omnilus barbato-fimbriatis. Nees in Mart. Bras. 2. p. 329. In Brasilia australi. 4.

64. A. virginicus I. paniculae spicis conjugatis; rachi lanata; flosculis muticis, masculo tahescente. L. sp. 1482. Anatherum Spr. Holcus virgiuicus Muehlenb. In America boreali et Brasilia. 24.

65. A. vaginatus Elliot; panicula gracili subappressa; spicis solitariis conjugatis vagina brevioribus; floribus geminis, hermaphrodito aristato; arista recta scabra. Elliot. hot. 1. p. 118. In America septentrionali. 4.

66. A. leucostachyus $\boldsymbol{H}$. et $\boldsymbol{K}$. culmo ramoso; nodis vaginis foliisque glabris margine scabris; rachi pedicelloque floris neutrius albo-plumosis; glumis hermaphroditis acuminatis; arista vix exserta. H. et K. 1. c. Anatherum domingense $\mathbf{k}$. et $\mathbf{S}$. In Cumana et Brusilia. 4.

6\%. A. lanuginosus $\boldsymbol{H}$. et $\boldsymbol{K}$. culmo ramoso; nodis vagiuisque glabris; fol. gtahris; spicis ternis; rachi pedicelloque floris neutrius albo-plumosis; glumis hermaphroditis scabrig, inferiore bifido-dentala. H. ct K. I. c. In Quito. 21. 
68. A. tristachyus $H$. et $K$. culmo ramoso; nodis glabris; vaginis foliisque scabris serrulatis; glumis hermaphroditis et masculis acutis apice scabris basi barbatis; arista glumis duplo longiore. H. et K. 1. c. In Nova Andalusia. 4.

69. A. eriostacliyns Presl; culmo superne ramoso; fol. linearibus scabris; rachi pedicelloque neutrins floris albo-plumosis; plumis flores excedentihus; glumis floris hermaphroditi glabris; palea hermaphrodita superiore laevissima nitida, PresI Rel. Haenk. 1. p. 339. In ins. Philippinis.

ro. A. flavescens Presl; culmo erecto nodisque glabris; vaginis pilosis; fol. 1ate linearibus subtus glaucis; glumis floris hermaphroditi $\mathbf{1}$-nerviis, carina hispido-scahris; superiore 2dentata, inferiore lidentato-mucronata; palea superiore bilaciniata. Presl. 1.c.

\section{In Peruvia.}

\%1. A. spathiflorts Kunth; culmis caespitosis rigidis apice in paniculam contractam ramificatis; fol. plicatofiliformibus, versus basin villoso-ciliatis; glumis lanceolatis acutis nervis scabris, superiore ciliata. Hypogynium Nees in Mart. Bras. 2. p. 366. In Brasilia. 24.

72. A. ternatus Nees; culmo subramoso compressiusculo glabro; fol. strictis carinatis, junioribus supra villosis; rachi albo-villosissima; mascula spicula mutica. Nees 1. c. Saccharum Spr. In Brasilia. 4.

\%3. A. plumosus Willd. culmo ramoso; nodis barhatis; vaginis apicem versus pilosis; rachi pubescente; glumis hermaphroditis sericeis, masculis pubescentibus; arista longissima basi plumosa. H. et K. Nov. Gen. 1. p. 185. Trachypogon Nees 1. c. In Nova Andalusia. 4.

\%t. A. ligularis hunth; culmo ramoso; nodis sericeis; fol. glaucis scabris; vaginis glabris; ligula lanceolata; glumis utriusque spiculae villosis; arista longissima basi pilosa. Tracliypogon Nees 1. c. In Brasilia. 4.

75. A. ternarius Michx. ramis remote alternis solitariis simplicibus plerisque tristachyis ; spicis distanter alternis bifidis; villis involucri gluma brevioribus; valvula intina aristam lougam ex incisura contortam emit- tente. Michx. am. 1. p. 57. In Virginia et Carolina. 4.

76. A. sericeus $\boldsymbol{R}$. $B r$. spicis $3-6$ digitatis sericeis aristatis; involucro nullo; glumis exterioribus ovalibus obtusis juxia apicem longissime barbatis ; fol. setaceo-acuminatis; geniculis barhatis. I. Br. prodr. 1. p. 201. In Nova Hollandia.

\%\%. A. hirsutus $H$. et $\boldsymbol{K}$. culmo ramoso nodis lanatis; fol. vaginisque hirsutis; rachi piloso-lanata; pedicello floris neutrius ciliato-scabro; arista longissima pubescente. H. et K. Nov. Gen. 1. p. 186. In Mexico. 4.

18. A. hirtifolius Presl; culmo simplici? nodis lanato; vaginis ore foliisque utrinque hirsutis; rachibus spicularum mascularum ciliato-barbatis, barba spiculis breviore; glumis nentrius floris ciliatis apice scabris. Presl. 1. c. In Mexico. 4.

99. A. mollicomus Funth; culmo ramisque canaliculatis apice nodisque superioribus villosis; ligula abbreviata fimbriata; spiculis 4-seriatis sericeopilosis longe aristatis; sterilibus pedicellatis muticis; arista scabra spiraliter torta. Kunth Gram. 1. p. 365. t. 96. A. pubescens Willd. In ins. Mauritii et Timor.

80. A. annulatus Forsk. spicis geminatis ternisve; calycibus nervosis ciliatis, hermaphrodito sessili aristato, neutro mutico pedicellato; rachi pilosa; culmo ramoso. Willd. Sp. 4. p. 910. Delile Aeg. 3. t. \%. f. 2. A. affinis Spr. In Aegypto et India orientali. 4 .

81. A. aristatus Poir; spicis ternis quaternisque; floribus geminatis, altero sessili longe aristato, altero pedicellato mutico; fol.vaginisque laxe pilosis. Poir. Enc. suppl. 1. p. 585. In ins. Franciae.

82. A. carinätus Nees; culmo simplici compresso glabro; fol. brevibus planis vaginisque patenti-villosis; rachi spiculaeque masculae pedicello albo-plumosis; mascula spicula mutica. Nees in Mart. Bras. 2. p. 330. In Brasilia australi. 4.

83. A. trispicatus Sclult. spicis tribus; flore utroque hermaphrodito aristato; calycibus lanceolatis ciliatis. Roxb. ind. 1. p. 261. In Calcutta. $\odot$.

81. A. lanceolatus Roxb. fol. Ianceolatis basi cordatis et amplexicanlibus setoso-ciliatis; spicis ternis pe- 
dunculatis; flore lıermaphrodito sessili aristato; valva exteriore calycis margine argute pectinato-serrata. Roxb. ind. 1. 1. 262. In Coromandelia.

8.5. A. scundens Roxb. spicis 3-6 digitatis; calyce Ianceolato; corollis masculis $\mathbf{1}$-valvibus aristatis. Roxb. ind. 1. p. 262. In India orientali.

86. A. pertusus Willd. spicis 4-7 confertis sericeis aristatis; rachihus barbatis; glumis exterioribus oblongis pulsescentibus, medio foveola impressis; fol. caulinis setaceis. 1h. Br. prodr. 1. p. 201. Holcus pertusus L. In Nora Hollandia et India orientali. 4.

s\%. A. pilosus Klein; spicis digitatis subsenis; floribus geminatis basi villosis, altero hermaphrodito aristato sessili, altero masculo mutico pedicellato; rachi glabra. Willd. sp. 4. p. 920. In India orientali.

SS. A. Bladhii Retz; subscandens; nodis pubescentilus; spicis 3-6, subpaniculatis; corollis masculis $\boldsymbol{2}$-valvibus, hermaplroditis 1-valvibus aristatis; floribus geminatis. Roxb. ind. 1. p. 263. In India orientali et China.

8.9. A. incurvatus Retz; spicis filiformilus subdigitatis ; floribus geminatis, femineo pedicellato aristato masculo sessili mutico; calycibus 1-valvibus. Hetz Obs. 5. p. 21. In Tranguebaria.

90. A. orthos Schult. strictus; apice ramosus; fol. basi ciliatis; valva exteriore itriusque calycis foveolata. A. strictus lioxb. ind. 1. p. 265. In India orientali.

91. A. Ischaemum I. fol. linearibus canaliculatis pilosis; spicis digitato-cymosis; glumis striatis; valva inferiore spiculae hermaplıoditae pedicellisque pilosis. H. et K. 1. c. p. 539. schkuhr t. 342. Host. Gram. 2. t. 2. Jacq. austr. t. 384. Sclureb. Gram. t. 33. In Europa australi, Graecia, Caucaso, Prom. b. spei et India orientali. 4.

92. A. provincialis Lam. spicis 4-5, erectis subdigitatis; pedicellis villosis; spiculis geminis, altera hermaphrodita 1-aristata. DC. Gall. 3. p. 96. In Gallia anstruli. 24.

93. A. villosus Thunb. spicis digitatis; floribus aristatis sessili pedunculatoque; calyce culmoque villosis. Thunb. prodr. p. 20. Pollinia villosa Spr. In Prom. b. spei.
94. A. affinis $\boldsymbol{R}$. Br. spicis $3-\overline{5}$, digitatis villosis aristatis; involucro nullo; glumis exterioribus ovalibus obtusis nervosis margine ciliatis; fol. setace 0 -acuminatis. R. Br. prodr. 1. p. 201. In Nova Hollandia.

9.5. A. chloridiformis Gutudich. fol. vaginis nodisque tomentoso-hirsutis; spicis digitato-quaternis; rachi pilosa ciliata. Gaudich. in Freyc. it. bot. 412. In ins. Mariae Annae.

- 96. A. radicans Lelım. spicis racemoso-digitatis subduodenis; fusculis adpressis ciliatis basi rachique sericeo-lanatis; culmo adscendente basi radicante. Lehm. Hort. Hamb. 1828. In Prom. b. spei. 4.

\section{c. Spicae paniculatae.}

9\%. A. intermedius $\boldsymbol{R}$. $\boldsymbol{B} \boldsymbol{r}$. spicis pluribus paniculatis aristatis; involucro nullo; rachibus harbatis; fol. caulinis subulatis scabris. R. Br. prodr. 1. p. 202. In Nova Hollandia.

98. A. argenteus DC. culmo simplici; nodis barbatis; vaginis glabris; ramulis pedicellisque alho-plumosis; glumis hermaphroditis basi barbatis apice ciliatis; flore nentro minimo. Humb. et K. Nov. Gell. 1. p. 188. Saccharum argenteum Bronss. Jacq. Eclog. Gram. 5. t. 5. Erianthus saccharoides Willd. Trachypogon argenteus Nees. In Mexico, Quito, Peruvia et Montevideo. 4.

99. A. laguroides Dc. paniculae oblongae ramis dichotomis; pedicellis rachibusque lanatis; nodis glabris. DC. Cat. p. 78. Trachypogon laguroides. Nees. In Mexico et Brasilia. 4.

100. A. saccharoides Sw. paniculae ramis simplicibus; flosculis geminatis, lermaphrodito aristato sessili, altero mutico tabescente. Sw. Fl. ind. 1. p. 205. In Jamaica.

101. A. alopecuroilles $L$. panicula simplici oblonga elongata; spicis verticillatis; floribus aristatis geminatis; rachi lanata; lana floribus longiore. Willd. sp. 4. 911. In America boreali et Jumaica. 4.

102. A. comosus Spr. spicis paniculatis laxis; rachi hirsuta; flosculis glabris; arista torta elongata; fol. grlabris ciliatis; nodis culmi villosis. spr. Nov. prov. No. 5. In Nova Hollandia et Aegypto. 
103. A. festucoides Presl; nodis vaginisque glabris; spicis elongatis nultifloris verticillatis paniculatis; spiculis secundis binatis pilis stipatis; glumis hispidis lanceolatis. Presl 1. c. In Luะonia.

101. A. Haenkei Presl; fol. anguste linearibus scal)ris; spicis in panicula verticillatis; spiculis secundis pilis stipatis; pedicello neutrius rachique ciliato-barbatis. PresI I. c. p. 340. In ins. Mariae Annae et Luzonia. 4.

105. A. holcoides Kunth; nodo superiore barbato; fol. convolutis vaginisque glabris; spiculis basi pilis rufescentibus cinctis muticis, pedicellata minore feminea. Kunth Gram. 2. p. 49. t. 160. Anatherum Nees. In Brasilia.

\section{Rachis paniculata.}

106. A. Sorghum Brot. nodis pubescentibus; vaginis foliisque glabris margine serrulato-scabris; ramis pubescenti-pilosis; pedicello piloso. H. et K. Nov. Gen. 1. p. 190 . Holcus Sorghum L. Solghum vulgare Pers. Host. Gram. 4. t. 2. Holcus Durra Forsk. In India orientali. $\odot$.

107. A. niger Kunth; panicula rara pyramidali; ramis pendulis; glumis nigris Iucidis. Holcus nigerrimus Ard. Saggi di Padov. 1. t. 5. f. 1. Sorghum nigrum $\mathbf{R}$. et $\mathbf{S}$. Patria?

108. A. cernuns Roxb. erectus; 5-15-pedalis; radiculis e geniculis inferioribus erumpentibus verticillatis; glumis villosis fimbriatis; corolla 3valvi fimbriata. Roxb. ind. 1. p. 273. Holcus cernuus Willd. Sorghum Willd. Host. Gram. 4. t. 3. In Bengalia. 4.

109. A.bicolor Roxb. erectus; panicula diffusa; ramis patentibus compositis et supradecompositis; calycibus dorso glabris margine fimbriatis; corolla 2 -valvi. Roxb. ind. 1. p. 272. Holcus bicolor L. H. Sorghum Mieg. in Act. Helv. 8. t. 4. f. 4. Sorghum vulgare $\beta$. bicolor Pers. In Persia et India orientali. $\odot$.

110. A. mbens Kunth; calycibus oblongis acutis nitidis margine ciliatis; seminibus compressis; panicula patente. Sorghum rubens Willd. en. p. 1036. S. vulgare $\beta$. rubeus Pers. Patria? $\odot$.

111. A. saccharatus Roxb. erectus; paniculis verticillatis; ramificationibus nutantibus ; calyce piloso ; corollis muticis, hermaphrodita 3-, neutra 1-valvi. 13oxb. ind. 1. p. 274. Holcus L. sorghum saccharatum Pers. Iost. Gram. 4. t. 4. In India orientali et Arobia. $\odot$.

112. A. Caffrorum Kunth; glumis villosis; seminibus compressis inermibus. Holcus Caffrorum Thunb. prodr. p. 20. H. cafer Ard. Saggi di Padov. t. 1. f. 1. Sorghum Arduini Jacq. Gram. 25. t. 18. In Prom. b. spei.

113. A. halepensis Sibth. Graec. t. 68. norlis pubescentibus; vaginis foliisque glabris, margine scabris; panicula ramosa; glumis hermaphroditis pubescentibus; pedicello piloso. A. avenaceus $H$. et K. Nov. Gen. 1. p. 189. Holcus halepensis L. Schreb. Gram. t. 18. Host. Gram. 1. t. 1. Trachypogon avenaceus Nees. In Europu australi, Syria, Mauritenia, ins. Cuba; in Brasilia et Nova Hollandia cultus. 4.

111. A. decoloraus $\boldsymbol{H}$. et $\boldsymbol{K}$. nodis pubescentibus; fol. margine serulato-scabris; glumis hermaphroditis pubescenti-pilosis; pedicello piloso; arista nulla. H. et K. Nov́. Gen. 1. p. 190. Holcus Willd. In Nova Andalusia. 4.

115. A. propinquus Kunth; nodis holosericeis; fol. setaceo-acuminatis glabris, collo dense pilosis; rachi hirsuta; glumis hermaphroditis pedicellisque neutris pilosis. A. affinis. Presl. Patria?

116..A. fuscus Presl; nodis vaginisque pilosis; fol. serrulato-scabris; paniculae ramis filiformilus 3-6-floris; spiculis ovato-lanceolatis acutis hirsutis, lateralibus masculis pedicello hirsuto suffultis. Presl. Mel. Haeuk. 1. p. 342. In Luzonia. 4.

11\%. A. tropicus $5 \mathrm{pr}$. panicula effusa; spicis 8-13-floris; rachi pedunculisque plumoso-barbatis; glumis villosis muticis; fol. scaberrimis; geniculis barbatis. Holcus fulvus $\mathrm{R}$. Br. prodr. 1. p. 199. $\beta$. timorensis Kunth Gram. t. 97. In Nova Hollandia, Moluccis et $\beta$. in Timor. 4.

118. A. fulvus Spr. paniculae erectae ramis capillaribus; pedicellis fosculisque fulvo-villosis; arista lirsuta torta Iongissima; geniculis barbatis. Spr. syst. 1. p. 287. In Bengalia. 
119. A. strictus IIost. Gram. 1. $\boldsymbol{t}$. 2. floribus aristatis basi villosis geminis, altero sessili, altero pedicellato; corolla trivalvi, valvula intermedia bifida. Willd. sp. 4. p. 911. Sacclarum strictum Spr. Hipidiun Trin. In Iungaria, Gallia et Orienie. 4.

120. A. avenacens Michx. fol. asperis vaginisque glabris; panicula nuda subpyramidatim ohlonga multiflora; floribus rufescentilsus; glumae valva altera villosa. Michx. Fl. 1. p. 58. A. uutans Muchlenh. A. ciliatus Elliot. A. stipoides H. et K. Trachypogon stipoides Nees. Sorghum parviflorum Hamilt. In America boreali, Nova Granata, Brasilia et Cuba. 4.

121. A. incompletus Presl; culmo erecto stricto inferne ramoso ad 110dos barhato; rachi glaberrima; pedunculis hispidis; palea inferiore hinervia bidentata extus pilosa; arista longissima. Presl 1. c. In Mexico. 4.

122. A. alternans Presl; nodis pilosis; vaginis glabris; paniculae ramis fasciculatis altemis capillaribus; spiculis basi pilis stipatis; palea superiore hermaphroditi minutissima. Presl 1. c. In Peruvia. 4.

123. A. scaberrimus Irunth; nodis sericeis; fol. vaginisque scaberrimis; ligula subcoriacea truncata; articulis pedicellis spiculisque dorso lanatis; seta filiformi. Trachypogon Nees. In Brasilia. 4.

121. A. nutans $T$. panicula ramosa coarctata nutante; floribus geminatis aristatis ; calycibus hirsutis, hermaphrodito sessili, masculo pedicellato acuto. Willd. Spec. 4. p. 906. In America boreali et Jamaica. 4.

125. A. Gryllus $L$. panicula effusa patente; pedunculis imberbibus; glumae hermaphroditae valvula strigosociliata, uasculae valvula basi harbata; vaginis imis suhsericeis. Holcus Gryllus R. Br. prodr. 1. p. 199. A. paniculatus Lam. ill. t. 810 . f. 1. PolIinia Gryllus Spr. Chrysopogon Trin. In Europa australi, Burbavia, India orientali et Nova Hollandia. 4.

126. A. caerulescens finth; fol. scabris; vaginis nedisque barbatis; panicula effusa; glumis acutis pubescentibus basi barbato-involucratis. Holcus Gaudich. in Freyc. it. bot. 411. t. 27. In Novia Hollandia.
12\%. A. micranthus Kunth; panicula effusa capillari; pedunculis 3-floris ; glumis muticis; fol. planis scabris; geniculis barbatis. Ilolcus $\mathbf{R}, \mathbf{B r}$. $\mathbf{l}$. c. Anatherum parviflorum spr. In Nove Ifollantia. Valde variat.

128. A. pallidus Kinnti; panicula effusa; pedunculis glumisque imherbibus, hermaphroditae valvula exteriore strigoso-ciliata; paniculis imberbibus. Holcus h. Br. 1. c. Pollinia pallida Schuit. In Nora Hollandia.

129. A. australis Spr. panicula effusa; spicis 8-15-floris; rachi pedunculisque plumoso-barbatis; glumis pubescentibus; fol. scabris; geniculis barbatis. Holcus plumosus $\mathbf{H}$. Br. I. c. Sorghum plumosum Beauv. In Nova Hollandia.

130. A. elongatus Spr. panicula elongata; spicis 5-floris; pedunculis imherbibus; glumis glabris muticis, exteriore substrigoso-ciliata; fol. triquetris carina marginibusque asperis. Holcus A. Br. 1. c. Sorghum Beauv. In Nova Hollandia.

131. A. muricatus Retz; fol. Iongis angustis; ramis paniculae patentihus; floribus hermaphroditis masculisque muticis; corollis trivalvibus. Roxh. ind. 1. p. 269. A. squarrosus L. Agrostis verticillata Lam. Anatherum muricatum Beauv. Agr. t. 22. f. 10. In Coromandelia et Bengalia.

132. A. acicularis Retz; panicula contracta erecta; pedunculis 3-floris; floribus masculis hinis pedicellatis acuminatis, femineo sessili aristato. Retz Obs. 5. p. 22. Raphis trivalvis Lour. Trin. ic. t. 8. 9. Centrophorum chinense Trin. Fund. t. 5. Chrysopogon acicularis ibid. In China, India orientali, Moluccis et ins. Maigiou. 4.

133. A. subulatus Presl; culmo basi repente ramoso; fol. abbreviatis lanceolato-linearibus; ramis paniculae simplicissimis; calcare e ramis secedente hirsuto; gluma inferiore binucronata; paleis ciliatis. Presl. I. c. In Luะonia. 4.

13.. A. Nardus L. paniculae ranuis stupradecompositis proliferis. L. sp. p. 1482. In India orientali. 4.

135. A. arundinaceus Willd. panicula ramosa nutante; florihus ternis, hermaphrodito ariatato hasi pedicellatisque barbatis, masculis lateralibus muticis. Willd. 6p. 4. p. 906. In Guinea. 
136. A. verticillatus Roxb. fol. longis valde pilosis; panicula conica; ramificationibus 3-floris; flore uno hermaphrodito sessili biaristato. Roxb. ind. 1. p. 267. In India orientali.

13\%. A. punctatus Roxb. erectus; simplex; fol. magnis longis crebris; paniculae ramis secundis; valvis exterioribus floris hermaphroditi et neutrius foveolatis. Roxb. ind. 1. p. 268. In India erientali.

138. A. fascicularis Roxb. erectus; ramosus; paniculis compositis e ramis fasciculatis; floribus geminatis, hermaphroditis aristatis. Roxb. ind. 1. p. 268. In India orientali.

139. A. glaber Roxb. erectus; ramosus; glaber; panicula ovata verticillata; ramis ramosis; floribus geminatis, hermaphroditis aristatis, neutris muticis; corolla 1-valvi. Roxb. ind. 1. p. 271. In India orientali.

110. A. montanus Roxb. Ad hasin fruticosus; repens; fol. linearibus erecto-patulis glabris; spiculis teruis, media sessili hermaphrodita; gluma calycis inferiore rufo-ciliata; arista longissima fusca flexuosa. Chrysopogon Trill. In India orientali.

111. A.laxus Willd. erectus; 1-15pedalis; panicula ovata laxa; calyce piloso; corollis fimbriatis. Roxb. ind. 1. p. 275. A. serratus Thunb. In India et Japonia.

142. A. miliaceus Roxb. erectus; 6-10-pedalis; paniculae amplae ramis verticillatis patentissimis vel nutantibus. Roxb. ind. 1. p. 2\%6. A. filiformis Schult. In India orientali.

143. A. Bergii $R$. et $\mathbf{S}$. panicula composita densa; glumis bifloris lucidis; flosculo utroque arista tortuosa divaricata. A. avenaceus Berg. Cap. p. 356. In Prom. b. spei.

114. A. scrobiculatus Kunth; culmo ramoso; nodis foliisque glabris; spicis fasciculato-paniculatis; glumis spiculae neutrius maximis dorso medio glanduloso-scrobiculatis. Trachypogon Nees in Mart. Bras. 2. p. 347. In Brasilia. 24.

145. A. minarum Kunth; nodis sericeis; fol. lineari-elongatis scahris; ligula ad latera herbacea; pedicellis incrassatis rudimentisque masculis geminis plumosis; gluma inferiore hasi harhata, apice ciliata. Trachypogon Nees in Mart. Bras. 2. p. 349. In Brasilia.

\section{Species dubiae.}

116. A. monandrus Roxb. erectus; filiformis; apice instructus ramis erectis filiformihus; valva exteriore calycis et corollae in utrisque aristata; flore hermaphrodito 1-andro. Koxb. 1. c. In India orientali.

117. A. caricosus I. spica solitaria imbricata; seminibus hirsutis; aristis nudis contortis. Linn. sp. p. 1480. In India orientali et Japonia.

115. A. nervosus Rottl. gluma hermaphroditi sessilis 1-flora 2-valvi, masculi pedicellati biflora; valvula exteriore glumae praesertim masculi nervosa, colorata margine et pedicello pilosis. Willd. in Act. Berol. 4. p. 218. In India orientali.

149. A. muticus $L$. spicis digitatis subternis; flosculis alternis sessilibus muticis. L. sp. p. 1482. Anatherun Beauv. In Prom b. spei.

150. A. melanocarpus Elliot; spicis fasciculatis; floribus solitariis involucratis; arista longissima. Elliot. Bot. 1. p. 146. Stipa Muehlenb. Cymbonogon spr. In America boreali.

1.51. A. tetrastachyus Elliot; panicula gracili erecta; "spicis solitariis 4-fidis ; floribus geminatis, hermaphrodito aristato; fol. pilosis. Elliot. Bot. 1. p. 150. In Anerica boreali.

152. A. Sprengelii Kunth; paniculae effusae ramis capillaribus; pedicellis longissime valvisque exterioribus barbatis; fol. inferioribus ohtusiusculis ciliatis; vaginis pilosis. Pollinia spr. Pug. 2. p. 10. In Bengalia. 4 .

153. A. Crupina Kunth; fol. glabris serrato-ciliatis; ligula pilosa; panicula effusa; pedicellis in axillis pilosis; valvis fertilihus ovalibus, pilis sursum arrectis. Sorghum Crupina Lk. Hort. 1. p. 246. Patria ignota. 4.

15t. A. barbinodis Lag. panicula oblonga contracta; pedunculis alterue geminis fasciculato-polystachyis; aristis contortis ; culmo ramoso; geuiculis dense barbatis. Lag. Elench. 3. In Mexico. 4.

15.5. A. ylaucus Mruehlenb. culno nodisque glabris; fol. glaucis; superiorihus margine scahris; pedunculis lateralibus 2 sub spica bifida; involucro cymbiformi hasi villoso. Muehlenb. Descr. p. 278. In Carolina australi. 
156. A. Besseri Kunth; calycibus ovatis acutiusculis superne nervosis subpubescentibusque; seminibus aristatis; panicula patente. Sorghum nervosum Bess. in scluut. Mant. 3. p. 669. In China.

15\%. A. cotulifer Thunb. panicula patula villosa; arista tortili nuda; pedicellis incrassatis pateraeformibus. Thumb. Jap. p. 41. In Japonia.

158. A. megapotamicus Spr. spica terminali imbricata longissima; flosculis serice - villosis; aristis longissimis hirsutis secundis. Spreng. Cur. post. p. 33. Heteropogon Schult. Ad Rio Grande.

159. A? dubius Kunth; rachi articulata pilosa; flosculis glabriusculis appressis; fol. longissimis glabris serrulatis; culmi nodis longe pilosis. Auatherum Spr. Ad Rio Grande.

160. A. 'Zeae $R$. et $S$. culmis ramosis foliisque glahris angusto-linearibus convolutis strictis; ligula pilosa; spicis erectis bractea lineari multoties longioribus. R. et S. syst. 2. p. 818. In St. Fe de Bogota.

161. A. virgatus Hamilt. caule subnudo subulato; fol. subulato-convolutis glaberrimis basi ciliato-pilosis; spiculis in bracteis nidulantibus. Hamilt. prodr. p. 9. In Antillis.

162. A. microstachyus Hamilt. culmo basi compresso distiche folioso; fol. glaberrimis; vaginis ancipitibus fance nudis; panicula ramosissima; rachi pilosa. Hamilt. prodr. p. 8. In Antillis.

163. A. depanperatus Kunth; paniculae pauciflorae ramis capillaribus; pedicellis harbatis; flosculis foliisque glabris. Pollinia spr. Pug. 2. p. 10. In Bengalia.

167. A. juncifolius Hamilt. culmis caespitosis; fol. glaberrimis convoluto-setaceis; ligulis hifidis acutis; rachi dense pilosa. Hamilt. prodr. p. 9. In Santa Cruz.

165. A. Muehlenbergianus Schult. culmo semitereti; fol. linearibus margine scaberrimis; spicis bifidis; flore intermedio bracteato triquetro. Muehleub. descr. p. 279. In Carolina septentrionali.

166. A. ramosus Forsh. spicis terminalibus conjugatis; spiculis geminis 1-fioris, mascula mutica pediccllata; culmo ramoso. Forsk. Aeg. p. 173. In Aegypto.
16\%. A. peduncularis Kunth; spicis subsolitariis terminalibus longe pedunculatis; flosculis 1-andris; fol. basi pilosiusculis; culmo filiformi stricto. Pollinia monandra spr. syst. 1. p. 288. In India orientali.

168. A. flabelliformis Roxb. spicis vaginatis; rachi pilosa; fol. vaginantibus subtriquetris; culmo ramoso; geniculis barbatis. Spreng. syst. 1. p. 283. In Fiengalia.

169. A. yracilis Spr. spicae solitariae pedicellisque plumosis; flosculis dissitis, masculo obsoleto; fol. setaceis elongatis rigidis glabris; culmo ramoso. spreng. syst. 1. p. 284. In Hispaniola.

180. A? nitidus Kunth; glumis 1floris vilkosis; floribus omuibus muticis. Holcus nitidus Vahl 1. p. 101. Anatherum Spr. In India orientali.

1\%1. A. capillaris Kunth; glumis bifloris nudiusculis; flosculo hermaphrodito mutico, masculo aristato; pedunculis glabris. Holcus capillaris Thunb. prodr. p. 20. Sorghum R. et S. In Fiom. b. spei.

172. A. latifolius Krunth; glumis trifloris; flosculo primo inermi, duobus margine aculeatis ; fol. subovatis. Holcus L. sp. p. 1486. In India orientali.

173. A. setifolius Funth; glumis bifloris muticis acutis; fol. filiformisetaceis. Holcus setifolius Thunb. cap. 1. p. 412. Sorghum $R$. et $\mathbf{S}$. Anailierum Spr. In Prom. b. spei. 4.

174. A. rufus Rich. fol. linearibus planis; panicula ramosissima coarctata; ramis articulatis; glumis aureo-pilosis. Eriochrysis cayeunensis Beauv. t. 4. f. 11 . In Cajenna, Cumana et Brasilia. 24.

185. A. crinitus Thunl). jap. t. $\%$. culmo ramoso; geniculis barbatis; fol. planis; floribus spicatis aristatis. Saccharum paniceum Lam. Perotis polystachya Willd. Pogonatherium crinitum Beauv. Agr. t. 11. f. 7. Kunth Gram. t. 161. 162. In India orientali.

176. A. aureus Bory it. 1. $p$. 367. $t$. 21. culmo adscendente; fol. planis; spicis fasciculato-digitatis articulatis; spiculis pilis aureis dense obsitis. Eulalia aurea Kunth Gram. t. 93. Saccharum Spr. Eriantlus Beauv. In ins. Borboniae. 4. 
464. DIECTOMIS Beauv. (1812).

1. D. fastigiata Beanv. Agr. $t$. 23. $f$. 5. nodis glaberrimis; fol. anguste linearibus subpilosis; ligula longissima; barba basilari spiculam hermaphroditam superante. Presl Hel. Haenk. 1. p. 332. Kunth Gram. t. 6t. Pollinia spr. Andropogon Sw. In Jamaica, Nova Andalusia, Brasilia et Mexico. 4.

2. D. angustata Presl; culmis erectis nodisque glaberrimis; fol. angustissime linearibus scahris; ligula nulla; spicula hermaphrodita barbam hasilarem superante. PresI 1. c. In Mexico. 24.

3. D. laxa Nees; spiculae neutrius gluma inferiore superiorem aequante; ligula trumcata. Nees in Mart. Bras. 2. p. 340. In Brasilia. $\odot$.

\section{ISCHAEMUM. L. (173\%).}

\section{Spicae solitariae.}

1. I. fragile $\boldsymbol{R} . \boldsymbol{R} r$. spica tereli; racheos articulis pedicellisque obovatis ventricosis intus concavis membranaque seariosa tectis ; geniculis barbatis. R. Br. prodr. 1. p. 205. In Nova Hollandia,

2. I. laxum R. Br. spica subnutante; racheos pedicellique angulis barbatis; glumis submembranaceis nervosis glabris, pedicellata biflora; flosculis masculis muticis $\mathbf{R}$. Br. prodr. 1. p. 205. In Nora Hollandia.

3. I. Sehima Spr. spica simplici; spiculis conjugatis bifloris ; flore masculo mutico hermaphrodito aristato. Sehima ischaemoides Forsk. descr. p. 178. In Yemen.

\section{Spicae conjugatae.}

4. I. murinum Forst. fol. Ianceolatis; calycibus aristatis; corollis maoculis muticis, femineis aristatis ; arista geniculata; rachi ciliata. IVilld. sp. 4. p. 940. In ins. Tanna.

5. I. triticeum $\boldsymbol{R}$. Br. racheos pedicellique angulis barbatis; glumis imberbibus laevibus : interioris carina superne alata; vaginis imis hirsutis; geniculis barbatis. $\mathrm{R}$. Br. prodr. 1. p. 205. In Nova Hollandia.
6. I. muticum L. culmo erecto subramoso; vaginis margine oreque pilosis; geniculis glabris superioribus vix pilosis; spicis arcte rachi glaberrimae adpressis; glumis laevissinis. Brongn. in Dup. it. bot. p. 68 . I. involutum Labill. In.India orientali, Nova Caledonia, Amboina et Moluccis. 4.

\%. 1. australe $\mathrm{R}$. Br. racheos pedicellique angulis barbatis; glumis imberbibus laevibus; perianthii hermaphroditi arista inclusa brevissima; geniculis harbatis. IR. Br. prodr. 1. p. 205. In Nova Hollandia.

8. I. timorense Inunth; repens; culmis erectis et geniculato-adscendentibus; nodis barbatis; gluma inferiore 11-13-nervia superue 2 -carinata 2 cuspidata; floribus hermaphroditis longe aristatis. Kunth Gram. 1. t. 98. In ins. Timor.

9. I. Urvilleanum Kunth; cuImis repentibus apice adscendentibus distachyis compressis; nodis pubescentibus ; glumis navicularibus; racheos pedicellique angulis ciliatis. Dup. it. bot. p. 69. t. 12. In Brasilia.

10. I. villosum R. Br. racheos pedicellique angulis barbatis; glumis laevibus, exteriore basi villosa; fol. scabris; vaginis laevibus; geniculis barhatis. H. Br. prodr. 1. p. 205. In Nova liollandia.

11. I. aristatum L. fol. Ianceolatis; fosculis undis; calycis sessilis valvula exteriore utrinque binodulosa corollaque arista tortili elongata. I. imberbe Retz Obs. 6. p. 35. Meoschium aristatum Beauv. Agr. t. 21. f. 4. In China et India orientali. 4.

12. I. filiforme Willd. fol. filiformibus; corollae arista tortili elongata. Willd. sp. 4. p. 9\%. I. aristalum Thunb. In Prom. b. spei.

13. I. barbatum Retz; fol. lanceolatis; calycibus trifloris basi harbatis margineque ciliatis; margine utrinque binoduloso. Retz obs. 6. p. 35. I. aristatum Houtt. syst. 12. t. 93. f. 4. Meoschium Beauv. In Java.

11. I. semisugittatum Roxib. annuum ; fol. ovato-lanceolatis semisagittatis secundis; calycibus ommibus bifloris; valvis exterioribus transverse rugosis. Roxb. ind. 1. p. 322. In Bengalia.

15. I. ciliare Retz; fol. Ianceolatis; calycibus bifloris; pedicellis ciliatis; flore utroque femineo; arista torta 
geniculata. Retz obs. 6. p. 36. Arthraxon Beauv. t. 11. f. 6. Pollinia Spr. In China.

16. 1. rugosum Salisb. ic. $t$. 1. erectum; ramosum; fol. lanceolatis; spicis conjugatis; flore utroque aristato; calycibus obliquis obtusis duris transverse rugosis. Roxb. ind. 1. p. 322. In India orientali.

1\%. I. Colladoa R. Br. culmo ramoso; fol. cordatis lauceolatis acutiusculis; vaginis cymbaeformibus. Colladoa distachya Cav. ic. t. 160 . In ins. Philippinis et America. 4.

18. I. conjugatum Roxb. partim repens; fol. brevibus acutis basi latis et cordatis; spicis conjugatis quasi coadunatis; valvis exterioribus calycis lanatis. Hoxb. ind. 1. p. 323. In Calcutta.

19. I. geniculatum Roxb. culmis geniculatis repentibus glabris; fol. ensiformibus; calycibus bifloris glabris aristatis. Roxb. ind. 1. p. 324. In Bengalia.

20. I. tenellum Roxb. basi repens; fol. linearibus; spicis geminatis; valva exteriore floris sessilis truncata, reliquis cuspidatis. Roxb. ind. 1. p. 324. In India orientali.

21. I. glabratum Presl; culmo repente adscendente; vaginis hirsutis; ligula truncata; spiculae sessilis gluma obtusa bidenticulata; arista brevissima. Presl. 1. c. In ins. Philippinis.

22. I. minus Presl; culwo repente adścendente; fol. anguste linearibus; ligula trumcata; glumis inferioribus sub apice scabris, spiculae sessilis bifido-dentata 4-nervia; arista brevi. Presl. 1. c. In ins. Philippinis.

3. Spicae digitatae vel panicula tae.

23. I. gujanense Kunti ; culmis ramosis ; ramis 2-4-staclyyis; nodis barbatis; glumis exterioribus scabriusculis striatulis apice bifidis; vaginis superne pilosiusculis. "Kunth Gram. 1. p. 168. In Gujana.

24. I. Latifolium Kunth; culmo ramoso; articulis barbatis; gluma exteriore apice hifida; ligula abbreviata pilosa; fol. planis lanceolatis vaginisque glabris. Kunth Gram. 1. p. 168. et 371. t. 99. Andropogon Spr. Spodiopogon Nees. In ins. Trinitatis,
Guadelupe, Martinicae et Brasilia. 4.

25. I. digitatum Brongn. culmo erecto simplici nodisque glaberrinis; spicis 5-6, approximatis glaberrimis; glumis acutis, superiore breviter aristata, carinis vix cristatis. Brongn. iu. Dup. it. bot. p. 70. t. 13. In ins. Bourou.

26. I. intermedium Brongn. culmo erecto simplici glabro; nodis barbatis; foliorum lamina ad basin marg!nis tantum longe pilosa; glumis ovatis acutis; carinis breviteraristatis. Brongu. 1. c. In ins. Carolinae.

2\%. I. fasciculatum Brongn. culmo compresso; nodis villosis; fol. linearibus utrinque pilosis; vaginis villosis; racheos pedicellorumque angulis barbatis; glumis oblongis acutis dorso longe villosis; aristis violaceis. Brougn. 1. c. In ins. Mauritii.

28. I. polystachyum Presl; culmo erecto; nodis barbatis; vaginis pilosis; ligula truncata; rachi pedicellisque angulis villosis; gluma superiore spiculae sessilis apice bifido-dentata. Presl in Rel. Haenk. 1. p. 328. In ins. Mariae Annae.

29. I. pallidum Kunth; paniculae ramis strictis angulato-scabris confertim fasciculatis; arista ad dimidiam spiculam exserta. Arundinella pallida Nees in Mart. Bras. 2. p. 465. var. $\alpha$. culmo simplici et $\beta$. culmo altiori ramoso. In Brasilia. 4.

30. I. hispidum H. et $\boldsymbol{K}$. fol. vaginisque piloso-scabris; spicula altera Ionge pedicellata; flore inferiore neutro; superiore hermaphrodito hasi barbato et artículato. H. et K. Nov. Geu. 1. p. 194. Kunth Gram. t. 100. Andropogon virens Spr. Arundinella Mikani Nees. Arund. brasiliensis Raddi. Riedelia Mikani Trin. In Cumana, Quito, Brasilia, Mexico et ins. Martinicae. 4.

31. 1. peruvianum Kunth; fol. angustis utrinque varinisque pubescentipilosís; ligula truncata emarginatobifida. Thysonache peruviana. Pres! in liel. Haenk. 1. p. 352. In Peruvia. 4 .

\section{Species dubiae.}

32. I. rottboelloides $\boldsymbol{R}$. $\boldsymbol{B r}$. spicis filifornibus glaberrimis laevibus alternatim fasciculatis; fol. ciliatis; ge- 
niculis imberlhibus. R. Br. prodr. 1. p. 206. In Nova Hollandia.

33. I. repens Roxb. repens; fol. brevibus aculis; spicis geminatis; floribus omnibus polygamis et muticis; glumis calycinis cuspidatis rachique glabris. Hoxb. ind. 1. p. 325. In Pulo-Penang.

34. 1. cuspirlatum Roxb. fluitans in aqua dulci; parte summitatis emersum; fol. linearibus glabris; valva exteriore calycum in acumen longum ensiforme undatum producta. Roxb. iud. 1. p. 325. In Bengalia.

35. I. importunum Lour. paniçula coarctata; corollis 1-valvibus. Lour. Coch. p. 794. In Cochinchina. 4.

36. I. melicoides Koenig; spica simplici secunda multifora; corollis basi barbatis aristatis; aristis rectis. Willd. sp. 4. p. 941. In India orientali.

\section{APLUDA L. (1737).}

1. A. aristata $L$. arista floris hermaphroditi exserta. L. sp. p. 1487. Schreb. Gram. t. 42. Lam. ill. t. 841. Andropogon glaucus Retz. In India orientali et Africa interiore. 4.

2. A. mutica $L$. arista floris hermaphroditi brevi inclusa. L. sp. p. 1486. Lam. ill. t. 811 . f. 1. Calamina mutica Beauv. In India orientali et INloluccis.

3. A. humilis Kunth; culmo basi repente erecto apice ramoso; fol. linearibus setaceo-acuminatis; vaginis involucrantibus scabris; glumis glabris. Calamina Presl. 1. c. In Luzonia.

4. A. geniculata Roxb. perennis; repens et scaudens; obsolete geniculata; fol. lanceolatis; flore hermaphrodito et masculo in quolibet calyce utroque mutico. Roxb. ind. 1. p. 327. Ad ripam Gangetis.

5. A. villosa Schreb. panicula abbreviata, partiali bidentata; flore octo aristato villoso. Schreb. Gram. 2. p. 92. In India orientali.

6. A. digitata $L$. spicis digitatis secundis. L. sp. suppl. 434. In India orientali.
46\%. ALLOTEROPSIS Prest (1831).

1. A. distachya Presl in Rel. IIaenk. 1. $\%$. 3H. t. 1\%. In California. 24. Gramen facie Urochloae cimicinae.

\section{POGONOPSIS Prest (1831).}

1. P. tenera Presl in Rel. Haenk. 1. p. 333. t. 46. In Mexico. $\odot$. Gramen caespitosum ramosum. Spicae terminales longe pedunculatae, laterales vaginis subinclusae.

\section{XEROCHLOA R. Br. (1810).}

1. X. imberbis $\boldsymbol{R}$. Br. spiculis subulatis parum curvatis; valvula interiore flosculi masculi glabra. $\mathrm{R}$. Br. prodr. 1. p. 197. Rottboelia Xerochloa Spr. In Nova Hollandia.

2. X. barbata R. Br: spiculis lanceolatis strictis; valvula interiore flosculi masculi barbata. R. Br. prodr. 1. p. 197. Rottboellia spr. In Nova Hollandia.

480. THELEPOGON Roth. (1823).

1. T. elegans Roth. Nov. sp. p. 62. Rottboellia Heyne. In India orientali.

\section{4\%1. ARTHROPOGON Nees (1829).}

1. A. villosus Nees in Mart. Bras. 2. p. 320. Kunth Gram. 3. t. 200. In Brasilia. 4. Culmus simplex. Folia lineari-lanceolata. Ligulae margo ciliatus. Panicula simplex, ramis erecto-patulis.

\section{GRAMINA DUBIA.}

Zeugitis americana Willd.Apluda Zengitis L. In Jamaica. 4.

Tripogon bromoides R. et $\mathbf{S}$. syst. 2. p. 600. Festuca Heyne. Avena mysorensis Spr. In India orientali.

Limnas Stelleri Trin. Fund. $p$. 116. t. 6. ejusd. ic. t. 1S. In Camtschatka.

A crather um miliaceum Lk. Hort. 1. 1 . 320. In Nepalia. 4.

Pterium elegans Desv. Journ. 
Rhytachne rotthopllioides Desv. in Hamilt. prodr. p. 12. In Antillis. X.erochloa arundinacea Lichtenst. In Prom. b. spoi.

Cariochloa montevillensis $\mathbf{S} p r$. Cur. jost. p. 30. In Montevideo.

\section{THE ICXNA.}

\section{ELEGIA L. (1871).}

1. E. juncea Th. Restio thyrsifer Rottb. ic. 3. I. 4. In Prom. i. spei. 4. Planta restiacea culmo duro tenaci; vaginis foliaceis apice mucronatis; spathis laxis spicas glomeratas tegentibus.

\section{LEPYRODIA R. Br. (1810).}

1. L. hermaphrodita R. Br. culmo simplicissimo; spicis simpliciusculis; floribus hermaphroditis. In Nova HolTandia.

2. L. scariosa R. Br. culmo simplicissimo; spicae compositae ramis imbricatis divisis; perianthii valvis interioribus mimoribus. $\mathbf{R} \cdot{ }^{\cdot} \mathbf{B r}$. In Nova Hollandia.

3. L. stricta R. Br. culmo simplicissimo; vaginis strictis; spicae compositae ramis subapproximatis; valvis perianthii subaequalibus. In Nov. Hollandia.

4. L. gracilis $\boldsymbol{R}$. Br. culmo subramoso; vaginis strictis; spicae compositae ramis inferioribus remotiusculis; perianthii valvis exterioribus brevioribus. 11. B. In Nova Hollandia.

5. L. elongate $\mathbf{S p r}$. culno subramoso gracili; vaginis reflexis sublanatis; spiculis masculis sessilibus remotis, femineis subpedunculatis; squamis mucronatis. Calorophum Labill. Nov. Holl. t. 228. Ieptocarpus squarrosus Nees. Restio lateriflorus. R. Br. In Nora Hollandiu.

\section{ANARTHRIA R. Br. (1810).}

1. A. scabra R. Br. culmis simplicissimis planis foliisque margine scabris; perianthii masculi foliolis linearibus, feminei interioribus minoribus. In Nova Hollandia. 4.

2. A. laevis $\boldsymbol{R}$. $B r$. culmis simplicissimis planiusculis foliisque margine laevibus; perianthii masculi foliolis ovali-lanceolatis, femineis subaequalibus. In Nova Hollandia.

3. A. gracilis R. Br. culmis simplicissimis compresso-filiformibus foliisque conformibus margine laevibus; spica racemosa divisa. In Nova Hollandia. 4.

4. A. panciflora R. Br. culmis simplicibus ancipiti - filiformibus folioque subconformi laevihus; racemo paucifloro laevi; pedunculis geminatis. In Nova Hollandia. 4.

5. A. prolifer $\boldsymbol{C}$ R. Br. culmis prolifero-ramosis ancipitibus foliosis; floribus subspicatis solitariisve. $\mathbf{R}$. Br. In Nova Hollandia.

\section{4\%5. GALURUS Spr. (1825).}

1. G. spiciflorus Spr. Caturus $\boldsymbol{L}$. Acalypha Burm. ind. t. 61. f. 2. In ins. Moluccis. †. Frutex Coryli facie; fol. ovato-oblongis serratis subtus lanatis ; spicis' axillaribus; pedunculis elongatis.

\section{HOLOSTEUM DiosC.}

1. H. diandrum Sw. ic. t. \%. caule procumbente ramosissimo; fol. subrotundis ; floribus diandris ; stipulis utrinque quaternis. DC. In Jamaica. $\odot$.

2. H. mucronatum Moc et Sessé; puibescens; caule procumbente; fol. cordatis; pedunculis 3 -floris. In Mexico.

3. H. succulentum $\boldsymbol{L}$. fol. ellipticis carnosis glabris; petalis subtrifidis calyce minoriluss. Pursh. Polycarpon uniflorum Walt. In Noveboraco. $\odot$.

4. H. hirsutum $L$. fol. orbiculatis hirsutis; floribus sessilibus. In $M a-$ labaria. $\odot$

5. H. umbellatum $\boldsymbol{L}$. fol. radicalibus ellipticis glancis glabris, caulinis majoribus ovatis; floribus umbellatis; pedunculo communi viscoso-puhescente, valvis circiuatis. DC. Schk. t. 20. E. B. 27. FI. Dan. 1204. Gaertil. t. 130. In Europa. ๑. Spithameum. Fl: albi.

\section{7\%. LECHEA L. (1751).}

1. L. villosa Ell. undique hirsuta; fol. oblongo-lanceolatis mucronatis; panicula foliosa pyramidata; floribus fasciculato-racemosis secundis bre- 
vissime pedicellatis. Lam. ill. t. 52. f. 2. L. unajor Pursl. In Canada. 2.

2. I. minor Michx. glabriuscula; fol. lineari-lanceolatis acutis; panicula foliosa ; ramis elongatis undique floriferis; floribus breviter pedicellatis; caule assurgente. Pursh Fl. am. Lam. ill. t. 52. f. 1. In Canada. 4.

3. L. thymifolia Michx. undique adpresso-cano-villosa ; fol. linearibus acutis; panicula foliosa elongata; pedicellis brevissimis; floribus parvis cano - tomentosis. In Carolina. 24. Tlyymo serpyllo similis.

4. I. tenuifolia Michx. sparse pilosa; fol. angustissimis; ramulis paniculae divaricatae alternis. In $\mathbf{C}^{\prime} a$ rolina.

5. L. verticillata Willa. repens; geniculata; hispicla; fol. oblongo-ovatis serrulatis; floribus pedunculatis verticillatis. Elatine ammanuoides W. E. Bergia Hook. Bot. Misc. suppl. t. 28. B. pentandra Camb. In India orientali. 4.

\section{MONTIA Mich. (1729).}

1. M. fontana L. Fl. Dam. 131. E. B. 1206. Schr. t. 20. Sv. B. 510. Herba pollicaris-spithama. Fol. lineari-oblonga carnosula. Cor. alba. $A d$ fontes Europae. 4.

\section{POLYCARPON Loefl. (1758).}

1. P. tetraphyllum $L$. fol. quaternis carnosulis obovatis stipulis scariosis ovatis cuspidatis; pedunculis corymbosis. E. B. 1031. Krok. sil. t. 42. Mollugo L. P. diphyllum Cav. ic. t. 151. f. 1. In arenosis Earopae. $\odot$.

2. $\boldsymbol{P}$. Apurense $\boldsymbol{H}$. et $\boldsymbol{K}$. petalis emarginatis ; fol. 5-10 subverticillatis. H. et K. Nov. Gen. 6. p. 40. Ad Orinoccum. $\odot$. Caulis diffusus. $\mathbf{C y}-$ mae dichotomac.

\section{MINUARTA Loef. (175s).}

1. M. dichotoma Loefl. it. t. 1. f. 3. floribus subsessilibus fasciculatis; fol. floralibus brevioribus; sepalis subaequalibus; foliorum mucrone obliquo. In collibus Hispaniae. $\odot$.
2. M. montana Loefl. it. t. 1. f. 1 . florum fasciculis bracteas subaequantibus; sepalis subaequalibus; foliorum mucrone erecto. In Hispania, Iberia et Tauria. $\odot$.

3. M. campestris I,oefl. florihus distincte pedicellatis folia floralia acquantibus aut superantibus; sepalis valde inaequalibus. In Hispania. $\odot$.

\section{TILLAEA Mich. (1729).}

1. T. muscosa L. Micheli yen. $t$. 20. E. B. 116. Rchb. ic. $330-332$. In arenosis Europae. $\odot$. 1-2-pollicaris; ramosa; saepe rufescens.

\section{S\%. KOENIGIA L. (176\%).}

1. K. islandica L. Fl. Dain. 418, Gaertn. t. 128. In Islandia et Lapponia. Planta uncialis et 2 -uncialis subramosa; fol. olsovatis succulentis; fior. exiguis fasciculatis.

\$. K. nepalensis Don; caule erecto retrorsum hispido; fol. ovatis acutis ; floribus terminalibus glomeratis. Ino Nepalia.

\section{DONATIA Forst. (17\%5).}

1. D. fascicularis Forst. gen. $t .5$. Polycarpon magellanicum L. In Terra ignea. Planta muscosa pygmaea; fol. imbricatis lanceolatis coriaceis obtusiusculis; floribus solitariis.

\section{PROSERPINACA L. (1711).}

1. P. palustris $L$. fol. alternis lanceolatis serrulatis; pedunculis axillaribus solitariis. Miclix. Gaertn. t. 24. Juss. Ann. t. 30. f. 1. In Canada. 4.

z. P. pectinata Lam. ill. $t$. 50. f. 1. fol. omnibus pimnatifido-pectinatis; nucis angulis obtusis. In Georyia et Carolina. 4.

\section{HOUTTUYNIA, Thunb, (1784).}

1. H. cordata Thunb. Hook. $\boldsymbol{B}$. M. 2731. Polypara cochinchinensis Lour. In Nepalia, Japonia et Cochinchina. hadix repens. Caul. herbaceus erectus; fol. cordatis nervosis; spatha caudida. 


\section{A $\mathbf{S} \mathbb{S} \mathbb{S}$ IV.}

\section{TETRA NDRIA.}

\section{MONOGYNLA.}

\section{A. Flores perfecti.}

I. Corolla monopetala. a. Fructus superi.

486. Firoburaria. Flores in capitulun giohosum aggregati. Receptaculum paleaceum. Involucrum imbricatum. Cal, et corolla 5 -fida. Caryopsis calyce obvoluta. Globulariae.

48\%. Stillbe. Flores polygami capitato - spicati. Receptaculum paleaceum. Involucrum nullum. Cal. dıplex: exterior 3-, interior 1-phyllus, 5-fidus. Cor. faux villis clausa. Caryopsis calyce interno tecta. Globulariae.

488. Mrattuselnkea. Flores fasciculato - capitati. Receptaculum paleaceum. Cal. 1-partitus. Cor. tubo gracili limbo 4-fido. stylus filiformis. Caryopses $2-4$ intra calycem. Globularicie.

489. Alionia. Involucrum sub3-florum 1-3-phyllum. Cal. corollinus 4-fidus basi persisteus. Nectarium staminiferum urceolatum. Nucula calyce tecta. Nyctagineae.

400. Cailicanor. Cal. 4-fidus. Cor. subcampanulata 4-loba. stamina exserta. Bacca 4-sperma. Verbenaceae.

451. 10 giphila. Cal. 4-dentatus. Cor. tubulosa 4-loba. Stylus bifidus. Drupa 4-locularis 4-sperma. Verbenaceae.

49\%. Petitia. Cal. 4-dentatus. Cor. infundibuliformis 4-fida. Stigma capitatum. Drupa 1-pyrena: nucula 2-1oculari. Verbenaceae.

43. Wallenia. Cal. 4-Iobus. Cor. tubulosa 4-Iocularis. Antherae erectae. Stylus subulatus brevis. Bacca 1-sperma. Vejbenacens.

49. 40.10zus. Cal. tubulosus 4-dentatus cum fructu coalescens. Cor. 4-fida: laciniis reflexis. Stigma emarginatum. Bacca 2 -sperma. Verbenaceae.

495. Chifiantleus. Cal. 4fidus. Cor. tubulosa 4-fida. Stamina corollae inserta. Caps. 1-locuiaris 4-valvis, 4-sperma. Verbenucene.

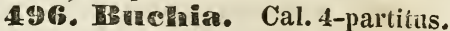
Cor. 4-partita. Filamenta brevissima corollae inserta : antheris 2-locularibus. Stigma 3-partitum. Fructus chartaceus 3-locularis, loculis 1-spermis. Verbenaceae.

45\%. Stepliano Cal. 5-partitus. Cor. subcampanulata ventricosa 5-fida inaequalis. Capsula polysperma, dissepimento valvis contrario. Acantheae.

488. EaDatia. Cal. 4-dentatus inaequalis. Cor. tubuloso-urceolata 4-loba, inter lobos squamata. Stylus subulatus. Fructus baccatus, 4locularis, 4-spermus. Semina ossea. Sapoteae.

495. Pouteria. Cal. 4-paritus persistens. Cor. campanulato-urceolata 4-partita cum setis 4 inter lobulos. Antherae didymae dorso adnatae. Stylus 4-angularis. Caps. 1locularis 4-valvis 4-sperma. Styraceac.

500. Phelline. Cal. 4-dentatus persistens. Cor. rotata 4-partita. Stylus 4-dentatus. Caps. corticata 4locularis, loculis 1 -spermis. Siyrucecue.

501. Nuxia. Cal. subcampanulatus 4-fidus persistens. Cor. tubulosa 4-fida reflexa. Stigma truncatum. Caps. polysperma. Personatae.

50\%. IBruchder. Cal. 4-fidus aequalis. Cor. campanulata -fida. 
stamina inclusa. Stigma clavatum. Caps. 2-locularis 2-valvis, valvis 2-fidis. Personatae.

503. Scoparia. Cal. 4-partitus aequalis. Cor. rotata 4-partita; fauce pilis coronata. Stigma obtusum. Caps, 2-locularis 2-valvis, valvis 2Silis. Personatae.

501. Centunculus. Cal. 4partitus persistens. Cor. supera subrotata 4-fida. stigma truncatun. Caps. glohosa circumscissa polysperma. Brimuluceae.

505. Plamtago. Flores spicati s. capitati. Cor. supera subrotata 4-partita. Stylus simplicissimus. Caps. circumscissa 2-locularis 2-1-sperma. Plantagineae.

506. Sanguisorba. Flor. capitati. Cal. 2-sepalus. Cor. supera subrotata 4-fida persistens. Stigma 4-lobum. Drupa exsucca 4-angula sub-1-sperma. Rosacene.

$50 \%$. Heucanotis. Cal. 4-partitus. Cor. tubulosa basi gibba 4-fida. Antherae sagittatae. Stylus stignate annulato. Bacca 1-3-sperma. Contortae.

508. Kasiostoma. Cal. brevissimus $\mathbf{5}$-partitus, basi squamulis suifultus. Cor. intus villosa 4 -fida. Caps. corticata 1-locularis 2-sperma. Contortae.

509. Exacumn. Cal. 4-partitus persistens. Cor. 4-fida tubo globoso. Antherae subrotundae longitudinaliter dehiscentes. Stylus declinatus. Caps. compressa 2-locularis 2sperma. Gentianeat.

510. Coutoubea. Cal. subcampanulatus 4-partitus. Cor. hypocrateriforınis 4-partita. Filamenta hasi cum appendiculis. Stigma bilolum. Caps. semibilocularis polysperma. Gentianeae.

511. Pladerea. Cal. sub-4-angularis inaequaliter 4-dentatus. Cor. infundibuliformis. Stam. 1. maxinum. Stigma 2-lobum. Caps. semibilocularis polysperma. Gentianeae.

51. Vitareane. Cal. sub4-fidus. Cor. tubo angulato limbo 4partito. Antherae sagittatae. stylus hasi bifidus. Caps. inter styli brachiola dehiscens. Gentianeae.

513. Sebaea. Cal. 4-partitus angulis alatis. Cor. 4-fida marcescens. Antherae post anthesin apice calloso recurvae. Caps. semibilocularis, valvis margine inflexis. Gentianeae.

51.4. Houstomia. Cal. 4-fidus persistens. Cor. infundibuliformis, tuho elongato. Stylus brevissimus, stigmate acuto bifido. Caps. didyma 2-locularis. Semina pauca. Gentianeae.

515. Polypremum. Cal. 4phyllus. Cor. rotata 4-fida fauce barbata. Stamina brevissima. Stylus truncatus. Caps. bilocularis polysperma. Gentianeae.

516. Andrewsia. Cal. 4-fidus appressus. Cor. campanulata 4 -fida persistens. Stigma incrassatum 2-10bum. Caps. 1-locularis 2-valvis. Gentianeae.

51z. rensera. Cal. 4-partitus. Cor. 4-partita patula: lacinias medias occupat glandula orbicularis barbata. Caps. 1-locularis 2-valvis. Semina alata. Gentianene.

51.8. Salvatora. Cal. minutus 4-lobus. Cor. 4-fida, laciniis revolutis. Bacca 1-sperma. Chenopodeae.

519. HIairia. Cal. 4-fidus. Cor. campanulata 4-fida. Caps. 4-10cularis 4 -angula angulis dehiscens. Ericeae.

520. Cardmeria. Cal. 4-fidus. Cor. rotata coriacea 4-fida. Stamina brevissima. Bacca 2 -locularis. Semina 2 urceolata. Ericeae.

521. Pennea. Cal. disepalus. Cor. campanulata 4-fida. Filamenta brevissima. Stylus 4 -angulus, stigmate 4-lobo. Caps. 4-locularis 4-valvis. Ericene.

522. Foussea. Cal. 4-partitus coriaceus persistens. Cor. subanpullaeformis 4-partita reflexa. Stigma peltatum. Bacca ovato-pyramidata. Sem. numerosa. Solaneae.

52 3. Cylind ria. Cal. tubulosus brevis 4-fidus. Cor. tubulosa 4fida: laciniis cucullatis. Filamenta subnulla. Stigma 4-fidum. Bacca exsucca 1-sperma. Sem. lanuginosum. Solaneae.

524. Aragoa. Cal. 4-5-sepalus persistens. Cor. hypocrateriformis, fauce villosa, limbo 4-fido regulari. Antherae cordatae. stigma globosum. Caps. 2-locularis 4-valvis, loculis 4-spermis. Sem. peltata alata. Solaneae. 
b. Fructus inferi.

525. Patrinia. Cal. 4-5dentatus persistens. Cor. campanulata 5-loba. Caps. 3-locularis, calyce coronata bractea laterali adnata. Valerianeae.

5:6. Dpeneularia. Involucrum 1 - phyllum campanulatum 3-6florum dentatum. stigna glohosum. Caps. 3-locularis, loculis $\mathbf{2}$ abortientibus calyce coronata. Valerianeae.

52 ช. Hipsaeus. Involucrum polyphyllum persistens. Receptaculum conicum, paleis sulpungentibus. Cor. 4-fida. Achenium coronula urceolata terminatum. Aggregatae.

525. Scabiosa. Involucrum duplici serie. Receptaculum paleaceo-setaceum. Cor. tubulosa 4-fida. Achenium tetraedrum. Aggregatae.

\section{Rubiaceae.}

a. Fructibus 1-2-spermis.

529. Ceplnalanthus. Receptaculum setosum. Involucrum nullum. Cal. 4-fidus. Cor. infundibuliformis 4-fida. Caps. calyce persistente coronata. Semina angulata.

530. Mitelnella. Flores bini germine insidentes. Cal. 4-fidus brevis. Cor. infundibuliformis 4-fida. Filamenta brevissima. Stigma 4-partitum. Baccae binae coadunatae calyce coronatae. Sem. 4.

531 . A crodiryoz. Receptaculum commune subglohosum villosum. Involucrum nullum. Cal. et Cor. 4fida. Bacculae 1-spermae in baccam compositam succulentam confluentes.

539. Deelieuxia. Cal. 4-fidus. Cor. infundibuliformis 4-fida, fauce barbata. Stigma bifidum acutum. Drupa dipyrena compressa; pyrenis subcoriaceis 1-spermis.

533. Ernodea. Su. Cal. 4partitus parvus. Cor. hypocrateriformis, tubo elongato 4-gono, fauce nuda. Stigma obtusum. Bacca 2 -locularis; loculis 1-spermis.

534. Cumcea. Cal. minimus 4-dentatus. Cor. tubus fauce villis clausus. Stigma bifidum. Bacca 2locularis 2-sperma.

535. Bacomia. Cal. 4-lobns liber. Cor. infundibuliformis, fance villosa, limbo 4-partito. Bacca exsucca 2-locularis 2-sperma.
536. Froelnlielnia. Cal. 4dentatus. Cor. laciniis apice incrassatis triquetris. Bacca exsucca 1sperma, seminis integumento laxo.

$53 \%$ a 3 retr. Cal. minimus campanulatus obsolete 4-dentatus. Cor. infundihuliformis, tubo gracili elongato, laciniis limbi lanceolatis. Bacca 2locularis, suh 1-sperma.

535. 'retramenium. Cal. parvus ohtuse 4-dentatus. Cor. infundibuliformis 4-partita. Antherae lineares. Bacca drupacea depressa: putaminis vertice 4-partito.

539. Txorg. Cal. exigutus 4partitus. Cor. tuho elongato, limbo 4partito patentissimo. Bacca bilocularis disperma.

510. Tertrea. Cal. 4-partitus: lohis ovalibus ohtusis ciliatis. Cor. hrevis 4-fida, fauce pilis obsita. Drupa oblongo-compressa calyce coronata dipyrena. Sem. compressa pendula.

541. IFy dropliythum. Cal. integer. Cor. tubulosa fauce villosa, 4-fida. Bacca 2 -sperma. Semina integumento tenaci.

54:. Sidferodemal rom. Cal. 4-dentatus minimus. Cor. tubo cylindrico elongato incurvo, limbo 4-lobo subreflexo. Bacca 2-locularis. Semina solitaria dissepimento affixa.

543. Sa juosma. Cal. 4-dentatus persistens. Cor. 4-fida fauce hirsuta. Stigma bifidum. Bacca ova. lis unbilicata 1-2-sperma.

54. 16y droplayax. L. Cal. 4-partitus: laciniis subcarnosis. Cor. infundibuliformis, fauce barbata, laciniis revolutis. Drupa exsucca sulcatoangulata bilocularis dissepimento contrario.

545. Chomelia. Cal. tubulosus limbo 4-fido recurvo. Cor. tubo cylindrico Iongissimo, limbo 4 -fido patentissimo. Filamenta brevissima. Drupa ovalis, nuce 4-sulca biloculari, loculis 1-spermis.

546. Seolosanthus Tahl; Cal. 4-fidus. Cor. tubulosa sub 4-gona limbo revoluto. Drupa 1 -sperma.

54\%. Cumminghamnia. Cal. 4-dentatus exiguus. Cor. urceolata hypocrateriformis 4-fida. Discus perigynus glandulosus. Drupa nuce 2loculari 2-sperma.

548. Coussamen. Cal. 4-dentatus. Cor. tubo brevissimo; limbi 27 
lacinis patentissimis. Stigma 4-10bum. Bacea 1-locularis 1-spcrma.

549. Fetesia. Cal. 4-deniatus deciduus. Cor. iufundibuliformis 4 -fida. Drupa dipyrena, pyrenis 1-spermis. Semina meniscoido-umbilicata.

550. Le tuis. Cal. 4-dentatus. Cor. campaunlato-rotata 4-fida. Bacca 1-sperma didyma.

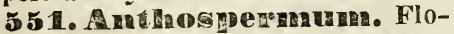
res dioeci. Cal. minimus 4 -dentatus. Cor. tubo brevissimo, 4-partita. Siigmata 2. Caryopses geminae ovatae.

552. Cånivan. Cal. 4-dentatus. Cor. subrotata 4-partita. Stylus apice 2-paritus. Caryopses geminae asperae aut lispidae.

553. A g perenta. Cal. 4-dentatus. Cor. campanulata vel infundibuliformis 4 -fida. Caryopses geminae.

55 4allantia. Cal. 4-dentatus persistens. Cor. rotata. Acheniun calyce denticulato coronatum.

555. Sloer andia. Cal. 4-fidus. Cor. infundibuliformis 4-fida. Stigmata 2, globosa. Caryopses geminae calycis denticulis coronatae.

556. Crucianella. Involucrum 1-florum paleaceum $2-3$-phylIum. Cal. o. Cor. tubo filiformi, limbo 4-fido. Stylus inaequaliter bifidus. Caryopses duae.

55\%. Sperrmacoee. Cal. 4dentatus persistens. Cor. infundibuliformis 4-fida. Caps. 2-locularis calyce coronata. semen solitarium.

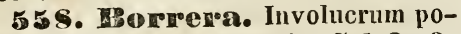
lyphyllum : foliolis setaceis. Cal. Z-3fidus: laciniis subulatis, setis 5-alternis. Cor. infundibuliformis 4-fida. Caps. 2-locularis 2-partibilis.

55.. Throios tus 2-4-dentatus, denticulis nonnullis interdum accessoriis. Cor. 4-fida. Caps. chartacea calyce coronata 2locularis; coccis indehiscentibus 1spermis.

560. Crusea. Calycis tubus ovato-didymus profunde fissus, lobis 4 lineari-subulatis hirtis 4 accessoriis minimis. Cor. tubo apice obconico, fauce glabra 4-fida. Fructus dicoccus coccis 1-spermis.

561. Gaelia. Cal. tubus ovatus, dentes 2 , subulati accessorii subnulli. Cor. infundibuliformis, tubo gracili, linbo 4-fido acuto. Stigma bilobum. Caps. membranacea 2-locularis 2-valvis.
569. IDidalia. Cal. persistens $2-4-$ sepalus, sepalis 2 longioribus. Cor. infundibulifoumis 4-partila. Sligma bifidum. Caps. ovata 4-gona 2locularis 2-valvis. Sem. inde sulcata.

563. Thessiemo. Cal. tubus ovatis limbus 4-lobus, lobis subaequalibus, accessoriis nullis. Cor. infundibuliformis, fauce glabra, limbo 4-lobo. Caps. 2-loculai's 2-valvis. Semina dissepimenio affixa.

564. Sey Hay tubus ovatus: limbus brevissime tubulosus truncaius subintegerrimus. Cor. infundibuliformis, intus tubo hirsuto, limbo 4-fido. Drupa baccata 8-sulcata dipyrena.

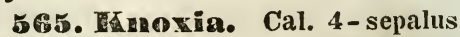
inaequalis deciduus. Cor. tubo filiformi. Stigmata 2, capitata. Caps. 2partibilis 2-sperma.

\section{b. Fructibus 4-spermis.}

566. Hasianthus. Flores axillares bracteis magnis oppositis. Cal. 4-partitus, Iaciniis linearibus. Cor. infundibuliformis, 4-fida. Bacca pilosa calyce coronata 4-sperma.

56\%. Ifry yonecortia. Flores basibus petiolorum senitecti. Cal. subinteger. Cor. tubulosa 4-fida, annulo barhato. Bacca ovata 4-locularis 4-sperma.

568. HDara alia. Cal. 4-dentatus, dentibus bifidis. Cor. regularis 4-fida. Stigmata 2, subulata. Caps. globosa 4-valvis 2 -locularis, loculis dispermis. Sem. globosa.

569. П7. subinteger. Cor. tubo brevi limbo 4fido. Stigma crassiusculum. Bacca sicca depressa, nuce 4-loculari 4sperma. Sem. hinc convexa, inde concava.

\section{c. Fructibus polyspermis.}

5\%0. Hyrostria. Cal. minimus sub-4-dentatus. Cor. subcampanulata semi-5-fida, fauce tomentosa. Fructus pyriformis 8-striatus; nucibus 8-spermis.

5 ช1. Evosmia. Cal. parvus 4-dentatus. Cor. subrotata 4-fida. Stigina incrassatum. Fructus ovatus calyce coronatus 4-locularis, loculis polyspermis. 
ธระ. Gonzallea. Cal. urceoIatus 4-fidus persistens. Cor. infundibuliformis tubo elongato, limbo 4partito. stigma 4-fidun. Drupa depresso-globosa 4-pyrena, pyrenis polyspermis.

5r3. Coccory eqselum. Cal. 4-partilus. Cor. infundibuliformis 4partita. stylus apice bifidus. Bacca subrotunda 2-locularis: Ioculis polyspermis.

5* 4. Hofrmannia. Cal. parvus 4-dentatus. Cor. hypocrateriformis tubo brevissimo. Antherae sessiles lineari-lanceolatae. stigma subemarginatum. Bacca sub-4-gona, 2locularis.

585. 플. tatus persistens. Cor. tubulosa limbo 4-partito. Stylus 4-sulcus, stigmatibus 4. Bacca calyce coronata polysperma, seminibus duplici serie cruciatim dispositis.

5 ร์. Cates Waea. Cal.4-dentatus s. 4-fidus persistens. Cor. tubo longissimo limbo 4-fido. Stigma bidentatum. Bacca calyce coronata 2-locularis. Semina imbricata squamata.

5ร ร. Carprianea. Cal. turbinatus 4-fidus laciniis scariosis. Cor. tuho filiformi, fauce veutricosa intus hirta. Caps. calyce coronata bilocularis 2-valvis.

539. NInEctia. Cal. 4-8partitus. Cor. tubulosa fauce coarctata, limbo 4-partito intus lirto. stigma bifidum. Caps. 2-valvis, valvis introflexis. Semina orbiculata marginc membranacea.

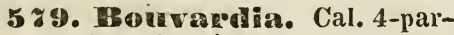
titus dentibus interjectis. Cor. tubuIosa 4-fida. Stigna bilobum. Capsula 2-locularis. Semina marginata.

580. Tedyoris. Cal. 4-partitus. Cor. tubulosa 4-fida. stylus simplex, stigmate bifida. Caps. didyma bilocularis: apice inter dentes calycis dehiscens.

581. Dremiandia. Calycis tubus subglobosus, limbo $\mathbf{4 - d e n t a t o , ~}$ dentes sinu latissimo separati. Cor. breve tubulosa limbo 4-fido, fauce vilIosa aut glabra. Caps. subglobosa.

582. Cenpotincer. Cal. tubus subcompressus: limbus brevis truncatus sub-1-dentatus. Cor. tubus basi inflatus, faux villosa, lobi carinati. Stylus nullus. Caps. compressa utrinque ala duplici secus pedicellum decurrente marginata.

583. Hofandia. Cal. tubus obovatus: limbus 4-dentatus. Cor. tubus longus teres: lobi ovali-lanceolati sacpe mucrone cuspidati. Caps. glohosa membranacea. Semina innumera.

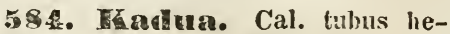
misphaericus: limbus 4-fidus 4-dentatusve. Cor. coriacea: tuho longo 4fido. Stylus filiformis. Caps. glohosa 2-locularis. Sem. innumera minima angulata.

585. Apatis. Cal. tubus obovatus dentatus, dentibus acutis. Cor. hypocrateriformis limbo 4 -fido, fauce subglabra. stigma bilobum. Caps. obovata calyce coronata 2 -locularis apice hians. semina in singulo loculo $4-8$ ovata.

586. Hechicallis. Cal. tubus hemisphaericus, lobis 4 , dentibus 1-3 inter lobos singulos interjectis. Cor. tubo longo tereti: limbo brevi obtuse 4-lobo, fauce imberbi. Caps. subdidyma. Semina in singulo loculo 8-20, ovato-angulata.

58\%. Hueya. Cal. tubus hemisphaericus, dentes 8-geminati. Cor. tubus brevissimus, limbus 4-lobus, lobis obtusis. Caps. globoso - didyma 8-valvis.

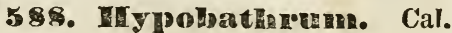
limbus parvus 4-dentatus. Cor. parva subcampanulata fauce villosa, limbo patente 4-fido. Drupa calyce coronata bilocularis loculis 2-pyrenis, pyrenae 1-spermae.

589. Fithosanthes. Cal. limbus minimus 4-dentatus. Cor. globosa fauce villosa: limbo 4-fido. Stigma subclavatum apice 4 -dentatum. Drupa succulenta obovata imbricala infiata.

590. Gymectotes. Cal. linıbus hrevis integerrimus. Cor. 4-5partita intus villosa. Stam. 4-5. Stigma bifidum verrucosum. Drupa globosa haccata umbilicata 4-pyrena; pyrenis 1-spermis.

5\%1. Coeldospermunr. Cal. limbus urceolatus iutegerrimus deciduas. Cor. tubo brevi limbo patente 4-6-fido; lobis linearibus. Stigma bifidum. Drupa globosa umbilicata 4-pyrena; pyrenis 1-spermis. 


\section{Corolla pleiopetala.}

a. Fructus superi.

592. Epimedium. Cal. coloratus 4 -sepalus, basi bracteolis suffultus. Petala 4 ovalia. Nectaria petaliformia cucullata. Folliculus bivalvis.

593. Philagomia. Flores dioeci. Cal. 4-dentatus. Petala 4. stigma peltatum magnum. Capsula 4-1ocularis: loculis dispermis.

59.1. Ptelen. Flores dioeci. Cal. brevis 4-partitus. Petala 4 longiora patentissima. Stylus brevis. stigma bilobnm. Samara bilocularis. Sem, oblonga.

545. Seringia. Cal. 4-lobus. Petala 4 patentia ovata. Antherae bilobae. Stylus subnullus. Stigma minimum. Samara bilocularis loculo altero abortiente.

596. Frayepea. Cal. 4-partitus. Petala 4 basi concava, apice in filamentum longum abeuntia. Stylus aullus, Drupa olivaeformis, nuce lignosa 1 -sperma.

5\$ ช. Samaara. Cal. 4-partitus exiguus. Petala 4 ovata basi lacuna longitudinali. Antherac subcordatae. stigma infundibuliforme. Drupa 1sperma.

598. Evodia. Cal. 4-partitus persistens. Petala 4 calycem subaequantia. Discus perigynus urceolatus 4-lohus. Stylus 4-sulcus. Stigma 4lol,um. Caps. 4-cocca, coccis 2-valvibus 1-spermis.

599. Zieria. Cal. 4-partitus. Petala 4. Glandulae 4 staminiferae. Antherae cordatae. Cocci 4 bivalves.

600. Donetia. Cal. campanulatus 4-fidus. Petala 4, linearia subreflexa. Stylus simplex stigmate acuto. Bacca 1-sperma.

601. Skimmia. Cal. 4-partitus minimus persistens. Petala $4 \mathrm{mi}-$ nima concava. Bacca obsolete 4-sulca 4-sperma.

608. Lepta. Cal. 4-partitus. Petala 4 ovata: Antherae didymae. Bacca 4-loba 1-sperma.

603. Prixa. Cal. 4-partitus brevissimus, Petala 4 lanceolata. Antherae globosae. Stigma capitatum.
604. Curtisia. Cal. 4-partitus. Petala 4 ovata obtusa. Antherae ovatae. Stigma 4-fidum. Drupa subglobosa nuce 4-loculari: loculis 1spermis. Celastrinae.

605. Botryceras. Involucrum multifidum laciniis bifidis curvatis. Cal. 4-partitus persistens. Stylus arcuatus. Nux?

606. Cissus. Cal. minimus obsolete dentatus. Petala 4 persistentia. Stigma acutum. Bacca 1sperma. Ampelideae.

60\%. Allasia. Cal. 5-fidus inferus. Petala 4 supera pilosissima. Antherae bilohae. Stylus subulatus. Bacca 1-locularis polysperma.

605. Siphanthera. Flores aggregati. Involucrum polyphyllum. Cal. campanulatus 4-dentatus, interjectis foliolis longioribus. Antherae basi processu obcordato. Stylus clavatus. Caps. bilocnlaris polysperma. Malastomeae.

\section{b. Fructus inferi.}

609. Connus. Cal. 4-dentatus. Petala 4. Drupa disperma. Flores umbellati. Caprifoliae.

610. Auculoa. Flores monoeci. Cal. truncatus persistens obsolete 4-dentatus. Petala 4. Antherae ovatae didymae. Bacca 1-sperma.

611. Alossoma. Cal. turbinatus 4-dentatus persistens. Petala 4. Antherae apice in ligulam membranaceam productae. Stigmata 4. Drupa 1-sperma.

612. MTontinia. Flores dioeci. Cal. 4-dentatus. Petala 4 obtusissima. stylus bifidus stigmatibus peltatis. Caps. ovalis bivalvis. Sem. compressa foliacea inbricata. Onagreae.

613. Trapa. Cal. 4-partitus. Petala 4. Stylus conicus, stigmate capitato. Nux 2-4-cornuta tota vitello repleta. Hydrocaryae.

614. Ammannia. Cal. campanulatus 8-deutatus, dentibus alternis minoribus. Petala 4 aut $O$. Caps. 4-locularis polysperma. Salicariae.

615. Ludwigia. Cal. 4-partitns persistens. Petala 4 aut nulla. Caps. 4-locularis 4-valvis polysperma. 
B. Flores imperfecti.

I. Fructus inferi.

PROTEACEAR.

A. Fructus clausi.

a. Antherae distinctae.

1. Flores dioecibracteati.

616. Aulax. Flores $d$ racemosi $\&$ subcapitati. Cal. corollinus 4-sepalus. stigma clavatum obliquum. Nux ventricosa barhata.

61\%. Teucadtendion. Flores capitati. Nux squamis strobili dilatatis inclusa.

\section{Flores hermaphroditi.}

aa. Antherae apicibus concavis cal $y$ cis inmersae.

$\alpha \alpha$. Ovarium 1-spermum.

619. Petroplaila. Cal. corollinus totus deciduus. Stigma fusiforme apice attenuatum. Strobilus ovatus. Nux lenticularis linc comosa.

619. Isopogon. Cal. corollinus persistens. Stigma fusiforme. Nux sessilis ventricosa undique comosa.

620. Proten. Involucrum imbricatum persistens. Cal. corollinus bilabiatus. Squamae 4 hypogynae. Nux undique barbata apice caudata.

6:1. Leucospenominn. Involucrum et receptaculum similia. Cal. tubulosus subbilabiatus. Nux sessilis ventricosa laevis.

62: P. Minnetes. Inv. et recept. Proteae, paleis deciduis. Cal. aequalis 4-partitus. stigma cylindricum gracile. Nux ventricosa sessilis laevis.

623. Serrotura - Recept. convexum, paleis persistentibus. Cal. 4fidus, bracteis suffultus. Squamae 4 hypogynae. Nux brevissime pedicellata ventricosa.

624. Nivenia. Involucrum 4phyllum 4-florum fructiferum induratum. Cal. 4-fidus deciduus. Stigma clavatum. Nux ventricosa sessilis.

625. Sorocepinalus. InvoIucrum 3-6-phyllum. Recept. nudum. Cal. 4-fidus. Stigma verticale clavatum. Nux ventricosa brevissime pedicellata.

G26. Spatalla. Involncrum 2-4-phyllum 1-4-florum. Cal. -fi- dus. Stigma obliquum dilatatum. Nux ventricosa brevissime pedicellata.

6ะ \%. A crum 1-florum calyciforme. Cal. 1fidus infra circumscissus. Stigua verticale. Nux ventricosa.

\section{$\beta \beta$. Ovarium dispermum.}

628. Guevinn. Cal. 4-sepalus: senalis 3 revolutis. Glan:lulae 2-lypogyuae. Drupa putamine osseo 1-sperma.

bb. Antherae exsertae mediu vel basi calycis insertae.

$\alpha \alpha \cdot$ Glandula e hypogynae. stamira sterilia 4 .

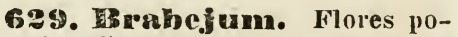
lygami. Cal. 4-sepalus. Vaginula perigyna glaudulosa. Drupa exsucca 1-sperma tomentosa.

630. TPersobnia. Flores hermaphroditi. CaI. 4-sepalus regularis, sep. recurvis. Glandulae calnosae. Drupa haccata nuce 1-2-loculari.

631. Cenarolnemes. Flores hermaphroditi. Cal. 4-sepalus regularis. Drupa baccata.

$\beta \beta$. Glandulae nullae hypogynae.

633. Agastachys. Cal. 1'cgularis 4-partitus. Stigma 1-laterale. Germen sessile 3-gonum 1-spermum.

633. Symaphoymenna. Cal. 4-sepalus regularis. Filamenta apice coalita. Stigma truncatum. Germen 2-spermum.

cc. Antherae tubo calycis a din a t a e.

634. Erown karadia. Cal. hypocrateriformis 4-partitus regularis. Autherae inclusae. Nux fusiformis pedicellata, apice dilatato panuoso.

dd. Stamina hy poyna.

635. T3ellendena. Cal. 4sepalus regularis patens. Stigma simplex. Nux compressa sub-1-sperma.

b. Antherae cohacrentes vicinarum lobis proximis loculum constituentibus, taudem distinctis.

636. Simsia. Cal. 4-sepalus 
regularis, laminis reflexis. Siignma dilatatum concavuu. Nux obconica.

63\%. Conogpenonana. Cal. tubulosus ringens; lacinia suprema basi fornicata. Nux obconica pilis rigidis coronata.

635. Symandrea. Cal. tubulosus ringens; lacinia suprema latiore. Stigma filamento superiori sterili connatum. Nux obovata pilis rigidis coronata.

\section{B. Fructus dehiscentes.}

\section{a. 1-1 oculares.}

a. Ovarium 2-spermum.

aa. Autherae apicibus calycis concavis im mersae.

635. Aำ 4-sepalus. Sligma conicum. Folliculus 1-spermus. Semen apterum.

640. Graevillea. Cal. irregularis 4-sepalus: sepalis secundis. Glandulae hypogynae. Stigma obliquum depressum. Folliculus 1-locularis. Semina apice vel undique alata.

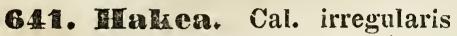
4-sepalus; sepalis secundis. Sugma e basi dilatato mucronatum. Folliculus 1-locularis. Semina apice longe alato.

bb. Antherae exsertae, laciniis calycis revolutis.

642. Hamaridenotia. Involucrum coloraum 1-7-florum. Recept. planum nudum. Cal. tubulosus 4-fidos. Folliculus 1-locularis. Sem. marginata.

643. Xylonue Iynn. Flores polycami spicati. Involucrum nullum. Ca.1. 4-sepalus regularis. Glandulae lypogynae 4. Folliculus 1-locularis, loculo excentrico. Sem. apice alata.

640. Droites. Flores spicati. Invol. nullum. Cal. 4-sepalus regularis. Glandulae hypogynae 4. Folliculus 1-locularis; loculo subcentrali. Sem. apice alata.

645. Hoprora. Flores racemosi. Involucium nuilum. Cal. 4-sepaIus reguiaris. Stigma clavatum. Folliculus 1-locularis. Sem. utxinque alata, nucleo centrali.

\section{ß. Ovarium 4-spermum.}

646. Hais.tatia. Cal. 4-sepaIus regularis. Glandulae hypogynae 4. Folliculus stylo persisience coronatus 1-locularis. Sem. apice alata.

\section{ү. Ovarium polyspermum.}

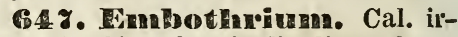
regularis hinc Iongiiudinaliter fissus 4-fidus. Stigma clavatum. Folliculus 1-locularis. Semina apice alata.

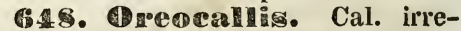
gularis hinc longitudiualiter fissus 4dentatus. Glandulae hypogynae nullae. Folliculus cylindricus. Semina apice alata.

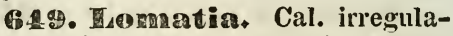
ris, sepalis distinctis secundis. Glandulae hypogynae 3 secundae. Germen longe stipitatum. Stylus sigmate obliquo. Folliculus oblongus. Sem. apice alata, ala marginala.

650. Steme campars. Cal. irregularis, sepalis distinctis secundis. Glandila hypogyna solitaria. Germen stipitatum. Folliculus linearis. Sem. basi alata.

b. Fructus biloculares dissepimento libero bifido.

651. Frandsia. Flores spicati. Cal. 4-partitus. Squamae hypogynae 4. Folliculus ligneus dispermus. Semina apice cuneato-alata.

65\%. 10. commune imbricatum. Receptaculum paleaceum. Cal. 4-partitus. Squamae hypogynae 4. Folliculus ligneus dispermus.

653. HPInge. Involucrum imbricatum polyphyllum. Receptaculum paleaceum. Cal. corollinus 4-fidus, lacinia suprema emarginata. Semina nuda receptaculo affixa.

654. Cansien?. Cal. globosourceolaius 4-dentatus. Stam. imo calyce inserta. Antherae subrotundae non exsertae. Drupa pisiformis 1sperma.

655. Drapetes. Flores aygregato-fasciculati. Receptaculum barbatum. Cal. corollinus infundibuliformis: limbo 4-fido. Caryopsis calyce tecta. Thymeleae.

656. Struthoina. Cal. corollinus bracteatus, limbo 4-fido. Glan- 
dulae squamaceae 8 in fauce. Bacca 1-sperma. T'hymeleae.

65\%. Concephaing. Flores dioeci capitati. Cal. tubulosus 3-4fidus. Filamenta clavata. Stigma tubulosum. Nux calyce baccato vestita 1-sperma. Uricecue.

653. Rivima. Cal. 4-partitus persistens. Stylus brevis stigmate obtuso. Bacca 1-sperma. Chenopodecie.

65y. Cryptocanpus. Cal. campanulato-urceolatus 4-5-dentatus. Filamenta basi comnata. Antherae didymae. Achenium calyce inclusum. Chenopodeae.

650. Fineranthes. Cal. 4fidus persistens: laciniis concavis, 2 majoribus aristatis. Filamenta basi connata. Utriculus $\mathbf{1 - s p e r m u s ~ c a l y - ~}$ ce tectus. Chenopodeae.

661. Canchinomesma. Cal. urceolatus 4-fidus; laciniis oppositis maiusculis recurvatis. Stylus $2-3-$ fidus. Caryopsis nuda calyce tecta. Chenopodeae.

66?. Anisncantha.

Cal. campanulatus 4-fidus; post anthesin auctus. stam. 3-4. Stylus 2-partitus. Utriculus 1-spermus, calyce nucamentace 0 apice spinis 4 inaequalibus instructo inclusus. Chenopodeae.

663. Nyssamthes. Cal. 4partitus irregularis; bracteis spinescentibus. Stam. 2-4, basi connata, squamulis interpositis. Utriculus 1-spermus. Chenopodeae.

661. Fmalermun. Flores subinde polygami. Cal. 4-fidus glandulosus. Autherae apice glanduliferae. Germen apice connatum. Folliculus 1-spermus. Diosmeae.

685. (1)olaria. Cor. calycina bracteis 2 foliaceis suffulta campanulata 4-fida. stigma emarginatum. Caps. 1-locularis 2-valvis 1-sperma. Gentianeae.

666. PIajantinemuna. Cor. calycina 4-partita rotata subrevoluta. Antherae ovales. Bacca globosa 23-sperma. Sarmentaceae.

66\%. Aleluenilla. Cal. patens 8-fidus, laciniis alternis minoribus. Discus glandulosus perigynus. styli $1-5$. Caryopsis solitaria in fundo calycis. Rosaceae.

668. Connetes. Involucrum 4-phyllum 3-florum. Cor. 4-petala. Stylus filiformis stigmate 3-fido. Caps. 3-cocca.
669. IDaplunitis. Flores subdioeci. Cal. 4-sepalus bracteatus. Stylus simplex. Fructus?

6ร0. Med yearpus. Cal. 4partitus. Antherae bilobae. Stylus brevissimus. Stigmata 3 villosa. Caps. baccata 3-locularis. semina integumento succulento cincta.

6\%1. Kagenula. Cal. 4-sepalus persisiens. Discus perigynus 4-lobus. Antherae incumbentes. Bacca lagenaeformis 2-locularis 2-sperma.

II. Fructus superi.

6ร2. Viสeum. Flores dioeci. Cal. subiulus. Cor. 4-petala. Antherae subsessiles petalis adnatae. Stigma sessile orbiculatum. Bacca 1-sperma. Lorantheae.

6ร3. Elaeagnns. Cal. corollinus campanulatus 4-fidus. Stam. calyci inserta. Drupa 1-sperma.

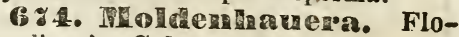
res dioeci. Cal. 4-sepalus. Stylus radiatus. Nux.

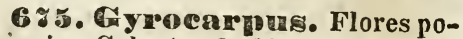
lygami. Cal. 4-8-fidus. Antherae 2-loculares. Stylus brevissimus. Drupa apice bialata. Laurinae.

6r6. Samtallame. Cor. calycina urceolata 4-fida. Glandulae nectariferae fauci insertae. Stigma 3-4-lobum. Drupa apice marginata. Santaleae.

6ร ร. Fugarnus. Cal. corollinus turbinatus semi-4-fidus. Antherae 4-lobae. Discus perigynus glandulosus 4-lobus. Stylus brevissimus stigmata 4. Drupa baccata globosa. Santalear.

6y5. Detanoillum. Cor. hypocrateriformis, tubo 4-gono brevi, limbo 4-partito carnoso. Stylus turbinatus, stigmate crassiusculo. Bacca 1sperma. Sem. integumento 8-gono involutum.

6r9. Catonia. Cal. 4-sepalus persistens. Stylus simplex. Bacca disperma calyce coronata.

680. Tymmostacloys. Flores in spadice cylindrico e spatha minuta. Cal. 4-partitus. Stigma sessile. Bacca 1-sperma.

\section{DIGYNIA.}

\section{Flores perfecti.}

681. Tufronia. Cal. 4-sepalus. Petala 4 integra. Caps. com- 
pressa 1-locularis bivalvis disperma. Caryophylleae.

689. IIy pecoum. Cal. disepalus. Petala 4 inaequalia interiora caepe triloba. Caps. siliquaeformis articulata: articuli 1-spermi. Papaveraceae.

683. Hamamelis. Cal. 4fidus basi externa squamis binis suffultus. Petala 4 ligulata, basi squama lineari imcumbente. Caps. semiinfera 2-locularis apice bivalvis, valvis bifidis. Cocci 1-spermi. Berberideae.

68. Dicoryphe. Cal. tubulosus 4-lobus. Petala 4. Stam. 8, 4 sterilia. Caps. sub-8-gona bicornis. Cocci 2 in fundo haerentes 1-spermi, apice elastice dehiscentes. Hamamezideae.

685. Pagamea. Cal. turbinatus 4-fidus. Cor. urceolata 4-fida intus villosa. Styli capillares. Bacca calyci immersa 2-locularis: nuculis dispermis. Rubiaceae.

656. Selaneflera. Flores dioeci. Cal. 4-partitus persistens. Peta1a 4. Stigmata subsessilia bifida. Bacca bilocularis, loculo altero abortiente. Rhamneae.

68\%. Nentera. Cal. minimus superus 4-dentatus. Cor. infundibuliformis 4-fida. Drupa baccata $2-3-$ sperma. Rubiaceae.

\section{Flores incompleti.}

658. Antineis. Flores monoeci. Involucrum cyathiforme apice multifidum nultiflorum. Cal. 4-sepalus. Semina in drupam ex involucro aucto formatam confluentia.

689. Milorus. Flores monoeci amentacei. Cal. 4-partitus. Stigmata 2 sessilia. Baccae cum calyce concretae aggregatae. Caps. sub-2-sperma. Amentaceae.

690. Planera. Flores polygani. Cal. campanulatus membranaceus 4-5-fidus. Stigmata 2 glandulosa. Amentaceae.

691. Crucita. Cal. 4-sepalus extus bracteatus. Sepala interiora margine tenuissimo lacero. Chenopodece.

692. IIyrien. Flores amentacei dioeci. Squamae 1-florae. Antherae hipartitae. Drupa baccata. Amentaceae.

\section{TRIGYNIA.}

693. Boscia. Cal. 4-dentatus. Cor. 4-petala. Caps. 4-locularis. Terebinthaceae.

694. Paclnysandra: Flores spicati monoeci. Cal. 4-partitus bracteatus. Filamenta complanata. Styli recurvi. Caps. 3-loeularis loculis 2spermis. Tricoccae.

695. Hymenella. Cal. 4-partitus patens. Petala 4 oblonga. Stamina basi coronula petaloidea juncta. Caps. 3-looularis. Caryophylleae.

\section{TETRAGYNIA.}

696. Sagina. Cal. 4-partitus. Petala 4, calyce minora, aut nulla. Caps. 1-locularis 1-valvis polysperma. Caryopliylleae.

69 r. Mïnchia. Cal.4-sepalus persistens. Petala 4. Antherae bilobae. Caps. 1-locularis apice dehiscens 8-dentata polysperma. Caryophylleae.

698. Hendiola. Cal. 4-partitus, laciniis inciso-dentatis. Petala 4. Caps. 8-cocca: coccis 1-spermis. Lineae.

699. IBullareda. Cal. 4-partitus. Petala 4. Squamae lineares ad basin petalorum. Folliculi 4 polyspermi intus deliscentes. Crassuleae.

g00. Brucea. Flores polygami. Cal. 4-partitus. Petala 4. Discus perigynus 4-lobus. Stigmata 4, papillosa. Drupae 4, 1-spermae. Terebintluaceae.

z01. IIyginda. Cal. minimus 4-partitus. Petala 4 patentia. Stigmata 4. Drupa 1-sperma. Celastrinae.

y02. Ilex. Cal. 4-dentatus persistens. Cor. 4-fida vel 4-petala. Stigmata vel distincta vel in unum coalita. Bacca 4-pyrena nuculis 1-spermis. Celastrinae.

ro3. Hiqueria. Cal. 4-partitus, bracteis duplicibus bifidis. Petala 4 concava. Filamenta compressa. Caps. 4-locularis 4-valvis, stylis coronata polysperma.

ro4. Cicea. Flores diclini. Cal. 4-partitus, intus glandulis 4 alternis. Cor. 0. Antherae 2-loculares. Styli bifidi. Fructus baccatus 4-coccus, coccis sub-1-spermis. Tricoccae.

ro5. Potamogetom. Cor. 
calycina 4-petala. Antherae 2-loculares. Nuculae 4. Alismaeae.

g06. Huppia. Flores spicati. Cal. nullus, Cor. nulla. Antherae 4 biloculares, squamis suffultae. Pollen crlindricum geniculatum. Nuculae gibbae. Najades.

ซor. Dttonia. Flores amentacei racemosi. Cal. o. Cor. o. Stigmata 4. Achenium 4-loculare. Albumen corneun. Pipereae.

\section{IIONOCYNIA.}

\section{GLOBALARIA Clus (1601).}

\section{* Herbaceae.}

1. G. vulgaris $L$. caule simplicissimo; fol. rad. spathulatis retusis, caul. lanceolatis acutis. Schk. t. 21. Sturm. 27. B. M. 2256. Sv. B. 304. In calcareis Europae 4. F1. caerulei.

2. G. nudicaulis $L$. scapo subuudo. Jacq. austr. t. 239. Tratt. t. 194. In calcareis Europae. 4. Scap. 3 4-poll. Fol. integerrima spathulata. El. caerulei.

3. G. incanescens Viv. caule herbace 0 simplicissimo; fol. rad. orbiculato-spathulatis 3-nerviis pulverulentis. Viv. Rchb. ic. 1097-98. In alp. Etruriae. 4.

4. G. linifolia Lam. fol. rad. rigidis apice 3-dentatis, caul. angustis acuminatis. Lam. G. vulgaris Brot. In Hispania. 4.

5. G. spinosa Mill. fol. rad. crenato-aculeatis, caulinis integerrimis mucronatis. Mill. dict. In Hispania. 4. 7-poll. Fl, caerulei.

6. G. orientalis Mill. canle subnudo; capitulis alternis sessilihus ; fol. lanceolato-ovatis integris. Mill. dict. In Natolia. 4. Pedalis. Capitula 7 10 alterna.

\section{** Fruticosue.}

7. G. bellidifolia Tenor. caule fruticoso repente; fol. spathulato-cumeiformibus crenatis; scapo nudo; capitulo terminali. Ten. neap. In Calabria. $\hbar$.

8. G. nana Lam. scapis nudis brevissimis; fol. ovato-spathulatis integerrimis; caule prostrato diffuso ramoso.
DC. ic. gall. t. 3. Tratt. t. 193. In Gallia. ち. 3-poll. Capit. carnea.

9. G. cordifolia $\boldsymbol{L}$. suffruticosa prostrata ; fol. ovato-spathulatis ; calyce aequali. Jacq. austr. t. 245. Tratt. t. 192. In Europa austr. et Tauria. ち. Caul. stolonifer atrofuscus. Capit. pallide caerulea.

10. G. bisnagarica $L$. caule fruticoso; fol. rad. cuneiformibus retusis, caulinis lanceolatis. L. Plukn. t. 58. f. 5. In sylvis Bisnagariae. ђ.

11. G. Alypum L. caule erecto; fol. obovato-spathulatis ; cor. lah. sup. brevissimo bifido inf. longissimo 3dentato. Garid. Aix. t. 42. Tratt. t. 191. In Europa meridionali. ち. 2ped. Fl. pallido-caerulei.

12. G. salicina Lam. caule erecto; fol. lanceolato-linearibus integerrimis ; flor. axillaribus subsessilibus solitariis. G. longifolia. Ait. B. R. 68.5. Sloane Hist. I. f, 5. f. 3. In Madera. ち. 3-ped. Fl. caerulescentes.

\section{8\%. STILBE Berg. (176\%).}

1. S. Pinastra $L$. fol. senis linearibus; spicis erectis hirsutis. S. vestita Berg. cap. t. 4. f. 6. Comm. H. t. 110. In Prom. b. spei. ち.

2. S. ericoides $\boldsymbol{L}$. fol. quaternis lanceolatis revolutis; spicis oblongis erectis L. In Prom. b. spei. ち. Pedalis. Fl. rubri.

3. S. cernua Thunb. fol. quaternis patentissimis; spicis cernuis. L. In Prom. b. spei. ち. Pedalis. Fl. albi.

4. S. virgata Lam. ill. l. 856. $f$. 3. fol. minimis ovatis imbricatis; flor. capitulatis; ramis virgatis; ramulis verticillatis saepe bifidis. Poir. In Prom. b. spei. ち.

5. S. myrtifolia Lam. fol. ovatolanceolatis acuninatis dense imbricatis; flor. term. fasciculatis. Poir. In Prom. b. spei. 卢.

\section{S8. MATTUSCHKEA Schreb. (1789).}

1. M. hirsuta Vahl; fol. oppositis ovato-oblongis 3-nerviis hirsutis; calycibus 4-partitis. M. Perama R. et S. Perama hirsuta Aubl. guj. t. 18. In Gujana. $\odot$. Palmaris. HI. Iutei capitati. 
2. M. hispida $\boldsymbol{H}$. et $\boldsymbol{K}$. fol. ternis linearibus; calycibus 2-partitis. H. et K. N. Gen. Ad Orinoccum. $\odot$. Herbula 5-9-poll. Fl. lutei.

3. M. galioides $\boldsymbol{H}$. et $\boldsymbol{K}$. fol. oppositis et ternis linearibus glabris; caJycibus 2-partitis. H. et K. Ad Orinoccum. $\odot$. 8-9-poll. Fl. Iutei.

4. M. incana Sello; fol. oppositis linea:i-lanceolatis enervibus incanis; calyce 2-4-partito. Spr. In Brasilia. Sello.

\section{ALLTONIA Loefl. (1758).}

\section{* Involucrum 5-fidum.}

1. A. violacea $L$. fol. cordatis ; calycibus 5-fidis 3-floris. L. In Cnmana. 24. Caul. debilis. Fl. purpureocaerulei.

2. A. nyctaginea Michx. fol. cordatis; pedunculis solitariis; calycibus pubescentibus. Michx. am. Ad ripas flum. Tenasse. 24. Habitus Mirab. Jalappae.

3. A. ovata Pursh; caule diffuso dichotomo; fol. ovatis scabriusculis; involucro semi-5-fido; laciniis reticulato-venosis. Pursh am. Ad flum. Missonrin. $\odot$.

4. A. aggregata Spr. fol. oblongis scabris breve petiolatis; pedunculis solitariis axillaribus cernuis ; involucro villoso. Mirabilis Cav. All. albida. Walt, In Caroline. $\odot$.

5. A. linearis Pursh; caule erecto tereti; fol. linearibus subcaruosis; floribus racemosis; pedicellis aggregatis; staminibus longe exsertis.- Calymenia angustifolia Fras. In America boreali.

6. A. decumbens Spr. caule tereti decumbente humili; fol. integerrimis linearibus sessilibus; pedunculis axillaribus parum pubescentibus; involucro 3-floro. Calymenia Nutt. gen. In America boreali. 4. Caul. 6-poll. alti. Fl. pallide rubri.

7. A. hirsuta Pursh; caule erecto angulato; fol. lanceolatis nervosis utrinque hirsutis; calycibus hirsutissimis sub-3-floris. Pursh am. In Luisiana. Calymenia Nutt.

\section{** Involucrum 3-phyllum.}

8. A. incarnata $L$. fol. oblique cordatis; calycibus 3 -phyllis 3 -floris; caule decumhente viscoso. L'Herit. Stirp. t. 31. In Peruvia. ๑. Fl. rubri.

\section{CALLICARPA. L. (1711).}

* Foliis denticulatis crenatis.

1. C. americana $L$. ramis pruinoso-tomentosis; fol. late ovalibus, utrinque attenuatis dentato-serratis subtus tomentosis; cymis sessilibus petiolo brevioribus. Lam. ill. t. 69. f. 1. Burchardia Du Ham. t. 44. Plukn. t. 136. f. 3. In America boreali. $\hbar$. 5-ped. Baccae rubrae.

2. C. canc L. fol. ovatis denticulatis per petiolum semi-decurrentibus subtus villeso-canis; paniculis dichotomis. Vahl. C. tomentosa Lam. C. americana Lour. B. M. 2167. In India orientali, Java et Cochinchina. ち. 3-ped. Baccae nigrae.

3. C. acuminata $H$. et $\boldsymbol{K}$. ramis foliisque subtus albo-tomentosis ovatoellipticis longe acuminatis denticulatis; corymbis dichotomo-ramosissimis; H. et. K. C. Bonplandiana Sclıult. In Nova Granata. ち. Fl. suaveolentes. Baccae rubrae.

4. C. lanata $I$. fol, ovatis basi rotundatis integerrimis subdenticulatis supra rugosis; subtus ramisque lanato-tomentosis. Vahl symb. Gaertn. fruct. t. 94. C. pedunculata. R. Br. C. incana Roxb. C. dentata Rotl. In India orientali et Nova Hollandia. ち. Arhor magna. Fl. purpurei.

5. C. rubella Lindl. B. R. 883. fol. cordato-oblongis autrorsum dilatatis acuminatis crenato-dentatis utrinque ramisque villoso-tomentosis. In China.

6. C. Ireynii Roth; pube stellata hirsuta; fol. ovato-oblongis utrinque attenuatis inaequaliter dentatis subtus tomentosis. C. acuminata Roxb. In Sillet. $\hbar$.

1\%. C. subintegerrima $H$. et $\boldsymbol{K}$. ramis foliisque subtus floccoso-tomentosis ellipticis acuminatis apice denticulatis ; corymbis dichotomo - ramosissimis. H. et K. N. Gen. C. mollis Heq. In Nova Granata. ち.

8. C. cuspidata Roxb. fol. ellipticis dentatis cuspidatis subtus lanatis; corymbis axillaribus calycibusque granulato-lanatis. Roxb. ind. In Mo- 
luccis. ђ. Frutex elegans. Baccae puipureae.

9. C. lanceol vria Roxb. pilosa; fol. lanceolatis utrinque attenuatis serrulatis acuminatis subtus hirsutis; cymis compaciis. Roxl). ind. In sylvis Silhet. b. Frutex elegans. Baccae albae.

10. C. macrophylla Tahl; fol. lanceolato-ellipticis crenatis attenuatis, supra rugosis, subtus ramisque tomentoso-incanis. Vahl symb. t. 53. In India orientali. $\hbar$.

11. C. reticulata Su' fol. elliptico-lanceolatis subserratis utrinque reticulatis rugosis, subtus tomentoso-incanis. Sw. prod. In Jamaica. Fl. extus tomentosi.

12. C. ferruginea Sw. fol. latolanceolatis serratis subtus scabriusculis; cymis terminalibus axillaribusque. Sw. pr. In Jamaica. ち. Ramis foliisque pulvere ferrugineo tectis. Baccae purpureae bilobae.

13. C. bicolor Juss, fol. ovatolanceolatis subtus albo-tomentosis; pedunculis axillaribus dichotomis. Juss. Ann. Mus. VII. In Nove Anglia. ち. Rami tomentosi. Flores numerosi parvi.

11. C. longifolia Lam. fol. Iatolanceolatis acuminatis utriuque glabris medio minute serratis. Lam. ill. $t$. 69. f. 2. B. R. 861. Hook, exot. fl. 133. In Malace.. ち. liami 4-goni articulati. Fl. minuti.

15. C. purpurea Juss. fol. lanceolatis serratis punctatis sessilibus; racemis dichotomis baccis 3-spermis. Juss. Aun. Mus. VH. In Canton. ‡. 3-ped. Baccae violaceae.

16. C. triloba Lour. caule scandente; fol. 3-lobis; pedunculis dichotomis. Lour. Coch. In China et Cochinchina. ち. Fl. pallidi.

17. C. adenantlera $R$. Br. fol. ovatis basi apiceque acutls minutissime dentatis glandulis conspersis subtus cinereo-tomentosis. R. Br. pr. In Nova Hollandia.

\section{** Fol. integerrimis.}

18. C. arborea Roxb. fol. Ionge petiolatis oblongis ventricosis subtus pilosis; paniculis axillaribus subglobosis dichotomis. Roxb. ind. In Chittagong et Nepalia. ち. Arbor magua.
Fl. parvi numerosi laece purpurei. Baccae globosae nicidae purpureae.

19. C. integrifolia Jaci. Am. $t$. 173. $f$. \%. fol. ovatis acutis subtus subtomentosis; racemis densis; tubo corollae calyce 4-plo longiore. Willd. sp. In Carííagena. 古. Arbor 12-ped. Fl. odori albi. Baccae pisit. virides basi alhae.

20. C. villosa Tahl; fol. oblongoovatis subtus venoso-reticulatis villosis; racemis axillaribus pedunculis multifloris. Vahl symb. In India orienlali.

\section{Species dubiae.}

21. C. umbellatu Lour. fol. turbinato-ovatis glabris alternis; umbellis sessilibus. Lour. Coch. In sylvis Cochinclinae. ђ. Arbor ramis adscendentibus. Fl. albo-virides.

22. C. cordifolia $R$. et P. fol. cordatis ovatisque acutis integerrimis ; cymis brachiatis. Fl. peruv. t. 77. f. a. In nemoribus Peruviae. $\hbar$. Arbor 1518-ped. Fl. ochroleuci.

\section{AEGIPHILA Jacq. (1767).}

1. A. martinicensis $L$. fol. ovatolanceolatis acuminatis glabris; ramis diffusis; paniculis terminalibus axillaribusque; calycibus glabris. Sw. A. glabra. Lam. ill. t. 70. f. 1. Jacq. ohs. t. 27. Ejusd. pict. t. 16. In Martinica et Montserrat. ち. Frutex Orgyalis. Fl. albi.

Z. A. arborescens Willd. fol. ovatis acuminatis supra glahris; cymis capitatis dichotomis axillaribus; fructibus (luteis) globosis. Willd. sp. Vahl Eclog. t. 10. Manabea Aubl. t. 24. In sylvis Cajennae, Gujanae et ins. Trinidad. ち. Arb. 10-ped.

3. A. villusa Willd. fol. oblongis subtus ramulisque villoso-tomentosis; cymis capitatis bifidis. Willd. sp. Lam. ill. t. \%. f. 2. Manabea Aubl. Guj. t. 23. In Cajenna. ち. Frutex 8-ped. Hlor. virides.

4. A. laevis Uilld. fol. ovato-oblongis acuminatis venosis ramisque 4-gonis laevibus; paniculis patulis; calycis dentibus obsoletis. A. laeta H. et. K. A. Iutea Lam. ill. t. 70. f. 3. Nanabea Aubl. Guj. t. 25. In Cajennc. ち. Caul. 4-angulus. Fl. flavi. Bacca flavicans. 
5. A. elata $S w$. fol. ellipticis acuninatis; staminibus exsertis; pistillo abbreviato; calyc.4-lobis. Sw. Knoxia Brown jam. t. 3. f. 3. In Gujana et Jamaica. ‡. Scandens. Fl. flavi.

6. A. foetida $S w$. fol. ovato-lanceolatis subtus petiolisque hirsutis; pedunculis axillaribus solitariis. Sw. In Jamaica. $\hbar$. Frutex 2-ped. odore Hyoscyami. Baccae rubrae.

7. A. trifida $S u$. ind. fol. ovatolanceolatis glabris; pedunculis axillaribus trifidis confertis; calycibus 4-gonis 4-dentatis. In Jamaica. 24. Frutex parvus. Baccae magnae nigrae.

8. A. macrophylla $H$. et $K$. ramis glabris; fol. ovatis acutis basi rotundatis integerrimis subcoriaceis glaberrimis; corymbis 3-fido-dichotomis. $\mathbf{H}$. et K. A. Iaevigata Juss. In Cumana. 方. 3-orgyalis. Fl. albi.

9. A. Mutisii Bonpl. N. Gen. ramis foliisque subtus albidis lanatotomentosis supra hirtis acuminatis integerrimis; paniculis foliatis. Kuntl. A. salutaris H. et K. In Nova Granata. t. Arbor 50-ped. Fl. albi.

10. A. mollis Bonpl. ramis foliisque lirto-lanatis obovato-oblongis acuminatis basi angustatis, apice subdentatis; staminibus vix exsertis, H. et K. N. Gen. 1. t. 130. Ad Orinoccum. $\downarrow$. Frutex ramis fuscescentibus.

11. A. multiflora $R$. et P. fol. oblongis; flor. congestis axillaribus. Fl. peruv. t. 76. In Peruvia. ち. Frutex ligi10 durissimo, 15-18-ped. Fl. rubri.

12. A.? viburnifolia. Juss. fol. petiolatis subcoriaceis ovatis integris; corymbis axillaribus et terminalibus. Juss. Ann. Mus. V1I. In Philippinis. ђ. Fl. ignoti.

\section{PETITIA Jacq. (1763).}

1. P. domingensis Jacq. fol. ovato-ohlongis acuminatis subtus incanotomentosis. Jacq. am. t. 482. f. 6. pict. t. 259. f. 5. In Domingo. ђ. Arbor ramis 4-gonis. Fl. albi.

2. $P$. quinduensis $H$. et $K$. fol. ovato-lanceolatis acuminatis subtas glabris. H. et K. N. Gen. In Nova Granata. t. Arbor 2-orgyalis. Fl. albidi.
483. WALLENIA Sw. (1788).

1. W. laurifolia Su: fol. oblongoacuminatis glahris; panicula terminali. Poir. Sloane Hist. t. 145. f. 5. In Portorico et Jamaica. ち. Frutex 10 -20-ped. FI. exigui albi.

2. $\mathrm{W}$. anyularis Jacq. Schoenbr. t. 30. fol. obtusis; ramis ramulisque angulatis. In India orientali. Frutex 20-30-ped. Fl. flavo-virentes.

3. W. laxiflora Mart. Nov. Gen. t. 237. In Brasilia. ђ.

\section{POLYOZUS Lour. (1790).}

1. P. bipinnata Lour. fol. bipinnatis; racemis lateralibus. Lour. Coch. In sylvis Cochinchinae. $\hbar$. Arbor magna ramosissima. Fl. viridi-lutei.

2. P. lanceolatc Lour. fol. lanceolatis; racemis terminalibus. Lour. Coch. Circa Canton Sinarum. \$. Frutex 4-ped. Fl. rubercentes.

\section{CHILIANTHUS Burchell (1521).}

1. C. arboreus Burch. Scoparia Thunb. Callicarpa paniculata Lam. In Africa australi. $\hbar$. Arbor excelsa crassa. Fol. opposita lanceolata integerrima subtus tomentosa. Fl. minimi albi.

\section{BUCHIA Kunth (1815).}

1. B. plantaginea $\mathrm{H}$. et $\mathrm{K} . \mathrm{N}$. Gen. $t$. 132. Herba caule rubro. Fol. opposita oblonga. Fl. acutissime imbricati albi. Ad Orinoccum. 4.

\section{9\%. STEPHANOPHYSUM Pohl (1831).}

1. S. brevifolium Pohl. ic. t. 155. fol. oblonge acuminatis serratis glabris ; Iaciniis corollae subrotundis, apice denticulo instructis. Pohl. Circa Rio Janeiro. ち. 2-ped. Fl. rubri.

2. S. longifolium Pohl. ic. t. 156. fol. lanceolatis acuminatis serrulatis glabris; laciniis corollae subrotundis 
emarginatis. Poul. Ad Rio Janeiro. †. 3-ped. Fl. rubri.

\section{LABATIA Sw. (1788).}

1. L. sessiliflora $\boldsymbol{S} w$. floribus sessilibus; fol. tomentosis. Willd. sp. In Hispaniola. ち. Frutex orgyalis. Fl. uninute albidi.

2. L. pedunculata Willd. floribns breviter pedunculatis; fol. glabris. Willd. sp. Pouteria gujanensis Aubl. Guj. t. 33. Lam. ill. t. 72. In Gujana. t. Arbor 40-ped. Fl. subvirides.

\section{POUTERIA Aubl. (17\%5).}

1. P. macrocarpa Mart. N. Gen. t. 160 et 161. fol. oblongo-lanceolatis; floribus aggregatis; baccis maguis pulverulento - scabriusculis. In Brasibia. ち. Arbor vastissima 50 -ped. alta. Fl. albi.

\section{PHELLINE Labill. (1821).}

1. P. comosa Labill. Nov. Caled. $\boldsymbol{t}$. 3s. Frutex fol. fastigiatis spathulatis dentatis glabris ; floribus paniculatis; gemmis lanuginosis. In Nova Caledonia. ఫ.

\section{NUXIA Commers. (1789).}

1. N. verticillata Lam. ill. t. 11. fol. verticillatis teruis ovatis glabris; panicula terminali diffusa. Lam. Aegiphila Nuxia Willd. In ins. Franciae. ち. Arborescens.

\section{BUDDLEA L. (1733).}

\section{a. Spicis paniculatis. * Fol. integerrimis.}

1. B. madagascariensis Vahl; ramis sub-4-gonis; fol. ovato-lanceolatis rugulosis subtus ferrugineo-tomentosis; racemis terminalibus. Lam. ill. t. 69. f. 3. B. M. 2824. In Madagascar. 市.

2. B. saligna Willd. ramis sub-4gonis glabriusculis; fol. lanceolatis acutis levolutis subtus alhido-tomentosis; panicula terminali diffusa. B. salicifolia Jacq. Sclıoenbr. t. 29. In Prom. b. spei. $\hbar$. Fl. albi.

3. B. virgata $L$. fol. lineari-oblongis obtusis integris serice o-incanis; ramis filiformibus incanis. In Prom. b. spei. †. Orgyalis, hab. Hyssopi.

1. B. incompta $L$. ramis flexuosis teretibus; fol. fasciculatis ovatis incanis. In Prom. b. spei. ち. Frutex pedalis. Fl. albi.

5. B. abbreviata $H$. et $K$. ramulis abhreviatis tomentosis; fol. oblongolanceolatis utrinque acutis subtus ferrugineo-tomentosis. B. integrifolia. Willd. Mss. In Mexico. ち. Orgyalis. Fl. albi.

6. B. interrupta $H$. et $K$. ramis teretibus foliisque subtus ferrugineotomentosis oblongis acutis integerrimis; spicis verticillatis. H. et K. In Quito. ち. Capitula magnitudine pisi majoris.

7. B. discolor Roth; fol. lanceolatis basi attenuatis integerrimis subtus albo-tomentosis; spicis interruptis. Roth N. sp. In India occidentali. $ђ$. - 8. B. paniculata Wall. ind. fol. lanceolatis acuminatis integerrimis supra villosis subtus dense hirsutis; racemis brevibus hirsutis; flor. fasciculatis. In Nepalia. ち. Arbor parva. Fl. fragrantes albi.

9. B. occidentalis $\boldsymbol{L}$. ramis teretibus glabris; fol. lanceolatis acuminatis subintegerrimis subtus tomentosis; spicis interruptis. $R$. et $P$. peruv. $t$. 83. Lam. ill. t. 69. f. 1. Plukn. t. 210. f. 1. In Jamaica et Peru. t.

\section{* Foliis serratis dentatis crenatis.}

10. $\boldsymbol{B}$. americana $\boldsymbol{L}$. ramis sub4-gonis foliisque subtus tomentosis oblongis utrinque attenuatis serratis; flor. racemoso-spicatis. B. callicarpoides et C. floribunda Kuntli. In Caribaeis et Mexico. $\hbar$.

11. B. betonicaefolia Lam. ill. fol. ovato-oblongis crenulatis rugosissimis; spicis interruptis paniculatis. Lam. In Peruvia. ち. Caul. tuberculatus. Fl. pubescentes.

12. B. thyrsoidea Iham. ill. fol. lanceolato-linearibus serratis sessilibus; racemo spicato terminali. Lam. In Montevideo. $\hbar$. Frutex elegantissimus ramis flavicantibus. 
13. B. acuminata $H$. ei $\boldsymbol{K}$. ramis 4-gonis pubescentibus; fol. oblongis utrinque acuminatis, serratis subtus ferrugineo-tomentosis ; florihus glomeratis. H. et K. B. intermedia. Kunth. B. serrata Roth. In Mexico. 5 .

11. B. mollis $\boldsymbol{H}$. et $\boldsymbol{K}$. ramulis 4gonis incano-tomentosis; fol lanceolatis acutis undulato-crenulatis subtus fuscescenti-tomentosis; paniculis ramosissimis. In Quito. 24. Arbor 23-orgyalis. Fl. flavi.

15. B. longifolia $H$. et $K$. ramis 4-angulis glabriusculis; ramulis foliisque subtus ferrugineo-tomentosis oblongo-lanceolatis serrato-crenulatis. H. et K. Nov. Gell. t. 186. In Peruvia. 古. Arbor 3-orgyalis ramosissima. Fl. suaveolentes ferrugineo-tomentosi.

16. B. cordat $\boldsymbol{H}$. et $\boldsymbol{K}$. ramis 4angulis glabriusculis, ramulis foliisque subtus ferrugineo-tomeniosis ovatis acutis cordalis crenulatis. H. et K. Nov. Gell. t. 183. In Mexico. $\hbar$. Arbuscula elegantissima.

1\%. B. incana R. et P. peruv. $t$. 80. $f$. $\mathrm{B}$. fol. oblongo-lanceolatis crenulatis supra rugosis subtus tomentosis; floribus capitatis bracteatis; panicula trichotoma patente. In Peruvia. . Arbor 6-7-orgyalis. Fl. flavi.

18. B. verbascifolia $H$. et $\boldsymbol{K}$. ramis 4 -gonis ad nodos compressis foliisque subtus flavido-tomentosis supra glabris ovato-ellipticis duplicatoserratis; floribus glomeratis densis.

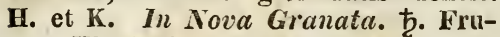
tex. Fl. flavi.

19. B. dentata $H$. et $K$. ramis teretibus; ranulis foliisque subtus ferrugineo-tomentosis valde angustatis ovatis argute serratis. Prope Caracas. †. Frutex 3-4-ped. Fl. ferrugineo-tomentosi.

20. B. Poireti Spr. fol. ovatoacuminatis laxe dentatis subtus pubescentibus ; racemis terminalibus brevissimis tomentosis. B. acuminata Poir. In India. ち. Rami 4-anguli.

21. $B$. salvifolia Lam. fol. cordatis lanceolatis crenatis rugosis subtus tomentosis; floribus paniculatis. Willd. sp. Jacq. Schoenbr. t. 28. In Prom.

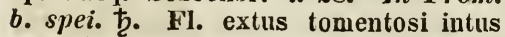
sanguinei.

22. B. parviflora $H$. et $\boldsymbol{K}$. ramis obsolete 4-gonis striatis; ramulis pubescentibus; fol. ovato-oblongis cre- nato-serratis subtus fuscescenti-tomentosis ; paniculis trichotomo-ramosissimis. H. et K. In Mexico. ち. Arbor. Fl. parvi albi.

23. B. micropliylla H. et K. ramis teretibus glabris; ramulis foliisque subtus ferrugineo-tomentosis ovato-oblongis versus apicem serrulatis. H. et R. In IMexico. ち. Frutex? Fl. albi.

2-4. B. salicifolin Vahl; fol. Ianceolatis extrorsum serratis, subtus iomentosis; pedicellis multifloris ; floribus nutantibus. Valıl symb. In Bononia. ち.

b. Spicis simpliciusculis.

25. B. salicina Lam. fol. oblongolanceolatis subdentatis petiolatis subtus alho-tomentosis; spicis gracilibus ter-

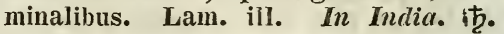
Frutex ramis elongatis, tomento albido.

26. B. spicata R. et P.peruv.t.81. f. a. fol. ovatis utrinque acutis serratis; spicis longissimis simplicihus. In Peruvia. ち. Frutex 10-12-ped. Fl. flavi.

2\%. B. asiatica Lour. fol. Ianceolaco-linearibus rugosis glabris subserratis; spicis elongatis continuis. In Cochinchina. ち. Frutex 3-ped. Fl. albi.

28. B. Neemila Buchan. fol. lanceolatis subserratis; petiolis alatis connatis; spicis subternis; bracteis lanceolatis. In India orientali. Truncus 15-ped. Fl. candidi fragrantes.

\section{c. Floribus verticillatis.}

29. B. brasiliensis Jacq. fol. oblongis irregulariter dentatis counatis basi auriculatis; floribus verticillatis. B. M. 2713. B. Neenida Hortal. B. perfoliata Humb. In Brasilia et Mexico.

30. R. sessiliflora $H$. et $\boldsymbol{K}$. ramis teretibus glabris; ramulis foliisque incano-tomentosis lanceolatis utrinque angustato-acumiuatis integerrimis subsessilibus. H. et K. Nov. Gen. t. 182. In Mexico. ち. Arbor procerrima, ramis albicantibus. Fl. flavi.

31. B. verticillata $H$. et $K$. ramis teretibus glabris; ramulis foliisque tomentosis supra incanis subtus fuscescentibus oblongis; floribus axillari- 
bus verticillatis. $\boldsymbol{H}$. et K. Nov. Gen. t. 184. B. sessiliflora Npr. In Mexico. ち. Cor. pallide flava.

32. B. scordioides II. et $\boldsymbol{K}$. ramis teretibus foliisque tomentosis sessilibus oblougis obtusis crenatis rugosis subtus ferrugineis; floribus axillaribus verticillatis. H. et $K$. Nov. Gen. t. 183. In Mexico. ち. Frutex facie Teucrii scordii. Cal. albido-tomentosus.

\section{d. Floribus capitatis.}

33. B. globosa Lam. ill. t. 69. $f$. 2. fol. lanceolatis acumiuatis crenulatis subtus albo-tomentosis; capitulis globosis pedunculatis. B. M. 174. Hoppe Act. Harlen. XX. t. 11. B. capitata Jacq. ic. t. 30\%. Feuill. peruv. t. 38. In Chili et Peruvia. ђ. 1520-ped. F1. mellei coloris.

34. B. connata $R$. et $P$. fol. lanceolatis connatis crenatis; stipulis reniformibus; pedunculis solitariis capitatis. Fl. peruv. t. 80. B. M. 2853. In Peruvia. Ђ. Caules diffusi ramosissimi. Fl. flavi.

35. $\boldsymbol{B}$. diffusa $\boldsymbol{R}$. et $\boldsymbol{P}$. peruv. $t$. SO. subscandens; fol. ovatis subcordatisque acutis; stipulis reniformibus reflexis. In Peruvia. ち. Caulis ramosissimus. Fl. flavi.

36. B. polycephala $\boldsymbol{H}$. et $\boldsymbol{K}$. caule herbaceo? volubili 4-gono foliisque subtus ferrugineo-tomentosis ovatolyratis acuminatis basi connatis; capitulis globosis. H. et K. In Peruvia. 4.

37. B. rugosa $H$. et $K$. ramis teretibus foliisque subtus ferrugineotomentosis rugosis lanceolatis acutis crenatis breviter petiolatis; capitulis paniculatis glohosis. H. et K. I. c. In Nova Granata. t. Frutex. Fl. densi ferrugineo-tomentosi.

e. Floribus corymbosis vel solitariis axillaribus.

38. B. indica Lam. fol. ovatis integris petiolatis subtus tomentoso-ferrugineis; corymbis axillaribus brevissinis. Lam. Enc. B. diversifolia Vahl. In Java. ち.

3.9. B. volubilis Lam. fol. linearibus acutis integerrimis; caule volubili; cymis axillaribus tomentoso-ferru- gineis. Lam. ill. In ins. Bourbon. ђ. Cor. tubus brevissimus.

40. 13. ternata Iour. fol. ternatis acuminatis; pedunculis 1-floris. Lour. Cochincl. p. 91. In Cochinchina. †. 2-ped. F1. albus.

\section{SCOPARIA I. (1712).}

1. F. aulcis $\boldsymbol{L}$. fol. ternis; floribus pedunculatis. Jacq. Gaertn. Fruct. $t$. 53. Plukn. t. 215. S. termata Forsk. f. 1. In Jamaica, Curassao et Aegypto. $\odot$. Caulis 6-angularis 3-ped. Fl. albi.

2. S. procumbens Jacq. fol. quaternis; floribus sessilibus. Jacr. An.

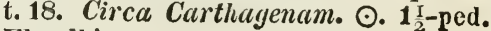
Fl. albi.

\section{CENTUNCUTUS Dill. (1\%19).}

1. C. minimus $\boldsymbol{L}$. fol. alternis ovatis ; floribus sessilibus. Nees Gen. pl. fasc. XII. E. B. 531. F1. Dall. 178. Curt. Lond. t. 11. Mich. Gen. t. 18. f. 3. Vaill. paris. t. 4. f. 2. C. simplex Fries. Wl. Dan. 1567. In arenosis Europae. $\odot$. Cor. fugax alba s. rubella.

2. C. lanceolatus Michx. fol. Ianceclatis decurrentibus; floribus pedicellatis. Michx. am. In Carolina. $\odot$. 4-poll. floribus albis.

\section{PLANTAGO Plin.}

\section{A. Acaules.}

a. Foliis integris. * Latiusculis.

1. P. major $L$. fol. petiolatis ovatis glabriusculis subdentatis; scapo tereti; spica cylindrica. Willd. Schk. t. 24. Fl. Dan. 461. Hayne Arz11. V. t. 13. P. minima DC. nana Tratt. t. 42. limosa Kit. bracteata Moench. In Europa. 4. Fol. 3-11-nervia. Scapi pedales.

2. P. crassa Wr. fol. ohovatis nitidis undulatis subcarnosis rigidis vix petiolatis; scapo inferme compresso; floribus basi remotis. Jacq. 'Coll. t. 16. P. bullata Don. In Italia. 4. Fol. atro-viridia. 
3. $P$. asiatica $L$. fol. ovatis glabris subdentatis; scapo angulato; spica fosculis distinctis L. Gmel. sib. 4. t. 37.? P. exaltata Horn. corclata Lam. glabra Nutt. kentuckensis Miclix. erosa Wall. In Sibiria, Clina et simerica boreali. 4.

4. P. Gouani Gmel. fol. ovatis nervosis integerrimis petiolatis asperis; petiolis basi lanatis; capsula 4sperma. P. Comuti Gowan. Ad littora maris mediterranei. 24.

5. P. Loureiri $\mathbb{R}$. et $\mathbf{S}$. fol. ovatis subacutis 5 -nerviis glabris; scapo tereti; spicis longissimis ; caps. 4-sperma. P. major Lour. In China ot Cochinchina. $\odot$. Folia semipedalia.

6. P. brutia Ten. fol. ovatis nervosis dentatis; scapo angulato; spica oblonga compacta. l'. uliginosa Baumg. In Calabria. 4.

7. $\boldsymbol{P}$. gentianoiles Sm. prodr. fol. ovato-oblongis subrepandis 3 -nerviis scapoque tereti glaberrimis; spica cylindrica gracili. In Asia minore. 21. Fol. Gentianae acaulis. Spica uncialis.

8. P. australis Lam. fol. ovatolanceolatis petiolatis obtusis integerrimis 5-nerviis; scapo gracili; bracteis villosis. Lam. ill. In Buenos Ayres. 24. Magna. P. Ianceolatae affinis.

9. P. tomentosa Lam. fol. ovatis tomentosis; scapo sulcato; spica cylindrica. Lam. ill. In Montevideo. 4. Fol. crassa villosissima pollicem lata; spicis longissimis.

10. P. maxima Jacq. ic. $t$. 26. fol. oblongis cucullatis villosis nervosis subdenticulatis; scapo tereti altissimo; spica cylindrica imbricata. Gmel. sib. IV. t. 35. In Nibiria et Canada. 4 .

11. P. media $L$. fol. ovatis hreviter petiolatis subintegerrimis utrinque pubescenti-villosis ; caps. 2-4-sperina. Wl. Dan. 581. Curt. Lond. t. 14. E. B. 1559. Hayne V. t. 14. In Europa et Caucaso. 24. Antherae albidae saporis Anygdalarum amararum.

12. D. decumbens Bernh. fol. lanceolatis utrinque attenuatis; scapo profuncle sulcato adscendente; spicis ovatis; sepalis carina harbatis. Rchb. excurs. p. 396. In Germania. 24. Наbitus P. Janceolatae.

13. P. truncata Chamiss. hirsutissimo-tomentosa; fol. lanceolatis basi attenuatis; spicis clavatis elongatis basi laxis; capsula 2-loculari, 2-sperma. Clıamiss, in Linnaea. In Chili. 4 .

14. P. lanceolata $I$. fol. lancenlatis utrinque acuminatis; spica brevi ovata cylindrica; scapo angulato; caps. disperma. Fl. Dan. 437. E. B. 507. Hayne V. t. 15. Sturm 7. $\beta$. humgarica W. K. t. 203. In graminosis Europae. 4.

15. P. macrocarpa Chamiss. in Limnea. fol. lanceolatis integerrimis erectis glabriusculis; scapo subangulato; spica cylindrica densiflora; caps. maxima. In ins. Alenticis.

16. P. camtschatica Lk. fol. oblongis denticulatis nervosis pilosis; scapo adscendente angulato hirto; hracteis ohtusis. Lk. en. p. 120. In Camtschatca. 4 .

1\%. P. virginica $I$. fol. lanceolato-ovatis pubescentihus subdenticulatis ; spicis cylindricis pubescentibus ; scapo angulato. Moris. III. s. 8. t. 15. f. 8. Peliv. t. 1. f. 10. In Virginia. $\odot$.

18. P. capensis Thunb. fol. oblongo-lanceolatis integerrimis; scapo striato-glabro; spica elongata; floribus distinctis. Thunb. cap. In Prom. b. spei. $\odot$.

19. P. altissima Jacq. olss. t. 83. fol. Ianceolatis 5-nerviis subdentatis glabris; spica ohlongo-cylindrica ; scapo angulato. Willd. In Pannonia, Gallia et Italia. 4. Scapus 3-pedalis.

20. P. Montana Lam. fol. lanceolạtis 5-nerviis suhglabris; spica ovata subglobosa nuda; scapo tereti bispido. DC. P. atrata Hoppe. P. Ianceolata $\beta$. atrata. Pers. P. sphaerocephala. Poir. In alpibus Europae medice. 24. Rad. nigricans.

21. P. victorialis Poir. fol. lineari-lanceolatis hirsutis; spica globosa 12-20 flora basi subhirsuta; bracteis flore brevioribus; scapo tereti pubescente pilis rufescentibus basi circumdato. Poir. Enc. Ger. Galloprov. t. 12. P. argentea Vill. nutans Lam. pilosa Kit. holosericea Gaud. In Europa anstrali. 4.

22. P. sericed W. Kit. $t$. 151. fol. lanceolatis utrinque attennatis subdenticulatis nervosis sericeis; scapo tereti substriato; spica ovata compacta; 
sepalis carinato-alatis. P. argentea DC. P. capitata Hoppe. In Hungaria. 4.

23. P. Layopus $I$. fol. lanceolatis utrinque attenuatis 3-nerviis subdenticulatis hirsutiusculis; scapo tereti subangulato; bracteis villosis. Sibtl. gr. t. 144. Weinn. t. 820 . f. a. Moris. III. sect. 8 . t. 16. f. 13. P. intermedia Lapeyr. P. arvensis Presl. In Europa austiali. 4.

24. $P$. caroliniana Walt. fol. Ianceolatis elongatis integerrimis glaberrimis; scapo tereti; spicis elongatis. Walt. Carol. p. 85. In Curolina. $\odot$. 25. P. sparsiflora Hichx. rariter proerula; fol. lanceolatis subintegris; spica longa gracili; floribus solitariis sparsis glahris. Michx. Fl. p. 94. P. interrupta. Poir. In Carolina et Georgia. $\odot$. Fl. albido-ruhelli.

26. P. minuta Pall. it. app. $t$. E. fol. lanceolatis obliquis hirsutis; spica ovata ylabra; bracteis ovatis; scapo hirsuto foliis breviore. Bieb. Circa Astrachan et in Iberia. $\odot$.

27. P. varia $\boldsymbol{R}$. Br. fol. lanceolatis elongatis $\mathbf{3}$-nerviis subdentatis pilosis; scapo filiformi; spica cylindrica ; floribus distinctis. In Nova Hollandia. $\odot$.

28. ciliata Desf. Atl. $t$. 39. f. 3.? fol. incanis anguste lanceolatis; scapo folia adaequante hirsuto; capitulis florum rotundis aphyllis; corollis ciliatis. Desf. In Numidia. $\odot$. Scap. 2-poll. Fl. pallide-rubelli.

29. P. attenuata Wall. fol. Ianceolatis subobliquis obtusiusculis nervosis subdentatis; petiolis basi lanatis; scapo 5-angulari hirsuto; calycibus ciliatis. Wall. In Nepalia.

30. P. barbata Forst. fol. spatlulato - lanceolatis dentatis; capitulis sub-4-floris. Forst. Com. Goett. IX. t. 4. Ad fretum Magellanicum.

31. P. rigidiuscula $H$. et $K$. caespitosa; fol. sessilibus ovato-lanceolatis obtusis coriaceis $\mathbf{1 - n e r v i i s}$ integerrimis nitidis ; floribus solitariis axillaribus. H. et K. Nov. Gen. t. 126. f. 2. In Quito. 4.

32. P. mexicana Lk. en. p. 121. fol. lanceolato-linearibus integerrimis sparse pilosis; scapo tereti basi piloso; bracteis lanceolatis carina pilosis. In Mexico. 4.

33. P. gnaphalodes Nutt. fol. lanceolato-linearibus integerrimis villoso- sericeis; scapo tereti; spica ovatastaminibus brevissimis. Ad Missou; ri. 4.

34. P. tumida $L k$. fol. linearilanceolatis subdenticulatis subsericeis; scapis adscendentibus adpresse pilosis; bracteis calycibusque sericeis; caps. tumidis. Lk. en. p. 121. In Chili. $\odot$. scap. ped.

35. P. gracilis Poir. fol. lanceolato-linearibus serrulatis nudiusculis 3-nerviis; spica cylindrica gracili. Poir. Enc. In Hispania. 4.

36. P. saxatilis Bieb. fol. linearilanceolatis integerrimis scapoque teretiusculo pubescentibus; spicis ovatis; bracteis latis scariosis apice flosculisque basi pilosis. Bieb. Cauc. p. 109. In Cancaso et Iberia. 4.

3\%. P. limensis Pers. fol. lanceolatis linearibus trinervibus; denticulis rarissimis; spica ovata cylindrica. $P$. hirsuta 12. et $P$. peruv. t. 78. In Lima.

38. P. Myosurus Lam. minuta; fol. lineari-lanceolatis trinerviis glabris ; scapo tereti subpiloso ; spica cylindrica. Lam. ill. In IIontevideo. Myosurum minimum refert.

39. P. carnosa Lam. fol. Ianceolato-linearibus concavis succulentis pubescentibus; scapo tereti hirsuto; spica oblonga compacta. Lam. ill. In Prom. b. spei. 4.

40. P. remota Lam. fol. linearilanceolatis nudis basi lanatis; spicia longis glabris; floribus remotis. Lam. ill. In Prom. b. spei. Scapi 15-20poll. alti.

41. P. scorzoneraefolia Lam. fol. lineari-lanceolatis falcatis nervosostriatis integerrimis basi pilosissimis; spica gracili. Lam. ill. In America.

42. P. hispida $\boldsymbol{R}$. Br. fol. linearilanceolatis dentatis scapoque incanohirsutis; spica oblonga. In Nova Hollandia.

43. P. Bellardi All. ped. $t$. 85. $f$. 3. Fl. graec. $t$. 116. fol. lineari-lanceolatis patenti-pilosis; scapo tereti divergenti-villoso; spica ovato-cylindrica. P. lanata Poir. pilosa Cav. ic. t. 249. In Europa australi. $\odot$.

41. P. eriostachya Ten. fol. Ianceolatis sub-3-7-nervilis denticulatis basi lanatis pilosisque; scapis adscendentibus sulcatis; spica ovata densissima testaceo-velutina. Rclib. excurs. p. 395. In Litorali. $\odot$. Ha- 
bitus P. Janceolatae. Spreng. ad P. Lagopum ducit.

\section{** Foliis linearibus.}

45. P. Weldenii Rchb. excurs. $p$. 496. tenella; fol. lineariluus obtusis glabris; scapo strigoso; spica pauciflora; hracteis rotundato - acuminatis ciliato-laceris. Ichb. P. parvula et numila Weld. In Dalmatia. ๑.

16. P. alpina L. fol. lanceolatolincaribus acuminatis 1-nerviis planis; scapo tereti puberulo; spica oblonga; iracteis ovatis acutis glabris. Sturm 51. P. ovina Vill. P. bidentata Murrith. In alpibus Europae. 24. 2-6-uncialis.

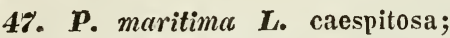
fol. semiteretibus ant lineari-lanceolatis subtus convexis basi lanatis; scapo tereti; bracteis carnosis. P. subulata Roth. P. Wulfenii spr. P. squamata Fl. Dall. 691. 243 et 1634. E. B. 175. In Europae maritimis et ad salsa loca. 4.

48. P. serpentina Lam. caespitosa; fol. linearibus ciliato-serrulatis hasi nudis; spica tereti elongata scapoque pubescente; hracteis ante anthesin comosis. P. Wulfeni W. et $\mathbf{K}$. P. aspera Gaud. In Europa austraii. 2 .

49. P. recurvata $L$. fol. recnrvatis linearibus canaliculatis hirsutis ciliatis; scapo tereti elongato villosotomentoso; bracteis appressis hirsutis. Spr. P. subulata Wulf. P. hirsuta Thumb. In Europa australi et Asia minore. 24.

50. $\boldsymbol{P}$. salsa Pull. fol. linearibus glabris integerrimis planiusculis sub)tus convexis elongatis laxis; scapo subhirsuto; florihus confertis. In Tauria. 24.

51. P. tenuiflora fit. fol. linearibus subintegerrmis obtusis carnosis; scapo tereti; spica erecta; floribus distantibus. IV. et Ir. t. 39. In Hunyaria, Tuuria et Asia minore. $\odot$.

52. '. teretifolia Sieb. fol. teretifiliformibus g!ahris; scapo tereti adpresse piloso; spica cylinuirica; bracleis ovatis acutis. Sieb. Ho. P. maritima Delile. In Aeaypto. $\odot$.

53. P. tenvis $L k$. fol. linearibus integerrimis ciliatis basi nudis; scapo tereti pubescente; spica ovali; bra- cteis longe acutatis pubescentibus. Fl. portug. 1. p. 426. In Insitania. $\odot$.

51. P. ovata Forsl. fol. linearibus utrinque hirsutis; scapo erecto hirsuto; spica ovato-oblonga ; corollae laciniis ovatis, Forsk. Aeg. p. 21. In Aegypto.

55. $P$. linearis $H$. et $K$. fol. sessilibus linearibus apice angustatis ohtusis striatis glabris; spicis oblongocylindraceis; corollis obtusis subrotundis. H. et K. Nov, Gen. 1I. p. 229. In Quito. 4.

56. P. radicata Lk. fol. linearisulucanaliculatis integerrimis pilosis ad hasin villosis; scapo tereti pubescente; spica cylindrica; bracteis ex ovali acutatis. Fl. portug. In Lusitania. 4.

5\%. P. scirpoides Lam. fol. linearibus longissinis trinervibus nudis; scapo tereti; spica ovata. Lam. ill. In Hispania. Habitus scirpi.

58. $\boldsymbol{P}$. notate Lag. fol. linearibus remote dentatis; dentibus hasi intus pilorum fasciculo stipatis; spicis ovatis lanatis. Lag. gen. In IIispania. $\odot$.

59. P. patayonica Jacy. fol. lanceolatis linearibus subcanaliculatis integerrimis lanato-pilosis; scapo tereti hirsuto; spicis cylindricis. Jacq. ic. t. 306. In Patagonia. $\odot$. Radix et folia albida. Antherae flavae.

60. P. sessiliflora Lapeyr. caespitosa; fol. suhcapillarihus planis ciliatis imbricatis; spicis globosis sessilibus. Lap. Abr. p. 72. In Pyrenceis montibus. Caespites densi albi.

61. P. pusilla Nutt. pube minuta; fol. linearihus integerrimis basi angustatis subcarnosis; scapo tereti filiformi; calyce rigido; stamiuibus inclusis. Nutt. Gell. p. 100. In collibus aridis salsis Missouri. $\odot$.

62. P. crelica $L$. fol. linearibus; scapo tereti hrevissimo lanato; spica subrotunda nutante. L. sibth. graec. t. 147. Moris. Ill. s. 8. t. 16 f. 25. In Creta et Cypro. $\odot$. Fol. pedalia villosa.

63. P. subulata $I$. fol. linearibus canaliculatis integerrimis inferne ciliis rigidiusculis hasi pilosis; scapo tereti pubescente. P. punctata Lapeyr. Moris. IlI. s. 8. t. 17. f. 29. In Europa australi. 4.

61. P. pauciflora I Iam. fol. linearibus flaccidis in petiolum attenuatis glabris subintegerrimis; spica ovata 
pauciflora; hracteis scariosis glabris. Lam. ill In freto Magellanico. 24.

65. P. multiceps il. et $K$. radice multicipite; fol. sessilibus linearihus ohtusis argenteo-sericeis; spicis ovatis cermuis; pedunculo compresso sericeo. H. et K. In Mexico. 4.

66. P. mubigena $\mathrm{H}$. et $\mathrm{K}$. caespitosa; fol. sessilibus anguste linearibus acutis niveo-sericeis; spicis subrotundis paucifloris; pedunculo sericeo. H. et K. Nov. Gen. t. 126. f. 1. In Quito. 24.

6\%.P. jorullensis $\boldsymbol{H}$. et $\boldsymbol{K}$. fol. petiolatis linearibus acuminatis hasi in petiolum angustatis striatis glabris; spicis oblongo-cylindraceis; pedunculo adpresso-piloso. H. et K. In Nova Hispania. 4.

6s. P. glomerata Poir. minuta; fol. linearibus angustissimis villosociliatis; scapo filiformi subpubescente. Poir. Enc. In Teneriffa. Vix 2-poll. spica 4-6-flora.

69. P. hispidula $\boldsymbol{R}$. et $\boldsymbol{P}$. acaulis; fol. linearibus integerrimis; scapis longissimis scabris; spica longa. Fl. peruv. t. 78. In Chili. Scapus filiformis.

F0. P. aristata Michx. Fl. fol. lineari-subsetaceis ; spica ohlonga; loracteis aristatis elongatis patcntibus. In America boreali. 4.

71. P. philippica Cav. fol. subulatis ovatis villosis; scapo nudo folia aequante; spicis ovatis. Cav. ic. 1.359. f. 2. In ins. Philippinis. 4. Folia $1 \frac{1}{2}-$ poll. angustissima. Cor. alba.

\section{b. Holis pinnatifidis.}

\%2. P. Serraria $\boldsymbol{L}$. fol. Ianceolatis 5-nerviis dentato-serratis; scapo tereti. L. Moris. 11I. s. 8. t. 16. f. 19. Barrel. ic. 749. In Apulia et Barbaria.

73. P. macrorrhiza Poir. fol. spathulatis inciso-dentatis; dentilus imbricatis mucronatis; scapo tereti piloso. Vahl. Bocc. sic. t. 15. f. 2. Moris. III. s. 8. t. 17. f. 36. Ad vias Tuneti. 24. Cor. rufesceus. P. Coronopodi affinis.

74. P. ceratophylla Lk. fol. lanceolatis dentato-pimmatifidis hirtis basi lanatis; scapo tereti pubescente; bracteis ex ovali longe acutatis sulsquarrosis. Fl. portug. t. 7t. P. coronopitolia. Brot. In Lusitania. 2. Had. crassa. Spica densa; bracteae virentes.

\%5. P. Coronopus $\boldsymbol{L}$. scapo tereti; fol. subcarnosis pinnatifidis Jipinnatifidisve. H(hb. a. integralis Gaud. Blakw. t. 490. Plukn. t. 203. f. 5. P. neglectit Guss. - $\beta$. cororopifolia. Roth. P. Cornuti. Jacq. ic. t. 27. P. Jacquini. 12. et s. P. Cupani Guss. Ad littoru marium europaeorum. $\odot$.

76. P. Loefflingii $\boldsymbol{L}$. fol. linearibus subdentatis; scapo tereti; spica ovata; bracteis carinatis membranaceis. Loeffl. it. Jacq. Vind. t. 126. I $\iota$ Hispania et Prom. b. spei. $\odot$. Differt a P. Coronopode statura minore.

\%\%. P. triantha Spr. fol. Ianceolatis inciso-dentatis glaberrinis; scapo subtrifloro. P. carmosa R. Br. In terra Ian Diemen.

8. P. brasiliensis Sims. B. M. 2616. subcaulescens ; fol. lineari-lanceolatis integerrimis ciliatis nervosis; spica cylindrica elongata glabra; stylis longissimis. Sims. In Brasilia (Sello).

\section{B. Caulescens.}

\%9. $\boldsymbol{P}$. amplexicaulis $\boldsymbol{C a v}$. caule erecto simplici brevi; fol. lanceolatis suhcarnosis integerrimis amplexicaulibus pilosis; capitulis oblongis aplyylis. Willd. Cav. ic. t. 125. P. lagopoides. Desf. atl. t. 39. f. 2. In Uispania et Barbaria. $\odot$.

80. P. vaginata Tent. caule simplici vaginato erecto fructicoso; fol. ovato-lanceolatis denticulatis 7-nerviis; spicis teretibus longissime pedunculatis hirsutis. Vent. Cels. t. 29. In Mauritania et Canariis. ち. Rad. nigrescens. Caul. 4-5-ped. Spicae villosissimae.

81. P. lanuta Willd. Hb. caule abbreviato; fol. lanceolatis utrinque attenuatis subintegerrimis lanatis; pedunc. pilosis axillaribus; spica ovatooblonga. P. villosa Moench. P. monspelieusis W. P. microcephala Poir. In India orientali et Persia.

82. P. velutinc Poir. caule snffruticoso ramoso adscendente vaginato ; fol. linearibus subinvolutis serice ovillosis; pedunculis axillaribus rectis pilosis; bracteis oblongis scariosis apice barbatis. P. argentea Tenor. P. albicans schousb. In Calabria et Marocco. 
83. P. cylindrica Forsk. tomentoso-lanuginosa; fol. lineari-lanceolatis; spicis cylindricis oblongis; bracteis concavis flore brevioribus. Poir. Enc. suppl. Circa Cahiram. Folia 6-7poll. longa.

8. P. arborescens Poir. fol. filiformibus contertis glaherrimis pedunculo longioribus; capitulis paucifloris aphyllis; caule arborescente. Poir. In ins. Canariis. ち. Rami lignosi cortice griseo.

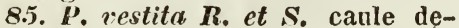
cumbente suffuticoso; fol. lineari-subulatis incurvis sericeis; spica ovata. i. sericea, R. et P. peruv. t. 79. f. 6. In collibus aridis'Tormae. Caul. sublignosus dichotomus.

86. $\boldsymbol{P}$. congesta $\boldsymbol{R}$, et $\boldsymbol{P}$. caule fufruticoso patente; fol. lineari-subulatis; spica ovato-oblonga. Fl. peruv. 1. p. 51. In Peruvia. Caulis simplicissimus fol, numerosis integerrimis vestitus.

8\%. P. Cynops $L$. caule suffruticoso ranıso; fol. linearibus subcanaliculato - triquetris integerrimis hirtis; capitulis involucratis. Hayne v. t. 18. P. surfuticosa. Lam. P. generensis DC. Moris. 8. 8. f. 17. f. 1. In Europra et Sibiria. ,

88, $P$. afic $L$. caule ramoso fruticoso; fol. lanceolatis dentatis; capitulis aphyllis. Moris. 8. 8. t. 17. f. 4. Bocc. sic. t. 7. f. a. b. In Sicilia et Barbaria. $\hbar$. Caul. pedalis.

89. $\boldsymbol{P}$. princeps Chamiss. fruticosa; elata ; ramosa; fol. amplexicaulibus lincari-lanceolatis glaberrimis; spica sparsiflora laxa; caps. 1-loculari 1-sperma. Chamiss. In ins. Sanduichianis. T.

90. P. coriacea Schlecht, suffruticelsu; fol. lineari-lanceolatis coriaceis integerrimis; spicis crassis cylindricis; antheris magnis longe exsertis; caps. 2-sperma. sichlechtend. Linnaea. Ad Rio Grande (Sello).

21. P. Psyllium L. annua; viscide pubescens; fol. lineari-lanceolatis planis subdentatis; capitulis nudis; fuliolis calycinis subaequalibus. Blakw. t. 412. Hayne 5. t. 1\%. Sibtl. graec. t. 149. P. nitida. $\mathrm{H}$, et $\mathrm{S}$. In Europa.'๐.

92. $\boldsymbol{P}$. indica $\boldsymbol{L}$. caule ramoso herhaceo; fol. integerrimis linearilous reflexis; capitulis foliosis. L. P. arenaria W. K. to 51. P. sicula Presl.
P. divaricata Zuccagn. In Germ. Hung., Transsylvanici, Tauria, Sibiria, India orientali. $\odot$.

93. P. stricta Schousb. caule ramoso herbaceo erecto; fol. linearibus canaliculatis integerrimis ; capitulis aphyllis. Schousb. Marocc. p. 55. Moris. s. 8. t. 17. f. 2. Circa Magador, in Hispania et Aegypto. $\odot$. Difr. a P. Psyllio fol. angustioribus.

91. P. Ispaghula Roxb. annua; caulescens ; fol. lineari-lanceolatis utrinque attenuatis 3 -nerviis sublanatis; pedunc. Iongitudine foliorum ; capitulis cylindricis; caps. bilocularibus. 1Roxb. ind. 1. p. 421. In India orientali culta. $\odot$. Caulis vix ullus s. brevissimus. Fl. sordide albi.

95. $\boldsymbol{P}$. pumila $\boldsymbol{L}$. caule ramoso lierbaceo glabriusculo; fol. filiformicanaliculatis ; bracteis lanceolatis elongato-acuminatis patulis; cor. tubo elongato. P. exigua Murr. Comm. Goett. 1778. t. 5. P. stricta Sieb. In Graecia, Aegypto et India orientali. $\odot$.

96. P. parviflora Desf. fol. oppositis linearibus ciliatis; pedunculis folio brevioribus; spicis rotundis; bracteis adpressis calycem aequantibus. Desf. atl. 1. p. 101. In Barbaria. $\odot$. Caules 2-poll. numerosi. Flor. minimi pallide rufescentes.

97. P. robusta Roxb. fruticosa; subramosa; fol. terminalibus linearibus integerrimis caducis; spicis axillaribus cyliudricis longe pedunculatis. Antomnarchi dern. mom. de Napoleon II. p. 315. In mont. elevatis ins. Helenae. 方.

\section{SANGUISORBA Fuchs. (1512).}

1. S. officinalis $\boldsymbol{L}$. spicis ovatoturbinatis; staminibus corolla brevioribus; foliolis cordato-ovatis serratis. Fl. Dall. 97. Schk, t. 27. E. B. 1312. Hayne vil. t. 22. Sv. B. 305. In pratis Europae. 4. 3-6-ped. Cal. atropurpureus,

2. S. auriculata Scop. spicis ovato-subcylindricis; staminibus corolla brevioribus; fol. interrupte pinnatis; foliolis majoribus cordato-minoribus truncato-ovatis argute serratis. Boccolle Mus. t. 9. S. praecox Bess, In Europa australi. 4. 
3. S. media L. spicis cylindricis; staminilus corolla longioribus; calycibus ciliatis. Willd. Moris. s. 8. t. 18. f. 2. In Canada. 4. Caul. 2-ped. spica pollicaris rulira.

t. s. canadensis L. spicis cylindricis longissimis; staminihus corolla multoties longioribus. Willd. Moris. s. 8. t. 18. f. 12. Barrel. ic. 739. In Canada et Sibiria. 4. 2-3-ped. Cal. albo-virentes.

5. s. temifolia Fisch. spicis cylindricis; staminibus corollam superantibus; fol. pinnatis subtus glaucescentibus; foliolis ovato-lanceolatis elongatis dentato-serratis. Fiscl. in litt. Patria ignota. 24.

\section{LEUCONOTIS Jack. (1523).}

1. L. anceps Jack. in Linn. Trans. XII. p. 121. In Sumatra. Frutex magnus, ramis 4-gonis. Folia opposita oblonga acuminata lucida. Flores corymbosi flavi.

\section{LASIOSTOMA Schreb. (1789).}

1. L. cirrhosum Willd. fol. oppositis obovatis 3 -nervibus; ramis cirhiferis. Spr. N. Entd. 1. p. 282. Houllamon gujanensis Aubl. guj. t. 36. Lam. ill. t. 81. var. $\beta$. cirrhis nullis. In Gujana. ち. Frutex 7-8-ped. ramis longissimis. Fl. albi.

2. L. cornifolium Spr. $\boldsymbol{N}$. Entr. ramis ecirrhatis; fol. alternis ovatis acuminatis nitidis subtus incanis venosis; cymis axillaribus. Spr. In Brasilic. Planta dubia.

3. L. divaricatum Meyer; ramis divaricatis; fol. obovato-oblongis basi attenuatis triplinervibus; floribus racemoso-corymhosis pedicellatis. Meyer Essequeb. 1. 83. In Essequebo. Ђ.

4. I. tuberosum Spr. ramis ecirrhatis carnosis; fol. oppositis oblongis acutis; caps. baccatis 4-spermis; radice tuberosa. Spr. Myrmecodia Jack. In Sumatra et Amboina. $\hbar$.

5. L.? stans Willd. IIss. caule fruticoso erecto; floribus paniculatocorymbosis fauce villosis. Schult. mant. 3. p. 64. In Brasilia. ち. Fl. minuti.

\section{EXACUM L. (1717).}

\section{a. Pistillo declinato. Stigma- te simplici.}

1. E. filiforme Willd. corollarum limbo patente; caule filiformi subranoso; fol. radicalibus subrotundis, caulinis subulatis. E. B. t. 235. Fl. Dan. 324. Vaill. paris. t. 6. f. 3. Gentiana L. In pahudosis Europae. $\odot$. Caulis tenellus dichotomus. Fl. aurei.

2. E. musillum DC. caule ramosissimo dichotomo; fol. oblongis 3nerviis; laciniis calycinis subulatis subpatulis; cor. limbo comnivente. DC. Fl. Fr. Chironia inaperta IVilld. Hayne 1. t. 30. Gentiana pusilla Lam. Hippocentaurea Vaill. par. t. 6. f. 2. In inundatis Europae. $\odot$.

3. E. quadrangulare Willd. calycibus truncatis 4-dentatis 4-angularibus longitudine tubi ventricosi recti. Willd. sp. Gentiana Lam. In siccis Limae. $\odot$.

4. E. pedunculatum L. foribus terminalibus; calycis foliolis ovatis; fol. lanceolatis 3-nerviis impunctatis. Vahl. Plukn. t, 343. f. 3. In Zeylonia. $\odot$. Caul. palmaris. Fl. violacei.

5. E. sessile $\boldsymbol{L}$. floribus lateralibus terminalibusque; caps. nutantibus; fol. cordatis. Vahl symb. In Zeylonia. $\odot$ Fl. albidi.

6. E. bicolor Roxb. erectum; 4gonum; fol. sessilibus ovatis j-nerviis; floribus axillaribus; apicibus laciniarum corollae albae caeruleis; antheris erectis. Roxb. Fl. ind. 1. p. 413. In India orientali. $\odot$. Caul. 1-2-ped. Fl. magni.

\%. E. tetragonum Roxb. erectum 4-gonum; fol. sessilibus lanceolatis 5-nerviis; floribus numerosis terminalibus; staminibus styloque declinatis. Roxb. 1. c. In pratis Bengaliae. $\odot$. 2-4-ped. Fl. magni elegantissime caerulei.

8. E. tenuifolium Aubl. calycibus 4-partitis; laciuiis lanceolato - subulatis; panicula dichotoma. Willd. Aubl. Guj. t. 26. f. 2. E. violaceum. Lam. In humidis Cayennae et Gujanae. $\odot$. 6-7-poil. Fl. violacei.

9. E. teres Wall. caule tereti; fol. lineari-lanceolatis acuminatis bası attenuatis subsessilibus 3-nerviis; pedunculis oppositis 3-floris; laciniis 
cor. lanceolatis. Wall. in Roxb. FI. ind. In Silhet. 2-ped. Fl. magnus intense caerulcus.

10. E. erectum Roth; caule 4-gono erecto ramoso inferne scabro; fol. ovatis obtusis 3-nerviis; dentibus calycinis tubum corollae aequantibus. Hoth N. Spec. Orthostemon erectus $\mathbf{R}$. Br. In India orientali et Nova Hollandia.

11. E. punctatum $\boldsymbol{L}$. fol. ohlongis subsessilibus 3 -nerviis glaudulosopunctatis; staminibus exsertis. In India orientali.

12. E. verticillatum Willd. caule superne 4-gono villoso; floribus verticillatis; calycibus reflexis. Plum. ic. 81. f. 2. Gentiana L. In America. Caul. simplicissimus pedalis.

13. E. hyssopifolium Villd. caule superne 4-rono ranoso; fol. linearibus 3-nerviis; floribus verticillatoglomeratis; calycis laciniis erectis capsula brevioribus. Gentiana verticillaris. Ietz. Burm. afr. t. 7\%. f. 3. In Malabaria. Caulis palmaris et pedalis. Fl. fulvi.

11. E. quitense Spr. caule ramosissimo 4-gono; ramis dichotomis; fol. inferioribus oblongis, sup. lanceolatis; noribus longe pedunculatis; laciniis calycis tubum aequantibus. Erythraea H. et K. Nov. Gen. III. p. 178. In Quito. ๑. Fl. rosei. Exaco pusillo proximum.

15. E. erubescens Spi. caule simplici tereti; fol. Ianceolatis aculis 3nerviis amplexicaulibus; laciniis corollac paniculatis. Dejanira schlechtend. In Brasilia.

16. E. verfoliatum Mart. Nov. Gen. $t$. 183. caule simplici teretiusculo; fol. late ovatis acutis obscure 3-nerviis amplexicaulihus; floribus paniculatis; laciniis corollae rotumdatis. Dejanira pallescens Schlecht. Exacum spr. In lirasilia.

1\%. E. amplexifolium Mart. I. c. t. 18t. fol. sessilibus ohlongis acuminatis $\mathbf{5}$-nerviis pellucido-marginatis; floribus dense congestis; laciniis corollae rotundatis. Dejanira nervosa Schlecht. Exacum tetragonum Roxb. E. nervosum Spr. In Brasilia. 24.

\section{CODTOUBEA Aubl. (1775).}

1. C. racemosa Meyer; fruticosa; fol. lanceolatis utrinque acuminatis; racemis strictis elongatis. Meyer Ess. In Essequebo. †. 2-ped. Fl. albi.

2. C. spicata Aubl. Guj. t. 27. lerbacea; ramis teretibus; fol. oblongis acutis; calycibus acuminato-cuspidatis. Exacum Vahl. C. alba Lam. ill. t. 79. In Gujana, Brasilia et Nova Granata. $\odot$. Digitalis. Fl. albi.

3. C. minor $\boldsymbol{H}$. et $\boldsymbol{K}$. herhacea; ramis 4-angularibus; fol. oblongis acutis; spicis terminalibus $\mathbf{H}$. et $\mathbf{K}$. Ad Orinocum.

4. C. ramosa Aubl. Guj. t. 2 . floribus subspicatis pedicellatis oppositis; fol. lanceolatis; caule ramoso; calycis laciniis acuminatis. Valıl. C. purpurea Lam. t. 89. In Gujana.

\section{PLADERA Roxb. (1821).}

1. P. pusilla Roxb. caule 4-gono; fol. cordatis sessilibus; floribus 1-andris; calyce corollam occultante. Hoppea dichotoma Vahı. In Coromandelia. 2-poll. Fl. Iutei.

2. P. viryata Boxb. caule ramoso 4-gono; fol. sessilibus lanceolatis 3nerviis; florihus terminalihus subpaniculatis. Roxb. ind. 1. p. 401. Exacum diffusum L. Gentiana diffusa Vahl. Eanscora R. Br. In Indice orientali. $\odot$. 2-ped. Fl. pallide rosei.

3. P. perfoliata Roxb. caulc erecto 4-alato; fol. caulinis lanceolatis 3nerviis; noralibus perfoliatis. Canscora Lam. Casjan-Cora liheede X. t. „2. In India orientali. $\odot$. Fl. pallide rosei.

4. P. decussuta Roxb. caule erecto 4-alato; ramis decussatis; fol. ovatolanceolatis 3-nerviis; pedunculis terminalibus sub-3-floris. Roxb. E. alatum Hotl. In Bengalia. $\odot$. Fl. albi.

5. P. sessilifiora Roxb. caule erecto 4-alato; fol. sessilibus oppositis ovatis integris; floribus sessilibus. Exacum heteroclitum Willd. Gentiana L. In Coromandelia et Bengalia. ○. Spithamea. Fl. pallide rosei. 
512. MITRASACME Labill. (1801).

1. Cal. 4-fidus. Stamina inclnsa. Stylus ad anthesiubasi bifida. Stigma bilobum.

a. Pedunculi umbellati.

1. M. polymorpha $\boldsymbol{R}$. Br. caule erecto hirsuto; fol. lato-linearibus subciliatis subtus pilosiusculis; calycibus apice imberbibus. In Nov. Holl.

2. M. squarrosi R. Br. caule multiplici piloso; fol. lato-linearibus confertis; apicibus recurvis basi ciliatis margine cartilagineis. In Nor. Holl.

3. $\boldsymbol{M}$. cinerascens $\boldsymbol{R}$. $\boldsymbol{B r}$. ramis adscendentibus pilosis; internodio ultimo longiore glabriusculo; fol. lineari-lanceolatis mucronulo setaceo ciliatis glabris. In Nov. Holl.

4. M. canescens $\boldsymbol{R}$. Br. radice perenni; ramis adscendentibus; internodiis omnibus pilosis; fol. linearibus obtusis hirsutis; calycibus apice barbatis. In Nov. Hollandia.

5. M. prolifera $\boldsymbol{R}$. Br. caule ramoso humili; fol. lineari-lanceolatis glabris; corollae fance barbata; caps. globosa. In Nova Holl.

6. M. paludosa B. Br. ramis adscendentibus; fol. lanceolato-linearibus glabris; corollis subrotatis; antheris apice exsertis. In Nova Holl.

\%. IM. ramosa $\boldsymbol{R}$. Br. caule basi simplici superne ramoso; fol. linearibus pilosis ; pedicellis pilosis ; corollae tubo calycem pilosum aequante. In Nova Holl.

8. Mr. pygmaea $\boldsymbol{R}$. Br. fol. radicalibus ovali-oblongis; calyce setace 0 mucronato ; capsulis ovatis apice exsertis; scapis radicalibus capillaribus. In Nov. Holl.

9. M. elata R. Br. scapis radicalibus elongatis; fol. rad. stellatis oblongis; corolla hypocrateriformi; tubo calycem ter superante. In Nov. Holl.

10. M. stellata $\boldsymbol{R}$. $\boldsymbol{B r}$. caule pubescente; fol. lanceolato-linearibus acutis glabris 1-nervibus, sumnis approximatis stellatis. In Nor. Holl.

11. $M$. connata $R$. Br. caule piloso repente; fol. ovatis petiolatis ciliatis; pedunculis axillaribus solitariis; calycibus hispidis. In Nov. Holl.

12. M. capillaris Wall. fol. lanccolatis 3 -nerviis pilosis basi meщ- brana ciliata junctis; pedunculis capillaribus bracteatis. In Nepalia.

\section{b. Pedunculi uniflori.}

13. M. phascoides $\boldsymbol{R} . \boldsymbol{B r}$. acaulis; floribus $3-4$, sessilibus; fol. linearilanceolatis pilosis. In Nov. Holl.

11. M. pilosa Labill. Nov. Iroll. $t$. 49. caule repente piloso; fol. ovatis petiolatis ciliatis; calycibus hispidis. Poir Enc. suppl. t. 913. f. 1. In Nov. Holl.

15. M. serpyllifolic $\boldsymbol{R} . \boldsymbol{B r}$. caule repente; ramis diffusis adscendentibusve; fol. ovatis petiolatis ciliatis ; calycibus glabris; stigmate subindiviso. In Nov. Holl.

16. M. alsinoides $\boldsymbol{R}$. Br. pedunculis solitariis lateralibus; fol. ovatolanceolatis glabris; caule dichotomo erecto. In Nov. Holl.

1\%. M. laricifolia $R$. Br. caule simplici; pedunculis pubescentibus; fol. subulato-linearibus setaceo-mucronatis glabris; marginibus recurvis basi ciliatis. In Nov. Holl.

18. M. multicaulis $\boldsymbol{R}$. Br. caule multiplici, partialibus indivisis erectis hirsutis; fol. linearibus pilosis ; corollae tubo calycem totum pilosum subaequante; capsulis ovatis. In Nova Holl.

\section{Calyx bifidus.}

19. M. paradoxa R. Br. caule erecto; fol. lineari-lanceolatis ; umbella terminali; caps. inclusa. In Nov. Holl.

3. Calyx plicatus, lobis concavis. stamiua exserta.

20. M. ambigua R. Br. scapis capillaribus umbellatis; fol. oblongolanceolatis. Ii. Br. In Nov. Holl.

\section{SEBAEA R. Br. (1810).}

1. S. cordata R. Br. caule dichotomo; fol. cordatis; calycis foliolis cordatis striatis membranace 0 -carinatis. Exacum L. Burm. afr. t. 74. f.5. Seb. Mus. t. 22. f. \%. Plukn. t. 275. f. 4. In Prom. b. spei. $\odot$.

2. S. aurea R. Br. fól. sessilibus; calycis laciniis apice recurvis mem- 
branace0-alatis; staminibus exsertis Exacum L. Lam. ill. t. 80. Plukn. t. 275, f. 3. In Prom. b. spei. $\odot$. Facies Chironiae Centaurii. FI. Intei.

3. S. sulplurea Schlechtend. caule sub-4-gono ramoso; fol. sessilibus late ovatis acutis; calyce anguste angulato. In Prom. b. spei. $\odot$.

4. S. albens $R$. Br. caule 4-gono dichotomo; fol. subdecurrentibus cordatis; calycis laciniis erectis. Exacum L. Burm. afr. t. 74. f. 4. In Prom. b. spei. $\odot$. Palmaris. Fl. albi.

5. S. ovata $R$. $B r$. caule ramoso dichotomo; fol. ovatis sessilibus nervosis; pedunculis 1-floris elongatis; calycis laciniis acuminatis. Exacum Labill. Nov. Holl. t. 52. In Nov. Holl. 7-8-pollicaris.

6. S. gujanensis Spr. caule 4-gono subramoso; fol. lanceolatis acuminatis; pedunculis axillaribus 1-floris; laciniis calycinis ovatis acuminatis. Exacum Aubl. Guj. t. 26. f. 1. E. purpureum Lam. In Cayenna. ๑. 8poll. Fl. purpurascentes.

\%. S. jorullensis Spr. caule simplici subtrifloro; fol. lanceolato-linearibus acutiusculis; flore intermedio subsessili; laciniis calycinis subulatis. Erythraea jorullensis Bonpl. Schultesia stenophylla Mart. t. 182. In Brasilia. $\odot$.

8. S. cymosa Jorosz; floribus terminalibus 4-fidis; calycibus glabris venoso-nervosis; caule simplici angulato; fol. orbiculatis integerrimis. Jorosz diss. p. 10. $\beta$. S. minima ibid. In Prom. b. spei. $\odot$. 4-poll. FI. lutei.

9. S. carinata Spr. caule 4-gono; fol. oppositis lanceolatis integerrinis 3-nerviis. Exacum Roxb. In Zeylonia. ○. 6-12-poll. Fl. Iutei.

10. S. sulcata Spr. caule ramoso sulcato; fol. subsessilibus lanceolatis carnosis; caps. globularibus. Exacum Roxb. In Bengalia. $\odot$. 6-12poll. Fl. caerulei.

11. S. crassulaefolia Schlechtend. caule 4-gono ramoso; fol. amplexicaulibus cordato-subrotundis acutis subcoriaceis nervosis; calycibus argute carinatis. Schi. Limaea. In Africa australi. $\odot$.

12. S, capitata Schl. caulo simplici folioso; fol. confertis ovatis 3nerviis; panicula coarctata terminali; floribus 4-fidis. Schl. Liunaea. In Prom. b. spei.

13. S. brasiliensis spr. caule ramoso 4-gono; fol. sessilihus lanceolatis; pedunculis terminalibus subsolitariis; lohis corollae crenulatis. schultesia crenuliflora Mart. N. G. t. 180. In Brasilia.

11, S. gracilis Spr. caule gracili basi ramoso paucifolio; fol. sessilihus lanceolatis nervosis; ramis $\mathbf{1}$-floris; corollae lohis ovatis. Schultesia Mart. t. 181. In Brasilia.

\section{HOUSTONIA L. (1737).}

1. $\boldsymbol{H}$. caerulea $L$. fol. radicalibus ovato - spathulatis, caulinis linearilanceolatis; pedunc.1-floris; laciniis cor. acutis; caule composito. Lam. ill. t. 79. f. 1. Tratt. Gartenpfl. t. 42. B. M. 370. Lodd. B. C. 950. In Virginia et Carolina. 24. Palmaris. Fl. caerulei.

2. H. patens Ell. caule difuso; ramis divaricatis scabris; fol. spathulatho-lanceolatis ciliatis; laciniis corollae obtusis. H. pusilla Gmel. Syst. In America boreali.

3. H. minima Beck. caule erecto simplici scabriusculo; fol. spathulatis ciliatis; pedunculis terminalibus 1-floris; laciniis calycis late ovatis acutis erectis. Ad fl. Missouri.

4. H. longifolia Willd. fol. lanceolatis utrinque attenuatis; floribus corymbosis fasciculatis. Lam. ill. t. 79. f. 2. Gaertı. t. 49. f. 8.? B. M. 3099. In America boreali. 4 . Digitalis. F1. albi.

5. H. tenuifolic Nutt. caule erecto dichotomo glabro; fol, linearibus; pedunculis corymbosis setaceis. In Amer. bor.

6. H. purpurea $\boldsymbol{L}$. caule erecto ramoso pubescente; fol. ovato-lanceolatis; corymbis terminalibus. Lodd. B. C. 1621. Hedyotis umbellata Walt. Knoxia purpurea Lam. H. varians Michx. H. pubescens Rafï. In Amer. bor.

\%. H. rotundifolia Mich.r. caule repente; fol. suborbiculatis, hasi abrupte angustatis breve petiolatis crassiusculis; ped, axillaribus 1-floris. Michx. Fl. am. Anonymos procumbens Walt. In Amer. bor. 4. Sempervirens. Fl. albi.

8. H. serphyllifoliı Michx. caule procumbente ramosissimo; ramis fili- 
formilus subrepentibusve; fol. spathulatis obtusis ; pedunc. elongatis 1-floris. B. M. 2822. In Amer. bor. 4. Fl. caerulei.

9. H. tenella Pursh; caule repente filiformi; fol. orbiculatis acutis nervosis; pedunculis terminalibus $\mathbf{1}$-floris longissimis. Pursh Fl. 1. p. 106. In Amer. bor. 4. Fl. purpurei.

\section{POLYPREMUMI L. (1711).}

1. P. procumbens $L$. Lam. ill. $t$. \%1. f. 11. P. Linnaei Michx. Petiv. phyt. t. 5. f. 6. In Carolina. $\odot$. Caulis sulcatus scaber dichotomus. Folia opposita linearia serrulata basi membrana nexa. Flores terminales brevissime pedicellati candidi.

\section{ANDREWSIA Spr. (1817).}

1. A. verna Spr. caule simplici; pedumculis sparsis subcorymboso-elongatis; laciniis corollae oblongis acutis calyce duplo longioribus; stylo germine longiore. Centaurella Michx. Fl. amer. to 12. f. 2. Centaurium Pers. C. aestivalis Pursh. In Amer. bor. $\odot$.

2. A. autumnalis Spr. caule subramoso; fol. paucis subulatis; pedunculis racemosis; calyce sub-4-sepalo corolla breviori; stylo brevissimo. Centaurella paniculata Michx. Fl. amer. t. 12. f. 1. Bartonia tenella Muehlenl,. Sagina virginica Willd. Centaurium Pers. In Amer. bor. $\odot$. Pedalis. Fl. parvuli albidi.

\section{1\%. FRASSERA Walt. (1788).}

1. F. Walteri Michx. F. carolineusis Walt. In paludosis Curolinae. $\odot$. 3-6-ped. Fl. viridi-purpurascentes.

\section{SALVADORA Garcin. (1749).}

1. S. persica $L$. fol. oblongis integris crassis. Vahl syml. t. 4. Lam. ill. t. 81. Hoxb. Corom. t. 26. Cissus arborea Forsk. In Arabia et Persia. †. Fl. sessiles virides.

2. S. capitulata Lour. fol. ovatis acuminatis; capitulis axillaribus. Lour.
Cochin. 1. p. 112. In sepibus et sylvis Cochinchinae. $\hbar$. Arbor mediocris ramosissima. Bacca lutea.

3. S. biflora Lour. fol. lanceolatoovatis; floribus geninis. Lour. 1. c. In Cochinchina. ち. Arbor 10-pedalis. Bacca lutea.

4. S. surinamensis Spr. fol. alternis oblongis utrinque attenuatis petiolatis integerrimis subtus discoloribus; paniculae ramis patentibus; calycilous patulis. Wallenia myriantha Kchb.? In Surinamo.

\section{BLAIRIA L. (1737).}

a. Antheris muticisexsertis.

1. $\boldsymbol{B}$. ericoides $\boldsymbol{L}$. fol, oblongoacerosis pilosis imbricatis; calycibus 4-phyllis; bracteis ternis longitudine calycis. Wendl. Coll. t. 25. Petiv. Gaz. t. 2. f. 10. In Prom. b. spei. ђ. Statura Ericae vulgaris. Fl. albopurpurei.

2. B. muscosa L. fol. teretibus obtusis asperiusculis; calycibus 1-phyllis pilosis; corollis campanulatis superue pilosis; stigmatibus peltatis. Erica albeus Thunb. In Prom. b. spei. $\hbar$.

3. B. fasciculata Willd. fol. lanceolatis ciliato-scabris; capitulis erectis; calycibus hirtis angulatis. Erica Thunb. B. hirsuta Lichtenst. In Prom. b. spei. Ђ.

4. B. paucifolia Wendl. Coll. $t .43$. fol. ternis ovalibus petiolatis; calyce 1-phyllo campanulato 4-dentato hirsuto ; corolla clavata. In Prom. b. spei. t. Fl. incaruati.

5. B. articulata $L$, fol. ovatis glabris; florum capitulis cernuis. Willd. sp. Wendl. Coll. t. 44. Lam. ill. t. 78. E. articulata Thunb. In Prom. $b$. spei. ち. Fruticulus facie Ericae vulgaris. Fl. incarnati.

6. B. scabra Villd. fol. lanceolatis hispidis erecto-adpressis; calycibus hirsutis; corolla glabra clavata. IVendl. Coll. t. 31. Erica Thunb. In Prom. b. spei. ち. Frutex pedalis. Fl. purpurascentes.

\%. B. pusilla $\boldsymbol{L}$. fol. linearibus piloso-hispidis dorso sulcatis; floribus racemosis cernuis. Erica Thunb. In Prom. b. spei. t. Fl. minuti. 
b. Antheris muticis inclusis.

8. B. purpurea $L$. fol. ovatis adpressis ciliatis; ramis flexuosis glabris; floribus umbellatis. Erica Thumb. In Prom. b. spei. ‡.

\section{c. Antlieris aristatis.}

9. B. dumosa Wendl. Coll. t. 38. fol. erectis semiteretilus dorso sulcatis margine scabris; floribus aggregatis terminalibus cernuis. In Prom. $b$. spei. ち. Frutex pedalis dumosus. Fl. rosei.

10. B. glabella Willd. fol. oblongis imbricatis adpressis glaberrimis; floribus fasciculatis cernuis; corolla tubulosa glaberrima. Erica Thunb. Seb. Thes. t. 20. f. 2. In Prom. b. spei. t. FI. purpurei.

11. B. ciliaris $L$. fol. subovalibus erecto-adpressis dorso sulcatis; corolla tubulosa; calycibus fimbriatis profunde partitis. Wendl. Coll. t. 49. In Prom. b. spei. ந.

\section{GALDNERIA Wall. (1821).}

1. G. ovata Wall. in Roxb. Fl. ind. ed. 1. p.400. in ed. 2. deest. In Bengalia et Nepalia. †. Frutex maguus scandens. Folia ovato-lanceolata integerrima lucida. Flores corymbosi carnosi albi.

2. G. glabra Wall. fol. ovato-oblongis acuminatis; pedunc. 1 -floris. In Nepalia.

\section{PENAEA L. (1737).}

\section{a. Floribus terminalibus.}

1. P. myrtilloides Thunb. fol. lanceolatis; bracteis viridibus acutis. $P$. myrtoides L. In Prom. b. spei. $\hbar$. Arbuscula erecta pedalis. Fl. lutei.

2. P. finticulosa $L$. fol. oblongis obtusis; bracteis orbiculatis acutis; ramis dichotomis. In Prom. b. spei. †. Fruticulus ramosissimus pedalis.

3. P. formosa Thunb. fol. ovatis glabris decussatis; bracteis oblongis coloratis. In Prom. b. spei. $\hbar$. Frutex erectus. Fl. aggregati rufescentes.

4. P. mucronata $\boldsymbol{I}_{\text {. }}$ fol. cordatis acuminatis glabris imbricatis; ramis dichotomis. Meerb. t. 51. f. 3. Vell- ten. Malm. t. 87. In Prom. b. spei. †. Frutex 2-ped. Fl. rubri.

5. P. squamosa $L$. fol. rhombeocuneiformibus carnosis; bracteis ciliatis glutinosis. In Prom. b. spei. t. Fruticulus 2-pedalis.

6. P. acuta Thunb. fol. ovatis acutis subimbricatis; floribus umbellatis acutis. In Prom. b. spei. ち. Calllis cinereus. Fl. purpurascentes.

\%. P. Sarcocolla Berg. fol. rhombeo-ovatis oppositis; bracteis cuneatis coloratis. Thumb. Mag. Am. Nat. Cur. Berol. 1. t. 3. f. 1. P. fucata Willd. In Prom. b. spei. Ђ. Fruticulus pedalis. Fl. lutei.

8. P. Cneorum Lam. fol. linearilanceolatis laxiusculis; floribus congesto-capitatis; bracteis foliis minoribus. Meerb. t. 51. f. 2. In Prom. b. spei. †. Frutex 2-ped. Fl. lutei.

9. P. nitida Lour. fol. oblongis congestis revolutis confertis; corollae laciniis filiformibus. In Cochinchina. .

\section{b. Floribus lateralibus.}

10. P. marginata $L$. fol. cordatis marginatis; floribus axillaribus sessilibus. In Prom. b. spei. ち. Frutex 3-ped.

11. P. Iateriflora $I$. fol. ovatis acutiusculis; floribus bracteatis sessilibus. Mag. Am. Nat. Cur. Berol. t. 3. f. 2. In Prom. b. spei. ち. Frutex pedalis. Flores lutei.

12. P. tomentosa Thunb. fol. oblongis acutiusculis confertis ramisque tomentosis; floribus sessilibus. Mag. Am. Nat. Cur. Berol. t. 3. f. 3. In Prom. b. spei. t. Frutex pedalis.

\section{ROUSSEA SM. (17S.9).}

1. R. simplex Sm. fol. obovatis acutis denlatis. In ins. Mascarenlis.

2. R. salicifolia $\mathbf{S m}$. fol, linearilanceolatis elongatis integerrimis glabris. In Montevideo.

\section{CYLINDRIA Lour. (1790).}

1. C. rubra Lout. Rumple IV.t. 93. In Cochinchina. ち, Arbor mediocris ranis adscendentibus; fol. lauceolatis subserratis; floribus rubris; baccis nigris. 


\section{ARAGOA H. et K. (181s).}

1. A. cupressina $\boldsymbol{H}$. et $\boldsymbol{K}$. Nov. Gen. $t$. 216. fol. squamaeformibus ovato-deltoilleis arcte adpressis margine obsolete lanatis. In Nora Granata. ち. Frutex ramosissimus. Folia ramosa. Fl. Iutei.

2. A. abietina H. et K. l. c. t. 21\%. ramis glabris; fol. linearibus; patulis obsolete ciliatis; fauce nuda. In No:a Granata. 卢.

\subsection{PATRINIA Juss. (1S10).}

1. P. sibirica Juss. caule bifarian piloso; fol. subcarnosis rad. oblongis, caeteris pinnatifidis; fructu paleae adnato. Valeriaua L. V. ruthenica Willd. Fedia Gaertn. t. 86. f. 3. - Amm. ruth. t. 3. In Sibiria. $\odot$.

2. $\boldsymbol{F}$. intermedia $\boldsymbol{R}$. et $\boldsymbol{S}$. caule glabro; fol. pimnatifidis, laciniis linearibus acutis, inferiorum dentatis, superiorum integerrimis; fructu paleae adnato. Fedia intermedia Hornem. In Sibiria et China. 4.

3. P. rupestris Juss, caule subpubescente; fol. membranaceis pimmatifidis, laciniis lanceolatis, terminali maximo. Valeriana sibirica Willd. B. M. 714. Fedia rupestris Vahl. Gmel. sib. 3. t. 24. In Sibiria. $\odot$. et 24 .

4. P. scabiosuefolia $L k$. caule glabro; fol. radicalibus ovatis inciso-serratis lyratisque, caulinis piunatifidis; lacinia terminali longissimo; fructu 3-quetro nudo. sweet br. fl. gard. t. 154. Lodd. B. C. 1340. Fedia steev. In Dahuria. 4.

5. P. villosa Juss. caule villoso; fol. villosis radicalibus petiolatis auriculatis, canlinis sessilibus dentatis; corymbo denticulato. Val. villosa Thunb. jap. t. 6. Fedia Vahl. In Japonia. 4.

\section{OPERCELARIA Gaertn. (1785).}

1. O. hispida $\mathbf{s p r}$. caule diffuso sulcato 4-gono; pilis numerosis asperis; fol. minimis ovatis pilosis; capitulis pedicellatis in ramorum dichotomia nutantihus, C. aspera Juss. Ann. Mus. 4. t. 70. f. 1. In Nov. Holl. 4 .
2. O. sessiliflora Juss. l. c. t. 80. f. 2. glabra; caulibus diffusis gracilibus vix sulcatis; fol. linearibus; capitulis minimis hemisphaericis in ramorum dichotomia sessilibus. In Nov. Holl. 4.

3. O. apiciflora Labill. N. Holl. t. 45. glahra; caule diffuso gracillimo sulcato; fol. oblongo-linearibus brevibus; capitulis terminalibus minimis hemisphaericis; foliis circiter 4 involucratis. In Nov. Holl. $ち$.

4. O. spermacocea Labill. N. Holl. $t$. 4\%. glahra; caule fruticuloso erecto; fol. linearibus sub-3-quetris; stipulis utrinque in unicam bidentatam concretis; capilulis sphaericis in ramorum dichotomia pedunculatis. In Nova Holl. $\hbar$.

5. O. vaginata Labill. N. Holl. $t$. 46. glabra; canle erecto basi sublignoso subangulato; fol.linearibus ; stipulis in vaginam longe concretis, apice utrinque bidentatis; capitulis globosis nudis terminalibus. In Nov. Holl. $\downarrow$.

6. O. livtella DC. caule subangulato apice pilosiusculo; ranis elongatis linearibus stipulisque lanceolatosubulatis; setis longiusculis hirtellis; capitulis ex dichotomia ramorum nutantibus. DC. prodr. IV. p. 616. In Nova Holl. 4.

\%. O. hyssopifolia Juss. Ann. Mus. t. 1. $f$. 1. caule erecto subangulato, pube ninima pilosiusculo; fol. anguste lanceolatis margine subciliatis; capitulis nutantibus globosis. DC. 1. C. In Nov. Holl. 24. et 光.

8. O. ligustrifolia Juss. $\boldsymbol{l}$. c. $t$. $\% 1$. $f$. 2. caule 4-gono inter nodos glabro, pube minina pilosiusculo; fol. lanceolatis; stipulis utrinque basi concretis in unicam acute bilobam. In Nov. Holl. ち. et 4 .

9. O. paleata Young Trans. Linn. 3. $t$. 5. glabra; caule herbaceo 4-gono erecto; fol. ovato-lanceolatis acutis; stipulis utrinque concretis in unicam acute bilobam; capitulis nutantibus globosis. Cryptospermum Youngii Pers. In Nov. Holl. 4.

10. O. ocymifolia Juss. Ann. Mus. t. *1. $f$. 3. glahra; caulibus diffusis 4-gonis sulcatis; fol. ovato-oblongis petiolatis; stipulis in unicam utrinque concretis; capitnlis globosis nudis. In Nor. Holl. 4.

11. O. rubioides Juss. caulibus 4gonis adscendentibus glabris; fol. lanceolatis margine revolutis, margine et 
subtus nervo medio scabris; capitulis uudis. In Nov. Holl. 4.

\section{Species dubiae.}

12. O. aspera Gaertn. $t$. 24. fol. ohlongis scabris venosis; capitulis pedunculatis axillaribus. o. aspera spr. In Nor. Keelundia.

13. O. diphylla Gaertn. caule ... fol. ... capitulis ex dichotomia ramorum stipitatis sphaericis; involucris partialibus setose hispidis. Ihubioides diphylla soland. M. B. In Nov. Zeelandia.

\section{DIPSACUS Plin.}

1. D. sylvestris $\boldsymbol{L}$. paleis rectis lineari-lanceolatis subsetaceis; fol. ovato-lanceolatis. Jacq. austr. t. 402. FI. Dan. 965. In Europ. et Sib. $\odot$. 2-4-ped. Fl. violacei.

2. D. laciniatus $L k$. paleis rectis lineari-subulatis; fol. connatis sinuatis. Jacq. aust. t. 403 . In Europa et Sib. $\odot .6-8$-ped. Fl. albi.

3. D. divaricatus Presl; paleis arcuatis; fol. caul. connatis interrupte pinnatis. PresI sic. In Sicilia. $\odot$. 2-ped. Fl. pallide rosei.

4. D. Fullonum $\boldsymbol{L}$. paleis recurvis rigidis; fol. serratis summis integris. E. B. 2080. D. sativus Gm. In Europa spontanea et culta. $\odot$. 2-3ped. Fl. albi.

5. D. sinuatus Willd. fol. pinnatifido-sinuatis; laciniis laciniato-dentatis. Willd. Mss. In alp. Ghilanensibus.

6. D. ferox Poir. paleis subulatis rectis rigidis; caule foliisque undique echinatis. Tratt. Arcl. 235. In Corsica et Sardinia. $\odot$.

7. D. Gmelini Bieb. paleis membranaceis acuminato-aristatis ; involucri foliolis deflexis. Bieb. In Tauria et Sibiria. $\odot$.

8. D. strigosus Willd. paleis setaceis flore duplo longioribus; fol. appendiculatis, summis basi laciniatis ciliatis. Willd. Mss. In Persia.

9. D. pilosus L. fol. petiolatis anriculatis integrisve; caule inferne hispido; capitulis hemisphaericis. Jacq. austr. t. 248. Fl. Dan. 1448. E. B. $87 \%$.

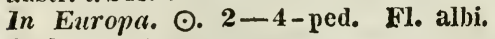
Antherae atropurpureae.
10. D. strictus Don; caule inermi pilis retrorsis villoso; paleis cuneatooblongis canescenti-ciliatis. Don. Nep. D. inermis Wall. In Nepalia. $\odot$.

11. D. inermis Coult. caule inermi glabro; ramis sub capitulo globoso hispidis. D. mitis Don. Nep. In Nepalia. $\odot$. Caul. 4-ped. Fl. ochroleuci.

12. D. asper Wall. involucris deflexis; fol. indivisis 3-sectisque utrinque subaculeato-scabris. Wall. Hb. 1829. In India orientali.

13. D. Lesshenaultii Coult. involucro patulo; fol. lyrato - pinuatifidis utrinque villosissimis. Coult. In India orientali.

\section{SCABIOSA. Vaill. (1722).}

I. Cephalaria Schrad. Succisa Spr. Lepicephalus Lag. Involucellum 4-andrum 8-sulcatum corona $4-8$-dentata terminatum.

\section{Perennes.}

1. S. alpina $\boldsymbol{I}$. paleis acuminatis puhescentibus; antheris viride striatis; caule striato velutino. Succisa Bessl. Hort. Eyst. t. 8. f. 1. In Europa et Graecia. 24. Fl. flavi.

2. S. tatarica Gmel. paleis acuminatis puhescentibus; antheris viride striatis; caule basi petiolisque retrorsum villoso. S. elata Hchb. ic. 744. Succisa Spr. In Sibiria et Caucaso. 4. Fl. flavi.

\section{Annaae.}

3. S.transsylvanica $I$. paleis arista purpureo-nigrescente; caule tereti inferne sparse piloso. Jacq. Vind. t. 111. Hchb. ic. 234. S. Trenta Hacq. alp. t. 4. In Europa. $\odot$. Fl. disci albidi, radii caerulescentes.

4. S. Joppensis Rchb. Hort. t. 17. paleis holosericeis breve acuminatis; capitulis ovatis; involucri squamis rotundatis. Ad sepes Joppae. ๑. Fl. ochroleuci.

5. S. syriaca $D C$. paleis latis longe aristatis rufescentibus; fol. oblongo-lanceolatis serratis; caule subhispido. In Hisp. et Gallia. ๑. 3-4ped. Fl. albi. 
6. S. decurrens Thunb. paleis apice purpurascentihus villosis; foliorum lobis decurrentibus divergentibus; caule sulcato. In Prom. b. spei. $\odot$. Pedalis. Fl. albi.

\%. S. centanroides $\boldsymbol{D C}$. paleis muticis luteo-allidis; foliorum lobis integerrimis decurrentilus; caule tereti. Succisa ambrosioidis, centauroides et laevigata spr. Sm. Gracc. t. 103. s. laevigala W. K. hung. t. 230. s. corniculata W. K. t. 13 . lichb. ic. 488. s. uralensis Rchb. ic. 487 . S. cretacea Bieb. In montanis Europae, Orientis et sibiriae. 4. 4-5-ped. Fl. flavi.

8. S. lencantha L. paleis exterioribus alpressis sericeis obtusis; fol. pimratifidis; caule tereti. Coult. dips. t. 1. f. 9. Kchb. ic. 537. Cepl. lencantha et albescens 1 . et $S$. In Europa, Oriente et Sibiria. $\odot$. Fl. albi.

9. S. rigida $L$. paleis obtusis; fol. ovali-oblongis serratis; caule tereti hispido. Coum. Hort. t. 93. In Prom. b. spei. 24. Fruticulosa. Fl. albi.

10. S. attenuata L. paleis obtusis; fol. lincaribus integris trifidisque; caule tereti subvilloso. S. trifida Thumb. In

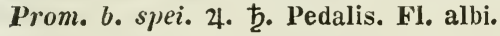

\section{Species dubiae.}

11. S. graeca; paleis imbricatis; fol. pinnatis; foliolis decurrentibus inciso-serratis glabris. S. decurrens Sm. graec. In monte Athone. 4.

12. S. humilis Thunb. glabra; paleis obtusis pubescentibus; fol. linearibus dentato-pinnatifidis. Thunb. cap. In Prom. b. spei.

13. S. ustulata Thunb. glabra; paleis imbricatis acutis villosis apice purpurascentibus; fol. lyratis. Thunb. cap. In prom. b. spei.

14. S. scabra T'hunb. piloso-scabra; paleis ovatis obtusis apice purpurascentibus ; fol. pimatifidis rigidis. Thunb. jap. In Prom. b. spei. $\hbar$.

II. Kna utia. (Scabiosa et Knautia auct.) Involucellum compressum 4-foleolatum, apice denticulatum fructum arcte cingens.

15. S. orientalis Lag. involucri cylindrici foliolis 5-10 erectis; calycis ciliis obsoletis; fol. oblongis inci- sis integrisque. Knautia L. Lam. ill. t. 58. Schk. t. 22. In Oriente. $\odot$. 1-2-ped. Fl. dilute rubri.

16. S. mopontica Lag. calycis cilyndrici foliolis 8-10 lanceolatis; fol. serratis superioribus lanceolatis integerrimis. In Oriente. $\odot$. Fl. purpurascentes.

1\%. S. Irrillei; involucro patulo 10-12-phyllo; involucellis apice bidentatis; fol. inferioribus pimnatifidis. Knautia Coult. dips. t. 1. f. 10. In ins. Leri. $\odot$. Caul. ramosissimus. Fl. caerulescentes.

18. S. hybrida All. involucro 1113-plyllo; involucelli dentibus 2 multisetis; calycis ciliis 20-2t obsoletis. Trichera R. et $\mathbf{S}$. Ceph. bidens R. et s. S. bidens Sm. graec. t. 104. In Europa australi. $\odot$. Pedalis. Fl. rubro-caerulei.

19. S. arrensis $L$. involucri foliolis ohtusiusculis; fol. sessilibus villosohirsutis, caulinis pinnatifidis; caule hispido. E. B. 6.59. $\beta$. collina Duby. $\gamma$. canescens Coult. $\mathbf{s}$. integrifolia Coult. S. uralensis Rchb.? In pratis Europae. 24. 1-2-ped. Fl. purpureo-caerulescentes.

20. S. sylvatica $L$. involucri foliolis subacutis; foliorum lanceolatorum petiolis alatis basi connatis; caule hispido. Jacq. obs. t. 72. Savi pis. t. 2. f. 1. $\beta$. Iongifolia Duby. S. Iongifolia WV. K. t. כ. In montanis Europae. 4. 3-5-ped. Fl. purpureo-vioIacei.

21. S. montana Bieb. involucri foliolis acutis angustis; fol. oblongis serratis, inferioribus integris laciniatisque. In pratis montanis Caucasi. 4. 6-ped. Fl. albi.

22. S. ciliata Rchb. ic. 436. involucri foliolis ciliatis; fol. hispidis, caulinis inciso-dentatis cordato-aniplexicaulibus perfoliatisque; caule hispidissimo. S. pubescens Wableub. In pratis Moraviae. 4. Fl. sordide albi.

\section{Specis dubiae.}

23. S. diversifolia Baumy. involucri foliolis cordato-hispidis; fol. rad. pinnatifidis laciniis subfalcatis integris; caule hispido ramoso. In pratis Transsylvaniae. 4.

21. S. Legionensis Lag. involucri foliolis 18 flores excedentibus; fol. lanceolatis acuminatis remote dentatis; 
caule pilis retroversis hispido. Asterocephalus Spr. In montibus Legionensibus Hispaniae. 4.

III. Pterocephalus Vaill.Spr. Involucrum duplici serie 4-6phyllum. Involucellum dentatum aut aristatum. Receptaculum paleaceum s.villosum.

\section{a. Annuac.}

25. S. papposa L. receptaculo paleaceo ; involucello longe aristato; fol. pinnatifidis; laciniis linearibus; caule herbaceo erecto. Pter. Vaillantii Lag. S. involucrata sibth. gr. t. 113 . $\beta$. diandra Pter. diandrus Lag. Ceplialaria R. et S. In Lusitania, Hispania, Graecia et Creta. $\odot$. Fl. caerulei.

26. S. brevis; molliter villosa; involucelli corona membranacea vix dendiculata; fol. pinnatifidis; caule herbaceo. Pter. Coult. dips. t. 1. f. 16. Patria ignota. $\odot$.

27. S. flumosa; pubescens; involucelli corona obsoleta; fol. inferioribus late lanceolatis serratis, mediis lyratis; caule herbaceo erecto. Knantia L. Sibtl. gr. t. 111. S. papposa Gaertn. t. 86. Ceph. Willichii et s. plumosa R. et S. In Oriente, Iberia, Graecia et Creta. ๑. 1-2-ped. Fl. violacei.

28. S. palaestina; sericeo-villosa; involucelli basi 8 -foveolata; fol. inf. obovato-oblongis, sup. parvis decurrentibus. Knautia L. S. brachiata et Sibthorpiana fl. graec. t. 109. $\gamma$. s. multiseta Vis. dalm. t. 1. In ins. Cypri, Scio et Palaestina $\gamma_{0}$ in Dalmatia. $\odot$.

\section{b. Perennes frutescentesve.}

\section{* Fol. dirisis dentatisve.}

29. S. lusitanica; paleis et involucri foliolis scariosis hirsutis; foliorum laciniis linearibus; caule adscenlente sparse piloso. Pte:. lusitanicus DC. Ceph. plumosa 13. et s. S. plumosa Hoffmss. In Lusitania. 4.

30. S. Broussonetii; calycis plumis 6-7 linearibus undique pilosis involucello vix duplo longiorihus. Pterocephalus Coult. in litt. 1824. et DC. prodr. IV. p. 663. In Gibraltaria. 4.
31. S. tomentosa Sibth. calycis setis 6 scahris; fol. dentato-pimatifidis tomentoso-incanis ; caule procumhente fruticoso. DC. S. Sphakiotica R. et s. In C'reta. 24.

32. S. perennis Vaill. involucello pubescente; stignate longitudinali; fol. lirsutis; caule procumbente fruticoso. S. pterocepliala sibth. gr. t. 112. Pter. Parnassi Spr. In Parnasso. 4. 古.

\section{** Fol. integris.}

33. S. nivea Agardh; fol. inf. orbiculatis caulinis obovato-spathulatis omnibus integerrimis cauleque niveotomentosis. DC. In Hispania. 4.

34. S. spathulata; pappo colorato 14-radiato; fol. rotundato-spathulatis tomentosis. Knautia Lag. Prope Ellin Murciae et in Granata. 支.

35. S. cana; involucello lagenaeformi pubescente esulcato ; fol. obovato-oblongis canis; stigmate emarginato. Pter. Coult. dips. In Oriente inter Amadam et Kermancha. 4.

36. S. lasiosperma; involucellis dense tomentosis; fol. brevissime petiolatis integerrimis tomento denso candicantibus. Pter. dumetorum var. pusilla Coult. S. fruticulosa Sm. In Canaria magna. ‡.

3\%. S. dumetorum Brouss. fol. ovato-oblongis integerrimis glabris; floribus subcorymbosis; caule fruticoso. Brouss. in Willd. en. p.146. In Teneriffa.

IV. Scabiosae verae (Asterocephalus et Succisa Spr. partim, Scabiosa L.) Involucrum polyphyllum. Involucellum 8 - foveolatum subcylindricum. Calyce 5-aristato.

A. Asterocephalus Coult. Involucelli basis teres. Corona ampla membranacea.

38. S. caucasica Bieb. involncro villosissimo; corona 24-nervia; fol. rad. lanceolato-linearihus integerrimis; caule herhaceo. Coult. dips. t. 2. f. 1. $\beta$. elegans. sclerostemma connatum Schott. Scab. elegans B. M. 886. In America. 24. Capitula maxima pallide caerulea. 
39. S. cretica L. fol. lanceolatis subintegerimis involucrisque pubescenti-canis; corona 20-28-nervia; caule fructicoso. Coult. dips. t. 2. f. 2. S. arborea P. Alp. exot. t. 34. In rupibus siciliae et Cretae. $\hbar$. Fl. caeruleo-purpurascentes.

10. S. Camlollei Wall. Mb. corona 20-nervia subdentata; setis $\mathbf{5}$ nigris; fol. linearibus integerrimis glabriusculis. DC. In Nepalia. 古.

11. S. araminifolia $L_{\text {. }}$ fol. linearihus integerrimis argenteo-sericeis; caule herbaceo 1-floro. W. K. humg. t. 188. B. R. 835 . Coult. dips. t. 2. f. 3. In alpibus Europaeis. 4.

42. S. prolifera l. fol. oblongolanceolatis subintegerrimis pubescentibus ; corona 30-36-nervia; caule herbaceo dichotomo. sibth. gri. t. 107. Coult. t. 2. f. 4. In Cupro, Aegypto et Barbaria. 24. Fl. pallide flavi.

13. 5 . stellata $L$. fol. sublyratis, lobo terminali maximo dentato; capitulis longe pedunculatis; corona 40nervia. Coult. t. 2. f. 5. S. rotata Biel). In agris regionis Mediterraneae. $\odot$. Cor. albo-caerulescens.

H. S. Munspeliensis Jac\%. fol. ommibus pinnatis ciliatis; capitulis longe pedunculatis; corona 32-35-nervia. s. simplex DC. Desf. Atı. t. 39. Jacq. ic. t. 24. In Gallia, Hispania et Barburia. $\odot$. Fl. albidi.

45. S. Vahlii Coult. dips. t. 2. f. 6. cauledivaricato-ramoso; fol. obovatoohlongis grosse dentatis; corona 3235-nervia; calycis linbo longe pedunculato. s. palaestina L. Jacq. Vind. t. 96. In Palaestina et Aleppo. $\odot$.

46. S. ucranica $L$. caule ramoso; fol. basi ciliatis; involucelli basi hemisphaerica foveolis ovato-linearibus; corona 20-2t-nervia. DC. Hchb. ic. 489. Scop. del. t. 16. S. sicula L. I. divaricata Jacq. Vind. t. 15. In Europa anstrali. 4. Fl. viride vel caeruleo-flavescentes.

47. S. aleppica Coult. dips. $t$. 2. $f$. 8. involucelli basi elongata foveolis linearibus aequali; corona 20-24nervia; calycis limbo longe pedunculato. Coult. Inter Baydad et Aleppum. $\odot$.

48. S. micrantlia Desf. fol. hirsutis rad. lanceolatis serratis; pedunculis elongatis; calycibus flore longioribus; fructu oblongo. Desf. Ann. Mis. XI. p. 168. t. 25. In Armenia. ๑. 2-ped. Hl. rosei.

49. s. Olivieri Conlt. t. 2. f. 10. caule ramosissimo dichotomo; fol. lineari-oblongis villosis; capitulis parvis ; calyce subsessili. DC. Inter Bagidar et fiarmancha. Herba gracillima. Caul, albidus, Fl. albi.

50. S. isetensis $L$. capitulis pedinculisque alhido-tomentosis: involucelli hasi elongata villosa; fol. olabris pinnatifidis. \$s. rupestris Biel.s. rupestris et isetensis $\mathbf{r}$. et $\$$. Gnel. sib. 2. t. 88. f. 7. In Siviria et Culcaso. 4. Fl. alhi.

51. S. crenatu Cyr. pl. rar. neap. $t$. 3. caule adscendente hasi suffruticoso; fol. glabris pimnatificlis dentatisve; capitulis longe pedunculatis. $s$ coronopifolia sibth. gr. t. 114. s. crenata et coronopif. R. et $\mathbf{S}$. In Culabria et Gruecia. 4. Fl. carnei.

52. S. pectinata Lay. caule patulo ; fol. subcarnosis pimatifido-pectinatis canaliculatis. Lag. elench. 1803. In Arabia. $\odot$.

5.3. S. Iyrata Forst. caule simplici; fol. inferioribus oblongis grosse et obtuse serratis, superioribus hasi pinnatifidis. Vahl. symb. Ad Dardanellas. $\odot$.

5t. S. acutiflora Rchb. ic. 506 . involucello margine spongioso; fol. inf. spathulatis lineari-pinnatifidis selratis; capitulo fructifero ovato. DC. In Europa australi. 21. Fl. persicini.

B. Viduc Coult. Invol ucelli basis rotundata plicata. Corona minima inflexa.

55. S. atropurpurea $L$. fol. rad. lanceolato-ovatis lyratis grosse dentatis; capitulis fructiferis ovatis. B. M. 247. In hortis culta, in Indic orientali spontanea. $\odot$. Fl. atropurpurei rosei rarius albi.

56. S. maritima $L$. fol. rad. pinnatifidis; laciniis dentatis; summis linearibus; capitulis fructiferis glohosis. DC. In aridis Siciliae, Galliae et Italiae. $\odot$.

5\%. S. daucoides Desf. Att. t. 3 s. caule subsimplici; fol. inferic "bus lyratis; involucri foliolis pinna adis. In collibus Algiviae. $\odot$.

58. S. ambigua Ten. neap. glabra; fol. crenatis carnosis lucidis, radic. obovatis; tubo corollae longis- 
simo; cor. spongiosa involuta. DC. Iu arvis maritimis Neapolis. 4. Fl. purpurei vel violacei.

C. Succisa. (Asterecephalus et Suc(isa spr.) Involucelli basis nulla. Hoveolis exaratis. Corona membranacea patula brevis.

\section{* Corollis 5-fidis.}

59. S. africunc $\boldsymbol{L}$. caule su ruticoso; fol. lyratis grosse dentatis hirsutis; involucello tubo obconico. DC. Coult. t. 2. f. 12. S. altissima Jacq. Vind. t. 185. In Prom. b. spei. 古. Cor. alba. Foliorum forma variabilis.

60. S. Fischeri DC. fol. omnibus pimnatifidis. glabriusculis; involucri foliolis cor. radiantes aequantilus; calycis setis 5 pallidis corona duplo Iongioribus. In Dahuria. 24. Fl. caerule-purpurei.

61. S. semipapposa Salzm. hirsuta; subcanesceus; caule herbaceo ramoso; involucri foliolis linearibus ciliatis demum reflexis. DC. Circa ranyer.

62. S. lucida Vill. fol. Iucidis spathulatis lanceolatisve serratis; pappi radiis nigris; capitulo fruct. globoso. Hchl. ic. 560. \$. norica Vest. s. stricta IV. K. t. 158. In alpibns Europucis. 7. Fl. incarnato-violacei.

63. S. amoena Jacy. Ecl. t. 59. caule basi subtomentoso; pedunculis apice pilis reversis; fol. inf. oblongis obtusissimis basi auriculatis ciliatis. §. nitida Bemh. In imp. Rutheno. 2 . 2 -ped. Hl. rosei.

64. N. ochroleuca L. caule ramoso hirsutiusculo; fol. rad. lyrato-pinnatifidis utrinq. puhescentibus; calycis setis fuscescentilus. Jacq. obs. t. 83. austr. t. 439. S. tenuifolia Roth. Asteroceph. polymorptis IVallr. s. Columbaria $\beta$. ochroleuca Richb. ic. 536. In Europa et Sibiria. 4. Fl. ochroleuci.

65. S. panciseta $D C$. caule foliisque rad. Iyrato-pinnatifidis hirsutis; calycis setis $1-3$ nigris corona triplo longioribus. Savi pis. t. 2. f. 6. s. Saviana lichb. Hort. t. 53. In agris circa Pisam, Carraram et Sarzonam. 24. Fl. violacei.

66. S. Columbaria $L$. canle ramoso glabriusculo; fol. rad. obtusis crenatis membranaceis utrinque pedunculisque 3-fidis pubescentibus; cap. fruct. globoso. E. B. 1311. Rchb. ic. 535. In Europa et Sibiria. 24. Valde polymorpha. DC. in prodr. 10. p. 659. sequentes varietates eummeravit.

$\beta$. Columuae, fol. villosis; fructumm setis 3-5 deciduis. S. Columnae Ten. neap. t. 7.

$\gamma$. banatica, caule pilis reflexis; fol. hirsutis. s. Banatica IV. K. t. 12. Fl. pallide rosei.

$\delta$ - agrestis, caule hasi pedumcilis superne hirsutis pilis reversis ; foliorum lobis linearibus hirsutis. S. agrestis W. K. t. 20\%. In pratis Hungariae. $\odot$.

E. grammuntia, caule vix hirsuto; pedunculis sub capitulo pilis reversis; corollis sub-4-fidis. S. grammuntia L. Fl. lilacini.

S. ceratophylla, caule fistuloso villoso; lobis foliorum falcatis. s. ceratophylla Ten. neap. t. 8.

ク. commutata, caule glabro; fol. rad. glabriusculis longe petiolatis. s. commutata R. el s. In Sibiria.

6\%. S. pyrenaica All. ped. $t$. 2.5. f. 2. et 26. $f$. 1. tota cinereo-tomentosa; fol. rad. oblongis crenatis; corona 20-nervia. DC. s. maritima Vill. s. mollissina Vis. s. tomentosa Cav. ic. t. 183. In lapialosis Europae australis. 24. Fl. purpureo-rubetli.

68. S. holosericen Bertol. tota pube velutina molitier cano-tomentosa; fol. inf. lanceolatis obtusis crenatis; involucri foliolis linearibus. DC. Ast. sericeus spr. In Apenninis Appuanis, Dalmatia et in Pyrenaeis. 4.

69. s. Webiana Don. B. R. $81 \%$. tota pube molli subsericea cano-tomentosa; fol. inf. petiolatis obovatis crenatis; calycis setis nigris. DC. In Phrygia. 24. Fl. ochroleuci.

\%. S. mollis Willd. fol. inf. st1pradecompositis, lobis omnium tenuissimis filiformibus margine subpilosis; pedunculis longissimis. Rchb. ic. 534. S. capillata R. et s. Patria ignota. 4.

\% 1. S. pumila Poir. tota hispidopilosa cinerea; caule subsimplici; fol. rad. Iyratis; involucri foliolis lance0latis villosis. DC. In Prom. b. spei. 4.

\%. S. suaveolens Desf. pube brevissima subcaulescens; caule stricto; fol. rad. oblongis integerrimis; capitulis fruct. globosis. Coult. t. 2. f. 14. 
S. canescens IV. K. t. 53. In collibus Europcle. 24. Fl. violacei.

73. S. dichotoma Willd. glabritscula; caule dichotomo; capitulis in axillis subsessilibus globosis; fol. ohlongis integris; setis calycis patulis brevissimis. Coult. t. 2. f. 15. S. parviflora Desf. In Manritania et Nicilia. 4. Fl. incarnati.

7t. s. urceoluta Desf. glahra; fol. subcarnosis, rad. ohlongis ohtuse sinuato-pinnatifidis; involucri foliolis basi concretis. DC. Conlt. t. 2. f. 16. s. rutaefolia Vahı. s. divaricata Lam. In Lusitania, Corsica, Sicilia, regno Tunetano. 4.

\section{** Corollis $\mathbf{4}$-fidis.}

\%5. S. Succis $\boldsymbol{L}$. radice praemorsa; fol. radicalibus ovato-lanceolatis integerrimis, caulinis connatis; involucri foliolis $\mathbf{2}-\mathbf{3}$-seriatis. DC. Fl. Daıl. 289. Engl. B. 878. In Euroqu. 4. Fl. violacei.

76. S. australis Wulf. glabriuscula; fol. ovatis acuminatis integerrimis margine pubescentiluus; cap. ovatis; involucelli tubo lagenaeformi; corona ohsoleta. Coult. t. 2. f. 18 . Rchb. ic. 505. In paludosis Italiae, Syriac et Pannoniae. 24. Fl. ochroleuci.

\section{Species non satis notae.}

a. Fol. integris serratisve.

77. S. limonifolia Vahl; caule fruticoso; fol. radicalibus coriaceis subtus reticulatis incano-tomentosis; cor. 6-fidis. DC. In rupibus Siciliae $\hbar$. Fl. caerulei.

78. S. saxatilis Cav. ic. $t .181$. caule herbaceo glabro; fol. lanceolatis integerrinis subtus tomentosis, caulinis paucissimis; setis 5 purpmreis. In fissuris riprum V́alentiae. $\odot$. Fl.albi.

8.9. S. nitens $R$. et $\mathbf{s}$. caule herbaceo; fol. indivisis ellipticis serratis lucidis petiolatis; cor. radiantibus 5fidis. DC. s. lucida Ait. In Azoricis. 2 .

80. S. amiplexicaulis $I$. caule herbaceo brachiato; fol. amplexicaulibus lanceolatis integerrimis, radicalibus 3-fidis. Patria ignota.

S1. S. cochinchinensis Lour. caule simplicissimo subnudo; fol. lanceolatis indivisis undulatis, radicalibus serrulatis; iuvolucro 3-phyllo; pappo piloso. In Cochinchina et China. Fl. purpurei.

b. Fol. lyratis aut pinnatifidis. * Cor. 4-filis.

82. S. Dahurica Willd. fol. pinnatipartitis; lobis linearibus pinnatifidolaciniatis cauleque subtomentosis; cor. 4-fidis. In Dahuria.

83. S. hirta Willd. fol. omnibus pinnatifidis cauleque hirtis; lobis lineari-lanceolatis. In Sibiria.

\section{** Corollis 5-fidis.}

81. S. cornucopia Viv hirsuta; fol. radicalibus ellipticis dentatis; involucello 3-fido; semine 3-aristato. In Liguria et Sicilia.

85. S. integrata Hoffmss. fol. infimis oblongis integris, inferioribus lyratis, sumnis pinnatifidis nullisve. In Lasitania. 4.

86. S. hispunica Willd. fol. pinnatifidis; Iobo terminali lanceolato subdentato; corollis calyce Iongioribus. Willd. In Hispania. 4.

87. S. coronopifolia Willd. fol. rad. lanceolato-spathulatis argute dentatis; caulinorum lobis linearibus divaricatis. In Sibiria.

88. S. heraclec Willd. fol. inferioribus pinnatifidis, sup. pinnatilobatis. DC. Ad fretum Gaditunum.

8.9. S. inclina 18 . et s. caule villoso; fol. incanis pimatipartitis; lohis linearibus. S. ucranica. Bieb. In Tauria.

90. S. syriaca Vest. tenue villosa; ramosissima; multiflora; fol. omnibus pinnatifidis; involucri foliolis patentissimis linearibus. Vest. in Flora 1821. In Syria.

91. S. Scopolii Ll. caule pilis reversis superue villoso; fol. hirtis, radicalibus oblongis crenatis; involucri foliosis linearibus adpresse pilosis. Lk. In Europa australi. 4. F1. ochroleuci.

92. S. reversa Ledeb. fol. rad. ohovatis obtusis crenatis patenti-puhescentibus; pedunculis pilis reversis; involucro corollas $\mathbf{5}$-fidas superante. Patria ignota. 4.

93. S. rhisentha Viv. fol. radicalibus ellipticis; pedunculo rentrali radicali 1-cephalo; involucri foliolis 5 linearibus. In montibus c'yrenaicis. 
9-1. S. Hladniliana Host. caule stricto ramoso pubescente; fol. hispidis, inf. obovatis crenatis; calycis setis 5 atropurpureis. In montanis Carnioliae. 21.

95. S. Gemonae; caule ramoso glabro adscendente; fol. infer. oblongis crenatis laciniatisve; pedunculis setis reflexis; involucri foliolis linearisubulatis. S. humilis Host. austr. Proje Gemonam. Fl. al!sidi.

96. S. neglecta Horn. fol. omnibus lyratis; pedunculis longissimis; involucri foliolis corollas $\check{y}$-fitlas radiautes superautibus. In Italia. $\odot$.

97. S. laciniata Licht. puhescens; caule dichotomo; fol. inf. obovatooblongis obtuse inaequaliter serratoincisis. In Prom. b. spei. Fl. pallide violacei.

98. S. anyustifolia Ho/fmss, Verz. 1828. caule glaberrimo; fol. pubescentibus, caulinis pinnatifidis lyratisve; pedunculis apice pilis reversis. P'atria ignota. 4.

99. S. campestris Ress. fol. hilsutis, rad. obovatis integris pimatifidisve, caulinis obovato-lanceolatis incisis. In Volhynia.

\section{CEPHALANTHUS I. (173\%).}

1. C. occidentalis $I$. fol. oppositis ternisve ovatis ovalibusve acuminatis; pedunculis capitulo multo longioribus. DC. Duhan. arb. t. 54. Schk. t. 21. Lois. herl, amat. t. 272. C. oppositifolius Moenc!. In Canada et Mexico. 4.

2. C. Sarandi Cham. fol. oppositis ternisve oblongis acuminatis brevissime petiolatis; pedunculis vix capitulo longioribus. Buddlea glabrata Spr. ex Cham. In Brasilia. ந̧.

3. C. salicifolius H. et Bonpl. aequin. $t$.98. fol. oppositis ternatisve Iineari-lanceolatis brevissime petiolatis; capitulo solitario Ionge pedunculato. Prope Acupulco. t.

4. C. naucleoides $D C$. fol. oppositis 3-4-verticillatis ovalo-lanceolatis acuminatis breve petiolatis subtus ramulisve villosis; capituilis terminalibus. Nanclea tetrandra hoxb. In Silhet. ந. Fl. flavi.
Species dubiae.

5. C. pilulifer Lam. fol. oppositis approximatis ovatis obtuse acuminatis laevihus hrevissime petiolatis; pedunculis subfoliaceis. In India orientali. $\hbar$.

i. C. piluliflorus Willd. fol. ellipticis utrinque attenuatis obtusiusculis; capsulis terminalibus axillaribusque numerosis. H. ets. Putria ignota.

7. C. stellutus Lour. caule arboreo; fol. teruo-verticillatis lanceolatolinearilus glahris; calycis laciniis 4 subulatis; corollae limbo reflexo. In Cochinchina. b. Fl. albi.

8. C. montanus Lour. caule arboreo; 1ol. alternis ovatis acuminatis supra asperis subtus tomentosis; peduuculis axillarihus solitariis; floribus dioicis apetalis 4 -fillis; semine papposo. In China. 卢.

\section{MITCIELIA L. (1751).}

1. M. repens L. fol. subrotundis; floribus ad apicem pedunculi duobus ovario concretis. Plukn. alm. t. 444. f. 2. Cat. car. t. 20. Inter muscos Americae borealis. 2\%. Fl. albo-purpurascentes.

\section{ACRODRYON Spr. (182.5).}

1. A. orientale spr. caule arlioreo; fol. oppositis ternisve ovatis acuminatis reflexis; pedunculis terminalibus diversis; fructibus baccatis. Cephalantlius Lour. et DC. In China. Arbor magna. Fl. albi. Bacca edulis rubra.

2. A. anyustifolium Spr. caule arboreo; fol. oppositis lanceolato-linearibus; capitulis terminalibus; calycis lobis sululatis piloso-glandulosis; fructibus baccatis. Cephalanthus Lour. In Cochinchina. $\downarrow$. Nl. pallidi. Baccae in globum aggregatae.

\section{DECLIEUXIA H. et $\mathrm{K}$. (1815).}

1. D. chiococcoides $\boldsymbol{H}$. et $\boldsymbol{K}$. Nov. Gen. $t$. 2s1. frnticosa; glabra; fol. oppositis sessilibus oblongo-lanceolatis acutis basi cuneatis margine subrevolutis. Houstonia fruticosa IVilld. 
Mss. In Nora Andalusia. ち. Frutex 4-pedalis.

2. D. thyinbroides Mart. et Zucc. frutıcosa; ramosissima; fol. fasciculato-verticillatis sessilihus linearihus acutis utrinque attenuatis ramulisque scahriusculis. In Irosilia. b.

3. D. mexicama DC. fruticosa; glahra; fol. oppositis termisve sessilibus oblongo-lanceolatis hasi obtusis apice acutis; corymho pedunculato 4-5partita. D. chiococcoides Bartl. In Mexico. Fruticulus $1 \frac{1}{2}$-ped.

4. I). satureioines Murt. et Zucc. fruticosa; ramosissina; fol. linearilanceolatis sessilihus oppositis vel verticillato-senis ramisque hirsutosca!ris. DC. In Brasilia. 古.

J. I). yulioides Polu; suhherbacea; glabra; ramis teretibus; fol. ternoverticillatis linearibus; verticillis distantihus; paniculis cymosis. DC. In Brasilia. 4 .

6. D. Marioides Mart. et Zucc. fruticosa; caule ramisque molliter puhescentibus; fol. ternis ovato-lanceotis suhsessilibus glabriusculis margine revolutis. DG. In Irrasilia. $\hbar$.

\%. D. spergulifolia Mart. et Zucc. fruticosa; glahra; fol. lineari-subulatis oppositis sessilibus; racemis dichotomis terminalibus. In Brasilia. $\hbar$.

8. D. oenanthoides Hart. et Zuncc. herbacea; glabra; caule subsimplici; fol. quaternis sessilibus remotis lineariIanceolatis acutis; racemis bifidis. In Brasilia. t).

9. D. foliosa Polel (sub P'syllocarpo.); fruticosa;-tota scalriuscula; ramis 4-gonis; fol. oppositis lineari-oblongis utrinque acuminatis; cyma ter-

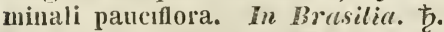

10. D. cordiger" Mart. ct Zucc. suffruticosa; sulsimplex; pubescentiscahra; fol. oppositis decussatis approximatis sessilibus ovatis cordatis acutis dorso concavis; fleribus racemosis. Psyllocarpus PohI. In Bra-

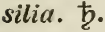

11. D. glauca Mart. et Schlecht. Limnae 182\%. fruticosa; glabra; glaucescenti-pruinosa; fol. oppositis sessilibus ovatis acutissimis erecto-adpressis coriaceis; panicula subglobosa. In Brasilia. b.

12. D. passerina Mart. et "zucc. fruticosa; glabra; fol. oppositis decussatis sessilibus adpressis 4 -fariau im- bricatis ovatis acutis $3-5$-nervibus. In Brasilia. 市.

13. D. daphnoides Mart. et Zucc. fruticosa ; ramis vireatis; fol. oppositis decussatis 4-farian suhimbricatis ovato-subcordatis acutis, subtus 7-9nerviis piloso-scabris. In Brasilia. $t$.

17. D. imbricata Polll; fruticosa; glabra; ramis teretihus; fol. opposicis decussatis erecto-ovatis cuspidatis rigidis; costa media utrinque 4-costulata. In Brasilia. t.

15. D. vherioides Mart. et Zucc. fruticosa; glahra; ramis innovando subumbellatis viruatis; fol. oppositis decussatis sessilibus erecto-patentibus 4-fariam imhricatis ovato-suborbiculatis acutis 5-nerviis. DC. In Brasilia. 方.

16. D. origanoides Zucc. fruticosa; hirsuto-scabra; ramis dichotomis teretibus; fol. oppositis remotiusculis brevissime petiolatis suborbiculatis acutis multinerviis. In Brasilia. $\hbar$.

17. D. mollis Zucc. fruticosa; fol. oppositis ovato-lanceolatis subrhombeis hasi in petiolum brevissimum attenuatis acutis venoso-costatis molliter viltoso-scabriusculis; fol. dichotomo-paniculatis. In Brasilia. ந.

18. D. rubioides Zucc. fruticosa; glabra; fol. oppositis decussatis ovatis a $z$ tis basi rotundatis cordatis supra nitidis ; florilus dichetomo-pauiculatis. In Brasiia. ?!

1.9. D. lysimachioides Zucc. herbacea vel suffruticosa; molliter pubescens; ramis simplicibus erectis; fol. ternis ovatis utrinque attenuatis acutis. In Brasilia. $\hbar$.

20. D. ulba Zuicc. fruticosa; scabra; fol. oppositis decussatis ovatis acutis sessilibus basi rotundatis; $\mathbf{f l}$ racemosis. In Brasilia. $b$.

21. D. divergentiflora Poht; suffruticosa; ramis teretibus velutinosubhirsutis; fol. oppositis sessilibus ovatis vix aculis ulrinque tenuissime velutinis; fl. cymosis. In Brasilia. b.

22. D.・pulverulenta Mart. Cham. suffruticosa; tota suhtomentosa; fol. teruis sessilibus ovatis acutis acuminatisve; fl. cymosis. In Brasilia.

23. D. polygaloides Zucc. suffirnticosa ; ramis virgatis erectis; fol. ternis quaternisque sessilibus lanceolatis acutis erectis; fl. paniculatio. In Brasilia. $\hbar$. 
24. vincoilles Mart. et Zucc. fruticosa; glabra; fol. teruis oppositisve ovatis utrinque attenuatis acutis sessilibus nitidis; $\mathbf{f}$. dichotomo-paniculatis. In Brasilia. $\hbar$.

25. D. priinosa DC. suffuticosa; wlahra; glauca; ramis teretibus; fol. oppositis sessilibus orbiculato-ovatis mucronatis; fl. cymosis. Psyllocarpus Pohl. In Brasilia. $ђ$.

25. D. mucronata Mart. et Cham. suffruticosa; glaberrima; fol. oppositis sessilibus ellipticis obovatisque basi cuncatis apice mucronatis; fl. cymosis. In Brasilia. t.

27. D. glabra DC. suffruticosa; glabra; caule sub-1-gono; fol. oppositis petiolatis elliptico-oblongis utrinque acuminatis; fl. cymosis. In Brasilic. $\hbar$.

28. D. psychotrioides DC. suffiulicosa; glabra; fol. oppositis breve petiolatis ellipticis longe acuminatis basi acutis; $\mathrm{n}$. cymosis. In Cayenna, Panama et Mexico. $\hbar$.

29. D. herbacea Cham. et Schlecht. herbacea; glabra; ramis subbialatis; fol. oppositis petiolatis ovato-lanceolatis attenuatis acutis; fi. cymosis. Knoxia brasiliensis Spr. In Brasilia. b.

30. D. prunelloides Klotsch Mss. tota hirsuto-scahra; caule simplici erecto ramisque plane compressis canaliculatis; fol. oppositis brevissime petiolatis lanceolato-ellipticis acutissimis basi cuneatis multinerviis. In graminosis Africae australis. 4. Pedalis Prumellae facie,

\section{ERNODEA Sw, (1788).}

1. E. littoralis $S w$. fl. ind. $t$. 4. Caule decumbente suffruticoso. Fol. oppositis subsessilibus lanceolatis aut ellipticis. Fl. pallide lutescentes. In littoribus ins. Caribaearum, Jamaicae, Guadelupae et Porto-Rico, Bacca lutea,

\section{4, CUNCEA Hamilt, Don, (1825).}

1. C, trifida Ham. prodr, 1. $p$. 13.5. Ernodea nepalensis Spr. In Nepalia. 24. Caul. subtomentosus. Fol. opposita petiolata utrinque pubescentia. Fl, cymosi parvì lutei.

\section{BACONIA DC. (1807).}

1. B. corymbosa DC. diss. $t$. 1. In Sierra Leona. $\beta$. angustifolia in sylvis Gambiae et Cayor. ち. Frutex glaber. Fol. opposita petiolata ovalia. Fl. corymbosi albidi.

\section{FROEHLICHIA Vahl. (1796).}

1. F. paniculata Yahl Ecl. t. 10. f. 3. Billardiera ibid. Coussarea Froeh-

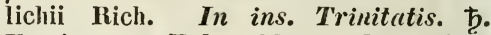
Fruticosa. Fol. oblongo-lanceolata utrinque acuminata. Fl. corymbosi albi. Pedunculi compresso-angulati.

\section{PAVETTA L. (1747).}

\section{a. Asiaticae.}

1. P. indica L. fol. ovali-oblongis utrinque acuminatis petiolatis; stipulis latis acutis subconcretis; fl. corymbosis; stylo longissimo. B. R. 198. Ixora paniculata Lam. Ix. pavetta Roxb. Pavelta Kheede 5. t. 20 . In India orientali. ち. Frutex 3-ped. Fl. albi.

2. P. tomentosa Roxb. fol. petiolatis ovatis oblongis utrinque tomentosis; paniculis tomentosis; ramulis 3-fidis. Ix. tomentosa Roxb. P. tomentosa Roth. In India orientali. $\hbar$. Fl. numerosi fragrantes albi. Bacca globosa.

3. P. moníana Blume; fol. longe petiolatis utrinque acuminatissimis; corymbis puberulis; calycibus acute dentatis. In Java. ち.

4. P. odorata Blume; fol. breviter petiolatis oblongis utrinque acutis apice saepe obtusiusculis coriaceis glabris; calycibus obtuse dentatis. In Java. ち. Fl. albidi odoratissimi.

5. P. macropliylla Blume; fol. breviter petiolatis oblongis obtusissimis coriaceis glabris; calycis et corollae laciniis obtusis. In Java. ‡. Fl. albi.

6. P. reticulata Blume; fol. oblongis utrinque acuminatis coriaceis infra reticulatis; laciniis calycis acutis, corollinis acuminatis. In montosis Javae. $\hbar$. Caulis 4-ped. Fl. albi.

\%. P. longipes DC. fol. ovali-oblongis acuminatio petiolatis glabris; 
stipulis acuminatis; fructu ovato didymo apice nudo. In ins. Timor. b.

8. P. paludosa Blume; fol. breviter petiolatis oblongis obtusiusculis menuhranaceis glahris, terminalibus cordato-oblongis sessilibns; corymbo trichotomo longe pedunculato colorato; dentibus calycis obtusis. In Java. ち.

9. P. hispidula W. et A. fol. hreve petiolatis oblongo-lanceolatis utrinque acuminatis ramisque supra hispido-pubescentibus subtus tomentosis; calycis dentilus recurvis. W. et $A$. In India orientali.

10. P. sylratica Blume; fol. ohlongo-lanceolatis utrinque longiter acuminatis membranaceis glahris subtus in axillis costarum puberulis; calycibus obsolete denticulatis. In $\boldsymbol{J} a$ ia. t. Flor. alli parvi.

11. P. brecifolia DC. fol. ovalibus aculis basi acuminatis membranaceis slahris; corollae tubo vix lohis Iongiore. In montibus Neelgherris, Ind. orientulis. $\hbar$. In sicco nigrescit.

12. P. Rotlicuna DC. ramulis calycibusque villoso-incanis; fol. ellipticis petiolatis subpilosis, junioribus tomentoso-canis; stipulis triangulis intus glabris; corollae fauce barhata; stylo setaceo glahro. P. villosa Roth. In India orientali. ‡.

13. P. sumatrensis Roth; fol. petiolatis oblongo-ellipticis glabris subtus ad costas strigosis; floribus pentandris tomentoso-albidis; corollae tubo filiformi. In Sumatra. 古.

14. P. longiflora Vahl; fol. Ianceolato-ellipticis ramisque glahris; stipulis intus pilosis ; floribus 4 -ffdis. Ixora occidentalis Forsk. In Arabia felici. †. $\beta$. jarana corollae tubo longissimo. P. longifolia Blume. In Java.

15. P. villosa Iahl; ramis calycibusque villosis incanis; fol. hreviter petiolatis lanceolato-ellipticis, junioribus utrinque villoso-canescentibus. Ixora villosa Poir. In Arabia felici. b.

\section{b. Africanae.}

16. P. ou ariensis Beaur. fol. Ionge petiolatis ovato-oblongis utrinque attenuatis membranaceis glahris; calycis lohis ovalibus; stylo clavato. Ixora Poir. In Africa aeruinoctiali. t. Fl. albi, tance villosissimi.
17. P. Caffra Thunb. fol. obovatis subsessilihus glabris ; stipulis membranaceis commatis; floribus subunbellatis; calycis dentibus setaceis. Ixora Poir. Crinita capensis Houtt. Pfl.-syst. 5. t. 40. f. 1. In Prom. b. spei. b. Fl. albi.

18. P. parvifiora Afz. fol. oblongis utrinque attenuatis; stipulis acutis; pedunculis dichotono-nmbellatis; calycibus corollisque villosis. In Guinea. 古.

19. P. Smeathmanni DC. fol. ovalibus breve acuminatis coriaceis laevibus; calycis dentibus oblongis ciliatis; corollae limbo globoso. P. parviflora smeathm. In Sierra Leona.

20. P. subglabra Schum. ramis teretibus subglahris; fol. ovatis acuminatis hasi subciliatis; petiolis subhirsutis; stipulis intus ciliatis. In Guinea. ち. stigma globosum.

21. Henipaefolia Schim. ramis teretibus pubescentibus; fol. oblongolanceolatis acuminatis nitidis glahris subtus petiolisque pubescentibus; stipulis setaceo-acuminatis. In Guinea.

22. $\boldsymbol{P}$. canescens $D C$. ramulis hirsuto-canis; fol. ellipticis hasi attenuatis breve petiolatis reticulato-venosis supra pubescentibus subtus villosocanescentihus. In Angola. $ち$.

23. P. lanceolata Žeyh. glaherrima; ramis teretibus; fol. subsessilibus lanceolatis basi attemuatis apice obtusiusculis, coriaceis supra nitidis; stipulis connatis memhranaceis truncatis bisetaceis. In Africa australi. ち. 8-ped.

\section{c. Madagascarienses.}

21. P. anthophylla Rich. glaberrima; fol. brevihus ovali-acutis subcarnosis; stipulis latis; stylo longe exserto. In Madagascar.

25. P. cinerea A. Rich. griseo-tomentosa; fol. subovalibus acutis basi sensim angustatis subtus criseo-tomentellis; stipulis connatis. In Madagascar.

26. P. gracilis A. Rich. glaberrima; fol. elliptico-oblongis acutissimis suhsessilibus; stipulis comnatis angustato-Ianceolatis; floribus longissimis. In Madagascar. 卢.

\section{d. Australasicae.}

2\%. P. Opulina DC. fol. ovaiolanccolatis; corymbis coarctatis glo- 
hosis terminalibus. Coffea opulina Forst. Chiococea Spr. In Nora Caledonia. t.

28. P. sambucina DC. fol. oblongo-lanceolatis acutis glabris; cyunis corymbosis terminalibus. Coffea Forst. Chiococea spr. In ins. Amicorum. $\hbar$.

\&9. P. triflora DC. fol. ovatolanceolatis acuminatis; pedunculis terminalibus ternis 1-floris. DC. Chiococca spr. In ins. Taheiti. $\hbar$.

\section{Species dubiae.}

30. P. anyustifolia $R$. et $S$. fol. lineari-lanceolatis utrinque attenuatis; calycis dentibus acutis. Pavetta indica Burm. ind. t. 13. f. 3. Ixora Lam. In India orientuli. t.

31. P. amplexicutis pers. glabra; fol. amplexicaulibus ovalibus; corollae Iaciniis acutis lanceolatis. In India orientali. $\hbar$.

32. P. arenosa lour. ramis hrachiatis; fol. lanceolatis tuberculatis nitidis; calyce baccato 5-dentato. In

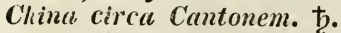

33. P. parasitica Lour. caule parasitico ramosissimo; fol. verticillatis ovatis tomentosis; fl. glomeratis; calyce 4-gono villoso trumcato. In hortis Cochinchinae. 支.

\section{TETRAMERIUM Gaertner fil. (1805).}

1. T. odoratissimum Gaertn. fruct. t. 196. fol. oblongo-lanceolatis acuminatis glabris; ramulis 4-gonis ; panicula 3-fida. Coffea occidentalis Jacq. am. t. 47. Ixora americana sw. Haramea DC. Plun. ic. am. ed. Burm. t. 156. f. 2. In ins. Caribaeis, Domingo, Jamaica, Portorico, Guadelupe, Panuma et Mexico. ち. Fl. albi odoratissimi.

2. ' '. caeruleum Nees; fol. ovatoellipticis utrinque acutis; stipulis dilatatis; calycis dentibus acutis. Faramea DC. In Brasilia. t. Wl. anethystini.

3. 2'. Hontevidense Cham.etschlecht. fol. oblongis utrinque acuminatis ; bacca calyce cyathiformi coronata. Faramea DC. In Brasilia. $\odot$.

-4. T. stipulaceum Cham. et Schlecht. fol. ohlongis basi atenuatis apice acutis; stipulis latis; calyce 4 - ? dentato acuto; hacca globosa. Faramea DC. In Erasilia. 方.

5. 'T. latifolium Cham. et Schlecht. fol. ovalibus abrupte acuminatis; stipulis latis; calyce 4-gono 4-dentato. Faramea DC. In Rio Janeiro. 古.

6. 'T. Guayaquilense; fol. oblongis acuminatis subsessilihus; stipulis ohlongis utrinque bifidis; floribus fasciculatis. Faramea DC. T. multiflorum BartI. Circa Bahiam. legit Salzmann. 卢.

\%. 'T. jasminoides $\boldsymbol{H}$. et $\boldsymbol{K}$. Nov. Gen. $t$. 28\%. fol. oblongis acuminatis parallelo-venosis; stipulis amplis ; calyce longe 4-dentato acuto. Faramea DC. Coffea flavicans Willd. In Nova Granata. 24.

8. T. sessilifolium H. et $\boldsymbol{K}$. l. $\boldsymbol{c}$. fol. cordato-oblongis acuminutis sessilibus; stipulis ovatis acuminatis; calyce urceolato 4 -dentato. Faramea DC. Ixora spr. In sylvis Orinocensium. .

Species dubiac. Ferameae spec. DC.

9. T. axiliflorum; fol. cordatoovatis acuminatis; stipulis longe aristatis; ramis conpressis. Feramea DC. Circa Bahiam legit Salzmann. †. Fl. igniti.

10. 1. multiflorum; fol. ovali-ellipticis acuminatis ahrupte petiolatis; stipulis counatis vaginaeformibus. Farainea Iich. In Gujana.

11. I. calyciflorum; fol. ellipticis acuminatis; stipulis non connatis ; floribus serrulatis; calycis limbo amplo. Faramea Hicl. In Gujana. ち.

12. T. sessiliflorum; umbellis terminalibus solitariis simplicibus sessilibus; calyce 4-denticulato. Faramea Aubl. Guj. t. 40. f. 2. In sylvis Gujanae. t.

13. I. sertuliferum; pedunculis terminalibus solitariis teretiusculis umbellam simplicem apice ferentibus ; calyce truncato. Faramea DC. In Cuba.

14. T. truncatum; pedunculis terminalibus apice compressis; calyce truncato. Faramea DC. In Gujana. 市.

15. T. corymbosum; pedunculis terminalibus apice compressis ; calyce 4dentato. Faramea Aubl. Guj. t. 40. i. 1. In Gujana. 4. 
16. T. albescens; ramis umbelliferis; fol. oblongis utrinque acuminatis nitidis pallide viridibus; pedunculis ancipitibus. Faramea DC. In Gujanc.

17. T. Martini; fol. ovalibus anplis; antheris exsertis; calyce vix dentato; ramulis compressis, Faramea DC. In Gujana.

\section{IXORA L. (1747).}

\section{a. Floribus coccineis flammeis rose isque.}

1. I. grandiflora Ker. B. R. 154. fol. cordato-oblongis acutis glabris nitidis sessilibus; calyce fructus connivente. I. coccinea L. Burm. Zeyl. t. 57. Plukn. t. 59. f. 2. 1. In Tanjore, China et Zeylonia. ち. Frutex elegans. Umbellae amplae cccineae.

2. I. Bandlinca Roxb. fol. cordato-amplexicaulihus sessilibus oblongis acutiusculis; corymbo coarctato; bacca calyce patente coronata. B. R.513. Schetti liheede 2. t. 2. I. coccinea L. I. arhorea Lodd. B. C. 609? In India orientali. $\hbar$. Ilid. a poëtis saepe celebrata. Fl. intense coccinei.

3. I. stricta Roxb. caule fruticoso ramoso; fol. ohlongis utrinque glabris sessilibus; corymhis hemisphaericis; calycis laciniis obtusis, corollae obtusissimis. Rumph 4. t. 47. I. coccinea Curt. B. M. 169. Schuev. ic. t. 1. I. speciosa IVilld. I. incarnata Roxb. Pavetta Blume. In China, Ja$\boldsymbol{v} a$, Manilla et Moluccis. $ち$. Fl. flammei.

4. I. crocata Lindl. B. R. 782. fol. ovali-lanceolatis coriaceis; laciniis corollae obovatis; stylo medio subpiloso. I. chinensis Lam. In Clina.

5. I. incarnata DC. fol. cordatooblongis obtusis sessilibus; calycis laciniis acutis, cor. ovali-acutis. Pavetta incarnata Blume. In Moluccis et in Java culta. $ち$. Fl. pallide rosei.

6. I. Wallichii II. et A. fruticosa; fol. lanceolatis acuminatis subsessilibus, subtus nervis corymbisque pubescentibus; cor. laciniis reflexis. 1. undulata Wall. lit. In India orientali. ち. Fl. pallide rubri.

\%. I. Notoniana Wall. frutescens; fol. obovato-oblongis acuminatis gla- hris; corymbis longe petiolatis; calycis segmentis ohlongo-linearihus. Wall. Cat. 11. 6132. In Neelghervis. ち. Fl. rubri.

8. I. fulyens Roxb. fol. lanceolatis acutis subsessilibus glabris; calycis laciniis cordatis; bacca biloha. I. lanceolata Lam. I. Iongifolia. Sm. Rumpl. 4. t. 46?. In IIoluccis. ち. Fl. et baccae purpureae.

9. I. tenuiflor a Roxb. fol. ohlongis breve petiolatis obtusis laevibus; calycis laciniis cordatis obtusis; cor. tubo gracili. In Moluccis. $\hbar$.

10. I. congesta Roxb. fol. breve petiolatis oblongis coriaceis parallele grosse venosis; fl. subsessilibus; calycis laciniis subreniformibus. In Moluccis. t.

11. I. pendula Jack; fol. ellipticolanceolatis glaberrimis; ramis compressis; corymbis pendulis. Jack. nal. misc. 1. n. 2. p. 11. In India orientali. †. Fl. rubri.

12. I. rosea W'all. fol. ovato-oblongis acutiusculis coriaceis, supra nitidis subtus villosiusculis; laciniis corollinis coriaceis. B. R. $5 \frac{1}{40}$. B. M. 2428. B. C. 729. In collibus Bengaliae. 5 . Fl. rosei.

13. I. amboinica DC. fol. ovatooblongis acuminatis subsessilibus undulatis glahris; laciniis calycis et corollae acutis. Pavetta Blume. In Amboina. $\hbar$.

1.. I. javanica DC. fol. ovatooblongis acuminatis glabris subsessilibus; laciniis calycis obtusis, corollinis ovalibus rotundatis. Pavetta Blume. In sylvis montosis Javae. Fl. saturate miniati.

15. I. panciflora Blume; fol. oblongis acuminatis basi acutis glahris subsessilibus; dentibus calycis acutis corollinis ovalibus. In Java. $\hbar$.

16. I. salicifolia $D C$. fol. linearilanceolatis acuminatissimis glabris; laciniis calycis acutis corollinis lanceolatis acuminatis. Pavetta Blume. In Jav $九$. ‡. Fl. punicei.

\section{b. Floribus albis.}

1\%. 1. blanda Fer. B. R. 100. fol. ovato-lanceolatis subacutis subsessilibus; calycis dentibus acutis, corolliuis obovatis obtusis. I. alba hoxb. In India orientali.

15. I. macrophylla Bartl. fol. cu- 
neato-obovatis acutis glabris subsessilibus; pedunculis elongatis; cabycis dentibus obsoletis; stigmate exserto; lobis revolutis. Bartl. In ins. Mavilla. $\hbar$.

19. I. cuneifolia Roxb. fol. latocuneatis acuminatis glabris; floribus congestis; calycis laciniis oblongis conicis. B. I1. 618. B. C. 1215 . In Serampore. $\hbar$.

20. I. barbata Roxb. fol. oblongis lucidis subsessilibns basi cordatosubrotundis; corollis ad faucem pilis albis longis harbatis. B. M. 2505. In India orientali. $\hbar$.

21. I. undulata Roxb. fol. latolanceolatis acuminatis undulatis glabris; bacca transverse ovali subdidyma. In sylvis Bengaliae. $\hbar$.

22. I. lanceolata Colebr. fol. approximatis longissimis lineari-lanceolatis acuminatis subsessilibus glabris; bracteolis coloratis; antheris basi profunde bifidis. In Travancore. $\hbar$.

23. I. arborea Roxb. fol. ellipticooblongis obtusis subundulatis subsessilibus laevibus; calycis dentibus acutis. I. Pavetta B. rep. t. 78. et Pers. In India orientali. $\hbar$.

24. 1. brachypoda DC. fol. sessilibus elliptico-oblongis obtuse acuminatis; stipulis concretis truncatis mucronatis; calycis limbo obsolete 5-dentato. In Africa aequinoctiali.

25. I. acuminata Roxb. fol. Ianceolatis acuminatis petiolatis laevibus glaucis, floralibus amplexicaulibus; calycis lobis ensiformibus. In India orientali. $\hbar$. Fl. magni alhi.

26. I. parviflora Vahl symb. t.52. fol. subsessilibus lanceolato-oblongis glabris; stipulis 3-angularibus acutis; calycis dentibus obtusiusculis. In India orientali.

2\%. I. brachiata Roxb. fol. subpetiolatis lanceolatis obtusis glabris; corollae tubo filiformi; lobis obovatis emarginatis. In Bengalia. ‡. Baccae intense purpureae.

2S. I. decipiens DC. fol. subpetiolatis oblongo-lanceolatis apice acutis obcordatisque; stipulis basi latis aristatis; stylo piloso. I. parviflora Roxb. In montibus Coromandeliae. Fl. fragrantes.

29. 1. villosa Roxb. fol. subpetiolatis late cuneatis subtus villosis ; ramis corymborum trichotomis villosis; calycis laciniis oblongis ciliatis. In silhet. $\hbar$.

30. 1. mubiflora DC. fol. sessilibus obovato-oblongis basi cuneatis subcordatis apice acuminatis utrinque in nervis, corymbis corollisque hirtopuberulis; stipulis longis subulatis. In India orientali. $\hbar$.

31. I. nigricans $\boldsymbol{R}$. $\boldsymbol{B r}$. glabra; fol. oblongo-lanceolatis subpetiolatis utrinque nitentibus; stipulis calycisque laciniis subulatis. W. et A. prodr. p. 428. 1R. Br. in Wall. Cat. 6154. In India orientali. $\hbar$.

Species dubiae.

32. I. alba L. fol. ovato-lanceolatis; flor. fasciculatis. Pluku. t. 109. f. 2. Hheede 2. t. 14. In India. $\hbar$.

33. I. montana Link. fol. oblongis apice latioribus obtusis basi cuneatis cordatis subsessilibus glabris; corymbo terminali fastigiato. In India orientali.

34. 1. violacea Lour. scandens; fol. lanceolatis subsessilibus pilosis 9-nerviis; cymis axillaribus. In $\mathrm{Co}$ chinchina. $\hbar$. Fl. violacei.

35. I. novemnervia Lour. scandens; fol. ovato-lanceolatis subsessilibus 9-nerviis asperis; cymis hemisphaericis; cor. tubo longissimo. In desertis Cochinchinae. ‡. Fl. albi.

36. I. thyrsiftora Poir. fol. subsessilibus ovato - cuneatis obtusis utrinque glabris subtus incanis; stipulis ovatis acutis; calycis dentibus setaceis. In Prom. b. spei. ђ.

3\%. I. laxiflora Sm. fol. ellipticooblongis acutis basi in petiolum attenuatis, basi sumnorum rotundata; lobis corollae convexis in disco barbatis. In Sierra Leona. ђ.

510. TERTREA DC. (Schiedea A. Rich.) (1830).

1. T. martinicensis A. Rich. In

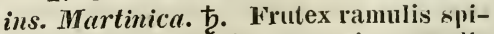
nescentibus. Folia opposita ovalia acuta breviter petiolata membranacea glabra. Flores parvuli racemosi. 


\section{HYDROPHYTUMI Jack (1825).}

1. H. Formicarum Jack; fol. subsessilibus ovalibus apice rotundatis. Kumph. 6. t. 55. Lasistoma Spr. In Moluccis et Sumatra. $\hbar$. Truncus intus cavus et formicarum domus.

2. H. montanum Blume; fol. breviter petiolatis oblongis obtusis. In montibus Juvae. $\hbar$. Basis caulis saepe intumescit.

\section{SIDERODENDRON Schreb. (1789).}

1. triflorum Tahl; pedunculis in axilla geminis 3-floris. - Sideroxyloides ferreum Jacq. am. t. 175. f. 9. Pluk1l. t. 221. f. 2. In Montserrat et Martinica. $\hbar$.

2. S. multiflorum A. Rich. pedunculis axillaribus 3 -partitis; ramis lateralibus 3-fidis, medio bis 3-fido. In Gujana. 市.

3. S. paniculatum Willd. Hb. paniculis axillaribus pedunculatis hirtellis; ramis subdichotomis; fol. cordatis ovatis acute mucronatis subsessilibus. Psychotria cordifolia. H. et B. In America meridionali. $\hbar$. Fl. caerulei glabri, fauce villosa.

\section{SAPROSMA Blume (1826).}

1. S. arboreum Blume bijdr. caule arboreo; fol. petiolatis ellipticooblongis; floribus confertis terminalibus aut axillaribus. In sylvis montosis Javae. ‡.

2. S. fruticosum Blume bijdr. caule fruticoso; fol. subsessilibus oblongolanceolatis; floribus confertis terminalibus. In Java ad montem Parang. t.

\section{HYDROPHYLAX L. fil. (1781).}

1. H. maritima L. fil. Roxb. Corom. 3. t. 233. Sarissus anceps Gaertn. t. 25. In maritimis Malabariae et Coromandeliae. 24.' Herba subrepens. Folia opposita ovato-oblonga carnosa. Fl. axillares sessiles pallide lilacini.
2. II.? Madayascariensis Willd. Hb. fol. lanceolatis acutis sessilibus arcte imbricatis vaginatis. In Mladagascar legit Commerson.

\section{CHOMELIA Jacq. (1763).}

1. C. spinosa Jacq. am. t. 13. fol. subsessilibus ovatis acumiuatis glabris; pedunculis axillaribus subtrifloris; calycis corollaeque laciniis acutis. Ixora Lam. In Curthagena et $\mathbf{S t}$. Domingo. †. Fl. albidi noctu fragrantes.

2. C. fasciculata Sw. fol. ovatis acutis glabris breviter petiolatis; pedunculis 2-3-axillaribus 1-floris; calycis lobis spathulatis. Ixora Sw. Inter sepes Novae Granatae.

3. C. obtusa Cham. et Schlecht. fol. ellipticis basi subacutis sessilibus glabris; pedunculis axillaribus $1-3-$ floris; calycis et corollae lobis obtusis. In Brasilia. 古.

4. C. pubescens Cham. et Schlecht. fol. subsessilibus ovatis acutis in nervis supra pilosis subtus sericeis; pedunculis axillaribus 1-floris. In $\mathrm{Br} a$ silia. ち.

\section{SCOLOSANTHUS Vahl (1796).}

1. S. versicolor Tahl Eclog. $t$. 10. fol. obovatis supra lucidis; spinis simplicibus bipartitis geminisve. Chomelia Spr. Catesbaea parviflora Lam. ill. t. 6\%. f. 2. In ins. Sanctae Crucis et Portorico. $\hbar$. Fl. purpureo-crocei.

2. S. triacanthus DC. fol. oblongis subglaucescentibus; spinis plerisque 3-fidis. Catesbaea triacantha Spr. In St. Domingo. ち.

\section{1\%. CUNNINGHAMIA Schreb. (1789).}

1. C. sarmentosa Willd. Malaena Aubl. Guj. t. 41? Lam. ill. t. 66. f. 2. In Gujana super arbores. ఫ. Frutex sarmentosus inter arbusculas scandens. Fol. opposita ovato-acuta. Fl. parvi caerulescentes.

\section{COUSSAREA Aubl. (1795).}

1. C. violacen Aubl. Guj. t. 38. fol. ovatis acuminatis; 1loribus termi- 
nalibus subsessilibus. In Gujana. ఫ. Bacca violacea.

2. C. racemosa A. Rich. Mém. Mus. 5. p. 173. fol. elliptico-acuminatis; stipulis caducis; florihus minimis pedunculatis racemosis terminalibus axillaribusque; baccis albidis. In Gujana.

3. C. macrocarpa A. Rich. fol. ellipticis acuminatis; stipulis caducis; floribus racemosis vix pedunculatis; baccis nigris. In Gujana.

4. C. syuamosa Lam. fol. ovatooblongis; cymis squamosis axillaribus; calycis limbo subcylindrico. Lam. ill. In Caribaeis.

\section{PETESIA P. Brown (1758).}

1. P. grandis Bartl. fol. oppositis, rhombeo-ovatis utrinque acuminatis junioribus utriuque villosis, subtus in nervo venisque villosulis, inter venas radiato-striatis. In Mexico. $ђ$.

2. nitida Bartl. fol. oppositis oblongis utrinque attenuatis glabris subtus reticulato-venosis; areolis radiatostriatis. In ins. Philippinis et Marianis. 古. Cor. parva tomentoso-hirsuta.

3. P. ternifolia Bartl. fol. ternato-verticillatis obovat 0 -oblongis utrinque acutis; pedunculis 5-7-floris. In ins. Luzon.

4. P. lispida Rartl. fol. oppositis membranaceis ohovato-oblongis utrinque acuminatis supra nervo venisque subtus hispido-setosis. In L Luzonia.

5. P. tomentosa Jacq. am. fol. oblongis ntrinque attenuatis tomento vix conspicuo mollissimis. In sylvis Carthagenae.

6. P. spicata $S w$. fol. ellipticis attenuatis glabris subtus pubescentibus; petiolis hirtis. In apricis Jamaicae. $\downarrow$.

\%. P.? simplicissima Lour. caule herbaceo simplicissimo 4-gono; fol. lanceolato-linearibus glabris; calyce 5-fido. In Cochinchina.

\section{RUBIA Plin.}

A. Pedunculis involucratis.

a. Foliis 1-nerviis. * Baccis glabris.

1. R. Walteri $\boldsymbol{D C}$. caule $4-$ gono lateribus pilosiusculo; fol. ovatis mem- hranaceis scabris; fore 1 in involucro scssili. h. peregrina Walt. IR. Brownii Michx. In Carolina et Floride. 4.

2. I. Guadelupensis Spr. caule 4-gono angulos versus basin aspero; fol. oblongis mucronatis carina margineque aculeatis. In Guadelupe. 4.

3. R. indecora Cham. et Schlecht. caule 4-gono scabro-piloso; fol. obIongis subcuneatis obtusis mucronatis membranaceis; marginibus remote pilosis. In Brosilia. 24. Bacca in involucro sessili.

A. R. chilensis Mol. caule laevi teretiusculo; fol. ohlongo-linearibus mucronatis nervis marginibusque sparse pilosis; pedunculis apice bracteolisque hirulis. In Cliti. 4.

5. R. ramosissima Pohl in litt. caule 4-gono versus angulos sparse piloso; fol. oblongis obtusis basi subcuneatis 1-Herviis subtus piloso-subhispidis, supra glabratis lucidis. I/ Brasilia. 4.

6.R.valartioides Cham. et Schlecht. caule 4-gono; fol. sessilibus ovatis acutis membranaceis 3-nerviis ad margines piligeris; floribus in involucro sessilibus. In Erasilia. ち. Caul. basi scaber.

\%. R. nitida H. et K. Nov. Gen. t. 280. caule 4-gono ad angulos reflexo-piloso; fol. ellipticis margine revolutis, supra glabris nitidis; flore in involucro sessili. In Quito. ち.

8. R. vilis Cham. et Schlecht. glabra; caule 4-gono; angulis foliorumque marginibus retro scahris; fol. oblongis obtusis membranaceis; bracteis oblongis acutis. In Brasilia. 4.

9. $\boldsymbol{R}$. ciliat $\boldsymbol{D C}$. caule procumbente ramosissimo 4-gono glahro; fol. 4is lincari-lanceolatis ciliatis reflexis; pedunculis apice 4-phyllis; corollae laciniis setaceis. Galium ciliatum $\mathbf{R}$. et P. G. involucratum $\mathbf{H}$. et $\mathbf{K}$. In Peruvia. 24. Fl. purpurei.

10. R. monantha DC. caule procumbente ramoso 4-gono subglabro; fol. subovalibus longe ciliatis supra hispidis Galium monanthum Bartl. In montibus Peruviae.

11. P. crocea $D C$. caule procumbente ramoso; ramis 4 -gonis; fol. qwateruis linearibus ciliatis subtus scabriusculis; pedunculis 1 -floris apice $4-$
phyllis. Galium croceun R. et $\mathbf{P}$. 
In Peruria ad Tarma et Ifuanuco. Fructus rubro-crocei.

12. R. lıerigata DC. glaberrima; caule cacspitoso ramosissimo diffuso; fol. quaternis ovato-oblongis; pedunc. solitariis apice 4-phyllis. Galium Bartl. In Mexico. $\odot$.

13. R. ovalis DC. caule subscandente 1 -gono hirsuto; fol. quaternis oblongo-ovalibus acuminatis demum reflexis; pedunculis apice sub fiore bracteas ovales acutas gerentibus. Galium R. et P. In Peruvia.

14. R. corymbosa DC. caule repente filiformi; ramis corymboso-dichotonis 4-gonis; fol. lanceolato-oblongis approximatis sessilibus subciliatis glahris. Galium $\mathrm{R}$. et $\mathrm{P}$. In montibus 'Tarmae.

\section{* Baccis pilosis scabrisve.}

15. R. hypocarpa DC. caule 4gono secus angulis villis longis hispido; fol. ovali-oblongis hirsutis; bracteis oblongis subhirsutis. Vaiantia L. R. Brownii spr. In Jamaica. 24 .

16. R. Rellun Cham. et Schlecht. tota scabra et hirta; caule acute 4anculo; fol. ovato-ellipticis obtusis mucronatis submembranaceis margine ciliatis hirto-scalris. Feull. obs. t. 45. 11. chilensis Willd. In Chili. 4. Bacca rubra.

17. $R$. orinocensis $\boldsymbol{H}$. et $\boldsymbol{I}$. caule 4-gono glabro; ramis pilosis; fol. subsessilibus oblongis acutis pilosis. $\mathbf{K}$. Brownii spr. Ad Orinocum. " 4 .

15. $R$. incana $H$. et $K$. caule 4gono villoso-incano; fol. ovatis breviter acuminatis margine revolutis nervoque medio piloso-hispidis. In Andibus Quintuensinm. 4.

19. R. livta $H$. et $h^{2}$. canle 4-gono hirto; fol. subsessilibus oblongis acutis mucrouatis hirtis; haccis scabris. Prope urbein Quito. 4.

b. Fol. 3-nervi is; baccis glabris.

20. R. noxia Sl. Hil. caule 4-gот no secus allgulos retrorsum piloso; fol. sessililus ellipticis obtusis brevissime cuspidatis membranaceis pellucidis scabro-pilosis. In Brasilia. Bacca alla.

21. R. aspera Poll; canle 4-gono angulis retrorsum scabris; fol. sessi- libus ovalibus brevissime mucronulatis membranaceis margine subscabris; bracteis ovalibus. In Brasilia. 4. Bracteae viride pallide flavescentes. Bacca nigricans.

22. R. diffisa Pohl; caule 4-gono hispido; fol. sessilibus ovalilıus acutis membranaceis margine scabro-hispidis; bracteis ovatis hispidulis. In Brasilia. 2. Bacca nigricans.

\section{B. Pedunculis non involucra- $t i s$.}

\section{a. Cordifoliae; caulibus her- bace is.}

23. $R$. cordifolia $L$. caule herbaceo; fol. quaternis cordato-oblongis petiolatis 3-nerviis supra marginibusque scabris. Pall. it. t. L. f. 1, ed. gall. t. 92. In Sibiria. 4. Bacca rubra.

24. R. Javana DC. prod. p. 588. fol. quaternis petiolatis ovato-oblongis $\tilde{o}$-nerviis cauleque scabris. $\mathbf{R}$. cordifolia BIume. In Java. 4.

25. R. Munjista Roxb. fol. quaternis petiolatis cordatis acutis 7-nerviis cauleque hispido-scabris; flor. pentandris. R. cordata Thumb. In Nepalia et Japonia. 4.

26. B. alata Wall. fol. quaternis petiolatis lanceolatis ovatis $\mathbf{3}$-nerviis acuminatis scabris; caule angulis 4alato dentato-scabro. In Nepalia. 4.

2\%. R. petiolaris DC. prodr. IV. p. 588. fol. quaternis petiolatis obIongo-lanceolatis acuminatis 1-nerviis; narginibus pedunculis caulisque angulis aculeato-scabris. In Prom. $b$. spei. 4.

\section{b. Suffruticosae.}

28. R. fruticosa Kit. 1. p. $11 \%$. fol. ellipticis margine carinaque aculeatis; caule frutescente aspero. Jacq. ic. rar. t. 25. I1. canarieusis et galioides Poir. In Teneriffa. ち. Cor. flavescens.

29. R. acalyculata Cav.ic. t. 19.5. caule subherbaceo laevi 6-gono; fol. petiolatis ovato-lanceolatis nervo subtus et margine retrorsum aculeatis. In Madras. $\hbar$.

30. R. laevis Poir. voy. 2. p. 111. caule laevi; fol. octonis lineari-lanceolatis mucronatis laevibus. In littore Barbariae. $\hbar$. 
c. Tiuctoriae; caulibus herb ace is.

31. R. anyustifolia $L$. fol. quaternis linearibus supra marginibus et ciulis angulis aculeatis; corollae laciniis apiculatis. Lam. ill. t. 60. f. 2. In Madera et Lasitania. 4.

33. R. longifolia Poir. fol. subquaternis subpetiolatis lanceolatis elongatis acuminatis, subtus margine cauleque aculeato-scabris; cor. laciniis cuspidatis. In Corsica. 4.

33. R. tinctorum L. fol. subquaternis lanceolatis supra laevibus margine carina et ad angulos caulis aculeato-scabris; cor. laciniis callosoacuminatis. Hayne XI. t. 5. Schk. t. 23. Lain. ill. t. 60. f. 1. H. peregrina Murrey. In Europa australi spontanea. 4.

34. $R$. peregrina $L$. fol. subquaternis lanceolatis supra nitidis laevibus margine carina et ad angulos canlis aculeato-scabris ; cor. laciniis cuspidato-aristatis. Engl, bot. 851. R. anglica Huds. R. tinctorum $\alpha$. Lam. In Europa australi et media. $\hbar$.

35. R. lucida $L$. fol. senis ellipticis lucidis, marginibus et ad angulos caulis aculeato-scabris. sibtl. gr. t. 142. R. tenuifolia D'Urv. R. rotundifolia Poir. In asperis Europae.

36..R. Bocconi petugn. inst. bot. 2. $\%$. 25.5. fol. quatemis ovatis supra luciolis margine carina et caulis angulis scabris. Ten. fl. nap. t. 10. Bocc. mus. t. 75. Barr. ic. 547. In agro Neapolitano et sicilia. ち. Wl. albo-virescentes.

3\%. R. splendens Hoffmss. fl. port. t. 85. fol. quaternis senisque obverse oblongis acutis cauleque aculeatoscabris; cor. laciniis aculeatis. $\mathbf{R}$, sylvestris Blot. Ad sepes Lisboae. 4.

39. R. Olivieri A. Rick. caule suffruticoso sub-6-gono retrorsum scabro; ramis pulverulentis pubescentibus; fol. senis obovalibus margine hispidis. In ins. Scio.

39. R. Thunbergii DC. tota glabra; fol. saepissime quateruis. Asp. laevis Thunb. fl. cap. p. 151. In Prom. b. spei.

\section{Species dubiae.}

40. R. equisetoides Cham. et Schlecht. ramis compresso-4-gonis re- trorsum scabris; fol. minimis adpresso-erectis sub-3-angulis acutis. In Brresilia. 24. Baccae glabrae.

11. R.ephedroides Cham.et Schlecht. glabra; caule subtereti; ramis acute 4-gonis scabriusculis; fol. anguste ellipticis acutis laevibus. In Brasilia. 4. Baccae glabrac.

42. R. scabra $H$. et $K$. canle 4gono angulis retrorsum scabris; fol. seuis sessilibus oblongo-lanceolatis margine subrevolutis serrulatis. In Andibus quinduensibus $\odot$.

43. $R$. debilis $H$. et $\boldsymbol{K}$. caule 4gono angulis retrorsum aculeatis; fol. oblongis acutis mucronatis planis, margine et carina retrorsum aculeatis. In Quito. 4. Fruct. iguotus.

\subsection{ANTHOSPERMUM L. (1737).}

a. Floribus hermaphroditis.

1. A. Lichtensteinii Cruse; caule fruticoso ramoso glabro; fol. opposilis linearibus, margine ciliatis. spermacoce ericaefolia Licht. in $R$. et $\mathbf{s}$. syst. 3. p. 281. In Prom. b. spei. ђ.

b. Floribus dioecis axillaribus.

2. A. Bergianum Cruse; caule lignoso ramoso superne hirsuto; fol. ternis connato-perfoliatis lineari-lanceolatis imbricatis ciliatis. In Prom. 6 . spei. 4.

3. A. aethiopicum I. caule lignoso ramoso puherulo; fol. oppositis ternisque lineari-lanceolatis glabris margine revolutis ; floribus subvericillatospicatis. Gaertn. t. 19.5. Linn. Hort. cliff. t. 2\%. Plukn. t. 183. f. 1. In Prom. b. spei. ち.

4. A. hirsutum Cruse; caule lignoso ramoso superne hirsuto; fol. oppositis lanceolato-linearibus acutis patentibus margine subrevolutis basi pilosis. A. lanceolatum sieb. In prom. b. spei. ち.

5. A. lanceolatum Thunb. caulo herbaceo glabro sul)-4-gono; fol. oppositis lanceolato - liueáribus acutis glabris patentibus; fructibus ovato-oblongis. A. herbaceum. L. In Prom. b. spei. ђ.

6. A. spathulatum Spr. caule lignoso puberulo; fol. oppositis subspa- 
thulato-lanceolatis acutis patentibus. In Prom. b. spei. 古.

8. A. ferrugineum Ecklon et Zeyher; caule suhherhaceo ramosissimo hinc inde puherulo ramis in apice puberulo-scabridis; fol. oppositis oblongovel ovato-lanceolatis acutis rigidis glahris sulfalcatis; floribus verticillatis. In Africa australi. 4. 2-ped. Caul. glaberrimus splendens.

9. A. ciliare I. caule lignoso ramosissimo puberulo; fol. oppositis lanceolatis acutis ciliatis; fructibus glabris obovatis splendentibus. Gaertn. t. 195. f. 6. Plukn. t. 344 . f. 5. In Prom. b. spei. ђ.

10. A. scabrum Thunb. caule lignoso a basi ramoso; raw is ad apicem scabriusculis; fol. oppositis linearibus acuminatis 4-gonis margine et carina serrulato-scabris; fruct. splendentibus. In Prom. b. spei. $\downarrow$.

\section{c. Floribus dioecis panicu- latis.}

11. A. paniculatum Cruse; caule ramoso lignoso puberulo; fol. oppositis subspathulato-linearibus; floribus paniculatis ; fruct. 3-costatis. In Prom. b. spei. 古.

12. A. rigidum Ecklon et Zeyh. caulihus strictis lignosis e radice ramosissimis ; fol. oppositis lineari-lanceolatis acutis subscabris margine revolutis glaberrimis ; floribus verticillatis. In Africa australi. t. Semipedalis. Flor. purpurascentibus.

\section{GALIUM Scop. (18/6).}

I. śpecies perennes.

1. Leiogalia DC. fol. 6-10-ra$r$ is im e $4-5-$ is; floribus cy in 0 so-paniculatis hermaphroditis albis; fructibus glabris.

1. G. sylvaticum I. fol. octonis verticillatis lato-lanceolatis laevibus subtus glaucis, floralibus binis; caule geniculato nodoso; pedunc. virgineis nutantibus. G. laevigatum Vill. G. internedium schult. G. glaucum Fl. Dan. 609. In Europa. 4. 2-pedale glaucescens.

2. G. aristatum L. fol. octonis lanceolato-linearibus cuspidatis laevibus utrinque viridihus; pedunc. capil- laribus; corollis mucronatis. G. linifolium Lam. G. Schultesii Vest. G. glaucum Sut. In Germania australi et Gallia. 4.

3. G. paschale Forsk. caule dehili glabro laevi; fol. octonis linearilanceolatis margine retorsum scabris mucronatis. Circa Bysantium.

t. G. incurvum Sibth. gr. t. 132. caule paniculato; fol. octonis linearibus glabris aristatis deflexis incurvis; cor. laciniis muticis. In ins. Cretu. 24.

5. G. subtrifirum Reinw. caule virgato obverse scabriusculo; fol. subsenis brevibus anguste spathulatis subscabris. In montibus Javae.

6. G. apiculatum Sibth. gr.t.129. caule incano; fol. senis lanceolatis scahriusculis; corolla apiculata. In Parnasso. 4.

\%. G. incanum Sibth. gr. t. 130. fol. senis linearibus cauleque incanis; pedunculis 3-floris; corollae lobis aristatis. In Parnasso.

S. G. obliquum Vill. dauph. $t .8$. caule adscendente 4 -gono inferne villoso; fol. octonis inf. obovatis villosis, sup. linearibus glabris; corollis acuminato-setaceis. G. mucronatum Lam. In Europa media. 4.

9. G. laeve Thuill. caule diffuso adscendente decumbenteve laevi glabro; fol. octonis lanceolatis acutis mucronatis glabris, imis obovatis. G. austriacum Jacq. austr. t. 80. G. pusillum E. B. 74. G. glabrum Sut. G. sylvestre Rchb. In Europa. 4.

10. G. alpestre Gaud. caespitosım; glabrum; adscendens ; rigidulum; fol. octonis obverse lanceolatis margine laeviusculis; corolla non aristata. $G$. anisophyllum, pusillum, montanum et argentuun Vill. In alpinis Galliae et Germaniae. 4.

11. G. Bocconi All. caule adscendente 4-gono inferne pubescente; fol. octonis lanceolatis mucronatis, iufumis latioribus pubescentibus. G. sylvestre hirsutum $M$. et K. G. unbellatum Lam. G. scabrum Pers. G. nitidulum Thuill. G. asperuu Schreb. G. Marchandi Lapeyr. G. multicaule eriophyllum Wallr. Bocc. Mus. t. 101. Barr. ic. t. 75. Ad sepes Gulliae, Germuniae et Italiae.

12. G. pumilum Lam. ill. $t .60$. f. 2. fol. suboctonis lineari-setaceis erectiusculis laevibus; pedunculis sul- 
nmbellatis; corollae laciniis 3-nerviis; radice repente. G. trichophyllum All. G. hypnoides Vill. In uliginosis Europae. 4.

13. littorale Guss. caule rigido 4gono; ramis approximatis; fol. suboctonis lanceolato-oblongis apice dilatatis mucronatis margine subserratis patentibus s. reflexis. In maritimis Sicilitue. 21.

11. G. supinum Lam. caule procumbente filiformi subramoso laevi; fol. senis obovato-linearibus margine aculeato-scabris. G. sylvestre pumilum M. et K. G. multicaule polyphylIum Wallr. Juss, act. par. 1714. t. 15. In Europa. 4.

15. G. tyrolense Willd. caule flaccido 4-gono laevi; fol. senis obovatolanceolatis mucronatis margine scabris; corollae lobis aristatis. G. splendens Hornem. In mont. Tyrolensibus. 24.

16. G. cinereum All. ped. $t .19 \%$. f. 1 . caule erecto ramosissimo hasi lignescente 4-gono laevi; fol. subsenis lineari-ellipticis subtus glaucis rigidis mucronatis margine reflexis; corollae lobis mucronato-setaceis. In apricis Galliae. 4.

1\%. G. erectum Huds. caule erecto superne ranioso 4 -gono laevi aequali ; fol. subsenis lineari-lanceolatis mucronatis rigidis margine aculeatoserrulatis; cor. Iobis acuminatis. G. lucidum All. ped. t. 87. f. 2. G. scabrum Jacq. austr. t. 422. In Europa. 4 .

18. G. Mollugo $I$. caule flaccido geniculato-noduloso; fol. octonis ellipticis obtusiusculis mucronatis margine scabris. Fl. Dan. 455. E. B. 1673. Sv. Bot. 357. In Europu. 4. Caul. $1 \frac{1}{2}$-ped. Fl. albi.

19. G. fruticosum Willd. caule suffruticoso glabro 4-gono; fol. quaternis linearibus obtusissimis glabris; cor. Iaciniis acuminatis. in Creta. $\hbar$.

20. G. mediterranenm DC. caule adscendente 4-gono laevi; fol. infimis quaternis obovatis mucronulatis, reliquis senis lineari-subulatis; cor. laciniis aristatis. In Corsica. 24.

21. G. maximum Moris; glabrum; caule laeviusculo ramosissimo erecto; fol. senis linearibus margine antrorsum scabriusculis. In Sardinia. 4.
22. G. ibericum Gaud. glahrum; canle decumbente ramosissimo; fol. obovatis apiculatis aculeato-serratis senis quaternisque; cor. laciniis filamentosis. In petrosis Helvetiae. 4.

23. G. pyrenaicum Gou. ill. t. 1. f. 1. caespilosum; glaberrimum; flavescens; fol. senis linearibus acutissimis erectis approximatis basi subtumidis. G. muscoides Lam. In $\boldsymbol{P y}_{y}$ renaeis. 4.

21. G. Vilursii Req. caule flaccido filiformi glahro ramosissimo; fol. quaternis senisque oblongo-linearibus mollibus mucronatis margine laeviusculis; cor. laciniis muticis. G. megalospermum All. ped. t. 79. f. 4. In alpibus Pyrenceorum. 24.

25. G. nliginosum $\boldsymbol{L}$. caule dehili angulis scabris; fol. senis linearilanceolutis margine nervoque retrorsum serrato-aculeatis mucronatis rigidis. E. B. 1972. schrad. spic. t. 1. f. 1. Fl. Dan. 1509. Hook. Lond. t. 21. In turfosis Europae. 2!.

26. G. Hetodes Holfmss. caule debili difuso scahro; fol. quinis senisque lanceolato-linearibus mucronulatis supra margineque scabris. G. uliginosum Brot. In paluilosis Lasitaniae. 4.

27. G. palustre $L$. caule flaccido; fol. subspathulatis lineari-ellipticis inaequalibus; cor. lohis ovatis muticis. FI. Dan. 423. E. B. 185\%" Hook. Lond. t. 20. G. torfaceum schlech. G. constrictum Chanb. G. debile Desv. In paludosis Europae. 4.

28. G. suberosum Sibth. gr. t. 128. caule diffuso ramosissimo laevi; fol. quatemis lanceolatis acutis glabris. In montibus Cretae. 4.

2.9. G. satureinefolium T'rev. callle flaccido angulis scahris; fol. senis quaternisque lineari-lanceolatis inaequalibus; fructibus sphaeroideis emarginatis. In arundinetis Tamriae. 4.

30. G. trifidum $\boldsymbol{L}$. caule procumbente hispidulo; fol. quaternis senisque ohlongo-linearibus obtusis glabris; cor. Iobis obtusis. F1. Dan. 48. In alpibus Europae. 24. Planta tenella 2-4-pollicaris.

31. G. tinctorium $L$. caule diffuso laevi; fol. 4-senis linearibus acutis subscabris; cor. Iobis obtusis. In America boreali. 4.

32. G. obtusum Torrey; caule procumbente 4-gono laevi; fol. qua- 
ternis lanceolatis ohtusis margine nervoque asprellis; cor. lohis acutis. Circa Boston. 4.

33. G. asprellum Michx. caule diffuso ramosissimo $\mathbf{4 - g o n o , ~ a n g u l i s ~}$ retrorsum scabris; fol. senis lanceolatis actminatis nervo margineque aculeatis; cor. lohis muticis. In humidis Canadae et Virginiae. 4.

3t. G. helvelicum Weig. caule caespitoso debili glabro; fol. oblongolinearibus mucronulatis attenuatis margine scabris; cor. laciniis obtusis. G. baldense spr. In Europa australi. 2 .

3.5. G. hercynicum Weig. caule procumbente glabro; fol. oblongis acute mucronatis glabris; fructu didymo tuberculis parvis gramuloso. DC. ic. t. 25. G. saxatile Moench. G. multicaule var. Wallr. In sylvis montosis Eurouge. 4.

36. G. asperifolium Wall. caule ramoso debili 4-gono, angulis pilis recurvis scabro; fol. oblongo-linearibus cuneatis mucronatis supra sparse scabris subtus recurvo-pilosis. G. parviflorum Don. In Nepalia.

3\%. G. aetnicum Biv. radice repente; caule 4-gono laevi; fol. mucronatis margine serrulato - aculeatis, inf. spathulatis, sup. linearibus; cor. laciniis aristatis. Guss. fl. sic. ined. t. 63. f. 1. G. trinacrimm R. et $\mathbf{s}$. G. aetnense Presl. Iii Sicilia. 4.

35. G. frutescens Car: ic. t. 206. f. 1. caule suffruticoso erecto; ramis 4-gonis glabris; fol. senis linearibus glabris mucronatis margine revolutis. In Hispania. 4.

39. G. debile Hoffmss. caule debili 4-gono ramoso scabriusculo; fol. linearibus brevissime mucronulatis margine scabriusculis, aculeis antrorsis. In pratis Lusitaniae. 4.

40. G. junceum Nibth. gr. $t .2 \%$. caule erecto laevi; fol. quaternis ol)ovato-linearibus obtusis glabris. In ins. Creta. 4.

2. PlatygaliaDC. Perennia; fol. latis quaternis; flor. hermaphroditis plerumque albis; fructibus glabris.

41. G. tataricum Trev. caule 4angulo, angulis retrorsum scabro; fol. lanceolatis acuminatis 1-nerviis scabris. In 'l'artaria. 4.

42. G.latifolium Michx. caule erecto laevi; fol. ovali-lanceolatis acuminatis 3-nerviis membranaceis ; nargine nervisque minutissime lispidulis. In montibus Carolinae. 24. FI. alropurpurei.

43. G. rubioides $\boldsymbol{I}$. caule stricto 4-gono glabritusculo; fol. ovato-oblongis 3-nerviis rigidis subtus scahris; bracteis ovato-ohlongis. Buxb. Cent. t. 29. G. dilfusim schuad. In Europa et Sibiria. 4.

4. G. articulatum Lam. caule adscendente nodoso 1-gono; fol. ovalolanceolatis 3-nerviis margine scabris; bracteis ovatis. Valantia Lam. ill. t. 843. f. 3. G. rubioides Bieb. G. articulatum et geniculatum. R. et S. In Tauric et Oriente. 24. Flores ochroleuci.

4.5. G. valantioides Bieb. caule suberecto basi ramoso angulis laevibus; fol. rlombeo-lanceolatis obtusis 3-nerviis utrinque scabridis; panicula ramosissima. In Caucaso.

3. Trichogalia. Perennia; fol. 4-decimis; floxibus cymosopaniculatis hermaphroditis saepissime albis; fructibus hispidis.

46. G. caspicum Stev, totum villosum; caule obsolete 4-gono; fol. inf. octonis lanceolato-oblongis, summis oppositis; ramulis fructibusque villosis. In Persia. 4.

1\%. G. rotundifolium $\boldsymbol{L}$. caule diffuso glabro; fol. subrotundo-ovatis 3 nerviis ciliatis; fructu glohoso setis uncinatis hispido. G. decipiens Elırh. Asperula laevigata $\beta$. Lam. Bocc. sic. t. 6. f. 1. Moris. sect. 9. t. 21. f. 5 . Barr. ic. t. 323. In Europa. 4.

48. G. ellipticum Willd. caule erecto hirsuto; fol. ovalibus trinerviis hirsutis; fructu globoso setis uncininatis hispido. G. Barrelieri Salzm. B. ic. t. 324. Bocc. sic. t. 6. f. 1. G. rotundifolium v. b. $R$. et $S$. G. coalifolium. Schott. In Corsica, Sardinia et Sicilia. 24.

19. G. obovatum $\boldsymbol{H}$. et $\boldsymbol{K}$. caule subsimplici piloso; fol. quaternis petiolatis obovatis acutis ciliatis; fructi- 
hus unciuato-hispidis. In Quito. 4. Cor. albo-violacea.

50. G. Javaricum Blume; ramis 4-gonis hirtis; fol. obovato-subrotundis 3-nerviis margine subtusque in venis pubescentibus. In montosis $\boldsymbol{J a -}$ vae.

51. G. Neesianum Req. caule adscendente suberecto ramoso 4 -gono molliter hirsulo; fol. subrotundo-ovatis brevissime cuspidatis 3-nerviis hirsutis; fructu setis uncinatis hispidissimo. G. hirsutum Nees et Buch. hor. phys. ber. t. 22. G. ovalifolium scliott. In Tenerifia. 4.

52. G. elegans Wall. caule diffuso adscendente 4-gono hirsuto; fol. ovalibus 3-nerviis subtus margineque villosis; fructu setis uncinatis hispido. In Nepalia. 4. Radix repens. Fructus minimi.

53. G. Hamiltonii Spr. caule erecto ramoso piloso; fol. oblongis acutis utrinque pilosiusculis; fructibus hispidis. G. latifolium Don. In Nepalia. 4.

54. G. hirtiflorum Req. caule debili ramoso scabro; fol. liuearibus obtasiusculis supra glabris; subtus scabridis; cor. extus setosa; fructu setis uncinatis hispido. G. ciliatum Don, G. Aparine Fl. ind. In Nepalia Wall. 2.

55. G. uncinulatum DC. caule debili diffuso ramoso 4-gono, basi hispido; fol. ovalibus acutiusculis utrinque hispidis 3-nerviis; fructibus uncinulatohispidissimis. In Mexico. 4 .

56. G. eriocarpon Bartl. in $h$. Haenk. suffruticosum glabrum erectum; fol. oblongis 1-llervibus; fructibus setis fructu longioribus apice uncinatis hispidissimis. In Chili. ち.

5\%. G. trichocarpum DC. caule dichotomo ramosissimo glabro 4-gono, angulis retrorsum scabris; fol. quaternis oblongo-linearibus carina margineque scabris; fructibus uncinatohispidis. In Chili.

58. G. boreale DC. caule stricto 4-gono glabriusculo; fol. lineari-lanceolatis 3-nerviis glabris; bracteis ovato-orbiculatis. G. hysopifolium Hoffm. G. rubioides Poll. Fl. Dan. 1024. E. B. 105 In Europa. 4.

59. $G$. septentrionale $R$. et $S$. caule stricto 4-gono ad nodos puberulo; fol. oblongo-lanceolatis 3-nerviis basi ciliatis; bracteis oblongis acutis.
G. horeale Pursh. In America boreali. 4.

60. G. circcezans Michx. caule erecto laevi; fol. ovalibus obtusis laevibus 3-nerviis margine et secus nervos ciliato-scabris; fructu cernuo setis uncinatis hispido. G. borealc Walt. G. brachiatum Muchl. G. circaeoides $\mathrm{h}$. et s. In Canada et Nova Hollandia. 4.

61. G. brackiatum Pursh; caule flaccido elongato brachiato ramoso hispido; fol. oblongo-lanceolatis acuminatis glabris margine carinaque setacco-ciliatis; fructibus uncinato-hispidis. In Nova Anglia et Virginia. 24.

62. G. cuspidatum Muhl; caule prostrato glabro; fol. subsenis lanceolatis acuminatis subciliatis; cor. laciniis acuminatis; fructibus albopilosis. In Carolina et Georgia.

63. G. hispidulum Michx. caule procumbente ramosisimo hispido; fol. ovali-lanceolatis acuminatis margine revolutis rugosis utrinque hispidis. In Carolina inferiore. 4.

61. G. puncticulosum Michx. cauercto ramoso glabro; fol. ovatis obtusis glabris nargine nervoqne pubescentibus pellucide punctatis. G. punctatum Pers. G. Bermudianum Pursh. In humidis Carolinae. 4.

6.5. G. triflorum Michx. caulo procumbente 4-gono hispido aut glabriusculo; fol. oblongis cuspidatis 1-nerviis margine scabridis; fructu setis uncinatis hispido. Willd. berol. t. 66. G. cuspidatum Muhl. G. suaveolens Wahlenb. G. bryophyllum Goldb. In America boreali, Unalaschlia et Suecia. 4.

66. G. maritimum $L$. totum villoso-hirtum; caule ramosissimo 4-gono; fol. ultimis oppositis lanceolato-linearibus acutis; cor. extus fructibusque piloso-hispidis. Barr. ic. t. 81. Bocc. mus. t. 86. In apricis Nicaede et Oriente. 24. Cor. rubens.

67. G. brachyphyllum Schult. glabriusculum ramosissimum procumbens; fol. senis summis oppositis lanceolatis mucronatis reflexis; fructibus pubescenti-scabris. G. brevifolium Stev.

In calcareis Caucasi. 24.

68. G. graecum $L$. caule suffruticuloso basi subramoso; ramis hispidis erectis; fol. senis puberulis strictis; 
fructihus Jonge hispidis. Sibtlı, gr. $t$. 136. Lodd. B. C. 1373. Pr. Alp. exot. t. 166. In apricis Graeciae et Cretae. 2. Fl. minimi purpurascentes.

69. G. canum Req. caule suffruticuloso caespitoso ; ramis hirsutissimocanis; fol. lanceolatis margine revolutis hirsutis subtus canis; fructibus hispidis. In Syria. 4. Fl. minimi purpurascentes.

\%0. G. micranthum Pursh; caule ramosissimo divaricato retrorsum aculeato; fol. brevibus lanceolatis mucronatis glabris margine carinaque aculeatis; fructibus hispidis. In America boreali. 4.

4. Coccogalia DC. Perennia? fol. quaternis; floribus longe pedunculatis hermaphroditis ; fructibus granulatis.

71. G. cotinoides Cham. et Schlecht. caule debili 4-gono angulis retrorsum spinuloso; fol. sessilibus lanceolatis nervo et margine scabris; fructibus minutim tuberculatis. In Chili.

72. G. lanuginosum Lam. caule ramis pedunculisque pilis longis mollibus densis alho-lanuginosis ; fol. lanceolatis acutis glabris margine scabris; fructu glabro minution tuberculato. In India orientali.

73. G. tomentosum Thumb. caule scandente glabro ramosissimo 4-gono, angulis hispido-serratis; ramis pilis albis densissime tectis; fol. oblongis serrato-scabris. G. maritimum Thunb. In Prom. b. spei.

7. G. capitatum Bory et Chaub. fol. 6-8-nis lineari-lanceolatis mucronulatis pilosiusculis scabris; caulibus 4-angulis ramosissimis flexuosis; floribus capitatis; fructu corollisque pilosis exiguis. In Morea. 4.

5. Erythrogalia DC. Perennia; fol. senis; floribus hermaphroditis cymoso-paliculatis pur-

pureis; fructibus glabris.

75. $\boldsymbol{G}$. purpureum $\boldsymbol{L}$. caule erecto suffruticoso ramosissimo glabro; fol. lineari-setaceis; cor. laciniis apiculatis; fructu glabro. Nocca et Balb. fl. sic. t. 3. G. rubrum Scop. G. sylvestre Schleich. In Europa et Graecia. 占.
76. G. rubrum L. caule herbaceo debili glahro; fol. linearibus patulis glabris ; corollae lohis apiculatis ; fructu glabro. Nocc. et Balb. fi. Sic. $t$. 4. G. purpureum Schleich. In Europa. 4.

6. Xanthogalia. Perennia; fol. 6-decimis; florihus luteis omnibus hermaphroditis paniculatis.

7\%. G. rupestre Vis. caule erecto 4-gono tenuissime velutino apice glabro; fol. lineari-lanceolatis subcumeatis nucronatis glabris, margine subscabris; cor. lobis acuminatis; fructu glabro. In rupestribus Dalmatice. 24.

78. G. verum $L$. caule suberecto 4-gono; fol. linearibus sulcatis margine revolutis laevibus; fructibus glabris s. hirtis. G. verum $\alpha$. lenophyllum Wallr. $\beta$. traeliyphyllum IVallr. Mill. ic. t. 129. Fl. Dan. 1146. Mart. fl. rust. t. 51. $\gamma$. trachycarpon DC. G. ruthenicum Villd. G. verosimile Schult. In apricis et pratis Europae et Sibiriae. 24. Fl. Intei.

79. G. vero-mollugo Wallr. caule 4-gono subpubescente; fol. sublanceolatis linearibus scabriusculis stubtus puberulis; cor. acutis ochroleucis. $G$. Mollugo $\beta$. Rchb. In Germania. 4.

80. G. Tunetanum Lam. caule erecto tereti canescente; fol. linearibus pubescentibus mar.gine revolutis asperis; fructibus hispidis. In sepibus Algeriae. 4.

81. G. minutum $L$. caule decumhente laevi; fol. Ianceolatis mucronatis serrato-aculeatis glabris incurvis; pedunculis reflexis; fructibus carnosis. In imp. Ruthenico. 4.

82. G. humifusum Bieb. caule pro strato ramosissimo villoso; fol. linearibus patentissimis villosis; fructibus pubescentibus. In Caucaso et Tauria. 4. Fl. ochroleuci.

83. G. arenarium Lois. glahrum; caule prostrato ramosissimo; fol. lineari-oblongis apiculatis crassis margine revolutis; fructibus glabris subcarnosis. G. minutum Aubr. In arenosis maritimis Galliae. 4. Fl. lutei.

\%. Ericogalia DC. Perennia aut suffruticosa; fol. quaternis senisque; inflorescentia axillari; flor. hermaphroditis.

81. G. ericoides Lam. caule suf$30 *$ 
fruticoso ramosissimo pubescente; fol. lineari-lanceolatis margine revolutis apiculatis rigidulis glabriusculis; flor. axillaribus subsessilibus; fructu rigido piloso. In Montevideo et Chili. $t$.

S5. G. hirtum Iam. radice lignosa; caule herbaceo 4 -rono ramoso, folioso hispido; fol. sessilibus lanceolatis utrinque hirlis; cor. lobis acutis. G. reflexum Pohl. G. megapotanicum Spr. In Brasilia. 古.

86. G. camporum Pohl; slaberrimum; caule erecto 4-gono; fol. sessilibus linearibus acutis patulis margine revolutis longe ciliatis; fructu tenuiter granulato. In Brasilic.

8\%. G. amatymbicum Ecklon et Zeyh. totum scabro-hispidum; caule 1laccido filiformi 4 -gono ramosissimo; fol. 6-is sessilibus lanceolatis acutis; pedunculis capillaribus 1 -floris; fuctibus pilis brevissimis dense tectis. In Africa australi. 4.

88. G. Inumile Cham. et Schlecht. caule diffuso 4-gono filiformi piloso glabroque; fol. subpetiolatis ellipticis ntrinque acutis planis cuspidatis ciliatis; corollis apice pilosis; fructu globoso-didymo pubescente. In lirasilia.

8. Maschalligalia. Perennia; fol. quaternis; inflorescentia axillari; floribus polygamis ochroleucis.

89. G. coronatum Sm. caule procumbente, a hasi ramoso laevi; fol. ellipticis obtusis subaveniis margine basique ciliatis; fructu glabro. sibth. gr. t. 25. (3) glaherrimum. Valantia humifusa Willd. In monte Olympo, Tauria et Iberia. 4.

90. G. tauricum $\boldsymbol{R}$. et $\mathbf{S}$. caule decumbente ramoso hispido; fol. ellipticis reticulatis hispidis; pedunculis ciliatis bracteatis deflexis; fructibus pube hrevi hispidis. Valantia Pall. In Tauria. 4.

91. G. vernim Scop. caule erecto subramoso; fol. ovali-ellipticis revolutis 3 -nerviis ciliatis ; floribus polygamis; fuctilus glabris. Schk. t. 23. FI. Dan. 1116. Sv. Bot. 165. Valantia glabia W. K. hung. t. 32. G. Hallevi R. et. S. In:Europa. 4.

92. G. persicum DC. glaberrimum; laeve; erectum; multicaule; fol. oblongis $\mathbf{3}$-nerviis non ciliatis ; : fructibus glabris. In Persia. 4.
II. Species annuae. Aparine.

9. Cruciatae. Val antiae species L. Floribus polygamis; fructibus glabris aut pilosis.

93. G. retrorsum IOC. caule erecto simplici angulis retrorsum aculeato-hispido; fol. oblongis villoso-ciliatis; pelunculis fructiferis reflexis; fructibus glabris. G. pedemontanum Bieb. Valantia pedemontana W. K. lıung. I. 22. In Sicilia, Pannonia et Cancaso. $\odot$.

9). G. pedemontanum All. fol. ol)longis cauleque gracili simplici hispidis; pedunculis axillaribus pilosis, fructiferis reflexis. Valantia pedenontana Bellard. act. taur. V. t. \%. AII. auct. t. 5. V. hispida Lumn. G. chlorauthum Brot. In siccis Europae. $\odot$. Gracillimum, pedale. Fl. flavi.

9.5. G. Cruciata scop. fol. quaternis elliptico-oblongis 3 -nerviis reticulatis hirsutis pedunculis ramosis hispidis glabrisve bracteatis; fructibus glabris demum deflexis. Valantia cruciata L. Sturm 1. \%. Gallum E. B. 143. G. Valantia Fl. Wett. V. chersonensis Willd. V. ciliata Presl. In Europa. 4.

96. G. Gibraltaricum Schott. caule piloso angulos muricato; fol. infimis ovatis, summis oppositis, omnilus margine revolutis hispidis; cor. lobis cuspidatis. In montibus Gibraltariae. $\odot$ Fl. lutei.

97. G. piggmaeum DC. glaberrimum; a basi subranosum ; fol. quaternis subrotundis; fructibus globosis cernuis glabris. Valantia muralis Bieb. V. pusilla tev. In Iberia. $\odot$. Herba pusilla; fl. lutei.

98. G. corlatum R. et S. glabrum; erectiusculum; a basi ramosum; fol. obovatis inaequalibus floralibus sessilibus ovato-cordatis deflexis; fructibus glabris. In Oriente ad radices Libani. $\odot$.

10. Xanthaparines. Annua; fol. quaternis octonisque; inflorescentia cymoso-paniculata; floribus luteis hermaphroditis; fructibus glabris.

99. G. campestre Schousb. caule erecto 4 -gono angulis scaberrimis fol. ellipticis mucronatis margnie sca- 
bris; cor. lobis lanceolatis. In Barburia. $\odot$. Fl. ochroleuci.

100. G. ylomeratum Desf. atl. $t$. 40. cálule erecto ramoso; paniculato 4-gono angulis asperis; fol. linearilanceolatis mucronatis ad maryines serrulato-scabris; cor. lobis acutissimis aristatis. In Burbaria inter segetes. $\odot$.

101. G. viscosum Tahl; caule adscendente 4-gono laevi ramoso; fol. ohovatis lanceolatisque margine antrorsum serratis; pedunc. filiformibus; fuctibus viscosis. In montosis Tuneti. $\odot$. Fl. allido-flavescentes.

11. Leiaparines DC. Annua; fol. quaternis octonisve; inflorescentia cymoso-paniculata; floribus albis hermaphroditis; fructibus glabris.

102. G. Crvillei Req. caule erecto hasi ramoso glabro; fol. linearibus margine revolutis erectis glabris; fructibus glabris. G. fforibundum d $\mathbf{d}^{*} \mathbf{v}$. In aridis Archipelayi. $\odot$.

103. G. divaricatum Lam. caule adscendente ant erecto superne ramoso; fol. linearibus acutis hispidulis; pedicellis flore duplo longioribus; frutibus glabris. DC. ic. rar. t. 21. In Gallia, Liguria et Sicilia. $\odot$.

104. G. temissimum lieb. caule debili adscendente ramosissimo, angul is subscabris; fol. linearibus acutis scabris; pedicellis pedunculi longitudine; fructibus glabris. In Tauria, Caucaso et lberia. 4. Fl. parvi albo-virides.

10.5. G. anglicum Huds. fol. subsenis lineari-lanceolatis cuspiclatis antrorsum aculeatis ahbreviatis; caule a basi diffuso aculeato; cor. flavicantibus minutis ; fructihus granulatis. E. B. 384. G. gracile Walle. B. pructibus lispidis; G. parisicnse L. G. litigiosum DC. ic. rar. t. 26. Rochel. pl. bann. t. 8. f. 21. In Europa. $\odot$.

106. G. apricum Sibth. gr. t. 126. caule piloso difuso; fol. quaternis ob)ovatis uniformibus margine scabris. In rupibus Creiae et Áchipelatii. $\odot$.

10\%. G. Gaudicleaudii DC. caule debili decumbente 4-gono lispidulo; fol. oblongis linearibus margine revolutis hirtellis; corollae lobis acutiusculis; fructu glabro. In Nova
Hollandia legit Gaudichaud. $\odot$. Caul. 8-10-poll.

12. Euaparines. Aunua: caulibus scabris; fol. 4-snis; inflorescentia axillari floribus saepius hermaphroditis; fructibus granulatis hispidisve d i d ymo-globosis.

108. G. saccharatum All. caule debili ramoso, angulis retrorsum aspero; fol. lineari-lanceolatis maroine antrorsum scabris; pedunc. fructiferis recurvis folii longitudine; fructibus globoso-didymis verrucosis. G. verrucosun sin. E. B. 2173. Valantia Gmel. bad. V. Aparine L. Vaill, par. t. 4. f. 3. 1. In arvis Europae. $\odot$.

109. G. tricorne With. fol. suboctonis retrorsum aculeolatis; pedunc. trifloris; fiorihus ommibus pedicellatis; fructu granulato. F. B. 16+1. Vaill. par. t. 4. f. 3. Valantia Fotl. G. spurium Rotli. In Europa. ○. Pedale procumbens et scandens. Fl. albi.

110. G. spurium $L$. fol. subsenis lineari-lanceolatis margine cauleque retrorsum aculeatis; pedunculis ramosis divaricato-patentibus; fructibus reniformibus laevibus. G. agreste Wallr. G. hispidum Roth. B. fructibus hispidis; G. infestum W. K. t. 202. G. Vaillantii DC. Vaill. bot. par. 4. f. 4. In Europa. ๑. Pedale. FI. albi.

111. G. scaberrimum Tahl; caule angulato retrorsum scabro; fol. linearibus patulo-rentexis internodio longioribus mucronatis, supra scaberrimis, margine et carina aculeato-scabris; fructu globoso didymo setis uncinatis hispido. G. hispidum Willd. In Aegypto. $\odot$.

112. G. Aparine $L$. fol. octonis lanceolatis carinatis scabris retrorsum aculeatis; geniculis vilosis; caule flaccido. E. B. 816. Fl. Dan. 495. In Europa, Asia, America. ๑. 2-4ped.

113. G. aparinoides Forst. caule debili angulis antrorsum aculeatis; geniculis aequalihus glabris; fol. oblongis margine carinaque retorsum aculeatis; fructibus setis uncinatis hispidis. In umbrosis Arabiae. $\odot$.

111. G. australe $D C$. caule debili procumbente ramoso 4 -gono pilosiu_ 
sculo; fol. oblongis mucronato-acutis pilosiusculis margine subrevolutis; fructibus setoso-hispidissimis. In Nova Hollandia.

115. G. tenerum Schleich. fol. senis obovatis setaceo-mucronatis margine retorsum aculeolatis; caule filiformi glahro; fructu hispido. In alpibus altissimis Helvetiae, $\odot$. 2-poll.ped.

116. G. microspermum Desf: atl. canle erecto 4-gono glabro ; ramis divaricatis; fol. linearibus acutis denticulatis; fructibus hispidis. In Barbaria et Sardinia. $\odot$.

117. G, setaceum Lam. caule filiformi erecto inferne scabro; fol. lineari-setaceis margine scabris, infinis oblongis; fructu setis uncinatis hispido. G. microcarpum Vahl. G. capillare Cav. ic. t. 191. f. 1. G. capillare et microcarpum: Spr. G. floribundum Sm. et Sibth. gr. t. 134? In Europa et Graecia. $\odot$. Fl, rubri.

118, $G$, Sibthorpii $R$, et $s$. caule laevi; fol, linearibus revoluto-setaceis ccabris infimis ohovatis; pedicellis capillaribus; fructibus pilosissimis. G. capillare Smith. In Graecia. $\odot$.

119. G. brevifolium Sibth. yr. $t$. 135. caule villoso; fol. obovatis aristatis scabris; pedunculis trichotomis terminalibus; corollae laciniis aristatis; fructibus hispidis, In Graecia. $\odot$.

120. G. album Forsk. caule erecto ramoso pubescente; geniculis coloratis; fol. oblongis mucronatis margine subserrulatis scabris, subtus vilIosis; fructu hispido. In Smyrna.

121. G. recurvum Req. caule deblli decumbente ramoso glabriusculo; fol. obovato-oblongis basi angustatis apice acutiusculis glabris; pedumculis fructlferis deflexo-incurvis hirsutis; fructu minimo hispido. G, micranthum d'Urv. Sherardia muralis Sibth. In Graecia. $\odot$.

13. Asperae DC. Annua; fol. quaternis senisque; inflorescentia laterali; fructibus hicpidis oblongis microcarpiis angustis elougatis.

122. $G$. filiforme $R$. et $S$, caule simplici hispido 4-gono; fol. quaternis oblongis remote ciliato-denticulatis reticulatis glabris; fructibus oblongis paleaceis. G. minimum R. et S. Aparine minima All. Sherardia muralis $L$. In Teneriffa. $\odot$.

123. G. verticillatum Danth. fol. lanceolato-linearibus hispidis summis deflexis; flor. verticillatis; fructibus erectis hispidis. G. murale Bieb. In Sicilia et Gallia. $\odot$.

124. G. fragile Pourr. fol. ovatolanceolatis glabris; flor. solitariis in summitate pedunculatis. In Hispania. $\odot$. Fl. sordide albi.

\section{Species dubiae. * Europaea.}

125. G. Soleirolii Lois nouv. not. \%. caule debili angulato puluescente; fol. ovato-lanceolatis acutis hirsutis; fructibus perparum rugosis. G. corsicum Spr. In maritimis Corsicae. 4.

126. G. Goldlachicum Kluk. canle procumbente diffuso 4-gono; fol. anguste lanceolatis aristatis apice pilis cinctis; floribus umbellatis; fructibus globosis. In Gallicia.

12\%. G. pentandrum Kit. in Schult. oestr. fl. caule erecto ramoso; fol. lineari-subulatis apice albo-maculatis; racemo paucifloro; floribus 5-andris; fructu didymo. In Gallia. FI. flavescentes.

128. G. ochroleucum Kit. caule erecto 4-angulo laevi; fol, 8-is lineari-subulatis margine scaberrimis longe mucronatis; fl. campanulato-infundibuliformibus. In rup. Austriae. 4.

129. G. montanum $L$. caule debili scabro; fol. quaternis linearibus laevibus; corymbis :̈-fidis. In Germania, Gallia et Anglia. 4.

\section{** Orientalia.}

130, G. hierosolymitanum $I$, amoen. fol. 10-is lanceolato-linearibus; umbellis fastigiatis. In Palaestina. 4.

\section{**** Asiatica.}

131. G. tuberosum Lour. radice tuberosa oblonga; caule procumbente simplici; fol. 4-5-is lanceolatis glabris glaucis; pedicellis congestis axillaribus 1 -floris longiusculis; fructu aspero. Cultum in Cochinchina. 4.

132. G. strigosum Thunb. act, Ups. 7. t. 4. f, $1-9$. caule decumbente 4-gono secus angulos scabro; 
fol. senis ellipticis acuminato-spinosis; floribus axillaribus breviter pedunculatis. In Japonia.

\section{***** Capensia.}

133. G. mucronatum Thunb. calllibus pubescentibus debilibus 4-gonis; fol. senis linearibus mucronatis glabris margine revoluto-serratis; ramis paucifloris; fructu glabro. In Prom. b. spei. 4 .

131. G. horridum Thunb. caule suffruticoso erecto $t$-gono secus angulos scabro; fol. octonis linearibus aculeato-serratis reflexis. In Prom. b. spei. ち.

13.5. $G$. glabrum Thunb. caule flexuoso-erecto 4 -gono glabro angulis serratis; fol. senis ohovato-oblongis acutis margine replicato - serrulatis glabris; pedunculis amplis. In Prom. b. spei.

136. G. asperum Thumb. caule flexuoso-erecto piloso secus angulos retrorsum scabro; fol. senis oblongis glabris margine replicato-serrulatis; floribus paucis. In Prom. b. spei.

13\%. G. expansum T'tunb. caule 4-gono laevi; ramis divaricatis pubescentibus; fol. senis linearibus mucronatis glabris margine revolutis reflexis; panicula trichotoma patente divaricata; fructu laevi. In Prom. b. spei.

138. G. capense Thunb. caule hasi frutescente erecto ramoso; ramis teretibus pubescentibus; fol. 6-octonis linear-lanceolatis margine revolutis glabris; pedunculis dichotomis; fructu glabro laevi. In Prom. b. spei. ち.

\section{****** Boreali-americana.}

139. G. unifloruu IVichx. caulibus flaccidis laevibus; fol. quaternis linearibus acutis glabris; pedunculis axillaribus solitariis 1-floris brevissimis; floribus cernuis; fructu glabro. In Curolinu. 4.

1.t0. G. parriflorum Rafin, caulibus diffusis augulatis glabris; fol. quinis senisve lineari-lanceolatis actltissimis glabris; foribus paniculatis numerosissimis. In Neu-Castle et Delaware. Fl. albi minimi.

141. G. spinulosum Rnfin. diffusum ; fol. 4-senis cunciformihus cuspidatis spinulosis scabris; pedunculis lateralibus dichotomis unultifloris; fructibus scabris. In Marylandia.

142. G.? mexicunum H. et K. Non. Gen. caule retrorsum aculeato; fol. octonis linearibus acuminato-pungentibus glabris margine revolutis nervoque medio retrorsum aculeatis internodio duplo brevioribus; fructibus hispidis. In Mexico. $\odot$.

143. G. leucocarpon DC. caule diffuso 4-gono laevi ramoso; fol.quaternis mucronatis glahris; pedunculis axillaribus 1-floris; fructu glabro. G. mucronatum $\boldsymbol{H}$. et $\mathbf{P}$. $\mathbf{G}$. pedunculatum R. et $\mathbf{S}$. In aridis ad Tarmam Pernviae.

114. G.? denticulutum Bartl. Hb. Haenk. caule diffuso ramoso hispidulosetoso; fol. quaternis ovatis cuspidatis setis distantibus dentato-ciliatis utrinque subhirsutis 1-nerviis; pedicellis capillaribus; fructibus glabris. In Mexico.

1.5. G, hirsutum $R$. et P. peruv. caulibus procumbentibus 4-gonis ramosissimis hirsutis; fol. quaternis lanceolatis reflexis hirsutis; pedunculis axillaribus 1-floris; fructibus scabris. In Peruria. $\odot$.

146. G. piliferum $\boldsymbol{H}$. et K. Nov. Gen. caule debili retrorsum aculeato; fol. octonis lineari-lanceolatis acuminato - piliferis glabris margine subrevolutis nervoque medio retrorsum aculeatis internodio multo brevioribus; fructibus hispidis. In Nova Granata. $\odot$.

11\%. G. canescens $H$, et $\boldsymbol{K}$. Nov. Gen. caule glabriusculo; ramulis foliisque piloso-villosis quateruis ovatis acuminatis triplinerviis subtus cauescentibus internodio multo brevioribus; ramulis floriferis bifidis; fructibus uncinato-hispidis. In Quito. $\odot$ ?

1.15. G. Caripense $H$. et $\boldsymbol{K}$. caule glabro retrorsum aculeato; fol. octonis super senis oblongo-lanceolatis mucronutis margine retrorsum aculeolatis internodio multo brevioribus; fructibus lispidis. In sylvis Cumanae. $\odot$ ?

149. G. lappaceum $\boldsymbol{R}$. et $\boldsymbol{P}$. caulo subscandente ramosissimo villoso 4gono ; fol. oblongis obovatisve quateruis hispidis, summis ternis lanceolatis; fructibus setis hispidis. In Peruvia. 
Patria iguota.

150. G. dichotomum Lehm. caule dichotomo frutescente quadrangulo; fol. quateruis obovato-Ianceolatis; fructibus glabris. 4.

1.51. G. rigidum Ait. caule erecto tereti piloso scabriusculo; fol. verticillatis linearibus supra scabris; paniculis divaricatis. 24 .

152. G.namaquense Eclilon et Zeyl. canle decumbente 4-angulari ramoso; fol, 5-is lanceolato-linearibus cuspidatis divergenti-reflexis supra aculeis adpressis subtus glabris. In Africa australi, Caul. purpurascens.

\section{ASPERULA Dodon. (1559).}

1.Perennes; corollis tubulos o-infundibuliform i bus.

1. A. tinctoria L. erectiuscula; fol. linearibus floralibus ovatis; floribus plerisque 3-fidis. Sv. B. 214. In sax. Europae. 24. 1-ped. Fl. albi. Rad. crocea.

2. A. laevigata L. fol. quaternis oblongis obtusis margine scalris venosis; ramis divaricatis ; fructu scabro. Moris. hist. 3. t. 24. f. 4. Hah. Galii rotundifolii. In Europa anstrali.24.

3. A. taurina $L$. fol. quaternis ovato-lanceolatis acutis 3-nerviis ; flor. longe tubulosis fasciculatis basi hirsutis. A. trinervia Lam. Barr. ic. 547. In Europa meal. 4. Hl. Iilacini.

4. A. hexaphylla All. peal. t. 18\%. f. 3. adscendens; fol. senis rigidulis glalıris laevibus linearibus; flor. unbellatis; bracteis acutis. In alp. Pedemontii. 4. Fl. purpurei.

5. A. cynanchica $\mathcal{L}$. caule elongato flaccido; fol. quaternis linearibus internodiis brevioribus, floralibus acuminato-aristatis. E. B. 33. In Europa. 2l. Fl. lacteo-rubescentes.

6. A. lirta Ramond. bull. $n .41$. t. 9. $f: 1,2,3$. caespitosa; erectiuscula; fol. senis linearibus acntis hirtis internodio longioribus; fructibus glahris. In Pyrenaeis. 24. FI. albi extus purpurascentes.

\%. A. Congifiora W. K. lung. $t$. 150. fol. linearibus glabris cuspidatis, infimis abbreviatis quaternis, sup. elongatis; laciniis corollae surstim deorsum dentatis. A. faccida Ten. B. aristata L. fil. Fl. flavo-virentibus. In alp. Germaniae. 24. Fl. rubri.
8. A. rupestris Rchb. glabra; viridis; diffuso-flaccida; fol. subsenis lineari-lanceolatis acutis margine revolutis scabris; cor. obtusa. Galium Vis. In Dalmatia. 4.

9. A. montana Kit. fol. linearibus acutis inferioribus senis, sup. 4-nis, summis oppositis; caule laevi erecto; floribus extus scabris. In Europa. 4.

10. A. ciliata Roch. fol. linearilanceolatis inf. senis, sup. quaternis margine scabro-revolutis, summis oppositis ovato-lanceolatis ; fructu granulato. Roch. Baln. t. 9. f. 22. In Banatu. 24.

11. A. galioides $\boldsymbol{M}$. B. glanca; fol. 8-nis linearibus; caule paniculato; corolla campanulata. Gal. glaucum Jacq. austr. t. 81. G. companulatum Vill. t. 2. Gmel. t. \%. Ad rupes Europae. 24. 1-2-ped. Fl. albi.

12. A. odorata L. fol. 8-nis lanceolatis; florum fasciculis pedunculatis; fructu hispido. Fl. Dan. 562. schk. t. 23. E. B. 755. In umbrosis syluaticis Europae. $4 . \quad \frac{I}{2}$-ped. Fl. albi odorati.

13. A. supina Bieb. glahra; caule Lasi ramosissimo procumbente; fol. ohovatis; bracteis minimis elongatis. In calcareis Tauriae. 24. Aff. A. cynanchicae sed FI. albi.

11. A. lutea Sm. caule erecto; fol. linearibus glabris; floribus pubescentibus fasciculatis subaristatis. Sibth. gr. t. 120. In monte Parnasso. 4. Fl. flavescentes.

15. A. brevifolia Vent. Cels. t. 63. glabra; decumbens; fol. brevissimis distantibus; stylo ad basin bipartito. In mont. Carcamaniae.2. Fl. intense purpurei.

16. A. hirsutu Desf. suberecta; fol. linearibus acutis margine revolutis; floribus fasciculato-umbellatis ; bracteis minimis. A. repens Brot. lus. t. 10. A. algerica Pers. In Algeria. 4: Fl. purpurascentes.

17. A. tomentosa Ten. fl. neap. t. 9. adscendens; lota velutino-tomentosa; fol. linearibus margine revolutis, infinis obovatis. Prope Neapolin. 4.

18. A. incana Sibth. gr. t. 11. fol. senis linearibus incanis; floribus fasciculatis terminalibus pubescentibus. In montibas Cretae. $2 \%$.

19. A. Arcadiensis Sims. B. M. 21-16. hispidula; decumbens; fol. senis oblongo-ovatis acutis margine revolu- 
tis; stylo apice summo bifido. In $\mathrm{Ar}$ cadia. 21. FI. rosei.

20. A. debilis Letleb. piloso-hispida; fol. lineari-lanceolatis supra scahris carina laevibus; cor. infundibuliformi; fructu granulato. In T'utvia. 24 .

21. A. nitilla Sibth. gr. t. 124. glabra; caule diffuso dense caespitoso; fol. ovalibus linearibusque nitidis glancescentibus; cor. aristata; tubo ampliato. In Olympo Bithynico. 24. 17. purpurei.

22. A. scabra Presl del. may. caule scahro geniculato; fol. oblongis, summis minimis aristatis pubescentihus; corollis rugoso-scal)ris mucronatis. A. digyna Duf. A. macrorrhiza Lk. In arillis Siciliae. 4 .

23. A. alpinu Bieb. tota tenuissime pubescenti-scabra ; caule procumbente ramosissimo; fol. linearibus. In al $)$. Caucasi. 24.

2t. A. cretacea Willd. caule caespitoso prostrato; fol. senis lanceolatis; verticillis imbricato-approximatis. In cretaceis Syriae. 4.

25. A. littoralis Sibth. gr. t. 122. caule scabro; fol. linearibus scabris; floribus pilosis; fructu hispido. $A d$ littora maris Euxini. 24.

26. A. neglecta Guss. pl. rar. t. 13. $f$. 1. hirta; caule adscendente; fol. acutis infimis obtusis; fructu globoso hispido. In aridis Aprutii et Sardinicie. 24. Fl. intus albidi extus purpurascentes.

2\%. A. nitens Guss. l. c. t. 13. f. 2. caule caespitoso decumbente; fol. nitidis glaberrimis; fructu muricatotuberculato. Ibid. 4.

28. A. rigida Sibth. gr. t. 121. caule diffuso pubescente; fol. linearihus; floribus sparsis; fructu glabro. In collibus Cretae. 4.

29. A. suberosa sibth. gr. t. 123. caule caespitoso adscendente; fol. linearibus subincanis; rad. suberosa. In rup. Graeciae. 4.

30. A. longifolia Sibth. gr. t. 118. fol. lineari-lanceolatis deflexis margine scabriusculis; paniculis capillaribus; fructu laevi. Ad pagum Belgrad. 4.

2. Annuae; corollis tubulosis infundibuliformibus.

31. A. arvensis $L$. fol. senis lineari-Ianceolatis; florum fasciculis sessilibus; bracteis involucrantibus; fructu glahro. In agris Europae. $\odot$. $\frac{1}{2}$-ped. Nl. lilacini.

32. A. ciliuris DC. caule adscendente angulato glabro; fol. lanceolatolinearibus acutis bracteisque ciliis rigidis serratis; stylo exserto. In Persia. $\odot$.

33. A. trichodes Gay; caule erecto ; fol. glabris subulato-filiformibus; cor. minimis extus pubescentibus; fructu ovato brevissime pulbescente. In Persia. $\odot$. Fl. albido-virides.

\section{Galioideae; perenues; co-} rollis campanulatis.

31. A. rivalis Sibth. gr. t. 11\%. fol. octonis ovali-lanceolatis cauleque succulento fragili retrorsum aculeatis. Rchb. ic. 199. A. Aparine schott. In Gallicia, 'Tauria, Volhynia et Rossia. 24. F'l. albi.

3.5. A. subrelutina DC. caule pube minima velutino; fol. lato-linearibus obtusis subvelutinis; floribus minimis. In Persia. 24.

36. A. lumifusa Bieb. caule prostrato ramosissimo hispido 4-gono; fol. -linearibus reflex0-patentibus margine hispido-scabris. In Cancaso. 4.

\section{Species dubiae.}

\section{3\%. A. umbellata Willd. Hb. In} Hungaria.

35. A. involucrata Bergr. caule decumbente; fol. quaternis obovatoelongatis obtusis glabris. In fruticetis Orientis.

39. A. Tournefortii Sieb. exs. caulle stiffruticoso erecto; fol. obovatooblongis glaucis; verticillis approximatis; floribus subfasciculatis hispidis. In Creta. $\hbar$.

\section{VALANTIA Tournef. (1806).}

1. V.muralis $L$. caule foliis calycibusque glahris. Moris. hist. 3. s. 9. t. 21. f. 2. In asperis Europae australis. $\odot$. Planta humilis.

2. V. hispida L. caule hispido; fol. ciliatis; calycibus pilosis. Galium Gaerti. t. 24. f. 1. G. Calepharophon R. et S. In Teneriffa, Hisp., Ital., ins. Balearicis et Barbaria. $\odot$. 
55.5. SHERARDIA Dillen. (1819).

1. S. arvensis $L$. fol. subsenis Ianceolatis cuspidatis scabris; floribus capitatis involucratis. Schk. t. 22. Fl. Dall. 439. E. B. 891. In agris Europae. $\odot$. Fl. roseo-lilacini.

2. S. pusilla Bory et Chaub. prostrata; fol. Ianceolato-oblongis; floribus solitariis axillaribus; fructu truncato. In Morea. 24. Herba pusilla.

\section{CRUCIANELLA L. (173\%).}

a. Floribus spicatis.

1. C. angustifolia $L$. spicis linearibus basi interruptis; fol. senis linearibus; caule erecto. Lam. ill. t. 61. Barr. ic. 550. In siccis Europae australis. $\odot$. Fl. albidi.

2. C. latifolia I. spicis linearibus; fol. subsenis inferioribus ovatis, summis linearibus; caule erectiusculo. sibth. gr. t. 139. Barr. ic. 549. In subulosis Europae et Graeciae. $\odot$. Fl. albido-subvirescentes.

3. C. monspeliaca $\mathrm{L}$. spicis cylindrico-elongatis; fol. acutis, caulinis quaternis ovatis, rameis quinis linearibus. Sibth. gr. t. 140. C. Iatifolia $\gamma$. monspeliaca DC. In Europa australi et Graecia. $\odot$.

4. C. glauca A. Rich. suffruticulosa; erecta; glauca; fol. linearibus margine revolutis; bracteis ciliatis; floribus pentandris. In Persia. 4.

5. C. ciliatc Lam. diffusa; fol. linearibus acutis; spicis subinterruptis; fructu undique tuberculis obtusis obsito. C. diffusa Roth. In Oriente. $\odot$.

6. C. putula $L$. ramis patulis; fol. senis linearibus subscabris; floribus pentandris; fructu laeviusculo. C. peutandra Duf. In Hispania. ๑. Fl. flavi.

\%. C. aegyptiaca L. diffusa; fol. linearibus margine revolutis glabriusculis, infimis ovatis; bracteis lanceolatis scabris. C. herbacea Forsk. In Aeg!nto. $\odot$.

8. C. Gilanica Trin.mém. petersb. 1818. $t$. 12. procumbens; fol. linearilanceolatis scabris; bracteis ovatis subciliatis. In Persia. 4. Rad. repens.

b. Floribus capitatis.

9. C. maritima $L$. suffruticulosa; procumbens; ramosissima; glauca; gla- hra; fol. lanceolatis marginatis mucronatis. Barr. ic. 355. In Mediterranea. 4. Fl, ochroleuci.

10. C. capitata Labill. pl. syr. t. 3. procumbens; glauca; glabra; fol. sublinearibus; spicis capitatis ovatis; hracteis membranaceis lanceolatis ; cor. 5-nervis. In cacumine Libani. 4.

11. C. stylosa Trin. I. c. t. 11. caule procumbente; fol. Ianceolatis cauleque hispidlis; stylo clavato longissime exserto; apice brevissime bifido. In Provincia Ghilan.

12. C. mubescens Willd. erecta; fol. linearibus pubescentibus; capitulis pedumculatis axillaribus et terminalibus; cor. 5-andris. In Creta. $\odot$.

c. Floribus fasciculatis; fasciculis oppositis subpeduncula-

tis inter rupteracemosis.

13. C. molluginoides Bieb. erecta; fol. 8-12 verticillatis lineari-lanceolatis maryine revolutis; carina villosa; bracteis ovato - lanceolatis villosis. Asperula 1hchb. ic. 424. In Caucaso, Armenia et Hungaria. 4.

14. C. aspera Bieb. procumbens; fol. subsenis linearibus obtusiusculis margine revolutis cauleque scahris; bracteis ovatis ciliatis. C. prostrata Adams. In Iberia. 4.

15. C.glomeruta Bieb. caulibus adscendentibus sterilihus hirsutis; fol. linearibus nargine revolutis scabris subglaucis; florum capitulis oppositis. In collibus Iberiate. 4. Fl. ochroleuco-pubescentes.

C. Americana Mill. et C. hispida Mill. sunt species dubiae.

\section{5\%. SPERMACOCE Dillen. (1732).}

\section{a. Verticillatae.}

1. S. tenuior $\boldsymbol{L}$. caule 4-angulo; fol. lanceolatis subpetiolatis supra et margine scahris; staninibus inclusis; fructibus ovalibus hispidulis. Dill. Elth. f. 359. Lam. ill. t. 62. f. 1. In Americu. $\odot$.

2. S. portoricensis Bulb. caule dichotomo; fol. elliptico-oblongis utrinque acuminatis subpetiolatis glabris; fructibus puberulis apice truncatis. In Portorico legit Bertero. 
3. S. longiflora Aubl. Guj. t. 21. caule dichotomo acute 4-gono; fol. ovali-oblougis utrinque acuminatis, supra et margine scabris, subtus pilosulis. In Gujana. ち.

1. S. caerulea Pohl; caule sub-1gono puberulo; fol. elliptico-oblongis acutis petiolatis, subtus puberulis; fructu ovali pubescente. In Brasilia.

5. S. riparia Cham. et Schlecht. glaberrima; caule laxo fistuloso; fol. lanceolatis acutis margine scabris. In Brasilia. 4.

6. S. hebecarpa DC. caule 4-gono; fol. ovatis acutis basi attenuatis subtus in nervis pubescentibus; fructu puberulo apice truncato. Circa $\mathrm{Ca}$ racas.

7. S. diffusa $\boldsymbol{H}$. et $\boldsymbol{K}$. caule procumbente hirto; fol. lanceolatis utrinque retrorsum scaloris margine serrato-scabris; stipulis setoso-ciliatis. In Varinas. $\hbar$.

8. S. suffrutescens Jacq. Schoenbr. t. 322. caule diffuso sub-4-gono glabro; fol. ovato-lanceolatis acuminatis lineatis maryine scabris; stipulis setosis. Patria ignota.

9. S. linearis $H$. et $K$. caule 4gono pubescenti-hirto; fol. linearibus supra et margine scabris, subtus hirtellis; stigmate subcapitato. Bigelowia Spr. Ad Orinocum. ち.

\section{b. Africanae.}

10. S. palmetorum DC. adscendens; caule 4-gono hirsuto, ramulis compressis; fol. ovali-lanceolatis supra scabris lineatis, subtus hirsutis nervosis, In Gambia et Cayor.

11. pilosa $D C$. caule 4-gono, angulis obtusis pilosis; fol. ovatis acutis utrinque scabris; calycis Iobis reflexis. Diodia Schum. In Guinea.

12. S. phyllocephala DC. erecta; glabra; subramosa; caule 4-gono; fol. linearibus 1-nerviis, floralibus basi dilatatis; capitulis paucissimis. In sabulosis Africae. $\odot$.

13. S. stachydea DC. villoso-hirta; caule erecto 4 -gono, ramulis compressis; fol. linearibus acutis capitulis plurimis; seminibus magnis nitidis. In Africa, $\odot$. Pedalis.

11. S. galeopsidis DC, caule 4gono erecto hirsuto; fol. lanceolatolinearibus scabris; fructu grosse ve-
Iutino, calycis lobis longiore. In arenosis Senegambiae. $\odot$. Pedalis.

15. S. Ruellice DC. caule erecto 4-gono hispido; fol. lanceolato-linearibus acuminatis puberulo-hispidis; fructus valvulis demum apice valde hiantibus. In Africa. $\odot$. Pedalis.

16. S. chaetocephala DC. caule erecto basi tereti apice $\mathbf{4 - g o n o}$ angulis scabris; fol. linearibus elongatis acuminatis glabris; fructu pallido membranaceo apice puberulo. In A frica. $\odot$. Sesquipedalis.

\section{c. Mauritiana et Madaga- scarienses.}

1\%. S. flagelliformis Poir. fol. oblongo-lanceolatis subasperis erectis; flor. verticillatis; ramis flagelliformibus. Poir. In ins. Franciae. ๑. Rami pendentes. Fl. sessiles.

15. S. serpllyllifolia Willd. scabra; fol. ellipticis margine revolutis; verticillis paucifloris; caule diffuso. IVilld. Mss. In Madayascar.

19. S. muriculata DC. caule 4gono, angulis tuberculis asperis; fol. elliptico-lanceolatis acuminatis supra scabridis; fructu ovato pubescente. In ins. Mauritii et Borboniae.

\section{d. Indicae.}

20. S. Roxburghiana $\boldsymbol{W}$. A. caule 4-angulo adscendente glabro; fol. oblongo-lanceolatis acuminatis subscabris; fructu hemisphaerico compresso lispido. W. A. In Dindygul et Travancore. $\odot$.

21. S. Kleinii $W$. et A. caule 4angulo glabro; fol. cuneato-ovatis acutis sessilibus glabris; fructu hispido. S. ocymoides Hb. Madras. In India orientali.

22. S. stricta $\boldsymbol{L}$. fol. lineari-lanceolatis lineatis, nembrana ciliata connexis. Bigelowia Spr. In India orientali. $\odot . \quad \frac{1}{2}$-ped.

23. S. Burmunni DC. canle gracili 4-gono ramoso; fol. oblongo-linearibus utrincue acuminatis supra et margine scabris. S. corymbosa Burm. non L. In India orientali.

2. . S. scaberrima Blume; caule scandente; fol. ovali-lanceolatis asperis; stipulis setosis; fructu glabro. BI. In Java. 
25. S. Kispida $\boldsymbol{L}$. fol. obovatis subobliquis; floribus axillaribus subgeminis. L. Murr. Comm. Goett. III. t. 5. Burm. zeyl. t. 20. f. 3. In Zeylonici. $\odot$. HI. violacei.

26. S. scabra Willd. fol. subrotundis cauleque hispido-scabris ; floribus verticillatis; staminibus exsertis. Willd. Rheede 9. t. g6. In Coromandel et Timor. $\odot$. FI. magni.

2\%. S. articularis $\mathbf{L}$. fol. ellipticis obtusiusculis subscabris. L. In $\mathrm{Co}$ romantel. $\odot$. Caul. ruber, ramis procumbentibus. Fl. albi.

\section{Species dubiae.}

28. S. flexuosu Lour. canle flexuoso; geniculis setosis; fol. ovato-lauceolatis crassis. Lour. In Cochinclina. ち. Fl. albus.

29. S. hedyotidea DC. caule 4-gono glabro; stipulis rhombeis; thyrso brachiato; corolla intus tomentosa. Hedrotis fruticosa Retz. In Indic orientali. $\hbar$.

30. S. procumbens $\boldsymbol{L}$. fol. linearibus; corymbis lateralibus pedunculatis. L. syst. S. corymbosa L. sp. In India orientali.

31. S. semierecta Roxb. caule adscendente; ramis brachiatis alterne minorilus; fol. ovatis; caps. turbinata pilosa. Iroxb. 1. p. 371. In Sumatroce.

32. S. costata Poxb. diffusa; villosissima; fol. lato-lanceolatis oblongis nervosis; staminibus exsertis. Roxb. In Moluccis. $\odot$. 3-ped. Fl. pallide rosei.

33. S. nana Roxb. erecta; simplex; subteres; laevis; fol. petiolatis lanceolatis laevihus; floribus axillaribus terminalibusque sessilibus. Iroxb. In ms. IIominoae. $\frac{\mathrm{I}}{2}$-ped.

34. S. lineatu R. erecta; ramosa; pilosa; fol. breve petiolatis lanceolatis linearibus acuminatis lineatis; staminibus exsertis. In Moluccis.

3.5. N. plilippensis S $m$. syst. caule erecto foliisque oblongis venosis asperis; stipulis dentatis; staminibus exsertis; fructibus glabris. Spr. In ins. Philippinis.

36. S. laevis Lam. glabra; fol. lanceolatis subpetiolatis; floribus sessilibus subverticellatis; capsulis laevibus. Sloane hist. I. t. 94. f. 2. In Domingo. Fl. numerosi.
3\%. S. stellata $R$. et S. floribus terminalihus capitatis. Willd. Mss. In Domingo.

35. 5. rotata Poit. glahra; fol. ovatis mucronatis; floribus capitatoverticillatis; stipulis setis nudis; calycibus villosis; caule diffuso adscendente 4-augulo. R. et S. In Domingo.

3.9. S. remota Lam. fol. linearilanceolatis internodiìs hrevioribus; flovibus dense verticillatis; verticillis distantibus. Lam. ill. In Domingo. Fol. asperrima pollicaria.

40. S. ocymifolice Willd. floribus verticillatis; staminibus inclusis; setis stipularum verticillis longioribus; ramulis foliisque subius pubescentibus. W. Mss. In Inalia occidentali.

41. S. obscurc DC. canle 4-gono; fol. ovato-oblongis utrinque attennatis lineatis ; stipulis connatis setoso-ciliatis; verticillis globosis; cor. intus villosis. In Cuba et Fispaniola.

42. S. strigosa Thunb. et otto $p l$. bros. caule ramoso piloso; fol. ovatis hirsutis ; floribus verticillatis. In Brelsilia.

43. S. elliptica Thunb. et Otto $p t$. bras. caule simplici glabro; fol. ellipticis glabris; floribus axillaribus. In brasilia.

4. S. ceplaclotes Willı. capitulo terminali involucrato; fol. lanceolatis integerrimis; caule ramoso erecto. W. Mss. In arenosis Brasiliae.

45. S. assurgens R. et P. $l$. peruv. t. 92. fol. Ianceolatis linearibus margine scabris; verticillis parvis. In Lima. 4. Caul. 1 $1 \frac{\mathrm{I}}{2}$-ped. purpurascens.

46. S. inconspicua Bartl. ramis adscendentihus subhexagonis pube pulverulentis; fol. lineari-oblongis utrinque acuminatis. In Peruvia. b.

4\%. S. gracilis R. et P.fl. peruv. $t$. 92. $f$. $a$. glabra; fol. Ianceolatis angustis; ramis inferioribus oppositis, superioribus dichotomis; verticitlis minimis. In Peruvic. $\odot$. $\frac{1}{2}-p e d$. Fl. albi.

45. S. Oldenlandia DC. caule ramosissimo repente filiformi; fol. ovatis subpetiolatis nitidis; fructu hispido. in humidis Chili. Oldenlandia uniflora 1 . et $P$.

49. S. lumifusa Willd. caule procumbente; fol. oblongo-lanceolatis glabris margine ciliato - serrulatis; calyee urceolato 4 -gono sinuato pin- 
natifido. Prope Santa Fe de Bogotu. $\hbar$.

50. S. evioclata DC. adscendens; ramis suhangulatis hirsuto-tomentosis; fol. oblongis acuminatis scaberrimis margine serrato-scabris. In Peruvia. $\hbar$.

51. S. sexamynlaris Aubl. Guj.t. 22. I: S. glahra; prostrata; caule flexuoso fi-gono; fol. ovatis acutis petiolatis; capitulis terminalibus. S. hexagona Willd. In Gujuna.

52. 5. prostrati Aubl. Guj. t. 20. f. 3. elabra; caule herbaceo prostrato opposite ramoso 4-gono; fol. subsessilibus ellipticis acutis laevibus; floribus verticillatis. In Gujana.

53. S. radicans Aubl. Guj. t. 20. f. 4. glabra; caule herbaceo alterne ramoso prostrato radicante; fol. subsessilibus lanceolatis acutis; floribus verticillatis. In Gujana. 4.

5t. S. caerulescens Aubl. Guj. t. 19. $f$ : 2 . caule recto 4 -gono; fol. ovatis acutis pilosiusculis laevihus; staminibus exsertis. In Gujana et Cayenna. Fl, caerulei.

55. S. Latifolia Aubl. Guj. t. 1.9. f. 1. caule erecto 4-gono; fol. ovatis acuminatis petiolatis asperis; stipularum setis hispidis; caps. ovata subvillosa. In Gujrence et C'ayenna.

56. S. polycephala Bartl. caule erecto ramoso villoso; fol. ovato-Ianceolatis acuminatis pilosis subtus lineato-venosis. In Mexico.

5\%. S. echioides $\boldsymbol{H}$. et $\boldsymbol{K}$. caule 4-gono erecto hispido; fol. lanceolatis acuminatis petiolatis hispid!s; stipulis hispidis ciliato-setosis. In Mexico. 4.

58. S. diversifolia $\boldsymbol{H}$. et $\boldsymbol{K}$. erecta; ramis 4-gonis retrorsum scabris; fol. linearihus margine remote serrulato-scabris, inf. minutis; caps. hispida; Knoxia simplex IVilld. Hb. In Mexico. $\odot$.

5.9. S. reclinata Nees hort. Berol. p. 50. glabra; adscendens; fol. lanceolatis acutis laevihus suhaveniis; capitulo hemisphaerico; calyce fructuque glabris. In Mexico. 4.

60. S. lasiantha Raf. fl. lud. p. \%6. caule dehili ramis diffusis; fol. sessilibus, ohlongis acutis nervosis; nervis scabris; corolla intus lanata. In Louisiana.

61. S. giabra Michx. am. glabra; procumbens; fol. Ianceolato-ovatis ; verticillis multifloris. $\mathrm{R}$. et $\mathrm{s}$. Ad ri- pas fluviorum Ohio et Missisippi. Diodia Pers. Fl. albi.

62. S. involucrata Pursh; hispidissima; erecta; caule alterne ramoso; fol. ovato-lanceolatis acuminatis utrinque hirsutis; cor. tubo longissimo. In Carolina. Fl. albi.

\subsection{S. BORRERA Meyer. (1818).}

\section{a. Americanac.}

$$
\text { * calyce 2-dentato. }
$$

1. B. globularioiles Cham. et Schlecht. glabra; erecta; ramulis 4gonis; fol. anguste lanceolatis acuminatis margine scabris; staminibus exsertis. Spermacoce fruticosa PohI. In Brasilia. ち. Capitula Piso paulo majora.

2. B. verticillata Meyer Esseq. glabra; ramulis 4-gonis; fol. oppositis lineari-lanceolatis acuminatis; capsula glabra ovali. Spermacoce L. In Brasilia et Caracas. நॄ.

3. B. stricta Meyer Esseq. $t$. 1. $f$. 1 -3. caule virgato glabro; fol. linearibus acutis petiolatis suboppositis ; capsula glabra oblonga. In Portorico. $\boldsymbol{L}$.

4. B. dichotoma Cham. et Schlecht. caule compressiusculo 4-gono ramulis dichotomis; fol. lanceolatis acutomucronatis margine serrulatis; caps. punctato-scabra ovata. spermacoce H. et K. In Peruvia. $\hbar$.

5. B. podocephala DC. caule ramoso ad nodos puberulo; fol. linearibus glabris margine revolutis; caps. glabra oblonga. In Mexico? 4.

6. B. distans Cham. et Schlecht. caule erecto 4-gono angulis retrorsum aculeato; fol. lanceolatis glabris margine serrulato-scabris; caps. oblonga superne viliosa. Spermacoce H. et K. In Mrexico. 4.

\%. B. Neesiana DC. glahra; caule 4-gono; fol. lanceolatis acutis costa margineque scabris; calyce fauce ciliis clausa; dentibus setaceis. Spermacoce linifolia Nees. In Brasilia. 4. 8. B. spinosa Cham. et Schlecht. caule sub-1-gono; angulis submuricatis ; fol. lanceolato-linearibus acuminatis basi attenuatis; nervo subtus in tubercula aculeiformia. hinc inde pro- 
ducto. In Jamaica, Martinica et Mexico. 4.

9. B. minima DC. herlhacea; pusilla; subramosa; caule 4-gono; fol. oblongo-linearibus utrinque acuminatis; capitulis terminalibus ; involucro 4-phyllo. In Brasilia legit Pohl. Herba digitalis.

\section{** calyce 4-dentato.}

10. B. asperula $D C$. canle herbaceo sub-4-gono; fol. ollongo-linearibus acutis glabris; carina denticulis subaculeata; ovario pilosiusculo. In Bahia. $\odot$.

11. B. subulata DC. erecta; subramosa; caule 4-gono; fol. linearisubulatis margine scabris; capitulis terminalibus involucro 8-phyllo cinctis. Spermacoce Pav. In Mexico. $\odot$.

12. B. gracillima DC. gracilis; parce ramosa; fol. lineari-subulatis; capitulis terminalibus; involucro 2phyllo. In Brasilia legit Pohl. 4.

13. B. tenera DC. caule ramoso gracili 4-gono; fol. linearibus acutis glabris; caps. ovali glabriuscula calycis dentibus 3-4 subulatis coronata. Spermacoce Pohl. In Brasilia. $\odot$.

14. B. pumila DC. caule gracili retrorstim piloso; fol. linearibus actminatis margine revolutis scabris; caps. ovali apice puberula. Spermacoce Pohl. In Brasilia. $\odot$.

15. B. tenuis $\boldsymbol{D C}$. caule tenui ad angulos puberulo; fol. lanceolatis linearibus acutis utrinque pubescentibus scahris; antheris inclusis. Spermacoce Pohl. In Brasilia. $\odot$.

16. D. cupularis DC. caule subangulato-pubescenti subscabro; fol. ovali-oblongis acuminatis petiolatis glabris; stipulis summis connatis cupulaeformibus. spermacoce pusilla Pohl. In Brasilia. $\odot$.

1\%. B. ramisparsa DC. caule dichotomo 4-gono; fol. ovali-oblongis utrinque aculis; caps. minima ovata; calycis dentibus 2 minimis. Spermacoce Pohl. In Brasilia. $\odot$.

18. 13. parviflora Meyer Esseq. $t$. 1. caule 4-gono angulis subpilosis inferne subulatis; fol. ovali-oblongis utrinque attenuatis pilosis. Spernacoce aspera Vahl. In Peruvia. $\odot$.

19. B. Bartlingiana DC. caule diffuso radicante 4-gono angulis alatis piloso-hispidis; fol. ovalibus subacutis setoso-pilosis. Bigelowia elata Bartl. In Mexico.

20. IB. Tampicana DC. glahra; diffusa; angulis ramorum lacvibus; fol. oblongo-linearibus acutis 1 -nerviis; caps. parva ovata glabra. In Mexico legit Beerlandier. $\odot$.

21. B. diffusa DC. glabra; caule diffuso dichotomo; fol. linearibus margine revolutis; stipulis setiferis ; involucris 4-8-phyllis reflexis. In Brasilia legit pohl.

22. B. remotifolia DC. canle gracili 4-gono pilosiusculo; fol. oblongolinearibus subsessilibus acutis supra et margine scabris subtus pubescentibus. Spermacoce Pohl. In Brasilia.

23. B. cornifolia DC. caule erecto tenui-tomentoso 4-gono; fol. petiolatis oblongis acutis subtus flavicanto-puhescentibus; caps. subglobosa subpubescente. Spermacoce Fisch. In $\mathbf{B r} \boldsymbol{r}$ silia. $\odot$.

21. B. brachystemonoides Cham. et Schlecht. caule 4-gono retrorsum piloso-scabro; fol. lanceolatis ellipticis acutis; caps. oblongo-conica sursum villosa. In Brasilia. $\odot$.

25. B. capitellata Cham. et Schlecht. caule fistuloso; fol. petiolatis ovatis lineatis acuminatis ; caps. oblongo-elliptica superne hirtella. Spermacoce Willd. Hb. In Nova Granata.

26. B. scabiosoides Cham. et Schlecht. caule fistuloso tereti; fol. lanceolatis acutis margine scabris; caps. oblonga glabra; involucris longe pilosis. In Brasilia.

27. B. capitata DC. caule prostrato ramis adscendentibus; fol. lanceolatis margine scabris; caps. glabra turbinata. Spermacoce R. et P. peruv. t. 91. f. 1. In Peruvia. ђ.

28. B. Aturensis Cham. et Schlecht. fol, anguste linearibus glabris margine serrulatis ; caps. piloso-pubescente oblonga. Spermacoce $\mathbf{H}$. et $\mathrm{K}$. $A d$ Orinocum.

29. B.eryngioides Cham. et Schlecht. caule erecto 4-gono; fol. linearihus acutis margine revolutis; caps. elliptica pubescente calyce 4-dentato, adjectis denticulis 4 minimis, coronato. In Brasilia. ‡.

30. B. satureiaefolia Cham. et Schlecht. ramulis 4-gonis; fol. linearilanceolatis acntis glabris margine revolutis; caps. glabra. In Brasilia. †. 
31. B. Sideritis Cham. et Schlecht. scabrido-pilosa; caule 4-gono subulato; fol. sessilibus ovato-oblongis 4nerviis; cor. extus barbata ; caps. ovoidea pilosa. In Brasilia. 4.

32. B. scandens bC. caule adscendente debili subscandente ramoso; ramis 4-gonis striatis; fol. ovatis glahris in petiolum subattenuatis; caps. ovali glabra. Dicdia sarmentosa spr. sloane hist. t. 28. f. 4. In Guadelupe.

33. B. affinis DC. caule 4-gono angulis piloso-scabro; fol. oblongolanceolatis acuminatis scahriusculis; stipularum setis flaccidis $7-9$; caps. ovali glabra calyce inaequaliter 8dentato coronata. In Brasilia legit Poll.

34. B. microphylla DC. glabra; caule adscendente 4-gono; fol. lanceoIato-linearibus acutis; caps. ovali tenuissime pubescente. Spermacoce Pohl. In Brasilia. Fol. $7-8$ lin. longa.

35. B. rubro-stipulata DC. canle stricto simplici angulis retrorsum vilIosis; fol. ohlongo-linearibus utrinque acutis; antheris exsertis. spermacoce Pohl. S. brasiliensis spr. In Brasilia. $\odot$. Pedales.

35. B. elongata DC. ramis elongatis hirsutis teretibus; fol. oblongolanceolatis acuminatis utrinque pubescentibus. spermacoce Pohl. In $\mathrm{Br}^{\prime} \mathrm{a}-$ silia. Rami pedalis.

37. B. ferruginea $D C$. caule duro erecto ramoso hirsuto; fol. oblongis acutis oblique 3-4-nerviis scabro-hirsutis; caps. puberula. spermacoce st. Hil. pl. us. t. 13 . s. globosa Pohl. In Brasilia. ち. Fl. rosei aut albi.

35. B. Iutescens DC. caule tereti molliter et dense hirsuto apice retrorsum pubescente; fol. sessilibus lanceolatis acuminatis villoso-hirsutis; bracteis reflexis; caps. oblonga apice villosa. Spermacoce Pohl. In Brasilia.

39. B. Haenlieana $D C$. caule stricto ramoso 4-gono angulis pilosis; fol. Iinearibus acutis margine subrevolutis scabriusculis; involucro 4phyllo subreflexo. Bigelowia psylloides Bartl. In Mexico.

40. $B$. strictissima $D C$. caule sub) nodos pulverulento-puberulo; fol. linearibus acutis glabris subaveniis; caps. oblonga gIabra. Spermacoce Pohi. In Brosiliu.

11. B. tenella Cham. et Schlecht. canle retrorsum adpresse pilosulo; fol. oblongo-linearibus acuminatis pube minima scabris; caps. oblonga sursum hirta. In Brasilia. ち. Pedalis. var. fol. angustiorilus. s. orinocensis Willd. et caule tenuissimo velutino. Spermacoce laviandulaefolia Pohl.

42. B. linoides DC. glaberrima; fol. linearibus subacutis margine revolutis; stipulis in acumina setacea $1-3$ rigida abeuntibus; caps. ovali glahra. spermacoce Pohl. In Brasilia. $\hbar$.

13. B. psylloides $\boldsymbol{H}_{\text {. et }}$ K. Nov. Gen. t. 278. sub spermacoce; caule retrorsum scabro; fol. lineari-lanceolatis utrinque hirtellis margine serrulato-scabris. In Mexico. $\hbar$.

4. B. flavescens DC. diffusa; glaberrima; fol. oblongis acutis hasi attenuatis; caps. ovali. Spermacoce Pohl. In Brasilia. ち. Tota flavescens.

45. B. scabrida DC. caule 4-gono ad angulos scahro; fol. lanceolatis acutis utrinque oblique 4-nervosis scabris; caps. oblonga glabra. Spermacoce Pohl. In Brasilia.

46. B. asclepiadea Cham. et Schlecht. glabriuscula; caule erecto alato 4-gono, apice puberulo; fol. Ianceolatis acutis 4-nerviis glabris; caps. elliptica. In Brasilia. $\hbar$.

47. B. nervosa Polll; tota pubescenti-scabra; caule 4 -gono striato; fol. lanceolatis oblique $4-5$-nervosis; stipulis in lignlas $3-5$ lineares acutas fissis. In Brasilia. $\hbar$.

45. B. pratensis Polı; glaberrima; caule subsimplici angulis subulatis; fol. sessilibus oblongis acutis 6-7venosis; stipulis 3 -angularibus apice 3-5-dentatis. In Brasilia. 5 .

49. B. Poya DC. glaberrima; fol. sessilibus oblongo-ellipticis acutis 6nervosis; stipulis in setas longas fissis; antheris exsertis. Spermacoce st. Hil. I. c. t. 12. In Brasilia. 4. Fl. cyanei. Rad. enretica Ipecacuanlae succedanea.

50. B. platyplylla DC. tota hispidulo-scabra; angulis caulis subulatis; fol. lanceolatis acutis basi attenuatis 4-5-nervosis; stipulis in $5-7$ setas longissimas desinentibus. Spermacoce Pohl. In Brasilia. 4. 
51. B. gymnocephala DC. caule inter angulos striato sulcato gläbro; angulis subulatis serrulato-scabris; fol.ovatis acutis basi attenuatis; calycis dentibus conico-subulatis. In Rrasilia.

52. B. cymosa Cham. et Schlecht. glabra; ranis fiexuosis 4-gonis; fol. elliptico-lanceolatis acuminatis coriaceis; stipulis connatis; capitulis subaphyllis: Spermacoce spr. In $B_{r} a-$

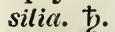

53. B. virgata Cham. et Schlecht. ramis fistulosis 4-gonis angulis pubescentibus; fol. lanceolatis utrinque attenuatis margine scaloris; caps. pubescente elliptica, calyce $2-6$-dentato coronata. Circa Rio de Janeiro. 4.

54. B. saponariaefolia Cham. et Schlecht. caule prostrato 4-gono fistuloso ramoso; fol. sessilibus acuminatis margine scabris; caps. oblonga, calyce inaequaliter 4-dentato coronata. In Brasilia.

55. B. arida $D C$. caule pubescente apice glabro; fol. linearibus acutis nervo subtus apice scabro, marginibus revolutis serrato-scabris; caps. ovalioblonga subpuberula. Bigelowia Spr. In Portorico.

56. B. ericoides Cham. et Schlecht. ramulis 4 -gonis; fol. linearibus ohtusiusculis $\mathbf{1}$-nerviis oppositis s. fasciculato-verticillatis ; caps. cylindricoturbinata. In Brasilia. ち.

5\%. I. anthospermoides DC. glabra; ramis virgatis 4 -gonis; fol. linearibus acutiusculis enerviis; calyce anguste 4-lobato. In America australi.

58. B. euputorioides Cham. et Schlecht. fruticosa; pubescens; ramis obtuse 4-gonis; fol. ovato-oblongis acutis lineatis; caps. oblonga pubescente. In lirasilia. $\hbar$.

59. B. centranthoides Cham. et Schlecht. caule adscendente fistuloso obtuse 4-gono; fol. elliptico-lanceolatis utrinque attenuatis scahris; caps. hirtella obconico-cylindrica. In IBrasilia. 4.

60. B. Pohliana DC. ramis hirsutis compressis; fol. Ianceolatis acuminatis lineatis supra pubescentibus; calycis tubo canescenti-hirsuto. Hydrophylax pusilla Pohl. In Brasilia.

61. B. angustifolia Cham. et Schleclit. erecta; glabra; caule 4 -gono; fol. lanceolato-linearibus margine revolutis; fol. floralibus minimis. In Brasilia. 4.
62. B. corymbosa Bartl. glabra; caule tereti erecto; fol. Ianceolatis acuminatis venoso-lineatis margine Iaevihus; caps. ovato-oblonga glabra. spermacoce 13 . et $P$. peruv. t.91. f. a. s. Peruviana Pers. In Peruvia. $\hbar$.

63. B. verbenoides Cham. et Schlecht. glabriuscula; caule superne 4-gono; fol. anguste lanceolatis acutissimis supra scabris; caps. subcylindrica glabra. In Brasilia. 4.

61. I3. valerianoides Cham. et Schlecht. caule 4-gono fistuloso; apice retrorsum scabro; fol. Ianceolatis acutis nervis scabro-hirtis; caps. subcylindrica scabriuscula. In Irasilia. 4.

65. B. laxa Cíam." et Schlecht. caule fistuloso 4-gono; ramis oppositis patulis; fol. lanceolatis utrinque attenuatis laxis membranaceis margine scabris. In Brasilia. 4.

66. B. equisetoides Cham. et Schlecht. radice lignosa; caule ad nodos constricto ; fol. anguste linearibus strictis filiformibus margine revolutis; stipulis fuscescentibus ciliato-setosis. In $\mathrm{Br} \cdot \mathrm{C}-$ silia. 4.

6\%. B. umbellata Spr. caule ramoso nitido; fol. lanceolatis utrinque attenuatis glabris; stipulis basi.connatis setosis; caps. pubesceute. Bigelowia spr. syst. In Brasilia.

68. B. aralioides Cham. et Schlecht. caule herbaceo fistuloso 4-gono apice ramoso; fol. lanceolatis acuminatis subcoriaceis; cymis pubescentibus. In Brasilia.

\section{b. Africanae.}

69. B. Kohautiana Cham.et Schlecht. ramulis 4-gonis; fol. oblongo-Iinearibus mucronatis; verticillis globosis; caps. pubescente calyce $\mathbf{z}$-dentato coronata. Dill. Elth. f. 348. Spermacoce verticillata L. In Senegalia, Guinea et Madagascar.

\%0. B. adscendens Cham.et Schlecht. caule adscendente; fol. lineari-lanceolatis acutis; stipulis dentatis dentatosetosis. Spermacoce Willd. Hb. In Madagascar.

\%1. B. radiata DC. caule tereti pilis patentibus hispidulo; fol. oblongolinearibus acuminatis glabris glaucis 1-nerviis; capitulis depressis; caps. oblonga apice puberula; calyce 4-dentato. In senegalia. $\odot$. 


\section{c. Indic ae.}

72. B. pusilla DC. caule tenello 4-gono sub nodis hispido; fol. linearibus acutis glabris subtus pallidis; caps. ovali pilosiuscula. Spermacoce Wall. Bigelowia Spr. S. triaudra Hamilt. In Nepalia. $\odot$.

558. b. HEXASEPALUM Bartl. in Haent. Rel. (1525).

1. II. angustifolinm Bartl. In Mexico. t. Suffrutex adscendens ramosissimus glaber ramis diffusis flexuosis compressis. Fol. opposita elongato-linearia margine scabra. Flores axillares.

559. TRIODON Cham. et Schlecht. (1829).

1. T. anthospermoides Cham. et Schlecht.fruticosus; ramosissimus; glaber; sulpubescens; ramulis acute 4-gonis; fol. sessilibus linearibus oppositis; calyce hirtello multidentato. DC. In Brasilia.

2. T. glomeratus $D C$. fruticosus; ramosissimus; glaber; ramis acute 4gonis; fol. oblongo-linearibus; stipularum setis brevibus. Diodia brasiliensis Spr. Rubia glomerata Pohl. In Brasilia. 市.

3. T. polymorphus Cham.et Schlecht. fruticosus; ramosissimus; glaber; ramis 4-gonis; fol. subpetiolatis oblongo-linearibus oppositis; calyce bidentato. In Brasilia. †. var. $\alpha$. micropleyllus Cham. et Schlecht. apice pubescens; fol. minoribus firmioribus; calyce hirtello 4-dentato. In Provincia Rio de Janeiro. $\beta$. intermedius $\boldsymbol{C}$. et $\mathbf{S}$. glabriusculus; fol. planis molliusculis; calyce glabro 4-dentato. In Brasilia t. $\gamma$. macrophyllus C. et S. glaber; internodiis elongatis; fol. planis tenuioribus majoribus; calyce glabro bidentato. In Brasilia

\section{CRUSEA Cham. et Schlecht. (1829).}

1. C. calocephala DC. caule tereti lierbaceo villoso; fol. oblungolanceolatis acuminatis; stipularum setis 7-9 hispidis. Spermacoce hirta Pav. In Mexico. $\odot$.

2. C. rubra Cham. et Schlecht. caule 4-gono herbaceo hispido; ramis oppositis; fol. ovatis acuminatis hirsutis; stipularum setis $7-9$ hispidis. spermacoce Jacq. Schoenlor. t. 256. s. strigosa Sims B. M. 1558. S. longiflora $\mathbf{H}$. et $K$. $\mathbf{S}$. rubra et strigosa schult. In Vera-Cruz et ins. Cuba. $\odot$.

3. C. coccinea DC. caule $4-g 0110$ basi suffruticoso glabro; fol. ovatolanceolatis petiolatis acuminatis glahris; stipulis 3 glabris, media longiore. Spermacoce coccinea Pav. In Nova Hispania. †. Fl. coccinei.

4. C. brachyphylla Cham. et Schlecht. caule teretiusculo fistuloso reverse hirsuto; fol. late ovatis subpetiolatis discoloribus parce pilosis; capitulis terminalibus; fol. involucratis. In Mexico.

\section{STAELIA Cham. et Schlecht. (1829).}

1. S. thymoides Cham. caule ramosissimo adscendente puberulo; stipulis acute 3 -lobis; verticillis paucis. In Brasilia.

2. S. galioides $\boldsymbol{D C}$. caulibus glabris parce ramosis virgatis elongatis; stipulis multisetis; verticillis paucis. Spermacoce galioides Pohl. In $\mathrm{Bra}$ silia.

3. S. reflexa DC. caulibus glabriusculis ramosissimis ranis virgatis; fol. linearibus margine subrevolutis; stipulis 3-dentatis; fol. floralibus reflexis. In Brasilia.

\section{DIODIA L. (Diodia et Sperma- coce auct.) (1743).}

\section{Eudiodia. Caps. membrana-} ceae. Flores axillares.

$$
\text { * Calyce bidentato. }
$$

1. D. virginica $I$. caule procumbente pubescente; fol. ovali-lanceolatis; floribus axillaribus solitarie oppositis sessilibus; fructu hirsuto. Michx. am. Jacq. ic. t. 29. Lam. ill. t. 63. In Virginia et Carolina. 4. Caulis rubescens. Fl. albi.

2. D. tetragona Walt. caule repente 4-gono; fol. subcordatis; stipulis subulato-fimbriatis. Walt. carol. p. 87. In humidis Carolinae. 4.

3. D. hirsuta Pursh; hirsutissima; caule procumbente 4-gono; fol. linea- 
ri-lanceolatis; corollis intus dense harhatis; fruclu ovato hirsuto. Pursh. am. 1. p. 106. D. hispida Muehl. In America boreali. 4 . Fl. albi.

t. D. simplex Sur. caule herbaceo simplici erectiusculo laevi; fol. ovatolanceolatis. Nw. prodr. p. 29. In Jumaica. semipedalis. Fl. albi.

5. D. verticillata Vahl; glabra; caule herhaceo simplici erecto laevi; fol. lanceolatis verticillatis margine scabris. Vahl. symb. II. p. 28. In ins. Sanctae-Crucis. Pedalis.

6. D. villosu fl. mexic. inerl. callle herbaceo declinato 4 -gono villoso; fol. lanceolatis acuminatis supra et margine scalıris; fructu ovato. In Nova Hispania.

\section{** Calyce 4-dentato.}

7. D. teres Walt. caule tereti velutino procumbente; fol. lineari-lanceolatis velutino-pubescentibus; cor. intus harbata; fructu ovato pubescente. Spermacoce diodina Michx. In America boreali. $\odot$. Fl. albi.

8. D. hyssopifolia Cham.et Schlecht. suffruticosa; ramosa; ramis hirtellis; fol. linearihus acutis glabris glaucescentibus; fructu ovato-turbinato hirtopuberulo. spermacoce $\mathrm{H}$. et $\mathrm{K}$. $A d$ Orinocum. 4.

9. D. prostrata Sw. caule suffruticoso subdiviso; ramis prostratis filiformibus; fol. linearibus hirsutiusculis revolutis. Sw. prodr. p. 30. In Jamaica. $\hbar$. $\beta$. longiseta DC. D. prostrata Bartl. In Mexico.

10. D. domingensis DC. glabra; caule procumbente filiformi; fol. linearibus revolutis; stipularum setis rigidis. D. prostrata Spr. In Dominyo et Hispaniola.

11. D. scandens Sw. caule scandente suffiticoso; fol. ovato-lanceolatis rigidis scabris; (fructu ovato-oblongo). Sw. prodr. In Domingo. 8-10-ped. Fl. albi.

12. D. sarmentosa Su. caule flaccido fruticoso; ramis oppositis patentiluss; fol. oblongis acutis scabriusculis; (fructu ovali sub-4-gono). Sw. Spermac. radula Spr. In Jamaica et Portorico. ђ. Scandens. Fl. albi.

13. D. latiflora $I C$. ramis teretibus velutino-puberulis; fol. Ianceolatis aristatis puberulo-scabris; fructu olovato-globoso. Sperm. harhata Spr.

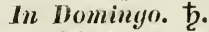

14. I). yrandiflora DC. caule virgato flexuoso; fol. linearilous cuspidatis glabris margine serrulato-scahris hasi ciliatis; fructu puberulo. spermacoce spr. In Dominyo. 4.

1.5. 1). conferta DC: caule adscendente hirsuto; fol. ovatis acuminatis sessilibus pilo longo terminatis margine serulato-scabris. Spermacoce schott. In Brasilia. $\hbar$.

16. D. burbata DC. caule procunbente scabro, ramis 4-gonis pubescentiluss; fol. lanceolatis villosis. Spermacoce Lam. In Domingo.

17. I). setiyera DC. caule adscendente basi suffruticuloso 4-gono hirsuto; fol. sessililus ovato-lanceolatis basi subcordatis apice seta terminatis, basi ciliis maximis. Circa Bahia. $\hbar$.

18. D. polysetu DC. ramis cauleque simplici virgato 4 -gono pilis longis patulis hispidis; fol. lanceolatis acutis ; fructibus subrotundis. In Portorico. b.

19. D. maritima Schum. $p l$. guin. caule prostrato 4 -gono, laterihus sulcatis; fol. ovalihus oblongisve malgine serrulato-scabris; fuctu ovalioblongo. Spermacoce commutata Schult. S. serrulata Beauv. fl. am. t. 23. In Guinea, Portorico et Oware. $\hbar$.

20. D. rigida Cham. et Schlecht. caule repente 4-angulari hirto; fol. lanceolatis apice piliferis, serrulatis subtus hirto-pilosiusculis. Spermacoce Kunth. S. apiculata et rigida Willd. Hb. In Caracas et Domingo. ち.

21. D. articulata DC. caule tereti noduloso molliter hispido; fol. linearibus acutis revolutis; fructu obovatooblongo. Spermacoce Pohl. In Brasilia. $\hbar$.

22. D. rosmarinifolia Pohl; caule erecto simplici molliter hispido; fol. linearibus pilo longo apiculatis, subrevolutis et seriulato-scabris; fructu ovali. In Brasilia. $\hbar$.

23. D. arenosa $D C$. caule decumbente 4-gono; fol. lanceolato-linearibus sessilibus acuminatis revolutis scabris; fructı obovato-globoso pubescenti - scabro. Spermacoce Pohl. In Brasilia. $\hbar$.

21. D. multillora DC. caule ramisque virgatis depresso-1-gonis hirsutis; fol. lanceolatis sessilibus acutis 
lineatis utrinque villoso-scabris; fructu obovato. In Brasilia. $\hbar$.

2.5. D. muriculata DC. caule adscendente ramis 4 -gonis piloso-hirsutis; fol. sessilibus ovatis cuspidatis infra verticillos reflexis supra pilosomuricatis; fructu subgloboso pubescente. In Balia. 5 .

26. D. discolor DC. caule pubescente adscendente $\mathbf{4 - g o n o ; ~ f o l . ~ I a n - ~}$ ceolatis utrinque acuminatis glabris subtus canescentihus; fiuctu hirto fragili. spermacoce Neyer. In Surinamo.

2\%. D. hispidula A. Rich. caule erecto 4-gono; fol. ohlongo-lanceolatis acutis glahris; spicis elongatis interruptis; calycis tubo setulis scabro. In Brasilia.

28. D. rudicans Cham. et Schlecht. caule radicante opposite ramoso 4gono; fol. lanceolatis acutis oblique nervosis subtus pallidis; fructu ovato sessili. In Domingo.

\section{c. Calyces 5-10-dentati.}

29. D. radula Cham. et Schlecht. caule debili 4-yono; fol. lanceolatoovatis acutis lineatis scabro-pubescentihus; calyce ciliato. spermacoce Willd. Hb. In Brasilia. 4.

II. Dasycephala. Caps. membranaceae. Flores capitati.

30. D. palustris Cham. et Schlecht. canle alato 4-gono angulis retrorsum scahris; fol. ellipticis subcuneatis obtusis apiculatis. In Brasilia. $ђ$.

31. D. dasycepliala Cham. et Schlecht. glahriuscula; herhacea; adscendens; fol. lanceolatis suhpetiolatis margine scabris glaucescentihus; calyce hirsuto 2-dentato. In Brasilia.

32. D. alata Nees; caule erecto glahro inferne dichotomo 4-gono, angulis memhranaceis spinulosis; fol. ovatis cuspidatis margine scabris. In Brasilia. 古.

33. D. llogotensis Cham.et Schlecht. ramis quadrangulis scabris; fol. oblongo-lanceolatis glabris serrulatis; fructu glabro obovato. Spermacoce H. et K. Circa Santa-Fe de Bogota. 古.

3t. D. indecora DC. caule decumbente ramosissimo scabro; fol. ob- longo-linearibus acuminatis glabris; fructu ovali oblongo-glabro. In Mexico.

\section{TESSIERA DC. prodr. (1830).}

1. $T$. lanigera $\boldsymbol{D C}$. undique lana alha longa vestita; caule virgato tereti. Diodia Spr. Spermacoce Pohl. In Brasilia.

2. ' $\boldsymbol{T}$ '. lithospermoides DC. suffrnticosa; suherecta; ramosa; pube velutina breve couferta; tota cinerascens; fructibus demum glabratis. Spermacoce Bartl. in Haeuk. Rel. In Mexico. ち. 4.

\section{SCYPHIPHORA Gaertn. fruct.} t. 196. $\left(1796^{\circ}\right)$.

1. S. hydrophylacea Gaertn. et Blume. Rich. Hem. Mus. 5. t. 1 t. f. 1. In maritimis Holuccanarum. $\hbar$. Frutex. Fol. opposita avenia. Flores corymbosi axillares.

\section{KNOXIA L. (1717).}

1. $\boldsymbol{K}$. Zeylanica $\boldsymbol{L}$. floribus spicatis; fol. glabris; calyce inaequali. $L$. Lam. ill. t. 59. f. 1. Burm. ind. t. 13. f. 2. In Zeylonia. Pedalis. Fl. albi.

2. K. sumatrensis DC. caule erecto 4-gono tomentoso; fol. lanceolatis remotis subpetiolatis villosis; coronae tubo gibbo laevi. Spermacoce lietz. K. stricta Gaertu. t. 25. In India orientali $\hbar$.

3. K. Wiglitiana Wall. frutescens; glabra; caule 4-gono ramis teretibus lougis; fol. lanceolatis subcoriaceis ohtusis; fructu compresso orbiculari. Wall. L. II. 618t. In Courtallum.

t. K. teres $D C$. caule erecto tereti villoso; fol. lanceolatis villosis; ramis corymbi alternis spicaeformibus; corollae tubo tereti recto fauce villosissima antheras fovente. Spermacoce hoxb. In India orientali. $\hbar$.

5. Ki: exserta $D C$. caule rigido superne villoso; fol. lanceolatis petiolatis remotis; staminibus styloque bificlo-exsertis; fuctu ovato. spermacoce Hoxb. In India orientali et $\mathrm{Ne}$ pulia,

6. K. glabra DC. canle tereti glabro erecto; fol. lineari-lanceolatis lae- 
vilus; stylo piloso stigmate clavato; caps. globulari laevi. Spermacoce Roxb. S. insularis. In Pulo-Pinang. t. Cor. campanulata.

7. K. luevis DC. caule rigido tereti laevi; fol. subsessilibus lanceolatis glabris; corollae infundibuliformis fauce barbata antheras fovente; stigmate bifido. Spermacoce Roxb. s. Roxburghiana Schult. S. Roxburghii Spr. In Bengalia. $\odot$.

8. K. Heyniana DC. caule obsolete 4-gono scabriusculo; fol. Ianceolatis costatis margine scabris utrinque punstato - asperis; corymbo trichotomo. Spermacoce Hoth. In India orientali.

9. K. plantaginea Wall. pl. as. rar. $t$. 32. caule herbaceo subsimplici; fol. subradicalibus elongato-1anceolatis pilosis, caulinis distantibus linearibus; cor. tubo longissimo. In India orientali. 24. Fl. caerulei.

10. $\boldsymbol{K}$. lineata $D C$. caule erecto villoso; fol. ovato-lanceolatis parallele-venosis; stipularum setis pilosis staminibus inclusis. Spermacoce Blume. In Java. $\odot$ ?

11. K. hirsuta Arn. ramis ramulisque teretiusculis hirsuto-subvillosis; fol. oblongis supra glabriusculis subtus hirsuto-pilosis; stipulis setosofimbriatis; caps. compresso-orbiculari pilosa. Nees Pug. p. 26. In Ceylano. ち.

12. K. platycarpa Arn. ramis teretibus glabris; ramulis utrinque linea pilosa notatis; fol. oblongo-lanceolatis glaberrimis margine ciliolatis; fructu compresso deltoideo-ovato; calycis dente unico foliaceo caeteris minutis. Nees 1. c. In Ceylano.

566. LASIANTHUS Jack. (1825). (Mephitidia Reinw. et DC. prodr.)

\section{a. Calycis limbo partito.}

1. L. cyanocarpus Jack; suffruticosus; hirsutus ; fol. obl ongis acuminatis basi attenuatis; bracteis involucratis. In Sumatra et Java. ち. Cor. flava. Bacca caerulea.

2. L. attenuatus Jack; suffruticosus; villosus; fol. oblongis apice attenuatis, basi rotundato - su bcordatis snpra glabris; bracteis lanceolatis involucratis. In Sumatra. $\hbar$. Cor.flava. Baccae ca exuleae.
3. L. inaequalis Blume; fruticosus ; hirtus; fol. oblongis acuminatis basi inaequali - rotundatis ; bracteis involucratis. In Java. Cor. alba uti omnes sequentes.

1. L. Rlinozerotis Blume; fruticosus; fol. oblongis acuminatis hasi rotundatis supra glabris, infra et ramis calycibusque hirtis; floribus confertis axillaribus. In Java. ち.

5. I. capitatus Blume; fruticosus; fol. oblongo-lanceolatis acuminatis basi attenuatis supra glabris infra et ramis pedunculis calycibusque hirtis. In Jara. 古.

6. L. tomentosus Blume; fol. oblongis longiter acuminatis basi acutis supra glabris subtus incanis ramisque tómentosis; flor. axillaribus. In Java. 方.

\%. I. obscurus Blume; fruticosus; fol. oblongis acuminatis basi suboblique attenuatis supra ad costam subtus

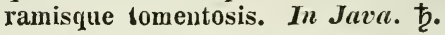

8. L. lucidus Blume; fruticosus; ramis glabris; fol. ovato-oblongis lanceolatisve cuspidatis supra lucidis infra ad marginem et in venis subpubescentibus. In Java. ち.

9. L. stipularis Blume; fruticosus; fol. oblongis acuminatis basi attenuatis ramisque glabris ad apicem ciliatis; stipulis maximis rotuudatis calycibus hirtis. In Java. t).

10. L. laevigatus Blume; fruticosus; fol. oblongis acuminatis hasi acutiusculis ramisque glabris; fasciculis axillaribus; calyce 3-partito. In Java.

11. L. latifolius Blume; fruticosus; fol. ovalibus utrinque acutis reticulato-venosis ramisque glabris; floribus

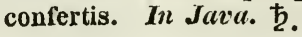

\section{b. Calycis limbo brevisisso.}

12. L. inodorus Blume; fruticosus; fol. oblongis aut oblongo-lanceolatis utrinque acuminatis glabris in venis infra puberulis ; floribus confertis; bracteis obtusis cinctis. In Java. $\hbar$.

13. L. hexandrus Blume; fruticosus; fol. lanceolatis longiter acuminatis, supra ad costam et in venis infra ramulisque strigoso-pubescentibus. In Java. $\mathrm{t}$. 
c. Calycis limbo brevidentato.

14. L. venosus Blume; fruticosus: fol. breviter petiolatis oblongis acuminatis basi oblique attenuatis venosissimis, supra glabris in venis subtus

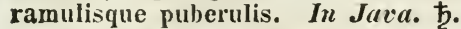

15. L. sylvestris Blume; fruticosus; fol. breviter petiolatis oblongo-lanceolatis utrinque acuminatis glabris venosis, in venis infra ramulisque pube adpressa; fructibus $4-5$ pyreuis. In Java. 5 .

16. L. reticulatus Blume; fruticosus; fol. breviter petiolatis oblongis acumiuat is basi acutis supra glabris, infra reticulato-venosis in venis ramisque subtomentosis. In Java, 支.

17. L. murpureus Blume; fruticosus; fol. lanceolatis longiter acuminatis ramulisque glabris; pedunculis confertis 1-floris. In Java. $ђ$.

18. L. stercorarius Blume; fruticosus; fol. lanceolatis longiter acuminatis basi acutis glabris, in veuis infra ramulisque pube adpressa. In Java. 古.

\section{MYRMECODIA Jack. (1825).}

1. M. inermis Gaudich. Voy. t. 95. tuberibus inermibus; fol. obovato-oblongis; calycis limbo subintegro; stigmate simplici tomentoso. Rumpl. 6. t. 55. f. 2. M. tuberosa Jack. Lasiostoma Spr. Super arbores Molucrarum parasitica. †. 4.

2. M. armata DC. tuberihus aculeis seriatis ohtectis; fol. cuneato-ohlongis; calycis limbo integerrimo; stigmate 4-loho. M. tuberosa Blume. M. echinata Gaudich. 1. c. t. 96. Super arbores Javae. 4. $\hbar$.

\section{DUNALIA Spr. (1821).}

1. D. tuberosa Spr. Peplis tetranIra I. Jacq. am. t. 180. f. 29. Oldenlandia tuberosa Lam. Hedyotis Sw: obs. t. 1. f. 2. In umbrosis ad radices arborum ins. Caribaearum, Jamaicae et Domingo. $\odot$. Herba pusilla. Fol. cordato-ovata subtus pubescentia. Fl. axillares albi.

\section{MYONIMA Comm. (1789).}

\section{a. Eructa 4-pyreno.}

1. M. obovata Lam. ill.t. 68. f. 1. fol. obovatis obtusis; baccis obtuse 4-gonis. Lam. In ins. Borbonice. Frutex elegans. Baccae rubrae magnitudine baccae Uvae Ursi.

2. M. myrtifolia Lam. ill. t. 58. f. 2. fol. lanceolato - ovatis acutis; baccis sphaericis. Lam. M. Ianceolata Willd. In ins. Borboniae. ち. Cortex et lignum rufescens.

3. M. multiflora A. Rich. fol. ovato-lanceolatis basi cordatis; cymis paniculatis; tubo limbo breviore. Ixora micrautha Lam. ill. t. 66. f. 2. Hheede 10. t. 57. Faramea corymbosa Sieb. In ins. Mauritii. $\hbar$.

\section{b. Fructu 2-pyreno.}

4. M. umbellata Bartl. fol. obovatis coriaceis; pedunculis axillaribus multifloris; dentibus calycinis brevissimis; baccis subrotundis. In iins. Luzon. ち.

\section{PYROSTRIA Comm. (1789).}

1. P. oleoides Lam. ill. t. 65. f. 3. fol. oblongis obtusis; stipulis glabris; drupis 8-spermis. P. salicifolia Willd. In ins. Borboniae. 占.

2. P. hexasperma Roxb. fol. oblongis acutis; stipulis pilosis; ramulis corymbi recurvis; drupis 6-spermis. In India orientali. $\hbar$.

3. P. orbicularis A. Rich. fol. ovali-orbiculatis basi subcordatis sessilibus apice obtusis; stipulis glabris; pedunculis 1-floris. In ins. Borboniae. 古.

4. P. cordifolia A. Rich. fol. ovalibus acutis basi subcordatis brevissime petiolatis; stipulis counatis vaginaeformibus; corollae lobis ovali-acutis. In ins. Nauritii.

5. P. polymorpha A. Rich. fol. orbiculatis s. lineari-lanceolatis variegatis obtusis; stipulis acutis inter se basi vix comnatis caducis; involucello tomentoso 3-4-dentato. In ins. Mauritii. $\hbar$.

6. P. macrophylla A. Rich. fol. ovali-oblongis subcordatis, subtus: 
scrobiculatis; stipulis glabris; involucro diphyllo. In ins. Mauritii. $\hbar$.

\section{5\%1. EVOSMIA. H. et B. (1811).}

1. E. caripensis H. et. B. aeq. $t$. 134. fol. ovalibus utrinque acuminatis; racemis laxis petiolo paulo longiorihus; pedicellis elongatis. In humialis Cumanae. $\hbar$.

¿. E. aggregata Spr. fol. lanceolatis acuminatis; floribus fasciculatis; pedicellis calyce brevioribus. O-higginsia R. et $P$. peruv. t. 83. f. 6 . Higginsia Pers. In Andibus. ち.

\section{GONZALEA Pers. (1805).}

\section{Bacca carnosa.}

1. G. pendula Pers. fol. ovatis acutis bullato-crenatis; ramis floridis pendulis; calycis dentibus subobtusis. Gonzalagunia dependens $\boldsymbol{K}$. et $\mathbf{P}$. peruv. t. 86. In Peruvia. ち. Fl. purpureo-rosei. Bacca nigra.

\section{Bacca exsucca.}

2. G. tomentosa H. et B. aeq. $t$. 61. fol. oblongis acuminatis petiolatis subtus albo-tomentosis; stipulis breve ovatis acutis. In Peruvia. $\hbar$. Fl. albi.

3. G. nivea Bartl. fol. ovali-oblongis basi cuneatis apice acuminatis, subtus racemoque niveo-tomentosis; stipulis subulatis. In Mexico. $\hbar$.

t. G. pulverulenta $H$. et $\boldsymbol{B}$. fol. lanceolatis hasi obtusis subtus ramisque pulverulento-puhescentibus ; stipulis subulatis. In Peruvia. ち. Fl. alti.

5. G. Panamensis Pers, fol, ovato-lanceolatis integerrimis; stigmate 4-fido. Pers. syn. Buena panamensis Cav. ic. t. 571. In Panama. $\downarrow$. Caul. 5-7-pedal. Fl, villosi flavo-rubelli.

6. G. cornifolia $H$. et $K$. fol. oblongis aut ovato-oblongis acuminatis basi acutis petiolatis subtus pubescentibus; stipulis ovato-subulatis, In Nova Granata. 市.

7. G. spicata DC. fol. oblongis acuminatis utrinque puhescentibus; stipulis apice subulatis; calycis laciniis subulatis. Lygistum spicatum
Lam. Coccocypselum spicatum H. et K. In Havana, Portorico et Guadelupe. $\hbar$.

8. G. incanescens DC. fol. supra pubescentibus subtus adpresse sericeovillosis canescentibus; calycis lobis oblongis. In Tabago?

\section{COCCOCYPSELUM P. Brown. (1856.)}

1. C. repens Su. caule herbaceo repente; fol. ovatis; floribus confertis axillaribus sessilibus. C. herbaceum Lam. ill. t. 64. Brown Jam. t. 6. f. 2. Condalea repens $\mathbf{R}$. et $P$. peruv. t. 84. In montosis Jamaicae. 24. Fl. purpurascentes. Bacca caerulescens.

2. C. umbellatum Poir; fol. ovatis acutis nitidis pubescentibus; pedunculis folio dimidio brevioribus; capituli bracteis subulatis. Condalea repens R. et P. peruv. t. 84. f. a. C. Condalea Pers. C. capitatum Willd. Hh. In peruvia. 24. Fl. purpurascentes. Bacca caerulea.

3. C. ovatum Cham. et Schlecht. adscendens; basi radicans; fol. ovatis basi obtusissimis apice acutis minute et adpresse pubescentibus; pedunculis strigoso-pubescentibus; capitulis 8-10floris. In Brasilia, 4.

t. C. lanceolatum Pers. caule herbaceo radicante; fol. lanceolatis integrerrimis ; pedunculis multifloris. Pers. Condalea lanceolata $\mathrm{R}$. et P. In Pemuvic. Fl. pallide violacei. Bacca caerulea.

5. C. hirsutum Bartl. adscendens; undique hirsutissimum; fol. lato-ovatis acutis breve petiolatis; pedunculis fructiferis recurvis. Patria ignota. 4.

6. C. canescens Willd. Hb. prostratum; repens; fol. ovatis utrinque pubescenti-sericeis; capituli bracteis 5-6 oblongis acutis. C. repens H. et K. Schwenkfeldia aspera spr. In Caracas, Popaya et Brosilia. 4.

7. C. aureum Cham. et schlecht. fol. oblongis acutis parallele venosis aureo - sericeis; capitulis axillaribus sessilibus; bracteis $4-5$ angustis. Schwenkfeldia spr. In Brasilia. 4.

8. C. nummularifolium Cham. et Schlecht. prostratum; repens; hirsutissimum; fol. breve petiolatis ovato-rotundatis obtusissimis; bracteis linearibus. In Biusilia. 4. 
9. C. campanuliforum Cham. et Schlecht. fol. late ovatis hasi subcordatis apice hreve apiculatis utrinque villosis; petiolis caulihus pedunculisque mollibus hispidissimis. Hedyotis campanuliflora Bot. Mag. 2840. C. violaceum Desf. In Brasilia. 4.

10. C. cordifolium Nees; repens; fol. cordatis ohtusis hirsutis; pedunculo demum petiolo aequali; calycihus petiolisque villosissimis. In Brasilia. 4. Fl. albi. Bacca caerulea.

11. C. erythrocephalum Cham. et Schlecht. ramis simplicibus hirsutis; fol. ovatis acutis basi ohtusis ntrinque hirsutis subtus purpurascentibus. In Brasilia.

12. C. pedunculare Cham. et schlecht. adscendens; pilis adpressis pubescenti-strigosum; fol. Ianceolatooblongis margine revolutis; pedunculis demum reflexis. In Brasilia. 4.

13. C. Tontanea H. et K. fol. ovatis subacutis utrinque pubescenti-subhirsutis; bracteis subulatis; antheris breve exsertis. Tontanea Gujanensis Aubl. Guj. t. 40. T. repens Pers. Bellardia repens Willd. B. Tontanea R. et s. In Cayeuna et Gujana. 4. Fl. albi vel caerulei.

1. C. glabrum Bartl. serpens; undique glaberrimum; fol. ovatis sul)cordatis acutiusculis; capitulis axillaribus paucifloris, fructiferis deflexis. In Panama. 4.

15. C. obovatum Pers. caule erecto suffruticoso; fol. obovatis acuminatis; pedunculis aggregatis; florihus racemosis. Pers. syll. Condalia obovata. 1. et Pav. In Peruria. 5. 3ped. Fl. albi. Bacca pupurascens.

16. C. sessile pers. caule erecto suffruticoso ; fol. oblongis acutis ; floribus sessilibus congestis axillaribus. Pers. Syn. Condalia 1R. et P. In Perucia. 方. 3-ped. Fl. et Bacca purpurea.

\section{1. HOFFMANAIA Sw. (1788).}

1. H. pedunculata $S w$. ind. 1. $f$. 5. In nemoribus montium Jamaicae. ђ. Suffruticosa. llami hirsuti. Fol. ovato-acuminata supra punctis aspera subtus hirsuta. Fl. rubro-lutei. Bacca coccinea.
2. I. amicorum Spr. fol. ovatis coriaceis obtusis basi cuneatis breve petiolatis ; calycis Iobis calloso-apiculatis. Bikkia australis $\alpha$. Forsteriana $\beta$. conmersoniana $\gamma$. Gaudichandiana DC. Portlandia tetraudra Forst. In ins. maris Pacifici.

\section{HELOSPORA Jack. (183.5).}

1. H. flavescens Jack, in Linn. Trans. 14. t. 4. f. 3. In sumatia. t. Arbuscula glahra. Fol. opposita ovato-lanceolata $3-5$ poll. Ionga. Cor. flavescens.

\section{5\%6. CATESBAEA Gronov. (1743).}

\section{a. Flores penduli. Stamina exserta.}

1. C. Latifolia Lindl. B. R. 8.5. fol. obovatis lucidis convexis spina subbrevioribus; cor. tubo longissimo apice obconico. In Curibats. t. Fl. ocliroleuci.

2. C. spinosa L. fol. ovatis utrinque subacutis spina sublongioribus; cor. tubo longissimo cylindraceo apice obconico; bacca ovali. Bot. M. 131. Lam. ill. t. 67. f. 1. C. longiflora Sw. Catesb. 2. t. 100. In Bahama. ち. Fl. ochroleuci.

3. C. Vacassorii Spr. fol. ellipticooblongis obtusis supra nitidis ramulisque spinescentibus glabris; peci. 1floris. Cinchona spinosa Vavass. jour. phys. 1790. t. 2. Lamb. Cincl. t. 13. In Domingo. $\hbar$.

b. Flores erecti. Stamina inclusa.

4. C. parviflora Sw. fol. ovalibis rigidis margine revolutis mucronatis ramulisque glahris; cor. tobo abbreviato t-gono; bacca subrotunda. Vahl Ecl. 1. t. 10. f. 1. In Jamaica. ち.

5. C. campanulata La Sagra; fol. ovato-subrotundis coriaceis ramulisque glaherrimis ; spinis oppositis folio longioribus; cor. albbreviatis. In Cuba. $\downarrow$.

6. C. purvifolia DC. fol. ovatis subrotundis mucronatis ulahris; spinis axillaribus subulatis folio paulo longioribus; ramulis hirtellis; floribus 
brevissime pedicellatis. C. parviflora var. domingensis spr. Gardenia Dietr. Lex. Randia Lam. ill. t. 156. f. 2. In Domingo. 卢.

7. C. erecta fl. mex. fol. ovalioblongis acutis; ramulis oppositis patentibus inernibus; floribus subterminalibus sessilibus; tubo cor. longissimo. In Mlexico. Fl. albus.

\section{CARPHALEA Juss. (1789).}

1. C. madagnscariensis Lam. ill. t. 59. C. corymbosa Willd. In Madayascar. †. Frutex aridus hyssopifolius. Fol. sessilia linearia acuta. El. terminales.

\section{7s. MANETTIA Mutis. (1771).}

a. Calyx 8-rarissime 10-fidus; $10 b u l i s$ accessoriis adjectis.

1. M. reclinata $L$. caule herbaceo reclinato debili ramoso; fol. ovatis acutis subtus pubescentibus; pedicellis oppositis hirsutis. In Mexico. ‡. Fl. albi.

2. M. racemosa $R$. et $\boldsymbol{P}$. peruv. t. 89. pubescens; fol. ovatis oblongisve acuminatis; stipulis semicircularibus; flor. subracemosis. M. nutabilis Pers. Nacibaea Poir. In Jamaica. $\hbar$. 8-12-ped. Fl. purpurei.

3. M. coccinca Willd. fol. ovatis acuminatis; racemis multifloris; caule volubili fruticoso. Willd. sp. Nacibaea Aubl. Guj. t. 37. f. 1. In Gujana. . Arbor sarmentosus facie Clematitis. 11. coccinei.

4. M. Lyyistum Su. fol. ovatis acutis venosis; caule flexuoso-voluhili suffrutescente. Sw. prodr. p. 37. Lygistum axillare Lam. ill. t. $6 \%$. f. 2. Brown jam. t. 3. f. 2. In Jamaica. 市.

5. IM. havanensis $\boldsymbol{H}_{\text {, et } \boldsymbol{K} \text {. caule }}$ volubili ramis angulatis; fol. ovatooblongis acuminati glabris. In $\mathrm{Cu}$ ba. .

6. M. cuspidata Bert. glabra; caule volubili; ranis filiformibus sub-1-gonis; fol. ovali - oblongis acuminatis; stipulis latis brevissimis. In Jamai$c a$, ins. 'Trinitatis et in Mexico. $\hbar$.
7. M. uniflora $\boldsymbol{H}$. et $\mathrm{K}$. caule suffruticoso scandente; ramis 4-gonis hispidulis; fol. ovato-oblongis angustato-acuminatis supra pilosiusculis subtus glabris. In Nova Andalusia.

\section{b. Cal. 4-fidus; 10 bulis acces- soris nullis.}

8. M. cordifolia Mart. sp. mad. bras. 1. $t$. \%. caule herbaceo volubili tereti scabriusculo; fol. ovatis basi cordatis apice acutis pubescentibus. Bot. Mag. 3202. In Brasilia. 4. Hl. coccinei.

9. M. glabra Cham, et Schlecht. glaberrina; caule volubili; fol. cordatis acuminatis; pedunc. 1-floris axillaribus. In Brasilia. ち. Fl. coccinei.

10. M. gracilis Cham. et Schbecht. puberula; volubilis; fol. petiolatis ovato-lanceolatis acuminatis; pedunculis axillaribus 1-noris. In Brasilia. 4.

11. M. pubescens Cham.et Schlecht. volubilis; tota cinereo-puhescens; fol. petiolatis ovatis basi obtusis apice acuminatis; stipulis acumine parvo; laciniis calycis tubo longioribus. In Brasilia. 24.

12. M. villosa Cham. et Schlecht. volubilis; ramulis pube asperula cinereo-tomentosis; fol. petiolatis ovatis subacuminatis basi subacutis ; stipulis 3-angulis; calycis laciniis linearibus; caps. ovata villosa. In Brasilia. $\hbar$.

13. M. attenuata Mart. caule scaudente subtereti scabriusculo; fol. ovato-lanceolatis utrinque attematio subtus pubescenti-tomentosis. In Brasilia. 2. Fl. punicei.

14. M. acutifolia $\boldsymbol{R}$. et $\boldsymbol{P}$. peruv. t. 89. $f$. 1. glabra; caule tereti volubili; fol. lanceolatis acutissimis petiolatis; stipulis acuminatis adpressis basi latis. M. acutiflora $\mathrm{R}$. et s. Nacibaea acutifl. Poir. In Peruvia. $\hbar$. Fl. purpurei.

15. M. umbellata $R$. et $P$. peruv. t. 90. f. $a$. fol. ovatis subcordatisque; stipulis conuatis acuminatis; pedunculis umbellatis multifloris. Nacibaea Poir. In Peruria. ђ. Fl. caerulei.

16. M. rosea Poll; ramis subvolubilibus compresso-angulatis subpubescentibus; fol. oblongis acuminatis glabris; stipulis latis acuminatis. In Brasilia. $\downarrow$. Fl, rosei. 
17. M. fimbricata Cham. et Schlecht. volubilis; glaberrima; fol.. petiolatis ellipticis acuminatis basi acutis; lobis calycis ovato-lanceolatis; cor. laciniis margine dense fimbriatis. In $\mathrm{Br}$ asilia. $\hbar$.

18. M. picta Willd. fol. ovatis acutis; calyce 4-dentato; caule volubili fruticoso. Nacibea alba Aubl. Guj. t. 37. f. 1. Constrichia alba A. Rich.

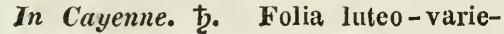
gata.

19. M. pseudodiodia Cham. et Schlecht. caule volubili obscure 4gono glahro apice linea ciliata notato ; fol. petiolatis late ovalibus acuminatis; stipulis triangulis ciliatis; cor. extus grumoso - tomentosa. Diodia pedunculata Spr. In Brasilia. 24.

20. M. ciliata Cham. et Schlecht. caule volubili 4 -angulo angulis acutis ciliatis; fol. breve petiolatis lanceolatis acuminatis ciliatis subcoriaceis; stipulis ciliatis acumine reflexo; cor. extus ferrugineo-tomentosa. In $\mathrm{Bra}$ silia. 古.

21. M. albiflora Schott. caule lierbaceo ramis 4 -gonis pilosiusculis; fol. oblongis utrinque acuminatis pubescentibus; stip. cuneatis. In Brasilia.

22. M. Gaertneri DC. caps. ovatis compressis bisulcis, calycis limbo 4-partito coronatis. Nacibea Gaertn. t. 197. f. 5. Patria ignota.

23. M. secundiflora DC. herbacea; scandens; fol. ovatis lanceolato-linearibus; racemis axillaribus subsecundis ebracteatis. Paederia Poir. Nacibea angustifolia Vahl. In Domingo. 24?

\section{BOUVARDIA Salisb. (1805).}

a. Fol. verticillatis; corollae tubo intus barbato.

1. B. linearis $\boldsymbol{H}$. et $\boldsymbol{K}$. ramis teretihus junioribus pulescenti-hirtellis; fol. ternis linearibus revolutis subtus canescenti-lirsutis. In Mexico. ち. Fl. inçaruati.

2. B. andustifolia $\boldsymbol{H}$. et $\boldsymbol{K}_{\text {. }}$ ramis teretibus glabriusculis ; fol. ternis lanceolatis margine revolutis supra glabris subtus tenuiter hirtellis. In Mexico. b.

3. $\boldsymbol{B}$. hirtella $\boldsymbol{H}$. et $\boldsymbol{K}$. ramis teretibus; ramulis foliisque utrinque hir- tellis lanceolatis margine revolutis. Prope urbem Mexico. $\hbar$.

4. B. quaternifolia DC. ramulis striato-angustatis subpuberulis; fol. quaternis lanceolatis acuminatis supra scabris subtus pubescentibus. In Mexico. Ђ. Fl. coccinei.

5. B. Jacquini $\boldsymbol{H}$. et $\boldsymbol{K}$. ramulis 4-gonis; foliis subtus hirtellis, supra glabriusculis ternis oblongis; calycis lobis cor. quintuplo brevioribus. Ixora americana Jacq. Schoenbr. t. 257. I. ternifolia Cav. ic. t. 305. Houstonia coccinea Andr. t. 106. Herb. am. t. 116. B. triphylla $\alpha$. Salisb. Ker. B. R. 10\%. Prope urbem Mexico. 1-2-ped. Fl. coccinei.

6. B. obovata $H$. et $K$. ramis 4gonis striatis foliisque glabriusculis quateruis obovatis; corymbis trichotomis. In Mexico. t. 1-3-ped.

\section{b. Fol. oppositis; corollae tubo imberbi.}

7. B. versicolor Ker. B. R. 245. ramis teretibus glahris junioribus velutiuis; fol. oppositis lanceolatis ciliolatis ; corymbis nutantibus. In America? t. Fl. coccinei intus flavescentes.

8. B. triflora $H$. et $K$. ramis teretibus glabris; ramulis subhirtellis; fol. oppositis lanceolato-oblongis angustato-acutis basi subrotundis tenuissime hirtellis. Cestrum spermacociflorum Willd. Hb. In Mexico. $\hbar$.

9. B. longiflora $\boldsymbol{H}$. et $\boldsymbol{K}$. ramis compresso-4-gonis glabris; fol. oppositis oblongis angustato - acutis hasi cuneatis glabris. Aeginetia longiflora Cav. ic. t. 572. f. 1. In Mexico. ち. Fl. albi.

10. B. Cavanillesii DC. suffruticosa; fol. oppositis ovato-lanceolatis acuminatis subtus subvillosis; caps. transverse ovata subdidyna. Aeginetia multiflora. Cav. ic. t. 572. f. 2. In Mexico. $\hbar$.

11. B. corrlifolia $D C$. suffruticosa; fol. oppositis brevissime petiolatis cordatis acutis; corymbis 8-10-floris. Ixora fl. mex. In Mexico. $\downarrow$. Cor. sordide e flavo coccinea. 


\section{S0. HEDYOTIS L. (1717).}

a. Pedicellis axillaribus 1-floris solitariis subgeminatis.

1. $H$. intermedia $W$. et A. diffusa; subscabra; fol. lineari-lanceolatis; calycis segmentis subulatis; caps. glalira turbinato-oblonga. H. Burmanniana Wall. In India orientali. $\odot$. et $\odot$.

2. II. brachiata Wight; subscabra; basi ramosa; ramis erecto-adscendentibus ; fol. lineari-subulatis rigidis mucronatis margine revolutis. Plukn. t. 114. f. 2 ? In India orientali. $\odot$.

3. H. Neesiana Aln. diffusa; ramis sulcatis superne 4-gonis; fol. ovato-oblongis acuminatis subsessilihus supra nitidis minutissime callosopunctatis; calycis laciniis oblongis ciliato-scabris. Nees. pug. p. 23. In Ceylano.

4. H. gracilis DC. prodr. decumbens; elongata; scabrido-puberula; fol. linearibus acutis; stipulis setaceo-multifidis. DC. In Nova Caledonia.

5. H. adscensionis DC. proatr. caule suffruticoso ramoso glabro; fol. linearibus acutis margine revolutis; calycis lobis linearibus DC. In ins.

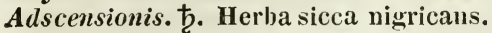

6. H. puuciflora Bartl. in Hb. Haenk. ramis 4-gonis laevibus; fol. linearibus acutissimis revolutis; stipulis multisetis. DC. In ins. Luson. $\downarrow$.

\%. H. nitida $W$. et $A$. diffusa; ramis 4-gonis elongatis glahris; fol. oblongo-lanceolatis utrinque acuminatis subsessilihus supra scabris. Wight. In India orientali.

8. II. biflora R.Br. glabra; fol. elliptico-oblongis basi attenuatis; calycis laciniis 3-angulari-acuminatis; caps. turbinata. Br. in Wall. 1. 1. 879. Oldenlandia biflora L.? In India orientali. $\odot$. et $\odot$.

b. Floribus axillaribus glomerato-verticillatis subsessilibus.

9. H. tenelliflora Blume bijolr. caule suffruticoso geniculato procumbente; fol. subsessilibus lanceolatis margine scabris subtus aveniis; stipulis longe setaceis. DC. In humidis Javae. ђ.

10. II. angustifolia Cham. et Schlecht. canle ramoso 4 -gono angulis hirtellis; fol. linearihus angustissimis acutis margine revolutis scabris; stipulis hirtis membranaceo-finbriatis DC. In ins. Luzon. $\odot$.

11. H. Boscii DC. prodr. glabra; caule herhaceo adscenclente gracili 4gono; fol. linearibus; stipularum setis fructu ovato brevioribus. In Carolina legit Bosc. Fol. pollicem longa. Sem. minutissima.

12. H. auricularia $L$. caule subsimplici 4-gono apice suhhirsuto; fol. lanceolato-ovatis nervosis; stipulis setoso-ciliatis. DC. Pheede 10. t. 32 . Burm. 'Zeyl. t. 108. f. 1.? H. nervosa Lam. In Zeylonia, Malabaria, silhet et Nepalia. 4.

13. H. geniculata Roxb. debilis; decumbens; nodosa; teres; laevis; fol. subsessilibus lanceolatis laevibus; floribus breve pedunculatis. Koxb. ind. In ins. Malaicis.

11. Lapeyrousii DC. prodr. caule erecto apice subangulato vix ramoso; fol. oblongo-lanceolatis utrinque acnminatis glabris; stipulis multisetis; caps. globosis. DC. In ins. Vanikoro. $1 \frac{1}{2}$ - ped.

15. H. crassifolia Blume; caule diffuso parum hirsuto; fol. Irevissime petiolatis lauceolatis cuspidatis subaveniis scahris ; stipulis setigeris ; filamentis exsertis. DC. In umbrosis Javae.

16. H. crataeyonum Spr. caule tereti glabro articulato; fol. lanceolatis acuminatis venosis scabris; stipulis setaceo - laceris. Oldenlandia verticillata $L$. Rumph. amb. 6. t. 10. In Amboina.

17. H. hispida Retz; caule diffuso ramoso 4-uono ad nodos radicante; fol. sessilibus lanceolatis margine hispidis; stipulis plurisetis. DC. O1denlandia Poir. In Molncis et Chinu.

18. H. rotundifolia $\mathbf{S} \mathrm{m}$. decumbens; subramosa; fol. petiolatis late ovatis subtrinerviis; stipulis scariosis ciliatis; caps. hispidis. DC. In arenosis Indiue orientalis.

19. H. articularis $R, B r$. frutescens; glabra; ramis obtusangulis; fol. approximatis sessilibus oblongo-lanceolatis revolutis coriaceis subpapillosis ; corolla puberulo-villosa. Wight. prodr. In Nellgerrhies. $\hbar$.

20. H. macrophylla Wall. Cat. caule firmo acute 4-angulo glabro; fol. petiolatis ovalibus utrinque sub- 
acutis supra scabris; fructu obovato. W. et A. prodr. H. nodiflora Wall. In India orientali.

21. H. verticillaris Wall.? glabra; fol. lineari-lanceolatis oppositis s. verticillatis; stipulis lanceolatis ; stigmate bifido, W. et Arn. prodr. In Inelia orientali.

22. H. Walleri Nees; ramis compressis pubescentibus; fol. breviter petiolatis ovato-lanceolatis acuminatis basi acutis subtus pubescenti-hirsutis. Nees pug. In Ceylano.

23. H. nodulosa Arn. fruticosa; ramis subcompressis hirsutis ; fol. breviter petiolatis oblongo-lanceolatis apice attenuatis basi cuspidatis subtus adpresso-hispidis; fructu dicocco hispido. In Ceylano. ち.

c. Pedunculis axillaribus multifloris; floribus congestis.

21. H. capitata Lam. caule tereti subsimplici pubescente; fol. subpetiolatis ovato-lanceolatis acutis nervosis supra glabris subtus velutinis; stipulis setace - laceris. DC. In India orientali.

25. H. lineata Roxb. diffusa; pilosa; fol. sessilibus ovato-lanceolatis parallele-venosis; capsula rotunda pilosa. DC. prodr. In Chittagong Indiae orientalis. $\odot$.

26. H. ulmifolia Wall. adscendens; molliter hispida; fol. ovali-lanceolatis acutis nervosis; nervis villosis; stipulis cupulatis acuminatis; calycis laciniis acutis. H. lineata Don. In Nepalia. 4.

27. H. serpyllifolia Poir. caule herbaceo ramoso pubescente subangulato; fol. ovatis acuminato-mucronatis subciliatis; calycis tubo puhescentihispido. DC. var. caule repente; OIdenlandia repens Burm. ind. t. 15. f. 2. In ins. Borboniae, Madras et Zeylonia.

23. H. uniflora DC. glabra; caule repente ramoso delili; fol. ovatorotundatis obtusis; stipulis minimis; calycis tuho hispidulo. DC. prodr. Oldenlandia $R$. et $P$. peruv. In Perucia.

29. H. glomerata Ell. caule suberecto herbaceo pubescente ramoso; fol. lanceolatis basi attenuatis pube- scentilus; stipulis acute hidentatis; calycis tubo hispido. Oldenlandia Michx. H. auricularia WValt. In Carolina et Virginia.

30. H. Goreensis DC. diffusa ; multicaulis; caulibus subangulatis ad nodos puberulis; fol. Ianceolatis acutis glabris; calycis laciniis apice revoluto-uncinatis. DC. prodr. In Africa aequinoctiali legit Perrottet.

31. H. Iheellii W. et A. lierbacea ; adsceudens; glabra ; fol. ovalibus ohtusis acute acuminatis; pedunculis dichotomis; caps. compressa didyma. Wight prodr. Hheede 10. to 25. In India orientali.

32. H. Lessertiana Arn. ramulis compressiusculis ; fol, oblongo-lanceolatis acuminatis petiolatis rigidis; stipulis tubulosis truncatis setosis; caps. oblongo-obovata dicocca. Nees pug. In Ceylano. நे.

d. Paniculis ant corymbis terminalibus laxis rarius axillaribus.

33. H. pruinosa $W$. et $A$. caulc subfrutescente tereti ramisque angulatis glabris; fol. petiolatis oblongolanceolatis utrinque acuminatis glabris; stipulis pinnatifidis; caps. turbinata. Wight. prodr. H. corymbosa Hb. Madr. In India orientali.

34. H. Wightiana Wall. herbacea; diffusa; pilosa; caule hasi 4-angulo; fol. ovatis s. ovalibus acutis subpetiolatis; stipulis integris lineari-acutis; caps. compressa Wall. In Neelgerrhies.

35. H. monosperma $W$. et A. herhacea; procumbens; radicans; caule ramisque versus apicem pilosis; fol. petiolatis deltoideo-ovatis acutis ; caps. compresso-globosa. Wigth prodr. In Neelgherries.

36. $H$. deltoidea $W$. et $A$. herbacea; procumbens; caulibus flexuosis; petiolis inflorescentiaque glahris; fol. deltoide - ovatis acutis; pedunculis trichotomis. Wight prodr. In India orientali.

37. H. affinis $W$. et A. herbacea; procumbens; radicans; caule flexuoso ramoso superue villoso; fol. delluideoovatis acutis hasi attenuatis; corymbis hirsutis; calycis laciniis cuneatolanceolatis. Wiglit prodr. In montibus Dindigul. 
38. H. Lechenaultiana W. et A. herhacea; repens; caule ramoso piloso; fol. late ovatis acuminatis acutis basi corlatis villosis; caps. $6-8-$ sperma. Wight prodr. In Neelgherries.

39. $H$. caerulea $W$. et $A$. annua; e radice ramosa diffusa; fol. setaceis hirsutis; stipulis hirsutis; pedunculis dichotonis. Wight prodr. In Tanyore. $\odot$.

40. H. plantaginifolia Nees; caespitosa; radice crassa; caulihus brevilus scapiformibus ramosis; fol. rad. magnis linearihus acuminatis 5-7 nerviis glaberrimis; cor. fauce albobarbata. Nees pug. In Ceylano.

41. H. Richardiana Arn. luerbacea; diffusa; radicans; fol. ovatis subacuminatis acutis subtus pallidis Jirsutulis; caps. compressa obovata disperma; seminihus tereti-oblongis. Nees pug. In Ceylano.

42. H. nummularia Arn. herbacea; diffusa; caulibus hirsutis elongatis; fol. subsessilibus late ovatis obtusiusculis basi rotundatis utrinque pilis articulatis hirsutulis. Nees pug.

In Ceylano.

43. H. nummulariformis Arn. herbacea; diffusa; radicans; caulibus elongatis glaberrimis ntrinque linea obscura pubescente notatis; fol. orbiculari-ovatis glaberrimis hrevissime petiolatis. Nees pug. In Ceylano.

44. H. tubutaris $R$. Rr. glabra; erecta; fol. ovatis acutis ; corollae tubo longo gracili. Oldenlandia Don. H. minima Heyne ex Dou. In Nepaiia. $\odot . \frac{1}{4}-\frac{\mathrm{I}}{8}-$ ped.

45. H. mysorensis Heyne; pubescens; caulibus 4-gonis; fol. ovatis acutis ciliatis subtus petiolisque ferrugineo - pubescentibus.

Oldenlandia Don. In Nepulia. $\odot$. Pedalis.

46. H. mubernal $R$. Br. undique pubescens; fol. lineari-lauceolatis mucronatis; pedunculis axillaribus vel e canlis dichotomiis. Oldenlandia Don. In Nepalia. $\odot$. $\frac{1}{2}-$ ped.

4\%. If. stylosa R. Br. fruticulosa; glabra; ramis obtuse 4-angulis; fol. ovalibus s. oblongo-lanceolatis acuminatis petiolatis; stipulis 3-angulariovatis; caps. ovoidea dicocca. If. Lechenaultii. DC. In Neelgherries. ț.

48. H. laxa Don; caule herhaceo debili dichotomo angulato glabro; fol. ovatis acutis utrinque pilosiusculis ci- liatis; stipulis setaceo-partitis. Don. prodr. In Nepalia. 4. Habitus 0phiorhizae.

19. H. vaginata Blume; snffruticosa ; glabra; fol. lanceolatis acuminatissimis nervosis; stipulis longe vaginatis utrinque in setam unicam puberulam exsertis; fauce corollae barbata; staminibus exsertis. In ins. Ternate Moluccanarum. $\hbar$.

50. H. scundens Roxb. caule erecto tereti scandente laevi; fol. breve petiolatis late lanceolatis laevibus; stylo apice villoso; stigmate bilamellato. DC. In Sillet. 4.

51. H.? arborea Roxb. in Beats voy. fol. breviter petiolatis oblongis acuminatis lucidis apice recurvis; vagina inaequaliter 2-3-dentata; caps. globosis. In ins, Helena. $\hbar$.

52. H. ciliolata Torr. fol. spathulatis sessilibus ciliatis; pedunculis 3chotonis; caule ramoso. DC. In America boreali.

\section{OLDENLANDIA I. (Hedyotis part. auct.) (1737).}

a. Pedicellis axillaribus 1-floris, solitariis rarogeminis ternisve.

1. O. brachypoda DC. glabra; decumbens; fol. linearibus ; stipulis utrinque bisetis; corolla tubulosa. Hedyotis radicans Bartl. In Java, ins. P/hilippinis et Nepalia. $\odot$.

2. O. ramosissima Fisch. caule herbaceo diffuso; fol. Ianceolatis obtusiusculis; stipulis dentatis; fructibus sulssolitariis sessilibus. Hedyotis spr. Patria iynota.

3. O. subulosa DC. herbacea ; caespitoso-diffusa; ramosissima; tota pilis sparsis brevihus asperula; fol. linearibus acutis; stipulis membranaceis plurisetis; pedicellis fructiferis deflexis. DC. In Senegalia legit Perrottet.

4. O. viparia DC. caule 4-gono glabriusculo; fol. linearibus acutis scabridis; corolla tubulosa calycis longiludine. DC. prodr. Ad flumen seneyal.

5. o. capensis Thunb. canle decumbente ramoso villoso; fol. liuearibus acutis glabris; calycis lobis ciliatis; fauce corolla villosa. DC. Hedyotis Lam. In Prom. b. spei. $\odot$. 
6. O. linearis DC. glabra; erecta; ramosa; caule 4-gono; fol. linearibus acutis; stipulis plurisetis; calycis dentibus brevissimis. DC. In sabulosis Senegaliae. $\odot$.

\%. O. Iancifolia DC. caule simplici debili dichotomo repente glabro; fol. lineari-lanceolatis glabris margine scabriusculis; stipularum setis distantibus. Hedyotis schum. In Guinea.

8. O.herbucea DC. slabra; decumbens; fol. linearibus s. Inneari-lanceolatis; stipulis multisetis; cor. tubo cylindraceo. DC. Ihlieede mal. 10. t. 23 et $\mathbf{3 5}$. Hedyotis L. In India orientali et ins. Madagascar. $\odot$.

9. O. tennifolia Forst. caule erecto -gono ramoso; fol. linearibus utrinque attemuatis; stip. subciliatis subscariosis; pedunculis florentibus reflexis. DC. Hedyotis Spr. In ins. Tanna.

10. O. scabrila DC. canle suberecto ramoso 4-gono secus allgulos scabro ; fol. linearibus acutis : cor. tubulosa vix calyce longiore. o. tenuifolia Burm. ind. t. 14. f. 1. In Nepalia. $\odot$.

11. O. graminifolia DC. decumbens; ramosissima; glahriuscula; fol. linearibus; stipulis setaceo-2-3-fidis; corolla vix calyce longiore. DC. $\mathrm{He}$ dyotis L. suppl. In India orientali. $\odot . ?$

12. O. pumila DC. caulibus decumbentibus 4 -gonis subscabris; fol. subsessilibus ellipticis utrinque acutis margine scahris; stipulis setaceo-23-fidis. Hedyotis L. In Tranquebaria et Java. $\odot$.

13. O. linifolia DC. fol. linearibus utrinque attenuatis; pedunculis 1-floris folio longioribus. Hedyotis Willd. Hb. In Indiu.

1t. O. virgata DC. gracillima; glabra; caule 4-gono; fol. linearibus; stipulis hrevissime setulosis demum truncatis; floribus fructibusque minimis. DC. Hedyotis Willd. Ad Sievru Leona in Guinea. $\odot$.

15. O. asperula DC. glabra; caule erecto 4-gono; fol. distantibus linearibus basi ciliatis; stipula integra cupulari truncata. DC. In Ceylano legit Lechenault.

16. O. diffusa Roxb. caule tereti flaccido patulo scabro; fol. linearilanceolatis acutis laevibus; stipula demum multiseta. DC. In Banda Indiae orientalis. $\odot$.Cor. alba.

\section{Pedunculis $2-3-m u l t i f l o r$ is.}

1\%. O. biflora $I$. pedunculis bifloris petiolo longioribus; fol. Ianceolatis. Hedyotis 12. et s. O. dicholoma Willd. Hb. Gerontogea Cham. et schlecht. In India orientali et ins. Philippinis. $\odot$.

15. O. longifolia DC. procumbens; glabra; ranis divergentibus; fol. linearibus sub papillosis, superiorilus margine scabris; stipulis subciliatis DC. Hedyotis Schum. Jn Guinea.

19. cristallina Roxb. diffusa; ramosissima; caule 4-gono; fol. sessilibus lanceolato-oblongis subttis cristallinomaculatis ; stipulis junioribus pluridentatis DC. In Bengalo. $\odot$.

20. O. corymbosu L. erecta; diffusa; caule 4-gono laevi; fol. linearilanceolatis; stipulis membranaceis 3setis; stigmate subcapitato. In Giujuna et Prom. viridi Africue. $\odot$. Hed. laxa s. herbacea Hoitul.

21. O. rumosu laxb. diffusa; glabra; caule t-gono; fol. sessilibus lineari-lanceolatis subtus pallidioribus; stipulis membranaceis 3-4-setis; corolla subrotunda fauce barbata. Hedyotis Blume. In Pegu et Java. $\odot$. Fl. albi parvi.

22. U. umbellata $L$. umbellis nudis lateralihus alternis; fol. linearibus; (stipulis setaceis; capsula subrotunda.) L. Hedyotis Lam. Hoxb. Corom. t. 3. Plukn. t. 219. f. 4. In India. 24. Rad. rufescit. Caul. 4-6-poll. Habitus Helianthemi vulgaris.

23. O. capillaris DC. caule adscendente tereti-t-gono secus angulos subscabro ramosissimo; fol. linearilanceolatis scalıriusculis; stipulis setoso-multifidis. DC. In Madras legit Schulz. $\odot$.

24. O. paniculata $L$. glabra; ramis 4-gonis; fol. ovato-lanceolatis; stipulis parvis indivisis; cor. tubo gibbo. DC. Burm. ind. t. 15. f. 1. Hedyotis racemosa Lam. ill. t. 62. f. 2. Gerontogea racemosa Cham. et schlecht. In Moluccis, India orientali et ins. Plitip jinis. (-).

25. O. pentandra DC. procumbens; glabra; fol. cordato-lanceolatis vel ovato-oblongis sessilibus discoloribus; racemis axillaribus nudis; flor. 5-au- 
dris. DC. Hedyotis Schum. In Guinea.

26. O. multiflora Cav. ic. t. $57 \mathbf{1}$. f. 2 . caule ramoso sulcato adscenlento; fol.subsessilibus ovato-oblongis; stipulis parvis indivisis. DC. Circa Manillam.

27. 0. crassifolia Bartl. glabra; diffusa; ramis $4-g 0 n i s ;$ fol. ovatis oblongisve obtusis carnosis; pedicellis flore brevioribus; calycis laciniis lanceolatis. DC. In ins. Luzon.

28. 0. strigulosa Bartl. lierbacea; ramosa; suberecta; fol. ovato-oblongis supra minutissime calloso-punctatis, subtus adpresse strigulosis; pedicellis vix ullis. In ins. Marianis.

29. O. ovalifolia $\boldsymbol{D C}$. subacaulis villosa; caule simplici brevi; fol. ovatis ciliatis subtus albidis; pedunculis trichotomis gracilibus. DC. Hedyotis c. ic. t. 573. f. 1. In Manilla. $\odot$.

30. O. alata Koen. glabra; erecta; caule 4-gono ramoso; fol. subsessilibus elliptico-oblongis latevibus subcarnosis; stipulis latis eroso-dentatis; panicula terminali foliacea. DC. Hedyotis ramosissina Blume. H. paniculata Lam. In India orientali et Juvu. $\odot$.

31. O. macrophylla Lepr. glabra; erecta; ramosa; fol. sessilibus lanceolatis acuminatis; stipulis indivisis; pedicellis $4-5$-jugis oppositis. DC. In Africa aequinoctiali.

32. O. lactea Cham. et Schlecht. caule tereti puhescente; fol. linearilanceolatis utrinque acutis planis; stipulis bidentatis scariosis; corollis intus villosis. Hedyotis lactea Willd. H. cymosa Spr. In India orientali. $\odot$.

33. O. foetida Forst. suffruticosa; fol. spathulatis; stipulis subintegris; corymbo trichotomo. DC. Hedyotis spr. In ins. 'Iongatabu. ந.

34. O. microtheca Cham.et Schlecht. herbacea; erecta; ramosissima; fol.petiolatis ovato-Ianceolatis acuminatis supra scahris; stipulis exiguis dentato-ciliatis. DC. In umbrosis Mexici legit Deppe.

3.5. O. Deppeana Cham. et Schlecht. fruticulosa; ramosissima; erecta; glahra; fol. petiolatis ovato-lanceolatis in petiolum attenuatis acmuinatissinis; stipulis alhidis glauduloso-pubescentibus setoso-ciliatis. Gerontogea Deppeana L. et 0. In Mexico. b.
36. O. spergulacea DC. erecta; hirsuta; fol. ovali-oblongis; stipulis cupulatis mucronatis ; calyce glabro ; cor. tubulosa; stylo demum a basi bipartito. DC. In Nepalia Wall. $\odot$. Digitalis. Hahitu spergulae.

3\%. O. conostyla DC. erecta; glabra; ramosa; fol. oblongis breve petiolatis; stipulis indivisis 3-angularibus ; calycibus puberulis; cor. lobis revolutis obtusis. Hedyotis Gaudich. in Freyc. Voy. t. 94. In ins. Sandwichianis.

\section{Species dubiae.}

35. O. hispida Roth; tota setis hispida; caule adscendente diclotomo tereti; fol. petiolatis ovato-lanceolatis; stipulis setoso-dentatis ; cor. calycinis lobis duplo longiore. Hedyotis indica $\mathbf{R}$. et $\mathbf{S}$. In India orientali.

3.9. O. aspera Roth; tota papillis exasperata; caule stricto filiformi tereti; fol. lineari-subulatis; stipulis lineari-subulatis subdentatis; calycis dentibus linearibus. Hedyotis spr. In India orientali.

40. O. affinis $\boldsymbol{R}$. et $\mathbf{S}$. erecta; ramosissima; ramis 4 -gonis ad angulos scabris; fol. linearibus acuminatis tenuissime ciliatis; stipulis 3-dentatis. DC. Hedyotis dichotoma Roth. In India orientali. Cor. caerulea.

11. O. hirsuta $L$. caule herbaceo diffuso calycilousque hispidis; fol. ovatis acutis petiolatis venosis; pedunculis axillaribus umbellas paucifloras gerentihus. Hedyotis hirsuta Spr. In Java. ('Thunb.)

42. O. pusilla Roth; caule ramoso 4-gono aspero; fol. linearibus acuminatis; racemis axillaribus simplicibus paucifloris. Hedyotis attenuata IVilld. In India orientali.

43. O. debilis Forst. fol. ovatis sessilibus; umbellis axillaribus; pedunculis pancifloris. In ins. Tongatabu.

44. O. Zanguebariae Lour. herbacea; multiflora; fol. linearibus glabris; pedunculis terminalihus paucifloris erectis; stigmate lanceolato. Hedyotis IR. et S. In Africa orientali.

45. O. depressa Willd. caule diffuso; fol. ellipticis petiolatis glabris; pedunculis axillaribus geminis 1-floris. 
Hedyotis depressa 11 . et $\mathbf{S}$. In India orientali.

\section{S2. GONOTHECA Blume (1826).}

1. G. Blumei DC. Heslyolis pterita Blume bijdr. In collihus Javae. $\odot$. Fol. Ianceolata subsessilia. Stipulae dentatae.

\section{KOHALTIA Cham. et Schlecht.} (Knoxiae et Hedyotillis Spec. auct.) (132\%).

1. K. grandiflora $D C$. fol. linearilus inferioribus latiorilus sublanceolatis, summis temuissimis subulatis; stipulis membranaceis inf. cuspidatis caeteris hisetis ; cor. Iobis ovalibus mucronatis. DC. In Senegalia leg. Bacle. $\hbar$.

2. K. senegalensis Cham.et Schlecht. fol. linearibus floralibus subulatis; stipulis membranaceis margine angustissimis hisetis; cor. lohis lanceolatis. Knoxia Rchb. in Sieb. Hb. In Sene-

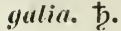

3. K. stricta DC. fol. linearibus margine sulorevolutis; stipulis maroine angustissime petiolos jungentibus lureve bisetis; cor. lohis oblongo-linearibus DC. Iledyotis sm. In senegalia et Sierva Leona. $\odot$. Rad. alha.

4. K. longiflor $D C$. fol. linearihus vix acutis; stipulis brevibus multisetis; setulis subpatentibus membranulae longitudine; cor. tubo longissimo. In ifrica anstrali.

5. K. cynanchica DC. fol. linearihus acutis; stipulis membranaceis petiolos jungentibus; setis utrinque reflexis denum deciduis; cor. Iobis linearibus acutis. DC. In Africa australi. 占.

6. K. setifera DC. fol. linearibus cuspide mucronatis margine subrevolutis; stipulis memhranaceis 4 -fidis. In Africa anstrali. ち.

\%. K. gracilis DC. fol. linearibus; ramulis pedunculisque compressis; stipulis truncatis fimbriatis demum nudis; floribus Iongissine pedunculatis; cor. lobis lineari-lanceolatis subohtusis. Hedyotis stricta WVall. In Nepalia. $\odot$.

8. K. amatymbica Ecklon et 'Leyh. glaucescens; caule simplici plano compresso; fol. sessilibus linearibus cu- spitatis angustissimis erectis superue canaliculatis; stip. setaceis trifidis; flor. terminalibus umbellatis. In Africu australi. 4. Herba 1-I -

\section{KADUA Cham, et Schlecht.}

1. K. Cookiana Chum. et Schlecht. ramis oppositis teretilus ; fol. linearibus acutis mareinibus revolutis; caps. apice rostrata. DC. In ins.O-W $u$ -

2. K. cordata Cham. et Schlecht. ramulis teretiusculis; fol. superioribus subsessilibus cordatis acuminatis ; caps. turbinato-liemisphaerica erostrata. DC.

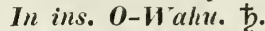

3. K. Mensiesiana Cham.et Schlecht. ramis 4-gonis; fol. ellipticis petiolatis obtuse acuminatis subtus ad basin pubescentibus; stipulis glanduloso-truncatis ; pedunculo compresso pubescente. DC. Hedyotis coriacea sim. In ins. o-W Whu.

4. K. Romanzolfiensis Cham. et Scllecht. ramis 4-gonis dense foliosis; fol. obovatis ohtusis ant subacuminatis hreve petiolatis coriaceis; stipulis mucrone subglanduloso. DC. In ins. corallignu Romanzofiii.

5. K. acuminuta Cham. et Schlecht. ramis subteretibus dense foliosis; fol. lanceolatis longe acuminatis subcoriaceis; stipulis 3-angulari-acuminatis; drupa obovata. In ins. O-Wahu. $)$.

6. K. affinis Cham. et schlecht. ramis 4-gonis; fol. elliptico-lanceolatis acutis basi obtusis breve petiolatis ; stipulis membranaceis subdentatis. In ins. O-Wuhu. $\hbar$.

\section{ANOTIS DC. (1831) (Hedyotis R. et P.)}

1. A. filiformis DC. fol. linearibus acmminatis; canle ramosissimo repente; floribus terminalibus solitariis. Hedyotis R. et P. peruv. t. 87. f. 6. In andibus Perncianis. 4. Habitus Galii. Fl. albi.

2. A. conferta DC. caule repente ramosissimo; fol. linearibus apiculatis; floribus terminalibus solitariis. Hedyotis F. et P. peruv. t. 87. f. a. In alpibus Peruriae. 4. Fl. alla.

3. A. hipmoides DC. caulibus suffruticosis repentibus caespitosis; fol. 
sessilibus lineari-lanceolatis glabris apice piliferis; stipulis apice subulatis. Hedyotis $\mathbf{H}$. et K. In frigidissimis Andium.

4. A. juniperifolia $D C$. caule prooumbeute-ramossimo; fol. linearibus margine revolutis; floribus terminalibus ternis. Hedyotis $\mathbf{R}$. et $\mathbf{P}$. peruv. t. 87. In frigidis Tarmae et Cantuae. 24. $\frac{1}{2}$-ped.

5. Cervantesii DC. fol. linearibus acutis; floribus terminalibus confertis; caule simplici diffuso. Hedyotis pumila Willd. Hb. In Mexico. 4. Fl. violacei.

6. A. thymifolia DC. fruticosa; erecta; ramosissima; ramulis hirtellis; fol. sessilibus linearibus margine revolutis glabris; stipulis acute bifidis; caps. 8-sperma. Hedyotis $\mathbf{R}$. et $\mathbf{P}$. peruv. t. 88 . f. a. H. thymifolia $H$. et K. H. coarctata Willd. H. hyssopifolia Cav. ic. t. 575. In Peruvia. t. Fl. albi.

8. A. laricifolia DC. suffruticosa; erecta; ramosa; glabra; fol. sessilibus linearibus acutis margine subrevolutis; antheris exsertis. Hedyotis Cav. ic. t. 575. f. 1. In Chili. t. Cor. rubro-fusca.

9. A. setosa DC. fruticosa; erecta; ramosissima; fol. breve petiolatis ovatis acutis ciliato-serrulatis; stipulis connatis ovatis apice multisetis. Hedyotis R. et $\mathbf{P}$. peruv. t. 88. f. a. In andibus Peruviae. $\hbar$. Fl. purpurei.

10. A. ericoides $D C$. fol. fasciculatis linearibus sulcatis; floribus terminalibus subcorymbosis. DC. In Nova Granata. ち.

11. A. lanceolata DC. glabra; caule erecto 4-gono angulis subulatis; fol. sessilibus acutis glabris; stipulis lanceolatis membranaceis; caps. globosa. Hedyotis Poir. In Carolina. $\odot$.

12. A. rotundifolia DC. caule herbaceo prostrato ramoso; fol. suborbiculatis breve petiolatis glabris vix ciliatis; stipulis minimis. Houstonia rotundifolia Michx. In maritimis $\mathrm{Ca}$ rolinae et Floridae. 4.

13. A. Salzmanni DC. caule prostrato herbacco ramoso; fol. suborbiculatis glabris subciliatis; stipulis vix ullis; cor. campanulata. Circa $\mathrm{Ba}$ hiam. ち. Cor. carnea.

14. $A$. serpens $D C$. caule repente suffruticoso ramosissimo; fol. subro- tundo-ovatis ellipticisque petiolatis margine spinuloso-ciliatis. Hedyotis H. et K. Nov. Gen. t. 289. H. microphylla Willd. Hb. In monte ignivomo Antisanae Quitensium. ち. 4.

\section{RACHICALLIS DC. (1830).}

1. R. nitida DC. fruticosa; ramosissima; ramis confertis densissime foliosis; fol. linearibus acutis carnosis revolutis utrinque glabris nitidis; stipulis connatis apice 3 -fidis. Prope Santa-Fe de Bogota. ち.

2. R. rupestris $D C$. fruticosa; ramosissima; ramis tortuosis suberosis; foliis confertis stellato-fasciculatis oblongis carnosis revolutis margine supra nitidis; corollis villosis; tubo curvato. Hedyotis rupestris Sw. H. americana Jacq. sloane Jam. t. 292. f. 1. In Cuba et Jamaica. 支.

3. R. caracasana DC. suffuticosa; ranosissima; ramulis superue foliosis; fol. oblongis acutis margine revolutis glabris nitidis patentibus. Hedyotis H. et K. In Caracas. ち.

\section{5\%. LUCYA DC. (1530).}

1. L. tuberosa DC. Peplis tetrandra L. Jacq. am. t. 180. f. 29. Oldenlandia Lam. Hedyotis $\mathbf{S w}$. obs. $t$. 1. f. 2. Dunalia Spr. In umbrosis siccis ins. Caribaeis Jamaicae et Domingo. $\odot$. El. albi parvi.

\section{HYPOBATHRUM Blume (1825).}

1. H. frutescens Blume bijdr. In sylvis Javae. ち. Frutex habitu Coffeae. Folia disticha. Fl. dense conferti axillares umbellati.

\section{LITHOSANTHES Blume (1825).}

1. L. biflora Blume bijdr. In montosis sylvaticis Javae. $\hbar$. Frutex habitu Farneliae. Fol. parva trapeziformia subsessilia. Pedunculi biflori axillares filiformes. 
590. GYNOCHTODES Blume (1825).

1. G. coriacea Blume bijdr. In

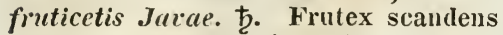
glaber. Folia opposita oblongo - ovalia acuta coriacea glabra. Flores conferti axillares.

\section{COELOSPERMUM Blume (182.5).}

1. C. scandens Blume bijdr. fol. ovalilus acutis; florilus subumbellatis folia summa superantibus. In montosis Juvae. $\hbar$.

2. C. corymbosum Blume; fol. oblongis utrinque acmunatis; floribus subumbellatis, foliis superioribus triplo brevioribus. In Java. ţ.

\section{EPIMEDIUM Dodon. (1558).}

1. E. alpinum L. fol. radicalibus nullis, caulinis biternatim sectis; foliolis cordato-Ianceolatis acuminatis serratis; serraturis aristatis. Schkuhr. t. 24. In Europae montanis umbrosis. 4. Spithameum. Cal. purpurasceus. Cor. flava.

2. E. pinnatum Fisch. fol. radicalihus pinnatifidis; scapo aphyllo. In Persia. 4. Fl. erecti.

3. E. diphyllum Hook. Bot. Mag. 3413. petiolis dichotomis filiformibus racemum 1-lateralem gerentibus; geniculis tumidis pilcsis; foliolo solitario in utroque ramo; petalis planis. Lodd. B. C. 1858. In Japonia. 4. Cor. alba.

4. E. elatum Jayuem. Voy. de l'Inde $t$. 4t. sine descriptione. In India orientali. 4 .

\section{PHILAGONIA Blume (1825).}

1. P. procera Blume; Arbor procera fol. pinnatis lanceolatis integerrimis glabris; cymis terminalibus 3partitis. In Java. ђ.

\section{PTELIA L. (1751).}

1. P. trifoliata $\boldsymbol{L}$. fol. ternatis; foribus paniculatis dioicis. Du Hamel Arb. II. t. 43. Schmidt Oestr. Baumz. t. 76. In America boreali. $\hbar$. Frut. 8-12-ped. Fl. virides.

2. P. microplylla Lam. fol. simplicibus lanceolatis subsessilinus; fructibus 3-alatis. Lam. ill. In Carolina. t. Arb. s. fiut. Planta dubia.

\section{SERINGIA Spr. (1818).}

1. S. ovata Spr. Ptelidium ovatum Aub. Thouars Wov. Gen. Madagasc. fasc. I. t. t. In Mallagascar. ち. Arhor 12 -ped. ramis oppositis. Folia petiolata firma viridi-flavicantia integerrima margine reflexa. Fl. minimi paniculati.

\section{MAYEPEA Aubl. (19\%5).}

1. M. gujanensis Aubl. Guj. t. . . Chioranthus tetrandra Vall. In Gujana. ち. Arbor fol. alternis lanceolatis; pedunculis axillaribus cymosis bracteatis.

\section{9\%. SAMARA L. (1781).}

a. Fol. pinnatis.

1. S. laeta $L$. floribus confertis pedicellatis; fol. ovatis obtusis. Sw. Memecylon umbellatum Fl. Zeyl. Burm. Zeyl. t. 31. In Ceylano. ち. Rami purpurascentes. Fl. lutei.

2. S. paniculata Roxb. foliis oblongis acuminatis basi aequalibus; paniculis axillarilus; stigmate trilobo. In Indiu orientali. Drupae oblongae.

3. S. polygama Roxb. fol. oppositis ; foliolis oblongis coriaceis lucidis; floribus paniculatis terminalibus polygamis. In ins. Moluccis.

t. S. Blackburnia Spr. foliolis oblongis ohtusis basi inaequalibus; paniculis axillaribus. Blackburnia pinnata Forst. gen. t. 6. In ins. Norfolk.

\section{b. Fol. simplicibus.}

5. S. Izquierda Spr. fol. simplicilus ovatis acuminatis; pedunculis aggregatis umbelliferis. Izquierda aggregata. R. et P. peruv. In Peruvia.

6. S. Helicia spr. fol. simplicibus ovatis acuminatis subserratis; 
racemis terminalibus; petalis revolutis. Helicia cochinchinensis Lour. In Cochinchina.

\section{S. FrODIA Forst. (1975).}

\section{Folia ternata.}

1. E. hortensis Forst. gen. $t$. $\%$ foliol. lanceolatis ramulisque pubescentibus; paniculis axillaribus petiolisque pubescentibus. Fagara Evodia L. fil. in ins. Amicorum et nov. Hebridis. ち.

2. E. lutifolic DC. foliol. ovatis acutis subtus lanuginosis; paniculis axillaribus petioli longitudine. DC. prodr. Ampacus Rumph. 2. t. 61. In Amboina.

3. E. triphylla DC. foliolis ovatis acuminatis subtus glabris; paniculis lateralibus brachiato-pyramidatis petioli circiter longitudine. DC. Fagara triphylla Lam. Ampacus angustifolia Rumph. 2. t. 62. In Amboina et Pliilippinis. $\hbar$.

4. E. obtusifolia DC. foliolis ovalibus obtusis utrinque glabris; paniculis axillaribus petiolo fere brevioribus DC. In ins. Manritimis. $ち$.

5. E. febrifuga st. Hit. bull. philom. 1833 ejusil. Pl. us. Bres. t. t. foliolis lanceolato-ellipticis subacuminatis; panicula terminali pubescente; nectario simplici. DC. In Brasilia. ち.

6. E. longifolia Rich. fol. saepius trifoliatis; foliolis lanceo!ato-linearibus margine subsinuatis, apice obtusis punctato-pellucidis glabris; floribus spicatis minimis. In Nova Guinea.

\section{ZIERIA Sm. Linn. Trans. (17.98).}

1. Z. Ianceolata R. Br. ramulis pubescentibus; foliolis lanceolatis planis acutis pellucido-punctatis; pedımculis trichotomis longitudine foliorum. 7. Smithii Andr. rep. t. 606. Sims B. M. 1395. Bonpl, nav. t. 24. In Nova Hollandia. ち.

2. Z. macropliylla Bonpl. nav.? ramulis pulveraceis; foliolis oblongis utrinque acutis planis glabris pellucido-punctatis; racemis trichotomis folio brevioribus. In Nora Hollandia. .
3. 'z. laevigata $\mathbf{S m}$. ramulis glabris; foliolis glabris margine revolutis petiolo longioribus; pedunculis bis trifidis; corymbis folio brevioribus. In Nova Hollandia.

1. \%. cytisoides $\mathrm{s}$. ramulis villosis; foliolis obovatis utrinque villosis; pedunculis 3-ficlis foliiferis. DC. In Noca Cambria. 古.

5. 'Z. arborescens Sims B. M. 139.5. caule arboreo; foliolis suhtus tomentosis impunctatis; pedunculis petiolo longioribus. In Nova Hollandia. 古.

6. 2. microphylla Bonpl. ramulis sericeis; foliolis linearihus margine revolutis superne glabris subtus sericeis; pedunculis subtrifloris. In Nova Hollundiu. 古.

\%. Z. panciflor, $\mathrm{Sm}$. ramulis petiolisque pilosis; foliolis lineari-obovatis interdum margine revolutis; pedunculis 1-3-floris. Ad Port Jackson. ち.

8. Z. pilosa Rulye trans. Limn. 10. t. 1\%. f. 2. foliolis lanceolatis subtus pilosis; pedunculis 1-floris. In Nova Cambria. ђ.

9. Z. hirsuta DC. ramis petiolis capsulisque hirsutis; foliolis ohlongolinearibus petiolo triplo longioribus subtus hirsutis margine subrevolutis; pedunculis 1-floris. In Nova Hollandia. 方.

\section{MONETIA Herit. (1784).}

1. M. barlerioides Herit. Stirp. t. 1. spinis quaternis; fol. utrinque glabris. Azima 4-cantha Lam. Azima nova seba Thes. t. 13. f. 1 . In Indic orientuli et Prom. b. spei. ち. Frut. 3-4-ped.

2. M. diacantha Willd. spinis oppositis; fol. subtus pubescentibus. Spr. In India orientali. $\hbar$.

3. M. paleacea spr. ramis paleosis pilosis; fol. laevibus ellipticis. Camforosma paleacea Thunb. In Prom. b. spei. Ђ.

\section{SKIMMIA Thunb. (1781).}

1. S. japonica Thunb. Banks t. 5 . In Japonia. $\hbar$. Caulis fruticosus, ra mis 4-gonis. Folia oblonga versu 
apicem crenulala sempervirentia. Panicula terminalis.

\section{LEPTA Lour. (18.90).}

1. I. triphylla Lour. Cochinch. fol. ternatis; racemis axillaribus. In sylvis Cochinchinue. $\hbar$, Arbor 10-ped. ramosissimus. Fl. alhi minimi.

\section{ORIXA Thumb. (17St).}

1. O. japonica Thunb. jap. Othera Orixa Pers. In Japonia. b. Frutex flexuosus. Folia subus pallide villosa.

\section{CURTISIA Ait. (1789).}

1. C. furginea Ait. Keu. Lam. ill. t. 71. Junghansia Gmel. Sideroxylon Burm. Afi. t. 83. In Prom. b. spei. ち. Arhor excelsa. Fl. cinereo-tomentosi.

\subsection{BOTRYCERAS Willd. (1811).}

1. B. laurinum Willd. Mag. nat. Forsh. Fr. in Berl. 1811. t. 10. f: 10. In Nova Hollandia. Frutex orgyalis. Fol. alterna petiolata lanceolata coriacea nitida serrata. Fl. virides minuti.

\section{CISSLS L. (1\%1\%).}

a. Fol. in tegris.

1. C. vitiginere $L$. fol. cordatosubrotundis sublohatis angulato-repandis, suhtus ferrugineo-pubescentibus. Vitis Limaei WVall. Plukn. t. 337. f. 4. In India. Baccae pyriformes nigrae.

2. C. repanda Talli; fol. cordatis integris sublobatis repandis adultis utrinque glabris. Vitis $\mathbf{W}$. et A. C. indica Rottl. In India orientali. 5 .

3. C. culnatu Roxb. fol. rotundatocordatis acuminatis setaceo-serratis supra glalıris subtus ramulisque teretibus velntinis; stipulis ovato-orbiculatis; florihus nutantibus. DC. In Indiu orientali. ち.
4. C. Intifolia Vahl; fol. cordatis ovatis acuminatis setace 0 -serratis, supurne glabris subtus ferrugineo-villosis; ramis 4-gonis; stipulis oblongis. Inumplt t. 164. f. 1. In India orientuli.

5. C. glance Roxb. ind. fol. cordatis acuminatis interdum sublobatis setace-serratis utrinque petiolis pedunculisque glabris; stipulis lato-sufulcatis obtusis; baccis 1 -spermis. C. latifolia Lam. Rheede mal. t. 11. In Muduguscar et India orientali.

6. C. indicu Rottl. fol. subrotundocordatis acuminatis setace 0 -serratis sultus pubescentibus ; ramis teretiusculis petiolisque tomentosis. DC. In India orientali. $\hbar$.

\%. C. cordifolia $\boldsymbol{L}$. fol. cordatis integerrinis pedunculatis trifidis dichotomis. Plum. ic. t. 259. f. 3. In America calidiori. ち. Baccae caeruleae.

8. C. rotundifolia Irahl; fol. cordato-subrotundis glabris serratis; umbellis simplicibus. Saelanthus rotundifolius. Forsk. ic. t. 4. In Aegypto. t.

9. C. cresia $A f z$ fol. cordatis angulato-sinuatis setaceo-dentatis uitinque rugosis scabris subtus tomentosis; sarmentis teretibus glauco-pruinosis. In Guinea. 方.

10. C. repens Lam. fol. cordatoovatis subdentatis ramisque glahris; floribus umbellatis; caule repente. Hheede mal. 7. t. 48 . C. cordata Roxh. Vitis W. et A. In Nalabaria. ち. Caul. succulentus. Fl. atropurpurei. Baccae ruhellae.

11. C. muncticulosa Rich. fol. Iato-cordatis obtusissimis; acumine abrupto obtuso; serris remotis setaceis; ramis punctatis. In Cayemna. ち.

12. C. uvifera $A$ fz. fol. subpeltatocordatis integerrimis glabris basi maculatis; sarmentis teretibus glabris. In Guinea. ち.

13. C. discolor Blume; fol. cordato-oblongis acuminatis setaceo-serratis discoloribus ramulisque anculatis glabris; cymis oppositifoliis sub-5fidis folio brevioribus. In Java. $\hbar$.

1f. C. nodosc Blume; fol. subcordato-oblongis cuspidatis setaceo-serrulatis glabris; corymbis oppositifoliis dichotomis; pedicellis umbellatis; caule tereti herbaceo nodoso. In Jaca. ђ. 
15. C. tiliacen H. et K. glabra; fol. subrotundo-ovatis cordatis aroute dentatis subcoriaceis; ramis 4-oonis; cymis dichotomis. In Mexico. $\hbar$.

16. C. quarlrangnlaris $L$. fol. subcordato-ovatis serratis glabris carnosis; caule 4 -gono alato. Saelanthus 4-gonus Forsk ic. t.2. Rumph. s.t. +4 . In Arabia. t.

1\%. C. compressicanlis R. et D. peruv. t. 100. fol. cordatis acutis serratis puhescentibus; floribus mmellatis; pedmenlis partialibus dichotonis; crale 4-gono compresso. In ruderatis prope Cleancay. 古. Bacca nigropurpurea.

18. C. Javanu DC. fol. subcortatis ovato-lanceolatis acuminatis glabris subserratis; serraturis setaceis adpressis; ramis subteretibus sulcatis. In Java. ち.

19. C. pentagona Roxb. fol. cordatis rariter sublobatis serulatis acuminatis laevibus; ramulis lucidis pentagonis angulis rotundatis lateribus sulcatis. In sylvis Chittagong. t).

20. C. sicyoides $\boldsymbol{L}$. fol. cortatis ovatis glabris crassiusculis setaceoserratis; serraturis adpressis; ramulis teretibus. sloane hist. t. 14. f. 1. Lam. ill. t. 84. f. 1. In Jamaica et Guadelijua.

21. C. smilacina $H$. et $K_{\text {. }}$ fol. ovato-oblongis suhacuminatis basi oblique truncatis supra glabris subtus ramisque angulatis hirtellis; cymis pedunculisque glabris. C. sicyoides Poir. Ad ripus fuminis Magdalenae. t.

22. C. ovata Lam. fol. ovatis acuminatis setace - serratis glabris; serraturis adpressis. Brown jam. t. 4. f. 2. In C'uadelupa et Jamaica. ち.

23. C. obscura DC. fol. ovatolanceolatis acuminatis glahris; serraturis paucis aristatis adpressis. In America meris. ђ. Paniculae ramosissimae. C. ovata Rich.

24. C. fuliginea $\boldsymbol{H}$. et $\bar{K}$. fuligineoferruginea ; fol. subrotundo-ovatis profunde cordatis remote denticulatis supra hirtellis subtus molliter tomentosis; ramulis pedunculisque hirsutotomentosis. Ad ripas fl. Magdalenae. $\hbar$.

2.5. C. umbellata Lour. fol. ovatis glabris integerrimis; umbellis compositis; corollis intus lanatis. Ad Cantonem sinarum. b.
26. C. canescens Lam. fol. ovatoohlongis inaequaliter cordatis dentatis subtomentosis canescentibus; ramis angulatis; pedimculis cymisfue villoso-tomentosis. In Permvia. 古.

2\%. C. umbrosa 1 . et $\boldsymbol{K}$. fol. ohlique cordato-ovatis argute dentatis supra pilosiusculis sublus tomentosopubescentibus; ranis 4-gonis hirtellis. In umbrosis ham. Magdalenae. $ち$.

28. C. prodncta A/: fol. ovatooblongis acuminatis subsetaceo-denticulatis; florilus paniculatis; sarmentis longissimis striatis compressis. In Guinea. 方.

29. C. tuberosa Fl. mex. ined. fol. ohovatis elahris grosse serratis aut trifidis; lohis incisis ; radice tuberosa. In Sora llispamia. b.

30. C. antarctica lent. fol. ovatis subcordatisve laxe serratis ylabriusculis; nervis hasi glaudulosis; petiolis ramisque ferrugineo-pubescentilus. C. glandulosa Poir. In Nova Hollandia. $\overline{\text { ந. }}$

31. C. glundulosa Gmel. fol. ovatis acutis serrato-dentatis carnosis. pedirellis et calycis hasi glandulosis. In Arubia. 方. Haul. tulserosa.

3\%. 6. micrantha poir. fol. glabris ovatis subtri!ohis; Iobis subserratis acutis terminali longiore; pedunculis apice 5 -fidis umbellatis. In st. Domingo. t.

33. C. rugosa DC. fol. cordatis trifidis 5-fidisque rugosis; lloribus racemosis. In montibus Jamaicae. நृ. Baccae nigrae.

3t. C. tomentosa Lam. fol. sub5-gonis obtuse dentatis supra glabris subtus tomentoso-ferrugineis; petiolis compressis. In ins. Borboniae. $\hbar$.

3.5. C. angulata Lam. fol. ovatis suhpentagonis angulato-lobatis subtus tomentosis; pedunculis planis folio longiorihus. In India orientali.

36. C. capensis Willd. fol. subcordatis 5-angularilus dentatis subtus ferrugineo-tomentosis; floribus subcapitatis. Vitis Thunb. In Prom. $b$. spei. t.

37. C. trilobata Lam. fol. subtirilobatis 3 -fidisque; lobis ovatis acutis dentatis subcarnosis; ramis teretibus. C. heterophylla Hb. Madr. Vitis Rheedii W. et A. V. heterophylla IVall. Bheede mal. 5. t. 45. In Malaboria. b. 
38. C. incequalis Heyne Hb. glahra; caule 4-angulo; ful. ovatis s. oblongo-lanceolatis acuminatis basi oblique cordatis trumcatis setaceoserratis. Vitis inaequalis W. et A. V. diversifolia IValI. C. sicyoides Klein Hb. In Tracuncore.

\section{b. Foliistrifoliatis.}

39. C. acidu L. fol. trifoliatis carnosis glabris; foliolis ohovato-cuneatis apice dentatis hasi integerrimis. Jacq. sichoeultr. t. 33. Plum. t. 259. f. 3. In America calidiori. ந.

-6. C. setosa Rorib. fol. 3-5̃foliatis sessilibus carnosis glabris; foliolis ovalibus undulatis grosse ef inaequaliter setaceo-serratis; stipulis cordatis. In India orientali. 方.

41. C. carmosa Roxb.junior; dense pubescens; caule compresso striato; stipulis oblongis; fol. 3-foliatis longe petiolatis rotundato-ovatis s. obovatis acutis s. obtusis crenato-serratis. In Intia orientali. $\hbar$.

4. C. trifoliata Jiec\%. am. fol. trifoliatis carnosis glahris; foliolis ohovatis serrato-incisis aculis; ramis subulatis. Sloane t. 112. f. 5.? In

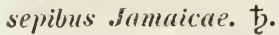

f3. C. caustica 'luss. /l. ant. t. 16. ful. trifuliatis; folio!is ovatis obtusis; ramis teretibus geniculatis succulentis; petiolis canaliculalis. In ins. Caribaeis. b. Fl. sauguinei.

4t. C. cmarginelle sir. foliolis obovatis emarginatis remote crenatis glabris; ramis petiolisque t-gonis. In ins. Curibaeis. ţ.

5.5. C. papillosa blume: foliolis obovoto-oblongis acmunatis grosse arguteque serratis ghahris coriaceis; corymbis axillaribus divaricatis; caule lignoso papilloso ramosissimo. In Jura. 古.

-66. C. geniculata lilume; foliolis oblongis acuminatis obtuse denticulatis membranaceis al costam utrinque pubescentibus, lateralibus senicordatis; corymbis dichotomis geniculatis; caule sufliruticoso teretiusculo. In Jara. t.

4\%. C. riodocurya lilume; foliolis ovato-ellipticis acuminatis memhanaceis glahris grosse inaequaliter dentatis, lateralibus semicordatis; caule sub-1-gono. In Java. ち.

48. C. hirtella diume; foliolis ovato-oblongis membranaceis inaequa- liter serratis subtus petiolisque tomentosis; corymbis dichotomis axillaribus. In Jara. 古.

49. C. salutaris H. et $\boldsymbol{K}$. foliolis oblongis argute serratis pellucidopunctatis supra hirtellis subtus terrugineo-hirtis; ramis pedmeulisque hirtellis striatis. In aridis Novae Andalusial. b.

50). C. obovata Vahl; fol. trifuliatis membranaceis glabris; foliolis obovatis integerrinis mucronatis; pelunculis trichotomis folio longioribus. DC. In ins. St. Crucis. ち.

51. C: punciflora Dr. fol. trifoliatis glabris rigidis; foliolis obovatis subintegris basi cuneatis apice obtusis; pedunculis pancifloris folio brevioribus. in Fiom. l. spei.

.i. r. ternata Gmel. fol. sessilibus tritoliatis rigidis glaloris; foliolis ovato-cordatis acutis serratis: ranis teretihus. Saelanthus ternatus Forsk. In Arabia. b.

53. C. lucida Poir. fol. trifoliatis lucidis olalnis; foliolis ovatis denticulato-setaceis; ramis compresso-1-gouis subulatis glandulosis. In C'uyennu. t.

5\%. C. quadrialata $\boldsymbol{H}$. et $\mathrm{K}$. fol. trifoliatis glahris; foliolis obtusis crenato-denticulatis pellucido-punctatis, intermedio ovato basi acuminato; ramis 4-gonis t-alatis. In islu parumana mission Orinocens. 支.

5.5. C. microcarpa Vahl; fol. trifoliatis membranaceis glabris; foliolis oblongis serratis mucronulatis; ramis angulatis. Plum. et Burm. ic. t. 259. f. 4. In ins. Caribaeis. t.

.56. C. aculiflora Poir. fol. trifoliatis membranaceis glabris; foliolis ovatis dentato-sululatis; lobis acutis; ramis angulosis subcompressis. In India orientali. 市.

.7\%. C. erosa Rich. fol. trifoliatis membranaceis glabris; foliolis chlongoovatis hasi subacutis eroso-subulatis; petiolo submarginato; cymis longe pedunculatis. DC. In Cajenna. ち.

58. C. Timorensis DC. fol. 3-foliatis membranaceis glabris; foliolis petiululatis ovatis acntis late dentatis; paniculis laxis triclotomis. In ins. 'imor. ђ.

59. ¿. alata Jacq. am. t. 152. f. 10. fol. trifoliatis hirsutis; foliolis ovato-cordatis acutis serratis; ramis membranace0-angulatis. Sloane list. 
t. 144. C. trifoliata L. In Jamaica et Carthagena. 方.

60. C. pubescens $H$. et K. fol. 3foliatis supra puberulis subtus canescenti-pulescentibus; foliolis acutis argute denticulatis, medio basi cuneato. Ad flum. Maydalenae. $\hbar$.

61. C. rhombifolia Vahl; fol. 3foliatis pulsescentibus; foliolis serrulatis, lateralibus semicordatis, medio rlombeo-ovato; ramis angulatis. In ins. Trinitatis. ち.

62. C. cirrosa Pers. fol. trifoliatis camosis villosis; foliolis ovatis serraiis; ramis petiolisque compressis; baccis hirsutis. Vitis cirrhosa Thumb. In Prom. b. spei. ђ.

63. C. cinerea Lam. fol. trifoliatis crassiusculis pubescentibus; foliolis dentatis ovatis, lateralihus subcordatis; ramis angulosis; petiolis teretibus. In Indiu orientuli. $\hbar$.

61. C. crenutu Iahl; fol. trifoliatis; junioribus villosis; foliolis subrotundis crenatis. Vitis trifolia L. Rumph. 5. t. 166. f. 2. C. obtusifolia Lam. In India orientali. $\hbar$.

65. C. angzistifolia Roxb. dioeca; fol. trifoliatis utrinque laevibus; foliolis lanceolatis serratis; stipulis ovatis aculis; caulibus compressissimis. In Sumatia. ち.

\section{c. Foliis digitatis.}

66. C. quinata Ait. fol. 5-foliatis; foliolis ohovato-cuneiformihus superme

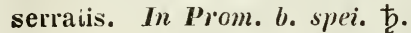

6\%. C. pentapleylla Willd. fol. palmato- 5-foliatis glahris; foliolis ovatis serratis acuminatis. Vitis pentaphylla Thunb. In Japonia. 古.

6s. C. striata R. et P. peruv. $t$. 100. fol. palmato-5-foliatis glahris; foliolis sessilibus ohlongo-lanceolatis serratis; caule striato flexuoso; cymis coarctatis. In Peruvia. 占.

69. C. mexicana Fl. mex. fol. paluıto-5-foliatis glabris; foliolis petiolulatis ohlongo-lanceolatis serratis ; caule sub-t-yono. In Mexico. $\hbar$.

\%0. C. granulosa R. et P. peruv. $\boldsymbol{t}$. 101. fol. palmato-5-foliatis glabris; foliolis obovato-dentatis; caule angulaio granuloso; cymis patentibus. In graeruptis Peruvicue. ఫ.

71. C. palmata Poir: fol. palmato5-foliatis glabris; foliolis sessilibus lanceolatis angustis dentato-setaceis ; ramulis 4-gonis. In ins. Franciute. 5 .

72. C. dicersifolin DC. fol. glahris, radicalibus simplicibus mediis 3foliatis stummis 5 -foliatis; fol. acuminatis attenuatis acute crenatis; petiolis linea pubescente. C. helerophylla l.k. Palria ignota. 卢.

73. C. foeminea hoxb. fol. digitatis lucidis; foliolis petiolatis lato-lanceolatis integris subcrenatisve stylo nullo. In sylv is montosis Indiae orientalis. $ち$.

7. C. elonyata Roxb. fol. digitatis laevibus; foliolis petiolulatis ob)longis acutis remote serratis; stipulis hracteisque cordatis; ramulis subcompressis. Hoxb. ind. In Coromundelia et Benyalia. 方. Baccae magnitudine Cerasi.

8.5. C. anviculate Roxb. fol. 5foliatis; foliolis petiolulatis oblongis acutis obtuse serratis superue laevihus subtus villosis; stipulis auriculaeformibus; ramulis teretilus villosis. In Mysore. $\hbar$. Caulis arbores excelsissimas scandit. Baccae rotundae colore et maguitudiue Cerasi.

186. C. dichotomu Blume; fol. coriaceis glahris; foliolis ovato-lance latis acuminatis glanduloso-serratis; corymhis dichotomis folio brevioribus. Blume. In Java. 卢.

87. C. thyrsiflora Blume; foliolis ovato-oblongis acutis serulatis subtus ramisque rubiginoso-tomentosis; thyrsis cirrifloris. In fara.

8. quinuzucfolia Soland. foliolis ohlongis utrinque atlemuatis serratis glahris; ramis teretibus nodosis laevilus. Bot. Mag. 2443. In Brasilia. ち.

d. Foliis pedatis 5-9-foliatis; foliolo medio solitario, lateraribus geminis terinisve.

9.9. C.japonica Wrilld. fol. pedato5-foliatis glabris; foliolis ovalibus aristato-serratis lateralibus obtusis; pedunculis folio longioribus. In Japonia. 4.

80. C. naupalensis $D C$. fol. pedato5-foliatis glahris ; foliolis ovalihus aculis hasi allenuatis aristato-serratis; pedunculis peiiolo brevioribus. In vapuulia. Tull.

S1. C. corincea DC. fol. pedato$\mathrm{j}$-foliatis glabris subcoriaceis; foliows 
ovalibus utrinque subattenuatis late et distanter crenatis; pedunculis petiolo brevioribus. DC. In ins. Timor.

82. C. lanceolaria Roxb. fol. pedato-5-foliatis glabriusculis subcoriaceis; foliolis fanceolatis acuminatis irregulariter subserralis; cymis pedunculatis petioli fere longitudine. C. dioeca Roxb. Rheede mal. 7. t. 8. In India orientuli. 古.

83. C. semulata Roxb. fol. pedato-5-foliatis; foliolis oblongis serrulatis; caule laevi. C. glabrata Blume. In Chittugong. t.

\&-t. C. lieterophylla Poir. fol. pedato-j-foliatis wlabris; foliolis superioribus rlombeis crenatis, inferioribus obliquis obtusis; caule fistuloso Atriato. C. leucocarpa Blume. In Java. t.

8.5. C. peilata Lam. fol. pedato7-9-foliatis subtus pubescenti-tomentosis; foliolis lanceolatis acuminatis serratis; ramis petiolisque incanis. hlieede mal. 7. t. 10? In India orientali. 卉.

86. C. tuberculata Blume; foliolis oblongis acuminatis serratis glabris coriaceis; corymbis petiolo brevioribus; caule compresso tuberculato. In Jaで. 方.

s;. C. mutabilis Blume; foliolis oblongis acuminatis, lateralibus obtusiusculis remote serratis; serraturis scariosis; baccis $3-4$-spermis. In Jara ђ.

88. C. scariosa Blume; foliolis ovalibus obtusiusculis coriaceis apice grosse serratis; serraturis apice scariosis; caule rimoso. In Jura. ち.

89. C. Ineviguta Blume; foliolis ovatis acutis glanduloso-serrulatis laevibus coriaceis; caule tereti ver-

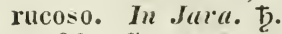

90. C. inrolucrata $5 \mathrm{mr}$. foliolis ollongis acuminatis repando-dentatis; floribus polygamis fasciculatis invoIucratis. Pterisanthes cissoides Blume. In Jaca.

\section{e. Fol. decompositis.}

91. C. pinnata Russ. fol. pinnatis trifoliatisque glabris membranaceis; foliolis ovatis incisis. Russ. Beschr. alepp. In Aleppo. ђ.

92. C. oblinua R. et P. perur. $t$. 101. f. 6. fol. simpliciter pinnatis pu- bescentibus; foliolis $2-3$ oblique cordatis. In peruvia. 古.

93. C. Happia Lam. fol. subbipinnatis laevibus subcarnosis; foliolis ovatis integerrinis. In ins. Frounciale. ち.

94. C. orientalis Lam. ill. t. 81. f. 2. fol. bipinnatis glabris; foliolis ovatis serratis. In Oriente. $t$.

9.5. C. comnivens Lam. fol. subbipinnatis glabris; foliolis ovatis obtusiusculis subdentatis; petalis conniventibus. In Madagascar. 支.

\section{0\%. ALLASIA Lour. (1790).}

1. A. Payos Lour. Arbor ful. digitatis pilosis; pedunculis multifloris. in Africa orientali.

\section{SIPIIANTHERA Poll (1827).}

1. A corilate Pohl ic. br. t. 8t. fol. cordatis subrotundis crenato-dentatis puberulis; florum fasciculis multifloris breve pedumculatis; antherae rostro loculos subaequante. In Bra-

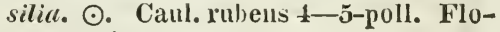
res rosei.

2. S. subtilis Poll t. 85. f. 1. fol. ovatis crenatis glanduloso-pilosis ad collum confertis caeterum distantibus; florum fasciculis longe pedunculatis; antherae rostro loculis dimidio breviore. In Brasilia. $\odot$. Caul. simplex 2-3-poll. Hil. rosei.

3. S. tener 4 Pohl. t. 85. f. 2. fol. prioris; caule apice subramoso; antherae rostro brevissimo. In Brasilia. $\odot$. Planta pygmaea.

\section{CORNUS Virg.}

\section{Nudiflorae.}

a. Fol. alternis.

1. C. alternifolia L. fol. alternis ovatis acutis subtus canis; corymbis patentibus. LiHerit. cor. t. 11. Guimp. Ab). t. 43. A Carolina ad Canadam. Arbor 15-20-ped. Fl. albi. Fructus violace-nigri.

\section{b. FoI. oppositis.}

2. C. paniculata I'Herit. cor. $t$. 5. ramis ereclis; fol. ovatis acumina- 
tis glabriusculis; corymbis thyrsoideopaniculatis; ovario sericeo. Sclumidt oestr. Bmz. t. 68 . C. racemosa DC. A Carolina ad Canadam. ち. Arbor 6-ped. Fl. albi centro purpurascentes. Drupae virentes.

3. C. oblonga Wall. fol. oblongis acuminatis basi acutis subtus glaucis et scahris, ad axillas nervorum excavato-glandulosis ; coryubo patente paniculato. C. paniculata Hamilt. In Nepalia. $\hbar$.

4. C. stricta Lam. ramis strictis; fol. ovatis acuminatis utrinque viridibus adultis glabris nascentibus vix subtus pubescentibus. schmidt oestr. Bmz. t. 67. C. fastigiata Michx. C. sanguinea Walt. C. cyanocarpos Gmel. In America boreali. ち. 616-ped. Drupae caeruleae.

5. C. sunguinea $L$. ramis rectis; fol. concoloribus subtus puberulis; corymbis depressis planis. L'Herit. corn. Engl. B. 249. Fl. Dan. 481. Guimp. Abl. t. 3. Rami rubro-fusci. Drupae molles caeruleae.

6. C. alba $L$. ramis recurvatis; ramulis glabris; fol. lato-ovatis acutis pubescentibus subtus canis; corymhis depressis. Pall. fl. ross. t. 31. C. stolonifera Michx. C. tatarica Mill. In Sibiria et America boreali. $\hbar$.

\%. C. sericea L'Herit. corn. $t$. 2 . ramis patulis; ramulis lanuginosis; fol. ovatis acuminatis subtus subferrugineosericeis; corymbis depressis lantginosis; nucleis compressis. C. caerulea Lam. C. cyanocarpos Mnch. C. asperifolia Michx. C. alba Walt, In America boreali. $\hbar$.

s. C. circinnata L'Herit. cor. $t .3$. ramis verrucosis; fol. orbiculatis subacuminatis rugosis subtus tomentosoincanis; corymbis depressis. Schmidt oestr. Bmz. C. tomentosula Miclix. C. rugosa Lam. In Virginia et Canada. 方.

9. C. macrophylla W'all. ramis laevibus; fol. late ovatis acuminatis basi rotundatis subtus glaucis adpressissime setosis; axillis subglandulosis; floribus secundis. In India orientali et Nepalia. ち. Drupa magnitudine Piperis nigri.

10. C. excelsa $I$. et $K$. ramis patulis; ramulis foliisque subtus pubescentibus supra pilis minutis consper- sis ovatis acuminatis subtus pallidioribus. In Mexico. 24.

11. C. Toluccensis $H$. et $K$. ramis dichotomis patulis; fol. ovato-oblongis angustato-acuminatis utrinque puberulis subtus pallidioribus; cymis alarihus nudis. In Mexico circa urbem Tolucea. 支.

\section{Involucratae.}

\section{a. Floribus albis capitatis.}

12. C. capitata $\boldsymbol{W}^{\top} a l l$. ramis patulis laevibus; fol. lanceolatis utrinque acuminatis pube adpressa minima subscabris; involucro magno scabro. In Nepalia. 5 . Involucrum flavum.

13. disciflora /l. mex. ic, ined. ramis laevibus; fol. lanceolatis utrinquc acuminatis breve petiolatis; floribus sulisessilibus umbellato-capitatis; involucri foliolis in discum 4-lobum concretis. In Mexico. †. Drupa compressa rubra.

13. C. japonica Thunb. arborea; ramis striatis; fol. ovatis acuminatis hasi integris subtus pallidis; umbellis decompositis 3-5-radiatis. Vilumum japonicum Spr. In Japonia. t. Fl. albi. Drupa compressa rubra.

\section{b. Floribus flavis umbellatis.}

15. C. mascula L. ramis glabriusculis; fol. ovalibus acuminatis utrinque sparse puperulis; floribus aute folia nascentibus; fructu ovali. Guimp. Abbild. t. z. Hayne term. hot. t. 35. In Europa. ち. Fructus purpureus s. flavescens.

16. C. fiorida $\boldsymbol{L}$. ramis nitidis; fol. ovatis acmininatis subtus pallidis utrinque adprssse pilosis; floribus umbellatis post folia nascentibus; involucro maximo. Bot. Mag. 526. Guimp. Abb. t. 19. In Carolina et Canada. $\hbar$.

3. Sublerbaceae; truuco subrepente.

1\%. C. canadensis $L$. caulihus simplicihus herhaceis; fol. superioribus verticillatis subpetiolatis ovatis venosis; floribus umbellatis. Bot. Mag. 880. Kern. t. 636. In Carolina et Canada. ち. Habitus Paridis quadrifoliae. Fi. parvi albo-rubescentes. Drupae rubrae. 
18. C. suecica $L$. caulibus herbaceis subramosis; fol. onmibus oppositis sessilihus ovatis a hasi nervosis; umbella pedmculata. Fl. Dan. t. 5. Enyl. Bot. 310. Svensk bot. 201. In Europa, Asia, Famtschatka, Groenlandia et Lapponia. $\hbar$. Flores atropurpurei. Drupae rulirae.

19. C. Iatifolia De Bray; ramis implicitis patulis; fol. ovato-subrotundis subtus glaucis; cymis convexis. De Bray Denkschr. hot. Gesellsch. II. p. 35. Ad Dünae ripas prope holienhusen. ち. Baccae violaceo-nigrescentes.

20. C. polygama Rafin. fl. ludov. ramis strictis laevibus glabris; fol. oppositis sessilibus oblongis integris obliquis acuminatis subtus canis. In Lonisiana. †. Frutex 15-ped. Rami rubri. Petala alba.

21. C. jernlacea Jacq. est ex $R$. et $\mathbf{S}$. indescripta.

\section{AUCUBA Thunb. (1\%s1).}

1. A. japonica Thunb. jap. t. 12. et 13. Bot. Mag. 119\%. Eubusis di-

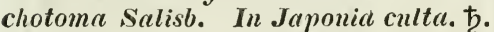
Folia albido-maculata. Fl. parvi fusci.

\section{GLOSSOMA Schr. (1789).}

1. G. Votomita R. et S. Votomita Gujanensis Aubl. Guj. t. 3.5. Gloss. arborescens Willd. In Gujanae syl-

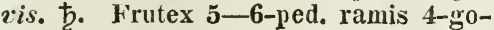
nis. Fl. albi.

\section{MONTINIA. L. (18S1).}

1. M. acris L. Pluku. t. 333. Burm. Afr. t. 90. f. 1.2. II. caryophyllacea Thunb. Smith spic. t. 15. $M$. frutescens Gaertn. $t$. 33. Lam. $t$. 808. In Prom. b. spei. Frutex ramis foliisque ohlongis obtusis glabris alternis; floribus albis terminalibus. spr.

\section{TRAPA. L. (173\%).}

1. T. natans $L$. fructibus 4-cornutis; cornubus cruciatim oppositis acu- tis apice retrorsun barbulatis 2 patentibus 2 adscendentilus. sichk. t. 25. Mirb. ann. t. 19. In Europae et Sibiriae stagnis et aquis limosis. $\odot$. Fl. albi.

2. T. quadrispinosa Roxb. fructibus 4-cornutis cruciation oppositis rigidis acutis spinosis. In Sylhet lacubus natans. Caet. ignota.

3. 'I'. bispinosa Roxb. Corom. $t$. 231. fructibus bicornibus; cornubus oppositis rigidis acutis spinosis harbellatis; fol. subquadratis serrulatodentatis suhtus tomentosis. Rheede mal. 11. t. 32. In India orientali. $\odot$.

4. $T$. bicornis $L$. fructibus bicornibus; cornubus oppositis crassis obtusissimis apice subrecurvis; fol. quadratis integris dentatisve. Gartu. fruct. t. 89. 1c. chin. 1821. t. 22. In China prope Cantonem.

5. T. cochinchinensis Lour. fructibus bicornibus; comubus oppositis crassis obtusissimis apice recurvatis; fol. oblongis apice incisis subtus tomentosis. Lour. In Cochinchina.

\section{AMIIANVIA Houst. (173\%).}

\section{Apetalae.}

1. A. parviflora $D C$. caule erecto 4-gono glahro; fol. ohlongis sessilibus; calycibus 4-dentatis; caps. globosa. In India orientali. $\odot$. Herba tenella.

2. A. filiformis DC. mem. caule erectiusculo a hasi romoso; fol. linearibus; umbellis axillarihus pedunculatis; caps. globosa calycem 1 -dentatum superante. In Seneyalia. $\odot$.

3. A. senegalensis Lam. ill. t. $7 \%$ f. 2. caule erecto tereti a hasi ramoso florifero apice 4-rono; fol. lanceolato-linearibus sessilihus basi cordatis; caps. glohosa calycem duplo superante. Lythrum multiflorum Perr. In senegalia. $\odot$.

4. A. indica Lam. caule erecto ramoso tereti; ramis sub 1 -gonis erectiusculis; fol. lanceolatis hasi attenuatis; corymbis multifloris breviter pedunculatis. In India orientali. $\odot$.

5. A. microcarpa DC. caule erecto ramoso tereti; ramis 4-gonis; fol. lanceolato-linearibus sessilibus basi 
subcordatis; caps. obovata calycis longitudine. In ins. Timor.

6. A. aegypliaca Willd. canle erecto ramoso basi tereti apice 4-gono; ramis patulis; fol. lanceolatis sessilibus basi attenuatis patulo-deflexis; floribus conferto-verticillatis. Delile aeg. t. 15. f. 3. In Aegypli oryzetis. ค. Cal. 8-dentatus.

\%. A. vesicutoria Rorb. caule erecto ramoso; ramis indivisis; fol. sessilibus lanceolatis basi attenuatis; floribus in axillis sessilibus confertoverticillatis. Plukn. t. 136. f. 2. Burm. ind. t. 18. f. 3. A. baccifera L. In cultis humidis Indiae orientalis. $\odot$. Herba acris odore muriatico.

8. A. hostatı DC. caule ramoso diffuso basi radicante sub-4-gono glabro; fol. hasi obtuse hastatis amplexicaulibus lineari-lanceolatis. Isnardia I. et P. peruv. t. 85. f. 6. I. sulliastata Dietr. In puludosis Peruvicu. $\hbar$,

9. A. elatinoides DC. mem. soc. h. n. geneve 3. $t$. 3. $f$. B. caule hasi decumbente; ramis erectis filiformisub-t-gonis; fol. sessilibus omnibus oppositis oblongis ovatisque. Lythrum uniflormm Perrott. In senegalia. $\odot$.

10. A. borysthenica DC. caule ramoso diffuso; fol. oblongis aut ovatolanceolatis, inferiorihus oppositis, sup. alternis; floribus axillaribus sessilibus. Peplis sprengel. Ad Borysthenem proye Kien. $\odot$.

11. A. occidentalis DC. canle adscendente hasi radicante subsimpluci; fol. lanceolatis basi in petiolum attenuatis; flor. axillaribus sessilibus. Peplis spr. In Portorico. Cal. 8-dentatus.

12. A. glauca Walt. fol. glaucis lineari-oblongis, floralibus subreflexis; florihus numerosis in axillis foliorum, dense verticillatis sessilibus; stylo brevi. W. et Aru. prod. 1. p. 305. In India orientali.

\section{Tetrapetalae; calycibus 8- dentatis.}

13. A. caspica Bieb. caule 4-gono erecto ramoso; fol. lanceolatis basi attenuatis; floribus axillaribus glomeratis sessililous; petalis 4 minimis. DC. All fluv. Cyrum versus mare Cuspium. $\odot$.
14. A. ramosior $L$. caule 4-gono erecto ramoso; fol. lineari-Ianceolatis basi dilatata subsemiamplexicaulibus; floribus inferioribus compacto-verticillatis, superioribus solitariis. A. purpurea Lam. In Virginia et Carolinı. $\odot$.

15. A. latifolia $\boldsymbol{L}$. caule 4-gono erecto ramoso; fol. lineari-lanceolatis basi obtuse cordato-auriculatis; floribus sessilibus. DC. SIoane hist. 1. 7. f. 4. Lam. ill. 1. 77. f. 1. In Jamaica et Curolinu. $\odot$. Petala alba.

16. A. humilis Niclex. caule basi procumbente tenero 4-gono ramoso; fol. lineari-lanceolatis hasi attenuatis; floribus axillaribus solitariis sessilibus; petalis orbiculatis. DC. A. ramosior Torr. In paludosis Carolinae et Virginiate. $\odot$.

17. A. verticillata Lam. ill. t. $8 \%$. f. 3. caule erecto 4-yono ramoso; fol. lanceolatis sulssessilibus basi attenuatis; floribus in axillis sessilibus congesto-verticillatis; petalis obovatis. DC. Cornelia verticillata Hardw. sp. 2. t. 1. Prope Florentium, in India orient. et Chinu. $\odot$. Cal. 4-dentatus.

18. A. cordata Wight; fol. oblongis basi subcordatis sessilibus; floribus sessilibus $2-3$ in axillis foliorum; calyx semiglohosus. W. et Arn. prodr. 1. p. 304. In Indiu orientali.

19. A. densiflor" Roth. fol. sessilibus lineari-lanceolatis hasi subcordatis; ramis floriferis spicaeformilus; hracteis patenti-recurvis sulssqarrosis. Roth. sp. p. 99. In India orientali. ○. Caul. repens. Fl. alhi.

20. A. multiflora Roxh. caule recto 4-gono angulis aculis, faciebus convexis; fol. linearibus basi dilatata cordato - sawittatis semiamplexicaulibus; petalis subrotundis. DC. In agrois circa Calcultum. $\odot$. Petala rubra.

21. A. debilis Ait Kew. canle allgulato ramoso; fol. Janceolatis hasi attenuatis; floribus fasciculatis axillaribus; petalis ohovatis. In Indic orientali. $\odot$. Petala pallide purpurea.

22. A. diffusa Willd. caule auscendente ramoso suyerne 4-gono; ramis diffusis; fol. lanceolatis obtusiusculis basi angustatis, sup. leviter cordatis. Patria iynota. $\odot$. Petala alba.

23. A. rotundifolia Roxb. caule diffuso basi repente apice adscenden- 
te; fol. subsessilibus suborbiculatis; floribus in axillis supremis spicas constiluentibus. DC. In Nepalia et Bengulo. $\odot$. Caul. 2-3-poll.

3. Pentandrac; petalis et staminibus 5, calycibus 10-den$t$ a $t$ is.

2.1. A. pentandiva Roxb. caule basi repente simplici superne erecto ramoso; ramis simplicibus; fol. sessilibus lanceolatis; floribus axillaribus solitariis. DC. In humidis Indicte orientalis. $\odot$.

25. A. nand Roxb. caule basi repente superne erecto ramoso; ramis ramosis; fol. sessilibus sagittatis. In humidis Indiae orientalis.

4. Dyplostemoneae DC.; petalis 4-7; staminibus petalorum num ero duplis.

26. A. dorlecundra DC. mem. t. 2 . fol. lineari-lanceolatis acutis sessilibus basi obtuse subauriculatis; petalis 6-7; staminibus 12-14. Lythrum grandiflorum Perrottet. In Senegalia. $\odot$. Herba viridi-glancescens. Petala violacea.

27. A. sanguinolentr Sw. fol. lineari-lanceolatis acutiusculis, hasi obtuse cordato-auriculatis semi amplexicaulibus; petalis 4 ; staminibus 8 . A. octandra $\beta$. Poir. In fossis Jumaicae. $\odot$.

28. A. octandra $I$. fol. linearilanceolatis sessilibus basi acute auriculato-cordatis; floribus axillaribus subsessilibus; petalis 4 ; staminibus 8 . Roxls. Corom. t. 133. A. coccinea Pers. In India orientali. $\odot$.

29. A. auriculata Willal. Hort. Berol. $t$. \% fol. lineari-lanceolatis sessilibus basi obtuse auriculato-cordatis; corymbis multifloris; petalis 4 ; staminibus 8. Delile aeg. t. 15. f. 2. A. racemosa Poir. suppl. Lythrum ramosum Perrottet. In orysetis Aegypti et humidis senegaliae. $\odot$.

\section{species dubiae.}

30. A. mbra Humilt. caule erecto subsimplici 4-gono basi radicante; fol. oblongis obtusis sessilibus; floribus sessilibus solitariis; ramulis floriferis oppositis vix folio longioribus. In $\mathrm{Ne}$ gralia. $\odot$. Caul. 3-1-poll.
31. A. rosea Poir. suppl. caule tenero; ramis filiformibus; fol. linearibus sessilibus acutiusculis, floralibus minimis; floribus solitariis; caps. globosa. In India orientali. FI. parvi rosei.

32. A. repens Rottl. caule radicante 4-gono; fol. subpetiolatis oblongis obtusiusculis; floribus axillaribus sessilibus. In India orientali.

33. A. pallida telim. caule erecto 4-gono; fol. lanceolatis acuminatis hasi dilatato-cordatis; floribus glomerato-verticillatis. Patria ignota.

34. A. viridis Willt. fol. lanceolatis basi altenuatis; florihus conglomerato-verticillatis apetalis. Patric ignotu.

3.5. A. sagittat $D C$. ramis sub-4gonis glabris herbaceis; fol. sessilihus linearibus basi obtuse sagitatis; caps. subglonerato-verticillatis globosis sub4-gonis apice 4-dentatis. Jussiaea sagittata Poir. In st. Domingo.

36. A. pinnatifida L. caulibus procumbentibus radicantibus compressis; fol. sparsis linearibus pinnatifidis; 10bis filiformibus; floribus axillaribus; caps. 4-gona. In Javu.

\section{LUDHIGIA Roxb. (1821).}

\section{A. Ludwigiaria.}

1. I. jussiaeoides Lam. erecta; glabra; fol. lanceolato-linearibus utrinque acuminatis; caps. elongata teretiuscula. In India orientali et ins. Mauritii.

2. L. fruticulosa Plume bijrlr. erecta; glabra; fruticosa; $\tilde{5}$-gona ; fol. lanceolatis obtuse acminatis nargine temuissime ciliolatis; floribus geminis; caps. linearibus 4-gonis. In ins. Java.

3. L. leucorrhiza Blume bijdr. erecta; glabra ; lierbacea; 5-gona ; fol.alternis lineari-lanceolatis ohtusiusculis margine subtiliter ciliolatis; caps. elongatis clavatis 4-gonis. In Java. kad. fusiformis.

4. L. Iytlıroides Blume bijılr. erecta glabra 5-gona; fol. linearibus obtusiusculis; floribus pedicellatis ad apicem pedicelli bibracteolatis; caps. 4-gona subturbinata abbreviata. In India orientali. 
5. L. erigata $\boldsymbol{L}$. caule erecto laevi brachiato; fol. alteruis lanceolatis; caps. subculsica 4-angulata; petalis minimis. L. triflora Lam. L. alternifolia Burm. In India orientali. $\odot$.

6. L. parviflora Roxb. erecta; glahra; floribus sessilibus hasi bibractenlatis ; caps. lineari-suh-4-gona. Hheede mal. 2. t. 49. Jussiaea caryophyllea var. $\beta$. Lam. In Bengalia. $\odot$. Planta parva. Petala minima.

\%. L. diffusa Hamilt. diffusa; glabra; fol. lanceolatis; floribus subsessilibus; caps. prismatico-4-gonis ohtusangulis pedunculatis folio dimidio brevioribus. In aquosis Indiae orientalis. $\odot$.

8. I. prostrata Roxb. ramis inferiorihus prostrato-repentihus; floribus sessilibus solitariis ant ad axillas plurihus; caps. filiformibus ; seminibus in quoque loco 1 -seriatis. In Pegu. $\odot$. Caul. 1-2-ped.

9. I.? trifolia Burm. erecta; herhacea; lacvis; fol. oppositis ternisve petiolatis ovato-lanceolatis; florihus suhterminalibus perlunculatis. Isnardia trifolia Poir. In Jav:a.

\section{B. Isnardia DC. Iudwigia L. Petala 4.}

a. Fol. alternis.

10. I. alternifolia DC. caule erecto ramoso glabriusculo; fol. alternis lanceolatis suhtus et maroine suhseabriusculis ; caps. ohovato-glohosis alato-4-gonis; lohis calycinis margine coloratis. Plukn. t. 203. f. 2. et t. 412. f. 2. Iudwigia Gaertn. t. 8. I/. microcarpa Michx. I. salicifolia Poir. C. uniflora Rafn. In America boreali. $\odot$. Petala flava.

11. I. linearis DC. caule erecto ramoso glahro superne angulato; fol. alternis linearibus acutis glahris; caps. oblongis turbinatis sub-4-gonis; lohis calycis lineari-lanceolatis. Ludwigia Walt. L. angustifolia Michx. In ayuosis Carolinae. $\odot$. Petala obovata flava.

12. L. viryata DC. canle erecto viruato subpuliescente; fol. linearihus ohtusis glahris; floribus in racenum terminalem dispositis; caps. globoso4-gonis. Ludw. Iutea Bosc. In Carolina. $\odot$. Petala flava.

13. I. hirsuta $R$. et $\mathbf{S}$. caule erecto ramoso subdiffuso piloso-hirsuto; fol. alternis lanceolatis utrinque subhirsutis; caps. globoso-1-gonis. Ludwigia Walt. In paludosis a Nova Caesarea ad Carolinam.

1.1. I. mollis Poir. caule erecto ramosissimo molliter villoso; fol. lanceolato-oblongis; florihus subcongestis ; petalis minimis calycinis lohis minorihus; caps. glohosis. Ludwigia Michx. L. rudis WValt. L. hirtella Rafin. In uliginosis Carolinae. 4.

1.5. I. capituta DC. canle erecto ramosissimo molliter villoso; fol. lanceolato-ohlongis; floribus subcongestis; caps. glohosis. Lurw. capitata Michx. L. suffruticosa Walt. In uliginosis Carolinae. 24. Flores flavi.

\section{b. Fol. oppositis.}

16. I. pedunculata DC. caule procumbente radicante pubescente; fol. oppositis lanceolatis; pedunculis axillaribus 1-floris Iongrissimis; caps. clavato-oblongis. Ludw. pedunculosa Michx. Ludw. arcuata Walt. In puludosis Virginiae et Carolinae.

17. I. repens DC. caule repente glabro; fol. oppositis obovatis ; pedicellis axillaribus 1 -floris folio brevioribus; petalis ovatis calyce multo minoribus; caps. ohlonga 4-gona. Ludw. repens $\$$ w. ind. t. 8 . In Jamaica.

\section{Dantia Thonars. Isnardia L. Petala uulla.}

a. Fol. oppositis.

18. I. palustris L. caule procumbente radicante glabro; fol. oppositis in petiolun attentitis ovatis acutis; florihus axillarihus solitariis sessilibus. Sichkuhr. t. 25. In Europa, Sibiria et Persia. $\odot$. B. americana DC. fol. utrinque mavis acuminatis. Ludw. apetala Walt. L. nitida Michx. In fossis Amer. borealis. $\odot$.

\section{b. Fol. alternis.}

19. I. alata DG. caule diffuso ramoso glahro distinctissime anculato; fol. cumeato-lanceolatis Jecurrentihus glahris; caps. cuhicis suhalatis. Ludw. alata Ell. In umbrosis Americae boreulis.

20. L. microcarpa Poir. caule procumbente subalato glaberrimo; fol. alternis spathulato-obovatis ad mar- 
gines glanduloso-dentatis; caps. minimis suhfuadratis. Iodwigia Michx. Ludw. glandulosa Pursh. In humidis Carolinae. $\odot$.

21. L. sphaerocarpa DC. canle erecto ramoso glabro vix subangulato; fol. alternis lineari-lanceolatis ulrinque acutis, juniorihus subpubescentihus: forihus axillaribus sessilibus apetalis: caps. globosis parvulis pubescentihus. Ludwigia EII. In paludosis Carolinae. 4 .

22. I. cylindrica DC. caule erecto ranoso suhangulato gfahro; fol. alternis lanceolatis vix denticulatis; florihus axillarihus sessilihus; calycinis lohis subserratis; caps. cylindricis. Ludw. cylindrica Ell. hrachycarpa Lan. Ludw. heterophylla Poir. In Georgia. 4.

23. I. Lanceolata DC. caule erecto virgato angulato glahro; fol. alternis angustato-lanceolatis glabris subdecurrentibus; floribus sessilibus axillaribus apetalis ; caps. cubicis alatis. In paludosis Georgiae et Curolinae. 2.

\section{Species dubiae.}

21. I. ramosa DC. caule procumbente radicante ramoso glabro; fol, oppositis lineari-lanceolatis; floribus ad axillas subsessilihus. Ludw. ramosissima Roth. Putriu ignota. 24. Petala allsa.

25. L. aurantiaca $D C$. caule recto ramoso; fol. sessilibus ovato-Ianceolatis altemis acutis glabris; floribus axillaribus; petalis longitudine calycis. In America boreali. Fl. aurantiaci.

\section{AULAX Berg. (1\%67).}

1. A. pinifolia Berg. fol. filiformibus canaliculatis. Spr. Burm. afr. t. 70. f. 3. Protea L. B. bracteata Thunb. diss. t. 1. In Prom. b. spei. t.

2. A. umbellata Berg. fol. planis spathulato-linearibus. Protea aulacea. Thunb. diss. t. 2. P. umbellata L. In Prom. b. spei. 支.
61\%. LEUCADENDRON L. (1737).

a. Nux ventricosa; stylo caIyceque persistente.

1. L. argenteum R. Br . arhoreum; fol. lanceolatis argenteo-sericeis ; ramis calycibusque sericeis; bracteis tomentosis. Plukn. t. 200. f. 1. Protea Lam. ill. t. 53. f. 1. in Prom. $b$. spei. $\hbar$.

2. L. plumosum R. Br. fruticosum; fol. lineari-lanceolatis ohliquis glabriusculis; fructibus villosis. Protea parviflora L. Thunh. diss. t. 4. P. obliqua Thunb. P. plumosa Nit. In Irom. b. spei. ђ.

3. L. retusnm R. Br. fiuticosum; fol. spathulatis glabris apice calloso-retusis ; ramis tomentosis; fructibus glabris. In prom. b. spei. 5 .

t. L. spathulatum R. Br. fruticosum; fol. spathulatis apice callosorecurvis rauisque giabris; fructibus glahris. In From. b. spei. 方.

.. L. sessile B. Br. fruticosum; fol. oblongo-lanceolatis basi rotundatis. In From. b. spei. ち.

b. Nuxventricosa; stylus deciduss; calyx persisteus.

6. L. angustatum R. Br. fol. spathulatis concaviusculis ramisque glahris; calycibus plumosis; squamis strobili comniventibus fructibusque pubescentibus. In Prom. b. spei. 古. Frutex ramis strictis. Nux maguitudine seminis Viciae.

\%. L. imbricatum R. Br. fol. lanceolato-linearibus glabris basi rotundatis glabrinsculis ; ramis villosis; squamis strobili sericeis cuneatis ; fructihus comosis mucronatis. Protea Levisanus L. L. buxifolium R. Br. WendI. Hort. t. 14.? In Africa. ち. Frutex ramosissimus.

8. L. Levisamus Berg. fol. spathılatis apice callosis ramulisque villosis; fructibus comosis muticis. Plukn. t. 343. f. 7. Wendl. t. 1. Protea $L$. P. hirsuta Willd. Hb. In Prom. $b$. spei. $\hbar$.

9. L. tortum R. Br. fol. linearibus obtusiusculis tortis glahris; ramulis calycibusque sericeis ; fructibus comosis muticis. Protea Thunb. In Prom. b. spei. Ђ.

10. L. cinereum Thunb. fol. spathulato-linearibus argenteis; nucibus 
ohovato-cuneatis villosiusculis muticis. Protea alba Thunb. In prom. b. spei. 古.

11. L. corymbosum R. Br. fol. lineari-suhulatis imhricatis glabris; strobili squamis acutis apice recurvis ; nucibus subcompressis obcordatis margine pilosis. Protea Thunh. diss. Andr. Rep. t. 495. In Prom. b. spei. ђ.

c. Nux mareinata vel alata; stylus calyxquedeciduus. Squamae strobili distiuctae.

12. I. decorum R. $\boldsymbol{B r}$. fol. oblongis venosis callo recurvo, adultis glabris, junioribus ramisque sericeis; squamis extus tomentosis; nucilous marginatis impresso-punctatis. Protea Lallreola Lam. In Prom. b. spei. ђ.

13. L. syarrosum B. Br. fol. Ianceolato - oblongis ; callo recurvo antice sulco lineari; amenti feminei squamis oblongo-ovatis dilatatis ciliatis, strobili undulatis recurvis. Protea strobilina L. Boerh. Lugd. Bat. 2. c. tab. In Prom. b. spei. $ђ$.

14. L. concolor R. Br. fol. spathulato-oblongis callo antice sulurotundato adultis glahris; ramis pubescentibus; amenti feminei squamis retusis, basi tomentosis margine ciliatis. Protea glohosa Andr. Rep. t. 307. Bot. Mag. 878. P. strobilina Schrad. sert. Han. t. 1. In Prom. b. spei. t.

15. L. grandiflormm R. Br. fol. lanceolato-ohlongis, floralibus coloratis; ramis tenuissime tomenlosis; amenti fem. squanis fucatis. Euryspermum Salisb. In Prom. b. spei. ђ.

16. I. ovale R. Br. fol. oblougoovalibus sub aveniis, callo obtuso, adultis margine tomentosis; strobili squamis lanceolato - ovatis acutis glabris. Protea strobiliua Thumb. In Brom. b. spei. 古.

17. I. venosum R. Br. fol. ollougo-lanceolatis venosis glabris; callo acuto; strobili squamis ovato-lanceolatis acutis; nucibus apteris. In Prom. b. spei. 市.

13. L. decurrens R. Br. fol. lanceolato-spathulatis hasi allenuatis subdecurrentibus ramisque glabris; samaris obcordatis alatis cinereis convexis. Protea pallens Thunh. P. Chamelea Lail. In prom. b. spei. ち.

19. L. glabrum $R$. Br. fol. lineari-lanceolatis aveniis adultis ramisque glabris; strobili squamis obtusissimis subretusis; samaris alatis nigris. In Prom. b. spei. t.

20. L. strictum R. Br. fol. linearibus mucrone subulato glabris; hracteis involucrantilus ovatis acutis ; strobili squamis dilatatis rotundatis glabris; fructibus impresso-punctatis. Protea conifera Andr. Rep. 541. P. conica Lan. In Prom. b. spei. $\hbar$.

21. L. virgatum R. $\boldsymbol{B r}$. fol. linearibus acutis pellucido-marginatis ramisque glaberrimis; strobili squamis ovatis incano - tomentosis; samaris alatis emarginatis. In Prom. b. spei. ち. Folia ramosa hasi torta. Strobilus magniludine Avellanae.

22. L. adscendens R. Br. fol. lineari-lanceolatis acutis, floralibns apice coloratis; strobili squamis incano-tomentosis; caulibus sublepressis. Plukn. 4. 229. f. 6. Weinm. 4. t. 903. a? In Prom. b. spei. 方.

23. L. concinmum IR. IBr. fol. lanceolatis-oblongis ohtusiusculis aveniis ramisque glaherrimis, floralihus semicoloratis; strohili squam is argenteotomentosis; samaris alatis emarginatis. In prom. b. spei. ち. Frut. 10ped.

21. I. saligmum R. Br. fol. lanceolato-linearibus acutissime mucronatis subserices; strohili squamis subtomentosis retuso-bilohis; samaris angustissime alatis. Corocarpodendron Boerh. Bat. c. tah. Protea saligna L. In Prom. b. spei. $ち$.

2.5. L. uliginosum R. Br. fol. lauceolato - linearibus utrinque argenteis; tomento arcte adpresso; ramis tomentosis; samaris apteris. Breyn Cent. 21. t. 9. P. saligna Thumb. in Prom. b. spei. 古.

26. L. floridum $\boldsymbol{R}$. Br. fol. lanceolato-linearihus sericeis supra villosis; callo apicis acuto ; floralibus ramisque hirsutis; samaris apteris. Pluku. t. 229. Protea saligna Audr. liep. t. 572? In Prom. b. spei. 古.

d. Squamae strobili connatae. samara foliaceo-compressa gla bra. Folia subfiliformia.

2\%. I. platyspermum B. Br. fol. superiorihus lineari-spathulatis; callo obtuso; strobili squamis duplicatis Iongitudinaliter arrectis; samaris 
hiculatis; stigmatis articulo superiore barbato vix duplo longiore. In Nova Hollandia. .

9. P. phylicoides $\boldsymbol{R}$. Br. fol. indivisis teretilus exsulcis strobilum ovatum vix aequantibus; squamis ovatis ramisque incanis; tomento appresso. In Nora Hollandia. ந.

10. P. linearis $\mathbb{R}$. $B r$. fol. planis teretibus aveniis; mucronulo uncinato; squamis amenti enervihus late ovatis acumine hrevi; perianthio villosissimo. In Nova Hollandia. 㠳.

b. stigma inarticulatum hispidiusulum. Nux compressa. strobilus squamis distinctis. Folia filiformia bipinnatifida.

11. $P$. rigida $\boldsymbol{R}$. $B r$. fol. triternatis; laciniis divaricatis; calycilons barbatis; laminarum apiculis glabris. In Nora Hollundia. $\hbar$.

12. P. pulchella R. Br. fol. 3-fidobipinuatis; laciniis erectis; calycibus sericeis; laminarum apicibus tomentosis. Protea sichral. sert. Han. t. 7. Cav. ic. t. 550. Bot. May. 796. P. dichotoma Cav. ic. t. 551. In Nova Hollandia. 古.

13. P. sessilis Sieh. fol. trifido-hipinnatis; laciniis super canaliculatis divaricatis; strohilis subsessilihus; squamis dilatatis retusis cum acumine totis extus perianthiisque sericeis; uncihus intus marginibusque comosis. In Nova Ilollandia. ち.

14. i. canescens Cunningh. fol. bi-tripimatifidis filiformibus sericeis super sulcatis; strobilis subovatis sessilibus; squamis late ovatis acutis extus sericeis; nucibus intus marginibusque comosis. In Nova liollandia. 方.

1.5. P. crispata R. Br. fol. biternatis filiformibus sericeis super sulcatis ; strobilis sessilibus ovatis ; squamis ovatis acuminatis ramulisque tomento crispato incanis. In Nor. Hollandia. ち.

16. '). fastigiata R. Br. fol. trifido-bipinnatis; laciniis erectis fastigiatis teretiusculis muticis; calycibus glabris; strobilis terminalibus sessilibus; squamis lanatis. In Nora Hollandia. ち.

1\%. N. Serruriae R. Br. fol. trifido-bipinmatis subsessilibus teretiuscu- lis super sulcatis; pinnulis inferioribus bifidis; perianthio hirsuto; s(robilis subglobosis axillaribus sessilibus; squamis ovatis acutis onnibus sericeis. In Nova Hollandia. ち.

18. P. pedunculata R. Br. fol. 3pinnatifidis; laciniis canaliculatis divaricato-patulis; calycilus glabriusculis; strohilis pedunculatis; squamis glabris. In Nova Hollandia. ち.

\section{c. Nux alata.}

1.9. P. diversifolia R. Br. fol. 23-pinuatifidis planis; laciniis mucronatis; calycihus barbatis; strobilis axillaribus pedunculatis; squamis lanatis cohaerantibus. In Norce Hollandia. t.

20. 'P. squamata R. Br. fol. 3fidis; lobis limeari-lanceolatis, lateralibus saepius 2-3-fidis; strobilis axillaribus scssilibus; squamis apice scariosis glabris. In Nova Hollandia. $b$.

21. P. trificla R. Dr. fol. 3-fidis; lobis spathulato-lanceolatis saepissithe indivisis; strobilis axillaribus sessilihus; squamis apice scriceis. In Hova IIollandia. $ち$.

22. P. striate R. Br. fol. trifidobipimatifidis planis striatis scalıris; laciniis lineari-lanceolatis mucronatis; strobilis axillaribus sessilibus subglohosis; squanis exterioribus glabris reliquis sericeis; uncibus globosis apice angustatis. In Nova Hollandia. ち.

23. I. macrostachya R. Br. fol. trifido-hipinnatifidis; laciniis linearilanceolatis mucronatis; strobilis terminalibus cylindraceis; nucibus lenticularibus comosis. In Nova Hollandiu. t.

2.. P. divaricata R. Br. fol. trifido-bipinnatis super sulcatis; pinnulis divaricatis pungentibus; perianthiis sericeis; aurenti squamis tomentosis; cuspide subulato glabro; samara planiuscula utrinque glabra hasi barbata. In Yova Hollandia. 方.

25. P. propinuza R. Br. fol. hiteruatis planis; lobis lanceolato-linearibus mucronatis subvenosis; strobilis axillaribus sessilibus; squamarum dimidio superiore sericeo. In Nora Hollandia. ち.

26. $\boldsymbol{P}$. biloba $\boldsymbol{R}$. Br. fol. planis ternatis; foliolis hifidis interjecto mucronulo; lohis dimidiato-ovatis venosis mucronatis; strobilis axillaribus; 
squamis sericeis. In Nora Hollandia. $\hbar$.

27. P. dubia $\boldsymbol{R}$. Br. fol. pinnatis canaliculatis; pinnis subulato-linearibus imis pinuatifidis mediis bifidis superioribus indivisis; ramulis villosis; pilis strictis patulis tomentoque crispato; amentis terminalibus. In Nora Hollandia. t.

\section{ISOPOGON R. Br. (1810).}

a. strobilus globosns; squamis deusissime imbricatis, tardius deciduis.

1. I. teretifolins R. Br. fol. 2-3ternatis filiformihus exsulcis; ramulis tomentosis; calycis tubo sericeo; laminis longitudinaliter barbatis. In $\mathrm{No}$ va Hollandia. $\hbar$.

2. I. petrophiloilles $\boldsymbol{R}$. Br. fol. indivisis teretibus exsulcis; strohilo sulhgloboso basi depresso; squamis tomentosis; bracteis involucrantibus. In Nova Hollandia. ち.

3. I. dirergens $R, B r$. fol. pimnatis teretibus glahris super sulcatis; laciniis saepius indivisis; terminali longiore; strobilo oblongo ovato sessili densissimo. In Nova Hollandia. ち.

4. I. pedunculatus $R$. Br. fol. trifido-pinnatis glabris teretibus super sulco angustissimo; Iaciniis lateralibus bifidis; terminalis 3 -fidae media breviore; ranulis glaberrimis; strobilo ovato; pedunculo tomentoso. In Nov. Hollandia. $\hbar$.

5. I. asper $\stackrel{\boldsymbol{R}}{\text {. } \boldsymbol{B} r \text {. fol, pinnatis }}$ punctatis asperis semileretilus supra canaliculatis; amentis aggregatis; perianthiis glabris. In Nova Hollandia. 5 .

6. I. anethifolius $\boldsymbol{R}$. $B r$. fol. subbipinnatifidis filiformilus supra sulcatis; laciniis erectiusculis; ramis olabris; calycis tubo puhescente, laminis infra glabris apice barbato. Protea Salisb. P. acufera Cav. ic. t. 549. In Nova Hollandia. t.

\%. I. formosus $\boldsymbol{R}$. $\boldsymbol{B r}$. fol. bipinnatifidis sub-3-ternatis filiformihus supra canaliculatis; laciniis divaricatis; ramulis tomentosis; calycibus glabris laminis apice pilosiusculis. Bot. reg. 1288. In Nova Hollandia. ђ.

8. I. anemonifolius $I$. Br. fol. 3fido-pinnatifidis bipinnatifidisque; laci- niis linearibus planis patenti-erectis subtus laevilus; strobili squamis stupposis. Protea Bot. Mag. 697. Andr. Rep. 332. Lodd. B. C. 1337. P. tridactylides Cav. ic. t. 518 . In Nova Hollundia. 5 .

9. I. petivlaris R. Br. fol. trifidobipinnatifidis; laciniis linearibus mucronatis planis divaricatis utrinque striatis puhescentibus scahriusculis; strobili squamis lanatis. In Nova IIollandia. †.

10. I. tripartitus $\mathrm{R}$. Br. fol. planis circumscriptione cuneiformilus petiolatis 3-partitis trifidisque; lobis lineari-lanceolatis integerrimis; ramis tomentosis. In Nora Hollandia. $t$.

11.I. ceratophyllus R. Br. fol. 3-fidobipinnatifidis; laciniis linearibus planis divaricato-patulis utrinque striatis mucronatis; floralihus basi dilatatis. In Nova Hollandia. 古.

12. I. longifolius $\boldsymbol{R}$. Br. fol. lineari-lingulatis, superioribus integerrimis, inferiorihus passin trifidis; calycibus sericeis; stigmate glabro. In Nova Hollandia. $\hbar$.

13. I. trilobus $R$. Br. fol. cnneatis planis 3-lobis basi attenuatis petiolatis; lobis integerrimis; ramulis tomentosis. In Nova Hollandir. ந.

14. I. Loudoni Baxt. fol. Ianceolatis lingulatisve integerrimis; apiculo sphacelato ramis perianthiisque glabris; apicibus laminarum sericeis; stigmate fusiformi barbato; strobilis hemisphaericis. In Nova Hollandia. $\downarrow$.

1.5. I. latifolius R. Br. fol. cumeato-ohovatis glabris; nervo venisque primariis subtus manifestis; ramulis tomentosis; strobilis depresso-globosis; receptaculo hemisphaerico. In Nova Hollandia.

b. Receptaculum commune plam num vel convexiusculum; pas leis deciduis.

16. I. cuneatus R. $B r$. fol. oblongo-cuneatis obtusissimis ; involucri bracteis tomentosis; calycibus glabris; stigmate fusiformi. In Nova Hollandia. $\mathrm{t}$.

17. I. attenuatus $\boldsymbol{R} . \mathrm{Br}$. fol, elongato-oblongis mucromulatis basi attenuatis; capitulis solitariis; calycis laminis apice barbatis; stigmate cylindraceo. In Nova Hollandia. t. 
18. J. polycephalus R. Br. fol. lineari-oblongis mucronulatis; ramulis tomentosis; capitulis subaguregatis; bracteis omnibus lanatis; stignate cylindraceo. In Nova Hollandia. †.

19. I. buxifolins $R$. Br. fol. ovatis sessilibus acutis; apicihus recurvis; caulihus proliferis; capitulis solitariis obvallatis; bracteis subulatis; stigmate fusiformi. In Nova Hollandia. †.

20. I. axillaris R. Br. fol. cuneato-lingulatis mucronulatis; capitulis axillaribus paucifoliis; bracteis involucrantibus ovatis imbricatis; calycis Jaminis Jongitudinaliter harbatis ; stigmate fusiformi. In Nova Hollandia. 南.

21. I. uncinatus $R$. Br. fol. gladiatis integerrimis; apiculo circinato; caule abhreviato; capitulis aggregatis. In Nova Hollandire. $\hbar$.

22. I. spathulutus R. Br. fol. cuneato-ohovatis lineari - spathulatisve; apiculo acuto; caule prolifero; capitulis solitariis obvallatis. In Nova Hollandir. $\hbar$.

23. I. Baxteri R. Br. fol. dilalato-cuneiformilus, fruticis adulti trifidis; lobis incisis; laciniis mucronatis; juvenilis indivisis apice dentato ; capitulis aggregatis; receptaculo plano. In Nova liollandia. 市.

\section{PROTEA L. (1737).}

\section{a. Capitula terminalia.}

1. P. cyanoides $L$. fol. subrotundis petiolatis; involucris sericeis ; hracteis interioribus acutis imberbilous; stylo infra mediun pubescenti. Andr. Rep. 288. Bot. Mag. 770. In Prom. b. spei. 方.

2. P.Iatifolia R. Ir. fol. late ovatis semicordatis sessilibus; involucro sericeo tomentoso; bracteis interioribus apice dilatato; calyce tomentoso ; sty10 puhescenti. P. spectabilis Licht. Bot. Mag. 1717. Bonpl. Malnı. t. 59. In Prom. b. spei. ち. Frut. 6-8-ped. Fol. olutusissima.

3. $\boldsymbol{P}$. compracta R. Br. fol. oblongo-ovatis cordatis marginatis; invoItucro sericeo tomentoso ciliato imherbi; calycis aristis longitudine Iaminarum; stylo glahro apice curvato. In Prom. b. spei. t.
4. P. longifiora Lam. fol. ovatooblongis sessilibus basi subcordatis; ramis tomentosis; involucro sericeo; bracteis intimis sericeo-ciliatis; calycis aristis hrevissimis. Weinm. Phyt. 4. t. 902. a. b. sm. exot. bot. t. 81 . In Prom. b. spei. b.

5. P. coccinea $R$. $B r$. fol. ohovatis ohtusissimis sessilihus venosis ramisque glahris; involucri bracteis interioribus spathulatis apice harbatis: stylo glabro. P. rangiferina Hortul. In Jrom. b. spei. t. Frut. 4-o-ped.

f. P. speciosa $L$. fol. obovatooblongis lasi angustatis ramisque glatbris, involucri bracteis ommihus sericeis; stylo pubescenti; aristis calycis apice lanatis. Andr. Kep. t. 110. Bot. Mag. 1183. In Prom. l. spei. t.

\%. I. mucropllylla R. Br. fol. elongato-ohlongis marginatis venosis glabris basi subattenuatis; involucti hracteis omnihus tomentosis, intimis lingulatis imberhibus; stylo apice curvato. In Prom. b. spei. ち. Frut. 810-ped.

8. P. formosa $R$. Br. fol. angusto-ohlongis venosis obliquis ; marginibus ramisque tomentosis; involucri bracteis ciliatis, intimis lingulatis imberhihus; calycihus aristisque tomentosis; stylo apice incurvato. Bot. Mag. 1713. P. coronata Andr. Rep. 469. In Prom. b. spuei. ち.

9. P. melaleuca R. B'rr. fol. lineari-lingulatis marginatis ciliatis; ramis pilosiusculis; involucris elongato-turbinatis ; hracteis alho-ciliatis, exteriorihns squarrosis, interiorihus dorso nigro-tomentosis. P. coronata Lam. P. speciosa nigra Andr. Rep. 103. P. Lepidocarpon Ker. Bot. Mag. 674. In Prom. b. spei. b.

10. P. Lepidocurpon R. Br. fol. lineari-lingulatis scahriusculis nitentihus ramisque glabris; involucri hracteis interiorilus dorso marginihusque nigro-harhatis; stylo puhescenti. P. cristata Lam. ill. P. grandiflora var. Andr. Rep. 301. In Prom. b. spei. t.

11. P. neriifolia $\boldsymbol{K}$. Br. fol. lineari-lingulatis laevihus opacis basi extus ramisque tomentosis; involucri bratcteis interioribus dorso argenteo-sericeo margine nigro-barbato. Bot. Heg. 208. Clus. Exot. 38. f. XV. In Prom. b. spei. ђ.

12. P. pulchella Andr. Rep. 2\%0. et 281. fol. lineari-lingulatis margi- 
natis interioribus scabriusculis; ramis subtomentosis; involucri hracteis interioribus apice sericeo-marginibus nigro-harloatis. P. nereifolia spr. In Prom. b. spei. ち.

13. P. patens $\boldsymbol{R}$. Br. fol. angustoohlongis subundulatis marginatis hasi suluattenuatis ramisque villosis procumhentihus; involucro hemisphaerico; hracteis sericeis, interiorum harha nigro-purpurea; stylo infra puhescenti. P. speciosa patens Andr. Rер. 5\$3. In Africa australi. $\hbar$. Frutex procumbens.

14. P. incompta R. Br. fol. lingulato-ohlongis summis ramisque hirsutis; involucri bracteis interioribus apice orbiculato-dilatato margine harhato; calyce lanato; stylo glahro. Boerh. Lugd. Bat. t. 189. In Prom. b. spei. ち. Frutex erectus. Rani hirsutissimi.

15. P. longifolia Andr. Rep. 132. 144. et 133. fol. elongato-linearibus hasi attenuata; involucri turhinati bracteis glahris acutis imberbibus; stylo pubescenti apice curvato. In Prom. b. spei. $\hbar$.

16. P. mellifera $R$. Br. fol. lanceolato-lingulatis basi attenuatis ; involucro turhinato; bracteis glaliriusculis imherhibus viscidis; aristis calycis albo - lanatis; stylo glabro. Weinm. 4. t. 896. P. repens L. - Bot. Mag. 346. Wendl. hort. t. 1: In

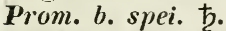

17. P. grandiflora Thumb. fol. oblongis sessilibus ramisque glalıris; involucro hemisphaerico imberhi nudiusculo ; calyce tomentoso; aristis brevissinis; stylo glabro. Weimm. t. $\mathbf{8 9 1}$. Bot. Mag. 2447. In Prom. b. spei. ち.

18. P. abyssinica Willd. fol. Ianceolato-lingulatis ohtusiusculis, basi subangustata; involucro hemisphaerico; hracteis obtusis imherbibus; calyce tomentoso; aristis hrevissimis; receptaculo villoso; caule arborescenti. Gaguedi Bruce Ahhyss. 5. p. 52. c. tab. duabus. In Abyssinia. $\hbar$.

19. P. Scolymus Thunb. fol. lineari-Ianceolatis acutis submucronatis basi attenuatis; involucro hemisphaerico; bracteis glabris obtusis; calycibus muticis; receptaculo villoso. Plukn. t. 440. f. 1. Weinm. t. 893. f. 6. Andr. Rep. 409. Wendl. Sert. t. 20. Bot. Mag. 698. In Prom. b. spei. ち.
20. P. mucronifolia Salisb. fol. lanceolato-linearihus mucronatis; pungentihus hasi obtusa; hracteis involucri lanceolatis mucronatis glabris. Bot. Mag. 953. Audr. Kep. 500. P. odoratissima Mass. In Prom. b. spei. 5 .

21. P. nana Thunb. fol. subulatis mucronatis; involucris mutantilus hemisphaericis; bracteis glabris ohtusis. sill. exot. bot. t. 44. In Prom. b. spei. 古.

22. P. pendula R. Br. fol. linearilanceolatis mucronulatis, terminalibus ramorum floriferorum recurvorum reclinatis; bracteis involucri ohtusis deunum glabriusculis. In Prom. b. spei. ち. Frutex erectus.

23. P. tenax R. Br. fol. Iinearilanceolatis planis hasi attenuatis margine scabriusculis; ramis decumbentihus; involucro liemisphaerico sericeo ohtuso. In Prom. b. spei. ち. Frutex diffusus.

21. P. canaliculata Andr. Rep. 4.3\%. fol. linearibus aveniis supra concaviusculis ramisque glahris decumbentibus; involucro obtuso; hracteis interioribus subsericeis; aristis calycis penicillatis. In Prom. b. spei. ち. Frutex subdecumbens.

2.5. P. acaulis $\boldsymbol{R}$. Br. caulibus ahhreviatis; ramis depressis; fol. obovato-oblongis marginatis venosis basi attenuatis; involucris hemisphaericis inclinatis; calycihus muticis. Bot. Mag. 206.5. Weinm. t. 898. b. Linn. syst. Nat. XII. t. 2. In Proin. b. spei. $\hbar$.

26. P. elongata $R$. Br. caulibus nanis; fol. elongato-lanceolatis (pedalibus) planis marginatis venosis laevibus; basi valde attenuata lineari; involucro hemisphaerico inclinato. In Prom. b. spei. 卢.

2\%. P. angustata $R$. Br. caulibus nanis; fol. lanceolato-linearibus; planis marginatis venosis laevibus invoIucro hemisphaerico inclinato; bracteis glabris obtusis; calycibus muticis. In From. b. spei. ち.

28. P. revoluta $\boldsymbol{R}$. $\boldsymbol{B r}$. caulihus nanis; fol. canaliculato-semiteretibus laevibus; involucro hemisphaerico inclinato; bracteis glahris obtusis; calycibus muticis. In Prom. b. spei. $b$. Frutex humilis ramis adscendentibus.

29. $\boldsymbol{P}$. tenuifolia $\boldsymbol{R}$. $\boldsymbol{B r}$. caulihus nanis; fol. canaliculato-semiteretibus 
scahris; involucro hemisphaerico ; bracteis tomentosis unguibus laminisque hirsutis; aristis brevissimis. In Prom. b. spei. $ち$. Folia numerosa punctis elevatis scabra.

30. $\boldsymbol{P}$. laevis $\boldsymbol{R}$. Br. caulihus nanis decumbentibus; fol. elongato-linearibus laevibus aveniis marginibus recurvis ; involucro hemisphaerico; bracteis ohtusis subsericeis. Bot. Mag. 2439. In Prom. b. spei. ち. Caul. brevissimus decumbens glaber.

31. I. scubra R. Br. caulibus nanis; fol. elongato-linearibus scalıris obsolete venosis margine suhrecurvis; involucro turhmato-hemisphaerico ; bracteis oblusis tomentosis. In Prom. b.

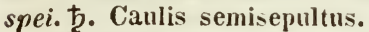

32. P. repens 'Tlumb. caulibus nanis; fol. elongato - linearibus scahriusculis margine revolutis; involucro turbinato; bracteis ohtusis tomentosis. Weinm. t. 897. a. In Prom. b. spei. ந.

33. P. Lorea $\mathrm{R}$. $\mathrm{Br}$. caulihus nanis; fol. teretilus clongatis laevibus; involucro turbinato subpedunculato; bracteis acutiusculis sericeis; stylo apice curvato. In Prom. b. spei. t. Calllis brevissimus.

3t. P. turbiniflora R. Br. caulibus nanis; fol. elongato-lanceolatis marginatis subundulatis laevibus; involucro subturbinato; bracteis tomentosis obtusis, calycis aristis lana crispa. P. caespitosa Andr. Hep. 5\%6. In Prom. b. spei. ち. Caules caespitosi. Folia subpedilia.

35. P. Scolopendrium R. Br. caulihus nanis; fol. elongato-lanceolatis marginatis lacvibus; involucro turbinato; hracteis lanceolatis acuminatis apice tomentosis. In Prom. b. spei. t. Caulis foliis brevior.

\section{b. Flores Iaterales.}

36. P. cordata Thunb. florilus lateralibus; fol. cordatis subrotundis nervosis; hracteis invloucri glabris. Thunb. diss. t. 5. P. cordifolia Bot. Mag. 649. In Prom. b. spei. 5 .

37. P. amplexicuulis R. br. fol. cordatis ovatis ampiexicaulihus divaricatis apice recurvis; bracteis invoIncri puljescentibus. P. repens Andr. 453. In l'rom. b. spei. ђ.

33. P. humilis $\mathbf{I}$. $\mathrm{Br}$. fol. linearibus acutis ( 2 uncialibus) receptaculo conico; paleis acutis. Protea humili- fiora Andr. Rep. 532. In Prom. $\boldsymbol{~}$. spei. t. Caulis namus.

39. P. acerosa $\boldsymbol{R}$. Br. floribus lateralibus; fol. subulatis receptaculo convexiusculo; paleis obtusis. Andr. Kep. 371. In Prom.b. spei. t. Caulis brevis.

\section{LEUCOSPERMUM R. Br. (1810).}

\section{Capitulum amentaceum.}

a. stylo calycen superante.

1. I. lineare R. Br. calyce hirsuto; fol. linearihus revolutis apice calloso-harbatis; involucro tomentoso. Protea linearis Thunb. diss. 1. 4. In Prom. b. spei. Ђ.

2. L. attemuatum R. Br. fol. cuneato-linearibus tridentatis aveniis basi attenuatis; involucris ramisque tomentosis. In Africa australi, $\hbar$. Frutex 3-ped.

3. L. Tottum R. Br. fol. linearioblongis integris venosis basi obtusa; bracteis involucri glabris ciliatis; stigmate hinc gibboso. In Africa austraii. t.

t. I. medium R. Br. fol. lineariohlongis 2-3-dentatis integrisve; bracteis involucri tenuissime pubescentibus ciliatis; capitulis cernuis. Protea formosa Andr. Rep. 17. In Africa austruli. t.

5. L. ellipticum R. Br. fol. oblongis 3-4-dentatis hasi ohtusis 2-unciaIibus; bracteis involucri tenuissime puhescentibus ciliatis; capitulis erectis. Protea elliptica Thumb. P. vestita Lam. P. conocarpa Poir? In Africa australi. $\hbar$.

6. I. mutans $\boldsymbol{R}$. Br. fol. ovatis oblongisve $\mathbf{3}-\mathbf{5}$-dentatis; involucri bracteis tomentosis incanis; capitulis nutantibus; stigmate obliquo turbinato. In Africa australi. $\hbar$.

7. L. conocurpum R. Br. fol. ovalihus 3-9-dentatis; ramis bracteisque hirsutissinis; calyce villosissimo; stigmate oblongo-conico. Protea Thunb. Lam. ill. t. 53. f. 3. Weinm. Pliyt. t. 899. f. b. In Africa australi. $\hbar$.

8. L. grandiflorum R. Br. fol. oblongo-lanceolatis 3-dentatis integrisque; ramis hirsutissimis; bracteis involucri glabris ciliatis; calyce villosis- 
simo; stigmate oblongo-cylindraceo. Protea villosa Poir. In A/rica australi. 卢.

9. L. puberum R. Br. fol. lanceolatis ellipticisve integris uncialibus pubescentibus; ramis hirsutis; hracteis involucri incano-villosis eltipticis longe acuminatis. Protea pubera $\mathrm{L}$. In Africa australi. $\downarrow$.

10. L. buxifolium R. Br. fol. ovalibus obtusis integris unguicularibus; ramis hirsutis; bracteis involucri orbiculato - ovatis breviter acuminatis glabriusculis ciliatis, In Africa australi. $\hbar$.

11. L. patulum $\boldsymbol{R} . \mathrm{Br}$. fol. spathulato - linearilus integris, adultis glahris; ramis divaricatis tomentosis; capitulis pedunculatis; calyce tomentoso-villoso; stigmate ovato. In Africa australi. $\hbar$. Frutex humilis ramosissimus.

12. L. spathulatum R. Br. fol. spathulatis hasi lineari, adultis glabris uncialibus; ramis hirsutis patulis; bracteis tomentosis acuminatis; calyce vilioso. In Afivica anstrali. $\hbar$.

13. I. marginutum spr. fol. spathulato-linearihus apice callosis venosis margine lanato-sericeis; floralibus coloratis; hracteis villosis; calycibus glabris. Protea marginata Willd. In Prom. b. spei. $\hbar$.

\section{b. Stylo calycem aequante.}

14. L. tomentosnen R. Br. fol. linearibus cuneatisve 3 -dentatis tomentosis; bracteis lanceolatis tubum calycis subaequantibus; caule erecto. Protea tomentosa Thunb. P. candicans Andr. Rep. 294. In Prom. b. spei. t.

15. L. Hypophyllum $\boldsymbol{R}$. Br. caule procumbente; fo!. linearibus tridentatis ; bracteis orbiculato-ovatis tomeutosis tubo calycis dimidio brevioribus. Plukn. t. 440. f. 3. Weinu. t. 902. f. a. Protea Hypophylla Thunb. Africa australi,

2. R eceptaculum planiusculum, bracteis angustis leciduis.

16. I. molle $\mathrm{R}$. Br. fol. ellipticis acutis 2 -3-dentatis integrisve subsericeo-pubescentibus mollibus; bracteis exterioribus glabriusculis; stigmate ovato. In Africa australi. t.
17. L. crinitum R. Br. fol. ovatooblongis obtusis 3-5-dentatis integrisve basi angustatis pubescentibus denum glabris scabriusculis; bracteis villosis. Protea crinita Thunb. In Africa australi. $\hbar$.

15. L. oleaefolium Berg, fol. ovali-oblongis sublanceolatisve 3-dentatis integrisve, adultis glabris; bracteis omnihus villosis; stigmate oblongo. Protea criniflora. L. P. crinita Jacq. in Willd. Hb. In Africa australi. $ђ$.

19. $L$. diffusum $R$. Br. fol. cuneato-linearilus integris 2-3-dentatisve basi angustatis; ramis procumbentilus; bracteis tomentosis lanceolatis acuminatis calyce dimidio brevioribus. Protea heterophylla Thumb. In Africa australi. ち. Frutex prostratus.

\section{MIMETES Salisb.}

\section{a. Capitula axillaria.}

1. M. Lirta R. Br. fol. acutis integerrimis; involucris coloratis acuminatis 8-10-floris; laminis calycis plumosis. Weinm. t. 899. Rchb. Hort. t. 92. Protea hirta L. In Africa australi. $ђ$.

2. M. capitulata R. Br. fol. acutis integerrimis; involucris coloratis acutis semiexsertis pubescentihus 8-10floris; stigmate apice conico-incrassato. In Africa australi. $b$.

3. M. pauciflora R. Br. fol. obtusis integerrimis sericeis; involucris coloratis acutis villosiusculis sub-4floris; stigmate cylindraceo. In Africa australi. 5 .

4. H. cucullata R. Br. fol. linearioblongis 3-dentatis glabris; involucris subdimidiatis acuminatis glabriusculis; stigmate subulato acutissimo. Plukn. t. 304. f. 6. Weimm phyt. t. 918. In Prom. b. spei. t. Frutex 3-ped.

5. M. Hartoyii R. Br. fol. linearioblongis 3-dentatis, adultis niveolanatis; involucris subdimidiatis; bracteis acuminatis pubescentibus. Rchb. Hort. t. 93. Weinm. phyt. t. 906. a. Protea cucullata $\beta$. Lam. In Africa australi. t. Arbuscula orgyalis.

b. M. Hibbertii $\boldsymbol{R}$. Br. fol. argenteis oblongo-ellipticis $\mathbf{3}$-dentatis integerrimisve; involucris subdimidiatis; bracteis obtusis exterioribus glabris. 
In Africa australi. $\hbar$. Frutex 5-6ped.

\%. M. Massoni R. Br. fol. argenteis ovatis integris; involucris aequilateralibus calyce dimidio brevioribus; bracteis subrotundis coriaceis. In Africa australi. $\hbar$. Frutex erectus. hami sericei.

\section{b. Capitula terminalia.}

8. Mr. thymelaeoides R. Br. caule erecto; fol. ovalibus obtusis pubescentibus semiuncia brevioribus; capitulis sulaggregatis; stylis infra medium pubescentilus. Leucadendron thymelaeoides Berg. In Africa australi. $\hbar$.

9. M. myrtifolic $\boldsymbol{R}$. Irr. canle erecto; fol. lineari-oblongis ohliguis integris vel 2-3-dentatis uncia breviorihus; stylo "Iahro; capi(ulis subsolitariis. In Africa custrali. t. Frutrex parvus. Hami brumei.

10. M. diraricata $R$. Br. caule procumbente; fol. ovalihus obtusis pubescentibus; stylo glahro. Protea divaricata Thumb. In s/rica anstruli. $\hbar$.

11. N. mipurea It. Br. canle procumbente; ranis adscendentilus; fol. lincari-suhulatis canaliculatis; laminis calycis glahris. Leucadendron proteoides L. Protea purpurea L. mant. In Africa australi. $\frac{\hbar}{}$.

\section{SERRERIA R. Ir. (1810).}

a. Capitula simplicia.

1. S. glaberrima $R$. $\mathbf{B r}$. capitulis axillaribus pedunculatis; bracteis Iaminisque calycis glahris; fol. indivisis passingue 3-fidis; caule procumbente. In Africa austruli. $\hbar$. Frutex prostratus glaher.

2. s. cymnea $\boldsymbol{R} . \mathrm{Br}$. capitulis axillarihus terminalibusque pedunculatis; hracteis glahris subciliatis; calycihus curvatis sericeis; fol. hipimnatis; caule procumbente. In Africa australi. $\hbar$. Frutex jrocumbens.

3. N. acrocarpa R. Br. capitulis axillaribus pedunculatis; bracteis tomentosis; calycilus curvatis sericeis ; mucibus hasi puhescenti styli mucronatis; fol. hipinnatifidis; caule erecto. In Africa australi. t. Frutex hipedalis. Fol. 2-uncialia.
4. S. elevata $R . B r$. capitulis axillaribus pedunculo hrevioribus; bracteis cuneato-orhiculatis tomentosis; calycibus hreviter barbatis curvatis; nucibus submuticis; fol. bipinnatis; caule

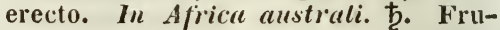
tex orgyalis. Rami tomentosi.

5. s. Aitoni R. Br. bracteis cuneato-suhrotundis mucronato - glahriusculis; calycihus plumosis; nucibus mucronatis; fol. tripartito-hipimnatis sericeis; caule erecto. In Africa unstrali. $\hbar$. liami stricti pedales tomentosi.

6. S. simplicifolia $R$. Br. bracteis villosis ; calycihus harbatis; fol. indivisis ramisque trifidis; caule erecto. In Africa anstrali. $\hbar$. Fruticulus pedalis glaber.

7. s. diffusc $R$. Br. bracteis Ianceolato-ovatis acmminatis; calycihus barbatis; fol. trifidis v. pimnatifidis subinde simplicilus uncialihus ramisque glahris; caule procumbente. In Africa australi. 方. Frutex diffusus pedalis.

8. s. pinnate R. Br. bracteis lanceolatis acuminatis villosis dimidio calyce longioribus; calycis unguihus subsericeis; laninis apice barbatis; fol. pinnatifidis trifidisve; caule procumhente piloso. Protea pimnata Andr. Hep. 512? In Africa australi. ந.

9. s. arenaria R. Br. bracteis lanceolato-ovatis acuminatis villosis calycis laminis tribus plumoso-harbatis; fol. 3-fidis pimmatifidisque canle puhescente. In Africa austruti. frutex erectus vel decumbens pedalis.

10. s. cyunoidles R. Mr. hracteis orbiculato-ovatis acuminatis villosis; calycis laminis tribus longitudinaliter plumoso-harhatis ; fol. patulis ; caule erectiusculo. Protea cyanoides 1. In Africa anstrali. $\hbar$. Frutex humilis.

11. s. furcellata $R$. Br. bracteis lanceolatis exterioribus pedunculisque glabris, interioribus villosis; calycibus barlatis; fol. 3-fidis, laciniis 2-3-fidis fastigiatis ramisque glahris; caule erecto. In Africa australi.

12. S. scariosa $R$. $B r$. hracteis lanceolatis rlahriusculis calyces sericeos aequantihus apice patulis; pedunculis squarrosis; fol. hipimmatis laciniisque divaricatis ramisque glahris; caule erecto. Protea sphaerocephala Poir. In Africa anstrali. ち. liami rubicundi partum flextosi. 
13. S. pedunculata R. I?r. hracteis late ovatis tomentosis; calycihus curvatis plumoso-harlatis; lamina interiori villis adpressis sericea; fol. bi-tripinnatifidis canleque erecto hilsuto. Protea pedunculata Lam. P. glomerata Andr. Kep. 264. In Afiricu austruli. t. Frutex orgyalis.

14. S. scopariu R. Br. bracteis late ovatis villosis; calycibus barbatis; fol. 3-ternatis patulis uncia hrevioribus ramisque hirsutis; caule decumbente. In Africa australi. b. Rami adscendentes.

15. S. hirsuta Thumb. hracteis lineari - lanceolatis hirsutis; calycibus plumoso-barhatis; fol. bipinnatis uncialihus: ramis hirsutis; caule erecto. Protea phylicoides Thumb. In Africa

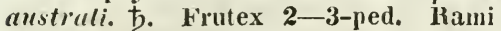
umbellati.

16. S. Stilbe $R$. Br. bracteis hirsutis ovatis acumine recurvo; calycibus barhatis; fol. $2-3$-teruatis uncia brevioribus; ramis pubesceutibus; caule erecto. In Africa austrati. நृ.

17. S. Nivenii $R$. Br. bracteis lanceolatis extimis glabris, interioribus sericeis; calycibus barbatis; fol. bipinnatifidis subuncialibus, summis capitulum sessilem superautibus ramisque glanerrimis; caule decumbente. Protea decumbens Andr. Rep. 349. In Africa anstrali. Ђृ. Frutex spithameus.

18. S. villosu R. Br. bracteis lanceolatis acuminatis tomentusis; calycis Iaminis harhatis; unguihus tomentosis; fol. subhiternatis, superioribus capitulum sessilem superantibus; ramis hirsutis; caule erecto. Protea villosa Lam. P. phylicoides Poir. In Africa anstrali. ち. Frutex 2-pedalis.

19. S. foeniculucen R. Br. hracteis glabris ovatis acuminatis; calycibus sericeis; fol. bipinuatis sesquiucialibus, superiohus capitulum superantibus ramisque glabris; caule erecto. In Africa australi. $\hbar$. Frutex 2-pedalis.

20. S. ciliata R. Br. bracteis subulatis glabris margine hirsutis dimidio capitulo longiorihus; calycibus sericeis; fol. subbipinuatis ramisque glabris; caule erecto. In Africa ausliaii. ち. Frutex ramosissimus. Rami rubicundi.

21. S. congesta R. Rr. bracteis subulatis margine hirsutissimis dimidio capitulo longioribus; calycibus barbatis; fol. suhhiternatis semiuncialibus; ramis pilosinsculis; caule erecto. In Africa australi. $ђ$. Frutex ramosissimus.

22. S. nitida $\boldsymbol{R}$. $\mathrm{Br}$. pedunculo squarroso; bracteis capitulo parum breviorilus, exterioribus subulatis, interiorihus villosissimis sericeis; calycis laminis plumoso-harhatis; fol. uncia longioribus. Protea cyanoides Thunb. In Africa australi.

23. S. suarrosa R. Br. pedunculis ramuliformihus squarrosis; bracteis dimidium capituli superantibus, exterioribus linearibus glabris, interioribus lineari-lanceolatis pilosis; calycis laminis penicillatim harbatis. In Africa anstrali. b. Frutex erectus glaherrimus ranosissimus.

24. S. phylicoides R. Br. pedunculis ramuliformihus squarrosis; bracteis dimidium capituli superantihus, extimis lineari-subulatis, interioribus lanceolatis, utrisque glahris; calycis laminis penicillato-harbatis; fol. $1^{\text {I }}$ uncialibus. Leucadendron phylicoides Berg. Protea sphaerocephala L. P. abrotanifolia Andr. Rep. 50\%. In Africu ustrali. ђ. Frutex glaberrimus ramis rubleundis.

2.5. S. aemula R. Br. bracteis exterioribus lanceolatis tomentosis ciliatis, interioribus villosis minoribus; calycis laminis omuibus plumoso-barbatis; fol. bipinnatidis. In Africa australi. t. Frutex 3-4-ped. Rami tomento tenuissimo cinerascentes.

26. S. fiorida R. Br. hracteis capitulo pedunculato longioribus, exterioribus glabris oblongo-lanceolatis acuminatis, interiorihus inclusis lineari-Ianceolatis ciliatis; fol. pinnatifidis hipinuatifidisque. Protea florida Thunb. In Africa australi. $\hbar$.

\section{b. Capitula composita; partia-} libus cougestis.

2\%. S. decumbens R. Br. caule prostrato foliisque glahris 3-fidis; laciniis indivisis; capitulis partialihus sul)4-floris. Protea decumbens Thunb. In Africa australi. t. Frutex prostratus glaber basi divisus.

28. S. adscendens $R$. Br. caule procumbente foliisque glabris pinnatifidis $\mathbf{2}$-pinnatifidisque, pedunculis partialibus incano-tomentosis; calycibus 
curvatis, Protea adscendens Lam. In Africu australi. $\hbar$. Frutex glaber. Raninubicundiquandoque adscendentes.

29. S. flagellaris R. Br. caule procumbente foliisque pilosis bipinnatifidis ; pedumculis partialibus subtomentosis; calycilous strictis. In Africa australi. $\hbar$. Frutex prostratus basi divisus.

30. S, rubricaulis $R, B r$. caule erecto foliisque glabriusculis subbipinnatifidis uncialibus; capitulis partialibus paucifloris; bracteis ovatis acuminatis glabris; stigmate cylindraceo, Protea spliaerocephala Thunb. In Africa australi, ђ. Inami stricti rubicundi,

31. S. glomerata R. Br. caule erecto foliisque glahris bipinnatifidis uncia longioribus; capitulis partialibus multiforis; bracteis exterioribus glabris, interioribus subsericeis; pedunculo conumuni squarroso stigmate clavato. Burn. Afr. t. 99. f. 2, Protea slomerata Lam, In Africa anstruli. t2. Frutex ramis rubicundis,

32. S. decipiens $\mathrm{R}$. Br. caule erecto; ramulis pubescentibus; fol. bipinnatifidis; capitulis partialibus pancifloris communique breviter pedunculatis; bracteis onnibus villosissimis; calycilus sericeis. \$. compar 11 . Br. In Africa anstrali. t. Frutex ramosissimus 4-5-ped.

33, S. Roxburylii $R$. Br. caule erecto; fol. 3-ternatis fastigiatis semiuncia brevioribus; capitulo communi partialibusque scssilibus paucifluris. In Africa australi. t. Frut. 3-4-ped.

34. S. Burmamil R. Br. capilutis corymhosis sul)-10-floris; calycihus fastigiatis sericeis apiceve nudiusculis pedunculo partiali brevioribus; fol. hipiunatifidis setaceis vix biuncialihus. Burm. afr. t. 99. f. 1. Protea serraria L. In Africa anstrali.

35. S. tridentata R. Br. capitulis globosis; floribus viginti pluribus imbricatis; bracteis pedunculisque partialibus sericeis; fol. triternatis digitalibus cauleque glaberrimis. Protea tridentata Thumb. P. argentifiora Andr. Rep. 447. In Africa australi. $\hbar$.

o. Capitulis diatinctis corym-

36. S. elongata R. Br. pedunculo communi elongato partialibus bracteisque glabris; acumine subulato recurvo dimidium haseos ovatie superan- te; fol. 2-3-pinnatifidis digitalihus. Leucadendron elongatum Berg. Protea glonierata Thunb. P. thyrsoides Lam. In Africa australi. $ち$. Frutex erectus $1 \frac{1}{2}$-ped.

3\%. S. critmifolia $\boldsymbol{R}$. $\boldsymbol{B r}$. pedunculo communi elongato partialibusque glabris; capitulis sub-3-gintifloris; bracteis glaberrimis; mucrone-brevissimo ohtuso erecto; fol. $2-3$-pinnatifidis digitalihus. In Africa custrali. t. Frutex simplex. Fol. 3-t-ped.

\section{NIVENIA R. Br. (1810).}

a. Folia superiora indivisa latiora.

1. N. Sceptrum R. Br. fol. obovatis lanceolatisve planiusculis margine simplicibus; calyce sericeo vilIis adpressis. Protea. Sceptrum Gustavianum sparm. in Act. Holm. 1777. t. 1. P. alopecuroides Lain. In Afirica australi.

2. N. marginata R. Br. fol. latioribus quam lougis cucullatis marginatis; calyce sericeo; villis adpressis; involucri foliolis acutis apice glabriusculis. In Africa ustrali. Hami umbellati stricti.

3. N. spethulata R. Br. stylis latioribus quam Iongis cucullatis marginatis; iuvolucri foliolis obtusis; calyce harbato; stylo glabro; stigmate clavato oblongo. Protea spathulata Thunb. diss. 58. t. 5. In Africa austruli. ち. Folia infima 2-3-pinnatifida filiformia canaliculata.

4. N. purviforu R. Br, fol. Jatioribus quam longis cucullatis; calycibus barbatis; stylo lanato; stigmate conico capitato. Protea siceptrum Lain. P. Gustaviana Poir. In Africa australi. ち. Frutex ramosissimus.

\section{b. Folia omia bipinnatifia.}

5. N. spicata R. Br. ramis tomentosis; bracteis adpressis ovatis involucro calyceque tomentosis; stylis villosissimis. N. critmifolia R. B. Protea Lagopus Andr. liep. 243. Protea spicala L. In Africa australi. b. Frutex erectus ramis tenuissinc tomentosis.

6. N. media $R, B r$. ramis incanis ; pedunculis elongatis; bracteis lanceolatis; involucris acutissimis calyceque 
tomentosis; stylo inferne puhescente; stigmate gracili. Protea spicata Andr. Rep. 234. Paranonus sceptriformis Salisb. In Africa australi. ち. Frutex 6-8 pedalis.

7. N. Layoms $R$. Br. ramulis pilosis; spicis subsessilibus cylindricis; capitulis imbricatis; bracteis lanceolatis subulatis; involucri foliolis subrotundis calyceque tomentosis; stylo inferne pubescente. Protea Lagopus Thumb. In Afirica australi. $ђ$. Frutex erectus. Rami unbellati.

8. N. mollissima $\boldsymbol{R}$. Br. spicis pedunculos vix aequantibus; fol. sericeis 3-ternatis mollissimis; calycis unguibus tomentosis; laminis barbatis. In Africa australi. $\hbar$. Frutex tomentosus.

9. $\boldsymbol{N}$. capitata $R$. Br. capitulo communi globoso subsessili; unguibus laminisque calycis barbatis; fol. semiuncialibus, ramulorum inferioribus glalıris. In Africa australi. $\hbar$. Futex 3-pedalis.

\section{SOROCEPHALUS R. Br. (1810).}

a. Spica nudiuscula. Involucrum 1-3-florum. Nux basi in te gra.

1. S. sctaceus $R, B r$. involucris 1-floris; fol. setaceis incurvis ramulisque hirsutis. In Africa australi. b. Frutex erectus. Rami virgati umbellati.

2. S. salsoloides R. $\boldsymbol{B r}$. involucris 1-floris; fol. triquetro-filiformilus incurvis glabris. In Africa australi. †. Frutex erectus ramosissimus. Ramuli tenuissime pubescentes.

3. S. imberbis $\boldsymbol{R}$. Br. involucris trifloris; laminis calycis acuminihusque bractearum glabris. in Africa australi. ち. Frutex ramosissimus.

1. S. spataloides R. Br. involucris trifloris subpedicellatis; calycis laminis barbatis. In Afirica australi. ち. Frutex erectus. Hami tenuissime pubescentes.

b. Spica subinvolucrata. Involucra 4-6-flora. Nux basi emarginat a.

5. S. tenuifolius $\boldsymbol{R}$. Br. fol. filiformilus; capitulis paucifloris; calycis lamints plumoso-barbatis, interiori nu- diuscula. In Africa australi. ఫ. Frutex 3-4-ped. hami rubicundi.

6. S. lanatus R. Br. fol. triquetro-filiformibus supra sulcatis; capitulis multifloris ; calycis laminis omuibus barbato - plumosis. Protea lanata Thunb. diss. t. 30. In Africa australi. b.

\%. S. imbricatus R. Br. fol. lanceolatis subtus scabris unguibus calycis glanduloso-pilosis; stigmate clavato. Protea Thunl. diss. t. 5. Andr. Rep. t. 527. In Africa australi. ђ. Frutex er ectus.

8. S. diversifolius $\boldsymbol{R}, \boldsymbol{B r}$. fol. spathulato-lanceolatis subtus laevibus, infimis bipinuatifidis; unguibus laminisque calycis barbatis; stigmate cylindraceo. In Afirica australi. $ち$. Erutex 2-pedalis.

\section{SPATALLA Salisb.}

a. Involucra 1-flora. Stigma concavum cochleariforme. Calyx ina equalis.

1. S. mollis $\boldsymbol{R}, \boldsymbol{B r}$. involucro diphyllo; foliolis integerrimis; fol. strictis ramulisque villosis. In Africa australi. $\hbar$. Frutex ramosissimus.

2. S, pedunculata $\boldsymbol{R}$. Br. involucro diphyllo; foliolo latiori 3-dentato; spica imbricata; pedunculo foliis 3-quetris incurvis longiore; bracteis sericeis involucro brevioribus. In Africa australi. ち. Frutex ramosissimus.

3. S. nivea R. Br, involucro diphyllo; foliolo latiori 3-dentato; spica imbricata; pedunculo foliis rectiusculis acutissimis hreviori; hracteis foliaceis villosiusculis involucra aequantibus. In Africa australi. $\hbar$. Frutex ramosissimus.

4. S. ramulosa $R, B r$. involucro diphyllo; foliolo latiori 3-fido; spica subsessili imluricata; bracteis superioribus longitudine pedicellorum; fol. acute mucronatis. Leucadendron racemosum L. Protea Thunb. In Africa australi. b. Frutex ramosissimus.

5. S. laxa R. Br. involucro diphyllo; fol. latiori 3-fido; racemo subpedunculato laxiusculo; bracteis superioribus pedicello breviorilıus. In Africa australi. b. Frutex 4-6-ped.

6. S. bracleata R. Br. involucro diphyllo; foliolo latiori profunde 3-fido; 
spica pedunculata imbricata; fol. incurvis glabriusculis. Protea racemosa L. In Africa australi. ち. Frutex 6-7-ped.

\%. S. sericea $\boldsymbol{R}$. $\boldsymbol{B r}$. involucro diphyllo; foliolo latiori 3-partito; spica sessili imbricata; bracteis involucra subsessilia aequantibus; fol. semiuncialihus ramulisque sericeis. In Africa australi. $\hbar$. Frutex ramosissimus.

8. S. prolifera R. Br. involucro 4-phyllo; foliolis apice sphacelatis; spica conico-capitata; floribus subsessilibus. Protea Thunb. diss. 27. t. 4. In Africa anstrali. ち. Frutex 1 -ped.

9. S. pyramidalis $R$. Br. involncro 4-phyllo; foliolis acuminatis pedicellos subaequantibus; spica erecta solitaria sessili oblongo-pyramidali foliis semiuncialibus duplo longiore. In Africa australi. Ђ. Frutex ramosissimus.

10. S. polystachia $\mathrm{R}$. $\mathrm{Br}$. involucro 4-plyllo; foliolis apice patulis; spicis nutantibus agregatis pedunculatis; fol. uncialibus curvatis. In Africa australi. t. Frutex ramosissimus.

b. Involucra 3-5-flora. S.tigma convexiusculum. Cal. suba equalis.

11. S. incurva R. Br. spicis racemosis sulpedunculatis; bracteis involucro tomentoso breviorilus; fol. incurvis; calycihus inaequalibus. Protea incurva Thunb. diss. t. 3. In A/ri-

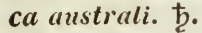

12. s. mopingua R. Br. spica suhpedunculata; bracteis foliaceis suhulatis involucra subsessilia tomentosa subbiflora aequantibus; fol. semiuncialilus strictis ramulisque villosis; calycibus subaequalibus. In Africa australi. 4.

13. S. caudata R. Br. spica sessili; bracteis involucrisque ovato-lanceolatis glabriusculis ciliatis; fol. glabris acuitis. Protea caudata Thumh. diss. t. 2. In Africa australi. t. Frutex ramosissimus.

14. S. Thumbergii R. Rr. spica sessili; hracteis involucrisque ovatolanceolatis villosis; fol. calyce longioribus acutis canaliculatis ramisque pilosis. Protea caudata Thumb. In Africa australi. $\hbar$. Frutex ramosissimus.
15. S. brevifolia $R$. Br. fol. calyce brevioribus obtusiusculis subsericeis triquetris; spicis densis hracteis involucrisque pubescentihus. In Africa australi. $\hbar$. Frutex ramis umbellatis virgatis pubescentilus.

\section{ADENANTHOS Labill. (1890).}

1. A. obovata Labill. fol. obovatis integerrimis glabris. Labill. Nov. Holl. 1. 37. In collibus saxosis Nov. Holl. 市.

2. A. cuneata I,abill. l. c. $t$. 36. fol. cuneatis sericeis apice dentatocrenato. In Nor. Holl. 5 .

3. A. sericea Labill. $l$. c. $t .38$. fol. filiformibus biternatis sericeis ; floribus axillarihus solitariis; stylo glabro. In Nor. Holl. ち.

4. A. Ipiculata KR. Br. fol. filiformilus 3-fides pilosis; laciniis lateralibus bifidis simplicihusve omnihus apice subtus glandula colorata; stylo glabro. In Nor. Holl. ち.

5. A. terminulis R. Br. fol. filiformibus trifidis; laciuiis lateralihus bifidis; stylo villoso. In Nor: Holl. $\hbar$.

\section{GUEIINA. Mollin. (1782).}

1. G. Arellena Mollin Chil. Nebu etc. Fenill. 3. t. 33. Quadria heterophylla R. et P. perur. $t$. 99. $f: 6$. In sylris Chilensibus t. Arhor. Fol.aIterna pinuata. Drupa carnosa.

\section{BR.ABEJUM L. (1737).}

1. B. stellatifolium L. Arbor hexaphylla etc. Plulin. t. 20.5. f. 3. Breyn Cent. t. 1. Houtt. Syst. t. 37. Lam. ill. $t$. 847. 13. stellitum Thumb. In Africa anstrali. t. Ailor. Fol. verticillata serrato-dentata.

\section{PERSOONIA Sm. (18.98).}

1. P. teretifolia R. I?r. fol. filiformihus exsulcis; pedunculis 1-fluris solitariis; antheris acuminttis; stylis ovario hrevioribus. In Nor. Holl. t.

2. P. saccata $R$. Br. fol. filiformilus exsulcis elongatis laxis; perianthii foliolo antico medio saccato; 
antheris acuminatis; ovario glabro; stylo ahbreviato. In Nov. Holl. $\hbar$.

3. P. microcarpa $\boldsymbol{R}$. Br. fol. filiformibus canaliculatis; pedunculis solitariis geminis ternisve; antheris muticis; stigmate cernuo. In Nova Hollandia. நृ.

1. P. Fraseri R. Br. fol. filiformibus suhtus bisulcatis, adultis glabris; pedunculis axillarihus solitariis ramulisque cinereis; pube brevi patente. In Nov. Holl. ђ.

5. P. pinifolia $R$. Br. fol. filiformibus laxis; spica foliata elongata pyramidali; fol. floralibus abbreviatis; ovariis dispermis glabris. P. juniperina Labill. Nov. Holl. t. 45. In Nov. Holl. t.

6. P. tenuifolia $\boldsymbol{R}$. Br. fol. filiformibus super sulcatis patulis laxiusculis Iaevilus mucronulo innocuo, floralihus conformilus; fructibus glabris; stylo proportionato. In Nov. Holl. $\downarrow$.

7. P. Chamaepithys R. Br. fol. lineari-filiformihus mucronatis pungentibus scabriusculis patulis subter canaliculatis; capitulo foliato demum laterali; ovario lanato; stylo elongato glabro. P. guidioides sieb. In Nov. Holl. 古.

8. P. acerosa Sieb. fol. filiformibus glabris laevilus innocuis super canaliculatis; spica foliata demum laterali; fructibus glabris. prope Port Jackison. 方.

9. P. hirsuta Pers. fol. linearibus hirsutis scahris margine recurvis; pedunculis axillaribus; ovariis $\mathbf{1}$-spermis sericeis. In Nov. Holl. $\downarrow$.

10. P. fastigiata R. Br. fol. lineari-filiformilus arcuato-incurvis muticis pubescentibus suhtus canaliculatis; pedunculis confertis suhumbellatis; ovariis stylisque villosis. Prope Port Jachison. 卢.

11. P. currifolia $R$. Br. fol. linearilus acutis mueronatis arcuato-incurvis scahris marginihus revolutis subtus canaliculatis; fructibus stylisque glahris. In Nor. Houl. .

12. P. mollis R. Br. fol, ohlongolanceolatis villosis subtus mollissimis; calycilus barbatis; ovariis dispermis glahris. In Nov. Holl. t.

13. P. striata $R$. Br. fol. Iinearihus utrinque elevato-striatis murronatis glabris; pedunculis axillaribus re- curvis; perianthiis pistillisque glahris; antheris acunimatis. In Nova Hollandia. $\hbar$.

14. P. Caleyi R. Br. fol. linearibus glabris laevihus patentihus strictis marginibus recurvis; pedunculis axillaribus brevissimis ramulisque sericeis; perianthiis aristatis; pistillis imberbibus. In Nov. Holl. $\hbar$.

15. P. linearis Andr. Rep. t. $7 \%$ fol. angustato-linearibus elongatis glabris; pedunculis erectis calycibusque pubescentibus; pedicello ovarii inarticulato; caule arborescenti; cortice laevi. Vent. Malm. t. 32. Bot. Mag. 760. In Nov. Holl. ђ.

16. P. lucida R. Br. fol. Ianceolato-linearibus elongatis glahris; pedunculis erectis calycibusque pubescentibus; pedicello ovarii inarticulato; caule arborescenti; cortice scarioso lamelloso. In Mor. Holl. $ђ$.

17. P. angulata R. Br. fol. lanceolato-linearibus acutis basi attenuatis glaberrimis super concaviusculis; ramulis angulatis glabris; pedunculis axillaribus solitariis. Prope Port Jackson. $\hbar$.

18. P. virgata R. Br. fol. linearibus oblongo-linearibusve sparsis verticalibus glaberrimis margine la evibus; pedurculis erectis calycibusque glabris; caule arhorescenti; cortice laevi. In Nova Hollandia. 古.

19. P. flexifolia $R$. Br. fol. Ianceolato-linearibus mucronatis confertis luasi tortis utrinque laevibus punctis cristallinis micantibus; marginibus scabris; calycilus glabris. In Nova Hollandia. 支.

20. P. rigida $R$. $B$ r. fol. ovatocuneatis mucronatis basi attenuatis margine recurvis adultis punctato-scabris; novellis ramulisque pubescentibus; perianthiis hirsutis. P. spathulata Cunningh. In Nova Hollandia. 古.

21. P. sericea R. Br. fol. cuneatolanceolatis ohovatisve mucronulatis planis venosis laevibus, adultis glabriusculis, junioribus ramulisque sericeis; pedunculis axillaribus; pistillis villosis. In Nov. Holl.

22. P. scabra R. Br. fol. linearilanceolatis mucronulatis utrinque scahris punctis cristallinis aliisque minutissimis opacis conspersis; calycibus pubescentibus. In Nov. Holl. $\frac{\hbar}{\text {. }}$ 
23. P. spathulata R. Br. fol. lanceolato-spathulatis mucronatis concaviusculis utrinque scaberrimis puuctis cristallinis. In Nov. Holl. $ち$.

24. P. mutans $R, B r$. fol. linearibus laevibus; pedunculis axillaribus recurvis calycibusque glabris. In Nov. Holl. $\hbar$.

25. P. revoluta Sieb. fol. oblongis obtusis muticis coriaceis aveniis marginibus recurvis, subtus subsericeis; pube appressa; pistillis glabris. P'. daphnoides Cumningh. In Nov. Holl. $\hbar$.

26. P. oblongata R. Br. fol. lanceolato-oblongis mucronatis laevibus planis ramisque glabris; pedunculis axillaribus recurvis; pistillis ovariique pedicello glaberrimis. In Nova Hollandia. $\hbar$.

27. P. myrtilloides sieb. fol. clliptico-lanceolatis mucronatis planis obcolete 1-nerviis subaveniis ramulis sericeis; perianthiis aristatis pedunculisque pubescentibus. P. oleifolia Cunningh. In Nov. Holl. ђ.

28. P. Cunningleamii R. Br. fol. late ellipticis ovatisve acutis mucronatis glabris; ranulis sericeis; perianthiis aristatis pedunculisque glabris. In Nov. Holl. 支.

29. P. oxycoccoides Sicb. fol. oblongo-lanceolatis lineari-lanceolatisve acutis glaberrimis laevilus; pedunculis axillarihus solitariis drupisque glabris nutantibus. In Nov. Holl. t.

30. P. thymifolia Cumningh. fol. ovatis acutis super minutissime punctatis scahriusculis; pedunculis axillarihus solitariis; perianthiis muticis erectis drupisque glabris nutantibus. In Nov. Holl. 古.

31. P. microphylla R. Br. fol. ohovatis ohtusis super convexis ramulisque pubescentihus; perianthiis muticis erectis drupisque glabris nutantibus. In Nov. Holl. 古.

32. P. falcata R. Br. fol. elongato-lanceolatis basi attenuatis subpetiolatis falcatis aversis coriaceis; antheris acuminatis; caule arlorescenti; cortice lamelloso. In Nor. Holl. t).

33. P. lunceolata Anilr. Rep. Ft. fol. lanceolatis ellipticisve laevihus mucrouatis glabris; pedunculis axillaribus 1-floris; calycibus pule adpressa subsericeis; pedicello ovarii inarticulato. $\beta$. P. latifolia Audr. Kep. 280. In Nor: Holl. $\hbar$.
31. P. salicina Pers. fol. lanceolato-oblongis inaequilateralibus aversis; racemis lateralibus pedunculisque axillaribus 1-floris; calycibus glabriusculis; caule arborescenti; cortice scarioso - lamelloso. Linkia laevis Cav. ic. t. 389? In Nor. Holl. t.

3.5. P. daphnoides $R . M r$. fol. ellipticis mucronatis basi attenuatis venosis glabris utrinque marginibusque laevibus; caule prostrato. In Nov. Holl. $ち$.

36. $\boldsymbol{P}$. ferruginea $\mathrm{Sm}$. exot. bot. t. 83. fol. ellipticis aequilateralibus venosis adversis; pedunculis axillaribus multiforis calycilusque ferrngineo-tomentosis; caule erecto. P. laurina Pers. In Nor. Holl. b.

37. P. cornifolia Cumningh. fol. ellipticis aculis acuminatisve glabris laevilus venosis; petiolis brevissimis ramulisque cum ovariis sericeis; pedunculis 1-2-floris. In Nov. Holl. $ち$.

38. P. marginata Cunningh. fol. obovatis late ovalibusque mucronulatis venosis paginis marginibusque scabriusculis; pedunculis axillarihus 1-2-floris; antheris dorso sericeis; caule difluso. In Nor. Holl. ђ.

39. P. prostrata R. Br. fol. ovalibus ohtusis margine puhescentibus; pedunculis axillaribus 1 -paucifloris; caule procumbente. In Nov. Holl. b.

40. P. attemuata $R$. Br. fol. lineari-lanceolatis elongatis utrinque attenuatis planis glaberrimis laevihus aveniis; racemis axillarihus paucifloris; pedunculis tomentosis; pistillis glahris. In Nor: Holl. ち.

41. P. media R. Br. fol. latiusculo-lanceolatis aequilateris utrinque attenuatis venosis; pedunculis axillavihus $2-3$ racemosis solitariisque. In Nov. Hall. t.

42. P. elliptica R.Br. fol. ellipticis venosis; racemis lateralibus ; calycihus glabris; pedicello ovarii articulato. In Nor. Holl. t.

13. P. articulata fi. Br. fol. elonwato-lauceolatis aequilateralibus glaliris; calycilus ylabriusculis: ovarii pedicelli articulo inferiori glandulas liypogynas aequante. In Nor. Holl.

t4. P. Congifolia R. Br. fol. clonrato-linearihus falcatis; racenis latcralihus pedunculisve unifloris; calycihus pube adpressa tectis; ovarii pedicelli articulo inferiori glandulis hypogynis longiore. In Nov. HoH. ち. 
45. P. graminea R. Br. fol. rameis linearibus longissimis margine recurvis; racemis secundis multifloris; calycibus glabris; caule suffruticoso abbreviato. In Nov. Holl. $\hbar$.

\section{CENARRHENES Labill. (180t).}

1. C. nitida Labill Nov. Holl. $t$. 50. In ins. V'an Diemen. t. Arbor glabra. Fol. alterno-plana dentatoserrata nitida.

632. AGASTACHYS R. Br. (1810).

1. A. odorcita R. Br. In Nov. Holl. t. Frutex glaberrimus. Folia sparsa integerrima. Bracteae cucullatae.

\section{SYMPHYONEMA R. Br. (1810).}

1. S. paludosum R. Br. laciniis foliorum subulatis seniteretibus; rachibus bracteisque glaberrimis. In Nov. Holl. ち.

1. S. montanum R. Br. foliorum laciniis glahris linearibus 1 -nervibus ; rachibus bracteisque glahris s. pubescentibus. S. abrotanoides sieb. Hb. Rechb. Hort. t. 107. In Nov. Holl. $\hbar$.

\section{FRANKLANDIA R. Br. (1810).}

1. F. fucifolia Flint. Fag. II. $p$. 601. $t$. 6. In Nov. Holl. $\hbar$. Frutex glaber. Fol. alterna filiformia dichotoma. Spicae indivisae.

\section{BELLENDENA R. Br. (1810).}

1. B. montana R. Br. In Nov. Holl. ち. Frutex glaherrimus. Folia sparsa plana apice trifida. Samara colorata margine altero sulcato.
636. SIMISLA R. Br. (1810).

1. S. tenuifolia $\boldsymbol{R}$. Br. capitulis nudis; paniculae ramis subunifloris bracteolatis. In Nov. Holl. 古.

2. S. anethifolia $\boldsymbol{R}$. Br. capitulis involucratis bracteolatis imbricatis; paniculae ramis multifloris; ramulis capitula subaequantibus. In Nov. Holl. t).

3. S. latifolia R. Br. fol. dichotomis aversis; laciniis linearibus planis. In Nov. Holl. 1923. Baxter. $\hbar$.

\section{3\%. CONOSPERMUM Smith.(1793).}

a. Calycis Iaciniae acutae, tubo vix Iongiores: Conosperma vera R. Br.

1. C. ellipticum $S m$. fol. ovali-obIongis obtusis mucronatis aveniis; pedunculis axillaribus. In Nov. Holl. $\downarrow$.

2. C. imbricatum Sieb. fol. ellipticis acutiusculis concaviusculis aveniis imbricatis; corymbo composito terminali; partialium pedunculis axillaribus. In Nov. Holl. ђ.

3. C. lanceolatum R. Br. fol. lineari-lanceolatis acutissimis aveniis planis strictis glabris subimbricatis modiceve patentibus; corymbo composito terminali. In Nov. Holl.

4. C. propinquum $R$. Br. fol. lineari-lanceolatis mucronatis basi attenuatis 1-nervibus aveniis patentibus ramulisque adultis glabris; corymbo composito incompto. In Nov. Holl. $\downarrow$.

5. C. spicatum R. Br. fol. linearibus mucronatis planis subsericeis modice patentibus; spicis elongatis laxiusculis pedunculatis axillaribus. In Nor. Holl. $\hbar$.

6. C. ericifolium $\mathbf{S m}$. fol. subulatofiliformibus imbricatis; spicis axillaribus pedunculo brevioribus. In Nov. Holl. $\hbar$.

ซ. C. distichum R. Br. fol. flliformibus subdistichis patentibus arcuatoincurvis glabris; spicis axillaribus; perianthiis lanatis; galea calva. In Nor. Holl. b.

8. C. longifolium Sin. exot. bot. $t$. 82. fol. oblongis linearibusve, planis venosis; pedunculis elongatis scapiformiluus; corymbis decompositis; calycis limbo extus pubescenti tubum vix aequante. In Nov. Holl. 
9. C. tenuifolium $\boldsymbol{R}$. $\boldsymbol{B r}$. fol. lineari-filiformibus subcanaliculatis aveniis; pedunculis scapiformibus; corymbis simplicibus; calycis limbo extus pubescenti tuho longiore. In Nov. Holl. $\hbar$.

10. C. caeruleum $R$. $B r$. fol. ohIongis lanceolatisve planis venosis; corymbis compositis; calycis limbo glaherrimo tubo longiore. In Nov. Holl. $\mathbf{t}$

11. C. triplinervium $R$. $B r$. fol. lingulato-ohlongis elongatis basi attenuatis planis triplinerviis venosis glabris; rachibus bracteisque lanatis. In Nov. Hollandia. $\hbar$.

\section{b. Calycis laciniae caudatae; Chilurus.}

12. C. teretifolium R. Br. fol. teretibus pedunculisque elongatis; corymbis compositis. In Nov. Iloll. 方.

13. C. petiolare $\mathrm{R}$. $\mathrm{Br}$. fol. lineari-gladiatis planis venosis nervosomarginatis petiolatis; capitulis sessilibus e spiculis congestis paucifloris; perianthii pilis patulis; hacteis oblongo lanceolatis acuminatis. In Nor. Holl. 卢.

14. C. capitatum R. Br. fol. linearihus elongatis tortilibus; capitulis sessilibus e spiculis pauciforis congestis. In Nov. Holl.

\section{c. Incertae tribus.}

15. C. filiforme $\boldsymbol{R}$. $\mathrm{Br}$. fol. filiformibus subdistichis curvatis; spicis axillaribus indivisis. In Nor. Holl. t.

16. C. fexwoswm R. Br. fol. lingulatis elongatis venosis nervoso-marginatis; caule paniculato angulato flexuoso inferme folioso; perianthii lacinis linearihus ohtusis. In Nov. Holl. 1829. Baxter. ち.

\section{SYNAPIIEA R. Br. (1810).}

1. S. farosa R. Irr. fol. oblongocuneiformihus indivisis trilohisve; lohis integris; petiolis spicisque glabris; stigmate bicorni. In Nor. Holl. t.

2. S. dilatata 1 . Br. fol. apice dilatatis 3-Iobis; lohis inciso-dentatis; petiolis spicisque villosis; stigmate hicorni. Conospermum reticulalum sm. In Nor. Holl. ち.
3. S. petiolaris $R$. Br. fol. rameis petiolos subaequantibus 3 -partitis; 10bis divisis planis, infimis trilohis integrisve; spicis elongatis ramosis; stigmate acuto. Polypodium spinulosum Burm. ind. t. 6\%. f. 1. In Nova Hol landia.

4. S. polymorpha $R$. Br. fol. rameis hrevissime petiolatis 3-partitis canaliculatis: Iohis subdivisis 3-lobisque; spicis simplicibus pedunculo longioribus; stigmate acuto. In Nova Hollandia. $\hbar$.

\section{ANADENIA R. Br. (1510).}

1. A. mulchella R. Br. fol. pinnatifidis pilosiusculis; lohis cumeiformilus apice 3-fidis v. inciso-pinnatifidis; folliculis viscidis. In Nor. Holl. $\hbar$.

2. A. trifila R. Br. fol. cuneiformilus 3-plinerviis aveniis 3 -fidis subtus argenteis; lohis integerrimis lateralibusve $2-3$-dentatis. In Nora Ilollandia. ち.

3. A. Caleyi R. Br. fol. pinnatifullis: laciniis apice $2-3$-fidis; Iohis semilanceatis mucronatis pungentilus marginihus refiractis, adultis super glahriusculis suhtus perianthiisque cinereo-pubescentilus. In Nor. Holl. $b$.

t. A. ilicifolia R. Br. fol. cuneiformibus venosis subtus argenteis hasi attenuatis extra medium pinnatifidoincisis. In Nov. Holl. $\hbar$.

\section{GREVILLEA R. Br. (1810).}

A. Lissostylis. Fol. omnia integerrima. Flores fasciculati v. racemosi. stylus glaber. Folliculus ecostatus.

1. G. punicea R. Br. fol. ellipticoohlongis basi subattenuatis marginibus refractis ramulis foriferis racemoque ahhreviato recurvis; pistillis uncialihus; barba interiore calycis ohlonga. Emhothrium sericeum $\beta$. sm. Nov. Holl. t. 9. f. 5. B. In Nor. Holl. t.

2. G. laurifolia Sieb. fol. oblongis ovalihus ovatisque cum mucronulo petiolatis, supra glaherrimis subtus sericeis; caule procumbenti; ovario barbato. In Nov. Holl. t.

3. G. oleoides sieb. fol. lineari-ohlongis elongatis ohtusis mucronulo 
sphacelato basi attenuatis marginibus refractis, supra glahris subtus sericeis; pistillis uncialibus. Rchb. Hort. t. 10t. In Nor. Holl.

4. G. dubia R. Br. fol, ellipticis marginibus reftactis; ramis ramulisque tomentosis; floribus racemoque abbreviato-recurvis; pistillis uncia brevioribus. In Nor. Holl. t.

5. G. diffisa Nieb. fol. lineari-oblongis oblusis cum mucronulo basi subattenuatis marginibus refractis, supra glabris subtus sericeis; caule ramosissimo; ramulis floriferis recurvis; harba interiore dimidio unguium breviore. In Nor. Holl. t.

6. G. sericea R. Br. fol. ellipticis oblongisve ohtusis mucronatis marginibus refractis; ramulis floriferis erectis; racemis subrecurvis; harba interiore calycis dimidio inferiore unguium breviore. Embothrium sericeum Sm. Nov. Holl. t. 9. f. 1. 2. 3. 4. Andr. Rep. 100. Bot. Mag. 862. Emb. cytisoides. Cav. ic. t. 386. f. 2. In Nov. Holl. $\hbar$.

\%. G. linearis $R$. Br. fol. lineariIanceolatis acutis mucronatis marginibus refractis; stylis apice glaberrimis. Emhothrium linearifolium Cav. ic. t. 386. f. 1. E. lineare Andr. Kep. 272. E. sericeum $\beta$. sm. Nov. Holl. t. 9. f. 6. In Nou. Holl. ち.

8. G. strictu $\boldsymbol{R}$. $\boldsymbol{B} r$. fol. lanceolato-linearilus acutis mucronatis marginibus refractis costaque denticulatoscabris; stylis apice sericeis. In Nov. Holl. ち.

9. G. sulpleurea Cunningh. fol. lineari-subulatis erectiusculis super convexis glaberrimis laevibus margine revolutis; ramis tomentosis. G. aciphylla sieb. G. acifolia spr. G. acicularis schult. In Nov. Holl. 卢.

10. G. riparia $R$. $B r$. fol. elongato-linearibus marginibus refractis costaque laevibus; stylis apice glaberriuis ; pistillis quadrilinearibus; barba interiori calycis densa. In Nov. Holl. 5 .

11. G. parviflora R. Br. fol. subulato-linearibus marginibus refractis costaque laevibus; calycibus ferrugineis; harba interiore obsoleta; pistillis bilinearibus: pedicello ovario vix aequante. In Nov. Holl. 5 .

12. G. juniperina R. Br. fol. subulatis fasciculatis divaricatis marginibus refractis; ramulis villosis teretiu- sculis; pistillis pedunculo partiali quadiuplo longiorihus. In Nov. Holl. t.

13. G. trinervis R. Br. fol. suliulato-lanceolatis mucronatis pungentibus divaricatis, supra glabris trinervibus marginibus refractis, subter perianthiisque sericeis. In Nov. Holl. $\hbar$.

14. G. anstralis R. Br. fol. lanceolato-subulatis margine subrecurvis, supra pube decidua conspersis, subtus sericeis; ramis ramulisque tomentosis teretibus. In Nor. Holl. $\hbar$.

15. G. tenuifolia $R$. Brr. fol. suhulatis margine revolutis; fasciculis sessilibus; pistillis bilinearibus. In ins. I'an Diemen. 支.

16. G. pauciflora R. Br. fol. lineari-oblongis planiusculis obtusis nucronulatis, supra laevihus, subtus subsericeis; fasciculis 2-3-floris erectis. In Nov. Holl. ち.

17. G. aspera R. Br. fol. linearioblongis obtusis mucronulatis, supra laevilus subtus subsericeis, inferioribus glabriusculis; fasciculis $\mathbf{2}-\mathbf{3}$-floris erectis ; calycibus pistillum subaequantibus. In Nov. Holl. $ђ$.

18. G. concinna $R$. $B r$. fol. linearilus indivisis margine revolutis, adultis super glabratis, subter ramisque sericeis pilis appressis; racenis recurvis secundis multifloris; stigmate dilatato planiusculo obliquo. Sweet Fl. austr. t. 7. In Nov. Holl.

B. Ptychocarpa. Fol. omnia integerima. Flores fasciculati v. breve racemosi. Stylus hirsutus v. tomentosus. Ovarium subsessile. Folliculus costatus.

19. G. arenaria R. Br. fol. oblongis obtusis mucronulatis; racemis recurvis paucifloris; pistillis tomentosis. In Nov. Holl.

20. G. canescens R. Br. fol. ohlongo-obovatis obtusis mucronulatis, super pubescentibus mollibus subter velutinis incanis pilorum crurihus adsceudentibus; racemis recurvis; perianthiis sericeis laminis acutis ; pistillis tomentosis. G. cinerea Cunningh. In Nov. Holl. 古.

21. G. obtusiflora $R$. Br. fol. lineari-oblongis mucrone brevissimo marginibus recurvis, adultis super punctato-scabris subtus argenteis pilis 
arcte adpressis; racemis paucifloris; stylo hirsuto. In Nov. Holl. t.

22. G. montana R. Br. fol. lanceolatis acutis supra laeviusculis subtus sericeis; floribus geminatis pedunculis glabris; pistillis hirsutis ; tomento ranulorum arcte adpresso. In Nov. Holl. 5 .

23. G. ferruginer Sieb. fol. oblongis obtusis mucronatis, adultis super scabris subter cinereo-tomentosis; racemis paucifloris. In Nov. Holl. $\hbar$.

24. G. acuminata R. Br. fol. Ianccolatis subacuminatis, supra punctatoscabris suhtus cinereo-tomentosis; racemis paucifloris porrectis recurvisve; pistillis hirsutis; calycibus demum glabriusculis. In Nov. Holl. $ち$.

25. $\boldsymbol{G}$. cinerea $\boldsymbol{R} \cdot \mathbf{B r}$. fol. ellipticis obovatisve mucronatis, supra scabriusculis subtus cinereo-tomentosis; racemis paucifloris recurvis; pistillis hirsutis; calycibus pedunculisque lanatis. In Nov. Holl. b.

26. G. myrtaceu sieb. fol. late ovalihus acutis mucronatis seniuncialihus, supra scabris subtus tomentosis cinereis; racemis paucifloris recurvis; pistillis hirsutis. In Nov. Holl. t.

27. G. mucromulata R. Br. fol. obovatis obtusis mucronulatis, supra scabris nitentibus, subtus parum sericeis; racemis ahbreviatis; pistillis hirsutis; calycibus pilosiusculis pube appressa. In Nov. Holl. ђ.

28. G. Bameri R. Bi. fol. oblongis obtusis mucronulatis utrinque glabriusculis s. pubescentibus; pistillis hirsutis; calycibus peduneulisque glaberrimis. G. canescens llook. exot. f. t. $216 . \beta$. G. daphnoides siel. Hb. In Nov. Holl. t).

29. G. floribunda R. Br. fol. oblongis obtusis cum mucrone brevissimo sphacelato subter tomento copiosiore cinereis; racemis refractis basifloris; perianthiis lanatis obtusis; pistillum villosum subaequantibus. In Nov. Holl. 卢.

30. G. lanigera Cunningh. fol. oblongo-linearibus obtusis mucronulo obsoleto marginibus revolutis utrinque ramulisque cinereo-tomentosis; racemis abbreviatis; stylis hirsutis. In Nor. Holl. ђ.

31. G. ericifolia $R, B r$ fol. lineari-subulatis maryine recurvis, super scabris pubescentibus, subter sericeis; racemis recurvis; perianthiis cxtus glaberrimis; stylis hirsutis. In Nov: Holl. $\hbar$.

32. G. glabella R. Br. fol. filiformi-subulatis glabris strictis, super augulatis laevilus, subter sulcatis; spicis recurvis; perianthiis extus stylisque glaberrimis. In Nov. Holl. $\hbar$.

33. G. diroricata R. Br. fol. filiformi-subulatis patulis divaricatisve, super convexis punctato-scabris, subler sulcatis; spicis recurvis; perianthiis extus stylisque glaberrimis. In Nov. Holl. $\hbar$.

31. G. rosmarinifolia Cunningh. fol. lineari-subulatis mucronatis marginilus revolutis, super couvexis scabriusculis, subter pube appressa sericess; racemis recurvis; pedunculi apice dilatato calyciformi. Sweet fl. austr. t. 30. Lodd. B. C. 1479. Gr. riparia sieb. In Nov. Holl. $\hbar$.

C. Eriostylis. Fol. omnia integerrima. Flores fasciculati, subumbellati. Pistillum lanatum pedicellatum. Folliculus c costatus.

3.5. G. fusciculata R. Br. fol. Ianceolato-linearibus marginibus revolutis, super scabris aveniis, subter argenteis; umbellis sessilibus 4-6-floris; pistillis hirsutis; stigmate cochleariformi mutico. In Nov. Holl. ち.

36. G. depauperata R.Br. fol.ovalihus ellipticisve mucrone sphacelato maryinibus recurvis; super scabris, sultus incanis; pilis appressis; pistillis hirsutis; stigmate ovato convexiusculo mutico. In Nov. Holl. ђ.

3\%. G. occidentalis $\boldsymbol{R}$. Br. fol. lanceolatis, supra punctatis scabris subtus sericeis; fasciculis axillaribus terminalibusque; calycibus utrinque stylisque lana patula cinereis; stigmate mutico. In Nov. Holl. $\hbar$.

35. G. spliacelata R. Br. fol. oblongis lanceolatisve, supra punctis mimutis scabriusculis subtus sericeis; fasciculis terminalibus; calycibus extus ferrugineo-tomentosis intus stylisque cinereo-lanatis. In Nov. Holl.

3.9. G. phylicoides R. Br. fol. lineari-lanceolatis, supra punctato-scabris superioribus villosis, subtus pubescentibus cinereis; stigmatibus ovalibus appendice duplo Iongioribus. In Nou. Holl. t. 
40. G. buxifolia $R$. Br. fol. ellipticis supra punctatis scahris subtus tomento adpresso cinereis; stigmatibus orbiculatis appendicem recurvum - vix aequantibus. Embothrium Sm. Nov. Holl. t. 10. Andr. Rep. 218. E. genianthum Cav. ic. t. 387. In Nov. Holl. ђ.

D. Plagiopodia. Fol. integerrima v. divisa. liacemus thyrsiformis. Pedicellus ovarii arrectus apici obliquo pedunculi, cui utrinque foliola duo calycis unum supra alterum inserta.

41. G. Goodii R. Br. fol. integermis oblongis undulatis venosis utrinque glabris; racemis elongatis pedunculatis; caulibus prostratis. In Nov. Holl. ち.

12. G. venusta $R$. Br. fol. pinnatifidis $v$. trifidis passimque indivisis subtus sericeis; racemis erectis; calycihus glaherrimis; stylis hirsutissimis. In Nov. Holl. ђ.

13. G. anelhifolia R. Br. fol. 3teruatis; laciniis subulatis mucronatis pungentibus divaricatis marginibus arcte revolutis; perianthiis pedunculisque glaberrimis; bracteis caducis. Anademia Cumingh. In Nor. Holl. $ђ$.

14. G. triternata R. Br. fol. triternatis; laciniis subulatis divaricatis mucronatis pungentihus marginihus revolutis, subtus cum perianthiis pedunculis bracteisque sericeis. Anademia Cunningh. In Nov. Holl. $\hbar$.

15. G. ilicifolia $\boldsymbol{R}$. Br. fol. cuneatis utrinque venosis extra medium incisis; lobis triangularibus mucronatis pungentibus adultis super glabratis subter argenteis pilis arcte adpressis; perianthiis ovariisque sericeis; stigmate dilatato obliquo. Anademia 11. Br. prodr. In Nov. Holl. ち.

16. G. acanthifolia Cunningh. in Field's N. S. Wales p. 32s. c. tab. fol. pinnatifidis utrinque glaberimis marginibus refractis; laciniis plerisque 2-3-fidis; lobis spinescentilus; racemis densis erectis; perianthiis ovariisque villosissimis. Hook exot. FI. t. 216. Loddig. B. C. 1153. In Nov. Holl. 古.

47. G. Gaudichaudii R. Br. in Gaudich. Voy. t. 46. fol. pinnatifidis adultis supər glaberrimis, subter pilis raris appressis; laciniis oblongo-lanceolatis mucronatis indivisis venosis; nervis lateralibus a margine planiuscule distinctis; racemis erectis; perianthiis sericeis; ovariis hirsutis. G. acanthifolia var. quercifolia Cunningh. In Nor. Holl. 方.

48. G. pungens $\boldsymbol{R}, \boldsymbol{B r}$. fol. pinnatifidis supra glabris subtus argenteis; laciniis subulato-linearibus mucronatis pungentibus; racemis refractis; calycibus pistillisque glaberrinis. In Nov. IIoll. 方.

19. G. Dryandri R. Br. fol. pinnatis subtus sericeis; foliolis elongatolinearibus; racemis pedunculatis porrectis longissimis; caule patulo. In Nov. Holl. ち.

50. G. longifolic $\boldsymbol{R}$. Br. fol. Ianceolato - linearihus elongaiis medio grosse serratis passimque integerrimis, sulter sericeis pilis strictis adpressis, super glabris lacvibus venosis; perianthiis ovariisque sericeis. In Nov. Holl. $\hbar$.

51. G. asplenifolia R. $\boldsymbol{B r}$. fol. elongatis linearibus pinnatifido-incisis integerrimisque subtus tomentosis; calycibus pubescentibus stylisque glabris. In Nov. Holl. ち.

52. G. Caleyi R. Br. fol pinnatis super pubescentihus, subter cinereis appresso-tomentosis ; laciniis oblongolinearibus integerrinis; perianthiis ovariisque hirsutis; stigmate dilatato. $G$. bechnifolia Cunningl. Mss. In Nov. Holl. ち.

53. G. Baxteri R. Br. fol. pinnatis utrinque sericeis; laciniis angustato-linearibus mucrouatis sulumcialibus; racemis erectis; perianthiis pistillisque sericeis; stiguate dilatato. In Nov. Holl. 古.

54. $\boldsymbol{G}$ ? crithmifolia R. Br. fol. pinnatis pubescentibus adultis glahriusculis; laciniis angustato - linearibus marginihus recurvis; racenis erectis; rachi ramulisque tomentosis. In Nor. Holl. 方.

55. $\boldsymbol{G}$ ? pectinata $R$. Br. fol. pinnatis glabris; foliolis subulatis riuridis parallelo-approximatis semunicialibus, super impresso - biseriatis. In Nov. Holl. $ち$.

56. G. Banksii R. Br. fol. pinnatifidis subtus sericeis; laciniis elongato-lanceolatis; calycibus tomentosis: stylis glabris; ovariis sessilibus. R. Br. In Nov. Holl: b. 
57. G. Chrysodendron $\boldsymbol{R}$. Br. fol. pinnatifidis bipinuatifidisque angustatolinearibus elongatis; racemis cylindraceis; floribus subverticillatis; calycibus tomentosis basi persistente; stylis glabris. In Nov. Holl. ち.

58. G? rigens Cunningh. fol. pinnatis; foliolis oppositis angustato-linearibus apice subulatis biuncialibus marginibus recurvis, super glabriusculis tenue striatis, subtus 1 -nerviis sericeis. In Nov. Holl. $ち$.

59. $G$ ? Synapheae $R . B r$. fol. trifido-pinnatifidis marginatis adultis glabriusculis; laciniis lineari-lanceolatis mucronatis; lateralibus semitrifidis indivisisque; caule diffuso. In Nov. Holl. $\hbar$.

60. G? bipinnatifida $R . B r$. fol. bipinnatifidis planis reticulatis marginatis adultis glahriusculis; laciniis mucronatis; caule diffuso; spicis elongatis. In Nov. Holl. ち.

61. G? quercifolia $\boldsymbol{R}$. Br. fol. obIongis sinuatis mucrouatis reticulatovenosis glabris in petiolum attenuatis. In Nov. Holl. ђ.

62. G. Cunninghamii $\boldsymbol{R}, \mathrm{Br}$. fol. cordatis subsessilibus inciso-dentatis; dentibus spinescentibus utrinque reticulatis glaberrimis; perianthiis extus pistillisque glabertimis; barha interiore rara. G. carduifolia Cumingh. In Nov. Hotl. †.

E. Cycloptera. Folliculi liguei subrotundi basi stylo mucronati. Semina undique alata.

63. G. heliosperma $\boldsymbol{R}$. Br. fol. pinnatis sublipimnatisque glabris; pinnis oblongi-linearibus v. oblongis inferioribus petiolatis; racemis divisis erectis; calycibus pistillisque glaberrimis. In Nov. Holl. †.

61. G. angulata R. Br. fol. ovalioblongis angulatis spinoso-dentatis basi cuneata, adultis glabriusculis reticulato-venosis; pistillis perianthiisque extus glaberrimis; barba interiore densa pilis strictis. G. ilicifolia Cunningh. In Nov. Holl. t.

65. G. agrifolia $\boldsymbol{R}$. Br. fol. cuneato-obovatis extra medium angulatis et spinoso-deutatis, adultis utrinque glabriusculis pube minutissima reticulato-venosis; racemis nutantibus; pistillis, perianthiisque extus glabris intus denso barbatis. In Nov. Holl. b.
66. G. robusta Cunningh. fol. bipinnatifidis laciniis acutis, super glabris venosis subtus canescentibus; racemis paniculatis; perianthiis pistillisque glaberrimis; stigmate e basi dilatata oblique conico. G. venusta Cunningh. non R. Br. In Nov. Holl. t.

6\%. G. refracta $R$. $B r$. fol. pinnatis passim indivisis; foliolis elongatolinearibus subtus aryenteis; racemis refractis divisis; calycibus sericeis; pistillis glaberrimis. In Nov. Holl. $\hbar$.

68. G. heterophylla Cunningh. fol. pinnatifidis indivisisque elongato-lanceolatis saepius acuminatis basi attenuatis super glahris; venis primariis acutangulis parallelis subter sericeis; racemis refractis; perianthiis sericeis; pistillis glaberrimis. In Nov. Holl. $\hbar$. 69. G. ceratoply lla R. Br. fol. 2-3-fidis indivisis subtus nervosis sericeis; laciniis elongato-linearibus ; folliculis glaberrimis ovalibus. In Nov.

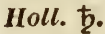

70. G. mimosoides R. Br. fol. integerrimis ensiformibus planis nervosis ramisque glabris; folliculis obavatis hispidis. In Nov. Holl. $\hbar$.

71. G. polystachya R. Br. fol. lineari-ensiforuibus integerrimis laxis subtus sericeis nervosis; racemis terminalibus alternis; pistillis semiuncia longioribus; stigmate obliquo concavo; papilla centrali. In Nov. Holl. $\hbar$.

72. G. angustata $R$. Br. fol. indivisis angustato-linearibus longissimis acutis; basi decurrente cicatrice postice attenuata, super convexiusculis obsolete striatis glahriusculis subtus sericeis 3-nervibus medio valido lateralibus obsoletis. In Nov. Holl. $\downarrow$.

73. G. pyramidalis Cunningh. fol. pinnatis $3-4$-jugis passim bipinnatis aversis adultis glabris; pinnis gladiatis subfalcatis utrinque attenuatis nervoso-striatis; rachi ancipiti antice plano-compressa; racemis paniculatis. In Nov. Holl. ђ.

74. G. obliqua R. Br. fol. semibipinnatifidis 5-6-jugis aversis adultis sericeis; pinnis elongato-linearibus planis striatis; rachi teretiuscula; racemis paniculatis; rachi bracteisquo glabris. In Nov. Holl. ち.

75. G. Leucadendron Cunningh. MIs. fol. bipinnatis aversis sericeis; pinnulis compresso-filiformibus ; racemis paniculatis; racli glabra; folliculis viscidis. In Nov. Holl. $\mathbf{\hbar}$. 
76. G. striata $R . B r$. fol. lineariensiformibus integerrimis striatis subtus multinervibus sericeis; racemis terminalibus alternis; pistillis semiuncia brevioribus; stigmate verticali depresso-conico. In Nov. Holl. †.

7\%. G. lorea R. Br. fol, teretilus pendulis longissimis; stigmate truncato-pyramidato. In Nov. Holl. $\hbar$.

88. G. gibbosa R. Br. fol. elongatolanceolatis integerrimis pubescentibus 1-nervibus venosis; racemis elongatis; stigmate conico; folliculis gibboso-incrassatis. In Nov. Holl. $\hbar$.

\section{HAKEA Schrad. (1795).}

1. Fol. omnia filiformia indivisa. Involucrum nullum.

1. H. lorea $\boldsymbol{R}$. $\boldsymbol{B r}$. fol. teretibus subexsulcis pendulis longissimis; apice hinc striato depressato obsoleto; perianthiis pedunculisque tomentosis; ramulis glabriusculis. In Nov. Holl. $\hbar$.

2. H. Cunninghamii R. Br. fol. teretibus exsulcis pendulis apice sphacelato attenuato; racemis erectis; caps. ecalcaratis compressis intus laevibus; ramulis tomentosis incanis. H. longifolia Cunningh. In Nov. Holl. $\hbar$.

3. H. Fraseri $\boldsymbol{R}, \boldsymbol{B r}$. fol. teretibus exsulcis glaberrimis recurvis; racemis subcorymbosis; parianthiis pedunculisque sericeis pilis appressis; ramulis glabris. In Nov. Holl. ђ.

4. H. pugioniformis Cav.ic.t.533. fol. filiformibus indivisis glabris; calycibus sericeis hirsutisve; caps. lanceolatis acuminatis rectis utrinque infra medium transversim cristatis. Banksia glabra Schrad. Sert. t. 17. Conchium pugioniforme et longifolium Smith. Lambertia teretifolia Gaertn. Fruct. t. 217. In Nov. Holl. .

5. H. rugosa $R, B r$. fol. fliformibus indivisis glabris fructu parum longioribus; caps, obovatis curvatis refractis utrinque cristatis rugosis; acumine subulato laevi adscendenti; caule diffuso. In Nov. Holl. ち.

2. Fol. omnia filiformia indiis a. Involucrum imbricatum.

6. H. epiglottis Labill. Nov. Holl. t. 40. fol. filiformibus indivisis glabris fructu duplo longioribus; caps. curvatis refractis utrinque rugosis ecristatis; mucrone adscendenti subulato carinato; seminum ala obovata; caule erecto. Cochium teretifolium Gaertn. Fruct. t. 219. In Nov. Holl. $\downarrow$.

7. H. virgata $\boldsymbol{R}, \mathrm{Br}$. fol. teretibus exsulcis minutissime pubescentibus; mucrone recto attenuato spliacelato; racemis axillaribus abbreviatis; rachi ramulisque tomentosis incanis; caps. ecalcaratis. In Nov. Holl. $\downarrow$.

8. H. nodosa $\boldsymbol{R}$. Br. fol. filiformibus indivisis compressiusculis; caps. gibbosis obtusis nodosis seminumque ala obovatis; calycibus glabris; pedunculis pubescentibus. In Nova Hollandia. 支.

9. H. propinqua Cunningh. fol. teretibus exsulcis glabris fructu brevioribus; ramulis angulatis tomento appresso perianthiis glaherrimis; pedunculis hirsutis pilis patulis; stigmate mutico; caps. ecalcarata tuherculata. H. pachyphylla Sieb. In Nov. Holl. $\hbar$.

10. H. flexilis $\boldsymbol{R}$. Br. fol. filiformibus indivisis parum compressis; caps. ellipticis acutiusculis modico convexis laevibus. In Nov. Holl. $\hbar$.

11. $\boldsymbol{H}$. leucocephala $\boldsymbol{R}$. Br. fol. teretibus indivisis fructu duplo longioribus; ramis erectis virgatis subflexuosis; caps. ovatis infra gibbosis supra compressis ; seminibus albo-cinereis. In Nov. Holl. $\hbar$.

12. H. obliqua $\boldsymbol{R}, \boldsymbol{B r}$. fol. teretibus indivisis; ramis tomentosis; glandula hypogyna adnata apici obliquo pedunculi; calycibus sericeis; caps. gibbosis subnodosis. In Nov. Holl. $\hbar$.

13. $\boldsymbol{H}$. adnata $R$. Br. fol. teretibus exsulcis mucronulo patenti; pedicellis ramulisque sericeis; caps. ecalcaratis gibbis apice compressis; seminibus utrinque alatis. In Nov. Holl. $\mathbf{t}$.

14. H. sulcata $\mathrm{R}$. Br. fol. filiformibus indivisis undique sulcatis divaricatis. In Nov. Holl. ђ.

15. H. tephrosperma R. Br. fol. teretibus exsulcis glabris mucrone sphacelato patenti fructu duplo longioribus; caps. gibbosis apice compressis bicalcaratis; calcari obtuso brevissimo; seminibus cinereis. In Nov. Holl. $\hbar$.

16. H. lissosperma $\boldsymbol{R} . \boldsymbol{B r}$. fol. filiformibus indivisis undique exsulcis glabris fructu duplo longioribus; caps. 34 * 
gibbosis intus laevibus; calcaribus brevissimis; seminibus ala obovata.

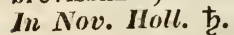

17. H. gibbosa Cav. ic. t. 534. fol. filiformibus indivisis subtus basi obsoletissime sulcatis ramisque subpubescentibus; ramulis pedunculisque hirsutis; calycibus glabriusculis; caps. gibbosis intus lacunosis; nucleo lacunoso basi marginato. Banksia sm. t. 22. f. 2. Hakea pubescens schrad. Conchium cornutum Gaertn. Fruct. $t$. 219. In Nov. Holl. 古.

18. H. acicularis $R$. Br. fol. filiformibus indivisis glabris subtus infra medium obsolete sulcatis longitudine fructus; ramulis ultimis subsericeis; pedunculis hirsutis calyces glaberimos subaequantibus; caps. gibhosis subrugosis. Banksia tenuifolia Salisb. Hakea sericea Schrad. Conchium aciculare Vent. Malm. t. 111. In Nov. Holl. $\hbar$.

19. H. decurrens $\boldsymbol{R}$. Br. fol. teretibus patulis glabris, subtus infra medium sulco insculptis; ramulis angulatis glabris; caps. hicalcaratis ovato-lanceolatis compressis laevibus; pedicellis subsericeis. In Nov. Holl. $\hbar$.

20. H. vittata R. Br. fol. filiformibus indivisis exsulcis glabris fructu duplo longioribus; caps. ovatis convexiusculis intus lacunosis; seminis ala obovata; ramulis tomentosis. In Nov. Holl. 古.

21. I1. cycloptera R. Br. fol. filiformibus indivisis fructu duplo longiorilus ramulisque glaberrimis; caps. gibbosis intus lacunosis; seminibus utrinque alatis, ala inferiore nucleum aequante. In Nov. Holl. 方.

22. H. patula $\boldsymbol{R}$. $\boldsymbol{B r}$. fol. teretibus exsulcis patulis divaricatisve; perianthiis pedunculisque glabris; caps. bicalcaratis subsolitariis; seminis ala semilanceolata. In Nov. Holl. ち.

23. H. suaveolens $\boldsymbol{R}$. $\boldsymbol{B r}$. fol. filiformibus pinnatifidis passimque indivisis supra sulcatis; florilus racemosis glabris; rachi tomentosa; caps. gibbosis. In Nov. Holl. t.

3. Fol. plura filiformia indivisa, aliqua plana.

24. H. sulcata $R$. $B r$. fol. plerisque angulato-filiformibus undique sulcatis, inis quandoque spathulatis basi attenuatis; caps. sessilibus ecalcaratis. In Nov. Holl. t.
25. H. microcarpa R. Br. fol. integerrimis glahris rameis teretibus, infimis planis; calycibus pedunculisque glaherrimis; caps. bicalcaratis umbellatis folio multoties brevioribus. In Nov. Holl. 古.

26. I. trifurcata R. Br. fol. filiformibus $2-3$-fidis indivisisque subtus sulcatis, passim planis ovalibus integerrimis; calycibus hirsutis; caps. compressis ecalcaratis. Conchium trifurcatum sm. In Nov. Holl. $\hbar$.

2\%. H. varia $\boldsymbol{R}$. Br. fol. superioribus filiformibus divisis simplicibusque, inferioribus planis pimuatificlis laciniis linearibus subulatisve ; caps. bicalcaratis. In Nov. Holl.

\section{Folia omnia filiformia di- visa.}

28. H. intricata R. Br. fol. filiformibus piunatifidis; laciniis indivisis bifidisque exsulcis; caps. ccalcaratis laeviluss; involucri squamis glaberimis. In Nov. Holl. 方.

2.9. H. lissocarplea R. Br. fol. filiformilus pinnatifidis trifidisve pilosia scabris; laciniis exsulcis indivisis et bifidis; involucri squamis glaherrimis; caps. hicalcaratis. In Nor. Holl. 古.

30. H. lasiocarpha $\boldsymbol{R}$. IHr. fol. compresso-filiformihus pinnatifidis glabris laevihus; rachi longitudinaliter laciniisque basi sulcatis supra teretihus; involucri squamis lanatis; caps. brevissime et obtuse bicalcaratis. In Nov. Holl. $\hbar$.

31. H. bipinnatifida R. Br. fol. Gliformilus triternatis bipinnatifidisve; ramulis et squamis inferioribus involucri glabris, superioribus apice subsericeis. In Nov. Holl. 卢.

\section{Folia omnia vel aliqua inci- sa et dentata.}

32. H. tuberculata $R$. Br. fol. inferioribus cuneatis extra medium dentato-incisis, superioribus pinnatifidis laciniis suhulatis; corymbis ramulos laterales terminantihus perianthiis pedunculisque glaberrimis; caps. bicalcaratis valvis tuberculatis. In Nov. Holl. 卢.

33. H. attenuata R. Br. fol. cuneatis apice dentatis piunatifisisque passiun lanceolatis integerrimis basi 
attenuatis; caps. bicalcaratis. In Nova Hollandia. 卢.

34. H. linearis $\boldsymbol{R}$. Br. fol. angustato-lanceolatis spinuloso-dentatis minutissime punctatis; ramulis pedunculoque communi brevissime pubescentihus; caps. bicalcaratis. In Nova Hollandia. ђ.

3.5. H. florida R. Br. fol. angustato-lanceolatis spinuloso-dentatis minutissime punctatis marginibus scahriusculis; caps. hicalcaratis convexiusculis. In Nora Hollandia. $\hbar$.

36. H. ilicifolin $R$. $B r$. fol. circumscriptione ovalihus opacis sinuatodentatis spinulosis suhpetiolatis; ramis tomentosis; caps. hicalcaratis ovatis gil)hosis apice compressis intus scrobiculatis. In Nova Hollandia. 古.

37. H. cristata $R$. Br. fol. cumeato-obovatis spinuloso-dentatis immerse venosis ramulisque glaberrimis; caps. bicristatis, cristis inciso-dentatis. In Nora Hollandia. $\hbar$.

38. $\boldsymbol{H}$. nitida $\boldsymbol{R}$. $\boldsymbol{B r}$. fol. lanceolatis oblongisve basi attenuatis spinuloso paucidentatis integrisque nitidis subvenosis ramulisque glaberrimis; caps. bicalcaratis intus laeviusculis. In Nova Hollandia. $\hbar$.

3.9. H. Baxteri $\boldsymbol{R}$. Br. fol. flabellato-cuneatis apice rotundato multidentato lateribus integrerrimis, adultis glabris immerse venosis; caps. ecalcaratis gibbosis. In Nova Hollandia. $\hbar$.

40. H. amplexicaulis $\boldsymbol{R}$. Br. fol. sinuato-dentatis nitidis subvenosis; basi dilatata cordata amplexicauli; caule prostrato; ramis glahris; caps. ecalcaratis. In Nova Hollandia. ţ.

41. H. glabella R. Br. fol. cmeatis v. integerrimis v. angulatis 3-dentatis; dentibus spinescentilus; basi cordata amplexicauli ramulisque cum involucri squamis glaberrimis; caps. ecalcaratis. In Nove Hollandia. th.

42. H. prostrata 12. Br. fol. allgulato-dentalis apice dilatatis cuneatis; hasi cordata amplexicauli; caule prostrato; ramis pubescentibus; caps. ecalcaratis. In Nova lollandia. $\mathbf{b}$.

43. I. ceratophylla R. Br. fol. pinnatifidis bipinnatifidisque linearibus planis; calycibus ferruginco-tomentosis; caps. ecalcaratis. In Nova Hollandia. $\hbar$.

41. II. undulate R. IRr. fol. ohovatis trinervibus reticulato-venosis undulatis spinoso-dentatis; caps. ecalcaratis tumidis. In Nova Hollandia. $\hbar$.

45. $\boldsymbol{H}$. denticulata R. Br. fol. obovato-oblongis obtusis; marginibus longitudinaliter denticulatis; basi cordata amplexicauli; ramulis angulatis. In Nova Ilollandia. $\hbar$.

\section{Fo1. omnia integerrima.}

46. H. oleifolia $R$. Br. fol. Ianceolatis integerrimis 1 -nervibus obsolete venosis, mucronulo spinoso, superioribus pubescentibus; ramulis tomentosis; caps. terminalibus bicalcaratis gibhosis. In Nova Hollandia. $\hbar$.

1\%. H. corymbosa R. Br. fol. integerrimis lanceolato-linearibus mucronatis pungentibus marginatis 1nervibus subaveniis laevibus; ramulis squamisque involucri incanis; perianthiis glahris; stigmate snbcylindraceo; caps. ecalcaratis ovatis gibbis. In Nova Hollandia. ち.

48. H. lasiantha R. Br. fol. integerrimis lanceolato-oblongis obsolete nervosis laevibus; mucronulo sphacelato; perianthiis pedunculisque lanatis ; squamis involucri glabris. In Nova Hollandia. $ち$.

49. H. incrassata $R$. Br. fol. integerrimis anguste lanceolatis obsolete trinervibus; apiculo sphacelato; caps. refractis ohovatis gibbosis laevibus ecalcaratis; apiculo adscendenti. In Nova Hollandia. $\hbar$.

50. H. saliyna $\boldsymbol{R}$. Br. fol. elongato-lanceolatis integerrimis 1-nervibus apice sphacelato; omnibus ramulisque glaberrimis; caps. axillaribus gihbosis; apice compresso utrinque carinato. Embothrium Andr. Rep. t. 215. Conchium salicifolium Gaertn. Fruct. t. 219. In Nova Hollandia. t.

51. H. ericintha $\boldsymbol{R}$. Br. fol. integerrimis lineari-lanceolatis elongatis immerse 1-nervibus subaveniis; perianthiis pedunculisque sericeis; caps. ecalcaratis ovatis ventricosis. In Nova Hollandia. $\hbar$.

52. H. marginata R. Br. fol. lanceolatis integerrimis marginatis 1-nervibus mucrone spinoso, summis puhescentibus; caps. ecalcaratis acuminatis nitidis subsessilibus. In Nova IIollandia. $\hbar$.

53. H. stenocarpa $\boldsymbol{R}$. Br. fol. integerrimis linearibus apiculo acuto 
sphacelato marginatis 1-nervibus; venis obsoletis; caps. lineari-subulatis falcatis ecalcaratis. In Nova Hollandia. $\hbar$.

54. H. falcata $\boldsymbol{R}$. Br. fol. integerrimis linearibus subfalcatis trinervibus aveniis; apiculo acuto sphacelato; caps. subovatis acuminatis ecalcaratis. In Nova Hollandia. $\hbar$.

55. H. ruscifolia Labill. Nov. Holl. $\boldsymbol{t}$. 39. fol. ellipticis ovatisve petiolatis integerrimis spinoso-cuspidatis supra punctato-scabris subius tomentosis; ramulis hirsutis; caps. ecalcaratis punctatis scabriusculis. In Nova Hollandia. $\hbar$.

56. H. cinerea $\boldsymbol{R}, \boldsymbol{B r}$. fol. linearilanceolatis elongatis integerrimis trinervibus obsolete venosis scabriusculis apiculo sphacelato; caps. lanceolatis acuminatis sulicompressis ecalcaratis. In Nova Hollandia. 5 .

57. H. ulicina $R$. Br. fol. linearibus 3-nervibus aveniis rigidis mucrone pungenti; caps. ecalcaratis ovatis acutis erectis. In Nova Hollandia. 5 .

58. H. laurina $\boldsymbol{R}$. Br. fol. integerrimis elliptico-lanceolatis muticis basi attenuatis nervosis marginatis petiolatis ; caps. ecalcaratis gihhis laevibus. In Nova Hollandia. 5 .

5.9. H. Pandanicarpa R. Br. fol. integerrimis oblongo-linearibus basi attenuatis immerse nervosis aveniis apiculo sphacelato; caps. gribhosis obovatis tesellatis; tuberculis conicis; seminilsus undique alatis. In Nova Hollandia. 5 .

60. H. dactyloides Cav. ic. $t$. 5.3.5. fol. integerrimis triplinervibus venosis obovato - oblongis vel lineari-lanceolatis aversis; ramulis angulatis; pedicellis pilosis; calycibus glabris; capsulis ecalcaratis; cortice verrucoso. Banksia Gaertn. Frut. t. 47. f. 2. Conchium Vent. Malm. t. 110. In Nova Hollandia. $\hbar$.

61. H. cucullata $R$. Br. fol. integris subrepandis cucnllatis reniformicordatis acutiusculis nervosis reticulato-venosis; caps. ecalcaratis. In Nova Hollandia. $\hbar$.

62. H. elliptica R. Br. fol. integ errimis 5-nervihus reticulato - venosis ellipticis ovalibusque nuticis; pedicellis calycibusque glabris; capsulis ecalcaratis acutis gibbosis; cortice nitido. Couchiue Sm. In Nova Lollandia. t.
63. H. clavata Labill. Nov. Holl. $t$. 41. fol. integerrimis lingulatis cartilagineo-carnosis mucronatis enervibus; floribus racemosis glabris; caps. bicalcaratis. In Nova Hollandia. $\hbar$.

6f. $H$. arborescens $R$. $B r$. fol. integerrimis lingulatis linearibusve obsolete nervosis muticis; involucris nullis; umbellis pedunculatis; pedicellis calycibusque tomentosis; caps. ecalcaratis. In Nova Hollandia. $\hbar$.

65. H. stenophylla Cunningh. Mss. fol. angustato - linearibus enervibus muticis capsulis ecalcaratis ventricosis ovatis acutis. In Nova Hollandia. $ち$.

66. H. macrocarpa Cunningh. Mss. fol. linearilus elongatis integerrimis obsolete nervosis sericeis; florihus racenosis; caps. ecalcaratis ellipticis acutis intus laevibus. In Nova Hollandia. ち.

\section{LAMBERTIA Sm. (1798).}

1. I. uniflora R. Br. involucris 1-floris; fol. obovatis mucronatis glahris reticulatis; folliculis hinc cuspidatis inde ecornibus. In Nova Hollandia. t.

2. L. ericifolia $\mathbf{L}$. Br. involucris 7-floris; foliolis interioribus perianthii dimidio hrevioribus; stylis glabris; folliculis hinc cuspidatis inde ecornilous; fol.' linearihus muticis marginibus revolutis. In Nova Hollandia. $\hbar$.

3. $\boldsymbol{L}$. inermis $\boldsymbol{R}$. $\boldsymbol{B r}$. involucris 7-floris; foliolis interioribus calycis dimidio brevioribus; stylis glabris; folliculis hinc cuspidatis inde ecornibus; fol. oblanceolatis obovatisque muticis. In Nova Hollandia. 古.

4. L. formosa Sm. Linn. 'Trans. t. 20. involucris 7-floris; foliolis interioribus calycem aequantibus; stylis pilosis; folliculis hinc cuspidatis inde bicornibus; fol. lineari-lanceolatis cuspidato-mucronatis marerine revolutis. Andr. Rep. t. 69. Cav. ic. t. 547. Protea nectarina IVendl. Sert. t. 21. In Nova Hollandia. 古.

5. L. propinqua $\boldsymbol{K}$. Br. involucris 7-floris; foliolis interioribus perianthia suhaequantibus; stylis glabris; folliculis bicornibus undique echinatis; fol. lineari-oblongis obtusis cum mucronuto integerrimis passinque tridentatis glabris reticulatis planis. In Nora llollandic. $t$. 
6. L. echinata $\boldsymbol{R}$. $B r$. involucris 7-floris; foliolis interioribus dimidium perianthii superantibus; stylis glabris; folliculis bicornibus undique echinatis; fol. infra cuneato-linearibus, apice dilatato lobato lobis mucronatis. In Nova Hollandia. 卢.

\section{XYLOMELUM R. Br. (1810).}

1. X. pyriforme $\boldsymbol{R}$. Br. fol. oblongo-lanceolatis acuminatis, paginis discoloribus superiore nitente; perianthiis tomento appresso et pube patenti tectis; stylo primum infra medium barbato demum glabrato. $X$. salicinum Cunningh. Mss. In India orientali. 古.

2. $\boldsymbol{X}$. occidentale $\boldsymbol{R} . \mathrm{Br}$. fol. subellipticis, inferioribus rami floriferi passim dentatis, superioribus integerrimis, paginis omnium subsimilibus opacis, utriusque epidermide glandulifera; perianthiis extus rachique tomento appresso incanis; stylo longitudinaliter lanato. In Nova Hollandia. .

\section{ORITES R. Br. (1809).}

1. O. diversifolia $\boldsymbol{R}$. Br. fol. planis lanceolatis dentatis integerrimisve subtus tomentosiusculis; folliculis sutura truncata leviterve excisa. In ins. Ian Diemen. ち.

2. O. revoluta R. Br. fol. margine revolutis linearibus integerrimis subtus incano-tomentosis; folliculis sutura rotundata. In ins. Van Diemen. $\hbar$.

4. O. excelsa $R$. Br. fol. elongato-lanceolatis planis glabris reticulatis intererrimis passimque paucidentatis; racemis paniculatis; perianthiis glaberrimis; ovario pubescenti. In Nova Hollandia. $\hbar$.

4. O. acicularis $R, B r$. fol. teretibus super sulcatis; folliculis glabris; seminibus utrinque alatis. Oritina $\mathrm{Br}$. Limn. Trans. In Nova Hollandia. 卢.

\section{RHOPALA Aabl. (1785).}

1. R. mentana Aubl. Guj. t. 32. fol. alternis integrerrimis ovatis com- plicatis breviter acuminatis reticulatovenosis; pedunculo cum calycibus ovariisque ferrugineo-tomentosis. R. montana Vahl. Gaertn. Fruct. t. 217. In Gujana. 古.

2. R. media $\boldsymbol{R}$. $\boldsymbol{B r}$. fol. alternis integerrimis ovatis planis acuminatis in petiolum decurrentibus immerse venulosis; pedicellis calycibusque pubescentibus. In Gujana. ‡.

3. R. nitida Rudge Guj.t. 39. fol. alternis integerrimis ellipticis hreviter acuminatis planis racemum axillarem subaequantibus; pedicellis cum calycibus ovariisque glabris. In Gujana. $\hbar$.

4. R. moluccana R. Br. fol. alternis integerrimis ellipticis planis venulosis subreticulatis spica longioribus; pedicellis calycibusque glabris. In ins. Moluccanis. ち.

5. $\boldsymbol{R}$. cochinchinensis $\boldsymbol{R}$. $\boldsymbol{B r}$. fol. alternis ovato-ellipticis breviter acuminatis planis extra medium subserratis racemum axillarem subaequantibus; pedicellis cum calycibus ovariisquo glabris. Helicia Lour. In sylvis Cochinclinae. $\hbar$.

6. R. serrata $\boldsymbol{R}$. Br. fol. alternis late ellipticis parum acuminatis serratis racemo axillari longioribus: basi subattenuata integerrima; paginis discoloribus; pedicellis cum calycibus ovariisque tomentosis. In ins. Moluccanis. $\hbar$.

7. R. dentata $\boldsymbol{R} . \boldsymbol{B r}$. fol. alternis ovato-lanceolatis utrinque attenuatis racemo axillari parum brevioribus: acumine lineari; calycibus ovariisque tomentosis. In Gujana. ఫ.

8. R. peruviana R. Br. fol. alternis ovatis serratis lanuginosis sulutus ferrugineis racemo axillari brevioribus. Embothrium monospermum R. et $\mathbf{P}$. peruv. t. 98. In montibus frigidis $\mathrm{Pe}$ ruviae.

9. R. diversifolia $\boldsymbol{R}$. Br. fol. alternis simplicibus pinnatisque venosissimis subtus pubescentibus racemo axillari brevioribus ; folliculis acinaciformibus tomentosis. Embothrim pinnatum $R$. et $P$. peruv. t. 99. In ruderatis Peruviae. t).

10. R. sessilifolia Rich. fol. quaternis subsessilibus cuneato-oblongis subacuminatis integerrimis; racemis terminalibus verticillatis umbellatisve. 
R. hameliaefolia Rudge Guj. t. 31. In Gujana. †.

\section{KNIGHTIA R. Br. (1809).}

1. K. excelsa R. Br. in Linn. Trans. X. t. II. In Nov. Zeelandia. ち. Arbor excelsa 80-ped. caudice strictissimo, coma pyramidali. Folia numerosa lanceolato-oblonga profunde scrrata coriacea nitida suhtus venosa 4-5" longa. Rachis ruberrima. Folliculus oblongo-lanceolatus.

\section{EMBOTIRIUM Forst. (1775).}

1. E. coccineum Forst. Gen. $t$. 8 . $g-m$. fol. ovali-oblongis obtusis mucronulatis; paginis discoloribus; ramulis squamatis. Lam. ill. t. 55. f. 2. Ad fretum Magellanicum. $\hbar$.

2. E. lanceolatum R. et P. peruv. t. 96. fol. lanceolato-linearibus; ramis esquamatis. In collibus Chili. t).

\section{OREOCALIIS R. Br. (1SO9).}

1. O. grandiflora R. Br. Embothrium Lam. ill. E. emaryinatum $R$. et 1 . peruv. $t$. 95. In montibus peruviae. Ђ. Frutex speciosus. Folia sparsa integra, paginis discolorilus. Hacemus thyrsoideus. Flores coccinei glaberrimi.

\section{LOMATIA R. Br. (1S09).}

1. L. silaifolia $\boldsymbol{R} . \boldsymbol{B r}$. fol. hipinnatifidis pimnatifidisve glaberrimis reticulatis sublentatis; racemis elongatis divisis simplicibusve glaherrimis Embothrium smith Nov. Holl. t. 8. E. herbaceum Cav. ic. t. 388. var. $\alpha$. angustifolia; fol. bipimnatifida pinnulis cuneato-linearibus incisis mucronatis. B. latifolia; fol. pinnata, foliola inferiora pimnatifida superiora incisa vel dentata lineari-lanceolata venis utrinque prominulis reticulata. $\gamma_{\text {. pimu- }}$ ta ; fol. pinnata; foliolia lineari-lanceolata pauci-dentata; dentibus muticis, super reticulata subter venis inmersis obsoletis. In Nova Hollandia. 支.

2. L. simuata R. Br. fol. sinuato- pinnatifidis : lobis inciso-dentatis; adultis super glabris, subter pube rara adpressa; ramulis angulatis pubescentibus; racemis axillaribus. In Nova Hollandia. $\hbar$.

3. L. tinctoria $R$. Br. fol. pinnatis bipinnatifidisve glabris: pinnulis linearibus distichis 1-nervibus subaveniis obtusiusculis mucrontlatis; racemis elongatis glabris indivisis. L. polymorpha R. Br. Embothrium Labill. Nov. Holl. t. 42. et 43 . In ins. Iran Diemen. t.

4. L. ferruginea R. Br. fol. bipimnatifidis tomentosis: pimulis lanceolatis ovatisve; racemo terminali foliis breviore. Embothrium Cav. ic. t. 385. In America anstrali. t.

5. I. ilicifolia R. Br. fol. ovatis ohlongis elliptico-lanceolatisve spinoso-dentatis reticulatis; racemis elongatis; pistillis glaberrimis. In Nova

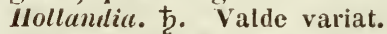

6. L. Fraseri R. Br. fol. ovalioblongis obtusis dentatis basi acuta subcureata integerrima; adultis subter sericeis; pistillis glaberrimis. In Nora Hollamila. $ち$.

7. I. Iongifolia R. Br. fol. lineari-lanceolatis elongatis glabris remote serratis; racemis axillaribus pedunculis calycilusque pilosiusculis. In Nova Hollandia. 5 .

8. L. dentatu $R$. $B r$. fol. ovalibus serrato-dentatis petiolisque glaberrimis; racemis lateralihus ablueviatis; calycilus pilosis; ovario tomentoso. Embothritim 1t. et P. peruv. t. 94. f. a.

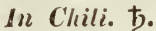

9. L. oblimen $R$. $B r$. fol. ovatis serratis glahris; racemis axillaribus; calycibus ferrugineo-pilosis; stigrmate deciduo. Embothrium hirsutum Lam. E. obliquum Cav. ic. t. 97. In Chili. t.

\section{STENOCARPUS R. Br. (1812).}

1. S. Forsteri R. Br. fol. oblongis obtusis enervilus. Embothrium umbellatum forst. Gen. t. 8. f. a-f. Lam. ill. t. 55. f. 1. In Nova Caledonia. 方.

2. S. salignus R. Br. fol, elongato-lanceolatis basi trinervibus. In Nova Hollandia. 方.

3. S. Cunninghamii R. Br. fol. oblongis obtusiusculis hasi altenuatis nervis $3-5$ alte immersis; perianthiis 
pedunculo communi partialibusque umbellae ramulisque tomentosis. In $\mathrm{No}$ va Hollandia. $\hbar$.

\section{BANESIA Linn. fil. (1781).}

1. B. mulchella R. Br. fol. acerosis integerrimis muticis; calycis unguibus lanatis; stigmate depresso capitato. In Nova Hollandia. $\hbar$.

2. H. spleaerocarpa R. Br. fol. acerosis integerrimis mucronulatis; calycis unguihus laminisque hirsutis; stigmate subulato; strobilis globosis; folliculis ventricosis. In Nova Hollandia. ち.

3. B. nutans R. Br. fol. acerosis integerrimis mucronulatis; amentis nutantibus; calycibus sericeis; folliculis apice dilatatis depressis. In $\mathrm{No}$ ra Hollandia. $\hbar$.

4. B. ericifolia $L$. fol. acerosis emarginato-bidentatis, marginibus integerrimis; amentis elongatis; calycibus sericeis; stigmate capitato. Cav. ic. tab. 538. In Nova Hollandia. 古.

5. B. spimulosa Sm. Nov. Holl. $\boldsymbol{t}$. 4. fol. apice 3-dentatis dente intermedio longiore; marginibus spinulosodentatis integerrimisve; calycihus basi intus imberbibus; stigmate subulato. Cav. ic. tab. 537. In Nova Hollandia. 占.

6. B. Cunninghamii Sieb. fol. linearilus planiusculis longitudinaliter vel apice spinoloso-dentatis integrisve: subter incanis aveniis; bracteis omnibus amenti tomentosis obtusis. Hchb. Hort. tab. 81. In Nova Hollandia. .

\%. B. collina $\boldsymbol{R} . \boldsymbol{B r}$. fol. linearibus spinuloso-dentatis subtus venosis; bracteis amenti obtusis apice tomentosis; caule fruticoso. In Nova Hollandia. 市.

8. B. occidentalis B. Br. fol. linearibus extra medium spinuloso-dentatis subtus aveniis; bracteis amenti apice glahris; calycibus marcescentibus; folliculis ventricosis tomentosis; caule fruticoso. In Nova Hollandia. 市.

9. B. littoralis R. Br. fol. elongato-linearibus spinuloso-dentatis hasi attenuatis subtus aveniis; calycibus deciduis; folliculis compressis bracteisque strobili apice tomentosis; caule arboreo. In Nova Hollandia. $\hbar$.
10. R. marginata R. Br. fol. linearibus truncatis mucronulatis integerrimis vel dentatis; ramulis ultimis hirsutis; bracteis omnibus amenti glabris; caule fruticoso. Cav. ic. tah. 544 et 545. In Nova Hollandia. 占. Frutex orgyalis.

11. B. depressa $\boldsymbol{R}$. Br. fol. elongato-cuneatis truncatis mucronulatis spinuloso-dentatis subtus olsolete costatis; bracteis amenti omnibus tomentosis obtusis; ramulis ultimis tomentosis. In Nova Hollandia. $\hbar$.

12. B. anstralis $\mathrm{R}$. Br. fol. linearibus truncatis mucronulatis margine recurvis integris subtus reticulatovenosis; ramulis ultimis tomentosis; calycis laminis carina obsoletissima sericea; caule arboreo. In Nova Hollandia. 卢.

13. $\boldsymbol{B}$. insularis R. Br. fol. lineari- vel cuneato-oblongis subrotundis cum mucronulo sparsis verticillatisve subtus reticulato - venosis; bracteis amenti obtusis extrorsum tomentosis; folliculis compressis apice glabris. In

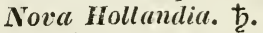

14. B. integrifolia $L$. fol. verticillatis oblongo-lanceolatis integris mucronulatis ; folliculis tomentosis ; caule arboreo. Cav. ic. tal). 516. In Nova Hollandia. Ђ. Arbor parva veI magna.

15. B. compar R. Br. fol. sparsis lingulato-oblongis emarginatis muticis dentatis integrisve subtus reticulato-venosis niveis; ramulis bracteisque tomentosis; caule arboreo. In Nora Hollandia. $\hbar$.

16. B. verticillata $R$. $B r$. fol. verticillatis lingulato - oblongis obtusis muticis, subtus aveniis niveis; hraeteis amenti tomentosis obtusis involucrantibus hirsutis; caule arboreo. In $\mathrm{No}$ va Hollandia. 市.

17. B. coccinea R. Br. fol. alternis cuneato-ovatis dentatis truncatis costatis reticulato-venosis basi transversis; hracteis subulatis calycihusque lanatis; stigmate pyramidali. In Nova Hollandia. 支.

18. 13. paludosa R. Br. fol. subverticillatis cuneato-oblongis subtruncatis basi attenuatis extra medium dentato-serratis margine subrecurvis subtus costatis reticulato-venosis; calycibus sericeis; caule fruticoso. In Nova Hollandia. 支. 
19. B. oblongifolia Cav. ic. tab. 5+2. fol. sparsis angustato-oblongis truncatis dentato-serratis subtus costatis reticulato-venosis; petiolis ramulisque tomentosis; calycihus sericeis. B. asplenifolia Salisb. B. salicifolia Cav. In Nova Hollandia. $ち$.

20. B. longifolia Cav. obovatooblongis spinuloso-serratis hasi acutis subtus costatis reticulatis cinereo-tomentosis; calycibus unguibus sericeis laminis glabris; caule fruticoso. B. robur Cav. in tab. 543. In Nova Hollandia. ち.

21. B. marcescens $R$. Br. fol. cumeiformibus planis sparsis truncatis extra medium dentato-serratis: basi acutiuscula; ramis lomentosis. B. praemorsa Audr. Rep. 258. In Nova Hollandia. t.

22. 13. media R. Br. fol. cuneatolinearibus truncatis dentato-serratis basi attenuatis, subter reticulatis venosis venulisque glabratis lacunis tomentosis; perianthii mguibus sericeis.

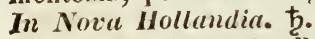

23. B. attemuata R.Br. fol. elongato-linearihus truncatis hasi attenuatis extra medium serratis subtus coctatis reticulatis areolis tomentosis; bracteis apice hirsulis; folliculis tomentosis. In Nova Hollandia. 支.

2.1. B. Caleyi R. Br. fol. linearihus truncatis serralo-dentatis basi attenuatis: subtus venoso-costatis venuloso-reticulatis, lacunis tomentosis; stigmate ungulato-cylindraceo; angulis hispidulis. In Nova Hollandia. $\hbar$.

25. B. Baueri R. Br. fol. linearicuncalis elongatis serrato-dentatis subter venoso-costalis venuloso-reticulatis; lacmis tomentosis; perianthiis sericeis; aristis filiformihus villosis laminas superantibus. In Nova Hollandia. $\hbar$.

26. B. Menziesii R. Br. fol. lato-linearibas truncatis dentalis: subler venoso-costatis venuloso-reticulatis venis venulisque pubescentibus, lacunis tomentosis; perianthiis sericeis; folliculis tomentosis. In Nova Hollandia. 5 .

2\%. B. elatior R. Br. fol. elongato-linearihus subtruncatis serratis isubtus reticulatis; bracteis calycibusque tomentosis; stylo glaberrimo; stigmate ovali-clavato. In Nova Holcandia. 5 .

25. $\boldsymbol{~}$. serrata $L$. fol. lato-linea- ribus elongatis truncatis serratis: subtus reticulatis glabriusculis; stylo imo pulveraceo puhescente; stigmate insulcato; caule arboreo. Lam. ill. tab. 54. f. 1. White's Voy. t.2. Andr. Rep. tah. 82. B. conchifera Gaertn. t. 48. f. 1. B. serrata Cav. ic. tab. 540. B. dentata Wendl. Hort. tab. 8. In Nova Hollandia. $\hbar$.

29. B. cemula $R$. Br. fol. latolinearibus elongatis truncatis profunde serratis subtus reticulatis; calycibus sericeis; stigmate capitato exsulco nitido apice 4-angulo; caule fruticoso. B. serrata White's Voy. t. 33. In Nova Hollandia. $\hbar$.

30. B. dentata $I$. fol. cuneatooblongis truncatis sinuato-dentatis undulatis basi acutis: subtus costatis venulosis niveis; calycihus sericeis; folliculis tomentosis. In Nova Hollandia. 卢.

31. B. quercifolia $\boldsymbol{R}$. Br. fol. oblongo-cuneatis subtruncatis glabris serrato-incisis: incisuris mucronatis; calycis laminis aristatis; folliculis glahriusculis. In Nova Hollandia. $\downarrow$. 32. B. speciosa R. Br. fol. linearibus pinnatifidis subtus niveis; calycis laminis folliculisque glabris. B. grandis Willd. In Nova Hollandia. $\downarrow$.

33. B. Solandri R. Br. fol. cuneatis truncatis pinuatifido - incisis; lohis semiovalibus subtus incanis nervosis venuloso-reticulatis. In Nova Hollandia. t.

3. B. repens Labill. Voy. t. 23. fol. pinnatifidis; lobis sinuatis vel dentatis; caule prostrato. In Nova Hollandia. $\hbar$.

35. B. Baxteri R. Br. fol. pinnatifidis truncatis; lohis 3-angularibus acutis subtus nervosis venoso-reticulatis; lacunis tomentosis; ramulis villosis; amentis globosis. In Nova Hollandia. 卢.

36. B. Goodii R. Br. fol. ollongis sinuato-dentatis, suhtus venosocostatis venuloso-reticulatis; lacunis tomentosis; caule abbreviato. In Nova Hollandia. 古.

37. B. prostrata $R$. Br. fol. elongatis sinuato-pinnatifidis lobis integerrimis: subtus venuloso-reticulatis; lacunis tomentosis; caule prostrato tomentoso. In Nora Hollandia. ఫ.

38. B. ilicifolia $R$. Br. fol. cuneatis inciso-serratis suhtus glabriusculis; amentis brevissimis; calycibus 
unguibus diu cohaerentibus. In Nova Hollandia. $\hbar$.

39. B. dryandroides Baxt. fol. linearibus pinnatifidis lobis isoscelotriangularibus subtus tomentosis enerviis a veniis; amentis ovatis. Sweet fi. austr. t. 56. In Nova Hollandia. $\hbar$.

40. B. Brownii Baxt. fol. linearibus pinnatifidis ; laciniis linearibus parallel0-approximatis adscendenti-falcatis subtus incanis 1-nerviis; amentis cylindraceis. In Nova Hollandia. †.

\section{DRYANDRA R. Br. (1810).}

1. D. floricunda R. Br. fol. cuneif. inciso-serratis; calycis laminis glabris; stigmate subclavato obtuso. In Nova Hollandia. $\mathbf{t}$.

2. D. cuneata R. Br. fol. cuneif. inciso-serratis; calycis laminis barbatis; stigmate subulato-filiformi acuto. In Nova Hollandia. $\hbar$.

3. D. armata $R$. $B r$. fol. pinnatifidis; lobis triangularibus spinoso-mucronatis ; stylo basi pubescente; stigmate subulato sulcato. In Nova Hollandia. $\hbar$.

4. D. Serra R. Br. fol. elongatolinearibus inciso-pinnatifidis subter niveo-tomentosis; perianthio sericeo. In Nova Hollandia. $\hbar$.

5. D. concinna $\boldsymbol{R}$. Br. fol. latolinearibus pinnatifido-incisis subtus niveo-tomentosis; perianthio glabro; unguibus villosis. In Nova Hollandia.

6. $D$. foliolata $\boldsymbol{R} . \boldsymbol{B r}$. fol. elongato-linearibus inciso-pimnatifidis truncatis; perianthio villosissimo; stigmate basi incrassato. In Nova Hollandia. b.

\%. D. squarrosa R. Br. fol, linearibus dentato-incisis acutis subtus niveis; involucri squamis aristatis apice recurvis. In Nova Hollandia. ち.

8. D. falcata R. $B r$. fol. pinnatifidis ; lobis triangularibus falcato - recurvis spinoso-mucronatis; stigmate clavato exsulco. Hemiclidia Baxteri h. Br. In Nova Hollandia. $ち$.

9. D. formosa R. Br. fol. elongato-linearibus pinnatifidis; lobis sca1eno-triangularibus subtus niveis ; involucris tomentosis. In Hova Hollandia. $\bar{t}$.
10. D. Baxteri $R$. Br. fol. elongato-linearibus pinnatifidis marginibus incrassato-recurvis subtus niveo-tomentosis; perianthiis villosis. In Nova Hollandia. $ち$.

11. D. mucromulata $R$. Br. fol. elongato - linearibus pinnatifidis subtus niveis; involucris tomentosis; canle subsimplici. In Nova Hollandia. ఫ.

12. D. plumosa $R$. $B r$. fol. elongato-linearibus pinnatifidis margine subrecurvis subtus niveis; involucri foliolis intus plumoso-aristatis. In Nova Hollandia. $\hbar$.

13. D. obtusa R. Br. fol. linearibus pinnatifidis caule decumbente tomentoso longioribus subtus niveis; involucri foliolis extus ovatis. In Nova Hollandia. $\hbar$.

14. D. arctotides R. Br. fol. linearibus pinnatifidis subtus niveo-tomentosis; perianthiis villosis ; tubo imberbi. In Nova Hollandia. $\hbar$.

15. D. nivea Labill. Voy. $t$. 24. fol. linearibus pinnatifidis; lobis mucronulatis subtus niveis; involucri bracteis lanceolatis ciliatis. In Nova Hollandia. $\hbar$.

16. D. Fraseri $\boldsymbol{R}$. Br. fol. linearibus pinnatifidis caule erecto multo brevioribus; involucri squamis pubescentibus; stigmate sulcato. In Nova Hollandia.

17. D. longifolia $R$. Br. fol. longissimis pinnatifidis subtus cinereo-tomentosis; involucri foliolis margine ciliatis; caule tomentoso. In Nova Hollandia. $\hbar$.

18. D. seneciifolia R. Br. fol. subtus niveis integerrimis vel piunatifidis ; involucri squamis plumoso-villosis ; perianthiis pilosis. In Nova Hollandia. $\hbar$,

19. $\boldsymbol{D}$. tenuifolia R. Br. fol. elongato-linearibus pinnatifidis subtruncatis subtus niveis; involucri bracteis tomentosis. In Nora Hollandia. ち.

20. D. bipinnatifida $R$. Br. fol. caule squamato longioribus bipinnatifidis super pilosis subíus tomentosis margine revolutis. In Nova Hollandia. 5 .

21. D. nervosa $R$. Br. fol. pinnatifidis; lobis parallelo-nervosis ; caulo erecto lumili; perianthiis aristatis, apice laxe penicillatis. In Nova Hollandia. 支.

22. ע. calophylla R. Br. fol. pinnatifidis; lobis semi-ovato-lanceolatis; 
caule abbreviato; ramis floriferis prostratis; perianthiis villosis apice penicillatis. In Nora Hollandia. ち.

23. D. pteridifolia R. Br. fol. pinnatifidis caule tomentoso-longioribus; lobis margine revolutis basi dilatatis; involucris tomentosis. In Nova Hollandia. 方.

2t. D. bleclinifolia R. Br. fol. pinnatifidis canle tomentoso longioribus; lobis linearibus mucronulatis maregine recurvis. In Nova Hollandia.

\section{PHYLA Lour. (1790).}

1. P. chinensis I,our. In China. Herha fol. oppositis ovato-lanceolatis apice serratis; pedunculis axillaribus.

\section{CANSIERA Juss. (1789).}

1. C. scundens Roxb. Corom. tab. 103. ramis scandentihus; fol. ovatolanceolatis; floribus spicato-fasciculatis axillaribus. C. Rheedii Gmel. Tratt. Arch. t. 41. Hheede 7. t. 4. In Ind. orient. t. Frut. $10-12$-ped. sempervirens.

2. C. madagascariensis Spr. ramis erectis; fol. lincari-lanceolatis; floribus paniculatis axillaribus. Potameia Thouarsii 12. et s. In Malagascar. ఫ. Frut. expansus. Flor. parvi globosi.

\section{DRAPETES LAM. (1792).}

1. D. muscosa Lam. in Journ. d'hist. nat. t. 10. f. 1. Ad fretum Mayellan. $\odot . ?$ Hal). Passerinae et Guidiae. Caul. filiformis decumbens 3-5-poll, ramosus. Fol. decussatim opposita ovata piloso-barbata. Fl. parvi.

\section{STRUTHIOLA L. (176\%).}

1. Str. virgata $I$. fol. lanceolatis ciliatis; bracteis longitudine germinis. Str. ciliata Andr. Hep. 1. 14!. et t. 139. Str. lateriflora Horn. Str. longifora Lam. ill. t. 78. Burm. Afr. t.

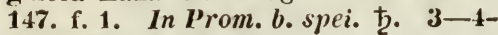
ped. Flor. albi.
2. Str. pubescens Retz; fol. linearibus ciliatis; bracteis gernine longioribus. B. M. 1212. Str. virgata Sm. exot. bot. t. 46 . In Prom. b. spei. 2-3-ped. Corolla rubra.

3. Str. glabra L. fol. linearibus ramisque tetragonis glabris. Str. erecta Thunb. Wendl. ohs. t. 2. f. 10. str. 4-gona Retz. Burm. Afr. tab. 47. f. 1. Str. tuberculosa Lam. In Prom. b. spei. ち. Pedatis. Cor. alba.

4. Slr. juniperina Retz; fol. linearibus acutis patentibus; corollis calycihusque nudis (antheris inclusis). Str. erecta sims. B. M. 222. Str. lucens Poir. In Prom. b. spei. Ђ. Ertticulus glaber. Cor. alba.

5. Str. nana 1. fol, linearibus obtusis pilosis ; florihus terminalibus fasciculatis tomentosis. In Prom. $b$. spei. Ђ. Caul. lienosi humillimi 3 poll. longi. Cor. extus rubella intus ochrolenca.

6. Str. angustifolia Iam. fol. oppositis erectis linearibus dorso trisulcatis; ramis composilis villosis. Lam. ill. In Prom. b. spei. ち. Caul. cinereo-fusci. Flor. ochroleuci.

\%. Str. imbricata Andr. Rep. $t$. 113. fol. ovatis sulcatis 4-fariis confertis margine ciliatis; glandulis corollinis 4. Str. striata Lam. In Prom. b. spei. $\hbar$. Fruticulus cortice nigrofusco, libro albissimo sericeo. Cor. flavescens.

8. Str. tomentosa Andr. Rep. $t$. 331. fol. ovatis concavis callosis tomentosis imbricatis; nectario duodecim partito. str. chrysantha Lichtenst. In Prom. b. spei. ђ.

9. Str. orutu 'íhunb. fol. oppositis ovato-ohlongis ramisque rugosis glabris; antheris subexsertis. Andr. hep. t. 119. sitr. lanceolata liet $\%$. sitr. myrsinites Lam. In From. b. spei. 方. Caules favescentes. Cor. alba.

\section{5\%. COROCEPHALUS Blume (15\%.う).}

1. C. suareolens Blume. In . Juva. t. Frulex scandens; fol. alternis elliptico-oblongis repandis; capitulis subcorymbosis axillaribus lateralibusque. 


\section{RIVINA Plum. (1703).}

1. R. humilis I. racemis simplicibus; fol. pubescentibus. Lanı. ill. t. 91. f. 4. Plukn. t. 112. f. 2. In India occillentali. ち. Caul. 1-ped. Baccae rubrac.

2. R. luevis $L_{\text {o }}$ racenis simplicibus; fol. ovatis acuminatis glabris planis; caule tereti. Lam. ill. t. 81. f. 2. 12. humilis Mill. H. acuminata Humb. R. Ianceolata IV. R. latifolia Lam. In Ind. occ. ち. Tota glabra. Flor. rulsicundi.

3. C. brasiliensis Willd. racemis simplicibus; fol. ovatis oblique cordatis undulato-rugosis glabris; caule

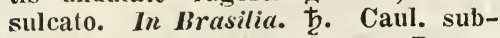
lignosi. Cor. extus virens. Baccae sanguineae.

t. R. purpurascens Schrad. Gen. nov. $t$. 5. racemis simplicibus; fol. ovatis glabris ciliatis; petiolis pubescentibus. Willd. R. puberula Humb. In Ind. occ. ち. Fol. subpurpurea. Flor. rubicundi.

5. R. secunda $R$. et P. peruv. $t$. 102. $f$. a. glabra; fol. ovatis acuminatis obsolete denticulatis; calyce bilabiato. In Peruvia. †. Fruticulus 2-ped. Cor. albida. Baccae nigrescentes.

6. R. octandra $L$. racemis simplicibus; floribus octandris dodecandrisque. Brown Jam. t. 23. f. 2. Jacq. obs. t. 2. R. dodecandra Jacq. Am. pict. t. 21. In America australi. $\hbar$. Arbor 20-ped. sarmentosa. Flor. albi. Baccae violaceae.

\section{CRYPTOCARPUS Kunth (181\%).}

1. C. globosus Humb. et Kunth. Nov. Gen. $t$. 123. fol. rhombeo- ovatis; pedunculis terminalibus et axillaribus polystachyis; calycibus 4-dentatis fructiferis globosis. Boerhaavia rhomboidea Willd. In Cuba. 4 .

2. C. pyriformis Humb. et Kunth. Nov. G. $t$. 12f. fol. ovatis obtusis; paniculis terminalibus; calycibus 5dentatis, fructiferis pyriformibus. In Andibus Peruviae. 4.

660. PTERANTHUS Forsk. (1775).

1. P. echinatus Desf. Sibth. graec. t. 153. Lonicera cervina L'Herit.
Stirp. t. 65. In arenosis Tuneti, Arabiae et ins. Cypri. $\odot$. Caulis palmaris dichotomus ramosissimus. Fol. linearia. Flor. virides parvi.

\section{CAMPHOROSMA L. (1747).}

1. C. monspeliaca I. caespitosa; tomentosa; cana; caulibus adscendentilous simplicissimis. C. peremis Pall. ill. t. 57. Regn. Bot. t. 351. schk. t. 26. Buxb. Cent. t. 28. f. 1.? Iam. ill. t. 57. C. acuta Host. In Enropce anstrali et Asia med. 2. Sesquiped. Antlierae obsolete purpureae.

2. C. ruthenica $M$. Lieb. villosa; fol. subulatis; floribus axillaribus glomerato-spicatis tomentosis; bracteis lanceolatis. In Tuuria et Caucaso. 4. Quam naxime affinis. C. monspeliacae sed habitu graciliori et fol. brevioribus distincta.

3. C. annua Pall. ill. t. 58. piloso-lanuginosa; caule erecto alterue ramoso. In Russia australi. $\odot$. Ihad. simplicissima. Caules rubentes. Antherae flavae.

4. C. orata W. et Kit. hung. $t$. 63. fol. triquetro-subulatis subcarnosis floribusque axillari-subsolitariis obovatis apice pilosis. In arenosis Hungariae. $\odot$.

\section{ANISACANTHA R. Br. (1S10).}

1. A. divaricata R. Br. In Nor. Holl. . Fruticulus glaber; fol. alternis; floribus axillaribus.

\section{NYSSANTHES R,Br. (1810).}

1. N. erecta $R \cdot B r$. perianthiis 4andris pubescentibus 5-nervibus; fol. oblongo-lanceolatis acutis; mucronulo brevissimo; caule erecto. In Nova Hollandia. $\hbar$.

2. N. media $R$. Br. perianthiis diandris pubescentibus 3-nervibus; fol. ovali-oblongis obtusiusculis; mucrone pungente. In Nova Hollandia. 4.

3. N. diffusa $R$. Br. perianthiis diandris glabris 5-nervibus; fol. rameis ovali-oblongis, mucrone pungente; caule diffuso. In Nova Hollandia. 
664. EMPLEURUM Soland. (1789).

1. E. serrulatum Ait. In Prom. b. spei. ち. Fruticulus elegans; fol. lanceolatis . serrulatis pellucido-punctatis; floribus allis minutis.

\section{OBOLARIA L. (1737).}

1. O. virginica L. Plukn. t. 209. f. 6. In America boreali. Planta pusilla erecta simplex; fol. subrotundis carnosis subcoloratis; flor. pallide caeruleis.

\section{MAJANTHEMUM Web. (1780).}

1. M. bifolium DC. fol. ovatocordatis petiolatis. Convallaria L. Fl. Dan. 291. B. M. 510. Hedouté t. 216. f. 2. In Europa. 24. 3-4-poll. Fl. racemosi albi minimi. Baccae coccineae.

2. M. canadense Desf. caule birarius trifolio; fol. cordato-oblongis subsessiibus utrinque glaberrimis; flor. 4-andris. lied. t. 216. f. 1. Convallaria Miclix. In Amer. bor. 24. 26-poll. Cor. alba minima. Fortasse varietas M. bifolii.

\section{6\%. ALCHEMILLA Trag. (1539).}

1. A. vulgaris $L$. fol, rad. reniformibus ad tertiam partem 7-9-10bis; lobis subsemiorbiculatis circumcirca serratis. Kocli. Fl. Dan. 639. Sturm. 2. In pratis et pascuis Europae. 4. var. $\beta$. fol. subsericeohirsutis. A. montana W. A. alpina B. hybrida L. Plukn. t. 240. f. 1.

2. A. pubescens M. Bieb. fol. rad. reniformibus ad tertiam partem 7-9lobis, lobis breviter ohovatis truncatis antice acute serratis margine integerrimis. Koch. In Alpibus Europae. 4.

3. A. fissa Schummel; fol. radicalibus reniformibus ad medium 7-9fidis; lobis obovatis antice inciso-dentatis margine integerrimis. Koch. Rchb. crit. t. 4. f. 10 . Sturm 1.56. A. minor Tausch. A. pyrenaica Duf. In Alpibus Europae. 4.

4. A. alpina $L$. fol. radicalibus digitato-5-7-partitis; laciniis lanceolato-cuneatis obtusis apice adpressoserratis subtus sericeis. Koch. Fl. Dan. 29. Sturm 1. 51. In Alpibus Europae. 4.

5. A. pentaphylla $L$. fol. rad. ad basin 5-partitis; Iaciniis 3 intermediis obovato-cuneatis antice inciso-4-6dentatis; lateralibus hifidis 1-pluridentatis, dentibus porrectis. Bocc. Mus. t.1. In Alpibus Europae. 4.

6. A. aphanoides Mutis; fol. multipartitis; caule erecto pubescente; racemis subverticillatis terminalibus. In Nova Granata. 4.

7. A. nivalis Humb. et Kunth Nov. Gen. $t .560$. caulihus erectis aut procumbentibus superne ramosis; fol. vaginato-amplexicaulibus multifidis externe sericeo-lirsutis; floribus terminalibus subternis sessilibus diandris sub4-gynis. Kunth. In Peruvia. 4.

8. A. rupestris Kunth; caulibus ramosis repentibus; fol. profunde 3partitis subtus piloso-sericeis; laciniis serrato-incisis; stıpulis integris; flor. diandris 3-gynis. In Qnito. 4. A. Aplıani similis.

9. A. hirsuta Kunth; caule ramoso erecto; fol. profunde 3-partitis pilosis; laciniis flabellato-multifidis ; stipulis 1-3-fidis; flor. diandris 3-gynis. In America meridionali. 4.

10. A. sibbaldiaefolia Humb. et Inunth $N$. Gen. $t$. 561. caulibus superne corymlioso-multifloris; fol, profunde 3-partitis subtus adpresso-pubescentibus; laciniis inciso-serratis; stipulis 2-4-fidis. In Mexico. 4.

11. A. pectinata Kunth; caulibus filiformibus dichotomis; fol. subtus argenteo-sericeis, radicalihus subreniformibus longissime petiolatis; stipulis 3-5-fidis; floribus sub-5-gynis. In Nova Granata. 4.

12. A. orbiculata R. et P. Fl. peruv. villosa ; fol. orbiculato-reniformilus lobatis; floribus spicato-corymbosis. Aphanes orbiculata Pers. In Peruvia. 4. Caulis ramosissimus.

13. A. pinnata R. et P. fol. pinnatis ; pinnis 2-3-fidis. Aphanes Pers. In Peruvia. Stolonifera. Caules repentes.

14. A. Aphanes Leers; rol. 3-partitis; laciniis 3-fidis pubescentibus; floribus axillaribus glomeratis monandris. IVilld. Fl. Dan. 973. Schk. t. 26. Aphanes arvensis L. Alchemilla ar- 
vensis Scop. In agris Europac. $\odot$. 1-2-poll. prostrata.

15. A. capensis Thunb. fol. reniformibus sublobatis repando-crenatis hirsutis; floribus axillaribus glomeratis involucratis. In Prom. b. spei. 24. var. $\beta$. glabrescens; fol. glabrescentibus ibid.

16. A. elongata Eclon et Zeyh. caule angulari elongato adpresse pubescente; fol. reniformibus palmatolobatis subtus vix puberulis; stipulis crenato - incisis; corymbis axillaribus dichotomis. In Prom. b. spei. 4. var. $\beta$. montana; caule breviore plerumque hirsuto.

17. A. cornucopioides $R$. et $S$. fol. hirsutis petiolo dilatato stipulisque incisis amplexicaulibus subsessilibus tripartitis, laciniis $\mathbf{2}-\mathbf{5}$-fidis; floribus axillaribus glomeratis. Aphanes Lag. gen. In arvis circa Madritum. $\odot$.

\section{COMETES Burm. (1768).}

1. C. surattensis Burm. ind. t. 15. f. 1. Plukn. t. 380. f. 1? C. alterniflora $L . \quad$ In Suratte. $\odot$. Caulis herbaceus. Fol. opposita obovata acuminata. Pedunculi 1-flori.

\section{DAPHNITIS Spr. (1825).}

1. D. capensis Spr. fol. oblongis integris medio serratis. Laurophyllus Thunb. In Prom. b. spei. $\hbar$. Arbor erecta. Flor. paniculati minuti.

2. D. madagascariensis Spr. fol. bilobis medio glanduliferis lobis anguIatis. Dilobeia Aub. Thouar. D. Thouarsii R. et $\mathbf{S}$. In Madagascar. $\hbar$. Arbor excelsa. Flores parvi paniculati.

670. HEDYCARPUS Jack. (1825).

1. H. malayanus Jack. In Sumatra. Arbuscula; fol. alternis ovatis acuminatis; floribus racemosis.

\section{LAGENULA Lour. (1790).}

1. L. pedata Lour. In montibus Cochinchinae. †. Arbor mediocris, caule scandente cirrhoso ramoso. Fol. quinato-pedata tomentosa. Flos alloviridis.

\section{VISCUM Virg.}

\section{a. Apliylla.}

1. $\boldsymbol{V}$. capense $L$. caule obtuse 4gono ramosissimo articulato; ranis decussatis; floribus subsenis verticillatis sessilibus; bacca globosa. Thunb. Razomowshia hort. Mosc. In Prom.

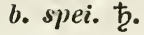

2. Y. Oxycedri DC. caule ramosissimo articulato; ramulis subcompressis; vaginulis pelviformibus. Hazomowskia caucasica Hoff. l. Mosc. 1808. 1. 1. f. 1. a-i. In Junipero Oxycedro Hispaniae, Iberiae et prope Tiflin.

3. I. angulatum Heyne; ramis angulatis 4-gonis articulatis. In Ind. orient. b.

†. V. taenicides Comm. ramosissimum; caule ramisque compressis articulatis lineari-oblongis; vaginulis truncatis. In ins. Mauritii et Borboniae. ‡. Fl. parvi. Planta siccata nigrescit.

5. V.japonicum Thunb. caule prolifero ramoso compresso. In Japonia. 古.

6. V. dichotomum Don; ramis compressis articulatis; articulis ovalioblongis longitudinaliter striatis; floribis ternis sessilibus ad apices articulorum aut ramorum. V. nepalense Spr. Viburnum dichotomum Ham. In Nepalia. ‡.

\%. V.elongatum Wall. ramis compressis articulatis; articulis lineariohlongis basi subattenuatis ; floribus subterminalibus subverticillatis; verticillis 1-3-floris. In Silhet. ち.

8. $V$. fragile Wall. ramis compressis articulatis; articulis linearioblongis substriatis medio crassiusculis; fasciculis florum terminalibus 1 3-floris. In India orientali. $\downarrow$.

9. $V$. attenuatum $D C$. ramis compressis articulatis; articulis ad apicem ad basin sensim attenuatis lineari-cuneatis substriatis; fasciculis florum ad apices articulorum oppositis sessilibus 3-5-floris. In India orientali. $\downarrow$.

10. V. articubatum Burm. ramis compressis articulatis; articulis elongatis substriatis; fasciculis forum ad 
apices articulorum oppositis sessilibus 1-3-floris. In Java super Annonas. ち. $\beta$. Timorense; ranis sublierbaceis; articulis ultimis apice acutis.

11. V. moniliforme Blume; caule inferne teretiusculo; ramulis ancipitibus articulatis; articulis nudis; floribus verticillatis sessilibus. In arboribus Javae. ち.

12. I.tunatorme DC. ramis compressis articulatis trichotomis elongatis; articulis oblongis"; floribus ad apices articulorum terno-fasciculatis subsessilibus. V. articulatum Pohl in litt. In Brasilia. 卢.

13. $V$. opmentioides $I$. ramis compressis articulatis; articulis late ovatis; spicis ad articulationes aut apices ramorum articulatis; fasciculis florum series duas oppositas membramula marginata gerentibus. Sloane Jan. t. 201. f. 1. V. monstrosum Bart. V. opuntioides WVilld. In Jamaica. \$.

14. V. vaginatum Humb. et Bonpl. caule 4-gono; ramulis tereti-compressis; articulis apice vagiumlam bidentatam gerentibus; floribus in sinu vaginae 2 oppositis sessilibus. In pinetis Mexici. 方.

15. 1 . cupulatum DC. caule 4gono; ramis compressis; articulis sterilibus elongatis, fertilibus brevissimis fructus duos tantum gerentibus; vaginulis brevissimis; hractea cupulari membranacea orbiculata sub bacca ovata. V. vaginatum spr. In Domingo l. Bertero b.

16. I. Domingense $\mathrm{Spr}$. caule ramisque teretibus; vaginis amplis pelviformilous bifidis; margine albido subscarioso. In Domingo. ち.

17. I. gracile IDC. caule tereti; ramis subcompressis articulatis; articulis linearibus elongatis; spicis terminalibus compressis articulatis; floribus secus margines utrinque seriatis distantibus. In Caribaeis. t.

18. I. chilense Illook in Reech. voy. caule tereti ramoso; ramis ramulisque oppositis compressis articulatis aphyllis; floribus $2-3$ ad genicula sessilibus. In Cliti. †.

1.9. V. robustum Eclon. et Zeyh. aphyllum; caule ramosissimo ramisque articulatis teretilus decussatis; floribus in axilla vaginae sessilibus; vaginis patelliformibus decussatis. In Africa australi ad frutices parasiti- cum. b. Planta sulphurea fragilissima.

2. Foliosa; floribus fascicula$t$ is a umbellatis DC.

1.9. I. album L. caule dichotomo ramosissimo; ramis teretibus; fol. lanceolatis obtusis enerviis; floribus terminalibus sessilibus suhquinis glomeratis. Blackw. t. 184. Dietr. Forstf. t. 92. Duham. arb. t. 104. Rich. ann. mus. 12. t. 27. In arboribus Europae. to.

20. V. stellatum IIam. ramosissimum; ramulis verticillatis teretibus; fol. oblongis obtusis hasi attenuatis subtus 5-nerviis; floribus terminalibus glomeratis. In Nepalia. ち. Hab. Visci albi.

21. $r$. orientale Willd. ramis teretibus; fol. ohlongis obtusis basi attenuatis 3-nerviis; ped. axillaribus subtrifloris. In India orientali et Java. $\hbar$.

22. I. Heyneanum DC. ramis teretibus; ramulis compressiusculis; fol. ovatis utrinque acutis quintuplinerviis; ped. axillaribus aggregatis 3-noris. V. orientale Heyue Hb. In India orientali. t.

23. I. monoicum Roxh. ramis teretibus articulatis; ramulis striatis; fol. elliptico-ohlongis utrinque acuminatis 5-nerviis; fasciculis axillaribus brevissimis. In Ind. orient. 方.

24. I. falcatum Wall. Miss. ramis teretibus; fol. elliptico-oblongis acuminutis falcatis basi acutis 5-nerviis; fasciculis florum axillaribus sessilibus 3-floris. In India orientali. $\hbar$. Flor. ninimi.

25. I. oralifolium IVall. Mss, ramis teretibus; fol. ovalibus obtusis $\tilde{j}$-nerviis basi in petiolum brevem subangustatis; floribus fasciculato-lernis interrupte spicatis. In Ind. orient. $\downarrow$.

26. I. obtusatum Hall. Mss. ramis teretihus; fol. ovalibus obtusis subcumeatis 5-nerviis; floribus axillaribus 1-3-subsessilibus. In regno Avae India orient. $\hbar$.

27. I. heteranthum Wall. Mss. ramis angulatis denum teretibus; fol. ellipticis obtusis basi cuneatis subtus 5-nervis; involucro capituli 5 -6-flori 3-5-phyllo. In Nepalia l. Wall. Baccac ovalo-globosae.

2s. V. platyphyllum Spr. cur. 
post. ramulis alternis angulatis; fol. alternis ovatis obovatisque petiolatis basi attenuatis subtus nervosis; umbellulis sub-4-floris; involucellis 5 -fidis persistentibus. V. latifolium Ham. In Nepalia.

29. I. umbellatum Blume bijolr. ramis alternis junioribus angulatis; fol. ohovatis 3-nerviis; nervis lateralibus bifidis; umbellulis pedunculatis axillaribus confertis; flor. masculis pentandris. In arboribus Javae. 卢.

30. I. capitellatum Sm. in Rees cycl. caule ramoso tactu aspero; fol. concavis obtusis; pedunculis axillaribus; baccis capitatis ovalibus. In Zeylona. †. Caul. $4^{\prime \prime}$ altus. Fol. 1" longa.

31. I. triflorum DC. ramulis striis plurimis subangulatis; fol. ovatis obtusiusculis subuudulatis basi subattenuatis subtus 3 -nerviis; pedunculis 3 floris 3-bracteatis; bacca globosa. In ins. Mauritianis. $\hbar$.

32. V. venosum DC. ramis striatoangulatis; fol. ovatis ovalibusque obtusis hasi attenuatis breve petiolatis 5-nerviis; nervis ramosis; haccis globosis. V: capeuse Bory. In ins. Mauritiunis. †. Planta siccata nigrescit.

33. V. rotundifolium L. fil. caule ramisque 6 -gonis articulatis; fol. sessilibus rotundatis acutis; pedunculis trifloris brevibus. In Prom. b. spei. $\hbar$.

3. Foliosa; floribus spicatis; spicis articulatis; articulis vagiuulatis DC.

\section{* Ramis teretibus.}

34. T. torulosum DC. ramosissimum; ramis teretibus; fol. subrotundo-ovatis aut ellipticis olliquis; floribus arcte seriatis inmersis. V. buxifolium spr. Lorantlius torulosus Kunth. In Quito. ちூ.

3.5. V. trinervium Lam. ramis teretibus articulatis trichotomis; fol.obovatis ohtusis basi augustatis trinerviis; spicis densis; baccis rotundis. V. verticillatum L. Plum, ad Burm. t. 258. f. 2. In St. Domingo. ち. Baccae croceae.

36. V. buxifolium Lam. ramis teretibus articulatis; articulis brevibus crassiusculis; fol. ohovatis ohtusis 1nerviis sessilibus, Plum. ed. Burm. t.
258. f. 3. In aridis St. Domingi. Baccae niveae.

3\%. I. sanmuroides $D C$. ramis toretibus ; fol. ovatis acutis acuninatisve brevissime petiolatis subtus tuberculato-punctulatis; nervo medio prominulo; spicis gracillimis. V. latifolium Lam. V. racemosum Aubl. In Cayema. ち.

38. I. tereticaule $D C$. ramis teretibus laevibus; fol. ovatis acutis planis enerviis aveniis brevissime petiolatis; flor. femineis 3-fidis. V. latifolium Sw. In arboribus Jamaicae. ち. $\beta$. Cubense; fol. margine subudulatis. In ins. Cuba.

39. V. Ifartinicense DC. glabrum; ramis teretibus; fol. ovato-lanceolatis acuminatis 3-nerviis brevissime petiolatis crassis; flor. 4 verticillatis. In Hartinica. 古.

40. $V$. flarescens Pursh; ramulis teretihus oppositis verticillatisque; fol. cuneato-obovatis 3-nerviis; spicis interruptis. V. album Walt. V. verticillatum Nutt. V. lencocarpum Raf. In arboribus a Pensylzania ad Carolinam. ち. Baccae albescentes diaphanae.

41. V. crassifolium Poll in litt. ramis teretibus; fol. late ovalibus utrinque attenuatis crassis enerviis hreve petiolatis; spicis axillaribus 46-verticillatis; flor. 4-stichis; baccis ovato-globosis. In Brasilia l. Pohl. ち.

42. V. leptostachyum $D C$. ramis teretibus; fol. oblongo-lanceolatis utrinque acutis trinerviis; spicis trichotomis elongatis subpaniculatis gracilibus articulatis; vaginulis pelviformilus; baccis ovato-rotuudis non immersis. V. macrostachyum Spr. V. aphyllum baccis aureis Plum. ed. Burn. t. 258. f. 1. V. opuntioides $\beta$. Lam. In St. Domingo et Hispaniola. 古.

13. T. Perrottetii DC. ramis teretibus; fol. lanceolatis oblique falcatis subobtusis basi cuneatis 5-7-nerviis; vaginulis bifidis. In Gujana. t. Flor. 6-stichi.

4. I. brachystachyum DC. ramis teretibus; fol. oblongis obtusis basi attenuatis tenuiter 5-nerviis; spicis axillaribus ovatis paucifloris; baccis ovato-globosis. In Mexico l. Berland. $\hbar$.

4.5. V. rubrum L. caulibus teretibus simplicibus; fol. oblongis obtusia 
hasi in petiolum attenuatis; spicis subinteruptis ; flore 3-partito; bacca glohosa. In ins. Bahamensibus sujra Swieteniam Mahagoni. $\hbar$.

46. I. Merterianum DC. ramis teretihus dichotomis; fol. oblongo-lanceolatis utrinque atlenuatis hasi acutis hrevissime petiolatis; spicis axillaribus articulis 4 -stichis. V. dichotomum spr. In St. Domingo l. Bertero. 古.

47. I. Schottii Polil in litt. ramis teretibus; fol. oblongo - lanceolatis urinque attenuatis et subacuminatis subaveniis; racemis axillaribus; florihus trifidis; haccis ovatis. In Brasilia $l$. Schott. $\hbar$.

48. I. macrostachyon Jacq. coll. 2. t. 5. f. 3. ramis teretibus; fol. lineari-lanceolatis subsessilibus olutusis aveniis; spicis axillaribus filiformilous; vaginulis pelviformihus; flor. 3-partitis. In arboribus Murtinicue et Trinitatis. b. Flor. minimi.

49. V. piperoides IC. pendulum; dichotome ramosissimum; ramis teretibus articulatis; articulis apice hidentatis; fol. oblongis apice angustatis suheusiformihus. V. dichotomun var. Spr. Loranthus piperoides $\mathbf{H}$. et $\mathbf{K}$. Prope C'arthagenum. ந.

50. V. anyustifolium DC. ramosissimum; ramis teretibus subverticillatis; fol. petiolatis lineari-lanceolatis subensiformibus; flor. 4-seriatis rachi immersis. V. stenophyllum spr. In Andibus Peruviue. t.

51. I. affine Pohl in litt. ramulis sub-4-gonis; fol. lineari-lancenlatis obtusis basi attemutis tenuissime 5nerviis; vaginulis minimis; baccis ovatis. In Brasilia l. Pohl. t.

52. I. velutinum DC. ramis teretibus pube molli hirsuto-velutinis; fol. lineari-ohlongis utrinque attenuatis acutisque hasi 3 -5-nerviis, junioribus subvelutinis; vaginis hifidis ciliatis; haccis 4-stichis. In valle Toluccano Mexici l. Berland. t.

5.3. I. ensifolium Pohl in litt. ramis teretibus; fol. lineari-oblongis utrinque acuminatis petiolatis hasi tenuiter 3-5-nerviis; spicis verticillatis; vaginulis hifidis; flor. 6-stichis; baccis globosis. In Brasilia $l$. Polll. ђ.

\section{** Ramis ancipitibus compressis- ve. DC.}

54. V. interruptum DC. fol. ollongo-lanceolatis ohtusis basi attenuatis petiolatis subenerviis; venis $3-5$ tenuissimis; vagiuulis subtruncatis: articulis apice fructiferis. V. Janceolato-ellipticum Pohl. In Brasilia $\ell$. Polit. t.

5.5. I. anceps $\mathbf{S} \mathrm{m}$. ramulis ancipitilus; fol. ohlongo-lanceolatis obtusis hasi attematis 3-nerviis. In Portorico et Hispaniola ad arbores $l$. Bertero. ђ.

56. V. hexastichum DC. ramulis ancipitihus; fol. ellipticis utrinque attenuatis suhohtusis hasi acutis petiolatis pennucrviis; vaginulis truncatis; haccis hexastichis glohoso-depressis. In Cuba mope Havanam l. de la Osisu. 方.

57. I. Mmlulatum Polel in litt. ramulis ancipitibus; fol. ovalibus oblongisve hasi attenuatis obtusiusculis crassiusculis undulatis suhaveniis; vaginulis subtruncatis. In Brasilia $l$. Pohl. t.

58. V. macropliyllum Spr. ranulis apice compressis; fol. late ovatix ovalihusve petiolatis nervo medio crasso; spicis sul)-4-gonis; haccis semiimmersis ovatis. In rrberilus ins. Caribaearum, st. Dominyi et Portorici. t.

5.9. I. flavens S'pr. ramulis ancipitibus; fol. ovatis apice subattenuatis ohtusis hasi j-nerviis hrevissime petiolatis; spicis axillaribus; haccis ovatis. In rumis arborum Jamaicue et Pontorici. to.

60). I. Crussulae Eclon et Zeyll. caule ramosissimo; fol. sessilihus oppositis suborhiculatis carmosis; bract eis scaphatermilous. In A fivicu anstr. ad Crussulas fruticosus parasiticum. ち. Planta fragilissima. Baceae rubrae.

*** Ramis ramulisque 4-gonis. DC.

61. V. 3-yonum DC. ramis oppositis; fol. ellipticis sublanceolatis hasi attenuatis apice oltusis 3-nerviis ant 5-nerviis; spicis axillarihus. V. angustifolium spr. Loranthus sessilis H. Balb. Ad sylvas maritimas Portorici el Guadelupae l. Bertero. t.

62. V. mucronatum $\mathrm{DC}$. fol. oh- 
longo-ovatis hasi attenuatis apice obtusis mucronatis nervo medio et utrinque saepe altero distinctis. $\quad \mathrm{r}$. myrtilloides spr. In St. Domingo $\iota$. Bertero. ђ.

6:3. I. pennivenium $D C$. fol. subalteruis ovalihus breve petiolatis obtusis, nervo medio subtus prominulo, venis lateralibus pinnatis ramosis; baccis oblongis. In Gujana gullica l. Perrottet. ち.

6+. I. Kunthianum DC. ramosissimum; ramis-articulatis; fol. subsessilibus oblique oblongis $\mathbf{3}-\mathbf{5}$-nerviis apice rotundatis basi cuneatis; haccis glohosis rachi immersis. $V$. trinervium Spr. Lorauthus viscifolius Kunth. In arboribus mrope Guayaquil. †.

6.5. I. yualrangulare DC. Iamosissimum; ramis subalatis; fol. lanceolato-ohlongis ohtusis subensiformibus 5-nerviis; baccis glohosis 4-seriatis sessilibus. Loranthus Kunth. V. rubrum var. Spr. In arboribus Nonae Granatue. ち.

66. V. oblongifolium DC. fol. oblongis ohtusis basi attenuatis subenervits aut basi sub-1-nerviis; spicis axillaribus. In montanis Guadelupae. ђ.

67. I. microphyllum Pohl in litt. ramis junioribus subcompressis; fol. lineari-ohlongis ohtusis basi attenuatis enerviis; vaginulis minimis; articulis sub-1-floris. In Brasilia $\iota$. Pohl. $\downarrow$.

\section{***** Ramis ramulisque 6-gonis.}

68. V. Eucleae Eclon et Zeyh. fol. oppositis sessilibus ovatis acutis ohtusisve glaucescentibus 3-5-nerviis; bracteis minutis oppositis. In Africa australi supra Eucleas. ђ. Baccae rubidae.

69. I. glaucum Eclon et Zeyh. ramosissimum; glaucum; fol. sessilibus ovatis vel orhiculatis mucronatis 3nerviis; floribus verticillatis; pedunc. 3-5-floris pseudo-umbellam formantibus. In Africa australi, in frutetis densis parasiticum. \$. Baccae rubrae numerosissimae.

\section{Species nou satis notae DC.}

70. $V$. purpureum $L$. ramis teretihus; fol. obovatis obtusis petiolatis; racemis axillaribus folio paulo longiorihus; floribus oppositis distantibus 3 -6-jugis; baccis obovatis. ins. Bahamensibus super Hippoman'm Mancinellam. Catesh. t. 95. fig. inf.

71. I. verticillatum I,um. caule tereti striato; ramulis verticillatis teretihus. Sloane hist. t. 201. f. 2. in ramis arborum Jamaicue. $\hbar$.

72. I. pauciflorum L. fil. caule striato; ramis alternis; fol. alternis sessilibus oblongis; floribus sparsis solitariis brevissime pedunculalis. In prom. b. spei, parasiticum. ђ. Baccae flavo-albae.

73. I. obscurum Thunb. caule erecto rugoso; ramis alternis; fol. ellipticis aveniis inaequalibus. In Prom. b. spei. . Baccae luteo-alhae.

7+. I. antarcticum Forst. fol. ohlongis ovatisve utrinque angustatis ohtusis enerviis; racemis termiualibus articulatis suh-5-floris. Tupeia antarctica Clam. In arboribus Novue Zeelandiae.

75. I. Kaempferi DC. In Japonia l. Kaempfer.

76. V. distichum Endl. prodr. $\mathrm{Fl}$. Norf. n. 118. In ins. Norfolk. $\hbar$.

\section{ELAEAGNUS Tournef. (1719).}

1. E. angustifolia $L$. fol. lanceolatis utrinque argenteo-lepidotis lucidis. Lam. ill. t. 73. f. 1. Guimp. t. 4. Schmidt oestr. Baumz. t. 134.135. B. H. 1156. E. hortensis M. B. E. orientalis et spinosia L. In Europa anstr., Sibiria et Oriente. $\downarrow$. Arhor 15-20-ped. Flor. fragrantes extus squamis micantihus argenteis, intus flavis.

2. E. pungens Thunb. ramulis apice spinescentihus; fol. oblongo-undulatis; floribus axillaribus binis. In Japonia. ந. Arbor 6-ped. Fol. subtus punctis ferrugineis.

3. E. triflora Roxb. fol. oblongis obtusis subtus lepidoto - ferrugineis; ramis cirrhoso-scandentibus subspinosis ; pedunculis axillarihus 3-floris. Burn. Zeyl. t. 39. f. 1. In Sumatra. ち. Caulis nagnus cortice atropurpureo. Flor. parvi alli.

4. E. latifolia Spr. inermis; fol. rotundato-ovatis argenteis. E. macrophylla Thunb. In Japonia. ђ. Arborea.

5. E. conferta Roxb. fruticosa; scandens; fol. alternis oblongo-aculminatis subtus squamis argenteis; flor. 
conferlis. In India orient. et Nepalia. . Frutex satis magnus. Flor. parvi straminei. Drupa succulenta rubra.

6. E. arborec Roxb. arborea; ramulis saepe spinosis acutis; fol. oblongis lateque lanceolatis integerrimis subtus argenteis; fructu cylindrico oblongo. In India orient. (Garrou:llills). t. Arbor magna. Fructus edulis.

\%. E. glabra Thunb. inermis; fol. ovato-oblongis acuminatis; floribus axillaribus subsolitariis. In Juponiat. †. Caul. arboresceus; rami rufescentes punctato-scabri. Fol. subtus rufescenti-squamosa.

8. E. Umbelluta Thunb. inermis; fol. obovatis obtusis; floribus axillaribus aggregatis; pellunculis nore longioribus. Thumb. jap. t. 14. In monte Falcona Japoniae. t. Frutex ramis ferrugineo-fuscescentihus, punctato-scabris. Pedunculi nutantes.

9. L. multiflora Thumb. inermis; fol. ohovatis obtusis; foribus axillaribus acrgregatis; pedunculis flore longioribus. In Japonia. t. Frutex ramis fusco-ferrugineis punclato-scahris.

10. E. fermuginea Rich. arisuscula; fol. ellipticis valde acuminatis integerrimis supra viridihus subtus ferrugineis; floribus fermgineis. Mém. d. 1. soc. d'hist. nat. 'Tom. 1. 2. p. 40 4. In Java lechen. ち.

11. E. acuminata Hort. Angl. inernis; fol. ovalibus acuminatis sul)undulatis supra glabresceutihus subthis argenteis. Link. en. Patria ignoti. 方.

12. E. aryentea Pursh; fol. ohlongis utrinque attenuatis supra lepidotis subtus argenteis; pedunculis nutantibus. Colla Hort. Hip. t. 28. Ad fl. Missuri. 支.

13. E. rigida Blume; inernis; fol. oblongo-lanceolatis utrinque acutis rigidis supra punctatis suhtus argenteis fusco-lepidotis; pedunculis axillaribus subternis 1-floris. In Java. ち. Aff. E. angustifoliae.

1. E. juranica Blume; caule scandente; ramis subspinosis; fol. ovali-oblongis ohtusiusculis basi rotundatis supra nitidis suhtus spadiceoarmenteis; pedunc. subumbellato-multifloris; fructu olivaeformi. In Java. b.
1.5. E. crispa Thunb. inermis ; fol. elliptico-oblongis obtusis basi acutinsculis crispato-undulatis supra punctatis subtus argenteis. In Japonia.

\section{MOLDENHAUERA Spr. (1525).}

1. M. scandens Spr. Caranilla Thunb. In Prom. b. spei. t. Frutex ramis flexuosis; fol. oblongis hirsutis subtus ferrugineis.

\section{GYROCARPUS Jac\%. (1763).}

1. G. americanus Jacq. am. t. 188. f. 80. fol. subcordatis trilobis indivisisque. Lam. ill, t. 850 f. 1. G. Jacquini Gaertn. t. 97. In sylvis Carthayenue. $\hbar$. Arbor elegans baccis rugosis.

2. G. asiaticus Willa. fol. ovatis trilohis indivisisque. G. Jacquini Hoxh. Corom. t. 1. In India orientali. $\bar{b}$. G. americano affinis.

3. G. spheropterus R. Br. fol. cordatis utrinque tomentosis subtus cinereis; alis druparum ohovato-oblongis. In Nor. Ilollandia. $\hbar$.

1. G. rujosus R. Rr. fol. floralibus subcordatis angulato-lrilobis, supra glabriusculis subtus tomentosis mollibus; lohorum sinubus latissimis. In Nova Hollandia. $\downarrow$.

\section{6\%6. SANTALIM Val. Cord. (1.561).}

1. S. myrtifolium Spr. fol. opposilis lanceolatis. Sirium Roxb. Corom. Hayne 10. t. 2. In montibus Circars. ち. Frutex magnus. Flor. parvi rubentes.

2. S. ovatum R. Br. fol. ovatooblongis acutis; pedunculis indivisis trifidisve. In Nov. Holl. t.

3. S. venosum R. Br. fol. ovalioblongis obtusiusculis glaucis; racemis brachiatis indivisis. In Nor. Holl. t.

\#. S. oblongatum R. Br. fol. angusto-oblongis obtusis coriaceis glaucis; racenis brachiatis. In Nova IIollandia. t.

5. S. Freycinetianum Gaudich. in Freyc. Voy. $t$. 45. fol. lanceolatis ob- 
tuxiusculis venosis complicato-subfalcatis; flor. racemosis roseis; caule arboreo. In ins. Hahou. Sanducensi. t.

6. S. ellipticum Gaudich. $l$. c. fol. ovato-oblongis obtusis hasi subcuneato-obliquis coriaceis subtus aveniis; floribus racemosis virescenti-flavescentilus; caule fruticoso. In ins. Wahou Sanducicensi. 古.

\%. S. obtusifolium R. Br. fol. oblongis obtusis coriaceis glaucis aveniis; racemis paucifloris. In Nova Hollandia. 方.

8. S. culbum L. fol. ovato-ellipticis; racemis axillaribus terminalibusque; squanis corollae rotundis obtuse acuminulatis. Rumph. 2. t. 11. Hayne 10. t. 1. Düss. 14. t. 1. In Thal. orient. t. Arbor magna. Flor. ferrugineo-purpurei. Baccae caeruleonigrae.

9. S. lanceolatum R. Br. fol. Ianceolatis elongatis utrinque attenuatis coriaceis glaucis aveniis; racemis bracliatis. In Nov. Holl. $\hbar$.

10. S. paniculatum Hook. et Arn.? ad Beech. Voy. p. 90. In ins. Wahou.

\section{8\%. FUSANUS L. Murr. (18\%t).}

1. F. spicatus $\boldsymbol{R}$. $\boldsymbol{B r}$. fol. linearioblongis ohtusiusculis ; spicis axillaribus compositis. In Nova Hollandia. t. Arboreus.

2. F. acuminatus P. Rr. fol. Ianceolatis uncinato-acuminatis; racemo terminali. In Nova Hollandia. 古. Frutex.

3. F. compressus I. fol. ovatis mucronatis petiolatis; panicula terminali decomposito-trichotoma aphytla. Lam. ill. t. 842. Colpon compressum Berg. cap. t. 1. f. 1. In Prom. $b$. spei. t. Frutex 6-ped.

4. F. crolssifolius R. Br. ramulis 4-gonis; fol. linearihus ohtusis sul)carnosis; pedunculis axillaribus paucifloris. In Nova Hollandia. $\downarrow$.

6\%'S. OCTARILLUNI Lour. (1790).

1. O. fruticosum Lour. In s!ylvis Coclinchince. $\hbar$. Frutex masnus, ramis scandentibus. Fol. alterna lanceolata glahra integerrima. Cor. alba. Baccae rubrae.
679. CATONIA P. Brown (1756).

1. C. Brownii Poir. C. maryintta st. Ilil. In Jamaica. t. Frutex fol. oppositis ovatis parallelo-venosis.

\section{SO. GYMNOSTACHYS R. Br. (1810).}

1. G. anceps R. Br. In Nover Hollandia. Planta aroidea radice tuberosa; fol. gramineis; scapo ancipiti.

\section{HTIXIA}

\section{BEFFONAA Sauray (17+7).}

1. B. tenuifolia $\boldsymbol{L}$. nervis calycinis rectis parallelis ; tuberculis seminum verruciformibus ohtusis. Koch. B. annua Gaud. Engl. Bot. 1313. In Helvetia, Gallia, Anglia et Tanria. 4. Flor. albi.

2. B.? perennis Pourr. caule apice ramoso; ramis filiformibus elongatis; striis calycinis arcuatis convergentibus. Lam. t. 8\%. f. 2. In Gallite et Fallesia. 24.

3. I3. Oliveriana Ser. caule apice ramoso; ramis filiformibus elongatis; striis calycinis rectis parallelis; fol. brevissimis squamaeformibus. In Persia circa leheran. $\odot$ ?

4. A. macrocarpa Ser. caule ramosissimo dichotomo; ramis filiformibus lougissimis; sepalis ovatis obtusis; striis rectis parallelis; seminilus globoso-compressis margine echinatis. In l'ersia. 4.

\section{HYPECOUM Dioscor.}

1. H. procumbens $L$. siliquis articulatis compressis arcuatis; petalis trilobis, externis dorso glabris. Lam. ill. t. 88. schk. t. 27. In agris maritimis Lasituniae. $\odot$. Flor. flavi.

2. H. littorale Wulf. in Jacy. Coll. et ic. rur. t. 309. siliquis articulatis compressis arcuatis; petalis omnibus integris lineari-spathulatis externis dorso pubescentibus. In maritimis Curinthiae. $\odot$. Differt a H. procumhente petalis exterioribus majoribus.

3. H. imberbe Sibth. gruec. t. 156 . siliquis articulatis compressis arcua- 
Us ; sepalis dentato-fimbriatis; petalis ommibus imberbibus. In ins. Cypro. $\odot$. Cal. dentato-fimbriatus.

4. H. patens Willd. Hort. ber. $t$. 5. siliquis articulatis teretilus curvatis; petalis glahris exteriorihus subintexris cordiformibus, interiorilus tripartitis. Mnemosilla aegyptiaca Forsk. In desertis prope Alexundriam. $\odot$. Petala flava.

5. H. pendulum $L$. siliquis nodosis teretibus pendulis; petalis glabris 2 exterioribus ovato-ohlongis pendulis, 2 interioribus 3-partitis. Mill. ic. t. 250. f. 1. In ayris IIspaniae. $\odot$. Petala pallide flava.

6. H. erectum I. siliquis inarticulatis erectis compressis; petalis glabris exterioribus cuneiformibus sub3-lubis, interioribus 3-fidis, loho medio parvo. Amm. Rulh. t. 9. In Dahuria. $\odot$. sepala minima.

\%. H. aequilobum Viv. Fl. Lib. $t$. 3. $f$. 3. glaherrimum; fol. pinuatis ; foliolis incisis lineari-filiformilus; petalis omnihus unguiculatis, majoribus trilohis, minoribus 3-fidis; Iaciniis linearibus; siliquis erectis. In Italia. $\odot$. Petala lutea.

\section{HAMAMELIS L. (17.51).}

1. H. virginica Pursh; fol. ohovatis acutis dentatis sinu parvo cordatis. Wangenh. t. 29. f. (i2. Kern. t. 617. Duh. t. 114. Catesh. III. t. 2. In saxosis Americae septentr. t. 5ped. Flor. lutei. H. chinensis (Loropetalum $\mathbf{R}$. Br.) videtur varietas $\mathbf{H}$. virginicae.

\section{DICORYPIIE Thouars (1806).}

1. D. stipulacea St. Hil. Thouurs Afric. austr. $t$. $t$. D. I'monarsii $R$. et $s$. In Malagascar. Frutex fol. alternis ohlongis integerrimis; stipulis ovatis inaequalibus; florihus fasciculatis terminalibus.

\section{PAGAMEA Aubl. (1775).}

1. P. gujanensis Aubl. guj. t. 1 H. In Gujanu et Brosilia. $\hbar$. Frutex fol. oppositis oblongis aculis venosis; racemis axillaribus terminalibusque; floribus albis.

\section{SCHEFFERA Jacq. (1763).}

1. S. completa $\mathbf{S w}$. florihus 4-petalis axillaribus. Sw. prodr. Ejusd. FI. ind. t. 7. f. A. Sloane Hist. t. 209. f. 1. In Jamaica et Hispaniola. $\downarrow$. Arbuscula s. frutex. Flor. pallidi dioeci.

2. S. lateriflora $\mathbf{S} w$. florihus lateralibus apetalis. sw. Flor. ind. t. 7. f. 13. In Hispaniola. ち. Arbuscula trunco orgyali.

\section{NERTERA Banks. Gaertn. (1788).}

1. N. depressa Smith ic. ined. $t$. 23. caespitosa; caulibus radicantibus; fol. ovatis pedunculatis integris. Tratt. Arch. t. 129. x. repens. Fi. peruv. t. 90. Firthrodanum alsine forme Thouars F'lor. Tirist. t. 13. In Nora Granata. $\odot$. Parva repens. Cor, viridis.

2. Y. assurgens $R$. et $\boldsymbol{S}$. caulibus repentilus; fol. subsessilibus marginihus calloso-undulatis. Erythrodanum majus Thouars Fl. Trist. t. 42. In ins. 'Tristun d'Aunna. Habitu Cerastii aquatici.

3. N. tetiasperma Humb. fol. ovatis petiolatis integerrimis; drupis 4pyreuis. In Quito. $\odot$.

\section{S8. ANTIARIS Lechen. (1S12).}

1. A. toxicaria Lechen. Ann. Mus. 16. $t$. 22. fol. subovato-ellipticis asperis; pedunculis solitaris. Blume Rumphia t. 25. In Java. ђ. Arhor magina 100-ped.

2. A. innoxia Blume Rumphia $t$. 57. fol. elliptico-ohlongis acutis margine revolutis subtus reticulato-venosis ferrugineo-tomentosis. A. toxicaria Hook. B. H. t. 17. In Jac a. 方. Arbor 60-80-ped.

\subsection{MORUS Virg.}

1. M. allor I. fol. profunde cordatis hasi inaequalibus ovatis lohatisve 
inaequaliter serratis laeviusculis. $\mathbf{W}$. schk. t. 290. Guimp. t. 238. M. tatarica Pall. In China et Persia. †. Fructus albus.

2. M. rubra $L$. fol. cordatis ovatis acuminatis trilobisve aequaliter serratis scabris subtus pubesceuti-mollibus; spicis fenineis cylindricis $\mathbf{W}$. Plukn. t. 246. f. t. Dendr. brit. t. . In Canulu et Floridr. t. Amenta longitudine Betulae albae. Arbor poly gama.

3. M. nigra $L$. fol. cordatis ovatis lobatisve inaequaliter dentatis scahris. Blackw. t. 126. Kern. t. 24t. Duls. arh. III. t. 1. In maritimis Italice et Persiue. t. Fructus niger.

t. H. indica I. fol. ovato-oblonyis hasi inaequaliter indivisis semitrilohisve inaequatiter serratis glabris. VV. Rumph. 7. t. 5. Hheede 1. t. 49. In India orientali. $\hbar$. M. albae affinis.

5. M. latifolia Poir. fol. cordatis indivisis ovatis serratis scahris reticulato-venosis. IV. In ins. Borboniue. ђ. Fol. 4-pollicaria.

6. 11. anstralis Poir. fol. ovatis serratis indivisis scabris; baccis barbatis. In ins. Borboniae. ち. Siyli barbati.

\%. M. Mauritiana Jac\%. ic. rar. t. 61\%. ejusd. Fraym. 9. t. 5. f. 3. fol. oblongis utrinque attenuatis indivisis integerrimis. In ins. Manritii. $ち$.

8. M. celtidifolia Humb. et liunth; fol. ovato-oblongis longissime acuminatis hasi rotundatis argute serratis 3-nerviis supra scabrisculis. In Quito spontunea et culta. $\hbar$.

9. H. corylifoliu Humb. et Kunth; fol. subrotundo-ovatis acuminatis basi rotundatis argute serratis $\mathbf{3}$-nerviis glabris. In Quito. $\hbar$.

10. M. constunfiuopolitana Poir. fol. cordatis late ovatis indivisis serratis trinerviis utrinque glabris; axillis venarum sublus villosis. M. byzantina sieb. In Thracice et Cretr.

11. M. insularis sipr. fol. oblongis obtusis hasi attenuatis integerrimis triplinerviis glaberrimis. In ins. Marchionis de Heulosa Forst. $\hbar$.

12. M. scubra Willd. fol. cordatis 5-fidis ntrinque scahris: laciniis acuminatis hasi attemuatis aequaliter serratis. M. canadensis Poir. In Amer. bor. t.

13. M.juvanica Filume ; fol. ovaliohlongis acutis basi leviter subcordit- tis ad apicem exigue denticulatis; culule fruticoso. In Java. ち. Flor. masc. 3-andri.

\section{PLANERA J. F. Gmel. (1791).}

1. P. Richardi Michx. fol. subcordato-oblongis crenato-dentatis subsessilihus scaherrimis; fructibus laevibus. Uluus nemoralis Ait. U. polygama hich. Rhamnus carpinifolius Pall. ross. 2. t. 10. In Cancaso austrati et Amer. bor. $\hbar$.

2. P. Abelicea R. et S. fol. ellipticis aequaliter serratis basi inaequalibus subtus tomentosis discoloribus; fruclu inflato gihbo. Ulmus sn. In Creta. ち. Arbor magna.

3. P. Gmelini Michx. fol. manifeste petiolatis oblongo-ovalibus sensim angustatis basi obtusis aequaliter serratis; caps. scabra. P. aquatica Gmel. In Carolina. ち. Arbor magna facie Ulmi.

\section{CRUCITA Loefl. (155s).}

1. C. americana Lam. C. hispanica Willd. In Cumana. ђ. Caul. 4-5-ped. Fol. opposita lanceolata integerrima. Flor. spicati minimi.

\section{MYRICA L. (1737).}

1. M. Gale $L$. fol. lanceolatis apice suhserratis hasi cumeatis ; amenti squamis acuminatis. Fl. Dan. 327. EngI. Bot. 563. schk. t. 322. Guimp. t. 200. In turfosis Germaniae et Amer. boreal. . Frutex humilis.

2. M. cerifera $L$. fol. oblongis hasi attenuatis apice subserratis; amenti squamis subacutis; baccis globosis. IV. Wangenh. am. t. 10I. Calest. t. 69. Plukn. t. 48. f. 9. In Amer. bor. $\hbar$.

3. M. pensylvanica Lam. fol. ohlongis basi attenuatis grosse serratis; amenti squamis acutis; baccis glohosis. W. M. carolinensis Wangenh. Amer. t. 102. Catesl). t. 13. A Pensylvania ad Floridam. t. 4-5-ped. +. M. mubscens Humb. et bonpl. tol. lanceolatis utrinque attenuatis ad- 
presso-serratis subtus pubescentibus; squamis amenti linearibus; baccis subgibbosis. W. In Nova Granata. ‡, Fol. sesquipollicaria.

5. M. Fuya Ait. fol. elliptico-lanceolatis subserratis; amentis masculis compositis; drupa nucleo 4-loculari. In Lusitania et Madera. $\hbar$.

6. M. segregata Jac\%. ic. $t$. 625 . polygama; fol. lanceolatis integerrimis reticulato-venosis; amentis paucifloris laxis. W. In Brasilia. 卢.

7. M. serrata Lam. fol. lanceolatis inaequaliter acuminato-serratis; anentis elongatis laxis. Burm. Afr. t. 98. f. 1. Plukil. t. 424. f. 3. In Prom. b. spei. Ђ.

8. H. tuercifolia $\boldsymbol{L}$. fol. oblongis opposite simuatis. Jacq. Frag. t. 1. f. 4. Comel. Hort. t. 31. In Prom. b. spei. ђ.

9. M. cordifolia $L$. fol. sulncordatis serratis sessilibus. Walt. Hort. t. 3. Pluku. t. 319. f. \%. Burm. Afr. t. 98. f. 3. In Prom. b. spei. ち.

10. Mr. mexicanu Villd. fol. obIongis hasi attenuatis integerrimis apice subcrenatis glahris; amentis compositis; partialibus globosis ; squamis ohsoletis. In Mexico. 古

11. H. xalapensis Ilumb. et liunth; fol. oblongo-lanceolatis hasi cumeatoangustatis integerrimis aut apice serratis glabris nitidis; nervo medio pubescente. In Mexico. 方.

12. M. macrocarpa liumb. et Kunth; fol. lanceolatis serratis subcoriaceis subtus tenuissime pubescentibus; amentis androgynis axillaribus solitariis. In Perucia. 古.

13. N. arguta Humb. et Kunth Nor. Gen. $t$. 98. fol. oblongo-lanceolatis basi angustatis argute serratis bubtus pubescentibus; anentis androgynis. In Nova Granata. 方.

14. M. polycarpa Humb. et Kunth; rol. lanceolatis serratis basi integerrimis et angustatis glabris; nervo venisque subtus puberulis. In Nova Gramata. $ち$.

15. H. caracasana Humb. et Kunth; fol. approximatis ellipticis utrinque acutis serratis coriaceis glabris; nervo puberulo; amentis femineis axillaribus. In Caracas. ち.

16. M. esculentı Hamilt. fol. spathulatis integerrimis coriaceis nitidis; amentis $\delta$ axillaribus; caule arboreo. In Nepalia.
17. M. octandra Hamilt. fol. oblongis apice attenuatis subintegerrimis glalıris; amentis $\delta$ solitariis petiolo longioribus floribus 8-audris. In $\mathrm{Ne}$ palia.

\section{TIIIGNIA.}

\section{ROSCIA Thunb. (179t).}

1. R. undulata Thunb. In Prom. b. spei. ち. Arlior 6-ped. Fol. terua foliolis ellipticis sessilibus integris acutis. Flor. cinerei minutissimi.

\section{PACHYSANDRA Michx. (1803).}

1. P. procumbens Michx. Amer. t. 45. In Amer. bor. Herba spithamea caule adscendente; fol. ovatis apice crenatis; spica laxa basilari.

\section{HYMENELLA DC. (1821).}

1. II. moeluringioides DC. In Mexico. 2.? Buffonia tenuifolia Moc et Sessé fl. mex. ined. ic. Caules debiles; fol. linearia acuta glabra; pedicelli solitarii 1 -flori axillares; flores parvi albi.

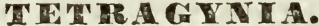

\section{SAGINA L. (1737).}

1. S. cerastoilles $\mathbf{S m}$. caule difftso dichotomo; fol. spathulatis ovatisque recurvis; pedunculis fructiferis reflexis; petalis obcordatis; laciniis calycinis lanceolatis acutis. DC. \$m. Engl. bot. 166. In Anc;lia. $\odot$.

2. S. procumbens L. glabra; ranis procumbentihus; fol. linearibus mucrouatis; pedunculis fructiferis adscendentihus; laciniis calycis subrotundis. DC. Eugl. hot. 880. sichk. t. 27. Sturm t. 30. In agris et pascuis Europac. $\odot$. Herba laete virens.

3. N. ciliata Fries Su. Bot. 562. caule diffuso; fol. linearihus aristatis hasi ciliatis; pedunculis defloratis apice hamatis; fructiferis erectis; sepalis exterioribus 2 acuminato-mucroua- 
tis; var. $\beta$. fol. basi ciliis paucissimis Koch. S. depressa schulz. Starg. p. 10. In agris et arvis Europae. $\odot$. 4. S. bryoides Fröhl. repens; fol. linearibus mucronatis denticulato-ciliolatis patentissimis; pedunculis scapiformibus erectiusculis. In subalpinis Europae. $\odot$.

5. S. apetala $\boldsymbol{L}$. caulibus adscendentilus ramosis; fol. linearibus basi ciliatis; pedunculis defloratis semper erectis. Gmel. had. t. 1. Engl. bot. 881. Curt. Lond. t. 14. In agris et pascuis Europae. $\odot$. Petala minima.

6. S. stricta Fries; caule a basi ramoso ramisque erectis; fol. linearibus glabris apiculatis; pedunculis defloratis semper erectis. $\mathbf{S}$. maritima Don Engl. bot. 2195. In Europa ad littora maris. $\odot$.

\%. S. Quitensis Humb, et Kunth; caulibus filiformibus procumbentibus; fol. subfalcatis; pedunculis axillaribus 1-floris supra medium bracteatis; fructiferis elongatis rectis; floribus subpentandris. In ripa arenosa RioBlanco. $\odot$.

8. S. fasciculate Poir. caulibus repentibus radicantibus articulatis; ranis suberectis; fol. fasciculatis secundis; pedunc. axillaribus 1-floris. Circa Algeriam. 24.

9. S. filiformis Pourr. caulibus electis ramosissimis geniculatis; fol. linearibus glabris; pedunculis axillaribus terminalibusque dichotomis. In Pyrenacis. $\odot$.

10. S. urceolata Viv. fl. cors. ๆ. 3. glabra; fol. subulatis aristatis in urceolum membranaceum connatis; pedunc. axillaribus 3 -floris; sepalis ovatis; floribus apetalis. Viv. In montibus Corsicae australis. $\odot$.

\section{9\%. MOENCIIA Ehrh. (1788).}

1. M. erecta Ehrh. caule subbifloro; floribus 4 -andris. Sagina $L$. sm. Engl. bot. 609. Vaill. t. 3. f. 2. M. glanca Pers. In pascuis et ericetis Europae. $\odot$.

\section{RADIOLA Dill. (1718).}

1. R. linoides Gmel. Linum $\boldsymbol{R} a-$ diola L. R. millegrana Sm. Vaill. bot. par. 4. f. 6. In arenosis humi- dis Europae. ๑. Planta pusilla caule dichotome ramoso. Hol. opposita minima. Flor. albi.

\section{BULLIARDA DC. (1799).}

1. B. Vaillantii DC. pl. grass. $t$. 17. caule erecto dichotomo; fol. oblongis acutis; pedicellis folio longioribus. Tillaea aquatica Lam. T. Vaillantii Willd. Vaill. bot. par. t. 10. f. 2. In humidis umbrosis Galliae. $\odot$. Cor. pallide carnea.

2. B. aquatica DC. caule erecto subdichotomo; fol. lineari-lanceolatis; florihus sessilibus aut brevissime pedicellatis. Tillaea aquatica L. In Sueciae, Noruegice et Germaniae humidis. ○. B. prostrata; caule procumbente. Tillaea sclik. in Ust. anu. 2. t. 3. Fl. Dall. 1510.

\section{\%00. BRUCEA J. S. Mill. (1780).}

1. B. antidysenterica Mill. foliolis integerrimis subtus in nervis ferrugineo-villosis; racemis simplicibus spiciformibus. Bruce it. ed. gall. t. 43. B. ferruginea L'Her. st. t. 10. In Abyssinia. ち. Frutex fol. impari-pinnatis.

2. B. gracilis DC. foliolis serratis utrinque tomentosis; racemis simplicibus spiciformilus. Ailantes Salisb. In India orientali. ち. Stam. 5-6.

3. B. sumatrana Roxb. foliolis serratis subtus villosis; racemis saepius compositis. Rumph. 7. t. 15. Gonus amarissinus Lour. B. sumatrensis spr. In Sumatra, Moluccis, China et Cochinchina. ち.

\section{\%01. MYGINDA Jacq. (1763).}

a. Fol. subtus pubescentibus. DC.

1. M.? microphylla DC. fol. ovato-oblongis obtusis integerrimis subtus ramulisque pubescentibus ; fructibus solitariis subsessilibus stylo filiformi superatis. Ilex microphylla spr. In st. Domingo. $\downarrow$.

2. M. rotundata Lam. fol. ovatosubrotundis creuatis subtus pubescen- 
tibus petiolatis; pedunculis subsimplicihus pancifloris. DC. In Antillis. $ち$.

3. M. Uragoga Jacq. am. t. 16. fol. ovatis subcordatisve subsessilibus acuminatis serratis pubescentibus; corymhis his trifilis DC. Houtt. syst. t. 19. f. 6. Lam. ill. t. 76. Browne jam. t. 1\%. f. 1. In maritimis Americate calidioris et ins. st. Martini. 占.

\section{b. Fol. utrinque glabris DC.}

t.' M. ilicifolia Lam. fol, ovatosubrotundis dentato-spinosis glahris subtus pallidis; pedunc. axillaribus furcatis; fructu stylo persistente mucromato. DC. In st. Dominyo. 古.

5. M. my/rsinoides Ilumb. et linnih N. Gen. t. 620. fol. suldistichis ellipticis acutis basi rotundatis serrulatis hreviter petiolatis glahris; floribus 5-andris. In Peruria. 5 .

6. M. myrtifolia Nutt. fol. oblongis obtusis serratis margine revolutis glahris; pedunc. hrevissimis subsolitariis; stylo longo 4-lobo. Ilex myrsinites Pursh. In mont. Amer. bor. t.

\%. M. pallens Sm. in Rees Cycl. fol. ellipticis ohtusissimis crenatis laevilus fere sessilibus; pedunculis bifurcatis; stylo apice 4-lobo. DC. In Antigua. †. Pelala undulata.

8. M. Rhacoma $S u$. ind. fol. lanceolato-ovatis ohfusiusculis crenatis subpetiolatis glahris; pedunculis dichotomis cymoso-umhellatis; stylo hrevi apice 4-Joho. DC. Hhacoma Crossopetalum L. Browne jam. t. 17. f. 1. In Jamaica, St. Domingo et prov: Cumana. ந.

9. M. Intifolia Su. int. fol. ellipticis crenatis laevilus hreviter petiolatis; pedunc. dicholomis paucifloris; stiumatihus 4 sessilibus. M. integrifolia et Guadelupensis. Spr. In Martinicre et st. Dominyo. t.

10. M.? brasiliensis. sm. syst. fol. ohlongis utrinque attentatis coriaceis infererrimis nitidis reticulatis; paniculis axillaribus folio brevioribus. In Brosilia. t.

11. M.? Gongohna DC. fol. oblongis hasi rotundatis apice hreviter acuminalis marginatis remote serratis; forihus axillarihus sessilihus; ramis teretilus. Cassine Gongona Mart. in Isis 1824. In Brasilia. நூ.

\section{ILEX Lonicer (1563).}

1. I. aquifolium $L$. fol. ovatis acutis nitidis undulatis dentatis; dentibus et apice spinosis; pedunc. axillarihus 1-floris hreviluss. Engl. hot. 496. Dietr. Forst. t. 56. Fl. Dan. 508. I. echinatum Mill. serratum Desf. In umbrosis Europae. Ђ. Frutex decumhens vel erectus 1 -3-ped. Baccae coccineae in hortis sacpe luteae.

2. I. brulearicu Desf. fol. ovatis acutis nitidis planis inlegris aut dentato-spinosis. I. aquifoliun $\delta$. Lam. I. Maderensis IVilld. In ins. Balearicis et Madera. $\frac{7}{}$.

3. I. Perulo Ait. fol. ovatis cum acumine integris aut parcissime dentatis nitidis; 1. Madereusis Lam. $\beta$. obtusa Duham. ed. nov. t. 10. In Maelera. ち. Baccae ruhrac magnae.

4. I. canuriensis Poir. fol. ovatolanceolatis planis subacutis integerrimis nitidis; pedunculis petiolo longioribus. In ins. Canuriis. t. Baccae nigrae.

5. I. opaca Ait. fol. ovatis planis coriaceis acutis sinuato-dentatis spinosis glaluris non lucidis; calycis dentibus acutis. I. quercifolia Meerh. ic. 2. t. 5. Plukn. t. 196. f. 3. In lutmillis a Pensylrania ad Canudam. ţ. Baccae rubrae.

6. I. laxiflora Lam. fol. ovatis sinuato-tenfatis spicosis coriaceis ylahris; stipulis subulatis; calycis dentihus acutis. In Curolina. $\hbar$. Baccae flavae.

7. 1. Chinensis Sims B. M. $20 \pm 3$. fol. oblongis utrinque attenuatis margine cartilagineis denticulatis; dentihus vix pungentihus; petiolis costaque media villosa. In China. t).

8. I. Dahoon Wall. fol. Ianceolato-ellipticis subintegerrimis margine revolutis; costa media petiolo ramulisque villosis; pedunc. corymboso-paniculatis. I. Cassine Willd. Hort. herol. t. 31. B. laurifolia Nult. In paludosis a Carolina ad Florialam. ţ.

9. I. Cussine Ait. lol. ovalo-lanceolatis argute serratis planis; costa media petiolo ramulisque glahris. Aquifoliun carolineuse Catesh. 1. 31. I. caroliniana Mill. I. cassinoides Lí. In umbrosis Carolinar et Floridae.

10. C. angustifolia Hilld. en. fol. lincari-lanceolatis apice serratis margine revolutis; costa media ramulis- 
que glabris; cymis lateralibus pedunculatis. I. myrtifolia Walt. I. rosmarinifolia Lau. $\beta$. ligustrifoliu Pursh; fol. oblongo-obovatis omnibus integerrimis. In yaludosis a Virginia ad Georgiam. ђ.

11. I. vomitoria Ait. fol. oblongis ellipticisve utrinque obtusis crenatoserratis ramulisque glabris; floribus umbellatis. Cassine vera Catesb. t. 57. C. peragua Mill. ic. t. 83. f. 2. I. ligustrina Jacq. ic. t. 310. I. Casseana Michx. I. religiosa Bart. I. floridana Lam. In maritimis Carolinue et Floridae. 古.

12. I. ovalifolia Meyer; fol. ovalihus serrato-crenatis coriaceis margine subrevolutis glabris; floribus racemosis. DC. In Essequebo. ந.

13. I. elliptica H. et K. non Don. fol. ellipticis utrinque rotundatis apicem versus argute serrulatis crasse coriaceis glaberrimis supra nitidis; pedunculis 1-floris ramulisque hirtellis. In Peruvia circa Contumusa. \$.

14. I. scopulorum $H$. et k. fol. ovato-suhrotundis et obovatis apice rotundatis obsolete crenatis coriaceis supra glahris nitidis; pedunc. 5-7floris ramulisque hirto-pubescentibus viscosis. In Quito. ‡.

1.). I. rupicola $H$. et $K$. fol. subrotundo-ellipticis obtusis crenato-serratis crasso-coriaceis glaberrimis utrinque nitidis; pedunc. sub-3-floris. Prope Loram. $ђ$.

16. I. myrtifolia Lam. ill. fol. ovatis utrinque acutis integerrimis; foribus fasciculatis lateralibus dioecis.

In ins. Caribais. †. Facies sideroxyli.

17. I. salicifolia Jacy. Coll. .5. $t$. 2. f. 1. fol. elongato-lanceolatis utrinque acuminatis coriaceis glahris medio denticulatis; cymis axillaribus. In ins. Mauritii. $\hbar$.

18. I. dipyrena Wall. in Roxb. Fl. ind. fol. ohlongis acuminatis hreviter petiolatis laevibus vix undulatis remote serratis; serraturis spinosis; baccis dipyrenis. In Nepalia. Don. $\hbar$.

19. I. odorata Hamilt. in Don Nep. fol. ovali-ohlongis ohtuse acuminatis crenulatis petiolatis; umbellis sessilihus glomeratis. In C'hittagong. $\hbar$.

20. I. nepalensis; fol. ellipticis integerrimis utrinque acutis; umbellis globosis. I. elliptica Don prodr. (non (iunth). In Nepalia. $b$.
21. I. Paltoria Pers. fol. ovalihus crenatis coriaceis glabris confertis vix petiolatis; ramulis subvelutinis. In Peruvia et Nova Granatu. ち. Stigma magnum 4-gonum.

22. I. Macoucoua Pers. fol. ovalibus subovatis apice interdum ohtuse attemuatis emarginatis coriaceis glabris integerrimis; pedunculis cymosis. Macoucoua gujanensis Aubl. Guj. t. 34. I. acuminata Willd. Cassine maurocenia sieb. In Gujana, Cayenna, st. Domingo et Mauritii. $\hbar$.

23. I. paruguariensis st. Hil. glaherrima; fol. cuneato-lanceolatoveoblongis ohtusiusculis remote serratis; pedunc. multipartitis; stigmate 4-10bo.

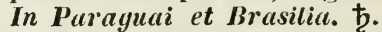

24. I. cymosa Blume; fol. oblongis olituse acuminatis integerrimis glabris; cymis dichotomis. In Java. ఫ. Arbor 50 ped. alta. Bacca 8-pyrena.

25. I. spicata Hlume; fol. oblongo-lanceolatis integerrimis coriaceis glaherrimis; spicis axillarihus. In Java. ち. Frutex passim parasiticus. Bacca 6-8-pyrena.

26. I. integra Thunh. fol. cuneato-oblongis obtusis integerrimis coriaceis glaberrimis subaveniis; pedunc. confertis axillaribus $\mathbf{1}$-floris. In $\mathbf{J a}$ ponir. $\hbar$.

27. I. rotunda Thunb. fol. inferioribus ohovato-rotundatis obtusiusculis, superiorihus elliptico-oblongis integerrimis glabris umbellatis axillaribus. In Japonia. $\hbar$.

28. I. macrophylla Blume; fol. ovato- vel ovali-oblongis ohtusis basi acutis serratis coriaceis glabris supra lucidis; racemis axillarihus; ramis glabris striatis. Blume ex Japonia sub nomine I. latifoliae accepit. ఫ.

29. I. triflora Blume; fol. ovalilanceolatis utrinque acutis serrulatis aveniis in nervo medio ramulisque puberulis. In Japonia. $\hbar$. Aff. I. chinensi.

\section{Species dubiae.}

30. I. cassinoides Dum. Cours bot. cult. 6. fol. alternis ellipticis brevissime petiolatis integerrimis mucronulatis supra nitidis subtus pallidiorihus coriaceis sempervirentihus. Coll. hort. rip. Patria ignota. \$. 
31. I. obcordata Sw. fol. obcordatis coriaceis integerrimis nitidis enerviis; stipulis minimis aculeatis. DC. In montibus caeruleis Jamaicae. $\downarrow$.

32. I. emarginata Thunb. fol. obovatis emarginatis crenatis margine revolutis; floribus axillaribus binis pedicellatis. In Japonia prope Nauyasaki. ち.

33. I.? cuneifolia $I_{\text {. }}$ fol. cuneiformilus glabris aequaliter 3-cuspidatis. In Amer. merid. †. B.bonariensis; fol. ovato-cuneiformibus glabris 3-cuspidatis; lobo medio Iongiore. Ad Buenos Ayres. $\downarrow$.

34. 1. madayascariensis Lam. fol. ovatis acutis spinosis glabris; pedicellis axillaribus 1-floris; loaccis ovatis dispermis. In Madagascar. ち.

35. I. asiatica L. fol. lato-lanceolatis obtusis integerrimis. In India orientali. $\hbar$.

36. I. crenata Thunb. fol. ovatis crenatis obtusis; pedunc. rameis sparsis subtrifloris ceruuis. In Japonia.

37. I. serrata Thumb. fol. ovatoacutis ciliato-serratis; pediculis axillaribus solitariis 1-lloris cermuis. In Japonia. 古.

38. I. latifolia Thunb. fol. ovatis obtusiusculis serratis supra nitidis margine revolutis; pedicellis aggregatis. In Jiponia. t.

39. I. lonyifolia Neuu.bras. 2. Bot. Zeit. 1S21. fol. oblongis spinosis utrinque sexsinuatis unelatis apice 3-den-

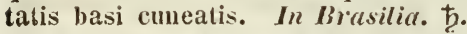

40. I. bumelioirles II. et K. ramulis glabris; fol. obovatis mucronatis basi decurrentibus subintegerrimis coriaceis supra nitidis; pedmuc. $3-4$, unifloris. In Quito prope Loxam. 古.

41. I. myricoides $H$. et $\mathbf{K}$. fol. oblongis aculis basi cumeatis serrulatis subcoriaceis ramisque glabris; pedunc. 3-floris; floribus 4-petalis. In montosis Novale Girantale. t.

12. I. hippocrateoides $\boldsymbol{H}$. et $\boldsymbol{K}$. fol. oblongis subacmminatis crenatoserrulatis reticulato - venosis coriaceis subnilidis ramulisque glabris; pedunculis dichotomo-3-5-floris; floribus 4-petalis. In America merial. t.

4i3. I. laurina H. et hi. fol. lanceolato-oblongis acuminatis basi acutis remote serrulatis reticulatis coriaccis ramulisque glabris; pedunc. 1-1 3-floris longitudine petioli. In Amer. anstr. $\hbar$.

\section{r03. RIQUERIA R. et P. (1798).}

1. R. avenia $R$. et $P$. peruv. 1. p. 70. In nemoribus Peruviae. $\hbar$. Frutex 15-ped. Rami oppositi. Fol. oblonga opposita avenia. Cor. Alava subcarnosa.

\section{CICCA L. (1767).}

1. C. disticha spr. fol. pinnatis; foliolis alternis ovato-ohlongis; racemis lateralibus. Averrhoa acida $L_{\text {. }}$ Phyllanthus Iongifolius Jacq. Frankia ramiflora Bertero. In Ind. orient. et occid.

2. C. nudiflora Lam. fol. pimmatis; foliolis ovatis; floribus in petiolo communi glomeratis. In Java. 卢.

\section{\%05. POTAMOGETON Diose.}

\section{A. Germanici.}

Sect. I. Pectinati: caules teretes; fol. tennissima conformia ligula adilata. Flores glomerato-spicati.

1. P. marinus L. fol. lineari-subulatis aculissimis, basi arcte vaginantibus; nuculis rugosis obovatis. Dict. Cah. 27. P. pusillus Bocc. sic. t. 27. f. 5. P. maritimus Plukn. t. 216. f. 1. P. piliformis Pers. In maritimis Germaniae. 方.

2. $\boldsymbol{P}$. pectinatus $\boldsymbol{L}$. fol. linearibus sulsetaceis aculissimis 1-nervihus; nuculis lumatis laevibus. Fl. Dan. 1746. Vaill. par. t. 32. f. 5. P. zosteraceus Fries. In staynis et fluviis. 4.

sect. II. Compressi; caules compressi; fol. linearia conformia; ligulae discretae.

3. P. musillus $L$. caule filiformi subcompresso; fol. linearibus $3-5-$ nervibus; nuculis oblongo-ellipticis cariuatis. P. compressus Koch lil. P. $\alpha$ major et $\beta$. minor Fries. P. pus. $\gamma$. tenuissimus Koch. syu. Vaill. t. 32. f. 4. E. B. 215 . FI. Dall. 1451. Jillnaea II. t. 4. f. 5. In ayuis staynantibus, rivis et fluviis. 4. 
4. P.obtusifolius M. et K. FI. caule compresso ohtusangulo; fol. hasi angustatis 3-5-nervihus obtusis; spicis ovatis; nuculis ovalibus carinatis. Chan. Limnat II. t. 4. f. 8. p. gramineum sim. E. B. 1253. P. compressum Roth. In lacubus et piscinis. 4.

5. P. acutifolius Ehrh. caule complanato-alato; fol. linearibus multinervihus rotundato-acuminatis ; nuculis reniformihus arcuato-carinatis. Rchb. ic. 309. Linnaea 11. t. 4. f. 9. Fl. Dan. 1747. P. compressum DC. P. laticaule Wrahl. In aquis stagnantibus et rivulis. 4.

6. P. compressus $I$. caule complanato-alato; fol. linearibus multinervihus nucronulatis; spicis cylindricis Ionge pedunculatis; nuculis obovatis obtuse carinatis. Loes. pruss. t. 66. P. Zosteraefolius Schum. Rchb. ic. 308. Fl. Dan. 1805. P. complanatus Willd. P. cuspidatus Schrad. ex Koch. In ayuis stagnantibus. 4.

Sect. III. Ineterophylli; fol. difformia variabilia; flores in spica spadiciformi aequaliter spars a.

\%. P. crispus $L$. fol. semiamplexicaulibus lineari-oblongis 3-nerviis unrulatis serratis; nuculis rostratis. Fl. Dan. 927. E. B. 1012. Limnea II. t. 5. f. 12. In aquis stagnantibus. 4.

8. P. perfolirtus $L$. fol. cordatoamplexicaulibus obovatis nervosis planis serrulatis; nuculis lunatis apiculatis ecarinatis. Loes. pruss. t. 65. Fl. Dall. 196. E. B. 163. Linnaea II. t. 5. f. 13. P. Loeselii R. et S. Cum mraecedenti. 4.

$9 . P$. lucens $\boldsymbol{L}$. fol. suhmersis in petiolum brevem attenuatis ovali-Ianceolatis lucentibus cuspidatis serrulatoscabris; nuculis lunatis ecarinatis. Fl. Dan. 195. E. B. 376. P. serratus Wel. C'um maecedenti. 24. Var. foliorum magnitudine et latitudine.

10. P. praelongus Wulf: fol. semiamplexicaulibus oblongo-lanceolatis nervosis apice naviculatibus; nuculis Ianatis acutato-carinatis. Rchb. ic. 323. Fl. Dan. 1687. P. acuminatus Wahlenb. P. lucens Web. P. flexicaulis Dethard. In fluviis et lacubus. 4.

11. P. rufescens Schrad. fol. basi altenuatis demersis lanceolatis sub- sessilibus summis patentibus petiolatis; nuculis acute carinatis. Hochlo. ic. 322. P. serratus liotli. P. fluitans sm. E. B. 2268. P. obtusus Gaud. t. IV. P. purpurascens Seidl. P. semipellucidus Koch et $/ \mathrm{i} z$. In rivutis et aquis stugnantibus. 4.

12. P. gramineus $\boldsymbol{L}$. fol. submersis Ianceolato-linearilus sessilibus utrinque acuminatis lucidis opacis; pedunc. incrassatis; nuculis ovatis carinatis. Fl. Dall, 222. P. $\alpha$. graminifolius $\beta$. heterophyllus et $\gamma$. '/izii Koch syn. In aquis fluentibus et stagnanibus. 4.

13. P. nitens Web. fol. submersis semiamplexicaulibus lanceolatis serrulatis muticis rigidis nitidis; nuculis ohlongis ovalibus subcarinatis. P. culvifolius Hartm. P. $\alpha$. sulicifolius et B. heterophyllus Koch syn. In staguantibus et fluentibus. 24.

1t. P. trichoides Cham. Linnaen II. $t$. II. f. 6 . fol. setaceis 1-merviis aveniis ; spicis sulinterruptis longe pedunculatis. In piscinis et lacubus. 4. Pedal. et ultra.

15. P. plantagineus Du Croz. fol. onuihus petiolatis diaphanis, inf. lanceolatis, sup. suhcordato-ovatis duplo Iongioribus ; pedunc. suhaequalibus; nucula 3-carinata. Gaud. t. 3. P. coloratus Hornem. Fl. Dan. 1449. P. Hornemanni Mejer. In ayuis stagnantibus. 2 .

16. P. fluitans Roth; fol. omnihus in petiolum attenuatis utrinque acutis, submersis membranaceis, natantibus coriaceis; nuculis acute carinatis. P. natans $\gamma$. angustatus Koch FI. P. oblongus Meyer. In fluviis. 24.

1\%. $p$. oblongas liv. fol. omnibns in petiolum attenuatis, submersis membranaceis, natantibus coriaceis; nuculis ecarinatis. Viv. fragm. t. 2. Linnaea II. t. 6. f. 19. P. nataus a. vulgaris Koch syn. P. parnassifolius sichrad. In aynis stagnantibus.

15. P. natuins $L$. fol. omnibus petiolatis coriaceis natantilus; petiolis submersis aphyllis; nuculis carinatis. Fl. Dan. 1625. E. B. 1822. Schk. t. 28. Linnaea VI. f. 20. P. natans $\beta$. explanatus Koch syn. In ayuis stagnantilus vulgaris. 4.

19. P. densus $L$. fol. ovato-acuminatis oppositis; spica demum incurva; sepalis ovatis sessilibus. E. B. 
397. Fl. Dan. 1264. Limuaea t. IV. f. 1. P. $\alpha$.lancifolius et $\beta$. angustifolizs Koch syn. P. oppositifol. DC. In aquis stagnantibus. 4.

\section{B. Exotici.}

20. P. augnstanus Balb. fol. inferioribus longissime petiolatis ovatolanceolatis, super confertis sessililus linearibus; pedunculis elongatis. In Pedemont. 4.

21. P. octandrus Poir. fol. inferiorihus lineari-subulatis summis ovatis acutis; floribus octandris; caule ramoso. Hydrogeton heteropyllum Lour. In Cochinclina. 4.

22. P. tuberosus Roxb. ind. fol. alternis linearibus undulatis sessilibus integerrimis submembranaceis; radice tuberosa. P. indicus Iroth. In Ind. orient.

23. P. lanceolutus $\mathrm{S} m$. fol. lineari-lanceolatis acutiusculis nervoso-venosis; pedunculis aequalibus paucifloris; caule tereti simplici. In Cambria.

2t. P. tenuifolius H. et $\boldsymbol{K}_{\text {. N. }}$. Gen. I. p. 370. caule tereti? fol. linearibus acutis 3 -nerviis, inferioribus latioribus obtusiusculis; vaginis internodio longioribus. In Nova Granata. 4.

2.5. P. angustissimus $\boldsymbol{H}$. et $\mathbf{K}$. cauIe tereli; fol. angustissine linearihus acutis 3-nerviis, caulinis saepius alternis, floralihus suboppositis; flor.verticillatis; verticillo infimo distante. In Nora Hispania. 4.

26. P. panciflorus Pursh; fol. linearibus 1 -nerviis hasi aequalihus eglandulosis; pedunculis incrassatis paucifloris; caule tereti. P. gramini- folius Michx. P. exstipulatus W. In Carolina et Nova Caesurea. 4.

2\%. P. striatus $I$. et $P$. fol. linearibus striatis obtusis mucronatis; spica laxa; caule compresso. In Chili. 4.

28. P. indicus Roxb. ind. gracilis; fol. longe petiolatis lanceolatis acutis coriaceis superior. oppositis; pedunc. aequalibus. In Ind. orient. 4 .

2.9. P. crenulutus Don: fol. lineari-lingulatis ohtusis crenulatis membranaceis 3-nerviis sessilibus, summis oppositis. In Nepalia.

\section{RUPPIA L. (1737).}

1. R. maritima $L$. antherarum sacculis oblongis. Rchb. ic. 307. Ad littora maris. 4.

2. R. rostellata Koch; antherarum sacculis subglobosis R. obliqua Meyer Mss. Ad littora maris et ad salinas. 4.

3. R. antarctica Labill. Nor. Holl. t. 25t. fol. linearihus apice truncatolidentatis hasi ligulatis. Gaudich. in Freyc. Voy. t. 40. f. 2. In maritimis Nov. Holl.

4. R.? didyma Su. Act. Holm. 182.5. vaginis supremis ampliatis; pedunculis incrassatis subhifloris; nuculis rostratis basi connatis. In ins. Bartholom. et Carib. 4.

\section{\%0\%. OTTONIA Spr. (1819).}

1. O. Anisum Spr. Grundz. $t .3$. f. 4. 5. In Brisilic. ち. Frutex fol. alternis oblongo-lanceolatis integerrimis; racemis oppositifoliis. Partes omnes Anisum redolent. Spr. 


\section{I A S S I S V.}

PEN'TANDRIA.

\section{MONOGYNLA.}

a. Flores perfecti.

I. COROLLA MONOPETALA.

A. Flores superi.

a. monospermi.

\section{Caryopses achenia vel} utriculi.

ros. Mirabilis. Involucrun 5-fidum 1-florum. Cor. calycina 5-fida. Urceolus nectarifer. Antherie subrotundae. Nucula. Nyctayineue.

809. Alonemia. Involucrum 5phyllum multiflorum. Cor. calycina 5-loha. Antherae ol,longae. Nucula angulata. Nyctugineae.

810. Trieyela. Involucrum 3-phyllum 1-florum. Cor. calycina. Antlierae oblongae. Semen oblongum in hasi corollae. Nyctagineae.

81. Howbago. Cal. tubulosus 5-gonus 5-dentatus. Cor. hypocrateriformis 5-fida. Stigma 5-fidum. Semen 1, stylo coronatum. Plumbagineas.

ร12. Woselia. Cal. 5-phyllus; phyllis transversin undulato-sulcatis. Cor. tubulosa 5-loba. stigma 5-fidum. Fructus. Plumbagineae.

\%3. Veigelia. Cal. 5-sepalus; sepalis subulatis. Cor. campanulata semi-5-fida. Antherae hasi 2fidae. sligma peltatum. sem. 1, nudum. - -

\%1. Cuiechamala. Cal. brevissimus inaequaliter 5 -dentatus. Cor. gracilis 5-fida. Antherae lineares. stigma capitatum. - -

715. Cllueus. Cal. disepalus deciduus. Cor. 5-partita, tuho brevissimo. Antherae biloculares. Stigma simplex. Utriculus 1 -spermus. Portuluceat.
\% 6. Wmumonia. Capitulum involucratum. Cal. 5-fidus hracteis suffultus. Cor. infundil, 5-partita. Antherae connatae. Utriculus.

g1\%. Corymbiume. Cal. prismaticus bracteatus disepalus. Cor. tubo brevissimo; limbo 5-fido. Antherae coalitae. Caryopsis papposa. Aggregatae.

\section{Nuces. Asperifoliae.}

y18. Ceninthe. Cal, 5-sepalus. Cor. tubuloso - camipanulata :dentata. Antherae hastatae auriculis filiformibus tortis. Nuces?

819. Coldeniz. Cal. 5-partius. Cor. infundibuliformis $\tilde{5}$-fida. Antherae ovales. Stigma bifidum. Nuces apice subulatae.

ร:0. Heliotropium. Cal. 5-fidus. Cor. hypocrateriformis 5-fida plicata. Stigma conicum.

\%ะ1. Cannla. Cal. 5-partitus. Cor. tubulosa 5-dentata. Antherae sagittatae. Nuces lapideae $\boldsymbol{2}$, commatae. Borragineae.

g:2. Hithospermum. Cal. 5-partitus. Cor. infundibul. limbo barbato 5-fido. Nuces ovatae basi planae.

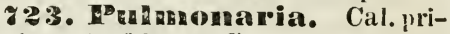
smaticus $\tilde{5}$-fidus. Cor. campanulata 5-fida; fauce subbarbata. stigma emarginatum. Nuces turbinatae basi plauae.

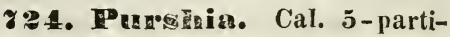
tus. Cor. tululosa limbo ventricoso. Antlerae sagittalae. stylus cor. duplo longior. Nuces turbinatae:

ชะ. THollise. Cal. 5-partitus. Cor. infundil). Antherae oblique incunbentes. Nuces magnae difiormes hasi planae.

ร 26. Dnosma. Cal. 5-partitus. Cor. tubuloso-campanulata. Autherae basi lateraliter nexae. Nuces ovatae lapideae basi planae. 
ระร. Eclniumn. Cal. 5-partitus. Cor. campanulata inaequaliter 5-fida. Filamenta inaequalia. Nuces gigartodes angulate basi applanatae.

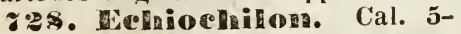
partitus. Cor. tubo gracili incurvo; limbo 2-labiato $\frac{1}{2}$-fido. Nuces glabrae turbiculatae.

วะ9. 耳yeopgis. Cal. 5-fidus in fructu inflatus nutans. Cor. infundibul. falce barbata, tubo curvato. Nuces turbinatac hasi foratae.

ร 30. Colsnnamenia. Cal. 5partitus maximus 5 -gouns coloratus. Cor. campanulata 5-dentata. Antherae sagittatae. Nuces osseae.

831. Cramiospermum. Cal. oblongus 5-partitus. Cor. cylindrica 5-dentata. Filamenta capillaria. Nuces hemisphaericae hasi foveolatae.

\%3:. Diocles. Cal. 5-partitus. Cor. infundibul. villosa 5-Ioha. Antherae oblongae. Sitylus bifidus. Stigrmata capitata. Nuces pyramidatae.

\% 33. Nilyosotis. Cal. 5-filus post anthesin clausus. Cor. hypocrateriformis lauce squamosa. Nuces basi foveolatae, glabrae vel scabrae.

ร34. Gxun Hona. Cal. 5partitus. Cor. hypocraterif.; fauce fornicihus coarctata 5-fida. Antherae peltatae. Nuces hasi umbilicatae.

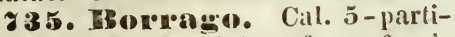
tus. Cor. rotata 5-loha; fance foruicibus emarginatis et filamentis subulatis alternis obsessa. Nuces (urbinatae.

336. Ancinusa. Cal. 5-partitus, frucliferus inflatus. Cor. infundib. fauce fornicibus erectis clausa. stigua bilobum. Nuces turbinatae.

ร 3.. Stomatechinas. Cal. 5-angularis 5-fidus. Faux cor. fornicibus carnosis extus muricatis clausa. Antherae acuminatae. Nuces subrotumilae.

938. Symmplsytun. Cal. 5partitus. Cor. cylindrico-campanulata, fauce fornicibus subulatis clausa. Antherae suloulatae. Stigma obtusum. Nuces ovatae.

ร 39. Dobostemnn. Cal.5-partitus. Cor. infundibulitormis. Fornices erectae dorso staminiferae. Nuces 4, basi non perforatae.

8 10. rioricinodesmen. Cal. 5-partitus. Cor. subrotata; fauce nuda 5-fida; laciniis cuspidatis. Antherae in contum spiralem collectae, villis dorso bifariis.
41. Apeñongo. Cal. fructifer compressus maximus. Cor. infundibul. fornicibus clausa. Nuces compressae columna centrali affixae.

z 1月2. Cynoglossung. Cal. 5-partitus. Cor. infundib. fauce fornicata. Antherae ovatae. Nuces echinatae vel laeves s. memhrana cinctae.

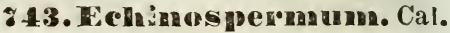
5-fidus. Cor. hypocrateriformis; tubo angulato fauce 5-radiato; limbo 5-lobo undulato. Nuces 4, 2-loculares.

\section{Drupae vel baccae.}

y 4. PIonotoca. Cal. 5-partitus. Cor. infundil). 5-fida. Discus cyathiformis lobatus. Antherae bivalves. Drupa baccata 1-sperma. Epacritleae.

85. Dallesia. Cal. 5-fidus. Cor. infundibul. fauce inflata 5 -fida; laciniis aculis. Antherae sagittatae. stiuma oblongum. Drupae 2, 1-spermae. Contortae.

: 46. Conedia. Cal. 4-5-dentatus. Cor. campanulata 5-7-fidit, fance saepe pilosa. Antherae biloculares. Stylus bifidus. Drupa 1-pyrena 1-5-locularis. Asperifoliae.

\% 8. Wryciuze. Cal. 5-dentatus. Cor. infundibul. 5-loha; lobis 2fidis. Antherae sagittatae. Stigma 4-dentatum. Bacca cerasiformis 1sperma. Comrolvulaceae.

g 18. Arodisia. Cal. 5-dentatus. Cor. hypocraterif. tuho hrevissimo; laciniis reflexis. Antherae lanceolatae. Bacca 1-sperma. Myrsineae.

\% 4. Ny nise. Flores dioeci. Cal. 5-4-fidus. Cor. 5-4-partita. Antherae crectae 2 -loculares. stigma laciniatur. Bacca drupacea pisiform. Myrsineae.

g50. Fmbelia. Cal. 5-fidus. Cor. profunde 5-partita. Antherae peltatae. stimma truncatum. Baccae Myrsines. Myrsineae.

ร51. Bumelia. Cal. 5-partitus. Cor. 5-partita. Squamae 2 ad hasin laciniarum. Antherae subcordatae; squamis petaloideis accessoriis denticulatae. Sapotae.

ร52. Sidemoxyou. Cal. parvus $\mathbf{5}$-fidus persistens. Cor. rotata 5-loha cum appendicibus petaloideis. Antherae incumbentes. Bacca 1-sperma. - - 
853. 'Flnela. Cal. bracteatus tubulosus 5-fidus papillosus. Cor. hypocrateriformis 5-fida. Antherae oblongae. Stigma 5-partitum. Bacca 5-gona. - -

\section{Fructus follicularis.}

ร54. 1egicerns. Cal. 5-sepalus coriaceus persistens. Cor. infundib. 5-fida. Antherae biloculares. Stigma simplex. Folliculus arcuatus 1-spernus. - -

b. Fructus dispermi.

\section{Membranacei.}

ร.5. Poเlymenia. Cal. 5-partitus. Cor. infundibul. plicata. Stigmata 4-6 acuta. Caps. disperma. Convolvulaceae.

ร56. FBDnanaia. Cal. 5-partitus persistens. Cor. campanulata 5fida. Antherae dorso affixae. Stigma capitato-lobatum. Caps. 2-loc. 2sperma.

ร5\%. Nurucon. Cal. turbinatus 5-lobus. Cor. infundib. 5-loba. Antherae incumbentes. Stigma bilamellatum. Caps. coriacea 2 -locularis. Convolvulaceae.

\section{Drupae vel baccae.}

y58. Cerbera. Cal. 5-dentatus. Cor. infundib. fauce 5-fida. Antherae stigmati lobato adhaerentes. Contortae.

ร59. Arduina. Cal. 5-partitus persistens. Cor. infundibulif. 5fida. Stamina inclusa. Stylus bifidus. Bacca disperma. Contortae.

z60. Contesia. Cal. truncatus 10-dentatus. Cor. infundibulif. 5fida. Stylus bifidus. Stigma globosum. Bacca disperma. Convolvulacene.

g61. Hunteria. Cal. 5-dentatus. Cor. infundib. stigma bilobum. Baccae 2, 1-2-spermae. Sapoteae.

862. Grentwera. Cal. campanulatus 5 -dentatus, basi bracteis suffultus. Cor. 5-dentata. Bacca drupacea 2-pyrena. Longanieae.

ร 63. Dicaryum. Cal. 5-dentatus persistens. Cor. 5-dentata fauce pilosa. Stigma obtusum. Drupa disperma. Strychneae.

\section{c. Eructus 3-spermi.}

\section{Membranacei.}

y 61. Prilox. Cal. prismaticus 5-fidus. Cor. hypocraterif. 5-loba. Caps. 3-locularis 3-valvis 3-sperma. Polemoniaceae.

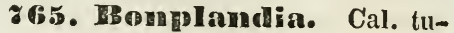
bulosus 5-dentatus. Cor. infundib. 5partita. Stamina declinata. Caps. 3locularis 3-valvis. Rutacede.

รfig. Cry ntantiln. Cal. 5sepalus. Cor. tuhulosa 5-fida, squamis 5-cucullatis. Stigma 3-fidum. Caps. 3-valvis. Rhamneae.

\section{Fructus drupacei baccati.}

y 6. Choytostoman. Cal. ventricosus coloratus. Cor. 5-dentata. Fornix stipitatus 5-dentatus. Stigma capitatum. Bacca 3-sperma. Buetinereae.

965. Candellia. Calyx imbricatus coriaceus. Cor. fauce villosa. Stylus apice incrassatus bifidus. Bacca 1-locilaris 3-sperma. Contortae.

\section{d. Fructus 4-spermi.}

\section{Membranacei.}

\% 69. Hy Herolinyilum. Cal. 5-partitus. Cor. tubulosa 5-loba. Filamenta medio pilosa. Caps. 1-locularis 2-valvis 4-sperma. Hydrophylleae.

\% ร. Phacelia. Cal, 5-partitus. Cor. campanulata 5-fida. Stylus bifidus. stigma acutum. Caps. 2-valvis 4-sperma. Hydrophylleae.

g. Nemeoploila. Cal. 10partitus, laciniis reflexis. Cor. 5-fida. Antherae versatiles. Caps. 1-locularis 1-sperma. Hydrophylleae.

y 2 . Navaruetia. Flores capitati involucrati. Calycis dentibus 3-dentatis. Cor. tubo 5-gono. Caps. 2-locularis 4-sperma. Hydrophylleae.

ร ร. Porama. Cal. 5-partitus. Cor. campanulata 5-fida. Antherae subrotundae. Stigma capitatum. Caps. calyculata 2-locularis 3-sperma. Convolvulaceae.

y 7. IBrewerit. Cal, 5-partitus. Cor. infundib. plicata. Caps. 2-locularis 4-sperma valvata. Convolvulaceae. 


\section{Fructus drupacei baccati.}

ร ร.5. PTrañipa. Cal. 5-partitus imbricatus. Cor: campanulata plicata extus tomentosa. Antherae sagittatae. stigma peltatum 10-sulcatum. Drupa 4-sperma. Convolvulaceae.

ร g. 6rogreia. Cal. 5-sepalus comnivens. Cor. plicata obsolete 5-loba. Antherae sagittatae. stigma didymo-capitatım. Bacca 4-ioc. 4-sperma. Convolvulaceae.

ร ร. Tect persistens. Cor. infundib. 5-fida. Antherae globosae. stigma bilobum. Drupa hirsuta spongioso-suberosa 4sperma. Viticeue.

z z 5. Tourefortia. Cal. 5partitus. Cor. tuho glohoso, limbo 5fido. Antherae acuminatae. Stigna integrum. Drupa 4-locularis 2-4sperma. Asperifoliae.

ร 89. ABeurerpia. Cal. subbilabiatus 5-dentatus. Cor. infundib. 5fida. Antherac oblongo-hastatae. Stigmata 2 capitata. Drupa 4-pyrena. Asperifoliae.

รso. Preslea. Cal.5-partitus. Cor. infundibul. 10-dentata, dentibus alternis minoribus. Faux fasciculis pilorum 5. Drupa 4-pyrena. Asperifoliae.

g81. Enretia. Cal. irregulariter 5-dentatus. Cor. subcampanulata 5-fida. Antherae hasi bilolae. Drupa 2-pyrena, ossiculis 2-4-spermis. Asperifolice.

ร92. Hebudia. CaI. 5-partitus. Cor. campenulata 5-fida. Antherae erectae 2-loculares. Stigma bilobum. Drupa 4-pyrena 4-sperma. Asperifoliae.

ร83. Ellisia. Cal. 5-partitus. Cor. sulicampanulata 5-loha emarginata. stigma bifidum. Receptaculum 2-valve t-spermum. Asperifoliae.

g8. Menais. Cal. 3-sepalus persisteus. Cor. tubulosa 5-loba. Antherae subulatae. stigmata 2 oblonga. Bacca glohosa 4-locularis 4sperma. Asperifolice.

255. Hedrula. Lour. Cal. cyathiformis 5-partitus persistens. Cor. rotata 5-partita. Antherac sagittatae. stigma emarginatum. Bacca 1-Iocul. 1-sperma. - -

8 86. Couma.

CaI. 5-fidus. Cor. infundibuliformis. Stamina bre- vissima. Antherae sagittatae. Stigma bifidum. Drupa 3-5-pyrena. Contortae.

e. Fructus penta-decaspermi.

\section{Membranacei.}

g8\%. Coris. Cal. campanulatus 5-dentatus. Cor. tubulosa 5-fida, laciniis bificlis. Antherae erectae oblongae. Caps. 5-valvis. Placenta 5dentata. Primuleae.

g89. Andînosace. Cal. 5-gouns 5-dentatus. Cor. hypocraterif. fauce glandulosa. Caps. 5-valvis 5-10-sperma. Primuleae.

g59. Houglasia. Cal. angtllatus 5-dentatus. Cor. infundib. 5dentata, fauce callo lineari sub quovis sinu instructa. Caps. 1-locul. 5-valvis 5-sperma. Primuleae.

\section{Drupacei vel baccati.}

ร 90. Humbertia. Cal. coriaceus 5-partitus. Cor. tubulosa 5loha. Antherae subsagittatae. Sitylus incurvus. Bacca substipitata 2-10cularis. Convolvulaceae.

891. Sy youelia. Cal. 5-fidus hracteatus. Cor. Luhulosa fauce villosa. Squamae hypogynae 5. Drupa suhexsucca, putamine osseo. Epacrideae.

ร.92. Astrolomar. Cal. 5-fidus hracteatus. Cor. ventricosa ad basin tubi villosa, limho brevi barbata. Discus cyathif. Drupa 5-sperma. Epacridecie.

g93. Stenanthera. Cal. 5partitus multibracteatus. Cor. tubuloso-ampullacea, limho 5-fido semibarbato. Drupa subexsucca putam. 5-spermo. Epacrideae.

994. Nelichrus. Cal. 5-fidus multil)racteatus. Cor. rotata; laciniis semibarbatis; ad basin fasciculi 5 glandularum. Drupa exsucca, putam. 5spermo. Epacribae.

995. Cyathodes. Cal. 5-fidus multilracteatus. Cor. infundib. 5-fida. Discus perigynus 5-dentatus. Drupa baccata 5-10-sperma. Epacrideae.

g96. Hissant hne. Cal. 5-fidus bracteis duabus suffultus. Cor. fance villosa vel nuda. Discus perigynus 5lohus. Bacca baccata putamine osseo 5-spermo. 
ร9\%. Севсоподов. Cal. 5fidus bihracteatus. Cor. infundib. limbo dense barbato. Drupa baccata 2-5-sperma. Epacrideae.

998. Henstielnc. Cal. 5dentatus hibracteatus. Laciniis limbi cor. barha deflexa. Drupa subbaccata, putamine 5-loculari celluloso. Epacrideae.

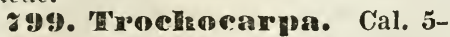
fidus bibracteatus. Cor. infundils. limbo barbato. Discus perigynus 5-lobus. Drupa baccata, putamine 10-lobo 10spermo. Epacrideae.

900. Decaspona. Cal. 5 -fidus bihracteatus. Cor. campanulata limbo barbato. squamae hypogynae 5 , basi commatae. Bacca 10-pyrena. Epacrideae.

801. Nolane. Cal. campanulatus 5-partitus. Cor. infundib. limbo 5-10-lobo. stylus simplex. stigmate capitato. Drupae 5 exsuccae $2-3-10-$ culares. Asperifoliae.

80: ' ' ' persistens inaequalis. Cor. campanulata subbilabiata laciniis super. reflexis. Urceolus membranaceus. Drupa 4-locularis 8-sperma. Solaneae.

803. Choryonolnym. Cal. 5-partitus. Cor. campanulato-rotata. stigma peltato-10-lobum. Pomum globosum 5-10-loculare. Sapoteae.

804. Tucuura. Cal. 5-partitus. Cor. campanulata 5-partita. Stigma obtusum. Pomum 5-10-loculare, loculis 1-spermis, putamine seminum osseo. Sapoteae.

805. Dneruinia. Cal. 5-partitus persistens. Cor. subcampanulata 10-loba lobis interioribus minoribus. Antherae posticae. Bacca globosa 5sperma. M!yrsineae.

SD6. Heca. Hlores monoeci. Cal. 5-fidus. Urceolus 5-fidus, laciniis hifidis. Antherae incumbentes. Stigma incrassatum lacerum. Bacca 5-6sperma. Sapoteae.

\section{f. Fructus polyspermi.}

\section{Membranacei.}

$\alpha \alpha$. Uniloculares. aa. Capsulae.

80y. Eutoca. Cal. 5-partitus persistens. Cor. subcampanulata. Antherae biloculares. Caps. 1-locularis 2-valvis polysperma. Hydrophylleae.

\section{Primuleae.}

908. Contusa. Calycis 5-fidi laciniis dentatis. Cor. subrotata; faux tuberculis clausa. Antherae 2-loculares. Caps. 1-locularis apice 5-dentata.

80\$. Anagalis. Cal. 4-partitus persistens. Cor. rotata 5-partita. Filamenta inferne hirsuta. Caps. globosa 1-locularis circumscissa. Semina angulata.

810. Eyinarelaia. Cal. 5partitus persistens. Cor. rotata 5-partita. Filamenta hasi subcomata. Caps. globosa j-10-valvis.

811. Hubinia. Cal. 5-partitus. Cor. subbypocraterif. 5-partita. stylus persistens. Caps. evalvis.

812. Cyclanew. Cal. semi5-fidus. Cor. rotata reflexa. Filamenta minima. Antherae sagittatae. Caps. baccata 5-fariam dehiscens.

813. Hodecatheop. Cal. 5partitus laciniis reflexis. Cor. 5-partita reflexa. Antlerae sagittatae in rostrum connatae. Caps. 5-dentata.

814. Soldanella. Cal. 5-fidus. Cor. subcampanulata linibo finhriatolacero. Caps. cylyudrica apice multidentata.

815. Primenla. Flores subumbellati involucrati. Cor. tubulosa fauce nuda vel glandulosa. Stigma capitatum. Caps. cylindrica apice 10dentata.

816. Fettonia. Cal. 5-partitus. Cor. hypocraterif. 5-loba. Stylus persistens. Caps. globosa evalvis.

81. Pretentellain. Cal. campanulatus 5-fidus. Cor. infundib. 5-fido plicato. Antherae cordatae. stigna peltatum 2-lobum. Caps. 2valvis valvis bifidis.

815. Calitonelnon. Cal. 5sepalus. Cor. infundil. fauce angulato limbo plicato 5-fido. Antherae subrotundae. Caps. conica 1-locularis bivalvis.

819. Tammondia. Cal. 5-fidus. Cor. rotata 5-partita. Antherae longitudinaliter dehiscentes. Caps. 1-10cularis bivalvis. Solaneae.

820. Sessea. Cal. tubulosus 5-dentatus. Cor. infundib. limho plicato. Filamenta curvata villosa. Stigma bilobum. Caps. bivalvis valvis bifidis. Personatae. 
821. IBncopa. Cal. 5-partitus inaequalis, laciniis 2 inferioribus deflexis. Cor. hypocraterif. 5-loba. Antherae sagittatae. Caps. membranacea. Personatae.

\section{Gentianeae.}

822. Ery titus 5-gonus. Cor. infundib. 5-fida. Antherae defloratae spirales. Caps. 2-valvis, valvis introflexis.

S:3. Sabatia. Cal. 5-12partitus. Cor. urceolata 5-12-loba. Antherae demum stignateque spiratim tortae. Caps. valvis inflexis,

824. Higpiora. Cal. 5-fidus cum caps. demum concrescens. Cor. campanulata 5-loba. Antherae 2-10culares. Caps. bipartibilis valvis inAexis.

825. Chiromia. Cal. 5-fidus post anthesin tunescens. Cor. campanulata 5-fida. Antherae oblongae erectae. Caps. cum calyce concreta.

826. Nongmecia. Cal. tubulosus 5-angularis. Cor, infundih. 5fida. Antlerae siccitate non mutatae. stigma bilamellatum. Caps. 2-valvis.

8\&z. Litu. Cal. tubulosus 5fidus coloratus persistens. Cor. tuho longissimo 5-fido. Antherae didymae. Stigma capitatum. Caps, valvis inflexis.

8ะ5. NTenyanties. Cal. 5partitus persistens. Cor. infundil). 5fida, intus dense villosa. Antherae basi bilobae. Caps. bivalvis.

929. Villarsin. Cal. 5-partitus. Cor. 5-partita hasi hirsuta. Antherae cordatae. Glandulac circa ovarium 5. Caps. subcarnosa compressa. sem. marginato-alata.

\section{bb. Fructus folliculares gemini.}

\section{Contortae.}

1. semina comosa.

a. Faux corollae nuda.

\$30. Wehites. Cal. 5-partitus. Cor. infundily. Antherae apice cassae in conum circa stigma connatae. Siquamae 5, perigynae. Stigma crassiusculunı.

831. Heammontia. Cal. 5sepalus patens. Cor. campanulato- ventricosa maxima 5-fida. Antherae sagittatae cum stigmate cohaerentes. Ovarium singulare.

832. Uallneis. Cal. 5-partitus. Cor. hypocraterif. 5-fida. Antherae sagittatae cum stigmate clavato colıaerentes. Squamae hypogynae 5.

833. Telnocarpus. Cal. 5fidus. Cor. hypocraterif. laciniis falcatis. Antherae sagittatae. Filamenta 5 sterilia. Stigma ovatum acuminatum.

834. Folarolucina. Cal. 5partitus laciniis subulatis. Cor. hypocraterit. Antherae lanceolatae longitudinaliter polliniferae. stylus brevissimus stimmate cylindrico.

635. padeynunas. Cal. 5-fidus. Cor. campanulata 5-fida, 5-denticulata. Antherae sagittatae postice cassae conum circa stigma capitatum formantes.

836. Cryptotendis. Cal. 5fidus. Cor. laciniis 5 , cum 5 denticulis alternantes. Antherae sagittatae. siquamae 5 perigyuae. Stylus nullus. stigma suliconicum.

83 \%. 'Thenarellia. Cal. 5-partitus. Cor. hypocraterif. 5-fida. Filamenta memiranacea apice incurva. Antlerae sagittatae. stigma 5 -gonum. Squamae perigynae 5 .

S38. Istonia. Cal. 5-fidus. Cor. lypocraterif. $\bar{s}$-partita. Antherae liberae longitudinaliter polliniferae. stioma dilatatum subbifidum. Folliculi longissimi.

\section{b. Faux corollae coronata.}

539. Trestomia. Cal. 5-partitus. Cor. hypocraterif. Cor. faucis duplex, exterior annularis indivisa, interior squamis 5. Autherae sagittatae connatae.

810. HaIfouria. Cal. hasi 10 -squamatus. Cor. infundib. tubo crenulato. Antherae sagittatae mucronatae. Stigma angulatum.

811. Nerium. Cal. 5-partitus. Cor. faux coronata squamulis laceris. Antherae sagittatae cohaerentes apice filamentoso. stigma truncatum.

942. Stropliantius. Cal. 5-partitus. Limbi laciniis cor. caudatis filiformibus. Antluerae sagittatae aristatae. Squamae 5, perigynae. 
843. Wrophria. Cal. 5-sepalus, basi squamis 5 cinctus. Faux cor. squamis multifidis coronata. Antherae sagittatae. Stylus filiform. apice dilatato.

\section{Semina nuda.}

84. Cinca. Cal. 5-partitns. Cor. hypocraterif. fauce 5-plicata; laciniis limbi oblique truncatis. Antherae membranaceae biloculares. Stigma peltatum.

3.5. 'Tabermaennotana. Cal. 5-fitus. Cor. hypocraterif. fauce fornicilus clausa. Antherae sagittatae. stigma peltatum. Semina pulpae immersa.

8.6. Cameraria. Cal. 5dentatus. Cor. infundibul. laciniis limbi obliquis. Antherae acuminatae apice in filum productae. Folliculi reflexi hasi lobati.

64\%. Aspidosperma. Cal. 5-partitus. Cor. tubo ventricoso. Antherae ovatae biloculares longitudinaliter dehiscentes. Stigma clavatum. Folliculi obovati lignosi.

848. mastiaia. Cal. 5-fidus. Cor. faux barbata. Antherae ovatae. Stigma peltatum. Semina teretia apice truncata.

849. Allamanda. Cal. 5partitus. Cor. infundib. ventricosa 5fida. Antherae sagittatae. Anuulus perigynus. Stigma orbiculo duplici peltatum. Caps. compressa.

850. Habata. Cal. campanulatus brevissime $\mathbf{5}$-dentatus. Cor. campanulata 5-fida. Antherae sessiles. Caps. 4-gona, stylo persistente coronata. Contortae?

$\beta \beta$. Capsulae aut folliculi 2loculares.

951. Tritreola. Cal. 5-partitus persistens. Cor. urceolata. Stigma indivisum. Caps. bifurcata 2-10cutaris.

952. Tyonsia. Cal. 5-fidus. Cor. 5-partita. Antherae sagittatae postice cassae cum medio stigmate cohaerentes. siylus dilatatus. Squamae hypogynae connatae.

853. Silvernoria. Cal. 5-partitus. Cor. subrotata 5-loba. Stami- na $4,5,7$ et 8 . Stigma capitatum. Caps. compressa 2-locularis. Personatae.

854. Verbascumn. Cal. 5fidus. Cor. rotata inaequaliter 5̆-loha. Filamenta barbata. stigma incrassatum. Caps. valvis inflexis. Personatae.

855. Hyoscyamus. Cal. campanulatus $\mathbf{5}$-fidus. Cor. infundib. oblique 5-loba. stigna capitatum. Caps. operculo circumscisso 2-locularis. Solaneae.

856. Nicotiana. Cal. tubulosus 5-fidus. Cor. infundil). limbo plicato. Caps. apice 4-dentata. Solaneae.

8.5\%. Petumia. Cal. 5-partitus, laciniis subspathulatis. Cor. infundib. stigma bilobum. Caps. apice bifida bilocularis. Solaneae.

855. Tekmannia. Cal. disepalus. Cor. ringens tubo gracili incurvo. Stamina exserta. Solcneae.

859. Caman kia. Cal. tubulosus 5-gonus 5-fidus. Cor. hypocraterif. 5-partita limbo inaequali. Caps. teres polysperma. Solanecie.

860. Fabiara. Cal. 5-fidus. Cor. infundib. limbo revoluto plicato. Filamenta 2 longiora. stigma emarginatum. Convolvulaceae.

861. Nienembergia. Cal. basi tubulosus 5-partitus. Cor. tubo elongato 5-lobo. Filamenta basi connata. stigma infondib. Caps. 2-locularis 5-valvis. Solanede.

86:. Convelvulus. Cal. 5partitus nudus vel bracteatus. Cor. campanulata limbo plicato. Stigma capitatum vel fissum. Caps. 1-2-34-locularis. Convolvulacecie.

863. Ifetzia. Cal. 5-partitus laciniis inaequalibus Ianceolatis. Cor. tubulosa villosa 5-dentata. Antherao sagittatae. stigma bifidum. Caps. 2locularis. Convobrulaceae.

86. Temiostonna. Cal. turbinatus 5-fidus. Cor. urceolato-infundib. intus villosa. Antherae oblongae. Stigma sulcatum didymum. Caps. 2-locularis. Sem. angulosa.

865. Togania. Cal. 5-partitus. Cor. campanulata fauce villosissima. Antherae oblongae versatiles. stigna clavatum 2-lohum. Caps. 2locularis, Sem. peltata. Gentianeae. 
866. Spigelia. Cal. 5-partitus. Cor. infundil). 5-fida. Stamina inclusa. Stylus cum stigmate articulatus. Caps, didyma bilocularis. Sem. angulata. Gentianecte.

86\%. Cigianthus. Cal. campanulatus 5-fidus. Cor. infundih. 5fida. Antherae sagittatae. Stigma lilamellatum hicrure. Caps. 2-locularis. Sem. angulata. Gentianeae.

868. Splnemoelen. Cal. urceolatus 5-fidus hasi bracteatus. Cor. minor calyci aduata. Stylus nullus. stigma capitatum. Caps. circumscissa polysperma. Aizoidecae.

665. Velleia. Cal. 3-5-sepaIus inaequalis. Cor. tubulosa limho 2-lahiato, laciniis alatis undulatis. Antherae distinctae. Caps. bilocularis. Goodeniae.

\section{$\gamma \gamma$. Capsulae 3-10 culares.}

8\%0. IDiapeneia. Cal. 5-partilus hibracteatus. Cor. hypocraterif. 5-loha. Antherae hiloculares. Stigma ohtusum. Caps. trilocularis. Sem. membrana ohvoluta. Ericeae.

8\%1. Holemonimu. Cal. urceolatus 5-fidus. Cor. subcampanulata 5-loha. Filamenta dilatata, antheris incumbentibus. Stigna $\mathbf{3}$-fidum. Caps. trilocularis. Sem. apice alata. Polemonieare.

Qร 2. Cantun. Cal. mecolatus 3-5-fidus. Cor. infundil). 5-fida. Stigma 3-filum. Caps. 3-locularis 3valvis. Sem. apice alata. Polemonicae.

83. Tilia. Cal. campanulatus 5-fidus. Cor. infundib. 5-fida patens. Antherae hiloculares. Stigma 3-fidum. Caps. 3-locularis 3-valvis. Sem. angulata. Polemonieae.

8\% 1. Ig Ditzia. Cal. 5-partitus hasi hracteis serratis. Cor. 5-loha. Caps. 3-locularis 3-valvis polysperma. Polemoniear.

8\%.5. Collomein. Flores aggregati involucrati. Cal. 5-fidus glandulosus. Cor. tubulosa 5-fida. Antherae ovales. Caps. 3-locularis 3valvis loc. 1-2-spermis. Polemonieae.

8ร6. Colorea. Cal. campanulatus 5-fidus alato-5-angulatus. Cor. 5-loba, lobis 3-lohis. Filamenta demum spiratim torta. Caps. obovata a-5-locularis. Sem. marginata. Bisuoniear.

\section{$\delta \delta$. Capsula 4-10cularis.}

8ร ซ. Datura. Cal. tubulosus 5-fidus hasi pelto persistente. Cor. plicata 5-dentata. Stigma bilamellatum. Caps. echinata vel inermis semi-4-locularis. Solaneae.

\section{ع. Capsulae 5-10culares.}

8\%9. Azalea. Cal. 5-dentatus. Cor. infundil). 5-fida. Stam. inaequalia. Caps. 3-5-locularis. Semina nuda. Ericeae.

8ร9. Epacris. Cal. coloratus bracteis suffultus. Cor. tubulosa imherbis. Antherae horizontales. Squamae 5, perigynae. Caps. placentis columnae centrali adnatis. Epucrideae.

850. Drencoblinylum. Cal. 5-partitus. Cor. tubulosa 5-fida. Antherae dorso adnatae. Stigma trilohum. Squamae 5 hypogyua. Caps. placentis pendulis. Epacrideae.

831. 耳ysiuema. Cal. coloratus multibracteatus. Cor. laciniis dextrorsum flexis. Antherae horizontales. Squamae 5 perigynae. Caps. placentis columnac adnatis. Epacrisleue.

882. Andenesonia. Cal. coIoratus bracteatus. Cor. limho basi harhato. Antherae infra medium affixae. Squamae perigynae subcomnatae. Caps. placentis columnae adnexis. Epracrideae.

893. Squendia. Cal. coloratus. Cor. rotata 5-fida. Antherae comnatae harhatae vel nudae. Squamae nullae. Caps. columnae adnexis. Epacrideae.

864. Fopoceletin. Cal. foliaceus. Cor. hreviter campanulata 5fida imberbis. Antherae septo marginato. Squamae nullae. Caps. columnae adnexac. Epacrideae.

855. Cosmelia. Cal. foliareus imbricatus. Cor. tubulosa. Antherae apicibus ciliatis. Squamae 5 hypogynae. Caps. Ponceletiae. Epacrideae.

856. Cystantine. Cal. foliaceus. Cor. clausa calyptraeformis transverse dehiscens basi truncata. Squamae 5 hypogyua. Epacrideae.

8ร. Micloea. Cal. membrauaceus ebracteatus. Cor. Cystanthis. 
Squamae 5 lypogynae.

Caps. placentis ab apice pendulis. Epacrideae.

8.8. Thionotes. Cal. elracteatus. Cor. tubulosa limbo imberbi. Filamenta lubo semiadlıaerentia. Śquamae 5 hypogynae. Epacrideae.

889. Cumprovis. Cal. tuhulosus 5-partitus tuberculosus. Cor. tubulosa bilabiata. Antherae ovatae erectae. Sitigma 5-lobum. Caps. subrotunda 5-locularis.

\section{Fructus baccati.}

\section{Uniloculares.}

890. Strodenos. Cal. 5-delltatus. Cor. tubulosa 5-partita. stizma capitatun. Bacca crustacea. Sem. pellata. Contortae.

841. 'Tlecoplinersta. Cal. 5dentatus. Cor. campanulata 5-loha. stamina in urceolo perigyno. Bacca placenta centrali libera. Contortue.

652. Heonia. Cal. 5-lohus. Cor. rotato - campanulata. Filamenta in tubum 5-oromm comnata. Antherae didymae 4-valves. Bacca corticosa. Contortae.

853. Dornema. Cal. 5-partitus laciniis ovatis. Cor. rotata 5-loha. Antherae subsessiles 4-gonae. Squamulae 5 perigynae. Bacca sicca globosa striata. Sem. angulata.

894. Thanconinia. Cal. ninimus 5-partitus. Cor. limbus 5-fidus patentissimus. Stigma bifidum. Bacca polysperma.

\section{Solaneae.}

895. Cestrume. Cal. nrceolatus 5-dentatus. Cor. limho plicato 5fido. Stamina saepe denticulata. Caps. 1-locularis polysperma.

846. Hanctes. Cal. 5-fidus. Cor. tuho subgloboso limbo patente 5-fido. stigma 5-lobum. Bacca excorticata diaphana 1 -locularis polysperma.

958. Nand rengonea. Cal. 5fidus. Cor. campanulata 5-fida. Bacca carnoso-spongiosa. Sem. reniformia.

898. A tropar. Cal. 5-partitus. Cor. infundib. rotataque 5-10-fida. Stamina subexserta. Bacca 2-locularis placentis liheris.

899. U102. Cal. ovatus inflatus 5-partidus coloratus. Cor. tubu- losa fauce gibbosa limbo patente minimo. Bacca hilocularis calyce tecta.

g00. Hollis. Cal. 5-fidus. Cor. suhrotata. Antherae longitudinaliter dehiscentes. Bacca bilocularis calyce inflato tecta.

D01. Capbicum. Cal. 5-fidus. Cor. rotata plicata 5-fida. Antherae comniventes longitudinaliter dehiscentes. Bacca polymorpha bilocularis. sem. dissepimento adnata.

902. Solanuma. Cal. 5-10partitus. Cor. rotata plicata 5-10fida. Antherae comniventes. Bacca 2- 3- 4-locularis. Semina glahra.

903. Hycomensicon. Cal. 5-6-partitus. Cor. rotata 5-6-loha. Antherae membrana apice elongata connatae. Bacca 2-3-locularis. Sem. villosa.

904. Vitheringia. Cal. urceolatus 5- 4-fidus. Cor. campanulato-rotata tubo gibhoso. Antherae longitudinaliter dehiscentes. Bacca 2-I0cularis.

905. Dier.lonelaia. Cal. urceolatus 5-dentatus. Cor. infundibul. Filamenta 3-partita cuspide medio antherifera. Bacca 2-locularis.

g06. Daborosa. Cal. 5-dentatus. Cor. tubulosa 5-fida. Filamenta subclavata. Stigma bilobum. Bacca 2-Iocularis.

90\%. Anis dust Cal. campamulatus inflatus angulatus 5-dentatus. Cor. 5-Ioba. stam. basi cohaerentia. Bacca bilocularis operculo 4-valvi.

908. Hyciunn. Cal. 5-dentatus saepe lateraliter fissus. Cor. infundib. Filamenta basi villosa. Bacca bilocularis, dissepimento incrassato.

909. Carissa. Cal. 5-dentatus. Cor. infundib. Bacca 2-locularis. Sem. conipressa.

910. Vilughibeia. Cal. 5partitus. Cor. hypocraterif. limbo 5partito undulato. Antherae sagiltatae. Bacca bilocularis. Sem. in pulpa nidulantia.

Fructus baccati $4-5-m u l t i l o-$ culares.

91. Camax. Cal. 5-partitus. Cor. rotata 5-loha. Stigmata 4. Bacca ovalis villosa 4-locularis. Sem. in pulpa nidulantia.

912. Nicandrea. Cal. 5-partitus. Cor. campanulata subintegra. 
Antherae ovatae. Bacca $4-5$-locularis. Solaneae.

913. Solandra. Cal. campanulatus 5-fidus. Cor. ventricosa, limbo undulato 5-fido. Antherae versatiles. Bacca 4-locularis. Soluneae.

914. Desfontainia. Cal. 5partitus, Cor. campanulata 5-loba. Antherae biloculares extus dehiscentes. Stigma capitatum. Bacca 4-loc. Solaneae.

\section{Fructus ignoti.}

915. Barreria. Cal. 5-dentatus. Cor. 5-partita, laciniae superne concavae scrobiculo duplici, super.ovato bifido infer. 3-fido. Antherae 4gronae.

916. Torreya. Cal. 5-lohus coloratus. Cor. limbo 5-fido reflexo. Filanenta spiralia. Antherae didymae. Germen nucem referens. Nyctayineae.

11. Trattinickia. Cal. campanulatus 3 -dentatus. Cor. campanulata 3-dentati. Stylus subulatus.

418. Mina. Cal. carnosus 5fidus laciniis mucronatis. Cor. ventricosa 5-angularis. Antherae biloculales. Glandula ramosa perigyma.

D19. Diplocalymuna. Cal. duplex ext. hivalvis inter. 10-dentatus. Cor. infundibul. subplicata. Antherae sagittatae. Stigma urceolatum 2-10bun. Convolvilaceae.

920. Nectumia. Cal. 5-partitus. Cor. hypocraterif. faux amulo coronata. Antherae erectae biloculares. Stylus filiformis. Stigma bifidum. Solaneae.

\section{B. Fructus inferi.}

a. Capsulares.

\section{ג. Caps. 1-locularis.}

921. Gpermadictyon. Cal. 5-fldus. Cor. infundib. limbi 5-fidi laciniis ovatis. Stigma 5-fidum. Caps. 5-fariam apice dehiscens. S'em. reticulata. Rubiaceae.

922. Heloraia. Cal. semiinferus persistens. Cor. rotata 5-loha. Antherae comniventes. Stylus subulatus. Caps. polysperma. Rubiuceae.

923. Samallas. Cal. semiinCerus 5-fidus. Cor. campanulata, lim- bo 5-fido denticulis inter lobos. Caps. apice 3-dentata. Primuleae.

5) 1. Fysipengar. Cal. 5-fidus inaequalis. Cor. subbilabiata $\frac{2}{3}-$ loba. Antherae connatae barbatae. Stigma bilobum ciliatum. Lobelieae.

925. Hodla. Cal. turbinatus 5-partitus laciniis dentatis. Cor. infundib. 5-partita. Squamae 5 hypogynae. Antherae comniventes. Sem. angulata scabra. Campanuleae.

$$
\text { B. Caps. 2-loculares. }
$$

D26. Hecontea. Cal. 5-partitus, laciniis subulatis. Cor. tubulosa 5-partita. sitigmata recurvata. Fructus coriaceus compressus, nuculis binis alatis. Rubiaceae.

уะ ร. Praelnomia. Cal.5-partitus. Cor. infundib. fauce villosa. stigma bifidum. Caps. 2-locularis 2sperma basi dehiscens. Rubiacece.

9:8. Caneglaora. Involucium 3-6-florum. Cal. proprius 5-6-fidus. Cor. campanulata 5-6-loba. Stigma bifidum. Caps. globosa 2-locularis. Rubiaceae.

y:9. Trondeletia. Cal. 5-partitus sub-5-sepalus. Cor. infundib. fauce inflata. stigma bifidum. Caps. glohosa, loculis disfermis. Rubiacecue.

930. Chimarolnis. Cal. integer persistens. Cor. infundil. 5-fida, laciniis medio hirsutis. Antherae ovales erectae. Caps. valvis apice bifidis. Rubiaceae.

931 . Si punea. Cal. 5-partitus. Cor. infundil., כ̈-fida. Antherae conniventes. Caps. globosa angulata 2-valvis. Sem. numerosa aptera. Rubiaceae.

y32. Mrencenemum. Cal. turbinatus obsolete dentatus. Cor. campaniformis 5-partita. stigma bilobum. Caps. glohosa polysperm. sem. obsolete marginata. Rubiacene.

933. Cinchonaa. Cal. 5-dentatus. Cor. infundib. 5-fida. Antherae linearis 2-loculares longitudinaliter dehiscentes. Sem. alata margine lacero. Rubiaceae.

b3 1. Hanclnetin. Cal. ovatus 5-dentatus. Cor. 5-loba. Stigmata 2, linearia acuta. Caps. olovata calyce coronata. Scmina sericea. Rubiaceae. 
935. Pinkmeya. Cal. 5-partitus. Cor. tubulosa puhescens, laciniis revolutis. Antherae versatiles. stigma bilobum. Caps. polysperma. Sem. alata. Rubiaceae.

936. Exostennma. Cal. 5dentatus regularis. Cor. tubo longissimo. Stigma incrassatum. Caps. polysperma. Sem. alata margine integerrimo. Rubiaceae.

๑3 ช. Missaenda. Cal. irregulariter 5-fidus. Cor. infundib. 5partita. Stigma bifidum. Sem. solida uon alata. Rubiacelue.

938. Hymenomogon. Cal. 5-dentatus. Cor. longe tubulosa 5fida. Caps. 4-valvis Sem. utrinque membrana appendiculata. Rubiaceae.

939. Lecananthus. Cal. carnosus amplus 2-4-lobus. Cor. calyce minor, limbo 5-fido. Caps. 2locularis polysperma. Rubiaceae.

d40. Alseis. Cal. 5-partitus. Cor. cyathiformis fauce barhata 5 -fida. Stigma 2-partitum. Germen 2-loculare multiovulatum. Rubiaceae.

11. Danais. Flores subdioeci. Cal. 5-dentatus. Cor. infundib. intus hirsuta. Stigma bifidum. Caps. globosa apice deliscens. Sem. alata. Rubiaceae.

942. Dentella. Cal. 5-partitus, laciniis subulatis. Cor. infundib. laciniis $\mathbf{3}$-dentatis. Stigma $\mathbf{2}$-fidum. Caps. globosa, polysperma. Rubiaceae.

93. Portlandia. Cal. 5-sepalus persistens. Cor. ventricosa amplissima limbo 5-fido. Antherae lineares erectae. Caps, apice dehiscens. Sem. elliptica scabra. Rubiaceae.

94. Ophiorndaiza. Cal. turhinatus 5-dentatus. Cor. tubulosa intus lirsuta 5-fida. Stylus apice bifidus. Discus epigynus bilobus. Sem. minuta. Rubiacene.

945. Sickingia. Cal, 5-dentatus. Cor. campanulata 5-dentata. Antherae lineares erectae. Stylus subulatus. Caps. subrotuuda lignosa. Rubiaceae.

\$4. Irenesteria. Cal. globosus 5-partitus. Cor. longa 5-loba fauce nudiuscula. Stigma bifidum. Fructus baccatus apice areolatus. Sem. minima. Rubiaceae.

91\%. Augusten. Cal. oblongus 5 -partitus, laciniis acuninatissi- mis. Cor. infundibuliformis 5-partita. stylus basi hirsutissimus. Caps. oblonga. Rubiaceae.

948. Hobelia. Cal. 5-dentatus. Cor. tubulosa irregularis $\frac{2}{3}$-fida. Antherae barbatae comnatae. Indusium ciliatum sub stignate. Lobelieae.

D49. Si thocampylus. Cal. 5-partitus. Cor. irregularis tubo declinato 5-fido. Antherae connatae barbatae. Caps, ovata 2-loc. 2-valv. Campanuleae.

950. Kontoma. Cal. 5-partitus. Cor. tubulosa. Antlerae counatae 2-aristatae. stigma capitatum. Caps, bilocularis. Lobelieae.

פ51. Hechenaudin. Cal. 5partitus. Cor. tubulosa bilabiata $\frac{2}{3}-$ fida. Stigma obsoletum in fundo indusii bilabiati. Caps. prismatica 4-valvis. Goodenieae.

๑5 2. Goodenia. Cal. 5-partitus. Cor. 1-2-labiata 5-partita, laciniis diaphanis. stigmatis indusium simplex subciliatum. Caps. 2-locularis. Sem. compressa.

953. Vendandia. Cal. tuho globoso. Cor. tubulosa 5-fida. Stigma bilobum. Caps. 2-valvis. Sem. minima numerosa. Rubiaceae.

\$4. Forogesia. Cal. turbinatus 5-fidus. Cor. intus furfuracea 5partita. Stigma bilobum. Caps. polysperma apice 2-valvis. Saxifragae.

\$5. PSilobiume. Cal. amplus 5-partitus. Cor. 5-fida. Stigma clavatum 10-alatum. Fructus siliquaeformis polyspermus.

956. Arostemma. CaI. 4-5-dentatus. Cor. rotata 4-5-partita. Stigma globosum. Caps, disco operculari coronata. sem. nunerosa angulata.

\section{$\gamma$. Caps. 3-5-loculares.}

95\%. Plotenuna. Cal. 5-fidus. Cor. 5-partita. Stigma 2-3-fidum. Caps. 3-locularis placenta centrali. Campanuleue.

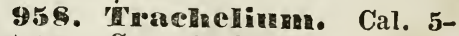
dentatus. Cor. tuho longissimo 5-fido. Stigma subtrilobum. Caps. 3-locula$r$ is basi poris dehiscens. Campanuleae.

959. Campanuma. Cal. 5fidus. Cor. campanulata 5-fida. Stigma 3-こ-fidum. Caps. 3-5-locula- 
ris, poris lateralihus vel apice dehiscens. Campanuleae.

960. Wienvilla. Cal. 5-fidus bracteatus. Cor. infundib. irregulariter 5-fida. Stigma capitatum. Caps. 4-locularis polysperma. Caprifolia.

b. Fructus baccati drupacei.

$$
\text { a. 1-2-spermi. }
$$

961. Felotiden. Cal. 5-partitus. Cor. infundib. 5-partita. stigma hisulcum. Bacca 1-sperma. Semen globosum. Rubiaceae.

$96 \%$. Gacennimin. Cal. 1-lateralis 3-fidus. Cor. infundib. 5-fida. Antherae sessiles. Stigma bilobum. Bacca 1-sperma.

963. Aidin. Cal. tuhulosus 5dentatus. Cor. hypocraterif. fauce lanosa. Antherae sessiles. Stigma chlongum. Bacca 1-sperma.

96. It. Iswas. Cal. campanulatus 5-lobus. Cor. campanulata pilosissima limbo 5-fido. Antherae biloculares. Stigma 5-fidum.

g65. Helicanthen. Cal. trumcatus coloratus, squama carnosa suffultus. Cor. hypocraterif. Antherae spiratim revolutae. Urceolus perigynus 5-fidus.

966. Diaspasis. Cal. 5-fidus. Cor. hypocraterif: tuho fisso pube colaerente. Stigma indusio semibivalvi. Drupa exsucca 1-sperma. Goodenieae.

96\%. Dannpiena. Cal. ahbreviatus vel obsoletus. Cor. hilabiata extus barhata pilosa. Antherae connatae. Drupa 1-sperma.

\&6\%. Selnoenfia. Cal. duplex ext. inferus 2-fidus, inter, intewer. Cor. campanulata 10-sulca. Stylus hasi glandula cinctus. Stigma :j-10bum. Drupa 1-sperna. Caprif.

569. Hesyelneta. Cal. urceolatus 5-fidus. Cor. infundil). fauce harhata, limho 5-fido revoluto. Drupa dipyrena sulcata calyce coronata. Rubiaceae.

5\% 5-phyllus. Cor. infundibuliformis fauce harbata 5-fida. stam. harhata. stimma ovatum bifidum. Bacca? Rubiacear.

9 ร. IPalicouren. Cal. urceolatus 5-fidus. Cor. tuhulosi basi ventricosa linc giblsa infra medium harliata. Drupa Psychotriae. Rubiaceae.

פร2. Ceplanelis. Flores capitati involucrati. Cal. minimus 5dentatus bracteis suffultus. Cor. fauce harhata. Stigma hipartitum. Drupa Psychotriae. Rubiaceae.

9) 3. Fอน gex. Cal. 5-fidus. Cor. tuhus longissimus, laciniis limbi refractis. Stigma bilamellatum. Bacca disperna. Rubiacene.

9) 4. Cofrea. Cal. minimus 5dentatus. Cor. infundib. fauce nuda. stigma bifidum. Caps. dipyrena. Sem. testa chartaceo-membranacea involuta. Rnbiaceae.

975. Chaiocea. Cal. urceolatus 5-fidus. Cor. infundib. fauce barhata. Stigma indivisum. Bacca drupacea didyma disperma. Rubiaceae.

9) 8. Taedleria. Cal. 5-fidus. Cor. infundib. intus hirsuta. stylus 2-partitus. Bacca disperma. sem. globosa. Rubiacene.

у) ร. Senoissa. Cal. 5-fidus. Cor. infundib. laciniis limbi $\mathbf{3}$-fidis. Antherae sessiles. Stylus bifidus. Bacca disperma. Rubiacene.

9 8. Cameniuma. Cal. 5- 4fidus. Cor. tubo ahbreviato, limbo 4-5-fido. Stam. 4-5. Stigma capitatum. Bacea dipyreua, pyrenis osseis. Rubiaceat.

\section{B. Fructus baccati drupacei, 3-5- 6-spermi.}

989. Plocanan. Cal. urceolatus 5-dentatus. Cor. 5-fida, laciniis linearibus. Stigma obtusum. Bacca 3-locularis 3-sperma. Sem. oblonga. Rubiaceae.

930. Collastonia. Cal. 5-fidus. Cor. hypocraterif. calyce major. Bacca trilocularis 3-sperma. Rubiacear.

91. 'Triostenamm. Cal. 5partitus. Cor. tuhulosa calycem aequans. Stigma capitatum. Bacca tripyrena. Caprifolia.

\$):. Cunicera. Cal. 5-deutatus. Cor. (ubulosa hasi gribha limbo 2-labiato 5-fido. Bacea 1-3-locularis suh-3-sperma. Caprifolia.

983. Symotocria. Cal. 4-5dentatus. Cor. subcampanulata ahbreviata 5-fida. Stigma glohosum. Bacca t-locularis. Caprifolia. 
984. Plominda. Flores capitati. Cal. 5-dentatus. Cor. infundih. stigma bifidum. Drupa angulata 4sperma. Rubiaceae.

95. Screvola. Cal. 5-fidus persistens. Cor. tubulosa hinc fissa, laciniis alatis. Indusium stigmatis ciliatum. Drupa 4-sperma. Goodenieae.

956. Gueturda. Flores submonoeci. Cal. campanulatus subintegerrimus. Cor. tubo longissimo. Stigma capitatum. Drupa 4-6-locularis. Rubiacene.

98\%. Nomatelia. Cal. 5-dentatus. Cor. infundil. 5-fida. stylus bifidus. Stignata ohtusa. Bacca sulcata 5-locularis 5-sperma. Rubiaceae.

959. Cuvien a. Cal. 5-partitus. Cor. 5-fida persistens, laciniis acutissimis apice spinescentihus. Stigma umbraculiforme sub-5-gonum. Rubiacene.

959. Ancylantinus. Cal. 5fidus persistens. Cor. tubulosa incurva limbo 5-fido inaequali. Stigma 5lobum. Ovarium 5-loculare. Rubiaceae.

\$50. Vangueria. Cal. minimus 5-dentatus. Cor. parva campanulato-globosa, intus hirta. Bacca pomiformis umbilicata 5 -locularis. $\boldsymbol{R} u$ biaceae.

951. Hichtemsteinia. Cal. duplex semisuperus 1 -phyllus $3-5$ dentatus. Cor. 5-fida. Filamenta extra corollam connata. Bacca 5-sperma.

$\gamma$. Fructus baccati, drupacei, polyspermi.

992. Hamelea. Flores capitati in receptaculo. Cal. 5-dentatus. Cor. infundil. 5-fida. Stylus longissimus. Fructus drupacei congesti dicocci, coccis polyspermis. Rubiacene.

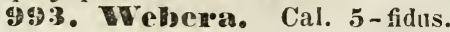
Cor. faux ampliatus, laciniis recurvis. Stigma 10-angulare. Caps. 2-locularis loculis 4-5-spermis. Rubiaceae.

95 4. Framelira. Cal. minimus 5-dentatus. Cor. 5-angularis 5-fida. Stigma ohtusum. Bacea 5-locularis polysperma. Rubiaceae.

ษ. 5ch 5-partitus. Cor. tubulosa pilosa 5fida. Stigma 5-fidum. Bacca 5-locularis polysperma. Rubiaceae.

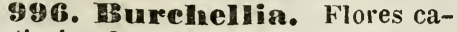
pitati involucrati. Cal. 5-partitus.
Cor. tubulosa clavata. Stigma clavatum. Bacca 2-Iocularis polysperma. Rubiaceae.

9y . Stylocoryma. Cal. urceolatus 5 -dentatus. Cor. infundibul. j-fida. Antherae lineares. Stylus clavatus. Bacca bilocularis polysperma. Rubiaceae.

959. Genipa. Cal. truncatus integer. Cor. hypocrateriformis. Stigma clavatum. Bacca 4-locularis. sem. in pulpa nidulantia. Rubiaceae.

999. Carrotenia. Cal. sul)-5partitus. Cor. tubo cylindrico, laciniis obliquis. Stigma hilobum. Bacca hilocularis. Sem. 2-1-serialia. Rubiacear.

1000. Chameliera. Cal. 5partitus laciniis acutis. Cor. tubulosa כ-partita fauce villosa. Fructus ovoideus coriaceo-camosus 2-locularis, polyspermus. Rubiaceae.

1001. Xanthoes. Cal. tubus urceolatus subintegerriuus. Cor. rotata, fauce fasciculis villorum 5 instructa. Stigma 5-lobum. Bacca glohosa calyce coronata 5 -locularis polysperma. Rubiacene.

100\%. Alibertia. Cal. tubulosus 5-dentatus. Cor. tubulosa 5partita. Antherae lineares. Stigmata 5 linearia. Bacca globosa 5-locularis polysperma. Rubiacecue.

1003. Hippotis. Cal. spathaceus hinc fissus integerrimus. Cor. tuho curvato 5-lobo. Urceolus perigynus 5-crenulatus. Bacca 2-locularis polysperma. Rubiaceae.

1004 . Ueriama. Cal. campamulatus 5-dentatus. Cor. tubo Iongissimo. Stigma clavatum. Bacca seminibus compressis 4-serialibus. Rubiaceale.

1005. Solerir. Cal. turbinatus 5-fidus. Cor. tubo longissimo recurvo, faux pilis cincta. Stylus setaceus. stygma 3-fidum. Bacca cortice duro. Rubiaceae.

100). Dryantian. Cal. apice constrictus acutissime $\mathbf{5}$-fidus. Cor. tubo longissimo. Antherae acutissimae. Fructus 2 -locularis. $\boldsymbol{R} u$ biaceae.

150\%. Esertiera. Cal. turbinatus 5-dentatus. Cor. fauce villosa. Stylus hasi glandula cinctus. Stigma bilamellatum. Bacca 2-locularis. Rubiaceae. 
1008. Heycesteria. Cal. inaequaliter 5-partitus. Cor. supra basin gibba. Stigma capilatum. Stan. exserta. Bacca 5-locularis 5-sperma. Caprifolia.

HOळ. Sellien. Cal. 5-partitus. Cor. tubulosa hinc fissa, laciniis limbi secundi 5 -partiti lanceolatis. Stigma truncatum. Bacca 1-locularis 1-sperma.

1010. IBneobotrys. Cal. 5dentatus hracteis duabus suffultus. Cor. campanulata 5-fida. Stylus brevissimus. Bacca 1-locularis polysperma. Ericeae.

\section{COROLLA POLTPETALA.}

\section{A. Fructus superi.}

a. Cor. 4-petala.

1011. Stroemia. Cal. patens 4 -sepalus. Petala 4 unguiculata. stamina basi comnata. Siliqua 1-10cularis bivalvis. Sem. in pulpa. Capjurideae.

\section{b. Cor. 5-petala.}

$\alpha$. Fructus 1-2-spermi.

1012. Mintella. Cal.5-sepalus reflexus. Petala subrotunda. Filamenta longissima ante anthesin spirales. Bacea corticata 1-sperma. Chrysobalaneare.

1013. Bpilia. Cal. 5-dentatus parvus. Petala 5. Glandulae perigynae clavatae. Stylus nullus. Bacca globosa 1-sperma. Rhamneae.

1014. Villarezia. Cal. minimus, foliolis imbricatis. Petala obIonga patentia. Antherac subcordatae. Stigma truncatum. Nux 4 -gona 1sperma. Intaceae.

1015. Huenten. Cal. campanulatus 5-dentatus. Petala ovata caJyce appressa. Stigma hifidum acutum. Drupa nuce 1-sperma. Rhamuerce.

1016. Hencina. Cal. 5-fidus persistens. Petala 5. Antherae cordatae biloculares. Stigma truncatum. Caps. apice dehiscens 1-sperma.

101\%. 'Trujanos. Cal. duplex ext. trifidus inter. 5-fidus. Pelala ovata. Antherae subsessiles cum glandulis 5 alternantes. Stigma 3 -fidum. Utriculus 1-spermus.
118. Sabia. Cal. 5-partitus. Cor. 5-petala. Stam. hasi cohaerentia petalis opposita. Drupa 1-sperma.

1015. SyHallesmais. Cal. spathaceus coloratus hinc fissus. Petala 4-5. Antherae sagitlatae. Germen glohosum 1-spernum.

1020 . Conyiacearpus. Cal. 5 -sepalus subcoloratus. Petala unguiculata subrotunda. Glandulae 5, appendiculis petaliformibus. stigma ohtusum. Nux clavata.

10:1. Ventillago. Cal. tuhulosus 5-dentatus. Petala squamaeformia. Stigma obtusum. Fructus evalvis 1-spermus apice longissime alatus. Malpighiae.

102:. Grutbielnaugha. Cal. hemisphacricus 5-partitus. Petala unguiculata patentissima. Filamenta hasi comnati. Germina $3 ; 1$-sperma. Ialpighiae.

10:3. Digera. Calycis sepalis inaequalibus margine membranaceis. Petala 3, in tubum comniventia. Nectaria biloha. stigma hidentatum. Drupa 1-sperma. Chenoporlece.

1024. Heneotedin. Cal. 5lobus persistens. Petala ovita. Antherae subrotundae reniformes 2 -loculares. Bacca subglobosa uncibus 1-2. Rhamneae.

10:5. Handerilia. Cal. 5sepalus. Petala cum staminibus alterna. Stigma hilobum. Caps. bilocularis 2-sperma.

$1026 . C y+110 . C a l .5$-fidus. Petala patentia villosa. Antherae subcordatae. Stiermata 2 , glaudulosa. Caps. baccata bivalvis disperma. Ericene.

$102 \%$. Frymenarthen. Cal. 5-sepalus imbricatus. Petala demum reflexa. Stamina cohaerentia. squamulae totidem. Caps. subsaccata. Violeae.

\section{B. Fructus 3-i.j-spermi.}

1028. Wicheroin. Flores polygami. Cal. 4-5-fidus. Petala 4-5. stigmata 3, revoluta. Caps. tricocca, coccibus bivalvihus 1-spermis. Śemina corticata. 'Tricoccae.

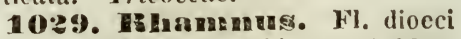
aut polygami. Cal. turbinatus 5-fidus. Petala $4-5$ minora. Antherae biloculares. Bacca 2-3-sperma. semina strophilo cartilaguieo. Rhamnear. 
1030 . Tizyoyers. Cal. turhinates 5-fidus. Petala disco glanduloso inserta. Antherae biloculares. stylus suldivisus. Drupa $2-3$-pyrena. Rhamneae.

1031. Colletia. Cal. urceolatus 5-fidus. Petala squaniaeformia aut nulla. Antherae 1-formes. Siylus 3-dentatus. Caps. tricocca, calyce vestita. Rhamnear.

1032. Cemadeduss. Cal. campanulatus 5-fidus. Petala unguiculata fornicata. stigmata 3. Caps. sicca 3-cocca. Rhamneue.

1033. Celastnes. Cal. 5-lobus. Petala unguiculata plana. Discus glandulosus. Antherae subcordatae. Stigmata 3. Caps. 3-locularis, loculis 1-spermis. Rhamneae.

103 4. Sterocanders. Cal. minutus 5-partitus. Petala 5, basi latiora. Stamina 5, inter lohos disci eqlandulosi 5-lobi inserta. Caps. 23-valvis 3-6-alata. Sem. arillata. Celastrineae.

1035. Fistmoxyon. Cal. minimus 5-lohus. Petala 5, subcarnosa. Ovarium z-loculare, disco carnoso sulcato insidens. Drupa exsucca glohosa 2-locularis. Celastrinecie.

1036. Draitenus. Hlores polygami. Cal. 5-fidus persistens. Petala patentissima. Discus carnosus perigynus. stigma 2-3-Iobum. sem. arillata. Rhamneae.

$103 \%$. fidus. Petala squamaeformia concava. stylus brevissimus triqueter. Stigmata 3. Caps. 3-cocca 3-sperma. Rhamneae.

1035. Horenin. Cal. 5-partitus patens. Petala convoluta. Stylus simplex. Stigmata 3. Pedunculi succulenti. Caps. 3-cocca. Rhamnecte.

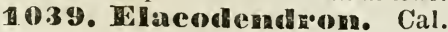
minimus 5-lobus. Petala basi latiora. stylus brevissimus. Drupa exsucca $2-5$-locularis loculis 1 -spermis. Rhamneae.

10 10. Pollycandin. Cal. mininus 5-lobus. Petala rotunda. Antherae suhrotundae. Stylus brevissimus. Stigma sublobatum. Sem. arillo calyciformi laciniato. Rhamnecie.

101. Huonymus. Cal. 45-partitus. Petala patentia. Discus nectarifer peltatus in fund. calycis. Caps. 3-5-locularis. Sem. in arillo fungoso. Rhamneae.
1042. Starvia. Flores capitati. Receptaculum lanalum. Petala oblonga. stylus bifidus. Caps. 1-35-sperma. Bruniece.

1043. Winterlia. Cal. urceolatus 5-10-costatus. Stamina cum petalis alterna. Caps. 3-valvis 3-sperma. Caryophyllecie.

10.4. Claytomia. Cal. bivalvis. Petala unguiculata staminifera. Stigma 3-fidum. Caps. 3-sperma. Portulacede.

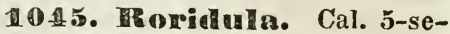
palus persistens. Petala oblonga aequalia. Antherae Ianceolatae semibifidae. Stigma 3-lohum. Caps. 3-valvis. Semina scrohiculata. Droserece.

1016. Ayemia. Cal. 5-fidus. Petala apice stellam glanduliferam formantia. Urceolus 5-dentatus staninifer. Stigma 5-lohum. Caps. 5, pentacoccae. Buettnerecte.

10\%. partitus. Petala apice cucullata aut auriculata dorso in ligulam producta. Tubus staminifer 5-10-dentatus. Caps. subechinata. Buettnereae.

10 4. Aneidea. Cal. 5-partilus deciduus. Petala unguiculata spathulata. Filamenta medio barbata. Antherae hiloculares. Stigma 5-lobum. Cocci 5. Rutacene.

1045. Spirarathena. Cal. cupulaeformis 5-gonus 5-fidus. Petala linearia subfalcata. Antherae post anthesin spiratim revolutae. Cocci 5 , 1-spermi. Rutacecte.

1050. Tiosman. Cal. 5-partitus ant 5-sepalus. Petala patentia. Discus perigynus lobatus. Antherae apice glanduliferae. Cocci 5, 2-valvis. Rutaceae.

1051. Hasionetrollum. Cal. corollinus campanulatus bractea 3-partita suffultus. Petala squamaeformia. Caps. 3-sperma. sem. strophilo laciniato. Lasiopetaleae.

1052. Guichenguia. Cal. corollinus persistens $\mathbf{5}$-fidus bractea 3-partita suffultus. Petala squamaeformia. Antherae rima longitudinali dehiscentes. Ibid.

1053. THonassia. Cal. campanulatus $\tilde{5}$-fidus bractea 3 -partita suffultus. Petala squamaef. Filamenta basi connata. Antherae rima laterali dihescentes. Sem. strophilo crenato. Ibid. 
1054. Wallevin. Cal. 5-partitus persistens. Petala patentia. Filamenta capillaria. Antlerae subrotumdae. Stylus setaceus. Drupae 5, 1-spermae. Ochneae.

1055. Futherais. Cal. 5-sepalus. Petala patentia. Antherae apice poro gemino dehiscentes. Sitylus filiformis. Bacca 5-sperma. Sem. arillata.

1056. Melicytus. Flores dioeci. Cal. 5-dentatus. Petala patentissima. Stamina clavata cyathiformia. Antherae 4-sulcatae. Bacca 5-locularis. 'T'erebinthaceae.

105\%. Dlinia. Cal. campanulatus 5-dentatus. Petala sublinearia. squamae basi petalorum concavac. Antherae didymae. Stigma subbifidum. Drupa 5-sperma.

1(1)5. Thedalia. FI. diclini. Cal. 5-dentatus. Pelalit patentissima. Antherae subrotumdae $\mathbf{2}$-loculares. Stylus 5-sulcus. Drupa 5-locularis. Terebinthacear.

1059. Fsentbecixia. Cal. 5partitus. Petala ovato-oblonga patentia. Discus perigyus urceolatus. Antherae subcordatae. Germen tuberculato-glandulosum. Rutaceue.

1060. Asoden. Cal. 5-sepalus subimbricatus. Erceolus periyynus 5-lohus. stylus clavatus. Caps. 3-valvis 3-6-sperma. Violeae.

1061. Conolionia. Cal. 5sepalus subimbricatus. Petala acqualia. Filamenta lilera suluulata. Antherac subcordatac processu dorsali memhranaceo. Caps. Alsodeae. Ioleae.

106:. Ture Eimaia. Flores poJygami. Cal. 5-partitus persisteus. Discus 10-crenatus. Sitylus trifidus. Bacca 3-locularis. Semina ossea. Rhamneae.

1063. Vitis. Cal. minimus 5dentatus. Petala apice fornicata subcohaerentia. Stigma capitatum. Bacca oligosperma. Viniferae.

\section{$\gamma$. Fructus 10-polyspermi.}

1064. FEntia. Cal. 5-dentafus. Petala apice uncinata. Antherae dorso affixae hiloculares. Stigma 5lohum. Caps. 5-locularis, loculis 2spermis. Rutacene.

1065. Culonendion. Cal. 5-partitus. Petala unguiculata. Stam. sterilia tuberculata apice glandulifera. Caps. 5-locularis 5-valvis, loculis 2spermis. Rutaceae.

1066. Diefyoloma. Cal. 5partitus. Petala lanceolata apice uncinata. Squamac 5 lanatae staminiferae. Stigma 5-lobum. Caps. 5. sem. reniformia dorso alata. Ibid.

206\%. Hittosponum. Cal. 5-sepalus deciduus. Petala unguibus in tubum comniventia. Caps. 3-locularis, loculis 3-4-spermis. Sem. nitida. Pittosporecte.

1065. Ġ̉llardenia. Cal. 5partitus coloratus. Petala in tubum conniventia. Stigma bilobum. Bacca bilocularis polysperma. Sem. laevia. Ibid.

1069. Bursaria. Cal. 5-fidus. Petala linearia. Stylus brevis. Caps. compressa bipartibitis dicocea, coccis 2-3-valvibus. sem. resinosa. Ibid.

1020. Heryogain. Cal.5-partitus imbricatus, involucratus bracteae tripartitae lacinia clavata. S'ligma cruciatum. Bacca 5-locularis. Gultijerue.

10\% 1. Ifyelnocañus. Flores diclini. Cal. 5-sepalus. Petala hasi squamis nectariferis. Bacca glohosa. Sem. rugosa. Flacourtieae.

10 \%:. Calispenmuma. Cal. 5-fidus persistens. Petala concava. stigma crassum. Bacca 1-locularis. sem. nidulantia plurima. - -

1083. EBrexia. Cal. 5-fidus persisteus. Petala rotundata caduca. Urceolus fimbriatus staminifer. Antherae hiloculares. Stigma 5-lobum. Drupa 5-angularis.

10 4. Escallonia. Cal. semiglohosus 5-dentatus. Antherae 2-loculares. sitigma hilobum. Caps. baccata 2-locularis hasi irregulariter rumpens. Escallonieae.

1075. Flindersia. Cal. 5fidus. Petala oltusa plana. Discus perigynus cyathiformis 10 -plicatus subcrenatus. Caps. lignea echinata. sem. apice alata. Melieae?

1)g. Cedrela. Cal. 5-dentatus. Petala erecta in tubun comniventia. Stigma 5-gonum. Caps. 5-valvis. Nem. compressa apice alata. Cedreleae.

108\%. Anclietea. Cal. 5partitus. Cor. irregularis, petalo quinto maximo calcarato. Cajs. maxima 
inflata. Sem. compressa alata grandia. Violene.

108. A 8 . 5-partitus. Petala 5 unguiculata spathulata unguibus longis. Antherae mucronatae. Caps. 1-locularis 3-valvis. Jioleae.

10 \%. ChIossanonen. Cal. 5-sepalus, sepalis minimis. Cor. irregularis petalo maximo calcarato. stigma lunato-hicorne. Caps. 1-locularis 1-valvis. Tiolece.

1080. Noisettia. Cal. 5-sepalus. Cor. irregularis petalo quinto maximo. Filamenta subcomata apice memhrana aucta. Caps. 1-locularis 3-valvis. Tioleae.

1081. Conynostylis. Cal. 5-sepalus subaequalis, petalo quinto maximo. Filamenta membranacea apice ligula aucta. Caps. lignescens. sem. subquadrato-compressa. Tiolecue.

108\%. Filbanthus. Cal. postice gibbus. Petalum inferius hasi saccatum medium elongatum bifidum. Filamenta connata. stigma acutum. Caps. obovata 3-valvis. Tiolecie.

1083. Sollea. Cal. 5-sepalus truncatus. Cor. irregularis ecalcarata petalo quinto maximo. Filamenta apice in ligulam producta. Stylus uncinatus. Violecue.

1081. Viola. Cal. 5-partitus basi productus. Petalum supremum cornutum. Filamenta in membranam producta. Stigma uncinatum. Caps. 1-locularis 3-valvis. Violeae.

1055. Fupatiens. Cal. disepalus caducus. Petala 4, quinto al-ortiente, inferius calcaratum. stigma 5-gonum. Cal. 5-locularis 5-valvis, valvis spiratim tortis.

1086. Taveralia. Cal, 5-sepalus. Petala breviter unguiculata. Squamulae 5 petaloideae. Filamenta brevissima. Caps. trilocularis 3-valvis. Drosereae.

108 \%. Sauragesia. Cal. 5sepalus. Petala ovata. Corona fimbriata inter petala. Antherae biloculares. Caps. 3-locularis 3-valvis. Droserea.

1058. Hyblis. Cal. 5-sepalus. Petala 5. Antherae apice biporosae. stigma bilobum. Caps. 2-locularis bivalvis polysperma. Drosereae.

1089. Galax. Cal. 5-partitus. Petala 5. Stamina 10, 5 sterilia. Fi- lamenta subulata. Caps. 3-locularis polysperma. Ericeae.

1050. 面er. Cal. 5-fidus minimus coloratus. Petala lanceolata. Antherae subrotundae incumbentes. stigma obtusum emarginatum. Caps. 2-valvis.

1091. Frumia. Flores agregati. Receptaculum pilosum. Cal. 5sepalus. Petala unguiculata. Antherae ovato-oblongae. Drupa bilocularis polysperma. Brumiene.

109\%. Hengabolatia. Cal. 5-partitus. Petala 5. Germen pedicellatum. Legumen oblongum compressum Leguminosce.

1093. Droynania. Cal. 5partitus, Petala bifida. Filamenta hasi subcomnata. Stigma trifidum. Caps. 1-locularis 3-valvis 5-polysperma. Caryophylleae.

1094. HIollia. Cal. 5-partitus: laciniis membranaceis. Petala 5. stigma 3-lobum. Caps. 1 -locularis 3-valvis, polysperma. Paronychiae.

1095. Wa palus. Petala 5-10 angusta. Stylus setaceus. Caps. baccata sphaerica 1Iocularis 1-valvis. Sem. subangulata. Primuleae.

1096. Wibelia. Cal. 5-partitus. Petala in tubum conniventia apice reflexa. Antherae approximatae. stigma bilobum. Germen biloculare.

\section{B. Fructus inferi.}

a. Corolla 3-petala.

1098. Strelitzia. Spathae 1phyllae. Cal. coloralus 3-petaloideus subbilahiatus. Cor. irregularis genitalia involvens. Stigmata 3. Caps. 3-valvis. Museae.

$$
\text { b. Cor. 5-petala. }
$$

1098. Thibes. Cal. ventricosus 5-fidus coloratus. Antherae biloculares intus dehiscentes. Stylus 2-3fidus. Bacca 1-locularis 1-sperma. Ribesiae.

1099. Heetrea. Cal. 5-dentatus, dentibus deciduis. Petala lanceolata. Antherae incumbentes basi bifidae. Bacca 5-sperma calycis limbo coronata. Aralieae. 
1100. Splnaerocarya. Cal. 5-partitus. Squamae 5, fimbriatae inter calycis lacinias. Drupa nuce 1sperma.

1101. Carpoletra. Cal. turbinatus 5-dentatus. Petala et stamina alterna. stigma capitatum. Bacca globosa 5-locularis 5-sperma.

110:. npectronia. Cal. turhinatus obsolete 5 -dentatus, ore villis clauso. Antherae geminae sub squamis calycis. stigma ovatum. Bacca oblonga 2-sperma.

1103. Gounnia. Flores polygami. Cal. campanulatus 5-fidus. Petala cucullata. Antherae suhrotundae petalis tectae. Caps. subulata 3sperma. IRhumneae.

104. Cummenaria. Cal. campanulatus 5-fidus. Petala cuculliformia. Antherae petalis reconditae hiloculares. Caps. papyracea 3-cocca. Rhamneal.

105. Strumpfia. Cal. minimus 5-dentatus. Petala ovato-ohJonga. Antherae sessiles connatae. stigma obtusum. Caps. 1-sperma.

106. Gromovia. Cal. 5-partitus subcoloratus. Petala linearia. Stigma capitatum. Bacca 1-sperma. Cucurbitaceae.

110 \%. Argoplaynum. Cal. 5-fidus. Petata lanceolata. Úrceolus 5-gonus apice multifido-fimbriatus. Caps. 3-locularis.

110. Wasione. Flores capitati involucrati. Cal. 5-fidus. Antherae coalitac. Stigma clavatum subhilohum. Caps. 2-lucularis. Camjanuleae.

109. Eigntfontia. Cal. 5sepalus. Petala lanceolata. Filamenta fornicata. stigma $3-5$-fidum. Caps. 3-5-locularis. Campanuleae.

110. Cypia. Cal. 5-partitus. Cor. 5-pelala subbilabiata. Filamenta comiventia pilosa. stigma clavatum. Caps. bilocularis. C'amganuleae.

111. Iagdecia. Flores umbellati involucrati. Cal. 5-sepalus serratus. Petala appendiculis bifidis. Caryopsis calyce coronata. Umbelliferce.
** Flores imperfecti.

A. Fructus superi.

Amerantheae et Chenopodeae.

a. Alteruifoliae.

1112. Celosia. Cal. 5-partitus coloratus bibracteatus. Cupula 5-dentata staminifera. Stigma divisum. Caps. circumscissa, polysperma.

113. HEenzelia. Cal. 5-sepalus bibracteatus. Tubus staminifer 5partitus laciniis 3-fidis. Caps. circumscissa polysperma.

1114 . Cetisbudesia. Cal. 5-partitus coloratus bibracteatus. Cupula 10 -dentata alterne staminifera. sligmata 4. Caps. circumscissa polysperma.

11. Clatostacinys. Cal. 5-sepalus demum reflexus. stylus nullus. Stigmata 3 , linearia revoluta. Caps. polysperma.

1 16. Anaronthus. Flores monoeci. Cal. 3-5-sepalus. Stam. 3-5. stylus profunde 2-3-partitus. Utriculus circumscissus 1-spermus.

$111 \%$. Chammisor. Cal. 5sepalus hihracteatus. Cupula edentata staminifera. Antherae loculares. Utriculus circumscissus 1-spermus. Sem. arillatum.'

118. ¿̈rm. Cal. 5-sepalus lanatus bibracteatus. Cupula staminea 10-partita. Stigma bifidum. Utriculus 1-spermus.

119. 'Trichinium. Cal. 5sepalus, sepalis fructiferis plumosis, bihracteatus. Cupula staminifera edentula. Utriculus 1-spermus.

1120. Ptilotus. Cal. 5-sepalus bibracteatus, sepala medio lana cohaerentia. Filamenta connata. Stigma capitatum. Utriculus 1-spermus.

1121. Deeringia. Cal. 5partitus, trihracteatus. Filamenta dilatata comnata. stigmata 3 . Bacca triloba polysperma.

1122 . 'Tragamum. Cal. persistens 5 -fidus trihracteatus. Filamenta lihera. Antherae sagittatae. Nux lignosa 1-sperma calyce inclusa.

1123 . Connulaca. Cal. 3hracteatus villis involutus 5-fidus lacinia una dorso demum spinifera. Antherae 2-loculares. Utriculus 1-spermus calyco inclusus. 


\section{b. Oppositifoliae.}

1121. Achyranthes. Cal. 5 -sepalus hracteis 2 spinescentibus suffultus. Cupula staminifera cum squamulis dentatis aut fimbriatis. Utriculus 1 -spermus.

1125. Desmochaeta. Flores glomerati perfecti, interjectis totidem fasciculis uncinitis. Cal. 5-sepalus. Cupula staminifera 5-partita. Stigma capitatum. Utriculus 1-spermus.

1126. Fupralia. Flores gemini bihracteati, altero abortiente in uncinos abeunte. Cupula staminifera 10-partita. Utriculus 1-spernus.

1128 . Altermantherr. Cal. 5-sepalus, hihracteatus. Cupula staminifera 10-dentata, denticulis sterilibus subdentatis. Utriculus 1 -spermus.

11:28. Nogiphames. Cal. 5sepalus bihracteatus stipitatus basi 5glandulosus. Tubus cylindricus 10-fidus laciniis 5 antheras ferentibus.

129. Pfafia. Cal. 5-sepalus bibracteatus. Tubus staminifer 10-fidus laciniis inciso-fimbriatis. Stigma sessile. Utriculus 1-spermus.

1130 . Gunn phrema. Cal. 5sepalus, bracteis 2-concavis suffultus. Tubus staminifer 5-fidus, laciniis denticulato-incisis. Utriculus 1-spermus.

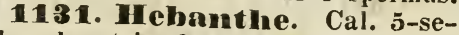
palus bracteis 2 concavis suffultus: sepala interiora lana stricta cincta. Tubi staminiferis laciniis $\mathbf{3}$-fidis. Utriculus 1-spermus.

$11 \%$. Iresine. Flores diclini lanati. Cal. 5-sepalus hihracteatus. Cupula staminifera edentula. Stigmata 2-3. Utriculus 1-spermus.

1133. PIniloxerus. Flores hermaphroditi post anthesin mutati. Cal. 5-sepalus 3-bracteatus. Cupuia staninifera edentula. Utriculus 1spermus.

113 1. IInplotheca. Cal. 5fidus dense tomentosus bibracteatus, post anthesin muricatus. Stigma penicillato-multifidum.: Utriculus 1-spernitus.

1135. Aylmeria. Cal, 5-sepalus bibracteatus. Tubus staminifer 10-fidus. Caps, evalvis polysperma.

1136 . Boussingaultin. Cal. membranaceus persistens, limbo duplici, exter. bi-inter, 5-partito. stigma 3-lobum. Utriculus 1-spermus.

\section{Paronychieae.}

113 \%. Hllecebrum. Cal. 5sepalus bibracteatus. Sepala cucullata cornuta dorso incrassata. Caps. 5-valvis 1-sperma.

1138. Paromyelnia. Cal. 5partitus ebracteatus. Sepala sulicucullata subaristata. Utriculus 1-spermus stylo coronatus.

113\%. Anychin. Cal. 5-sepalus sepalis sub apice saccatis. Stigmata 2-3. Utricnlus $1-$ spermus calyce cinctus.

110. Guilleminea. Cal. campanulatus 5 -fidus. Stylus apice emarginatus. Utriculus 1-spermus calyce cinctus.

111. Cymmocarpus. Cal. subcampanulatus $\mathbf{5}$-fidus coloratus. Antherae bilobae. Stigma 3-dentatum. Utriculus 1-spermus calyce tectus.

$$
\text { Chenopodeae. }
$$

1142. Anrealera. Cal. bipartitus, dorso coronatus. Stigmata 2. Caryopsis calyce bialato tecta.

113. Hablizia. Cal. 5-sepalus rotatus. Antherae globosae didymae. Stigma 3-lobum. Utriculus circumscissus 1-spermus.

114. Caroxylon. Cal. 5partitus 2-bracteatus. squamae membranaceae ovatae. Stigmata 2. Caryopsis calyce cincta squamis coronata.

145. Thagodia. Flores polygami. Cal. 5-partitus. Fructus baccatus 1-spermus calyce cinctus.

\section{Rhamneae.}

1146. Almatea. Cal. coloratus 5-gonus 5-fidus. Stam. hypogyna. Caps. obcordata hilocularis 2 -valvis. sem. membrana olivoluta.

114. Condalia. Cal. urceolatus 5-fidus basi persistens. Antherae basi bilobae. Discus perigyuus glaudulosus. Drupa 1-sperma.

1148. Pemmantia. Flores polygami. Cal. corollinus 5 -sepalus. Stigma 3-lobum. Drupa triquetra sub3-sperma.

114. Exocarpus. Flores polygami. Cal. 5-partitus. Stylus 
brevissimus. Nux 1-sperma peduuculo applicato baccato imposita. Santaleae.

1150. Cervantesia. Cal. 5partitus in fructu auctus carnosus. Discus 5-lobus in fundo calycis. Nux 1-sperma calyce cincta. Santaleae.

151. Amanoa. Flores androgyno-diclini. Cal. 5-partitus bracteatus. Discus hypogyuus glandulosus. 5-lobus. stigmata 3. Caps. drupaeformis. Tricoccae.

152. Flueggea. Flores dioeci. Cal. 5-partitus. Antherae extrorsum dehiscentes. Stigmata 3 , hifida reflexa. Caps, baccata $\mathbf{2}-\mathbf{3}$-locularis. Thicoccue.

1153. Antidesma. Flores dioeci. Cal. parvus 5-dentatus. Annulus carnosus staminifer. Antherae didymae. Drupa 1 -sperma. Rosaceae?

1154. Liennia. Cal. 5-fidus bibracteatus. Annulus glandulosus stauinifer. Drupa 1-sperma. Rosaceue.

155. Ceratomia. Flores poIygani. Cal. 5-partitus. Filamenta longissima. Antherae magnae didymae. Legumen 4-angulare. Leguminosae.

1156. Glaux. Cal. 5-partitus coloratus. Stamina hypogyna. Siylus eonicus. Caps. 1-locularis 5-sperma. Primuleae.

\section{B. Fructus inferi.}

15\%. Phyliea. Cal. corollinus 5-fidus. Squamulae cucullatae intra calycem stamina obtegentes. Caps. tricocca subbaccata. R/hamneae.

159. Thesium. Cal. corollinus 5-fidus. Stamina extus villosa. Antherae 2-loculares. Nux 1-sperma striata. Santuleae.

1159. Leptomeria. Cal. rotatus 4-5-fidus. Discus epigynus 5-4-lobus. Antherae biloculares. Stigma emarginato-bilobum. Drupa baccata. Santuleae.

1160. Choretrum. Cal. corollinus 5-partitus basi bractea seu calyculo 5-dentato suffultus. Antherae 4-loculares. Stigma stellatum. Santaleae.

1161. Inmiltomia. Flores dioeci aut polygami. Cal. 5-fidus.
Discus perigyuus 5-dentatus. Antherae basi subharbatae. Drupa 1-sperma. Suntuleae.

1162. Nyssa. Flores polygami. Cal. 4-partitus deciduus. Stam. in masculis 10 in hermaphroditis 5. Stylus incurvus. Drupa 1-sperma. Santaleae.

1163. Cevallia. Cal. corollinus 10-partitus. Antherae conniventes sagittatae intus longitudinaliter dehiscentes appendiculo membranaceo. Nux 1-sperma.

1164. Dyoselnilos. Cal, corollinus 5-sepalus. Antherae subrotundae. Stigma 2-3-fidum. Drupa 1-sperma. Thymeleae.

165. Compenrpus. Flores capitati. Cal. urceolatus 5-fidus deciduus. Antherae cordatae. Sitrobilus e fructibus imbricatis suberosis 1-spermis. Combretaceae.

\section{DIGYNIA.}

$\alpha$. Flores perfecti.

I. Corolla 1-petala.

Fructus superi.

Contortae.

a. Carisseae : drupiferac s. ba c ciferae.

1166. Mrawolfin. Cal. 5partitus persistens. Cor. infundil. 5fida. Antherae erectae simplices. styli connati. Drupae 2, 1-spermae.

116 \%. A Iyxia. Cal. 5-fidus. Cor. hypocraterif. fauce nuda. Styli subcohaerentes. Drupae 2, 1-spermae. semen subbipartitum.

1168. Coprosma. Flores polygami. Cal. 5-partitus. Cor. campanulata $5-7$-fida. Stamina $5-7$. Styli divaricati. Bacca disperma.

169. Melodinus. Cal. 5dentatus. Cor. faux obsessa squamis 2-fidis. Styli connati. Bacca globosa polysperma.

b. Apocyneace. Fructus folliculares.

11\%. Plumeria. Cal. minimns 5-fidus. Cor. infundib. fauce nuda laciniis obliquis. Stigmata emar- 
ginata. Folliculi ventricosi. Sem. basi alata.

11 \%. Paelnypolium. Cal. 5-sepalus. Cor. hypocraterif. pilosa, laciniis spathulatis. Antherae sagittatae. Folliculi ventricosi.

11 \%. Cryptostegin. Calycis laciniis inciso-dentatis. Squamae tubi cor. bifidae antheras obtegentes. Glandulae stigmatis 5 spathulatis.

123. Heniploea. Cal. 5fidus. Cor. 5-partita; cormua 5 aucta. Antherae plicis gynostegii reconditae simplices manubriatae.

11 \% 4 . Hemidesmus. Cal. 5-fidus. Cor. 5-partita. Squamae 5obtusae. Antherae succedaneae imberhes.

1 1.5. Gymanamthera. Cal. 5-fidus. Cor. hypocraterif. Squamae ad faucem 5, aristatae. Antherae Periplocae. Antherae succedaneae imberbes.

\section{c. Asclepiadeae.}

11 ร. 'Secamone. Cal. 5fidus. Cor. rotata. Corona perigyna pentaphylla. Antherae quaternae gynostegio affixae.

11 ร. Stapelia. Cal. 5-fidus. Cor. sulbcarnosa rotata 5-fida. Corona perigyna plerumque duplex, externa ligulas, interua rostra formans.

11 8. I Ieurnia. Cal. 5-fidus. Cor. campanulata 10-dentata. Corona perigyna duplex, externa lohos fissos, interua cornicula subulata formans.

11 g. Hrachystelma. Cal. 5-fidus. Cor. campanulata 5-fida sinubus angulatis. Corona 1-phylla 5loba. Gynostegii mensiranulae plicatae nullae.

180. Caralluma. Cal. 5partitus. Cor. subrotata 5-partita. Corona 10-phylla, foliolis 5, 2-partitis subulatis. Gynostegium externum.

181. Boveerosia. Cor. subcampanulata 5-fida. Corona staminea 15-Ioha duplici serie. Massae pollinis 4-gonae. Folliculi laeves teretes attenuati.

1182. Hutselnimia. Cor. subcampanulata 4-fida intus pilosa. Corona 20-Ioba. Massae pollinis margine hinc pellucido.

183. Erionetalum. Cor. subcampanulata 5-fida. Corona 15-loba. Massae pollinis juxta basin affixae erectae stigmati incumbentes hinc margine pellucidae. Folliculi graciles.

184. Pterostelma. Cor. rotata 5-fida. Corona staminea 5phylla, foliolis membranaceis. Antherae memhrana terminatae. Massae pollinis erectae approximatae. Stigma apiculatum.

185. Pliysostelma. Cor. rotata repande dentata. Corona staminea 5-phylla foliolis inflatis. Antherae memhrana terminatae. Massae pollinis basi affixae erectae subcylindraceae. Stigma depressum.

1186. Heterostemmn. Cor. rotata 5-partita. Corona staminea 5phylla, foliolis dilatatis intus precessu auctis. Massae pollinis obsolete 4gonae.

15\%. Pentasachme. Cor. subrotata profunde 5-fida, fauce squamulis 5 coronata. Corona staminea nulla. Massae pollinis pendulae apice pellucido.

118. Toxnenrpus. Cor. rotata 5-fida. Coroua 5-phylla, foliolis intus lacinula auctis. Massae pollinis 20. Stigma rostratum. Foll. divaricati.

1159. Streptocaulon. Cor. rotata 5-partita, fauce 5 squamis aristatis coronata. Massae pollinis granulosae solitariae. Foll. divaricatissimi.

1190. Ceropegia. Cal. 5partitus. Cor. basi ventricosa tuho infundibuliformi. Corona perigyna duplex, exter. 5-loba, inter. 5-phylla.

111. Hoya. Cal. 5-partitus. Cor. rotata 5-fida. Processus gynostegii 5, carnosi. Stigma papillosum in medio gynostegii prominulum.

192. Tyopleora. Cal. 5fidus. Cor. rotata 5-partita. Processus gynostegii 5, carnosi, angulo interiori edentulo. Stigma muticum.

1183. Peroularia. Cal. 5fidus. Cor. hypocraterif. tuho urceolato. Processus gynostegii 5, lamellosi intus edentuli vel lacinula aucti.

-115) . Disclinilin. Cal. 5-partitus. Cor. urceolata 5-fida. Processus gynostegii 5, foliola bifida. Stigma muticum.

195. Gymmemna. Cal. 5-fidus. Cor. suburceolata 5-fida. Faux saepe coronata denticulis aut squamulis inter lacinias. 
1.96. Ṡrzecolbolas. Cal. 5fidus. Cor. subrotita 5 -fida fance nuda. Folliculi ventricosi carnosi. Sem. marginata.

119\%. Diratelen. Cal. 5-fidus. Corolla tubulosa limbo hypocrateriformi. Corona gynostegii lobata. Folliculi costati. sem. nuda.

1198. Gomoloburg. Cal. 5fidus. Cor. sulrotata 5-fida. Corona gynostegii 5-loha subcarnosa.

1155 . Asele pias. Cor. 5-partita revoluta. Corona cucullis 5 cornigeris coustat. Folliculi glabri.

1:000. Compologeanous. Cor. 5-partita reflexa. Corona cucullis inIIIs aceralis saepe 1 -dentatis constat. Folliculi ventricosi echinati.

1201. Wenslenia. Cor. 5-partita laciniis erectis comniventilus. Coroua 5-partita petaloidea, laciniis truncatis dente gemino aristato lerminatis.

$120 \%$. Dxyoreinas. Cor. rotata patens. (iymosterium exsertum. Corona 5-phylla, foliolis acutis indivisis. Folliculi laeves.

1203. Xysunabobun. Cor. campanulata hasi ventricosa. Corona prominula e laminis 5 ohtusis calnosis. Folliculi paleacei.

reo. Calotronds. Cor. suhcampanulata basi in angulis saccata. Curona e laminis gynostegrio adpressis lanceolatis revolutis 2-dentatis.

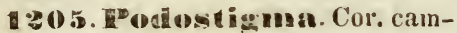
panulato-rotata. Gynostegium stipitatum. Corona e foliolis compressis erectis apice liheris recurvis.

1 206. Lasemacestomia. Cor. hypocrateriformis, latue barhata. Corona e foliolis camosis lunato-bilobis.

120 \%. Nachosects. Cal. 5partitus bracteatus. Cor. carnosa hasi ventricosa limbo patente $\tilde{5}$-fido. Gynosteriun breve scutelliforme.

1203. Camalnia. Cal. 5-partitus. Cor. citmpanulata limbo 5-partito. Corona apici gynostegii imposita e foliolis 5 subulatis basi incrassittis.

209. Cymanelumu. Cor. 5partita rotatic. Corona petaloidea, cum antheris alternans 5-loba seu duplex, exter. 10-fida, inter. 5-partita.

1910. Ditassa. Cor. 5-partita rotata intus harbata vel glandulosa. Corona duplex, exter. 5-partita. inter. 5-phylla antherisque opposita.
1211. Himnia. Cor. subrotata. Corona duplex, exter. brevis 5-partita denticulis interjectis, inter. 5-phylla foliol. suhulatis. Folliculi hispidi.

12 1. Sancostemma. Cor. rotata 5-fida. Corona duplex, exter. cyathiformis s. annulata crenata, inter. 5-phylla carnosa. Folliculi laeves.

1013. HPillibertia. Cor. urceolato-rotata 10-dentata. Corona duplex, exter. in fundo corollae amulatae, inter. 5-phylla in apice gynostegii himucronati.

121. Eustegin. Cor. rotata 5-fida. Corona triplex 5-phylla interior cum exterioribus alternans, media foliolis trilohis.

1:15. Detaplexis. Cor. rotata 5-fida. Corona 5-partila, laciniae cum antheris alternantes. Gynostegium rostratum.

1216. Oxypetalums. Cor. campanulata, lacinits elongatis acutissimis. Corona 5-phylla carnosa. Stigmata e gymostegio longe producta.

1213. HInysumthus. Cor. campanulata hasi ventricosa. Corona 5-phylla sublibera carnosa foliolis apice cucullatis. stigmata apiculata.

1.218. Ifolestemuna. Cor. suhrotata 5-fida, tuho intus annulato. Gynoslegium mulicum.

1219 . Detastelna. Cor. subcampanulata fauce coronata dentilus 5 exsertis in tuhum decurrentibus. Gynostegium muticum.

1:20. Vicroloma. Cor. urceolata tubo ventricoso angulato, fauce unda. Squamae 5 medio tubo insertae cum totiden fasciculis villorum.

1291. Armuja. Cor. campanulata hasi saccis 5 nectariferis. Hilamenta latissima auriculata dentata.

$122 \%$. Asteplinmus. Cor. subcampanulata, fauce tuboque nudis. Gynostegium apiculatum.

\section{Gentianeae.}

1223. Gentiana. Cal. campanulatus 4-5-fidus. Cor. sulcampanulata 4-5-fida fauce nuda ant harbata. Caps. 1-locularis apice bivalvis.

12:1. Swertia. Cal. 4-5partitus. Cor. rotata laciniis basi biglandulosis aut campanulata hasi tuberculata vel calcarata. Caps. Gent. Semina alata. 
1225. Hochefortia. Cal. 5partitus. Cor. infundib. כૅ-loha. styli subulati pilosi. Caps. 2-locularis seminil)us angulosis.

\section{Convolvulaceae.}

1226. Fvolvulus. Cal. 5partitus. Cor. subrotala 5-fida. Stiymata incrassata. Caps. subbilocularis, loculis dispermis.

122\%. Infonnen. Cal. 5partitus laciniis 2 maximis. Cor. campanulata. stigmata globosa. Caps. 2-locularis loculis sub-1-spermis.

12\%8. Nevropeltis. Cal. 5sepalus persisteus; bracteis orbiculatis membranaceis reticulato-venosis suffultus. Cor.5-fida. Caps. 1-sperma.

$12 \geq 9$. Cressa. Cal. 5-partitus. Cor. sublypocraterif. Stigmata capitata. Caps. bivalvis 1-sperma.

1230. Dichondm. Cal. 5partitus. Cor. subrotata. styli basilares. stigmata capitata. Utriculi gemini 1-spermi,

1231. Cammoner. Cal. 5partitus, Iaciniis linearibus. Cor. rotata 5-partita. Antlierae didymae. Drupa globosa nuce 6-sperma.

1232. Falkia. Cal, 5-dentatus. Cor. infundib. plicata. Caryopses 4.

1223. Cuscuta. Cal. 4-5lobus. Cor. globosa persistens 4-5fida hasi intus squamosa. Caps. 2locularis basi dehiscens loculis dispermis.

\section{Hydroleae.}

1234. Hydrolea. Cal. 5-partitus. Cor. subcan!panulata. stam. basi dilatata. Antherae sauittatae. Caps. 2-3-locularis polysperma.

1235. Wignmalia. Cal. 5partitus persistens. Cor. infundib. 5partita. Antherae sagittatae. Stigmata subpeltato-depressa. Caps. 2-locularis.

1236. Namn. Cal. 5-partitus persistens. Cor. subrotata 5-fida. Antherae reniformi-bilobae. Caps. bivalvis bilocularis.

123 \%. Wamelhostoma. Cal. bracteatus 5-partitus. Cor. tubulosa 5partita. Caps. bilocularis.

\section{Coholla pentapetala.}

A. Fructus superi.

1238. Picrammia. Flores dioeci. Cal. 3-5-partitus. Petala 3-5. Stamina $3-5$. Stigmata 2 . Drupa nucleo biloculari dispermo. 'Terebinthacene.

1239. Trenicosta. Florer polygami. Cal. 4-5-fidus. Petala $4-$ 5. Discus 5-dentatus perigynus. Bacca didyna 1-sperma. Menispermeate.

1280. Geuclnera. Cal, velltricosus 5-dentatus. Petala calyci inter dentes imposita. Antherae sayittatae. Caps. bilocularis. Saxificbgecue.

124. Velezia. Cal. tubulosus gracilis 5-dentatus. Petala parva emarginata unguibus filiformibus. Caps. 1-locularis polysperma. Caryophylleue.

B. Fructus inferi.

1242. Holigarra. Cal. 5partitus. Petala 5. Germen 1-loculare. Bacca inferior 1-locularis. Araliucece.

1213. Panax. Flores umbellati. Involucrum polyphyllum. Cal. minimus persistens. Petala revoluta. Bacca scrotiformis. Araliaceae.

124. Cussonia. Cal. 5-dentatus. Petala 3-gona acuta. Bacca disperma. Ibidem.

12 5. Whia. Cal. 5-sepalus patens. Petala ovata concava. Antherae biloculares. Caps. 1-locularis bivalvis polysperma. Onagrae.

1246. Jinconia. Cal. 5-dentatus. Petala cum dentibus calycis alternantia. Cocci duo membranacei 1-spermi. Brunieae?

124\%. Xanthosia. Cal. 5partitus. Petala 5. Fructus biparlihilis. Embelliferae.

1218. Plnylis. Cal. minimus, hifidus. Petala obtusa revoluta. Antherae oblongae. Stigmata 2 reflexa. Caps. 2-locularis. Rubiuceae.

13.5. DuInegia. Flores e nervo foliorum medio. Cal. 5-dentatus. Discus orbicularis germen obtegens. Bacca semibilocularis 2-3sperma. 
Umbelliferae
$56-250$.

1. Orthospermae. Albumen intus planum aut planiusculum.

* Umbellis simplicibus aut imperfectis; Vittis fructus nullis.

1. Hydrocotyleae. Fructus a latere compressus.

1250. Mydrocotyle. Cal. tubus subcompressus. Mericarpia evittata, jugis 5 filiformibus, carinali et lateralibus saepe obsoletis intermediis 2 accretis.

1251. Dimetopia. Cal. dentes ohsoleti. Fructus didymus. Mericarpia subglohosa ad commissuram suhcoutracta disparia uno muricato altero echinato.

\section{$1 \%$ :} maruo ohsoletus. Petala acuta Fru ctus basi profunde cordato-bilobus subfoliaceus apice emarginatus.

253. Hidiseus. Cal. margo ohsoletus. Petala ovalia ohtusiuscula. Fructus compressus orbiculatus asper bivittatus. Mericarp. a latere compressissima.

1:54. Trachymene. Cal. 5dentatus. Petala elliptica. Fructus ovatus solidus muricutato-rugulosus dorso costatus. Mericarpia 5-juga.

1955. Astrotriclea. Cal. tuhus ovatus 5-dentatus. Petala ovalia. Mericarpia ovato-oblonga ad commissuram contracta, jugis obtusissimis.

1256. Xanthosia. Cal. ovato-compressus 5-lobus. Petala stipitata cuspidata replicata. Fructus ovatus compressus striato-nervosus.

125\%. Howlesin. Cal. compresso-suh-4-gonus 5-dentatus. Petala elliptica acuta. Fructus ovatus ad raphen valde contractus turgidus sub-4-gonus.

1358. Fragosa. Cal. 5-dentalus persistens. Petala ovalia integra. Fructus ovatus fere didymus; mericarpiis a dorso compressis.

1259. Azorella. Cal. 5-dentatus persistens. Petala ovalıa integra. Fructus ovatus ad raphen conuactus a dorso subcompressus.

1260. Pectophytum. Cal. margo integer. Petala inaequalia apico subluflexa. Eructux ovato-ellipti- cus; mericarpiis semiovalibus 5-costatis.

2. Mulineae. Fructus ad commisuram contractus paralle biscutatus; mericarpiis dorso complanatis.

1261. Bolnx. Cal. margo minimus. Patala ovalia integra. Fructus 4-gonus, faciebus concavis; mericarpiis 5-jugis.

126:. MInIinum. Cal. 5dentatus persistens. Petala ovatooblonga acuta. Fructus tetraptarus aut parallele hisulcatus.

1263. Wrusa. Cal. integer vix conspicuus. Petala ovalia. Fructus ovalis; mericarpiis compressissimis evittatis angulis in spinulas uncinato-stellatas expansis.

1264. Thunnea. Cal. vix 5-dentatus. Petala lanceolata integra. Fructus ovatus subacutus; mericarpiis dorso suhcompressis intus planis.

126. Diposis. Cal. ohtuse 5-dentatus. Petala ovalia. Fructus orliculatus hiscutatus; mericarpiis a dorso compressis commissura angusta junctis.

1:66. Spananthe. Cal. limbus 5-dentatus. Petala elliptica recta. Fructus ovatus ad raphen compressissimus dorso utrinque plano compressus.

126\%. Pozoa. Cal. 5-dentatus persistens. Petala integra. Fructus prismatic0-4-gonus 5 -costalus calyce coronatus apice emarginatus.

1268. Asteriscium. Cal. dentes ovati. Petala acumine inflexo emarginata sinu calloso. Fructus compressus 4-gono-prismaticus.

3. Saniculeae. Fructus ovatoglobosus.

1269. Actinotus. Cal. tuhus apice contractus 5-lohus. Petala 0. Fructus ovatus villosus 5-striatus.

12 ร0. Samicula. Cal. tubus echinatus. Petala erecta conniventia emarginato-infracta. Fructus subglohosus setis uncinatis ohssesus.

128 . Hafuetin. Umbella capitata. Involuerum 6-phyllum umhella longius. Fructus ovatus solidus subtricostatus valleculis convexis. 
12 ร.. Astrantia. Umbellae fasciculiformes involucra umbellas aequantia subcolorata. Fructus oblongus utriculis sulcatis rugosis cinclus.

1283. Alepiden. Cal. tubus minute tuherculatus. Petala inflexa. Fructus ovatus extus tuberculatus.

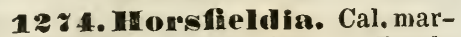
go obsoletus integerrinus. Petala ovata cuspidata. Fructus compressus villosus. Frutex aculeatus.

1: ร 5. Erymorim. Flores capilati. Receptaculum paleaceum. Involucrum sulsspinosum. Petala in1lexa. Fructus paleaceo-squamati.

** Cmbellis compositis seu perfectis. Vittis in fructu variis rarissime nullis.

4. Ammineae. Fructus a latere compressus aut didymus.

1286. Pumia. Cal. margo 5dentatus. Petala ovata integra incurva. Fructus subrotundus aut ovatus didymus ruguloso-plicatus.

12 ร. Cicuta. Cal. margo 5dentatus foliosus. Petala obcordata cum lacinula inflexa. Fructus subrotundus a latere contractus didynus.

128. Zizia. Cal. margo obsoletus aut brevissime 5 -dentatus. Petala elliptica in acumen longum inflexum attenuata. Fructus subrotundus vel ovalis.

12 ร.. Pentacrypta. Cal. ... Petala lanceolata acuminata inflexa. Fructus oblongo-ellipticus latere compressus.

1250. Apium. Calycis margo olssoletus. Petala subrotunda integra. Stylopodium compressum. Fruclus subrotundus a Iatere compressus.

1251. Petroselinunn. Calycis margo obsoletus. Petala subrotunda incurvata in lacinulam inflexam coarctata. Stylopodium breve conicun subcrenulatum.

128:. Wyelleria. Cal. margo obsoletus. Petala ovata acumiue iıcurvo. Fructus ovatus subdidymus stylopodio hrevi stylisque reflexis coronatus.

1283. Troinia. Cal. margo obsoletus. Petala in Iacinulam involu- tam coarctala. Fructus a latere compressus ovatus. Sem. gilbho-convexum.

1254. Felsocindium. Cal. margo subobsoletus. Petala ovata apice inflexa. Fructus a latere compressus ovatus vel oblongus.

125.5. Discojleura. Cal. dentes subulati. Petala ovata integra, apiculo replicato. Fructus ovatus subdidymus.

1:86. Heptocaulis. Cal. margo obsoletus. Petala elliptica integra. Fructus a latere compressus: ovatus.

128\%. Ptychotis. Cal. margo 5-dentatus. Petala obovata bifidoemarginata. Fructus a latere compressus ovalus v. oblongus.

1258. Falcaria. Cal. tubus in sterilibus nullus in fertilibus cylindricus 5-dentatus. Petala obovata curvata. Fructus oblongus a latere coinpressus.

1259. Sison. Cal. margo obsoletus. Petala subrotunda curvata profunde emarginata. Fructus subrotundus compressus ovatus.

1290. Anmi. Cal. margo obsoletus. Petala obovata cum lacinula inflexa emarginato-biloba. Fructus a latere compressus ovato-oblongus.

1291. Aegopoelium. Cal. margo obsoletus. Petala obovata emarginata cum lacinula inflexa. styli longi deflexi. Fructus compressus ovatus.

1292. Carum. Cal. margo obsoletus. Petala regularia obovata cum lacinula inflexa. Stylopodium depressum. Fructus a latere contractus.

1293. Hunium. Cal. margo obsoletus. Petala obovata emarginata cum lacinula inflexa. Fructus a latere contractus lineari-oblongus.

1294. Cryptotaenia. Cal. margo obsoletus. Petala subintegra in lacinulam augustatam inflexa. Fructus lineari-oblongus, stylopod. coronatus.

1295. Pimpinella. Umbellae primum nutantes. Fructus a latere contractus ovatus stylopodio pulvinato stylisque reflexis apice subapitatis coronatus.

1296. Siuna. Cal. margo vix כ-dentatus. Stylopodium pulvinatune margine depressum. Fructus a latere compressus subdidymus. 
129\%. Tupleurinn. Petala suhrotunda integra arcte involuta. Hructus a latere compressus stylopodio depresso coronatus. Flores flavi.

5. Seselineae. Fructus sectione transversali teres aut teretiusculus aut mirocarpiis dorso compressis.

1298. Hichtensteinin. Cal. acute 5-dentatus. Petala in acumen lougum producta. Fructus teretiusculus stylopodio conico acuminato corouatus.

129. Demantlne. Cal. margo 5-dentatus. Petala olovata emarginata. stylopodium conicum. Fructus cylindraceo-ovatus angulato-costatus.

母300. Dasyloma. Cal. margo obsoletus. Sitylopodia depressa. Fiructus ovatus. Niericarpia semiovata jugis 5 corticoso-cellulosis quorum 2 maximis.

1301. Cymoseindium. Cal. deutes 5-suhulati. Petala obovata elliptica. sitylopodium conicum stylis brevissimis. Fructus ovali - oblonguts.

1302. Aethusa. Cal. margo ohsoletus. Petala ohovata emarginata exteriora subradiantia. Fructus ovato-globosus. Involucella 3-phylla secunda.

1303. Foenieulum. Cal, margo tumidus ohsoletus 5-dentatus. Petala suhrotunda involuta lacinula quadrala retusa. Fructus subteres.

130 4. Deverra. Cal. margo ohsolelus. Petala ovata acuminata acumine inflexo. Fructus ovatus ant suhrotundus a latere subcompressus.

1305 . Seseli. Cal. maryo 5dentatus. Petala ohovata emarginata vel integra. Fructus ovalis vel ollongus. Valleculae 1-vittatae. Com'missura bivittata.

1306. Polemnnmia.

Cal. margo obsolete 5-dentatus. Petala elliptica in acumen apice dilatatum desinentia. Fructus oblongus semiteres.

30 \%. Milomntis. Character seseleos sed calycis Iohi tenues suhulati elongati colorati decidui. Folia piunatisecta.
1308. Cuniclum. Cal. margo ohsoletus. Petala ohovata emarginata. Fructus subleres. Mericarpia jugis 5 aequalibus alatis ala submembranacea.

1309. Thaspium. Cal. margo 4-dentatus. Petala elliptica in acumen longun attenuata. Fructus ellipticus a latere contractus.

1310. Athamantha. Cal. margo 5-dentatus. Petala ohovata emarginata ant integra lacinula brevissima. Fructus in collum attenuatus hispidus.

1311 . Cigusticume. Cal.margo 5-dentatus vel obsoletus. Petala alha ohovata acuta emarginata brevissime myuiculata. Fructus sub)compressus.

1312 . Silnes. Cal. margo ohsoletus. Petala obovato-oblonga integra vel emarginata. Fructus subteres. Commissura 4-6-vittata.

1313. NHeum. Cal. margo obsoletus. Petala integra basi apiceque acuta. Fructus suliteres. Valleculae multivittatae. Commissura 6-8 vittala.

131 s. Crithmeum. Cal. margo olssoletus. Petala subrotuuda integra involuta. Fructus subteres, pericarpio cellulis magnis spongioso.

6. Angeliceae. Fructus dorso mericarpiorum compressus: raphesubcentralimargiuibus mericarpiorum in alam expansis.

1315. Tevisticum. Cal. margo obsoletus. Petala incurva subrotunda integra cum lacinula brevi. Fructus a dorso compressus, bialatus.

1316. Selinum. Cal. margo ohsoletus. Petala ohovata emarginata. Fructus a dorso compressus raphe centrali utrinque bialatus.

$131 \%$. Distericuma. Cal. 5dentatus dentibus latis. Petala unguiculata obovata emarginata. Fructus a dorso compressus ntrinque bialatus.

1318. Angeliea. Cal. margo obsoletus. Petala lanceolata integra acuminata. Fructus a dorso compressus raphe centrali utrinque bialatus.

1319. Arelnangelica. Cal. margo hreve 5-dentatus ellipticus acumine incurvato. Fructus a dorso subcompressus margine alatus. 
7. Peucedaneae. Fructus a dorso mericarpiorum compressus: raphe marginali, marginibus in alam expansis.

1320 . Opoponax. Cal. obsoletus. Petala suhrotunda involuta cum laciunla. styli brevissimi. Fructus a dorso plano-compressus margine dilatato convexo.

1321. Werula. Cal. breve 5dentatus. Petala ovata integra acuminata. Fructus a dorso plano-compressus margine complanato dilatato cinctus.

132\%. Peucedanum. Cal. margo 5-dentatus. Petala ohovata inflexa. Fructus a dorso lenticulari compressus margine dilatato complanato cinctus.

1323 . Inuperatoria. Omuia Pencedani, sed ca'ycis margo obsoletus. Fol. bi-aut triternati-secta.

1324. BuDon. Cal. margo ohsoletus. Petala obovata integra involuta. Fructus a dorso lenticularicompressus margine dilatato cinctus.

1325. Amethum. Cal. margo ohsoletus. Petala subrotunda involuta. Fructus a dorso lenticularicompressus. Mericarpia jugis filiform. 3 acute carinatis 2 subobsoletis.

$13: 6$. Pastimaca. Cal. margo minute denticulatus. Petala subrotunda integra involuta. Mericarpia jugis tenuissimis 3 intermediis aeque distantihus 2 contiguis.

$132 \%$. Herreleum. Cal. 5dentatus. Petala emarginata cum lacinula inflexa, exteriora bifida. Carpophorum bipartitum. Semen compressum.

13\%5. Tozimia. Cal. 5-dentatus. Petala ohovata emarginata inflexa. Fructus a dorso plano-compressus medio convexus plus minus hirsutus.

8. Tordylineae. Fructus a dorso mericarpiorum compressus: raphe marginali, marginibus dilatato - incrassatis plicatis dentatisve.

1329. Hasselfuistia. Cal. margo 5-dentatus. Petala obovata emarginata cum lacinula inflexa. Fructus plano-compressus margine alatus rugoso-iuberculatus.
1330. 'Tonedy yitum. Cal. margo 5-dentatus. Petala ohovata emarginata cum lacinula inflexa. Fructus compressus margine rugoso-tuberculatus.

9. Silerineae. Fructus a dorso mericarpiorum compressus: jugis omnibus apteris secundaris interdum subnullis.

1331. Krubera. Cal. margo 5-dentatus. Petala ohovata emarginata cum Iacinula inflexa. Fructus a dorso lenticulari-compressus.

1332 . Aasyllis. Cal. margo obsoletus. Petala lanceolata incurva. Fructus ovalis a dorso compressis.

1333 . Siller. Cal. margo 5dentatus. Petala obovata emarginata cum lacinula inflexa. Fructus a dorso lenticulari-compressus.

10. Cumineae. Fructus a latere mericarpiorum subcontractus, jugis omnibus apteris.

1334 . Cuminum. Cal. dentes 5 lanceolati setacei inaequales persistentes. Petala oblonga emarginata cum lacinula inflexa. Fructus latere contractus.

1335. Trepdearpus. Cal. 5-dentatus: dentibus subulatis deciduis. Petala obcordata inflexo-emarginata. Fructus pyramidato-angulatus.

11. Thapsieae. Fructus a dorso mericarpiorum compressus vel subteres, jugis secundariis in al a m expalisis.

1336 . Fhapia. Cal. 5-dentatus. Petala elliptica acuminata acumine inflexo vel involuto. Fructus a dorso compressus.

$133 \%$. Laserpitiums. Cal. margo 5-dentatus. Petala ohovata emarginata cum lacinula inflexa. Fructus a dorso compressus 8-pterus.

12. Daucineae. Fructus a dorso mericarpiorum subcom pressus aut teres: jugis primariis lateralibus plano commiss rali impositis secundariis in aculeos liberos aut in alambasi connatos expansis.

1338. rredlia. Cal. margo 
obsoletus. Petala obovata emarginata cum lacinula inflexa. Fructus a dorso plano-compressus.

1335 . Droya. Cal. margo 5dentatus. Petala exteriora radiantia obovata emarginata cum lacinula inflexa. Fructus a dorso lenticularicompressus.

13 40. Daucus. Cal. margo 5-dentatus. Petala obovata emaryinata cum lacinula inflexa. Fructus a dorso subcompressus ovatus aut oblongus.

II. Campylospermae. Albumen intus sulco longitudinali ob margines involutos notatum.

13. Elaeoselineae. Fructus cylindraceus a dorso mericarpiorum subcompressus, jugis primariis filiformibus secundariis 2 lateralibus in alamexpans is.

134. CIneoselinum. Cal. margo 5-dentatus. Petala obovata emarginata cun lacinula inflexa. Fructus a dorso subcompressus.

11. Caucalineae. Fructus a Iatere compressus subteres, jugis primariis lateralibus plano commissurali inmositis omuibus secundarisque inaculeos setasve expansis.

1342. Cumcalis. Cal. dentes 5 ovato-lanceolati. Petala olovata emarginata exteriora radiantia profunde bifida. Fructus a latere subcompressus.

134. Turogenia. Calyx dentibus 5 setaceis. Petala obovata emarginata cum lacinula inflexa. Fructus subdidymus.

13 . Torilis. Cal. dentes 5, triangulari - lanceolati acuti persistentes. Petala obovata eniarginata, majora bifida. Fructus a latere compressus.

15. Scandicineae. Fructus a latere compressus aut contractus clongatus saepe rostiatus.

1345. Scandix. Cal. margo obsoletus sub-5̌-dentatus. Petala ob- ovata truncata. Fructus compressus rostro longissimo.

13 46. Anthriscus. Cal. margo obsoletus. Petala obovata truncata saepe brevissima. Fructus a latere contractus rostratus, rostro semine breviore.

13 \%. Chaeronghyllum. Cal. margo obsoletus. Petala obovata cum lacinula inflexa. Fructus contractus a latere compressus vel contractus.

134. Caldasia. Cal. margo obsoletus. Petala ovalia apice integro extus pilosa. Fructus a latere subcompressus ovato-oblongus.

13 1\%. Firnolnis. Cal. margo obsoietus. Petala ohovata emarginata cum lacinula inflexa. Fructus a latere compressus. Semen membrana duplici tectum.

16. Smyrneae. Fructus turgidus a latere compressus vel coutractus.

1350. Ingoecia. Cal. 1obi 5, pectinati magni. Petala calyce hreviora obcordato-hifida lobis cristatis. Fructus ovalus puhescens.

1351. Dliviera. Cal. margo 5-dentatus. Petala profunde obcordata fere bipartita, lohis superne undulatis reflexis. Fructus obovatus hirsutus.

1352. Anisocladium. Cal. lobi in floribus umbellae exterioribus, exteriores maximi foliacei. Petala maxima obcordato-bifida.

1353. Cehinoplnorra. Cá. margo 5-dentatus. Petala ohovata emarginata exteriora hifida. Fructus ovatus subteres receptaculo cavo inclusus breviter rostratus rostro emerso.

1354. Hetopus. Flores polygami dioeci. Cal. margo 5-dentatus. Petala lanceolata acumine incurvo acuto integro.

1355. Cacluris. Cal. margo suli-5-dentatus. Petala ovata integra apice involuta aut inflexa. siylopodia compressa. Fructus turgidus.

1356. Frenges. Cal. margo 5-dentatus. Pelala ovata integra apice involuta. Stylopodia depressa in fructu vix promiuula.

$135 \%$. Nagyoloris. Cal. margo obseletus. Petiala obcordata cum 
lacinula inflexa. Fructus ovatus villoso-tomentosus. Semen vittis tenuissimis vestitum.

135. Irermas. Cal. margo 5-partitus foliosus persistens. Petala ovali-oblonga acuta carinata integra. Fructus ovatus. Fol. indivisa.

1359. Conium. Cal. margo obsoletus. Petala obcordata subemargiuata cum lacinula inflexa. Fructus a latere compressus ovatus. Flores albi.

13 60. Arreacaelin. Cal. margo obsoletus. Petala lanceolata aut ovata. Stylopodia conica crassa. Styli demum deflexi. Fructus ovato-ohlongus.

1361 . Pleumosperranum. Cal. maryo 5-dentatus. Petala obovata integra subattenuato - inflexa. Fructus a latere subcompressus ovatus.

1362. Irymenolaena. Cal. margo obsoletus. Petala obovata integra. Fructus ovatus aut oblongus.

1363 . Plnysosmermum. Cal. margo 5-dentatus. Petala obovata subemarginata cum lacinula inflexa. Fructus compressus, mericarpiis reuiformi-globosis, didymus.

1364 . Snnyruium. Cal.margo obsoletus. Petala lanceolata vel elliptica acuminata, acunine inflexo. Fructus a latere contractus, mericarpiis reniformi-giohosis didymus.

1365. Sealigeria. Fructus didymus ovali-globosus solidus ecostatus, raphe excavata, vittis quaternis.

17. Coriandrineae. Fructus a latere contractus et didymus aut globosus, jugis primariis seculdariisque apteris et saepe vix distinctis.

1366. IBifore. Cal. margo obsoletus. Petala obovata emarginata radiantia hifida. Fructus didymus. Mericarpia suhgloboso-ventricosa grauulato-rugosa.

136\%. Astoma. Omnia Biforae sed fructus evidentius didymus, commissura angusta non perforata nec apice dilatata.

1368. Atrems. Cal. dentes acuti persistentes. Fructus subdidymus globoso-ventricosus rugulosus, costis 5 prominulis; raphe angusta clausa.
1369. Conorandrum. Cal. dentes 5 acuti persistentes. Fructus globosus 10-costatus; raphe membraua obducta vittata. Albumen semilunare.

Flores imperfecti.

13 \% . Gumnillea. Cal. campanulatus 5-fidus. Cor. 0. Caps. bilocularis birostris polysperma.

13 \%. Chailletia. Petioli floriferi. Cal. 5-partitus. Squamae cum staminibus alternantes. Drupa bilocularis.

13 \% 2 . Celtig. Flores dioeci. Cal. 5-partitus. Styli 0. Stigmata divaricata bifida. Drupa baccata 1sperma. Amentaceae.

13 ช 3. Ulmans. Cal. 4-5-8lobus campanulatus. Stamina $4,5,8$. Samara. Amentaceae.

$$
\text { chenopodeae. }
$$

13 ช 4. Chenogodium. Cal. 5-partitus denum haud mutatus. Stamina receptaculo inserta. Utriculus 1-spermus.

13 85. Euchylaema. Cal. 5partitus demum baccatus. Stam. basi calycis inserta. Fructus baccatus 1spermus.

13 \%. Amaloasis. Cal, 5-sepalus 3-bracteatus demum baccatus. Fructus 1-spermus.

13 \% tus demum appendiculatus. Stamina basi calycis inserta. Embryo spiralis vel curvatus.

1388. Hentaria. Cal. 5-sepalus. Stamina 10, quorum 5 sterilia. Utriculus 1-spermus.

13 \% 9. Ficrotea. Cal. 5-partitus. Stamina 5-8. Styli 2-4. Acheniun echinatum.

1380. Aclemogramana. Cor. calycina 5-petala caduca, petalis striatis. Stamina cum petalis alternautia. Germen trilobum glandulosum.

\section{TRIGYNIA.}

* Flores perfecti.

I. Fructus superi.

A. Corolla 1-petala.

1381. Reiclselin. Cal. 5-partitus. Cor. campanulata 5-fida calyce 
minor. Antherae incumbentes. Styli setacei. Caps. 3-locularis circumscissa. Convolvulaceae.

\section{B. Corolla 5-petala.}

1382. Stacklnousia. Cal. 5partitus. Petala unguibus coalita. Stam. inaequalia. Stigmata simplicia acuta. Caps. tricocca.

1383. Snlmasia. Cal. 5-partibus persistens. Petala hypogyna. Stylus 0. Sitigmata 3. Caps. 3-locularis 3-valvis polysperma. Cistecte.

1384 . Nirerekia. Cal. 5-sepalus persistens. Petala unguiculata integra. Antherae suhglobosae-biloculares. Caps. inflata depresso-globosa. Caryophylleue.

1355. 1 nyois. Cal. tubulosus 5-dentatus. Petala fauce hidentata laminis bipartitis. Caps. circumscissa 1-sperma.

1386. Xanthoxylom. Flores dioeci. Cal. brevis $3-5$-partitus. Petala longiora. Styli $\mathbf{3}-\mathbf{5}$. Cocci $\mathbf{2}, \mathbf{3}, 5$, bivalves 1 -spermi, Rutaceue?

$138 \%$. Ainuthus. Flores polygami. Cal. 5-dentatus. Petala patentia. Stamina in floribus masculis 10. Stigma peltatum. Samarae 3-5. Rutaceae?

1389. Cussine. Cal. 5-fidus minimus. Petala patentia cum staminilus alternantia. Sityli 0 . Stigmata 3. Drupa 3-locularis 3-sperma. Rhamneae.

1359. Staphylea. Cal. 5partitus coloratus. Stamina receptaculo glanduloso inserta. Styli $2-3$. Caps. 2-3, membranaceae inflatac. Rhamneae.

1350. Paliurug. Cal. 5-fidus. Petala unguiculata. Discus carnosus perigynus. Drupa suberosa alata 3Iocularis 3-sperma. Rhamneae.

1391. Semecnruus. Flores subdioeci. Cal. 5-fidus. Petala ohlonga. Discus urceolatus perigymus. Nux reniformis il receptaculo carnoso. Terebinthaceae.

1392. Thus. Flores suhdiclini. Cal. 5 -fidus. Petala ovata patentia vel nulla. styli et stigmata 3. Bacca 1-sperma. Terebinthaceae.

1393. Astromium. Flores dioeci. Cal. 5-sepalus. Petala ovata. Glandulae 5, nectariferae. Achenium calyce acuto tectum. Terelinthaceae.
139 s. Spathelia. Cal. 5-partitus coloratus. Petala oblonga. Filamenta dilatata utrinque dentata villosa. Styli nulli. Drupa 3-locularis. Terebinthaceae.

1355. 'Trericeros. Cal. 5-partilus. Petala oblonga. Bacca coriacea tricornis trilocularis. Terebinthaceae.

1396. Incepedea. Cal. 5sepalus subimbricatus. Petala hrevissime unguiculata. Discus perigynus 10-lobus, Fructus baccalus 3-cuspidatus. Ilippocruteue.

1398 . Turneron. Cor. 5-fida. Petala patentia. Stigmata multifida. Caps. 1-locularis 3-valvis. sem. arilIo memhranaceo. Inoseae?

1398. Schumarineria. Cal. tuhulosus 5-dentatus deciduus. Filamenta capillaria. sityli capillares. Caps. Inearis sub-3-dentata. Sem. rugosa.

1395. Iralestoerbin. Cal. ventricosus 10-striatus 5-dentatus. Petata basi squamis denticulatis. Caps. 1-locularis 3-valvis 3-sperma. Halesherbiae.

1400. Portulacaria. Cal. disepalus coloratus. Petala hypogyna obovata. stylus 0 . Stigmata nuricata, Fructus 3-queter alatus. 1spermus. Portulaceue.

101. Telephimm. Cal. 5partitus persistens, Petala integra. stigmata sessilia recurva. Caps. 3valvis basi 3 -locularis polysperma. Paronychiae.

102. Corrigioln. Cal. 5sepalus margine membranaceus. Petala integra. Stigmata sessilia. Nucula 1-sperma. Paronychiae.

\section{Fructus inferi.}

1403. Holigarma. Flores polygami. Cal. 5-partitus. Petala villosa. Nux 1-sperma. 'Terebinthacene.

104. Grisclinaia. Flores poIyami. Cal.5-dentatus. Petala ohovata. Antherae hiloculares. sityli lanceolati. Fructus 1-speruus.

105. Sumbucus. Cal. 5dentatus. Cor. rotata. Stigmata 3. Bacca subtrisperma. Caprifolia.

1.66. Viburumm. Cal. 5dentatus. Cor. 5-loha. Stimmata 3. Bacea 1-sperma. Caprifolia. 
140\%. Manconia. Flores dioeci. Cal. 3-partitus. Cor. 5-partita. Antherae 1-loculares. styli bifidi. Fructus carmosus. C'ucurbitacene.

1108. Paselnanethas. Flores polygami. Cal. tuholosus 5-fidus. Petala 5. Antherae lineares. Sitigmata 3, brevissima. Bacca 6-sperma. Pussifloreae.

\section{** Flores imperfecti.}

1409. PBarmaceum. Cal. 5 -sepalus margine scariosus. Stanina saepe 3. styli 3. Caps. 3-locularis trivalvis polysperma. Caryophyllae.

1 10. Ginginsia. Cal. 5-partitus nuargine scariosus. Discus perigynus carnosus $\mathbf{5}$-lobus. Stigmata cristaeformia. Caps. 1-loc. Portulacelle.

111. Hasella. Cal. 5-7-fidus coloratus. Stigmata lateralia. sem. unicun in calyce baccato. Chenopodeae.

1412. Beta. Cal. 5-partitus. Stigmata sessilia. Semen 1, in calyce durescente. Chenopodece.

1 13. Fosea. Cal. 5-partitus imbricatus. stigmata sessilia. Drupa 1-sperma. Chenoporleae.

1 1. Sceurinega. Flores dioeci. Cal. 5-partitus. stam. disco glanduloso inserta. Stigmata 2 -loba. Caps. 3-cocca. Cocci 1-spermi. Tricoccae.

145. Porantinera. Cal. 5sepalus corollimus. Stamina curvata. Antherae 4-loculares apice glandulosae. Caps. 3, polyspernae.

11 6. Keraudrenia. Cal. 5-partitus persistens. Filamenta conniventia. Antherae biloculares. Styli apice cohaerentes. Caps. 3-loc. Lasiopetalecte.

\section{TETRAGYNIA.}

11\%. Paruassia. Cal. 5partitus. Petala subrotunda. Squamae glandulis stipitatis cinctae petalis oppositae. stigmata 4. Caps. 1loc. Drosereae.

\section{PENTAGINIA.}

I. Flores perfecti.

1418. Galipen. Cal. 5-fidus. Petala oblongo-linearia conglutinata.
Stam. saepe ad unum abortientes. Antherae bilobae. Cocci 5, bivalves. Cusparieae.

1115. Hilocanpus. Cal. 5fidus. Petala 5, uncinata. Stamina subulata antheris subrotundis. styli apice in stigma 5-lobum coaliti. Cocci 5. Butaceae.

1420. Commenesonia. Cal. 5-partitus. Petala hasi saccata. Stam. 3-cuspidata. Caps. 3-5-valvis echinata, setis villosis. Buettnereae.

1 2. Spondylococeus. Cal. 5-sepalus. Petala obtusa. stigmata ciliata. Caps. 5-locularis polysperma.

129. Drosena. Cal. 5-partitus persistens. Stam. apice dilatata. Styli emarginati bipartiti aut multifidi. Caps. 3-5-valvis. Sem. membrana obvoluta. Drosereae.

1123. Aldrovanda. Cal. 5partitus persistens. Styli indivisi capitati. Caps. 1-locularis 5-valvis 10sperma. Droserecue.

1424. Sibloaldia. Cal. campanulatus semi-10-fidus, laciniis alternis minoribus. styli sublaterales decidui. Caryopses nudae 5-10." Potentillecie.

1.25. Statice. Flores capitato-paniculati. Cal. 1-phyllus plicatus scariosus. Petala 5, subconnata. Utriculus 1-spermus calyce inclusus. Plumbagineae.

1426. Anmeria. Flores fasciculato - capitati. Involucrum imbricatum basi tubulo productum. Receptaculum paleaceum. Plumbagineae.

14\% \%. Aegialitis. Cal. coriaceus plicatus. Petala 5, basi connata. stigmata capitata. Fructus cylindricus 1-spermus. Plumbagineae.

1428. Tinum. Cal. sub-5-sepalus. Petala 5, cum staminibus annulo perygyno inserta. Caps. 10-locularis loculis 1-spermis. Lineae.

1429. Crassula. Cal. tubulosus 5-partitus. Petala basi connexa. Squamae 5, perigynae nectariferae. Caps. 5, acuminatae. Sedeae.

130. Tetrandinyle. Cal. 5partitus, laciniis angustis. Petala 5, conniventia. Filamenta setacea. Squamae 5 minutissimae, apice lumulatotrucatae. Carpella 5, polysperma. Sedece.

131. Splnaeritis. Cal. 5partitus, lobis linearibus. Cor. gamopetala profunde 5-fida, lobis re- 
flexis apice callosis. Squamae 5-lineares. Carpella 5, 6-8-sperma. Sedeae.

1432. Thisantlea. Cal. profunde 5 -fidus. Petala 5 , basi connata. Squamae nullae. Carpella 5, 12-sperma. Sedcae.

1.433. Euneconna. Flores polygami. Cal. 5-partitus. Petala glanduloso-pilosa. Glandulae 10. Fructus 5, 1-spermi basi coaliti. Terebinthaceae.

1434 . Goupia. Cal. 5-dentatus persistens. Petala patentia, intus ligula aucta appendiculata. Bacca 5sperma. Rhamneae.

1435. Aralia. Cal. 5-dentatus aut integer. Petala 5 margini imposita. Fructus baccatus stylis coronatus 5-10-pyrenus. Aralieae.

1436 . Sciodn phyllum. Cal. integer. Petala 5-7, apice cohaerentia. Stamina 5-7. Fructus carnosus stylis coronatus 5-7-locularis. Aralieae.

\section{** Flores imperfecti.}

$143 \%$. Ciesekia. Cal. 5-sepalus corollinus. Stam. basi dilatata. Caps. 5, 1-spermae subcoalitae. Sedece.

1435. Gaya. Cal. corollinus marcescens. Stam. 10 basi coalita, alterna sterilia. Antherae rima dorsali dehiscentes. Cocci 5. Lasiopetaleae.

\section{POLYGYNIA.}

1439. Myosurus. Cel. 5-sepalus, basi productus solutus. Petala unguibus tubulosis. Caryopses numesosae spicatae. Ranunculaceae.

140. Xantoripiza. Cal. 5sepalus corollinus. Petala 2-loba truncata stipitata. Caps. 5, semibivalves 1-spermae. Ranunculaceae.

141. Sclaizandra. Flores monoeci. Cal. imbricatus 9-phyllus. Antherae apice coalitae. Stigmata brevia. Baccae congesto-spicatae. $M e-$ nispermeae?

\section{IIDNOGENIA.}

\%08. MIIRABILIS Parkins. (1640).

1. M. dichotoma $\boldsymbol{L}$. cor. calycem triplo superante; fol. ovatis nitidis. Plenk. t. 139. In Mexico. 4. Flor. noctu fragrantissimi.

2. M. hybrida Lep. cor. calycem 6-tuplo superante; limbo obtuso; fol. subcordatis glabris. In Nov. Granata. 24. Limbus cor. ruber.

3. M. Jalappa $L$. cor. calycem 6-plo superante; limbo acuto; fol. subcordatis glabris. Plenk. t. 137. Rumph. V. 89. B. M. 371. In Ind. orient. 4.

4. M. longiflora $L$. tubo cor. Iongissimo villoso; fol. cordatis subsessilibus villoso-viscosis. Plenk. t. 138. Sm. exot. bot. t. 23. In Mexico. 4. Cor. alba.

5. M. suaveolens $H$. et $K$. flor. solitariis; calyce viscoso; tubo cor. longissimo ; fol. cordatis glandulosociliatis. In Mexico. 4.

\section{ABRONIA Juss. (1789).}

1. A. umbellata Juss. Tricratus admirabilis L'Herit. Monogr. c. ic. In California. $\odot$. Semipedalis. Fol. opposita ovata integerrima. Flor. incarnati.

2. A. mellifera Dougl. fol. ovatis subsinuatis glutinosis. In California. $\odot$. Procumbens. Cor. sordide alba.

\section{TRICYCLA Cav. (1800).}

1. T. spinosa Cav. ic. $t$. 598. In Buenos Ayres. ち. Fruct. 10-12-ped. ramis rufis, spinis hifidis. Fol. fasciculata linearia. Cor. Iutea.

\section{PLUMBAGO Clús. (1576).}

1. $P$. scandens $L$. fol. petiolatis ovatis glahris; caule flexuoso scandente. Jacq. Am. pict. t. 13. In Nova Granata. 5. 3-8-ped. Cor. alba.

2. P. zeylanica $L$. fol. petiolatis oblongo-ovatis glabris integerrimis; caule erecto filiformi. Rheede $\mathbf{x}$. $\mathbf{t}$. 8. In India et Nova Hollandia. †. $1 \frac{1}{2}$-ped. Cor. alba.

3. $P$. rosea $L$. fol. ovatis petiolatis glabris subdenticulatis; caule geniculis gibbosis. Iheede $X$. t. 9. B. 
M. 230. In Intia orientali. ち. Cor. rosea.

4.P. auriculatı Lam. caule erecto gracili; ramis striatis; fol. obovatis glabris; petiolis auriculatis caulem amplexantibus. In Ind. orient. $\$$. Cor. rubra.

5. P. capensis Thunb. fol. petiolatis oblongis integris subtus glaucis; caule erecto. P. tristis Ait. In Prom. b. spei. †.

6. P. europaea $L$. fol. lanceolatis amplexicaulihus scabriusculis; caule divaricato; bracteis lanceolatis. Schk. t. 36. Plenk. t. 95. In Europa et Caucaso. 4. Cor. purpurea.

7. P. caerulea $H$. et $K$. ramis sulcatis volubilibus glanduloso-viscosis; fol. ovato-oblongis anplexicaulibus glabris; spicis glandulosis. In Peruvia. 2. Cor. caerulea.

8. $P$. mexicana $H$. et $K$. ramis angulatis glabris; fol. ovato-oblongis acutis petiolatis; spicis glabris. In Iexico. 4. Cor. violacea?

9. P. micrantha Ledeb. Fl. Ross. t. 21. herbacea; caule basi muriculato superne ramis cum foliis semidecurrentibus bracteisque ovatis glaberimis. In Russia. $\odot$. Flor. caerulei.

\section{VOGELIA LAT. (1792).}

1. V. africana Lam. ill. t. 149. Frutex ramis gracilibus; fol. obcordatis tuberculatis integerrimis; spicis arcte imbricatis. In Prom. b. spei. $\hbar$. Frut. parvus.

\section{WEIGELIA Thunb. (1780).}

1. W. japonica Thunb. fol. sessilibus ovato-lanceolatis. Thunb. Fl. jap. t. 16. In Japonia. ち? Ramuli 4-goni. Cor. purpurea.

2. W. coraeensis Thunb. fol. petiolatis ohovatis. Kaempf. ic. t. 45. In Japonia. ち. Rami decussati.

\section{QUINCHAMALA Willd. (1798).}

1. Q. chilensis Willd. Lam. ill. t. 142. Fl. peruv. t. 10\%. f. 6. Feuill. 1.14. In Peru et Chili. Hab. Thesii. Cor. extus purp. intus lutea. Sem. nigrum.
2. Q. patagonica Spr. Ariona tuberosa Cav. In Patagonia. Caules numerosi filifornes. Cor. tomentosa lutescens.

\section{ELLUCUS Lozan. (1809).}

1. $U$. tuberosus Loz. In Quito. Rad. tuberosa. Caul. ramosus angulatus. Fol. cordata. Flor. racemosi nutantes.

\section{BRUNONIA Sm. (1810).}

1. B. sericea Sm. Linn. Trans. $X$. $t$. 29. fol. undique scapisque longitudinaliter sericeis villis adpressis; calycis apicibus coloratis. In Nova Hollandia. $ђ$.

2. B. australis Sm. l. c. t. 28. fol. undique scapisque infra villosis; pilis patulis; calycis laciniis longitudinaliter plumosis. In Nova Hollandia. $\odot$.

\section{CORYMBIUM L. (173\%).}

1. C. scabrum $L$. fol. Ianceolatis canaliculatis nervosis recurvatis ylabris caule brevioribus. Lam. ill t. 723. f. 1. Burm. afr. t. 70. f. 1. In Prom. b. spei. 4.

2. C. glabrum L. glaberrimum; fol. ensiformibus planis nervosis. Hayne term. t. 30. f. 3. Lam. t. 723. f. 3. Plukm. t. 272. f. 4. C. villosum $L$. In Prom. b. spei. 4.

\section{CERINTHE Plin. (Gaertn. $t$.} 67. f. 1.)

1. C. major $I$. corollae limbo campanulato ventricoso; filamentis anthera brevioribus. schk. t. 30. B. M. 333. In agris Europae. $\odot$. Cor. livide purp.

2. C. retorta Sibth. gr. $t .171$. cor. supra medium ventricosa adscendente fance constricta; antheris filamenta aequantihus. C. purpurea Vis. In Graecia et Europa. $\odot$.

3. C. aspera Roth; cor. limbo campanulato ventricoso; filamentis anthera longioribus. Fl. gr. t. 170. Rchb. ic. 983. In Graecia et Europa. ○. 
4. C. strigosa Rchb. ic. 98t. cor. medio ventricosis utrinque contractis externe bicarinatis plicatisque; filam. anthera breviorihus. C. major sturm. 12. In Europa. $\odot$.

5. C. minor $I$. cor. acute 5-fidis concoloribus; laciniis erectis ; fol. albo-maculatis. Kchb. ic. 481. C. acuta Mnch. In agris Europae. $\odot$. Cor. lutea.

6. C. maculata $L$. cor. acute 5fidis maculatis laciniis erectis; fol. concoloribus. Rchb. ic. 482 . In Alpibus Europae. $\odot$.

\%. C. glabra Mill. cor. acute 5fida; laciniis apice reflexis; fol. glabris immaculatis. C. alpina Kit. Rchb. ic. 658. In Alp. Europue. $\odot$.

8. C.? auriculata Ten. fol. maculatis, caulinis basi constrictis auriculis ampliatis caulem amplexantibus; cor. purpureis, fundo luteo. In Ltcania. $\odot$.

9. C.? longiflora Viv. cors. fol. caulinis ovato-oblongis ; cor. luteis tubuloso-infundih. profunde 5-dentatis; dentibus acutis. In ins. Tavolara. $\odot$.

\section{COLDENIA L. (1747).}

1. C. procumbens $L$. seminibus extus mucronato-angulatis; fol. ohovatis latere superiore suhlanatis. Plukn. t. 64. f. 6. In Ind. orient. $\odot$. Planta depressa.

2. C. dichotoma Lehm. seninibus laevilous; fol. ohlongo-obovatis lineatis rugosis. Lithospermum Fl. peruv. t. 111. In Peruvia. Cor. caerulea.

\section{HELIOTROPIUM Theophr.}

\section{A. Spicis ebracteatis, novellis spira-} libus.

\section{a. Fructicosa.}

1. H. amplexicaule Vahl; fol. semiamplexicaulibus lanceolatis obtusis sulcanescentibus; spicis aggregatis. In Brasilia. $\hbar$. Cor. lilacina.

2. H. perurianum $L$. fol. lanceolato-ovatis; spicis numerosis aggregatis corymbosis. B. M. 141. In Peruvia. ち. 2-ped. Cor. caerulescens.

3. $H$. corymbosum $R$. et $P$. fol. ovatis utrinque attenuatis rugosis pu- hescentihus; spicis ramosis. H. grandiflorum schrnk. H. non. t. 1. Patria igmota. $\hbar$. Cor. caerulea.

t. H. oppositifolium R. et P. peruv. t. 108. f. 6. fol. ovatis acutis latis integerrimis ; spicis dichotomo-corymhosis. In Peruvia. ち. 5-ped. Cor. alba.

5. H. lanatum H. et K. fol. ovatis acutis integerrimis crassis albolanatis; spicis dichotomo-multifidis. H. argenteum Lehm: In Nov. Granata. $\hbar$.

6. H. incanum $R$. et P. peruv. $t$. 10s. $f$. $a$. fol. ovatis acutis crenatis lineatis rugosis; spicis dichotomo-corymbosis. In Peruvia. ち. 3-ped. Cor. alla.

\%. H. lanceolatum R. et P. peruv. t. 101. $f$. $a$. fol. lanceolatis asperis subpetiolatis ; spicis dichotonı-corymbosis. In Peruvia. ち. Caulis lignosus. Cor. pallide caerulea.

8. H. citrifolium Iehm. fol. oblongis utrinque attenuatis glaberrimis supra nitidis; spicis coarctato-corymhosis. In Amer. austr. ち.

9. H. linifolium Lelim. fol. linearihus strigulosis; spicis racemosis filiformilus. In Prom. b. spei. ち. 1-ped. Flor. minuti.

10. H. Zeylonicum Lam. fol. linearihus suhtus villosis margine revolutis; spicis filiform. suhsolitariis. Burm. ind. t. 16. f. 2. In Zeylona et India. $\hbar$.

11. H. syenites Spr. caule villosissimo; fol. ovato-oblongis attenuatis integerrimis villosis; spicis filiform. solitariis. H. villosum Sieb. cinereum R. Br. Kunzii Lelım. In Aegypto. $\hbar$.

12. H. inundatum Sw. fol, oblongis obtusis hirsutis; spicis 4-nis erectis. In Jamaica et Vera Cruz. ち. Caul. ramosissimi. Fol. parva albida.

13. H. decumbens Lehm. caule decumbente; fol. ovato-ellipticis strigosis; spicis filiform. coujugatis ternatisque. In Cumana. $\hbar$. Hami depressi. Flor. confertissimi.

14. H. pilosum R. et Pav. peruv. t. 110. $f$. a. caule procumbente; fol. lanceolatis integerrimis acutis pilosis; spicis 4-nis. In Peruvia. †. Totum albidum. Cor. alba.

15. H. microcalyx R.P. peruv. $t$. 109. f. 6. fol. ollongis lanceolatis; spicis oppositifoliis dichotonis; cal. 
minimis 4-dentatis. In Peruvia. $\hbar$. Cor. albida.

16. H. humile Lam. caule depresso basi lignoso; fol. lanceolato-ovatis acutis piloso-villosis repandis. In Caribatis. t. 1-ped. Cor. albida.

17. H. glandulosum R. I?r. fol. ovalibus rugosis tomentosis; spicis conjugatis; calycibus glandulosis. In Nov. Iloll. t).

18. H. erosum Lehm. caule decunbente; fol. oblongis obtusis in petiolum attenuatis eroso-denticulatis retrorsum hispidis. In T'enerifla. ち. Cor. alba.

19. H. eriocarpon Delil. caule erecto ramosissimo; fol. ovatis villosis margine undulatis revolutis verrucosis. In Aegypto. $\hbar$.

20. H. maroccanum Lehm. caule stricto hispido; fol. lanceolatis substrigosis undulatis revolutis; spicis conjugatis. In Marocco. $\hbar$.

21. H. undulatum Iahl; caule procumbente; fol. lanceolatis hispidis miargine revolutis undulatis; spicis conjugatis; cor. villosis. Desf. Atl.t. 41. In Aegypto. ‡. Caul. ped. Cor. alba.

22. H. stenophyllum Hook. in Buch Toy. densissime foliosum; fol. fasciculatis angustissime linearibus carnosis margine revolutis subscabris. In Chili. ち.

\section{b. Herbacea.}

23. $\boldsymbol{H}$. europaeum $\boldsymbol{L}$. fol. ovatis integerrimis rugosis punctato-villosis; caule erecto. Plenk. ic. t. 74. In Europa et Caucaso. $\odot$. Flor. albi.

21. H. suaveolens M. B. fol. ovatis integerrimis rugosis tomentosis; cal. Ianati laciniis tubum cor. aequantibus. In Cancaso et Persia. $\odot$.

25. H. villosum Desf. ann. Mus. $\boldsymbol{X}$. $t$. 33. villosissimum; fol. ovatis; spicis solitariis aut conjugatis. In ins. Archipelagi. $\odot$. Caul. 2-ped. Cor. alba.

26. H. supinum $L$. caule decumbente piloso; fol. subovalibus integerrimis plicatis subtus lanato-tomentosis. Tournef. Voy. t. 23. In Europa australi. $\odot$.

27. H. ellipticum Ledeb. fol. ellipticis utrinque rotundatis integerrimis pilosis; calyce tomentoso. Eichw. casp. t. 4. Ad mare Caspicum. $\odot$. 2-ped. Cor. alba.
28. H. obovatum Roxb. caule decumbente subramoso; fol. obovatis petiolatis aveniis utrinque sericeis. In Nepalia. $\odot$.

2.9. H. Intifolium Irehm. erectum; glahriusculum; fol. ovatis acutis hasi angustatis sessilibus ciliatis. H. scorpioides H. et K. In Cumana. $\odot$.

30. II. curassaricum L. caule ereto ; fol. spathulato-linearibus integerrimis glaucis glaberrimis. H. chenopodioides W. Plukn. t. 36. f. 1. In Amer calid. $\odot$. Cor. alba.

31. H. dasycarpum Ledeb. caule ramosissimo divaricato hispido; fol. ovatis acutis petiolatis; caryopsibus villosis. Eichw. casp. tah. 5. Prope Krasnowodsk. $\odot$. Cor. alba.

32. H. filiforme $H_{\text {. et }} \boldsymbol{K}$. Nov. Gen. $t$. 20t. procumbens; strigosopilosum; fol. lanceolato-spathulatis obtusis; spicis filiformibus. In Nova Granata. $\odot$.

33. H. cinereum $\boldsymbol{H}$. et $\boldsymbol{K}$. l. c. $t$. 206. erectum? patenti-villosum; fol. obovatis obtusis; spicis 3 , ebracteatis. In Nova Granata. $\odot$.

31. $\boldsymbol{H}$. gracile $\boldsymbol{R}$. $\mathrm{Br}$. caule erecto; fol. oblongo-Ianceolatis acutiusculis canescentibus strigosis; spicis subsolitariis. In Nov. Holl. $\odot$.

35. H. microstachyon $R$. et $\boldsymbol{p}$. caule procumbente; fol. ovato-oblongis petiolatis pubescentibus subtus incanis; spicis aggregatis. In Peruvia. $\odot$.

36. H. parviflorum $\boldsymbol{L}$. fol. oppositis oblongo-ovatis petiolatis; spicis simplicilus dichotome conjugatis. Dill. Elth. t. 175. In Ind. orient. $\odot$. Cor. alba.

37. II. tiaridioides Cham. et Schl. Linnaea IV. $t$. 5. f. 3. caule fruticoso ramoso; fol. late lanceolatis supra elevato-punctato-scabris subtus tenuissime pubescentibus; germine basi glanduloso. In Brasilia.

38. H.? monostachyum Cham. et Schl. spicis adultis semipedalibus; caule dichotomo; fol. subtus pilis adpressis strigosis. In Brasilia. ђ.

39. H. sillaefolium Cham. et Schl. fol. ovato-lanceolatis subtus viscide pilosis, junioribus subsericeis; stigmate impresso conico pilosulo. In Brasilia. $t$.

10. H. phylicoides Cham. et Schl. fol. ovato - acutis sessilibus verticillato-ternis; villis argenteis subviscidis. 
In Brasilia. t. Frut. spithameus. Cor. allo-villosa.

41. H. symzystachyum $R$. et $P$. caule procumbente villoso ; fol. ovatooblongis venoso-rugosis integerrimis pilosis; spicis longissimis. In Lima. $\odot$.

42. H. coromandelianum Retz; fol. ohovatis villosis integris; spicis simplicibus conjugatisve; seminibus punctatis. In Ind. orient. $\odot$. Cor. alha.

43. II. oralifolium Forsk. fol. ovalibus planis integerrimis cauleque sericeo-villosis; seminilus pubescentibus. In Arabia et Nor. Holl. $\odot$.

44. H. nalabaricum Rets; fol. ovatis plicalis strigosis integerrimis; spicis subsolitariis. H. europaem Burm. ind. t. 16. f. 1. In Ind. orientali. $\odot$.

45. H. capense Lehm. caule erecto ramoso; fol. ovato-rolundatis plicato-integerrimis supra strigosis subtus subtomentosis. In Prom. b. spei. $\odot$.

46. H. rotundifolium sieb. caule erecto ramoso tomentoso; fol. subrotundis incanis supra sericcis subtus tomentosis; spicis longissimis. In Palaestina. $\odot$.

\section{Spicis ebracteatis.}

\section{a. Fruticosa.}

4\%. H. lineatum Vahl; caule procumbente; fol. ovalibus villosis revolutis subtus venoso-lineatis; fructibus villosis. In Aegypto. $\hbar$. Cor. alba.

43. H. Ottonis Lelim. caule erecto; fol. lineari-lanceolatis erectis incano-sulsericeis ; spicis solitariis elongatis. In Caracas. $\hbar$.

19. H. fruticosum L. fol. lineariIanceolatis pilosis margine revolutis; spicis solitariis caule fruticoso. In Caribaeis. $\hbar$.

50. H. ternatum Valil; caule erecto ramoso; fol. ternis lanceolatis supra calloso-punclatis subtus incanis; bracteis linearibus. H. hirtum Lelım. H. hispidum H. et K. In Nov. Gramata. $\hbar$.

51. F. cullosum Spr. caule erecto ramoso calloso-hispidulo; fol. alternis sessilibus lineari-lanceolatis revolutis calloso-punctatis. In Aegypto. Ђ.

52. H. brasilianum Roth; caule ramosissimo papilloso-strigoso; fol.
spathulato-Ianceolatis mucronatis integerrimis calloso-hispidis. In Brasiliu. ち. Cor. alba extus strigosa.

5.3. H. strigosum $W$. caule ramoso; fol. lineari-Ianceolatis papillosostrigosis. In Guinea. ち.

54. H. polyphyllum Lehm. caule ramoso; fol. petiolatis lineari-lanceolatis confertis planis integerrinis; spicis solitariis. In Amer. austr. Cor. alba pilosa.

5.5. H. ocellatum Cham. et Schl. fol. Ianceolatis basi attenuatis petiolatis, subtus strigosis; cor. extus strigoso-pilosa. In Brasilia. $\odot$. Palmaris.

56. H. myosotoides Lehm. caule erecto purpurascente; fol. lineari-lanceolatis planis strigillosis; spicis solitariis; cal. remotis. In Nov. Grunata et Asia minore. $\hbar$.

57. H. Iroltleri Lehm. caule erecto; ramis divaricatis; fol. alternis petiolatis ovato-lanceolatis hispidis; spicis solitariis. In Ind. orient. ち.

58. H. thymifolium Lelım. caule depresso hispidiusculo; fol. oblongis strigosis; spicis solitariis elongatis; bracteis calyce longioribus. Patria ignota. $\hbar$.

59. H. campechianum $\boldsymbol{H}$. et $\boldsymbol{K}$. caule procumbente; fol. lanceolatis utrinque attenuatis petiolatis strigosis; spicis solitariis elongatis. In Mexico.

60. H. persicum Rurm, ind. t. 19. f. 1. fol. lineari-lanceolatis villosis recurvatis ; caule fruticoso; spicis foliosis. In Persia. ち. Albo-sericeum.

61. H. fasciculatum R. Ir. caule ramosissimo strigoso; fol. linearibus fasciculatis sessilibus revolutis hispidis; florihus sparsis. In Nova Hollandia. $\hbar$.

62. H. marifolium Retz; caule procumbente; ramis filiformibus; fol. sfarsis petiolatís ovato-lanceolatis acutis pilosis; spicis solitariis. In Ind. orient. $\hbar$.

63. H. paniculatum $\boldsymbol{R}$. Br. caule ramosissimo foliisque linearihus revolutis strigosis; spicis alternis paniculatis; bracteis calyce brevioribus. In Nov. Holl. ђ.

61. H. glabellum R. Br. caule ramosissimo glabro; fol. lineari-filiformibus subtus pilosiusculis; spicis raris; hracteis calycis Iongitudine. In Nov. Holl. $\hbar$. 
65. H.? anomalum Hook, in Beech. Toy. fol. lineari-lanceolatis inferne attenuatis strigoso-hispidis; racemis glomeratis; nucibus 5. In ins. Whitsunday. ђ.

\section{b. Herbacea.}

66. II. laxiflorum Roth; caule erecto ramosissimo strigoso; fol. lineari-lanceolatis revolutis sultus sericeis; spicis laxis. H. pauciflorum $\mathbf{h}$. Br.? In Nor. Holl.? ๑.

6\%. H. tenuifolium $\boldsymbol{R}$. Br. caule erecto tomentoso; fol. lineari-filiformibus; bracteis subulatis calyce sericeo breviorihus. In Nov. Holl. $\odot$.

68. H. rentricosum R. Br. caule erecto ramoso strigoso; fol. linearibus revolutis; spicis multifloris; tubo corollae ventricoso. In Nov. Holl. $\odot$.

69. II. scabrum Retz; caule prostrato diffuso; fol. confertis suboppositis lineari-lanceolatis obliquis revolutis strigosis; spicis solitariis. In India orientali.

go. H. bracteatum R. Br. caule erecto ramoso foliisque lanceolatis planis strigosis; hracteis calycem subsuperantibus. In Nov. Holl. $\odot$.

\%. H. foliatum $\boldsymbol{R}$. Br. caule ramoso adscendente strigoso; fol. lanceolatis; bracteis lanceolatis subpetiolatis calycem excedentibus. In Nov. Holl.

72. H. rostratum R. Br. caule folioso prostrato; fol. lanceolatis acuminatis planis subsessilibus. In Nov. Holl. $\odot$.

73. H. Roxburgliii Spr. caule erecto ramoso hirsuto; fol. ovato-oblongis; spicis paniculatis secundis. $\mathbf{H}$. paniculatum Roxb. In India orientali. $\odot$. p. 20 .

H. aegyptiacum Lehm. pug. 1. H. coriaceum Lehm. pug. 1. p. 20.

\section{CANALA Pohl (1832).}

1. C. heliotropioides Pohl ic. $t$. 112. fol. ovato-acutis supra stellatopilosis subtus lutescenti-tomentosis; cor. 5-denticulatis. In Brasilia. 4. Cor. coccinea.

2. C. macropliylla Pohl; fol. oblongis acutis supra glabris, subtus pilosiusculis; cor. 5-dentatis ; calycibus pilosis. Ad Rio Janeiro.

3. C. rubiaefolia Pohl; fol. hinis, superioribus quaternis lanceolato-acuminatis calycihusque glabris; corollis 5-dentatis. In Brasilia.

\section{LITHOSPERMUM Diosc.}

\section{a. Fruticosa.}

1. I. fruticosum $\boldsymbol{I}_{\text {. }}$ canle erecto ramosissimo; fol. linearibus revolutis strigoso-hispidis subtus incanis. I/. rosmarinif. Pers. Barr. ic. 1168. Garid. Aix. t. 15. In Europ. austr. $ђ$.

2. L. prostratum Lapeyr. caule prostrato ramoso; fol. lineari-lanceolatis hispidis; cor. tubo intus dense villoso. L. diffusum Lag. Lois. Gall. t. 4. In Gallia et Ilispania. t. Cor. purpureo-caerulea.

3. L. humifusum $L$. caule repente; fol. lanceolatis acutis rigidis hispidis; flor. solitariis. Heliotropium $\mathbf{H}$. et $\mathbf{K}$. Nov. Gell. t. 205. In Cuba. ђ.

4. I. sericeum Lelim. caule erecto trichotome-ramoso superne villoso; fol. oblongo-lanceolatis supra sericeis subtus subvillosis canesceutibus. In Virginia. $ち$.

5. L. ciliatum Forsk. caule erecto ramosissimo superne muricato; fol. ovatis cordatis margine callosis setoso-ciliatis. Viv. aeg. t. 2. f. 16. In Aegypto. Ђ.

6. L. divaricatum Sieb. caule erecto ramoso glabriusculo; fol. lanceolatis sessilibus incano-strigosis; florihus sparsis. In Palaestina. $\hbar$.

7. L. callosum Vahl; caule erecto Inuricato; fol. ohlongis obtusiusculis calloso-hispidissimis strigosis; bracteis setoso-ciliatis. L. angustif. Forsk. In Aeg!ypto. ђ.

8. L. hispidulum Sm. caule caespitoso depresso diffuso; fol. ohovatis obtusis hispidis; fruciibus tuberculatis. In ins. Rhodo. $\hbar$.

9. L. fle:ruosum Lehm. caule decumbente flexuoso; fol. ovatis supra scabris subtus hispidis; fructibus calIoso-muricatis. Cynoglossum muricatum Thunl. In Prom. b. spei. $b$.

10. L. incanum Forst. canle decumbente; fol. confertis lineari-lanceolatis apice subdilatatis sericeo-pilosis incauis. In ins. Amicorum. $\hbar$. 
b. Herbacea.

Strigosa, pilosa.

a. Floribus pallidis luteis flavis.

11. L. arvense $I$. fol. Iongis aveniis; pedunc. demum incrassato-clavatis; nuculis rugoso-granulatis. E. B. 123. Fl. Dan. 456. In ayris Eusopae. $\odot$. Cor. albida.

12. $L$. officinale $L$. fol. oblongolanceolatis venosis; cor. calycem vix superantibus; fructibus lucidis. E. B. 134. FI. Dan. 108t. Schk. t. 29. In Europa. 4. Cor. ochrolenca.

13. L. latifo:ium Michx. caule erecto ramoso; fol. oblongis utrinque attenuatis calloso-strigosis subtus venosis ; fruct. punctatis. In Amer. bor. 2. Cor. Iuteola.

14. L. orientale Vahl; ramis floriferis lateralibus; bracteis cordatis amplexicaulibus. Sibth. gr. t. 154. Dill. EIth. f. 66. B. M. 515. In Oriente 24. Cor. Iutea.

15. L. hirtum Lehm. caule erecto simplici superne hirto; fol. linearilanceolatis obtusis calloso-hirsutis. Batschia carolinensis Pers. In Virginia. 24. Cor. sat magna.

16. L. canescens Lelım. caule erecto simplici villoso; fol. oblongis obtusis emarginatis incano-villosis; racemis elongatis. Batschia Michx. $t$. 14. In Iirginia. 24. Cor, aurea.

17. L. longiflorum Spr. sericeovillosum; fol. linearibus; calyc. linearibus longis; laciniis cor. crenatoincisis. Batschia Pursh. In Amer. bor. 24. Cor. lutea.

18. L. mandunense Spr. caule decumbente foliisque linearibus villosis; laciniis cor. fimbriato-crenatis. Batschia decumbens Nutt. Ad Missouri. 4.

19. L. conspicuun Spr. caule ramoso; fol. ohlongis ohtusis strigosis; floribus spicatis; limhi laciniis integerrimis. In Amer. bor. 4.

20. L. strictum Lehm. caule simplicissimo stricto; fol. linearibus acutis adpressis supra strigosis subtus glabriusculis; flor. spicatis. In Amer. austr. 4.

21. L. angustifolium Michx. pumilum; procumhens; fol. anguste linearibus pilis brevibus adpressis; seminibus nitidis punctatis. In Amer. bor. ๑. Cor. alba.
22. I. scabrum Thunb. fol. lanceolatis papilloso-scabris hirsutis; seminilous laevihus. In Prom. 6. spei. 1-ped. sem. alba.

23. L. cupeifolium Pers. caule procumbente; fol. cuneiformibus ; flor. axillarihus solitariis; sem. nitidis. In Peruria. ๑. Cor. alba.

2t. L. aggreyatum R. et P. fol. ovatis obtusis rugosis; caule prostrato; floribus aggregatis subsessilibus. In peruvia. ๑. Cor. alba.

25. H. distichum Orteg. caule erecto superie ramoso ; fol. strigosis spathulatis lanceolatisque acutis; floribus ovatis distichis. In Cuba.

26. L. lineutum Lehm. caule erecto ramoso; fol. strigosis venoso-lineatis ohovatis lanceolatisque; calycis laciniis hirsutis elongatis. Patria ignota.

27. $\boldsymbol{L}$. apulum $\boldsymbol{L}$. caule erecto simplici ; fol. confertis lineari-lanceolatis acutis pilosis; fructihus muricatis. Sibth. gr. t. 158. Myosotis L. Plukn. t. 16. f. 5. In Europa australi. $\odot$. Cor. lutea.

28. L. micranthum Viv. caule erecto simplici foliisque lineari-lanceolatis hispidis; spicis secundis; calycihus hispidissimis. Ad Syrtim maj. Afric. bor. $\odot$.

2.9. L. crussifolium Lelım. caule adscendente incano; fol. spathulatolanceolatis cancscentibus strigosis; fructibus rugosis. In Asia minore.

30. L. decumbens V'ent. caule decumbente ramoso hispido; fol. lanceolatis acutis calloso-hispidis; ca!ycibus basi 5-gonis; fruct. tuberculatis. Ad Euphratum.

31. L. muricatum R. et $\boldsymbol{P}$. fol. lanceolato-linearibus; cor. calycem aequante; seminibus muricatis. In Chili. $\odot$. Cor. alba.

32. L. ramosum Lehm. caule erecto ramosissimo; fol. lineari-lanceolatis obtusiusculis hispidis ciliatis; fructihus granulatis. In Mexico. $\odot$. Cor. alba.

33. L. papillosum Thunb. caule adscendente simpliciusculo; fol. oblongo-lanceolatis revolutis papilloso-hirsutis; fructibus rugosis. In Prom. $b$. spei. Fl. albi.

34. L. cornutum Meyer; hirtum; caule erecto; fol. oblongis callosis ciliatis; calycibus fructiferis basi 5cornutis. Ledeb. Fl. ross. t. 25. In Altaico. $\odot$. Cor. Iutea. 
3.5. I. hispillum $R$, et $P$. fol. Ianceolatis sessilibus apice revolutis; seminibus rugosis. In Perucia. $\odot$. 1ped. Cor. flava.

\section{b. Floribus pnrpureis caeru- le is.}

36. $L_{\text {. }}$ villosum $I$. caule adscendente simplici villosissimo; fol. linearibus obtusis incano-villosis, floralihus ovato-oblongis. In Gallia et Calabria.

3\%. L. tinctorium $D C$. cattle adscendente ramoso hispido; fol. linearibus obtusiusculis calloso-lispidis ; fructibus tuberculatis. Anchusa Willd. Sibth. gr. t. 166. In Europa australi. 24 .

38. L. purpureo-caeruleum $\boldsymbol{L}$. suffruticosum; corollis calycem vix duplo cuperantihus; caulibus floriferis erectis sterilibus repentibus; fol. lanceoIatis. E. B. 117. Jacq. austr. t. 14. In Europa. ђ.

39. L. graminifolium Fiv. Fragm. I. $t$. 5. fruticulosum; fol. linearibus demum revolutis subtus albis subtiliter strigosis. Plukn. t. 42. f. 7. In Liguria et Sicilia. $\hbar$. Cor. azurea.

40. L. villosulum. Lelım. caule erecto glabriusculo; fol, cordato-ovatis acuminatis nervosis, subtus sericeis; calycibus villosis. In mont. Cargratı. 4.

41. L Arnebia Lehm. fol. lineariIanceolatis obtusis; spica solitaria term. secunda; - sem. laevibus. L. tinctorium Vahl symb. t. 28. In Aegypto. $\odot$.

42. I. tenuiflorum $I_{\text {a }}$ fol. linearilanceolatis strigosis; calycibus longitudine cor., fructiferis comniventibus. Jacq. ic. t. 313. In Aey!npto et $\mathrm{Cy}$ pro. $\odot$. Cor. minutissima.

43. L. pumilum l.ehm. caule caespitoso; fol. imbricatis linearibus ohtusis substrigosis; fructibus rugosis. In Amer. boreali. 4 .

14. $L$. dispermum $I$. canle erecto ramoso; fol. lineari-lanceolatis obtusis pilosis; calycis laciniis demum incurvis ; fructibus punctatis. L. retortum Pall. In Europ. et sib. $2 \%$.

45. L. strigosum $M$. $B$. caule ramosissimo strigoso-hispido; fol. lanceolatis acutis; spicis paniculatis secundis; cor. minimis. In '́auria. 4.
46. L. Schreberianum Spr. caule simpliciusculo; fol. omnihus ovatis hispidis, caulinis sessilibus; calyce hirsuto. Pulmonaria pumila Schrank. In Camtschatka.

\section{Glabra.}

47. L. Pallasii Meyer; glaherrimum; caule erecto debili; fol. rad. cordato-ovatis, caul. ovatis; cor. calyce 3-plo longiore. Ledeh. 1. c. t. 23. In Altai. 4. 1-ped. Cor. amoene azurea.

48. I. davuricum Lehm. caule erecto simplici glabro; fol. supra scabris subtus glahris, ovatis ohlongisve; fructihus rugosis. Ptlmonaria sims. B. M. In Dar:uria. 4.

19. L. simplicissimum Lehm. 'caule erecto simplicissimo foliisque ovato-ohlongis acuminatis subundulatis glahris ; calycibus asperis. Pulmonaria Ledeb. In Sibiria. 4.

50. L. denticulatum Lelım. caule erecto; fol. ovato-oblongis utrinque attenuatis denticulatis sublus glabris. Pulmonaria silirica Pursh. In Amer. bor. 2. Cor. purp.

51. L. sibiricum Lehm. glaherrimum; caule erecto; fol. sulscarnosis, rad. cordatis obtusis, caul. acutis ; floribus racemosis. P. sibirica L. Ledeb. t. 207. In Sibiria. 4.

52. L. maritimum Lelim. caule procumbente ramoso; fol. ovatis punctatis glabris subcarnosis. Pulmonaria L. P. parviflora Michx. Ad littora mar. Europ. et Amer, bor. 4.

53. L. pulchrum Lehm. caule erecto angulato laevi; fol. glaberrimis nervosis glaucis, infer. in petiolum decurrentibus. Mill. ic. t. 202. B. M. 160. Plukn. t. 227. f. 6. Mertensia pulmonarioides Roth. In Virginia et Canarla. 4. Cor. caerulea.

51. L. paniculatum Lehm. fol. ovato-oblongis acuminatis pilosiusculis; cal. abbreviatis 5-partitis hispidis. Pulmonaria Ait. Ad fretum Huds. 4.

5.5. I. maryinatum Sir. caule erecto glaherrimo; fol. rad. ohovato-oblongis longe petiolatis, caul. ciliatis; calycibus ciliatis. P. lanceolata Purslı. P. marginata Nutt. Ad flum. Missouri.

56. L. javanicum spr. canle repente; fol. linearibus glabris; flor. 
sulısessilibus axillaribus. Heliotropium orientale L. In Java. ఫุ.

L. corymbosum Lehm.? mug. 2. p. 27. L. Drummondii Lehm. mug. 2. p. 26. L. lycopsoides Lelim. pug. 2. p. 28. et ruderale Dougl. Lelım. pug. 2. p. 28.

\section{PULMONARIA Plin.}

1. P. azurea Bess. hispida; fol. anguste lanceolatis, radical. petiolatis, caulinis subdecurrentibus. Kchb. ic. 694. P. angustifol. Sv. Bot. 544. P. montana Wulf. In Gallia, Vollyyn. et 'Transsylv. 4. Fl. azurei.

2. P. angustifolia L. hispida; fol. oblongo-lanceolatis, radical. petiolatis, caulinis amplexicaulibus. Rclıb. ic. 605. P. tuberosa schk. In Europa. ち. Kad. nodosa. Cor. violacea.

3. P. mollis Wulf. stricta; molliter et sericeo-pubescens; fol. radical. ellipticis acuminatis longe petiolatis, caulinis semiamplexicaulibus. Hchb. ic. 696. B. M. 2422. P. angustifolia Bess. In Europa. 4. Cor. violacea.

4. P. oblongata Sclirad. hispida; fol. ovato-oblongis in petiolum attenuatis supremis sessilibus. Hchb. ic. 697. P. angustifolia $\beta$. Koch. Syn. F1. Dan. 483. In Europa. 4. Fl. violacei.

5. P. saccharata Mill. hispida; stricta; fol. ovato-ellipticis utrinque acuminatis, radical. longissime petiolatis, canl. sessilibus. Hchb. ic. 698. In Europa. 4. Fol. albo-maculata.

6. P. officinalis $L$. fol. radicalibus demum cordatis. Rchb. 699. S'v. Bot. 135. E. B. 118. FI. Dan. 482. In Europa, 4. Cor. rubro-violacea. Fol. alho-maculata.

7. P. pilosa Cham. et Schl. molliter pilosa; fol. radic. subcordatoovatis acutissimis infra longe pilosis; pedunculis cernuis sub calyce incrassatis; fornicibus minutis glandulosis. In America. 4. Cor. caerulea.

\section{PURSHIA Spr. (1817).}

1. P. Lispida Lehm. fol. oblongis acutis venosis strigoso-hispidis; Iaciniis corollae suhulatis pilosis. Lithospermum virginianun $\mathbf{L}_{\text {. }}$ Onosmodium Michx. In Virginia. 4.

2. P. mollis Lehm. fol. oblongolanceolatis obtusiusculis sub-3-nerviis incano-villosis; laciniis cor. ovatis glabris. Lithosp. carolinianum L. In Pennsylvania et Carolinia. 4.

\section{MOLTKIA Lehm. (1817).}

1. M. punctata Lehm. fol. spathulato-lanceolatis obtusis strigosis ; fructibus scrobiculato-rugosis. In Galatia. 4. 1-ped. Semina impressopunctata.

2. M. caerulea Lelim. fol. lanceolatis acutis sericeis; nucihus rugusis. Onosma Willd. In America. 4. 1ped. Cor. purpurea.

3. M. cyrenuica Spr. fol. ohlongolanceolatais acutis hispidis; fructibus tuberculatis. Nonea phaneranthera Viv. In agro Cyrenaico. 4.

\section{ONOSMA Diosc.}

\section{a. Setis vel pilis stellatis.}

1. O. fruticosum Labill. Syr. III. t. 6. caule fruticoso ramosissimo; fol. oblongis revolutis incanis strigosis; flor. nutantibus. In Persia et Cypro. ち. 1-ped. Flor. sulphurei.

2. O. angustifolium Lehm. caule simplici; fol. linearilus revolutis incanis stellulato-lispidis ; flor. racemosis nutantibus. In Apulia. 4.

3. O. erectum $\mathrm{Sm}$. caule simplici caespitoso; fol. linearibus apice latioribus tuberculato-hispidis ; flor. racemosis erectis. Silhth. gr. t. 173. In Creta. 4. Cor. crocea.

4. O. stellulatum Kit. caulihus aggregatis; fol. lanceolatis lepidoto-stellulatis canescentibus hispidis; flor. pendulis. O. nıontanum Sm. O. tauricum M. B. In Croatia, Tauria et Graecia. 4.

5. O. rigidum Ledeb. Fl. ross. $t$. 238. caule ramoso; fol. oblongis un- 
dulatis ohtusiusculis stellato-hispidis otrigosisque; flor. erectis. In T'auria. 24.

6. O. arenarium W. Kit. Hung. var. $t$. 279. caule ramoso; fol. lanceolatis ohtusis luberenlato-stellulatis hispidiusculis strigosisque; florib. obliquis. In Ifunyaria. 24. Cor. flava.

7. O. giganteum ram. caule superme ramoso; fol. ohlongo-lanceolatis, supremis suldcordatis tuherculatostellulatis hispidis; flor. nutantibus. In 'T'aria et Asia minore. 4.

\section{b. Setis vel pilis solitaris.}

8. o. setosum Ledeb. Fl. Ross. $t$. 196. tuherculato-hispidum ; setis patentissimis; fol. subtus glahris ad costam hispidis ovatis; caryops. reticulato-rugosis. Prope Astrachan. 24. 1-ped. Cor. flava.

9. o. polypliyllum Ledeb. $l$. c. $t$. 24. sericeun; pitis prostratis; caulihus caespitosis; fol. confertissinis oblongo-linearibus enerviis margine revolutis. In Tauria. 4.

10. o. Gmelini Leileb. $l$. c. t. 280. tuberculato-hispidum; caule simplici adscendente; fol. caulinis oblongo-linearibus rotundatis; fructibus pendulis. In Sibiria. 4.

11. 0 . echioides $L$. caule ramorissimo; fol. lanceolatis floralibus cordato-ovatis undato-sinuatis tuberculato-hispidis. Sibth. gr. t. 172. Jacq. austr. t. 295. In Europa australi. 4. Cor. flava.

12. O. echinatum Desf. Atl. t. 13. caule superne ramoso; fol. linearilanceolatis tuberculato-hispidis; fructibus rugulosis. In Alyeria. 4. 810-poll. Cor. flava.

13. O. tinctorium N. B. caule ramosissimo; fol. oblongis hirtis ; tuberculis ohsoletis; floribus secuudis; filamentis hrevissimis. In 'Tauria et Transsylv. 4. Fl. albi.

14. O. rupestre $M$. $B$. caule simplicissimo aulscendente; fol. abhreviatis lincari-lanceolatis supra luberculato-hirsutis subtus glabris ad costam hispidissimis. In Cuucaso. 4.

1.5. O. saxatile Lehm. caule ereclo ranoso; fol. lineari-lanceolatis obtusis tuberculato-hispidis; racemis longissinis; cor. longissimis. Anchu- sa Pall. it. III. t. F. f. 1. In pururia. 4. Cor. purpureo-caerulea.

16. O. diraricatum Lehm. caule ramoso divaricato; fol. lanceolutis utrinque attenuatis hispidis; racemis foliosis. O. orientale Pall. Ad mare Caspium. 24.

17. O. micranthum Pall. it. Ir. t. L. caule ramoso divaricato; fol. oblongis longe petiolalis, subtus incanohispidis; racemis ehracteatis. In Sibirire. 24. Cor. rubra.

18. O. syriacum Labill. syr. III. t. 5. caule ramoso glanduloso pilosoviscoso; fol. ohlongis denticulatis pilosis; cor. dentibus reflexis. In $\boldsymbol{l}^{\prime} \alpha$ laestina. 24. Cor. caerulescens.

19. 0 . orientale $\mathrm{L}$. fol. lineari-hirtis; cor. uutantibus cylindricis acutis; fructibus pendulis. In Oriente. 24. Cor. flavescens.

20. O. simplicissimum M. B. caule erecto simplicissimo; fol. linearibus acutiusculis strigosis subtus sericeis canescentibus; cor. laciniis reflexis. 0. sihiricum Lam. In Russia. 4.

21. O. trinervium Lelim. caule sinplicissimo; fol. linearibus acutis 3nerviis supra calloso-hispidis subtus strigosis. O. strigosum H. et $\mathbf{K}$. In Mexico. 4.

22. O. sericemm M. B. caule ramoso; fol. oblongo-lanceolatis petiolatis sericeo-villosis; cor. laciniis reflexis. In Cancaso. 4.

23. O. stamineum Ledeb. tuberulato-hispidum; pilis patentibus; fol. oblongis ovatisve; cor. dentibus reflexis. Eichw. casp. t. 3. Ad mare Caspinm. 4. Cor. caerulea.

\section{ECHIUM Numen.}

\section{Fructicosa.}

1. $\boldsymbol{E}$. fruticosum $\boldsymbol{L}$. caule tomentoso; fol. spathutato-lanceolatis rigidis aveniis sericeo-villosis; spiculis confertis. B. R. 36. E. africanum P. In Prom. b. spei. t. Cor. purp.

2. E. aryenteum $L$. caule foliisque lanceolatis acutis sericeo-villosis; spica terminali simplici foliosa. E. fruticosum Jacq. E. ferox Andr. Rep. t. 39. In Prom. b. spei. ち. Fl. caerulei.

3. E. candicans L. caule ramoso; fol. lanccolatis utrinque attenuatis ve- 
nosis sericeo-argenteis ; panicula conica. E. nervosum Ait. In Madera. †. Flor. caerulei.

4. E. densiflonm DC. caule subsimplici; fol. lanceolatis acuminatis venosis sericeo-villosis; pauicula densa spicaeformi. In ins. Canar. $\hbar$. Flor. cyanei.

5. $\boldsymbol{E}$. molle $\mathrm{Lag}$. caule ramoso candicante; fol. anguste lanceolatis acutis argenteo-pubescentibus; pauiculis ovatis. E. lasiophyllum Lk. In ins. Canar. ち.

6. E. fastuosum Jacq. caule ramoso villoso; fol. oblongo-Ianceolatis oblique acuminatis venosis villosopilosis; thyrsis ovatis confertissimis. E. candicans DC. In ins. Canar. $\hbar$. Flor. azurei.

7. E. simplex $D C$. caule simplici; fol. ovato-lanceolatis utrinque sericeis; panicula spicaeformi; spiculis bifidis. In ins. Canar. ђ. Nlor, albidi.

8. E. trichotomum Thunb. caule glahro subtrichotomo; ramis foliisque lanceolatis imbricatis tomentosis. In Prom. b. spei. ち. Flor. albi.

9. E. hispidum Thunb. caule glabro ramoso; fol. lanceolatis rigidinsculis hispidis; spicis compositis. In Prom. b. spei. $\hbar$. Flor. alli.

10. E. strigosum $\mathrm{Sw}$. caule villoso; fol. lanceolatis obtusis carinatis utrinque strigosis; spiculis 2-partitis. In Prom. b. spei. ち. Flor. violacei.

11. E. petraeum 'Tratt. En. $t$. 8 . caule erecto ramosissimo; fol. linearilanceolatis obtusis pubescentibus subtus albis revolutis. E. rosmarinifolium Vahl. In Dalmatia. ち. Cor. purpureo-caerulea.

12. E. spathulatum Viv. caule subramoso foliisque spathulatis tubercuIato-hispidis; staminihus inclusis. In Africa boreali. $\hbar$. Flor. violacei.

13. $\boldsymbol{E}$. distachynm Viv. caule decumbente foliisque linearibus revolutis tuberculato-hispidissimis; spicis secundis reflexis, Ad syrtim maj. Afr. bor. $\hbar$. Flor. caerulei.

1.1. E. aculcatum $D C$. caule ramoso albicante; fol. linearihus sericeis costa margineque spinulosis; pauiculis glomeratis. In ins. Canar. $\hbar$. Cor. flava.

15. E. giganteum $\boldsymbol{I}$. caule pilis hrevissimis adpressis subincano; fol. lanceolatis attenuatis subscabris; pauicula pyramidata. Vent. Malm. t.71.
In Teneriffa. ‡. Altissima. Flor. albi.

16. E. strictum $\boldsymbol{L}$. caule stricto ramoso ; fol. oblongo-lanceolatis pilosis; cor. subcampanulatis; racemis compositis. Jacq. Schuenbr. t. 35. E. foliosum Lehm. In Teneriffa. $\hbar$. Flor. caerulei.

17. E. lineatum Jacq. Ecl. $t$. 42. caule stricto albo-pubescente; fol. ovato-lanceolatis hirsutis; spiculis paniculae bifidis. E. virescens DC. In T'eneri/fa. ち. Cor. caerulescens.

18. E. brachyanthum Horn. caule ramoso hirsuto; fol. lanceolatis in petiolum decurrentibus venosis callosohirsutis. In Madera. ち. Cor. alba.

19. E. bifrons DC. ramis alhicantibus; fol. lanceolatis in petiolum attenuatis supra subcallosis subtus sericeis venosis. In ins. Canariis. ち. Fl. albi.

20. E. formosum Pers. caule ramoso glabro; fol. nitidis lanceolatis supra scabris; cor. tubo longissimo. E. grandiforum Andr. Hep. t. 20. In prom. b. spei. $\hbar$. Flor. purp.

21. E. scabrum Lehm. caule superne villoso; fol. sessilibus lanceolatis aveniis utrinque calloso-strigilosis; bracteis falcatis. In Prom. $b$. spei. $\hbar$. Flor. pallide caerulei.

22. E. paniculatum Thunb. caule pubescente ramis angulatis; fol. piloso-lispidis. In Prom. b. spei. ち. Flor. alhi.

23. E. trigonum Thunb. caule villoso; fol. oblongis canaliculatis piloso-hispidis. In Prom. b. spei. $\hbar$.

2-f. E. verrucosum $\$ w$. ramis incanis ; fol. imbricatis lineari-lanceolatis hispidis subtus papilloso-setosis. In Prom. b. spei. t. Cor. albida.

25. E. capitatum $L$. caule piloso; fol. hispidis ; floribus capitato-corymbosis aequalibus; calycibus hirtis. In Prom. b. spei. $\hbar$. Flor: rubri.

26. E. sphaerocephalum Tahl; caule ramoso glabro; fol. confertissimis lanceolatis obtusis canaliculatis calloso-strigosis. In Prom. b. spei. $\frac{\hbar}{2}$

27. E. glaucophyllum Jacy. ic. $t$. 312. ramis calycibusque glabris; fol. lanceolatis glaucis aveniis ad oras strigosis, facie glabris. E. laevigatum Lam. Andr. Rep. t. 165. In Prom. b. spei. Ђ. Cor. purpurea. 
2S. E. glabrum Vahl; caule glabro superne incano; fol. lanceolatis subfalcatis suhtus calloso-punctatis calycibusque pilosis. E. falcatum Lañ. In Prom. b. spei. b. Flor. alli.

29. E. Suartzii Lehm. caule ramoso glabro; fol. lineari-lanceolatis glahris margine calloso-punctatis ciliatis; spiculis sub 3-fidis. In Prom. b. spei. 古 Flor. caerulei.

30. E. laevigatum $L$. caule glabro; fol. lanceolatis glabris ciliatospinosis. In Prom. b. spei. ち.

31. E. tinctorium Viv, aeg. $t$. 2 . f. 13. hispidum; fol. lineari-oblongis; calyce hispidissimo; cor. hispida; laciniis stigmatis capitellatis. In Aegypto. $\hbar$. Hlor. caerulei.

\section{b. Herbacea.}

32. E. verecundum Viv. aeg. $\boldsymbol{t}$. 2. f. 11. caulibus decumbentibus; fol. radic. longe petiolatis tuberculatohispidis oblongis; staminibus corolla 3-plo brevioribus. In Aegypto. 4.

33. $E$. vulgare $L$. caule tuberculato-hispido; fol. lineari-lanceolatis hispidis; racemo spicaeformi; stam. corolla longiorilous. Fl. Dall. 445. E. B. 181. Schk, t. 32. In Europa et Amer. bor. $\odot$. Flor. caerulei.

34. E. caudatum Thunb. caule basi lignoso villoso; fol. oblongo-lanceolatis setoso-hispidis; spica ovatooblunga. In Prom. b. spei. Flor. albi.

35. E. spicatum $\boldsymbol{L}$. caule simplici hirto; fol. lanceolato-linearibus hirsutis; spica composita lineari. In Prom. b. spei. 24. Flor. albi.

36. R. Wierzbickii Habrl. adscendens; tuberculato-setosum foliisque oblongo-lanceolatis hispidis; racemis pyramidato-patentibus. In Europa. $\odot$. Ab Ech. vulgari vix diversum.

37. 'E. Nichifferi Lang. simplex; strictum foliisque lanceolatis strigosohispidis ; pyramidato-patenti-ramosum. B. Zeit. 1827. t. 1. In Ifunyaria. $\odot$. Hab. F. vulgaris.

38. E. incamum Thunb. caule simplici canescente; fol. lineari-ensiformilus calloso-asperulis; racemo lineari. In Prom. b. spei. $\odot$. Flor. caerulei.

39. E. acutifolium Lelım. caule simplici strigoso; fol. lanceolatis acu- minatis in petiolum attenuatis villosis; spiculis brevilus. In Persia. $\odot$.

40. E. thyrsoideum Juss. caule simplici hirsuto; fol. ohlongo-lanceolatis asperis; floribus thyrsoideis; staminibus cor. longioribus. Patria ignota.

41. E. rubrum Jacq. austr. app. t. 3. caule erecto e racemis hrevibus longe spicato foliisque lineari-lanceolatis hispidis. Tratt. austr. t. 35. In Europa australi. $\odot$.

42. E. papillosum Iehm. caule simplici calloso-villoso; fol. oblongolanceolatis ohtusis papilloso-strigosis; spiculis reflexis. In Nibiria. $\odot$.

43. E. glomeratum Poir. caule simplicissimo hispido; fol. oblongoianceolatis asperis; racemo longissimo. In syria. $\odot$. Caul, altissimus. Flor. purpurei.

14. E. italicum $\boldsymbol{L}$. fol. linearilanceolatis strigoso-hirsutis, infer. nervosis ; staminibus exsertis. E. altissimum Jacq. app. t. 16. E. B. 2081. In Europa australi et Angl. $\odot$. Flor. albidi.

45. E. pyrenaicum Desf. caule strigoso-hirto; fol. lineari-lanceolatis strigoso-hispidissimis; ramis pyramidatis. E. asperrimum Lam. E. pyramidale Lapeyr. In Gall., Ital. et Afric. bor. Hlor. flavi.

46. E. flavum Desf. Att. t. 45. caule simplici; fol. lanceolatis hirsutissimis; staminibus cor. subregulari longioribus. E.? luteum Lapeyr. In Afric. bor. $\odot$. Flor. flavi.

4\%. E. mistulatum Sibth. ar. $t$. 180. fol. lineari-oblongis repandis tuberculato-hispidis; caule crecto; staminibus exsertis. In Sicilia. $\odot$. Flor. violacei.

45. E. Rauuolfii Delil. Aeg. t. 19. f. 3. caule hispidissimo; fol. spathulato-oblongis punctulato-tuherculatis hispidis; spicis elongatis. E. margaritaceum Lehm. In Aegypto. Flor. albi.

49. E. tuberculatum $L k$. caule simplici stricto; fol. lineari-lanceolatis. revolutis canescentibus tuberculato-hispidis. E. vulgare Brot. In Lusitania. 4. Flor. caerulei.

50. E. lusitanicum I. caule simplici hirsuto; fol. lanceolatis basi attenuatis venosis villosis; staminibus' 2 longissimis. E. italicum Lk. In Hisp. et Lusit. Flor. caerulei. 
51. E. violaceum $L$. caule ramoso; fol. oblongis subcordatis hispidiusculis; spicis elongatis simplicihus; staninihus cor. longitudine. E. creticuni Lam. FI. gr. t. 182. In Europa australi. $\odot$. Flor. violacei.

5\%. E. orientale $\mathbf{L}$. caule ramoso; fol. cauliuis ovatis; flor. solitariis lateralibus. Tournef. it. f. 10\%. In Oriente. $\odot$. Fl. pallide caerulei.

53. E. graudillorum Dest: Att. $t$. 46. fol. pubescentibus, infer. ovatooblongis; caule piloso tuberculoso. In Barbaria. $\odot$. Flor. violacei.

5屯. E. plantagineum $I_{\text {. }}$. caule erecto paniculato-ramoso; fol. radic. petiolatis ovato-ohlongis lineatis, caulinis villosis. sibth. gr. t. 179. E. Itsitanicum Lk. In litt. maris mediterr. $\odot$. Fl. violacei.

55. E. elegans Itehm. caule a basi ramoso; fol. lineari-lanceolatis subrepandis tuherculato-hispidis. E. hispidum Sibth. gr. In Italia. $\odot$. Flor. punicei.

56. H. creticum $I_{\text {. }}$ caule echinato; fol. ovatis s. ovato-oblongis hispidis; calycibus fructiferis distantibus. Sibtl. gr. t. 183. In Creta et Oriente. $\odot$. Flor. caerulei.

57. E. bonariense Poir. caule erecto piloso; fol. infer. spathulato-linearibus, super. lanceolatis sagittatis strigosis; spicis revolutis. st. Hil. pl. bres. t. 25. In Buenos Ayres. Flor. caeruleo-violacei.

58. E. angustifolium Iam. caule erecto hispido ; fol. linearihus angustissimis strigosis; cor. pilosa staminilous breviore. In Hispania. Flor. caerulei.

59. E. setosum Vahl; fol. linearilanceolatis cauleque suffruticoso procumbente hispidis incanis. Delil. aeg. t. 17. f. 2. In Aegypto. ち. Flor. rubri.

60. E. sericeum Vahl; fol. lineari-cuneatis cauleque adscendente ramoso-diffuso incanis. E. prostratum Delil. In Aleg!pto. 4. Flor. rosacei.

61. E. maritimum $W$. fol. radical. spathulato-lanceolatis villoso-strigosis; staminibus cor. hrevioribus. E. setosum Delil. Barr. ic. 1012. Bocc. mus. t. 78. In Ital. et Nicilia. $\odot$.

62. F. tenue Roth; caule tenui ramoso, foliisque lanceolatis tuherculato-hispidis; staminilus cor. parva hrevioribus. E. lıumile Desf. In A/rica boreali. $\odot$.
63. E. parviflorum Roth; fol. lanceolatis strigosis; calycilus maximis; caule adscendente ramoso. E. micranthum schousb. E. calycinum Viv. E. ovatum Poir. Ad litt. maris mediterr. $\odot$.

6t. E. diffusum Sibth. gr. t. 153. fol. lineari-spathulatis tuberculatis hispidis; staminibus inclusis; caule prostrato diffuso. In Creta. $\odot$. Flor. punicei.

6.5. E. Iongifolium Delil. Aeg. $t$. 16. $f$. 3. caule e"ecto simplici; fol. lineari-lanceolatis elongatis tuberculato-lispidis. In Aegyjto.

\section{ECHIOCHILON Desf. (1S10).}

1. E. fruticosum Desf. Atl. t. $4 \%$. In regno Tunetuno. ఫ. 2-ped. Lami hirsuti. Folia subulata aspera. Flor. axillares parvi caerulei.

\section{LYCOPSIS Diosc.}

1. L. picta Lehm. caule procumbente ramosissimo ; fol. lineari-lanceolatis undulatis obsolete dentatis calloso-hispidis. Anchusa M. B. In Tauria $\odot$. Flor. variegati.

2. L. caspica helim. caule erecto simpliciusculo; fol. lanceolatis utrinque attenuatis integerrimis hispidis. Onosma W. Ad mure casp. et in Sibiria. $\odot$. Flor. rubri.

3. L. virginica I. caule pusillo hispidissimo; fol. infer. spathulatis integerrimis; racemis solitariis. In Virginia.

4. I. ciliata $W$. caule stricto; fol. oblongo-lanceolatis denticulatis hispidis, floralibus acuminatis. In Armenia. Flor. Iutei.

5. L. obtusifolia $\boldsymbol{W}$. caule adscendente; fol. ohlongo-Ianceolatis subintegerrimis pilosis, floralihus acutis. In ins. Archipel. Hlor, caerulei.

6. I. Sibtiorpiano fiehm. caule procumbente; fol. lanceolatis ohtusis integerrimis pilosis. Anchusa ventricosa Sm. In Creta et Africa boreaii. Hlor, alli.

\%. L. alpestris Lehm. caule adscendente; fol. oblongo-lanceolatis eroso-dentatis hispidis; calycibus obtusis hirtis. Anchusa stev. In C'utcaso. Flor. lutei. 
8. L. rosea Lehm. caule procumbente foliisque oblongis obtusis glutinoso-hispidis. Anchusa M. B. A. versicolor stev. In Caucaso. $\odot$. Flor. rosei.

9. I. vesicaria $\boldsymbol{L}$. caule procumbente; fol. lanceolatis integerrimis piloso-hispidis; cor. tubo brevissimo. Nonea nigricans Auct. In Europa australi. $\odot$.

10. L. pulla I. subcorymbosa; bracteis calyce longioribus foliisque lanceolatis tomentoso-hispidis. Jacq. austr. t. 188. Nonea DC. In Europa. $\odot$. Flor. nigri.

11. L. lutea Lehm. caule adscendente ramoso; fol. ohlongis subintegerrimis obtusis birsutis, floral. subcordatis. Anchusa M. B. A. duhia Nocca. Nonea DC. In Europa custr. $\odot$. Flor, lutei.

12. L. confertiflora Clarke; ramis decumbentihus diffusis asperrimis foliisque longe lanceolatis integerrimis calloso-hispidis. In Pulaestina.

13. L. echioides Lehm. caule erecto ramosissimo; fol. lanceolatis integerrimis subsericeis pilosis. Anchusa M. B. In Armenia et Caucaso.

14. L. setosa Lehm. caule erecto simplici; fol. oblongo-lanceolatis denticulatis strigoso-setosis, floral. ovatis. In Iberia.

15. L. Colsmanniana Lehm. caule erecto ramoso; ramis divaricatis ; fol. lineari-lanceolatis integerrimis hispidis. Patria ignota. Flor. purpurei.

16. L. cyrenaica Spr. caule erecto foliisque spathulato-oblongis calloso-villosis; spicis densis secundis. Anchusa bracteolata Viv. In agro Cyren.

730. COLSMANNIA Lehm. (1818).

1. C. flava Lehon. In Asia minore? 2. Semipecialis; flavo-villosa; fol. spathulatis erectis sericeis; racemis secundis; floribus flavis.

\section{ซ31. CRANIOSPERMUM Lelm.} (1818).

1. C. subvillosum Lehm. In Sibiria. 4. Herha dodrantalis villosa; fol. spathulatis villosis; racemis subcapitatis; floribus roseis.

\section{DIOCHEA Lehm. (1821).}

1. D. hispillissima Lehm. Anchusa asperrima Delile. In Aegypto. Planta ramosissima verrucoso-hispidissima ; fol. lanceolatis; spicis foliosis; corollis ochroleucis.

\section{MYOSOTIS Diosc.}

1. Fructibus laevibus, floribus caeruleis.

1. M. grandiflora $H_{\text {. }}$ et $\boldsymbol{K}$. Nov. Gen. $t$. 199. caule subsimplici; fol. strigosis ohtusis, caulinis lanceolatooblongis; calyc. clausis. In Quito. 2.

2. M. latifolia Poir. caule simpliciusculo erecto; fol. longe petiolatis ovato-lanceolatis pilosis; calyc. acutis villosis. In ins. Canar. 4.

3. M. sylvatica Eler\%. calycibus profunde 5 -fidis patulo-pilosis pilis uncinatis; cor. limbo plano. Sturm 42. M. montana Bess. In Europa. $\odot$. 。

4. M. alpestris $\mathbf{S m}$. caule obtuse angulato hirsuto; racemis villoso-hirsutis; limbo cor. plano. Sturm 42. M. rupicola E. B. 2559. M. lithospermifolia Horn. Sturm 42. M. sylvatica B. alpestris Koch. In Alp. Europae. $\odot$.

5. M. palustris With. calyce 5dentato adpresse piloso; stylo calycem subaequante; rhizomate oblique repente. M. scorpioides IV. sturm 42. In paludosis Europae. 24.

6. M. caespitosa Schulz; nucibus glabris; calyce 5-fido adpresse piloso; stylo brevissimo; radice descendente. Sturm 42. M. lingulata $R$. et s. M. uliginosa schrad. In Europa.

\%. M. Chorisiana Cham. et Schl. calycibus adpresso-strigoso-pilosis; caule filiformi; fol. lineari-acutis strigoso-pilosis ciliatis; nucibus sub-ëquetris rugosis. In Brasilia. $\odot$.

8. M. Forsteri Lehm. caule adscendente; fol. obovato - spathulatis strigoso-hispidis; racemis fililormibus; calyc. hispidis. In Nova Zeelandia. 4.

9. M. foliosa Lehm. caule erecto simplicissimo; fol. spathulato-lanceo- 
latis; racemis foliosis subcapitulatis. In America austr. 4.

10. M. villosa Ledeb. Fl. Ross. t. 215. albo-villosa; caulihus caespitosis; caryopsidibus detruncatis marginato-dentatis deutibus inflexis. In Sibiria. 4.

11. M. aretioides Cham. et Schl. caespitosa; pulvinata; densa; fol. sessilibus densissimis lanceolatis; inflorescentia cymoso-ylomerata. In $\mathbf{B r a}$ silia. 4.

12. M. rupestris Pall.it. III. app. t. E. f. 3. tota sericea; caulibus caespitosis; fol. linearibus; caryopsidibus detruncatis marginatis margine edentulo. In Sibiria. 24.

13. M. arvensis Sibth. cor. patula; calyce fructifero clauso pedunculis longiore. E. B. 2558. M. arenaria Schrad. M. stricta Lk. In arenosis Europae. 24.

1t. M. intermedia $L k$. cor. patuIa; calyce fructifero clauso pedunculis multo breviore. Sturm 42. M. arvensis Auct. In agris Europae. $\odot$.

15. M. collina Ehrh. cor. calyceque fructifero patulis; stylo brevissimo. Sturm 42. M. hispida Schl. M. arvensis Lk. In agris Eumopae. $\odot$.

16. M. versicolor Roth; corolla calyceque fructifero patulis; stylo Iongissimo; fol. supremis suboppositis. Sturm 42. E. B. 480. In Europa. ๑.

17. M. sparsillora Milian; cor. lohis rotundatis; calycilus fructiferis regularibus basi uncinato-pilosis; pedunc. demun reflexis. Sturm 42. In umbrosis Europae. $\odot$.

18. M. laxa I,elm. cante filiformi; pedicellis longissimis demum divergentibus; calyce fructifero patente. In Amer. bor. $\odot$.

19. M. corymbosa $R$. et $P$. fol. linearibus acutis; caulibus divaricatis; Ioribus corymbosis. In Chili. $\odot$. 6-8 poll. Cor. allsa.

20. M. involucrata Stev. caule basi ramosissimo prostrato; racemulis glomeratis ; pedunc. fructiferis cernuis. In Caucaso. $\odot$. Pygmaea.

21. M. spatluluta Forst. caule fliformi procumbente; fol. ovatis petiolatis calloso-bispidis; calyce incano-piloso. In Nova Zeelandia. $\odot$.

22. M. pusilla Lois. fol. spathulatis incano-pilosis; pedicellis folio brevioribus; tubo corollae calycem superante. In Corsica. $\odot$. b. Fructibus scabris aut ru-
gulosus.

23. M. nana Vill. t. 13. nucibus margine aculeato-fimbriato cinctis. Eritrichina schrad. Sturm 42. In Europa media 4. 1-2" poll. Flor. pulchre caerulei.

21. M. peduncularis Trev. caule subramoso; fol. subrotundis glabriusculis ciliatis; pedicellis apice incrassatis; calyce patentissimo. Ad Astrachan. 4.

25. M. clavata. Ledeb. caule ramoso erecto; fol. spathulato-lanceolatis undulatis calloso-hispidis; racemis foliosis erectis; fruct. graunlatis. In Sibiria.

26. Mr. pectinata Pall. it. app. $t$. E. $f$. f. seminibus apice setosis; racemis rectis; fol. ovato-lanceolatis villosis. In rupibus muscosis Sibirive. 4.

2\%. M. ciliata Rud. Mém. Petersb. I. $t$. $X I$. caulibus foliisque oblongolanceolatis canescentiłus strigoso-pilosis; caryops. dentibus ciliatis. In Sibiria. 4.

28. M. tenuiflora Viv, caule erecto foliisque spathulatis tuherculatohispidis; fructibus tuberculatis. In agro Cyrenaico. 24.

29. M. granulosa $R$. et $P$. seminibus granulosis; fol. linearibus hispidis punctatis albicantibus; floribus secundis. In Lima. ๑. 5-6-poll. Cor. alba.

30. M. humilis $\boldsymbol{R}$. et $\boldsymbol{P}$. seminibus rugosis; fol. linearibus; caulibus brevilus; flor. lateralibus secundis. In Peruvia. ๑. 3-poll. Cor. alba.

31. M. micrantha Pall. in litt. caulibus diffusis decumbentibus; fol. angusto-lanceolatis strigosis; nucilus rugosis; costis prominulis. Ad Holgam. Cor. Iutea?

30. M. albida $H$. et $K$. caule erecto ramosissimo; fol. linearihus hispidis allidis sessilibus; calycibus clausis; drupis scabris. In Mexico. $\odot$.

33. M. glomerata Nutt. caule erecto; fol. spathulatis hispidis; spicis glomeratis bifidis; calycibus hispidissimis. Cynoglossum Pursh. Ad $/ l$. Missouri.

34. M. Hacquetii; nucibus margine laevi cinctis. M. terglouensis Hacq. 
pl: alp. t. 2. f. 6. M. nana Wulf. Eritrichium Koch. In Alp. granit. 4 .

35. M. nemorosa Eess. fol. strigoso-hispidis; calyc. 5-dentatis strigosis; caule glahro nitido; racemis laxis; pedicellis fructiferis calycem subaequantibus. In Vollynia. 4.

36. M. obovata Ledeb. subsericea; caulibus caespitosis simplicibus; fol. obovato-ohlongis; racemis geminis; pedicellis flores vix superantibus. In Davuria. 4.

37. M. fulva Hook in Beech Voy. caule erecto simplici foliisque latoliuearibus obtusiusculis hispido; calyce densissine piloso. In Chili. 4. Pedalis. Cor. alba.

\section{EXARRHENA R. Br. (1810).}

1. E. suaveolens R. Br. In ins. Van Diemen. Herba Myosotis facie; floribus albis.

\section{F34. BORRAGO Braunschuig (1560).}

1. B. officinalis $L$. fol. omnibus alternis; calycibus patentibus. E. B. 36. Schk. t. 31. Sturm 8. Ex Oriente in Europa culta. ๑. Cor. caerulea.

2. B. orientulis $\boldsymbol{L}$. fol. cordatis petiolatis; staminihus exsertis villosis. sihth. gr. t. 175. Kern. t. 118. Circa Bysantium. 2. Cor. purpureo-caerulea.

3. B. cretica $W$. hispida; fol. ovatis; corollarum laciniis reflexis linearihus, Desf. Anm. Mus. X. t. 34 . Sibtl. gr. t. 176. In Creta. 24. Cor. pallide rosea.

4. B. crassifolia Vent. H. Cels. $t$. 100. glauca; caule laevi; fol. decurrentihus supra scaberrimis; cor. laciniis patentissimis. In Persia. 4. Cor. carnea.

5. B. longifolia Desf. Atl. $t .41$. fol. lineari-lanceolatis sessilibus alternis; calycihus hasi hirsutissimis. In Barbaria. ๑. Cor. caerulea.

6. B. laxiflora Horn. fol. alternis oblongis sessilibus; dentibus calycis adpressis; cor. nutante campanulata. Patria ignota. Cor. parva.

\section{ANCIIUSA Theophr.}

\section{Calyces 5-partiti infructu erecti.}

1. A. arvensis LK. caule basi simplici; fol. lanceolatis; cor. tubo immerso. E. B. 938. Fl. Dan. 435. sclik. t. 31. Lycopsis L. In agris Europae. $\odot$. Pedalis. Cor. caerulea.

3. A. Barrelieri Gmel. fol. ovatolanceolatis cauleque simplici hispidis; pedunculis 3-fidis. Barr. ic. $\mathbf{3 3 3}$. Buglossum All. In Europa australi. 4. Cor. azurea.

3. A. strigosa Labill. syr. III. $t$. 4. fol. ovato-lanceolatis denticulatis aculeatis; seminibus calycis longitu-

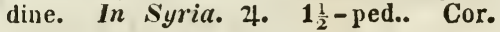
caerulescens.

4. A. paniculata Ait. racemis conjugatis panicula!is bracteatis; tubo cor. venosae styloque calycem excedentibus; caule foliisque strigoso-hirsutis. A. italica Trev. t. 18. A. officinalis Desf. In Europa australi et Africa. 4.

5. A. Milleri $W$. fol, oblongis denticulatis hispidis, super. sessilihus; calycibus setoso-hispidis; caulibus diffusis. Lycops. Horn. Patria ignota. $\odot$. Cor. violacea.

6. A. macrophylla Desf. caule debili superne ramoso; fol. radical. ovalihus, caulinis lanceolatis acutis integerrimis strigosis. In Marocco. Cor. pallide flava.

7. A. myosotidiflora Lehm. fol. radicalibus longissime petiolatis reniformi-cordatis, caulinis sessilibus ovatis acutis; calyciluus reflexis. A. macrophylla M. B. In Caucaso. 4.

8. A. villosa $S p r$. caule ramoso; fol. Ianceolatis integerrimis villosis; racemis axillarihus; calycibus obtusiusculis. Patria ignota.

9. A. semperirens $L$. racemis capitatis conjugatis foliosis basi diphyllis; fol. ovalibus utrinque acutis. E. B. 45. Hook Lond. t. 91. In agris Europae. (-). Cor. caerulea.

10. A. stylosa M. B. cnule erecto superne ramoso; fol. lanceolatis basi attenuatis undulato-denticulatis hispidis; bracteis calycibusque subulatis. In Tauria.

11. A. procera Bess. caule erecto ramoso; fol. lanceolatis decurrentibus, floralibus sessilibus cordato-Ianceola- 
tis ; spicis imbricatis secundis. In $\mathrm{Po}$ dolia.

12. A. variegata Lehm. caule adscendente simplici; fol. oblongis semiamplexicaulibus repando-dentatis verrucoso - strigosis bispidis; fornicibus pubescentibus. Lycopsis L. L. bullata Cyr. In Italia et Graecia.

13. A. ovatu Lefem. fol. ovatis integerrimis scabris; calycibus erectis; racenis longissimis; fornicibus pedicelliformibus. Lycopsis L. In Oriente. $\odot$. Cor. cyanea.

14. A. echinata Lam. caule adscendente simpliciusculo setoso; fol. Ianceolatis sessilihus setoso-hispidissimis; spicis foliosis. In Syria. 24. Cor. caerulescens.

15. A. parviflora $W^{\top}$. fol. linearibus cauleque ramosissimo hispidis; racemis paucifloris confertis. In Oriente.

16. A. aggregata Lelim. caule diffuso strigoso; fol. lineari-oblongis obtusis hispidissintis; floribus spicatoaggregatis. A. parviflora sm. In Grictia.

17. A. tinctoria $L$. fol. oblongis; bracteis calycem $\mathbf{5}$-partitum superantibus; laciniis corollae staminibus brevioribus. sibth. gr. t. 166. In Cypro et Peloponneso. 4.

18. A. hispirla Forsk. pedunculis axillaribus dephyllis brevibus; caule retrorsum hispido; fol. lanceolatis iepando-dentatis hispidis. In Aegypto. Cor. violacea.

19. A. tenella Horn. caule debili dichotomo; fol. ovatis hispidis; pedunculis remotis in fructu nutantibus. A. Zeylanica Jacq. Eclog. t. 29. In China. $\odot$.

20. A. caespitosa Lam. caule decumbente paucifloro; fol. spathulatolinearibus elongatis villoso-strigosis; calycihus ohtusis. In Creta.

21. A. oppositifolia H. et K. Nov. Gen. $t$. 200 . caule hasi radicante adscendente ramoso; fol. spathulato-linearibus elongatis strigoso-ciliatis. A. Iinifolia Lehn. In peruvia. 4.

22. A. pygmaeu $H_{\text {. et }} \boldsymbol{K}$. caule repente ramoso; fol. linearibus strigoso-hispidulis; floribus sessilibus. In Quito. $\hbar$.

23. A. tuberosa $H$. et $\boldsymbol{K}$. radice tuberosa; caule simplici; fol. lineariinus sessilibus hispidulis; spica terminali foliosa. In Mlexico. $\odot$.
2. Calyces fructiferi campanulati subinflati nutantes.

2t. A. officinalis $\boldsymbol{L}$. spicis dense imbricatis; bracteis ovatis; calycibus post anthesin glohoso-comiventibus; fol. lanceolatis integerrimis. Hchb. ic. 469. FI. Dan. 572. E. B. 662. A. incarnata Schrad. In Europa. 4.

25. undulata $L$. fol. lanceolatis dentatis undulatis strigoso-hispidis; racentis spicaeformibus compactis. In Europa austr. 4.

26. A. ocliroleuca M. B. fol. lanceolatis strigosis margine hispido-ciliatis; bracteis lineari-lanceolatis. B. M. 1608. In Transsylvania et Tauria. $\odot$.

2\%. A. angustifolia $\boldsymbol{L}$. racemis conjugatis subsecundis; stylo demum calycem duplo longo; fol. lanceolatis hispidis. Rchb. 967. Barr. ic. 1207. In Europa australi. Cor. purpurea.

28. A. Gmelini Ledeb. canle fruticuloso simpliciusculo; fol. linearibus acuminatis strigosis; bracteis calyce patenti hrevioribus. In Podolia et sibiria. 4.

2.9. A. capensis Thunb. fol. Ianceolatis callosis villosis; racemis trichotomis. Andr. Hep. t. 336. In Prom. b. spei. 1-2-poll. Cor. caerulea.

30. A. leucoifolia Lehm. fol. spathulato-linearibus sericeis; spicis solitariis; bracteis lanceolatis basi attenuatis. In Armenia. 4.

31. A. hybrida Tenor. fol. oblongo-lanceolatis undulatis simuato-dentatis hispido-villosis; bracteis cordatoovatis calyce brevioribus. In Neapoli.

32. A. alpestris Stev. caule adscendente ; fol. sulspathulato-lanceolatis eroso-denticulatis hispidis setosociliatis. In Caucaso.

33. A. Ayardhii Lehm. caule ramoso; fol. oblongo-lanceolatis integerrimis hispidis subdecurrentibus; racemis laxis. Patria ignota. 4.

3\%. A. verrucosa Lam. fol. oblongo-lanceolatis utrinque attenuatis repando-dentatis verrucoso-hispirlissimis; pedunculis intrafoliaceis. Asperugo aegyptiaca L. Jacq. Vind. t. 21. Lycopsis Pers. A. flava Forsk. In Aegypto.

3.5. A. clavata Viv. aegypt. t. 2. f. 12. tub e rculato-hispida; canescens 
fol. radical. ohlongis in petiolum attenuatis sinuatis undulatis; pedicellis dilatatis. Prope Kulivam.

36. A. arralis Rchb. ic. 480 . spicis demum longissimis laxis; bracteis ovato-lanceolatis; fol. anguste lanceolatis denticulatis; caule divergenti-hispido. A. arvensis Tsch. In Europa. $\odot$.

37. A.crispa Moris; strigosissima; diffusa; fol. oblongis basi attenuatis repantlo-dentatis; cal. sulgglohosis; seminibus 3-quetris. In sardinia et C'orsica. $\odot$.

\section{\%36. STEMATECHIUM LelT. (1818).}

1. S. papillosum Lehm. In Prom. b. spei. Ђ. Frutex ramosus; fol. lineari-lanceolatis papilloso-hispidis; racemis terminalibus; floribus caeruleis.

\section{3\%. SYMPHYTUM Diosc.}

1. S. cordutum W. Kit. Hung. $t$. 7. simplex; fol. petiolatis cordato-acuminatis; cor. limbo ampliato. Rchb. ic. 395. s. cordifol. Baumy. In Hunguriu. 4. Cor. Inteola.

2. S. tuberosum L. simplex; fol. ovatis semidecurrentibus, summis oppositis; cor. dentihus reflexis. Jacq. ohs. t. 63. E. B. 1502. In Europa australi. 4.

3. S. macrolepis Gay; subramosum; cor, dentibus ovatis erectis ; fornicibus exsertis. \$. bulhosum schimp. Hchh. ic. 367. In Germania. 4.

4. S. orientale L. ramosum; fol. ovatis petiolatis, supremis oppositis sessilibus; cor. limbo campanulato. st. tauricum W. R(hb. ic. 422. B. M. 1787. s. bullatum Horn. In Hungariı. 4 .

5. S. officinale $L$. forniciluus acuminatis; rol. ovato-lanceolatis decurrentibus; calyce tubum cor. aequante adpresso; slylo recto. Fl. D. 664. E. B. 817. In Europa. 4. Fl. alhi.

6. S. patens Sibth. fornicibus obtusis; fol. ovato-lanceolatis decurrentibus; stylo sub stigmate genuflexo. S. officinale s'chk. t. 30. Sv. B. 418. In Europa. 4. Cor. violacea.
7. S. pereqrimum Ledeb. fol. inferoribus oblongis longe petiolatis hirsutis, super, ovatis sessilibus glatriusculis; calycibus villosis. In 'cclolia. 4.

8. S. brochum Bory et Chuub. pilis rigidis hispidum ; fol. ovatis acutissimis; racemis hasi $\mathbf{1 - f o l i a t i s ; ~ f a n - ~}$ cis dentihus exsertis. In Moreu. 4. Flor. luteo-albidi.

\section{LOBOSTEMA Lehm. (1828).}

1. L. echioides Lehm. in Linnate 1830, t. 5. f. 1. In prom. b. spei. t. Frutex parvus ramosus. Folia sessilia elliptico-lánceolata punclis albocallosa. Flor. caerulei.

\section{TRICHODESMA R. Br. (1810).}

1. T. indicum Lehm. fol. suhcordato-lanceolatis ohtusiusculis semiamplexicaulihus calloso-strigosis; laciniis calycis hasi auriculatis. Borrago L. T. amplexicaule lichb. In India orientali.

2. T. Zeylanicum R. Br. fol. lanceolatis acutis suhpetiolatis basi attenuatis subtus mollissimis; calycibus hasi integris. Borrago L. In Nov. Holl.

3. T. africanum Iehm. fol. ovatooblongis acutis petiolatis cauleque calloso-echinatis ; calycibus basi integris. Borrago L. In Aegypto.

\section{ASPERUGO Plin.}

1. A. procumbens L. Fl. Dan. 5.j2. Schk. t. 31. E. B. 661. Fl. gr. t. 18\%. in Europa. $\odot$. Herha hispida caulihus procumbentibus; fol. oblongo-lanceolatis; cor. caeruleo-purpureis.

\section{CYNOGLOSSEM Diosc.}

1. Nucibus echinatis.

1. C. officinale $I$. fol. tenue tomentosis, radicalihus elliptico-spathulatis ; raneis cordato-lanceolatis. E. B. 921. Fl. Dan. 1147. C. bicolor. In Europn, Asiu, America et Africa. $\odot$. Cor. allia disco purpureo. 
2. C. sylvaticum Sm. fol. Iucidis supra glabriusculis subtus scabris, super. cordato-oblongis. C. montanum Lam. E. B. 1642. C. officinale $\beta$. L. C. apenninum Koth. In Europa. (-). Flor. sordide rubri.

3. C. pictum Ait. fol. acutis subtomentosis, infer. oblongis in petiolum attenuatis, super. cordato-amplexicaulibus; cor. reticulatis. B. M. 2431. Fl. post. t. 24. C. cheirifolium Jacq. C. creticum Vill. In Europa australi.

4. C. clandestinum Desf. Atl. $t$. 42. fol. lanceolatis villosis; cor. calycem aequantibus, apice tomentoso-pubescentibus. C. officinale Brot. In Lusit. et Afr. boreal. $\odot$. Cor. violacea.

5. C. Dioscoridis Vill. fol. oblongis aveniis hispidis amplexicaulibus. C. virginicum IV. C. valentinum Lag. C. elongatum Horn. In Gall, austr. $\odot$. Cor. rubella venosa.

6. C. virginicum $\boldsymbol{L}$. fol. linearilanceolatis basi angustatis hirtis, summis amplexicaulibus; laciniis calycis ovato-lanceolatis. In Virginia. $\odot$. Cor. caerulea.

7. C. canescens $W$. fol. petiolatis denticulatis lanceolatis hirtis subtus molliter pilosis 3-nervi-venosis; calyc. laciniis obtusis. C. micranthum Desf. C. hirsutum Jacq. In India orientali. $\odot$. Cor. caerulea.

8. C. lanceolatum Forst. fol. lanceolatis utrinque attenuatis supra punctis albis scalıris; calyc. laciniis ollongis. C. hirsutum Thunb. In Arabia et Prom. b. spei.

9. C. limense $\boldsymbol{W}^{\mathrm{r}}$. fol. oblongis acuminatis sessilibus glabris; cor. laciniis margine allis. Feuill. per. t. 49. Prope Limam. Pedalis. Cor. caeruleo-alba.

10. C. lispidum Thunb. fol. ohlongis obtusis setaceo-liispidis; staminibus cor. brevioribus. In Prom. $b$. spei. Flor. rufescentes minuti.

11. C. tomentosum Lelim. fol. aureo-tomentosis oblongo-linearibus seniamplexicaulibus; racemis multifloris. In Italia.

12. C. holosericeum Stev. fol. candido-holosericeis lanceolatis acutis; floribus cernuis; cor. laciniis obtusissimis. In Caucaso.

13. C. hirsutissimum Lelim. fol. ntrinque papilloso-hirsutissimis Ianceo- latis acutis semiamplexicaulibus. In Africa.

11. C. lanuginosum Lehm. fol. Ianatis lineari-lanceolatis acutis semiamplexicaulibus; racemis laxis. $\boldsymbol{P a}$ tria iynota.

15. C. viridiflorum Lehm. fol. supra glabris suhtus tomentosis oblongis acutis, inferiorihus petiolatis; racemis erectis. In Sibiria?

16. C. stamineum Desf. fol. supra sericeis subtus glauco-tomentosis lanceolatis obtusis; cor. calycem aequante. In Asia minore. Cor. rosea.

17. C. apenninum $L$. fol. radical. petiolatis ovatis maximis, caulin. lanceolatis; spicis confertis; calycihus villosis. Gaertn. t. 67. f. 4. In Europa anstr. $\odot$. Cor. rubella.

18. C. mollissimum Lehm. fol. snpra glabriusculis subtus pubescentibus longe petiolatis ohlongis; racemis comipactis. In Persia.

19. C. cheirifolium $\mathrm{L}$. fol. Ianceolatis obtusis incano-tomentosis; cor. calyce duplo longioribus. C. argenteum Lam. Anchusa lanata L. In Europa austr., Asia minor., Africa boreali. $\odot$.

20. C. dccurrens $R$. et $P$. fol. lanceolatis decurrentibus venosis; caule anguloso alato. In Chili. Cor. campanulata albo-caerulescens.

21. C. revolutum $R$, et $P$. cor. calyce duplo longioribus; fol. lanceolatis, caulinis sessilibus; racenis apice revolutis. In Peruvia. Cor. albocaerulescens.

22. C. suaveolens $\boldsymbol{R}$. $\boldsymbol{B r}$. fol. lanceolatis strigosis, superioribus semiamplexicaulibus. In Nova Hollandia.

23. C. divaricatum Lehm. ramis divaricatis; fol. infer. petiolatis oblongis, super. sessilibus lanceolatis subtus pubesentibus. In Sibiria.

21. C. longiflorum Lelım. tubo cor. calycem duplo superante; fol. lanceolatis acutis calloso-muricatis. In Syria.

25. C. pauciflorum $R$. et $P$. hispidum; fol. lanceolatis inferne angustatis; pedunculis sub-7-floris. In Chili. $\odot$.

26. C. clavatum Viv. fol. stellatoincanis oblongis obtusis; squamis cor. clavato-cylindricis emarginatis. In agro Cyrenaico. 
2\%. C. japonicum Thunb. caulibus prostratis; fol. oblongis villosis serrulatis. In Japonia. Cor. purpurea.

25. C. diffusum Roxb. caule adscendente diffuso; fol. ovato - spathulatis mucronatis strigoso-pilosis; racemis foliosis. In Bengalia.

2.9. C'. latifolizm R. Br. caule prostrato aculeato; fol. ovatis acuminatis scabris; pedunc. extrafoliaceis. In Nov. Holl.

30. C. paniculatum Hook in Beech Toy. adpresse pilosum; fol. lanceolatis acuminatissimis, ciliatis subtus canosericeis; pedicellis fructiferis longissimis. In Chili. ち. Suffutex 1-2ped.

\section{Nucibus compressis margi- natis.}

31. C. lateriflorum Ham. ill. t.92. f. 2. fol. linearibus acutis angustis pilosis; seminibus compressis radiatim aristatis. In Chili et Lima. ๑. Caul. filiformis. Cor. alba.

32. C. pilosum $\boldsymbol{R}$. et $\boldsymbol{P}$. fol. linearibus; floribus solitariis foliis alternantibus; nuculis cristato-lamulosis. In aridis Limae.

33. C. Nuttallii spr. fol. spatlulato-oblongis obtusis pilosis; nucibus scabris margine muricatis. C. pilosum Nutt. Ad fl. Missouri.

31. C. magellense T'en. fol. linearilanceolatis, superior. basi latioribus utrinque villoso-lanatis; racemis compactis. In Neapoli.

3.5. C. Columnae Ten. fol. ovatolanceolatis amplexicaulibus incano-villosis; nucibus margine inciso-radiatis, centro muricatis. In Neapali et Sicilia.

36. C. cristatum Schreb. fol. lineari-lanceolatis obtusiusculis basi attenuatis; nucibus centro muricatis margine inciso-radiatis. In Armenia.

3\%. C. angustifolium $W$. fol. linearibus ohtusiusculis pilosis; cor. calycem duplo superante; nucibus laevibus membrana margine denticulata. C. emarginatum Lam. C. racemosum Sclireb. In Armenia.

38. C. glasífolium $W$. fol. lanceolatis papillosis margine denticulatoscabris; nucibus centro muricatis, margine alatis. Desf. Anm. Mus. X. t. 53. In Armenia.

39. C. umbellatum $W$. fol. lanceolatis cano-pubescentibus; racemis um- bellatis lanatis; nucibus laevibus. In Hungaria et Nibiria.

40. C. laevigatum $L$. fol. ovatolanceolatis glabriusculis; racemis corymhosis ; laciniis cor. linearihus; nucibus laevibus. Lam. ill. t. 92. f. 3. Kindera tetraspis Pall. In Sibiria.

41. C. lanatum Lam. fol. ovatolanceolatis canescentibus villosis; floribus racemosis; laciniis cor. linearibus; mucibus laevibus. In Armenia.

\section{Nucibus membrana urceola. ta instructis.}

42. $C$. nitidum $W$. fol. oblongolanceolatis nervosis, supra glabris nitidis, subtus pubescentibus; racemis elongatis ebracteatis. C. Iusitanicum Brot. In Lusitania.

43. C. cappadocicum $\boldsymbol{W}$. fol. scabris nervosis, radic. cordato-ovatis acuminatis longe petiolatis; racents laxis. Omphalodes cornifolia Lehm. In Asia minore.

44. C. Omplualodes $\boldsymbol{L}$. fol. radicalibus ovato-cordatis, caulinis ovatis petiolatis. Scop. t. 3. Sturm. $33 \mathrm{Om}$ phalodes verna Mnch. In Europes austr. 4. Cor. amoene caerulea.

45. C. brassicaefolium lag. fol. glaucis laevissimis, infimis spathulatis, superioribus cordatis amplexicaulibus. Omphalodes amplexicaulis Lelım. In Hispania.

46. C. littorale Spr. fol. radicalibus spathulatis, caulinis sessilibus oblongis, super. basi dilatatis papillosis margine strigosis. Omphalodes Lehm. Ad litt. maris in Gall.

47. C. linifolium L. fol. glancis obtusiusculis lanceolatis denticulatociliatis; racemis ebracteatis. Omphalodes Moench. In Europa australi. $\odot$.

48. C. myosotoides Labilt. fol. tu= berculato-pilosis, radical. spathulatolanceolatis, caulinis lineari-lanceolatis sessilibus. In Libano et Creta.

49. C. scorpioides Jacq. caule diffuso; fol. lanceolatis scabris; pedunculis axillaribus 1 -floris. Sturn 21. Omphalodes Lehn. In Bohemia. 4. Cor. coelestina. 


\section{ECHINOSPERMUM Lehm. (1518).}

1. E. zeylanicum Itehm. fol. subcordato-ovatis calloso-hispidis; racemis longissimis; nucibus dense glochidatis. In Keylonia.

2. E. virginicum Lehm. fol. ovatooblongis acuminatis nervoso-venosis scabris; racemis recurvis divaricatis; uucibus dense glochidatis. Myosotis L. In Amer, bor.

3. E. javanicum Lehm. fol. ellipticis lanceolatis acutis supra strigosis subtus hirsutis; racemis laxis; nucibus dense glochidatis. In juva.

1. E. borbonicum Lehm. caule suffruticoso; fol. lanceolato - linearihus elongatis; racemis erectis; nucibus dense glochidatis. Myosotis Lam. In Mascarenhis.

5. E. deflexum Iehm. fol. oblongolanceolatis hirsutis; racemis erectopatentihus inferne bracteolatis; glochidibus nucum marginalibus basi connatis. In Lapponia et Hungaria.

6. E. Lappula Lehm. erectum; cano-villosum; racemis subfastigiatis ; fructu erecto; nucularum glochidibus biserialibus subliberis. Rchb. in Sturm. 43. Myosotis L. In Europa, Asia et Amer. bor. $\odot$. Flor. caerulei.

7. E. heterocanthum Ledeb. fol. tuherculatis patulo-pilosis; calycilus demum patentissimis ; caryopsibus aculeis glochidatis biserialibus, interior. basi connatis. Prope Astrachan. $\odot$.

8. E. intermedium Ledeb. ic. Fl. Ross. $t$. 180. fol. tuberculato-hispidis; caryopsibus margine aculeis glochidatis uniserialibus approximatis lorizontalibus, lateribus rugosis. Ad flum. Katunga. $\odot$.

9. E. strictum Ledeb. l. c. t. 27. ful. tuberculatis patulo-pilosis; caryopsibus margine aculeis glochidatis 1-serialibus erectis, disco carinato tuherculato, tuberculis obtusis rugosis. Ad finm. Irtysch. $\odot$.

10. E. tenue Ledeb. l. c. t. 182. fol. cauleque hispidis; calyce fructifero divaricato; caryopsibus margine aculeis glochidatis 1-serialibus distantibus brevilus. Prope Smejou. $\odot$. Cor. azurea.

11. E. microcarpon Ledeb. $l$. c. $t$. 183. caule foliisque sericeis; calycihus fructiferis erectis; caryopsibus margine aculeis glochidatis 1 -seriali- bus approximatis. In Altai. 24. Cor. azurea.

12. E. brachycentrum Ledeb. l. c. i. 302. caulihus foliisque subsericeis; calycibus fructiferis erectis; caryopsibus aculeis brevissimis marginatis. In mont. Altaico. 4 . Cor. caer. et rubra.

13. E. semiglabrum Ledeb. l. c. $t$. 2s. fol. oblongis superne glabris subtus caulibusque ramosis hispidis; aculeis caryopsium glochidatis longissimis. In mont. Altuico. $\odot$. Cor. alha.

14. E. macranthum Ledeb.l.c.t.2.9. fol. tuberculato-hispidis; aculeis caryopsium glochidatis basi dentatis. In mont. Altaico. $\odot$. Cor. caerulea.

15. E. tuberculosum Ledleb, ramis divaricato - reflexis; fol. tuherculatohispidis; aculeis caryopsium conicis glochidatis. Eichw. caps. t. 6. Prope Astrachan. Cor. azurea.

16. E. circinatum fol. basi subcordatis oblongis reticulato-venosis incanis; aculeis caryopsium majoribus lanceolatis. Solenanthus Ledel. 1. c. t. 26. In mont. Altaico. 4 . Cor. caerulea.

\section{3b. TIARIDIUM Lehm. (1818).}

1. T. inılicum Lehm. caule herbaceo hirsuto; fol. ovato-cordatis hirsutis rugosis hirtis decurrentibus. Heliotropium L. In India orientali et America boreali.

2. T. velutinum Lehm. caule herbaceo villoso; ramis decumbentibus; fol. ovatis incano-villosissimis; spicis secundis. In India orient.

3. T. elongatum Lehm. caule suffruticoso decumbente; fol. rhomboideolanceolatis acuminatis hirtis. In Brasilia.

\section{MONOTOCA R. Br. (1810).}

1. M. elliptica R. Br. fol. oblongis integerrimis ohtusiusculis utrinque glabris. Styphelia Sm. In Nov. Holl. ई̋. Arbuscula humilis.

2. M. albens $R$. Br. fol. oblongolinearibus cuspidatis subtus albis; spicis solitariis. In Nov. Holl.

3. M. lineata $R$. Br. fol. oblongis mucronatis subtus glancis tenuissime striatis; pedunc. sub-3-floris. Styphe- 
lia Lahill. N. Holl. t. 61. In Nov. Holl. ђ. 6-7-ped.

t. M. scoparia $R$. $B r$. fol. oblongo-linearibus revolutis; racemis brevissimis recurvis. Styphelia sm. In Nov. Holl. ち. Frutex ramis numerosis.

5. M. empetrifolia $\boldsymbol{R}$. Br. fol. ovalihus mucronatis patentissimis subtus striatis albidis; caule prostrato. In ins. I an lliemen. ち.

6. Mr. Pumilio spr. fol. minutis ovatis adpressis oppositis; spicis solitariis. Needhamia $\mathrm{R}$. Br. In Nov. Holl. ち. Fruticulus pusillus. Cor. alba.

\section{TALLESIA R. et P. (1798).}

1. V. dichotoma $\boldsymbol{R}$. et $\boldsymbol{P}$. peruv. t. 151. fol. ovatis acutis undulatis; racemis dichotomis. V. eymbifolia Ort. chiococcides Kunth. Hauwolfia glabra Cav. ic. t. 397. In Peruria. ち. Arbuseula 8-10-ped. Cor. alba.

2. I'. punctata spr. fol. oblongis utrinque attenuatis pellucido-punctatis; cor. extus tomentosa. In Brasilia. $\hbar$.

\section{CORDIA Plum. (1703).}

\section{Cordiae verae. Flores co-} rymboso-paniculati.

a. Foliis glabris asperis pubescentibus.

1. C. Myxa L. fol. ovatis supra glabris; corymbis laterálibus; cal. 10striatis. Plukn. t. 217. f. 2. et 3. Delil. Aeg. t. 19. C. Sehestena Forsk. africana Lam. domestica Hoth. ohliqua W. In India orientali, Arabia et Aegypto. ち. Arbor. Flor. candidi.

z. C. Nebestena L. fol. ovatis subrepando-crenatis scabris; cal. cylindrico. Lam. ill. t. 96. f. 1. Jacq. am. t. 44. B. M. 794. Tratt. 354. Catesb. t. 91. In Ind. occid. ち. Cor. fuscolutea.

3. C. Dillenii Spr. fol. ovato-oblongis repando-serratis utrinque scahris; cal. 3-dentatis. Dill. EIth. f. 331. C. Selsestena W. In ins. Baham. †.

t. C. calyptrata Bert. fol. attenuato-subrotundis dentatis supra pun- ctato-asperis; cal. sulcato truncato. Ad st. Martiam Amer. austr. $\hbar$.

5. C. striyosa Spr. fol. rhomboideis grosse dentatis utrinque strigosis; cal. strigoso campanulato. In Hispuniola. $\hbar$.

6. C. asperrima Spr. fol. ovatooblongis ohtusis crenulatis, supra punctato-asperis, subtus hispidis tomentosis; floralibus fulvo-tomentosis. In Brasilia. $\hbar$.

7. C. monoica Roxb. fol. ovatis crenatis scaherrimis; cor. infundibuliformi. In India orientali. $\hbar$.

8. C. Toqneve Aubl. Guj. t. 90. fol. cordato-ovatis acuminatis intererrimis tomentosis. In Gujuna. t. 5-6ped. tota tomentosa. Cor. alla.

9. C. salvifolia Juss, fol. ovatolanceolatis obtusis rugosis asperrimis subtus reticulato-venosis. In Guadelupa. 古.

10. C. domingensis Lam. fol. ovatis integerrimis asperis subtus albicantilus; cal. cylindricis. In Domingo. ち. Rami fusco-nigri.

11. C. scaberrima $\vec{H}$. et $K$. fol. oblongis utrinque acuminatis rugosis serratis scabris; calyce hispido. In Peruvia. ђ.

12. C. dentata Valil; fol. ovatooblongis utrinque attenuatis dentatis, supra scabris, subtus pubescentibus; calyce campanulato incano. In Ind. occid. ち. Cor. alba.

13. C. rotundifolia $R$. et P. peruv. t. 118. $f$ : 2. fol. subrotundis ovalibusque crenatis scabris; cal. sulcato pubescente. C. lutea Lam. In Peruviu. ち. 12-ped. Cor. flava.

14. C. frondosa Schott; fol. ovatis acuminatis integerrimis, supra punctato-stellatis, subtus albido-tomentosis; cal. truncatis sulcatis tomentosis. In Brasilia. $\hbar$.

15. C. nodosa Lam. fol. suhternis ovato-oblongis acuminatis; ramulis nodosis hispidis; calyce barbato. C. Collococcus Aubl. Guj. t. 86. In Guj. et Cayenna. ち. Cor. alba.

16. C. spinescens $L$. fol. ovatis acutis serratis scabris; petiolis subspinescentihus. In Ind. orient. $\downarrow$. Rami ferruginei.

17. C. macrophylla $L$. fol. ovatis villosis sesquipedalibus; calyce cyathiformi. sloane Hist. t. 221. f. 1. C. Sellowiana Cham. et schl. In Ind. $39 *$ 
occirl. et Brasilia. †. Arbor 60-ped. Cor. alba.

18. C. buxifolia Juss. fol. coriareis ovato-sulicuneatis integerrimis punctato-asperis. In Inul. occill. t.

19. C. exultata Lam. fol. ovatis basi acutis asperis nitidis; floribus 5fidis. C. aspera Forst. In Gujana ot ins. Amicor. $\hbar$. Arbor excelsa. Cor. campanulata.

20. C. Rumphii Islume bijds. fol. longe petiolatis ovato-oblongis acmmivatis subrepandis infra ad axillas nervorum pubescentibus: cal. 3-dentato intus tomentoso. limuph II. t. 75. In fara. 卢.

21. C. suaveolens Bulume bijdr. fol. ovatis obtusiusculis subrepandoangulatis integerrimisve ad nervos infra tomentosis. In Java. ち. Atbor 4.0-ped.

23. C. bantamensis Blume bijdr. fol.ultimis subverticillato-teruis, ovalibus coriaceis subintegerrimis subtus tomentosis; calyce $\mathbf{3 - 5}$-dentato sericeo tomentoso. In Java. t.

23. C. diospyrifolia Cham. et Schl. fol. ellipticis ovatisve utrinque pilis raris adspersis; cal. 5-fidus intus sericeo-pilosus. In Brasilia. $\hbar$.

24. C. obscura Cham. et Schlecht. fol. subsessilibus ovatis acutis integerrimis subsericeis; calyce ovoideo pubescente. In Brasilia.

25. C. Mnñeco Kuntli; fol. cordatoelliptico-oblongis obtusiusculis remote dentatis, supra strigosis, subtus fuscovilloso-tomentosis. Ad $l l$. Magdalen. 古.

26. C. decandra Hook. in Beech Voy. $t$. 10. fol. lineari-lanceolatis attenuatis scabris sessilibus, margine revolutis, subtus pubescenti-canis; cal. 10-dentatis nigro - pubescentibus. In Chili. t). Frut. 8-10-ped. Flor. magni althi.

\section{b. Fol. glabris.}

27. C. acuminata Wall. arhorea; glaherrima; fol. ovato-oblongis acutis coriaceis integerrimis; cal. laciniis lanceolatis ciliatis. In Ind. orient. ち.

28. C. maynoliafolia cham. et Schl. macrophylla; fol. cuneatis acuninatis sub-3-cuspidatis glaherrimis. In Brasilia. †. Rami dense foliosi. Flor. sessiles.
29. C. salicifolia Cham. et Schl. fol. lanceolatis acuminatis reticulatovenosis subpellucidis glaberrimis; cal. intus arcte piloso $\mathbf{2}-\mathbf{5}$-dentato. In Brasilia. ち. Cor. pallida.

30. C. crenata Delil. aeg. fol. sulovato - rhomboideis utrinque glabris, apice crenato-serratis; stigmate filiformi. C. Myxa Forsk. In Aegypto. 古.

31. C. indica Lam. fol. subrotumdo-ovatis glabriusculis; calycibus obtusis laccris tubum cor. aequantibus. C. paniculata Roth. In Ind. occid. $\downarrow$.

32. C. chinensis Lam. fol. ohlougis supra nitidis subtus reticulato-venosis; axillis venarum villosis; cal. truncato. C. reticulata Roth. In China. ђ.

33. C. subcordata Lrm. fol. subcordatis integerrimis superne laevilus; calyce cylinárico 3-dentato. C. orientalis R. Br. In Ind. orient. et Nov.

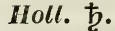

31. C. corilifolia $H$. et $\boldsymbol{K}$. fol. oblongis oltusis cordatis infegerrimis, supra glabris, subtus subpubescentibus; calyce campanulato. In Nov. Granata. 5 .

35. C. Gerascanthus Jac\%. am. t. 175. f. 6. pict. $t$. 259. f. 12. fol. oblongis utrinque longe attenuatis integerrimis glabris; calycibus lepidototomentosis. In Ind. occid. et Mexico. ち. Cor. rubella.

36. C. gerascanthoides $H$. et $K$. fol. oblongo-lanceolatis utrinque acuminatis integerrimis glabris supra nitidis; cal. sulcato hispido. In Cuba. ち.

3\%. C. tetranil'a Aubl. Guj. t. $8 \%$. fol. inaequaliter cordato-oblongis obtusiusculis integerrimis supra glabris subtus discoloribus asperis; cor. 4-fida.

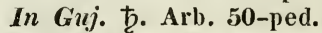

38. C. serrata Juss. fol. cordatis glaberrimis argute serratis; cal. "11ceolato 5-loho. In Ind. orient. t. Cor. parva alba.

39. C. Collococca L. fol. oblongoovatis integerrimis; cal. interne pilosis; fructu villoso rubro. Sloane Hist. t. 203. f. 2. In Jamaica. ち.

40. C. flavescens Aubl. Guj. t. s.9. fol. ovato-oblongis acuminatis reticulato-venosis glahris; drupa viridi flavescente. C. echitioides Lam. In Gujana. ち.

11. C. micrantha Sw. fol. ellipticis acutis integerrimis membranaceis 
venosis; cal. brevissimo striato. Jumuica. ђ. Cor. minima.

t2. C. elliptica su. fol. oblongis apice attenuatis integrrimis subcoriaceis; drupis acuminatis. In Jamaica et Domingo. t. Arbor mas,na.

43. C. tetriphylla Aubl. Guj.t. Ss. fol. verticillato-quaternis obovatis basi angustatis; fructu olivaeformi. In Gujunu. ち. Arbuscula 6-7-ped. Cor. alba.

4. C. lacris Jac\%. Schoenbr. t. 10. fol. ovatis laevibus utrinque repandis. Circa Caracas. 古. Frut. 15-ped. Cor. rugosa rubella.

4.5. C. laeviyata Iam. fol. ovatis venosis nitidis; staminibus inferme villosis. In Antillis 节.

\$6. C. senegulensis Juss. fol. memhranaceis ovatis acuminatis glaberrimis; Aloribus 4-fidis 4-andris. Ad senegal. 古. Arbor. 20-ped.

17. C. nerrosa Lam. fol. alternis oppositisve ovato-oblongis acuminatis suhtus nervosis flavicantihus; cal. glabris. In Gujana. 古. Arbor ramis scabris.

18. C. dichotoma For'st. fol. ovatoohlongis subdentatis supra glabris subtus pubescentibus; cal. sulcatis. In Nor. Holl. et Nov. Cated. t. Arbor ramis hispidis.

19. C. Cerlana R. et S. fol. ovato-ohlongis; floribus paniculatis. Cerdana altiodora $\boldsymbol{H}$. et $\mathbf{P}$. peruv. t. 18 !. In Perue. ђ. Arbor excelsa cortice foetidio.

50. C. Patagomula Ait. fol. oblongo-lanceolatis utrinque glabris, superioribus serratis; ramulis pilosis. Dill. Elth. f. 293. P. americana L. In Patıgonia. ち. Flor. alli.

51. C? Aubiosa flume bijdr. fol. elliptico-oblongis obtuse acuminatis setaceo-serratis; calyce tubuloso striato. In Java. ち.

2. Varroniae. Spicatae, capi-

\section{a. Spicatac.}

52. C. integrifolia R. et S. fol. oblongo-lanceolatis utrinque attenuatis stpra scabris subtus incanis; spicis elongatis pubescentibus. Varronia Desv. Journ. bot. I. t. 10. In Hispuniola. 古.
53. C. graveolens $\boldsymbol{H}$. et $\boldsymbol{K}$. fol. oblongis acutis hasi angustatis dunittis, supra scabris, subtus cano-pubescentibus; cal. pubescente. C. spicata W. Ad Orinoc. ち.

54. C. martinicensis R. et S. fol. ovato-obiongis acuminatis hasi cuneatis duplicato-serratis rugosis asperis. Varronia Jacq. amer. t. 32. pict. t. 12. In Martinica.

5.5. C. portoricensis S $\mathbf{s}$. fol. Ianceolatis hasi attenuatis dentato-scrratis mucronatis scabris utrinque concoloribus. In Portorico. $\hbar$.

56. C. floribunda $5 \mathrm{~m}$. fol. oblongo-lanceolatis utrinque attemuatis crenato-serratis rugosis subtus cano-tymentesis. C. salviaefolia $H$. et $\mathbf{L}$. Varron. Desv. In Amer. austr. 1).

5\%. C. fermuginea $H$. et K. fol. ovatis acutis denticulatis supra pilosi.s subtus ferrugineo - tomentosis; calyce hirsuto. Varronia Desv. 1. c. t. 9. C. laxiflora H. et K. In Nov. Grunutu. b.

58. C. tomentosa $R$. et $S$. fol. ovato-oblongis acutis serratis utringuc lanatis; calyce lirsulo fauce pilosa. C. Ianata H. et K. Varronia Lam. In Nov. Granceta. 古.

59. C. canescens $\boldsymbol{H}$. et $\boldsymbol{K}$. fol. lanceolatis acutis serratis rugulosis, supra scabris, subtus cano-tomentosis; calyce cano-pubescente. In Nove Grunata. 古.

60. C. viparia H. et X. Nor. Gen. t. 20\%. fol. ovato-oblongis acuminatis denticulatis, supra scahris, subtus ferrugine 0 -tomentosis; calyce ramisque dense ferrugineo-hirsutis. In Nov. Granata. 支.

61. C. macrostachya Spr. fol. ovatis acutis dense serratis rugosis subtus asperis; flor. confertis; nuculo albo. Varronia 13 . et P. peruv. t. 117. f. a. In Peruria. t. Cor. alha.

62. C. curassarica R. et s. fol. lanceolatis serratis subtus pubesceutilus; spicis ohlongis; calyce subulato. Varr. martinicensis ham. In Americ. austr. ち. Frut. 15-ped. Cor. alba.

63. C. gujanensis R. et S. fol. oblongo-ovatis basi attenuatis arouto serratis; spicis minutis, basi rarissinis. Varronia Desv. V. martinicensis Aubl. In Gujant. 方.

61. C. anyustifoliu R. et S. fol. linearibus revolutis subdentatis, supra scabris, subtus tomentosis. Variunia 
Desv. V. curassavica Lam. In ins. Caribaeis. 古.

6.5. C? multispicata Cham. et schl. fol. ovatis acuminatis dentatis hasi integerrimis pubescentibus; spicis oblongo-clavatis. In Brasilia. $\hbar$.

\section{b. Subcapitatae.}

66. C. globosa R. et S. fol. ovatolanceolatis serratis; spicis ylobosis hispidis; caule dichotomo. Varronia globosia et bullata L. Sloane Hist. t. 194. f. 2. In Caribais. ち.

6\%. C. dasycephala $H$. et $K$. fol. ovato-oblongis acuminatis grosse serratis utrinque strigoso-hispidis; fance cor. pilosa. Varronia Desv. In Nova Andalusia. $\hbar$.

68. C. Bonplandiana $H$. et $K$. fol. ovatis acuminatis basi breviter angustatis duplicato-crenatis, supra papu10so-scaberrimis, subtus piloso-tomentosis. In Amer. austr. $\hbar$. Cor. alla.

6.9. C. grandillora H. et K. fol. ovatis acuminatis hasi angustatis serratis, supra serico-strigosis, subtus dense pilosis; calyce sericeo strigoso. Varrouia Desv. In Amer. austr. ந̋. Cor. alba.

70. C. macrocephala $H$. et $K$. fol. ovato - oblongis utrinque angustatis crenatis, subtus cano-tomentosis; calyce ferrugineo tomentoso. Varronia Desv. In Peruv. ち. Cor. alla.

ri. C. lanceolata $H$. et $K$. fol. su!nsessilibus lanceolatis crenato-serratis rugosis, supra hispidis, subtus cano-puhescentilous; capitulis globosis. In Nov. Granata. $\hbar$.

9:. C. mariyuitensis $H$. et $K$. fol. subsessilibus Ianceolatis apice crenato-serratis rugulosis, supra scabris, subtus ferrugineo-tomentosis. In Nova Granata. ち.

73. C. patens $H$. et $K$. fol. ovatis acuninatis argute denticulatis, supra strigoso-scabris, subtus fusco-tomentosis; calycibus strigosis. In Nov. Granuta. b. Cor. alba.

7九. C. serrutifolia $H$. et $K$. fol. oblongis utrinque attenuatis grosse serratis, supra scabris, subtus pubescentibus ; capitulis globosis. In Mexico. 卢.

7.5. C. ulmifolia Spr. fol. ovatolanceolatis acumiuatis serratis utrinque scahris, subtus discoloribus ; caly(i)us glohosis. Varronia 1-sperma?
Jacq. Schoenhr. t. 39. Circa Caracrs. ち. Arbuscula ramosissima. Cor. alba.

76. C. Lantanvides Sipr. fol. subrotundo-ovatis obtusis crenatis rugosis, subtus canescentilus ; capitulis paucifloris. Varronia crenata $R$. et $\mathbf{P}$. peruv. t. 146. f. 6. In,Peruvia. Arbuscula. Cor. alha.

77. C. guazumaefolia $R$. et $S$. fol. ovato-lanceolatis acutis dentatis subtus hirsutis rugoso-venosissimis. Varronia Desv. In Brasilia. Cor. tubulosa.

98. C. lineata R. et S. fol. lanceolato-linearibus subtus tomentosis serratis ; pedunc. petiolo adnatis. Varronia L. V. humilis Jacq. Brown. Jam. t. 13. f. 2. Plukil. t. 328. f. 5. In Jamaica. ђ.

79. C. Lima R. et $\boldsymbol{S}$. fol. ovatis obscure dentatis scrobiculatis subtus subpubescentibus ; capitulis paucifloris. Varronia Desv. In Hispaniola. $\hbar$.

80. C. villosa, Spr. fol. oblongis obtusis venoso-lineatis utrinque albido-villosis undulato-crenatis; capitulis brevissime pedunculatis. In Hispuniola.

81. C. Radula Spr. fol. oblongis obtusis basi attenuatis rigidis rugosis hispidis supra nitidis; cal. hispidis. Varronia scaberrima Bert. In Hispaniola. $\hbar$.

82. C. calocephala Cham. et Schl. fol. ovatis subcordatis oltusis crenatis sulitus incanis; reti vasculoso fuscescente; cal. dentibus setaceis hirsutis. In Brasilia. ち. Capitulum maguitudine Cerasi.

83. C. sessilifolia Cham. et Schl. hirsuta; aspera; fol. Ianceolatis acutis subduplicato-serratis hirsutis ; cal. delltibus subsetaceo-acuminatis. In Brasilia. 古.

\section{Floribus subcymosis.}

84. C. mirabiloides $R$. et S. fol. ovatis acutis petiolatis; petiolo supra basin articulato-inflexo; cor. hypocraterif. Tournefortia serrata L. Varronia Jacq. Am. t. 33. In Domingo. ち. 8.5. C. bifurcuta R. et S. fol. ovato-lanceolatis acutis serratis; spiculis secundis revolutis. Varronia dichotoma R. et $P$. peruv. t. 146. f. 2. V. parviflora Ortega. In peruvia. $\hbar$. Drupa coccinea. 
86. C. alba R. et S. fol. subcordato-ovalis acutis crenato-dentatis glabris; pedicellis glomeratis. Varronia Jacq. Plukit. t. 152. f. 4. In Ind. occid. $\hbar$. Drupa albescens.

\section{ERYCIBE Roxb. (1798).}

1. E. paniculata Roxb. Corom. $t$. 159. In Coromandelire. †. Frutex scandens procera. Fol. oblongo-Ianceolata integerrima. Flor. numerosi parvi ferruginei.

\section{ARDISIA Sw. (1788).}

\section{a. Folits integerrimis.}

1. A. acuminata $W$. fol. oblongis utringue attenuatis supra nitidis subtus glabris ; paniculis axillaribus terminalihusque. A. lateriflora sw. In Int. occill.

2. A. tinifolia $S u$. fol. ellipticis integerrimis nervosis; caule arhoreo. Anguillaria Lam. sloane Hist. t. 205. In Jumuica. ち. 15-25-ped. Cor. rubella.

3. A. coriacea $\mathbf{S} u$. fol. oblongis ohtusis coriaceis nitidis aveniis; panicula terminali. Anguillaria Poir. In Antillis. †. Arbuscula. Cor. subcoccinea.

4. A. paniculata Ro.rb. fol. oblongo-lanceolatis elongatis obtusiusculis reflexis; panicula decomposita; flor. nutantihus. A. colorata Lk. A. pyramidalis koth. In Ind. orient.

5. A. racemosa $s p r$. fol. ohovatooblongis subrevolutis coriaceis utrinque nitidis, subtus tenuissime punctatis; racemis strictis axillaribus. In Brasilia. ち.

6. A. latifolic $R$. et s. fol. lanceolato-ovatis obtusis integerrimis coriaceis; racemis simplicilus. AnguilIaria Lain. In Antillis. ち.

7. A. solanucea Roxb. fol, oblongis utrinque attenuatis glaucescentibus; corymbis 3-partitis suhumbellatis. Anguillaria umbellata Roth. In India orient. 卢.

8. A. pyramidalis Car. ic. t. 502. fol. ohlongis utrinque attenuatis obtusis; panicula pyramidali. A. orinocensis et turbacensis H. et K. In Au- tillis et America austr. b. Arhor 25-ped. Cor. rulsra.

9. A. humilis Vahl; fol. oblongoellipticis coriaceis venosis; paniculis umbellatis. Anguillaria Keylanica Lam. ill. t. 136. f. 2. Burm. Zeyl. t. 113. In Zeylona. ち.

10. A. parasitica Sw. fol. sessilihus lanceolato-ovatis lineatis subtus maculatis; caule fruticoso ; racemis filiformibus. In Domingo. $\hbar$. Arbuscula ramosissima. Cor. albida.

11. A. fermuginea $\boldsymbol{H}$. et $\mathbf{K}$. fol. ohlongis acuminatis supra glahris stibtus fusco-pubescentibus; ramis ferrugineo-tomentosis. In Nova Grancta. 占.

12. A. compressa $H$. et $K_{\text {. ramu- }}$ lis compressis foliisque ovato-oblongis subacuminatis subintegerrimis glahris; flor. umbellato-fasciculatis. In Nov. Andulusia. 支.

13. A. revolut Bonpl. fol, ovatooblongis revolutis; panicula terminali simpliciuscula. In Mexico. †.

14. A. micrantha $I$. et $K$. fol. oblongis utrinque attenuatis glanduloso-punctatis subintegerrimis; pedunculis umbelliferis. In Amer. uustr. $t$.

1.5. A. lepidota $H$. et $K$. ramulis ferrugineo-tomentosis; fol. ovato-oblongis hrevissime acuminatis integerrimis glabris subtus lepidotis. In Nov. Granata. ち.

16. A. foetirla W. Hb. fol. ovatooblongis coriaceis supra nitidis subtus aveniis; bracteis ovatis concavis. In Americu austr. 卢.

17. A. Copallina A. DC. ic. Mex. ined. fol. lanceolatis utrinque acutis nitidis; panicula composita; lobis cor. ovatis acutis reflexis. In Mexico. t.

18. A. Missionis Wall. Cat. glabra; fol. oblongo-lanceolatis ; panicula terminali laxa longitudine foliorum; lohis cal. ovato-acutis. In India orientali. 卢.

19. A. neriifolia Wall. Cat. fol. oblongis acuminatis longe petiolatis; cal. laciniis minimis acutis ciliatis; antheris cuspidatis. In mont. Silhet. t.

20. A. polycephale Wull. Cat. fol. oblongis acutis amplis margine revolutis; pedunc. compressis; lobis calycinis obtusis. Ad flum. Atran. b.

21. A. munctulosa; foi. ovato - acuminatis coriaceis utrinque punctalis; pedunc. compressis; laciniis 
cal. ovato-acutis subciliatis. In Singupore. $\hbar$.

23. A. attenuata Wall. Cat. fol. oblongo-lanceolatis utrinque acuminatis margine magis punctatis; flor. racemosis; cal. laciniis ovato-acutis subciliatis. Circa T'avoy. 古.

23, A. oxyphylla Vall, Cat, glahra; fol. ellipticis utrinque acutis margine magis punctatis; pedicellis laxe umbellatis; cal, laciniis ovatis subciliatis, In ins, Penany. $\hbar$.

28. A. eugeniaefoliı Wall. Cat. fol. oblongo-lanceolatis basi acutis apice acuminatis coriaceis; pedicellis et calyce velutinis; stylo exserto. in mont. Silhet. $\hbar$.

25. A, arborescens Wall. Cat. glabra; fol. oblongo-lanceolatis acutis coriaceis; pedunc. axillaribus elongatis rigidis; cal. Iobis ovato-acutis. In regno Harmanno. 古.

26. A. Amlerstiana A. DC. fol. oblongis acutis; pedunc. pedicellisque velutinis; laciniis cal. ovatis obtusis ciliatis dorso velutinis. A, reflexa Wall. Prope Amherst. $ち$.

27, A. oblonya A. DC. fol. oblongis acuminatis punctatis; pedunc. pedicellisque glabris; lobis cal. obtusis subciliatis, A. attenuata Wall.partim. In Tavoy. $\hbar$,

28, A, oxyantha Wall. fol. Ianceolatis utrinque acuminatis tenuibus; pedunc. 1-floris filiformibus; cal. 1aciniis subciliatis. In mont. Silket, $\hbar$.

29. A. reflexa Wull. Cat. partim; fol. oblongis acutis superue glabris subtus pubescentibus; pedunc, reflexis; pedicellis calycisque laciniis dense pilosis. In Martabania. $\hbar$.

30. A. grandifolia A.DÉ. fol, ohlongis amplis cuspidato-acutis glabris subtus pilosis; ramis petiolisque hispidis; cal. laciniis acutis subciliatis. A. nacrophylla Wall, Circa Tavoy. t.

31. A. purpurea Blume bijdr. fol. oblongis utrinque acuminatis integerrinis coriaceis glabris; laciniis calycis rotundatis. In Java. ち.

32. A. mucronuta Blume bijar. fol, oblongis acuminatis apice aristato-mucronatis integerrimis coriaceis glabris; panicula abbreviata. In $J a-$ va. 方.

33. A, sanguinolenta Blume bijdr. fol. ablongis acuminatis basi acutis integerrimis coriaceis glabris; pauicula divaricata; dentibus cal. acutis. In Java. ђ.

34. A. scandens Blume bijdr. fol. ovalibus apice rotundatis vel obtusis basi acutis integerrimis; paniculis nutantibus; caule scandente. In Java. 5 .

35. A. tenuiflora Blume bijds. fol. oblongo-lanceolatis obtusiusculis integerrimis glabris; paniculis divaricatis; caule scandente. In Java. $ち$. Flor. minutissimi.

36. A. punctata Blume bijalr. fol. oblongo-lanceolatis obtusiusculis integerrimis glahris subtus punctatis; umbellis nutantibus. In Javu. $\hbar$.

3\%. A. lucida Blume bijar. fol. oblongo-lanceolatis utrinque acuminatis integerrimis coriaceis glabris; laciniis . calycis rotundatis. In Java. 方.

38. A. obovata Blume bijdr. fol. obovatis superue rotundatis s. obtusis integerrimis coriaceis glabris tenuiter parallelo-striatis; calycis laciniis rotundatis. In Java, $\hbar$.

39. A. marginata Blume bijdr. fol. lanceolatis utrinque acuminatis integerrimis glabris subtus tenuiter pumctatis transverse parallelo-striatis. In Juva, ђ.

40. A. cymosa Blume bijdr. fol. oblongis obtusiusculis basi attenuatis integerrimis glabris transverse striatis; petiolis ramulis pedunculisque ferrugineo-leprosis. In Jara. ち.

11. A. laevigata Blume bijdr. fol. oblongis utrinque acuminatis integerrimis coriaceis glabris; laciniis calycis acuminatis. In Juva. $b$.

4. A. macrophylla Hb. Reinw. fol. oblongis aouminatis basi obtusis integerrimis coriaceis subtus umbellulisque tomentosis. In Java. $ち$.

43. A. avenis Blume bijdr. fol. lanceolatis apice obtusiusculis basi angustatis integerrimis coriaceis glabris subaveniis. In Java. $\hbar$. Arbor 20-ped.

41. A. propinqua Kunth; ramulis verrucosis; fol. elliptico-oblongis utriuque attenuatis integerimis membranaceis obsolete glanduloso-punctatis. Ad Orinocum. $\hbar$.

45. A. cestrifolia Iunth; ramulis subangulatis; fol. oblongo-lanceolatis utringue attenuatis integerrinis membranaceis glabris epunctatis ; flor: $\mathbf{4 - 5}-$ andris. In Nov. Granala. ђ.

16. A. durifolice finth; ramis teretibus; fol, ovato-oblongis obtusis in- 
tegerrimis coriaceis glabris; floribus 5-andris. In Nor. Granata. †.

47. A. Roxburghiana; fol. lanceolatis margine coloratis glandulosis rlabris umbellis globosis Ionge pedunculatis. A. glandulosa koxb. In lud. or.

†. A. panciflor Ileyne; fol. lanceolatis acuminatis integerrimis glabris; pedunculis filiformibus $2-3-f_{0-}$ ris. In India orient. $\mathbf{b}$.

4.9. A. anceps Wall. ramis scandentibus ancipitibus; fol. Ianceolatis acuminatis integerrimis subtus reticulato-venosis coriaceis; pedunc. glabris complanatis. In silhet. $\hbar$.

50. A. tuberculata Uall. ramis compressis; fol. obovato-oblongis integerrimis coriaceis nitidis glandulosopunctatis; panic. ramis teretibus tuberculatis. In India orientuli. $\hbar$.

51. A. complanate IIall. ramis subscandentibus teretibus; fol. oblongo-lanceolatis acuminatis subtus reticulato venosis; panic. ramis complanatis villosis. In ins. freti Malacc. $\hbar$.

\section{b. Foliis serratis crenatis.}

52. A. excelsa Ait. fol. obovatocoriaceis glabris cartilagineo-serrulatis; racemis axillaribus simılicibus. Anguillaria balımensis Gaertn. fr. t. 7\%. f. 1. In Madera. ち.

53. A. serrulatu $S u$. fol, ovatolanceolatis acuminatis rugosis; caule fruticoso pubescente. A. arguta $\mathbf{H}$. et K. In Nov. Granata et ins. Antill. ђ.

5\%. A. tetrandra H. et K. fol. olilongis acuminatis undulato-crenatis glahris supra nitidis; flor. fasciculatoumbellatis tetrandris. In Nov. Go anata. t.

55. A. lentiginosa Ker. B. R. 533. fol. oblongo-lanceolatis utringue attenuatis coriaceis crenatis; pedicellis floribusque glandulosis. A. crenata B. M. In China. ち.

56. A. crenulatí Vent. Choix. de pl. t. 5. fol. ovato-lanceolatis actiminatis repando-crenatis punctatis; floribus subumbellatis. In Antillis. $\hbar$.

58. A. Cavanillesii R. et S. fol. sparsis lanceolatis serratis; racemis terminalibus compositis. Anguillaria Cav. ic. t. 503. In Antillis. ఫૃ. 1520-ped,

58. A. brasiliensis Spr, fol. Ianceolato-oblongis utrinque attenuatis membranaceis opacis obsolete serrulatis supremis integerrimis. In Brasilia. t.
59. A. membranacea Wall. Cat. glabra; fol. approximato-oblongo-lanceolatis acuminatis hasi longissime attenuatis irregulariter crenulatis; cal. Iaciniis ovato-acutis. In mont. Silhet.

60. A. Wullickii A. DC. fol. obovatis acutis vel obtusis repando-cremulatis in petiolum angustatis; laciniis calycis ovato-acutis subciliatis. A. sanguinolenta Wall. Cat. Ad ripas Jrruucaddy et Atrun. .

61. A. Cubana A. DC. fol. ovatooblongis obtusiusculi sundulatis superne glabris subtus pilosiusculis; pedunc. ferrugineis ; lcbis cor. velutinis. In $\mathrm{Cu}$ ba. t.

62. A. Icara Wall. Cat. fol. oblongo-Ianceolatis basi acuminatis apice acutis denticulatis superne pilosiusculis; Iaciniis cal. subulatis. A. DC. Limn. Trans. XVII. t.7. In liengalia. ち. 63. A. odontophylla Wull. Cat. A. DC. Lim. Trans. XIII. t. 6. fol. lanceolato-oblongis utrinque acutis longe petiolatis argute dentatis puberulis; lohis cal. ovato-acutis ciliatis puberulis. A. pavonia Hamilt. In Bengalia. $\hbar$.

6t. A. Tavoyana A. DC. ramis extremitate pubescentibus; fol. oblongolanceolatis utrinque acuminatis subtus pilosis punctatisque subcrenulatis; cal. laciniis extus pilosis. Circa Taroy. 方.

65. A. Linulleyana; fol. lanceolatis basi attenuatis coriaceis glanduloso-subcrenatis glabris; floribus cernuis punctatis. A. punctata Lindl. B. R. 827. A. macrocarpa Wall. In Chinc et Nepal. $ђ$.

66. A. villosa Roxb. fol. Ianceolatis crenulatis subtus ramisque villosis; umbellis villosissimis. In ins, fret. Malacc. ち.

6\%. A. hymenandra Wall. fol. obovatis acutis grosse crentis glabris subtus reticulato - venosis; antheris alatis apice caudatis. In sillet. t.

68. A. fuliginosa blume bijdr. fol. oblongis acuminatis basi cuneatis denticulatis glabris, junioribus ranulisque ferrugineo-tomentosis; dentibus cal. acutis. In Java. $\hbar$.

69. A. glandulosa Blame bijdr. fol. oblongo-lanceolatis utrinque attenuatis margine glandulosis et repandocrenulatis tenuissime venosis; cymis recurvis. In Java. ち.

80. A. japonica Blume bijalr. fol. subverticillatis (5-nis) breviter petio- 
latis acutis argute serratis glahris; caule fruticuloso. In Japonia. t.

\%1. A.denticulata Blume bijar. fol. ohlongis utrinque acuminatis apice ohtusiusculis superne denticulatis glahris; laciniis cal. obtusis; flor. 4-andris. In Java. ち.

42. A. pumila Rlume bijdr. caule suffruticoso inferme procumbente radicante; fol. lanceolato-ellipticis acutis obsolete crenulatis; laciniis cor. cu-

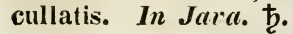

\%3. A. quinquegona Blume bijdr. fol. lanceolatis utrinque acuminatis obsolete cremulatis glabris; dentibus cal. acutis ; fructibus depresso-j-gonis. In Java. ち.

74. A. mollis Blume bijdr. fol. oblongo-lanceolatis utrinque acuminatis crenulatis punctatis subtus villosulis; laciniis cal, acutis. In Java. ‡.

\%5. A. Blumeana; fol. ohlongolanceolatis utrinque acuminatis subrepandis glahris subtus tenuiter leprosis; ramulis ancipitibus. A. anceps. Blume. In Java. $\hbar$.

r6. A. speciosa Blume bijir. fol. oblongis acuninatis basi sulattenuatis obsolete denticulatis coriaceis glabris; laciniis cal. rotundatis. In Java. ち.

77. A. glabratu Blume bijlr. fol. oblongo-lanceolatis utrinque acuminatis laevihus; laciniis calycis obtusis. In Java. 卢.

78. A. Lhotskya DC. glahra; fol. oblongis integris ohtusiusculis punctatis; cal. lobis acutis. In Brasilia. $\hbar$. Arbor. Cor. alba luteo-marginata.

79. A. bracteosa A. DC. fol. obIongis subacutis integris coriaceis ovato-acutis; antheris ovoideis. In Ilexico. $\hbar$. Arbor ligno fusco. Cor. albo-rosea.

80. A. esculenta Pav. fol. ovatooblongis subacutis integris coriaceis glabris punctatis; petiolis marginatis; antheris 3-angularibus acutis. In Amer. merid. $\hbar$.

\section{MYRSINE. L. (1787).}

1. M. africana $\boldsymbol{l}$. fol. ellipticis acutis apice serratis; filamentis cor. duplo longioribus; stylo exserto. M. rotundifolia Lam. Comm. Hort. t. 6t.
Pluckn. t. 80. f. 5. In Prom. b. spei. ち. Cor. pallida punctis scabra.

2. M. retusa Ait. fol, ohovatis obtusis apice emarginato-denticulatis; flor. axillaribus confertis; stylo incluso. Venten. Cels. t. 86. B. C. 409. In ins. Azoreis. ђ. Cor. purpurea.

3. M. ciliata $\boldsymbol{H}$. et K. Nov. Gen. t. 245. fol. ellipticis subintegerrimis retusis ciliatis; pedunc. umbellatocongestis. In Amer. anstr. ち.

4. M. ardisioides $H$. et $K$. fol, oblongis subacuminatis hasi cumeatis integerrimis membranaceis glabris; pedicellis glahris. In Peruvia. $b$.

5. M. Manglilla R. Br. fol. ohIongis utrinque rotundatis sempervirentibus subtus albidis; flor. brevissime pedunculatis. Sideroxylon Lam. Bumelia W. In Peruvia. $\hbar$.

6. M. Athrupliyllum R. Br. fol. linearibus confertis nitidis; umbellis antherisque sessilihus. Athrupyllum lineare Lour. In Cochinchinu. ち.

7. M. Rapanea R.Mr. fol. ohovato-oblongis coriaceis laevihus; flor. fasciculatis sessilibus. Hapanea gujanensis. Aubl. t. 46. Lam ill. t. 122. f. 1. In Gujana. Frut. 4-5-ped. Cor. alba.

8. M. popayensis Bonpl. fol. oblongis utrinque attenuatis obtusiusculis revolutis, supra nitidis, subtus pubescentibus; umbellis subsessilibus. In Nova Granata.

9. M. coriacea $R$. Br. fol. oblongis acutis coriaceis integerrimis; floribus axillarihus glomeratis 4 -fidis. Samara sw. In Jamaica. $b$.

10. M. Samara R. Br. fol. ellipticis; corymbis axillaribus aggregatis. Samara pentandra Ait. In Prom. b. spei. ち. Arbor floribus parvis.

11. M. melanophleos $\mathrm{R}$. Br. fol. oblongo-lanceolatis subcoriaceis integerrimis; pedunc. aggregatis. Sideroxylon Jacq. Vind. t. 71. Manglilla Pers. In Prom. b. spei. $\hbar$.

12. M. spicata $H$. et $K$. fol. ohovato-oblongis apice rolundatis integerrimis glabris supra glauco-pruinosis ; cor. 4-5-partitis. In Americe australi. $\hbar$.

13. M. mitis Spr. fol. oblongolanceolatis acuminatis coriaceis integertimis; pedunc. subsolitariis axillarihus. Sideroxylon L. In Prom. b. spei. †. 
14. M. venulosa Spr. fol. ohovato-oblongis coriaceis revolutis nultinerviis; pedunc. aggregatis. sideroxylon Willd. In Prom. b. spei. நृ.

15. M. canariensis spr. fol. oblongis obtusiusculis reticulato - venosis; flor. sessilibus agregatis. Scleroxylon W. In Teneriffa. ఫ.

16. M. variabilis $R$. Br. fol. obovato-ohlongis integris dentatisve; flor. umbellatis sub-4-fidis; antheris sessilibus. In Nov. Holl. ち.

17. M. crassifolia $R$. Br. fol. obovatis integerrimis; flor. axillaribus sessilibus aggregatis. In Nora Hollandia. ђ.

18. M. urceolata $R$. Br. fol. lanceolato-oblongis integerrinis; floribus 4-fidis, cor. mascula urceolata. In Nov. Holl. $\hbar$.

19. M. Irvillei A. DC. glabra; fol. ovatis obtusis integris pellucide pumctatis; cal. Iohis minimis dentiformibus. In Nov. Zeelandia. 古.

20, M. lucida Wall. Cat. fol. Ianceolatis integerrimis margine punctatis glabris; lobis calycinis subciliatis ovato-acutis. In regno Burmanno. $\hbar$.

21. M. Porteriana Wall. Cat. glabra; fol. lanceolatis utrinque acutis integris; flor. sessilibus glomeratis; cal. ciliato. In Penang. $\hbar$.

22. M. Wightiana Wall. glabra; fol. oblongo-lanceolatis acutis integris punctato-scabris; cal. ciliato. In Ind. orient. $\hbar$.

23. M. madagascariensis A. DC. fol. oblongis obtusis integris glabris coriaceis crassis subtus nigro-punctatis; bacca globosa pedicellata. In Madagascar. ち.

24. M. floridana A. DC. glahra; fol. ovatis oblongis integris coriaceis subtus punctatis; fasciculis paucifioris. In Floridu. 占.

25. M. Trinitatis A. DC. fol. ellipticis utrinque acutis glahris integris suitus punctatis; flor. pedicellatis minimis. M. coriacea Sieb. In ins. Trinitatis. 古.

26. M. salicifolia A. DC. fol. ellipticis utrinque acutis integris; petiolis pilosis; cal. ciliato; baccis globosis maculis oblongis. Bumelia Bert. In Guudelupa. ち.

27. M. Berterii A. DC. ramis pu- berulis; fol. oblongo-lanceolatis subacutis integris, superne glabris, subtus petioloque puberulis; flor. subvelutinis. In Hispaniola. ち.

28. M. rufescens A. DC. ramis et nervis foliorum velutinis rufescentibus ; fol. oblongo-lanceolatis acutis integris; flor. 4-andris. Prope Rio Janeiro. ち. Arbor 10-ped.

29. M. penduliflora Icon. Mex. ined. glabra; fol. ovato-ohtusisculis in petiolum angustatis integris; umbeltis pendulis; dentihus cal. minimis. In Mexico. ち. Cor. albo-rosea.

30. M. micrantha; pedunc. velutinis; fol. lato-oblongis obtusis glahris; paniculis pyramidatis; flor. velutinis minimis. Badula A. DC. In Borbonia. $\hbar$.

31. M. insularis; glabra; fol. ovatis obtusis coriaceis; pedunc. folio breviorihus; pedicellis alternis calyce 5-partito. Badula A. DC. In Borbonia. ђ.

32. M. Sieberi; fol. obovatis obtusis petiolatis pellucido - punctatis glabris; cal. ciliato; antheris cuspidatis. Badula A. DC. in Limn. Trans. XVII. t. 5. In ins. Mauritii. ち.

33. M. ovalifolia; glabra; fol. ovalibus utrinque acutis membranaceis nigro - punctatis; alahastris valde punctatis. Badula A. DC. In Borbonia. $\hbar$.

34. MI. crassa; glabra; ramis crassis ; fol. ellipticis vel oblongis obtusis coriaceis; pedicellis alternis hrevibus. Badula A. DC. In Borbonia. 卢.

3.5. M. angustifolia; fol. Ianceolatis utrinque acutis subintegris punctatis glaberrimis; pedunc. velutinis rigidis. In Borbonia. 支.

36. M. latifolia Spr. fol. oblongis integerrimis utrinque punctatis ; floribus numerosis glomeratis. Caballeria R. et P. In Peruvia. $\hbar$.

37. M. oblonga spr. fol. oblongis subtus punctatis floribus aggregatis pedunculatis. Caljalleria R. et P. In Perucia. ђ.

33. M. pellucida Spr. fol. ohovato-oblongis integerrimis punctatis pellucidis; punctis supra rotundatis subtus linearibus. Caballeria $\mathbf{R}$. et P. In Perucia. 
39. M. venosissima Spr. fol. ohlongo-lanceolatis integerimis pellucido-punctatis. Caballeria R. et P. In Perucia.

10. IN. ferruginea Spr. ramulis tomentosis; fol, lanceolatis glabris punctatis; flor. conglomeratis sessilibus. Caballeria 1. et P. In Peruvia. t.

41. M. dentata Spr. fol. obovatis oblongisve acuminatis punctatis, super. dentatis; stylo longo; stigmatibus depressis. Caballeria 1. et $\mathbf{P}$. In $\mathrm{E} e-$ ruvia.

42. IM. dependens Spr. ramis dependentibus; fol. agglomeratis condensatis ovatis cordatisve; flor. 4-andris. Caballeria 1. et P. In Perucia. 古.

43. M. Barthesia R. et S. fol. ohlongo-lanceolatis laevihus integerrimis; panic. elongatis axillaribus. Anguillaria Lam. Badula Juss. In Zeyiona. ち. Cor. alba.

44. M. Potıma Don; fol. ellipticis mucronulatis serrulatis glabris nitidis; umbellis sessilibus; cor. 4-fidis dioecis. M. bifaria Wall. In Nepatia. t.

45. M. sessilis Don; fol. ohlongis acuminatis nitidis apice denticulatis; umbellis sessilibus; stigmate bilobo. In Nepalia. $\hbar$.

46. M. subspinosa Don; fol. lanceolatis acuminatis rigidis glabris spinuloso-serrulatis; munellis sessilibus puhescentibus. In Nepalia. $\hbar$.

4\%. M. semiserrata Wall. arborea; fol. confertis lanceolatis attenuatis antice angute serratis resinoso-punctatis: stigmate laciniato-fimbriato. In

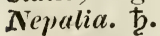

48. M. capitellata Wall. arborea; fol. ohlongo-lanceolatis acuminatis integcrrimis coriaceis; capitulis sessilihus; stigmate subintegro. B. M. 3222. In Nepalia. 古.

49. M. pachysandra Wall. arborea; fol. oblongo-lanceolatis acuminatis integerrimis brevilus ; fasciculis glandulosis; stigmatibus 3-angulariDus crassis. In Ind. orient. $\hbar$.

50. M. aurantiaca Wall. fruticosa; scandeus; glabra; fol. ovato-lanceolatis acutis integerrimis coriaceis supra nitidis; filamentis longissimis. In Ind. orient. $\hbar$.
51. M. Richardiana Endl. Sultonia australis Rich. Fl. Nov. Zeel. $t$.

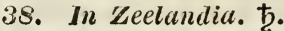

\section{\%50. EMBELIA Buvm. (1768).}

1. E. floribunda Wall. fol. Ianceolatis acuminatis integerrimis ; racemis compositis; cor. revolutis glanduloso - pubescendibus. E. esculeuta Don. In Nepalia. ち.

2. E. Pragushia Don; fol. ellipticis crenulatis; racemis simplicibus; cor. concavis glabris. M. undulata Wall. In Nerualia.

3. E. Ribes Burm. ind. $t$. 23. fruticosa; scandens; fol. alternis peliolatis oblongis obtusis; racemis hirsutis; cor. concavis pilosis. In India orientali. 古.

4. E. robusta Roxb. arborea; fol. ovali-ohlongis integerrimis glabris; racemis axillaribus solitariis; cor. patulo-reflexis villosis. In India orientali. 古.

5. E. vestita Roxb. fruticosa; scandens; fol. oblongo-lanceolatis subserrulatis racemis axillaribus. In $\mathbf{l n}$ dia orientali. $\hbar$.

6. E. villosa Wall. fruticosa; scandens; ramis calloso-maculatis pillosis; fol. ovato-oblongis utrinque attenuatis suhtus pilosiusculis. In India orientuli.

\%. E. mutans Wall. fruticosa; ramis pendulis; fol. subhifariam approximatis lanceolatis acuminatis undulatis nitidis. In Silhet.

8. E. canescens Juck. fruticosa; scandens; villosa; fol. subcordatooblongis acuminatis subtus pilosiusculis; petiolis sulcatis margine glanduloso-crispatis. In fret. malace. $\hbar$.

9. E. ferruginea Wull. Cat. ramis junioribus et pedunculis tomentosis ferrugineis; fol. ovalo-rotundatis integris coriaceis, superne glahris, subtus rubiginosis stellatim pilosis. All ripas Irracealdi. $ち$.

10. E. victa Viall. Cat. ramis et pedunc. velutinis ferrugineis; fol. ovalibus glabriusculis renote denticulatis; calyce et cor. velutinis. In Ind.

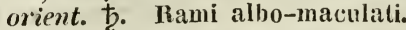

11. E. purviflora litall. Cat. fol. bifariis parvis approximatis ovato-acu- 
tis basi obtusis integris glabris nitidis; flor. parvis. In silhet.

12. E. urophylla Wull. Cat. gIaberrima; fol. ovato-lanceolatis utrinque acuminatis integris coriaceis nitidis; pedicellis brevissinis. In Singapore. t.

\section{BIADHIA Thunb. (1781).}

1. B. japonica Thmub. jap. t. 18. fol. teruis serratis glalris ; caule basi decumbente. In Juponia. ち. Caul. pedalis. Flor. cermui rubri.

2. B. villosa Thunb. jap. $t .19$. fol. serratis villosis. In Japonia. 4. Caul. filiformis digitalis.

3. 13. crispa T'mub. fol. oblongis crispis glahris. In Japonia. ち. spithameus. Bacca rubra.

4. H. glabra Tíunb. fol. oppositis serratis glabris ; caule erecto. In Jagromia. Ђ. Caul. frutescens pusillus. Bacca rubra.

\section{\%51. BUMELIA Sw. (17SS).}

\section{a. Spinos a e.}

1. B. lycioilles IW. fol. Iato-lanceolatis obtusiusculis basi attenuatis utrinque glabris, Duh. arb. ed. 2. t. 8. In smer. bor. t. 8-10-ped. Cur. alba.

2. B. oblongifolia Nutt. fol. oblongis obtusis integerrimis glabris; ramis tortuosis spinosis; flor. glomeratis. Ad fl. Missisippi.

3. B. crenulata Spr. fol. oblongolanceolatis basi attenuatis utrinque glaberrinis crenulato-serratis; pedunc. 1-floris. In Portorico. $\hbar$.

4. B. tenax $\boldsymbol{W}$. fol. obovato-lanceolatis sulfus gilvo-argenteis sericeis; pedunc. axillaribns confertis. B. chrysophylloides Pursh. Chrysophyllum carolinense. Jacq. obs. t. 5t. In Amer. bor. $\hbar$.

5. B. multiflora $R$. et $S$. fol. ovato-cuneatis obtusis glahris coriaceis; pedunc. divisis fasciculatis lateralibus. sideroxylon Lam. In Trom. 6. spei. t.

6. B. reclinata Venten. Chioix. pl. t. 22. dumosa; diffusa; reclinata; ra- mis sterilibus divaricato-ramulosis ; fol. parvis olovalibus glaberrimis. Sideroxylon Michx. In Nov. Georgia. $\frac{\hbar}{2}$.

7. B. strigosa $5 \mathrm{~m}$. fol. oblongis obtusis subtus strigosis; rauis spinulosis. Sideroxylon W. Patria ignota. t.

S. B. ferox schl. frutice glaberrimo; ramulis spinescentibus; fol. coriaceis cuncatis obtusis lanceolatisve glaucescentilus; floribus axillarilus glomeratis. In Mexico. $\downarrow$. Cor. alba.

\section{b. Inerm es.}

9. B. nigra $S w$. fol. terminalihus oblongo-lanceolatis utrinque glahris margine undulatis; ramis Iaxis. Acluras nigra Poir. In Jamaica. $\hbar$. Truncus altus.

10. B. retusa Su. fol. cuneato-ovatis retusis rigidis; pedunc. confertis axillaribus. Gaertul. Fr. t. 102. f. 3. In Jamaica. $\hbar$. Arlor humilis.

11. B. salicifoliu $\$ w$. fol. lanceolato-ovatis acuminatis; pedunc. confertis axillaribus. Achras L. Browne Hist: t. 206. f. 2. In Jamaica. ఫ. Flor. parvi albidi.

12. B. montana $S \mathcal{H}$. fol. oblongis obtusis; pedunc. longioribus axillaribus distinctis. Achras Poir. In Jamaica. ち. Rami subverucosi.

13. B. foetidissima $\mathbf{U}$. fol. lanceolato-oblongis obtusis subenarginatis ; pedunc. confertis axillaribus. Sideroxylon L. In Domingo. ち. Arliuscula 12 -ped. Flor. foetidissimi alhi.

11. B. pentagona $S u$. fol. Ianceolatis acuminatis nitidis; pedunc. axillaribus; drupis $\tilde{5}$-gonis. In Domingo. †. Cor. alba.

15. B. rotundifolia $\mathrm{S} w$. fol. suborhiculatis marginatis venosis coriaceis utrinque glabris. Achras Poir. In Jamaica. $\hbar$. Cor. alla.

16. B. cuneata su. fol. cuneatis ohovatis utrinque ylabris. SideroxyIon Lan. Achras Poir. In India occidentali. $\hbar$. Cor. minima.

17. B. Asuba spr. fol. oblongis utrinque attenuatis nitidis venosis; pedunc. solitariis axillaribus. In Hispaniota. 
752. SIDEROXYLON Dill. (1732).

a. Spinosa.

1. S. spinosum L. fol. lanceolatis integerrimis subcoriaceis subtus glaucis fasciculatis; flor. sessilibus. Comm.

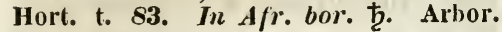
Cor. viridis.

2. S. tomentosum Roxb. fol. oblongis utrinque attenuatis subtus pubescentibus juniorihus tomentosis; pedunc. confertis. S. armatum Rotli. In India orient. $\hbar$.

\section{b. In ermia.}

3. S. inerme $L$. fol. oblongo-lanceolatis obtusis; flor. lateralibus ; pedunc. brevissimis. S. atrovirens Lam. ill. t. 120. f. 1: Dill. Elth. f. 344. In Prom. b. spei. ち. 5-ped. Cor. albida.

4. S. pallidum Spr. fol. terminalibus ellipticis vemosis glaherrimis pallentibus; pedunc. 1-floris confertis. Bumelia Sw. In Jamaica. t.

5. S. Nastichodendron Lam. fol. oblongo-lanceolatis utrinque attenuatis sempervirentibus supra nitidis subtus parallelo-venosis; pedunc. calycibusque splendide tomentosis. In $\mathrm{Hi}$ spaniola. $\hbar$.

6. S. nitidum Iam. fol. oblongis basi attenuatis coriaceis glaberrimis subtus venosis; pedunc. axillaribus 1floris aggregatis. In Ind. occid. t.

7. S. sericeum Ait. fol. obovatis subtus sericeo-tomentosis ; pedunculis aggregatis floribusque villosis. Sersalisia R. Br. In Nov. Holl. ђ.

8. S. guadelupense Spr. fol. ovatis ohlongis * obtusiusculis coriaceis glaberrimis subtus parallele venosis; pedunc. 1-floris. In Guadelupa. $\hbar$.

-9. S. argenteum Thunb. fol. obovato-oblongis subretusis subtus tomentosis; pedunc. 1-floris confertis. hoemera Thunb. Sersatisia obovata R. Br. In Nov. Holl. ち.

10. S. grandifolium Wrall. fol. obovato ellipticis cortaceis glabris integerrimis; pedunc. confertis pubescentibus basi squamatis. In Silhet. $\hbar$.

\section{THELA Lour. (1790).}

1. Th. coccinea I,our. caule scandente; fol. semiamplexicaulibus; caly- ciluus corolla concolorilus. In China et Cochinchina. ち. Suffrutex. Flor. coccineus.

2. Th. alluc Lour. caule scandente; fol. petiolatis; calycibus discolorilus. In China et Cochinchina. $ち$. suffrutex. Cor. alba.

\section{AEGICERAS Gaertn. (1738).}

1. A. frayrans Koenig; fol. sparsis ovato-ellipticis coriaceis glabris; flor. umbellatis albis. Rhizophora corniculata L. Rumph. 3. t. 77. et t. 83. In Moluccis. $\hbar$.

2. A. obovatum Blume bijalr. fol. ohovatis retusis venosis; floribus umbellatis ; fructibus cylindraceo-subulatis subarcuatis. In Java. †.

3. A. ferreum Blume bijdr. fol. spathulatis margine subrecurvis subaveniis; fructibus cylindraceo-subulatis arcuatis. Rumph. 3. t. 79. In Javu. $ち$.

\section{POLYMERIA R. Br. (1810).}

1. P. pusilla R. Br. fol. orbiculatis subenarginatis; pedunc. 1-floris solitariis; seminibus villosiusculis. In Nov. Holl.

2. P. tuadrivalvis $\boldsymbol{R} . B r$. fol. cordatis obtusis supra glabris subtus venis pubescentibus; caps. 4-valvi disperma; seminibus tomentosis. In Nov. Holl.

3. P. lanata $\boldsymbol{R}$. Br. fol. cordatis obtusis mucronulatis utrinque seminibusque lanatis; pedunc. 1-floris. In Nov. Holl.

4. P. ambiyua $R$. Br. fol. cordatis oblongis ohtusis mucronatis supra grabriusculis subtus lanatis; pedunc. 1-3-floris. In Nov. Holl.

5. P. calycina R. Br. calycis foliolis inaequalibus, exterioribus basi cordata ; seminibus glabris; fol. ovatis pubescentibus. In Nov. Holl.

\section{BONAMIA Thouars (1806).}

1. B. madagascarensis Poir. Thouars ins. Afr. austr. t. 5. In Madagascar, $\hbar$. Frutex orgyalis. Fol. alterna ovata undulata glabra. Flor. paniculati albidi. 


\section{MURLCOA AUb. (1785).}

1. M. violacea Aubl. Guj. t. 54 . Convolvulus macrospermus Villd. In Gujanu. ち. Frutex sarmentis scandeus arbores altissimas. Fol. ohlonga semiplicata. Flor. corymbosi caerulei.

\section{CERBERA Mill. (1759).}

1. C. Tanghin Hook. B. Mr. 2.968 . fol. confertis; ramis erectis; flor. paniculatis terminalihus. Tanghinia venifera Poir. In ins. Mauritii. ち. Flor. rosei. Drupa pyriformis viride purpurea.

2. C. Allovai $L$. fol. ovatis acutis; laciniis cor. undulatis; calycibus reflexis. Lam. ill. t. 170. f. 1. Andr. Rep. t. 231. In Brasilia. t. $30-$ 50 - ped.

3. C. ovata Cav. ic. t. 270. fol. ovatis sparsis subsessilibus; flor. terminalibus subquinis. In Nova Hispania. t. 3-ped. Cor. flava.

t. C. fruticosa Roxb. fol. oblongis utrinque altenuatis glabris; pedunc. subcorymbosis; drupis obliquis urceolatis. In Pegu.

5. C. salutaris Lour. fol. fructibusque ovalibus; paniculis oppositifoliis bracteatis. C. oppositifolia Lam. Rumph. 3. t. 84. In China et Cochinclina. क.

6. C. cuneifolia H. et $K$. fol. oblongo - cuneatis apice rotundatis supra puherulis, subtus lirto-pubescentibus; pedunc, subdichotomis. In Mexico. $\hbar$.

7. C. nitida H. et K. fol. oblongolanceolatis acuminatis margine subrevolutis, supra nitidis subtus molliter pilosiusculis. In Nova Granata. $\hbar$.

8. C. borbonica Spr: fol. ovatis quaternis nitidis argute striatis; flor. corymbosis. Rauwolfia striata Poir. Ochrosia borb. Pers. In ins. Borboniae. $\hbar$. Cor. ochroleuca.

9. C. chinensis syr. fol. quaternis oppositisque lanceolatis integerrimis; panicula racemosa. Dissolena verticillata Lour. In China. 古.

10. C. Odallum Ilamilt. fol. lanceolatis obtusiusculis in petiolum decurrentibus coriaceis venosis; drupa 2sperma. C. Manghas Ait. In Ind. orient.

11. C. lactaria Hamilt. fol. lanceolatis acutis petiolatis venosis; ra- cemis terminalibus; drupa 1-sperma. C. Manghas Gaertu. fruct. t. 123.124. Rumph.2. t. 81. Rheed. I. t. 39. In inl. orient. $\hbar$. Arhor lactescens. Cor alba.

12. C. maculatu 11 . fol. lancelatis utrinque attenuatis undulatis venosis maculatis; cymis divaricalis. Ochrosia Jacq. ic. t. 321. In ins. Borbon. ち.

13. C. peruviana Pers. fol. lineari-lanccolatis confertis longis; pedunculis hrevissimis paucifloris. C. Thevetia R. et P. In Peruvia. $\hbar$.

14. C. theretioides Bonpl. fol. lineari-lanceolatis venosis revolutis subtus pilositusculis; stigmate 5-gono 2dentato. In Nov. Holl.

1.5. C. Thevetia I. fol. linearibus longissimis confertis glabris supra nitidis; drupa 2-sperma. Jacq. Am. t. 34. pict. t. 47. Plukn. t. 207. f. 1. In Ind. occid. t. Arbor venenosa. Flor. flavi.

\section{ARDUINA Mill. (1759).}

1. A. bispinosa $L$. fol. ovatis culspidatis rigidis; ramis glabris spinis bifidis; flor. fasciculatis. In Prom. $b$. spei.

2. A. edulis Spr. fol. ovatis acutis rigidis; ramis villosis spinis simplicibus geminis; pedunc. terminalibus sub-5-floris. Carissa Valı. In Arabia. t.

\section{CORTESIA Cav. (1797.)}

1. C. cuneifolia Cav. ic. $t$. $37 \%$. In Buenos Ayres. Ђ. Arbuscula 45-ped. Fol. alterna cuneiformia 3fida tuberculato-hispida. Flor. ochroleuci.

\section{HUNTERIA Roxb. (1S23).}

1. H. corymbosa Roxb. In ins. freti Malacc. $\hbar$. Arbor alta. Folia opposita oblonga integerrima glabra. Flor. corymbosi albi.

\section{GERTNERA Lam. (1791).}

1. G. vaginata Lam. ill. $t .16 \%$. Andersonia iv. In ins. Mascaren. ti. Arbor. Fol. opposita oblonga utrinque 
attenuata coriacea. Stipulae cylindricae truncatae apice filamentosae.

\section{\%63. DICARYUM Will.Hb.(1S19).}

1. D. subdentatum Willd. Hb. fol. ellipticis acute subdentatis supra nitidis coriaceis; petiolis vaginatis; racemo terminali. In Peruvia.

2. D. servalatum Willd. Hb. fol. oblongis acuminatis serrulatis; paniculis axillaribus. In Peruvia.

\section{\%61. PHLOX L. (1751).}

1. P. pyramidalis $\mathrm{Sm}$. fol. cordato-ovatis acutis glabris; caule scabro maculato; laciniis corollinis truncatis. P. Iatifolia Michx. B. C. 342. In Carolina. 24.

2. P. ovat $\boldsymbol{L}$. fol. nitidis, radicalibus ovatis, caulinis ovato-oblongis ; corymbis fastigiatis ; cor. laciniis retusis. P. nitida Pursh. In Virginia. 24. Flor. rubri.

3. P. carolina $L$. fol. ovato-lanccolatis glahris; caule pubescente; ramulis 3-floris; laciniis cal. lanceolatis erectis cor. rotundatis. B. M. 1344. P. triflora Michx. In Cgrolina. 24. Cor. purpurascens.

t.P. paniculata L. fol. lanceolatis planis margine scabris; caule laevi; corymbis paniculatis; cor. laciniis rotuudatis. Dill. Elth. f. 203. In Carolina. 24. Caul. altus. Cor. ruhra.

5. P. unilulata Ait. fol. oblongo-lanceolatis subundulatis margine scabris; cor. laciniis subretusis. In Curolina. 4. Flor. caerulei.

6. P. maculata $I$. caule erecto scaliro maculato; fol. ohlongo-lanceolatis glabris margine asperis; cor. laciniis rotundatis. P. suaveolens Ait. Jacq. Vind. t. 127. In Amer. bor. 4. Cor. rubra.

7. P. divaricate $I$. fol. ovatolanceolatis cauleque diffuso pubescentibus; laciniis cor. emarginato-obcordatis. B. M. 16:3. In Amer. bor. 4. Cer. pallide caerulea.

8. P. reptans Michx. caule sterili prostralo radicante, florifero erecto superue puhescente; fol. ovato-lanceolatis; cor. laciniis serrulatis. P. stolonifera Curt. B. M. 563. P. pro-

\section{strata Ait. In Carolina. 4. Cor.} caerulea.

9. P. acuminata Pursh; caule angulato superne pubescente; fol. ovato-lanceolatis subtus pulescentihus; cal. laciniis cuspidatis. B. M. 1880 . In Carolina. 24. Flor. Iaete purpurei.

10. P. carnea Ker. B. M. \$1.5.5. caule glabro linea scabra; fol. lanceolatis semiamplexicaulibus glahris; laciniis calycis marginatis. In America boreali. 24. Cor. carnea.

11. P. su/fruticosa Vent. caule hasi suffruticoso glahro; fol. Ianceolatis glaberrimis supra nitidis aveniis; cal. laciniis cuspidatis. B. R. 68. In Amer. bor. . Cor. purpureo-violacea.

12. P. ylaberrima $W$. fol. lanceolato-linearihus cauleque corymboso paucifloro glaberrimis; laciniis calycis apice subrecurvis. Dill. Elth. f. 202. In Virginia. 4. Cor. rubra.

13. $P$. pilosa $L$. caule adscendente piloso; fol. lineari-lanceolatis hirsutis; laciniis cor. rotundatis. B. M. 1308. P. amoena Sims. B. N. 1307. In America boreali. 24. Cor. dilute purpurascens.

14. P. aristata Michx. fol. linearilanceolatis cauleque viscidulo-pubescentibus; laciniis cal. longissime cuspidato - subulatis. In Carolina. 4. Cor. purpurea.

15. P. speciosa Pursh; caule suffruticoso ramosissimo; fol. linearihus hasi dilatatis glabris; laciniis cor. emarginatis. B. M. 1351. In Amer. bor. 4 .

16. P. silirica $\boldsymbol{L}$. fol. linearibus elongatis pubescentibus; pedunc. terminalibus 1-fioris calycibusque patulis villosis. Gmel. Sib. 4. t. 46. f. 2. In Sibiria. 24.

1\%. P. setacea $\boldsymbol{L}$. canle prostrato; fol. linearibus fasciculatis cuspidatis ciliatis; laciniis cor. obcordatis. B. M. 415. B. nivalis Lodd. B. C. 780. In Amer. bor. 24. Cor. alba.

18. P. subulata $I$. fol. linearibus fasciculatis cuspidatis cauleque caespitoso hirsutis; cal. laciniis acuminatis adpresse villosis. B. M. 411. In Amer. bor. 24. Cor. purpurea.

1.9. P. Hoodii Richards. caule caespitoso; fol. subulatis margine lanatis; flor. sessilibus solitariis; laciniis cor. ohovatis. In Amer. hor. 4.

20. P. bifiora $\boldsymbol{R}$. et $\boldsymbol{P}$. pubescens; fol. lineari-lanceolatis inferioribus op- 
positis; pedunc. axillaribus geminis. In Chili. $\odot$. Cor. purpurea.

21. P. Drummondii Hook. B. M. 3417. caulibus erectis; fol. lancealatis, caulinis cordato-oblongis subamplexicaulibus; cor. laciniis apice subemarginatis. In Amer. bor. 4. Cor. pallide caerulea.

22. P. mrocumbens Lodd. B. C. 1722. caulibus procumbentibus glanduloso-pilosis; fol. lanceolato-linearibus acutis; cal. glanduloso-pilosi laciniis acutis, cor. subretusis. In Amer. boreal. 4. Cor. rosea.

\section{BONPLANDIA Car. (1800).}

1. B. geminiflora Cav. ic. t. 532. Caldasia heterophylla Willd. H. Berol. t. 71. In Nova Inispania. $\odot$. Herba pilosa. Fol. alterna Ianceolata serrata. Flor. caerulei.

\section{CRYPTANDRA Sm. (1798).}

1. C. ericaefolia $\mathbf{S} m$. Linn. trans. 10. $t$. 18. caule apice subsericeo; fol. linearibus acutis glabris; capitulis terminalibus; bracteis sericeis. C. capitata sieb. Ad Port Jackson. ち. Flor. extus sericei.

2. C. amara Sm. l. c. t. 18. f. 2. caule apice subincano; fol. alternis densis spathulatis obtusis; bracteis integris styloque glabris. C. ericaefolia sieb. In Nov. Holl. $\hbar$.

3. C. obovata Sieb. caule glabro; fol. alternis petiolatis obovatis crassiusculis glabris; bracteis integris; calyce glabro. In Nova Hollandia. 卢.

4. C. spinescens Sieb. glabra; ramis spinosis; fol. alteruis oblongis obtusis basi subattenuatis; bracteis fusco-scariosis subdentatis. In Nova Hollandia. \$.

\section{6\%. CRYPTOSTOMA Schreb. (1789).}

1. C. laurifolia Schreb. Moutabea gujanensis Aubl. Guj. t. 274. In Gujana. b. Frutex scaudens. Fol. ova- to-oblouga glabra. Flores albi racemosi.

\section{LANDOLFIA Beauv. (1806)}

1. L. owariensis Beauv. Fl. d'owar. t. 21. Paederia Spr. In Guinea. Frutex erectus. Fol. opposita ovatolauceolata glabra. Flor. corymbosi.

\section{HYDROPHYLLUM Joucquet (1659).}

1. H. virginicum $\boldsymbol{L}$. fol. pinnatifdis; laciniis obovato-lanceolatis inciso-serratis. Schk. t. 35. Lam. ill. to 97. f. 1. In Amer. bor. 24. 6-9-poll. Cor. alba.

2. $H$. canadense $\boldsymbol{L}$. fol. cordatis 5-lobo-angulatis dentatis glabris. Lam. ill. t. 97. f. 2. In Amer.bor. 4. Cor. alba.

\section{PHACELIA Juss. (1789).}

1. P. circinnata Jacq. fol. pinnatis ternatis hispidis rugosis lineatis; spicis glomeratis secundis hispidissimis. P. B. californica Cham. et Schl. Hydrophyllum magellanicum Lam. Journ. d'hist. nat. t. 19. In Patagonia. $\hbar$. Cor. incarnata.

2. P. peruviana Spr. fol. pinnatis, super. simplicilus hirsutis; spicis apice revolutis. Aldeaea pinnata $\mathbf{R}$. et $P$. peruv. t. 114. In Peruvia. 4.

3. P. platycarpa Spr. fol. pinnatis incano-pubescentibus; foliolis cuneatis 3-fidis; caps. compressa hirsuta. Convolvulus Cav. In Nova Hoblandia.

4. P. fimbriata Michx. fol. pinnatifidis sessilibus supra hispidis subtus glaloris; laciniis lanceolatis acutis; lohis corollae fimbriato-ciliatis. $P_{0}$ lemonium W. In Carolina. 4.

5. P. heterophylla Pursh; fol. pinnatifidis petiolatis hispidis; laciniis lanceolatis nervosis; racemis bifidis densifloris; lobis cor. integerrimis. In Amer. bor.

6. P. bipinnatifida Michx. fol. pinnatifidis petiolatis pubescentibus; laciniis incisis; racenis bifidis crenatis; lobis cor. integerrimis. In America boreali, 24. 
7. P. malvaefolia Cham. et Schl. caule ramoso pilis articulatis glandıloso; fol. cordato-ovatis serratis; supra pilis sparsis horidis subtus leviter pilosis. In California. $\odot . ?$

8. P. congesta Huok. B. M. 34.52. pulsesceus; fol. inaequaliter pinnatis; pinuis piunatifidis inciso-lobalis ; racemis coryuhosis multifloris. In Texas. $\odot$. Flor, pallide caerulei.

\section{7\%1. NEMOPHILA Bart. (1818).}

1. R. phacelioiles Bart. B. M. 2373. fol. pinnatifitis scabris, lohis obtusis ciliatis; pedunculis oppositifoliis. N. Nutallii Coll. rip. t. 5. In Amer. bor. $\odot$.

2. N. paniculate Spr. fol. radicalibus subpinnatifidis, caulinis sublobato-angulosis hirsutissimis. Hydrophyllum appendiculatum Michx. In Amer. bor. $\odot$.

3. N. insignis Benth. B. R. 1703. fol. oppositis pinnatifidis; calycis sinubus reflexis; ovariis multi-ovulatis. B. M. 3485. In California. $\odot$. Cor. azurea.

\section{NAVARRETTA R. et P. (1799).}

1. N. involucrata R. et P. peruv. In Pernvia. $\odot$. Caul. $\frac{1}{2}-p e d$. pubescens vix ramosus. Fol. alterna, laciniis linearibus. Cor. purpurea.

\section{PORANA Burm. (1768).}

1. P. volubilis Burm. ind. $t .21$. fol. distantibus ovato-acuminatis ; flor. laxe paniculatis. In Java. ち. Caul. fruticosus.

2. P. acuminata $\mathrm{Fl}$. d'ow. $t .49$. caule lignoso glabro volubili; fol. petiolatis integris apice aristatis longe acuminatis. In ouare. $\hbar$.

3. I'. racemosa Jacq. fil. ecl.t. 16.5. fol. cordato-ovatis acuminatis pubescentibus; racemis secundis; laciniis cor. acutis. P'atria ignota.

4. P. paniculata Roxb. fol. cordatis acuniuatis villosis; paniculis ramosissimis pendulis; cor. Iimbo obtuso. In Bengalia. 4 .

\section{9\%1. BREWERIA R. Br. (1810).}

1. B. linearis $\boldsymbol{R}$. $\mathbf{B r}$. fol. lanceolato-linearibus complicatis villosis. In Nov. Holl.

2. B. linifolia Spr. fol. sparsis linearibus glabriusculis; caule scabro simplici; pedunc. corymbosis. In Montevideo.

3. B. media $\boldsymbol{R}$. Br. fol. subcordatolanceolatis villosiusculis. In Nov. Holl.

4. B. pannosa R. Br. fol. subcordato-ovatis panmoso-tomentosis; calycibus inaequalibus. In Nov. Holl.

\section{MARIPA Aubl. (17\%5).}

1. M. scandens Aubl. t. 91. caule fruticoso scandente; fol. ovato-oblongis glabris; panicula diffusa bracteosa; cor. patula; stylo elongato. In Gujana. 古.

2. M. erecta Meyer; caule arboreo erecto; fol. oblongis glabris; panicula stricta; limbo cor. erecto sty-

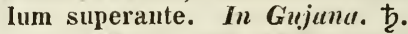

3. M. villosa Spr. caule erecto suffruticoso ; fol. sessilibus subrotundis villosis ciliatis; racemo stricto bracteoso. In Brasilia. ఫ.

\section{ARGYREIA Lour. (1790).}

1. A. arborea Lour. caule arboreo; fol. rugosis ovatis ; racemis terminalibus, In China et Cochinchina. ち. Arbor 8-ped. Flor. rubri.

2. A. acuta Lour. fol. Ianceolatoovatis acutis; corymbis axillaribus. In Sina. ち. Caulis fructicosus scandens. Cor. alba.

3. A. cuneata Ker. B. R. 661. caule fruticoso scandente; fol. obovatis mucronatis venosis subtus sericeis; pedunc. 3-floris. Isettsomia Roxh. Ipomoea atrosąnguinea B. M. In $\mathbf{I n d}$. orient. $\hbar$.

4. A. obtusifolia Lour. fol. ovatis obtusis; paniculis subterminalibus. In Cochinchina. $\hbar$. Frutex scaudens. Flor. albi. Bacca rubra. 


\section{8\%. TECTONIA L. fil. (1781).}

1. T. yrandis L. Lam. ill. t. 136. Rheede mal. 4. $t$. 27. Rumpl. 3. $t$. 18. Arbor excelsa. Fol. opposita ampla ovato-oblonga integerrima aspera. Hlor, albi.

\section{TOLRNEFORTIA L. (1738).}

1. Messerschmidieae: laciniis cor. Iinearibus; drupa 4-pyrena.

\section{a. Caulis fruticosus.}

1. T. fruticosa $\boldsymbol{R}$. $\boldsymbol{B r}$. caule erecto; fol. petiolatis lanceolatis hispidiusculis; panicula dichotoma cymosa. In 'Teneri//a. ち. Frutex 5-ped.

2. 'T. angustifolia $R$. et S. fol. petiolatis angustis lineari-lanceolatis. In ins. Canur. ち. Cor. subcaerulescens.

3. T. munctata Spr. caule scandente; fol. oblongis utrinque attenuatis ciliatis supra albo-punctatis; flor. spicatis. In Martinica. Messerschm. Nees.

4. T. volubilis Spr. caule voluhili; fol. ovato-oblongis scahris; racemis paniculatis pubescentibus. T. psilostachya H. et K. In Jamaica, Mexico et Quito. 市.

5. $\boldsymbol{T}$. scandens $\boldsymbol{W}$. caule scandente; fol. ovato-oblongis glahris aculis; spicis paniculatis terminalibus. 'T. volubilis 12. et P. In Perucia. ђ.

6. 'T. polystachya R. et P. t. 119. f. a. fol. ovatis acutis rugosis hirsutis; pedunc. terminalibus corymbosodichotomis. In Peruria. 方. Cor. alba.

\%. T'. sericea Vahl; fol, ovatolanceolatis subtus tomentosis sericeis; spicis lateralibus terminalibusque. In ins. Montservut. $\hbar$. Flores parvi.

8. T. relutina $\boldsymbol{H}$. et $\boldsymbol{K}$. caule scandente; fol ovato-ohlongis utrinque lanato-tomentosis; fructibus hispidis. In Mexico. ђ.

9. T. tomentosa Mill. fol. cordatis subtus tomentosis; spicis hrevibus racemosis; caule volubili. Prope Carthagenam. †. Cor. sordide alha.

10. T. polyochros Spr. caule scandente; fol. lanceolatis petiolatis supra villosiusculis subtus albo-lanatis; fructibus scabris. In Jamaica.
11. T. ferruginea Lam. fol. subcordatis acutis subtus villosis; caule subvolubili; ramis hirsutissimis. In Domingo. ந. Flor. parvi calyce villoso.

12. T. nmbellata H. et K. N. Gen. t. 202. fol. Ianceolato-oblongis acutis angustatis utrinque temissime strigosis; cal. pulsescentibus. In Mexico. t.

13. ' $\boldsymbol{T}$. floribunda $\boldsymbol{H}$. et $\mathrm{K}$. volubilis; scandens; fol. ovato-oblongis acuminatis basi rotundatis subtus calycibusque cano-tomentosis; drupis scoccis. In Non. Andalusia. ђ.

1.t. T. Longifolia R. et $\boldsymbol{P}$. peruv. t. 150. $f$. b. fol. oblongo-lanceolatis obliquis veuosissimis, margine subrevolutis. In Peruvia. ち. Sem. 4-trona.

15. T. syringaefolia rall; fol. subcordato-ovatis acuminatis glabris; spicis ramosis. In Cayenna. $\hbar$. Cor. extus villosa.

16. 'H'. corynibosa $W$. Hb. caule scandente; fol. oblongis utrinque attenuatis venosis; spicis paniculatis coarctatis; tubo cor. elongato; laciniis acuminatis. In Ind. occid. et smer. austr. $\hbar$.

17. T. microphylla Bert. caule scandente; fol. ovatis obtusiusculis mucronatis punctato-asperis; spicis dichotomis; fructibus glabris. In $4 n-$ tillis. $\hbar$.

18. T. minuta Bert. caule erecto; fol. lanceolato-linearibus obtusis scabris; spicis bifidis paucifloris. In Jamaica. $\hbar$.

1.9. T. elegans Cham. et Schl. fol. petiolatis ovato-ellipticis acuminatis utrinque adpresso-pilosis; calyce mimuto; laciniis erecto-ciliatis; ramis subangulatis piloso-striatis. In Mexico. Ђ.

20. T. heliotropioides Hool, B. M. 3096. ramis herhaceis hirsutis; fol. ellipticis obtusis utrinque pubescentibus margine undulatis; racemis dichotomis. In Buenos Ayres. ఫ. Flor. rosei.

\section{b. Caulis herbaceus.}

21. T. Arguzia R. Br. fol. ovatooblongis incano-tomentosis; cor. fauce pervia; lacinuis obtusis. Act. Petrop. 1763. t. 11. In Tauria et Sibiria. 4. Caul. spithameus.

22. T. sessilifolia Poir. fol. sessilibus linearibus revolntis villosis; flor. 
corymbosis terminalibus. In Buenos Ayres. 21.

2. Pittoniae: laciniis cor. 5-fidis; drupa dipyrena ossiculis bilocularibus.

a. Caulis arboreus fruticosus erectus.

23. T. hirsutissima , Spr. ramis teretibus; fol. oblongis utrinque attenuatis supra hispidis subtus strigosovillosissimis; spicis revolutis; calyciisus fructibusque hispidis. In India occidentali. 4.

24. 'T. caracasana $\boldsymbol{H}$. et $K$. fol. ovalo-ohlongis acuminatis hasi angustatis, suprastrigosis, subtus hirto-tomentosis; pedunc. sub-8-stachyis ; cal. strigosis. T. acutifolia W. Hb. In Caracas. 古.

25. 'T. fuliqinosa H. et $\boldsymbol{K}$. Nov. Gen. t. 203. ramis compresso-4-gonis; fol. ohlongis utrinque attenuatis subtus fuligineo-tomentosis; fruct. glabris. In Jamaica, Amer. ausir. ţ.

26. T. Loxensis II. et $K$. ramis teretibus; fol. ovatis acuminatis basi angustatis, supra strigoso-hirtis, subtus calycihusque subcano-tomentosis; drupis glabris. In Quito. t.

2\%. 'I'. hispida II. et K. ramis subangulatis; fol. ovatis acuminatis utrinque piloso-hispidis subtus canescentibus; pedunc. dichotomo-multifidis 10stachyis; cal. hispidulis. In Amer. austr.

28. T. cuspilata $H$. et $I$. ramis teretibus; fol. ohlongo-ellipticis acuminato-cuspidatis basi acutis utrinque pilosis, suhtus in venis hirsutis; pedunc. polystaclyyis. In Quito. $\hbar$.

29. 'T. canescens $H$. et $K$. ramis teretiusculis; fol. ovato-ohlongis acuminatis basi angustatis sulsessilibus, supra strigoso-villosis, subtus canotomentosis; cal. hispidis; drupis glabris. In Cumana. $\hbar$.

30. 'I. su/lruticosa $R$. et P. caule suffruticoso; fol. sublanceolatis incanis. Sloane Hist. t. 162. f. 4. In Jamaica. ち. Cor. alha.

31. I. incana kam. ill. t. 95. $f$. 3. caule fruticoso; fol. lanceolatis nndulatis subtus incanis; spicis termiualibus. In Hispaniola. $\hbar$.

32. 'T. scabra lam. fol. oblongis petiolatis scaberimis reflexis pedunc. ramosis terminalibus; baccis conicis. In Domingo. $\hbar$. Bacca rufescens.
33. 'T. argentea $L$. erecta; sericeotomentosa ; fol. ovatis; cymis decompositis; cor. rotata; stigmate lifido. Rumph. amb. 4. t. 85. In Amboina

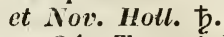

34. T. mutabilis Vent. Choix de $p l$ t. 3. fol. ovatis integerrimis scahris; spicis cymosis brevilus; lobis cor. crenulatis. In Java. ち. Frutex ramosissimus. Cor. albo-virens.

3.5. T'. scabriala H. et $\boldsymbol{K}$. ramis teretibus; fol. oblongo-ellipticis utrinque acutis, supra hullatis muricato-pilosis, stihtus hirto-pilosis canescentibus; cal. drupisque strigoso-hispidis. Ad $f l$. Magdatenae. $\hbar$.

36. 'T'. gnaplialioides $\boldsymbol{R}$. $\mathrm{Br}$. fol. linearibus obtusis utrinque sericeolanatis; spicis hifidis pancifloris; caule frutescente. Heliotropium L. Jacq. ain. t. 133. Plukn. t. 193. f. 5. In Jamaica. $\grave{b}$ 6-ped. Cor. alba.

3\%. T. leucophylla H. et K. ramis teretibus; fol. ohlongo-cllipticis acuminatis hasi rotuudatis, supra glabris nitidis, subtus tenuissime albo-tomentosis; cal. tomentosis. In Nov. Granata.

38. T. viryata $\boldsymbol{R}$. et P. peruv. $t$. 50. f. $a$. fol. ovato-oblongis subundulatis hispidulis integerrinis; pedunc. terminalibus subdichotomis. In Peru-

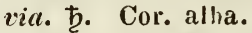

39. T. arborescens Lam. fol. ovato-lanceolatis petiolatis, juniorihus subtomentosis; spicis ramosis brevissimis; caule subarborescente. In India. 市.

40. T. cymosa $L$. fol. ovatis integerrimis nudis; spicis cymosis. Jacq. ic. t. 31. sloane Hist. t. 212. f. 2 . In Jamaica. ち. Caul. 9-ped. Cor. caruea.

41. T. bicolor $S w$. fol, ovatis actminatis glabris superne rugosiusculis; spicis cymosis recurvis. In Jamaica. †. Frut. orgyalis. Cor. alha.

42. $T$. laevigata Lam. ramis suhangulatis; fol. ovato-ellipticis acuminatis coriaceis glabris; pedunc. paniculato-multifidis; fruct. glabris. In Amer. austr. $\hbar$.

43. T. undulata $R$. et $P$. peruv: t. 149. $f$. b. fol. oblongo-lanceolatis lineatis rugosis; pedunc. polystachyis. In Cumanu. $ђ$. Cor. alla.

14. $T$. angusti/lora $R$. et $P$. fol. ovatis venosis acumine obliquo; pe- 
dunc. bifurcatis; corollis angustis. In Peruvia. t. 5-ped. Cor. alha.

4.5. '1. maculata Jacy. fol. ovatis acuminatis petiolatis utrinque glabris; spicis ramosissimis pendulis. In Curthayena. Ђ. Frutex. Cor. flava.

16. 'T. megapotamica spr. fol. obJongis glabris medio dentatis subtus Davicantihus; calycibus hirsutis. $A \vec{a}$ liio Grande. ち.

17. T. viridiflora Wall. fol. petiolatis ovatis acutis integerrimis subtus villosis; spicis compositis dichotomis recurvis. Heliotrop. Lelım. Lithosperm. Hoxh. In Ind. orient. $\hbar$.

18. 'I'. bifirla Lam. fol. ovatis coriaceis glabris spicis axillaribus conjugatis divaricatis. $\quad \boldsymbol{m}$ ins. Mascarenkis. ந.

49. 'I'. ternifolia $H$. et $\boldsymbol{K}$. ramis teretibus; fol. ternis oblongis utrinque angustatis acutis membranaceis glabris. All fl. Amasomum. $\hbar$.

50. 'T'. cornifolia $H$. et $\boldsymbol{K}$. ramis teretiusculis; fol. obovato-oblongis acutis hasi angustatis rigidis utrinque scabriusculis; cal. scabriusculis; drupis glabris. In Quito. 古.

51. T. glabra Aubl. ramis teretibus; fol. oblongis utrinque attenuatis glaberrimis integerrimis; pedunc. dichotomis; calycibus strigosis. In $\mathrm{Bra}$ silia. $\hbar$.

52. T. paniculata Cham. et Schl. fol. petiolatis, hasi cuneatis, apice acuminatis membranaceis teunissime pubescentihus; paniculis amplissimis; fruct. pubescentibus. In Brasilia. ち.

53. T. tuberculosa Cham. et Schl. herbacea; fol. lanceolatis sinuato-undulatis breviter crispatis acutis subtus strigosis; cal. minimo calloso-ciliato. In Prom. b. spei. ち.

54.. T. Irvilleana Cham. et Schl. ramis angulatis scabris striatis sulcatis; fol. ovatis acutis subtus subtomentosis ; pyrenis cellulosis 2 -spermis. In Luะonia.

\section{b. Caulis volubilis scandens.}

5.5. T. nitila $\boldsymbol{H}$. et $K$. ramis angulatis; fol. subellipticis acuminatis hasi acutis coriaceis glahris, supra nitidis; calycihus puberulis; drupis glabris. In Quito. 古.

56. T. latifolia Vent. ramis teretihus; tol. ovato-oblongis acutis repaudis glalsis punctatis; petiolis ge- niculatis; fructibus glabris. In Inct. occ. b.

57. $\boldsymbol{T}$. orientulis $\boldsymbol{R} . \boldsymbol{B r}$. fol. late ovatis acutis glahris; cymis dichotumis. In Nor. Holl.

58. T. sarmentosa Lam. fol. orato-ohlongis acutis petiolatis; spicis ramosis hrevissimis; caule scandente. In ins. Mascarenlis. $\hbar$.

5.9. ' $\boldsymbol{T}$ '. brasilensis Poir. fol. ohlique ovatis acuminatis asperis subsinuatis subtus albidis; ramis striatis sarmentosis. In Brasilia. $\hbar$.

60. T. montunce Lour. fol. ovaiolanceolatis rugosis; spicis terminalibus subsimplicilous recurvis; caule scandente hirsuto. In Cochinchina. t.

61. T. tetrayona Blume bijar. calile sarmentoso scabro; fol. ovato-oblongis acuninatis integerrimis supra glahris subtus scabriusculis; cor. tubo 4-gono. In Java.

\section{BEURERIA Jacq. (1750).}

1. B. succulenta Jacq. am. pict. t. 4.5. obs. $t$. 26. fol. ovatis integerrimis laevibus; cal. glalris; drupa succulenta. Cordia Botureria L. Eliretia Lam. In Ind. occ. $\hbar$. 1o-ped. Cor. alba.

2. B. exsucca Lam. fol. ovatis lanceolatis glaberrinis margine reflexis; baccis exsuccis 4-gonis. Jacq. anı. t. 175. f. 17. pict. t. 259. f. 13. In Amer. merid. Arbor 15-ped. Cor. candida.

3. B. revoluta $\boldsymbol{H}$. et $\boldsymbol{K}$. ramis foliisque glahris ovatis obtusis margine integerrimis et revolutis ; corymbis dichotomis; calycibus pubescentibus. In Nova Hispania. 专

\section{PRESLEA Mlart. (1826).}

1. P. paradoxa Mart. Nov. Gen. t. 164. caule ramosissimo diffuso foliisque angustato-lanceolatis acutis incano-hirtis. In Bahia. 4. 4 ped. longa. Cor. flava.

781. EIIRETIA P. Br. (1756).

a. Foliaglabra.

1. E. tinifolia L. fol. oblongis integerrimis utrinque glabris; panicula 
terminali ranosissima. Tiew Ehret. t. 24. Sloane Hist. t. 203. f. 1. In Jamaica et Cuba. ち. Arbor 30-ped. Cor. candida.

2. E. laxa Jacq. Schoenbr. t. 11. Fragm. $t$. 5. fol. oblongis obtusis; ramis reclinatis; paniculis laxis. In ins. Berbonia. 古. Arbuscula 20-ped. Cor. albido-viridis.

3. E. internodis Herit. stirp. t. 24. fol. ovato-ohlongis acutis glahris; paniculis axillaribus laxis. In ins. Huscurentis, $\hbar$.

1. E. grandiflora Poir. fol. ovatis laevihus inaequilateris; flor. corymbosis; calyce subpubescente cinereo; laciniis cor, subrotundis, In $\mathrm{Do}_{-}$ mingo. 卢.

5. L. ternifolia H. et K. Nov. Gen.t. 209. ramis teretiusculis glabriusculis; fol. ternis oblongis obtusis integerrinis glabris calycihusque subpunerulentis. In Veneanela. $\grave{t}$.

6. E. lueris Roxb. fol, ovatis glahris subrugosis; spicis lateralihus secundis divaricatis, E, punctata Roth. In Ind. or. et Nor. Holl. $ђ$.

ร. E. glabra Roth; fol. subrotundo-ovalihus integerrimis glahris; calycibus subinflatis. In India orientaii. t.

§. E. monteridensis Spr. fol. oblongis obtusiusculis integerrimis apice subserratis coriaceis, supra nitidis in axillis venarum villosis, In Montevilleo. $\hbar$.

9. E. dubia Jacq. fol. ollongis acutis integerrimis glahris; pedunculis aggregatis 1-floris. In Jamaica. $t$.

10. E, acuminata R. Br. fol. ohlongis acuminatis serratis paniculaque decomposita glaberrimis. In Nova Hollandia. $\hbar$.

11. E. membranifolia $R$. Br. fol. lanceolatis elongatis membranaceis integerrimis glaberrimis ; cymis dichotomis. In Nov, Holl. t.

1\%. E. saligna R. $B r$. fol. linearilanceolatis subfalcatis elongatis integerrimis; cymis dichotomis; flor. polygamis. In Nor, Holl. $\hbar$.

13. E. buxifolia Roxb. fol, fasciculatis ohovatis nitidis scabris; fructibus 5-locularilus, Cordia retusa Valıl. In Ind. orient. 古.

14. E. microphylla Lam. fol. subverticillatis obovatis supra punctatis; pedunc, axillaribus sub-1-floris. In Ind. orient. $\hbar$.
15. E. spinosa Jac\%. am. t. 80. f. 15. pict. $t$. 2.59. f. 14. spinosa; fol. oblongis hasi attenuatis sulirepandis; fructihus 6-locularilus. In Ins. Plitlippinis. $\hbar$. 3-4-poll. Cor. flavescens.

16. E. javanica Blume bijdr. fol. alternis ovalibus utrinque attennatis integerrimis glabris; cal. profunde 5fidis. In Java. $\hbar$. Arbor 60-ped.

17. E. dichotoma Blume bijdr. fol. oblongis acuminatis integerrimis coriaceis glabris; flor. secundis; cal. obtuse 5-dentatis. In Java.

18. E. pyrifolia Don; fol. ovatis acutis serratis glabris, floralihus olIongis; floribus confertis. E. serrata Hoxh. In Nepalia,

19. E. umbellulata Wallich. arborea; fol. ovatis subretusis undulatis glaberrimis; umbellis sparsis puhescentibus; cor. rotatae laciniis subrecurvis. In Ind. orient. $\hbar$.

\section{b. Folia aspera pubescentia.}

20. E. aspera Roxb. fol. alteruis ovatis scaberrimis; florihus corymboso-spicatis secundis. In India orientali. 古.

21. E. Radula Poir. fol. coriaceis ohovatis ohtusis punctis scaberrimis; flor. laxe corymbosis. In Domingo. $\hbar$. Cor. albida.

22. E. macrophylla Wall. arborea; ramis verrucosis; fol. ovato-oblongis argute serratis supra hispidulis subtus pubescentibus. In Nepalia. ఫ.

2:3. E. setosa Roxb. fol. cordatoovatis setoso-hispidis; spicis secuudis recurvis dichotomis paniculatis. In Ind. orient. $\hbar$.

21. E. uniflora Roxb. fruticosa; fol. subsessilibus oblongis integerrimis pilosis; floribns solitariis subsessilibus. In ins. Moluccis. ఫ.

25. E. virgatu Su. fol. oblongis integerrimis superne scabris; ramis filiformibus; pedunc. 1-floris; calycihus hirsutis, In Nova Hispania. ち. 6-8-ped.

26. E. tomentosa Lam. ill. t. 201. f. 1. fol, ovatis superne scabris subtus tomentosis; cal. obtusis. In Jamaica et Dominyo. ђ. Cor. allua.

2\%. E. bogotensis sm. fol. ohlongis acutis supra ylabris subtus incanotomentosis; cal. truncatis tuberculatis 
turhinatis. E. tomentosa H. et K. t. 208. In Nova Granata. †.

28. E. heterophylla sin. fol. fasciculatis ohovatis integris 2-dentatisque calloso-lispidis, fructibus 6-10cularibus. In ins. Philipjinis. ђ .

\section{RHABDIA Mart. (1826).}

1. R. lycioides Mart. t. 195. In Brasilia. †. Frutex 5-ped. Fol. lanceolata margine undulata pubescentihirtula. Flor. laterales. Cor. alba limbo roseo-purpureo.

\section{ELLISIA L. (1764).}

1. E. Nyctelaea $L$. caule erectiusculo hirsuto; fol, pimatifidis pilosis; laciniis lanceolatis dentatis; pedunc. ceruuis. Ehret. select. t. 99. Gaertı. t. 184. f. 6, In Tirginia, $\odot$. Cor. alla.

2. E. ambigua Nutt, decumbens; ramosa; fol. hirsutis lyrato - pinnatifidis; segmentis angulato-dentatis. Ad fl. Missuri. $\odot$. Cor. alba.

\section{'81, MENAIS Loefl, (175\%).}

1. Mr. topicaria Willd. In Amer. austr. ち. Caules subvillosi, Fol, alterna ovata integra aspera.

\section{ROTULA Lour. (1790).}

1. R. aluatica Lour. In paludibus Cochinchinae. Ђ. Frutex 4-ped, Fol. ovata ohlonga integerrima minima. Cor: dilute caerulea. Bacca rubra,

\section{COUMA Aubl. (1775).}

1. C. Iujunensis Aubl. Guj. t.392. Cerbera tripliylla Rudye. In Gujanu. ந. Arhor excelsa. Fol. teruata ublonga glabra. Flor. paniculati, rosei.

78\%. CORIS Diosc. Matth. (1560).

1. C. monspeliensis I. I,am. ill. $t$. 202. B. R. 536. B. M. z131. In
Europ. austr. †. Fruticulus humilis, ramis puhescentilus. Fol. linearia coriacea. Cor. laete lilacina.

\section{ANDROSACE Matth. (1560).}

a. Umbelliferae.

1. A. maxima $L$. fol. ellipticolanceolatis dentatis; cal. rotatis dentatis; cor. immersa, fauce laevi. Jacq. austr. t. 331. Lam. ill. t. 98. f. 1. In Europ. et Sibir. ๑. 6-poll. Cor. alba.

2. A. elongata $L$. glabra; fol. lanceolatis dentatis; umbella fructifera elongata; cor. calyce angulato brevioriltus. Jacq. obs. t. 19. austr. t. 830. Sclik. t. 33. A. nana Horn. In Europ. ๑. 2-4-poll. Cor. alba.

3. A. septentrionalis $\mathrm{L}$. fol. lanceolatis dentatis glabris lucidis; cal. angulatis; cor. exserta. Lam. ill. $t$. 93. f. 3. Fl. Dan, t. \%. B. M. 2021. A. brevifolia Vill. In Europ. ๑. 38-poll. Cor. alba,

4. A. lactea L. glabra; fol. linearibus integerrimis; pedunc. elongatis ; cor. calyce subangulato majoribus. Jacq. austr, t. 133. B. M. 608. A. panciflora Vill. In Europ. ๑. 3-6-poll. Cor. alba,

5. A. carnea $\boldsymbol{L}$. scapo stellato-piloso; fol. lineari-attenuatis integerrimis rigidis. Rchb. ic. 786. B. Cab. 40. Aretia L. In Alp. Europ. 24. 2-5poll. Cor. carnea.

6. A. valerianoides Lehm. fol. ohlongo-lanceolatis dentatis glahris sulciliatis; umbella capitata multiflora suhtomentosa; cor. calycem excedente. In Asia minore, $\odot$.

\%. A. lactillora Fisch. fol. lanceolato-linearibus elongatis glabris apice inciso-dentatis ; cor. calycem excedente. A, alismoides Horn. A. coronopifolia Andr. t. 617. Gmel. sil. IV. t. 43. In Sibiria. 24. Cor. alba.

S. A. primulina spr. fol. lanceolatis acutis pimnatifido-serratis utrinque scapoque pubescentibus; unbella 3-flora; fauce cor. villosa. A. primuloides Don. A. pusilla Wall. In Nepalia.

9. A. filiformis Retz; glabra; fol. petiolatis ovatis denticulatis glancescentilus; cor. calycem excedentibus; laciniis integerrimis. Gmel. sil. IV. $t$. 44. f. 4. In Nibiriu. $\odot$. Scapi nแmerosi. Cor. minutissima alha. 
10. A. odoratissima Schreb. Dec. pl.t. 4. subpilosa; fol. imbricatis lineari-triquetris glanduloso-ciliatis ; laciniis cor. ovatis. In Cappadocia. 4. Cor. alba.

11. A. villosa $I_{1}$. fol. conniventirosulatis oltusis incano-harbatis. Jacq. Coll. I. t. 12. Rchb. ic. 788. In Alp. Europ. 4. 1-2-poll. Cor. carnea fance crocea.

12. A. occidentalis Pursh; tenuissime pubescens; fol. involucrisque oblongo-spatlulatis integerrimis; calyce angulato. Ad $f l$. Missuri. $\odot$. A. elongatae affinis.

13. A. Lehmanniana Spr. Diar. Isis. t. 9. fol. ovali-oblongis hirsutis ciliatis venosis integerrimis; umbella capilata; cal. laciniis obtusis. In Oriente.

11. A. incana Lam. piloso-incana; fol. lanceolatis minimis sericeis glonerato-caespitosis; pedicellis involucro longioribus. In Sibiria. Scapi alibido-pilosi.

15. A. Chamaejasme Wulf. fol. lanceolatis explanatis longissime ciliatis; scapo villoso. Rchl.. ic. 789. 790. B. Cah. 232. A. villosa Jacq. austr. t. 332. In Alp. Europ. 4. Cor, alba disco purpureo.

16. A. albana Stev. Linn. Trans. $\boldsymbol{X I}$. $t$. 33. fol. spathulatis inciso-dentatis ciliatis; umbella capitata villosa; cor. calycem excedente. In Cauca\&o. 2. Cor. pallide carnea.

1\%. A. carinata Torr. fol. congestis ovato-lanceolis acutis carinatis ciliatis; scapo villoso; cal. laciniis obtusis. Ann. of the Lyc. of New-York 1. t. 3. f. 1. In Amer. bor.

18. A. sarmentosa Wall. sarmentis elongatis radicantibus; fol. aggregatis spathulatis mucronatis integerrimis villosissimis. A. lanuginosa Wall. cat. In mont. Emodi.

19. A. rotundifolia Sm. Ex. bot. $t$. 113. fol. subrotundis crenatis longe petiolatis subvillosis; cor. calycem aequante. In Ind. orient. Cor. albido-rosea.

20. A. cordifolia Wall. fol. cordato-ovatis obtusis sinuatis crenatis petiolatis villosis; involucris setaceis; cor. calycem campanulatam superante. In Nepalia.

21. A. Gmelini Gaertn. fol. reniformibus grosse crenatis pilosiusculis longe petiolatis; calyce corollam ex- cedente. Ledeb. ic. Fl. ross. t. 170. Gmel. Sil). 4. t. 43. f. 1. In Sibiria. 4. Cor. alba.

\section{b. Flores solitarii.}

22. A. Aretia Lapeyr. fol. linearilingulatis simpliciter pilosis; cal. dentibus lanceolatis tubum cor. aequantibus. Aretia helvetica schk. t. 32. Andr. bryoides DC. ic. gall. t. 7. In Helvetia. 4. 1-6-poll. Cor. alba.

23. A. argentea Lapeyr. ic. ined. t. $6 \%$. fol. imbricatis incano-lanatis; capsulis intra calycem pedunculatis; receptaculo stellato. Aretia tomentosa. Schleich. Labr. Schwz. Pfi. f. 26-28. In Europ. med. 4 . Cor. carnea.

24. A. alpina Lam. ill. $t$. 98. $f$. 3. fol. lanceolato-spathulatis sparsim simplici-furcatoque pubescentibus. Hall. ic. t. 11. en. t. 8. A. ciliata DC. ic. gall. t. 6. In Alp. Europ. 4. Cor. alba.

25. A. diapensioides Lapeyr. Fl. pyr. t. 3. fol. sublinearibus carinatis ciliatis recurvis; calycibus calyculatis. A. pyrenaica Lam. In Pyrenaeis. 4. Cor. alba.

26. A. Vitaliana Lapeyr. fol. linearihus acutis rigidis rosulatis subtus margineque stellato - pubescentibus. Primula L. Aretia IV. B. Cab. 66. In Alp. Europ. . Cor. magna lutea.

2\%. A. caespitosa Lelım. caule frutescente ramoso; fol. imbricatis lanceolatis ciliatis basi vaginantibus; pedunc. calycibusque glabris. In Persia.

28. A. frutescens Lapeyr. pyr. $t$. 48. caule ramoso frutescente; fol. imbricatis oblongis obtusiusculis villosis annotinis reflexis; pedunc. calycibusque villosis. A. cylindrica DC. In Pyrenaeis. $\frac{1}{2}$.

29. A. dasyphylla Bunge; scapis bilbracteatis; fol. linearibus dense imbricatis conniventilons subtus calycibusque ovatis villosis. Ledeb. ic. ross. t. 15. In mont. Altaicis. 4. Cor. alba.

30. A. Heerii; fol. lineari-lingulatis furcato-pilosis pilis internixtis simplicibus; flore subsessili; cal. dentibus dilatatis. Aretia Heg. Labr. f. 7-9. In Alp. Helvetiae. 4. Cor. caerulescens.

31. A. arctica Chamiss. fol. oblongis rigidis maryine revolutis, supra 
dense furcato-pubescentilus, subtus glaberrimis. In ora occid. Amer, arct.

\section{DOLGLASIA Lindl. (182\%).}

1. D. nivalis Lindl. B. R. 1856. In nive montium scopulosorum Amer. bor. ち. suffrutex pubescens, pube rigide ramosa. Fol. linearia semiamplexicaulia. Flor. purpurei.

\section{HUMBERTIA Juss. (17S9).}

1. I. madagascariensis Lam. ill. t. 105. $\mathrm{Sm}$. ic. t. \%. In Madagascar. ち. Arbor alta. Fol. sparsa ovatolanceolata integerrima. Flor. magui similes Couvolvuli.

\section{STYPHELIA ST. (1793).}

1. St. latifolia $R$. Br. fol. late ovatis acutis imbricatis margine scabris; floribus erectiusculis. In Nov. Holl. ђ.

2. St. tubiflora Sm. Nov. Holl. $t$. 14. fol. lineari-obovatis mucronatis supra scabriusculis margine revolutis; foribus nutantibus. In Nov, Holl. $\hbar$.

3. St. reflexa Rudge; fol. oblougis acutis revolutis; racemis terminalibus subcapitatis. In Nov. Holl. $ち$.

4. St. triflora Andr. Rep. $t$. 72. fol. elliptico - vel oblongo-lanceolatis planis glaucis ; ramulis plabris ; flaribus corymboso-approximatis. In Nov. Holl. $\hbar$.

5. st. viridis Andr. Rep. t. 312. fol. ovato-oblongis mucronulatis plauis supra laevibus margine scalris; floribus divaricatis. In Nov. Holl. $\hbar$.

6. St. Lueta R. Br. Rchb. Hort. $\boldsymbol{t}$. 99. fol. imbricatis oblongo-lanceolatis planis glaucis denticulatis scabris; ranulis pubescentibus; caule erecto. In Nov. Holl. $\hbar$.

7. St. adscendens $R$. Br. fol, lanceolatis planis marginibus dentatociliatis scabris, subtus glaucis; striis manifestis; caule diffuso. In Nor. Holl. 支.

8. St. longifolia $\boldsymbol{R}$. Br. fol. elongato-lanceolatis apice attenuatis supra concaviusculis margine laevibus; rumulis pubescentibus. In Nova Hollandia. $\hbar$.

9. St. involucrata R. Br. fol. oblongo-lanceolatis nervosis; ramulis pulescentibus; calycibus ciliatis. Pentachondra R. Br. In ins. Van Diemen. $\begin{gathered}\text {. } \\ \text {. }\end{gathered}$

10. St. glaucescens Sieb. fol. lanceolatis mucronatis integerrimis subtiliter striatis glaucis; pedunc. 1-floris. In Nov. Holl. ђ.

792. ASTROLOMA R. Br. (Styphelia Spr.) (1810).

1. A. humifusum R. Br. prostratum ; ramosissimum ; fol. lanceolatolinearibus supra convexiusculis margine ciliatis. Ventenatia Cav. ic. t. 348. In Nov. Holl. ђ.

2. A. prostratum $R$. Br. ramosissimum; tandem erectiusculum; fol. lanceolato-linearibus ciliatis supra planis subtus convexiusculis. In Nov. Holl. †.

3. A. denticulatum $R$. Br. procumbens; nunc erectiusculum ; fol. lanceolatis planis ciliatis; ciliis basi dilatata. In Non. Holl. 古.

4. A. pallidum R. Br. diffusum; ramis adscendentibus; fol. lanceolatis sessilibus ciliatis imbricatis supra concaviusculis. In Nov. Holl. $ち$.

5. A. compactum R. Br. diffusum; ramulis adscendentibus brevissimis; fol. ovato-lanceolatis ciliatis petiolato-attanuatis supra concaviusculis. In Nov. Holl. $\hbar$.

6. A. tectum R. Br. erectum; subramosum ; fol. lanceolato-oblongis planis imbricatis naruine scabris, denticulis brevissimis obtusis. In Nova Hollandia. $\hbar$.

\section{STENANTHERA R. Br. (1810).}

1. S. pinifolia R. Br. In Nor. Holl. ち. Frutex crectus. Fol. confertissima acerosa. Flor. axillares erecti, tubo coccineo, limbo flavo vir rescente.

794. MELICHRUS R. Br. (1810).

1. M. rotatus $\boldsymbol{R}$. Br. cor. rotatis; calycibus villosis; fol. lanceolato- 
linearihus utrinque marginihusque pilosis. Ventenatia procumbens Cav. ic. t. 349. In Nov. Holl. ち.

2. M. urceolatus R. Br. cor. urceolatis; calycibus glabris; fol. lanceolatis apice attenuatis, marginibus denticulatis. In Nov. Holl. ђ.

\section{ซ9.5. CYATHODES R. Br. (1810). (Styphelia Spr.)}

a. Corollae laciniae barbatae, axi intus simplici.

1. C. glauca Labill. Nov. Holl. $t$. 81. drupa 8-10-loculari; fol. interrupte confertis subverticillatis patulis divaricatisque lineari-lanceolatis. In Nov. Holl. ち.

2. C. straminea $\boldsymbol{R}$. Br. drupa 5loculari; fol. interrupte confertis subverticillatis ovalihus ohtusis muticis patulis subtus multinervibus. In Nov. Holl. .

3. C. dealbata $R$. Br. drupa 2-5loculari; fol. linearilus erecto-patulis mucrone tahescente subtus 1-3-nervibus; caule procumbente. In Nov, Holl.t.

b. Corollae laciniae imberbes axi intus saepius elevato.

4. C. parvifolia $\mathrm{R}$. $\mathrm{Br}$. fol. lineari-lanceolatis patulis hrevissime ciliatis, sulutus 5-nervihus; nervis omnibus simplicilus, In Nov. Holl. $\hbar$.

5. C. oxycedrus Labill. . c. t. 69. fol. linearibus patulis margine nudis, subtus 3-5-nervibus; nervis omnibus simplicibus. In Nov. Holl. 古.

6. C. abietina Lubill. l. c. t. 68. absquc flore; fol. lineari-lanceolatis confertissimis imbricatis. In Nova Hollandia. 市.

\section{\%96. LYSSANTHE R. Br. (1S10). (Styphelia Spr.)}

a. Calyx ebracteatus.

1. I. sapida $\boldsymbol{R}$. $\mathrm{Br}$. racemis $2-3$ foris recurvis; fol. oblongo-linearihus mucronatis margine revolutis subtus dealhatis striatis. In Nor. Holl. ち.

2. I. subulata $R$. $\mathrm{Ir}$. racemis $\downarrow-$ 5-floris crectis; fol. lineari-subulatis; ramulis glahris; drupis 10 -striatis. In Nor. Holl. $\hbar$.

3. L. strigosa $\boldsymbol{R}$. Br. racemis subspicatis ereclis paucifloris; fol lincari- subulatis ; ramis pubescentibus ; drupis vix sulcatis. In Nov. Holl. $\hbar$.

b. Cal. 2-bracteatus.

4. L. montana R. Br. fol. oblongo-linearibus obtusis muticis subtus glaucis. In Nov, Holl. ち.

5. L. daphnoides R. Br. fol. elliptico-lanceolatis concaviusculis mucrone calloso brevissimo; cor. laciniis glaberrimis. Styphelia Sm. In Nov. Holl. †.

6. L. ciliata R. Br. fol. ellipticolanceolatis planis mucrone pellucido; marginibus serrulato-ciliatis. In Nov. Holl. t.

797. LEUCOPOGON R. Br. (1810). (styphelia Spr.)

a. Spicae axillares multiflorae. Drupa baccata.

1. L. Lanceolatus R. Br. spicis nutantihus aggregatis; drupis ovalibus; fol. lanceolatis planis 3-nerviis; ramulis glabris. St. parviflora Andr. Kep. t. 287. st. Gnidimm Vent. malm. t. 13. In Non. Holl. ち.

2. L. australis $R$. Br. spicis erectis ; drupis depresso-globosis 5-locularibus; fol. lineari-lanceolatis mar-

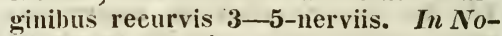

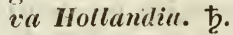

3. L. Richei Labill. Nov. Holl. $t$. 60. spicis erectis; drupis 5-locularibus; fol. ohlongo-lanceolatis extra medium latiorihus; marginibus recurvis. In Nov. Holl. ђ.

4. L. affinis R. Br. spicis erectis; drupis ovalibus 2 - 3 -locularibus; fol. elongato-lanceolatis planis. In Nov. Holl. $ち$.

5. I. intermutiis $R$. $R r$. spicis terminalibus; fol. ad apicem ramorum verticillato-confertis ellipticis patentibus multinerviis. In Nora Hol.. $\hbar$.

6. I. verticillutus $R$, $B r$. spicis aggregatis, fructiferis mutantihus; drupis putamine 5-gono; fol. interupte verticillatis ohlongo-lanceolatis apice attenuatis. In Nov. Ifoll. t.

\%. L. Cymbulae Jabill, Nor. Cal. $t$. 39. fol. petiolatis contrestis lanceolatis concavis rufis; bracteis ciliatis. In Nor. Caled. 5 .

8. I. fasciculatus Rich. arboreus; fol. confertis linearihus acuminatis; racemis spicatis cernuis. In Nora Zeelandiu. 
b. Spicae axillares pauciflorae. Drupa exsucca.

9. L. apiculatus $\boldsymbol{R}, \boldsymbol{B r}$. fol. lanceolato-oblongis erectis concaviusculis maryine laevibus mucromulo calloso; drupis crustaceis depresso-turbinatis. In Nov. Holl. $\hbar$.

10. I. polystachyus $R$. Br. spicis 7-10-floris; fol. lineari-lanceolatis muticis convexiusculis; ramulis virgatis; drupis exsuccis apice depresso. In Nov. Holl. $ђ$.

11. L. multiflorus $R$. Br. spicis folio hreviorilus; fol. lanceolatis subacuminatis mucronatis inıbricatis, marginibus laevibus; calycibus hracteisque margine lanatis. In Nova Hollandia. $\bar{b}$.

12. L. rubricaulis $R$. Br. spicis 4-5-floris; calycibus bracteisque glabriusculis; fol. lineari-oblongis ohtusis muticis, marginilus subrecurvis denticulatis. In Nov. Holl. $\hbar$.

13. L. villosus R. Br. spicis terminalibus; fol. lineari-oblongis muticis erecto-patulis utrinque ramulisque villosis marginibus denticulatis. In Nov. IIoll. $\hbar$.

11. I. obovatus R. Br. spicis terminalibus; fol. obovato-oblongis obtusis mucronulatis margine subrecurvis. Styphelia Labill. Nov. Holl. t. 67. In Nov. Holl. ђ.

15. L. revolutus $R$. Br. spicis 45-floris; calycihus bracteisque tenuissime pubescentibus; fol. lineari-oblongis subtus lineatis margine recurvis. In Nov. Holl. ђ.

16. L. margarodes $\boldsymbol{R} . \boldsymbol{B r}$. spicis subtrifloris; fol. linearibus obtusis muticis marginibus recurvis; drupa hasi haccata, supra compressa. In Nov. Holl. 支.

17. L. muticus R. Br. spicis $3-$ 6-floris; fol. lineari-ohlongis obtusis muticis erecto-patulis, marginibus laevibus subrecurvis; drupis angulatis. In Nor. Holl. $\hbar$.

18. L. trichocarpus R. Br. spicis suhnutantibus 3 -floris; fol. lineari-oblongis ohtusis mucronulatis; drupis angulatis pilosis. styphelia Labill. I. c. t. 66. In Nov. Holl. ち.

19. I. ericoides $\boldsymbol{R}$. Br. spicis approximatis $3-4$-floris; fol. oblongolinearibus mucronatis margine recurvis; calycibus membranaceis. Epacris spuria Cav. ic. t. 347. f. 1. In Nov. Holl. $\hbar$.

20. L. mopinquus R. Br. spicis sub-3-floris; fol. lanceolato-linearibus setace - mucronatis maryinibus revolutis extrorsum denticulatis. In Nov. Holl. ち.

21. L. viryatus $R$. Br. fol. linearibus apice acutissimis imbricatis patulis margine ciliatis; calycilous bracteisque submembranaceis. styphelia Labill. t. 64. In Nov. Holl. $\frac{\hbar}{}$.

22. L. collinus R. Br. fol. oblongo-linearibus muticis erectis marginihus recurvis denticulatis; bracteis foliaceis. Styphelia Labill. t. 65. In Nov. Holl. ‡.

b. Spicae axillares v. terminales. Fol. cordata.

23. L. amplexicaulis $\boldsymbol{R}$. Br. fol. cordatis anplexicaulibus muticis subtus minute pubescentibus ramulisque villosis. Styphelia Rudge Limn. Trans. t. 8. In Nov. Holl. .

24. L. alternifolius $R$. Br. fol. alternis reniformibus amplexicaulibus acutis muticis; spicis paucifloris; ramulis glabris; drupis bilocularibus. In Nou. Holl. †.

2.5. L. distanis R. Br. fol. ovatis subcordatis divaricatis muticis supra convexis subtus pubescentibus; drupis 5-locularibus depresso-obovatis. In Nov. Holl. t.

26. I. reflexus $R$. Br. fol. ovatis subcordatis muticis reflexis divaricatisve subtus concavis pilosis; drupis 5-locularibus. In Nor. Holl. ђ.

27. I. glabellus $R$. Br. bracteis foliaceis calycibusque glahris; fol. alternis late cordatis acutis muticis ramulisque glabris. In Nov. Holl. $\hbar$.

d. Spicae terminales. Fol. non cordata.

28. I. denudatus Sieb. fol. linearibus acutis erectis glahris integerrimis; floribus aggregatis. In Nor. Holl. ち.

29. L. microphyllus R. Br, fol. ovalibus obtusis muticis planis patoinis concoloribus; drupis 1-2-locularibus. Perojoa Cav. ic. t. 349. f. 2.

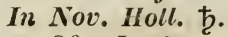

30. L. tamariscinus $R$. Br. fol. imbricatis adpressis ovatis muticis 
concavo-convexis subtus lineatis ramulisque glabris. In Nov. Holl. 支.

31. L. gracilis $\boldsymbol{n}$. Br. fol. lanceolato-linearibus erectis concavo-convexis nuticis subtus nervosis 3-lineatis ; drupis 2-locularibus. In Nor. Holl. ち.

32. I. striatus $R$. Br. fol. ellipticis muticis erectis suhtus convexiusculis nervosis; ramulis glabris; liracteis calycihusque subfoliaceis nudis. In Nov. Holl. 古.

33. L. nervosus R. Br. fol. ellipticis imbricatis breve petiolatis muticis supra planis subtus convexiusculis; nervis elevatis ramulisque pubescentibus. In Nov. Holl.

34. L. carinatus $R$. Br. fol. lanceolatis muticis imbricatis supra planis subtus carinatis marginibus denticulatis; ramulis pubescentibus. In Nov. Holl. ち.

35. L. assimilis R. Br. fol. Ianceolato-linearibus imbricatis adpressis muticis sultus convexis striatis, concoloribus denticulatis. In Nov. Holl. $\hbar$.

36. I. cucullatus R. Br. fol. ovatis obtusis muticis cucullatis imbricatis sessilihus suhtus liueatis margine nudis. In Nov. Holl. ち.

e. Pedunculi axillares biflori seu 1-flori. Drupa exsucea.

3\%. L. fastigiatus Sieb. fol. Ianceolatis cuspidatis apice serrutatis erectis striatis; cal. glaberrimis. In Nov. Holl. ち.

38. L. malayanus Malayn. misc. 1. fol. lanceolatis acutis integerrimis suhíus glaucis punetatis; stipulis axilIaribus erectis. In Peninsula Maiacc. ந.

39. I. pendulus $\boldsymbol{R}$. Br. fol. obIongo-linearilus erecto-patulis unucrone innocuo, marginilus laevibus; drupis elevatis ventricosis. In Nov. Holl. ち.

40. I. biflorus R. Br. pedunc, hifloris recurvis; fol. patulis linearilanceolatis planis mucrone pungente.

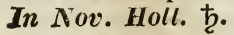

41. L. setiger $\boldsymbol{R}$. $\boldsymbol{B r}$. pedunc. hifloris recurvis calyce longioribus; fol. patulis lanceolato-linearihus acuminatis mucrone setaceo pungente. In Nov. Holl. ‡.
12. I. acuminatus $R$. $B r$. pedunc. brevissimis ereetis sublhiforis; fol. erectiusculis linearibus acutissimis planis mucrone setaceo. In Nova Hollandia. ђ.

43. I. cuspidatus $R$. Br. pedunc. brevissimis erectis $1-\mathbf{z}$-floris; fol. modice patentibus ohovato-ohlongis cuspidatis margine scabris denticulatis. In Nov. Holl. $\hbar$.

41. I. imbricatus $R$. Br. pedunc. brevissimis erectis 1-2-floris; fol. imbricatis ovalibus obtusis cuspidatis, marginibus laevibus, In Nov. Holt. t.

45. L. ruscifolizs $\boldsymbol{R}$. $\mathrm{Br}$. pedunc. brevissimis erectis subbifloris; fol. erecto-patulis ovato-ellipticis mucronatis onsoletissime denticulatis. In Nov. Holl. †.

46. L. pauciflorus $\boldsymbol{R}$. $B r$. peduno. brevissimis erectis subbifloris; fol. angusto-lanceolatis modice patentibus planis, mucrone brevissimo calloso. In Nov. Holl. ђ.

4\%. L. leptospermoides $\boldsymbol{R}$. Br. fol. linear-lanceolatis nodice patentibus acutissimis rigidulo-mucronulatis, marginibus minute denticulatis. In Nov. Holl. ち.

43. L. rotundifolius $R$. Br. fol. subrotundis ovatisve petiolatis planis mucronulatis, marginihus pellucidis tenuissime ciliatis. In Nov. Holl. $\hbar$.

49. L. juniperinus $\boldsymbol{R}$. $\boldsymbol{B r}$. fol. divaricatis lanceolato-linearihus setace 0 - mucronatis, marginibus recurvis hrevissime denticulatis. In Nov. Hollandix. $\hbar$.

50. $\boldsymbol{L}$. deformis $\boldsymbol{R}$. Br. fol. erectopatulis lanceolato-linearihus concaviusculis mucronatis obsolete denticulatis. In Nov. Holl. ‡.

51. L. flexifolius $\boldsymbol{R}$. Br. fol. confertissimis imbricatis linearibus mucronatis tortilibus scabro-denticulatis. In Nov. Holl. ఫ.

52. L. esquamatus R. Br. fol. sparsis erecto-patulis lanceolatis subacuminatis mucronatis planis aversis,

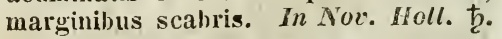

53. L. Forsteri Rich. arboreus; fol. sparsis linearibus cuspidatis serrulatis; floribus sessilibus solitaris. In Nov. Zeelandia. 


\section{ACROSTTCHE R. Ir. (1810).}

1. A. direricuta R. Mr. fol. Ianceolatis mucronatis divaricatis planis utrinque viridihus; spicis axillaribus. In Nor. Holl. $\hbar$.

2. A. aggregata R. Br. fol. obIongo-lanceolatis concaviusculis suhtus glaucis marginibus laeviluss. In Nor. Holl. 古.

3. A. ramiflora R. Br. fol. lineari-lanceolatis mucronatis divaricatis subtus discolorihus nervosis marginibus recurvis. In Nor. Holl. t.

4. A. serrulatus R. Irr. fol. lineari-lanceolatis cuspidatis patulis pilosis et glahriusculis, maruinibus serrulato-ciliatis. In Nov. Moll. 方.

5. A. putula R. Br. fol. ovatolanceolatis acuminatis mucronatis planiuseulis ramisque divaricatis. In Nov. Holl. t.

6. A. ovalifolia R. Br. fol. ovatis ovalibusque obtusis muticis planis margine laevihus; spicis axillaribus; drupis subcellulosis. In Nor. Holl. $ђ$.

\%. A. cordata R. Br. fol. cordatis planis subtus striatis; floribus axillaribus hinis solitariisve. Styphelia Labill. Nov. Holl. t. 63. In Nora Hollandia. ђ.

8. A. depressa $\boldsymbol{R}$. $\boldsymbol{B r}$. fol. ovatis selbcordatis mucronatis divaricatis supra convexis subtus venosis; caule depresso; spiculis rameis. In Nova Hollandia. ந.

\section{TROCHOCARPA R.Br. (1810).}

1. T. laurina $R . B r$. In Nor. Holl. ᄒ. Styphelia cornifolia. Rudge Linn. 'Trans. t.9. Arbor parva liyno durissimo. Fol. laurina. Flor, albi.

\section{DECASPORA R. Br. (1S10).}

1. D. disticha R. Br. fól. Ianceolatis aculissimis planis subtus nervosis petiolo bies longioribus. Cyathodes Labill. I. c. t. 82. In Nov. Hollandia. $\hbar$.

2. D. thymifolin R. Br. fol. ovatis acutiusculis muticis petalo vix 4-plo longiorihus suhtus obsolete 5 -nervibus; ramulis pubescentibus. In Nova Hollandia. $\hbar$.

\section{S01. NOLANA L. (176t).}

1. N. prostrata L. fol. ovato-ohIongis; calycibus pyramidatis; laciniis triangulari-sagittatis. L. fil. dec. 1.t. 2. Atropa Gouan H. mons. t. 82. In Peruviu. $\odot$. Cor. pallide caerulea.

2. N. spathulata R. et $\boldsymbol{P}$. peruv. t. 113. f. a. caule erecto; fol. cordato-3-angularibus; calycis laciniis spathulatis. In Peruvia. $\odot$.

3. N. inflata R. et P. peruv. $t$. 112. f. a. caule prostrato; fol. radic. longe petiolatis ovato-lanceolatis; cal. inflato. In l'eruvia. $\odot$. Pedalis. Cor. alho-violacea.

t. N. revoluta $R$. et $P$. peruv. $t$. 113. $f$. b. caule procumbente; fol. confertis linearibus margine revolutis; cal. ventricosis. In Perucia. $\odot$. $\frac{1}{2}$-ped. Cor. caeruleo-violacea.

5. $N$. coronata $R$. et P. peruv. $t$. 112. f. b. caule prostrato; cal. laciniis subcordatis; cor. fauce villosa. In Peruvia. $\odot$. Caul. ramosissimus. Cor. albo-caerulea.

6. N. paradoxa Lindl. B. R. 862. caule prostrato foliisque ovatis obtusis petiolatis hirsutis; linho cor. 10loho; nuculis coronatis 1-spermis. In Chili. $\odot$.

\section{TRIGUERA Cav. (1790).}

1. T. ambrosiaca Cav. diss. app. $\boldsymbol{t}$. A. caule sulcato alato; fol. superioribus obovatis dentatis pnbescentibus decurrentibus. Lam. ill. t. 114. Circa Cordona. $\odot$. 1-ped. Cor. purpureo-violacea.

2. T. inodora Cav. fol. ovatolanceolatis integerrimis glabris vix decurrentibus. Cum priore. 4. Caul. 6-8-poll. Flor. laete violacei.

\section{SO3. CHRYSOPHYLLUM L. (1638).}

a. Fol. subtus vestitis.

1. C. Cainito L. fol. ovatis parallele striatis subtus tomentoso-nitidis. Jacq. am. t. 37. f. 1. pict. t. 51. B.M. 3072. In Ind. occ. $\hbar$. Arbor procera. Flor. parvi inodori albidi.

2. C. splendens $\mathbf{S} \mathrm{mr}$. fol. ellipticooblongis supra nitidis subtus ferrugi- 
neo-tomentosis Iucidis. Nycterisition ferrugineum $R$. et $P$. peruv. t. 187. In Peruvia. $\hbar$.

3. C. monopyrenum Sw. fol. oblongis acuminatis subtus tomentosoaureis; fructu ovato 1-pyreno. Burm. Amer. t. 69. B. M. 330s. In Ind. occ. ち. Cor. tomentosa. Bacca caerulea.

4. C. angnstifolium Lam. fol. lanceolatis parallelo-striatis nitidis subtus tomentoso-ferrugineis; baccis olivaeformibus. In Nomingo. $\hbar$. Affuis Oleae.

5. C. bicolor Poir. fol. ovatis subacuminatis subtus puhescenti-aureis argenteisque; fructu pyriformi. In Portorico. $\hbar$.

6. C. argenteum Jacq. am. t. 38. pict. $t$. 5 t. fol. falcato-ovatis subtus tomentoso-nitidis. In Martinica. $ち$. Fructus sordide purpurei.

7. C. microcurpon $\$ w$. fol. ovatis glahris subtus pubescentilus; baccis oblongis obliquis 1-spermis. In Hispaniola. Ђ. Cor. alba. Fructus dulcissimus.

8. C. macrophyllum Lam. fol. obovatis supra nitidis subtus ferrugineosubsericeis parallele venosis. Bumelia nervosa Vahl. C. Cainito Aubl. In Gujana. ち.

b. Fol. subtus gla bris.

9. C. glabrum Jac\%. am. t. 38. f. 2. pict. $t$. 55. fol. ovato-oblongis utrinque glaberrimis; fructu ellipticolaevi. In Martinica. ‡. Arbor 15ped.

10. C. pyriforme Willd. fol. utrinque glabris ovato-oblongis acuminatis; fructu pyriformi luteo laevi. C. Macoucou AunI. Guj. t. 92. In Gujanc. $\downarrow$. Arbor 30-ped. Cortex lactescens.

12. C. pomiforme Bert. fol. oblongis utrinque attenuatis glaberrimis opacis tenuissime parallele venosis coriaceis; fructu pomilormi. In $\mathrm{Ja}$ muicu. $ђ$.

13. C. Michino H. et $K$. fol. obovatis ohtusiusculis basi acutis utrinque glaberrimis concoloribus; fructibus glutinosis. In Nov. Granuta. ち.

1t. C. rugosum su: fol. oblongis acuminatis utrinque glabris; fructu acuminato rugoso. In Jamaica. $\hbar$. Fol. magna. Cal, ferrugineus.

\section{LUCUMA Juss. (178.9).}

1. L. mammosa Juss. fol. cuneiformi-lanceolatis; floribus solitariss. Achras L.A. Sapota major. Jacq. am. t. 182. f. 19. pict. t. 59. In Amer. austr. ち. Arlsor magna. Cor, albida.

2. L. Caimito R. et $S$. fol. olovato-lanceolatis; florilus aggregatis tetrandris. Acliras $\mathbf{R}$. et $\mathbf{P}$. peruv. t. 240. In mont. Andium. ち. Arbor frondosissima.

3. L. obovata $H$. et $K$. fol. obovato-ellipticis apice rotundatis basi acutis, membranaceis glabris; cal. fuscescenti-tomentosis. Achras 1R. et P. peruv. t. 239. In Peruvia. ђ.

4. L. Bonplandii $\boldsymbol{H}$. et $\boldsymbol{K}$. fol. obovato-oblongis obtusis inferue cuneatis chartaceis; petiolo calycihusque pubescenti - tomentosis. In Havanna culta. $\hbar$.

5. L. Serpentaria $H$. et $\boldsymbol{K}$. fol. obovato-oblongis apice rotundatis hasi acutis coriaceis glaberimis supra nitidis. In Cuba. †.

6. L. compechiana $H$. et $K$. fol. oblongis acuminatis hasi acutis membranaceis glabris nitidis; calycibus pedunculoque temuissime canescentitomentosis. In Mexico. $\hbar$.

7. L. salicifolia Bonpl. fol. Ianceolatis subacuminatis basi angustatis memlıranaceis glabris nitidis; calycibus pedunculoque tenuissime tomentosis. In Mexico. ち.

8. L. Temare Bonpl. fol. lanceolatis subacuminatis hasi angustatis undulatis membranaceis glabris. Ad Orinocum. ち.

\section{JACQUINIA L. (1761).}

1. J. arborea Vahl; fol. subquaternis ovato-oblongis obtusis coriaceis glaberrimis; pedicellis apice incrassatis. In Ind. occ. et Amer. austr. 30-ped. Flores albi.

2. J. armillaris Jacq. am. $t$. 39. pict. t. 56. fol. ovato-cuneiformibus; ramis nodosis verticillatis. In Amer. calid. ち. 4-6-ped. Cor. alba Jasminum spirans.

3. J. muescens H. et K. Nov. Gen. t. 246. fol. sparsis summis subverticillatis ovato-oblongis mucronato-spiniferis subtus pubescentibus. J. mucronata W. Ad flum. Amazonum. 
4. J. Berterii Spr. fol. sparsis subspathulatis acutiusculis coriaceis glaberrimis; corymbis panciforis. In Hispaniola. $\hbar$.

5. J. ruscifolia Jacq. prict. t. 5\%. fol. Ianceolatis acuminatis; ramis aculeatis. Dill. Elth. f. 119. I $n$ Amer. austr. t. 3-ped. Flor, penduli.

6. J. macrocarpa Cav. ic. t. 483. fol. rugillis lanceolatis; floribus aurantiis; haccis cerasiformilus. Ad Panamam et Acapulco. $ђ$. Arbuscula 8-ped. Cor. 10-lohata.

7. J. ferruginea spr. fol. alternis linearibus strictis cuspidatis subcoriaceis subtus ferrugineis venosis; pedunc. paucifloris. In Hispaniola. $\hbar$.

\section{LEEA Royen (1740).}

1. L. sambucina $W$. caule sulcato angulato glabro; fol. subbipinuatis. Aquilicia Cav. diss. t. 218. - Rumph. 4. t. 45. Bheede 2. t. 26. In Ind. orient. ち. 10-12-ped. Cor. albida.

2. L. spinosa spr. caule petiolisque spinosis; fol. pinnatis subtus villosis; foliolis oblongis serratis; panicula terminali. Aralia L. In C'itina et ins. Holucc. $\hbar$.

3. I. aeynatu ${ }^{\circ}$. caule tereti puhescente; fol. pinnatis subtus pubescentilus argute serratis. L. hirsuta Blume. In Ind. orient. ち. Arhor. Corymbi 3-chotomi.

t. L. crispa $L$. caule angulato fimbriato; fol. pinnatis glabris sultus parallele venosis. L. pimnata Andr. Rep. 355. In Prom. b. spei. 24. 3-ped. Flor. nivei.

5. L. scubra Roxb. caule angulato scabro; fol. pinnatis serratis utrinque hispidis. L. hirta Horn. In Ind. orient. 支.

6. 1. robust Roxb. caule tereti 1-sulcato glabro; fol. hipinuatis acuminatis inaegualiter serratis subtus scabris; fol. infinis ternatis. In Java. ち.

7. I. rubra Blume; caule tereti sulcato; fol. hipimatis adveniis subtus asperis; foliolis infimis ternatis ovato-lanceolatis obtuse serratis. In Java. ち.

8. L. jaranica Blume; caule tereti punctato scabro; fol. hipinnatis glahris argute serratis. In Java. ち.
9. L. aculecita Ilume; caule teretiusculo sulcato aculeato: fol. pinnatis glaberrimis grosse serratis. In Java. ち.

10. L. Staphylea Rorb. ramis teretibus; fol. supradecompositis grlabris; foliol.Ineari-ohlongis acuminatis serrulatis. Aquilicia Otillis Gaertn. t. 218. In Ind. orient. ち.

11. I. integrifolia Roxb. fol. supradecompositis subtus puhescentibus; foliolis lanceolatis acuminatis inteᄈerrimis. In Ind. orient. $\hbar$.

\section{S0\%. EUTOCA R. Br. (1823).}

1. E. Franklinii $\boldsymbol{R}, \boldsymbol{B r}$. erecta ; fol. pinnatifidis pilosis; laciniis lanceolatis dentatis. FrankI. Voy. t. ¿\%7. B. H. 1180. B. M. 2985. Ad fl. Missisippi. $\odot$. 6-10 uncialis. Cor. pallide caerulea.

2. E. Menziesii R. Br. erecta; fol. linearibus pilosis; racemis elongatis. Hydrophyllum lineare Pursh. In Amer. bor. $\odot$.

3. E. parviflora R. Rr. diffusa; fol. subsessilihus pinnatifidis; laciniis ohlongis integris; racemis solitariis. Polemonium dubium W. Phacelia Pursh. In Amer. bor. $\odot$.

t. E. bursifolia Spr. fol. pinnatis hirsutiusculis ; foliolis ovato-suhrotundis dentatis, extremo maximo lobato; calycibus hirsutis. Polemonium W. In Mexico. $\odot$.

5. E. pimpinelloirles Spr. fol. pinnatis glahris; foliolis sessilibus ovatis inciso-dentatis; calycihus pubescentibus. Polemonium IV. In Mexico. $\odot$.

6. E. sericea Grah. B. M. 3003. caule suberecto hasi ramoso; fol. yinnatifidis sericeis; filamentis cor. triplo Iongioribus. In Amer. bor. 24. 1-ped. Cor. violacea.

\%. E. viscosa Benth. B. R. 1808. glanduloso-pilosa; fol. cordato-ovatis serrulatis; racenis elongatis fuscatis; caule erecto. B. M. 357\%. In c'alifornia. $\odot$. 2-ped. Cor. amoene caerulea.

8. E. diraricata Benth. B. R. 1782. caule dichotome divaricato; fol. ovatis indivisis; placentis 10-20-0vulatis. In California. $\odot$. Decumbens. Cor. lilacina. 


\section{0s. CORTUSA Matth. (1560).}

1. C. Matthioli L. calycibus corolla hrevioribus. Jacq. ic. t. 32. B. M. 987. Andr. Rep. t. 1. In Alp. austr. et Sibir. 24. Herba ped. Fol. cordata. Hlor. rosei.

\section{ANAGALLIS Diosc.}

1. A. phoenicea Lam. caule prostrato; fol. ovatis 3 -nerviis; Iaciniis cal. integerrimis corolla glandulifera brevioribus. A. arvensis L. Hayne 2. t. 45. E. B. 529. FI. Dan. 88. Schk. t. 36. In agris Europae. $\odot$. Cor. phoenicea.

2. A. caerulea Schreb. caule suberecto; fol. ohlongo-ovatis 5-nerviis; laciniis calycis serrulatis corollam eqlandulosam a equantibus. Hayne 2. t. 46. A. Monelli L. Cum priori. ๑. Cor. caerulea.

3. A. Latifolia $L$. caule compresso; fol. cordatis amplexicaulibus. Hchb. ic. In Inungaria. $\odot$. Cor. caerulea fundo purpurascente.

1. A. Monelli Curt. B. M. 319. adscendens; ramis ramosis subpaniculatis; fol. Janceolatis $3-5$ verticillatis 3-nerviis. A. verticillata All. ped. t. 85. f. 4. A. latifolia B. M. 2389. A. B. Willmoreana B. M. 3380 . In Italia et Tuuria. $\odot$. Pedalis. Cor. maxima azurea.

5. A. parriflora Link; caule decumbente herbaceo; fol. oppositis ovatis sub-3-lierviis; calycibus integerrimis cor. crenulatam aequantibus. In Lusitania. $\odot$. Cor. caerulea.

6. A. collina Schousb. fol. Ianceolatis subternis sessilihus; caule tereti hasi fruticoso; ramis diffusis angulosis. A. frutisosa Vent. Choix t. 14. B. M. 831. In Marocco. ち. 2-3ped. Cor. minuta.

\%. A. repens DC. caule ramisque repentibus; fol. sessilibus ovatis oppositis; pedicellis folio subaequalibus. In Gallia anstr. 4.?

8. A. crassifolia Thore; caule repente; fol. alternis subrotundis crassis subpetiolatis; pedunc. folio breviorilus. DC. ic. t. 4. In turfosis circa Dax. 24.? Cor. alba.

9. A. tenella $L$. caule repente; fol. ovatis acutiusculis; stignate acuto. Gmel. Fl. bad. 1. t. 3. Fl. Dan. 1205.
Curt. Lond. t. 15. In ericetis Europae. (-). Cor. rosea.

10. A. alternifolia Cav. ic. $t$. 506. $f$. 2. caule erecto ramoso; fol. alternis suboblongo-ovatis; pedunc. elongatis. In Chili. Cor. dilute rubra.

11. A. ovalis $R$. et P. peruv. $t$. 11.5. $f$. $a$. caule erecto; fol. ovalibus cum acumine brevi; floribus subsessilibus. In Peruvia. ๑. 4-5-poll. Cal. et cor. minima.

12. A. pumila Sw. caule subramoso; fol. alternis ovatis; pedunc. fol. aequantibus; stylo brevissimo. Centunculus pentandrus $\mathrm{R}$. Br. In Jamaica et Nov. Holl.

\section{S10. LYSIMACHIA Trag. (1551).}

\section{a. Pedunculis multifloris.}

1. I. vinlgaris $L$. fol. ovato-acuminatis; floribus paniculatis; calycibus corolla eglandulosa dimidia capsulaque brevioribus. Fl. Dan. 689. Hayne 8. t. 15. L. guestphalica Weilie $L$. verticillata M. B. In Europa et Asia. 4. Cor. lutea.

2. L. decurrens Forst, racemis terminalibus simplicibus; fol. oppositis decurrentibus lanceolatis. In Nov. Hebrid.

3. L. Ephemerum $\boldsymbol{L}$. fol. linearilanceolatis; racenis terminalibus; petalis obovatis patulis. Till. pis. t. 40. f. 2. Murr. Comm. 1782. t. 2. In Sibiria, Pyrenaeis et Japonia. 4.

4. L. dubia Ait. fol. Ianceolatis petiolatis; racemis termiualibus; petalis conniventibus; staminihus cor. brevioribus. sibth. gr. t. 188. I. atropurpurea Murr. 1. c. 1782. t. 1. In Caucaso et Oriente. 4.

5. L. atropurpurea $\boldsymbol{L}$. spicis terminalibus; staminibus corolla acuta longioribus; fol. Ianceolatis giaucis subtus punctatis. In Asia minore. 24.

6. L. stricta Ait. racemis simplicibus laxis elongatis ; laciniis cor. lanceolatis patulis ; fol. lanceolatis utrinque attenuatis punctatis. L. racemosa Michx. In America bor. 4.

7. L. lanceolata Pursh; glaberrima; fol. quaternis lanceolatis acuminatis; pedunc. 4-nis multifloris; cor. laciniis ovatis acutis. In Carolina. 4. Cor. lutea. 
8. L. anyustifolia Michx. racemis terminalibus ahlueviatis; Iaciniis cor. oblongis; fol. linearibus elongatis verticillatis punctatis. In Carolina. 4. Flores parvuli lutei.

9. I. thyrsiflora $L$. racemis axillarihus pedunculatis ovatis compactis; staminibus corollam superantihus; fol. lanceolatis sessilibus elongatis puuctatis. Fl. Dan. 517. E. B. 176. Nauenburgia Mnch. In Europa. 4. Fl. lutei.

10. I. javanica Blume; racemis terminalibus elongatis; laciniis corollae ohovatis; fol. lato-lanceolatis utrinque acuminatis in petiolum decurrentibus. In Java. 4.

11. L. darurica Ledeb, ic. Fl, ross. $\boldsymbol{t}$. $21 \boldsymbol{t}$. racemis terminalihus compositis; fol. oppositis ternis quaternisque oblongis margine reflexis. In regione Transbuiculensi. 4. Cor. lutea.

12. L. secunda Don; fol. petiolatis ovatis acutis integerrimis; racemis terminalibus spicatis secundis; floribus cernuis. L. lobelioides Wall. In Nepalia. 4.

\section{b. Pedunculis 1-floris.}

13. L. verticillata Pall. fol. verticillatis oblongo-lanceolatis; petalis obovatis acutis glanduloso-ciliatis ; caule puhescente. In Pannonia et Tauria. 24. Cor. flava.

1t. L. yuadrifolia L. fol. subsessilibus quaternis quinisque ovalihus acuninatis punctatis; cor. Iaciniis ovalibus integris. Lam. ill. t. 101. f. 2. L. hirsuta Michx. In Amer. bor. 4 .

1.5. L. ciliata L. suhpuhescens; fol. oppositis longe petiolatis subcordato-ovatis margine pubescentibus petiolis ciliatis; laciniis cor. crenulatis. Walt. Hort. t. 12. In Amer. bor. 4.

16. L. menctata $L$. fol. oppositis 3-4-nisque ovato-lanceolatis subtus pubescentilus ; petalis ovato-acutis glanduloso-ciliatis; caule lirto. Jacq. austr. t. 366. In Austria et Bohemia. 24. Cor. lutea aureo-punctata.

17. I. longifolia Pursh; glaberrima ; ramosissima; fol. oppositis sessilibus longissimis; cor. laciniis serrulatis. L. 4-flora B. M. 660. In Amer. bor. 2. Planata speciosa.

18. L. hybrida Michx. fol. oppositis longe petiolatis lanceolatis basi sensim acutis; petiolis ciliatis ; floribus cernuis; cor. laciniis crenulatis. I. angustifulia W. In Amer. bor. 4. Cor. parva lutea.

19. I. revolute Nutt. fol. oppositis sessilibus linearihus margine revolutis glabris; pedunc. cernuis ; laciniis cor. crenulatis; dentibus inter filamenta. In Amer. bor.

20. I. heterophylla Michx. fol. oppositis imis suhorbiculatis subpetiolatis, super. linearibus sessilibus hasi ciliolatis; floribus cermuis. In Amer. bor. 4.

21. I. nemorum $\boldsymbol{L}$. fol. ovatis acutis; floribus solitariis flexuosis; caule procumbente. Fl. Dan. 174. E. B. 527. Ephenerum Dod. In Europ. nemoribus. 24. Spithamea. Cor. Iutea.

22. L. Nummularia l. fol. ovatosubrotundis; pedunc. solitariis strictis; caule repente; filamentis glandulosis. E. B. 528. Fl. Dan. 493. Schk. t. 36. In Europa. 2. Cor. lutea.

23. I. maculata R. Br. pubescens; fol. ovatis; pedunc. axillarihus petiolo brevioribus. In Nov. Holl. $\hbar$.

24. L. japonica Thumb. Jap. $t .16$. caule adscendente; fol. subcordatis ohtusis villosiusculis; pedunc. demum reflexis. L. debilis Wall. In Japonia. $\odot$.

25. I. anagalloides Sibth. graec. t. 190. fol. ovatis ohtusis; caule ramosissimo difuso; staminibus laevibus. In Creta. 24. Cor. flava.

26. L. Limum stellatum $\boldsymbol{I}$. caule ramosissimo glahro; fol. lanceolatis sessilibus; calycihus cor. najoribus. sibth. graec. t. 189. Asterolion stellatum Lk. In Gall. et Graecia. ๑. Cor. albo-vireus.

2\%. L. alternifolia ITall. caule erecto 4-gono foliisque alternis petiolatis ohlongis utrinque attenuatis puhescentibus. L. evalvis Wall. L. 4gona Don. In Nepalia.

28. L. pyramidalis Wall. caule erecto tereti; fol. oppositis, inferior. ovato-lanceolatis; superior. linearihus corollam supera ntibus. L. heterophylla Don. In Nepalia.

29. L. cuspilata Blume; pedunc. 1-floris 1-3 fasciculatis cernuis; fol. elliptico-oblongis cuspidatis utrinque hirsutis subtus pallidioribus. In $J(a-$ va. 4. 
30. L. uliginosa Blume; pedunculis 1-floris solitariis; fol. suloppositis ovatis hasi parum attemuatis. In Java.

31. L. asorica Hort. Hafn. fol. hrevissime petiolatis ovato-lanceolatis lateralibus recurvis; cal. foliolis sul)ulatis; caule erecto. B. M. 3273. in ins. Azoricis.

\section{s11. IUDINIA Venten. (1800).}

1. I. manritiana $\mathbf{s} m$. fol. sparsis spathulatis punctatis; pedunc. axillaribus 1-floris; limbo curollae patente. I. spathulata Vent. H. Cels. t. 96. In ins. Bowrbon.

2. L. atropurmurea Link et Otto ic. $t$. 2\%. fol. suhternis spathulatis impunctatis; racemis terminalibus; limbo cor. erecto. In Prom. b. spei.

\section{CYCLAMEN Nicand.}

1. C. europaeum $L$. fol. cordatis acutis lentatis pallide zonatis haseos lobos subincumbentibus; cor. laciniis ovali-lanceolatis aculis. Jacq. ausir. t. 401. Sichk. t. 35. In Europa anstrali. 24. Cor. rosea.

2. C. persicum Will. fol. reniformi-cordatis crenatis; laciniis corollae ohlongis ohtusis. B. M. 44. In Gruecia. 24. Cor. alha fundo purpurea.

3. C. herleraefolium Ait. fol. cordato-7-9-angulatis cremulatis ; cor. laciniis late ovatis acutis. B. M. 1001. Tratt. tah. 251. C. latifolium sihth. gr. t. 185. In Europ. austr. 24. Cor. rosea.

4. C. neapolitamim Ten. t. 118. fol. cordatis angulatis crenatis; laciniis cor. ovatis ohtusis. B. M. 23. 41. C. hederifolium Koch. syu. In Italia. 4. Cor. rosea.

5. C. repundum sibth. gr. t. 186. fol. tenue membranaceis cordatis repandis; angulis obtusis integerrimis mucronatis; cor. laciniis oblongis. In Graeciu et Enrop. austr. Inter omnia tenuissinum. Cor. rosea.

6. C. C'oum Nill. fol. cordato-reniformibus integerrimis; laciniis cor. oblongis obtusis. B. M. 4. B. Cab. 108. in Euroy., Taur. et Graec. 4. Cor. purpurea.

\%. C. aestivum Park. fol. cordatis remote dentatis integerrimisque; lubis hasi distantibus; cor. laciniis fauce ampla patente. Moris s. 13. t. 7. f. 17. C. europaem Lam. ill. t. 100. B. R. 1013. In Italia. 4.

8. C. ficariifolium Rchb. fol. profunde cordatis circuitu ovatis sinuato5 -angulis cremulatis acuminatis; cor. laciniis lanceolatis. C. europaeum E. B. 848. C. hederaefolium Horm. In Europu. 24.

9. ('. sublirstatum lickb. fol. cordato-triangularibus crenatis hasi angulatis; cor. Iaciniis late ovalibus acutis. In Helretia. 4.

10. C. linearifolium DC. fol. linearibus obtusis integerrinis; Iaciniis cor. lanceolatis. In Gallia. 4.

I1. C. indicum I. fol. cordato-orbiculatis obtusiusculis denticulatis; laciniis cor. pendulis. In Keylon. 4.

\section{S13. DODECATHEON I. (1751).}

1. D. Meadia I. fol. ohlongis repando-dentatis; mmellis multifloris laxis; bracteis ovalibus. B. M. 12. lanı. ill. t. 99. In Amer. bor. 24. scapus 8-9-poll. Cor. dilute purpurea.

2. D. integrifolium Nichx, fol. oblongo-ovalibus subspathulatis integerrimis; umbellis paucifloris strictis. Plukil. t. 79. f. 6. In Anier. bor. 4. Flor. pallide caerulei.

3. D. firigidum Cham. fol. sulsspathulatis repando - dentatis ; umhellis paucifloris; pedunc. glandulosis divaricatis; bracteis subulatis. In Amer. bor. 4 .

\section{S11. SOLDANELLA C.Gesn. (1550).}

1. S. alpina L. fol. reniformi-rotundis planis; pedicellis glandulososcabrusculis; cor. aequaliter ad medium fimbriata. B. M. 49. sturm. 1. 20. In Alp. Europ. med. 24. Cor. lilacina. 2. S. montana $U^{\top}$. fol. cordatorotundis subcucullatis varie flexis; pedicell. glanduloso-puherulis ; cor. ultra medium inaequaliter laciniata. B. Cah. 871. B. M. 2163. In Alp. Europ. 4. Cor. saturate caerulea.

3. s. minima Hoppe in sturm 20. fol. orbiculatis hasi non emarginatis; pedicellis glanduloso-puherulis; filamentis antheras subaequantibus. In 
Alp. Eurnp. 2\%. Fol. nummularia. Cor. caerulescens.

4. s. musilla Baumg. sub-1-flora; fol. corlato - reniformibus; pedicello glanduloso - scabriusculo; filamentis antheras suhaeguantibus. Sturm 41. B. Cah. siz.. In Alp. Europ! 4. Flos magutus roseus.

\subsection{PRIMULA Matth. (1.560).}

a. Folia villosa seu pubescentia.

1. P. pracnitens kier. fol. cordatis lohato-dentatis hirsutiusculis; umbella prolifera; involucro laciniato; calyce hasi truncato subventricoso multifido; cor. laciniis dentatis. P. chinensis Lindl. B. 13. . . In China. 4.

2. P. cortusoidles L. fol. cordatis petiolatis duplicato-crenatis glabris suhtus all venas pilosis; petiolis villosis; umiella erecta. Tratt. tab. 422. 442. В. М. 399. Andr. liep. 7. In Silriria et Japonia. 24. Cor. rubella. Valde variat.

3. I'. suareolens Bertol. fol. cordatis petiolatis crenatis subtus alhotomentosis; cal. angulatis; limbo cor. concavo brevissimo. Lehm. t. 1. In Italia. 4. Cor. lutea.

1. P. veris $W$. fol. dentatis rugosis suhtus hirsutis; umbella multiflora; flor. omnibus nutantibus; cal. angulatis; cor. limbo concavo brevissimo. P. officinalis Jacq. E. B. 5. Hayue 3. t. 34. Dict. sc. nat. cah. 4. H. Dan. 433. In Europa. 24. Cor. lutea fundo crocea.

5. P. acaulis All. perl. fol. obovato-ohlongis dentatis rugosis subtus villosulis; umbclla radicali; cor. limbo plano. sturm 14. Fl. Dan. 194. E. B. 4. P. vuluraris sm. In Europa. 24. P. hrevistyla DC. P. grandiflora Lam. Var. in hort. fl. roseis B. M. 229. Cor. pallide lutea.

f. P. elatior $I$. fol. dentatis rugosis utrinque hirsutis; flor. umbellae exteriorihus nutantihus; cal. angulatis ; cor. limbo plano. P. veris $\beta$. E. B. 513. Hayne 3. t. 35. P. inodora Hoffm. B. Columnae Tenore t. 13. In Europa. 4. Cor. inodora pallide lutea.

7. P. Flueggeana L. fol. ovatoohlongis denticulatis rugosis supra glabriusculis subtus pubescentibus; caly- cibus patulis profundissime 5 -partitis; lim!o cor. plano. Lehm. t. 2. $\beta$. acanlis Hogere in Act. Mus. Paris. 12. t. 5\%. In Ihispania et Germ. 4. Cor. coriacea.

8. P. amoena M. B. fol. petiolatis ohovatis ohtusis ohsolete dentatis rugosis subfus inc:anis; umbella tomentosa; cor. limbo plano. Lehm. t. 3. Iu Alp. Cancasi. 2). Cor. amocne purpurea.

9. ID. Palbisii Lehm. fol. ohovatis uhcusis pubescenti-villosis grosse serratis margine ciliatis; cal. laciniis ovatis margine ciliatis. In Italia. 4. Cor. lutea.

10. P. riscosa All. t. 5. f. 1. fol. ohovato-linguaeformibus integerrimis sinuatis villoso-viscosis; involucri foliolis ovatis membranaceis. In $\{l\}$. Pedemont. 24.

11. P. pubserens hois. fol. oblongis crenatis subhirsutis viscosis margine ciliatis, scapo calycibusque pubescenti-viscosis. P. villosa fo. Pers. Jacq. Misc. t. 18. f. 2. B. M. 14. P. hirsuta Lam. In Europ. 24. Cor. flavescens.

12. P. villosa .Jacq. fol. ohlongoovalibus serrulatis villosis palliule viridihus; scapo z-3-floro; calycihus globosis; cor. tubo villosiusculo. Jacq. anst. app. t. 27. P. hirsuta All. P. viscosa Lam. In Alp. Europat. 4. Cor. caerulescens.

13. P. ciliata Sclurank; fol. obovato-cuneiformihus grosse crenaloserratis villosulis subviscosis opacis; calycihus campanulatis. Rchb. ic. 853. P. nivea Host. In Europ. Alp. 4. Cor. pallide ochrolenca.

1f. P. latifolia Lapeyr. fol. obovato-spathulatis tenuibus repandoserratis scapo umbellague erecta viscidulis; calycis dentihus acuninatis. 13chb. ic. 85̃3. P. villosa sieb. In Pyrenaeis. 4. Cor. violacea seu alba.

15. P. denticulata Sm. fol. ovatolanceolatis acutiusculis argute denlatis revolutis subvilloso-glutinosis; laciniis limbi emarginutis. In Nepalia. 24.

16. P. Allionii Lois. gall. tab. 3. f. 1. fol. ohovato-cuneiformibus puhescenti-glutinosis suhintegris incanis; scapo 1-2-floro; cal. ovatis obtusis, In fissuris rup. Gall. 4. Cor. carneo-albescens. 
1\%. P. truncata Lel!m. fol. sul)pubescentibus subglutinosis apice truncatis 5-dentatis; cor. laciniis bipartitis: lacinulis truncatis. Lehm. t. 8. P. minima $\beta$. Bam. P. Jiraseckiana Tratt. In Alp. Salisb. 4. Cor. minuta carnea.

18. P. aretioides Lehm. t. 9. fol. imbricatis lineari-spathulatis superue serratis villosis; scapo 1 -floro foliis hreviore; tubo cor. cylindrico longissimo. In Persia. 24. Cor. lutescit.

19. P. macroculyx Bunge; fol. cordato-ovatis in petiolum decurrentibus denticulatis molliter pubescentibus; cal. cumeato-campanulatis ampliatis. In Altaico. 24. Cor. lutea.

20. P. Candolleana Rchb. ic. S02, 803. fol. elliptico-oblongis obtusis crassiusculis integerrimis ciliatis supra scapoque villoso pubescentibus; calycibus obtusissimis. P. integrifolia M. et K. In Aly. Helvetiae. 24. Cor. persicina.

\section{b. Folia glabra.}

21. P. prolifera W'all. fol. spathulato-oblongis dentatis petiolatis; scapo longissimo; umbellis verticillatis. In Nejalia. 24.

22. P. verticillata Forsk. fol. erectis oblongis acutis serratis suhtus farinosis; involucris foliaceis; tubo cor. longissimo. B. M. 2843. In Arabia. 4.

23. $\boldsymbol{P}$. crassifolia Lehm. $\boldsymbol{t}$. 9. fol. obovatis glahris crenato-serratis in petiolum decurrentilus; flor. umbellae nutantibus; laciniis limbi integerrimis. In Oriente. 24. Cor. carnea.

21. P. Pullasii Lelım. t. 3. fol. obovato-oblongis eroso-dentatis glabris subundulatis; umbella pubescente; cal. ovatis hiantibus; cor. limbo plano. In Alp. Altaicis. 24. Cor. lutea.

25. P. altissima Uon; fol. cordatooblongis obtusis inaequaliter dentatis rugosis; petiolis longissimis; involucri foliolis dentatis. P. reticulata Wall. In mont. Emodi. 4.

26. P. speciosa Don; fol. subcordato-oblongis obtusis eroso-dentatis reticulato-renosis; petiolis praelongis dilatatis; foliolis involucri integerrimis; cor. laciniis bifidis. In mont. Emedi. 4.

2\%. P. Auricula I. fol. rigidis ovato-spathulatis crenato-serratis ciliolatis; caly cibus subfariuosis ; laciniis cor. profunde ad faucem hipartitis. Jacq. austr. t. 413. Sturm 14. In Alp. Europae. 24. Cor. laete lutea.

28. P. Palinuri Pentagn. fol. obovato-spathulatis obtusis dentato-crenatis; umbella nutante; involucri foliolis inaequalibus maximis. Jacq. Eclog. t. 43. 'Ten. Neap. t. 14. B. M. 3414. In rup. Palinuri. ち. Cor. lutea.

29. P. microcalyx Lehm. t. 4. fol. obovato-cumeiformibus profunde dentatis glabris; involucri foliolis rotundato-ovatis minimis; calycihus brevissimis hiantiluss. In Comit. Nicaeens. 4. Cor. ruhella.

30. P. murginata Curt. B. M. 191. fol. ohovato-oblongis crenato-dentatis glahris alho-maruinatis; involucri foliolis ovatis. In Alp. Europ. 24. Cor. amocne ruhella.

31. P. rotundifolia Wall. fol. cordato-subrotundis grosse serratis subtus farinosis; petiolis longissimis; lohis cor. rotundatis integerrimis. In mont. Emodi. 24.

32. P. macropleylla Don; fol. oblongis argute serrulatis mucronatis suhtus farinosis; lobis corollae olicordatis. In mont. Emodi. 4.

33. P. Stuartii Wall. fol. lanceolatis acutis serratis glabris suhtus subtiliter farinosis; Iolis corollae 4-dentatis. In mont. Emodi. 4.

3t. l'. longiflora All. ped. $t$. 39. f. 3. fol. ovali-lanceolatis serratis glahris; umhella nutante; tuho corollae longissimo. B. Cab. 5+2. In Alp. Europ. 4.

3.5. P. farinosa $L$. fol. obovatolanceolatis crenatis glahris; umbella erecta; fauce corollae glandulosa. E. B. 6. Sv. B. 442. Fl. Dall. 125. In Europ. 24. Cor. lilacina.

36. P. pusilla Goldie; fol. subspathulatis repando-dentatis subtus scapoque farinosis; calycibus acutis. P. farinosa Nutt. In Canada. 4.

37. P. Hornemanniana Lehm. t. 4. fol. lanceolato-obovatis dentatis subpetiolatis; umbella pauciflora stricta; involucri foliolis lanceolatis; calycihus ventricosis rugulosis. P. stricta Hornem. P. farinosa Sm. Fl. Dan. 1385. In Lapponia. 24. Cor. rubella.

38. P. scotica Hook. fol. spatlulato-lanceolatis denticulatis utrinque favo-farinosis; fance cor. glaudulosa ; stigmate 5-fido. In Scotia. 4. 
39. P. Longifolia Curt. B. M. 392. fol. ohlongis obtusis denticulatis glaherrinis; involucris po!yphyllis suhulais reflexis; laciniis cal. linearibus. In cuacaso. 4.

40. P. niralis Pall. fol. spathulatolanceolatis repando-dentatis glabris; foliolis involucri hasi commatis. Pall it. 3. t. G. f. 2. In Nibiriu. 24. Cor. violacea.

1h. P. exaltutu hehm. fol. obovato-ohlongis integerrimis glahris; umbella multiflora; limbi laciniis hifidis; lulis ovatis acutis. In sibiria. 4.

12. P. dururicu lehm. fol. sessilibus lanceolato-spathulatis suhintegerrimis glahris; floribus nutantihus; involucri foliolis ovatis ohtusis. B.M.1219. In Al). Daruiae. 4. Cor. rosea.

43. P. altaica Lehm. t. 5. fol. olnlongo-lanceolatis glahris petiolatis; floribus nutantibus; involucti foliolis linearibus acutis; calyce tubum aequante. III Aly. alloticis. 24. Cor. carneo-albescens.

4. P. sibirica Jacq. fol. integerrimis obovato-subrotundis glabris 1-nerviis; umbella nutante; involucri foliolis auriculatis. P.intermedia Ledeb. P.rotundifolia Pall. Gmel. sih. 4. t. 46. f. 1. In Sibiria. 4. Cor. alhescit.

4.5. P. yigantea Jacy. fol. rhombeoovatis glabris ohtusis superue serratodenticulatis; involucri polyphylli foliolis subulatis. Lehm. t. 6. In Sibiriu. Cur. carneo-albescens.

46. P. mayellanica Lehm. t. 6. fol. rhombeo-ovatis acutis crenato-dentatis in petiolum decurrentibus; umbella pulverulenta; calycibus ovatis. Ad fret. If agellanicum. 4. Cor. carnea.

47. P. mistassinica Michx. fol. petiolatis ovali-spathulatis denticulatis glabris; umliella pauciflora; involucro 3-phyllo; limho cor. reflexo. Lehm. t. 7. In Canada. 4.

48. P. efallicensis Horn. fol. integerrimis petiolatis glabris niargine parum revolutis; cal. suhtus glohosis 5gonis; limbi laciniis corollae semibifidis. Lehm. t. \%. Fl. Dan. 1511. In Groenlandia. 24. Cor. Alavo-virens.

4.9. H. norvegicu Retz; fol. ovatis integerimis petiolatis glabris; umbella subtriflora; calycibus campanulatis; cor. cyathiformi. Fl. Dan. 188. P. funnarchica Jacq. In Norvegic. 24. Cor. violacea.

50. P. algida Adam; fol. ovatis subhasiatisque argute serratis glabris; calycibus profunde $\mathbf{5}$-partitis ; limbi laciniis ohcordatis bifidis. Lehm. 1. 7. P. Iongifolia M. B. In Cancuso. 4.

51. P. glutinosa L. fol. oblungolanceolatis obtusis superne serratis viscoso-glutinosis; involucri foliolis coloratis. Jacq. austr. app. t. 26. In Al). Europate. 4.

52. P. carniolica Jacq. ap). t. 1 . fol. adpresso-crenato-serratis elliptico-lanceolatis acutis glabris; unthella subcernua pauciflora; calycibus acutissinis. 11chb. ic. 850. In Al\%. Europ. 24. Cor. lilacina.

53. P. integrifolia Jac\%. austr. 1. 32\%. fol. clliptico-oblongis ohtusis membranaceis margine cartilaqineo-ciliatis; calycihus obtusissimis. Rchls. ic. 69. P. spectabilis Tratt. t. 435. ß3. fol. dentatis Lelm. t. 8. In $A l \% . E u-$ rop. 24. Cor. maxima rosea.

51. P. ylaucescens Noretl. fol.oblongo-fanceolatis acutis glahris rigidis cartilagineo-marginatis subdenticulatis. P. integrifolia Wulf. stum 24. B. Cah. 886. B. M. 912. P. caly cina Dub. Rchb. ic. 70. In Alp. Europ). 4. Cor. rosea.

55. P. chinensis Lour. fol. cordato-ovalis acuminatis integerrimis; involucro diplyyllo; laciniis cor. integris. In Clina.

56. P. Floerkeana Schrad. fol. olovatis basi cuneatis e medio incisodentatis subviscidis; calyce obtusissimo. Lehm. t. 8. P. minima et grandiflor'a Lam. P. hrevistyla DC. B. M. 229. In Alp. Europ. 24. Cor. rosea et coccinea.

57. P. minimu L. fol. cumeiformihus nitidis extrorsum acute incisu-dentatis; scapo brevissimo 1-floro. Jacq. obs. t. 14. austr. t. 315. B. 13. 581 . Rchb. ic. 891 - 799. In Alp. Europ. 4. Cor. persicina.

58. P. saxifragifolia Lehm. t. 9. fol. obovato-cuneatis petiolatis serrato-lohatis; umbella 2 -3-flora; calycibus profunde 5-partitis. In ins. inalaschlia. 24.?

59. P. hypesborea Spr. fol. ohlongis obtusis crenatis suhpuhescentiinus: scapo 1-floro; calycibus obtusis. In ins. Aleúticis. 4.

\section{S16. HOTTONIA Boerh. (1710).}

1. II. palustris I. florihus verticillato-racemosis; internodiis teretibus; cor. calycem excedente; fol. pectinato- 
pinnatis. Fl. Dan. 487. E. B. 364. Schk. t. 35. In paludosis Europ. 4. Pedalis. Cor. carnea.

2. H. infiala Ell. flor. verticillatis pedunculatis; internodiis inflatis; corolla calycem aequante; fol. pectinato-multifidis. H. palustris Pursh. In Georgia. 21.

3. $\boldsymbol{H}$. sessiliflora Vahl; flor. verticillatis sessilibus; fol. inferioribus 2-pinnatis, superioribus 3-partitis. In Ind. orient. 4.

\section{1\%. METTERNICHIA Mikan (1825).}

1. M. principis Mikan delect. bras. fasc. 3. ic. 1. In Brasilia. ђ. Arhor 20-25-ped. Fol. petiolata lanceolatoovalia integerrima basi acuta utrinque glabra. Flores axillares magni albi.

\section{CALIBRACHOA Lexary.(1825).}

1. C. mexicana Lexarg. descr. nov. थeg. fusc. 2. In Mexico. Cor. alha longitudine staminum.

\section{RAMONDIA Rich. (1505).}

1. R. pyrenaica Rich. R. scupigera St.Hil. Verbascum Myconi Willd.B.M. 236. In Pyrenceis. 4. Fol. radic. ovata profunde crenata. Flor. purpurei.

\section{SESSEA R. et P. (1798).}

1. S. stipulata R. et P. peruv. $t$. 115. fol. lanceolatis cordatisque; racemis paniculatis. In l'eruvia. 方. Frutex 5-6-ped. Cor. flava.

2. S. dependens $R$. et P. peruv. $t$. 116. fol. cordato-oblongis; racemis Iongissimis pendulis. In Peruvia. $\hbar$. Arbor 25-30-ped. Cor. lutea.

3. S. petiolaris Spr. fol. oblongis acuminatis subtus pulverulentis; pedunc. brevissimis. Cestrum $\boldsymbol{H}_{\text {. }}$ et $\mathbf{K}$. In Peruvia. 古.

\section{BACOPA Aubl. (1798).}

1. B. aquatica Aubl. Guj. t. 49. In Cajenna. 4. Caulis herhaceus carnosus. Fol. opposita lanceolata sessilia crassa. Flores axillares caerulei.

\section{ERYTHRAEA Renealm (1611).}

(Griseb. Gent. p. 127-1.19.)

1. E. ranosissima Pers. caule hunili a basi ramoso; fol. imis ovatis super. oblongo-lanceolatis acuminatis; floribus fastigiatis. Chironia inaperta W. C. pulchella E. B. 458. E. pulchella Hornem. Fl. dan. 163\%. E. inaperta sclıl. E. Gerardi Bug. Vaill. par. t. 6. f. 1. C. pulchella Fries. E. pyrenaica Pers. In pratis humidis Europ. Asiae minor. et Nibir. $\odot .3$-poll. ad 1-ped. Cor. rosea.

z. E. chilensis Pers. caule tenui adscendente ramoso; fol. oblongo-linearibus; cyma laxa multoties diclotoma; floribus longissime pedicellatis 5-4-fidis. Gent. peruviaua Lam. E. Cachanlahuan R. et S. Feuillée journ. 1. t.35. In Chili. 1 -ped.

3. E. texensis Griseb. caule tenui erecto superne ramosissimo; fol. lanceolatis obtusiusculis summis linearibus; cyma gracillima multoties dichotoma; tubo cor. 5-fidae tenuissima. In Mexico. Hb. Hook.

4. E. Centaurium Pers. caule erecto alato superue ramoso; fol. elliptico-oblongis utrinque inaequaliter acutiusculis; floribus laxe glomeratis; cor. lohis ovalibus, Gentiana L. Fl. dan.617. E. B.414. Hayne 1. t. 29. Schmidt diss. f. 1-5. Sclık. t. 59. E. grandiflora Biv. Hchb. ic. 572. H. major Lk. port. t. 65. Chir. suffruticosa salzm. In Europ. et Afr. bor. (). 1-ped. Cor. rosea.

5. E. latifolia $\mathbf{S m}$. caule erecto crassiusculo a basi ramoso; fol. ovalibus oblongisve obtusis utrinque rotundatis; floribus sessilibus dense glomeratis. E. tenuiflora Lk. port. t. 67. E. centaurioides h. Goett. E. arenaria Presl. delic. E. rumosissima et conferta Wuert itin. In Europ. austr. $\odot$.

6. E. linarifolia Pers. caule superne dichotomo; fol. imis rosulatis spathulatis superioribus oblongo-linearibus obtusis; floribus laxis; cor. Iobis obtusis. E. conıpressa Hayne. E. linifolia et angustifolia Lk. Barr. ic. 423.436. Rchb. ic. 88. schmidt diss. f. 6. B.humilis; Gent. chloodes Brot. Lk. port. t. 66. f. b. E. littoralis Sm. E.B.2305. $\gamma$. tenuifolia; E. uliginosa WV. et Kit. t. 258. In lumidis Europ. occ. $\odot$. Cor. rosea.

\%. E. portensis Lk. port. $t .66 . f_{0} \boldsymbol{a}_{\text {. }}$ caulibus caespitosis prostratis ramosis; fol. subrotundis obtusis 3-nerviis; cor. lobis obtusis. In Lusitania. 1-ped. Cor. pulchre rosea.

8. E. diffisa Woods Mss. caulibus caespitosis adscendentibus ; fol. elliptico-subrotundis spathulatisque 3-nerviis; cor. lobis acutiusculis. Gent. scilloides 
L.? In ins. Azor. 3-t-unc. Cor. intense rosea.

9. E. Roxburylii Don; caule stricto diffuse ramoso; fol. imis rosulatis obovato-oblongis obtusis ; caulinis linearibus acuminatis; cor. lobis angustis. Ch. centaurioides hoxb. In Peninsula Ind. or.

10. E. caspica Fisch. Mss. caule stricto superne ramoso; fol. inferiorihus elliptico-oblongis ohtusis; cyma duplo-quater dichotoma stricta; tubo cor. Iobisque angustissimis. In Asia occ. Habitus E. maritimae.

11. E.trichantha Grisel, caule adscendente ramosissimo fastigiato; fol. oblongo-lanceolatis acutiusculis; cymis aggregatis; lobis cor. linearibus angustissimis. In California. $\frac{I}{2}$-ped. Cor. persicina.

12. E. Mühlenbergii Griseb. caule inferne simplici; fol. ovato-oblongis obtusiusculis ; cymis ter dichotomis; flore alari pedicellato ; cor. lobis oblongolanceolatis. E. Centaurium Beck Fl. am. In California et Am.bor.3-6-unc.

13. E. spicata Pers. caule stricto superne ramoso; fol. elliptico-oblongis basi rotundatis; cymis spicaeformibus dichotomis; flore alari sessili. Gentiana L. Lk. Fl. port. t. 68. Fl. graec. t. 268. In Europ. et Asia minore. 1-2-ped.

14. E. australis $R$. Br. caule stricto superne ramoso; fol. elliptico-oblongis; cyma subspicaeformi; flore alari brevissime pedicellato. In Nov. Holl.1-ped.

15. E. maritima Pers. caule stricto superne ramoso; fol. elliptico-oblongis obtusis superioribus acuminatis; cyma stricta; flore alari pedicellato; cor. Iobis acutiusculis. Chir. occidentalis DC. Bocc. mus.t. 76. Cav.ic. t. 296. Barr. 46\%. Flor. graec. t. 23\%. F.lutea R. et $\mathbf{S}$. Ch. Iutea Bert. Gent. pumila Gouall. Barr. ic. 468. In maritimis Europ. austr. $\frac{1}{2}-1$-ped.

16. E. elodes $R$. et $\mathbf{S}$. caule erecto subsimplici hirsuto; fol. rotundis; cyma 6-10 flora; cor. tubo calycem aequante, lobis acutis. Chir. uliginosa Lapeyr. E. uliginosa Schm. diss. In Pyrenaeis. 24. $\frac{1}{2}-1$-ped. Cor. aurea.

\section{SABBATIA Adans. (1763).}

1. S. angularis Pursh; caule erecto 4-gono subulato; fol. ovatis obtusis amplexicaulibus; pedunc. elongatis corymbosis. Cluironia L. In Amer. bor.
2. s. chloroides Pursh; caule sinplici 4-gono; fol. lanceolatis acutis nervoso-venosis; ramis 1-floris; calycibus 9-partitis. Chironia lodecandra Walt. In Amer. bor. Decumbens. Flor. magni rosei.

3. S. calycosa Pursh; caule simplici subangulato; fol. ovalibus 3nerviis; floribus solitariis; calyce 10 partito. Chironia Michx. In Carolina. (). Cor. rosea.

4. S. gentianoides Ell. caule simplici subangulato; fol. linearibus acutis elongatis; floribus axillaribus sessilibus; calycibus 9-partitis. Rchb. Hort. t. 118. In Georgia. $\odot$.

5. S. brachiata Ell. caule simplici teretiusculo; fol. lanceolatis; ramis brachiatis 3-floris; cor. calyce duplo longiore. In Georgia. $\odot$.

6. S. paniculata Pursh; caule 4angulo erecto; fol. lanceolato-linearibus; panicula multiflora brachiata; calyce cor. triplo breviore. Chironia Michx. In Carolina. 24. Cor. alba.

7. S. stellaris Pursh; caule erecto tereti; ramis dichotomis 1-floris; fol. lanceolatis acutis; laciniis cor. obovatis. Bartram ic. t. 13. In Carolina. $\odot$. Cor. rosea.

8. S. corymbosa Baldw. caule erecto suliangulato; fol. ovato-oblongis obtusiusculis; floribus corymbosis 6-partitis. Chironia lanceolata W'alt. In Carolina. $\odot$.

9. S. gracilis Salisb. caule angulato dichotomo; fol. spathulatis; pedunc. 1floris; calyce subulato 5-partito. Chironia campanulata L. In Carolina. $\odot$.

10. S. mulchella Spr. caule filiformi subramoso; fol. radicalibus subrotundis, caulinis subulatis; calycibus sub-1-partitis. Exacum Pursh. In Carolina. $\odot$.

11. S. australis Schlecht. caule erecto 4-angulo; fol, radic. obovatis, cauliuis lineari-lanceolalatis; pedunc, elongatis 1-floris. Ad flum. Platam.

12. S. macrophylla Hook. Hb. caule fastigiato-ramoso; fol. ovatis 5-nerviis basi connatis acutis; calycis lobis setaceis. Prope Covington. 1-2-ped.

13. S. campestris Nutt. caule 4-gono 2-3-chotome ramoso; fol. ovatis obtusis; calycis tubo 5-alato. Hook. Hb. In Amer, bor. $\frac{\mathrm{I}}{2}-1$-ped. Cor. rosea. 
824. HIPPION Spr. (182t).

1. H. verticillatum Spr. caule scabriusculo simplici 4-gono; fol. lanceolatis 3-nerviis; floribus verticillatis; calycibus reflexis; laciniis cor. mucronatis. Gentiana L. Plum. ic. 81. f. 2. In Amer. austr. 1-ped.

2. H. hyssopifolium Spr. caule 4gono subramoso; fol. linearibus nervosis; floribus verticillatis; calycilus capsula breviorihus. Gentiana L. Burm. afr. t. 74. f. 3. In Ind. or. CauI. 1-ped. Cor. fulva.

\section{CHIRONIA Linn. (1\%3\%).}

1. C. fintescens L. fol.ohlongo-lanceolatis acutiusculis ; cor. lobis obovatis obtuse apiculatis tuho tenui duplo longioribus. C. decussata Vent. Cels. t. 31. Lam. ill. t. 108. f. 1.- B. M.:37. et 707. C. angustifolia. B. M. 818. Burni. afr. t. 74. f. 1. $\gamma$. C.orthostylis Lichb. exot. t. 245. In Prom.b. speit. Frutex 4-ped. Cor. rosea.

2. C. Inverii Griseb. fol. imis spathulato-linearibus obtusis; sepalis lanccolatis acuminatissimis; cor. lobis acutissimis. In Prom. b. spei. 24. 23-ped. Cor. purpurea.

3. C. mudicanlis $L$. fol. margine laeviusculis epunctatis $\mathbf{1 - 3}$-nerviis ovalibus linearihusve; cor. lobis acuminatis. C. jasminoides Lam. ill. t. 108. f. 2. Linn. trans. 7. t. 12. f. 3. B. elongata Eckl. In Prom. b. spei. ந. 1-ped. Cor. purpurea.

4. C. peuncularis tindl. B.R.1803. fol. cordato-lanceolatis margine scabris 5-nerviis punctatis; cor. Iobis ellipticis cuspidatis. C. Barcleyana $\mathbf{H}$. berol. In Prom. b. spei. 1-ped.

5. C. maritimu Eclil. fol. oblongolanceolatis margine scabris 1-nerviis epunctatis; cor. lobis lanceolato-acuminatis. In Prom. b spei. 1-ped. Cor. purpurea.

6. C. jasminoides L. caule 4-gono; fol. oblongis obtusis mucronulatis margine cartilagineo ad lentem crenulato: cor. Iohis ovalibus. C. uniflora Lam. ill. t. 10\%. f. 3. In Prom. b. spei.4. 1-2-ped. Cor. purpurea.

\%. C. tetrayonu L. caule 6-gono; fol. ovatis acntis margine cartilaginco; calycis lohis ovatis foliaceis; cor. tubo post anthesin impliato. Limu. Trans. 7. t. 12. f. 2. In Prom. b. spei. 1-ped. Cor. rosea.
8. C. scabriala Griseb. caule 4-gono; fol. ohlongis obtusis utrinque scabridopunctatis margine cartilagine 0 ; cor. loho tenuissimo. In Prom. b. spei. ち. suffirutex. Cor. purpurea.

9. C. perfoliatu Eckl. caule 4-gono; fol. ex basi perfoliata ovatis ohtusis margine serrulatis; cor. lobis olovatooblongis. In Prom. b. spei. Cor. rosea.

10. C. linoides $\mathrm{L}$. caule tereti; fol. subulatis cuspidato-pungentibus margine cartilagineo; cor. lobis ovalibus. C. vulgaris Clıan. Curt. B. M. 511. C. lycioides Auct. Breyn Cent. t. 90. Bum. afr. t. 74. t. 2. In From. b. spei. $\frac{1}{2}-$ 1-ped. Cor. purpurea.

11. C. buccifer 6 . caule 6-g0no; fol. linearibus cuspidatis margine laevi; endocarpio pulposo. B. M. 233. In Prom. b. spei. ち. Frutex diffusus 2-ped. Cor. purpurea.

12. C. serpyllifolia Lellm. caule teretiusculo; fol. ovatis ohtusissinis margine crenulatis; stigmate clavato. In From. b. spei. 方. suffutex.

13. C. parvifolia M. el Drege; caule suffruticuloso ramosissimo; fol. ovatis minutis reflexis; cor. laciniis subovatis acutissimis. In Afr. austr. 4.

14. C. Latifolia M. et Dreye; caule psendo-dichotomo; fol. ovato-lanceolatis acutis patulis; cor. laciniis oblongis acutissimis. In Afr. anstr.

15. C. speciosa M. et Drege; caulo herhaceo flexuoso debili; fol. lanceolatis-recurvato-cuspidatis subcordatis reflexis; cor. laciniis oblongis acutis. In Afr. austr. Flos maximus.

16. C. arenariu M. et Drege; caule fruticuloso ramoso dense folioso; fol. linearilus obtusiusculis erectis; laciniis cor. obovatis obtusissimis apiculatis. In Afr. custr. 古.

\section{MYRMECIA Schreb. (1789).}

1. M. gnjumensis Aub. Guj. t. 29. Arbuscula glahra; fol. oblongis. M. scandens Fir. Tachea Mart. t. 189. In Brasilia. ђॄ. Cor. Lutea.

\section{2\%. IITA Schreb. (1789).}

1. L. aphyllu G. Dietr. caule subaphyllo 1-floro; laciniis cor. acutis. Gentiana Jacq. am. t. 60. f. 3. Exacum W. In Martinica $\odot$. Tenella. Cor. flavescens.

2. L. breviflora Spr. caulc sub-3floro; fol. ucmbranaccis; cor. tubo 
calyce 3-plo longiore. Voyra Lam. In Gujance. Caul. 2-poll. Cor. flava. 3. L. rosea $\mathbf{W}$. floribus geminatis; laciniis cor. acutis. Voyra Lam. ill. t. 109. Aubl. Guj. t. 83. f. 1. In Gujana. 2. liadix tuberosa.

4. L. caevulea $U$. floribus geminatis; cor. laciniis rotundatis. Voyra Aubl. Guj. t. 83. f. 2. In Gujana. 4. Cor. caerulea.

5. L. spathacea Spr. caule multifloro; bracteis subspathaceis; cor. laciniis oblongis. Voyra Lam. In Gujana. Cor, caerulea.

\section{MENYANTHES Dalechamp. $\left(1586^{\circ}\right)$.}

1. M. trifoliata $\boldsymbol{L}$. In paludosis Europ. et Amer. bor. 24. E. B. 49.5. Fl. Ilan. 5t1. Scllk. t. 38. Caulis repens; fol. ternatis oblongis serratis. Flor, racemosi albidi.

\section{VILLARSIA Tenten. (1803).}

1. $\boldsymbol{V}$. nymphoides Tent. fol. cordato-orbiculatis repando-integerrimis ; cor. seminilousque ciliatis. Menyauthes L. E. B. 217. FI. Dan. 339. In stagnis Europ. 24. Cor. flava.

2. I. Humboldtiana Kunth; natans; fol. profunde cordatis integerrimis; cor. fimbriatis; seminibus margine nudis. V. cordata Ell. In Nov. Granata. 24. Cor. flav0-alba.

3. $V$. geminat $\boldsymbol{R}$. Br. fol. cordatis integerrimis; laciniis cor. crenulatis ; seminihus margine nudis. Menyanthes sarmentosa sims. B. M. 1323. In Nov. Holl. 24. Cor, lutea.

4. I. cristata Spr. fol. cordatis mdulato-crenulatis; laciniis cor. margine crispis medio cristatis; seminibus compressis. Menyanthes Roxh. Corom. t. 105. In Coromandelia. $\odot$. Flor. albissimi.

5. I. peltata $\mathbf{R}$. et $\mathbf{S}$. fol. peltatoreniformihus integerrimis; petiolis floriferis. Menyanthes nymphoides Thunb. Act. ups. VII. t. 4. f. 2. In Japonia. 4.

6. I. indica Vent. fol. cordatosubrotundis nervosis nutantibus; cor. interne pilosis. Menyanthes L. B. M. 658. Rumph. 4. t. 72. f. 3. In Ind. or. et ins. Mascaren. 4. 2-ped. Cor. alba.

F. V. macroplyylla $R$. et S. fol. cordato-orlhiculatis crassiusculis obsolete repandis 3-costatis; cor. interne pilosis. Menyanthes Roth. In Ind. or. Cor. lutea.

8. I. lacunosa I'ent. fol. reniformipeltatis crenulatis coriaceis subtus lacunosis; cor. margine glabris. Menyanthes brachysperma Michx. In Amer. bor. 24. Cor, alba.

9. V. reniformis $\boldsymbol{R}$. Br. fol. nudis reniformilus integerrimis; caule elongato nudiusculo; floribus paniculatis. In Nov. Holl.

10. $\boldsymbol{V}$. parnassifolia $R . B r$. fol. radicalibus cordato-ovatis repandodentatis; caule elongato paniculato; cor. laciniis acutis crenulatis. Swertia Labill. t. 97. Menyanthes exaltata B. M. 1029. In Nov. Holl. 4. Cor. flava.

11. I. ovata Vent. Cboi.x t.9. for. ovatis erectis; florihus racemoso-paniculatis; cor. ciliatis. Menyanthes L. M. compressa Thunb. In Prom. $b$. spei. 4.

\section{ECHITES P. Broun (1\%56).}

\section{Staminibus inclusis.}

1. E. longiflora Desf. fol. cordatoacutis undulatis sessilibus subtus tomentosis; caule fruticoso sarmentoso.

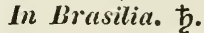

2. E. rubricaulis Poir. fol. ovatis acuminatis subtus nervosis pubescen-

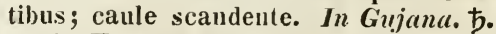

3. E. angustifolia Poir. fol. angustissimis acutis; folliculis angustis subtorulosis longissimis. In Domingo. Caulis scandens.

4. E. bispinosa Thunb. fol. Ianceolatis glabris; aculeis binis extrafoliaceis connatis; cor. infundibuliformi. In Prom. b. spei. ち. Frutex 1-ped. Cor. rubra.

5. E. succulenta Thunb. fol. linearibus subtus tomentosis; aculeis binis extrafoliaceis patentibus; cor. infundibuliformi. Nov. Act. Petrop. XIV. t. 9. f. 2. In Prom. b. spei. ち. Frutex 1-ped. Cor. rufescens.

6. E. petraea Hil. fol. cordato-linearibus acutis nndulatis revolutis sub- 
tus incano-tomentosis; pedunc. axillaribus. Ad flum. Platam.

\%. E. Telume Hil. fol. ovato-oblongis cuspidatis lanatis. E. guaranitica Hil. In Brasilia. ち.

8. E. virescens Hil. hirsuta; fol. ovato-ohlongis acutis subtus tomentosis. In Brasilia. 支.

9. E. pinifolia Hil. hispida; fol. quaternis linearibus revolutis subtus incano-tomentosis. In Brasilia. $\hbar$.

10. E. biflora Jacy. am. t. 21. caule sarmentoso; fol. ohlongis obtusiusculis glabris; cor. infundibulitormi. Plum. ic. t. 96. In Int. occ. ち. Frutex 20-ped. Cor. candida.

11. E. sagittuta R. et $P$. fol. ohlong0-subsagittatis acuminatis ciliatis; caule voluhili aspero. In Peruvia. $\hbar$. Caulis purpurascens.

12. E. macrantha Spr. fol. ohlongis utrinque attenuatis subtus reticuIato-tomentosis; cor. infundibuliformi ; caule erecto. E. grandiflora Roth. In Ind. orieut. $\hbar$. Cor. rosea.

13. E. domingensis Su. caule voJuhili; fol. cordato-ovatis rigidiusculis; pedunc. racemosis. Jacq. ic. t. 53. In Jumaica et Ilispaniola. $\hbar$. Flor. magni flavi.

14. E. glomerata Poiv. fol. membranaceis ovato-acuminatis glahris; flor. axillaribus agglomeratis; caule scandente. In Domin!yo. ఫૃ.

15. E. umbellutu Jac\%. fol. ovatis ohtusis mucronatis ; pedunculis umbellatis; caule volubili. Jacq. an. t. 22. sloane t. 131. f. 2. In Jumuica, Cuba $e_{i}$ Domingo. $\hbar$. Frutex 15-ped. Cor. candida.

16. E. Vittorea $H$. et $K$. fol. oblongis cuspidato-mucronatis glahris; flor. umhellatis; cor. hypocrateriformi; caule volubili. In Cubu. 古.

17. E. citrifolia H. et K. fol. ovato-oblongis acuminatis glaherrimis supra nitidis; petiolis 2-glandulosis; racemis bifidis; cor. hypocrateriformi. In Nora Grunata. ђ.

15. E. boyotensis H. et K. t. 24.3. fol. oblongis acuminatis suhtus pulverulento-puberulis glaucescentibus; petiolis basi 2 -glandulosis; racemis hifidis. In Nora Granata. ђ.

19. E. congesta H. et K. fol. cordato-subrotundo-ovatis breviler acuminatis subtus molliter hirto-canescentibus; florihus racemosis capitalo-con- gestis. In Nova Granata. ђ. Cor. allo.

20. E. riparia $H$. et $K$. fol. cordatoohlongis acutis subtus molliter hirtopubescentibus hasi glandulosis; raceuis sub-6-floris. In Nova Granata. t. Cor. alha.

21. E. torosa Jacq. am. t. 27. pict. $t$. 34. fol. lanceolatis acuminatis ; flor. subracemosis; folliculis torulosis longissimis. Lam. ill. t. 174. f. 1. In Jumaica. b. Cor. flava.

22. E. trifida Jac a. am. t. 24. pict. t. 31. fol. ovato-oblongis acuminatis; pedunc. trifidis multifloris; calycibus obtusis. In Ind. occ. ち. Frutex. Cor. purpurea.

23. E. acuminata $R$, et P. peruv. t. 13t. $f$ : $a$. fol. ovato-oblongis ackminatis glabris basi $\mathbf{5}$-glandulosis; flor. racemosis; caule volubili. In Peruvia. ち. Cor. alla.

24. E. circinalis $S w$. fol. ellipticis glaberrmis ; pedunc. axillaribus articulatis multifloris ; laciniis cor. undulatis; caule volubili. In Hispaniota. ち. Cor. alba.

2.5. E. Asperuginis Su. fol. ohlongis aculis superue asperis; pedunc. racemosis; folliculis filiformilous; caule volubili. Plum. ic. t. 26. In Ind. occ. ђ. Cor. alla.

26. E. ayylutinosa Jacq. am. $t$. 23. pict. $t$. 30 . fol. ovatis emarginatis acuminatis; pedunc. racemosis ; folliculis apice conglutinatis; caule volubili. In Dominyo. ち. Cor. alba.

27. E. insignis syn. fol. ovatooblongis hasi attenuatis glaherrimis; corymhis axillaribus folio ireviorihus. E. grandiflora Meyer. In Gujanu. நृ. 28. E. repens Jacy. am $t$. 28. pict. t. 3.5. fol. lanceolato-linearibus; pedunc. racemosis; folliculis torulosis. In Domingo. †. Frutex elegans. Cor. rubra.

29. E. Heynii $\mathbf{S p r}$. fol. ovatis acuminatis supra pubescentihus subtus incano-tomentosis; corymbis dichotomis; cor. olstusis. E. dichotoma Roth. In Ind. orient. 古.

30. E. vestita R. et S. fol. ovalilanceolatis supra puhescentihus subtus tomentosis; corymbis dishotomis; laciniis cor. ohtusis. E. tomentosa koth. In Ind. orient. ђ.

31. E. antidysenterica Roth; fol. ovato-lanceolatis glabris obsolete cre- 
nulatis ; corymhis dichotomis; cor. pubescente. In Ind. orient. ђ.

32. E. tomentosa Vahl; fol. subcordato-ohlongis glahris supra nitidis; ramis racemi hrevissimis. In Amer. austr. ђ. Caulis voluhilis. Cor. alla.

3.3. E. subspicata V'ahl; fol. subcordato-ohlongis attenuatis glahris supra nitidis; pedunc. elongatis; pedicellis dichotomis. In America anstrali. 方.

34. E. dichotoma Bompl. fol. ovato-oblongis acuminatis cordatis glabris; racemis dichotomis; cor. hypocrateriformibus. In Amer. austr. $\hbar$.

3.5. E. laxa $R$. et $P$. peruv. $t$. 131. $f$. b. subvillosa; fol. cordatis acutis basi multiglandulosis; pedunc. racemosis paucifloris. In Perucia. Cor. alla.

36. E. suberecta Jacq. am. $t$. 26. pict. $t$. 33. fol. oblongis obtusis mucronatis subtus pubescentihus; racemis multifloris; cor. extus hirsuta. In Ind. occ. ち. Frutex 6-10-ped. Cor. flava.

37. E. caryopliyllata Roxb. fol. ovatis mucronatis; panicula terminali; calycibus patentilus. B. M. 1919. Kheede 7. t. 55. In Ind. or. ђ. Cor. albicaus.

38. E. difformis Wall. caule volubili; fol. ovali-lanceolatis hasi acutis infimis linearibus; floribus fasciculato-corymhosis, E. puherula Michx. In Amer. bor. $\hbar$. Cor. lutescens.

39. E. nitida Vrehl; fol. oblongolanceolatis basi subcordetis glahris supra nitidis; racemis axillaribus oppositis. In Amer. merid. ち. Cor. alba.

10. E. reticulata Ròth; fol. ohlonois acutis glabris reticulato-venosis; hracteis imbricatis; caule voluhili anguloso. In India orientali. $\hbar$.

41. E. cristata Roth: caule erecto tereti; fol. ovalibus nucronatis subtus tonientosis; corymlis axillaribus; cor. infundibuliformi. In India orientali. $\hbar$.

42. E. symphytocarpa Meyer; fol. subsagittato-ohlougis ohtusis subtus tementosis; folliculis apice commatis. In Grjana. ந.

43. E. Pala Hamilt. fol. verticillatis obtusis; paniculae ramis verticillatis; folliculis filiformibus longissimis. E. malaharica Lam. In Ind. orient. $\hbar$. 4t. E. syplititica L. fol. ohlongolanceolatis acuminatis glaherrimis; pedicellis cyuroso-umbellatis. E. paniculata Poir. In Amer. austr. $\hbar$.

4.). E. coriacea Ilume; fol. lanceolatis coriaceis glaluris; corymbis 2-3-fidis; cor. infundibuliformi intus hirsuta. In Jara. ђ. Cor. flavescens.

46. E. inflata lilume; fol. elliptico-lanceolatis acuminatis coriaceis glahris parallelo-venoso-reticulatis; flor. corymbosis. In Java. ち. Flor. albi.

4\%. E. densiflora Blume; fol. breviter petiolatis ohlongo-lanceolatis coriaceis glahris; flor. corymbosis fastigiatis. In Java. ち. Cor. alha.

48. E. nutans Anders. fol. ohlongis utrinque attemuatis subtus rubrovenosis villosis; pedunculis nutantibus; cor. Iaciniis crispatis. B. M. 2473. In ins. Carib. 支.

4.9. E. pubescens Hook. in Beech Joy. caule voluhili ferrugineo-puhescente; fol. ovatis acuminulatis molliter puhescentihus; pedunc. axillaribus solitariis. In Cliti. t. Flores albi.

50. E. bantumensis blume; fol. elliptico-ohlongis acuminatis parum attenuatis reticulato-venosis; costis ramulisque tomentosis; flor. corymbosis; cor. hirsuta. In Java. ち.

\section{b. Staminibus exsertis.}

51. E. corymbosa Jacy. am. t. 30. pict. $t$. $3 \%$. fol. lanceolato-ovalibus glahris; panicula corymhosa terminali imultiflora. Parsonsia R. Br. In Domingo. t. Caul. voluhilis. Cor. rubra.

52. E. floribunda $N u$. fol. ovatis acuminatis nervis parallelis; panicula coryhosa; laciniis cor. acuminatis. Parsonsia $\mathbf{R}$. Br. Forsteriana Meyer. In Hispaniola. t. Cor. alla.

53. E. jaranica; fol. oppositis ovato-ohlongis acuminatis coriaceis glabris; corymhis trichotomis; fance cor. nuda. Parsonsia Blume. In Jav.

54. E. barbata; fol. hreviter petiolatis oppositis ternisve oblongis acuminatis glahris in axillis infra tomentosis; fauce cor. harbata. Parsonsia Blume. In Jara. ち.

5.). E. spicata Jucq. am. t. 2.9. pict. t. 36. fol. subovatis distichis amplis; spicis axillaribus folio brevioribus. In Cartagena. ‡. Scandit ar- 
bores vicinas ad 60 ped. et ultra. Flor. numerosi candidi.

56. E. myrtifolic Poir. fol. oblongis utrinque attenuatis glabris; floribus subumbellatis folio brevioribus. In Madayascar. b.

57. E. bractecita $\boldsymbol{H}$. et $\boldsymbol{K}$. fol. ellipticis mucronato-cuspidatis supra pubescenti-hirtis, subtus tomentoso-liirtis; hracteis magnis coloratis. In Nora Granatı. ‡. Cor. aurantiaca.

58. E. paludosa Vahl; fol. oblongis obtusis glabris; umbellis elongatis. In Amer. anstr. $\hbar$.

59. E. mollissima $\boldsymbol{H}$. et $K$. fol. oblongis acuminato-cuspidatis supra molliter hirtis subtus tomentosis; bracteis lanceolato-subulatis. In Nova Granata. .

60. E. macrophylla $H$. et $\boldsymbol{K}$. fol. cordato-oblongis cuspidatis subtus tomentosis; racemis axillaribus; bracteis subulatis. Ad Orinocum. $5 . ?$

61. E. gracilis $H$. et K. fol. obJongo-lanceolatis suhtus hirtis; racemis axillarihus paucifloris; hracteis Ianceolato-subulatis. Ad Orinocum. $t$. Cor. flava.

62. E. velutina Spr. fol. cordatis ovatis acutis pubescentibus ; cymis pedunculatis oppositis. Parsonsia R. Br. In Nova Hollandia.

63. E. mollis Spr. fol. lanceolatis acuminatis villosis; cymis bifidis. Parsonsia H. Br. In Nov. Holl.

61. E. lanceolata Spr. fol. Ianceolatis acuminatis glabris; cymis bifidis. Parsonsia R. Br. In Nova HolZandia.

\section{BEAUMONTIA Wall. (1825).}

1. B. grandiflora Wall. Echites grandiflora Roxb. B. R.911. In Ind. or. $\downarrow$. Frutex scaudens. Fol. elliptico-ohlonga coriacea. Flor. corymbosi albi.

\section{VALLARIS N. L. Burm. (1768).}

1. V. Pergulanus Burm. fol. ovatis acutis glabris; flor. corymhosis; caule volubili. Pergularia glabra $\mathbf{L}$.
Rumph. 5. t. 29. f. 2. Houtt. syst. 3. t. 20. f. 1. In Java. ち. Cor. alba.

2. J. Heynii Spr. fol. oblongis acutis glaberrimis; pedunc. racemosis pubescentibus; caule fructicoso e:ecto. Pelthanthera solanacea Roth. In Inel. or. b.

3. I. controversa spr. caule volubili; fol. cordatis acuminatis 5-nerviis; corymbis axillaribus subcapitatis. Convolvulus binectariferus Wall. In Ind. or. ђ.

4. V. laxiflora Blume; fol. ovatooblongis acuminatis glabris ; corymhis axillaribus et terminalibus trichotomis longiter pedunculatis. In Java.

\section{ICHNOCARPUS R, Br. (1809).}

1. I. trutescens $R$. Br. caule fruticoso erecto; fol. oblongis glabris; paniculae axillaris ramulis fasciculatis. Apocynum L. Burm. Zeyl. t. 12. f. 1. In Zeylano.

2. I. Af:elii R. et S. caule fruticoso volubili; fol. oblongis acuminatis ; paniculis axillaribus terminalibusque. Apocynum frutescens Af $\boldsymbol{z}$. In Guinea. ち. Cor. alsa.

3. I. Loureivi spr. caule fruticoso suberecto; fol. ovato-oblongis obtusis subcoriaceis; pedunculis subtrifloris axillarilus. Apocynum africanum Lour. In Africu orient. $\hbar$.

\section{HOLARRHENA R.Br. (1509).}

1. H. mitis R. Br. Carissa mitis Tahl Symb. 3. t. 59. In Ind. or. t. Frutex ranis dichotomis. Fol. oblonga petiolata. Flor. corymbosi. Cor. cinerascens.

\section{APOCYNUM Matth. (1560).}

1. A. androsaemifolium $\boldsymbol{I}$. fol. ovatis subtus incano-pubescentibus; cymis paniculatis; tubo cor. calycem his superante. Lam. ill. t. 176. f. 1. B. M. 280. In Virginir et Canada. 5. 1-2-ped. Flor. rosei.

2. A. cannabinum $\boldsymbol{L}$. fol. oblongis utrinque attenuatis subtus glabris; cymis paniculatis; tubo cor. calycem 
aequante. Plukn. t. 13. f. 1. In Amer. bor. t. Cor. viridis.

3. A. mubscens R. Br. fol. ovatooblongis mucronatis utrinque cymaque pubescentibus; calyce corollam aequante. In Virginia. ђ.

t. A. hypericifolium Ait. fol. sul)cordato-lanceolatis integerrimis acutis hrevissime petiolatis subtus glabris; flor. cymosis; tubo cor. calycem aequante. Jacq. Hort. t. 66. In Amer. bor. et Sibiria. t. Flor. albi.

5. A. ventum $L$. fol. oblongo-ellipticis mucromatis glahris; cymis paniculatis; tubo corollae calycem aequante. Loh. hist. 372. f. 1.2. Zannicl. ist. t. 76. In Europ. austr. et Caucaso. ђ. 2-ped. Flor. albi.

6. A. canariense Lam. frutescens; fol. ovatis acuminatis; folliculorum apicibus recurvis. Plukn. t. 260. f. 3. In ins. Canariis. ђ. Flores parvi.

7. A. puniculatum Lam. caule frutescente volubili; fol. ovato-lanceolatis acutis glabris; flor. paniculatis. A. Acouci Aubl. Guj. t. 107. In Gujana. ち. Flores minimi albi.

8. A. tiliaefolium Lum. caule suffruticoso voluhili; fol. cordato-subrotundis acuminatis longe petiolatis. Rheede 9. t. 15. In Ind. or. ち. Cor. magna intus villosa.

9. A. reticulatum $L$. caule volubili; fol. ovatis venosis glaberrimis; flor. cymosis. Rumph. 5. t. 40. f. 2. In Cochinchina et Ind. or. ђ. Cor. albo- virens.

10. A. cotinifolium Lam. fol. ohovatis obtusis petiolatis glabris; flor. corymbosis terminalibus. In Java. Cor. campanulata.

11. A. ayylomeratum Poir. fol. ellipticis utrinque obtusis submucronatis; flor. cymosis agolomeratis; cor. fauce pilosa. Rumph.? 5. t. 175. f. 1 . In Domingo et Ind. or.? †.

12. A. Jurentus Lour. fol. ovatis pilosis; racemis dichotomis axillaribus; caule volubili. In Cochinchina. †. Caulis ruber lactescens.

\section{CRYPTOLEPIS R.Br. (1809).}

1. C. Buchanani R. Br. In Ind. orient. Frutex volubilis. Fol. subtus discoloria. Corymbi sessiles axillares brevissimi.

\section{THENARDIA Kunth (1818).}

1. T. floribunda H. et K. 3. $t$. 240. fol. ovato-ohlongis acuminatis gla!ris; corymbis mulifloris axillaribus pedunculatis. In Mexico. ち. Caul. volubilis. Cor. albida.

2. 'T. umbellata Spr. fol. ovatis acuminatis subtus tomentosis; panicula terminali corymbosa. Apocynum umbellatum Aubl. Guj. t. 108. In Cajenua. ち. Cor. purpurascens.

3. 'T. scabra syr. fol. ovato-ellipticis undulatis subtus glaucescentibus; flor. cymosis; cor. extus scahropubescente. Echites scabra Labill. Nov. Caled. t. 31. In Nova Caledonia. $\hbar$.

\section{ALSTONIA R. Br. (1809).}

1. A. scholaris R. Br. fol. subverticillatis ovato-oblongis obtusis venosis; cymis breviter pedunculatis; limbo cor. harhato. Echites L. A. plumosa Labill. N. Cal. t. 32. Rheede 1. f. 45. Rumph. 2. t. 82. In Ind. orient. et ins. Molucc. $\hbar$. Arbor. Flor. albi.

2. A. spectabilis R. Br. fol. quateruis elliptico - oblongis acuminatis costatis; cymis peduncucatis; cor. limho barhato; folliculis longissimis. In ins. Timor.

3. A. venenata R. Br. fol. quaternis oblongo-lanceolatis acuminatis hasi attenuatis ; cymis dichotomis ; limho cor. imberbi; folliculis abbreviatis. In Ind. orient. $\hbar$.

4. A. costuta R. Br. fol. oppositis oblongis acuminatis costatis; cyuis effusis; limbo cor. imberhi; folliculis longissimis. Echites Forst. In ins. Societ. $\hbar$.

5. A. spathulata Blume; fol. oppositis 4 -nisque spathulatis apice rotundatis glahris; umbellis terminalibus; fauce corollae subbarbata. In Java. t.

6. A. villosa Blume; fol. subsessilibus 4-nis elliptico-oblongis remote costatis infra villosis; cymis effusis. In Java. ち.

7. A. sericea Blume; fol. 3-nis 4-nisque lanceolatis utrinque acuminatissimis infra sericeo-pubescentibus; fauce cor. barbata. In Java. ち. 
8. A. neriifolia Wall. fol. verticillatis lanceolatis acuminatis parallele venosis suhtus villosis; cymis sessilibus pubescentibus; fauce cor. villosa. In Nepalia. ђ.

9. A. Incillu Don: fol. oppositis oblongis acuminatis glabris lucidis reticulatis; cymis terminalibus; cor. fauce barbata. In Nepalia. t.

\section{PRESTONIA R. Br. (1809).}

1. P. tomentosa R. Br. fol. oblongis ramisque tomentosis; corymbis congestis axillaribus. In Brasilia. $\hbar$. Frutex volubilis.

2. P. hirsuta $\boldsymbol{R}, \mathrm{Br}$. fol. oblongoovalihus acuminatis hasi excavatis subtus villosis; racemis multifloris. Echites 12. et P. per. t. 136. In Peruvia. \$.

3. P. mollis H. et K. t. 212. fol. ovato-oblongis acutis subcordatis supra hirtellis subtus pulescentilus; flor. racemosis. In Amer. anstr. 古. Cor. flava.

4. P. glabrata Ronpl. fol. ovatoohlongis hrevisime acuminatis cordatis glabris; floribus racemosis. In Quito. 卢.

5. P. peruviana Spr. fol. cordatosubrotundis acuminatis tomentosis glanduliferis; pedunc. racemosis. Echites R. et P. per. t. 135. In Peruvia. ђ. Cor. flava.

6. P. quingangularis spr. fol. obovatis acuminatis; pedunc. racemosis. Echites Jacq. am. t. 25. pict. t. 32. In Amer. austr. $\hbar$. Flor. magni virides.

810. BALFOURIA R. Br. (1809).

1. B. saligna R. Br. In Nov. Holl. . Arhor. Fol. lato-linearia subfalcata. Flores cymosi axillares.

\section{NERIUM Diosc.}

1. N. Oleander $L$. fol. ternis lineari-lanceolatis coriaceis subtus venosis; foliolis faucis trifidis acuminatis. schk. t. 53. Wuh. arh. t. 12. In Ind. orient. $\hbar$. Cor. rosea, alba et plena.
2. N. odorum Ait. fol. ternis lineari-lanceolatis subtus venosis; foliolis faucis multifidis apice filamentosis. Hayne term. t. 22. f. 1. Rheede 9. t. 1. In Ind. orient. ち. Flores odori.

3. N. salicinum Forsk. fol. ternis lineari-lanceolatis enerviis. In Arabia. 方.

1. N. diraricatum Lour. fol. oppositis ohlongis acuminatis undulatis; ramis divaricatis; florihus congestis; foliolis faucis subulatis. In Cochin-

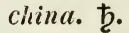

\section{STROPHANTUS DC. (1802).}

1. S. dichotomus DC. fol, oblongis; petiolis stipulatis; ramis dichotomis; pedunc. subcorymbosis. Echites undulata L. Burm. ind. t. 26. Hehb. Hort. t. 159. In Ind. orient. b. Cor. rosea.

2. S. sarmentosus DC. Bull. no. 46. $t$. 8. $f$. 1. fol. ovatis acutis ; floribus glomeratis axillaribus terminalibusque; caule sarmentoso. Amm. Mus. 1. t. 27. In A/r. occirl. ђ.

3. s. laurifolius DC. fol. ohlongis subternis; floribus glomeratis terminalihus; caule erecto. In Africa occidentuli. $\hbar$.

4. S. scundens R. et S. fol. ovato-ohlongis acuminatis; cor. laciniis longissimis; caule scandente. Nerium Lour. In Coclinclima. ち. Cor. rubra. 5. S. hispridus DC. fol. ovato-oblongis sessilibus cauleque erecto hispidis; pedunc. dicholomis. In Africa occid. $\hbar$. Cor. rubra.

6. S. alterniflorus Spr. fol. ovatis acuminatis glabris; umbellis axillarihus alternis; caule scandente. Apocynum Lour. In Cochinclina. ఫ.

\section{WRIGHTIA R. Br. (1S09).}

1. W. antidysenterica $R$. Br. fol. ovato-oblongis acutis glahris; corymhis terminalıhus; folliculis apice nexis. Nerium L. Plenk t. 119. Burm. Zeyl. t. 77. In Zeyl. et Cochinchina. ђ. Arbuscula 6-10-ped.

2. W. zeylanica R. Br. fol. ovatoohlongis acutis glabris; corymbis terminalibus paucifloris; folliculis distin- 
ctis. Nerium I. Burm. zeyl. t. 12. f. 2. In Leyluno. ち. Cor. purpurea.

3. W. dubia spm. fol. ovalo-lanceolatis subumdulatis glabris; pedunculis 1-florss; squamis tulji alternis obtusis. Cameraria sims. B. R. 933. In Inl. orient. 古.

4. Wr.tinctoria R. Br. fol. oblongis aculis glaherrimis; corymbi terminalis ramis dichotomis; folliculis distinctis. Nerium Rottl. Zimmerm. Reis. XI. p. 132. c. ic. In Ind. orient. †.

j. W. mbescens R. Fr. fol. onlongis ulrinque acuminatis sericeotomentosis; corymbis densis rigidis; folliculis cohaerentibus. In Ind. or. et Hor. Holl. ђ.

\section{TINCA Plin.}

1. I. minor 1 . caulibus floriferis erectis; sarmentis procumhentihus; fol. elliptico-lanceolatis margine laevihus persistentihus. Blackw. 1. 39. E. $91 \%$. Guimp. t. 27. In Europa. ち. Cor. pallide caerulea.

2. I. herbacea W. Kit. $t$. 9. herhacea; procumbens; fol. ohlongo-lanceolatis ciliato-serrulatis. B. M. 2002. B. R. 301. In Hungaria. 24. Pedunc. folio longior. Cor. vilacea.

3. I major $L$. caule erectiusculo; fol. ovatis splendentibus sempervirentilus margine ciliatis; dentibus calycis setaceis. E. B. 514. V.media Delile. In Europ. austr. ち. 2-ped. Cor. magna violacea.

1. I. pusilla $I$. caule herhaceo erecto 5 -angulari; fol. lanceolatis glabris; pedunc. subgeminis. Murr. Comm. gott. 1782. t. 2. f. 1. Rleede 9. t. 33. In Ind. or. $\odot$. Cor. purpureo-caerulea.

5. I. rosea $L$. caule erecto suffiruticoso; fol. ovato-oblongis ohtusis villosiusculis; petiolis basi bidentatis; flor. brevissine pedunculatis. B. M. 248 . In Asia aejuinoct. †. 1-2-ped. Cor. rosea et alba.

\section{TABERNAMONTANA Plum. (1703).}

1. T. macrophylla Poir. fol. ovatis ohtusis laevibus; pedunc. axillaribus 3-fidis; calycibus obtusis. T. co- riacea Lk. In Brasilia. †. Caul. rugosus. Cor. altha.

2. 'T' muritirna poir. fol. nppositis ovatis obtusis petiolatis membranaceis ; racemis articulatis fravilibus pendulis. T. ohtusa sim. In Ind. or. ち. Cor. ochroleuca.

3. T. stunumosu Sm. fol. ovatis ohtusis coriaceis lucidis venosis; cymis terminalihus; pedunc. bracteatis. Vahea gummifera Lam. In Ind. or. †. Cor. ochrolenca.

t. 'T. citrifolia I. fol. ovatis lucidis subcoriaceis undulatis ; flor. cymosis axillarihus; laciniis cor. linearihus. Lam. ill. t. 170. f. 1. Plum. ic. t. 248. f. 2. In Ind. orc. 卢. Arbuscila 1215-ped. Cor. flava.

5. 'T. alba Nill. fol. oblongo-ovatis acuminatis oppositis; floribus corymbosis terminalibus calycihus acutis. T. citrifolia Jacq. aur. t. 175. f. 13. In Ind. occ. ち. Cor. alba.

6. T. elustica spr. fol. ovatis acuminatis nervosis; flor. paniculatis urceolatis; caule scandente. Urceola loxb. In Ind. orient. ђ.

7. T. Pundacyui Poir. fol. ovatolanceolatis acuminatis glahris venosis; corymhis axillarihus folio brevioribus; calycihus obtusiusculis. sommerat it. t. 19. In Guinea. ち. Arbuscula. Cor. alba.

8. T. psycliotrifolin II. et K. glahra; fol. obovatis acutis; pedunc. dichotomis corymhosis; calycis laciniis lanceolatis recurvis. In Nov. Anulalusia. ち. Cor. allia.

9. 'T'. littoralis $H$. et $\boldsymbol{K}$. glahra; fol. elliptico-oblongis utrinque atienuatis reticulato-venosis; calyce hasi squamuloso. In Mexico. ђ. Cor. flava.

10. T. ripuria H. et K. glabra; fol. ohlongis acuminatis margine undulatis; pedunc. dichotomis ; calycis laciniis undulatis. In Nov. Grancuta. ち. Cor. flava.

11. T. cymosa Jucq. am. t. 131. f. 11. fol. ovato-lanceolatis acutis integerrimis; cymis axillarilus mullifloris; laciniis calycis Janceolatis. T. multiflora Lk. In Nov. Granata. †. Arbuscula 6-15-ped. Cor. rufescens.

12. T. discolor Su. fol. ovatolanceolatis; pedunc. axillaribus bifloris; calycihus acutis. In Jamaica. $\hbar$. 5-6ped. Cor. alho-flavescens.

1:3. T. populifolia Poir. fol. latoovatis acuminatis; floribus parvis pa- 
niculato-cymosis; cor. minimis. T. parviflora Poir. In Amer. austr. Frutex. Cor. alba.

14. T. muricata $L k$. fol. ovatooblongis acuminatis supra bullatis subtus foveolatis; pedunc. cymosis. In Brasilia. $\hbar$.

15. T. ebracteata R. Br. fol. ovalibus cymisque pubescentibus; pedunc. patulis ebracteatis. In Nova Hollandia. †.

16. T. mubscens $R . B r$. fol. elliptico-ohlongis subacuminatis subtus ramulisque pubescentibus; calycibus pilosis; bracteis minutissimis. In Nov: Holl. 古.

1\%. T. orientalis R. Br. fol. lanceolato-oblongis acuminatis ramisque glaberrimis; cymis decompositis glabris; bracteis deciduis. In Gujana. $ђ$.

18. T. echinata Aubl. Guj. t. 103. fol. oblongis utrinque attenuatis venosis; florihus axillarihus fasciculatospicatis; folliculis echinatis. In Gujana. $\hbar$. Suffutex. Cor. flava.

19. $T$. coronaria $W$. fol. oppositis oblongis acuminatis glahris; tulo cor. elongato. Nerium Ait. Jacq. ic. t. 52. In Ind. orient. $\hbar$.

20. T. divuricata $R$. $B r$. caule sarmentoso; ramis divaricatis; fol. ovato-lanceolatis glabris. Nerium $\mathbf{L}$. In Zeylona. ち.

21. T. amygdalifolia Jacr. am. t. 181. f. 15. pict. $t$. 3.5.9. fol. oblongis utrinque attenuatis glabris; pedunc. dichotomis; antheris exsertis. Cestrum nervosum Mill. In Carthagena. ち. Cor. candida.

22. T. Sananho $R$. et P. peruv. t. 1-14. fol. ohlongis acuminatis ; corymbis biquadrificlis; fructibus ovatoacuminatis. T. 4-stachya $H$. et $K$. In Peruvia. ち. 12-15-ped. Cor. ochroleuca.

23. T. umbrosa II. et K. glabra ; fol. elliptico-oblongis acutis; corymbis dichotomis; calycis laciniis patulis. In Nov. Granata. ち. Cor. alba.

2t. T. laurifolia I. fol. ovalibus integerrinis glahris; pedunculis paucifloris; calycibus obtusis. In Ind. occ. et Brasilia. $\downarrow$.

25. T' odorata Vahl; fol. oblongis acutis reticulato-venosis subtus subdiscolorilus; pedunc. 4-nis 1-floris. Cameraria Tamaquarina Aubl. t. 102.
T. jasminoides H. et K. In Cajenna, Nova Granata. ち. 3-4-ped.

26. $T$. arcuata $R$. et P. peruv. $t$. 143. fol. obovatis oblongis acuminatis; folliculis revoluto-armatis. In Peruvia. ち. Arbor 20-30-ped. succo lacteo. Cor. ochrolenca.

2\%. T. grandiflora L. caule dichotomo; calycibus inaequalibus laxissimis. Jacq. am. t. 31. pict. t. 41. Lam. ill. t. 170. f. 2. In Nov. Granata. Arbuscula 8-ped. Cor. alba.

28. 'T. heterophylla Iahl; fol. elliptico-lanceolatis hasi corlatis undulatis acuminatis glabris; floribus racemosis. In Cajenna. $ち$.

29. T. fasciculata poir. fol. fasciculatis ovato-acuninatis nervosis; ramis oppositis articulatis nigris. In Cajenna. †. Cor. parva alba.

30. T. persicarifolia Jacq. ic. $t$. 320.fol. elongato-lanceolatis utrinque acuminatis subtus pallidis; pedunc. racemosis. T. multiflora sim.? In Mascareukis. ђ. 10-ped. Cor. ochroleuca.

31. T. floribunda Blume; fol. oblongis basi acutis membranaceis glabris; corymhis geminatis; cor. laciniis ohtusis undulatis. In Java. $\hbar$.

32. T. pauciflora Blume; fol. oblongo-lanceolatis acuminatis membranaceis glabris; fasciculis florum bifidis; cor. Iaciniis ohliquis. In Java $\hbar$.

33. $T$. sphaerocarpa Blume; fol. elliptico-ohlongis obtusis basi acutis coriaceis glahris; floribus corymbosis; cor. laciniis rotundatis undulatis. In Java. ち.

34. T. Undulata Vahl; fol. lanceolatis utrinque attenuatis undulatis venosis; pedunc. cymosis; calycilus incrassatis ; folliculis incurvis. In ins. Trinitatis 古.

3.5. T. neriifolia Tahl; fol. lanceolatis utrinque atteunatis venosis subtus pallidis; pedunc. axillaribus pancifloris; calycibus acutis. In Portorico. $\$$.

36. T. speciosa Poir. fol. lanceolatis elongatis utrinque attenuatis venosis membranaceis; corymbis axillaribus multifloris; calycibus olstusis. In Cajenna. $\bar{b}$.

37. T. obtusifolia Poir. fol. spathulato-lanceolatis venosis glabris; floriluus racemosis. In Madagascar. $\not{b}$. 38. $T$. bovina Lo? fol. fanceolatis glabris; pedunculis axillaribus sub- 
5-floris; folliculis recurvis. In Cochinchina. 古. Frut. 4-ped. Cor. alba.

3.9. 'T. bufalina Lour. fol. Ianceolatis; pedunc. binatis 1-floris pendulis. In Cochinchina. ち. Frutex 5-ped. Cor. alba.

40. T.? verrucosa Blume; caule scandente; ramis verrucosis; fol. ovali-ohlongis acuminatis glabris; pedunc. umbellato-trifidis. In Java. $\hbar$.

11. 'T. polyantha Blume; caule scandente; fol. oblongo-lanceolatis acuminatis glahris; floribus fasciculato-paniculatis parvis. In Java. ‡.

\section{CAMERARIA Plum. (1703).}

1. C. latifolia $L$. fol. ovatis acutis lucidis parallele venosis; pedunc. corymbosis. Jacq. am. t. 182 . f. 86. pict. t. 39. Andr. Rep. t. 261. In Inel. occ. ち. Arbor procera. Cor. alba.

2. C. zeylanica Retz; fol. ovatolanceolatis acuminatis transverse venosis; corymhis terminalibus axillaribusque. In Keylano. ち. Cor. alba.

3. C. obesa $\mathbf{S p m}$. fol. sparsis obovatis mucronatis aveniis subtus tomentosis; trunco basi tuberoso. Nerium Forsk. In Arabia. $ђ$.

4. C. angustifolia $L$. fol. linearibus; pedunculis corymbosis. Plum. ic. 72. f. 2. In America australi. $\hbar$.

\section{1\%. ASPIDOSPERMA Mart. (1526).}

1. A. tomentosum Mart. $t$. 34. fol. terminalihus fasciculatis suhsessilibus oblongis repandis venosis utrinquc tomentosis; cymis compositis aygregatis. In Brasilia. ђ. Arbor 10-15ped. Cor. alla.

2. A. macrocarpon Mart. $t$. 3.5. et 36. fol. suhcordato-oblongis obtusis petiolatis coriaceis subtus tomentosis. In Brasilia. †. Arbor 1015-ped. Cor. albida.

3. A. refractum Mart. cortice solido; ramulis dichotomo-refractis ; fol. ovalis acutis puhescentibus; cymis simplicibns paucifloris. In Irasilia. $\hbar$.

4. A. bicolor Mart. cortice solido; ramis squarrosis; fol. petiolatis obovatis obtusis supra glabris subtus tomentoso-canis. In Brasilia.
5. A. pyrifolium Mart. cortice solido; fol. petiolatis ovatis acutis utrinque glabris. In Brasilia.

\section{AMSONIA Walt. (1788).}

1. A. latifolia Nichx. fol. oblongis utrinque attenuatis subtus puberulis ; folliculis oblongis. Tabernaemontana Amsonia Ait. Pluckn.t. 115. f. 3. In Amer, bor. 24. Cor. pallide caerulea.

2. A. salicifolia Pursh; caule laevigato; fol. lineari-lanceolatis utrinque acutis glaherrimis. In America boreali. 4. Flor. copiosi racemosi.

3. A. an!hustifolia Michx. fol. angusto-linearibus erectis pubescentibus; caule conspicue pubescente. Ventell. Choix t. 29. In Amer. bor. 24. Cor. caerulea.

\section{ALLAMANDA L. (1791).}

1. A. cathartica $L$. fol. quaternis ovato-oblongis acutis subtus ferrugineis. B. M. 338. Herit. Stirp. t. 24. Aubl. Guj. t. 106. In Gujana. ち. Frutex scandens. Flores flavi.

2. A. verticillatc Desf: fol. subsenis ovato-oblongis obtusis glaberrimis. Patria ignota.

\section{ANABATA Willd. (1819).}

1. A. odorata W. Rauwolfia oppositifolia Spr. In Amer. austr. $ち$. Frutex glaber. Fol. opposita ohlonga glabra. Flores umbellati albi.

\section{MITREOLA Rich. (1S23).}

1. M. ophiorrhizotdes Rich. Ophiorrhiza Mitreola L. In Ind. occ. et Carolina. ๑. Herba simplex glabra. Folia ovato-oblonga. Flores cymosi albi.

\section{LYONSIA R. Br. (1809).}

1. L. staminea R. Br. In Nov. Holl. ち. Frutex volubilis. Fol. opposita. Cyma terminalis dichotoma. 
852b. ROMANZOVIA Cham.(1820).

1. R. unalaschensis Cham. In ins. Alenticis. $\odot$. Herba digitalis. Folia reniformi-cordata lobata petiolata. Hlores racemosi albidi.

\section{SIBTHORPIA L. (1\%6t).}

1. S. retusa Kunth; fol. cordatoreniformibus lohatis; lohis retusis; floribus 5-andris. In Nova Hispania.

2. S. europaea I. fol. peltatis cordato-reniformibus lohato-crenatis; floribus 4-andris. In Anglia et Lusitania.

3. S. pichincensis $\boldsymbol{H}$. et $\boldsymbol{K}$. fol. cordatis sub-7-lobis; floribus 5-andris. In Quito.

4. S. peregrina Spr. fol. reniformibus orbiculatis crenatis; floribus 7andris. Disandra prostrata L. In Mauritania et Madera.

\subsection{VERBASCUM Plin.}

a. Folia decurrentia, semidecurrentia t petiolata.

1. I. Schraderi Meyer; fol. crenulatis tomentosis a folio ad folium decurrentibus; filamentis albo-lanatis, 2 Iongioribus glabris vel superne parce pilosis anthera sua hinc breviter decurrente quadruplo longioribus. V. Thapsus schrad. V. pallidum Necs. V. elongatum IV. In collib. Europae. $\odot$. Cor. flava.

2. I. Thapsus $L$. fol. crenatis tomentosis tomento lutescente onmibus a folio ad folium decurrentibus; filamentis albo-lanatis, 2 longioribus glahris vel superme parce pilosis anthera sua hinc longe decurrente, sesqui-vel duplo longioribus. V. thapsiforme et V. cuspidatum Sclırad. Cum priori. $\odot$. Cor. flava.

3. V. yossypinum MI.B. fol. supra viridibus subtus lana floccosa niveis oblongo-lanceolatis; racenis caudatis; staminibus subaequalibus. In Iberia. $\odot$.

t. I. niveum Tenor. fol. oblongis subcrenatis candide denseque floccosotomentosis; racemo spicato denso. V. candidissimum DC. In Gallia. $\odot$.
5. I. auriculatum Nibth. gr. fol. elliptico-oblongis crenatis basi auriculatis utrinque tomentosis; racenis paniculatis. In Graecia et Asia minore. $\odot$.

6. V. ambigum Lej: fol. crenatis tomentosis ellipticis ovatisq!e; florum fasciculis subremotis; antheris hinis ohlongis. V. thapsiforme nigrum Schiede. In Europu. $\odot$. Cor. flavissima.

7. I. phlomoides L. fol. crenatis tomentosis, superioribus semi-decurrentihus; filamentis albo-lanatis, 2 glahris vel parce pilosis. V. rugulosum W. V. australe schrad. 1. t. 2. In Germaniu. $\odot$. Cor. flava.

8. I. montanum scirud. fol. crenatis lutescenti-tomentosis; pedicellis florigeris calyce brevioribus ; filamentis ommibus albo-lanatis, 2 apice glalnis. V. crassifolium sichleich. In collibus Helveliae. (-).

9. I. spurium Koch; fol. crenatis semidecurrentibus tomentosis; canle superne acute angulato; filamentis ommibus alho-lanatis. V.crassifolium schleich. In lielvetia. $\odot$. Cor. flava.

10. I'. ramigerum schrad. $t$. \&. fol. crenatis suldecurrentilus adpresse canescenti-tonentosis; caule superne acute angulato; pedicellis florigeris calyce longioribus ; filamentis ommihus allo-lauatis. V. thapsiformeLychnitis schiede. In collibus Europue. $\odot$. Cor. magna lutea.

11. I. nothum fioch; fol. crenatis suhdecurrotibus luteo - cinerascentetomentosis, superioribus longe cuspidatis; caule tereti; filamentis dilute purpureo-lanatis. In collibus et aut vias Europae. $\odot$. Flores magni lutei.

12. V. collinum sichad. fol. crenatis semidecurentibus tomentosis; tomento lutescente; caule superne acute angulato; filamentis ommibus purpureo-lanatis; antheris nullis decurrentibus. V. Thapso-nigrum schied. V. ambiguum Lej. In nemorosis Europae. $\odot$.

13. I'. adulterinum Koch; fol. crenatis subdecurrentibus canescenti-tomentosis; caule superne acute angulato; filamentis omnibus purpureo-lanatis. V. thapsiforme-nigrum schied. In pascuis Europae. $\odot$. Flores speciosi flavi.

1t. V. sinuatum $L$. fol. tomentosis sinuatis superioribus crenatis; race. mis paniculatis; filamentis omnibu. 
purpureo-lanatis. In aridis Europae. $\odot$. Flores flavi.

15. V. versiflorum schrad. fol. crenatis breviter decurrentibus canescenti-tomentosis; caule tereti; filamentis violaceo-lanatis. In Bohemia. $\odot$. Flores ferruginei rubri.

16. 1. ovalifolium Sims. B. M. 1037. caule erecto simplici; fol. ovalibus sessilihus dentato-crenatis superne glabriusculis. In Tauria. 4. Cor. flava.

\section{b. Foliis non decurrentibus.}

17. T. compacium M. B. fol. ovatis subtus tomentosis, inferioribus petiolatis; floribus solitariis dense spicatis. Till. pis. t. 50.? In Caucaso. $\odot$. Cor. pallide flava.

18. V. gnuphalodes $M . B$. fol. oblongis acutis crenatis subtus lana floccosa niveis; racemis caudatis. In Tauria. 4.

19. V. monspessulanum Pers. fol. supra glabris subtus tenuissime tomentosis, caulinis ovato-oblongis inaequaliter crenato-serratis; pedicellis calyce duplo longioribus. In Gallia austr.

20. I. hyoserifolium Schrad. fol. leviter tomentosis, inferioribus Ianceolatis sinuato-repandis, summis cordato-ovatis auriculatis; pedicellis aggregatis. In Asia minore.

21. V. angustifolium Tenore; fol. inferioribus petiolatis lanceolatis crenulatis, superioribus amplexicaulibus ovato-ohlongis; spica simplici compacta; filamentis albo-barbatis. In Calabria. $\odot$. Pedalis.

22. I. spectubile $\boldsymbol{M}$. $\boldsymbol{B}$. fol. cordatis crenatis supra villosis subtus tounentosis; racemis elongatis hirsutis; caps. villosis. In Tauria. $\odot$.

23. $I$. Lychnitis $L$. fol. erenatis supra glabriusculis subtus pulverulento-tomentosis, inferioribus elliptico-oblongis, superioribus sessilihus ovato-acuminatis; ramis pyramidatopaniculatis ; filamentis albo-lanatis. Fl. Dan. 586. V. album Mill. V. Weldenii Braun. In collibus Europae. ○. Cor. flava. Antherae croceae.

2t. I. speciosum Sclirad. hort. Goett. $t$. 16. fol. integerrimis undulatis tomentosis, inferioribus oblongis, caulinis cordato-auriculatis sessilibus; flor. paniculatis; filamentis albo-lana- tis. V. Iongifolium DC. In Austria et Gallia. $\odot$. Flor. parvi lutei.

2.5. I. floccosum W. Kit. luung. $t$. 71. fol. dense albo-tomentosis, radic. oblongo-ellipticis, superioribus longe acuminatis semiamplexicaulihus; caule ramisque teretibus; filamentis albolanatis. V. pulverulentum sm. In collibus Europae. $\odot$. Flores flavi.

26. V. pulverulentum Vill. fol. crenatis supra tenue, subtus densius canescenti-tomentosis, superioribus acuminatis; caule superne ramisque obtuse angulatis; racemis patentibus; filamentis albo-lanatis. In Gallia orient. $\odot$. Cor. flava.

27. I. Schottianum Schrad. t. 3. f. 2. fol. crenatis utrinque supra tenuius, subtus densius tomentosis, radic. ovali-oblongis petiolatis; ramis paniculatis; filamentis purpureo-lanatis. In collibus Austriae. $\odot$. Cor. flava.

2s. V. chryserium Schrad. fol. integerriuis tomentosis ovato-oblongis, superior. ovatis amplexicaulibus; racemis paniculatis; antheris aequalibus.

\section{In Palaestina.}

29. $\boldsymbol{V}$. nigrum $\boldsymbol{L}$. fol. crenatis subtus subtomentosis, caulinis inferioribus oblongo-ovatis basi cordatis; caule superne acute angulato; raceno elongato; filamentis purpuren-lanatis. Fl. Dan. 1088. E. B. 59. B. thyrsoideum $\gamma$. ovatum K. et W. In Europa. 4 . Cor. flava.

30. V. lanatum Schrad. t. 2. f. 1. fol. subtus lanato-tomentosis, inferioribus petiolatis subsinuato-duplicat 0creuatis; caule superne angulato; racemo simplici; filamentis purpureo-lanatis. In Carinthia. $\odot$. Cor. flava.

31. V. pyramidatum M. B. fol. nudiusculis, inferioribus oblongis duplicato-crenatis, superioribus late cordatis sessilibus; laciniis calycis ovatis; caule angulato. In Tauria et Caucuso.

32. $\Gamma$. longifoliun Tenore Neap. $t$. 21. fol. subintegerrimis tomentosis, radicalibus longissimis, caulinis anplexicaulibus utrinque densissime tomentosis supra luteo-aureis. In pascuis montium Abrutii. $\odot$. Cor. Llava.

33. I'. leptostachyum DC. totum candide tomentostum; fol. oblongis tomentosis, superioribus ovatis integerrimis semiamplexicaulibus; racemo elongato gracili. In Gallo austr. $\odot$. Cor. flava. 
34. V. majale DC. fol. oblongolanceolatis acutis, inferioribns petiolatis, superioribus sessilibus inaequaliter dentatis subtus albido-tomentosis; caule denum purpurascente simplicissimo. Circa Montpellier. (.) Cor. magna flava.

3.5. V. grandiflorum schrad. fol. grosse crenatis nitidis supra nudis subtus leviter pubescentibus, inferioribus oblongis, superioribus cordatis; racemis elongalis; filamentis disparibus. Patria iynota. $\odot$.

36. V. ovatum schrad. Hort. Goett. t. 25. fol. ovatis obtusis petiolatis crenatis subtus leviter tomentosis; racemis paniculatis; pedicellis calyce longioribus, Patria ignota. $\odot$.

3\%. V. Blattaria $L$. fol. glabris, inferioribus obovato-oblongis hasi attenuato-sinuatis; racemo glanduloso. Celsia beterophylla Pers. In Europa. $\odot$. Cor. flava intus violaceo-barbata.

38. $V$. phoeniceum $I$. fol. subtus pubescentibus, radical. petiolatis ovatis oblongisve crenatis; racemo glanduloso-piloso. B. M. 885. B. Cab. 637. In Europa media. $\odot$. Pedale. Cor. magna violacea.

39. I. rubiginosum W. K. lung. t. 197. fol. crenatis subtus pubescentibus oblongis ovato-oblongisve s. ovato-acutis; racemis paniculatis; pedicellis calyce multoties longioribus. V. caucasicum Fisch. V. cupreum sims. In Hangaria et Podolia. $\odot$. Cor. rubro-ferruginea intus lutea.

to. 1. virgatum With. fol. cauleque glanduloso-pilosis, radicalibus sublyratis, caulinis ohlongis dentatis; fasciculis florum foliosis. V. blattarioides Lam. Flor. Port. t. 28. E. B.550. In Anglia, Hispania et Tuuria.

41. V. undulatum Lam. fol. stellato-pubescentihus, inferioribus lyrato-sinuatis undulatis densissime tomentosis, superioribus serratis amplexicaulibns floccosis; caule virgato. V. plicatum sm. Silhth. gr. t. 226. In Gruecia. -). Cor. flava extus tomentosa.

42. I. yallicum $W$. fol. oblongoovatis cordatis petiolatis crenatis subtus tenuissime tomentosis, inferioribus pinnatifidis. Vill. delph. t. 13. V. dentatum Lap. In Gallia. 2.

43. V.bannaticum Schrad. fol. inferioribus ovali-oblongis petiolatio tri- plicato-crenatis basi pinnatifidis tomentosis, caulinis sessilibus; racemis paniculatis. In Bannatu.

44. I. haemorrhoilale Ait. fol. ovato-oblongis basi attenuatis obsolete crenulatis tomentosis; racemis spicatis elongatis; fasciculis florum ebracteatis. In Madera. $\odot$.

t5. I. puniceum schrad. Hort. Goett. $t$. 1\%. fol. crenatis pubescentibus, inferioribus cordatis olitusis petiolatis, summis amplexicaulibus acuminatis; pedicellis geminis hractea Iongiorihus. In Europa media. $\odot$. Cor. pallide fuscescens.

46. J. simplex Lubill. Syr. dec. f. $t$. 5. caule simplicissimo; fol. ellipticis crenatis utrinque tomentosis, inferioribus petiolatis. Circa bumascum. 4.

47. I. bugullaefolium Lam. fol. inferiorilus late ovalis crenatis glabris petiolatis, superiorilus inciso-serratis pilosiusculis ; racemo sulispicato; floribus solitariis. In Thracil. $\odot$.

48. I. betonicaefolium Desf. Ann. Mus. 10. $t$. t. villosum; caule simplici; fol. cordato-oblongis crenatis; racemo conferto; staminibus disparibus. In Armenia. 1-2-ped. Cor. flava.

49. I. pinnatifidum Vall; fol. pinnatifidis sublinearibus rugosis nudiusculis; ramis strictis patentilous; floribns lanatis glomeratis; bracteis ternatis. V. hipinnatifidum sims. B. M. In Tauria et Graecia. $\odot$.

50. I. ceratophyllum schrad. fol. utrinque tomentosis, inferioribus subbipinnatifidis; laciniis lanceolatis obtusis inciso-dentatis ; floribus glomerato-spicatis spica composita. In Asia minore. $\odot$.

51. I. spinosum $L$. caule folioso spinoso frutescente; fol. spathulatis tomentosis. Alp. exot. t. 36. In Creta. †. Frutex $\frac{1}{2}$-ped. Cor. parva citrina.

52. V. syriacum Sclirad. fol. oblongo-lanceolatis ohtusis integerrimis lanato-tomentosis; floribus glomeratospicatis. In syria. $\odot$.

53. V.? candidissimum DC. fol. oblongis utrinque attenuatis crenatis densissime candide floccoso-tomentosis; floribus remole verticillato-spicatis. In agro Monspel. $\odot$. 
51. V. bicolor Padarro; totum dense candide tomentosum; fol. infimis petiolatis ovali-acutis crenatis hasi auriculatis incisisque; florum fasciculis compactis lanato-floccosis. Rchb. ic.... Prope Nizzam. (-). Cor. laete flava.

\subsection{HYOSCFAMLS Diosc.}

1. II. niger $I_{\text {. }}$ fol. sessilihus semidecurrentibus ovato-ohlongis sinuato-dentatis; floribus subsessilihus. E. B. 591. sichk. t. 44. Fl. Dall. 1552. H. agrestis Kit. In Europ. $\odot$. Villoso-viscidus. Cor. ochroleuco-lucida violaceo-reticulato-venosa.

2. H. albus L. fol. petiolatis cordatis cuneato-rhombeisque obtuse sinuatis obtusis; florihus subsessilibus. Blackw. t. 111. Plenk. t. 98. In Europa anstrali. $\odot$. Villosus. Cor. albida aut fatte violacea.

3. H. canariensis Ker. B. R. 180. fol. inferioribus late cordato-truncatis inciso-angulatis; angulis inferior. dentatis supremis spathulatis. H. anreus DC. In ins. Canar. $\odot$. Cor. ochroleuca fundo violacea.

f. H. muticus I. $_{\text {. fol. petiolatis }}$ acutangulis; calycihus muticis; bracteis indivisis. H. Datura Forsk. In Aegypto. $\odot$. 1 -ped. Cor. extus albida intus purpurea.

5. II. pusillus I. fol. petiolatis oblongo-lanceolatis subdentatis; flor. pedunculatis; calycis dentibus mucronato-cuspidatis. Plukn. t. 37. f. 5. In Persia. $\odot . \quad \frac{1}{2}$-ped. Cor. flava fauce nigra.

6. H. physaleides $L$. fol. petiolatis subcordato-ovatis integerrimis; florilus pedunculatis; calycibus inflatis subglobosis. B. M. 852. Linn. Amoen. acad. 7. t. 6. f. 1. In Sibiria. ๑. 1ped. Cor. purpurascens.

F. H. orientalis M. B. fol. deltoideo-ovatis repandis; calycibus fructus tumidis; genitalibus exsertis. In Caucaso. 4 .

8. H. pallidus W. Fit. fol. amplexicaulibus angulatis, radicalibus angulato-dentatis ; flor. sessilibus; corollis flavis. In Hungaria. $\odot$. H. nigro simillimus.

9. H. reticulatus $I$. fol. caulinis petiolatis cordatis sinnatis acutis; flo- ribus integerrimis; cor. ventricosis. Camer. Hort. t. 22. In Creta, Syric et Aeyypto. $\odot$. Cor. rubra.

10. H. Senecionis $W$. fol. petiolatis subtrilohis inciso-dentatis; floribus pedunculatis; corollis aequalibus planis. In Aegypto. 24. Cor. aurea.

11. H. Scopolia $L$. fol. petiolatis ovato-oblongis integerrimis; flor. axillarihus nutantilus campanulatis subtruncatis. scopolina atropoides $\mathbf{R}$. et s. B. M. 1126. Hilar. t. 6. Jacq. ohs. t. 20. In Austria et Bavaria. 4. 1-ped. Cor. purpureo-violacea.

12. $H$. aurens $W$. fol. petiolatis ovatis acutis angulato-dentatis villosis; corollae laciniis 3 majoribus undulatis. B. M. 78. Sibth. wr. t.231. If. auriculatus Tenore. In Europ. austr. 4. Cor. aurea.

\section{NICOTIANA Dalechamp (1586).}

\section{a. Corollae laclni is acutis.}

1. N. Tabacum L. fol. oblongolanceolatis acuminatis sessilibus, inferioribus decurrentibus; fauce cor. inflata; limbi laciniis acuminatis. N. macrophylla et dilatata Lk. lancifolia Willd. yharrensis et loxensis Kunth. Plenk. ic. t. 99. Blackw. t. 146. In America. $\odot$. Cor. limbus roseus.

2. N. fruticosc $L$. caule suffuticoso ; fol. oblongo-lanceolatis acuminatis petiolatis; cor. fauce inflata. $\mathbf{N}$. chimensis Fisch. Mill. ic. t. 185. f. 1. In Clina et Prom. b. spei. ち. 3-4ped. Cor. rosea.

3. $\boldsymbol{N}$. anyustifolia $\boldsymbol{R}$. et $\boldsymbol{P}$. peruv. t. 130. $f$. $a$. caule ramoso; fol. pe tiolatis lanceolatis; cor. fance inflata N. longiflora Cav. In Chili. ๑. 2-3ped. Cor. alba.

4. N. musilla $L$. caule dichotomo; fol. sessilibus, radicalihus ovali-oblongis; calycibus hrevissimis. N. tenella Cav. N. humitis Mill. ic. t. 185. f. 2. In Mexico. $\odot$. Cor. alba.

5. N. ytutinosa $L$. fol. petiolatis cordatis glutinosis; floribus racemosis secundis; calycibus corollisque ringentihus. Andr. Kep. t. 484. In Amer. aequinoct. $\odot$. Cor. rubro-flava.

6. N. cerinthoilles Horn. fol. cordatis petiolatis glutinosis; floribus paniculatis; limbo corollae regularis la- 
ciniis brevissimis acutis. In Brasilia. $\odot$.

\%. N. repanda $W$. fol. amplexicaulibus lyratis subrepando-undulatis glabris; floribus racemosis; tubo cor. gracili longissino. N. lyrata Kunth. In Cuba. $\odot$.

8. N. glauca Grah. B. M. 383\%. caule suffiticoso; fol. inaequaliter cordato-ovatis acutis ohsolete sinuatis longe petiolatis; cor. laciniis brevissimis. In Irrasilia. $\odot$. Caul. 20ped. Cor. viride lutea.

9. N. plumbaginifolia $\mathbf{W}$. caule herbaceo diffuse ranoso tuberculatoaspero; fol. sessilibus obovatis undulatis; cor. tubo longissimo. N. acutifolia Hil. Ad Rio Grande. $\odot$.

\section{b. Corollac laciniis obtusis.}

10. N. rustica $L_{0}$ caulc tereti; fol. petiolatis ovatis; cor. tubo exserto; limbi lohis rotundatis. Blackw. t. 237. In America. $\odot$. 2-4-ped. Cor. flavo-vikens.

11. N. viscosa Lehm. fol. sessilibus oblongis obtusis basi dilatatis semiamplexicaulibus viscosis; calycibus obtusis. In Buenos Ayres. $\odot$.

12. N. bonariensis tielım. fol. sessilibus ovato-lanceolatis acutis subrepandis pilosis; calycibus acutis. In Buenos Ayres. $\odot$.

13. N. undulata $R$. et $P$. peruv. t. 130. $f$. 6. caule angulato; fol. petiolatis lanceolatis undulatis; calyce bilabiato. N. pulmonariaefolia Kuntlı, In Peruvia. ๑. 3-ped. viscosa. Cor. lutea.

14. N. vincaeflora Lag. fol. sessilibus oblongo-lanceolatis subserrulatis; tubo cor. elongato ; caule superne aspero. In Amer. aequinoct. $\odot$.

15. N. paniculata 1. fol. petiolatis subcordato-ovatis integerrimis ; foribus paniculatis; calycilus acuminatis. Fl. peruv. t. 129. f. b. Fcuill. t. 10. In Peruvia. ๑. 2-3-ped. Cor. Iutesceins.

16. N. suaveolens Lehm. fol. ovato-oblongis undulatis villosiusculis in petiolum decurrentibus; tubo corollae longissimo; caule villoso. N. undulata. R. Br. Vent. Malm. t. 10. In Nov. Holl. $\odot$. 2-ped. Cor. lutea.

17. Langsdorfii Nees ; fol. oblongo-lanceolatis acutis sub-integerrimis sessilibus cauleque villosis; limbo corollae truncato. In Brasilia. $\odot$.

18. N. andicola $H$. et $K$. fol. sessilibus lauceolatis acutis hasi augustatis; paniculis glutinoso-pilosis; calyce emarginato. In Peruvia. $\odot$.

19. N. quadrivalvis Pursh; fol. petiolatis oblongis; cor. tubo calyce dupto longiore; capsula 4-valvi subglobosa. Lehm. Nicot. t. 4. In Amer. hor. $\odot$. Cubitalis. Cor. albo-caerulescens.

20. N. acuminata Graham. B. M. 2919. lierbacea; pubescens; fol. latolanceolatis acuminatis undulatis; calyce glanduloso-pubescente; cor. laciniis rotundatis. In America. $\odot$. Flor. albi.

21. N. nana Lindl. B. R. 833. acaulis humillima; fol. lanceolatis integerrimis pilosis; pedunc. 1-floris axillaribus; calyce inflato viscidulo. In Amer. bor. $\odot$.

22. N. rotundifolia Lindl. Misc. no. 110. patenti-villosa; caule paniculato; fol. decurrentibus ovato-oblongis; filamentis 4 longioribus ; caps. calycis longitudine. In Nov. Holl.

\section{5\%. PETUNIA Juss. (1803).}

1.P. nyctaginiflora Juss. Ann. Mus. II. $t$. 17. f. 2. caule hirto; fol. ovato-oblongis pubescentibus cor. calyce 4-plo longioribus. Nicotiana Lehm. Ad Rio de la Plata.

2. P. parviflora Juss. Ann. Mus. i1. $t$. 1\%. $f$. 1. fol. oblongis subfasciculatis cauleque prostrato villosis; pedunc. brevissimis 1-floris. Nicotiana Lehm. Ad Rio de la Plata. ๑. Cor. rubra.

3. P. violacea Hook. B. M. 35556 . caule debili viscido-piloso; fol. brevi petiolatis acutis; cor. laciuiis rotundatis acutis. Salpiglossis integrifolia B. M. 3113. Niereubergia Sw. In Montevideo. $\odot$.

\section{LEHMANNIA Spr. (1817).}

1. L. tomentosa Spr. Nicotiana $R$. et P. peruv. t. 129. f. a. In Peruvia. ち. Caul. 15-20-ped. Fol. acuta integerrina venis purpureis. Pani- 
cula viscosa villosa. Cor. glabra purpurea.

\section{S59. LAMARCKIA Pers. (180t).}

1. L. coccinea Rich. In Cayenna. Planta ylaberrima. Folia oblonga acumiunta nitidissima. Cor. coccinea.

\section{FABIANA R. et P. (1799).}

1. F. imbricata $R$. et $P$. peruv. t. 122. fol. ovatis imbricatis minimis. In Chili. ந. Lesinosa ranosissima. Cor. lilacina.

2. I. thymifolia Hil. suffruticosa; glanduloso-pubescens ; fol. linearibus; floribus axillaribus nutantibus. Ad Iio Gionde. 古.

\section{S61. NIEREMBERGIA R. et P. (17.99).}

1. N. repens R. $t$ t P. peruv. $t$. 123. canle liguoso repente; fol. petiolatis ellipticis glalris; caps. oligosperma. N. spathulata H. et K. In Nora Granata. 方.

2. N. antunstifolia H. et K. t. 1.98. fol. lineari-lanceolatis sessilibus glahris; caps. polysperma 4-valvi; caule herbaceo diffuso. In Mexico et frontevilleo. ち. Cor. pallide cacrulea.

3. N. pubescens spr. fol. oblongolinearibus glanduloso - pilosiusculis; caps. polysperma 2 -valvi; caule liEnoso diffuso. N. viscidula Kunth $\mathbf{N}$. graveolens Hil. In Monterideo. $\hbar$.

A. N. filicanlis Lindl. B. R. 1619 . erecta; glabra; ramis diffusis filiformibus; calycis laciniis lineari-acuminatis: filamentis pubescenti-plandulosis. B. M. 3370. In Buenos Ayres. ந. 1-ped. Cor. alha fundo violacea.

.5. N. calycina Hook. I3. M. 3381. pubescenti-eilandulosa; caule herinaceo procumbente; fol. oppositis alternisque obovatis petiolatis; calycibus magnis campanulatis foliaceis. In Merico. ち. Cor. alba fundo lutea.

6. N. ypacilis Hook. B. M. 3109. caule herbaceo crectiusculo foliisque lineari-spathulatis pubescentibus; caps. polysperma. In Buenos Ayres. $\odot$. 1-ped. Cor. alba centro caerulea.

\section{CONTOLIELUS Plin.}

a. Caule volubili.

* Fol. compositis.

1. C. ternatus spr. fol. ternalis; foliolis ovatis repando-crenatis glaberrimis; ealycibus obtusis glutinosis. Iponoea Jacr. schönbr. t. 37. patria ignota. b. Cor. alba.

2. C. quinuefolius $L$. fol. quinato-digitatis glahris subserratis lanceolatis mucronatis; ramulis hirsutis; pedunc. bifloris, In Borboniu. Cor. apice barbata.

3. C. Irispaniolae Spr. fol. quinato-digitatis glabris lanceolatis selratis cuspidatis; caule hirto; calycibus obtusis. In Ifispaniola.

†. C. cissoirles Lam. fol. quinatodigitatis oblongis dentatis glabris cuspidatis; caule hirto; pedunc. sub 6floris; calyce acuto. C. riparius et calyciuus II. et K. In Amer, austr. et Cuba. 4 . Cor. alba.

5. C. glaber Aubl. glaberrimus; fol. digitato-quinatis; foliolis attenuatoacuminatis integerrimis; pedunc. ramosis divaricatis. In Cayenua. 4. Cor. alba.

6. C. quinatus Spr. fol. digitatis; foliolis lanceolatis petiolatis; pedunc. 1-floris. Inomoea L. Catesb. t. 91. I. quinata R. Br. C. digitatus Hunb. In Bahama, Caracas et Nov. Holl. Cor, violacea.

7. C. bellus spr. fol. pedato-quinatis; foliolis oblongis oblusis mucronatis glaberrimis; pedunc. 1-floris se taceis; calyce acuto. Ipomoca pulchella Roth. In Ind. or.

8. C. venosus Vahl; glaberrimus; fol. digitato-quinatis; foliolis petiolatis acuminatis integerrimis; pedunc. multifloris. Ipomoea $\mathbf{R}$. et $\mathbf{S}$. In ins. Mascarenlis.

9. C. Cavanillesii Spr. fol. qrinato-digitatis pilosis integerrimis. Ipo-moea pentaphylla Jacq. ic. t. 319. I. pilosa Cav. ic. t. 323. In Americu. ๑. Caul. 38-ped. Cor. purpurascens.

10. C. pentuphyllus I. fol. quinato-digitatis oblongis ovatis integerrimis hirsutis; pedunc. multifloris flexuosis ; catycihus hispidissinis ; rauris unuricato-hispidis. C. hirsutus Roxb. In lid. occ. 4 .

11. C. pendulus Spr. fol. qุuina- 
to-digitatis; foliolis oblongo-lanceolatis integerrimis glabris; pedunc. 1-floris tuberculatis. C. pedatus Roxh. Ipomoea $\mathbf{~ 3 . ~ B r . ~ C . ~ m u c r o n a t u s ~ F o r s t . ~ I n ~}$ ins. Tauna et Nov. Holl. 4.

12. C. Brownii Spr. patulo-hirsutus ; fol. quinato-digitatis; foliolis ohlongo-lanceolatis; pedunc. 1-floris ; calycibus glabris obtusis. Ipomoea hirsuta R. Br. In Nov. Holl.

13. C. macroculyx R. et $P$. peruv. t. 118. f. a. fol. quinatis oblongolanceolatis integerrimis; pedunc. longissimis racemoso-dichotomis. In Peruvia. 24. Cor. alba.

14. C.tenuifolins Vahl; fol, digitatis quinis; foliolis linearibus; pedunc. sub4-floris. In Ind. or.

1.5. C. heptaphyllus W. fol. septenato-digitatis lineari-lanceolatis binis, inferioribus 2-partitis; pedunc. sub-2-floris. In Ind. or.

16. C. macrorrisus $L_{\text {. }}$ fol. septenato-digitatis oblongis sinuato-repandis; pedunc. 5-floris; calycibus oblongis. Plum. et Burm. ic. t. 90. f. 1. In Inil. occ. 4 . Cor. coccinea.

17. C. septenatus Spr. fol. scptenato-digitatis integerrimis glahris; pedunc. Immellatis hrevissimis. Ipomoea L. Plum. et Burm. ic. t. 92. f. 2. In Ind. occ.

18. C. Horsfalliae; glaberrimus; fol. quinato-digitatis lanceolatis margine undulatis; eymis dichotomis. Ipomoea Hook. B. M. 331j. In Afr. 4. Cor. amoena rosea.

\section{b. Foliis pinnatifide.}

19. C. Quamoclit Spr. fol. pinnatis pimnis liniari-filiformilus; pedunc. 1floris. Ipomoea L. Lam. ill. t. 104. f. 1. B. M. 244. In Ind. or et Amer. bor. $\odot$. Cor. coccinea.

20. C. pinnatifidus $\boldsymbol{H}$. et $\boldsymbol{K}$. foi. pimato-7-fidis glabris; laciniis lanceolatis subintegerrimis; pedunc. sub-2foris; calycibus subrotundis. In Cuba.

\section{c. Foliis palmatis.}

21. C. Platensis; fol. septenatopalmatis; lohis cumeato-oblongis oltusis; pedunc. 2-4-floris; calyce obtuso. Ipomoea Herb. B. IR. 333. B. M. 3685. Ad Rio de Plata. Cor. car-
22. C. althaeoides $I$. fol. cordato-sinuatis sericeis; lobis repandis; pedunc. bifloris. C, argyraceus DC. Barr. ic. 312. In Europa et Africa. 4. Cor. lilacina.

23. C. tenuissimus Sm. fol. pedatis sericeis nitidissimis; lohis linearibus obtusis; pedunc. 1 -floris. Sibtl. gr. t. 195. C. sericeus Forsk. In Graec. et Aegypt. 4.

21. C. alceaefolius Lam. hirsutus; fol. omnibus profunde laciniatis suhpalmatis; pedunc. paucifloris folio longioribus. In Prom. b. spei. Cor. ochroleuca stella fuscescente.

2.5. C. dasyspermus Spr. fol. septenato-palmatis laevihus; petiolis tuherculato-asperis; pedunc. 1-floris. Ipomoea R. et s. I. stipulacea Jacq. sichoenbr. t. 189. In Montevideo. $\hbar$. Cor. purpurascens.

26. C. agyregatus spr. fol. pilosis palmato-7-lohis; laciniis ovatis acutis ; floribus aggregatis involucratis. In Cochinchina.

27. C. dissectus L. fol. 7-partitis; laciniis inciso-pinnatifidis glabris; pedunc. 1-floris; calycihus acutis; caule piloso. Ipomoea W. I. sinuata Orteg. Willd. Phyt. t. 2. f. 3. In Gujana et Nor. Iloll. $\hbar$.

28. C. tuberosus Spr. fol. 7-partitis; laciniis lanceolatis acutis integerrimis; pedunc. 3 -floris ; radice tuberosa. Ipomoea L. Sloane Hist. t. 96. f. 2. Plukil. t. 276. f. b. In Jamaica. 4. 5-6-ped. Cor. alba.

29. C. digitatus Spr. fol. 7-partitis glabris; laciniis lanceolatis ohtusis; pedunc. 3-floris compressis. Ipomoea L. Plum. ic. 92. f. 1. In Amer. austr. 4-5-ped. Cor. purpurea.

30. C. cuiricus Vahl; fol. 5-partito-pedatis glabris; laciniis lanceolatis serrulatis nucronatis; pedunculis sub-3-floris. B. M. 699. Ipomoea palmata Forsk. Barr. ic. 30. In Aegypto. 4.

31. C. copticus $L$. fol. inferioribus 3 -superioribus 5 -partitis glahris; laciniis lanceolatis serrulatis; pedunc. ancipitibus 3-floris. Ipomoea coptica Roth. In Aegypto. Cor. alba.

32. C. Pes tiyridis $5 \mathrm{pr}$. fol, palmato-7-partitis sericeo-hirsutis; laciniis ovato-oblongis mucronatis integerrimis; floribus fasciculatis cauleque hirtis. Ipomoea L. Kniph. Cent. 9. t. 53. Dill. Elth. f. 411. In Ind. or. $\odot$. nea. 
33. C. Papiria Spr. fol. 5-partitis cordatis; laciniis lanceolatis; pedunc. 1-floris; radice tuberosa. Ipomoea 13. et P. peruv. t. 120. f. a. In Peruria. 24. Cor. purpurascens.

34. C. heterophyllus $\mathbf{S} \mathrm{mr}$. fol. sub7-partitis sericeo-villosis; laciniis oblongis duahus ad mediam minimis. Ipomoea Ortega Jacq. fragm. t. 42. f. 4. In Inl. occ. 24. Cor. caerulea.

3.5. C. diversifolius $5 \mathrm{mr}$. fol. sub7-partitis glabris; laciniis linearibus dentato-pinnatifidis; calycibus nervosis regosis. Ipomoea $\mathrm{R}$. Br. In Nov. Holl.

36. C. bryonifolius Sims. B. M. 943. fol. 7-lobo-palmatis hispidis; 10ho medio sinuato; pedunc. longissimis articulatis. In C'hina. Cor. laete rubra.

3\%. C. macrocarpus Spr. fol. profunde 7-lohis; laciniis oblongis integerrimis; pedunc. 1-floris ; caps. maximis. C. gossypifolius $H$. et. K. In Cuba. 24. Semina tomentoso-pubescentia.

38. C. chilensis Pers. fol. profundissime 5-partitis; laciniis linearibus media productiore; pedunc. 1-floris. C. dissectus. Cav. ic. t. 480. f. 1. In Chili. 4-ped. Cor. rubella.

39. C. rosens $H$. et $K$. fol. cordatis 5-fidis; laciniis ohlongis integerrimis; pedunculis multifloris; laciuiis calycis ovatis apice rotundatis. Ipomoea 5-loha W. Hb. Ad Orinocum. 4. Cor. rosea.

\section{d. Foliis lobatis.}

40. C. insignis $\mathbf{S p r}$. fol. cordato5-lobis suhtus coloratis nervosis; pedunc. corymbosis; calycihus obtusis. Ipomoea Ker. B. R. I. gossypifolia W. In Ind. or. 4.

11. C. paniculatus $I$. fol. cordatis profunde 7-lo!is glahris subtus concoloribus venosis; pedunc. paniculatis multifloris; calycihus obtusis. Ipomoea R. Br. I. mauritiana Jacq. schoenhr. t. 200. Rlieede XI. t. 49. In Ind. or., Nova Holl. et Amer. austi. 24. Cor. dilute purpurea.

42. C. vitifolins $\mathrm{L}$. fol. cordatis sinnato-5-lohis subtus allido-villosis; lobis acuminatis dentatis; pedunc. multifloris cauleque pilosis. Burm. ind. t. 18. f. 1. Pluku. t. 25. f. 3. In Ind. or.
43. C. Slocuei Spr. fol. cordato5-lohis pubescentibus; lobis lanceolatis obtusis mucronatis. Ipomoea parviflora Valıl. Sloane Hist. t. 97. f. 1. In ins. st. Crucis. $\odot$. Cor. parva.

41. C. Ingmlaris $L$. fol. cordatis 5-angularis integerrimis villosis ; pedunc. multifloris. Burm. ind. t. 19. f. 2. In Java. Cor. aurantiaca.

45. C. arenarius Vall; fol. 4-10his obtusis glahris; pedunc. 1-floris suhteruis; calycibus oblongis. Cor. tubulosa. In ins. Azor. et Antill.

46. C. mubscens $\mathrm{IV}$. fol. cordatis 3-5-lobis; pedunc. 1 -floris erectis; calyce dorso barhato: radice fusiformi. Ipomoea varia Roth. In Ind. occ. Cor. purpurea.

47. C. hederaceus $L$. pilosus; fol. cordatis 3-lohis; lobis acutis; calycihus hirsutis recurvis. Ipomoea $\mathrm{K}$. $\mathrm{Br}$. Jacq. ic. t. 36. B. M. 188. I. barbata Koth. C. Nil. Michx. In Virginia. $\odot$. Cor. saturate caerulescens.

48. C. laniger W. Hb. fol. cordatis profunde 3-lobis pilosiusculis; 10bis lateralibus sinuatis, medio ovato acuto; calycis laciniis hirtis linearibus. Patria igneta.

49. C. permvianns Spr. fol. cordatis 3-lobis; lobis cuspidatis ; pedunc. 1-floris; calycis laciniis linearibus basi hirsutissimis. Ipomoea cuspidata R. et P. peruv. t. 119 . f. a. In $\mathrm{Pe}-$ ruvia. $\odot$. Cor. purpurascens.

50. C. Dillenii Desr. fol. cordatis integris 3-lohisque; florihus solitariis suhsessilibus. Ipomoea R. et $\mathbf{S}$. Dill. Elth. f. 93. In Aethiopia. $\odot$. Cor. caerulea fundo albida.

51. C. Nil $L$. fol. cordatis villosis 3-lohis; lobis ovatis acutis; pedunc. 1-floris. C. trilobus Thunb. In Prom. b. spei et Ind. or.

52. C. trichocarmes Spr. fol. cordato 3-lohis villosis maryine coloratis; lobis acuminatis basi angulatis; laciniis calycis ciliatis; caps. hirsuta. Ipomoea Ell. I. carolina Pursh. Catesb. car. t. 91. In Carolina. Cor. violaceo-purpurea.

53. C. mutabilis Spr. fol. cordatis integris 3-Iohisve supra strigosis sul)tus tomentosis; pedunc. nultifloris; limbo cor. amplissimo. Ipomoea Ker. B. 13. 39. In Amer. austr. 4. Cor. cyanea.

54. C. caeruleus Spr. fol. cordatis 3-lobis pilosis; lobo medio pro- 
ducto; pedunc. sub-2-floris; laciniis calycis lanceolatis hirsutis. Ipomoea Hoxb. In Ind. or.

5.5. C. Neei Spr. fol. cordatis 3lobis basi dentatis glabris; pedunc. 2-fidis; calycibus acutis; staminibus exsertis ; caps. 4-loculari. Calboa vitifolia Cav. ic. t. 476. Macrostemna Pers. In Amer. bor. 4. 8-ped. Cor. luteo-purpurea.

56. C. setosus Spr. fol. cordatis trilobis sinuatis dentatis; pedunc. incrassatis trichotomo-corymbosis ramisque et petiolis muricato-setosis. Ipomoea Ker. In Brasilia.

57. C. Jalappa $L$. fol. cordatis integris 3-5-lobisve sinuatis rugosis hirsutis subtus tomentosis; lobis sul)crenatis; limbo corollae repando-lobato; seminihus lamatis. Ipomoea macrorrhiza Michx. Mém. Mus. t. $40-41$. B. R. 342. Pluk. t. 94. Düss. 8. t. 7. In Mexico. 4. Cor. albo-purpurea.

58. C. africanus Nicols. fol. cordatis 3-lobis glabris; sinu haseos latissimo; Ioho medio producto; tubo corollae cylindrico inflato. ipomoea cathartica Poir. In Domingo. Cor. rubra magua.

59. C. trilobus Desr. fol. cordatis 3-lobis glahris; pedunc. 3-floris; caps. pilosa. Ipomoea L. In Amer. austr. Cor. violacea.

60. C. acuminatus Tahl; fol. cordatis 3-lohis glabris; lohis acuminatis pedunc. sub-4-floris strictis; calycibus acuminatis. Ipomoea enstachyana Jacq. ohs. t. 36. C. pudihundus Lindl. B. H. 999. In ins. Carib. Cor. purpurea.

61. C. hederuefolius Spr. fol. trilobis cordatis; pedunc. multifloris racemosis. Ipomoea L. Plum, et Burm. t. 93. f. a. In Ind. occ. $\odot$. Cor. caerulea.

62. C. hepaticaefolius Spr. fol. trilobis hirsutis; floribus aggregatis. Iponoea L. Burm, ind. t. 20. f. 2. In Zueylona et Cochinchina. Cor. caerulea.

63. C. Ruizii Spr. fol. cordatis 3lobis, lobis acuminatis, lateralibus extrorsum excavatis; pedunc. involucratis. Ipomoea villosa $R$. et $P$. peruv. t. 121. f. 1. In Peruria. ๑. Cor. purpurea.

it. C. tomentosus $L$. fol. trilobis tomentosis; caule lanuginoso. sloane
Hist. t. 98. f. 2. Plukn. t. 64. f. 4. In Jumaica. Cor: purpurea.

6.5. C. angulatus spr. fol. cordatis argulosis subtrilobis; pedunc. multifloris folio longioribus. Ipomoea Lam. In Ind. orient. et ins. Mascarhen. 24. Cor. coccinea.

66. C. trifilus H. et $K$. fol. cordatis trifidis pubescentibus; pedunc. 3-floris; calycibus glabris inaequalibus. C. hepaticaefolius IV. Hb. Ad Orinocum. 4. Cor. purpurea.

6\%. C. ourariensis Spr. fol. cordatis sublohatis dentatis hirtis; petunc. aggregatis 1-floris hispidis; calycihus hirsutissimis. Ipomoea P. Beauv. Oware t. 82. Circa urb. Oucare.

68. C. portoricensis Spr. fol. profunde cordatis subtrilohis glabris; 10his lateralibus hrevissimis; pedunc. 3-floris; tubo corollae inflato. In Portorico.

69. C. jamaicensis Spr. fol. profunde cordatis 3-lohis simuatis subtus villosis canescentibus; pedunc. 1-floris; calycibus glaberrimis. In $\mathrm{Ja}$ maica.

\%0. C. platanifolius I'ahl; fol. cordatis 3-lobis; Iobis Iateralibus dentato-angulatis; pedunc. sub-3-floris; catycibus glabris. C. indicus Feuill. 3. t. 1. Plukn. t. 167. f. 3. In Amer. austr. 4.

71. C. sanguineus Spr. fol. cordato-3-lobis liastatiscue; pedunc. superne cymoso-3-chotomis; staminibus longe exsertis. Ipomoea Vahl. B. R. 9. In ins. St. Crucis. 4. Cor. minuta.

72. C. dichrous $R$. et S. hirtus; volubilis; fol. subcordatis $\mathbf{B}$-lobis subtus incanis; pedunc. multifloris. C. bicolor Desr. Ad Seneyal. Cor. parva.

73. C. longiflorus i $\$$ m fol. cordatis integris 3 -lohisque acutis glabris; petiolis 2-glandulosis; pedunc. bifloris demum incrassatis; cor. Iongissimis. Ipomoea R. Br. In Forll Hollandia.

7. C. anyustissimus R. Rr. fol. 3-partitis pubescentibus; laciniis lateralibus 2-3-fidis, media longiore lineari; pedunc. 1-noris; calycibus mucronatis. In ins. I'an Vicmen.

7.5. C. Hoolieriames; fol. cordatis 3-lohis; lobis lato-ohlongis; pelunc. 3-7-floris; cor. undulata. Ipomoea Hook. B. M. 3665. In Buenos Ayres. 4. Cor. rubro-violacea. 
76. C. bignonioilles Spr. radice tuberosa; fol. 3-lobis dentatis; lobis posticis sili incumbentibus; pedunc. 3-floris pendulis; limbo corollae crispato. Ipomoea Hook. B. M. 2645. In Cayenna.

\section{e. Foliis cordatis integris.}

\section{a. Pedunculis 1 -floris.}

7\%. C. discolor H. et K. t. 212. fol. cordato-ovatis ohtusis mucronatis mollissimis subtus candidis villoso-tomentosis; pedunc. folio lougioribus; calycihus pubescentibus. AdOrinocum. 4. Cor. violacea.

78. C. sulfultus H. et K. $t .211$. hirtus; fol. cordato-subrotundis acuminatis dentato-angulatis; florihus subspicalis bractea cordata suffultis. In Mexico. 24. Cor. purpurea.

79. C. obvallatus spr. fol. acutis integerrimis glabris; pedunc. bractea cordata colorata brevioribus secundis; calycibus acuminatis. Ipomoea Cav. I. spicata Kunth. In Mexico. ち. Cor. incarnata.

80. C. bracteatus Vahl; fol. cordatis integris acuminatis pubescentibus ; calycibus bracteaceis; cor. villosa. In ind. or.

81. C. sidaefolius Bonpl. fol. acuminatis villosis; pedunculis glabris superue racemosis; calycilus acutis glabris. C. laevicaulis IV. Hl. In Nov. Andalusia et Teneriffa. ち. Cor. alba.

82. C. rupestris $W$. fol. cordatooblougis acutis; pedunc. 1-floris; caIycibus Ianceolatis acutis patentibus. Pall. it. 3. t. K. In Sibiria. 4. Cor. violacea.

S3. C. tiliaefolius Desr. fol. cordato-subrotundis obtusis integerrimis; calyce obtusissimo; fructu maximo; caule liguoso. Ipomoea hengalensis Roth. In Ind. orient. et Prom, b. spei.

8. C. ciliolatus Michx. fol. profunde cordatis ciliatis; pedunc. folia superantibus; calycibus obtusis. In Amer. bor. 4.

8.5. C. Forskolei Delile Aeg. t. 18. $f$. 3. fol. obtusis subtus pilosis; pedunc. ternis reflexis; seminihus tomentosis; calycibus acutis. Ipomoea verticillata Forsk. In Arabia.

86. C. solanifolius $5 \mathrm{pr}$. fol. cord.tis acutis integerrimis; pedunc. 1- floris solitariis folia aequantibus. Plum. et Burm. ic. 94. f. 1. In Amer: austr. $\odot$. Cor. rosea.

8\%. C. lencanthus Spr. fol. cordatis acuminatis integerrimis; pedunc. 1-floris solitariis folio brevioribus. Ipomoea Jacq. ic. f. 318. Scop. del. .2 t. 4. In imer. anstr. $\odot$.

88. C. alatus Spr. fol. acuminatis glabris integerrimis ; petiolis marginatis; pedunc. 4-alatis; bracteis caducis. Ipomoea R. Br. In Nov. Holl.

89. C. abruptus S $\mathrm{m}$. fol. acutiusculis glabris; sinu baseos clauso; pedunc. petiolos aequantibus; calycibus obtusis. Ipomoea R. Br. In Nov. Holl.

90. C. bicolor Tahl; fol. cordatis villosis basi angulato-lohatis; pedunc. 1-floris; foliolis exterioribus calycis bracteaeformibus. In Ind. or.

91. C. obscurus Spr. fol. subovatis pubescentibus integerrimis; pedunc. calycilusque obtusis incrassatis ; limbo cor. creunlato. In Ind. or.

92. C. Fallia Jacy. Schoenbr. $t$. 198. fol. cordato-ovatis inciso-dentatis suhpilosis; pedunc. longissinis 1floris; caule hirto. In Prom. b. spei. Cor. albide-incarnata.

93. C. trinervis Thunb. fol. oppositis ovato-oblongis 3-nerviis glahris; pedunc. brevissimis 1 -floris. In $J a-$ ponia.

94. C. Purga; fol. cordatis acnminatis glabris; pedunc. $1-2$-floris; laciniis calycis coloratis 2 brevioribus. Ipomoea Wender. Düss. 3. t. 14. I. schiedeana Zniccar. In Mexico. 4. 10-ped. Cor. purpurea.

9.5. C. timorensis; villosiusculus; fol. cordato-ohlongis integerrimis 10batisve; pedunc. 1--2-floris; laciniis calycis villosis subcordatis. Ipomoea Blume. In Java.

96. C.villosulus; fol. hastato-cordatis acuminatis integerrimis sulitus villosulis; pedunc. 1-2-floris; calycis laciniis acuminatissimis. Ipomoea Bitume. In fava. Cor. purpurascens.

97. C. aculeatus; glaber ; fol. cordato-subrotundis acuminatissinis integerrimis; pedunc. incrassatis 1-floris; caule inferne triquetro aculeato. Ipomoea Blume. In Java. Cor. viritis.

98. C. pulcher; fol. cordato-ovatis mucronulatis integerrimis subtus puberulis; calycis laciniis rotundatis 
subsericeis. Ipomoea Blume. In Juva. Cor. purpurascens.

99. C. insuavis; fol. cordato-subrotundis acuminatis glabris margine ciliatis; calycis laciniis acutis; caule hirto. Ipomoea Blume. In Java. Cor. albida, fundo atropurpureo.

\section{B. Pedunculis bifloris.}

100. C. crenatus Jacq. ic. t. 31.5. tomentosus; fol. cordato-oblongis obtusis subrepaudis; limbo cor. acuto. C. erosus Desr. In Amer. austr. 4. Cor. parva allida.

101. C. plicatus Desr. tomentosus; fol. cordatis acutis angulato-serratis rugosis plicatis; pedunc. subbifloris. In Prom. b. spei.

102. C. grundiflorus $I$. fol. subovatis obtusis integerrimis glabris; petiolis pubescentibus; calycibus coriaceis; cor. maxima. Rheede II. $t$. 50. In Ind. or. 24. Cor. alba.

103. C. gangeticus Roxh. fol. cordato-subrotundis obtusis subtus villosis punctatis; laciniis calycis reniformibus. In Ind. or.

104. C. melanostictus Cham. et Schl. puherulus; fol. cordato-sulurotundis obtusissime lobatis acutis subtus nigro-punctatis molliter puhescentilus. In ins. St. Thomae. 4. Cor. rubra.

105. C. phocniceus Spr. fol. cordato-subsagittatis acuminatis dentatis glabris; pedunc. subhifloris elongatis; calycihus truncatis mucronatis. Ipomoea lioxb. In Ind. or.

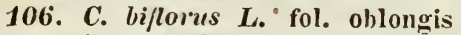
pubescentibus; pedunc. hirsutis; lobis corollae 3-fidis. In China.

10\%. C. gemellus Vuhl; fol. subrotumdatis pilosis; pedunc. secundis patentibus; calycibus ad hasin partitis linearibus patulis. Ipomoea Roth.

In Ind. or. et Java.

108. C. asarifolius Desr. for. reniformibus latis venosis; pedunc. subbifloris; calycibus obtusis. Ipomoea R. et S.. In Afi. occ.

109. C. lucunosus Spr. glahra; fol. cordatis subrepando-panduraeformilus acuminatis subtus scrobiculatis; calycihus lanceolatis. Ipomoea $L$. Dill. Elth. f. 102. In Amer, bor. $\odot$. Cor. purpurascens.

110. C. Meyeri Spr. fol. cordatis acuminatis glabriusculis; pedunc. bre- vissimis; calycibus ad hasin partitis hirsutis; laciniis cuspidatis. C. cuspidatus W. Hb. Patria ignota.

111. C. pilosus $W$. fol. cordatis acutis integerrimis supra pilosis; calycihus hirsutis; laciniis lanceolatis. In Ind. or.

112. C. setifer Spr. fol. cordatoauriculatis glabris; pedunc. subbifloris; calycibus anplis apice setiferis; ramis villosis. Ipomoea Poir. In Cayenna. Cor. ruhra.

113. C. sibiricus $I$. fol. cordatis acuminatis laevibus; calycibus conniventibus glabris. In Sibiria. $\odot$. Cor. subincarnata.

\section{y.Pedunculis 3-floris.}

114. C. pannifolius Dryand. fol. oblongis cordato-hastatis rigidis hirsutis; pedunc. bracteatis; calycilous lanceolatis. In ins. Cunariis.

11.5. C. Dryandri spr. fol. oblongis acutis villosiusculis; pedunc. rectis; calycihus reflexis glabris; limho cor. integerrimo. C. suffruticosus Dryaud. C. suberosus W. Hb. In ins. Cunariis.

116. C. aristolochiarefolius $\mathrm{W} . \mathrm{Hb}$. fol. cordato-ovatis acuminatis glabris dentato-angulatis divergentibus; laciniis calycis acutis rugosis. In Caracas. 24. Limhus cor, violacens.

11\%. C. jurasiticus H. et K. canle aculeat 0 -muricato; fol. subrotundis acuminatis utrinque in venis puhescentihus ciliatis; laciniis calycis nucronatis. C. circinatus W. Hb. In Caracus. 4. Cor. caerulea.

118. C. superbus $H$, et $K$. fol. cordato-subrotundo-ovatis acuminatis subtus strigoso-hirtis ciliatis ; laciniis calycis hispidis. C. sanguineus IV. Hb. In Nov. Hisp. 24. Cor. purpurea.

119. C. purpureus $\mathrm{L}$. fol. cordato-ovatis puhescentibus; calycibus hispidis. Ipomoea lam. B. M. t. 113. Hil. t. 3. Dill. Elth. f. 94. 97. In Americu. $\odot$. Cor. maxima purpurea, violacea, rosea et alba.

120. C. latiflorus Desr. fol. cordato-ovatis acuminatis glahris; pedunc. apice incrassatis; calycihus coriaceis; cor. tuho longissimo. Ipomoea noctiluca B. R. 917. In Indiis.

121. C. lamuginosus Vuhl; fol. cordato-subhastatis acutis ferrugineotomentosis; lobis basi bidentatis; ca- 
lycihus hirsutissimis. In Ind. orient. Cor. purpurascens.

122. C. flavus W. fol. cordatis repando - sublohatis; denticulis apice mucronatis; pedunc. bifidis $\mathbf{5}$-floris elongatis. Burm. ind. t. 30. f. 2. In Ind. or.

123. C. panduratus $L$. pubescens; fol. cordato-oblongis acutis panduraeformihus; pedunc. rigidis subincrassatis; calycihus glahris conniventibus. Dill. Elli. f. 99. In Amer. bor. 4. Cor. albo-purpurea.

124. C. T'urpethum $L$. fol. cordatis subangulatis mucrouatis pubescentihus; laciniis calycis exterioribus maximis; caule 4-alato. Blackw. t. 379. Pluck. t. 105. In Ind. or.

12.5. C. mollis H. et K. fol. cordatosubrotundis acuminatis supra strigosis subtus molliter pubescentihus; laciniis calycis subulatis. C. cyuanchifolius W. Hb. In Nov. Granata. 24. Cor. violacea.

126. C.muricatus $L$. fol. cordatosubrotundis mucrouatis glabris subtus glaucis; pedunc. incrassatis; calycibus laevihus. Ipomoea Jacq. Schoenhr. t. 323. I. turbiuata Lag. In Ind. or. $\odot$. Cor. purpurea.

127. C. anceps $L$. fol. cordatoovatis obtusis laevibus; pedunc. incrassatis calycihusque bracteatis villosis; caule ramisque ancipitibus. In Ind. orient.

128. C. mammosus Lour. fol. acuminatis repandis glabris; radicibus tuberosis. In Cochinchina.

129. C. Ser Spr. hirtus; fol. cordatis acutis; pedunc. submultifloris brevihus; calyce cordato. C. sinensis Desr. In China.

130. C. furinosus $L$. fol. cordatis acuminatis repandis; pedunc. 3-floris; caule farinoso. Jacq. sclioenbr. t. 35. In Graecia. 24. Cor. incarnata.

131. C. serotinus DC. fol. subrotundo-ovatis integerrimis pubescentibus; pedunc. folio longioribus; calycibus villosis. In Americ. bor.

132. C. bahiensis Spr. fol. cordato-lanceolatis acuminatis subcoriaceis glabris; calycibus obtusissimis glaberrimis; seminibus lanatis. Ipomoea erioperma Bertero. In Brasilia.

133. C. chryseoides Spr. fol. acuminatis subdentato-repandis glabris; calycibus hemisphaericis obtusissimis emarginatis. Ipomoea Ker. B. R. In China 24.

134. C. Martii Spr. fol. cordatoovatis acutis subangulatis villosis; pedunc. folia subaequantibus; calycibus inaequalibus. Dufourea lieterantha Mart. In Brasilia.

135. C. eriocarpus Spr. fol. lanceolatis acuminatis integris; pedunc. brevissimis; calycilus acuminatis capsulisque pilosis. Ipomoea $\mathrm{K}$. Br. In Nov. Holl.

136. C. trianthus Vahl; fol. suhsagittatis lanceolatis obtusis mucronatis; pedunc. fol. breviorihus; calycibus obtusis; cor. apice pilosa. In Ind. or.

137. C. lilacinus; fol. cordatis acuminatis supra puhescentibus subtus mollibus; pedunc. 2-3-floris; calycis Iaciniis acutis pubescentibus. Ipomoea Blume. In Java. Cor. lilacina.

138. C. semilligynus Roxb. fol. cordato-ovatis acutis villosis; pedunc. petiolo brevioribus; cor. extus pubescente. In Ind. or.

139. C. Harduickii Spr. fol. cordatis acutis subpuhescentihus; pedunc. 2-3-floris demum nutantibus; lacinii.s calycis sagittatis ciliatis. C. calyciuus Roxb. In Ind. or.

\section{f. Pedunculis 4-5-floris.}

140. C. violaceus Spr. fol. cordatis integerrimis ; floribus confertis; cor. limbo repando. Ipomoea L. Plum. spec. t. 93. f. 1. Sloane Hist. t. 98. f. 1. In Amer. merid. 4. Cor. purpurea.

111. C. glandulifer Spr. caule hirsuto; fol. cordato-subrotundis acutis integerrimis villosis; calycibus inaequalibus glandulosis. Ipomoea $R$. et P. peruv. t. 121. f. a. In Lima. Cor. purpurea.

112. C. striatus Vahl; fol. cordato-hastatis glabris; pedunc. folio longioribus; calycihus obtusiusculis ; cor. glabra extus striata. In Ind. or.

1.13. C. sessilifiorus Spr. fol. cordato-lanceolatis integerrimis pilosis; pedunc. lirevissimis; calyce subulato; caps. pilosa. Ipomoea Roth. In Ind. orient.

111. C. ferrugineus Vahl; ferrugine -tomentosus; fol. cordato-ovatis acuminatis; pedunc. sub-4-floris folia 
subaequantibus; laciniis calycis exterioribus maximis; caule lignoso. C. cuntumsis H. et K. In Amer. austr. Cor. caerulea.

14.5. C. pentanthus Jacq. ic. t. 316. caule fruticoso; fol. cordato-oblongis acuminatis subrepandis glabris; pedunc. sub-5-floris; calycibus ciliatis. In Ind. orient. $\hbar$. Cor. caerulea.

146. C. dumetorum $\boldsymbol{H}$. et $\mathrm{K}$. fol. cordato - ovatis acuminatis utrinque glabris subtus glaucescentibus; calyce oblongo rugoso. In Nov. Granatu. $\odot$.

1+\%. C. circinnatus $\mathrm{W}^{\text {. }}$. fol. reniformi-cordatis acutis glabris ciliatis integerrimis; petiolis pubescentibus; calycihus ohtusis; caps. stylo coronata. In Caracas.

118. C. bogotensis $W$. fol. cordato-ovatis acuminatis subtus cano-tomentosis; laciniis calycis sericeo-hispidis lanceolato-acummatis. In Nov. Gronatu. 24. Cor. purpurea.

1+.9. C. cholulensis S.M. fol. profunde cordatis ovatis acuminato-cuspidatis, supra pubescentibus subtus glabris; calycilus obtusis glabris. Ipomoea Kuitlı. In Nov. Granatr. $\odot$. Cor. coccinea.

150. C. vubro-caeruleus; glaber; fol. profunde cordatis hreve acuminatis; pedunc. incrassatis i-4-floris; calycis laciniis allo-marginatis. Ipomoea Hook. B. M. 3297. In Mexico. ๑. Cor. azurea.

\section{E. Pedunculis multifloris.}

151. C. Schiedeanus; fol. profunde cordatis subrotundis acuminatis 9-nerviis reticulato-venosis; cor. amplissimis. Ipomoea Hanilt. non Zuccar. in Lindl. Coll. ad B. K. 1. 10. In Mexico. Cor. caerulea.

152. C. trichotosus; pilosissimus; fol. cordato-ovatis acuminatis integerrimis parallele venosis; florilus umhellatis ; calycis laciniis lanceolatis corollaque externe hispidis. lpomoea Blume. In Juva. Cor. lilacina.

1.53. C. verrucosus; fol. cordatoovatis acutis ciliolatis laevibus; pedunculis incrassatis umbellatis; calycis laciniis ovalihus verrucosis. Ipomoea Blume. In Java. Cor. atro-purpurea limbo lilacino.

15t. C. amoeus ; fol. cordato-subrotundis acuminatis integerrimis utrinque mollisissimis; calycis laciniis acu- minatissimis. Ipomoea Blume. In $\mathrm{Ja}$ va. Cor. purpurea.

15.5. C. nymphaefolius; fol. subcordato-rotundis subrepandis glabris; pedunc. hifidis multifloris; calycis laciniis oblusis mucronulatis. Ipomoea Blume. In Java. Cor. sulphurea.

156. C. coccineus $5 \mathrm{pr}$. fol. cordatis acuminalis glabris; pedunc. racemosis; calycibus verruculatis subulatis. Ipomoea L. B. M. 221. Hil. t. 6. In Ind. occ. $\odot$. Cor. coccinea.

157. C. luteolus Spr. fol. cordatis acuminatis subangulatis; pedunc. subdichotomis. Ipomoea Jacq. ic. t. 35. In Guatimala. $\odot$. Cor. aurantiacoIntea.

158. C. Heynii spr. fol. cordatoovatis obtusis canescentilus pilosiusculis; pedunc. corymbosis ; calycibus bracteatis tomentosis; cor. extus canescente. Ipomoca canesceus Roth. In Ind. orient.

159. C. multiflorus H. et K. glaher; fol. cordato-ovalis acuminatis ; pedunc. subpaniculatis; calycis laciniis oblongis obtusis. C. prolifer. WV. I1). In ins. Cuba. 4.

160. C. abutiloides $H$. et $K$. fol. cordato-ovatis supra glahris subtus cano-tomentosis; corymhis trichotomis; laciniis calycis ohlongis obtusis. In Quito. 24. Cor. violacea.

161. Bona nox Spr. glaherrima; fol. cordatis panduraeformibus glabris; calycibus acuminatis glahris; cor. tubo longissimo. Ipomoea L. B. M. 572. Jacq. Schoenbr.t. 36. Plukn. t. 276. f. 3. In Nov. Hisp. et Ind. occ. $\odot$. Cor, alla.

162. C. esseculuensis Spr. fol. cordato-ovatis acuminatis glabris subtus glaucescentilus; pedunc. cymosis; calycilus glabris scariosis. Ipomoea cymosa Meyer. In Esseyuebo.

163. C. cymosus Desr. fol. cordato-oblongis acutis undulatis glabris; pedunc. cymosis incrassatis ; calycibus ohtusis muriculato-rugulosis. Ipomoea dumetorum $\mathbf{W}$. Hb. In Ind. or.

164. C. involucratus Spr. pubescens; fol. cordato-rotundatis integerrimis; involucris subconnatis. Ipomoea P. Beauv. Ow. t. 89. In Ourre.

165. C. triqueter Vahl; fol. cordatis acutis subvillosis; pedunc. incrassatis; bracteis coloralis deciduis; caule 3-carinato. In ins. Carilucis. 
166. C. nmbellatus $\mathrm{L}$. fol. cordatis glabris; petiolis stipulatis; pedunculis apice incrassatis; seminibus sericeis. In Jurl. occ.

167. C. strigosus Spr. fol. cordato-lanceolatis integerrinis subtus strinosis ; corymbis ramosissimis; calycibus sericeo-strigosissimis. Ipomoea hoth. In Ind. orient.

168. C. Rothii Spr. fol. cordatis acuminatis ntrinque strigosis; pedunc. cymosis; calycilus acuminatis; corollis truncatis. Ipomoea cymosa Rotli. In Ind. or.

169. C. renustus Spr. fol. cordatis acutis glabris; pedunc. trichotomocymosis incrassatis 4-gonis; calycibus carnosis; limbo cor. 5-lobo crenulato. Ipomoea tricolor Cav. ic. t. 208. Patric itmotı. $\odot$. Cor. caerulea.

1\%0. C. hispidus Vall, fol. cordato-ovatis hirsutissimis; pedunc. umbellatis; pedicellis abbreviatis. In Ind. or.

181. C. racemosus Spr. fol. cordato-ovatis obtusis integerrimis subtus sericeis; pedunc. racemoso-paniculatis; pedicellis hispidis. Ipomoea Poir. In Hispaniola. Cor. albida.

172. C. filiformis Desr. fol. cordato-oblongis obtusis integerrimis mucronatis; pedunc. cymosis filiformibus. Ipomoea Jacq. am. t. 19. pict. t. 26. In ins. Antill. 4. Cor. purpurea.

173. C. micrantleus $\mathrm{W}$. Hb. fol. cordatis acuminatis angulato-dentatis subtus pilosiusculis; sinu baseos latissimo; calycibus glabris acutis. $\boldsymbol{P a}$ tria ignota.

irt. C. repandus Desr. fol. cordatis oblongis repandis acuminatis ; pedunc. cymosis. Ipomoea Jacq. am. t. 20. pict. t. 27. In Amer. austr. $\odot$. Cor. coccinea.

17.5. C. velutinus $\mathrm{Spr}$. fol. cordatis obtusis integerrimis tomentosis; sinu baseos truncato; calycibus glabris obtusis. Ipomoea R. Br. In Nov. Holl.

176. C. congestus Spr. fol. cordatis acuminatis integerrimis tomentosis ; pedunc. multiforis; calycibus subulatis. Ipomoea 13. Br. In Nov. Holl.

17\%. C. bifidus V'ahl; fol. cordatis oblongis acumiuatis subtus villosiusculis; pedunc. bifidis umbelliferis; calycibus obtusis. Ipomoea Roth. In Ind. or.

178. C. urceolatús Spr. tomentosus; fol. cordatis subreniformibus in- tegris; cymis sessilihus; calycibus orbiculatis pilosis; cor. tubo urceolato. Ipomoea B. Br. In Nov. Holl.

179. C. cordifolius ithunb. fol. cordato-hastatis dentatis; pedunc. hifido-umbellatis. In Prom. b. spei.

180. C. fastigiatus Roxb. fol. cordatis subangulatis glabris longe petiolatis; pedunc. incrassatis folia superantibus; calycibus mucronatis. In Ind. or.

181. C. nummularius Vahl; fol. cordato-oblongis mucronatis villosiusculis integerrimis; pedunc. subunbellatis; laciniis calycis exterioribus latioribus. In Amer. austr.

182. C. canariensis L. fol. cordato-oblongis subsessilibus fulvo-villosissimis; pedunc. multifloris; caule lignoso. B. M. 1228. Plukil. t. 325. f. 1. In ins. Canariis. ち. Cor. purpureo-violacea.

183. C. parriflorus Vahl; fol. cordatis acuminatis glabris; pedunc. ınultifloris calycibusque acuminatis villosis. Burn. ind. t. 21. f. 3. In Java. Cor. caerulea.

181. C. ramosissimus poir. fol. cordatis integerrimis; canle filiformi; pedunc. umbellato-cymosis. C. cymosus R. et P. peruv. t. 197. f. b. In Peruvia. Cor. Iactea.

185. C. domingensis Desr. fol. cordatis; racemis numerosis secundis; calyce acuto glabro. In Domingo.

186. C. tiliaceus $\boldsymbol{W}$. fol. cordatis acuminatis glabris; lobis baseos divaricatis; pedunc. racemoso-corymbosis. In Brasilia. 4.

157. C. candicans $W$. suffruticosus; fol. cordatis mucronatis integerrimis supra glabris; petiolis in utroque latere sulco apice glandulifera exaratis. In Ind. or.

188. C. carneus Spr. fol. cordato-subrotundis integerrimis glabris; pedunc. multifloris; cor. marginatis. Ipomoea Jacq. am. t. 18. pict. t. 25. In Americ. austr. 24. Cor. carnea.

189. C. muximus $L$. fol. cordatis ovatis acuminatis integerrimis glaberrimis ; caule petiolisque glabris. Rheede II. t. 53. In Keylona. 4.

190. C. sphaerostiyma Car. ic. $t$. 181. fol. cordatis subvillosis ; floribus umbellatis; stigmatihus divaricatis. In Mexico. $\odot$. Cor. carnea.

191. C. Plumerii Spr. fol. cordato-oblongis mucronatis; pedunc. ra- 
mosis nultifloris subverticillatis. C. parviflorus Desr. Burm. am. t. 94. f. 2. Plım. Ms. t. 62. In Ind. occ. Cor. parva purpurascens.

192. C. rerlicillatus $I$. fol. cordatis oblongis nudis; pedunc. umbellatis hifidis multifloris. Plum. ic. 94. f. 2. In America. Cor. caerulescens.

193. C. norliflorus Desr. fol. sul:cordato-ovatis subtomentosis; pedunc. bifidis multifloris; calycihus acutis. In ins. Curibueis. 24. Cor. alla.

194. C. canescens $H$. et $K$. canescenti-tomentosus; fol. cordato-ovatis acuminatis; pedunc. multifloris; calycis laciniis 3 maxinuis. In Amer. austr. Cor. caerulea.

195. C. anreus Rich. fol. cordatoohlongis glahris ciliatis; pedunc. elongato capitato; cor. calycem subaequanle. In Amer. austr.

196. C. gujanensis Aubl. guj.t.52. fol. cordato-ovatis subtus calycibusque tomentosis; pedunc. elongatis; florihus corymboso-capitatis. In Gujana. 4. Cor. alla.

197. C. polycarpos W. Hb. fol. cordato-oblongis supra pubescentihus subtus incano-tomentosis; calycibus acuminatis. In Hexico.

1.98. C. tamnifolius Neyer; fol. cordato-subhastatis acuminatis cauleque pilosis; floribus agregatis. Ipomoea L. Dill. Elth. f. 410. In Carolina. $\odot$. Cor. caerulea.

199. C. capitatus Vahl; fol. cordato-ovatis ciliatis; capitulis pedunculatis involucratis extus hirsutis; cor. extus hispida. C. crinitus Desr. In Ind. or.

200. C. ciliatus Vahl; fol. cordato-ovatis acuminatis suhtus flavo-villosis; capitulis pedunculatis hirsutissimis; calyce subulato. In Cayenna.

201. C. coelestis Forst. fol. cordato-suhrotundis ohtusissimis 5 -nerviis pubescentilus ; pedunc. umbellatis 3 fidis. In Nor. Hebrid.

202. C. Hamiltonii Spr. fol. cordatis cuspidatis puliescentilus; pedunc. multifloris; laciniis calycis acutis pilosis. Ipomoea cuspidata Hamilt. In Nepalia.

203. C. pileatus spr. fol. profunde cordatis villosis involucro 4 -angulari peltato 4-6-floro. Ipomoea Hoxb. In China. f. Foliis sagittatis lastatis.

\section{* Pedunculis 1-floris.}

204. C. arvensis $L$. fol. sagittatis utrinque acutis; hracteis minutis a flore remotis. E. B. 312. Fl. Dan. 459. C. corsicus B. et S. In Europa. 4. Cor. alba, stella rosea.

205. C. Wheleri Vahl; fol. cordatis sagittatis glaherrinis; filamentis hasi villosis; seminilus tomentosis. Ipomoea Poir. Cav. ic. t. 10\%. In Hispun. et Afric. bor. 4. Cor. purpurascens.

206. C. sagittifolius Michx. glaberrimus; fol. oblongo-sagittatis ; sinu profundissimo; pedunc. incrassatis; calycis laciniis ovalibus. Catesb, t. 35. Ipomoea Pursh. In Carolina. 4. Cor. rosea.

207. C. Catesbaei spr. tomentosus; fol. sagitlatis oblongis acuminatis; hracteis ovalibus. Calystegia Pursh. In Curolina. Cor. magna purpurea.

208. C. bracteatus lalil; fol. hastato-trilohis glabris; hracteis lanceolatis acutis; cor. extus villosa. In Ind. or.

209. C. maryinatus Spr. fol. sagittatis acutissimis postice subdentatis; hracteis ohtusis; pedunc. undulatomarginatis. Calystegia H. Br. In Noe. Holl.

210. C. sylvaticus W. Kit. t. 261. fol. sagittatis; pedunculis teretibus; calyce biluracteato involucrato. In Hunyaria. 4. Cor. maena alba.

211. C. Sepium I. fol. sagittatis acutis; auriculis postice truncatis subdentatis; bracteis cordatis acutis; pedunc. 4-angulis. FI. Dan. 458. E. B. 313. Sturm 1. Calystegia H. Br. In Europ., Asia med., Amer. bor. et ins. maris pacifici. 24. Cor. alha.

212. C. subvolubilis Meyer; Ledeb. ic. Fl. ros. t. 205. caule sulvilloso; fol. cordato-sagittatis lohis rotundatis, superior. acuminatis hastatis; bracteis cordatis pilosis margine dense villosis. In Davuria. 24. Cor. pallide rubicunda.

213. C. pellitus Neyer; Ledeb. $l$. c. t. 206. villosus; fol. ovato-oblongis mucronatis basi subcordatis; hracteis cordatis acutis villosis. In Russia. 4.

214. C. chinensis fier; fol. hastatis subcaruosis glabris; auriculis ob- 
tusiusculis integris; pelunc. suhincrassatis; calyciluus obtusis. In China.

215. C. japonicus Thunb. fol. hastato-lanceolatis acntis; auriculis postice 1-dentatis; caule simplici. In Japonia. Folia subsecunda.

216. C. macrosolen Spr. fol. hastato-3-lobis hirsutis; lobis oblongis obtusiusculis; tubo cor. Iongissimo. Ipomoea longiflora IV. Patria ignota. 4.

21\%. C. denticulatus Spr. glaber; fol. hastatis lanceolatis aculissimis; lobis posticis dentatis; calycis laciniis oblongo-lanceolatis. Ipomoea R. Br. Rheede 11. t. 55. In Ind. orient. et Nov. Holl. Cor. alho-flavescens.

218. C. angustifolius I'ahl; fol. hastato-linearibus ohtusis mucronatis glabris; auriculis subintegerrimis. Ipomoea Jacq. ic. t. 317. In Ind. or.

219. C. gracilis Spr. fol. hastatis basi biglandulosis utriuque acutis; calycibus rugosis acutis; seminibus hilo barbatis. Ipomoea $\mathrm{A}$. Br. In Liov. Holl.

220. C. plebejus Spr. fol. hastatocordatis acuminatis integris pubescentilus postice rotundatis; calycihus acuminatis pilosis; seminibus lanatis. Ipomoea R. Br. In Nov. Holl.

221. C. remotus $\boldsymbol{R}$. Br. fol. hastatis lineari-oblongis integris pubecentibus; calycibus ovatis mucronulatis. In Nov. Holl.

222. C. filicaulis Tahl; fol. hastatis lanceolato-linearibus obtusis mucronatis; auriculis mucronato-dentatis; pedunc. superne incrassatis; calycibus oblongis. In Gujana.

223. C. bicuspidatus Fisch. fol. hastatis lanceolatis margine scaberrimis; auriculis reflexis bicuspidatis; calycibus obtusis glabris. In Dahuria.

221. C. Mechoacanha Titm. fol. hastatis subtrilobis; pedunc. incrassatis. In Brasilia.

225. C. puichellus $H$. et $\boldsymbol{K}_{\text {. fol. }}$ hastato-cordatis ovato-oblongis basi dentato-angulatis utrinque glabris; calycis laciniis oblongis obtusis. In Peruvia. ๑. Cor. purpurea.

\section{*** Pedunculis bifloris.}

226. C. hirsutus $M, B$, fol. cordato-liastatis acutis hirsutis; auriculis dentato-angulatis; caule hirsuto. C. $_{6}$ atriplicifolius Poir. In Tauria et $\mathbf{S} y-$ ria. 24. Cor. lutescens.

227. C. emaryinatus $L k$. fol. sagittato-hastatis; auriculis emarginatis bicuspidatiș pilosiusculis; calycibus acutis. Patria ienota.

228. C. lapatilifolius Spr. fol. hastato-panduraeformibus ; auriculis suhrotundo-angulatis; calycibus obtusis; caule ramisque tuberculatis. C. acetosellaefolius Desr. In ins. MIasc.

229. C. montevidensis Spr. fol. hastatis lanceolatis glabriusculis; auriculis divaricatis emarginato-angulatis; calycibus scariosis. In Montevirleo.

230. C. incanus Vahl; fol. sagittatis lanceolatis obtusis tomentoso-sericeis; auriculis dentato - angulatis; calycibus acutis corollaque villosis. In Americ. ausir.

231. C. Hermanniae Herit. fol. sagittato-cordatis oblongis basi sinuato-repandis utrinque serice-tomentosis; calycibus acuminatis. In Peruvia.

232. C. glaucifolius $\mathbf{S p r}$. fol. sagittatis postice truncatis glaucis longe petiolatis; calycibus acutis. Ipomoea L. Dill. Elth. t. 87. In Mexico. 4. Cor. purpurea.

233. C. javanicus Garc. fol. sagittato-hastatis lucidis glabris; pedunc. superne incrassatis; tubo cor. longissimo. Ipomoea hastata L. I. sagittae folia Burm ind, to 18. fo 2. In Juva. Cor. flava.

23t. C. Malcolmii Roxb. fol. sagittatis glabris; auriculis dentato-angulatis; pedunc. clavatis; Iaciniis calycis ovatis. In Persia.

235. C. hastatus Forsk. fol. hastato-lanceolatis subtus villosis; auriculis obtusis; peduno. geminis villosis ; calycibus acuminatis. C. Inastifoliug Poir. In Aegypto.

\section{永平斗 Pedunculis subtrifloris.}

836. C. tuinensis; fol. cordatos hastatis pabescentihus; calycibus bracteatis ovatis. C. involucratus IV. In Guinea et ins. Mascarenh.

23\%. C. incurnatus Vahl; fol. sagittatis oblongis acutis glabris; lobis divaricatis acutis integerrimis. C. glaucescens Kunth. In Quito et Curas6ao. $\odot$. Cor. purpureo-violacea.

238. C. erubescens Sims B. M. 106\%. fol. cordato-sagittatis postice sinuato - repandis; calycibus ovatis 
mucronulatis. In Nov. Holl. 4. Cor. pallide rosea.

239. C. Scammonia $L$. fol. sagittatis postice truncatis; pedunc. teretibus; calycibus obtusissimis. Plenk. t. 92. Silth. gr. t. 192. In Creta. 4. Cor. alba.

210. C. acutangulus Spr. fol. sagittato-3-angularibus auriculis dentatis; limbo corollae lobato. Ipomoea 18. et P. t. 119. f. b. In Peruvia. $\odot$. Cor. coccinea.

211. C. bonariensis Cav. ic. V.t. 48. f. 2. fol. hastatis hasi cuneatis apice setula termiuatis; calycilsus acutis. Circa Buenos Ayres. Cor. alba.

\section{****** Pedunculis multifloris.}

212. C. quinqueflorus Vahl; fol. sagittato-ovatis attenuatis glabris crenato-subrepandis; pedunc. pubescentibus; lobis corollae apice barbatis. In ins. Mascarenh.

243. C. dentatus Tahl; fol. hastatis glabris; auriculis dentatis; pedunc. incrassatis muricatis; calycibus obtusis. In Aegypto.

211. C. hastigerus spr. fol. hastato-3-fidis glabris; lacinia intermedia lanceolata maxima; calycihus mucronatis. Ipomoea H. et K. In Mexico. 4. Cor. incarnata.

215. C. sagittifer $\boldsymbol{H}$. et $\boldsymbol{K}$. fol. oblongo-lanceolatis acuminatis profunde cordato-sagittatis glabris subtus in venis pubescentibus; calycis laciniis subrotundis. In Cuba. 4 .

246. C. breviflorus Spr. fol. sagittato - cordatis integerrimis glabris glaucescentibus; calycilus plicatorugosis. Ipomoea Meyer. In Gujana.

247. C. ruber Vahl; fol. hastatis glabris emarginatis; auriculis obtusissimis divaricatis integerrimis; umbellis involucratis. In Americ. austr.

218. C. crenutifolins $R$. et $\boldsymbol{P}$. peruv. t. 118. $f$. $a$. fol. sagittatis crenatis; pedunc. unbelliferis involucratis. In Peruvia. $\odot$.

349. C. sphaerocephalus Roxb. fol. sagittato-cordatis oblongis utrinque villosis; capitulis sessilibus. C. atropurpureus Wall. Ipomoea Don. In Nepalia. Cor. parva purpurea.

\section{g. Foliis oblongis ovatis li nearibus.}

250. C. peltatus Forst. fol. peltatis subrotundis glabris; pedunculis multifloris racemosis; caule lignoso. Rumph. V. t. 197. In Amboince et ins. societ. ち. Caul. longissimus. Cor. alba.

251. C. Kleinii Spr. fol. late ovatis obtusiusculis glabris venosis pedunc. racemoso-paniculatis; calycilus glahris. C. racemosus Klein W. Hh). In Ind. or.

252. C. havanensis Jac\%. obs. $t$. 15. $f$. 3. fol. oblongis nitidis; pedunculis 1-floris. In Havana. Cor. parva allida.

253. C. sericeus $I$. fol. oblongis ohtusiusculis subtus tomentoso-sericeis; pedunc. umbellatis; calycibus pilosis. C. mollis Burm. ind. t. 17. f. 1. Ipomoea Blume. In Ind. or. Cor. purpurea.

25t. C. nitidus Desr. fol. oblongis acutis utrinque sericeis suhtus argenteis; pedunc. 1-floris; calycihus ovatis. In Ind. or. et ins. Philippin.

2.5.5. C. chenopodioides Desr. fol. ovatis serrato-sinuatis pilosiusculis; floribus solitariis subsessilibus. $\quad P_{a}$ tria ignota.

256. C. multivalvis R. Br. fol. ovatis acutis ramisque villosiusculis; pedunc. corymbosis multifloris; calycibus inaequalibus. C. corymbosus $\mathbf{L}$. In Nov. Holl.

25\%. C. mataxocarpus Spr. fol. oblongis glabris subcoriaceis mucronatis; pedunc. 2 -floris ; calycibus ovatis; caps. cylindricis sericeis. In Nov. Granata.

2.58. C. lachnaeus Spr. fol. oblongo - lanceolatis mucronatis utrinque densissime lanatis; racemis axillaribus imbricatis foliosis. In Hispaniola.

259. C. quinquepartitus I'ahl; fol. ovato-oblongis obtusissimis emarginatis mucronatis glabris; pedunc. 2-fidis multifloris; cor. 5-partita. In ins. Carib.

260. C. Batatilla $H$. et $K_{\text {. }}$ fol. ovatis acuminatis supra pubescentibus subtus molliter tomentosis et canis; Iaciniis calycis subrotundis obtusis pubescentibus; seminibus comosis. In Cumana et Caracas. 古.

261. C. esculentus Spr. fol. subrotundo-ovatis acutis nervosis glabris: 
pedunc. subtrifloris; radice tuberosa. Ipomoea Catesbai Meyer. In Amer. austr.

262. C. Rottleri Spr. fol. ovatis acutis longe petiolatis parallele venosis subpubescentibus; pedunc. multifloris; bracteis lanceolatis calyces superantibus. In Ind. or.

263. C. salicifolius Desr. fol. lanceolatis utrinque attenuatis cuspidatis glahris; pedunc. 1-floris; calycis laciniis exterioribus maximis; caps. villosa. In Antillis.

26t. C. fruticulosus Desr. fol. ovato-lanceolatis angustis; pedunc. 1-floris; caule fruticoso. In ins. Canariis. $\hbar$.

265. C. unifloms Burm. ind. $t$. 21. f. 2. fol. lanceolatis cuspidatis sessilibus glabris; pedunc. bracteatis ; calycibus ovatis amplis. C. enarginatus Vahl. Ipomoea Blume. In Java. 4. Cor. alba.

266. C. simplex Spr. fol. Ianceolatis integris; floribus solitariis. Ipomoea simplex Thunb. In Prom. $b$. spei.

26\%. C. tridentatus $\boldsymbol{L}$. fol. spathulato-linearibus apice 3 -dentatis basi dilatatis dentatis; pedunc. 4-gonis; calycibus cuspidatis. Ipomoea Roth. In Ind. or.

26s. C. gramineus Spr. fol. elongato-linearibus mucronatis integerrimis glabris; pedunc. 1-floris; calycibus obtusis; cor. Iongissimis. Ipomoea $\mathbf{R}$. Br. In Nov. Holl.

269. C. Reinuardtianus; fol. elliptico-oblongis basi rotundatis integerrimis subtus puberulis; pedunc. paucifloris; calycis laciniis sericeovillosiusculis, 3 magnis. Ipomoea Blıme. In ins. Timor.

2\%0. C? Blumii; fol. lineari-lanceolatis mucronatis basi auriculatis dentatis; ped. 1-floris; laciniis calycis acuminatis. Ipomoea filicaulis Blume bijdr. In Java.

271. C. linifolius; pilosiusculus; fol. linearibus integerrimis utrinque obtusis mucronulatis interdum basi subliastatis; pedunc. paucifloris; calycibus obtusis. Ipomoea Blume. In Java.
2. Caule decumbente prostrato repente.

a. Fol. palmatis, 10 batis.

2\%2. C. littoralis $\boldsymbol{L}$. fol. oblongis lobato-palmatis ; pedunc. 1-floris; callle repente. C. albus Burm. Amer. $t$. 90. f. 2. In Antillis. Cor. alba.

273, C. lasiunthus Cav. ic. t. 779. f. 1. fol. palmato-laciniatis tomentosis; lacinia media ampliore pinnatifida; florihus solitaris. In Chili. Cor. alha.

27. C. multifidus Thunb. fol. palmatis; lohis septenis linearibus integris; pedunc. 1-floris; caule decumbente. In Prom. b. spei.

275. C. obtusilobus Michx. fol. sinuato-lobatis suhhastatis camosis; lohis lateralibus hifidis, medio emarginato; calycibus acuminatis ; cor. campanulatis. In Amer. bor.

286. C. Batatas Michx. rad. tuberosa; caule repente; fol. cordatis liastatis angulato-lohatis 5-nerviis; pedunc. Iongis multifloris; cor. campanulata. Plenk. ic. t. 106, Rumph 5. t. 130. Rheede 7. t. 50. In India utracue colitur. 4. Cor. intus purpurea extus alba.

27\%. C. edulis Thunb. fol. cordatis 3-lobis integrisve glabris; caule repente tubifero. In Japonia. 4.

278. C. sublobatus $L$. fol. cordatis sublobatis repando-dentatis pilosiusculis ; florihus ternis sessilibus involu* cratis. In Ind. or.

\section{b. Fol. sagittatis, hastatis.}

2\%9. C. capensis $W$. fol. hastatis lohis semibifidis; pedunc. subbifloris; caule decumbente villoso. In Prom. b. spei.

280. C. sagittatus Thunb. fol. hastato-sagittatis; pedunc. 1-floris; calllibus prostratis. In Prom. b. spei.

281. C. acetosaefolius Vahl; fol. oblongo - lanceolatis subliastatisque glaberrimis subtus venosis; pedunc. 1-floris elongatis; caule repente. In Amer. austr.

282. C. Sibthorpii $R$. et $\mathbf{S}$. fol. cordato-hastatis pilosis basi angulatis; pedunc. sub-1-floris; caps. hirsuta. C. sagittifolius Sibth. gr. t. 198. In Graecia. 4.

233. C. veptans Poir. caule repente; fol. sagittato-lanceolatis ; auri$43 *$ 
culis rotundis ; pedunc. 1-floris. Rumph. 5. t. 155. f. 1. In India. 4. Cor. rubra.

284. C. repens I'ahl; caule repente; fol. sagittato-lanceolatis postice obtusis; pedunc. suhtrifloris. Ipomoea Roth. Rheede 2. t. 52. In Ind. or, et Arabia. 4.

285. C. Adansonii Desr. fol. hastatis linearibus; stipulis geminis subfiliformilus; calyce mucronato. $\boldsymbol{A} d$ flum. Senegal.

286. C. stipulaceus Roxb. fol. cordato-sagittatis mucronatis glabris; auriculis repandis; pedunc. multifloris; calycibus glabris; lobis cor. obcordatis. In Ind. or.

28\%. C. pentagonus Roxb. ramis b-gonis; fol. cordato-sagittatis villosis ; auriculis subangulatis; pedunc. umbelliferis rigidis; calycibus glabris. In ins. Molucc.

285. C. Wallichiamus Spr. canle prostrato; fol. hastato-3-lobis obtusis utrinque glabris; auriculis emarginatis; bracteis cordatis. Calystegia hederacea Wall. In Nepalia.

i 289. C. Clappertonii Spr. caule repente; fo'. sagittatis glaherrimis; auriculis acutiusculis integerrimis ; pedunc. 1-floris. Ipomoea R. Br. In Afr. bor.

290. C. paradoxus $\mathbf{S p r}$. lumifusus; tomentosus; fol. oblongis cordato-sagittatis aculis; pedunc. 1-floris; calycibus acuminatis. Calystegia Pursh. In Amer. bor. Cor. magna alba.

\section{c. Foliis cordatis integris.}

291. $C$. corymbosus $I_{\text {. }}$ caule repente; fol. cordatis pubescentibus; pedunc. multifloris; calycihus obtusis sericeis. Burm. Amer. t. 89. f. 2. Ipomoea lioth. In Ind. occ. Cor. nivea.

293. C. Beladambu Spr. fol. cordatis nervosis glabris; pedunculis sub3-floris; calycibus inaequalibus; caule suffuticoso repente. Ipomoea repens Lam. Wheede 2. t. 58. In Ind. or. 4. Cor. magna alba.

2.93. C. campanulatus Spr. fol. cordatis; pedunc. multifloris; perianthio exteriore orbiculari; cor. canpanulatis lobatis. Ipomoea L. Rheede 2. t. 56. In Ind. or. $\odot$. Cor. purpureo-alba.

29. C. secundus $R$. et $P$. peruv. t. 117. f. 2. col. cordatis acuminatis subtus incanis; pedunc. secundis Ion- gissimis umbellifloris; caule decumbente. In Peruvia. Cor. caerulea.

295. C. siculus L. caule prostrato; fol. cordato-ovatis; pedunc. 1-floris; bracteis oblongo-lanceolatis calycem ciliatum demun excedentibus. Fl. gr. t. 196. B. R. 445. In Sicilia. $\odot$. Cor. azurea.

296. C. elongatus W. fol. cordatoovatis cuspidatis; bracteis lineari-subulatis; calycibus subciliatis. C. pseudo-siculus Cav. In ins. Canariis. 4. Cor. alba.

297. C. ebracteatus Desr. fol. cordato-sagitlatis postice obtusis; pedunc. ebracteatis. In Brasilia. Cor. parva albida.

293. C. Imperati Tahl; fol. panduraeformibus integrisve emarginatis basi cordatis; pedunc. 1-floris; caule repente. C. stoloniferus Cyr. C. sinuatus Pentagn. Barr. ic. 856. In Neap. et Afr. bor. Cor. subochroleuca.

299. C. carnosus $\mathbf{S p r}$. fol. cordatis emarginatis carnosis glaherrimis; pedunc. sub-1-floris; calycibus aequalibus; caule prostrato. Ipomoea $\mathbf{R}$. Br. In Nov. Holl.

300. C. incisus Spr. fol. cordatodentato-incisis superioribus hastatis villosiusculis; pedunc. 1-floris glabris; calycibus acuminatis. Ipomoea R. $\mathbf{B r}$. In Nov. Holl.

301. C. cinerascens Spr. fol. subcordato-ovatis oblongis incisis subsericeis; pedunc. 1 -floris villosis; calycibus acutis glabris. Ipomoea R. Br. In Nov. Holl.

302. C. Soldanella $\boldsymbol{C}$. caule prostrato; fol. reniformi-subrotundis glaberrimis; pedunc. 1-floris; bracteis binis ovalibus involucratis. E. B. 314. Plenk. ic. t. 39. Regnault. t. 402. Ad littora maris borealis meditterranei. $\odot$.

303. C. reniformis Spr. fol. reniformibus subrepandis crassiusculis; pedunc. teretiusculis; bracteis cordatis; caule prostrato. Calystegia IR. Br. In Nov. Holl.

301. C. ruyosus $\boldsymbol{W}$. fol. reniformicordatis obtusis integerrimis glabris; pedunc. paucifloris; calycilus obtusis rugulosis. C. reniformis Roxb. In Ind. or. 
d. Foliis subrotundis, oblongis, lanceolatis.

305. C. Pes caprae L. repens; glalscrrimus; fol. sulrotundis enıarginatis bilobisve hasi subtus higlandulosis; calycibus obtusis. Herm. Lugd. t. 175. liumph. 5. t. 159. f. 1. C. brasiliensis L. C. bilohatus lhoxb. C. maritimus Desr. lpomoea maritima R. Br. I. brasiliensis Meyer. I. orbicularis Ell. I. crassifolia Cav. In Nov. Holl. et Bras. 24. Cor. purpurea. 306. C. ruderarius Bonpl. fol. oblongis obtusis pubescentibus; pedunc. 3-floris folio brevioribus; calycibus glabris acutis. In Cuba.

307. C. ayuaticus Walt. fol. ovato-lanceolatis mucronatis tomentosis subsessililuus; pedunc. sub-3-floris; calycibus villosis acutis. C. tenellus Desr. C. trichosanthes Michx. Plukn. t. 166. f. 4. In Carolina. Cor. alla. 308. C. Sherardi Pursh; fol. ellipticis retusis puhescentibus; floribus solitariis subsessilibus. In Carolina. Cor. alba.

309. C. martinicensis Jacq. am. $t$. 17. pict. t. 29. fol. ellipticis glabris; pedunc. 1-floris. Ipomoea Meyer. In Ind. occ. $\odot$. Cor. alla.

310. C. Senegambiae Spr. fol. ovato-oblongis acutis supra nitidis subtus fulvo-tomentosis; floribus dense cymosis; calyciluus acutis sericeis. C. cymosus Thunb. In Afr. occ.

311. C. tricolor L. fol. lanceolatoovatis glahris; caule declinato; floribus solitariis. B. M. 27. Hil. t. 3 . C. meonanthus Lk. In Europ. austr. ○. Cor. fundo lutea limbo caeruleo.

312. C. pentapetaloides $L$. fol. lanceolatis obtusis nudis lineatis; ramis declinatis; floribus solitariis sub5-fidis. C. prostratus Iroth. Abth.t. 3. In Graecia. $\odot$. Cor. caerulescens fundo allo.

313. C. undulatus Cav. ic. t. 2\%\%. f. 1. caule prostrato tereti; fol. ovato oblongis sessilibus; floribus axillaribus solitariis sessilibus. C. evolvuloides Desf. Atl. t. 49 . Sibth. gr. t. 198, C. humilis Jacq. Coll. 4. t. 22 . f. 3. In Hispan. et Aliric. bor. $\odot$. Cor. rubella.

314. C. piloselloides Desr. fol. spathulato-lanceolatis in petiolum decurrentibus villosis; pedunc. eiongati.y subbiforis laxe ramosis pilosis; cal. villosis; caule decumbente. In Asia minore.

315. C. lineatus $I$, fol. Ianceolatis sericeis lineatis petiolatis; pedunc. bifloris; calycibus sericeis subfoliaceis. Silth. gr. t. 199. Barr. ic. 1132. In Hispan., Lusit, et Graec. 24. Cor. purpurea.

316. C. erianthus W. Hb. fol. Iinearibus elongatis basi attenuatis nudiusculis; caule ramoso lanato; peduno. 1-floris ; cor. extus lanatis. In Amer. bor.

317. C. Rheedii Wall. fol. ohlongo-lanceolatis acutiusculis; pedunc. sub-3-floris ; laciniis calycis exteriorihus cordatis scariosis. liheede 2. t. 54. In Nepal. et Ind. or.

318. C. caespitosus Roxb. fol. lineari-lanceolatis glabris; pedunc. petiolos superantibus; bracteis 3-4-floris; calycilus glabris margine callosis. In Ind. or.

\section{Caule erecto.}

a. Herbaceo vel suffrutlooso. $\alpha$. Foliis integris.

319. C. frondosus W. Hb. fol, oblongis spathulatis obtusis mucronulatis; junioribus ramulisque stellato-puhescentibus; pedunc. sub-4-foris; calycibus acutis. Patria ignota.

320. C. Besseri Spr. fol, spadiulatis in petiolum decurrentibus sericeis lineatis; pedunc. brevissinnis 2-fioris; calycibus acutis; caule suffruticoso. C. lineatus Bess. In Podolia.

321. C. fuffruticosus Desf. Atl. $t$. 48. caule adscendente villoso; fol. lineari-lanceolatis; pedunc. axillaribus 1-floris. In Afr. bor. et Graecia. Cor. pallide rosea.

322. C. Cneorum $\boldsymbol{H}_{\text {. }}$ fol. lanceolatis argenteo-sericeis ; floribus umbellatis; calycilus villosis. B. M. 459. Sibth. gr. t. 200. In Europ. med. †. Cor. albida roseo-vittata.

323. C. saxatilis Vaht; hirsulissimus ; fol. linearihus ; floribus capitatis ; calycilus acuminatis. Bocc. Mus. t. 96. C. capitatus Cav. ic. t. 18\%. C. lanuginosus spicaefolius et secundus Desr. In Europ. austr., Tauria, Asia minore et Sibiria. 2. Cor. alla. 324. C. Cantabricus I. caule ramoso erectiusculo; fol. lineari-lance- 
latis acutis; calycibus pilosis; pedunc. subhifloris. Jacq. austr. t. 296. In Europ. austr. 4. Cor. carnea.

325. C. Dorycnium $L$. caule frutícoso dichotomo; fol. sublinearibus sericeis; calycibus ohtusis nudiusculis minimis. In Graecia. ち.

326. C. linearis Curt. B. M. 28.9. caule erecto fruticoso; fol. linearibus acutis piloso-sericeis; floribus terminalibus umbellato-paniculatis; calycibus pilosis. C. Tournefortii sieb. In Gallia et Hispan. ち. Cor. albida.

32\%. C. microphyllus Sieb. fol. linearibus sessilibus ramisque virgatis villosis; pedunc. 1 -floris; calycibus acutis; caule ramoso suffruticoso. In Aegypto, ђ.

328. C. lanatus Tahl; fol. linearibus sessilibus ramisque virgatis vilJosis; pedunc. 1-floris; calycibus acutis; caule ramoso basi suffruticoso. Sibtl. gr. t. 202. C. Forskolii Delile t. 18. f. 3. In Aegypto et Graecia. ந. Cor. rosea.

329. C. salviaefolius Sieb. fol. oblongis obtusiusculis subsessilibus venosis lanato-villosis; florilus fasciculatis involucratis; caule fruticoso ramoso. In Palaestina.

330. C. serpyllifolius $\boldsymbol{H}$. et $\boldsymbol{K}$. fol. subcordato-oblongis obtusis pubescentibus; pedunc. 1-floris filiformibus; caule diffuso. In Nov. Hispan.

331. C. parvifolius Spr. fol. spathulatis sessilibus subcoriaceis glabris; pedunc. subcorymbosis; calycibus subulatis. Ipomoea microphylla Roth. In Ind. or.

332. C. oenotheroides $\boldsymbol{L}$. fruticosus erectus; fol. linearibus canescentibus; pedunc. axillaribus erectis 1 -floris bracteatis; calycibus lanceolatis glabris. In Prom. b. spei. Cor. fulva.

333. C. Tahlii Spr. fol. oblongoellipticis obsolete dentatis subtus incano-subsericeis; pedunc. multifloris ; calyoibus sericeis minimis. C. denticulatus Vahl. In Amer. austr.

334. C. spithameus L. fol. subcordato-oblongis obtusis incanis; pedunculis 1-floris; bracteis ovatis acutis; caule erecto. In Amer, austr.

335. C, stans Michx. erectus; tomentosus; fol. oblongo-lanceolatis acuminatis cordatis postice obtusis; pedunc. 1-floris elongatis; bracteis ovatis; caule inferne florifero. Caly- stegia tomentosa Pursh. In America bor'eali.

336. C. floribundus $H$. et K. t. 210. frutescens; cano-tomentosus; fol. ovato-oblongis acuminato-mucronatis cordatis; floribus cymosis. Evolvulus macrophyllus W. Hb. In Amer. austr. ち. Cor. caerulea.

33\%. C. floridus $\boldsymbol{L}$. fruticosus; prostratus; canus; fol. lineari-lanceolatis glabris; thyrso terminali pyramidali composito. Jacq. ic. t. 34. In rupibus Teneriffae. $\hbar$. Cor. dilute rubra.

338. C. holosericeus M.Bieb. Cent. t. 21. fol. lineari-lanceolatis acutiusculis sericeis ; pedunc. 2-floris foliosis; calycihus subfoliaceis basi gibbis. In Tauria.

339. C. Ammanni Desr. fol. linearibus sericeo-lanatis; pedunc. 1-floris patentissimis; calycibus ovatis acutis corollisque sericeis. In Silhet.

340. C. prolifer Vahl; fol. linearibus supra glabris subtus sericeis; capitulis terminalibus; bracteis ovatis extus hirsutissimis. In Amer. austr.

341. C. helianthemifolius Poir. villosus; fol. sessilibus minimis anguste lanceolatis acutis; caule fruticoso. Plum. Ms. t. 47. f. b. In Amer. austr. ち. Cor. caerulea.

342. C. scoparius $L$. caule fruticoso; ramis virgatis; fol. linearibus pilosiusculis ; pedunc. sub-3-floris ; calycibus sericeis ovatis acutis. Venten. Choix. t. 24. In Teneriffa. $\hbar$. Cor. alba.

313. C. aturensis $H$. et $K$. caule ramoso virgato; fol. squamaeformibus glabris; pedumc. bifforis spicatis. Ad Orinocum. 24. Cor. alba.

344. C. intermedius Lois. fol. Ianceolatis pubescentibus; pecunc. sub1-floris; bracteis calyce longioribus; caule simplicissimo. In Gall. austr. 24. 315. C. palustris Cav. ic. t. 660. f. 2. caule erecto ramoso; fol. lanceolatis pilosis; flor. axillaribus solitariis minutis subtomentosis. In Acapulco. 2. Cor. fiavida.

3\#6. C. persicus $L$. fol. ovatis tomentosis; pedunc. 1-floris. Gmel. it. 1II. t. 7. In Persia ad Pontum Euxinum. 4. Cor. alba.

3\&\%. C. hivtus $L$. fol. cordatis subhastatisque villosis; caule petiolisque pilosis; pedunc. multifloris. In Ind. occ. Cor. flava. 
318. C. Robertianus Spr. fol. oblongis semilhastatis ohtusis integris, vel hasi pinnatifidis apice dentatis; pedunc. 1-floris hrevissimis; calycilus acuminatis. Ipomoea heterophylla $\mathbf{R}$. Br. In Nov. Holl. ち.

34.9. C. pannosus Spr. fol. oblongis obtusiusculis panuoso-tomentosis ; pedunc. 1-floris; caule suffruticoso. Ipomoea pamusa R. Br. In Nov. Holl. 古.

350. C. erectus Spr. fol. oblongolinearibus obtusis tomentosis; pedunc. sub-1-lloris; caps. 6-valvi; caule herbaceo. Ipomoea erecta $\mathrm{K}$. Br. In Nov. Holl. ђ.

3.51. C. llexuosus Spr. fol. ovatolanceolatis acutis tomentosis; pedunculis subhifloris; calycibus ovatis acuminatis; caule apice flexuoso. Ipomoea biflora R. Br. In Nov. Holl. 4.

3.52. C. relusus Colla H.rip. app. $t$. S. caule frulicoso; fol. ovatis integerrimis apice retusis nitidis subcarnosis; petiolis biglandulosis; bracteis bifidis. In Guadelupa. ఫ.

35.3. C. scabatius Viv. suffruticosus ; decumbens; villosus; fol. rotundatoovatis subemarginatis; pedumc. $2-3-$ floris; calycis ovati laciniis ovatoacuminatis. In Liguria.

\section{B. Foliis divisis.}

351. ternifolius Spr. fol. petiolatis ternatis linearibus; pedunc. 1-floris; calycilus acuminatis; caule simplici herbaceo. Ipomoea Cav. ic. t. 478. f. 1. In Mexico. Cor. purpureo-violacea.

355. C. capillaceus $H$. et $\boldsymbol{K}$. fol. sessilibus multipartitis capillaceis glabris; pedunc. 1-floris; calycibus acutis dorso rugoso-muriculatis. Ipomoea muricata Cav. In Nov. Granata. Cor. purpurea.

356. C. laciniatus Desr. fol. Iaciniatis glabriusculis; laciniis linearifiliformibus subtrifidis; pedunc. 1-floris; calycihus ovatis acutis glabris; caps. villosa. In Montevideo.

35\%. C. eriospermus Desr. fol. septenato-digitatis linearibus integerrimis glabris; pedunc. 1-floris articulatis; seminibus lanatis. In Hispaniola.

b. Caule arboreo vel fruticoso. 358. C. arborescens $W$. fol. cordato-ovatis tomentosis subtus reticu- lato-venosis; pedunc. multifloris ; calycibus seminibusque lanatis. In Amer. austr. ち. Cor. alba intus purpurea.

359. C. macranthus H. et $\boldsymbol{\kappa}$. arboreus; fol. oblongo-lanceolatis acuminatis basi rotundatis glabris; calycibus albo-lanatis. In Mexico. Cor. alla lanata.

360. C. firmus spr. fol. cordatoovatis obtusis dentatis brevissime petiolatis; pedunc. 1-floris; calycibus obtusis. Iponoea stans Cav. ic. $t$. 250. In Mexico. $\hbar$. Cor. dilute violacea.

361. C. malabaricus $L$. fol. cordatis acutis pubescentibus; pedunc. umbelliferis folio longioribus; bracteis obtusis sericeis calyci adpressis. Ipomoea bracteata W. In Malabaria. $\hbar$.

362. C. paréiraefolius Bert. fol. ovatis hasi truncatis acuminatis integerrimis subtus incanis reticulato-venosis; pedunc. cymosis 4-floris. In. Nov. Granata. $\hbar$.

363. C. altissimus Spr. fol. cordato-oblongis subtus sericeo-villosis; pedunc. terminalibus geminis; bracteis calycibusque coloratis. Ipomoea altissima Bertero. In Hispaniola. $\hbar$.

364. C. bufalinus Lour. fol. cordato-sagittatis glabris ; pedunc. multifloris. In Cochinchina. $\hbar$.

36.5. C. ovalifolius Vahl; glaber; fol. ovalibus integerrimis emarginatis; pedunc. 1-7-floris; calycibus ovatis. Ipomoea ramosa Roth. In Ind. occ. $\hbar$.

366. C. ellipticus $\mathbf{S p r}$. fol. ellipticis integerrimis subtus pubescentibus; corymbis axillaribus; calycibus glabris obtusis; caule fruticoso cinerascente. Ipomoea Roth. In India orientali. 占.

36\%. C. imbricatus Spr. fruticosus; albido-tomentosus; fol. ovalibus utrinque obtusis integerrimis; racemis axillaribus; bracteis obovatis concavis intus glaberrimis. Ipomoea Roth. In Ind. or. $\hbar$.

368. C. osyrensis Hayne; fol. cordato-0vatis obtusis supra scabris subtus densissime tomentosis; floribus subcapitatis ; calyce tomentoso ; cor. extus strigosis. Ipomoea Roth. In India orientali. $\hbar$.

369. C. Hystrix Vahl; fol. oblongis minimis; ramis ramulisque patentibus sericeis spinescentibus ; florihus capitatis; cor. 5-dentata. C. spinosus Forsk. C. armatus Delile Ae- 
gypt. t. 18. f. 2. In Arabia et Aegypto. $\hbar$. Cor. parva.

3\%0. C. spinosus Burm. ind. $t$. 19. f. 4. fruticosus ; fol. lanceolatis eericeis; pedunc. 1-floris; ramis floriferis spinosis. C. fruticosus Pall. it. II. t. M. In Persia et Sibiria. t. Cor. albicans.

371. C. erinaceus Ledeb. in Eichw. casp. t. \%. sericeus; ramis longissimis; fol. lineari-elongatis; pedunc. sub-1foris; sepalis ellipticis corollisque sericeis. Ad mare caspium. ந. 1-2-ped. Cor. rulira.

372. C? filifolius Itook, in Beech. Voy. fruticosus; ramosissimus diffusus; fol. angustissime linearibus teretibus; floribus axillaribus solitariis. In Chili. $\hbar$. Cor. cacrulea.

\section{species dubiae.}

373. C. flavescens; caule volubili; fol. cordato-ovatis integerrimis trilobisve; cymis pedunculatis densiforis. Lepistemon flavescens Blume bijdr. In Java. $\odot$.

3\% 4. C. maritimus; caule repente; fol. subrotundo - cordatis enarginatis mucronulatis margine ciliolatis; peduuc. 1-floris; calycibus cuspidatis. C. littoralis Blume bijdr. In Java.4. Cor. lilacina fundo purpurascente.

375. C. radicans Blume bijdr. cauJe inferne repente; fol. corlatis aristatis integris angulatisve ad costam utrinque puberulis; pedunc. bifidis multifloris; calycibus rotundato - emarginatis. In Juva. 2. Cor. sulphurea.

\section{RETZ1A Thunb. (1986).}

1. R. spicata Thunb. Act. Holm. I. t. 1. f. 5. caule fruticoso ramoso; fol. 4-nis sessilibus lanceolatis obtusis integerrimis; floribus sessilibus aggregatis. Lam. ill. t. 103. In Prom. 6 . spei. Ђ. 4-ped. Cor. rufescens.

2. R. roelloides $\mathbf{S p r}$. erectum; canle filiformi; fol. lanceolatis ciliatis; panicula pauciflora pedunculata nuda. Polemonium Thunb. In prom. $\boldsymbol{b}$. spei,

3. E. campanuloides Spr. erectum; glabrum; fol. lineari-lanceolatis integris erectis; floribus solitariis terminalibus. Polemonium Thuml). In Prom. b. spei.
86. GENIOSTOMA Forst. (1775).

1. G. rupestre Forst. char. $t .12$. fol. oblongo-lanceolatis glabris nervoso-venosis; cymis axillaribus pedunculatis; ramis angulatis. In Nou. Hebrid. Arbor. Cor. rosacea.

2. G. br'usiliense Spr. fol. oblongis utrinque attenuatis membranaceis ramis nodosis ; cymis pedunculatis terminalibus bracteatis. In Brasilia. Sello.

3. G. spinescens Spr. fol. oblongis utrinque attenuatis subcoriaceis subtus discoloribus triplinerviis; ramis nodosis spinescentibus ; corymbis pedunculatis terminalibus. In Brasilia. Sello.

4. G. borbonicum Spr. fol. ovatis obtusiusculis glabris; corymbis lateralibus, Anassera borbonica Lam. In Borbonia. $\hbar$.

5. G. febrifugum Spr. fol ovatooblongis obtusiusculis basi solutis coriaceis nervosis subtus villosis; pauiculis Iateralibus. Anassera Mart. In Brasilia. $\hbar$.

6. G. acuminatum Wall. ramis 4angulis subscandentibus; fol. oblongolanceolatis acuminato-cuspidatis coriaceis supra nitidis subtus strigillosis; umbellis axillaribus. In fret. Malacc. $\hbar$.

\section{LOGANIA R. Br. (1810).}

1. Fruticosae; calyce obtuso. a. Vagina intrapetiolari; floribus corymbosis.

1. L. latifolia R. Br. fol. obovatis acutis ramulisque laevibus; corymbis terminalibus trichotomis. Exacum Labill. tal. 51. In Nov. Holl. ఫ.

2. $\boldsymbol{L}$. crassifolia $\boldsymbol{R}$. Br. fol. ovato-subrotundis mucronatis coriaceis; ramis scabris; canle diffuso. In Nov. IIoll. t.

3. L. ovata R. Br. fol. ovatis subsessilibus ramulisque laevibus; caule erecto. In Nov. Holl. $\hbar$.

4. L. elliptica R. Br. fol. ovatoellipticis utrinque acutiusculis subsessilibus; ramulis laevibus; caule erecto. In Nov. Holl.

5. L. longifolia $\boldsymbol{R}, \mathrm{Br}$. fol. lanceolatis acutis ; vagina petiolorum truncata; corymbis trichotomis. In Nove Holl. 


\section{b. Stipulis setaceis laterali- bus.}

6. L. floribunda $\boldsymbol{R}$. Br. fol. lanceolatis utrinque attenuatis laevibus; racemis axillaribus coinpositis; pedicellis pubescentibus. Evosmia albiflora Audr. Hep. t. 420. In Nova Hollandia. $ち$.

\%. L. revoluta $\boldsymbol{R}$. Br. fol. linearibus scabris revolutis; racemis axillaribus simplicibus; pedicellis pubescentibus. In Nov. Holl. 支.

S. L. fasciculata $\boldsymbol{R}$. Br. fol. spathulato-linearibus obtusis laevibus; corymbi terminalis pauciflori pedicellis scaberrimis; caule diffuso. In Nova Hollandia. 卢.

9. L. angustifolia Sieb. fol. lineari-lanceolatis cuspidatis subtus tomentosis; stipulis obsoletis; floribus axillaribus corymbosis. In Nov. Holl. ‡.

\section{Calyce acuto.}

10. L. serpyllifolia $\boldsymbol{R}$. Br. suffruticosa; fol. ovatis; stipulis interpetiolaribus calycibusque ciliatis; floribus terminalibus subcorymbosis. In Nov. Holl. $\hbar$.

11. L. pusilla R. Br. herbacea; fol. ellipticis; stipulis interpetiolaribus 3-angularibus; floribus axillaribus solitariis. In Nov. Holl.

\section{SPIGELIA L. (1747).}

1. S. Anthelmia $L$. caule herbaceo ramoso; fol. oblongis utrinque attenuatis summis quaternis; racemis spicatis; staminibus corolla brevioribus. Plenk. ic. t. 88 . Browne t. 37. f. 3. In Amer. austr. 2. Cor. rubella.

2. $\boldsymbol{S}$. hamellioides $\boldsymbol{H}$. et $\boldsymbol{K}$. canle herbaceo simplici; fol. ovato-oblongis acuminatis summis sub-4-nis; staminibus cor. brevioribus. S. Humboldtiana schl. In Nova Granata. 4.

3. S. peduncularis $\boldsymbol{H}$. et $\boldsymbol{K}$. canle herbace o subsimplici; fol. oblongis longissime acuminatis superioribus sub4-nis; spicis longe pedunculatis. $\mathbf{S}$. pedunculata W. Hb. In Quito. 4. Cor. purpurea.

4. S. speciosa H. et K. t. 226 . caulibus herbaceis simplicibus; fol. subrotundis aculis sessilibus; stamini- bus exsertis. In Mexico. 24. Cor. incarnata.

5. S. marylandica $\boldsymbol{L}$. caule simplicissimo; fol. oppositis sessilibus lanceolato-ovalibus. B. M. 80. Hayne term. t. 44. f. 5. In Amer. bor. Cor. coccinea.

6. S. scabra Schl. herbacea; fol. ovato-lanceolatis rigidiusculis subtus scabris; staminibus inclusis; laciniis calycis capsula longioribus. Ad flum. Platam. Sello. 4.

\%. S. Flemmingiana Schl. herbacea; fol. oblongo-lanceolatis superioribus 4-nis stamiuibus inclusis; dentibus calycis minimis basin capsulae laevis subaequantibus. In Brasilia. Sello, $\odot$.

8. S. Beyrichiana Schl. herbacea; fol. petiolatis ovatis, floralibus 4-nis; laciniis calycis basi capsulae laevis paullo longioribus. In Brasilia. 4.

9. S. laurina Schl. fruticulosa; glaberrima; fol. elliptico-oblongis utrinque attenuatis; dentibus calycis minimis. S. glabrata Mart. t. 193. In Brasilia. ‡. Cor. rosea.

10. S. Selloi Spr. fruticosa; stellato-tomentosa; fol. ovatis acutis; genitalibus exsertis; laciniis corollae lanceolatis. S. Sellowiana Schl. Its

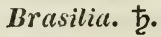

11. S. Olseriana Schl. fruticosa; stellato-tomentosa; fol. subcordatoovatis acutis; staminibus inclusis; laciniis corollae obtusis. S. pulverulenta Mart. t. 192. In Biasilia. ち. Cor. rosea.

12. S. pulchella Mart. $t$. 194. caule herbaceo sulcato-angulato superne subaphyllo; fol. minutis linearibus; spicis solitariis; fructibus glabris. In Brasilia. 4. Cor. coccinea.

13. S. pusilla IMart. caule herbaceo 4-gono decumbente foliisque petiolatis ovatis acutiusculis pubescentibus; staminibus inclusis; fructibus glabris. In Brasilia. $\odot$. Cor. alba.

11. S. Schlechtendaliana Mart. herbacea; caule ramisque 4-gonis; fol. oppositis 4-nisque sessilibus angustato-lanceolatis acuminatis subtus pubescentibus; spicis solitaris; coccis laevigatis. In Brasilia. 4. Cor. rosea.

15. S. spartioides Cham. et Schl. fruticulosa; erecta; ramosissima; ramis 4-gonis; fol. oppositis parvis li- 
neari-lanceolatis supra scabris; calyce minimo. In Brasilia. $\hbar$.

16. S. MIartiana Cham. et Schl. herbacea; erecta; scabriuscula; caule ramisque teretiusculis ohsolete 4-nerviis; fol. oppositis sessilihus anguste lanceolatis 3-nerviis; spicis solitariis. In Brasilia. 4.

\section{6\%. LISIANTHUS P. Br. (1756).}

a. Staminibus exsertis.

1. L. exsertus $S w$. fol. ovato-lanceolatis; pedunc. 3-chotomis ; genitalibus longissimis. In Jamaica. ந̋. Arbor parva, 10-12-ped. Cor. ochroleuca.

2. L. callosus Bert. fol. oblongis basi inaequalibus acutis; petiolis calloso annulo ramos amplectentibus; pedunc. corymbosis; stamiuibus longissimis. In Jamaica. Cor. ochroleuca.

3. L. exaltatus Sw. fol. ovatooblongis; corollis subcampanulatis 5fidis crenatis; pedunc. longissimo terminali. Plum. et Burm. am. ic. 81. f. 1. In Amer. austr. $\odot$. Cor. ochroleuca.

4. L. umbellatus Sw. fol. elongatis obovatis; florilous umbellatis; lacinits corollae brevissimis oltusis erectis. In Jamaica. 4 . Cor. flava.

5. L. cordifolius $\boldsymbol{L}$. fol. cordatoovatis sessilibus; pedunc. solitariis; laciniis corollae acutis. Brown jam. t. 9. f. 2. In Jamaica. ち.

6. L.grandiflorus Aubl. guj. t.79. fol. ovatis acuminatis sessilibus; floribus paniculatis; corollae limbo undulato; lobis reflexis. In Gujana et Cayenna. ๑. Flor. cernui flavescentes.

\%. L. alatus Aubl. Guj. t. 80. fol. oblongis acuminatis glabris; caule 4gono alato. In Gujana. $\odot . ~ 3-p e d$. Cor. virescens.

8. L. purpurascens Aubl. t. 99. fol. ovatis sessilibus glabris; floribus paniculatis; corolla cernua incurva; caule 4-gono. Lam. ill. t. 107. f. 2 . In Gujana. $\odot$. Cor. purpurea.

b. Staminibus corollam aequantibus aut brevioribus.

9. L. Zeylanicus Spr. fol. Ianceolatis utrinque attenuatis uervosis gla- hris ; pedunc. subtrifloris. Chironia trinervis L. Exacum Zeylanicum Roxb. Burnt. ind. t. 87. In Zieylona. ๑. Cor. caerulea.

10. L. madagascarensis Spr. fol. ovatis mucronatis 3-nerviis pubescentibus; panicula terminali laxa. L. trinervis Lam. In Madagascar. $1_{2}^{\mathrm{I}}$-ped. Cor. ruhens.

11. L. glaucifolius Jacq. ic. $t .33$. fol. elliptico-lanceolatis obtusiusculis glahris; caule tereti; pedunc. 1-floris strictis. In Ind. occ. 2-ped. Cor. purpurea.

12. L. caerulescens Aubl. t. 92. fol. lanceolatis acutis glabris; caule 4-gono alato; calyce cernuo 5-phyllo. In Gujana. $\odot$. 1 -ped. Cor. caerulescens.

13. L. pratensis $\boldsymbol{H}$. et $\boldsymbol{K}$. caule herbaceo simplici 4-angulari subalato paucifloro; fol. linearibus obtusis. Ad Orinocum. $\odot$. Cor. caerulca.

14. L. angustifolius $H$. et $K$. caule herbaceo ramoso tereti; fol. lanceolato-linearibus acutis; spicis terminalibus simplicibus. Ad Orinocum.๑.

15. L. bifidus $H$. et $\boldsymbol{K}$. caule herbaceo simplici obsolete 4-gono; fol. lanceolatis acutis; spica terminali bifida. L. fistulosus Poir. Ad Orinocum. $\odot$. Cor. virescens.

16. L. trifidus H. et $K$. caule herbaceo ramoso 4-angulari alato; fol. ovatis acutis; spicis terminalibus 3fidis. In Nov. Granata. $\odot$. Cor. virescens.

1\%. L. spathulatus Bonpl. caule herbaceo simplici tereti paucifloro; fol. oblongo-spathulatis obtusis. Helia oblongifolia Mart. t. 191. Ad Orinocum. ๑. Cor. virescens.

18. L. acutanyulus R. et P. peruv. t. 122. $f$. $a$. fol. sessilibus inferioribus cordatis superioribus ovatis; caule 4-gono; panicula dichotoma. In Peruvia. 4. 6-ped. Cor. lutea.

1.9. L. speciosus schl. caule 4-gono simplici; fol. sessilibus ovatis ohtusis nervosis marginatis; panicula trichotoma; floribus cermuis. In Brasilia.

20. L. viscosus $R$. et P. peruv. $t$. 12.5. fol. oblongis breviter petiolatis venosissimis; caulo 4-gono sulcato; corymbis terminalibus viscosis. In Peruvia. ち. Cor. luteo-viridis.

21. L. latifolius $S w$. fol. Ianceolato-ovatis acuminatis; pedunc. tri- 
chotomis; laciniis corollae erectis. $\mathbf{L}$. macrophyllus H. et K. In Jamaica et Nov. Granata. . Cor. flava.

22. L. firigidus $\mathbf{S w}$. caule suffruticoso 4-gono; fol. ovatis acuminatis nervoso-venosis petiolatis; panicula 3-chotoma; tubo corollae ventricoso. L. acuminatus Desr. In Guadelupa et Domingo. 2. Cor. flava.

23. L. glaber $L$. fol. ovatis petiolatis; corymbis terminalibus; ramis 3-gonis; caule fruticoso. L. corymhosus et revolutus. 13 . et $P$. peruv. $t$. 124. Sm. ic. t. 29. In Amer. austr. Cor. Intea.

24. L. calygonus $\boldsymbol{R}$. et P. peruv. t. 126. $f$. b. fol. lanceolatis ovatis breviter petiolatis; caule obsolete 4gono; pedunc. 1-floris; calyce 5-gono; laciniis corollae fimbriato-ciliatis. L. anomalus $\mathbf{H}$. et $\mathrm{K}$. In Amer. austr. Cor. lutea.

25. L. ovalis $R$. et $P$. caule fruticoso tereti; fol. ovalibus aveniis breviter petiolatis; pedunc. corymbosis dichotomis. In Peruvia. ち. 10-12ped. Cor. lutea.

26. L. carinatus Lam. ill. t. $10 \%$. f. 3. caule fruticoso; ramis 4-gonis; fol. subrotundo-ovatis acutis sessilibus; calycilus alatis; tubo corollae elongato. In IVIadagascar. $\hbar$. 1 2 - ped.

27. L. campanulatus Lam. fol, ovatis acutis petiolatis; pedunc. elongatis 1-floris; calyce turbinato; laciniis corollae obtusis. In Amer. austr. $\odot$. 1-2-ped.

28. L. pedunculatus Schl. caule simplici 4-gono; fol. sessilibus ovato-oblongis acutis; pedunc. terminali 2-fido; calycis corollaeque laciniis acutis. L. eleyans Mart. t. 177. In Brasilia. 4. 2-3-ped. Cor. coccinea.

29. L. chelonoides L. fol. oppositis subcomnatis oblongis; racemis subsecundis nutantubus; calycis foliolis ovatis apiculatis. L. viridiflorus Mart. t. 173. In Brasilia. $\odot$. 2-ped. Cor. virescens.

30. L. parvifolius Lam. eaule subfiliformi; fol. linearibus ; corymbo terminali paucifloro. In Amer. austr.

31. L. scandens Spr. caule volubili filiformi teretiusculo; fol. linearibus acuminatis patentissimis; racemis paucifloris; calyce subulato. In $\mathrm{Hi}$ spaniola.
32. I. alpestris Mart. $t$. 181. caule sub-1-alato; fol. ovato-orbicularibus obtusis marginatis 3-nerviis; pedunc. solitariis cernuis. In Brasilia. $\odot$. Caul. $1 \frac{\mathrm{I}}{2}$-ped. Cor. pallide violacea.

33. L. pendulus Mart. caule alato; fol. sessilibus ovato-oblongis 3 5-nerviis; pedunc. elongatis flexuosis; calycis laciniis acuminatis. In Brasilia. $\odot$. $1 \frac{\mathrm{I}}{2}$-ped. Cor. pallide violacea.

31. I. pulchervimus Mart. t. 176 caule sub-4-gono; fol. sessilibus bre-• viter ovatis acuminatis margine membranace -revolutis; paniculis dichotomis; calycis laciniis ovatis acutis. In Brasilia. 4. 3-ped. Cor. ampla coccinea.

35. L. tenuifolius $\mathbf{S p r}$. caule simplici alato; fol. linearibus margine revolutis; pedunc. terminali solitario; floribus cernuis. L. angustifolius Mart. t. 178. f. 1. In Brasilia. $\odot .1 \frac{1}{2}-p e d$, Cor. pulchre coccinea.

36. L. paniculatus Spr. canle 4gono; fol. petiolatis lanceolatis triplinerviis; paniculae laxae ramis flexuosis ; corolla glanduloso-pubescente. Irlhachia elegans Mart. t. 179. In Brasilia. ๑. 2-ped. Cor. caerulea.

3\%. L. Russelianus Hook. B. M. 3626. glaucus; fol. ovatis acutiusculis 3-5-nerviis; floribus paniculatis; calycilus profunde partitis; laciniis longissime subulatis. L. glancifolius Nutt. In Texas. ○. 2-ped. Cor. ampla pallide violacea fundo atra.

\section{SPHENOCLEA Gaertn. (1788).}

1. S. zeylanica Gaertn. t.21. Ponyatium indicum Lam. In Asia, Afirca, America aequinoct. et Aegypto. Herba aquatica pedalis. Folia oblonga obtusa integerrima. Flores spicati flavo - virescentes.

\section{VELLEIA SM. (1798).}

a. Cal. 5-plyllus. Cor. basi calcarata.

1. V. paradoxa R. Br. pubescens; fol. obtuse dentatis. In Nov. Holl.

2. V. aryut $\boldsymbol{R}$. Br. glabra; fol. argute dentatis. In Nov. Holl. 
b. Cal. 3-phyllus. Cor. basi hino gibiosiugcula.

3. $\boldsymbol{Y}$. spathulata R. Br. glahra; bracteis dichotoniarum distinctis; fol. spathulatis hasi integerrimis; axillis barhatis. In Nova Hollandia.

4. V. mubescens $R$. Br. bracteis dichotomiarum distinctis; fol. dentatis; calycis foliolis oblongo-ovatis acutis. In Nov. Holl.

5. V. perfoliata $\boldsymbol{R} . \boldsymbol{B r}$. glabra; practeis dichotomiarum maximis connatis subrotundis dentatis. In Nov. Holl.

6. F. trinervis Labill. $t$. \%\%. fol. radicalibus spathulatis repandis $3-$ nerviis; scapo dichotomo bracteato. In Nov. Holl. Goodenia tenella Andr. Rep. 466. B. M. 1137. Euthales trinervis R. Br. In Nov. Holl.

V. V. lyrata R. Br. glabra; bracteis dichotomiarum distinctis; fol. lyratis hasive inciso-dentatis; calycis foliolis ovato-orbiculatis. In Nova Hollandia.

\section{DIAPENSIA L. (1735).}

1. D. Iapponica $L$. fol. coriaceis revolutis radicalibus; pedunc. sub-1floro erecto. Fl. Dan. 47. Wahlenb. lapp. t. 9. B. B. M. 1180. In Lapponia et Amer. bor. 4. Flores albi.

2. D. cuneifolia Pursh; fol. lanceolato-cuneatis inferne pubescentibus; antheris horizontalibus basi rostratis. Pyxidanthera barbulata Michx. In Amer. boreali. $\hbar$. Flores parvi albi.

\section{POLEMONIUM Diosc.}

1. P. caeruleum $\boldsymbol{I}$. fol. pinnatis; Iloribus erectis; calycibus corollae tubo longioribus. E. B. 14. Sturm 1 . 27. Tratt. 751. P. gracile Willd. In Europ. et Asia bor. 24. Flores caerulei et albi.

2. P. mexicanum Cerv. fol. pinnatis polyphyllis; foliolo terminali trilobo; floribus cernuis; calycibus villosoviscidis. B. R. 480. In Mexico. 4. Flores caerulei.

3. P. humile Pall. fol. pinnatis pubescentibus; foliolis oblongis integerrimis; caulc suffuticoso multifloro; calycihus hirsutis; laciniis corollao obtusissimis. In Sibiria. 4.

4. P. acutiflorum W. Hb. fol. subradicalibus pinnatis glabris; foliolis oblongis integerrimis; caule suffruticoso multifloro; calycibus basi hirsutis; laciniis corollae ciliatis. $P$. boreale Adam. In Amer. bor. et occ. et in Sibir. 4.

5. P. reptans $W$. fol. pinnatis septenis; floribus terminalibus nutantibus; calycibus glaberrimis; radice repente. Mill. t. 209. In Amer. bor. 24. Cor. caerulea.

6. P. pulchellum Bunge Ledeb. $p l$. ross. $t$. 20. caule pubescente nudiusculo; fol. radic. pinnatis; pinnis oblongis acutiusculis, summis glanduloso-ciliatis. In Altaico. 24. Cor. caerulea et alba.

\%. P. capitatum Esch. pl. calif. 1826. $p$. 2S2. fol. inferioribus pinnatis; pinnis linearibus sessilibus, supremis sessilibus; floribus capitatis. In California. 24. Elores magni caerulei.

8. P. pulcherrimum Hook. B. $M$. 2979. caulibus adscendentibus foliosis calyceque pubescentibus; foliolis ovatis glabris; paniculis subcorymbosis; laciniis corollae ovalibus. In montibus Bocky. 24. Spithameum. Flores caerulei.

9. P. Richardsoni Graham. Mss. Hook. B. M. 2800. caule erecto piloso; fol. pinnatis; foliolis ovato-rotundatis mucronatis subtus pubescentibus; florilus corymbosis nutantibus; corollis crenulatis. In Amer. bor. 4. Vix digitalis. Cor. pallide caerulea.

\section{CANTUA Juss. (1789).}

1. C. pyrifolia Juss. Ann. Mus. III. $t$. \%. fol. petiolatis ovato-lanceolatis integerrinis glabris; floribus corymbosis erectis. Lam. ill. t. 106. f. 1. Periphragmos flexuosus. $R$. et $P$. t. 131. In Peruvia. $\hbar$.

2. C. ovata Cav. ic. $t$. 363. fol. subpetiolatis ovato-oblongis acuminatis glabris integerrimis in ramulis utrinque bidentatis; pedunc. 2 -3-phyl10; lobis cor. obcordatis; staminibus exsertis. In Peruvia. Cor. caeruleorubra.

3. C. ligustrifolia Juss. foetida; fol. coufertis sessilibus ovato-lancco- 
latis integerrimis glabris; cor. fauce villosa; staminibus exsertis. Periphragmos foetidus. $H$. et P. peruv. t. 132. In Peruria. ち. Cor. violacea.

4. C. quercifolia Juss. fol. petiolatis ovatis crenato-sinuatis; florihus dense corymbosis; corollae tubuIosae laciniis acutis; staminibus exsertis. In Pernvia.

5. C. buxifolia Lam. ill. t. 106. f. 2. fol. subsessilibus obovatis acuminatis integerrimis junioribus pubescentibus; staninilous inclusis. Aun. Muss. III. t. 8. In Peruvia. 古.

6. C. tomentosa Cav. ic. $t$. 364. fol. sublanceolatis sessilihus utrinque tomentosis; staminilus corollae subaequalibus. In Peruvia. Cor. dilute rubra.

\%. C. cordata Juss, ramulis sarmentosis; fol. cordatis pubescentibus; floribus axillaribus; staminibus exsertis; corollae laciuiis obtusis. In Peruvia.

8. C. megapotamica Spr. fol. oblongo-lanceolatis utrinque attenuatis glaberrimis integerrimis supra nitidis; paniculis axillaribus. Ad Rio Grande.

\section{GILIA R. et P. (1798).}

1. G. laciniata $\boldsymbol{R}$. et Pav. peruv. t. 123. fol. pimnatifidis; laciniis sinuatis ; foribus capitatis. Cantua breviflora Juss. In Peruvia. $\odot$. 1-ped. Cor. purpurascens.

2. G. coronopifolia Pers. fol. pinnatifidis; laciniis linearibus integerrimis; floribus paniculatis ceruuis. Ipomopsis elegans Michx. Sm. exot. bot. t. 13. Dill. f. 312. In Amer. bor. $\odot$. Cor. splendide rubra.

3. G. parviflor $\mathbf{S} p \boldsymbol{v}$. suffruticosa; fol. pinnatifidis; laciniis linearibus elongatis; pedunc. 1-floris; corolla calycem subaequante. B. M. 2883. Ipomopsis inconspicua Smith 1. c. t. 14. In Amer. bor. $\odot$. Caulis ramosissimus. Cor. pallide caerulea.

4. G. glomeriflora Spr. fol. pinnatifidis; laciniis linearibus integris; floribus pedunculatis glomeratis; caule suffuticoso. Phlox pinnata Cav. ic. t. 528. f. 1. Cantua Juss. Ad Rio rle la Plata. $\hbar$. Cor. ochroleuca.

5. G. agyregata Spr. fol. tenuissime pinnatifidis; floribus aggregatis subsessilibus; laciniis corollae erectis angustis ; stylo incluso. Cantua Pursh. Ipomeria Nutt. Al flum. Missisippi. $\odot$. Cor. scarlactina.

6. G. pungens Dougl. Mrss. B. M. 2.97\% pubescenti-glandulosa; fol. hracteisque pinnatifidis; laciniis incisis subulatis pungentibus; floribus glomeratis. In Columbia. $\odot$. Caulis viscide glandulosus. Cor. azurea.

7. G. gracilis Dougl. Mss. glanduloso-pubescens; caule valde ramoso; fol. lineari-oblongis obtusis; calycis segmentis longis subulatis. In Amer. boreali. $\odot$. Vix pedalis. Flores rosei.

8. G. achilleaefolia Benth. B. R. 1682. caule erecto glabriusculo; fol. tripinnatisectis; Iaciniis lineari-subulatis; corymbis capitatis longissime pedunculatis; calycibus sublanatis. $B$. M. 3440. In California. $\odot$. Cor. violacea.

9. G. tricolor Benth. B. R. 1701. caule erecto glabro folioso; fol. bipinnatisectis; laciniis lineari-subulatis; corollis calyce subtriplolongioribus. В. M. 3463. In Amer. bor. $\odot$.

10. G. tenuiflora Lindl. B. R. 18s5. caule erecto superue viscoso; fol. pinnatifidis glabris; corymbis laxis longe pedunculatis; corollis calyce 4-plo Iongioribus. In California. $\odot$. Flores rosei fundo caerulei.

11. G. capitata Hook. B. M. 2698. glabra; fol. pimnatifidis; laciniis superiorum linearibus incisis ; florum capitulis longe pedunculatis. B. R. 1170. In Amer. bor. $\odot$. 2-ped. Cor. laete caerulea.

\section{HOITZIA Juss. (17S9).}

1. H. caerulea Cav. ic. $t .366$. caule suffruticoso; fol. subsessilibus linearibus denticulato-spinosis. Cantua Poir. In Mexico. $\hbar$. Cor. dilute caerulea.

2. H. Cervantesii $H$. et $K$. ramis glanduloso-hirtellis; fol. subsessilibus oblongo-lanceolatis argute serrulatis; floribus geminis; bracteis apice serrulato - aculeatis glanduloso-pilosis. H. spicata W. Hb. In Mexico. ђ. Cor. violacea.

3. H. coccinea Cav. ic. $t$. 365. fol. subsessilibus ovatis; florihus solitariis brevissime pedunc.; bracteis 
lanceolatis subserratis venosis hirtis. Cantua Hoitzia W. In Mexico. ち. Cor. coccinea.

4. H. aristata $H$. et $K$. fol. petiolatis ovatis duplicato-serratis; floribus congestis; bracteis ovatis dentato-aristatis diaphanis viridi-venosoreticulatis, exterioribus cordatis. In Mexico. $\hbar$.

5. $\mathrm{H}$. conglomerata $\mathrm{H}$. et $\boldsymbol{K}_{\text {. }}$ ramulis villoso-glandulosis; fol. breviter petiolatis ovatis aryute serratis; floribus solitariis seu glomeratis; bracteis lanceolatis serrulato-aculeatis glanduloso-pilosis. H. capitata W. In Mexico. $\hbar$. Cor. violacea.

6. H. glandulosa Cav. ic. t. $36 \%$ caule suffruticoso aspero; fol. ovatolanceolatis petiolatis; ramis sublinearibus. Cantua Poir. In Mexico. ち. Cor. rubra.

\%. H. Loeselia Spr. fol. ovatis serratis; racemo axillari; bracteis subrotundo-ovatis dentato-ciliatis. Loeselia ciliata L. Gaertn. t. 62. f. 3. In Nova Hisp.

8. H. nepetaefolia Schl. caule stricto subcompresso; fol. caulinis cuneatis in petiolum attenuatis apice acutis serratis acmuninatis ciliatis. In Mexico. Flores caeruleo-purpurei.

9. H. squarrosa Esch. pl. calif. caule ramoso-pubescente; floribus capitatis; fol. pimnatis calyceque mucronatis. In California. $\odot$. 1-2-ped.

\section{COLLOMIA Nutt. (1818).}

1. C. linearis Nutt. leviter pubescenti-pilosa; caule erecto subsimplici; fol. erecto-patentibus anguste lanceolatis integerrimis; floribus capitatis; calyce glanduloso. B. M. 2893. B. R. 1166. C. Cavanillesii Hook. Phlox linearis Cav. ic. t. 527. In Chili. $\odot$. Cor. rosea.

2. C. grandifiora Dougl. B. $\boldsymbol{R}$. 11\% t. fol. late lanceolatis nitidis saepe serratis subpubescentibus; capitulis viscosis; corollae limbo obliquo. B. M. 2894. In Amer. austr. $\odot$. 1ped. Cor. intense miniata.

3. C. heterophylla Hook. B. M. 2895. pubescens; caule erecto ramoso; fol. inferioribus bipinnatifidis, superioribus integris; capilulis pauciflo- ris. Gilia Dougl. Mss, In Amer, bor. $\odot \mathbf{1}_{2}^{\mathrm{I}}$-ped. Cor. lilacina.

4. C. coccinea Lindl. B. R. 1621.

\section{8\%6. COBAEA Cav. (1791).}

1. C. scandens Cav. ic. $t .15,16$. et 500. caule scandente; fol. abrupte pinnatis ; foliolis oblongo-ovatis hastatis. B. M. 851. Andr. t. 342. In

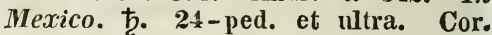
lutea dein violacea.

2. C. lutea Don; fol. pimnatis; foliolis oblongis acutis; laciniis calycis lineari-lanceolatis mucronatis. In Guayaquil. $\hbar$. Cor. lutea.

\section{7\%. DATURA Garc. ab Orto (1563).}

a. Capsulis echinatis.

1. D. Stramonium $\boldsymbol{L}$. fol. ovatis glabris angulato-dentatis; spicis divergentibus. E. B. 1288. Blackw. t. 313. In Amer. et Europ. ๑. 1-3ped. Cor. alba.

2. D. muricata Lk. fol. ovatis acutis repandis glabris; fructibus muricatis; caule viridi. Patria ignota. $\odot$. Cor. alba.

3. D. ferox $\boldsymbol{L}$. fol. cordatis sublobatis pubescentibus; fructibus erectis spinosis; spinis summis elongatis convergentibus. Barr. ic. 1172. In China. $\odot$. Cor. alba.

4. D. Tatula I. fol. petiolo nervisque rubris; caule lierbaceo maculato. In Europ. et Amer. $\odot$. Cor. violacea.

5. D. Metel $L$. fol. cordatis subintegris pubescentibus; caps. nutantibus globosis echinatis. Ludw. Ectyp. t. 158. D. alla Rumph. 5. t. 87. Hheede 2. t. 28. In Asia. ๑. Cor. alba.

6. D. quercifolia $\boldsymbol{H}$. et $\boldsymbol{K}$. herbacea; fol. sinuato-pimatifidis subtus in venis hirtellis; dentibus corollae acuminatis. In Mexico. $\odot$.

\%. D. guayaquilensis Bonpl. fol. ovatis acutis repandis pilosiusculis; fructibus spinosis pendulis; caule colorato. In Quito. ๑. Cor. violacea. 
b. Capsulis inermibus.

8. D. arborea $L$. fol. ohlongis integerrimis pulverulentis ; floribus pendulis ; fructibus glabris nutantibus. Feuill. t. 46. Fl. peruv. t. 128. Brugmansia Pers. D. suaveolens W. In Amer. austr. 4. 8-10-ped. Cor. alla. 7-8-poll. Ionga.

9. D. sanguinea $R$. et $P$. fol. lanceolatis angulatis congestis; pericarpiis oblongo-cylindricis pendulis; caule fruticoso. Brugmansia bicolor Pers. In Permia. ち. Frutex 25-ped. Cor. superne rubra.

10. D. laevis $L$. fol. ovatis angulato-dentatis glahris; fructibus erectis; caule lierbaceo fistuloso. D. inermis Jacq. Vind. t. 82. In Africa. $\odot$. Cor. alba.

11. D. fastuosa $\boldsymbol{L}$. fol. acute angulatis subpubescentibus; fructibus tuberculatis nutantibus; caule maculato. D. rubra Rumpl. 5. t. 243. f. 2. Knorr. t. 8. In Amer. austr. et Aegypto. $\odot$. Caulis rufus albo-punctatus. Cor. violacea.

12. D. ceratocaula Jacq. fol. ovato-oblongis subtus incano-tomentosis. Jacq. Sclioenbr. t. 339. B. M. 3352. D. macrocaulis Roth. In Mexico et Cuba. $\odot$. Cor. intus alba extus violacea.

\section{AZALEA L. (1737).}

1. A. procumbens $L$. fol. ellipticis revolutis supra nitidis sulcatis; ramis procumbentibus radicantilus. Fl. lap. t. 6. f. 2. Fl. Dan. 9. E. B. 865. Cliamaeledon Lk. In Europ. et Amer. bor. ᄒ. Cor. rosea.

2. A. rosmarinifolia Burm. ind. t. 3. $f$. 3. fol. lineari-lanceolatis margine reflexis hirsutis; floribus solitariis. In Japonia et Java. ち. Cor. flava.

3. A. fragrans Adams; fol. ruguloso-punctatis subtus discoloribus ellipticis obtusis; floribus subcapitatis; genitalibus inclusis. In Sibiria. ђ. Cor. rosea.

4. A. indica $L$. fol. ovato-oblongis acutic villosis; floribus solitariis; calycilus pilosis. A. v. laeteritia B. R. 1700 et A. v. variegata B. H.1716. In Ind. or. et Japonia. t.. Cor. coccinea.
5. A. pontica $L$. fol. oblongis hasi angustatis nitidis ciliatis elabris: c0rollae tubo glanduloso piloso. B. M. 433. Andr. t. 16. Pall. Hoss. t. 69. B. sinensis B. R. 1253. $\gamma$. versicolor B. R. 15ã9. In Asia minore et Caucoso. ち. 2-3-ped. Cor. flava.

6. A. mudiflor $\boldsymbol{L}$. fol. oblongis basi angustatis ciliatis glabris; corymbo terminali; cor. externe pilosis; staminibus corolla longioribus. B. M. 180. $\beta$. scintillans B. R. 1461. $\gamma$. thyrsiflora B. 1. 1367. In Amer. bor. $ђ$. Cor. albida et carnea.

\%. A. speciosa $W$. fol. lanceolatis utrinque attenuatis ciliatis; laciniis calycis spathulatis; cor. extus pilosa; staminibus exsertis. A. calendulacea Michx. B. R. 1407 et 1462. A. periclymenoides Pursh. In Amer. bor. ち. Cor. pallide rosea.

8. A. viscosa L. fol. obovato-oblongis glabris ciliatis; ramis hispidis; calycibus brevissimis acutis; corolla extus piloso-viscosa. Meerb. t. 9. In Amer. bor. Ђ. Cor. alba.

9. A. canescens Michx. fol. oblongis cano-pubescentibus subtus tomentosis; calycibus brevissimis inaequalibus; corolla glabriuscula. Ehret. t. 48. A. bicolor et subnudiflora Pursh. In Carolina. 古. Flor. pallide rosei.

10. A. nitida Pursh; fol. spathulato-lanceolatis mucronatis coriaceis glabris supra nitidis ciliatis; corolla extus piloso-viscosa; staminibus exsertis. In Amer. bor. ‡. Cor. alba pallide rubra tincta.

11. A. glauca Lam. ill. t. 110. $f$. 2. ramulis hispidis; fol. ovato-0blongis glabris subtus glaucis; corolla extus piloso-viscosa; staminibus exsertis. A. hispida Pursh. In Amer. bor. ち. Cor. alba fragrantissima.

12. A. arborescens Pursh; fol. obovatis glabris ciliatis subtus glaucis; laciniis calycis foliaceis oblongis; corolla nudiuscula. In Pennsylvania. ち. Frutex elegantissimus 1012-ped. Flores rosei.

\section{EPACRIS Forst. (17\%5).}

a. Foliis ovatis lanceolatis.

1. E. nivalis Iodd. B. C. 1824. fol. ovato-lanceolatis patentissimis nudiusculis infra nervosis apice attenua- 
tis mncronatis marginibus scabris; calycihus ciliatis. B. M. 3253 . B. H. 1531. In Nov. Holl. ち. Cor. alba.

2. E. impressa Labill. $t$. 58. fol. Ianceolatis patentissimis nudiusculis venosis mucronatis marginibus scabris; floribus pendulis; cor. tubo prismatico. B. M. 3407. In Nov. Holl. 古.

3. E. cercueflora Grah. B. M.32-13. fol. lanceolatis patentissimis nudiusculis subaveniis mucronatis marginibus scabris; floribus secundis ; corollae tubo ovato. In ins. Van Diemen. $\hbar$. Flores pallidi.

4. E. onosmaeflora Cunningh. fol. lanceolato-ellipticis acuminatis 5-nerviis petiolatis margine ciliatis; ramulis incurvis; calyce acutissimo. B.M. 3108. In Nov. Holl. ђ. Cor. albida.

5. E. myrtifolia Labill. $t$. 55. fol. ovatis acutis mucronnatis planis crassis; staninibus inclusis. E. serpyllifolia R. Br. In Nov. Holl. $ђ$.

6. E. crassifolia M. Br. fol. ovalibus obovatisque obtusis muticis planis cartilagineis basi acutis; calycibus margine lanatis ; caule procumbente. In Nov. Holl. $\hbar$.

7. E. ruscifolia R. Br. fol. Ianceolato-ellipticis petiolatis acuminatis; floribus sparsis pendulis; corollis cylindraceis. In Nov. Holl. $ち$.

8. E. heteronema Labill. $t$. 56. fol. eiliptico-lanceolatis acuminatis concaviusculis subtus striatis; calycibus acutissimis; ramulis hirsutis. B. M. 3257. In ins. Van Diemen. $\hbar$.

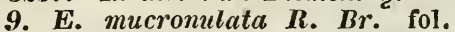
lanceolatis cuspidatis erecto-patulis; calycihus acutis. In ins. Van Diemen. t.

10. E. obtusifolia $\mathbf{S m}$. exot. bot. t. 40. fol. lanceolatis erectis subimbricatis; apice calloso obtusiusculo; floribus nutantibus; calycibus obtusis longitudine tubi; staminibus inclusis. In Nov. Holl. 支.

11. E. exserta R. Br. fol. lanceolatis acutis erectis supra planis subtus convexiusculis; antheris Ionge exsertis. In Nov. Holl. ち.

12. E. paludosa R. Br. fol. anguste lanceolatis acuminatis subtus striatis margine scabris; calycibus acuminatis; staminibus inclusis. In Nov. Holl. $\hbar$.

13. E. Lanuginosa Labilb. $t$. 5\%. fol. Ianccolatis acuminatis margire scabris; calycibus acutissimis longitudine tubi marginibus lanuginosis; stylo hirsuto. In Nov. Holl. $\hbar$. Cor. albida.

1t. E. sparsa R. Br. fol. oblongo-lanceolatis mucronatis petiolatis aveniis; floribus sparsis nutantibus; tubo corollae calycem acutum subaequante. In Nov. Holl. ち.

15. E. rivularis Sieb. fol. subsessilibus ovatis acuminatis reflexo-patentibus; calycibus acutis corollam subaequantibus. In Nov. Holl. ち.

16. E. rigida Sieb. fol. ovato-oblongis obtusiusculis subsessilibus cartilagineis subtus carinatis patulis; calycibus obtusis tubum corollae aoquantibus. In Nov. Holl. $\hbar$.

\section{b. Foliis basi vaginantibus.}

17. E. longifolia Forst. fol. lineari-lanceolatis strictis elongatis rigidis; racemis lateralibus flexuosis. In Nor. Zeelandia. $\hbar$.

18. E. rosmarinifolia Forst. fol. linearibus obtusis rigidis; floribus lateralibus solitariis. In Nor. Zeelandia. .

\section{c. Foliis cordatis.}

19. E. grandiflora $S m$. fol. patnlis acuminatis planis; floribus pendulis; corollis cylindricis calyce quater longioribus. E. Iongiflora Cav. ic. t. 344. B. M. 982. In Nov. Holl. ђ. Cor. punicea.

20. E. riparia $\boldsymbol{R}$. $B r$. fol. planis acuminatis patulis; calycis foliolis setace 0 -acuminatis tubum corollae subaequantilus. In Nov. Holl. $\downarrow$.

21. E. pulchella Cav. ic. $t$. 345. fol. concaviusculis rigido-acuminatis ; spica basiflora; calycis foliolis acuminatis. B. M. 1170. In Nov. Holl. t. Cor. rubens.

22. E. microplyylla R. Br. fol. patulis cucullatis acutis; floribus terminalibus; calycibus obtusiusculis tubun corollae aequantibus. B. M. 3658. In Nov. Holl. ђ. Cor, alhida.

23. E, purpurascens R. Br. fol. cucullatis recurvo-cuspidatis; calycibus acumiuatis tubum corollae aequantibus. E. pungens B. M. 844. In Nov. Holl. t. Cor. purpurea. 


\section{DRACOPHYLLUM Labill. (1795).}

1. D. squarrosum R. Br. fol. squarrosis ensiformi-lanceolatis; ramis floriferis vix longitudine spicae. Epacris Poir. In Nov. Holl. $\hbar$.

2. D. gracile $R$. $\boldsymbol{B} r$. fol. subulatolanceolatis patulis recurvisve; ramis adpressis; spica ovata. Epacris spr. In Nor. Holl.

3. I). cripilutum R. Br. fol. caulinis ensiformi-lanceoiatis erectuisculis, rameis adpressis; floribus spicato-capitatis. B. H. 362\%. In Nov. Holl. 市.

4. D. secundum R. $\boldsymbol{B r}$. fol. semivaginantibus cucullatis; racemo secundo; pedicellis squamatis. B. MI. 3264. Prionotes spr. In Nov. Hollandia. ち. Cor. alba.

\section{LISINEMA R. Br. (1810).}

1. I. pentapetalum $R$. Br. corollis pentapetalis; unguibus longitudinaliter distinctis calyce longioribus extus glahris. In Nov. Holl.

2. L. ciliatum L. Br. corollis pentapetalis; unguibus apice cohaerentibus longitudine calycis extus glabris. In Nov. Holl. $ђ$.

3. L. Lasiantlum R. Br. corollis pentapetalis; unguibus extus lanatis limbo 4-6-plo longioribus. In Nov. Holl. t.

4. I. consyicuum R. Br. corollis 1-petalis; tubo 5-fido calycem superante; fol. lanceolato-subulatis adpressis. In Nov. Holl. 支.

5. L. pungens R. Br. corollis 1petalis; tubo integro calycem aequante; fol. ovatis acuminatis patulis. Epacris Cav. ic. t. 346. B. M. 1199 . E. odorata Sm. In Nov. Holl. $\downarrow$. Cor. rubescens.

6. L. ruscifolium Sieb. fol. semiamplexicaulibus ovato-ohlongis cuspidatis ciliatis laevilus; calyce subulato tuluum corollae aequante. In Nov. Holl.

882. ANDERSONIA R. Br. (1810). a. Flores bibracteati.

1. A. sprengelioides $\boldsymbol{R}$. $\boldsymbol{B}$ r. fol. patulis; acumine plano. In Nov. Holl. ఫ.
2. A. parrifolia R. Br. fol. adpressis; acumine triquetro. In Nor. Holl. b.

\section{b. Flores multibracteati.}

3. A. cacrulea R. $\mathbf{R r}$. fol. modice patentibus; novellis calycibusque extus patentibus. In Nor. IIoll. $ђ$.

4. A. spuarosa R. Br. fol. squarrosis divaricatis recurvisve glabris nuargine nudis; calycibus stylisque glabris; caule crecio. In Nov. Holl. ந.

5. A. depressa R. Br. fol. squarrosis divaricatis recurvisve pubescentibus nuargine ciliatis; calycibus glabris; stylis medio pilosis; caule depresso. In Nov. Holl. $\hbar$.

6. A. micrantha R. $B r$. fol. adpressis; stylis infra medium pubescentibus. In Nov. Holl. $\hbar$.

\section{SS3. SPRERGELIA Sm. (1894).}

1. S. incarnata Sm. tract. $t$. 2. antheris comnatis barbatis; calycibus coloratis ; fol. longe acuminatis. Andr. Rep. t. 2. In Nov. Holl. ち. Cor. carnea.

2. S. montana R. $\mathrm{Rr}$. antheris liberis imberbibus; calycibus senicoloratis; fol. breve acuminatis. In Nov. IIoll. 支.

\section{S4. PONCELETIA R. Br. (1810).}

1. P. sprengelioides $\boldsymbol{R}, \mathrm{Br}, \mathrm{In}$ Nor. Holl. $\hbar$. Fruticulus paludosus erectus virgatus. Folia cucullata semivaginata. Flores terminales.

\section{COSMELIA R. Br. (1810).}

1. C. rubra R. Br. Epacris rubra Spr. In Nov. Holl. ち. Frutex paludosus. Folia cucullata. Flores solitarii cernui rubri.

886. CYSTANTHE R. Br. (1810).

1. C. sprengelioides $\boldsymbol{R} . \mathrm{Br}$. Int Nov. Holl. $\downarrow$. Frutex habitu Sprengeliae. 


\section{RICHEA R. Br. (1810).}

1. R. Aracophylla R. Br. Labill. t. 16? In Nov. Holl. ち. Frutex habitu Dracophylli montani.

\section{PRIONOTES R. Br. (1810).}

1. P. cerinthoides $\boldsymbol{M}$. $\mathrm{Br}$. fol. Ianceolatis seriatis subsessilibus; pedunculis solitariis squamatis pendulis. Epacris Labill. t. 59. In Nov. Holl. t.

\section{CAMPYLUS Lour. (1790).}

1. C. sinensis Lour. In China austr. $\downarrow$. Fintex scandens. Folia cordata integerrima tomentosa petiolata. Flores racemosi carnei.

\section{STRYCHNOS Wachendorf $(17 \pm 7)$.}

1. S. Nux vomica $L$. inermis; fol. ovatis petiolatis; cymis subterminalibus. Hoxb. Corom. t. \%. Plenk. ic. t. 117. Gaertn. t. 179. f. 1. Rheede 1. t. 37. In Ind. or. ђ. Arbor mediocris. Flores albidi. Fructus magnitudine Aurantii.

2. S. colubrina $\boldsymbol{L}$. inermis; fol. ovatis acutis subsessilibus ; cirrhis simplicibus. Plenk. ic. t. 118. Rheede t. 7. f. 1. In Ind. or. ђ.

3. S. potatorum L. fol. oppositis ovatis acutis quintuplinerviis venosis; cymis axillaribus. Hoxb. Corom. t. 5? In Madras. Arbor ramis oppositis. Flores allissimi fragrantissimi.

4. S. madagascarensis $A$ ub. inermis ; fol. ovatis acutis ; corollis 4-partitis fauce villosis; fructu maximo 1spermo. In Madagascar. 古.

5. S. Pseudochina Hil. $t$. 1. fol. ovatis acutis demum obtusis 5-nerviis subtus rubro-tomentosis; racemis axillaribus paniculatis villosis. In Brasilia. b. Arbor 12-ped. Cor. viridialba. Bacca Iutea.

6. S. muricata hosteletzli. fol. ovali-ellipticis obtusiusculis 3-ncrviis glabris; cymis terminalibus; bacca globosa muricata. Rumpl. 2. t. 38 . In ins. Timor et ins. affinit. t. Arbor 6-8-ped. Bacca luteo-fusca.
7. S. spinosa Lam. ramis spinosis; fol. obovatis acutis $\bar{y}$-nerviis glabris; cymis axillaribus; calyce corollae longitudine. Plukn. t. 170. f. 4. In Madayascur. ち. Arbor 10-12-ped. Bacca aurantiaca.

8. S. axillaris Colebr. scandens; sarmentis simplicibus incrassatis; fol. oblongis acuminatis' 3-plinerviis; cymis axillaribus; hacca 1-sperma. In Ind. or. $\hbar$. Frutex. Flores albi. Bacca aurantiaca.

9. S. Tieute Lechen. scandens; sarmentis simplicibus incrassatis; fol. oblongis acuminatis 3-nerviis glabris. Ann. Mus. 3. t. 23. Blume Rumphia t. 25. In Java. ち. Frutex venenatus. Bacca rubro-fusca.

10. S. lucida R. Br. fol. ovatis acutiusculis coriaceis nitidis I-nerviis; nervis 2-parlitis. In Nov. Holl. ち.

11. S. Ignatii Berg. fol. ovatis acutis integerrimis glabris venosis; ramis scandentihus; pedunc. sub 4-floris; fructibus polyspermis. xIgnatia antara L. phil. Trans. t. 21. f. 4-6. In Plilippinis. $\hbar$. Bacca pyriformis sublignosa.

12. S. brachiata $R$. et $P$. peruv. t. 57. fol. oppositis ovatis ohliquisque acuminatis 5-nerviis; caule brachiato tereti; floribus corymbosis. In Peruvia. ち. Arbuscula ramosissima scandens. Cor. alba. Bacca magna viridis.

13. S. ligustrina Blume Rumphia t. 25. In Java. ち.

14. S. bicirrhosa Lechen. caule scandente; cirrhis bifidis oppositifoliis; fol. oblongis cuspidatis 3-plinerviis; fructibus 1-spermis. In Ind. or. $\downarrow$.

\section{THEOPHRASTA Royen (1710).}

1. T. americana $L$. fol. repandodentatis acutiusculis. Plum. ic. 126. In Amer. austr. ち. 4-5-ped. Fructus croceus. Semina rubra.

2. T. longifolia Jacq. Schoenbr. t. 116. fol. mucronato - dentatis acuminatis simplicibus; racemis sparsis reclinatis. T. macrophylla Lk. In Domingo. ち. 5-ped. Cor. aurantiaca.

3. $\boldsymbol{T}$. Latifolia $\boldsymbol{W}$. fol. oblongis utrinque attenuatis petiolatis serrulatis mucronatis; racemis erectis axillaribus. In Amer. austr. $\hbar$. 
4. $T$. pungens $\boldsymbol{W}$. fol. lanceolatis elongatis coriaceis subpetiolatis spinoso-serratis sinuatis; racemis laxis dentatis; dentibus calycis margine laceris. In Amer. anstr. $\hbar$.

5. T. Jussieri Lindl. fol. oblongis ohtusis rigidis undulatis spinoso-dentatis marginatis suhenerviis; racemis axillaribus corymbosis; floribus cernuis. Patria ignota. ち.

6. $T$. cochinchinensis spr. fol. petiolatis ovato-lanceolatis integerrimis nitidis; corymbis terminalibus. Oncinus Lour. In Cochinchina. $\hbar$.

\section{LEONIA R. et P. (1898).}

1. L. glycycarpa $R$. et P. peruv. t. 222. paniculis racemosis axillaribus pendulis. L. racemosa Mart. t. 168 et 200. In Peruvia et Brasilia. t. Arhor 40-ped. Cor. ochroleuca.

2. L. cymosa Mart. $t$. 169. et 200. cymis axillarihus patulis. In Brasilia. 古. Arbor 10-15-ped. Cor. lutea.

\section{DORAENA Thunb. (1784).}

1. D. japonica Thunb. jap. In Japonia. 古. Arbor 6-ped. Folia oblonga acuminata. Flores racemosi albi.

\section{S94. HANCORNIA Gomez (1812).}

1. H. speciosa Gomez; fol. oblongo-lanceolatis coriaceis acutiusculis glabris; pedunc. terminalibus sub 3floris. In Brasilia.

2. H. mbescens Mart. fol. oblongis acuminatis ramisque pubescentibus; cymis terminalihus sessilibus dichotomis. In Brasilia. to.

\section{CESTRUMI L. (1737).}

\section{a. Filamenta denticulata vel} glandulos a.

\section{a. Foliaglabra.}

1. C. Parqui L. fol. lanceolatis attenuatis subundulatis opacis; pedunc. terminalibus cymosis. C. virgatum $\mathbf{R}$. et P. Feuill, t. 32. f. 1. C. salicifo- lium H. et K. In Montevideo et Chili. t. 6-8-ped. Cor. albido-lutescens.

2. C. salicifolium Jacr. Sclioenbr. t. 326. fol. lineari-lanceolatis subcoriaceis; pedunc. racemosis. In Ind. occ. $\hbar$. Cor. albo-virens.

3. C'. undulatum $R$. et $p$. peruv. t. 15.5. fol. ovatis acutis undulatis; pedunc. axillaribus terminalibusque paucifloris. In Peruvia. $\hbar$. 15-ped. Cor. flava.

4. C. venenatum Thumb. fol. Ianceolato-oblongis coriaceis ; floribus sessilibus. In Prom. b. spei. $ђ$.

5. C. nocturnum $\mathrm{I}$. fol. oblongis attenuatis membranaceis opacis; pedunc. axillaribus cymosis. Dill. f. 185. In Amer. anstr. ち. 6-9-ped.

6. C. citrifolizin llet $z$; fol. ovatis acutis nitidis coriaceis venosis; pedunc. axillaribus abbreviatis. Patria ignota. 支.

\%. C. lanrifolium Herit. stirp. $t$. 31. fol. ellipticis coriaceis nitidissimis; floribus fasciculatis pedicellatis." In Amer. ausir. b. 6-9-ped. Flores flavicantes.

8. C. macrophyllum Tent. Choix. t. 8. fol. ovato-ohlongis acuminatis glaberrimis; floribus fasciculatis sessilibus. In Ind. occ. ち. 6-7-ped. Flores lactei.

9. C. euanthes Sclel. glabrum; fol. ellipticis vel ohlongis basi attenuatis apice lucidulis subcoriaceis; racemis axillarihus; calycis dentibus obtusis apice tomentosis. In Mexico. $\hbar$.

\section{b. Folia pubescentia.}

10. C. dumetorum Schl. ramis glabris; fol. ellipticis acuminatis basi acutis opacis suitus puberulis; floribus racemosis; calyce villoso acuto. In Mexico. $\hbar$.

11. C. hirtellum Schl. ramulis hirtellis; fol. lanceolatis basi acutis apice acuminatis membranaceis pubescertibus; calycis dentihus hirtellis elongato-triangularibus acutissimis. In Ilexico. $\hbar$.

12. C. vestioides Schl. ramis pubescentibus; fol. oblongis subsessilibus basi longe attenuatis apice subobtusis; coriaceis subtus puberulis; calycis dentibus subbarbato-mucronulatis. In Mexico. $\hbar$. 
13. C. hirsutum Jacy. Schoenbr. t. 321. fol. oblongis altenuatis utrinque pubescentibus subtus stellatotomentosis; stipulis falcatis; spicis axillaribus. Patria ignota. ち. 8-ped. Cor. virelis.

11. C. exstipulatum Ledeb. fol. oblongis acuminatis villosis; stipulis nullis; spicis terminalibus. Patria ignot $\iota$. $\hbar$.

15. C. tomentosum I. ramis foliis ovato - lanceolatis calycibusque incano-pubescentibus; Horibus confertis terminalihus. In Amer. austr. $\hbar$.

16. C. alaternoides Ifumilt. fruticostum; fol. alternis ovatis undulatis coriaceis nitidis subtus subpubescentibus; racenis subsessilibus. B. M. 2929. In Ind. occ. ち. Cor. pallide lutea.

\section{b. Filamenta edentula.}

$$
\text { a. Folia glabra. }
$$

1\%. C. affine H. et $K$. fol. lanceolato-oblorgis acuminatis membrauaceis glahris; spicis axillaribos abbreviatis; laciniis corollae ovatis acutis. C. peruvianum W. Hl. In Quito. t. Cor. albido-vireus.

18. C. diurnum $I$. fol. lanceolatis; laciniis corollae reflexis obtusis. Dill. Elth. f. 186. C. pallidum Lam. In Cuba. ち. 10-12-ped. Flores albidi.

19. C. vespertinum I. fol. oblongis acutis subuembranaceis opacis; florihus axillaribus aggregatis; laciniis corollae acuminatis. Jacq. Schoeubr. t. 328. Murr. Comm. 5. t. 8. In lnd. occ. ђ. Arbor 2-org. Cor. viridis.

20. C. auriculatum Herit. fol. ollongis acuminatis membranaceis glabris; petiolis 2 -auriculatis; floribus pubescentilus; corollae lacinis inflexis. In Amer. austr. ち.

21. C. tinctorium Jac\%. Schoenbr. t. 332. fol. lanceolato-ovatis ; floribus peuicellatis; corollis acutis demum reflexis. In Caracas. 方. Arbor 4-ped. Flores albi. Bacca atro-violacea.

22. C. scandens Vahl; fol. ovato attenuatis glabris; racemis axillariluus subcompositis; ramis scandentibus. In Amer. austs.

23. C. paniculatum $I$. et $\boldsymbol{K}_{\text {. }}$ voInbile; fol. geminis ovato-oblongis acutis glabris; paniculis termiualibus; tubo corollae tenuissimo. In Caracas. t. Flores virescenti-alhi.

-1. C. fustiyiatum Jacy. Schoenbr. t. 330. fol. oblongis coriaceis nitidis; stipulis ovatis obtusis ; pedunculis elongatis ; laciniis corollae obtusis revolutis. P'atria ignota. †. 4-ped. Cor. alba.

2.5. C. foetilissimum Jacr. Schoenbr. t. 329. Fragm. t. 42. f. 2. fol. ovato-lanceolatis membranaceis opacis; panicula conferta; laciniis corollae emarginatis confertis. In lnu. occ. $t$. 10-ped. Cor. flavicans.

26. C. odontospermum Jucq. fol. lanceolatis acutis coriaceis; racemis brevibus axillaribus; floribus sulısessilibus; laciniis corollae revolutis; seminibus apice denticulatis. Patria ignota. 方. Cor. nivea.

2\%. C. oppositifolium Lam. ill. $t$. 112. f. 2. fol. oppositis lanceolatis; nervosis subcoriaceis; floribus fasciculatis subsessilibus axillaribus. In Africa. $\hbar$. Flores parvi.

28. C. racemosum $\boldsymbol{R}$. et $\mathbf{P}$. peruv. t. 15\% f. 6. fol. Ianceolato-ovatis acutis; racemis brevibus compositis, intermedio productiore. In Peruvia. t. C. laevigatum Schl. Bacea violacea.

29. C. buxifolium H. et $\boldsymbol{H}_{\text {. }}$ fol. approximatis ellipticis oblusiusculis subcoriaceis glabris nitidis; florihus axillaribus sessilibus. In Nov. Granuta. t.

30. C. mariquitense $\boldsymbol{H}$. et $\boldsymbol{K}$. fol. oblongis acutis memhranaceis glabris; floribus axillaribus solitariis terminalilusque congestis; laciniis corollae ovatis acutis. C. bogotense W. In Nov. Granata.

31. C. confertum R. et P. peruv. t. 153. fol. ovato-ovalibus acuminatis coriaceis confertissimis; florilus axillaribus congestis sessilibus. In Ple-

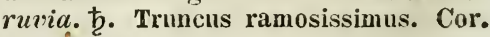
lutescens.

32. C. conglomercitum $R$. et $P$. peru\%. $t$. 156. fol. lanceolatis aculis; floribus axillaribus numerosissimis conglomeratis sessilibus. In Peruvia. $\frac{b}{}$. Hami copiosissimi. Cor. flava extus purpurea.

33. C. corymbosum Schl. glahrum; fol. elliptico- s. obovato-oblongis basi cuneatis subcoriaceis lucidulis; floribus corymbosis; calycis laciuiis apice barbulatis. In Brasilia. t. 
3-1. C. multiflorum Schl. glabrum; fol. ellipticis utrinque acuminatis apice acutis subcoriaccis opacis; racemis axillarihus subspicatis; calycis dentibus ohtusis margine ciliolatis. In llrasilia.

3.5. C. amictum Schl. glaherrimum; fol. Ianceolatis utrinque acutis Iucidulis; racemis subspicatis bracteatis; calycis dentibus acutis ciliolatis; filameutis reverso-pilosis. In Brasilia. $\hbar$.

\section{b. Folia subtus pubescentia.}

36. C. latifolium Lam. fol. ovatooblongis acutis membranaceis subtus ramisque pulverulento-villosiusculis ; racemis axillaribus brevissimis; laciniis corollac acutis. In ins. '́rinitatis.t.

37. C. cauliflorum Jacq. Schocubr. t. 325. fol. ellipticis subtus pulverulento-tomentosis; florihus pedunculatis aggregatis; corollis campanulatis. In Martinica. †. 8-ped. Cor. virens.

33. C. strigillatum R.et P. perux. t. 156. fol. cordatis acutis; pedunc. geminis racemoso-paniculatis altero breviore. In nemoribus Peruviae. ђ. 12-ped. Cor. virens.

39. C. longi/lorum R. et P. t. 151. fol. ovato-oblougis acutis; pedunc. terminalibus paniculato-racemosis; cor. tubo longissimo curvato. In Peruvia. ち. Cor. purpurascens. Bacca purpurea.

10. C. hirtum Sw. fol. subcordatis acutis subtus ramulisque hirtis; floribus subspicatis axillaribus. In $\mathrm{J} a-$ maica. 卢. Arbor 12-ped. Baccae nigrae.

41. C. thyrsoidenm $\boldsymbol{H}$. et $\boldsymbol{K}$. fol. ovato-oblongis acutis supra glabris subtus tenuissime puherulis; paniculis terminalibus ramosissimis. In Mlexico. $\hbar$. C. Parqui affiue.

12. C. tenuiflorum $H$. et $K$. fol. ovatis acuminalis tenuiter membranaceis subtus tomentosis; spicis axillaribus 8-12-floris; trbo corollac tenuissimo. C. ovatum Willd. $A d O_{1}{ }^{-}-$ nocum. ந. Cor. alba.

43. C. calycinum $\boldsymbol{H}$. et $\boldsymbol{T}$. ramis foliisque sublus stellulato-tomentosis et canescentibus ovalo-ellipticis subacuminatis; floribus spicatis; calyce clongato. In Peruvia. ち.

4. C. paucifiorum Mart. fol. oblongo-Ianceolatis aculis subtus pube- scentibus; florihus solitaribus sessilibus axillaribus. In Brasilia. $b$.

45. C. roseum H. et K. $t .19 \%$. fol. oblongis obtusiusculis utrinque molliter lirto-pubescentibus; pedunc. 4-6-floris; calyce tubuloso pubescente. In Mexico. ち. Cor. roséa.

46. C. bracteatum Lk. fol. Ianceolatis undulatis pubescentibus; stipulis oblique cordato-reniformibus; bracteis spathaccis; floribus fasciculatis. Hook. B. M. 2974: In Brasilia. ち. Flor. pallide virides.

17. C. pendulinum Jacq. ramis pendulis; fol. ovato-oblongis acuminatis membrauaceis reticulato-venosis subtus pubescentibus; laciniis cor. obtusis iuflexis. In Nov. Granata. t.

\section{DARTUS Lour. (1790).}

1. D. Perlarius Lour. In ins. Moluccis et Cochinchina. Ђ. Arbor fol. oblongis serratis subtus tomentotis; floribus corymbosis albis.

\section{9\%. MANDRAGORA Theophr.}

1. M. vernalis Bertol. acaulis ; fol. late ovatis obtusis glabris; calycis corollaeque laciniis ovatis; bacca globosa. Atropa Mandragora L. Blackw. t. 364. Brandt et Rat\%elo. Giftpfl. t. 18. In Alp. Europae. 4. Cor. albida. Bacca flava.

2. H. autumnalis Bertol. fol. Ianceolatis acutis ciliatis; calycis corollaeque laciniis acuminatis; bacca ovata. Atropa Mandragora Fl. graec. t. 232. In Europ. et Graecia 4.

\section{S. ATROPA L. (1737).}

\section{a. Fruticosae.}

1. A. umbellata $R$. et $\boldsymbol{P}$. peruv. t. 151. f. a. fol. suibcordato-ovatis angulatis pubescentibus; pedunc. umhellatis; laciniis corollac revolutis. A. villosa Zucc. In Peruviu. 古.

2. A. frutescens $L$. fol. cordaicovatis obtusis; pedunc. confertis. Lam. ill. t. 114. f. 2. Physalis suberosa Cav. ic. t. 102. Barr. ic. 1173. P. frutescens DC. In IIispania. ち. Arbuscula 4-6-ped. Cor. Ilavescens. 
3. A. bicolor $\boldsymbol{R}$. et $\boldsymbol{P}$. fol. ovatis angulatis glabris; pedunc. 3-4-floris. In Peruvia. ђ. Caul. 6-7-ped. Cor. rubro-viridis.

1. A. punctata Spr. fol. ovatooblongis acutis supra glabris subtus pulverulentis; pedunc. aggregatis 1floris; corollis punctatis extus pulverulentis. saracha Fl. peruv. t. 178. Bellinia R. et $\mathbf{s}$. In Peruvia. t. Cor. grandis flavo-purpurascens,

5. A. billora $\boldsymbol{R}$. et $\boldsymbol{P}$. peruv. $t$. 181. $f$. $b$. fol. ovatis acutis integerrimis; pedunc. bifloris; staminibus corolla longioribus. In Peruvia. 古 2ped. Cor. purpurascens.

6. A. viridifiora H. et K. t. 196. caule voluhili; fol. geminis ellipticoovatis subacuminatis integerrimis hirtellis ; floribus nutantibus ; corolla 10fida. In Nor. Granata. 方.

7. A. aristata Poir. fol, oblongis inteoris glabris; ramis, petiolis pedunculisque lanuginosis; dentibus calycis aristatis. In ins. Canariis. ђ.

\section{b. Herbaceae.}

8. A. Belladonne $I$. caule dichotomo; fol. geminis inaequalibus ovali-ellipticis acutis. Jacq. austr. t. 309. Fl. Dan. 75 . Schk. t. 45. In Europa. 24. 2-4-ped. Cor. livida intus fusco-purpurascens.

9. A. aspera $\boldsymbol{R}$. et $\boldsymbol{P}$. fol. geminis subsinuatis altero minore; floribus solitariis cernuis; corollis sub-10-fidis. In Peruvia. $ち$.

10. A. lirtella Spr. fol. ovatooblongis acutis scabris; ramis asperis; pedunc. elongatis 1 -floris filiformibus. In Brasilia. 古.

11. A. Rothii Poir. fol. ovatis acutis in petiolum decurrentibus pubescentibus; ramis hirsutis; pedunc. umbelliferis cernuis. A. umbellata Roth Jacq. Schoenbr. t. 493. Saracha DC. In Amer. austr. 24. Cor. albido-flavescens,

12. A. contorta Spr. fol. ovatis angulato-dentatis integerrimisque floralibus superioribus geminatis; umbellis multifloris. saracha contorta FI. peruy. t. 180. f. a. In Peruvia. $\odot$. Cor. albo-flavescens.

13. $A$, procumbens Cav, ic. $t$. 72. fol. ovatis integerrimis ciliatis in petiolum decurrentibus; pedunc. 3 -floris cernuis calycibusque hirsutis. Sara- cha procumbens Fl. peruv. t. 180 . f. b. Atropa plicata Roth. In Peruvia. $\odot$. Cor. ochroleuco-alha.

11. A. dentata Spr. fol. ovatis in petiolum decurrentibus subdentatis; pedunc. 4-floris subpubescentibus; corollis villosis. Saracha dentata $R$. et P. peruv. t. 179. f. b. In Peruvia. 24. Caulis ramosissimus. Cor. albo-violacea.

\section{ULLOA Pers. (1805).}

1. U. parasitica Pers. Juanulloa R. et P. perux. $t$. 185. In Peruvia. 4. Caulis dependens florifer aphyllus, ramis purpureis. Folia oblonga acuminata. Cor. punicea.

\section{PIIYSALIS L. (1737).}

a. Frutescentes.

1. $\boldsymbol{P}$. somnifera $\boldsymbol{L}$. floribus aggregatis brevissime pedunculatis; fol. ovatis acutis integerrimis. P. flexuosa L. Jacq. Ecl. t. 22. et 23. Rheede 4. t. 55. In Europ. australi et Ind. or. ђ

2. $P$. curassavica $L$. floribus solitariis; fol. ovato-repandis. P. origanifolia Lam. Plukn. t. 111. f. 5. In Curassao. 4.

\section{b. Herbaceae, perennes.}

\section{Corolla inmaculata.}

3. P. viscosa $L$. pilis brevibus 24-furcatis pubescenti-scabra; calycibus fructus pallidis; fol. ovatis integris dentatisve. P. pensylvanica $\mathbf{L}$. Dill. Elth. f. 10. Jacq. Vind. t. 136. P. Jacquini L. In America. 2. Cor. lutea.

4. P. Alkekengi $L$. pilis simplicibus pubescens; calycibus fructus rubris; fol. integriusculis acutis. Blackw. t. 161. Schk. t. 45. P. Halicacabum. Scop. In Europa. 24. Pedalis. Cor. alba.

\section{Cor. maculata.}

5. $\boldsymbol{P}$. heterophylla Nees monogr. villosa; antheris Iuteis; caulo procumbente flexuoso; fol. late ovatis cordatisve valde inaequalibus. $P$. to- 
mentosa et nutans Walt. In Amer. boreali. 24. Cor. Iutea.

6. P. chenopodifolia Lam. canotomentosa; antheris violeceis; caule erecto dichotomo; fol. deltoideo-ovatis angulato-dentatis. P. tuberosa Willd. In Peruvia. 24. Cor. Alava.

\%. P. perueviana $\boldsymbol{L}$. antheris violaceis; caule erecto dichotomo; fol. cordatis acuminatis angulatis integrisve. P. edulis B. M. 1068. In Peruvia. 24. Cor. lutea.

c. Herbaceac, annuae.

1. Corolla lutea ininaculata. * Pedunculis flore duplo longioribus.

S. P. laurifolia $\boldsymbol{H}$. Ber. fol. Ianceolatis subdentatis; caule dichotomo. P. angulata $\mathbf{R}$. et P. P. Ianceolata Michx. In Peruvia $\odot$. Flos nutans.

9. P. Linkiana Nees; fol. ovatis argute dentatis acuminatis; caule subdiffuso. P. dubia Lk. Moris. 3. t. 3. f. 22. In Brasilia. $\odot$.

** Pedunculis vix flore longioribus.

10. P. angulata L. glabra; calycibus fructus acute 5-angulis; fol. ovato-oblongis grosse aequaliter dentato-serratis. Dill. Elth. f. 12. P. peruviana Walt. P. minima Wall. $P$. angulata $\beta$. Dill. f.11. In Ind. utraque $\odot$. Cor. lutea.

11. P. indica Lam. minute puberula; caule erecto divaricato dichotomo; calycibus fructus scabris subangulatis; fol. ovatis subdentatis. P. parvifiora R. Br. P. psendo-angulata Blume. Kumph. 6. t. 26. P. divaricata Don. In Cochinchina, Jara, Ind.or., Nov. Holl. et Nepalia. $\odot$.

12. P. minima L. sparse villosa; caule diffuso; calycibus fructus subangulatis pedicellisque villosis; fol. cordal 0 - ovatis acuminatis serratodentatis. P. parviflora Lag. P. Lagascae R. et S. P. villosa Roth. P. peruviana Nutt. P. Rothiana $\mathbf{R}$. et $\mathbf{S}$. hheede X. t. 110. In Vera Cruz et Ind. or. $\odot$.

2. Corolla lutea in fundo maculata.

a. Calyx fructus vesiculosus bacca amplior.

13. P. aequata Jacq. glabriuscula; crecta; calycibus fructus ovatis ae- qualibus. P. ixocarpa Brot. Putria ignota. $\odot$.

1.t. $P$. foetens Poir. viscoso-puhescens; divergenti-ramosa; calycibus fructus ovatis subaequalibus. $P$. foetidissima Lag. In Amer. austr. ๑. Cor. sulphurea.

15. $P$. pubescens $\boldsymbol{L}$. calycilus fructus ovato-pyramidalibus acute 5-angulis. P. barbadensis Jacq. ic. t. 39. Dill. Elth. f. 9. In Amer. bor. et Ind. or. $\odot$.

\section{b. Calyx fructus maturi baccam ar- cte cingens apertus.}

16. P. philadelphica Lam. glabrinscula; caule erecto dichotomo ramisque strictis; fol. oblique ovatis acuminatis repando-angulatis. $P$. clenopodifolia W. P. atriplicifolia Jacq. fragm. t. 85. f. a. P. ovata Poir. P. megistocarpos Zuccagn. In Amer. bor. $\odot$.

17. P. prostrata Herit. caule ramosissimo prostrato foliisque cordatoellipticis repando - dentatis villosis. Jacq. ic. t. 38. Andr. t. 75. P. limensis Hetz. In Peruria. $\odot$.

\section{CAPSICUII Fuchs (1513).}

1. C. annum $\boldsymbol{L}$. fructibus oblongis pendulis erectisque; petiolis glabris; caule herbaceo. Plenk. ic. t. 107. C. longum DC. cordiforme, cerasiforme, 4-gonium et anguiosum Mill. In Ind. or. et Amer. austr. $\odot$. Cor. alba. Magnitudo et color fructus valde variat.

2. C. frutescens $\boldsymbol{L}$. caule fruticoso; fructibus subsolitariis oblongis suberectis; petiolis glahris; calyce subtruncato. Lam. ill. t. 116. f. 2. Rumpl. 5. t. 88. f. 3. Hheede 2. t.56. C. baccatum L. ovatum DC. grossum W. conicum Lam. pyramidale Mill. cerasiforme IV. licolor Jacq. Fragm. t. 99. f. 1. purpureum Horn. havanense Kuntl. In Ind. or. et Am. austr. ち. Cor. violacea et alha.

3. C. chinense $L$. caule frutescente; fructibus ovatis geminis pendulis; petiolis foliisque puhescentibus; calyce acuto. C. ciliare W. microcarpum DC. luteum Lam. pendulum W. violaceum Kunth. C. fastigiatum Blume. 
In Asia, Amer, et Afric. t. Cor. lutea et violacea.

\section{SOLANUM Plin。}

\section{A. Inermia.}

\section{a. Foliis pinnatis so piunati- fidis.}

\section{Racemis corymbosis.}

1. S. tuberosum $L$. fol. interrupte piunatis pilosis; foliolis basi inaequalibus; corollis 5 -angulatis; radice tubifera. Plenk. ic. to 1\%0. S. Parmentesii Molin. In Chili: 2.

2. S. appendiculatum Dun. $t .81$. fol. temato-quinatisectis infra petiolum stipulatis $s$. appendiculatis; racemis corymbosis pancifloris. In Inexico.

3. s. pinnatum Cav. ic. t. 439. f. 1. caule herbaceo sulcato; foliorum segmentis decurrentibus. In Chili. $\odot$. Cor. flava. Bacca nigra.

4. S. Caldasii Dun. t. 85. f. 2. caule herbaceo; fol. inaequaliter pinnatisectis mollibus tomentosis subtus albescentibus; racemis dichotomis cymosis. In Quito.

5. S. ochrantlion Dun. t. 85. f. 1. caule fruticoso scandente; fol. inaequaliter pimatiseotis utrinque tomentosis subtus albicantibus; racemis dichotomis. In Quito. t.

6. S. juglandifolium Dun $t$. 86 . canle fruticoso scandente rugoso; fol. rugosis; segmentis subcordalis ovatooblongis acuminatis ; racemis dichoto-

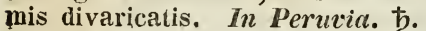

\%. S. Secifortianum Andr. Rep. $t$. 507. caule scandente herbaceo; fol. pinnatisectis undulatis, superioribus lanceolatis; racemis cymoso-paniculatis. in Amer. austr.

8. S. pendulum R. et P. peruv. t. 184. f. a. caule fruticoso; fol.' irregulariter pimnatisectis; segmentis 2-6 oblique cordatis; racemis dependentibus furcatis. In Peruvia. t. 12ped. Cor. ptirpurascens.

9. S. diversifolium Bonpl, fol. pinnatis ternatis simplicibusque pubescentibus; foliolis oblongis acuminatis integerrimis, terminali naximo. Dum. Sol, t. 88, In Caracas. t.

10. S. laciniatum Ait. B. M, 339 . fol. pimnatifidis integrisque glabris; laciniis lanceolato-linearibus; racenis lateralibus folio brevioribus; corollae laciniis emarginatis. S. pimnatifidun Lam. aviculare Forst. reticulatum Herit. In Peruvia et Nov. Holl. Cor. violacea.

11. S. glaberrimum Dun. t. 133. caule glaberrimo sulcato; fol. saepe pinnatifidis; lacinia terminali elongata; ramis aggregatis multifloris; corolla 5-fida; laciniis acutis. In ins. Timor. $\odot$.

12. S. quercifolium $\mathrm{L}$. fol. pimnatifidis subtus scabris; racemis cymosis; canle herhaceo flexuloso scabro. Fenill. t. 15. S. runcinatum R, et P. In Peruvia. 24. Cor. violacea.

13. S. radicans L. dec. I. t. 10. fol. profunde pinnatifidis glabriusculis; laciniis lanceolatis acutis; racemis petiolum aequantibus; caule herbaceo prostrato radicante. $\mathbf{S}$. quercifolium R. et P. In Peruvia. Cor. purpurascens.

14. S. Commersoni Poir. fol. $1 y-$ rato-decursive pimatis pilosis corollis 5-fidis. In Rio de la Plata.

\section{Pedunculis axillaribus.}

15. S. mite R. et P. peruv. $t .173$. f. $a$. canle herbaceo radicante; foliorum segmentis oblongis; baccis globosis. In Peruvia. $\odot$. Cor. alba minima.

16. S. conicum $\boldsymbol{R}$. et $\boldsymbol{P}$. peruv. t. 182. f. $b$. caule herbaceo; foliorum segmentis oblongo-lanceolatis; pedunc. axillaribus subternis spicatis; baccis conicis. In Peruvia. ๑. 2-ped. Cor. dilute violacea.

1\%. S. diffusum R. et P. peruv. t. 1\%1. $f$. b. caule suffruticoso; ramis virgatis diffusis; foliorum segmentis oblongis; racemis pancifloris. In $\mathbf{P e}$ ruvia. t. Cor. violacea.

18. is. iviflorim Nutt. fol. pinnatifidis glabris; laciniis acutis undulatodentatis subrevolutis; pedunc. sub-3floris. In Amer. bor. ๑.

\section{b. Foliis teruatis.}

19. S. ternatum R. et P. $t$. $17 \%$. f. $a$. caule suffruticoso 3-gono scandente radicante; pedunc. pancifloris. In Peruvia. ђ. Cor. purpureo-violacea.

20. S. hebephorum Dun. Sol.t. $8 \%$. caule herbaceo subangulato pubesces- 
te; racemis solitariis longe pedunculatis simplicibus. In Pernivia.

\section{c. Foliis siunato-lobatis.}

21. S. Dulcamara $L$. caule fruticoso scandente; fol. cordatis glabris, superioribus auriculato-hastatis; cymis suprafoliaceis. Hayne 2. t. 39. Fl. Dan. 607. Sv. Bot. 20. S. littorale v. villosa Thunb. In Europa. t. Cor. violacea. Baccae purpureae.

22. S. leptanthon Sess. fol. oblongis in petiolum attenuatis glabris undulato-repandis; racemis dichotomis cymosis; caule herbaceo tereti. Dun. t. 28. In Peruvia. $\odot$. Bacca rubroviolacea.

23. S. corymbosum Jacq. ic. t. 40. caule herbaceo angulato; fol. ovatolanceolatis sublobatis glabris; racemis corymbosis. In Peruria. 24. Cor. violacea.

2-1. S. Bulbocastanum Sess. radice tuherosa; caule herbaceo foliisque ovato-repandis auriculatis villosis; pedunc. subumbellatis 1 -floris. Dun. t. 3. In Mexico. Cor. alba.

25. S. Tegore Aubl. Guj. t. 84. canle fruticoso hirsutissima; fol. sinuato - cordatis. In Cayenna. ち. 6ped. Bacca lutescens.

26. S. Topira H. et $\boldsymbol{K}$. caule herbaceo tomentoso; fol. subovatis acutis sinuato-angulatis, supra adpresse pilosis, suhtus tenuiter cano - tomentosis. Dun. t. 92. f. a. In Amer, austr. $\odot$.

2\%. S. grandiflorum R. et P. peruv. t. 168. f. b. canle arboreo; fol. ovatis sinuatis integerrimisque supra hispidis subtus lanuginosis; racemis recurvis ; floribus secundis. Dum. t. 30. In Peruvia. ち. 3-6-org. Cor. magna violacea.

23. S. quitense $\mathbb{L}$ am. caule suffruticoso ; fol. subcordato-sinuato-angulatis ntrinque tomentosis; racemis Jateralibus hrevissinis hirsutissimis. Duu. t. 92. f. b. Fl. peruv. t. 170. f. b. Feuill. t. 46. In Peruvia. t. 6ped. Cor. allio-violacea.

20. S. lyratum thanb. rol. inferioribus lyratis, superioribus hastatis utrinque tomentosis; floribus paniculatis; caule herbaceo. In Japonia.

30. S. pymaeum Cav. ic. t. 439. f. 2. caule pollicari herbaceo; fol. ovatis 3-lohis; lobo intermedio elongato. In Buenos Ayres. $\odot$. Cor. dilute caerulea.
31. S. macrocarpum $L$. fol. oblongis obtusis hasi attenualis sinuatolobatis glaberrimis; pedunc. abbreviatis paucifloris. Nill. ic. to 294. In Amer. austr. Flores caerulei.

32. S. calycinum Sess. fol. ohlongis sinuato-repandis glabris; pedunc. solitariis 1-floris; calycihus demum crescentibus; caule herhaceo tortuoso. Dum. t. 29. In Mexico. 4. Cor. caerulea.

33. S. vagnum Heyne; fruticosum; inerme; fol. ovato-oblongis repandosinuatis jumiorihus subtus ramulisque, novellis pubescenti-tomentosis; calycis laciniis longe acuminatis. In Ind. orient. $\hbar$.

34. S. Neesianum; frutescens; puhescenti-hirtum; pubescentia stellata; fol. ovatis integerrimis vel subrepandis; racemo terminali; anthera una longiore. S. calycinum Nees. In ind. or. ţ.

\section{d. Foliis angulato-dentatis.}

\section{$\alpha$. Caule fruticoso.}

3.5. S. quadrangulare Thunb. fol. ovatis obtusiusculis glabris angulatis integerrimisque; ranis 4 -angulis ; floribus paniculatis. In Prom. b. spei.

36. S. suffruticosum Schousb. caule suffruticoso; fol. ovatis dentato-angulatis glabris ciliatis; umbellis extrafoliaceis pedunculatis. In Barbaria? ち. 4-ped. Cor. alba. Bacca nigra.

3\%. S. bracteatum Thunb. fol. ovatis acutis serratis glabris; ramis divaricatis 4 -angulis crispis; racemis foliosis. In Prom. b. spei.

\section{B. Caule herbaceo.}

38. S. racemifiorum Dun. caule herbaceo scahro; fol. ovatis repandoangulatis scabris; haccis sulcatis. s. scabrum Jacq. Sclioenbr. t. 333 . In Amer. austr. Cor. alba.

39. S. cestrifolizm Jacq. fol. oblongis rugosis angulato-dentatis glabris; pedunc. umbellato-corymbosis; corollis 5-partitis. Patria iynota.

40. S. aetliopicum I. caule herbaceo; fol. ovatis repando-angulatis glabris; pedunc. sub-1-fioris cernuis; baccis tomentosis. In Africa et Asia tropica. $\odot$. 
41. S. Zuccagnianum Dur. t. 11. caule subherbaceo; fol. ovatis angulato-repandis glabris basi inaequalibus; pedunc. cernuis. $\mathbf{S}$. scabrum Zuccagn. Patria ignota. $\odot$. Cor. alba.

12. S. nigrum L. caule herbaceo; ramis compresso-teretihns foliisque ovatis acutis repandis glabris; umbellis nutantibus. Fl. Dan. 460. Sv. Bot. 61. Schk. t. 46. Rchh. ic, 1284 . s. pterocaulon ihid. non Dun. In Europa, Asia, Africa et America. $\odot$. Bacca atra.

43. S. villosum Lam. angulis ramorum subtuherculatis ; fol. ovatis sinuato-dentatis cauleque tomentosovillosis; pedicellis fructiferis apice incrassatis deflexis. S. hirsutum et Kumphii Dun. Dill. Elth. f. 353. Humph. 6. t. 26. f. 2. In Europa, Asia et Africa. $\odot$. Cor. alba. Baccae croceo-rubrae.

41. S. chenopodioides Lam. caule subherbace ; fol. ovato-oblongis repando - sinuatis subhirsutis, juniorihus tomentosis. Feuill. t. 14. In Chili. $\odot$. Flos albus. Bacca albescens.

45. S. humile Bernh. angulis ramorum subtuberculatis; fol. ovatis rhombeis repando-dentatis cauleque suhglabris. S. luteo-viresceus Gmel. Rchb. ic. 1X. In Europ. $\odot$. Flos albus. Bacca luteo-viridescens.

46. S. miniatum Rernh. angulis ramorum prominulis tuberculatis; fol. ovatis subdeltoideis sinuato-dentatis cauleque patenti-villosis. S. villosum Mill. S. alatum Much. S. puniceum Gmel. Rchh. ic. IX. In Europa. $\odot$. Baccae miniatae.

47. S. flavum Kit. caule herbaceo; ramis dentato-angulatis strigoso-puhescentibus; fol. ovatis sinuato-angulatis. S. ochroleucum Dum. In Europa. $\odot$. Cor. ochroleuca.

18. S. pterocaulon Dun. ranis angulatis; angulis spinoso-dentatis ; fol. ovato-rhoubeis sinuatis; umbellis nutantibus. Rchb. ic. 1284. Dill. EIth. f. 256. S. melanocerasum W. s. judaicum Bess. S. nigrum Curt. Lond. t. 41. In Europa. $\odot$. Baccae nigrae.

4\%. S. olevaceum Irchb. caule herbaceo ramisque leviter dentato-angulatis; fol. ovatis subundulatis serratosinuatis; umbellis nutantibus. Ihchb. ic. 1285. In Europa. $\odot$. Cor. lilascens, Bacca atro-nitidissiuna.
50. S. rubrum Mill. caule herbaceo erecto fastigiato-ramoso; ramis arrecto-patulis subangulatis patentipubescentibus; fol. subcordato-rhombeis ohtuse sinuatis ohtusis; baccis miniatis. In Europa. $\odot$.

51. S. Gilo Tin. fol. ovato-oblongis hasi cuneatis angulato-dentatis utrinque floccoso-tomentosis; pedunc. 1-floris. Patria ignota.

e. Foliis integerrimis.

a. Calycibus 5-partitis.

\section{Caule fruticoso.}

\section{aa. Pedunculis multifloris.}

52. S. muricatum Ait. caule radicante adscendente; turionibus muricatis; fol. oblongo-lanceolatis pubescentibus simplicibus; racemis bifidis. s. variegatum Fl. peruv. t. 162. f. a. Feuill. t. 26. In Peruvia. ち. Cor. magna alha centro violacea. Bacca alba edulis 1-2-palmaris.

53. S. caripense $H$. et $\boldsymbol{K}$. scandens; ramulis villoso-pilosis; fol. subsimplicibus elliptico-oblongis acutiusculis integerrimis sericeo-pilosis basi biauriculatis; racemis bifidis. Dun. t. 89. In Cumana. ち.

51. S. oliganthon Dun. $t$. 90. caule scandente; fol. ovato-oblongis basi inaequalibus auriculatis tomentosis; floribus terminalibus. Ad Orinocum. 古.

55. S. betaceum Cav. ic. t. 524. fol. cordatis ovato-oblongis utrinque pilosiusculis margine undulatis; racemis pendulis. s. crassifolium Orteg. In Nov. Hisp. †. Cor. dilute rubescens. Bacca lateritia.

56. S. oblicuum R. et P. peruv. t. 65. $t$ : $a$. caule suffruticoso; fol. cordatis oblique acutis; racemis revolutis; foribus secundis. In Peruvia. ち. 6-12-ped. Cor. purpureo-violacea.

5\%. S. racemosum $\boldsymbol{L}$. caule fruticoso; fol. lanceolatis repandis undulatis acutis. Jacq. am. t. 36. pict. $t$. 50. In ins. Martinica et Guadelupa. t. Flos albus.

58. S. viridiflorum R. et P. peruv. t. 173. $f$. b. caule fruticoso; fol. cordatis villosis; racenis dependentibus. In Peruvia. $\hbar$. 6-ped. Cor. virens. 
59. S. cirrhosum $\boldsymbol{H}$. et $\boldsymbol{K}$. caule scandente cirrhoso; fol. ovato-oblongis integris trilobisve; loho intermedio llaximo; racemis paniculatis. Dun. t. 91. In Cumana.

60. S. trituetrum Cav. ic. t. 259. caule frutescente 3-quetro; fol. cordato - delloideis acuminatis glabris; umbellis oppositifoliis pedunculatis. In Nor. Hispun. ち. 4-ped. Cor. alha.

61. S. microcarpon Vuhl; caule fruticoso; fol.ohlongo-lanceolatis subrepandis; racemis Iateralibus. Dum. t. 10. S. diphyllum Forsk. In A $e-$ gypto. t. Cor. alla. Bacca rubra.

62. S. pulchum Dun. $t$. 38. caule fruticoso; ramis rugosis glabris; fol. oblongo-ovatis sulpetiolatis; racemis

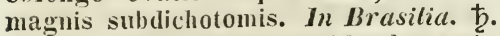

63. S. anonaefolium Humb. caule arboreo glabro; fol. lanceolato-acuminatis supra glahris nitidis subtus nervosis pilosis; racemis subcorymbosis. Duu. t. 96. In Nov. Granata. b.

61. S. Pseudochina Hil. t. 21. arboreum; fol. lanceolatis acutis supra glabris; axillis venarum subtus barbatis; racemis paucifloris divaricatis. In Brasilia. ち.

6.5. S. spirale Roxb. fol. oppositis lanceolatis integerrimis glabris; racemis Iateralibus; novellis spiralibus; laciniis calycis glanduiosis. In Silhet. $\hbar$.

60. S. patulum Pers. caule fruti$\cos 0$; ramis pulverulentis; fol. oblongo-lanceolatis utrinque praecipue subtus pulverulentis; racemis laxis; pedicellis geminatis. $\mathbf{s}$. lanceolatum $\mathbf{R}$. et P. peruv. t. 164. f. b. In Peruvia. ち. Cor. violacea.

(i7. S. longiflorum Tahl; caule fruticoso; fol. oblongis subtus tomentosiusculis; racemis hifidis cymosis; corollis 5-partitis. Dum. t. 9. In cayenna. ち.

68. S. nitidum R. et P. perux. $t$. 163. $f \cdot a$. caule fruticoso; ramis glahris nitidis; fol. ovato-lanceolatis acutis; racenis subcymosis tomentosopulverulentis. In Perutia. ち. Cor. albido-violacea.

j9. S. pulverulentum Pers. ramis pulverulentis ; fol. lanceolato-linearibus subtus nervosis undulatis; racemis pulverulentis; pedicellis geminatis. S. angustifolium $\mathrm{h}$. et $\mathrm{P}$. peruv. t. 163. f. b. S. stenophyllum Dun. t. 97. In Peruvia. ‡. Cor. albo-violacea.
\%0. S. crispum R. et Pav. peruv. t. 158. f.c. caule fruticoso; fol. ovatis subcordatisque undulato-crispis acuminatis; floribus corymbosis. In Peruria. ち. 3-org. Cor. dilute vioIacea.

91. S. aureum Dun. t. 99. caulo fruticoso volubili; fol. petiolatis ovatis supra nitidis subtus pilosiusculis; racemis dichotomis tomentosis fuscoaureis. In frigidis montis Chimborasso. ち.

2. S. macrantherum Sess. caule scandente lignoso fruticoso; fol. petiolatis acutis subtus tomentosiusculis; racemis paniculatis laxis. Dun. t. 100 . S. dulcamarioides Poir. In Americ. austr. †. Habitus s. Dulcamarae.

93. S. integerrimum Dun. caule fruticoso; fol. lato-lanceolatis integerrinis subtus tomentosis; racemis terminalilus. In Brusilia. $\hbar$.

7. S. bombense Jac\%. Ecl. t. 21. caule fruticoso; fol. ovalibus utrinque attenuatis glahris; racemis trifidis cymosis. Dun. t. 101. In Amer. austr. ち. Arbuscula 12-ped. Cor. alba.

75. S. pubigerum Dun. t.6. caule erecto fruticoso; fol. ovato-lanceolatis utrinque attenuatis pubescentibus; racemis dicho - trichotomisque. In Mexico. †. 3-5-ped. Cor. alba parva.

76. S. terminule Forsk. caule fruticoso decumbente; fol. ovato-lanceolatis subintegerrimis pilosis; umbellis terminalibus. In Arabia felici. 古. Cor. alba.

7\%. S. asperum Vahl; caule fruticoso; fol. ovato-ellipticis asperis; cyma longe pedunculata tomentosa. Dun. t. 7. In Amer. austr. Cor.parva alha.

8. S. Radula Iahl; caule fruticoso; fol. oblongo-ellipticis supra scaberrimis subtus cymisque terminalibus pedunculatis tomentoso-scabrillsculis. Dun. t. 35. In Cayenna. 方. Cor. alha.

\%9. S. lepidotum Dun. t. 102. caule arboreo tereti; fol. ovato-lanceolatis foliatis supra scabriusculis subtus tomentoso-squamulosis utrinque nitidis; racemis subdichotomis. In Nov. Granata. 卢.

so. S. verbascifolium $L$. fruticosum; fol. ovato-oblongis acuminatis integerrimis tomentosis; axillis aphyllis; corymbis dichotomis pedunculatis. Jacq. Vind. t. 13. In Cochinchina, 
Nov. Holl., Ind. or. et Amer. austr. †. 6-7-ped. Cor. alba.

81. S. riparium pers. caule fruticoso ; fol. oblongis acuminatis incanis tomentoso-pulverulentis ; corymbis terminalibus dichotomis. S. dichotomum R. et Pav. peruv. t. 166. f. b. In Peruvia. ђ.

82. S. laurifolium $\boldsymbol{L}$. caule arboreo; fol. ovato-oblongis acutis supra glabris subtus tomentosis; panicula dichotoma; pedicellis cymosis. Dum. t. 8. In Amer. austr. ち. Arbor. Bacca nigra.

83. S. auriculatum Ait. caule fruticoso; fol. ovato-oblongis acumiuatis lanatis; foliolis axillaribus semicircularibus. S. mauritianum scop.? del. t. 8. In Madagascar et Mascarenh. ђ. Cor. violacea.

84. S. crotonifolium Dun. t. 103. $f$. b. caule fruticoso tomentoso; fol. ovato-oblongis acuminatis tomentosis; racemis bifidis; calycis laciinis acutis. Circa Carthagenam. 方.

85. S. irachyphyllum Dun. t. 101. caule fruticoso tomentoso; fol. geminatis ovato-lanceolatis acuminatis supra asperis subtus albo-tomentosis. In Amer. anstr. $b$.

86. S. luteo-album Pers. caule fruticoso; fol. ovatis acutis utrinque pubescentibus; racemis cymosis. $\$$. pubescens $\mathrm{R}$. et $P$. peruv. t. 169 . f. b. In Peruvia. †. Cor. albo-lutescens.

8\%. S. chloranthon Spr. fol. obIongis basi attenuatis supra nitidis glaberrimis subtus stellata pube tomentosis; pedunc. subumbellatis; cor. minuta viridi. In Brasilia. ち.

88. S. dichotomum Lour. caule suffruticoso; fol. cordato-lanceolatis ; pedunc. dichotomis. In China. ち. Bacca rubra.

89. S. filiforme R. et P. perur. $t$. 150. $f$. $b$. caule fruticoso; fol. ovatis corlatisque obtusis; pedunc. filiformibus hifidis subumbellatis. In p'eruvia. †. Cor. aibo-caerulea.

90. S. tetrandrum R. Br. suffuticosum ; erectum; fol. geminis oblongo-ovatis integris menbranaceis pube rara conspersis; floribus 4-fidis. In Nov. Holl. 市.

91. S. laxm Spr. fol. ovatis acutis glabris venosis; ramis cirrhiferis scandentibus; pedunc. racemosis laxis. In Montevideo. ఫ.
92. S. viride Forsk. suffruticosun; fol. ovato-ohlongis acutis integris planis membranaceis glabris; racemis corymbosis. In Nor. Holl. $\hbar$.

93. S. nutans $\boldsymbol{R}$. et P. peruv. $t$. 166. f. a. fruticosum ; fol. oblongoovatis acuminatis subtus lanuginosis; racemis brevissimis; floribus secundis nutantihus. In Peruvia. ఫ. Cor. alba brevis.

94. S. venosum Dun. t. 105. caule arborescente; fol. oblongo-lanceolatis acutis supra glabriusculis subtus pulverulento-tomentosis. In monte Quindiu. $\hbar$.

95. S. pubescens $W$. phyt. I. $t .3$. caule tomentoso frulicoso; fol. ovatis basi decrescentibus integerrimis pubescentibus; racenis umbellatis. In Ind. or. ち. Cor. purpurascens.

96. S. Vellozirmum Dun. $t$. 37. ramis foliisque maximis oblongo-lanceolatis subtus leproso-tomentosis; racemis multifidis. In Brasilia. ‡. Folia pedalia.

97. S. gnaphalioides Pers. caulo fruticoso; fol. lanceolatis repandis glabris nitidis; umbellis oppositifoliis tomentosis. s. calycephalum $\mathbf{h}$. et $\mathbf{P}$. In Peruvia. $\downarrow$. Cor. violacea. Bacca nutans atro-rubra.

9S. S. laevigatum Dun. t. 106. caule fruticoso glahro; fol. solitariis ovato-lanceolatis acuminatis glabris; cymis brevilus paucifloris. In Nov. Granata. ந.

99. S. nudum Dun. $t$. 10\%. caule fruticoso; fol. solitariis geminisve altero minore ovato-lanceolatis utrinque attenuatis glaberrimis; pedicellis uulantibus. In Mexico. $\hbar$.

100. S. diphyllum I. caule fruticoso; fol. geminis altero .oblongo utrinque attenuato ohtuso aliero minore obovato; umbellis floriferis cernuis fructiferis erectis. Jacq. ic. $t$. 322. In Ind. or. t. Cor. alba.

101. S. arboreum Dun, $t .198$. caule arhoreo; fol. ovato - oblongis utrinque acuminatis nitidis, superioribus geminis altero minimo; cymis parvolis simplicibus, In Amer. austr. $\mathfrak{b}$. Arbor. 40-ped.

102. S. acuminatum $\boldsymbol{R}$. et $\boldsymbol{P}$. peruv. $t$. 159. $f$. $a$. fruticosum; fol. geminis ovatis acumine stricto; floribus racemosis secundis. In Perueia. b. Cor. parva alba. 
103. S. foetidum $\boldsymbol{R}$. et $\boldsymbol{P}$. caule rruticoso; fol. ohlongis utrinque attenuatis glahris pendulis; cymis brevibus nutantibus. Dum. to 109. In Peruria. ち. Foetidissimum; org. Cor. albo-caerulea.

10t. S. triste Jac\%. am. t. 40. grict. $t$. 49. caule fruticoso; fol. geminis Ianceolato-oblongis subrepandis acuminatis; cymis brevibus. s. oblongum h. et P. peruv. t. 165 . f. h. In Amer. anstr. $\hbar$. Cor. allo-violacea.

10.5. S. comifolium Dum. t. 110. caule fruticoso; fol. geminis, altero minore obovato-sessili, ellipticis acuminatis subtus nervosis; umbellis subsessilibus. In Amer. anstr. $\hbar$.

106. S. leucocarpon Rich. ramis virgatis; fol. geminis, altero ter minore saepe suborliculato, ellipticolanceolatis 1-lateralibus; cymis paucifloris. Dun. t. 38. In ins. St. Marthae. 古.

10\%. S. psychotrioides Dun.t.111. caule arhoreo; ramis angulatis tuberculatis; fol. geminis oblongo-lancelatis acuminatis; racemis paucifloris. Ad flum. Hagrdalenae. $\grave{b}$.

108. s. oboratum Jnn. t. 112. caule arboreo; fol. solitariis nunc ovato-ellipticis acminatis nunc obovatooblongis obtusis supra nitidis glabris suhtus pilosis. In Pernivia. 古.

109. S. Bassovia Duu. câle fruticoso; fol. ovato-oblongis utriaque attenuatis glahris; cymis parvis axillarilus. Bassovia sylvatica Aubl. Guj. t. 85. Lam. ill. t. 102. In Gujana. நे. Frutex 9-ped. Cor. virescens.

110. s. bigeminatum Nees Sol. ind. caule suffruticoso; fol. oblongis utrinque acuminatis altero minore, supra dissite setulosis; pedunc. subgeminatis. In Trarancore. $\hbar$.

111. S. macrodon Irall. Cat. canle fruticoso erecto; fol. inferioribus ohlongo-lanceolatis utrinque acuminatis ramulisque hirtis; calycibus suh-10dentatis. Ad Pundua ind. or. $\hbar$.

112. S. ardisioides Blume; caule fruticoso; fol. subalternis oblongo-lanceolatis utrinque acuminatis supra basin ohtuse denticulatis; floribus cymoso-umbellatis; calycibus 4-fidis. In Java. $\hbar$.

113. S. Blumii Nees; caule suffiruticoso dichotomo; fol. geminis altero majori oblongo utrinque acuminato; florihus aggregatis; calyce integerrimo. In Juva.

11. s. parasiticum Blume; caulo fruticoso nodoso; fol. solitariis oblongo-lanceolatis acuminatis basi acutis glabris ; floribus aggregatis; calyce integerrimo. In Java.

11.5. S. sanduicense Hook. in Beech loy. caule fruticoso; ramulis canescentibus; fol. subintegris ovatis subtus pubescenti-canis; calyce minuto. In ins. Sanduicensibus.

116. s. umbelliferum Esch. calif. caule suffuticoso erecto; fol. ovalibus aculis integerrimis pubescentibus; unbellis terminalibus. In California. ち. Orgyale fistulosum. Cor. magna purpurea.

\section{bb. Pedunculis 1-floris.}

11\%. S. Pseudocapsicum L. caule fraticoso; fol. oblongo-lanceolatis subrepandis; pedunc. sub-1-floris extrafoliaceis. Sabh. H. rom. t. 59. In Hzledera. ち. Cor. alba. Bacca coccinea.

118. S. argenteum Dun. t. 3.9. ramis leproso-argenteis; fol. ovatooblongis utrinque nitidis subtus leproso-argenteis supra viridibus glaberrimis, In Rio Janeiro. t. Flores parvi.

119. S. urceolatum Pers. caule fruticoso; fol. oblongis acuminatis undulato-repandis; pedunc. oppositifoliis 2-3-floris. S. oppositifolium $\mathrm{n}$. et P. peruv. to 168. f. a. In Peruvia. t. 6-ped.

120. S. sericeum R. et P. perur. t. 161. f.b. caule fruticoso; fol. ovato-lanceolatis sericeis integerrimis; pedunc. hifloris. In Peruvia. †. 3ulnare. Cor. violaceo-caerulea. Bacca ruhra.

121. S. brevifolium Bonpl. fol. subcordato-rotundis obtusis glabris; pedunc. solitariis oppositifoliis; ramis scandentibus. In Quito. $\bar{t}$.

122. S. havanense Jacq. t. 35. pict. $t$. 48. caule fruticoso ; fol. ovato-lanceolatis acutis nitidis glaberrimis; baccis ovalikns. In Martinica, Jamaica et Peruvia. ţ. 5-ped. Cor. caerulea.

123. S. conocarpon Rich. caule fruticoso; fol. geminis ternisve integris ohtusis sessilibus; baccis ovalibus acutissimis. Dun. t. 30. In Ind. occ. Ł. Cor. caerulea. 
121. S. aggregatum Jacq. ic. $t$. 323. caule fruticoso; fol. subovatis obtusis pedunculisque ex eadem gemma pluribus; corollis campanulatis. Atropa solanacea et Sol. guineense L.

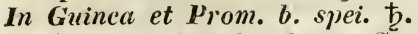

12.5. S. monteridense spr. fol. oblongis basi attenuatis subrepandis utrinque scabris; ramis pulverulentis; pedunc. erectis. In Montevideo. $\hbar$.

126. s. laeve Dun. $t$. 36. ramis glaberrimis; fol. geminis altero minore oblongo-lanceolatis acuminatis integris; pedunc. intrafoliaceis. In Java. .

\section{Caule herbaceo.}

12\%. S. nodiflorum Jacq. ic. $t$. 326. caule fruticoso; ramis teretibus foliisque glabris ovatis integerrimis; florihus subumbellatis. In Ind. occ. et. ins. Mascavenh. $\odot$. 10-ped. Cor. alba.

128. S. gnineense Lam. ramis glabris angulato-dentatis ; fol. ovatis glabris integerrimis; floribus numerosis subumbellatis. Dill. EIth. f. 354. In Guinea. $\odot$. Cor. parva alha.

129. S. erythrocurpon Neyer; fol. ovato-oblongis utrinque acuminatis integerrimis; racemis subumbellatis. In Essequebo. 21. 2-3-ped. Cor. alba. Bacca rubra.

130. S. triangulare Lam. caule herbaceo trigono; fol. oblongo-ovatis integerrimis nudis; florihns paniculatis. In Ind. or. ๑. 2-ped. Cor. pallide violacea.

131. S. jteropodon Dun. $t .94$. caule alato; fol. geminis decurrentibus ovato-oblongis crispis subtus pulveruleuto-tounentosis; pedunc. basi alatis. In Quito.

132. S. oblongifolium Bonpl. fol. geminis petiolatis oblongo-ellipticis subtus pilosiusculis; racemis hifidis pilosis recurvis. Duu. t. 95. In Nov. Granata.

133. S. loxense Dun. t. 98. caule tomentoso scaudente; fol. subcordatis ovato-lanceolatis supra hirsutis subtus lannginosis; racemis divaricatis. In sylvis Loxae.

131. S. pyrifolium Lam. caule subherbace ; fol. longe petiolatis ovatis integris utrinque glahris; racemis paniculatis; calycibus obtusis mucronatis. Dun. t. 34. In Martinica.
13.5. S. incurvum $\boldsymbol{R}$. et $\boldsymbol{P}$. peruv. t. 161. $f$. $b$. pubescens; caule herbaceo; fol. ovatis acuminatis; racemis geminis altero breviori; pedicellis incurvis secundis. In Peruxia. ђ. 2ped. Cor. alho-violacea.

136. S. anceps R. et P. peruv. $t$. 169. f. $a$. caule herbaceo; fol. oblongo-lanceolatis; pedunc. 2-3, brevissimis; baccis conicis ancipitibus. In Peruvia. 24. 3-ped. Cor. virens. Bacca conica alba.

13\%. S. lycioides $\boldsymbol{L}$. fol. oblongis subtus canescentibus; ramis spinescentibus patulis; pedunc. 1-floris. Jacף. ic. t. 46. S. candicans Dum. In Peruvia. ち. Bacca rubra.

\section{B. Calycibus multipartitis.}

138. S. mollissimum Blume; caule suffruticoso inani; fol. geminis supra hirsutis infra dense tomentosis oblongis ovatisque ; floribus aggregatis ; calycibus 10-fidis. In Java. ち.

139. S. uniflorum Dun. t. 12. caule dichotomo divaricato; ramis glabris punctis exasperatis; fol. geminis ovatis nitidis. In Hispaniola. ち. Cor. stella 5-radiata.

1-H0. S. Mozinianum Dun. $t .43$. caule herbaceo piloso; fol. subsessilibus ovato-Ianceolatis acutis pilosis; pedunc. solitariis; calyce 10-fido. In Mexico. $\odot$. Cor. violacea. Bacca flava.

111. S. speciosum Dun. caule arboreo; ramis flexuosis; fol. oblongis acuminatis undulatis solitariis geminisve; cor. margine crenulatis. Burm. am. t. 245. f. 5. In ins. Caribaeis. ち. Cor. grandis. Bacca rubra.

112. S. neglectum Dun. caule fruticoso; fol. ovatis undulatis; pedunc. solitariis geminisque; laciniis calycinis reflexis. Burm. am. t. 245. f. 4. $I n$ ins. Caribaeis. †. Bacca coccinea.

143. S. fugax Jac\%. ic. t. 321. caule fruticoso dichotono divaricatissimo; fol. angustis oblongo-lanceolatis; pedunc. solitariis longissimis; calyce 10-dentato. In Caracas. †. 6ped. Cor. albida.

111. S. stellatum Jacq. Coll. 3. t. 5. f. 2. ic. $t$. 32.5. caule fruticoso scandente flexnoso; fol. ovato-lanceolatis glabris actiminatis; pedunc. subgeminatis; calycibus inaequaliter den- 
tatis. In Amer. austr. ち. Cor. magna caerulea.

145. S. retrofractum V'ahl; caule fruticoso; ramis retrofractis; pedunc. filiformilus ; fol. ovatis glabris; calycibus truncatis edentulis. Dun. t. 5 . In Americ. anstr.

146. S. geminatum Vahl; caule scandente; fol. ovatis integerrimis calycilusque 10-dentatis glabris; pedunc. geminatis. In Cayemna. ち.

147. S. biflorum Lour. caule fruticoso; fol. ovatis utrinque villosis; pedunc. geminis; calycibus 10 -fidis; s. Iysimachioides Wall. In China, Cochinchinu et Nepalia. ち. 3-ped. Cor. alba. Bacca rubra.

148. S. pauciflornm Iahl; ramis villoso-tomentosis; fol. ovatis integerrin:s subtus tomentosis; pedunc. geminis. In Martinica.

149. S. tricolor Sess. caule tereti dichotomo; fol. geminis ovatis tomento nitido obductis; pedunc. 4; anthera una duplo longiore. Dun. t. 41. In Mexico. t. Cor. alha. Bacca rubra.

150. s. sylvaticum Dun. t. 11t. caule fruticoso scandente glaberrimo; fol. petiolatis ovatis apice acuminatis; pedunc. subternis 1 -floris; calycibus 10-fidis. In Cumana. ち.

1.51. S. phillyreoides Dun. t. 11.5. caule angulato fruticoso dichotomo; fol. lanceolatis acuminatis subtus puhescentibus; pedunc. aggregatis. In Nov. Granata. ち.

152. S. lentum Cav. ic. $t .308$. fruticosum; decumbens; fol. ovatis acutis subtus incano-tomentosis; pedunc. geminis tomentosis ; calycis dentibus filiformiinus. In Nov. Hispania. ち. Cor. dilute violacea.

153. S. virgatum Lam. caule fruticoso; ramis virgatis; fol. ovato-oblongis acutis sulitus pedunculis calycibusque tomentosis; filamentis inaequalibus. Dum. t. 40. In ins. Canar. et Carib. †. Cor. violacea.

151. S. glandulosum R. et P. geruv. $t$. 16\%. $f$. b. caule suffruticoso scandente; fol. geminis ovato-cordatis; pedunc. $3-5$ intra foliaceis; calycis dentibus glanduliformibus. In Peruvia. ち. Cor. alba.

15.5. S. cutacense $H$. et $K$. fol. geminis ovatis acutis utrinque sericeopilosis subtus incanis; ramis tomen-

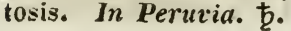

156. S. lasiophyllum Dun. t. 118. caule fruticoso; ramis dichotomis hispidis; fol. geminis lanceolatis utrinque acuminatis hispidis; pedunc. geminis 1-floris. In Nov. Granata. ち.

15\%. S. lanuginosum Dun. t. 116. caule fruticoso; ramis apice lanuginosis; fol. ovatis margine undulatis subtus nervosis lanuginosis. In Quito. 古.

1.5s. S. chrysophyllum Dun.t. 11\%. caule frutescente volubili; fol. oblongis acutis supra stellato-pubescentibus fusco-tomentosis; ramulis scandentibus aureo-ferrugineis. In Quito. ち.

159. S. scandens $I$. caule herbaceo volubili; fol. cordatis ovatis dependentihus subtus mollissimis; floribus umbellatis terminalibus. In $\mathrm{Su}$ rinamo.

160. S. lineatum R. et P. peruv. t. 158. $f$. b. fol ovatis acuminatis lineatis subtus villosis; pedunc. 1-floris hirtis; laciniis calycis elongatis. In Peruvia. ち. Cor. alba.

161. S. biformifolium $\boldsymbol{R}$. et $\boldsymbol{P}$. perux. $t$. 161. $f$. a. caule suffruticoso flexuoso; fol. geminis oblongo-lanceolatis altero minino orbiculato; calyce 10-dentato. In Peruvia. ち. Bacca luteo-rubra.

162. S. acutifolium $R$. et Pav. peruv. $t$. 162. $f$. $b$. caule suffruticoso flexuoso; fol. geminis ternisve lanceolatis hispidulis; pedunc. intrafoliaceis. In Peruvia. †. Cor. alba. Bacca aurantiaca.

163. S. pachypetalum Spr. fol. oblongis repandis decurrentibus villosis; fasciculis axillaribus; corolla glabra carnosa. S. crassipetalum IVall. In Nepalia.

16\%. S. erianthon Don; fruticosum; fol. ovato-oblongis acutis integerrimis utrinque ramisque stellatotomentosis; corymbis lanatis; cor. campanulata. In Bepalia. $\hbar$.

16.5. S. violuefolium Schott; caule radicante; fol. geminis inaequalilous utrinque hirsutis: altero cordato, altero reniformi; calycibus $\mathbf{1 0 - f i d i s . ~ I n ~}$ Brasilia.

\section{B. Spinoso-aculeata.}

\section{a. Foliis pinnatifide.}

166. S. heterodoxon Dun. caule herbaceo piloso aculeatissimo; fol. 
subbipinnatifidis ; laciniis runcinatis pilosiusculis utrinque aculeatis; antheris declinatis, infima longiori. Dun. t. 25. In Mllexico. ๑. 2-3-ped. Cor. caerulescens.

16\%. S. Fontanesianum Dun. $t .96$. caule sublignoso annto aculeato piloso; fol. profunde pinnatifidis; laciniis sinuatis; antheris parvis infima apice fusca curvata. Patria iynota. $\odot$. Cor. lutea.

168. S. rostratum Dun. $t$. 2.t. caule aculeato piloso; pilis apice stellatis; fol. pinnatifidis laciniis obtusis; antheris declinatis conformibus, infima maxima productissima. In Mexico. $\odot$. 2-3-ped. Cor. lutea.

169. S. heterandrum Pursh. am. $\boldsymbol{t}$. $\%$. caule foliisque aculeatis; fol. ovatis pinnatifidis utrinque hirsutis; bacca calyce echinato-inclusa. $A d$ ripas Missouri. $\odot$.

170. S. cornutum Lam. caule aculeato glabro; fol. pinnato - pinnatifidis aculeatis; corollis irregularibus; anthera infima maxima productissima. Juss. Aun. Mus. 3. t. 9. In Nov. Hispania. ち. Cor. lutea magnia.

171. S. Balbisii Dun. t. 3. f. 1 . caule fruticoso villoso aculeato; fol. pinnatifidis; laciniis sinuato-dentatis; racemis cymosis. \$. decurrens Balb. t. 1. S. viscosum Lag. brancaefolium Jacq. Ecl. t. \%. S. inflatun Fornem. S. mauritianum Roth. In America australi. ђ. Cor. alba.

17\%. S. tectum Pers. caule fruticoso aculeato; fol. bipinnatifidis sinuatis utrinque villosis aculeatis; caIycibus aculeatis baccam tegentibus. Cav. ic. t. 309. In Mexico. ち. Cor. Ilava.

173. S. Faladares Vand. caule suffruticoso aculcato subpiloso; fol. pinnatis incisis utrinque aculeatis; racemis lateralibus compositis. In $\mathrm{Br}^{\mathrm{r}} \mathrm{-}$ silia. $\hbar$

19f. S. Hystrix R. Br. caule herbaceo diffuso; aculeis confertissimis subulatis rectis; fol. oblongis pinnatifido-sinuatis glabris calycibusque aculeatissimis. In Nov. Holl.

175. S. pyracanthum Lam. caule aculeato suffruticoso; fol. oblongis acutis sinuato-pinnatifidis tomentosis; aculeis rectis subcoccineis. Sm. exot. bot. t. 64. Jacq. Schoenbr. t. 470. S. xanthocarpon schrad. In Africa. Cor. purpureo-caerulea.
176. S. viryinianum $\boldsymbol{I}$. caule erecto aculeato ; fol. binnatifido-sinuatis undique aculeatis; laciniis margine ciliatis; racemis aculeatis. Dill. Elth. f. 316. In Americ. bor. $\odot$. Cor. violacea.

18\%. . Jacquini W. caule decumbente diffuso aculeato; fol. pinnatifidis utrinque aculeatis gla!ris; laciniis sinuatis obtusis margine nudis. $\mathbf{S}$. virginianum Jacq. ic. t. 332. In Ind. or. $\odot$. Cor. caerul co-purpurea.

188. S. cinereum R. Br. caule lierbace 0 ; aculeis rectis subulato-setaceis; fol. oblongis pinnatifido-sinuatis subtus tomentosis cinereis utrinque calycibusque aculeatis. Ad Port. Jackson.

189. S. armatum R. Br. caule herbaceo diffuso; aculeis confertis rectis setace - subulatis; fol. oblongis sinuato-pinnatifidis utrinque glabris calycibusque aculeatis. Dum. t. 6t. In Nov. Holl. 方.

180. S. Heynii R. et S. fol. ovatis profuncie sinuato-pinnatifidis stura stellato-puhescentibus suhtus niveotomentosis; pedunc. 1 - Igris. S. pinnatifidum Roth. In Ind. or.

181. S. sodomaeum $L$. fol. pinnatifido-sinuatis glabriusculis ciliatis aculeatis; lobis obtusis aculeis validis sparsis; calycibus aculeatis. Fl. graec. t. 235. S. Hermanni Dun. t. 2. f. h. Lam. ill. t. 115. f. 1. In Calabria, Sicilia et Africa.

182. S. capense $S p r$. caule suffruticoso aculeato; fol. pinnatifido-sinuatis glahris aculeatis; laciniis rotundatis ; pedunc. sub-1-floris. S. Milleri Jacq. ic. t. 330. In Prom. b. spei. $\hbar$. Cor. alba.

\section{b. Foliis lobatis sinuatis.}

\section{$\alpha$. Caule fruticoso.}

183. S. agreste Roth; fol. subcordato-ovatis obtusis sinuato-angulatis utrinque stellato-tomentosis ; corymbis subsessilibus; calycibus aculeatis. In Ind. or.

131. S. rigidum Lam. aculeatum; frutescens; lumile; fol. ovatis sinuato-angulosis aculeatis nudiusculis; aculeis rectis albidis. Patria ignota. ち. Cor. alba.

185. S. Richardi Dun. t. 6\%, f. 1. caule tomentoso; fol. sinuato-lobatis; 
lobis obtusis utrinque tomentoso-scabris aculeatis subtus cinereis; floribus paniculatis. Patria ignota. $\mathbf{b}$.

156. S. violaceum Jacy. fragm. t. 133. f. 1. caule aculeato; fol. 10bato-sinuatis subtus tomentosis; racemis simplicibus; calycibus aculeatis. In Incl. or. \$. Cor. caerulescens.

187. S. Anguivi Lam. caule aculeato; fol. ovatis sinuato-angulatis subtus tomentosis; calycibus inermibus. Dun. t. 74. In Madagascar. ち. Bacca rubra.

158. S. rigescens Jac\%. Schoenbr. t. 42. caule aculeato suffuticoso; fol. subovatis obtusis sinuato-lobatis; pilis stellatis fasciculatis adspersis.

Prom. b. spei. t. Cor. violacea.

18.9. S. acetosaefolium Lam. caule suffruticoso aculeato glabro; fol. obtusis sinuatis subpanduraeformilous; aculeis minimis recurvis; floribus racemosis albidis. Burm. ind. t. 22. f.2. In Ind. or. $\hbar$. Cor. alba.

190. S. trilobatum L. caule aculeato fruticoso; fol. lobatis subtrilobis obtusis glabris; floribus racemosis violaceis. Plukn. t. 316. f. 5. In Jumaica. 支.

191. S. sessilifiorum Dun. $t .73$. ramis tomentosis subinermibus; fol. subcordatis maximis sinuato-angulatis ntrinque tomentosis sericeis; fioribus sessilibus. In Brasilia. 市.

192. S. macranthum Dun. $t .92$. caule aculeato lanuginoso; fol. maximis subcordatis acuminatis augulatolobatis ntrinque lanuginosis subtus aculeatis. In Brasilia. ఫ.

193. S. crinitum Lam. caule aculeato; fol. ovatis sinuato-angulatis tomentosis nervo medio aculeatis; petiolis, pedunculis calycilusque echinatissimis subcrinitis; baccis villosis. Dun. t. 71. In Cayenna. t.

194. S. latifolium loir. caule fruticoso aculeato; fol. petiolatis cuneatis sinuato-lobatis utrinque piloso-aculeatis; racemis pauciforis. Dun. t. 66. In America. $\hbar$.

195. S. acerifolium Bonpl. caule aculeatissimo hirsuto; fol.3-5-lobis 35-angulatis hirsutis aculeatis; racemis brevibus paucifloris. Dun. t. 131. In Cumana. ち.

196. S. flavescens Dun. t. 6\%.f. 2. caule aculeato canescente; fol. cordatis sintratis obtusis utrinque aculeatis tomentosisque subtus flavescen- tibus; pedunc., calycibus baccisqne hirsulissimis. In ins. Trinitatis: $\hbar$.

1.9\%. S. lasiocarpon Dun. fol. subcordatis simuato-angulatis utrinque tomentoso - lanuginosis aculeatisque. Hheede 2. t. 35. In Malabaria et Java. ち. Cor. alba.

198. S. stramonifolium Jacq. ic. t. 41. fol. cordatis sinuatis acute lobatis utrinque villosis aculeatisque; pedunc. calycibusque inermibus. In Amer. austr., Afr. or. et Ind. or. t. Cor. alba.

199. S. incarceratum $\boldsymbol{R}$. et $\boldsymbol{P}$. peruv. $t$ : 186. $f$. $a$. caule aculeato; fol. geminis cordatis sinuato-angulatis acuminatis; baccis oblongis intra lacinias calycum cancellatis. In Peruvia. . Cor. albo-violacea.

200. S. aculeatissimum Jacq. ic. t. 11. caule aculeatissimo; fol. subcordatis lobatis; lobis acutis dentatis utrinque villosis aculeatisque; baccis globosis. In Amer.austr. $\hbar$. Cor. nivea.

201. S. marginatum $L_{\text {. fol. sub- }}$ cordatis sinuato-lobatis subtus tomentoso-incanis supra margine albis; baccis 3-locularibus globosis. Dun. t. 3. f. A. Jacq. ic. t.45. In Afr. austr. ち. Cor. purpurascens.

202. S. indicum L. fol. oblongis sinuato-angulatis tomentosis; laciniis dentato-sinuatis; pedunc. paucifloris ; fructibus pyriformibus. Runuph.5. t. 86. f. 1. Dill. Elth. f. 319 . In Ind. or. $\mathfrak{t}$. Cor. cacrule0-purpurea.

203. S. heteracanthum Dun. t. 6.5. caule aculeis recurvis; fol. sinuatolohatis pilosiusculis utrinque aculeis rectis; racemis bifidis. In Africa? ち. 20t. S. fiscutum L. fol. ovatooblongis sinuato-lobatis obtusis subtomentosis; pedunc. bifidis; baccis glohosis. Jacq. ic. t. 42. In America. t. Cor. violacea.

20.5. S. procumbens Lour. fol. ovatis 5-lohis ntrinque villosis aculeis recurvis; floribus congestis terminalibus. Iir Cochinchince.

206. S. lividum W. Hb. fol. subcordatis sinuato-lobatis supra virentibus subtus incano-tomentosis aculeis validis; calycibus aculeatis. In $M a$ dagascar. $\hbar$.

20\%. S. platyphyllum Bonpl. caule suffruticoso parce aculeato; fol. petiolatis oblongis "sinuato-angulatis scabriusculis; floribus racemosis; pedi- 
cellis dichotomis. Dun. t. 130. Ad

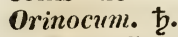

208. S. albidum Dun. canle arboreo aculeato; fol. sinuatis, inferioribus lobatis subtus incanis; racemis multifidis. S. incanum R. et $\mathbf{P}$. peruv. t. 175. f, b. In Peruvia. ђ. 4-org. Cor. alba.

20.9. S. acutilobum Dun. t. 63. ramis subinermibus tomentoso-pulverulentis; fol. petiolatis corlatis sinuato-angulatis utrinque pulverulento-tomentosis; racemis cymosis. In Para. $\hbar$.

210. S. paniculatum L. caule petiolisque aculeatis; fol. sinuato-angulatis supra glabris; floribus paniculatis terminalibus. In Brasilia. Cor. lactea caerulescens.

211. S. hispidum Pers. canle fruticoso aculeato hirsutissimo; fol. 10hatis acuminatis; racemis iateralibus dichotomis inermibus. 11 . et $P$. peruv. t. 176. f. b. In peruvia. ఫ. 10-12ped. Cor. alba.

212. S. Maccai Rich. caule fruticoso vix aculeato; fol. basi subcordatis sinuato-lobatis sinubus rotundatis; lobis sinuato-angulatis subtus canescentibus. Dum. t. 61. Maccai Meriall. t. 6. In Cayenna. $\hbar$. Bacca rubra.

213. S. ferrugineum Jacq. Schoenbr. t. 33t. caule fruticoso aculeis glabris; fol. ovatis lobatis sinuatisve subtus ad nervum petiolisque aculeatis tomentosis. P'atria ignota. †.

211. S. torrum Sw. caule fruticoso aculeis curvis; fol. subcordatis ovatis sinualis tomentosis aculeatis; calycibus inermihus. S. stramonifolium Lam. ficifolisn Orteg. In Ind. occ. ち. Cor. alha.

315. S. nemorense Dun. caule scandente; fol. geninis glabris, unico majori sinuato - angulato, altero integerrimo; racemis filiformibus longissimis. S. laciniatum R. et P. peruv. t. 177. f. a. In Peruvia. 占.

216. S. toxicarium Lam. fruticosum; aculeatum ; fol. Iobato-angulosis tomentosis basi ohliquis emarginatis aculeis utrinque sparsis; racemis sessilibus. Dun. t. 50. In Gugana. ち. Bacca flava.

21\%. S. carolinense $L$. caule aculeato; fol. ovato-oblongis tomentosis sinuato-angulatis acuminatis; racemis laxis. Jacq. ic. t. 332. Dill. Elth. f. 348. In Carolina. $\odot$. Cor. nivea.

218. S. pungetium $R$. et $P$. caulo luerbaceo; aculeis rectis acerosis; fol. ovato-ohlongis pinnatifido- vel repando-sinuatis membranaceis utrinque pilosis, calycibusque aculeatis Dun. t. 70. In Nov. Holl. $\odot$.

219. S. campanulatum R. Br. caule herbaceo; aculeis confertissimis rectis subulatis; fol. ovatis angulatolohatis utrinque hirsutis calycilusque aculeatissimis. B. M. 3672. Cor. pallide caerulea. In Nov. Holl. $\odot$.

220. S. orinocense Dun. $t .132$. caule herlaceo aculeatissimo; fol. cordatis sinuato-angulatis utrinque tomentosis aculeatis; haccis hispidis calyce subtectis. Ad Orinocum. 4.

221. S. ferox $\boldsymbol{L}$. caule aculeato herhaceo; fol. cordatis angulatis tomentosis calyhibusque aculeatis ; baccis hirsutis calyce tectis. Dum. t. 68. In Malabaria. ந.

222. S. melanoxylon LK. fol. cordatis oblongis sinuatis tomentosis subtus incanis; pedunc. solitariis; calycibus obtusis aculeatis ; cor. 6-partita. Patria ignota. Cor. violacea.

223. S. campechiense $I$. caule herbaceo aculeatissimo hirto; fol. cordato-oblongis Iobatis; lobis dentatis; calycibus aculeatissimis. Dill. Elth. f. 347. In Nov. Hispania. $\odot$ ' Cor. pallide violacea.

221. S. myriacanthum Dun. t. 19. caule aculeatissimo hirsuto; aculeis mollibus aciculiformibus; fol. cordatis sinuato-angulatis acutis utrinque villosissimis aculeatisque. Patria ignota. 古.

225. S. mammosum $\boldsymbol{L}$. caule villoso herbaceo sparse aculeato; fol. subcordatis Iobatis utrinque aculeatis villosissimis; haccis mammiformilous. sloane Hist. t. 12. f. 1. S. villosissimum Zuccagn. In Ind. occ. et Carolina. $\odot$. Cor. pallide caerulea.

226. S. platanifolinm Sims $\boldsymbol{B}$. M. 261S. fol. 5-lobis utrinque subtomentosis; lobis acutis inciso-dentatis; umbellis nutantibus; fructibus variegatis. In Amer. austr. ち.

22\%. S. ciliatum Lam. caule herbaceo; fol. subcordatis sinualo-lobatis ciliatis; pedunc. brevibus paucifloris; haccis subglobosis sulsiccis. Dun. t. 18. Patria ignota. $\odot$. Cor. caerulescens. 
228. S. Hernandesii Sess. caule fruticoso aculeato tomentoso; fol. geminis sinuatis acutis tomentosis; pedicellis umbellatis; baccis 6-locularibus. Dun. t. 59. In Mexico. 4. .Cor. alba.

22.9. S. tridynamum Pers. caule aculeato subtomentoso; fol. sinuatis obtusiusculis tomentosis; calycibus supra costam aculeatis; antheris 3 apice recurvis. In Alexico. $\odot$. Cor. violacea.

230. S. pseudo-sappaceum Blume; caule aculeato suffruticoso; fol. sinuato-angulatis basi inaequalibus supra glabriusculis subtus tomentoso-pulverulentis ; corymbis dichotomis ; floribus secundis. In Jara. ち.

231. S. canescens Blume; caule foliisque aculeatis; fol. sinuato-lobatis basi subobliquis utrinque petiolis ramulisque stellato-tomentosis; floribus subumbellatis; baccis pisiformibus. In Java. 方.

232. S. cyanocarpon Blume; callle subaculeato herbace ; fol. oblongis utrinque acutis sinuato-angulatis; pilis stellatis hirsutis; pedunc. 1-floris nolliter aculeatis; baccis globosis. In Java. $\odot$.

233. S. Wigthii Nees Act. Leopold. XIIII.t. 18. fasciculato-hirsutum; caule aculeato; fol. subcordato-ovatis sinuatis acutis subaculeatis; baccis globosis calyce lirsuto tectis. In Ind. occ. $ち$.

231. S. barbisetum Nees; fasciculato-hirsutum; caule aculeato; fol. ellipticis sinuatis utrinque hirsutissimis aculeatisque; laciniis angulatis; floribus racemosis secundis. S. melongena Wall. In Ind. or. 4.

\section{c. Foliis repandis.}

\section{a. Fruticosa.}

235. S. obtusifolium Bonpl. caule fruticoso tomentoso; fol. discoloribus oblongis siuuato-repandis ontusis aculeatis tomentosis; pedunc. solitariis bifidis; calycibus aculeatis. Dun. t. 110. In Mexico. 古.

236. S. molle Bonpl. caule suffruticoso aculeato; ramis tomentosis saepe inermibus; fol. ovato-lanceolatis integris s. sinuato-repandis tomentosis nollibus; aculeis nervi pusillis; floribus umbellatis. Dun. t. 120. In Caracas. ち.
23\%. S. scabrum Vahl; ramis flexuosis; fol. ternis ellipticis subsinuatis piloso-scabris; racemis lateralibus; fol. calycilusque aculeatis. Dun. t. 120. In Amer. merid. $\hbar$.

233. S. formosum Dun. t. 127. caule fruticoso aculeatissimo hirsuto; fol. subcordatis ovato-lanceolatis acuminatis tomentoso-lanuginosis; racemis multifloris. Ad Orinocum. b.

239. . . ovalifolium Dun. $t$. 128. caule fruticoso tomentoso; fol. ovalibus subrotundatisque supra scabris subtus tomentosis canescentibus; racemis bifidis brevibus. Ad flum. II agdalenae. $\hbar$.

210. S. amazonicum Ker. B. R. caule fruticoso tomentoso inermi; fol. oblongo-ovatis repandis vel sinuatolobatis ; racemis cymosis; corollis irregularibus; staminibus tridynamis. In Mexico. 市.

211. S. aciculare Sw. caule aculeato fruticoso; aculeis subulato-acerosis; fol. cordato-subrotundis repandis, utrinque aculeatis supra stellatohirsutis, subtus tomentosis; pedunc. axillari longissimo multifloro. In $\mathrm{Br}^{*} \mathrm{a}$ silia. $\hbar$. Cor. caerulea.

212. S. album Lour. caule subinermi suffruticoso; fol. oblongis angulatis parce aculeatis; pedunc. multifloris; baccis globosis. In Antillis et Cochinchina. $\hbar$. Cor. alba.

213. S. Trongum Poir. caule suffruticoso aculeato; fol. angulato-sinuatis utrinque aculeatis; floribus solitariis. Humph. 5. t. 86. f. 1. In ins. Molucc. $\hbar$. Cor. purpurea.

214. S. sanctum $L$. caule fruticoso tomentoso; fol. ovato-repandis basi obliquis utrinque tomentoso-incanis; aculeis tomentosiusculis; baccis globosis. S. incauum Forsk. In Pulaestina et Aegypto. ‡. Cor. purpureocaerulescens.

215. S. coagulans Forst. caule fruticoso; fol. ovato-oblongis sinuato-repandis subtus albo-tomentosis, nervo medio glabriusculis; bacca globosa. Del. Aeg. t. 23. f. 1. Jacq. Schoenlur. t. 469 . In Arabia. t. Cor. flava.

216. S. incanum $I_{\text {. }}$ caule fruticoso ; fol. ovatis sinuato-repandis utrinque tomentosis aculeatis subtus canis; pedunc. solitariis; haccis ovatis. S. zeylanicum scop. del. to 1. In ins. 45 . 
Mascarenh. et Zeylona. ち. Cor. caerulea.

247. S. undatum Lam. caule suffruticoso; fol. ovatis sinuato-repandis subtus tomentosiusculis utrinque aculeatis ; pedunc. sub-1-floris. S. pseudo-undatum Blume. Hheede mal. t.37. In Malabaria et Java. 古.

248. S. lanatum Dun. t. 129. caule aculeato arboreo; fol. oblongis solitariis geminisque; corymbis ramis subdichotomis. R. et P. peruv. t. 174 . f. b. S. asperum Pers. In Peruvia. ち. 20-25-ped. Cor. alba.

24.9. S. elegans Dun. $t$. 58. caule tomentoso aculeato; fol. oblongo-acuminatis utrinque tomentosis aculeatis sinuato-repandis subtus flavo-candidis; racemis tomentosis aculeatis. In Nov. Holl. ђ. Cor. violacea.

250. S. Brownii Dun. fol. lance0latis elongatis repandis , supra scabriusculis subtus tomentosis; corymbis umbellatis; calycibus coloratis ramisque subinermibus. $\mathbf{S}$. violaceun R. Br. In Nov. Holl. ち. Cor. violacea.

251. S. glutinosum Dum. $t$. 54. caule fruticoso erecto sparse aculeato; fol. oblongo-lanceolatis hasi cordatis acutis utrinque tomentosis ulutinosis mollibus; racemis lateralibus glutinosis. Patria ignota. ち. Cor. caerulea.

252. S. oporium $W$. caule fruticoso inferue aculeato; fol. oblongolanceolatis repando-angulatis integrisque; racemis lateralibus terminalibusque. S. macrophyllum Dun. t. 16. S. cymosum Orteg. In Mexico. $\hbar$. Cor. caerulea.

253. S. Poke Dun. t. 56. ramis subglabris aculeatis; fol. ovato-ohlongis subintegris aut sinuato-angulalis subtus tomentosis inermibus; racemis brevibus paucifloris. In Jaขa. ち.

254. S. fastigiatum $W$. caule subinermi fruticoso; fol. ovato-oblongis sinuato-repandis pubescentibus; corymbo terminali pedunculato. Dum. t. 16. et 2. In Mexico. t. Cor. pallide caerulea.

255. S. bonariense $\pi_{\text {. }}$ caule subinermi fruticoso; fol. ovato-oblongis sinuato-repandis scabris; corymbo extrafoliaceo pedunculato. Dill. f. 351. In Buenos Ayres. ఫ. Cor. alba.
2.56. ․ ambiguum Dun. $t .113$. ramis scandentibus pilosis aculeatis; fol. inferioribus solitaris, superioribus geminis ovato-ellipticis angulatis subsinuatis utrinque piloso-scabriusculis; florihus racemosis. In ins. Martinica. ち.

2.5\%. S. quadriloculare Spr. fol. ovatis repando-angulatis subtus stellatotomentosis; aculeis caulinis confertis erectis; umbellis oppositifoliis paucifloris; haccis hirsutis 4-locularibus. S. hirsutum Roxb. In Inel. or. ந. 258. \$. volubile Su. caule scandente; fol. angulatis margine denticulatis ; petiolis, rachibus calycihusque aculeatis. Plum. Mss. t. 4. f. 3. In Nova Hispania. ち. Cor. caerulea.

2.59. S. heterophyllum lam. fol. ternis inaequalibus supra scabris subtus tomentosis; raccmis calycibusque inermibus. Dun. t. 63. In Gujana. b. Corolla grandis.

260. S. cuneifolium Dun. t. 22. caule fruticoso; fol. geminis longe cuneatis superme simualo-angulatis; angulis acutis; racemis brevibus; calycihus subulatis. In Cayenna et Hispaniola. ђ.

261. S. jamaicense $\mathbf{S w}$. caule fruticoso; fol. cuneatis medio latiorilous utrinque tomentosis; rachihus calycilusque aculeis reflexis. In Jamaica. \$. Cor. alba aut pallide cacrulea.

262. s. brevipile Dun. $t$. 21. callle fruticoso; fol. geminis sessilihus obtusangulis utrinque tomentosis ; calycilus 5-partitis. In Ind. occ. 古.

263. S. coccineum Jac\%. ic. $t .43$. caule fructicoso aculeato; fol. ovatis subcordatis subrepandis tomentosis uno alterove aculeo; calyce acuto; baccis cocciueis. In Ind. occ. ђ. Cor. purpurascens.

261. S. hybridum Jacq. Vind. $t$. 113. caule fruticoso aculeato; fol. ovatis subinermilus acutis repandis tenellis dorso et ad oras violaceo-pulverulentis. In Guinea. ち. Cor. rugosa pallide caerulea.

26.5. S. tomentosum $\boldsymbol{L}$. caule fruticoso aculeato, aculeis acerosis; fol. cordatis inermilius subrepandis undulatis utrinque tomentosis tenellis purpureo-pulverulentis; laciniis calycis obtusis. Bocc. sic. t. 5. Triumf. t. 6. In Amer. austr. ち. Cor. caerulea.

266. S. eriophyllum-Dun. $t$. 50. ramis candido-tomentosis aculeatis; 
fol. utrinque tomentosis candidis sinuatis obtusis breviter petiolatis; calycibus lanuginosis subcampanulatis. In Nov. Holl. Cor. caerulea.

26\%. N. cordifolium Bun. $t$. 135. caule hirsuto aculeato; fol. longe petiolatis cordatis angulato-repandis utrinque villosis inermibus; racemis simplicibus lateralibus. In Rio Janeiro. ந.

268. S. hirtum Vahl symb. $t$. 21. fruticosum; fol. cordato-angulatis tomentosis aculeatis; pedunc. Iateralibus agrregatis calycibusque hirsutissimis. In ins.. Trinitatis. b.

269. s. gracilillorum Dun. t. 4\%. ramis glabriusculis aculeatis; actileis suberectis; fol. ovato-ohlongis basi inaequalibus simuatis utrinque aculeatis pilosiusculis; pilis minutissinis distan(ibus; floribus umbellatis. In Java.

280. S. bahamense $I$. caule fruticoso; fol. lanceolatis repandis obtusis ulargine reflexis. Dill. Eltlı. f. 350. sloane Hist. t. 11. f. 3. $\ln$ ins. $\mathrm{Ba}-$ hamensious. $\hbar$. Cor. alba vel violacea.

271. S. leprosum Ortega; caule fruticoso; fol. discoloribus omnibus sinuatis utrinque aculeatis subtus incanis; pedunc. paucifloris; calycibus aculeatis. In Chili. ち. Cor. graudis dilute caerulea.

\section{b. Herbacea.}

272. S. esculentum Dun. Sol. $t .3$. f. $\boldsymbol{E}$. caule aculeato suhherbaceo; fol. ovatis subsinuatis tomentosis aculeatis; floribus multipartitis; seminibus nudis. S. Melongena L. Plenk. t. 123. S. insanum L. mant. In Asia et Afr. trop. $\odot$. Bacca magna ovalis purpurea, flava, aut cinerea.

283. S. origerum Dun. caule subherbaceo subinermi; fol. ovatis subrepandis tomentosis inermibus; baccis ovato-oblongis; seminilus pulposis. s'. Melongena Murr. Blackw. t. 5 $19 . \quad I n$ Avobia. $\odot$. Fructus violaceus, albus et variegatus.

\section{d. Foliis integerrimis; fruti- cosa.}

274. S. igneum $L$. caule frutico80; fol. lanceolatis acuminatis basi utrinque revolutis. Dun. Sol. t. 2. f. a. Burm. Amer. t. 245. f. 1. S'. sub- armatum IV. In Ind. occ. 巿. Cor. alba.

275. S. polyacantion ram. aculeatissimum; fol. lineari-lanceolatis subrepandis subsessilibus obtusis utriuque villosis aculeatis; pedunc. axillaribus. S. parviflorum Cav. ic. t. 236. In Dominyo. $\hbar$.

276. S. polygamum rahl; caulc fruticoso petiolisque aculeatis; fol. ovato-oblongis subintegris supra scabriusculis subtus tomentosis aculeatis. Duin. t. 49. In ins. Caribaeis. $\odot$.

2\%\%. S. Ayuartia Dun. fol. ovatis ohtusis dense tomentosis; aculeis sparsis reflexis; floribus polygamis 4-fidis; pedunc. sub-1-floris. Aquartia aculeata Jacq. tomentosa. Lam. In Hispaniola. $\odot$.

278. S. crotonoiles Lam. caule fruticoso; fol. discoloribus ellipticolanceolatis supra glabris subtus tomentosis ineruibus; racemis brevibus. Dun. t. 13. S. reliculatum Dun. t. 48. In ins. Carib. ち. Cor. albida.

289. S. elueagnaefolium Cav. ic. t. 213. caule fruticoso; fol. discoloribus, iuferioribus sinuatis aculeatis, superioribus integris inermibus; pedunc. paucifloris. In Chili. t. Cor. caerulea.

280. S. furfuraceum $\boldsymbol{R}$. $\boldsymbol{B r}$. caule futicoso; aculeis acerosis; fol. angusto lanceolatis integerrimis, supra parce aculeatis glabrisque, subtus tomentosis cinereis; umbellis $3-4$-floris. In Nov. Holl. $\hbar$.

281. S. orbiculatum Dun. t. 44. caule aculeato; aculeis acerosis rubris; fol. suborbiculatis utrinque tomentosoleprosis parvis; floribus subgeminis. In Nov. Holl. $\frac{\hbar}{}$.

282. S. microphyllum Dun. fol. subrotundis glabriusculis inermibus; caule fruticoso ramosissimo; aculeis geminis opposilis; pedunc. 1-floris; floribus 4-fidis. Aquarlia microphylla Lam. In Hispaniola. ち.

283. N. stelligerum Sm. exot. bot. $t$. 88 . caule fruticoso; aculeis raris acerosis rectiusculis; fol. integris subinermilus supra glabris subtus tomentosis cinereis ; floribus corymbosis. s. discolor H. Br. In Nov. Holl. 古. Cor. pallide purpurascens.

281. S. dianthophorum Dun. $t .45$. caule aculeis paucissimis acerosis; fol. oblongo-ovatis integris utrinque tomentosis inermibus; pedunc. bifloris. 
S. biflorum R. Br. In Nova Hollandia. 卢.

285. S. ellipticum $\boldsymbol{R}$. Br. caule fruticoso; aculeis rectis basi tomentosis; fol. oblongo-ovalibus obtusis integris utrinque tomentosis calycibusque aculeatis. In Nov. Holl.

286. S. horridum R. Br. caule tereti piloso aculeato; fol. longe petiolatis ovato-oblongis integris utrinque villosis pedumculisque 1-floris aculeatis. Dun. t. 46. In Nova Hollandia. 古.

28\%. S. aturense Bonpl. fol. geminis petiolatis elliptico-lanceolatis acum natis scabris nervo medio aculeatis $\mathrm{i}$; racemis tomentoso-scabris ; calycibus aculeatis. Dun. t. 122. Ad

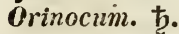

285. S. brachyanthum Dun. t. 121. caule arhoreo; aculeis brevissimis; fol. geminis discoloribus lanceolato-ellipticis subtus tomentosis; racemis cymosis. In Cumana. †.

259. S. javitense Bonpl. aculeis rameis recurvis in petiolo et nervo medio rectis; fol. ovatis sinuatis subtus tomentosis; raccmis subsessilibus; laciniis corollae longe linearibus. S. Juripeha Rich. Dun. t. 15. S. monachophyllum Dun. t. 125. Ad Orinocum. 卢.

290. S. lancerefolium Jacq. ic. $t$. 329. caule scandente; fol. lanceolatoohlongis utrinque attenuatis scabriusculis subtus aculeatis; racemis brevibus inermibus. In Amer. austr. Cor. alha.

291. S. micranthum Lam. fol. ovato-lanceolatis acuminatis subtus tomentosiusculis; aculeis minimis raris recurvis. S. Jussievi Dun. t. 52. In Amer. austr. $\hbar$.

2.92. S. umbrosum Bonpl. caule aculeato tomentoso hirsuto; fol. solitariis geminisve lanceolatis acuminatis tomentoso-hirsutis discoloribus; racemis simplicibus tomentoso-hirsutis Dun. t. 126. In Cumana. ち.

293. N. rubiginosum Vahl ic. $t .13$. ferrugineo - tomentosum; aculeis recurvis; fol. ellipticis integermis acutis supra glabris subtus tomentosis; cymis terminalibus. S. ochroneurum Lk. In Cayenna. †. Cor. violacea.

294. S. velutinum Dun. $t$. 53. caule scandente tomentoso; fol. ova- to-sblongis basi inaequalibus acutis tomentoso-sericeis subtus parce aculeatis; racemis terminalibus paucifloris. In Cayenna. 卢.

2.95. S. coriaceum Dun. $t$. 1 . scandens; fol. glabris lancealato-ellipticis acutis; racemis lateralibus folia aequantibus. In Cayenna. ち. Arbores altissimas scandit. Cor. caernlea.

296. S. subinerme Jacq. Am. t. 40. f. 3. caule fruticoso subinermi; fol. lanceolato-ellipticis integerrimis supra glabris subtus tomentosis; cymis farinosis; calycis laciniis obtusis. In Ind. occ. 24. Cor. laete caerulea.

297. S. lanceolatum Cav. ic. $t$. 21.5. caule fruticoso tomentoso subaculeato; fol. lanceolatis longis integerrimis subtus tomentosis canescentibus; corolla 5-fida angulato-plicata. S. mexicanum Sess. In Mexico. ‡. 6-ped. Cor. dilute caerulea.

298. S. Vespertilio Ait. caule fruticoso; fol. cordatis integris; racemis saepe multifidis; calycibus inermibus; corollis subirregularibus; anthera infima productiore. Wendl. Hort. t. 21. Nycterium cordifolium Vent. malm. t. pict. In Canariis. 古.

299. S. giganteum Jac\%. ic. $t$. 328. caule fruticoso aculeis tomentosis; fol. lanceolatis acutis inermibus supra glabris subtus tomentosis incanis; racemis dichotomis. In Prom. b. spei. ђ. Cor. extus nivea intus violacea.

300. S.? Hookerianum Spr. inerme; fruticosum ; glabrum; fol. petiolatis oblongis coriaceis nitidis integerrimis subvenosis; pedunc. sub-1-floris; calyce 5-partito bilabiato. \$. coriaceum Hook. B. M. 2708. In Mexico. $\hbar$.

301. S.? Dillenii Schult. caule herbaceo; ramis teretibus subangulatis; fol. ovato-ovalibus; cymis fructiferis arrectis. Rchb. ic. IX. Dill. Elth. f. 355. In sylvis Hungariae. ๑. 3pedale. Folia Belladonnae.

302. S.? atrovirens Plukn. t. 62. f. 2. spinosum, atrovirens et undique glahrum; fol. branchae ursinae divisuris. In India. $\hbar$.

303. S.? brasilianum Plukn. $t$. 451. $f$. 4. folio integro mucronato glahro, papas americani fioribus in summitate caulis. Plukn. In Brasilia. 
301. S.? trifoliatum Jurm. ind. t. 22. f. 3. caule fruticoso; fol. ternatis ovatis integerrimis. Burn. In Coromandelia. $\hbar$.

30.5. S.? Pluknetii Schult. indicum; laurinis angustioribus foliis maximum. Plukn. t. 277. f. 2. In India.

306. S.? chinense Plukn.t. 62. f. 1. incanum; chinense; minus spinosum; floribus parvis vere umbellatis; fructu majore aureo. Pluku. In China. ち.

30\%. S. bauerianum Endl. prodr. fl. Norf. n. 109. In ins. Norfolk.

\section{LYCOPERSICUM Anguill. (1560).}

1. L. pimpinellifolium Dun. glabrum; caule herbaceo; fol. aequaliter pimatisectis; segmentis integerrimis; pedicellis nudis. In Peruvia. Habitus solani esculenti.

2. I. regulare Dun. $t$. 81 . subvillosum; caule subherbaceo; fol. regulariter pinnatisectis canescentibus; pedunc. pedicellisque saepe ebracteatis. Fatria ignota. 4. Cor. laete flava.

3. L. peruvianum Mill. villosum; cancscens; caule subherbaceo; fol. stipulaceis inaequaliter pinnatisectis; segmentis ohtusiusculis; pedunc. pedicellisque bracteatis. Jacq. ic. 327? Feuill. t. 25. I. dentatum Dun. t. 82. B. M. 2814. In Peruviu. 2.

4. L. hirsutum Dun. t. 83. fol. interrupte pinnatis hirsutis; foliolis dentato-crenatis; pedunc. racemosis subhracteatis; calycibus corollam subaequantibus. In Permvia.

5. L. esculenium Dun. Sol. $t .3$. f. 3. fol. interrupte pinnalis pilosis; foliolis incisis subtus ylaucescentibus; pedunc. racemosis; florilus globosis. Solanum Humboldtii W. S. Lycopersicum L. S. pseudolycopersicum Jacq. Plenk. t. 122. Blackw. t. 133. In Amer. austr.

6. L. pyriforme Dun. $t$. 26. fol. interrupte pimatis pilosis; foliolis incisis subtus glancescentihus; pedunc. racemosis ; fructilus oloconicis. S. pomiferum Cav. In Amer. austr. $\odot$. Cor. flava.

7. L. procumbens Dun. caule herbacco procumbente; fol. pinnatifidis glabris; floribus solitariis axillaribus.
Solanum Mill. Patria ignota. $\odot$. Cor. ocliroleuca.

\section{WTTHERINGIA Herit. (1783).}

\section{a. Fruticosae.}

1. W. Solanaceu Herit. Sert. t. 1. caule piloso subherbaceo angulato; fol. ovato-lanceolatis pilosiusculis; pe-dunc. 1-floris umbellatis petiolo longiorihus. Lam. ill. t. 82. In Amer. merid. 4, 1-ped. Cor. dilute lutea.

2. W. stramonifolia Bonpl. caule arboreo; ramis angulatis pubescentibus; fol. inaequaliter subcordatis dendato-angulatis villosis; umbellis sessilibus; filamentis superne barbatis. In Mexico. 古.

3. W. macrophylla Dun. t. 78. ramis subangulatis glabriusculis; fol. ovalo-ellipticis acutis subrepandis; umbellis sessilibus; filamentis barbatis. In Nov. Granata. $\hbar$.

1. W. ciliata Kunth; fruticosa; ramis teretibus glabris; fol. oblongis acutis basi angustatis integerrimis ciliatis glabris geminis; pedunc. elongatis. In Sova Granata. $ђ$.

5. W. mollis Kunth; fruticosa; ramis teretibus cano-tomentosis; fol. ovatis ntrinque acuminatis integerrimis, supra pubescentibus, subtus molliter tomotosis inaequalibus; pedunc. elongatis. In Peruvia.

6. IV. rhomboilea Dun. $t$. 78. caule fruticoso; fol. geminis subcordatis ovalo-rhombeis utrinque tomentosis; pedunc. 1-noris umbellatis axillaribus. In monte Quindiu. ち.

\%. W. dumetorum Dun. $t$. \%9. fol. ovatis utrinque acuminatis tomentososericeis superioribus geminis; pedunc. 1-floris umbellatis. In Nov. Granata. 市.

8. W. viparia H. et $K$. ramulis angulatis ? hispido-pilósis; fol. suboblique obovato-oblongis acuminatis basi acutis. In Nov. Granata. $\hbar$.

9. W. crassifolia Dun. caule fruticoso sarmentoso; fol. ovatis integris vel sinuato-angulatis pilosis ohtusiusculis; panicula subdichotoma reclinata. Dill. Eith. f. 352. In Prom. b. spei. 占.

10. W. angustifolia Dun. $t .80$. ramis flexuosis teretibus subtomentosis; fol. lanceolatis glabris; racemis paucifloris. In Quito. ち. 
11. Wr. aspera Spr. caule scandente teretiusculo aspero; fol. oppositis aequalibus petiolatis integerrimis asperis; pedunc. racemosis; floribus secundis. In Brasilia. 4.

12. W. umbellata Dun. t.2\%. caule herhaceo alato piloso; fol. ovatis utrinque attenuatis sinuato-dentatis pilosis ; racemis subsolitariis ; pedicellis umbellatis. In Domingo. $\odot$ ?

13. W. montana Dun. radice tuherosa; caule herbaceo piloso; fol. pilosis ovatis integris $s$. dentato-repandis; pedunc. 1-floris 8. multifloris. B. M. 2768. Solauum montanum Feuill. t. 46. Fl. peruv. t. 160. f. b. In Peruvia et Chili. 4. Tripollicaris. Cor. rosea.

11. W. phyllantha Dun. caule herbaceo alato; fol. pilosis cuneiformibus apice sublohatis decurrentibus; racenis e foliis nascentibus. Solanim phyllanthum Cav. t.359. f. 1. In Perucia. $\odot$. Cor. dilute caerulea.

15. $W$. pinnatifida Dun. caule herbaceo alato; fol. pilosiusculis decurrentibus; laciniis obtusis sinuatis; pedunc. paniculatis ebracteatis. solanum pinnatifidum $R$. et $P$. peruv. $t$. 170. f. b. In Peruvia. $\odot$. Cor. alba.

16. W. multifida Dun. caule herbaceo; fol. 2-pinnatifuis pilosiusculis in petiolum decurrentibus; laciniis obtusis dentatis; petiolis amplexicaulibus; pedunc. basi foliatis. Solanum pimatifidum R. et P. peruv. t. 171. f. a. In Peruvia. Cor. saturate caerulea.

1\%. W. picta MIart. t. 22\%. In Brasililia $\hbar$.

18. W. divaricata Mart.t.278. In Brasilia. †.

19. W. diploconus Mart. $t$. 229. In Brasilia. $\hbar$.

\section{DIERBACHIA Spr. (1825).}

1. D. solanacea Spr. Dunalia soianacea Humb. et K. t. 19t. In Nova Granata. b. Frutex alternifolius pube stellulata. Folia integra. Unbellae extraaxillares sessiles. Cor. albida.

\section{JABOROSA Juss. (1789).}

1. J. integrifolia Lam. ill. $t .111$. fol. ovatis subintegerrimis ; flore longe tubuloso. In Buenos Ayres.

2. J. runcinata Lam. fol. sinuatolyratis dentatis; flore brevi subcampanulato. In Buenos Ayres.

\section{0\%. ANISODUS LK. (1S21).}

1. A. lucidus Lk. Nicandra anomala Lk. et Otto Abb. t. 35. In Nepalia. Herha ramosa; fol. oblongis subtus pubescentibus; pedunc. 1-floris cernuis; floribus viridi-fuscis.

\section{LYCIUII Diosc.}

\section{a. Spinosa.}

1. L. afrum $L$. fol. linearibus subcarnosis basi attenuatis fasciculatis; ramis spinescentibus pendulis; staminibus subinclusis. Mill. ic. t. 171. f. 1. Plenk. t. 127. Micheli t. 105. f. 2. In Africa et Palaestina. $\hbar$. Arbuscula 12 -ped. Cor. violacea. Bacca lutea.

2. L. rigidum Thunb. fol, linearibus fasciculatis; ramis strictis spinescentibus; staninibus tubum corollae aequantibus; dentibus calycis ciliatis. L. afrum $\beta$. Trew. Ehret. t. 24. f. 1. L. carnosum Dun. In Prom. b. spei. ち. Cor. violacea.

3. L. ruthenicum Murr: fol. fasciculatis linearibus basi attenuatis subcarnosis; ramis divaricatis geminis spinescentibus; staminibus subexsertis. Murr. Comm. 1799. t. 2. L. tataricum Pall. Ross. t. 49. $\beta$. caspicum t. 49. f. A. L. tenue W. L. microplyyllum Duh. In Asia. ち. 6-ped. Cor. rosea.

4. I. barbarum $I$. fol. lanceolatis alternis; ramis dependentibus; gemmis spinescentibus; calycibus trifidis; staminibus limbum corollae aequantibus. Schkuhr. t. 46. Hayne term. t. 10. f. 5. In Asia, Africa et Europa. ђ. Cor. violacea.

5. L. europaeum $L$. fol. oblongolanceolatis obtusis ohlique flexis; ramis laxis spinescentibus; staminibus corollae limbo brevioribus. sibth. gr. 
t. 230. In Europa. $\downarrow$. Flores albido-rubri.

6. L. boerhariaefolium $L$. spinosum; fol. ovatis integerrimis acutis glaucis; floribus paniculatis. Herit. stirp. t. 83. L. heterophyllum Murr. Conmm. 1785. t. 2. Grabowskia boerhaaviaef. Schl. In Peruvia. 古. Frutex pulcherrimus. Cor. alba aut dilute violacea.

\%. L. tetrandrum $\boldsymbol{L}$. spinosum; fol. ovatis obtusis; ramis angulatis; c0rollis 4-fidis. L. horridum Thunb. In Prom. b. spei. ち.

8. L. cinereum Thunb. fol. lance0latis glabris; ramis spinescentibus; peduno. brevissimis; staminibus subexsertis. Cestrum lycioides. Licht. In Prom b. spei.

9. L. obovatum $\boldsymbol{R}$. et P. peruv. $t$. 183. $f$. $c$. spinosum; fol. obovatis obtusissimis; spinis foliosis, vetustioribus nudis; floribus paucis nutantibus. In Peruvia. $\downarrow$. Cor. purpure0-violacea.

10. L. horridum H. et $\boldsymbol{K}$. spinosissimum; fol. fasciculatis obovatis obtusis glabris ; floribus axillaribus solitariis pendulis; corollis tubulosis ; staminibus subinclusis. In Peruvia. †. Cor. violacea.

11. L. ciliatum Schl. ramis elongatis scandentibus; ramulis subspinescentibus; fol. sparsis late ovatis acutis denticulato-ciliatis glabris. In $\mathrm{Bra}$ silia. †. Cor. extus glanduloso-puberula.

12. L. cestroides Schl. ramulis spinescentibus; fol. late lanceolatis acutis glabris; calycis tubulosi dentibus acutissimis; cor. margine pubescentibus, In Brasilia. ఫ.

\section{b. Inermia.}

13. $\boldsymbol{L}$. arborescens $\mathrm{Spr}$. caule frotescente; pedunc. confertis; cor. revolutis; fol. oblongis. L. Cestrum Lam. In Jamaica. $\hbar$. Cor. albida.

11. L. umbellatum $R$. et Pav. pevuv. $t$. 18: $f$. $b$. fol. oblongo-lanceolatis; pedunc. rameis; floribus umbellatis; calycibus 5-gonis. In Peruvia. t. Arbor 15-ped. Cor. violacea.

15. L. guayaruilense $H$. et $\mathbf{K}$. arboreum ; fol. elliptico-oblongis acutis supra puberulis, subtus molliter tomentoso-pubescentibus; umbellis extraaxillaribus sessilibus; corollis infun- dibuliformibus; staminibus exsertis. In Quito. ђ.

16. L. floribundum Bonpl. volubile? fol. oblongis acutis supra glabris subtus pubescentibus; umbellis extraaxillaribus sessilibus; staminibus exsertis. In Peruvia. ち. Cor. alba.

17. L. fuchsioides Bonpl. aequinoct. $t$. 42. ramulis puberulis; fol. obovato-oblongis obtusiusculis glabris; unhellis sessilibus; corollis tubulosis; limbo 5-dentato; staminibus exsertis. In Quito.

18. L. loxense $\boldsymbol{H}$. et $\boldsymbol{K}$. arboreum; ramulis pubescenti-tomentosis; fol. ovatis subacuminalis utrinque puberulis; umbellis sessilibus. In Peruvia. Ђ. Cor. flava.

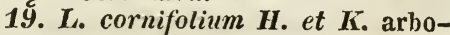
reum; ramulis canescenti-tomentosis; fol. subrotundo-ovatis subacumiuatis complicatis subtus fuscescenti-tomentosis; corollae limho 10-fido. L. ovale R. et s. In Quito. ち.

20. L. umbrosum H. et $\boldsymbol{K}$. arboreum; ramulis hirto-pubescentibus; fol. oblongis acuminatis glabriusculis, floralibus rhomboideis; unbellis sessilibus; cor. 10-dentata hirtella. In Nov. Granata. 市.

\section{CARISSA L. (1\%6\%).}

1. C. Carandas $L$. fol. oblongis obtusis laevibus integerrimis reticulato-venosis; spinis axillaribus 2-fidis; pedunc. corymbosis. Lam. ill. t. 118. f. 1. Ann. Mus. 8. t. 32. f. 2. Roxb. Corom. t. 7\%. In Ind. or. ђ. Arbor 15-ped. Flores Jasmini facie.

2. C. spinarum L. fol. ovatis acutis denticulatis laevibus; spinis geminis; pedunc. 3-floris. Lam. ill. t. 118. f. 2. Runuph. \%. t. 19. f. 1. In ins. Molucc. Ђ. Arbor. Cor. alba.

3. C. ovata $R$. Br. fol. ellipticooblongis acutis mucronatis integerrimis margine lineatis; spinis divaricatis. C. diffusa Roxb. In Ind. or. et Nov. Holl. 5 .

4. C. scabra R. Br. fol. ovatis mucronatis utrinque scabris; ramis diffusis spinosis. In Nov. Holl. ち.

5. C. lanceolata R. Br. fol. anguste lanceolatis; ramis spinosis ; laciniis corollae subulatis. In Nov. Hollandia. 
6. C. Xylopicron Aub. Obs. des il. custr. p. 21. c. ic. fol. ovato-aciminatis nervosis glaberrimis; pedunc. lateralibus spinosis; ramis cymosopyramidatis; fructibus oblongis. In ins. Mascarenh. $\hbar$. Arbor parva.

\%. C. madagascarensis Aub. fol. ovato-rotundatis; fructibus rotundatis. In Madagascar. $\hbar$.

8. C. hirsuta Roth; spinosa; fol. subrotundo - ovatis venosis utrinque subtomentosis ; ramis cinereo-tomentosis; laciniis corollae lanceolatis. C. villosa Roxb. In Ind. or. †.

9. C. inermis Vahl; fol. cordatoovatis mucronatis integerrimis; pedumc. terminalibus ternis. In Ind. or. $\hbar$.

10. C. axillaris Roxb. spinis oppositis recurvis ; fol. oblongis ; corymbis multifloris. In ins. Mascarenh.

\section{WILLUGHBEIA Scop. (1788).}

1. $W$. scandens $W$. caule scandente; ramis cirhiformibus floriferis; fol. oblongis glabris; fructibus 1-10cularibus. Pacuria Aubl. Guj. t. 105. In Gujana. Ђ. Flores flavi.

2. W. edulis Roxb. caule scandente; fol. elliptico-oblongis; pedunc. cymosis axillaribus petiolo hrevioribus; fructibus maximis 1-locularibus. In Ind. or. 古.

3. W. acida $\boldsymbol{W}$. caule erecto; fol. oblongis glabris; floribus axillaribus sessilibus; fructibus 2-Iocularibus. Ambelaria acida AubI. t. 104. In Gujana. ђ. Arbuscula 6-ped. Flores albidi.

4. W. zeylanica Spr. caule erecto; ramis 4-gonis; fol. obovatis obtusissimis integerrimis; pedunc. subternis. Fagraea Thunb. act. t. 4. In Zeylona. †. Frutex 2-ped. Cor. magna.

5. W.javanica Blume; caule scandente cirrhifero; fol. oblongo-lanceolatis apice obtusiusculis tenuiter parallelo-venosis; pedunc. cymosis. In Java. 古.

6. H'. celebica Blume; caule scandente; fol. elliptico-ohlongis acnminatis venosis; pedunc. cymosis axillaribus petiolo aequalibus. In Java. $\downarrow$.

\section{CAMAX Schreb. (1789).}

1. C. fraxinea W. Lam. ill. $t$. 121. Aubl. t. \%8. In Gujana. ђ. Frutex 15-ped. Folia numerosa verticillata impari-pinnata; foliolis oblongis acuminatis integerrimis. Flores parvi rufescentes. Bacca flava.

\section{NICANDRA Adans (1763).}

1. N. physalodes Gaertn. t. 131. fol. oblongis sinuato-angulatis dentatis glabris. Alropa L. Calydermos erosus IR. et P. peruv. Jacq. obs. t. 98. In Peruvia. $\odot$. Cor. caerulea.

2. N. indica is. et S. fol. ovatooblongis integerrimis glabris. Physalis indica Lam. Barr. ic. 1129. Humph. 6. t. 26. f. 1. In Ind. or. $\odot$.

\section{SOLANDRA Sw. (17S\%).}

1. S. grandiflora $\boldsymbol{R}$. et $\mathbf{S}$. floribus sessilibus; laciniis corollae obtusissimis. Sw. Act. Holm. 1787. t. 11. Fl. ind. t. 9. Ann. Mus. 8. t. 4. f. 1. Jacq. Schoenbr. t. 45. Datura sarmentosa Lam. In Jamaica. ち. Arbuscula scandens. Cor. violacea.

2. S. viridiflora Ker; floribus pedunculatis; laciniis corollae acuminatis revolutis. In Brasilia. $\hbar$.

\section{DESFONTAINEA R. et $P$. (1798).}

1. D. spinosa R. et P. peruv. $t$. 156. fol. ovato-dentatis spinosis; caIycibus villosis. In Peruvia. Arbuscula 12-ped. Cor. coccinea.

2. D. splendens Bonpl. aeq. t. 45. fol. oblongis dentato-spinosis; calycibus glabris. In Peruvia. ち. Arbuscula 6-8-ped. Cor. laete rubra.

\section{4b. CERIUM Lour. (1790).}

1. C. spicatum Lour. Lil Cocrialchina. Herha simplex. Hadix repens. Folia lanceolata multinervia integerrima glabra. Flores spicali albi. 


\section{BARRERIA Scop. (1780).}

1. B. theobromaefolia W. Paraqueiba grjanensis. Aubl. t. 4\%. Lam. ill. t. 131. In sylvis Gujanae. ந. Arbor 50-ped. Flores parvi albi.

\section{TORREYA Spr. (1821).}

1. T. paniculata Spr. N. Entd. 2. p. 121. In Brasilia.

\section{TRATTINICKIA Willd. (1805).}

1. T. rhoifolia $\boldsymbol{W}$. In Brasilia. $\downarrow$. Arbor. Folia pinnata stipulata. Flores glumerati albi.

\section{MINA Lexaz. (1824).}

1. M. lobata Cerv. In Mexico.๑. Caulis volubilis ramosus. Folia cordato-triloba, subtus scabra subhirsuta, supra glabra. Pedunculi racemosi bifidi longissimi. Flores lutei dein rubri.

\section{DIPLOCALYMMA Spr. (1822).}

1. D. volubile Spr. Patria ignota. Herba volubilis. Convolvuli facie. Fol. cordato-oblonga acuta 3nervia hirsuta. Flores solitarii albi.

\section{NECTOUXIA H. et K. (1818).}

1. $N$. formosa $H$. et $K$. t. 193. Atropa arenaria Willd. In Iriexico. $\odot$. Herba. Folia solitaria seu gemina integra. Pedunculi 1-flori. Cor. fava nigrescens.

\section{SPERMADICTYON Roxb. (1816).}

1. S. suaveolens Roxb. corom, $t$. 236. fol. lanceolatis; capitulis florum umhellatis pedunculatis terminalibus; calyce glanduloso-hirto. Hamiltonia Roxb. cat. B. R. 318. In Ind. or. ち. Cor. alba.
2. S. azureum Lindl. B. R. 1235. fol. ovato-lanceolatis breve acuminatis utrinque scabris; calyce villoso. Hamiltonia scabra Don. In Nepalia. 4. Flores suaveolentes caerulei.

3. S. pilosum Spr. rigidun; valde pilosum; fol. Ianceolatis; florum fasciculis axillaribus bracteatis. Hamiltonia Don. In ins. Molucc. ち.

\section{BELONIA Plum. (1\%03).}

1. B. aspera $S w$. ramis inermibus; fol. ovatis dentatis subtus hispidis; floribus corymbosis. Lam. ill. t. 149. In Ind. occ.

2. B. spinosa $\mathbf{S} w$. ramis spinosis; fol. ovatis dentato-angulatis subtus incanis; pedunc. axillaribus 1 -floris. In Hispaniola.

\section{SAMOLUS Plin.}

1. S. Valerandi $L$. caule erecto; fol. obovato-spathulatis integris; racemo subpaniculato; pedicellis bracteatis. s. floribundus $H$. et K. Fl. Dan. 198. Schk. t. 40. E. B. 703. Sedum alsinefolium All. ped. t. 22. f. 2. In salsis et fossis Europae, Asiae, Africae et Americae. $\odot$. Pedalis. Cor. alba.

2. S. americanus Spr. fol. inferioribus obovatis, superioribus oblono:is utrinque attenuatis; corymbis laxis; pedicellis elongatis. In Nov. Caesarea.

3. S. campanuloides $\boldsymbol{R}$. $\boldsymbol{B r}$. fol. inferioribus obovatis, caulinis lanceolatis; caule punctato scabro; floribus racemosis; cor. calycem triplo superante. Campanula porosa. In Prom. b. spei.

4. S. ebracteatus H. et K. t. 129. caule erecto simplici; fol. oblongis acutiusculis crassiusculis ; racemis axillaribus longe pedunculatis; capsulis depresso-globosis. In Cuba. b.

5. S. junceus R. Br. caule erecto subsimplici tereti subaphyllo; foliolis stipulaeformibus remotis; fol. radicalibus obovatis spathulatisque; racemo paucifloro; calycibus acutis. In Novo Holl.

6. S. littoralis $\boldsymbol{R}$. $\boldsymbol{B r}$. caule tereti ramoso folioso; fol. radicalibus spathulatis, caulinis lanceolatis; calycis 
laciniis acutis. S'lueffieldia repens Forst. S. incana Labill. t. 54. In Nov. Holl.

\%. S. ambiguns $\boldsymbol{R}$. Br. fol. remotis lineari-subulatis; caule ramoso; racemis raris; calycibus obtusis basi intrusa. In Nov. Holl.

\section{LYSIPOMA H. et K. (1S18).}

1. L. montinioides $\mathrm{H}$. et K. $t .266$. f. 2. caule repente; fol. spathulatis subcarnosis; pedunc. axillaribus; laciniis calycis inaequalibus obtusis. Lobelia limoselloides $\mathbf{K}$. et S. In Quito. 24.

2. L. reniformis $\boldsymbol{H}$. et K.t. 266 . f. 1. caule repente; fol. orbiculatoreniformibus emarginatis; floribus axillaribus solitariis; laciniis calycis acqualibus acutis glabris. Viola algida W. Hb. In Quito. 4.

3. L. aretioides $I I$. et $K$. $t$. $26 \%$. f. 1. caespitosa; caulibus abhreviatis; fol. stellato-congestis oblongo-spathuIatis acutis rigidis; laciniis calycis acutis ciliatis. Lobelia glandulosa W. Hb. In Peruvia. 4.

4. L. acculis H. et K. t. 267. $f$. 2. caespitosa; acaulis; fol. radicalibus stellato-congestis linearibus obtusis rigidis; pedunc. radical. 1-floris; calycis laciniis obtusis. Lobelia androsacea W. Hb. In Peruvia. 4.

\section{ROELLA L. (1737).}

1. R. incurva Hb. Banks. fol. lineari-acuminatis apice incurvatis, inferioribus setaceo-ciliatis, superioribus laciniato-dentatis ; lobis calycis laciniato-dentatis; cor. longitudine calycis. In Prom. b. spei. $\hbar$.

2. R. ciliata $\boldsymbol{L}$. fol. erectis lineari-accuninatis ciliatis, superioribus longioribus integris; floribus solitariis; lobis calycis ciliatis et laciniato-dentatis; cor. ampla variegata. Plukn. t. 252. f. 4. Comm. Hort. t. 79. B. M. 378. B. Cab. 1156. Herb. de l'amat. t. 332. In Prom. b. spei. 4. Cor. pallide violacea.

3. R. reticulata $L$. fol. subulatis ciliatis; floribus solitaris; lobis calycis subciliatis integris brevibus. Petiv. mus. f. 157. In Prom. b. spei. b. Cor. alba.
4. R. Thunbergii A. DC. Camp. fol. lanceolatis ciliatis; floribus solitariis; caule glabro. Campanula ciliata Thunb. In Rrom. b. spei. 4.

5. R. Dunanthii A. DC. Camp. fol. suberectis lineari-acuminatis ciliatis; floribus solitariis vel glomeratis; 10bis calycis intus pubescentibus remote dentatis. In Prom. b. spei. ち. Caul. 1-ped. Cor. albida.

6. R. cinerea A. DC. fol. erectis lineari-subulatis remote denticulatis hasi suhtomentosis; foribus solitariis vel fasciculatis; lohis calycis integris glabris. Campanula Thunb. Mém. petersb. 4. t. 6. f. 4. In Prom. b. spei. ち. 1-ped. Cor. allida.

\%. R. spicata 'I'lunb. fol. lanceolatis ciliatis; floribus terminalibus aggregatis. In Prom. b. spei. ち. Caul. fruticosus brevissimus. Cor. alba.

8. R. Stuarrosu' L'unzb. fol. ovatoacutis decurrentibus apice cuspidatis margine ciliatis setaceo-dentatis; floribus glomeratis; bracteis latis ovatoacuminatis; calyce ciliato. Ih. filiformis Lam. ill. t. 123. f. 2. In Prom. b. spei. ち. Suffrutex 1-ped. Cor. albida.

9. R. muscosa Thunb. fol. patentibus ovato-aculis remote serratis glabris; floribus solitariis; lobis calycis ovato-acuminatis integris glabris vel subciliatis. In Prom. b. spei. 4. Planta humillima. Cor. caerulea.

10. R. minor Ecl. pusilla; caule suffruticoso erecto pilosissimo; fol. patentibus linearibus albo-villosis; floribus solitariis; bracteis calyceque dentibus longissinis ciliatis. In Prom. b. spei. Ђ.

11. R. Eclonianc Buek. MIss. callle ramoso flexuoso; fol. fasciculatis sessilibus lineari-acuminatis ad basin ciliatis integris; floribus fasciculatis; calycis lohis ciliatis longissimis. In Prom. b. spei. 方.

12. R. gracilis Buek. Mss. gracillima; caule suffruticoso ramoso; fol. brevissimis alternis subulato-linearibus glabris; floribus solitariis; calycis lobis longissimis integris s. iaciniato-dentatis. In Prom. b. spei. ち.

13. R. ericoides Ecloil et 'zieyh. non Spr. caule ramoso lignoso; fol. lineari-subulatis glabris; calycis laciniis acuminatis. In Prom. b. spei. $ђ$.

11. R.bryoides Ecl. et Zeyh. cauIc ramoso lignoso glabro; fol. sessi- 
libus reflexis lineari-acuminatis ciliatis; calycis lobis ciliatis incurvo-patulis lineari-acuminatis. In Prom. $b$. spei. t.

15. R. secunda Ecl. et Zeyh. caule ramoso lignoso glabro vel velutino; ramis paniculatis; fol. sessilibus lineari-acuminatis denticulatis hasi ciliatis; calycis Iaciniis ovato-lanceolatis. In Prom. b. spei. $\hbar$.

16. R.? decurrens Herit. sert.t. 6 . fol. patulis decurrentibus ovato-oblongis hasi ciliatis suhintegris; floribus solitariis; lohis calycis acuminatis ciliatis corolla triplo brevioribus. In Prom. b. spei. $\odot$.

1\%. R.? pedunculata Berg. fol. linearihus angustis glahris basi spinoso-ciliatis; pedunc. solitariis; hracteis calycisque laciniis acutis ciliatis. In Prom. b. spei.

18. R. bracteata Thunb. fol. acutis integris limeari-3-gonis reflexis glahris; floribus teminalibus subsolitariis; bracteis ovato-acuminatis ciliatis. In Prom. b. spei.

19. R. glauca Eclon. et Zegh. enum. n. 386. sine descript. In Prom.b. spei 4.

20. R. prostrata Eclon et Zey/l. ibid. sine descript. In Prom. b. spei.

\section{LECONTEA Rich. (1830).}

1. L. argentea A. Rich. fol. ovalibus abrupte acuminatis hasi ohtusis suhtus argenteo-tomentosis; spicis fasciculatis; fructibus oblongo-ovalibus. Rich. mém. t. 20. f. 1. et 2. In $N a-$ ilagascaria. ந..

2. L. Bojeriana A. Rich. fol. cordiformilus tomentosis apice abrupte acuminatis; spicis fasciculatis brevissimis revolutis; fructibus suborbicularibus. In Madagascaria. 卢.

\section{2\%. MACHAONIA Bonpl. (1SOS).}

1. M. aruminata Bonpl. aeq. $t$. 29. inermis ; fol. ovato-ellipticis breviter acuminatis utrinque pubescentibus. Prope Guayayuil. ђ.

2. M. brasiliensis Cham. et Schl. inermis; fol. ohlongis late lanceolatis acuninatis; venis suhtus pubescentibus. Cinchona brasiliensis Hoffm. In Brasilia. ђ. Cor. parva alba.

3. HI. spinosa Cham. et Schl. ramulis spinescentibus; fol. elliptico- lanceolatis utrinque acnminatis glabris. In Brasilia. 古.

\section{CANEPHORA Juss. (1789).}

1. C. axillaris Lam. ill. $t .151$. f. 1. fol. ellipticis acutis breve petiolatis; pedunc. axillaribus a basi ad apicem incrassatis apice in cupula 56-loba flores gerentibus. In Madayascar. ђ.

\section{RONDELETIA PlIm. (1703).}

$$
\text { a. Calyce 5-10bo. }
$$

1. R. laurifolia Sw. fol. Ianceolato-ohlongis acutis glabris; stipulis deltoideis; floribus racemosis ; cor. tubo hrevissimo adpresse villoso. Brown. jam. t. 2. f. 2. In Jamaica et Guadelupa.

2. R. racemosa Su. fol. Ianceolato-ovatis acuminatis petiolatis glahris; stipulis suhdeltoideis; racenis sul-axillarihus trichotomis patulis. Brown. 1. c. t. 2. f. 3. In Jamaica. ち.

3. R. thyrsoidea Su: fol. oblongis acutis petiolatis membranaceis, supra ramisque glabris, subtus pubescentihus; stipulis late ovatis acutis rigidis. In Jamaica. ち. Cor. luteo-albida ferrugiuea.

- R. R. umbellulata Su'. fol. lanceolato-ovatis acutis subhirsutis petiolatis; stipulis hirsutis acumine setoso ; pedunc. trichotomis. In Jamaica. ち. Cor. magna extus pubescens, fusco-flavicans.

5. R. tomentosa $\mathbf{S} w$. fol. ovatis acuminatis petiolatis membranaceis supra hirtis subtus villoso-tomentosis incanisque. In Jamaica. ち. Flores parvi albi s. fusco-lutei.

6. $R$. incona $S w$. fol. ovato-lanceolatis petiolatis supra glabris subtus hirsuto-scahris incanescentibus; stipulis brevissimis truncatis albidociliatis. In Jamaica et Hispaniola. $\hbar$. Cor. Iutescens.

\%. R. hirta Sw. fol. oblongis acuminatis subpetiolatis subtus nervosis hirtis rigidis; pedunc. axillaribus trichotomis; calycis lobis linearibus. Gaertn. t. 84. Lodd. 356. In Jamaica. 卉. Cor. lutescens.

8. R. panamensis DC. prodr. fol. ovali-ohlongis utrinque acuminatis supra glabris subtus albidis in nervo 
venisque pilosis; stipulis 2 -angularibus acutis extus villosis. $\mathbf{R}$. hirta Bartl. In Panama. 古.

9. R. lirsuta sw. fol. oblongis acuninatis utrinque hirsutis subtus pallidis brevi-petiolatis; stipulis ovato-lanceolatis; ramulis, pedunculis floribusque hirsutis. In Jamaica. $\hbar$.

10. R. trifolia Jacq. am. $t$. 43. fol. ternatis breve petiolatis oblongolanceolatis supra glabris subtus leviter tomentosis; petiolis ramulisque hirsutis; paniculis axillaribus. In $\mathbf{J} a-$ maica. $\hbar$.

11. R. laevigata Ait. fol. oblongis ellipticisve acuminatis glabris subtus pallidioribus petiolatis; stipulis deltoideis extus glabris intus barbatis. In Cuba. 4.

12. $R$. americana $I_{1}$. fol. lanceolatis utrinque acuminatis subpetiolatis glabris; stipulis deltoideis extus pubescentibus; pedunc. oppositis. In Cuba. ち. Hlores albi.

13. R. cumanensis $\boldsymbol{H}$. et $\boldsymbol{K}$. fol. oblongis acuminatis subsessilibus glabris subtus pallidioribus; stipulis subdeltoideis subtus ciliato-sericeis. In Nov. Andalusia. $\hbar$.

14. R. microdon DC. prodr. fol. ovalibus oblongisve utrinque acutis brevissime petiolatis; stipulis utrinque bipartitis obtusis persistentibus; calyce truncato brevissimo 5 -dentato. Ad Havannam. ち. Flor. albi.

15. R. odorata Jacq. $t$. 42. fol. vix petiolatis ovatis cordatisve acutiusculis supra sparse scabris subtus pallidioribus. In Havanna. R. coccinea. Fl. mex.

16. R. Iongiflora Cham. et Schl. fol. lanccolatis in petiolum angustatis acuminatis margine reflexis in axillis vellarum barbatis; cor. Iaciniis ellipticis acuminatis. In Brasilia. \$.

\section{b. Calyce 4-10 bo.}

1\%. R. virgata $S w$. fol. cordatis subrotundis brevissime petiolatis glaberrimis; stipulis minutis acutis; ramis filiformibus patentibus; pedunc. elongatis 3-fidis. Hedyotis cordifolia Spr. In Hispaniola. $\hbar$. Flores fusco-purpurei.

18. R. discolor $H$. et $\boldsymbol{K}$. fol. ovato-oblongis acuminatis margine revoIutis petiolatis suhtus albo-tomentosis; stipulis lineari-subulatis; paniculis sessilibus. Hedyotis discolor Spr. In Nov. Granata. ந. Cor. rubra.

19. R. pubescens $H$. et $K$. fol. oblongis acutis petiolatis, supra tenuissime puberulis, subtus ramulisque canescenti-pubescentibus; stipulis lanceolato-subulatis; paniculis terminalibus. In Nov. Granata. $\hbar$.

20. R. elongata Bartl. fol. elliptico-oblongis utrinque acuminatis, supra pubescentibus, subtus albido-tomentosis demum calvescentibus; stipulis lanceolatis; paniculis terminalibus. In Mexico. $\hbar$.

21. R. leucophylla $\boldsymbol{H}$. et $\boldsymbol{K}$. fol. lineari-lanceolatis acuminatis subsessilibus, supra pubescentibus, subtus albis ramulisque lanato-tomentosis; paniculis longe pedunculatis. Hedyotis Spr. In Mexico. ち. Flores rubri.

22. R. Berteriana DC. fol. ovalibus acutis basi subcuneatis petiolatis supra pubescenti-villosis subtus moIliter villoso-tomentosis canis; stipulis acuminatis villosis. In Domingo. $\hbar$.

23. R. pilosa $\mathbf{S w}$. fol. ovato-lanceolatis oblongisve subsesşilibus venosis superne asperulis; stipulis latis deltoideis villosis; pedunc. calycibusque pilosis. R. triflora Vahl. Symb. t. 53. Hedyotis spr. In ins. Caribaeis et St. Crucis et Martinica. $\hbar$.

21. R. buxifolia Vahl Ecl. $t$. 12. fol. obovato-oblongis brevissime petiolatis apice mucronulatis superne lucidis; stipulis deltoideis parvis ; pedicellis brevissimis 1-floris. Catesbaea inermis et Ixora buxifolia Spr. In Mont-serrat et Portorico. $\hbar$.

25. $R$. royenaefolia DC. prodr. fol. obovato-oblongis brevissime petiolatis obtusis submucronatis utrinque pube brevi incanescentibus; stipulis lanceolatis acutis. In Domingo. $\hbar$.

26. R. leptacantha DC. prodr. spicis oppositis; fol. late ovalibus subacutis utrinque glabris, junioribus ramulisque subpilosis; pedunc. 3-5-floro. In ins. Cuba. ђ.

27. R. brachyacantha DC. prodr. spinis oppositis ; fol. elliptico-oblongis basi acutis apice acuminatis, supra glabris, subtus ramulis floribusque villosis; pedunc. 3-4-floro. In $\mathrm{Br}^{*} \mathrm{a}-$ silia. ‡. 
28. R. parriflora Poir. fol. oblongis hasi cumeatis apice obtusis et acuminatis petiolatis glaherrimis subtus coriaceis; floribus corymbosis. In ins. Martinica. 支.

29. R. rliynchospora $\boldsymbol{H}$. et $\boldsymbol{K}$. fol. oblongo-ellipticis acutis breviter petiolatis, supra ramisque pubescentilius, suhtus canescenti-tomentosis; seminibus utrínque rostratis. In Nov. Granata. t.

30. R. disperma Jac\%. am. t.59. fol. ovalibus ohtusis petiolatis glahris; racemis axillarihus compositis laxis 3fidis; fructu subbaccato dispermo. In Carthayena. 卢.

31. R. coriacea spr. non Wall. fol. ovali-oblongis coriaceis, supra nitidis, subtus ramulisque velutinis; stipulis semiorbiculatis; dente medio subulato pungente. In Brasilia. ‡.

\section{CHIMARRHIS Jacq. (1762).}

1. C. cymosa Jac\%. am. 61. fol. ovatis utrinque acuminatis; corymbi ramis alternis; capsulis obovatis brevissimis. In Martinica. †. Cor. alba.

2. C. turbinata DC. prodr. fol. ovalibus apice obtusis basi acutis; corymbi ramis oppositis; caps. turbinatis. In Cayenna.

\section{SIPANEA Aubl. (17\%5).}

1. S. pratensis Aubl. Guj. t. 56. caule hasi repente; fol. ovato-lanceolatis scabriusculis hasi ciliatis; floribus sessilibus subterminalibus subcorymbosis. Virecta pratensis Valı. In Cayenna. $\odot$. Cor. rosea.

2. S. dichotoma. H. et $K$. fol. lanceolatis utrinque villoso-sericeis; panicula terminali dichotoma. Virecta Spr. Ptychodea dichotoma Willd. Hb. Ad Orinocum. 4. Cor. rosea.

3. S. glomerata H. et K. fol. ohlongo-lanceolatis margine undulatis utriuque sericeo-incanis; floribus glomeratis terminalibus axillaribusque. Virecta Spr. Ad Orinocum. 4. Cor. flava.

4. S. biflora L. fil. caule repente; fol. ovatis obtusis; pedunc. terminali. e dichotomia ramorum orto bifloro. Rondeletia bitlora Rottb. pl. surin. $t$.
2. f. 2. Gaertn. t. 184. Virecta virens Vahl. In Brasilia. $\odot$.

\section{MACROCNEMUM P. Broun. (17.56).}

1. M. jamaicense $\boldsymbol{L}$. arboreum; fol. oblongo-ovalibus petiolatis laevihus; stipulis ovato-3-angularibus petiolo multo brevioribus; corymbis longe pedunculatis. Sw. olss. t. 3. f. 1. In Guadelupe. 市.

2. IV? stipulaceum Roxb. fol. subsessilihus lanceolatis laevihus; stipulis ovalihus amplissimis; corymbis supradecompositis. In Moluccis. $\hbar$.

3. M? parviflorum Roxb. dumosum; fol. breve petiolatis lanceolatis laevibus; stipulis anmularibus truncatis ; cor. acetabuliformi. In Moluccis.

1. M? tetrandrum A. Rich. fol. elliptico-lanceolatis apice basique acutis discoloribus subtus tomentosis; floribus racemosis parvulis 4-andris; calyce lanuginoso. In Brasilia. $\hbar$.

5. M? tubulosum A. Rich. fol. Iato-ovalibus apice acuminatis basi sensim dimidiatis; petiolis pubescentibus; calycis dentum uno in folium amplum lato-subcordiforme petiolatum desinente. In Brasilia.

6. M. corymbosum R. et P. peruv. $t$. 189. fol. ovato-ohlongis acuminatis hasi cordatis sessilibus plicatis coriaceis; corymbis magnis; dentibus calycis obtusis. Condaminea DC. In Nova Granata. ち. Cor. purpurea.

\%. II. tinctorium $\boldsymbol{H}$. et $\boldsymbol{K}$. fol. rotundato oblongis acutis petiolatis utrinque glabris; florihus capitato-congestis. Condaminea DC. Ad Orinocum.

8. M. microcarpum R. et P. peruv. t. 188. f. $a$. fol. ohlongis obtuse acuminatis subtus pubescentibus; racemis terminalibus calycis dentibus minutis. Condaminea DC. In Peruvia. †. Cor. alba.

9. M. venosum $\boldsymbol{R}$. et $\boldsymbol{P}$. perur. $\boldsymbol{t}$. 190. $f . b$. fol. ovali-oblongis acuminatis vonosissimis lineatis; nervo venisque puberulis; stipulis connatis; floribus sessilibus. Condaminea DC. In Peruvia. $\hbar$. Flores parvi alhi. 10.M? ylabratum Bartl.Hb. Haenk. fol. obovatis breviter acuminatis basi attenuato-cuneatis glaberrimis lineato- 
venosis; stipulis bilobis; panicula terminali. Condaminea DC. In Peruvia. ‡.

\section{CINCHONA L. (1849).}

\section{Stigma bifidum subclava- $t u m$.}

a. Corollis extus sericeis tomentosisve.

1. C. Condaminea Bonpl. aeq. $t$. 10. fol. oblongis utrinque acuminatis glabris nitidis subtus ad nervos in axillis scrobiculatis; cor. limbo lanato; capsulis ovatis. Lamb. Cinch. f. 1. In Perucia. ち. Corolla rosea. Cortex vulgo dicitur Cascarilla fina seu Quinquina de Loxa.

2. C. scrobiculata Bonpl. aeq. $t$. 4\%. fol. ovali-oblongis utrinque acutis jtabris supra nitidis subtus ad axillas venarum scrobiculatis; capsula ovatooblonga. Circa Jaen de Bracamores. †. Cor. rosea. Vulgo dicitur $\mathrm{Ca}$ scarilla fina.

3. C. lancifolia Mutis; fol. ovatolanceolatis utrinque glaberrimis eglandnlosis; panicula brachiata magna; corollis exterme sericeis ; capsula olslonga. $\alpha$. nitidı $\mathbf{R}$. et Pav. peruv. t. 191. $\beta$. lanceolata $R$. et P. t. 223. C. glabra Ruiz. $\gamma$. angustifolia huiz. suppl. t. 1. f. 1. In Nov. Granata et Pevuvia. ち. Cortex vulgo dicitur Quinquina orange.

4. C. pubescens Vahl act. Hafn. 1. $t$. 2. fol. ovatis seu cordatis coriaceis supra puhescentibus glabriusculisve subtus tomentosis; pauicula brachiata; corollis extus pubescentibus intus hirsutis. Lamb. f. 2. C. cordifolia Mutis. C. ovata R. et P. t. 195. C. hirsuta R. et P. t. 192. C. heterophylla Pav. In Andibus Peruviae. t. Cortex dicitur in officinis Quintuina joune s. Quinguina amarilla.

5. C. purpurea R. et P. t. 193. fol. late ovalibus basi subcuneatis apice breve subcuspidatis supra glabris subtus pubescentibus; panicula ampla; cor. extus leviter tomentosa intus hirsuta; caps. cylindrica. In Peruvia. ち. Folia purpurascentia. Cor. purpurea.

6. C. macrocalyx Par. fol. ovatis subrotundis vix aculis coriaceis utrin- que glaberrimis; paniculis corymbosis; cor. extus leviter tomentosa; lobis supra hirsutis. In Amer. austr. ち. Cor. purpurea.

\%. C. Humboldtiana R. et S. fol. ovatis subobtusis supra nitidis subtus pubescenti-sericeis; panicula brachiata pauciflora; corolla extus sericea fauce glabra intus apice villosa; caps. ovata. C. ovalifolia Bonpl. aeq. t. 19. In Peruvia. $\hbar$.

8. C. magnifolia R. et P. t. 196. fol. late ovalibus subacuminatis glabris; nervis subtus ad latera villosis; panicula brachiata; corollis extus sericeis. C. latescens Poir. C. grandifolia Poir. C. oblongifolia Mutis. In Peruvia. ђ. Cor. alba odorata.

9. C. macrocarpa Valıl; fol. ellipticis coriaceis supra glaberrimis subtus subhirsuto-pubescentibus; panicula triclotoma; corollis adpresse pilosis intus hirsutis. Lamb. t. 3. In Santa. Fé de Bogota. $\hbar$.

10. C. crassifolia Pavon; fol. oblongis subobtusis basi attenuatis coriaceis utrinque glabris, junioribus in venarum axillis villosissimis; ramis ancipitibus paucifloris; fructu ovalioblongo. Circa Quito et Loxam.

11. C. aichotoma $R$. et P. $t$. $19 \%$ fol. oblongo-lanceolatis glabris, junioribus subtus subsericeis; floribus corymhosis; capsulis cylindraceo-sericeis. In Peruvia. ఫ. Cortex amarissimus.

12. C. acutifolia R. et P. t. 225. fol. ovatis acutis glabris subtus ad venas subvillosis; panicula brachiata pedunculata; corolla extus sericeopubescente intus lanuginosa; caps. oblongis. In Peruvia. ち. Cor. candida.

13. C. micrantha R. et P. t. 194. fol. Iate ovalibus obtusis glabris subtus ad veuas subpubescentibus; panicula brachiata maxima; corollis sericeo-tomentosis; caps. oblongis. In Peruvia. ち. Cor. alba.

11. C. glandulifera R. et P.t. 221. fol. ovato-lanceolatis supra glabris nitidis ad axillas venarum glandulosis subtus villosis; panicula subcorymbosa. In Peruvia. ఫ. Cor. albo-rosea.

\section{b. Corollis glabris.}

15. C. caduciflora H. et B. aeq. fol. ovalibus glabris erectis in axillis 
venarum pilosis; panicula brachiata; corolla glabra caducissima; caps. oblonga. C. magnifolia Bonpl. aeq. t. 39. In Peruvia. t. Ramuli rubri. Flores albi.

16. C. rosec $R$. et $P$. $t$. 199. fol. ovalihus hasi subattenuatis apice obtuse acumiuatis utrinque glabris; paniculis confertis; corolla extus glabra intus tomentosa. C. fusca liuiz. In Peruvia. ち. Cor. rosea.

17. C. Pelalba Pav. fol. subrotundis vix apiculatis in petiolo et utrinque in nervis hirsuto-velutinis supra subpuberulis; stipulis ovalibus; panicula ramosissima. In Amer. merid. $\hbar$.

13. C. Muzonensis Goudot. fol. ovato-oblongis acutis basi attenuatis; sipulis revolutis; panicula hrachiata; corollae albae limbo imberbi. In sylvis Columbiae. $\hbar$.

\section{Stigmata 2 linearia. Remt- jia $\boldsymbol{D C}$.}

19. C. ferruginea Hilar. pl. us. bras. $t$. 3. fol. ohlongo-lanceolatis subangustatis; racemis interruptis vix ramosis. Macrocnemum Vand. In Brasilia.

zo. C. Vellozii Hilar. fol. ovatis utrinque acuminatis; racemis interruptis vix ramosis. In Brasilia. $\hbar$.

21. C. Remijiana Hilar. fol. late ellipticis obtusis cuspidatis in summum petiolum subdecurrentibus; racemis interruptis vix ramosis. Remijia Hilarii DC. C. Remyana Spr. In Brasilia. $\hbar$.

22. C. paniculata; fol. oblongis acutis basi attenuatis undulatis coriaceo-crassis; paniculis axillaribus verticillato-ramosis; ramis interrupte racemosis. Remijia paniculata DC. In Brasilia. 市.

3. Stigma clavato - capitatum sublobatum. Hymenodyctium Wall. Cinchona Roxb.

23. C. excelsa Roxb. corom. $t .106$. fol. oblongis velutinis; floralibus coIoratis bullatis; stipulis cordatis serratis; floribus paniculatis. In Ind. or. t. Cortex amarus adstringens.

2t. C. thyrsiflora; fol. ovatis veIntinis; floralibus coloratis reticulatis; thyrsis terminalibus et axillaribus nu. tantibus; stipulis oblongis; glanduli? coloratis fimbriatis. Hymenodyctiol Wall. In Bengalia. 古.

2.5. C. fiacida; fol. ovatis ellipticis laevibus superne lucidis; floralibus nervoso-reticulatis convexis discolorihus; stipulis oblongis spathulatis; racemis pendulis. Hymenodyction flaccidum Wall. tent. fl. nep. t. 22. In Nepalia. 市.

26. C. obovata; fol. obovatis acuminatis laevihus; floralibus lanceolatis acuminatis venoso-reticulatis convexis glaucis; stipulis ovatis acutis. $\mathbf{H y}$ menodyction Wall. In Ind. or. $\hbar$.

\section{Stigma, bifidum acutum. Buence Pohl.}

27. C. acuminata Poir. fol. ovalihus breve acuminatis utrinque glam bris ; floribus solitariis sessilibus. Cosmibuena acuminata $R$. et $P$. peruv. t. 226. In Peruvia. Cor. glaberrima.

28. C. obtusifolia; fol, ovalibus ovatisque ohtusis utrinque glaberrimis; floribus corymbosis; cor. lobis ovatis acutis patentibus. Cosmihuena et Cinchona grandiflora $\mathbf{R}$. et $\mathbf{P}$. t. 198. In Nov. Granata et Peruvia. ‡ै.

29. C. hexundra; fol. ovalibus obi tusis subtus ramulis floribusque ochrao ceo-villosis; cor. 5-6-fidis 5-6-an1dris. Buena Pohl ic. to 8. In R-o Janeiro. $\hbar$.

\section{POUCHETTA Rich. (1830).}

1. P. africana A. Rich. Gardenia parviflora $\mathbf{S m}$. In Africa. ち. Fiutez glaher. Fol. ovata acuminata petiolata. stipulae ovatae cuspidatae. Flores paniculati. Cor. parva glabra.

\section{PINKNEYA Michx. (1805)。}

1. P. pubens Michx. am. $t .13$. Cinchona caroliniana Poir. In Georgia et Carolina. ち. Frutex arborescens. Folia ovalia. Flores majusculi pubescentes. 
936. EXOSTEMMA Bonpl. (1808).

1. E. caribaeum R. et S. fol. ovato-lanceolatis acuminatis glabris; pedicellis axillaribus 1 -floris; calyce obtuse 5-dentato. Cinchona carihaea Jacq. am. t. 179. f. 65. obs. t. 17. Lamb. t. 4. C. jamaicensis Wright. Andr. rep. t. 481. In Ind. occ. ち. Cor. rosea.

2. E. longifiorum R. et S. fol. Iineari-lanceolatis utrinque attenuatis glabris; pedicellis hrevissimis ; calycis dentibus longis lineari - lanceolatis. Cinchona Lamb. t. 12. In Ind. occident. $\hbar$.

3. E. canescens Bartl. fol. ovatooblongis acuminatis utrinque ramulisque canescenti-villosis ; pedunc. axillaribus 1-floris. In Mexico. $\hbar$.

4. E. angustifolium R. et S. fol. lineari - lanceolatis subtus calycibusque pubescentibus; pedunc. terminalibus corymbosis; calycis dentibus lineari-subulatis. Cinchona Sw. act. holm. 1787. t. 3. Lamb. t. 9. In Domingo. ち. Cor. rosea.

5. E. coriaceum R. et S. fol. ovalibus vix acutis coriaceis utrinque glabris nitidis; ramis floribusque glabris; pedunc. axillarihus 2-3-floris; calycis dentibus acutis. Cinchona coriacea Poir. In Domingo. $\hbar$. Cor. rosea.

6. C. lineatum R. et S. fol. ovatis acuminatis; ramis floribusque glabris; pedunc. corymbosis terminalibus; calycis laciniis linearibus; caps. 5-gona. Cinchona Vahl act. Hafn. 1. t. 4. Lamb. t. 6. In Domingo. $\downarrow$. Cor. rosea.

\%. E. parviflorum Rich. fol. ovalibus muticis ad axillas nervorum poroso-glandulosis; petiolis, ramis pedunculisque pulescentibus; foribus fasciculatis. In ins. Cavibreis. ђ.

8. E. brachycarpum R. et S. fol. ellipticis obtusis; ramis floribusque glabris; pedunc. terminalibus corymbosis; caps. ovatis costatis. Cinchona Sw. Linds. trans. soc. roy. Edinb. 1794. t. 5. Lamb. t. 8. In Jamaica. 卢.

9. E. floribundum $\boldsymbol{R}$. et $\boldsymbol{S}$. fol. ellipticis acuminatis; ramis floribusque glabris; pedunc. corymbosis ; calycis dentibus acutis; caps. turbinatis. Cinchona floribunda Sw. Lamb. t. 7. C. montana Badier. journ. phys. 1789. t. 1. In Ind, occ. t. Cor. rosea.
Cortex in officinis dicitur Quinquina Pitton.

10. E. capitutum Spr. fol. ovatis coriaceis glabris; floribus capitatis; calyce minimo $\mathbf{5}$-dentato; cor. tubo longo; laciniis revolutis. In Amer. 古.

11. E. philippicum R. et S. fol. confertis ovalihus acutis; ramis floribusque glabris; pedunc. corymbosis; calycis dentibus acutis; filamentis hirsutis. Cinchona philippica Cav. ic. t. 329. In ins. Philiprinis. t).

12. E. peruvianum II. et Bonpl. aer. $t$. 38. fol. ovatis oblongis acutis basi rotundis, superioribus cordatis; corymbis terminalibus sessilibus; pedumculis calyceque pubescentibus; cor. extus sericea. In Peruvia. ち. Cor. rosea.

13. E. corymbiferum $\boldsymbol{R}$. et $\boldsymbol{S}$. fol. oblongis lanceolatis acutis; ramis floribusque glabris; ramulis axillaribus apice bifoliis corymbiferis; calycis dentibus acutis. Cunchona Lamh. t. 5. In ins. Tongatabu. ち.

14. E. corymbosum $\mathbf{S u}$. fol. oblongo-lanceolatis acutis; ramis floribusque glabris; corymbis terminalibus brachiatis; calycis dentihus sublinearibus. Portlandia $R$. et P. peruv. t. 190. f. a. In peruvia. ђ.

1.5. E. dissimiliforum $R$. et $\mathbf{S}$. fol. cordato-oblongis glaberimis; limbo corollae tubo longiore; caps. sublinearibus angustissimis. Cinchona Mutis. In Amer. anstr. ち.

16. E. cuspidatum Hilur. pl. bras. t. 3. f. A. fol. lanceolat 0 - ovatis cuspidatis nervosis subtus villosis; panicula terminali; calyce campanulato; cor. extus filamentis medio villosis. In Brasilia. ‡. In officinis cortex Quina do mato dicitur. Cor. alha.

17. E. australe Hilar. t. 3. f. B. fol. ovatis nervosis inferne subvillosis; panicula terminali sessili 3-partita; calyce campanulato; filamentis glabris; stylo villoso. In Brasiliu. ţ.

18. E. formosum Cham. et schl. fol. ovato-ellipticis utrinque acutis subgranulosis; panicula trichotoma pyramidata; calycis limbo integerrimo; cor. fauce villosa. In Brasilia. ђ.

1.9. E. Sonzanum Murt. Reis. fol. obovato- seu ovato-aculis glabris ; corymbis pancifloris ; caps. ohovatis conıpressis; seminibus oblongis. In $\mathrm{Br} \cdot-$ silia. $\mathrm{t}$. 


\section{3\%. MLSSAENDA Raj. (1704).}

a. Calycis bipartiti l obo quinto basi producto in folium petiolatum maximum desinente.

1. Mr. speciosa Poir. fol. ovatis acutis ad nervos villosis; stipulis lanceolatis; corymbo subvilloso; calycis dentibus obtusis. Macrocnenum Jacq. Schoenbr. t. 43. In Mexico. ち. Cor. rosea.

2. IM. acutiflora Bartl.in h. Haenk; fol. ovalibus acuminatis basi acutis glabris; nervo venisque subtus pubescentibus; corymbo trichotomo pubescente; calycis dentibus acutis. In Mexico. ち.

3. N. frondosa $L$. fol. ovalibus acuminatis; ramulis corymbisque puberulis; stipulis subulatis; corymbo terminali subpaniculato; calycis dente uno petiolato membranaceo acuminato. Lam. ill. t. 15\%. f. 1. Hheede 2. t. 1\%. M. Zeylanica Burm. t. 76. In Ind. or. $\hbar$. Cor. rosea.

t. M. glabra Vahl; fol. ovalibus acuminatis ramulisque glabris; calycis laciniis lato-lanceolatis. Lodd. b. Cah. 1209. Rumph, 4. t. 51. In Ind. or. t.

5. M. sumatrensis Roth; fol. ellipticis subtus cum petiolis ramisque tomentosis ; corymbis terminalibus; calycis folio bracteiformi subrotundo pubescente venoso-reticulato. In Ind. or. $\hbar$.

6. M. acuminata Blume; fol. lanceolatis utrinque acuminatissimis ad costam corymbosque pubescentibus ; caIycis lobis linearibus acuminatis. In Java.

7. M. hispida Don prodr. fol. ovatis acuminatis pilosis; petiolis, ramulis, corymbis calycilbusque pilosissimis; cal, laciniis ovali-lanceolatis. In $\mathrm{Ne}$ palia. ち.

8, M. erythrophylla Sclumn. ramulis velutinis; fol. ovatis cuspidatis, subius villoso-lomentosis, supra pubescentibus; stipulis villosis deciduis. In Guinea. 古.

9. M. luteola Delile in Caill. pl. afr. t. 1. $f$. 1, fol. subsessilibus ovato-lanceolatis acutis subtus tomentosis ; calycis dentibus subulatis. Ophiorrhiza lanceolata Forsk. M. lanceola- ta Spr. In Arabia. ち. Cor. Aavescens.

10. M. Isertiana DC. prodr. fol. ellipticis breve petiolatis ramulisque glaberrimis ; floribus corymboso-paniculatis; pedunc. corollisque villosocanesceutibus; calycis lobo maximo rotundato. M. macrophylla Schum. In Guinea. t.

11. M. Mubescens Ait. fol. ovatooblongis acuminatis in nervis pubescentibus; stipulis utrinque geminis subulatis; lobis calycis subulatis; cor. tubo gracili. B. M. 2099. Lodd. b. Cab. 451. In China. t. Cor. lutea.

12. M. corymibosa Roxb. fol. obIongis ramulisque laevibus; stipulis basi cordatis apice cuspidatis; calycis laciniis setaceis, una bracteiformi ovato-lanceolata. In Zeylona et Malabaria. 古.

13. M. macrophylla Wall. ramulis serice 0 -pilosis ; fol. ovatis acuminatis pubescentibus; stipulis lato-ovatis bifidis apice acuminatis recurvis; corymbis pilosissimis. In Nepalia. ‡。. 14. M. incana Wall. pubescentiincana; fol. ovato-oblongis subsessilibus subtus albis; stipulis lato-lanceolatis adpressis. In Nepalia. $\hbar$.

15. M. cuneifolia Don; fol. cuneato-oblongis acuminatis utrinque ramulisque pubescentibus; stipulis lanceolatis acuminatis; laciniis calycis subulatis; cor. tubo villoso. In Nepalia. $\mathbf{t}$.

\section{b. Calycis lobi subaequales; capsula apice nuda.}

16. M. Landia Lam. ill. $t$. $15 \%$. f. 2. Pol. ovatis acuminatis utrinque pubescenti-villosis; ramulis, petiolis corollisque villosis; calycis lobis triangulari-lanceolatis. M. Iatifolia Poir. Hondeletia Landia Spr. In ins. Mauritii. t.

17. M. Stadtmanni Michx. fol. ovalibus brevi-cuspidatis subtus vix pubescentibus; ramulis, corymbis corollisque pubescentibus; cal. laciniis elongato-lanceolatis. Oxanthus cymosus Rchb. M. Landia Sm. In ins. Mauritii. $\hbar$.

18. M. arcuata Lam. fol. ovalioblongis acuminatis subtus in nervis subpilosis; inflorescentia glabra; ca1ycís laciniis lineari-subulatis. In ins. Mauritii. $\bar{b}$. 
19. M. eleyans Schum. fol. ovalibus lreve cuspidatis ramulisqne glabris ; inflorescentia pubescente; calycis laciniis linearihus; cor. tubo hispidissimo. In Guinea. ち.

20. M. sericen Blume; fol. ovatooblongis aeuminatissinis basi attenuatis glabris; in venis inflorescentiaque sericeis; cor. tomentosa. In Moluccis. 古.

c. Calycis lobi aequales setacei. Folia subverticillata.

21. M. citrifolia Lam. fol. ternoverticillatis ovatis subsessilibus coriaceis ramulisque glabris; stipulis basi latis acutis. In Madagascar. ち. Cor. nava.

22. M.? longifolia I,am. fol. terno-verticillatis lanceolatis oblongis pube brevissima subtomentosis; stipulis basi latis acutis ; capsulis cordato-striatis. In Madagascar. ち.

23. M.? glomerata Lam. fol. ovatis acutis subtus glabriusculis superne petiolisque fusco-velutinis; ramis subvillosis; floribus glomeratis; calyce campanulato 5-6-dentato. Rondeletia spr. In Gujana. ђ.

21. M.? discolor 'Ihouar; hirsuta; fol. scabris supra strigosis subtus piloso-canescentihus; floribus corymhosis persistentibus. Patria ignota. ち.

25. M. echitioides $W$. fol. oblongis acutis glabris; floribus corymbosis; caule volubili. l'atria ignota. $\hbar$.

26. M. chinensis Lour. fol. fasciculatis lanceolatis glabris; foribus solitariis terminalibus; bacca 4-loculari polysperma. In China. .

2\%. M. tetranilra Schult. fol. laevibus glahris acutis; corymhis 3-partitis; floribus 4-andris. Macrocnemum 4-andrum Cav. Patria i!nota. $\hbar$.

28. M. candidissima $\ddot{R}$. et $\mathbf{S}$. (Calycophyllum DC. prodr.) fol. ovatis obtuse acuminatis; corymbis terminalibus; calycis limbo truncato; cor. campanulata fauce harbata. Macrocnemum Vahl symb. t. 30. Ad Orinocum. 古.

29. M. coccinea Poir. fol. lanceolato-ellipticis; corymbis paniculatis axillaribus; calyce obtuse $\mathbf{5}$-dentato; corolla subinfundibuliformi. Macrocnemum Vahl Symb. t. 29. Calyco-

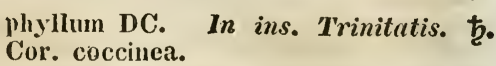

30. M. tubulosa; fol. ovalibus basi acutis apice acuminatis utrinque tenue velutinis; cor. extus pubescente; calyce orbiculato. In Brasilia. †.

31. M. Lucullia Don; fol. petiolatis ellipticis supra glahris subtus in nervis villosis; stipulis latis cuspidatis. Lucullia gratissima sweet hr. fl. Gard. t. 145. Cinchona Wall. tent. nep. t. 21. In Nepralia. t. Cor. rosea.

\section{HYMENOPOGON Wall. (152\%).}

1. H. parasiticus Wall. In Ind. or. super arbores et rupes. \$ Frutex parvus curvus. Ramuli compressi. Folia acuminata membranacea subtus villosa. Hlores longissimi inodori.

\section{LECANANTHUS Jack. (181.1).}

1. L. mbescens Jack. in mal. misc. In Singampore Ind. or. ち. Frutex radicans caule $4-g 0 n o$. Folia opposita breve petiolata. Flores dense aggregati pallide rubentes.

\section{ALSEIS Henr. Schott. (1829).}

1. A. floribunda Schott. In Brasilia. †. Arbor mediocris. Folia oblonga acuminata utrinque pilosiuscula. Flores spicati. Hami ochroleuci.

\section{DANAIS Comm. Juss. (178.9).}

1. D. fragrans Comm. fol. ohlongis; corymbis confertis; capsula non sulcata calyce patulo coronata. Lam. ill. t. 166. f. 2. Gaertu. t. 195. $D$. fragrans $\beta$. coronata Pers. In ins. Muuritii. $\hbar$. Cor. aurantiaca.

2. D. laxiflora DC. moilr. fol. obovatis; corymbis laxis subpaniculatis; capsula non sulcata calyce erecto coronata. In ins. Mauritii et Borboniae. $\hbar$.

3. D. rotundifolia Poir. fol. ovatis subrotundis apice subacutis; corymbis confertis; capsula non sulcata calycis limbo non dentato coronata 
Cinchona chlorrhiza Bory. In ins. / hus ; floribus terminalibus fasciculatis. Mlauritii. 支.

t. D. sulcatc Pers. fol. ovatis; caps. sulcata lobis calycinis foliaceis coronata. In ins. Nlauritii. $\hbar$.

\section{DENTELLA Forst. (1785).}

1. D. repens Forst. gen. $t$. 15. Lam. ill. $t$. 118. Oldenlandia repens L. In Java, Timor, Luconia, Coromandelia et Nova Caledonia. $\odot$. Herba repens caespitosa paludosa. Fol. oblonga glabra basi ciliata. Flores albi.

\section{PORTLANDIA P. Brown (1756).}

1. P. grandiflora $L$. fol. lanceolato-ellipticis; floribus axillaribus pedicellatis solitariis. Smith. ic. t. 6 . B. M. 286. Jacq. am, to 44. In Jamaica. ち. Cor. aílsa.

2. P. coccinea $S w$. fol. ovatis subrotundis coriaceis; floribus axillaribus pedicellatis solitariis. P. coriacea Spr. In Jamaica. ち. Cor. coccinea.

\section{OPHIORRHIZA L. (1717).}

1. O. oblongifolia DC. prodr. caule suffruticoso; apice pedunculisque pubescentibus; fol. oblongis obtusiusculis basi attenuatis supra glabris subtus pallidis subvelutinis; stipulis parvis triangulari-acutis. In ins.Luconia. $\hbar$.

2. O. Mungos $L$. caule suffuticoso; fol. elliptico-lanceolatis utrinque acuminatis glabris papyraceis; stipulis exiguis truncatis. Rich. mém. 1. t. 2. In Java et Sumatra.

3. O. villosa Roxb. canle suffruticoso erecto villoso; fol. obovato-oblongis lanceolatisve; stipulis ensiformibus; cymisque longe peduncrlatis villosis. In Ind. or. 4.

1. O. marginata Blume; caule suffruticoso erecto; fol. lanceolatis utrinque acuminatis glahris margine scabris; stipulis semi-lanceolatis; cyuis terminalibus subtrifidis. In Java. 4.

5. O. fusciculata Don; caule suffruticoso erecto; fol. ellipticis acuninatis supra glabris subtus pubescenti-

In Nepalia. 4.

6. O. rugosa Wall. caule herbaceo basi repente adscendente villoso; fol. elliptico-lanceolatis utrinque attenuatis lucidis subtus subpubescentibus; cymis 2-3-fidis. In Ind. or. 4. Cor. alba.

7. O. canescens Blume; caule herhaceo; fol. oblongo-lanceolatis utrinque attenuatis subtus albicantibus subpubescentibus; stipulis latis; cymis sub-t-fidis. In Java. 4.

8. O. trichocarya Blume; caule herhaceo tomentoso; fol. breviter petiolatis ovato-lanceolatis acutiusculis subtus in venis capsulisque subpubescentilus; stipulis subulatis; cymis dichotomis. In Java. 4.

9. O. longiflora Blume; caule suffruticoso ; fol. oblongo - lanceolatis utrinque acuminatis infra hirsutis; stipulis semi-lanceolatis aouminatis; tubo corollae longissimo velutino. In sylvis Javae.

10. C. sanguinea Blume; caulo herbaceo; fol. ovato-ellipticis acuminatis; stipulis foliaceis ovato-oblongis passim bifidis; cymis pedunculatis termiualibus. In Java. 4.

11. O. quadrifida Blume; caule herbaceo; fol. ovatis vel oblongis utrinque acutis laevibus; stipulis linearihus obtusis; cymis 4 -fidis. In Java. 4.

12. O. japonica Blume; caule herbaceo radicante; fol. ovatis vel oblongo-lauceolatis supra scabriusculis subtus puberulis; corymbo terminali dichotomo; cor. laciniis intus hirsutis. In Japonia. 4.

13. O. prostrata Don; caule prostrato radicante pubescente; fol. ovatis ellipticisve supra asperis subtus pubescentibus; lobis calycinis oblongis. In Nepalia. 4.

11. O. tomentosa Jack; tota dense et mollissime villosa; caule erecto ramoso; fol. lanceolato-oblongis tenuiter acumiuatis subtus petiolisque villosis; stipulis subulatis; cyma pedunculata. In ins. Penang et Sumatra. 4.

15. 0. neylect $九$ Blume; caule herbacen erecto atropurpureo glabro; fol. oblongo-lanceolatis acuminatis subtus pallidis; pedunc. ferrugineo-puberulis; cymis 8-1-fidis, In Java. 4. 
16. O. heterophylla Jack; caule erecto tomentoso ; fol. subrotundo-ovatis inaequalibus; cyma terminali parva. In Sumatra. 4 .

17. O. acuminata DC. prodr. caule suffruticoso superne petiolisque rufovelutinis; fol. lanceolatis acuminatis glabris; nervis subtus velutinis; stipulis aristatis. 0 . umbellata Bartl. In ins. Lucon, et Sorzogon.

18. O. Richardiana Gaudich. in Freyc. Voy. t. 9\%. suffuticosa; glaberrima; fol. oblongis utrinque acuminatissimis margine laevibus petiolatis; dentibus calycis brevissimis. In ins. Moluccis ち.

19. O. perpusilla Blume; caule erecto nano simplici; fol. ellipticis glabris; flore terminali solitario nutante; calycis dentibus obtusis. In Java. $\odot$ ?

20. O? subumbellata Forst. caule fruticoso; fol. lanceolatis acutis; umbellis axillaribus 3 -fidis. In ins. Otaheiti. $\hbar$.

\section{SICKINGIA Willd. (1801).}

1. S. Erythroxylon Willd. fol. rhombeo-oblongis apice dentatis subtus pubescentibus. In sylvis circa Caracas. †.

2. S. longifolia $W$. fol. oblongoovatis integerrimis glabris. $A d \boldsymbol{C} a-$ racas. $\ddagger$.

\section{MENESTORIA DC. (1830).}

1. M. tocoyenae DC. prodr. fol. obovatis obtusis basi cuneatis subsessilibus supra glabris subtus pallidis ad nervos adpresse villosis. In $\mathrm{Ne}$ palia. $\hbar$.

2. M. hamelliae DC. prodr. fol. ovalibus utrinque acuminatis Ionge petiolatis subtus ad nervos puberuloscabris. In Nepalia. $\hbar$.

3. M. mussaenda DC. fol. ovatis acutis breve petiolatis subtus pallidis utrinque puberulis; petiolo, stipuiis nervoque rufo-hirsutis. In Nepalia. $\hbar$.

4. M.? rigida DC. fol. cuneatis retusis mucronulatis glabris; stipulis ovatis acutis. Gardenia rigida Don. In Nepalia. ђ.

\section{4\%. AUGUSTEA Pohl (1S31).}

1. A. lanceolata Pohl ic. t. 101. fol. brevissime petiolatis lanceolatis stipulisque glabris; floribus fasciculatis ternis; bracteis lanceolatis planis ciliatis. In Brasilia. ち. Caul. ulnaris. Cor. rubra.

2. A. parifolia Pohl ic. t. 102. fol. brevissime petiolatis lanceolatis utrinque acutis; stipulis bracteisque glabris; floribus fasciculatis; calycis laciniis oblongis basi retusis. In Brasilia. ち. Cor. caerulescenti-rubra.

3. A. oblongifolia Pohl. ic. t. 103. fol. breve petiolatis oblongis utrinque acuminatis supra glahris subtus pilosiusculis ; stipulis, bracteis pedunculisque piloso-tomentellis; floribus fasciculatis. In brasilia. $\hbar$. Caul. orgyalis. Cor. rubra.

4. A. attenuata Pohl ic. t. 101. fol. breve petiolatis oblongis acutis in petiolum attenuatis ciliatis glahris; stipulis intus pilosis; florihus fasciculatis; bracteis lanceolatis canaliculatis intus villosis. In Brasilia. †. Frutex. Cor. caerulescenti-rubra.

5. A. glaucescens Pohl ic. t. 105. fol. breve petiolatis confertis oblongis utrinque attenuato-acutis glaberrimis; stipulis 3-angularilus cuspidatis ; floribus fasciculatis ; bracteis lanceolatis intus pilosis. In Brasilia. ‡. Caul. biulnaris. Cor. caerulescentirubra.

\section{LOBELIA L. (173\%).}

1. Arboreae, fruticosae.

a. Fol. dentatis serratis crenatis.

1. L. arborea Forst. caule arboreo; fol. petiolatis ovato-oblongis serrato-dentatis; pedunc. axillaribus s0litariis 1-floris. In ins. Societatis. $\downarrow$.

2. L. Caoutchut H. et $\mathrm{K}$. arborea; fol. oblongis acutis basi rotundatis margine glanduloso-denticulatis subtus ferrugineo-tomentosis ; tubo corollae integro. In Popaya. ち. Cor. rubra.

3. L. ferruginea INutis; arborea? fol. obovato-oblongis acutiusculis obsolete denticulatis subtus ferrugineotomentosis; corollae tubo integro. $\mathbf{L}$. 
asclepiadea W. Hb. In Nov. Granata. ち. Cor. rubra.

t. L. barbuta Cav. ic. t. 519. fol. ovato-lanceolatis acutis denticulatis subtus ferrugineo-tomentosis; pedunc. axillaribus solitariis; genitalibus longe exsertis. In Amer. austr. ఫ. Cor. rubra.

5. L. Columnae Mutis; fruticosa; fol. oblongis utrinque rotundatis crenatis coriaceis, supra rugosis glabris nitidis, subtus fuscescenti-tomeutosis; tubo cor. integro. smith ic. t. 22. In Nov. Granata. $\hbar$.

6. I. mulverulenta pers. fol. ovatis petiolatis, superue glabris rugosis, subtus albo-tomentosis ; corollis campanulatis pulverulentis. L. campanulata. Cav. ic. t. 517. In Peruvia. ђ. Caul. 8-ped. Cor. rubra.

\%. L. beslerioides H. et K. t. 269. fruticosa; fol. oblongo-ellipticis apice rotundatis denticulatis utrinque hirtellis; tubo corollae integro. In Popaya. 方. Cor. rubra.

8. L. umbellata H. et K. t. 268. fruticosa; fol. oblongo-lanceolatis acuminatis dénticulatis subtus pubescentihirtis; floribus umbellatis longe pedunculatis. In Peruvia. ち. Cor. alba.

9. L. gigantea Cav. ic. $t$. 513. fruticosa; fol oblongo-lanceolatis acuminatis crenulatis reticulato-rugulosis supra glabris subtus pubescentibus venisque cano-tomentosis; floribus longissime pedunculatis. In Nov. Granatu. ち. Cor. rubra.

10. L. livta Cav. ic. t. 520. fol. oblongis acuminatis serratis; pedunc. axillaribus longissimis; caule hirto fruticoso. In Quito. ち. 5-6-ped. Cor. coccinea.

11. I. elliptica $I$. et $K$. fol. ellipticis denticulatis rugulosis subtus villosiusculis; pedunc. solitariiis elongatis; calycilous foliaceis ontusis patenti-reflexis. In Amer. austr. b.

12. L. nivea $W$. caule arboreo; fol. ellipticis margine revolutis dentatis, supra rugosis lucidis, subtus pedunculis corollisque niveo-tomentosis. In Nov. Granutu. ち.

13. I. reticulata $\amalg$. caule arboreo; fol. ovato-lanceolatis acuminatis crenatis rugoso-venosis subtus pubescentilus ; corymbo terminali racemoso. Ad Orinocum. t.
14. L. retrorsa $W$. caule arboreo; ramis scabris; fol. petiolatis ellipticis mucronatis retrorsum serratis rugoso-venosis; floribus racemosis. In Amer. austr. ち.

15. L. grandis Mutis; fruticosa; fol. oblongis acutis crenato-serrulatis glabris; umbellis terminalibus bracteatis: corollis hirtellis. In Nova Grancita. ち. Cor. rubra.

16. L. mucronata Cav. ic. t. 516. fol. sparsis sessilibus ovato-oblongis serrulatis mucronatis villosis glaucis. In Chili. ち. Caul. 6-ped.

1\%. L. Bonplandiana $R$. et $P$. caule arhoreo; fol. Ianceolatis aryute serrato-dentatis planis puhescentibus breviter petiolatis; pedunc. axillaribus folio brevioribus. $\mathbf{L}$. dentata $\mathbf{W}$. IIb. In Amer. austr. $\hbar$.

13. L. volubilis $H$. et $K . t .271$. caule fruticoso volubili; fol. cordatoovatis acuminatis argute dentatis subtus tenuissime puberulis; corollis glabris. L. cordata IV. Hb. Ad Orinocum. Ђ. Cor. coccinea.

19. L. glabrata H. et K. t. 270. fruticosa; glabra; fol. oblongo-ellipticis acutis basi rotundatis superue obsolete dentatis; laciniis calycis tubum corollae aequantibus. In Nova Granatu. ち. Cor. virescens.

20. L. Mutisiana $I$. et $K$. fruticosa; fol. oblongis brevissime acuminatis basi subacutis remote et obsolete dentatis glabris subtus hirtis; corollis glabris rubris. In Nov. Granata. b.

21. L. biserrata Cav. ic. t. 514. fol. ovato-lanceolatis hiserratis ; floribus axillaribus solitariis; filamentis corollae adnatis; caule fruticoso. In Peruvia. 古 Caul. 3-ped. Cor. luteo-coccinea.

22. L. decurrens Cav. ic. t. 521 . fol. ovato-lanceolatis biserratis decurrentibus glabris; calycis laciniis serrato-incisis. In Chili. ち. 5-ped. Cor. coccinea.

23. L. conglobata Lam. fol. cineiformi-oblongis denticulatis nitidis; racemo conglobato terminali; calycis laciniis dentato-fimbriatis. Plum. ic. Mss. t. 117. In Martinica et Domingo. ち. 1-ped. Cor. coccinea.

2t. L. arguta Lindl. B. R. 973. fol. lineari-lanceolatis serrulatis glaberrimis; pedunc. axillaribus 1-floris; 
calycibus glabris. In Chili. ち. Cor. luteo-purpurea.

25. L, robusta Grah. B, M. 3138. caule fruticoso; fol. ohovato-lanceolatis acuminatis grosse dentatís glahris nitidis; racenis terminalibus. . In ins. Hayti. ち. Cor. purpurea.

26. L. Grimesiana Gandich. arhorea; lactescens; ramulis tuberculato-aculeatis; fol. piunati-partitis ; laciniis grosse serratis; racemis axillaribus. Cyanea Grimesiana Gaudich. in Freyc. Voy. t. 74. In ins. Sandwicensibus. ђ. Cor. cyanea.

2\%. L. Rollandia Gaudich. ramosa; fol. magnis oblongo-lanceolatis duplicato-dentatis subtus hirtellis; calycibus glabris; laciniis ovatis obtusis; racemis depauperatis. Rollandia lanceolata Gaudich. in Freyc. Voy. t. 74. In ins. Sanduicensibus, ち. Frutex lactescens. Cor. alba.

28. L. oblongifolia Gaudich. fol. longissime petiolatis ohlongis acutiusculis crenatis; calycibus 5-partitis. Clermontia Gaudich. in Freyc. Voy. t. 71. In ins. Sanduicensibus. ‡. Cor. albida.

29. L. Clermontiana Gaudich. fol. oblongo-lanceolatis acutis crenatis; calycibus 5-fidis. Clermontia persicifolia Gaudich. in Freyc. Voy. t. 72. In ins. Sandwicensibus. $\hbar$. Cor. rose0-violacea.

30. L. grandiflora Gaudich. fol. ovato-oblongis subacuminatis dentatocrenatis; floribus maximis; calycibus 5-fidis. Clermontia grandiflora Gaudicl. in Freyc. Voy. t. \%5. In ins. Sandwicensibus. †. Cor. caerulea?

31. L. crispa; ramosa; fol. maguis oblongis inferue valde angustatis argute dentatis glabris margine undulato-crispis; calycibus pubescentilus; laciniis ovatis obtusis, Rollandia Gaudich. In ins. Sandwicensibus. ち.

32. L. subcordata; ramosa; fol. ovatis argute dentatis glabris; calycibus 5-dentatis. Delissea Gaudich. in Freyc. Voy, t. 7\%, In ins. Sandwicensibus. $\hbar$. Cor. pallide rosea.

33. L. undulata; caule simplicissimo; fol. oblongis argute grosseque dentatis glabris margine undulatis; calycibus 5-dentatis. Delissea Gaudich. in Freyc, Voy. t. 78, In ins. Sanduicensibus. $\hbar$. Cor. rosea.

34. L. ilelisseana Gaudich. ramo(6) fol, Qblongis duplicato-denticula- tis utrinque hirtellis ; calycibus 5-dentatis. Delissea Gaudich. in Freyc. Voy. t. g6. In ins. Sandwicensibus. 古. Cor. pallide rosea.

35. L. ceratophylla ; fruticosa; hirsuta; adscendens; fol. subsessilibus lineari-lanceolatis obtusis remote pinnatifido-dentatis; dentibus apice callosis; calycis laciniis lineari-lanceolatis obtusis ciliatis. Rapuntium ceratophyllum Presl Mss. In Prom. $b$. spei. t.

36. L. superba Cham. et schl. arborea; palmaeformis; caule simplicissimo stricto; fol. glabris oblongoobovatis acuminulatis undulatis denticulatis margine revolutis; pedunculis nutantibus; floribus capitatis. In Prom. b. spel. ち. Biorgyalis. Fol. $2 \frac{1}{2}$-ped.

\section{b. Foliis integerrimis.}

3\%. L. Burmanniana; L. fruticosa; hirsuta; prostrata; fol. ovatis dentatis crenatis lanatis; floribus lateralibus solitariis; pedunc. longissimis. Hapuntium Burm. Afr. t. 40. f. 2. In Prom. b. spei. Ђ. Cor. caerulea.

38. L. scandens $H$. et $K$. caule fruticoso scandente; fol. oblongis obtusis integerrimis subcamosis margine revolutis glabris; spicis terminalibus. L. obtusifolia W. Hb. In Peruvia. ち. Cor. coccinea.

39. L. loxensis $\boldsymbol{W}^{\top}$. Hb. fol. oblongis obtusis petiolatis revolutis, supra rugulosis nitidis, subtus floccoso-tomentosis ferrugineis; floribus racemosis. In peruvia. ђ.

40. L. Tupa L. fol. Ianceolatis aculis decurrentibus subtus albo-tomentosis; racemo terminali bracteato. B. H. 1612. Feuill. per. t. 29. In Chili. †. 4-5-ped. Cor. coccinea.

11. L. Andropogon Cav. ic. t. 515. fol. ovato-acutis glabris mollibus; pedunc. solitariis ; floribus glabris. In Quito. †. 5-6-ped. Cor. coccinea.

42. L. spartioides; caule ramosissimo; fol. sessilibus linearibus acutiusculis basi ciliatis; floribus villosis racemosis; calycis laciniis acuminatis. Rapuntium Presl. Mss. In Prom. b. spei. $\hbar$.

\section{Suffuticosae.}

43. L. surinamensis $L$. fol. oblongis acuminatis serratis glabris; po- 
dunc. axillaribus 1-floris; ciniis lineari-lanceolatis. In Amer. austr. ђ. Cor. pallide ruhra.

11. L. assurgens $\boldsymbol{L}$. fol. lato-lanceolatis serratis inferne denticulatis decurrentibus; racemis compositis terminalibus. In Jamaica. ち. 5-ped. Cor. sanguineo-rubra.

45. L. acuminuta Sw. fol. lanceolatis utrinque attenuatis serrulatis; racemo terminali multifloro. L. salicina Lam. Sloane hist. t. 95. f. 2. In Jamaica. ち. 3-ped. Cor. pallide flava.

46. I. mucropoda $S w$. fol. elliptico-oblongis serrulatis villosis ; floribus axillaribus Ionge pedunculatis. In Brasilia. ち. Cor. coccinea.

4\%. L. racemosa Sims; fol. oblongo-lanceolatis utrinque attenuatis spinuloso-serratis; racemo terminali; pedicellis patentibus. In ins. Caribaeis. $\hbar$.

48. L. tomentosa Thunb. fol. linearibus inciso-dentatis tomentosis; pedunc. elongatis filiformilous ; floribus hirsutis. Rapuntium Presl. In Prom. b. spei. ち.

49. $L$. pinifolia $L$. fol. linearilanceolatis carinatis glabris imbricatis erectis integerrimis; pedunc. terminalibus floribusque villosis. Andr. Rep. t. 273. Rapuntium Presl. In Prom. b. spei. ち. Cor. caerulea.

50. L. Bridgessi Hook. B. M. 3671. glabra; simplex; fol. lanceolato-submembranaceis sensim anguste acuminatis minute serratis basi decurrentibus; laciniis calycis ciliato-serratis. In Chili. t. 3-4-ped. Cor. carnea.

\section{Herbaceae.}

\section{a. Foliis pinnatifidis.}

51. L. sonchifolia Su. fol. incisosinuatis superioribus subpinnatifidis; laciniis lanceolatis denticulatis; racemo terminali. In Nov. Hisp. 2-ped. Cor. purpurascens.

52. H. laciniata Lam. fol. lanceolatis pinnatifido-dentatis glabriusculis; laciniis subdentatis; corymbo terminali. In Domingo. 1-ped. Cor. viride rubra.

53. L. heterophylla Labill. Nov. Holl. t. \%t. canle angulato simplici; fol. inferioribus dentato - pinnatifidis, superioribus linearibus integerrimis cauleque glabris; lacinia inferiore corollae media obcordatia. In Nov. Holl. 1-ped.

51. L. tenuior R. Br. pilosinscuIa; canle filiformi diviso; fol. ovatis piunatifidis, superioribus linearibus 3fidis integerrimisve; capsula subcylindracea. In Nor. Hollandia.

55. L. gracilis Andr. Rep. t. 310. fol. inferioribus subovatis inciso-pinnatifidis, superioribus lineari-lanceolatis glabris; racemo subsecundo; cor. labio superiore barbato. B. M. $7+1$. In Nov. Holl. et Prom. b. spei. ๑. Cor. caerulea.

56. L. muscoides Cham. et Schl. pusilla; tenera; humistrata; glaherrima; repens; fol. subrotundis profunde digitato-5-7-fidis; laciniis mucronulatis ellipticis. In Brasilia. 4.

5\%. L. megapotamica Spr. caule erecto ramoso foliisque linearibus angustissimis erecto-patulis glabris; floribus terminalibus corymbosis. Ad Rio Grande; Sello. ђ.

55. L. polyplylla Hook. in Beech. Voy. t. 33. caule simplici; fol. oblongo-lanceolatis, superioribus bracteiformibus argute serratis glaberrimis; floribus axillaribus; calyce hemisphaerico pubescente. In Chili. $\mathbf{b}$.

59. L. purpurea Linil. B. $\boldsymbol{R}$. 1325. fol. lanceolatis serrulatis glabris ; floribus racemosis; bracteis ovatis integris; calyce sphaerico. In Chili. ђ. Cor. amoene purpurea.

60. L. recurvifolia Spr. fol. pinnatifidis recurvis petiolatis; laciniis bifidis; pedunc. solitariis elongatis lateralibus $\mathbf{2}$-floris. L. pedunculata Sims B. M. 2251, Hapunt. Simsii Presl. In Prom. b. spei.

61. L. triquetra $L$. fol. lanceolatis pinnatifido-dentatis ; racemo terminali aphyllo. L. corymbosa Bot. M. 2693. Nonopsis Presl. In Prom. b. spei. \$. Cor. caerulea.

62. L. coronopifolia L. fol. lanceolatis dentatis; pedunc. longissimis cauleque erecto hirtis. In Prom. $b$. spei. 24. Cor. elegantissime caerulea.

63. L. Senecionis Spr. fol. sessilibus pinnatifidis pilosiusculis; laciniis subclentatis ; pedunc. axillaribus solitariis elongatis. Isostoma axillaris Lindl. B. H. 264. In Nov'a Hotlandia. 
64. L. pinnatifida Cham. et Schl. ramosa; fol. oblongo-lanceolatis utrinque acutis remote pinnatifidis sinuatoduplicato-dentatis; dentihus callosomucronatis ; racemis axillarihus; calycibus corollisque hirtis. In Prom. $b$. spei. 4.

\section{b. Foliis crenatis dentatis serratis.}

$\alpha$. Perennes; erectae.

65. L. longiflora $L$. fol. lanceolatis dentatis; pedunc. brevissimis lateralibus; tubo corollae filiformi longissimo. Jacq. am. t. 200 ejusd. Vind. t. 2\%. Sloane jam. t. 101. f. 2. In Cuba et Jamaica. 24. 1-ped. Cor. alba.

66. L. fulgens $\boldsymbol{H}$. et $K$. fol. lanceolatis denticulatis margine revolutis cauleque pubescentibus; racemo terminali. Willd. Hort. B. t. 93. Bonpl. Malm. t. \%. In Mexico. 2. 2-ped. Cor. coccinea.

6\%. I. splendens Humb. fol. angusto-lanceolatis deuticnlatis margine planis cauleque glaberrimis; racemo terminali. Willd. Hort. B. t. 86. L. formosa hoth. In Mexico. 24. 3-1ped. Cor. coccinea.

68. L. foliosa Humb. canle herbaceo erecto simplici folioso; fol. sessilihus decurrentibus lanceolatis duplicato-dentatis glabris; floribus axillaribus subspicatis; corollis hirtellis fissis. In Quito. ђ. Cor. pallide purpurea.

69. L. dracunculoides W. hl. caule erecto; fol. lineari-lanceolatis denticulatis sessilibus; pedunc. axillaribus. In Americ. austr. 4.

ro. L. Cardinalis L. fol. oblongolanceolatis cartilagineo - denticulatis cauleque erecto glabris; racemo terminali subsecundo subfolioso. B. M. 320. In Amer. bor. 24. 1-2-ped. Cor. coccinea.

71. L. camtschatica Pall. caule folioso glabro simplicissimo; fol. ohlongo-lanceolatis serrulatis sessilibus glahris; pedunc. axillaribus. I. sessilifolia Lam. In Camtschutia. 4. 1-ped.

72. I. anygdalina W. Hb. caule erecto ; fol. ovato-acuminatis serratis; pedunc. axillaribus; corollis fissis. In Amer, austr.
\%3. L. Berteriana Spr. fol. remotis longe petiolatis ovato-oblongis acuminatis eroso-subcrenatis membranaceis glaberrimis; caule scandente. L. scandens Bert. In Guadelupa.

71. L. laxillora Ifumb. caule erecto simplici; fol. subsessilibus oblongis acuminatis serrulatis glabris; spica terminali secunda; corollis hirtellis fissis. L. fissa W. In Mexico. Cor. coccinea.

75. L. rigidula Humb. caule erecto simplici; fol. subsessilibus oblongo-lanceolatis subacuminatis argute serrulatis rigidis, supra glabris, subtus rugoso-hirtellis ; floribus longe pedunculatis; cor. hirtellis fissis. In Nov. Hispania. 4.

76. L. persicifolia Lam. caule erecto simplici; fol. angusto-lanceolatis subpetiolatis serratis nudis; pedunc. axillarilus. In Guadelupa. 1 1 ped. Cor. purpurascens.

7\%. L. Cavanillesii $R$. et $\mathbf{s}$. caule herbaceo; fol. ovato-lanceolatis serrulatis subsessilibus; pedunc. solitariis axillaribus folio longioribus. L. persicifolia Cav. ic. t. 518. In Nov. Hisp. 3-ped. Cor. rubra.

88. L. xalapensis Humb. caule erecto paniculato ramoso; fol. longe petiolatis ovato-deltoideis irregulariter crenatis, supra hirtellis, subtus glabris; spicis terminalibus pedunculatis. In Mexico. 4. Cor. caerulea.

79. L. tenera $\boldsymbol{H}$. et $\boldsymbol{K}$. caule erecto simplici; fol. sessilibus, radicalibus lanceglatis, caulinis linearibus remote denticulatis glabris; spica terminali pauciflora longe pedunculata; laciniis calycis glabris. In Quito. 4. Cor. caerulea.

80. L. pauciftora II. et Kr. caule erecto simplici; fol. sessilibus, radic. lanceolatis, caulinis linearibus remote denticulatis glabris aut hirtellis; spica terminali pauciflora longe pedunculata; laciniis calycis hirtellis. In Hexico. 24. Cor. cacrulea.

81. 1 . rupestris H. et $K$. caule erecto subramoso; fol. sessilihus hirto-pubescentibus dentatis, inferioribus oblongis ovato-oblongisve ohtusis, superioribus lanceolatis acutis; cal-cibus hirtis. L. polygalaefolia W. Hb. In Nov. Granata. 24. Cor. caerulea. 82. L. veronicaefolia $W$. Hb. fol. pulescentibus, radic. obovato-obtusis, caulinis lanceolatis acutis serrulatis; 
racemis terminalibus; laciniis calycis lanceolatis. In Amer. custr. 4.

83. L. phyteumoides W. Hb. fol. lanceolato-linearibus glahris sessilibus sparsis; floribus terminalibus racemosis secundis; laciniis cor. glabris linearibus. In Amer. austr. 4.

81. L. cordigera Cav. ic. t. 523. fol. ovatis acutis amplexicaulihus villosis denticulatis; pedunc. axillaribus solitariis. In Chili. 4. 3-ped. Cor. pulchre coccinea.

85. L. pyramidalis $\boldsymbol{W}$. fol. lanceolatis acuminatis serrulatis glabris; racemis foliosis paniculatis; laciniis calycis acuminatis serrulatis. In $\mathrm{Ne} e-$ palia. 4.

86. L. comosa Cav. ic. $t$. 512. $f$. 1. fol. lanceolatis dentatis subtus pulverulentis; corymbo terminali foliorum coma suffulto. In Nov. Hispania. ち. 2-ped. Cor. Iutescens.

8\%. L. nicotianaefolia Roth; fol. oblongo-lanceolatis elongatis utrinque attenuatis serrulatis pilosiusculis; racemo terminali pubescente multifloro; floribus pubescentibus; antheris inberbibus. In Ind. or. 4.

83. L. cirsiifolia Lam. caule erecto simplici; fol. lineari-lanceolatis dentatis; dentilus subulatis distantibus; racemo terminali. Plum. Mss. t. 106. In Amer. austr.24. Caul. 1ped. Cor. flavo-virens.

89. L. stricta $S w$. fol. radicalibus ovato-cuneiformibus serrulatis glabris caespitosis; caule simplici rigido spicato. In ins. Antillis. 24. Caul. 1-ped.

90. L. syphilitica $L$. fol. ovatooblongis utrinque acutis inaequaliter serratis; floribus axillaribus solitariis; calyce reflexo pedunculisque hirto. Jacq. ic. t. 597. In Amer. bor. 4. 1-ped. Cor. caerulea.

91. L. amoena Hichx. glaberrima; fol. lato-lanceolatis serratis; spica multiflora secunda; calycis laciniis integerrimis; cor. laciniis ovatis acutis. Ann. Mus. 18. t. 1. In Amer. bor. 4. 2-3-ped. Cor. laete caérulea.

92. L. Claytoniana Michx. simplex; minutim pubescens; fol. olslongis obtusis subintegerrimis imis spathulatis; spica nuda virgata parviflora. L. spicata Lam. L. pallida Mülıl. L. goodenioides Willd. Hort. B, t, 30, In
Amer. bor. 24. 1-3-ped. Cor. caerulea.

93. C. Chamaepithys Lam. fol. linearibus canaliculatis apice bidentatis tomentoso-hirtis; pedunc. Iongissimis nudis 1-floris. L. scahra Nees. Dobrowskia Eckloniana Presl. In Prom. b. spei. 4. 4-poll. Cor. albido-violacea.

94. L. alata R. Br. glabra; erecta; caule 4-gono subulato; fol. decurrentibus linearihus cuneatisve divaricato-dentatis; capsula cylindracea. L. cuneiformis Labill. t. 72 et 73. In Nov. Holl. 4. 1 -ped. Cor. caerulea.

95. L. Nutalliana $R$. et $\mathbf{S}$. caule erecto minute scabro subramoso; fol. oblongo-linearibus denticulatis obtusis remotiusculis; floribus laxe racemosis distantibus; pedunc. coloratis; segmentis subulatis. In Amer. bor. 4 . Cor. caerulea.

96. L. dentata Cav. ic. t. 522. caule erecto glabro subramoso; fol. inferioribus ovato-lanceolatis extrorsum inciso-dentatis, superioribus lanceolatis; racemo secundo. In Nov. Holl. 21. 1-ped. Cor. caerulea.

9\%. L. dioeca $\boldsymbol{R}$. Br. fol. caulinis Ianceolatis suhdentatis; forihus masculis corymbosis terminalibus, foemineis axillarihus solitariis. In Nova Hollandia. 4.

98. L. scapigera R. Br. caule abbreviato; fol. ovato-lanceolatis subdentatis; scapo 1-floro; cor. subregulari infundibuliformi; antheris imberbibus. In Nov. Holl. 4.

99. L. tenuifolia; glabra; caule paniculato-ramoso; fol. sessilibus anguste linearibus obsolete denticulatis; pedicellis axillaribus; floribus pubescentibus; calycis lobis ovalibus. Rapuntium Ecklon et Zeyli. In Prom. b. spei. 4.

100. L. exaltata Poll ic. t. 166. fol. sessilibus alternis lanceolato-acuminatis hasi subattenuatis denticulatis glaherrimis; floribus racemosis; calyce piloso. In Erasilia. 4 . Caul. fistulosus simplicissimus 5-ped. Cor. alba.

101. I. thapsoidea Schott. in Pohl ic. $t$. 16\%. fol. sessilibus lanceolatis hasi attenuatis longissimis denticulatis ciliatis pilosiusculis; floribus racemosis; bracteis acuminatis pilosis. 
In Brasilia. 4. Caul. 6-ped. Cor. caerulea.

102. L. trialata Hamilt. caule erecto exacte 3-quetro glabro; fol. subrotundis repando-dentatis subpetiolatis; pedunc. 1-floris folio longioribus. L. micrantha Hook. B. M. In Nepalia. 24.

103. L. excelsa Lechen. fol. petiolatis oblongo-lanceolatis denticulatis dense villosis; racemis terminalibus densifloris bracteatis; laciniis calycis linearibus tubum aequantibus. In Ind. or. 4.

104. L. tetragona Blume; caule 4-gono erecto; fol. ovatis obtusis basi subdecurrentibus sinuato-dentatis glabris; racemo elongato terminali. In Java. 24.

105. L. ambigua Cham. et Schl. caule simplicissimo ?; fol. oblongolanceolatis utrinque acutis basi attenuatis sinuato-duplicato-dentatis ; dentibus calloso-mucronulatis subtus hirtis reticulato-venosis; cor. hirta. In Prom. b. spei. 4.

106. L. calycina Cham. et Schl. caule simplicissimo; fol. ohlongo-lanceolatis utrinque acutis basi attenuatis inaequaliter eroso-crenulatis, subtus reticulato - venosis fuscescenti-tomentosulis. In Prom. b. spei.

10\%. I. Krausii Grah. B.M. 3012. caule glabro erecto ramoso; fol. lanceolatis subsessilibus decurrentibus argute serratis utrinque glabris; pedunc. axillaribus solitariis. In Domingo. 24. Cor. miniata.

108. L. Dobrouskyana; scabra; caule erecto ramoso; fol. sessilibus lineari-lanceolatis acutis marginatis siliato-puberulis 2-3-dentatis ; calyce 10-nervio ; cor. extus sericeo-pubescente. Dobrowskya stricta Eckl. et Zeyh. In Prom. 6. spei. 4.

\section{B. Perennes; procumbentes.}

109. I. cuneifolia $L k$. fol. suhcordato-ovatis acutis serratis glabriusculis petiolatis; peduncul. racemosis terminalibus. Lk. et Otto ic. t. 39. Repuntium ovatum Presl. In Prom. b. spei. 4 .

110. L. inundata $R$. Br. repens glabra caespitosa; fol. subrotundis dentato-repandis, pedunculo cbractea- to glabro longioribus; staminibus epipetalis. In Nov. Holl. 4.

111. L. varifolia Sims. 1692. foliis lanceolato-linearibus dentatis integerrimisque ; floribus subsolitariis terminalibus. Rapuntium Presl. Parastranthus Don. In Prom. b. spei. 4.

112. L. fenestralis Cav. ic. t.512. f. 2. caule herbaceo suberecto; fol. linearibus dentatis semiamplexicaulibus spica terminali; genitalibus tubo brevioribus. L. rapunculoides Kunth.

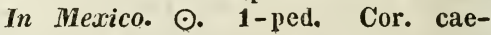
rulea.

113. L. collina Kunth; caule procumbente adscendente; fol. lanceolato-linearibus acutis denticulatis glabris sessilibus; spicis adscendentibus. L. linifolia W. Hb. In Mexico. $\hbar$. Cor. caerulea.

111. L. campanuloides Thumb. fol. lanceolatis acutis obsolete serratis glabris basi ciliatis subsessilibus; pedunc. rigidis elongatis. L. erinoides Thunb. In Japonia 4.

115. L. radicans Thunb. fol. lanceolatis undulatis subdentatis decurrentibus glabris; caule radicante; pedunc. 1-floris solitariis. In Japonia. 4.

116. L. rhizophyta Spr. fol. inferioribus obovatis repando-dentatis glabris, superiaribus subsessilibus decurrentibus, summis ciliatis integerrinis; pedunc. hrevissimis. L. decumbens B. M. 2Z\%\%. Rapuntium PresI. In Prom. b. spei. 4.

11\%. L. begoniaefolia Wall, fol.subrotundo-cordatis dentatis basi inaequalibus petiolatis villosis; pedunc. axillaribus 1-floris; calycibus subdentatis. In Nepalia. 4.

118. $L$. erinoides $L$. caule prostrato filiformi ; fol. petiolatis oblongis dentatis; laciniis calycis suldentatis. Rapuntium Mill. Herm. Lugd. t. 109. B. M. 3609. In Prom. b. spei. $\odot$. $\frac{1}{2}$-ped. Cor. caerulea.

119. L. zeylanica $L$. caule procumbente; fol. ovatis serratis acutis inferioribus ohtusis; pedunc. 1-floris; caps. villosis. Seb. Thes. t. 22. f. 12? L. nummularia Lam. In Ind. or. 4.

120. L. lutea $\mathrm{L}$. caule procumbente; fol. Ianceolatis serratis; floribus sessilibus subspicatis. " B. M. 1319. Hapuntium Presl. Burm. afr. t. 39. Parastranthus simplex Doll. In Prom. b. spei. 4. Cor. lutea. 
121. L. mubscens Ait. caule angulato prostrato; fol. lanceolatis dentatis hirtis; pedunc. axillarilus 1-floris L. repens L. In Prom. b. spei. 4. Cor. caerulea.

122. L. stipularis Roth; fol. ovalibus grosse serratis nervosis decurrentibus pubescentibus; stipulis oppositis patulis; caule pubescente ancipiti alato; calycibus coloratis. In Ind. or. 4.

123. L. bicolor Curt. B. M. 514. caule angulato prostrato; fol. glabris serratis, inferiorilus ovatis petiolatis; petiolis ciliatis; pedunc. 1-floris. In Prom. b. spei. 4. Cor. dilute caerulea.

124. I. concolor R. Br. fol. oblongis crenatis subsessilibus; pedunc. 1-floris folio brevioribus; caule tereti adscendente. In Nov. Holl. 4 . Cor. caerulea.

125. L. quadrangularis $\boldsymbol{R}$. Br. caule adscendente 4 -gono foliisque ovatis dentatis subsessilihus glabris; pedunc. axillaribus elongatis; laciniis cor. angustissimis. L. purpurascens B. Br. In Nov. Holl.

126. L. membranacea $R$. $B r$. fol. subrotundis repando-dentatis membranaceis subtrinerviis glabris; pedunc. folia superantibus; laciniis calycis subdentatis. In Nov. Holl. 4.

12\%. L. fluviatilis $\boldsymbol{R}$. Br. fol. subrotundo-ovalibus dentatis ciliatis; pedunc. pubescentilus elsracteatis folio brevioribus; staminibus epipetalis; caule repente. In Nov. Holl.

128. L. pedunculata $R$. $B r$. fol. remotis ovatis acutis angulato-dentatis subciliatis; pedunc. elongatis subbracteatis; staminibus epigynis; ramis adscendentibus. In Nov. Holl.24.

129. L. anfulata Forst. fol. suhrotundis repando-dentatis; pedunculis axillaribus solitariis; caule simplicissimo. In Nor. Zeelandia. 4.

130. I. serpens Lam. fol. ovatis crenatis glahris; pedunc. axillaribus folio brevioribus; caule subramoso. In ins. Mascarenh. 2. Caulis gracilis. Cor. caerulescens.

131. L. ilicifoliu Ker. B. R. fol. ovato-lanceolatis profunde remote dentatis; dentibus acutis; pedunc. axillaribus; folio duplo triploque longioribus. In Nov. Holl. 4 .
132. I. minuta $L$. fol. radicalibus ovatis; scapis capillaribus 1-floris. In Corsica et Afr. bor. 4 . Cor. nivea.

133. L. minima Ker. $\boldsymbol{B} . \boldsymbol{R}$. fol. ovatis crenatis petiolatis; pedunc. longissimis; bracteis teruatis. In Prom. b. spei. 4.

134. L. pygmaea Thunb. fol. orbiculatis serratis petiolatis utrinque cauleque villosis; pedunc. elongatis capillaribus hirsutis. In Prom. $b$. spei. 4.

135. K. irrigua $R$. $B r$. fol. subrotundis crassiusculis dentato-crenatis petiolatis; pedunc. 1-floris folio breviorihus; staminihus epigynis; caule repente. In ins. Van Diemen. 4.

136. L. ericoides Presl; caule filiformi diffuso puberulo; fol. sparsis oppositis ternatisve sessilibus linearihus acutis rigidis denticulatis; florihus spicatis; cor. extus hirsuta. Rapuntium Presl. In Prom. b. spei. 4.

13\%. L. incisa; pubescens; caule decumbente angulato ramoso; fol. petiolatis cordato-ovatis acutis duplicato-inciso-dentatis in petiolum decurrentibus; floribus axillaribus racemosis; cor. glaberrima. Rapuntium incisum Pres1. Mss. In Prom. b. spei.4.

138. L. caespitosa Blume; caule 4-gono diffuso procumbente; fol. sessilibus ohlongis obtusis superne denticulatis laevibus; pedunc. axillaribus elongatis 1-floris. In Java. 4.

139. L. succulenta Blume; caule repente subramoso; fol. petiolatis ovatis mucronulato-dentatis; pedunc. axillaribus 1-floris; laciniis calycis ciliatis. In Java. 4.

1+0. L. montana H. Rwdt. caule procumbente ramoso teretiusculo; fol. oblongo-lanceolatis acuminatis aryute serratis glabris; pedunc. axillaribus 1-floris. In Jara. 4.

111. L. nummularioides Cham. glahra; caule prostrato subradicaute; fol. cordato - ovatis obtusis obsolete sinuato-crenatis integerrimisve carnosulis; flor. axillaribus. In Brasilia.24. $\frac{1}{2}$-ped. Cor. caerulea.

142. L. hederacea Cham. et Schl. glabra; caulibus filiformibus repentibus; fol. alternis petiolatis orhiculatis crenato-dentatis acutiusculis; filamentis epigynis subciliatis; fructu pyriformi. In Brasilia. 4. 1-ped. Cor. caerulea. 
113. L. Mrundtiana Cham. et Schl. lumifusa; puberula; caule angulato prostrato filiformi; fol. lanceolatis nervoso-scahridis inciso-serratis; antheris omnibus harbatis. In prom. $b$. spei. 4. 1-ped. Cor. caerulea.

1H. I. Bergiana Cham. et Schl. glabra; radice repente; caule decumbente ramoso; fol. lineari-lanceolatis acutis tenuiter denticulatis; germine lineari compresso; firctu antrorsum deflecto. Grammatotheca PresI. In Prom. b. spei. ఫ. 8-10-poll. Cor. caerulea.

115. L. flava; caule diffuso; fol. sessilibus linearibus argute callosoque serrulatis; racemis 2 -floris; calyce hirsuto. Rapuntium Presl. In Prom. b. spei. 4.

\section{$\gamma$. Annuae.}

146. I. urens I. caule erectiusculo; fol. inferioribus obovatis denticulatis, superioribus lanceolatis serratis; racemo terminali secundo. E. B. 955. Curt. Lond. t. 63 . L. Farsetia Vand. L. serrulata Scliott. In Angl. et Europ. austr. $\odot, 1$-ped. Cor. caerulea.

147. L. glaníulosa Walt. erecta; subramosa; subpubescens; fol. lanceolatis glanduloso-serrulatis subcarnosis; floribus racemosis; calycis laciniis revolutis dentatis. L. crassiuscula Michx, In Carolina. $\odot$. 1-ped. Cor. albida.

148. L. inflata $L$. caule hirto; fol. dentato-serratis, inferiorihus ovatooblongis, superiorihus ovatis; pedunc. axillaribus 1-floris; caps. inflatis Bigel. t. 19. Bart. t. 16. In Amer. bor. $\odot$. 1-2-ped. Cor. pallide violacea.

149. L. Cliffortiana $L$. caule erecto; fol. cordatis obsolete dentatis petiolatis; corymbo terminali. Hort. Cliff. t. 26. In. Amer. bor. et Ind. occ. $\odot$. $1 \frac{\mathrm{I}}{2}$-ped. Cor. purpurascens.

150. K. Michanxii Nutt. fol. inferioribus orbiculatis, superiorilus ovalibus crenatis; petiolis glabris ; racemo spicato ehracteato parvifloro. L. Cliffortiana Michx. In Virginia. $\odot$.

151. L. monticola H. et $\boldsymbol{K}$. caule erecto subsimplici ; fol. petiolatis ovatis obtusis sulcordatis duplicato-serratis utrinque tenuissime hirtellis; spica terminali longe pedunculata. L. palmaris Wr. Hb. In Nov. Granata. $\odot$. Cor. caerulea.

1.52. I. micrantha $\boldsymbol{H}$. et $\boldsymbol{K}$. caule erecto paniculato ; fol. petiolatis ovatis acuminatis dentato-serratis subglabris; spicis terminalibus subsessilibus ; laciniis calycis glabris. L. ruderalis W. Hb. In Quito. $\odot$. Cor. caerulea.

153. L. subtilis $\boldsymbol{H}$. et $\boldsymbol{K}$. caule erecto subramoso; fol. brevissime petiolatis argute dentatis, supra hirtellis, subtus glabris articulatis lanceolatisve; florihus longe pedunculatis spicatis. L. Draba W. Hb. In Quito. $\odot$. Cor. caerulea,

15t. L, Erinus $L$. fol. sessilibus lanceolatis versus apicem serratis; pedunculis axillaribus elongatis. B.M. 901. L. Breyuii Spr. Rapuntium Presl. In Prom. b. spei. $\odot$. 1-ped. Cor. violacea.

15.5. $L$. bellidifolia $\boldsymbol{L}$. fol. ovatis dentatis hirsutis sulppetiolatis; pedunc. capillaribus elongatis subracemosis; caule simplici erecto hirsuto. Rapmtium Presl. In Prom. b. spei. $\odot$. $\frac{1}{2}-$ ped. Cor. caerulea.

156. L. crenata Thunb. caule volubili ; fol. lanceolatis crenatis glabris. In prom. b. spei. ๑. Caul. 1-3-ped. Cor. caerulea.

1.5\%. L. anceps $\boldsymbol{L}$. fol. lanceolatis decurrentibus; pedunc. axillaribus; caule ancipiti decumbente. Rapuntium Presl. In Prom. b. spei. $\odot$. Cor. caerulea.

158. L. repens Thunb. caule decumbente foliisque obovatis cientatis subpetiolatis villosis; pedunc, folio brevioribus. In Prom. b. spei. $\odot$.

159. L. patula L. fol. ovatis sinuato-dentatis villosis; caulibus patulo - diffusis; floribus pedunculatis cernuis. In Prom. b. spei. $\odot$. 1-ped.

160. L. thermalis Thunb. fol. ovatis serratis acutis supra glabris subtus calycihusque hispidis; caule diffuso strigoso. Ad thermas in Afric. austr. $\odot$. Cor. lutea.

161. I. secunda $L$. glabra; fol. infimis ohlongis dentatis, superioribus lanceolatis integris; pedunc. racemosis secumdis. In Prom. b. spei, ๑. Cor. alha.

162. L. fervens Thunb. fol. ovatoohlongis serratis glabris; pedunc. 1floris. In Prom. b. spei. $\odot$. Caul. spithameus. Cor. caerulea. 
163. I. mubrula Michx. fol. oblongis obtusis repando-serrulatis pubescentihus; forihus alternis subsessilibus secundis; bracteis serrulatis. B. M. 3292. In Amer. bor. $\odot$.

164. I. bifida 'Thumb. caule erecto hifido pubescente; fol. ovatis dentatis glabris. In Prom. b. spei. $\odot$. Caul. 1-2-poll. Cor. caerulea.

16.5. L. Laurentic L. caule prostrato ramoso; fol. Ianceolato-ovalihus crenatis; pedunc. solitariis 1-floris Iongissimis. L. tenella Bivon. L. minuta DC. I. setacea Sm. Mich. gen. t. 14. Bocc. Mus. t. 20 . In Europ. austr. $\odot .1-3$-poll. Cor. caerulea.

166. I. gruina Car. ic. t. 511. f. 2. caule superue nudo; fol. alternis Ianceolato - linearihus dentatis; racemo florum terminali. In Nov. Hispan. ๑. 1-ped. Cor. caerulea.

16\%. L. Heyniana $\boldsymbol{R}$. et $\mathbf{S}$. caule filiformi erecto alato; fol. subrhombeis serratis decurrentibus hasi setoso-ciliatis; pedunc. axillarihus solitariis. L. decurrens Roth. In Ind. or. et Hispuniola. $\odot$.

168. L. Humboldtiana R. et $\mathrm{S}$. caule debili; fol. subrotundis acutis sessilibus margine cartilagineo-serratis; floribus sessilibus axillaribus. L. sessilifolia W. Hh. In Peruvia. $\odot$.

169. L. tenella $L$. fol. linearihus subdecurrentibus margine cartilagineis subdentatis glahriusculis ; pedunc. elongatis; calycibus pubescentilus. L. 1dentata Ait. Dohrowskya Massoniana PresI. L. campanulata Lam. In Prom. b. spei. ๑. 4-5-poll. Cor. caerulea.

170. I. debilis I. fol. linearibus margine incrassato-denticulatis sessilibus glabris; pedunc. terminalibus flexuosis; caule filiformi simplici. Richb. Hort. t. 115. Monopsis debilis Presl. In קrom. b. spei. ○. 2-5̃-poll. Cor. violacea.

171. L. cinerea Thunb. fol. linearibus tomentosis spinuloso-dentatis sessilibus; racemis spicatis terminalibus. In Prom. b. spei. $\odot$. Caul. palmaris. Cor. alla.

172. L. filiformis Lam. fol. linearibus dentatis sessilibus glahris; racemis spicatis terminalibus. Cav. ic. $t$. 511. f. 2. In ins. Mascarenh. ๑. 1ped. Cor. violacea vel alba.
173. L. madayascariensis $\mathrm{R}$. et $\mathrm{S}$. fol. inferioribus ovatis, superioribus lanceolatis denticulatis decurrentibus; floribus axillaribus longitudine foliorum; caule prostrato. L. decurrens W. Hb. In Madagascariu. $\odot$.

171. 'H. Brouneana $R$, et $S$. glabra; caule tereti parum ramoso; racemo secunde; fol. linearibus inferioribus deutatis; cor. labio superiore ciliato; laciniis acutis; caps. hinc gibba. L. stricta R. Br. In Nova Hollandia. $\odot$.

17.5. L. rosea W'all. caule erecto villoso glaucescente; fol. lanceolatoensiformibus acuminatis denticulatis ; racemis terminalibus paniculatis; pedicellis nutantibus secundis bracteatis. In Nepalia.

186. L. camporum Poll ic. t. 165. fol. subdecurrentibus lineari-acutis renote dentatis margine ciliatis glabris; floribus spicatis suhpedicellatis; hracteis oblongo-acuminatis subdentatis pilosis. In Brasilia. $\odot$. 1-ped. Cor. azurea.

17\%. I. reniformis Cham. et Schl. herbacea; hirtella; caule subcapillari ramoso repente; fol. suhorliculatoreniformilus olssolete angulatis reticulato-venosis; antheris dorso glabris. In Brasilia inter muscos. $\odot$. Cor. caerulea.

178. L. aquatica Cham. et Schl. glabra; caule erecto vel fluitante crassiusculo exsiccatione complanato; fol. sessilibus anguste lanceolatis acutis obsolete serratis 1 -nerviis; antheris barbatis. In Brasilia. $\odot$. Cor. cuerulea.

c. Foliis subintegerimis et in tegerimis.

179. I. gibbosa Iubill. t. \%1. glabra; caule tereti simplici; fol. linearibus integerrimis subcarnosis; racemo secundo multifloro; labio superiore imberbi; caps. hinc gibha. In Nov. Holl. 24. 6-ped. Cor. caerulea. 180. I. parrifolia $R$. Br. crlabra; caule subpaniculato tereti; ramis sub1-floris pedunculiformilus; cor. labio superiore imberbi; inferioris laciniis ohlongis acutis. In Nov. Holl.

181. L. paniculata $L$. ramis paniculato-dichotomis; fol. linearibus integerrimis, inferioribus verticillatis, superioribus oppositis; pedunc. geminis. 
Rapuntium Presl. Burm. Afr. t. 38. f. 3. In Prom. b. spei. 1-ped. Cor. caerulea.

182. L. graminea Lam. caule erecto simplicissimo; fol. lineari-ensiformibus nudis; racemo longo simplici. In Peruvia. 2-ped. Cor. cuccinea.

183. L. chinensis Lour. caule repente; fol. lanceolatis integerrimis; floribus solitariis terminalihus. In China. ๑. Caul. filiformis 5-poll. Cor. dilute caerulea.

181. I. Kalmii $L$. caule erecto; fol. lanceolato-linearibus obtusiusculis alternis; racemo terminali. In Amer. bor. $\odot$. 1-ped. Cor. caerulea.

185. L. hirsuta $L$. hirsuta; prostrata; ramosa; fol. ovatis obtusis sessilibus; pedunc. terminalibus filiformibus floribusque hirsutis. Rapuntium Presl. In Prom. b. spei. 4. $\frac{1}{2}$-ped. Cor. caerulea.

186. I. depressa $I$. caule decumbente ramoso; fol. oblongls lanceolatis oltusis glabris; pedunc. axillaribus elongatis. In Prom. b. spei. Caul. palmaris. Cor. atropurpurea.

18\%. L. simplex Thunb. caule erecto; fol. linearibus villosis nargine incrassatis revolutis; peduuc. elongatis villosis. L. scahra var. Thunb. In Prom. b. spei. ๑. Palmaris. Cor. caerulea.

188. L. Linearis Thunb. caule tereti laevi simplici; fol. linearibus obtusis glahris sessilibus; pedunc. axillarihus. In From. b. spei. 4. Caul. spithameus. Cor. caerulea.

18.9. I. setacea Thunl. fol. filiformi-setaceis cauleque tereti ramoso glaherrimis; pedunc. terminalibus subsolitariis. Hapuntimn Presl. L. nematophylla spr. Act. Gorenk. 1811. f. 11. In Prom. b. spei. 4.

190. L. nanc H. et hi. $t .272$. stolcnifera; caule abbreviato erecto; fol. spathulatis integerrimis crassiusculis glabris; floribus longe pedunculatis; laciniis calycis glabris. In Mexico. 24. Cor. caerulea.

191. L. Dortmanna $L$. fol. linearibus hilocularihus; scapo subaphyllo apice racemoso; caps. demum erectis. E. B. 140. H'. Dan. 39. Hook. Lond. t. 57. In Europ. boreal. lacus. 4. Pedalis. Cor. pallide lilacina.

192. L. paludosa Nutt. scapo subaphyllo apice racemoso; fol, radic. aggregatis lineari-oblongis obtusis planis carnosis lucidis margine obsolete crenulatis. In Amer. bor.

193. L. hypocrateriformis $\boldsymbol{R} . \mathrm{Br}$. fol. linearibus integerrimis cauleque simplici glabris; floribus racemosis; cor. hypocrateriformi; antheris imberbibus. B. M. 3075. In Nova Hollandia.

191. L. Eckloniana; glaherrima; caule debili decumbente ramisque angulatis filiformi; fol. spathulatis basi attenuatis acute dentatis; pedicellis axillaribus; laciniis cor. acutis. Rapuntiun Presl Mss. In Hrom. b. spei. 4.

\section{SIPHOCAMPYLUS Pohl (1831).}

1. S. macranthus Pohl ic. $t .168$. fol. alternis oblongo-ovatis acutis ciliato-denticulatis glaberrimis; antheris hirsutis. In Brasilia. ち. 3-ped. Cor. caerulescenti-rubra.

2. S. camus Polil $t$. 169. fol. ovato-acutis crenatis subtus puhescentibus; laciniis calycis hirtis; antheris nudis. In Brasilia. ち. 2-3-ped. Cor. caerulescenti-rubra.

3. S. crenatifolius Pohl $t$. 180. fol. alternis acutis oblongis duplicatocrenatis subtus puhescentibus; antheris 2 apice hirsutis. In Brasilia. 2-ped. Cor. caerulescenti-rubra.

t. S. villosulus Pohl ic. t. 171. fol. alternis ovato-acutis duplicatoserratis hirtis subtus villosulis; cor. tubo pilosiusculo; calyce hirto. In Brasilia. ち. 2-ped. Cor. caerulescenti-rubra.

5. S. longepedunculatus Poll ic. $t$. 172. fol. cordato-acuminatis denticulatis; floribus longissime pedumculatis ; cor. calycibusque glabris. In Brasilic. ђ. 3-ped. Cor. caerulescentirubra.

6. S. cardiophyllus Pohl ic. $t$. 173. fol. cordato-acuminatis subundulatis hrevissime remote denticulatis glaberrimis; floribus solitariis longe pedunculatis glabris. In Brasilia. $\mathfrak{\not}$. 3-ped. Cor. caerulescenti-rubra.

\%. S. nitilus Poll ic. t. 17٪. fol. alternis cordato-acutis argute duplicato-seratis glaberrimis nitidis suhtus opacis; calyce corollisque pubescentilus. In Brasilia. †. 2-ped. Cor. caerulescenti-rubra. 
8. S. corymbiferus pohl ic. t. 175. fol. alternis cordato-acuminatis emarginato-duplicato-dentatis ciliatis glabris subtus pilosiusculis; calyce corollaque glahris. In Brasilia. 4. $1 \frac{\mathrm{I}}{2}$-ped. Col. caerulescenti-rubra.

9. s. psilophyllus Pohl. ic. t. 176. fol. ternatis quaternisque ohlongoacuminatis denticulatis glahris; calyce corollaque glabris. In Erasilia. 4. 2-ped. Cor. caerulescenti-rubra.

10. S. duploserratus Pohl ic. $t$. 17\%. fol. ternatis ovato-acutis duplicato-serratis basi rotundatis integerrimis hirtis; calyce corollaque hirtis. In Brasilia. 4. 2-ped. Cor. caerulescenti-rubra.

11. S. Westinianus Pohl; fol. 34-nis oblongis acutis duplicato-serratis glabris ciliatis subtus pubescentibus; calyce puherulo. Lobelia Rchb. Hort. t. 180. In Brasilia et Prom. b. spei. 4. Planta valde varians.

12. S. quadridentatus Cham. et Schl. herbaceus; glabrescens; fol.longe petiolatis ovalibus acuminatis subsinuato-dentatis utrinque rigidulis. In Hexico. Cor. coccinea.

13. S. verticillatus Cham. et Schl. fol. verticillatis elliptico-oblongis acutis serrulatis reticulato-venosis; pedunc. verticillatis; antheris dorso glabris. In Brasilia. 4. 3-ped. Cor. rubra.

11. S. betulaefolius Cham. et Schl. fruticulosus; erectus; glaher; fol.sparsis petiolatis sulocordato -3 - angularihus acuminatis duplicato-serratis; laciniis calycis serrulatis. In Brasilia. 4 . Ulnaris. Cor. rubra.

15. S. convolvulaceus Cham. et Schl. fruticosus; scandens; volubilis; fol. sparsis ovato-lanceolatis acuninatis margine reflexis obsolete denticulatis; dentilus calycis parvulis. In Brasilia. ‡. Cor. rubra.

16. S. imbricatus Cham. et Schl. utrinque pubescens; caule sublignoso nervoso angulato scutelliformi-cicatricato; fol. imbricatis cordato - ovatis acutiusculis serrulatis, margine subreflexo. In Brasilia. ち. 1-ped. Cor. rubra.

17. S. lycioides Cham. et Schl. glaber; fol. sessilibus lanceolatis angulatis calloso-serrulatis; racemo terminali; calyce fructifero nutante. In Brasilia. 4. Cor. rubra.

\section{ISOSTOBIA Lindl. (1836).}

1. I. axillaris Lindl. B. R. 961. Lobelia Senecionis Spr. In Nov. Holl. 4. Folia omnia sessilia pinnatifida pilosiuscula; laciniis subdeutatis. Pedunculi axillares elongati 1-flori. Cor. subregularis.

\section{LECHENAULTIA R.Br. (1810).}

1. L. formosa $\boldsymbol{R}, \boldsymbol{B r}$. floribus axillaribus solitariis ebracteatis nutantibus; cor. bilabiata glabra. Lodd. B. Cah. 1066. B. R. 916. In Nov. Holl. t. Cor. coccinea.

2. L. expansc R. $\boldsymbol{B r}$. forihns axillaribus subcorymbosis bracteatis; cor. 1-labiatis ciliatis. In Nov. Holl. $\hbar$.

3. L. tubiflora R. Br. floribus subterminalibus solitariis subsessilibus; corollis tuhulosis curvatis ; limbo connivente. In Nov. Holl. †.

4. L. filiformis R. $B_{r}$. fol. alter nis compresso-filiformibus; floribus oppositifoliis. In Nov. Holl. $\odot$.

5. i. humilis Spr. acaulis; fol. radicalibus teretiusculis; scapis simplicibus; foribus fasciculatis bracteatis. Anthotium R. Br. In Nova Hollandia. $\odot$.

6. L. multiflora Lodd. B. Cab. 1579. In Nov. Holl.

\section{GOODENIA Sm. (179-1).}

\section{Corolla bilabiata flava.}

\section{a. Pedunculis bracteatis.}

\section{* Terminalibus.}

1. G. bellidifolia $\mathbf{S m}$. caule nudo; fol. radicalibus planis lanceolato-spathulatis dentato-incisis; spica simplici pubescente. In Nov. Holl.

2. $G$. stelligera $R$. $B r$. caule nudiusculo; fol. radicalibus caruosis semiteretibus linearibusve glahris subdentatis; spica simplici pubescente. In Nov. Holl.

3. G. paniculata Sm. canle paucifolio; fol. radicalibus elongato-lanceolatis dentato-incisis; panicula pubescente; pilis ovarii glandulosis Cav. ic. t. 50\%. In Nov. Lioll.

4. G. humilis $\boldsymbol{R}$. $\boldsymbol{B} \boldsymbol{r}$. caule paucifolio; fol. radic. elongato-lanceolatis 
subdentatis; panicula pubescente; ovarii pilis acutis. In Nov. Holl.

5. G. gracilis R.Br. glabra; caule paucifolio; fol. radic. lineari-lanceolatis elongatis crassiusciulis; ovariis glabris. B. Cab. 1032. In Nov, Holl.

6. G. decurrens $\boldsymbol{R}$. Br. glaberrima; caule polyphyllo; fol. caulinis ohlongis dentatis decurrentibus; spica racemosa basi divisa. In Nov. Holl.

7. G. armerifolia Sieb. caule stricto glabro paucifolio; fol. linearibus abbreviatis; calycibus breviter pedunculatis villosis; corollis barbatis. In Nov. Holl.

8. G. pubescens Sieb. fol. ovatis inciso-dentatis glabriusculis; ramulis pubescentibus; floribus subsessilibus. In Nov. Holl.

\section{** Pedunculis axillaribus.}

9. G. ovata Sm. suffruticosa; glabra nunc fucata; fol. ovatis acutis dentato-serratis; axillis barhatis ; calycis laciniis subulato-filiformibus; seminibus 1-seriatis. Andr. Rep. t. 68. Cav. ic. t. 506. In Nov. Holi. .

10. G. acuminata $R$. Br. suffuticosa; erecta; glabra; fol. ovatis acutis dentato-serratis; axillis imberbibus; calycis laciniis planis; seminibus 2-seriatis. In Nov. Holl. ち.

11. G. varia $\boldsymbol{R}$. $\mathrm{Br}$. suffruticosa; glabra; fol. ovatis obtusiusculis dentatis coriaceis; axillis nudis; corollis stylisque glabris; capsula ovata. In Nov. Holl. . Suffutex valde varians.

12. G. yrandiflora Sims B. M. 890. herbacea; erecta ; glandulosopubescens; ramis striato-angulatis; fol. inferioribus lyratis; rameis ovatis; stylo Iongitudinaliter lanato. In Nov. Holl. 24.

13. G. heterophylla $\mathrm{Sm}$. herbacea; erectiuscula; pubescens; pilis eglandulosis; fol. ovatis inciso-lobatis; stylo wlabro. Cav. ic. t. 508. In Nov. Holl.

14. G. rotundifolia $\boldsymbol{R}$. Br. herbacea; erectiuscula; fol. subrotundis inviso-serratis membranaceis; stylo glabro; caps. ovata. In Nov. Holl.

15. G. barbata R. Br. erecta; glanduloso-pubescens; scabra; fol. lanceolato - linearibus integris; cor. fauce barbata; stylis longitudinaliter hirsutis. In Nov. Holl. 4 .
16. G. geniculata R. Br. herbacea ; pubescens; eglandulosa ; fol. longe lanceolatis subdentatis; pedunculis scapiformilus, fructiferis geniculatoreflexis. In Nov. Holl. $\odot$.

17. G. lanata R. Br. pubescens; subacaulis; ramis prostratis; fol. obovatis obtusis subdentatis hirsutis, junioribus lanatis; cor. laciniis margine lanatis. In Nov. Holl.

18. G. hederacea Sm. pubescens; subacaulis; ramis filiformibus prostratis; fol. ovalibus dentatis, radicalibus nunc lobatis; cor. Iaciniis margine nudis. In Nov. Holl.

19. G. glabra R. Br. glabra; subacaulis; ramis prostratis ; fol. subovatis paucidentatis : rameis subsessilibus; cor. extus glabra. In Nov. Holl.

\section{b. Pedunculis ebracteatis.}

20. G. mollis R. Br. fol. subcordato-ovatis acutis serratis villosis; pedunc. axillaribus; cor. tubo saccato. In Nov. Holl.

21. G. elongata Labill. t. 75. pilosa; fol. radic. spathulatis, caulinis lanceolatis subintegerrimis ; pedunc. fructiferis reflexis. In Nov. Holl.

22. G. hispida R. Br. strigoso-hirsuta; erecta; fol. caulinis sessilibns elongato-lanceolatis subdentatis; pedunc. fructiferis erectis; calyce hispido. In Nov. Holl.

23. G. coronopifolia $\boldsymbol{R}$. Br. glabra; fol. radic. pinuatifido-dentatis, caulinis integerrimis; pedunc. solitariis alternis, fructiferis erectis. In Nov. Holl.

24. G. tenella $\boldsymbol{R}$. Br. adpresse pubescens; caule simplici v. nullo; fol. lanceolatis ; pedunc. elongatis, fructiferis erectis. In Nov. Holl.

25. G. filiformis $\boldsymbol{R}$. Br. glabriuscula; caule simplici; fol. radic. filiformibus, caulinis minoribus; pedunc. terminalibus subumbellatis. In Nov. Holl.

26. G. quadrilocularis $\boldsymbol{R}$. Br. glabra; erecta; fol. subovalibus dentatis; floribus spicatis axillaribusve. In Nov.

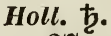

27. G. dubia $S p r^{\circ}$ fol. inciso-dentatis cauleque annuo pilosis; pedunc. 1-floris axillaribus; stylo 3-fido; caps. 1-loculari. Calogyne pilosa R. Br. In Nov. Holl. 
2. Cor. bilabiata caeruleas. $a l b a$.

28. G. murpurascens R. Br. fol. radic. elongato-lanceolatis cauleque nudo glabris; panicula effusa. In Nov. Holl.

29. G. pterygosperma R. Br. fol. radic. linearibus subdentatis cauleque simplici glabris; floribus alternis ; calyce obtusiusculo ovariisque glabris. In Nov. Holl.

30. G. caerulea $\boldsymbol{R}$. Br. glabra; caule subsimplici paucifloro; fol. radic. linearibus, caulinis remotis; calyce acuto ovariisque glandulosis. In Nov. Holl.

31. G. incana R. Br. incano-tomentosa; fol. caulinis remotis oblongo-linearibus; corollis extus ovariisque lanatis. In Nov. Holl.

\section{Corolla 1-labiata.}

32. G. scapigera R. Br. glabra; erecta; fol. dentatis; spica terminali pedunculata; calycis laciniis subulatis ovario hinc tubulifero longioribus. In Nor. Holl.

33. G. viscida R. Br. glabra ; fucata; erecta; fol. lanceolatis dentatis; pedunc. axillaribus unifloris brevissimis; stigmate bifido. In Nov. Holl.

34. G. repens Labill. t. 76. glabra; repens ; fol. lanceolatis carnosis. In Nov. Holl.

35. G. Pumilio R. Br. repens; pubescens; fol. ovatis membranaceis terminalibus confertis; pedunc. e summis alis 1-floris. In Nov. Holl.

\section{WENDLANDIA Bartl. (1830).}

\section{a. Floribus 5-andris.}

1. W. paniculata DC. arborea; fol. sessilibus ovali-oblongis acuminatis laevihus; stipulis reniformihus. Rondeletia Roxb. In Ind. or. $\$$. Cor. parva alba.

2. W. tinctoria $D C$. arhorea; fol. petiolatis oblongo-lanceolatis subtus pubescentibus; stipulis 3 -angularibus cuspidatis. In Bengalo. ‡. Cor. parva alba.

3. W. glabrata DC. arhorea; fol. petiolatis oblongo-lanceolatis utrinque glabris; stipulis 3 -angularibus cuspi- datis. Roudeletia tinctoria Blume. In Java. b.

4. iv. exserta DC. fol. petiolatis late lanceolatis pubescentibus subter tomentosis; stipulis semilunatis reflexis. Rond. exserta Roxb. R. thyrsiflora Rotl. In Bengalo. $ђ$.

5. U. proxima DC. arborea; fol. ellipticis acuminatis subtus ramulisque tomentosis ; panicula hirsutissima; floribus confertissimis. Rondeletia Don. In Silhet. $\hbar$.

6. $W$. densiflora DC. arborea; fol. petiolatis ovato-oblongis acuminatis coriaceis; panicula dense tomentosa; floribus confertis. Rondeletia Blume. In Java. ち.

7. W. cinerea DC. arborea; superne cinereo-tomentosa; fol. petiolatis lanceolatis supra villosis subtus tomentosis; stipulis apice recurvatis. In Nepalia.

8. W. Lazonensis DC. ramulls, petiolis nervisque foliorum puberulis; fol. ovali-oblongis utrinque acuminatis; stipulis semiorbicularibus obtusis coriaceis. W. multiflora Bartl. In Latzonia. ち.

9. W. coriacea DC. arborea; undique laevis; fol. petiolatis oblongolanceolatis acuminatis basi acutis coriaceis lucidis; stipulis ligulato-cuspidatis. Rondeletia Roxb. In Nepalia. Cor. alba.

10. W. puberula DC. subhírsntopulserula; fol. petiolatis ovali-oblongis utrinque acutis supra glabris; stipnlis latis cuspidatis adpressis; stigmate clavato. In Nepalia. $\hbar$.

11. W. pendula $D C$. frnticosa; ramis pendulis; fol. Ianceolato-ovatis acuminatis subtus subscabris; stipulis Ianceolatis adpressis; cor. tubo filiformi. In Nepalia. $\hbar$.

12. W. longifolia $D C$. fruticosa; ramis laxis; fol. elliptico-oblongis acuminatis basi acutis subtus villosis; stipulis lanceolatis erectis saepe hidentatis; bracteis calycibusque glandulosis. Rondeletia Koxb. In Silhet et Nepalia. $\hbar$. Cor. flava.

\section{b. Floribus 4-andris.}

13. W? spicata DC. subarborea; fol. ellipticis acuminatis basi attenuatis villosis; stipulis oblongis acutis; panicula dense villosa; cor. tubo fili- 
formi. Rondeletia Roxb. In Indi orientali. $\hbar$.

11. W? tetrandra DC. fruticosa; ramis 4-gonis; fol. sessilibus lanceolatis laevihus ; stipulis pinnatifidis; floribus axillaribus glomeratis. hondeletia Roxb. In penang. ђ.

15. W? corymbosa DC. fol. ovato-lanceolatis; pedunc. plerumque terminalibus dichotomo-corymbosis ; florihus 1-lateralibus tetrandris. Hondeletia Roxb. In Pulo-Penang. ち. Cor. alba rubro-tincta.

16. W. Lausonice DC. arborea; ramulis 4-angulis; fol. lanceolatis acuminatis glabris; corymbo terminali 3-chotomo; fructibus oblongis. Lawsonia purpurea Lam. Rheede 4. t. 87. In Malabaria. $\hbar$.

17. W. fruticulosa; suffruticosa ; rufo-villosa; fol. oblongo-lanceolatis; stipulis bifidis; pedunc. 3 -chotomis multifloris. Xanthophytum fruticulosum Blume. In Java. $\hbar$.

18. W. javanica; suffruticosa ; glabra; erecta; fol. oblongis utrinque acuminatis; spicis axillarihus ahrupte glomeratis nutantibus. Chiococca spicata Blume. In Java. ђ.

954. FORGESIA Comm. Juss. (17S9).

1. F. borbonica Juss. Deforgia borbonica Lam. ill. t. 125. In Bor-

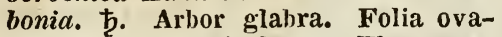
to-lanceolata reticulata. Flores paniculati.

\section{PSILOBIUM Jack (1826).}

1. P. nutans Jack; laeve; pedunc. nutantibus 3-6-floris. In sumatra.

2. P. tomentosum Jack; tomentosum; floribus ad axillas sessilibus. In Ind. or. $\hbar$.

\section{ARGOSTEMMA Wallich (1825).}

1. A. sarmentosum Wall. caule pubescente basi repente sarmentoso; fol. ovatis obtusis subsessilibus subtus villosis. In Ind. or. Flores albi.
2. A. verticillatum Wall. pubescens ; erectum; caespitosum; fol. 4verticillatis lineari-lanceolatis subfalcatis; floribus 4-5-andris. In Nepalia. Flores albi.

3. A. rostratum Wall. laeve; erectum; fol. anguste lanceolatis acuminatis petiolatis; stipulis recurvis; umbella pedunculata; corollae lobis antherisqne acuminatis. In Silhet. Flores albi.

4. A. pictum $W^{\top}$ all. Iaeve; hrevicaule; fol. ovatis subcordatis acutis nervis reticulatis brevissime petiolatis; umbella pedunculata. In Penang.

5. A. borragineum Blume; caule basi repente apice scabro; fol. ellipticis utrinque acutis petiolatis subtus puberulo-hirtis; foribus umbellatis demum secundis. In Java. $\odot$. Flores albi.

6. A. montanum Blume; caule tomentoso hirsuto adscendente; fol. ovatis acuminatis ciliatis petiolatis supra hirtis subtus in nervis setoso-villosis; floribus umbellatis. In Java. Flores albi.

7. A. pauciflorum Blume; caule inferne repente supcrne ramoso scabro; fol. petiolatis ovatis acutis basi attenuatis hirsutis; umbella pauciflora In Java. ๑. Flores albi.

8. A. uniflorum Blume; caule inferne repente pubescenti-hirto; fol. oppositis, altero minimo vix stipulam excedente, altero lanceolato; pedunc. terminali 1-floro. In Java. $\odot$. Flores albi.

\section{PHYTEUMA Matth. (1560).}

\section{a. Flores fasciculati.}

1. P. comosum $\boldsymbol{L}$. fol. grosse dentatis, radicalibus longe petiolatis cordatis ovato-rotundatis, caulinis ovatolanceolatis acutis; bracteis maximis grosse dentatis. Barr. ic. 889. Jacq. austr: app. t. 50. In Alp. Europ. 24. 2-4-poll. Cor. violacea.

\section{b. Flores capitati.}

2. P. globulariaefolium Sternb. fol. radic. confertis obovatis latis apice subdentatis, caulinis sessilibus ovatolanceolatis subciliatis; capitulo pauciforo; bracteis latissimis ovato - rotun- 
datis ciliatis apice subdentatis. Iichb. ic. t. 365. In Alp. Europ. 4. 1-2poll. Cor. caerulea.

3. P. paucifiorum h. fol. integris, radic. confertis brevilus angustis lineari- vel ohovato-Ianceolatis, caulinis sessilibus lineari-lanceolatis; bracteis ovato-acutis ciliatis hasi subdentatis. Rchb. ic. t. 36t. P. globulariaefolium Hegetschw. Heis. t. 13. el 15. In Alp. Europ. 24. 2-poll. Cor. intense caerulea.

t. P. hemisphaericum $\boldsymbol{L}$. fol. integris, radic. linearibus angustis, caulinis lineari-lanceolatis; hracteis ovato-acuminatis sulnintegris ciliatis. Rchh. ic. t. 363. Lam. ill. t. 124. f. 2. Barr. ic. 523. 1. P. intermedium Hegetscliw. Heis. t. 17. In Alp. Europ. 24. 2-4poll. Cor. caerulea.

5. P. Caraestice Birol; fol. radic. confertis lanceolatis longe petiolatis subintegris, caulinis lineari-lanceolatis subserratis; bracteis patentibus vel reflexis latis ovato-acuminatis acute serratis glabris. P. serratum Viv. In Corsica. 4. 3-4-poll. Cor. violacea.

6. P. humile Schleich. fol. radicalibus confertis lineari-lanceolatis basi angustatis suhintegris; bracteis ovatolanceolatis longe acuminatis dentatoserratis subciliatis. Rchb. ic. 546. In $A$ lp. Europ. 24. 2-3-poll. Cor. caerulea.

\%. Pieberi Spr. fol. radic. petiolatis ovato-rotundatis crenatis, canlinis superioribus amplexicaulihus acute dentatis; bracteis ovato-acuminatis pilosis grosse dentatis. Iichb. ic. t. 214. P. Charmelii sieb. In Alp. Europ. 2. 2-5-poll. Cor. intense caerulea.

8. P. orbiculare $L$. fol. radic. petiolatis lanceolatis subcordatis crenatis, caulinis sessilibus lineari-lanceolatis; bracteis ovato-acutis integris. Jacq. austr. t. 437. Hook. loud. t. 35. P. cordata Vill. Sims. B. M. 1466 . In Alp. Europ. 4. 4-6-poll. Cor. intense caerulea.

9. P. Charmelii Vill. t. 11. f. 3. fol. polymorphis, radic. longe petiolatis cordatis ovato-acutis grosse serrato-dentatis, caulinis inaequali-serrato-dentatis ; capitulo sphaerico; bracteis lineari-lanceolatis brevibus. Barr. ic. 526. In Alp. Europ. 4. 6-10poll.
10. P. Scheuchzeri All. ped. t. 39. f. 2. fol. radic. petiolatis ovato-lauceolatis obtuse serratis, caulinis lineari-lanceolatis acute serratis; bracteis longissimis reflexis. Rchb. t. 360. P. ovata Lam. P. corniculatum Gaud. In Alp. Pedem. 4. 1 -ped. Cor. caerulea.

11. P. scorzoneraefolium vill. dangh. $t$. 12. f: 2. fol. radic. cordatoovatis, caulinis lineari-lanceolatis ; capitulo ovoideo; bracteis reflexis limearibus glabris; stigmatibus 2 . Rchb. ic. t. 249. P. Scheuchzeri $\beta$. Pers. P. betonicaefolium. Sims B. M. 2066. In Alp. Europ. 4. 1-2-ped. Cor. intense caerulea.

12. P. Inichelii All. ped. t. 7. f. 3. fol. radic. limeari-lanceolatis; capitulo ovoideo; bracteis reflexis linearibus pubescentibus; calycibus medio pilosis; stigmatibus 2. Rchl. ic. t. 348. In monte Cenisio. 4. 1-ped. Cor. caerulea.

13. P. betonicaefolium Vill. dauph. t. 12. f. 3. fol. inferioribus oblongoacuminatis serrulatis, superioribus lineari-lanceolal is integriusculis; capitu10 subebracteato; stigmatibus 3. Rehb. ic. 350. P. betonicaefolium Gaud. P. Michelii Lam. et DC. In Alp. Europ. 4. $\frac{1}{2}$-ped. Cor. caerulea.

14. P. veronicaefolinm Schrad. in litt. fol. inferioribus longe petiolatis cordatis longe lanceolatis dentato-serratis, superioribus sessilibus linearilanceolatis serulatis; spica cyludracea; bracteis setaceis glabris. In Alp. Tyrol. 24. 2-ped. Cor. caerulea.

15. P. persicaefolium Hoppe; fol. inferioribus petiolatis ovato-oblongis crenulatis, caulinis lineari-lanceolatis subintegris; spica oblonga; bracteis lineari-lanceolatis glabris. P. scorzoneraefolia Lam. In Carinthia. ち. 1-2-ped. Cor. caerulea vel alba.

16. P. spicatum $\mathbf{I}$. fol. inferioribus longe petiolatis cordatis ovato-acutis biserratis, superioribus ovato-lanceolatis; spica cylindrica elongata; bracteis linearibus subulatis glabris; stigmatibus 2. Barr. ic. 892. Lam. ill. t. 124. f. 1. Fl. dau. 362. Schk. t. 39. B. M. 2347. In Europ. 1-3-ped. Cor. alba ochroleuca vel caerulescens. 17. P. Halleri All. fol. inferiorihus longe petiolatis cordato-ovatis acutis duplicato-grosse serratis; spica ovato-oblonga; bracteis lanceola- 
tis glabris; calycibus glabris; stigmatibus 2. P. ovatum sclim. In Alp. Europ. 24. 2-3-ped. Cor. atro-violacea.

18. P. nigrum Schm. fol. inferioribus petiolatis cordato-ovatis acutis crenulatis, superioribus lineari-lanceolatis serrulatis; spica ovoidea; bracteis reflexis linearibus; calyce glahro; stigmatibus 2. In Bohemia. 24. 1-2ped. Cor. nigro-violacea.

1.9. P. Balbisii A. DC. fol. radic. petiolatis cordato-ovatis acutis, caulinis sessilibus ovato-acuminatis; spica cylindraceo-oblonga; bracteis linearibus pilosiusculis; stigmatibus 3 . P. cordata Ballb. In Pedem. 4. 4-6poll. Cor. alba.

\section{c. Flores laxe spicati.}

20. P. tenuifolium A. DC. caule simplici inferme glahro superne scabriusculo; fol. caulinis linearibus integris angustissimis; floribus spicatis. Circa Byzantium. 1-ped.

21. P. limoniifolium Sibth. graec. t. 218. caule romoso; fol. radic. Ionge petiolatis glaberrimis lanceolatis subdentatis; spica longa interrupta; caps. ovoidea. P. stricta B. M. 2145. P. virgata Lodd. b. Cab. $\cdot 667$. P. styJosum Schrank. H. mon. t. 49 . In Oriente. 24. 2-3-ped. Cor. caerulea. 22. P. collinum Guss. pl. rar. $t$. 19. caule subsimplici; fol. radic. lanceolatis utrinque attenuatis scabriusculis repando-denticulatis ; spica subinterrupta ; caps. turbinata scabra. In Italia. 4. Cor. caerulea.

23. P, lobelioides Willd. phyt. $t$. 4. f. 2. caule subsimplici scabriusculo; fol. scabris, radic. petiolatis lineariJanceolatis acute denticulatis; floribus oparsis breve pedicellatis; calycibus scaloris. In Armenia. Caul. $\frac{1}{2}-$ ped.

21. P. lanceolatum $W$. glabrum; caulibus ramosis; fol. radicalibus confertis breve petiolatis. Desf. Ann. Mus, 11. t. 5. Choix de pl. t. 24. In Armenia. $\frac{1}{2}$-ped. Cor. albida.

25, P. repandum Sibth. caule glabro; fol. radic. confertis petiolatis elliptico-oblongis repandis glabris; petiolis hasi imbricatis; bracteis fimbriatis. In Olympo Bithyno. $4.2-4-$ poll.

26. $\boldsymbol{P}$. rigidum $\boldsymbol{W}$. caule simplictssimo glabro; fol. radic. lineari-lan- ceolatis; dentibus minutissimis margine munitis; floribus sparsis. In Oriente. 27. P. canescens W. et Kit. hung. t. 11. scabrum; caule simplici; fol. caulinis sessilibus ovato-lanceolatis crenulatis; floribus longe petiolatis. In Hungaria et Tauria. 24. 1-3-ped. Cor. violaceo-caerulea.

28. P. salicifolium $\boldsymbol{W}$. et Kit. caule simplicissimo glahro; fol. inferioribus petiolatis ovato-lanceolatis serrato-dentatis, superioribus sessilibus Ianceolatis acute serratis; spica brevi; calycibus glabris. In Banatu. 4 . 8-poll.

29. P. campanuloides Bieb. caule simplici glabro; fol. ovatis obtusis s. ovato-acutis crenatis; spica brevi densa; calyce glabro. B. M. 1015. P. ellipticum Sibth. gr. t. 217. In Cau-

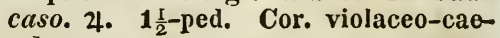
rulea.

30. P. amplexicaule $\boldsymbol{W}$. glabrum; caule simplicissimo; fol. caulinis subamplexicaulibus ovato-acutis basi acute serratis; calycis lobis capillaribus. Sibth. gr. t. 219. In Armenia. 4. $1 \frac{1}{2}$-ped. Cor. violacea.

31. P. sibiricum Vest; capitulo multifloro; floribus omuibus bracteatis; bracteis oblongis rigidis; fol. cuneato-linearibus dentatis. In Sibiria.

32. $P$. inaequatum Kit. capitulis subglobosis; fol. radic. oblique cordato-lanceolatis serratis, superioribus integerrimis. In Alp. comitatus Arvensis.

33. P. minutum Agardh; fol. radic. spathulato-ovatis sinuatis, caulinis spathulatis integerrimis obtusis. In summis Sierrae Texedae. 24. Cor. caerulea.

34. $P$. pinnatum $L$. glaberrimum; fol. radicalihus pinnatis. Silsth." gr. t. 226. Rchb. Hort. t. 137. Petromarula pinnata A. DC. In Creta. 4. 2-4ped. Cor. caerulea vel alba.

\section{TRACHELIUM Pon. (1618).}

1. $\boldsymbol{P}$. caeruleum $\boldsymbol{L}$. fol. ovato-acntis grosse serratis subpetiolatis; corolla violacea hypocrateriformi; tubo longo angustissinı; stigmate 3-fido. Barr. ic. 683. In Alp. Europ. 4. 
1-3-ped. Cor. lougissime tubulosa violacea.

2. T'. angustifolium Schousb. fol. lincaribus angustis integerrimis obtusis sessilibus; cor. albida infundibuliformi; tubo elongato; stigmate bifido. In regno IIuroccuno. 4. 1-ped. Cor. albida.

\section{CAMPANULA Dodon. (1557).}

\section{Campanula e verae. Cor. cam-} campanulata.

1. Medium DC. Sinus calycis appendicibus obtecti. Caps. 35-locularis valvis semper ad basin sitis dehiscens.

\section{* Stigmata 5. Caps. 5-locularis.}

1. C. crispa Lam. glabra; fol. laevibus grosse crenato-dentatis, radicalibus bidentatis laciniatis; floribus pyramidatim racemosis; cor. extus scabriuscula. Tourn. Voy. p. 518. c. ic. In Armenia. 24. 1-ped. Cor. caerulea.

2. C. Celsii A. DC. velutina; caule adscendente; fol. irregulariter lobatis; lobo terminali crenato ovatoacuto; cor. tubulosa velutina. C. tomentosa Vent. Cels. t. 18. In Graecia. $\odot$. Caulis 1 -ped. purpurascens. Cor. dilute violacea.

3. C. rupestris Sibth. gr. t. 213. caule adsceudente piloso; fol. incanocinereis irregulariter pinnatis crenulato-dentatis; floribus laxe racemosis; cor, tubulosa velutina. C. lanuginosa W. In Boeotiae et Peloponnesi rupibus. $\odot$. $\frac{1}{2}$-ped. Cor. dilute caerulea.

4. C. tomentosa Lam. incano-tomentosa; fol. radic. petiolatis irregulariter lyratis crenato-dentatis; cor. tubulosa sericea lobis calycis acuminatis vix longiore. In Oriente. 1ped. Cor. alba.

5. C. lyratc Lam. hispida; fol. inferioribus petiolatis cordatis ovatoacutis crenatis; floribus racemosis; cor. tubulosa. nervis subpilosa. In Oriente. 2-ped.

6. C. Andrewsii A. DC. villosa; fol. radic. lyrato-pimnitifidis pinnulis incisis, caulinis cordato - rotundatis grosse dentatis; floribus laxe racemoeis; cor. campanulata tubulosa: C. laciniata Andr. IRep. t. 385. In Gruecia. $\odot$. 1-2-ped. Cor. pallide cyanea.

ฑ. C. laciniate A. DC. caulibus subvelutinis; fol. radic. lanceolatis grosse laciniatis; peliolis marginalis lobatisve; floribus paniculatis; cor. campanulata ampla. Tourn. cor. t. 260. In Archipelago. ๑. 2-ped. Cor. pallide caerulea.

S. C. anchusaefolia Sibth. gr. t.212. caulibus ramosis subvelutinis; fol. pilosis ovato-lauccolatis, radic. petiolatis laciniatis; floribus paniculatis; cor. cyliudrica ampla. In Graecia. ๑. 1-ped. Cor. pulchre cyanea.

9. C. tubulosa Lam. pilosa; petiolis foliorum inferiorum longis brevilobatis; lobis ovato-acutis serratodentatis; cor. velutina tubulosa. Desf. Aun. Mus. t. 17. In ins. Creta. $\frac{1}{2}-$ ped. Cor. violaceo-cinerea.

10. C. betonicaefolia Sibth. gr. $t$. 210. caule erecto; fol. elliptico-0l)longis vel ovato-acutis crenato-dentatis; lobis calycis ovato-acutis; cor. tubulosa. In monte Olympo et Bithyno. $\odot$. $1 \frac{1}{2}$-ped. Cor. basi pallide flavescens lobis purpureo-caeruleis.

11. C. corymbosa Desf. Ann. Mus. 11. t. 15. Choix. t. 30. caule erecto; fol. ovato-acutis crenato-dentatis, radic. petiolatis; lobis calycis longe acuminatis ; cor. campanulato-tubulosa. In ins. Creta. 2-ped.

12. C. pelviformis Lam. caulibus adscendentibus; fol. radic. petiolatis ovatis crenato-dentatis; calycis lobis longe ovato-acuminatis; cor. campanulata ampla. Ann. Mus. t. 16. In Creta. 1-ped. Cor. griseo-caerulea.

13. C. Medium $\boldsymbol{L}$. caule erecto; fol. sessilibus ovato-lanceolatis crenato-dentatis; Iobis calycis ovatoacuninatis sinubus reflexis; cor. canpanulata inflata. Hilar. pl. Fr. t. 72. Hill. veg. t. 7. In Europ. austr. $\odot$. 1-2-ped. Cor. alba vel purpurea.

\section{*゙^ Stigmata 3. Capsula 3-locu- laris.}

11. C. Adami Bieb. A.DC. Camp. t. 11. f.1. fol. subciliatis, radic. longe petiolatis cuneato-spathulatis apice grosse dentatis; lobis calycis acuminatis pilosiusculis. Bieb. Cent. t. 16. In Caucaso, 24. 3-4-poll. Caespitosa. 
15. C. Biebersteiniana R. et S. A. DC. Camp. t. 10. f. 1. glabra; fol. molliter ciliatis, radic. spathulatis apice dentatis; lobis calycinis oblongo-lanceolatis; sinum appendicihus avato-acuminatis. C. tridentata schreb. dec. 3. t. 2. C. rupestris Bieb. In rupestribus Caucasi. 24. 2-4-poll.

16. C. pilosa Pall. fol. basi molliter ciliatis, radic. Ionge lanceolatis petiolatis crenulatis; lohis calycis ciliati ovato-acuminatis; cor. infundibuliformi ore barbata. In Sibiria. 4. 3-poll. Cor. caerulea.

1\%. C. Saxifraga Bieb. fol. subciliatis, radic. longe petiolatis lanceolato-spathulatis crenulatis, caulinis sessilihus integris ligulatis; calycis laciniis acuminatis. A. DC. Camp. t. 10. f. 2. In Caucaso. 4. 2-4-poll. Cor. alisa.

13. C. ciliata stev. caule pilosiusculo; fol. pilis rigidis ciliatis, radic. subsessilibus ovato-lanceolatis crenulatis nitidis, caulinis ligulatis; lobis calycis lineari-acuminatis ciliatis. In Caucaso. 4. 4-5-poll, Cor. caerulea.

1.9. C. altaica A. DC. Camp. $t$. 10. $f$. 3. fol. radic. petiolatis Ionge lanceolatis crenatis glabris, caulinis ligulatis subdentatis; calycis tubo pubesceute; lobis ovato-acuminatis villosis. C. sayanensis Fisch. C. frigida Pall. In Altaicis et Persia. 4. 2-poll. Cor. caerulea.

20. C. dasyantha liieb. fol. radic. ovato-acutis petiolatis crenatis glabriusculis, caulinis sessilious lanceolatis; lobis calycis ovato-lanceolatis appendicibus minimis subulatis. Rchb. ic. 178. DC. Camp. t. 10. f. 4. In

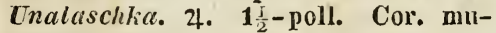
gila caerulea.

21. C. Allionii Vill. dauph. $t$. 10. caule pilosiusculo; fol. radic. linearilanceolatis subintegris ciliatis, imis obtusiusculis; lobis calycinis lineariacuminatis appendicibus ovato-acntis ciliatis. All. ped. t. 6. f. 3. C. nana Lam. In Giallia. 24. 4-6-poll. Cor. caerulea vel alba.

22. C. Pallasiana R. et $\mathbf{S}$. caule 1-floro lobisque lanceolatis serratis petiolatis glabris; flore untante; laciniis acutis. In Sibiria. 24.

23. C. saxatilis L. glabra; canlihus erectis; fol. crenatis, radicalibus rosulatis subspathulatis, caulinis ova- to-acutis; lobis calycis acuninatis; stylo exserto. Barrel. ic. 813. In Creta. 3-4-poll. Cor. caerulea.

21. C. heteropliylla L. glaberrima; caulibus erectis simplicibus; fol. integris, radic. subspathulatis, caulinis ovato-rotundatis; lobis calycis acutis; sinubus subdentatis. Sibth. gr. t. 208. Touru. it. 243. In Archipelago. 4. 6-9-poll. Cor. dilute caerulea.

25. C. Olivieri A. DC. Camp. $t$. 9. pubescens; cinerea; caulibus erectis simplicibus; fol. subintegris, radic. spathulatis, caulinis ovatis; lobis calycinis acuminatis; sinubus subdentatis. In Graecia. 4. 8-9-poll. Cor. subvelntina.

26, C. candida DC, pauciflora; pallide incana; caulibus erectis simplicibus; fol. radic. spalhulatis subintegris, caulinis ovatis sinuato-dentatis; 10bis calycis acuminatis. In Oriente. 3-5-poll. Cor. glabriuscula alba.

2\%. C. calaminthaefolia Lam. pubescens cinerea; caulibus decumbentibus ramosis; fol. dentatis; radic. rosulatis subspathulatis, canlinis obovatis; sinubus calycis brevissimis dentiformibus. Desf. ann. Mus, 11. t. 12. In ins. Naxo. 6-8-poll. Cor. pallide rubra.

28. C. edulis Forsk. hispida; radice crassa; caule erecto simplici 1floro; fol. ovato-lanceolatis subcrenulatis; calycis lobis lineari-lanceolatis corolla hispida aequalibus; sinum appendicibus reflexis. In Arabia felici. $\frac{I}{2}$-ped. Cor. hispida pallide rosea.

29. C. strigosa Russel; pilosostrigosa; caule erecto; ramis dichotomis ; fol. lanceolatis integris; lobis calycis subulatis; sinum appendicibus obtusis. C. Busseliana R. et S. In Oriente. 2-5-poll.

30. C. dichotoma IL. rigide pilosa; caule erecto; ramis diclotomis; fol. caulinis ovato-acutis subcrenatis; 10bis calycis longe subulatis. Jacq. Coll. t. 12. Sibth. gr. t. 211. Iichb. ic. 441. In Europ. austr. ๑. 3-6-poll. Cor. caeruleo-purpurascens.

31. C. mollis I. velutina; cinerascens; caulihus adscendentibus; fol. subintegris, radic. rosulatis spathulatis, caulinis ovatis; floribus laxe paniculatis. B. M. 404. C. velutina Desf. Atl. t. 51. C. microphylla Cav. 
In Africa. 24. 2-4-poll. Cor. pallide caerulea.

32. C. stricta $L$. caule ramoso piloso; fol. ovato-lanceolatis acutis serratis pilosis; floribus subsessilibus solitariis; lobis calycis lanceolatis. Desf. aun. Mus. 11. t. 13. pl. syr. 5. t. 4. In Armenia et Graecia. 24. 12-ped. Cor. caerulea.

33. C. sarmatica Ker. B. R. 23\%. B. M. 2019. B. Cab. 581. caule simplici striato pubescente; fol. subtomentosis cordatis lanceolato-hastatis crenato-dentatis; floribus sparse racemosis; calycis tuho dense piloso; Iobis corollaque extus velutinis. C. betonicaefolia Bichler. C. gummifera W. In Cancaso. 24. 1-ped. Cor. dilute caerulea.

34. C. alliariaefolia $W$. caule simplici tereti pubescente; fol. subtus incanis crenulatis, inferioribus subreniformibus; calycibus corollaque extus velutinis. Salisb. par. t. 26. Buxb. Cent. 5. t. 18. C. lamiifolia Bieb. In Cancaso. 1-2-ped. Cor. alba vel ochroleuca.

35. C. violaefolia Lam. humilis; pauciflora; pilosa; fol. radic. petiolatis ovato-rotundatis cordatis crenatis, caulinis ovato-ohlongis dentatis; calycis lobis ciliatis longe acuminatis. C. Violae Pers. In Sibiria. 3-4-poll. Cor. magna alba.

36. C. punctata Lam. pilosa ; canle simplici pauciforo; fol. ovato-acutis, radic. longe petiolatis cordatis; lobis calycis ciliatis longe lanceolatis ; corolla punctata. B. M. 1723. Schrnk. H. moll. t. 87. Gmel. sil. 3. t. 30. In Sibiria. 4. $\frac{1}{2}$-ped. Cor. sordide alba rubro-punctata.

37. C. divergens $\mathbf{W}$. pilosa; caule paniculato; fol. radic. spathulatis crenulatis, caulinis lanceolato - acuminatis; lobis calycis setaceo-pilosis acuminatis. C. spathulata W. et Kit. hung. t. 258. C. nutans Vahl. cernua Ball). In Sibiria et Hungaria. $\odot$. $1 \frac{1}{2}-$ ped. Cor. violaceo-caerulea.

38. C. sibirica I. setaceo-pilosa; fol. crenulatis, radic. obovatis obtusis; panicula multiflora; lobis calycis longe acuminatis. Jacq. austr. t. 200. B. M. 659. Gmel. sib. 3. t. 29. ejusd. It. t. 34. In Asia bor. et Europ. orient. $\odot$. 1-ped. Cor. violaceo-caerulea.
39. C. parviflora Lam. caule piloso dichotomo-ramoso; fol. crenatodentatis, radic. longe petiolatis ovato-ohlongis obtusis hasi inaequaliter incisis; calycis pubescentis lobis acuminatis. Desf. Alnn. Mus. 11. to 14. In Iberia. 4. 1-2-ped. Cor. caerulea.

40. C. cancasica Bieb. humilis; caule erecto ramoso scabro piloso; fol. crenulalis ovatis lanceolatisve; lobis calycis acuminatis hirto-ciliatis. In Caucaso. 2. 3-poll. Cor. violacea.

41. C. affinis $R$. et $S$. caulibus hispidissimis setis deflexis; fol. caulinis lineari-lanceolatis setace 0 -ciliatis longissimis. In peninsula Hispanica. 4 .

42. C. barbata $L$. canle subsimplici tereti piloso; fol. villosis subintegris, radic. confertis lanceolatis; racemo paucifloro; calycis lobis 3-angularibus acuminatis; cor. ore barbata. Moris 5. t. 3 f. 35. Jacq. obs. t. 37. B. Cab. 788. Krok. Sil. t. 38. B. M. 1258. In Helvetiae Alpibus. 4. $\frac{1}{2}-$ ped. Cor. pallide caerulea.

43. C. alpina L. humilis ; caule sulsimplici sulcato; fol. lineari-lanceolatis crenato-repandis lanuginosis; lobis calycis acuminatis. Jacq. austr. t. 118. B. M. 957. In Alp. Europ. 4. 3-5-poll. Cor. caerulea.

44. C. speciosa Pourr. caule simplici; fol. sessilibus crenato-repandis, radic. lineari-lanceolatis; floribus pyramidatim racemosis; lobis calycis lineari-acuminatis ciliatis. C. longifolia Lapeyr. Pyr. t. 6. hicaulis t. 7. In Pyrenaeis. 4. 3-4-poll. Cor. caerulea.

45. C. cichoracea Sibth. gr. t. 209. pilosa; caule angulato ramoso; fol. undulato-crenatis, radic. obovatis irregulariter laciniatis; hracteis cordatis ovatis; lobis calycis pilosi ovatoacutis. C. capitata B. M. 811. In Thessalia. ๑. 3-ped. Cor. purpureo-caerulea.

46. C. lingulata $W$. et $K$. lung. t. 64. hispida; fol. sessilihus undulato-crenatis, inferiorihus lingulato-spathulatis; bracteis ovato-acutis; lobis calycis oblongis obtusis setaceo-ciliatis. Rchb. ic. 780. 781. In Hungaria. $\odot$. 1-ped, Cor. caerulea. 
2. Eucodon. Sinus calycis appendicibus non obtecti.

a. Capsula 3-100ularis valvis ad basin sitis dehiscens.

47. C. Jacquini DC. glabra; caule firmo glabro; fol. remote serratis obovatis; capitulo laxo ebracteato; lobis calycis velutini acuminatis. Phyteuma Jacquini sieb. In Creta. 4. 3-poll.

48. $C$. petraea $I$. caule sublignoso incano; fol. crenatis subtus incanis, radic. petiolatis ovato-lanceolatis; capituli densi bracteis obtusis; lobis calycis incani linearibus obtusis. lichb. ic. 77\%. Plukn. t. 152. f. 5. Moris 5. t. 4. f. 44. In Europ. austr. 24. Caul. 1-ped. Cor. alba.

49. C. foliosa Ten. subpilosa; canle tereti; fol. duplicato-serratis, radic. ovato-acutis subcordatis; bracteis ovato-acuminatis; Iobis calycis longe acuminatis ciliatis denticulatis; cor. intus velutina. C. foliosa Ten. nap. t. 18. Rchb. ic. 764. In Neapol. 24. Caul. 1-ped. Cor. violaceo-caerulea.

50. C. glomerata $L_{\text {. }}$ pubescens; caule tereti; fol. serratis, radic. ovato-acutis; bracteis ovato-acuminatis; lobis calycinis acuminatis. Fl. dan. 1328. Hchb. ic. 751-755. C. speciosa B. M. 2649. C. aggregata Balb. et Nocc. Rchb. ic. 760. B. Cab. 505. C. elliptica Kit. Rchb. ic. 763. 764. In Europa et Sibiria. 4. Planta valde varians. 2-poll. - 1 $\frac{1}{2}-3$-ped. Flores capitati violaceo-caerulei. Caulis saepe 1 -florus $2-3$-poll. altus.

51. C. Cervicaria $\boldsymbol{L}$. rigide pilosa; caule sulcato; fol. subintegris, radic. lineari-lanceolatis obtusiusculis brevi-petiolatis, caulinis lineari-acuminatis; bracteis ovato-acutis; lobis calycis oblongis. Fl. dan. 1787. B. Cab. 452. Richb. ic. 778. In Europ. ๑. 1-2-ped. Cor. caerulea.

52. C. multiflora W. Kit. hung. $t$. 263. pilosa; caule sulcato; fol. undulato-crenatis, inferioribus ovato-lance $0-$ latis caulinis acuminatis ; spica interrupta; capsula obtuse triangulari. Iichb. ic. 779. C. macrostachya W. In Hungaria. 24. 1-ped. Cor. pallide violaceo-caerulea.

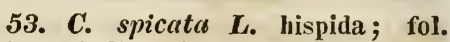
subintegris liuearibus; spica laxa; floribus sparsis. All. ped. t. 46. f. 2. et t. 47. f. 1. In Alp. Italiae. $\odot .1-$ 2-ped. Cor. caerulea.

54. C. thyrsoidea L. caule sulcato; fol. integris pilosis lanceolato-linearibus; floribus dense pyramidatim spicatis; calycis lobis acuninatis ciliatis. Jacq. olss. t. 21. austr. t. 411. In Alp. Europ. 4. $\frac{1}{2}$-ped. Cor. ochrolenca.

b. Capsula valvis ad basin sitis dehiscens nutans.

55. C. latifolia 1. caule simplici laevi; fol. amplis duplicato-serrulatis cordatis ovatisque; lobis calycis longe acuminatis; cor. maxima infundibuliformi. Engl. B. 302. Fl. Dan. 85. et. 782. C. eriocarpa Bieb. In Europa. 2. 1-2-ped. Cor. caerulea, alba vel albo-caerulea.

56. C. Trachelium $L$. caule angulato; fol. cordato-lanceolatis acute serratis calycibusque hispidis; pedunc. axillaribus paucifloris. E. B. 12. Fl. Dan. 1026. Hook. Lond. t. 109. C. urticaefolia W. In Europa. 4. 23-ped. Cor. caeruleo-violacea vel alba.

5\%. C. rapunculoides $L$. caule scabriusculo; fol. scabris ovato-acuminatis, radic. petiolatis cordatis crenulatis, caulinis serrulatis; floribus longe spicato-racemosis; calycis lobis lineari-lanceolatis demum reflexis. E. B. 1369. Fl. dan. 132\%. C. infundibuliformis B. M. 2632. Rehb. ic. 700. C. trachelioides Bieb. Rchb. ic. 701. C. ncranica Bess. In Europa et Sibiria. 4. 2-4-ped. Cor. 1-poll. longa caeruleo-violacea.

58. C. bononiensis $L$. scabra ; caule simplici; fol. serrulatis ovato-acuminatis supra atro-viridibus, radic. cordatis; floribus numerosis racemosis; laciniis calycis acuminatis. Rchb. ic. 211. C. obliquifolia Ten. nap. t. 17. C. ruthenica Bieb. B. M. 2633. C. simplex DC. Rchb. ic. 222. In Europ. orient. 4. 2-ped. Cor. caerule 0 -violacea.

59. C. collina Bieb. pl.ross. $t .42$. caule simplici; fol. inferioribus longe petiolatis ovato-oblongis crenulatis, superioribus lineari-acuminatis ; floribus secundis longe racemosis. B. A. 
927. In Caucaso et Iberia. 24. 1ped. Cor. intense caerulea.

60. C. paucifiora Desf: ann. Mus. 11. $t$. \%. caule ramoso; fol. dentatoserratis, radic. ovato-rotundatis petiolatis, caulinis ovatis; floribus paueis terminalibus. In Creta. 1-1 $\frac{1}{2}-$ ped. Cor. caeruleo-violacea.

61. C. nemorosa A. DC. caule simplici; fol. radic. longe petiolatis cordatis ovato-oblongis crenatis, caulinis sessilibus longe acuminatis serratis; floribus laxe racemosis. C. elongata Portensclıl. In Austria et Movaria. 4. $1 \frac{1}{2}$-ped. Cor. caerulea.

62. C. rhomboidalis $L$. caule subsimplici; fol. sessilibus ovato-acutis serratis; floribus paucis laxe racemosis pedunculatis ; laciniis calycis subulatis; caps. ovoidea. B. Cab. 603. Barr. ic. 567. C. azurea B. M. 551. C. venosa W. en. In Alp. Europ. 4. 1ped. Cor. caerulea.

63. C. trichocalycina Ten. nap. $t$. 16. caule simplici; fol. breve petiolatis ovato-acutis grosse serratis; floribus paucis racemosis; laciniis calycis reflexis longe capillaribus. C. alburnica Brigant. In Italia. 4. 1-ped. Cor. pallide violacea.

64. C. carnica Schiede; caule adscendente debili paucifloro; fol. glabris, inferioribus obovatis vel lanceolatis, superioribus linearibus; laciniis calycis longissimis reflexis. In Carniolia et Carinthia. 24. 6-8-poll. Cor. caerulea.

65. C. Hostii Baumg. fol. sessilibus sparsis subdenticulatis aculeatociliatis lanceolato-linearibus; caule pubescente. In Austria. 24. 6-12-poll.

66. C. petiolata A. DC. glaberrima; simplex; pauciflora; fol. radic. longe petiolatis cordatis rotundatis dentatis, petiolis marginatis, caulinis lanceolatis remote dentatis; lobis calycis erectis subulatis. In Armenia. 1-ped, Cor. caerulea.

67. C. linifolia Lam. canle erecto; fol. radic. paucis petiolatis ovatis sinuatis, caulinis linearibus integris; laciniis calycis longis erectis. B. Cab. 1267. C. uniflora Vill. t. 10. C. valdensis All. ped. t. 6. f. 1. Barr. ic. 487. C. 'linifolia Haenke. In Europ. austr. 24. $1 \frac{\mathrm{I}}{2}$-ped. Cor. caerulea.

68. C. rotundifolia $L$. glabra; fol. turionum reniformibus dentatis, caulinis linearibus integerrimis. E. B. 866 .
Fl. Dan. 855. Fl. Lond. t. 21. C. Scheuchzeri B. Cab. 485. In Europa et Sibiria. 24. Valde variat. Cor. caerulea.

69. C. caespitosa Scop. carn. $t$.4. fol. radic. petiolatis ovatis, caulinis lanceolatis serratis, supremis linearibus; caule multifloro paniculato; calycis laciniis subulatis. C. pusilla Haenke. C. Bellardi All. ped. t. 85. f. 5. C. pumila. B. M. 512. C. pubescens Schm. Rchb. ic. 159. 160. In Alp. Europ. 24. 3-1-poll. Cor. intense caerulea.

r0. C. aristata Wall. glaberrima; canle erecto 1-floro; foI. radic. petiolatis lanceolatis acutis undulatis, caulinis sessilibus linearibus; caps. longissime obconica. In Ind. or. 24. 1ped. Cor. pallide caerulea.

71. C. sylvatica Wall. scabra; pilis rigidis brevibus tecta; caule erecto paucifloro; fol. caulinis linearibus; laciniis calycis linearibus. C. integerrima DC. In Nepalia. 4. 6-10-poll. Cor. caerulea.

72. C. vesula All. pedunc. $t . \%$. $f$. 1. fol. glabris ovalibus dentatis; caule subuudo; calyce glabro. In Pedemontio. 4.

73. C. dubia A. DC. glabra; caule 1-floro; fol. caulinis crenatis erectis angustis, inferioribus lineari-lanceolatis petiolatis, superioribus longe acuminatis; lobis calycis subulatis. In ins. Terrae-Novae. 4-5-poll. Cor caerulea.

71. C. pratensis A. DC. caule humili 1 -floro superne magis folioso; fol. omnibus petiolatis ovato-acutis subcrenatis; laciniis calycis longe acuminatis. In Terra-Nova. 4. $\frac{1}{2}-$ ped.

155. C. pulla $\boldsymbol{L}$. caule humili 1floro; fol. glabris crenulato-dentatis, inferioribus subpetiolatis ovato-rotundatis; calycis laciniis longe acuminatis. Jacq. obs. t. 18. ejusd. austr. t. 285. B. Cab. 554. B. M. 2492. In Alp. Europ. 24. 2-4-poll. Cor. atrocyanea.

76. C. excisa Schleich. glabra; humilis ; caule 1-floro; fol. inferioribus lineari-acuminatis; lohis calycis setaceis demum reflexis. Rchb. ic. 159. 160. B. Cab.561. Gaud. helv.2. t. 2. In Alp. Helvetiae. 24. 3-4-poll. Cor. caerulea. 
7\%. C. Waldsteiniana R. et $\mathrm{s}$. glabra; caule erecto flexuoso rigido simplici pauciforo; fol. sessilibus lanceolatis serratis, inferioribus ohtusis, superioribus longe acuminatis; lobis calycis subulatis subdenticulatis. Rchb. ic. 180. C. flexuosa W. Kit. liung. t. 136. C. rupestris Host. In Croatia. 4. 6-8-poll. Cor. caeruleo - violacea.

\%8. C. aparinoides Pursh; glahra; caule debili adscendente simplici pancifloro angulis retro-scabro; fol. lineari-obovatis remote denticulatis retrorsum scabris; caps. sphacroidea. C. erinoides Mühlenb. In America boreali. $\odot$.

79. C. flexuosa Michx. glabra; caule superne paniculato; fol. sulisessilibus lanceolatis utrinque acuminatis grosse serratis; lobis calycinis capillaceis; stylo subexserto. In Carolina. 4 .

80. C. divaricata Michx. glabra; caule superue paniculato; ramis divergentibus; fol. subsessilibus ovato-lanceolatis utrinque acuminatis ; lobis calycis capillaceis. In Carolina et

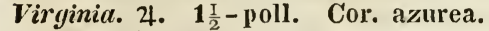

81. C. cana Wall. tomentosa; caule adscendente ramoso; fol. sessilibus approximatis lanceolatis dentatis subtus incanis; calycis laciniis lanceolatis dentatis; cor. pilosa ; caps. turbinata. In Nepalia. 4. 6-10-joll. Cor. caerulea.

82. C. canescens $W_{\text {V hispida; cau- }}$ le erecto; fol. radic. lanceolatis crenulatis, caulinis remotis repando-denticulatis; floribus numerosis racemosis parvis. C. Benthamii W. Hb. In Nepalia. $\odot$ ? 1-ped.

83. C. colorata Wall. caule ramoso pubescente; fol. sparsis lanceolatis acutis repando-denticulatis; pedunc. elongatis; calycis tubo pilosissimo obconico. In Nepalia. 24. $\frac{\mathrm{I}}{2}$-ped. Cor. parva extus velutina.

81. C. pallida Wall. canescentipilosissima; caule erecto ramoso; fol. ellipticis sinuato-crenatis petiolatis, supremis sessilibus; calycibus setosis; cor. pilosa. In Nepalia, 1-2-ped. Cor. alba.

85. C. ramulosa Wall. caule erecto piloso ramoso; fol. lanceolatis sessilibus crenato-dentatis ; calycis pilosi lobis latis acutis subdentatis; caps. turbinata. In Nepalia. 24. 12-ped. Cor. caeruleo-violacea.

86. C. Alphonsii Wall. humilis; 1llora; caule pubescente; fol. caulinis sessilibus lanceolatis acutis minimis denticulatis subtus incanis; laciniis calycis acutis pulsescentibus. In Ind. or. 4.

87. C. Erinus $I$. hispi:ia; fol. ovatis vel olovatis dentatis; floribus sessilibus; Iobis calycis 3-angularibus acuminatis erectis; cor. parva tubulosa. Sibth. graec. t. 214. Roucela Erinus Dumort. In Europ. aust. $\odot$. 4-8-poll. Cor. pallide rosea vel alba. 88. C. drabaefolia Sibth. yr. $t$. 215. hispida; fol. elliptico-oblongis dentatis; floribus pedicellatis; calycis laciniis semper erectis; cor. calyce sesquilongiore inflata. In Graecia. $\odot$. Cor. albo-caerulea.

89. C. Rhodensis A. DC. pilosa; fol. integris ovatis; floribus terminalibus ; lobis calycis 3-angularibus erectis demum patulis; cor. campanulata

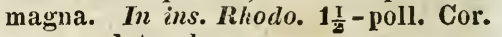
campanulata elegaus.

\section{c. Capsula erecta.}

90. C. damascena Iabill. syr. 5 . $t$. 5. pubescens ; fol. radic. ovato-obovatis acutis subintegris incanis, caulinis ovato-acutis; lobis calycis velutini subulatis; caps. ovoidea. Juxta Damascum. 2-t-poll.

91. C. aryentea Iam. humilis; fol. radic. lineari-ohovatis argenteo-tomentosis suhintegris, superioribus oblongis; lobis calycis velutini 3-angularibus; caps. turbinata. In Armenia. 4. 3-poll. Cor. velutina.

92. C. syriaca $R$, et $S$. fol. radicalibus spathulato-oblongis, caulinis ovalihus sessilibus suhsinuatis; caule simplici ad apicem paucilloro. In Syria.

93. C. garganica Mich. fol, radicalibus reniformibus longissime petiolatis, caulinis cordatis, omnibus crenato-dentatis pubescentibus; floribus axillaribus subfasciculatis ; cor. 5partitis. C. Elatiues Pentagn. In Neap.

94. C. elatinoides Morett. tomentosa; fol. acute dentatis petiolatis oblougis vel ovato-acutis; floribus dense racemosis; tubo calycis ovoideo. In 
saxosis Irrixiensium. 4. $1-6$-poll. Cor. caerulea.

9.5. C. Elatiines $\boldsymbol{L}$. caule adscendente ; fol. cordatis grosse et acute dentatis ovato-acutis, inferioribus rotundatis; florihus laxe racemosis; calycis tuho sphaerico. All. ped. t. 7. f. 2. Barr. ic. 453. In $A l \%$. Pedemontii. 4. 3-4-poll. Cor. caeruleo-purpurea.

96. D. macrorrhiza Gay; radice crassa; caule adscendente; fol. radic. petiolatis parvis rotundatis cordatis clentatis, floralibus linearibus; Lobis calycis acuminatis patenti-reflexis. In apricis Niceae. 4. 6-12-poll.

97. C. Portenschlagiana A. DC. Camp. $t$. 13. $f$. A. caule suberecto; fol. inter se aequalibus petiolatis cordatis rotundatis acute anguloso-dentatis; floribus racemosis; lobis calycis subulatis. In Dalmatia. 4. 4--6-poll. Cor. lilacina.

98. C. Billardieri A. DC. Camp. t. 13. f. B. glabra; caulibus adscendentibus; fol. radic. longe petiolatis parvis cordatis 3-5-fidis; lob is dentatis; floribus paucis laxe racemosis; laciniis calycis filiformilus. In $\mathbf{S} y-$ ria. 24. 3-4-poll. Cor. caerulea.

99. C. Morettiana Rchb. ic. 199. et 500. pilosa; humilis; 1 -flora; fol. crenato-dentatis parvis, radic. petiolatis cordatis rotundatis, caulinis ovato-acutis. C. filiformis Morett. In Dalmatia et Tyrolo. 24. 1-2-poll. Cor. caerulea.

100. C. Reyneri Perp. caule suberecto firmo ramoso; fol. subsessilibus ovatis remote serratis, inferioribus minoribus obovatis; lobis calycis longe acuminatis; caps. obovata. Rchb. ic. 354. 355. In Alp. Brixiensibus. 4 . 1-4-poll. Cor. caerulea.

10\%. C. isophylla Morett. caule suberecto firmo; fol. ommibus inter se aequalibus petiolatis rotundis cordatocrenatis; foribus corymbosis; lobis calycis acuminatis. Rchb. ic. 344. In Liguria. 4. 3-4-poll. Cor. caerulea.

102. C. fragilis Cyrill. pl. $t, 11$. f. 2. caule adscendente diffuso ramoso ; fol. radic. longe petiolatis cordatis rotundatis obtuse crenato-lobatis; stylo exserto ; caps. ovoidea. C. diffusa Vahl. C. crassifolia Nees amoen. bot. t. 4. Barr. 453. In Italia. 4. 2-4-poll. Cor. magna caerulea.
103. C. versicolor Sibth. gr. $t$. 20\%. glabra; caule adscendente; fol. serratis, radic. petiolatis ovato-acutis subcordatis; floribus longe spicatoracemosis stylo exserto; Iaciniis calycis demum reflexis. Andr. Rep. t. 396. In Graecia. 4. 6-12-poll. Cor. intense violacea.

101. C. Tenorii Morett. caule adscendente; fol. coriaceis, radic. longe petiolatis ovato-ohlongis acute serrulatis, caulinis grosse serratis; floribus racemosis; lobis calycinis linearibus. C. corymbosa Ten. C. versicolor Guss. In reyno Neapolitano. 24. $\frac{1}{2}-$ ped. Cor. caerulea.

105. C. pyramidalis Cam. glabra; fol. glanduloso - dentatis, inferioribus petiolatis ovato-oblongis subcordatis; floribus numerosis pyramidatim racemosis; lolois calycinis acuminatis patentibus. Hilar. pl. de Fr. t. 416. 'In Carinthiae et Carnioliae rupestribus. $\odot$. 4-5-ped. Cor. dilute caerulea.

106. C. Lactiflora Bieb. pl. ross. t. 10. caule ramoso; fol. sessilibus ovato-lanceolatis acute serratis ; floribus laxe paniculatis; lobis calycis latissimis serrulatis. B. R. 241. B. M. 1973. C. hispida WV. Hb. In Caucaso. 4. 1-2-ped. Cor. lactea vel dilutissime caerulea.

d. Capsula valvis lateraliter versus apicem sitis dehiscens erecta. Lobi calycis saepe denticulati.

10\%. C. Scouleri A. DC. caule sinplici paucifloro; fol. ciliatis argute serratis ovato-acutis vel ovato-lanceolatis; floribus racemosis; calycis lohis capillaceis. In Amer. bor. 4. 5-6-poll.

103. C. planiflora Lam. glaberrima; caule simplici; fol. sessilibus coriaceis nitidis, radic. confertis ovatis crenulatis, caulinis linearibus; floribus spicato-racemosis; lobis calycis ovato-acutis. Muting pl. cur. t. 123. C. americana Mill. In Amer. bor. 4. $\frac{1}{2}$-ped. Cor. alba.

109. C. americana $L$. caule simplici; fol. radic. ovato-acutis subcordatis petiolatis serratis, caulinis ovato-lanceolatis acuminatis ; floribus longe spicatis; lobis calycis longe acuminatis; caps. cylindrica sulcata. C. obliqua Jacq. schoeubr. t. 336. C. 
acuminata Mich. In Amer. bor. 4. 2-ped. Cor. cacrulea.

110. C. fulgens Wall. simplex; crecta; pilosa; fol. lanceolatis utrinque acuminatis subpetiolatis serratis; floribus racemosis; laciniis calycis lineari-subulatis; caps. ovoidea 10ncrvia. In Nepalia. 1-ped.

111. C. peregrina L. hispida; canle simplici multifloro anguloso; fol. crenatis, inferioribus obovatis superioribus ovato-acutis; florihus subspicatis; lobis calycis acuminatis. Jacq. Schoenbr. t. 337. B. M. 1257. C. lanuginosa Lam. In Libano. 4. 2-1poll. Cor. fundo atro-caerulea.

112. C. primulaefolia Brot. phyt. lus. $t$. 20. caule hispido multifloro simplici; fol. inaequaliter duplicatocrenatis ovato-lanceolatis; floribus spicato - racemosis; lobis calycis basi latis denticulatis; caps. obconica. C. Trachelium Brot. In Lusitania. 4. 1-2-ped. Cor. caerulea.

113. C. alata Desf. atl. $t$. 50. caule paucifloro simplici glabro; fol. irregulariter dentatis glabris, inferioribus ovato-acutis, caulinis lanceolatis; floribus capitato-racemosis ; calycis tubo hispido. In Atlante. Cor. caerulea.

114. C. ptarmicaefolia Lam. canle multifloro simplici; fol. radic. confertis lineari-lanceolatis serrulatis; floribus sessilibus laxe spicatis; calycis tubo sphaerico. Desf. ann. Mus. t. 6. In Armenia. $\frac{1}{2}-p e d$. Cor. violacea.

115. C. carpathica Jac\%. Vind. $t$. 5\%. glabra; ramosa; fol. inferioribus longe petiolatis ovato-rotundatis cordatis dentatis; florihus laxe paniculatis; lobis calycis acuminatis. B. M. 11\%. In Hungaria. 24. 1-2-ped. Cor. caerulea.

116. C. silenifolic Fisch. caule simplici paucifloro; fol. molliter ciliatis, radic. lanceolatis longe petiolatis integris; lobis calycis acuminatis ciliatis; caps. longc ovoidea. Gmel. sib. 3. t. 32. In Da?uria et Sibiria. 4. 1-ped. Cor. magna caerulea.

11\%. C. Sterenii Bieb. caulc simplicissimo 1-floro; fol. radic. obovatis petiolatis crenulatis, caulinis sessilibus subintegris; calycis glabri lobis acuminatis; caps. elongata. C. Vittinghoffiana 12 . et s. C. Infundi- bulum Vest. Rchb. ic. 158. In Caucaso. 4. 1-1 $\frac{\mathrm{I}}{2}$-ped. Cor. caerulea.

11S. C. persicifolia $\mathrm{L}$. caule subsimplici; fol. glabris rigidis crenulatis, radic. lanceolato-ovatis, caulinis lineari-lanceolatis; floribus laxe racemosis; lobis calycis acuminatis; caps. 3-sulcata. Fl. dan. 1187. Sibth. gr. t. 205. $\gamma$. macrantha B. M. 397. persicifolia calycina Rchb. ic. t. 77. In Europ. et Oriente. 24. 1-2-ped. Cor. ampla caerulea vel alba in hortis saepe plena.

119. C. pyrenaica A. DC. caule simplici 1-floro molliter piloso; fol. radic. rotundatis subcrenatis, caulinis lanceolatis utrinque acutis. In $P y_{-}$ renaeis. 1-ped.

120. C. Rapunculus $L$. caule simplici; fol. inferioribus obovatis breve petiolatis subintegris, caulinis lance olatis; floribus spicato-racemosis; 10bis calycis longe subulatis tenuissimis ; caps. 3-sulcata. E. B. 382 . Fl. dan. 1326. Sv. Bot. 629. C. elatior Fl. port. t. 80 . C. verruculosa Fl. port. t. 81. In Barbaria, Europ. austr. et Caucaso. (.) 2-3-ped. Cor. caerulea vel alba.

121. C. Lambertiana A. DC. canle simplici multifloro piloso; fol. caulinis sessilibus ohlongo-acuminatis irregulariter denticulatis pilosiusculis; floribus racemoso-spicatis; calycis lobis acuminatis grosse et acute dentatis. In Glilan Persiae. $1 \frac{1}{2}$-ped. Cor. alba.

122. C. virgata Labill. syr. 2. $t$. 6. caule simplici multifloro; fol. radic. lanceolatis crenulatis petiolatis, caulinis sessilibus; calycis tubo scabro; lobis subulatis erectis. In Libano. $\odot$. $1 \frac{1}{2}-$ ped.

123. C. Herminii Hoffmsgg. et Lk. Fl. port. $t$. 19. glabra; caule adscendente simplici; fol. subintegris, radic. lanceolatis, caulinis lineari-lanceolatis; petiolis basi ciliatis; lobis calycinis longe capillaceis reflexis. In Lusitania. $\odot$ ? $\frac{1}{2}$-ped. Cor. pallide cyanea.

121. C. patula $I_{\text {. }}$ caule divergenti-ramoso; rol. radic. confertis obovatis crenatis caulinis linearibus inlegris; lobis calycinis longe acuminatis basi serratis. Fl. Dall. 373. E. B. 4\%. Hook Lond. t. 51. C. decurrens Thore. In Europa austr. $\odot$. $1 \frac{1}{2}$-ped. Cor. caerulea vel alba. 
125. C. erinoides $L$. caule humili paucifloro angulis scabro; fol. parvis lineari-lanceolatis glabris crenulatis; lohis calycis longe subulatis integris. Herm. Iugd. t. 111. In Hispania. $\odot$. 4-6-poll.

126. C. matritensis A. DC. caule humili paucifloro; fol. lineari-lanceolatis subintegris; lobis calycinis longe subulatis; capsula obconica elongata. Circa Matritum. ๑. 4-5-poll. Cor. violacea.

12\%. C. ramosissima Sibth. gr. $t$. 201. caule ramoso multifloro piloso; fol. ovato-lanceolatis crenatis; calycis tubo piloso; caps. obconica nervis pilosa. In Graecia. ๑. 3-5-poll. Cor. caeruleo-violacea.

128. C. Lureyi Poll. fl. vern. $t$. 2. f. 1. caule ramoso paucifloro; fol. glabris sessilibus, inferioribus crenatis obovatis, supremis linearibus integris; calycis tubo hispido; lobis denticulatis patulis; caps. strigoso-pilosa. B. M. 2j1. In agro Veronensi. $\odot$. 6-10poll. Cor. caerulea fundo alba.

129. C. decumbens A. DC. Camp. t. 11. $f$. A. caule decumbente simplici paucifloro; fol. radic. rotundato-spathulatis sinuatis, caulinis obovatis crenato-dentatis; calycis tubo piloso; caps. sphaeroidea. In Hispania. $\odot$.

130. C. Loeflingii Brot. caule ramosissimo nultifloro angulis scabriusculo; fol. crenulatis, inferioribus obovatis reniformi-rotundatis, superioribus amplexicaulibus; calycis lobis longe acuminatis. Brot. phyt. Lus. t. 18. Fl. port. to 82. C. Broussonetiana R. et \$. In Lusitania. $\odot$. $\frac{I}{2}$-ped. Cor. caerulea vel violacea.

131. C. retrorsa Labill. syr. 5. $t$. 3. caule paucifloro angulis retrorsum scabro; fol. inferioribus obovatosubrotundatis petiolatis subsinuatis glabris; lobis calycinis longe acuminatis serrulato-scabris ; caps. obconica elon-

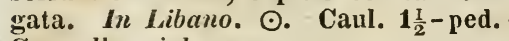
Cor. albo-violacea.

132. C. Zoysii Wulf. caule subtriforo; fol. integerrimis, radic. ellipticis petiolatis, caulinis sessilibus oblongis; corolla urceolata ore stellatoplicato barbato. Jacq. ic. 334. Sturm 22. In summis Alp. styriae. 4. 2-3poll. Cor. dilute caerulea.

133. C. cenisic L. caespitosa; caulibus adscendentibus 1 -floris; fol. integris, radic. rosulatis obovatis ob- tusis; calyce hirsuto; lobis linearilanceolatis; caps. ovoidea. Rchb. ic. 179. All. pedem. t. 6. f. 2. In $A l p$. Helvetiae et Italiae. 24. 1-2-poll. Cor. magna cyanea.

134. C. spathulata Sibth. gr. $t$. 203. caule adscendente 1-floro piloso; fol. inferioribus petiolatis obovatis crenatis, superioribus lanceolatis; calycis tubo obconico; lobis lineari-acuminatis dentatis. In olympo Bithyno et Parnasso. 4. Caul. $\frac{1}{2}$-ped. Cor. caerulea.

13.5. C. algida Fisch. humilis; caule 1-floro; fol. radic. confertis lanceolato-obovatis setaceo-denticulatis; petiolis ciliatis; calycis tubo villoso; lobis acuminatis denticulatis. C. lasiocarpa Cham. A. DC. Camp. t. 11. f. 4. In Kamtschatka et ins. Aleuticis. 24. 2-3-poll.

136. C. uniflor $L$. caule 1-floro; fol. subintegris, inferioribus obovatis petiolatis, superioribus linearibus; calycis villosi lobis lineari-acuminatis; caps. cylindrica. Linn. lapp. t. 9. f. 5 . 6. Fl. Dan. 1512. C. Gieseckiana Vest. In America et Europ. bor. 4. 2-4-poll. Cor. intense azurea.

13\%. C. fastigiata A. DC. Camp. t. 12. f. B. scabra; humilis; fol. inferioribus obovatis subintegris, mediis obovato-lanceolatis grosse 3-5-dentatis; caps. obconica. In Aragonia. ๑. 1-3-poll. Cor. caerulea.

II. Wahlenbergia schrad. Capsula trilocularis semisupera, valvis supra tubum calycis dehiscens. Stylus pilosus. Ovarium calycis tubo connatum. Stigmata $z-5$.

1. Calyx et cor. 5-loba. Stamina 5. Caps. 2-3-10cularis, valvis brevissime dehiscens. semina ovata plana.

138. C. graminifolia $L$. fol. linearibus canaliculatis; florum capitulo terminali; cor. laciniis patulis. W. et Kit. hung. t. 15t. Fl. gr. t. 206. Barr. ic. 332. Wahlenbergia graminifolia et Kitaibelii A. DC. In Italia, Sicilia, Hungaria et ins. Zacyntho. 4. 3-poll. Cor. caeruleo-violacea.

139. C. tenuifolia $W$. et Kit. $t$. 155. caulibus pilosis; fol. linearibus integris margine setoso-pilosis; bractei ovato-acuminatis setoso-ciliatis; 
calycis lobis setace - ciliatis. Wahleubergia A. DC. In Croatia. 4. 3-5-poll. Cor. violaceo-cacrulea.

140. C. Ilalmatica; caulibus glabris; fol. lineari-lanceolatis integris hirto-ciliatis; bracteis longe ovatoacuminatis integris ciliatis; calycis Iobis 3-angularibus ciliatis. Wahlenbergia A. DC. In Dalmatia. 24. 3-poll. Cor. caerulea.

111. C. Pumulio Portenschl. en. $t$. 2. caespitosa; caulibus hrevissimis valde foliosis; fol. linearibus integris subtus glabris margine revolutis apice pedicellato-adpresse pilosis; lobis calycis foliaceis. In Dalmatia. 4. Planta lumillima. Cor. azurea.

b. Cor. et cal. 5-1obi. stamina 5. Capsula 3-5-locularis. Semina ovoidea nitida.

142. C. capensis $L$. caule erecto subramoso inferne piloso; fol. ovatolanceolatis pilosis irregulariter dentatis; calycis tubo pilosissimo; capsula pilosa. Mém. petrop. 4. t. 6. f. 3. Wahlenbergia DC. Camp. t. 18. Roella decurrens Andr. Rep. 238. In Prom. b. spei. $\odot$. 1-2-ped. Cor. intus atro-caerulea.

1\$3. C.diffusa; caule debili ramosissimo glabro; fol. lineari-acuminatis subdenticulatis; calyce subpilosiusculo; capsula sphaerica glabra. Wahlenbergia A. DC. In Prom. b. spei. 1-ped.

141. C. linearis $L$. caule flexuoso erecto filiformi basi simplici glabro; fol. linearibus integris glabris; calyce glabro vel pilosiusculo; tubo sphaerico; caps. sphaerica glabra. Thuub. Mém. Petrop. 4. t. 5. f. 3. In Prom. b. spei. $\odot$. Palmaris.

145. C. flaccida; pilosiuscula; caule erecto simplici parum folioso; fol. oppositis alternisque ovato-acutis integris; calycis tubo ovoideo; caps. ovoidea sphaerica. Wahlenhergia $A$. DC. In Prom. b. spei. 3-4-poll.

146. C. debilis; caule herbaceo dehili ramosissimo; ramis filiformibus dichotomis; fol. lanceolatis margine cartilagineo-denticulatis glabris; cor. minima; caps. globosa. Wahlenbergia Ecklon et Zeyli. In Prom. b. spei.

147. C. diversifolia; caule procumbente ramoso subfolioso; fol. ovatosubrotundis crenato-dentalis; tubo ca- lycis ovoideo; capsula obconica. Walılenhergia A. DC. In Prom. $b$. spei. 6-9-poll.

1.18. C. madagascariensis; caule erecto ramoso glabro subfolioso; fol. strictis ovato-acutis crenatis glabris; calyce pilosiusculo tubo sphaerico. In Madagascar. $\frac{1}{2}$-ped.

119. C. procumbens Thunb. glabra; sulppilosa; caule repente ramoso valde folioso; fol. oppositis verticillatisque ovatis subintegris; capsula ovoidea sphaerica. Wahlenbergia repens Schrad. W. procumbens A. DC. Camp. t. 15. In Prom. b. spei. 4. 3-6poll. Cor. pallide caerulea.

150. C. hederacea $L$. glahra ; caule teuui adscendente; fol. longe petiolatis cordatis rotundatis obtuse 5-7angulosis; caps. hemisphaerica. Iil. dan. 330. E. B. 73. Wahlenbergia A. DC. In Europ. austr. 4. 4-10-poll. Cor. pallide caerulea.

151. C. gracilis Forst. caule subramoso glabriusculo ; fol. alternis oppositisve lineari-lanceolatis sinuato-dentatis glahris; calyce ovoideo. B. M. 691. C. vincaeflora. Vent. Malm. t. 12. C. capillaris B. Cab. 1406. C. littoralis Lahill. Nov. Holl. t. 70. Wahlenbergia A. DC. In Nov. Holl., ins. Van Dimen et Nov. Zeelandia. ○. 1ped. Cor. cyanea.

152. C. marginata Thunb. pl. jap. dec. 3. ic. caule ramoso glabro; fol. alternis oppositisve lanceolato-linearibus undulato-subserratis margine pilosis; tubo calycis ovoideo. Wahlcnbergia A. DC. 4 . $\frac{1}{2}$-ped. Cor. parva.

153. C. lavendulaefolia Blume; caule filiformi angulato striato; ramis $1-3$-floris; fol. sessilibus linearibus obtusis obsolete remote serrulatis; cor. ovarium parum superante. Wahlenbergia A. DC. In Java.

151. C. quadrifida $\boldsymbol{R}$. $B r$. caule filiformi angulato striato foliisque linearibus pilosiusculis; floribus 4-fidis; cor. ovarium vix superante. In Nov. Holl.

155. C. saxicola R. Br. glabra; caule abbreviato; fol. confertis lanceolatis subdentatis; pedunc. 1-floris scapiformihus; floribus 4 -fidis; caps. subglobosa. In Nov. Ifoll.

156. C. Sieberi; caule ramoso basi dense hispido; fol. subdenticulatis 
acutis, inferioribus lanceolatis pilosis; calyce glabro; tubo ovoideo; caps. subovoidea. Wahlenbergia A.DC. In Nov. Holl.

157. C. Zeyheri; caule simplici angulato sparse piloso; fol. alternis semiamplexicaulihus, inferioribus ovatolanceolatis serrato-dentatis; pedunc. longissimis ; calycis lohis $\mathbf{3}$-angularibus. Wahleubergia Ecklon. In Prom. b. spei.

158. C. Ecklonii; caule a basi ramoso piloso superne paniculato; fol. linearihus acuminatis integris ciliatis; calycis tubo hemisphaerico minimo lohis Iongissimis. Wahlenbergia Buch. Mss. In Prom. b. spei.

15.9. C. suellendamensis; caule a hasi ramoso pilosiusculo superne paniculato; fol. sessilibus linearibus angustis remote dentatis ad basin ciliatis; calycis tuho minimo lobis longissimis. Wahlenbergia Ecklon et Zeyh. In Prom. b. spei.

160. C. Buchii; caule a basi divergenti-ramoso hispido; fol. alternis sessilihus lineari-lanceolatis acuminatis denticulatis pilosis; calyce retrorsum hispido; lobis ciliato-denticulatis. Wahlenbergia pilosa Ecklon et Zeyl. In Prom. b. spei.

161. C. chondrophylla;-caule herbaceo procumbente ramosissimo ramisque diffusis glabris; fol. lineari-lanceolatis glabris acutis remote denticulatis margine cartilagineis. Wahlenbergia Ecklon et Zey'h.

162. C. stellarioilles; caulibus adscendentibus filiformibus 4 -gonis glabris; fol. oppositis lanceolatis acutis margine revolutis; nervo subtus piloso; laciniis calycis lanceolatis. Wahlenbergia Cham. et schl. In Prom. b. spei. 4.

163. C. dehiscens Roxb. caule ramoso vel simplici basi subpiloso; fol. lanceolato-obovatis pilosiusculis undulato-dentatis; calyce glabro; corolla infundibuliformi. Wahlenbergia Al. DC. In Bengalia. $\odot .1$-ped. Cor. alba.

161. C. agrestis Wrall. caule a basi ramoso piloso folioso; fol. linearibus angustis subintegris margine undulatis; pedunc. subdichotomis erectis; caps. obovoidea. Wahlenbergia DC. In Nepalia. $\odot$. 1-ped. Cor. caerulea.
165. C. indica; caule ramoso basi pilosiusculo; fol. linearibus pilosiusculis integris acuminatis; calycis tubo ovoideo glabro; caps. obconica. Wahlenbergia A. DC. In Ind. or. in mont. Neelgherries. $\frac{I}{2}$-ped.

166. C. riparia Lepr. basi pilosa superue glabra; fol. paucis undulatodentatis subpilosis ovato-lanceolatis aculis; calyce glabro; tuho ovoideo angusto. Wahlenbergia DC. In Senegulia. $\odot$. 1-ped.

16\%. C. Iumilis; basi pilosa; superne glahra; fol. lineari-lanceolatis, superiorihus ligulatis; calyce glabro; tuho ovoideo angusto; capsula ovoidea. Wahlenbergia A. DC. In Senegalia. $\odot$. 3-poll.

168. C. denudata; glaberrima; caule simplici paucifloro; fol. linearilanceolatis margine undulatis subintegris; calycis tubo ohconico elongato; caps. longe obovoidea. Wahlenbergia A. DC. In Prom. b. spei. 1-ped.

169. C. cernua Thunb. ném. Petrop. 4. $t$. \%. f. 1. ramosissima; hasi pilosa; fol. ovato-acutis irregulariter dentatis pilosis; calycis tubo olconico; lobis margine revolutis serrulato-ciliatis. Wahlenbergia A. DC. In Prom. b. spei. $\odot$. $1 \frac{\mathrm{I}}{2}$-ped. Cor. caerulea.

170. C. undulata Thunb. caule adscendente basi simplici piloso; fol. subamplexicaulibus ovato-lanceolatis grosse crenatis pilosis; calycis lohis latis serrato-ciliatis. Wahlenhergia A. DC. In Prom. b. spei. $\odot$. $1 \frac{1}{2}$-ped.

171. C. nudicuulis; caule ramoso basi pilosiusculo; fol. obovatis vel lanceolatis undulato-crenatis pilosiusculis; calyce glahro; tubo sphaerico; lobis integris. IVahlenberyia DC. In Prom. b. spei. Caules numerosissimi pedales.

172. C. androsacea; caule simplici nudo paucifloro glabro; fol. radicalibus rosulatis ovato - lanceolatis acutis denticulatis pilosis; calycis tuho hemisphaerico; lobis latis integris. Wahlenbergia DC. In Prom. b. spei. $\odot$. $\frac{I}{2}$-ped.

173. C. Irebsit; caule snbherbaceo filiformi procumbente retrorsum scabro; fol. confertis patulis lingulatis seu ovato-oblongis sinuato-dentatis reflexo-marginatis pilosiusculis ; laciniis calycis oblongis pellucidis mar- 
gine scahris. Wahlenhergia Cham. et Schl. In Prom. h. spei.

174. C. nutabunda Guss. neap. $t$. 18. hasi pilosa; fol. imis lanceolatoohovatis suhintegris margine nervisque pilosis seu irregulariter denticulatis ; calycis tubo ovoideo; caps. ohovata. Wahlenhergia A. DC. In Calabria. Cor. alha.

175. C. exilis; caule ramosissimo hasi pilosiusculo; ramis glabris filiformilus; fol. lineari-subulatis integris subpilosis; calycis tubo obconico; caps. ohovoidea angusta. Wahlenbergia A. DC. Camp. t. 16. In Prom. b. spei. $\odot$. 2-6-poll.

176. C. denticulata Burch. caule ramosissimo glabro vel superne scabriusculo; fol. linearibus angustis acuminatis glabris remote denticulatis; calycis tubo hemisphaerico; lohis denticulatis. Wahlenbergia A. DC. Camp. t. 16. In Prom. b. spei. $\odot$. 4-poll.

17\%. C. Dunantii; caule ramoso rigido; fol. lineari-lanceolatis angustis acuminatis integris pilosis; tuho calycis hemispliaerico parvo; lobis longe subulatis. Wahlenhergia A. DC. In Prom. b. spei. $\odot$. Caul. $\frac{1}{2}-$ ped.

178. C. Massonii; pusilla; caule ramoso piloso; fol. linearibus angustis integris; tuho calycis hemisphaerico parvo; lobis capillaribus; caps. sphaerica. Wahlenbergia A. DC. In Prom. b. spei. 3-poll.

17.9. C. paniculata Thunb. mém. Petrop. 4. t. \%. f. 4. caule ramosissimo piloso; fol. linearilus subdenticulatis integrisve; tuho calycis pilosi ovoideo angusto; lobis acuminatis inlegris; caps. ovoidea. Wahlenbergia A. DC. In Prom. b. spei. ๑. 2-6poll.

180. C. banksiana; caule glalıro superne paniculato; fol. linearihus angustis remote denticulatis acuminatis; tuho calycis glaherrimo sphaerico; lobis angustis denticulatis. Wahlenberria A. DC. In Prom. b. spei. 4-5poll.

181. C. hispidula Thunb. it. $t$. 4. ramis crassis hispidis; fol. lineari-lanceolatis acuminatis pilosiusculis rigidis denticulatis; calycis tubo hispido ovoideo; lobis longissimis. Wahlenbergia A. DC. In Prom. b. spei. ๑. 1-3poll.

182. C. sqinulosa; humilis; ramosissima; ramis rigidis glabris vel sca- briusculis ; fol. linearibus angustis denticulatis rigidis acuminatis; calycis lohis margine revolutis ciliatis. Wahlenhergia A. DC. In Prom. b. spei. $\odot$. 1-2-poll.

183. C. setucea; mém. Petrop. t. 5. f. 4 . basi ramosa glabra; fol. sparsis filiformi - linearihus integris margine revolutis; laciniis calycis setaceis. Wahlenhergia capillacea DC. In Prom. b. spei.

2. Cal. et cor. 3-5-1obi. Stamina 3. Caps. 2-locularis. Semina 3-quetra.

181. C. cervicina; pilosa; caule ramosissimo; ramis divergentibus pilosiusculis ; fol. lineari-lanceolatis denticulatis; capsula sphaerica. Cervicina campanuloides Delile Aeg. t. 5 . f. 2. In Aegypto. $\odot$. 2-poll.

3. Cal. et cor. 3-5-lobi. Stamina 3. Semina ovoidea nitida.

185. C. lobelioides L. glahra; simplex; erecta ; fol. denticulatis, inferioribus lanceolatis ohovatis; calycis tuho oliconico angusto; cor. cyliudracea. Wahlenhergia A. DC. t. 17. In ins. Madera. $\odot . \frac{1}{2}-1$-ped. Cor. roseoalbida.

4. Cal. et cor. 5-1obi. stamina 5. Caps. 2-locularis. Semina lenticularia nitida.

186. C. linearioides Lam. caule erecto hasi simplici glahro vel scabriusculo; fol. lineari-acuminatis angustis glahris subdenticulatis; calycis tubo glabro ohconico; caps. obconica. C. filiformis $\mathbf{K}$. et P. peruv. t. $\mathbf{2 0 0}$. f. C. C. arida H. et K. Wahlenhergia DC. In Amer. merid. 4 . 1-ped. Cor. caerulea.

5. Cal. et cor. 5-lohi. Stamina 5. Caps. 2-3-10cularis. Semina ovata plaua.

18\%. C. Fernandeziann; caule suhlignoso erecto folioso glahro vel piloso; fol. lanceolatis acutis serratis glabriusculis; lobis calycis subserratis. Wahleubergia A. DC. Jn ins. 


\section{Juan Fernandez. 4. 1-ped. Cor. alba.}

1s8. C. st. Helenae; caule lignoso erecto folioso glabriusculo ; fol. linearibus acutis serratis glabris pilosis; Iohis calvcis sulserratis; caps. turhinata. Wahlenliergia foliosa A. DC. Camp. t. 14. In ins. st. Helenae. $\hbar$. 1-i-ped. Cor. alba.

18\%. C. clirost ; glahra; caule suhherbaceo procumbente; fol. linearilanceolatis leviter serratis; calycis tubo olconico elongato; laciniis integris; capsula obconica. Wahlenbergia A. DC. In ins. St. Helenae. 4. 6-8-poll. Cor. albida.

190. C. ensifolia Lam. frutescens; simplex; caule crasso erecto medio valde folioso; fol. longe lanceolatis acuminatis ciliatis argute serratis; dentilus setaceis; lobis integris. Wahlenhergia A. DC. In ins. Barboniae. $\hbar$. 1-ped. Cor. sordide lutea.

191. C. ovuta; fol. ovatis petiolatis repando-denticulatis; floribus axillarihus solitariis pedumculatis erectis. Wahlenlergia Don Nep. In Nepalia. ๑. -5-uncialis.

\section{I. Adenophora A. DC. Fila-} menta membranacea valle ciliata yuasi cohaerentia. Nectarium cylindricum styli basin cingens. Stigmata 3. Caps. 3-locularis lateraliter 3-valvis ad basin dehiscens. Semina ovata complanata.

a.

Folia ovato - lanceolata grosse serrata.

192. C. sinensis; fol. alternis ovato-lanceolatis acute serratis gtahris; floribus spicato-racemosis; lobis calycis lineari-lanceolatis integris glabris; stylo subexserto. Adenophora A. DC. Camp. t. 6. In Climu. 24. 1-ped. Cor. caerulea.

193. C. tricuspidata Fisch. fol. alternis serratis glabriusculis, radic. petiolatis rotundatis, caulinis sessilihus ovato-lanceolatis; florihus racemosis; lohis calycis triangularibus dentatis. Adenopliora denticulata Ledeb. Relib. Hort. t. 2. In Dahuria. 1-ped. Cor. caerulea.

194. C. verticillatu Pall. it. 3. t. G. t. 1. fol. verticillatis serrato- dentatis, radic. petiolatis suhrotundis, caulinis ovato-lanceolatis; lohis calycis sululatis; stylo longe exserto. Adenophora A. DC. In İuluria. 24. 1-2-ped. Cor. dilute cyanea.

19.5. C. Perestiaefolia $\boldsymbol{R}$. et $\mathrm{S}$. fol. sulverticillatis, caulinis ovatoohlongis acuminatis grosse serratis scahro-ciliatis; calycis lohis lanceolatis margine scahris; stylo suhexserto. Adenopliera latifolia. A. DC. In Dahuria. 1-ped. Cor. cyanea.

196. C. Lamarkii; fol. altemis ovato-lanceolatis acute serratis ciliatis; florihus racemosis; lobis calycinis erectis lanceolatis integris glalris; stylo longitudine corollae. Adenophora A. DC. et Fisch. In Sibiria. 1-2-ped. Cor. caerulea.

19\%. C. liliifolic $L$. fol. alternis, radicalihus peliolatis ovato-rotundatis cordatis crenato-dentatis, caulinis sessilibus ovaio-lanceolatis grosse serratis; floribus numerosis paniculatis; calycis lohis subdentatis. Jacq. Schoenhr. t. 335. B. $h$. 236. W. et Kit. t. 217. C. intermedia R. et $\mathbf{S}$. Adenophora stylosa fichb. hort. t. 45. A. suaveolens Rchb. hort. t, 32. In Sibiria, podolia et Hungaria. 4. 1-4-ped. Cor. caerulea vel albido-caerulescens.

198. C. stylosa Lam. fol. alternis petiolatis, inferioribus obovatis sinuatis, superiorilus ovato-acuminatis suhcordatis serratis; floribus racemosis; lohis calycis exsertis. Adenophora Fisch. non hchb. ex A. DC. In Sibiria. 24. 1-ped.

199. C. periplocuefolia Lam. fol. alternis petiolatis ovato-acutis obcordatis crenato-serratis; floribus pancis; lobis calycis 3 - angularibus subdentatis; cor. apice truncata. In Sibiria. 2-3-poll. Cor. pallide cyanea.

200. C. coronopifolia $R$. et $s$. fol. alternis, radic. petiolatis ovato-rotundatis cordatis crenato-dentatis, caulinis sessililius lineari-lanceolatis glaherrimis laevibus; lobis calycis lanceolatis integris. Adenophora Rchb. hort. t. 23. In Dahuria. 24. 1-ped.

\section{b. Folia angustiora linearia} integra vel subintegra.

201. C. Gmelini; fol. caulinis alternis erectis linearihus angustissimis integris glahris laevibus; floribus sccumdis; Tohis calycinis erectis lanceo48 * 
latis integris; corolla campanulato-infundibuliformi; stylo incluso. Gmel. t. 33. In Dahuria. 4. 1-ped. Cor. caerulea.

202. C. coronata Ker. B. R. 149. fol. radic. petiolatis ovato-rotundatis cordatis crenato-dentatis, caulinis alternis erectis lineari-lanceolatis remote subserratis scabriusculis; floribus paniculatis; lobis calycinis linearibus integris. Adenophera marsupiiftora Rchb. hort. t. 15. In Dahuria. 4. 1-3-ped. Cor. caeruleo-violacea.

203. C. triphylla Thunb. fol. ternis linearibus ; floribus verticillato-ternis. In Japonia.

IV. Prismatocarpus. Cal. et cor. 5-lobis. Stamina 5; antheris inter se libris. Stylus basi persistens. Stiymata 2. Caps. 2-locularis tota infera prismatica vel cylindrica ab apice versus basin in 5 lacinias rupta.

204. C. diffusa; suffrutescens; fol. linearibus angustissimis integris; floribus laxe paniculatis; pedunc. divergentibus rigidis; bracteis subulatis; lobis calycis ovato-acuminatis glabris. Prismatocarpus diffusus A. DC. Trachelium diffusum Thunb. In Prom. $b$. spei. $\hbar$. 1-ped. Flores minimi.

205. C. interrupta; suffrutescens; fol. lineari-subulatis integris ciliatosetaceis; floribus laxe paniculatis; pedunculis nudinsculis; bracteis subulatis; lobis calycinis acuminatis glabris. C. ericoides Lam. Prismatocarpus paniculatus A. DC. Camp. t. 20. P. interruptes A. DC. ibid. In Prom. b. spei. ち. 1-ped.

206. C. subulata 'Thunb. mém. Petrop. 4. $t$. 6. suffrutescens; fol. lineari-subulatis angustis integris basi ciliatis; floribus laxe paniculatis; lobis calycinis acuminatis glabris. Prismatocarpus Al. DC. Lightfootia ciliata Spr. syst. In Prom. b. spei. ち?

207. C. altiflora Poir. suffrutescens; fol. lineari-subulatis integris ciliatis; floribus pancis apice pedunculorum approximatis; bracteis subulatis; Iobis calycis ovato-acutis velutinis. Prisnatocarpus Herit. Roella erecta Hb. Banks. In Prom. b. spei. t. 1-ped.

208. C. fruticosa Hb. Banks. suffrutescens; fol. linearibus angustissi- mis erectis integris subciliatis; floribus paucis racemosis; bracteis subulatis; lobis calycinis ovato-acutis glabris. Prismatocarpus Herit. P. fruticosus et Ecklonii A. DC. In Prom. b. spei. †. 1-ped.

209. C. longirostris Hb. Banks. caule herbaceo; fol. linearibus longis erectis undulato-dentatis; floribus ad apices ramorum ; bracteis subulatis ; 10bis calycis lineari-acuminatis glahris. Prismatocarpus crispus A. DC. C. plicata Pers. In Prom. b. spei. 24. 6-8poll.

210. C. lineurifolia; caule herbaceo; fol. paucis linearibus angustis basi subciliatis; floribus spicatis subsolitariis; bracteis latis ovato-acuminatis ciliatis ; lobis calycinis oblongolinearibus glabris. Prismatocarpus A. DC. In Prom. b. spei. 4. 1-2-ped. Cor. caerulea.

211. C. sessiliflora; herbacea; simplex; fol. lineari-acuminatis erectis glabris serrato-dentatis; floribus subfasciculatis; bracteis ovato-acutis setaceo - ciliatis ; lobis calycinis lineariacuminatis glabris. Prismatocarpus strictus A. DC. Lightfootia sessilifiora Spr. In Prom. b. spei. 4.

212. C. Prismatocarpus Ait. B. M. 2733. sublignosa; fol. ovato-oblongis patulis serratis; floribus subfasciculatis; bracteis fol. similibus; lobis calycinis lanceolatis glabris. Prismatocarpus nitidus Herit. stirp. t. 3. In Prom. b. spei. 4. $\frac{1}{2}-1$-ped. Cor. albida.

213. C. sessilis; sublignosa; fol. patulis linearibus angustis integris; floribus solitariis in axillis foliorum superiorum; lobis calycinis subulatis glabris. Prismatocarpus Ecklon. In Prom. b. spei. 24. Ramosissima. $\frac{1}{2}-$ ped.

214. C. juncea; caule ramoso inferne lignoso; ramis longissinis; fol. inferioribus decurrentihus sessilibus ovato-acutis denticulatis margine revolutis subtus hirsutis; floribus racemosis; calycis tuho hrevissimo. Prismatocarpus junceus Ecklon et Zeyh. In Prom. b. spei.

215. C. Candolleana; fruticulosa; ranis erectis dense foliosis; fol. attenuato-linearibus acutis margine revolutis; bracteis dilatatis pinnatifidis; laciniis calycis lanceolatis. Prismato- 
carpus Candolleanus Cham. et schl. In Hrom. b. spei. ђ.

216. C. Bergiana; ramis angulatis puhescentibus dense foliosis; fol. linearibus acutis canaliculatis ohsolete ciliatis recurvis; bracteis subulatis minutis. Prismatocarpus Cham. et Schl. In Prom. b. spei.

217. C. tenerrima; caule suffruticoso erecto ramoso; ramis filiformibus puhescentilus glabris; fol. sessilibus linearibus acutis glabris; floribus subspicatis; calycis tubo brevissimo; lobis acuminatis integerrimis. Prismatocarpus Ecklon et Zeyler. In Prom. b. spei. ந.

V. Codonopsis. Cal. 5-fidus vel truncatus. Cor. 5-loba. Stamina 5. Stigmata 3, ovata crassa. Capsula 3-locularis.

218. C. viridis; caule adscendente voluhili; fol. alternis vel oppositis puberulis subtus incanis subcrenulatis; cor. anipla luteo - virescente. Codonopsis Wall. In Nepalia. 4. 1-2ped. Ramosissima.

219. C. purpurea; caule adscendente sulovolubili manifeste articulato; fol. stricte oppositis glahris subtus glaucescentihus subcrenulatis; cor. intense purpurea. Codonopsis Wall. In Nepalia. 4.

220. C. truncata; caule erecto; fol. argute serratis; involucro cum basi calycis connato. Codonopsis Wall. In regione Birmanensium. 1-2-ped. Cor. albida.

221. C. Punduana; caule erecto; fol. remote setaceo-denticulatis; involucro a calyce pene distincto. Codonopsis parviflora Wall. In montibus Pundua. 2-ped. Cor. albida.

VI. Microcodon. Cal. 5-fidus. Cor. 5-loba minima cylindracea persistens. Filamenta tenuissima. Stigmata 5, Caps. 5-locularis 5valvis.

222. C. Microcodon; caule ramoso; ramis simplicibus; fol. linearibus acuminatis; florihus glomeratis. Microcodou glomeratum A. DC. Camp. t. 19. C. hispidula Ecklon. In Prom. b. spei. $\odot$. 4-5-poll.

223. C. sparsiflora; caulc ramoso; ramis subdivisis; fol. lincari-lau- ceolatis ; floribus solitariis. Microcodon A. DC. M. Candolleauum Ecklon et Zeyh. Wahlenbergia hispidula Scluad. In Prom. b. spei. ○. 2-3poll.

221. C. pygmaea; caule subsimplici ciliato; fol. amplexicaulibus lineari-lanceolatis denticulatis acutis; floribus glomeratis; bracteis linearilanceolatis ciliato-dentatis; calyce hispido. Microcodon pygmaeum Ecklon et Weyl. In Prom. b. spei.

225. C. brevibracteata; caule ramoso crecto; fol. alternis lineari-lanceolatis glahriusculis, superioribus denticulatis; floribus glomeratis; bracteis ovato-lanceolatis acuminatis hasi ciliatis. Microcodou Eckl. et Zeyl. In Prom. b. spei.

226. C. longebracteata; caule brevissimo ramoso; ramis pilosissimis; fol. lineari-lanceolatis serratis; florihus glomeratis longissime bracteatis; calycis lohis ventricosi pinnatifido-ciliatis. Microcodon Ecklou et Zeyher. In Prom. b. spei.

VII. Specularia A. DC. Cal. 5lobus tubo prismatico obconico. Cor. rotata 5-loba. Filamenta membranacea pilosa. Stigmata 3, filiformia. Caps. longe prismatica 3-locularis 3-valvis.

22\%. C. pentagonia $\boldsymbol{L}$. caule ramoso majori; florihus terminalibus solitariis; calyce piloso; pilis raris rigidis; tubo longo prismatico; lobis patentibus longis lineari-lanceolatis; corolla longitudine loborum calycis. Desf. ann. Nus. 11. t. 18. B. H. 56. Specularia pentagonia DC. In Oriente. $\odot$. 1-ped. Cor. fundo alba ad medium partem cyanea ad lobos violacea.

223. C. falcata $\boldsymbol{R}$. et $\boldsymbol{S}$. caule simplici; fol. longc spicatis; calyce glabro vel scabriusculo ; tubo prismatico; lohis longissimis lanceolatoacuminatis apice reflexis corolla duplo longioribus. Prismatocarpus Ten. nap. t. 20. Specularia DC. In Italice et Sicilia. $\odot$. 1-ped. Cor. rosea. 229. C. Speculum $L$. caule ramoso; ramis 3-floris; calyce glabro veI pubcscente; tubo prismatico apice angustiori; lohis lineari-lanceolatis patulis demum reflexis. B. M. 102. Silhtl. gr. t. 216. Specularia Speculum DC. 
Prismatocarpus hirtus Ten. nap. t. 19. Inter segetes Europ. unstralis. $\odot$. 4-6-poll. Cor. violacea fundo albovirescells.

230. C. hybrida L. caule simplici; calyce scabro; tuho prismatico superne angustiore; lobis erectis brevibus ovato-lanceolatis. Noris 5. t. 2. f. 22. Specularia hybrida DC. Inter seyetes Europ. austr. $\odot$. 2-6-poll. Cor, roseo-caerulea.

231. C. cort; caule humili subsimplici; floribus pancis superne approximatis; calyce puhescente; tuho prismatico; lobis erectis lanceolato-subulatis. specularia coa A. DC. In

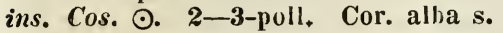
caerulea.

23:3. C. Ghilcensis Pall. ined. caule suliramoso; fol. lanceolatis acuminatis serratis; florilus sul racemosis; calycis laciniis corolla longioribus acuminatis serratis. Specularia A. DC. In provincia Ghilan Persiae. $\odot$.

233. C. perfoliata L. caule erecto simplici; floribus longe spicatis; calyce plahro; tubo obconico; lobis erectis lanceolatis. C. hiflora $R$. et P. peruv. t. 200. f. b. C. flagellaris H. et K. Nov. Gen. t. 265. In Amer. bor. $\odot$. 1-ped. Cor. caerulea.

VIII. Symphyandra A. DC. Cal. et cor. 5-lobi. Stumina 5. Filamenta libera membranacea ciliata; antheris in tubuni ionym apice 5dentatum connatis. Sitimata 3 filiformia. Caps. 3-locularis 3-valvis ad basin dehiscens.

231. C. cretica; glaberrima; caule erecto herbaceo; fol. ovato-acutis irregulariter sermulis, inferioribus amplissimis; floribus racemosis nutantibus; lobis calycis longe acuminatis. C. nutans sieb. symphyandra DC. In Creta. 1 -ped. Cor. ochroleuca.

23.5. C. armena stev. caule erecto virgato rigido piloso ; fol. ovatoacutis grosse serratis; floribus solitariis; calycis simubus reflexis minimis. Symphyandra A. DC. In C'aucaso. 4. Pedalis. Cor. caerulea velutiua.

236. C. ossetica Bieb. caule simplici humili; fol. petiolatis cordatis duplicato-serratis; calycihus ylahris; laciniis longis denticulatis. Symphyan- dra A. DC. In Iberia. Caul. palmaris. Cor. intus caerulea pilosa.

IX. Musschia A. DC. Stamina 5 apice cuspidata. Stigmata 5. Caps. 5-locularis 10-nervia lateraliter fissuris transversis numerosis inter nervos deliscens.

237. C. aurea $L$. caule suffuticoso; fol. oblongo-lanceolatis duplicatoserratis; floribus paniculatis erectis; laciniis calycis oblongis coloratis. Vent. Malm. t. 116. B. R. 57. Jacq. Schoenbr. t. 472. Musschia aurea $A$. DC. Camp. t. 4. f. A. In Muderce et Teneriffa. 1-ped. Cor. aurea profunde 5-partita.

Speoies, incertae.

23S. C. javanica; caule scandente; fol. longe petiolatis ovato-cordatis ; floribus solitariis sparsis. Campanumoea Blume. In Java. 4.

239. C. celebica; caule erecto; fol. hreviter petiolatis oblongo-lauceolatis; floribus subcorymbosis te:minalibus. Campanumoea celebica Blume. In Celebes.

210. C. yrandiflora Jacy. Vind. 3. t. 2. glaberrima; fol. ovato-lanceolatis grosse serratis; corolla maxima suh-5-fida. B. M. 252. Herb. de l'amat. t. 112. Wahlenhergia schrad. Platycodon A. DC. In Sibiria et Dahuria. 4. 1-ped. Cor. intense caerulea.

241. C. homullanthium Ledeb. superne pilosiuscula; fol. Ianceolatis vei lineari-lanceolatis; cor. profunde 5-fida; stigmatibus 3 ; caps. 3-loculari. C. Redowskiana Chanı. et schl. Platycodou A. DC. In Sibiril. 24. 1ped.

242. C. liunlaris Lam. caule folioso glabriusculo; fol. ligulatis ohtusis ciliatis integerrimis; flore erecto subbarbato. In Hort. Paris.

z+3. C. asperrima Zaccagn. fol. lastatis tomentosis dentato-spinosis; floribus axillaribus; cor. extus tomentoso-lispidis. In Asia minore.? $\frac{1}{2}-$ ped.

211. C. decurrens 'Zucca!̣n. caule alato; fol. decurrentibus dentatis hispidis; cor. extus tomentoso-hispida. Futria? 
24.5. C. aspera Möuch; caule tereti stricto simplicissimo; fol. oblongis sessilibus crenatis; pedunc. 3-floris. Patria ignota.

216. C. cymbalaria Nibth. fol. reniformibus incisis glaberrinis nitidis; caulihus diffusis. In Graeciu.

2.1\%. C. rigescens Pull. fol. lanceolatis; caule stricto simplici pubescente; floribus racemosis; calycibus ciliatis. Ad lacum Baical.

215. C. adsceridens I'est; fol. subsparsis inferioribus, suhpetiolatis ovatis dentatis, superiorihus oblongis integerrimis cauleque adscendente glabris; flore solitario nutaute. In Sibiria.

249. C. heterodoxa Vest; fol. oblongis glabris; floribus axillarihus pedunculatis patulis; calyce brevi; laciniis lanceolatis suhulatis. In Sibiria. 4.

250. C. lunariaefolia Hb. W. fol. ovatis profunde cordatis petiolatis duplicato-serratis; floribus secundis. $\boldsymbol{A} d$ C'aucasum. 4.

2.j1. C. Kituibeliana R. et S. fol. inferiorihus obovato-cuneiformibus crenatis, superioribus integerrimis; caule simplicissimo 1-floro. C. microphylla Kit. In Hungaria. 4.

2.52. C. eleyans $R$. et $S$. fol. linearihus lanceolatis integerrimis sessilihus, inferioribus latioribus subpetiolatis ad petiolum attenuatis laevibus; canle pubescente; calycis laciniis pungentibus. In Sibiria. 24. 1-ped.

253. C. camtschatica R. et s. fol. radic. cordatis dentatis, caulinis oblongo-Ianceolatis integerrimis; caule capillari sub-1-floro; calyce reflexo. In Camtschutka. 4.

\section{9 b. MERCIERA A. DC. (1830).}

1. M. tenuifolia A. DC. Camp.t. 5. fol. valde ciliatis; cor. foliis longiore caerulea apice solum 5-loha; lohis lanceolatis patentibus dorso pilosis; stylo subexserto. Trachelium Thunh. in Prom. b. spei. Ђ̆. $\frac{\mathrm{I}}{2}$-ped. Cor. caerulea.

2. H. brevifolia A. DC. fol. subciliatis; corolla longitudine foliorum alba apice 5-loha; iohis lanceolatis patentibus glabris; stylo corolla duplo longiore. In Prom. b. spei. ち. Suffrutex ramosus. Cor. albida.
3. M. leptoloba A. DC. fol. ciliatis; cor. fol. subhreviore alba 5-fida; lobis lineari!,us erectiusculis glabris; stylo longitudine corollae. In prom. b. spei. ち. suffrutex. Cor. alba.

\section{DIERVILLA Tournef. (1706).}

1. D. canadensis $U$. fol. hrevi-petiolatis ovatis acuminatis serratis pctiolisque glabris. Lonicera Diervilla L. D. Iutea Pursh. D. Tournefortii Michx. D. Acadiensis Duhau. t. 87. In Amer. bor. Flor. flavi.

2. D. japonica DC. fol. brevissime petiolatis ovatis acuminatis serratis; venis petiolisque supra hirlis. Weigelia japonica Thunb. jap. t. 16. In Japonia. $\hbar$. Cor. purpurea.

3. D. Corcueensis DC. fol. petiolatis obovatis serratis acuminatis rlabris; petiolis amplexicaulibus ciliatis. Weigelia Thunb. Kaempf. t. 45. In Japonia. ‡.

\section{RUTIDEA DC. (1807).}

1. R. parviflora DC. subhispida; fol. elliptico-oblongis; floribus spicatis. In Sierra Leone. $\hbar$. Cor. sicca nigricans,

2. R. mollis Blume; tomentosohirsuta ; fol. elliptico-oblongis; florihus paniculatis. In Pulo-Pinang. $\hbar$.

\section{ZUCCARINIA Spr. (1827).}

1. Z. ornatı Spr. Jackia W'all. In Ind. or. ఫ. Arbor excelsa. Fol. opposita obovato-elliptica cuspidata sublus ramisque ferrugineo-villosa. Flores spicati albi.

\section{AIDIA Lour. (1\%90).}

1. A. cochinchinersis Lour. In Cochinchina. $\hbar$. Arbor magna ligno durabili. Folia opposita integerrima lanceolata. Flores racemosi albi.

\section{DASUS Lour. (1790).}

1. D. verticillatus Lour. In Cochinchina b. Arbor fol. lanceolatis 
subtus tomentosis; floribus verticillatis albis.

\subsection{HELICANTHERA Lour. (1790).}

1. H. parasitica Lonr. In Cochinchina. ち. Frutex parasiticus. Folia lanceolata glabra. Flores spicati coccinei.

\section{DLASPASIS R. Br. (1810).}

1. D. filifolia R. Br. In Nov. Holl. Herha glabriuscula erecta; fol. alternis teretiusculis; pedunc. 1-floris axillaribus.

\section{6\%. DAMPIERA R. Br. (1810).}

1. D. undulata R. Br. suffuticosa; erecta; tomentosa; fol. petiolatis subrotundis dentalis undulatis subtus nigro-barbatis; villis plumosis. In Nov. Holl. ђ.

2. D. rotundifolia $\boldsymbol{R}$. Br. suffruticosa ; erecta; tomentosa; fol. petiolatis subrotundis integris planis; cor. extus nigro-barbatis. In Nova Hollaudia. 古.

3. D. ovalifolia $\boldsymbol{R}$. $\boldsymbol{B r}$. furfuraceotomentosa; fol. petiolatis ovalibus subintegris planis supra scabris; cor. extus nigro-barbatis. In Nova Hollandia. $\mathbf{b}$.

4. D. purpurea $\boldsymbol{R}$. Br. suffuticosa; tomentosa; fol. petiolatis ovatis dentatis supra scabris; cor. extus nigro-plumoso-barbatis. In Nova Hollandia. †.

5. D. ferruginea R. Br. suffruticosa; tomentosa; fol. petiolatis ovatis repando-dentatis; cor. extus lanatis. In Nov. Holl. $\hbar$.

6. D. hederacea R. Br. herbacea; procumbens; tomentosa; fol. petiolatis subcordatis angulato - incisis, summis integerrimis; cor. extus cinereo-barbatis.In Nov. Holl.

7. D. incana $\boldsymbol{R}$. $\boldsymbol{B r}$. suffruticosa? mcano-tomentosa; fol. sessilibus ol)ovato-integerrimis. In Nov. Holl. $\downarrow$.

8. D. cuneatc $\boldsymbol{R}$. Br. herbacea; orecta; pubescens; fol. sessilibus dentatis obovato-cumeatis; cor. extus laeltis. In Nov. Holl.
9. D. linearis $\boldsymbol{R}$. Br. herbacea; erecta; pubescens; fol. sessilibus linearibus paucidentatis imis cuneatis; floribus spicatis; cor. extus lanatis. In Nov. Holl.

10. D. fasciculata R. Br. herbacea; caule compresso-trigono; fol. cuneatis subdentatis; floribus spicatis; cor. adpresso-pilosis. In Nov. Holl.

11. D. oblongata $\boldsymbol{R}$. Br. herbacea; caule compresso-3-gono; fol. sessilibus ohlongis integris seu paucidentatis ; pedunc. brevissimis; cor. adpresso-pilosis. In Nov. Hotl.

12. D. stricta $R$. $B r$. caule compresso-3-gono; fol. sessilibus cuneatis subdentatis cuneatis; cor. extus piloso-adpressis. Ann. Mus. 18. t. 2. f. 1. 2. Goodenia Sm. In Nov. Holl.

13. D. parvifolia $R$. Br. herhacea; erecta; caule compresso 3-gono paniculato; fol. sessilibus lineari-lanceolatis; florihus solitariis sessilibus. In Nova Hollandia.

\section{SCHOEPFIA Schreb. (1789).}

1. S. americana Schreb. Codonium arborescens Vahl act. hafn. 1. t. 6. In ins. Caribaeis. $ђ$. Arbuscula ramis glabris; fol. alternis oblique ovatis integerrimis nitidis; pedunc. axillaribus 1-floris.

\section{PSYCHOTRIA L. (1759).}

1. Pedunculis axillaribus.

1. P. excelsa H. et K. Nov. Gen. $t$. 282. ramulis teretibus puhescentibus; fol. oblongo-acuminatis membranaceis glabris ; floribus 4-andris. Prope Xalapam. ち. Cor. alba. Drupa rubra.

2. P. emetica Mutis; suffituticosa; simplex; piloso-tomentosa ; fol. oblongo-acuminatis membranaceis ciliatis subtus pilosiusculis; pedunc. axillaribus racemosis. Bonpl. aeq. t. 126. Cephaëlis Pers. In Amer. austr. $\hbar$. Cor. alba. Bacca atro-caerulea.

3. P. hirta W. superne lirta; fol. ohovato-oblongis utrinque acuminatis subtus hirtis; pedunc. axillaribus 3floris. In Nov. Granata. $\bar{~}$.

4. P. macrophylla $\boldsymbol{R}$. et P. perue. t. 202. f. $a$. herbacea; glabra; ramis 
teretibus; fol. ovali-lanceolatis acuminatis amplis membranaceis; ramis dichotomis, In Peruvia. 4. Drupa violacea.

5. P. Willdenouii DC. fol. oblongis utrinque attenuatis subpetiolatis coriaceis nitidis subtus pubescentibus; stipulis 2-lohis. P. magnoliaefolia W. In Amer. austr. $\hbar$.

6. P. uliginosa $\mathbf{S w}$. herbacea; fol. lanceolato-oblongis acuminatis nitidis; stipulis commatis acutis; cor. fauce villosis; seminibus cristatis. In $J a-$ maica. $\hbar$.

7. P. laevis $D C$. fol. ovalihns basi acutis apice breve cuspidatis; stipulis crassis acumine reflexo; fructibus globosis nudis. P. Phytolacca Spr. In Porto-Ricco. $\hbar$.

8. P. agnata $D C$. fol. anguste ohlongis utrinque attenuatis supra lucidis subtus nervo utrinque barbato. In St. Domingo. $\hbar$.

9. P. neurotricha $D C$. fol. ellipticis oblongis utrinque acuminatis glabris subtus nervo utrinque seriatim piloso; stipulis acute bidentatis; fructibus subobovatis. In Porto-Ricco. $\hbar$.

10. P. triflora Schum. fruticosa; ramis brachiatis; ramulis sub-4-gonis; fol. ovatis obtuse acuminatis subtus pubescentibus; stipulis reniformi-cordatis acutis integris. In Guinea. ち.

11. P. multiflora Schum. fruticosa; decumbens scandensve; glaberrima; fol. oblongo-ovatis apice attenuatis; paniculis axillaribus subcapitatis. In Guinea.

12. P. umbellata Schum. ramosissima; glabra; ramulis alterne compressis; fol. vix petiolatis lanceolatis; bacca globosa apice umbilicata. In Guinea. t. Cor. albida.

13. P. Kolly Sclum. fruticosa; glabra; ramulis compressis; fol. petiolatis ovato-ellipticis acutiusculis; stipulis ovatis acutis; tubo corollae

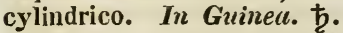

14. O. obvallata Schum. herbacea; repens; petiolis apice subhirsutis; fol. oblongo-cordatis obtusis glabris; stipulis cordato-acutis ; floribus involucratis. In Guinea. ‡.

1.5. P. philippensis Cham. et Schl. glabra; resinosa; ramulis 4-gonis; fol. ovatis obtusissimis petiolatis coriaceis; stipulis brevissimis. In Luzonia. $\hbar$.
2. Pedunculis terminalibus.

a. Americanae.

16. $P$. reticulata $R$. et $P$. peruv. t.212. $f$. $b$. herbacea; pubescens; ramis 4-gonis; fol. ovato-lanceolatis acuminatis venoso-reticulatis subcoriaceis ; stipulis concretis bifidis. In $\mathrm{Pe}$ ruvia. 24. Cor. lutea.

17. P. acutiflora DC. fol. oblongis acuminatis ciliatis subtus pubescentibus, utrinque nervo ramulisque hirsuto - tomentosis ; cor. mucronatocuspidatis. Guettarda acutiflora Bartl. In Guayaquil. $ち$.

13. P. pilosa R. et P. t. 20s. f. 2. pilosa suffruticosa; ramis 4-gonis; fol. oblongis utrinque acuminatis; stipulis bifidis; calycis dentibus acutis. In Peruvia. $\hbar$. Bacca caerulea.

19. P. cymosa R. et P. peruv. $t$. 206. $f$. $b$. glabra; suffruticosa; ramis compresso-4-gouis; fol. oblongo-lanceolatis acutis supra nitidis; calycis laciniis longe subulatis. In Peruvia. Cor. villosa alba.

20. $\boldsymbol{P}$. magnoliaefolia $H$. et $\boldsymbol{K}$. non $\boldsymbol{W}$. glabra; ramulis compressis; fol. ellipticis utrinque obtusiusculis submembranaceis; stipulis oblongis obtusis. In Quito. 卢.

21. P. glomerata $H$. et $K$. glabra; ramulis compressis; fol. oblongis aut obovato-oblongis acutis membranaceis; stipulis lanceolatis ciliatis; floribus paniculatis. In Peruvia. $\hbar$.

22. P. rugulosa $H$. et $K$. glabra; ramulis compressis; fol. lanceolatis longe acuminatis subcoriaceis rugulosis subtus foveolatis; fructu globoso didymo. In Peruvia. $\hbar$.

23. P. viridis $R$. et P. peruv. $t$. 210. $f$. $b$. glabra; ramulis suh-4-gonis; fol. oblongis acuminatis ad basin subtus foveolatis; stipulis connatis; bacca globosa. In Peruvia. ‡. Cor. viridis.

21. P. repanda $\boldsymbol{R}$. et $\boldsymbol{P}$. glabra; ramulis sub-4-gonis; fol. lanceolatooblongis repandis; stipulis basi connatis lanceolatis ciliatis; ramis pani-

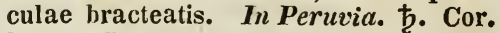
lutea. Bacca purpurea.

25. P. foveolata $R$. et $P$. peruv. t. 20\%. $f$. b. fol. anguste lanceolatis utrinque acuminatis, subtus in axillis venarum glanduloso-foveolatis; stipulis ovalibus deciduis. In Peruvia. $\mathbf{b}$. 
Cor. luteo-virescens. Bacca purpureo-virescens.

26. P. divaricata $H$. et $K$. glahra; ramulis teretilsus; fol. Ianceolato-oblongis acutis membranaceis subtus foveolatis ; floribus pedicellatis. In Quito. 古.

2\%. P. viryata $R$. et P. $t$. 209. f. a. glabra; fol. oblongo-ellipticis acuminatis coriaceis subtus venosoreticulatis; stipulis obtuse bifidis; fructu ovali. In Peruvia. $\hbar$. Folia amara. Cor. sulphurea. Bacca atro-caerulea.

28. P. cuneifolia DC. glabra; fol. ohovatis longe cuneatis cuspidatis; stipulis parvis deciduis; pantculae ramis oppositis. P. glabrata Bartl. In Peruviu. ђ. Bacca 10-striata.

2.9. P. Haenkeana DC. glahra; fol. ovali-oblongis utrinque acuminatis; stipulis utrinque bifidis acuminatis; cyma contracta. P. pedunculata Bartl. In Mexico. $\hbar$.

30. P. trifida R. et P. $t$. 209. $f$. b. glahriuscula; ramulis obtuse-4-gonis; fol. lanceolatis acuminatis supra nitidis suhtus pubescentibus; stipulis basi connatis bifidis; ramis cymae tripartitis. In Peruvia. $\hbar$. Cor. parva. Bacca nigra.

31. $\boldsymbol{P}$. capitata $R$. et P. $t .206$. f. a. glabriuscula; ramulis 4-gonis; fol. oblongis acuminatis venosissimis subtus puhescentibus; stipulis bifidis. Cephaëlis peruviana spr. In Peruvia. ち. Bacca atra.

32. P. villosa R. et P. t. 20\%. f. $a$. superue rufo-hirsuta; fol. ohlongis utrinque attenuatis subtus puberulis; stipulis ovato-oblongis acutis. In Peruvia. $\hbar$.

33. P. micrantha $H$. et $K . t .281$. villis rufescentibus hirta; fol. ohovato-ellipticis acuminatis basi ouneatis suhcoriaceis; stipulis bidentato-aristatis. P. rufescens W. In Peruvia. ち. Cor. extus hirsuta.

34. P. subtomentosa R. et $P$. $t$. 210. f. a. pubescenti-tomentosa ; ramulis obtuse 4-gonis; fol. lanceolato-ohlongis acutis; stipulis connatis acute bifidis. In Peruvia. $\hbar$.

3.5. P. alba R. et P. peruv. $t$. 205. f. a. glabriuscula; ramulis compressis: fol. elliptico-vhlongis utrintue acutis sultus pilosis foveolatis; stipulis ovato-oblongis. P. ardisiaefolia H. et K. P. densiflora W. In Lrasilia. ち.
36. P. Leiocurpa Cham. et Schl. glabriuscula; fol. anguste lanccolatis utrinque acuminatis membranaceis; stipulis connatis bidentatis; florihus 4-audris. In Brosilia. $\hbar$.

37. P. nitidule C'ham. et schl. glalerrima; fol. lanceolatis acuminatis brevissime petiolatis; stipulis 3angularibus acutis; cymae radiis compressis. In Erasilia. $\hbar$.

38. P. formosa C'uam. et schl. fol. glabris obovatis acuminulatis basi cuneatis pergamentaceis; stipulis ovatis acutis parvis deciluis; cor. lobis apice harbatis. In lirasilia. $ђ$.

39. P. nonatelioides Cham. et Schl. glabra; ramulis compressis; fol. Ianceolatis basi acutis apice longe acuminatis membranaceis; stipulis bilobatis. In Brasiliu.

40. P. cuspridutu Bred. glahra; laevis; fol. ovalihus hasi cuneatis apice acuminatis, vetustis axillis scrohiculato-villosulis; stipulis bidentatis truncatis. In Brasilia.

41. P. noxid Nt. Ilil. pl. bres. $t$. 21. f. A. ramulis compressis bifariam puberulis; fol. lanceolatis acuminatis breve petiolatis; stipulis 2-partitis; bracteis acuninatis ciliatis. In Brasilia. ち.

42. P. elliptica Ker. B. R. $60 \%$. glabra; fol. ellipticis utrinque attenuatis nitidis memloranaceis; stipulis vaginosis ohlato - ovatis subfimbriatoerosulis. In Brasilia. ち.

43. P. chuenotricha DC. glaherrima; ramulis compressis; fol. ellipticis utrinque acuminatis laevihus; stipulis brevibus utrinque bifidis; cor. ad faucem pilosissima. Ad Buliam Brasiliae. ち. Cor. allo-flavescens.

44. P. barbiflora llC. glaberrima; ramulis compressis; fol. ovalibus basi acutis apice acuminatis supra lucidis; stipulis hiaristatis; cor. limbo hirsutissimo. Ad Baliam. $\hbar$.

15. P. baliensis IIC. glaherrima; ramulis compressis; fol. ellipticis hasi attenuatis apice acuminatis supra lucidis; stipulis utrinque biligulatis; cor. imlierbibus. Ad Bahiam. ђ. Frutex 3-ped.

16. P. sambucina $l k$. glatra; fol. ovato-lanceolatis acuminatis petiolatis; stipulis deciduis; paniculae ramis verticillatis. In Brasilia.

47. P. Lonyifolia Hoffmsegg. fol. ovato-ohlongis acuminatis basi cunea- 
to-attenuatis; stipulis bifidis; panicula terminali. In B́rasilia. ち. Fol. pedalia.

tS. P. grandifolia Hoffmsegy. fol. oratis acutis; stipulis bifidis ohtusis; floribus paniculatis. In Irasilia. 古. Fol. semipedalia. Cor. flava.

49. P. erythrocurpa Cham. et Schl. pubescens ; fol. late Ianceolatis basi cuneatis pubescentibus; cyma trichotoma; floribus parvis hirtellis. In Merico.

j0. P. justicioides Cham. et Schl. pubescens; fol. late lanceolatis utrinque acuminatis petiolatis; stipulis profunde bifidis; fructu 8-angulo. In Mexico. $\hbar$.

.51. P. Mapouria R. et S. glahra; fol. obovatis breve et abrupte acuminatis hasi cuneatis; stipulis ovatorotundis deciduis; fructu globoso striato. Mapouria gujanensis Aubl. guj. t. 67. Simira uitida Poir. In Gujana. ち.

52. P. mapourioides DC. glabra; fol. ellipticis basi cuneatis apice breve acuminatis; stipulis ovatis foliaceis deciduis; fructibus ovatis striatis. In Gujana. $ち$.

53. P. Simira $R$. et $S$. glabra; fol. elliptico-ovatis abrupte acuminatis parallelo-venosis subtus pallidioribus; stipulis ovatis acuminatis; baccis ovalibus. simira tinctoria Aubl. Guj. t. 65. P. parviflora $W$. In Gujana. 古.

51. P. Patrisii DC. glabra; fol. elliptico-oblongis acuminatis; stipulis ellipticis subacutis deciduis; fructu ovato striato coronato. In Gujana. $\hbar$.

5.5. $P$. sororia $D C$. glabra; fol. elliptico-oblongis utrinque acuminatis; stipulis elliptico-3-angularibus acutis deciduis; fructu sulghloboso striato apice subtruncato. In Gujana.

56. P. ficigemma DC. glabra; fol. ovalibus utrinque acuminatis; stipulis oblongis acuminatis deciduis; fructu ovato striato; gemma oblonga. In Gujana. ち.

57. P. racemosa Rich. glabra; fol. elliptico-oblongis utrinque acuminatis subtus lucidis; stipulis bifidis; lobis acuminatissimis; fructu compresse stria-

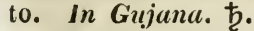

58. P. flexuosa W. glabra; subherhacea; ramulis compressis; fol. ovalıbus acuminatis membranaceis; stipulis bipartitis acuminatis; bacca globoso-compressa subdidyma. Nonatelia paniculata Aubl. Guj. t. 70. f. 2. In Cayenna. ち.

59. P. defiexa DC. glahra; ramulis pedunculisque compressis ; fol. ovato- ant ovali-lanceolatis acuminatis membranaceis; stipulis utrinque hinis; paniculae ramis depressis ad axillam harbigeris; floribus minimis 4-andris. In Gujana. ந.

60. P. puniculata DC. glahra; fol. ovatis utrinque acuminatis venosis; stipulis commatis bidentatis ; bacca globosa compressa subdidyma. In Amer. austr. $ち$.

61. P. bracteata DC. glahra; fol. oblongis acuminatis subsessilibus rigidis supra lucidis margine revolutis; stipulis linearii)us; fructu globoso striato. In Gujana. $\hbar$.

62. P. platıpoda i) C. glabra; fol. ovalibus oblongisve acuminatis parallelo-nervosis; stipulis connatis utrinque bidentatis; fructibus rotundatis depressis grosse costatis. In Gujana.

63. P. brevipes DC. glabra; ramulis compressis; fol. ellipticis acuminatissimis supra lucidis; stipulis linearibus ; fructu subrotundo-compresso striato. In Gujana. ち.

61. P. carthagenensis Jacq. am. t. 1\%4. f. 22. glahra; fol. obovatoellipticis attenuatis subcoriaceis; stipulis ovatis submembranaceis rufis deciduis; cor. fance villosa. In Carthagena et $\mathbf{S t}$. Domingo. $\hbar$.

65. $P$. calycina $H$. et $K$. glabra; ramulis compressis; fol. lanceolatis longe acuminatis membranaceis; stipulis oblongis obtusis; calycibus cucullato-spathaceis. In Nov. Granata. 古.

66. P. salicifolia $H$. et B. glabra; ramulis compressis; fol. lanceolatis utrinque acuminatis membranaceis ; stipulis oblougis acutis fuscescentibus; fructu sphaerico. In Nov. Granata. $\hbar$.

67. P. anceps H. et K. glabra; ramulis ancipitilus; fol. oblongis utrinque acuminatis supra nitidis subtus in axillis venarum scrobiculatis; stipulis ovatis. In Nov. Granata. ђ.

68. P. lucida H. et K. t. 288. glabra; ramulis ancipitibus; fol. lanceolato-oblongis utrinque acuminatis coriaceis supra nitidis; stipulis ovatis; fructu subgloboso. P. viburnoides WV. Ad ripas flum. Magdalenae. $\hbar$. 
69. $P$. cornifolia $H$. et $K$. glahia ; ramulis teretibus; fol. subsessilibus subrhombeo-ovatis acuminatis basi cuneatis membranaceis; fructibus subrotundis compressis. Ad Orinocum. $\downarrow$.

70. P. viburnoides $\boldsymbol{H}$. et $K$. glabra; ramulis compressis; fol. oblongis utrinque acuminatis coriaceis supra nitidis; stipulis ovatis acutis; calyce ciliato. Ad Orinocum. $ち$.

71. P. Borjensis $\boldsymbol{H}$. et $\mathrm{K}$. glabriuscula: ramulis pulverulentis compressis; fol. lanceolatis utrinque acuminatis membranaceis margiue undulatis subnitidis. P. ligustrina $W \cdot A d$ Orinocum. 5 .

72. P. giaucescens $H$. et $K$. ramulis teretibus hirtis; fol. oblongo-lanceolatis basi acutis margine undulatis subcoriaceis subtus foveolatis et pubescentibus; fructu subgloboso elliptico. P. divaricata W. Ad Orinocum. ち.

73. P. rufescens Spr. superue cum fol. ovato-oblongis acuminatis ferrugineo-hirtis; stipulis ovalibus obtusis. In Amer. austr. $\hbar$. var. $\alpha$. ferruginea; ramulis sub-3-gonis; stipulis subacutis semipollicaribus. P. rufescens H. et K. - $\beta$. lirta ; ramulis compressis; floribus subternis; stipulis oltusis. P. hirta H. et K. $-\gamma$. Haenkeana; ramulis compressis; stipulis obtusis; calycibus hirtis. P. rufescens Bartl.

194. $P$. diervilloides $\boldsymbol{H}$. et $\boldsymbol{K}$. tenuissime hirto-pubesceus; ramulis compressis; fol. ovatis acuminatis basi rotundatis membranaceis; stipulis oblongis obtusis; calycibus hirtis. Pro-

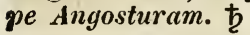

75. P. orinocensis DC. fol. suhpetiolatis subrotundis ovatis acutis nitidis; stipnlis bilobis; corymbis divaricatis. P. cornifolia W. Ad Orinocum. 市.

76. P. latifolia W. Hb. fol. ovatis utrinque acutis costatis; stipulis acute bidentatis; panicula terminali elongata. Ad Orinocum. $\hbar$. Fol. pedalia.

7\%. P. laevigata Willd. fol. oblongo-ovatis petiolatis basi attenuatis glabris; stipulis bidentatis ; panicula terminali. In Amer. austr. $\hbar$.

78. P. Hundensis $W$. fol. oblongis utrinque acuminatis sulumembranaceis; stipulis oblongis obtusis; pa- nicula corymboso-trichotoma. In Amer. austr. $\hbar$.

79. P. cumanensis $W$. fol. oblongis; stipulis ovato-acutis; cymis paucifloris. In Cumana.

80. P. sessiliflor $a$. herhacea; fol. oblongis utrinque acuminatis; stipulis emarginato-hidentatis; floribus congestis sessilihus. Ad Orinocum. $\downarrow$.

81. P. furcata DC. glahriuscula; ramis bifurcatis teretibus; fol. ovatooblongis acuminatis; stipulis bidentatis parvis; pedicellis crassis brevissimis. Cephaelis furcata Bartl. In Panama. $\hbar$.

82. P. biaristata Bartl. glabra; ramulis subcompressis; fol. oblongis utrinque attenuatis coriaceis; stipulis late ovatis hiaristatis. In Mexico. $\downarrow$.

83. P. mollis Poir. ramulis teretiusculis; fol. elliptico-oblongis utrinque acumiuatis memhranaceis; stipulis ovatis acute bidentatis. In Mexico. 古.

81. P. hebeclada DC. superne pubescens ; fol. elliptico-oblongis utrinque acuminatis; stipulis acute hifidis; rachi paniculae compressa. P. pubescens Bartl. In Mexico. $\hbar$.

85. P. Aureola Bartl. pubescentisubvelutina; ramulis compresso-teretibus; fol. oblongo-lanceolatis atteunatis venis parallelis nervoque flavidis; stipulis late ovatis. In Mexico. $\hbar$.

86. P. scabriuscula Bartl. ramulis compressis, juniorihus pedunculisque pubescentibus; fol. oblongo-lanceolatis attenuatis supra glabris; stipulis ovatis hiaristatis; fructibus globoso-didymis. In Acapulco. $\hbar$.

87. P. Mexicana $W$. fol. oblongis utrinque acuminatis submembranaceis; stipulis bipartitis acutis; panicula angustata. In Mexico.

88. P. padifolia $W^{\prime}$. fol. oblongis acuminatis venis subtus pilosiusculis; stipulis bipartitis lineari-subulatis; panicula corymbosa terminali. In $\mathrm{X} a$ lapa. ђ.

89. P. lanceolata Nutt. ramulis foliisque lanceolatis utriuque acuminatis subtus ferrugineo-pubescentibus; stipulis amplexicaulibus subrotundis sphacelatis. In Florida. ち. Bacca rubra.

90. P. undata Jacq. Schoenbr. $t$. 260. glabra; fol. ovali-lanceolatis utrinque acuminatis undulatis; stipulis 
connatis ovatis; cor. tubo villoso. In Bahama. ち.

91. $\boldsymbol{p}$. foribunda $\boldsymbol{H}$. et $\mathbf{K}$. glabra; ramulis compressis; fol. elliptico-oblongis utrinque acuminatis coriaceis; stipulis oblongis obtusis; cy-

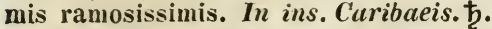

92. P. tenuifolia $\mathbf{S} w$. glabra; fol. oblongis utrinque acutis membranaceis; stipulis ovatis deciduis hifidis acuminatis; cor. fauce villosa. In $\mathrm{Hi}$ spaniola. ち.

93. P. nervosa $\mathrm{Sw}$. glabra; fol. ovatis basi acutis apice acuminatis nervosis subundulatis; stipulis oblongis acuminatis emarginatis deciduis; fauce cor. villosa. In Jamaica. $\hbar$.

91. P. laxa $\mathbf{S u}$. fol. ovatis acutis vix nervosis brevissime petiolatis; stipulis ovatis acuminatis deciduis; bacca oblonga. In Jamaica. †.

95. P. oligotricha DC. fol. ellipticis utrinque acuminatis membranaceis in axillis foliorum pubescentibus; stipulis ovatis membranaceis rufis; fauce corollae barbata. In Jamaica et Portorico.

96. P. chimarrhoides DC. glabra; fol. oblongo-lanceolatis utrinque acuminatis membranaceis; stipulis ovatis olitusis ferrugineis; fauce cor. basi villosa. In ins. Caribaeis. $ち$.

97. P. capitellata DC, ramulis compressis glabris; fol. ellipticis basi brevissime cuneatis apice acuminatis membranaceis gla!ris; stipulis setaceo-biligulatis. In ins. Trinitatis. $ђ$.

93. P. oligantha DC. glabriuscula; fol. oblongis basi cuneatis nervosis; nervis scabriusculis; stipulis bifidis; lohis 1-angularilus acutis ; fructu ovato. P. lineata Spr. In Domingo. ち.

99. $P$. portoricensis $D C$. superne ferrugine 0 -hirsuta ; fol. ellipticis utrinque acuminatis velutino-rubescentibus; stipulis ovatis amplis membranaceorufis; fance cor. villosa. P. hirsuta Spr. In Portorico.

100. P. Berteriana DC. fol. ovato-oblongis utrinque acuminatis supra glabris subtus puberulis; cor. tubo hrevi. Nonatelia pubescens Spr. In Domingo et Portorico. t.

101. P. bracteata $\mathrm{S} p r$. fol. ovalioblongis utrinque acuminatis glabris; stipulis ovali-oblongis ohtuse bidentatis ; ramis 4-gouis. Nonatelia officinalis Spr. In Jamaica et Domingo. t.
102. P. pubescens Sw. superne pubescens; fol. ovatis utrinque acuminatis; stipulis acute et breve bidentatis. In sepibus Jamaicae et Domingo. 5 .

103. $P$. horizontalis $S w$. ramis teretibus horizontalibus laevibus; fol. lanceolato-ovatis acutis subtus paniculisque pubescentibus; stipulis ovatis minutis deciduis. In Domingo. $\hbar$.

104. P. corymbosa Sw. glabra; fol. lanceolato-ohlongis acuminatis nitidis; stipulis bidentatis; pedunc. coloratis; cor. fauce nuda. In Caribaeis. ђ. Bacca didyma subcompressa.

105. P. nutuns Sw. glabra; fol. lanceolatis acutis nervosis; stipulis bidentatis nuarcescentibus deciduis acutis; panicula fructifera nutante. In Hispaniola. $\hbar$.

106. P. congesta Spr. glabra; fol. Ianceolatis basi acutis apice acuminatis; stipulis deciduis; fauce cor. barbata; antheris inclusis. In Jamaica. b.

107. P. patens Sw. glabra; fol. ovato-lanceolatis acuminatis rigidulomembranaceis distichis ; stipulis bidentatis; panicula secunda; cor. fauce nuda. In Jamaica et Domingo. $\hbar$.

108. P. myrtiphyllum sw. glabra; fol. lanceolato-ovatis enerviis nitidis rigidis; stipulis ovatis deciduis; ramis secundis; cor. fauce villosa. In Jamaica. $\mathbf{b}$.

109. P. parasitica Sw. sarmentosa; radicans; glabra; fol. ovatis acuminatis aveniis subsucculentis; stipulis amplexicaulihus retusis; cor. fauce pubescente; bacca subglobosa. Viscoides pendulum Jacq. am. t. 51. f. 1. In ins. Caribaeis. 5 .

110. P. marginata Sw. glabra; fol. lanceolato-ovatis acutis margine cartilagine 0 -setosis; stipulis ovatis acuminatis deciduis; bacca ovata nigra. In ins. Caribaeis et Mexico.

111. $P$. hirsuta $S w$. ramis, paniculis, petiolis foliisque ferrugineo-hirsutis; fol. lanceolato-ovatis acutis; stipulis lanceolatis indivisis; bacca ovata pubescente rubra. In sylvis Jamaicae. $\hbar$.

112. P. patens Sw. glabra; fol. lanceolato-ovatis acutis; stipulis ovato-acuminatis integris deciduis; panicula pedunculata patentissima; fauce cor. villosa; bacca oblonga coccinea. In Jumaica. $\mathbf{t}$. 
113. P. Westii DC. glahra; ramis teretibus; fol. oblongo-ellipticis utrinque attenuatis memhrauaceis; stipulis deciduis; cor. oblonga nuda; antheris linearihus. In Portorico. $\hbar$.

11t. P. polyuntha Dé: glabra; fol. ellipticis utrinque acuminatis rigidulo - membranaceis; stipulis ovatis acuminatis; panicula ranosissima; fauce cor. barbata. In Domingo, $\hbar$.

11.5. P. citrifolia su. glahra ; fol. ellipticis acuminatis subcoriaceis; stipulis ovato-acuminatis persistentibus; cor. fauce nuda; bacca oblonga. In ins. Caribaeis. $\hbar$.

116. P. laurifolia $S w$. glahra; fol. lanceolato-ovatis acutis crassiusculis nitidis; stipulis ovatis acuminatis deciduis; filamentis ciliatis; cor. fauce harbata. In Jamaica et Hispaniola. Ђ. Bacica laete sanguinea.

11\%. P. Brounii Sw. glabra; fol. ellipticis utrinque attenuatis suhcoriaceis subtus pallidioribus ; stipulis ovatis caducis; haccis ovatis. Brown jam. t. 17. f. 2. P. asiatica Lam. ill. t. 161. f. 1. In Portorico. $\hbar$.

118. P. balbisianu DC. glabra; fol. ellipticis utrinque subacuminatis rigidulis; stipulis ovatis deciduis; cor. fauce uuda. P. lucida Spr. In Jamaica. $\hbar$.

11.9. P. revoluta DC. glabra; fol. ellipticis utrinque hreve acuminatis coriaceis margine revolutis; stipulis oblongis rufo-membranaceis deciduis; cor. fauce villosa. P. glahrata spr. In Domingo et Isispaniola. $\hbar$.

120. P. glabratu Sw. glahra; fol. ovatis ohtusis nilidis; stipulis parvis ovatis acutis ferrugineis deciduis ; calycis margine subintegro. In Jamaica. b.

121. P. exsertu EC. glahra; fol. ohlongis subohtusis hasi cuneatis coriaceis supra nitidis; stipulis lanceolatis acutis hasi stibcomatis deciduis; fance cor. glabra. In Domingo et Hispaniola. $\frac{\hbar}{\text { b. }}$

122. P. plat yphylla DC. glahra; stipulis bipartitis; lohis 3-anyularibus acutis; fol. ellipticis utrinque acuminatis memhranaceis; ramulis 4-gonis; fauce cor. glahra. P. monophylla Vent. In portorico. $\hbar$.

123. P. grandis sw glabra; fol. ohovatis hreve acuminatis hasi cuneatis; stipulis deltoideis margine revolutis persistentibus. In Jamaica. $\hbar$.
124. P. pedunculata Spr. glabra; fol. ovali-lanceolatis hasi acutis apice acuminatis rugosiusculis; stipulis hidentatis persistentiluus. P. attenuata W. In Jamaica. ち.

12.5. P. ungustifoliu Poir. glabra; fol anguste lanceolatis apice obtusis hasi acumiuatis; stipulis bidentatis acuminatis; bacca globosa. In Domingo. ち. Cor. flava.

126. P. barbata Poir. subherhacea; glabra; fol. ovatis acuminatis membranaceis; ramis compressis subangulatis. In Martinica. 24.?

12\%. P. bicolor Bredem. glabra; fol. oblongo-lanceolatis hreviter petiolatis; stipulis bidentatis setosis; floribus paniculatis; pedunc. coloratis croceis. In Martinica. $\hbar$.

128. P. Phytolacca Poir. glahra; fol. ovatis utrinque hreviter acuminatis petiolatis subcarnosis; panicula brevi cymosa; fructibus globosis. In imer. allstr. ち.

129. coriacea Poir. glahra; fol. ovatis utrinque hreviter acuminatis petiolatis suhcarnosis; florihus paniculatis confertis; fructibus globosis. In Anier. uustr. $\hbar$.

130. P. aristata R. et S. fol. oblongis utrinque acuminatis supra nitidis subtus in venis pubescentibus; stipulis connatis aristato-bidentatis; pa-, nicula hirta. In Amer, austr. t.

131. P. splendens spr. fol. lanceolatis basi angustatis ohtusiusculis nitidis; stipulis deciduis; corymbis paucifloris. P. lucida W. Ad flum. nigrum Amer. austr.

132. P. lampophylla Spr. fol. anguste lanceolatis elongatis utrinque attenuatis coriaceis supra nitidis subtus glaberrimis aveniis; stipulis ahhreviatis caducis. P. salicifolia W. In Amer. austr. ち.

133. P. attenuata $W$. fol. ovatoellipticis longissime acuminatis meulhranaceis; stipulis bidentatis; cyma terminali. In Amer. austr. †.

134. P. dichotoma $W$. fol. ovatoohlongis acutis; stipulis bifidis; spicis dichotomis. In Amer. austr.

13.5. P. commutata $D C$. fol. ellipticis utrinque acutis suhmemhranaceis; stipulis ohlongis ohtusis amplexicaulilus; panicula corymhosa terminali. P. elliptica W. In America australi. $\hbar$. 
136. P. membranucea $W$. fol. olsovato-oblongis acuminatis membranaceis; stipulis ovatis acutis. In America uustr. $\hbar$.

\section{b. Africanae.}

137. P. Mubica Caill. et Delile; fol. ellipticis superne glabris basi et apice sulhacutis subtus ill nervis puhescentibus; stipulis 3 -angularihus; stylo longe exserto. In Africa. $\hbar$.

138. P.? p.sathurvides I)C. glahra; fol. ohlongis utrinque acutis coriaceis petiolatis; stipulis ovatis ohtusis deciduis; calyce truncato; cor. profunde 5-partita. In ins. Manritii.

13.9. P. obtusifolia Lam. ill. $t$. 161. f. 4. glahra; fol. ohovatis cunealis ohtusissimis in petiolum brevissimum attenuatis; stipulis utrinque binis lineari-cuspidatis. In Madayascar. ђ.

\section{c. Asiaticae.}

140. P. serpens $L$. suffruticosa; ramosissima; tortuosa; glahra ; fol. ovatis utrinque acutis coriaceis; stipulis ohtusis indivisis fuscis deciduis; pedunculis ramulisque ancipitibus. In clina. ђ

141. P. Roxburghii DC. ramulis oppositis complanatis pubescentibus demum laevihus; fol. ellipticis utrinque acuminatis membranaceis supra lucidis subtus pubescentilus; stipulis ovatis apice recurvis acute bifidis. In Moluccis. \$.

142. P. sphaerocarpa Wall. glabra; ramulis compressis; fol. ellipticis acumiuatis coriaceis ; stipulis ovatis apice recurvis acute bifidis; corymho compacto villoso. In Silhet. $\hbar$. Bacca pallide ruhra.

1+3. P. truncata Wall. glabra; axillis petiolorum pilosis; ramulis subcompressis ; fol. ovatis acuminatis longe attenuatis coriaceis; stipulis latis ovatis indivisis coriaceis deciduis; cor. fauce larhata. In Ind. or. $\hbar$.

14. P. connuta Wall. glahra; ranis conpressis; fol. lanceolatis acuminatis basi longe attenuatis coriaceis ; stipulis ovatis cuspidato-acutis subrecurvis; bracteis comnatis sublohatis. In Ind. or. ఫ.

1.5. P. Reeresii Wall. glabra; r:anulis subcompressis; fol. oblongo- lanceolatis utrinque acutis laevibus glancis coriaceis; stipulis late ovatis adpressis oblusis; ramis decussatis; cor. fauce dense barbata. In Clina. 古.

1\$6. P. aurantiaca W'all. glabra; ramulis complanatis; fol. lanceolatis acuminatis; stipulis ovatis acuminulatis; cor. tubo longo; fance villosa. In Java. 古.

1+7. P. denticulata W'all. adscendens; basi repeus; caule glabro tereti superne compresso; fol. ovatis breve acuminatis coriaceis lucidis; stipulis subcordatis apice subdentatis; cor. subrotata. In Nepalia. ち. Bacca globosa purpurea.

18. P. adenophylla Wall. glabra; fol. lanceolatis acuminatis lucidis ad axillas glandulosis; stipulis ovatis ol)tusis basi comnalis deciduis; bracteis aristatis. In Silliet. $\hbar$.

149. P. curviflora Wall. glabra; ramulis teretibus; fol. Ianceolato-oblongis acuminatis hasi attenuatis longe petiolatis membranaceis; nervis subtus ultimis glandulosis; racemo ovali compacto. In Ind. or. $\hbar$.

150. P. ophioxyloides W'all. laevis ; subscandens; dichotoma ; fol. lanceolatis breve petiolatis acuminatis; stipulis ovatis cuspidatis bifidis; cor. lobis incurvis. In sillet. $\hbar$.

1.51. P. polyneura DC. glahra; ramulis pedunculisque compressis ; fol. elliptico-ovatis breve acuminatis coriaceis; stipulis ovatis setaceis; cor. hrevi fance glabriuscula. In Nepalia. $\hbar$.

152. P. Wallichiana Spr. fol. ovalihus acuminatis serrulatis nervosis glabris; stipulis simplicibus; paniculis glomeratis; dentibus calycis rotundiatis membranaceis. P. nervosa Don. In Nepulia. $\hbar$.

1.53. P. vayinuns DC. glabra; fol. ovato-oblongis apice cuspidatis hasi attenuatis; stipulis in tubum concretis intrafoliaceis apice bifidis 2-dentatis; calyce campanulato truncato. In Zeylano. $\hbar$.

15-1. P. Malayuna Jack: fol. Iate lanceolatis; stipulis indivisis; paniculis terminalibus corymbosis; cor. fauce barbata. In Pulo Pinang. ђ. Cor. alba.

1.55. P. tortilis Blume bijdr. caule herhaceo inferue repente; fol. ovato-oblongis attenuatis supra laevibus 
Infra reticulatis parum tomentosis; stipulis ovatis bifidis; floribus secundis; baccis 1-costatis. In Java. $\hbar$.

156. P. divergens Blume; fol. oblongo-lanceolatis utriuque acuminatis coriaceis supra glabris infra pallidioribus; stipulis bifidis ciliatis; drupis ovalibus costatis. P. divaricata Blume. In Jara. $ђ$.

15\%. P. lurida Blume bijdr. fol. cuneato-oblonyis acuminatis nembranaceis glabris; stipulis lato-ovatis bidentatis adpressis; pedunc. calycibusque coloratis; drupis glohosis. In Java. t.

158. P. gandarussaefolia Blume; fol.breviter petiolatis lineari-lanceolatis utrinque acuminatis membranaceis glabris; stipulis ovatis acutis. In Java. $\hbar$.

159. P. montana Blume; fol. ol)longis utrinque acuminatis membranaceis glabris; stipulis membranaceis petiolum semiamplectentilsus; pyrenis dorso 1-costatis rugosis. P. robusta Blume. In Java. $\hbar$.

160. $P$. rostrata Blume; fol. breviter petiolatis oblongo - lanceolatis acuminatissimis membranaceis glabris; stipulis ahbreviatis subconnatis; pyrenis dorso 1-costatis laevibus. In Java.

161. P. tetrandra Blume; fol. breviter petiolatis oblongis utrinque acuminatis membranaceis glabris infra reticulatis; stipulis abbreviatis acutis; floribus 4-andris. In Java. $ђ$.

162. P. Rhinocerotis Reinu, fol. cuneato-oblongis acutis coriaceis supra glabris infra corymbisque tomentosis; stipulis 2-3-fidis; drupis siccatis sulcatis. In Java. ち.

163. P. viridiflora Reinw. fol. ol)longo-lanceolatis utrinque acuminatis membranaceis glabris; stipulis ovatis obtusis margine membranaceis ciliolatis; drupis siccitate 10-costatis. In Java. ち.

161. P. sylvatica Blume; fol. Iongiter petiolatis oblongo-lanceolatis acuminatis glabris; stipulis ovatis superne membranaceis; drupis ellipticoglobosis siccitate costatis. In Java.

165. P. expansa Blume; fol. elliptico-oblongis utrinque acuminatis nembrauaceis glabris; stipulis ovatis basi connatis; cor. tubo cylindraceo. In Java. ந.

166. P. laxiflora Blume; caule radicante scandente; fol. breviter pe- tiolatis elliptico-oblongis utrinque attenuatis menbranaceis glabris; stipulis connatis. In Java. ち.

167. P. sarmentosa Blume; caule radicante scandente; fol. breviter petiolatis lanceolatis utrinque acuminatis tenuiter veliosis coriaceis glabris; stipulis connatis; drupis elliptico-globosis. Iu Java. ち.

168. P. leucocarpa Blame; caule radicante scandente; fol. breviter petiolatis lanceolatis utrinque acuminatis coriaceis glabris, superioribus in verticillum approximatis; floribus capitatis; drupis globosis laevibus. In Java.

169. P. pauciflora Bartl. glabra; ramulis compressis; fol. anguste oblongis acutis basi longe acuminutis subcoriaceis glaucescentibus; stipulis lanceolatis deciduis; calyce truncato. In Luzonia.

1\%0. C. ixoroides Bartl. glabra; ramulis compressis; fol. oblongis basi longe attenuatis subcoriaceis glancescentibus; stipulis 3 -angulari-ovatis acutis deciduis; fructibus globosis. In Luzonia. †.

171. P. Mariana Bartl. glabra; ramulis pedunculisque compressis; fol. oblongis basi longe attenuatis subcoriaceis; stipulis caducis; calyce cantpanulato truncato demunı irregulariter fisso. In ins. Marianis. $\hbar$.

172. P. membranifolia Bartl. glabra; fol. ovato-oblongis ovalibusque breviter acuminatis membranaceis subtus venosis; stipulis membranaceis acute bidentatis erosis; antheris exsertis. In Luzonia.

173. P. linearis Bartl. ramulis teretibus; paniculis, petiolis foliisque subtus ferrugineo-hispidis; fol. elongatolinearibus supra glabris; stipulis membranaceis ovatis. acuminatis; cor. villosa. In ins. Manilla. $ち$.

17t. P. manillensis Bartl. glabra; ramulis subcompressis; fol. ellipticooblongis acuminatis basi attenuatis subcoriaceis subtus discoloribus; stipulis ovatis; fructibus ovato-oblongis. In Manilla. ђ.

\section{d. Australasicae.}

175. P. collina Iabill. sert. Cal. t. 4\%. ulabra; ramis teretiusculis; fol. lanceolato-oblongis utrinque attenuatis; stipulis ovatis caducis; pedunc. 
compressis; bacca subrotunda. In Nova Caledonia. 占.

176. P. loniceroides Sieb. tota ferrugineo-hirsuta; fol. ellipticis oblongisve utrinque subacutis; stipulis lauceolatis acuminatis deciduis; bracteis ovatis acutis; bacca ovata calyce 5dentato coronata. In Nov. Holl. 古.

17\%. P.? speciosa Forst. arborea; fol. oblongo-lanceolatis; involucro terminali sub-3-floro. Cephaëlis Spr. In Taheiti. ち.

178. P. daphnoides Cunningh. fruticosa; dichotoma; glabra; ramis furcatis; fol. obovato-attenuatis; stipulis parvis suborbicularibus bidentatis; fauce cor. villosa. B. M. 3228. In Nov. Holl. Cor. albida.

\section{0. antonia poli. (1832).}

1. A. ovate Pohl ic. t. 109. fol. ovali-ellipticis glaberrimis. In fruticetis Brasiliae. ‡. Orgyalis. Cor. alba.

\section{PALICOUREA Aubl.(17\%5).}

a. Floribus corymbosis cymosisve.

1. P. Sellouiana DC. glabra; ramis teretibus; fol. ellipticis utrinque acntis margine undulatis longe petiolatis; stipulis obtuse bidentatis; ramis paniculae angulato - compressis. Ad Rio Janeiro. 卢.

2. P. fastigiata $\boldsymbol{H}$. et $\boldsymbol{K}$. glabra; ramulis sub-4-gonis; fol. elliptico-aut ovato-oblongis acuminatis basi acutis membranaceis ; stipulis bidentatis; fructu subgloboso. Psychotria fastigiata Spr. Ad Orinocum. 卢.

3. P. tabernaefolia DC. glabra; ramis teretibus; fol. amplis mollibus lanceolato-acuminatis petiolatis; calycis laciuiis subulatis; cor. tubo gracili. Psychotria Poir. In Domingo. ち.

4. P. hebeantha DC. glabra; ramulis teretibus; fol. elliptico-oblongis acuminatis basi acutis; stipulis utrinque binis acutis parvis vix ligula junctis; cor. obtusis 4-fidis pulverulentotomentosis. In Brasilia. ち.

5. P. Marcgravii St. Hilar. pl. bras. t. 22. f. A. ramulis sub-4-gonis; fol. oblongis acuminatis subpetiolatis; stipulis 3-fidis; corolla papilloso-tomentosia. Calvania Vellosi R. et $\mathbf{s}$. In Brasilia. 古.

6. P. apicata H. et K. Nov. Gen. $t$. 285. glabra; ramis teretibus; fol. oblongis breviter acuminatis coriaceis; stipulis connatis bidentatis; fructibus urceolo persistente apicatis. Psychotria lineata W. In monte silla. $\downarrow$.

\%. P. Paretta DC. glabra; ramis teretibus; fol. lanceolato-ovatis acuminatis tenuibus nervosis; stipulis membranaceis bidentatis; fructu subrotundo-didymo. Sloane jam. t. 202. f. 2. Lam. ill. t. 161. f. 3. Pavetta pentandra Sw. In Jamaica. t. Cor. odoratissima.

8. P. tinctorice $\boldsymbol{R}$. et $\boldsymbol{S}$. glabra; fol. oblongis acuminatis coriaceis subtus foveolatis; stipulis lanceolatis basi connatis; cor. fauce harbata; filamento hirsuto. Psyclotria $\mathbf{R}$. et $\mathbf{P}$. peruv. t. 211. f. a. In Peruvia. ち.

9. $\boldsymbol{P}$. xanthina $D C$. glabra; ramis teretibus ; fol. ovato-vel ovali-lanceolatis basi acutis apice acuminatis membranaceis; stipulis brevissimis subbidentatis; cor. extus puberula curva. In Gujana. ち.

10. P. punicea DC. glabra; ramulis teretibus; fol. oblongo-lanceolatis acutis ntrinque nitidis; stipulis subulatis; paniculis puniceis. Psycliotria Fl. peruv. t. 42. f. a. In Peruvia. $\hbar$.

11. P. crocea DC. glabra; fol. ovatis lanceolatisve acuminatis subrigidis; stipulis binis linearibus; cor. tubuloso-obconica; bacca subdidyma. Brown. jam. t. 13. f. 1. Psychotria Sw. In Jamaica. $\downarrow$. Panicula croce0-colorata.

12. P. pedunculosa DC. fol. elliptico-oblongis utrinque acuminatis subcuspidatis rigidulis; stipulis ovalibus deciduis ; cor. infundibuliformi; lobis revolutis. Psychotria Rich. In Gujana. 卉.

13. P. chionantha DC. glabra; fol. ovatis breve cuspidatis basi subacutis rigidulis; stipulis ovalibus mox deciduis; antheris exsertis; fructu obovato-pyriformi. In Brasilia. $\hbar$. Cor. nivea.

11. P. umbellata $D C$. ramulis 34-gonis; fol. elliptico-oblongis acuminatis basi attenuatis rigidis; stipulis concretis vaginantibus utrinque biden- 
tatis; corymbo subumbellato. In Gujana. $\mathrm{t}$.

\section{b. Floribus paniculatis.}

15. P. triphylla DC. glabra; fol. ternato-verticillatis elliptico-oblongis utrinque acuminatis vix petiolatis; stipulis lineari-subulatis; racemo puberulo. In Gujana. ち. Drupa compressa.

16. P. verticillata DC. ramulis 4-gonis glabris; fol. quaterno - verticillatis lanceolato-oblongis glaberrimis; stipulis bifidis; paniculis pubertllis; fructu orbiculari-ovato. Psychotria longifolia Hilar. pl. bras. t. 22. f. B. In Brasilia. b.

17. P. quadrifolia Rudge Guj. $t$. 42. caule 4-gono; fol. quaterno-verticillatis oblongo-lanceolatis acuminatis; stipulis intrafoliaceis vaginantibus. In Gujana. ந.

18. P. tetraphylla Cham. et Schl. ramulis obtuse 4-gonis laevibus; fol. quaterno - verticillatis ovalo-lanceolatis attenuatis sublus hirto-pubescentibus; stipulis bifidis acutis ciliatis; cor. extus glabra. In Brasilia 4.

19. P. macrobotrys $\mathbb{R}$. et S. ratmulis teretibus glabris; fol. longe lanceolatis acuminatis subtus velutinopubescentibus; panicula velutino-pubescente; rachi suh-4-gona. Psychotria Fl. peruv. t. 203. f. a. In Peruvia. t.

2U. P. macrocarpa H. et $\boldsymbol{K}$. ramis teretibus glabris; fol. obovatooblongis subacuminatis basi cmeatis subcoriaceis sultus hirtellis; stipulis bifidis glabris ; cor. glabris; fructu globoso. Psychotria anacardifolia W. In Nova Granata. $\hbar$.

21. P. amethystina $D C$. ramulis sub-4-gonis pilosulis; fol. oblongis acuminatis supra glabris subtus in nervis villosis ; paniculis hirsutis ; fructibus ovalibus. Psychotria Hl. peruv. t. 203. f. b. In Peruvia. $\hbar$.

22. P. Iongibracteata DC. ramulis 4-gono-teretibus glabriusculis; fol. oblongis acuminatis brevissime petioIatis subtus pubescenti-pilosis; stipulis conuatis acuminatis; bacca subrotundo-compressa. In lpanama. $\hbar$.

23. P. obovata D)C. ramulis olitu6e 4-gonis; fol. obovatis acuminatis anplis venosis subtus pubescentibus; stipulis subconnatis ovatis breve bi- lobis; calyce ciliato; hacca globosa purpurea. Psychotria Fl. peruv, t. 204. f. a. In peruvia. ち.

24. 1. mitis DC. ranulis obtuse 4-gonis; fol. lanceolatis utrinqne acutis subtus glabris supra minutissime velutinis ; stipulis connatis ovatis emarginatis; dentibus ohtusissimis. Psychotria Fl. peruv. t. 208. f. b. In Peruvia. Ђ. Cor. lntea.

25. P. laxa R. et S. glabra; ramulis 4-gonis; fol. oblongis acuminatis supra nitidis ; stipulis laevibus bifidis; Iobulis ovatis ohtusis; panicula longa laxa, fructifera dependente; bracteis reflexis. Psychotria R. et P. peruv. t. 212. f. b. P. brachiata Dietr. In peruv. t.

26. I. "hyacintlifiora $\boldsymbol{R}$. et $\mathrm{s}$. glalra; ramulis obtuse 4 -gonis; fol. obovatis acuminatis amplis; stipulis bifidis; lobulis ovatis obtusis ; corollae infundibuliformis lobis reflexis. Psychotria Fl. peruv. to 213. fo a. In Peruvia. t.

ฉ\%. P. sutphurea DC. glabra; ramulis obtuse 4-angulis; fol. obovatocuneatis apiculatis coriaceis nervosis supra lucidis; stipulis obtuse bilobis. Psychotria Fl. peruv. t. 203. f. a. In peruv. $ち$. Herba amarissima.

28. P. flavescens H. et K. ramulis sub-4-gonis hirto-villosis; fol. oblongis acuminatis subcoriaceis supra hirtis subtus aureo-tomentosis; stipulis villosis commatis bidentatis; cor. hirtis. Psychotria Spr. In Peruvia. $\hbar$.

2y. P. thyrsiflor $D$ DC. glahra; ramulis obtuse 4-gonis; fol. lanceolatis acutis; stipulis utrinque binis ligula connexis dentiformibus; bacca ovata. Psychotria Wl. peruv. t. 204. f. b. In Peruvia. ち. Cor. Intea. Bacca purpure0-nigra.

30. $\mathbb{P}^{\prime}$. alpina $D C$. ramulis $4-$ gonis; fol. lanceolato-ovatis menibranaceis reticulatis subciliatis; petiolo pubescente; stipulis connexis linearibus ciliatis; cor. elongatis diaphanis. Psychotria Sw. In Jamaica. ち. Cor. flava, rubra, purpurea aut cacrulea.

31. P. eriantha DC. raumulis teretibus; fol. ellipticis hasi acutis apice acuminatis supra glabris sublus hirsutis; stipulis subulatis nembrana junctis; cor. tubulosa extus hirsutissima. Psychotria alpina Poir. In $\mathrm{Do}$ mingo. $b$. 
32. P. speciosa H. et $\boldsymbol{K}$. ramis glabris teretibus; fol. oblongis acuminatis basi acutis membranaceis nitidis; stipulis glabris; cor. hirta. In Nor. Grancata. 古.

33. P. elliptica $\boldsymbol{H}$. et $\boldsymbol{K}$. ramulis 4-gonis glabriusculis ; fol. suhrotundoellipticis acutis coriaceis rigidis subtus hirlis; stipulis ovato-lanceolatis hirsutis; cor. glahra. Psychotria cincinata W. Ad Orinocum. $\hbar$.

34. P. longiflora DC. ramis teretibus laevibus; fol. ovato-lanceolatis acuminatis magnis coriaceis subtus pubescentibus; cor. tubo longissimo basi attenuato. Psychotria longiflora Poir. In Cayenna. 古.

35. P. Domingensis DC. glahra; ramis teretilus; fol. Ianceolato-ovatis acutis nitidis petiolatis; floribus sessilibus cylindraceis incurvis; haccis nitidis nigris. Psychotria Jacq. In Domingo. Ђ.

36. P. croceoides Desv. fol. latoovatis acuminatis basi attenuatis nitidis glaberrimis; paniculis longe pedunculatis. In Antillis. ち. Lami crocei.

3\%. P. coccinea DC. glabra; fol. elliptico-oblongis utrinque acuminatis membranaceis; stipulis setaceis ligula brevi connexis; cor. tubulosa; limbo erecto. Psychotria Poir. In Domingo et Portorico. $\hbar$.

3S. P. longifolice $\boldsymbol{H}$. et $\boldsymbol{K}$. glabra; ranis teretibus; fol. lanceolato-oblongis acuminatis hasi acutis membranaceis nitidis; stipulis caducis; cor. glabriusculis. In Nov. Granata. †.

39. P. nicotianaefolia Cham. et Schl. ramulis, paniculis, stipulis foliisque subtus minutissime pubescentibus; fol. ovato-lanceolatis utrinque acuminatis membranaceis; stipulis truncatis bidentatis; cor. pubescente. In Brasilia. 市.

40. $P$. angustifolia $H$. et $\boldsymbol{H}_{\text {. }}$ ramulis tenuissime hirtellis; fol. ohlongo-lanceolatis acuminatis basi acutis membranaceo-rigidis discoloribus glabris ; stipulis bidentatis ; fructu globoso didymo. Ad Orinocum. $\hbar$.

41. P. calophylla DC. glabra; ramis teretibus; fol. oblongis basi acutis apice acuminatis subpetiolatis; stipulis concretis acuminatis ; cor. pulverulaceo - tomentosa, In Gujana. $\hbar$.
12. P. petiolaris H. et $\boldsymbol{K}$. glahra ; fol. elliptico-oblongis acuminatis membranaceis longe petiolatis; stipulis comnatis apice acute hifidis; paniculis minutissime pubescentibus. Psychotria spr. In Nor. Andalusia. $\hbar$.

43. P. Gujanensis Aubl. Guj.t. 66. glabra; fol. ovalibus breve acuminatis membranaceis petiolatis; stipulis ohtuse hifidis subconnatis; panicula ramosissima erecta; cor. cylindracea extus farinosa. Psychotria Palicourea Sw. In Gujana. ђ.

41. P. Haenkeanc DC. ramulis obtusissime 4-gonis; fol. petiolatis cllipticis basi acutis apice ohtusissimis subtus velutinis; stipulis triangularibus acutis; panicula ramosissima; cor. glabra. Cinchona Haenkeana Bartl. In Peruvia. ち. Cor. purpurea.

45. P. barbinervic DC ramis teretibus glabris; fol. ovalibus cuspidatis rigidulis in nervis subtus barbatis; stipulis adpressis obtusissimis hilobis; cor. subtomentosa. Psychotria macrophylla et lutea Spr. In Portorico et Domingo. t.

46. P. costata $\Pi$. et $\Pi$. ramulis villosis; fol. oblongis acuminatis basi acutis membranaceis glabris subtus hirtis in nervo discoloribus; stipulis hirtis hifidis; cor. extus hirtella intus harbata. Psyclotria aristata W. $A d$ Orinocum. $\hbar$.

4\%. P. noxic Mart. glahra; fol. ntemliranaceis ohlongis acuminatis basi rotundatis hreviter petiolatis; paniculis divaricatis; pedicellis subtrifidis; cor. velutinis, In Brasilia. $\hbar$.

18. P. sonans Mart. tota glabra; fol. coriaceis oblongis utrinque attenualis acuminatis aut retusis ; panicula racemosa pyramidata; cor. velutinis. In Brasilia. ந.

19. P. diuretica Mart. fol. tandem margine incrassato revolutis subtus inter costas venasque velutinis; floribus tenuiter velutinis. In Brasilia. t.

50. P. officinalis Mart. tota aureo-pubescenti-scabriuscula; fol. anguste ellipticis breviter petiolatis mucronulatis; corymbis coarctatis. In Brasilia. b.

51. P. curatc Mart. fol. quaternis membranaceis rigidiusculis oblongis obovatisque longe petiolatis subtus aureo-flavis glabris; cor. tenuiter velutina. In Bresilia. ち. 
52. P. strepens Mart. cortice suberoso; fol. coriaccis rigidis utrinque glabris sulsessilibus lato-ovatis margine incrassato-revolutis subtus flavescentibus; cor. tenuissime velutinis. In Brasilia. $\hbar$.

53. $P$. rigida $H$. et $K$. glabra; ramis obtuse 4-gonis; fol. ellipticis basi rotuudatis subsessilibus coriaceis nitidis; cor. tenuissime puhescentibus; staminibus exsertis. Psychotria rigi-

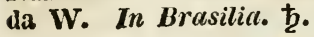

\section{CEPHÄ̈LIS Sw. (1788).}

a. Capitula bracteis duabus connatis magnis patentibus coloratis involucrata. Tapogomea Aubl.

1. C. tomentosa $W$. superne cum foliis ovato-cordatis hirsuta; stipulis acuminatis villosis; involucri foliolis late cordatis. Tapogomea Aubl. Guj. t. 61. In Gujana, ins. Trinitatis et Mexico. $\hbar$. Bracteae coccineae.

2. C. punicea $W$. glaberrima; stipulis obtusis; capitulis longe pedunculatis; involucri foliolis obtusis capitulo longiorihus. In Jamaica. t). lnvolucra punicea.

3. C. elata $S w$. glaberrima; stipulis obtusis; capitulis globosis Ionge pedunculatis; involucri foliolis obtusis capitulo vix aequalibus. In Jamaica. ђ. Involucra purpureo-rubra.

4. C. ruelliaefolia Cham, et Schl. tota pilis brevibus vestita; fol. late lanceolatis acutis; stipulis 3-angularibus apice bifidis; capitulis 3-cephalis; bracteis lanceolatis. In Brasilia. t.

b. Capitula bracteis distinctis ovato-oblongis subadpressis involucrata. Calliococca Schreb.

\section{Frutescentes; capitulis peduncu- latis.}

5. C. justiciaefolia Rudge Guj. $t$. 48. glabra; ramis dependentibus nodosis; fol. ovali-lanceolatis; stipulis trunoatis bidentatis; capitulis longe pedunculatis; bracteis late lanceolatis. In Gujana. 古.

6. C. stipulacea Blume; caule snffraticoso subsimplici; fol. cuneato-ob- longis acuminalis glabris; stipulis semi-orhiculatis; capitulis brevissime pedunculatis; bracteis rotundis. In Java. 古.

\%. C. ligularis Rich. glabra; fol. petiolatis ovalibus; stipulis latis emarginatis ; pedunc. compressis solitariis ; calyce vix 5-dentato. Schradera liudge Guj. t. 88. Tratt. t. 84. In Gujana.

8. C. salicifolia $\boldsymbol{H}$. et $\boldsymbol{K}$. glahra; fol. subsessilibus lanceolatis acuminatis nitidis; stipulis subulatis hasi concretis; involucri foliolis cordatis. In Nov. Andalusia. 支.

9. C. glabra $W$. ramis teretibus, junioribus rufo-villosis; fol. ovatooblongis aculis glabris subtus in venis pubescentibus; stipulis bipartitis acutis. Tapogomea glabra Aubl. Guj. t. 63. In Gujana. ఫ̋. Cor. baccaque caerulea.

10. C. bracteocardia DC. ramis junioribus suhvelutinis; fol. ellipticooblongis utrinque acuminatis subtus in venis puhescentibus; stipulis subulatis; capitulis pubescentibus. In Bahia. 支.

11. C. ambigua DC. ramis teretibus pubescentibus, junioribus compressis; fol. elliptico-oblongis utrinque acuminatis subtus pubescentibus; bracteis subcordatis apice obtusissimis. In Brasilia. $\hbar$.

12. C. crocea Meyer; glabra; ramulis suh-4-gonis; fol. ovalibus utrinque acuminatis subtus in venis pubescentibus; stipulis linearibus geminis; bracteis 8, lincaribus. In Gujana. 古. Cor. crocea.

13. C. Humboldtiana Cham. et Schl. glahra; fol. elliptico-lanceolatis utrinque acuminatis firmis nitidis; stipulis dentiformibus; capitulo globoso; bracteis ovato-acutis. In America austr. $ち$.

14. C. dichotoma Rudge Guj. $t$. 44. glabra; ramis dichotomis; fol. breve petiolatis ovali-lanceolatis; stipulis bidentatis; bracteis suborbiculatis. In Gujana. 占.

15. C. Swartzii DC. glabra; ramulis sub-4-gonis; fol. ovato-lanceolatis acuminatis nervosis petiolatis; stipulis latis concretis demum ciliatis; bracteis concavis; paleis obtusis. C. violacea sw. In ins. Caribaeis. Cor. et bacca caerulea. 
2. Frutescentes; capitalis sessilibus.

16. C. violucer W. glahra; ramis subteretibus; fol. ovalihus acuminatis breve petiolatis; stipulis connatis apice subscariosis; capitulis globosis declinatis; paleis acutis. Tapogomea Aubl. t. 60. In Gujana. ち. Cor. et baccae violaceac.

17. C. muda Cham. et Scht. glabra; fol. elliptico-lanceolatis subacnminatis memhranaceis breve petiolatis; stipulis parvis acutis; bracteis membranaceis pellucidis. In Brasilia. $\hbar$.

15. C. muscosa su. grabra; fol. ovato-oblongis utrinque attenuatis breve petiolatis; stipulis vaginantibus bidentatis; bracteis oblongis; paleis dentatis. Morinda muscosa Jacq. am. t. 35. In Martinica et Gujana. ち.

19. C. axillaris Sw. glabra; fol. petiolatis oblongis utrinque acuminais ; stipulis ovatis concretis membranaceis obtusis; capitulis axillaribus; bracteis paleisque obtusis. In ins. Caribueis. $\hbar$.

20. C. oblonga DC. glabra; ramis dichotomis teretibus; fol. oblongis utrinque acuminatis breve petiolatis; stipulis acuminatis demum truncatis ciliatis; bracteis oblongis. In Gujana. .

21. C. prunifolia $H$. et $K$. ramis teretibus pubescentibus; fol. oblongis acutis mucronatis glabris nitidis; stipulis bidentatis; dentihus sulcatis; bracteis 4 spathulatis. Ad Orinocum. ち. Cor. caerulea.

22. C. Evea DC. glabra; ramulis 4-gonis; fol. ovali-oblongis breve petiolatis; stipulis oblongis; bracteis ovatis; floribus 4-andris. Evea gujaneusis Aubl. Guj. t. 39. C. tetrandra. W. In Gujana. ち. Cor. alba.

\section{Herbaceae.}

23. C. purpurea $\boldsymbol{W}$. caule repente adscendente superne rufo-hispido; fol. oblongis acuminatis subtus hispidis margine ciliatis; stipulis hispidis ; bracleis paleisque ciliatis. Tapogomea purpurea Aubl. t. 63. f. 3. In Gujana. 24. Cor. purpurea.

21. C. alba $W$. caule repente hirto; fol. Iate ovatis acutis petiolatis villosis; stipulis lanceolatis; capitulis termivalibus; bractcis 5 ciliatis. Ta- pogomea Aubl. t. 62. f. 4. In Guja-

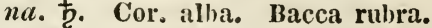

25. C. Ipecacunnha A. Rich. caule adscendente demum erecto apice subpubescente; fol. oblongo-ovatis supra scabris subtus pubesceutibus; stipulis setace-fissis; capitulis demum pendulis. Mart. med. bras. t. 1. Hilar. pl. bras. t. 6. C. emetica Pers. In Brasilia. 24. Rad, repens grisea.

26. C. rubra Ho//msegg. caule dichotomo geniculato; fol. ovatis acuminatis petiolatis glabris subtus pubescentihus; stipulis hidentatis; bracteis eapituli 6 inaequalibus. In Brasilia. 4. Fol. purpureo-venosa.

27. C. colorata Hoffinsegg. caule herlbaceo simplicissimo glabro; fol. oblongis utrinque acuminatis subtus scabritusculis; stipulis utrinque bisetosis ; capitulo peờnculato. In Brasilia. 2 .

28. C. pubescens Hoffmsegg. caule simplici herbaceo pubescente; fol. ellipticis utrinque acutis ad venas pubescentibus; capitulo pedunculato terminali; involucro polyphyllo. In Brasilia. 24.

29. C. Hoffmanseggiana $\boldsymbol{R}$. et $\boldsymbol{S}$. caule herbaceo ramoso; ramis 2-3chotonis; fol. oblongis utrinque angustatis acuminatis; capitulo terminali; involucro 4-phyllo, In Brasilia.

30. C. gemmifera $W$. fol. obovatis utrinque acuminatis glabris; capitulis globosis geminis longe pedunculatis involucratis. Patria iynota.

31. C. bidentata Thunb. fol. oblongis acuminatis; capitulis globosis terminalibus; involucris diphyllis bidentatis. In Sierra Leona.

32. C. involucrata $W$. stipulis distinctis basi glandulosis; capituli bracteis exterioribus elongatis acuminatis, interioribus 2 mucronatis. Carapichea Gujanensis Aubl. Guj. t. 68. C. Aubletii DC. In Gujana. ђ.

33. C. Patrisii; stipulis concretis apice bidentatis ; capituli bracteis ovatis acutis ; fol. ovali-acuminatis. $\mathrm{Ca}-$

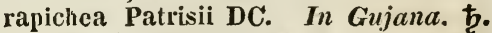

34. C. calycina Lindl. coll. $t$. 21. fruticosa; fol. subsessilibus oblongolanceolatis; stipulis ovaiis deciduis; bracteis foliaceis ovatis; paleis linearibus. Suteria calycina DC. In Brasilia. †. Frutex glaber. Cor. alba. 
35. C. sessiliflora Wh. stipulis indivisis; fol. ovalibus basi acutis ; capitulis sessilibus; floribus 4 -andris; fauce cor. nuda. Patahea coccinea Aubl. t. 45. Lam. ill. t. 65. In Gujana. $ђ$.

36. C. tenuiflora; fol. ollongis ntrinque acutis membranaceis; stipulis lanceolato-linearibus + hasi connatis; fauce cor. nuda; calyce truncato. Patabea DC. In Gujana. t.

3\%. C. cymosa Spr. fol. ovatis basi obtusis; stipulis apice hificlis; cymis pedunculatis ; floribus 5-6-andris ; cor. fauce villosa. Psychotria Maypurensis W. Patalnea alba DC. Ad Orinocum. ち. Cor. alba. Cal. violaceus.

3S. C. coriacea Cham. et Schl. fol. ovatis acutis subacuminatis basi corciato-rotundatis reticulato-venosis subtus puberulis; inflorescentia viscido-pubescente; corollis papilloso-puberulis. In Brositia.

39. C. tentis Cham. et Schl. fol. petiolatis anguste ovatis acuminatis utrinque acutis membranaceis scabriusculis; cor. vix pilosis. In $\mathrm{Br}^{\mathrm{a}}$ silia. \$.

\section{RUDGEA Salisb. (180\%).}

1. R. Zanceaefolia Salisb. trans. Linn. 8. t. 18. fol. lanceolatis acuminatis; cor. tubo lohis calycinis sedecim Iongiore. In Gujana. b.

2. R. ovalifolia Salisb. $t$. 19. fol. ovalibus breviter acuminatis; cor. tubo lobis calycinis sexies longiore. In Gujana. 市.

\section{COFFEA L. (173\%).}

\section{Coffeae verae.}

1. Calycis tubus brevissimus post anthesin non excrescens. Faux corollae saepius nuda. Coffe Raj.

\section{a. Pedunculis axillaribus; floribus 5-8-andris.}

1. C. arabica $I_{1}$, fol. ohlonga-ovatis acuminatis glabris; pedunc. axillaribus brevibus aggregatis; cor. 5-fidis; staminibus exsertis; hacca ovata. B. M. 1303. "ratt. 400, Tuss, fle ant. t. 18.
Herl. amat. t. 285. In Arabia felici, Aethiopia, Ind. or. et Amer. austr. $\hbar$. Arbor 15-20-ped. Cor. alba. Bacca cerasiformis ruhra.

2. C. Mauritiana Lam. ill. $t .160$. f. 2. fol. ovalibus utrinque acutis venoso-reticulatis; pedunc. axillaribus 1-floris solitariis brevissimis; bacca oblonga hasi acuta. C. sylvestris W. In ins. Borbonia. 市.

3. C. bengalensis Roxb. fol. ovali-oblongis utrinque acuminatis; floribus subaggregatis sessilibus; stipulis indivisis acuminatissimis; antheris inclusis. In Ind. or. et Nepalia. ђ. Cor. alba. Bacca nigra.

4. C. microcarpa $D C$. fol. elliptico-oblongis breve acuminatis ramulisque glaberrimis; floribus interrupte racemosis; fructibus ellipsoideis calycis limbo cupulato coronatis. In $A / i$. aequin. $ђ$.

5. C. laurina Smeathm. fol. oblongo-lanceolatis mucronatis basi cuneatis coriaceis glaberrimis; racemis axillaribus; cor. fauce villoso; antheris exsertis. In Sierra Leona. ち.

6. C. stipulacea DC. fol. ellipticis aut oblongis petiolatis utrinque acuminatis; stipulis foliaceis oblongis acttis longitudinaliter striatis deciduis; pedunc. longissimis. In Gujana. ђ.

\%. C. pedunculata Roxb. fol. ellipticis subsessilibus laevibus; pedunc. terminalibus axillaribusque fasciculatis 1-floris; cor. tubo gracili laevi. In Moluccis. ち.

\section{b. Pedunculis axillaribus; floribus te- trandris.}

8. C. Gujanensis Aubl. Guj. t. 57. fol. lanceolatis obtuse acuminatis glaberrimis; pedunc. axillaribus aggregatis brevissimis 1-floris; cor. 4-fidis; hacca globosa. Ixora Spr. In Gujana. $\frac{\hbar}{\text {. Bacca violacea. }}$

9. C. rosea Fl. mex. fol. ovalioblongis ntrinque acuminatis glabris; pedunc. axillaribus $\mathbf{5}$-floris; cor. 4fidis; lobis revolutis; antheris exsertis; hacca globosa. In IVexico. ち. Cor. rosea. Bacca rubescens.

10. C. tetrandra Roxb. fol. latolanceolatis acutis lucidis; stipulis bifidis; pedunc. axillaribus terminalibusque subfasciculatis longis gracilibus 1-floris; cor. 4-fidis; bacca globosa. ln Ind. or. to. 
11. C. densifiorce Blume; fol. ovali-oblongis acuminatis infri pulsescentibus; floribus confertis axillaribus; cor. 4-partilis. In sylvis Javae. th.

12. C. anyustifolia froxb. fol. Ianceolatis rigidis nitidis; paniculis axillaribus; cor. fauce barbata; antheris exsertis. In Archipelago Malaico. t.

13. C. racemosa $\mathbb{R}$. et P. t. 21t. $f$. $a$. fol. oblongo-0valibus acuminatis glabris; stipulis bifidis; floribus nutantilus $\tilde{j}$-fidis; antheris exsertis ; hacca ovali. Rudgea spr. In Peruvia. 古.

14. C. Zanyuebariae Inour. fol. ovato-lanceolatis glabris; pedunc. axillaribus 1-floris; cor. 6-7-fidis; bacca oblongo-ovata angulato-nervosa. Amajoua africana Spr. In Zanguebaria Africae. 支.

15. C. indica Poir. fol. ovato-0!)longis acuminatis glabris; stipulis brevissimis indivisis; paniculis divaricatis ; pedicellis elongatis ; fructibus parvis ohovatis. In Java. $\hbar$.

16. C. odorata Forst. fol. ovatis acutis; cymis pedunculatis corymbosis axillaribus; floribus 4-fidis. Ixora odorata spr. Chiococca odorata Hook. In ins. Tanna. $\hbar$.

\section{c. Paniculis terminalibus; floribus 4-5-andris.}

1\%. C. paniculata Aubl. Guj. t.58. fol. ovatis oblongis acuminatis nitidis; ramis 4-gonis; stipulis acutis caducis; floribus 1-fidis. Tetramerium spr. In Gujana. †. Flores albi. Bacea cacrulescens.

18. C. mozambicana DC. fol. ovato-lanceolatis tuberculato-scabris; racemis terminalibus erectis hrachiatis; pedunc. 4-gonis. C. racemosa R. et s. In ins. Mozambica. ち. Bacca parva rubra.

19. C. semiexserta Colebr. fol. oblong-lanceolatis acuminatis; corymbis terminalibus. In Ind. or. Bacca purpurea Pisi magnitudine.

20. C. jasminoiries Cham. et Schrl. fol. peliolatis ovato-ellipticis acuminatis aculis venosis; stipulis late ovatis deciduis; calyce ciliolato. In Brasilia. t. Rami juniores compressi.
2. Calycis tubus post anthesin excresceus ct haccam collo coronans denticulis tandem

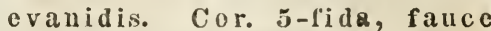
glabra. stigma bifidum. Horni i DC.

21. C. parquioides Cham. et Scht. fol. subsessilibus oblongo - ellipticis utrinque acutis glabris margine reflexo, subtus scrobiculis oblongis harbatis; germine limbo calycino cupuliformi coronato. In Brasilia. ち.

22. C. subsessilis R. et P. t. 215. f. inf. fol. glabris coriaceis sessilibus oblongo-lanceolatis acuminatis hasi excavalis; stipulis ovatis; racemis axillarihus trichotomis. C. macrophylla Dietr. In Peruvia. ち. Bacca rubra. Pedunculi 4-goni.

23. C. umbellata R. et P. t. 215. f. sup. fol. glabris coriaceis petiolatis oblongis acuminatis nervosis; stipulis subrotundis; floribus congestis umbellatis involucratis. In Andibus Peruviae. t.

21. C. acuminata R. et P. t. $21 t$. $f$. $b$. fol. petiolatis ovalibus acuminatis glabris ad axillas venarum villosis; stipulis ovatis deciduis; floribus congestis. In Permia. t. Cor. alba. Bacca ovalis rubra.

3. Faux corollae barbata. stipulae fimbriato- aut ciliato-dentatae. Pancrasia DC.

\section{a. Stipulae ciliatae.}

25. C. ciliata R. et P. t. 216. f. a. fol. oblongis acuminatis; stipulis truncatis ciliis obvallatis; racemis subpaniculatis terminalihus; floribus $\mathbf{4 - 5}$ fidis. Rudgea Spreng. In Peruvia. Bacca rubra.

26. C. foveolata $R$. et P.t. 216. $f$. $b$. fol. oblongo-ovalibus acute acuminatis ad axillas venarum foveolatis; stipulis ovatis apice ciliato-glandulosis; antheris exsertis. Psychotria Spreng. P. scrohiculata Spr. fil. In Peruvia. ち. Cor. alha extus purpurea. Bacca depressa pubra.

2\%. C. mexicana DC. fol. oblongis acuminatis subtus reticulato-venosis; stipulis cristatis; corymbis terninalibus 3-fidis; calyce truncato obtuso. Rudgea mexicana Bartl. In Mexico. t. 
2s. C. nitida R. et P. t. 217. f. a. fol. oblongis obtuse acuminatis nitidis; stipulis truncatis ciliatis; floribus sessilibus; antheris inclusis. Hudgea Spr. In Peruvia. ‡. Cor. alba. Bacca rubra.

29. C. laurifolia $\boldsymbol{H}$. et $\boldsymbol{K}$. fol. obIongis subacuminatis coriaceis nitidis; stipulis ciliato - multifidis; corymbis terminalibus; baccis ellipsoideis. C. coriacea W. Ad Orinocum. t.

30. C. verticillata R. et P. $t$. 21\%. $f$. b. fol. oblongo-lanceolatis obovatisque acuminatis; stipulis ovatis ciliatis; paniculis terminalibus; ramulis 4-no-verticillatis; antheris exsertis. Hudgea Spr. In Peruvia. †.

31. C. magnoliaefolia Cham. et Schl. fol. ovato-oblongis acuminatis acutis basi obtusis nembranaceis pellucidis supra nitidis; cor. villosissimis. In Brasilia. $\hbar$.

32. C. major Cham. et Schl. glabra; fol. ellipticis utrinque breviter acuminatis reticulato-venosis; stipulis adultis rotundatis obtusis; cor. fauce villosa. In Brasilia. $\hbar$.

33. C. minor Cham. et schl. glabra; fol. ovato-ellipticis hasi cordatis brevissime petiolatis venoso-reticulatis; panicula cymosa; stipulis setiformi-cuspidatis. In Brasilia. $\hbar$.

34. C. viburnoides Cham. et Schl. floribus paniculatis subcapitellatis ; stipulis adultis deltoideis non cuspidatis ; ramis 4-gonis; calycibus corollisque pubescenti-tomentosis ; fol. ovatis coriaceis subtus tomentosis. In

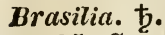

35. C. gardenioides Cham. et Schl. inflorescentia pyramidata cum calycibus pubescentibus; stipulis deltoideis ciliatis ; fol. elliptico-oblongis acuminatis margine reflexis supra lucidis scabriusculis; scrobiculis barbatis. In Brasilia. $\hbar$.

36. C. parvifolia Cham. et Schl. ramis stipulisque lanıginosis; ciliis subpectinato - ciliatis; fol. ellipticis obtusiusculis venoso-reticulatis; scrobiculis barbatis. In Brasilia. $\hbar$.

37. C. lanceolata Cham. et Schl. glabra; fol. subpetiolatis lanceolatis utrinque acutis reticulato - venosis ; scrobiculis barbatis; stipulis ovatolanceolatis acuminatis apice ciliatis; capitulo multifloro. In Brasilia. $\hbar$.

38. C. nodosa Cham. et Schl. ramis 4-gonis apice dilatatis; capitulo sessili; floribus E-andris; fol. petiolatis elliptico-lanceolatis subcoriaceis reliculato-venosis. In Brasilia. t.

\section{b. Stipulis non ciliatis indivisis bi- dentatis.}

39. C. longifolia $\boldsymbol{R}$. et P. $\boldsymbol{t}$. 218. f. a. fol. lanceolato-oblongis undulato-repandis; stipulis ovatis indivisis non ciliatis; antheris exsertis. In Peruvia. ち. Cor. alba. Bacca globosa rubra.

40. C. bidentata; R. et P. t. 218 . f. b. sub C. microcarpa; fol. lanceolatis acutis; stipulis utrinque bidentatis; cymis axillaribus terminalibusque patulis; antheris vix exsertis. In Peruvia. ђ. Cor. albida. Bacca rubicunda.

41. C. spicata H. et K. Nov. Gen. t. 286. fol. elliptico-oblongis acutis coriaceis nitidis; stipulis connatis utrinque bidentatis; cor. lobis apice calloso-cornutis. Rudgea Spr. In Nov. Granata. ђ.

42. C. oleifolia $H$. et $K$. fol. oblongis subacuminatis coriaceis nitidis; stipulis truncatis; corymbis terminalibus. Tetramerium oleaefolium Spr. Prope Santa F'́-de-Bogota. ‡.

4. Bacca basi turbinata aut acuminata. Stipulae ovatae deciduae margine ciliatae. Cor. 4-6-fida. Stigma bifidum. Straussia DC.

43. C. Luzoniensis Cham. et Schl. fol. lanceolatis utrinque acutis margine reflexis; stipulis ovato-oblongis subscariosis deciduis; cyma terminali sessili; floribus 4-6-fidis; fauce barbata. In Luzonia. ち. Rami fistulosi.

14. C. Kaduana Cham. et Schl. fol. cuneato-obovatis in axillis venarum subscrobiculatis margine reflexis; cyma pedunculata 5-radiata; cor. fauce nuda; calyce ciliato. In ins. O-Wahu. ち.

45. C. Mariana Cham. et Schl. fol. ellipticis utrinque acutis ad axillas venarum scrobiculatis; stipulis ovatis deciduis, margine ciliato; cor. 5-fida fauce barhata; calyce non ciliato. In ins. O-Wahu. $\hbar$.

46. C. Chamissonis Hook. in Beech roy. fol. elliptico-oblongis in axillis venarum scrobiculatis margine infexis 
utrinque glaberrimis; stipulis ovatis caducis ; cyma terminali ; cor. fauce nuda. In ins. Sanduicensibus, †.

\section{Chasalia.}

Cal. urceolatus integer aut 5-1obus lobis linearibus. Cor. tubo elongato. Stigmata 2 linearia. Bacca ovata 2-pyrena. Senien arcuatum lunatum c ompressum. (Psychotriae, Cof-

feae et Nonateliae spec. Sieb.)

4\%. C. capitata; fol. oppositis ovalibus obovatisque brevissime apiculatis; stipulis ovatis acuminatis petiolo longioribus; floribus spicato-capitatis. Psychotria Sieb. Chasalia DC. In ins. Iraritii. 方.

48. C. psychotrioides; fol. oppositis obovato-oblongis obtusiusculis coriaceis basi cuneatis brevissime petiolatis; stipulis ovatis obtusis; rachi ramisque paniculae compressis. Chasalia DC. In ins. Mauritii. $\hbar$.

49. C. chasalioides; fol. oppositis ohlongis obtusiusculis basi cuneatis; stipulis ovatis acutis; panicula terminali pedunculata. Coffea capitata Sieb. Chasalia coffeoides DC. In ins. Mauritii. Ђ.

50. C. Fontanesii; fol. oppositis; obovato-oblongis obtusiusculis basi attenuatis; stipulis ovalibus obtusis deciduis; panicula terminali pedunculata; rachi ramisque compressis. C. cymosa W. Chasalia Fontanesii DC. In ins. Borboniae. $\hbar$.

51. C. obovata; fol. oppositis obvatis acutiusculis basi cuneatis; stipulis vaginatis 4-fidis; lobis acuminatis ; corymbis 3-chotomis; floribus capitatis. Psychotria Sieb. Chasalia DC.

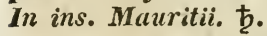

52. C. divaricata Tausch. fol. oppositis ovato - oblongis basi Ionge cuneatis; stipulis ovatis obtusis membrauaceis deciduis; panicula corymhosa; cor. laciniis rectis acutis. Chasalia DC. Musaenda lanceolata Poir. In ins. Mauritii. ఫ.

53. C. Boryana; fol. termato-verticilatis ellipticis utrinque acutis longe petiolatis; stipulis deciduis; panicula trichotoma; cor. laciniis ovatis subpatulis. Chasalia DC. In ins. Mauritii. b.
51. C. grandifolia; fol. termo verticillatis ellipticis utrinque acuminatis memhranaceis longe petiolatis; stipulis ovatis acuminatis; panicula tlyysoidea. Chasalia DC. Psychotria sieb. In ins. Mauritii. ђ. Ramuli obtusissime 3-goni.

55. C. clusiaefolia; fol. termatoverticiliatis ovato-oblongis obtusis coriaceis basi attenuatis; stipulis ovatis obtusis adpressis; pedunc. compressoangulatis dense corymbosis. Nonatelia Rchb. Chasalia DC. In ins. MIauritii. $\hbar$.

\section{CHIOCOCCA P. Brown (1756).}

1. C. racemosa Jacq. fol. ovalibus utrinque acuminatis; stipulis apiculatis; racemis multiforis; staminum filamentis puberulis. Andr. rep. 284. Tratt. 631. Hook fl. exot. 93. Dill. Elth. f. 295. C. phaenostemon Cham. et Schl. In Caribaeis et Mexico. Frutex varians. Cor. alba. Bacca nivea.

2. C. densiflora Mart. med. bras. t. 6. fol. ovatis subcordatis; stipulis basi latis apiculatis; racemis multifloris; filamentis dense harbatis. In Brasilia. . Flores albidi odorati.

3. C. anguifuga Mart. med. bras. t. 5. fol. ovatis acuminatis; stipulis latissimis brevissime cuspidatis ; racemis paniculatis. C. brachiata $\mathbf{R}$. et $\mathbf{P}$. t. 219. f. 6. C. racemosa $H$. et $\mathbf{K}$. C. parviflora et paniculata W. In Brasilia, Peruvia et ins. Cuba. ђ. Rad. insigniter diuretica.

4. C. barbata Forst. erecta; fol. ovatis utrinque subacutis; pedunc. brevibus axillaribus 1-floris; cor. fauce barbatis. In ins. Societatibus. $\frac{\hbar}{}$.

5. C. javanica Blume; caule fruticoso parasilico; fol. oblongo-lanceolatis utrinque acuminatis glabris supra velutino-nitentibus; corymbo terminali trichotomo. Coffea javanica Blume cat. In Java. ţ.

6. C. barbigera; fol. acntis; corollis intus barbatis. Descliaea leucocarpa Fl. mex. Marcharis DC. In Mexico. $\hbar$.

7. C. nudiflora; fol. mucronatis; cor. intus glabris. C. axillaris $\mathbf{E l}$. 
mex. In Mexico. †. Frutex 8-ped. Bacca ovato-globosa magnit. Pisi vulgaris.

\section{PAEDERIA L. (1767).}

\section{a. Scandantes.}

1. $\boldsymbol{p}$. foetida $\boldsymbol{L}$. fol. oblongis lanceolatisve hasi cordatis glabris; paniculis axillaribus oppositis; bracteolis minimis; antheris inclusis; bacca ovata sulicompressa. Lam. ill. t. 166. f. 1. Rumph. t. 160. Kaempf. ic. t. 9. In Ind. or. et Japonia. ち.

2. P. recurva Roxb. fol. lanceolatis acuminatis glabris; corymbis terminalibus recurvis; antheris inclusis; bacca glohosa sicca substriata. In Ind. or. ち. Bacca magnit. et colore Hibis rubiri.

3. P. tomentosa Blume; fol. cordato-ovatis acutis infra tomentosis; paniculis axillaribus et terminalibus elongatis foliosis. In Java. $\hbar$.

4. P. verticillata Blume; fol. terno-verticillatis elliptico-oblongis acnminatis glabris; paniculis axillaribus terminalibusque elongatis foliosis. In monte Salac.

\section{b. Erectae.}

5. P. erecta Roxb. erecta; fol. subsessilibus lato-lanceolatis laevibus; paniculis terminalibus erectis; staminibus breve exsertis. In Ind. or. $\hbar$.

6. P. ternata Uall. erecta; trichotonı; brevis; ramulis 3-angularibus; fol. terno-verticillatis oblougolanceolatis; corymbis trichotomis ; calycis limbo campanulato sub-5-dentato. In Ind. or. $\hbar$.

ฑ. P. Valli-Kara Jiss. scandens; ramis teretibus villoso-tomentosis; fol. late ovatis ácutis subcordatis supra pilosis subtus lannginosis; corymbis axillaribus multifloris. Rheede 7. $t$. 18. In Malabaria. $ち$.

S. P. sessiliflora Poir. adscendens; fol. lanceolatis glabris; petiolis hasi geniculatis ; racemis folio sublongrioribus brachiatis paniculatis; 0loribus subsecundis. In ins. Mauritii. $\hbar$.

9. P. brasiliana DC. fol. coldatooblongis subtus ramisque pilosis; pa- nicula terminali ramosissima hirsuta. In lbrasilia. ち.

\section{7\%. SERISSA Comm. (1789).}

1. S. foetiala Comm. Lam. ill. $t$. 151. f. 3. Lycium japonicum Thunb. jap. t. 17. B. I1. 36\%. I. foetidum 1. Buchozia coprosmoides Herit. In Japonia, Clina et Cochinchinu. t. Frutex ramis albidis. Fol. sessilia. Flor. fasciculati albi.

\section{CANTHIUM Lam. (17S3).}

1. Calycis tubo 4-5-dentato. a. Inermia pentandra.

1. C. Cornelia Cham. et Schl. ramis, pedunc., calycihus petiolisque vilIosis; fol. ovalihus basi obtusis apice acutis utrinque villosulis; cymis densis. Pavetta Rclib. In Senegalia.

2. C. subcorlatum DC. fol. ovatis subcordatis acutiusculis subtus ramulisque pubescentibus; pedunc. cymosis multifloris; fructihus subcompressis subcordatis. In Africa aey.

3. C. didymum Gaertn. $t$. 196. fruticosum; glahrum; laeve; fol. breve petiolatis ohtusis et ovalibus subtus glandulosis; fructu didymo. In Coromandelia. $\hbar$.

4. C. moluccanum Roxb. fruticosum; fol. ohlongis; corollae tubo gibbo styli longitudine; stigmate turbinato. In ins. Molaccanis. $\mathbf{b}$.

5. C. fasciculatum Bume; arboreum; fol. elliptico-lanceolatis glahris; floribus fasciculatis axillaribus. In sylvis Javae. ち.

6. C. glabrum Blume; arboreum; inerme; fol. ovato- vel elliptico-oblougis obtusis basi acutiusculis glahris; cymis axillaribus ramosis multifloris. In Java. 古.

\%. C. mite Bartl. inerme; glahrum; fol. petiolatis ovatis acuminatis sul)tus ad axillas venarum glandulosis; floribus cymosis axillaribus. In L $\boldsymbol{L}$ sonia. ち.

8. C. obovatum Rlotsch Mss. fruticosum; glabrum; fol. breve petiolatis ovalibus ovatisque obtusis basi atteunatis supra nitidissimis; cymis densc 
multifloris. In Prom. b. spei. t. 1012-ped.

9. C. pyrifolium Klotsch Mss. arhoreum; glabrum; fol. breve petiolatis ovalibus vel ovali-oblongis utrinque obtusis nervosis supra nitidissimis in axillis venarum glandulosis. In Prom. b. spei. t. Arbor 15-ped.

\section{b. Tetrandra.}

10. C. nitens DC. glabrum; fol. petiolatis late ovatis subobtusis supra nitidissimis; racemis compositis. In India orientali. 方.

\section{c. Spinosa 4-andra.}

11. C. parviflorum Lam. fruticosum ; ramulis glabris; spinis oppositis horizontalihus; fol. ovatis subpetiolatis saepe fasciculatis; floribus racemosis; haccis globosis. Roxh. Corom. t. 51. Wehera tetrandra W. Theede 7. t. 36. In Coromandelia. 支. Bacca flava.

12. C. hebecladum DC. finticosum; ramulis velutinis; spinis oppositis angulo acuto ortis; fol. obovatis glabris vix spina longioribus; pedicellis 1-1loris axillaribus. C. parviflorum Bartl. In ins. Luzon.

\section{d. Spinosa pentandra.}

13. C. Mundianum Cham. et Schl. glabriusculum ; fruticosum ; erectum; ramis oppositis spinescentibus; fol. ovato-oblongis membrauaceis ; petiolo interne pubescente. In Prom. b. spei. $\hbar$.

14. C. horridum Blume; fruticosum; erectum; spinis patentibus rectis; fol. parvis subsessilibus ovatooblongis utrinque ramulis stipulisque pubescentibus. In Java. $ち$.

15. C. parviflorum Roxb. fruticosun; spinosum; fol. ovalibus; fol. confertis axillaribus; cor. tubo globoso. Plukn. t. 133. f. 3. In Ind. or. ђ.

16. C. angustifolinm Roxb. fiuticosum ; spinosum; fol. Innceolatis lucidis hreve petiolatis; floribus axillaribus breve pedicellatis; baccis subrotundis retusis. In Ind. or. ち. Cor. et baccae flavae.

1\%. C. Rheedii DC. fruticosum; spinosum; fol. ovali-lanceolatis acuminatis brevissime petiolatis lucidis; baccis subrotundo-ovatis compressis.
Rheede 5. t. 37. In Malabaria. ち. Cor. et baccie virides.

18. C. pedunculare Cav. ic. $t .136$. fruticosum; spinosum; fol. ovatis actutis subsessilibus puberulis; pedunc. axillaribus folio longioribus. In ins. Plialippinis. 古.

19. C. lycioides A. Rich. spinis supra axillaribus simplicibus; fol. parvulis oblongo-ovalibus acuminatis pilosiusculis; stipulis latis apice abrupta longe acuminatis; floribus axillaribus solitariis. In Manilla. $\hbar$.

20. C. clinense Pers. fruticosum; spinosum; fol. obovatis; foribus sessilibus hirsutis. Gardenia spinosa Thumb. diss. t. 2. f. 4. In Clina. ち. Cor. alba.

21. C. scundens Blume; scandens; spinis divaricatis aut recurvis; fol. subpetiolatis oblongis acuminatis infra ramulisque puhescentibus; fructibus aidymis. In Java. t.

2. C.? anomocarpon DC. glabrum; ramis divaricatis demum spinescentibus; fol. ovalibus acuminatis breve petiolatis; pedicellis gracilibus elongatis saepe deflexis. In Sierra Leona.

\section{Calyx indivisus. Cor. ab- breviata.}

23. C. acuminatum; fol. ovatis vel elliptico-oblongis acuminatis subsessilibus glabris; cymis abbreviatis interfoliaceis; pedicellis 1-floris. Gynopachis Blume. In Java. ђ.

24. C. tomentosum; fol. sessilibus subcordato-oblongis acuninatis supra nitidis subtus in venis corymbisque dichotonis rufo-tomentosis. Gynopachis Blume. In Java. 方.

25. C. corymbosum; fol. subsessilibus elliptico-oblongis obtusiusculis glalıris ; corymbis trichotomis divaricatis. Gynopachis Blume. In Java. ち. 26. C.? indicum; fruticosum ; spinis oppositis; fol. alternis serratis. Rumph. \%. t. 3.? Damnacanthus indicus Gaertn. t. 182 . In Ind. or. t.

2\%. C.? Billardierii; fruticosum; glabrum; ramulis spinosis; fol. oppositis lanceolatis utrinque attenuatis parvis; floribus axillaribus solitariis deflexis; calyce 4-fido, C. 4-fidum Labill. Nov. Holl. t. 9!. Marquisia Billardierii IRich. In Nor. Holl. 
28. C.? viridiflorum; fruticosum; / verticillatis terminalibus sessililus. ramis 4 -gonis; fol. oppositis petiola- Guimp. t. 6. Dict. cal. 30. E. B. tis coriaceis acutis ; floribus axillaribus congestis. C. dubium Lindl. B. 12 . 1026. Diplospora viridiflora DC. In China. 古.

\section{PLOCAMA Ait. (1789).}

1. P. pendula Ait. Gaertn. $t .196$. Bartlingia scoparia Rcleb. Hort. $t$. 11. In Canariis. ち. Frutex habitu Asperulae tinctoriae. Fol. opposita linearia angusta subcoriacea. Flores axillares et terminales solitarii albi.

\section{S0. COLLADONIA Spr. (1825).}

1. C. tinifolia Spr. Psychotria W. Hb. In Amer. austr. $\hbar$. Frutex ramis teretibus. Fol. obovato-oblonga acuta subtus reticulato-venosa glabra. Paniculae rigidae ramis angulatis incrassatis.

\section{TRIOSTEUM Mill. (173\%).}

1. T. perfoliatum $L$. fol. oblongolanceolatis connatis ; floribus axillaribus sessilibus verticillatis. Schk. $t$. 41. Big. bot. med. t. 9. T. majus Miclix. Dill. Elth. f. 378. In Amer. bor. $\hbar$. Flores et baccac intense purpurei.

2. T. angustifolium Pohl; fol. oblongo-lanceolatis subcomnatis; pedunc. axillaribus 1-floris subgeminis. T. minus Michx. Plukn. t. 101. f. 2. In Amer. bor. 24. Flores flavi.

3. T. himalayanum Wall. pilis longis hirsutum; fol. lanceolatis acutis basi connatis; racemis terminalibus verticillifloris. In Nepalia. Baccae flavae pilosae.

1. T. hirsutum Roxb. suffruticosum; hirsutum; fol. breve petiolatis Ianceolatis integris acuminatis ; floribus axillarilus sessilibus; bracteis numerosis. In Ind. or. $\hbar$.

\section{LONICERA L. (173\%).}

1. Caprifolium DC. Baccae solitariae calyce coronatae. Caulis scandens. Flores capitato-verticillati.

1. L. Caprifolium L. fol. deciduis, sunmis counatis perfoliatis; Doribus

799. Duham. t. 48. L. pallida Host. fid sepes Luropae. t. Cor. amoene rubrae.

2. L. etrusca Santi riagg. t. 1. fol. deciduis obovatis obtusis pubescentibus, summis connato-perfoliatis acutis glabris; capitulis subternis. In Europ. austr. $\hbar$.

3. L. implexa Ait. glalserrimas fol. sempervirentibus subtus glaucescentibus, infimis oblongis distinctis, mediis subperfoliatis, summis urceolato - connatis; floribus verticillatis. B. M. 640 . B. balearica Viv. L. balearica DC. fl. fr. In ins. Balearicis et Sicilia.

4. L. cyrenaica Viv. fl. lib. $t .8$. f. 1. glaberrima; fol. ellipticis subtus glaucis, superioribus basi truncata confluentibus; floribus verticillato-capitatis. In Cyrenaicis Libyae. †.

5. L. longiflora DC. ramis glabris; fol. oblongo-lanceolatis omuibus petiolatis glabris supra lucidis; pedunc. bifloris. Caprifolium longiflorum B. R. 1232. In Nepalia. t. Cor. ochrolenca. Baccae niveae.

6. L. Periclymenum L. fol. deciduis omnibus distinctis; florum capitulis ovatis imbricatis terminalibus. E. B. 800. Fl. Dan. 908. Schk. t. 40. Hayne Arzn. t. 38. Ad sepes Europae mediae. $\hbar$. Cor. ochroleucorosea.

7. L. flava Sims B. M. 1318. glaberrima; fol. ovatis subtus glaucis margine cartilagineis, superioribus connato-perfoliatis; floribus subverticillatis; cor. lohis oblongis obtusis. Caprif. Fraseri Pursh. In Amer. bor. $\hbar$. Hlor. navi demum aurantiaci.

8. I. pubescens Sweet. br. fl. Gard. 191. fol. late ovato-ellipticis breviter petiolatis pubescentibus ciliatisque sulttus glaucis, summis perfoliato-connatis; spicis verticillato-capitatis glanduloso-pubescentibus. Caprif. Hook. exot. Fl. t. 2\%. In Amer. bor. ந.. Flores flavi.

9. L. Douglasii DC. fol. ovalibus utrinque acutis petiolatis glahris ciliatis extus tomentosis, summis connatis; floribus capitato-spicatis. $\mathrm{Ca}$ prifol. Donglasii Lindl. In Amer. bor. $\hbar$. Cor. flavescens pubescens.

10. L. parviflora Lam. glaberrima; fol. deciduis subtus glaucis, sumwis conuato-perfoliatis; floribus ver- 
ticillato-capitatis hasi gibbis; filamentis barbatis. I. media Murr. Comm. Goett. 1786. t. 3. In Amer. bor. ち. Cor. 1lavescit.

11. L. grata Ait. fol. sempervirentibus obovatis subtus glaucis glabris, summis connato-perfoliatis; floribus verticillatis terminalibus. $\mathrm{Ca}-$ prifolium gratum Pursh. Hort. angl. t. 8. In Amer. bor. Cor. flavo-rubells.

12. I. sempervirens Ait. fol. perennantibus oblongis subtus glaucis supra nitidis, summis connato-perfoliatis; spicis terminalibus subuudis. B. M. 781. et 1753. B. H. 556. In Carolina. ந. Cor. coccinea.

13. L. ciliosa Poir. fol. subanplexicaulibus sessilibus petiolatisque ovatis subtus glaucis margine conspicue ciliatis, summis connato-perfoliatis; cor. tubo hirsuto medio ventricoso. Caprifol. cilosum Pursh. Caprifol. occidentale Lindl. B. 1R. 1457. In Amer. bor. $\hbar$. Flor. lutei.

11. L. pilos $(W$. fol. ovato-oblongis cuspidato-acutis ciliatis subtus in venis pilosis, summis conuato-perfoliatis; floribus verticillato-capitatis. Caprifol. pilosum H. et K. Nov. Gen. t. 298. In Nov. Hispania. ち. Hlores purpurei.

15. I. hispidula Dougl. B. $\boldsymbol{R}$. 1761. tota hispida; pilosa; umbellis pedunculatis; staminibus exsertis; fol. petiolatis cordato-ovatis obtusis subtus glaucis; caule filiformi. In Amer. bor. ち. Flor. parvi.

2. Xylosteum DC. Pedicelli axillares apice bibracteati biflori. Baccae geminae distinctae aut concretae.

\section{a. Caulibus scandentibus.}

16. I. macrantha $D C$. ramis voIubilibus hispidis; fol. ovatis basi subcordatis apice acuminatis subtus tomentoso-hispidis ; cor. longissima. Caprifol. macranthon Don. Xylosteum scandens Hamilt. In Nepalia. ち. Fl. Alavi. Baccae atro-purpureae.

17. L. confusa $D C$. ramis volubilibus pubescentibus; fol. rotundatoovatis acutis utrinque pedunculisque velutinis; floribns thyrsoideis; calyce corollisque puhescentibus. L. japonica Andr. Lep. 583, B. K. t. 70. Herb. am. t. 132. In Japonia, China et Nepalia. ち. Cor. flava.

15. $L$. chinensis Wats. dent. brit. t. 11\%. ramis flexuoso-volubilibus, junioribus subpilosis; fol. ovatis petiolatis acutis integris subtus puberulis; pedunc. axillaribus. B. M. 3316. L. flexuosa B. Cal). 1037. B. R. 712. In China, Nepalia et Japonia. ち. Flores extus rubentes.

19. L. javanica DC. caule scandente; fol. ovato-oblongis acuminatis basi rotundatis ciliatis subtus glancotomentosis; pedunc. terminalibus corymbosis. In Java. ち.

20. L. Loureiri DC. caule scandente; fol. ovato-oblongis acuminatis hasi subcordatis utrinque pilosiusculis; pedunc. bifloris; floribus dense capitatis. Caprifol. Blume. In $\mathrm{Ja}$ va. 卢.

21. L. Lechenaultii Wall. ramis volubilibus villosis; fol. ovatis subcordatis acutis integerrimis subtus villosis; pedunc. bifloris brevissimis. In Ind. or. ち.

22. L. glabrate Wall Mss. ramis volubilibus laevibus; fol. ovatis acuminatis basi obtusis glabris; pedunc. petiolo longioribus canescentibus multifloris; pedicellis apice bifloris; cor. tubo apice incurvo. In Nepalia. $\hbar$.

23. L. acuminata Wall. ramis volubilibus laevibus; fol. ovato-cordatis subacuminatis pilosiusculis membranaceis integerrimis; pedunc. villosis bifloris; cor. infundibuliformi. In Nepalia. $\hbar$.

2t. L. diversifolia Wall. ramis volubilibus; fol. ovatis cuspidatis acutis basi subcordatis subtus villosis; calycis limbo subcampaututo; cor. basi gibba villosa. In Ind. or. $\hbar$.

25. L. ligustrina Wall. ramis subvolubilibus, junioribus pilosis; fol.ovato-lanceolatis subpetiolatis integerrimis lucidis ciliatis acutis ; calycis limbo truncato; baccis membrana communi obtectis. In Nepalia. ‡. Cor. flavo-alba.

26. L. lanceolata Wall. caule suberecto dumoso; fol. lauceolatis acuminatis pilosis basi acutis subtus glaucis ; pedunc. villosis. In Nepalia. ち. Baccae nigrae.

27. L. canescens Schousb. ramis foliisque pube brevissima canescentibus; fol. petiolatis cordato-ovatis ob- 
tusis; pedunc. bifloris. I. biflora Desf. atl. t. 52. In Mauritania et Sicilia. $\downarrow$.

\section{b. Caulibus erectis.}

28. L. tatarica L. glaberrima; caule erecto; fol. cordato-ovatis integerrimis vix acutis; baccis distinctis demum connatis. Pall. Fl. ross. t. 36. Jacq. ic. t. 37. B. H. 31. Guimp. t. 87. In Tartaria. $\hbar$. Flores rosei.

29. L. ciliata Muhl; caule erecto; fol. ovatis subcordatisve ciliatis sub)tus villosis; pedunc. bifloro; cor. basi ventricoso - calcarata. Xylosteum ciliatum Pursh. L. canadensis Spr. In Amer. bor. Ђ. Baccae rubrae.

30. L. puniced Sims B. IN. 2169. fol. subcordato-ovatis glabris integerrimis concoloribus; tubo corollae basi subgibbo. Patria ignota. ち. Flores punicei.

31. L. pyrenaica $L$. fol. obovatolanceolatis glabris integerrimis subtus graucis; pedunc. hifloris; baccis distinctis. Duham. t. 15. In Pyrenais. ఫ. Habitus fere Lonicerae nigrae.

32. L. Yylosterm $I$. pedunculis bifloris flore longioribus; haccis didymis; fol. ovalihus pulescentihus. E. B. 916. Fl. Dan. 808. Guimp. t. 9. In Europa it Cancaso. ち. Cor. alba. Baccae coccineae, albae, llavae et nigrae.

33. I. nigja L. pedunculis bifloris; baccis distinctis; fol. ellipticis integerrimis. Guimp. t. 8. Jacq. anstr. t. 314. In subalpinis Europae medice. ち. Cor. albido-rubella. Baccae nigrae.

34. I. brachypoda DC. caule ramoso apice patentim vilosissimo; fol. ovato-0blongis acutis heve petiolatis glabris; nervo puherulo; bacea globosa glabra. L. nigra Thunb. In Japonia. 古.

35. L. gibbosc $W$. fol. brevissime petiolatis ovato-oblongis acmunatis subtus pubescentibus; pedunc. bifloris ; bracleis linearibus; cor. basi gibba; baccis basi connatis. Xylosteun mexicanum H. et K. Nov. Gen. t. 297. In Mexico. ち. Cor. coccinea.

36. L. Riociniana DC. fol. petiolatis elliptico-oblongis acuminatis basi oltusis subtus pubescentibus; calycis tubo basi gibloo; baccis hasi subconnatis. In Mexico. t. Cor. flavescens post anthesin sanguinea.
3\%. L. involucrata Banks; caule denisso ; fol. oblongis obtusis basi acuminatis subtus pilosis; pedunc. incurvo-patulis; hracteis magnis ovatis foliaceis ; cor. hasi gibba. B. IR. 1179. In Amer. bor. 古.

38. L. Ledeboniri Eschlich. fol. oblongis acuminatis subtus in venis pubescentibus; bracteis 4 duabus subrotundis acutis glabris, duabus strigosopubescentibus. In Nova California. $\hbar$.

3.9. L. Pallasii Ledeb. ic. Fl. ross. t. 131. fol. ellipticis utrinque pilosis; ramulis junioribus lirsutis; filamentis longitudine corollae; baccis suhglobosis. L. altaica et caerulea Pall. ross. t. 37. In Altai. Bacca atro-violacea.

40. L. hispida Pall. fol. ovatoellipticis acutis basi cordatis setosociliatis; floribus pendulis; baccis distinctis. Ledeb. ic. Fl. ross. t. 212. In Altai. ち. 2-3-ped. Cor. flavo-viridis. Baccae purpureae.

\section{Baccae omnino in unicam umbili- catam concretae.}

41. L. Alpigena L.-pedunc. bifloris; baccis coadumato-didynis; fol. ovali-lanceolatis. Guimp. t. 10. Jacq. austr. t. 27. L. sibirica Vest. In Europae et Sibiriae subalpinis. t. Cor. fusco-rubra. Baccae rubrae punctis 2 atris.

12. L. microphylla $\boldsymbol{W}^{\text {. Hb. bac- }}$ cis subcoadumatis; fol. ellipticis vel orbiculato-ellipticis basi attenuatis vel rotundalis ntrinque subvillosis subtus glaucescentihus. Ledeh. ic. FI. ross. t. 213. In Altai. t. Cor. flavoviridis. Baccae minutae.

13. L. Webbiana Wall. fol. oblong-ovatis acuminatis basi obtusis brevissime petiolatis margine et subtus piloso-ciliatis; baccis scmicon-

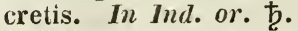

4. L. Govaniana Wall. fol. elliptiois lanceolatisve utrinque acutis membranaceis glabris; bracteis linearibus ovarii longitudine; cor. basi gribbis; baccis concretis. In Ind. or. ち.

45. L. angustifolia Wall. fol. oblongo-lanceolatis acuminatis glabris; bracteis linearibus; baccis omnibus concretis; cor. extus pubescentiluns. In Nepalia et Sirmore. t. Cor. pallida.

46. L. caerulea i. fol. ovalibus integerrimis pubescentibus; bracteis 
2 setaceis; haccis concretis in unicam globosam biumbilicatam. Jacy. austr. t. 17. B. M. 1965. In Gullia et Helvetic. ち. Bacca atro-cacrulea.

4\%. L. villosa Mulil; ramulis villosis; fol. oblongis ohovatis obtusis utrinque villosis; pedunc. hrevissimis; bracteis 2 setaceis; cor. pubescente; bacca 6-8-sperma. Xylosteum Michx. In Amer. bor. t. Cor. Ilavescens. Bacca atro-purpurea.

45. I. velutina DC. fol. venosis brevissime petiolatis ovalibus obtusis utrinque ramulisque villoso-tomentosis; bracteis setaceis; fructu globoso circa umbilicum ciliato. In Terra Nova. ђ. Bacca nigro-caerulescens.

49. L. orientalis Lam. fol. brevissime petiolatis ovato-lanceolatis acutis integerrimis glahriusculis; baccis concretis in unicam didymo-glohosam 10-spermam. L. caucasica Pall. In Iberia et Asia minore. ち. Bacca nigra.

50. L. iberica Bieb. fol. petiolatis cordatis subrotundis tomentosis integerrimis; hracteis oblongis ciliatis; haccis ad mediam concretis globosis. Xylosteum ihericum Bieb. cent. 1. t. 13. In Iberia circa Tiflin. ち. Cor. lucida.

51. I. quinquangularis Hardw. dumosa; fol. petiolatis ellipticis acutis integerrimis brevibus bifloris; baccis 5-loculariluus. In Ind. or. $\hbar$.

52. L. quadrifolia $W$. fol. quaternato - verticillatis ovato-lanceolatis glabris; pedunc. geminatis bifloris; bracteis linearihus; baccis distinctis. Patria ignota. $‡$.

\section{SYMPHORIA Pers. Pursh. (1S1t).}

1. S. racemosa Pursh; floribus interrupte racemosis; cor. intus barbata. B. 11. 2211. B. Cab. 230. S. leucocarpa Hortul. In Canada. ђ. Cor. rosea. Baccac niveae.

2. S. vulgaris; floribus in racemulos axillares subsessiles capitatoglomeratis. Lonicera Symphoricarpos L. S. glomerata Pers. Dill. Elth. f. 360. In Amer. bor. t. Cor. rosea. Baccae rubrae.

3. S. microphylla spr. floribus axillaribus solitariis; fol. subrotundoovatis obtusiusculis pubescentibus.
Symphoricarpus H. et K. Anisanthus ivilld. In Mexico. $\hbar$.

4. S. glaucescens Spr. floribus axillaribus solitariis; fol. ellipticis acutis glabriusculis subtus glaucescentihus. symphoricarpus H. et $\mathbf{K}$. In Mexico. 方.

5. S. montana spr. floribus axillaribus solitariis; fol. ovatis acutosubmucronatis glabriusculis. Symphoricarpus $\mathbf{H}$. et $\mathbf{K}$. In Mexico.

\section{MORINDA Taill. (1722).}

a. Flores 5-andri. Stigma bifidum. Baccae 2-1-pyrenae.

1. MI. citrifolia $L$. ramulis 4-gonis; fol. ovalibus utrinque attenuatis lucidis; stipulis membranaceis obtusis; baccis in massam ovatam concretis. Gaertn. t. 29. Rheede t. 52. C. $\beta$. papyracea et $\gamma$. latifolia DC. In Malabaria.

2. M. tinctoria Roxb. glahra; subarborea; fol. ohlongis subsessilibus; capitulo ovato. M. citrifolia Hunt. In hud. orient. ఫ. Cor. alba. Fructus edulis.

3. M. bracteata Roxb. glabra; arborescens; rigida; fol. oblongis nitidis breve petiolatis; stipulis latis apice semicircularibus; pedunc. solitariis bracteatis. Rumph. t. 98 . In Ind. or., ins. Molucc. et Philippinis. $\hbar$.

4. M. exserta Roxb. arborea ; ramulis 4-gonis iuterdum villosis; fol. ovalibus acutis subtus tomentosis; stipulis emarginatis; capitulis rotundis. In Bengalo. $\downarrow$. Baccae concretae 4spermae.

5. H. geminata $D C$. ramis 4-gonis puberulis; fol. obovatis ovalibusque hasi cuneatis subpetiolatis subtus pubescentibus; pedunc. geminis; stigmate antherisque ad faucem. In syliis Cambiae. 古.

6. M. multiflora Roxb. subarborea; fol. ovali-oblongis acutis margine undulatis subtus tomentosis; pedunc. compositis villosis; capitulis subglohosis. In Ind. or. ち. Bacca edulis 4-sperma.

\%. H. Mubscens Sm. ramis juniorihus tomentosis; fol. elliptico-lanceolatis utrinque acuminatis glabris; venis villosis; pedunc. pilosis; capitulo 
globoso paucifloro. In ins. Mauritii. ђ.

8. M. squarrosa Ham. finticosa; erecta; glabra; fol. ellipticis lanceolatisque undulatis; pedunc. oppositifoliis; capitulo ovato fructifero nodoso. In dumetis Ind. or. ち. Baccae lividoalbidae pulpa alba diaphana repletae.

9. M. angustifolia Roxb. fruticosa; stricta; glahra; fol. Ianceolatis sessilihus bullatis; stipulis connatis subcordatis acutis; capitulis globosis ; baccis distinctis. Roxl. corom. t. 23\%. In Ind. or. ち. Baccae caeruleo-nigrae.

10. M. persicaefolia Hamilt. suffruticosa; diffusa glabra; ramulis 4gonis; fol. ellipticis acutis brevissime petiolatis; stipulis subulatis petiolo Iongioribus; capitulis 10 -floris. In

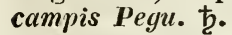

11. M. Turbacensis $\boldsymbol{H}$. et $\boldsymbol{K}$. pubescenti-lirtella; volubilis; fol. ohovato-ohlongis acutis; stipulis basi connatis acutis pubescentihus; capitulis brevissime pedunculatis; cor. extus villoso-hirta. In Nova Granata. $\hbar$.

12. N. Royoc L. glabra ; basi procumbens ; fol. lanceolatis. utrinque acuminatis petiolatis; stipulis latis brevissimis mucronatis; capitulis parvis axillaribus. Jacq. Vind. t. 16. Plum. gen. t. 25. Plukn. t. 212. In Dominyo, Cuba et Mexico. 支.

13. Ir. peduncularis $H$. et K. glabra; erecta; fol. elliptico-oblongis acuminatis nitidis; stipulis connatis abbreviatis acuminatis; capitulis axillaribus longe pedunculatis. Ad Orinocum. t. Cor. alba glabra.

14. M. retusu Lam. glabra; arborea; fol. obovatis obtusis basi attenuatis breve petiolatis supra Iucidis; stipulis connatis membranaceis; capitulis globosis. In Madagascar. $\hbar$.

15. M. palmetorum DC. fruticosa; glabra; fol. ovali-lanceolatis acuminatis hreve petiolatis; stipulis late ovatis cuspidatis membranaceo-foliaceis; capitulis solitariis globosis. In sylvis humidis Africae. $\hbar$.

16. M. stenophylla S $\mathrm{mr}$. ramis teretiusculis glabris, junioribus sub-4gonis cinereo-tomentosis; fol. elliptico-lanceolatis utrinque acuminatis petiolatis tomento brevissimo cinereis; stipulis demum reflexis. Kumph. 3. t. 98. In Ind. or. $\hbar$.
17. M. aspera $W$. et $A$. ramis junioribus compressis subpubescentibus; fol. oblongo-lanceolatis acuminatis basi attenuatis supra rugosis subtus hirsutis; stipulis late ovatis; capitulis glohosis. Wight. In Ind. or. $\hbar$.

18. M. tomentosa Heyne; ramulis angulatis glabris ; fol. subcordatoovatis acuminatis subtus cinereo-tomentosis; petiolis caualiculatis. In Incl. or. $\hbar$.

1.9. M. Mudia Hamilt. subarborea; ramulis 4-gonis tomentosis; fol. cordato-ellipticis acuminatis ntrinque tomentosis brevissime petiolatis ; stipulis saepe bifidis. In sylvis Granatae.

20. M. Chachuca Hamilt. subarborea; ramulis 6-gonis; fol. ellipticis acutis supra scabris subtus pubescentibus ad axillas costarum barbatis; stipulis semicircularibus bifidis. I sylvis Granatae. ‡.

21. M. nodosa Hamilt. subarborea; ramulis subobtusangulis; fol. oppositis glahris ellipticis acutis brevissime petiolatis; stipulis marcescentibus; capitu!is fructiferis ovoideis nodosis. In Ind. or. $\hbar$.

22. M. Coreic Hamilt. arborea; ramis obtusangulis glabris; fol. ellipticis acutis undulatis glabris brevissime petiolatis; pedunc. glabris apice bracteatis; capitulo subrotundo. In Ind. or. ち. Flores albi magni.

23. M. umbellata $L$. arborea; erecta; fol. petiolatis lanceolato-ovatis; pedunc. confertis; ramos terminantibus. In Zeylona. ち. Planta dubia.

24. M. microphylla Bartl. glabra; subscandens; ramis teretibus; fol. ovato-ohlongis acutis; stipulis triangulari-ovatis acuminatis ; capitulis quaternis ad apices ramorum umbellatis. In Luzonia. .

25. M. cochinchinensis $D C$. arborea; ramis patentibus; fol. lanceolatis hispidis; pedunculis confertis lateralibus. M. umbellata Lour. In sylvis Cochinchince. ఫ.

26. M. scandens Roxb. fruticosa; scandens; glabra; fol. ohlongo-lanceolatis utrinque acuminatis breve petiolatis; stipulis membranaceis obtusis; pedunc. umbellatis. In Ind. or. \$.

2\%. M. sarmentosa Blume; scandens; fol. oblongo-lanceolatis acuminatis glabris; pedunc. geminis ternis- 
ve; capitulis sub-4-floris. In sylvis Javae. 古.

28. MI. laxa Bartl. fol. ohlongis utrinque acuminatis memhranaceis subtus ramulisque puhescentihus; stipulis semicircularibus cuspidatis; floribus umhellatis. In Mexico. $\downarrow$.

b. Flores 1-andri. Stylus apice bifidus. Bacca 1 -pyrena loculis 1spermis.

2.9. M. tetranara Jacq. fruticosa; diffusa; glabra; fol. lanceolatis subtus in axillis nervorum ciliato-glandulosis; stipulis truncalis; pedunc. unihellatis. Hheede 7. t. 27. Cor. intus harhata.

30. M. parrifolia Bartl. fruticosa; glabra; ramis sterilibus volubilibus; fol. lineari-ohlongis cuspidatis utrinque glabris; stipulis in vaginam truncatam commatis; floribus umbellatis. In ins. Lazon. 市.

c. Flores 4-andri. Stylus clavatus indivisus. Bacca 1 -pyrena loculis 1 -spermis.

31. M.? phylliraeoides Labill. nov. Cal. t. 19. glabra; fruticosa; erecta; fol. elliptico-oblongis acutis breve petiolatis; stipulis memhranaceo-marcescentihus; capitulis paucifloris. 'In Nov. Caledonia. $\hbar$.

\section{d. Flores 5-andri. Bacca 2-locu-} laris loculis 2-spermis.

32. M. chrysorrhiza DC. fruticosa; ramosissima; ramulis glabris ohtuse 4-gonis; fol. oblongo-ellipticis subpetiolatis subtus pubescentibus; stipulis subrotundis integris ; capitulis

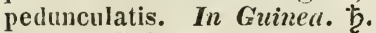

33. M.? macroplylla Desf. caule erecto; ramis quadrangulis; fol. late ellipticis acutis glahris hreviter petiolatis; stipulis hinis ovatis patentibus.

Patria ignota. ち.

31. M.jasminoides Camningh. B. M. 33.51. ramis 4-gonis sterilibus voluhilihus; fol. Ianceolatis supra nitidis in axillis foveolato-bullatis. In Nov. Holl. ţ. Cor. lutea.

\subsection{SCAEVOLA L. (176\%).}

a. Flores pedunculati axillares.

1. S. spinescens $\boldsymbol{R}$. $\boldsymbol{B r}$. fruticosa; ramis spinescentibus; fol. obovatis in- tegerrimis; laciniis cor. fimbriati. In Nor. Holl. 古.

2. S. strictı R. Br. herbacea; fol. lineari-lanceolatis suhdentatis; laciniis cor. parallelo-venosis. In Nova Hollandia.

3. S. hispirla Cav. ic. t. 510, herhacea ; hispida; fol. lineari-lanceolatis subintegerrimis; laciniis cor. avoniis. Goodenia ramosissima Sm. Nov. Holl. t. 5. In Nov. Holl.

4. S. Plumierii I'ahl; fruticosa; fol. ohovatis carnosis suhpetiolatis; calycilus truncatis; alis cor. crispi.. Lam. ill. t. 124. f. 1. Am. Mus. 18. t. 1. Catesh. car. t. 79. Rumph. 4. t. 54. Lobelia Plumierii Jacq. am. t. 179. f. 88. Scaevola Lohelia IV. In Hispaniola et ins. Bahamensibus. $\hbar$.

5. S. Toenigii Vahl; fruticosa; fol. ohovatis carnosis ulupetiolatis; bracteis margine villosis; floribus corymhosis. B. M. 2732. Cerbera salutaris Lour. Taccada Lk. s. Lohelia Herb. In Ind. or. et ins. Molucc. $\hbar$.

6. S. sericea Forst. fol. obovatis integris repandisve utrinque ramisque tomentosis mollihus; cymis corollisque extus tomentosis. In Nov. Holl. et Nov. Caled.

\%. S. Thunberyii Eclil. et Zeyh. fruticosa; glahra; fol. obovatis carnosis sulpetiolatis integerrinis; floribus cymoso-spicatis; bracteis subulatis ad hasin alho-villosis; calycibus campanulatis truncato-6-dentatis. S. Lobelia Thuuh. In Prom. b. snei. $\hbar$.

8. S. Chamissoniana Gaudich. fruticosa; erecta; glabra; fol. oblongis utringue acuminatis argute denticulatis ; axillis harbatis; floribus cymosis; cor. pubescentihus. Gaudich. in Freyc. voy. t. 82. S.? Gandichaudiana Cham. et schl. In ins. Sanduicensibus. ち.

9. S. tomentosu Gaudich. Freyc. voy. t. 81. fruticosa; erecta; fuscescenti-tomentosa pube stellulata; fol. rhombeo-ovatis ohtusis sinuato-dentatis; cor. puhescente; fructu dispermo. In Nov. Holl. ち.

10. S. montana Gaudich. fruticosa; erecta; glabra; fol. lanceolatis acutis hasi angustatis integerrimis subfalcatis; calyce urceolato obtuse õlobo; hracteolis linearibus integerrimis. In ins. Sanduicensibus. $\hbar$.

11. S. glabra Hook. in Beech. voy. fruticosa; erecta; glabra; fol. cuneatoobovatis oblique acuminatis longe pe- 
tiolatis remote glanduloso-denticulatis axillis harhatis; cor. glahra. In ins. Sunduicensibus. $\bar{b}$.

12. S. mollis Hook. l. c. fruticosa; erecta; dense puhescens; fol. oblongolanceolatis supra glahris subtus sericeo-tomentosis petiolatis glandulosodenticulatis; axillis harbatis; pedunc. divaricatis; cor. serice - tomentosa. In ins. Sanduicensibus. ந.

13. S. Mensiesiana Cleam. et Schl. fruticosa; erecta; fol. ohovatis lanceolatisve obtusis acutiusculis integerrimis antrorsum paucicrenatis serratisve subcumeatis, in axillis harbatis; calycis dentibus ciliatis; cor. extus pilosis; stylo villoso. In ins. O-W $t$ hu. ђ. Frutex ramosissimus.

\section{b. Floribus sessilibus axilla- ribus.}

14. S. attenunta R. Rr. fruticosa; pilosa; fol. lanceolatis dentatis; hracteis integerrimis; cor. extus hirsutis; stylis villosissimis. In Nova Hollandia. 市.

15. S. nitida R. IRr. fruticosa; glaberrima; fol. ellipticis argute dentatis; cor. extus glahris; marginibus stylisque villosissimis. In Nov. Hollandia. 支.

16. N. crassifolia Labill. Nov. Holl. t. 8. suffuticosa; adscendens; glaherrima; fol. subcarnosis dentatis ohovatis passim lanceolatis ranulisque saepe fucatis. In Nor. Holl. $\hbar$.

17. s. globulifera fabill. l. c. t. 79. fruticosa; glaberrina; fol. lanceolatis acutis pancidentatis amplexicanlibus; bracteis lineari-lanceolatis; fructibus 4-locularibus. In Nov. Hollandia. 支.

18. S. aemula $\boldsymbol{R}$. Br. herhacea; fol. olovatis dentatis glabriusculis bracteis lanceolatis; calyce lobato; harba styli stricta colorata indusium aequante; ovario 2 -loculari. Sc. saligna Forst. In Nov. Holl.

19. S. cuneiformis Labill. $l$. $c$. $t$. so. herbacea; pilosiuscula; fol. cuneatis dentatis; spica inferne divisa; barba styli stricta colorata indusium aequante. In Nov. Holl.

20. S. sinuata R. Br. herbacea; pubescens; fol. obovatis dentato-sinuatis; spica composita; spiculis paucifloris; bracteis ellipticis; calyce lo- hato; harha styli stricta colorata. In Nov. Holl.

21. S. humilis R. Br. herhacea; pubescens; fol. argute dentatis, infimis obovatis, superioribus lanceolatis; spica simplici; bracteis subdentatis. In Nov. Holl.

32. S. microcarpa Cav. ic. t.509. herhacea; pubescens; fol. subrotundoohovatis dentatis; spica simplici ; bracteis dentatis; tubo corollae styloque villosis. Goodenia albida sm. S. pallida R. Br. In Nor. Holl.

23. S. suaveolens R. Br. herhacea; pubescens; fol. spathulatis subcarnosis ciliatis suhstrigosis; hracteis lineari-lanceolatis; stylo barbato. Goodenia calendulacea Andr. rep. t. 22. In Nov. Holl. 2 .

21. S. caespitosa R. Br. sufinticosa; glahra; fol. lineari-lanceolatis revolutis suhintegerrimis; axillis nudis; calyce 5-loho; ovario 2-loculari. In Nov. Holl. tᄒ.

2.5. S. revoluta R. Br. fruticosa; pubescens; fol. oblongo-lanceolatis revolutis; bracteis lanceolatis; calycc ohsolete crenato; ovario biloculari. In Nor. Holl. ち.

26. S. linearis R. $\boldsymbol{B r}$. fruticosa; ramosissima; pilosa; fol. linearibua bracteisque revolutis; spica terminali; ovario 1-spermo. In Noc. Holl. t.

2\%. S. paludosa R. Br. subherbacea : ramosa; pilosa; fol. lineari-lanceolatis spicas axillares subaequantibus; ovario 1-spermo. In Nova Hollandia. 方.

28. S. angulata R. Br. suffruticosa; erecta; ramis angulatis; fol. ohIongo-lanceolatis; spica simplici; bracteis foliaceis; calyce 5 -fido. In Nou. Holl. 古.

29. S. Rillurdierii; fruticosa; fol. ohovato-oblongis coriaceis repandis glabris; cymis axillaribus pedunculatis pilosis; floribus sessilibus. S. mon:ana Lahill nov. Caled. In Nov. Culedonia. $\hbar$.

30. S. oppositifolia Roxb. fol. oppositis breviter petiolatis ellipticis integerrimis glahris; pedunc. axillarihus paucifloris. In ins. Molucc. ந. 
9S6. GUETRARDA Osbet. (175\%).

1. Calycis limbus post anthesin deciduus. Cad amba DC.

1. G. speciosu $\boldsymbol{L}$. fol. cordato-ovatis ohtusis suhtus puhescentibus; stipulis lanceolatis acuminatis deciduis; cynis pedunculatis velutinis; fructu depresso; areola superue notata. Lam. ill. t. 15\%. f. 2. Catamba Sonn. voy. t. 128. Hheede 4. t. $4 \%$ et 48 . In ins. Ind. or. B. glabrata DC. in Mexico. b. Cor. alba.

2. Calycis limbus persistens truncatus aut irregulariter subdentatus.

a. Cor. tubo sericeo, villoso aut pubescente; cirupa $\$-8$-locularis.

2. G. argentea Lam. ill. t. 15t. f. 1. fol. ovatis acuminatis glabris suhtus serice 0 -velutinis; stipulis extus villosis ovatis; cymis pedunculatis bifidis velutinis. G. speciosa Aubl. In Caljenna. 方.

3. G. havanensis $\boldsymbol{D C}$. fol. obovatis basi subacutis apice mucrouatis, supra scabris subtus pubescenti-tomentosis; stipulis acuminatis; pedunc. hirsutis; cyma 3-fida. In Cuba circa Havanam. 占.

t. G. ambigna DC. fol. cordatoovatis mucronatis scabris subtus tomentosis ; cyma bifida; fructu globoso reticulato; calyce tubuloso coronato. Brown jam. t. 20. f. 1. In Jamaica et Guadelupa. ち.

5. G. cordata H. et K. fol. cordato-ovato-ellipticis supra pilosiusculis subtus albido-tomentosis; stipulis ovatis acutis; cymis 3 -fidis; fioribus 6-meris. In Nov. Grancita. ఫ.

6. G. rugosa Su. fol. cordatoovatis mucronatis supri scahris subtus tomentosis; pedunc. compressis villosis; cyma bifida; tubo cor. villoso. In Ind. occ. ち.

\%. G. scabra Lam. ill. t. 154. f. 3. fol. obovatis mucronatis coriaceis superne scabris subtus reticulatis pubescentibus; stipulis lanceolato-acuminatis; petiolo compresso villoso. Vent. choix t. 1. Matthiola scabra L. Burm. am. t. 173. f. 2. In America. 5 .

8. G. viburnoides Cham. et Schl. fol. ovatis acutis longe petiolatis supra glabrescentibus, subtus cum ramu- lis inflorescentiaque sericeo-tonentosis; ramis expansis ; drupa globoso-depres-

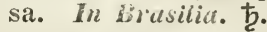

9. G. platypoda DC. fol. ovalibus mucronulatis hasi acutis breve petiolatis supra glabris, subtus canescentibus; stipulis 3 -angularibus acutis; pedunc. compressis; calyce tubuloso sub-

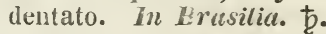

10. G. mollis DC. fol. ellipticis suhmucronatis supra pubescentihus, subtus villoso-tomentosis; cyma capitata villosa; tubo cor. villoso. G. elliptica spr. In Domingo et Hispaniola. 方.

11. G. xylosieoides $\boldsymbol{H}$. et $\boldsymbol{K}$. fol. ohlongis acutis basi rotundatis supra glabris, subtus pubescentibus in venis ramulisque hirtis; stipulis lanceolatis; cyma 3-7-flora. Dicrohotryum divaricatum W. Ad Orinocum. ţ.

18. G. parvifiore Tahl; fol. ohlongis utrinque glabris laevibus nervo medio puberulis; stipulis subulatis ninimis; ovario striato; calycis tubo obscure bifido. lxora pentandra West. In ins. Cariúaeis ể Mexico. 市.

13. G. odorata Lam. ill. t. 1.5f. f. If fol. ovalibus utrinque acutis supra glabris, subtus in nervo, petiolis ramulisque villosiusculis; stipulis subulatis; calycis tubo inaequali. Laugieria odorata Jacq. am. t. 17\%. f. 2. in Cartlagenae et Havanae fruticetis. $\frac{1}{}$.

14. G. membranacea Sw. fol. ovatis acuminatis membranaceis utrinque hispido- scabris; pube minutissima ctrva; floribus secundis 4-meris; calycis limbo subbifido truncato. In Hispuniolc. $\hbar$. Cor. albida.

15. G. elliptica $S w$. fol. ellipticis obtusis subtus ramulisque pubescentihirtis; cyma hifida; floribus 4-andris. In Jamuica. t. Flores parvi.

16. G. microphylla Bartl. fol. ovato-ohlongis supra glabriusculis subtus pubescentibus; calycis 4-fidi laciniis acutis; cor. extus sericea lobis rotundatis. In Luzonia. ち.

1\%. G. uriguensis Cham. et Schl. fol. elliptico-oblongis acuminatis subtus ramulisque cum infiorescentia subtomentosis; calycis limho brevissimo subtruncato; cor. sericea. In Brasikia. ђ. 
o. Cor. serīcea 4-fida; drupa 2-3locularis.

18. G. prostrata Bartl. fol. ovatis sell ovato-lanceolatis acuminatis utrinque villosiusculis subtus venisque sericeis; pedunc. cymoso-bifidis; ramis curvatis. In Mexico. $\hbar$.

19. G. armatc Bartl. spinis hinc inde oppositis; fol. ovatis acuminatis subtus ramulisque hirto-tomentosis; pedunc. cymoso-bifidis; cal. laciniis 4, angustis. In Mexico. ईे.

20. G. paniculata Eartl. fol. ovatis acuminatis supra glabris subtus ramulis corollisque extus sericeo-tomentosis. In Mexico. $\hbar$.

3. Calycis limbus brevis ad basinfere 5-partitus; cor. lobis sericeis margine crispis. Ulolobus DC.

21. G. crispiflora Vahl Ect. $t$. 6. fol. late ovatis acuminatis basi obtusis; nervis lateralibus inferioribus approximatis. In ins. Mont-Serrat. $\hbar$.

22. G. hirsuta Pers. fol. ovatooblongis acuminatis basi acutis; stipulis petiolo longioribus; drupis ovatis. Langieria hirsuta $\mathbf{R}$. et $\mathbf{P}$. peruv. t. 145. f. a. In Peruvia et Nov. Granata. 支.

23. G. dependens DC. fol. ovalioblongis acuminatis basi acutis; stipulis petiolo hrevioribus; drupis oblongis 3-4-locularibus. Laugieria $\mathbf{h}$. et Pav. peruv. t. 145. f. b. G. crispiflora $\beta$. Pers. In Peruvia. $\hbar$.

4. Calycis limbus truncatus aut dentatus. Cor glabra 4-5-10ba. Laugeria DC.

24. G. coriacea Pers. glaberrima'; fol. elliptico-ovatis subcoriaceis obtusiusculis; stipulis acuminatis deciduis; pedunc. compresso bifido. Laugeria coriacea Vahl. In ins. MontSerrat et Guadelupa. \$.

25. G. resinosa Pers. fol. lanceolatis utrinque attenuatis glabris subtus glaucis; stipulis in vaginam ciliatam subtruncatam concretis; ramulis cymisque resinoso-viscosis. Laugeria Vahl Eclog. t. 10. f. 6. In ins. MontSerrat et Guadelupe. $\hbar$.
26. G. Fontunesii DC. caule arborescente; fol. late ovatis acuminatis ramulisque villosis divaricatis; stipulis ovatis acutis deciduis. Patric iynota. t.

27. G. umbellata Spr. fol. oblongis utrinque glaberrimis; ramis tuherculatis compressis superne dilatatis; pedunc. aggregatis; floribus 5-andris glabris. In Brasilia. ち.

25. G. Antirhoea; fol. terno-verticillatis obovato-oblongis hasi cumeatis apice acuminatis utrinque glahris; drupis ohlongis. Antirhoea verticillata DC. Melanea verticillata Lam. ill. t. 66. f. 1. In ins. Borbonia. 卉. Drupa magnitudine seminis 'Tritici.

29. G. dioeca; fol. oppositis ternisve obovatis basi cuneatis hrevissinie acuminatis glabriusculis subtus ad axillas venarum glanduloso-pilosis; floribus dioecis. Antirhoea Bory. In ins. Mauritii. ђ.

30. G. frangulacea Sieb. fol. oppositis ovatis basi subacutis apice subacuminatis' glabriusculis; axillis eglandulosis; floribus hermaphroditis; drupis ovatis. Antirhoea DC. In ins. Manritii. 市.

\section{8\%. NONATELIA Aubl. (1775).}

1. N. racemosa Aubl. Guj. t. 72. fol. elliptico-oblongis utrinque acuninatis petiolatis; stipulis lineari-suhulatis; thyrso paniculato. Psychotria

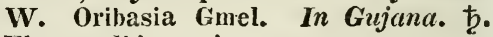
Flores albi parvi.

2. N. ponamensis DC. fol. oblongis utrinque acuminatis petiolatis; stipulis ligula connexis lineari-subulatis; thyrso terminali paniculato abbreviato. N. divaricata Barti. In Pana$m a$. 卢.

3. N. violacea Aubl. $t$. \%3. fol. ellipticis acuminatis basi in petiolum angustatis; stipulis solitariis ovatis obtusis deciduis; thyrso multifloro. Psychotria W. Oribasia Gucl. In Gujana. Ђ. Cor. alba. Bacca violacea.

4. N. officinalis Aubl. Guj. t. 70. f. 1. fol. ovatis acutis glabris; stipulis concretis in vaginam 4-dentatam; panicula corymbosa; involucro parvo 3-phyllo. Psychotria involucrata Sw. In Jamaica. $\mathbf{b}$. 
5. N. lutea Aubl. Guj. t. 75. fol. lato-ovatis acuminatis; stipulis obtusis 2-Iohis; paniculis erectis; cor. tuho praelongo; laciniis acutis. Psychotria W. In Gujana. ち. Cor. Iutea.

6. N. longiflora Aubl. t. 71. fol. lanceolatis acuminatis hasi acutis glabris; stipulis connato - vagiuantibus utrinque bilobis acutis; thyrso pariculato paucifloro; cor. tuho incurvo. Psychotria IV. In Gujana. ち. Bacca purpureo-rufescens.

\%. N. grandiflora $\boldsymbol{H}$. et $\boldsymbol{K}$. fol. elliptico-oblongis acuminatis hasi acutis glabris; stipulis connatis bifidis; corymbis pedunculatis terminalibus. $A d$ Urinocum. 卢.

8. N. macrophyllum $\boldsymbol{H}$. et $\boldsymbol{K}$. fol. ovat is acuminatis membranaceis supra glahris subtus teuuissime pubescentibus; paniculis pedunculatis. Scliwenkfeldia macrophylla spr. Ad Orinocum. Ђ.

9. N. formosa Rich. fol. ellipticis longe acuminatis abrupte petiolatis supra glabris subtus tomentoso-rugulosis; spica terminali; cor. longe tubulosa intus villosissima. In Gujana. †. Flores rosei.

10. N. divaricata A. Rich. fol. ellipticis acuminatis basi in petiolum attenuatis; floribus 5-6 aggregatis; fructu globoso 4-pyreno 4-sulcato. In Gujana. ち.

11. N. hispida Wall. fol. eblongis acuminatis basi obliquis subtus villosis; stipulis lineari-lanceolatis basi latis; floribus sessilibus axillaribus verticillatis bracteisque hispidis. In silhet. $\$$.

12. N. secundiflora Spr. Arbuscu1a; fol. obovatis apice obtusiusculis hasi cuneatis coriaceis subtus pubescentibus ; floribus spicatis allois. Hetinophyllum secundiflorum H. et Boupl. aeq. t. 25. Ad Orinocum. 占.

\section{CUVIERA DC. (1807).}

1. C. acutiflora DC. Ann. Mns. 9. t. 15. C. africana Spr. In Sierra Leona. 支. Frutex glaber. Folia ovali-oblonga acuta subsessilia. Elores pauiculati.
989. ANCYLANTHUS Desf. (181s).

1. A. rubiginosa Desf. Mém. Mus. t. t. 2. In Angola Africae. ち. Frutex ramulis villosis. Fol. elliptica reticulata. Stipulae coriaceae. Flores axillares hirsuti.

\section{VANGUERIA Juss. (1789).}

1. V. edulis Vahl; inermis; fol. ovatis membrauaceis glabris; cymis infra folia ortis. Lam. ill. t. 159. V. cymosa Gaertn. t. 193. V. Commersonii Jacq. Schoenbr. t. 44. In IIadagascar. t.

2. I. spinosa Roxb. spinis decussatis; fol. ovato-oblongis laevibus; cymis axillaribus fasciculatis. Meynia spinosa Lk. In Bengalo et Clina. $\hbar$. Bacca flava edulis.

3. V. infuusta Burch.pl. afr. austr. voy. 259. inermis; fol. tomentosis ovato-subrotundis saepe acuminatis; cymis axillaribus. In Africa. ち. Fructus non edulis.

4. V. velutina Hook. B. M. 3014. ubique velutina; fol. cordato-ovatis. In Iadagascar. . Frutex. Elores pallide virides.

\section{IICHTENSTEINIA Wendl. (1806).}

1. L. oleaefolia Wendl. Coll. $\boldsymbol{~}$. 39. Loranthus Cham, et Schl. L. speciosus Dietr. In Prom. b. spei. Rami teretes. Folia opposita oblonga sericea penninervia. Pedunc. axillares brevissimi. Cor. tumida lobis deflexis.

\section{NAUCLEA L. (1764).}

1. Calycis tubus oblongus 5partitus. Capsula sessilis basi non attenuata. Calycis lobi acuti aut nulli.

\section{a. Capsulis capituli inter se concretis.}

1. N. undulata Roxb. arborea; ramis brachiatis; fol. petiolatis ova10-oblongis undulatis nitidis; 6tipuiis longitudine petiolorum; pedunc. ter- 
minalihus solitariis. In ins. Moluccis. . Flores flavl fragrantes.

2. N. glaberrima Bartl. ramis agonis; fol. ovatis utrinque gianris planis; stipulis ovalihus petioli Iongilidine; pedunc. solitariis. In ins. Luzon. $\hbar$.

3. N. coadunata Roxb. arborescens; fol. petiolatis late ovatis cordatis ohtusis coriaceis laevihus; stipulis ohovatis; pedunc. solitariis. N. cordata Roxb. int. In Ceylona. b. Cor. flavae fragrantes.

4. N. Bartlingii IDC. ramis compresso-teretibus; fol. subsessilibus basi cordatis oblongis acutis supra nitidis subtus ramulisque puhescentibus; stipulis ovatis obtusis; fructibus subtomentosis. N. mollis Bartl. In ins. Luzon. ந.

\section{b. Capsulis capituli inter se liberis.}

5. N. macrophylla Roxb. arborea; fol. amplexicaulihus anguste ovalibus ohtusis subtus villosis; stipulis lineari-lanceolatis; pedunc. solitario recurvo. In Amboina. ち. Cor. pallide flava.

6. N. sessilifolia Roxb. arborea; fol. ohlongis sessilibus hasi subcordatis amplexicaulibusque apice rotundatis; floribus solitariis; caps. 4-valvibus. In syivis Chittagong. 古.

\%. N. ovalifolia Roxb. arborea; fol. sessilibus ovalibus ellipticis; capitulis terminalibus solitariis. $\quad$ in $/ n d$. or.

8. N. Cadamba Roxb. arborea: glabra; fol. petiolatis coriaceis ovatis hasi obtusis apice acuminatis; stipulis 3-angularibus; pedunc. solitario glohoso. N. citrifolia Poir. Ihheede 3. t. 33. In Ind. or. 古.

9. N. parvifolia Roxb. corom. $t$. 82. arhorea; wlahra; ramis brachiatis; fol. petiolatis obovatis ohtusis; stipulis ovalihus; capitulis globosis; calyce truncato. N. orientalis Gaertu. t. 30. In Ind. or. t. Cor flavo-virens.

O. N. glabra Roxb. fol. ellipticis laeviluss; stipulis linearibus; pedunc. terminalibus ternis; calycis lohis 3angularibus; stigmate globoso. In ins. Moluccis. to.

11. N. encelsce lilume; fol. ovalibus acatis hasi rotundis coriaceis gla- bris; stipulis oblongis pubescentibus; pedunc. teminalibus ternis. In $\mathrm{S} a-$ va. $\bar{b}$.

12. N. obtusa Iilume; fol. ovatooblongis obtusis coriaceis glabris subtus in axillis costarum puberulis; slipulis ohlongis ohtusis. In Java. 古.

13. N. rotundifolia Roxb. caule arboreo; fol. petiolatis rotundato-ovalibus obtusis; stipulis oblongis obtusis multinerviis; capitulis subpedunculatis. In ind. or. $ち$.

11. N. afiecana $\mathbb{W}$. subarborea; glabriuscula; fol. ovalihus acutis petiolatis; stipulis oblongis aculis; capitulis glohosis; autheris exsertis reflexis. Cephalanthus africauns hchb. Uncaria inernis W. in Ust. del. t. 3. In Guiner ad Seneglal. t. B. Insonensis. N. africana. Cham. et Schl. In Luzonia.

15. N. Cinchonae DC. fol. ovatis basi obtusis apice acutiusculis supra glabris subtus pallielis; panicula elongata; bracteis ovato-oblongis sub ramis deflexis. Cinchona globifera Pav. In Amer. austr. $ち$.

16. N. microcephala Delile; fruticosa glabra; fol. 4-no-verticillatis lanceolatis in petiolum attenuatis; stipulis in annulum 4-dentatum concretis; capitulis glohosis. In Africa. ち. Cor. minima puhescens.

1\%. N. lanceolata Elume; fol. breviter petiolatis oblongo-lanceolatis utrinque acuminatis coriaceis glabris; stipulis oblongts obtusis. Cephalanthus orientalis Blume cat. In $\mathrm{Ja}$ $v a . \dot{b}$.

18. N. granclifolia DC. fol. obovatis vel ovato-oblongis obtusis basi acutis subundulatis glabris; stipulis ovalibus; pedunc. terminalibus. N. macrophylla Blume. In Juva. $\hbar$.

19. N. corlata Blume; fol. subrotumdo-cordatis apice retusis glahris; stipulis obloneis rotuntatis basi coadunatis longiludiue petiolorum; pedunc. terminalibus solitariis. $n$ Jana. b.

20. N. orientalis Lam. ill. $t$. 153. f. 1. subarborea; glabra; fol. ovalioblongis suhpetiolatis utrinque laevihus; stipulis ohlongis; pedicellis axillaribus; capitulo globoso. Baucalus I3umph. 3. t. 55. f. 1. In Ind. or. et Java. 古.

21. N. canescens Bartl. ramis 4gonis velutinis; fol. breve petiolatis ellipticis subacuminatis subtus cane- 
sccutilus; pedunc. compressis; capitulis tomentosis. In ins. luzon. ђ.

22. Y. luzonensis; glabra; ramulis 4-gonis; fol. petiolatis cordatosubrotundis hreviter acuminatis subtus pallidioribus; perlunc. compressis medio articulatis; capilulis glohosis canescenti-tomentosis rotundifolia Bartl. In ins. Luson. t.

\section{* Calycis laciniae elongatue clavae- formes.}

23. N. cordifolia Roxb. corom. t. 5:3. arborea; fol. petiolatis cordatis subrotundis subtus villosis; stipulis ovalibus; capitulis globosis. In Coromandelia. t). Cor. flava.

2t. N. purpurea lioxb. cor. $t .54$. subarlorea; rlabra; fol. petiolatis ovali-oblongis utrinque acmunatis ; stipulis ovalibus obtusis deciduis; calycis lobis 5 clavatis. In Ind. or. 市.

2.5. N. calycina Eartl. fol. petiolatis oblongis utrinque attenuatis ; stipulis deciduis; calycis lobis 5 clava-

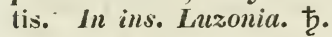

26. N. stipulosa $D C$. arborea; fol. late obovatis glabris subtus in nervis ramulisque pubescentibus; stipulis ovatis maximis foliaceis; cor. extus villosis; calyce truncato integerrimo. N. macrophylla Perr. et Lepr. In paludosis Gambiae. ț.

27. N. morinduefolia Blume; arborea; fol. ovalibus acutis basi rotundatis costatis glabris suhtus in axillis venarum depresso-glandulosis; stipulis spathulatis coloratis viscidis. In montosis Javae.

28. N. mollis Ilume; fol. ovalibus acutis basi roturdatis iuterdum subcordatis infra ramulisque villosiusculis. In montosis salac. ち.

2. Calyx tubuloso-urceolatus 5-fidus. Capsulae pedicellatae clavatae basi attenuatae. Uncaria schreb.

29. $\boldsymbol{N}$. Gambir Hunt. trans, limn. t. 22. ramis teretibus; fol. ovato-lanceolatis acutis hreve petiolatis utrinque laevilus; stipulis ovatis; pedunc. axillarihus solitariis, inferioribus in spinas uncinatas conversis. Rumph. 5. t. 34. f. 2. et 3. In Inil. or. ђ. Cor. rosea.
30. N. aciciu Hunt. ramis 4-gonis laevilus ; fol. ovatis acuminatis utrinque Iaevihus; stipulls ntrinque binis acuminatis; pedunc. axillaribus solitariis 1-cephalis post anthesin recurvis. 13 umpl. 5. t. 21. f. 1. In Ind. or. ち.

31. N. sclerophylla llunt. ramis 4-gonis pubescentibus; fol. ellipticis acutis rigidis subtus pubesceutihus; stipulis lumatis bilobis. Uncaria lioxb.

In Ind. or. $\hbar$.

3\%. N. Incaria; fol. ovalibus petiolatis utrinque laevilus acutis; pedunculis axillaribus polycephalis capsulisque villosis. Uncaria Roxb. In Ind. or. ţ.

33. N. pilosa Blume; ramulis soriceis suh-1-gonis; fol. ovatis acuminatis cordatisve utrinque pilosis brevissime petiolatis; stipulis hipartilis geminisve lanceolatis. Uncaria pilosa Hoxb. N. scandens Sm. In Chittagony et Java. t.

31. N. lanosa Poir. ferrugineo-pilosa; fol. lanceolatis ovatis acuminatis; stipulis utrinque geminis ovatis membranaceis recurvis; capsulis longe pedicellatis. N. setigera Blume. Uncaria lanosa Wall. Rumpl. 5. t. 34. f. 4. In Java et Sumatra.

3.5. N. Silhetana; ramis 4-gonis pubescentibus; fol. petiolatis late ovatis acuminatis supra lucidis suhtus villosis grosse nervosis reticulatisve; stipulis caducis; capitulis valde tomentosis. Uncaria macrophylla Wall. In silhet. $\hbar$.

36. $N$. insignis; rumulis acutis 4gonis; fol. breve petiolatis anguste cordatis subrotundo-ellipticis supra lucidis subtus reticulato-venosis; pedunculis compressis recurvis. Uncaria insignis DC. In ins. Luzon. ђ.

3\%. N. cirritiflora L. fol. ovatooblongis laevilus; stipulis bifidis; pedunc. recurvis apice floriferis. Uncaria Roxb. In ins. Moluce. ち.

38. N. glabrata IBlume; fol. ol)longo-lanceolatis acuminatis ramisque t-gonis glahris; stipulis bifidis; pedunc. solitariis supra medium articulatis demum uncinatis. Uncaria DC. In Jara. 古.

39. N. pedicellata Blume; fol. ovalihus acutiusculis hasi rotundatis cordatisve supra nitidis infra reticulatis ramulisque 4-gonis ferruginen-tomentosis; floribus louge pedicellatis. 
Cncaria Hoxb. In ins. Molucc. et Java. 古.

40. N. ferruginea Blume; fol. ovalibus actuminatis basi rotundatis supra nitidis infra reticulatis ramisque 4-gonis subferrugineo-tomentosis; stipulis hipartitis; pedunc. medio articulatis. Uncaria DC. In Jaca. ђ.

\$1. N. ferrea Biume; fol. hrevisfime petiolatis ovato-ohlongis acuminatis hasi cordato-rotundis supra puhescentihus subtus tomentosis; pedunc. medio articulatis. Uncaria DC. In saia. t.

A2. N. sessilifructus; fol. ollongis supra laevibus subtus mollibus; pedunc. axillaribus $1-3$-cephalis et terminalibus polycephalis; caps. sessilibus. Uncaria DC. In Chittagong. $\hbar$. lirulex alte scandens.

43. N. Gujonensis; ramulis 4-gonis; fol. petiolatis ovatis acutis glahris: stipulis utrinque solitariis 3 -angularibus; pedunc. infimis in spinas compressas uncinatas mutatis. Ourouparia Gujanensis Aubl. Guj. t. 68. N. aculeata Lam. ill. t. 153. f. 2. Hayne tern. t. 29. f. 5. In Gujana. $\hbar$.

11. N. tomentosa Willd. arborea; ramulis 4 -gonis glabris; fol. ovatoellipticis acutis subtus tenuissime pubescenti-tomentosis supra nitidis; stipulis late ovatis; pedunc. villosis in paniculam dispositis. Uncaria DC. In Nov. Granata. $\hbar$.

\section{WEBERA Schreb. (1789).} (Cupia R. et S. et DC. prodr.)

\section{Stigma indivisum.}

1. W. corymbosa $W$. fruticosa; fol. lanceolato-oblongis nitidis; corymbis terminalibus; cal. lobis 5 tuhun corollae aequantihus; caps. maturis 4spermis. Cupia lheede 2. t. 23. B. 13. 126. Canthium Pers. In Coromandelia et Malabaria. $\hbar$.

2. W. macrophylla Roxb. fol. late lanceolatis acuminatis; panicula terminali villosa; cor. tubo longo villoso; baccis 5-8-spermis. In ins. prince of Wales. t. Flores ampli albi.

3. W. densiftor Wall. subarborea; fol. ohlongo-lanceolatis hasi acutis; paniculis rotundatis lateralibus sul)- sessilibus densifloris; cor. fance barbata. In Pulo-Pinang.

4. W. oppositifolia hoxb. frulicosa ; fol. lanceolato-ohlongis firmis nitidis; panicula fol. opposita spicis pancis rigidis articulatis subrecurvis composita; cor. tubo ad faucem vil10so. In Clittugong. $\hbar$.

5. W. odlorota Roxb. fruticosa s. arborea; fil. lanceolatis acuminatis nitiais; corymbo terminali hracteisque pilosis; bacca loculis 3-4-ovulatis. In sillet. $\grave{b}$.

\section{Stigma bilobum.}

6. W. auriculata Wall. arborea; laevis ; fol. ovato-oblongis acuminatis subsessilibus hasi cordatis auriculis inaequalibus; paniculis brachiatis; pedunc. compressis; cor. fauce inflata obovata barbata. In collibus PuloPinang. $\hbar$.

\%. W. truncata Wall. fruticosa; volubilis; fol. ovatis acutis; panicula terminali; pedunc. compresso; cor. fauce nuda; ovario 4-ovulato. In Pinang. $\hbar$.

8. W. scandens Roxb. fruticosa; scandens ; nitida ; fol. oblongis acuminatis; cymis axillaribus; calyce subcampanulato; stigmate in lamellas 2ovales fisso. In Sillet. $\downarrow$.

9. W.? cymosa $W$. ramis pubescentibus; fol. ovatis acutis nitidis; cymis axillaribus pedunculatis multifloris; stigmate capitulato bilobo. Ihondeletia Poir. Canthium Pers. In Ind. or. $\hbar$.

10. W.? thyrsoidea Roth; ramis lignosis fusco-pubescentibus; fol. oblongo - ovatis utrinque acuminatis; thyrso densissimo terminali; cor. extus glalira intus pilosa. Canthium thyrsoideum $1 \mathrm{R}$. et $\mathbf{S}$. In Ind. or. $\hbar$.

11. W. Zeylanica; Tarenua Zeylanica Gaertn. t. 28. f. 3. In Zeytona. ち. Bacca globosa 8-striata calycis ímbo coronata. Semina semilunata cuneato-compressa. Caelera ignota.

\section{HAMELIA Jacq. (1\%62).}

a. Folia verticillata.

1. H. patens Jac\%. am. t. 50. fol. ternis ovali-oblongis utrinque acumi- 
natis villoso-pubescentibus; cymis coloratis in umbellam terminalem dispositis. sm. exot. bot. t. 24. H. coccinea Sw. Duhamelia patens Pers. In Amer. austr. et Ind. occ. ち. Cor. coccinea. Baccae nigrae.

2. H. xorullensis H. et K. fol. ternis elliptico-oblongis acuminatis basi supra glahris subtus pubescentibus; cymis 5-6-stachyis terminalibus; corollis campanulato - ventricosis. In Mexico. $\hbar$.

3. H. sphaerocarpa $\boldsymbol{R}$. et $\boldsymbol{P}$. peruv. $t$. 221. $f$. $b$. fel. ternis oblongis utrinque hirsutis; cymis coloratis in paniculam terminalem dispositis; corollis cylindraceo-5-gonis. Duhamelia splıaerocarpa Pers. In Peruvia. ち. Cor. puniceo-coccinea.

4. H. latifolia Rich. fol. tern is ovato-lanceolatis acuminatis hasi acutis utrinque glahris; cymis dichotomis paucifloris in umbellam terminalem dispositis; cor. cylindricis. In ins. Trinitatis. $\hbar$.

5. H. suaveolens $\boldsymbol{H}$. et $\boldsymbol{K}$. fol. ternis quaternisve oblongis acuminatis glabris; cymis 5-6-radiatis ramosis; floribus sessilibus; corollis tubulosis hasi ventricosis. Duhamelia odorata R. et S. Ad ripas flum. Magdalenae. †. Cor. purpurea.

6. H. ventricosa $S w$. fol. teruis glaberrimis ovali-oblongis acuminatis; racemis terninalibus; floribus pedicellatis; cor. tubuloso-campanulatis ventricosis. H. grandiflora L'Her. sert. angl. t. 7. Salisb. parad. t. 55. B. R. 1195. In Jamaica. ち. Arbor. Cor. 1lava. Bacca coccinea.

\section{b. Folia opposita.}

\%. H. chrysantha Sw. fol. oppositis ovali-oblongis cuneatis acuminatis glaherrimis; florilsus pedicellatis; corollis cylindricis. Duhamelia Pers. Browne jam. t. 14. f. 1. Plum. et Burm. amer. t. 218. f. 1. In Jamaica. 古.

8. H. lutea Rohr; fol. oppositis ovalibus acuminatis basi acutis glabris; cymis terminalibus; floribus subsessilibus; cor. brevi fauce ventricosa. H. chrysantha Jacq. ic. t. 335. In ins. St. Crucis et ad Caracas. $\hbar$. Cor. lutea.

9. H. axillaris Su. fol. oppositis ovato-lanceolatis glabris; caule suf- frutescente; floribus cymosis secundis sessilibus; corollis tubuloso-5-gonis ; bacca ovali-oblonga calycis dentibus subulatis coronata. In Jamaica et

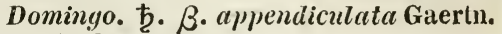
t. 91. f. 4 .

10. H. rostrata Bartl. fol. oppositis ternisque ovatis acuminatis subtus petiolis ranulisque pubescentibus; floribus cymosis pubescentibus; corollis glabris; bacca ovato - globosa rostrata. In Mexico. $\hbar$.

\section{SCHUENKFELDIA Willd. (1789).}

\section{a. Floribus pentandris.}

1. S. cinerea (Sabicea Aubl. t. 75.) fol. ovatis acutiusculis supra junioribus villosis denum glahris subtus dense albo-tomentosis; stipulis late ovatis suhacutis; florihus fasciculatis bracteatis. In Gujuna et Cayenna. 古.

2. S. hirta $S w$. fol. ovato-lanceolatis acuminatis utrinque hirsutis; stipulis cordato - ovatis membranaceis magnis; involucro 4 -phyllo. Sabicea Sw. In Amer. austr. $\hbar$.

3. S. hirsuta Spr. fol. elliptico-oblongis acuninatis supra pilosis suhtus hirsutis; stipulis subrotundo - ovatis acutis reflexis; floribus fasciculatoverticillatis sessilibuś. Sabicea villosa R. et s. Ad Orinocum.

4. S. eriantha; fol. elliptico-ohlongis acuminatis supra pilosis subtus cano-tomentosis; ramis hirsutissimis; stipulis ovatis acutis intus glabris; cor. tubo extus pilosissimo. In $\mathrm{Ba}$ hia. 卢.

5. S. triflora; caule virgato velutino; fol. hreve petiolatis oblongo-lanceolatis acuminatis subtus pallidis villosis; bracteolis ciliatis; ovario longo glabro calyce coronato. Triosteum triflorum Vahl. Sabicea DC. In Madagascar. $\hbar$.

6. S. diversifolia $\mathbf{S} m$. fol. suhtus ramulisque incanis geminis, majori lato elliptico subtus incano, minori bracteiformi; floribus sessilibus glomeratis. Sabicea DC. In Madagascar et ins. Mauritii. $\hbar$.

7. S. villosa; fol. oblongo-lanceolatis in acumen longissimum attenuatis; stipulis oblongis deciduis; bracteis nu- 
merosis. Urophyllum Jack. et Wall. In ins. Pulo-binang. t.

S. S. giabra; laevis; ramis 4-gonis; calyce suhintegro; fol. oblongolanceolatis acutis glabris; stipulis elongatis villosis. Urophyllum Jack. et Wall. In ins. Pulo-pinang. $\hbar$.

\section{b. Floribus 4-andris.}

9. S. aspera $\boldsymbol{W}$. fol. ellipticis acuminatis supra asperis subtus villosis; stipulis ovali-oblongis acutis; florihus fasciculatis sessilibus. Sabicea Aunl. cuj. t. 86. In Gujana. ち. Bacca rubra.

10. S. umbellata R. et S. jeruv. t. 200. $f$. 2. fol. ovalibus acuminatis hasi acutis utrinque puhe alpressa scahris subtus pallidis; stipulis ovatis patulis; floribus corymbosis. Sabicea Pers. In Peruvia. $ち$.

11. S. pumila; caule herbaceo wlabro; fol. ohlongo-lanceolatis glabris serice 0 -ciliatis; stipulis subulatis; capitulis pedunculatis axillaribus. Sabicea Bartl. In Peruvia. $\hbar$.

\section{BURCHELLIA R. Br. (1810).}

1. B. capensis R. Br. in Ker. B. R. $t$. 466. fol. ovatis acutis pubescentibus; stipulis latissimis hrevissimis apice cuspidatis; antheris summo tubo adnatis. Lonicera bubalina Thumb. Cephaëlis bulalina Pers. In Prom. $b$. spei. t. Flores pallide purpurei.

2. B. purviflora Lindl. IS. R. $\$ 991$. fol. ovali-lanceolatis glabriusculis; stipulis ovatis hreve cuspidatis; antheris medio tubo insertis. B. buhalina B. R. 2339. Canephora capitata Lam. ill. 1. 151. f. 2. In Prom. b. spei. bे.

99\%. STYLOCORYNA Cav. (1798).

1. S. racemosa Cav. ic. 368. fol. elliptico-oblongis basi acutis apice acuminatis glahris; paniculis axillaribus dichotomis laxis folio hreviorihus; cor. lypocrateriformi. Gaertn. t. $19 \%$. f. 3. In ins. Philippinis. $\hbar$.

2. S. fragilis blume; fol. ellipticooblongis ulrinque acutis glaliris subtus minutissime substrigosis; corymbo uerminali fastigiato densifluro; corolla hypocrateriformi. Wahlenhergia fra- grans Blumo. Ceriscus fragrans Nees. in ins. Jar a. 古.

3. S. tomentesa Ilume; ramulis, petiolis pedmenlisque dense tomentosis; fol. ovalibus acutis in venis infra pubescentibus; cymis axillaribus densifloris. In Jacu. ち.

1. S. pubescens liuli. fol. ohlongis acuminatis utrinque ramulisque pubescentibus; cyma terminali pedunculata 5-radiata. In ins. fuzon. Hanuli compresso-t-goni oppositi.

5. S. macrophigltu Eartl. fol. elliptico-oblongis it!iigue acuminatis ramulisque glahris; panicula terminali fastigiata; floribus extus pelicellisque pubescentibus. In ins. Manilla. $\hbar$.

6. S. Pandaki DC. elabra; spinis sparsis; fol. oblongis apice minute apiculatis; racemis axillaribus ahhreviatis; pedicellis fasciculatis 1-floris. Gardenia Pandaki Vahl. In Ind. or. 市.

\%. S. laxiflora Bbume; fol. oblongis utrinque acuminatis in venis infra substrigosis; corymbo terminali trichotomo divaricato laxifioro. In ins. Java. ち.

8. S. malabarica DC. spinis oppositis folio triplo hevioribus; fol. oblongo-ovatis obtusis basi cuneatis glabris subtus ad axillas glandulosopilosis; calycis limbo 5-dentato. Gardenia fragrans Roxb. corom. t. 197. Posaqueria Roxh. fl. In Coromandelia et Malabaria. ち. Flores parvi odori.

\section{GENIPA Plum. (1\%03).}

1. G. americana $\boldsymbol{L}$. fol. ohlongolanceolatis utrinque glaherrimis; pedunc. axillaribus dichotomis corymbosis. Plum. et Burm. t. 136. Gaertu. t. 190. Gardenia Genipa Sw. In Brasilia et Domingo. $\downarrow$.

2. G. Caruto H. et K. fol. obovatis obtusis supra glahris subtus pubescenti-tomentosis; pedunc. terminalihus $2-3-$ floris; pedicellis pedunculo longioribus. Ad Orinocum. t.

3. G. pubescens DC. fol. ovatis obtusis supra glahris suhtus puhcscenti-velutinis; floribus ternis brevissime pedicellatis subterminalibus. In Havana. $ち$.

4. G. oblongifolia R. et P. perun. t. $2: 20$. $f$. 4 . fol. oblongo-ovatis obtu- 
tis supra lucidis suhtus pulicscentihus maruine subrevolutis ; floribus racemosis. In Peruicu. 古.

5. G. striifiora DC. fol. ellipticis membranaceis utrinque acuminatis glabris hreve petiolatis; stipulis parvis deciduis; pedicellis 1-floris; stigmate crasso bilobo. In Brasilia. $\hbar$.

\section{Species dubiae.}

6. G. Meriana Fich. tota lirsuta; fol. oblongo-ohovatis; floribus in summitate congestis; fructu villosissino gioboso; calycis tubo coronato. Mierıal. sur. t. 43 . In Surinamo. t.

\%. G. buffalina Lour. aculeis rectis oppositis; fol. ovatis glabris fasciculatis; florihus solitariis; calyce rotunde 5-fido; hacca exsucca subrotunda. In Cochinchina. ち.

S. G. esculenta Lour. caule simplicissimo; spicis rectis oppositis; fol. ovatis glahris fasciculatis; floribus solitariis; calyce acute 5-fido; bacca carnosa subrotunda. In Cochinchina. $\hbar$.

9. G. flava Lour. aculeis paucis fparsis rectis; fol. lato-lanceolatis glabris; floribus solitariis terminalibus; cor. subpilosa. In China. . Flores lutei.

\section{GARDENIA Ellis (1759).}

\section{Inermes.}

a. Laciniis calycis decurrentibus, cor. tubo cylindraceo.

1. G. florida $\boldsymbol{L}$. inermis; fruticosa; erecta; fol. ellipticis utrinque acutis; floribus solitariis subterminalibus sessilibus hypocraterimorphis; calycis Iaciniis lanceolato-subulatis; haccis elongato - turbinatis costatis. B. $\mathbf{R}$. 449. G. jasminoides sol. phil. trans. t. 20. Pluku. t. 448. f. 4. In China. ち. Flos albus odoratus.

2. G. radicans Thunb. diss. $t$. 1. f. 1. inermis; fruticosa; caule radicante; fol. lanceolatis; floribus solitariis subterminalibus subsessilibus; calycis laciniis lineari-lanceolatıs. Andr. Kep. 491. B. R. 73. In Japonia. 古. Flos albus.

3. G. tomentosa Rlume; inermis; ramulis, foliis calycilusque velutinotomentosis; fol. obovato-cuneatis ; ca- lycis tubo angulato-costato, dentibus 10 subulatis. In ins. Jura. t.

4. G. calyculatu Ro.xh. inermis; arborea; fol. petiolatis ovatis acuminatis laevibus; floribus involucratis; calycis laciniis ensitormibus; antheris tubo inflato inclusis. In Ind. or. Hlores ampli albi fragrantes.

5. G. costatu Roxb. inermis; arhorea; fol. cuneiformi-ohlongis laevihus costatis; floribus terminalihus; calycis laciniis resiniferis caducis; bacca drupacea ovali 5-costata. In Ind. or.

6. C. carinata Wall. arhorea; incrmis; subresinosa; fol. elliptico-ovatis costatis subtus villosis; floribus terminalihus solitariis; calycis limbo truncato; cor. tubo longissimo. In Ind. or. Ђ.

\%. G. grandifora Lour. inermis; arborea; fol. lanceolatis nitidis; floribus solitariis 6-andris; calycis laciniis reflexo-falcatis; hacca ohlonga utrinque suhacuta. In Cochinchina. †. Flores albi magni.

8. G. Taitensis DC. inermis; glabra; ad apices ramorum resinosa; fol. obovatis subsessilibus; stipulis latis connatis subacuminatis; calycis tubo angulato, $I n$ ins. Taiti. $\hbar$.

9. G. Maruba Sieb. inermis; fol. oppositis ternisve ohovatis coriaceis glabris; calyce angulato 5-fido; laciniis subulatis patentibus. In Japonia. $\hbar$.

10. G. sulcata Gaertn. $t .194$. bacca obovata s. elliptica basi attenuata sulcis ohtusis angulata 1-loculari; seminihus in pulpa nidulantibus. Patria ignota.

\section{b. Calycis lacinits nondecur- reutibus.}

11. G. mutabilis Reinu: inermis; fol. cumeato-oblongis utrinque attenuatis apice obtusiusculis coriaceis glabris; calyce obsolete 5 -dentato; cor. tubo elongato. G. Reinwardtiana Blume. In arcilipelayo moluccano. $\hbar$.

12. G. latifolia Ait. inermis; arborea; fol. subsessilibus ovatis obovatisque in axillis venarum glandulosopilosis; corollis lypocrateriformibus 7-11-andris; bacca drupacea 1-locnlari 5-valvi. Roxb. corom. t. 134. G. Iatifolia Gaertu. t. 193. In Ind. or. ち. Cor. alba. Bacca lava. 
13. G. luciala Roxb. inermis; suharborea; gemmis resinosis; fol. oblongis laevihus lucidis; floribus solitariis; calycis lobis 5 suhulatis; hacca drupacea; nuculo bivalvi. G. resinosa Hoth. In Ind. or. et ins. Luzonia. †.

14. G. arborea Roxb. inermis; aiborea; fol. ovato-oblongis; floribus terminalihus subsessilihus; cor. lubo filiformi ; bacca drupacea; nuculo 4-5valvi. In lnd. or. ђ. Flores pulchri odori magni.

15. G. gummifera L. inermis ; fruticosa; gemmis resinosis; fol. ohlonyis obtuse acuminatis; floribus sessilibus solitariis; calycis laciniis ovatis acutis brevissimis. Thunb, diss. t. 2. f. 3. G. inermis Dietr. In Zeylona. 古.

16. G. clusiaefolia Jacq. Coll. app. t. 4. f. 3. inermis; fruticosa; glabra; fol. obovatis retusis subemarginatis coriaceis; pedunc. ramosis ; cor. lıypocrateriformi. Catesh. Car. t. 59. In Bahema. 占. Cor. alba.

1\%. G. tetrasperma Roxb. inermis; fruticosa; fol. ohovato-cumeatis laevibus; floribus axillaribus; calyce subulato; hacea rotunda suh-4-sperma.

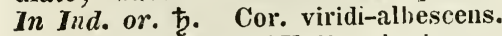

18. G. tubifera Wall. suharborea; inermis; fol. cumeato-oblongis petiolatis scahriusculis subtus pubescentibus; drupa rotunda calyce truncato coronata. In Ind. or. $\hbar$.

19. G. anisophylla Jack. arborea; inermis; fol. dense villosis ellipticis; stipulis basi concretis intus harbatis; corymbis villosis; drupa villosa ovali. In ind. or. ђ.

20. G. formosa Cham. et Schl. inermis; fol. breve petiolatis suborbiculatis brevissime acuminatis suhtus petiolis floribusque cano-tomentosis; stigmate 2-Iamellato. In Brasilia. ఫ.

\& 1. G. Sellowiana Cham. et Schl. inermis; glabra; fol. late lanceolatis breve petiolatis supra nitidis; stipulis intra petiolos commatis; cymis $3-5$ floris; calyce 5-dentato; stigmate bi-

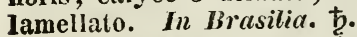

22. G. hexandra $W$. inermis; fol. obovatis suhtus pubescentibus; floribus subhexandris; corollis utrinque hirtis. In Amer. austr. $\hbar$.

23. G. Thunbergii $L$. inermis ; fruticosa; fol. ellipticis acutis glahris; floribus terminalibus solitariis sessilibus 8-andris; calyce tubnloso.
100\%. Thunbcrgia capensis Mont. act. holn. t. 11. G. verticillata Lam. G. crassicaulis Salish. par. t. 16. Bergkias Somn. it. t. 17. 18. In Prom. $b$. spei. 古.

24. G. Rothmamia I. inermis; arborea; fol. oblongis acutis glabris brevissime petiolatis subtus glanduloso-pilosis; cor. fauce campanulata. sims B. M. 690. Rothmannia capensis Thumb. act. f. 2. In Prom. $b$. spei. $\hbar$.

25. G. ternifolia Thoun. inermis; glahra; fol. ternis ohovatis hasi cuneatis subsessilibus involucello truncato brevi basi cinctis; calyce brevissime deutato. In Guinea. 古.

26. G. iriacantha DC. glabra; ramis ternis spinescentibus; fol. ternis obovatis hasi subsessilibus; calyce tubuloso semi-5-fido; lobis acutis; cor. lobis crassis ohovatis. In sylvis Gambiae. ‡. Bacca ovato-globosa.

27. G. medicinalis Vall; glahra; spinis ternis rigidis; floribus terminalibus sessilibus solitariis; calycis limho bifido laciniis 3 -fidis; cor. tuho dilatato; lobis obovatis. In Guinea. $\hbar$.

\section{Spinosae.}

28. G. Amoena Sims B. M. 1904. fruticosa; spinis axillaribus brevibus rectis; fol. ovalibus acutis glahris breve petiolatis; floribus sessilibus; cal. tubo brevidenticulato; cor. tubo longo. In Ind. or. $\hbar$. Cor. purpurea.

29. G. turgida Roxb. arborea; spinosa; fol. obovatis basi in petiolum attenuatis laevilus; floribus subsolitariis; calycis limbo tubuloso 5-dentato. In Ind. or. $\hbar$.

30. G. montana Roxb. arborea; spinis rigidis brevibus; fol. oblongis ohtusis sessilibus margine revolutis; floribus fasciculatis breve pedicellatis; cor. 5-7-fida; hacca drupacea; nucleo 5-6-valvi. In Ind. or. $\hbar$. Flor. albi odori demum flaccidi.

31. G. campanulata Roxb. fruticosa; ramulis brevibus apice spinosis; fol. lanceolatis laevibus utrinque aculminatis; florihus fasciculatis; calycis limbo campanulato brevissime 5 -dentato; cor. subcampanulata. In Ind. or. $\hbar$. Cor. pallide ochroleuca.

32. G. Blumeana DC. fruticosa; spinosa; fol. lanceolatis glabris; flo- 
ribus subsolitariis; calycis laciniis ovatis obtusiusculis; cor. sulıcampanulata. G. campanulata Blume. In Juvu. 方. 33. G. Neuberi Eclil. et 'Leyh. fruticosa; elabra; spinosa; fol. subsessilibus ovalibus acutis coriaceis supra nitidissimis; calycis dentibus margine pellucidis; cor. tuho clavato. In Prom. b. spei. ち. Bacca magnit. ovi Passeris.

species mihi non satis notac.

34. G. volubilis Low. inermis; volubilis ; fruticosa ; fol. lanceolatis acnminatis hreve petiolatis glabris; pedunc. axillaribus longis; cor. fauce dilatata; bacca subrotunda biloculari. ln China. 古.

35. G.? pubescens Roth; inermis; fol. subrotundo-ovalihus utrinque acuminatis, junioribus subtus ramulisque fusco-tomentosis; floribus corymbosis ; calyce minute $\overline{5}$-dentato. In Ind. or. $\hbar$.

36. G.? brasiliensis $5 \mathrm{pr}$. inermis; fol. oblongis coriaceis; ramulis hirsutis; pedunc. axillaribus $\mathbf{2}-\mathbf{3}$-floris ; calycis laciniis subulatis. In Brasilia. 古.

3\%. G.? densa Wull. fruticosa; rigida; ramis ramosis decussatis apice spinosis; fol. fasciculatis oboratis sessilibus laevihus; floribus solitariis sessilibus; lobis cor. lanceolato-acuninatis. In Nepalia. ђ.

38. G.? scandens Thunb. diss. 9. t. 2. f. 5. fruticosa; scandens; spinis rectis hrevissimis decussatis; fol. ovatis glabris; pedunc. axillarihus solitariis 1-floris; cor. tubo tereti. G. jasminoides hetz. In China. b.

39. G.? patula Horsf: spinis uncinatis petiolo breviorilus; fol. ovatis acutis; corymbis axillaribus. In $\mathrm{Ja}$ va.

to. G.? stipularis Rottl. fruticosa ; spinis setaceis; fol. ellipticis utrinque acutis; forihus sessilibus solitariis terminalihus; calycis laciniis obtusis. In Ind. or. $ち$.

11. G.? fugifoliu W. Hb. spinis ramulorun quaternis terminalihus; floribus solitariis; fol. subrotundis ovatis subtus pubescentibus rigidis plicato-venosis. In Amer. anstr. $ち$.

42. G.? cornifolia $D C$. fruticosa; spinosa; ramis glabrıs; fol. acuminatis subcoriaceis ramulisque pubescen- tibus; floribus corymhosis; calyce 1dentato; cor. extus villosa 4-partita. Gard. parviflora H. et K. Nov. Gen. t. 393. In Nov. Granata. t.

43. G.? microcarpa Bartl. spinis raris lorevibus rectis; fol. oblongis coriaceis supra lucidis utrinque ranulisque glaberrimis; stipulis subulatoacuminatis. In ins. Luson. ち.

44. G.? concolor; fol. breviter petiolatis ellipticis ovatisque hasi acutis apice acuminatis pellucidis glahris suhtus ad venas barlatis. Gardeniola concolor Cham. et Schl. Scepseothamuls gardenioides Cham. et Schl, vix differt. In Brasilia. $ち$.

4.5. G.? vinosa; fol. hreviter petiolatis ellipticis obtusissime acumiunlatis hasi acutis supra nitidis glahris suhtus tenuiter puberulis. scepseothamuus Cham. et s'chl. In Brusilia. t.

46. G. rotunia; fol. subsessilibus ovalihus obtusissimis hasi subcoriaceis supra nitidis glahris subtus brumeopallidis pubescentibus ad venas barhatis. Scepseothamus Cham. et sichl.

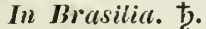

4\%. G.? Lechenaultii; fruticosa; ramulis teuuibus; fol. oblongis acuminatis basi acutis brevissime petiolatis; stipulis acutis deciduis; pedunc. axillarihus 3-4-floris. Dondisia Lechenaultii DC. In Ind. or. 5 .

48. G. jusminiflora; fruticosa; ramosissima; fol. oppositis ovali-ohlongis acuminatis; stipulis minimis acutis. Heinsia DC. In Sierra Leona. t. Flores albi.

\section{CHAPELIERA Rich. (1S2S).}

1. C. malayascariensis A. Rich. In Madayascar. $\hbar$. Frutex. Folia opposita coriacea elliptico-acuta glaberrima. stipulae integrae. Flores axillares.

\section{AXANTHES Blume (1826).}

1. A. macropliylla Blume; caule fruticoso; ramis ultimis suh- $\mathbf{t - g}$-gnis; fol. oblongis acuminatissimis hasi acutis supra nitidis subtus sericeis; capitulis axillaribus sessilibus. In Ja$v a$. t. 
2. A. tomentosa Blume; ramis geniculatis velutino-tomentosis; fol. ohlongis acuminatissimis subtus velutino-tomentosis; pedunc. confertis axillaribus. In $\operatorname{sav} \alpha$. 方.

3. A. strigesa lilume; caule arborescente; ramis ultimis geniculatis strigosis; fol. oblongis utrinque attenuatis supra glabris subtus strigosis; flor. axillaribus confertis. In Java. ђ.

4. A. arborea Blume; caule arhorescente; ramis teretilus glabris; fol. ohlongo-lanceolatis utrinque acuminatis glahris; floribus cymosis. Wallichia arinorea liwrdt. In Java. $\hbar$.

5. A. Timorensis DC. ramulis terelibus petiolisque villosis; fol. ohlongis utrinque acuminatis superne glabris subtus adpresse villosis; fioribus cymosis. In ins. 'Timor.

6. A. corymbos a Blume; caule arborescente; ramulis ultimis sul)-4-gonis puherulis; fol. glaucis oblongolanceolatis utrinque acuminatissinis supra nitidis subtus pubescentibus. In Java. \$.

\section{ALIBERTIA Rich. (1828).}

1. A. edulis Rich. Mém. Par. 5. t. 21. f. 1. Gardenia Poir. In Gujana. ち. Arbuscula. Folia opposita coriacea ohlongo-acuminata. Stipulae commatae. Flores subsessiles.

\section{HIPPOTIS R. et $P$. (1799).}

1. H. biflora R. et P. peruv. $t$. 201. In Peruria. t. Frutex villosus. Folia ovato-ohionga acuminata. Stipulae ovatae extus villosae. Flores et baccae purpurei.

\section{UCRIANA Willd. (1789).}

a. Calycis limbus brevissimus s-dentatus.

1. $\boldsymbol{U}$. longifora; caule 4-gono simplicissimo; fol. lanceolatis ohlongis utrinque acuminatis glabris; florilus subsessilibus aggregatis. Tocoyena Aubl. Guj. t. 50. U. speciosa W. Lam. ill. t. 163. f. 1. In Gujana. ந.
2. U. macrophylla; ramis 4.-gonis; fol. Late ovatis brevissime acuminatis glabris; stipulis subroturdis coriaceis; floribus racemosis. U. insignis W. Tocoyena $H$. et $K$. G. insignis $R$. et s. Ad finm. Magdalende. $\hbar$.

3. U. Congifolia $\mathbf{S} p r$ ramis teretihus; fol. ovato-oblongis acutis glabris nitidis margine revolutis; stipulis ovatis acuminatis; floribus racemosis. U. Humboldtii Sur. Tocoyena H. et K. In Nov. Granata. ち.

4. U. Mutisii Spr. ramis teretibus; fol. oblongis acutiusculis glabris nitidis margine subrevolutis; stipulis ovatis acuminatis; floribus corymbosis. Tocoyena H. et K. In Nov. Granata. 市.

5. T. hirsuta; fol. ellipticis breve cuspidatis superne puhescenti-villosis subtus velutino - hirsutis. Tocoyeua Moricand Hb. In Brasilia. ち.

b. Calycis limbus profunde 5partitus. Menestoria DC.

6. U. Wallichii; fol. ohovatis ohtusis basi cuneatis subsessilibus supra glahris subtus pallidis secus nervos adpresse villosis. Mencstoria Tocoyenae DC. In Repalia. $\mathbf{b}$.

\%. U. Hamelliae; fol. ovalibus utrinque acuminatis longe petiolatis subtus puberulo-scabris. Menestoria Hamclliae DC. In Nepalia. ち. Ranuti compressi.

8. U. Mussaendae; fol. ovatis acutis breve petiolatis subtus pallidis utrinque puberulis; petiolo, stipulis nervoque medio rufo-hirsutis. Menestoria DC. In Nepalia. 市.

9. $U$. rigida; fol. cuneatis retusis mucronulatis glabris; stipulis ovatis acutis. Menestoria DC. Gardenia rigida Don. In Nepalia. ‡. Frutex depressus ramosissimus.

\section{SOLENA Willd. (1\%98).}

a. Stamina fauco corollae exserta ina equalia.

1. S. longiflora $W$. fol. oblongoacuminatis hasi acutis; stipulis ohlongis; cor. tubo incurvo apice nutante. Posoqueria Aubl. Guj. t. 51. Lam. ill. t. 165. In Gujana. ђ. Cor. tubus 
1-ped. Baccac flavae magn. ovi gallinacei.

2. S. latifolin IRudge Guj. t. 40. fol. ovatis acuminatis hasi obtusis aut ohcordatis; stipulis Jatis :-angularihus; cor. tubo erecto limbo irregulari. Tocoyena Lan. ill. t. 163. f. 1. Posoqueria Jatifolia 12 . et s. In Gujana. 古.

3. S. decora; fol. ovatis breve cuspidatis hasi obtusis subcordatis; stipulis ovalilus magnis coriaceo-foliaceis; cor. tuho recto. Posoqueria decora DC. In Gujana. ち. Flores corymbosi.

4. S. Trinitatis; fol. ovatis breve cuspidatis hasi obtusis subcordatis; stipulis oblongis subobtusis membranaceo-foliaccis subvaginantibus. Posoqueria DC. In ins. Trinilatis. $\hbar$.

5. S. har anensis; fol. ovalibus acutis membranaceis hasi subobtusis; stipulis lanceolatis acutis; cor. tubo recto. Posoqueria DC. In C'nba. 古.

6. S. arracilis Rudge Guj. t. $\$ 1$. fol. ovali-ianceolatis; stipulis ohlongis; calyce acute 5-dentato; cor. tuho curvo limho irregulari. Josoque-

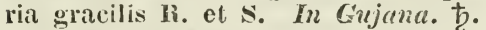

\%. S. revoluta; fol. elliptico-ovatis hreve cuspidatis margine revolutis; stipulis deciduis; cor. tubo recto fauce villosa. Posoqueria revoluta Nees. P. insignis Neuw. In Brasilia. ఫৃ.

b. Antherae sessiles intra faucem inclusae. Randia DC. Flores albi.

\section{* Frutices spinosi.}

a. Fbores axillares solitarii brevi-perlicellati.

8. S. Randia; ramulis glabris; fol. obovatis glaherrimis subsessilibus basi cuneatis; floribus axillarihus sessilibus; cor. fance pilosa. Landia latifolia Lam. ill. t. 156. f. 1. Gardenia aculeata Ait. O. Randia Sw. Sloane jam. t. 8. f. 1. hist. t. 2. f. 4. B. mitis. Handia mitis L. Gardenia Handia B. M. 1811. Sloane t. 161. f. 1. In ins. Caribaeis et in Mexico. †.

9. S. obovata; ramulis tomentosohirtis; fol. ohovatis glahris; spinis rectis patulis; foribus solitariis; cor. fance sericea. Randia obovata H. et K. In Nov. Granata. b.
10. S. pubescens (R. et P. perur. t. 120. f. b.) fol. ohovatis acutis muhescentibus; spinis oppositis axillarihus; florihus solitariis sessilibus hasi bracteis adpressis cinclis. handia ohovata R. et s. Gardenia obovata Dietr. In Peruvia. t.

11. S. rotundifolia; spinis ramisque subverticillatis; fol. subrotundis ovatisque utrinque pubescentibus rugosis; florihus solitariis sessilihus; cor. calyce duplo longiore. Lavidia rotundifolia I. et P. Giardenia Dietr. In Pernvia. 方. Bacca lutescens.

12. S. eclinocurpa; spinis verticillatis quaternis patulis; fol. ovatis acuminatis subvillosis ad apices ramortum confertis; floribus solitaris; fructu globoso echinato, Randia ecirinocarpa fl. mexic. ined. In Mexico. $\hbar$.

13. S. dumetorum; spinis opporitis; fol. ovalibus ohtusiusculis lasi cuneatis glabris; floribus sessilihus solitaris; cor. villesa. Ilandia dumetorum Lam. ill. t. 156. f. 4. h. spinosa Blume. Posogueria dumetorim lioxb. Gardenia spinosa Thunh. diss. 7. t. 2. f. 4. Ceriscus malabaricus Gaertn. t. 28. In Ind. or. ち. Bacca flavescens.

11. F. uliginosa; spinis subterminalibus oppositis; ramis 4-gonis; fol. o!longis subcuneatis glabris; floribus solitariis sessilibus; calycis tubo subintegerrimo fauce villosa. Gardenia uliginosa Retz. Koxb. corom. t. 153. In Coromandelia. $\hbar$.

15. S. longispina; spinis oppositis alterne horizontalibus; ramis longis patulo-dependentibus; fol. obovatocumeatis laevibus; calycis lobis ovato-acutis: cor. extus villosa. Randia DC. Posoqueria longispina lioxb. In Coromandelia. $\hbar$.

16. S. nutans; spinis oppositis patulis; ramis longe dependentibus; fol. anguste obovato-oblongis; florihus axillaribus; cor. extus sericea. Randia DC. Posoqueria nutans Roxb. In Ind. or. t. Hlores odori.

3. Flores in axillis aut ad apices ramorum fasciculatis racemosisve.

1\%. S. calycina; ramulis brachiatis apice 4-spinosis; fol. ohovatis hasi cuncatis apice acuminatis acutis membranaceis subtus pubescentibus. Ran- 
dia calycina Cham. et Schl. In Brasilia. 市. Frutex.

15. S. parviflora; spicis oppositis brevissimis; fol. ovatis petiolatis glahris; racemis villosis; florihus axillaribus subfasciculatis hreve petiolatis; calycis limho 5 -dentato. Gardenia somnerati Spr. Landia parviflora Lam. In Ind. or: ち.

19. S. floribunda; spinis axillaribus rigidis; fol. oppositis fasciculatisve ohovatis cuneatis laevibus; lohis calycis lanceolatis; cor. extus sericea. Randia floribunda DC. Posoqueria Roxb. In Coromandelia. ち. Flores demum flavi.

20. S. multiflora; arborea; spinis oppositis recurvis; fol. lanceolatooblongis laevibus; calycis lobis semilunaribus; cor. tubo longo gracili. Fandia Iongiflora Lam. ill. t. 156. f.3. Posoqueria lougiflora hoxb. Gardenia

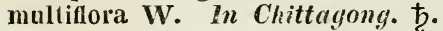

21. S. fusciculata; spinis axillaribus patentibus; fol. ovato-oblongis suhsessilibus laevihus; florum fasciculis subsessilibus in ramorum dichotomia; calycis dentibus subulatis. Posoqueria fasciculata Roxb. In Silhet. $t$.

22. S. rigida; spinis oppositis supra medium nodoso-cicatrisatis; ramis 4-gonis calycibusque villosis; fol. ovatis; hacca pubescente. Posoqueria rigida lioxb. In Nepalia. ち. Bacca purpurea.

23. S. stricta; ramis rigidis decussatis; fol. oblongis acutis breve petiolatis; tubo corollae hrevi intus piloso; bacca globosa. Macrocnemum strictum IV. Hi). Rondeletia stricta Roth. Randia stricta Roxb. In Bengalo. 卢.

24. S. scandens; caule scandente aculeato; aculeis recurvis; fol. ovalilus acuminatis coriaceis glahris; pedunc. 3-floris ; tubo cor. brevi; calyce truncato. Tocoyena scandens Blume. In Sava. b.

25. S. tetrandra; spinis sparsis rectis; fol. ovatis acuminatis hasi angustatis subcoriaceis ramulisque pubescentibus; stipulis ovatis acuminatis; floribus 4-andris; cor. extus pilososericea. Randia DC. Gardenia parviflora H. et K. Nov. Gen. t. 293. In Nova Granata. ち.

26. S. armata; spinis quaternis patulis; fol. ovatis utrinque acutis; floribus brevi-pedicellatis; calycis 10- his lincari-cuneiformibus; tubo cor. Iongo cylindrico glabro. Mussaenda spinosa L. Jacq. am. t. 49). Gardenia armata Sw. G. tetracantha Lam. In sylvis Carthagenae, Nartinicae et Lucice. $\hbar$.

27. S. ferox; spinis decussatis patentibus acutis; fol. ovatis ovalibusque superne glabris subtus puhescer:tihus; stipulis pellucidis; floribus cymoso-fasciculatis; calycis tubo turbinato. Randia ferox DC. Gardenia ferox Chan. et Schl. In Brasilia. $\hbar$.

28. S. capritata; spicis ad apices ramorum quaternis rigidis; fol. ovatis acutis utrinque ramulisque hirsutis; floribus capitatis; cor. extus villosa. Fandia capitata DC. In Hexico.

29. S. tetracantha; ramis oppositis horizontalibus 4-spinosis; fol. lanceolatis acuminatis tomentosis; calycis limbo tubuloso; cor. tubo longo villoso. Nussaenda tetracantha Cav. ic. t. 435. Gardenia armata Bartl.

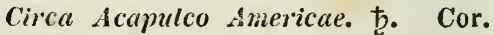
flava.

30. S. Humboldtiana; ramis teretiusculis glahris apice bispinosis; fol. ellipticis brevissine acuminatis pubescentibus nembranaceis; cor. pubescentibus. Mussaenda pubescens H. et K. Gardenia Humboldtiana $\mathbf{H}$. et $\mathbf{S}$. G. pubescens Bartl. Prope Guayaquil. ந.

31. . nitida; ramulis apice bispinosis subangulatis; fol. ovato-ellipticis acutis glabris nitidis; floribus terminalihus geminis; corollis glabris. Mussaenda nitida $\mathbf{H}$. et $\mathbf{K}$. In Nov Granata. ち.

32. S. triflora; spinis oppositis suhulatis; piliolis ramulisque hirsutis; stipulis ovatis cuspidatis; pedunc. axillaribus 3-floris; calycibus campanulatis. Handia Don. In Nepulia. t.

33. S. horrida; ramis reclinatis; ramulis decussatis; spinis oppositis corniformibus; fol. ovato-lanceolatis glahris; racemis 3-chotomis. Randia horrida $\mathbf{R}$. et $\mathbf{S}$. Oxyceros horricla Lour. In Cochinclina. ち. Bacca nigra.

34. S. sinensis; spinis breviluns subobliquis; fol. lanceolatis nervosis glabris; racemis brevibus terminalibus. Randia chinensis spr. Oxyceros sinensis Lour. In China. 


\section{* Frutices inermes.}

35. S. Bourieana; fruticosa; glabra; fol. hreve petiolatis obovato-oblongis acuminatis subtus in venis obsolete puhescentibus. Randia Bowieana Hook. 13. M. 3109. In Erasilia. ந். Cor. albo-lutescens.

36. S. maculata; ramulis pubescentibus; fol. ovalibus laevibus ad axillas nervorum subtus glandulosis; cor. tubo longissimo apice dilatato. Rothmannia longitlora salisb. par. t. 65. In Guinea. tூ.

3\%. S. speciosa; glahra; fol. elliptico-oblongis superne lucidis; floribus in axilla ultima solitariis; cor. tuho longissimo extus adpresse pubescente; lohis acuminatissimis. Randia DC. In Cayenna. †.

35. S. FInssaendae; fol. ovatis lanceolatisve acutis subtus in venis puhescentihus; florihus solitariis sessilibus; calycis laciniis subulatis; cor. extus villosa; lolis acuminatis. Mussacuda formosa Jacq. am. t. 48. Gardenia maritima Váhl. G. Mussaendae Tinunl. In Amer. austr.

39. S. Ruiziana; fol. lanceolatis acutis breve petiolatis supra glabris subtus sublirsutis; floribus solitariis sessilibus; calycis hirsuti laciniis subulatis; cor. extus hirsuta tubo longissimo. Gardenia longiflora R. et P. peruv. t. 219. In Peruviu. ђ.

40. S. macrantha; fol. ovali-ohlongis acuminatis subciliatis; floribus terminali!)us sessilibus; calycis laciniis suhulatis patentibus; tubo cor. apice dilatato; lobis revolutis. Randia Iongifora Salish. parad. t. 93. Gardenia longiflora Ait. G. macrantha 13. et s. In Sierra Leona. $\hbar$.

11. S. longistyla; fol. ovalious superne villosis subtas petiolisque villoso-tomentosis; stipulis ovatis scariosis deciduis; floribus fasciculatocorymbosis; calycis lobis usque ad basin partitis erectis lanceolatis ciliatis. Randia DC. In Ǵcimbia. ち.

42. S. madagascariensis; fol. ovatis acutis breve petiolatis glabris coriaceis; floribus axillarilus basi hibracteatis; cor. Iobis oblongis obtusis extus cum tuho velutinis. Gardenia madagascariensis Lam. In Madayascur. 古.

43. S. genipcteflora; fol. ovalioblongis utrinque acuminatis breve petiolatis coriaceis glahris; stipulis lanceolatis; pedunc. axillaribus brevissinis; cor. tubo cylindraceo. Randia DC. In Sierra Leona. $ђ$.

11. S. 'Talanfiana; fol. ovall-oblongis hasi acutis apice obtusis coriaceis glahris; stipulis hrevilus indivisis; floribus axillaribus solitariis rolio paulo hrevioribus; cor. Iobis velutino-

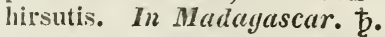

\section{OXYANTIIUS DC. (1508).}

1. O. speciosus DC. B. M. 1992.

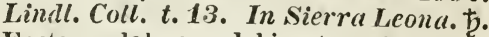
Frutex glaher vel hirsuto-pubescens; fol. ellipticis acuminatis; florilus racemosis; calycis dentibus acutis s. acuminatissimis.

\section{0\%. BERTLERA Aubl. (1975).}

1. Fructus dentibus calycinis erecto-conniventibus subulatis coronatis.

1. B. Gujanensis Aubl. guj. t. 69. fol. ovali-oblongis acutis nervis villosis; stipulis utrinque indivisis acuminatis ; florihus racemoso-thyrsoideis. Lam. ill. t. 165. In Gujana et Cayenna. ち. Rami villosi.

2. B. mucronata Gaertn. $t$. 192. f. \%. fol. ...; flor. ...; fructibus striatis; calycinis dentibus erecto-conniventibus coronatis secus paniculae ramos pedicellatis. Patria ignota. $\hbar$.

3. B. painstris A. Rich. fol. eIliptico-oblongis acutis hirsutis vervis approxinatis; stipulis utrinque bifulis; floribus subcymosis; fructibus non striatis hirsutis. In Gujana. t. Suffritex ferrugineus.

2. Fructus deutibus calycinis patentibus a terectis non conniventibus coronatis.

4. B. berbonica A. Rich. glabritscula; fol. lanceolato-ellipticis acuminatis petiolatis; stipulis indivisis setaceo-acuminatis; racemo thyrsoideo; dentibus calycis acutis. In ins. Borboniae. 市.

5. B. rufa A. Rich. fol. ellipticis acutis brevissime petiolatis rufo-sericcis; stipulis lobis connatis acutis intus scriceis; racemo elougato; pedicellis sericeis; futctu villoso. In ins. Borboniae. 市.

6. B. Zaluzania Gaertn. t. 192. 
glabriuscula; fol. subcoriaceis lanceolato-ellipticis breve petiolatis; stipulis indivisis petioli longitudine; racemo thyrsoideo floribusque villosis ; caIyce vix deutato. Mussaenda race-

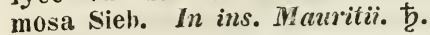

3. Calycis tubus ovatus aut turbinatus. Bacca iutus crustace a.

7. B. jẫanicu Blıme; caule sinplici; fol. petiolatis cuneato-ohlongis acumiuatis supra sparse subtus in nervis hirsutis; corymbis divaricatis axillarihus cernuis; cor. tuho brevi. In Jara. 古.

8. B. fasciculatic Rhime; caule subramoso; fol. cuneato-oblongis acuminatis supra glabris stobtus in venis strigosis; corymbis hrevihus axillaribus; cor tubo elongato; fauce veluti110. In Iava. 方.

9. B. lateriflora lilume; canle ramoso; fol. subsessilihus cuneato-ohJongis acuminatis supra giahris subtus in venis puberulis. In montosis Jarae. ち. Cor. rubens.

\section{LEYCESTERIA Wall.(1821)}

1. L. formosa Wall. In Nepalia. ђ. Frutex elegans ramis elongatis. Folia ovato-lanceolata acuminata. Flores fasciculati abi seu purpurel. Baccae intense purpureae.

\section{SELIIERA Cav. (1799).}

1. S. ralicans Cav. ic. t. 181. Ann. Scienc. 1. t. 5. Goodenia radicans Pers. In Mexico. Herba prostrata radicans. Folia spathulata integerrima. Flores pedunculati albocaerulei.

\section{BAEOBOTRYS Forst. (1785).}

1. B. nemoralis Forst. gen. t. 11. fol. obovatis remote retrorsum dentatis glahris; racemis compositis spicatis. In Nov. Hebrid.

2. B. iudica Roxb. fol. ovato-oblongis acuminatis grosse serratis; ramis subcompositis axillarihus terminalibusque. B. ovata W.IIJ. In Ind.or. t.

3. B. lanceolata $1 \mathrm{~V}$. fol. lanceolatis serratis; racemis supradecompositis axillaribus. Maesa lanceolata Forsk. Vahl symb. t. 6. In Arabia.
1. 13. paniculata; glaherrima; fol. late ellipticis utrincue acutis maximis dentatis; racemis elongatis gracilibus.

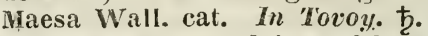

5. B3. oruta; glahra; fol. ovatoacuminatis subcordatis integris utrinque nitidis; racenis axillaribus elongatis. Naesa ovata A. DC. in Linn. trans. 18. t. \%. In Penang. ђ.

6. 13. missionis; glahra; fol. ovato-acuminatis integris; racemis folio brevioribus. Maesa A. DC. In Ind. or. $\hbar$.

7. B. tomentosa Hamilt. fol. ohlongis acuminatis serratis ramulisque incano-tomentosis; racemis multifloris paniculatis. B. macropliylla Wall. Maesa tomentosa Don. In Nepalia.

8. B. ramentaceu Roxb. fol. Ianceolatis acutis integerrimis gIabris; paniculis ramentaceis. In silhet. $\hbar$.

9. I3. argented Mall. fol. ovatis acuminatis areute sinuato-dentatis pubescentibus subtus argenteis; racemis axillaribus ahbreviatis ; floribus fasciculatis. In Ind. or. ந.

\section{STROEMIA Vahl (1790).}

1. S. rotundifolia Valil; inermis; apelala; fol. orbiculatis ramisque glabris. Cadaba rotundifolia Forsk. In Arabia et Abyssinia. 古.

2. S. glandulosa Uall, inermis; apetala; fol. subrotundis scabris; ramis apice glanduloso-pilosis. Cadaba glandulosa Forsk. In Arabiu. நे.

3. S. indica Lam. inermis; 4-petala; 4-andra; fol. oblongis glahris mucronatis. Claome fruticosa L. Burm. ind. t. 46. f. 3. In Ind. or. $\hbar$.

4. S. longifolic Brown; inermis; 4-petala; 4-andra; fol. oblongo-linearibus glabris. Cadaba longifolia DC. In Abyssinia. 古.

5. S. Ilubia; inermis; 4-petala; 4andra; fol. subellipticis pulvere glauco farinosis. Cadaba farinosa Brown. In Arabia et Senegalia. $\hbar$.

6. S. farinosa Vahl; inermis ; 4petala; 5-andra; fol. ovali-oblongis 1-nerviis pulvere glauco farinosis. Cadaha farinosa Forsk. In Arabia et senegalia. $\hbar$. Flores flavi.

\%. S. trinervia; ineruis; 4-petala; 6-andra; fol. trinerviis ovato-orbiculatis. Cadaha trinervia DC. In Persia prope Ispahan. $\hbar$. 
S. S. capparoides; stipulis spinosis; floribus 4-petalis 6-andris; fol. oblongo-lanceolatis penninerviis Cadaba capparoides DC. In Nov. Holl. ち.

\section{HYRTELLA L. (1737).}

1. H. triundra $、 u$. petalis ovatis; racemis compositis; rachi pubescente; fol. oblongis acuminatis glabris. If. americana Jacq. am. 8. t. 8. H. paniculata Lam. In ins. Caribaeis. ந. Cor. alha.

2. H. Cosmibuena Lam. florihus 3andris; petalis emarginatis; racemis compositis pubescentihus; fol. oblongis acuminatis subtus pubescentibus. Cosmihuena 13. et P. prodr. H. peruviana Pers. H. racemosa flor. peruv. t. 227. f. B. In Peruvia. ђ.

3. H. mollicoma $\boldsymbol{H}$. et $\boldsymbol{K}$. floribus 3-andris; petalis subrotundo-ellipticis; paniculis elongatis pilosis; fol. oblongis acuminatis basi acutis subcoriaceis, supra glabris, nitidis subtus molliter fuscescenti-pilosis. In Nov. Granata. ち.

4. I. pendula Sol. floribus 3-4andris; racemis compositis pubescentibus ; fol. oblongo-lanceolatis acuminatis basi cordatis subtus subscabris. In America. $ち$.

5. H. castanea Sm. floribus 3-andris; petalis ovatis calycis longitudiue; racemis terminalihus ramılisque hirsutissimis ; fol. hirsutis ohlongolanceolatis hasi subcordalis apice acuminatis. In Nova Hispania. ち. Petala sordide rubentia.

6. H. rugosa Pers. floribus 3-andris; petalis ohlongis calyce longioribus; racemis ramulisque hirsutissimis; fol. ovato-lanceolatis acuminatis superne nitidis sultus reticulatis pilosiusculis. H. portoricensis W. Hb. In Fortorico.

\%. H. lirsuta Lam. florihus 4-5andris; racemis aggregatis compositis ramulisque hirsutis; fol. ovalibus acutis subtus in nervis pilosis. H. paniculata Vahl symb. t. 31. H. aggregata Poir. In Cayenna. ђ.

8. H. glandulosa spr. Anl. t. \%. f. 1-t. floribus 5-andris; calycibus pedicellisque glandulas stipitatas gerentibus; racemis compositis ; fol. ovato-ohlongis acutiusculis in nervis flavido-villosis. In Brasilia. ఫ.
9. H. racemosa Lam. florihus 5andris; calycihus extus eglandulosis: raccuis simplicibus axillaribus solitariis glabratis; fol. oblongis acuminatis glabris subtus in nervis pilosis. H. americana Aubl. Guj. t. 98. In Gujana et Cayenna. b. Cor. caerulescens.

10. H. oblongifolia $\mathrm{W}$. florihus 56-andris; calycihus extus glandulosis; racemis simplicibus axillaribus glahratis; fol. ohlongis acuminatis glabris. In Nova Hispania. ち. Cor. rosea.

11. H. hexandra $\boldsymbol{H}$. florihus 6andris; racemis ternis simplicibus hirtellis; fol. oblongis obtusiusculis glahris; nervo subtus pubescente; petiolis pedunculisque pubescentibus. Ad Orinocum. $\hbar$.

12. H. hebeclada Moric. floribus 6-andris; racemis terminalibus simplicibus; ramis petiolatis nervisque foliorum velutinis; fol. ovalibus superne subpuberulis inferne subhispidis. In Brasilia. ち.

13. H. apetala Meyer; florihus 9andris apetalis; calyce patente; fol. ovato-oblongis acuminatis glahris; racemis compositis terminalibus. In Surinamo. $\hbar$.

14. H. polyandra $H$. et $\boldsymbol{K}$. Nov. Gen. t. 565. floribus $18-20$-andris 5petalis; paniculis terminalibus ramosissimis cano-tomentosis; fol. ohlongis aut obovato-oblongis breviter acuminatis hasi acutis, supra glabris nitidis, subtus albo-tomentosis. In Acapulco. Ђ.

15. H. canomensis Spr. racemis axillaribus bracteatis pendulis villosis; florihus polyandris; fol. oblongis subtus ferrugineis. Moquilea canomensis Mart. Nov. Gen. t. 166. In Brasilia. ђ.

16. H. tomentella schott; racemis termiualibus ferrugineo-tomentosis; floribus 6-7-andris; fol. oblongis utrinque attenuatis supra glabratis subtus hirsutis. In Brasilia. ђ.

17. H. angustifolia Schott; racemis simplicibus nutantibus hirtis; floribus 7-9-andris; fol. subcordatolineari-lanceolatis acutis utrinque hirsutis. In Brasilia. ఫ.

\section{Species dubiae.}

18. $H$. scandens $W$. floribus 7-andris; racemis axillaribus terminalibus51 * 
que; fol. distichis oblongis basi rotundatis apice acuminatis nitidis glauris; canle scantente. In Prasilia. 支.

19. I. nemorosa W. Hb. floribus 8-andris; racemis terminalibus; fol. distichis oblongis hasi rotundatis apice acuminatis nitidis ylabris; caule erecto. In Brilsilia. 方.

20. H. octrindra TH. Hb. floribus 8-andris; panicula terninali; fol. oblongis coriaceis. In Erasilia. 方.

1. H. Aca!nacensis fl. mex. ic.ined. foribus 8-andris 4-petalis; racemis villosis simplicibus axillaribus; fol. ohovatis acuminatis glabris. In Mlexico. b. Cor. purpurca.

2. It. dodecandra fi. mex. ic. incal. floribus $12-13$-andris; racemis terminalibus paniculatis; fol. ovaliohlongis acutis. In Mexico. ち. Petala rosea.

23. N. nitila $\boldsymbol{W}^{\top}$. $\mathrm{Hb}$. racemis terminalibus pubescentibus; fol. ohlongis acuminatis nitidis basi angustatis. In Cuba. 兮.

\section{OPYHA Roxb. (17.99).}

1. O. amentacea Roxb. Corom. $t$. 158. In Ind. or. 卢. Arbuscula. Foia simplicia ohlonga integerrima. Floses racemosi hracteati virescentes. Bacca globosa succulenta.

\section{TILEAREZIA R. et P. ( 1802$)$.}

1. V. mucrenate R. et P. peruv. t. 291. f. b. In Peravie. t. Alhor Citro similis. Nolia ovata coriacea mucronata lucidi. Flores raccmosi davescentes.

1015. HUER'EA R. et P. (1502).

1. H. glandulosa $\boldsymbol{R}$. et $\boldsymbol{P}$. peruv. c. 22\%. f. a. In l'eruvia. t. Arbor :0-ulnaris cortice fusco. Folia impari-pimata pedalia hasi glandulosa. flores racemosi parvi flavescentes.

1016. ICACINA Adr. Juss. (1823).

1. I. senegalensis Analr. Juss. Act. soc. hist. nat. paris. 1. t.9. In Se- negambia. t. Arhor. Folia alterna ovato-oblonga integerrima glabra. Nlores paniculati terminales.

\section{1\%. TREJANOA Lexarza (1825).}

1. L. mexicana. In MIexico. 古.

\section{SABIA Colebr. (181\%).}

1. F. Lanceolata Colebr. Linn.trans. 12. t. 11. fruticosa ; fol. alternis lanceolatis acutis paniculatis terminalibus. In Silhet. ‡. Flores viridi-purpurei.

2. S. parviflora Wall. fol. ovatolanceolatis cuspidatis margine membranaceis undulatis; ramulis pubescentibus; pedunc. axillaribus paucifloris; floribus digynis. In Nepalia. t.

3. S. crompanalata Itall. fol. oblongo-lanceolatis acuminatis margine membranaceis ciliatis; pedunc. axillaribus 1-floris; petalis concavis. In Nepalia. 方.

\section{SYNDESMIS Wall. (1826).}

1. S. elegans Wall. In ins. freti malacc. 古. Arbuscula. Folia sparsa lanceolata coriacea. Flores corymhosi terminales. Calyces coccinei. Cor. candida.

\section{CORYNOCARPUS Forst. (1785).}

1. C. laevigatus Forst. gen. $t .16$. In Nor. Zeelrindia. ち. Arbor. Folia obovata integra velosa glaberrima. Panicula magna. Hlores albi.

\section{VENTILAGO Gaertn. (1\%8S).}

1. V. maderaspatana Gaertn. $t$. 49. scandens; fol. ovatis integerrimis glabris. Roxb. Corom. t. 76. liumph. 5. t. 2. In Ind. or. ち. Arbuscula. Flores parvi virescentes.

2. I. denticulata $\boldsymbol{W}$. fol. ovatis crenatis pubescentibus; ramis paniculae villosae divaricatis. In Ind. or. †. Frutex scandens. 
3. I. oblongifolia l?lume; fol. oblongis acuminatis basi oblique rotumdatis rerratis glahris sulutus in axillis venartm tomentosis ; racenis interruptis foliosis. In Jara. 市.

\section{GAUDICHALDIA H. et $\mathrm{K}$. (1821).}

1. G. cynanchoides Humb. et $\boldsymbol{K}$. Nor: Gen. $t$. 145. caule volubili; fol. petiolatis cordatis; raccmis axillaribus terminalibusque. In Mexico. ђ.

2. G. guaraniticu Hilur. caule voluhili fruticoso; fol. petiolatis ovato-ohlongis obtusis hreviter nucronatis; petiolis apice higlandnlosis; nmbellis axillaribus 2-3-floris. In $\mathrm{Br}^{\circ} \mathrm{a}-$ silia. t.

3. G. linearifolia Filar. caule suffruticoso erecto; fol. linearibus subsessilibus distantihus; umbellis terminalihus. In Erasilia. 5 .

4. G. sericea Hilar. caule suffruticoso erecto; fol. Dreviter petiolatis suhtus sericeis intermediis ovato-lanceolatis; pedunculis filiformibus $1-2-$ floris. In Brasilia.

\section{DIGERA Forsk. (1775).}

1. D. arrensis Forsk. In Arabia et Ind. or. Herha decumbens ramosa. Folia alterna lanceolata integerrima rugosa glahra. Flores axillares rubri. Achyranthes polygonoides lietz.

\section{PERRO'TETIA Lunth (182.5).}

2. P. quinduensis If. et K. Nor. Gen. t. 622. In Nor. Grancita. ち. Frutex. Folia alterna petiolata ob$10 n g a$ acuminata remote denticulata mcmbranacea subtus tomentosa. Hlores racemosi niuuti rubri.

\subsection{IHARPULLLA Roxb. (1S2G).}

1. II. cupanioides Roxb. In Ind. or. Arbuscula. Folia aliuple pimnata glabra; foliola 1-6-juga oblonga acuta integrrima. Flores paniculati sulphurei.

\section{CYRILLA Y. (1767).}

1. C. caroliniana Nichx. fol. cuneato-lanceolatis acutis membranaceis nervosis; spicis gracilibus; petalis pedicello longiorihus. Jace. ic. $t . \quad+\frac{\mathbf{i}}{6}$ Itea caroliniana Lam. ill. t. 11\%. f. 2. sw. ohs. 4. t. 4. f. 1. Herit. stirp. t. 66. In Amer. bor. ち. Frutex orgyalis. Floros albi.

2. C. antillana Fichx. fol. cuneato-ohlongis obtusis coriaceis subtus enerviis; spicis crassiorihus; petalis pedicello subbrevioribas. In Jamuicu.t.

\section{2\%. IIYMENANTHERA R. Br. (1818).}

1. H. angustifolia L. Br. fol. Iinearibus integerrimis. In ins. Tun Diemen. 古.

2. H. dentata R. Br. fol. oblongis denticulatis. In Nov. Holl. ち.

\section{RICHERIA Vahl (1\%96).}

1. R. grandis Fahl Ecl. $l$. \&. In Amer. ausir. ち. Arbor magua. Rami cicatrisati. Folia ohovala seu clliptica acuta integerrima subcoriacea glabra. Flores spicati axillares.

\section{RIIAMNUS Nicand.}

a. Cor. 5-fida. Stamina 5. Bacca 3-sperma. Alaternus.

1. R. Aluternus L. fol. ovatis ellipticis Ianceolatisve coriaceis glaberrimis serratis; floribus dioecis breviter racemosis. Duhan. ed. 2. t. 14. In Europ. austr. Frutex valde varians.

2. R. hybridus Herit. stir). $\boldsymbol{t}$. 5 . fol. oblongo-acuminatis serratis glahris nitidis semi-coriaceis; floribus androgynis. Patria ignota. $\hbar$.

3. R. glandulosus Ait. fol. ovatis obtuse serratis glabris, subtus in axillis inferiorihus glandulosis; floribus hermaphroditis racemosis. Vent. malm. t. 3.. In Madera et ins. Canariis. $\hbar$.

1. R. integrifolius $D C$. fol. elliptico-oblongis mucronalis integerrimis; floribus apetalis hermaphroditis: race. 
mosis. H. coriaceus Nees hor. phys. 1. 22. In Teneriffa. $\hbar$.

5. R. surinamensis Scop. del. $t .5$. fol. ellipticis argute dentatis nitidis; floribus axillaribus paucis apetalis hermaphroditis. In Surinamo. $\hbar$.

6. R. longifolius Dum. Cours, fol. ovali-oblongis utrinque acutis serratis glabris nitidis; axillis subtus pilosis. 1. Willdenoviana schult. H. longifolius L. In Amer. bor.? †.

\%. R. prinoides Herit. sert. 6. $t$. 9. fol. ovato-lanceolatis acuminatis serratis lucidis; floribus pedicellatis axillaribus geminis polygamis.

Prom. b. spei. ち. Drupa nigra.

8. R. celtidifolins Thunb. fol. ovatis serratis glabris; foribus pedicellatis solitariis axillaribus apetalis. Burm. afr. t. 88. In Prom. b. spei. ђ.

9. R. splendens Blume; caule scandente; fol. nervoso-venosis ovatis obtuse acuminatis basi subcordatis crenulatis; cymis axillaribus bifidis. In Java. ち.

10. R. affinis Blume; fol. venosis suboppositis ovato-oblongis longiter acuminatis basi rotundatis serrulatis glabris; spicis paniculatis axillaribus. In Java. ち.

11. R. californicus Eschh. pl. calif. inermis; floribus hermaphroditis 1gynis fasciculato-umbellatis; bacca disperma; fol. ovalihus serrulatis. In California. b. Frutex 2-orgyalis. Flores flavo-virides.

b. Flores 4-fidi 4-andri. Fructus baccatus 4-spermus. Frutices spinosi.

12. R. catharticus $L$. spinescens; erectus; patenti - ramosus ; fol. ovatis crenato-serratis ; serraturis superioribus glandula terminatis; floribus polygamis. Fl. Dan. 850 . schk. t. 46. Hayne V. t. 43. Guimp. t. 13. E. B. 1629. Sv. B. 307. In Europ. t. 6-10-ped. Drupa atro-nigra. $\beta$. hydriensis Hacq. t. 2. f. 2. fol. majoribus hasi attenuatis. Circa Hydriam.

13. R. lucidus Roxb. arborescens; spinis recurvis validis; fol. oppositis subrotundo-oblongis emarginatis integerrimis nitidis; pedunc. axillaribus paucifloris abbreviatis. In ins. Mara. †.

11. R. leprosus Blume; caule scandcnte; ramis adultioribus spinosis; fol. suboppositis subcordato-ovatis ohtusis serrulatis venosis, junioribus subtus furfureis; pedunc. 1-floris. In $J a-$ va. 古.

15. R. incanus Roxb. fol. ovatooblongis integerrimis supra glabris subtus albido-pilosis; stipulis filiformiluss; corymbis axillaribus. In ins. Molucc.

16. R. virgatus Roxb. erectus; ramis virgatis; fol. oppositis ovalibus utrinque acuminatis serrulatis; floribus paucis. R. catharticus Hamilt. In Nepalia. ち.

1\%. R. tinctorius W. et Kit. hung. $t$. 25.5. erectus; fol. ovatis crenatoserratis; petiolis villosis; floribus confertis dioecis; baccis obcordatis 3-1spermis. R. cardiospermus W. Hb. In Ranatu et Syrmia. ђ.

18. $R$. infectorius $L$. procumbens diffususve ; fol. ovato-lanceolatis serrulatis glabriusculis; floribus dioecis utrinque sexus petaliferis. Clus. hist. 1. p. 111. ic. In Europ. austr. Fructus arcte tinctoreus in officinis dicitur graine d'Avignon.

19. R. saxatilis $L$. procumbens suberectusve; fol. ovato-lanceolatis serrulatis glabriusculis; floribus dioecis, foemineis apetalis. Jacq. austr. $t$. 53. In Europ. austr.

20. $\boldsymbol{R}$. oleoides $\mathbf{L}$. diffusus suberectusve; fol. oblongis obtusis integris coriaceis glabris subtus venosoreticulatis. In Sicilia, Mauritania et Graecia. 古.

21. R. buxifolius Poir. diffusus; fol. ovatis integerrimis mucronatis glabris coriaceis utrinque viridibus. In Numidia. $\hbar$. A priore vix diversus.

22. R. pubescens Poir. diffusus; fol. ovatis integerrimis coriaceis pubescentibus. R. oleoides Lam. In Gallia. ђ.

23. If. amygdalinus Desf. diffusus; foi. lanceolatis obtusis integerrimis coriaceis glabris. In Atlantae rupestribus. $\hbar$.

21. R. crenulatus Ait. erectus; fol. oblongis obtusis subserratis sempervirentibus glabris subtus venoso-reticulatis. In Teneriffa. ち.

2.5. R. prunifolius Sm. depressus procumbensve; fol. obovatis obtusis crenatis nudis; floribus polygymis. In Creta. $ђ$.

26. R. lycioides $L$. erectus; fol. linearibus integerrimis obtusis glabris; 
forihus hermaphroditis. Cav. ic. t. 182. In hisjumiu. ち. Bacca nigra.

2\%. R. Lrytiroxylon P'ill. fl. Ross. t. 6 2. et 6i3. ejusd. it. t. 90 . erectus; fol. lineari-lanceolatis serratis glabris; fioribus hermaphroditis; haccis oblongis. In sibiria. 卢.

28. R. pumilus I. inernis; repens; fol. petiolatis ovali-lanceolatis subacuminatis crenato-serratis. Cav. ic. t. 181. Jacq. Cull. 2. t. 11. R. Wulfenii spr. Frangula WVulfenii Rchb. 13. rupestris sicop. carn. t. 5. In suais Europue. ち.

29. R. Sibthorpianus schult. diffusus; fol. ovato-rhombeis subintegerrimis lineatis villosis; floribus dioecis. 13. pubescens sibtl. gr. t. 329. In P’arnusso. ち.

30. R. alpinus $L$. tortuosus; fol. ovali-lanceolatis crenato-serratis glabris in nervulis lineatis; floribus dioecis. Hall. act. Gött. II. t. 16. Fl. Helv. t. 43. Guimp. t. 15. In mont. Europae. 古.

31. R. daluzicus Pall. fl. ross. $t$. 61. erectus; fol. oblongo-ovatis serratis glabris venosis; floribus dioecis; foemine erum stigmate bifido. Amm. ruth. t. 33. In Daluuria. ち.

32. R. Purshianus DC. erectus; fol. ovalibus denticulatis breve acuminatis subcordatis subtus pubescentilus; pedunc. his bifidis; haccis depresso-globosis. R. alnifolius Pursh. In Amer. bor. $\hbar$.

33. R. carolinianus Walt. erectus; fol. ovali-oblongis integriusculis glahris; nmbellis pedunculatis ; floribus hermaphroditis; baccis globosis. In Amer. bor.

31. R. serrulatus $\Pi$. et K. t. 617 . ranulis villoso-hirtis; fol. ohlongis utrinque acutis argute serrulatis glabris viscosis. In Mexico. ち.

c. Flores 5-fidi 5-andri. Fructus 4-spermus. Frangula.

3.5. R. Frangula L. glaber; fol. ovalibus integerrimis subrepandis; cortice albo-punctato. Fl. Dan. 288. Schk. t. 46. E. B. 250. Guimp. t. 14. Frangula vulgaris Rchb. In Europ. ち. 10-12-ped. Drupae nigrae.

36. R. latifolius Herit. sert. $t$. $s$. fol. ellipticis acuminatis integerinis, jumioribus calycibusigue villosis; חo- ribus hermaphroditis. In ins. Azoricis. ち.

3\%. R. sunguineus pers. fo!. ovatis aut oblongis acuminatis integerrimis lineatis calycibusque glabris; 1loribus fasciculatis hermaphroditis. $\mathbf{l}$. Sanguino Ort. In Galicia. ђ.

38. R. Humboldtianus Schult. H. et K. Nor. Gen. t. 6/8. fol, oblongo-ellipticis obtusis basi rotundatis integerrimis, sutus calycihusque glanduloso-punctatis. In Amer. uustr.

d. Folia opposita. Fructus biloculares.

3.9. R. umbellatus Cav. ic. t. 504. fol. oppositis ovatis acutis integris nervis pemnatis lineatis glahriusculis; pedunc, axillaribus umbellatis. In Me:rico. $\hbar$.

10. R. biflorus fl. mex. ic. fol. oppositis integris ovatis utrinque acutis nervis penuatis lineatis; pellunc. axillaribus 2-floris. In Mexico. $\frac{b}{}$

41. R. ternillorus fl. mex. ic. fol. oppositis ovalibus subacutis dentatis subtus ramulisque ferrugineis; pedic. 3 axillarilus 1 -floris. In Mexico. $\hbar$.

42. R. eleyans H. et K. Nov. Gen. $t$. 619. fol. ovato-oblongis serulatis glabris nitidis; floribus paniculatoconglomerato-spicatis; stigmate sessili 3-plici. In Amer. 市.

\section{e. Species dubiae.}

* Spinosae.

43. $R$. theezans $L$. ramis apice spinosis divaricatis;, fol. ovatis glabris serrulatis; floribus spicatis. In Chinc. 古.

4. R. trigynus Don; spinosus; fol. suboppositis ovatis acuminatis glabris lucidis serrulatis basi retusis; spicis interruptis. Zizyphus lıamosa et oppositifolia Wall. In Ind. or.

4.5. R. senticosus $\boldsymbol{H}$. et $\boldsymbol{K}$. spinosissimus; subaphyllus; spinis longissimis decussato-oppositis; fol. ovatis; floribus fasciculatis. In Peruria. $b$.

46. R. Guayaquilensis $H$. et $K$. ramosissimus; ramulis 4-angularibus; spinis sparsis suhulatis; fol. ellipticis mucronatis subtus cano-hirtis. Prope Guayaijuil. ђ. 


\section{** Inermes integrifoliae.}

4\%. In. microphyllus W. Hb. procumbens; ramosissimus; ramis tortuosis; fol. lineari-lanceolatis obtusis glabris; pedunc. axillarihus 1-floris. II. et K. Nov. Gen. t. 616. In Irexico. t.

48. R. tetragonus L. fil. fol. oppositis ovatis integris glabris sessilibus; floribus subpaniculatis incompletis; baccis 1 -spermis. In Prom. $b$.

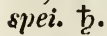

19. R. polyfolius ralil; fol. lanceolatis integerrimis subtus ramulisque tomentoso-niveis; floribus axillaribus sessilibus hermaphroditis $3-g y-$ nis. In Nov. Zeelandia. ち.

50. R. zizyphoides Spr. fol. ovato-lanceolatis integerrimis acutis subtus incauro-tonentosis; floribus paniculatis; caps. baccata tricocca. In ins. Societatis. $ђ$.

51. R. myrtinus Furm. fol. oblongo-ovatis integerrimis subtus lucidis. In Coromandelia. 市.

52. R. brasiliensis Spr. fol. oblongo-lanceolatis utrinque attenuatis coriaceis supra nitidis; pedunc. axillaribus 1-floris aggregatis. In Brasilia. ち.

53. $R$. ramifloms Rich. glaberimus; fol. lanceolato-oblongis nitidis; floribus minutis glomeratis. In Cayennce. t.

54. R. racemosus Duham. fol. ovato-rotumdis lacvihus subtus tomentosis ciliaribus petiolisque ferrugineis. Celastrus Hamelii Spr. Patria ignota.

**** Inermes dentatae aut serratae.

55. R. lanceolatus Pursh; arborescens ; fol. lanceolatis serrulatis utrinque acutis subtus pubescentihus. In collibus Tenasse. $\hbar$. Baccae nigrae.

56. R. minutiflorus Pursh; inermis; fol. suboppositis ovalibus serrulatis glahris; florihus minutissimis dioccis spicatis; hacca globosa 3 -loculari.

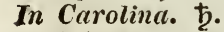

5\%. R. cassinoides Lam. fol. ovatis coriaceis glaucis obsolete dentatis; ramulis angulatis; floribus axillaribus. In Damingo. ち.

5s. R. fitiformis Roth; fol. ovatolanccolatis serratis nitidis sublus ad costas petiolisque puhescentibus; spicis paniculatis filiformibus. In Ind. or. t).

5.9. R. corymbosus Tahl; fol. coriaceis ellipticis subserratis; floribus pedunculatis corymbosis. In Ind. occidentali. $\bar{b}$.

60. R. parvifiorus Klein et Willd. rol. stibcoriaceis nitidis serratis ovatoacuminatis ; foribus laxe spicatis ; spicis paniculatis. In fud. or. $\hbar$.

61. R. quitensis $\boldsymbol{H}$. et $\boldsymbol{K}$. fol. obovato-oblongis ohtusis mucronatis serratis basi integerrimis coriaceis; ramulis angulatis. In Quito. ち.

63. I?. Wilhor Huce. In Hort. Dorp. ex DC. proals. p. 28.

63. 1R. cinerascens Blume; fol. ovalibus parallelo-venosis acutis integerrimis glabris subtus cinereis; floribus racemosis. In Java. 市.

\section{ZIZYPHUS Dodon. (1559).}

a. Folia glabra sen subtus in nervis pubescentia.

1. $Z$. vulyaris Iam. ill. $t$. 155. $f$. 1. fol. ovatis retusis denticulatis; aculeis geminis, altero recurvo; drupa ovato-ohlonga. Hhammus Kizyphus L. Pall. fl. ross. t. 59. Dulam. 3. t. 16. In Syria et Europa. 古.

2. 2. sinensis Lam. fol. ovato-oblongis acutis serratis glabris; ramulis pubescentibus aculeis geminis pateutibus rectiusculis; petalis reflexis; drupis ovatis. In China. 古.

3. 'z. Lotus Lam. fol. ovato-oblongis ohsolete crenatis glahris; aculeis geminis, altero recurvo petiolis longiore; drupis subrotundis. Desf. act. par. 1788. t. 21. In Africa et Sicilia. 市.

4. Z. mucronata $W$. fol. cordatoovatis mucronatis crenulatis glabris; aculeis geminis, altero recurvo; drupis subglobosis. Z. bubalina Licht. In Prom. b. spei. ந. Arbor 25-ped.

5. Z. heterogena Poir. fol. ovatis acuminatis serrulatis lucidis; aculeis greminis, altero recurvo ; pedicellis solitariis 1-floris. Plukn. t. 312. f. 4. In Persia. 市.

6. Z. Spina Christi $W$. fol. ovatis obtusis dentatis glabris subtus puhescentibus; aculeis patentibus, altero recurvo; corymbis villoso-toneutosis. 
Ihlamus I. Z. Napeca Lam. Nahoa Alp. aeg. t. 4. In Aegyगto. ţ.

ร. Z. Fapeca $\mathrm{H}$. fol. ovatis obtusiusculis serratis utrinque lacvibus; aculeis geminis recurvis; pedunc. corymbosis. Hhamuns Napeca L. Plukn. t. 216. f. 2. Rumph. 2. t. 42 . In Zeylona. 卢.

8. 'Z. Bsaclei DC. fol. lato-ovatis acuminatis crenulatis glabris; aculeis sulgeminis, altero recurvo; drupa orato-globosa. In Senegulia. $\hbar$.

9. "z. reticulata $\boldsymbol{D C}$. fol. ovalibus subdenticulatis reticulatis subtus puhesceutibus; aculeis geminis rectis; corymbis axillaribus; stigmate :3-dentato. Paliurus Vahl Ecl. t. 23. In Amer. austr. ち.

10. 2. rugosa Lam. fol. late ovalibus rugosis serrulatis subtus subpuherulis; aculeis subgeminis recurvis; corymbis dichotomis recurvatis tomentosis. Plukn. t. 29. f. \%. In Ind. or.

11. Z. horrida Roth; fol. ovatis obtusis crenulatis subtus ad costas pubescentibus; aculeis geminis recurvis; corymbis dichotomis axillaribus. In Ind. or. ち.

12. $Z$. incurva Roxb. fol. ovalihus obtuse acuminatis crenulatis 5 -nerviis hasi obliquis; petiolis nervisque pubescentibus; cymis bifidis. In Nepalia. t.

13. Z. paniculata Roth; fol. oblongo-ovalibus subacuminatis serrulatis scahris, subtus ad nervos puberulis; aculeis geminis recurvis; panicula elougata; nuce 1-sperma. In Ind. or. $\hbar$.

11. Z. obliqua Roth; fol. ovatosubrotundis mucronatis supra glabris; nervis profunde exaratis, subtus reticulo venarum elevato densissimo ru-

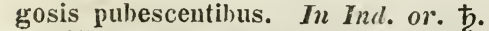

15. Z. celtilifolia $D C$. fol. ovatis hasi obliquis, superioribus acuminatis subintegris 3-nerviis subtus cum petiolo et ramulis pubescentibus; aculeis solitariis recurvis glaberrimis. In ins. 'itimor. ち.

16. Z. latifolia Roxb. fol. ovatis basi obliquis apice acutis glabris crenulatis 3-nerviis sultus in nervis puberulis; ramis inermilus ; corymbis axillaribus. In $\mathrm{Ind}$. or. $\hbar$.

1\%. Z. Timorensis DC. fol. ovatoohlongis acuminatis hasi obliquis utrinque glabris crenato-serrulatis 3-ner- viis ; ramis itrermibus; corymbis axillaribus. In ins. 'Timor.

13. Z. Caracuitu Hamilt. arborea; aculeo altero recurvo; fol. subrotundis serrulatis glabriusculis; pedunc. axillaribus multifloris; capsulis ovalibus. In Ind. or. t.

19. Z. fiexuosa Wall. fruticosa; aculeo altero recurvo; fol. lanceolatis ohtusis creuatis nitidis; floribus axillaribus subsolitariis. In Ind.or. $b$.

20. 2. calophylla Wall. aculeis recurvis; fol. ovato-ohlongis creuulatis glaberimis lucidis; corymbis paniculatis terminalibus. In ins. fieti Malaccensi. $\hbar$.

21. Z. eleyans Wall. aculeis minutis deciduis; ramis pubescentibus filiformilus; fol. bifariis Ianceolatis serrulatis subtus pubescentibus. In peninsula Mialacc.

22. Z. Ploribundi Wall. caule subscandente; fol. ovatis acutis subintegerrimis coriaceis supra nitidis subtus glancis nervosis; fructibus subcylindricis. In Nepalia. t.

23. ZZ. flavescens Wall. caule scandente; fol. ovato-oblongis subintegerrimis supra opacis subtus glaucis; floribus fasciculato-racemosis. In montibus Emotli. ђ.

21. 'Z. tinervia Roxb. arborescens; fol. ovato-oblongis $\mathbf{3}$-nerviis obtuse serratis glabris nitidis; floribus axillaribus fasciculatis; fructibus globosis. In Ind. or. $\hbar$.

25. Z. javanensis Blume; caule scandente; aculeis solitariis recurvis; fol. 5-nerviis elliptico-oblongis duplicato-serrulatis glabris; corymbis pubescentilus. In Java. ち.

26. Zu. Paliurus $\boldsymbol{W}$. ramulis altero latere pubescentibus; fol. ovatis 3nerviis; ala fructus crenulata. Rhamuus Paliurus L. Paliurus aculeatus Lam. ill. t. 210. P. australis Fl. gr. t. 210. In Europ. austr.

\section{b. Folia subtus sericea aut to- mentosa.}

27. Z. Oenoplia Mill. fol. ovalilanceolatis obliquis utriuque acuminatis suhintegris subtus flavo-ferrugineosericeis; aculeis recurvis solitariis. Bum. 'Zeyl. t. 61. In Coromandelia et Nepalia. ち.

28. 2 . Xylopyrus $\boldsymbol{W}$. fol. subcoir dato-ovatis acutiusculis inacqualite- 
scrratis obliquis subtus, ramisque canotomentosis; aculeis solitariis parvis recurvis ; corymbis tomentosis. In ind. or. 占.

2.9. T. orthacantha DC. fol. ovatis subintegris obtusis subtus petiolis ramulisque cano-tomentosis; coryuhis axiliaribus tomentosis. In Senegalia. $\hbar$.

30. Z. Jujeba Lam. fol. subrotundo-ovatis obtusis subintegris subtus petiolis ranulisque tomento brevissimo canis; aculeis recurvis; corymbis axillaribus. Rumph. 2. t. 36. Hheede 4. t. 41. In China et Cochinchina. t).

31. Z . sororia Schult. fol. sulrotundo-ovatis obtusis mucronatis serrulatis subtus tomentosis; aculeis nullis; corymbis axillaribus divaricatis. Z. trinervis Roth. In Ind. or. ђ.

32. Z. rotundifolia Lam. fol. subrotundo-ovalibus subdentatis stibtus tomentosis; aculeis geminatis, altero recurvo. Pluku. t. 197. f. 2. Z. nummularia Gmel. In Zeılona. ఫ.

33. '2. orbicularis Schult. fol. cordato-orhiculatis ovatisque mucronatis inaequaliter serrulatis tomcntosis; aculeis recurvis; corymbis glomerulatis; fructibus tomentosis. Z. rotundifolius Roth. In Ind. or. 市.

31. Z. tomentosia Poir. fol. ovato-subrotundis argute serulatis subtus petiolis ramis forihusque tomento molli canis; aculeis oeminis, altero recurvo; fructibus glabris. In Domingo. 古.

35. 2 . rotundata $D C$. fol. ovatis obtusis subohliquis subcrenulatis subtus petiolis ramulis florihusque cinereo-velutinis; fictibus ovatis obtusis glahris. Inhamms mauritianus Willen. In ins. Nauritii. $\hbar$.

36. 2. mauritiana Lam. fol. ovalibus subrotundis ontusis subtus petiolis ramulis floribusque albo-tomentoso-fermgineis ; fruclibus oblongis acuminatis. In ins. IMauritii.

3\%. Z. oxycarpa DC. fol. ovatis suhacutis basi attenuatis obliquis argute semulatis subtus petiolis ramuli.ique cano-velutinis; fructibus oblongis acuminatis. In lnd. or. t.

39. 'Z. exserta DC. fol. ovalis serrulatis suhtus tomentosis; aculeis nullis; calyce intus 10-glanduloso. Hhamnus trinervis. Cav. ic. t. 505. f. 1. In ins. Luzon. b.
39. 2. microphylla Roxb. ranis hifariis flexuosis; aculeo altero recurvo; fol. ovatis serrulatis subtus lanatis; floribus fasciculatis. Ad or am Coromandeliae.

\section{Species dubiae.}

40. Z. angulata lam. fol. subrotundo-ovalihus subdentatis utrinque glabris; aculeis geminatis rectis ; ramis 4 -gonis angulis prominentibus. Patria ignota. 卢.

41. Z. havanensis H. et $\boldsymbol{K}$. ramulis 5-angulatis flexuoso-tortuosis glabris; spinis rectis; fol. sulbrotundoovatis subcordatis obsolete crenulatis; calycibus ferrugineo-tomentosis. In ins. Cuba. 古.

12. 2 . agrestis Schult. fol. oblongis integerrimis glabris; aculeis geminis rectis brevibus; floribus racemosis apetalis; drupis globosis; nuculo 3-loculari. Rhamnus Lour. In Cochinchina. 方.

43. Z. soporifera Schult. fol. lanceolatis enerviis inlegerrimis; aculeis sparsis rectis; floribus axillaribus solitariis; drupis subrotundis 1-spermis. Kumph. 2. t. 37. In since. ち.

14. Z. capensis Poir. fol. ovatooblongis glabris; aculeis geminis rectis; florihus digynis; caule frutescente. Scutia capensis Commers. In Prom. b. spei. ち.

15. Z. virgata; ramulis glabris; fol. oblique cordatis ellipticisve trinerviis lucidis; fructus ala integerrima. Paliurus Dou. B. H. 2535. In Nepalia. $\hbar$.

46. 2 . Aubletii; aculeis sparsis rectis; fol. ovatis crenulatis glabris; corymbis axillaribus pubescentibus; baccis orbiculatis. Paliums Aubletii Schult. Aubletia ramosissima Lour. In Cantone. ち.

4\%. Z. volubilis Willd. ramis volubilibus; fol. ovalibus mucronatis subundulatis; floribus dioecis 5-petalis; drupis oblongis. Rhamnus L. Jacq. ic. 336. Oenoplia schult. Bergamia DC. In Carolina et Virginia. ţ.

48. Z. lineata; ramis pubescentibus inermilus; fol. ovatis repandis subtus reticulatis; floribus hermaphroditis ; stigmate simplici. Rhamnus Lam. Osb. t. \%. In China. 古.

49. Z. Burmanniana; ramis subhirsulis incruibus; fol. ovatis planis: 
floribus 4-fidis; fructibus globosis. Rhamnus Burm. ind. t. 88. In L'eylonu. ち.

50. Z. Poiretiana; ramis pubescentibus; stipulis spinosis mininuis; fol. ovalibus reticulatis; floribus solitariis 5-petalis; fructihus suhrotundis. Bhamuus lineatus Poir. Plukn. t. 122. f. 42. In Ind. ち.

51. 'Z. Loureiriana; ramis glahris procumbentilus inermibus ; fol. ovatis subcrenatis planis; floribus 10-petalis 5-andris. Ihamnus lineatus Lour. In Cochinchina. ち.

\section{COLLETIA Commers Juss. (1789).}

\section{a. Flores apetali.}

1. C. spinosa Lam. ill. t. 129. fol. integerrimis ellipticis; pedicellis flore Jrevioribus. C. horrida W. B. M. 3644 . C. polyacantha Schult. In Brasilia, Chili et Peruvia. 古.

2. C. serratifolia Vent. choix. $t$. 15. fol. ellipticis argute serratis; pedicellis flore longioribus. Rhamuus Spartium Domb. In Peruvia. ち.

\section{b. Flores 5-petali.}

3. C. obcordata Vent. cels. $t .92$. fol. obcordatis integerrimis 3-nerviis; foribus axillaribus spicatis. Rhamnus Hetanilla Domb. In Peruvia. $\hbar$.

4. C. Ephedra Vent. cels. t. 16. fol. nullis; floribus in ramulorum nodis sessilibus spicato-glomeratis. In Peruvia. ち.

5. C. multiflora fl. mex. ic. ined. fol. integris ohlongis; pedicellis 1-floris; florihus 5-petalis. In Mexico. Ramuli spinosi.

6. C. disperma fl. mex. ic. fol. integris oblongis; pedicellis $\mathbf{1}$-floris 2-3-fasciculatis; florihus 5 -petalis ; baccis oblongis 2-Iocularibus. In Mexico. b.

7. C. velutina Spr. fol. alternis ohlongis serratis subtus villosis; pedunc. axillaribus cymosis floribusque tomentosis. In Brasilia. ち.

\section{CEANOTHLS L. (1751).}

\section{a. Petala calyce breviora.}

1. C. Sarcomphalus DC. fol. ovatis ovalibusque coriaceis glabris integerrimis obtusis aut emarginatis; pedunc. axillaribus racemoso-corymbosis. Rhamuus L. In Jamaica.

2. C. ferreus DC. fol. ohlongoovatis coriace 0 -memhranaceis glabris nitidis integerrimis emarginatis; pedunc. axillarihus corymbosis. Mhamuus Vahl symb. t. 58. In ins. St. Crucis et Guadelupa. 5 .

3. C. laerigatus DC. fol. oblongis obtusis integerrinis coriaceis subaveniis glahris; floribus axillaribus 2-3pedicellatis. Rlımmus Vahl. In ins. st. Crucis et Guadelupa. 方.

4. C. circumscissus Gaertn.t. 106. fol. obovatis obcordatisque suboppositis integerrimis coriaceis glahris ; aculeis sparsis; pedunc. aggregatis axillaribus. Ihhamnus L. In ins. Manritii. t.

5. C. capensis DC. fol. cordatis ovatisve obtusissimis integris glabris; aculeis solitariis recurvis; umbellis axillaribus. Rhammus Thunb. In Prom. b. spei. .

6. C. Zeylanicus Rotí; fol. subrotundo-cuneatis suhemarginatis obsolete crenatis nitentihus; aculeis oppositis ; pedunc. axillaribus aggregatis. Celastrus Schult. In Zeylona. $\hbar$.

\%. C. asiaticus $L$. fol. ovatis acuminatis serratis glabris; pedunc. axillaribus corymhosis petiolo brevioribus. Cav. ic. t. 440. f. 1. Lam. ill. t. 129. In Zeylona et Nepalia. $\downarrow$.

8. C. mubiflorus DC. fol. ellipticoohlongis acutis serratis glabris; floribus axillaribus congestis velutinis. In ins. Timor. 古.

9. C. sphaerocarpus DC. fol. oblongis acuminatis serratis glabris; pedunc. axillaribus subracemosis; fructihus pellucidis sphaericis; seminibus 3-gonis. Rhamnus Sw. In Jumaica.

10. C. Guineensis DC. fol. elliptico-oblongis utrinque aculiusculis $\mathrm{co}$ riaceis glabris integerrimis brevissime petiolatis; cymis corymhosis canovelutinis. Ihamnus paniculatus Thouars. In Guinea. ち.

11. C. pubescens R. et P. fl. peruv. t. 228. f. $u$. fol. ovatis acuminatis 
pubescentibus acute serratis; pedunc. axillaribus brevissimis dichotomo-mubellatis. In Andibus. ち. Baccae nigrae.

12. C. granulosus R. et P. peratv. t. 228. $t$. $b$. fol. ovato-oblongis acuminatis medio subserratis glahris nitidis cum petiolis pubescentibus; floribus umbella!is. In Peruvia. $\hbar$.

13. C. infestus H. et K. Noi. Gen. t. 61t. fol. oppositis anguste lanceolatis subpungentibus integerrimis crassiusculis glabris; ramulis hirtellis; floribus fasciculatis. In Finexico. $\hbar$.

1. 1 . C. macrocarpus Cav. ic. $t$. 2\%0. fol. ovatis basi cordatis subrotundis vix acutiusculis serratis subtus ramulisque subtomentosis; fioribus gloneratis; fructibus pendulis. In Nova Hispania. t.

15. C. colubrinus Lam. fol. ovatis suluacuminatis integris subtus ramulis floribusque ferrugineo-villosis; floribus subaggregatis. Rhamnus L. Jacq. Vind. t. 50. Comm. t. 90. In Amer. austr. $\hbar$.

16. C. reclinatus Herit. fol. ellipticis acutis integerrimis subtus petiolis; ranulis floribusque pubescentibus; ranis pendulis; floribus aggregatis. Zizyphus domingensis Duham. Browne jam. t. 29. f. 2. In Jamaica et Domingo. $\hbar$.

1\%. C. mistacinus DC. fol. cordatis obtusis integerrimis supra glabris subtus pilosiusculis; ramis cirrhosis; floribus umbellatis. Rhamnus Ait. In Abyssinia. ந.

18. C. cubensis Lam. fol. elliptico-oblongis subacutis integerrimis superne velutinis subtus ramulis floribusque tomentoso-incanis; pedunc. corymbosis. Jacq. Vind. t. 49. In Cuba et Domingo. $\hbar$.

19. C. Altmani DC. fol. ovalibus obtusis serrulatis superne subvelutinis subtus ramulis floribusque tomentosis canescentibus; pedunc. axillaribus corymbosis. In Mexico. $\hbar$.

b. Petala lobis calycinis longiora longe unguiculata.

20. C. azureus Desf. fol. abova20-0blongis obtusis acute serratis superme glabris subtus cano-tomentosis; thyrsis elongatis; rachi tomentosa. B. 1. 291. C. caeruleus Lag. B. C'ab. 100. In Mexico. ち.
21. C. tardifolias Hort. Hafn. fol. cordato-ovatis trinerviis serratis subtus tomentosis; thyrsis elongatis. In Amer. bor. $\hbar$.

22. C. americanus $\boldsymbol{L}$. fol. ovatis acuminatis serratis trinerviis subtus pulescentihus; thyrsis elongatis; rachi pubescente. Mill. ic. t. 5\%. B. M. 1479. In Amer. bor. $\hbar$. Flores alli.

23. C. ovatus Desf. fol. ovatis ovalibusque serratis 3 -nerviis utrinque pedunculisque ylabris; thyrsis abbreviatis. In Amer. bor. $b$.

21. C. perennis Pursh; fol. ovalibus subsermlatis glabris; paniculis thyrsoideis terminalibus axillaribusque. In Amer. bor, 市.

25. C. intermedius Pursh; fol. obIongo-ovalihus acutis mucronato-serratis triplinerviis subtus pubescentibus; paniculis longissime pedicellatis. In sylvis 'íenasse. 占.

26. C. sanyuineus Purste; fol. oblong 0 -obovatis serratis subtus pubescentibus; paniculis axillaribus thyrsoideis brevissime pedunculatis. Ad ripas IIissouri.

2\%. C. microphyllus Michx. fol. oblongis obtusis integris glalris subfasciculatis; ramis strictis suberectis; corymbis Iaxis. In Amer, bor. ђ.

28. C. serpyllifolius Nutt. fol. elliptico-ovatis serrulatis obtusis; ramis filiformibus decumbentibus; paniculis axillaribus. In Florida.

29. C. buxifoliuls H. et K. Non. Gen. t. 615. fol. ovato-ellipticis obtusis glanduloso-serrulatis $3-5$-nerviis glabris subtus innervis adpresse pilosis; floribus racemosis. In Mexico.

\section{c. Fructus 3-alati.}

30. C. africanus L. fol. lanceolatis ohtusis serratis glaberrimis subcoriaceis reticulato - venosis. Plukn. t. 126. f. 1. Seba thes. t. 22. f. 6. Willemetia africana Brongn. In Prom. b. spei. $\hbar$.

31. C. scandens; pubcscens; caule scandente multangulari; ramulis cirrhosis; fol. ovatis et subrotundis cordatis mucronatis; fructibus tricoccis. Willemetia sçandens Eckl. ct Zeyh. I. Proml. 6. spei. t. 
species dubiac.

32. C. trifueter Wall. futicosus; fol. ovato-ohlongis acuminatis serrulatis subtus pubescentibus; pedunc. agrregatis; fructibus $\mathbf{3}$-quetris. In Nejalia. t.

3.3. C. mocinianus DC. fol. ovalibus integris 1-nerviis subtus ramulisque pubescentibus; pedunc. Iateralihus dichotomis patucińloris. C. macrocarpus fl. mex. ic. In Mexico. t.

3. C. puncifiorus tl. mex. ic. fol. obovato-ohlongis glabris integris sul)dentatisve; racenis lateralibus hrevibus pancifloris. In Mexico. $\hbar$.

35. C. paniculatus Roth; fol. subrotundo-ovalibus acuminatis serratis puhescentibus; paniculae terminalis ramis subcorymbosis. Celastrus Rothiants schult. In Ind. or. t.

36. C. celtidifolius schl. arboreus; fol. cordato-ovatis longe acuminatis 3-nerviis adpresse obsolete serratis subtus molliter pubescentibus. I $\quad \mathrm{J} a$ lapa. t.

37. C. thyrsiflorus Eschh. pl. calif. fol. ovalibus 3-nerviis serrulatis glahris; caule multangulari; paniculis thyrsoideis axillaribus. In California. ち. Frutex 2 -orgyalis. Petala albia.

\section{CELASTRLS L. (1737).}

a. Inermes; folits integerimis.

1. C. filiformis Thunb. scandens; glaber; fol. lanceolatis oppositis; ramulis filiformibus flexuosis; floribus axillaribus subsessilibus. In Prom. b. spei. Ђ.

2. C. crispus Thunb. erectus; ramosissimus; fol. obovatis obtusis undulatis glabris; ranulis pubescentibus; floribus axillaribus umbellatis hirtis. In Prom. b. spei. ந.

3. C. obtusus 'Tlumb. eiectus; glaher; fol. obovatis obtusissimis margine revolutis; paniculis axillaribus. In prom. b. spei. b.

1. C. laurinus 'Thunb. erectus; glaher; fol. ovato-oblongis obtusis sul)emaryinatis margine suhrevolutis; paniculis axillaribus. in Prom. b. spei. $\hbar$.

5. C. oleoides ham. erectus; gláher; fol. ovato-lanceolatis acutis petiolatis; petiolo basi subamplexicauli; corymbis paucifloris. C. oleifolia Pers. In p'roz. b. spei. b.

6. C. pterocaryus DC. erectus; glaber; fol. ovalis subemaryinatis ; racemis brevihus axillaribus; caps. trivaivihus 3-alatis. Burm. aft. t. 9\%. f. 1. In Prom. b. spei. 古.

\%. C. rostratus Thunb. erectus!; glaber; fol. oblongo-ovatis inaequa,libus ohtusiuscule acuminatis; floribus paniculatis; capsulis squamis inermibus aculeatis. In Prom. b. spei. ち.

8. C. tricuspidatus Iam. erectu; ; glaher; fol. oblongo-ovatis ohtusis laevibus; racemis axillaribus simplicibus; fructibus 3-gonis. Olea capensis Buclioz. In Promi. b. spei. ந.

9. C. lucidus L. erectus; glaber; fol. ovalibus s. subrotundis niticlis marginatis; pedicellis axillaribus confertis brevissimis. Herit. stirp. t. אis. Cassia concava Lam. Plukn. t. 230. f. 4. In prom. b. sjei. ち.

10. C. Microphyllus Thunb. erectus; glaber; fol. ovatis obtusis approximatis; paniculis terminalibus dichotomis. In From. b. sjuei. ち.

11. C. ellipticus Thunb. erectus; glaber; fol, eliipticis oppositis; paniculis simplicibus axillaribus. In prom. b. spei. 古.

12. C. macrocarpus $\boldsymbol{R}$. et $\boldsymbol{P}$. peniv. t. 230. f. 16. erectus; glaber; fol.ohlongo-lanceolatis; acumine emarginato; pedicellis axillaribus hrevissimis. In Peruviu. 支.

13. C. bivalris mal. misc. erectus; fol. oppositis lanceolatis acuminatis; pedunc. paucifloris; floribus apetalis; caps. 1-spermis. In ins. Halaicis. 古. Arillus sem. kermesinus.

14. C. bullutus L. scandens; fol. ovatis acutis petiolatis; panicula terminali. Plukn. t. 28. f. 5. In Ilisyaniola. $\hbar$.

15. C. verticillatuss Roxb. arhoreus; fol. subverticillatis oblongo-lanceolatis unciulatis integerrinis glahris; pedunc. umhe!liferis ; caps. oligospermis. In vepulia. 古.

16. C. robustus lroxb. arhorea; fol. alternis lanceolatis integerrimis nitidis; racenis axillarihus folia aequantibus ; capsula 2-sperma. In Silhet.

1\%. C. oppositus Wall. fruticosa. ramulis 4-gonis; fol. opposilis lancenlatis 0 ! tusis integerrimis ; pedunc. axillaribus 3 -floris. In Ind. or. $\frac{b}{}$. 
b. Inermes; foliis dentatis vel crenat is.

18. C. rupestris Eckl. et Zeyh. el:ectus; glaber; fol. oblongo-ellipticis acutis remote denticulatis; floribus axillaribus subternis. In Prom. $b$. s)ei. Ђ. 5-6-ped.

19. C. Mucronatus Eclil. et Zeyh. electus; glaler; fol. ovali-ohtusis vel el liptico-acuminatis mucronatis remote cremulatis; floribus axill. solitariis. In P.rom. b. spei. ந.

20. C. collimis Ecklon et Zeyh. er ectus; glaber; fol. oblongo-obovatis ob tusinsculis repando-crenatis ; floribus axillaribus solitariis. In Prom. b. spei.

21. C. alpestris Blume; fol. ovato-oblongis acutissimis glandulososertulatis glabris in axillis venarum glituduloso-depressis; floribus corymbosis. In Java. 支.

22. C. repandus Elume; fol. ovatooblongis longiter acuminatis subrep ando-crenatis laevilus; paniculis axillarihus. In Java. ђ.

23. C. scundens L. scandens; glaber; fol. ovalibus acuminatis serratis; racımis terminalibus. Duham. t. 95 . Schk. t. 4\%. In Amer. bor. ち. Cor. albiz. Bacca miniata.

24. C. punctatus Thunb. ramis scandentibus punctatis; fol. ovatis serratis. In Japonia et China. ち. Arillus seminis flavus.

25. C. nutans Roxb. scandens? glaber; fol. ovalibus serratis acuminatis apice mucronato-aristatis ; floribus paniculatis terminalibus. In $M y-$ sore. $\hbar$.

26. C. paniculatus $W$. fol. ovatis acuminatis obtusis serratis; panicula elongata terminali. In Ind. or. $\hbar$. Nami fusco-punctati. Flores parvi.

2\%. C. alnifolius Don; fol. ellipticis acminatis serratis nervosis ntrinque opacis glabris; pedunc. axillaribus solitariis 1-floris. In Nepalia. $\hbar$.

28. C.microcarqus Don; fol. ovatis crenatis utrinque puhescentibus basi acutis; pedunc. axillaribus 1 -floris subsolitariis. In Nequlia. $\hbar$.

299. C. acuminatus Thunb. erectus; glalier; fol. ellipticis acutis crenatis; floribus axillaribus subhinis. C. populifolius Lam. In Prom. b. spei. ち. 3-ped. Flor. cermui.
30. C. cassinoides Herit. stirp. $t$. 10. erectus; glaber; fol. ovatis utrinque acutis serratis perenuantihus; pedicellis $2-3$ axillaribus brevissimis. in lrom. b. spei. Ђ. Arluuscula.

31. C. Iycioides Brouss. erectus; glaher; fol. subrotundo-ovatis obtusis crenatis coriaceis; pedicellis axillaribus brevissimis. In ins. Canariis. $ђ$.

32. C. striatus Thunb. erectus; glaber; ramulis striatis foliisque oppositis ovatis acmminatis serratis; pedunc. sparsis 1-floris. In Japonia. $\hbar$.

33. C. edulis Vahl; erectus; glaber; fol. oppositis alternisque ellipticis ohtuse serratis; cymis axillarihus dichotomis. In Yemen. ち. Ramuli compressi.

34. C. trigymus Lam. erectus; glaber; fol. oblongo-ovatis obtuse subserratis; umbellis axillaribus; stylo nullo; caps. trivalvibus. C. cyprius Willem. In ins. Dlauritii. ち.

35. C. mocumbens Thunb. decumbens; glaher; fol. ovatis dentatis; floribus axillaribus sessilibus; caps. 4 5-valvilus. In Prom. b. spei. ち. $\frac{\mathrm{I}}{2}$-ped.

36. C. cymatodes $\mathbf{S} p r^{\text {. fol. obova- }}$ tis undulato-dentatis reticulato-venosis; floribus axillaribus sessilibus. In Prom. b. spei. 方.

3\%. C. cernuus Thunb. fol. ovatis obtusis serratis; pedunc. axillaribus 1-floris cernuis. In Prom. b. spei. $b$.

38. C. undatus Thunb. erectus; glaber; fol. obovato-subcuneiformilus undato-dentatis; floribus axillaribus sessilibus. In Prom. b. spei. ち.

3.9. C. crenatus Forst. fol. ovatis crenulatis; cymis axillariluss. In ins. Marchionis maris pacifici. $\hbar$.

10. C. Heyneanus Roth; erectus; glaber; fol. ellipticis obtuse serrulatis ; cymis axillaribus, fructiferis maximis divaricatis. C. serrulatus Roth. In Ind. or. 古.

41. C. dilatatus Thunb. erectus; glaber; fol. obovatis cuspidatis apice serratis ; floribus terminalibus. In Japonia. Ђ. Fructus caernlei.

42. C. myrtifolins $L$. erectus; glaber; fol. ovatis serrulatis; floribus racemosis. Sloane hist. t. 193. f. 1. In Jamaica. ち. Arbor 18-20-ped. ligno durissimo.

43. C. tetragonus Thunb. erectus; glaber; fol. ovatis serratis oppositis; 
ramis 4 -gonis; paniculis terminalibus. In prom. b. spei. 方.

12. C. unudrun!fulutus schrad. erectus; glaher; ramulis junioribus 4-angulis; fol. alteruis ohlongo-ovalilus spinoso-dentatis nitidis. Ilex acutangula riees. In Brusilia. b.

4.). C. iicifolius schrar. erectus; glaber; fol. alternis oblongis truncaiis subsinuato-spinosis supra lucidis subtus opacis discoloribus. Hex truncata Nees. In Brasilia. 古.

46. C. articulatus Tiunb. erectus; glaher; fol. alternis rotundatis serratis acuminatis; pedunc. axillaribus subtrifidis. C. orbiculatus Lam. C. auriculatus Witm. In Japonia. ち.

4\%. C. ilicinus Burch. erectus; glaber; fol. aliernis ovato-rhomheis grosse serratis subtus pallidis; pedicellis infra medium articulatis. In Prom. b. spei. ђ.

18. C. alatus Thunb. erectus; glaber; ramis alatis; fol. oppositis brevissime petiolatis acuminatis; pedunc. 1-floris supra medium biglandulosis.

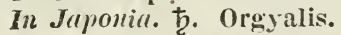

4\%. C. retusus Poir. erectus; glaber; fol. ovatis ovalibusque acuminatis apice emarginatis retusisve serrato-crenatis; pedunc. congestis $1-f l 0-$ ris. C. emarginatus $\mathbf{H}$. et $P$. peruv. t. 229. f. a. In Peruvia. 古. Arbuscula 20-ped.

50. C. confertus R. et P. peruv. erectus; glaber; ramis aggregatoverticillatis; fol. confertis ovalihus subrotundisque serrulatis; floribus congestis. In Peruvia. ఫ.

51. C. rhamnoiles Poir. ramis diffusis; fol. ovatis lanceolatisve acutis argute serratis glahris; pedicellis 1-floris confertis. In Prom. b. spei.t.

52. C. Rothianus schalt. fol. subrotundo-ovalibus acuminatis serratis puhesceutibus; panicula terninali; ramis subcorymbosis. C. paniculatus Roth. In Ind. or. Ђ.

5.3. C. mexicanis Moc et Sesse; erectus; glaber; fol. ovato-oblongis acutis serratis; pedicellis axillarihus 3-filis 3-floris. In Mexico. $ђ$.

54. C. ? magellanicus DC. fol. ovato-lanceolatis acutis obtuse serratis; florihus axillaribus subsessilibus; fructihus compressis 2-spermis. Cassia Lam. Ad fretum mugellan. $\hbar$.

5.5. C. dependens Uall. fruticosus; scandeus; fol. alternis pendulis ob- longis acuminatis serratis glahris; glandulis reniformibus inter stamina. C. Inultiflora Roxb. In Nepalia. 方.

56. C. monospermus Roxb. liuticosus ; scandeus; fol. obovato-ohlongis serrulatis nitidis; paniculis axillaribus terminalibusque elongatis; caps. 1-spernis. In Ind. or.

56. C. panciflorus IVall. fruticosus; erectus; fol. lanceolatis acuminatis sulserratis glaberrimis; pedunc. 6-S-floris; caps. 6-sperma. In ins. fieti Malace. $\hbar$.

58. C. stylosus Wall. fruticosus; scandens; fol. ovato-lanceolatis acuminatis serrulatis; pedunc. racemosis paucifloris; caps. globosa stylo elongato coronata. In Nepulia. $\hbar$.

c. Spinosi; foliis integerrimis.

59. C. excisus Thunb. aculeis recurvis; fol. orbiculatis excisis ; pedunc. axillaribus brevissimis subumbellatis. ln Prom. b. spei. 古.

60. C. lineatus Thunb. spinis foliosis; fol.linearibus; paniculis axillaribus. In prom. b. spei. $\hbar$.

61. C. integrifolius Thunb. spinis foliosis; fol. ovato-reflexis; paniculis axillaribus. In Prom. b. spei. $\hbar$.

62. C. integer Thunb. spinosus; glaher; fol. ovatis emarginatis; paniculis axillaribus. In prom. b. spei. $ђ$.

63. C. emaryinatus $W$. spinis foliosis; fol. obovatis glabris saepius emarginatis; umbellis pedunculatis. In Ind. or. $\hbar$.

61. C. rigiclus Thunb. spinosus; glaber; ramis subsecundis; fol. ohovatis integerrimis excisis; floribus axillaribus sessilibus. In Prom. $b$. spei. 古.

\section{d. Spinosi; foliis dentatis.}

65. C. rufus ITull. arhoreus; glaber; aculeis axillaribus rectis; fol. lanceolatis acuminatis serrulatis glaberrimis; pedunc. capillaribus corymbiferis. In Nepalia. $\hbar$.

66. C. Wallichiamus; fruticosus; erectus; ramis flexuosis spinosis; fol. obovatis coriaceis argute serratis; spinis corymbiferis. C. rigidus Wall. In Inu. ur.t.

6\%. C. senegalensis $\mathrm{L}$. spinis majorilus foliosis; ramis teretibus; fol. ovato-oblongis glabris subglaucis inaequaliter dentatis; cymis minimis. C. 
Phyllanthus Herit.

Arbuscula 2-3-pe d.

68. buxifolins $L$. spicis majoribus foliosis ; fol. lanceolato-obovatis ohtusis serratis glabris coriaceis; ramis angulatis. Houtt. pfl. syst. 3. t. 21 . f. 1. B. M. 20\%0. In Prom. b. spei. ђ. $\leftleftarrows-3$-ped.

69. C. multifiorus Lam. spinis inferiorihus longissimis, rameis parvis subfoliaceis; fol. ohovato-rhomhoideis scrratis glabris; ramis subangulatis. In Africa. b. 4-6-ped.

\%0. C. vigracanthus L. spinis nudis; ramis teretibus; fol. obovatis ellipticisve serratis integrisve lucidis; pedunc. axillaribus pancifloris. B. M. 1157. Nill. ic. t. 87. In Prom. 6. spei. Frutex ruber 2-ped.

71. C. campesiris Eckl. et Zeyh. spinis foliosis subdeflexis; fol. obovatis vel spathulatis fasciculatis dispositis glalris; floribus paniculatis. In p'rom. b. spei. t.

72. C. nemorosus Eckl. et Zeylh. spinosus; glaber; fol. obovatis ovalibus vel ellipticis dentato-crenatis repandisve; florihus axill. subcymosis. In Prom. b. spei. t.

73. C. patens Eckl. et Zeyh. spinosus; glaber; fol. ohovato-oblongis basi attenuatis vel spathulatis remote crenato-serrulatis; floribus subcymosis. In Prom. 6. spei. t.

74. C. goniecaulis Echl. et Zeyh. subspinosus; glaber; fol. obovatis vel ohlongis basi attenuatis crenatis coriaceis; ramis 4-angulis; floribus cynosis. In Prom. b. spei. $\hbar$.

95. C. rhombifolizs Eckl. et Zeyh. spinosus; glaber; fol. rhombeis obtusis grosse serratis coriaceis; cymis axillaribus; spinis brevissimis. In Prom. b. spei. 市.

\%6. C. heterophyllus Eckl. et Zeyl. ranosissimus; spinis foliosis dehilibus ; fol. ohovato-oblongis rlomboideis longe attenuatis mucinato-serratis integerrimisve glabris coriaceis. In Prom. b. spei. $\hbar$.

7\%. C. humilis Eckl. et Zeyh. spinosus; glaber; fol. arcte obovatis retusis basi attennatis crenato - serrulatis subfasciculatis; floribus paniculatis. In Prom. b. spei. $ђ$.

78. C. parvifotius Hickl. et Zeyh. spinosus; gla!)er; fol. ellipticis acutis vel lanceolatis obtusis elilarginatis subserrulatis coriaceis; cynis axillarihus. In prom. b. spei. t. 4-ped.

79. C. spathaephylus Echl. etZeyh. subspinosus; glaher; fol. late spathulatis crenatis quandoque emarginatis; cymis axillaribus. In Prom. b. spei. †.

80. C. venenatus Eckl. et Zeijh. spinis longissimis; fol. olovato-ohlongis crenato-serratis basi longissime attenuatis glahris; cymis creherrimis dichotomis. In from. b. spei. $\hbar$.

81. C. empleurifolius Eckil. et Zeyh. subspinosus; glaher; fol. lanceolatis acutis vel obtusis emarginatis oblongo - ellipticis crenato-serratis; cymis axillaribus. In Prom. b. spei.

82. C. polyanthemos Eckl. et Zeyll. spinis subfoliosis; fol. oblongo-ohovatis coriaceis glahris vix crenulatis; corymbis axillaribus longe pedunculatis. In Prom. b. spei.

S3. C. stenophyllus Echl. et Zeyh. spinis foliosis; fol. linearibus utrinque acutis vel apice obtusis repando-dentticulatis integerrimisve; corymbis axillaribus. In Prom. 6. spei. ђ.

84. C. rotundifolius Thunb. spinis patentibus; fol. petiolatis subrotundis obsolete dentatis. In lrom. b. spei.

85. C. fiexnosus Thunb. spinis filiformibus; ranis flexuosis; fol. glabris ovatis undato-serratis; pedicellis plurimis axillaribus 1-floris. In Prom. b. spei. 古.

86. C. parriflorus Vahl; spinis nudis; fol. ovatis crenatis glabris; pedunc. filiformibus dichotomis folio longiorihus. In Arabia. t.

8\%. C. montants Roth; spinis junioribus foliosis et floriferis; fol. obovatis obsolete serratis margine cartilagineis; cymis axıllaribus dichotomis divaricatis. In Ind. or. $\hbar$.

88. C. zeylanicus Rotit; aculeis axillaribus oppositis petiolo brevioribus; fol. subrotundo-cumeatis apice suhemarginatis olssolete crenatis nilentibus. In Ind. or. ţ.

89. C. ovatus Hill. hort. Keu. $t$. 16. inermis; fol. ovatis petiolatis integris; floribus axillaribus confertis. In Éahama.

90. C. mauritianus Willem. fol. iernatis subtus tomentosis; panicula terminali. In ins. Manritii. th. 
91. C. decolor Caill. voy. MIorée 2. $t$. 64. $f$ : $b$. inermis; fol. ovali-oblongis subcrenatis basi attenuatis; pedunc. axillaribus 6-3-floris; floribus subumbellatis. In Aegypto. $\hbar$.

\section{ASTEROCARPLS Eckl. et Zeyh. (183.5).}

1. A. litoralis Eckl. et Zeyh, erectus; glaber; fol. ohlong-ovatis lanceolatisve oltusis hasi inaequilateris; cymis axillaribus sessilibus paucifloris. In Prom. b. spei. ち. Frutex 1-2-ped.

2. A. typicus Eclil. et Zeyh. erectus; glaher; fol. oblongo-ellipticis obtusis inaequilateris; floribus axillaribus cymoso-subternis. Celastrus pterocarpus DC. Ii prom. b. spei. ち. Frutex 8-10-ped.

3. A. Burmanni Eckl. et Zeyh. erectus; glaber; fol. ovalibus s. ovali-oblongis obtusis inaequilateris; floribus axillaribus subcymosis. Evonynuts Burm. afr. t. 9\%. f. 1. In Prom. b. spei. ち. 1-3-ped.

屯. A. nervosus Eckl. et Zeyh. erectus; glaber; fol. late ovalibus obovatisque inaequilateris utrinque exacte nervosis; floribus cymosis. In Prom. b. spei. Ђ.

5. A. arboreus Eclil. et Zeyh. erectus; glaber; fol. obovatis subrhombeis vel ovato-oblongis obtusis subemarginatis; floribus cymosis cymis multifloris. In Prom. b. spei. ち. Arbor 20-ped.

6. A. stenopterus Eckl. et Zeyh. erectus; glaber; fol. subrotundis ellipticis obovatis subrhombeis vel oblongis inaequilateris basi attenuatis; paniculis dichotomo-cymosis. In Prom. b. spei. 卢. Arbor 15-20-ped.

7. A. tetrapterus Eclil. et Zeyh. erectus; glaber; fol. obovatis ellipticis subrotundis vel oblongis inaequilateris emarginatis basi attenuatis; paniculis axillaribus. In Prom. $b$. spei. $\hbar$.

1035. MYSTROXYLON Eckl. et Zeyh. (1835).

1. M. óligocarpum Eckl. et Zeyh. erectum; glabrum; fol. ellipticis oblongis vel late ovalibus subacuminatis subretusis reticulato-venosis ; fructihus subsolitariis globosis. In Prom. b. spei. 古.

2. N. eucleaeforme Eckl. et Zeyh. erectum; glabrum; fol. ovalibus ellipticis rel ovatis ohtusis inaequilateris coriaceis margine vix revolutis subrepandis; fructibus $3-7$ subglobosis. In lrom. b. spei. $\hbar$.

3. M. athranthum Eickl. et 'Leyh. glahrum; erectum; fol. ovalibus vel subrotundis inaequilateris obtusis crenatis s. profunde excisis reticulatoverosis nitidis coriaceis; fructibus ovato-acuminatis. In prom. b. spei. ち. Arbor 15-ped.

4. M. psilocarpum Eckl. et Zeyh. erectum; glabrum ; fol. ovato-oblongis obtusis inaequilateris profunde emarginatis grosse subuudulato-crenatis; fructibus atro-maculatis. In Prom. b. spei. $\hbar$.

5. M. sessiliflorum Eckl. et Zeyh. erectunı; glabrum; fol.ovato-oblongis obtusis subundato-crenulatis obsolete venosis coriaceis apice retusis ; fructibus apiculatis. In Prom. b. spei. t. Arbor 15-20-ped.

6. H. sphaerophyllum Eckl. et Zeyh. erectum; glabrum; fol. subrotundo-ovatis obtusis crenatis utrinque venosis coriaceis; fructibus globosis. In Prom. b. spei. $\hbar$. Arbor $30-10-$ ped.

\%. M. pubescens Eckl. et Zeyh. erectum ; fol. ovato-ohtusis coriaceis emarginatis crenato-dentatis supra venosis; fructibus ohovatis. In Prom. b. spei. t. Arbor 15-20-ped.

8. M. Kubu Eckl. et Zeyh. In Prom. b. spei. ந. Arbor 20-ped.

9. M.reticulatum; erectum; glahrum; trichotomum ; fol. ovalibus acuminatis obovatis emarginatis coriaceis rigidis margine subrevolutis; floribus paniculatis. In Prom. b. spei. ち. Lauridia reticulata Eckl. et Zeyl. Frutex 10-ped. Flores 4-meri. Drupa 1-10cularis 1-sperma.

\section{MAYTENUS Feuill. (1 25).}

1. $M$. octogonus $D C$. fol. ellipticis obtuse angulatis subenervibus obtusis. Celastrus Herit. Senacea octogona 
Lam. Zizyphus peruvianus L. In Peruria. $\overline{\text {. }}$

2. M. uliginosus $\boldsymbol{H}$. et $\boldsymbol{K}$. ramis tcretihus sparsis; fol. obovato-ellipticis utrinque rotundatis obsoletc repando-dentatis subcoriaceis glahris. Celastrus orhicularis schult. In Quito. $\bar{t}$.

3. M. clilensis DC. fol. ellipticooblongis basi attenuatis apice acuminatissimis margine serratis. Feuill. peruv. t. 20. Celastrus Maytenus W. C. uncinatus R. et P. peruv. t. 230 . f. A. In Chili. $\hbar$.

4. M. verticillatus DC. ramis aggregato-verticillatis ; fol. oblongo-lanceolatis serratis; pelunc. 1-3-floris. Celastrus verticillatus $\mathbf{H}$. et $\mathbf{P}$. peruv. t. 229. f. b. In Peruvia. t.

\section{3\%. POMADERRIS Labill. (1801).}

a. Floribus 5-petalis.

1. P. phylliraeoides Sieb. fol. elliptico-oblongis integerrimis coriaceis subtus villoso-velutinis canis; cymis corymbosis confertis. In Nova Hollandia. †.

2. P. lanigera Sims B. M. 1823. fol. oblongo-lanceolatis integerrimis coriaceis superue subvelutinis subtus ferrugineo-lanatis. Ceanothus laniger Andr. Hep. t. 569. P. ferruginea et viridi-rufa sieb. In Nov. Holl. $\hbar$.

3. P. elliptica Labill. Nov. Holl. t. 86. fol. ellipticis obtusis superne glabris subtus tomento brevissimo adpresso-albis. B. M. 1510. In Nov. Holl. b.

4. P. discolor Vent. malm. $t$. 58. fol. ovato-lanceolatis acuminatis superne glabris sulhtus tomento brevissimo albis. P. acuminata Lk. P. multiflora et discolor Sieb. In Nov. Holl. .

5. P. intermedia Sieb. fol. ellipticis utrinque acuminatis superne glabris subtus cum paniculis, calycibus pedicellisque velutino-canis. In Nov. Holl. $\mathfrak{t}$.

6. P. andromedaefolia Cunningl. fol. Ianceolato-ovalihus supra glahris subtus niveo - tomentosis; colymbis confertis; calycibus petalisque reflexis.
B. M. 3219. In Nov. Holl. t. Flores fusco-lutei.

b. Floribus apetalis paniculatis.

7. P. betulina Cunningh. florum capitulis subpaniculatis; fol. ovalibus obtusis penninerviis subtus ferrugineolanatis. Hook. B. M. 3212. In Neu Süd Wales. ఫ. Cor. lutea.

8. P. apetala Labill. Nov. Holl. t. 8\%. fol. ovato-lanceolatis acuminatis irregulariter serratis, subtus villis stellatis cano-tomentosis reticulatis. In Nov. Holl. Ђ.

9. P. aspera Sieb. fol. ovato-lanceolatis acuminatis irregulariter serratis, superne pube stellata "scabris, subtus villis stellatis cano-tomentosis. In Nov. Holl. ђ.

10. P. lignstrina Sieb. fol. ovatolanceolatis, superne glabris, subtus molliter tomentoso-velutinis; villis simplicibus subsericeis. In Nova Hollandia. 支.

11. P. phylicifolia Lodd. B. Cab. t. 120. fol. linearibus, superne sulnscabris, subtus cano-tomentosis; paniculis foliosis. In Nov. Holl. $\hbar$.

\section{Species dubiae.}

12. P. globulosa; fol. ohovatis integerrimis, subtus ramulis floribusque tomentosis; capsulis usque ad apicem dehiscentibus. Ceanothus globulosus Labill. t. 85. In Nov. Holl. .

13. P. spathulatı; fol. obovatis integerrimis, subtus ramulis floribusque tomentosis; paniculis axillaribus corymbosis. ' Ceanothus Labill. t. 84. In Nov. Holl. ђ.

11. P. capsularis; fol. ovato-cordatis acuminatis serratis; caps. trivalibus dehiscentibus. Ceanothus capsularis Forst. In ins. Taiti. t.

15. P. Wendlandiana; fol. oblongo-lanceolatis acutis, supra glabris, subtus ferrugineo-tomentosis; paniculis axillaribus terminalibusque. Ceanothus schult. In Nov. Holl. t.

\section{HOVENIA Thunb. (1781).}

1. H. dulcis Thunb. fol. ovatis acuminatis serrulatis basi aequalibus 
trinerviis. Kaempf. am. p. 809. ic. Lam. ill. t. 131. In Japonia et Nepalia. 古.

2. H. incequalis DC. fol. ovatolanceolatis acuminatis serrulatis hasi inaequalibus 3 -nerviis; nervo altero basi bipartito; petiolo apice dilatato. In Nepalia. $\hbar$.

3. H. acerba Lindl. B. R. 501. fol. ovatis integerrimis acuminatis basi subcordatis 3 -nervits aequalibus. In California. $\hbar$.

\section{ELAEODENDRON JaCq. (1781).}

1. E. orientale Jacq. ic. $t$. 45. fol. integris dentatisve linearibus lanceolatis ant ovatis petiolo multo longioribus; florihus saepius $\mathbf{5}$-andris. E. indicum Gaertn. t. 5\%. Lam. t. 132. In ins. Manritii et Madagascar. ち.

2. E. anstrale Vent. malm. $t .11 \%$. fol. dentatis crenatis oblongo-lanceolatis coriaceis petiolo multo longioribus; floribus saepius 4-andris. Portenschlagia australis Tratt. t. 250. et P. integrifolia Tratt. t. 284. In Nov. Holl. t.

3. E. glaucum Pers. fol. ellipticis subserratis petiolo vix triplo longioribus ; floribus cymosis 5-andris. Schrebera albens Ret\% obs. b. t. 3. Mangifera glauca Rottb. act. 2. t. 4. f. 1. In Ind. or. $\hbar$.

4. E. xylocarpon $D C$. fol. ovatis integris aut subsinuatis glaucis coriaceis hrevissime petiolatis; corymbis dichotomis; floribus 5-andris. Cassine xylocarpa Vent. choix. t. 23. In ins. st. Thomas. ち.

5. E. rotundatum DC. fol. ovatorotundatis obtusis integerrimis aut subdenticulatis coriaceis brevissime petiolatis; cymis confertis; floribus dioecis. In ins. St. Thomas.

6. E. croceum DC. fol. ellipticis coriaceis serratis; serraturis aristatospinosis. In Prom. b. spei. ち.

7. E. tomentosum W. Hb. fol. oblongo-lanceolatis tomentoris; floribus 5-andris. In Amer. austs. $\hbar$.

8. E. trinerve Hort. madrit. fol. ovatis cordatis trinervibus crenatis; ramis spinosis. Patria ignota.

\section{POL YCARIIA Juss. (178.9).}

1. P. phyllantioirles Jam, ill. $t$. 15) 2. P. epipliylla sim. In Madagascrir. ఫ. Frutex glaher. Folia alterna coriacea in petiolum attenuata apice saepe profunde emarginala in sinu flores 1-5-sessiles gerentia.

\section{H. ETONYMLS Theophr.}

\section{a. Europaei.}

1. F. europaens $L$. ramis laevibus; fol. lanceolato-ovatis tenuissime serratis ; pedunc. sub-3-floris; Iohis capsularum obtusis. E. B. 362. F!. Dall. 1049. Gaertn. t. 113. Nchk. t. 48. Guimp. t. 16. In Europ. ち. Frutex 6-8-ped. Flores albo-virentes. Fructus subkermesinus.

2. E. rerrucosus Scop. pedunc. filiformi-teretihus subtrifloris; floribus 4-andris; capsulis ohtuse 5-gonis; fol. ovatis acuminatis glabris. Jacq. austr. t. 49. Guimp. t. 17. In Europ. austr. ち. Frutex 5-6-ped. Caps. rosea.

3. E. latifolius $L$. pedunc. elongatis filiformihus cymosis ; floribus 5andris; capsulis subulato-5̆-gonis; fol. ovato-ohlongis acuminatis. Jacq. austr. t. 289. Kern. t. 88. In Europ. austr. †. Frutex 12-16-ped. Caps. dilute kermesina.

4. E. nanus Bieb. ranis laevibus subherbaceis ; fol. lanceolatis integerrimis suboppositis; pedunc. 1-3-floris; florihus 4-fidis. In Cancaso. $\hbar$. Suffrutex facie Cneori tricocci.

\section{b. Americani.}

5. E. atropurpureus Jacq. rind. t. 120. ramis laevihus; fol. lance 0 latis petiolatis serratis; pedunc. multifloris compressis; petalis orbiculatis; caps. sulcato- angulatis. In smer. bor. $\hbar$.

6. E. americanus $I$. ramis laevibus; fol. elliptico-lanceolatis serratis subsessilibus; pednnc. 1-3-floris; caps. verrucoso-echinatis. Duham. 3. t. 9. Plukn. t. 115. f. 5. $\beta$. sarmentosus Nutt. In Amer, bor. ち.

7. E. angustifolius Pursh; ramis laevibus; fol. oblongo-aut lineari-ellipticis subfalcatis subintegerrimis; 
pedunc. 1-floris; caps. verrucoso-muricatis. In Georgiu. ち.

8. E. oboratus Nutt. caule prostrato radicante; surculis erectis obtuse 4-angulis; cortice apice inflato; fol. lato-obovatis ohtusis acute serrulatis; calycibus inflatis. In Pensylvania. b.

\section{c. Asiatici.}

9. E. micrantlins Don; fol. oblongis acuminatis serrulatis glabris lucidis; pedunc. 3-fidis multifloris folio brevioribus. E. glaber Hoxb. In Nepalia. 古.

10. E. lacer Don; fol. olovatis serrulatis glabris; pedunc. axillaribus 3-chotomis folia superantibus. E. frigidus Wall. In Nepaliu. ち.

11. E. lucidus bon; fol. lanceolatis acuminatis argute serratis glahris lucidis; umbellis lateralinus oppositis pedunculatis. E. grandiflorus Wall. In Nepaliu. 古.

12. E. tingens Wall. arboreus; fol. suhdecussatis ovato-lanceolatis serrulatis, supra rugosis coriaceis; pedunc. dichotomis; bracteis fimbriatis; capsula 5-sperma. In Inıl. or. 支.

13. E. fimbriatus Wrall. fol. oppositis ovato - lanceolatis acuminatis argute serrulato-fimbriatis; pedunc. umbelliferis; caps. late alata. In penins. Malacc. $\hbar$.

11. E. yrossus Wall. fol. suboppositis longe petiolatis ovatis acutis serratis coriaceis nitidis; pedunc. filiformibus dichotomis. In Ind. or. $\hbar$.

15. E. vagans IVall. fruticosus; scandens; fol. ovato-lanceolatis serratis glaberrinis; peduuc. filiformibus dichotomis; caps. globulari. In $\mathrm{Ne}$ palia $\hbar$.

16. E. echinatus Wall. scandens; radicans; fol. ovato-lanceolatis serratis glaberrimis; pedunc. filiformibus dichotomis; caps, echinata. B. M. 2767. In Ind. or. $\hbar$.

17. E. dichotomus Heyne; ramis dichotomis; fol. lineari-lanceolatis acuminatis integerrimis glabris; pedunc. fasciculatis dichotonis; caps. clavata. In Ind. or. $\hbar$.

18. E. indicus Heyne; ramulis sub4-angulis; fol. lanceolatis acuminatis integerrimis coriaceis, supra nitidis; pedunc. sub-3-floris; caps. clavata apice 5-alata. In Inil. or. $\hbar$.
19. E. garcinifolins Roxb. ramulis teretibus; fol. oppositis lanceolatis acuminatis integerrimis laevibus; pedunc. 3-floris ; caps. 3-valvi 1-sperma. In Ind. or. $\hbar$.

20. E. japonicus Thunb. ramis oppositis; fol. ovatis obtusis dentatis coriaceis; pedunc. compressis 2-3chotomis; floribus 4-fidis; caps. glohosa 3-4-sulcata. Ust. del. 1. t. 4.

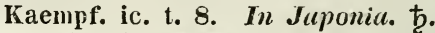

21. E. chinensis Lour. caule herbaceo scandente; fol. cordatis denticulatis asperis; pedunc. lateralibus; bacca libera ovata 10-gona. In Cantone. $\hbar$.

22. E. javanicus Blume; fol. oppositis oblougis obtusiusculis superne remote serrulatis; petalis fimbriatis; caps. 5-gonis. In Java. $\hbar$.

23. E. Sieboldianus Blume; fol. oppositis ohlongo-lanceolatis argute serrulatis giahris infra puberulis; pedunc. apice 5-floris; floribus 4-andris; caps. acute 4 -gonis verrucosis. In Java. $\hbar$.

2.1. E.subtriflorus Blume; fol. suboppositis ovali-Ianceolatis acumiuatis argute scrrulatis glabris; pedunc. apice suhtrifloris; floribus 4-andris; caps. 4-lobis. In Java. ‡.

25. E. Thunberyianus Blume; fol. suboppositis elliptico-ohlongis utrinque attenuatis argute serrulatis glahris; pedunc. axillaribus; floribus 4-andris; caps. 4-lobis. In Java.

\section{STAAVIA Thunb. (1787).}

1. S. radiata Thunb. fol. Ianceolato-3-gonis ; ramulis villosis ; involucri foliolis flores paulo et paleas receptaculi vix superantibus. Phylica radiata L. Plukn. t. 454. f. V. Breyn cent. t. 82. In Prom. b. spei. ち.

2. S. glutinosa Thunb. fol. linearilanceolatis trigonis; ramulis glabriusculis; involucri foliolis flores et paleas triplo superantibus. Wendl. coll. t. 22. Brunia glutinosa L. Plukn. t. 431. f. 1. In Prom. b. spei. 5.

3. S. adenandruefolia Eckl. et Zeyh. ramis puberulis; fol. lanceolatoobtusis apice 3 -gonis calloso-ustulatis iucurvo-patentibus; capitulis corymbosis. In Prom. b. spei. Ђ.

4. S. nuda Brogn. fol. linearibus 
ciliatis. S. pinifolia И. Hb. In Prom. b. spei.

\section{WINTERLIA Spr. (1S25).}

1. U. uliginosa Spr. Sellouia aliginosa Roth. In Ind. or. $\odot$. Herla palmaris. Folia opposita oblonga integerrima. Flores axillares albi.

\section{CLAYTONIA Gronov. (1743).}

1. C. perfoliata Don. fol. enerviis, summis concretis discoideis, radic. petiolatis rhombeo-ovatis; flor. racemosis ; petalis integris aut subemarginatis. B. M. 1336. C. cubensis 30npl. Ann. Mus. 7. t. 6. pl. aeq. t. 26. In Cuba, Mexico et Virginia. $\odot$. Flores parvi alhi.

2. C. alsinoides Sims B. M. 1309. fol. summis oppositis sessilibus ovatis acuminatis; petiolis acute bifidis. Limnia alsinoides Haw. In sinu Nootka. ๑. Flores albi.

3. C. lanceolata Pursh; fol. nervosis, summis oppositis sessilibus ovato-lanceolatis, radic. petiolatis lanceoJatis; florihus acute hifidis. B. M. 2243. Limnia sibirica Haw. In Nibiria. $\odot$. Flores rosei.

4. C. unalaschensis Fisch. fol. nervosis, summis oppositis sessilibus rhombeo-ovatis, radic. petiolatis ovatolanceolatis acuminatis ; petiolis emarginato-lifidis. C. bifila W. Hb. In Unalaschlia. $\odot$.

5. C. arctica Adams; fol, enerviis carnosis, summis oppositis sessilibus ovatis, radic. subspathulatis; racemo secundo; petalis ohovatis emarginatis. C. Joanniana K. et $\$$. In Nithivi $\odot$. flores ampli alhidi s. pallide flavi, fance aurantiaca.

6. C. Chumissoi Ledeh. fol. suhmembranaceis venosis, radicalibus petiolatis ovalibus acutis, summis sessilibus late ovatis; racemo secundo; petalis obovatis emarginatis. In ins. st. Georgii. $\odot$. Flores nagni alhi.

\%. C. rirfiniana L. fol. sub-1-nerviis ohlongis linearibusve, summis oppositis sessilihus elongatis; sepalis petalisque integris. B. M. 941. Plukn. i. 102. f. 3. DC. pl. grass. t. 131. C. caroliniana Michs. In Irirginia, Nora
Anglia et Carolina. $\odot$. Lad. tuberosa. Flores albi et rosei.

8. C. muriflora Moç; fol. enerviis, caulinis alternis ellipticis acutis hasi allenuatis; racemis paucifloris; petalis acute et hreve hifidis. In sinu Nootka. $\odot$. Flores rosei.

9. C. acutifolia pall. in W. Hh. fol. oblongis nervosis acutis; petalis emarginatis. $\quad I n$ sibiria. $\odot$. Ladix fusiformis lateraliter stipata. Caul. 3-4-palmaris.

10. C. tuberosa Pall. in H. $\mathrm{Hb}$. fol. lineari-lanceolatis attenuatis ; petalis retusis; radico tuberosa. In Sibiria. $\odot$. Caul. digitalis.

11. C. nemorosı W. Hb. fol. ovatis, superioribus ternis; racemo geminalo. In umbrosis Jaritae, 4.

\section{5, RORIDELA L, MUTr. (178t).}

1. R. dentata L. Lam. ill. t. $1+1$. B. musciscapa Gaertn. t. 62. f. 8. In Prom. b. spei. t. Sufrutex 1-3pedalis; fol. confertis linearibus ciliato-glaudulosis.

\section{AYENIA L. (1756).}

1. A. pusilla L. fol. ovatis glabriusculis argute serratis; caulibus prostratis. Cav. ic. t. 117. Slloane hist. t. 132. f. 2. Mill. ic. t. 118. In ins. Caribaeis et peruvia. $\odot$.

2. A. laerigata $\$ u$. fol. ovatis glaberrimis integris; urceolo in dentes 10 praeter stamina exserto. In fruticetis Jamaicae. 方.

3. A. tomentosa L. fol. ovato-subrotundis tomentosis; urceolo in dentes 5 praeter stamina exserto. In $\mathrm{Cu}$ mana. $ち$.

4. A. sidaefolia Loefl. it. fol. ovato-oblongis duplicato-serratis subtus tomentosis. In Amer. austr. $ђ$.

5. A. magna $\mathbf{L}$. fol. cordatis ovato-acuminatis serratis pubescentilus; pedunc. multifloris petiolo longioribus. A. cardiopetala fl mex. In Cumana et Mexico. ђ.

6. A. cordifolia fl. mex. ic. ined. fol. cordatis serratis puhescentibus; pedicellis plurimis aggregatis petiolo brevioribus. In Merico. $\odot$. 
1047. BUET'T'NEIBIA Loefl. (17.5\%),

\section{a. Inermes.}

1. B. dasyplyylla Gay; fol. ovatolanceolatis inaequaliter serratis utrinquo hirsutis; petalorum mucrone calycem superante. Commersoniana diphylla Andr. rep. t. 603 . In terra Van Diemen. $\hbar$.

2. B. pannosa $D C$. fol. ovato-lanceolatis inaequaliter dentato-serratis superne pubescentihus subtus hirsutis; petalorum mucrone segmentis calyciuis hreviore. In Nov. Holl. ち.

3. B. hermanniaefolia Gay; fol. ovatis inaequaliter dentato-crenatis rugulosis subtus tomentosis; petalorum mucrone segmentis calycinis breviore. In Nov. Holl. $\hbar$.

4. B. macrophylla $H$. et $K$. fol. cordatis ovato-subrotundis ohtusis serrato-crenatis basi macula rosea notatis ramisque pubescentihus; pedunc. multifloris. In Nov. Granata. 4.

5. B. herbacea Roxb. corom. t. 2.9. fol. cordatis acuminatis dentatis eglandulosis; petalorum mucronibus hrevissimis reflexis. In montibus Coromandeliae. 21.

6, B. grandifolia $D C$. fol. cordatis 7 -nerviis obtusis submucronatis ovatis integris utrinque glabris; petalorum mucronibus brevissimis. In Ind, or.

\%. B. catalpaefolia Jacq. schoenbr. $\boldsymbol{t}$. 46. fol. cordatis integerrinis longe acuminatis glaliris; caule scandente. In Caracas. $\hbar$. Flores albi.

s. B. aspera Colebr. fruticosa; ramis teretibus pulescentibus; fol. late cordatis integerrimis subtus pilosiusculis 5-nerviis; fructibus valide armatis. In lnd. or. $\hbar$.

9. B. pilosi Roxb. fruticosa; volubilis; ramis sulcatis; fol. 5-6-augulis dentatis acutis subtus 7 -nerviis; glandula in medio nervo; nubellis proliferis. In Ind. or. ち.

10. B. Jackiana Wall. fruticosa; scandens; ramis teretibus ferrugineis; fol, oblongis acutis integerrimis stellato-pilosis; floribus corymbosis. In Ind. or. $\hbar$.

11. B. melastomaefolia Hilar. fol. ovato-ellipticis glahris integerrinis 3-plinerviis; panicula spicata elongata. In Brasilia.
12. I3. Gayana Hilar. fol. oblongo-lanceolatis acuminulis integerrimis glahriusculis; umbellis axillaribus pedunculatis. B. laevigata schott. Pohl ic. t. 145. In Brasilia.

13. B. elliptica Poht ic. t. 146. caule erecto 5-angulo ad lentem puberulo; fol. petiolatis oblongo-ellipticis subacutis mucronatis puberulis 3nerviis; pedunc. umbelliferis. In brasilia. 古.

14. Il. affinis Pohl ic. t. 147. caule erecto 5-angulo; fol. petiolatis ovato-acutis mucronatis giahris 3-nerviis; pedunc. umbelliferis. In Brasilia. ち. 3-ped. Cor. rubra.

15. B. oblongata Pohi. ic. t. 148. caule erecto 5-angulo glahro; fol. brevissime petiolatis lanceolato-ellipticis mucronatis 3 -nerviis glabris; pedunc. umbelliferis. In Brasilia. ち. 2-ped. Cor, rubra.

16. P. ramosisima Poll ic. t. 119. caule erecto tereti glahro ramosissimo; ramis 17-gonis; fol. brevissime petiolatis lineari-lanceolatis mucronatis glabris 3-nerviis; paniculis ranosissimis. In Brasilia. ち. 6-ped. Cor. rubra.

1\%. B. jaculifera Pohl ic. t. 150. caule subflexuoso glabro 4 -gono simplici; fol. longissime petiolatis angustis lanceolato-acuminatis mucronatis glahris; pedunc. umbelliferis. In Brasilia. t. 3-ped. Cor. lutea.

18. B. scalpellata Poil ic. t. 151. canle erecto subflexuoso aspero 5gono; fol. longe petiolatis angustis lanceolatis ; rameis hastatis mucronatıs asperis; florihus racemosis terminalihus. In Brasilia. ち. 2-ped. Cor. purpurea.

19. Ri. sidaefolia Hilar. fruticosa; scandens; ineruis; fol. cordatis acuminatis integerrimis glabris suhtus pubesceutibus ; corymbis axillaribus multifloris. In lirasilia. 方.

\section{b. Aculeatae.}

20. B. dentata Pohl ic. t. 1.52. caule erecto tereti piloso ramosissimo; ramis sub-4-gonis; fol. caulinis cordato - subrotundis, rameis ovalibus emarginato-dentatis dentibus spinosis; panicula ramoso-diffusa. In Brasilia. b. 2-ped. Cor. purpurea.

21. B. virycla Pohl ic. t. 153. caule erecto suhangulato ramoso gla- 
hro; ramis 5 -gonis petiolisque brevissine aculeatis; fol. lineari-lanceolatis acute mucronato-dentatis wlabris; janicula ramosa. In Brosilia. †. 2ped. Cor. purpurea.

¿2. 1). scabru loht ic. $t .15 t$. caule stricto subaugulato simplici glahro; fol. petiolatis lanceolato-ellipticis scal ris apice serrato-mucronatis; panicula abhreviata. In Brasilia. 万. 2uhnaris. Cor. purpurea.

23. B. celtrides Hilar. fol. subcordato-ohlonwis acuminatis serratis supra asperis subtus pubescentibus; paniculis axillaribus. In Brusiliu. $\hbar$.

24. B. sauiltuejolia Hilur. F'l. bras. $t$. $2 \%$. caule suffruticoso; rol. sagillatis a!cutis summo apice dentatis; petiolo longissimo 3-gono; racemo terminali. In Brasilia. $\hbar$.

25. It. hirsuta R. et P. /. perur. fol. cortatis acutis crenatis subtus hirsutis; costa petiolisque aculeatis; pedunc. congestis compositis. In Peruvia. 古.

26. B. mollis H. et K. Nor. Gen. t. 4S1. $f$. a. et $b$. fol. cordatis acuminatis crenatis molliter tomentosis basi macula rosea notatis; ramis aculeatis villosu-tomentosis. Prope Sunta Fee de Poyota. b.

27. B. cordata Lam. fol. cordatoovatis serratis pubescentibus; costa petiolisque aculeatis; pedunc. 3 -floris. Cav. diss. t. 150. In Peruvia. 5 .

28. R. sulcata R. et P. peruv. fol. cordato-ovatis serratis pubescentibus; costa petiolisque aculeatis; pedunc. 3-5-floris; caule 5-sulcato.

\section{Peruvia. †.}

2.9. B. lanceolata fl. mer. ic, ined. fol. cordato-lanceolatis rariter serratis acuminatis petiolisque inermibus; caule aculeato scandente anguloso. In Niexico. ち. Petala allia setis purpureis.

30. B. oratu Lam. fol. ovatis dentato-serratis glabris; petiolis inermibus; caule erecto; ramis $\mathbf{5}$-angularihus aculeatis. Cav. diss. t. 149. f. 1. In Peruria. t.

3f. B. microphilla L. fol. ellipticis integerrimis apice subdentatis emarginatis; aculeis stipularibus. Cav. diss. 1. 118. f. 2. In America et Domingo. $\hbar$.

32. If. tereticaulis $L$, $\mathrm{m}$. fol. Ianceolatis acuminatis integerrinis; rachi petiolis, canleque tereti aculeatis. Car. diss. t. 149. f. 2. In Amer. austr. ち.

3.3. Is. scubra L. fol. lanceolatis dentatis hasi suhhastatis; rachi, petiolis cauleque angulato subsarmentoso aculeatis. Cav. diss. t. 148. f. 1. Aubl. Guj. t. 96. In smer. austr. 5 .

34. B. carthagenensis Jac\%. fol. caulinis acutis, rameis ovato-lanceolatis obtuse acumiuatis integris; costa, petiolis ramisque aculeatis. Prope Curthuyenum. †.

35. I. acuminata Brel. fol. ovatis acuminatis inermilus ; petiolis subaculeatis; caule tereti aculeato. Ad Carucas.

36. H. salicifolia $\boldsymbol{H}$. et $\boldsymbol{K}$. fol. lanceolatis glahris; caule angulato; petiolis rachique foliorum aculeatis. In Cumunu. .

3\%. B. corylifolia H. et B. fol. oblongis subcordalis serratis acutis; caule aculeato. In Amer. austr.

\section{ALMEIDEA. Hilar. (1883).}

1. A. lilacina Hilar. fol. Ianceolatis; floribus thyrsoideis; pedunc. puberulo; petalis obtusis. In ltrasilia. 5 .

2. A. rubra Hilar. fol. lanceolatis oblongis; floribus racemosis; pedunc. glabro; petalis obtusissimis. In Brasilia. ђ.

3. A. caerulea Hilar. fol. oblongis hasi attenuatis apice obtusis interdum emarginatis; racemis terminalibus; pedurc. glabro; petalis obtusis. Aruba caerulea Mart. Act. bonn. XI. t. 27. In Brasilia. t.

4. A. alba Hilar. fol. obovato-cuneiformibus cuspide ohtuso; racemis bifidis secundis; pedunc. nudo; petalis obtusis. Aruba alba Mart. 1. c. t. 28. In Brasilia. $\hbar$.

5. A. Longifolia Hilar. fol. lanceolatis oblongis; floribus racemosis; pedunc. puhescente; petalis obtusis. In Brasilia. ђ.

6. A. acuminata Hilar. fol, oblongo-lanceolatis utrinque acutis; floribus terminalibus racemoso-panicula(is; pedunculo pubescente; petalis obtusis. In Brasilia. ‡. Flores lilacini. 


\section{SPIRANTHERA Hilar. (1823).}

1. S. odoratissima Hilar. Trephanthus jasminiodorus Mart. nov. act. boun. 11. t. 31. In Brasilia. 古. Frutex ramis patentibus. Folia ternata ovato-acuminata. Flores paniculati rosei.

\section{DIOSMA L. (1\%3\%).}

a. Discus perigyus apice nudus sublobatus. Eudiosma Bartl. et Wendl.

\section{* Foliis oppositis.}

1. D. succulenta Wendl. Coll.t. 1. fol. 4-fariam imbricalis ovatis obtusiusculis cariuatis crassiusculis ; corymbis paucifloris. D. decussata Lain. D. oppositifolia $\mathbf{R}$. et s. In Prom. b. spei. ђ.

2. D. oppositifolia I. fol. oppositis sparsisque lineari-suhulatis carinatis margine scahro ciliatis. D. pectinata Thunb. D. subulata Wendl. coll. 1. t. 8. In Prom. b. spei. †.

3. D. scabra Lam. fol. oppositis decussatis-linearibus mucronato-recurvis scabris ciliatis; floribus subbinis. In Prom. b. spei. $\hbar$.

4. D. thyrsophora Echl. et Zeyll. fol. lineari-lanceolatis ontusis apice glauduloso-incrassatis subtrigonis reflexis; laciniis calycis margine ciliatis. In Prom. b. spei. ち.

\section{** Foliis alternis patulis.}

5. D. rubra $I$. fol. sparsis lineari3-quetris cuspidatis hasi ciliatis glabris; capsulae cornubus rectis. B. $\mathbf{R}$. 563. D. vulgaris Schl. Linn. In Prom. b. spei. ち.

6. D. ericoides $\boldsymbol{L}$. fol. confertis 3-gonis obtusis patulis glabris; floribus subbinis terminalibus. In Prom. b. spei.

7. D. hirsuta L. fol. sparsis linearibus cuspidatis villosis; ramis pedunculisque hirsutis. In Prom. b. spei. ђ.

8. D. ambigna Burtl. et Wendt. fol. sparsis linearibus cuspidatis carinatis ciliatis erectiusculis; pedunc. pubescentibus; capsulae cornubus subrecurvis. In Prom. b. spei.
9. D. linearis Thunb. fol. linearibus obtusis patulis; ramis pedicellisque glahris; floribus terminalibus subsolitariis. In Piom. b. spei. $\hbar$.

10. D. longifolia Bartl. et Wr. fol. confertis linearibus cuspidatis elongatis ciliatis patulis; capsulae cornuhus uncinatis. 1). tenuifolia W. rubra Lam. In Prom. b. spei. 古.

11. D. Simsiana Eclil. et Zeyh. fol. confertis 3-gonis obtusis floribus terminalibus solitaris. In prom. $b$. spei. ђ.

12. D. virgata Meyer; fol. confertis linearibus cuspidatis strictis adpressis margine scahris; floribus glomeratis. D. Meyeriana Spr. In Prom. b. spei. $\hbar$.

13. D. aculeophylla Eckl. et Zeyh. fol. lineari-acutis subteretibus apice reflexo-puugentibus imbricatis; calycis laciniis reflexis; petalis obovatis. In Prom. b. spei. 方.

14. D. glabrata Meyer; fol. sparsis trigono-linearibus erectis apice uncronato-recurvis margine serrulatoscabris; pedunc. calycibusque glaberrimis. D. aspalathoides Lam. In Prom. b. spei. t.

15. D. Iepressa Eckl. et Zeyh. fol. carinato-subtrigonis basi attenuatis apice recurvo-mucronulatis margine pellucido-scabriusculis; petalis late obovatis. In Prom. b. spei. $\hbar$.

16. D. ramosissimu Bartl. fol. confertis lineari-3-gonis obtusissimis strictis glabris; floribus subsolitariis; petalis obtusis. D. cupressina Lam. In Prom. b. spei. 市.

17. D. cupressina $\mathbb{L}$. fol. 4-fariam imbricatis oblongo-lanceolatis citrinatis acutis; petalis acuminatis. D. dichotoma Berg. In Prom. 6. spei. ち.

b. Filamenta disci perigyni glandula terminata longitudine staminum fertilium.

a. Petala unguiculata. Agathos ma Wendl. et Bartl.

18. D. lediformis Eckl. et Zeyh. glaberrima; fol. elliptico-oblongis acutis adpressis intus concavis apice inflexis subtus pellucide punctatis; floribus umbellatis. In Prom. b. spei.

19. D. bifida Bartl. et H. fol. lanceolatis mucronatis punctatis grla- 
bris; pedunc. terminalibus subglobulosis. Jacq. Coll. t. 20. f. 1. In Prom. b. spei. ち.

20. D. servuriaefolia Eckl. et "zeyh. ramulis glabris; fol. lineari-lanceolatis obtusiusculis convexo-carinatis erecto-patulis apice hamoso-incurvatis margine carinaque pilosis; floribus umbellatis. In Prom. b. spei. ち.

21. D. Iancifolia Eckl. et Zeyh. ramulis puherulis; fol. ovali-ohlongis acuminatis pungentilus piloso-scahriusculis reflexis subtus glandulosopunctatis; floribus umbellatis. In Prom. b. spei. ち.

22. D. involucrata Eckl. et Zeyh. ramulis puberulis; fol. ovali-oblongis apice gibhoso-incrassatis extus scabro-puberulis glanduloso-punctatis; floribus subcapitatis. In Prom. $b$. spei. 支.

23. D. collina Eclil. et Zeyh. ramulis puberulis; fol. minutis sub-3-gonis crassiusculis apice inflexis extus scahris bifariam glandulosis; floribus umbellatis. In Prom. b. spei. $\hbar$.

21. D. biophylla Eckl. et Zeyh. ramulis puberulis lanceolatis ohovatisque acuminatis pungentibus reflexis nitidis extus molliter pilosis impressopunctatis. In Prom. b. spei. $\hbar$.

2.5. D. Schlechtendaliana Eckl. et Zey h. fol. confertis lanceolatis apice margineque revoluto-incrassatis glandulosis ciliatis; pedunc. lirsutis. D. serpyllacea Lichtenst. In Prom. $b$. spei. $\hbar$.

26. D. sedifolia schlecht. ramis glabris; fol. subtrigonis obtusis margine carinaque ciliatís dein tuberculatoscabris; floribus subumbellatis. In Prom. b. spei. ち.

27. D. robusta Eckl. et Zeyh. ramulis puberulis; fol. linearibus utrinque acutis apice gibbosis subtus pubescentibus; floribus umbellatis. In Prom. b. spei. ち.

23. D. yonayuensis Eclil. et Zeyl. ramulis glabris; fol. lineari-obtusis subtrigronis adpressis subtus impressopunctatis utrinque hirtellis; floribus umbellatis. In Prom. b. spei. $\hbar$.

29. D. trachyphylla Ecíl. et Zeyll. ramulis hirtellis; fol. linearibus erecto-patulis margine subrevolutis subtus impresso-punctatis utrinque hirtellis; foribus umbellatis. In Prom. b. spei.
30. 1). montana Schl. ramulis subglahris; fol. lineari-3-gonis acutis nargine carinaque longa ciliatis inpresso-punctalis; floribus subumbellatis; filamentis inferne pilosis. In Prom. b. spei. t.

31. D. nigro-montana Eckl. et Zeyl. ranulis glabris; fol. linearibus utrinque acutis subpungentibus subtrigonis apice reflexis subtus impressopunctatis ; flocibus subumbellatis. In Prom. b. spei. 方.

32. D. Joubertiana Schl. fol. lanceolato-trigonis acutis margine carinaque ciliatis dein scabris; floribus subumbellatis; filamentis inferme pilosiusculis. In Prom. b. spei. $ち$.

33. D. acuminata Willd. Wendl. coll. $t$. 28. fol. ovatis cordatis longe acuminatis ciliatis demum patentibus; pedunc. umbellatis villosis; calycibus glandulosis. In Prom. b. spiei. $\hbar$.

34. D. imbiricata Wendl. coll. t. 9. sub fucco; fol. ovatis acuminatis confertis inloricatis punctatis ciliatis; capitulis terminalibus umbellatis; filamentis basi barbatis. In prom. $b$. spei. 方.

35. D. vestita Lichtenst. sub Bucco; fol. ovatis ovato-lanceolatisque ciliatis 4-gono-imbricatis; capitulis terminalibus. In Prom. b. spei. 支.

36. D. asperifolia Eckl. et Zeyh. ramulis puberulis; fol. minutis subcordato-lanceolatis extus aspero-hirtellis apice inflexis; floribus capitatis; filamentis filiformibus ciliatis. In Prom. b. spei. $\hbar$.

37. D. barosmaefolia Eckl. et Z्Z. ramulis glabriusculis; fol. planis lineari-lanceolatis hasi attenuatis glanduloso-subcrenatis margine revolutis subtus bifariam punctatis; floribus umbellatis. In Prom. b. spei. $\hbar$.

38. D. glauca Eckl. et Zeyh. hirtella; fol. linearibus utrinque acutis extus 4-fariam glandulosis margine inflexis ; floribus subcorymbosis; filanentis inferne puberulis. In Prom. b. spei. 支.

3.9. D. Linifolia Lichtenst. fol. linearibus acutis planis glabris scabriusculis margine pellucido-punctatis; florilus umbellato-capitatis. In Prom. b. spei. $\hbar$.

40. D. mollis Bartl. fol. patentibus oblongis obtusiusculis carinatis rugosis utrinque pilosis; pedunc. ca- 
pillaribus suhglanduloso-pilosis. Prom. b. spei. 支.

41. J. ciliuta I.k. fol. sparsis ovato-lanceolatis acutis denticulatociliatis revolutis; pedunc. glaberrimis. In From. b. spei. t.

12. b. hybrida Spr. fol. patulis oh!ongis obtusis carinatis apice gihbo3-gonis carina margineque ciliatis; pedunc. calycihusque glaberrimis. In irom. b. spei. 古.

13. D. filipetala Eckl. et Zeyh. ramulis puberulis; fol. planis linearibus erecto-patulis apice calloso-incrassatis margine revolutis suhtus inpresso-punctatis; floribus umbellatis.

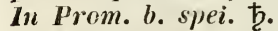

11. D. obtusa Wendl. Coll. t. 13. sub Bucco; fol. sparsis patentissimis ohlongo-lanceolatis obtusiusculis carina margineque ciliatis; pedunc. elongatis glanduloso-villosis. In Prom. b. spei. 方.

15. D. thymifolia Schl. glaberrima; fol. ovalibus suborbiculatibusve planis patentissimis subtus glandulosopunctatis; floribus subumbellatis. In prom. b. speei. 古.

46. D. pilifera Schl. ramis pubescentibus; fol. ellipticis acutis longe inflexo-cuspidatis glanduloso-crenatis epunctatis glahris; filamentis sterilibus; apice incurvo. In Prom. b. spei. ந.

4\%. D. orbicularis Bartl. fol. sparsis patentissimis subrotundo - ovatis glaherrimis crassiusculis subtus epunctatis ; pedunc. pubescentibus ; laciniis calycis subrotundis. In Prom. $b$. spei. 卢.

45. D. Marifolia Eckl. et Zeyjl. ramulis puberulis; fol. minutis planis ovato-oblongis obtusis reflexis margine revolutis glanduloso - subcrenulatis utrinute pubcrulis; floribus umbellatis. In brom. b. spei.

4.9. D. suareolens Eckl. et Zeyh. ramulis puhescentihus; fol. minutis ovato-ohlongis revolutis planis apice gland:loso-incrassatis margine longe ciliatis; filamentis ciliatis. In lorom. b. sjei. t.

50\%. 1). stadensis Eckl. et Zeyl. ramulis glabriusculis fol. nimutis crecto-patulis glabris lineari-ohlongis margine subrevolutis; glaudulis pellucielis subcrenulatis. In Prom. b. spei. t.

if. I) microphylla Heyer; glabcuima; fol. patulis oblongitis obtusis carinatis; pedunc. petalisque elongatis. In Prom. b. spei. $\hbar$.

52. D. Cerefolinm lent. malm. $t$. 93. fol. lanceolato - linearibus acutis subimbricatis ciliatis ; capitulis terminalibus; pedicellis calycibusque villosis. In Prom. b. spei. b.

53. D. acerosa Eckl. et Žeyh. ramulis glahriusculis; fol. lineari-teretilus utrinque acutis mucronato-pungentibus extus impresso-punctatis; florihus subumbellatis. In Prom. b. spei. ђ.

54. D. prolifera Wendl. coll. $t .7 \%$. sub Bucco; fol. lanceolatis aggregatis pilosis punctatis apice harbatis patulis; umbellis confertis multifloris. In Prom. b. spei. 古.

55. D. hyponeyra Eckl. et Zeyjl. ramulis puberulis; fol. planis linearilanceolatis glahris erecto-patulis subtus pellucide punctatis apice clavatogibbosis. In rrom. b. spei. $\hbar$.

56. D. Thunbergiana schl. fol. imbrucatis lanceolatis carinatis ciliatis apice incurvis; pedunc. hirsutis. D. ciliata Thunb. D.? Bartlingiana Eckl. et Zeyl. In Prom. b. spei. ち.

5\%. D. parviflora 1 . et $W$. fol. sparsis lineari-3-gonis nucronatis glabris obsolete punctatis. In prom. $b$. spei. ち.

58. D. cuspilata $B$. et W. fol. sparsis-3-gono-suhulatis punctatis subciliatis; pedunc. fastigiatis elongatis. Bucco Wendl. Cóll. t. 28. In Prom. b. spei. 古.

5.9. D. Eckloniana Scht. ramulis puberulis; fol. linearihus acutiusculis margine revolutis utrinque hirtellis; floribus umbellatis; filamentis basi ciliatis. In Prom. b. spei. ђ.

60. D. patentissima Eckl. et Zeyh. ramulis glahris patentissimis; fol. linearibus pungentihus erecto - patulis glahris subtus hitariam et margine pellucido - punctatis. In Prom. b. spei. t.

61. D. geminifolia Eckl. et Zeyh. ramulis pulsescentions; fol. lineariacuminatis subadpressis glabris subtus glandulosis; filamentis medio dilatatis puberulis. In Prom. b. spei. b.

62. D. adenocaulis Eckl. el 'he! h. ranulis puberulis; fol. lineari-acutis remote ciliatis suhtus mlandulono-ncabridis; florilus umbellatis; filamentis puberulis. In Prom. b. spei. ち.

63. I. aulonoplita Nikl. et Zeysh. glabra; fol. linearibus utrinque acatis 
udpressis extus glandulosis; filamentis sterilibus petaliformihus apice bifidis. In prom. b. spei. ђ.

64. D. nodosa Thunb. glaherrima; ramosissima; fol. subiubricatis trigonis angustissimis obtusis subtus carinatis exsulcis. In From. b. spei. ち.

6.5. I). Litenhugensis; ramulis pubescentilus; fol. lineari-sul)-3-gonis undique pilosis; floribus umbellatis; filamentis sterilihus patentim pilosis. D. ericoides schl. In Prom. b. spei. ђ. „6. D. herseliaefolia Eckl. et Zeyh. glaberrima; fol. minutis lineari-obtusis subtrigonis margine diaphanis, suhtus pellucide glandulosis; filamentis sterilibus inferne puberulis. In Prom. b. spei. 古.

6\%. D. lasiophylla Spr. fol. inbricatis apice incurvis lanceolatis obtusiusculis subtus hirsutis; ramis suhverticillatis; pedunc. pubescentilus. D. villosa W. D. hirta B. R. D. pubescens Thunb. Wendl. coll. t. 2. In Prom. b. spei. ち.

68. D. ylabra Eckl. et Zeyh. pedunc. glabris; fol. confertis lanceolatis crassis apice gilobosis pilosiusculis. In Prom. b. spei. 古.

69. D. thydilles Willd. fol. linearisubulatis glabris adpressis; ramis verticillatis; floribus umbellatis; pedunc. pubescentihus. D. erecta $\delta$ glaberrima sclu. In Prom. b. spei. $\hbar$.

80. D. patula Nieyer; fol. sub-3gono-linearihus obtusis supra glaberrimis subtus exsulcis scabris; pedunc. calycibusque pubescentibus. In Prom. b. spei.

71. D. decumbens Eckl. et Zeyh. ramulis puberulis; fol. minutis linearilanceolatis obtusis subimbricatis extus hirtellis 4-fariam glandulosis; filamentis sterilibus medio ciliatis. In Prom. b. spei. ђ.

72. D. erecta Bartl. fol. imbricatis 3-gonis obtusis glabriusculis; pedunc. villosis. D. brevifolia Spr. In Fiom. b. spei. .

73. D. chortophila Eckl. et Zeyh. glaherrius; fol. minutis lineari-sul)3-gonis "subadpressis apice inflexis calloso-incrassatis margine revolutis subtus convexo-glandulosis; floribus umbellatis. In Prom. b. spei. 古.

71. D. platypetala Eckl. et Zeyh. ramis hirtellis; fol. subplanis subadpressis extus margine subrevoluto et subtus pellucide glandulosis hirtello- ciliatis; floribus umbellatis; filamentis sterilihus attenuatis reflexis. In Prom. b. spei. 方.

75. I). cyminodes Furtl. et Zeyh. glaherrima; fol. minutis lineari-acutis apice inflexis subtus bifariam impresso-punctatis; florihus umbellatis; filamentis inferne ciliatis. In R'rom. b. spei. ந.

76. 1). nigra Eclil. et Zeyh. ramulis hirtellis; fol. minutis lineari-obtusis carinato-suhtrigonis adpressis margine scahrido-ciliatis subtus implesso-punctatis. In Prom. b. spei. ち.

7\%. D. fastigiatre Eckl. et Zeyh. ramis puberulis; fol. minutis glahris suhadpressis suhovatis apice glanduloso-mucronatis extus impresso-punctatis; filamentis medio dilatis ciliatis. In From. 6. spei. $\hbar$.

c. Staminibus sterilibus hrovissimis glandula terminatis. A cmadenia Rart t. Eckl.etZeyh.

\%8. D. flaccida Eckl. et Zeyh. fol. ovali-ollongis vel lanceolatis mucrouatis margine subcrenulatis pellucidopunctatis oppositis flaccidis; petalis obovatis. In rom. b. spei. $\hbar$.

79. D. tetraciona Bartl. fol. 4-fariam imbricatis rhomboideo-subrotundis complicatis margine scabris apice dilatatis; floribus amplis. In Prom. b. spei. 占.

80. D. Mundiana Eckl. et Zeyh. fol. subovatis obtusis margine subrevolutis ciliatis apice inflexis; calycis laciniis nitidis pellucidis rotundatis. In Prom. b. spei. ち.

81. D. laerigata Spr. fol. 4-fariam imbricatis ellipticis complicatis obtusis glaberrimis; foribus sessilibus solitariis; filamentis disci sterilihus brevissimis. D. tetragona Thunb. Iı Prom. b. spei. ち.

82. D. obtusata Thunb. fol. confertis sub-3-gono linearibus acutis; floribus sessilibus solitariis; filamentis sterilibus brevissimis. In prom. $b$. spei. Ђ.

83. D. pungens $B$. et $\boldsymbol{W}$. fol. 4fariam imbricatis ellipticis complicatis glabris; florihus solitariis sessililus; petalis barbatis. In Prom. b. spei. ఫૃ.

81. D. juniperina Bartl. fol. confertis sub-3-gono-linearibus acutis subpetiolatis; floribus sessilibus solitariis ; 
filamentis sterilibus brevissimis. In Prom. b. spei. $\hbar$.

85. D. muraltioides Eckl. et Zeyh. fol. linearibus sub-3-gonis acutis pungentibus pellucido-marginatis adpressis imbricatis; laciniis calycis oblongis lateralibus diaphano-membranaceis ciliatis. In Prom. b. spei. ఫ.

d. Unguibus petalorum basi canaliculatis, stamina sessilia basi recipientibus. Coleonema Bartl. - Eckl. et Zeyh.

86. D. alba Thunb. fol. sparsis linearibus cuspidatis serrulato-scahris; filamentis sterilibus petalorum plica involutis. D. $\beta$. virgata Schl. et $\gamma \cdot$ gr $a-$

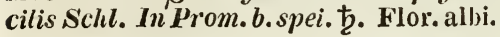

e. Staminibus sterilibus glandula terminatis. Adenandra Willd.

8\%. D. mundiaefolia Eckl. et Zeyh. sub Adenandra; fol. ovalibus s. ovatioblungis margine revolutis impressopunctatis glanduloso-mucronatis nitidis; floribus viscido-pedunculatis ; petalis ad basin subpuberulis. In Prom. b. spei. ‡.

88. D. brachyphylla Schl. sub Adenandra; fol. parvis ovalibus obovatis subrotundisve glaberrimis hasi adpressis apice patentibus margine revolutis; calycis laciniis glabris ovatis obtusis. In Prom. b. spei. ち.

89. D. fragrans B. M. 1519. fol. ovato-ohlongis glandulosis sparsis; pedunc. glutinosis aggregatis; petalis emarginatis. Adenandra $\mathrm{R}$. et $\mathrm{S}$. In Prom. b. spei. ђ.

90. D. intermedia Eckl. et Zeyh. sub Adenandra; fol. lineari-lanceolatis margine subrevolutis glabris; laciniis calycis ovatis obtusis petalisque glabris. In From. b. spei. 支.

91. D. maryinat $I$. fol. cordatis, inferioribus ovatis superioribus lanceolatis; umbellis terminalibus. Adenandra 13. et s. In Prom. b. spei. t.

92. D. humilis Eckl. et Zeyh. sub Adenandra; fol. basi subcordatis ovato-oblongis margine revolutis memhranaceis; laciniis ad apicem invotutis. In Prom. b. spei. $\hbar$.

93. D. viscida Eckl. et reyh. sul Alcnandra; fol. ovalibus margine revoluto-impresso-punctatis apice 1- glandulosis confertis nitidis; petalis rotundato-retusis. In Prom.b. spei. $\downarrow$.

94. D. Meyeri; fol. confertis summis densissime imbricatis ovatis acuminatis glaberrimis; calycibus subsessilibus petalisque ciliatis. Adenandra cuspidata Meyer. In Prom. $b$. spei. Ђ.

9.5. D. Irichtensteiniana; fol. confertis ovato-ohlongis integerrimis calycibusque vix pedunculatis pubescentibus. Adenandra villosa Lichtenst. In Prom. b. spei. ち.

96. D. rotundifolia Eckl. et Zeyh. sub Adenandra; fol. rotundatis glanduloso-crenulatis apice reflexis densissimis glabris; calycis laciniis orbiculato-acutatis. In Prom. b. spei. $\hbar$.

97. D. gracilis Eckl. et Zey/l. sub Adenandra; fol. ovali-rotundatis glanduloso-crenulat is carinato-inflexis glaberrimis; calycis laciniis margine diaphanis; petalis suborbiculatis. In Prom. b. spei. ち.

f. Staminibus sterilibus latiusculis subpetaloideis exunguiculatis, apice obscure glanduliferis. Barosma Willd. et alior.

98. D. crenata I. fol. suboppositis lanccolatis petiolatis patentibus serrulatis glanduloso-punctatis glabris; pedunc. axillaribus subdivisis. D. serratifolia Curt. B. M. 456. Lodd. B. Cab.373. Parapetalifera serrata Wendl. Coll. t. 34. In Prom. b. spei. ち.

99. D. betulina Thunb. fol. obovato-cuneatis crenatis subtus punctatis patentissimis; floribus axillaribus

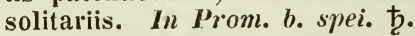

100. D. latipolia Thunb. fol. oppositis obovato-oblongis sessilibus serrulatis subtus epunctatis glabriusculis; ramis villosis; floribus subsolitariis. In Prom. b. spei. ち.

101. D. graveolens Iichtenst. fol. ovatis integerrimis imbricalis glabris; floribus axillaribus perlunculatis soli-

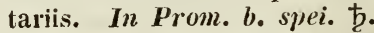

102. D. ovata Thumb. fol: oppositis ovato-subrotundis obtusis glaberrimis integerrimis subtus punctatis; florihus axillaribus pedunculatis. B. M. 1616. Bucco ovata IVendl. coll. t. 20. In Prom. b. spei. ち.

103. D. alpina Eckl. ol zip yh. sub Barosecs; fol. ovatis incrassato-cre- 
natis apice inflexis margine revolutis pellucido-punctatis densis nitidis; petalis vix unguiculatis. In Prom. $b$. spei. ந.

104. D. vennsta Eclil. et Zeyh. sub Barosma; fol. ohovato-cuneatis vel rotundatis incrassato-crenulatis pellucido-punctatis erecto-patulis glabris; laciniis calycis ohtusis carnosis. In Prom. b. spei. 古.

10.5. D. pulchella $I_{\text {. }}$ fol. confertis ovatis glaherrimis margine incrassatis glanduloso-crenatis; pedunc. axillaribus folia excedentibus. In Prom. b. spei. 古.

106. D. scoparia Eckl. et Zeyh. sub Barosma; fol. elliptico-oblongis vel subovatis margine impresso-punctatis subrevolutis patulis nitidis; calycis glanduloso - incrassati laciniis ovato-rotundatis minutis. In Prom. b. spei. t.

10\%. D. oblonga Thunb. fol. sparsis ohovato-oblongis coriaceis nitidis margine incrassatis revolutis integerrimis ; ramulis pubescentibus. In Prom. b. spei. 卢.

108. D. ternata Eclil. et Zeyh. sub Barosma; fol. ternis oblongis utrinque attenuatis subovalibus margine crassiusculo impresso-punctatis nitidis; calyce glanduloso nitido, laciniis minutis. In Prom. b. spei. 古.

109. D. pauciflora Eckl. et Žeyh. sub Barosma; fol. oblongis utrinque attenuatis ovalinusque margine subrevolutis impresso-punctatis; laciniis calycis ovato-obtusis minutis. In Prom. b. spei. 古.

110. D. foetidissima $S p r$. fol. subternis linearihus obtusissimis revolutis; floribus terminalihus subumbellato-aggregatis. In Prom. b. spei. ち.

111. gnidiodes; ramulis puberulis; fol. minutis oblongo-ellipticis ovalibusque subcarinatis suliglandulosopunctatis; filamentis sterilibus crassiusculis patentim pubescentilus, apice attenuato. Agathosma sichl. In Prom.

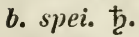

112. D. dioeca Ker. B. R. 502. fol. sparsis, superioribus ternis lanceolatis utrinque attenuatis glandulosopunctatis patentibus; pedunc. subaggregatis. Barosma Bartl. In Prom. spei. $\hbar$. g. Filamentis sterilibus nullis; petalis intus hirsutis; stylo elongato. Macrostylis et Euchaetis Bartl.

113. D. barbata Spr. fol. confertis lanceolatis erectis; floribus umbellato-capitatis. Macrostylis lanceolata Bartl. In Prom. b. spei. $ђ$.

11f. E. barbigeru Thunb. fol. oppositis cordatis amplexicaulibus cuspidatis glabris; corymbis terminalibus subsessilibus. Macrostylis barbigera Bartl. In prom. b. spei. 古.

11.5. D. squarrosa; fol. sparsis ovatis obtusis squarroso-recurvis glabriusculis; floribus capitatis. Macrostylis Bartl. In Prom. b. spei. ち.

116. D. elata; fol. lineari-lanceolatis convexo-carinatis subpungentibus apice inflexis margine pellucidoscabriusculis er ecto-patulis; laciniis calycis petalisque lanceolatis. Euchaetis Eckl. et Zeyh. In Prom. b. spei. ち.

117. D. alomerata; fol. confertis lanceolatis carinatis acutis appressis glabris; floribus glomeratis. Euchaetis glomerata Bartl. In Prom. b. spei. $ち$.

118. D. abietina; fol. Ianceolatoacuminatis mucronatis acute convexocarinatis margine pellucido-scabriusculis ciliatis imhricatis; petalis obovatooblongis. Euchaetis Bartl. et Zey.h. In Prom. b. spei. ђ.

119. D. flexilis; fol. oblongo-lanceolatis obtusiusculis submucronatis convexo-carinatis margine pellucidoscabris erecto-patulis; calycis laciniis ovatis obtusis apice inflexis. Euchaetis Eckl. et Zeyh. In Prom. $b$. spei. 直.

\section{LASIOPETALUM SM. (1789).}

1. L. ferrugineum $\mathrm{Sm}$. in Andr. rep. $t$. 20s. segmentis calycinis utrinque tomentosis. Vent. malm. t. 59. B. M. 1766. Gay diss. t. 3. Rchl).

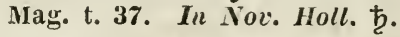

2. L. parrillorum Rudge in trans. Linn. 10. $t$. 12. $f$. 2. segmentis calycinis intus glabris. Gay diss. t. 4. In Nov. Holl. 


\section{GUICHENOTIA Gay (1821).}

1. G. ledifolia Gay diss. $\boldsymbol{t}$. 5 . Mém. Mus. $t$. 20. In Nov. Holl. ந. Frutex totus canescens. Folia ternato-verticillata lineari-lanceolata integra.

\section{THOMASIA Gay (1821).}

a. Pentandrae.

1. T. murpurea Gay diss. $t .6$. fol. lineari-ellipticis integris; stipulis foliaceis; capsulis stipitatis profunde 3-sulcatis. Lasiopetalum purpureum B. M. 1755. L. purpurascens Herb. amat. t. 294. In Nor. Holl. ђे.

2. T. foliosa Gay $t$. \%. fol. ovatis cordatis ohtuse $\mathbf{5}-\boldsymbol{7}$-lobis; stipulis minutis; petalis nullis; caps. tomentosis 3-sulcatis. In Nov. Holl. $ち$.

b. Decandrae.

3. T. solanacea Gay $t$. 6. petalis quinis. Lasiopetalun 3-phyllum sim. L. solanaceum B. M. 1486. In Nov. Holl. ち. Folia maxima.

4. T. triphylla Gay; fol. sinuatoangulatis dorso glabriusculis; petalis nullis ; capsula mucronata. Lasiopetalum 3-phyllum Labill. Nov. Holl. t. 88. In Nov. lícll. 古.

5. T. quercifolia Gay; fol. trilobis subtus hispido-tomentosis, petalis nullis; caps. mutica. Lasiopetalum quercifolium Andr. rep. t. 459 . B. M. 1485. In Nov. Holl. t.

\section{WALKERIA Schreb. (1789).}

1. W. serrata $W^{\prime}$. fol. serratocrenatis; racemis subcorymbosis; calycinis lobis lanceolatis. Meesia serrata Gaertı. t. 70. liheede 5. t. 48. In Halabaria et źeylona. ち.

2. W. integrifolia $\boldsymbol{D C}$. fol. integris; racemis simplicibus elongatis; calycinis lobis brevissimis. In Gujana. ђ. Petala coriacea.

\section{EUTHEMIS Jack. (1S22).}

Y. E. leucocarpa Jacy. fol. petiolatis lanceolatis spinuloso-serrulatis glaberrimis nitidis; racemis erectis ramosis; ramis apice gemmiferis. In Penins. Malacc. $\hbar$.

2. E. minor Jack; fol. anguste lanceolatis obsolete serratis glaberrimis venoso-striatis; racemis simplicibus; fructibus acuminatis angulatis. In Malacca. ఫ.

3. E. elegantissima Wall. fol. elliptico-lanceolatis acuminatis subtilissime serrulatis; venis reticulatis ad marginem confluentibus. In Malacca.

\section{MELICYTUS Forst. (17\%5).}

1. M. ramiflorus Forst. gen. t. 62. fol. dentatis oblongo-cuneatis utrinque glabris. Lam. ill. t. 812. f. 1. M. umhellatus Gaertn. t. 44. f. 5. In Nova Zeelandia. $\hbar$.

\section{5\%. OLINIA Thunb. (1797).}

1. O. cymosa Thumb. Syderoxylon cymosum L. In Prom. b. spei. ђ. Frutex ramis 4-gonis; fol. oppositis ovatis integerrinis lucidis. Floribus paniculatis albis.

\section{TODDALIA Juss. (1789).}

1. T. aculeata Pers. ramis aculeatis; fol. obovatis subserratis pellucide punctatis; racemis axillariluss. Paullinia asiatica L. Bheede 5. t. 41. $\beta$. nitida Lam. ill. t. 139. f. 1. Burm. Zeyl. t. 24. Scopolia Sm. In Ind. or. 市.

2. T. panicalata Lam. ill. t. 139. f. 2. ramis inermilus glabris; foliolis ohovatis ohtusiusculis; floribus paniculatis 4-fidis. T. inermis Pers. Scopolia inermis Sm. In ins. Mauritii. 5 .

3. T. lanceolata Lam. ramis inermibus glabris; foliolis lanceolatis acuminatis; paniculis terminalibus; floribus 4-fidis. In ins. Mauritii. $ち$.

1. 'T. cengustifolia Lam. ramis inermibus puhescentibus; foliolis anguste lanceolatis; racenis lateralibus folio brevioribus. In ins. Mauritii. $\hbar$.

5. T. megapotamica; foliolis lanceolatis abrupte acuminatis integerrimis opacis glabris; paniculis axilla- 
rihus divaricatis; florihus 5-fidis. Scopolia spr. All Rio Grunde. Ђ.

6. T. renosat foliolis spalhulatolanceolatis mucronatis glaberrimis supra lucidis sulstus parallele venosis; ramis verrucosis. All Rio Grande. ţ.

\section{ESEVBECKIA Mart. (1832).}

1. E. maurioides Mart. Nov. Gent. t. 232. fruticosa; fol. alternis trifoliatis; petiolis marginatis; foliolis sessilibus ovato-ohlongis acuminatis ; panicula composita. In Brusilia. ち. 34-ped. Cor. alha.

2. E. latifolia Mart. l. c. t. 234. fruticosa; fol. alternis umnilus trifoliatis petiolis dilatatis; foliolis sessilibus ohovato-ohtusiusculis mudulatocrenulatis; panicula contracta. In $\mathrm{Br}$ asilia. †. Frutex 3-4-ped. Cor. alba.

3. E. grandiflora Mart. l. c. arborescens; fol. allernis 1-foliatis obovatis obtusis basi cuneatis; petiolis apice incrassatis; paniculis parvifioris. In Brasilia. $\hbar$. Flores maximi.

4. E. prmila Pohl ic. 128. fruticosa; fol. trifoliatis; foliolis sessilihus oblongis subacutis; floribus paniculatis; pedunculo glahro. In Brasilia. t. 1-ped. Cor. alla.

5. E. febrifuga Mart. vide Evodia felrifuga $p_{0} 188$.

\section{ALSODEA Thouars (1506).}

1. A. pauciflora Thouars $p l$. afr. t. 1\%. urceolo staminum simplici; fol. cuneatis hreviter petiolatis; floribus paucis subcorymbosis; pedunc. reflexis. In Madagascar. 占.

2. A. "rborea Thouars l. c. urceolo staminum simplici; fol. longe petiolatis deflexis; floribus paniculatis. In Madaguscar. †.

3. A. anynstifolin Thouars l. c. t. 1\%. $f$. I. urceolo staminum cingulato; fol. oblongo-lanceolatis dentatis; racemis spicatis. In Halugascar. ち.

4. A. latifolia Thouar's l. c. t. 18. f. 2. urceolo staninum cingulato; fol. ovatis obtuse acuninatis; racemis glabris densis. In Marlagascar. ち.

5. A. pubescens Thouars $t$. 18. $f$. 1. urceolo staminum cingulato; fol. ovalibus basi cuneatis serratis; race- mis laxis pubescentibus. In Madagascar. $\hbar$.

6. A. raeemosa Mart. Nor. Gen. t. 20. urceolo staminum cingulato fimbriato; fol. oppositis elliptico-lanceolatis acuminatis integris. In Brasilia. ち. Cor. allia.

\%. A. paniculuta Mart. $t$. 21. fol. alternis ovato-oblongis acuminatis subintegerrimis glabris; floribus paniculatis; filamentis acutis serrulatis.

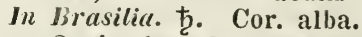

8. A. physiphora Mart. l. c. t.1.9. fol. lanceolatis vel olovato-lauceolatis repando-serrulatis glahris; racemis secundis; filamentis acutis dorso barluatis. In Brasilia. ‡. Cor. alba.

\section{CONOHORIA Aubl. (17\%5).}

1. C. Riana DC. fol. ovatis serratis apice longe acuminatis; squamis staminnm acuminatis; racemis spiciformihus. Riana gujanensis Aubl. Guj. t. 94. Alsodea prunifolia Spt. In Gujana. 市.

2. C. ulmifolia $\boldsymbol{H}$. et $\boldsymbol{K}$. Nor. Gen. $t$. 191. fol. oppositis oblongis acuminatis dentalis glabris; racemis terminalilus. Alsodea spr. In lov. Granata. 市.

3. C. Passoura DC.Mss. fol. ovatis integriusculis apice breviter acuminatis; sepalis lanceolatis acutis; squamis staminum acutis. C. flavescens Aubl. Guj. t. 93. Passoma Aubl. suppl. t. 380. In Gujana. ち.

t. C. Rinorea; fol. alternis dentatis ohlongis; floribus racemosis; loculis antherarum apice cohaerentibus stipitatis. Alsodea spr. Rinorea gujanensis Aubl. Guj. t. 93. In Gujana. $\hbar$.

5. C. ou ariensis Spr. sub Alsollea; fol. alternis lanceolatis repandis; racemis terminalihus. Cerauthera subintegrifolia Beauv. fl. ow. t. 66. In Guinea. 市.

6. C. dentata; fol. lanceolato-ovatis ; petalis lanceolato-ovatis. Ceranthera deutata Beauv. fl. ow. t. 65. In regno Ouariensi. 古.

7. C. Aubletii; fol. ellipticis acuminatis sultus rufo-velutinis; foribus solitariis geminisve; caps. acumiuata glabriuscula. Piparea dentata Aubi. Guj. t. 386. In Cayenna. †. 
8. C. Perrini; fol. oppositis oblongis utrinque attenuatis subtus discoloribus; pedunc. cymosis, terminalibus; filamentis apice barbatis. Alsodea Spr. In Amer. austr. ち.

9. C. castaneatolia Hilar. fol. alternis oblongo-lanceolatis argute serratis mucronatis; racemis simplicibus; pedicellis pubescentibus. Alsodea Spr. In Brasilia. ち.

10. C. Cuspua H. et B. arborea; excelsa; fol. elliptico-oblongis obtusis integerrimis glabris supra nitidis; pedunc. simplicibus bracteatis. Alsodea Cuspa Spr. In Nov. Graucita. 古.

11. C. megapotamica; fol. elliptico-oblongis integerrinis venoso-reticulatis subtus subpubescentibus; pedunc. cymbiferis bifidis; filamentis dorso barbatis. Alsodea spr. In Brasilia. ち. (Sello).

\section{TURPINIA Vent. (1303).}

4. T. paniculata Ient. choix $t .31$. paniculae ramis superioribus alternis. Dalrymplea domingensis Spr. In Domingo et Mexico. $ち$.

2. T. pomifera DC. ramis omnibus oppositis. Dalrymplea pomifera Roxb. corom. t. 279. In Ind. or. ち. Fructus aurantiacus.

\section{VITIS Varr. Cat.}

\section{a. Foli is indivisis.}

1. V. indica $L_{\text {. }}$ fol. cordatis acnminatis subdentatis superne lucidis subtus pubescentibus. Hheede mal. $\%$ t. 6. V. cordifolia Roth. In Ind. or. †. Fructus globosus niger.

2. $\boldsymbol{V}$. indivisa $\mathbf{L}$. fol. cordatis acuminatis angulato-dentatis venis subtus pubescentibus; corymbis dichotomis. Ampelopsis cordata Michx. Cissus Ampelopsis Pers. In America boreali. $\hbar$.

3. $V$. tiliaefolia $W$. fol. cordatis serratis subtus incanis. In America bor. $\hbar$.

4. V. riparia Michx. fol. cordatosubrotundis inciso-dentatis angulatisve subtus pubescentibus. V. incisa Jacq. Schoenbr. t. 427. In Amer. bor. $\hbar$.

5. $V$. cordifolia Michx. fol. cordatis acuminatis inciso-dentatis utrin- que glabris. V. vulpina Walt. In Amer. bor. $\hbar$.

6. V. rotundifolia Michx. fol, cordato - subreniformibus subaequaliter dentatis utrinque nitidis; floribus gloinerato-racemosis. IIn Amer. bor. $\hbar$. Bacca magna intense caerulea.

\%. I. Wallichii DC. fol. cordatotruucatis apice acuminatis acute dentatis utrinque Iaevibus; racemis folio brevioribus. In Nepalia. $ち$.

8. V. flexuos T'hunb. fol. cordatis acutis dentatis subtus villosis; caule flexuoso; paniculis elongatis. In $\mathbf{J}$

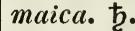

9. V. Purani Hamilt. fol. cordatis dentato-serratis acuminatis coriaceis subtus petiolisque villosis; thyrsis oppositifoliis spicatis brevibus. In Nepalia. ђ.

10. V. truncata Blume; fol. basi truncatis ovatis acuminatis obtuse glanduloso-serratis subtus in venis pubescentibus; floribus paniculatis. In Java. 古.

11. V. cymosa Blume; fol. cordatis acuminatis setoso-serrulatis subtus tomentosis; cymis pedunculatis trifidis folio brevioribus. In Java. ち.

12. V. glaberrima Wall. canle carnoso 4-gono; fol. subcordato-oblongis obtusiusculis mucronato-dentatis 3-nerviis laevibus; umbellis corynbosis. In ins. freti Malacc. $\hbar$.

13. V. gracilis Wall. caule filiformi; fol. cordato-ovatis acuminatis argute dentatis supra pubescentibus subtus ramulisque ferrugineo-villosis; spicis filiformihus cirrhiferis. In ins. freti Malace. $\hbar$.

\section{b. Foli is lobatis.}

14. V. viniferc $\boldsymbol{L}$. fol. Iohato-sinuatis nudiusculis. Blackw. t. 154. In Asia australi indigena nunc ubique fere culta. $\hbar$. Conf. quoad varietates innumeras $R$. et schult. 5 . p. 300. et Duham. arb. 2. t. 1-6.

15. $V$. Labrusca $L$. fol. cordatis angulato-3-lobis dentatis subtus incans-tomentosis. Jacq. Schoenbr. $t$. 426. Plum. ic. t. 289. f. 1. In Canada el F'lorida.

16. V. vulpina I. Jac\%. Schoenbr. t. 42.5. fol. cordatis lobato-sinuatis inciso-serratis acuminatis glabris subtus subpubesceutibus; racemis opposi- 
tifoliis. V. aestivalis Michx. In Amer. bor. $\hbar$.

17. Г. glabrata Roth; fol. cordatis subtrilobis obtuse serratis glabris; paniculis cirrliferis. In Ind. or. $\hbar$.

18. V. africana $\mathbf{S} p$ r. fol. cordatis obtuse lobatis crenatis tomentosis; paniculis cirrhiferis. Botrya africana Lour. In Africa or. $\downarrow$.

1.9. V. capensis Timub. fol. subcordatis 5-angularibus obtuse dentatis subtus ferrtigineo-tomentosis ; floribus capitatis tomentosis. V. 3-fida Foth. V. rugosa Wall. In Prom. b. spei et Ind. or. ђ.

20. V. hispida Eckl. et Zeyh. fol. basi cordatis sinuato-5-lohis cuspidato-dentatis utrinque hispido-scabris lobo intermedio producto ceterisque acuminatis. In Prom. b. spei. ђ.

21. Ir. triloba Roth; fol. cordatis trilohis inciso-dentatis tomentosis; racemis ovatis densis tomentosis. V. tomentosa Roth. V. Ianata Roxb. In Ind. or. $\hbar$.

22. I. heterophylla Thunb. fol. indivisis $\mathbf{3 - 5}$-lobisque inciso-serratis glabris; panicula dichotoma. In $J a-$ ponia et Java. $ђ$.

23. V. palmata Vahl; fol. cordatis palmatis glabris laciniis incisis dentatis; umbellis racemosis. In Amer. bor. 5 .

2\%. I. orientalis Clem. fol. palmatis sinuato-dentatis lanatis; floribus racemosis. V.patiens et dapsilis Clem. In Hispania culta. $\hbar$.

25. V. parvifolia Roxb. fol. cordatis subtrilobis crenato-serratis glabris; thyrsis oppositifoliis. In Bengalia.

26. V. barbata Wall. ramis cylindricis glanduloso-setosis ; fol. cordato-subrotundis 3-Iobis sinuato-dentatis 3-nerviis glabriusculis; glomerulis cirrhiferis; floribus 4-fidis. In Ind. or. $\hbar$.

2\%. V. glandulosa Wall. ramis villosis; fol. cordato-ovatis 3 -lobis subtus villosis axillis venarum foveolatis; corymbis dichotomis. In $\mathrm{Ne}$ palia. \$.

\section{c. Foliis compositis.}

28. V. cirrloosa Thunb. fol. ternatis obovatis acute serratis villosis; cirrhis nodorum simplicibus; panicula patentissima. In Prom. b. spei. ち.
29. V. ternata Roth; fol. ternatis oblongis duplicato-serratis subtus tomontosis lateralibus obliquis; ramis cirrhisque tomentosis. V. cinnamomea Wall. In Ind. or. $b$.

30. $\mathrm{V}$. laciniosa $\mathrm{L}$. fol. quinatis glabriusculis; foliolis multifidis; panicula patente. Corn. can. t. 1 3. V. vinifera var. 24. Il. et S. Patria iynota. $\hbar$.

31. 1. javanica Spr. fol. simplicibus ternatisque cordatis crenato-serratis glabris; corymbis dichotomis. Ampelopsis heterophylla Blume. In Java. 方.

32. V. semicordata W'all. fol. ternatis subtus villosis; foliolis acuminatis argute serratis, lateralibus semicordatis; cymis oblongis. In Nepalia.

33. V. bracteolata Wall. fol. ternatis subtus pubescentibus; foliolis acuminatis argute serratis, lateralihus seniovatis; cymis diffusis; floribns 4andris. In Ind. or. b.

31. V. mollissima Wall. fol. ternatis villosissimis; foliolis acuminatis inaequaliter crenatis; cymis divaricatis; foribus 4-andris. In ins. fret. Malacc. $\hbar$.

35. V.pentaphylla Thunb. fol. quinatis glabris; foliolis oblongis acuminatis serratis; racemis axillaribus laxis. In Japonia. 古.

36. V. hederacea Ehrh. fol. quinato-digitatis nitidis; foliolis oblongis acuminatis mucronatis; racemis compositis. V. quinquefolia Lam. Cissus quinquefolia Pursh. In Canada et rirginia. $\hbar$.

3\%. V. capreolate Don; fol. quinatis oblongis acuminatis setaceodentatis coriaceis subtus pubescentibus; umbellis 4-radiatis folio brevioribus. In Nepalia. $\hbar$.

38. V. rubifolia Wall. fol. pinnatis 5-jugis subtus glaucis pubescentibus; foliolis cordato-oblongis acuminatis argute serratis; ramis corymbisque villosis. In Bengalia. $\hbar$.

39. V. heptaphylla $L$. fol. septenato-digitatis glabris; foliolis oblongis mucronatis integerrimis; floribus spicato-verticillatis. In Ind. or. $\hbar$.

40. V. pinnata Vahl; fol. pinnatis glabris; foliolis ovatis acuminatis dentato-serratis; pedunc. umbellatis. Patria ignota. 
41. V. arborea Mill. fol. decompositis wlahris; foliolis ohovato-rhomboideis inciso-lohatis; racenis cirrhisque dichotomis. Cissus stans pers. Ampelopsis bipinnata Michx. In Amer. bor. 市.

\section{HORTYA V'andell. (1788).}

1. H. obovata rand. in Roem. script. bras. p. 1ss. In Brasilia. b. Arhor. Folia alterna subcuneiformia integra punctato-pellucida. Hlores corymbosi.

\section{CALODENDRON Thunb. (1782).}

1. C. capense Thunb. Lam. journ. i. 3. Dictamnus Calodendron Limn. f. Pallasia capensis Houtt. In Prom. b. spei. b. Arhor. Folia opposita simplicia integra.

\section{DICTYOLOMA Andr. Juss. (182.5).}

1. D. Vandellianum Andr. Juss. Mém. Mus. 12. t. 24. In Brasilia. ち. Arbor fol. pinnatis margine glandulosis; corynhis lateralibus dichotomis; floribus tomentosis.

\section{PITTOSPORUM Banks (1888).}

1. P. coriaceum Ait. fol. olnovatis obtusis coriaceis glaberrimis nitidis subtus reticulatis; pedunc. umbellatis calycihusque villosis. Lodd. B. Cab. 560. Andr. rep. t. 151. In Madera. †.

2. P. viridifiomum Sims. B. $\boldsymbol{M}$. 1684. fol. obovatis retusis hasi cuneatis nitidis subtus reticulatis; panicula suhglolosa. P. capense et arbutifolium Hortul. P. Simense Desf. In Prom. b. spei. ち. Flores flavovirentes Jasminum spirantes.

3. P. Tobira Ait. fol. ohovatis obtusis coriaceis glaberrimis; pedunc. 1 -floris umbellato-aggregatis pubescentibus. B. M. 1396. Kaempf. am. 797. Evonymus Tohira Thunl. In Japonia. $\mathbf{t}$.
1. P. undulatum Andr. rep. t. 3993 . fol. ovali-lanceolatis utrinque attenuatis undulatis petiolisque glahris; pedunc. aggregatis ramoso-multifloris pubescentibus. Vent. Cels. t. 76. Ulerb. amat. t. 36. B. 1. t. 16. In Nov. Holl. 占.

5. P. revolutum Ait. fol. ellipticooblongis obtusiusculis subtus pubescentibus margine revolutis; pedunc. aggregato-umbellatis villosis. B. R. 186. B. Cab. 506. In Nov. Holl. ち.

6. P. tomentosum lionpl. nav. $t$. 21. fol. ovali-ohlongis utinque acutis superue glabris subtus ramisque pubescenti-tomentosis margine subrecurvis; pedunc. aggregatis. In Nov. Holl. ‡.

\%. P. fulvum Rudge trans. Linn. t. 20. fol. late lanceolatis obtusis in petiolis nervisque tomentosis; pedumc. aggregatis; calycilus patulis. In Nov. Holl. $\frac{\hbar}{2}$.

8. P. ferrugineum Ait. fol. ellipticis utrinque acuminatis superue glahris sultus ferrugineo-tomentosis; pedumc, aggregato-umhellatis. Sims B. M. 2075. Rimph? 7. t. 13. In Guinea. 卢.

9. P. hirtum W. en. fol. ovatooblongis subtus pubescentihus adultis calnescentibus; petiolis ramulisque hirtis. P. hirsutum Lk. In ins. Canariis. t.

10. P. laurifolium W.en. fol. oblongis obtusis coriaceis; pedunc. 1floris lateralibus aggregatis. In ins. Tenerifla. 古.

11. P.? pluylliraeoides DC. fol. oblongis mucronatis coriaceis planis glaberrimis subaveniis; pedicellis lateralihus 1-floris. In Nov. Holl. ‡.

12. P. cornifoliun Cunningh. $\boldsymbol{B}$. M. 3161. caule fruticoso gracili; fol. oppositis elliptico-lanceolatis glahris, summis verticillatis; pedunc. villosis. In Nov. Zeelandia. $\$$. Cor. rubrofusca.

13. P.? tenuifolium Gaertn. $t$. 59. capsulis trivalvihus subglohosis rugosis. In Australasia. $\hbar$.

11. P.? umbellatum Gaertn. capsulis bivalvihus subglobosis extus punctis elevatis scabris. In Australasia. b. 
1068. BILLARDERIA Sm. (1791).

a. Foli is integris.

1. B. scandens Sm. exot.bot. t. 1. ramis scandentibus junioribus villosis; fol. lineari-oblongis integris; pedicellis 1 -floris villosis; baccis velutinis. B. canariensis Wendl. coll. t. 15. In Nov. Holl. ち. Cor. ochroleuca.

2. B. mutabilis Salisb. parad. $t$. 48. ramis scandentibus, juniorihus subvillosis; fol. lanceolato-linearibus integris; haccis glabris. B.M. 1313. In Nov. Holl. †.

3. B. fusiformis Labill. Nov. Holl. t. 90. ramis vix scandentibus, juniorihus vix villosis; fol. ovali-oblongis integris; paniculis paucifloris; baccis fusiformilus villosis. In ins. Van Diemen. 5 .

4. B. Congiflora Labill. $l$. c. t. 8.9. ramis scandentibus, junioribus vix pubescentihus; fol. oblongis linearibusve integris; pedicellis 4-floris glabris; haccis subglobosis torosis glabris. B. M. 1507. In ins. Van Diemen. ち.

5. B. angustifolia $D C$. ramis scandentibus, junioribus pubescentibus; fol. linearibus integris planis glabris; pedicellis 1-floris baccisque oblongis glabris. In Nov. Holl. ђ. Cor, ochroletca.

6. B. rosmarinifolia DC. ramis scandentibus glabris; fol. linearibus margine revolutis nervosis subreticulatis glabris. In Nov. Holl. ђ.

b. Foliis partim subdentatis incisisve.

\%. B. parviflora DC. ramis scandentibus, junioribus subvillosis; fol. oblongis glabris integris aut apice paucidentatis; pedicellis $1-2$-floris; hracteolis hispidis. In Nov. Holl. ち. Cor. subcaerulescens.

E. B. variifolia $D C$. ramis filiformilus villosis; fol. ohlongis subvillosis integris aut dentato-subpinnatifidis; pedicellis villosis. In Nov. Holl. ち.

\section{BURSARIA Cav. (1789).}

1. B. spinosa Cav. ic. t.350. Itea spinosa $B . M .176 \%$ Andr. rep. t. 311. Cyrilla spinosa Spr. In Nov. Holl. t. Hrutex ramosissimus; fol. ohlongo-cuneatis aveniis integerrimis; floribus paniculatis albis.

\section{RUYSCHIA Jacq. (1863).}

1. R. Souroubea $W$. fol. ohovatis obtusis; floribus laxe spicatis. Nour. gujanensis Aubl. Guj. t.97. S. Aubletii Meyer. In Gujana et Brasilia. $\hbar$.

2. R. clusiaefolia Jacy. am. t. 51. f.2. fol. ovato-ellipticis; floribus dense spicatis. In Gujana et Caribaeis. ђ.

3. R. amazonica Mart. N. Gen. t.292. fol. cuneato-ohovatis acutis mucronulatis; bracteis 2-partitis. In Irusi-

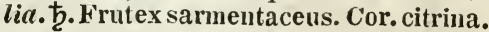

4. R. Spixiana Mart. $t$. 293. fol. lato-obovatis tandem emarginatis; bracteis 3-partitis. In Brasilia. நृ. Cor. amrantiaca.

5. R. corollina Mart. $t$. 2.91. fol. ovato-oblongis acuminatis; bracteis 3-partitis laciniis concavis. In Brasilia. ђ. Arbuscula floribus coccineis.

6. R. buhiensis Mart. fol. inaequaliter oblongis apice rotundatis mucronulatis. In Bras. ‡. Arbuscula floribus luteis.

\section{HYDNOCARPUS Gaertn. (1788).}

1. H. inebrians Vahl; H. venenata Gaertn. t. 60. f. 3. In Zeylona. ち.

1072.CALISPERMUM Lour.(1790).

1. C. scandens Lour. In Cochinchina. †. Frutex scandens floribus albis.

\section{BREXIA Thouars (1810).}

1. B. madagascariensis Ker. B. R. 730. fol. oblongis obtusis integerrimis. In Madagascar. $\hbar$.

2. B. spinosa Lindl. B. R. 872. fol. lanceolatis elongatis marginatis spinosis. In Madagascar. ‡.

\section{ESCALLONIA Mutis (1781).}

1. E. myrtilloides R. et S. fol. serrulatis mucronulatis subvenosis. Sm. ic. t. 30. stereoxylon patens Fl. ner. t.234. f.b. In Peruv. ち. 24-ped. Cor. alba.

2. E. serrata sm. ic. $t$. 31. fol. 53 * 
serratis subretusis aveniis. In Amer. austr. ち. Arl). ramosissima. Flor. lactei.

3. E. tortuosa H. et K. ramis tortuosis ; fol.obovatis acutis glandulosocrenulatis nitidis venosis. In Quilo. ち.

1. E. corymbosa Pers. fol. oblongis serrulatis ; calycibus denticulatis. Stereoxylon Fl. pernv. t.234. f. a. In Peruvia. ち. Arbor facie Myrti. Fl. alhi.

5. E. berberifolic $H$. et $K$. fol. obovatis crernulato-dentatis reticulatovenosis; ramis patulis. In Quito. ち.

6. E. alpina Poepp. et Endl. t.13. fol. spathulato-ohlongis acutis apice argute serratis subus pubescentibus. In Peruvia. t. 2-ped. Cor. purp.

7. E. Poeppigiance $D C$. ramulis fusco-pubescentibus; fol. ovali-acutis serratis subtus resinoso-punctatis. In Chili. 5 .

8. E. Sellowiana DC. glabra; fol. lanceolatis basi attenuatis serratls subtus resinoso-punctatis. E. resinosa B. Cham. et schI. In Brasilia. ந.

9. E. vaccinioides Hil. fol. cuneatoobovatis denticulatis subtus nigropunctatis. In Brasilia. ち. Flor. albi.

10. E. canescens Hil. bras. t. 181. rol. oblongo-obovatis obtusis apice remote subspinuloso-dentatis subtus incano-tomentosis; racemo composito. In Brasitia. ち. 5-ped. Cor. alba.

11. E. obtusissima Hil. ramulis bracteatis calycibusque hirsutis; fol. obovatis obtusissinis apice argute dentatis. In Brasilia. 卢.

12. E. humilis hil. fol. cuneatoobovatis rugosiusculis apice serratis; panicula brevissima. In Brasilia. $\not$.

13. E. spiraeoilles Hil. fol. obovatooblongis obtusis apice dentato-serratis subtus glanduloso-punctatis; panicula composita. In Brasiliu. ち. Pet. alba.

14. E. farinacea Hil. fol. cuneato-obovatis obtusis mucronatis apice serratis utrinque albo-farinosis et glanduloso-punctatis. In Brasitia. $\hbar$.

15. E. florirla Poepp. et Endl. $t$. 14. glaberrima; fol. lineari-lanceolatis utrinque acuminatis apice serrulatis; racemis confertis. In Chili. $\downarrow$.

16. E. montevirlensis DC. glabra; fol. cuneato-oblongis acutis serrulatis subtus resinoso-punctatis. $\mathbf{E}$. floribunda $\beta$. Cham. et SchI. In Bras. 5.

17. E. myrtoidea Bert. glabra; fol. lanceolatis serratis; racemo terminali; calycibus reflexis. In Brasilia. $\mathrm{b}$.
18. E. Berteroniana DC.glabra ; resinoso-viscosa; fol. ellipticis serratis supra lucidis; racemo. spicato. In Chili. 古.

19. E. resinosa Pers. fol. oblongoovatis serrulatis; flor. racemosis; petalis obovatis. Stereoxyl. Fl. per. t.235. a. In Perucia. ち. 18-ped. Flor. albi.

20. E. rubru Pers. fol. obovatooblongis acuminatis serratis; petalis spathulatis. Stereoxyl. Wl. per.t.235. b. In Peruvia. ち. 12-ped. Flor. rubri.

21. E. revoluta Pers. fol. obovatis denticulatis revolutis; racemis thysoideis. Stereoxyl. Fl. peruv. t.236. a.

In Peruvia. ち. 18-ped. Pet. alba.

22. E. mulverulenia Pers. fol. oblongo-ellipticis serrulatis pulverulentis; flor. racemosis. Stereoxyl. Fl. per. t. 237. a. In Peruv. t. 12-ped. Pet. subviridia.

23. E. penduta Pers. fol. Ianceolatis acutissimis integriusculis; racemis longissimis pendulis. Stereoxyl. Fl. peruv. t. 237. b. In Peruvia. 40-ped. Pet. rubra.

24. E. paniculata R.etP. Fl.per.t. $238+f . b$. fol. Ianceolato-oblongis obsolete serrulatis; fol. racemoso-paniculatis. In Peruvia. b. 15-ped.

25. F. cuneifolia R. et $\boldsymbol{P}$. peruv. t. 238. $a$. fol. cuneiformibus semulatis; floribus corymbosis; petalis crenulatis. In Peruvia. ち. 8-ped. Flor. albi.

26. E. floribunda $H$. et $K$. fol. oblongis obtusiusculis serrulatis subglutinosis venulosis; panicula foliosa. In Nov. Granata.

2\%. E. discolor Vent. choix $t$. 5t. fol. cuneiformi-lanceolatis integerrimis discoloribus; flor. paniculatis. E. 'Tubar Mutis. In Nov. Granata. ち.

28. E. megapotamica Spr. fol. spathulatis longe mucronatis argute glanduloso-serratis subtus punctatis venulosis glutinosis. In Brasilia.

29. E. chlorophylle Sclil. fol. obovatis mucronatis integerrimis subtus caesio - pulverulentis ; flor. racemosis. In Brasilia. $\hbar$.

\section{FLINDERSIA R. Br. (1S14).}

1. F. australis $\boldsymbol{R}$. $\boldsymbol{B r}$. fol. ternatis quinato-pinnatisve ; paniculis divaricatis ramosissimis pubescentibus. Flinders it. t. 1. In Nov. Holl. t. 
2. F. amboinensis $\boldsymbol{R}$. $\mathrm{Br}$. fol. pinnatis sub-5-jugis; pedunculis trunci pendulis subraceurosis. In ins. Malace. ђ.

\section{CEDRELA P. Br. (1756).}

1. C. odorata $L$. fol. pinnatis; foliolis ovato-oblongis integerrimis supra nitidis; calycibus corollisque nudis. Pluku. t. 157. f. 1. Sloane hist. t. 220. f. a. Browne jam. t. 10. f. 1. In Amer. austr. ち. Arbor procera. Flores parvi flavi.

2. C. Toona Roxh. fol. pinnatis; foliolis ovali-lanceolatis longius acuminatis obliquis subserratis; panicula dichotoma ramosissima; calycibus corollisque ciliatis. In Ind. or. $\hbar$.

3. C. febrifuga; fol. pinuatis; foliolis ovato-oblongis acuminatis integerrimis venis subtus concoloribus. In Juva. 卢.

\section{8\%. ANCHIETEA Hilar. (1821).}

1. A. salutaris Hilar. pl. us. brés. t. 19. fruticosa; erecta; fol. ovatis subdentatis glabris subtus resinosopunctatis; stipulis scariosis ciliatis; pedunc. nutantibus 1-floris. Noisettia pyrifolia Mart. Nov. Gen. t. 16. In Brasilia. $\hbar$.

2. A. Roquefeuillana Spr. fruticosa ; scandens; fol. oblongo-lanceolatis acutis crenato-serratis; pedunc. subracemosis; labello subrhombeo obtuso. In Brasilia. ち.

\section{AMPHIRRHOX Spr. (1827).}

1. A. longifolia Spr. Spathularia longifolia Hilar. mém. mus. 11. $t .21$. In Brasilia. ち. Frutex foliis oblongolanceolatis subdentatis glabris; floribus racemosis albidis.

\section{0\%9.GLOSSARRHENMart.(1822).}

1. G. floribundus Mart. Nor. Gen. t. 15. fol. ovato-oblongis utrinque attenuatis acutis et acute dentato-serralis; pedunc. axillaribus. Sweigoeria floribunda Hilar. Mém. mus. 11. t. 22. B. In Brasilia. †. Frutex 35-ped. Flores albi.
2. G. pauciflorus Mart. fol. e basi longe attenuata obovatis spathulatis obtusis creuato-serratis; pedunc. axillaribus. In Brasilia. t.

\section{S0. NOISETTIA Funth, (1821).}

1. N. frangulaefolia $\boldsymbol{H}$. et $\boldsymbol{K}$. Nov. Gen. $t$. 499. f. $a$. et $b$. fol. oblongoellipticis acutis basi rotundatis obsolete serrulatis complicatis utriuque puberulis; Aoribus fasciculato-congestis. In Peruvia. 5 .

2. N. orinocensis $H_{\text {. et }} \boldsymbol{K}$. fol. ovatis oblongis acutis basi obtusis serrulatis supra glabris subtus pubescentibus; floribus axillaribus. Viola excelsa i. et $\mathbf{s}$. Ad Orinocum. $\hbar$.

3. N. galiopsifolia Hilar. canle herbaceo glaberrino subalato; fol. lanceolatis acutis serratis; floribus racemosis; petalo infero cucullato cuspidato. N. Iongifolia Nees. In Brasilia. 古.

4. $\Lambda$. orchidiflora Ging. caule gracili laevi; fol. Ianceolatis serrulatis longe petiolatis; floribus 4-6 fasciculatis; calyce obtuso pedicello paullo breviore. Viola Rudg. pl. rar. t. 10. Jonidium R. et S. In Gujana. t.?

\section{CORYNOSTYLIS Mart. (1822).}

1. C. Hybantius Mart. Nov. Gen. t. 17. et 19. Viola Hybanthus Aubl. Guj. t. 319. In Brasilia. ち. Frutex scandens; fol. alternis oblong0-ovatis serratis; floribus racemoso-fasciculatis ocliroleucis.

2. C. Loefflingii Spr. caule fraticoso scandente; ramis pendulis; fol, oblongis obtusis integerrimis glabris; pedunc. 1-floris pendulis. Viola Hybanthus Loefl. In Amer. austr. $ᄒ$.

3. C. Berterii $\mathbf{S} \mathrm{pr}^{\circ}$. caule erecto striato; fol. ovatis acuminatis integerrimis; racemis axillaribus; petalo cuccullato inflato. Calyptricon DC. $A d$ flum. DIaglalenae. 占.

4. C. diandra spr. caule scandente herbaceo; fol. alternis oblongis; pedunc. 1-floris; calcari elongato; staminibus ternis. Viola diandra $\mathbf{L}$. In Amer. austr. $\hbar$. 


\section{HYBANTHUS Jacq. (1763).}

1. H. havanensis H. et K. t. 4.94. caule erecto aculeato ramoso; fol. oblongis remote serratis; floribus albidis petalo infimo apice biloho; pedunc. bifidis subracemosis. Jonidiun Jacquiniauum R. et \$. $\beta$. Humboldtianus DC. Prope Havanam ins. Cubae. $\hbar$.

2. H.? mexicanus Ging. caule acute aculeato; fol. oblongis ; petalo infimo apice acuminato; pedunc. 1-fioris fasciculatis. In Mexico. $\hbar$.

\section{SOLEA Spr. (1S00). (Jonidium Vent. et DC.)}

\section{a. Foli is alternis.}

1. S. anomala Spr. puherula; caule ramoso ; fol. alternis lanceolato-oblongis acuminatis serratis supra glabris subtus canescentibus; sepalis ovatis acutis serice - pubescentibus. Jonidium Humb. et $K$. Nov. Gen. t. 500. In Nov. Granata.

2. S. verbenacea Spr. caule herbaceo pubescente; fol. ovato-ellipticis crenato-serratis utrinque pilosis; stipulis lineari-subulatis; labello basi bigibbo. Jonidium $H$. et $K$. 1 . c. $t$. 497. In Mexico. $\odot$. Flores pallide caerulei.

3. S. parietariaefolia Spr. caule ramoso pubescente; fol. alternis ovato-lanceolatis acuminatis dentatis subpubescentibus; stipulis subulatis calycibusque ciliatis. Jonidium DC. Viola melauosperma Bert. In Peruvia. $\odot$.

1. S. monopetala Spr. caule suffruticoso ramoso; fol. linearilus obtusis integerrimis; stipulis subnullis; labello spathulato-emarginato. Pigea filiformis DC. In Nov. Holl. $\odot$.

5. S. calycina Spr. caulibus ramosis; fol. linearibus integerrimis; labello lanceolato acuto; sepalis ovatis acuminatis. Pigea calycina DC. In Nov, Hollandia. $\odot$.

6. S. enneasperma Spr. caule suffruticoso basi ramoso; fol. sparsis lanceolatis subserratis; stipulis sub)vlatis; pedunc. pubescentibus. Viola frutescens Roth. In Ind. or. $\hbar$.

\%. S. erecta Spr. caule stricto filiformi glabriusculo; fol. linearibus mucronatis remote denticulatis stri- silia. ctis; stipulis lanceolatis ciliatis; floribus nutantihus. In Ind. or. $\odot$.

8. S. purvifiora Spr. caule lierbaceo diffuso ramoso; fol. ovatis serratis obtusis petiolatis confertis ; pedunc. axillarihus; labello bilobo. Viola $L$. In Amer. austr. $\odot$.

9. S. capensis spr. caule suffruticoso; fol. obovalis olssolete serratis pubescentibus; pedunc. axillaribus filiformihus; labello obovato. Viola Thuub. In Prom. b. spei. $\hbar$.

10. S. glutinosa Spr. caule herbaceo superne viscoso; fol. ellipticis serratis in petiolum decurrentihus glabris; stipulis subulatis; pedunc. pilosis; labello ohcordato. Jonidium Vent. Viola Poir. In Buenos Ayres. 4.

11. S. buxifolia Spr. caule ramoso glaherrimo; fol. obovatis integerrimis revolutis; pedunc. axillaribus elongatis; labello suhrotundo hasi gibho. Jonidium buxifolium Vent. In Madagascar. 4.

12. S. Ipecacuanha Spr. caule erecto ramoso; fol. alternis ellipticis serratis glabris ciliatis; stipulis lanceolatis scariosis cuspidatis; Iabello lato subemarginato. Viola Ipecacuanha L. Jonidium Hilar. t. 11. B. M. 2453. Desc. t. 121. Disss. S. 5. t. 21. In Brasilia. ち. Cor. alha.

13. S. Calceolaria Spr. caule herbaceo simplici; fol. sessilibus lanceolatis serratis pilosis; stipulis subulatis; lahello subrotundo. Viola L. Jonidium Desc. t. 123. In America australi. $\odot$.

11. S. Itoubou $\$$ pr. caule ramoso villoso; fol. ovatis subsessilibus serratis acutis tomentosis; stipulis lanceolatis dentatis; pedunc. axillarihus filiformibus; labello reniformi cucnllato. Viola Itoubou Aubl. Guj. t.318. In Gujana. ち.

15. S. sylvatica Spr. suffruticosa; pubescens; fol. alternis ovatis acuminatis dentatis; stipulis linearibus integerrimis ; pedunc. solitariis; calycibus acuminatis; lahello suhrhombeo mucronulato. Jonidium Hilar. In Brasilia.

16. S. bicolor $\mathbf{S p r}$. fruticosa; villosa; fol. alteruis Ianceolatis deutatis; stipulis linearihus integerrimis; floribus racemosis; labello rotundato mucronato. Jonidium IIilar. In $\mathrm{Br}^{\circ} \mathrm{a}$ - 
17. s. Lanuta spr. suffuticosa; lanata; fol. alternis ellipticis obtusis integerrinis mucronatis; stipulis scariosis; labello late obcordato. Jonidium Hitar. In Brosilia. 古.

18. s. Pouye Spr. suffruticosa; hirsutissima; fol. alternis sulosessilibus subcordato-ovatis obsolete dentatis; stipulis scariosis; labello maximo olscordato. Jonidium Hilar. t. 9. In Brasilia. †. $1 \frac{1}{2}$-ped. Cor. alha.

19. s. scariosa spr. suffruticosa; hirsuta; fol. alternis lanceolatis acuminatis serratis; stipulis scariosis; laciniis calycis pinnatifidis; labello orbiculari. Jonidium Hilar. J. villosissimum Hilar. In Brasilia. 古.

20. S. alba Sm. suffruticosa; pubescens; fol. alternis lanceolatis serrato-ciliatis; stipulis scariosis; calycibus ciliatis pilosis; labello rotundato. Jonidium Hilar. In Brasilia. $\begin{aligned} & \text {. } \\ & \text {. }\end{aligned}$

21. S. setigera spr. frulicosa; fol. oblongo-lanceolatis acuminatis dentatis; stipulis ciliato-setosis; laciniis calycis pinnatifidis; labello oblongo 3-nervio. Jonidium Hil. In Brasilia. ち.

22. S. communis Spr. suffruticosa; herhacea; pubescens; ramosa; fol. Janceolatis dentatis glabris; stipulis linearibus integerrimis; pedunc. subracemosis. Jonidium Hil. In Brasilia. $\hbar$.

23. S. nana Spr. suffruticosa; pubescens; fol. lanceolatis dentatis; stipulis linearibus; calycibus acuminatis; labello complicato obcordato. Jonidium Hil. In Brasilia. $\hbar$.

21. S. guaranitica Spr. suffuticosa; glabra; fol. alternis lanceolatis dentatis; stipulis linearibus; floribus pendulis; lahello orbiculari crenulato. Jonidium Hilar. In Brasilia. b.

25. S. urticuefolia Spr. ramosa; viscoso-puhescens; fol. subsessilihus subcordato-ovatis acutis serratis glabris; pedunculis paucifloris; calyce integerrimo; labello quadrato. Jonidiun Mart. spec. t. 4. Düss. s.5. t.22. In Brasilia. 24. Cor. caerulescens.

26. S. brevicuulis Spr. simplex; fol. petiolatis obovatis crenatis pilosiusculis; stipulis lanceolatis nervosis; pedunc. erectis; labello orbiculari. Jonidium Mart. t. 3. In Brasilia. ђ. 3-1-poll. Cor. pallide caerulea.

\section{b. Follis oppositis.}

2\%. S. atropurpurea Spr. suffruticosa ; fol. oppositis ovato-lanceulatis acutis obsolete serratis; stipulis caducis; floribus racemosis; labello ohcordato. Jonidium Hilar. In Brasiliu. ち.

25. s. bigibbosa $\mathbf{s p r}$. fruticosa; pubescens; fol. oppositis oblongo-lanceolatis acuminatis obsolete dentatis; calycibus acuminatis ciliatis; labello spathulato bigibboso. Jonidium Hil.

In Brusilia. ち.

29. S. strictu Spr. caule súffruticoso ramoso; fol. oppositis lanceolatis subserratis; stipulis setaceis; labello unguiculato angusto. Jonidium strictum Vent. Viula Poir. In Domingu et Tor. Hispania. 4.

30. S. verticillata sm. caule ramoso pubescente; fol. oppositis sessilibus stipulisque lanceolatis subintegerrimis ciliatis; pedunc. filiformilus axillaribus; labello spathulato. Viola Orteg. Jonidium polygalacfolium Vent. malm. t. 27. H. et K. Nov. Gen. t. 496. Schrad. Jour. 1800, t. 6. In Nov. Hispania et Mexico. 24. Flores viridilutei.

31. S. oppositifolia Spr. caule suffruticoso; ramis brachiatis ; fol, oppositis lanceolatis argute serrativ glabris; floribus racemosis. Viola L. In Cumana. ђ.

32. S. linifolia spr. caule subramoso; pubescente; fol. linearibus olstusis confertis; stipulis subulatis; pedunc. folio brevioribus. Viola linifolia et thesiifolia Poir. In Africa occid. et Madagascar. $\odot$.

33. S. microphylla Spr. caule fruticoso ramosissimo; ramis bifariam pubescentibus; fol. oppositis oblougis serratis pilosiusculis; labello panduraeformi. Jonidium $H$. et $K$. Nov. Gen. t. 495. In Quito. ち. Flores purpurei.

34. S. viscidula Spr. caule lignoso erecto ramoso viscoso; fol. oppositis lanceolatis remote serrulatis; stipulis minutis. Jonidium $\mathbf{H}$. et $\mathbf{K}$. $\boldsymbol{A d}$ Orinocum. ち.

3.5. S. riparia $S p r$. caule herbaceo erecto subramoso bifariam pubescente; fol. inferioribus oppositis lanceolatis crenato-serratis glabris subciliatis; stipulis minutis. Jonidium $\mathbf{H}$. et K. In Nov. Granata. 
36. S. circaeoides $\mathrm{Spr}$. caule herbaceo bifariam pulsescente; fol. oppositis ovatis acutis serratis glabris; stipulis lineari-falcatis; Iabello oblongo obtuso. Jonidium H. et K. Nov. Gen. t. 498. In Nov. Granata $\odot$. Cor. vlolacea.

\section{VIOLA Virg.}

\section{Acaules.}

\section{a. Foliis divisis.}

1. D. pinnata $L$. fol. multifidis glalris; laciniis iucisis obtusis; petiolis pedunculos superantibus. Rchb. ic. 84. 85. In Alp. Europ. et Asiae. 4. Elores pallide violacei.

2. V. dissecta Ledeb. ic. fl. ross. t. 232. fol. tripartitis; laciniis multifidis dentatis glabris; sepalis ovatolauceolatis acutis calcari porrecto subbrevioribus. In Sibiria. 24. Flores intense violacei.

3. $V$. digitata $W$. Hb. fol. palmatis subtus petiolisque pubescentibus; laciniis lanceolatis inciso-dentatis; pedunculis petiolos superantibus. V. dactylodes $\mathbf{R}$. et $\mathrm{S}$. Gmel. sib. 4. $t$. 49. f. 2. In Sibiria. 4.

4. . pedata $L$. fol. multipartitis pedatis subtus petiolisque glabris; laciniis spathulatis bidentatis; antherarum processibus latis solidis. B. M. 89. B. Cab. 536. V. digitata Pursh. V. atropurpurea lafin. V. ranunculifolia Poir. In Amer. bor. $\hbar$. Cor. violacea.

5. V. multifida W. Hb. fol. tripartitis; laciniis nultifidis linearibus dentatis; petiolis pubescentibus; stipulis linearibus elongatis. V. pinnata Gmel. Sib. 4. t. 48. f. 4. In Sibiria. 4.

6. V. palmata $L$. fol. cordatis 10bato-laciniatis subtus petiolisque pilosis; petalis fauce barbatis. B. M. 535 . In Amer, bor. 24. Cor. purpurea.

\section{b. Foliis indivisis.}

\section{* Cordatis, reniformibus.}

7. V. odorata $\boldsymbol{L}$. acaulis stolonifera; fol. lato-cordatis pubescentibus; pedunc. fructiferis prostratis. E. B. 619. FL. Dan. 309. Hayne 3. t. 2. sv. B. t. 8. In Europa, Asia et Africa bor. 24. Flores violacei rosei et albi in hortis pleni.

8. V. sagittata Ait. fol. cordatosagittatis oblongis acutiusculis basi incisis dentatis; scapo folia superante; petalo infimo cucullato. B. Cab. 1471. V. dentata Pursh. In Amer. bor. 24.

9. V. suavis IM. B. stolonifera; fol. pubescentibus; calycibus obtusis; petalis superioribus oblongis obtusis, infimo emarginato. Rchb. ic. 65\%. V. italica Mill. In Tauria. 4. Cor, violacea fundo albo.

10. V. hederacea Labill. Nov. Holl. t. 91. stolonifera; fol. cordatis repandis subtus pubescentibus; pedunc. elongatis. B. Cab. 1133. In Nov. Holl. 4.

11. V. palustris L. fol. reniformicordatis cordatisve glabris; stipulis ovatis glanduloso-serrulatis liberis; capsula nutante. E. B. 444. F1. D. 83. In palud. Europ. et Sibir. 4. Cor. pallide lilacina.

12. V. asarifolia Pursh; fol. dilatato-reniformibus acutis crenato-dentatis in petiolum attenuatis pubescentibus; pedunc. folio brevioribus; petalo infimo barbato. In Carolina. 4.

13. V. betonicaefolia $\mathrm{Sm}$. fol. cordato - sagittatis lanceolatis crenatis glabriusculis; calycibus lanceolatis. In Nov. Holl. 2.

11. I. aspera $W^{\top} a l l$. fol. profunde cordatis villosis; stipulis setoso-laceris; calycibus acutis; petalis lateralibus barbatis; calcari conico falcato. In Nepalia. 4.

15. Y. japonica Langsd. fol. cordatis glabris; stipulis linearilus subulatis ; calycibus acutis; calcari obtuso abbreviato. In Japonia. 4.

16. V. Hookeriana $H$. et $K$. Nov. Gen. $t$. 492. f: 2. glaberrima; fol. reniformibus profunde cordatis crenatis; stipulis dentato-ciliatis; petalis violaceis apice rotundatis. In Mexico. 4.

1\%. V. palmaris Hamilt. fol. longe petiolatis cordatis acuminatis crenatis pilosiusculis; calycibus acutis ; petalis barbatis; calcari saccato. In Nepalia. $\hbar$.

18. V. magellanica Forst. fol. roniformibus orbiculatis subcrenatis glabris; calycibus acutis; calcari brevi obtuso, In Terra ignea.

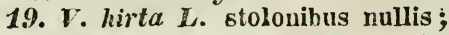
fol. cordatis supra pubescentibus sub- 
tus petiolisque hirtis; petalis emarginatis intermediis barbatis. Rchb, ic. 94. E. B. 894. FI. Dan. 618. Hayne 3. t. 1. In Europa et Caucaso. 24. Inodora.

20. I. collina Bess. stolonibus uullis; fol. cordatis subtus petiolisque hirtis; petalo infimo enarginato, intermediis obsolete barbatis. Rchb. ic. 92. 93. In Europa. 4. Flores parvi suaveolentes.

21. V. ambigua $\mathrm{H}_{\text {. et }} \mathbf{K i t}$. $t .190$. fol. cordato-oblongis obtusiusculis creuatis glabris; baseos lobis cucullatoinflexis inaequalibus; caps. 6-sulcata pubescente. In Europ. austr. 24. Flor. pallide lilacini odorati.

22. I. sororia W. H. Berol. t.72. fol. cordatis subrotundis crenatis pubescentibus; calcari abbreviato calycibusque obtusis; petalis lateralibus barbatis. In Amer. bor. 4.

23. I. campestris M. B. stolonibus nullis; fol. cordato-oblongis piIoso-hirtis, sinu baseos aperto utrinque arcuato; calycibus obtusis. Rchb. ic. 89-91. In Hungaria. 4.

24. V. uliginosa Schrad. fol. cordatis glabris; petalis omnibus basi saccatis; caudice repente. Rchb. ic. 107. V. scaturiginosa Wallr. V. nitens Host. In turfosis Alp. Europ. 4.

25. $\boldsymbol{V}$. cordata Wall. fol. late cordatis acutis creuatis glabris; pedunc. Iongissimis; calycibus acutis; petalis mediis barbatis. In America boreali. 4.

26. V. variegata Fisch. fol. subcordato-subrotundis glaberrimis subtus discoloribus; petiolis pubescentibus; calycibus acutis; calcari obtuso. In Dahuria. 4.

27. V. cucullate Ait. rhizomate carnoso crasso; fol. cordatis acutis serratis glabriusculis; laciniis calycis nervosis; petalis imberbibus. B. M. 1795. In Amer. bor. 4.

28. T. villosa Walt. fol. cordatis obtusis crenatis canescentibus villosissimis; calycibus acutis; petalis superioribus barbatis. In Carolina. 4.

29. I. rotundifolia IIichx. fol. cordatis obtusis crenulato-dentatis; petiolisque planiusculis subpubescentibus; calycibus obtusis; petalis lateralibus barbatis. V. calthaefolia Poir. V. clandestina Poir. In Amer. boreali. 4
30. V. blanda IV. hort. Berol. $t$. 24. fol. cordato-reniformilus remote serratis glahnis; pedunctilo petiolos subaequante; calycihus obtusiusculis; petalis imlierbibus. In Amer. bor. 4.

31. V. ovate Nuti. fol. cordatoohlongis obtusis crenatis ; petiolis marginatis pedunculisque hirsutis; calycibus acutis; petalis lateralibus barbatis. In Amer. bor. 4.

32. V. macroceras Bunge; glabra; fol. cordatis crenato-serratis acutis; sepalis obtusiusculis glahris; petalis 2 mediis barbatis; stigmate marginato. Ledel,. ic. Fl. ross. t. 219. In Sibiria. 24. Flores violacei.

33. V. imberbis Ledeb.ic. Fl. ross. t. 236. fol. cordatis aculis serratis pilosiusculis; sepaiis Ianceolatis acuminatis basi ciliatis; calcari elongato incrassato. Prope urbem Narym. 4. Flores violacei.

31. I. Dehnhardtii Ten. cat. stolonifera; glaherrima; fol. cordatooblongis grosse dentatis utrinque scabriusculis; petalis orbiculatis crenulatis; seminibus scabris, In sylvis circa Neapolin. 4.

** Foliis oratis oblongis lanceolatis.

35. V. primulaefolia $L$. fol. ovatis basi subcordatis; petiolis marginatis; stipulis liberis; sepalis Ianceolatis obtusis; petalis 2 barbatis, infimo acuminato. In humidis Carolinae. 24. Elores odorati.

36. T. alpina Jacq. obs. t. 2. fol. longe petiolatis ovato-subrotundis crenatis; stipulis exiguis linearibus dentato-ciliatis adhaerentibus; calcari obtuso. Jacq. austr. t. 242. In $A l p$. Europ. austr. 24.

3\%. V. Patrinii DC. fol. ovatooblongis glabris; calycibus lanceolatis ; petalis duobus barbatis. I. primulaefolia $\beta$. Lour. In Asia. 4.

38. P. lumilis H. et ho. Nov.Gen. t. 492. $f$. 1. glaberrima; fol. subrotundis obtusis integerrimis vel obsolete crenatis; petiolis pedunculisque glabris; stipulis apice dentato-ciliatis; petalis albis luteo-nervosis. In Mexico. 4.

39. V. microphylla Poir. fol. ovato-lanceolatis cremulatis crassiusculis pubescentibus; petiolis basi stipulatis; scapo filiformi folia excedente; peta- 
lis lateralibus barbatis. In Patagonia. 4.

40. V. philippica Cav. ic. t. 529. f. 2. fol. ovato-oblongis obtusis crenulatis petiolo longioribus; scapis 1foris bibracteatis. In ins. Luzonia et Manilla. 24. Cor. violacea.

11. I. Gmeliniana R. et S. fol. ovato-lanceolatis pubescentibus creuatis subsessilibus; stipulis ciliatis. Gmel. sib. 4. t. 49. f. 2. In Sibiria. 4.

42. V. lanceolata $L$. fol. Ianceolatis in petiolum attenuatis crenulatis glabriusculis; petalis imberbibus. In Sibiria et Amer. bor. 4.

43. J. spathulata W. Hb. fol. spathulatis subsessilibus subintegerrimis scapoque incano-villosiusculis; calcari ah)reviato obtusiusculo. In Persia boreali. 2 .

41. V. pygmaea Juss. fol. sessilibus linearibus obtusis carnosis glabris integerrimis basi stipulatis; stigmate 2-Iobo. In Peruvia. Cor. pallide caerulea.

45. V. Sieberiana Spr. fol. longe petiolatis obovato-subrotundis dentatis glabris; scapo gracili bibracteato; flore nutante; calcari hrevissimo. V. spathulata Sieb. In Nov. Holl. 4.

46. V. acuta Biey. fol. ovatolanceolatis obtusiusculis obsolete crenulatis basi subdecurrentibus; stipulis linear-lanceolatis; petalis acutis imberbibus; calcari brevissimo. In Amer. bor. 4.

4\%. V. caespitosa Don; fol. oblongis utrinque rotundatis glabris crenulatis; petiolis marginatis; calycibus acutis; petalis obovatis integris lateralibus barbatis. $\boldsymbol{V}$. Patrinii $\gamma$. DC. In Nepalia. 4.

2. Caulescentes.

a. Stipulis indivisis subserratis.

* Herbaceae.

48. V. epipsila Ledeb. caule prostrato repente; fol. reniformi-cordatis crenatis glabris; calycihus olutusiusculis; calcari obtusissimo. In Livonia. 4.

19. I. Leuisiana Ging. caule stolonifero; fol. reniformi-cordatis ; stipulis magnis ovatis ciliatis; petalis barbatis; calcari hrevi. V. repens Lewis. In Amer. bor. 24.

50. V. diffiesce Ging. caule simplici decumbente; fol. ovatis crenatis in petiolum decurrentibus stipulisque lanceolatis dentatis ciliatis; calcari emarginato. In Nepalia. 4.

51. V. purpurascens Schmidt? caule procumbente; fol. reniformi-cordatis obtusiusculis; calycibus acutis; caps. pubescente. In liohemia. 4.

52. I. stipularis $\mathbf{S} w$. caule hasi radicante adscendente; fol. ovato-lanceolatis crenatis glabris; stipulis lanceolatis ciliatis; pedunc. filiformibus; calcari hrevissimo. V. persicarifolia Poir. In ins. Carib. 4.

53. V. fratrans Sieb. caule simplicissimo 1-floro; fol. spathulato-ohlongis petiolatis enerviis villosiusculis; calycibus acutis; calcari abbreviato. In Creta. 2 .

5*. T. umiflorc L. caule 1-floro; fol. subcordato-ovalis acutis dentatis nervosis pubescentibus; calycibus acutis; calcari saccato. In Sibiria.

5.5. $\quad r$. biflora L. caule bifloro; fol. reniformihus serratis. Fl. Dan. 46. Krok. sil. 43. B. M. 289. In Alp. Europ. et Asiae. 24. Flores parvi flavi.

56. V. serpens Wall. caule gracili; fol. profunde cordatis glabriusculis; stipulis lanceolatis dentatis; floribus minutis; petalis duobus medio barbatis; calcari obtusissimo. In Nepalia. 4.

5\%. V. minuta M. B. caule simplici sub-1-floro; fol. subrotundis crenatis; stipulis integerrimis ciliatis. In Caucaso. 24.

58. V. nummulariaefolia All. fol. subcordatis ovalibusque integerrimis; stipulis exiguis adhaerentibus; calcari abbreviato. Rchb. ic. 140. All. ped. t. 9. f. 4. In Alp. Europ. 4. Flores dilute violacei.

59. R. rupestris Schmidt; fol. reniformibus crenulatis; sepalis calcar aequantibus; stipulis Ianceolatis. Sclimilt Abh. 1. f. 10. Rchb. ic. 141. V. nummulariaefolia Host. In Alp. Bohem. 4.

60. Y. conspersa Rchl. caule simpliciusculo paucifloro; fol. cordatoorbiculatis crenatis glabris subtus punctatis ; stipulis onlongis dentatis; calycibus acutis; calcari obtuso. V. uliginosa MühI. In Nov. Caesarea.21. 
61. V. arenaria $D C$. caulihus procumbentibus adscendentilus pube brevissina subcanescentibus; fol. cordatis obtusis crenulatis; stipulis ohlongis planis petiolo brevioribus. V.Allionii Pio diss. t. 1. f. 2. Rchb. ic. 142-146. V. livida Rchb. 147, 149. In Europa, Tauria et Caucaso. Flos caeruleus.

62. I. qumila Jill. caule simplici; fol. ovato-ohlongis acutis crenatis glahris; petiolis marginatis; stipulis serratis; calycibus acutis. V. lancifolia Thore Rchb. ic. 204. In Delplinatu. 4.

63. I. striuta Ait. caule basi ramoso; fol. cordatis acutis creuatoserrulatis petiolisque glabris; stipulis fimbriatis; pedunc. elongatis; calcari obtuso. V. debilis Nichx. In Amer. bor. 4.

6. I. canina $L$. caulibus procumbentibus adscendentibusque glabris vel subpubescentibus; fol. e basi cordata ohlongo-ovatis acutiusculis; stipulis caulinis intermediis oblongo-lanceolatis fimbriato - serratis petiolo pluries brevioribus; capsula trumcata apiculata. V. canina lucorum Rchls. ic. 154. 155. var. minor Rchb. 150-153. V. ericetorum schrad. V. flavicoruis Sm. In Europ., Asia et Amer. bor. 4. Flos violaceus.

65. V. Langsdorffi Fisch. caule adscendente; fol. cordato-subrotundis; stipulis ovatis setoso-dentatis; calycibus obtusiusculis; calcare saccato obtusissimo. In ins. Alenticis.

66. I. ochroleuca Lewis; caule adscendente; fol. cordatis acutis; stipulis maximis ohlongis remote dentatis; calycibus acuminatis; calcari elongato. V. striata Pursh. In Amer. bor. 4.

6\%. V. lancifolia Bess. caule erectiusculo; fol. cordato-oblongis crenulatis pilosiusculis; stipulis lanceolatis dentatis; calcari emarginato bi1obo. In Podol. et Galicia. 4.

68. V. stagnina Kit. caulibus erectis glabris; fol. e cordata hasi oblongo-lanceolatis petiolo superue subulato; stipulis caulinis intermediis Ianceolatis acuminatis fimbriato-serratis petiolo dimidio breviorilus. V. lactea Rchb. ic. 208. V. montana Rechb. ic. 207. In Europa. 24. Flos lacteus.

69. V. Ruppii All. caulibus erectis glabris; fol. cordato-ovatis antice subacuminato-angustatis ; petiolo superne alato; stipulis foliaceis fumbriato-dentatis intermediis petiolo duplo brevioribus. V. stricta Hornem. Fl. Dall. 812. Relıb. ic. 205 et 206. In nemorosis Europae. 4.

r0. I. persicifolia Roth; caulibus erectis foliisque glaherrimis; fol. ex ovata hasi lanceolatis in petiolum alatum repaudis; stipulis caulinis mediis foliaceis inciso-dentatis petiolo Iongioribus. V. pratensis Mart. V. lactea K. et Z. V. liuppii Presl. Rchl. ic. 99. f. c. d. e. f. In pratis nemorosis Europae. 24. Flos cacruleus rarius albus.

1. V. pubescens Ait. caule simplici paucifloro foliisque cordato-ovatis acutis crenato-denticulatis pilosis; pedunc. filiforibus; stipulis ovatis subintegerrimis; calcari brevissimo. V. pellsylvanica Miclix. In Amer.bor. 24.

\%. V. eviocurpa liewis; caulo adscendente ramoso; fol. subreniformi-cordatis acutis scahris; stipulis ovatis; calcari brevissimo subsaccato; fructibus dense villosis. In $\mathrm{Ca}$ rolina.

\%3. V. corchorifolia Domb. caule erecto pubescente; fol. basi inaequalibus ovatis acutis setoso-serulatis; stipulis lanceolatis setoso-laceris ; calcari : latissimo saccato. In Peruvia. 4.

1.t. $T$. canadensis $L$. caule elongato ramoso puhescente; fol. late cordatis ovatis acutis triplinerviis; stipulis lanceolatis subintegerrimis; pedunc. filiformihus; calycibus acuminatis. V. alliflora Lk. In Canada. 4. 85. I. hastata Michx. fol. liastatis sinuato-serratis brevissime petiolatis; stipulis minutis denticulatis; calycibus acutis; calcari obtuso. In Amer. bor. 4. Flozes lutei.

96. V. macnlate Cav. ic. t. 539. caule abbreviato; fol. ovatis; stipulis ovatis apice fimbriatis; staminibus apice emarginatis; stigmate apice sulplano; calcari brevi obtuso. V. pyrolaefolia Poir. In Chili. 4. Flores lutei.

\%\%. I. mirabilis $L$. caulibus eroctis unifariam petiolisque carina pilosis; fol. late cordatis breviter acuminatis crenulatis; stipulis oblongo-lanceolatis acuminatis ciliatis; floribus corollatis. Jacq. austr. t. 19. In Eu- 
rop. med. 24. Flos odotatus pallide violaceus.

r8. $\boldsymbol{V}$. cheiranthifolia $\boldsymbol{H}$. et $\boldsymbol{K}$. $\boldsymbol{l}$. aey. t. 32. velutina; radice crassa lignosa; caulibus adscendentibus; fol. lanceolatis integerrimis; stipulis linearibus; calcari tubuloso subacuto. In Tenerifict. 2 .

199. I. scrotiformis DC. caule ramoso; fol. linearibus obtusiusculis inlegerrimis; stipulis subulatis; calcari saccato. In From. b. spei. 24.

80. V. tripartita Ell. caule decumbente piloso; fol. tripartitis; laciniis lanceolatis basi attenuatis subintegerrimis ; pedunc. elongatis. V. trifida Spr. In Georgia.

s1. V. tridentata Menz. caule ramoso; fol. obovatis 3-dentatis coriaceis glabris; calcari brevissimo. In ins. Statenland. 4.

S2. V. gracillima Hilar. caule filiformi erecto glaberrimo; fol. late cordatis ohsolete dentatis subtus farinosis; calycibus acuminatis. In Prasilia.

83. Ir. subdimidiata Hilar. caulescens; glaberrima; fol. cordato-ovatis dentatis; stipulis oblongo-lanceolatis incisis ciliatis; pedunc. folio brevioribus; calycibus acuminatis. In Brasilia.

81. V. cerasifolia Hilar. caulescens; glaberrima; fol. reniformibus crenulatis; stipulis lanceolatis acutis dentatis; pedunc. folio brevioribus; stipulis oblongo-lanceolatis incisis ciliatis basi auriculatis. V. conferta var. Hilar. In Brasilia.

85. T. Hamiltoniana Don; repens; glaberrima; fol. reniformibus crenulatis; stipulis lanceolatis acutis den1atis; pedunc. folia subaequantibus calycihus acutis. V. glandulifera Wall. In Nepalia.

86. V.arcuata Blume; decumbens; glabra; fol. reniformi-orbiculatis acutiusculis serratis venis pubescentibus; stipulis ovato-oblongis ciliatis hasi subserratis. In Java.

8\%. Vilosa Blume; caule stolonifero; fol. cordatis crenulatis pilosiusculis; stipulis setaceo-incisis ciliatis. In Java.

88. T. cenisia All. pedem. $t$. 22. f. 6. filiformi-multicaulis; fol. ovatospathulatis crassiusculis integerrimis; stipulis integris palmatifidisve; sepalis membranace -marginatis; calcari subulato. In Alp. Pedemontii. 4. Flores violacei.

89. T. Talderia All. pedem. t.21. f. 3. subdiffusa; fol. inferioribus spathulatis crenatis superioribus lanceoIato-linearibus; stipulis lineari-lanccolatis; calcari subulato corollam excedente. $\quad$. heterophylla Bertol. V. Bertolonii Pio diss. t. 3. f. 2. $r$. cenisia $\beta$. pubescens Koch syn. In Alp. Pedemontii. 4. Flores saturate caerulei.

90. . Wallichiana Ging. caule erecto; fol. reniformi-cordatis ; stipulis lanceolatis denticulatis; calycibus acuminatis; calcari elongato; stigmate bifido. V. reniformis Wall. In. Nepalia. 24.

91. V. Nutallii Pursh; caule pubescente; fol. ovato-oblongis acutis obsolete dentatis nervosis in petiolum attenuatis; stipulis integerrimis; pedunc. folia aequantibus. Ad flum. Missouri. 2 .

92. T. rostrata Nutt. caule basi ramoso sarmentoso; fol. cordato-ovatis acutis crenulatis glahris; stipulis linearibus elonyatis fimbriatis; calcari elongato reflexo. In Amer. bor. 4.

\section{** Fruticosae.}

93. V. scandens Humb. et $\boldsymbol{K}$. Nov. Gen. $t$. 193. caule fruticoso scandente glahro; fol. subcordatis argute serratis; stipulis dentato-ciliatis; calcari brevi saccato. In Peruric. 4.

91. V. arguta Inumb. caule fruticoso volubili; fol. ovatis acutis profunde cordatis argute sarratis supra puberulis subtus pubescentibus; petiolis villosis; stipulis dentato-ciliatis. In Peruvia. ち. Cor. incarnata.

95. V. rubella Cav. ic. $t$. 3.51. f. 1. caule fruticoso; fol. ovato-oblongis acutis punctatis serratis; stipulis lanceolatis ciliatis; calcari ohtuso. V. Chamissoniana Ging. In Chili. 古.

96. V. capillaris Pers. fol. hasi inaequalibus ovatis acutis serratis; stipulis lanceolatis elongatis fimbriatis; calcari saccato brevissimo. V. stipularis Cav. ic. t. 351. f. 2. In Amer. custr.

9\%. V. arborescens $\boldsymbol{L}$. caule striato suffruticoso; fol. lineari-lanceolatis subdentatis confertis; stipulis linearibus integerrimis; calcari obtusissimo. 
V. suberosa Desf. V. arhorea Forsk. Barr. ic. 568. In Euroy. austr. et Afr. boreali. t.

98. I. Cotyledon Ging. caule crasso tortuos 0 ; fol. confertissimis spatluulatis margine cartilagineis integerrimis glabris; calcari brevissimo; stigmate bifido. In Chili. 古.

99. I. decumbens $\boldsymbol{L}$. caulibus ramosissimis procumbentibus; fol. linearibus angustissimis integris; stipulis subulato - linearihus; stigmate uncinato nudo. In Prom. b. spei. ந.

\section{b.Stipulis pinnatifidis; stigma- te urceolato.}

100. I. tricolor $I$. fol. crenatis inferioribus cordato-ovatis; stipulis lyrato-pinnatifidis lacinia media crenata; radice simplici; caulibus adscendentibus ramosis. V. saxatilis schmidt. V. hammatica Kit. V. Kitaibelii $\mathbf{R}$. et $\mathbf{S}$. V. arvensis Burr. Hayme Arzu. 3. t. 4. Sv. Bot. 4t. Fl. Dan. 623. E. B. 1287. In alfis Europ., A siae et Afr. bor. $\odot$. Cor. violacea petalis inferioribus luteis, flava, caerulea et variegata.

101. I. rothomagensis Desf. fol. crenatis, inferioribus ovato-cordatis ; stipulis pinnatifidis lacinia media latiore integerrima; caulibus prostratis ramosissimis. B. AI. 1493. In agris Europ. $\odot$. Flos dilute lilacinus.

102. V.lutec $\mathrm{Sm}$. fol. crenatis, inferioribus ovato-cordatis; superioribus lanceolatis stipulis digitato-inultipartitis; caudiculis repentibus filiformibus. V. grandiflora Huds. Pchb. ic. 302. E. B. 721. Tratt t. 43 . V. sudetica IV. In Anglia et Europ. 4. Cor. flava.

10:3. V. declinata $W$. et Kit. t. 223. fol. crenatis, inferioribus ovatis oblongisve, superioribus lanceolato-linearibus; stipulis digitato-multipartitis; calcari adscendente. V. gracilis Sibtl. gr. t. 222. In Italia, Sibiria et Asia minore. $\odot$. Cor. tota violacea petalo infimo basi luteo.

101. V. chrysantha Sclirad. sul)simplex; fol. lanceolato-oblongis crenatis; stipulis pinnatifidis ciliatis ; calcari calycem aequante. Rchb. hort. I. 114. In Alp. Helvetiae. 24. Flos magnus luteus.

10.5. I. cornutu I. caule adscendente 3-gono; fol. cordatis serratis; calcari calycem superante subulato; petalo impari breve acuminato. B. M. 791. Rchb. ic. 429. In $A$ lp. Europ. mediae. 24. Flos magnus dilute lilaciuns.

106. $V$. calcarata $I$. fol. crenatis ovatis oblongisque; stipulis integris vel 3-fido-dentatis subpinnatifidisque; calcari Iongitudine petalorum; caule simplicissimo. V. Zoysii Jacq. Coll. 4. t. 11. f. 1. In pascuis $A \iota_{j}$. Europ. 4. Cor. violacea et flava.

10\%. V. altuica Pall. caule simplici glabro; fol. subrotundo-ovatís in petiolum attenuatis creratis subcarnosis; stipulis lyratis iucisis; flore resupinato; petalis subreniformibus undulatis. V. grandifiora $\mathrm{L}_{\text {. }}$ In $\mathrm{Si}$ biria. 24. Corolla colore varia.

10s. V. amoence $\mathbf{S} y m$. ex $\mathbf{S m}$. E. B. 128. caule abbreviato; fol. subrotundo-oblongis; stipulis obtuse pinnatificlis; calycilous acutis suldenticulatis; petalis amplis; calcari obtuso abhreviato. V. oreades M. B. In Scotice et Tauria. 4. Flos purpureus.

109. I'. bicolor Pursh; caule simplici angulato; fol. inferioribus spathalato-subrotundis dentatis, superioribus lanceolatis integerrimis; stipuli 3 pectinato-pimuatifidis. In Amer. bor. et Sibiria. 4.

110. I. tracheliaefolia Ging. suffruticosa; glabra; fol. breviter petiolatis cordato-ovatis acuminatis arguto serratis; stipulis lanceolatis integerrimis. In ins. Sanduicensibus. 4 .

111. V. elatior Fries; caulihus erectis superne foliisque pubescentibus; stipulis caulinis mediis foliaceis oblongo-lanceolatis inciso-dentatis petiolo Iongioribus. V. persicifolia Koch fl. germ. Rchi. ic. 100 . V. montana Roth. In pratis Germaniae. 4.

\section{IMPATIENS Dodon. (1559).}

\section{a. Pedunculis 1-floris.}

1. I. Balsamina $I_{\text {. }}$ fol. lanceolatis superioribus alternis; pedicellis aggregatis; calcaribus flore longioribus. Balsamia hortensis Desv. I. coccinea Sinı. B. M. 1256. In Ini. $o r$. $\odot$. Variat. in hortis flore pleno albo roseo et rubro. 
2. I. cornuta $I$. fol. alternis lanceolatis; pedicellis aggregatis ; calcaribus flore multo longioribus. Burm. Keyl. t. 16. f. 1. Balsamina cornuta DC. In Zeylona. $\odot$.

3. I. chinensis $I_{\text {. }}$ fol. ovatis subserratis oppositis sessilibus; pedunc. solitariis; calcari arcuato obtuso corollam aequante. In China. Cor. purpurea.

t. I. mysorensis Roth; fol. alternis oblongo-lanceolatis remote dentatis; caule simplici filiformi; calcaribus rectis flore hrevioribus; pedunc. geminis. In Ind. or. $\odot$.

5. I. latifolia $L$. fol. ovatis serraturis lanceolatis; pedunc. solitariis; calcaribus flore longioribus. P. mollis Wall. var. Rheede 9. t. 48. In Ind. or. $\odot$. Cor. pallide ruhra.

6. I. mutila Lour. pedunc. subsolitariis; fol. oppositis lanceolatis serratis; calcaribus saccatis. In Cochinchina. $\odot$.

1. I. cochleata llour. fol. oppositis oblongis subserratis ; pedunc. elongatis; calcaribus cochleatis compressis; radice repente. In Chine uustrali. $\odot$.

8. 1. fasciculat tuam. fol. oppositis lineari-lanceolatis; pedunc. axillarihus aggregatis. Balsamina Hook. exot. fl. t. 13\%. I. heterophylla Wall. Hheede 9. t. 4\%. 49. et t. 50. In $M a$ labaria. $\odot$. Flos purpureo-caerulescens.

9. I. rosmarinifolia Retz; fol. oppositis linearibus serrato-spinulosis; pedunc. solitariis; calcari abbreviato. In Reylona. $\odot$. Flos parvus.

10. I. oppositifolia I. pedunc. aggregatis subracemosis; fol. oppositis Iinearibus denticulatis; calcari brevissimo. Rheede 9. t. 31.? In Zeylona. $\odot$. Flos purpureo-caerulescens.

11. 1. bifida 'rimb. fol. alternis oblongis serratis; pedunc. solitariis; calcari bifido corollam multo superante. In From. b. spei. $\odot$.

\section{b. Pedunculis 3-floris.}

12. I. triflora $L$. pedunculis brevissimis; fol. lineari-lanceolatis longissimis; calcaribus arcuatis flore pedicelloque longioribus. Burm. Zeyl. t. 16. f. 2. In Zeylona. $\odot$.
13. I. natans W. fol. oblongo-lancenlatis serratis; calcari brevissimo. In Ind. or. $\odot$.

14. I. Nolitangere $L$. fol. oblongoellipticis inaequaliter dentatis mucronatis flaccidis; calcari incurvo flore hreviore. E. B. 937. Fl. Dall. 35\%. Schk. t. 2\%0. In Europ., Amer. bor. et Asia med. $\odot$. Flores Iutei.

1.5. I. fulva Nutt. fol. rhombeooratis obtusis mucronato-dentatis; petalo calcarato elongato; calcari emarginato resupinato. I. biffora W. In Amer. bor. $\odot$. Flores fulvi.

16. I. pallida Nutt. fol. rlombeoovatis acutiusculis mucronato-dentatis; calcari recurvo brevissimo. In Amer. bor. $\odot$.

17. I. parviflora DC. floribus erectis folio brevioribus; fol. ovatis acuminatis mucronato-serratis; calcari recto. Ledel. ic. fl. ross. t. 89. In Russia ad Irtim. $\odot$.

18. 1. tripetala $.20 x b$. pedunc. brevissinis; fol. ovalibus acuminatis nucronato-dentatis, inferioribus ciliatis. In ind. or. ๑.

19. I. scabrida Wall. pedunc. 3-4floris folio brevioribus; fol. subtus glaucis glahris ovatis mucrouato-dentatis acutis. I. Hamiltoniana Dou. In Nepalia. $\odot$. Flores flavi.

20. I. trilobata Cólebr. pedunc. sub-1-floris folia oblongo-lanceolata serrata glabra subaequantibus; calcari conico acuminulato. In Ind. or. $\odot$.

21. I. urticaefolia Wall. pedunc. petiolos subaequantibus; fol. ovatis acuminatis glanduloso-crenatis sparse pilosis nitidis; calcari amplo. In Emodi montibus. $\odot$.

22. I. cristata Wall. fol. lanceolatis acuminatis setace 0 -serratis pubescentibus; calcari incurvo. Ad terminos Mongoliae. $\odot$.

23. I. calycina Wall. pedunc. subbifloris; fol. alternis ovatis acuminatis argute serratis pubescentibus; calycibus amplis villosis; calcari adscendente. In Nepalia. $\odot$.

21. I. grandis Hayne; floribus maximis; calcari longissimo; fol. longe petiolatis ovatis acuminatis serratis. In Ind. or. $\odot$.

25. I. fruticosa Lechen; fol. ovalibus utrinque acuminatis; serraturis infimis glandulosis superne subscahris subtus pubescenti-velutinis. In Ind. or. ち. 
c. Pedunc. multifloris racemosis.

26. 1. racemosa Wall. fol. oblongis utrinque attenuatis dentatis glahris; calcari recurvo teuui florem aequante. In Nepalia. $\odot$. Flores parvi flavi.

2\%. I. Ieptoceras Wall. pedunc. 6-8-floris erectis racemosis; fol. glahris ohlongis utrinque attenuatis serrato-mucronatis; calcari longissimo. I. micrantha Don. I. longicornu Wall. In Nepalia. $\odot$.

28. I. insignis Wall. pedunc. 8-?0floris erectis fol. longioribus; fol. glabris oblongis utrinque attenuatis mucronato-dentatis; calcari longissimo. In Nepalia. $\odot$. Cor. purpurea.

29. I. sulcata W'all. pedunc. oppositis multifioris folio lrevioribus; fol. oppositis ovato-ohlongis argute serratis ; calcari incurvo; caule profunde sulcato. In montibus Emodi. $\odot$.

30. I. bicormuta Wall. pedunc. elongatis corymbiferis ; florihus fasciculatis hracteatis; nectarii ore appendiculato cornuto; calcari conico apice filiformi; fol. ovato-lanceolatis acuminatis serratis. In Nepalia. $\odot$.

31. I. umbellata Hayne; pedunc. apice umhelliferis; calcari longissimo; fol. ovatis obtuse acuminatis crenatis. In Ind. or. $\odot$.

32. I. odorata Don; racemis corymbosis folio hrevioribus; calcari pedicellos aequante; fol. lineari-lanceolatis serratis glabris. In Nepulia. $\odot$.

33. I. fimbriata Hook. exot. fl. t. 116. racemo terminali capitato; bracteis purpureo-fimbriatis; calcari subulato incurvo; fol. oblongis acuminatis serrato-ciliatis. In silhet. $\downarrow$.

34. I. scapifiora Hayme; scapo corymbifero; calcari longissimo; fol. radicalibus cordato-subrotundis obtusis multinerviis integerrimis. In $\mathbf{l n d}$. or. $\odot$.

\section{IAIVRADIA Vand. (1788).}

1. L. montana Irart. Nov. Gen. t. 23. fol. alternis subsessilibus ovatis mucronatis marginatis calloso-denticulatis venosis glalris; floribus racemosis. L. glandulosa Hilar. In
2. L. alpestris Mart. l. c. t. z2. fol. confertis lineari-lanceolatis acutis patentissimis integerrimis ; stipulis sctaceis subdivisis; floribus paniculatis. L. ericoides Hilar. In Brasilia.

3. I. elegantissima Hilar. suffruticosa; fol. minutis imbricatis sessilihus ovatis obtusis glahris; stipulis pilosis. Sauvagesia Hilar. Mím. Mus. In İrasilia. b.

1. I. Vellozii Hilar. sufruticosa; simpliciuscula; fol. alternis lanceolatis utrinque attenuatis mucronatis calloso-serratis; stipulis plumosis. In Brasilia. 方.

5. L. capillaris Hilar. suffruticosa; ramosissima; fol. lanceolatis glanduloso-serratis venoso-lineatis; pedunc. pancifloris. In Brasilia. $\hbar$.

\section{8\%. SAUVAGESIA Jacq. (1763).}

1. S. Adima Aubl. Guj. t. 100. f. A. caule hasi radicante adscendente ramoso; fol. alternis oblongis utrinque attenuatis marginatis crenatis; perlunc. axillaribus 1-floris. In Amer. austr.

2. S. erecta $L$. caule erecto simpliciusculo; fol. lanceolatis marginatis subserratis, inferioribus stipulisque elongatis confertis; floribus racemosis. In Amer. anstr. et Ind. occ. $\hbar$.

3. S. orata Mart. l. c. t. 24. f. 2. herlacea; caule adscendente basi ramoso; fol. breviter petiolatis ovatolanceolatis crenatis; floribus terninalibus paniculatis. In Brasilia. $\hbar$. 1ped. Cor. pallide rosea.

4. S. pusilla Nirart. l. c. t. 24. 7 : 1. annua; caule erecto ramoso; fol. linearibus; stipulis capillari-pinnatifidis; pedunc. 1-foris; corona fimbriarum nulla. S. tenella Lam. In Brasilia. $\odot$. Flores roseo-violacei.

5. S. sermyllifolia Mart. $t$. 25. caule erecto friticoso; fol. subsessilibus approximatis lanceolatis acutis crenato-marginatis ; racemis terminalihus. s. sprengelii Hilar. s. erecta spr. N. Entd. In Brasilia. t. 2-3ped. Flores rosei.

6. S. linearifolia Hilar. suffruticosa; ramosa; fol. linearibus acutis obsolete serratis; stipulis bifidis ciliatis; calycibus acutis apice barbatis. s. fruticosa Mart. In Brasilia. $\hbar$.

\section{Brusilia.}




\section{BYBLIS Salisb. (1808).}

1. B. linifiora Salish. parad. $t$. 9.5. In Nov. Holl. Herba simplex. Folia linearia piloso-glandulosa. Flores caerulei.

\section{GALAX L. (1751).}

1. G. aphylla L. Erytrorrhiza rotunitifolia Michx. am. t. 36 . Gaertn. t. 210. Solandra Vent. Haim. $t .69$. Blandorfia Andr. rep. t. 3-13. In Viryinia. $\odot$. Folia radicalia cordatosubrotunda serrata. Flores albi in scapo pedali.

\section{ITEA Gronov. (1\%43).}

1. I. virginica $I$. Ehret. select. t. 98. Gaertn. t. 20.9. In Amer. bor. ち. Arhor ramis spinosis; fol. spathulatis emarginatis subcrenatis; foribus racemoso-paniculatis.

\section{BRENIA L. (173\%).}

1. B. lanuginosa Thunb. fol. semiteretibus tenuibus patulis apice sphacelatis basi ramulisque pilosis; capitulis globosis. Wendl. coll. t. 11. Plukn. t. 318. f. 4. Berzelia Brongn. In Prom. b. spei. \$.

2. B. comosa Thunl. fol. trigonis patulis glabris obtusis apice ustulatis; capitulis globosis. Berzelia Brongn. In Prom. b. spei. 卢.

3. B. paleacea Wendl. coll. $t .21$. fol. 3-gonis apice fuscis arcte adpressis imbricatis; capitulis terminalibus; involucri foliolis coloratis. Berzelia Brongn. In Prom. b. spei. ち.

4. B. intermedia ; fastigiato-ramosissima; fol. lineari-3-gonis patulo-reflexis apice calloso; bracteis calyceque pilosis. Berzelia schl. In Prom. $b$. spei. $\hbar$.

5. B. ericoides Wendl. coll. t. 5\%. fol. linearibus brevibus acutis trigonis ad dimidium pilosis apice fusco-callosis patulis; capitulis globosis. Berzelia Brongn. In Prom. b. spei. 古.

6. B. rubra $\boldsymbol{W}$. fol. linearibus obtusis canaliculatis glabris patentissimis; capitulis lateralihus aggregatis. Berzelia Brongn. In Prom. b. spei. $\hbar$.
\%. B. superba Don; fol. semiteretibus patentibus incurvis pilosis apice aristato-sphacelatis. Rchb. hort. $t$. 100. Berzelia Brongn. In Prom. b. spei. 古.

8. J. arachnoidea Wendl. coll. $t$. 62. fol. linearibus tenuibus acuminatis subtrigonis arachnoideis apice fuscocallosis patulis; capitulis globosis minimis. Berzelia Eckl. et Zeyl. In Prom. b. spei. 方.

9. B. brevifolia; fastigiato-ramosa; fol. ovato-lanceolatis obtusis sub-3quetris apice calloso-ustulatis, junioribus villosis; capitulis avellanae magnitudine. Berzelia Eckl. et Zeyh. In Prom. b. spei. t.

10. B. abrotanoides Burm. afr. t. 100. f. 1. fol. lineari-lanceolatis reflexo-patentibus basi ciliatis; capitulis subglobosis corymbosis. Wendl. coll. t. 45. Berzelia Brongn. In Prom. b. spei. ђ.

11. B. formosa; fastigiato-ramosa; fol. lanceolato-linearibus 3-gonis obtusis glabris subrecurvato-patentibus apice sphacelatis; capitulis magnitudine Cerasi. Berzelia Eckl. et Zeyh. In Prom. b. spei. 市.

12. B. cordifolia; erecto-ramosa; pubescens; fol. subcordato-ovatis subemarginatis patenti-reflexis apice callosis ; petalis leviter bicrustaceis. Ber-

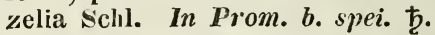

13. B. nodiftora $L$. fol. trigonis incurvis acutis imbricatis; capitulis tomentosis terminalibus. Breyn Cent. t. 10. Wendl. Coll. t. 35. Brongn. Brun. t. 36. f. 1. In Prom. b. spei. 古.

11. B. globosa Thunb. fol. trigonis incurvis acutis imbricatis villosis; capitulo terminali glabro. In Prom. $b$. spei. Ђ.

15. B. verticillata Thunb. fol. trigonis obtusis glabris erecto-imbricatis apice nigris; capitulis terninalibus; ramulis verticillatis fastigiatis. In Prom. b. spei. ђ.

16. B. alopecuroides Thunb. fol. trigonis acutis glabris imbricatis incurvis; capitulis globosis glabris in ultimis ramulis lateralibus. In Prom. b. spei. t.

17. B. microphylla Thunb. fol. ovato-3-gonis carnosis glabris dense imbricatis; ramis divaricatis; capitulis terminalibus villosis. Raspalia micropliylla Brongu. t. 3\%. In Prom. $b$. spei. $\hbar$. 
13. B. Thunbergiana; fol. trigonis apice fuscis arcte adpressis imbricatis ; capitulis terminalibus; involucri foliolis coloratis; receptaculi paleis multo minoribus. B. paleacea Thunb. IVendl. coll. t. 21. Berandia paleacea Brongu. t. 37. f. 2. In Prom. b. spei. ち.

19. B. fragarioides $W$. fol. trigonis laxe imbricatis hispido-ciliatis; capitulis terminalibus. Berandia Schl. In Prom. b. spei. ち.

20. B. passerinoides Schl. dichotome ramosissuma; ramis erectis gracilibus; fol. minutis obovato-ellipticis dense imbricatis caule arcte adpressis; capitulis minutis. In Prom. b. spei. t.

\section{HUMBOLDTIA Vahl (1794).}

1. II. laurifolia W. Batschia laurifolia Vall symb. $t$. 56. In Zeylона. . Arbor ramis articulatis flexuosis. Fol. pari-pinnata $4-5$-juga. Flores racemosi.

\section{DRYMARIA R. et S. (1819).}

1. D. frankenioides $\boldsymbol{H}$. et $\boldsymbol{K}$. Nov. Gen. t. 515. ramosissima; glandulosohirtella; viscidula; canescens ; fol.lanceolato-oblongis; petalis 6-fidis; ovariis 50-spermis. In Mexico. $\odot$.

2. D. stellarioides $\boldsymbol{W}$. Hb. canle apice dichotomo pancifloro; fol. sessilibus glabris; calyce viscido pubescente; petalis bifidis; ovariis 50-spermis. H. et K. 1. o. t. 516. In Mexico. $\odot$.

3. D. cordata R. et $\mathbf{S}$. caule foliisque glabris ovato-subrotundis acute mucronatis hasi obsolete cordatis ; pedunculo dichotomo; ovariis 7-10spermis. Holosteum cordatum L. Lam. ill. t. 51. f. 2. In Jamaica et Nov. Andalusia. $\odot$.

4. D. divaricata $H$. et $K$. caule foliisque glabris late subrotundo-ovatis acutis; pedunc. irregulariter ramosis; ovariis 8-spermis. In Peruvia. $\odot$.

5. D. ovata R. et S. caulibus superne ramisque villosis; fol. petiolatis ovatis mucronatis puberulis; peta- lis profunde bifidis; ovariis 13-15spermis. In Quito. $\odot$.

\section{MOLLIA Willd. (1806).}

1. M. Polycarpon Spr. caulibus filiformibus patulis; fol. obovatis ; florihus congestis terminalibus; petalis integerrimis. Hagea Bivon. In Sicilia. 24. 1-2-poll. Petala alba.

2. M. latifolia $W$. caule suffrnticoso diffuso; fol. obovatis mncronatis verticillatis, ranulorum oppositis; ca1 ycibus scariosis. Lahaya $\mathbf{R}$. et $\mathbf{S}$. In ins. Canariis. ‡. Calyx argenteus.

3. M. aristata Spr. fol. Ianceolatis aristatis sericeis; floribus fasciculatis. Illecebrum aristatum Ait. In ins. Canariis. 5 .

4. M. gnaphalodes Spr. caule suffruticoso prostrato; fol. oblongis tomentosis; floribus terminalibus congestis. Illecebrum gnaphalodes Schousb. Hagea Pers. In Aegypto. $\hbar$.

5. M. diffusa W. Hort. ber. $t .11$. caule ramoso diffuso; fol. spathulatis verticillatis subsenis; calycibus margine membranaceis. Polycarpea Teneriffae Lam. Hagea Pers. In Teneriffa. $\odot$.

6. M. alsinifolia Spr. fol. oppositis oblongis subcarnosis cauleque ramoso glabro; floribus congestis terminalibus. Hagea alsinifolia. Bocc. Mus. t. 38. In Sicilia. $\odot$. Flores albi.

7. M. fragitis Spr. fol. verticillatis lanceolatis apice mucronato-pungentibus revolutis; caule ramosissimo pubescente; calycibus scariosis. Polycarpea fragilis Delile Aeg. t. 24. Corrigiola repens Forsk. In Aegypto. $\odot$.

8. $M$. stellata $W$. caule ramosissimo diffuso; fol. senis linearibus planis pellucido-maculatis; floribus corymboso-dichotomis; calycibus scariosis. Achyrautlies stellata et tenuifolia W. spec. In Guinea. b. 3-poll. 9. $M$. corymbosa $\boldsymbol{W}$. caule diffuso ramoso; fol. quaternis lanceolato-linearibus mucronatis fasciculato-verticillatis. Polycarpea Lam. Bocc. Mus. t. 39. Pluk. t. 86. f. 6. Burm. Zeyl. t. 65. f. 2. In Zeylona. ち. Flores albi. 
10. IU. spadicea $\mathbf{U}^{r}$. fol. fasciculatis linearibus acutis glabris; caule herbaceo simplici erecto lanato ; floribus corymhosis; calycibus scariosis coloratis. Celosia corymbosa hetz. Rheede 10. t. 66. In Ind. or. 4.

\section{EUPAREA Gaertn. (1788).}

1. E. amoena Guertn. t.50. f. 5. In Nov. Holl. Herba procumbens facie Nummulariae sed 4-plo minore. Flores corollae Anagallidis phoeniceac.

\section{WIBELIA Pers. (1805).}

1. IV. gujanensis Pers. fol. oblongis integerrimis utrinque glahris; pedunculis racemosis; calycis laciniis acutis. Paypayrola gujanensis Aubl. Guj. t. 99. Payrola Lam. ill. t. 125. In Gujana. †. Cor. flava.

2. W' brasiliensis Spr. fol. oblongis scabris; pedunc. aggregatis 1foris; laciniis calyciniis obtusis. In Brusilia.

\section{STRELITZIA Ait. (1789).}

1. S. ovata Dryand. scapo folia superante; fol. ovato-ohlongis petiolo brevioribus. S. Reginae B. M. 119. 120. Andr. Rep. 432. Tratt. tal. t. 300. In Prom. b. spei. 24. Flos minutus.

2. S. parrifolia Dryand. scapo petiolos aequante; foI. lanceolatis petiolo multo hrevioribus. S. juncea Alldr. var. petiolis subaphyllis. Rchl). exot. t. 181. In Irom. b. spei. 4.

3. S. Regince Ait. scapo petiolos subaequante; fol. ovalibus subtus glaucis petiolo longo brevioribus. Ait. Kew. t. 2. Redouté Lil. t. 77. 78. Wendl. Gart. Mag. 1810. t. 24. 25. In Prom. b. spei. 4. 1-2-ped. Petala aurantiaca. Nectarium caeruleum.

4. S. angusta Thunb. scapo petiolis breviore; fol. oblongis amplissimis petiolo brevioribus. Heliconia alba 4. In Prom. b. spei. $\hbar$.

\section{RIBES Fuchs (1512).}

$$
\text { a. Iner mia. }
$$

\section{* Flores racemosi.}

1. R. alpinum I. fol. 3-5-lohis obtusis subtus lucidis supra pilosis; bracteis lanceolatis ventricosis parce glandulosis flore longioribus; floribus dioecis. Fl. Dan. 968. Jacq. austr. t. 47. Guimp. t. 21. B. Cab). 1480 . Sv. Bot. 223. In Europa. ち. Flores lutei. Baccae purpureae.

2. R. resinosum Pursh; resinosoglandulosum; fol. $3-\tilde{z}$-lobis subrotundis crenato-serratis; petalis rhomboideis; bracteis linearibus pedicello longioribus. B. M. 1583. Berl. May. 3. t. 2. f. 10. In Amer. bor. $ち$. Baccae hirsutae.

3. $\boldsymbol{R}$. ciliatum Willd. glandulosum; fol. cordatis profunde 5-lobis crenatoserratis ciliatis; petiolis hirto-glandulosis. R. xorullense Kunth. In Mexico. Ђ.

4. R. albiflorum $\boldsymbol{R}$. et $\boldsymbol{P}$. peruv. t. 132. $f$. 6 . fol. subcordatis incisoserratis; racenis folio duplo longioribus peudulis; bracteis spathulatis ciliatis; antheris subsessilibus. Berl. Mag. t. 2. f. 18. In Peruvia. $\hbar$.

5. R. hirtum W. Hb. fol. subcordato-ovatis 3-lohis subtus hirto-pilosis; petiolis glandulifero-tonentosis racemosis reflexis; bracteis dentatociliatis. H. frigidum $H$. et $K$. Berl. Mag. t. 2. f. 13. In monte Antisana. $\hbar$.

6. R. fragrans Pall. Act. Petr. 5. $t$. 9. fol. glabris longe petiolatis $3-5-$ lobis; racentis erecto-rigidis ; floriluus campanulatis albis odoratissimis ; bracteis deciduis. In Sibiria. ち. Bacca rubicunda.

\%. R. atvopurpureum C.A. Meyer; fol. pubescentibus suborbiculatis cordatis 3-5-lobis; lobis acutis serratis; racemis nutantibus; calycibus campanulatis ciliatis; baccis glahris ebracteatis. Ledeb. ic. Fl. ross. t. 231. In Altaico. ち. Frutex habitu Rihes rubri.

8. R. heterotrichum C. A. Meyer; fol. pubescentibus setosis et glandulosis suborbiculatis trilohis; lobis obtusis dentatis; pedicellis bracteam aequantibus; baccis puberulis. Ledeb. ic. Fl. ross. t. 235. In Altaico. t.

Baccae aurantiaceac. 
9. R. procumbens Pall.ross. t. 6.5. fol. obtuse lohatis; Iohis serratis; racemis erectis; pedunc. Iongis setaceis; laciniis limbi floris livido-purpurascentilus acutis. In Dahuria. $ち$. Baccae gratissimae.

10. R. multiflorum Kit. fol. cordato-5-lohis subtus tomentosis; racemis longissimis pendulis; bracteis flore breviorihus; petalis cuneiformibus. B. M. 2363. Berl. Mag. t. 2. f. 11. In Croatia. 5 .

11. $R$. rubrum $L$. racemis glabris laxe nutantihus; floribus planatis; fol. obtuse $\tilde{5}$-lohis. $\alpha$. sylvestre, minus flores fundo hepatici $\beta$. sativum, majus flores viriduli. E. B. 1289. Fl. Dan. 967. schk. t. 48. Guimp. t. 19. In Europ. austr. ad rupes et culta. †. Baccae albae et roseae.

12. R. petrueum Wulf. racemis pilosiusculis porrectis; fol. acuminato8-lobis inciso-dentatis ciliatis; caule erecto. Jacq. ic. t. 49 . Guimp. t. 20. E. B. 704. In Europ. austr. ち. Flores rosei. Baccae obscure sanguineac.

13. R. spicatum Roxb. fol. cordato-rotundis trilobis subtus canescentibus; racemis longissimis pedicellisque bracteas excedentibus villosis; calyce petalisque reflexis. Rohs. in Limn. trans. 3. t. 21. E. B. 1290. Berl. Mag. t. 2. f. 16. In Croatia et Anglia. 卉. Baccae rubrae.

14. R. nigrum $L$. racemis pilosis pendulis; floribus oblongo-campanulatis; fol. 3-5-lohis subtus glandulosis. E. B. 1291. Fl. Dan. 556. Guimp. t. 22. In Europ. ђ. Baccae nigrae cimices redolent.

15. R. carpathicum Kit. racemis peudulis calycibusque villosis; bracteis truncatis; floribus planis; caule erecto. R. acerrimum Roch, In Carpathis, $\hbar$.

16. R. triste Pall. surculis simplicissimis virgatis; racemis pendulis glahris; corollis extus ruhicundis intus flavescentibus; petalis revolutis. In Sibiria. ち. Baccae nigrae.

17. R. trifidum Michx. fol. glabriusculis sublobatis; racemis laxe multifloris; laciniis calycis sub-3-fidis; petalis purpureis spathulatis. In Amer. bor. juxta Quebeck. ђ.

18. R. glandulosum R. et P. peruv. $t$. 233. $f$. 6 . fol. cordatis obtuse trilobis duplicato-serratis rugosis; racemis brevibus; calycibus glandulosis pulescentibus. Berl. Mag. t. 2. f. 20. In Chili. ђ.

19. I. campanulatumı U. Hb. fol. cordato-sub-z̃-lobis duplicato-crenatis subtus hirtis; petiolis ciliato-glandulosis; racemis pendulis; petalisoblongospathulatis. IR. affine Kunth. In Iexico. $\hbar$.

20. R. Kunthii Bert. Mss. fol. cordat $0-5$-lobis duplicato-serratis puberulis; racemis solitariis congestis; calycihus campanulatis; petalis spathulatis reflexis; stylis 3-1-fidis. 12 . campanulatum H. et K. In Mexico. $\downarrow$.

21. R. prostratum Herit. stivp. t. 2. reclinato-prostratum; fol. sul)palmato-3-lobis; bracteis subamplexicaulibus pedicello multo brevioribus; petalis subcuneiformibus. Berl. Mag. t. 2. f. 12. R. glandulosum Ait. In Amer. bor. $\hbar$.

22. R. Biebersteinii Berl. Mss, fol. cordato-acute $3-5-5$ - loh argute duplicato-serratis subtus villoso-tomentosis; racemis nutantibus; petalis minutis. In Caucaso. ち. Baccae nigrae.

23. R. rigens Michx, ramis rectis ; fol. supra glabris subtus puhescentibus reticulato-rugosis; lobis dentihusque acutis; racemis laxis multifloris. In Canada. ち. Baccae hispidae rubrae.

21. R. albinervium Michx. fol. ahbreviatis petiolatis leviter acute lobatis in nervis albis; racemis recurvatis. In canada. ち. Baccae ruhrae.

2.5. R. mayellanicum Poir. caulihus suhprostratis; fol. 3-lobis crenatoundulatis subtus glabris pallidioribus: racemis suberectis crassis; bractei. pedicello longioribus; petalis apice reflexis. Ad fretum Magellanicum. $\hbar$.

26. R. viscosum R. et $\boldsymbol{P}$. peruv. fol. cordatis $\tilde{5}$-lobis crenatis asperis viscosis 5-nerviis; racemis brevioribus simplicibus solitariis; bracteis lanceolatis longitudine calycis. In $\mathrm{Pe}$ ruvia. t. Cor. flava. Baccae parvae purpureae.

27. R. punctatum R. et P. perus. t. 233. f. $a$. fol. 3-lobis serratis suhtus punctatis; racemis pendulis brevilus; hracteis oblongis ciliatis punctatis; calycihus flavicantihus. Berl. Mag. t. 2. f. 19. B. IR. 1658. In Clili. ち. Cor. flava. Baccae rubrac.

28. $R$. recurvatum Hichx. ramis recurvatis; fol. subamplis pubescentibus acute 3 -Iobis glanduloso-punctib) 1 * 
culosis; racemis reflexis. Ad simum Hurlsonis. ち. Baccae nigrae.

29. R. laxillonum Pursh; fol. cordatis 5-lohis inciso-dentatis glahris; racemis laxis erectis longitudine foliorum; bracteis subulatis; pedicellis elongatis. In Amer. bor. $\downarrow$. Baccae globosae hispidac.

30. R. riscosissimum Pursh; pilis viscidis tectum; fol. cordatis obtuse 3-lobis serratis; racemis erectis brevibus; bracteis lincaribus; germinibus hirsutis. In Amer. bor. ち. Cor. lutea.

31. R. sanguineum Pursh; fol. cordato-3-lobis serratis venoso-lineatis supra glabris subtus tenui tomento albicantibus; racemis pubescentihus; petalis ovato-spathulatis. B. M. 3335. B. R. 1349. In Columbia. ந.

32. R. malvaceum $\mathrm{Sm}$. fol. cordato-5-lobis venosis serratis hispidis subtus villosissimis; bracteis ovatis acutis; racemis villosis; fol. longioribus; petalis furcatis. In California. t. Flores sanguinei.

33. R. floridum Herit. fol. utrinque glandulosis 3-lobis dentatis acutis ; racemis pendulis ; bracteis ciliatis lanceolatis subulatis; petalis apice suberosis. Berl. Mag. t. 2. f. 22 . r. nigrum $\beta$. L. IR. pensylvanicum Lam. In Amer. bor. $\bar{b}$.

31. R. inebrians Lindl. $\boldsymbol{B}$. $R$. 1781. fol. subrotundis leviter 3-5lobis inciso-dentatis ntrinque glanduIosis; petiolis pubescentibus pendulis; calycibus agrregatis glandulosis; laciniis recurvis. in Newyork. $\hbar$.

35. R. nureum. Pursh; glaberrimum; fol. ovato-3-lobis paucidentatis; racemis multifioris; bracteis pedicello Iongioribus; sepalis subrevolutis; petalis albis dein rubris apice erosis. B. M. 125. Berl. Mag. t. 2. f. 13. In Amer. bor. b. Baccae nigrae.

36. R. flavum Willd. Berl. Mag. t. 2. f. 24. fol. glabris parvis; lobis apice dentatis; racemis paucifloris; bracteis oblongo-lanceolatis caducis; petalis apice erosis semper albidis; stigmate vix hifido. Coll. rip. t. 1 . f. A. Patria ignota. ち. Baccae nigrae.

37. R. cereum Dougl. B. R. 1263. fol. cordatis lobatis serratis glanduloso-pubescentibus glaucis superne; racemis pendulis; bracteis ovatis den- tato-serratis. B. M. 3008. In Columbia. ち. Flores pallide virides.

38. R. bracteosum Dougl. Mss. fol. 5-lobis grosse biserratis pilosiusculis; racemis longissimis puberulis; bracteis linearibus pedicellorum longitudine. In ins. Sitcha. ち. Hacemi 6-9-poll. 50-flori.

3.9. R. affine Dougl. Mss. fol. 5lohis wrosse subbiserratis subtus margineque pubescentibus; racemis glanduloso-hispidis; bracteis lineari-lanceolatis; fructu hispido. In ins. Sitcha. ち.

40. R. tubulosum Esch. pl. calif. fol. corlatis 3 -lobis serratis rugosis subtus albo-pubescentibus; racemis erectis; calycibus tubulosis longis; bracteis ovato-lanceolatis. In Nov. California. ち. Caul. orgyalis. Cor. violacea. Baccae purpureae.

41. R. glaciale Wall. fol, cordato-subrotundis 5 -lobis pilosiusculis; lobis acuminatis inciso-serratis ; ramulis argenteo-nitidis; racemis erectis glanduloso-pubescentibus; bracteis ciliatis; fructibus glabris. In montibus Emodi. $\hbar$.

42. R. villosum Wall. fol. subcordato-subrotundis 3 -lobis obtusis resinosis pilosis; lohis serratis glanduloso-ciliatis; racemis erectis; ramis fructibusque villosis. In montibus Emodi. 市.

\section{b. Aculeata. \\ * Pedunculi 1-flori.}

43. R. Grossularia $L$. ramis acnleatis; bractea 3 -partita ; baccis glanduloso-birsutis. E. B. 1292. Guimp. t. 23. R. Uva crispa FI. Dan. 546. 1. hybridum Bess. In Europa. ‡.

11. R. Uva crispa L. ramis aculeatis; bracteis comnato-tubulosis; haccis pilosulis glabrescentibus. Schmidt ic. t. 1. Fl. Dan. 516. Reit. et Abel. t. 67. Guimp. t. 24. In Europ. ad rupes et in hortis cum multis varietatibus culta. $ђ$.

45. $R$. reclinatum $L$. ramis subaculeatis reclinatis; ovariis calycibusque glabris; petiolis foliis bracteisque 3-partitis ciliatis; fructu purpureo. In Europ. ந.

46. R. divaricatum Dougl. B. $\boldsymbol{R}$. 1359. ramis divaricatis setosis; act- 
leis 1-3 axillarihus deflexis ; fol. subrotuntis 3 -lobis inciso-dentatis; pedunculis 3 -floris nutautibus; calyce campanulato. In America boreali. t. Flores brumueo - violacei. Baccae glabrae.

47. $R$. ferox $S m$. aculeis 3 axillarihus; caule aculeis minulis undique vestilo; fol. 5-lobis; calyce piloso infundibuliformi; petalis obtusis erectis. In California. ち. Fructus piloso-glandulosus dein spinosus.

15. R. lacustre Poir. racenis laxis pendulis pilosis; caule aculeis minulis undique hispido; fol. lohatis sublus pilosiusculis; pedicellis hispidis oblongis. I1. oxyacanthoides Michx. In America boreali. $\hbar$. Cor. flavovirens.

49. R. Nenziesii Pursh; ramis hispidis; fol. sub-5-lobis inciso-dentatis sultus tomentosis; pedunc. subbifloris; calycis tubulosi limbo patente. In Amer. bor. ђ.

50. R. speciosum Pursh; sub gemmis triplicato-aculeatum; fol. cuneato-subrotundis inciso-crenatis glabris nervosis ; pedicellis germinibusque glanduloso-pilosis. B. M. 3530. B. R. 155\%. In Amer. bor. $\hbar$.

51. R. aciculare $\mathbf{S m}$.? aculeis axillaribus 5 omnino hispidulis; fol. 5-lobis; pedunc. 1 -floris nutantibus; calyce campaniformi laevi rubro; petalis albis ovatis. Ledeb. ic. Fl. ross. t. 230. In Sibiria. t.

52. R. caucasicum Alams; aculeis slipularibus ternis; pedunc. 1 -floris erectis ; fol. 5-lobis inciso-dentatis. Ad Caucasum. ち. Fortasse var. iR. Uvae crispae.

53. R. rotundifolium Michx. spina suhaxillari; fol. minutissime puberulis suborbiculatis modice lohatis; lobis subrotundo-obtusis; calycis limbo tuhuloso. In Carolina. t. Baccae glabrae.

54. R. stamineum $\mathrm{Sm}$. ramis hispidis; aculeis axillaribus; fol. subtrilobis laevibus; pedunc. subbifioris; bracteis rotundatis; calyce hemisphaerico hispido; stylis staniniousque exsertis. R. fuclisioides BerI. Mag. t. 3. In California. ち. Flores coccinei.

55. R. hirtellum Michx. spica subaxillari; ramis hreviter raroque hispidulis; fol. parvis semitrifidis; lobis paucis dentatis. In Canada. 市. Baccae rubrae.

56. R. gracile Michx. spina subaxillari hrevissima; fol. uraciliter potiolatis lobis acutis iucisis; pedunc. capillaribus subhifloris; calycibus tubuloso-campanulatis. In Virginia. $t$. Bacca purpurea.

5\%. R. microphyllum $\boldsymbol{H}$. et $\boldsymbol{K}$. spinis sulsolitariis rectis; fol. parvis suhreniformilus 5-fidis supra pubescentibus; pedunculis brevissimis 2 -floris; calycibus campanulatis. In Inexico. $\hbar$.

\section{** Flores racemosi.}

58. $\boldsymbol{R}$. diacantha $\boldsymbol{L}$, aculeis geminis stipularibus; fol. cuneiformibus 3 -parlitis glaberrimis; floribus Ionge pedunculatis; sepalis rotundatis flavescentibus. Berl. Mag. t. 2. f. 8. In Sibivia. t. Baccae globosae rubrae.

59. R. orientale Poir. subaculeatum ; fol. 3-5-lobis orbiculato-subreniformilus incisis hirsutis; Iobis parum profunde ohtusis; petiolis hirsuto-villosis; bracteis flore Iongiorilus. In Syriu. t. Flores flavo-virescentes.

60. R. saxatile Pall. aculeis sparsis ; fol. suborbiculato-cumeatis incisoserratis; pedicellis bracleum superanlibus; baccis glabris ebracteolatis. Ledeb. ic. Fl. ross. t. 239. In Sibiria. 古. Flores minimi viridi-purpuracentes. Baccae atro-purpureae.

61. R. Cynosbati $l$. racemis nntantibus paucifloris; floribus campanulatis; baccis hispidis; fol. sublobatis inciso-dentatis; stylis simplicissimis. Berl. Mag. t. 1. f. 3. In Canada et Japonia. 卢.

62. R. cuneifolium R. et $\boldsymbol{P}$. peruv. t. 233. $f$. c. fol. cuneiformilus incisotrifidis; pedunc. solitariis axillaribus 2-3-floris longitudine petiolorum. In Peruvia. $\hbar$. Baccae rubrae.

\section{HEDERA Viry.}

\section{a. Foliis simplicibug indivisis lobatisve.}

1. H. Helix $\boldsymbol{L}$. canle fibrillis radiciformibus scandente; fol. coriaceis glabris nilidis 5-angulato-5-1obis 80premis vetustisque ovalis acutis; um he - 
Iis simplicibus puhescentihus.

E. $B$. 1267. Fl. Dan. 1027. Sichk. t. 49. Guimp. t. 25. Sv. Bot. 397. In Europ., ins. Canariis ct Ind. or. $\hbar$, Baccae atro-virides.

2. H. corymbosa Chois. caule arboreo demisso dumoso; fol. sunmis cordatis ohtuse $\mathbf{5}$-angulatis, junioribus in nervis velutinis; floritus corymbosis. In ins. Canariis. $\hbar$.

3. H. arborea $\mathrm{Su}$. caule arboreo inermi; fol. ovalibus acuminatis; racemis terminalibus; umbellis pedunculatis; pedicellis flore longioribus. Aralia arhorea I. Jacq. Shoenbr. t. 51. In Jumaica et Portorico. ち.

4. Il. penilula Sw. ic. t. 9. caule arhoreo inermi; fol. ovato-lanceolatis integris ; umbellis subcapitatis ; pedunc. longissimis pendulis. In Jamaica. $\hbar$.

5. H. umbellifera DC. caule frutescente inermi; fol. Ionge petiolatis lanceolatis acuminatis rariter serratis; pedunc. 16 umbellatis trifidis; umbellulis capitatis subglohosis. Aralia umbellifera Lam. Kumph. 2. t. 12. In Amboina. $\hbar$.

(6. H. cuneata DC. caule arhoreo inermi; fol. petiolatis late oblongis acutis integerrimis hasi cuneatis membranaceis glabris; umbellis terminalibus multiradiatis; capitulis semiglobosis. In Brasilia. b.

7. H. nutans $S u$. canle arboreo inermi; fol. ellipticis acutiusculis coriaceis integris; umbelis nutantilus hemisphaericis; pedunc. erectiusculis. In Jamaica. ち.

8. H. rumillora DC. caule arboreo inermi; fol. petiolatis acutis integerrimis membranaceis glahris basi vix cumeatis; racemis paucis e ramis nascentibus; umbellis semiglohosis. Aralia ramiflora Pohl. In Brasilia. $\hbar$.

9. H. capilata Sim. ic. rar. t. caule arboreo inermi; fol. ellipticis acuminatis integris; racemo terminali composito; umbellis capitatis Ionge pedunculatis; floribus sessilihus. Aralia capitata Jacq. amer. t. 61. In Jamaica et Guadelupa.

10. H. muliflora ISC. caule inermi arboreo; fol. longe petiolatis obIongo-ellipticis acuminatis hasi subeuneatis integerrimis memliranaccis glahris; racemis raniculatis; capitulis ulobosis. Aralia muliflora pohl. In Irasilia. 卢.
11. Is. Mutisiana DC.caule arhoreo incrmi; fol. oblongis apice sulsserrulatis aculis basi rotundatis coriaceis glabris nitidis; racemis solitariis; floribus capitatis. Aralia Mutisiaua $\mathbf{H}$. et K. A. heterophylla Mutis. In Nov. Granata. .

12. H. aculifolia DC. caule arboreo; fol.subrotundo-ovatis acuminatis; umbellis corymbosis. Aralia acutifolia W. Hb. In Amer. bor. ђ.

13. H. avicenniarefolia DC. arhorea; inermis ; fol. oblongo-lanceolatis acntiusculis basi aculis integerrimis coriaceis subtus albido-tomentosis; corymbis ramosis; floribus capitatis. Aralia H. et K. In (buiio. b.

14. H. cumanensis DC. caule arboreo inermi; fol. ovatis acuminatis hasi cuneatis integerrimis subtrinerviis membranaceis glabris nitidis. Aralia H. et K. In Cumana. $\downarrow$.

15. H. catalpaefolia DC. canle arboreo; fol. subcordatis acuminatis integerrimis; racemo brevi basi bracleato; capitulis glohosis. Aralia WV. Hb. In Amer. austr. ђ.

16. H. septemnervia DC. caule arboreo inermi; fol. ovatis acuminatis hasi rotundatis $\boldsymbol{\gamma}$-nerviis subcoriaceis glabris; racemis paniculatis; capilulis subglobosis. Aralia H. et K. Iu Nova Gianata. 市.

17. II. turbacensis DC. caule arboreo; fol. longe petiolatis basi acu(is membranaceis glabris concoloribus saepe apice sub-3-fidis; racemis pauiculatis. In Nov. Granatı. ち.

18. H. discolor DC. caule arboreo; fol. petiolatis glabris hasi rotundatis supra nitidis sultus purpureo-ferrugineis, saepe sub-3-fidis; racemis pauiculatis. In ivov. Granata.

19. H. argeutaia DC. caule arboreo inermi; fol. peiiolatis coriaceis supra glabris uitidisque subtus argenteo-lepidotis, aliis 3 -nerviis apice 3 fidis lacinia intermedia subserrata. Aralia argentata $\mathbf{H}$. et K. Nov. Gell. t. 414. In Nova Cranata. 市. Arbor 18-ped. Petala alba.

20. H. crassinervia DC. caule arhoreo; fol. petiolatis basi acutis coriaceis supra glahris et nitidis subtus densissime fuscescenti-lepidotis ; racemis yaniculatis. In America austruli. ந. 
21. I. obtusiloba IC. caule arboreo? fol. petiolatis basi truncatorolundalis j-herviis coriaceis sublus fuscescenti-lepidotis 5-fidis; racemis paniculatis ; capitulis elliptico-rlobosis. Aralia ohtusiloba H. et K. In Nora Grunutu. t. Petiala alla.

22. H. angularis DC. caule arboreo; fol. 5-angularibus obtusis subtus tomentosis; florihus capitatis. Aralia W. H1). In Amer. austr. ち.

23. H. platunifoliu IIC. caule arboreo; fol. petiolatis coriaceis supra glabris nitidis subtus fuscescentitomentosis hasi truncatis $\mathbf{7}$-nerviis apice :-fidis; laciniis oblongis acuminatis integerrimis; racemis paniculatis. Aralia platanifolia $H$. et K. Nuv. Geu. 1. 415. In Peruvia. t. Arbor 3-4orgyalis. Petala alba.

24. $I$. acerifolia DC. caule arhoreo; fol. 5-lohis acuminatis integerrimis wlabris subtus lepidotis lucidis discoloribus. Aralia W. Hb. In Amer. atustr. ђ.

35. H. jatrophaefolia DC. caule arhoreo; fol. petiolatis coriaceis subtus fuscescenti-tomentosis 7-fidis. Aralia H. et K. In Nor. Granata. ち.

26. H. reticulata DC. caule alboreo; fol. 7-loho-palmatifidis suhtus incanis reticulato-rugosis; lobis oblongis acuminatis integerrimis. Aralia W. Hh. In Amer. cinstr. ち.

2\%. H. cheirophylla DC. fol. palmatim 5-fidis subtus ochroleucis; laciniis acuminatis dentatis; capitulis racemosis villoso-tomentosis, Aralia spr. In Amer. anstr.

28. It. floribunda DC. caule arboreo; fol. petiolatis supra glabris suhtus fuscescenti-tomentosis 7-9partitis; laciniis argute dentatis; capitulis elliplico - sulgglohosis. Aralia H. et K. Nov. Gen. t. 416 . A. Humholdtiana et incisa IV. Hh. In Wov. Granata. ち.

2.9. H. scundens DC. caule froti$\cos 0$ aculeato; fol. 5-lobis petiolatis; umbellis simplicibus lateralibus. Aralia palmata Lour. In China. $\hbar$.

30. II. ularis Schl. arborea; glaberrima; fol. Ionge petiolatis ovalibus integerrimis hasi cuneatis apice acuminatis; umbella composita; haccis nigris. In Mexico, $\$$.

31. H. Heinln Don; caule arboreo aculeato; fol. cordatis $\mathbf{5}$-iobis dentatis coriaceis glabris; unbellis glohosis racemoso-paniculatis. In Nepaíu.

b. Foliis composits digitatis pinna tisve.

32. H. frayrans lon; fol. ternatis glabris subtus erlaucis; foliolis ovatis setaceo-serratis; umbellis compositis multiradialis glabris. In Nepulia. $\hbar$.

33. H. tomentosa Don; fol. septenatis coriaceis subtus dense tomentosis; foliolis lanceolatis acuminatis integerrimis; umbellis racemosis. InNepalia. $\hbar$.

3‡. H. aculeata Don; fol. septenatis subtus pubescentibus; foliolis oblongis acuminatis serratis; unbellis racemosis tomentosis; caule arboreo aculeato. In Nepalia. $ち$.

35. H. parasitica Don; fol. pinnatis 2-jugis coriaceis glalıris subtus glaucis; foliolis oblongis acutis integerrimis; umbellis racemosis glabris; caule radicante subparasitico. In $\mathrm{Ne}$ palia. $\hbar$.

36. H. Xalapensis DC. caule arboreo; fol. longe petiolatis digitatis; foliolis 5-7 glabris supra nitilis subtus punctatis lanceolato-oblongis acutis basi angustatis integerrimis subcoriaceis; capitulis subglobosis. Aralia digitata W. Hb. In Mexico. $\hbar$.

3\%. H. ferruginea DC. caule arboreo; fol. longe petiolatis digitatis; foliolis 7 petiolatis oblongis acuminato-cuspidatis integerrimis coriaceis subtus tenuiter tomentosis, junioribus ferrugineo-lanatis. Aralia H. et K. In Quito. $ち$.

38. H. elata Don; caule auboreo inermi; fol. diutatis; foliolis 7 petiolatis lanceolatis acuminatis coriaceis integerrimis subtus glaucis hasi rotundatis; umbellulis glabris racemoso-paniculatis. H. terehintliacea Vahl. Hheede 7. t. 18 . In Nepalia. $\hbar$.

39. $H$. rugosa $D C$. caule fruticoso parasitico; fol. digitatis; foliolis 3-7 ovali - ohlongis acuminatis integerrimis infra fusco-tomentosis; panicula longissima. Aralia Blume. In Jur $\boldsymbol{\alpha}$. 古.

10. H. similima $D C$. caule fruticoso; fol. digitatis; foliolis $5-7 \mathrm{ob}-$ longis acuminatis remote serrulatis subtus reticulatis rugosis; panicula divaricala. Aralia Blume. In Java. b. 
41. H. aromatica $D C$. caule fruticoso; fol. digitatis; foliolis 7-9 oblongo-lanceolatis longiler acuminatis, basi oblique rotundatis; paniculis corymbosis. Aralia Blume. In Java.

42. IT. lutescens $D C$. caule fruti$\cos 0$; fol. digitatis; foliolis $7-9 \mathrm{oh}-$ longo-lanceolatis longiter acuminatis pergamaceis subaveniis supra lucidis; racemis confertis. Aralia Blume. In Java. \$.

43. $H$. disperma $D C$. caule fruticoso scandente; fol. digitatis; foliolis 5-7 oblongis acuminatis argute serratis glabris; racemo terminali leproso; fructibus 2-spermis. Aralia Blume. In Java. $\hbar$.

44. H. glomerulata DC. canle arboreo spinescente; fol. digitatis ; foliolis $5-7$ rarius ternatis oblongis acuminatis versus apicen serrulatis; panicula terminali longissima; ovariis

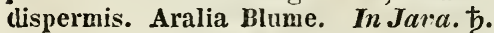

4.5. H. ovata Wall. fol. integris ovato-ellipticis coriaceis acuminatis subtus ferrugineis; floribus umbellatis. In Peninsula. $\hbar$.

\section{SPHAEROCARYA Wall. (1825).}

1. S. edulis Wall. In Nepalia. $\hbar$. Arbor foliis alternis oblongis acuminatis subcarnosis supra nitidis subtus reticulatis; floribus racemosis; fructibus edulibus.

\section{CARPODETUS Forst. (17\%5).}

1. C. serratus Forst. gen. $t$. $1 \%$. In Nov. Zeelandia. $\hbar$. Arbor foliis alternis oblongis glanduloso-serratis pilosiusculis; floribus cymosis albis.

\section{PLECTRONIA N. L. Burm. (1768).}

1. P. ventosa I. inermis; fol. oppositis oblongis integerrimis; corymbis axillarilus. Serissa capensis Thunb. Cruse Rub. t. 2. In Prom. b. spei. ఫ. Arbor 20-ped.

2. P. chinensis Lour. aculeata; fol. ternatis ohlongis clenatis; umbellis terminalibus. In China. $\hbar$.

3. P. spinosa Kilotsch; glabra; ramis teretibus spinosissimis; spinis oppositis validis; fol. ovalibus integer- rimis ; floribus racemosis. In Prom. b. spei. t. Frutex 6-ped.

4. P. citrifolia Fckl. et Zeyh. glabra; ramis sub-4-gonis; ramulis compressis; fol. subsessilibus oblongoovatis acuminatis margine revolutis; stipulis amplis rotundato - dilatatis, apiculatis. In Prom. b. spei. ち. Arbor 20-ped.

5. P. pauciflora Klotsch; glabra; ramis ramulisque teretibus; fol. ovatis acutis basi subcordatis; pedunc. oppositis axillaribus; stipulis cuspidatis. In Prom. b. spei. $\bar{b}$.

6. P. ciliata; fol. brevissime potiolatis cordato-ovatis utrinque adpresse pilosis margine ciliatis; pedunc. pilosis 1-floris. Psilostoma Klotsch. In Prom. b. spei. ち.

\section{GOJANIA Jacq. (1763).}

1. G. integrifolia Lam. fol. integerrimis ovalibus glabriusculis membranaceis. Patria ignota. $\hbar$.

2. G. domingensis $\boldsymbol{L}$. fol. ovatis acuminatis hinc inde serratis glabriusculis. G. glabra Jacq. amer. t. 179. f. 40. Plukn. t. 162. f. 3. et 201. f. 4. In Ind. occ. $ђ$.

3. G. striata Rich. fol. ovatis glabris nervosis crenatis emarginatis; ramis rachibusque striatis. $G$. domingensis AubI. In Gujana. $\hbar$.

4. G. smilacina Sm. fol. cordatis acutis minute serratis interdum pilosis; stipulis subulatis; pedunc. unbellatis. In Brasilia. $\hbar$.

5. G. cordifolia Raddi; fol. cordato-ovatis serrulatis pilosiusculis; floribus axillaribus terminalibusque capitatis hirtis. Ad Rio Janeiro. ந. Fl. lutei.

6. G. corylifolia Raddi; fol. subrotundo - vel suhovato-cordatis acutis subdenticulato-glandulosis subius pubescentibus; racemis longissimis. $A d$ Rio Janeiro. $\hbar$.

7. G. canescens Rich. fol. ovaliIanceolatis acutis subtus canescentibus; racemis axillaribus terminalibusque. In Gujana. ђ.

8. G. pubescens Lam. ill. t. 815. f. 1. fol. ovatis crenatis subpubescentibus; ramis simplicibus terminalibus in paniculam dispositis, inferioribus axillaribus. In Domingo. 市.

9. G. paniculate Spr. fol. ovatis acutis obtuse serratis triplinerviis gla- 
hris; spicis paniculatis elongatis; cirrhis nullis. In Ind. occ. ち.

10. G. crenata Lam. fol. ovatis crenatis subvillosis hreviter petiolatis; cirrhis terminalibus axillaribusque. In Amer. austr.

11. G. tomentosa Jacq. fol. subrotundo-ovatis acuminatis obtuse serratis subtus tomentosis; racemis terminalibus axillaribusque; fructibus 3-alatis. Gaertu. t. 183. f. 1. In ins. Caribaeis. $\hbar$.

12. G. stipularis fl. mex. ined. fol. ovatis glabriusculis serratis acuminatis basi subcordatis; stipulis maxinis semisagittatis basi obtusis acuminatis; fructibus 3-alatis. In Mexico. ち.

13. G. cyclocarpa $\mathbf{S m}$. fol. elliptico-oblongis acutis obsolete serratis, junioribus sericeo-ferrugineis; fructibus orbiculatis. In Ind. occ. $ち$.

14. G. aptera DC. fol. cordatoovatis subacutis grosse dentato-serratis utrinque ramisque molliter villosis; racemis axillaribus termiualibusque. In Amer. austr. $\hbar$.

15. G. denticulata $\$$. fol. ovatis integris acuminatis apice denticulatis subtus hirsutis; cirrhis terminalibus; floribus racemosis. In Ind. or. $\hbar$.

16. G. mauritiana Lam. fol. subcordato-ovatis subserratis utrinque serice 0 -tomentosis; racemis axillaribus; cirrhis ramulisque ferrugineo-villosis. In ins. Mauritii. $ђ$.

17. G. retinaria $D C$. fol. ovatis subacutis subserratis, junioribus subpubescentibus, adultis glabris; fructibus alato-3-quetris. Gaertn. t. 120. f. 4. Lam. t. 845. f. 3. In ins. Maıritii. t.

18. G. tiliaefolia Lam. fol. cordatoovatis acuminatis glabriusculis glanduloso-serratis; racemis pubescentihus; fructibus obovatis apteris. In ins. Borboniae. $\hbar$.

19. G. leptostachyce DC. fol. subcordato-ovatis grosse crenatis ramulisque glabris; racemis gracillimis clongatis ; fructibus obtuse 3-quetris. G. tiliaefolia Roxb. corom. t. 98. In Ind. or. $\hbar$.

\section{CRUMENARIA Mart. (1S22).}

1. C. decumbens Mart. Nov. Gen. t. 161. In Brasilia. Plauta annua; fol. subcordato-ovatis trinerviis; stipulis ciliatis; floribus axillaribus pedunculatis minutissimis.

\section{STRUMPFIA Jacq. (1763).}

1. S. maritima Jacq. Plum. ic. $t$. 251. In Ind. occ. ち. Frutex ramosissimus; cortice e foliorum lapsn annulato; fol. linearibus revolutis nitidis ternis confertis; floribus albis terminalibus pedunculatis.

\section{GROVOVIA Foust. (1727).}

1. G. scandens L. Jacq. ic. t. 333 . Lam. ill. t. 111. f. 2. G. Humboldtianı R. et S. In Vera Cruce. $\odot$. Herba scandens cirrhosa; foliis fere Bryoniae; pedunc. oppositis umbellatis; floribus spicatis.

\section{ARGOPHYLLUM Forst. (1785).}

1. A. nitidum Forst. Gen, $\boldsymbol{t}$. 15. Gaertn. t. 120. In Nov. Caledonia. Arbor foliis oblongis acuminatis supra nitidis subtus sericeis; floribus subcorymbosis flavo-virentibus.

\section{JASIONE L. (1737).}

1. J. montana $L$. caule erecto simplici tereti; fol. lineari-lanceolatis undulatis pilosis; pedunc. nudis; bracteis glabris Lam. ill. t. 427. f. 1. E. B. 882. In Europa. ๑. 1-ped. Cor. caerulea.

2. J. corymbosa Poir. caule erecto ramoso anguloso; fol. decurrentibus oblongo-linearibus subpilosis undulatis; pedunc. foliosis; bracteis pilosis. J. arenaria Salzm. In regno Tingitano. $\odot$. Caul. 7-poll. Flores caerulei.

3. J. perennis Lam. ill. t. 721. f. 2. caule erecto subsimplici; fol. subpilosis, radicalibus subovatis, caulinis oblongo-linearibus planis; pedunc. nudis; bracteis interne pilosis B. R. 505. B. M. 2198. B. Cab. 923. In Europa. 4. 1-ped. Flor. caerulei.

4. J. Insitanica A. DC. caulibus ramosis diffusis; fol. obovato-lanceo- 
latis pilosiusculis subsimuatis; pedunc. bracteatis; bracteis glabriusculis. In fusituniu. 2-3-poll. Flores caerulei.

5. J. humilis Jois. pubescens ; cauJihus adscendentibus simplicibus; fol. Jineari-obovatis planis, radicalihus rosulatis; pedunc. foliosis. J. perenmis $\Leftrightarrow$. minor Mert. et Koch. J. montana ß. Pers. In Europa. 24. CauJes numerosissimi $3-4$-poll. Flores caerulei.

6. J. foliosa Cav. ic. t. 116. f. 1. ylahra; caulibus adscendentihus simllicilus; fol. radicalibus rosulatis sulspathulatis, caulinis lineari-lanceolatis. In Ilispania. 4. 1-3-poll. Nlores violacei.

\%. J. tristis Bory; perennis; callJihus prostratis diffusis subsimplicihus; fol. alternis subspathulatis sessilibus riliato-tomentosis; florihus dense capitatis; bracteis ovatis coloratis. Infer saxa Nierrae Nevadae. Nlores iriseo-caerulei.

\section{IIGHTFOOTIA Herit. (1888).}

1. L. subulata Herit. sert. angl. t. 5. caule fruticuloso adscendente crectoque; fol. subulatis denticulatis; ficribus racemosis; petalis linearibus. Campanula L. In l'rom. b. speci. t. 1-ped. Flores numerosi.

2. J. longifolia A. DC. caule erer!o fruticuloso simplicissimo; fol. alternis erectis subulatis angustis subdenticulatis; floribus subspicatis; capsulae valvis brevissimis. Campanula sessiliflora Thunb. Act. Petr. 4. t. 5. f. 1. In Prom. b. spei. ந.

$\therefore$ L. unidentata A. DC. caule crecto lignoso simplici; fol. linearilanceolatis acuminatis basi dentatis; dentihus utrinque $1-2$-setaceis; florihus laxe racemosis. Campanula unidentata Thunb. Act. Petr. 4. t. 5. f. 2. In rrom. b. spei. ち. 1-ped. Flores rubri.

4. L.? adpressa A. DC. caule erecto lignoso simplici; fol. alternis reflexis lineari-lanceolatis setaceo-dentatis; floribus paniculatis. Campanula Thunb. 1. c. t. 7. f. 2. In Prom. b. spei. Ђ. 1-ped.

5. L. albens Spr. caule erecto lignoso ramoso; fol. saepius fascicu- latis patulis linearilus angustissinis integris; floribus racemosis. In Prom. b. spei. $\hbar$. Suffutex. Flores grisei.

6. L. tenellu A. DC. Camp. t. 3. f. B. caule erecto lignoso ramoso; fol. altemis ovatis obtusis reflexis crassis subintegris ; floribus racemosis. Campanula L. Thunl. I. c. t. 7. f. 3. Roella

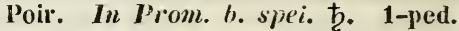

\%. L. fasciculuta A. DC. caule erecto lignoso ramoso; fol. alternis reflexis ovato-acutis crassiusculis remote denticulatis; foribus fasciculatis. Campanuia Thunb. 1. c. t. 6. f. 1. In Prom. b. spei. ந. Caul. 1-ped.

8. L. oxycoccoides Herit. sert. angl. $t$. 4. caule ranısissimo ramosodifiuso; fol. reflexis ovato-lanceolatis acutis basi denticulatis; floribus racemosis. Lobelia tenella L. fil. Camp. Ottoniana R. et \$. In Prom. b. spei. †. $1 \frac{1}{2}-$ ped.

9. L. tanceolata Idi. caule decumbente pubescente; fol. lanceolatis glabris subdenticulatis ; pedunc. pubescentibus; calyce glabro corolla duplo breviore. L. oxycoccoides spr. var. In Prom. b. squei. ђ.

10. L. muscosi Lk. caule decumbente glaliro; fol. lanceolatis glahris integerrimis, rameis oppositis; pedunc. glabris; calyce corolla breviore. In Prom. b. spei. Ђ. Cor. albo-caerulescens.

11. L. Loddigesii A. DC. caule fruticoso ramoso; fol. subreflexis ovato-lanceolatis acutis integris; florilsus laxe racemosis. L. tenella Lodd. IB. Cal. t. 1038. In Prom. b. spei. t. Cor. caerulescens.

12. L. lycopodioides A. DC. caule fruticuloso simplici folioso; fol. erectis, rameis alpressis lincaribus angustissimis; florihus sessilibus. In Prom. b. spei. $\hbar$.

13. L. oppositifotia A. DC. ramis rigidis; fol. oppositis subreflexis lineari-acuminatis angustis subdenticulatis; florilous subterminalibus. In Prom. b. spei. 4.

14. I. rubioides A. DC. ramis procumbentibus diffusis; fol. oppositis patulis vel subreflexis lanceolatis acutis remote denticulatis; floribus axillarihus terminalibusque. In prom. $b$.

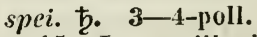

15. L. capillaris Eclil. et Zeylı. caule lignoso; ramis adscendentilus filiformibus superne paniculatis; fol. 
bus; calycis laciniis lineari-lanceolatis. In Prom. b. spei.

7. C. heterophylla Eckl. et Zeyh. fol. inferioribus ovatis acutis serratis utrinque leviter 1-lobis; calycis laciniis lanceolatis acutis. In Prom. b. spei.

8. C. angustiloba Eckl. et Zeyh. fol. tripartitis; laciniis inaequalibus utrinque integerrimis acutis planis; racemis laxis; bracteis 3-partitis; calycis laciuiis mucronatis. In Prom. b. spei.

9. C. Longipetala Eckl. et Zeyh. fol. 3-5-partitis coriaceis; laciniis linearibus integerrimis margine revolutis; floribus racemosis; laciniis 3 -angularibus acuminatis. In Prom. $b$. spei.

10. C. salicifolia Eckl. et Zeyh. fol. anguste lanceolatis utrinque acutis integerrimis remoteque serrulatis; floribus axillaribus; calycis laciniis Ianceolato - triangularibus. In Prom. b. spei.

11. C. volubilis $W$. fol. linearibus marginatis subdentatis; caule voluhili; pedunc. 1-floris capillaribus. Lobelia L. In Prom. b. spei. $\hbar$.

12. C. undulate Eckl. et 'Reyh. caule simplici ommino folioso; fol. radicalibus oblongo- vel ovato-lanceolatis crispis, caulinis lanceolatis dentatis; floribus racemosis secundis; bracteis oppositis capillaceis. In Prom. b. spei. †.

13. C. anomala Eckl. et Zeyll. caule subcompresso acutangulo; fol. anguste elongato-lanceolatis remote denticulatis; racemis elongatis; calycis laciuiis ovato-lanceolatis. In Prom. b. spei.

14. C. anyustifolia Eckl. et Zeyh. caule ramoso ramis divergentibus; fol. elongato-exacte linearibus angustissimis curvatis integerrimis remote denticulatis; racemis elongatis. In Prom. b. spei.

15. C. linarioides Eckl. et Zeyh. caule erecto basi ramoso ramis divergentilus; fol. anguste linearibus remote denticulatis; racemis flexuosis; calycis laciniis 3 -angularibus acutis. In Prom. b. spei.

16. C. campestris Eckl. et Zeyh. caule striato basi ramoso; ramis divergentibus; fol. alternis linearibus integerrimis obsoleteque denticulatis acutis; racemo nudo; bracteis ovatosetaceis. In Prom. b. spei.

17. C. digitata $W$. fol. digitatis linearibus integerrimis glabris; pedunculis 1-fioris; caule volubili; radice bulbosa. Lobelia Thunb. In Prom. b. spei.

18. C. latipetala Eckl. et Zeyh. fol. sessilibus; laciniis acutis integerrimis margine leviter revolutis; floribus racemosis; calycis laciniis triangularibus acuminatis. In Prom. $b$. spei. Flores pallide caerulei.

19. C. Eckloniana Presl; fol. sessilibus digitato-3-partitis; Iaciniis linearibus obtusis ciliatis obsolete denticulatis; floribus racemosis; calycis laciniis subulatis. In Prom. b. spei. Cor. intus villosa.

20. C. Zeyheriana Presl; fol. mediis sessilibus acutiusculis remote serratis, caeteris digitato-5-partitis; laciniis inaequalibus remote serratis; calycis laciniis acutissimis. In Prom. b. spei.

21. C. Dregeana Meyer; caule angulato; fol. petiolatis lanceolatis acutiusculis serrulatis serratisve; umbellis axillarihus subtrifloris; calycis laciniis linearibus. In Prom. b. spei.

22. C. dentariatolia Meyer et Drege; caule teretiusculo; fol. petiolatis, inferioribus ternatis; foliolis lateralibus 2-partitis; fol. floralibus 3-lobis; lobo medio maximo. In Prom. b. spei. 23. C. tomentosa Meyer et Drege; caule tereti puberulo; fol. trifoliatis; foliolis oblongo-lanceolatis mucronulatis in petiolum attenuatis; floribus axillaribus; calycis laciniis lanceolatis acutis. In Prom. b. spei.

21. C. polydactyla Meyer et Drege; caule teretiusculo; fol. breviler petiolatis trifoliatis; foliolis profundissime digitato-pinnatifidis; laciniis callosomucronulatis margine revolutis. In Prom. b. spei.

25. C. persicifolia Meyer et Drege; caule simplici angulato; fol. sessilibus lineari-lanccolatis acutiusculis remote serrulatis margine revolutis; floribus spicatis. In Prom. b. spei. t.

\section{LAGOECIA L. (1737).}

1. L. cuminoides $\boldsymbol{L}$. Sibth. gr. $t$. 213. Schk. t. 4S. Lam. t. 14\%. In Persia, Asia minore et Hispania. $\odot$. 
IIerba erecta. Folia pinnatisecta. Pedunculi oppositifolii. Flores umbellati albi.

\section{CELOSIA Trag. (1551).}

\section{Stylo simplici.}

1. C. argentea $I$. fol. linearilanceolatis; stipulis falcatis; pedunculis angulatis; spicis scariosis ovatocylindricis. Knorr. del. t. H. Martyn Cent. t. 7. In China et Japonia. $\odot$. Flores albo-rubri.

2. C. margaritacea I. fol. oblongis acuminatis basi valde angustatis; pedunc. communi angu'ato; spicis oblongo-cylindricis. Ihlieede 10. t. 38 . C. argentea Hortul. In Ind. or. et occ. $\odot$. Flores albo-rosei.

3. C. cristata L. fol. ovatis acuminatis ; stipulis falcatis; pedunc. communi striato; spicis oblongis compressis. Rumph. 5. t. 84 . C. coccinea et castrensis L. C. comosa Retz. Valde variat. In Ind. or., occ. et China. $\odot$. Spicae rubrae, coccineae et Inteae.

4. C. cernuce Anilr. fol. ovato-lanceolatis acuminatis spica composita terminali; spiculis alternis confertis linearibus; bracteis augustissimis caJyce longioribus. Patria iynota. $\odot$.

5. C. nitida Tahl; fol. ovato-deltoideis attenuatis; spicis terminalibus ramosis; floribus distinctis; caule suffrulicoso. sloane Hist. t. 91. f. 5.? In Ind. occ. $\odot$. Spica flavescens.

6. C. caudata Vahl; fol. ovatis acuminatis; racemis compositis laxis longissimis; caule exstipulato. Achyranthes paniculata Forsk. In Arabia. $\odot$.

\%. C. nodiflora $I_{\text {. }}$ fol. cuneifornibus acutiusculis; spicis globosis lateralibus. Jacq. Vínd. t. 98. Burm. Zeyl. t. 5. f. 2. Plukı. t. 133. f. 2. C. dichotomal Roth. In Zeylona. ○. 1-2ped. Flores albo-virentes.

8. C. aspera Roth; caule adscendente ramosissimo aspero-aculeato; fol. oblongis mucronatis remote dentatis ; spicis axillarihus fastigiatis ovatis. In Ind. or. $\odot$.

\section{Stylo 3-fido.}

9. C. longifolia Mart. Novं. Gen. t. 133. f. 3. suffruticosa; erecta; fol. lanceolatis acuminatis glabris; floribus glomerato-capitatis stigmatibus 4-5. In Brasilia. ち.

10. C. polygonoides Retz; fol. cordatis; caule hispido; racemo spicato laxo; floribus 3-gynis. In Malabaria. 4.

\section{BERZELIA Mart. (1826).}

1. B. glauca Spr. fol. alternis lineari-lanceolatis carnosis canis; corolla urceolari; limbo 5-dentato; stylo 3-partito. Celosia glauca Weudl. Coll. t. 2. In Prom. b. spei. ந.

\section{LETISBUDESIA Thouars (1806).}

1. L. virgata Jacq. ic. t. 339. fructicosa; glabra; fol. caulinis spathulatis, rameis lanceolatis; floribus aggregatis spicatis. Celosia Willd. Patria ignota. Flores viriduli.

2. L. trigyna $R$. Br. fol. ovatis acuminatis planis; racemo laxo; bracteis scariosis; pistillo 3-fido. Celosia Jacq. Vind. „t. 15. In Senegalia. $\odot$. Cor. alba.

3. L. spicata Thouars pl. Afr. $t$. 16. caule lignoso; fol. alternis ovatis integerrimis; floribus spicatis. In Madagascaria. $\hbar$.

t. L. arborescens $R$. $B r$. caule fruticoso volubili; fol. elliptico-oblongis subacuminatis glabris; paniculis terminalibus axillaribusque; floribus 3-gynis. In Nov. Holl. ち.

5. L. latifolia Blume; caule fruticoso; fol. alternis ovato-oblongis acuminatis; spicis axillaribus solitariis geminisve; pistillo tripartito. In Java. ந.

\section{CLADOSTACHYS Don (1525).}

1. C. arborescens Don; fruticosa; ramosa; glabra; fol. ovatis acutis; spicis paniculatis; calycibus glomeratis basi setosis. Celosia Spr. Achyranthes L. Desmochàeta DC. Blitum Runph. 5. t. 83. f. 2. In Ind. or. $\hbar$. 


\section{AMARANTHES Matthiol. (1551).}

a. Floribus 3-andris.

1. A. tenuifolius Willd. glomerulis axillaribus 3-andris; fol. linearilanceolatis cuneatis retusis; caule ramoso-diffuso. In Ind. or. $\odot$.

2. A. angnstifolius M. B. glomerulis axillaribus; fol. lineari-lanceolatis acutis mucronatis; caule ramoso erecto. In Caucaso. $\odot$.

3. A. lineatus R. Br. glomerulis aphyllis axillaribus terminalibusque subspicatis; calycibus obtusis mucronulatis; fol. lanceolatis mucronatis subtus lineatis; caule stricto. In Nov. Holl. $\odot$.

4. A. pallidus M. B. glomerulis subracemosis foliosis; calycibus acutis; fol. elliptico-oblongis; caule erecto subramoso. In Tauria. $\odot$.

5. A. persicarioides Poir. glomerulis subdiandris cymosis coufertis; calycibus acutis; fructihus depressis stylo bifido coronatis; fol. ovato-oblongis sinuato-erosis dentatis. A. diandrus Nees. A. canliflorus Lk. In Nepalia. $\odot$.

6. A. Acroglochin Spr. glomerulis cymosis patentibus; bracteis elongato-spinosis; fructibus depressis; fol. ovatis mucronato-dentatis; caule erecto. In Nepalia. $\odot$.

\%. A. albus I. glomerulis axillaribus; fol. obovatis retusis; caule 4gono simplici. Willd. Amar. t. 1. f.2. In Pensyleania. $\odot$.

8. A. graecizans I. glomerulis axillaribus; florihus 3-fidis; fol. obovatis emarginatis; canle teretiusculo ramoso. Willd. 1. c. t. 4. f. 7. In Virginia. $\odot$.

9. A. polygamus L. glomerulis 3-4-andris hrevissime spicatis; calycibus bracteisque uncinato-cristatis; fol. oblongo-lanceolatis emarginatis. In Ind. or. $\odot$.

10. A. undulatis R. Br. glomerulis subspicatis; calycibus obtusiusculis mucronatis; fructibus rugulosis; fol. ovatis obtusis undulatıs petiolum aequantibus. 'In Nov. Holl. $\odot$.

11. A. rhoinbeus $\boldsymbol{R}$. Br. glomerulis subspicatis gracilibus; fructibus rugulosis; foliis rhombeo-ovatis subretusis subtus lineatis. In Nova Hollandia. $\odot$.
12. A. interruptus R. Lr. glomerulis spicatis multifloris interruptis; fol. ohlongis obtusinsculis mucronatis. In Nov. Holl.

13. A. Blitum $L$. glomerulis suhspicatis ; florihus 3-phyllis; fol. ovatis retusis; caule diffuso. Lob. ic. 52. In Europa. $\odot$.

14. A. viridis $L$. glomerulis axillaribus geminatis; floribus masculis 3-phyllis; fol. ellipticis emarginatis margine undulato. Willd. 1. c. t. 8. f. 16. In Jamaica et Brasilia. $\odot$.

15. A. campestris $W$. glomerulis axillaribus sessilibus; fol. ovatis emarginatis; caule ramoso erecto. In Ind. orient. $\odot$.

16. A. polygonoides $\boldsymbol{L}$. glomerulis 3-phyllis; floribus foemineis infundibuliformibus; fol. rhomleo-ovatis emarginatis. Willd. 1. c. t. 6. f. 12. In Jamaica et Zeylona. $\odot$.

17. A. melancholicus L. glomerulis axillaribus pedunculatis subrotundis; fol. ovatis emarginatis; caule ramoso erecto. Willd. l. c. t. 9. f. 18. In Ind. or. $\odot$. Fol. sultus purpurea.

18. A. tricolor L. glomerulis subsessilibus ; fol. oblongo-lanceolatis coloratis. A. bicolor Nocc. In Ind. or. $\odot$. Fol. bi-tricoloria.

19. A. gangeticus L. glomerulis brevissime spicatis ovatis; fol. ovatolanceolatis emarginatis. Willd. t. 6. f. 11. In Ind. or. $\odot$. Caulis rufescens.

20. A. manyostanus L. glomerulis subspicatis axillaribus solitariis ; fol. rlombeo - subrotundis. Willd. l. c. t. 12. In Ind. or. $\odot$.

21. A. polystachys Willd. glomerulis spicatis; spicis axillaribus et termiualibus; fol. ovato-lanceolatis emarginatis. In Ind. or: $\odot$. Caulis debilis.

22. A. tristis L. glomerulis laxe spicatis ; fol. subcordato-ovatis emarginatis petiolo brevioribus. Willd. 1. c. 1. 5. f. 10. Rumph. 5. t. 82. f. 2. In Clina et Ind. or. $\odot$.

23. A. inamoenus Willd.t. \%. f. 1. glomerulis subspicatis 3-phyllisque axillarihus geminatis; fol. rhomleolanceolatis. Houtt. syst. t. 7. f. 1. In Japonia. $\odot$.

2f. A. liridus $L$. glomerulis subspicatis rotumdatis ; fol. ellipticis re- 
tusis; caule crecto. Mrilld. t. 1. f. 1. In Viruiniu. $\odot$. Planta alta.

2.5. A. olpracens 1. glomerulis axillaribus ramosis; fol. rugosis oblongis obtusissimis emaryinatis. Will. 1. c. t. 5. f. 9. In Inul. or. $\odot$.

26. A. gracilis Poir. glomernlis spicato-paniculatis; fol. rhombco-ovatis obtusis; caule erecto simplici. Chenopodium caudatum Jacq. In Guinea? $\odot$.

2\%: B. prostratus Balb. Misc. $t$. 10. grlomerulis spicatis; floribus 3 plyyllis; fol. rhombeo-ovatis obtusiusculis retusis; caule prostrato ramoso.

In Galliu et Itulic. $\odot$.

2E. A. scandens I. fol. ovatis; spicis intermptis compositis; spiculis inflexis; caule debili. In America. $\odot$. Caulis Iaxus.

2.9. A. deflexus Willd. l. c. t. 10. f. 20. spica hrevissima pauciflora; fol. rhombeo-lanceolatis; capsulis non dehiscentibus. Patria ignotr. ○. Caul. prostratus.

30. A. bullntus Bess. glomerulis deuse spicatis terminalihus ; spicis sessilibus ramosis apice suhcristatis; calycibus spinosis; fol. suhrhombeis bullatis. Putria ignota. $\odot$.

\section{b. Floribus pentandris.}

31. A. pumilus Nutt. glomerulis axillaribus simplicibus; fructibus oblongis calyce obtuso majorihus; fol. subrotundis obtusissimis subcarnosis petiolatis; caule erecto pumilo. In ins. longa Amer. bor. $\odot$.

32. A. curvifolius spr. glomerulis spicato-paniculatis; fol. oblongolanceolatis cuspidatis repando-crenatis pubescentibus; ramis petiolisque tomentosis. Patria iynota.

33. A. hybridus $L$. racemis pentandris decompositis congestis erectis; fol. ovato-lanceolatis. Willd. I. c. t. 9. f. 29. ß. hecticus IVilld. 1. c. t. $\%$ f. 13. et t. 11. f. 22. In Virginil. $\odot$.

3.t. A. strictus Hilld: $t .3, f: 5$. ramis compositis strictis; fol. ovatis concavis. In Itulia. $\odot$. Totus viridis.

35. A. paniculatus $L$. racemis supradecompositis; ramis patentibus puhescentibus; fol. ovato-lanceolatis. Willd. t. 2. f. 4. In Amer. bor. $\odot$. Fol. subtus in venis rubra.

36. A. retroflexus $I$. racemis supradecompositis confertis erectis; ra- mis pubescentibus; fol. ovatis undulatis. Willd. t. 11. f. 21. In Pensylvania. $\odot$.

37. A. flavus $L$. racemis compositis nutantibus; fol. ovato-lanceolatis. Willd. t. 3. f. 6. A. chlorostachys IVilld. t. 10. f. 19. In Inil. or. $\odot$. Hacemi flavi.

38. A. parisiensis Schk. t. 294. thyrsis conicis compactis rigidis; calyciius mucronatis; bracteis setuceis flores excedentibus. A. pachystachys Rchb. Patria ignota. $\odot$.

39. A. hypochondriacus $\boldsymbol{L}$. racemis compositis confertis erectis; fol. oblongo-lanceolatis mucronatis. In lirginia. $\odot$. Folia disco rufo-lucida.

10. A. sanguineus $L$. racemis sIIpradecompositis; ramis patentibus pubescentibus; fol. oblongis acutis. Willd. I. c. t. 2. f. 3. In bialcamu. $\odot$.

41. A. cruentus $L$. racemis compositis nudis patulis; fol. lanceolatcovatis. In China. $\odot$. Spicae sanguineae.

42. A. cuulatus $L$. racemis decompositis pendulis; fol. lanceolatoovatis; caule nutante. In Peruviu, Persia, 'Reylona et Russia. ๑. Racemi intense sanguinei.

13. A. speciosus Ker. B. M. 2227. ylomerulis dense spicatis subverticillatis; spicis decompositis; fol. oblongo-ellipticis subtus rubris; caule ereclo ramoso. In Nepalia. $\odot$.

t4. A. spinosus $L$. racemis terminalibus compositis; axillis spinosis. IVilld. 1. c. t. 4. f. S. Rumpl. 5. t. 83. f. 1. In Indiis. $\odot$.

\section{1\%. CHAMISSOA Kunth (1817).}

1. C. altissima H. et K. Nor: Gen. t. 125. caule fruticoso; fol. ovatooblongis acuminatis subtus pubescentibus; spicis ramosis; capsulis olobosis compressis. Acligranthes L. In Ind. occ. ђ. Cal. flavescens.

2. C. mucrocurpa $H$. et $K$. caule herbaceo; fol. oblongo-ovatis acuminatis glabris; capsulis lagenaeformibus calyce duplo longiorihus. In Amer. anstr. 4. Caul. scandens. Cal. albido-diaphanus.

3. C. commutata Spr. caule herhaceo erecto scabro; fol. lanceolatis in petiolum attenuatis glabris; capi- 
tulis oppositifoliis globosis. Achyr. alternifolia L. In Ind. or. 4.

4. C. arabica Spr. caule herbaceo erecto; fol. cordato-ovatis glabris ; spicis pedunculatis axillaribus; floribus remotis bibracteatis. In Arabia. $\odot$.

5. C. muricata Spr. caule suffruticoso; fol. ovatis nudiusculis; racemis spicatis; fasciculis florum remotis. Acliyranthes L. In ins. Molucc. $\downarrow$.

6. C. ciliata Spr. caule herbaceo foliisque ovatis acutis glabris; petiolis ciliatis; spicis axillaribus filiformibus; floribus renotis squarrosis asperis. Achyrantles Lam. In Ind. or. 4.

\section{A ̈̈RVA Forsk. (18\%5).}

1. A. lanata Juss. caule procumbente foliisque obovatis mucronatis subtus lanatis; spicis glomeratis axillaribus ovatis lanatis. Celosia $L$. Illecebrum W. Plukn. t. 5\%. f. 8. Houtt. syst. t. 43 . f. 1. Mill. dict. t.11. f. 1. In Ind. or. $\odot$.

2. A. javanica Juss. caule erecto foliisque oblongis obtusis supra lanato-tomentosis; spicis cylindricis confertis dense lanatis. Celosia L. Burm. ind. to 65. f. 2. Jacq. Vind. t. 85. In Ind. or. et Aegypt.

3. A. tomentosa Forsk. caule erecto foliisque lanceolatis complicatis floccoso-dense tomentosis albo-flavescentibus; floribus imbricatis. In Aegypto et Arabia. 4.

4. A. sanguinolenta Blume; caule suffruticoso decumbente; fol. oppositis ellipticis utrinque acutis; spicis axillaribus confertis; stigmate subcapitato. In Java. ‡.

\section{TRICHINIUM R. Br. (1810).}

1. $\boldsymbol{T}$. fusiforme $\boldsymbol{R}$. $\mathrm{Br}$. fol. angustissime linearibus ramisque glabris; capitulis subovatis; radice fusiformi. In Nov. Holl.

2. $\boldsymbol{T}$. gracile $R$. Br. fol. angustissime linearibus glabris; canle simpliciusculo; capitulo subgloboso; filamentis inaequalibus. In Nova Hollandia.

3. $\boldsymbol{T}$. distans $\boldsymbol{R}$. $\boldsymbol{B r}$. fol. angustissime linearibus ramisque glabris; spica elongata; floribus distinctis. In Nov. Holl.
4. T. spathulatum R. Br. fol. radicalibus obovatis glabris; spica cylindrica. In ins. Van Diemen.

5. S. macrocephalum R. Br. fol. caulinis lanceolatis undulatis ramisque angulatis glabris; spica oblonga; rachi lanata. In Nov. Holl.

6. T. incunum R. Br. fol. lanceolatis ramisque teretibus incano-tomentosis; spicis subovatis lateralibus terminalibusque. In Nov. Holt.

7. 'T'. corymbosum Gaudich. caule herbaceo apice corymboso 2-4-stachyo; fol. linearibus; spicis globosoellipticis; calycis laciniis piloso-villosis. In Nov. Holl.

8. T. polystachyum Gaudich. caule herbaceo paniculato polystachyo; fol. lanceolatis margine crispis pubescentibus; calycis laciniis dorso hirsutis. In Nov. Holl.

9. 'T. divaricatum Gaudich. calllibus lignosis polystachyis; ramis fastigiatis; fol. linearibus acutis glahris subcarnosis; spicis globosis; calycis sericei pilis longissimis. In Nov. Hollandia. 市.

10. T. obovatum Gaudich. in Freyc. roy. $t$. 49. caule lignoso; ramis polystachyis; fol. obovato-oblongis obtusis basi cuneatis integerrimis utrinque ramisque cano-tomentosis; spicis hemisphaericis. In Nov. Holl. $\downarrow$.

\section{PTILOTUS R. Br. (1810).}

1. $\boldsymbol{P}$. conicus $\boldsymbol{R} . \boldsymbol{B r}$. fol. ovalibus; filamentis obcordatis. In Nov. Holl.

2. P. corymbosus $\boldsymbol{R}$. Br. fol. lallceolato-linearibus ; filamentis filiformibus. In Nov. Holl.

\section{DEERINGIA R. Br. (1810).}

1. D. celosioides $\boldsymbol{R} . \boldsymbol{B r}$. caule fruticoso decumbente; fol. ovatis; spicis axillaribus terminalibusque; baccis polyspermis. B. M. 2717. In Nova Hollandia. $\hbar$.

2. D. indica Spr. caule erecto suffruticoso; fol. cordatis acuminatis; baccis 3-spermis. Celosia baccata Retz. In Java et Ind. or. $\downarrow$. 
1122. TRAGANUM Delile (1S13).

1. T. mudatum Delile Aeg. $t .22$. f. 1. In Aegypto. t. Suffrutex ramosus: fol. parvis iriquetris mucronatis; floribus axillaribus.

\section{CORNULACA Delile (1813).}

1. C. monacantha Delile Aeg.t.22. f. 3. In Aegypto. ち. Suffutex ramosus; fol. amplexicaulibus 3-angularibus hasi lanatis subulatis; floribus axillaribus post anthesin spinosis.

\section{ACHYRANTHES L. (17\%5).}

\section{a. Fruticosae.}

1. A. porrigens Jacq. Schoenbr. $t$. 350. fol. ovato-lanceolatis oppositis; spicis ellipticis subcorymbosis longissime pedunculatis; caule fruticoso. B. M. 530. B. Repos. t. 380. Celosia elougata Pers. In Peruvia. †. 2-ped.

2. A. pubescens Roth; caule erecto tereti foliisque elliptico-oblongis pubescentibus; floribus spicatis villosis mucronatis. lilecebrum Wall. $\boldsymbol{P a}$ tria ignota. b.

3. A. crispa Poir. canle fruticoso pubescente; fol. ovatis obtusis utrinque pubescentibus crispis; spica longissime terminali. In Amer. $\hbar$. Arbuscula 2-3-ped.

4. A. fruticosa Lam. caule erecto; fol. ovatis calycibusque glabris. Humph. 6. t. 12. f. 1.? In Ind. or. ち. Frutex 5-6-ped. Flores lucidi.

5. A. bidentata Blume; caule suffruticoso scandente; fol. elliptico-lanceolatis acuminatis ramulisque 4-gonis pubescentibus; bracteis basi 2-dentatis. In Java. 卢.

6. A. velutina Hook. in Beech voy. fruticosa; hirsuta; fol. ovalibus utrinque acutis sericeo-velutinis ; spica denum longissima. In ins. Sandwicensibus. ち. 3-ped.

\section{b. Herbaceac。}

\%. A. argentea Lam. fol. subrotundo-ovatis subtus argenteis puhescentibus acuminatis; calycibus reflexis. Sibtlı. gr. t. 244. A. sicula Roth. Bocc, sic. t. 9. In Sicilia. 24.
S. A. aspera $W$. fol, obovatis puhescentibus acutiusculis basi attenuatis; calycibus reflexis spicae adpressis. A. indica Roth. Mill. dict. t. 11. f. 2. Burn. Zeyl. t. 5. f. 3. Plukn. t. 10. f. 4. Rheede 10. t. 78. In Ind. or. et Prom. b. spei. 5 .

9. A. australis R. Br. fol. ovatis acutiusculis pubescentibus subrugosis; bracteis brevi-aristatis. In Nova Hollandia t.

10. A. canescens R. Br. fol. ovalibus tomentosis subtus cinereis; hracteis longe aristatis. In Nov. Holl. $b$.

11. A. sanguinolenta $I_{1}$. fol. ohlongo-lanceolatis pubescentibus; spicis terminalibus compositis villosis. Illecebrum W. Rumpl. \%. t. 2\%. f. ₹. In Ind. or. ち.

12. A. brachiata $L$. fol. oblongolanceolatis glabris; caule brachiato ramosissimo; spicis cylindricis aggregatis sessilibus villosis. Illecebrum W. Plukn. t. 334. f. 5. In India orientali. $\odot$.

13. A. Monsoniae Pers. fol. linearibus subulatis verticillatis; spicis compactis cylindricis villosis. Illecehrum L. Celosia Retz. Ach. pungens Lam. In Ind. or.

14. A. setacea Roth; caule erecto lanato; fol. oppositis linearibus angustissimis subulatis villosis margine revoluto-setaceis; floribus spicatis minimis. In Java. Cor. albo-virens.

15. A. linearifolia Sw. caule diffuso glabrato; fol. linearibus integer. rimis; capitulis oblongis; floribus extus villosis. In ins. Caribaeis. $\downarrow$.

\section{DESMOCHAETA DC.(1813).}

1. D. atropurpurea DC. caule suffruticoso foliisque ovatis acutis hirsutiusculis; setis flormm elongatis atroptirpureis uncinatis. Achyranthes lappacea L. Burm. Zeyl. t. 18. f. 1. In Ind. or. ђ.

2. D. flavescens DC. caule herhaceo; fol. ovato-oblongis suhtus villosis; setis elongatis lavidis uncinatis. Achyranthes patula L. A. echinata Retz. Plukn. t. 83. f. 2. In Ind. or. ๑.

3. D. prostrata $D C$. caule fiuticoso prostrato; fol. oppositis ovatis; florum fasciculis demum deflexis; setis brevissimis. Achyranthes L. Rumph. 6. t. 11: In Ind. or. et Afr. 
4. D. micrantha DC. caule suffruticoso erecto; fol. oppositis ovatis; florum fasciculis remotis demum reflexis; setis brevissimis flavidis. Achyranthes prostrata Lam. Plukn. t. 82. f. 2. In Java et Inal. or. t.

5. D. repens $R$. et $S$. fol. oppositis rhombeo-ellipticis cauleque puhescentihus; spica filiformi ; setis ferrugineis calycem aequantihus. Achyranthes Hoth. In Inil. or.

6. D. tomentosa $R$. et S. caule erecto ferrugineo-tomentoso; fol. ovatis mucronatis sericeo-pubescentibus; flosculis lanatis; fasciculo setarum uncinato. Acliyranthes Roth. In Ind. orient.

\%. D. achyranthoides $\boldsymbol{H}$. et $\boldsymbol{K}$. caule prostrato 4-gono foliisque oblongis acuminatis pilosis; bracteis ternis; setis glabris calycem superantibus. In Nov. Granata. \$.

\section{PUPALIA Mart. (1826).}

1. P. densiflora Mart. $t$. 158. $f$. 1. fol. oblongis ovatisque acuminatis adpresse pilosis; spicis solitariis; floribus reflexis, infimis remotis. Desmochaeta H. et K. In Brasilia. 4.

\section{ALTERNANTHERA Forsk.} (1785). [Illecebrum spr.].

a. Erectae.

1. A. angustifolia $\boldsymbol{R}, \mathrm{Br}$. fol. linearibus glaherrimis; glomerulis florum subglobosis; calycibus extus lanatis. In Nov. Holl.

2. A. villosa $H$. et $\boldsymbol{K}$. caule ramoso; fol. ovatis acuminatis ferrugineovillosis; capitulis subglobosis pedunculatis; calycibus pubescentibus. In Peruvia. 4.

3. A. gomphrenoides $\boldsymbol{W}$. $\boldsymbol{H} b$. caule ramoso scandente; fol. ovatis acuminatis pubescentibus; capitulis subglohosis sessilibus; calycibus glabris. In Peruvia.

4. A. paniculata $H$. et $\boldsymbol{K}$. caulo scandente ramoso glabro; fol. ovatooblongis acutis substrigosis; capitulis paniculatis: calycibus glabris. In $\mathrm{Cu}$ mana.

5. A. flavescens $\boldsymbol{H}$. et $\boldsymbol{K}$. caule subscandente foliisque obovatis gla- bris; capitulis solitariis pedunculatis; calycibus glabris. In Cumana.

6. A. sericea $H$. et $K$. caule suhvolubili; fol. oblongis acuminatis supra substrigosis subtus sericeis; capitulis solitariis; calycibus glabris. In Quito.

\%. A. truxillensis $H$. et $\boldsymbol{K}$. caule subvolubili; fol. obovato-mucronatis incano-tomentosis; capitulis oblongis aggregatis sessilihus; calycibus inaequalibus cuspidatis basi pubescentibus. In Peruvia.

8. A. rufa; caule diviso patentirufo-hirsuto; fol. oblongo-lanceolatis acutis pilosis; pedunc. refracto-paniculatis ; spicis cylindricis aphyllis. Brandesia Mart. t. 125. 127. 1. In Brasilia. 4.

9. A. puberula; tenuiter pubescens; caule diviso; fol. petiolatis oblongis acuminatis; pedunc. solitariis; spicis subglobosis; cor. pubescentibus. Brandesia Mart. t. 126. 127. 2. In Brasilia. 4.

\section{b. Procumbentes.}

10. A. Achyrantha R. Br. Mart. t. 152. fol. ovatis mucronatis opposito minore; laciniis calycis lanceolatis cuspidato-spinosis. Achyranthes repens L. A. mucronata Lam. A. radicans Cav. In Amer. austr. 4.

11. A. spinosa Horn. caule tomentoso dichotomo; fol. ovato-lanceolatis deflexis; floribus glomeratis; calycibus spinosis. A. axillaris DC. Patria ignota.

12. A. frutescens $\boldsymbol{R}$. Br. caule fruticoso folioso dichotomo; fol. oppositis pulverulentis. Illecebrum Herit. stirp. t. 37. $\beta$. Burm. am. t. 21. f. 2. Achyranth. halimifolia Lam. In Amer. austr. t. Caul. rufescens succulentus.

13. A. nodiflora $R$. Br. caule repente bifariam pubescente; fol. lanceolatis subintegerrimis basi attenuatis glabris; calyce acuto. Gomphrena sessilis L. A. caracasana $H$. et $K$. In Ind. or. et occ. 4.

14. A. nana $R, B r$. caule diffuso hirsuto; fol. obovatis pilosis; floribus axillaribus aggregatis; calycibus acuminatis glabris. In Nov. Holl.

15. A. denticulata $\boldsymbol{R}$. Br. caule procumbente foliisque spathulato-lanceolatis denticulatis glabris; axillis 
barbatis; calycilus acutis. In Hispaniola et Nor: Holl.

16. A. polygonoides R. Br. MIart. t. 1 $15-1.51$. caule repente hirsuto; fol. oblongis utrinque attemuatis ciliatis ; capitulis subpedunculatis; calycibus glabris acutis. Gomphrena L. Achyranthes Lam. In Amer. austr.

17. A. mulchella $H$. et $\boldsymbol{K}$. caule procumbente foliisque spathulatis lanatis; capitulis glomeratis ovatis; calycibus basi pilosis inaequalibus. Illecebrum diffusum spr. In Amer. australi.

18. A. canescens $H$. et $K$. caule prostrato foliisque linearihus crassiusculis pubescentibus; capitulis solitariis ovatis; calycibus basi pilosis inaequalibus. In Cumana.

19. A. mungens $H$. et $K$. caule repente villoso; fol. ovatis glabris; capitulis subglobosis sessilibus; calycibus spinosis. Ad Orinocum.

20. A. Iupulina $H$. et $K$. caule procumbente ramosissimo foliisque spathulatis acutis crassiusculis ciliatis glabris; calycibus obtusis. In Peruvil. 4 .

21. A. maritima; glabra; caulibus diffuso-ramosissimis prostratis; fol. obovato-lanceolatis crassiusculis acutis; floribus subpungentibus. Bucholzia Mart. t. 147. In Brasilia. 24.

22. A. ficoidea $R$. et $\mathbf{S}$. caulibus prostratis glabriusculis antice hifariam subpilosis; fol. late lanceolatis glabriusculis reticulato-venosis; capitulis hirtulis. Bucholzia Mart. In Brasilia. 4.

23. A. villosa; adscendens; caulibus subdichotomis foliisque ovato-lanceolatis acutis subtus albo-villosis; spicis cylindricis; corollis glabris. Brandesia Mart. t. 128. In Brasilia. $\odot$.

\section{MOGIPHANES Mart. (1826).}

1. M. hirtula Mart. $t$. 129. caule diviso adscendente foliisque ovatis acutis pubescenti-strigulosis; pedunc. solitariis; spicis ovato-cylindricis

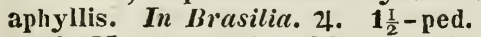

2. M. ramosissima Mart. $t$. 130. caule erecto ramosissimo; ramis brachiato - patulis foliisque lanceolatis acuminatis pubescentibus; spicis aphyllis. In Brasilia. 4. 4-6-ped.
3. M. multicaulis Mart. $t .131$. caule ramosissimo; ramis adscendentibus foliisque lanceolatis acutis subtus tenuiter striguloso-pubescentibus; spicis subfoliosis. In Brasilia. 4.

4. M. villosa Mart. $t$. 132. 134. f. 2. caule erecto diviso ramisque strictis subtrichotomis rufo-villosis; fol. ovatis acutis; spicis ovatis aphyllis. In Brasilia. 4. 4-ped.

5. M. brasiliensis Mart. $t$. 133. et 131. $f$. 3. caule erecto ramoso inferne piloso hirtulo; fol. oblongo-lanceolatis acuminatis pubescentibus; spicis globoso-cylindricis. Gomphrena Jacq. ic. t. 346. Philoxerus $\mathrm{R}$. et $\mathrm{S}$. In Brasilia. ち. 3-4-ped.

6. M. straminea Mart. $t .135$. caule erecto ramoso; ramis foliisque ovato-acumiuatis pubescentibus; pedunc. axillaribus; capitulis globosis. Gomphrena brasiliensis L. In Brasilia. 24. 3-ped.

7. M. diffusa Mart. caule erecto ramosissimo; ramis diffusis foliisque ovato-lanceolatis glabriusculis; pedunc. subtrifidis; spicis cylindricis. Celosia Hoffmsgg. In prov. Paraënsi. 2.

\section{PFAFFIA Mart. (1836).}

1. P. glabrata Mart. $t$. 122. subglabra; caule inferne ad nodos villoso; fol. elongato-lanceolatis; pedunc. simplicibus; spicis ovato-cylindricis. In Brasilia. 4. 3-4-ped.

2. P. sericea Mart. t. 123. sericeo-incana vel glabrescens; fol. oblongo-lanceolatis; pedunc. sub-3-fidis subcorymbosis; capitulis globosis; radice tuberosa. In Brasilia. 24. 2-ped.

3. P. velutina Mart. $t$. 124. velutino-villosa; fol.lato-ovatis obtusis; pedunc. simplicibus; spicis ovato-cylindricis. In Brasilia. - 1-1 $\frac{\mathrm{I}}{2}-$ ped.

4. P. tomentosa Mart. caule foliisque ovatis acutis subrepando-dentatis subtus tomentoso-albis; pedunc. elongatis; capitulis globosis. In Brasilia. 4.

5. P. hirtula Mart. pubescentihirtula; fol. linearibus; pedunc. subternis; capitulis globosis. In Brasilia. 4.

6. P. jubata Mart. villosissima; fol. lineari-lanceolatis; pedunc. simplicibus terminalibus; capitulis ovatoglobosis. In Brasilia. 4. 
\%. P. ynaphalioides Mart. tomentosa; fol. ohlongo-lanceolatis acutis; pedunc. terminali elongato simplici; capitule globoso. Gomphrena Vahl. In Brasitia. 4.

S. P. ylanca; subglabra; caule dichotomo-ramoso fistuloso foliisque elongatis lanceolatis glaucescentibus; peduuc. 3-chotomis; cor. basi harhatis. Sertüruera Mart. t. 126. 127. In Brasilia. 4.

9. $\boldsymbol{P}$. iresinoides; caule erecto suffruticoso solido; fol. lato-lanceolatis acutis pulsescentihus; ramis pedunculisque fulvo-pubescentibus. Altheranthera H. et K. Sertïnera Mart. t. 28. In Brasilia. †. 3-4-ped.

10. P. luzulaeflora; subtilissime pubescens; caule erecto fistuloso; fol. lato-lanceolatis acuminatis; corollis eburneis hasi villosis. Sertürnera Mart. In Brasilia. 24. 3-ped.

\section{GOMPHRENA L. (1737).}

\section{Capitatac.}

\section{a. Erectae.}

1. G. giobosa $L$. caule piloso; fol. oblongis pubescentibus; capitulis 2phyllis ; bractearum carinis alatis ; calycibus lanatis. B. M. 2815. Hheede i0. t. 37. Rumph. 5. t. 100 . f. 2. Breyn Cent. to 51. In Ind. or. $\odot$. Capitula purpurea.

2. G. perennis $\boldsymbol{L}_{0}$ fol. lanceolatis ; capitulis diphyllis; floribus 5-bracteatis; calycibus ciliatis. Dill. EIth. f. 22. In Bonaria. 24. Capitula flavescentia.

3. G. serrata $L$. caule erecto brachiato; capitulis solitariis terminalihus sessilibis; calycibus serratis. In America.

4. G. arborescens $L_{0}$ caule arborescente volubili piloso; fol. ovalibus coriaceis integerrimis; capitulis polyphyllis. In Amer. austr. $\hbar$.

5. G. officinalis Mart. t. 101.102. fermyineo-hirsutissima; caule adscendente; fol. ovatis; capitulis maximis; foliolis calycis carina crista dentata. In Irasilia. ந. 1-ped. Capitula coccinea.

6. G. hispida $L$. caule erecto; capitulis diphyllis; fol. crenatis. Hheede 9. t. 72. In Malabaria. Capitula candida.
7. G. angustifolia Vahl; fol. lineari-lanceolatis glabris; capitulis terminalibus oblongis sub-3-phyllis; caulo 4-gono. In Ind. or.

8. G. canescens R. Br. canle lanato; fol. linearibus pubescentibus; capitulo diphyllo. In Nov. Holl.

9. G. macrocephala Hilar. bras. $t$. 32. hitsutissima; caule adscendente; fol. oblongo-lanceolatis rufo-hirsutis; capituli maximi foliolis longissimis. In Brolasilia. t.

10. G. desertorum Nart. $t .103$. caule dichotomo adscendente foliisque lanceolatis subtus pubescentibus; capitulo diphyllo; calycis foliolis cristatis cor. lanata longiorihus. In Brasilia. 24. spithamea. Capitula alba.

11. G. leucocephala IFart. t. 110. caule erecto dichotomo; fol. anguste lanceolatis subtus villosis; capitulis 4-phyllis; foliolorum calycis carina serrulata. In Brasilia. ๑. 3-6-poll. Cap. alba.

12. G. eriophylla Mart. t. 10.9. caule erecto subsimplici; fol. ovatis acutis subtus alho-tomentosis; capitulis diphyllis; cor. extus sericea. In Brasilia. 24. 1-ped. Cap. alba.

13. G. Schlechtendalii Mart. caule erecto hirsutissimo; fol. ovalibus obtusis mucromulatis; capitulis sessilibus; bracteis calycibusque serratis. In Brasilia.

14. G. Haenkeana Mart. caule adscendente ramoso foliisque lanceolatis acutis villosiusculis; pedunc. elongatis solitariis; capitulis diphyllis. In Peruvia.

15. G. celosioides Mart. caule adscendente hrachiato foliisque ovatolanceolatis hirsutis; pedunc. elongatis; spicis diphyllis. Ad fl. Platam.

16. G. pulchella Mart. caule ramoso adscendente foliisque lanceolatis acutis strigosis; pedunc. elongatis; capitulis globosis diphyllis. In Montevideo.

1\%. G. 'villosa Mart. caule simplici; fol. ovato-lanceolatis mucronulatis villosis; capitulis diphyllis globosis. In Montevideo.

18. G. Selloviana Mart. $t$. $11 \%$. hirsuta; caule erecto simplici; fol. obiongis; pedunc. elongatis; capitulo maximo 2-4-phyllo. In Montevideo. Cap. niniata.

19. G. agrestis Mart. $t$. 114.115. 2. caule erecto ramoso foliisque lan- 
ceolatis strigoso-villosis; capitulis globosis diphyllis; carina calycum non serrata. In hrosilia. 24. 1-z-ped. Cap. testacea colorata.

20. G. nigricans Blart. t. 113.115. caule adscendente simplici foliisque lanceolatis villoso-lanatis; pelunc. elongatis strigoso-villosis; capitulis globosis diphyllis. In Brasilia. 4. 1 -ped. Cap. alba.

21. G. scapigera Hart. $t .116$. 11\%. $f$. 1. hirsutissima; adscendens; fol. radic. lanceolatis; pedunc. elongatis; capitulis $3-5$ phyllis; carinis calycis cristatis. In Brasilia.24. Capitula rosea.

22. G. fiava $L$. caule erecto angulato; fol. lanceolatis; pedunc. oppositis 2-fidis 3-capitatis; capitulo intermedio scssili. In Nov. Hispania.t.

23. G. lanata $R$. Br. canle calyceque lanatis; fol. linearibus villosiusculis. In Nov. Holl.

21. G. macrorrhiza Mart. t. 106. radice napiformi; caule adscendente dichotomo; fol. lato-lanceolatis subtus villosis; cor. extus tomentosa. In Brasilia. Caul. spithameus. Capitula pallide flava.

25. G. mollis Mart. 111. eaule erecto diviso foliisque lanceolatis acutis villoso-sericeo-incanis; pedunc. elongatis; capitulis aphyllis; foliolis calycis acuminatis. In Brasilia. 4. 2-3-ped. Cap. rosea.

26. G. debilis Mart. $t$. 10\%. radice fihrosa; caule erecto hasi diviso; fol. lineari-lanceolatis subtus villosis; pedunc. filiformibus strictis; capitulis aphyllis; cor. extus tomentosa. In Brasilia. $\odot$.

27. G. seriantha Mart. $t$. 10s. caule erecto foliisque lato-lanceolatis subtus deusissime alho-tomentosis; capitulis gilobosis aphyllis; cor. extus sericea. In Brasilia. 4.

25. G. rupestris Nees; caule erecto diviso; fol. linearibus acutis alhovillosis; pedunc. elongatis; capitulis glohosis aphyllis, G. Schultesia Mart. In Brasilia.

29. G. virgata Mart. $t$.118. caule sursum virgato ramoso pubescente; fol. linearibus acutis glabris; spicis 4-stichis; cor. lanata. In Brasilia. 4. 4-5-ped.

30. G. vaga Mart. $t$. 120. caule crecto dichotomo; ramis foliisque lanceolatis ovato-acuniuatis subtus ara- chnoideo-villosis; capitulis aphyllis; cor. stricte lanata. In Brasilia.4. 34-ped.

31. G. elegans Mart. $t$. 119. caule erecto dichotomo ferrugineo-pulverulento-hirtulo; fol. petiolatis ovatis acutis subtus venosis villosis; capitulis globosis aylyllis; cor. basi vilJosa. In Brasilia. 24. 2-3-ped.

32. G. incana Mart. $t$. 112. caule erecto foliisque oblongo-lanceolatis aculis villoso-incanis; capitulis globosis aphyllis; carinis calycis subdenticulatis. In Brasilia. 24.

33. G. angustiflora Mart. $t$. 121. glahra; caule erecto gracili acute angulato; fol. linearibus acutis glaucis; spicis sub-t-stichis aphyllis; corollae

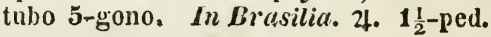

\section{b. Procumbentes.}

31. G. decumbens Jacq, Schoenbr. $t$. 482. caule foliisque oblongis subtus lanato-pubescentibus; capitulis subgeminis; tubo stamineo dentato. Ins Mexico. $\odot$.

35. G. humilis $\boldsymbol{R}$. Br. caule tomentoso; fol. linearibus villosiusculis; capitulis aphyllis; calycibus lauatis. In Nov. Holl.

36. G. bicolor Mirt. caule strigoso; ramulis fuscis; fol. lanceolatis utrinque attenuatis; capitulis sessilibus; bracteis denticulato-alatis. In Brasilia.

37. G. prostrata Mart. $t$. 11.5. caule diviso; fol. subcordato-ovatis acutis subtus villosis; capitulis globosis; bracteis foliaceis. In Brasilia. 4. $1 \frac{1}{2}$-ped.

38. G. Iemissa Mart. t. 117. caule dichotomo; fol. lanceolatis acutis subtus pubescenti-villosis; capitulis hemisphaericis; carinis calycis serrulatis ; cor. arachnoideo-villosa. In Brasilicl. 4. $\frac{I}{2}$ - ped.

\section{Spicatae.}

3.9. G. interrupta $L$. caule adscendente; fol. ohlongis subtus sericeis; spicis glomeratis paniculatis; floribus 1-gynis. Herit. stirp. t. 3. Celosia procumbens Murr. Comm. Goett. 1782. t. 5. In Ind. occ. $\odot$.

10. G. umaranthoides Roth; caule angulato flexuoso ; fol. alternis ovatoacuminatis mucronatis glabris; spicis 
filiformibus; noribus glabris. In India orientali.

\section{HEBANTHE Mart. (1826).}

1. H. paniculata Mart. $t .140$. 142. $f$. 1. caule foliisque oblongis utrinque acutis glabris; axillis barhatis ; panicularum rachibus rufo-pubescentibus. In Brasilia. 24. 3-ped. Cap. virescentia.

2. H. spicata Mart. t. 111. 142. f. 2. caule superne ramisque spicisque subsimplicibus ferrugineo-pubescenti-hirtulis ; fol. ovatis acutis subtus dense villosis. In Brasilia. 24. 3-4-ped.

3. H. virgata Mart. t. 113. 145. f. 1. caule superne ramulisque pedunculisque ferrugineo-striguloso-pulescentibus; fol. ovatis acuminatis supra glabriusculis. In Brasilia. ђ. Paniculae pedales.

4. H. pulverulenta Mart. t. 14. 14.5. $f$. 2. caule superne ramisque pedunculisque pulverulento-subincanis; fol. ovatis acutis; paniculis pyramidatis. In Brasilia. ‡. 4-ped. Flores subolivacei.

\section{IRESINE Patr. Brown (1756).}

1. I. polymorplea Mart. $t$. 153. 154. glahra ; caule acuto sub-6-gono fol. ovatis acuminatis in petiolum attenuatis margine serrulatis; panicula composita varia; spicis ovato - cylindricis. In Brasilia. 24. Species quam maxime varia. Flores virescentes.

2. I. elatior Rich. glabra; caule erecto; fol. lanceolato-oblongis utrinque acuminatis; capitulis ovatis. Hosea Mart. t. 155. J. celosioides Sw. In Brasilia. ๑. 2-4-ped.

3. I. aurata; caule superne ramisque paniculisque diffusis tenuiter fulvo-villosis; fol. oblongis utrinque acuminatis subtus pubescentibus; cor. lana subfulva. Trommsdorffia Mart. t. 139. In Brasilia. ち. 3-ped.

4. I. argentata; caule suffruticoso ramisque foliisque lato-ovatis acutis glabris; paniculis brachiatis patentibus subtestace 0 - pulverulentis ; cor. lana creberrima argenteo - nitida.
Trommsdorffia Mart. Achyranthes nodosa Bert. In IBrasilia. $\hbar$.

5. I. pulcerulenta; caule suffruticoso ramisque paniculisque pyranidalibus dense albido-tomentosis; fol. ovato-oblongis obtusis subtus albotomentosis supra pulverulentis. Trommsdorffia Mart. In Brasilia. $\hbar$.

\section{PHILOXERUS R. Br. (1810).}

1. P. vermicularis R. $B r$. canle repente geniculato foliisque cylindricis obtusis glahris; capitulis solitariis; calycibus glabris. Illecehrum L. Gomphrena Spr. In Ind. or., Nov. Holl. et Carolina.

2. P. diffusus $\boldsymbol{R}$. Br. caule prostrato lanato; fol. lanceolatis utrinque pubescentibus; capitulis oblongis; calycibus laevibus. Gomphrena spr. In Nov. Holl.

3. $P$. aggregatus II. et $K$. caule procumbente glabro; fol. lanceolatis utrinque attenuatis subcarnosis laevibus; capitulis diphyllis aggregatis. Gomphrena L. In Nov. Holl.

4. P. conicus; caule erecto; fol. linearibus revolutis; spicis conicis subternis; calycibus lanatis. Gomphreua Spr. In Nov. Holl.

\section{HOPLOTHECA Nutt. (1818).}

1. H. floridana Nutt. caule erecto glanduloso; fol. lanceolatis acutis piIosis ; spicis paniculatis remotis oppositis. Gomplirena Spr. In Florida.

2. H. lanata Mart. $t$. 146. fol. oblongo-lanceolatis acutis subtus lanato-villosis; spinis elongatis nudis. Gomphrena H. et K. In Brasilia. $\odot$. Cor. alba.

3. H. tomentosa Mart. fol. Iatoovatis obtusiusculis subtus sericeotomentosis incanis; pedunc. elongatis. In Brasilia. $\odot$.

4. H. sericea Mart. fol. angusle lanceolatis acutis subtus sericeo-villosis; pedunc. elongatis nudis; corollae fructiferae alis inciso-serratis. In Brasilia. $\odot$. 


\section{AYLMERIA Mart. (1826).}

1. A. violacea Mart. fol. lanceolato-linearibus pubescentibus ; corymbo laxo. Achyranthes spr. In Nova Hollandia.

2. A. rosea Mart. fol. verticillatis linearibus subulatis; corymbis terminalibus compactis. Achyranthes spr. In Nov. Holl.

1136. BOUSSINGAULTIA H. et K. (1825).

1. B. baselloides H. et K. Nov. Gen. $t$. 64.5. f. 2. In Quito. ち. Frutex volubilis. Folia alterna integerrima carnosa. Flores axillares albidi.

\section{ILLECEBRUM RUpp. (1718).}

1. I. verticillatum $L$. caule glabro ramoso procumbente; fol. subrotundo-ovatis; floribus verticillatis nudis; calycibus subcucullatis aristatis. Vaill. par. t. 15. f. \%. Schrad. jour. 1801. t. 4. E. B. 895 . Fl. Dan. 335. schk. t. 50. In Europa. $\odot$. Flores albo - cartilaginei.

\section{PARONYCHIA Clus. (1576).}

\section{a. Erectae.}

1. P. cymosa $D C$. caule ramoso erecto; fol. subteretibus glabris ; bracteis brevissimis echinatis. Sibth. gr. t. 245. Illecebrum Vill. In Gallia, Hispan. et Graecia. $\odot$.

2. P. capitata lam. cauliculis surrectis; fol. carinato-ohlongis apice ciliatis bracteisque appressis. sibth. gr. t. 247. Illecebrum L. In Europ. austr. 4.

3. P. nivea $D C$. caule suberecto ramosissimo; fol. patentibus villosis; bracteis maximis flores occultantibus. Barrel. ic. 687. Illecebrum Pers. In Gall. et Sicil. 4.

4. P. subulata DC. radice crassa; caule erectiusculo; fol. subulatis lonLis; floribus teruinalibus. Illecebrum Pers. Patria ignota.
5. P. striata $D C$. caule erecto cymoso-ramoso; calycibus striatis. IIlecebrum Pers. Patria ignota.

6. P. canariensis Juss. caule fruticoso; fol. oblongis acutis glabris; stipulis bracteisque abbreviatis; paniculis dichotomis. Hlecebrum L. In Teneriffa. $\hbar$.

ซ. P. dichotoma DC. caule erecto dichotomo; fol. distantibus oblongis muticis; floribus cymosis. Ilecebrum Pers. Patria ignota.

8. $P$. linearifolia $D C$. caule erecto villoso; fol. linearilus longis; capitulis terminalibus. Illecebrum Pers. Patria ignota.

9. $\boldsymbol{P}$. sessiliflora Nutt. caule ramoso diffuso; fol. linearibus glabrit reflexis; stipulis laceris subulatis; calycibus fornicatis. In Amer. bor.

10. P. bengalensis Juss, caule herbaceo foliisque lanceolatis acuminatis pubescentibus; spicis hirsutis. Illecebrum L. Acliyrauthes Lam. In India orientali.

11. P. Smithii Choisy; caule fruticoso erecto ramoso; fol. lineari-oblongis acuminatis enerviis; cymis paucifloris. In ins. Canariis.

\section{b. Procumbentes.}

12. $P$. hispanica $D C$. caule ramoso; fol. oblongis utrinque attenuatis ciliolatis; stipulis bracteisque scibriosis. Illecebrum Paronychia L. Sihth. gr. t. 246. I. narbonense Schrad. jour. 1801. t. 4. P. pubescens DC. It Europ. austr. 4.

13. P. polygonifolia Juss. caule prostrato ; fol. ovato-lanceolatis glabris. Illecebrum Vill. dauph. t. 16. Schrad. 1. c. t. 4. In Gall. austr. et Pyrenaeis.

14. P. serpyllifolia Juss. caule nodoso ramoso prostrato-repente; fol. obovato-lanceolatis margine ciliolatis subcarnosis. Illecebrum Vill. I. Kopela Hacq. pl. alp. 8. t. II. f. 1. In Gall. austr, et Pyren. 4.

15. $P$. brasiliana $D C$. caule diffuso; fol. pubescentibus aristatis. $P$. bonariensis DC. prodr. In Montevideo.

16. P. arabica Juss. caule procumbente; fol. sparsis congestis bracteas nitidas aequantibus. Delile acg. t. 18. Illecebrum L. In Arabia. $\odot$. 
17. 1 . aesinifoliu Juss. caule diffuso foliisque ovatis deflexis pilosis; bracteis villosis. Illecebrum L. Scop. del. t. 13. Patria iginota.

13. P. virginica Spr. caule procumbente glabro; fol. linearibus sulcatis subulatis; stipulis bracteisque bifidis. P. dichotoma Nutt. In V irginia.

19. P. aryyrocoma Nutt. caule procumbente caespitoso pubescente; fol. linearibus subulatis villosis; calycibus apice barbatis. Anychia Michx. in Carolina.

20. $P$. herniarioides Nutt. caule prostrato pubescente; fol. oblongoovalibus ciliatis aristatis; calycibus subulatis. In Carolina.

21. $\boldsymbol{P}$. chilensis $D C$. caule diffuso caespitoso; fol. oblongo-linearibus mucronatis glabriusculis; calyce mucronulato. In Chili.

22. $P$. aretioides $D C$. caule fruticuloso adscendente ramosissimo; ramulis hirsutis ; fol. sericeo-pubescentibus ovali-oblongis obtusis ; floribus capitatis. Illecebrum Pourr. In Hispanic. 方.

23. P.? ramosissima DC. caule diffuso ramosissimo; fol. confertis teretiusculis glabris apice pungentibus; floribus axillaribus paucis. Loefflingia Weium. In Chili. 4.

\section{ANYCHIA Michx. (1803).}

1. A. dichotoma Michx. caule retrorsum pubescente; fol. cuneato-oblongis; stipulis fore Iongioribus. Queria canadensis $L$. Orteg. dec. $t$. 15. f. 2. Gaertn. t. 128. In America boreali. $\odot$.

2. A. capillacea DC. caule glaberrimo laevi; fol. ovatis; stipulis flore brevioribus; floribus remotis. Queria Nutt. In Amer. bor. $\odot$.

\section{GUILLEMINEA H. et K. (1823).}

1. G. Itlecebrum $\boldsymbol{H}$. et $\boldsymbol{K}$. Nov. Gen. $t$. 518. Illecebrum densum $W$. IIb. In Quito. Herba diffusa ramosissima. Folia opposita spathulata glabra. Flores capitati.

\section{GIMNOCARPUS Forsk. (1880).}

1. G. Fruticosus Forsk. ilescr. $t$. 10. Vic. lib. t. 10. f. 1. Trianthemc Vahl. In desertis Barbariae et Aegypti. t. suffrutex diffusus. Folia opposita stipulacea fasciculata. Pedicelli axillares.

\section{ANREDERA Juss. (1789).}

1. A. spicata Pers. Basella vesicaria Lam. In Peruvia. Caulis scandens. Folia subcordata. Hlores spicati alterni.

\section{HABLIZIA M. B. (1810).}

1. H. tamnoides M. B. In Caucaso. Radix carnosa. Caules scandentes squamati. Folia cordata petiolata acuta scabra. Flores panicuIati.

\section{CAROXYLON Thutb. (1782).}

1. C. Salsola Thunb. Salsola aphylla L. In Africa australi. ち. Fruticosa; ramosissima; subaphyila. Hamis flosculorum rudimentis coopertis.

\section{RHAGOD1A B. Br. (1810).}

1. R. Billardieri R. Br. fol. lanceolatis integerrimis subtus glaucis pulverulentis; spicis ramosis. Chenopodium baccatum Labill. Nov. Holl. t. 96. In Nov. Holl. t.

2. R. crassifolia R. Br. erecta; fol. oblongo-linearibus carnosis integerrimis subtus pulverulentis; spicis ramosis. In Nor. Holl. 卢.

3. R. linifolia R. Br. decumbens; fol. lanceolato-linearibus integerrimis; fol. 1-2-andris. In Nov. Holl. ђ.

4. R. hastata $R$. Br. erecta; ramosa; fol. suboppositis rhombeo-liastatis integerrimis glaberrimis; spicis terminalibus aphyllis. In Nova Hollandia. 方.

5. R. parabolica $\boldsymbol{R}$. Br. erecta; fol. 3-angularibus obtusis pulverulentis; spica ramosa. in Noc. Hoil. 
6. R. spinescens R. Br. erecta; ramulis spinescentibus; fol. alteruis rombeo-hastatis integris utrinque pulvereo-incanis. Iu Nov. Holl. ち.

\%. R. metans R. Br. prostrata; ramulis fructiferis adscendentibus apice nutantihus; fol. oppositis hastato-lanceolutis acutis. In Nov. Holl. 4 .

1116. ALZATEA R. et P. (1791).

1. A. verticillata $R$. et $\boldsymbol{P}$. peruv. t. 24. f. 2. prodr. t. \%. In Peruvia. ち. Arbor. Folia obovata emarginata. flores coryubosi.

\section{1\%. CONDALIA Cav. (1799).}

1. C. micropluylla Cav. ic. $t .525$. fol. alteruis subsessilibus ovatis. In Chiti. ち. Zizyphus myrtoides Ort.

2. i. paradoxa spr. fol. oppositis comnatis decurrentibus crassis rigidis pungentibus; pedunc. congestis. in Montevideo. 古.

3. C. spinosa Spr. spicis axillarihus oppositis; fol. confertis subspathulato-linearibus glabris; pedunc. aggregratis nutantibus. AdRio-Grande sello. $\hbar$.

\section{PENNANTIA Forst. (18\%5).}

1. P. corymbosa Forst. gen. $t .6 \%$. In Nov. Zueel. Ђ. Arbor. Folia alterna oblonga obtusa glabra. Flores corymbosi albi.

\section{EXOCARPUS Labill. (1795).}

1. E. latifolius R. Br. arboreus; fol. petiolatis ovalibus nervosis; spicis axillaribus. In Nov. Holl. 古.

2. E. cupressiformis Labill. $t$. 11. arboreus; fol. minutis 3-angularibus patulis; spicis pedunculatis. In Nov. Holl. et ins. I an Diemen. $\frac{b}{}$.

3. E. sparteus $\boldsymbol{R} . \boldsymbol{B r}$. fruticosus; fol. minutis subulatis apice recurvis; ramis augulatis; spicis subpyramidatis breviter pedunculatis. In Nov. Holl. t.

4. E. lumifusus $\boldsymbol{R}$. Br. fruticosus; procumbens; fol. minutis 3-angulari- bus marcescentibus; spiculis sessilibus glomeruliformibus; floribus 4-fidis. In Nov. Holl. ђ.

5. E. strictus R. Br. fruticosus; erectus; fol. minutis 3-angularihus; ramis strictis angulatis; spiculis glomeratis sessilibus. In Nor. Holl.

6. E. aphyllus R. Br. fruticosus; erectus; ramis aphyllis strictis teretibus; spiculis glomeratis; stigmate

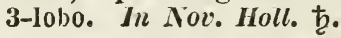

\section{CERVANTESIA R. et $P$. (179t).}

1. C. tomentosa $\boldsymbol{R}$. et $\boldsymbol{P}$. peruv. t. 211. f. 6. fol. linearibus oblongis; floribus racemosis subsessilibus. C. bicolor Cav. ic. t. 475. In Peruvia.. Arbuscula 12-15-ped. Flores albi.

\section{AMANOA Aubl. (175\%).}

1. A. gujanensis Aubl. Guj. t. 101. Juss. Euphorb. t. 2. f. 6. In Gujana. 古. Arbor procerus. Folia alterna oblonga acuta integerrima. Flores spicato-glomerati.

\section{FLUEGGEA Willd. (1806).}

1. F. Leucopyrus W. Juss. Euphorb. t. 2. $f$. \%. In Ind. or. †. Frutex ramis spinosis. Folia alterna orbiculata glabra integerrima. Flores axillares.

2. F. microcarpa Blume; fol. obovato-ellipticis glabris; ramis 4-gonis. In Java. 市.

3. F. jaranica Blume; ramulis in spinam desinentibus; fol. alternis ovali-oblongis acuminatis absolete remote serrulatis; floribus axillaribus solitariis. In Java. $\hbar$.

\section{ANTIDESMA J. Burm. (1738).}

1. A. alexiterium $L$. fol. oblongis utrinque attenuatis nitidis; racemis axillaribus filiformibus. Rheede 4. to 56. In Ind. or. $\bar{t}$.

2. A. zeylanicum $\boldsymbol{L}$. fol. ellipticis acuminatis glabris nitidis basi angusta- 
tis; racemis axillaribus geminis. Rheede 5. t. 26. In Ind. or. 卢.

3. A. Bunius spr. fol. oblongis acutis; ramis terminalibus elongatis; floribus sub-3-andris. Stilago L. In Amboina. 古.

4. A. diandrum Spr. fol. ovatooblongis; spicis solitariis terminalibus. In Ind. or. ђ.

5. A. sylvestre Lam. fol. ovatis ecuminatis glabris nitidis; racemis axillaribus. Theede 5. t. 26. In Ind. or. $\hbar$.

6. A. madagascariense Lam. fol. ovato-oblongis nitidis glabris; axillis venarum subtus perforato-glandulosis ; racemis axillaribus solitariis. In $M a^{-}$ dagascaria. $\hbar$.

\%. A. acidum Retz; fol. obovatis; spicis solitariis. In Ind. or. $ђ$.

8. A. pubescens Rosb. corom. $t$. 16\%. fol. ellipticis utrinque acutis subtus pubescentibus; racemis paniculatis terminalibus. Plukn. t. 39. f. 1. In Ind. or. $\hbar$.

9. A. paniculatum Roxb. fol. subrotundo-ellipticis utrinque rotundatis obtusis apice marginatis subtus pubecentibus. In Ind. or. $\hbar$.

\section{LICANIA Aubl. (1775).}

1. L. incana Aubl. t. 45. Lam. ill. t. 122. Hedycrea incana $W$. In Gujana. ち. Arbuscula. Folia oblonga acuminata subtus incaua. Flores parvi spicati terminales.

\section{CERATONIA Dodon. (1556).}

1. C. Siliqua $L$. inermis; foliolis ovalibus obtusis planis. Cav. ic. t. 113. Blackw. t. 209. Hayne 7. t. 36. In Graecia, Syria et Asia minore. $\hbar$. Arbor procera. Fol. pinnata 3-juga ovalia glabra. Flores racemosi rubri.

\section{GLAUX Dodon. (1556).}

1. G. maritima L. E. B. 13. Fl. nan. 548. Gaertn. t. 184. Schl. t.50. sv. Bot. t. 413. Hook. Lond. t. 188. In maritimis Europ. 24. Herba ra- mosa prostrata carnosa. Folia decussata lanceolata. Flores albi.

\section{PHYLICA L. (1737).}

\section{a. Floribus capitatis.}

1.P. abietina Eckl. et Zey?. fol. linearibus obtusis inflexo-apiculatis; ramis fastigiatis; capitulis terminalibus laxis. In Prom. b. spei. ち.

2. $\boldsymbol{P}$. ericoides $L$. fol. linearibus revolutis subtus tomentosis exstipulatis ; ramis subumbellatis; capitulis hemisphaericis. Berl. Mag. 8. t. 8. f. 1. In Prom. b. spei. ђ.

3. P. brevifolia Eckl. et Zeyh. fol. cordato-lanceolatis hamoso-inflexis margine subtus convolutis glabris; ramis fastigiatis. In Prom. b. spei. $\hbar$.

4. P. alpina Eckl. et Zeyh. fol. cordato-lanceolatis supra nitidis scabris subtus tomentosulis; ramis 3-chotomis. In Prom. b. spei. ち.

5. P. acmaephylla Eckl. et Zeyh. fol. cordato - lanceolatis mucronatis subtus tomentosulis; ramis sparsis. In Prom. b. spei. ђ.

6. P. acerosa $\boldsymbol{W}$. fol. linearibus acutis revolutis subtus villoso-tomentosis ciliatis; ramis verticillatis ; capitulis tomentosis. In Prom. b. spei.

\%. P. stipularis Thunb. fol. linearibus revolutis punctato-scabris subtus incanis; stipulis filiformibus coloratis; capitulis lanatis. In Prom. $b$. spei.

8. P. imberbis Thunb. fol. sparsis linearibus revolutis glabris; capitulis corymbosis villosis. P. brunioides Lam. In Prom. b. spei. ఫ.

9. P. parviflora $L$. fol. sparsis lanceolato-linearibus scabris subtus tomentosis; ramis villosis; capitulis tomentosis. In Prom. b. spei. $\hbar$.

10. P. empetroides Eckl. et Zeyh. fol. linearibus acutis erecto-patulis subrotundis marginibus subconvolutis; capitulis Iaxis. In Prom. b. spei. $\hbar$.

11. P. disticha Eckl. et Zeyh. fol. distichis lineari-lanceolatis obtusis adpressis margine revoluto et subius tenue tomentosis; cap. parvis. In

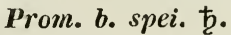

12. P. rosmarinifolia Iatm. fol. imbricatis linearibus revolutis subsecundis subtus incanis erectis; capitu- 
lis tomentosis. P. secunda Thunb. In Prom. b. spei. 古.

13. P. nitida lam. fol. linearibus revolutis patentibus supra nitidis subtus tomentosis; capitulis villosissimis. P. arhorescens Lk. In Prom. $b$. spei. t.

1t. P. reclinata W'endl. fol. confertis lineari-lanceolatis acutis revolutis reflexis; capitulis pancifloris ; calycibus patulis. In Prom. b. spei. 古.

1.5. P. trichotoma Thunb. fol. imbricatis 3-gonis obtusis glabris; ramis trichotomis hirsutis; capitulis villosis. In Prom. b. spei.

16. P. lanceolata Thunb. fol. lanceolatis acutis supra glabris subtus lanato-tomentosis; capitulis terminalilus; bracteis hirsutissimis. P. glabrata Thunb. atrata Lichtenst. Trichocephalus Ecki. et Zeyh. In Prom. b. spei. ち.

17. P. capitata Thunb. fol. lineari-lanceolatis rigidis patentibus hirsutis subtus revolutis tomentosis; hracteis capituli hirsutissimis. Wendl. coll. t. 50. In Prom. b. spei. ち.

18. P. rigida Eckl. et Zeyh. fol. cordato-lauceolatis acutis erecto-patulis subtus tomentosis, superioribus floralibusque plumosis; ramis atro-tomentosis; capitulis terminalibus maximis. In Prom. b. spei. Ђ.

19. P. strigosa Thunb. fol. ovatolanceolatis obtusis revolutis supra punctato-scabris subtus hirsuto-tomentosis; bracteis fulvo-villosissimis. In Prom. b. spei. 古.

20. P. buxifolia Thunb. fol. ovatis acutis subcoriaceis supra glabris subtus albo-tomentosis; capitulis paucifloris. Soulangia Brongn. In Prom. ๖. spei. ち.

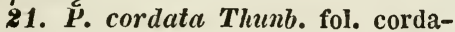
to-lanceolatis acutis supra glahris subtus tomentosis; capitulis latere ramiferis. Soulangia Brongn. In Prom. b. spei. ち.

22. $P$. callosa $T$ Thunb. fol. cordatoovatis acutis subtus tomentosis patentibus; capitulis terminalibus. Trichocephalus Brong. In Prom. b. spei. $ち$.

23. P. trachyphylla; fol. lanceolatis erecto-patentibus calloso-mucronatis introrsum arcuatis margine revoluto-scabris subtus tomentosis; ramulis fastigiatis pilosis; capitulis vilIosis. Trichocephalus Eckl. et Zeyh. In Prom. b. spei. ち.
21. P. litoralis; fol. cordato-lanceolatis erecto-patulis suhtus incanotomentosis margine revolutis; capitulis tomentosis. Trichocephalus Brongn. In Prom. b. spei. $\hbar$.

25. P. verticillata; fol. lineariacutis patentissimis verticillatis margine revolutis intus sulcatis extus tomentosis; ramulis subumbellatis; capitulis sublanuginosis. Trichocephalus Eckl. et Zeyh. In Prom. b. spei. ち.

26. P. gracilis; fol. cordatis lanceolatis erecto-patulis sublus incanotomentosis margine revolutis ciliatis; ramulis umbellatis fasciculato-villosis. Trichocephalus Eckl. et Zeyl. In Prom. b. spei.

2\%. P. rlizophora; fol. cordatolanceolatis obtusis superne glabris subtus albo-velutinis margine revolutis; capitulis villoso-tomentosis. Trichocephalus Eckl. et Zeyl. In Prom. b. spei. ち.

28. P. viryata; fol. lanceolatis acutis erecto-patulis margine revolutis ciliatis subtus albo-tomentosis; ramis virgatis; capitulis lanuginosis. Trichocephalus Eckl. et Zeyh. In Prom. b. spei. ђ.

29. R. elongata $W$. Hb. fol. Ianceolatis glabris; capitulo terminali tomentoso. Trichocephalus Eckl. et Zeyh. In Prom. b. spei. ち.

30. P. rubra $W$. $H b$. fol. lanceolatis acutis subtus tomentosis ; capitulis terminalibus. Trichocephalus Eckl. et Zeyl. In Prom. b. spei. $\hbar$.

31. P. microcephala $W$. Hb. foI. linearibus patulis revolutis; capitulis terminalibus. In Prom. b. spei. $ђ$.

32. P. eriophora Berg. fol. linearibus pilosiusculis suhtus tomentosis margine revolutis; floribus tomentosis. In Prom. b. spei. ち.

\section{b. Floribus racemosis spicatis paniculatisve.}

33. P. arborea Aubl. fol. confertis ovato-lanceolatis eveniis subtus tomentosis; capitulis axillaribus lanatis. In ins. Cunha. 古.

34. P. spicata L. fol. sparsis subcordato-lanceolatis acutis supra glabris subtus tomentosis; bracteis lanatis. P. pinea Thunb. Soulangia EckJ. et Zeyl. In Prom. b. spei. ち.

35. S. cylindrica Wendl. coll.t. fol. confertis linearibus acuminatis hir- 
sutis erectis; spicis cylindricis; lracteis lanatis. Berl. Mag. 8. t. 8. f. 5. In Prom. b. spei. t.

36. P. plumosa Thunb. fol. sparsis lineari-subulatis villosissimis patulo-revolutis subtus tomentosis ; floribus axillaribus. P. pumila Wendl. In Prom. b. spei. †.

3\%. P. cuspidata Eckl. et Zeshl. fol. cordato-cuspidatis erecto-patulis subimbricatis margine revolutis subtus tomentosis, summis pilosis; umbellis multifloris; florihus spicaeformibus. In Prom. b. spei. ち.

38. P. fulva Eickl. et Zeyh. fol. lineari-lanceolatis subadpressis rigidis subpungentibus margine revolutis subtus tomentosis; floribus spicatis. In Prom. b. spei. t.

39. P. recurvifolia Eckl. et Zeyh. fol. lineari-acutis subpungentibus rigidis pubescentibus subtus tomentosis apice recurvatis; floribus spicaeformi-

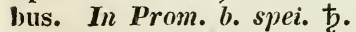

40. P. Willdenouiana Eckl. et Zeyh. fol. lineari-lanceolatis pungentibus erectis margine revolutis; ramis subcorymbosis; floribus sericeo-tomentosis. P. rosmarinifolia schl. In Prom. b. spei. 市.

41. P. gnidioides Eckl. et Zeyh. fol. linearibus calloso-mucronatis erecto-patulis subimbricatis glabris subtus tomentosiusculis margine revolutis; ranis subcorymbosis ; floribus sericeo-tomentosis. In Prom. b. spei. ち.

42. P. microphylla; fol. linearilanceolatis calloso-submucronatis brevibus patentim recurvatis margine revolutis nitidis extus tomentosis; floribus spicatis. Soulangia Eckl. et Zeyh. In Prom. b. spei. 古.

43. P. Intescens; fol. Ianceolatolinearibus obtusis apice callosis margine revolutis subtus tomentosis; ramis corymbosis. Soulangia Eckl. et Zeyh. In Prom. b. spei. ђ.

41. P. pubescens Ait. fol. linearibus acutis pilosis subtus tomentosis; floribus spicatis; bracteis villosis filiformibus. B. Cab. 695. In Prom. $b$. spei. $\hbar$.

45. P. villosa Thunb. fol. linearibus rigidis patulis supra nitidis suhtus tomentosis, superioribus villosis ; norihus aggregatis hirsutissimis. In Prom. c. spei. $\mathrm{b}$.

4o. P. imoricata Thunb. fol. im- bricatis cordato-ovatis floribusque racemosis g!abris. In prom. b. spei. b. 47. P. axillaris ham. fol. lineariIanceolatis glaherrimis subtus incanis; floribus axillarihus subracemosis. In prom. b. spei. 占.

18. P. vinifolia I. fol. sparsis linearibus obtusis glaberrimis; floribus paniculatis. In Prom. b. spei. $\hbar$.

49. P. racemosa Thumb. fol. ovatis glabris; paniculis terminalibus. In Prom. b. spei.

\section{THESIUM L. (1737).}

\section{a. Europaea.}

1. T. Linophyllum Rchb. ic. 645. radice repente; fol. lineari-lanceolatis 3-nerviis; filamentis anthera deflorata duplo longioribus; perigonio fructus involuto drupa triplo breviore. T. intermedium schrad. In pratis montanis. 4.

2. T. montanum Ehrh. radice ramoso-fibrosa multicipite; caulihus paniculatis; filamentis anthera deflorata duplo longioribus; drupis subrotundis; perigonio drupa triplo hreviore. Relıb. ic. 644. In montosis Europ. 4. Flores intus nivei.

3. T. ramosum Hayne; radice fusiformi; ramis elongatis racemosis; flamentis anthera deflorata brevioribus; drupis oblongis subsessilihus pedicello quadruplo longioribus; perigonio fructus involuto drupa triplo breviore. Hayne in Schrad. jour. I. t. 7. T. palatinatum Roth. In Austria. 4.

4. T. divaricatum Jan; caule apice ramoso; fol. linearibus; filamentis anthera deflorata hrevioribus; drupis cylindrico-oblongis pedicellatis ; pedicello dimidia drupa longiore; perigonio fructus involuto drupa triplo breviore. lichb. ic. 648. In montanis Europ. 24.

5. 'T. pratense Ehr\%, radice fusiformi; caulibus racemosis paniculatisve; ramulis fructiferis horizontaiter patentibus; drupis subglobosis ; perigonio fructus tubuloso apice involuto diupam aequante. Richb. ic. 64\% In matis montanis. 4.

6. 'T. alpimum $\mathbf{H}$. radice fusiformi; ramulis fructiferis erecto-patentibus secundis; drupis subglobosis; perigonio fructus tubuloso apice involuto drupam aequante vel longiore. Jac\%. 
austr. t. 416. sturm. 11. sv. Bot. 611. In ericetis subalpinis. 21. 1-ped.

7. '1. ebracteatum Hayne; radice repente; racemo simplici, fiuctifero apice bracteis sterilihus comoso; noribus unibracteatis. Hchb. ic. 649. T. comosum lioth. T. pratense Vahl. FI. Dan. 505. In graminosis Borussiae. 4. 3-4-poll.

S. T. rostratum MIert. et Koch; radice praemorsa multicipite; racemo simplici, fructifero hracteis sterilibus comoso; floribus 1 -bracteatis ; drupis baccatis succosis. Helıb. ic. 650 . In Alpibus Europ. 24. Drupa citrina.

9. T. lumile Vahl; spicato-ramosum ; ramis acutangulis ; fol. linearihus carnosis drupa in axilla sessili. lichb. ic. 947. In graminosis Dalmatiae. 4.

10. T. eleyans Rochel $\%$ palat. t. 4. f. 11. suffruticosum; ramis erectis apice paucifloris ; fol. anguste lanceolatis. Rchb. hort. t. 9. In Hungaria. ந.

\section{b. Altaica.}

11. T. repens Ledeb. ic. $t .233$. radice repente; caulibus simplicissimis; nuce globosa calyce deflorato duplo longiore; bracteis omnibus florem fructumque longe superantibus. In Altai. 21.

12. T. multicanle Ledeb. ic.t.23\%. caule supra medium ramoso; drupa oblonga cylindracea calyce deflorato duplo longiore. In collibus Altaicis. $\hbar$.

13. $T$. rupestre Ledeb. ic. $t$. $2+1$. caulibus numerosis simplicissimis racemo terminatis; drupa cum calycis deflorati tubo elliptica; calycis tubo ad faucem constricto. In fissuris rupium Altai. 4.

\section{c. Capensia.}

\section{* Foliis trigonis minutis.}

14. T. fragile Thunb. fol. ovato3-gonis carnosis; caule angulato fragili; floribus axillaribus. In Prom. b. spei. ち. Pedale. Habitus Salsolae. 15. 'T. lineatum Tiunb. fol. Ianceolatis remotis; ramis striatis erectis. In Pram. b. spei. ђ. 1-ped.

16. T. imbricatum Thunb. fol. acutis serrato-scabris; floribus terminalibus solitariis. In Prom. b. spei. Caul. palmaris.
1\%. T. spinosum Thunb. fol. spinosis; caule angulato compresso; floribus solitariis axillaribus. In Prom. b. spei. ち.

18. 'T. viryatum Lam. ramis erectis virgatis nudinsculis; fol. subulatis brevibus remotissimis; florihus subumbellatis terminalibus. In Prom. $b$. spei. t.

19. T. funale Thunb. fol. linearilanceolatis acutis; ramis striatis elongatis; floribus subspicatis. In Prom. b. spei. b.

20. 'I. spicatum Willd. fol. ovatotrigonis canleque filiformi erectis ; floribus spicatis imbricatis. In Prom. $b$. spei. $\hbar$. 3-ped.

21. T. strictum Thunb. fol. lineari-trigonis erectis; caule filiformi ; floribus subumbellatis. In Prom. $b$. spei. $\hbar$.

22. T. paniculatum Thunb. fol. lanceolato-3-gonis erectis; caule filiformi ; ramis angulatis floribusque paniculatis. In Prom. b. spei.

23. 'T. hispirlulum Lam. caulibus paniculatis diffusis; fol. lineari-subulatis hispidulis; floribus terminalibus sessilibus. In Prom. b. spei. ち. Fruticulus $\frac{I}{2}$-ped.

21. T. squarrosum Thunb. fol. lineari-3-gonis patenti-reflexis; caulo tereti; ramis floribusque paniculatis. In Prom. b. spei. ち. Frutex pedalis. 25. T. scabrum Thunb. fol. lineari-3-gonis imbricatis patenti-reflexis scabris; caule tereti; floribus terminalibus capitatis. In Prom. b. spei. $b$.

26. $T$. capitatum Thunb. fol. iineari-3-gonis mucronatis laeviluus; capitulis terminalibus; bracteis ciliatis. In Prom. b. spei.

\section{** Foliis oratis lanceolatisve.}

27. T. amplexicaule Thunb. fol. cordatis amplexicaulibus; racemis terminalibus. In Prom. b. spei. ち. 4-ped.

28. T. euphorbioides Thunb. fol. ovatis sessilibus; panicula terminali foliosa. In Prom. b. spei. ち. Frutex fusco-rufescens 1-pedalis.

29. T' Friesed Thunb. fol. lanceolato-oblongis obtusis planis; floribus spicatis lanatis. In Prom. 6. spei. 4. Caulis palmaris.

30. T. triflorum Thunb. fol. Ianceolatis; caule angulato; pedunc. tri- 
chotomis axillaribus compositis. Prom. b. spei. 支.

31. T. debile $s p r$. fol. lineari-filiformilus mucronatis elongatis alternis; caule humili; ramis decumbentibus. In Prom. b. spei. 4.

32. T. divaricatum Jan; caule ramosissimo; ramis fructiferis divaricatis; fol. linearibus; bracteis ternis carnoso-triquetris subulatis; fructibus subrotundis. In Hispania anstr. 4.

33. T.? serratum Kit. caule adscendente simplicissimo; fol. lanceolatis utrinque attenuatis medio serratis ; calycibus 4-fidis. In Bannatu. 4.

34. T. humifusum DC. caulibus prostratis numerosis elongatis; spicis gracilibus; pedunc. brevibus subaequalibus. In Gallia. 4 .

3.5. T. spathulatum Blume; fol. spathulatis coriaceis nervosis ; floribus subumbellatis axillaribus; caule parasitico. In Java.

\section{LEPTOMERIA R. Br. (1S10).}

a. Stigma 5-fidum.

1. L. Billardierii R. Br. subaphylla; ramulis angulatis suhsquamatis; bracteis lanceolatis; disci glandulis distinctis solutis. Thesium drupaceum Labill. t. 93. In Nov. Holl. ち. Arbuscula 5-6-ped.

2. L. acida $\boldsymbol{R}$. Br. subaphylla; ramulis angulatis; bracteis lanceolatis ; perianthii laciniis utrinque 1-dentatis; disci lobis semiadnatis. In Nova Hollandia. $\hbar$.

3. L. aphylla $R$. Br. ramis ramulisque teretibus aphyllis; bracteis obovatis; disci lobis adnatis. In Nov. Holl. $\hbar$.

1. L. xiphoclada Sieb. ramis angulatis compressis esquamatis; floribus glomeratis; bracteis caducis; laciniis calycis linearibus revolutis. In Nov. Holl. 古.

\section{b. Stigma emarginatum.}

5. L. scrobiculata $\boldsymbol{R}$. Br. spicis filiformibus multifloris; bracteis caducis; flosculis sessilibus; scrobiculis racheos semiimmersis. In Nov. Holl. b.
6. L. panciflora R. Br. spicis pancifloris; bracteis caducis; flosculis emersis. In Nov. Holl. $\hbar$.

\%. I. squarrulosa R. Br. floribus axillaribus folia patula denticuliformia superantihus; ramis ramulisque strictis. In Nor. Holl.

8. L. axillaris $R$. Br. floribus axillaribus pedicellatis folio subulato duplo brevioribus; ramulis laxiusculis. In Nov. Holl. ち.

9. L. acerba $R$. Br. aphylla; ramis ramulisque teretibus striatis; floribus glomeratis solitariisque. In Nov. Holl. $\hbar$.

\section{CHORETRUM R. Br. (1810).}

1. C. lateriflorum $\boldsymbol{R}$. Br. floribus axillaribus sessilibus solitariis. In Nov. Holl. †. Frutex ramosissimus.

2. C. glomeratum $R$. $B r$. floribus ramulos laterales terminantibus binis ternisve. In Nov. Holl.

\section{HAMILTONIA Muehlenb. (150\%).}

1. H. oleifera Willd. ramulis, foliis calycibusque pubescentibus; fol. ovali-oblongis acuminatis integerrimis. Pyrularia puberula Michx. Amer. t. 13. In Amer. bor. $ち$. Arbuscula 3-6-ped. Flores spicati parvi.

2. H. umbellata Spr. fol. obovatis mucronatis; floribus racemosis glabris. Thesium umbellatum L. Comandra Nutt. Plukn. t. 342. f. 1. In Amer. bor. 2. 1-ped.

3. H. sarmentosa Spr. fol. oblongis obtusis; umbellis axillaribus subtrifloris; radice repente. Comandra livida Richard. In Amer. bor.

\section{NYSSA L. (1737).}

1. N. villosa Michx. Arbr. t. 21. fol. ovalibus utrinque acutis integerrimis villosis; pedunc. 3-floris; nuce ovata striata. N. multiflora Wangenh. am. t. 16. f. 39. N. sylvatica Andr. N. integrifolia Ait. In Amer. bor. $\hbar$. Arbor 60-70-ped. Flores parvi virentes.

2. N. aquatica $L$. fol. oblongoovalibus integerrimis glabris; pedunc. 
femineis sulh-2-floris. N. biflora Michx. Catesby. Car. t. 41. In Amer. bor. 5. Arbor alta. Baccae atro-caeruleae.

3. N. candicans Michx. fol. brevissime petiolatis subcuneato-oblongis subtus subcandıcantilus; pedunc. femineis 1-floris; calyce tomentoso. N. capitata Michx. Arbr. t. 20. In Amer. bor. $\hbar$. Arbor 30-40-ped.

4. N. tomentosa Michx. fol. longe petiolatis remote serratis ovalibus acuminatis subtus tomentosis; pedunc. femineis 1-floris. N. grandidentata Michx. Arbr. t. 19 . In Amer. bor. ち. Arbor 80-ped. Fructus magni atrocaerulei.

5. N. denticulata Ait. fol. longe petiolatis cordatis ovalibusque acuminatis rariter angulato-dentatis glabris. N. angulisans Michx. N. uniflora Wangenh. Amer. t. 27. f. 57. Catesb. t. 60. In Amer. bor. ち. Arbor 80-100-ped.

6. N.? angulosa Poir. fol. cuneiformibus anguloso-dentatis. In Amer. bor. ち. Dubia species.

\section{CEVALLIA Lag. (1816).}

1. C. sinuata Lag. In Nov. Hispan. Herba strigosa. Folia alterna oblon- ga obtusa sinuata subtus tomentosa. Flores spicato-capitati.

\section{MYOSCHILOS R. et $P$.} (1799).

1. M. oblonga $R$. et P. perux: $t$. 212. $f$. a. In Chili. $ђ$. Arbuscula 6-8-ped. Fol. ovato-oblonga repanda. Flores spicati axillares purpurei.

\section{CONOCARPUS Houst. (1728).}

1. C. erectus Jacq. amer. $t$. 52. f. 1. pict. $t$. 188. caule erecto; fol. lanceolatis patulis racemosis. Catesb. t. 33. Plukn. t. 240. f. 3. Plum. t. 154. f. 2. In Ind. occ. et Amer. austr. $ち$. Arbor. 30-ped. Capitula flavida.

2. C. procumbens Jacq. amer. $t$. 52. f. 2. pict. $t$. 260. f. 22. caule procumbente; fol. obovatis. In Amer. austr. ђ. Frutex ramosissimus.

3. C. acutifolius $H$. et $B$. caule erecto; fol. lanceolatis utrinque acutis; capitulis florum solitariis axilla-

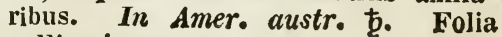
pollicaria. 



New York Botanical Garden Library

QK97.D5 sect.1

Dietrich, David Nat/Synopsis plantarum;

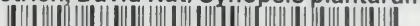

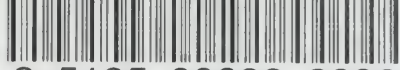

35185000932606

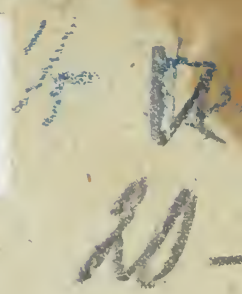


